





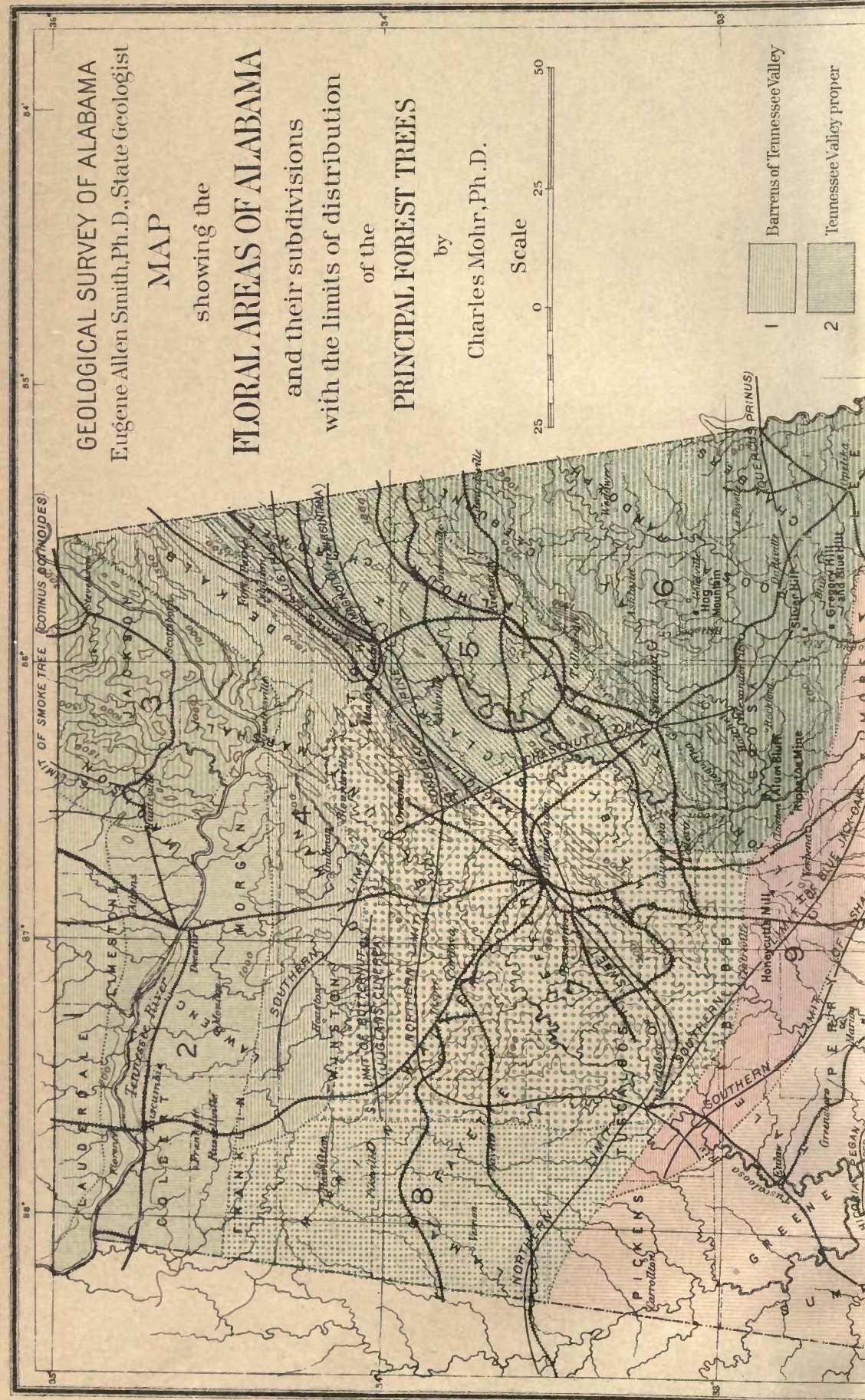




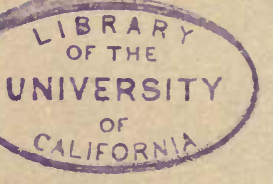




\section{GEOLOGICAL SURVEY OF ALABAMA.}

EUGENE ALlen SMITH, Ph. D.,

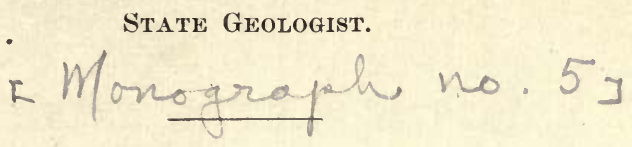

\section{PLANT LIFE OF ALABAMA,}

AN ACCOUNT OF THE DISTRIBUTION, MODES

OF ASSOCIATION, AND ADAPTATIONS OF

THE FLORA OF ALABAMA, TOGETHER

WITH A SYSTEMATIC CATALOGUE

OF THE PLANTS GROWING

IN THE STATE.

BY CHARLES MOHR, PH. D.

REPRINT OF VOL. VI, CONTRIBUTIONS FROM THE U. S. NATIONAL HERBARIUM, PUBLISHED JULY 31, 1901, BY THE

U. S. DEPARTMENT OF AGRICULTURE.

Prepared in cooperation with the Geological Survey of Alakama

\section{ALABAMA EDITION,}

WITH PORTRAIT AND BIOGRAPHY OF THE AUTHOR.

Printed at Government Printing Office, Washington, D. C.

ALABAMA EDITION

BOUND AND PUBLISHED BY THE BROWN PRINTING CO., MONTGOMERY, ALA., OCTOBER, 1901,

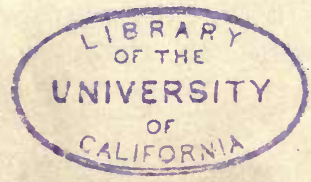




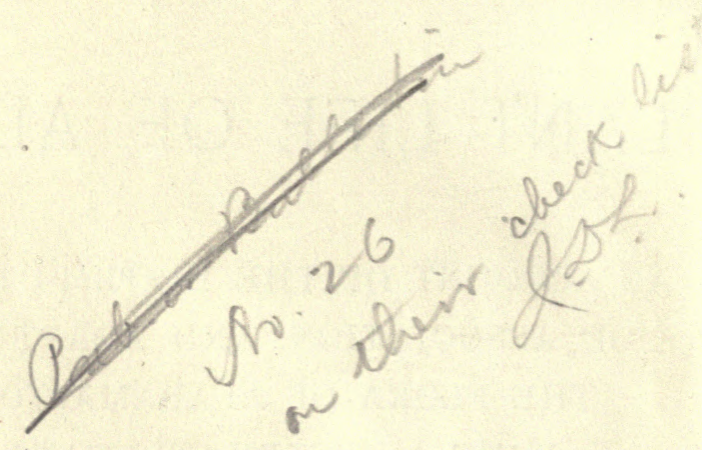

esifs jow 


\section{LETTER OF TRANSMITTAL.}

University of Alabama, August 1, 1901.

To His Excellency, William D.Jelks, Governor of Alabama:

Sir-I have the honor to transmit herewith a report on "Plant Life of Alabama," by Charles Mohr, Ph.D., with the recommendation that it be published as one of the reports of the Geological Survey. In compliance with the requirements of the law organizing the survey, which makes it the duty of the State Geologist to prepare reports on the Geological, Agricultural and other natural resources of the State, and in accordance with the plan outlined in my first report, 1874, this volume has been prepared by the one man in the State competent to do it. Dr. Mohr in this introduction beyond, has given a historical sketch of the origin and progress of the investigations which have led up to the present report, and to this sketch I will add that in 1880 we published a list of our combined collections, under the title "A Preliminary List of the Plants Growing Without Cultivation in Alabama." In this list were enumerated about 1,500 species and varieties of flowering plants and ferns. How much has been added since that time through Br. Mohr's efforts may be seen by comparison with the list in "Plant Life."

The present volume-according to our plan, the first part of a comprehensive report on the Botanical Resources of Alabama - is a classified catalogue of our indigenous and naturalized flora. The second art of this report, on the Economic Botany of the State, to the irreparable loss to science in general and to the State in particular, the author did not live to complete. This proposed volume was to have been a classified and descriptive catalogue of all our plants useful for timber, for ornament, for forage and food purposes, for medicinal use, for perfumery, etc., as well as of those undesirable because of their interference with desirabie growths or of their poisonous or other deleterious qualities. Such a book would have been of service to a very large number of our citizens, and we can only bewail the untimely death of the gifted man who alone of our acquaintance possessed the qualifications needed for such a work.

It will be seen that the present volume is far more than a bare list of our native plants, for, even considered merely as a catalogue, it has the merit of presenting the plants ac- 
cording to the most modern system of classification, with the synonymy of each species most carefully and conseientiously worked out, with the type locality, and full notes of its occurrences in Alabama.

The amount of labor and learning involved in this can be appreciated by the few only who have had similar work to do. The preliminary chapters on the floral regions of the State, and the geographical distribution of our native plants, their modes of association and adaptations, embodying all the latest results of botanical study, will interest and instruct even the specialist.

Foreseeing the difficulty, if not the impossibility, of having a book of so technical a character as "Plant Life" brought out under our supervision alone, and knowing that the authorities of the Department of Agriculture, through Dr. Mohr, had become interested in the work, it was proposed by me that the first publication should be undertaken by that Department, with the understanding that an edition for the Alabama Geological Survey should be printed at the same time with that for the Department, each edition to have its appropriate title page and letter of transmittal. 'This proposition was accepted, and we desire here to acknowledge our obligations to the Division of Botany and to Mr. Coville and the others who have rendered such signal aid in bringing out the book. In view of the untimely death of the author, we realize that we have been fortunate in having this aid, without which the book would not have been printed during his lifetime, and could not have received his last revisions.

It has been thought proper and desirable in this Survey edition to add a short biographical sketch of Dr. Mohr, condensed from the Pharmaceutische Rundschau, together with his portrait and that of another man whose name will ever be honorably associated with Alabama botany, Judge Thomas Minott Peters.

Respectfully,

Euglene A. Smith,

State Geologist. 


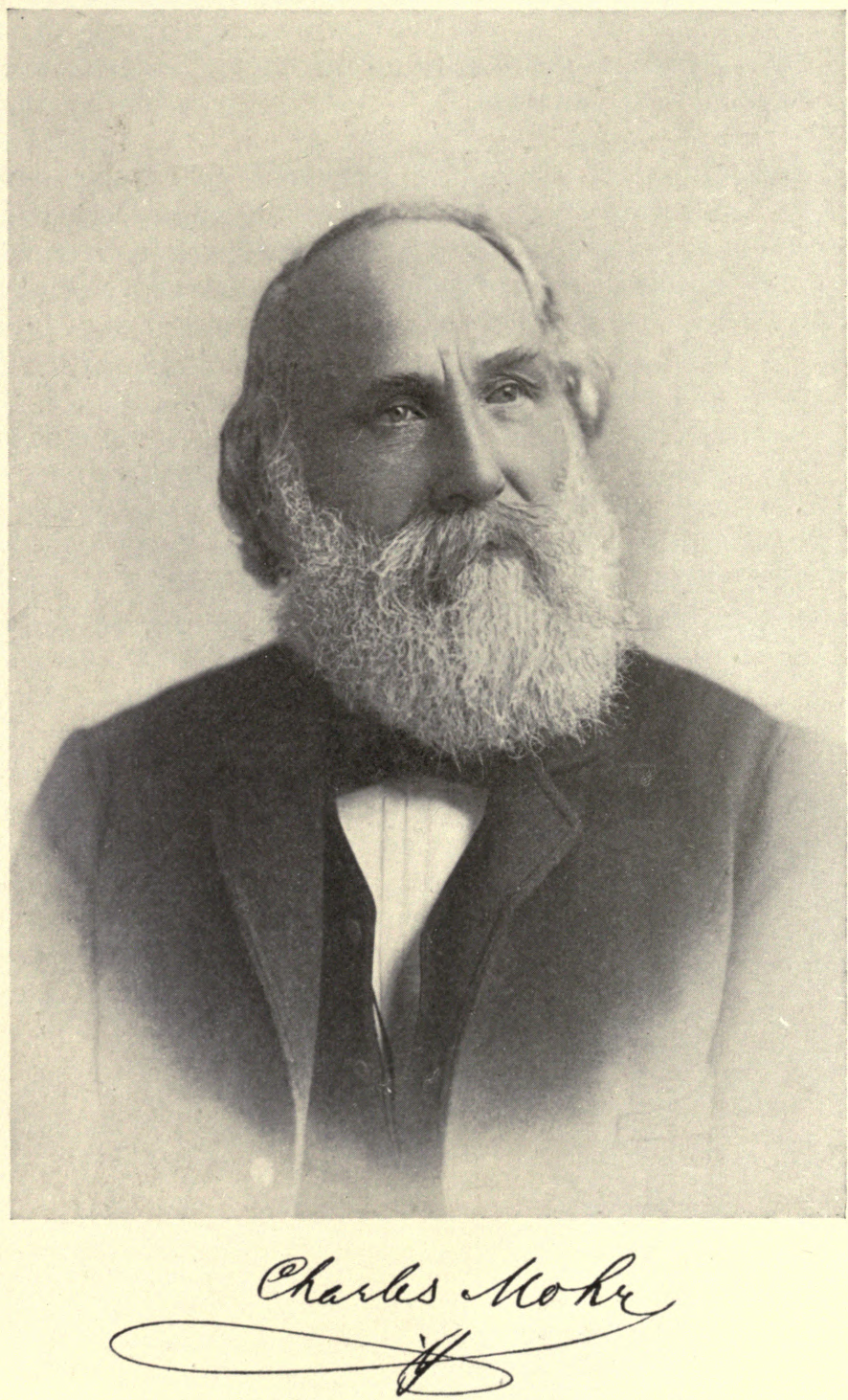


\section{CHARLES THEODORE MOHR.}

The subject of this sketch was born Dec. 28, 1824, in Esslingen, on the Neckar. Here, and at the Cloister Denkendorf, where his father had acquired an interest in a manufactory of chemicals, his earlier years and school days were spent.

After the death of his father, which occurred soon after the removal to Denkendorf, young Mohr after school hours was frequently called upon to assist in the conduct of the business. His taste for Natural History was first aroused by the reading of the famous Bridgewater Treaties, especially that of Buckland, and frequent walks with his great uncle, a pensioned forester of the district, who had for many years had his home in the Cloister of Denkendorf, laid the foundation of that love of the forest which he retained to the end of his life. Here he became acquainted with the various useful trees, and their peculiarities, and with many of the plants which possessed medicinal or poisonous properties.

At the termination of his school days Charles was expected to devote himself to the clerical work of the business, but he had slight inclination thereto, while on the other hand, he was greatly interested in the chemical details of the manufacture.

The return of his elder brother from his apprenticeship relieved him of this office work, and gave him the opportunity which he was not slow to improve, of increasing his knowledge of Nature. During his stay in one of the mining districts of the Schwartzwald, the brother had made a collection of ores and minerals, which he brought home with him. To the study of these Charles applied himself with his accustomed zeal, and thenceforward the two brothers made frequent excursions through forest and mountain in search of mineral and botanical specimens.

In 1842 Mohr entered the Polytechnic School at Stuttgart, with Fehling as his instructor in chemistry and laboratory work. Here he met with William Hochstetter, at that time apprentice in the Royal Gardens at Stuttgart, a part of whose duty it was to keep up a constant temperature in the hothouses. Mohr shared with him many of these night watches in order to improve the opportunity thus afforded for the study of exotic plants.

From this intercourse he became an inmate in the house of young Hochstetter, where he met the botanist 
Johann Hohenacker, then engaged in the publication of the plants collected by him in Asiatic Russia and of a herbarium of medicinal plants.

During the summer vacation of 1845 young Mohr was employed in arranging the duplicate specimens of the Polytechnic School, accumulated during many years, and in distributing them among the Real Schule of the land. In this work he made the acquaintance of August Kappler who for many years had been engaged in the collection of natural history specimens in Dutch Guiana. Mohr's application to accompany him on his next voyage as a collector especially of botanical specimens, met with favor, and when his work in the arrangement of the cabinet of the Polytechnic School was ended, he remained some weeks with Hohenacker, applying himself diligently to preparation for the proposed voyage. Hohenacker also undertook to publish the botanical collections which were to be made in Surinam.

In November, 1845, with Kappler, young Mohr left Stuttgart for Amsterdam, where they took passage in the bark Natalie, reaching the coast of Guiana towards the middle of March, 1S46. At that time a very severe drouth was prevailing, which made possible the collection of many interesting plant forms occurring in the swamps and marshes about Paramaribo. An expedition was made to the upper waters of the Surinam, in order to make before the rainy season a collection of living plants for the Belgian trade. On account of the dry weather this expedition did not prove very successful in the collection of insects and of herbarium specimens, but was more satisfactory as regarded the living plants. A few days after his return to Paramaribo from this expedition, Mohr was attacked with bilious fever which kept him confined to his hammock for several weeks. During the rainy season, which soon set in, nothing was done in the way of collecting, but the time was employed in preparations for the long excursion to the Maroni River and in writing up notes and in correspondence. At the end of the rainy season the expedition was made up the Maroni River to the borders of Cayenne, where the party encamped and applied themselves with great industry to the collections for which they had come.

Most of them were attacked by fever and dysentery, from which they rapidly recovered, but it was otherwise with young Mohr, who was kept confined to his hammock for many weeks, losing all this time from his work of collecting, to his great disappointment and grief. 
Returning to Paramaribo towards the end of September, and not regaining his strength, he concluded to return to Europe.

Accordingly in November, 1846, after a seven months' stay in Surinam, he took passage on the schooner Polaris for Rotterdam, which was reached in March following. In May, 1847, he accepted a position as chemist in the manufacturing establishment of the firm of Hochstetter \& Schickard, in Brunn, Austria. In this prosperous business he remained till the revolution of 1848 brought it to a close.

At the instigation of his elder brother, who had decided to emigrate to North America, he embarked in August, 1848, on the ship Spartan for New York, from which place he went first to Philadelphia, and then to Cincinnati, where he found employment with a German manufacturer of chemicals.

He soon made acquaintances among the educated people of the city, and in March, 1849, in company with about fifty young men, he left Cincinnati to seek his fortune in California. At Fort Laramie it became evident that further progress was impossible with the amount of baggage which they had, and in consequence all articles which were not absolutely needed were left behind, and the party was divided up into groups of six to twelve, and the journey continued. At Fort Hall, on the upper waters of the Lewis fork of Snake river, the party was compelled to abandon their wagons and to proceed with pack mules, and as the number of these was limited many had to go on foot. Here Mohr was obliged to leave his well filled herbarium and all his books. On the 10th of August they reached a settlement in the Sacramento Valley, the first since leaving the borders of Missouri 110 days before. Here Mohr remained engaged in placer mining, till protracted illness, brought on by heat and exposure, decided him to give up this mode of life and return to the East.

Having disposed of his mining interests, in company with an English comrade, he left the mines about the beginning of September, 1850, descended the river from Marysville to San Francisco, and went thence by steamer to Panama. In Panama he remained for a time in the hopes of recovering his strength more fully before undertaking to cross the isthmus; but he had the misfortune to have all his baggage, including his collection of plants and minerals, stolen from him, and to crown all, was attacked by fever. On the steamer from Chagres to New Orleans, he suffered a relapse of fever, which kept him prostrated till New Orleans was reached, and his recovery there was in the main due to the tender care of his countryman and companion, Duke Paul, of Wurttemburg. From New Or- 
leans he reached Cincinnati about the end of December, 1850. Upon the restoration of his health he purchased a joint interest with his brothers in a farm in Clarke county, Indiana, and in 1852 he was married. 'The hardships to which he had been exposed in California had rendered him subject to attacks of rheumatism and it soon became evident that a farmer's life was to him impossible. Accordingly he remored to Louisville, where, after a short time, he obtained a position as assistant in a German apothecary establishment, and after a vear's service here he became a member of an American firm. The business was much to his liking, and he soon renewed his interest in botany, making the acquaintance of Leo Lesquereux, through whose influence he directed his studies to the mosses. An attack of neuralgia, which affected the heart and confined him to his bed for a long time, warned him that his complete recovery would be slow in the changeable climate of Louisville, and he was advised by his physician to go South. He was thus again obliged to give up all the results of four years' profitable business and seek a new home. He went first to Louisiana, but not finding relief there, he proceeded to Vera Cruz, which he reached after a four weeks' voyage, early in the year 1857. Here he became interested in a pharmaceutical business, but on the approach of the rainy season decided to remove to the highlands between Cordova and Orizaba, where he was the guest of his countryman, Herr Sartorius. In the autumn of 1857 , in consequence of a political revolution in Mexico, he returned to the United States and established himself in the drug business in Mobile, Alabama. This profitable business suffered greatly during the Civil War, but meanwhile Mohr was employed by the Confederate government in manufacturing drugs from native resources and in testing the medicinal preparations smuggled into the country from Europe.

Towards the end of 1860 , at the request of Leo Lesquerenx, Dr. Mohr had begun his study of the mosses of Alabama, and a complete catalogue of these plants was contributed by him to the "Mosses of North America," published in 1884. A collection of the ferns of South Alabama was made at the same time, and thoroughly worked up, and the results turned over to Prof. Eaton for his "Ferns of North America."

In addition to these botanical works, Dr. Mohr, undertook in the interests of the "Grangers," many investigations of the fertilizing value of the ashes of the various woods of Alabama, and of pine straw and leaves, and of the hulls of cotton seed. He also delivered many lectures and wrote many articles on subjects connected with the improvement of the exhausted 
soils of the State, and the betterment of agricultural practice.

In the summer of 1876 he made an examination of the gold resources of the metamorphic region of the State, and had the opportunity during the journeys made for the purpose, to observe also the richness of our flora and especially of the great forests. The results of these observations were published in Berney's Hand Book of Alabama in 1878, under the titles "The Forests of Alabama and 'Their Products," and "T'he Grasses and Other Horage Plants of Alabama."

The collections of minerals of economic importance brought together during these excursions were placed on exhibition in Mobile in 1876, and in Atlanta in 1881, and a report of the same entitled "On the Economic Geology of Alabama," was is" sued in 1887. This collection went finally to the Department of Agriculture in Washington. A treatise on the Grasses and Forage Plants of Alabama was prepared for the Department of Agriculture in 1878 and 1879, and in May, 1878, was published in the Botanical Gazette an account of the useful plants of foreign origin which were acclimated in the Gulf States.

In the same year, in connection with the State Geological Survey, he began the arrangement of a herbarium of Alabama plants from the collections made by himself and Dr. Smith, and a "Preliminary List of the Plants Growing Without C'ultivation in Alabama," prepared by him, was published by the Geological Survey in 1880.

As a natural sequel to this preliminary work, came the preparation of a volume for the Geological Survey on the Plant Life of Alabama, which occupied more or less of his time and interest till his death.

In 1880, for the Tenth Census, he took charge of an investigation of the forestry conditions of the Gulf States, and the results of this investigation were published in Vol. IX of the Tenth Census Reports. While engaged in this work he also collected for the Arboretum at Harvard, and for the Jessup collection of the American Museum of Natural History, large sections of trunks of the typical forest trees. At the same time he brought together the material, afterwards worked up under his direction in book form, illustrating the forest and timber trees of Alabama, which now forms part of the Survey collection in the cabinet of the University of Alabama.

In 1882 he was invited by the chief of the Agricultural Department to superintend the arrangement and installation of the Agricultural and Forestry collections which had been brought together by the great railroad lines of the South, and exhibited in Atlanta in 1881. This congenial work occupied him for some time during which he was associated with the scien- 
tific men of the various departments in Washington greatly to his pleasure and advantage.

In 1883 he was employed by the Louisville and Nashville Railroad to make a full collections of the agricultural, forestry and mineral resources oceurring along the line of that road. These collections, together with many additions subsequently made, were placed on exhibition at the World's Exposition in New Orleans in 1884, where Dr. Mohr also had eharge of the exhibit of the agricultural and other natural resources of the state of Alabama. 'This exhibit was also displayed at the Louisville Exposition, and a descriptive catalogue of it was published under the title "The Natural Restources of Ala- vama," concerning which Prof. Lamson-Scribuer, in a lecture on Southern Botanists, says, "this is one of the few papers of its kind which possesses real scientific merit, and in no way can mislead the reader or prospective settler." In the following year (1884) he prepared a report on the soils, climate and agricultural resources of the territory traversed by the $L$. \& N. railroad lines.

The long continued work in the Exposition building in New Orleans during exceptionally unfavorable weather conditions, brought on a return of his rheumatic troubles, which greatly interfered with his subsequent work in the field.

In 1892 he turned over the management of his drug bnsiness to his son and devoted his entire time to the preparation of the "Plant Life of Alabama" and to the investigation of the Flora of North America for the Division of Forestry of the U. S. Department of Agriculture.

In the prosecution of these works he spent much time in arranging the herbarium of Alabama plants at the University of Alabama, mounting the specimens in the most beautiful style, and classifying them according to the system of Engler and Prantl. As a supplement to the collection of the native woods of Alabama above mentioned, he also prepared a set of about one hundred and fifty individual glass-front cases in which were displayed the specimens illustrating the foliage, flowers and fruit of the forest trees. In recognition of the importance of the work of Dr. Mohr in these collections illustrating the botany of the State, the herbarium has received the title of "the "Mohr Herbarium."

During these years also, in connection with the Forestry Division, were prepared his great work on the Pines, published in 1896, and his monographs on the Cypress, the Juniper, and the Red Cedar, which are now in press. Monographs on the hard wood trees were to follow next, the first of the series being that on the Oaks, which he had just completed when he died. 
In March, 1900, he removed from Mobile to Asheville, N. C., where he spent the remainder of his life in the preparation of the monographs above mentioned, and in reading the proof of "The Plant Life of Alabama," which had all passed through his hands in final revision, although he did not live to see the completed book, which was not issued till a week or two after his death.

In connection with this volume, Dr. Mohr had planned the preparation of another volume on the "Economic Botany of Alabama" for the Geological Survey, in which was to be given full accounts of the useful and noxious plants of the State. Unfortunately for the State of Alabama and for the science of Botany, he was not spared to complete this, the crowning work of his life.

During the two years of his residence in Asheville he had the opportunity of coming much in contact with the botanists of America. Especially did he enjoy his frequent visits to the Biltmore Herbarium, where he sought for new species among the specimens sent in by Mr. Beadle's collectors in the field. The genus Cratægus which presents so many interesting features especially occupied him there, as Mr. Beadle is working up this genus. Here also he had the opportunity of studying the Herbarium of Dr. Chapman, from which he obtained much valuable information. Frequent visits to the forests of the Biltmore estate, enabled him to collect many valuable notes on the hard woods of that section.

His last illness came on suddenly after a day spent at work in the Biltmore Herbarium.

The trying days of intense suffering preceding his death brought out strongly the beauty of his character; not a word of complaint; a kind word for every one around him; patient to the last; and a realization of the inevitable end, brave and unflinching. "How beautiful the world is" were among the last words he ever spoke.

In the lecture on Southern Botanists above alluded to, Prof. F. Lamson-Scribner has touched upon some of the striking characteristics of the subject of our sketch. He says "Mohr is possessed of a true scientific spirit and great enthusiasm in his botanical work. By the amount he has accomplished it is very evident that he has well improved his hours of leisure, and doubtless stolen much time from hours of needed recreation. But in this day and generation, one cannot stop to recreate, for if he does some more zealous worker will win the prize he seeks. Success from true merit seems now to depend upon one's powers of endurance." 
"Mohr has the distinction of having gone from the beaten track of systematic botanists and considered the plants he studied from an economic aspect. He has not only increased the sum of our knowledge, but has added to our powers of direct usefulness. I would say to those who in referring to botany are ever asking the question cui bono, carefully read the writings of Dr. Mohr; they afford a most able answer."

Personally Dr. Mohr was the most lovable and unselfish of men, totally devoid of affectation and pretense. He made friends with old and young wherever he went, inspiring all who knew him with love and respect both on account of his noble character and of the fullness and accuracy of his knowledge. His unselfish devotion to his favorite science came to be esteemed at something like its real worth during his lifetime, and the name of Charles Mohr will long be cherished in the country at large and in his adopted State in particular, by all who can appreciate true merit and greatness of character.

Euglane A. Smith. 
PLANT LIFE OF ALABAMA, BY

CHARLES MOHR. 



\section{LETTER OF TRANSMITTAL.}

\section{U. S. Department of Agriculture, Division of Botany, Washington, D. C., January 5, 1900.}

SiR: Under date of November 8, 1897, a letter was received from Dr. Eugene A. Smith, State Geologist of Alabama, as follows:

In connection with the work of the Geological Survey of Alabama, and as a part thereof, Dr. Charles Mohr, of Mobile, has prepared an elaborate account of the plant life in the State. Deeming this work a most important and timely contribution to our knowledge of the Southern flora, as it discusses the character, distribution, and general aspects of plant life in Alabama in a broad and philosophical manner, I believe that it would prove of interest to a larger section of our country than the region to which it is confined by its title. In order to secure, therefore, a more widespread distribution, allow me to suggest the propriety of publishing it as one of the contributions from the United States National Herbarium. I may add that I am induced to offer this valuable manuscript for publication to the National Herbarium because under present financial conditions of the State Survey its publication would probably be delayed for an indefinite time, and thus its immediate usefulness would be impaired.

Dr. Mohr is now and has been for several years a special agent of the Division of Forestry of this Department, and there being, therefore, no obstacle in the way of accepting this manuscript, I earnestly recommend compliance with the courteous suggestion of the State geologist of Alabama, Dr. Smith, and I desire to take this opportunity of acknowledging the obligations of this Division, both to Dr. Smith and to Dr. Mohr.

The report is in part a complete enumeration of the plants of Alabama and in part a discussion of the various natural belts and areas of vegetation into which the State is divided, with a full description of the vegetative characteristics of each.

I have, therefore, the honor to transmit the manuscript for your final approval, and recommend its publication as Volume VI of our series of Contributions.

Respectfully,

Frederick V. Coville, Botanist.

Hon. James Wilson,

Secretary of Agriculture. 



\section{PREFACE.}

The following description of the plant life of Alabama is the result of nearly forty years of sojourn and wanderings through the State, during which all parts were visited and the collections were made that serve as a basis of this work.

The writer has attempted more than has been usual in the descriptive works and the various floras of regions or States of this continent. He thought it not sufficient to give merely an enumeration of the plants known to be indigenous, together with those which are known as immigrants growing without cultivation in the State, and to supplement such enumeration with notes on geographical distribution and habitat, but he has attempted a deeper study, that of the relations of plant life in the field; that is, of its ecological conditions.

In this attempt the work of Merriam on the life zones and areas of the North American continent north of Mexico ${ }^{1}$ and Willkomm's "Grundzuege der Pflanzenverbreitung auf der iberischen Halbinsel (Leipzig, 1896)," have served as a general basis in respect to the distribution of plant life over wide geographical areas and limited regions embraced within them.

The writer has been especially fortunate in having been able to consult, before the completion of his task, the classic work of Warming, ${ }^{2}$ which may be considered as laying down for the first time, in a systematic manner, the principles of plant ecology. While these principles had been more or less foreshadowed by other writers, they were enunciated by Warming with such logical precision as to inaugurate a new departure in the study of plant life.

Since these methods of viewing plant life have not yet become familiar to most students of botany, it has seemed necessary to discuss them somewhat in detail in the introductory part of this volume. It is hoped that by describing the plant associations to be found in the different localities, not only the primary object of a floral work as a part of a geological survey will be subserved, but a new interest will be added to the study of botany, both for the botanist and the thoughtful layman, which may enable them to use the volume for practical purposes.

\footnotetext{
${ }^{1}$ See p. 29.
}

${ }^{2}$ Dr. E. Warming, Lehrbuch der Oekologischen Pflanzengeographie, German edition of Ir. E. Knoblauch, Berlin, 1896. 
In the preparation of this work the writer is indebted for assistance, first of all, to Dr. A. W. Chapman, the veteran Sou.hern botanist; to Prof. Charles S. Sargent for aid rendered in the free use of the library of the Arnold Arboretum and advice in perplexing questions of nomenclature, and to Mr. Charles Faxon, of the Arnold Arboretum, for bibliographical assistance; to Dr. N. L. Britton and Dr. J. K. Small, of the Columbia University; to Dr. William Trelease, of the Missouri Botanical Garden; to Prof. F. Lamson-Scribner, chief of the Division of Agrostology, United States Department of Agrieulture; to Mr. F. V. Coville, chief of the Division of Botany, and his assistant Mr. T. H. Kearney, jr.; and to Dr. J. N. Rose and Mr. Charles L. Pollard, assistant curators of the National Herbarium, for facilities afforded; also to Dr. Edward L. Greene, of the Catholic University, for his revision of doubtful and new forms of Compositae; and to Prof. L. H. Bailey for his help in Carex. Thanks are due, also, to Dr. B. E. Fernow, late chief of the Division of Forestry, for help rendered in the arrangement of the general part of the work for the press, and to Mr. George B. Sudworth, dendrologist of that Division; and lastly to Mr. C. D. Beadle, director of the Biltmore Herbarium, and his associate, Mr. F. E. Boynton, for their assistance while consulting the Biltmore Herbarium and Library.

The writer with pleasure takes this occasion to express his gratitude for the friendly aid extended to him by many of his fellow-citizens while engaged in the field, and to President Milton Smith, of the Louisville and Nashville Railroad, to the Hon. T. G. Bush, president of the Mobile and Birmingham Railway, and to Col. E. L. Russell, president of the Mobile and Ohio Railroad, for courtesies liberally extended to him in his travels through the State. Without the aid received from these sources the appearance of this volume could not have been accomplished.

Charles Mohr. 


\section{CONTENTS.}

Introduction Page.

History of the present botanical exploration of Alabama........... 11

Plan of the present work .................................... 12

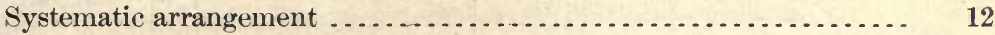

Nomenclature......................................... 13

History of the earlier botanical explorations of Alabama. . . . . . . . . 13

William Bartram.................................... 13

Samuel Botsford Buckley ............................... 16

Hezekiah Gates ..................................... 16

Thomas Minott Peters. . . . . . . . . . . . . . . . . . . . . . . . . . . . 17

Beaumont, Nevius, and recent collectors................... 17

General physiographical features of the State ..................... 18

Topography and geology .................................... 18

The Coastal Plain .................................... 18

Region of Crystalline Rocks................................ 19

Region of the Coal Measures............................... 20

Region of the Coosa Valley ................................ 21

Region of Tennessee Valley ................................ 21

River system........................................... 22

Tennessee River. ................................. 22

Alabama River.................................... 23

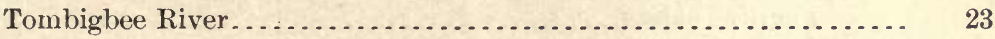

Coosa River.......................................... 24

Cahaba River and smaller streams........................ 24

Climate................................................. 24

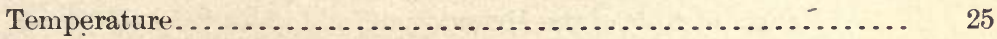

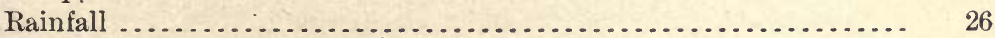

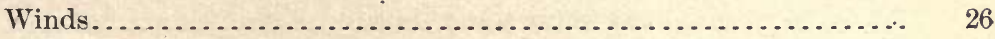

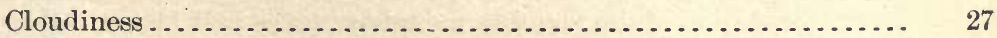

General principles of the distribution of plants. . . . . . . . . . . . . . . . . .

Plant zones of Humboldt, based on isothermal lines . . . . . . . . . . . . . . 28

Life zones established by Merriam . . . . . . . . . . . . . . . . . . . . . . . 29

Boreal region ........................................... 30

Arctic or Arctic-Alpine zone ......................... 30

Hudsonian zone.................................. 30

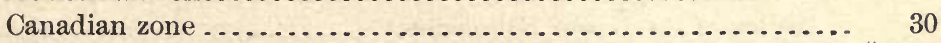

Austral region . . . . . . . . . . . . . . . . . . . . . . . . . 31

Transition zone .................................. 31

Upper Austral zone ................................ 31

Lower Austral zone ................................. 32

Tropical region......................................... 33

Secondary factors influencing plant distribution . . . . . . . . . . . . . . . 33

Distribution of species as depending upon geological history ............ 34 
General principles of the distribution of plants-Continued.

Plant formations and plant associations

Hydrophytic plant associations. ............................. 37

Xerophytic plant associations ............................. 37

Halophytic plant associations ............................ 37

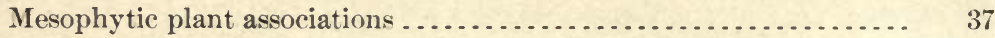

General character of the flora of Alabama ........................... 37

Systematical relations ........................................ 38

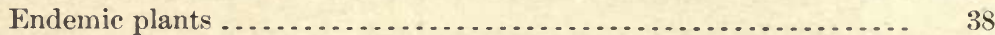

Relationship of the Alabama flora to that of adjoining regions ..... $\quad 39$

Relationship of the Alabama flora to foreign floras.............. 39

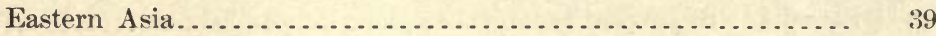

West Indies, Mexico, South America .................... 41

Europe and the Mediterranean region ..................... 43

Biological and ecological relations ............................ 44

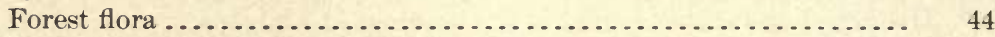

Shrubby plant associations........................... 44

Arboreal plant associations .......................... 45

Open land or campestrian flora (xerophile plant associations) ..... 48

Water and swamp flora (hydrophytic plant associations) .......... 48

Hydrocharidean class.............................. 48

Lithophytic and limnæan classes ..................... 49

Palustrian classes ...................................... 49

Organotopic flora....................................... 50

Epiphytic plant associations ........................ 50

Saprophytic and symbiotic plant associations............. 51

Parasitic plant associations......................... 52

Insectivorous plants.............................. 52

Introduced plants and their influence upon native plant associations . $\quad 53$

Naturalized plants.................................. 53

Adventive plants................................... 54

Fugitive plants...................................... 55

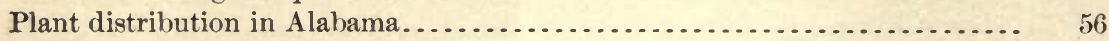

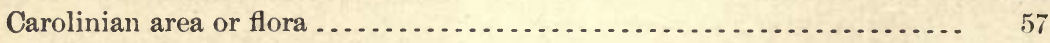

Mountain region .................................... 58

Ranges of hills of the Metamorphic and older Paleozoic strata... 58

Table-lands of the Warrior and Coosa Basins................... 69

Physiographical features and climate .................... 69

Vegetation of the plateaus, mountain slopes, and higher valleys. . $\quad 70$

Region of the Tennessee River Valley ..................... 80

Physiographical features and climate ................... 80

Vegetation of the table-lands and higher ridges............. 81

Vegetation of the lowlands, coves, and bluffs............. 86

Vegetation of the barrens and river hills.................. 88

Cultural plant formations........................... 89

Region of the Lower Hill country ........................ 89

Gravelly hills of short-leaf pine and hardwood trees .......... 90

Coal Measures of the Cahaba Valley and Warrior basin ....... 90

Louisianian area or flora................................ 94

Region of the Central Pine belt ........................ 96

Central Prairie region ................................. 97

Physiographical features......................... 97

Xerophile forests............................... 98

Mesophile forests................................ 99 
Plant distribution in Alabama-Continued.

Louisianian area or flora-Continued.

Central Prairie region-Continued.

Mesophile herbaceous plant associations .................. 102

Campestrian plant associations ......................... 104

Cultural plant formations......................... 105

Maritime Pine region................................ 106

Upper division of the Coast Pine belt, or region of mixed tree-

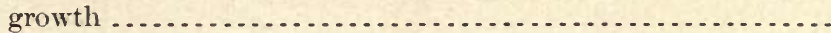

Lower division of the Coast Pine belt, or lower region of long-

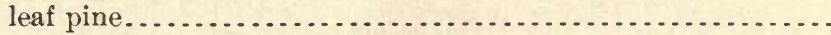

Physiographical features and climate.............

Rolling pine uplands or dry pine barrens...............

Pine-barren flats and hydrophytic plant associations.......

Region of the Coast plain or low flat pine barrens ............

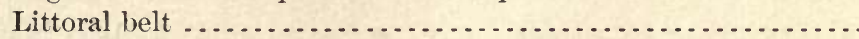

Cultural plant formations of the Lower Pine region and Coast

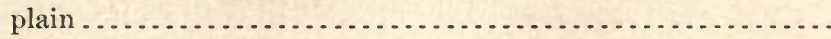

Systematic catalogue of the plants growing without cultivation in the State, including descriptions of new, rare, and little known species . . . . . . . . . .

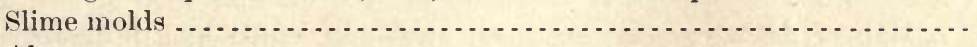

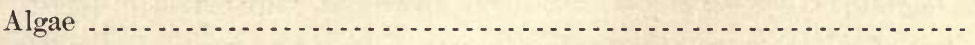

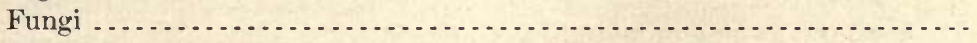

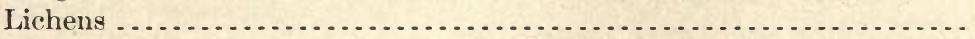

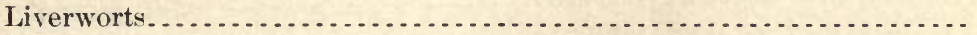

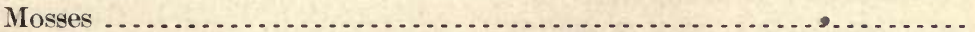

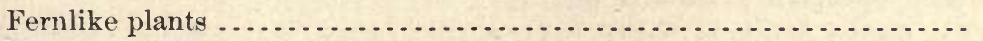

True flowering and seed-bearing plants ...........................

The spontaneous flora of Alabama in its relation to agriculture ...........

List of the plants cultivated in Alabama............................

\section{ADDITIONS TO TABLE OF CONTENTS.}

Letter of Transmittal................................. III Biographical Sketch of Charles Mohr..................... v. V

\section{ILLUSTRATIONS.}

Portrait of Dr. Mohr, Plate A. to face .................. V

Portrait of Judge Peters, Plate B. to face................. XVII 


\section{ILLUSTRATIONS.}

Puate I. Map of Alabama, showing floral areas and distribution of forest

Page. trees .................................... Frontispiece.

II. Sagittaria longirostra australis J. G. Smith................. 331

III. Sagittaria mohrii J. G. Smith ......................... 333

IV. Neviusia alabamensis Gray .............................. 539

V. Croton alabamensis E. A. Smith............................ 591

VI. Cotinus cotinoides (Nutt.) Britton.......................... 600

VII. Vaccinium melanocarpum Mohr ........................ 658

VIII. Oldenlandia littoralis Mohr ........................... 737

IX. Hieracium scribneri Small ............................. 752

X. Eupatorium smithii Greene \& Mohr .................... 761

XI. Eupatorium mohrii Greene ......................... 762

XII. Silphium mohrii Small .................................. 793

XIII. Silphium gatesii Mohr............................. 793 


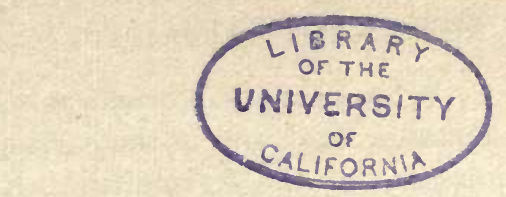

\section{PLANT LIFE OF ALABAMA.}

\section{INTRODUC'IION.}

\section{HISTORY OF THE PRESENT BOTANICAL EXPLORATION OF ALABAMA.}

In 1879 the botanical collections made by the State geologist of Alabama, Dr. Eugene A. Smith, in the northern section of the State, were submitted to the writer for classification, with the request that he take charge of the investigation of the flora of Alabama in connection with the Geological Survey. Having accepted this duty, the formation of a Normal Herbarium of the State was undertaken. To this end the collections of the writer, made in the Coastal plain, and particularly in the Lower Pine region and Littoral belt, were incorporated with the above collections, and thus the foundation was laid for the Normal Herbarium of the Geological Survey of the State, deposited in the Museum of the University of Alabama, which has served as a basis for this report. Subsequently, and during a long series of years, the writer has worked singly in the field at such intervals as his official duties would permit. Engaged in the investigation of the forests for the United States Census in 1880 and 1881, and later in making collections for the exhibits of the Louisville and Nashville Railroad, at the Exposition in Louisville, and the Cotton Exposition at New Orleans in 1884 and 1885 , extensive collections of plants were made and advantage was taken of the opportunities for the study of plant life in the field in all the different regions of the State. Further facilities in the same direction were enjoyed from 1890 to 1896 while engaged in the study of the forests and in the collection of the material for timber tests under the direction of Dr. Fernow, then chief of the Division of Forestry, Department of Agriculture.

During the summer and fall of 1892 several special trips to investigate more closely the flora of the State were undertaken for the Geological Survey of the State. These trips included visits to the so-called Canebrake (Central Prairie) region, the basin of the Coosa River, the eastern part of the mountain region, and the Tennessee Valley. In 1896 a visit was paid to the Chehawhaw Mountain and the higher valleys and denuded plains in Clay County, the most elevated district in the State. Very desirable contributions have been received during 
recent years from Prof. M. C. Wilson, of the Normal School at Florence. The large colleetions made in 1896 , and in the early part of the following season, by the biologists of the Agricultural Experiment Station, under the auspices of the Biological Survey of Alabama, connected with the Agricultural and Mechanical College at Auburn, and kindly submitted to the writer for examination. afforded many plants from localities not represented before in the Normal Herbarium, and from a section of the State of peculiar interest to the student of plant distribution, but heretofore almost unknown to botanists. They included a number of forms not previously observed in the State, some of them new to science.

\section{PLAN OF THE PRESENT WORK.}

In the general part of the work a short sketch of the physiographical features of the State precedes a chapter on the general aspect of the flora of Alabama, and its relation to that of adjoining States, and to the continental and extra-continental floras. In the paragraphs on geological and climatic conditions, the publications of the Geological Survey of the State and of Prof. P. H. Mell, in charge of the meteorological service of the State, have been depended upon.

In the general discussion of the geographical distribution of plants, the principles leading Dr. Merriam to the establishment of his life zones on the North American Continent north of Mexico have been adopted, these having already been successfully applied in the investigation of the distribution of animal as well as plant life in the part of our country west of the basin of the Mississippi River by Messrs. Merriam and Coville.

The delimitation of the floral divisions of the State introduced by the writer can only be regarded as tentative. The area, as yet, has been but superficially explored, and in many parts the borders of the divisions are but obscurely outlined, and need to be cleared up and rectified, while several gaps remain to be filled.

No effort has been spared to ascertain the distribution of each species and variety known from the State, first, over the globe, then, within the life zones of this continent, and last, within the floral divisions of the State. For this purpose the leading works on systematic botany, particularly North American botany, and all the arailable State and local floras and catalogues have been consulted.

\section{SYSTEMATIC ARRANGEMENT.}

In the catalogue of the plants growing without cultivation in Alabama the natural system of Engler and Prantl $^{1}$ has been followed. This embodies the results of the latest investigations of the natural relations of plants and their affinities in the light of the development

'Engler und Prantl, Die Natuerlichen Pflanzenfamilien, 1887 to 1900. 
of life from the lowest to the highest forms, the truly natural order, and at the present time generally accepted as such by biologists. The study of plants is now coming to be generally conducted in accordance with these views, and the natural system of the vegetable kingdom, as enunciated in the classical work cited, has already been adopted in the most important works on descriptive botany in this country which have lately made their appearance, and will without doubt be followed in similar publications during another generation.

\section{NOMENCLATURE.}

In nomenclature the principle of priority, regarded as the fundamental one, is strictly adhered to in the present work. This was first advocated by De Candolle at the International Botanical Congress at Paris in 1867, and its application was developed by American botanists at the meeting of the American Association for the Advancement of Science at Rochester, in 1892, and through the rules reported by the committee on nomenclature which were adopted at the next meeting of the botanical club of the association held at Madison, Wis., in August, 1893.

The applications of plants to the use of man are briefly alluded to under the abbreviated head of Economic, and a list of the cultivated piants of the State is given at the close of the volume. The fuller treatment of the relations of the plant life of Alabama to the necessities or comfort of mankind was at first contemplated as a part of this volume, but, on account of the expansion of the other matter, has had to be deferred.

\section{HISTORY OF THE EARLIER BOTANICAL EXPLORATIONS OF ALABAMA.}

In regard to its vegetable productions Alabama, like the rest of the territory fronting the Gulf of Mexico east of the Mississippi, remained until the last quarter of the eighteenth century a terra incognita.

\section{WILLIAM BARTRAM.}

The first description of these productions is given by William Bartram, ${ }^{1}$ in his account of his memorable travels through the Southern States, in the years 1773 to 1778 . This intrepid explorer of the botany of Southeastern North America entered the State to all appearance somewhere near the middle of its eastern border, at the old Muscogee town Uche (the site of which can at present not be exactly located), after a journey of three days reaching the Indian settlements at Tallassee on the Tallapoosa River. In his account of his travels from the Tallapoosa Valley to the coast Bartram depicts most graphically the

${ }^{1}$ Travels through North and South Carolina, Georgia, east and west Forida, etc. Philadelphia, 1791. 
features of the regetation prevailing in the floral regions traversed. He passed through the subtropical zone, recognized by the long wreaths of the Spanish moss investing the huge limbs of venerable evergreen oaks (the laurel oak, mentioned by him as Quercus hemisphaerica), and huge magnolias, with the Cretaceous plain before him, which the traveler describes as a country with a rich black soil resting upon a chalky testaceous limestone clad with tall grasses and a variety of other herbage, most conspicuous among it tall rosinweeds (Silphium), with their large spikes of golden yellow flowers and a resinous substance exuding from the bruises and splits of the stem; beyond the plains a broken ground of hills and vales covered with forests of stately trees-locust (designated as Robinia, but most likely the honey locust), linden, mulberry, elm, hickory, and black walnut, with the Southern crab apple, dogwood, and redbud for the smaller tree growth; further south a generally level plain, with a lighter soil, pebbles and sand mixing with the surface soil, covered with an open forest of oak, hickories, ash, red bucker̄e, and the smaller trees mentioned above, associated with an abundance of chestnut ${ }^{1}$ and with pines (Pinus lutea, i. e., short-leaf pine, Pinus echinata) interrupted by expansive cane meadows and detached groves, in strong contrast with the gravelly and rocky hills and vales supporting the forests mentioned above. The traveler speaks enthusiastically of the dense cool groves of dogwood and of the fragrant groves of sweet illicium and odorous calycanthus or spicewood covering the higher banks of the streams, together with the beautiful Halesia diptera (silver bells, Mohrodendrom), stuartia, storax bushes, azaleas, and particularly Magnotia auriculata (undoubtedly meaning Magnolia macrophylla), all overtowered by the stately large-flowered magnolia (Magnotia foetida). Across the Shambee (Escambia) River the country is described as low and open, descending for the next 80 miles to the southeast, exhibiting a landscape different from others, not unlike the low country of the Carolinas, consisting of grassy savannas, intersected by narrow forests along the water courses, hummocks, and swamps, with long-leaved pines "scatteringly planted among the grass, associated on the higher knolls and swells with barren oaks," the rivulets running swiftly over their gravelly beds, their banks adorned with evergreen andromedas, American olive, illicium, hollies, sweet bay, and azaleas. Descending to the lowlands toward the bay of Mobile, "cane swamps alternate with pine-clad knolls." Tensas, situated on the eastern arm of the great Mobile River, on a high bluff, about 30 miles above Fort Conde and the eity of Mobile, was reached in the early days of August (1777). After a short visit to Mobile Bartram returned to Tensas, where he obtained a canoe and explored

${ }^{1}$ The existence of the chestnut in the Upper Division of the Coast Pine belt is at present in some parts onlv indicated by the largestumps, which have during the long periods of time resisted decay. 
the flora of the banks of the river up to the Tombigbee. On one of these excursions he discovered the scentless wax myrtle, a small tree called by the French the wax tree, which possessed none of the fragrance of the common wax or candleberry tree (Myrica cerifera), and for this reason was described by this author as Myrica inodora. Sick with fever, he went in search of a plant of great repute as a remedy against malarial diseases. This he found about 30 miles higher up on the banks of the river, growing under the shelter of Stuartia virgin$i c a$, azaleas, and others of the shrubs noticed before. He recognized it as a species of Collinsonia, ${ }^{1}$ and named it $C$. anisata, on account of the fine scent of the plant, reminding one of sweet anise and lemon. There he also found the blue sage, Salvia azurea, "with its spikes of flowers of celestial blue," the scarlet calamintha (Clinopodium coccineum), and a plant of peculiar beauty described as Gerardia Alammea, easily recognized by his description as Macranthera fuchsioides Torr. The swamps are mentioned as covered by tall grasses and by cypress of astonishing growth, above which rise on the higher banks magnificent forests of magnolias, with Halesia diptera and other trees, the bullace grape with its juicy berries of various colors, crossvine, and American glycine (Krauthica ( Wisteria) frutescens), ascending these trees to their loftiest heights, and the dense shrubbery beneath them entangled by the trumpet vine, grape vines, and yellow jessamine. On his return from the Perdido River and from Pensacola, Bartram describes the grassy savannas with their sarracenias extending from the Apalachicola to the Mobile River.

Delighted with his rich harvest of "curious vegetables," but with his health shattered by malarial ferer, Bartram left the banks of the Tensas River and the Bay of Mobile for the banks of the Pearl River in search of medical aid. Returning to Mobile soon afterward, he started near the end of November, 1777, with a party of traders toward the Atlantic coast. After three days' travel he arrired again at the settlements of the Creek Nation, between the falls of the Moclassee (Tallapoosa River) and the Indian town Alabama, near the confluence of the Coosa and the latter river. After a short rest he again left the soil of Alabama by crossing the Chattahoochee River between the towns of Chehaw and Usetta (a short distance above the city of Columbus, Ga.).

At this point in his narrative this genuine lover of nature repeats his praises of the fragrant groves of illicium left behind him, stating that he never met with it north of latitude $33^{\circ}$ nor south of Mobile except at one place, namely, at Lake George, eastern Florida, in latitude $28^{\circ}$.

\footnotetext{
1 The citronella of the settlers, a decoction of it frequently used in fevers as a diaphoretic and invigorating drink.
} 
SAMUEL BOTSFORD BUCKLEY.

After the lapse of about three-quarters of a century, Samuel Botsford Buckley followed the footsteps of Bartram in the exploration of the flora of Alabama. Mr. Buckley was a native of New York but received his education at Wesleyan University, Middletown, Conn., where he graduated in 1836. After leaving college the enthusiastic young botanist was among the earliest to explore the southern Appalachian mountains, discovering many new plants and making the study of the trees his ehief object. Buckley reached Alabama by the principal road of travel leading from the Ohio Valley to the Gulf. Passing over the detached spurs of the Cumberland Mountains in Madison County, on his journey to Alabama and pursuing his favorite oceupation he discovered the interesting American smoke tree (Cotinus cotinoides (Nutt.) Britton), before known only from a single locality in the Indian Territory near the borders of Arkansas. Arriving in central Alabama, he settled in Wilcox County as teacher in an advanced school (about 1839). There, among the hills and vales of the Upper Division of the Maritime pine belt, and near the woods and grassy glades of the Central Prairie region, an inviting field was open to the botanist. In the prairie region he discovered that fine tree of the white-oak group named by him Quercus durandii (Q. breviloba (Torr.) Sargent), and in the hills, Thatictrum debile, besides a host of other interesting plants heretofore unknown from the Southern States. He described his discoveries in the Proceedings of the Philadelphia Academy of Science. Working without the advantage of a large botanical library he met with severe criticism; but many of his new species which at the time were not regarded as valid have now received their deserved recognition. In 1866 Buckley was appointed State geologist of Texas, and, eontinuing his botanical studies, he enjoyed ample opportunities for discovering many undeseribed plants. He never lost his interest in botany, and his last years were devoted to fruit raising and horticulture at Austin, Tex., where he died in 1884. Buckleya, a remarkable shrub of the North Carolina mountains, commemorates Buckley's zealous efforts in the cause of Southern botany.

\section{HEZEKIAH GATES.}

Dr. Hezekiah Gates, a native of New England and for many years a successful apothecary at Mobile, was the first collector of Alabama plants from the coast region, whence he contributed valuable material to Torrey and Gray for their Flora of North America, from the year 1836 to the early forties. He died at Mobile in 1850 (?). Prof. Asa Gray dedicated to his memory the genus Gatesia, a monotypical perennial of the Southwest, native from Alabama to eastern Texas; but unfortunately the name Gatesia has had to be given up, having been previously applied to another plant. 


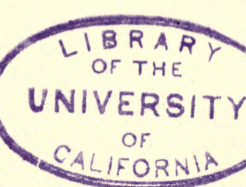




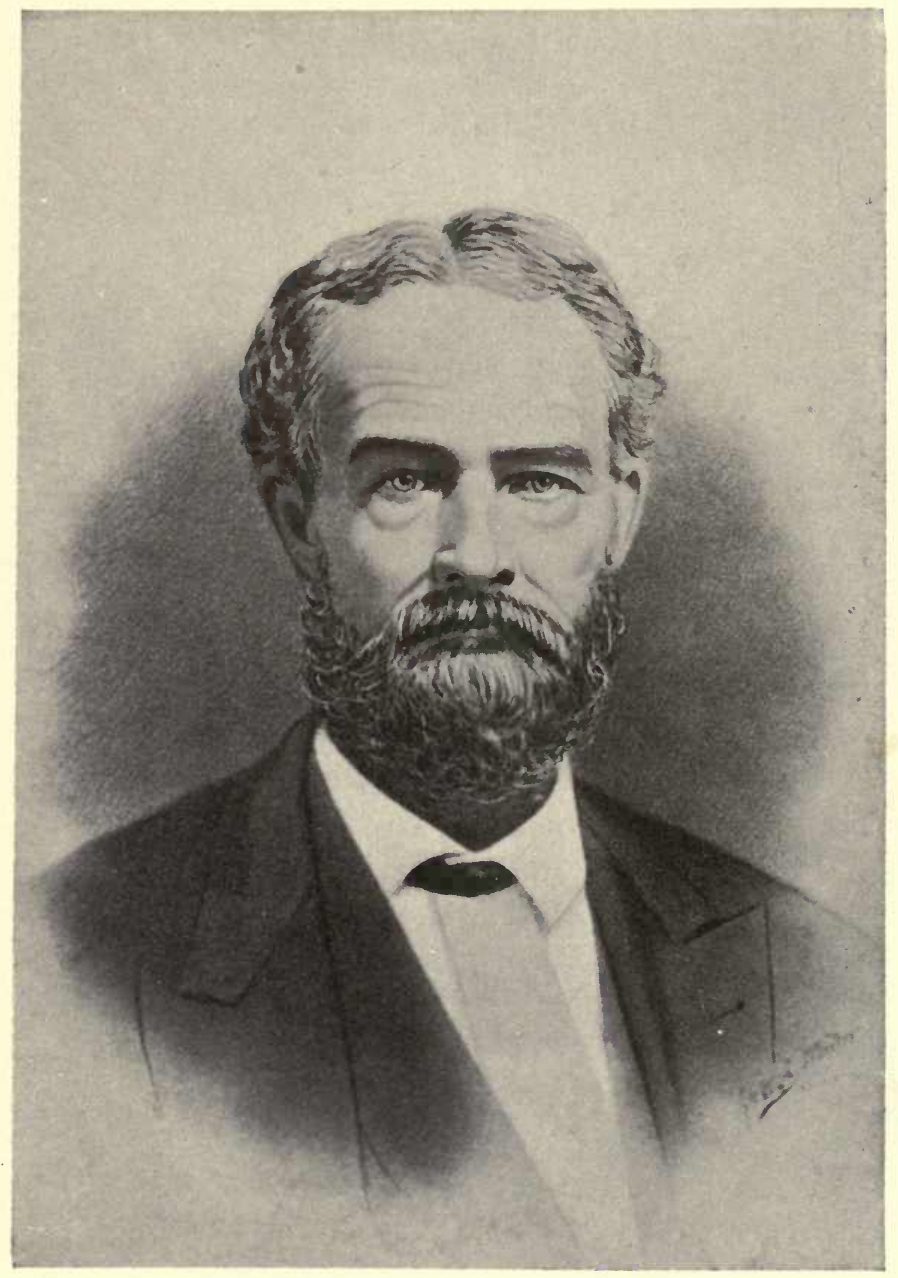

Tho minote Piters 
THOMAS MINOTT PETERS.

Thomas Minott Peters, of New England parentage, but a graduate of the University of Alabama, was engaged in the practice of law until his death, June 14, 1888. He served his State as a representative in the legislative assembly and afterwards as a State senator. In 1869 he was appointed a judge of the supreme court for a term of six years. In his love for botany he found recreation from his professional duties, and his greatest enjoyment was to wander through the adjacent mountains in search of plants. The study of lichens and fungi attracted him particularly, and he was one of the few mycologists working in the Southern field along with Curtis and Ravenel. Of his zeal and activity in this line the long list of Southern fungi of his contribution, published by M. A. Curtis and Berkeley, bears ample testimony. He was also a close observer and accurate student of the plants of higher orders. He first brought to light the delicate and extremely rare fern, Trichomanes petersii, described by Gray, with others like it hidden in the dark recesses of rocky defiles and the socalled "rock houses." He gave close attention to the species of Carex, furnishing the investigators of this difficult genus with material from a region unknown to botanists. In acknowledgment of the services rendered him, Boott, of London, one of the first authors on these plants, presented him with a copy of his magnificent work, Illustrations of the Genus Carex. These classical and valuable volumes Judge Peters bequeathed to the University of Alabama, his alma mater, together with his mycological herbarium and collection of Carices, all mounted and labeled. In 1880 the writer had the privilege of enjoying the company of this venerable botanist during his investigations of the forests in Lawrence and Winston counties, and also received from him much valuable information on the mountain flora of the State, made use of in the present work.

\section{BEAUMONT, NEVIUS, AND RECENT COLLECTORS.}

John F. Beaumont, of German extraction, was born in Pennsylvania in 1825. Judge Peters speaks of Beaumont as a man of a fair classical education, an enthusiastic student of botany, and a contributor to our knowledge of Alabama plants who, following his own example, became the active correspondent of Tuckerman and the other botanists already named. After some years spent as a missionary in Africa, he returned to Alabama, where he taught school. He died at Troy about the close of the civil war. He discovered that interesting grass, Luziola alabamensis, first described in Chapman's Flora (1860).

The Rev. R. D. Nevius collected plants in 1853-54 in the vicinity of Tuscaloosa. He is the discoverer of the singular shrub Neviusia, named $15894-2$ 
in his honor by Gray, which is confined to a single locality on the banks of the Alabama River.

More recently our knowledge of the flora of Alabama has been greatly enriched by the extensive collections made by Profs. F. S. Earle and L. M. Underwood in 1896, and also by those made the following spring and summer by Professors Earle and Carl F. Baker.

\section{GENERAI PHYSIOGRAPHICAL FEATURES OF THE STATE.}

\section{TOPOGRAPHY AND GEOLOGY.'}

Alabama, extending from the shores of the Gulf of Mexico in latitude $30^{\circ} 31^{\prime}$ to the rim of the highlands of Tennessee under the thirty-fifth parallel of latitude, presents two well-marked divisions which nearly coincide with the northern and southern halves of the State, and which are readily distinguished by climatic differences, topographical features, and geological structure, and by the aspect of the vegetation corresponding with these conditions. The upper or northern division embraces the mountainous region of the State, which offer's great complexity in its geological formation, almost every stratum of the various geological epochs being here represented. This gives rise to greater diversity of topography and soil than exists in any other of the Gulf States, thus producing that variety of resources which gives Alabama such a prominent position among her sister States.

The lower division, which occupies the southern half of the State, can be considered as a vast plain of great uniformity in its general features; gently undulating where the loose sedimentary strata of the Post-Tertiary formations prevail, and broken where the cherty ridges of the Tertiary and Cretaceous rocks offered greater resistance to erosion by water.

\section{THE COASTAL PLAIN.}

The sedimentary strata forming the Coastal plain cover three-fifths of the area of the State. In the lower part, in Mobile and Baldwin counties, this plain rises in gentle swells to 300 feet above the tidewater region, reaching at its northern limit an average elevation of about 500 feet above the sea. For a distance of from 80 to 100 miles from the seashore this plain is almost entirely covered with the mantle of sands and gravels of the Lafayette formation, the oldest of the Post-Tertiary strata, which give rise to soils varying from almost pure sand to loamy sand and generous sandy loams, and support a rather uniform but magnificent vegetation of coniferous trees. To the north of these terrains appear the limestones and marls of the

\footnotetext{
${ }^{1}$ Drawn chiefly from the Reports of the Geological Survey of Alabama, 1875 to 1896, by E. A. Smith, State Geologist.
} 
Tertiary formation, slightly dipping south and southeast. The warm, fertile, calcareous soils resulting from admixtures of these strata with the Lafayette loams support an arboreal vegetation of varied character. The lower members of this formation, Buhrstone strata, consisting of hard, flinty limestones, render the surface of the plain broken by cherty hills which rise above the underlying lignite marls. Further north these hills merge into the cretaceous plain, or "Black Belt," so called on account of the black lime soil, the great agricultural region of the State. This Black Belt is followed by a belt of gravels and sand, partly of the lowermost Cretaceous (Tuscaloosa) formation, partly of the Lafayette formation, in which sandy loams prevail, and which is from 5 to 30 miles in width, widening at its western border, where it suddenly takes a northern direction and forms the geological feature of that section of the State to the Tennessee River. This central belt of sands and pebbles forms the northern border of the great Coastal plain, separating the Paleozoic from the Mesozoic formations. Through its southern portion runs the border line between the two principal biological divisions of the State, the Austroriparian or Louisianian life area and the Carolinian life area (Merriam).

North of this Coastal plain rise the highlands of Alabama with their mineral wealth, which cover about two-fifths of the area of the State. The first terrace of this mountainous region forms the so-called "Fall line." Here the head of river navigation is reached, the tributaries of the Tombigbee and Alabama in this region making their way over rocky obstructions, over shoals and through rapids, to the main channels of the extensive drainage area south of the Tennessee River.

\section{REGION OF CRYSTALLINE ROCKS.}

Ascending this terrace at the falls of the Tallapoosa River, the most easterly of the tributaries of the Alabama, the region of crystalline or metamorphic rocks is reached. This extreme southern extension of the eastern Appalachian ranges consists of a congeries of crystalline rocks, to a small extent granitic, mostly of stratified gneiss, micaceous schists, argillaceous shales, and quartzites, wrinkled by many folds and deeply furrowed by the effects of erosion. The different degrees of resistance to this agency offered by these various rocks give rise to an ever-changing configuration of the surface, and to wide variations in the mechanical and chemical conditions of the soil. The folds of the highly siliceous slates and quartzites form sharp crested ridges of an elevation not reached in any other part of the State, while the stratified gneissic rocks and clayey slates most prone to decay under atmospheric influences form the undulating uplands. The sandy soils derived from the first mentioned siliceous rocks, often intermixed with the angular fragments of quartz and hard slates, render the surface obdurately sterile: while 
the latter rocks, decomposed and converted in situ into stratified clays, form the deep, warm soil of a region noted for its fertility.

The metamorphic region extends without any interruption from the central belt of sands and gravels along the eastern border of the State nearly to its northern boundary.

REGION OF THE COAL MEASULES.

The largest portion of the northern part of the State is occupied by the Coal Measures. There are three eoal fields recognized, more or less separated by other formations which will be presently referred to. The most southern of these fields is the Cahaba coal field, beginning above the shoals of the Cahaba River. This field is separated from the Warrior field by the Birmingham or Jones Valley toward the northwest, and from the Coosa coal field by the Cahaba Valley toward the southeast. The southern outlines of this region are extremely broken; the strata of the steep rugged hills disturbed by many folds and faults are deeply furrowed by erosion. The principal part of this region is formed by the Warrior coal field, a triangular area, with the southern corner at the shoals of the Warrior near Tuscaloosa. The topographical features of the western field are of much greater uniformity than those of the Cahaba field. In the lower part of the basin proper, where soft shales overlie the lower conglomerate of the Coal Measures, the surface is undulating, the highest swells rising most frequently to low hills. Toward the north the hills pass gradually into the table-lands formed by the heavy bedded sandstones of the upper conglomerate, which exhibit an almost horizontal stratifieation. These table-lands are the flattened summits of the several converging spurs of the Appalachian chain, known north of the Tennessee River as the Cumberland Mountains and south of the river as the Sand Mountains; the latter with escarpments fronting the Tennessee Valley toward the north, and toward the southeast, Blounts.Valley, which is formed by the southern extension of the Sequatchee fold. The table-land lying between Blounts Valley and Big Wills Valley in the southeast is known as the Raccoon Mountain. The table-land of the range forming the eastern border of Big Wills Valley is known as Lookout Mountain, the stcep escarpment of which fronts the Coosa Valley.

This highland area of the Coal Measures presents in its general aspect a somewhat rolling plateau. It rises to an elevation of from 1,000 to a little over 2,000 feet above the adjacent valleys. It slopes gently away from the greatest elevations in the north to the northwestern limits of the region, where the Coal Measures disappear under the deposits of more recent formations; and to the south, where it passes gradually into the lower hills in the Warrior coal basin proper. 


\section{REGION OF THE COOSA VALLEY.}

Between the region of crystalline rocks and the region of the Coal Measures a narrow area inserts itself, extending in a southwesterly direction along the course of the Coosa River for a distance of about 50 miles, located upon the line of the greatest disturbance caused by the Appalachian upheaval. Consisting of an anticlinal valley, the river valley proper, and a succession of vertically uplifted strata of Cam. brian and Silurian rocks with successive faults, the surface of this region is extremely broken and presents a mountainous aspect. 'To the southeast of the anticlinal, through which the river winds its way, the hard Lower Cambrian sandstone, offering the greatest resistance to the action of water, forms the most prominent ridges in the Alpine, Coldwater, and Ladiga mountains, reaching a height of from 1,800 to 2,000 feet above the sea. The upper aluminous strata of the Cambrian shales cover the floors of the valleys, where from want of drainage they give rise to the stiff impervious clay soils of the "flatwoods." Areas of these flatwoods are found in the anticlinal valley itself, which is for considerable distances covered by drifted sands and gravels. Where the cherty beds of the Silurian dolomite prevail, the surface in the valleys is more or less broken and the soil thin. The surface soil of the Coosa Valley along the banks of the river (i. e., in St. Clair County) is underlaid by the Subcarboniferous shales.

Running mainly parallel with the Coosa Valley and similarly intersecting the Coal Measures there are several smaller valleys similar to the Coosa Valley proper in their geological and topographical conditions.

REGION OF THE TENNESSEE VALLEY.

The remainder of the northern part of the State north and west of the Coal Measures is covered by the strata of the Subcarboniferous formation, which form the region drained by the Tennessee River. The river basin is about 45 miles wide, and toward its northern and southern limit is hilly, and often even mountainous. The plain through which the Tennessee River winds its tortuous way is from 12 to 15 miles wide. On the western frontier of the State the river level is about 480 feet above tide water, while near Huntsville it reaches an elevation of 612 feet.

West of the table-land of the Cumberland Mountains, already spoken of in connection with the Coal Measures, this plain or valley proper is bounded by the Highlands of Tennessee, described as a plateau of from 700 to 800 feet above the sea, through which numerous streams have cut their deep and narrow channels, rendering the surface very broken and hilly. South of the river the escarpment of the Sand Mountain forms the southern boundary of the valley. From the eastern part of Morgan County in a northwesterly direction the 
valley is traversed by the Little Mountain range, which owes its existence to the Subcarboniferous sandstones which have resisted erosion. The depression between the main range (Sand Mountain) and Little Mountain widens by their divergence into a broad valley of the same character as the main valley.

Where the uppermost eherty strata of the Subcarboniferous limestone form the surface rock the surface soil is light and more or less siliceous. This kind of soil prevails chiefly toward the northern limit of the valley. The soil of the river plain proper, resting upon the lower and more purely calcareous strata, is of great fertility.

\section{RIVER SYSTEM.}

Its extensive river system forms a most prominent feature in the physical geography of the State. Many of the larger tributaries of the main channels of drainage are navigable, and their innumerable feeders, the creeks and streams, traverse highlands and plains in all directions, affording an abundant water supply in every part of the State.

\section{TENNESSEE RIVER.}

Among the principal rivers is the Tennessee, most remarkable for its anomalous course. It rises in the mountains a short distance beyond the border of southwestern Virginia, and following mainly a southwestern course it becomes navigable at Knoxville. A short distance south of Chattanooga it cuts its ehannel through a southwestern range of the Cumberland Mountains, and enters Alabama at the northeastern corner at Bridgeport. From this point it flows in a nearly uniform southwestern course about 75 miles, when it reaches Guntersville. Here it turns abruptly to the northwest, reaching the Mussel Shoals, 10 miles below Decatur. These shoals are formed of hard, flinty rocks, over which the water rushes in a series of shallow caseades for a distance of about 38 miles, forming an insurmountable obstacle to navigation as far as Florence. From Florence the river is again navigable. It takes a northerly turn at Waterloo, and leaving the State near its northwest corner, continues in this direction, and after a course of 296 miles empties into the Ohio River at Paducah, $\mathrm{Ky}$., making the distanee from its source 1,037 miles.

The vast area south of the Tennessee River is in the main drained by the Tombigbee River and its tributaries, the larger being the Sipsey and Black Warrior; and the Alabama River with its tributaries, of which the chief are the Coosa and the Tallapoosa. These main channels of drainage find their outlet into the bay of Mobile through the Mobile River, which is formed by their confluence about 50 miles above the river delta. 
ALABAMA RIVER.

This is the largest and most important of the waterways of Alabama. It is formed by the confluence of the Coosa and Tallapoosa rivers, a little southeast of the center of the State. It cuts its way through the rotten limestone and underlying sands of the Cretaceous formation, and farther south through the limestones and marls of the Tertiary formation, flowing not infrequently between the vertical walls of high bluffs formed by the horizontal strata, at other times winding through wide low bottom lands of great fertility. In its lower course toward its confluence with the Tombigbee River it passes through beds of sand and pebbles of more recent formation, and pine-clad hills front its banks, with wide cypress swamps where the banks are almost perpetually submerged, or extensive hardwood forests where less subject to overflow. From the confluence of the Coosa and Tallapoosa to the confluence of the Tombigbee with the Alabama, the length of the latter is variously estimated at from 312 to 400 miles. The average depth from Mobile to Claiborne is from 6 to 7 feet, and from Claiborne to Montgomery it varies from 3 to 5 feet. The Alabama River passes through the richest agricultural region of the State, and through the Maritime Pine belt, its great timber region.

\section{TOMBIGBEE RIVER.}

This river is formed by the confluence of the Little Tombigbee or Upper Tombigbee and the Warrior River in Marengo County, a short distance above Demopolis, and unites with the Alabama River 243 miles south of that place. The course of the river is almost due south, traversing a country rich in agricultural products, its banks often spreading out in heavily timbered bottoms. The character of the country traversed is the same as of that crossed by the Alabama River. The Tombigbee River is throughout its course in the State navigable by steamers for nearly the whole year. The numerous feeders of the Little Tombigbee River take their rise on the southwestern rim of the Warrior highlands and among the gravelly hills in the southwestern extension of the watershed of the Tennessee basin. The most important tributary of the Tombigbee is the Black Warrior River with its two forks, the Locust and the Mulberry, both of which take their rise in the wild ravines of the Warrior table-lands. These forks unite on the dividing line between Walker and Jefferson counties, the river continuing its southwestern course for about 50 miles farther. On reaching Tuscaloosa the Warrior takes a more southerly direction and unites with the Little Tombigbee about 170 miles below Tuscaloosa. According to the late Professor Tuomey the fall of the Warrior River between its source and Tuscaloosa is nearly 1,000 feet, or 5 feet to the mile, and between the latter place and Mobile the 
waters which unite with the Warrior River have a fall of only 161 feet, or 5 inches in a mile. It is for this reason that the Warrior River rises during freshets to the height of 50 feet at Tuscaloosa, the water being suddenly checked by the diminished fall and therefore accumulating at that point. Above Tusealoosa the Warrior or Black Warrior River is not navigable.

\section{COOSA RIVER.}

This is the largest of the tributaries of the Alabama and is formed by the junction of the Oostenaula and Etowah rivers at Rome, in northern Georgia. After a southerly course of 100 miles, the river enters Alabama in Cherokee County, where, continuing its southerly trend, it joins the Tallapoosa River at a distance of 334 miles from Rome. The river is navigable from Rome to Greensport, a distance of 180 miles. From the latter point to Wetumpka, a distance of 137 miles, navigation is interrupted by a series of shoals and reefs of ragged rocks, but from the latter point it is navigable again to its confluence with the Tallapoosa River. The chief tributaries of the Coosa River take their rise in the Blue Ridge and the Alleghenies of Georgia. The banks of this river are mostly high. It passes through a country rich in its mineral, agricultural, and forest wealth.

\section{CAHABA RIVER AND SMALLER STREAMS.}

The Cahaba is one of the smaller tributaries of the Alabama, into which it empties 289 miles above Mobile. It takes its rise in the lower hill country in or near St. Clair County, draining a mineral region containing the coal field of the same name, and passing through the rich agricultural counties of Perry and Dallas. In former years steamers ascended from its mouth to Centerville, in Bibb County, a distance of 80 miles.

Smaller streams affecting the drainage of the Coastal plain east of the basin of the Alabama River are the Escambia River and the Choctawhatchee River, the former emptying into Pensacola Bay. The Chattahoochee River, with an almost directly southern flow, forms the boundary between Alabama and southwestern Georgia, forming by its confluence with the Flint River of the latter State the Apalachicola River, a deep stream, to its mouth inclosed mostly between extensive forest-clad swamps and cypress irakes, and emptying into Apalachicola Bay. The Chattahoochee River is navigable throughout the year between Bainbridge and Columbus, Ga. Its banks are lined with steep bluffs of the later Tertiary strata.

\section{Climate.}

Owing to its geographical position, extending from its northern confines to the Gulf shore, over five degrees of latitude, and further to 
the difference in elevation between its northern and southern sections, the State of Alabama is favored by a varied, but in its extremes not excessive climate. The climatic conditions give rise in the upper part of the State to a vegetation closely related in character to that prevailing in the cooler temperate zone, and in the lower division stamp upon it the features of subtropical regions. Such conditions admit the successful cultivation within its borders of almost all the chief crops and many other useful and ornamental plants raised in higher latitudes, and also the cultivation of the great industrial staple crops and others serving for the sustenance of man and domestic animals, originally derived from warmer zones.

\section{TEMPERATURE.}

Equally open to the influences of the warm and vapor-laden breezes from the Mexican Gulf and the intertropical Atlantic Ocean and the cool and drier aerial currents from the north unimpeded by mountain ranges or table-lands of very great elevation, the climate is mild and equable. The following table, transcribed from the diagram compiled by Prof. P. H. Mell ${ }^{1}$ from the records of the Alabama State weather service, showing for the entire State the monthly mean maximum and mean minimum temperatures and their average, exhibits the run of temperature during the course of the year. The regularity with which it proceeds within comparatively narrow limits from month to month, in the line of the mean maximum as well as the mean minimum temperature, both series keeping close to the line of the average temperature, makes the mildness and uniformity of the climate at once apparent.

Data of temperature by months (degrees F.).

\begin{tabular}{|c|c|c|c|c|c|c|c|c|c|c|c|c|}
\hline & Jan. & Feb. & Mar. & Apr. & May. & June. & July. & Aug. & Sept. & Oet. & Nov. & Dee. \\
\hline $\begin{array}{l}\text { Mean maximum } \ldots \ldots \ldots \\
\text { Mean average............. } \\
\text { Mean minimum } . \ldots \ldots \ldots\end{array}$ & $\begin{array}{l}54.4 \\
43.2 \\
35.5\end{array}$ & $\begin{array}{l}59 \\
49 \\
38.7\end{array}$ & $\begin{array}{l}64.3 \\
57 \\
46\end{array}$ & $\begin{array}{l}70 \\
65.2 \\
56.8\end{array}$ & $\begin{array}{l}75 \\
73 \\
65.8\end{array}$ & $\begin{array}{l}83 \\
80 \\
73.2\end{array}$ & $\begin{array}{l}86.7 \\
81 \\
75.5\end{array}$ & $\begin{array}{l}86 \\
78 \\
73.8\end{array}$ & $\begin{array}{l}82 \\
73 \\
66\end{array}$ & $\begin{array}{l}72 \\
64 \\
56\end{array}$ & $\begin{array}{l}61 \\
56 \\
44.2\end{array}$ & $\begin{array}{l}54 \\
48 \\
42\end{array}$ \\
\hline
\end{tabular}

The following gives similar information for the seasons and the average temperature of the year:

Data of temperature by seasons and for the year (degrees $F$.).

\begin{tabular}{|c|c|c|c|c|c|}
\hline & Spring. & Summer. & Autumn. & Winter. & $\begin{array}{l}\text { Whole } \\
\text { year. }\end{array}$ \\
\hline 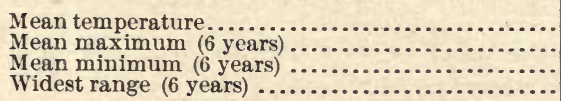 & $\begin{array}{l}63 \\
90 \\
30 \\
60\end{array}$ & $\begin{array}{l}80 \\
94 \\
38 \\
56\end{array}$ & $\begin{array}{l}63 \\
92 \\
26 \\
66\end{array}$ & $\begin{array}{l}50 \\
71 \\
15 \\
56\end{array}$ & 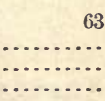 \\
\hline
\end{tabular}

${ }^{1}$ P. H. Mell, Climatology of Alabama, Bulletin 18, Agricultural Experiment Station, new series, August, 1890 , p. 31. 
The range between the lowest and highest mean temperatures for a period of twenty-three years covers $52^{\circ}$, with $35^{\circ}$ in January and $87^{\circ}$ in July for extremes. The widest range in the extremes of temperature observed once in that period covers $104^{\circ}$ between the absolute minimum of $2^{\circ}$ in .January ${ }^{1}$ and the absolute maximum of $106^{\circ}$ in July.

In the southern division of the State, which is mainly embraced within the isothermal lines of $65^{\circ}$ and $64^{\circ} \mathrm{F}$., the lines of mean annual temperature follow with but slight deviation the parallels of latitude. Between the isothermal line of $64^{\circ}$ and that of $60^{\circ}$ extends a central belt closely following the terrace that divides the northern and southern divisions of the State. The lines of mean annual temperature of $60^{\circ}$ and $62^{\circ}$ include its northern division.

RAINFALL.

The meteorological region including Alabama receives the supply of moisture for its precipitation principally from the Gulf of Mexico. In the distribution over time and space the rainfall is of great uniformity. According to the records of the State weather service, ${ }^{2}$ consisting of observations made at the 48 different stations through periods of from two to over thirty years, the annual rainfall for the entire State is about 52 inches. Of this amount 14.52 inches falls during the winter months, December, January, and February; 14.83 inches in the spring; 13.21 inches in the summer, and not quite 10 inches $(9.55)$ in the autumn. The greatest annual rainfall does not exceed 65 inches at any place and the least falls not below 41.75 inches. The number of rainy days in a year observed during a period of six successive years fluctuates between 74 and 117, according to the records kept at Montgomery; no periods of wet weather extend over five days. $^{3}$

Snow falls occasionally in the northern part of the State; usually one considerable snow fall occurs during midwinter. In the lower part it snows very rarely.

Such a plentiful and evenly distributed, but not excessive, supply of atmospheric moisture, in connection with a mild and equable temperature, is productive of a highly luxuriant vegetation, which is most strikingly exhibited in its arboreal growth.

WINDS.

In its correlation with temperature, precipitation, and cloudiness, wind exercises a potent influence upon the climate. The prevailing

\footnotetext{
${ }^{1}$ On February 13, 1899 (not included in the above period), the temperature fell at Tuscaloosa to $6^{\circ}$ or $7^{\circ}$ below zero $\mathrm{F}$. and at Mobile to $3^{\circ}$ below.

${ }^{2}$ P. H. Mell, Climatology of Alabama, op. cit., pp. 28, 29, 59.

${ }^{8}$ F. A. Smith, Agricultural Features of Alabama. Report of Geological Survey of Alabaina for 1880 and 1881.
} 
winds in Alabama come from the south, southeast, and southwest. According to the meteorological summary of the observations collated by the State service, covering a period of six successive years, the winds from these directions prevailed in forty-one out of the seventytwo months, and they are most likely to be followed by rain, most frequently by a heavy precipitation, when coming from the east, south, or southeast. The cool and dry winds from the north and northwest are least likely to be followed by rain. The western and northwestern currents prevailed during the period stated in twenty-three months, the north and northeasterly only in eight months. From the wind chart showing the average direction of the wind in Alabama from 1884 to 1889 , it appears that southeastern winds prevailed almost exclusively during the winter and earlier part of the spring, but with some northwestern winds; that winds from the northwest and northeast predominated in spring and in summer, and that in autumn the winds were from the south, southeast, or southwest, and more rarely from a northern direction. The differences in mean annual directions of the wind are but slight. In their rush toward centers of depression, the warm winds from the south, charged with moisture, impinging upon the cold currents from the north, produce a whirlpool, resulting in electrical storms, generally with a heavy rainfall, often assuming the force of a tornado. These tornadoes, moving generally in a northeasterly direction, are most frequent in the north-central part of the State, and happen most often in the latter part of the winter or in the spring.

\section{CLOUDINESS.}

South and southwestern winds are generally followed by a sunny sky, those coming from the east and northeast by a veil of clouds which strong blasts from the north are apt to rend and disperse. According to the meteorological summary quoted, ${ }^{1}$ in a succession of six years the number of clear days per year averaged 120 , of fair days 119 , and of cloudy days 116. No data are at hand for the deduction of the average duration of sunshine during this period.

\section{GENERAL PRINCIPLES OF THE DISTRIBUTION OF PLANTS.}

Wherever life finds support plant life thrives and is reproduced, but no one plant, except perhaps a few of the lowest forms, is found dispersed over every part of the globe. Every one of the multitude of forms which constitute the plant covering of the earth is by its organization restricted within certain limits. It grows and reproduces its kind in those places where conditions of climate and soil are most favorable for its particular needs. If all plants could adapt themselves

${ }^{1}$ P. H. Mell, Climatology of Alabama, op. cit., pp. 59 to 63. 
to their surroundings with equal facility, there would be no limit to their dispersion over every part of the globe where life exists, only with the reservation that in the struggle for the possession of the ground those of highest vitality, endowed with greatest power of reproduction and possessed of special facilities for dissemination, would overcome the less favored and eventually establish themselves, to the exclusion of others, upon the available space. It is by the diversity of their climatic requirements, their varying degrees of dependence upon the universal environmental factors - air, light, heat, and moisture (the last two being the principal ones)-that plants are restricted within specific limits.

The dependence of plant distribution upon heat is demonstrated by the different character of the vegetation under different parallels from the poles to the equator, and vertically in the ascent from the shore of the sea to the heights of the mountains. As Alexander von Humboldt graphically and eloquently expresses it: "Unlike in design and weave is the rarpet which the plant world in the abundance of its flowers has spread over the naked crust of the earth, more densely woven where the sun ascends higher on the cloudless sky, looser toward the sluggish poles, where the early returning frost nips the undeveloped bud and snatches the barely matured fruit. Every zone is endowed with peculiar charms--the tropical in the variety and grand development of its production, the northern in its fresh meadows and in the periodical revival of nature and the influences of the first breezes of the spring. Besides having its own special advantages, every zone is marked by a peculiar character." It is a fact well established by observation that the same or more or less closely related forms will often appear under similar climatic conditions in parts of the globe widely separated by oceans or deserts. This applies, if not to predominating specific and generic types, at least to representative orders. On the summits of mountains, covered for the greater part of the year with snow and ice; plants are found which are at home in the Boreal Zone; again, the flora of the equatorial zone bears the same general features around the globe. Plants with the same climatic requirements, calling therefore for the same physiological functions, necessarily show similarities in their morphological development, and thus we find that in different parts of the globe the plants exhibit a stronger or feebler resemblance morphologically.

\section{PLANT ZONES OF HUMBOLDT BASED ON ISOTHERMAL LINES.}

Alexander von Humboldt was the first to divide upon these principles the surface of the globe into botanical zones and to lay the foundation of the science of plant geography. Each of these distinct zones of plant life exhibits features which are absent or at most more or less feebly represented in the other zones. 
Recognizing heat as the prime factor in the distribution of plants, this great investigator of nature established the boundaries of plant zones by connecting the points having the same mean annual temperature. The resulting isothermal lines denote broadly the limits within which certain plants find their demands upon this factor satisfied. $\mathrm{He}$ established for plant as well as for animal life the following life zones: The Boreal, or Northern; the Austral, or Southern, and the Tropical Zone. The borders of these zones rarely conform with the parallels of latitude, but frequently diverge widely from them, according to the elevation of the land, moving northward when they pass over lowlands, moving southward when running over the mountains, and also affected by the prevailing aerial currents and proximity to the sea. Since, however, two points of the same mean annual temperature may present wide differences in the extremes of annual, monthly, or daily temperature, and since the physiological functions and the development process must be correlated with these conditions, the zonal divisions established upon these isothermal lines are in a high degree faulty.

\section{LIFE ZONES ESTABLISHED BY MERRIAM.}

The amount of heat required to accomplish the cycle from germination or the first movement in the unfolding bud to the maturity of the seed has been called the physiological constant of the species, which for a given species has been ascertained to remain the same wherever it may grow. To determine this constant the temperature of $43^{\circ} \mathrm{F}$. $\left(6^{\circ} \mathrm{C}\right.$.) has been assumed by physiologists in general as the lowest point at which germination and bud movement takes place. As to the method of establishing this physiological constant opinions differ widely, some investigators believing that the desired coefficient is obtained by multiplying the mean temperature of a certain period by the number of days, while others find it in the sum of the maxima shown by the thermometer exposed to the sun (maxima of insolation).

Merriam recognizes it as a law that the physiological constant rests upon the sum of the mean daily temperatures during the cycle of vegetation. ${ }^{1} \quad B y$ adding the mean daily temperatures above the assumed zero point of vegetation at numerous stations of observation from spring until such time in the fall as the temperature again falls to the zero point, and connecting stations of the same sum of these effective temperatures, lines are established which are regarded by Merriam as determining the northern limit of the species. In its southward distribution he finds a barrier in the

${ }^{1} \mathrm{C}$. Hart Merriam, "Laws of temperature control of the geographic distribution of terrestrial animals and plants," Nat'l Geogr. Mag., vol. 6, pp. 229 to 238, 3 col. maps, 1894; The geographic distribution of animals and plants in North America, Yearbook Dept. Agr. for 1897, pp. 203 to 214; Life zones and crop zones of the United States, Bull. No. 10, Div. Biol. Surv., U. S. Dept. Agr. 
mean temperature during a brief period covering the hottest part of the year.

These boundaries were found to conform with the limits of distribution of species as arrived at by field observations. Differences in moisture, the factor next in importance to heat in the distribution of life-on this continent most potent in its influence from east to west-determine the distribution of animals and plants within distinct areas of these life zones.

Based on these principles. Dr. Merriam recognizes in the North American continent three primary divisions or regions-Boreal, Austral, and Tropical - and seven transcontinental zones. His classification is as follows:

Boreal Regron......... $\begin{aligned} & \text { Arctic or Arctic-Alpine Zome. } \\ & \text { Hudsonian Zone. } \\ & \text { Canadian Zone. }\end{aligned}$

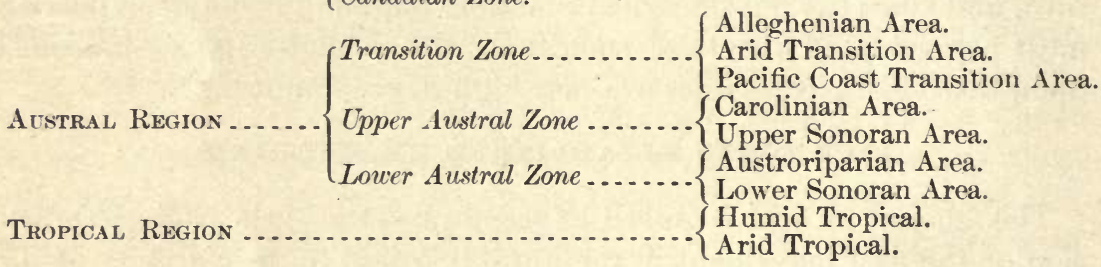

BOREAI, REGION.

This, as seen in the table, presents three belts or natural subdivisions.

ARCTIC OR ARCTIC-ALPINE ZONE.

This division, the first of the three, extends from the limit of tree growth to the polar lands. The greatest portion is covered with eternal snow and ice, and farther south it includes the summits of the mountains reaching above the line of arboreal growth, subject to the same conditions. This zone is recognized by some writers as the hyperboreal region, and as the realm of mosses and saxifrages.

HUDSONIAN ZONE.

The second, namely, the Hudsonian or subarctic zone, embraces the most northern part of the American forest. Its spruces, firs, and most of its birches and aspens extend from the shores of Labrador to Alaska. This zone is spoken of as the Northern Forest or Lacustrian Forest of the North.

CANADIAN ZONE.

This is the third subdivision, or the second of the northern belts of cone-bearing trees. In this zone pines, spruces, firs, and hemlocks outnumber the deciduous forest growth. In the southern and warmer parts of this belt the cultivation of the hardier cereals - oats, rye, barley-is possible, and potatoes and other root crops succeed. 
AUSTRAL REGION.

The great transcontinental Austral Region covers nearly the whole of the United States except northern New England, northern Michigan and Minnesota, and the higher mountains generally: It embraces three distinct life zones-Transition, Upper Austral, and Lower Austral.

TRANSITION ZONE.

This includes the vast forests of deciduous trees of the cooler temperate region of the continent. Here the outposts of the northern types meet those of a decidedly southern distribution. In its extension from east to west this zone presents three well-marked "areas," or floras.

Alleghenian Area.-The humid eastern division, the Alleghenian Area, extends from the coast of New England to the eastern border of the grassy plains west of the Mississippi River and pushes southward in a long arm along the heights of the Allegheny Mountains to Georgia and nearly to the border of Alabama. In its forests oaks, hickories, chestnuts, and locusts, with rhododendrons, azaleas, andromedas, and other shrubs of the heather family, mingle with the birches, aspens, mountain ash, ashes, the northern spruces, firs, hemlock, and pines, and other cone-bearing trees at home farther south. In addition to small grains, the indian corn (maize) is grown here; the potato, with a number of other root crops, is raised, and apples, pears, cherries, and plums, and a variety of berries and fruits of the orchard are common.

Central Continental Area.-This is the arid middle division of the Transition Zone, and comprises the dry plains and elevated table-lands extending from the eastern border of the former to the Cascade and Sierra Nevada mountains, and corresponds in part to the Central province of Gray and the northern prairies of other botanists.

Pacific Area.-This consists of the Pacific slope, west of these mountains, recognized by botanical writers as the Pacific floral region.

UPPER AUSTRAL ZONE.

This zone is naturally divided into a humid eastern and an arid western area or flora.

Carolinian Area.-The eastern division, or Carolinian area, comprises the lower part of the northern deciduous forest which covers the coast region south of New England; an interior portion of the Southern Atlantic States, including northern Georgia and the larger part of the upper half of Alabama; the basin of the Ohio River to the southern shores of Lake Michigan, and the great central valley of the Mississippi to near latitude $43^{\circ}$, finding its western limit between the ninetieth and ninety-fifth degrees of longitude. Here the tulip tree 
(Liriodendrom tulipifera), cueumber tree (Magnolia acuminata), persimmon (Diospyros viryiniana), sassafras (Sassafras sassafras), buckeye'(Aesculus spp.), sweet gum (Liquidambar styraciflua), the chestnut oak (Quercus acuminata), and Spanish oak (Quercus digitata) make their appearance. Chestnut (Castanea dentata) and black gum (Nyssa sylvatica) are common, and of cone-bearing trees the yellow pine (Pinus echinata) and scrub pine $(P$. virginiana) are met with. In this division the cultivation of Indian corn exceeds that of small grain. Sorghum and the sugar beet are successfully grown. The cultivation of the grape and peach adds to the variety of the fruits, as also in the corresponding division of the preceding zone.

The Upper Somoran Area.- This, the arid western division of the Upper Austral life zone, extends from the vaguely defined limits of the last division over the great western plains; beyond the Rocky Mountains it covers much of the great basin and parts of California.

LOWER AUSTRAL ZONE.

The Lower Austral zone, like the Upper Austral, is divided into a humid eastern and an arid western area.

Austroriparian Area or Louisianian Flora.-This consists of the eastern or humid division of the Lower Austral zone, and embraces in its southern reach the subtropical belt of North America. Beginning with a narrow strip of the Atlantic coast near the southern shores of Chesapeake Bay, this area covers the coastal plain of the Southern Atlantic States nearly to the southern extremity of Florida and the Gulf States to the center of Texas and the southern section of Indian Territory, finding its western limit between longitude $90^{\circ}$ and $95^{\circ}$. It follows the lowlands of the Mississippi River toward its junction with the Ohio. This Louisianian flora has been designated as the realm of the magnolia, southern pine, and dwarf palmetto. The greatest part of the arable land is devoted to the cultivation of cotton. Rice and sugar cane, particularly in the lower part of this division, contribute to home demands and furnish staple prodncts for export. The subtropical cowpea takes the place of clover for forage and as ameliorating crop. The sweet potato is the chief root crop, and corn is the only grain crop cultivated for breadstuff. Peaches and grapes are successfully grown, and in the lower belt the loquat or Japanese medlar, while in proximity to the Gulf the orange ripens its fruit.

Lower Somoran Area.-This flora, consisting of the western and arid extension of the Lower Austral zone, extends from the plains of western Texas to the Pacific Ocean. It is generally recognized as the cactus region, or the Mexico-Californian region. 
TROPICAL REGION.

This zone embraces in eastern North America a narrow belt along the coasts of the southern extremity of peninsular Florida and the surrounding keys, and contains part of the West Indian or Antillean flora.

\section{SECONDARY FACTORS INFLUENCING PLANT DISTRIBUTION.}

Besides the primary factors, heat, light, and atmospheric moisture, which regulate the distribution of life within the wide areas recognized as life zones, there are others which exercise a potent influence upon the distribution of plants in confining them to narrower boundaries. The former are due to geographical position, latitude and longitude, extent of land area, presence and position of mountain chains, and prevailing winds and oceanic currents, while the latter are dependent on minor local conditions, such as altitude, topography, proximity to large bodies of water, all of which influence the lesser fluctuations of temperature, precipitation, occurrence of frosts or other extremes, secondary currents of the air, and exposure to sunlight. In addition to these and of equal importance are the stratigraphical relations determining the chemical and physical character of the soil and subsoil, as well as the drainage of the surface and the soil beneath, which in itself must be considered as one of the most important of the secondary factors influencing distribution.

To this class of factors belong also the facilities possessed by different species for dissemination. These consist chiefly of biological agencies, special adaptations with which the fruits and seeds of many species are provided, to secure their dispersion. This is effected in various ways, particularly through the agency of animals. One means consists of fleshy, sweetish fruits tempting animals to feed upon them. In most instances the seeds are discharged with their vital power unimpaired and thus are transferred to distant localities, particularly when the fruit has served as food for birds. A second means consists of the prickles, hooks, or stiff, hooked hairs covering the surface of the hard fruits, by which they attach themselves to wandering animals.

Distribution of seeds is also effected. by atmospheric agency, the fruits or seeds being very minute or provided with broad, wing-like, or plumose attachments, which enable them to be wafted through the air. In some cases the sudden tearing asunder of the parts of the fully-matured hard fruit when touched causes the scattering of the seeds. Finally, some seeds are disseminated through their ability to float about in fresh or saline water without losing the power of germination. ${ }^{1}$

${ }^{1}$ O. Drude, Handbuch der Pflanzengeographie, 121 (1890). 
The opportunities for the dispersion of species by these means are more or less diminished by intervening extensive water and desert areas or high mountain ranges.

These primary and secondary factors, in their ever-varying combinations, are the conditions by which the various associations of species and their restriction within specific areas of greater or less extent are determined. Such areas constitute the floral regions; and the systematic relationship of the different species, their numerical proportions, and their various assemblages impart to each region its fioral character.

Suitable environment, that is, a proper combination of conditions of moisture, sufficient room and light, proper exposure, ete., determines the place in which a plant finds all the requirements for its existence met, that is, its habitat.

The conditions which outline its habitat, in combination with the greater factors of latitude, altitude, rainfall, etc., determine the distribution of plants over wider areas, in which the particular plant (species) may find few or many suitable localities, which areas constitute its range. Within this range the plant may be found in few or many places, isolated or gregarious, but outside of this range it does not occur.

\section{DISTRIBUTION OF SPECIES AS DEPENDING UPON GEOLOGICAL HISTORY.}

The distribution of plants can not always be explained on the ground of their dependence upon the atmospheric and terrestrial factors. The differences in climatic eonditions become too insignificant to explain the confinement of many species within extremely narrow limits, and at the same time topographic and other conditions of environment offer no satisfactory account. Premising the theory that the existing plants are the descendants of similar types which flourished in past periods of the history of our globe, in most instances an explanation is easily found on geological grounds. Viewed in this light, the occurrence of the hemlock (Tsuga canadensis), for example, with its northern companion, the sweet bireh, on the extreme southern extension of the Allegheny Mountains, in Winston County, Ala., in a completely isolated spot hundreds of miles distant from the range of its distribution, can be accounted for when they are regarded as the sole remnants of the northern arboreal flora which during the glacial period was pushed to lower latitudes and which on its recession, to cooler zones left these trees behind in the narrow valley of the Sipsey River, where at present the former shades the cliff-bound banks. The Torreya (Tumion taxifolium) and the Florida yew (Taxus floridana) of the valley of the Apalachicola River in western Florida, the American smoketree or chittamwond (Cotinus cotinoides) in its isolated localities in north Alabama and southwestern Missouri, and 
the Leitneria (L. Aloridana) in the latter locality and the swamps of the estuary of the Apalachicola River present similar striking instances of a strange localization, in some cases within an extremely limited range. The relation of these woody plants to the flora of a preceding geological period, of which the present is the progeny, is clearly proved by the remains of almost identical types found buried in the strata of the Middle Tertiary formation of southern Europe and the Rocky Mountains. If we regard these plants as the slightly modified descendants of types belonging to an ancient flora, which have survived the changes our globe has undergone and have found a refuge in their present localities, the mystery of their strange isolation finds a satisfactory solution. The confinement to a single spot on the Warrior of Neviusia alabamensis, with its nearest relation in Japan, and of Croton alabamensis to a secluded valley of Little Cahaba River, can be accounted for on the same ground.

\section{PLANT FORMATIONS AND PLANT ASSOCIATIONS.}

The same causes to which the restriction of a plant within a floral region is due, give rise to the grouping of species widely differing in their natural affinities but equally adapted to accommodate themselves to the same conditions. Such assemblages, forming groups of a definite character, are by the later writers on plant geography recognized as plant formations (Grisebach, Drude); or, with respect to their conditions of life, their ecological relations as plant associations by Warming. ${ }^{1}$ The former authors define a plant formation as a group of plants of a definite physiognomic character, such as a forest, a grassy swamp, the vegetation of a dune of the seashore. The group may be composed either of only one species, as the forests of long-leaf pine or the Southern canebrakes, or characterized by the predominance of species of the same family or allied families, as most coniferous forests and our forests of oaks and hickories, or composed of an aggregate of species of various affinities with some of their features in common, as is the case with most forests and prairies. These plant formations impress upon a flora its physiognomy, as was long ago noticed by Humboldt. The following plant formations, recognized by Engler and Drude, ${ }^{2}$ will be referred to in considering the distribution of plant life in Alabama:

1. Open plant formations, more or less interrupted, inhabiting-

a. The strand or beach.

b. The sands of seashore, hill, and plain.

c. Rocks and pebbles.

${ }^{1}$ Warming, Oekologische Pflanzengeographie, 1896.

${ }^{2}$ Engler und Drude, Die Vegetation der Erde: I, Pflanzenverbreitung auf der Iberischen Halbinsel, M. Willkomm, p. VII. 1896. 
2. Compact or continuous plant formations of a uniform type, consisting-

d. Of mosses or lichens.

$e$. Of cespitose grasses (meadows, grassy swales).

$f$. Of various herbs (prairies, pastures).

g. Of gregarious suffrutescent plants or low undershrubs.

$h$. Of gregarious larger, woody plants branched from the base (thickets).

$i$. Of arboreal vegetation (open and dense high forest).

$k$. Of paludial plants (riparian swamps, marshes, and bogs).

l. Of immersed aquatics, floating free or rooted in the soil.

Considering these natural groups or plant formations in their biological aspect and investigating the mutual relationship between the plant and the place where it lives (habitat), Warming finds that the properties by which a plant is able to adapt itself to the influence of the various factors to which it is exposed and to hold its own in competition with its associates are, deeply founded in peculiarities of anatomical structure as well as in the morphological development of its organs and the resulting physiological functions. The presence or absence of a type in any given plant formation finds its explanation in these peculiar modifications of its organism by which its mode of life is regulated, as well as in the ecological relations existing between its own life and the life of its associates.

On these principles Warming has proposed a new classification of the plant covering of the globe, recognizing four principal groups of associations based on ecological relations, namely:

(1) Hydrophytic vegetation, forming the associations of plants surrounded entirely or partially by water or growing in a constantly water-soaked soil.

(2) Xerophytic vegetation, forming the associations of plants confined to an arid soil and a dry atmosphere.

(3) Halophytic vegetation, making up plant associations restricted to a saline soil, wet or dry.

(4) Mesophytic vegetation, including the general vegetation preferring a soil and an air of medium humidity.

Of the various plant associations met with in Alabama, those composed chiefly of vascular plants will be more thoroughly discussed under this classification of Warming.

It is self-evident that there exist many intermediate forms between these groups, and these often render it extremely difficult to assign a certain plant association to a place in one or other of the above groups or classes.

Within each of these four principal groups the vegetation is composed of typical forms of plant life, distinguished as trees, shrubs, 
undershrubs (including the low perennials with a woody stem and branchlets partially dying at the close of the season of growth) and perennial, biennial, and annual herbs.

\section{HYDROPHYTIC PLANT ASSOCIATIONS.}

Of the associations of this group the following are recognized in the Alabama flora, consisting of plants: $(a)$ Floating free in water either on the surface or submerged; for example, the water fern (Azolla), duckweeds (Lemna, Spirodela), bladderworts (Utricularia), hornweed (Ceratophyllum), etc.; (b) connected with the soil, rooting either on rocks, as Podostemon, many fresh-water algæ, and some mosses (Lithophile associations), or in the loose soil, as the pondweeds (Potamogeton), ditch weed (Ruppia), eelgrass (Vallisneria), and of the higher cryptogams Nitella.

(c) Immersed only at their base and rooting in the slightly submerged or swampy soil, forming associations of paludial plants, as the vegetation of the grassy marshes and of bogs, and the shrubs and trees covering the alluvial swamps; for example, cypress swamps.

\section{XEROPHYTIC PLANT ASSOCIATIONS.}

These consist of the vegetation of the dry, exposed, drifting sands of the seashore and of dunes, and the woody vegetation of loose sands (Psammophile associations); also of the vegetation of dry prairies ("bald prairies"), and of the forests of the dry uplands, either of evergreen cone-bearing trees (pine barrens) or deciduous trees.

\section{HALOPHYTIC PLANT ASSOCIATIONS.}

These are composed mostly of aquatic plants, inhabiting the beach and saline marshes of the seashore.

\section{MESOPHYTIC PLANT ASSOCIATIONS.}

These embrace the plant associations confined to a soil and atmosphere of moderate humidity, as grassy swales, canebrakes, the arboreal vegetation of the subtropical forests of broad-leaved evergreen trees and shrubs, and the deciduous forest of the lowland with a fresh soil rich in humus, never or infrequently overflowed.

\section{GENERAL CHARACTER OF THE ALABAMA FLORA.}

The flora of Alabama stands in the number of species and varietal forms, as well as in the diversity of their characteristic associations, unsurpassed among those of adjoining regions. This wealth and variety of Alabama's plant life is easily explained when, on the one hand, its area is considered, extending over nearly 5 degrees of latitude, and on the other, the diversity of its topographical features, varying from the 
abrupt mountain ranges, with their broad table-lands, wide valleys, and rugged hills in the northern half of the State to the fertile Cretaceous plain in its center; and farther south, to the pine-clad hills and rolling uplands merging into the coast plain with its open and forest-covered swamps, and the sands and saline marshes of the seashore. The number of distinct species and varieties known can undoubtedly be increased, since thorough botanical investigation has been attempted by but a few. The closer exploration of any of its regions is sure to reward the botanist in bringing forms to light which have never been observed in the State, if indeed not new to science.

\section{SYSTEMATIC RELATIONS.}

The list of vascular plants growing without eultivation in Alabama, as given in this volume, numbers between 2,500 and 2,550 recognized distinct forms (species and varieties), including all the introduced, adventive, and fugitive forms. Of this number, 59 are spore-bearing plants-Pteridophyta. Of the seed-bearing plants-Spermatophyta12 species belong to the Gymnosperms, their ovules destitute of an inclosing ovary; the remainder to the Angiosperms, their seeds within an ovary. Of the latter, 707 distinct forms belong to the Monocotyledons, the division consisting of plants with the embyro of the seed bearing but a single cotyledon or seed leaf, and a little over 1,700 species and varieties belong to the Dicotyledons, comprising the angiosperms, with an embryo bearing two opposite cotyledonary leaves.

Among the families of the above divisions most prominent by number of species the Compositae ${ }^{1}$ (goldenrods, asters, sunflowers, hawkweeds, etc.) take the first place with 303 species, followed by the Poaceae with 289, Cyperaceae with 140, Leguminosae ${ }^{2}$ with 116 , Nepetaceae with 60 , Scrophulariaceae with 59, Rosaceae, including the plum and the apple tribe, with 54 . Of the families less prominent in number of species the Apiaceae have 46 species; Ranunculaceae, 43; Euphorbiaceae, 41; Orchidaceae, 40; Polygonaceae, 38; Liliaceae, ${ }^{3}$ 36; Alsinaceae, 33; Polypodiaceae, 43; Malvaceae, 26; Onagraceae, 25; Fagaceae (chestnuts, oaks), 26; and Ericaceae, ${ }^{3} 21$ species.

Among the genera excelling in number of species, Panicum stands first, with 71, Carex has fully 60, Aster 38, Cyperus 35, Rynchospora 31, Solidago 25, Eupatorium 25, Quercus 23, Paspalum 20, and Hypericum 20 species and varieties.

\section{ENDEMIC PLANTS.}

The number of plants endemic to Alabama is small, but suggestive. Only the following types are exclusively found within the limits of

${ }^{1}$ Carduaceae and Cichoriaceae.

${ }^{2}$ Mimosaceae, Caesalpinaceae, Viciaceae.

${ }^{3}$ Here used in the broader sense. 
the State: Neviusia alabamensis, Croton alabamensis, and Trichomanes petersii. This poverty in endemic forms is easily explained by the absence of any serious obstacles to plant migration from and to all parts of the eastern section of this continent. The gradual descent of the Allegheny Mountains to the Coastal plain rendered the influx of plants from the north and east easy. The oldest types flourishing on the most ancient strata succumbed gradually to the vicissitudes of eons of time and gave way to later invaders. Completely open on the east and the west, the denizens of the plant world from these directions found no hindrance in peopling the new soils of the secondary (Mesozoic and Cenozoic) formations', after their rise above the water.

RELATIONSHIP OF THE ALABAMA FLORA TO THAT OF ADJOINING REGIONS.

It results from these conditions that the plant-covering of the State coincides closely with the flora of the adjoining regions. In its southern portion it is very intimately related to the flora of western Florida, Mississippi, and eastern Louisiana, equally so to that of the maritime plain of North and South Carolina and Georgia, and in a less degree to that of western Louisiana and eastern Texas. In its central parts the same close connection exists with the flora of the middle region (Piedmont region) of these States and with that of southern Arkansas. The flora of the northern part of the State, with its mountains and the Tennessee Valley, presents a similar relationship with the flora of the Allegheny ranges south of the Potomac River, below an elevation of 2,000 or 2,500 feet above sea level, and with that of the southern extension of the Cumberland Mountains and the rim of the Highlands of Tennessee.

RELATIONSHIP OF THE ALABAMA FLORA TO FOREIGN FLORAS. ${ }^{1}$

EASTERN ASIA.

Asa Gray first directed attention to the intimate relationship existing between the flora of eastern North America and that of eastern Asia, particularly that of Japan. ${ }^{2}$ The eastern Asiatic element is in this part of our continent most pronounced southward. It is here most strikingly manifest in the arboreal and shrubby vegetation of the numerous genera of the catkin-bearing families, such as walnut, chestnut, oak, beech, hazlenut, ironwood, hornbeam (Ostrya), willow, wax myrtle; and of the coniferous family, such as pine, hemlock, cypress (Chamaecyparis), savin (Juniperus); to which are added elm, mulberry, linden, pear, plum, service trees (Amelanchier), maple, witch

${ }^{1}$ In this discussion the introduced and immigrated plants occurring in Alabama and the genera represented only by cosmopolitan species inhabiting the temperate and warmer regions all over the globe are disregarded.

${ }^{2}$ Asa Gray, Memoirs N. Y. Acad., vol. 6, part 1. 1859. 
hazel, sumac (Rhus), and ash, all of which are widely diffused throughout the temperate zones of eastern North America and in eastern Asia, a small number extending westward to the Altai Mountains and Himalayan India. The number of arboreal and frutescent genera is still further increased by those chiefly confined to the southeastern section of our continent, such as Magnolia and Illicium of the magnolia family; Persea and Benzoin of the laurel family; roses, honey locust, storax bushes, catalpa trees, and devil wood or American olive, of different families.

On closer comparison of the flora of Alabama with that of eastern Asia and principally of Japan, it is found that about 160 genera or nearly 26 per cent of the genera indigenous in Alabama, belonging to 66 families, have their representatives in eastern Asia. Besides the above common genera there occur others in those parts which in their essential characters differ but slightly from the nearest allies found in Alabama, forming with them such pairs as Glaucidium and Hydrastis, Sphaerostemon and Schizandra, Stephanandra and Neviusia, Corylopsis and Fothergilla, Paris and Modiola, Scilla and Quamasia, Roxburghia and Croomia, and some others.

The number of types indigenous to Alabama which are identical with species found in eastern Asia is small, amounting scarcely to forty. Though this number by itself considered is insignificant, it must be viewed together with the fact that every one of the genera common to Alabama and eastern Asia is represented in the latter region by one or several species closely allied to the forms found in Alabama, so closely in not a few cases,as to be difficult to separate.

The relation of these two floras is expressed in the following table:

Genera common to the flora of eastern Asia and that of Alabama.

\begin{tabular}{|c|c|c|c|}
\hline Classification. & $\begin{array}{c}\text { Number } \\
\text { of } \\
\text { genera. }\end{array}$ & Clussification. & $\begin{array}{l}\text { Number } \\
\text { of } \\
\text { genera. }\end{array}$ \\
\hline Pteridophyta: & & Dicotyledoneae: & \\
\hline $\begin{array}{l}\text { Filices } 1 . . . . . . . \\
\text { Ophioglossacea }\end{array}$ & $\begin{array}{l}6 \\
1\end{array}$ & $\begin{array}{r}\text { Archlchlamydeae- } \\
\text { Leguminosae } 2 . .\end{array}$ & \\
\hline Lycopodiaceae.............. & 1 & Ranunculaceae ................ & \\
\hline Total. & 8 & Apiaceae ..... & \\
\hline Gymn & & Betula & \\
\hline Pinoid & 2 & e........... & \\
\hline Cupres & 2 & Euphorbiaceae............ & \\
\hline Total & 4 & Nympha & \\
\hline & & Aristolochiaceae & \\
\hline $\begin{array}{c}\text { Monocotyledoneae: } \\
\text { Liliaceae } 2\end{array}$ & & Ulmaceae $\ldots \ldots \ldots \ldots \ldots \ldots \ldots$ & \\
\hline ............. & 6 & 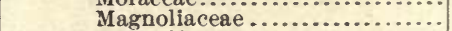 & 2 \\
\hline Cyp & 4 & Berberidaceae................... & \\
\hline & 3 & Fumariaceae...$\ldots \ldots \ldots \ldots \ldots \ldots$ & \\
\hline Pog & 2 & Rhamnaceae .................. & \\
\hline & 1 & e..................... & \\
\hline Alísmaceae .... & 1 & Juglandaceae $\ldots \ldots \ldots \ldots \ldots \ldots$ & \\
\hline Dioscoreaceac...................... & 1 & Salicaceae $\ldots \ldots \ldots \ldots \ldots \ldots \ldots$ & \\
\hline 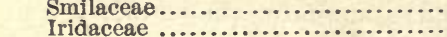 & 1 & 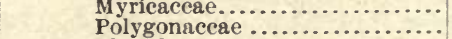 & \\
\hline & & & \\
\hline & & 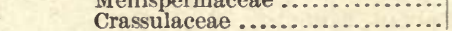 & \\
\hline
\end{tabular}

1 Including Polypodiacene, Hymenophyllaceae, and Osmundaceae. 2 Here used in the broader sense. 
Genera common to the flora of eastern Asia and that of Alabama-Continued.

\begin{tabular}{|c|c|c|c|}
\hline Classification. & $\begin{array}{c}\text { Number } \\
\text { of } \\
\text { genera. }\end{array}$ & Classification. & $\begin{array}{l}\text { Number } \\
\text { of } \\
\text { genera. }\end{array}$ \\
\hline 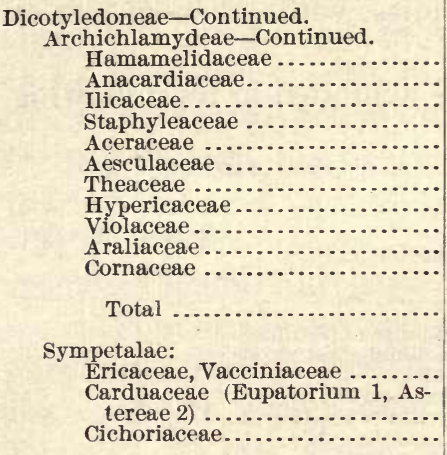 & $\begin{array}{l}1 \\
1 \\
1 \\
1 \\
1 \\
1 \\
1 \\
1 \\
1 \\
1 \\
1 \\
83\end{array}$ & 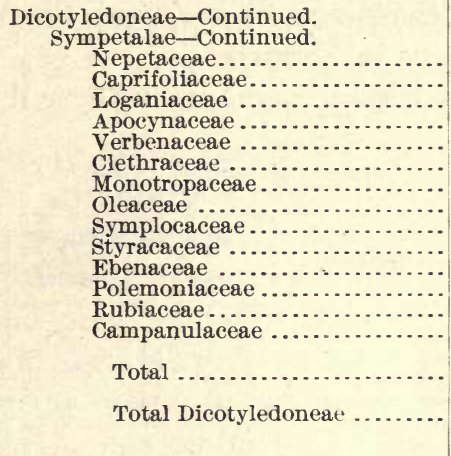 & $\begin{array}{l}4 \\
3 \\
2 \\
2 \\
2 \\
1 \\
1 \\
1 \\
1 \\
1 \\
1 \\
1 \\
1 \\
1\end{array}$ \\
\hline
\end{tabular}

WEST INDIES, MEXICO, SOUTH AMERICA.

Not less than 290 genera containing nearly 40 per cent of the plants indigenous to the Alabama flora are represented in the West Indian Islands, Mexico, Central America, and more rarely in South America as far south as Argentina. On the western coast of the continent but a few genera occur which have also their home with us. The number stated above is comprised within 22 families. About 140 species are common to Central America, Mexico, and the West Indian Islands. This relationship is most evident between the flora of that part of the State embraced within the Austroriparian area and the flora of the more elevated regions of tropical America with climatic conditions somewhat similar to those prevailing in southeastern North America. The flora of the subtropical regions of Alabama exhibits faintly the features of the vegetation of the neighboring tropics by the presence of a few genera of the epiphytal plant formation (Tillandsia, Epidendron, Polypodium), which in the abundance and variety of its forms constitutes one of the most striking characteristics of the tropical vegetable world. A scarcely stronger suggestion of tropical character in our flora is afforded in its arboreal vegetation by the presence of our dwarf palmettos (Sabal, Serenoa) with their short or prostrate trunks. Our deciduous-leaved trees are represented by 10 genera common to both regions, 2 species of oak (Quercus virginiana, Q. breviloba) and 2 of hickory (Hicoria pecan, H. myristicaeformis) being common to Alabama and the plains of northern Mexico near the Texan frontier. Our wax myrtle, hop hornbeam, mulberry, elm, box elder, haw, and sweet gum occur in the elevated regions of the eastern declivity of the Mexican Andes. Our evergreen magnolia is in the same region 
represented by the closely related genus Talauma. Of coniferous trees pines are abundant in the higher mountains of Mexico and Central America. Our slash pine, or Cuban pine, extends from the West Indian Islands to Honduras; Taxodium inhabits Mexico, and savin (Juniperus barbadensis) the West Indies, with other species of Juniperus in Mexico.

The common elements in these floras are exhibited in the following table:

Genera and species common to Alabama and tropical America.

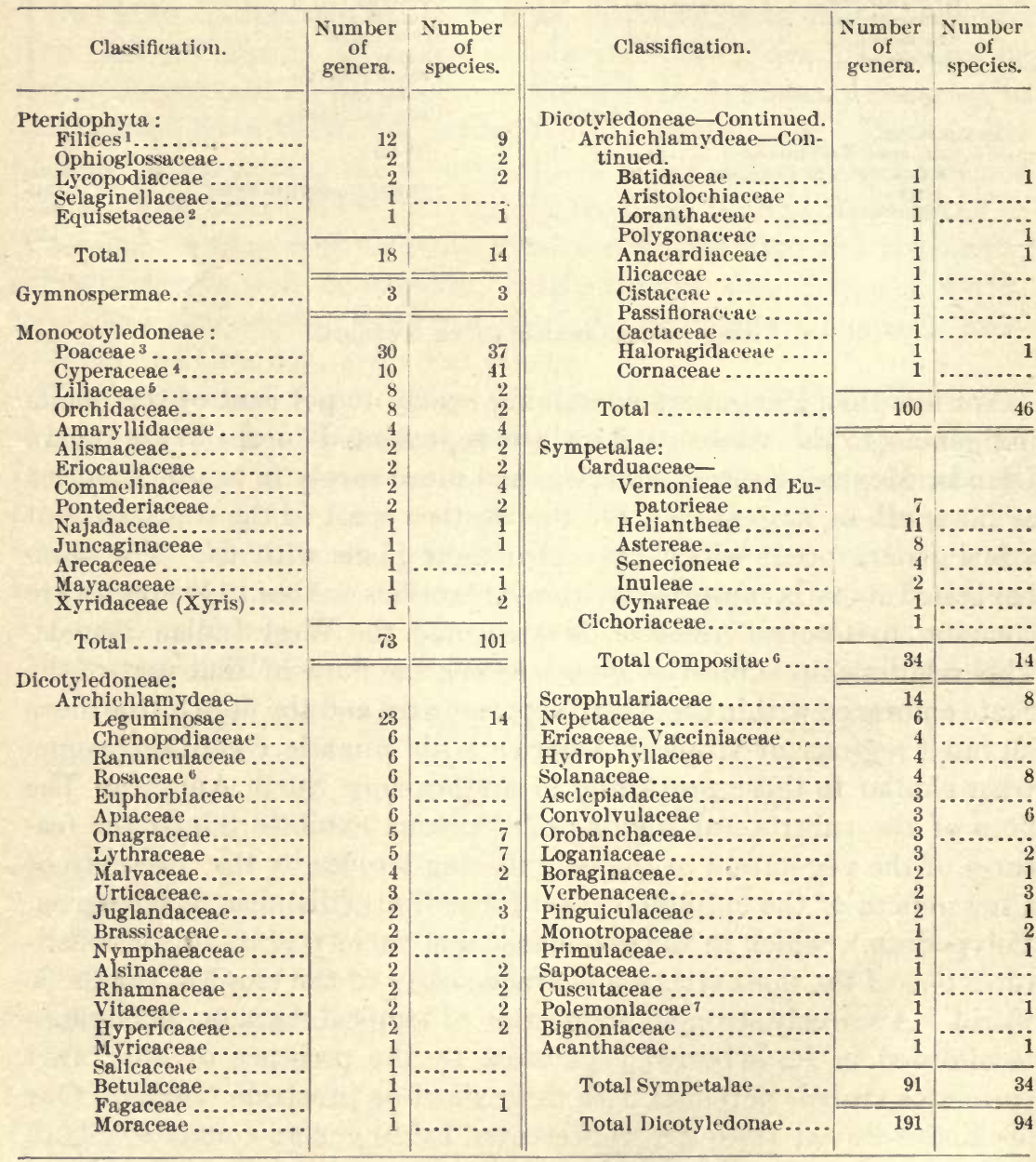

1 Including Polypodiaceae, Hymenophyllaceae, and Osmundacere.

2 Equisetum robustum.

${ }^{3}$ Chiefly Paniceae (Panicum, Paspalum) and Andropogoneae; all widely diffused from the West Indies to Argentina.

${ }_{4}^{4}$ Mostly of the genera Cyperus, Eleocharis, Scleria, and Rynchospora, 10 species of the last 2 genera being not met with, outside of the West Indies, in tropical America.

5 Here used in the broader sense. The species belong to Yucea and other genera, mostly Melanthioideae.

${ }^{6}$ Here used in the broader sense.

7 Phlox. 
EUROPE AND THE MEDITERRANEAN REGION.

The relationship between the flora of Alabama and that of Europe and the parts of Asia and Africa bordering upon the Mediterranean Sea is indicated by their having in common about 100 families with about 230 genera, this being nearly 35 per cent of the genera indigenous to Alabama, with 55 species which occur in Alabama and also in western Europe and in the Mediterranean region, chiefly the former. Of the arboreal plant formation nearly all of our deciduous catkinbearing trees and most of the shrubs are represented by closely allied species in those regions. Some of these genera are represented far to the north in the European-Asiatic forest belt, such as willow, cottonwood (Populus), birch and alder, and pine, while walnut, beech, oak, hornbeam, hazelnut, ash, maple, plum and cherry, pear and apple, and the savin are widely diffused over the more temperate regions of Europe. In the Mediterranean region our white cedar (Chamaecyparis) firds itself represented in the cypress (Cupressus), from which it differs by a mere technical character, and Celtis (hackberry), Cercis, and Storax are represented in the same region. It is a remarkable fact that in no one of these genera is the European species identical with that found in Alabama. The ferns and allied families are represented by 4 families with 12 genera; of these 7 belong to the ferns proper with 5 identical species, 2 to the Ophioglossaceae, 1 to the Lycopodiaceae, 1 to the Selaginellaceae, and 1 to the Equisetaceae.

The following table exhibits the relation of these two floras:

Genera and species common to Alabama and Europe, with Mediterranean Asia and Africa.

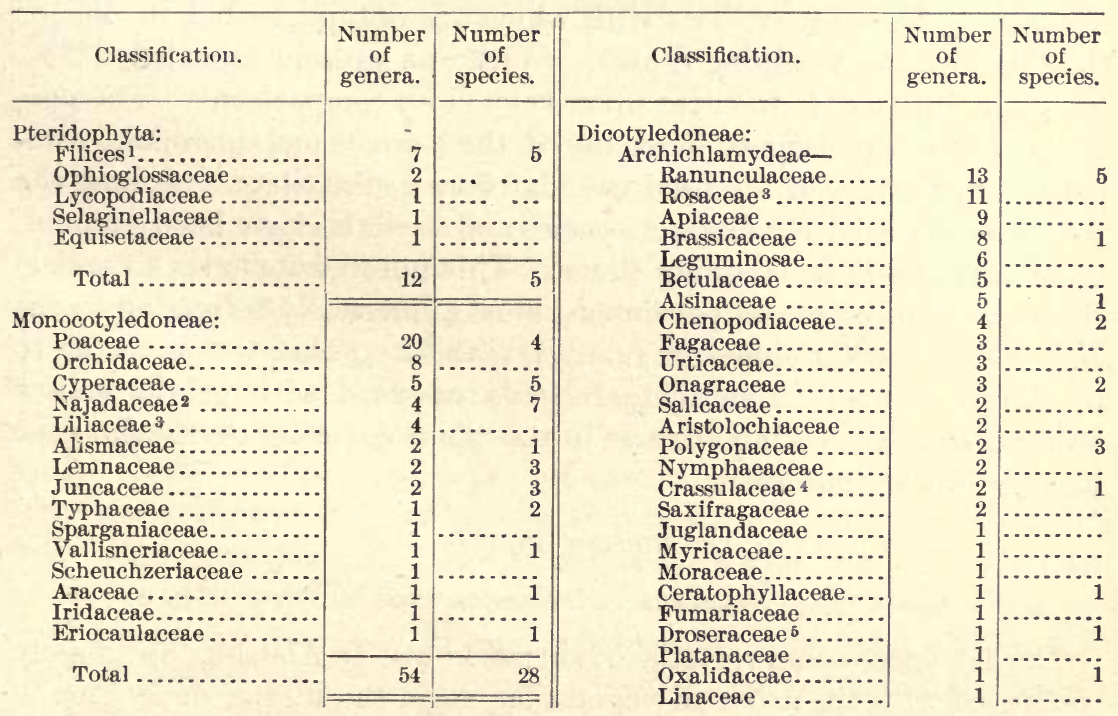

1 Including Polypodiaceae, Hymenophyllaceae, and Osmundaceae.

2 Including Potamogeton, 5 species.

${ }^{3}$ Here used in the broader sense. 4 Tillaea.

6 Drosera. 
Genera and species common to Alabama and Europe, elc.-Continued.

\begin{tabular}{|c|c|c|c|c|c|}
\hline Classification. & $\begin{array}{c}\text { Number } \\
\text { of } \\
\text { genera. }\end{array}$ & $\begin{array}{l}\text { Number } \\
\text { of } \\
\text { species. }\end{array}$ & Classification. & $\begin{array}{l}\text { Number } \\
\text { of } \\
\text { genera. }\end{array}$ & $\begin{array}{l}\text { Number } \\
\text { of } \\
\text { species. }\end{array}$ \\
\hline $\begin{array}{l}\text { Dicotyledoneae-Continued. } \\
\text { Archichlamydeae-Con- } \\
\text { tinued. }\end{array}$ & & & $\begin{array}{l}\text { Dicotyledoneae-Continued. } \\
\text { Sympetalae-Continued. }\end{array}$ & & \\
\hline Geraniaceae......... & 1 & & Scrophulariaceae.... & $\begin{array}{l}4 \\
4\end{array}$ & \\
\hline Polyg & 1 & & Solanaceae... & 4 & 1 \\
\hline Euph & 1 & & laceae.. & 3 & 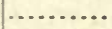 \\
\hline $\begin{array}{l}\text { Callitrichaceae ....... } \\
\text { Anacardiaceae }^{1} . . .\end{array}$ & 1 & & $\begin{array}{l}\text { Caprifoliaceae... } \\
\text { Ericaceae }\end{array}$ & $\begin{array}{l}3 \\
2\end{array}$ & $\cdots$ \\
\hline Ilicaceae ............. & 1. & & Monotropaceae...... & 1 & \\
\hline Staphyleaceae & i & $\ldots$ & Plumbaginaceae .... & 1 & \\
\hline Ace & 1 & ... & Styracaceae $4 . . . \ldots$ & 1 & .... \\
\hline e........ & 1 & $\ldots$ & oleaceae $^{5}$ & 1 & $\ldots$ \\
\hline Vita & 1 & …..... & ceae........ & 1 & .... \\
\hline Tilis & 1 & -.... & Asclepiadaceae...... & & \\
\hline Malva & 1 & ........... & Gentianaceae ....... & 1 & ..... \\
\hline $\begin{array}{l}\text { Cistaceae }^{3} \text {............... } \\
\text { Violacene }\end{array}$ & 1 & (n........ & Polemoniaceae....... & 1 & (.......... \\
\hline Lythraceae... & 1 & (n) & $\begin{array}{l}\text { Convolvulaceae...... } \\
\text { Cuscutaceae........ }\end{array}$ & 1 & (n........ \\
\hline gidaceae ... & 1 & . $\ldots \ldots \ldots$ & Verbenaceae ........ & 1 & ......... \\
\hline Araliaceae... & 1 & (........... & Plantaginaceae. & 1 & ........ \\
\hline \multirow{2}{*}{ Total } & 1 & & $\begin{array}{l}\text { Orobanchaceae } 6 . . . . \\
\text { Rubiaceae }^{7} . . . . .\end{array}$ & & \\
\hline & 109 & 19 & Valerianaceae.. & 1 & $\cdots \cdots$ \\
\hline \multirow{2}{*}{$\begin{array}{l}\text { Sympetalae: } \\
\text { Compositae. } \\
\text { Nepetaceae. }\end{array}$} & \multirow{2}{*}{$\begin{array}{r}12 \\
7\end{array}$} & & \multirow{2}{*}{$\begin{array}{r}\text { Total ............. } \\
\text { Total Dicotyledones......... }\end{array}$} & 53 & 3 \\
\hline & & ...... & & 162 & 22 \\
\hline
\end{tabular}

1 Cotinus in the Mediterranean region.

2 Hibiscus of the Mediterranean region.

3 Southern and western Europe.

4 Storax of the Mediterranean region.
5 Fraxinus.

${ }^{6}$ Orobanche and Phelypaea differ but slightly from our Thalesia (A phyllon).

7 Galium.

\section{BIOLOGICAL AND ECOLOGICAL RELATIONS.}

Viewing the plants of Alabama in their biological aspect, their habits of life, and the peculiar adaptations by which they establish and maintain themselves successfully among their various associations, no striking features are met with which are not presented in one or the other of the adjoining States. With our present knowledge it is, however, impossible to enter upon very close comparisons. The perennial plants are largely in excess of the annuals and biennials, comprising five-sixths of the total vascular flora of the State. Among the woody perennials, 343 distinct species and varieties have been counted, 32 with climbing or creeping stems. This number includes 45 undershrubs and suffrutescent perennials, most numerously belonging to the Hypericaceae (St. Johnswort family), with 12 species, which, owing to the large number of individuals gaily adorned with bright yellow flowers, form a striking feature in the plant covering of the flat pine barrens in the coast plain.

\section{FOREST FLORA.}

SHRUBBI PLANT ASSOCIATIONS.

The 171 species and varieties of shrubs known in Alabama, intimately connected with the arboreal vegetation, form the higher undergrowth and the brushy cover of the soil of the mixed forests in the southern 
part and prevail in the openings and along the borders of the deciduous forests in the northern half of the State. Twenty-four species of the woody plants are of the liana form, stout climbers, which ascend the highest trees, nearly half of their number belonging to the grape family. Outside of the forest the shrubs rarely aggregate into an independent "bush" formation of such extent as to make an impression upon the physiognomy of the vegetation and to form a proper plant association. In the coast region, however, the following species form to a limited extent thickets more or less free from larger trees:

Myrica cerifera (wax myrtle).

Myrica inodora (wax myrtle).

Ilex cassine (dahoon holly).

Ilex vomitoria (yaupon holly).

Osmanthus americanus (American olive).

Illicium floridanum (sweet illicium).

Symplocos tinctoria (horse sugar).
Rhododendron spp. (azalea).

Pieris nitida (andromeda).

Leucothöe axillaris (andromeda).

Kalmia latifolia (mountain laurel).

Vaccinium and Gaylussacia spp. (huckleberry, whortleberry).

Vaccinium arboreum (farkle berry).

Bosquets of groundsels (Baccharis halimifolia), with marsh elder (Iva frutescens), dot here and there the salt marshes of the seashore. The arborescent grasses of the bamboo tribe, the so-called cane, represented in eastern North America by Arundinaria macrosperma and A. tecta, form by their spread over wide areas a most peculiar and prominent feature in the vegetation of the State, known as canebrakes. The big cane, attaining not rarely a height of from 20 to 30 feet, occupies the more or less overflowed alluvial river banks. The so-called reed or switch cane, of smaller size, forms the impenetrable undergrowth of the forests of the humid and fresh soil depressions, and is most prevalent in the Cretaceous plain, designated as the canebrake region.

ARBOREAL PLANT ASSOCIATIONS.

As in most parts of eastern North America, forests constitute in Alabama the most extensive and predominating of plant formations. Under the influence of the mild climate of relatively low latitudes with an abundant rainfall evenly distributed throughout the year, conditions most favorable to tree growth, Alabama presents the aspect of a richly wooded country. From the mountain heights and valleys of the north to the shores of the Gulf the State is clad in a robe of forests scarcely surpassed in the diversity of their tree growth and timber wealth by those of any other part of eastern North America. Originally the tree covering was almost uninterrupted. It can safely be assumed that at present over 50 per cent of the area of the State remains under cover of the original forest growth, although more or less invaded by the ax in the more accessible localities. Of the 172 arboreal species recorded as growing without cultivation in the State, 15 are introductions from the warmer temperate and tropical regions, mostly of the Old World, and 3 from the States of the Southwest. 
Deciduous forests.-Deciduous-leaved forests prevail principally in the northern part of the State. They are marked by the same variety of forms and the same great abundance of eatikin-bearing or nut-bearing trees (amentaceous orders) which are characteristic of the forests of the lower Allegheny ranges as far north as southern New England and the lower Ohio Valley, with their walnuts, hickories, oaks, hornbeams, beech, cottonwoods, elms, tulip and cucumber trees of the magnolia family, cherries, plums, haws, and service berries.

Oi the 43 species of amentaceous and other apetalous trees known to occur in the State 39 are common also to the regions just mentioned. Of the 23 oaks occurring in Alabama, 10 are found in the more northern forests; of the 8 Magnoliaceae, 5; of the 8 plums and cherries, 4 ; of the 20 or more species belonging to the apple tribe, mostly haws, 7 ; of the 5 maples, 4 ; of the 4 elms, 3 , and all of the 6 species of ash.

In the mesophile forests, covering the valleys and terraces of a rich, moderately humid soil, oaks predominate, but many other genera are present. The following list exhibits the characteristic trees, all of which, except Magnolia acuminata cordata, extend north of the Ohio River:

Quercus alba (white oak).

Quercus minor (post oak).

Quercusdigitata (Q.falcata) (Spanishoak).

Hicoria ovata (hickory).

Hicoria minima (bitternut).

Juglans nigra (black walnut).

Liriodendron tulipifera (tulip tree).

Fagus americana (beech).

Carpinus caroliniana (hornbeam).

Fraxinus americana (white ash).

Magnolia acuminata and variety cordata (cucumber tree).

Acer saccharinum (A. dasycarpum).
Cornus florida (dogwood).

Ulmus americana, $U$. alata, $U$. pubescens (elm).

Celtis mississippiensis (Southern hackberry).

Sassafras sassafras (sassafras).

Diospyros virginica (persimmon).

Aesculus octandra (Ohio buckeye).

Quercus michauxii (cow oak).

Liquidambar styracifua (sweet gum).

Gleditsia iriacanthos (honey locust).

Fraxinus lanceolata (green ash).

The sweet gum here attains its largest dimensions. The last 5 prefer the lower bottoms subject to occasional overflow.

In the paludial forest, particularly of the alluvial region, with the soil submerged or constantly water-soaked, the cypress (Taxodium distichum) forms in the so-called cypress brakes the most imposing feature. This tree is found throughout the State, and in that portion belonging to the Louisianian area, it is associated with the tupelo gum (Nyssa aquatica) and the Carolina ash (Fraxinus caroliniana). Tue overcup oak (Quercus lyrata) prefers the shallow lagoons of the alluvial lands in the center of the State. Planer tree (Planera aquatica), water hickory (Hicoria aquatica), Carolina black gum (Nyssa biflora), apple haw (Crataegus aestivalis), and green ash (Fraxinus lanceolata) are 
frequent inhabitants of the forest-clad swamps of the alluvial district in its lower part.

Deciduous forests of xerophile trees and shrubs prevail on the dry mountain spurs, the table-lands, and the lower hills, the following forming the bulk of the arboreal vegetation:

Quercus prinos (mountain oak).

Quercus velutina (black oak).

Quercus marilandica (black jack).

Quercus coccinea (scarlet oak).

Hicoria glabra (pignut).

Hicoria alba (mockernut).

Hicoria carolinae-septentrionalis (Southern shellbark hickory).
Hicoria villosa (pale-leaf hickory).

Castanea dentata (chestnut).

Ulmus australis (Southern rock elm). Acer leucoderme (white-bark maple).

Acer saccharum and variety barbatum (hard maple).

Acer floridanum (Florida maple).

Oxydendrum arboreum (sourwood)

All of these, except Acer lencoderme, A. saccharum barbatum, and A. Aloridanum, belong also to the Northern forests. On the arid ridges with a poor siliceous soil Southern pines mingle freely with the hardwoods.

Evergreen forests. - The evergreen arboreal vegetation forms a most prominent feature of the flora of the State. The 31 species found in Alabama are nearly all distributed throughout the warmer temperate and subtropical regions of eastern North America. In the xerophile forests of the dry uplands the cone-bearing evergreens, embracing six species of pines, one type of the cypress tribe, and the red cedar, hold an important place in the tree-covering of the State, particularly the pines. These cover extensive areas, the long-leaf pine extending almost exclusively and with scarcely any interruption over many hundreds of square miles, while short-leaf and loblolly pine form a large element in the forest growth of the northern half of the State.

Broad-leaved evergreen trees and shrubs in great variety of species prevail in the mesophile semiswampy forests of the subtropical zone. In these forests the magnolia, single or in groups, finds its home with the white bay of the same genus, red bay, dahoon holly, yaupon, wax myrtles, ti-ti, American olive or devilwood, leatherwood, and large oaks with persistent leaves (live oak, etc.) or retaining their foliage during the greater part of the winter (laurel oak and water oak). A host of evergreen shrubs - the sweet illicium of the magnolia family, azaleas and andromedas of the heather family, holly, and others-form the dense undergrowth. Of conifers, the loblolly pine, with the Southern spruce pine and Cuban pine and, mostly in swampy localities, the white cedar, tower above the broad-leaved forms. The strange-looking Spanish dagger (Yucca aloifolia), an arborescent lily, with its trunk covered with rigid sharp-pointed leaves and, in the beginning of the summer season, crowned with ample panicles of snowy white flowers, forms a characteristic feature of the arboreal vegetation of the sands in the coastplain. 
OPEN-LAND OR CAMPESTRIAN FLORA (XEROPHILE PLANT ASSOCIATIONS.)

Under a climate so highly favorable to tree growth and with soil conditions which in general present no obstacles to the development of an arboreal vegetation, there is in Alabama, as in the adjoining States and the corresponding regions of the Southern Atlantic States, but little room left for the characteristic vegetation of open-plain or treeless mountain and hill country, especially if we exclude the vegetation of herbs and undershrubs of the open rolling pine barrens, of the pine flats of the coast with their scattered tree growth, and of the scantily shaded rocky crests of the mountains. It is only on the comparatively small tracts of the Cretaceous plain where the underlying limestone strata come near the surface and the covering of the rich black calcareous soil becomes too shallow to permit the roots of the trees to gain a firm hold, that arboreal vegetation is completely excluded. In these localities-the so-called bald prairies, low knolls, or broad swells of limited extent, with the soil not deep enough to be plowed-many of the typical plants of the eastern North American prairie have found a refuge, from which they have spread over the borders of fields, open waysides, pasture and waste grounds, and wornout and abandoned lands. In such localities the original types have to contend for the possession of the ground with many introduced and adventive weeds, the hardy offspring of species originating in the exposed plain. Most of the native typical plants of these remnants of the prairies, and of the open in general, are also common to the prairies of the Mississippi Valley from the Wabash to the ralley of the Colorado River in Texas. Most of the rosinweeds (Silphium laciniatum, etc.), species of sunflower (Helianthus), fleabanes (Erigeron), Rudbeckias, and other tall, coarse composites are characteristic of the prairie flora; most of the species of the pea family and most of the umbellifers and grasses inhabiting the prairies, open borders of fields, and pasture grounds in the central and northern part of the State, have also their home on the prairies of Illinois, Missouri, southern Arkansas, and eastern Texas.

\section{WATER AND SWAMP FLORA (HYDROPHYTIC PLANT ASSOCIATIONS).}

Plants of these associations are most prominently represented in the lower pine region of the Coast plain. Among the 227 species of vascular hydrophytes so far observed in Alabama 11 are pteridophytes, 139 species are monocotyledons, and 77 dicotyledons.

\footnotetext{
HY DROCHARIDEAN CLASS.
}

Of hydrophytes floating free in water, 9 species are known in the State. They are kept afloat by their thallus or thallus-like stems, as in Azolla and duckweeds (Lemna minor, L. trisulcata, Spirodela), or 
by the rosettes of their floating leaves, as in sundew (Drosera intermedia), water feather (Hottonia inflata), bladderwort (Utrioularia inflata), or by leaf-covered stems, as in hornwort (Ceratophyllum).

Of submersed hydrophytes rooting on the solid rocky bed of swiftly running brooks two species of Podostemon occur in the mountainous regions. They are moss-like plants, their roots provided with peculiar organs by the aid of which they fasten themselves closely to the rocks. More numerous species of different families constitute that association of submersed hydrophytes which take root in the soft soil (Limnæan associations). These are in some cases provided, in addition to the immersed foliage, with peculiarly constructed shield-like leaves floating on the surface, only their flowers being lifted above the water, of which the following are examples:

Castalia (water lily).

Nelumbo (water chinquapin).

Nymphaea (spatter-dock).

Limnanthemum lacunosum (floating heart).
Sagittaria natans (arrow leaf).

Potamogeton spp. (pondweeds).

Callitriche heterophylla (water star).

Others have the foliage entirely suomersed and of one form, as water crowfoot (Batrachium divaricatum), bladderworts (Utricularia vulgaris and U. purpurea), water milfoils (Myriophyllum spp.), with their leaves finely divided; Vallisneria, with long strap-shaped leaves, and numerous pondweeds (Heteranthera, Najas spp., Philotria, Zannichellia, and Ruppia), with the leaves from narrowly lanceolate to linear. These Limnæan aquatics, with their stems mostly emerging from the water at flowering, but their seeds ripening beneath it, form the frequently very dense vegetation of ponds, lakes, and semistagnant waters of the estuaries. Of this association, the species are especially numerous in the Coast plain.

\section{PAlustrian Classes.}

This association embraces the halophytes and fresh-water plants which root in a water-soaked soil, with their leaves and flowering stems above, and frequently their bases alone surrounded by water. They are nearly all perennials, with stout roots or strong running rootstocks (rhizomas), and cover the extensive open marshes of the tidewater regions and river alluvium. Large monocotyledonous plants of various kinds form the characteristic feature of this vegetation, of which the following are representatives:

Phragmites (tall reed).

Spartina spp. (cord grass).

Zizania, Zizianopsis (water rice).

Typha spp. (cattail).
Scirpus spp. (bulrush).

Cladium effusum (saw grass).

Scirpus maritimus (triangular-stemmed bulrush). 
The slender stems of these tall reeds and rushes sway to and fro above the humbler grasses (Homalocenchrus, etc.), round rushes (.Juncus spp.), galingales (Cyperus spp.), sedges (Carex spp.), and bur reeds (Sparganium sp.). These form the floor of the spongy soil, which is frequently of fathomless depth and more or less submerged. The monotony of the gramineous vegetation is often relieved by various showy flowers, namely:

Iris versicolor, Iris hexagona (blue flag).

Hymenocallis rotata (spider lily).

Sagittaria spp. (arrowhead).

Pontederia cordata (pickerel weed).

Hiliscus moscheutos (swamp rose mallow). Asclepias lanceolata (swamp milkweed).
Mesadenia (Cacalia) lanceolata (cacalia).

Lythrum lineare (lythrum).

Cicuta maculata (water hemlock).

Sium latifolium (water parsnip).

Rumex altissimus (swamp dock).

To the same class of hydrophytes belong the paludial plants confined to the salt marshes of the seashore and the outlying islands with their rigid salt grasses (Distichlis spicata, Spartina spp.), black rush (Juncus roemerianus), club-rush (Scirpus maritimus), and the species of the dicotyledonous orders mentioned above. The plants of these associations of halophytes are nearly all perennials with stout, frequently deeply rooted, running rhizomes. This vegetation of the swamps and salt marshes encroaches upon the water with the shoaling of the rivers and the formation of muddy banks in the inlets of the sea and on the open shore, and serves to break the force of the waves, and 'finally, by the close interlacing of the rootstocks, binds the loose soil into a solid matting as a bulwark against the ceaseless destructive action of the water and winds.

The paludial arboreal vegetation of the more or less submerged soil of the alluvial districts has already been spoken of, and the flora of the tree-clad swamps fringing the pine-barren streams and of the open pine-barren swamp will be fully discussed in treating of the several regions in which they occur.

ORGANOTOPIC FLORA.

These plants differ from all others in finding their habitat upon other living plants or their decomposed remains.

EPIPHYTIC PLANT ASSOCIATIONS.

The epiphytes are simple lodgers living upon trees in an atmosphere saturated with moisture, without depending for their nourishment on the tissues of the supporting plant. Only a few of the many species of these plants which lodge in the trees of the Tropies are represented in the flora of Alabama. They inhabit the trees of the damp or semiswampy forests of the Louisianian area. The Spanish moss (Tillandsia usneoides), a rootless plant of the Bromelia family, simulates in its habit the lichen Usnea of the Northern forests. This plant draws 
its nourishment solely from the air, and propagates itself chiefly by the detached strands of its thread-like stems entwined and fastened on the limbs and branches of the trees. Epidendron conopseum, a handsome orchid, inhabits large magnolias and hoary live oaks in the deepest recesses of the same swampy hammock lands, with numerous roots closely fastened to the bark of the largest limbs of these trees. Polypodium polypodioides ( $P$. incanum Sw.) and Polypodium vulgare are frequent inhabitants of trees. They are, however, found to grow also upon shaded rocks and prostrate trunks.

SAPROPHYTIC AND SYMBIOTIC PLANT ASSOCIATIONS.

Saprophytes are colorless plants which, as far as those belonging to the phanerogams are concerned, live upon the débris of the vegetable world, deriving their nourishment from the organic matter resulting from its decay. The largest number of saprophytes belong to the fleshy fungi and some of these live upon decaying animal matter. Being destitute of chlorophyll, their vascular system less developed, without breathing pores, their leaves reduced to mere scales, these plants are unable to elaborate the constituents needed for nutrition or to change carbonic acid from the air into assimilated food material. The number of seed-bearing saprophytes occurring in Alabama is small, and widely dispersed through the deep, shady forest, as Apteria Corallorhiza, and Hexalectris of the orchid family, and in grassy, damp swales Burmannias. Hemisaprophytes are green perennial herbs of the ordinary structure and habits, which for their nutrition are only partially and to varying degrees dependent upon organic matter. Some live in humid, peaty soils, mostly in the open, for example, some of our club mosses (Lycopodium carolinianum, L. cernuum) and a number of orchids (Limodorum, Pogonia, Habenaria spp.), while others can exist only in a humid soil, rich in vegetable matter, under cover of the forest.

Symbiots are pale, almost colorless, plants, of waxy appearance, in their organization similar to the saprophytes, and have been until recently regarded as truly parasitic in their mode of living. It has, however, been found that they do not subsist on decomposed vegetable matter, nor are they root parasites. They are true symbiots, being in their existence closely bound up with that of another plant which contributes to their necessities, but is equally benefited by this connection; Monotropa and Hypopitys, of the Indian pipe family, belong to this group. Immediately after their germination the rootlets of these plants are infested by the vegetative threads or spawn (mycelium) of a fungus which, as the plant develops, fastens itself upon every root, finally enveloping the rootstock with a thick film, the higher plant drawing its nourishment solely from the elaborated food of the fungus. 
PARASITIC PLANT ASSOCIATIONS.

True parasites are also destitute of chlorophyll, and leafless, but they take their nourishment from the living tissues of their host, subsisting entirely on its elaborated food materials. Three species of this class of parasites which foist themselves upon the roots of their hosts (root parasites) oecur in the Carolinian zone of Alabama, and are also frequently found in other parts of temperate North America, all belonging to the family of broom rapes (Orobanchaceae), namely:

Conopholis americana.

Thalesia uniflora.

Leptamnium (Epiphegus) virginianum.

Of the parasites which fasten themselves upon the stems of their host, 6 are found in Alabama, all belonging to the dodders or love vines (Cuscuta). These plants at the start root in the ground, but upon springing up, when they meet a plant suitable for a host they wind themselves around its stem and at places of close contact send haustoria through its bark to the wood, and, the cells of the two uniting, the parasite draws its food from the plant attacked. Thus firmly established, the part of the stem of the parasite conneeting it with the ground dies, and it depends henceforth entirely for its nourishment on its host. The chlorophyll-bearing shrubby parasites of trees are represented by a single species, the American mistletoe (Phoradendron flavescens).

The so-called hemiparasites-green herbs which fasten themselves by their lateral rootlets upon the roots of their host-are only partly dependent upon assimilated food material. These half-parasites belong mostly to the figwort family, examples being Canadian lousewort (Pedicularis canadensis), painted cup (Castilleja canadensis), and several Gerardias. The number of plants subsisting in this way has not been ascertained, but outside of the Scrophulariaceae, Comandra and Darbya are also supposed to be hemi-parasites.

INSECTIVOROUS PLANTS.

A class of these plants inhabit the bogs of peat mosses and the damp flat open pine barrens of the Coast plain, consisting of sarracenias (Sarracenia), sundews (Drosera), butterworts (Pinguicula); and others, viz, the bladderworts (Utricularia), inhabit stagnant or still-flowing waters of shallow pools, ponds, lakes, and streams, floating upon the surface of the water or immersed. It is evident that by the faculty of appropriating animal substances for their nourishment, nature has provided these plants with an additional supply of nitrogenous food which the sterile soil, extremely deficient in the elements required for plant nutrition, does not contain. In order that they may get hold of the animals serving them for food they are endowed with peculiar appliances of a highly specialized character, as, for example, the 
trumpet-shaped or urn-shaped leaves of the Sarracenias. In these the peculiar arrangement and structure of the hairy covering on their inside permits the easy access of the insects to the sweet seoretions hidden within and at the same time prevents their escape. In the sundews sensitive contractile viscid hairs cover the upper side of the leaves and entrap the insect upon its approach; in the bladderworts the hvaline bladders of the immersed leaves and stems serve as traps for the minute organisms swarming around them. Twenty-one species of insectivorous plants have been noted in Alabama, viz, 6 Sarracenias, 4 Droseras, 3 Pinguiculas, and 8 Utricularias.

\section{INTRODUCED PLANTS AND THEIR INFLUENCE UPON NATIVE PLANT} ASSOCIATIONS.

Fully one-sixth of the plants enumerated in the catalogue of the Alabama flora as growing without cultivation are immigrants from other regions, and but few of these are native in the more distant parts of this continent north of Mexico. They are mostly from the warmer temperate, subtropical, and tropical regions of the Old World. Those of widest distribution and which have gained the firmest foothold are wanderers following civilized man in his conquest of the wilderness. Originally children of the open plain, exposed to the extremes of heat, cold, drought, and excessive rain, these plants necessarily acquire the widest elasticity in adapting themselves to new surroundings and possess the greatest power of resisting adverse conditions.

Considering the way these foreign plants have established and are maintaining themselves in their new home, they may be regarded as naturalized when they have taken a permanent place among indigenous plants; adventive when restricted to cultivated lands or to the vicinity of human dwellings; and fugitive when they have gained only a temporary or precarious hold on the soil.

NATURALIZED PLANTS.

Naturalized plants, in a strict sense (De Candolle, A. Gray), are those which have established themselves firmly among the native plants and participate in their various associations over considerable areas. Their introduction is in many instances due to the direct agency of man. About 150 species of this class have been noted in Alabama, the greatest number (about one-fifth) belonging to the grasses. Fully one-half had their home originally in central and western Europe; one-seventh in the Mediterranean region; one-sixth in the subtropical and tropical regions of the Old World; about the same proportion come from subtropical and tropical America (West Indies and Mexico to southern Brazil and Argentina); and, lastly, three species are from the territory west of the Mississippi and immediately north of Mexico. 
It is often impossible to decide whether a plant should be considered naturalized or native, particularly when, though it grows in distant parts of the globe, every trace is obliterated of the time and manner in which it may have been introduced. Such instances are found in the Cherokee rose (Rosa laevigata), the common gourd (Lagenaria vulgaris), and the thornapple (Datura stramonium). The first, also at home in eastern Asia, is said to have been found by the whites on their first arrival at the villages of the Cherokees and Creeks; the second, dispersed over the warmer regions of the Old World, was frequently found about the habitations of the aborigines in the warmer temperate and subtropical zone of this eontinent, and the last was met with about the Indian villages on the banks of the James River in Virginia.

\section{ADVENTIVE PLANTS.}

These are foreign plants which have gained a firm foothold only on cultivated lands, or land abandoned by the cultivator, and are rarely found to stray beyond the waste places near his dwelling, lacking power to hold their own in the struggle with the indigenous plants for the possession of the soil. Strong feeders, of quick growth, these adventive plants are dependent upon soils rich in available nitrogenous plant food, such as is provided by the tiller of the soil for his crops or is accumulated in the rubbish about his habitations. Here belong the host of weeds which infest fields, gardens, and meadows, and consequently are in close connection with the eultural plant formations.

If it is difficult to draw the line between naturalized and indigenous plants, it is not less so to deeide whether a plant is thoroughly naturalized or merely adventive. Some of the species, at first merely adventive, acquire speedily the ability to accommodate themselves to their changed environment and thus become able to gain a firm hold upon the soil among the indigenous plants, not infrequently spreading widely if the proper opportunities for their dissemination exist. Some of the plants of quite recent advent from distant shores offer striking examples of this kind. The Japanese elover (Lespedeza striata), adventive from eastern Asia, and first observed at the port of Charleston, S. C., during the second quarter of this century, has now spread over thousands of square miles, west to Louisiana and southern Arkansas, and as far north as Maryland. This enormous spread was speedily effected by the droves of cattle and horses following the armies during the late war. Greedily eaten by the animals, the seeds being voided without being injured and readily germinating in the decaying droppings, this annual was soon permanently established in the open woods and pasture lands, over hill and lowland, throughout a vast extent of country. The bitterweed (Helenium tenuifolium), originally from the sunny plains west of the Mississippi River south of the 
Arkansas valley, was first observed in Mobile in 1866. It has spread along the embankments of the railroads to the mouth of the Ohio River, literally covering in many places the waste and uncultivated grounds, and reaching out along byroads and borders of fields and woodlands. In its northward spread this plant has largely taken the place of the mayweed (Anthemis cotula), a European weed of early introduction. Acanthospermum australe, of the Antillean flora, has, during the past thirty years, made its way along roadsides from the coast of Georgia to western Florida and Alabama, and toward the banks of the Mississippi River. As an example of a plant of more recent advent, which has gained a firm hold among the weeds and native plants of the waste heap, Melochia hirsuta deserves to be mentioned. First observed on recently turned soil at Mobile in 1875, and subsequently lost sight of for a number of years, it is now found to infest cultivated and waste places widely in the Coast plain; and as it ripens its seeds in abundance throughout the summer this weed proves most troublesome and difficult to eradicate.

Somewhat over forty species of adventive plants have been recognized in Alabama, fully one-half from Europe, and a small number from the warmer regions of the Old World; one-third from the West Indies and South America, and about one-sixth from the transMississippi region. The following weeds, classed among the adventive plants, are most conspicuous by their abundance all over the State, or, at least, in some one of the recognized botanical regions:

Leptochloa mucronata.

Hackelochloa granularis.

Cyperus rotundus.

Amaranthus retroflexus.

Amaranthus hybridus.

Amaranthus spinosus.

Spergula arvensis.

Portulaca oleracea.

Cassia occidentalis.

\section{Cassia tora.}

Sida rhombifolia.

Sida spinosa.

Coronopus didymus.

Veronica peregrina.

Veronica arvensis.

Lamium amplexicaule.

Richardia scabra.

FUGitive Plants.

Under this designation are understood those immigrant plants which have not firmly established themselves upon our soil and are liable to succumb to the vicissitudes of climate and accidental changes in the locality of their growth. In some instances their disappearance is to be ascribed to the absence of the specialized insects necessary to their fertilization and also to the occurrence of early and late frosts. They are mostly introductions coming with the ballast of ships and, showing but a slight tendency to spread from the place where they were landed, are mostly confined to ballast heaps. One hundred and fiftyseven species of these fugitives have been observed in Alabama, mostly on ballast about the port of Mobile and on the shores of Mobile 
Bay. About one-half are native in the West Indies, Mexico, southern Brazil, and Argentina; one-fourth are arrivals from the Mediterranean region and tropical regions of the Old World, and the rest are from central and western Europe.

Of the trees and shrubs introduced into cultivation in Alabama a comparatively small number have escaped. Such are rarely found to stray far from the localities where they have been cultivated, and they establish themselves mostly among the native plants along fences, about dwellings, on the borders of adjacent woodlands, and in hedgerows. Still smaller is the number which have escaped of the ornamental herbaceous exotic plants cultivated in our gardens. A few spring up voluntarily one season after another within the inclosure, such as Ammi majus, Ageratum mexicanum, Adicea microphylla herniarioides, but are never found outside of them, while a few others stray into the adjacent fields and waste places, the principal examples being:

Ipomoea purpurea.

Quamoclit quamoclit.

Viola tricolor.

Perilla frutescens.

Gynandropsis pentaphylla.

Gemmingia chinensis.

More numerous are the escapes from the gardens of potherbs, medicinal herbs, and otherwise useful plants. Such are:

Mentha piperita (peppermint)

Mentha spicata.

Mentha rotundifolia.

Nepeta cataria (catnip).

Marrubium vulgare (hoarhound).
Cnicus benedictus (blessed thistle).

Chrysanthemum parthenium (feverfew).

Artemisia vulgaris (mugwort).

Leonurus cardiaca (motherwort).

Ricinus communis (castor bean).

The greatest number of species escaped from cultivation or accidentally introduced belong to the grasses, which make up fully onefifth of the naturalized plants. These are mostly abundant and widely diffused, covering large areas and forming a conspicuous feature among the associations of the indigenous plant. Prominent species are:

Syntherisma sanguinale (crab grass). Capriola dactylon (Bermuda grass).

Paspalum compressum (carpet grass).

Dactyloctenium aegyptiacum (Egyptian crowfoot).

Paspalum dilatatum (hairy-flowered paspalum).

\section{PLANT DISTRIBUTION IN ALABAMA.}

In several instances, the boundaries of the life zones and areas, based upon the distribution of heat and moisture on this continent, as established by Merriam, can not at present be distinctly drawn in Alabama. The investigation of the plant covering of the State, the location of species, and the study of their relation to the factors controlling their distribution within its limits is as yet not sufficiently 
advanced to furnish the data required for this purpose. The frequent yet only indistinctly perceived overlapping of these zones adds to the difficulty of placing satisfactorily the lines by which they are separated. The efforts here made to lay down the lines of life zones and their subdivisions can only be regarded as tentative.

The following subdivisions of the life zones of Alabama have been recognized as floral regions; that is, as endowed with a flora of characteristic and distinct features, due to the presence of types which, if not confined exclusively to their limits, predominate within them and impart a peculiar character to their several associations. The prevalence of one or another of these associations or plant formations in the different sections of the same region determines the character of its subordinate floral divisions.

\section{CAROLINIAN AREA OR FLORA.}

A line drawn from the northwestern corner of the State to the lower part of Lee County, crossing the Coosa Valley near Childersburg, makes the limit of the highlands having an average elevation of 800 feet above sea level (E. A. Smith). This line coincides approximately with the isothermal line of $60^{\circ} \mathrm{F}$, and may be regarded as the boundary in Alabama of the Upper and Lower Austral zones, therefore of the Carolinian and Austroriparian or Louisianian areas. It winds its way from northwest to southeast and southward to the "fall line." Accepting this zonal line, a botanical limit is gained, northward of which is found a flora different in character from that to the southward, generally described as the flora of the great Central Mississippi Valley, and distinguished by the feeble representation, if not total absence, of the subtropical element and the exclusive prevalence of deciduous forests. Various shrubs and trees coincide in their limits of northern and southern distribution closely with this boundary line, and serve as unerring guides in pointing out its course. Such truly zonal plants are:

Pinus virginiana (scrub pine).

Quercus acuminata (yellow-bark chestnut oak).

Quercus prinus (mountain oak).

Quercus coccinea (scarlet oak).

Quercus rubra (red oak).

Acer leucoderme (white-bark sugar maple).

Prunus americana (American plum).

Azalea arborescens (sweet-scented azalea).

Stuartic pentagyna (fringed stuartia).

Butneria fertilis (mountain spicewood or smooth calycanthus).

Rhus aromatica (aromatic sumac).

Adelia ligustrina (southern privet).

These all find in Alabama their southern limit on this line. Although the vegetation of the Carolinian area presents in its broad features great uniformity, particularly in its tree growth, there exist in its range of nine degrees of latitude differences in the latitudinal distribution of heat, which necessarily affect the distribution of plants within its limits and present insurmountable obstacles to the extension of a number of species northward. Due to this temperature element, there is a most pronounced limit beyond which the successful cultivation of the cotton 
crop ean not be pushed, and which also presents a barrier to several trees and a number of other plants of Southern distribution that are only rarely met farther north, as, for example, the willow oak (Quercus phellos), loblolly pine (Pinus taeda), long-leaf pine (Pinus palustris), and cane (Arundinaria macrosperma). This line, roughly extending from the Atlantic eoast at the mouth of the Chesapeake Bay westward to southwestern Missouri and northern Arkansas, was located by Gray along latitude $36^{\circ} 30^{\prime}$, and by him regarded as the line of separation between the two principal floral divisions of eastern North America, namely, the flora of the northern United States and Canada and the flora of the Southern States. In Alabama it is only this lower belt of the Carolinian area, embracing the mountain region and the lower hills with which we are concerned.

\section{MOUNTAIN REGION.}

The extreme southern spurs of the Appalachian chains belong, with their western and eastern frontiers, to two distinct members of this mountain system. Their differences in topographical and stratigraphical conditions affect visibly the distribution and localization of species in the sections traversed by them.

RANGES OF HILLS OF THE METAMORPHIC AND OLDER PALEOZOIC STRATA.

Physiographical features and climate.-The spurs which enter the State at its eastern boundary are the continuation of the most easterly of the Alleghenian ranges, and are composed of metamorphic crystalline rocks skirted by the oldest sedimentary strata. They extend from the Coosa River to the Tallapoosa and include the most elevated parts of the State. The valleys reach an extreme elevation of about 1,000 feet above sea level, and the highest summits of the ridges reach an altitude of from 2,000 to 2,400 feet above the Gulf of Mexico. These ridges rise abruptly from the valleys and above the lower hills; their steep flanks are covered with the sharp-edged fragments of the siliceous rocks which crown their crests with bold cliffs.

The locality of Talladega (altitude 860 feet) coincides nearly with the center of this subdivision. The records of daily meteorological observations made at this town for only two successive years are at hand, which are embodied in the following table:

Data of temperature (degrees F.) and precipitation (inches) at Talladega for two years.

\begin{tabular}{|c|c|c|c|c|c|}
\hline & Annual. & Winter. & Spring. & Summer. & Fall. \\
\hline $\begin{array}{l}\text { Mean tempe } \\
\text { Absolute ma }\end{array}$ & $\begin{array}{l}63.7 \\
100\end{array}$ & $\begin{array}{c}43.7 \\
\cdots \ldots . .\end{array}$ & 64 & 80 & $\begin{array}{c}64.1 \\
\cdots \cdots . .\end{array}$ \\
\hline $\begin{array}{l}\text { Absolute minimum. } \\
\text { Mean precipitation. }\end{array}$ & ${ }_{49}^{15}$ & $\cdots \cdots$ & ii. 6 & io & 9. \\
\hline
\end{tabular}

This mean annual precipitation can be considered as representing that of the whole subdivision, with the exception of Lee County, on its southern border, where it rises to 54.4 inches. 
Xerophile forests. - The most prominent and characteristic feature in the vegetation of this subdivision of the mountain region is the xerophile forests of long-leaf pine which cover the arid rocky ridges to an elevation of 2,000 feet, as observed on the Chehawhaw Mountain, the highest in the State. These pine forests are open, almost entirely bare of undergrowth; only in the depressions on the flanks of the mountains a stunted growth of black-jack makes its appearance. At its vertical limit of distribution the pine is suddenly replaced by mountain oak, chestnut, and pignut hickory. Whenever on the summits of the pine-clad ridges at lower levels soil conditions more favorable to deciduous tree growth prevail the pine is obliged to give way to the hardwood trees. The pine timber on these mountains is somewhat stunted; the body of the trees is short and more or less knotty, and the old trees are frequently affected by dry rot, caused by the mycelium of polyporous fungi. It is little esteemed for lumber, but largely consumed for charcoal. There are, however, found exceptional tracts, with a timber growth unrivaled in density and perfection. Such heavily timbered forests of long-leaf pine have been observed, for instance, at Hollins, in Clay County. They extend for miles over a narrow valley and along the rounded foothills of the higher ridges which rise abruptly above them on either side. These particular tracts of forest are not surpassed in yield and quality of timber by the best pine timber lands elsewhere east or west of the Mississippi River, the trees showing most vigorous growth and remarkable uniformity in size and averaging from 20 to 24 inches in diameter breast high. By actual measurement they were found to be of a total height of from 110 to 120 feet, the greatest height growth of the species on record. Of the large number of felled trees examined in the logging camp not one was found defective. Of several taken at random measurements were made and the annual rings counted, with the following result:

\begin{tabular}{|c|c|c|c|}
\hline $\begin{array}{c}\text { Diameter } \\
\text { breast high } \\
\text { (inches). }\end{array}$ & $\begin{array}{c}\text { Length of } \\
\text { merchantable } \\
\text { timber (feet). }\end{array}$ & $\begin{array}{c}\text { Total } \\
\text { height of tree } \\
\text { (feet). }\end{array}$ & $\begin{array}{c}\text { Annual rings } \\
\text { on stump } \\
\text { 3 feet high. }\end{array}$ \\
\hline 22 & 50 & 110 & 150 \\
24 & 65 & 120 & 160 \\
25 & 45 & 116 & 155 \\
\hline
\end{tabular}

The sapwood in none of these trees exceeded 2 inches in thickness. A loblolly pine felled on the border of the brooklet watering the valley measured 25 inches in diameter across the stump and was found to be scarcely 50 years old.

The herbaceous vegetation on these pine-clad hills is of essentially the same character as that found on the uplands of the Central pine belt, denoting a dry soil. The hidden cause of such perfection in the development of the longleaf pine on a soil apparently as unpromising as any of the rolling pine barrens was clearly revealed by the 
examination of the subsoil. The argillaceous schist underlying the sandy surface was found completely decomposed, transformed into a friable loam rich in plant food and sufficiently porous to permit the slow percolation of the surface water and its unhindered access to the long taproot of the pine.

Open forests of longleaf pine responding to conditions similar to those prevailing on the flanks of the Talladega Mountains or Blue Ridge of Alabama, already mentioned, cover the lower cherty ridges in Calhoun County and the isolated peaks south of Talladega known as the Alpine Mountains, which rise to a height of 1,500 to 2,000 feet above the sea. These pine forests of the metamorphic highlands and of the Cambrian hills on their outskirts have in many localities become important since the development of the iron industry in these districts. During the past twenty-five years extensive areas have been denuded of their forests to yield the large supplies of charcoal demanded by this industry. Characteristic herbaceous species here found are:

Cracca virginiana.

Cracca spicata.

Lespedeza hirta.

Lespedeza repens.

Meibomia spp.

Eupatorium album.
Eupatorium aromaticum.

Solidago odora, and others.

Sericocarpus tortifolius.

Gaylussacia dumosa.

Vaccinium stamineum.

Heavy forests of longleaf pine cover the lower hills toward the Coosa River and the adjacent deposits of sands and gravels of the valley from Renfroe to Kymulga and to the banks of the Coosa River. A similar timber belt follows the drifted deposits from Gadsden, Etowah County, through Cherokee County and for a short distance beyond the Alabama and Georgia State line. The timber resources of these forests in the basin of Coosa River have furnished the supplies for an active lumber industry during the last twenty-five years. They are, however, rapidly becoming exhausted.

Wherever a richer and deeper soil covers the heights, the slopes of the mountains, and the lower hills, deciduous trees predominate, though rarely the shortleaf pine makes its appearance. The deciduous forests of these metamorphic mountains and Coosa hills differ only slightly from the xerophile forests of the same character in other divisions of the mountain region. Notable is the greater scarcity of tulip and cucumber trees, shagbark and pale-leaf hickory, elms, and lindens, which abound in other parts. On the rocky heights above 900 to 1,000 feet the following prevail:

Quercus prirus (mountain oak). (Quercus marilandica (black jack). Quercus velutina (black or yellow oak).
Quercus digitata (Spanish oak). Quercus minor (post oak).

More rarely occur: 
The chestnut, originally one of the most frequent trees of these forests, is at present rarely found in perfection. The older trees mostly show signs of decay, and the seedlings, as well as the coppice growth proceeding from the stump, are more or less stunted. It is asserted by the old settler's that this tree is dying out all over the mountain region, where at the beginning of the second half of the century it was still found abundant and in perfection. Wild cherry (Prunus serotina) is only found here and there in the richest spots, and red plum (Prunus ainericana) rarely along the banks of streams. In the mesophile forests of the bottom lands, as elsewhere north of the maritime belt, cow oak (Quercus michauxir), Texas oak (Quercus texana), willow oak (Quercus phellos), and hornbeam (Carpinus caroliniana) prevail. Mountain silverbell (Mohrodendron carolinum), redbud (Cercis canadensis), hard maple (Acer saccharum barbatum), catalpa (Catalpa catalpa), and dogwood (Cornus florida) follow the rich slopes fronting the streams; water oak (Quercus nigra L. (Q. aquatica Walt.)) ascends to the upper valley of Talladega Creek in Clay County (1,000 feet); various hawthorns (Crataegus flava, C. coccinea, and C. crus-galli) and Southern crabapple (Pyrus angustifolia) frequent the openings and borders of the woodlands, and swamp dogwood (Cornus sp.) the wet margins of streams. Rosa carolina was found on the Delta divide near the Idaho gold mine, in Clay County, the only locality for this rose known in the State. The American hazelnut (Comylus americana) in the forests of mountains in Clay and Cleburne counties frequently forms the dense brushy undergrowth. The frost grape (Vitis cordifolia), the most frequent of grapevines in this division, along the water courses covers shrub and tree with its festoons.

Xerophile herbaceous associations. - The flora of the pine-clad mountain slopes and the pine forests of the lower arid hills is decidedly of a xerophile character, denoting a sterile if not barren soil. Coarse grasses. (Andropogon furcatus, A. scoparius, and Erianthus alopecuroides) cover sparingly the steep declines with an association of numerous plants of the pea family and Compositae, all more or less in common with other parts of the mountain region. On a visit to the Chehawhaw Mountain, the Blue Mountains, and the Alpine Mountains, in Talladega County, in the latter part of September there were observed of Viciaceae and Caesalpiniaceae (Leguminosae):

Meibomia rugosa.

Meibomia marylandica.

Meibomia obtusa.

Meibomia rigida.

Meibomia laevigata (rare).

Meibomia glabella.

Meibomia michauxii.

Meibomia arenicola.

Lespedeza nutallii.
Lespedeza frutescens.

Lespedeza virginica.

Lespedeza hirta.

Lespedeza capitata.

Amorpha virgata.

Cracca virginiana.

Phaseolus polystachyus.

Cassia chamaecrista. 
Of Carduaceae (Compositae) were observed:

Lacinaria scariosa squarmulosa.

Lacinaria graminifolia.

Eupatorium album.

Eupatorium aromaticum.

Parthenium integrifolium.

Solidago odora.

Solidago nemoralis.

Sericocarpus bifoliatus.

Sericocarpus asteroides.

\author{
Silphium compositum. \\ Chrysopsis graminifolia. \\ Chrysopsis mariana. \\ Aster undulatus. \\ Aster undulatus diversifolius. \\ Aster camptosorus. \\ Aster patens. \\ Aster sagittifolius. \\ Aster laevis.
}

These are all characteristic of open situations on the sterile rocky ridges. The asters were of stunted growth. On these summits two conditions prevail, namely, rocky ridges without much soil supporting a xerophile or rupestrian flora, and depressions with a moist deeper soil supporting a mesophile flora.

With the disappearance of the long-leaf pine the deciduous-leaved trees make their appearance, the same which also form largely the tree covering of the lower mountain ridges, with their dry but more generous soil. The flora becomes more varied and types characteristic of these rocky heights more numerous. On their eliff-bound brow Prunus serotina neo-montana makes its appearance. This variety of the wild cherry is at once distinguished from the type by its low stature, searcely exceeding 25 or 30 feet; by the stem, which is somewhat crooked with the bark rough; the wide-spreading slender branches, which are slightly drooping; its broader, thick leaves, with a fine close pubescence beneath, and its rigid horizontally spreading racemes, the berries ripening in August. This tree was first observed in Alabama, in 1892, on the summit of the Alpine Mountains, near the signal station $(1,900$ feet), on the same range near Renfroe, nearly 1,000 feet lower, and on the summit of Chehawhaw Mountain, 2,400 feet. On the exposed cliffs forming the escarpment of the last Lonicera flava was found, trailing abundantly over the rocks, associated with Rubus villosus ( $R$. canadensis authors) and Smilax rotundifolia. It is also found on the lower ridges of the Alpine Mountains, near Renfroe, at an elevation of about 1,000 feet, and confined to a few localities on the eastern Alleghenian ranges in South Carolina and Georgia at similar altitudes. Pminus injucunda, a low, straggling shrub lately described from northwestern Georgia, and Vitis bicolor, or Le Conte's grape, are not infrequently met with on Chehawhaw Mountain, as well as on other summits of the metamorphic region (Alpine Mountains, 1,900 feet) and on the highest of the Coosa hills (Anniston, 1,000 feet). Le Conte's grape is recognized at first sight by the long stems of a bright reddish-brown (rufous) color stretching from rock to rock and overhanging the eliffs, the leaves sharply lobed, with deep narrow sinuses, 
pubescent beneath, the berries in compact rather oval clusters, purplish black without bloom, juicy, and sweet, ripening in the latter part of september. Robinia hispida and Rosa humilis are common on these rocks. Amorpha virgata and Viburnum acerifolium prefer slight declivities with a dry but somewhat less rocky soil. Among the other xerophile rupestrian associations, on the summit of Chehawhaw Mountain rock-tripe, a large lichen (Umbilicaria), covers with its black thalloid frond the bare crags, and forms a striking feature; it has also been observed to cover the rocks on the crest of Lookout Mountain (De Kalb County, 1,800 to 2,000 feet altitude), and is characteristic of the southeastern Alleghany ranges north to Pennsylvania. Of the few ferns frequenting these arid heights, Cheilanthes tomentosa is the most common. The long stipes of the fronds lie deeply buried among the smaller fragments of the rocks, where the fibrous roots, protected from the sun, find the needed supply of moisture. Dryopteris marginalis is rarely found in the sheltered rocky clefts. The coarse Andropogoneae, already named, under the scanty shade of mountain oaks, chestnuts, and pignut hickory, completely hide the ground with their luxuriant growth. The fine tufts of Stenophyllus capillaris, with Talinum teretifolium, cover the flat expanses of the rocks, bare of any other vegetation. Silene stellata and Anychia dichotoma prefer the shaded rocky shelves. Steironema tonsum, through the abundance of its bright golden flowers, is the most conspicuous among the herbs. This ornament of the cliffs, extending northward to the mountains of Kentucky, has also been observed on the open hills of the Delta divide (Clay County, altitude 1,600 feet). Lacinaria graminifolia, in dense tufts formed by its confluent tuberous root-stocks, covers the sunny rocks throughout this subdivision, while the following, more or less common throughout the southern extent of the Appalachian chain, are frequently met with in open rocky woodlands:

Campanula divaricata.

Dasystoma flava.

Solidago bicolor.
Solidago erecta.

Brachychaeta sphacelata.

Gerardia tenuifolia asperula.

Wherever the ridges spread out into wider expansions forming broad uplands, now denuded of their original forest growth and mostly subjected to cultivation, a xerophile campestrian flora has taken possession, with Compositae as its prominent feature. Such plains extend through the metamorphic region of South Carolina and Georgia to its southern limit in Alabama, with an elevation of from 1,600 feet (Clay County, about Delta) and 1,200 feet (Cleburne County, Chulafinnee) down to 860 feet in Lee County (Auburn). The borders of fields and woods, meadows and pastures, appear to be emphatically 
the home of golden-rods, rosinweeds, sunflowers, and Rudbeckias, besides numerous species of other genera of the same tribes as Heliopsis, Verbesina, and Coreopsis. The following species, common on the plains of the western Alleghenian area, inhabit the open throughout the Carolinian area from the lower Alleghenies to the Mississippi:

Solidago neglecta.

Solidago nemoralis.

Solidago erecta.

Solidago bicolor.

Silphium terebinthinaceum.

Silphium asperrimum.

Silphium intermedium.

Silphium dentatum.

Silphium trifoliatum.

Silphium laevigatum.

Helianthus microcephalus.

Helianthus hirsutus.

Helianthus hirsutus trachyphyllus.

Helianthus tracheliifolius.

Helianthus strumosus.

Helianthus schweinitzii.
Helianthus divaricatus.

Helianthus atropurpureus.

Helianthus tomentosus.

Rudbeckia triloba.

Rudbeckia heliopsidis.

Rudbeckia spathulata.

Verbesina aristata.

Heliopsis helianthoides (H. laevis).

Heliopsis minor.

Coreopsis verticillata.

Aster vimineus foliosus.

Aster lateriflorus.

Hieracium venosum.

Hieracium paniculatum.

Hieracium marianum.

Hieracium scribneri.

Mesophile plant associations. - The highest summits are frequently watered by numerous springs, giving rise to grassy swales and lively brooklets. In the almost perpetually damp soil of the first prevail:

Osmunda cinnamomea.

Scleria caroliniana.

Habenaria ciliaris.
Angelica villosa.

Solidago arguta.

Solidago odora inodora.

The damp banks of the brooks are shaded with a varied vegetation of shrubs and small trees of which the following are examples:

Kalmia latifolia.

Ilex opaca. ${ }^{1}$

Amelanchier canadensis. ${ }^{1}$
Aronia arbutifolia. ${ }^{1}$

Xolisma ligustrina.

Hydrangea arborescens cordata.

A dwarfed form of the sweet birch (Betula lenta) was found on the cliffs near the brink where a brooklet on Chehawhaw Mountain leaps over the precipitous escarpment. This tree, a species of noble dimensions in its home in the Alleghenian life area, finds here, reduced to a small shrub, its southern limit. Azalea viscosa glauca, with Zanthoriza apiifolia, ${ }^{1}$ frequent throughout the mountains and Coast plain, prefer the moistened rocks near the brink. In the open valleys from 1,000 to 2,000 feet above sea level-as, for example, in the Shinbone Valley and Talladega Valley in Clay County - the following associations of mesophile herbaceous plants have been observed.

${ }^{1}$ Growing also in the lower valleys and on the Coast plain. 
Inhabiting the damp margins of water courses and the borders of low woods are found the following:

Cyperus flavescens.

Polygonum sagittalum.

Impatiens biflora.

Impatiens fulva.

Oxalis grandis.

Parnassia asarifolia.

Onagra biennis. ${ }^{1}$

Ludwigia alternifolia. ${ }^{1}$

Gentiana saponaria.

Phlox maculata.

Phlox paniculata.

\author{
Steironema ciliatum. \\ Lobelia syphilitica. \\ Lobelia inflata. \\ Vernonia fasciculata. \\ Eupatorium maculatum amoenum. \\ Rudbeckia laciniata. \\ Helianthus tomentosus. \\ Coreopsis tripteris. \\ Verbesina alternifolia. \\ Polymnia uvedalia. ${ }^{1}$ \\ Carduus altissimus. ${ }^{1}$
}

In the open bottom lands, with their meadows and pastures, the following grasses and other glumaceous plants form the bulk of the vegetation:

\section{Paspalum boscianum. ${ }^{1}$ \\ Paspalum laeve. ${ }^{1}$ \\ Panicum agrostidiforme. ${ }^{1}$ \\ Panicum elongatum. ${ }^{1}$ \\ Panicum rostratum. ${ }^{1}$ \\ Panicum clandestinum. \\ Panicum commutatum. ${ }^{1}$ \\ Panicum latifolium. ${ }^{1}$}

\author{
Panicum polyanthes. ${ }^{1}$ \\ Syntherisma sanguinale. ${ }^{1}$ \\ Muhlenbergia diffusa. \\ Eleusine indica. ${ }^{1}$ \\ Sieglingia seslerioides. ${ }^{1}$ \\ Carex lurida. ${ }^{1}$ \\ Carex vulpinoidea. ${ }^{1}$
}

On the borders of fields with many of the above are found:

Cassia marylandica.

Cassia chamaerrista. ${ }^{1}$

Cassia multipinnata. ${ }^{1}$

Polygala curtisii.

Ipomoea hederacea.

Gerardia tenuifolia.

\author{
Physalis angulata. ${ }^{1}$ \\ Physalodes physalodes. \\ Diodia teres. ${ }^{1}$ \\ Diodia virginica. ${ }^{1}$ \\ Coreopsis pubescens. ${ }^{1}$
}

Vegetation of the southern edge of the Metamorphic hills.-An extensive collection of the vascular plants, made in the vicinity of Auburn, Lee County (850 to 900 feet altitude), near the border line of the Louisianian area, was kindly contributed by the Biological Survey of Alabama. From a district investigated botanically but slightly before, it proved of particular interest, showing the intermingling of Alleghenian types with many from the Coast plain and a number of local species sparsely scattered through the Carolinian and Louisianian areas, of which the following are remarkable examples:

\footnotetext{
Dryopteris floridana. ${ }^{1}$

Ophioglossum crotalophoroides. ${ }^{1}$

Lycopodium alopecuroides. ${ }^{1}$

Leptorchis liliifolia.

Juncus canadensis.
}

Lobelia amoena glandulifera.
Coleosanthus (Brickellia) cordifolius.

Eupatorium ageratoides.

Viola villosa.

Solidago neglecta.

Solidago pallescens.

${ }^{1}$ Growing also in the lower valleys and on the Coast plain. $15894-5$ 
Of these Dryopteris floridana had hitherto been known only from peninsular Florida and from Louisiana; Opliioglossum crotalophoroides and Lycopodium alopecuroides are known also from the coast plain of the Southern Atlantic and Eastern Gulf States, and the remainder extend hither from the Alleghenian area and the upper belt of the Carolinian.

The following, decidediy of northern distribution, seem to find on these highlands their southern limit of distribution:

Uvularia perfoliata.

Uvularia sessilifolia.

Vagnera racemosa.

Trillium stylosum.

Polygonatum biflorum.

Smilax ecirrhata.

Achroanthes unifolia.

Habenaria lacera.

Habenaria flava.

Darbya umbellulata.

Asarum virginicum.

Asimina triloba.

Hydrangea arborescens.

Philadelphus grandiflorus.

Sanicula marilandica.
Sanicula trifoliata.

Chimaphila umbellata.

Azalea viscosa glauca.

Xolisma ligustrina (the typical form).

Vaccinium vacillans.

Koellia pycnanthemoides̀.

Houstonia tenuifolia.

Houstonia longifolia.

Solidago amplexicaulis.

Brachychaeta sphacelata.

Aster shortii.

Aster sagittifolius.

Sericocarpus asteroides.

Silphium compositum.

Hieracium venosum.

The following belong to these hills in common with the Louisianian area, and reach here their northern limit:

Ophioglossum crotalophoroides.

Danthonia sericea.

Campulosus aromaticus.

Eatonia filiformis.

Cyperus stenolepis.

Cyperus haspan.

Peltandra sagittifolia.

Commelina erecta.

Xyris iridifolia.

Tofieldia pubens.

Chrosperma muscuetoxicum.

Trillium underwoodii.

Smilax pumila.

Polygala nana.
Polygala incarnata.

Hypericum drummondii.

Phacelia dubia.

Ipomoea barbigera.

Molirodendron dipterum.

Pieris nitida.

Collinsonia anisata.

Verbesina aristata ( $\boldsymbol{V}$. mudicaulis).

Aster purpureus.

Aster dumosus subulaefolius.

Eupatorium pinnatifidum.

Gaillardia lanceolata.

Solidago petiolaris.

Solidago brachyphylla.

Vegetation of the Lower Coosa hills, fertile valley lands, and flat woods. - On the extremely rugged area which forms the western outskirts of this region and the watershed between the Coosa and Tallapoosa rivers, xerophile plant associations prevail almost exclusively. The steep hills of siliceous cherts and obdurate sandstone, which reach scarcely an elevation of 1,000 or 1,200 feet, support an inferior growth of the upland oaks named before, and pignut hickory, with the longleaf pine scantily interspersed between the hardwood trees and stunted sassafras and persimmon, with sumac (Rhus copallina, R. glabra) for 
the undergrowth. Among the associations of herbaceous xerophile plants, which cover the exposed slopes and brows of these hills, the pea family with its bush clovers, tick-trefoils, etc., is most numerously represented in species as well as in individuals, while the Carduaceae present a number of golden asters, golden-rods, and blue asters, common throughout the mountain regions. Characteristic species are:

Lespedeza hirta.

Lespedeza capitata.

Lespedeza frutescens.

Lespedeza virginica.

Lespedeza nuttallii.

Meibomia obtusa.

Meibomia rigida.

Meibomia marilandira.

Meibomia glabella.
Meibomia bracteosa.

Strophostyles helvola.

Cracca virginiana.

Psoralea pedunculata.

Chrysopsis mariana.

Chrysopsis graminifolia.

Solidago ovata, etc.

Aster undulatus.

Aster patens.

On the summit of the ridges between Shoal Creek, east of St. Clair County, at an altitude of about 1,000 feet, Ilex monticola and Butneria fertilis (Calycanthus glaucus), both at home on the Alleghenian ranges from about New York to South Carolina, are strangely associated with the Carolina ash (Fraxinus platycarpa) from the swamps of the Coastal plain, here inhabiting the wet banks of brooks, and form an interesting group of mesophile shrubs. In rocky but somewhat rich soil on these ridges various species of blueberries abound beneath the hardwood trees, especially Vaccinium vacillans, a low, bushy form of $V$. corymbosum, and $V$. melanocarpum, the so-called wild gooseberry, remarkable for its large fruit. The berries of the last are of the size of a small garden gooseberry, of a shining plum purple, almost black color, juicy and palatable, and eagerly consumed by man and animals. This shrub, from $2 \frac{1}{2}$ to nearly 4 feet high, when in bloom is at once recognized by the abundance of its strictly racemose flowers, and when bending under the burden of its fruit presents a pretty sight. The berries ripen in the latter part of July. It is sparsely distributed over other parts of the mountain region, and occurs also in the Ozark Hills of the same geological formation in southwestern Missouri.

Where the floor of the Coosa rests upon the Silurian dolomites and subcarboniferous limestones, and the same strata form the first terraces of the hills, the soil is highly fertile. The flora is rich in the number of herbaceous species, belonging to many families and partly of campestrian and partly of sylvestrian character, and it stands in strong contrast with the flora of the arid rocky hills. In early spring Hepatica hepatica and Syndesmon thatictroides adorn the shelves. The mesophile association of herbs, mostly perennials, is particularly attractive during later spring and the earlier part of the summer, on account of the bright flowers of the Indian pink (Spigelia marilandica), the scarlet flower of the catchfly (Silene virginica), the purple flowers of Phlox 
amoena, $P$. maculata, and $P$. divaricata, the dazzling orange of the butterfly weed (Asclepiastuberosa), the pink of Monarda fistulosa and M. musselliana, the blue of Scutellaria versicolor and Phacelia bipinnata, and the golden flowers of Senecio balsamitae, S. earlei, and Coreopsis auriculata, while later in the season Solidago amplexicaulis, S. latifolia, S. curtisii, and S.caesia axillaris enliven these low hills.

The perfectly level tracts of a cold, gray, impervious soil, a perfect mire during the season of rain and a hard crusty mass torn by many fissures while baking in the summer's sun, form a peculiar feature in the topography and flora of the Coosa Valley. These flats extend for many miles in the main valley where the impervious Cambrian slates form its floor. They are for the greater part covered with a low forest of dwarfed trees, black jack, Texan oak, post oak scarcely over 20 feet high, with equally stunted loblolly-more rarely short-leaf and scrub pines-scattered among them. These dwarfed woods are rendered truly impenetrable by the multitude of shrubby hawthorns (Crataegus crus-galli, C. spathulata, C. apiifolia), Southern crab apple, persimmon, and black gum (Nyssa multiflora), entangled with the tough vines of bamboo briers (Smilax bona-nox, S. laurifolia) and forming a perfect maze of green. In the bare openings the following form the very open vegetation upon the ashy gray flats:

Rosa humalis.

Kneiffia suffruticosa.

Asclepias variegata.

Apocynum cannabinum.
Cracca virginiana.

Coreopsis crassifolia.

Juncus acuminotus debilis.

The last of these is the most frequent. Rosa humilis is here reduced to a height of 6 to 10 inches.

No grasses or cyperaceous plants inhabiting a damp soil are met with, a fact readily accounted for when the sharp extremes of wet and dry to which these flats are subjected and the total absence of decayed vegetable matter are considered.

Cultural plant formations.-A bout 25 per cent of the area of this subdivision is farm land more or less subjected to the plow; the rest is under tree covering. High forests in their original condition prevail on the steep mountains, which are not profitable for tillage, and in valleys remote from the highways of traffic. In the metamorphic area the lower hills and valleys with a warm loamy soil, resulting from the decomposition of the more basic schists and softer shales and augitic or feldspathic gneiss, worn down far beyond their original level, are of high and lasting fertility and almost entirely under cultivation, which is also to be said of the fertile lands of the Coosa Valley. Over one-half of the tilled lands are devoted to cotton, broad fields of which alternate with smaller ones of Indian corn (Zea mays), of small grains (mostly oats, wheat, and rye), and forage crops (clover and meadow grasses), with patches of the Chinese sugar cane or sorghum (Sorghum 
saccharatum), sweet potatoes (Ipomoea batatas), ground nuts (Arachis hypogaea), and more rarely the Irish potato, presenting a system of diversified farming like that practiced throughout the mountain region, with the difference that in the richer soils of this subdivision the production of cotton, the staple crop of the South, has assumed far greater proportions.

Among the cultivated fruit trees the peach takes the first rank, no other part of the State producing this fruit in greater perfection than the lower metamorphic hills and plains, where also the grape is successfully cultivated, and is, owing to the drier atmosphere, less liable than elsewhere to the injuries caused by fungoid diseases. Pears and apples are of a thrifty growth all over the mountain region and produce abundant crops of high quality, particularly the latter, in situations on the higher levels.

TABLE-LANDS OF THE WARRIOR AND COOSA BASINS.

PHYSIOGRAPHICAL FEATURES AND CLIMATE.

This area comprises about 4,500 square miles, including all of Cullman, Winston, Walker, and Blount counties, nearly all of Marshall and Dekalb, and small portions of Etowah and Cherokee counties, with the detached spurs of the Cumberland Mountains in the northeastern part of the Tennessee Valley in Jackson County. About threequarters of this area contains the coal measures, with their drainage level above the Subcarboniferous limestone lands.

The extreme southern spurs of the westerly Alleghanian ranges, including the Cumberland Mountains and all of the strata of the lower coal measures and underlying Subcarboniferous rocks, constitute this floral subdivision. It comprises the extensive table-lands drained by the Warrior River and of the coal field drained by the Coosa River, covering fully three-quarters of the area of the mountain region, and also the valleys with their water level not below 700 or 800 feet above the sea.

The lower Carboniferous sandstones and conglomerates form the surface rock of these table-lands. Their surface is furrowed by the narrow beds and deep gorges through which the numerous tributaries of the main channels of drainage have worn their way. The soil resulting from the disintegration of the strata is a light, more or less sandy, loam, and where shallow, full of thin rocky fragments.

The mean annual temperature on these highlands at their average elevation of from 800 to 1,500 feet is about $55^{\circ} \mathrm{F}$., with a mean of $45^{\circ}$ for the winter and $75^{\circ}$ for the summer months; average minimum $12^{\circ}$ in January, and maximum $87^{\circ}$ in August. The mean annual precipitation amounts to 55 inches; mean for the winter months 18 inches, for the summer months 14 inches. The larger streams forming the 
main channels of drainage have cut their bed through to the Subcarboniferous limestone. The calcareous strata constitute the floor of the wide valleys of erosion by which the diverging ranges are separated and also of their foothills.

VEgetation of the plateaus, Mountain slopes, AND higher VAlleys.

Xerophile forests. - An uninterrupted forest of a varied growth of deciduous-leaved trees and evergreen cone bearers originally covered this subdivision. On the broad expanse of the table-lands above 900 or 1,000 feet the tan-bark or mountain oak largely prevails, associated with post oak and Spanish oak, or more rarely with black-jack and black oak, occasionally with searlet oak, a rare tree in this State; also with mockernut, pignut hickory, and fine chestnut trees (the latter rapidly disappearing, having been eagerly sought for on account of their durable timber for fencings or wantonly destroyed for the nuts), and with white oak (Quercus alba) and highland gum (Nyssa sylvatica). Among the tree growth of smaller size the sourwood (Oxydendrum arboreum) is most frequent, here attaining its largest development, not infrequently becoming 40 feet in height and over a foot in diameter; together with dogwood, persimmon, sassafras, and the Southern palebark maple (Acer leucoderme), and in localities with a deeper soil, the Northern sugar maple (Acer saccharum' barbatum), tulip tree, box elder (Acer negundo), and angelica tree (Aralia spinosa). On Sand Mountain, in Cullman County, where these forests have been more closely investigated, the woodlands support from 25 to 35 timber trees of various species per acre, affording from 5,000 to 6,000 feet B. M. of merchantable lumber of all grades, the largest amounts being derived from the Spanish oak and the less valuable black oak (Quercus velutina). The lumber finds a ready market in the mining districts.

Wherever the mountain oak prevails pines are rarely seen. On the ridges of a lower altitude, with a thinner soil, the short-leaf pine (Pinus echinata) forms from 20 to 30 per cent of the timber growth, and, together with the loblolly pine (Pinus taeda), supplies pine lumber, which always finds a ready market. Dense groves of the latter cover the shallow depressions deficient in drainage, which are particularly frequent on the Warrior table-land. On these swales, from a fraction of an acre to several acres in extent, the loblolly pine arrives at its perfection, scarcely surpassed anywhere in its dimensions and in the quality of its timber. The trees average about 24 inches in diameter, with a height of from 110 to 120 feet, the trunks free of knots for a length of from 45 to 70 feet and with but a small proportion of sapwood.

The scrub pine (Pinus virginiana) is found on the most broken and poorest places at an elevation mostly above 1,200 feet, and is not frequent. 
Under the cover of the mostly rather open forest a variety of shrubs contribute to form a dense undergrowth. Blueberries (Vaccinium. vacillans, $V$. stamineum) are met with everywhere in the mountain region, and a bushy low form of the common azalea or honeysuckle (Azalea nudiflora), conspicuous by the abundance of its mostly snowwhite flowers, borne in close clusters, almost hides the ground. The fringed stuartia (Stuartia pentagyna), mountain holly (Ilex monticola), and its variety (I. monticola mollis), with soft hairy leaves, extend northerly on the lower of the western Alleghenian ranges to southeastern Kentucky, western Virginia, and Pennsylvania, and reach their southern limit on Sand Mountain. Ilex longipes extends from North Carolina and Tennessee to the Louisianian area, and the rare Ilex dubia is found on the richer slopes, with Darbya umbellulata, which of late has also been discovered on the edge of the metamorphic hills in Lee County. The last occurs also in a few localities in North Carolina and middle Georgia. Seven bark (Hydrangea quercifolia), one of the most ornamental shrubs, adorns the open woods and rocky hillsides throughout the region, being also common on the iower hills and extending to the Coast Pine belt. The following shade the rocky borders of the water courses:

Vaccinium tenellum (small-leaved huckleberry).

Kalmia latifolia (evergreen kalmia). Azalea arborescens (sweet-scented azalea).
Stuartia virginica (Virginia stuartia). Aronia arbutifolia (chokeberry).

Pyrus angustifolia (Southern crabapple).

The chokeberry, which is here of arborescent habit, presents a beautiful sight when loaded with its bright scarlet fruit, which remains from early autumn through the winter. The following add to the number of mesophile shrubs, which prefer a damper and deeper soil:

Chionanthus virginica (fringe tree). Pyrus angustifolia (Southern crab apple). Crataegus coccinea (scarlet haw).

Crataegus spathulata (sugar haw).
Crataegus crus-galli (cockspur thorn).

Crataegus mollis (downy haw).

Crataegus uniflora (winter haw).

\section{Of woody creepers and climbers-}

Smilax rotundifolia (horse brier),

Clematis virginiana (common virgin's bower),

are confined to the mountain region, extending to the Alleghenian area; while-

Bignonia capreolata (cross vine),

Tecoma radicans (trumpet vine),
Berchemia volubilis (supple-jack), Vitis aestivalis (summer grape),

are widely distributed in the Carolinian and Louisianian divisions.

Mesophile forests. - Where the sandstones give way to clayey shales more subject to erosion, the channels of the water courses become 
wider and the valleys are flanked by ridges of a gentler slope and are covered with deeper and richer soil. In these secluded valleys of the table-land, particularly where they begin to slope almost imperceptibly toward their southern and southwestern borders, the arboreal growth is of great luxuriance and variety. Besides many of the trees of the uplands, the following are found:

Quercus michauxii (cow oak).

Fagus americana (beech).

Vlmus americana (elm).

Juglans cinerea (butternut) (rare).

Tilia americana (basswood).

Tilia heterophylla (basswood).
Magnolia umbrella (umbrella tree).

Magnolia acuminata (common cucumber tree).

Magnolia macrophylla (large-leaf magnolia.

These deciduous-leaved magnolias in these sheltered valleys arrive at their best development, the last having been observed with a trunk fully 20 inches in diameter. In such a valley on the northern border of Winston County, near a branch of the east fork of the Sipsey River, the yellow-flowered magnolia (Magnolia acuminata cordata), first described as a distinct species ${ }^{1}$ by Michaux the elder, was discovered by the writer in 1882 . Since the original discovery of this rare and beautiful tree by this great investigator of the trees of eastern North America, on the banks of the upper waters of the Savannah River, the range of its distribution had remained obscure. It can now be said, however, to extend from upper South Carolina and the upper mountain region of Georgia to northwestern Alabama. Here this tree has been observed as large as a full-grown common cucumber tree, of which species Professor Sargent regards it as a variety. When unfolding under full exposure to the sun, the flowers are from a dingy canary to a golden yellow color, but are of a greenish tint when opening under the shade of the dense foliage. In the shape and size of the mature leaves the yellow-flowered variety can scarcely be distinguished from the typical form; it is only in the foliage of the young vigorous shoots that the heart-shaped form of the leaves is observed.

Entering near the same valley the cliff-bound channel of the Sipsey fork, one finds to his surprise the rocky defile shaded by groves of stately hemlock (Tsuga canadensis). This inhabitant of the coniferous forests of northern regions extends southward along the highest summits of the Appalachian ranges to Georgia and northwestern Alabama, where it follows this mountain torrent for a distance of about 10 miles, nearly to the falls of Clear Creek, in Winston County, there reaching its southern limit. In this valley the hemlock is accompanied by the sweet or cherry birch, Betula lenta, at home in the same northern life zone.

Xerophile and mesophile herbaceous plant associations.-Belonging to

${ }^{1}$ M. cordata Michaux, Flora, Vol. 1, p. 328 (1803). 
the former, many ferns peculiar to the mountain region take root in the chinks of the bare rocks. Such are:

Cheilanthes tomentosa.

Cheilanthes lanosa.

Cheilanthes alabamensis.

Pellaea atropurpurea.
Asplenium montanum.

Asplenium ruta-muraria.

Asplenium pinnatifidum.

In similar situations are found the following flowering plants:

Silene rotundifolia.

Arenaria stricta.

Silene caroliniana.

Lacinaria graminifolia.

Saxifraga virginica.

Senecio obovatus.

Other species of ferns on the border line of xerophile and mesophile associations prefer the more sheltered rocky ledges, as:

Asplenium parvulum.

Woodsia obtusa.

Polypodium vulgare.
Dicksonia punctilobula.

Camptosorus rhizophyllus.

Cystopteris fragilis.

Carex picta ( $C$. boottiana) covers in dense tufts the rocky shelves on the banks of the head waters of the eastern Sipsey fork, in Winston County, where this pretty and rare plant was collected by the late Judge T. M. Peters.

Associated with Carex picta are $C$. nigro-marginata, C. virescens, and $C$. digitalis, Tipularia unifolia (of a widely disrupted distribution from the Gulf coast to Lake Huron in the Alleghenian area), and the northern Peramium (Goodyera) repens. Therofon (Boykinia) aconitifolium inhabits the bare rocks forming the brink of streams, and Diamorpha pusilla is found in similar localities-both extending hither from the lower mountains of South Carolina and Georgia. Heuchera americana grows in more open, and H. migelii, Viola multicaulis, and Hepatica hepatica in deeply shaded situations; and where the rocky walls are constantly kept moist by the dripping water, Thalictrum clavatum, Viola rostrata, V. blanda, and V. striata are found.

In the open woods of a light dry soil where pines are mingled with the hardwood trees, and in the openings of old fields and pastures, where the progeny of the pine is apt to take possession of the ground, there are present numerous xerophile species, which are characteristic of the mountain region in general. Of these, the following glumaceous plants (grasses and sedges-Poaceae and Cyperaceae) are scantily diffused throughout woods and fields having a thin thirsty soil:

Erianthus alopecuroides. Andropogon scoparius. ${ }^{1}$ Andropogon furcatus. ${ }^{1}$ Chrysopogon avenaceus. ${ }^{1}$ Sieglingia seslerioides. ${ }^{1}$ Melica mutica. ${ }^{1}$

\author{
Eragrostis pectinacea. ${ }^{1}$ \\ Poa chapmaniana. ${ }^{1}$ \\ Carex laxiflora. ${ }^{1}$ \\ Carex laxiflora varians. ${ }^{1}$ \\ Carex cephalophora. \\ Carex leavenworthii.
}


Among the largely predominating Compositae tall rosinweeds and coarse sunflowers are conspicuous, particularly the former, which present a number of types rarely or not at all observed in the State outside of this subdivision; for example, Silphium mohrii and $S$. gatesii, both known from Cullman County; $S$. trifoliatum, ranging from the plains of the Ohio Valley to the Central Prairie region; $S$. laevigatum, Helianthus schweinitzii, and $H$. glancus, from the lower mountains of South Carolina and Georgia, and S. compositum, abundant throughout the region. The following are frequent in dry thin soils all over the Mountain region, some extending all over the State:

Helianthus atrorubens.

Helianthus hirsutus.

Helianthus microcephalus.

Helianthus divaricatus.

Heliopsis helianthoides.

Parthenium integrifolium.

Sericocarpus asteroides.

Aster divaricatus.

Eupatorium sessilifolium.

Solidago caesia. ${ }^{1}$

Solidago erecta.

Chrysopsis mariana. ${ }^{1}$

Brauneria purpurea.

Rudbeckia hirta. ${ }^{1}$

Rudbeckia spathulata. ${ }^{1}$

Coreopsis grundiflora. ${ }^{1}$

Coreopsis pubescens. ${ }^{1}$

Coreopsis auriculata. ${ }^{1}$

Carduus virginicus.

Andropogon virginicus. ${ }^{1}$
Lactuca hirsuta.

Lactuca sagittaefolic. ${ }^{1}$

Nabalus fraseri. ${ }^{2}$

Lechea racemulosa.

Lechea leggettii.

Koellia pycnanthemoides.

Blephilia ciliata.

Monarda fistulosa.

Monarda bradburiana.

Dasystoma virginica. ${ }^{1}$

Gerardia tenuifolia. ${ }^{1}$

Physalis virginianu.

Physalis pubescens.

Physalis pruinosa.

Sabbatia boykinii.

Thaspium aureum trifoliatum. ${ }^{1}$

Oxalis recurva. ${ }^{1}$

Tragia urticaefolia. ${ }^{1}$

Meibomia (many species).

Lespedeza (many species).

Vicia caroliniana ${ }^{1}$ and buffalo clover, Trifolium reflexum, are frequent on these table-lands, and Lathyms venosus in Alabama is confined to them.

Strictly mesophile herbaceons plant associations.-Ferns abound in the shade of the forests. Characteristic species are:

Adiantum pedatum.

Asplenium platyneuron. ${ }^{1}$

Phegopteris hexagonoptera.

Botrychium virginicum. ${ }^{1}$
Botrychium obliquum. ${ }^{1}$

Dryopteris noveborucensis.

Dryopteris marginata.

Dryopteris acrostichoides. ${ }^{1}$

Asplenium angustifolium, which is most frequent in the Ohio valley, occurs very rarely. Of grasses and sedges Muhlenbergia diffusa forms dense plots, and the following prefer the shade of woods:

Brachyelytrum erectum.

Festuca nutans.

Festuca shortii.

Poa sylvestris.
Poa autumnalis. ${ }^{1}$

Carex laxiflora. ${ }^{1}$

Carex laxiflora varians.

Carex laxiflora patulifolia.

\footnotetext{
${ }^{1}$ Occurs also in the Louisianian area.
}

${ }^{2}$ Nabalus Hook., as a strictly American genus, has been reinstated, differing in habits of growth and distribution and essential morphological characters from Prenanthes, with which it was connected by later authors, but which is exclusively confined to Europe. 
The following are frequent in the openings of woods and on their borders:

Vagnera racemosa.

Uvularia puberula.

Uvularia sessilifolia.

Iris cristata.

Syndesmon thalictroides.

Anemone quinquefolia.

Anemone virginica.

Ranunculus recurvatus.

Cimicifuga racemosa.

Trautvetteria carolinensis.

Viola hastata.

Viola multicaulis.

Viola pubescens.
Tiarella cordifolia.

Hypericum virgatum.

Scutellaria incana.

Phlox divaricata. ${ }^{1}$

Mertensia virginica.

Vincetoxicum hirsutum.

Gentiana villosa. ${ }^{1}$

Galium circaezans.

Houstonia caerulea.

Deringa canadensis.

Podophyllum peltatum. ${ }^{1}$

Sanguinaria canadensis.

On the higher shady banks of water courses are found:

Porteranthus (Gillenia) stipulaceus.

Porteranthus trifoliatus.
Stachys cordata.

Zanthorhiza apiifolia. ${ }^{1}$

In the more or less dense forest, covering hill and dale, are to be found:

Orchis spectabilis.

Cypripedium parviflorum. ${ }^{1}$

Arisaema quinatum.

Circaea lutetiana.

Hydrastis canadensis ${ }^{1}$ (scarce).

Bicuculla cucullaria.

Dentaria diphylla.

Cubelium concolor.

Panax quinquefolium. ${ }^{1}$
Aralia racemosa.

Sanicula marilandica (rare).

Phryma leptostachya.

Frasera carolinensis. ${ }^{1}$

Cynoglossum virginicum.

Obolaria virginica.

Solidago flexicaulis.

Solidago vaseyi.

The Solidago vaseyi has been collected near Holmes Gap (1,500 feet), and is known from a few localities on the highest ranges of the Carolinas and Georgia.

On the restricted flat semiswampy places, not infrequently met with on the Warrior table-land, open or slightly under cover, the following are most frequently seen:

\footnotetext{
Cyperus pseudo-vegetus. ${ }^{1}$

Carex lupulina. ${ }^{1}$

Carex lurida. ${ }^{1}$

Habenaria ciliaris. ${ }^{1}$

Xyris flexuosa. ${ }^{1}$

Rhexia virginica. ${ }^{1}$

Ludwigia alternifolia. ${ }^{1}$
}

Phlox maculata.

Lysimachia quadrifolia.

Gentiana elliottii. ${ }^{1}$

Bidens involucrata.

Coreopsis grandiflora.

Doellingeria infirma.

Mesophile plant associations of rock houses.-On the perpendicular walls at the head of the deep narrow gorges are found shelves of hard, resisting sandstone with the softer strata beneath them worn away by the action of the percolating surface water. The wide and deep exca- 
vations thus formed are called by the people of the country "rock houses." In these gloomy recesses, never visited by the direct rays of the sun, their roofs and walls constantly moistened by the water oozing from every crevice, some of the rarest and most delicate ferns find a shelter from wind and sudden changes of temperature. Trichomanes petersii, the tiniest of this order in the United States, and confined to northern Alabama, is at home in these rock houses, and thence it was first brought to light by Judge T. M. Peters, who discovered it on the banks of the head waters of Sipsey River. The filiform hor1zontal rhizomes are interwoven into dense patches, their fronds of dark green scarcely an inch high, somewhat resembling the thallus of a large liverwort. This fern was subsequently found in a similar locality on the western edge of the table-land by Prof. E. A. Smith, and later by the writer on its eastern border at the falls of Black Creek, in Etowah County. Trichomanes radicans is also a frequent inhabitant of these rock houses, being found on wet, deeply shaded, rocky walls northward to the Cumberland Mountains of Kentucky. The long creeping rootstock of this beautiful fern, adhering firmly to the rock, decorates the roof and walls of these recesses. Asplenium trichomanes, with its fronds of brightest green, and the thallus of a large liverwort (Dumortiera sp.) are the frequent companions of the above. Of plants of higher orders only a few have been observed in these cavities. Thin grass (Agrostis perennans) with its weak, decumbent stems, occurs here, where its foliage is scarcely ever affected by frost and never touched by the direct sunlight, and Heuchera rugelii is also quite frequently found on the damp ledges which form the threshold of the caves, but rarely penetrates beyond them.

Hydrophytic plant associations (paludial plants). - On the table-land beyond the channels of the large streams and their very numerous branches no areas of great extent of a water-soaked or submerged soil are found, and the narrow channels through which the water rushes toward the lowlands afford but little chance for the spread of a hydrophile vegetation. The wet grassy swales are inhabited by the following:

Andropogon virginicus.

Homalocenchrus (Leersia) virginicus.

Panicularia nervata.

Panicum rostratum.

Panicum commutatum.

Panicum polyanthes.

Panicum sphaerocarpon.

Carex lurida.

Carex lupulina.

Carex intumescens.

Carex squarrosa (rare).

Carex torta.
Carex granularis.

Eleocharis tenuis.

Eleocharis acicularis. ${ }^{1}$

Eleocharis ovata. ${ }^{1}$

Scirpus polyphyllus.

Dichromena colorata.

Kobresia pumila.

Juncus marginatus. ${ }^{1}$

Juncus (common species).

Cicuta maculata. ${ }^{1}$

Coreopsis tripteris. ${ }^{1}$

Eupatorium maculatum. ${ }^{1}$

${ }^{1}$ Occurs also in the Louisianian area. 
In the brooks where during its lowest stage the water becomes stagnant, a large Fontinalis, $F$. lescurii, is found. Hymenocallis occidentalis occurs in deep clefts of rocks barely rising above the water. Sagittaria latifolia, and S. longirostris australis are found on the miry banks of Ryans Creek, Cullman County, with Peltandra virginica. Orontium aquaticum is common in the streams of the wider valleys not above 1,000 feet. On the loose stones in the swiftly running brooks and shallow streams Podostemon abrotanoides, a type of the southern Alleghenies, is not rare on the Warrior table-land, and $P$. ceratophyllum of northern distribution is knowr in the State, but only from the vicinity of Auburn.

Vegetation of Lookout Mountain.-Near the northern frontier of the State the most easterly of the spurs of the Appalachian ranges belonging to this subdivision rises abruptly at Valley Head to an elevation fully 800 feet above Little Wills Valley, with its floor at this point 1,150 feet above tide water.

The summit of Lookout Mountain spreads out to a wide table-land of the same character as the plateau of the Warrior coal field, and terminates suddenly in the precipitous escarpment abutting upon the Tennessee River known as the most prominent landmark in the Tennessee basin. Near Mentone, Little River, a pretty stream which follows the southern extension of this table-land, leaps over a ledge intc its narrow channel, some 125 feet below. By reason of a rainfall more copious than in other sections of the mountain region ( 64.4 inches), and toward its northern extremity of a generally deeper and fresher soil, this mountain was recently covered with a fine hard-wood forest, chiefly of oaks, and was noted for the abundance of white oak timber (Quercus alba) and tan-bark oak; but this timber wealth is now almost exhausted. On its flanks the black locust (Robinia psendacacia) is found, one of the few localities in Alabama where it can be considered to be indigenous. The short-leaf pine is rarely met with on these heights. The scrub pine is more frequent, reaching its best development on rocky benches and declivities with a scanty covering of soil.

On the brow of this mountain, and particularly along the low, damp banks of Little River, there occurs a strong mingling of types that are at home in the Alleghenian area of the adjoining States and of North Carolina with plants of the lower ranges within the Carolinian area, giving rise to a varied flora, the like of which has not been observed in any other part of the mountain region of Alabama. When the low elevation of this extremely limited spot is considered (not quite 2,000 feet above the sea), the suffusion of types from different life zones admits of no explanation on the ground of climate or local influences controlling plant distribution, but points clearly to a disjunction of floral conditions due to geological changes. Among the woody plants peculiar to the Alleghenian area, Rhododendron catawbiense 
is the most prominent. In the beginning of summer, when covered with the profuse clusters of its purple or lilac flowers, this shrub, from 6 to 10 feet in height, massed in dense thickets along the baniks of Little River, forms one of the most attractive sights. The home of this shrub is ascribed to the highest erests of the southern chains of the mountains from western Virginia to Roan Mountain, on the border of North Carolina and Tennessee, at an altitude of 6,000 feet. It has, however, been found, by Mr. Small, at a much lower elevation on Table Mountain. At its extreme southern limit in Alabama it is associated with the Azalea arborescens and Kalmia latifotia. Of other shrubs Viburnum cassinoides, extending to the Canadian zone, is abundant on the banks of this stream. Viburnum dentatum, Rutus enslenii, and Celastrus scandens, of the same range of distribution, are frequent among the shrubs of the more exposed rocky heights. With these Alleghenian shrubs occur a host of other species, which are at home on the southern extremity of the lower ranges within the Carolinian area, and are more or less frequent throughout our mountain region. For example:

Butneria (Calycanthus) fertilis.

llex monticola.

Vaccinium melanocarpum.

Vaccinium pallidum.

Hydrangea arborescens cordata.

Philadelphus hirsutus.

Diervilla rivularis.

The Vaccinium pallidum is reported as scarce on some of the highest summits of North Carolina (Buckley). Crataegus biltmoreana, $C$. austromontana, and $C$. sargenti are new diseoveries made on the declivities of the mountain by Mr. Beadle of the Biltmore Herbarium in 1899, which have also become known from western North Carolina, eastern Tennessee, and northern Georgia. The prostrate stems of the northern Rubus hispidus cover open, miry places.

The large lichen, Umbilicaria pustulata papulosa, which covers the naked cliffs, forms an association strongly expressive of the Alleghenian character of the flora of this locality. In the soil, rich in humus, shaded by the rocks, and on the shaded ledges lining the banks of Little River, mesophile ferns are also abundant. Asplenium bradleyi, of very local distribution in the Cumberland Mountains of Tennessee and Kentucky, occurs here, together with the more frequent-

Asplenium parvulum.

Asplenium trichomanes.

Asplenium filix-foemina.

Dicksonia punctilobula.
Asplenium montanum.

Asplenium pinnatifidum.

Dryopteris marginalis.

The last three are xerophile species, occurring on somewhat exposed rocks. Other herbaceous southern Appalachian types here found are:

Galax aphylla.

Thalictrum clavatum.

Viola multicaulis.
Viola blanda.

Viola rostrata.

Eatonia pennsylvanica. 
Of these the first is the most prominent, frequenting springy, rocky banks and dripping ledges, and the others are all more or less frequent in similar localities throughout the mountain region. Sarracenia catesbaei and Isoetes engelmanni valida are paludial plants so far only known in the State from the banks of Little River near De Soto Falls. There occurs also Danthonia glabra, a most rare plant, lately described, from upper Georgia (Nash), with Danthonia compressa and Deschampsia flexuosa, so far not yet reported from any other locality in the State, while Carex virescens, Tiarella cordifolia, Asclepias quadrifolia, and Asarum macranthum frequent the rocky dells and more or less open copses. The tiny Arenaria brevifolia, known from a few localities in upper Georgia and the Cumberland Mountains of Tennessee, roots in crevices of rocks among the dark-green cushions of mosses (Grimmia, Hedwigia), with the three-leaf stonecrop (Sedum ternatum) and the round-leaf talinum (Talinum teretifolium), a fleshy perennial with rose-purple flowers adorning exposed rocks in the mountains northward to Pennsylvania. On the exposed rocks close to the edge and above the falls of Little River dense tufts of filiform leaves produced by a many-branched rootstock deeply sunk in the erevices attract the attention. Specimens of this plant in flower obtained in September proved to be Chondrophora virgata (Bigelovia Nutt). The identity of our plant with Nuttall's specimens is, however, not free from doubt. In the type collected by Nuttall in lower New Jersey and preserved in the Herbarium of the Academy of Sciences at Philadelphia the radical leaves, which furnish the decisive character, are wanting; furthermore, the similarity to Euthamia graminifolia ascribed by Nuttall to his type is not recognized in our plant. The locality quoted by Nuttall is also doubtful, his plant having never been found afterwards, although the ground has been closely investigated by later botanists.

Under the umbrageous cover of the high forest on the upper flanks of the mountain, in the deep soil, rich in humus, tall umbelliferous herbs are conspicuous, among which are Ligusticum canadense, frequent throughout the mountains northward to Pennsylvania, Thaspium pinnatifidum, and Thaspium barbinode, which extends north to the Ohio Valley. Together with these occur Oxalis grandis, Polygonatum commutatum, widely distributed through the Alleghenian area, Trillium stylosum of the southern Appalachian ranges, and Cypripedium acaule, found in more open boggy places.

Cultural plant associations. - Scarcely 20 per cent of the area of the table-lands is reduced to a state of cultivation; the rest consists of more or less devastated woodlands and of high forests, which, however, near the settlements and highways of commerce are largely stripped of merchantable timber and are suffering from the inroads of fire and cattle.

Scarcely more than a quarter of a century ago, before these table- 
lands were made easily accessible to the immigrant by the great trunk lines leading from the centers of population in the North to the Gulf coast, they were but sparsely inhabited. The earlier settlers who had squatted upon them depended for their support more on the chase than upon the cultivation of a soil which was looked upon as too poor to afford an adequate return. This, however, has all been changed by the influx of a population which was attracted by the mild and salubrious climate, and which, eoming with the determination to establish its home here, has succeeded in conquering the unpromising soil and developed its possibilities. With the rapid increase in population these lands have come much into demand, and under rational management almost every crop raised in the Northern States can be successfully grown on these table-lands by the side of cotton.

The meadow grasses of the North, with red clover and similar forage plants, do well here. Much attention is given to the production of breadstuffs, chiefly corn, to which the greater part of the arable land is devoted. Small grains, as wheat and rye, supply a part of the home demand. Irish and sweet potatoes are profitable summer crops, and nearly all of the root crops and vegetables grown in the temperate zone are produced here in abundance and perfection. Of small fruits, the strawberry has been found highly profitable, usually being harvested before the end of April. This fruit finds a ready sale in the distant northern markets. Orehards of fruit trees on a large scale do not yet exist, although apples, pears, and peaches are successfully grown. The cultivation of the grape was given great attention by the earlier of the German immigrants until the appearance of a fungaus disease proved a great drawback. But with the successful employment of remedies to subdue this disease viticulture, particularly of grapes for table use, has received a new impetus.

\section{REGION OF THE TENNESSEE RIVER VALLEY.}

PHYSIOGRAPHICAL FEATURES AND CLIMATE.

West of the detached spurs of the Cumberland Mountains, which form the northeastern continuation of the table-lands south of the basin of the Tennessee River, this valley is marked as an area of erosion, in which the waters have cut their channel altogether in the subcarboniferous limestone, the surface rock. The most distinctive feature of the vegetation of the Tennessee Valley consists in deciduous forests, generally of a mesophile composition, with decidedly northern types prevailing, and containing species in common with the Carolinian area in the Ohio Valley which are not found in any other part of Alabama. For example, of trees and shrubs there occur here:

Aesculus octandra (buckeye).

Aesculus glabra (buckeye).

Acer saccharum (sugar maple).

Cladrastis tinctoria (yellowwood).
Staphylea trifolia (bladderwort).

Symphoricarpos symphoricarpos (coralberry). 
Pines are almost totally absent in this valley, and it is only at its western limit, and chiefly south of the Tennessee River, in Colbert and Franklin counties, where deposits of sandy loams and gravels overlie the Subcarboniferous strata, that the character of the forest flora changes by the appearance of the short-leaf pine among the hardwood trees. The climate of the valley is somewhat extreme. According to the observations of the United States Weather Service at Huntsville (altitude 650 feet), made during a period of fourteen years, the mean annual temperature is $59.9^{\circ} \mathrm{F}$; ; for the winter, $41^{\circ}$; spring, $59.9^{\circ}$; summer, $75^{\circ}$, and for the fall, $59.7^{\circ}$. The lowest temperature once during this period was $9^{\circ}$ below zero; the highest, $96^{\circ}$. The average of annual minimum temperatures is $11^{\circ}$; the average of the highest temperatures, $92^{\circ}$. The range of temperature throughout the year is most clearly exhibited in the following table:

Absolute and average minima and maxima of temperature for each month.

\begin{tabular}{|c|c|c|c|c|c|c|c|c|c|c|c|c|}
\hline Month. & Jan. & Feb. & Mar. & Apr. & May. & June. & July. & Aug. & Sept. & Oct. & Nov. & Dec. \\
\hline & ○ & 0 & ○ & o & o & o & ○ & ○ & ○ & ○ & ० & ० \\
\hline Absolute minima . & -9 & 7 & 8 & 13 & 31 & 36 & 51 & 54 & 39 & 29 & 13 & 7 \\
\hline $\mathrm{e} \mathrm{mil}$ & 14.4 & 12.2 & 19.5 & 34.8 & 45.8 & 51.9 & 59.8 & 58.2 & 4 & 34 & 21 & 15 \\
\hline Absol & 75 & 75 & 84 & 86 & 90 & 92 & 95 & 96 & 91 & 86 & 78 & 68 \\
\hline Average maxima.. & 68 & 70 & 80 & 82 & 86 & 90 & 92 & 90 & 86 & 81 & 72 & 76 \\
\hline
\end{tabular}

The mean annual precipitation is 54.1 inches; for the winter, 14.68; spring, 15.41; summer, 15.16 ; fall, $8.85 .^{1}$

VEGETATION OF THE TABLE-LANDS AND HIGHER RIDGES.

Xerophile forests (cedar glades). - The limestone strata of the foothills which form the lower terraces of the higher ridges, undermined and dislocated by the action of water, are almost bare of soil. On these rugged grounds the red cedar (Juniperus virginiana) predominates, but a few other trees gain a foothold. Among them is the blue ash (Fraxinus quadrangulata), a fine timber tree of the Alleghenian area, which reaches its southern limit here, where it is of stunted growth, being rarely more than a tree of medium size. A peculiar varietal form of the white ash (Fraxinus americana curtissii) is not infrequently found with the last. It is readily distinguished by its low habit of growth, almost always beginning to branch below a height of 8 to 12 feet, the spreading branches somewhat drooping, the foliage pale, and the fruit smaller. In this locality the seeds have the embryo well developed. This tree has also been found by Curtiss in the calcareous hills of Eufaula, on the eastern border of the State, and is apparently not rare in the cedar brakes of central and southeastern Tennessee.

${ }^{1}$ P. H. Mell, Climatology of Alabama, bulletin 18, Alabama Experiment Station, new series, 1890, p. 23.

$15894-6$ 
On the rugged foothills and mountain slopes, and particularly on the broad, barren, limestone flats of the uplands in the eastern part of the valley north and east of the Tennessee River the red cedar forms extensive woods, of pure growth, interrupted only by bare openings where the rocky ground scarcely affords a foothold to shrub or herb. The trees in the cedar glades or cedar brakes are closely set and attain a height of from 50 to 75 feet, the trunk from 15 to rarely 24 inches in diameter, breast-high, frequently deeply ridged toward the base, knotty, and with the crown from 30 to 50 feet or more above the ground. Under these severe soil conditions the growth of the trees is exceedingly slow, particularly during the later stages of life. By counting the annual rings trees of the dimensions mentioned were found to be from 140 to 175 years old. Large supplies of the valuable timber of the cedar, used for piling and for telegraph and telephone poles, are drawn every year from the cedar glades. On the gentler slopes with a deeper soil covering, and in the narrow valleys with a damp and rich soil, red cedar occurs scattered among the hard woods and here reaches its greatest perfection. The trunk is smooth from the base and free from knots and limbs for the greater part of its height; the wood is straight-grained, soft, and easily worked, and possesses all the qualities for which it is so eagerly sought in the manufacture of pencil casings and the best qualities of hollow ware. Not long since this tree was abundant in the narrow valleys and rich coves south of the Tennessee River, but these resources are now becoming rapidly exhausted.

On the sunny exposures, in the openings and borders of the forest which covers the calcareous hills, where the soil is deeper, a variety of xerophile trees of small size and of shrubs of the lower belt of the Carolinian area are found mingled with the red cedar. Examples are:

Rhamnus caroliniana (buckthorn).

Bumelia lycioides (bumelia).

Bumelia lanuginosa (shittimwood).

Ostrya virginiana (hop hornbeam).
Crataegus coccinea (red haw).

Cornus asperifolia (rough-leaf dogwood). Viburnum prunifolium (black haw).

Xerophile herbaceous plant associations. - The herbaceous associations are naturally, in the main, of xerophile character. On the exposed rocky flats tiny cruciferous winter annuals fill every crevice. Leavenworthia aurea, $L$. uniflora, and $L$. tomulosa, the first harbingers of spring, are followed by Draba caroliniana and D.brachycarpa. With the advent of warmer weather all herbaceous vegetation withers on these arid cedar glades, which then continue to present the aspect of absolute barrens.

On the rocky banks and shelves of the sunny hillsides a varied array of characteristic herbs makes its flowery display. In the height of springtime, as observed on the southern slopes of Monte Sano-(near Huntsville) and on the northern declivity of the Warrior table-land 
near Moulton, the following prefer the slightly sheltered rocky shelves:

Allionia nyctaginea.

Ranunculus fascicularis.

Arabis laevigata.

Claytonia virginica.

Arenaria serpyllifolia.

Opuntia rafinesquii. ${ }^{1}$

Geranium maculatum. ${ }^{1}$
Lithospermum canescens.

Iithospermum tuberosum.

Salvia urticaefolia. ${ }^{1}$

Scutellaria campestris.

Polymnia canadensis radiata.

Bellis integrifolia.

Sedum pulchellum and Phacelia purshii adorn the interstices of the rocky fragments, and Arenaria patula the bare rocks. During the first summer months the golden flowers of Hypericum aureum and $H$. sphaerocarpon ${ }^{1}$ adorn the hills, giving way in the latter part of the season to blue and purple asters-Aster oblongifolius, ${ }^{1}$ A. laevis latifolius, $A$. cordifolius and others of the more commonly diffused species - and to the bright flowers of goldenrods, such as Solidago amplexicaulis and Brachychaeta sphacelata (B. cordata Torr. \& Gr.), which are confined to the lower southern Appalachian ranges.

West of the spurs of the Cumberland highlands isolated knolls rise above the wide river plain with its seemingly interminable fields of cotton, corn, and small grain. These hillocks, of a siliceous limestone which has resisted erosion, support with their scanty covering of soil a stunted growth of chinquapin oak (Quercus acuminata), wild plum (Prunus americana), honey locust (Gleditsia triacanthos), hop hornbeam (Ostrya virginiana), and shrubs common on dry calcareous soil, and are frequently destitute of large trees. The plants which find a refuge in these localities form an interesting combination of xerophile, campestrian, and sylvan associations. Under the shades of the denser clumps of the low trees have been noted:

\section{Poa sp.}

Leptorchis liliifolia. Cypripedium parviflorum. Delphinium tricorne.
Dentaria laciniata. Meibomia pauciflora. Mertensia virginica.

In exposed places the following species of the open plain have established themselves:

Arenaria patula.

Isanthus brachiatus.

Anemone caroliniana.

Hypericum prolificum (frequent).
Euphorbia obtusata (rare).

Kuhnistera gattingeri.

Grndelia lanceolata.

Amphiacharys dracunculoides.

The Kuhnistera is rendered attractive by its numerous spikes of rose-purple flowers. The last two are remarkable outposts, if not waifs, from the plains west of the Mississippi River.

Mesophile forests. - North of the Tennessee River the detached spurs of the Cumberland Mountains, capped with the sandstones and con- 
glomerates of the Coal Measures, rise to an elevation of from 1,200 to 1,500 feet above sea level. Their summits, spreading into table-lands of comparatively limited extent, support a more varied and heavier tree growth than the table-lands of the Warrior basin, differing chiefly by the total absence of pines and the appearance of species common also to the forests of the Ohio Valley, and as yet not observed in other parts of the State. Oaks form the predominating forest growth of these highlands-white oak, mountain oak, and fine black oak. As observed on Monte Sano and the adjoining ridges, the typical sugar maple (Acer saccharum) of the North is not rarely met with on the summit and the highest flanks in the richest spots. Its variety (Acer saccharum barbatum) with smaller and sharper-lobed leaves, is more frequent and is widely diffused over the rocky hills which extend southward to the tertiary ridges of the Upper Division of the coast pine belt, associated with the cucumber tree, silver-leaf linden (Tilia heterophylla), and sweet buckeye (Aesculus sctandra). A group of fine trees of this last species, which is rare in Alabama, was observed on a terrace of rich soil a short distance below the brow of Monte Sano. The trees measured from 25 to 30 inches in diameter and from 75 to 85 feet in height. This truly Alleghenian type, extending from the headwaters of the Ohio River in Pennsylvania along the mountains to the northwestern corner of Georgia, finds its southern limit at this point.

The valleys skirting the detached spurs of the Cumberland Mountains are for the greater part still covered with the original forest, which is practically untouched by the ax. It can be said that a considerable portion of the most valuable hardwood timber found in the State is hidden in these secluded valleys - as, for example, in the valley of the Paintrock River. It is stated that in this valley, of about 35 miles in length, the tulip tree or yellow poplar (Liriodendron tulipifera) abounds in its largest dimensions, with white oak, linden, white ash, large sassafras, and black walnut, and with red cedar of superior quality occupying the damp rocky recesses.

The ridges of Subcarboniferous limestone rarely exceed an elevation of 1,200 feet. Their tree growth is the same as that of the forests which cover the gentler slopes of the limestone ledges cropping out beneath the sandstones which cap the summit of the higher ranges. On the flanks, with a deeper soil covering, the tulip tree becomes more frequent among the oaks, associated with the maples mentioned, and, more rarely, with white ash and shell-bark hickory (Hicoria ovata). Black walnut (Juglans nigra) and wild cherry (Pmunus serotina) are but rarely found even on the richest spots. Fetid buckeye (Aesculus gla$b r a)$ is of rather rare occurrence on the more exposed slopes of the calcareous hills, and red cedar is mingled with the hard-wood trees. Of the trees of smaller size, the American smoke tree (Cotinus cotinoides) makes its appearance on the calcareous summits and upon the shelves 
where the sandstones overlie the calcareous rocks on the flanks of the higher mountains. This highly ornamental tree, one of the rarest of the Atlantic forests, is confined in the State to the mountains of Madison County, where it attains a height of from 30 to 50 feet, with a diameter of from 8 to 12 inches. The American smoke tree was first discovered by Nuttall on the limestone cliffs bordering Grand River, near the northeastern limit of Indian Territory. It was subsequently found in Alabama by Buckley, and has also been detected as far west as the Medina Valley, in western Texas. Having disappeared from the locality where it was first discovered, and subsequent to its discovery in Alabama not having been seen by any botanist, the tree remained in obscurity for the next forty years, until it was again brought to light by the writer in 1881. Later it was found by Mr. Bush ${ }^{1}$ in southwestern Missouri, and since then Professor Trelease has found it in several localities in the Ozark Hills of the same region. Being in the Tennessee Valley exposed to a temperature falling not rarely nearly to zero, this tree will prove hardy in almost every locality where the cultivation of its European relative is possible. In its native location it is readily reproduced by sprouts from the stump, almost all of the vigorous coppice growths which it forms - for instance, the one observed on the Gurley place (near Gurley)-being of this origin. Red plum (Prunus americana), red buckeye (Aesculus pavia), aromatic sumac (Rhus aromatica), redbud (Cercis canadensis), with seedlings of the red cedar, form the bulk of the undergrowth of the high forests, and coral-berry and shrubby St. John's wort (Hypericum prolificum) the bushy covering of the ground.

Mesophile herbaceous plant associations. - The herbaceous flora on these forest-clad heights is represented chiefly by mesophile plant associations, which seek the shelter of the forest, or its borders and more or less shady openings. Besides the species common throughout the mountain region, a number of others are here found which are widely distributed to the northern limit of the Carolinian area, but occur rarely if at all in other regions of the State. Examples are:

Disporum lanuginosum.

Uoularia puberula.

Uvularia grandiflora.

Caulophyllum thalictroides. ${ }^{2}$

Anemone virginiana.
Thalictrum dicicum.

Dentaria laciniata.

Pimpinella integerrima.

Washingtonia claytoni.

On the densely shaded bluffs of the Tennessee River at Sheffield landing a few mesophile species have been observed which deserve to be mentioned. Of woody plants the Northern yellow wood (Cladrastis tinctoria), a representative type of the lower southwestern Alleghenian ranges, frequent from Kentucky southward, reaches here its extreme

${ }^{2}$ Blue cohosh. 
southern station, reduced to a shrubby growth. A peculiar form of Alsine pubera (var. tennesseensis) found by Dr. Short in Kentucky, according to Dr. Small, with Henchera hispida hirsuticaulis, inhabits the deeply shaded, damp rocky shelves and clefts with Cystopteris fragilis, and the delicate fronds of the Northern Cystopteris bulbifera with the Southern maidenhair (Adiantum capillus-veneris) overhang dripping rocks.

VEGETATION OF THE LOWLANDS, COVES, AND BLUFFS.

Mesophile forest. - South of the Tennessee River the lowlands bordering Catoa, Flint, and Big Nancy creeks are covered with extensive hardwood forests. The dense tree cover consists chiefly of cow oak, Texas oak, willow oak, Spanish oak, and more sparingly of mockernut hickory, beech, and white ash, with hornbeam, papaw, deciduous holly (Ilex decidua), and hawthorns (Crataegus apiifolia, C. crus-galli, C. spathulata), common in damp fresh soils, as undergrowth.

The cow oak abounds in the bottoms along the streams in the perfection of its growth, trees from 30 to 40 inches in diameter not being rare. Three trees felled, representative of the average size of this valuable hardwood timber, showed the following dimensions:

Dimensions and age of cow oak timber.

\begin{tabular}{|c|c|c|c|c|}
\hline $\begin{array}{c}\text { No. of } \\
\text { sample. }\end{array}$ & $\begin{array}{c}\text { Diameter } \\
\text { breast high } \\
\text { (inches). }\end{array}$ & $\begin{array}{c}\text { Length of } \\
\text { stick of } \\
\text { merchant- } \\
\text { able timber } \\
\text { (feet). }\end{array}$ & $\begin{array}{c}\text { Total } \\
\text { height. of } \\
\text { tree (feet). }\end{array}$ & $\begin{array}{c}\text { Annual } \\
\text { rings on } \\
\text { stump 3 } \\
\text { feet high. }\end{array}$ \\
\hline 1 & 33 & 35 & 93 & 280 \\
2 & 36 & 39 & 103 & 220 \\
3 & 26 & 37 & 95 & 177 \\
\hline
\end{tabular}

The Texas oak or Southern red oak, the frequent companion of the above, is often found from $2 \frac{1}{2}$ to 3 feet in diameter and from 80 to 100 feet in height, dimensions attained at an age of from 150 to 175 years. The timber of the Southern red oak is considered little inferior to that of the white oak.

White ash (Fraxinus americana) is found scattered throughout the forest, particularly along the base of the declivities bordering the lowlands. Trees from $2 \frac{1}{2}$ to 3 feet in diameter have been observed in the valleys, as well as occasionally in other localities, extending to the border of the Louisianian area. Not being of gregarious habit, this tree is not abundant in any locality.

The benches of the Mountain Limestone which form the terraces of the wide fertile coves surrounding the head waters of the streams named are covered by a deep fresh soil rich in humus, productive of an excellent timber growth. On these terraces oaks predominate, and, above all, the white oak (in this region called ridge white oak to distinguish it from the swamp white oak or cow oak), together with 
post oak, Southern shagbark hickory (Hicoria carolinae-septentrionalis), black oak, Spanish oak, and more rarely black walnut, the last becoming scarce wherever it is accessible.

On these bench lands the white oak takes the place of the cow oak. There can be little doubt that the largest supplies of white oak timber in the State are preserved in these coves of the Tennessee Valley. The full-grown trees average from 2 to 3 feet in diameter. Four trees felled for investigation were of the following dimensions:

Dimensions and age of white oak timber.

\begin{tabular}{|c|c|c|c|c|}
$\begin{array}{c}\text { No. of } \\
\text { sample. }\end{array}$ & $\begin{array}{c}\text { Diameter } \\
\text { breast high } \\
\text { (inches). }\end{array}$ & $\begin{array}{c}\text { Length of } \\
\text { stick of } \\
\text { merchant- } \\
\text { able timber } \\
\text { (feet). }\end{array}$ & $\begin{array}{c}\text { Total } \\
\text { height of } \\
\text { tree (feet). }\end{array}$ & $\begin{array}{c}\text { Annual } \\
\text { rings in } \\
\text { stump. }\end{array}$ \\
\hline & 22 & 52 & 108 & 170 \\
1 & 25 & 35 & 115 & 180 \\
3 & 36 & 25 & 99 & 190 \\
4 & 28 & 38 & 102 & 162 \\
\hline
\end{tabular}

Five or six trees of these dimensions have frequently been counted upon an acre.

The Southern shellbark or shagbark hickory is also abundant in these coves, and large quantities of this timber are annually shipped to the manufacturing centers North and South. The saplings of this tree form the greater part of the undergrowth in the more open forest.

The Spanish oak (Quercus digitata (Q. falcata Michx.)) is at its best where the terraces merge into the lowland. Its sturdy trunk averages from 2 to 3 feet in diameter, with a total height of from 90 to 100 feet, affording clear sticks of timber 36 to 48 feet long. The age of such trees of full growth varies between 135 and 175 years.

The willow oak (Quercus phellos) is most abundant in wet, undrained flats of an impervious soil. In Alabama it is rarely found outside of this valley, but extends sparingly southward to the Central Prairie region. This oak seldom exceeds 80 feet in height, with an average diameter breast high of 25 inches, and spreads its massive limbs at a height of from 30 to sometimes 40 feet from the ground.

The large amount of hardwood lumber sawn at the mills on the banks of the Tennessee River (chiefly at Decatur) and at the numerous smaller factories along the Memphis and Charleston Railroad exhibits the rapid development of the industries depending upon the timber wealth of the Tennessee Valley.

Mesophile herbaceous plant associations. - The herbaceous flora of the forests of the bottom and bench lands comprises but a small number of mesophile species growing under their dense shade. Late in autumn the writer observed Chimaphila maculata and Galium circaezans, both northern types extending to the Canadian zone, and also Mitchella repens, common throughout temperate eastern North America. 
In the northern part of the Tennessee Valley and west of the outlying spurs of the Cumberland Mountains rises an undulating plain from 200 to 300 feet above the river level, broken by the deep narrow channels of the numerous tributaries of the river which take their rise in the "Highland Rim" of Tennessee. The soil is a sandy compact loam of whitish color, destitute of lime and vegetable matter and deficient in underdrainage, being underlaid by an impervious clay or hardpan. This plain is covered with an open forest of the upland oaks, which are common in the mountain region, black jack prevailing, accompanied by mockernut hickory. The trees are all of stunted growth, scarcely above medium size, with an undergrowth of dogwood, black haw, sourwood, and sumach. A low willow (Salix tristis) cover's acres of the level expanse, imparting by the ashy hue of its foliage a peculiar aspect to the low, bushy, deciduous forest. The herbaceous flora of these barrens exhibits the same want of variety as their woody growth. As noticed on a single visit to the barrens between the forks of Cypress and Shoal creeks, in Lauderdale County, in the early part of June, the paucity of the glumaceous plant formations was a surprise. Of grasses and Cyperaceae,
Andropogon virginicus,
Eleocharis tenuis,
Agrostis hiemalis,
Cyperus ovularis,

Panicum commutatum,

were scantily scattered between the herbaceous perennials, indicating a cold, ill-drained, rather poor soil. The following were among the herbaceous plants observed, the first being the most abundant:

Phlox maculata.

Steironema lanceolatum.

Steironema ciliatum.
Meibomia canescens.

Meibomia dillenii.

Coreopsis tripteris.

On the more exposed declivities, which admit of ready surface drainage, the same associations of xerophile herbs prevail which inhabit similar localities all over the State, mostly Leguminosae, consisting of bush clovers (Lespedeza spp.), tick-trefoils (Meibomia spp.) Stylosanthes, Psoralea, Cracca, and of other families, Coreopsis senifolia, Ceanothus americanus, and Polygala incarnata. Tick-trefoils, chiefly Japanese clover (Lespedeza striata), which overruns the ground around dwellings, afford the only pasturage to live stock.

On their descent to the river plain the channels of the water courses intersecting the barrens widen and the highland becomes divided by broader valleys into ridges, which encroach more or less upon the banks of the Tennessee River. These hills are mostly steep and densely wooded. With the dip of these strata toward the south the soil becomes looser and calcareous and the vegetation more luxuriant. The timber growth is of great diversity and of fair quality. White 
oak, post oak, and Spanish oak are most frequent, with chestnut, basswood, and tulip trees. As has been observed, the trees on these hills are of rather rank growth. Of smaller trees and shrubs, forming the dense copses and bordering the high forest, small-leaf sugar maple, redbud, dogwood, and hazelnut prevail. Box elder, winged elm, willow, with azaleas, whortleberries, farkleberry, and the poison laurel (Kalmia latifotia) shade the rocky banks of the swift mountain streams. The Carolina silverbell tree (Mohrodendron (Halesia) carolinum) also makes its appearance here, a strictly southern Appalachian type, frequently met with from the lower ranges of southwestern Virginia, along the mountains, to the lower hills in Alabama.

CULTURAL PLANT FORMATIONS.

Of the 4,500 square miles embraced within the region of the Tennessee Valley about 2,430 belong to the Valley proper, their red soil resting upon the more or less siliceous limestones of the subcarboniferous strata. Being highly productive, these lands are mostly cleared and under cultivation. Mainly in the hands of small owners, they are under a high state of cultivation, the effort being directed to the development of all the possibilities of the farm. Hence, proper attention is given to the raising of every kind of live stock and the cultivation of all the crops needed on the farm for the sustenance of man and beast. Fields of corn and small grain alternate with fields of cotton, in which crop from 12 to 15 per cent of the whole area of the valley is planted. The fresh green of the meadow and the clover field greet the eye, and, as in the gardens and orchards of the Warrior table-land, all the vegetables, root crops, forage plants, and a large part of the fruits of the temperate zones of the globe can be successfully grown in this valley. Peaches, pears, and apples are raised in perfection on the hills, and for the cultivation of the grape no other section of the State appears to be so well adapted. Red wines of high quality can be produced on the sunny slopes of the calcareous hills.

What has been said of the agricultural plant formations of this valley applies generally to the Coosa Valley proper and to the smaller outlying valleys from the foot of Lookout Mountain westward to Blount's Valley.

\section{REGION OF THE LOWER HILL COUNTRY.}

The line of demarcation between the mountain region and this part of the Carolinian area can not be distinctly drawn. South and southwest, where the strata of the same geological formation slope gradually away from the high table-land to the hills which rise from a lower water level, these regions overlap each other and the changes in the character of their flora are difficult to discern. Not less difficult is it to recognize their border line toward the south and southeast along 
the limit of the metamorphic hills. The change in the character of the flora in this ill-defined region is indicated by the absence of or decrease in the number of species possessed in common with the northern Alleghanies and the Ohio Valley and the appearance of Southern forms which never or but rarely occur in the mountain region. These hills have a number of species in common with the northern extension of the Carolinian area which find their southern limit in this region and impart to its flora a northern aspect. For this reason it might botanically be regarded as a subdivision of the mountain region of which these lower hills in their descent to the Coastal plain form the last terrace and of which stratigraphically they are an integral part.

GRAVELLY HILLS OF SHORT-LEAF PINE AND HARDWOOD TREES.

On the western descent of the Warrior table-land the coal measures disappear under heavy deposits of sand and gravels of a more recent formation, through which the water courses have cut their beds, resulting in the formation of rounded hills from 250 to a little over 300 feet high down to low undulating ridges, of considerable length and width between the hills. This belt of drifted deposits extending along the western border of the State across the Tennessee River forms the divide between the waters of the Tombigbee River and the Warrior basin, and is the northern extension of the central belt of drifted deposits which separates the older from the recent geological formations. It embraces nearly all of Colbert, parts of Franklin and Marion, all of Lamar, the western section of Fayette and Pickens, and the northwestern part of Tuscaloosa counties. Notwithstanding the differences in its geological condition, this subdivision can not well be separated botanically from the floral region under consideration. This upland area is at once distinguished by the frequency of the shortleaf pine among the hardwood trees, mostly upland oaks and hickories, the pine having originally constituted about one-half of the treegrowth. This proportion has, however, during later years, been greatly reduced, and the supply of pine timber is at present nearly exhausted. The forest presents almost the same aspect as that found on the table-lands. at or below the elevation of about 800 feet above the sea, which have a similar light and dry soil.

These gravelly hills, being closely connected with the Tennessee Valley and with the mountain region through the numerous prongs of the western edge of the Warrior table-land intersecting this subdivision, its herbaceous flora, mostly of the xerophile class, presents no peculiar characteristics.

COAL MEASURES OF THE CAHABa VALLEY AND WARRIOR Basin.

Crossing the southern rim of the Warrior coal basin and the Cahaba coal field an extremely hilly area is entered, most rugged along its southern borders. It comprises the eastern part of Marion and Fay- 
ette counties, the lower half of Winston, the southern edge of Cullman and much of Blount, all of Walker and Jefferson, a great part of Tuscaloosa, the northern border of Bibb, and portions of Shelby and St. Clair counties. The hills within this region rarely exceed 600 feet above sea level. The soil resulting from the disintegration of coal-bearing shales, frequently rocky and shallow, is poor and dry.

Xerophile forests. - The xerophile forests consist largely of deciduous trees of inferior size. These are upland oaks of the black and red oak group, with stunted post oak, more rarely chinquapin oak (Quercus acuminata) of a more or less arborescent habit; pignut hickory and pale-leaf hickory (Hicoria villosa), a tree of medium size, lately distinguished, occurring from Missouri, Tennessee, and North Carolina to Alabama, being frequent on the rocky hills of the siliceous conglomerates. White-bark maple (Acer leucoderme) and various hawthorns (Crataegus collina, C. coccinea, C. spathulata, C. mohri, and C. triflora), all common to this and the mountain region, form the vegetation of the dense copses and the undergrowth in these xerophile forests. On the outcrops of the subcarboniferous limestone the chestnut oak (Quercus acuminata), here in its best development, is not infrequent, and Texas white oak (Quercus breviloba), known commonly as pin oak, finds its northern limit on the calcareous hills near the Mulberry Fork of the Warrior River, in Blount County.

On the cliffs of sandstone which form the eastern brink of the Black Warrior River, a short distance above the city of Tuscaloosa, a monotypical shrub, Neviusia alabamensis, finds its only home. The numerous slender wand-like stems bear abundant white apetalous flowers in the earliest days of spring, when the leaves begin to appear. This unique shrub belongs to the Asiatic element of Alabama's flora, and is strictly confined to the above locality. It was discovered by the Rev. R. A. Nevius and Professor Wyman in 1858.

In Tuscaloosa County, between North River and the Black Warrior River, a tract of longleaf pine extends to the banks of Yellow Creek near Oregonia, and in the northern part of Walker County a dense forest of this pine covers an isolated area of sand and pebbles extending over several townships, and is in its timber growth not surpassed by the best pine lands, further south. South Lowell, Walker County, 450 feet above the sea, is near the center of this pine forest. The upland willow oak or blue jack, common in the lower Coast Pine belt, in this isolated pine forest reaches its most northern station. The herbaceous flora presents the same associations of xerophile grasses, Leguminosae, and Compositae, common in the maritime belts of longleaf pine. Noteworthy is Helianthus mollis, a rare plant widely diffused from the prairies in southern Missouri and Arkansas to Tennessee and upper Georgia, and known in Alabama also from another locality, viz, the pine forests near Gadsden, Etowah County. 
Mesophile forests.- The forests of the fertile valleys and the inclosing hillsides of a somewhat fertile soil are heavily timbered. The Southern hackberry (Celtis mississippiensis), honey locust, and large, sweet or red gum (Liquidambar styraciflua), become more frequent among the abundant cow oak, Southern red oak, Spanish oak, and the more scattered tulip trees, white ash, and hickories of the lowlands, and the scarce black walnut. The timber growth on the larger tributaries of the Warrior, particularly the Mulberry fork and its numerous branches (Cane, Lost, Wolf, and others) crossed by the writer, has been but slightly encroached upon. The loblolly pine is confined to the narrow bottoms along the banks of the streams. In the semiswampy bottom of the Luxapallila, of a cold, somewhat sandy, and compact soil, this pine is found of large dimensions, scattered among beech, sweet gum, willow oak, cow oak, water oak, and laurel oak, the last two now becoming more frequent than observed farther north. The hillsides with a fresh soil and the openings in these forests are in the spring and early summer adorned by the flowers of the umbrella tree (Magnolia tripetala), Fraser magnolia (M.fraseri), and large-leaf magnolia (M. macrophylla), by the bloom of the Carolina silverbell, and by the profusion of the delicate white-flowered spikes of the small-flowered buckeye (Aesculus parviflora) and the dense clusters of Hydrangea quercifolia, known as sevenbark, both of these shrubs, strictly southern Appalachian, extending along the mountains to South Carolina and southwestern Virginia, respectively, and southward to the Tertiary hills.

The importance of the forests of the "Hill Country of Alabama," the great mineral region of the State, in connection with the wealth hidden in the ground beneath them, can not be too highly appreciated. The mining of every ton of coal requires half a cubic foot of timber. To this demand of the miner must be added the large drafts upon these forests for charcoal and for lumber, which are augmenting with the rapid increase of the population at the centers of mining and other industries.

Herbaceous plant associations.-The herbaceous flora of the Lower Hills, with its associations of species common on the table-lands and in the higher valleys of the mountain region, mingling with forms more or less frequent in the Louisianian area, differs but slightly in its general character from the similarly mixed flora of the southern edge of the metamorphic region. Characteristic, however, is the occurrence of a few endemic types confined to a single locality in this region and of others of a peculiarly local distribution rarely found elsewhere in the Carolinian and Louisianian areas. Neviusia alabamensis has already been mentioned as a monotype endemic to this region. To this is to be added Crotom alabamensis, presently to be further discussed. Phacelia bipinnata brevistylis is known only from the banks of the Warrior River near 'Tuscaloosa, and Croomia panci- 
Alora is known in the State only from the same locality, though it is found also in western Florida on the banks of the Apalachicola near the Georgia State line. A notable instance of disjoined range is that of Solidago curtisii, which also occurs near Tuscaloosa. It is chiefly a plant of the high mountains of Virginia, North Carolina, and Tennessee. Eupatorium incarnatum, which is found on the banks of North River (Tuscaloosa County) ranges from northwestern Louisiana and eastern Texas to east Tennessee and South Carolina. The following species, recorded in the order of their times of flowering, descend from the Tennessee Valley and the mountain region and on these hills find their southern limit:

Sanguinaria canadensis.

Anemone quinquefolia.

Syndesmon thalictroides.

Isopyrum biternatum.

Uvularia grandiflora.

Uvularia sessilifolia.

Dentaria laciniata multifida.

Anemone caroliniana.

Anemone virginica.

Saxifraga virginiensis.

Viola sagittata.

Viola pubescens.

Actaea alba.

Bicuculla cucullaria.

Washingtonia longistylis.

Obolaria virginica.
Polemonium reptans.

Phacelia purshii.

Heuchera americana.

Heuchera villosa.

Porteranthus stipulacea.

Sabbatia boykinii.

Verbesina helianthoides.

Verbesina alternifolia.

Campanula divaricata.

Mimulus alatus.

Solidago nemoralis.

Solidago amplexicaulis.

Solidago flexicaulis.

Aster shortii.

Aster camptosorus.

In their extreme southern continuation the Alleghanian spurs penetrate the Central Pine belt in Bibb County, there reduced to low, short ridges. Their outcrops, consisting of the oldest Silurian sandstones and cherts and Subcarboniferous limestones, give rise on this narrow area to a diversity of soil conditions, and hence their plant associations, generally of xerophile character, present a remarkable variety. Among the arboreal vegetation Acer floridanum is found. This maple, below medium size, occurs also in middle Florida and on the Tertiary hills in the upper division of the coast pine belt. It is here for the first time encountered by one coming from the northern part of the State.

After a long series of years of doubt concerning the existence of Quercus breviloba in Alabama, it was found in this region by the writer on the limestone hills lining the Little Cahaba River in 1882, more than forty years after it was first credited to the State by Buckley, who also discovered this tree subsequently in southern Texas. Under the shade of an open grove formed by this stately oak, in a rocky valley near Pratts Ferry, Croton alabamensis was discovered by Dr. E. A. Smith, forming dense thickets several acres in 
extent. It is a shrub of a decidedly tropical habit, properly belonging to the West Indian subgenus Eleuteria, from 10 to 15 feet high, squarrosely branched from the base, and conspicuous by the scurfy covering of silvery scales on the branchlets and lower sides of the leaves. The flowers open from early in March to the middle of April. By the end of the latter month the foliage of the previous year is replaced by new leaves. It appear's certain that this interesting shrub is strictly confined to this secluded valley near the banks of Little Cahaba River. The abundant white, star-like flowers of the densely tufted Sedum nevii enliven the moss-covered rocks beneath these thickets of Croton. This pretty plant is also found near Tuscaloosa and is recorded from the mountains of southern Virginia and from the Cumberland Mountains in Tennessee. Yeatesia laetevirens, ${ }^{1}$ extending to northwestern Louisiana and eastern Texas, and Arabis patens, extending to the Alleghenian area, occur on the shaded rocky borders. Of xerophile plants, Campanula divaricata, frequent in the Metamorphic and Coosa hills, is found on exposed cliffs with Gilia coronopifolia, the latter ranging from the middle rountry of South Carolina to the plains of Arkansas and Texas. Of rarer plants occurring here are Marshallia lanceolata, ranging from Gieorgia to Tennessee and North Carolina, and Silene regia, conspicuous by its rich panicles of flaming scarlet flowers, also at home in the prairies of southern Illinois and of the lower Ohio. Many a fern from the mountains finds here the southern limit of its distribution on the rocky, shaded banks of brooklets and streams. Of such may be enumerated:

Phegopteris hexagonoptera.

Asplenium muta-muraria.

Asplenium montanum.

Asplenium parvulum.

Asplenium trichomanes.
Asplenium filix-foemina.

Cheilanthes lanosa.

Cheilanthes alabamensis.

Woodsia obtusa.

Dryopteris marginalis.

\section{LOUISIANIAN AREA OR FLORA.}

Descending from the hills of the older (Paleozoic) formations, consisting of the extreme southern members of the Appalachian mountain system, the Austroriparian or Louisianian area of the Lower Austral life zone is reached. This area within the State is thus coterminous with the vast Coastal plain. The elevation of this plain scarcely exceeds at any point 350 feet above sea level, and in its gradual decline to the Gulf shore presents great uniformity in its topography. Undisturbed by local influences due to great differences in elevation, the distribution of heat here follows the lines of latitude. In consequence the climate does not run to extremes. The following are data of temperature and rainfall obtained at Greenville, Butler County, the most 
centrally located station where meteorological observations have been made during a series of years:

\begin{tabular}{|c|c|c|c|c|}
\hline & \multicolumn{3}{|c|}{ Temperature (degrees F.). } & \multirow{2}{*}{$\begin{array}{l}\text { Mean pre- } \\
\text { cipitation } \\
\text { (inches). }\end{array}$} \\
\hline & Maximum. & Minimum. & Mean. & \\
\hline $\begin{array}{l}\text { Winter } \\
\text { Spring } \\
\text { Summer } \\
\text { Autumn }\end{array}$ & 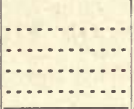 & (n......... & \begin{tabular}{l|}
51 \\
64 \\
79.4 \\
74
\end{tabular} & $\begin{array}{l}14.12 \\
16.10 \\
16.85 \\
11.33\end{array}$ \\
\hline Annual .... & 94 & 11 & 65 & 58.40 \\
\hline
\end{tabular}

The heat during the warmest season is tempered by the Gulf breezes prevailing from forenoon to late in the afternoon. The vapor-laden currents from the Gulf in their unhindered sweep over the plain discharge their moisture quite evenly throughout the year.

It has been shown that many of the plants frequent throughout the Carolinian area and types characteristic of the southern exposures of the Alleghany Mountains find their southern limit of vegetation on the hills bordering upon the coastal plain. A similar limitation has also been pointed out for a number of shrubs and trees, clearly marking the border line between the Upper and Lower Austral life zones. This zonal border, marked by trees strictly confined to the Louisianian area of the Lower Austral zone throughout its extent from east to west, not only in Alabama, but from the Atlantic coast to the eastern border of the Southwestern arid plains, deviates but slightly from the line of latitude $32^{\circ} 30^{\prime}$, and is clearly indicated by the northwestern limit of the following species:

Magnolia foetida (M. grandiflora L.) (magnolia).

Hicoriamyristicaeformis (nutmeg hickory).

Hicoria aquatica (bitter pecan).
Quercus laurifolia (laurel oak). Quercus lyrata (overcup oak). Quercus catesbaei (turkey oak). Pinus glabra (Southern spruce pine).

The evergreens, consisting of pines on the light siliceous soils and of broad-leaved species in the mesophile forest, predominate largely over the deciduous forest growth, and the frequency of types identical with tropical forms, or closely allied to them, impress upon the vegetation of this life area the character of the subtropical regions.

The cultural plant formations of these regions, and confined within the limits of this zone, are:

Gossypium herbaceum (cotton).

Zea mays (Indian corn).

Saccharum officinarum (tropical sugar cane).

Oryza sativa (rice).

Sorghum vulgare (Durrha, Kafir corn).
Sorghum halepense (false Guinea or Johnson grass).

Penicillaria spicata (cat-tail millet).

Panicum barbinode (Para grass).

Chaetochloa italica (Italian millet).

The growing of the cereals of this list replaces almost exclusively the cultivation of small grain. 
Of arboreal formations the peach, fig, pear, plum, pomegranate, and, in sheltered situations, the sweet and bitter orange and loquat, or Japanese medlar are cultivated, and also the grape. These fruits are, however, not yet planted sufficiently to form large orchards.

REGION OF THE CENTRAL PINE BELT.

Physiographical features.-A belt of sands and pebbles crosses the State almost centrally in a southeastern and northwestern direction and separates the Paleozoic formation from the more recent sedimentary (Mesozoic) strata. This belt, varying from about 10 to a little over 35 miles in width, extends from Russell County to a short distance west of Tuscaloosa County, where, with a sudden bend toward the north, it merges into the Lower Hills, which are clad with a mixed forest of short-leaf pine and upland hard-wood trees. Between the water courses the undulating surface frequently spreads out into more or less level table-lands.

Xerophile and mesophile forests. - Wherever the sandy loam forming the surface soil becomes deeper, the long-leaf pine is associated with post oak, Spanish oak, black oak, black-jack, pignut, and mockernut hickory, and where the more siliceous soil prevails the long-leaf pine alone forms continuous forests of a heavy timber growth, which furnish the supplies demanded by the active lumber industry established along the railroad lines traversing this belt.

Entering this region at the northern border, the turkey or barren oak and the blue jack make their appearance and are frequent companions of the long-leaf pine of the dry-pine barrens farther south; and of evergreen shrubs and trees, which line the streams throughout the maritime pine belt, the sweet illicium (Illicium floridanum), ti-ti (Cliftonia monophylla), and red bay (Persea carolina) are here met with. The limbs of the large trees, shading their banks, are now invested with the somber gray drapery of Spanish moss, and this, together with the appearance of the dwarf or blue palmetto (Sabal adansonii) and arborescent lilies ( $Y$ ucca aloifolia, Y. filamentosa), indicates that the subtropical region of the State has been entered. On the southern border of this central pine belt, in localities with a fresh moist soil, the magnolia is found from Russell County, at the eastern confine of the State, to Prattville and to York Station on the western boundary. The northern limit of the Southern spruce pine (Pinus glabra) proceeds very nearly along the same line.

Xerophile and mesophile herbaceous plant associations. - The following herbaceous plants of the Louisianian area find their northern limit in this region and are but occasionally found to obtrude beyond it 
upon the adjacent lower hills. Belonging to xerophile associations are:

Paspalum ciliatum.

Paspalum dasyphyllum.

Panicum nashianum.

Muhlenbergia trichopodes.

Eragrostis hirsuta.

Gymnopogon ambiguus. ${ }^{1}$

Cyperus filiculmis. ${ }^{1}$

Cyperus ovularis. ${ }^{1}$

Commelina nudiflora. ${ }^{1}$

\author{
Commelina virginica. ${ }^{1}$ \\ Bradburya virginica. ${ }^{1}$ \\ Meibomia stricta. ${ }^{1}$ \\ Breweria humistrata. \\ Clinopodium (Calamintha) carolinianum. \\ Verbena caroliniana. \\ Vernonia graminifolia. \\ Solidago petiolaris. ${ }^{1}$ \\ Lacinaria elegans. ${ }^{1}$
}

Belonging to mesophile associations:

Paspalum praecox.

Paspalum dilatatum.

Panicum melicarium.

Fuirena squarrosa hispida. ${ }^{1}$

Rynchospora axillaris.

Carex verrucosa. ${ }^{1}$

Carex debilis pubera. ${ }^{1}$

Carex baileyi.

Kobresia odorata.

Xyris iridifolia.
Xyris torta. ${ }^{1}$

Xyris caroliniana. ${ }^{1}$

Smilax laurifolia.

Atamosco (Zephyranthes) atamasco.

Pogonia divaricata. ${ }^{1}$

Gyrostachys praecox. ${ }^{1}$

Amsonia cilitata.

Jacquemontia tamnifolia.

Breweria humistrata. ${ }^{1}$

Brintonia discoidea. ${ }^{1}$

CENTRAL PRAIRIE REGION.

PHYSIOGRAPHICAL FEATURES.

This floral region comprises the plain of Cretaceous rocks which crosses the State in a belt from 35 to 45 miles wide, its mean elevation above the Gulf of Mexico scarcely exceeding 200 feet. It is inclosed at its northern and at its southern limit between the pineclad hills, which rise from 150 to 250 feet above the depression of the plain. Rarely perfectly level, the plain rises in broad swells above the sluggish water courses. Westward the water courses of this plain are the tributaries of the Tombigbee and Alabama rivers, and toward the east they empty into the numerous bays which indent the coast of western Florida or into the Chattahoochee River. It covers an area roughly estimated to exceed somewhat 5,000 square miles, embracing all, or nearly all, of Greene, Hale, Dallas, Lowndes, Montgomery, Macon, and Bullock counties, and parts of Sumter, Marengo, Perry, Autauga, Pike, and Russell.

The following climatic data are furnished by the records of the meteorological station at Montgomery, extending over twenty-two years:

Data of temperature and rainfall.

\begin{tabular}{|c|c|c|c|c|c|}
\hline & Annual. & Winter. & Spring. & Summer. & Fall. \\
\hline $\begin{array}{l}\text { Mean temperature } \\
\text { Rainfall } \\
\text { Cloudy days } \ldots \ldots \ldots \ldots \ldots \ldots \ldots \ldots \ldots \ldots \ldots \ldots \ldots \ldots \\
\end{array}$ & $\begin{array}{l}63.3 \\
51.4 \\
47\end{array}$ & $\begin{array}{l}50 \\
17.1 \\
55\end{array}$ & $\begin{array}{l}66.6 \\
16.74 \\
44\end{array}$ & $\begin{array}{l}80 \\
12.22 \\
47\end{array}$ & $\begin{array}{l}65.4 \\
83 \\
43\end{array}$ \\
\hline
\end{tabular}

${ }^{1}$ Less frequently found north of the Central Pine belt. $15894-7$ 
The last killing frost happens between the middle of February and latter part of April, on the average, about the 8th or 10th of March. The maximum temperature was in July $106^{\circ}$; the minimum in Januuary $5^{\circ} .{ }^{1}$ The course of the temperature, which has such a potent influence on plant growth, is best represented in the following series of the absolute and average minima and maxima for each month during the same period:

Series of maximum and minimum temperatures.

\begin{tabular}{|c|c|c|c|c|c|c|c|c|c|c|c|c|}
\hline & Jan. & Feb. & Mar. & Apr. & May & June & July & Aug. & Sept. & Oct. & Nov. & Dec. \\
\hline \multicolumn{13}{|l|}{ Maximum: } \\
\hline Absolute. & 75.5 & 81.2 & 86.3 & 90 & 99 & 105 & 106.9 & 103 & 98 & 96.1 & 83 & 79 \\
\hline $\begin{array}{l}\text { Average.. } \\
\text { Minimum: }\end{array}$ & 73.3 & 76.9 & 80.8 & 86.8 & 93.5 & 97.1 & 98.9 & 96 & 93 & 86.3 & 79 & 72.7 \\
\hline Absolute ................ & 5.4 & 14 & 25 & 30 & 44 & 48 & 60.8 & 59 & 40 & 31 & 21 & 8 \\
\hline Average............... & 19.3 & 24.5 & 33.2 & 40.5 & 50.7 & 61.1 & 69 & 65.5 & 52.7 & 40 & 29.1 & 22.8 \\
\hline
\end{tabular}

XEROPHILE FORESTS.

Post-oak prairies.-All over the region, particularly on the highest swells, the drifted clayey loams, sands, and pebbles mingle with the soil resulting from the decomposition of the underlying limestone strata, and give rise to light, more or less sandy, loams or heavy calcareous clay soils, covered with open xerophile forests of Spanish oak, black oak, black jack, post oak, the last predominating, associated with mockernut and pignut hickory. Where the heavy clay soils prevail, destitute of humus, water-soaked during seasons of rain and baking to a hard crust during droughts, these so-called post oak prairies have been but little encroached upon. Under the cover of the brush the gramineous plant formations predominate, while sedge grasses (Cyperaceae) abound in the more shaded and wet situations. For example, Eleocharis tuberculosa, E. ovata, ${ }^{1}$ and Cyperus pseudovegetus, ${ }^{2}$ on the borders of ditches and pools; Carex triceps, a very distinct southern type, occurring from South Carolina to central Texas, but not in this State north of the southern edge of the metamorphic hills; C. hirsuta, ${ }^{1} C$. oblita, C. sterilis, ${ }^{1}$ C. lurida,${ }^{1}$ common throughout the Carolinian area; $C$. oxylepis, C. cherokcensis, C. debilis pubera of a more southern range; together with Panicum melicarium, P. anceps, and Uniola laxa. ${ }^{1}$ In drier and more exposed places:

Scleria triglomerata ${ }^{1}$ (abundant). Allium canadense. ${ }^{1}$ Quamasia esculenta. ${ }^{1}$ Lobelia appendiculata.

Steironema ciliatum. ${ }^{1}$

Steironema lanceolatum. ${ }^{1}$

Penstemon hirsutus. ${ }^{1}$

Hibiscus incanus.

The last is a stately perennial of the Louisianian area known from a few localities between South Carolina and northwestern Louisiana.

${ }^{2}$ Rarely found north of the Central Pine belt. 
The ubiquitous bush clover's, Japanese clover, and tick-trefoils in a large measure take possession of the drier and lighter soil in the post oak woods.

Where the limestone strata come near to the surface and the soil is not of sufficient depth to support a heavier tree growth, the oaks and hickories give way to copses of small trees and shrubs, among which hawthorns of different species are most abundant. Characteristic species are:

Crataegus coccinea (scarlet haw.) ${ }^{1}$

Crataegus molle (black thorn). ${ }^{1}$

Crataegus crus-galli (cockspur thorn). ${ }^{1}$

Crataegus flava (summer haw.)

Crataegus viridis (red haw.)

Pyrus angustifolia (southern crab apple).
Prunus umbellata (prairie plum).

Bumelia lycioides (false sonthern buckthorn).

Rhamnus caroliniana (Carolina buckthorn).

Ptelea trifoliata (trefoil hop tree). ${ }^{1}$

These coppices form isolated boskets in the open or skirt the postoak prairies, and when covered in the spring with the snowy white flowers of hawthorns, plums, and crab apples or adorned in autumn with their lurid red and flaming scarlet fruits, impart to the landscape a peculiar charm, relieving the monotony of the interminable fields of cotton.

Hill prairies.-On the hills bordering the plain northward and southward and on the highest ridges within the plain, capped like the hills with drifted siliceous deposits, the short-leaf pine mingles with the hard-wood trees, while the longleaf pine makes its appearance on the most abrupt of their summits. Where on these hills the drifted soils have been removed by denudation, the rich black soil of the prairies or, calcareous marls prevails, covered either with the white oaks and hickories, or with cedar hammocks. These so-called hill prairies are mostly under cultivation, and the abandoned exhausted fields have been taken possession of by shortleaf and loblolly pine. East of the Alabama River, particularly on the divide between the waters of the Tallapoosa and those of the tributaries of the Chattahoochee, Choctawhatchee, and Conecuh rivers, the plain becomes broken into low hills, and the drifted deposits mingle largely with the soils of the rotten limestone. On these hills the timber growth, through the frequent interspersion of the shortleaf pine, assumes the same mixed character which prevails in the adjoining upper division of the Maritime pine belt.

In the ravines and the narrow valleys the Southern spruce pine (Pinus glabra) with magnolias and cucumber trees is of frequent occurrence.

MESOPHILE FORESTS.

Prairie region. - The term "prairie region," applied to this plain, refers less to the timberless tracts which originally formed a small fraction of its area than to the black, calcareous, highly fertile soil of 
these uplands, which, being rich in humus, as a result of the reaction of its calcareous constituents upon vegetable matter, closely resembles the equally productive soil of the western treeless prairies. Before its settlement by whites this region was largely covered by forests of a decidedly mesophile character, mostly of hardwood trees, in some localities mixed with red cedar. On the fertile uplands the forest has been almost entirely removed; the bottoms of the Alabama and Tombigbee rivers and their largest tributaries, where subject to overflow, are still heavily timbered with a mesophile growth of cow oak, overcup oak (Quercus lyrata), laurel oak (Quercus laurifolia), water oak, red or sweet gum -in such perfection as this tree attains only in the Atlantic forests of the lower latitudes-beech, mockernut (Hicoria $a / b a$ ), and bitternut hickory (Hicoria minima), all draped with Spanish moss. A fine elm is also frequently met with here of a sturdy growth, often fully 2 feet in diameter, the branchlets covered with corky flat expansions of the bark. Although not seen in flower or fruit this tree certainly is distinct from the white elm (Ulmus americana), and is doubtless identical with the Southern white elm lately discovered by Messrs. Sargent and Canby near Huntsville, and described in the succeeding catalogue. With the rise of the land above overflow, tulip trees, linden, mulberry, stately magnolias, hackberry, and red bay (Persea borbonica) mingle with the trees of the bottom. The diversity of the arboreal vegetation increases further on the broad swells of the uplands with a rich dark soil, as is apparent from the rather scanty remains of their tree covering observed between Uniontown and Demopolis. On these rich uplands the Texas white oak (Quercus breviloba), commonly known in this section as pin oak, is found most frequent and in the same perfection as in the rich bottom lands of southern Texas, rivaling in size the common white oak. This beautiful oak is at once recognized by the diverse shapes of the leaves, which frequently vary on the same tree from oblong-lanceolate and entire to broadly ovate or obovate and obtusely three-lobed at the apex; and also by the small fruit. The post oak, in its best-developed state, is frequently associated with the above. Black walnut, frequently mentioned in the records of earlier times, is at present extremely scarce; in fact, as a timber tree it has disappeared from these forests. The pecan (Hicoria pecan) and nutmeg hickory (Hicoria myristicaeformis) are frequently scattered among the oaks throughout the woodlands of this region in the basin of the Alabama and Tombigbee rivers. There can be no doubt about the pecan being indigenous to this region, although heretofore not regarded as a native of the eastern Gulf region outside of the Mississippi and Yazoo deltas. Groves of full-grown trees, which must have been in existence before the arrival of the first white settlers, are remembered by very old inhabitants. A few of these landmarks of the original forest growth still survive, surrounded by their offspring 
of succeeding generations, notably on a plantation near Faunsdale, Dallas County. Generally this tree has disappeared with the oak forest on the fertile lands, and is at present found only in the small groves of oaks saved from destruction to shade the grounds around the dwellings of the planters. The nutmeg hickory, when full grown, resembles the shagbark hickory in its pale, shreddy bark, but it is readily distinguished from the latter by the silvery hue of the lower surface of the leaves and the smaller fruit, with a thin epicarp inclosing the perfectly smooth nut, which simulates the nutmeg in size and shape. By the discovery of the nutmeg hickory in this region, and of its extension into Mississippi, the northern limit of the distribution of this tree from the Atlantic slope in South Carolina to Texas and northern Mexico, following with hardly any deviation, the same parallel of latitude, is now clearly established.

Of trees of smaller size the pawpaw (Asimina triloba), redbud (Cercis canadensis), Carolina buckthorn (Rhamnus caroliniana), and of shrubs the spice bush (Benzoin (Laurus) benzoin), form the undergrowth and frequent the openings. Vitis aestivalis, the vigorous summer grape, Vitis cinerea, Vitis rotundifolia, the slender-stemmed bullace grape, and the supple jack (Berchemia volubilis), ascend the highest trees without visible support below the lofty summits, where these members of the liana formation spread out their branches, and under a fuller exposure to the sun unfold their flowers and ripen their fruit. With these are associated a number of others of the same plant formation, namely:

Bignonia crucigera (cross vine).

Parthenocissus quinquefolia (Virginia creeper).

Ampelopsis arborea (Vitis bipinnata Torr. \& Gr.) (pepperidge vine). Ampelopsis cordata.

Tecoma radicans (trumpet vine).

These vigorous woody climbers cover with their festoons the borders of these forests as it were with an impenetrable curtain of green. Smaller woody and herbaceous perennial climbers entangling the bushes and smaller trees are:

Smilax bona-nox (greenbrier).

Smilax laurifolia (greenbrier).

Smilax lanceolata (greenbrier).

Brunnichia cirrhosa.
Cebatha carolina.

Aristolochia tomentosa.

Calycocarpum lyonii (cup vine).

- Schizandra coccinea.

The last is a type of the Louisianian area, sparsely distributed from South Carolina to northwestern Louisiana. Nowhere is the poison ivy (Rhus radicans) found of more luxuriant growth and in greater abundance than in the openings of the damp forests. Taking a firm hold in the bark of trees with its innumerable rootlets, the stem creeps up to the top of the highest trunks, which are completely hidden by the long horizontal branches of this creeper when covered with their soft, rich foliage. 
Cedar hammocks. - On the highest swells of the plain where the strata of the rotten limestone are overlaid by lighter loams poorer in humus, deep, and of perfect drainage, forests prevail of a mixed-tree growth, consisting of the following:

Fraxinus americana (white ash). Quercus laurifolia (laurel oak). Celtis mississippiensis (hackberry). Quercus texana (Southern red oak).
Ulmus americana (white elm).

Acer saccharum barbatum (small-leaf sugar maple).

Juniperus virginiana (red cedar).

Originally the red cedar formed about 30 per cent of the timber growth. The ground beneath is densely shaded by the following:

Asimina triloba (pawpaw).

Ilex decidua (deciduous holly).

Adelia ligustrina (Southern privet).
Zanthoxylum clava-herculis (Southern prickly ash).

The red cedar of these forests is of most vigorous growth, the smooth trunk free of limb for a height of from 30 to 50 feet and from 16 to 20 inches and over in diameter, and less affected by decay than in the northern part of the State. These cedar hammocks once formed detached tracts extending over many square miles. At present only a few remnants of them are left, and these are doomed to speedy destruction by the drafts made upon their valuable timber and through the injuries constantly inflicted upon the young growth by live stock.

MESOPHILE HERBACEOUS PLANT ASSOCIATIONS.

In the shade of these forests, as observed on the banks of Big Prairie Creek, the herbaceous plant associations are poorly represented by mesophile species more or less common throughout the Carolinian area. Some of the species are:

Adicea urticaefolia.

Impatiens biflora.

Thaspium aureum.

Vincetoxicum (Gonolobus) hirsutum.
Vincetoxicum laeve.

Irepocarpus aethusae.

Dioclea multiflora.

The Trepocarpus is frequent in eastern Texas, but has heretofore been known in the eastern Gulf States only as a fugitive on ballast in several localities. The Dioclea has been known from a few localities in Georgia, and especially along the Luxapallila River, near Columbus, Miss., and is abundant in the bottoms of the Mississippi and Yazoo deltas.

Canebrakes.-The most prominent feature in the vegetation of this region consists of the extensive tracts of cane, arborescent grasses of the bamboo tribe, which prevail throughout the depression of the plain. The large cane (Arundinaria macrosperma) inhabits the alluvial bottoms more or less submerged for the greater part of the year, and the small or switch cane $(A$. tecta) prevails in the open as well as in the 
forest on the low plains which rise above the water courses and are subject to overflow only at the time of high freshets. So conspicuous was this formation in the western part of the plain that it is called emphatically the "canebrake region." At present a comparatively small representation of the smaller eane remains. It occupied the most fertile lands, and these were claimed for the plow by the earliest settlers. Although the growth was so dense as to be almost impenetrable, it was easily eradicated, being susceptible to the effects of fire. The strips of the large cane which lined the banks of the larger streams subject to frequent overflow have for the most part remained intact. These two species, which resemble each other so closely in habit, differ greatly in their modes of reproduction, a subject of much interest of which but little is as yet known and one which invites the attention of the investigator of the ecological relations of plants, and no less that of the agriculturist, on account of the value of the canes as pasture plants. Arundinaria tecta rarely exceeds the height of 12 to 15 feet, and the slender culm branched from the base is seldom half an inch in thickness. Early in spring, apparently every three or four years, the paniculate flowers are produced on naked radical shoots scarcely exceeding 18 inches in height, while the tall flowerless canes are sent up every season from the long creeping rhizomes. Amundinaria macrosperma, from 15 to 30 feet high and frequently an inch and over in diameter, produces the panicles of its flowers in the axils of the branches at long and indefinite intervals of time. It is evident, therefore, that generations may pass by before the spectacle of such a canebrake in bloom is ever witnessed. For example, in the beginning of the summer of 1896 the inhabitants of Russell County were astonished suddenly to find the large canebrakes bending under the burden of their heavy, nutritious grains, which attracted large numbers of birds and beasts. The farmers regarded this as an entirely new plant, and, finding their stock grew fat upon the seed, stored away quantities of it, not only for future feeding, but under the delusion that if sown it would constitute a crop of small grain equal in value to any previously grown. But in the light of experience it is to be presumed that a period of not less than forty to fifty years has to pass before the propagation of this plant by sexual reproduction takes place. With the maturity of the seed the vitality of the plant is exhausted and the cane decays. In the succeeding season, from the spontaneous stocking of the ground with an abundance of seed, a new crop springs up. The seedlings produce no branches during the first year. These simple sprouts, which are known as "mutton cane," are tender and sweet and afford the best of pasturage. They are particularly sought after by bears, which find in the impenetrable density of the canebrake their securest retreats. 
Campestrian plant associations.

Bald prairies. - The eminences of the lower swells of the plain with the strata of the limestone near the surface and destitute of arboreal growth are called bald prairies. Wherever the soil is not too shallow to be cultivated, these open prairie lands are devoted to the production of corn, oats, or forage crops, and only the poorest spots remain in the original state. These bald prairies can be regarded as the true home of the original campestrian flora, which is peculiar to a calcareous soil rich in humus and with a sunny exposure. Many of its types are held in common with the plant associations prevalent on the grassy timberless plains of eastern North America. These types have spread all over the cretaceous depression wherever the forest has been removed, and find refuge also on the borders of fields and woods, and in waste places and abandoned grounds. Of grasses the following are most common in the open, except the last two, which prefer sheltered borders:

Paspalum laeve. ${ }^{1}$

Paspalum distichum.

Panicum flexile. ${ }^{1}$

Panicum autumnale. $^{1}$

Andropogon furcatus. ${ }^{1}$

Sieglingia seslerioides. ${ }^{1}$

Bouteloua curtipendula. ${ }^{1}$
Eragrostis capillaris. ${ }^{1}$

Eragrostis refracta. ${ }^{1}$

Eragrostis purshii. ${ }^{1}$

Poa compressa. ${ }^{1}$

Elymus virginicus. ${ }^{1}$

Bromus unioloides.

Uniola latifolia.

The following introduced and adventive weeds invade cultivated grounds, the last two named ineradicable and seriously injurious to the crops:

Paspalum dilatatum.

Sorghum halepense.

Eleusine indica. ${ }^{1}$

Cyperus rotundus.

Sorghum sativum.

Associated with the grasses are the following species widely distributed in the open of the Carolinian area:

Hypericum sphaerocarpum. ${ }^{1}$

Kuhnistera candida. ${ }^{1}$

Kuhnistera purpurea. ${ }^{1}$

Acuan illinoensis. ${ }^{1}$

Cassia multipinnata. ${ }^{1}$

Polygala mariana. ${ }^{1}$

Linum sulcatum. ${ }^{1}$

Euphorbia dictyosperma. ${ }^{1}$

Onagra biennis. ${ }^{1}$

Gaura michauxii. ${ }^{1}$

Polytaenia nuttallii. ${ }^{1}$

Asclepias obovata. ${ }^{1}$

Asclepiodora viridis.

Heliotropium tenellum.

Myosotis verna.
Verbena angustifolia. ${ }^{1}$

Verbena canadensis (V. aubletia). ${ }^{1}$

Eupatorium altissimum (rare). ${ }^{1}$

Eupatorium serotinum. ${ }^{1}$

Silphium laciniatum. ${ }^{1}$

Silphium scaberrimum. ${ }^{1}$

Silphium trifoliatum. ${ }^{1}$

Brauneria pallida. ${ }^{\mathrm{I}}$

Rudbeckia trilobata. ${ }^{1}$

Helianthus hirsutus. ${ }^{1}$

Helianthus divaricatus. ${ }^{1}$

Coreopsis lanceolata. ${ }^{1}$

Lepachys pinnata. ${ }^{1}$

Mesadenia plantaginifolia. ${ }^{1}$

${ }^{1}$ Also found north of the Central Pine belt. 
Of other herbaceous plants belonging to the same campestrian association and confined to the Louisianian area are to be mentioned Polygala boykinii and Xylopleurum speciosum, conspicuous on account of their large flowers of bright rose color, common on the prairies of central Texas, southern Arkansas, and northwestern Louisiana and appearing to be indigenous in Alabama, and Gaillardia pulchella, Rudbeckia amplexicaulis, and Monarda citriodora, of the same distribution but less frequent here, and perhaps adventive by the seed having come with the seed oats frequently brought from central Texas.

Sand hills near Montgomery.-A peculiar association of xerophile herbs, remarkable for the occurrence of types not observed elsewhere in the State, is found on the hills with a loamy, sandy soil, rising above the cypress swamps on the eastern banks of the Alabama River near the city of Montgomery. At the base of the hills occur:

Carduus elliottii.

Isopappus divaricatus.

Cnicus benedictus (naturalized from Tragia urticaefolia.

Europe).

The sides of the hills are covered with xerophile grasses:

Aristida dichotoma.

Eragrostis capillaris.

Eragrostis refracta.
Panicum cognatum.

Panicum flexile.

The grass is studded with:

Aster undulatus.

Aster patens.

Allionia hirsuta.

Silene ovata.

Kuhnia eupatorioides.

The northern Kuhnia is extremely rare in the State. Allionia hirsuta is at home in the prairies of the West from Minnesota to Texas. Silene ovata is found in the exposed ravines of these hills. It is also found in the Cumberland highlands of Tennessee, and is distributed somewhat widely in the mountains of the Carolinas and Georgia.

CULTURAL PLANT FORMATIONS.

This region constitutes the great agricultural region of the State, celebrated for its large production of cotton. With the decline in the price of this staple crop during late years greater attention has been given to the growing of breadstuffs and forage crops. Broad fields of Indian corn and oats are seen on every hand; and since an increased interest is taken in the raising of stock, the old fields exhausted by the continuous practice of the one-crop system are either being converted into wide pastures of Bermuda grass (Capriola dactylon) or, to hasten their recuperation, are planted in white melilot (Melilotus alba), known in these parts as Bokhara clover, which, like red clover, as an ameliorating forage crop for hay and for pasture, has proved of the greatest benefit on the exhausted calcareous prairie lands. In the beginning of the new era in the agriculture of the South, Sorghum halepense was extensively raised as a perennial hay crop. After it was 
found, however, that in this plant an almost ineradicable pestiferous weed had been introduced, its cultivation was restricted to low, undrained tracts, unfit for other crops. Although peaches, plums, pears, the fig, and grapes succeed on the ridges, the cultivation of these fruits is much neglected, and does not supply even a small part of the home demand.

.MARITIME PINE REGION.

The great belt of long-leaf pine forest, which extends almost without interruption from southeastern Virginia over the coast region of the Atlantic States to the lowlands of the Mississippi River, adjoins on its southern border the Central Prairie belt.

UPPER DIVISION OF THE COAST PINE BELT OR REGION OF MIXED TREE GROWTH.

Physiographical features - In the upper part of this pine belt, from South Carolina to eastern Mississippi, a mixed growth of pine and broad-leaved evergreen trees alternates with belts or rather strips of pure long-leaf pine forest. In Alabama this region of cone-bearing and broad-leaved evergreen and deciduous trees is confined within the limits of the older Tertiary strata, which in this State cover about onehalf of the area of the Coast Pine belt, although the beds of drifted sands and gravels of a more recent formation overlie the older rocks in large areas. In its climatic conditions this region differs but slightly from the foregoing. Its floral character is difficult to define. Broadly stated, it consists in the increased frequency of types which are at home in the Louisianian area, and in distinction from regions farther north, of a tree growth in which, though otherwise similar, the long-leaf pine in its highest development predominates. Equally difficult is the establishment of the limits of this floral region. It has been already mentioned that the tree growth in the eastern part of the Central Prairie region is scarcely to be distinguished from the forest flora of this region. Toward the west the border is more clearly outlined by the hilly uplands of the lowest Tertiary strata rising above the Cretaceous plain. The southern border of this region is frequently overlapped by the pure forests of long-leaf pine of the lower division of the Coast Pine belt, and it can be defined on stratigraphical grounds only by being identified with the lines which mark the most southern outcrops of the underlying Tertiary rocks. Defined on this basis the area in question contains about 9,000 square miles, occupying the following counties or portions of counties: Parts of Sumter; all or nearly all of Choctaw, Clarke, Monroe, Butler, Conecuh; portions of Covington, Montgomery, Bullock, Barbour, Pike, and nearly all of Coffee, Dale, and Henry. Along its northern border where the lignitic strata prevail the uplands rise to an elevation at the highest of about 400 feet above tide water, spreading out into table-lands of greater or less 
width, not rarely interrupted by steep ridges where the lowest Tertiary strata offered greatest resistance to erosion. The highest ridges are frequently capped with the sands and gravels of the Lafayette formation, which are under cover of the long-leaf pine, as are likewise the rugged hills of flinty clay stones and siliceous rocks of the buhrstone strata which traverse the central part of this region in a southeasterly and northwesterly direction, sloping toward the east. East of Patsaliga Creek the hills become less prominent, the softer strata of the Eocene Tertiary spread out into undulating table-lands, and the generous brown soil supports the mixed growth of xerophile and mesophile woody species, evergreen and deciduous, characteristic of the region. Toward the south the surface becomes less broken. East of the Alabama River the drifted deposits form broad table-lands between the streams, occasionally inclosing more or less extensive tracts with the calcareous strata of the Middle Tertiary for the surface rock, very similar in their soil and vegetation to the post-oak prairies of the preceding region. In Dale County and westward to the State line beds of white sand (Ozark sands) overspread the loamy sands and gravels, rendering the soil arid and sterile.

West of the Alabama River, in the southern part of Clarke and Choctaw counties, calcareous strata form the surface rock over large areas identical in their soil conditions and the character of their vegetation with the isolated tracts farther east just mentioned.

Xerophile forests. - The rocky ridges of the Buhrstone, or those capped with the more recent drifted strata, are covered with magnificent forests of long-leaf pine which are nowhere surpassed in their timber wealth within the range of this tree. This applies particularly to the forests which cover the hills between the Alabama and Tombigbee rivers. By careful estimates made upon a number of plots, selected at random, the yield of a single acre will vary from 10,000 to 18,000 feet and over of merchantable timber. In these forests, which grow from a deep warm soil consisting of sandy loams, dogwood and black jack form the scanty undergrowth. The rocky crests and most abrupt declivities of the highest of these hills afford but a scanty foothold to the pine. The rocky ground is sparingly covered by the following shrubs, all of them bushes, except the last, which is a creeper branching from the base:

Vaccinium stamineum (deerberry). Gaylussacia dumosa (dwarf huckleberry). Vaccinium myrsinites (bilberry).

Viburnum acerifolium (maple-leaved arrowwood).

Smilax bona-nox forma pandurata (bamboo brier).

Forests of long-leaf pine predominate wherever the older rocks are deeply hidden under the sands and gravels, and where this region passes imperceptibly into the pine uplands of the Lower Division of the Maritime Pine belt. The herbaceous plant associations in these 
pine forests do not differ from those forming the soil cover in the open pine forests of the adjoining Lower Pine belt.

Xerophile herbaceons plant association.-In the parts where the reaction of the decomposing limestone strata upon decaying vegetable matter has produced soil conditions similar to those which prevail in the Central Prairie region (which includes the more or less calcareous lands of the post oak prairies and cedar hammocks), the plant associations bear the same campestrian character. In Monroe and Clarke counties are found the same tall Compositae, together with various plants of other families, which are characteristic of that region. The following species are examples:

Helianthus tomentosus.

Helianthus hirsutus.

Silphium laciniatum.

Silphium asperrimum.

Silphium laevicaule.

Lepachys pinnata.
Lithospermum tuberosum.

Phacelia purshii.

Verbena canadensis.

Acuan (Desmanthus) brachycarpum.

Morongia horridula.

None of the above are met with farther south except the last two, which extend to the coast plain. Of xerophile and mesophile plants inhabiting shaded rocky dells and banks, the following find here their southern limit:

Hepatica hepatica.

Anemone decapetala.

Ranunculus recurvatus.
Panax quinquefolia.

Collinsonia canadensis.

Houstonia caerulea.

On the damp rocks which line the narrow channels of brooks deeply cut into the limestone strata, the maidenhair fern (Adiantum capillusveneris) occupies every crevice. Toward the southern confines of the region the following, which grow also in the adjoining region, are found:

Sida elliottii.

Callirhöe papaver.

Clinopodium carolinianum.

Scutellaria canescens punctata.

Koellia. albescens.

Stokesia laevis.

On the limestone bluffs inclosing the bed of the Alabama River, for instance near Claiborne, Dirca palustris, a shrub from the Alleghenian area, finds in deeply shaded situations its extreme southern outpost. Philadelphus inodomus with Ptelea trifoliata and the river grape (Vitis riparia) are also found on the bare ledges of these bluffs on the opposite sides of the river. In the southwestern part of this region where the calcareous prairie soils are mixed with the light loams, the red cedar once formed a large portion of the timber growth, making a feature analogous to the cedar hammocks of the Central Prairie region. The cedar hammocks of this region are at present, however, nearly all under cultivation, and the few still covered with cedar are rapidly being stripped of their valuable timber, mostly for use as pencil wood.

In the eastern extension of this region the loose Ozark sands form 
the arid surface soil, spreading over a large part of western Florida and southern Georgia. These are covered by very open pine barrens, and the latter are inhabited by a number of peculiar herbaceous species. Most widely diffused and abundant are:

Aristida stricta.

Panicum xanthospermum.

Eriogonum tomentosum.

Coleosanthus cordatus.

Eupatorium tortifolium.

Eupatorium lecheaefolium.

\section{Koellia nuda.}

Ceranthera linifolia.

Chrysopsis hyssopifolia.

Eupatorium leptophyllum.

Eupatorium coronopifolium.

Aristida stricta (wire grass) will be spoken of later as an inhabitant of the Lower Pine belt. 'These and other species common to this region and the dry pine barrens farther south form a scanty covering for the barren sands.

Mesophile forests.- On the lower flanks of the ridges and on the lower hills of the Central Pine region the short-leaf pine mingles with the long-leaf species and with the frequently named upland oaks and hickories, chinquapin (Castanea pumila), and basswood (Tilia heterophylla). As the declivities merge into the narrow valleys with a fresher soil more retentive of moisture, mesophile species gradually gain the upper hand. Representative trees are:

Magnolia foetida (magnolia).

Magnolia macrophylla (large-leaf cucum-

ber tree).

Fagus americana (beech).
Pinus glabra (Southern spruce pine).

Quercus nigra (water oak).

Quercus laurifolia (laurel oak).

There is a variety of shrubs in the openings and along the borders of the forest, among which are:

Styrax grandifolia (large-leaved storax bush).

Illicium floridanum (sweet illicium).

Aesculus parviflora (white-flowered buckeye).
Aesculus pavia (red buckeye).

Ilex longipes (holly).

Butneria (Calycanthus) florida (Carolina allspice, lowland calycanthus).

Chionanthus virginica (fringe tree).

The first of these is frequent in the Louisianian area from North Carolina to Louisiana. In these mesophile forests the same species of the liana formation which prevail in the Central Prairie region are equally frequent. To the small shrubby climbers are to be added Clematis catesbaei, rare from lower South Carolina to Florida and known in Alabama only from the vicinity of Suggsville, Clarke County; C. reticulata, infrequent from South Carolina to Texas; C. crispa, frequent on low, damp banks southward to the coast plain; and, finally, the yellow jessamine (Gelsemium), in damp and dry situations throughout the Maritime Pine belt.

Mesophile and paludial forests of the lowlands. - The lowlands of the flood plain of the Alabama and Tombigbee rivers and of their larger tributaries are heavily timbered. Their first terrace, overflowed only 
in the times of the heaviest freshets, is covered with a valuable hardwood timber growth of cow oak, Spanish oak, Texas or Southern red oak, white ash, honey locust, and mockernut hickory, destined to furnish large supplies for the future. On the almost perpetually submerged banks of both of these rivers a fine timber growth of bald cypress frequently forms brakes of considerable extent, occasionally accompanied by the tupelo gum.

It can be safely asserted that fully one-half of the area of this region is under cover of the long-leaf pine, and that in their timber wealth these forests surpass by far the pine forests of the lower division of the Maritime Pine belt. From estimates made in various districts it appears that fully 6,000 feet of merchantable timber can be with safety assumed as the average yield per acre.

Mesophile herbaceons plant associations.-The following herbaceous plants, extending hither from the mountain region, find here their southern limits:

Calycocarpum lyoni.

Cebatha carolina.

Cypripedium hirsutum.

Arisaema dracontium.
Frasera carolinensis.

Physalis ciliosa.

Physalis virginian

Vincetoxicum baldwinii, one of the rarest of Southern plants, elsewhere known only from a few localities in middle Georgia and Texas, and Thalictum debile are thus far known in Alabama only in this region.

Cultural plant formations. - In its cultural plant formations this region differs but slightly from the next region. The rich hill prairies, calcareous uplands, formerly bearing a mixed growth of pines and deciduous trees, as well as the bottom lands, are for the most part devoted to the cultivation of cotton. Larger or smaller patches of tropical sugar cane are cultivated on almost every farm. Corn, oats, and sweet potatoes and other root crops are raised to supply the home demand. Less attention is paid to the raising of forage crops, the cattle being left to shift for themselves throughout the year among the hills. In the northern part the peach is raised in perfection, ripening its fruit from the middle of May to August. Grapes can be harvested in July and August, and strawberries are marketed in the first weeks of April. The fig also bears abundantly.

LOWER DIVISION OF THE COAST PINE BELT, OR LOWER REGION OF LONG-LEAF PINE.

Physiographical features and climate.

As the Tertiary strata disappear under the heavy beds of sands and gravels of more recent formations, the topography of the country becomes more uniform, the broad ridges spread out into slightly undulating table-lands, which become somewhat broken in their descent to the drainage channels. The rolling pine uplands rise gradually to 
a height of from 220 to 300 feet above the flat woods and marshes and alluvial forests of the tide-water region. Where the level table-lands, devoid of surface drainage, are underlaid by impervious clays, spongy bogs surround the heads of water courses. On the rolling uplands with a porous siliceous soil the copious rainfall is readily absorbed, giving rise to innumerable springs, the feeders of the numerous limpid brooks and creeks by which this region is traversed. The area of the lower pine region is estimated to embrace a little over 7,000 square miles, including the following counties and parts of counties: Geneva, part of Covington, Escambia, part of Monroe, and all of Baldwin, Mobile, and Washington.

Both the climate and topography of this region exhibit great uniformity. Under the moderating influences of the proximity of the sea, the climate is generally mild. According to the records of the Mobile station of the United States Weather Bureau, extending over a period of twenty-three years, the mean annual temperature for that period was $66.9^{\circ}$, with the highest temperature $101^{\circ}$, observed in July, 1884 , and the lowest $11^{\circ}$, in January, $1886 .^{1}$

Mean monthly temperature with maxima and minima.

\begin{tabular}{|c|c|c|c|c|c|c|c|c|c|c|c|c|}
\hline & Jan. & Feb. & Mar. & Apr. & May. & June. & July. & Aug. & Sept. & Oct. & Nov. & Dec. \\
\hline 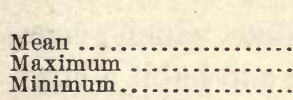 & $\begin{array}{l}\circ \\
50 \\
78 \\
11\end{array}$ & $\begin{array}{l}\circ \\
55 \\
78 \\
19\end{array}$ & $\begin{array}{l}\circ \\
59 \\
85 \\
25\end{array}$ & $\begin{array}{l}\circ \\
67 \\
90 \\
32\end{array}$ & $\begin{array}{l}\circ \\
74 \\
98 \\
46\end{array}$ & $\begin{array}{r}\circ \\
80 \\
100 \\
50\end{array}$ & $\begin{array}{r}\circ \\
81 \\
101 \\
64\end{array}$ & $\begin{array}{r}0 \\
80 \\
100 \\
57\end{array}$ & $\begin{array}{l}\circ \\
77 \\
96 \\
52\end{array}$ & $\begin{array}{l}\circ \\
70 \\
94 \\
34\end{array}$ & $\begin{array}{l}\circ \\
58 \\
83 \\
25\end{array}$ & \begin{tabular}{l}
\multicolumn{1}{l}{} \\
52 \\
79 \\
20
\end{tabular} \\
\hline
\end{tabular}

Data of temperature by seasons for period of twenty-three years.

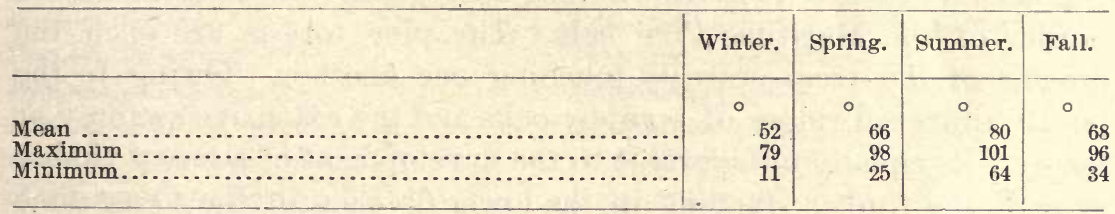

The latest killing frost for the period occurred April 24, 1884. The average date of last frost in spring was March 20. The average date of earliest frost in autumn was November 20.

The following data were obtained from Mr. J. A. Barry, observer for the Weather Bureau at Mobile:

Data of rainfall and clouds.

\begin{tabular}{|c|c|c|c|c|c|}
\hline $2-7=$ & Annual. & Winter. & Spring. & Summer. & Fall. \\
\hline 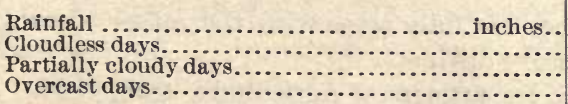 & $\begin{array}{r}66 \\
110 \\
153 \\
102\end{array}$ & $\begin{array}{l}14.5 \\
23 \\
36 \\
31\end{array}$ & $\begin{array}{l}19 \\
32 \\
37 \\
27\end{array}$ & $\begin{array}{l}19 \\
23 \\
47 \\
40\end{array}$ & $\begin{array}{l}13.5 \\
32 \\
33 \\
24\end{array}$ \\
\hline
\end{tabular}




\section{The rolling pine uplands or dry pine barrens.}

Xerophile forests. - On the hills and broad swells of the table-lands the long-leaf pine reigns supreme. The high forest is almost bare of undergrowth and its monotony is frequently unbroken for long distances, no other trees or shrubs appearing among the tall trunks of the pine, which spread their gnarled limbs at a height of from 40 to 65 feet above the ground. It is only in the accidental openings of the forest that a second growth of the predominating species takes possession of the ground, which, if interfered with by human agency, is replaced by black jack and Spanish oaks, notrarely accompanied by the dogwood (Cornus florida) and the glandular summer haw (Crataegus elliptica). This last, which is a pretty tree from 20 to 25 feet high, ranges from South Carolina to Mississippi, and in Alabama appears to be confined to this region. ${ }^{1}$ On the sterile ridges deeply covered with the mantle of loose white sands, which hide the sandy loams of the La Fayette strata, the long-leaf pine becomes stunted and is more or less replaced by the barren or turkey oak and blue jack, trees rather below medium size, often dwarfed and scrubby; and among the latter are dispersed-

\section{Vaccinium stamineum.}

Vaccinium myrsinites.

Vaccinium myrsinites glaucum.
Gaylussacia dumosa.

Asimina parviflora.

Ceratiola ericoides.

The last of these shrubs, representing the Empetraceae, which generally inhabit the boreal zone, resembles in its foliage and habit a large heather (Erica). It is truly characteristic of the arid pine barrens from Florida and adjacent parts of Georgia to Mississippi, and in Alabama it reaches its northern limit of vegetation near the northern border of the Maritime Pine belt. The pine forests are open, the crowns of the trees searcely touching one another. Owing to the poorly timbered ridges of scrubby oaks and the extensive swampy or boggy flats equally unfavorable to the development of a heavy timber growth, the timber standing in the lower division of the Coast Pine belt is considerably less in proportion to area than that found in the upper division.

On the better class of pine lands the quality of the timber is scarcely surpassed, as evinced by a close investigation of the timber resources of the rolling pine uplands near Wallace, Escambia County, which can be considered a typical district. ${ }^{2}$

The forests of long-leaf pine of this Lower Pine region furnish principally the enormous supplies of timber used by the sawmills situated in the tide-water region of Alabama and western Florida, with Mobile

${ }^{1}$ The specific character of this tree does not fully agree with the rather obscure type and it may on nearer investigation prove distinct.

${ }^{2}$ Bulletin 16, Division of Forestry, U. S. Department of Agriculture, 1896, p. 39. 
and Pensacola for the chief points of export, and they are also the source of the resinous products which find their market at Mobile. The depletion of their timber wealth with no heed given to their maintenance, and their destruction by the barbarous methods practiced in the extraction of their resinous product, together with the ravages of the fires which one season after another destroy the seedlings and the youngest timber, and with the injuries inflicted by herds of domestic animals which roam through these forests, not only are exhausting their present resources, but will inevitably and within a comparatively short time result in their extermination, notwithstanding the fact that in no other region within the wide range of distribution of the long-leaf pine are the conditions more favorable for the spontaneous reproduction of this most valuable timber tree.

Xerophile herbaceous plant associations.-Thanks to the abundant and evenly distributed rainfall, the floor of these open pine forests is covered with a carpet of grasses and other herbs, mostly perennials, which, under the mild climate of this zone, retains its verdure for the greatest part of the year. The grasses vastly predominate in the number of individuals, and in the diversity of forms they are scarcely exceeded by the species of the pea and composite families. The great bulk of the grasses consists of types of a Southern distribution, the majority being confined to the Louisianian area. But a small number reach the Carolinian area, and those only along the seacoast. The following are noteworthy species:

Andropogon tener.

Paspalum setaceum.

Paspalum floridanum. ${ }^{1}$

Paspalum ciliatifolium. ${ }^{1}$

Panicum filiforme. ${ }^{1}$

Panicum lanuginosum. ${ }^{1}$

Panicum pauciflorum. ${ }^{1}$

Panicum sphaerocarpon. ${ }^{1}$

Panicum pubescens.

Panicum angustifolium.

Aristida purpurascens.

Andropogon argyraeus.

Danthonia sericea.

Gymnopogon ambiguus.
Gymnopogon brevifolius.

Chrysopogon nutans linnaeanus.

Chrysopogon elliottii.

Paspalum plicatulum.

Paspalum bifidum (P. racemulosum Nutt).

Paspalum dasyphyllum.

Paspalum difforme.

Anthenantia villosa.

Panicum angustifolium.

Panicum neuranthum.

Panicum arenicola.

Panicum nashianum.

Aristida simplicifolia.

Aristida stricta.

Of the above species Gymnopogon brevifolius is a typical species of the Louisianian area, characteristic of dry pine barrens from North Carolina to eastern Texas, and Panicum neuranthum extends to the West Indies. Aristida stricta, or wire-grass, is extremely abundant in the coast region of South Carolina, Georgia, Florida, and the counties of Alabama east of the Perdido River, along the Florida State line, known as the "wire-grass counties," where on the loose white Ozark sand it almost alone forms the grassy covering. 
The following are of wide continental range east of the Rocky Mountains, extending to the Carolinian area, the first being the most abundant species of the dry pine barrens:

Andropogon scoparius. ${ }^{1}$

Chrysopogon avenaceus. ${ }^{1}$

Sporobolus junceus.
Sporobolus longifolius. ${ }^{1}$

Sporobolus neglectus. ${ }^{1}$

Sporobolus vaginaefloms. ${ }^{1}$

The following representatives of the Cyperaceae are found among the xerophile plant associations, mostly of the Louisianian area:

Cyperus martindalii.

Cyperus retrofractus. ${ }^{2}$

Rynchospora grayii.

Rynchospora intermedia.

Scleria ciliata.

\author{
Scleria elliottii. \\ Stenophyllus ciliatifolius. \\ Carex festucacea. ${ }^{1}$ \\ Carex muhlenbergii. ${ }^{1}$ \\ Juncus torreyi. ${ }^{1}$
}

The xerophile species of other families associated with these glumaceous plants are for the largest part at home in the Louisianian area. Fully two-thirds of the numerous Leguminosae and Compositae occurring in this region are confined to that area. Omitting the common species of wide distribution, the following, named in the succession of their flowering, give character to the xerophile herbaceous associations of the rolling pine uplands. As the first harbingers of spring, appear before and in the beginning of February:

Houstonia rotundifolia.

Epigaea repens. ${ }^{1}$

These are succeeded by:

Helianthemum carolinianum. Astragalus villosus.

Lupinus diffusus.

Iris verna.

Chrysogonum virginianum. ${ }^{2}$

Oxalis recurva.

Oxalis filipes. ${ }^{2}$

Ascyrum pumilum.

Phlox pilosa detonsa.

Phlox amoena. ${ }^{2}$

Lupinus nuttallii.

Limodorum parviflorum (Calopogon parviflorus Lindl.)

Chrosperma muscaetoxicum. ${ }^{2}$

Zygadenus angustifolius.

Pentstemon hirsutus. ${ }^{1}$
Viola palmata. ${ }^{1}$

Viola septemloba. ${ }^{2}$

Gyrostachys (Spiranthes) praecox. ${ }^{1}$

Gyrostachys gracilis. ${ }^{1}$

Lachnocaulon anceps. ${ }^{2}$

Asclepias humistrata

Michx.).

Asclepias michauxii.

Tetragonotheca helianthoides. ${ }^{2}$

Jatropha stimulosa. ${ }^{2}$

Scutellaria pilosa. ${ }^{2}$

Polygala nana.

Kneiffia linearis. ${ }^{2}$

Stillingia sylvaitica. ${ }^{2}$

Schwalbea americana. ${ }^{2}$

Sabbatia angustifolia. ${ }^{2}$

Helianthemum ramuliflorum.

During the summer months:

Buchnera elongata. ${ }^{2}$

Physalis virginiana. ${ }^{2}$

Erythrina herbacea.

Euphorbia corollata angustifolia.

Euphorbia floridana.

Zornia bracteata. 
Stylosanthes biflora hispidissima.

Galactia erecta (G. sessilifolia).

Euphortia humistrata. ${ }^{1}$

Rhynchosia simplicifolia. ${ }^{1}$

Chrysobalanus obtusifolius.

Rhynchosia galactioides.

Croton punctatum.

Cracca smallii.

Cracca hispidula. ${ }^{1}$

Cracca spicata flexuosa.

Cracca chrysophylla.

Psoralea canescens.

Galactia volubilis. ${ }^{1}$

Galactia volubilis mississippiensis.

Galactia floridana.

Lespedeza repens. ${ }^{1}$

Lespedeza virginica.
Hibriscus aculeatus.

Koellia albescens.

Ceranthera linearifolia.

Dasystoma pedicularia.

Ruellia ciliosa humilis.

Ruellia pedunculata.

Verbena carolina.

Vernonia graminifolia.

Chrysopsis graminifolia. ${ }^{1}$

Chrysopsis hyssopifolia.

Coreopsis major.

Solidago odora. ${ }^{1}$

Sericocarpus bifoliatus. ${ }^{1}$

Silphium asteriscus angustatum.

Meibomia rotundifolia. ${ }^{1}$

Meibomia stricta. ${ }^{1}$

Of the above Euphorbiu floridana ranges from western Florida to the Escambia River; Ceranthera linearifolia from lower Georgia westward to the Tensas River, Baldwin County; Ruellia pedunculata from western Louisiana to the western edge of Alabama; Chrysopsis hyssopifolia from the arid sand hills of western Florida to the eastern shore of Mobile Bay. In the autumn the dry pine barrens are adorned with their richest floral display, the forests being then brilliant with the purple spikes of the blazing stars (Lacinaria), the blue of asters and salvia, the scarlet of Clinopodium coccineum, and the gold of Chrysopsis and Solidago, not to mention others. The following are the prevailing species:

Lacinaria gracilis.

Lacinaria elegans. ${ }^{1}$

Lacinaria scariosa. ${ }^{1}$

Aster concolor. ${ }^{2}$

Ionactis linariifolius. ${ }^{2}$

Aster adnatus.

Aster patens tenuiculmis.

Trilisa odoratissima.

Salvia azurea.

Clinopodium coccineum (Calamintha coccinea Gray).

Chrysopsis trichophylla.

Solidago petiolaris. ${ }^{1}$
Solidago puberula pulverulenta.

Afzelia cassinoides (Seymeria tenuifolia).

Afzelia pectinata.

Kuhnistera pinnata.

Eupatorium aromaticum. ${ }^{1}$

Eupatorium coronopifolium.

Eupatorium leptophyllum.

Kuhnia kuhnia.

Helianthus radula.

Lechea minor. ${ }^{2}$

Lechea tenuifolia. ${ }^{2}$

Lechea villosa. ${ }^{2}$

Lechea leggettii. ${ }^{1}$

Clinopodium coccineum, the scarlet basil, is a low undershrub with dazzling flame-colored flowers, ranging from the sandy ridges of western Florida to the dry hills which front the eastern shore of the Mobile Bay and the coast plain near Mobile; also found in Mississippi. Helianthus radula is a truly characteristic plant of these pine uplands. The pinweeds (Lechea) are the homely representatives of the Cistus family. 


\section{Pine-barren flats and Hydrophytic plant associations.}

Toward the northern limit of this region the oldest strata of the Post-Tertiary (Neocene) beds of loose sands and compact more or less aluminous clays approach or attain the surface. The higher swells of the table-lands covered by the porous sands and gravels include level tracts of badly drained barrens underlaid by the older strata, flooded after every heavy rain, droughty during hot and dry weather. On these flats Cuban pine is thinly scattered and here reaches its northern limit of vegetation, at a distance of about 60 miles from the seashore.

Excepting the ink berry (Ilex glabra) scarcely any tree or shrub shades the ground; but a small number of grasses find a place among the coarse herbs forming the cover of the extremely poor soil of these flats. The bulk of the herbaceous vegetation consists of a few abundant mesophile species. The following are representatives species:

Andropogon virginicus. ${ }^{1}$

Anthaenantia rufa.

Paspalum glabratum.

Panicum polyanthes. ${ }^{1}$

Sabbatia campanulata. ${ }^{1}$
Sabbatia dodecandra. ${ }^{1}$

Helenium brevifolium.

Rhexia mariana. ${ }^{1}$

Rhexia stricta.

Cynoctonum sessilifolium.

There are also a number of paludial species with xerophile adaptations; that is, they are provided with strong, deeply embedded rootstocks to retain the needed supply of moisture during periods of hot and dry weather, and with rigid leaves of greatly reduced surface to prevent excessive transpiration. Among such plants may be mentioned species of Xyris and round rushes. In exposed shallow pools and ditches Sagittarias (Sagittaria chapmani, S. cycloptera) having rigid scapes and narrow stiff leaves are most frequent, the latter frequently reduced to narrow phyllodia. On the base of the pine-clad ridges bordering the flats Habenaria cristata and Psoralea simplex are not infrequently observed, the spindle-shaped or top-shaped roots of the latter deeply buried in the sand, where it is constantly moistened by springs.

In many localities the declivities of the table-lands are perpetually wet with the water which oozes from the porous silicious strata immediately overlying the impervious clay, and the depressions inclosed by them are frequently covered with a dense carpet of peat mosses, interwoven with the long filiform rhizomes of beak rushes, spike rushes, and one nut rush, the following being species:

Sphagnum macrophyllum.

Sphagnum imbricatum cristatum. ${ }^{1}$

Sphagnum recurvum. ${ }^{1}$

Rynchospora pusilla.

Rynchospora plumosa.
Rynchospora rariflora.

Rynchospora oligantha.

Eleocharis acicularis. ${ }^{1}$

Eleocharis tuberculosa. ${ }^{1}$

Scleria caroliniana.

${ }^{1}$ Found also in Carolinian area. 
With these are associated creeping club moss (Lycopodium alopecuroides) and many species of the paludial plants found also on the flats and in the swamps of the coast plain, including insectivorous sundews, bladderworts, and pitcher plants. Characteristic species are:

Limodorum pallidum.

Lophiola aurea. ${ }^{1}$

Gyrotheca tinctoria. ${ }^{1}$

Juncus trigonocarpus.

Eriocaulon decangulare. ${ }^{1}$

Drosera intermedia. ${ }^{1}$
Drosera filiformis. ${ }^{1}$

Utricularia juncea.

Utricularia subulata. ${ }^{1}$

Sarracenia purpurea. ${ }^{1}$

Sarracenia psittacina.

Sabbatia macrophylla.

The Sarracenias mentioned, which are the most prominent, rest their rosettes of urn-shaped leaves on the water-soaked peat moss. Sarracenia drummondii and S. rubra, with their trumpet-shaped, erect leaves, are abundant on the black peaty soil which covers the undulations where the impervious aluminous clays and compacted sands prevail. In the middle of the spring these plants produce their oneflowered scapes from stout rootstocks before the appearance of the leaves. In midsummer, when the leaves have attained their full growth, the boggy hillsides and depressions present to a superficial view the aspect of meadows richly adorned with flowers of white and roseate tints, imparted by the white, purple-veined tops of the leaves of these sarracenias. The display of these colors serves to attract insects, which, entering the leaves in search of the sweets secreted within, are entrapped, with no possibility of escape, and thus become sources of nourishment to these plants.

Mesophile and paludial forests.-Evergreens, nearly all of them types of the Louisianian area, predominate in the tree growth which shades the damp or wet, more or less sandy, banks of the numerous streams rising in the maritime pine belt. Magnolia, white bay, and oaks with entire, narrow, persistent or semipersistent leaves (Quercus laurifolia, Q. aquatica), with Cuban pine, loblolly pine, rarely shortleaf pine, pond cypress (Taxodium distichum imbricaria), and "juniper" or white cedar (Chamaecyparis thyoides) largely prevail over the deciduous black gum (Nyssa biflora), red gum, and swamp maples. Groves of the pond or upland cypress just mentioned-a variety closely connected with the type by intermediate forms-cover the shallow pine-barren ponds and semiswampy woods of a poor, sandy soil destitute of vegetable mold. This form of the cypress in the size and quality of its wood is greatly inferior to the typical cypress of the alluvial swamps, and is at once recognized by the leaves, which are closely appressed to the deciduous, annual shoots. By this peculiarity of the foliage a check to excessive transpiration is provided during the time of drought, when the sandy soil is laid bare to the sun and its supply of water is failing. The white cedar of the lower pine region is met with most frequently in the sandy swamps around the head 
waters of Perdido and Escambia rivers, and is there in full perfection. This tree attains a height of from 80 to 90 feet, with an average diameter of from 16 to 18 inches; trees over 24 inches in diameter are rarely seen. Being much sought for on account of the value of the timber, sound trees are at present frequent only in remote localities difficult of access. Among the trees of smaller size and the variety of shrubs forming the dense undergrowth of these forests the evergreens also predominate, of which the following species are examples:
Cliftonia monophylla.
Myrica cerifera. ${ }^{1}$
Cyrilla racemiflora.
Myrica inodora.
Ilex myrtifolia.
Kalmia latifolia. ${ }^{1}$
Ilex lucida.
Illicium floridanum.

Ilex glabra.

Prominent by reason of their abundance and their showy flowers are Pieris nitida and Leucothöe axillaris with Oxydendrum arboreum, all of the heath family; besides which may be mentioned:

Butneria (Calycanthus) florida.

Clethra alnifolia.

Mohrodendron (Halesia) dipterum (silver bells).
Viburnum nudum (opossum haw).

Viburnum nitidum (opossum haw).

Viburnum molle (opossum haw).

Styrax pulverulenta (storax bush).

Mesophile herbaceons plant associations. - The herbaceous plant associations in these mesophile woods are identical with those of the same character prevailing in the upper division of the coast pine belt. Frequent among them is Macranthera fuchsioides, conspicuous on account of its profusion of large racemes of scarlet flowers, a coarse biennial extending from western Georgia and eastern Florida into this State and to the northern limit of the Louisianian area.

REGION OF THE COAST PLAIN OR LOW FLAT PINE BARRENS.

Physiographical features.-On their descent to the coast plain the rolling pine uplands disappear under the silt of sandy loams or merge imperceptibly into the coast sands and the most recent lacustrine formations which line the shore. The sandy loams form the second terrace of the lowlands of the coast, rising to a height of from 10 to 30 feet above the low flood plains and river bottoms, which are subject to occasional overflow.

Mesophile forests. - Open forests of long-leaf pine sparsely interspersed with Cuban pine and loblolly pine once covered the plain. After the removal of the original timber growth the long-leaf pine was to a large extent superseded by the Cuban pine, groves of which in every stage of development occupy the clearings. Upon these clearings, made scarcely two-thirds of a century ago, Cuban pine has already attained the dimensions of useful timber, the trees averaging from 18 to 24 inches in diameter, with a height of from 85 to 100 feet. A number of trees felled upon one of these old clearings in the 
suburbs of Mobile furnished sticks of merchantable timber 30 to 40 feet in length, none of them having reached an age of over 60 years.

Mesophile herbaceous plant associations (Rynchospora formation).The terrace of sandy loams extends over the larger part of the coast plain. The ground being almost perfectly level and underlaid by a compact, somewhat impervious subsoil, is consequently more or less deficient in drainage, and being covered with a dense sod formed by the roots and rhizomes of low, perennial monocotyledonous plants, the ground remains damp and the decomposing vegetable matter, under the influence of sun and wind, is converted into an acid humus, giving rise to a peaty soil. This damp, mucky soil, in a semiboggy condition during seasons of rain, supports a vegetation of low, grass-like plants, mostly of the sedge family or sour grasses (Cyperaceae) of various genera, which in number vastly predominate over the true grasses (Poaceae), rushes (Junci), and golden-eyed grasses (Xyridaceae), which find their home in the flat, damp pine barrens of the plain. Horn rushes (Rynchosporae) largely prevail over the other representatives of the sedge family, and numerous species of this extensive genus, almost exclusively confined to eastern North America and the adjacent tropical zones, make up the largest portion of the sod vegetation, thus forming a more or less compact plant formation highly characteristic of this region. Among the mesophile associations which inhabit the seantily shaded, frequently open plain, with its sour, damp, shallow, and during the rainy seasons more or less boggy soil, there is found in many localities a tiny creeping peat moss (Sphagnum imbricatum) and other short-stemmed species ( $S$. compactum, $S$. intermedium), which are able to resist the effects of occasional droughts. The following Cyperaceae are typical, and predominate on the flat expanse of this terrace of the plain:

Rynchospora plumosa.

Rynchospora pusilla.

Rynchospora rariflora.

Rynchospora multiflora.

Rynchospora cymosa. ${ }^{1}$

Rynchospora ciliaris.

Rynchospora baldwinii.

Rynchospora chapmani.
Rynchospora divergens.

Rynchospora microcarpa.

Rynchospora gracilenta.

Rynchospora cymosa globularis.

Rynchospora oligantha. ${ }^{1}$

Kobresia odorata.

Kobresia monocephala.

With these are found the following rushes:

\section{Juncus elliottii.}

Juncus diffusissimus.

Juncus marginatus. ${ }^{1}$
Juncus marginatus aristulatus. ${ }^{1}$

Juncus bufonius fascicularis.

Grasses of the same region are-preferring the low flats with a more damp, sandy soil: 
Most frequent on the low swells:

Sieglingia chapmani.

Chrysopogon nutans linnaeanus.

Andropogon elliottii.

Andropogon tener.
Andropogon virginicus glaucus.

Andropogon virginicus dealbatus.

Muhlenbergia trichopodes.

Panicum longipedunculatum.

After the ground has been once turned by the plow the glumaceous plants which formed the original sod disappear forever, the ground being taken possession of by carpet grass (Paspalum compressum), a West Indian species most probably introduced, and the creeping fingergrass (Syntherisma (Panicum) serotinum). Nearly all of the sundews, sarracenias, gentians, and other species already mentioned among the associations which inhabit the sphagnous bogs of the pine hills also enter into the associations of this semi-paludial Rynchsopora formation.

During the latter part of January the Cuban pine unfolds its flowers, with Bartonia verna and Houstonia patens, and these are succeeded by the following:

Chaptalia semifloscularis.

Pinguicula lutea.

Pinguicula pumila.

Lupinus villosus.

Helianthemum carolinianum.

Drosera capillaris.

Drosera brevifolia.

Drosera filiformis. ${ }^{1}$

\author{
Euphorbia inundata. \\ Helenium vernum. \\ Helenium helenium. \\ Helenium integrifolium. \\ Polygala lutea. ${ }^{1}$ \\ Polygala polygama. ${ }^{1}$ \\ Limodorum multiflorum.
}

The Pinguiculas mentioned are insectivorous plants common in the pine flats from North Carolina to Florida and Mississippi. Euphorbia inundata is known only from the coast of western Florida and as far west as the eastern shore of the Mobile Bay near Point Clear.

Remarkable is the occurrence of Limodorum multiflorum in Mobile County (Fowl River Station). This beautiful orehid is otherwise known only from a few localities of peninsular and western Florida. It was first described by Chapman from the southern part of Florida and has been observed by the writer in the savannas near the upper waters of the St. Johns River. During the summer months bloom Linum floridanum, Polygala chapmani, Polygala hookeri, the latter two extending from western Florida to eastern Mississippi, and Zygadenus glaberrimus, ranging from the pine flats of North Carolina to Louisiana, together with the following:

Habenaria nivea.

Cracca hispidula. ${ }^{1}$

Polygala cruciata. ${ }^{1}$

Indwigia hirtella. ${ }^{1}$

Ludwigia linearis. ${ }^{1}$

Eryngium aquaticum.

Eryngium synchaetum.

Eryngium ovalifolium.

IIydrocotyle verticillata.
Centella stricta.

Sabbatia gentianoides.

Pterocaulon undulatum (P. pycnostachyrum Ell.).

Dasystoma pedicularia. ${ }^{1}$

Gerardia paupercula.

Ascymum stans.

Ascyrum hypericoides.

Hypericum spp. 
The species of Ascyrum and Hypericum constitute a characteristic open formation of low shrubs or suffrutescent perennials in the depressions surrounding shallow ponds, most striking during the latter part of the summer while covered with their golden-yellow flowers. Among the earliest appears Hypericum myrtifolium, followed by H. opacum, and last by $H$. aspalathoides, the most abundant, forming large patches. All are frequent from South Carolina to Mississippi. During the autumn Compositae with their bright yellow flowers prevail-for example:

Helianthus heterophyllus.

Chondrophora (Bigelovia) nudata. ${ }^{1}$

Solidago stricta. ${ }^{1}$

Solidago angustifolia.

\section{Coreopsis angustifolia.}

Bidens coronata leptophylla.

Baldwinia uniflora.

With these come azure-flowered lobelias, such as L. puberula, common from the coast of southern New Jersey to Louisiana and in the southern Alleghanies, and L. brevifolia, ranging from western Florida to Louisiana, and Ruellia noctiflora, rare on the coast of the Mississippi Sound and sparsely scattered through the corresponding region from Louisiana to Georgia and Florida, all more or less frequent in the first pine barrens from North Carolina to Florida and the eastern Gulf States-besides the following:

Eupatorium leptophyllum.

Eupatorium capillifoliurn. ${ }^{1}$

Eupatorium linearifolium. ${ }^{1}$

Eupatorium mohrii.

Eupatorium semiserratum. ${ }^{1}$

Eupatorium pubescens. ${ }^{1}$

Eupatorium verbenaefolium. ${ }^{1}$
Lacinaria graminifolia pilosa. ${ }^{2}$

Carphephorus pseudo-liatris.

Trilisa odoratissima. ${ }^{2}$

Baldwinia uniflora.

Gerardia skinneriana.

Gerardia paupercula.

Gerardia aphylla.

Of ferns and their allies Botrychium obliquum is not rare on exposed grassy knolls and banks, while Ophioglossum crotalophoroides with Lycopodium carolinianum, preferring moister situations, are truly typical plants of the coast plain.

Hammock lands.-More or less extensive tracts of a black soil, generally well drained, rich in the decayed remains of former vegetations, occur on this second terrace as it skirts the lower river swamps or the low swamps of the tide-water regions. Constantly acted upon by the multitudinous forms of lower animal and plant life - rainworms, snails, centipedes, and a host of bacteria and saprophytic fungi-this soil has become converted into a highly fertile mold, which supports the same luxuriant and diversified vegetation of trees and shrubs, chiefly broadleaved evergreens, which characterizes the mesophile forests of the Louisianian area generally, to which is added here the live oak, Quercus virginiana, the most attractive and grandest feature in the flora of the coast plain. This oak is a tree of the seacoast. It approaches, in a high state of development, the Carolinian area near the northern limit 
of eastern North Carolina and extends westward along the Gulf coast to central Texas and northern Mexico. In the Gulf States the live oak is rarely found above the thirty-first parallel of latitude. Of the magnificent groves which once lined the shores of the Gulf and its numerous inlets, but few remain. From its native hammocks this tree was transplanted to adorn and shade the abodes of the earliest settlers. Trees planted about seventy-five years ago, now frequently met with in the suburbs of Mobile and at the older country seats, are from 2 to 3 feet in diameter and from 60 to 70 feet in height, their sturdy trunks sending out massive horizontal limbs at a distance of from 10 to sometimes 15 feet above the ground, their shade frequently covering an area nearly 100 feet in diameter.

In these hammocks the magnolia attains its highest development, in diameter rivaling the Cuban and loblolly pines, with which it is often associated, and accompanied by the laurel oak, water oak, and beech, all draped with the wreaths of Spanish moss.

Of small trees and shrubs occurring here may be enumerated:

Osmanthus americanus (American olive, devil wood).

Ilex vomitoria (yaupon). ${ }^{1}$

llex opaca (common holly). ${ }^{1}$

Myrica cerifera (wax myrtle). ${ }^{1}$

Zanthoxylum clava-herculis (S outhern prickly ash).

Prunus umbellata (prairie plum).
Pymus angustifolia (Southern crab apple). ${ }^{1}$ Crataegus apiifolia (haw). ${ }^{1}$

Crataegus viridis (haw). ${ }^{1}$

Chionanthus virginica (Northern fringe tree). ${ }^{1}$

Vaccinium arboreum (farkleberry). ${ }^{1}$

Ilex caroliniana (holly).

Ilex coriacea (holly).

The evergreen American olive, rarely seen among the pine hills, occurs here frequently. The last two hollies are shrubs which, together with the others mentioned, form a dense undergrowth.

Where the hammocks merge into the alluvial lands, the soil becoming of a semi-swampy condition, the silver-bell tree (Mohrodendron (Halesia) dipterum) is found, most frequently with swamp dogwood (Cornus stricta), interspersed with titi (Cliftonia monophylla), leatherwood (Cyrilla racemiflora), holly (Ilex cassine) and blue palmetto (Sabal adansonii), evergreen fetterbushes (Pieris nitida, Leucothöe axillaris) forming the brushy soil cover. In the liana formation, Vitis cinerea mostly takes the place of the summer grape, and Sagaretia michauxii, which in the open and in dry soil is a straggling shrub 6 to 8 feet high, and is not rare on the coast from South Carolina to Florida and Mississippi, in these woods assumes the habit of a robust climber, ascending trees of great height. The stout root elimbers Decumaria barbara and the Virginia creeper are common. The American wistaria (Krauhnia fmutescens), with its compound racemes of sky-blue flowers, adorns the lower borders of the hammocks, which are further enlivened by the flame-colored flowers of the woodbine (Lonicera sempervirens), and, very early in the spring, by the golden 
flowers of the yellow jessamine (Gelsemium sempervirens), these followed by the white bloom of the Cherokee rose.

The frequent vines of the bullace grape, Brunnichia, Cissus, and Smilax, which entwine bushes and trees, add to the intricacy of the maze of shrubbery on the low hammocks. In their deepest recesses Epidendrum conopseum finds its home upon the limbs of old magnolias and hoary live oaks, being the only epiphytic orchid in the southeastern States outside of the narrow belt of the Antillean flora, skirting the coast of southern Florida and of the adjacent islands, the so-called Keys. Apteria setacea is strictly confined to the rich mold of the hammocks. This leafless saprophyte, of a pale bluish color, grows in dense clusters, its numerous contorted roots deeply buried in the ground. It is also not rarely found in Florida and southeastern Georgia. On the shady borders of the hammock are found, flowering early in the spring, Nemophila microcalyx and Asarum arifolium, followed by the Atamasco lily (Atamosco (Zephyranthes) atamasco) and hoary lupine (Lupinus villosus), and in the summer months by the following:

\section{Rhexia mariana. ${ }^{1}$}

Rhexia lanceolata.

Agrimonia incisa.

Amorpha glabra.

Sanicula canadensis. ${ }^{1}$

Paspalum michauxianum.

Paspalum ciliatifolium. ${ }^{1}$

Paspalum praecox.

Panicum viscidum. ${ }^{1}$

Panicum gibbum.

Panicum scabriusculum.
Panicum proliferum inflatum.

Panicum rostratum. ${ }^{1}$

Oplismenus hirtellus.

Eragrostis glomerata.

Carex hirsuta. ${ }^{1}$

Carex caroliniana. ${ }^{1}$

Carex debilis prolixa.

Melica mutica. ${ }^{1}$

Panicum verrucosum. ${ }^{1}$

Arundinaria tecta. ${ }^{1}$

We have here a mingling of mesophile and paludial types, all characteristic of the hammocks, the last three having also a wider range. Ferns are abundant in the damp shade. Dryopteris patens, a cosmopolitan species of subtropical and tropical regions, is confined in our territory almost exclusively to the hammocks. It is accompanied by the more frequent Dryopteris acrostichoides, Pteris aquilina (form near to caudata), Asplenium platyneuron, Woodwardia angustifolia, and W. virginica; the last in more moist situations. Lycopodium cernuum is remarkable as one of the few types extending from the tropics to the coast of the Louisianian area which appears to be indigenous with us. Where the terrace merges into the flats of the plain, the border of the hammock becoming frequently wet, tall wool grasses (Erianthus brevibarbis, E. strictus, E. saccharoides), coarse beard grass (Andropogon glomeratus), and royal fern (Osmunda regalis) form conspicuous features in the aspect of the vegetation.

Pine meadows.-Approaching the seashore the terrace of loamy silt passes imperceptibly into the flats of the purely siliceous coast sands, through which the sluggish water courses, subject to the ebb 
and flow of the tide, wind their way to the inlets of the Gulf. The fine sand forming the surface as well as the subsoil is closely packed, permitting the water to permeate but slowly, and in consequence is overflowed after every rainfall. The great poverty of the soil is manifest in the stunted growth of pines scattered over these flats and the dwarfed cypress and white cedar lining the sandy banks of the streams. The surface is exsiccated during the dry summer season, and supports a scanty growth of poverty grasses, particularly Aristida spiciformis and A. palustris, and the toothache grass (Campulosus aromaticus), with its stout aromatic rootstock deeply buried in the compacted sand, with which are found Scleria torreyana and Lilium catesbaei, and, during the late autumnal rains, the rare Gyrostachys brevifolia, known also from western Florida.

Paludial arboreal associations (cypress brakes). - The bottom lands of the Mobile River and the islands in the delta, overflowed at every freshet, are covered with a high forest of deciduous trees, common to them and the lowlands of the same character along the Tombigbee and Alabama rivers in their course through the Louisianian area. Where the banks are almost perpetually submerged they are covered with cypress. This largest of the Atlantic forest trees was formerly found in the upper part of the river delta in great perfection. The mighty trunks rise to a total height of from 100 to 120 feet and over, with a diameter, measured above the buttresses which expand the bases, of from 3 to over 5 feet. The annual rings of growth are extremely narrow and difficult to count. On elose investigation the age of full-grown trees can be estimated to vary between 300 and 500 years. They are the sole survivors in this part of the North American continent of an archaic type. The assemblage of these monarchs of the forest in the compact cypress brake, surrounded by the peculiar cone-shaped excrescences (cypress knees) rising from their roots 1 to 2 feet and more above the dark unruffled surface of the water, presents a feature in the arboreal flora of the present at once strange and imposing. As a result of the large demand for their valuable timber, the resources of these brakes in the delta and on the lower Alabama and Tombigbee rivers have been almost exhausted, and in this district the manufacture of eypress lumber has at present nearly ceased. The supplies of this timber nee ${ }^{2}$ ed for the manufacture of cypress shingles at Mobile are at present mostly drawn from the more remote brakes on the rivers named and their principal tributaries along their lower course. In these brakes the tupelo gum (Nyssa aquatica) is the only associate of the cypress, which it rivals in size, and the Carolina swamp ash is the only tree of small size thriving in the gloomy shade beneath these trees.

In the mire of the swamps above the level of long-continued overflows a variety of hard-wood trees mingle with the cypress and finally super- 
sede it on ground slightly above the ordinary water level. Black gum, water oak, water hickory, green ash, more rarely Southern red oak, elm, black cottonwood, and overcup oak of rather stunted growth form the high forest overshadowing the smaller trees, of which the most conspicuous are planer tree, red maple, hornbeam, Crataegus viridis, C. elliptica, and the apple haw (Crataegus aestivalis). This haw was observed on the flooded banks of Davids Lake, a large inlet of Mobile River, with a slender stem fully 30 feet high. It unfolds its flowers during the first days of spring (early in February) and ripens its highly palatable, fine-flavored fruit in the beginning of April. Styraxamericana, Osmanthus americanus, Ilexdecidua, Ilexlongipes, parsley haw (Crataegus apiifolia) form the shrubby undergrowth. The handsome silverbells, the dahoon holly, and the swamp dogwood occupy the drier outskirts of these swamps. In their interior the blue palmetto reaches its perfection, the trunk rising from 2 to 3 feet above the ground, the fan-shaped leaves with their stalks 8 to 10 feet long. Black willow and cottonwood cover the recent alluvium. But a small number of paludial plants are found in the depths of these swamps, viz:

Onoclea sensibilis. ${ }^{1}$

Osmunda regalis. ${ }^{1}$

Woodwardia virginica. ${ }^{1}$
Peltandra virginica. ${ }^{1}$

Hymenocallis occidentalis. ${ }^{1}$

In the openings the shallow pools are filled with-

Carex stipata maxima.

Carex vulpinoidea. ${ }^{1}$

Homalocenchrus oryzoides. ${ }^{1}$
Homalocenchrus virginicus. ${ }^{1}$

Polygonum portoricense.

Saururus cernuus (lizard's tail). ${ }^{1}$

Add to these, where the shade is deep, Azolla caroliniana and a fine Riccia in circular tufts which float on the surface. On the ground above the overflow are found-

Cyperus dissitiflorus,

Panicum gymnocarpum,

Gyrostachys odorata, ${ }^{1}$

Hypericum nudiflorum,

the last on the exposed borders of the pools.

Paludial and mesophile forests of the pine barrens.-Descending from the rolling hills to the flats of the coast plain the pine-barren streams overflow their low banks of shifting sands and gravel. In general the tree covering remains unaltered. When the soil is more deeply submerged, the pond cypress and white cedar prevail over the white bay, magnolias, etc., and where the water is more shallow and the ground less oozy Osmanthus americanus, Myrica inodora, and Ilex caroliniana are more frequent than among the hills. The miry spaces between the roots of the trees, which in these wooded shallow swamps run partially above the ground, are filled with peat mosses and the moss-like tufts of Mayaca aubletii and studded with coarse fernsOsmunda cinnamomea, O. regalis, Woodwardia angustifolia, and $W$. 
virginica. A host of Cyperaceae thrive in the shade of these swamps, as-

Eleocharis tuberculosa. ${ }^{1}$

Eleocharis acicularis.

Rhynchospora miliacea.

Rhynchospora axillaris. ${ }^{1}$

Rhynchospora fascicularis.

Rhynchospora gracilenta. ${ }^{1}$

Dulichium arundinaceum. ${ }^{1}$

Carex atlantica. ${ }^{1}$

With these grow-

Pinguicula planifolia,

Bartonia virginica, ${ }^{1}$

Habenaria clavellata, ${ }^{1}$
Carex leptalea. ${ }^{1}$

Carex sterilis. ${ }^{1}$

Carex baileyi.

Carex intumescens. ${ }^{1}$

Carex folliculata australis.

Carex elliottii.

Carex turgescens.

truly characteristic for these tree-clad pine-barren swamps, preferring their open borders. Here also are found-

Hypericum fasciculatum.

Rhexia ciliosa. ${ }^{1}$

Limodorum tuberosum.

Pogonia ophioglossoides. ${ }^{1}$
Pogonia divaricata. ${ }^{1}$

Aster paludosus.

Aster purpuratus.

Amondinaria tecta, formerly abundant in these swampy woods and in the hammocks, is now greatly reduced by the continued browsing of cattle.

Hydrophytic herbaceous plant associations.-One group of these belong to the open pine-barren swamps and ponds with a sour oozy soil filling the frequent depressions in the coast plain. In the stagnant water of the ponds flourish-

Castalia odorata.

Brasenia peltata.

Limnanthemum lacunosum.

Cabomba caroliniana.

Nymphaea advena.
Potamogeton diversifolius.

Utricularia inflata.

Spirodela polyrhiza.

Lemna minor.

Lemna trisulca.

With Castalia odorata occurs its variety with rose-purplish flowers. These all, with floating stems and leaves, form with Eleocharis interstincta, E. mutata, and E. cellulosa a mingling of the Hydrocharidian and Limnæan classes of hydrophytes. To the latter belong also the following types which inhabit the shallower pools and ditehes and root in loamy silt free from peat:

Sagittaria mohrii.

Sagittaria platyphylla.

Sagittaria chapmani.

Utricularia gibba.

Utricularia biflora.

\author{
Eleocharis vivipara. \\ Eleocharis camptotricha. \\ Cyperus compressus. \\ Cyperus haspan. \\ Juncus repens.
}

The following prefer the boggy borders of such pools:

Tillaea simplex.

Oldenlandia boscii.

Oldenlandia littoralis.
Eryngium prostratum.

Eryngium ovalifolium.

Pluchea foetida.

${ }^{1}$ Found also in the Carolinian area. 
The same associations of Sarracenias, sundews, pipeworts, orchids, and Dichromenas which characterize the bogs of the uplands prevail in the boggy marshes of the plain. In the surrounding mire a number of marsh plants occur which are wanting, or are very rare, in the boggy hills. Of such the following are abundant all over this area:

Lycopodium alopecuroides adpressum.

Manisuris rugosa.

Paspalum praecox.

Paspalum membranaceum.

Panicum stenodes.

Scleria torreyana.

Fuirena squarrosa hispida.

Fuirena squarrosa breviseta

Cyperus nuttallii.
Cyperus virens.

Cyperus haspan.

Xyris communis.

Xyris fimbriata.

Xyris serotina.

Xyris ambigua.

Rhexia stricta.

Lobelia paludosa.

Tofieldia racemosa.

The main channel of the gently flowing pine-barren streams is inhabited by a number of floating hydrophytes. Of the lower orders of plants Batrachospermum sp., with dark-green moniliform floating thallus over 1 foot in length, attaches its roots to logs and submerged roots of trees, associated with the large fronds of a water moss (Fontinalis disticha). Of flowering plants, occur in these waters: Hydrochloa fhitans, its long, floating stems in dense tufts frequently filling the bed of the streams; Nuphar sagittifolia, Utricularia purpurea, the golden club, Orontium aquaticum, and Scirpus cylindricus.

The still waters of the estuary of Mobile River and of the larger streams emptying into the upper part of the bay, fresh, except at long intervals, when it is slightly brackish, harbor a number of submerged species, forming in their dense mass subaquatic meadows, the feeding grounds of large flocks of waterfowl. The thread-like, many-branched stems of Nitella acuminata var. and a short-stemmed species of the same genus, growing in dense tufts, form the floor of this limnæan ${ }^{1}$ vegetation, which is then made up of the following, which open their flowers above or below the water:

Zannichellia palustris.

Ruppia maritima.

Ceratophyllum demersum.

Potamogeton crispus.

Potamogeton pusillus.

Potamogeton hybridus.
Potamogeton lonchites.

Potamogeton perfoliatus.

Myriophyllum laxum.

Utricularia vulgaris.

Batrachium divaricatum.

Sagittaria filiformis (rare).

Nelumbo lutea also appears, though but rarely. Vallisneria spiralis and the rarer Philotria (Udora) canadensis, remarkable in their mode of fertilization, are also frequently associated with the above.

Other hydrophytic herbaceous associations have their seat in the open river marshes. The islands in the lower part of the delta and the low banks of the streams in the tide-water region are covered with deep and extensive open marshes, the soft silt of which, rich in humus, supports an association of paludial plants (halophytes), which take root 
firmly in the soil, their mostly strong, interlacing rhizomes forming a dense sod, resisting the action of waves and winds. Reed-like grasses, large rushes, and tall umbelliferous plants are the most conspicuous features of this association. Species are-

Phragmites communis.

Spartina polystachya.

Spartina cynosuroides.

Zizania aquatica.

Zizaniopsis miliacea.

Panicum virgatum.

Panicum digitarioides.

Typha latifolia.
Scirpus lacustris.

Scirpus olneyi.

Scirpus fluviatilis.

Cladium effusum.

Cyperus articulatus.

Cicuta maculata.

Oxypolis teretifolia.

Sium cicutaefolium.

Zizania aquatica, Scirpus lacustris, and Typha latifolia are among the first to gain a firm hold on the muddy shoals, constantly formed by the deposits of silt with which the turbid waters are charged. The following plants constitute the lower and closer covering of the soil:

Cyperus erythrorhizos.

Cyperus strigosus.

Cyperus stenolepis.

Cyperus speciosus.

Carex lurida.

Carex albolutescens.
Carex alata.

Homalocenchrus hexandrus.

Andropogon glomeratus glaucopsis.

Rynchospora caduca.

Rynchospora corniculata.

Among other paludial plants which adorn the reed marshes are:

Ipomoea sagittata,

Mesadenia lanceolata,

Kosteletzkya virginica,

Boltonia diffusa,
Vernonia gigantea,

Sagittaria falcata lanceolata,

Sagittaria montevidensis,

Sagittaria viscosa (rare),

plants characteristic of such marshes from North Carolina to Louisiana. With these grow also-

\section{Lythrum lineare,}

Pontederia cordata,

Rumex altissimus,
Echinodorus radicans, Sagittaria latifolia,

of frequent occurrence as far as the northern limit of the Carolinian area; and Solidago sempervirens ranging from the coast of Nova Scotia southward. The Sagittarias often occupy considerable tracts almost exclusively. The dark waters of ditches and shallow pools at the outskirts of these marshes are filled with the floating stems of Jussiaea diffus $a$ and bordered by-

Hydrocotyle ranunculoides.

Hydrocotyle verticillata.
Ptilimnium capillaceum.

Aeschynomene virginica.

Ranunculus sceleratus.

Eleocharis montana, with its densely matted rhizomes, forms wide patches of shining bright green, rarely accompanied by Eleocharis palustris. Triglochin striata, Juncus scirpoides, and J. polycephalus are scattered through the marsh, and Vigna glabra and Willughbya scandens intertwine their stems among the grasses and sedges lining the muddy banks. Sesbania macrocarpa and Glottidium floridanum 
occupy almost alone the alluvial banks bordering the swamps, covered with the débris left behind after every overflow.

LITTORAL BELT.

This division of the coast plain comprises the outlying islands and the narrow strip under the influence of the salty tide. Either sandy or marshy, this Littoral belt presents three distinct formations in its flora: (1) The plant formation of the strand or sandy flat beach, with its shingle and salty pools; (2) the plant formation of arid drifting sands, (3) and lastly the salt marsh.

Halophytic plant associations of the strand.-The strand or sandy flat beach, of moderate extent, as found in Baldwin County, washed by the more or less brackish water of Mobile Bay and the smaller inlets to the east of this sheet of water, is almost destitute of vegetation. The flora of the strand lining the Gulf shore, always moistened by the salt spray of the surf and flooded by high tides, is poor in individuals and species. The species found are, many of them, at home on tropical shores, and they constitute a very open association of sandloving, salt-water plants (halophytes), similar to the Ipomoea pes-capreae formation of tropical strands. This fine halophyte of the morningglory family, from which this association has received its name, is not rare on our Gulf shore. Its interlaced stems form large patches, which at once attract the attention by the rich dark green of their fleshy broad leaves and by their large rose-purple flowers. Sesuvium portulacastrum inhabits the shallow salty pools with Cakile maritima geniculata, both frequent in the West Indies; also with Iva imbricata, a low shrubby perennial of southeastern North America, and Dondia (Sueda) linearis, common on the Atlantic and Gulf shores from New England to Florida and Mississippi.

Xerophile plant associations of the dry sands of Mobile and Perdido bays. - The benches of loose white sand extending along the shore of Mobile Bay and the land-locked waters of Perdido Bay present a varied vegetation of sand-loving plants (psammophytes), which are so scattering, however, as scarcely to hide the snow-white sands. When viewed under the glare of the noonday sun, the dark-green foliage of the stunted live oak, with gnarled limbs, stands out in strong contrast with the glistening sands. The stiff, leathery, narrow leaves, shining above and hoary beneath, peculiar to this maritime form, afford a safe protection against the injurious effects of excessive transpiration during a long-continued drought, when the sand is heated by the scorching rays of the summer sun.

The grasses are:

Panicum repens.

Panicum littorale.

Stenotaphrum secundatum (Saint Augustine grass).
Cenchrus incertus (sand bur). Cenchrus megacephalus (sand bur). Sieglingia purpurea (purple sand grass). Sieglingia americana (Southern sand grass.) 
Of these the first two are frequent perennials, both confined to the coast and ranging from Florida to Mexico, true sand binders with their running rhizomes deeply buried. The sand burs are annuals from the same regions.

Of the sedge family Cyperus lecontei, ranging from the coast of Florida to Louisiana, and the common Cyperus strigosus, are frequent. Other herbaceous plants here found are:

Euphorbia polygonifolia.

Salsola kali.

Froelichia floridana.

Siphonychia erecta.

Siphonychia diffusa.

Paronychia riparia.

Stipulicida setacea.
Polygonella gracilis.

Physalis angustifolia.

Linaria floridana.

Baldwinia multiflorct.

Heterotheca subaxillaris.

Oenothera humifusa.

Of these the first three range northward to New England and the Great Lakes. The remainder, except the last two, are typical littoral sand plants, ranging from the shores of North Carolina, Georgia, and Florida to Louisiana; the last two are perennials of about the same range.

A small group of low shrubs and suffrutescent perennials, highly characteristic types, mingle on the sandy benches above with these associations of herbs, all of which are at home in corresponding localities in southern Georgia and Florida. Chrysoma (Solidago) pauciflosculosa, known as golden rod, is the most frequent among them, an undershrub which is extremely conspicuous when covered with its profusion of golden yellow flowers, and later on account of its densely tufted stems retaining their foliage almost throughout the winter. With these are found Conradina canescens, confined to the shores of western Florida and Alabama, with the rare Polygonella polygama and Helianthemum arenicola, all sparsely diffused along the shore of western Florida. Cuscuta indecora, not observed in the State outside of this region, is frequently parasitic on the Chrysoma pauciflosculosa.

Xerophile plant associations of the dunes.-On the southern shore of Dauphine Island and on the main shore eastward to Perdido Bay hillocks of drifting white sands, thrown up by the unobstructed action of winds and waves, rise above the beach, frequently inclosing shallow swamps and pools between them. On these dunes the live oak makes a more or less scrubby growth, frequently not exceeding in size the sand oak (Quercus myrtifolia), with which it is associated. The latter is an evergreen shrub branched from the base and from 5 to 8 feet in height. These, with Ceratiola ericoides and dwarfed wax myrtles, form an association of xerophile evergreen bushes, augmented by Chrysoma panciflosculosa and Polygonella gracilis, the whole frequently intertwined with the stems of the woody creepers Ampelopsis incisa and Smilax auriculata. On the crests and steep sides of the hillocks the so-called sea oat (Uniola paniculata) forms open patches. 
The slender, wiry culms of this grass, 3 to 4 feet high, with seanty involute rigid leaves, when bending under the burden of the large, more or less contracted, panicles of the broad, many-flowered drooping spikelets, render the species one of the most striking types of psammophile plants. It inhabits the dunes from the southern frontier of Virginia through North Carolina south to Texas and the Mexican coast. By its stout running rhizome, deeply buried in the sand and sprouting from the rather distant nodes, a single plant soon colonizes the bare dune. The flowers appear to be mostly infertile, as no spikelets with well-matured grain have been observed in the specimens from our coast. Ipomoea carnosa, similar in its subterranean stems and root system to the above grass, is not infrequently found along with it, the numerous long prostrate stems bearing brightgreen leaves, which cover the sand. Opuntia crus-corvi and Siphonychia erecta are not rare in the same localities. The dead tops and branches of the sand pine (Pinus clausa) and tops of the Spanish dagger (Yucca aloifolia), with the trunks almost completely buried in the drifting sands, increase the impression of aridity on these desolate shores.

Mesophile plant associations of the dunes.-In the shallow sandy pools, formed mostly by the accumulations of rain water in the depressions and rendered more or less brackish by the influx of the waves of the sea during storm tides, many of the plants of the semiswampy coast plain mingle with types of various families not found outside of the littoral belt. Of the former class occur the following, the first two being most frequent:

Rynchospora torreyana.

Hypericum aspalathoides.

Linum medium.

Lechea torreyi.

Scleria pauciflora glabra.

\section{Of plants peculiar to the littoral belt occur:}

Scirpus americanus.

Fuirena scirpoidea.

Scleria gracilis.
Xyris torta pallescens.

Cassia (Chamaecrista) mississippiensis.

Open groves of Cuban pines cover the flats behind the dunes, merging frequently into the pine meadows of the coast plain.

Xerophile plant associations of the sandy dry hammocks.-Between Bon Secour and Perdido Bay low, sandy hills or ancient dunes, rising above the saline swamps, support a high forest of evergeen trees, principally live oak, but with a mixture of laurel oak and Cuban and long-leaf pine. On these dry, sandy hammocks the sand pine (Pinus clausa), frequent in peninsular and western Florida, reaches its western limit. In this locality the tree has been found from 50 to 60 feet high, rarely over a foot in diameter, breast high. Stunted Spanish oak, barren oak, blue jack, and the common wax myrtle form the undergrowth, and the procumbent stems of the saw palmetto deeply rooting 
in the sand often closely cover the soil. On the borders of these woods, and almost confined to them, Rynchospora dodecandra is frequent with the rare Carex dasycarpa, both of which oceur also in South Carolina.

Mesophile plant associations of the salt marshes covering the outlying islands. - Dauphine Island is the most easterly of the interrupted chain of islands which incloses the waters of Mississippi Sound; it is the largest that fronts the Alabama coast and was originally covered with the Cuban pine. The flora of this island presents no new features, the vegetation of its dunes, saline marshes, and pine flats being identical with that of the corresponding situations on the mainland.

The low islets closer to the main shore and flooded by every high tıde are bare of tree growth, and their borders, if not their whole surface, are almost always soaked by the briny sea, and are not rarely covered with a floor of fine salt. Where sand and shingle, thrown up by the waves, have raised the ground above continued overflow, evergreen shrubs preferring a saline soil (halophytes), such as Iva frutescens, Baccharis halimifolia and B. angustifolia, fringe their shores, together with Chenopodium berlandieri and Lycium carolinianum (sea cherry). Batis maritima, Salicomia bigelovii, and S. ambigua, low shrubby paludial halophytes, with Fimbristylis spadicea, form a dense, close cover of perpetual verdure on these islands.

Mesophile plant associations (halophytic) of the salt marshes on the main shore.-The shallow, tranquil waters of the numerous inlets of the sea, with their floor of deep, sandy mud, which receive the smaller pine-barren streams, are covered exclusively by the black rush (Juncus roemerianus). The rigid, sharp-pointed, leafless stems which rise 2 feet or more above the water, and are more or less crowded, present a rather compact plant formation highly characteristic of the vegetation of the littoral region of the Southern Atlantic and Gulf States. This formation might fitly be designated as the Southern Juncaceous formation. This rush also forms the great bulk of the vegetation of the extensive saline marshes lining the shore, which at low tide are above water and which by their position are protected against the violent action of the waves. In these marshes, associated with the black rush occur:

Fimbristylis castanea.

Fimbristylis puberula.

Spartina polystachya.

Cladium effusum.
Distichlis spicata.

Chaetochloa imberbis perennis

Paspalum vaginatum.

Also the following halophytes:

Limonium carolinianum.

Gerardia maritima.

Borrichia frutescens.

Cynanchum palustre.

In receding from the water front the marsh gradually rises above continuous overflow, and the ground affords a firmer foothold. In such situations the rushes and grasses disappear and a more or less 
open vegetation of low perennials and herbaceous plants of various families finds its home on the damp, often bare, ground, which is covered with a salty efflorescence. On such bare places the following are found:

Sabbatia stellaris.

Gratiola hispida.

Oldenlandia littoralis.

Monniera monniera (Herpestis monniera).

Lippia cuneifolia.
Tissa marina.

Atriplex arenaria.

Heliotropium curassavicum.

Eleocharis capitata.

Distichlis spicata.

Lippia cuneifolia is a prostrate perennial, with rooting, creeping stems.

In the submerged salt marshes, with a firmer floor, formed by deposits of a heavier silt, large-stemmed and broad-leaved rushes and grasses prevail, forming a compact halophile association of reeds, with deeply submerged stout rhizomes tightly interlaced. The slender, pale Spartina patens, with its stiff stems and erect involute leaves, chiefly prevails with the tall Scirpus robustus and Spartina polystachya, and with Kosteletzkya virginica altheaefolia and Ipomoea sagittata.

Shell hammocks.-On the shore of the sea and of the larger inlets, and along the banks of the bayou's narrow tortuous marine channels, heaps of bivalve shells, frequently many yards in length and from 6 to 15 feet and over in height, are encountered, the accumulation of refuse from the food supply which served a race of men unknown to history. Large live oaks, aged magnolias, and pignut hickories cover these heaps, along with dense copses of the red buckeye, the sea plum, and the lime-loving Carolina buckthorn, the last two not known from any other locality in the lower pine region. On these shell banks the West Indian red cedar (Juniperus barbadensis) is frequently found in full perfection, the sturdy trunk spreading out its almost horizontal branches, with their drooping branchlets, at from 12 to 18 feet above the ground. This tree is frequently found on the low hammocks lining the shores of the Gulf and its inlets from Mississippi to Florida and along the Atlantic shore to Georgia. On the driest summits of the shell heaps and on the sandy shores of the open sea, exposed to wind and tide, it is frequently of low stunted growth with the trunk divided from the base. Prickly pear in large patches frequently spreads over the open places; Evolvulus alsinoides, widely distributed in littoral regions within the tropics of the New and Old World, has been observed on the shell banks of Dauphine Island. Remarkable is the never-failing occurrence on these shell banks from South Carolina to Texas of Limnodea (Thurberia) arkansana in the scanty cover of herbs.

CULTURAL PLANT FORMATIONS OF THE COAST PINE BELT.

Of the 8,500 or 9,000 square miles covered by the rolling pine barrens and pine flats of the coast plain east of the Escambia and Conecuh rivers, not more than about 2 per cent is under tillage, and west of 
these rivers, in the counties of Covington and Geneva, and the lower part of Coffee, Dale, and Henry, about 10 per cent is under cultivation. The large areas of the farm lands are used for the pasture of cattle and sheep, which are left without attention to roam throughout the open pine forests and intervening swamps. The people of these sparsely inhabited regions depend for their livelihood mostly upon the timber and the resinous products of the longleaf pine forests. The land under cultivation is devoted principally to the growing of food crops, chiefly corn, sweet potatoes, rice, with some sugar cane, the several products scarcely sufficing to meet the home demand. It is only of late years that the possibilities of the soil of the better class of pine lands have received a proper appreciation. Wherever the sandy loams rest upon a more retentive, somewhat clayey subsoil, these lands, with the help of a slight outlay for fertilizers, never fail to give. satisfactory returns to the tiller. In the few localities where the experiment has been made the cultivation of cotton has proved successful. The tropical sugar cane is grown on every farm for the production of the largely consumed table sirup and raw sugar to cover the needs of the homestead. On the best of the pine land this crop will prove to be profitable, if undertaken on a more extensive scale. For on these lands the cultivation of the sugar cane is easier and less expensive than on the heavy alluvial lands, which frequently require large outlays for drainage. Moreover, the cane grown on these pine lands yields a juice of great purity and rich in erystallizable sugar.

With the increased facilities for transportation to distant northern markets, much attention has been given to truck farming all along the railroad lines, and the large shipments of eabbages and Irish potatoes and other vegetables and fruits made every spring show the increasing importance of this industry. Among fruits, strawberries and watermelons are raised in large quantities for shipment. On the rolling pine lands, with a suitable subsoil, peaches and grapes under proper modes of cultivation, succeed well.

This industry of truck farming is carried on most extensively on the Coast plain. Upon this low land, where the winter climate is tempered by the proximity of the sea, the warm, sandy loams produce crops which reach their perfection at an earlier date and with less risk of injury by frosty weather. During the winter and early spring the extensive fields of cabbages present a most peculiar compact plant formation of a biennial member of the Brassica tribe, alternating with a tuber-bearing, solanaceous annual-the Irish potato. The planting season of the various crops of early vegetables for northern markets extends from the middle of October to the middle of March. The mean temperature of this period averages about $57^{\circ}$, with a mean of all the monthly highest temperatures of $78^{\circ}$ for the coldest part of the growing season-December to February; conditions highly favorable for starting and fur- 
thering the growth of the principal crops named, besides other root crops of minor importance, such as radishes and turnips, and also kales, paas, beans, cucumbers, etc. The plants easily recover from the injuries inflicted by light frosts, particularly when these happen in cloudy weather and when the return of the sunshine is gradual. The warmth of the sun raises the temperature of the soil and gives a new impetus to growth in compensation for the check it has received. Sudden changes, however, to temperature below the freezing point, succeeded immediately by sunny weather, not infrequently prove disastrous to the crops. Cabbage plants are constantly transferred from the cold frames to the field from October to December, and the crop is marketed from December to May. Irish potatoes are generally planted from the beginning of January to the latter part of February, and yield the firstcrops in April. Peas are sown in January and early in February; beans, squashes, and sweet corn about the first of March, when tomatoes, cucumbers, and melons, which have started under glass, are transferred to the open. Large quantities of these vegetables reach the northern markets from April to the beginning of summer.

After these various crops have been harvested, chiefly gramineous plant formations take the place of those mentioned above. Field corn is frequently planted after the removal of the first crops of cabbage and Irish potatoes; crops of Italian or golden millet also frequently take their place; cowpeas are planted for fodder, but most frequently for the purpose of fertilizing the fields by plowing under. Far the largest part of the cultivated fields, however, is left to a luxuriant growth of weedy grasses, chiefly crab grass (Syntherisma (Panicum) sanguinale), bull grass (Paspalum boscianum), yard grasses (Eleusine indica, Leptochloa mucronata, Paspalum dilatatum), and the so-called Mexican clover (Richardia scabra), which furnish abundant, spontaneous crops of nutritious hay, and also pasturage to the close of the season. In fact, it may be said that forage crops of various kinds can be grown in succession throughout the year. Oats and rye furnish green pasture through the winter; vetch (Vicia sativa), cowpeas, and bur clover (Medicago maculata) will yield crops for soiling in the earliest days of spring. Oats cut in the milky stage are cured for dry feed in May and June. Cowpeas, millets, various kinds of sorghum, known as durrha or kafir corn, millo maize, and pearl millet; cattail millet, Hungarian grass, and the so-called Johnson grass (Sorghum halepense) furnish green forage and hay crops throughout the summer; to which, near the coast, can be added the Guatemala grass or teosinte (Euchlaena mexicana), the genuine Guinea grass (Panicum jumentomum), and Para grass (Panicum molle).

The cultivation of the orange on our coast is wholly confined to the sheltered coves on the shores of the large bays and of the Gulf. The loquat tree, or Japanese medlar (Eriobotrya japonica), has produced 
abundant crops of its luscious fruit, which ripens early in the spring. This tree has, however, during the past few years been threatened with destruction by the same blight which has proved so disastrous to the pear orchards throughout the region. Under the care of experienced cultivators, the raising of peaches as well as of the finer kinds of grapes is of much promise. The fig produces abundant fruit, which is consumed fresh or used for preserves; and the scuppernong grape yields its crops year after year with regular abundance. The cultivation of the fine kinds of pecan nut has greatly increased during the past 15 or 20 years, and the increasing crops of fine nuts are now seeking an outlet to distant markets.

Exotic subtropical arborescent flora.-The mildness of the climate of the coast region is most fully attested by the luxuriant and varied growth of woody exotics from subtropical and tropical regions of the Old and New World, which adorn our gardens and grounds, and which furnish many of the trees that shade our streets and dwellings. Of the shade trees are to be mentioned the China tree (Melia azedarach), the most frequent, and its variety of lower growth known as the umbrella China tree; also the paper mulberry (Broussonetia papyrifera). Of smaller-sized trees conspicuous by their profusion of flowers the crape myrtle (Lagerstroemia indica) takes the first place; to which are added:

Ligustrum japonicum (Japanese privet). Cinnamomum camphora (camphor tree).

Punica granatum (pomegranate).

Jatropha carthaginiensis (large cassava tree).

Sapium sebiferum (Chinese tallow tree).
Albizzia julibrissin (silk tree).

Acacia farnesiana (sweet opoponax).

Osmanthus fragrans O.major, (sweet olive). Michelia (Magnolia) fuscata.

Viburnum odoratissimum (Chinese viburnum).

Of evergreen coniferous trees the deodar cedar (Cedme deodara), Chinese cunninghamia (Cunninghamia chinensis), Chili pines (Araucaria spp.), the somber cypress (Cupressus sempervirens) of Mediterranean Europe, and the weeping cypress (Cupressus funebris) from Asia not rarely adorn the grounds about dwellings throughout the Lower Pine region. Of the large number of hardy shrubs, only the most frequent and prolninent can be mentioned, the hybrid Indian azaleas taking the first place. These shrubs, loaded with a profusion of flowers running from pure white through all shades of dazzling flame-color, vermilion, pink, and purple, are produced from the beginning to near the close of spring in a perfection scarcely ever surpassed. Many of these plants grow to a height of from 6 to 8 feet, covering square yards of ground with their low, wide-spreading branches. The single-flowered Camellia japonica, of almost tree-like growth, puts forth its abundance of flowers from the middle of January through the winter, as do several kinds of laurestines. The more tender varieties of the former, with double flowers, need for their perfect development a slight pro- 
tection against continued rains and spells of extreme cold. The fragrant pittosporum (Pittosporum tobira), jessamines, cape jessamine (Gardenia) are perfectly hardy. The century plant (Agave americana) not infrequently puts forth its candelabra-like flowering shafts, and yuccas (Yucca treculeana, etc.) from Mexico and the adjacent Texan region, and the tropical so-called sago palm (Cycas revoluta) and arrowroot palm (Zamia integrifolia) of southern Florida add to the number of decorative evergreen plants. 

SYSTEMATIC CATALOGUE OF THE PLANTS GROWING WITHOUT CULTIVATION IN ALABAMA, INCLUDING DESCRIPTIONS OF NEW, RARE, AND LITTLE-KNOWN SPECIES.

SIIME MIOIDS.'

\section{Subkingdom MYXOTHALLOPHYTA (MYXOMY- CETES). Slime Molds.}

Order PLASMODIOPHORALES.

Family PLASMODIOPHORACEAE.

FRANKIA Brunch.

Frankia alni (Wor.) Atkinson.

Ala. Bull. 133. Cornell Bull. 50.

Forming galls on roots of Alnus sp. Lee County, February, 1892 (Atkinson); July, 1896 (Underwood \& Earle).

Frankia ceanothi Atkinson, Bull. Torr. Club, 19:171. 1892.

Ala. Bull. 133. Cornell Bull. 50.

On roots of Ceanothus americanus. Lee County, Auburn, November, 1891 (Atkin8on); Lee County, May, July, 1896 (Underwood \& Earle).

\section{Order MYXOGASTIRALES.}

\section{Family TRICHIACEAE.}

Arcyria ferruginea Sauter.

ARCYRIA Hall.

Ala. Bull. 133.

Lee County, February, 1896 (Underwood \& Earle).

Arcyria punicea Pers.

Ala. Bull. 133.

Lee County, December, 1895 (Underwood); February, 1896 (Underwood \& Earle).

TRICHIA Håll.

Trichia affinis De Bary.

Ala. Bull. 135.

Lee County, February, 1896 (Underwood \& Earle).

Trichia chrysosperma (Bull.) DC.

Ala. Bull. 135.

Lee County, November, December, 1895 (Underwood).

Trichia varia Pers.

Ala. Bull. 135.

Lee County, December, 1895 (Underwood).

${ }^{1}$ Contributed by Prof. F. S. Earle, of the Biological Survey of Alabama, April, 1899. Collection made mostly in the vicinity of Auburn, Ala. 


\section{TUBULIN A Pers.}

Tubulina cylindrica (Bull.) DC.

Ala. Bull. 135.

Lee County, March, 1896 (Underwood \& Earle).

HEMIARCYRIA Rostf.

Hemiarcyria clavata (Pers.) Rostf.

Peters coll. Ala. Bull. 134.

On Pinus sp. (Peters).

Hemiarcyria funalis Morgan.

Ala. Bull. 134.

Lee County, December, 1895 (Underwood).

Hemiarcyria rubiformis (Pers.) Rostf.

Ala. Bull. 134.

Lee Connty, November, 189: (Underwood); February, 1896 (Underwood \& Earle).

Hemiarcyria serpula (Scop.) Rostf.

Peters coll. No. $105 . \quad$ Ala. Bull. 134.

(Peter8.) Lee County, December, 1895 (Underwood).

IYCOGALA Michx.

Lycogala epidendron (L.) Buxb.

Ala. Bull. 134.

Lee County, February, March, 1896 (Underwood \& Earle).

CALONEMA Morgan.

Calonema aureum Morgan.

Ala. Bull. 133.

On rotten wood. Lee County, December, 1895 (Underwood).

Ohio.

\section{Family CRIBRARIACEAE.}

CRIBRARIA Schrad.

Cribraria argillacea Pers.

Grevillea, 2:68, as Licea spermoides B. \& C. Ala. Bull. 134.

(Beaumont.)

\section{DICTYDIUM Schrad.}

Dictydium cernuum (Pers.) Nees.

Petere coll., as D. umtilicatum. Ala. Bull. 134.

(Peters.)

\section{PERICHAENA Fr.}

Perichaena corticalis (Batsch) Rostf.

Peters coll. No. 106. Ala. Bull. 134.

(Peters.)

\section{Family CLATHROPTYCHIACEAE.}

CLATHROPTYCHIUM Rostf.

Clathroptychium rugulosum (Wallr.) Rostf.

Peters coll. Ala. Bull. 133.

On Quercus, 1873 (Peters).

ENTERIDION Ehrh.

Enteridium olivaceum Ehrh.

Peters coll. No. 125a, as Licea applanata. Ala. Bull. 134.

(Peters.) 


\section{Family RETICULARIACEAE.}

RETICULARIA Bull.

Reticularia atra (A. \& S.) Fr.

Ala. Bull 135. Lee County, March, 1896 (Underwood \& Earle).

\section{Family DIDYMIACEAE.}

Didydium clavus (A. \& S.) Rostf.

Peters coll. Ala. Bull. 134.

August, 1855 (Peters).

\section{Family SPUMARIACEAE.}

SPUMARIA Pers.

Spumaria alba (Bull.) DC.

Peters coll. Ala. Bull. 135.

1865 ('Peter8).

\section{Family PHYSARACEAE.}

BADHAMIA Curt. \& Berk.

Badhamia decipiens (Curt.) Berk.

Grevillea, 2:66, as Physarum chrysotrichum B. \& C. Ala. Bull. 133.

On dead wood (Peters).

\section{LEOCARPUS Link.}

Leocarpus fragilis (Dicks.) Rostf.

\section{PHYSARUM Pers.}

Physarum cinereum (Batsch) Pers.

Ala. Bull. 134.

On grass and clover. Lee Connty, March, 1896 (Underwood \& Earle).

Physarum flavicomum B. \& Br.

Peters coll. Ala. Bull. 134.

1855 (Peters).

Physarum petersii B. \& C.

Grevillea, 2:66. Peters coll. No. 104. Ala. Bull. 134.

On dead wood (Peters).

Physarum pulchripes Peck.

Ala. Bull. 134.

Lee County, March, 1896 (Underwood \& Earle).

\section{FULIGO Hall.}

Fuligo septica (Link) Gmel.

Peters coll. No. 107. Ala. Bull. 134.

(Peters.) Lee County, April, 1896 (Underwood \& Earle).

\section{Family STEMONITACEAE.}

Stemonitis fusca Roth.

\section{STEMONITIS Gled.}

Ala. Bull. 135.

Lee County, February, 1896 (Enderwood \& Earle).

Stemonitis microspora Lister.

Ala. Bull. 135.

Lee County, February, March, 1896 (Underwood \& Earle). 
Stemonitis tenerrima B. \& C.

Ala. Bull. 135.

Lee County, November, 1895 (Underiood).

COMATRICHA Prouss.

Comatricha friesiana (De Bary) Rostf.

Ala. Bull. 133.

(Peter8.)

Comatricha typhina (Roth) Rostf.

Peters coll. Ala. Bull. 133.

(Peter8.)

\section{Family CERATIOMYXACEAE.}

CERATIOMYXA Schroet.

Ceratiomyxa mucida (Pers.) Schroet.

Ala. Bull. 133.

(Peters, Beaumont). Lee County, April, 1896 (Underwood \& Earle),

ALGAE.

As yet the study of the classes of true thallophytes, embracing the plants generally described as algae, has received scarcely any attention

in Alabama. The sandy shoals and the sandy shores washed by the waves along the eastern Gulf coast from Louisiana to northwestern Florida are unproductive of algae, and only a few species of the higher forms find their home on our shore. With the exception of Characeae and Lemaneaceae, it has been necessary to omit the so-called freshwater algae, as we know too little of them at present.

The successful efforts of Dr. George H. Taylor and the Messrs. K. M. Cunningham and William MeNeil in cleansing samples of the mud of Mobile Bay obtained from the almost fresh water of the estuary of Mobile River, the more or less brackish water of the upper bay and the brine of the lower bay have brought to light a considerable number of interesting forms of the diatom family, which are here placed on record. The work of these skillful and diligent collectors has been spoken of by Hon. J. D. Cox, LL. D., of Cincinnati, in the American Monthly Microscopic Journal. ${ }^{1}$ At the same time the following list has been furnished by Mr. Cox, to whom the cleansed material was at the time submitted for examination. The generic and specific names have been revised to conform with De Toni's Sylloge Algarum. 


\title{
Subkingdom EUTHALLOPHYTA.
}

\author{
Division EUPHYCEAE. \\ Order BACILLARIALES.
}

Family BACILLARIACEAE (DIATOMACEAE). ${ }^{1}$ Diatoms.

Subfamily DISCOIDEAE.

PARALIA Heib.

Paralia sulcata (Ehrenb.) Cleve. Melosira sulcata Kuetz.

Marine.

Now Jersey.

COSCINODIscus Ehrenb.

Coscinodiscus radiatus Ehrenb.

Marine.

New Jersey.

Coscinodiscus subtilis Ehrenb.

Marine and in brackish water.

New Jersey.

Coscinodiscus lineatus Ehrenb.

Salt and brackish water.

New Jersey.

Coscinodiscus excentricus Ehrenb.

Fresh, brackish, and salt water.

New Jersey.

ACTYNOPTYCHUS Ehrenb.

Actinoptychus undulatus (Bailey \&) Ralfs.

Marine mud.

Tampa Bay (G. H. Taylor). New Jersey.

Actinoptychus splendens (Ehrenb. ?) Shadb.

Brackish water.

Tampa Bay (G. H. Taylor). New Jersey.

Actinoptychus areolatus (Ehrenl.) Schmidt.

AULISCUS Ehrenb.

Auliscus caelatus Bailey.

Marine.

Tampa Bay (G. H. Taylor). New Jersey.

Auliscus sculptus (Wm. Smith) Ralfs.

Marine.

Now Jersey.

Auliscus pruinosus Bailey.

Marine.

Tampa Bay (G. H. Taylor).

Auliscus punctatus Bailey.

PSEUDAULISCUS Leud.-Fortm.

Pseudauliscus radiatus (Bailey) Rattray. Auliscus radiatus Bailey. 
EUPODISCUS Ehrenb.

Eupodiscus radiatus Bailey.

AULACODISCUS Ehrenb.

Aulacodiscus argus (Ehrenb.) A. Schmidt. Tripodiscus argus Ehrenb. Eupodiscus argus Wm. Smith.

Marine.

Tampa Bay (G. H. Taylor). New Jersey.

ACTINOCYCLUS Ehrenb.

Actinocyclus ehrenbergii Ralfs.

Subfamily BIDDULPHIOIDEAE.

CHAETOCEROS Ehrenb.

Chaetoceros varians (Lauder) Van Heurck. Bacteriastrum varians Lauder. $B$. curvatum Shadb.

\section{TRICERATIUM Ehrenb.}

Triceratium favus Ehrenb.

Salt or brackish water.

Tampa Bay (G. H. Taylor). New Jersey.

Triceratium alternans Bailey.

Marine.

New Jersey.

Triceratium punctatum Brightw. T. sculptum Shadb.

AMPHITETRAS Ehrenb.

Amphitetras antediluviana Ehrenb.

Marine.

Cosmopolitan.

ODONTELLA Agh.

Odontella aurita (Lyngb.) Agh. Diatoma auritum Lyngb. Biddulphia aurita Brébis. Marine mud.

New Jersey.

Odontella turgida (Wm. Smith) Van Heurck. Cerataulus turgidus Ehrenb.

Marine mud.

New Jerses.

CERATAULUS Ehrenb.

Cerataulus smithii (Roper) Ralfs.

TERPSINOت̈ Ehrenb.

Terpsinoë americana (Bailey) Ralfs.

New Jersey.

Terpsinoë musica Ehrenb.

Tampa Bay. New Jersey.

Subfamily FRAGILARIOIDEAE.

EUNOTIA Ehrenb.

Eunotia arcus Ehrenb.

Eunotia triodon Ehrenb.

Fresh water.

New Jersey. 
GRAMMATOPHORA Ehrenb.

Grammatophora marina (Lyngb.) Knetz.

Marine.

New Jersey.

Subfamily NAVICULOIDEAE.

NAVICULA Bory.

Navicula lyra Ehrenb.

Fresh and brackish (q) water.

New Jersey.

Navicula irrorata Grev.

Navicula permagna (B́ailey) Edwards.

Brackish or salt water.

Tampa Bay. New Jersey.

Navicula maculata Edwards.

Navicula distans (Wm. Smith) Ralfs.

Navicula caribaea Cleve.

Navicula didyma Ehrenb.

Marine.

New Jersey.

Navicula kennedyi Wm. Smith.

Marine,

New Jersey.

Navicula praetexta Ehrenb.

Marine.

New Jersey.

Navicula serratula Grunor.

Navicula longa (Gregory) Ralfs.

Navicula major Kuetz.

Fresh water.

New Jersey.

Navicula nobilis (Ehrenb.) Kuetz.

Fresh water.

New Jersey.

Navicula aspera Ehrenb. Stauroneis aspera Ehrenb. S. pulchella Wm. Smith. Marine.

Tampa Bay. New Jersey.

\section{DICTYONEIS Cleve.}

Dictyoneis marginata (Lewis) Cleve. Navicula marginata Lewis. Fresh water.

New Jersey.

$$
\text { FRUSTULIA Agh. }
$$

Frustulia lewisiana (Grev.) De Toni. Navicula lewisiana Grev.

\section{STAURONEIS Ehrenb.}

Stauroneis phoenicenteron (Nitzsch) Ehrenb.

Fresh water.

New Jersey.

PLEUROSIGMA Wm. Smith.

Pleurosigma validum Shadb. 
AMPHIPRORA Ehrenb.

Amphiprora costata O'Meara. ${ }^{1}$

PLAGIOTROPIS Pfitz.

Plagiotropis vitrea (Wm. Smith?) Grunow. Amphiprora vitrea Wm. Smith. Plagiotropis elegans (Wm. Smith) Grunow. Amphiprora elegans Wm. Smith.

CYMBELLA Agh.

Cymbella heteropleura (Ehrenb.) Kuetz.

AMPHORA Ehrenb.

Amphora proteus Gregory.

Brackish or salt water.

New Jersey.

Amphora clevei A. Schmidt.

Amphora cingulata Cleve.

NITZSCHIA Hassal.

Nitzschia scalaris (Ehrenb. ?) Wm. Smith.

Fresh or brackish water.

New Jersey.

Nitzschia sigmoidea (Nitzsch) Wm. Smith.

Fresh water.

New Jersey.

Nitzschia circumsuta (Bailey) Grunow.

Subfamily SURIRELLOIDEAE.

SURIRAYA Turp.

Suriraya febigerii Lewis.

Brackish water.

Tampa Bay. New Jersey.

Suriraya fastuosa Ehrenb.

Marine.

New Jersey.

CYSTOPLEURA Brébis.

Cystopleura zebra (Ehrenb.) Kuntze. Epithemia zebra Kuetz.

CAMPYLODISCUS Ehrenb.

Campylodiscus clypeus Ehrenb.

Campylodiscus limbatus Brébis.

Class CHLOROPHYCEAE. Green Algae.

Order PROTOCOCCALES.

Family HYDRODICTYACEAE.

HYDRODICTYON Roth.

Hydrodictyon reticulatum (L.) Lagerh.

Stagnant pools, ditches. Over the State.

United States, Canada, Europe.

${ }^{1}$ There is some uncertainty about this name.-Ed. 


\section{Order CONFEIRVALES.}

\section{Family ULVACEAE.}

ULVA L. Sea lottuce.

\section{Ulva lactuca (L.) Le Jolis.}

On piles and sunken timber, salt and brackish water. Mobile Bay.

Ulva enteromorpha Le Jolis.

Mobile Bay, with the last.

\section{Class CHARALES. ${ }^{1}$}

\section{Family CHARACEAE.}

CHARA Vaill.

Chara gymonopus humboldtii A. Br.

In swiftly running streams. Bibb County, Little Cahawba River (E. A. Smith).

Louisiana to New England. Europe.

Chara fragilis (L.) Desv.

In swiftly running streams. Little Cahawba River, Bibb County (E. A. Smith).

NITELLA Agh.

Nitella glaziovii Zell.

In deep, gently flowing water. Estuary of Mobile River. September, fruiting abundantly under the water 10 feet deep.

Nitella tenuissima A. Br.

In deep, still, brackish water. Upper part of Mobile Bay; dredged from a depth of 15 feet and over.

Nitella tenuissima A. Br., forma.

In large tufts. Baldwin County, above the mouth of Fly Creek on the muddy bottom. Abundant.

Nitella acuminata A. Br.

In deep water. Estuary of Mobile River with N. glaziovii.

Nitella acuminata subglomerata A. Br.

With the above.

Nitella acuminata brachyteles $\mathrm{A}$. Br.

With the last.

\section{Class PHAEOPHYCEAE.}

\section{Order CYCLOSPOIRALES.}

\section{Family FUCACEAE.}

\section{SARGASSUM Agh. Gulf weed.}

\section{Sargassum bacciferum Turu.}

Frequently washed ashore along the Mississippi Sound and on the strand of Baldwin County.

\section{Sargassum vulgare Agh.}

Rarely washed ashore on the outside shore and the outlying islands. 


\section{Class RHODOPHYCEAE. Red Algae.}

\section{Order NEMALIONALES.}

\section{Family LEMANEACEAE.}

LEMANEA Bory.

Lemanea fucina mamillosa (Kuetz.) Atkinson. L. mamillosa Kuetz.

In rivulets. North Alabama (Peters). Mobile.

North Carolina, Chapel Hill.

TUOMEYA Harv.

Tuomeya fluviatilis Harv.

On rocks in Warrior River near Tuscaloosa, 1857 (Tuomey).

Virginia near Fredericksburg (Bailey); Connecticut; Maine, Mount Desert Island.

\section{Family HELMINTHOCLADIACEAE.}

\section{BATRACHOSPERMUM Roth.}

Batrachospermum moniliforme Roth.

In brooks aud springs. Over the State; very variable. The Southern form inhabits in abundance swift-running pine-barren streams, attached to submerged timber and roots, with a thallus from 6 to 8 inches long of a deep green to olive-brown color. It has not been observed outside of the Coast Pine belt.

\section{Order IRIODYMENIALES. \\ Family SPHAEROCOCCACEAE.}

GRACILARIA Grev.

Gracilaria armigera Harv.

Mobile. Mississippi Sound, Cat Island, Dauphin Island.

\section{Family DELESSERIACEAE.}

CALAGLOSSA (Harv.) J.G. Agh

Calaglossa leprieuri J. G. Agh.

Brackish water. Estuary of Mobile River, on immersed trunks.

Warmer seas of the Old World.

New Jersey.

\section{FUNGI.}

About the middle of the present century, following the work of Baron von Schweinitz in the same field, the Rev. M. A. Curtis, of North Carolina, and the Rev. M. J. Berkeley, of England, devoted their attention to the study of the fungi of the Southern United States. With these mycologists cooperated Mr. Ravenel, of South Carolina, and Judge Peters, of Moulton, Ala. The latter proved a most active contributor, exploring a region hitherto a veritable terra incognita to science, and affording further light on the distribution of fungi in this part of our continent.

His collections were chiefly made during the period from 1854 to 
1864 in that part of the Tennessee Valley and of the mountain region of Alabama embracing Lawrence, Winston, and Walker counties. Peters submitted his collections to Curtis and also partly to Ravenel. The descriptions of his new species were published in the first to the third volumes of Grevillea (1872 to 1876) under the "Notice of North American Fungi," by Berkeley and Curtis, and a smaller number were issued in Ravenel's Fungi Caroliniani Exsiccati (1852 to 1860). In his manuscript catalogue of Alabama fungi, left, with his collection, to the University of Alabama, Peters enumerated a little over 500 species under 122 genera, most of them contained in three quarto volumes. These specimens are still in a fair state of preservation.

Early in the sixties G. A. Beaumont, an enthusiastic young botanist, joined Peters in the exploration of the cryptogamic flora of the State, but working in his own surroundings. After a short stay in Lawrence County, Beaumont collected iu southeastern Alabama near Brooklyn, in Conecuh County, and Troy, in Pike County. His specimens were also forwarded to Mr. Curtis and were duly noticed in the publications of the authors named above.

After a long lapse of years the investigation of the mycological flora of the State was most actively resumed by Prof. George F. Atkinson (Cornell University, New York), chiefly during the years 1889 to 1892, while in charge of the biological department of the Polytechnic Institute and the State Agricultural Experiment Station at Auburn, assisted by some of his graduate students, principally B. M. Duggar, 1889-90, and C. L. Newman, 18y0-91. The field work was chiefly confined to Lee County, and the results of his labors were published in the Bulletin of the Cornell University, vol. 3, No. 1, Ithaca, N. Y., June, 1897. In this Bulletin 644 species under 201 genera are enumerated, of which three genera and 61 species are described as new.

Prof. L. M. Underwood, while in connection with the biological department of the Polytechnic Institute (1895-96), and Prof. F. S. Earle, of the horticultural department, and since 1896 in the biological department of the same institution, continued with great zeal the labors of their predecessors in the field of Southern mycology. Their explorations were principally confined to the vicinity of the Institute. Professor Underwood made a trip to the mountain region of the State from its eastern limit westward to the section first explored by Peters. Professor Earle made, occasionally, some collections in Mobile County. His assistants in field work, Prof. C. F. Baker and Mr. Benton of the Alabama Experiment Station, are mentioned.

In 1897 appeared the Preliminary List of the known species of Alabama Fungi, by L. M. Underwood and F. S. Earle, as Bulletin No. 80 of the Alabama Experiment Station at Auburn. In this publication, as stated by the authors, are contained all the Alabama species referred to by Berkeley, all contained in the Peters collection, and those contributed by Peters and Beaumont to Ravenel's Exsiccati; besides these, 
those collected by Professor Atkinson or his associates and deposited in the herbarium of the Alabama Polytechnic Institute, the material collected by G. W. Carver of the Tuskegee Normal and Industrial Institute in Macon County, and the species reported upon by the authors in later papers from material collected in $\mathbf{1 8 9 5}$ and subsequently.

The following list of the Alabama fungi has been kindly furnished by Prof. F. S. Earle. The writer takes this occasion to express his gratitude for this valuable contribution to his catalogue of Alabama plants.

Introductory to this list Professor Earle makes the following remarks :

In the Preliminary List of Alabama Fungi, of Underwood and Earle, published during the summer of 1897 ' 1,110 species were noted as occurring in the State, and the distribution by counties was given. At about the same time Professor Atkinson published his list of 644 species, which appeared as Bulletin, Vol. 3, No. 1, of the Cornell University. Two hundred and thirty-two of the species were not given in Bulletin 80.

These two publications are the basis of the following list, though it contains a number of additional species not reported in either of them.

The nomenclature adopted is essentially that of Engler \& Prantl, Die Natuerlichen Pflanzenfamilien. This necessitates the change for good reason of a few of the Saccardian generic names that were used in the above publication. The sequence of orders and families is that of Engler \& Prantl's work, the genera and species being arranged alphabetically.

To this the writer has to add that, in order to bring his list into accord with the plan adopted in the present work, the genera had also to be systematically arranged according to the work of the above authors, and the authority for each genus had to be given. Further have been added citations for the more recently described species, ${ }^{2}$ the names of collectors in Alabama, and the distribution of species by States, as far as could be ascertained from the various State floras, occurrence in Europe being also noted.

\section{Division EUMYCETES. Fungi. Class PHYCOMYCETES. \\ Order CHYTIRIDIALES. Family SYNCHYTRIACEAE.}

SYNCHYTRIUM De Bary \& Woronin.

Synchytrium decipiens Farlow.

Ala. Bnll. 135. ${ }^{3}$

On Falcata comosa. Dekalb County, May, 1896 (Underwood \& Earle).

1 This Bulletin was dated April, 1897, but was not issued till about July 1.

${ }^{2}$ Except when the publication occurred in either the Alabama or the Cornell Bulletin.

3 "Ala. Bull." denotes Bulletin No. 80 of the Alabama Agricultural Experiment station, referred to in the introduction. 
Synchytrium fulgens Schroet.

Ala. Bull. 135.

On Oenothera laciniata. Lee County, April, 1896 (Underwood \& Earle).

Europe.

Synchytrium pluriannulatum (B.\& C.) Farlow.

Grevillea, 3:57, under Uromyces. Ala. Bull. 135.

On Sanicula sp. (Peters).

\section{Order MUCORALES.}

\section{Family MUCORACEAE.}

MUCOR (Micheli) Link.

Mucor beaumontii B. \& C.

Grevillea, 3:148. Ala. Bull. 136.

On Brassiea oleracea (Beaumont).

\section{SPORIDINIA Link.}

Sporidinia aspergillus (Scop.) Schroet.

Peters coll. No. 130, as Mueor ramosus Bull. Ala. Bull. 136.

On decaying Boletus sp. Lee County, July 10, 1896 (Underwood).

Europe.

\section{Order SAPROLEGNIAIES.}

\section{Family SAPROLEGNIACEAE.}

\section{SAPROLEGNIA Nees.}

Saprolegnia declina Humph.

Cornell Bull. 14.'

On dead flies in water. Lee County, Auburn (Atkinson).

Saprolegnia monoica Pringsh.

Cornell Bull.14.

On dead flies in water. Lee County, Auburn (Atkinson).

Europe.

Achlya americana Humph.

ACHLYA Nees.

Cornell Bull. 14.

On dead flies in water. Lee Counts, Auburn (Atkinson).

Achlya apiculata De Bary.

Cornell Bull. 14.

On dead flies in water. Lee County, Auburn (Atkinson).

Europe.

Achlya oblongata globosa Humph.

Cornell Bull. 14.

On dead flies in water. Lee County, Auburn (Atkinson).

\section{Order PERONOSPORALES.}

\section{Family ALBUGINACEAE.}

ALBUGO (Pers.) Kuntze. (Cystopus Lév.)

Albugo amaranthi (Schw.) Kuntze.

Ala. Bull. 136. Cornell Bull. 14, as Cystopus bliti (Biv.) De Bary.

On leaves of Amaranthus relroflexus. Lee County, Auburn, June 20, 1890 (Atkinson).

On leaves of Amaranthus spinosus. Lee County, Auburn, June 20, 1890 (Atkinson).

On Amaranthus sp. Hale County, May, 1896 (Underwood); Lee County, July, 1896

(Underwood \& Earle).

1"Cornell. Bull." denotes the Cornell University Bulletin, vol. 3, no.1, referred to in the introduction. 
Albugo candida (Pers.) Kuntze.

Ala. Bull.136. Cornell Bull.14, under Cystopns.

On Arabis rirginica. Lee County, April, 1896 (Underwood \& Earle).

On Lepidium virginicum. Lee County, March, 1890 (R. S. Edvards).

On Senebiera sp. Lee County, May, 1896 (Underwood \& Earle).

On Lepidium, cultivated cress, etc. Lee County, Auburn (Atkinson).

Europe.

Albugo ipomoeae-panduratae (Schw.) Swingle.

Ala. Bull.136. Cornell Bull.14, under Cystopus.

On Ipomoea batatas. Lee County, Auburn, July, 1890 (Atkinson).

On Ipomoea pandurata. Lee County, July, 1896 (Underwood \& Earle).

On Ipomoea purpurea. Lee County, June, 1890 (Atkinson).

On Jacquemontia (Ipomoea) tamnifolia. Lee County, July, 1896 (Underwood \& Earle).

Albugo portulacae.(DC.) Kuntze.

Ala. Bull. 136. Cornell Bull.14, under Cystopus.

On leaves of Portulaca oleracea. Lee County, Auburn, July 3, 1890 (Atkinson).

Albugo tragopogonis (Pers.) S. F. Gray.

Ala. Bull. 136. Cornell Bull. 14, under Cystopus.

On leaves of Ambrosia artenisiaefolia. Montgomery County, Pike road, June, 1890 (Atkinson).

On Tragopogon porrifolius. Lee County, May 5, 1890 (Atkinson).

Europe.

\section{Family PERONOSPORACEAE.}

\section{BASIDIOPHORA Roze \& Cornu.}

\section{Basidiophora entospora Roze \& Cornu.}

Cornell Bull. 15.

On leaves of an Aster or an Erigeron. Lee County, Auburn, February, 1890 (Atkinson). Europe.

Bremia lactucae Regel.

BREMIA Regel.

Cornell Bull. 15.

On leaves of Lactuca sp. Lee County, April, 1897 (Earle \& Baker).

Europe.

\section{PERONOSPORA Cornu.}

\section{Peronospora alsinearum Caspary.}

Cornell Bull. 15.

On leaves of Cerastium sp. Lee County, Auburn, February and December, 1890 (Atkinson).

Europe.

Peronospora alta Fkl.

Cornell Bull. 15.

On leaves of Plantago sp. Lee County, Auburn, April 17, 1890 (Atkinson).

Europe.

Peronospora arthuri Farlow.

Ala. Bull. 137. Cornell Bull. 15.

On leaves of Oenothera laciniata. Lee County, Auburn, March 24, 1890 (Atkinson).

Peronospora calotheca De Bary.

Cornell Bull. 15.

On leaves of Houstonia patens. Lee County, Auburn, March 23, April 15, 1890 (Atkinson).

Europe.

This is the same fungus mentioned below as P. seymourii Burrill. Both names are retained as it is impossible at present to decide which is the correct determination.

Peronospora lamii (Al. Braun) De Bary.

Ala. Bull. 137. Cornell Bull. 15.

On leaves of Lamium amplexicaule. Lee County, Auburn, January, 1890 (R.S. Edward8).

Europe. 
Peronospora parasitica (Pers.) Fr.

Ala. Bull. 137. Cornell Bull. 15.

On Brassica oleracea. Mobile, March, 1896 (Reese).

On leaves of several species of Cruciferae. Lee County, Auburn, in late winter and early spring (Atkinson).

On Cardamine hirsuta. Macon County, 1897 (Carrer).

Europe.

Peronospora plantaginis Underw.

Ala. Bull. 137.

On Plantago aristata. Lee County, May, 1896 (Earle).

Peronospora seymourii Burrill.'

Ala. Bull. 137.

On Houstonia patens. Lee County, March, 1896 (Underwood \& Earle).

Peronospora trifoliorum De Bary.

Cornell Bull. 15.

On leaves of Trifolium carolinianum. Lee County, Auburn, December 27, 1891;

Jannary 24, 1892 (Atkinson).

Europe.

Peronospora violae De Bary.

On Tiola rafinesqii ( $V$.tenella). Lee County, February, 1890 (Atkinson); Lee County, April, 1897 (Earle).

On Viola tricolor, the cultivated pansy. Lee County, April, 1897 (Earle).

Europe.

\section{PLASMOPARA Schroet.}

Plasmopara geranii (Peck) Berl. \& De Ton.

Ala. Bull. 137. Cornell Bull. 15.

On Geranium carolinianum. Lee County, Auburn, December to April, 1890 (Atkin8on); Lee County, March, 1896 (Underwood \& Earle).

Plasmopara halstedii (Farlow) Berl. \& De Ton.

Ala. Bull. 137. Cornell Bull. 15.

In leaves of Gnaphalium purpureum. Lee County, Auburn, June, 1890 (Atkinson).

On Bidens frondosa. Lee County, Angust, 1890 (Atkinson).

In leaves of Bidens sp. Lee County, Auburn, August 27, 1891 (Atkinson).

Plasmopara obducens Schroet.

Ala. Bull. 137.

On Impatiens aurea. Lee County, April, 1896 (Underwood \& Earle). Europe.

Plasmopara viburni Peck.

On Tiburnum nudum. Lee County, November, 1897 (Earle).

Plasmopara viticola (B. \& C.) Berl. \& De Ton. Ala. Bull. 137. Cornell Bull. 15.

On Parlhenocissus quinquefolia. Dallas County, May, 1896 (Underwood \& Earle).

On Fitis sp., various cultivated varieties. Lee County (Atkinson).

On Vitis rotundifolia. Lee County, October, 1890 (Atkinson).

\section{Order ENTOMOPHTHORALES.}

\section{Family ENTOMOPHTHORACEAE.}

Empusa apiculata Thaxter.

EMPUSA Cohn.

Cornell Bull. 14.

On a dipterons insect. Lee County, Auburn, January, 1890 (Atkinson).

Empusa muscae (Fr.) Cohn.

Ala. Bull. 136.

On dead flies. Lee County, May, 1896 (Underwood \& Earle).

Europe. 


\section{Class ASCOMYCETES.}

\section{Order EXOASCALFS.}

\section{Family EXOASCACEAE.}

\section{EXOAsCUS Fkl.}

Exoascus alnitorquus (Tul.) J. Knehn.

Ala. Bull. 175.

On Alnus rugosa. Lee County, 1890, April, 1891 (Atkinson); December, 1893 (Inggar); April, 1896 (Underwood of Earle).

Exoascus pruni Fkl.

Ala. Bull. 175.

On Prunus serotina. Lee County, 1891 (Atkinson).

On Prunus angustifolia. Lee County, 1890 (Atkinson).

New Jersey. Europe.

Exoascus deformans (Berk.) Fkl.

Cornell Bull. 13.

On leaves of Amygdalus persica, the peach. Lee County, Auburn (Atkinson).

Exoascus farlowii Sadebeck.

Ala. Bull. 175. Cornell bull. 13.

On Prunus serotina. Lee County, Auburn, 1892 (Atkinson).

Exoascus australis Atkinson, Bull. Torr. Club, 21:379. 1894.

Ala. Bull. 175. Cornell Bull. 13.

On the leaves of Carpinus caroliniana. Lee County, Auburn, April 30, 1892 (Atkinson).

Exoascus mirabilis Atkinson.

Ala. Bull. 175. Coruell Bull. 13.

On Prunus angustifolia. Lee County, Auburn, April, May, 1890, 1892 (Atkinson).

Exoascus rhizipes Atkinson.

Ala. Bull. 175. Cornell Bull. 13.

On Prunus triflora, the Japanese plum. Lee County, Auburn (Atkinson).

Exoascus varius Atkinson, Bull. Torr. Club, 21:378. 1894.

Ala. Bull. 176.

On Prunus serotina. Lee County, Auburn, May, 1891 (Atkinson).

\section{TAPHRIA Fr.}

Taphria coerulescens (Mont.) Fkl.

Ala. Bull. 176. Cornell Bull. 13.

On Quercus nigra (Q. aquatica). Lee County, Auburn, 1892 (Atkinson).

On Quercus phellos. Lee County, Auburn, 1890 (Atkinson).

On Quercus minor. Lee Connty, Auburn, 1890 (Atkinson).

On Quercus marilandica. Lee County, Auburn, 1890 (Atkinson).

On Quercus digitata. Lee County, Aulurn, 1890 (Atkinson).

On Quercus rubra (Atkinson.)

On Quercus brevifolia. Lee County, Auburn, 1891 (Atkinson).

New Jersey. Europe.

Taphria virginica Sadel. \& Seym.

Ala. Bull. 176.

On Ostrya virginiana. Lee Count.y, May, 1896 (Underwood \& Earle). 


\section{Order HEI,VELLALES.}

\section{Family GEOGLOSSACEAE.}

MITRULA Pers

Mitrula phalloides (Bull.) Sace.

Ala. Bull. 206.

(Beaumont.)

Damp soil in woods. Lee County, May, 1896 (Underwood \& Earle).

Europe.

\section{GEOGLOSSUM Pers.}

Geoglossum peckianum Cooke.

Peters coll., as G. glutinosum. Ala. Bull. 206.

Winston County, 1862 (Peters).

\section{LEPTOGLOSSUM (Cooke) Sacc.}

Leptoglossum alabamense Underwood, Bull. 'Torr. Club, 24: 82. 1897.

Ala. Bull. 206.

On the ground. Lee County, Auburn, July (Underwood).

\section{Family HELVELLACEAE.}

\section{MORCHELLA Dill.}

Morchella esculenta (L.) Pers.

Ala. Bull. 207.

In sandy pine woods. Mobile County, October (Mohr).

On the ground in low places. Lee County, March, 1896 (Underwood \& Earle).

New Jersey. Europe.

The most esteemed of edible species.

\section{Family RHIZINACEAE.}

\section{PSILOPEZIA Berk.}

Psilopezia flavida B. \& C.

Grevillea, 4:1. Ala. Bull. 206.

On wood of Quercus alba (Peters).

\section{RHIZINA Fr.}

Rhizina inflata (Schaeff.) Karst.

Ala. Bull. 206.

On the ground. Leo County, July, 1896 (Underwood of Earle).

Europe.

\section{Order PEZIZALES.}

\section{Family PEZIZACEAE.}

LACHNEA Fr.

Lachnea scutellata (L.) Sacc.

Peters coll. 1:32. Ala. Bull. 202.

On decayed wood (Peters).

Winston County, June, 1896 (Underwood).

Europe. 


\section{SPHAEROSPORA Sacc.}

Sphaerospora confusa Cooke.

Ala. Bull. 205.

On burnt ground in damp woods. Lee County, July, 1896 (Underwood \& Earle).

PLICARIELLA Sacc.

Plicariella exasperata (B. \& C.) Sacc.

Grevillea, $3: 152$, under Peziza. Ala. Bull. 200, under Barlaea Sace.

On burnt earth (Peters).

PEZIZa Dill.

Peziza acetabulum L.

Ala. Bull. 200, under Acetabula.

On ground in pine woods. Lee County, April, 1896 (Underwood \& Earle).

Ohio, New Jersey. Europe.

Peziza spissa Berk.

Grevillea, $3: 152$. Ala. Bull. 202, under Humaria.

On the ground (Peters).

Peziza macropus Pers.

Peters coll. 3:17. Ala. Bull. 203, under Macropodia.

July, 1855 (Peter8).

South Carolina, New Jersey. Europe.

Peziza pubida B. \& C.

Ala. Bull. 203, under Macropodia.

On the ground (Peters).

Peziza schweinitzii Sacc.

Ala. Buli. 203, under Macropodia.

I.ee County (Atkinson).

Peziza aurantia Pers.

Peters coll. Ala. Bull. 204.

On the ground. Lawrence County, November, 1864 (Peters); Lee County, Decem-

ber, 1896 (Earle).

Peziza badia Pers.

Ala. Bull. 204.

On the ground. Lee County, March, 1896 (Underwood \& Earle).

New Jersey.

Peziza chlora Schw.

Rav. Fung. Car. Exsic. 5 :39. Ala. Bull.204.

(Peters.)

Peziza cochleata L.

Peters coll. 1:26. Ala. Bull. 204.

(Peter8.)

Peziza decolorans B. \& C.

Grevillea, $3: 150$. Ala. Bull. 204.

On the ground (Peters).

Peziza petersii Berk.

Grevillea, 3:150. Ala. Bull.205.

On burnt ground (Peters).

Peziza vesiculosa Bull.

Lee County, Auburn, January 8, 1899 (Mr8. F. S. Earle).

New England, New Jersey. Europe.

OTIDEA Pers.

Otidea euplectra Cooke.

Grevillea, 3: 151, as Peziza phlebophora B. \& Br. var. Ala. Bull. 204.

On moist sandy soil (Peters). 


\section{Family ASCOBOLACEAE.}

ASCOBOLUS Pers.

Ascobolus brunneus Cooke.

Ala. Bull. 200.

On cow dung. Lee County, January, 1896 (Underwood \& Earle).

\section{Family HELOTIACEAE.}

BELONIUM Sacc.

Belonium eustegiaeforme (B. \& C.) Sacc.

Rav. Fung. Am. Exsic. 310, under Peziza. Ala. Bull. 200. Cornell Bull. 13.

On dead canes of Arundinaria tecta. Macon County, Shorter, July 16, 1890 (Atkin8on); Lee County, January, 1896 (Underwood \& Earle).

South Carolina.

\section{CHLOROSPLENIUM Fr.}

Chlorosplenium versiforme (Pers.) Karst.

Grevillea, 3:160. Ala. Bull.202.

On Quercus sp. (Peters).

SARCOSCYPHA Fr.

Sarcoscypha occidentalis (Schw.) Sacc.

Grevillea, 3 : 153. Ala. Bull. 205.

On the ground (Peters).

New York, Ohio.

LACHNELLA Karst.

Lachnella extricata (B.\& C.) Sacc.

Peters coll. Grevillea, $3: 152$. Ala. Bull. 202.

On some umbelliferous plant (Peters).

IANZIA Sacc.

Lanzia rugipes (Peck) Sacc.

Ala. Bull. 203.

Lee County (Atkinson).

OMBROPHILA Fr.

Ombrophila decolorans (B. \& C.) Sacc.

Grevillea, 4 : 6, under Bulgaria. Ala. Bull. 203.

On decayed wood of Quercus (Peters).

DASYSCYPHA Fr.

Dasyscypha arundinariae (Berk.) Sacc.

Ala. Bull. 202. Cornell Bull. 13.

On Arundinaria. Lee County, May, 1896 (Underwood \& Earle).

Dasyscypha calycina (Schum.) Fkl.

Peters Coll. 3:16. Ala. Bull. 202.

On Pinus (Peters).

Europe.

Dasyscypha leucoderma (Berk.) Rehm.

Ala. Bull. 202.

On Pinus. Lee County, March, July, 1896 (Underwood \& Earle). 


\section{ERINELLA Sacc.}

\section{Erinella sp.}

Peters coll. 1:28, as Peziza alboviolacea A.\& S. Ala. Bull. 202.

On Magnolia (Peters).

\section{HYMENOSCYPHA Fr.}

Hymenoscypha sacchariferum (Berk.) Link.

Grevillea, 3:157, under Peziza. Ala. Bull. 205, as Pseudohelotium sacchariferum (Berk.) Sacc.

On Liquidambar (Peters).

Hymenoscypha soleniiformis (B.\& C.)

Grevillea, 3 : 160, under Peziza. Ala. Bull. 205, under Pezizella.

On dead wood (Peters).

Hymenoscypha (Phialea) cyathoidea (Bull.) Gill.

Grevillea, 3:160, under Peziza. Ala. Bull. 205.

(Peter8.)

Canada, New England, Pennsylvania, New Jersey.

Hymenoscypha translucens Gill.

Cornell Bull. 13, under Pezizella.

On decaying wood. Macon County, Shorter, July 16, 1890 (Atkinson); Lee Connty, Auburn, winter 1891.

Hymenoscypha (Phialea) fructigena (Bull.) Gill.

Ala. Bull. 205.

On hickory shells. Lee County (Atkinson).

\section{Family MOLLISIACEAE.}

\section{BELONIDIUM Mont.\& Dur.}

Belonidium aurelia (Pers.) De Not.

Rav. Fung. Car. Exsic. 5 :41, under Peziza. Ala. Bull. 200.

On Liriodendron (Peters).

Pennsylvania, South Carolina. Europe.

\section{NIPTERA Fr.}

Niptera atro-fusca (B.\& C.) Underwood \& Earle.

Grevillea, 3:156, under Peziza. Ala. Bull. 203.

On dead wood (Peters).

\section{ORBILIA Fr.}

Orbilia vinosa (A. \& S.) Karst.

Peters coll. 3:26. Ala. Bull. 204.

On Liriodendron (Peters).

South Carolina. Europe.

\section{PYRENOPEZIZA Fkl}

Pyrenopeziza atrata (Pers.) Fkl.

Grevillea, 3 : 159, under Peziza. Ala. Bull. 205.

On Solidago (Peters, Beaumont).

OMBROPHILA Sacc.

Ombrophila decolorans (B. \& C.) Sacc.

Grevillea, 4:6, under Bulgaria. Ala. Bull. 203.

On Quercus (Peters). 


\section{Family CELIDIACEAE.}

AGYRIUM Fr.

Agyrium brunneolum B. \& C.

Grevillea, 4 :6. Ala. Bull. 200.

On roots of pine (Beaumont).

Agyrium rufum (Pers.) Fr.

Grevillea, 4:6. Ala. Bull. 200.

On dead wood of Tsuga canadensis. Winston County (Peters).

Europe.

\section{Family PATELLARIACEAE.}

\section{HYSTEROPATELLA Rehm.}

Hysteropatella prostii (Duby) Rehm.

Ala. Bull. 197, under Hysterium.

On Quercus. Lee County, February, 1896 (Underwood \& Earle).

Europe.

- patellaria Fr.

Patellaria atrata (Hedw.) Fr.

Ala. Bull. 203, under Lecanidion.

On Liriodendron. Lee County, February, 1896 (Underwood \& Earle).

New Jersey. Europe.

PATINELLA Sacc.

Patinella inquinans (Cooke) Sacc.

Ala. Bull. 204.

On dead wood. Lee County, March, 1896 (Underwood \& Earle).

\section{Family CENANGIACEAE.}

CENANGELLA Sacc.

Cenangella ravenelii (Berk.) Sacc.

Grevillea, 4:3, under'Tympanis. Ala. Bull. 200.

On Ilex prinoides (Peters).

\section{CENANGIUM Fr.}

Cenangium cephalanthi (Schw.) Fr.

Grevillea, 4:4. Ala. Bull. 200.

On Cephalanthus occidentalis (Peters).

Cenangium contortum B. \& C.

Peters coll. 1 : 149. Ala. Bull. 201.

On dead wood (Peters).

Cenangium magnoliae B. \& C.

Grevillea, 4:5. Ala. Bull. 201.

On Persea (Beaumont).

On Laurus (Peters).

Cenangium leptospermum B.\& C.

Grevillea, 4:5. Ala. Bull.201.

On Truga canadensis. Winston County (Peters).

Cenangium ustale (B. \& C.) Sacc.

Grevillea, $3: 152$, under Peziza. Ala. Bull. 201.

On decayed twigs (Peters). 
BULGARIA Fr.

Bulgaria inquinans (Pers.) Fr.

Rav. Fung. Car. Exsic. 5 : 43. Ala. Bull. 200.

On Quercus velutina. Lawrence County (Peters).

Georgia to New Jersey. Europe.

\section{DERMATEA Fr.}

Dermatea rubi (Lib.) Rehm.

Grevillea, 4:2, as Putellaria rhabarbarina Berk. Ala. Bull.204, as Pezicula rhabarbarina (Berk.) Tul.

On Cornus amomum (Peters).

Europe.

TRYBLIDIELLA Sace.

Tryblidiella rufula (Spreng.) Sacc.

Peters coll. 3:66. Ala. Bull. 198.

On Rhus (Pelers, Beaumont).

On dead twigs. Lee County, January, 1896 (Underwood \& Earle).

Tryblidiella rufula microspora (E. \& E.) Underwood \& Earle.

Ala. Bull. 198.

On Melia azedarach. Lee County, March, 1896 (Underwood \& Earle).

Order PHACIDIALES.

Family STICTIDACEAE.

XYLOGRAMMA Wallr.

Xylogramma graminis Atkinson.

Cornell Bull. 14.

On stems of Chrysopogon avenaceus. Lee County, Aulburn, November 1, 1891(Duggar).

\section{Family TRYBLIDIACEAE.}

\section{SCLERODERRIS Fr.}

Scleroderris arundinariae Atkinson.

Cornell Bull. 14.

On dead canes of Arundinaria tecta. Lee County, Auburn, July 27, 1890 (Atkinson).

Scleroderris concinna (B. \& C.) Sace.

Grevillea, 4:5, under Cenangium. Ala. Bull. 199.

On Sassafras (Peírs).

South Carolina.

URNULA Fr.

Urnula craterium (Schw.) Fr.

Ala. Bull. 206.

On the ground. Lee County, March, 1896 (Underwood \& Earle).

New Jersey, Ohio.

\section{Family PHACIDIACEAE.}

DOTHIORA Fr.

Dothiora asterinospora (E. \& E.) Sace.

Rav. Fung. Car. Exsic. 3:36, as Tympanis pinastra B.\& C. Ala. Bull. 199.

On Ilex (Peters).

On living bark of various trees. Lee County, January, February, March, 1896 (Underwood \& Earle). 


\section{PHACIDIUM Fr.}

Phacidium brunneolum Peck.

On Galium. Lee County, Auburn, 1897 (Earle \&. Baker).

Phacidium elegantissimum B. \& C.

Grevillea, 4: 8. Ala. Bull. 199.

On leaves of Ilex opaca (Peters).

\section{COCCOMYCES De Not.}

Coccomyves juniperi Karst. (?).

Peters coll. 1:150, as Rhytisma petersii B. \& C. Ala. Bull. 198.

On bark of Juniperus (Peters).

Coccomyces triangularis (Schw.) Sacc.

Ala. Bull. 198.

On oak. Lee County, April, 1896 (Underwood \& Earle).

\section{RHYTISMA Fr.}

Rhytisma acerinum (Pers.) Fr.

Ala. Bull. 199. Cornell Bull. 13.

On Acer rubrum. Lee County, Auburn, July 22, 1891 (Duggar \& Newman); November, 1895 (Underwood); March, 1896 (Underwood \& Earle); October, 1896 (Earle). Ohio, New Jersey. Europe.

Rhytisma curtisii B. \& Rav.

Ala. Bull.199. Cornell Bull. 14.

On leaves of Ilex opaca. Les County, Auburn, September 13, 1891 (Atkinson); Leo

County, April, 1896 (Underwood \& Earle).

South Carolina.

Rhytisma solidaginis Schw.

Ala. Bull. 198. Cornell Bull. 14.

On Solidago canadensis. Lee County, 1891 (Newman).

On various species of Solidago. Lee County, Auburn (Atkinson).

New York, New Jersey.

Rhytisma ilicis-canadensis Schw.

On Ilex verticillata. Lee County, Auburn, November, 1897 (Earle).

Rhytisma vaccinii (Schw.) Fr.

Ala. Bull. 199. Cornell Bull. 14.

On living leaves of Vaccinium arboreum. Lee County, Auburn, 1891 (Atkinson).

South Carolina, Now Jersey.

Rhytisma tostum B. \& C.

Grevillea, 4:9. Ala. Bull. 199.

On leaves of Quercus laurifolia (Beaumont).

Rhytisma decolorans Fr.

Ala. Bull. 199.

On Xolisma ligustrina. Lee County, January, 1896 (Underwood \& Earle); Macon County, August, 1896 (Carver).

\section{Order HYSTERIALES.}

\section{Family HYPODERMATACEAE.}

HYPODERMA DC.

Hypoderma ilicinum De Not.

Ala. Bull. 197.

On dead leaves of Quercus sp. Lee County, January, 1896 (Inderwood \& Earle).

On Quercus nigra (Q. aquatica). Lee County, July, 1896 (Underwood \&. Earle). 


\section{ANGELINA Fr.}

Angelina rufescens (Schw.) Duby.

Rav. Fung. Car. Exsic. 5 : 44, as Ascobolus conglomeratus Schw. Ala. Bull. 196.

On Quercus.(Peters).

South Carolina, New Jersey.

\section{LOPHODERMIUM ChEv.}

Lophodermium arundinaceum (Schrad.) Chev.

Ala. Bull. 198.

On Arundinaria sp. Lee County, January, 1896 (Underwood \& Earle).

Lophodermium culmigenum (Fr. ) Karst.

Ala. Bull. 198.

On dead sheaths of Arundinaria. Lee County, January, 1896 (Underwood \& Earle).

Pennsylvania.

Lophodermium cyrillicolum Tracy \& Earle.

Ala. Bull. 198.

On Cyrilla racemiflora. Lee County, April, 1896 (Underwood \& Earle).

Lophodermium petersii (B. \& C.) Sacc.

Grevillea, 4 : 13, under Hysterium. Ala. Bull. 198.

On Juniperus (Peters).

Lophodermium pinastri (Schrad.) Chev.

Ala. Bull. 198.

On dead needles of Pinus echinata. Lee County, March, 1896 (Underwood \& Earle).

Lophodermium rubiicolum Earle, Bull. Torr. Club. 25 : 365. 1898.

On Rubus. Lee County, March, 1896 (Underwood \& Earle).

\section{RHYTIDHYSTERIUM Speg.}

Rhytidhysterium scortichinii Sacc. \& Berl.

Cornell Bull. 12.

On Toxylon pomiferum (Maclura aurantiaca). Hale County, Gallion, August 14, 1894 (Duggar).

\section{Family DICHAENACEAE.}

DICHAENA Fr.

Dichaena faginea (Pers.) Fr.

Ala. Bull. 196.

On Fagus americana ( $F$. ferruginea). Lee County, March, 1896 (Underwood \& Earle).

Ohio. Europe.

\section{Dichaena sp.}

Grevillea, 4 : 158 . Ala. Bull. 196.

On Quercus (Peters).

\section{Family HYSTERIACEAE.}

\section{AULOGRAPHUM Libert.}

Aulographum confluens Earle.

On dead stems of Rubus. Lee County, February, 1896 (Underwood \& Earle).

Aulographum pinorum Desm.

Ala. Bull. 196.

On pine needles. Lee County, January, 1891.

GLONIUM Muhl.

Glonium chlorinum (B. \& C.) Sacc.

Grevillea, 4 : 12, under Hysterium. Ala. Bull. 197.

On Quercus nigra (Q.aquatica) (Beaumont). 
Glonium lineare angustissimum De Not.

Ala. Bull. 197.

On Liquidambar. Lee County, March, 1896 (Underwood \& Earle).

Glonium macrosporum Tracy \& Earle.

Ala. Bull. 197.

On Prunus serotina. Lee County, February, 1896 (Underwood \& Earle).

On Vitus rotundifolia. Lee County, February, 1896 (Underwood \& Earle).

On Rubus argutus (R. villosus). Lee County, April, 1896 (Underwood \& Earle).

Glonium parvulum (Ger.) Sacc.

Ala. Bull. 197.

On Liriodendron. Lee County, February, 1896 (Underwood \& Earle).

On Hicoria. Lee County, February, 1896 (Underwood \& Earle).

Glonium stellatum Muhl.

Rav. Fung. Car. Exsic. 3 : 43. Ala. Bull. 197.

(Beaumont.)

On rotten log. Lee County, January, 1896 (Underwood \& Earle).

South Carolina, North Carolina, Ohio.

\section{HYSTERIUM Tode.}

Hysterium erianthicola Atkinson.

Cornell Bull. 13.

On Erianthus sp. Lee County, Auburn, September 26, 1891 (Atkinson).

Hysterium insidens Schw.

Ala. Bull. 197.

On dead wood. Lee County, February, 1896 (Underwood \& Earle).

Hysterium macrosporum Peck.

Ala. Bull. 197.

On weathered pine wood. Lee County, February, March, 1896 (Underwood of Earle).

Hysterium pulicare Pers.

Ala. Bull. 197.

On Betula. Macon County, April, 1896 (Cnderwood).

Europe.

HYSTEROGLONIUM Rehm.

Hysteroglonium curtisii Duby.

Ala. Bull. 196, under Gloniella Sacc.

On dead stems of Vitis. Lee County, July, 1896 (Underwood \& Earle).

\section{HYSTEROGRAPHIUM Corda.}

Hysterographium mori (Schw.) Rehm.

Ala. Bull. 198.

On Gleditsia. Lee County, February, 1896 (Underwood \& Earle).

Hysterographium smilacina (Schw.).

Ala. Bull. 196, as Gloniopsis smilacis (Schw.) Underwood \& Earle.

On Smilax. Lee County, 1896.

Hysterographium vulvatum (Schw.) Rehm.

Ala. Bull. 198.

On Quercus sp. Lee County, February, 1896 (Underwood \& Earle).

On Vitis rotundifolia. Lee County, February, 1896 (Underwood \& Earle).

Hysterographium praelongum (Schw.) E. \& E.

Ala. Bull. 196, as Gloniopsis praelongum (Schw.) Underwood \& Earle.

On Morus. Lee County, April, 1896 (Underwood \& Earle).

\section{LEMBOSIA Lév.}

Lembosia angustifolia Tracy \& Earle.

On Ilex coriacea. Escambia County, Flomaton, August 8, 1898 (S. M. Tracy).

Lembosia illiciicola Tracy \& Earle.

Ala. Bnll. 198.

On Illicium floridanum. Mobile County, March, 1896 (Earle). 


\section{LOPHIDIUM Karst.}

Lophidium anomalum Atkinson.

Cornell Bull. 12.

On culms of Erianthus. Lee County, Auburn, November 12, 1891 (Duggar).

\section{Family ACROSPERMACEAE.}

\section{ACROSPERMUM Tode.}

Acrospermum foliicolum Berk.

On fallen leaves of Ulmus. Lee County, February, 1897 (Earle of liaker).

\section{Order PLECTASCALES (Aspergillales).}

\section{Family ASPERGILLACEAE.}

\section{ASPERGILLUS Micheli.}

Aspergillus glaucus (L.) Link.

Cornell Bull. 38.

On decaying leaves of Ipomoea. Lee County, Auburn, July 23, 1890 (Atkinson). Common.

\section{MELIOLA Fr.}

Meliola amphitricha Fr.

Ala. Bull. 182.

On Osmanthus americana. Lee County, October, 1896 (Earle).

Meliola bidentata Cooke.

Ala. Bull.182. Cornell Bull. 4.

On Bignonia capreolata. Lee County, Auburn, September 5, 1891 (Duggar); Mobile County, March, 1896 (Earle).

Meliola manca E. \& M.

Ala. Bull. 182. Cornell Bull. 4.

On leaves of Rubus argutus (R. villosus). Lee County, Auburn, October, 1891 (Atkinson).

On leaves of Myrica cerifera. Mobile County, March, 1896 (Earle).

Meliola martiniana Gaill.

Ala. Bull. 182.

On Persea palustris. Lee County, April, 1896 (Underwood \& Earle).

Meliola mitchellae Cooke.

Ala. Bull. 182.

On Mitchella repens. Lee County, March, 1896 (Underwood \& Earle).

Meliola nidulans (Schw.) Cooke.

Ala. Bull. 182. Cornell Bull. 4.

On living twigs of Cornus sp. Lee County, Auburn, November 8, 1891 (Atkinson). Lee County, April, 1896 (Underwood \& Earle).

Meliola palmicola Winter.

Grevillea, 4:158, as Meliola amphitricha. Ala. Bull. 182.

On Sabal sp. (Beaumont).

Meliola tenuis B. \& C.

Ala. Bull. 182. Cornell Bull. 4.

On leaves of Arundinaria tecta. Jee County, Anburn, Octoher, November, 1891 (Atkinson). 


\section{Order PERISPORI AI,ES.}

\section{Family ERYSIBACEAE.}

SPHAEROTHECA Lév.

Sphaerotheca castagnei Lév.

Ala. Bull. 180. Cornell Bull. 4.

On Bidens frondosa. Lee County, Auburn, October, 1889 (Atkinson); November, 1891 (Duggar).

On leaves of Erechtites hieracifolia. Lee County, November 5, 1891 (Benton \&.

Duggar).

On Lactuca sp. Lee County, October, 1896 (Earle).

Ohio, New Jersey. Europe.

Sphaerotheca humuli (DC.) Burrill.

Cornell Bull. 4.

On Humulus, the hop. Lee County, Auburn, autumn, 1889 (Atkinson).

Sphaerotheca lanestris Hark.

Ala. Bull. 180. Cornell Bull. 4.

On leaves of Quercus alba. Lee County, Auburn, August 21, December, 1891 (Atkinson).

Sphaerotheca pannosa (Wallr.) Lév.

Ala. Bull. 180.

On a cultivated species of Rosa. Lee County, 1890 (Atkinson).

Europe.

PODOSPHAERA Kunze.

Podosphaera biuncinata C. \& P.

Ala. Bull. 179. Cornell Bull. 5.

On leaves of Hamamelis virginiana. Lee County, October 28, 1891 (Duggar).

Podosphaera oxyacanthae (DC.) De Bary.

Grevillea, 4 :158, as Podosphaera kunzei Lév. Ala. Bull. 180. Cornell Bull. 5.

On Prunus cerasus (Peters).

On Crataegus sp. Lee County, Auburn, November, 1891 (Benton).

On leaves of Prunus americana. Lee County, Auburn, October 31, 1891 (Duggar).

On Malus malus. Lee County, April, 1896 (Earle).

Europe.

ERYSIBE Hedw.

Erysibe cichoracearum DC.

Ala. Bull. 176. Cornell Bull. 4.

On Ambrosia artemisiaefolia. Lee County, May, 1890 (Atkinson).

On Ambrosia trifida. Perry County, 1890 (Atkinson).

On Aster lateriflorus and A. tradescanti. Lee County, Auburn, 1891 (Atkinson).

On Helianthus annuus. Lee County, 1891 (Duggar).

On Willughbya scandens. Lee County, 1891 (Atkinson).

On Phlox sp Mobile County, 1890 (Carl Zimmer).

On Solanum carolinense. Lee County, October, 1891 (Atkinson); Macon County,

October, 1890 (Carver).

On Verbena urticaefolia. Lee County, October, 1891 (Duggar).

On Xanthium canadense. Lee County, October, 1889 (Atkinson); Macon County,

August, 1896 (Carver).

Over the State, and north to Canada.

Europe.

Erysibe communis (Wallr.) Link.

Ala. Bull. 177. Cornell Bull. 4.

On Onagra biennis. Lee County, May, 1890 (Atkinson).

On Pisum sativum. Lee County, May, 1890 (Atkinson).

On leaves of Denothera laciniata. Lee County, Auburn, June 3, 1890 (Atkinson).

Europe. 
Erysibe liriodendri Schw.

Ala. Bull. 177. Cornell Bull.5.

On leaves of Liriodendron tulipifera. Lee County, Auburn, Oetober 28, 1891 (Duggar).

Europe.

MICROSPHAERA Lév.

\section{Microsphaera alni (DC.) Winter.}

Ala. Bull. 177. Cornell Bull.5, as M. semitosta B. \& C.

On Alnus rugosa. Lee County, 1891 (Atkinson).

On Ilex sp. Lee County, 1891 (Atkinson).

On Hicoria sp. Lee County, 1890 (Atkinson).

On Platanus occidentalis. Lee County, 1891 (Atkinson).

On Syringa vulgaris. Lee County, October, 1896 (Earle); Macon County, Angust, 1896 (Carter); Bullock County, Union Springs (J.L. Moulton).

On Tecoma radicans. Lee County, 1891 (Atkinson).

New Jersey, Ohio. Europe.

Microsphaera diffusa C.\& P.

Ala. Bull. 177. Cornell Bull.5.

On Meibomia sp. Lee County, 1889 (Atkinson).

Ou Lespedeza striata. Lee County, 1889 (Atkinson); Macon County, October, 1896 (Carver).

Microsphaera erineophila Peck.

Ala. Bull. 178.

On Erineum of Fagus. Lee County, March, 1896 (Earle).

Microsphaera euphorbiae B. \& C.

Ala. Bull. 178. Cornell Bull. 5.

On Euphorbia nutans. Lee County, Auburn, October 21, 1891 (Duggar).

Microsphaera grossulariae (Wallr.) Lév.

Ala. Bull. 178. Cornell Bull. 5.

On Sambucus canadensis. Lee County, Auburn, October 13, 1891 (Atkinson).

Microsphaera quercina (Schw.) Burrill.

Ala. Bull. 178. Cornell Bull. 5.

On Quercus nigra (Q. aquatica). The form $M$. calocladophora Atkinson. Lee

County, December, 1890 (Atkinson); Macon Connty, August, 1896 (Carver).

On Quercus phellos. Lee County, 1891 (Atkinson).

On Quercus sp. Lee County, 1895 (Earle).

On leaves of Quercus marilandica, Q. minor, Q. rubra, etc. Lee Connty, Auburn (Atkinson).

New Jersey, Ohio.

Microsphaera ravenelii Berk.

Ala. Ball. 179.

On Apios apios. Lee County, October, 1896 (Earle); Macon County, August, 1896 (Carver).

Microsphaera semitosta B. \& C.

Ala. Bull. 179. Cornell Bull. 5.

On leaves of Cephalanthus occidentalis. Lee County, Auburn, 1891 (Atkinson).

Microsphaera vaccinii C. \& P.

Ala. Bull. 179. Coruell Bull. 5.

Ou Vaccinium sp. Lee County, October 18, 1891 (Duggar).

On Xolisma ligustrina. Lee County, October 10, 1896 (Earle).

\section{UNCINULA Lév.}

Uncinula circinata C. \& P.

Ala. Bull. 180.

On Acer rubrum. Lee Connty, 1891 (Atkinson).

Uncinula flexuosa Peck.

Ala. Bull. 180. Cornell Ball. 5.

On Aesculus pavia. Lee County, Wright's Mill, near Auburn, Jnly, Angust, 1890 (Atkinson). 
Uncinula geniculata Ger.

Ala. Bull. 180.

On Morus rubra. Lee County, 1891 (Atkinson).

Uncinula macrospora Peck.

Ala. Bull. 180. Cornell Buil. 5.

On leaves of Ulmus americana. Lee County, Auburn, August 6, 1890 (Atkinson).

Uncinula necator (Schw.) Burrill.

Ala. Bull. 180. Cornell Bull. 5.

On cultivated species of Vitis, the grape. Lee County, Auburn, 1889 (Atkinson). Ohio.

Uncinula parvula C. \& P.

Ala. Bull. 180.

On Celtis occidentalis. Lee County, 1889; Montgomery County, 1891 (Atkinson); Macon County, August, 1896 (Carver).

Uncinula polychaeta (B. \& C.) Mass.

Rav. Fung. Car. Exsic. 4:68. Grevillea, 4:159, under Erysiphe. Ala. Bull. 180. On Celtis occidentalis (Peters). 1891 (Atkinson).

\section{PHYLLACTINIA Lév.}

Phyllactinia suffulta (Reb.) Sacc.

Grevillea, 4:158, as Phyllactinia guttata Lév. Ala. Bull. 179. Cornell Bull. 5.

On Fagus (Beaumont).

On Alnus rugosa. Lee County, 1891 (Atkinson); Macou County, October, 1896

(Carver).

On Cornus florida. Lee County, November 3, 1891 (Atkinson).

On Carpinus caroliniana. Lee County, 1891 (Atkinson).

On Crataegus sp. Lee County, 1891 (Atkinson).

On Liriodendron tulipifera. Macon County, October, 1896 (Carver).

On Quercus nigra (Q. aquatica). Lee County, February, December, 1890 (Atkinson);

Macon County, August, 1896 (Carver).

On Quercus marilandica (Q. nigra). Lee County 1890 (Atkinson).

On Quercus phellos. Lee County, December, 1890 (Atkinson).

On Quercus minor. Lee County, November, 1895 (Earle).

On leaves of Ilmus alata. Lee County, 1890 (Atkinson); Macon County, Octoher, 1896 (Carver).

On leaves of Vlmus americana. Macon County, October, 1896 (Carver).

New Jersey, Ohio, Nebraska. Europe.

\section{Family PERISPORIACEAE.}

\section{DIMEROSPORIUM Fkl.}

Dimerosporium erysipheoides E. \& E.

Cornell Bull. 4.

On leaves of Panicum rostratum (P. anceps). Lee County, Auburn, August 24, 1891 (Atkinson).

\section{PARODIELLA Speg.}

Parodiella perisporioides (B. \& C.) Speg.

Ala. Bull. 182.

On Meibomia sp. Lee County, 1891 (Nevman \& Duggar).

\section{PERISPORIUM Fr.}

Perisporium zeae Desm. (?)

Rav. Fung. Car. Exsic. 3:65. Ala. Bull. 182.

On Zea mays (Beaumont).

\section{SCORIAS Fr.}

Scorias spongiosa (Schw.) Fr.

Ala. Bull. 183.

On Alnus rugosa. Lee County, February, 1896 (Earle).

On Fagus americana. Lee County, July, 1896 (Underwood \& Earle). 


\section{ANTENNARIA Link.}

Antennaria semiovata B. \& $\mathrm{Br}$.

Ala. Bull. 182.

On Magnolia virginiana (M. glauca) (Beaumont).

\section{APIOSPORIUM Kunze.}

Apiosporium elongatum B. \& Desm.

Ala. Bull. 181, under Capnodium.

On Bignonia (Peters).

Apiosporium sp.

Ala. Bull. 181, as Capnodium sp.

On Chrysanthemum sp. Lee County, 1889 (Atkinson).

On Nerium oleander. Lee County, 1890 (Atkinson).

\section{Family MICROTHYRIACEAE.}

Asterina comata B. \& Rav.

ASTERINA Lév.

Grevillea, 4:10. Ala. Bull. 181.

On leaves of Magnolia virginiana (M. glauca) (Peters). Mobile County, March, 1896

(Earle); Lee County, May, 1896 (Underwood \& Earle).

Sonth Carolina.

Asterina diplodioides B. \& C.

Grevillea, 4:9. Ala. Bull. 181.

On Leucothoe, probably L. catesbaei, cited as Andromeda acuminata (Peters).

Asterina pelliculosa Berk.

Grevillea, 4:10. Ala. Bull. 181. Cornell Bull. 4, as Dimerosporium orbiculare B. \& C.

On leaves of Ilex opaca. Lee County, Auburn, December 20, 1891 (Atkinson); Lee County, February, April, 1896 (Earle).

Asterina spurca B. \& C.

Grevillea, 4:10. Ala. Bull. 181.

On leaves and stems of Mesosphaerum rugosum (Hyptis radiata). Sonthern Alabama (Beaumont).

\section{MICROPELTIS Mont.}

Micropeltis alabamensis Earle, Bull. Torr. Club, 25 : 359. 1898.

On Magnolia acuminata. Lee County, April, 1896 (Underwood \& Earle).

\section{Order HYPOCRAEALES.}

\section{Family HYPOMYCETACEAE.}

\section{HYPOMYCES Fr.}

Hypomyces aurantius (Pers.) Fkl.

On Polyporus resinosus. Lee County, Auburn, February 22, 1896 (Underwood \& Earle).

The specimen reported under this name in the Alabama Bulletin, 185, should be referred to the following. See Bulletin Torrey Botanical Club, 25 : 363.

Hypomyces lactifluorum (Schw.) Tul.

Rav. Fung. Car. Exsic. 5:64, as H. aurantius. Ala. Bull. 185. Cornell Bull. 10.

On Cantherellus aurantiacus (Peters).

On various species of Lactarius and Russula. Lee County, Auburn, August, 1890

(Atkinson); Lee County, December, 1895 (Earle); Wiuston County, June, 1896

(.Underwood).

Hypomyces xylophilus Peck.

Ala. Bull. 185.

On rotten wood. Lee County, November, 1896 (Earle).

Ohio. 
CALONECTRIA De Not.

Calonectria curtisii (Berk.) Sace. ( () .

Ala. Bull. 183.

On Arundinaria sp. Lee County, January, 1896 (Underwood \&. Earle).

Calonectria polythalama Berk.

Grevillea, 4:46, ws Nectria. Ala. Bull. 183.

Ou Liquidambar (Peters).

\section{Family MELANOSPORACEAE.}

NEOCOSMOSPORA E. F. Smith.

Neocosmospora vasinfecta (Atkinson) J. G. Smith.

Ala. Bull.158. Cornell Bull. 48. In both under Fusarium.

In vascular ducts of stems of Gossypium herbaceum. Montgomery County, Mathews, June 16, 1891; Hope Hull, June 17, 1891; Pikeroad, July 9, 1891; near Montgomery, September 4, 1891 (Atkinson). Dallas County, Selma, 1892 (Atkinson).

In Hibiscus esculentus. Limestone County, Athens, 1891 (Atkinson).

On Vigna catjang (cowpea) and Phaseolus vulgaris (garden bean). Lee County, Auburn, July, August, 1898 (Earle).

\section{Family NECTRIACEAE.}

\section{NECTRIA Fr.}

Nectria episphaeria (Tode) Fr.

Ala. Bull. 185. Cornell Bull. 10.

On Diatrype stigma. Lee County, Auburn, February 22, 1891 (Atkinson); Lee County, March, 1896 (Underwood \& Earle).

On Eutypella sp. Lee County, February, March, 1896 (Underwood \& Earle).

Nectria meliae Earle, Bull. Torr. Club, $25: 364$. 1898.

On Melia azedarach. Lee County, March, 1896 (Underwood \& Earle).

Nectria rubicarpa Cooke.

Ala. Bull. 186.

On Gelsemium sempervirens (?). Lee County, February, 1896 (Underwood \& Earle). New Jersey.

Nectria saccharina B. \& C.

Peters coll. 1:165. Ala. Bull. 186.

Nectria viticola B. \& C.

Grevillea, 4:45. Ala. Bull. 186.

On branches of Vitis (Peters).

GIBBERELIA Sacc.

Gibberella pulicaris (Fr.) Sacc.

Ala. Bnll. 184.

On living roots of Gossypium herbaceum, the cotton plant. Lee County, November, 1889 (Atkinson).

\section{SPHAEROSTILBE Tnl.}

Sphaerostilbe coccophila Tul.

On Aspidiotus obscurus on oak bark. Lee County, January, 1897 (Earle).

Sphaerostilbe gracilipes Tul.

Grevillea, 4 : 46. Ala. Bull. 186.

On Platanus (Peters). 


\section{ELEUTHEROMYCES Fkl.}

Eleutheromyces subulatus (Tode) Fkl.

Cornell Bull. 10.

On decaying agarics. Lee County, Auburn (Atkinson).

\section{Family HYPOCREACEAE.}

\section{HYPOCREA Fr.}

Hypocrea apiculata C. \& P.

Ala. Bull. 184.

Lee County (Atkinson).

Hypocrea chromosperma C. \& P.

Peters coll. 3, No.23, labeled Daedalea sepium Berk. (\$).

A reexamination of the Peters specimen shows it to he the above species.

Hypocrea citrina (Pers.) Fr.

Ala. Bull. 184.

On Exidia glandulosa. Lee County, July, 1896 (Undenwood \& Earle).

Louisiana, South Carolina. Europe.

Hypocrea contorta (Schw.) B. \& C.

Peters coll. $3: 68$. Ala. Bull. 185.

Hypocrea petersii B. \& C.

Grevillea, 4 : 13 . Ala. Bull. 184.

(Peter8.)

Hypocrea polyporoidea B. \& C.

Grevillea, 4:15. Peters coll. 1: 152. Ala. Bull. 184.

On Fagus (Peters).

\section{Family CLAVICIPITACEAE.}

CORDYCEPS Fr.

Cordyceps capitata Fr.

Grevillea, 4 : 13. Ala. Bull. 183.

(Peter8.)

Europe.

Cordyceps ophioglossoides (Ehrh.) Link.

Peters coll. 1:54. Ala. Bull. 183.

Winston County, June, 1896 (Underwood).

\section{CLAVICEPS Tul.}

Claviceps sp. (Sclerotium stage only).

Ala. Bull. 183.

On Chrysopogon avenaceus. Macon County, August, 1896 (Carrer).

On Erianthus. Macon County, August, 1896 (Carver).

\section{ECHINODOTHIS Atkinson.}

Echinodothis tuberiformis (B. \& Rav.) Atkinson, Bull. Torr. Clnb, 21:224. 1894. Ala. Bull. 184. Cornell Bull. 10.

On Arundinaria tecta. Lee County, Auburn, August, October, 1891 (Atkinson). South Carolina.

\section{Order DOTHIDEALES.}

\section{Family DOTHIDEACEAE.}

\section{DOTHIDELLA Speg.}

Dothidella scutula (B. \& C.) Sacc.

On Persea. Escambia County, Flomaton (S. M. Tracy). 


\section{MONTAGNIELLA Speg.}

Montagniella heliopsidis (Schw.) Sacc.

Cornell Bull. 8.

On leaves of Heliopsis sp. Lee County, Auburn, summer and antnmn (Atkinson).

\section{MYRIOGENOSPORA Atkinson.}

Myriogenospora paspali Atkinson, Bull. Torr. Club, 21: 225.1894.

Cornell Bull. 11.

On leaves of Paspalum laeve. Lee County, Auburn, 1894 (Atkinson).

\section{OPHIODOTHIS Sacc.}

Ophiodothis atramentosa (B. \& C.) Earle, Bull. Torr. Club, 27:121. 1900.

Ala. Bull. 183. Cornell Bull.10. In both as Dothichloe hypoxylon (Peck) Atkinson.

On Andropogon virginicus. Angust 30, 1891 (Atkinson).

On Eragrostis tenuis. Lee County, Anburn, September, 1891 (Atkinson).

On Eragrostis campestris. September, 1891 (Atkinson).

Ophiodothis atramentosa aristidae (Atkinson) Earle, Bull. Torr. Club, $27: 122$. 1900.

Ala. Bull. 183. Cornell Bull.11. In both as Dothichloe aristidae Atkinson.

On stems of Aristida purpurascens. Lee County, Auburn, September 12, October 3, 1891 (Duggar \& Atkinson).

\section{PHYLLACHORA Nitsch.}

Phyllachora ambrosiae (B. \& C.) Sacc.

Grevillea, 4 : 105, under Dothidea. Cornell Bull.11. Ala. Bull. 195.

On Ambrosia artemisiaefolia (Beaumont). Lee County, Auburn, 1890 (Atkinson); Lee County, 1891 (Duggar).

On Ambrosia trifida. 1891 (Duggar).

Phyllachora beaumontii (B.\& C.) Cooke.

Peters coll. $1: 194 . \quad$ Ala. Bull. 195.

On Prunus caroliniana. Macon County (Beaunont).

Phyllachora cynodontis Niess.

Cornell Bull. 11.

On Sporobolus indicus. Lee County, Auburn, July 25, 1890 (Atkinson).

On leaves of Andropogon sp. Macon County, Shorter (Atkinson).

Europe.

Phyllachora cornuospora Atkinson.

Cornell Bull.11.

On leaves of Panicum elongatum. Lee County, Auburn, August 27, 1891 (Atkin8on).

Phyllachora graminis (Pers.) Fkl.

Ala. Bull. 195. Cornell Bull. 11.

On Andropogon virginicus. Lee County, 1891 (Duggar).

On Paspalum laeve. Lee County, 1891 (Duggar).

On Paspalum setaceum. Lee County, Auburn, 1891 (Newman).

On Panicum dichotomum and P. latifolium. Lee County, 1891 (Duggar).

On Panicum sp. Lee County, 1891 (Duggar); Macon County, March, 1896 (Carver).

On Panicum elongatum. Auburn, 1891 (Duggar).

On Sorghum halepense. Lee County, Auburn, 1891 (Duggar).

On Muhlenbergia diffusa. Lee County, Auburn, 1891 (Duggar).

On Eragrostis tenuis. Lee County, Auburn, 1891 (Duggar).

South Carolina, New Jersej, Ohio. Europe.

Phyllachora lespedezae (Schw.) Cooke.

Ala. Bull. 196. Cornell Bull. 12.

On Lespedeza sp. Lee County, Auburn, October 21, 1890 (Atkinson).

Phyllachora ulmi (Duv.) Fkl.

Ala. Bull. 196.

On Clmus sp. Macon County, August, 1896 (Carver).

New Jersey. 'Europe. 


\section{PLOWRIGHTIA Sacc.}

Plowrightia morbosa (Schw.) Sace.

Ala. Bull. 193. Cornell Bull.9.

On Prunus angustifolia. Lee County, Norember, 1895 (Underwood \& Earle).

On Prunus americana. Montgomery County, Pikeroad, 1891 (Atkinson).

On Prunus serotina. Lee County, February, 1896 (Underwood \&- Earle).

On Prunus triflora. Mobile County, January, 1896 (Earle).

On branches of Prunus umbellata. Lee County, Auburn, 1891 (Newman).

New Jersey.

\section{SCIRRHIA Nitsch.}

Scirrhia groveana Sacc.

Ala. Bnll. 196.

On Typha latifolia. Leo County, March, 1896 (Underwood \& Earle).

Scirrhia sporoboli Atkinson.

Cornell Bull. 9.

On stems of Sporobolus asper. Lee County, Auburn (Duggar \& Newman).

\section{Order SPHAERIALES.}

\section{Family CHAETOMIACEAE.}

\section{CHAETOMIUM Kunze.}

Chaetomium olivaceum C. \& E.

Cornell Bull. 6.

On dead stems of Gossypium herbaceum, Lee County, Auburn, October 7, 1891 (Atkinson).

Chaetomium pusillum E. \& E.

Cornell Bull. 6,

On old paper, covering a culture vessel in laboratory. Lee County, Auburn (Atkinson).

\section{Family SPHAERIACEAE.}

\section{CHAETOSPHAERIA Fkl.}

Chaetosphaeria brevispinosa Atkinson.

Cornell Bull. 6.

On leaf-sheaths of Arundinaria tecta. Lee County, Auburn (Atkinson).

Chaetosphaeria pannicola (B. \& C.) Sace.

Ala. Bull. 187.

On Vitis rotundifolia. Lee County, February, 1896 (Underwood \& Earle).

On a cultivated species of Vitis. Lee County, Jauuary, 1896 (Underwood \& Earle).

HERPOTRICHIA Fkl.

Herpotrichia rhodomphala (Berk.) Sacc.

Peters coll. 3 : 44 . Ala. Bull. 189.

On dead wood (Beaumont).

LASIOSPHAERIA Ces. \& De Not.

Lasiosphaeria pezizula (B. \& C.) Sacc.

Ala. Bull. 191.

On dead wood. Lee County, January, February, 1896 (Inderwood \& Earle).

Lasiosphaeria rhacodium (Pers.) De Not.

Ala. Bull. 191.

On rotten wood. Lee County, February, 1896 (Underwood \& Earle).

Europe. 
ROSELLINIA Ces. \& De Not.

Rosellinia aquila (Fr.) De Not.

Ala. Bull. 193. Cornell Bull. 9.

On dead branches of deciduous trees. Lee County, Auburn, February 22, 1891

(Atkinson).

On Liriodendron. Lee County, January, February, 1896 (Underwood \& Earle).

Nebraska. Europe.

Rosellinia pulveracea (Ehrh.) Fkl.

Ala. Bull. 193.

On Vitis roiundifolia. Lee County, Feloruary, 1896 (Underwood \& Earle).

Rosellinia subiculata (Schw.) Sacc.

Ala. Bull. 193.

On rotten wood. Lee County, February, 1896 (Underwood \& Earle).

TRICHOSPHAERIA Fkl.

Trichosphaeria underwoodii Earle, Bull. Torr. Club, 25 : 363. 1898.

On Arundinaria sp. Auburn, January, 1896 (Underwood \& Earle).

\section{Family CERATOSTOMATACEAE.}

CERATOSTOMA Fr.

Ceratostoma piliferum Fr. (Fkl.)

Grevillea, $4: 146$, under Sphaeria. Ala. Bull. 187.

On Quercus (Peters).

Europe.

LENTOMITA Niess.

Lentomita longirostrata Atkinson.

Cornell Bull. 7 .

On stems of Ambrosia artemisiaefolia. Lee County, Auburn, October 1, 1891 (Duggar).

\section{Family CUCURBITARIACEAE.}

FRACCHIAEA Sacc.

Fracchiaea calista (B. \& C.) Sacc.

Rav. Fung. Car. Exsic. 5 : $67 . \quad$ Ala. Bull. 189.

On Carpinus (Peters).

\section{Family AMPHISPHAERIACEAE.}

CARYOSPORA De Not.

Caryospora putaminum (Schw.) De Not.

Ala. Bull. 186.

On peach pits. Mobile County, December, 1895; Lee County, February, 1896

(Underwood \& Earle).

New Jersey. South Europe.

OHLERIA Fkl.

Ohleria rugulosa Fkl.

Ala. Bull. 192.

On dead wood. Lee County, February, 1896 (Underwood \& Earle).

New Jersey. Europe. 


\section{Family LOPHIOSTOMATACEAE.}

LOPHIOSTOMA Fr.

Lophiostoma niessleanum Sacc.

Cornell Bull. 7.

On dead stems of Ambrosia artemisiaefolia. Lee County, Auburn, October 1, 1891 (Duggar).

\section{Family MYCOSPHAERELLACEAE.}

GUIGNARDIA Viala \& Ravaz.

Guignardia bidwellii (Ellis) Viala \& Ravaz.

Ala. Bull. 191, under Laestadia. Cornell Bull. 6, under Carlia.

On Parthenocissus (Ampelopsis) quinquefolia. Lee County, Auburn, May 13, 1890 (Atkinson).

OnVitis rotundifolia. Lee County, 1890 (Atkinson).

On Vitis vinifera. Lee County, 1891 (Atkinson).

On a cultivated species of Vitis. Lee County, 1891 (Atkinson).

MYCOSPHAERELLA Johanson.

Mycosphaerella arundinariae (Atkinson).

Cornell Bull. 9, under Sphaerella.

On leaves of Arundinaria tecta. Lee County, Auburn (Atkinson).

Mycosphaerella baptisiicola (Cooke).

Cornell Bull. 9, under Sphaerella.

On leaves of Elymus. Lee County, Auburn, July 5, 1890 (Atkinson).

Mycosphaerella leptopleura (De Not.).

Ala. Bull. 193. Cornell Bull.9, under Sphaerella.

On rotting leaves of Secale cereale. Lee County, Auburn (Atkinson).

Mycosphaerella gossypina (Atkinson).

Ala. Bull. 193. Cornell Bull. 9, under Sphaerella.

On leaves of Gossypium herbaceum. Lee County, Alberta, 1890 (Cathcart); Lee County, Anburn, 1890 (Atkinson).

Mycosphaerella fragariae (Tul.) Lind.

Ala. Bull. 193, under Sphaerella. Cornell Bull.39, as Ramularia tulasnei Sacc.

On Fragaria vesca, in cultivation. Lee County, Auburn, October, 1890 (Atkinson);

Mobile County, December, 1895 (Earle).

Mycosphaerella colorata (Peck).

Rav. Fung. Car. Exsic. 3:71, as Depazea kalmicola Schw. Ala. Bull:193. Cornell Bull.9.

On Kalmia latifolia (Peters).

On leaves of Kalmia. Lee County, Auburn, 1891 (Atkinson).

\section{Family PLEOSPORACEAE.}

APIOSPORA Sace.

Apiospora apiospora (Dur. \& Mont.) Underwood \& Earle.

Grevillea, 4:144, under Sphaeria. Ala. Bull. 186.

On Arundinaria (Peters).

\section{DIDYMOSPHAERIA Fkl.}

Didymosphaeria polysticta (B.\& C.) Sacc.

Grevillea, $4: 149$, under Sphaeria. Ala. Bull. 188.

On Smilax (Beaumont).

HEPTAMERIA Rehm. \& Thuem.

Heptameria mesoedema (B. \& C.) Sacc.

Cornell I3nll. 6.

Ou stems of Eupatorium. Lee County, Auburn, September 17, 1891 (Inggar). 
LEPTOSPHAERIA Ces. \& De Not.

Leptosphaeria beaumontii (B. \&. C.) Sacc.

Grevillea, 4 : 145, under Sphaeria. Ala. Bull. 191.

On stalks of grass (Beaumont).

Leptosphaeria elymi Atkinson.

Cornell Bull. 7.

On leaves of Elymus. Lee County, Auburn, July 5, 1890 (Atkinsou).

Leptosphaeria eumorpha (B. \& C.) Earle, Bull. Torr. Club, 25 : 361. 1898.

Grevillea, 4:145, under Sphaeria. Cornell Bull. 6, as Didymosphaeria eumorpha

(B. \& C.) Atkinson.

On stems of Arundinaria tecta. Lee County, Auburn, September 19, 1891 (Duggar).

Leptosphaeria michotii (W'est) Sacc.

Cornell Bull. 7.

On Elymus. Lee County, Auburn, July 5, 1890 (Atkinson).

Europe.

Leptosphaeria orthogramma (B.\& C.) Sacc.

Ala. Bull. 191.

On Erianthus sp. Macon Connty, April, 1896.

Pennsylvania.

Leptosphaeria planiuscula (Riess) Ces: \& De Not.

Cornell Bull. 7.

On dead stems, probably of Compositae. Lee County, Auburn, May 15, 1891

(Atkinson).

Europe.

Leptosphaeria pomona Sacc.

Cornell Bull. 7.

On Malus malus. Lee County, Gold Hill, September, 1890 (Atkinson).

\section{METASPHAERIA Sace.}

Metasphaeria ambrosiaecola Atkinson.

Cornell Bull. 8 .

On dead stems of Ambrosia artemisiaefolia. Lee County, Auburn, October 1, 1891 (Duggar).

Metasphaeria graminum Sacc.

Cornell Bull. 8.

On dead leaves of Chrysopogon avenaceus. Lee County, Auburn, September 12, 1891

(Duggar).

Europe.

Metasphaeria infuscans E. \& E.

Ala. Bull. 191. Cornell Bull. 8.

On dead stems of Andropogon virginicus. Lee County, Auburn, September 12, 1891 (Duggar).

Metasphaeria nigro-maculans Earle, Bull. Torr. Club, 25 :362. 1898.

On Agave virginica. Lee County, Auburn, July 8, 1896 (Underwood \& Earle).

\section{OPHIOBOLUS Riess.}

Ophiobolus acuminatus (Sowb.) Duby.

Grevillea, 4:150, nnder Sphaeria. Ala. Bull. 192.

(Peter8.)

Europe.

Ophiobolus anguillides (Cooke) Sacc.

Ala. Bull. 192. Cornell Bull. 8.

On dead stems of Ambrosia artemisiaefolia. Lee County, Auburn, May, 1892 (Atkinson).

Ophiobolus glomus (B.\& C.) Sacc.

Grevillea, 4 :152, under Sphaeria. Ala. Bull. 192. Cornell Bull. 8.

On Ambrosia (Beaumont).

On stems of Ambrosia artemisiaefolia. Lee County, Auburn, May, 1892 (Atkinson). 
Ophiobolus porphyrogonus ('Tode) Sacc.

Cornell Bull. 8 .

On the cut end of a stem of Gossypium herbaceum. Lee County, Auburn, October 10, 1891 (Atkinson).

New Jersey.

PHYSALOSPORA Niessl.

Physalospora carpogena Atkinson.

Cornell Bull. 8.

On seeds of Rubus argutus (R. villosus). Lee County, December 3, 1891 (Duggar).

Physalospora disrupta (B. \& C.) Sacc.

Ala. Bull. 192.

On Smilax sp. Lee County, March, 1896 (Underwood \& Earle)

Physalospora ilicis (Schlich.) Sacc.

Cornell Bull. 8.

On Ilex opaca. Lee County, Autumn, 1891 (Atkinson).

Physalospora philoprina (B. \& C.) Sacc.

Bull. Torr. Club, $25: 362$.

On Ilex opaca: Lee County, Auburn, March, 1897 (Earle \& Baker).

Physalospora phlyctanoides (B. \& C.) Sacc.

Grevillea, 4:151, under Sphaeria. Ala. Bull. 192.

On stems of Dolichos (Beaumont).

\section{PLEOSPORA Rabenh.}

Pleospora herbarum (Pers.) Rabenh.

Grevillea, 4:150, under Sphaeria. Ala. Bull. 193.

(Beaumont.)

Pleospora americana E. \& E.

Cornell Bull. 9.

On leaves of Vigna catjang. Lee County, Auburn, June 30, 1890 (Atkinson).

On stems of Viola tricolor. Lee County, February 23, 1891 (Atkinson).

Pleospora nigricantia Atkinson.

Cornell Bull.9.

On fallen leaves of Gossypium herbaceum (Atkinson).

UROSPORELLA Atkinson.

Urosporella americana Atkinson.

Cornell Bull. 10.

On dead stems of an herb. Lee County, Auburn, Juiy, 1890 (Atkinson).

\section{Family MASSARIACEAE.}

MASSARINA Sacc.

Massarina chrysopogonis Atkinson.

Cornell Bull. 7.

On dead stems of Chrysopogon avenaceus. Lee County, Auburn, November 1, 1891 (Atkinson).

MASSARIA De Not.

Massaria epileuca B. \& C.

Grevillea, 4 : $156 . \quad$ Ala. Bull. 191.

On Morus rubra. Lee Connty, January, 1896 (Inderwood \&. Earle). 


\section{Family GNOMONIACEAE.}

GNOMONIA Ces. \& De Not.

Gnomonia sabalicola Earle, Bull. Torr. Club, 25 :361. 1898.

On dead petioles of Sabal adansonii. Lee County, Auburn, April 25, July 9, 1896 (Underwood \& Earle).

\section{Family CLYPEOSPHAERIACEAE.}

\section{ANTHOSTOMELLA Sacc.}

Anthostomella eliminata (B.\& C.) Sacc.

Grevillea, 4 : 148, under Sphaeria. Ala. Bull. 186

On Smilax (Peters).

Anthostomella sphaerotheca Earle, Bull. Torr. Club, 25 :360. 1898.

On dead petioles of Sabal adansonii. Macon County, Tuskegee, January 20, 1897 (Carver).

\section{CLYPEOSPHAERIA Fkl.}

Ciypeosphaeria sabaligera (B.\& C.) Sacc.

Grevillea, 4:147. Ala. Bull. 187.

On Sabal sp. (Beaumont).

TRABUTIA Sacc. \& Roum.

Trabutia quercina Fr.

Ala. Bull. 194.

On Quercus nigra (Q. aquatica). Lee County, April, 1896 (Underwood \& Earle).

Louisiana.

\section{Family VALSACEAE.}

\section{ANTHOSTOMA Nitsch.}

Anthustoma atropunctata (Schw.) Sacc.

Ala. Bull. 186.

On Quercus sp. Lee County, November, 1895 (Underwood).

\section{DIAPORTHE Nitschke.}

Diaporthe dichaenoides (B.\& C.) Sacc.

Grevillea, 4:98, as Melogramma. Ala. Bull. 187.

On Quercus (Beaumont).

\section{VALSA Fr.}

Valsa (Eutypa) spinosa (Pers.) Tul.

Ala. Bull. 188.

Un Quercus. Lee County, February, April, 1896 (Underwood \& Earle).

Europe.

Valsa (Eutypella) cerviculata Fr.

Ala. Bull. 188.

On Alnus rugosa. Lee County, February, April, 1896 (Underwood \& Earle).

Europe.

Valsa (Eutypella) heteracantha Ellis.

Ala. Bull. 188, as Eutypella glandulosa (Cooke) E. \& E.

On Melia azedarach. Lee Connty, March, 1896 (Underwood \& Earle).

Louisiana.

Ellis, who has since examined the specimens, determined them as above. 
Valsa (Eutypella) platani (Schw.) Cooke.

Rav. Fung. Car. Exsic. 5 : 62. Ala. Bull. 188.

On Platanus (Peters).

Louisiana, New Jersey.

Valsa (Eutypella) stellulata Fr.

Ala. Bull. 189.

On Melia azedarach. Lee County, Mareh, 1896 (Underuood \& Earle).

On Smilax sp. Lee County, Feloruary, 1896 (Cndervood \& Earle).

Texas, Louisiana, South Carolina, Pennsylvania, New Jersey. Europe.

Valsa (Euvalsa) americana B. \& C.

Peters coll. 3:67. Ala. Bull. 194.

Valsa (Euvalsa) munda B. \& C.

Grevillea, $4: 100$. Ala. Bull. 194.

On smooth yellow branches of Cornus (Peters).

\section{Family MELANCONIDACEAE.}

\section{MELANCONIS Tul.}

Melanconis hicoriae Atkinson.

Cornell Bull. 7 .

On branches of Hicoria ovata. Lee County, Aulurn, January, 1891 (Atkinson).

VALSARIA De Not.

Valsaria exasperans (Ger.) E. \& E.

Ala. Bull. 194.

On bark. Lee County, February, 1896 (Inderwood \& Earle).

Valsaria nudicollis (B.\& C.) Sacc.

Grevillea, 4:93, under Hypoxylon. Bull. Torr. Club, $25: 363$.

On pine wood. Lee County, January, 1896 (Underwood).

South Carolina.

\section{Family DIATRYPACEAE.}

\section{DIATRYPE Fr.}

Diatrype disciformis (Hoffm.) Fr.

Grevillea, 4 :95. Ala. Bull. 187.

(Peters.)

South Carolina, Pennsylvania, Ohio. Europe.

Diatrype platystoma (Schw.) Berk.

Rav. Fung. Car. Exsic. 5 : 55, under Hypoxylon. Ala. Bull. 187.

On Ostrya (Peters).

South Carolina, Pennsylvania, Ohio, New Jersey.

Diatrype stigma (Hoffm.) De Not.

Ala. Bull. 187. Cornell Bull. 6.

On dead oak limb. Lee County, Auburn, February 22, 1891 (Atkinson).

On dead limbs. Winston County, June, 1896 (Underwood).

South Carolina, New Jersey. Europe.

Diatrype tremellophora Ellis.

Ala. Bull. 187.

On Magnolia virginiana (M. glauca). Lee County, January, March, 1896 (Underwood \&. Earle).

New Jersey.

Diatrype virescens (Schw.) Ellis.

Grevillea, 4:95, ad Diatrype disciformis virescens. Ala. Bull.188.

On Fagus (Peters).

Georgia to New England. 
DIATRYPELLA Ces. \& De Not.

Diatrypella cephalanthi (Schw.) Saec.

Grevillea, 4:96, under Diatrype. Ala. Bull. 188.

On Cephalanthus occidentalis (Beaumont).

New Jersey.

Diatrypella nigro-annulata (Grev.) E. \& E.

Ala. Bull. 188.

On dead twigs. Lee Connty, June, 1896 ' Underwood \& Earle).

Diatrypella discoidea alni Cooke.

Ala. Bull. 188.

On Alnus rugosa. Lee County, January, May, 1896 (Underwool \& Earle).

Diatrypella quercina (Pers.) Nitsch.

Grevillea, 4:95, under Diatrype. Mla. Bull. 188.

On dead oak (Peters).

South Carolina, New Jersey. Europe.

Diatrypella vernicae Ellis.

Ala. Bull. 188, as D. quercina.

On dead twigs. Lee County, Auburn, February, 1896 (Underwood \& Earle), (teste Ellis).

Diatrypella prominens (Hedw.) E. \& E.

On Platanus. Macon County, Tuskegee (Carver).

\section{Family MELOGRAMMATACEAE.}

\section{ENDOTHYA Fr.}

Endothia gyrosa (Schw.) Fkl.

Ala. Bull. 188.

On Liquidambar. Lee County, March, 1896 (Underwood of Eurlc).

On Quercus. Lee County, February, 1896 (Underwood of Earle).

South Carolina.

MELOGRAMMA Fr.

Melogramma meliae Curt.

Ala. Bull. 191.

On Melia azedarach. Lee County, March, 1896 (Underwood \& Earle).

South Carolina.

\section{Family XYLARIACEAE.}

\section{NUMMULARIA Tul.}

Nummularia clypeus (Schw.) Fkl.

Ala. Bull. 192.

On Magnolia acuminata. Lee County, December, 1895 (Underwood).

On Alnus rugosa. Lee County, November, December, 1895 (Underwood).

On Quercus sp. Lee Connty, December, 1895 (Underwood); Macon County, August, 1896 (Carver).

On Vitis sp. Lee County, January, 1896 (Underwood \&. Earle).

Sonth Carolina.

Nnmmularia discreta (Schw.) Tul.

Grevillea, 4:94, under Hypoxylon. Ala. Bull. 192.

On Cercis (Peters).

New Jersey, Ohio. Europe.

Nummularia nummularia (Bull.) Atkinson.

Cornell Bull. 8.

On dead branches and trunks of deciduous trees. Lee County, Auburn, 1890

(Atkinson).

New Jersey, Ohio, South Carolina. Europe. 
Nummularia punctulata (B. \& Rav.) Sacc.

Ala. Bull. 192.

On Alnus rugosa. Lee County, March, 1896 (Underwood \& Earle).

On Quercus sp. Lee County, March, 1896 (Underwood \& Earle).

South Carolina.

Nummularia repanda (Fr.) Nitsch.

Peters coll. No. 66, under Sphaeria. Ala. Bull. 192.

On Cercis (Peters).

Europe.

\section{HYPOXYLON Bull.}

Hypoxylon annulatum (Schw.) Mont.

Ala. Bull. 189. Cornell Bull. 7.

On dead oak limb. Hale County, Gallion, August, 1890 (Duggar).

On Acer rubrum. Lee County, February, 1896 (Underwood \& Earle).

On Magnolia virginiana. Lee County, March, 1896 (Underwood \& Earle).

On Quercus sp. Lee County, February, March, 1896 (Underwood \& Earle).

New Jersey, Ohio.

Hypoxylon atramentosum (Fr.) Underwood \& Earle.

Ala. Bull. 189.

On dead wood. Lee County, December, 1895 (Underwood); Jauuary, February, 1896

(Underuood \& Earle).

Hypoxylon beaumontii B. \& C.

Ala. Bull. 189.

Conecuh County (Beaumont).

Fypoxylon callostroma (Schw.) B. \& C.

Grevillea, 4:51. Ala. Bull. 189.

On Ilex rerticillata (Beaumont).

Pennsylvania.

Hypoxylon caries (Schw.) Sace.

Ala. Bull. 189.

On Acer. Lee County, February, 1896 (Underwood \& Earle).

On dead wood. Lee County, March, 1896 (Underwood \& Earle).

Hypoxylon coccineum Bull.

Ala. Bull. 189.

On Alnus rugosa. Lee County, March, 1896 (Underwood \& Earle).

Louisiana, New Jersey, Ohio. Europe.

Hypoxylon crocatum Mont.

On Magnolia acuminata. Lee County, winter, 1896 (Earle).

Hypoxylon crocopeplum B. \& C.

Ala. Bull. 189.

On decayed bark. Lee County, December, 1895 (Underwood).

South Carolina.

Hypoxylon decorticatum (Schw.) Berk.

Ala. Bull. 190.

On bark. Lee County, February, 1896 (Underwood \& Earle).

South Carolina.

Hypoxylon fuscum (Pers.) Fr.

Ala. Bull. 190. Cornell Bull. 7.

On dead oak limb. Lee County, Auburn, autumu, 1889 (Atkinson).

On Quercus. Hale County, Gallion (Duggar).

On Alnus rugosa. Lee County, December, 1895 (Underwood).

On Ostrya virginiana. Lee County, February, 1896 (Underwood \& Earle).

Europe.

Hypoxylon howeianum Peck.

Ala. Bull. 190.

Lee County, February, 1896 (Underwood \& Earle)

New Jersey, Ohio. 
Hypoxylon insidens (Schw.) Berk.

Ala. Bull. 190.

On Liriodendron tulipifera. Leo County, February, 1896 (Underwood \& Earle). Texas.

Hypoxylon luridum Nitseh.

Ala. Bull. 190.

On Carpinus. Lee County, 1896 (Earle).

Europe.

Hypoxylon marginatum (Schw.) Berk.

Grevillea, $4: 49$. Ala. Bull. 190.

On Acer rubrum. Lee County, March, 1896 (Underwood \& Earle).

On Quercus nigra (Q.aquatica). Lee County, March, 1896 (Underwood \&. Earle).

On Quercus (Beaumont).

Ohio, New Jersey.

Hypoxylon perforatum (Schw.) Fr.

Ala. Bull. 190. Cornell Bull. 6.

On canes of Arundinaria tecta. Lee County, Auburn, August 23, 1891 (Duggar).

On Liquidambar. Lee County, January, 1896 (Underwood \& Earle).

On Quercus. Lee County, January, 1896 (Inderwood \& Earle).

On Smilax. Lee County, January, 1896 (Underwood \& Earle).

On Vitis. Lee County, January, 1896 (Underwood of Earle).

Hypoxylon petersii B. \& C.

Peters coll. 1:158. Journ. Linn. Soc. 10:384. Ala. Bull. 190.

On Quercus alba. Winston County (Peters).

Ohio. Cuba.

Hypoxylon investiens Schw.

Rav. Fung. Car. Exsic. 4:33. Ala. Bull. 190.

On Liriodendron (Beaumont).

On dead wood. Lee County, March, April, 1896 (Underwood \& Earle).

Texas.

Hypoxylon purpureum Nitsch.

Cornell Bull. 7.

On dead branches. Hale County, Gallion, August 14, 1894 (Duggar).

Europe.

Hypoxylon rubiginosum (Pers.) Fr.

Ala. Bull. 190.

On dead wood. Lee County, February, March, 1896 (Underwood \& Earle).

Louisiana, New Jersey, Ohio. Europe.

Hypoxylon rutilum Tul.

Ala. Bull. 191.

On bark of Quercus. Winston County, June, 1896 (Underwood).

Europe.

Hypoxylon serpens Pers.

Grevillea, 4 : 93. Ala. Bull. 191.

(Beaumont.)

South Carolina, New Jersey.

Hypoxylon subchlorinum Ell. \& Calk.

Ala. Bull. 191.

On Alnus rugosa. Lee County, February, 1896 (Underwood \& Earle).

On Carpinus caroliniana. Lee County, February, 1896 (Underwood \& Earle).

On Viburnum sp. Lee County, January, 1896 (Underwood \& Earle).

Fypoxylon xanthoceras B. \& C.

Ala. Bull. 191.

On Alnus rugosa. Lee County, February, 1896 (Underwood \& Earle).

New England.

Ustulina vulgaris Tnl.

USTULINA Tul.

Ala. Bull. 194.

On old stumps. Lee County, February, March, 1896 (Underwood \& Earle).

New Jersey, Ohio. Europe. 
DALDINIA De Not.

Daldinia concentrica (Schw.) Ces. \& De Not.

Ala. Bull. 187. Cornell Bull. 6.

On Magnolia acuminata. Lee County, November, 1895 (Tnderwood); Winston County, June, 1896 (Underwood).

On dead trunks of deciduous trees. Lee County, Pragne Junetion, Jnly, 1890 (Atkinson).

Daldinia vernicosa (Schw.) Ces. \& De Not.

Ala. Bull. 187.

On Magnolia virginiana (M.glauca). Lee Connty, December, 1896 (Earle).

New Jersey.

\section{XYLARIA Hill.}

Xylaria hypoxylon (L.) Grev.

Ala. Bull. 195. Cornell Bull. 10.

On Acer rubrum. Lee County, February, 1895.

On old stump. Lee County, Auburn, March, 1891 (Athinson).

Louisiana, New Jersey, Ohio. Europe.

Xylaria polymorpha (Pers.) Grev.

Ala. Bull. 195. Cornell Bull. 10.

On dead trunk of Magnolia. Macon County, Shorter, July 16, 1890.

Conidial stage: Lee County, April, 1896 (Underwood \& Earle).

Ascomycetous stage: Hale County, May, 1896 (Underwood).

Europe.

Xylaria corniformis Fr.

Ala. Bull. 194.

On Salix. Lee County, February, 1896 (Underwood \& Earle).

The conidial state (Isaria flabelliformis): Lee County, May, 1896 (Underuood \& Earle).

South Carolina. Europe.

Xylaria fulvella B. \&. C.

Journ. Linn. Soc. $10: 380$. Ala. Bull. 194.

On Salix. Lee County, February, 1896 (Underwood \& Earle).

Cuba.

PORONIA Willd.

\section{Poronia oedipus Mont.}

Rav. Fung. Car. Exsic. 3 : 46. Ala. Bull. 193.

On horse dung (Peters).

Texas, New Jersey. Europe.

\section{SPHAERIA Hall.'}

Sphaeria concentrica (B.\& C.) Bolt.

Grevillea, 4 : 155, under Depazea. Ala. Bull. 194.

On leaves of Asarum virginicum.

Sphaeria palmarum Mont.

Grevillea, $4: 147$. Ala. Bull. 194.

On Sabal (Beaumont).

\footnotetext{
'The precise relations of the two following Sphaeriales are doubtful. (Warle.)
} 


\section{Class BASIDIOMYCETES.}

\section{Order USTILAGINALFS.}

\section{Family USTILAGINACEAE.}

\section{USTILAGO Pers.}

Ustilago avenae (Pers.) Jensen.

Ala. Bull. 207. Cornell Bull. 16.

In inflorescence of Avena sativa. Lee County, Auburn, May, 1891 (Atkinson).

On Avena sativa. Lee County, May, 1896 (Underwood \& Earle).

Ohio.

Ustilago axicola Berk.

Grevillea, 3:59. Ala. Bull. 207, under Cintractia.

On Cyperus (Beaumont).

On Fimbristylis autumnalis. Lee County, September, 1896 (Earle).

Ustilago euchlaenae Arcang.

Ala. Bull. 207.

On Euchlaena luxurians. Lee County, October, 1895 (Underwood).

Ustilago rabenhorstiana Kuehn.

Ala. Bull. 207. Cornell Bull. 16, as $U$. cesatii Fischer.

On Syntherisma sanguinale. Lee County, Auburn, autumn, 1889 (Atkinson).

Mississippi, Ohio. Europe.

Ustilago sorghi (Link) Pass.

Ala. Bull. 208.

On Sorghum sp. Lee County, November, 1895 (Underwood).

Nebraska. Europe.

Ustilago sparsa Underwood.

Bull. Torr. Club, 24 : 86. 1897. Ala. Bull. 208.

On scattered ovaries of Dactyloctenium aegyptium. Lee County, November, 1895

(Underwood); October, 1896 (Earle).

Ustilago tritici (Pers.) Jensen.

Ala. Bull. 208. Cornell Bull. 16.

On Triticum vulgare. Lee County, Auburn, May, 1891 (Atkinson).

Ohio.

Ustilago utriculosa (Nees) Tul.

Ala. Bull. 208. Cornell Bull. 16.

Ou Polygonum hydropiper. Prague, June, 1890 (Atkinson).

In ovaries of Polygonum pennsylvanicum. Lee County, Auburn, October 18, 1891 (Duggar).

Ohio, New Jersey. Europe.

Ustilago zeae (Berkm.) Magn.

Ala. Bull.208. Cornell Bull. 16.

In the inflorescence, canes, and leaves of Zea mays. Lee Connty, Auburn, 1891

(Duggar \& Atkinson).

Nebraska. Europe.

\section{SOROSPORIUM Rudolphi.}

Sorosporium syntherismae (Schw.) Farlow.

Ala. Bull. 207. Cornell Bull. 16, as S. everhartii E. \& Gr.

On Andropogon glomeratus. Lee County, 1891 (Atkinson).

On Andropogon scoparius. Lee County, 1891 (Atkinson).

In inflorescence of Andropogon virginicus. Lee County, Auburn, 1891 (Atkinson).

\section{TOLYPOSPORELLA Atkinson.}

Tolyposporella chrysopogonis Atkinson.

Cornell Bull. 16.

On cnlms of Chrysopogon avenaceus. Lee County, Anburn, antumn, 1891 (Duggar);

March, 1892 (Atkinson). 


\section{Family TILLETIACEAE.}

ENTYLOMA De Bary.

Entyloma compositarum Farlow.

Ala. Bull. 207.

On Gnaphalium sp. Lee County, April, 1896 (Inderwood \& Earle).

Entyloma saniculae Peck.

Ala. Bull.207. Cornell Bull. 15.

On Sanicula sp. Lee County, 1892 (Atkinson).

\section{GRAPHIOLA Poit.}

Graphiola congesta Berk. \& Rav.

Ala. Bull. 207.

On Sabal adansonii. Lee Connty, July, 1896 (Underwood \& Earle).

\section{Order URFDINALES.}

\section{Family MELAMPSORACEAE.}

\section{CHRYSOMYXA Unger.}

Chrysomyza albida Kuehn.

Ala. Bull. 211. Cornell Bull. 16.

On Rubus argutus (R. villosus). Macon County, Shorter, July 16, 1890 (Atkinson); Lee County, Auburn, July 22, 1890, October 26, 1891 (Atkinson).

\section{COLEOSPORIUM Lév.}

Coleosporium amsoniae (Fkl.) Underw. \& Earle.

Peters coll. Ala. Bull. 211.

On Amsonia amsonia. 1864 (Peters). Lee County, July, 1896 (Underwood \& Earle).

Coleosporium elephantopodis (Schw.) Thuem.

Ala. Bull.211. Cornell Bull.16. In both as C. sonchi-arrensis (Pers.) Lév. in part.

On Elephantopus carolinianus. Lee County, 1890 (Atkinson, Duggar).

On Elephantopus tomentosus. Lee County, 1891 (Bennett. Newman).

On Elephantopus nudatus. Macon County, 1890 (Atkinson).

Coleosporium ipomoeae (Schw.) Burrill.

Ala. Bull.211. Cornell Bull. 17.

On Ipomoea sp. Lee County, 1890 (Atkinson).

On Convolvulus sepium. Lee County, September 8, 1891 (Atkinson).

On Ipomoea purpurea. Lee County, Auburn, August 17 (Duggar); September, 1891

(Newman).

On Ipomoea pandurata. Lee County, July, 1896 (Underwood \& Earle).

Very abundant.

Coleosporium sonchi-arvensis (Pers.) Lév.

Ala. Bull. 211. Cornell Bull. 16 .

On Aster dumosus, A. puniceus, A. tradescanti, and A. undulatus. Lee County, 1891 (Atkinson).

On Helianthus sp. Lee County, 1891 (Duggar, Atkinson).

On Lacinaria graminifolia. Lee County, 1891 (Duggar).

On Solidago rugosa and S. caesia. Lee County, 1891 (Atkinson).

On Solidago canadensis. Lee County, 1891 (Newman).

On Solidago sp. DeKalb County, May, 1896 (Underwood).

Ohio. Europe.

Coleosporium vernoniae B. \& C.

Grevillea, 3:57. Ala. Bull. 212. Cornell Bull. 16.

On leaves of Vernonia sp. (Beaumont).

On leaves of Vernonia altissima. Lee County, Auburn (Atkinson).

On Vernonia sp. Lee County, October, 1895 (Underwood).

Lonisiana, Ohio. 
MELAMPSORA Castagn.

Melampsora farinosa (Pers.) Schroeter.

Ala. Bull. 213. Cornell Bull. 17.

On Salix fragilis. Lee County, 1891 (Atkinson).

On leaves of Salix nigra. Lee County (Atkinson, Inggar).

On Salix sp. Lee County, 1891 (Duggar).

Nebraska.

Melampsora populina (Jacq.) Lév.

Ala. Bull. 213. Cornell Bull. 17.

On Populus deltoides (P. monilifera). Macon County, August, 1896 (Carver).

On leaves of Populus grandidentata. ${ }^{1}$ Lee County, 1889 (Atkinson).

On Salix sp. Macon County, August, 1896 (Carver).

Nebraska. Europe.

Melampsora scolopendri (Fkl.) Farlow.

Ala. Bull. 213.

On Woodwardia areolata. Macon County, August, 1896 (Carver).

Melampsora crotonis (Cooke) Burrill.

Cornell Bull. 20, as Pucciniastrum crotonis (Burrill) De'Toni.

On stems of Croton. Madison County, Huntsville, September 9, 1892 (Atkinson).

\section{PUCCINIASTRUM Otth.}

Pucciniastrum vacciniorum (Link) Dietel.

Ala. Bull. 218, as Thecopsora vaccinorum (Link) Karst.

On Vaccinium corymbosum, erroneously reported as Xolisma ligustrina. Lee County, October, 1896 (Earle).

Pucciniastrum agrimoniae-eupatoriae (DC.) Lagerh.

Ala. Bull.214. Cornell Bull. 22. In both as Caeoma agrimoniae Schw.

On leaves of Agrimonia parviflora. Lee County, Auburn, November 2, 1891 (Duggar).

On Agrimonia mollis ( ( ). Lee County, May, 1896 (Underwood \& Earle).

\section{Family PUCCINIACEAE.}

\section{GYMNOSPORANGIUM Hedw.f.}

Gymnosporangium clavipes C.\& P.

Ala. Bull. 212; same, 218, as Roestelia aurantiaca Peck. Cornell Bull. 17.

On Juniperus virginiana. Lee County, 1891 (Atkinson); Lee Connty, 1892 (Duggar).

In the Roestelia stage:

On Cydonia vulgaris. Lee County, 1891 (Atkinson, Newman).

On Crategus. Lee County 1891, 1892 (Atkinson); Benton County, 1891, 1892 (Duggar).

Very common.

On Cydonia japonica (Atkinson).

New Jersey.

Gymnosporangium globosum Farlow.

Ala. Bull. 212.

On Juniperus virginiana. Lee County, March, 1896 (Underwood \& Earle).

Gymnosporangium macropus Link.

Ala. Bull.212; same, 218, as Roestelia pirata (Schw.) Thaxter. Cornell Bull.17.

On Juniperus virginiana. Lee County, 1890 (Atkinson).

In the Roestelia stage:

On Malus coronaria and M. malus. Lee County, August, 1890 (Atkinson).

On Crataegus spathulata. Lee County, October, 1895 (Underwood).

On Malus angustifolia. Lee County, March, 1896 (Underwood \& Earle).

On Malus coronaria. Lee County, July, 1896 (Underwood \& Earle).

New Jersey.

${ }^{1}$ This host must be $P$. heterophylla, $P$. grandidentata not being known to occur in Alabama. 
Gymuosporangium nidus-avis Thaxter.

Ala. Bull. 212.

On Juniperus virginiana. Lee County, March, 1896 (Underwood \& Earle).

Rare.

\section{Gymnosporangium flaviformis (Atkinson).}

Ala. Bưll. 212, as Gymnosporangium sp.; Ala. Bull. 218, as Roestelia flaviformis Atkinson.

On Juniperus virgmiana. Lee County, March, 1896 (Underwood \& Earle).

In the Roestelia stage:

On ('rataegus spathulata. Lee County, October, 1895 (Underwood).

The suspected connection between the aecidial and teleutosporic forms has been abundantly proved by cultural experiments conducted by Dr. Roland Thaxter at Cambridge and by the writer (F.S. Earle) at Auburn. A full description is in preparation by Dr. Thaxter.

\section{UROMYCES link.}

\section{Uromyces andropogonis Tracy.}

Ala. Bull. 219. Cornell Bull. 20.

On Andropogon virginicus. Lee County, 1891 (Duggar); Macon County, August, 1896 (Carver).

On Andropogon sp. Lee County, October, 1895 (Underwood).

Uromyces elegans (B. \& C.) Lagerh.

Ala. Bull. 220, as $U$. medicaginis-falcatae (DC.) Winter. Cornell Bull. 20, as $U$. trifolii (Hedw.) Lév.

On Trifolium carolinianum. Leo County, 1890 (Atkinson).

\section{Uromyces eragrostidis Tracy.}

Ala. Bull.219. Cornell Bull. 20.

On Eragrostis tenuis. Lee County, Auburn, October 11, 1891 (Inggar).

Uromyces euphorbiae (Schw.) B. \& C.

Cornell Bull. 20.

On leaves of Euphorbia nutans. Lee County, Anburn, October, November, 1891

(Duggar).

Nebraska.

Uromyces hedysari-paniculati (Schw.) Farlow.

Peters coll., as Uredo appendiculata. Ala. Bull. 219. Cornell Bull. 21.

On Meibomia rotundifolia. Macon Comnty, August, 1896 (Carver).

On Meibomia paniculata. Lee County, September 13, 1891 (Atkinson).

On Meibomia. 1858 (Peters). Crenshaw County, Lapine, September 8, 1890 (Atkin8on); Perry County, 1891 (Atkinson). Louisiana, Ohio, Nebraska.

Uromyces hyperici (Schw.) Curt.

Ala. Bull.219. Cornell Bull. 20.

On leaves and stems of Hypericum mutilum. Prague Junction, September 6, 1890 (Atkinson); Lee County, Auburn, October 29, November 15, 1891 (Dugyar, Atkinson); October, 1896 (Earle).

On Hypericum virginicum. Lee County, November, 1895 (Underwood).

New Jersey, Ohio.

\section{Uromyces junci Desm.}

Ala. Bull.219. Cornell Bull.21.

On stems of Juncus sp. Lee County, Auburn, Angust, November, 1891 (Atkinson).

Nebraska.

Uromyces lespedezae (Schw.) Peck.

Ala. Bull. 219. Cornell Bull. 20.'

On Lespedeza procumbens. Lee County, 1891 (Newman, Duggar).

On Lespedeza hirta. Lee County, autumn, 1891 (Atkinson).

On Lespedeza repens. Lee County, antumu (Atkinson).

On Lespedeza stuvci and L. virginica. Lee County, antumn, 1890 (Atkinson).

On Lespedeza violacea, L. veticulata, and L. capitata. Lee Connty, Auburn, autumn (Atkinson).

On Lespedeza sp. Macon County, Angust, 1896 (Carver).

Ohio, New Jersey, Nebraska. 
Uromyces minutus Dietel.

Cornell Bull.21.

On Carex sp. Loe County, Auburn, Angust 27, 1891 (Duggar).

Uromyces phaseoli (Pers.) Winter.

Peters coll., as Uredo leguminosorum. Ala. Bull.219. Cornell Bull.20. In both as U. appendiculatus (Pers.) Link.

On Phaseolus vulgaris, the pole bean. Mobile County, 1890 (Atkinson). Lee Comnty;

Auburn, July to October, 1890 (Atkinson).

On Phaseolus sp. (Beaumont).

Europe.

Uromyces polygoni (Pers.) Fkl.

Ala. Bull.220. Cornell Bull. 20.

On leaves of Polygonum setaceum. Lee County, Anburn, June, 1890, September 8, 1891 (Atkinson).

On Polygonum sp. Lee County, Auburn, August 18, 1891 (Duggar); Hale County,

Gallion, 1892 (Duggar).

New Jersey, Nebraska.

Uromyces rhynchosporae E. \& E.

Ala. Bull.220. Cornell Bull.20.

On Rynchospora glomerata. Lee County, Auburn, July to October, 1890-91 (Duggar, Atkinson).

On Rynchospora sp. Macon County, August, 1896 (Carver).

Uromyces spermacoces (Schw.) Curt.

Ala. Bull. 220. Cornell Bull. 20.

On Diodia teres. Macon County, 1891 (Atkinson); October, 1896 (Carver). Lee County, Auburn, July 25, 1890 (Atkinson); 1893 (Duggar).

Uromyces toxicodendri Berk. \& Rav.

Grevillea, 3: 58, as Pileolaria brevipes Berk. \& Rav. Ala. Bull. 220. Cornell

Bull. 21. In the two latter as U. terebinthi (DC.) Winter.

On Rhus toxicodendron (Beaumont). Perry County, Uniontown, July 2, 1890 (At'in-

son); Lee County, Auburn, October 28, 1891 (Atkinson).

New Jersey.

Uromyces trifolii (A. \& S.) Winter.

Ala. Bull. 220. Cornell Bull. 20.

On Trifolium hybridum. Lee County, 1891 (Atkinson).

On Trifolium pratense. Lee County, 1891 (Newman, Duggar); Madison County,

May, 1896 (Underwood \& Earle).

On Trifolium sp. Lee County, 1890 (Atkinson).

Nebraska. Europe.

\section{PUCCINIA Pers.}

Puccinia americana Lagerh.

Ala. Bull. 213, as P. andropogi Schw.

On Andropogon argyraeus. Lee County, 1891 (Atkinson).

On Andropogon furcatus and A. scoparius. Lee County, 1891 (Duggar).

On Andropogon virginicus. Lee County, December, 1895 (Underwood); March, 1896

(Underwood \& Earle).

On Andropogon sp. Lee County, 1891 (Duggar).

Our Alabama material seems to belong to this species rather than to $P$. andropogi, as the two are distinguished by Lagerheim.

Puccinia amorphae Curt.

Ala. Bull. 220, under Uropyxis.

On Amorpha fruticosa. Macon County, 1890 (Atkinson); Lee County, October, 1895 (Earle).

Puccinia angustata Peck.

Ala. Bull. 214. Cornell Bull. 19.

On Scirpus cyperinus eriophorum. Lee County, Auburn, November 8, 1891 (Athinson).

Puccinia argentata (Schultz) Winter.

Ala. Bull. 214. Cornell Bull. 18.

On leaves of Impatiens biflora. Lee Connty, Parkinson's Mill, near Auburn, June 30, 1890, October 11, 1891 (Atkinson).

New Jersey, Ohio. Europe. 
Puccinia asperifolia (Pers.) Wittst.

Ala. Bull. 216. Cornell 13ull. 18. In both as P. rubigovera (Uredo stage).

On Avena sativa. Lee County, 1890 (Atkinson).

On leaves of Hordeum vulgare. Perry County, Uniontown, July 11, 1890 (Athinson).

On Secale cereale. Lee County, May, 1896 (Underwood \& Earle).

Puccinia asteris Duby.

Ala. Bull. 214. Cornell Bull. 17.

On Aster sp. Lee County, Auburn, October 22, 1891 (Duggar); Dekalb Connty,

May, 1896 (Underwood).

Lagerheim ${ }^{1}$ follows Dietel rather doubtfully in referring here also $P$. silphii Schw.

and $P$. ranthii Schw.

Ohio, Nebraska. Europe.

Puccinia atkinsonii Dietel.

Cornell Bull. 19.

On Carex lurida. Lee County, Auburn, Angust 29, October 11, 1891 (Atkinson);

September 22, 1891 (Duggar). Dekalb County, May, 1896 (Underwood).

Puccinia caricis (Schum.) Rebent.

Ala. Bull. 214. Cornell Bull. 18.

On Carex lurida. Lee County, 1891 (Atkinson).

On Carex sp. Lee Connty, August 29, 1891 (Duggar).

New Jersey. Europe.

Puccinia clavispora Ell. \& Barth.

Ala. Bull. 214.

On Chrysopogon avenaceus. Lee County, December, 1895 (Underwood); March, 1896

(Underwood \& Earle). Macon County, August, 1896 (Carver).

Puccinia convolvuli Cast.

Ala. Bull. 214.

On Conrolvulus sp. Dekalb County, May, 1896 (Underwood).

Nebraska. Europe.

Puccinia emaculata Schw.

Ala. Bull. 214. Cornell Bull. 17.

On Panicum maximum.2 Lee County, 1891 (Duggar, Newman).

On Panicum virgatum. Lee County, September 14, 1891 (Atkinson); March, 1896

(Underwood \& Earle).

Ohio, Nebraska.

\section{Puccinia fuirenae Cooke.}

Ala. Bull. 214. Cornell Bull. 18.

On tho leaves, sheaths, and culms of Fuirena sp. Lee County, Auburn, November 3, 1891 (Duggar).

On Fuirena squarrosa. Lee County, July, 1896 (Underwood \& Earle).

\section{Puccinia helianthi Schw.}

Ala. Bull. 217, as P. tanaceti DC. Cornell Bull. 17.

On Helianthus angustifolius. Lee County, Auburn, October 15, 1891 (Atkinson).

On Helianthus annuus. Lee County, Auburn, August 24, 1891 (Atkinson).

On Helianthus tuberosus. Lee County, Auburn, September 10, 1891 (Atkinson);

Macon County, August, 1896 (Carver).

On Helianthus sp. Leo County, 1890 (Atkinson).

New Jersey, Ohio, Nebraska. Europe.

Puccinia heterospora B. \& C.

Ala. Bull. 214. Cornell Bull. 18.

On Sida spinosa. Montgomery County, 1891 (Atkinson). Lee County, October, 18y5 (Earle).

Puccinia hieracii (Schum.) Mart.

Ala. Bull. 214. Cornell Bull. 18.

On leaves, stems, and bracts of Sitilias caroliniana. Lee County, 1890 (Atkinson); 1891 (Nevoman).

On Carduus sp. Lee County, Auburn, October 28, 1891 (Atkinson).

New Jersey, Nebraska. Europe. 
Puccinia hydrocotyles (Mont.) Cooke.

Ala. Bull. 215. Cornell Bull. 18.

On Hydrocotyle umbellata. Lee County, Auburn, November 9, 1891 (Duggar).

Puccinia investita Schw.

Ala. Bull. 215.

On Gnaphalium purpureum. Lee County, 1890 (Atkinson).

Puccinia lateritia B. \& C.

Rav. Fung. Car. Exsic. 3 :93. Ala. Bull. 215.1

On Spermacoce glabra (Peters).

Puccinia lobeliae Gerard.

On Lobelia puberula. Lee County (Earle \& Baker).

Puccinia menthae Pers.

Ala. Bull. 215. Cornell Bull. 18.

On Salvia azurea grandiflora. Van Dorn County, August 15, 1894 (Duggar).

On Koellia sp. Montgomery County, Highland Park, October, 1891 (Atkinson);

Lee County, 1891 (Atkinson).

New Jersey, Ohio, Nebraska. Europe.

Puccinia minuta Dietel.

Cornell Bull. 19.

On Carex verrucosa. Lee County, Auburn, August 29, 1891 (Atkinson).

Puccinia nigro-velata Ell. \& Tracy.

Cornell Bull. 18.

On Cyperus retrofractus. Lee County, Auburn, September 12, 1891 (Duggar).

On Cyperus rotundus. Lee County, Auburn, September 12, 1891 (Duggar),

On Cyperus echinatus. Lee County, August, 1897 (Earle \&'Baker).

This is said by Arthur to be the same as P. cyperi Arth.

Pucciuia panici Dietel.

On Panicum virgatum. Lee County, October, 1897 (Earle \& Baker).

Puccinia poculiformis (Jacq.) Willd.

Aia. Bull. 214. Cornell Bull.19. In both as P.graminis Pers.

On Sporobolus asper. Lee County, 1889 (Newman).

On leaves of Secale cereale. Lee County, Auburn, February 14, 1890 (Atkinson).

On Sieglingia seslerioides. Lee County, October, 1895 (Underwood).

On Triticum vulgare. Lee Connty, May, 1896 (Underwood \& Earle).

On Hordeum vulgare. Lee County, July, 1896 (Underwood \& Earle).

This determination needs revision. It is probable that as the species is now understood some of these specimens should be excluded.

Puccinia podophylli Schw.

Ala. Bull. 215.

On Podophyllum peltatum. Lee County, April, 1896 (Underwood \& Earle); Hale County, May, 1896 (Underwood); Madison County, May, 1896 (Underwood); Dekalb County, May, 1896 (Underwood).

Ohio.

Puccinia polygoni-amphibii Pers.

Ala. Bull. 215.

On Polygonum sp. Lee County, 1889 (Atkinson).

On Polygonum pennsylvanicum. Le日 County, 1890 (Atkinson), 1891 (Duggar).

Nebraska. Europe.

Puccinia polysora Underwood, Bull. Torr. Club, 24:86. 1897.

Ala. Bull. 215. C Cornell Bull. 18.

On Tripsacum dactyloides. Lee Connty, Auburn, October 14, 1891 (Duggar); Mobile County, October, 1896 (S. M. Tracy).

Puccinia pruni-spinosae Pers.

Ala. Bull.216. Cornell Bull.18.

On leaves of Prunus americana. Lee County, Auburn, October 29, 1891 (Duggar).

On leaves of Prunus serotina. Lee Connty, Auburn, October 3, 1891 (Duggar).

On leaves of Prunus angustifolia. Lee County, Auburn, October 25, 1890 (Atkinson).

On leaves of Amygdalus persica. Macon Connty, October, 1896 (Carver).

Nebraska. Europe. 
Puccinia purpurea Cooke.

Ala. Bull. 216. Cornell Bull. 19.

On Sorghum halepense. Perry County, Uniontown, October, 1892 (Duggar); Macon County, October, 1896 (Carver).

Puccinia rhamni (Pers.) Wittst.

Cornell Bull. 19, as P. coronata Corla.

On leaves of Avena sativa. Lee County, Auburn, spring, 1890 (Athinson).

Ohio, New Jersey.

Puccinia sanguinea Dietel.

Cornell Bull. 19.

On Sorghum vulgare, the Kafir corn. Lee Connty, Auburn, December 22, 1888 (Atkinson).

Puccinia saniculae Grev.

Ala. Bull. 216.

On Sanicula sp. Lee County, 1891 (Benton); Hale County, May 5, 1896(Underwood);

Tuscaloosa County, 1896 (Earle).

Puccinia seymeriae Burrill.

Cornell Bull. 19.

On leaves of Gerardia tenuifolia. Perry County, Uniontown, September 4, 1894. Determined by Mr. Duggar.

Puccinia silphii Schw.'

Ala. Bull.216. Cornell Bull.18.

On Silphium laevigatum. Lee County, Aubarn, July, 1891 (Atkinson).

On Silphium asteriscus. Lee County, April, July, 1896 (Underwood \& Earle).

Ohio, Nebraska.

Puccinia sorghi Schw.

Ala. Bull. 215, 216, partly as $P$. maydis Carradori. Cornell Bull 17.

On Sorghum cernuum. Lee County, 1888 (Newman).

On leaves of Zea mays. Lee County, Auburn, 1889 (Atkinson); August, 1891 (Nowman). Montgomery County, Mathews, October 10, 1891 (Atkinson).

New Jersey, Ohio, Nebraska. Europe.

Puccinia spegazzinii De Toni.

Ala. Bull.216. Cornell Bull. 18.

On Willughbya scandens. Lee County, Auburn, August, September, November, 1891 (Duggar).

Puccinia spermacocis B. \& C.

Grevillea, 3:53. Ala. Bull. 216.

On Spermacoce glabra (Peters).

Probably the same as $P$. lateritia, or possibly only Cromyces spermacoces.

Puccinia stromatica B. \& C.

Grevillea, 3:53. Ala. Bull. 216. ${ }^{2}$

On stems of Clematis sp. (Peters).

Puccinia verbesinae $\mathrm{Sch}$.

Ala. Bull. 211, under Aecidium. Cornell Bull. 19.2

On leaves of Verbesina occidentalis. Mobile County, July 14, 1890 (Atkinson); Dekalb County, July, 1896 (Underwood \& Earle).

Puccinia violae (Schum.) DC.

Ala. Bull.217. Cornell Bull.17.

On Viola sp. Lee County, Auburn, January 23, 1890 (Atkinson); July 22, 1890

(Atkinson); November 9, 1891 (Atkinson).

On Viola blanda. Winston County, June, 1896 (Underwood).

Nebraska. Europe.

Puccinia virgata Ell. \& Ev.

On Panicum virgatum. Lee County, January, 1897 (Earle \& Baker).

It is probable that some of the specimens on this host material cited in Alabama Bulletin, page 214, and Cornell Bulletin, page 17, under $P$. emaculata belong here.

'See note under P.asteris. ${ }^{2}$ See also Lagerheim, Uredin. Herb. I'ries. 
Puccinia windsoriae Schw.

Ala. Bull. 214. Cornell Bull. 17. In both as P. emaculata.

On Sieglingia seslerioides. Loe County, Auburn, Oetober 7, 1891 (Atkinson); September 30, 1891 (Newman).

Puccinia xanthii.Schw.

Ala. Bull. 217. Cornell Bull.17.

On Xanthium canadense. Perry Courty, 1891 (Newman); Macon County, August, 1896 (Carver).

On leaves of Xanthium strumarium. Lee County, Auburn, Angust, 1890 (Atkinson); October, November, 1895 (Underwood).

Louisiana, Ohio, New Jersey, Nebraska.

Puccinia xanthii ambrosiae Berk. \& Rav.

Cornell Bull. 17.

On leaves of Ambrosia trifida. Moutgomery County, Pikeroad, July 9, 1891 (Atkin8on); Montgomery County, Hope Hull, August, 1891 (Atkinson).

GYMNOCONIA Lagerh.

Gymnoconia hyptidis (Curt.) Lagerh. Uredo hyptidis Curt.

Lagerheim, Uredin. Herb. Fries.

On Mesosphaerum rugosum (Hyptis radiata). Specimens in the herbarium of Fries communicated by M. A. Curtis.

Gymnoconia interstitialis (Schlecht.) Lagerh.

Ala. Bull. 211, as Caeoma nitens Schw. Cornell Bull. 18, as Puccinia pekiana.

On leaves of Rubus trivialis. Lee County, Auburn (Atkinson); Mobile County, 1891

(Zimmer).

On Rubus argutus (R. villosus). Lee County, 1891 (Atkinson).

On Rubus sp. Lee County, April, 1896 (Underwood \& Earle).

PHRAGMIDIUM Link.

Phragmidium obtusum (Str.) Schum. \& Kunze.

Ala. Bull.213, as P. fragariastri (DC.) Schw. Cornell Bull.17.

On Duchesnea indica. Uredo stage: Mobile County, April, July, 1891 (Atkinson);

Lee County, February, April, 1896 (Underwood \& Earle); Tuscaloosa County, May,

1896 ( Underwood).

Teleutospores not seen.

New Jersey. Europe.

Phragmidium rubi-idaei (Pers.) Wint.

Ala. Bull. 213.

On Rubus cuneifolius. Lee County, July, 1896 (Underwood \& Earle).

Europe.

Phragmidium speciosum Fr.

Ala. Bull. 218, as Uredo miniata.

On Rosa humilis. Lee County, May, 1897 (Earle \& Baker). 'Telentospores on the stems; uredospores on the leaves.

New Jersey, Ohio, Nebraska.

Uredo alabamensis Dietel.

UREDO Lév.

Cornell Bull. 22.

On Chrysopogon avenaceus. Lee County, Auburn, October, 1891 (Dugyar).

Uredo azaleae Schw.

Ala. Bull. 218. Cornell Bull.22.

On Azalea nudiflora. Lee County, Auburn, November 9, 1891 (Benton).

Uredo fici Cast.

Ala. Bull.218. Cornell Bull. 22.

On Ficus carica. Mobile County (Atkinson); Lee County Auburn (Atkinson); Perry

County, Uniontown (Atkinson).

Louisiana.

Uredo muhlenbergiae Dietel.

Cornell Bull. 22.

On leaves of Muhlenbergia diffusa. Lee County, Auburn, August 31, 1890 (Atkinson). 
Uredo muelleri Schroet.

Cornell Bull. 22.

On leaves of Rubus argutus (R. villosus). Lee County, Auburn, autumn (Atkinson).

Uredo quercus Brond.

Ala. Bull.219. Cornell Bull. 22.

On leaves of Quercus alba. Lee County, Auburn, September 13, 1891 (Atkinson).

On leaves of Quercus minor. Lee County, Auburn, October 3, 1891 (Atkinson).

On leaves of Quercus nigra (Q. aquatica). Lee County, Auburn, November 5, 1891

(Duggar).

On leaves of Quercus sp. Lee County, Auburn, October 25, 1891 (Atkinson).

\section{PERIDERMIUM Chev.}

Peridermium cerebrum Peck.

Ala. Bull.213. Cornell Bull.22.

On Pinus taeda. Lee County, April, 1896 (Underwood \& Earle).

On Pinus echinata. Lee County, 1896 (Underwood \& Earle).

On Pinus virginiana. Winston County, June, 1896 (Underwood).

New Jersey.

Peridermium orientale Cooke.

Ala. Bull. 213. Cornell Bull.22.

On leaves of Pinus serotina. Lee County, Auburn, spring, 1891 (Atkinson).

On Pinus taeda. Lee County, April, 1896 (Underwood \& Earle).

On Pinus palustris. Lee County, April, 1896 (Underwood \& Earle).

On Pinus sp. Macon County, April, 1896 (Underwood); Dekalb County, May, 1896

(Underwood).

Aecidium asterum Schw.

\section{AECIDIUM Pers.}

Ala. Bull. 208. Cornell Bull.21.

On Aster sp. Dekalb Count;, May, 1896 (Underwood).

On Solidago canudensis. Lee County, 1892 (Inggar).

On Solidago sp. Lee Connty, 1891 (Newman \& Duggar); Dallas County, May, 1896

(Underwood); Dekalb County, May 1896 (Underwood).

Ohio, Nebraska.

Aecidium compositarum Mart.

Ala. Bull. 208.

On Eupatorium purpureum. Dekalb Connty, May, 1896 (Underwood).

On Eupatorium verbenaefolium. Dekalb Connty, May, 1896 (Underwood).

On Helianthus sp. Madison County, May, 1896 (Cnderwood).

On Silphium sp. Lee County, May, 1896 (Underwood \& Earle).

Louisiana, Ohio, New Jersey, Nebraska.

Aecidium epilobii DC.

Ala. Bull.209. Cornell Bull.21.

On Oenothera laciniata. Lee County, Auburn, April, May, 1892 (Atkinson).

Ohio. Europe.

Aecidium euphorbiae Gmel.

Ala. Bull. 209. Cornell Bull. 21.

On leaves of Euphorbia nutans. Lee County, Auburu, Novenber 11, 1891 (Atkinson).

Ohio, New Jersey, Nebraska. Europe.

Aecidium fraxini Schw.

On Fraxinus sp. Lee County, June, 1897 (Earle of Baker).

Aecidium gerardiae Peck.

Ala. Bull. 209.

On Dasystoma flava. Madison County, May, 1896 (Underwood).

Aecidium gnaphaliatum Sehw.

Ala. Bull. 209.

On Gnaphalium purpureum. Lee County, July, 1896 (Underwood \& Earle).

Aecidium hibisciatum Schw.

Ala. Bull. 209.'

On Hibiscus esculentus (Peters).

'See also Lagerheim, Uredin. Herb. Fries. 
Aecidium houstoniatum Schw. (\$)

Ala. Bull. 209, as A. oldenlandianum Ell. \& Tracy. Cornell Bull.21.

On leaves of Houstonia patens. Lee County, Auburn, February 16, 1890 (Atkinson). The specific position of these specimens is uncertain. They differ widely from the tropical $A$. houstoniatum, but they are certainly not $A$.oldenlandianum, which is on a very different host (Earle).

Aecidium hydnoideum B.\& C.

Rav. Fung. Car. Exsic. 4:94. Ala. Bull. 209.'

On Dirca palustris (Peters). Winston County, June, 1896 (Underwood).

Ohio.

Aecidium hypericorum B. \& C.

Ala. Bull. 209.

On Hypericum sp. ( Peters). A doubtfal species.

Aecidium impatientis Schw.

Ala. Bull. 209. Cornell Bull. 21.

On Impatiens aurea. Lee County, April, 1896 (Underwood \& Earle) ; Dekalb County, May, 1896 (Underwood).

On leaves of Impatiens biflora. Lee County, Auburn, April 22, 1890 (Atkinson); Lee

County, Parkinson's Mill near Auburn, spring, 1890 (Atkinson).

Ohio, Nebraska.

Aecidium leucostictum B. \& C.

Ala. Bull. 209.

On various species of Lespedeza. Dekalb County, May, 1896 (Underwood) ; Madison

County, May, 1896 (Underwood).

Aecidium lycopi Gerård.

Ala. Bull. 209.

On Lycopus virginicus. Lee County, May, 1892 (Duggar).

Aecidium mariae-wilsoni Peck.

Peters coll. No. 196, as Aecidium petersii B. \& C. Ala. Bull. 209.

On Viola papilionacea ( $V$. obliqua). Lee County, April, 1896 (Underwood \& Earle).

This is probably the true $A$. petersii; see note under that species. Our Aecidia on species of Viola are greatly in need of revision.

New York.

Aecidium orobi B. \& C.

Ala. Bull. 209.

A doubtful species. On Meibomia sp. (Peters).

Aecidium pentstemonis Schw.

Ala. Bull. 210.

On Pentstemon hirsutus. Lee County, May, 1896 (Underwood \& Earle).

Nebraska.

Aecidium petersii B. \& C.

Ala. Bull. 210.2

On Viola sp. (Peters).

The redescription of this species by Lagerheim and the specimens preserved in the Peters collection under this name (see Ala. Bull.209) both go to show thai it is the species commonly called $A$. mariae-wilsoni Peck by American authors. The specimens on Viola pedata, Alabama Bulletin 210, can not therefore belong here. They should probably be considered as the type of a new species.

\section{Aecidium plantaginis Ces.}

Ala. Bull.210. Cornell Bull. 21.

On Plantago virginica. Lee County, March, 1896 (Underwood \& Earle). Only once found.

Aecidium proserpinacae B. \& C.

Grevillea, 3: 60. Ala. Bull. 210.

On leaves of Proserpinaca sp. (Beaumont).

See Lagerheim, Uredin. Herb. Fries. 102.

${ }^{2}$ See also Lagerheim, Uredin. Herb. Fries. 
Aecidium pteleae B. \& C.

Grevillea, 3:60. Ala. Bull. 210. Cornell Bull.21.

On leaves of Ptelea sp. (Peters).

On leares of Ptelea trifoliata. Lee County, Wright's Mill near Auburn, July 8, 1891

(Duggar \& Nenoman).

Aecidium punctatum Pers.

Ala. Bull. 210.

On Anemone decapetala. Lee County, April, 1896 (Underwood \& Earle).

Ohio, Nebraska. Europe.

Aecidium sambuci Schw.

Ala. Bull.211. Cornell Bull.21.

On Sambucus canadensis (Peters). Lee County, Auburn, April, 1892 (Atkinson); Lee County, March, 1894 (Quaintance).

Ohio, Nebraska.

Aecidium saniculae Carm.

Ala. Bull. 211.

On Sanicula sp. Lee County, March, April, 1896 (Underwood \& Earle).

\section{Order AURICULARIALES.}

\section{Family AURICULARIACEAE.}

\section{AURICULARIA Bull.}

Auricularia auricula-judae (L.) Schroet.

Peters coll. 8. Ala. Bull. 220, under Hirneola.

1864 (Peter8).

On Hicoria sp. Lee County, March, 1896 (Underwood \& Earle).

Texas, New Jersey, Ohio, Nebraska. Europe.

Auricularia auriformis Schw.

Cornell Bull. 24, under Hirneola.

On decaying branches. Lee County, Auburn (Atkinson).

Ohio.

It is very doubtful if this is really different from the last species.

Auricularia scutelliformis B. \& C.

Grevillea, 2: 19. Ala. Bull. 220, under Hirneola.

On branches of Asimina (Peters).

\section{Family PILACRACEAE.}

\section{PILACRE Fr.}

Pilacre faginea (Fr.) B. \& Br.

Peters coll. 1 : 195, under Onegyna. Ala. Bull. 222.

Pllacre petersii B. \& C.

Rav. Fung. Car. Exsic. 3 : 39. Ala. Bull. 222.

On Ilex opaca (Peters).

On Carpinus. 1865 (Peters).

Europe.

\section{Order TREMELLALES.}

\section{Family TREMELLACEAE. ${ }^{1}$}

Exidia glandulosa (Bull.) Fr.

EXIDIA Fr.

Ala. Bull. 221.

On Alnus sp. Lee Connty, February, 1896 (Underwood \& Earle).

On Quercus sp. Lee County, March, 1896 (Underwood \& Earle).

On Liquidambar. Lee County, March, 1896 (Underwood \& Earle).

South Carolina, New Jersey, Ohio, New England. Europe.

${ }_{1}^{1}$ These determinations are tentative only. The American species of jelly fungi are greatly in need of critical study. 
Exidia truncata Fr.

Ala. Bull. 221; partly (p. 222) as Ulocolla foliacea (Pers.) Bref.: Cornell Bull. 24. On Vitis rotundifolia. Lee County, June 3, 1892 (Atkinson); February, 1896 (Underwood \& Earle).

On Alnus sp. . Lee County, February, 1896 (Underwood \& Earle).

On Quercus sp. Lee County, March, 1896 (Underwood \& Earle).

Pennsylvania, Ohio. Europe.

\section{TREMELLA Dill.}

Tremella dependens B. \& C.

Grevillea, 2 : 19. Ala. Bull. 221.

On Liriodendron (Peters).

Tremella encephala Willd.

Grevillea, 2:20. Ala. Bull. 221. In both under Naematelia.

On Quercus (Peters).

New Jersey, New England.

Tremella gigantea $\mathrm{B}$. \& C.

Grevillea, $2: 19 . \quad$ Ala. Bull. 221.

(Peters.)

Tremella mesenterica Retz.

Ala. Bull. 221. Cornell Bull. 24.

On decaying wood. Lee County, Auburn, antumn, 1891 (Atkinson).

On Alnus sp. Lee County, December, 1895 (Underwood); February, 1896 (Underwood \& Earle).

North Carolina, Ohio. Europe.

Tremella nucleata Schw.

Rav. Fung. Car. Exsic. 4:82. Ala. Bull. 221, under Naematelia.

On Tilia americana (Peters).

South Carolina, New Jersey, Ohio.

Tremella virens Schw.

Cornell Bull. 24.

On decaying oak branches. Lee County, Auburn, autumn, 1891 (Atkinson).

Tremella sp.

Peters coll. No. 96. Ala. Bull. 221.

On rotten wood of Hicoria alba (Peters).

TREMELLODON.

Tremellodon gelatinosum (Scop.) Pers.

Peters coll. No. 62, under Hydnum. Ala. Bnll. 222.

On Pinus sp. Leo County, March, 1896 (Underwood \& Earle).

Europe.

\section{Order DACRYOMYCETALES.}

\section{Family DACRYOMYCETACEAE.}

\section{DACRYOMYCES Nees.}

\section{Dacryomyces aurantia (Schw.) Farlow.}

Cornell Bull. 24.

On dead wood. Lee County, Auburn, 1890 (Atkinson).

South Carolina.

Dacryomyces azaleae Schw.

Cornell Bull. 24.

On dead branches. Lee Connty, Auburn, 1890 (Atkinson).

Dacryomyces chrysocomus (Bull.) Tul.

Ala. Bull. 222.

On rotten wood of Pinus sp. Lee County, January, February, 1896 (Underwood \&

Earle).

Ohio. Europe. 
Dacryomyces deliquescens (Bull.) Dub.

Ala. Bull. 222.

On rotten wood of Pinus sp. Lee County, March, 1896 (Underuood \& Earle).

Louisiana, South Carolina, New Jersey, Ohio.

Dacryomyces epiphyllus Schw.

Cornell Bull. 24.

On leaves of Arundinaria tecta. Lee County, Auburn, November 3, 1891 (Atkinson).

Dacryomyces stillatus Nees.

Ala. Bull. 222.

On rotten pine, and on other wood. Lee County, February, 1896 (Underwosd \&. Earle).

South Carolina, New Jersey, Ohio, New England. Europe.

\section{GUEPINIA Fr.}

Guepinia elegans B. \& C.

Rav. Fung. Car. Exsic. 5 : 23. Ala. Bull. 222.

(Peters.)

Guepinia petaliformis B. \& C.

Grevillea, 2:5. Ala. Bull. 222.

On dead wood (Peters).

Guepinia spathularia (Schw.) Fr.

Ala. Bull.223. Cornell Bull.24.

Lee County, Auburn, 1890 (Atkinson).

On Pinus. Lee County: December, 1896 (Earle).

On varions woods. Lee County, November, December, 1895 ( Undervood) ; July, 1896

(Underwood of Earle).

Texas, Lonisiana, Ohio, New Jersey.

\section{ARRHYTIDIA Berk.}

Arrhytidia flava B. \& C.

Ala. Bull. 222.

On rotten wood of Pinus. Lee County, February, 1896 (Underwood \& Earle).

Arrhytidia fulva B. \& C.

Peters coll. Ala. Bull. 222.

On rotten wood of Pinus (Peters). Lee County, January, 1896 (Underwood \& Earle).

\section{Order EXOBASIDIALES.}

\section{Family EXOBASIDIACEAE.}

\section{EXOBASIDIUM Woron.}

Exobasidium andromedae Peck.

Ala. Bull. 227.

On Xolisma ligustrina. Lee County, May, 1896 (Underwood \& Earle).

New Jersey.

Exobasidium azaleae Peck.

Ala. Bull. 227.

On calyces of Azalea nudiflora. Lee County, 1892 (Benton); April, 1896 (Underwood \& Earle).

Exobasidium discoideum Ellis.

Ala. Bull. 227.

On leaves of Azalea nudiflora. Lee County, April, May, 1896 (Lnderwood \&. Earle);

Winston County, June, 1896 (Underwood).

New Jersey.

Exobasidium vaccinii (Fkl.) Woron.

Ala. Bull. 227.

On flowers of Gaylussacia frondosa. Lee County, May, 1896 (Cnderwood \& Earle). On leaves of Vaccinium. Lee County, April, 1896 (Underwood \& Earle).

Now Jersey, Ohio. Europe. 


\section{MICROSTROMA Niessl.}

Microstroma juglandis (Berenger) Sacc.

Ala. Bull.138. Cornell Bull. 38.

On Hiving leaves of Hicoria alba. Lee County, Auburn, April 28, 1890 (Atkinson);

Perry County, Uniontown, July 12, 1890 (Atkinson).

\section{Order HYMENIALES (Agaricales).}

\section{Family HYPOCHNACEAE.}

HYPOCHNUS Ehrenb.

Hypochnus anthochrous (Pers.) Fr.

Ala. Bull. 228.

(Peters.)

\section{Family THELEPHORACEAE.}

\section{CORTICIUM Pers.}

Corticium armeniacum Sacc.

Ala. Bull. 223.

On Vitis (Peters, Beaumont).

Corticium caeruleum (Schrad.) Fr.

Ala. Bull. 223.

Lee County, November, 1895 (Underwood); January, 1896 (Underwood \& Earle).

South Carolina, Ohio. Europe.

Corticium calceum (Pers.) Fr.

Ala. Bull. 223.

On Pinus. Lee County, January, 1896 (Underwood \& Earle).

Lonisiana, Texas, Pennsylvania. Europe.

Corticium cervicolor B. \& C.

Grevillea, 1:179. Ala. Bull.223.

On smooth wood (Peters).

Corticium chlorinum B. \& C.

Grevillea, 1:179. Ala. Bull.223.

On Tsuga (Peters).

Corticium chrysocreas B. \& C.

Grevillea, 1:178. Ala. Bull. 224.

On Pinus (Peters).

Corticium cremoricolor B. \& C.

Grevillea, $1: 180$. Ala. Bull. 224.

On Ilex (Peters).

Corticium crocicreas B.\& C.

Grevillea, 1:178. Ala. Bull. 224.

On Vitis (Peters).

Corticium deglubens B. \& C.

Grevillea, 1:166. Ala. Bull. 224.

On Juniperus (Peters).

Corticium diminuens B. \& C.

Rav. Fung. Car. Exsic. 3:31. Grevillea, 2:3. Ala. Bull.224.

On Ostrya virginiana (Peters).

Corticium dryinum B. \& C.

Grevillea, 1:179. Ala. Bull. 225.

On Quercus (Peters).

Corticium ephebium B. \& C.

Grevillea, 1:178. Peters coll. No.80. Ala. Bull.225.

(Peters.) 
Corticium evolvens Fr.

Grevillea, 1 : 166. Ala. Bull. 225.

On Liquidambar (Peters).

New England.

Corticium filamentosum B. \& C.

Grevillea, 1:178. Ala. Bull. 225.

(Peter8.)

Ohio.

Corticium lactescens Berk.

Ala. Bull. 225. Cornell Bull. 28.

On Alnus rugosa. Lee County, Auburn, November 2, 1891 (Duggar).

Corticium laeve Pers.

Ala. Bull. 225.

On Liquidambar (Peters).

Louisiana, South Carolina, New Jersey, Nebraska.

Corticium martianum B. \& C.

Rav. Fung. Car. Exsic. $5: 30$. Ala. Bull. 225.

On Betula (Peters).

Corticium miniatum Berk. Not Cooke.

Peters coll. No. 85. Ala. Bull. 225.

On Liquidambar (Peters).

Corticium oakesii B. \& C.

Rav. Fung. Car. Exsic. 3 : 32 . Ala. Bull. 226.

On Ostrya virginiana (Peters). Lee County, January, February, 1896 (Underwood \& Earle).

New England, New York.

Corticium ochroleucum erimosum Berk.

Grevillea, 1: 166 . Ala. Bull. 226.

On Sassafras sassafras (Peters).

Louisiana, South Carolina.

Corticium petersii B. \& C.

Rav. Fung. Car. Exsic. $5: 28$. Grevillea, 1:177. Ala. Bull. 226.

On the ground (Peters).

Winston County, June, 1896 (Underwood).

Corticium polyporoideum B. \& C.

Grevillea, 1: 177. Peters coll. No.84. Ala. Bull. 226.

September, 1863 (Peters).

Corticium prasinum B. \& C.

Rav. Fung. Car. Exsic. 5:29. Grevillea, 1:179. Peters coll. Ala. Bull.228.

On the ground. September, 1864 (Peters).

Corticium radiosum $\mathrm{Fr}$.

Ala. Bull. 227.

Lee County, 1891 (Duggar).

Corticium scutellare B. \& C.

Grevillea, $2: 4 . \quad$ Ala. Bull. 227.

On oak (Peters).

Corticium siparium B. \& C.

Grevillea, 1:177. Ala. Bull. 227.

On Liquidambar (Peters).

Corticium viticolum Schw.

Rav. Fung. Car. Exsic. 3:34. Ala. Bull. 227.

On Vitis aestivalis (Peters).

South Carolina. 
CONIOPHORA DC.

Coniophora umbrina (A.\& S.) Fr. Peters coll. No. 70. Ala. Bull. 223. (Peters.)

South Carolina, Ohio.

\section{STEREUM Pers.}

Stereum albo-badium (Schw.) Fr.

Ala. Bull. 230. Cornell Bull. 28.

On dead oak branches. Lee County, Auburn, February 22, 1891 (Atkinson).

On varions twigs and branches. Lee County, December, 1895 (Underwood); Jan-

uary, February, 1896 (Underwood \& Earle). Common.

Louisiana, South Carolina, Ohio.

Stereum bicolor (Pers.) Fr.

Ala. Bull. 230. Cornell Bull. 28.

On stumps. Lee County, October, 1895 (Underwood); Fobruary, March, 1896

(Cnderwood \& Earle). Winston County, June, 1896 (Underwood).

Louisiana, Ohio. Europe.

Stereum candidum (Schw.) Fr.

Ala. Bull. 230.

Forming small patches on bark of large oaks. Lee County, December, 1895

(Underwood).

Ohio.

Stereum complicatum Fr.

On Carpinus. Lee County, January, 1897 (Earle \& Baker).

On Hicoria. Lee County, January, 1897 (Earle \& Baker).

Louisiana, Ohio.

Stereum fasciatum (Pers.) Fr.

Ala. Bull. 230.

On old logs. Lee County, November, 1895 (Underwood) ; March, 1896 (Underwood \&

Earle); December, 1896 (Earle).

Ohio.

Stereum frustulosum (Schw.) Fr.

Ala. Bull. 230.

On Quercus. Lee County, November, December, 1895 (Underwood); March, July, 1896 (Underwood \& Earle).

New Jersey, Ohio, Nebraska.

Stereum gausapatum Fr.

Ala. Bull. 230.

(Peter8.)

Stereum leveillianum B. \& C.

Ala. Bull.230. Cornell Bull. 28.

On dead branches of hickory. Lee County, February 22, 1891 (Atkinson).

Lee County, Auburn, November, 1895 (Underwood).

South Carolina.

Stereum nivosum Rav.

Ala. Bull. 230.

On Juniperus. Lee County, November, 1895 (Underwood); March, 1896 (Underwood

\& Earle). Common.

New Jersey.

Stereum ochro-flavum Schw.

On Quercus. Lee County, January, 1897 (Earle \& Baker).

Ohio.

Stereum pergameneum B. \& C.

Grevillea, 1:161. Ala. Bull. 230.

On decayed wood (Peters). 


\section{Stereum radians $\mathrm{Fr}$.}

Ala. Bull. 231.

On twigs. Lee County, November, December, 1895; January, 1896 (Underwood \& Earle).

Ohio.

Stereum ravenelii B. \& C.

Grevillea, 1:162. Ala. Bull.231.

On the earth in swamps (Peters, Beaumont).

Stereum sericeum (Schw.) Morgan.

Ala. Bull. 231.

On twigs. Mobile County, December, 1895. Lee County, December, 1895 (Underwood); January, 1896 (Underwood \& Eurle). Not common.

Ohio.

\section{Stereum spadiceum Fr.}

Base of old stumps. Lee County, Januars, 1897 (Earle \& Baker).

Louisiana, New Jersey, Ohio. Europe.

Stereum subpileatum B. \& C.

Ala. Bull. 231.

Lee County, November, 1895 (Underwood); April, 1896 (Underwood \& Earle); Winston County, June, 1896 (Underwood).

Louisiana.

Stereum versicolor (Schw.) Fr.

Ala. Bull. 231. Cornell Bull. 28.

On dead branches. Lee County, February 22, 1891 (Atkinson); November, 1895 (Underwood). Mobile County, December 1895 (Earle). Winston County, June, 1896

(Underwood). Common everywhere.

Ohio, New Jersey, Nebraska.

\section{THELEPHORA Ehrh.}

Thelephora botryoides (Schw.) Underwood \& Earle.

Ala. Bull. 232.

(Peters.)

Thelephora candida (Schw.) Fr.

Cornell Bull.28.

Macon County, Shorter, July 16, 1890 (Atkinson).

Thelephora filamentosa B. \& C.

Grevillea 1:148. Ala. Bull. 231.

On decayed herbs (Peters).

Ohio.

Thelephora gracilis Peck, Bull. Torr. Club, 25 :371. 1898.

Damp ground. Lee County, July, 1897 (Earle \& Baker).

Thelephora griseo-zonata Cooke.

Ala. Bull. 232.

On the ground. Lee County, December, 1895 (Underwood); October, 1896 (Earle). New Jersey.

Thelephora laciniata Pers.

Cornell Bull. 28.

In sandy places in turpentine orchards. Lee County, Auburn, antumn, 1889 (Atkinson); July 27, 1890 (Atkinson).

Europe.

Thelephora lobata Bertol.

Mem. Acad. Sci. Bol. 7 :360. Ala. Bull. 232.

Mobile County? (Gates).

Thelephora pedicellata Schw.

Ala. Bull. 233.

On Cornus (Peters).

On living shrubs (Crataegus, etc.). Lee County, November, 1895 (Underwood);

February, 1896 (Underwood \& Earle). 
Thelephora retiformis B.\& C.

On living brenches of Prunus. Lee County, January, 1897 (Earle \& Baker).

Thelephora schweinitzii Peck.

Peters coll. Ala. Bull. 233. Cornell Bull. 28.

On the ground (Peters). Lee County, Auburn, autumn, 1890 (Atkinson); October,

1895 (Underwood). Winston County, June, 1896 (Underwood).

Ohio.

Thelephora scoparia Pèk.

On the ground and on roots of grass. Lee County, June, 1897 (Earle \& Baker).

Thelephora sebacea Pers.

Peters coll., as Thelephora micheneri B. \& C. Ala. Bull. 233.

On leaves of Viola, etc. (Peters).

Incrusting various leaves and stems. Lee County, July, 1896 (Underwood \& Earle). New. Jersey, Ohio, New England. Europe.

Thelephora terrestris Ehrh.

Ala. Bull. 233.

Lee County, July, 1896 (Underwood \& Earle).

New Jersey. Europe.

\section{HYMENOCHAETE Lév.}

Hymenochaete agglutinans Ellis.

Ala. Bull. 229.

On living twigs. Lee County, February, 1896 (Underwood \& Earle).

New Jersey.

Hymenochaete corrugata (Fr.) Lév.

Rav. Fung. Car. Exsic. $5: 26 . \quad \Lambda$ la. Bull. 229.

(Peter8.)

Lee County, January, February, 1896 ( Cnderwood \&. Earle).

South Carolina, Pennsylvania, Ohio. Europe.

Hymenochaete curtisii (Berk.).

Ala. Bull. 230, under Stereum.

(Peters.)

On Quercus (Earle \& Baker).

South Carolina.

Hymenochaete epichlora (B: \& C.) Cooke.

Grevillea, 1:178, under Corticium. Rav. Fung. Car. Exsic. 5:24, under Corti-

cium. Ala. Bull. 229.

On Vaccinium (Peters).

On Symplocos (Peters).

Hymenochaete purpurea Cooke \& Morgan.

Ala. Bull. 230. Cornell Bull. 28.

On dead branches. Lee County, Auburn, February 22, 1891 (Atkinson); Novem-

ber, 1895 (Underwood).

Obio.

Hymenochaete setosa B. \& C.

Grevillea, 1:165. Ala. Bull. 230 .

On Quercus (Peters).

\section{CRATERELUUS Pers。}

Craterellus cantharellus (Schw.) Fr.

Grevillea, 1:147, as C. lateritius Berk. Ala. Bull. 228. Cornell Bull. 28.

On the ground (Peters). Lee County, Auburn, July, 1890 (Atkinson); July, 1896

(Underwood \& Earle). Winston County, June, 1896 (Underwood).

Ohio.

Craterellus cornucopioides (L.) Pers.

Ala. Bull. 229.

On the ground. Lee Connty, July, 1896 (Underwood \& Earle).

North Carolina, Sonth Carolina, Ohio. Europe. 
CyPhella Fr.

Cyphella fulva B. \& Rav.

Ala. Bull. 229.

On Alnus. Lee County, January, February, 1896 (Underwood \& Earle). New Jersey, Maine.

Cyphella furcata B. \& C.

Grevillea, 2:5. Ala. Bull. 229.

On Alnus (Beaumont).

SOLENIA Hoffm.

Solenia anomala (Pers.) Fr.

Ala. Bull. 247.

On Alnus. Lee County, January, May, 1896 (Underwood \& Earle). Europe.

Solenia villosa Fr.

Rav. Fung. Car. Exsic. 5:42. Ala. Bull. 247.

On Quercus (Peters).

Europe.

\section{Family CLAVARIACEAE.}

CLAVARIA Vaill.

Clavaria aurea Schaeff.

Ala. Bull. 228.

Lee County, October, 1896 (Earle).

New Jersey, Ohio. Europe.

Clavaria botrytis Pers.

Ala. Bull. 228.

Lee County, October, 1896 (Earle).

South Carolina, New Jersey, New England, Ohio. Europe.

Clavaria falcata Pers.

Ala. Bull. 228.

(Peter8.)

Clavaria fragilis Holms.

On the ground. Tallapoosa County, August, 1897 (Earle).

South Carolina. Earope.

Clavaria gracilis Pers.

Rav. Fung. Car. Exsic. 5 : 34. Ala. Bull. 228.

(Peter8.)

Europe.

Clavaria longicaulis Peck, Bull. Torr. Club, 25 : 371.1898

Moist earth. Lee County, July, 1897 (Earle of Baker).

Clavaria pulchra Peck.

Cornell Bull. 28.

On the ground. Lee County, Auburn, 1890 (Duggar).

Clavaria petersii B. \& C.

Rav. Fung. Car. Exsic. 5:33. Grevillea, 2:7. Ala. Bull. 228.

On dead wood (Peters).

Clavaria pistillaris $\mathrm{L}$.

Ala. Bull. 228.

On the ground. Lee County, November, 1896 (Earle).

Ohio.

Clavaria pyxdata Pers.

On rotten logs. Lee County, July, 1897 (Earle \& Baker).

Ohio. 
SPARASSIS Fr.

Sparassis crispa (Wulf.) Fr.

Peters coll. No.91. Ala. Bull.228.

Lawrence County (Peters). Lee County, December, 1896 (Earle).

Sparassis herbstii Peck.

Ala. Bull. 228.

On the ground. Lee County, July, 1896 (Underwood \& Earle).

\section{Family HYDNACEAE.}

ODONTIA Fr.

Odortia fimbriata B. \& C.

Peters coll. No.67. Ala. Bull. 236.

Lawrence County (Peters).

New Jersey, Ohio. Europe.

Odontia lateritia B. \& C.

Rav. Fung. Car. Exsic. 5:22. Grevillea, 1:147. Ala. Bull.236.

On Quercus (Peters).

PHLEBIA Fr.

\section{Phlebia radiata Fr.}

Petors coll. No. 66. Ala. Bull.237.

On Liriodendron. 1863 (Peter8).

Ohio. Europe.

Phlebia zonata B. \& C.

Peters coll. Ala. Bull. 237.

On Tilia. July, 1855 (Peters).

\section{RADULUM Fr.}

Radulum orbiculare Fr.

Ala. Bull. 237.

On dead wood. Lee County, December, 1895 (Underwood).

South Carolina, New Jersey, Penusylvania. Europe.

Radulum spinulosum B. \& C.

Grevillea, 1:146. Ala. Bull. 237.

(Peter8.)

NEOKNEIFFIA Sacc.

Neokneiffia aspera (Pers.).

Rav. Fung. Car. Exsic. $5: 31$. Ala. Bull. 236, under Kneiffiella.

On Juniperus virginiana (Peters).

Neokneiffia candidissima (B. \& C.).

Rav. Fung. Car. Exsic. 5 : $32 . \quad$ Ala. Bull.236, as Kneiffiella.

On Juniperus virginiana (Peters).

South Carolina, New Jersey, Ohio.

HYDNUM Fr.

Hydnum adustum Schw.

Ala. Bull. 233. Cornell Bull. 28.

Macon Connty, Shorter, July, 1890 (Atkinson); Lee County, 1891 (Atkinson); Winston County, June, 1896 (Underwood).

New Jersey, Ohio.

Hydnum chrysocomum Underwood.

Ala. Bull. 233.

Under decayed wood. Lee County, November, 1895 (Underwood). 
Hydnum cirrhatum Pers.

Ala. Bull. 233.

On Quercus (Beaumont).

South Carolina, Ohio. Europe.

Hydnum curtisii Berk.

Lee County, November, 1896 (Baker).

Hydnum erinaceus Bull.

Peters coll. No.60. Ala. Bull. 234.

On Quercus. 1863 (Peters).

On old log. Lee County, November, 1896 (Miss J. Skehan).

Ohio.

Hydnum fascicularia B. \& C.

Grevillea, 1:99. Ala. Bull. 234.

On Hicoria (Peters).

Hydnum flabelliforme Berk.

Ala. Bull. 234.

On standing trunks. Lee County, January, 1896 (Underwood \& Earle). Ohio.

Hydnum fragilissimum B. \& C.

Rav. Fung. Car. Exsic. 5 : 21. Ala. Bull. 234.

(Peters.)

Hydnum himantia Schw.

Peters coll. No. 56. Ala. Bull.234.

(Peters.)

Hydnum laeticolor B. \& C.

Grevillea, 1:99. Ala. Bull. 234.

On Quercus (Beaumont).

South Carolina.

Hydnum membranaceum Bull.

Rav. Fung. Car. Exsic. 5:20. Ala. Bull. 235.

(Peters.)

Europe.

Hydnum mucidum Pers.

Ala. Bull. 235.

On Hicoria (Peters).

On logs. Lee County, October, December, 1895 (Underwood); January, February,

1896 (Underwood \&. Earle).

Ohio. Europe.

Hydnum ochraceum Pers.

Ala. Bull. 235.

On logs. Lee County, Octuber, December, 1895 (Underwood); January, February, 1896 (Underwood \& Earle).

Ohio, New Jersey, Nebraska. Europe.

Hydnum pallidum C. \& E.

On Salix. Lee Connty, November, 1897 (Earle).

Hydnum parasitans B. \& C.

Grevillea, 1:100. Ala. Bull. 235.

On Ulmus americana (Peters).

Hyanum pulcherrimum B. \& C.

Ala. Bull. 235. Cornell Bull. 28.

Lee County, summer, 1890 (Atkinson); October, December, 1895 (Undernood): Hale

County, April, 1896 (Underwood). Winston County, June, 1896 (Cndervood). South Carolina, Obio.

Hydnum reniforme B. \& C.

Cornell Bull. 22.

Lee County, Auburn (Atkinson). 
Hydnum repandum L.

Peters coll. No. 61 . Ala. Bull. 235.

On the ground (Peters). Lee County, January, 1896 (Underwood \& Earle); November, December, 1896 (Earle).

South Carolina, Ohio, New Jersey, New England. Europe.

Hydnum rhois Schw. (?).

On Quercus. Lee County, January, 1897 (Earle \& Baker).

Hydnum septentrionale Fr.

Ala. Bull. 235.

On Tilia (Peters).

Ohio. Europe.

Hydnum setulosum B. \& C.

Peters coll. No. 59. Grevillea, 1:100. Ala. Bull. 235.

On Liquirlambar (Peters).

Hydnum spathulatum (Schw.) Fr.

Ala. Bull. 235.

On decaying wood. Lee County, November. 1895 (Underwood); January, 1896 (Underwood \& Earle).

Hydnum spongiosipes Peck.

Peters coll. No. 57, as H.ferrugineum (१). Ala. Bull. 235.

(Peters.)

PHAEODON Schroet.

Phaeodon atroviride (Morgan).

Journ. Cincinnati Soc. Nat. Hist. 18:38. Ala. Bull. 233. Cornell Bull.28. In all under Hydnum.

On old wood. Lee County, Auburn, 1890 (Atkinson).

Phaeodon aurantiacus (Batsch) Schroet.

Lee County, September, 1897 (Earle \& Baker).

Europe.

Phaeodon compactus (Pers.) Schroet.

Ala. Bull. 234, under Hydnum.

On the ground. Mobile County, December, 1895 (Earle).

Europe.

Phaeodon ferrugineus (Fr.) Schroet.

Ala. Bull. 234, under Hydnum.

Lee County, 1891 (Atkinson); November, 1896 (Earle).

South Carolina, Ohio, Pennsylvania, New Jersey.

Phaeodon imbricatus (L.) Schroet.

Ala. Bull. 234, under Hydnum.

In pine woods. Lee County, December, 1895 (Underwood); March, 1896 (E. F. Lee);

July, 1896 (Underwood \& Earle); December, 1896 (Earle). Rather conmnon. Europe.

Phaeodon subsquamosus (Batsch) Schroet.

Peters coll. No.55. Ala. Bull. 235, under Hydnum.

On the ground. 1864 (Peters).

Europe.

Phaeodon tomentosus (Schrad.) Schroet.

Ala. Bull. 233, as Caldesiella ferruginosa (Fr.) Sacc.

(Beaumont.) Lee County, May, 1896 (Underwood \& Earle).

Europe.

Phaeodon zonatus (Batsch).

Ala. Bull. 236, under $\mathrm{Hydnum}$.

Lee Connty, July, 1896 ( Inderwood \& Earle).

New Jersey, Ohio. Europe. 


\section{IRPEX Fr.}

Irpex coriaceus B. \& Rav.

Rav. Fung. Car. Exsic. $3: 21$. Ala. Bull. 236.

On Quercus. (Peter8.) Lee County, November, 1895 (Underwood).

South Carolina. Cuba, South America.

Irpex fuscescens Schw.

On Quercus. Lee County, November, 1895 (Underwood); .January, February, 1896 (Underwood \& Earle). Not uncommon.

Irpex schweinitzii B.\& C.

Grevillea, 1:102. Ala. Bull. 236.

(Beaumont.)

SISTOTREMA Pers.

Sistotrema confluens Pers.

On the ground among pine needles. Lee County, January, 1897 (Earle \& Baker).

\section{Family POLYPORACEAE.}

\section{Tribe MERULIEAE.}

\section{MERULIUS Hall.}

Merulius bellus B. \& C.

Grevillea, 1:69. Peters coll. No.52. Ala. Bull.238.

On Tsuga. 1858 (Peter8).

Merulius confluens Schw.

Cornell Bull. 28.

On dead branches. Lee County, Auburn, December, 1891 (Atkinson).

Merulius corium Fr.

Peters coll. Ala. Bull. 238.

1855 (Peter8).

Lee County, January, February, March, July, 1896 (Underwood \& Earle); December, 1896 (Earle). Common.

South Carolina, North Carolina, New England. Europe.

Merulius haedinus B.\& C.

Rav. Fung. Car. Exsic. 4:8. Grevillea, 1:69. Ala. Bull. 238.

On Tilia (Peters).

Merulius porinoides Fr.

Ala. Bull. 239.

On Quercus (Peters).

South Carolina, Ohio. Europe.

Merulius serpens Tode.

Ala. Bull. 239.

On Pinus. Lee County, January, 1896 (Underwood \& Earle).

Europe.

Merulius tremellosus Schrad.

Ala. Bull. 239.

Lee Connty, December, 1895 (Underwood); January, 1896 (Underwood \& Earle);

November, December, 1896 (Earle).

Louisiana, South Carolina, New Jersey, Ohio. Europe.

\section{Tribe POLYPOREAE.}

PORIA Pers.

Poria alabamae B.\& C.

Cornell Bull. 28.

On dead branches. Lee County, Auburn, 1890 (Atkinson). 
Poria barbaeformis B. \& C.

Grevillea, 1:53. Ala. Bull. 240, under Polyporus.

On Vitis. (Peter8.) Lee County, December, 1895 (Underwood); January, 1896 (Underwood \& Earle).

Poria beaumontii B. \& C.

Ala. Bull. 240, under Polyporus.

(Beaumont.)

Poria callosa Fr.

On rotten wood. Lee County, November, 1897 (Earle).

Poria chrysoloma Fr.

Ala. Bull. 240, under Polyporus.

On pine chips. Lee County, January, 1896 (Undervood \& Earle).

Poria corticola Fr.

Ala. Bull. 241, under Polyporus.

On bark. Lee County, December, 1895 (Underwood).

Ohio. Europe.

Poria ferruginosa Schrad.

Ala. Bull. 242, under Polyporus.

On fallen limbs. Lee County, December, 1895 (Underwood); January, 1896 ( Cnderwood \& Earle).

Ohio. Europe.

Poria pulchella Schw.

Peters coll. Ala. Bull.245, under Polyporus.

1855 (Peter8).

Poria purpurea Fr.

Ala. Bull. 245, under Polyporus.

On rotten wood. Lee County, February, 1896 (Underwood \& Earle).

Louisiana, New Jersey, Ohio. Europe.

Poria vaporaria Pers.

Ala. Bull.245, under Polyporus.

On various dead branches. Lee County, November, December, 1895 (Underwood); January, 1896 (Underwood \& Earle). Very common.

Poria vesiculosa B.\& C.

Peters coll. No. 39. Grevillea, 1:65. Ala. Bull. 247, under Polyporus.

On Pinus (Peters).

Poria viticola Schw.

Peters coll. No. 38. Ala. Bull. 247, under Polyporus.

On Vitis (Peters).

FOMES Fr.

\section{Fomes annosus Fr.}

Cornell Bull. 27.

On roots of rotten stumps. Lee County, Auburn, 1890 (Atkinson).

Europe.

Fomes applanatus (Pers.) Wallr.

Ala. Bull. 239, under Polyporus.

(Atkinson.) Rare in the State.

New Jersey, Ohio, Nebraska. Europe.

Fomes carneus Nees.

Rav. Fung. Car. Exsic. 5 : 14. Ala. Bull. 240, under Polyporus. Cornell Bull.27.

On Juniperus. Winston County (Peters).

On dead trunk. Lee County, Auburn (Atkinson).

Louisiana, South Carolina, New Jersey, New York.

Fomes connatus Fr. (?)

Ala. Bull. 240, under Polyporus.

On Gleditsia triacanthos. Lee County, February, 1896 (Underwood \& Earle).

Ohio. Europe. 
Fomes curtisii Berk.

Ala. Bull. 241, under Polyporus. Cornell Bull. 27.

On dead stump. Lee County, A uburn, 1890 (Atkinson).

On Quercus, etc. Lee County, October, November, December, 1895 (Underwood); June, July, 1896 (Underwood \& Earle).

Louisiana, New Jersey.

Fomes hemileucus B. \& C.

Ala. Bull. 243, under Polyporus.

On Liriodendron. Lee County, December, 1895 (Underwood); March, 1896 (Underwood \& Earle). Mobile County, December, 1895 (Earle).

Fomes lucidus (Leys.) Fr.

Ala. Bull. 244, under Polyporus.

On Tsuga. Winston County, June, 1896 (Underwood).

New Jersey, Ohio. Europe.

Fomes obliquus (Pers.) Fr.

Ala. Ball.244, under Polyporus.

Lee County, December, 1895 (Underwood); January, February, 1896 (Underwood of Earle).

Louisiana, Ohio. Europe.

Fomes reniformis Morgan.

Ala. Bull. 245, nnder Polyporns. Cornell Bull.27.

On dead trunk. Lee County, Auburn, 1890 (Atkinson).

Lee County, March, 1896 (Undervood \& Earle); Winston County, June, 1896 (Underwood).

Fomes rimosus Berk.

Ala. Bull. 246, under Polyporus.

On Robinia pseudacacia. 'Madison County, May, 1896 (Underwood); Dekalb County, May, 1896 (Underwood).

(Atkin8on.)

Fomes scutellatus Schw.

Ala. Bull. 246, under Polyporus.

On branches of Alnus. Jannary, 1896 (Underwood \& Earle).

Fomes supinus Schw.

Ala. Bull. 247, under Polyporus.

On Prunus angustifolia. Lee County, November, 1895 (Underwood); March, 1896 (Underwood \& Earle). Not uncommon.

\section{POLYPORUS Michx.}

Polyporus acanthoides (Bull.) Fr.

Peters coll. No. 35. Ala. Bull. 239.

Lawrence County (Peters).

Polyporus adustus (Willd) Fr.

Ala. Bull. 239. Cornell Bull. 27.

On dead trunk. Lee County, Auburn, 1890 (Atkinson).

On various trunks. Lee County, November, December, 1895 (Underwood); March, 1896 (Underwood \& Earle).

On Hicoria. Lee County, December, 1896 (Earle).

Polyporus aneirinus Sommf.

Peters coll. Ala. Bull. 239.

On Juglans. February, 1855 (Peter8).

New Jersey. Europe.

Polyporus arcularius (Batsch) Fr.

Ala. Bull. 239. Cornell Bull. 27.

On dead branches. Lee County, Auburn, 1890 (Atkinson).

On various fallen branches. Lee County, March, May, July, 1896 (Underwood \&.

Earle); Tuscaloosa County, May, 1896 (Underwood); Madison County, May, 1896

(Undericood).

Louisiana, New Jersey, Ohio. Europe. 
Polyporus delicatus B. \& C.

Grevillea, 1:37. Ala. Bull. 241.

(Peters.)

Polyporus dibaphus B. \& C.

Grevillea, 1:36. Ala. Bull. 241.

On Ilex opaca (Peters).

\section{Polyporus dichrous Fr.}

Cornell Bull. 27.

On dead branches. Lee County, Auburn (Atkinson).

Ohio. Europe.

Polyporus distortus Schw.

Lee County, 1897 (Earle of Baker).

Ohio.

Polyporus earlii Underwood, Bull. Torr. Club, 24 : 84. 1897.

Ala. Bull. 242.

On the ground. Lee County, November, 1896 (Earle).

Polyporus elegans (Bull.) Fr.

Ala. Bull. 242.

On fallen branches. Lee County, February, 1896 (Underwood \& Earle); Hale

County, May, 1896 (Underwood).

Ohio. Europe.

Polyporus ellisii Cooke.

Ala. Bull. 242, as Polyporus flavo-squamosus Underwood.

On clayey ground. Lee County, Auburn, November 23, 1896 (Mrs. F. S. Earle).

Polyporus endocrocinus Berk.

Ala. Bull. 242.

Hale County, May, 1896 (Underwood); Lee County, October, 1896 (Baker).

Polyporus flavovirens B. \& Rav.

Ala. Bull. 243.

On clayey banks in woods. Lee County, July, 1896 (Underwood \&. Earle).

Ohio, New England.

Polyporus gilvus Schw.

Ala. Bull. 243. Cornell Bull. 27.

On trunks and logs. Lee Count5, Auburn (Atkinson); November, December, 1895

(Underwood); March, 1896 (Underwood \& Earle); December, 1896 (Earle). Hale

County, May, 1896 (Underwood); Winston County, June, 1896 (Underwood). Common.

Polyporus hispidioides Peck.

Cornell Bull. 27.

In pine woods at base of trunks. Lee County, Auburn, August, 1890 (Atkinson)

Polyporus imbricatus (Bull.) Fr.

Cornell Bull. 27.

Lee County, Auburn, 1890 (Atkinson).

Europe.

Polyporus isidioides Berk. (?)

Ala. Bull. 243.

On trunks and branches. Lee County, December, 1895 (Underiood); January, March, 1896 (Underwood \& Earle). Hale County, May, 1896 (Underwood). Winston County, June, 1896 (Underwood).

Polyporus irregularis Underwoorl, Bull. Torr. Club, 24:85. 1897.

Ala. Bull. 243.

Under a pine log. Lee County, Auburn, February, 1896 (Underwood).

Polyporus marmoratus B \& C.

Ala. Bull.245, as Polyporus plebeius Berk.

On Prunus serotina. Lee County, April, May, 1896 (Underwood \& Earle).

On Magnolia. Mobile County, December (Earle).

Louisiana.

$15894-14$ 
Polyporus meliae Underwood, Bull. Torr. Club, 24 : 85. 1897.

Ala. Bull. 244.

On branches of Melia azedarach. Lee County, October 15, 1895 (Underwood,

Polyporus obtusus Berk.

Ala. Bull. 244.

On Quercus texana. Lee County, November, 1895 (Underwood). Rare.

New Jersey.

Polyporus picipes Morgan.

Ala. Bull. 245.

(Atkinson.)

New Jersey, Ohio.

Polyporus poripes Fr.

Ala. Bull 245.

Lee County, November, 1895 (Underwood).

New Jersey.

Polyporus retipes Underwood, Bull. Torr. Club, 24:85. 1897 Ala. Bull. 245.

In pine woods. Lee County, Auburn, December, 1896 (Mr8. F. S. Earle).

Polyporus resinosus (Schw.) Fr.

Ala. Bull. 246.

On a fallen trunk. Lee County, March, 1896 (Underwood \& Earle).

Ohio. Europe.

Polyporus schweinitzii Fr.

Ala. Bull. 246.

On the ground. Lee County, October, 1896 (Burton); November, December, 1896

(Earle).

South Carolina, New Jersey.

Polyporus sulphureus (Bull.) Fr.

Ala. Bull. 247.

Winston County, June, 1896 (Underwood).

(Atkinson.)

Louisiana, Ohio, New Jersey. Europe.

Polyporus varius Fr.

Cornell Bull. 27.

On roots of tree stump. Macon County, Shorter, July 16, 1890 (Atkinson).

Ohio. Europe.

Polyporus xanthus Fr.

Ala. Bull. 247.

On oak (Peters).

South Carolina, New Jersey.

POLYSTICTUS Fr. (Polyporus, Ala. Bull.).

Polystictus abietinus Fr.

Ala. Bull. 239.

On Pinus. Lee County, November, December, 1895 (Underwood); January, 1896

(Underwood \& Earle). Common.

Louisiana, Now Jersey, Nebraska. Europe.

Polystictus barbatulus Fr.

Ala. Bull. 239. Cornell Bull. 27.

On branches of Pinus palustris. Lee County, Auburn, February 22, 1891 (Atkinson);

Lee County, November, 1895 (Underwood).

Polystictus biformis Klotzscb.

Ala. Bull. 240. Cornell Bull.27.

(Beaumont.)

On dead trunks. Lee County, Auburn (Atkinson).

Polystictus cervinus Schw.

Ala. Bull. 240. 
Polystictus cinnabarinus (Jacq.) Fr.

Ala. Bull. 240. Cornell Bull. 27.

On dead trunks. Lee County, Auburn, 1890 (Atkinson).

On Prunus. Lee County, 1895; Winston County, June, 1896 (Underwood); Lee County, November, 1896 (Earle).

Polys cus crocatus Fr.

Cornell Bull. 27.

On trunks. Macon County, Shorter, July 16, 1890 (Atkinson).

South Carolina.

Polystictus dealbatus B. \& C.

Peters coll. No. 40. Rav. Fung. Car. Exsic. 3:10. Ala. Bull. 241.

July, September, 1864 (Peters, Beaumont).

Polystictus hirsutus (Wulf.) Fr.

Ala. Bull. 243. Cornell Bull. 27.

On dead branches. Lee County, Auburn, February 22, 1891 (Atkinson).

On trunks and branches. Lee County, December, 1895 (Underwood); March, April, 1896 (Underwood \& Earle). Mobile County, December, 1895 (Earle); March, 1896 (Earle). Hale County, May, 1896 (Underwood); Winston County, June, 1896 (Underwood). Very common.

Louisiana, Ohio, New Jersey. Europe.

Polystictus ilicincola B. \& C.

Rav. Fung. Car. Exsic. 5 : 17. Grevillea, 1:52, under Polyporus. Ala. Bull. 243.

On Ilex opaca (Peters).

Polystictus occidentalis (Fr.) Klotzsch.

Ala. Bull. 245.

(Beauniont.)

Polystictus molliusculus Berk.

On old stumps. Lee County, January, 1897 (Earle \& Baker).

Ohio.

Polystictus mutabilis B. \& C.

On oak stumps. Lee County, January, 1897 (Earle \&f Baker).

Lonisiana, South Carolina.

Polystictus parvulus Klotzsch.

Ala. Bull. 245.

Lee County, July, 1896 (Underwood \& Earle).

New Jersey, Ohio.

Polystictus pergamenus Fr.

Ala. Bull.245. Cornell Bull. 27.

On dead branches. Lee County, Auburn, 1890 (Atkinson).

On various trunks of deciduous trees. Lee County, October, December, 1895 (Underwood); January, February, 1896 (Underwood \& Earle); December, 1896 (Earle). Mobile County, December, 1895 (Earle). Winston County, June, 1896 (Underwood).

Polystictus perennis (L.) Fr.

Ala. Bull. 245.

Lee County, July, 1896 (Underwood \& Earle).

Europe.

Polystictus sanguineus (L.) Morgan.

Ala. Bull. 246.

On fallen trunks. Lee County, November, December, 1895 (Underwood); January, 1896 (Underwood \& Earle). Tuscaloosa County, May, 1896 (Underwood); Winston County, June, 1896 (Underwood).

Polystictus splendens Peck.

Peters coll. No. 37, as Polyporus perennis. Ala. Bull. 246.

August, 1864 (Peters). Lee County, July, 1896 (Underwood \& Earle).

Polystictus velutinus Fr.

Ala. Bull. 247.

Lee County, October, December, 1895 (Underwood); January, June, July, 1896

(Underwood \& Earle). Winston County, June, 1896 (Underwood).

Louisiana, New Jersey, Ohio. Éurope. 
Polystictus versicolor (L.) Fr.

Ala. Bull. 247.

On various deciūuous trees. Lee County, October, November, December, 1895 (Underwood); March, 1896 (Underwood \& Earle). Winston County, June, December, 1896 (Underwood).

Polystictus virgineus Schw.

Rav. Fung. Car. Exsic. 3 : 11. Ala. Bull. 247.

(Peters.)

Ohio.

TRAMETES Fr.

Trametes lactea Fr.

Peters coll. No. 41. Ala. Bull. 248.

Northern Alabama (Peters).

Louisiana, New Jersey.

Trametes petersii B. \& C.

Grevillea, 1:66. Ala. Bull. 248.

(Peters.)

Trametes rigida B. \& Mont.

Ala. Bull. 248.

(Beaumont.) Lee County, November, 1895 (Underwood).

Louisiana, South Carolina.

Trametes sepium Berk.

Ala. Bull. 248.

On Sassafras sassafras (Peters, Beaumont).

Lee County, November, 1895 (Underwood); January, July, 1896 (Underwood \& Earle). Louisiana, South Carolina, North Carolina, Connecticut.

daedalea Pers.

Daedalea ambigua Berk.

Ala. Bull. 237.

On Quercus. Lee County, April, 1896 (Underwood \& Earle).

Louisiana. Ohio.

Daedalea confragosa (Bolt.) Pers.

Ala. Ball. 237.

On Salix. Lee County, December, 1895 (Underwood); February, March, 1896

(Underwood \& Earle); October 1896 (Baker); November, 1896 (Earle).

New Jersey, Ohio. Europe.

Daedalea confragosa lenzitoides Peck.

Cornell Bull. 27.

On dead branches. Lee County, Auburn, 1890 (Atkinson).

Daedalea glaberrima B. \& C.

Ala. Bull. 237.

Lee County, December, 1895 (Underwood).

South Carolina.

Daedalea unicolor (Bull.) Fr.

Peters coll. No. 44, as D. cinerea. Ala. Bull.237.

(Beaumont.)

New Jersey, Ohio. Europe.

LENZITES Fr.

Lenzites berkelei Lév.

Ala. Ball. 238. Cornell Bull. 26.

(Beaumont.) Lee County; Auburn (Atkinson).

South Carolina.

Lenzites betulina (L.) Fr.

Ala. Bull. 238. Cornell Bull. 26.

On dead trnnks. Lee County, A uburn, February 22, 1891 (Atkinson).

Lee County, Octoler, December, 1895 (Underwood); November, 1896 (Earle).

Louisiana, Now Jersey, Ohio. Europe. 
Lenzites cookei Berk.

Cornell Bull. 26.

Lee County, Auburn, autumn, 1890 (Atkinson).

Lenzites corrugata Klotzsch.

Ala. Bull. 237.

Lee County, January, 1896 (Underwood \& Earle).

Louisiana, New Jersey, New England.

Lenzites crataegi Berk.

Ala. Bull. 238.

(Peters.)

South Carolina, North Carolina, Ohio, Pennsylvania, New Jersey.

Lenzites klotzschii Berk.

Ala. Bull. 238.

On Liquidambar. Lee County, October, November, December, 1895 (Inderwood);

January, 1896 ( Cnderwood \& Earle). Very common.

South Carolina, North Carolina, New England.

Lenzites repanda Fr.

Ala. Bull. 238.

(Peters.)

Lenzites rhabarbarina B. \& C.

Ala. Bull. 238.

On Pinus. Lee County, October, 1895 (Underwood); January, 1896 (Cnderwood \& Earle).

South Carolina.

Lenzites sepiaria Fr.

Ala. Bull. 238.

On Pinus. Lee County, January, 1896 (Undervood \& Earle). Hale County, May, 1896 (Underwood).

Louisiana, New Jersey, Ohio. Europe.

\section{GLOEOPORUS Mont.}

\section{Gloeoporus conchoides Mont.}

Peters coll. as Polyporus nigropurpurascens. Ala. Bull. 237.

(Peters.) Lee County, November, December, 1895 (Underwood) ; January, July, 1896 (Underwood \& Earle). Mobile County, December, 1895 (Earle). Hale Connty, May, 1896 (Underwood). Common.

West Indies, South America, South Africa.

FAvOLUS Fr.

Favolus alveolarius (DC.) Fairm.

Peters coll. No. 48. Ala. Bull. 237.

On Fagus. Lawrence County, 1863 (Peters).

Lee County, March, 1896 (Underwood \& Earle).

Europe.

Favolus rhipidium (Berk.) Fr.

Ala. Bull. 246, under Polyporus.

Etowah County, May, 1896 (Undervood). Rare.

Favolus tesselatus Mont.

Cornell Bull. 27.

On dead branches of Acer. Lee Connty, Auburn, 1891 (Atkinson).

\section{Tribe FISTULINEAE.}

\section{POROTHELIUM Fr.}

Porothelium fimbriatum (Pers.) Fr.

Peters coll. No. 52. Ala. Bull. 247.

On Betula. Winston County, 1861 (Peters).

Ohio. Europe. 
FISTULINA Bnll.

Fistulina pallida B. \& Rav.

Grevillea, 1:71. Ala. Bull. 252.

On base of white oak stump. Northern Alabama (Peters).

South Carolina.

Fistulina radicata Schw.

Peters coll. No. 24. Ala. Bull. 252.

At roots of old chestnut stump. Northern Alabama, September, 1868 (Peters).

Fistulina spathulata B. \& C.

Grevillea, 1: 71. Ala. Bull. 252.

At the base of an oak. Winston County (Peters).

\section{Tribe BOLETINEAE.}

\section{BOLETUS L.}

Boletus albus Pock.

Cornell Bull. 26.

Lee County, Auburn, August, 1890 (Atkinson).

Boletus affinis Peck.

Cornell Bull. 27.

Lee County, Auburn, summer, 1890 (Atkinson).

Boletus auriporus Peck.

Ala. Bull. 248.

Lee County, July, 1896 (Underwood \& Earle).

Ohio.

Boletus brevipes Peck.

Ala. Bull. 248. Cornell Bull. 27.

On sandy soil, under pines. Lee County, Auburn, December 20, 1891 (Atkinson).

Lee County, November, 1895 (Underwood); October, November, 1896 (Baker).

Boletus chromapes Frost.

Ala. Bull. 248.

Lee County, May, 1896 (Underwood \& Earle).

Northern States ( () .

Boletus chrysenteron Fr.

Cornell Bull. 27.

In open woods, on the ground. Lee County, Auburn, summer, 1890 (Atkinson).

Ohio. Europe.

Boletus edulis Bull.

Ala. Bull. 248. Cornell Bull. 26.

Woods, on the ground. Lee County, Auburn, Angust, 1890 (Atkinson); July, 1896

(Underwood \& Earle).

New Jersey, Ohio. Enrope.

Boletus felleus Bull.

Ala. Bull. 248.

Lee County, July, 1896 (Underwood \& Earle); October, 1896 (Earle).

New Jersey, Ohio. Europe.

Boletus ferrugineus Frost, var.

Ala. Bull. 248.

Lee County, July, 1896 (Underwood \& Earle).

Boletus fistulosus Peck, Bull. Torr. Club, 24 : 144. 1897.

Ala. Bull. 249.

Grassy woods. Lee County, Auburn, July, 1896 (Underwood).

Boletus fraternus Peck, Bull. Torr. Club, 24 : 145. 1897.

Ala. Bull. 249.

Shaded streets. Lee County, Auburn, July, 1896 (Underwood \& Earle). 
Boletus frustulosus Peck, Bull. Torr. Club, 24 : 146. 1897.

Ala. Bull. 250.

On clayey banks along roadsides. Hale County, Akron, July, 1896 (Underwood).

Boletus gracilis laevipes Peck.

Open woods. Lee County, July, 1897 (Earle).

Ohio.

Boletus granulatus $\mathrm{L}$.

Ala. Bull. 250. Cornell Bull. 27.

Pine woods, on the ground. Lee County, Auburn, July, 1890 (Atkinson); October, 1896 (Earle).

New Jersey. Europe.

Boletus griseus Frost.

Ala. Bull. 250. Cornell Bull. 26.

Lee County, Auburn, summer, 1890 (Atkinson); July, 1896 (Underwood \& Earle).

Boletus hemichrysus B. \& C.

Cornell Bull. 26.

Open woods, at base of a stump. Lee County, Auburn, July, 1890 (Atkinson.

South Carolina.

Boletus hirtellus Peck.

Ala. Bull. 250.

Pine woods. Lee County, October, 1896 (Earle).

Boletus leptocephalus Peck.

Dry open woods. Lee County, July, 1897 (Earle \& Baker).

Boletus morgani Peck.

Ala. Bull. 250.

Lee County, October, 1896 (Baker).

Boletus ornatipes B. \& C.

Ala. Bull. 250.

I.ee County, July, 1896 (Underwood \& Earle).

Boletus pallidus Frost.

Ala. Bull. 250. Cornell Bull. 27.

Woods, on the ground. Lee County, Auburn, July, 1890 (Atkinson); October, 1896 (Earle).

Boletus parvus Frost.

Ala. Bull. 250.

Lee County, July, 1896 (Underwood \& Earle).

Boletus retipes B. \& C.

Ala. Bull. 251.

Lee County, July, 1896 (Underwood \& Earle).

South Carolina.

Boletus rubinellus Peck.

Cornell Bull. 26.

Woorls, on ground. Lee County, Auburn, August, 1890 (Atkinson).

Boletus russellii Frost.

Cornell Bull. 26.

Woods, on ground. Lee County, Auburn, summer, 1890 (Atkinson).

Boletus tabacinus Peck, Bull. Torr. Club, 23:418. 1896.

Ala. Bull. 251.

Along roadsides. Lee County, May, 1896 (Underwood \& Earle).

Boletus underwoodii Peck, Bull. Torr. Club, 24 : 145. 1897.

Ala. Bull. 251.

Lee County, Auburn, July, 1896 (Underwood \& Earle). 


\section{BOLETINUS Kalchbrenner.' (BOLETOPsis Hennings.)}

Boletinus decipiens B. \& C.

Ala. Bull. 248.

Lee County, October, December, 1896 (Baker).

Boletinus pictus Peck.

Lee County, Auburn, June, 1897 (Earle \& Baker).

Boletinus ravenelii (B.\& C.)

Ala. Bull. 251, under Boletus.

Leo County, July, 1896 (Underwood \& Earle).

South Carolina.

Boletinus subluteus (Peck).

Ala. Bull. 251. Cornell Bull.26. In both under Boletus.

Lee County, Auburn, July, 1890 (Atkinson); October, November, 1896 (Earle).

\section{STROBILOMYCES Berk.}

Strobilomyces strobilaceus (Scop.) Berk.

Peters coll. No. 33. Ala. Bull. 252.

Lawreuce County (Peters). Lee County, July, 1896 (Underwood \& Earle).

Now Jersey. Europe.

\section{Family AGARICACEAE. ${ }^{2}$}

\section{Tribe CANTHARELLEAE.}

\section{CANTHARELLUS Lóv.}

\section{Cantharellus cantharellus (L.).}

Ala. Bull. 256. Cornell Bull. 25, as C. cibarius Fr.

Lee Connty, Auburu, Angust, 1890 (Atkinson); Winston County, June, 1896 (Underwood); Lee County, July, 1896 (Underwood \& Earle).

Ohio, New Jersey. Europe.

Edible; cummonly known as chantarelle.

Cantharellus cinnabarinus Schw.

Ala. Bull. 256.

Lee County, July, 1896 (Cndervood \& Earle)

New Jersey.

Cantharellus floccosus Schw.

Ala. Bull. 256.

Winston County, June, 1896 (Underwood).

Cantharellus infundibuliformis (Scop.) Fr.

Ala. Bull. 256. Cornell Bull. 25.

Lee County, Auburn, August, 1890 (Atkinson). Pileus very much lobed and irregular.

Winston Connty, June, 1896 (Underwood).

New Jersey. Europe.

Cantharellus petersii B. \& C.

Rav. Fung. Car. Exsic. 5:12. Ala. Bull. 256. Cornell Bull. 25.

On base of trees. Northern Alabama (Peters).

Lee County, Auburn, July, 1890 (Atkinson).

${ }^{1}$ Hennings has proposed the name Boletopsis for those species of Boletinae having an annulus (Engler \& Prantl, Pflauzenfam. 1 Teil, Abt. $1^{* *}: 194.1898$ ), but as noted by Underwood (Bull. Torr. Club, $25: 630$ ) the older name of Boletinus must be retained if the species belonging to it are to be included in the new grouping.

${ }^{2}$ Hennings's treatment of the Agaricaceae in the Natuerlichen Pflanzenfamilien does not seem to meet the full approval of American mycologists. It seems best, therefore, for the purposes of this catalogue to follow the generic names used by Saccardo in the Sylloge Fungorum rather than to make the many new binomial combinations that would be necessary if Hennings's treatment of the family were to be fully adopted.-F. S. Earle. 


\section{Tribe COPRINEAE.}

\section{COPRINUS Pers.}

Coprinus atramentarius (Bull.) Fr.

Ala. Bull. 258. Cornell Bull. 25.

Lee County, Auburn, autumn, 1890 (Atkinson); Lee County, March, 1896 (Underwood \& Earle).

New Jersey, Ohio. Europe.

\section{Coprinus comatus Fr.}

Ala. Bull. 258.

Lee County, April, 1896 (Underwood \& Earle). Edible.

New Jersey, Ohio. Europe.

Coprinus plicatilis (Curt.) Fr.

Peters coll. No. 13, as C. picaceus. Cornell Bull. 25.

Northern Alabama (Peters).

Coprinus sterquilinus Fr. (?).

Lee County, May, 1897 (Mrs. F. S. Earle).

Europe.

Coprinus virgineus Banning?

Lee County, June, 1897 (Baker).

\section{Tribe HYGROPHOREAE.}

GOMPHIDIUS Fr.

Gomphidius gracilis Berk. (?).

Lee County, November, 1896 (Baker).

Gomphidius rhodoxanthus Schw.

Ala. Bull. 259.

Lee County, July, 1896 (Underwood \& Earle); October, December, 1896 (Earle).

New Jersey.

\section{HYGROPHORUS Fr.}

Hygrophorus cantharellus Schw.

Cornell Bull. 24.

Lee County, Auburn, summer, 1890 (Atkinson).

Hygrophorus conicus (Scop.) Fr.

Peters coll. No. 12. Ala. Bull. 259.

Northern Alabama, October, 1864 (Peters).

New Jersey. Europe.

Hygrophorus nitidus B. \& Rav.

Lee County, April, 1897 (Mrs. F. S. Earle).

Hygrophorus olivaceo-albus Fr. (\$).

Lee County, December, 1897 (Earle).

Enrope.

NYCTALIS Fr.

Nyctalis asterophora Fr.

Peters coll. Ala. Bull. 262.

Parasitic on Lactarius. Northern Alabama, 1863 (Peters).

New Jersey. Europe.

Tribe LACTARIEAE.

LACTARIUS Pers.

Lactarius affinis Peck.

Cornell Bull. 26.

On the ground. Lee County, Auburn, October 19, 1890 (Atkinson). 
Lactarius chelidonium Peck.

Ala. Bull. 260.

Lee County, July, 1896 (Underwood \& Earle); October, November, 1896 (Earle).

Lactarius corrugis Peck.

Lee County, September, 1897 (Earle).

Lactarius deceptivus Peck.

Ala. Bull. 260.

Lee County, July, 1896 (Underwood \& Earle).

Lactarius deliciosus (L.) Fr.

Cornell Bull. 25.

On the ground in open woods. Lee County, Auburn, October 19, 1890 (Atkinson). New Jersey, Ohio. Europe.

\section{Iactarius fuliginosus Fr.}

Cornell Bull. 26.

Lee County, Auburn (Atkinson).

Europe.

Lactarius indigo (Schw.) Fr.

Ala. Bull. 260. Cornell Bull. 26.

On the ground in damp woods near stream. Lee County, Anburn, August, 1890 (Atkinson).

Lee County, July, 1896 (Underwood \& Earle); November, 1896 (Farle).

New Jersey.

\section{Lactarius insulsus Fr.}

Ala. Bull. 260. Cornell Bull. 25.

On the ground. Lee County, Auburn, summer, 1891 (Atkinson).

Lee County, July, 1896 (Underwood \& Earle); October, 1896 (Earle).

Europe.

Lactarius lignyotus Fr.

Cornell Bull. 26.

Lee County, Auburn (Atkinson).

Europe.

Lactarius pergamenus (Sw.) Fr.

Cornell Bull. 26.

In woods on the ground. Lee County, Auburn, August, 1890 (Atkinson).

Ohio. Europe.

Lactarius piperatus (Scop.) Fr.

Ala. Bull.260. Cornell Bull. 26.

In woods on the ground. Lee County, Auburn, Jnly, 1890 (Atkinson).

Hale County, May, 1896 (Underwood). Winston County, June, 1896 (Underwood).

Lee County, July, 1896 (Underwood \& Earle); October, November, 1896 (Earle).

New Jersey, Ohio. Europe.

Lactarius salmoneus Peck, Bull. Torr. Club, 25 : 369. 1898.

Lee County, July, 1897 (Earle \& Baker).

Lactarius scrobiculatus (Scop.) Fr.

Ala. Bull. 260.

Lee County, October, November, 1896 (Earle).

Europe.

Lactarius subdulcis Bull.

Ala. Bull. 260.

Lee County, July, 1896 (Underwood \& Earle).

New Jersey. Europe.

Lactarius subvellereus Peck, Bull. Torr. Club, 25 : 369. 1898.

Lee County, July, 1897 (Earle).

Lactarius theiogalus Bull.

Ala. Bull. 260. Cornell Bull. 25.

On the ground. Lee County, Auburn, July, 1890 (Atkinson).

Lee County, October, November, 1896 (Earle).

New Jersey. Europe. 
Lactarius vellereus Fr.

Ala. Bull. 260.

Lee County, October, November. December, 1896 (Earle).

New Jersey, Ohio. Europe.

Lactarius vellereus subrugosus Peck.

In pine grove. Mobile County, Springhill (Baker).

Lactarius volemus Fr.

Ala. Bull. 260. Cornell Bull. 25.

On ground. Lee County, Auburn (Atkinson).

Winstou County, June, 1896 (Underwood).

Lee County, July, 1896 (Underwood \& Earle).

RUssula Pers.

Russula adusta (Pers.) Fr.

Ala. Bull. 264. Cornell Bull. 26.

Lee County, November, 1896 (Earle).

Europe.

Russula albella Peck.

Ala. Bull. 264.

Lee County, October, November, 1896 (Earle).

Russula albidula Peck, Bull. Torr. Club, 25 : 370. 1898.

In pine woods. Lee County, Auburn, November, 1897 (Earle)

Russula brevipes Peck.

Ala. Bull. 264.

Lee County, December, 1895 (Under wood); October, 1896 (Earle).

Russula chamaeleontina Fr.

Ala. Bull. 264.

Lee County, November, 1896 (Earle).

Europe.

Russula delica. Fr.

Lee County, December, 1896 (Baker).

Europe.

Russula emetica Fr.

Ala. Bull. 264.

Lee County, November, December, 1896 (Earle).

New Jersey. Europe.

Russula foetens (Pers.) Fr.

Ala. Bull. 264. Cornell Bull. 26.

On the ground in woods. Lee County, Auburn, August, 1890 (Atkinson).

Lee County, October, 1896 (Earle).

New Jersey, Ohio. Europe.

Russula fragilis (Pers.) Fr.

Lee County, November, December, 1896 (Baker).

Europe.

Russula lactea (Pers.) Fr.

Lee County, November, December (Baker)

Europe.

Russula lepida Fr.

Ala. Bull. 264.

Lee County, October, 1896 (Earle).

Ohio. Europe.

Russula polyphylla Peck, Bull. Torr. Club, 25 :370. 1898.

Loe County, July, 1897 (Earle \& Baker).

Russula pusilla Peck.

Ala. Bull. 264.

Lee County, December, 1895 (Underwood). 
Russula vellerea Fr.

Lee County, December, 1896 (Baker).

Russula virescens (Schaef.) Fr.

Ala. Bull. 265.

Lee County, July, 1896 (Underwood \& Earle).

New Jersey, Ohio. Europe.

Edible.

\section{Tribe SCHIZOPHYLLEAE.}

\section{SCHIZOPHYLLUM Fr.}

Schizophyllum commune Fr.

Ala. Bull. 265. Cornell Bull. 26.

On standing trunks and branches. Mobile County, December, 1895 (Earle). Lee County, February, June, 1896 (Underwood \& Earle). Winston County, June, 1896 (Underwood).

On diseased timber; common throughout the State.

Louisiana, New Jersey, Ohio. Europe.

\section{Tribe MARASMIEAE.}

\section{XEROTUS Fr.}

Xerotus viticola B. \& C.

Peters coll., as $X$. nigrata. Ala. Bull. 265.

(Peter8.)

South Carolina.

LENTINUS Fr.

Lentinus lecontei Fr.

Ala. Bull. 260. Cornell Bull. 26.

On dead trunks. Lee County, Auburn, February 22, 1891 (Atkinson).

Louisiana, Now Jersey, Ohio.

Lentinus lepideus Fr.

Ala. Bull. 260. Cornell Bull. 26.

In woods. Lee County, Auburn, August, 1890 (Atkinson).

On pine wood. Lee County, May, June, July, 1896 (Underwood \& Earle); October, December; 1896 (Earle).

Lentinus ravenelii B. \& C.

Ala. Bull. 260.

(Beaumont.)

South Carolina.

Lentinus strigosus Fr.

Ala. Bull. 260.

Lee County, February, April, 1896 (Underwood \& Earle); Tuscaloosa County, May, 1896 (Underwood); Winston County, June, 1896. Rather common.

Lentinus tigrinus (Bull) Fr.

Peters coll. Ala. Bull. 260.

Northern Alabama (Peters). Leo County, April, 1896 (Underwood \& Earle).

Ohio. Europe.

Lentinus underwoodii Peck, Bull. Torr. Club, 23:414. 1896.

Ala. Bull. 260.

On Quercus. Macon Connty, July, 1896 (Underwood).

Ientinus ventricosus Peck, Bull. Torr. Club, 23:414. 1896.

Ala. Bull. 261.

On the ground. Lee County, December, 1895 (Undervood); November, 1896 (Earle). This curious species can hardly be a lentinus. The gills are not notched; the flesh is soft and watery, and it has a remarkable thick leathery veil. When these plants are revised, it will doubtless stand as the type for a new genus. 


\section{PANUS Fr.}

Panus dealbatus Fr.

Rav. Fung. Car. Exsic. 5 :9. Ala. Bull. 263.

On Fraxinus (Peters).

Ohio.

Panus dorsalis Bosc.

Cornell Bull. 25.

Summer, 1890 (Atkinson).

New Jersey, Ohio.

Panus laevis B. \& C.

Ala. Bull. 263.

Lee County, October, 1896 (Burton).

Panus nigrifolius Peck, Bull. Torr. Club, 25:370. 1898.

Lee County, July, 1897 (Baker \& Earle).

Panus stipticus (Bull.) Fr.

Ala. Bull. 263. Cornell Bull. 25.

On dead branches. Lee County, Auburn, August, 1890 (Atkinson).

Lee County, November, December, 1895 (Underwood).

Louisiana, New Jersey, Ohio. Europe.

Panus torulosus Fr.

Cornell Bull. 25.

Lee County, Auburn, summer, 1891 (Atkinson).

Europe.

\section{MARASMIUS Fr.}

\section{Marasmius anomalus Peck.}

\section{Cornell Bull. 26.}

Lee County, Auburn, summer, 1890 (Atkinson).

Ohio.

Marasmius atrorubens Berk.

Cornell Bull. 26.

Lee County, Auburn, summer, 1890 (Atkinson).

Marasmius capillaris Morgan.

Cornell Bull. 26.

Lee County, Auburn, July, 1890 (Atkinson).

Ohio.

Marasmius curreyi B. \& R.

Cornell Bull. 26.

On dead blades of Syntherisma sanguinale. Lee County, Auburn, August 3, 1891 (Atkinson).

Marasmius hinnuleus B. \& C. (\$).

Cornell Bull. 26.

Lee County, Auburn, July, 1890 (Atkinson).

Marasmius opacus B. \& C.

Cornell Bull. 26.

Lee County, Auburn (Atkinson).

Marasmius putredinus B. \& C.

On rotting wood. Lee County, Auburn, 1890 (Atkinson).

Marasmius rotula (Scop.) Fr.

Peters coll. Ala. Bull. 262.

Northern Alabama, September, Octoher (Peters). Lee County, May, 1896 (Underwood \& Earle).

Louisiana, New Jersey. Europe.

Marasmius salignus Peck.

Cornell Bull. 26.

Lee County, Auburn, July, 1890 (Atkinson). 
Marasmius semiustus B. \& C.

Cornell Bull. 26.

On decaying grass stems. Lee County, Auburn, July, 1890 (Atkinson).

Lee County, July, 1867 (Earle \& Baker).

Marasmius subnudus (Ellis) Peck.

Lee County, July, 1897 (Earle \& Baker).

Marasmius viticola B. \& C.

Peters coll., under Merulius. Ala. Bull. 262.

Northern Alabama (Peters).

HELIOMYCES LÉv.

Heliomyces decolorans B. \& C.

Rav. Fung. Car. Exsic. 5: 7. Ala. Bull. 259.

On dead wood. Northern Alabama (Peters).

\section{Tribe AGARICINAE.}

PSATHYRELLA Fr.

Psathyrella disseminata Pers.

Cornell Bull. 25.

On the grouud in cultivated fields. Lee County, Auburn, July, 1890 (Atkinson).

New Jersey. Europe.

\section{PANAEOLUS Fr.}

Panaeolus solidipes Peck.

Lee County, Jnly, 1897 (Baker).

Panaeolus sphinctrinus Fr.

Ala. Bull. 263.

On dung. Lee County, March, 1896 (Underwood \& Earle).

Europe.

Panaeolus retirugis Fr.

Lee County, July, 1897 (Baker).

Europe.

PSILOCYBE Fr.

Psilocybe foenisecii Pers.

Ala. Bull. 264.

Lee County, July, 1896 (Underwood \& Earle).

Europe.

Psilocybe subericaea Fr.

Ala. Bull. 264.

Low ground. Lee County, January, 1896 (Underwood \& Earle).

\section{HYPHOLOMA Fr.}

Hypholoma fasciculare Huds.

Cornell Bull. 25.

On the ground. Lee County, Auburn, summer, 1890 (Atkinson).

Ohio. Europe.

Hypholoma modestum Peck. ( 9 )

Ala. Bull. 259.

Lee County, July, 1896 (Underwood \& Earle).

Hypholoma perplexum Peck.

Ala. Bull. 259.

Lee County, November, 1896 (Earle).

Hypholoma sublateritium Schaeff.

Ala. Bull.260. Cornell Bull. 25.

In clusters by side of decaying log. Lee County, Auburn, December, 1890

(Atkinson).

Lee County, December, 1895 (Underwood).

Ohio. Europe. 


\section{CREPIDOTUS Fr.}

Crepidotus applanatus Pers.

Peters coll. No. 8, as Panus fabelliformis. Ala. Bull. 258.

On Hicoria (Peters).

Crepidotus applicatus Peck.

Ala. Bull. 258.

Lee Connty, May, 1896 (Underwood \& Earle).

Crepidotus dorsalis Peck.

Cornell Bull. 25.

Lee County, Auburn, summer, 1890 (Atkinson).

Ohio.

Crepidotus fulvotomentosus Peck.

Ala. Bull. 258.

Lee County, May, 1896 (Underwood \& Earle).

Crepidotus malachius B. \& C.

Lee County, July, 1897 (Earle \& Baker).

Crepidotus versutus Peck.

'Lee County, July, 1897 (Earle \& Baker).

Ohio.

Galera tenera Schaeff.

GALERA Fr.

Peters coll. Ala. Bull. 259.

(Peters.)

New Jersey, Ohio. Europe.

Inocybe vatricosa $\mathrm{Fr}$.

INOCYBE Fr.

Ala. Bull. 260.

On pine chips. Lee County, January, 1896 (Underwood \& Earle).

Cortinarius delibutus Fr.

CORTINARIUS Fr.

Ala. Bull. 258.

Lee County, October, 1896 (Earle).

Europe.

Cortinarius iodes B. \& C.

Ala. Bull. 258.

Lee County, October, November, 1896 (Earle).

Cortinarius porphyropus Fr.

Ala. Bull. 258.

Lee County, November, 1896 (Earle).

Europe.

Cortinarius purpurascens Fr.

Ala. Bull. 258.

Lee County, November, 1896 (Earle).

Europe.

Flammula flavida Pers.

FLAMMULA Fr.

Peters coll. Ala. Bull. 258.

October, 1864 (Peters). Lee County, December, 1896 (Earle).

Flammula sapinea Fr.

Ala. Bull. 258.

Mobile County, June, 1896 (Earle). Lee County, October, 1896 (Earle).

New Jersey, Ohio. Europe.

Flammula underwoodii Peck, Bull. Torr. Club, 23:415. 1896.

Ala. Bull. 258.

On pine trunks. Lee County, November, 1895 (Underwood). 


\section{NAUCORIA Fr.}

Naucoria semiorbicularis Bull.

Ala. Bull. 262.

Lee County, June, July, 1896 (Underwood \& Earle); Mobile County, June, 1896 (Earle).

New Jersey, Ohio.

PHOLIOTA Fr.

Pholiota sabulosa Peck, Bull. 'Torr. Club, 23:414. 1896.

A.la. Bull. 263.

In sandy soil. Lee County, December, 1895 (Underwood).

AGARICUS L.

Agaricus campestris L.

Ala. Bull. 253. Cornell Bull. 25.

In grassy lawns and tields. Lee County, autumn, 1890 (Atkinson); November, 1895

(Underwood); February, March, July, 1896 (Underwood \& Earle).

Cosmopolitan.

The common edible field mushroom.

Agaricus placomyces Peck.

Ala. Bull. 253. Cornell Bull. 25.

In woods. Lee County, Auburu, Juls, 1890 (Atkinson); Lee County, July, 1896 (Underwood \& Earle).

Agaricus silvaticus Schaeff.

Cornell Bull. 25.

In woods. Lee County, Auburn, August, 1890 (Atkinson).

Ohio. Europe.

STROPHARIA Fr.

Stropharia bilamellata Peck.

Ala. Bull. 265.

Lee County, July, 1896 (Underwood \& Earle).

Stropharia melasperma Bull.

Cornell Bull. 25.

Lee County, Auburn, summer, 1890 (Atkinson).

Europe.

CLAUDOPUS Worth. Smith.

Claudopus nidulans Pers.

Ala. Bull. 256.

Lee County, December, 1895 (Underwood); November, December, 1896 (Earle).

Europe.

CLITOPILUS Fr.

Clitopilus abortivus B. \& C.

Ala. Bull. 257.

Lee County, October, 1896 (Earle).

Ohio.

ENTOLOMA Fr.

Entoloma cuspidatum Peck.

Lee County, August, 1897 (Earle).

PLUTEUS Fr.

Pluteus cervinus Schaeff.

Ala. Bull. 264.

Lee County, 1891 (Atkinson); February, May, 1896 (Undemood \& Earle).

Ohio. Europe

Pluteus cervinus albipes Peck.

Lee County, April, 1897 (Baker). 
Pluteus curtisii Berk.

Peters coll. Ala. Bull. 264.

September, October, 1864 (Peters).

\section{PLEUROTUS Fr.}

Pleurotus applicatus Batsch.

Ala. Bull. 264.

On bark. Lee County, November, 1895 (Underwood).

On Vitis. Lee County, November, 1896 (Earle).

New Jersey, Ohio. Europe.

Pleurotus chioneus Pers.

Cornell Bull. 25.

On decaying wood. Summer, 1890 (Atkinson).

Europe.

Small; about $1 \mathrm{~cm}$. in diameter.

Pleurotus niger Fr.

Peters coll., as Agaricus ater. Ala. Bull. 264.

August, 1855 (Peters).

Ohio.

Pleurotus sapidus Kalchb.

Ala. Bull. 264. Cornell Bull. 25.

On dead limbs of trees. Lee County, Auburn, August, 1890 (Atkinson).

On various dead trunks. Mobile County, December, 1895 (Earle). Lee County,

January, 1896 (Underwood \& Earle); November, 1896 (Earle).

Ohio. Europe.

Pleurotus subbarbatus B. \& C.

Cornell Bull. 25.

Lee County, Auburn, July, 1890 (Atkinson).

\section{OMPHALIA Fr.}

Omphalia campanella Batsch.

Lee County, August, 1897 (Earle \& Baker).

New Jersey, Ohio. Europe.

Omphalia eximia Peck.

Lee County, August, 1897 (Earle \& Baker).

Omphalia grisea Fr.

Cornell Bull. 25.

On ditch bank in sandy soil. Lee County, Auburn, 1890 (Atkinson).

Europe.

Omphalia pubescentipes Peck, Bull. Torr. Club, 24:141. 1897.

Ala. Bull. 263.

Lee County, December, 1896 (Earle).

Omphalia subpellucida B.\& C.

Cornell Bull. 25.

Lee County, Auburn, summer, 1890 (Atkinson).

MYCENA Fr.

Mycena epipterygia Scop.

Ala. Bull. 262.

Lee County, December, 1896 (Earle).

New Jersey. Europe.

Mycena vulgaris Pers.

Lee County, February, 1897 (Earle \& Baker).

Europe.

Collybia albipilata Peck.

COLIYBIA Fr.

Ala. Bull. 257.

On dead cones of Pinus. Lee County, December, 1896 (Earle).

$15894-15$ 
Collybia dryophila Bull.

Peters coll. Ala. Bull. 257.

Angust, September, 1864 (Peters). Lee County, January, 1896 (Underwood \& Earle). Ohio. Europe.

Collybia luxurians Péck, Bull. Torr. Club, 24 : 141. 1897.

Ala. Bull. 257.

Under a brush heap. Lee County, July, 1896 (Underwood \& Earle).

Collybia platyphylla Fr.

Ala. Bull. 257.

Lee County, July, 1896 (Underwood \& Earle).

New Jersey, Ohio. Europe.

Collybia radicata $\mathrm{Relh}$.

Peters coll. Ala. Bull. 257. Cornell Bull.24.

Growing from buried roots. Lee County, Auburn, Jnly, 1890 (Atkinson).

September, 1864 (Peters). Tuscaloosa County, May, 1896 (Underwood); Lee County,

July, 1896 (Underwood \& Earle).

New Jersey, Ohio. Europe.

Collybia stipitaria Fr.

Peters coll. Ala. Bull. 258.

September, 1864 (Peter 8 ).

Ohio. Europe."

Collybia zonata Peck.

Ala. Bull. 258.

September, 1864 (Peter8).

Now Jersey, Ohio.

Clitocybe ectypa Fr.

CLITOCYBE Fr.

Cornell Bull. 24.

Lee County, Auburn, August, 1890 (Atkinson).

Europe.

Clitocybe ectypoides Peck.

Ala. Bull. 256.

Lee County, November, 1896 (Earle).

Clitocybe illudens Schw.

Lee County, November, 1897 (Earle \& Baker).

New Jersey, Ohio.

Clitocybe inversa Scop.

Ala. Bull. 256.

Lee County, July, 1896 (Underwood \& Earle).

Europe.

Clitocybe laccata Scop.

Ala. Ball. 257.

Mobile County, December, 1895 (Earle). Lee County, December, 1895 (Underwood);

January, March, 1896 (Underwood \& Earle); October, December, 1896 (Earle). Europe.

Clitocybe monadelpha Morgan.

Lee County, January, 1896 (Baker).

Ohio.

Clitocybe ochropurpurea Berk.

Peters coll., as Agaricus tyrianthus. Ala. Bull.257.

September, October, 1864 (Peters).

Lee County, November, December, 1896 (Earle).

TRICHOLOMA Fr.

Tricholoma brevipes Bull.

Cornell Bull. 25.

Lee County, Auburn, summer, 1891 (Atkinson).

Europe.

Tricholoma cuneifolium Fr.

Ala. Bull. 265.

In sandy soil. Lee County, Jamuary, 1896 (Cnderwood s. Earle).

Europe. 
Tricholoma equestris $\mathrm{L}$.

Ala. Bull. 265.

Lee County, November, 1896 (Earle).

Europe.

Tricholoma leucocephalum Fr.

Ala. Bull. 265.

Lee County, October, 1896 (Earle).

Europe.

Tricholoma russula Schaeff.

Ala. Bull. 265.

Lee County, November, December, 1896 (Earle).

Europe.

Tricholoma terreum Schaeff.

Ala. Bull. 265.

Lee County, January, 1896 (Underwood \& Earle).

Ohio. Europe.

Tricholoma tricolor Peck.

Ala. Bull. 265.

Lee County, November, 1896 (Earle).

ARMILLARIA Fr.

Armillaria appendiculata Peck, Bull. Torr. Club, 24 : 140. 1897.

Ala. Bull. 255.

Lee County, October, 1896 (Baker).

Armillaria bulbigera A. \& S.

Cornell Bull. 24.

Lee County, Auburn, December, 1890 (Atkinson).

Armillaria mellea Vahl.

Peters coll. Ala. Bull. 256. Cornell Bull. 24.

Alout stumps. October, November, 1864 (Peters).

Lee County, November, December, 1895 (Underwood); July, 1898 (Underwood \&

Earle); October, November, December, 1896 (Earle).

New Jersey. Europe.

\section{IEPIOTA Fr.}

Lepiota acutesquamosa Weinm.

Peters coll. Ala. Bull. 261.

October, 1864 (Peters).

Europe.

Lepiota americana Peck.

Cornell Bull. 25.

Lee County, Auburn (Atkinson).

New Jersey, Ohio.

Lepiota asperata Berk.

Cornell Bull. 25.

In grassy places. Lee County, Auburn, August, 1890 (Atkinson).

Iepiota cristata Alb. \& Schw.

Lee County, August, 1897 (Baker).

New Jersey, Ohio.

Lepiota delicata Fr.

Lee County, July, 1897 (Earle \& Baker).

Europe.

Lepiota earlei Peck, Bull. Torr. Club, 25 :368. 1898.

Lee County, August, 1897 (Earle)

Lepiota excoriata Schaeff.

Cornell Bull. 24.

In grassy places. Lee County, Auburn, July, 1890 (Atkinson).

Europe. 
Lepiota longistriata Peck, Bull. Torr. Club, 25 : 368. 1898. Lee County, August, 1897 (Mr8. F. S. Earle).

Lepiota mammaeformis Underwood, Bull. Torr. Club, 24 : 82. 1897.

Ala. Bull. 261.

At base of Broussonetia. Lee County, July, 1896 (Underwood).

Lepiota morgani Peck.

Ala. Bull. 262.

Lee County, Jnly, 1896 (Underwood \& Earle).

Ohio.

Lepiota procera Scop.

Ala. Bnll.262.

Leo County, November, 1896 (Earle).

Ohio. Europe.

Edible.

Lepiota subremota B. \& C.

Cornell Bull. 25.

In grassy fields and open woods. Lee County, Auburn, summer, 1890 (Atkinson).

\section{AMANITOPSIS Roze.}

Amanitopsis agglutinosus (B. \& C.) Sacc.

Cornell Bull. 24.

Lee County, Auburn, 1890 (Atkinson).

Amanitopsis farinosus (Schw.) Peck.

Lee County, July 7, 1897 (Earle \& Baker).

New Jersey.

Amanitopsis nivalis Peck.

Cornell Bull. 24.

Lee County, Auburn, August, 1890 (Atkinson).

Amanitopsis strangulatus (Fr.) Roze.

Ala. Bull. 255.

Lee County, November, 1896 (Earle).

Now Jersey, Ohio.

Amanitopsis vaginatus (Bull.) Roze.

Peters coll. Ala. Bull.255. Cornell Bull.24.

September, October, 1864 (Peters); Leo County, Auburn, July, August, 1890

(Atkinson); Lee County, July, 1896 (Underwood \& Earle).

New Jersey, Ohio, District of Columbia.

Amanitopsis volvatus (Peck) Sacc.

Ala. Bull. 255.

Lee County, July, 1896 (Underwood \& Earle).

Ohio.

AMANITA Fr.

Amanita abrupta Peck, Bull. Torr. Club, 24 : 138. 1897.

Ala. Bull. 253.

Lee County, July, 1896 (Onderwood \& Earle).

Amanita caesarea Scop.

Ala. Bull. 253. Cornell Bull.24.

Tuscaloosa County, May, 1896 (Underwood). Lee County, July, 1896 (Underwood \&

Earle); October, 1896 (Earle).

Ohio, Indiana. Europe.

Abundant; edible.

Amanita candida Peck, Bull. Torr. Club, 24 : 137. 1897

Ala. Bull. 253.

Lee County, October, 1896 (Earle).

Amanita chlorinosa (Peck) Underwood \& Earle.

Ala. Bull. 254.

Lee County, November, 1896 (Earle). 
Amanita frostiana Peck.

Lee County, July, 1896 (Underwood \& Earle).

Amanita muscaria L.

Ala. Bull. 254.

Lee County, October, 1896 (Burton); November, December, 1896 (Baker).

Southern New England, District of Columbia.

The "fly agaric"; poisonous. Frequent.

Amanita pantherina DC.

Cornell Bull. 24.

Lee County, Auburn, July, August, 1890 (Atkinson).

Ohio. Europe.

Amanita phalloides Fr.

Ala. Bull. 255. Cornell Bull. 24.

Lee County, Auburu, August, 1890 (Atkinson). Lee County, December, 1895 (Underwood); July, 1896 (Underwood \& Earle); October, 1896 (Earle). Mobile County, December, 1895 (Earle).

Europe.

A deadly poison, for which no antidote is known.

Amanita ravenelii B. \& C.

Cornell Bull. 24.

Lee County, Auburn, Angust, 1890 (Atkinson).

Amanita rubescens Fr.

Ala. Bull. 255.

Lee County, July, 1896 ( Underwood \& Earle).

New Jersey, Ohio, District of Columbia. Europe.

Amanita solitaria Bull.

Ala. Bull. 255. Cornell Bull. 24.

Lee County, Auburn, August, 1890 (Atkinson); Lee County, July, 1896 (Underwood \&. Earle).

Europe.

Amanita spreta Peck.

Ala. Bull. 255. Cornell Bull. 24.

In open woods. Lee County, Auburn, July, 1890 (Atkinson); July, November, 1896 (Earle).

Amanita strobiliformis Vitt.

Ala. Bull. 255.

Lee County, October, 1896 (Earle).

Europe.

Amanita virosa Fr.

Ala. Bull. 255.

Lee County, July, 1896 (Underwood \& Earle).

Europe.

Poisonous.

Order PHALLALES.

Family CLATHRACEAE.

CLATHRUS Micheli.

Clathrus columnatus Bose.

Ala. Bull. 265.

Lee County, November, 1896 (Baker).

\section{Family PHALLACEAE.}

MUTINUS Fr.

Mutinus caninus (Huds.) Fr.

Ala. Bull. 265.

Lee County, November, 1896 (Earle).

Ohio. Europe. 


\section{DICTYOPHORA DESV.}

Dictyophora duplicata (Bosc.) E. Fisher.

Ala. Bull. 265.

Winston County, June, 1896 (Underwood).

Ohio.

Dictyophora ravenelii (B. \& C.) Burton.

Ala. Bull. 265.

Lee County, May, 1896 (Underwood \& Earle).

New Jersey, Ohio.

PHALIUS Micheli.

Phallus rubicundus Bose.

Peters coll. Ala. Bull. 266.

Hale County, May, 1896 (Underwood).

\section{Order HYMENOGASTRALES.}

\section{Family HYMENOGASTRACEAE.}

OCTAVIANA Vitt.

Octaviana compacta Tul.

Ala. Bull. 268.

Lee County, July, 1896 (Underwood \& Earle).

Octaviana stephensii ravenelii Berk.

Cornell Bull. 23.

Lee County, Auburn, 1890 (Atkinson).

Now Jersey.

RHIZOPOGON Fr.

Rhizopogon rubescens Tul.

Peters coll. No.68. Ala. Bull. 268. Cornell Bull. 23.

On the ground. Lee County, Auburn, August, 1890 (Atkinson).

Winston County (P. P. Payne). Leo County, December, 1895 (Underwood); March, 1896 (Underwood \& Earle); Decomber, 1896 (Earle).

Now Jersey. Europe.

\section{Order LYCOPERDALES.}

\section{Family LYCOPERDACEAE.}

TyLOSTOMA Pers.

Tylostoma fimbriatum Fr.

Ala. Bull. 267.

Lee County, October, 1896 (Earle). Macon County, December, 1896 (Carver).

South Carolina. Europe.

\section{IYCOPERDON TOnrn.}

Lycoperdon acuminatum Bosc.

On living trunks. Lee County, February, 1897 (Earle \& Baker).

Ohio.

Iycoperdon asterospermum Dur. \& Mont.

Ala. Bull. 267.

Lee County, July, 1896 (Underwood \& Earle).

Ohio. 
Lycoperdon calyptriforme B. \& C.

Cornell Bull. 23.

Lee County, Auburn, July, 1890 (Atkinson).

North Carolina.

Lycoperdon cepaeforme Bull.

Ala. Bull. 267. Cornell Bull. 23.

Lee County, Auburn, 1890 (Atkinson); Lee County, July, 1896 (Underwood \& Earle). Ohio. Europe.

Lycoperdon curtisii Berk.

Lee County, December, 1897 (Earle \& Baker).

North Carolina, Ohio, New England.

Lycoperdon echinatum Pers.

Cornell Bull. 23.

Lee County, Auburn, 1890 (Atkinson).

Ohio.

Lycoperdon epixylon B. \& C.

Lee County, August, 1897 (Earle \& Baker).

Lycoperdon excipuliforme Scop.

Cornell Bull. 23.

Lee County, Auburn (Atkinson); common.

Europe.

Lycoperdon eximium Morgan.

Ala. Bull. 267. Cornell Bull. 23.

Lee County, Auburn, 1890 (Atkinson); Lee County, July, 1896 (Underwood \& Earle).

Lycoperdon fuliginosum B. \& C.

Cornell Bull. 23.

On decaying logs. Lee County, Auburn, Augnst 4, 1890 (Atkinson).

Lycoperdon gemmatum Batsch.

Ala. Bull. 267.

Lee County, July, 1896 (Underwood \& Earle).

Louisiana, New Jersey, Ohio. Europe.

Lycoperdon peckii Morgan.

Ala. Bull. 267.

Ohio.

Lycoperdon pedicellatum Peck.

Ala. Bull. 267. Cornell Bull. 23.

On ground in open woods. Lee County, Auburn, February 22, 1891 (Atkinson);

Tuscaloosa County, May, 1896 (Underwood).

Ohio.

Iycoperdon pusillum Batsch.

Ala. Bull. 267. Cornell Bull. 23.

Lee County, Auburn, 1890 (Atkinson); Lee County, July, 1896 (Underwood \& Earle). New Jersey, Ohio. Europe.

Lycoperdon pyriforme Schaeff.

Ala. Bull. 267.

Lee County, December, 1895 (Underwood); February, June, 1896 (Underwood \&

Earle); October, November, 1896 (Earle).

New Jersey, Ohio. Europe.

Lycoperdon rimulatum Peck.

Cornell Bull. 23.

Lee County, Auburn, 1890 (Atkinson).

Ohio.

Lycoperdon separans Peck.

Ala. Bull. 267. Cornell Bull. 23.

Lee County, Auburn, 1890 (Atkinson); Lee County, March, June, July, 1896

(Underwood \& Earle).

Ohio. 
L,coperdon turneri E. \& E.

Ala. Bull. 267. Cornell Bull. 23.

On the grouud in open woods. Lee County, Auburn, February 22, 1891 (Atkinson). Lee County, July, 1896 (Underwood \& Earle).

Ohio.

Lycoperdon wrightii B. \& C.

Cornell Bull. 23.

Lee County, Auburn, 1890 (Atkinson).

Louisiana, Ohio, Connecticut.

Calostoma Desv.

Calostoma cinnabarinum (Desv.) Mass.

Ala. Bull. 266.

(Atkinson.)

Calostoma lutescens (Schw.) Mass.

Calhoun County, Macon, February, 1898 (Carver); Mobile County (Mohr).

Texas, New Jersey.

Calostoma ravenelli (Berk.) Mass.

Ala. Bull. 266.

Loe County, March, 1896 (Underwood \& Earle).

\section{CaLvatia Fr.}

Calvatia craniiformis (Schw.) Fr.

Ala. Bull. 266.

Lee County, July, 1896 (Underwood \& Earle); November, 1896 (Earle).

Ohio

Calvatia cyathiformis (Bosc.) Morgan.

Ala. Bull. 266. Cornell Bull. 23, under Lycoperdon.

Lee County, Anburn (Atkinson). Lee County, October, 1895 (Underwood); January, July, 1896 (Underucood \& Earle); September, 1896 (Earle).

Louisiana, New Jersey, Ohio.

Calvatia fragilis (Vitt.) Morgan.

Ala. Bull. 266.

Lee County, July, 1896 (Underwood \& Earle).

North Carolina, South Carolina.

\section{CATASTOMA Morgan.}

Catastoma circumscissum (B. \& C.) Morgan.

Ala. Bull. 266.

Mobile County, December, 1895 (Underwood).

Maine.

Catastoma pedicellatum Morgan.

Ala. Bull. 266.

Lee County, July, 1896 (Underwood \& Earle); September, 1896 (Earle).

Ohio.

\section{CAULOGLOSSUM Grev.}

Cauloglossum transversarium (Bosc.) Fr.

In sphagnum swamp. Lee County, November, 1897 (Earle).

South Carolina.

\section{BOVISTELLA Morgan.}

Bovistella ohiensis (E. \& M.) Morgan.

Ala. Bull. 266. Cornell Bull. 22.

Common on the ground. Lee County, Anburn (Atkinson).

Lee County, December, 1895 (Underwood); April, July, 1896 (Underwood \& Earle);

October, November, December, 1896 (Earle). Winston County, June, 1896 (Underwood).

Ohio. 
BOVISTA Pers.

Bovista minor Morgan.

Ala. Bull. 266.

Lee County, December, 1895 (Undervood).

Ohio.

GEASTER Micheli.

\section{Geaster fimbriatus Fr.}

Ala. Bull. 266.

Winston County, June. 1896 ( Underwood).

South Carolina. South America, Europe, East Asia, Africa, Australia.

Geaster lageniformis Vitt.

Cornell Bull. 23.

Lee County, Auburn, August, 1890 (Atkinson).

Ohio.

\section{Geaster limbatus Fr.}

Ala. Bull. 266. Cornell Bull.23.

(Peter8.)

On the ground in open woods. Lee County, Auburn, February 22, 1891 (Atkinson). Lee County, March, 1896 (Underwood \& Earle); Winston County, June, 1896 (Underwood).

Ohio. Europe, South Africa.

Geaster minimus Schw.

\section{Ala. Bull. 267.}

Lee Connty, February, 1896 (Underwood \& Earle).

New Jersey.

\section{Geaster saccatus Fr.}

Peters coll. Ala. Bull.267. Cornell Bull. 23.

(Peters.) Lee County, Auburn, 1891 (Atkinson).

Ohio, New Jersey, New England.

Geaster triplex Jungh.

Cornell Bull. 22.

Shady places. Lee County, Auburn, 1890 (Atkinson).

Ohio.

\section{Order NIDULARIALES.}

\section{Family NIDULARIACEAE.}

\section{NIDULARIA Bull.}

Nidularia alabamensis Atkinson.

Cornell Bull. 23.

On decaying wood. Lee County, Auourn, July, 1890 (Atkinson).

\section{CRUCIBULUM Tul.}

\section{Crucibulum vulgare Tul.}

Ala. Bull. 267.

On the ground. Lee County, December, 1895 (Underwood); July, 1896 (Underwood \&. Earle).

New Jersey, Ohio. Europe.

CYATHUS Haller.

Cyathus stercoreus (Schw.) Des.

Lee County, March, 1897 (Earle \& Baker). 
Cyathus vernicosus (Bull.) DC.

Cornell Bull. 22.

On charred wood, etc. Lee County, Auburn, 1890 (Atkinson).

New Jersey, Ohio. Europe, Africa.

\section{Order SCLERODERMATALES.}

\section{Family SCLERODERMATACEAE.}

POLYSACCUM DC.

Polysaccum crassipes DC.

Ala. Bull. 268.

Lee County, October, 1895 (Underwood); July, 1896 (Underwood \&. Earle).

Europe.

\section{Polysaccum pisocarpum Fr.}

Ala. Bull.268. Cornell Bull.23.

On the ground in lawns. Lee County, Auburn, 1890 (Atkinson); Lee County, July, 1896 (Underwood \& Earle). Not uncommon.

New Jersey. Europe.

SCLERODERMA Pers.

Scleroderma geaster Fr.

Ala. Bull. 268. Cornell Bull. 23.

On the ground. Lee County, Auburn (Atkinson). Lee County, December, 1895

(Underwood); July, 1896 (Underwood \& Earle).

New Jersey.

Scleroderma flavidum E. \& E.

Ala. Bull. 26.

Mobile County, December, 1895 (Underwood). Lee Count:, March, 1896 (Underwood \& Earle); September, December, 1896 (Earle).

Scleroderma verrucosum (Bull.) Pers.

Ala. Bull. 268. Cornell Bull. 23.

On the ground. Lee County, Aubnrn, 1890 (Atkinson). Lee County, July, 1896 (Underwood \& Earle).

On sandy ground. Mobile County (Earle).

New Jersey. Europe.

Scleroderma vulgare Hornem.

Ala. Bull. 268. Cornell Bull. 23.

On the ground. Lee County, Auburn (Atkinson).

New Jersey, Ohio. Europe.

\section{ASTRAEUS Morgan.}

Astraeus hygrometricus (Pers.) Morgan.

Ala. Bull. 266. Cornell Bull.22, under Geaster.

On the ground in open woods. Lee County, Auburn, February 22, 1891 (Atkinson). Lee County, December, 1895 (Underwood); Mobile County, November, 1895 (Underwood); Winston County, June, 1896 (Underwood).

Texas, New Mexico, South Carolina, New Jersey. Europe.

\section{ARACHNION Schw.}

\section{Arachnion album Schw.}

Cornell Bull.23.

On the ground. Lee County, Auburn, 1890 (Atkinson).

New Jersey. 


\section{(FUNGI IMPERFECTI. ${ }^{1}$ )}

\section{Order MONILIALES (Hyphomycetes.)}

\section{Family MONILIACEAE (Mucedineae).}

Monilia fructigena Pers.

\section{MONILIA Pers.}

Ala. Bull.139. Cornell Bull. 38.

On fruit of Amygdalus persica. Lee County, Auburn, July 1, 1892 (Richards).

On fruit of Prunus triflora. Mobile County (Mohr).

Monilia megalosporium (B. \& C.) Sacc.

Journ. Linn. Soc. 10:363, under Oidinm. Ala. Bull. 139.

On dead bark.

\section{RHINOTRICHUM Corda.}

Rhinotrichum bellum B. \& C.

Grevillea, $3: 108$. Ala. Bull. 140.

On dead wood (Beaumont).

Rhinotrichum macrosporum Farlow.

Ala. Bull. 140. Cornell Bull. 39.

On dead capsules of Gossypium herbaceum. Autumn (Atkinson).

Rhinotrichum tenellum B. \& C.

Ala. Bull. 140. Cornell Bull.29.

On dead capsules of Gossypium herbaceum. Lee County, Auburn, October, 1890 (Atkinson).

\section{BOTRYTIS Michx.}

Botrytis curta (B. \& C.) Sacc.

Grevillea, $3: 110$, under Polyactis. Ala. Bull. 138.

Cn the under side of leaves of Magnolia sp. (Beaumont).

\section{OVULARIA Sacc.}

Ovularia obliqua (Cooke) Oud.

Ala. Bull. 139.

On Rumex sp. Lee County, July, 1891 (Duggar).

\section{SEPEDONIUM Link.}

Sepedonium americanum B. \& C.

Peters coll. 1:123. Ala. Bull. 140.

On rotten wood (Peters).

Sepedonium subochraceum B. \& C.

Grevillea, 3:147. Ala. Bull. 140.

On rotten wood (Peters). Lee County, July, 1896 (Underwood \& Earle).

\section{TRICHOTHECIUM Link.}

Trichothecium roseum (Pers.) Link.

Ala. Bull. 140. Cornell Bull. 39.

On leaves of Ficus carica. Lee County, Auburn, October, 1891 (Atkinson).

On leaves of Amygdalus persica. Lee County, Auburn, November, 1891 (Atkinson).

On carpels of Gossypium herbaceum. Lee County, Auburn (Atkinson).

Louisiana, New Jersey.

'The arrangement of this group is practically that of Saccardo's Sylloge Fungorum. 
DIDYMARIA Corda.

Didymaria spissa Harkness.

Cornell Bull. 38.

On living leaves of Solidago. Macon County, Shorter, July 16, 1890 (Atkinson).

\section{RAMULARIA Unger.}

Ramularia areola Atkinson, Bot. Gaz. 15 : 168. 1890.

Ala. Bull. 139. Cornell Bull. 39.

On leaves and bracts of Gossypium herbaceum. Lee County, Auburn, September 29, 1890 (Atkinson); Macon County, July, 1896 (Carver).

Ramularia liriodendri E. \& E.

Ala. Bull. 140. Cornell Bull. 38.

On living leaves of Liriodendron. Lee County, Auburn, October, 1889 (Benton).

On Liriodendron. Lee County, October, 1895 (Underwood).

Macon County (Carver).

Ramularia macrospora asteris Trelease.

Ala. Bull. 140.

On Aster sp. Lee County, May, 1896 (Underwood \& Earle).

Ramularia pratensis Sacc.

Cornell Bull. 38 .

On leaves of Rumex. Lee County, Auburn, July 20, 1891 (Duggar).

Ramularia virgaureae Thuem.

Ala. Bull. 140. Cornell Bull. 39.

On leaves of Solidago. Lee County, Auburn, March 27, 1890 (Atkinson).

On Solidago sp. Lee County, July, 1891 (Duggar).

Europe.

\section{PIRICULARIA Sacc.}

Piricularia grisea (Cooke.) Sacc.

Ala. Bull.139. Cornell Bull. 40.

On leaves of Paspalum sp. Lee County, July 11, 1890 (Atkinson).

On leaves of Chaetochloa italica. Lee County, August, 1890 (Atkinson).

On leaves of Paspalum plicatulum. Lee County, JulJ 25, 1891 (Atkinson).

On leaves of Syntherisma sanguinale. Lee County, July 1, 1891 (Newman).

On leaves of Panicum sp. Lee County, July, 1891 (Newman).

\section{SPOROTRICHUM Link.}

Sporotrichum globuliferum Speg.

Cornell Bull. 39.

On a dead hymenopterous insect. Lee County, Auburn (Atkinson).

OLPITRICHUM Atkinson.

Olpitrichum carpophilum Atkinson.

Cornell Bull. 59.

On dead capsules of Gossypium herbaceum. Pike Connty, Brundidge, September 5, 1891 (Atkinson).

CERCOSPORELLA Sacc.

Cercosporella persica Sacc.

Ala. Ball. 138. Cornell Bull. 46.

On leaves of Amygdalus persica. Lee County, Auburn, October 30, 1890 (Atkinson);

October 1, 1891 (Duggar). Macon County, August, 1896 (Carver).

Cercosporella pycnanthemi Atkinson.

Cornell Bull. 47.

On Koellia. Lee County, Auburn (Atkinson). 


\section{CHROMOSPORIUM Sacc.}

Chromosporium aeruginosum (Corda) Sacc.

Cornell Bull. 38.

On decaying wood. Lee County, Auburn, October, 1889 (Atkinson).

Chromosporium fulvum (B. \& C.) Sacc.

Journ. Linn. Soc. 10: 355, under Gymnosporium. Ala. Bull.138.

On Peziza psammophila (Peters).

\section{Family DEMATIACEAE.}

\section{CONIOSPORIUM Link.}

Coniosporium arundinellae Ellis \& Tracy.

Ala. Bull. 153. Cornell Bull. 39.

On leaves of Arundinaria tecta. Lee County, December 25, 1888 (Newman).

On dead leaves of Panicum sp. Lee County, Jauuary, 1890 (Atkinson).

Coniosporium arundinis (Corda) Sacc.

Ala. Bull. 153.

On Saccharum officinarum. Macon County, July, 1896 (Carver).

Coniosporium gramineum E. \& E.

Ala. Bull. 153. Cornell Bull. 39.

On culms of Arundinaria tecta. Lee County, 1891 (Atkinson).

\section{PERICONIA (Tode) Bon.}

Periconia pycnospora Fr.

Ala. Bull. 156. Cornell Bull. 41.

On dead stems of Vigna catjang. Lee County, Auburn, December, 1890 (Atkinson).

STREPTOTHRIX Corda.

Streptothrix atra B. \& C.

Grevillea, 3:107. Ala. Bull. 156.

On Juniperus (Peters).

On dead wood. Lee County, November, 1895 (Underwood).

Massachusetts, Pennsylvania, South Carolina.

ZYGODESMUS Corda.

Zygodesmus fuscus Corda.

Peters coll. $3: 67$. Ala. Bull. 156.

(Peters.)

GLENOSPORA B. \& C.

Glenospora curtisii Berk. \& Desm.

Ala. Bull. 153.

On living bark of Nyssa. Lee Count J, January, February, 1896 (Underwood \& Earle).

\section{HARPOCEPHALUM Atkinson.}

Harpocephalum dematioides Atkinson.

Cornell Bull. 41.

On leaves of Cinna arundinacea. Lee County, Auburn, September 15, 1891 (Newman).

\section{FUSICLADIUM Bon.}

Fusicladium effusum carpineum E. \& E.

Cornell Bull. 40.

On upper surface of leaves of Carpinus caroliniana. Lge County, Auburn, October 30,1891 (Atkinson). 
Fusicladium pirinum pyracanthae Thuem.

Ala. Bull. 153. Cornell Bull. 40.

On fruit of Crataegus pyracantha. Lee County, Auburn, July, September, 1891 (Duggar \& Newman).

SCOLECOTRICHUM Kunze \& Schum.

Scolecotrichum graminis Fkl.

Ala. Bull. 156.

On Arundinaria tecta. Lee County, October, 1891 (Duggar).

Scolecotrichum euphorbiae Tracy \& Earle, Bull. Torr. Club, 23:209. 1896

Ala. Bull.156. Cornell Bull.40, under Piricularia.

On Euphorbia nutans. Lee County, Auburn, August 7, 1891 (Duggar \& Newman); Lee County, September, 1896 (Earle); Macon County, August, 1896 (Carver).

\section{POLYTHRINCIUM Kunze \& Schum.}

Polythrincium trifolii Kunze.

Ala. Bull. 156. Cornell Bull. 40.

On leaves of Trifolium hybridum. Lee County, Auburn, February, 1890 (Edwards). On Trifolium reflexum. Lee County, May, 1896 (Undervood \& Earle).

\section{CLADOSPORIUM Link.}

Cladosporium fulvum Cooke.

Ala. Bull. 153.

On Lycopersicum esculentum, the tomato. Lee County, October, 1896 (Earle).

Macon County, August, 1896 (Carver).

New Jersey, Ohio.

Cladosporium gloeosporoides Atkinson.

Cornell Bull. 39.

On leaves of Ascyrum stans. Lee County, Auburn, Angust 29, 1891 (Atkinson).

On stems of Hypericum mutilum. Lee County, September 2, 1891 (Duggar).

Cladosporium gramineum Corda.

Ala. Bull. 153. Cornell Bull. 39.

On dead leaves of Avena sativa. Lee County, Auburn, January 22, 1890 (Newman).

On Chrysopogon avenaceus. ILe County, September, 1891 (Duggar).

Cladosporium herbarum (Pers.) Link.

Ala. Bull. 153.

On mummied fruit of Ficus carica (still hanging on tree). Lee County, February, 1896 (Underwood \& Earle).

Now Jersey, Ohio.

Cladosporium xyridis Tracy \& Earle.

On withered petals of Xyris. Lee County, September, 1897 (Earle \& Baker). Mississippi.

\section{SEPTONEMA Corda.}

Septonema spilomeum Berk.

Rav. Fung. Car. Exsic. 4: 87. Ala. Bull. 156.

On Quercus (Beaumont).

\section{HELMINTHOSPORIUM Link.}

Helminthosporium avenaceum Curt.

Cornell Bull. 47.

On dead straw of Avena sativa. Lee County, Auburn, June 26, 1891 (Atkinson).

Helminthosporium beaumontii Sacc.

Grevillea, 3 : 104, as H. dubium B. \& C. Ala. Bull. 154.

On the under side of leaves, apparently of Viburnum (Beaumont).

Helminthosporium flagelloideum Atkinson.

Cornell Bull. 47.

On leaves of Panicum sp. Lee County, Auburn, September, 1890 (Atkinson). 
Helminthosporium inconspicuum C. \& E.

Cornell Bull. 47.

On living and languid leaves of Secale cereale. Lee County, February 19, 1891 (Atkinson).

Louisiana, New Jersey.

Helminthosporium leersiae Atkinson.

Ala. Bull.154. Cornell Bull. 47.

On leaves of Homalocenchrus virginicus. Lee County, Auburn, September 13, 1891 (Atkinson).

Helminthosporium macrocarpum Grev.

Ala. Bull. 154. Cornell Bull. 47.

On dead twigs of Quercus. Lee County, Auburn, November 8, 1891 (Atkinson).

On dead twigs. Lee County, February, 1896 (Underwood \& Earle).

New Jersey.

Helminthosporium macrocarpum caudatum B. \& Br.

Ala. Bull. 154.

On dead twigs. Lee County, January, 1896 (Underwood \& Earle)

Helminthosporium ravenelii B. \& C.

Ala. Bull. 154. Cornell Bull. 47.

On inflorescence of Sporobolus indicus. Lee County, Auburn, June, 1890 (Atkinson);

Macon County, October, 1896 (Carver).

Louisiana. Cuba.

Helminthosporium tuberosum Atkinson.

Cornell Bull. 47.

On putrescent culms of Secale cereale. Lee County, Auburn, September, 1891 (Newman).

Helminthosporium turcicum Pass.

Ala. Bull. 154. Cornell Bull. 47.

On languid leaves of Sorghum halepense. Mobile County, Jnly 24, 1890 (Atkinson).

On Cinna arundinacea. Lee County, Auburn, September 15, 1891 (Atkinson).

On Elymus sp. July 5, 1890 (Atkinson).

CERCOSPORA Fr.

Cercospora acalyphae Peck.

Ala. Bull. 141. Cornell Bull. 43.

On leaves and stems of Acalypha ostryaefolia. Lee County, August 6, September 12, 1891 (Newman).

Cercospora agrostidis Atkinson, Journ. Elisha Mitch. Soc. 8:44. 1892.

Ala. Bull. 141. Cornell Bull. 43.

On leaves of Agrostis. Lee County, Auburn, July 23, 1891 (Duggar \& Newman)

Cercospora ageratoides E. \& E.

On Eupatorium rotundifolium. Lee County, October, 1896 (Earle).

Cercospora alabamensis Atkinson, Journ. Elisha Mitch. Soc. 8:51. 1892.

Ala. Bull. 141. Cornell Bull. 43.

On leaves of Ipomoea purpurea. Dallas County, Uniontown, July 12, 1890 (Atkinson); Lee County, August, 1891 (Newman); Macon County, August, 1896 (Carver).

Cercospora althaeina Sacc.

Ala. Bull. 141. Cornell Bull. 45.

On Althaea rosea. Dallas County, Uniontown, July 12, 1890 (Atkinson).

Cercospora althaeina modiolae Atkinson, Journ. Elisha Mitch. Soc. 8:60. 1892.

Ala. Bull. 141. Cornell Bull. 45.

On leaves of Modiola multifida. Lee County, Auburn, 1890 (Atkinson).

Cercospora anthelmintica Atkinson, Journ. Elisha Mitch. Soc. 8: 49. 1892.

Ala. Bull. 141. Cornell Bull. 43.

On leaves of Chenopodium anthelminticum. Lee County, Auburn, Angust 27, 1891

(Duggar).

Cercospora asterata Atkinson, Journ. Elisha Mitch. Soc. 8: 50. 1892.

Ala. Bull. 142. Cornell Bull. 43.

On leaves of Aster sp. Lee County, Auburn, November 25, 1891 (Atkinson). 
Cercospora atromaculans E. \& E.

Ala. Bull.142. Cornell Bull. 44.

On leaves of Cassia tora. Lee County, Auburn, September 10, 1890 (Atkinson).

On Cassia occidentalis. Lee County, October, 1895 (Underwood).

Cercospora atromarginalis Atkinson.

Ala. Bull.142. Cornell Bull. 45.

On leaves of Solanum nigrum. Lee County, Auburn, 1890 (Atkinson).

Cercospora avicularis Wint.

Ala. Bull. 142. Cornell Bull. 43.

On Polygonum punctatum. Lee County, August, 1891 (Atkinson).

Cercospora avicularis sagittati Atkinson, Journ. Elisha Mitch. Soc. 8:48. 1892. On leaves of Polygonum sagittatum. Lee County, October 1, 1891 (Duggar).

Cercospora beticola Sacc.

Ala. Bull. 143. Cornell Bull. 43.

On leaves of Beta vulgaris, the sugar beet. Lee County, Auburn, November 28, 1890 (Atkinson).

Ohio.

Cercospora bolleana (Thuem.) Speg.

Ala. Bulı. 143. Cornell Bull. 45.

On Ficus carica. Lee County, Auburn, September 4, 1890 (Atkinson); October, 1896 (Earle).

Mississippi.

Cercospora boehmeriae Peck.

Ala. Bull. 143. Cornell Bull. 44.

On Boehmeria cylindrica. Lee County, Auburn, November 7, 1891 (Atkinson); Macon County, Shorter, July 16, 1890 (Atkinson).

Cercospora canescens E. \& M.

Ala. Bull. 143.

On Phaseolus vulgaris. Lee County, July, 1891 (Newman).

Louisiana, New Jersey.

Cercospora catenospora Atkinson.

Ala. Bull.143. Cornell Bull. 46.

On Sambucus canadensis. Lee County, August 27, October, 1891 (Atkinson).

Cercospora cephalanthi E. \& K. Journ. Elisha Mitch. Soc. 8: 67. 1892.

Ala. Bull. 143. Cornell Bull. 46.

On leaves of Cephalanthus occidentalis (Atkinson).

Louisiana.

Cercospora cerasella Sacc.

Ala. Bull. 143. Cornell Bull. 42.

On leaves of Prunus avium. Lee County, Auburn, July 13, 1891 (Nevman); Gold

Hill, September, 1890 (Atkinson). Europe.

Cercospora cercidicola Ell.

Ala. Bull. 143. Cornell Bull. 42.

On leaves of Cercis canadensis. Lee County, Auburn, August 7, 1891 (Newman \& Duggar); Hale County, May, 1896 (Underwood).

Cercospora citrullina Cooke.

Ala. Bull. 143. Cornell Bull. 43.

On Citrullus vulgaris, the watermelon. Lee County, Auburn, September 3, 1890 (Atkinson).

Cercospora clitoriae Atkinson, Journ. Elisha Mitch. Soc. 8:62. 1892.

Ala. Bull. 143. Cornell Bull. 45.

On Clitoria mariana. Lee County, Auburn, Angnst 29, 1891 (Atkinson).

Cercospora clavata (Ger.) Cooke.

Cornell Bull. 42.

On leaves of Asclepias obtusifolia. Lee County, Auburn, Angust 19, 1892 (Richard8). 
Cercospora consociata Winter.

Ala. Bull. 144.

On Ruellia ciliosa. Lee County, July, 1896 (Underwood \& Earle).

Cercospora crinospora Atkinson.

Ala. Bull. 144. Cornell Bull. 45.

On Rynchospora glomerata. Lee County, Auburn, August 27, 1891 (Atkinson).

Cercospora crotonifolia Cooke.

Cornell Bull. 42.

On leaves of Croton sp. Lee County, Auburn, October 16, 1889 (Atkinson).

Cercospora cruciferarum E. \& E.

Cornell Bull. 42.

On 13rassica oleracea. Lee County, Auburn, August 29, 1892 (Richards).

Cercospora cruenta Sacc.

Ala. Bull. 144. Cornell Bull. 44.

On Vigna catjang. Lee County, Auburn, July 8, 1890 (Duggar); Macon County, October, 1896 (Carver); Perry County, July, 1891 (Atkinson).

Cercospora cucurbitae E. \& C.

Ala. Bull. 144. Cornell Bull. 43.

On Luffa acutangula, the dish-rag squash. Lee County, 1890 (Atkinson).

On Lagenaria vulgaris, the common gourd. Lee County, Auburn, September 10, 1891 (Duggar).

Cercospora depazeoides (Desm.) Sacc.

Ala. Bull. 144. Cornell Bull. 45.

On leaves of Sambucus canadensis. Lee County, Auburn, September 9, 1890 (Atkin80n).

\section{Louisiana.}

Cercospora desmodii E. \& K.

Ala. Bull. 144. Cornell Bull. 44.

On Meibomia mollis ( $\%$ ). Lee County, 1890 (Atkinson).

On Meibomia sp. Perry County, Uniontown, July 12, 1890 (Atkinson).

Mississippi, Ohio.

Cercospora diodiae Cooke.

Ala. Bull.144. Cornell Bull. 42.

On leaves of Diodia teres. Lee County, Auburn, July 16, 1891 (Duggar \& Newman). New Jersey.

Cercospora diodiae-virginianae Atkinson, Journ. Elisha Mitch. Soc. 8 : 58. 1892. Ala. Bull. 144. Cornell Bull. 44.

On leaves of Diodia virginiana. Lee County, Auburn, September 26, 1891 (Duggar).

Cercospora diospyri Thuem.

Ala. Bull. 145. Cornell Bull. 45.

On leaves of Diospyros virginiana. Lee County, Auburn, September26, 1891 (Duggar).

Cercospora effusa (B. \& C.) Ellis.

Ala. Bull. 145. Cornell Bull. 45.

On leaves of Lobelia amoena. Lee County, Auburn, October 11, November 3, 1891 (Atkinson).

Ohio.

Cercospora elephantopodis E. \& E.

Cornell Bull. 44.

On leaves of Elephantopus tomentosus. Lee County, Auburn, June 30, 1890 (Atkinson). Mississippi.

Cercospora erechtitis Atkinson, Journ. Elisha Mitch. Soc. 8: 66. 1892.

Ala. Bull. 145. Cornell Bull. 46.

On leaves of Erechtites hieracifolia. Lee County, November 5, 1891 (Duggar).

Cercospora erythrogena Atkinson, Journ. Elisha Mitch. Soc. 8:65. 1892.

Ala. Bull. 145. Cornell Bull. 46.

On leaves of Rhexia mariana. Lee County, July 22, 1890 (Atkinson).

On Rhexia virginica. Lee County, October, 1890 (Atkinson); Augnst 29, 1891 (Atkinson).

$$
15894-16
$$


Cercospora euphorbiaecola Atkinson.

Cornell Bull. 41.

On leaves of Euphorbia. Lee County, Auburn, August 16, 1892 (Richards).

Cercospora flagellaris E. \& M.

Ala. Bull. 145. Cornell Bull. 43.

On leaves of Phytolacca decandra. Lee County, Auburn, July 11, 1891 (Newman).

Cercospora flagellifera Atkinson, Journ. Elisha Mitch. Soc. 8:51. 1892.

Ala. Bull. 145. Cornell Bull. 43.

On Galactia volubilis. Lee County, Auburn, September 9, 1891 (Atkinson).

Cercospora fuscovirens Sacc.

Ala. Bull. 146. Cornell Bull. 45.

On leaves of Passiflora incarnata. Lee County, Auburn, October 2, 1891 (Duggar).

Cercospora fusimaculans Atkinson, Jouru. Elisha Mitch. Soc. 8:50. 1892.

Ala. Bull. 146. Cornell Bull. 43.

On leaves of Panicum dichotomum. Lee Connty, Auburn, August 15, 1891 (Duggar).

Cercospora galii E. \& Holw.

Ala. Bull.146. Cornell Bull. 42.

On Galium pilosum puncticulosum. Lee County, Auburn, July 22, 1890 (Atkinson).

On Galium sp. (Atkinson).

Cercospora gnaphaliacea Cooke ( $($ ) .

Bull. Torr. Club, $25: 366.1898$.

On Gnaphalium purpureum. Lee County, Auburn, February 21, 1897 (Earle \& Baker).

Cercospora gossypina Cooke.

Ala. Bull. 146. Cornell Bull. 46.

On the leaves, bracts, and cotyledons of Gossypium herbaceum, the cotton plant.

Lee County, October, 1890 (Atkinson). Common throughout the State.

The conidial stage of Mycosphaerella gossypina.

Cercospora hydrangeae E. \& E.

Ala. Bull. 146. Cornell Bull. 44.

On leaves of a cultivated species of Hydrangea. Lee County, Auburn, 1890 (Atkinson).

Cercospora hydrocotyles E. \& E.

Ala. Bull. 146. Cornell Bull. 44.

On leaves of Hydrocotyle umbellata. Macon County, Shorter, July 16, 1890 (Atkinson);

Lee County, August, 1891 (Duggar).

Louisiana.

Cercospora jatrophae Atkinson, Journ. Elisha Mitch. Soc. 8:64. 1892.

Ala. Bull. 146. Cornell Bull. 45.

On leaves of Jatropha stimulosa. Lee County, Auburn, July 2, 1890 (Atkinson).

Cercospora jussiaeae Atkinson, Journ. Elisha Mitch. Soc. 8:50. 1892.

Ala. Bull.147. Cornell Bull. 43.

On leaves of Jussiaea leptocarpa. Lee County, Auburn, September 2, 1891 (Duggar).

On leaves of Jussiaea decurrens. Lee County, Auburn, September 29, 1891 (Atkinson).

Cercospora leucosticta E. \& E.

Ala. Bull. 147.

On Melia azedarach. Lee County, November, 1895 (Underwood).

Cercospora liquidambaris C. \& E.

Ala. Bull. 147. Cornell Ball. 43.

On leaves of Liquidambar styraciflua. Lee County, Auburn, October 14, 1891 (Atkinson). Macon County, October, 1896 (Carver).

Cercospora lobeliae K. \& S.

Ala. Bull. 147. Cornell Bull. 43.

On leaves of Lobelia amoena. Lee County, Auburn, October 14, 1891 (Atkinson).

Cercospora ludwigiae Atkinson, Journ. Elisha Mitch. Soc. 8:58. 1892.

Ala. Bull. 147. Cornell Bull. 44.

On leaves of Ludwigia alternifolia. Lee County, Auburn, September 29, 1891 (Atkinson). 
Cercospora lycopi E. \& E.

Cornell Bull. 42.

On leaves of Lycopus rubellus. Lee County, Auburn, September 2, 1891 (Duggar).

Cercospora macroguttata Atkinson, Journ. Elisha Mitch. Soc. 8:64. 1892.

Ala. Bull. 147. Cornell Bull. 45.

On leaves of Chrysopsis graminifolia. Lee County, Auburn, July 13, 1891 (Atkinson).

Cercospora mali E. \& E.

Ala. Bull. 148. Cornell Bull. 44.

On leaves of Malus malus. Lee County, Gold Hill, September, 1890 (Atkinson).

Cercospora mikaniae E. \& E.

On Willughbya scandens. Lee County, September, 1897 (Earle \& Baker).

Cercospora moricola Cooke.

Ala. Bull. 148. Cornell Bull. 41.

On Morus rubra. Lee County, Auburn, July 22, 1890 (Atkinson).

Cercospora muhlenbergiae Atkinson.

Cornell Bull. 46.

On leaves of Muhlenbergia diffusn. Lee County, Auburn, October 3, 1891 (Atkinson).

Cercospora nymphaeae E. \& E.

Ala. Bull.148. Cornell Bull. 44.

On leaves of Castalia (Nymphaea) odorata. Lee Coun's, Auburn, September 2, 1891

(Duggar).

Macon County, October, 1896 (Carver).

New Jersey.

Cercospora occidentalis Cooke.

Ala. Bull. 148. Cornell Bull. 42.

On leaves of Cassia occidentalis. Lee County, Auburn, Septembe:, 1891 (Duggar).

Macon County, October, 1896 (Carver).

Cercospora omphacodes E. \& Hol.

Ala. Bull. 148. Cornell Bull.42. Bull. Torr. Club, $25: 366$.

On Phlox floridana. Lee County, Auburn, June 23, 1890 (Atkinson).

On Phlox maculata. Chambers County, June 22, 1897 (Earle).

Europe.

\section{Cercospora oenotherae-sinuatae Atkinson.}

Cornell Bull. 46.

On Oenothera laciniata. Lee County, Auburu, September 4, 1890 (Atkinson).

Cercospora pachyspora E. \& E.

Ala. Bull. 148. Cornell Bull. 43.

On leaves of Peltandra sagittaefolia. Lee County, Auburn, September 26, 1891 (Atkinson).

Cercospora pentstemonis E. \& K.

Ala. Bull. 148. Cornell Bull. 42.

On leaves of Pentstemon hirsutus. Lee County, Auburn, April 27, 1892 (Atkinson).

Cercospora persollata (B. \& C.) Ell.

Rav. Fung. Car. Exsic. 3: 85, under Cladosporinm. Ala. Bull. 148. Cornell Bull. 42. On leaves of Arachis hypogaea. (Beaumont). Lee County, Auburn, September 7, 1891 (Atkinson).

Cercospora petersii (B. \& C.) Atkinson.

Grevillea, 3:102, under Helminthosporium. Ala. Bull. 149. Cornell Bull. 44.

North Alabama (Peters).

On leaves of Sinilax glauca. Macon County, Shorter, July 16, 1890 (Atkinson); Lee County, Auburn, December 20, 1891 (Atkinson).

On Smilax laurifolia. Lee Connty, March, 1896 (Underwood \& Earle).

Cercospora pinnulaecola Atkinson, Journ. Elisha Mitch. Soc. 8:64. 1892.

Ala. Bull.149. Cornell Bull. 46.

On Cassia multipinnata, mistakenly reported as C. nictitans. Lee County, Auburn, October 1, 1891 (Duggar). 
Cercospora polygonacea E. \& E.

Ala. Bull.149. Coruell Bull. 43.

On leaves of Polygonum scandens. Lee County, Auburn, October 14, 1891 (Duggar).

Cercospora purpurea Cooke.

Ala. Bull. 149.

On Persea palustris. Lee County, April, 1896 (Underwood \& Earle).

Louisiana, Mississippi.

Cercospora rhuina C. \& E.

Ala. Bull. 149. Cornell Bull. 43.

On Rhus toxicodendron. Lee County, Anburn, June 30, 1890 (Atkinson).

On Rhus glabra. Lee County, Auburn, August 7, 1891 (Duggar \& Newman).

On Rhus copallina. Lee County, Auburn, June 30, 1890 (Atkinson); Lee County, November, 1895 (Underwood).

On Rhus vernix. Macon County, Shorter, July 16, 1890 (Atkinson).

Cercospora ribis Earle, Bull. Torr. Club, 25 :366. 1898.

On leaves of a cultivated gooseberry, Ribes sp. Lee County, Auburn, July 18, 1896 (Underwood \& Earle).

Cercospora richardiaecola Atkinson, Journ. Elisha Mitch. Soc. 8:51. 1892. Ala. Bull. 150. Cornell Bull. 43.

On leaves of Richardia africana. Lee County, Auburn, September 7, 1891 (Atkinson).

Cercospora rigospora Atkinson, Journ. Elisha Mitch. Soc. 8:65. 1892.

Ala. Bull. 150. Cornell Bull. 46.

On leaves of Solanum nigrum. Lee County, Auburn, July 5, 1890 (Atkinson).

Cercospora rubi Sacc.

Ala. Bull. 150. Cornell Bull. 44.

On leaves of Rubus cuneifolius. Lee County, Auburn, August, 1890 (Atkinson).

Cercospora sagittariae E. \& K.

Ala. Bull. 150. Cornell Bull. 45.

On leaves of Sagittaria latifolia. Lee County, Auburn, July 24, 1891 (Duggar \&. Newman).

Cercospora saururi E. \& E.

Ala. Bull. 150. Cornell Bull. 44.

On leaves of Saururus cernuus. Macon County, Shorter, July 16, 1890 (Atkinson).

Cercospora scolecotrichoides Atkinson.

Cornell Bull. 46.

On languid leaves of Arundinaria tecta. Lee County, Auburn, October 28, 1891 (Duggar).

Cercospora seriata Atkinson, Journ. Elisha Mitch. Soc. 8:59. 1892.

Ala. Bull. 151. Cornell Bull. 45.

On leaves of Sporobolus asper. Lee County, Auburn, July 24, August 7, 1891 (Duggar \& Newman).

Cercospora setariae Atkinson, Journ. Elisha Mitch. Soc. 8:50. 1892.

Ala. Bull. 151. Cornell Bull. 43.

On leaves of Chaetochloa glauca. Lee County, Auburn, September 17, 1891 (Duggar).

Cercospora silphii E. \& E.

Ala. Bull. 151. Cornell Bull. 45.

On leaves of Silphium compositum. Lee County, Auburn, June 30, 1890 (Atkinson).

Cercospora smilacina Sacc. ( $($ )

Ala. Bull. 151.

On Smilax sp. Lee County, May, 1896 (Underwood \& Earle).

Louisiana, New Jersey, Ohio.

Cercospora solanicola Atkinson, Journ. Elisha Mitch. Soc. 8:53. 1892.

Ala. Bull. 151. Cornell Bull. 44.

On leaves of Solanum tuberosum. Lee County, Auburn, June 19, 1891 (Atkinson).

Cercospora sordida Sacc.

Ala. Bull. 151. Cornell Bull. 45.

Ou leaves of Tecoma radicans. Lee County, Auburn, September 26, 1891 (Duggar).

Mississippi. 
Cercospora sorghi E. \& E.

Ala. Bull.151. Cornell Bull. 41.

On leaves of Sorghum halepense. Montgomery County, September 8, 1891 (Atkin . son); Macon County, August, 1896 (Carver).

Cercospora stylismae Tracy \& Earle.

Ala. Bull. 151.

On Breweria humistrata. Lee County, July, 1896 (Underwood \& Earle).

Mississippi.

Cercospora tephrosiae Atkinson, Journ. Elisha Mitch. Sac. 8:44. 1892.

Ala. Bull. 151. Cornell Bull. 42.

On Cracca (Tephrosia) hispidula. Lee County, Auburn, September 14, 1891 (Atkinson).

Cercospora tessellata Atkinson, Journ. Elisha Mitch. Soc. 8:59. 1892.

Ala. Bull. 152. Cornell Bull. 45.

On Dactyloctenium aegyptium. Lee Connty, November 6, 1891 (Atkinson).

Cercospora thaspii E. \& E.

Ala. Bull. 152. Cornell Bull. 45.

On Angelica villosa. Lee County, Auburn, July 22, 1890 ; July 23, 1891 (Duggar \& Newman).

Cercospora tropaeoli Atkinson, Journ. Elisha Mitch. Soc. 8:59. 1892.

Ala. Bull. 152. Cornell Bull. 45.

On a cultivated species of Tropaeolum. Lee County, Auburn, September 7, 1891 (Atkinson).

Cercospora truncatella Atkinson, Journ. Elisha Mitch. Soc. 8:44. 1892.

Ala. Bull. 152. Cornell Bull. 42.

On leaves of Passiflora incarnata. Lee County, Auburn, August ¿6, 1891 (Atkinson).

Cercospora tuberosa E. \& K.

Ala. Bull. 152.

On Apios apios. Macon County, August, 1896 (Carver).

Cercospora verbenaecola E. \& E.

Cornell Bull. 44.

On leaves of cultivated species of Verbena. Lee County, Auburn, Deceruber 24, 1891 (Atkinson).

Louisiana.

Cercospora vernoniae E. \& K.

Ala. Bull. 152. Cornell Bull. 41.

On leaves of Vernonia noveboracensis. Lee Connty, Augnst 29, 1891 (Atkinson).

On leaves of Vernonia angustifolia. Lee County, Auburn, August 16, 1892 (Richards).

Cercospora violae Sacc.

Ala. Bull. 153. Cornell Bull. 44.

On leaves of Viola odorata. Lee County, Auburn, July 25, 1891 (Atkinson).

On Viola villosa. Lee County, May, 1892 (Duggar).

Mississippi, Ohio.

Cercospora viticola (Ces.) Sacc.

Ala. Bull. 153. Cornell Bull. 44.

On the leaves of cultivated species of Vitis, the grape. Lee Connty, Auburn, 1891 (Atkinson).

Cercospora yuccae Cooke.

Cornell Bull. 41.

On leaves of Yucca (Atkinson).

Cercospora zinniae E.\& M.

Ala. Bull. 153. Cornell Bull. 42.

On leaves of Zinnia multiflora. Lee County, Auburn, summer, 1890 (Atkinson).

\section{HETEROSPORIUM Klotzsch.}

Heterosporium gracile (Wallr.) Sacc.

Cornell Bull. 47.

On leaves of Iris sp., in cultivation. August 1, 1891 (Duggar). 
Heterosporium interseminatum (B. \& Br.) Atkinson.

Ala. Bull. 15t, as Heterosporium sambuci Earle, and Helminthosporium interseminatum B. \& Br. Cornell Bull. 48.

On Solidagn canadensis. Lee Comnty, September, 1891 (Atkinson).

On Sambucus canadensis. Lee County, November, 1891 (Atkinson); March, 1896 (Earle).

\section{SPORODESMIUM Link.}

Sporodesmium quadratum Atkinson.

Cornell Bull. 40.

On leaves of Crataegus sp. Montgomery County, Highland Park, October 10, 1891 (Atkinson).

TETRAPLOA Berk. \& Br.

Tetraploa divergens Tracy \& Farle.

Cornell Bull. 48.

On leaves of Panicum elongatum. Lee County, Auburn, October 15, 1891 (Atkinson).

Tetraploa ellisii Cooke.

Cornell Bull. 48.

On culms of Arundinaria tecta. Lee County, Auburn, September 19, 1891 (Inuggar).

Louisiana, New Jersey.

\section{MACROSPORIUM Fr.}

Macrosporium antennaeforme B.\& C.

Grevillea, $3: 105$. Ala. Bull. 155.

On leaves of Celtis (Peters).

Macrosporium brassicae Berk.

Ala. Bull. 155.

On Brasssica oleracea, the cabbage. Washington County, July, 1896 (Underwood).

Macrosporium catalpae E. \& M.

Ala. Bull. 155.

On Catalpa catalpa. Macon County, October, 1896 (Carver).

Macrosporium cheiranthi (Lib.) Fr.

Grevillea, $3: 105 . \quad$ Ala. Bull. 155.

On Rosa sp. (Beaumont).

Macrosporium cookei Sacc.

Ala. Bull. 155. Cornell Bull. 40.

On leaves of Datura 8tramonium. Lee County, Auburn, August, 1891 (Duggar).

Macrosporium iridis C. \& E.

Ala. Bull. 155.

On Iris sp. Lee County, August, 1891 (Duggar).

New Jersey.

Macrosporium leguminum Cooke.

Ala. Bull. 155.

On pods of Vigna catjang. Macon County, August, 1896 (Carver).

Macrosporium pirorum Cooke.

Cornell Bull. 40.

On leaves of Pyrus communis. Montgomery County, Mathews, June 17, 1891 (Atkinson).

Macrosporium nigricantium Atkinson, Bot. Gaz. 16:62. 1891.

Ala. Bull. 155. Cornell Bull. 40.

On leaves of Gossypium herbaceum, the cotton plant. Lee County, 1891 (Atkinson);

Macon County, August, 1896 (Carver). In various parts of the State.

Macrosporium ravenelii Thuem.

Ala. Bull. 155.

On Meibomia mollis. Lee County, March, 1896 (Underwood \& Earle). 
Macrosporium solani F. \&. M.

Cornell Bull. 40.

On decaying red peppers, Capsicum annuum. Lee County, Auburn, summer, 1890 (Atkinson).

Louisiana, New Jersey.

Macrosporium sarcinula Berk.

Cornell Bull. 40.

On decaying fruit of Citrullus vulgaris. Lee County, Auburn, January 20, 1892 (Atkinson).

Macrosporium stilbosporoideum B. \& C.

Grevillea, $3: 105$. Ala. Bull. 156.

On leaves of Crataegus sp. (Beaumont).

TRIPOSPORIUM Corda.

Triposporium elegans Corda.

Cornell Bull. 48.

On leaves of Rubus argutus. Lee County, Auburn, October 30, 1891 (Atkinson).

\section{STYSANUS Coròa.}

Stysanus stemonites (Pers.) Corda.

Cornell Bull. 48.

On decaying rose leaves. Lee County, Auburn, June, 1890 (Atkinson).

\section{Family STILBACEAE.}

STILBUM Tode.

Stilbum arcticum Berk.

Cornell Bull. 48.

On dead Stereum versicolor. Lee County, Auburn (Atkinson).

Stilbum versicolor Pat.

Cornell Bull. 48.

On bird dung. Lee County, Auburn, August 14, 1890 (Atkinson).

\section{ISARIA Pers.}

Isaria radiata $\mathrm{B} . \& \mathrm{C}$.

Grevillea, $3: 62$. Ala. Bull. 156.

On pine wood (Peters).

Isaria verticillata Atkinson.

Cornell Bull. 48.

On underside of leaves of Quercus minor. Lee County, Auburn, November 11, 1891 (Duggar).

\section{- ISARIOPSIS Fr.}

Isariopsis linderae (E. \& E.) Sacc.

Peters coll. 142, as Helminthosporium petersii B.\& C. Ala. Bull. 157.

On Benzoin benzoin (Peters).

\section{Family TUBERCULARIACEAE.}

\section{TUBERCULARIA Tode.}

Tubercularia ailanthi Cooke.

Ala. Bull. 159.

On Juglans regia. Lee County, January, 1896 (Underwood \& Earle).

On Melia azedarach. Lee County, January, 1896 (Underwood \& Earle).

On Ficus carica. Lee County, Jannar, 1896 (Underwood \& Earle). 
Tubercularia vulgaris Tode (?).

Ala. Bull. 159.

On Morus sp., in cultivation. Lee County, January, 1896 (Underwood \&. Earle). Louisiana, New Jersey, Ohio.

\section{ILLOSPORIUM Mart.}

nllosporium minimum E. \& E. Proc. Acad. Nat. Sci. Phila. 1893: 465.1894. Ala. Bull. 159.

On rotten wood (Atkinson).

SPHACELIA Lév.

Sphacelia tripsaci Bornet.

Cornell Bull. 48.

On Tripsacum dactyloides. Hale County, Gallion, September 20, 1894 (Duggar).

VOLUTELLA Tode.

Volutella acalyphae Atkinson.

Cornell Bull. 49.

On stems of Acalypha ostryaefolia. Lee County, Auburn, September 12, 1891 (Newman).

Volutella oxyspora Atkinson.

Cornell Bull. 50.

On decaying cultivated beet. Lee County, Auburn, December, 1890 (Atkinson).

Volutella setosa (Grev.) Berk.

Ala. Bull. 160. Cornell Bull. 49.

On dead stems of various plants. Lee County, Auburn, 1891 (Atkinson).

Volutella tectaecola Atkinson.

Cornell Bull. 49.

On leaves of Arundinaria tecta. Lee County, Auburn, August 15, 1891 (Duggar).

FUSARIUM Link.

Fusarium alabamense Sacc.

Grevillea, 3: 98, as F. erubercens. Ala. Bull. 157.

On dead bark (Beaumont).

Fusarium cinnabarium (B. \& C.) Sacc.

Rav. Fung. Car. Exsic. 3: 80. Grevillea 3: 146, under Fnsisporium. Ala. Bull. 157. On Acer negundo (Peters).

On Carpinus caroliniana (Peters).

Fusarium graminum Corda.

Cornell Bull. 49.

Iu seeds and glumes of living Paspalum dilatatum. Lee County, Auburn, Novem-

ber, 1890 (Atkinson).

Fusarium helotioides B. \& C.

Grevillea, $3: 98$. Ala. Bull. 157.

On Ilex decidua (Peters).

Fusarium marginatum B. \& C.

Grevillea, $3: 97$. Ala. Bull. 158.

On stems of Smilax sp. (Beaumont).

Fusarium miniatum (B. \& C.) Sacc.

Grevillea 3:147. Ala. Bull. 158.

On pine wood (Peters).

On Vitis rotundifolia. Lee County, March, 1896 (Underwood \& Earle).

Fusarium oxysporum Schlecht.

Cornell Bull. 49.

On bolls of Go8sypium herbaceum. Common (Atkinson).

On bark of Melia azedarach. Common (dtkinson). 
Fusarium oxysporum lycopersici Sacc.

Cornell Bull. 49.

On internal portions of fruit of Lycopersicum, the tomato. Lee County, Auburn, 1890 (Atkinson).

Fusarium roseum Link.

Cornell Bull. 49.

On staminate aments of Alnus rugosa. Lee County, Auburn, January, 1890 (Atkinson).

Louisiana, New Jersey.

Fusarium sarcochroum (Desm.) Sacc.

Ala. Bull. 158.

On Melia azedarach. Lee County, August, 1891 (Newman)

Louisiana.

Fusarium solani Mar.

Ala. Bull. 158. Cornell Bull. 48.

On dead tubers of Solanum tuberosum. Limestone County, Athens, 1890 (Newman).

Fusarium ustilaginis K.\& S.

Cornell Bull. 49.

On Ustilago avenae. Lee County, Auburn, 1891 (Atkinson).

Fusarium vasinfectum Atkinson, Bull. Ala. Agr. Exper. Sta. 41:28. 1892.

Ala. Bull. 158. Cornell Bull. 48.

In vascular ducts of stems of Gossypium herbaceum, the cotton plant. Lee County, July, 1891 (Atkinson).

In Hibiscus esculentus (Atkinson.)

The conidial stage of Neocosmospora vasinfecta.

MICROCERA Desm.

Microcera coccophila Desm.

Ala. Bull. 159. Cornell Bull. 49.

On Aspidiotus obscurus, on living branches of Quercus nigra (Q.aquatica). Lee County, Aubarn, November 12, 1891 (Atkinson).

MYROTHECIUM Tode.

Myrothecium verrucaria (Alb. \& Schw.) Ditm.

Grevillea, 3:99. Ala. Bull. 159.

On grass (Beaumont).

New Jersey.

\section{EPICOCCUM Link.}

Epicoccum neglectum Desm.

Cornell Bull. 49.

On dead leaves of Avena sativa, and other hosts. Lee County, Auburn (Atkinson) Louisiana, New Jersey.

\section{Epicoccum vulgare Corda.}

Cornell Bull. 49. son).

On dead portions of leaves of Elymus. Lee County, A uburn, July 5, 1890 (Atkin-

\section{SPEGAZZINIA Sacc.}

Spegazzinia tessarthra (B. \& C.) Sacc.

Ala. Bull. 159.

On Saccharum officinarum. Macon County, August, 1896 (Carver).

Spegazzinia tricophila Atkinson.

Cornell Bull. 49.

On leaves of Rubus argutus (R. villosus). Lee County, Auburn (Atkinson). 


\section{Cerebelua Ces.}

Cerebella andropogonis Ces.

Ala. Bull. 207.

On Erianthus contortus. Macon County, August, 1896 (Carver).

Cerebella paspali Cooke \& Mass.

Ala. Bull. 207. Cornell Bull. 49.

On Paspalum compressum. Leo County, Auburn, August, 1891 (Atkinson); Macon County, October, 1896 (Carver).

Cerebella sorghi Tracy \& Earle, Bull. Torr. Club, 26:494. 1899.

Ala. Bull. 207, as $C$. andropogonis (iu part).

On Chrysopogon avenaceus. Macon County, August, 1896 (Carver).

\section{Order MELANCONIALES. Family MELANCONIACEAE.}

GLOEOSPORIUM Desm. \& Mont.

\section{Gloeosporium fructigenum Berk.}

Ala. Bull.161. Cornell Bull. 37, as G. ampelophagum (Pass.) Sacc.

On Malus malus. Lee County, August, 1891 (Atkinson).

On cultivated species of Vitis, the grape. Lee County, Auburn (Atkinson); Washington Count5, July, 1896 (Earle).

Gloeosporium fusarioides E. \& K.

Cornell Bull. 36 .

On living leaves of Asclepias sp. Lee County, Auburn (Atkinson).

Gloeosporium lagenarium foliicolum E. \& E.

Ala. Bull. 161.

On Citrullus vulgaris. Washington County, July, 1896 (Earle).

Gloeosporium quercinum West.

Cornell Bull. 37.

On leaves of Quercus. Lee County, Auburn, September 4, 1890 (Atkinson).

Gloeosporium septorioides Sacc.

Cornell Bull. 36.

On living leaves of Quercus nigra (Q. aquatica). Lee County, Anburn, August 22, 1892 (Richards).

Gloeosporium serotinum E.\& E.

Cornell Bull. 36.

On leaves of Prunus serotina. Lee County, Auburn, April, 1891 (Atkinson).

Gloeosporium vexans Atkinson.

Cornell Bull. 37 .

On stems of Melilotus alba. Lee County, Auburn, August, 1890 (Atkinson).

\section{COLLETOTRICHUM Corda:}

Colletotrichum cladosporioides (E. \& F.) Atkinson.

Ala. Bull. 160.

On Hypericum mutilum. Lee County, September, 1891 (Duggar).

Colletotrichum gossypii Southworth.

Ala. Bull.160. Cornell Bull. 35.

On the stem, leaves, and fruit of Gossypium herbaceum. Generally distributed throughout the cotton-growing region.

Colletotrichum jussiaeae Earle, Bull. Torr. Club, 24:29. 1897.

Ala. Bull. 160. Cornell Bull. 35.

On leaves of Jussiaea decurrens. Lee County, August 27, 1891 (Atkinson).

Colletotrichum lindemuthianum (Sacc. \& Mag.) Scribner.

Ala. Bull.160. Cornell Bull. 35.

On leaves, stems, and pods of Phaseolus rulgaris. Leo County, Auburu, August 6, 1891 (Nevman). 
Colletotrichum lineola Corda.

Cornell Bull. 35.

On leaves of Sorghum vulgare. Lee Connty, Auburn, July, 1890 (Atkinson).

On dead leaves of Sorghum halepense. Lee County, Auburn, July (Atkinson);

Montgomery County, September 8, 1891 (Atkinson).

Louisiana, New Jersey.

\section{CORYNEUM Nees.}

Coryneum disciforme ellipticum B.\& Br.

Ala. Bull. 160.

On Betula nigra. Lee County, April, 1896 (Underwood \& Earle)

Coryneum microstictum B. \& Br.

Grevillea, $2: 153 . \quad$ Ala. Bull. 160.

On Rosa (Peters).

\section{CYLINDROSPORIUM Unger.}

Cylindrosporium celtidis Earle, Bull. Torr. Club, 24 : 29. 1897.

Ala. Bull. 160. Cornell Bull. 36.

On leaves of Celtis mississippiensis. Montgomery County, Montgomery, November 10, 1891 (Atkinson).

Cylindrosporium gnaphalicolum Atkinson.

Cornell Bull. 36.

On living leaves of Gnaphalium sp. Lee County, July 24, 1891 (Duggar \&. Newman).

Cylindrosporium minor E.\& K.

Cornell Bull. 36.

On leaves of Fraxinus caroliniana ( $F$. platycarpa). Montgomery County, Pikeroad, July 9, 1891 (Atkinson).

Cylindrosporium padi Karst.

Ála. Bull. 160. Cornell Bull. 36.

On Prunus sp., in eultivation. Lee County, July, 1890 (Atkinson).

On leaves of Prunus angustifolia. Perry County, Uniontown, Jnly, 1890 (Atkinson).

On leaves of Prunus serotina. Lee County. Auburn, July 3, 1891 (Atkinson); Macou

County, August, 1896 (Carver).

Louisiana, New Jersey.

Cylindrosporium rubi E. \& E.

Cornell Bull. 36.

On the upper side of leaves of Rubus. Perry County, Uniontown, July 11, 1890 (Atkinson).

Cylindrosporium saccharinum E. \& E.

Ala. Bull. 160. Cornell Bull. 36.

On leaves of Acer rubrum. Lee County, October 14, 1891 (Duggar).

Cylindrosporium steironemae Atkinson.

Cornell Bull. 36.

On leaves of Steironema sp. Lee County, Auburn, May 9, 1892 (Atkinson).

Cylindrosporium ulmicolum E. \& E.

Ala. Bull. 161. Cornell Bull. 36 .

On leaves of Ulmus americana. Lee County, Auburn, October 23, 1891 (Duggar).

PESTALOZzIA De Not.

Pestalozzia annulata B. \& C.

Grevillea, $2: 155$. Ala. Bull. 161.

On Ilex sp. (Beaumont).

Pestalozzia concentrica B. \& C.

Grevillea, 2 : 156. Ala. Bull. 161.

On Crataegus sp. (Beaumont).

On Castanea pumila (Beaumont).

On Cydonia vulgaris. Washington County, July, 1893 (Earle).

South Caronina, North Carolina. 
Pestalozzia clavispora Atkinson.

Cornell Bull. 37.

On fallen leaves of Quercus rubra. (q) Lee County, Auburn, October 3, 1891 (Atkinson).

Pestalozzia flagellata Earle, Bull. Torr. Club, 24:30. 1897.

Ala. Bull. 162. Cornell Bull. 37.

On leaves of Quercus sp. Lee County, Auburn, August, September 26, 1891 (Duggar).

Pestalozzia minuta E. \& E.

Cornell Bull. 37.

On dead limbs of Hicoria ovata. Lee County, January, 1891 (Atkinson).

On bark of Vitis. Lee County, Auburn, February, 1891 (Atkinson).

Pestalozzia stictica B. \& C.

Grevillea, 2:155. Ala. Bull. 162.

On leaves of Tilia sp. (Beaumont).

South Carolina.

Pestalozzia turgida Atkinson.

Cornell Bull. 37.

On dead leaves of Crataegus. Lee County, Auburn, November 1, 1891 (Atkinson).

PESTALOZZIELLA Sacc. \& Ell.

Pestalozziella gossypina Atkinson.

Cornell Bull. 38.

On stems of Gossypium herbaceum. Lee County, Auburn, January 27, 1891 (Atkinson).

\section{MELANCONIUM Link.}

Melanconium oblongum Berk.

Grevillea, 2 : 153. Ala. Bull. 161.

On Juglans cinerea (Peters).

New England, New Jersey.

Melanconium sphaerospermum (Pers.) Link.

Cornell Ball. 37.

On stems of Arundinaria tecta. Lee County, Anburn, September 9, 1891 (Atkinson).

MYXORMIA B. \& Br.

Myxormia atroviridis $\mathrm{B} . \& \mathrm{Br}$.

Grevillea, 3:100. Ala. Bull. 161 .

On decaying bark of Rubus (Beaumont).

SEPTOGLOEUM E. \& E.

Septogloeum profusum (E. \& E.) Tracy \& Earle.

Cornell Bull. 38 .

On living leaves of Ulmus alata. (१) Montgomery County, Pikeroad, July 9, 1891 (Atkinson).

\section{STEGANOSPORIUM Sacc.}

Steganosporium irregulare (B.\& C.) Sacc.

Grevillea, 2 : 154, under Coryneum. Ala. Bull. 162.

On Betula sp. (Beaumont).

\section{Order SPHAEROPSIDALES.}

\section{Family SPHAEROPSIDACEAE.}

\section{PHYLLOSTICTA Pers.}

Phyllosticta acericola C. \& E.

Cornell Bull.31.

On leaves of Acer rubrum. Lee County, Auburn (Atkinson). 
Phyllosticta adusta F. \& M.

Cornell Bull. 31.

On seedling leaves of Citrus limon, the lemon. Lee County, Auburn, October 19, 1889 (Atkinson).

Phyllosticta amaranthi E.\& K.

Ala. Bull. 167. Cornell Bull. 31.

On leaves of Amaranthus retroflexus. Lee County, Auburn, August 5, 1891(Duggar).

Phyllosticta arida Earle, Bull. Torr. Club, $25: 367.1898$.

On Acer negundo. Lee County, Auburn, June 5, 1897 (Earle \& Baker).

Phyllosticta azedarachis Thuem.

Ala. Bull. 167.

On Melia azedarach. Lee County, July, 1891 (Duggar).

Phyllosticta batatae Thuem.

Ala. Bull. 167. Cornell Bull. 31.

On leaves of Ipomoea batatas. Lee County, Auburn, October 4, 1891 (Atkinson).

Macon County, October, 1896 (Carver).

Phyllosticta bumeliae Underwood \& Earle.

Grevillea, $3: 2$, as Sphaeropsis maculans B. \& C.

On leaves of Bumelia (Peters).

Phyllosticta catalpae E. \& M.

Ala. Bull.167. Cornell Bull. 31.

On leaves of Catalpa catalpa. Lee County, Auburn, August 15, 1891 (Atkinson).

Hale County, May, 1896 (Underwood).

New Jersey.

Phyllosticta circumvelata Winter.

Ala. Bull.167. Cornell Bull. 31.

On leaves of Liriodendron tulipifera. Lee County, Auburn, July 18, 1892 (Richard8).

Phyllosticta cruenta Fr.

Ala. Bull. 167.

On Vagnera (Smilacina) racemosa. Winstou County, June, 1896 (Underwood). Lee

County, July, 1896 (Underwood \& Earle).

Phyllosticta glauca Cooke.

Ala. Bull. 167.

On Magnolia virginiana. Lee County, November, 1895 (Underwood).

Phyllosticta gossypina E. \& M. ( ( )

Cornell Bull. 31 .

On dead leaves of Gossypium herbaceum. Lee County, Auburn (Atkinson).

Phyllosticta lactucae Atkinson.

Ala. Bull. 167.

On Lactuca canadensis. Lee County, June, 1891 (Newman).

Phyllosticta leucocarpae Atkinson.

Cornell Bull. 31 .

On leaves of Pyrus sp. Montgomery County, Pikeroad, July 9, 1891 (Atkinson).

Phyllosticta maclurae E. \& E.

Cornell Bull. 31.

On leaves of Toxylon pomiferum (Maclura aurantiaca). Lee County, Auburn, August, 1893, (Duggar).

Phyllosticta macroguttata Earle, Bull. Torr. Club, 25 :367. 1898.

Ala. Bull. 167. Cornell Bull.31. In both as P. desmodii E. \& E.

On Meibomia sp. Lee County, Auburn, June 28, 1892 (dtkinson).

On Meibomia dillenii. August 11, 1897 (Earle \& Baker).

Phyllosticta minima (B.\& C.) Underwood \& Earle.

Grevillea, $3: 2$, under Sphaeropsis. Ala. Bull. 168.

On Acer rubrum. Dekalb County, May, 1896 (Underwood). Lee Connty, May, 1896

(Underwood \& Earle). Winston County, June, 1896 (Underwood).

Now England. 
Phyllosticta phytolaccae Cooke.

Ala. Bull. 168. Cornell Bull. 31.

On leaves of Phytolacca decandra. Lee County, Auburn, July 18, 1892 (Richard8).

Phyllosticta pirina Sace.

Ala. Bull. 168. Cornell Bull. 31.

On leaves of Malus malus, the apple. Lee Countv, Goldhill, September, 1890

(Atkinson). Lee County, July, 1896 (Underwood \& Earle.)

On Pyrus communis. Montgomery Connty, Mathews, June 17, 1891 (Atkinson).

Phyllosticta podophylli (Curt.) Winter.

Ala. Bull. 168.

On Podophyllum peltatum. Dekalb County, May, 1896 (Underwood).

Phyllosticta rhododendri West.

Ala. Bull. 168. Cornell Bull. 31.

On leaves of Azalea nudiflora. Lee County, Auburn, July 18, 1892 (Richard8).

Phyllosticta serotina Cooke.

Ala. Bull. 168.

On Prunus serotina. Lee County, July, 1891 (Duggar).

New Jersey.

Phyllosticta siliquastri Sacc. \& Speg.

Ala. Bull. 168. Cornell Bull. 31.

On leaves of Cercis canadensis. Lee County, Wright's Mill, near Auburn, Augnst

7, 1891 (Duggar \& Newman).

Europe.

Phyllosticta sphaeropsoidea E. \& E.

Ala. Bull. 168.

On Aesculus pavia. Lee County, May, 1896 (Underwood \& Earle). Tuscaloosa County, May, 1896 ( Cuderwood).

Phyllosticta vaccinii Earle, Bull. Torr. Club, $24: 31.1897$.

Ala. Bull. 168.

On Vaccinium arboreum. Lee County, April 25, 1896 (Underwood \& Earle).

Phyllosticta violae Desm.

Cornell Bull. 31.

On Viola tricolor. Lee County, Auburn, January 29, 1891 (Atkinson).

Phyllosticta viticola Thuem.

Ala. Bull. 168.

On Vitis rotundifolia. Lee County, October, 1895 (Undervood).

\section{PHOMA Fr.}

Phoma astericola Atkinson.

Cornell Bull. 30 .

On stems and leaves of Aster. Lee County, Auburn (Atkinson).

Phoma campylospora B.\& C.

Peters coll. No. 113. Ala. Bull. 165.

On Panicum sp. (Peters).

Phoma chartarum B. \& C.

Grevillea, 2:83. Ala. Bull. 165 .

On white paper (Beauniont).

Phoma elongata (B. \& C.) Sacc.

Grevillea, $2: 181$, under Sphacropsis. Ala. Bull. 165.

On cultivated Gladiolus (Peters).

Phoma glandicola (Desm.) Lév.

Ala. Bull. 166.

On old acorns. Lee County, April, 1896 (Underwood of Earle).

India?, Europe.

Phoma gloeosporioides Atkinson.

Cornell Bull. 30.

Ou dead leaves of Quercus digitata. Lee County, Auburn, February, 1890 (Athinson). 
Phoma gossypii Sacc.

Cornell Bull. 30.

On dead stems of Gossypium herbaceum. Lee County, Auburn, January 27, 1891 (Atkinson).

Phoma lathyrina Sacc.

Cornell Bull. 30 .

On stems of Vigna catjang. Lee County, Auburn, October 16, 1889 (Atkinson).

Phoma maculifera Sace.

Grevillea, $2: 83$, as $P$. maculare. Ala. Bull. 166 .

On Doellingeria sp. (Beaumont).

Phoma melaleuca B. \& C.

Grevillea, 2 : 82 . Ala. Bull. 166.

On leaves of Aralia spinosa (Peters).

South Carolina.

Phoma micromegala (B. \& C.) Sacc.

Grevillea $2: 180$, under Sphaeropsis. Ala. Bull. 166.

On naked roots of pine (Beaumont).

Phoma subcircinata E. \& E.

Cornell Bull. 30.

On pods of Phaseolus lunatus, the butter bean. Lee County, Auburn (Atkinson).

MACROPHOMA Ber. \& Vogel.

Macrophoma diospyri Earle, Bull. Torr. Club, 24:30. 1897.

Ala. Bull. 165.

On green fallen fruits of Diospyros virginiana. Lee County, Auburn, July, 1896 (Underwood \& Earle).

SPHAERONEMA Fr.

Sphaeronema corneum E. \& E.

Cornell Bull. 33.

Ou languid leaves of Oenothera laciniata. Lee County, Auburn, July 26, 1891 (Atkinson).

Sphaeronema epigloeum B. \& C.

Peters coll. No. 110. Ala. Bull.171.

On Tremella sp. (Peters).

Sphaeronema spina B. \& Rav.

Grevillea, 2 : 177. Ala. Bull. 171.

On dead leaves of Fraxinus (Beaumont).

South Carolina.

SPHAEROPSIS Mont.

Sphaeropsis cydoniae C. \& E.

On Cydonia. Lee County, Derember, 1897 (Baker).

Now Jersey.

Sphaeropsis maclurae Cooke.

Ala. Bull. 172.

On Toxylon pomiferum. Lee County, March, 1896 (Underwood \& Earle).

VERMICULARIA Fr.

Vermicularia affinis Sacc. \& Briard.

Ala. Bull. 172.

On Panicum virgatum. Lee County, February, 1888 (Newman).

On Sieglingia seslerioides. Lee County, January, 1889 (Newman).

On Sorghum sp. Lee County, July, 1890 (Atkinson).

On Sorghum halepense. Montgomery County, September, 1891 (Atkinson).

Vermicularia circinans Berk.

Cornell Bull. 33.

On Allium in cultivation. Lee County, Auburn (Atkinson).

Pennsylvania, 
Vermicularia dematium (Pers.) Fr.

Grevillea, 3:6. Ala. Bull. 172.

On Phytolacca (Beaumont).

Pennsylvania, New Jersey.

Vermicularia eryngii (Cooke) Fkl.

Ala. Bull. 172.

On dead umbelliferous stem. Lee County, April, 1896 (Underwood \& Earle).

Vermicularia liliacearum Schw.

Ala. Bull. 172.

On Agave virginica. Lee County, July, 1896 (Underwood \& Earle).

Louisiana, Ohio.

Vermicularia sanguinea E. \& Hal.

Ala. Bull. 173.

On Sorghum vulgare, chicken corn. Perry Connty, July, 1890 (Atkinson).

On Sorghum sp., Jerusalem corn. Lee County, October, 1895 (Underwood).

\section{DOTHIORELLA Sace.}

Dothiorella macrospora (B. \& C.) Sacc.

Grevillea, 2 : 181, under Sphaeropsis. Ala. Bull. 164.

On Magnolia virginiana (M. glauca) (Peters).

Pennsylvania.

CYTOSPORA Ehrenb.

Cytospora grandis Peck.

Ala. Bull. 164.

On Rhus sp. Lee County, March, 1896 (Underwood \& Earle).

Cytospora persicae Schw.

Ala. Bull. 164.

On Amygdalus persica. Lee County, September, 1896 (Earle).

DIPLODIA Fr.

Diplodia gossypina Cooke.

Cornell Bull.29.

On old capsules of Gossypium herbaceum. Pike County, Brundidge, September 5, 1891 (Atkinson).

Diplodia herbarum (Corda) Lér.

Ala. Bull. 164. Cornell Bull. 29.

On dead stems of Lactuca sp. Lee County, Auburn, May 1, 1892 (Atkinson).

New Jersey.

Diplodia macrospora Earle, Bull. Torr. Club, 24 : 29. 1897.

Ala. Bull. 164.

On weathered stalks of Zea mays. Lee County, October, March, 1896 (Underwood \& Earle).

Diplodia maura Cooke.

Ala. Bull.164. Cornell Bull.29.

On branches of Pyrus communis. Mobile County, 1890 (Atkinsono). Lee County, 1890 (Atkinson).

New Jersey.

Diplodia maydis (Berk.) Sacc.

Ala. Bull. 164.

On old, withered stalks of Zea mays. Loe County, January, 1896 (Underwood of Earle).

DARLUCA Cast.

Darluca filum (Bir.) Cast.

Grevillea, 2 : 179. Ala. Bull. 164. Cornell Bull. 36.

On tea (Beaumont).

On Puccinia pruni-spinosae (on peach). Lee County, August, 1891 (Duggar).

On Uredo (on Andropogon). Lee County, August, 1891 (Iuggar \& Newman).

Louisiana. New Jersey, Ohio. 
HENDERSONIA Berk.

Hendersonia arundinaceae (Desm.) Sacc.

Cornell Bull. 29.

On dead stems of Chrysopogon avenaceus. Lee County, Auburn, November 1, 1891

(Duggar).

Hendersonia crataegicola Atkinson.

Ala. Bull. 165, as H. cydoniae Cooke \& Ellis. Cornell Bull 30.

On leaves of Crataegus flava. Lee Comnty, Auburn, August, 1890 (Atkinson).

Hendersonia erianthi Atkinson.

Ala. Bull. 165, as H. donacis Sace. Cornell Bull. 29.

On dead stems of Erianthus. Lee County, November 12,1891 (Duggar).

Hendersonia effusa B. \& C.

Ala. Bull. 165. Cornell Bull. 29.

On blades of Aristida purpurascens minor. Lee County, Auburn, October 11, 1891 (Atkinson).

Hendersonia officinalis Atkinson.

Cornell Bull. 29.

On dead leaves of Sassafras sassafras. Lee County, Auburn, July 29, 1891 (Duggar).

\section{PROSTHEMIUM Kunze.}

Prosthemium palmatum Earle, Bull. Torr. Clul, 24:31. 1897.

Ala. Bull. 168.

On rotten wood. Lee County, Auburn, March 28, 1896 (Underwood \& Earle).

STAGONOSPORA Sacc.

Stagomospora ischaemi Sacc.

Ala. Bull. 172.

On Andropogon furcatus. Lee County, September, 1891 (Duggar).

Stagonospora paspali Atkinson.

Cornell Bull. 33.

On Sieglingia seslerioides. Lee Connty, Wright's Mill, July 11, 1891 (Duggar).

On leaves of Paspalum laeve. Lee County, Auburn, July 18, 1891 (Atkinson).

\section{SEPTORIA Fr.}

Septoria alabamensis Atkinson, Journ. Elisha Mitch. Soc. 10:78. 1894.

Ala. Bull.169. Cornell Bull. 33.

On living leaves of Glechoma hederacea. Lee County, Auburn, January 29, February 27,1891 (Atkinson).

Septoria albo-nigra B. \& C.

Grevillea, 3:8. Ala. Bull. 169.

On living leaves (Peters).

Septoria bromi Sacc. $(q)$

Cornell Bull. 32.

On leaves of Elymus. Lee County, Auburn, July 5, 1890 (Atkinson).

Septoria brunellae E. \& H.

Ala. Bull. 169. Cornell Bull. 32. Journ. Elisha Mitch. Soc. 10:76. 1894.

On Prunella vulgaris. Montgomery County, Shorter, July 16, 1890 (Atkinson).

Septoria cacaliae E. \& K.

Ala. Bull. 169.

On Mesadenia (Cacalia) tuberosa. Lawrence County, June, 1896 (Underwood).

Septoria cerasina Peck.

Ala. Bull. 169.

On Prunus sp. Lee County, July, 1891 (Newman). 
Septoria cerastii Rob. \& Desm.

Ala. Bull. 169. Cornell Bull. 32.

On dead or languid leares of Cerastium arvense. Lee County, Auburn, March 25, 1891 (Atkinson).

On Cerastium viscosum. Lee County, March, 1896 (Underwood \& Earle).

Septoria confusa Atkinson.

Cornell Bull. 33.

On leaves of Jussiaєa leptocarpa. Lee County, Auburn, August 24, 1891 (Duggar \& Newman).

\section{Septoria dianthi West.}

Ala. Bull.170. Cornell Bull.32.

On cultivated Dianthus barbatus. Lee County, Auburn, March 20, 1891 (Atkinson).

Septoria erechtites E. \& E.

Ala. Bull.170. Cornell Bull. 32.

On Erechtites hieracifolia. Lee County, Auburn, September 10, 1891 (Duggar).

Septoria fraxini Desm.

Cornell Bull.33.

On living leaves of Fraxinus caroliniana ( $F$. platycarpa). Montgomery County, Pikeroad, July 9, 1891 (Atkinson).

Septoria galiorum Ellis.

Cornell Bull.31.

On dead stems of Houstonia patens. Lee County, Auburn, Febrnary 16. 1890 (Atkinson).

\section{Septoria graminum Desm.}

Ala. Bull. 170. Cornell Bull. 32 .

On Syntherisma (Panicum) sanguinale. Lee County, Auburn, August 29, 1891 (Atkinson).

New Jersey, Ohio.

\section{Septoria lactucae Pass.}

Cornell Bull. 32.

On leaves of Lactuca leucophaea. Lee County, Auburn, June 26, 1891 (Neroman).

Septoria lepidiicola E. \& M.

Cornell Bull.31.

On leaves of Lepidium virginicum. Lee County, Auburn, February 9, 1890 (Athinson).

Septoria neglecta Earle, Bull. Torr. Club, 24 :31. 1897.

Ala. Bull. 170.

On persistent living leaves of Quercus phellos. Lee County, Auburn, February, March, April, 1896 (Underwood \& Earle).

Septoria oenotherae West.

Ala. Bull. 170. Cornell Bull. 32.

On Oenothera laciniata. Lee County, March, 1896 (Underwood \& Earle). Lee County, Auburn (Atkinson).

Septoria pulchella B. \& C.

Grevillea, 3:8. Ala. Bull. 170.

On leaves of Andromeda (Peter 8 ).

Septoria rubi West.

Ala. Bull. 170. Cornell Bull. 32.

On leaves of cultivated Rubus. Lee County, Auburn, August 8, 1890 (Atkinson).

On Rubus sp. Dekalb County, May, 1896 (Underwood).

Septoria rubi alba Peck.

Ala. Bull. 170. Cornell Bull. 32 .

On living leaves of Rubus trivialis. Mobile County, April, 1891 (Zimmer Brother 8 ).

Lee County, Auburn (Atkinson).

Septoria sambucina Peck.

Ala. Bull. 171. Cornell Bull. 32 .

On Sambucus canadensis. Lee Connty, Auburn, August 24, 1891 (Duggar).

Louisiana. 
Septoria secalis Prill. \& Delacr.

Ala. Bull. 171.

On Secale cercale. Lee County, April, 1896 (Underwood \& Earle).

Septoria sonchifolia Cooke.

Cornell Bull. 32.

On leaves of Sonchus oleraceus. Lee County, Auburn, 1892 (Atkinson).

Septoria sonchina Thuem.

Ala. Bull. 171. Cornell Bull. 32.

On living leaves of Sonchus oleraceus. Lee County, Auburn, February 25, 1891 (Benton).

Septoria speculariae B. \& C.

Ala. Bull.171. Coruell Ball. 32 .

On Legouzia perfoliata. Lee County, Auburn, March 28, 1890 (Atkinson).

South Carolina.

Septoria stigma B. \& C.

Grevillea, 3:9. Ala. Bull. 171.

On leaves of Symplocos (Peters).

Septoria symploci E. \& M.

On Symplocos. Lee County, June, 1897 (Earle \& Baker).

Septoria verbascicola B. \& C.

Ala. Bull. 171.

On Verbascum blattaria. Madison County, May, 1896 (Underwood).

Septoria violae West.

Ala. Bull. 171. Cornell Bull. 32.

On Viola primulaefolia. Macon County, Shorter, July 16, 1890 (Atkinson).

Louisiana, Ohio.

Septoria virgaurea Desm. ( $\%)$

Ala. Bull. 171. Cornell Bull. 32.

On Solidago serotina. Lee County, Auburn (Atkinson).

Septoria xanthii Desm.

Ala. Bull. 171. Cornell Bull. 32.

On Xanthium sp. Perry County, Uniontown, Jnly 11, 1890 (Atkinson).

Septoria sp.

Bull. 'Torr. Club, $25: 368$.

On Silene virginica. Lee County, Auburn, May 29, 1897 (Earle \& Baker).

RHABDOSPORA Mont.

Rhabdospora verrucaeformis (B. \& C.) Sacc.

Grevillea, 3 : 11, under Septoria. Ala. Bull. 169.

On branches of Cephalanthus (Peters).

PHLYCTAENA Desm. \& Mont.

Phlyctaena gossypii Sacc.

Cornell Bull. 30.

On dead stems of Gossypium herbaceum. Lee County, Auburn, Jannary 27, 1891 (Atkinson).

Phlyctaena vagabunda Desm.

Grevillea, 2 : 100 . Ala. Bull. 165.

On stems of Phytolacca (Beaumont).

SPORONEMA Desm.

Sporonema camelliae Earle, Bull. Torr. Club, 24:32. 1897.

Ala. Bull. 172.

On living leaves of Camellia japonica. Lee County, Auburn, March, April, 1896 (Burton).

Sporonema ilicis Earle, Bull. Torr. Club, 24 :32. 1897.

On languishing leaves of Ilex opaca. Lee County, December, 1895 (Underwood); January, February, March, 1896 (Underwood \& Earle). 
PHLEOSPORA Wallr.

Phleospora anemonis E. \& $\mathrm{K}$.

On Anemone virginica. Chambers County, June, 1897 (Earle).

\section{Family ZYTHIACEAE (Nectrioidaceae).}

\section{STAGANOPSIS Sacc.}

Staganopsis pallida (B. \& C.) Sacc.

Grevillea, 3:6, under Hendersonia. Ala. Bull. 173.

On Cornus (Peters).

\section{Family LEPTOSTROMATACEAE.}

\section{PIGGOTIA B. \&. C.}

Piggotia fraxini B. \& C.

Ala. Bull. 174. Cornell Bull. 35.

On Fraxinus sp. Lee County, Auburn, autumn, 1890 (Atkinson). Lee County, November, 1895 (Underwood).

Pennsylvania.

\section{MELASMIA Lév.}

\section{Melasmia acerina Lév.}

Ala. Bull. 174. Cornell Bull. 34 .

On living leaves of Acer rubrum. Lee County, Auburn, September 15, 1891 (Atkinson).

Texas.

Melasmia gleditschiae E. \& E.

Ala. Bull. 174, as Leptostroma hypophyllum B. \& Rav. Cornell Bull. 35.

On leares of Gleditsia triacanthos. Lee County, Auburn, autumn, 1889 (Atkinson).

Lee County, November, 1895 (Underwood).

Louisiana, Ohio.

Melasmia quercuum Atkinson.

Cornell Bull. 34 .

On leaves of Quercus phellos. Lee County, Anburn (Atkinson).

Melasmia setariae Atkinson.

Cornell Bull. 34.

On Chaetochloa (Setaria) glauca. Lee County, Auburn, September 27-29, 1891 (Atkinson).

\section{DISCOSIA Lib.}

Discosia artocreas (Tode) Fr.

Grevillea, 3:6. Peters coll. Ala. Bull.173. Cornell Bull.34.

()n Aralia spinosa (P'eters).

On Fagus (Beaumont).

On Ilex (Beaumont).

On dead leaves of Prunus serotina. Lee County, Aubnrn, July 31, 1891 (Duggav').

On leaves of Acer rubrum. Lee County, July 22, 1891 (Atkin8on).

Discosia fagina Lib.

Grevillea, 3: 7. Ala. Bull. 173.

(Beaumont.)

Discosia minima B. \& C.

Grevillea, 3: 7. Ala. Bull. 173.

On leaves of Mlex sp. (Beaumont).

On Ilex opaca. Lee County, July, 1896 (Underwood \& Earle).

Discosía rugulosa (B. \& C.).

Grevillea, 3:7. Peters coll. 1, 1855. Ala. Bull. 173. Cornell Bull.34.

On leaves of Hicoria (Peter's)

On Hicoria ovata. Lee County, July, 1891 (Nerman). 


\section{ENTOMOSPORIUM Lév.}

Entomosporium maculatum Lev.

Ala. Bull.174. Cornell Bull.34.

On living leaves of Cydonia vulgaris. Lee County, Gold Hill, September, 1890 (Atkinson). Washington County, July, 1896 (Earle).

On a cultivated species of Amelanchier. Lee County, July, 1896 (Underwood \& Earle).

\section{IEPTOSTROMELLA SAcc.}

Leptostromella filicina (B.\& C.) Sacc.

Grevillea, 2: 84, under Cryptosporium. Ala. Bull. 174.

On dead ferns (Peters).

Pennsylvania.

LEPTOTHYRIUM Kunze \& Schum.

\section{Leptothyrium dryinum Sace.}

Ala. Bull. 174. Cornell Bull. 34.

On living leaves of Castanea pumila. Lee County, August 11, 1890 (Atkinson).

On leaves of Hicoria alba. Lee County, July 24, 1891 (Duggar \& Newman).

On Nys8a sylvatica. Lee County, 1892 (Richards).

Leptothyrium lychnidis B. \& C.

Grevillea, 2:83. Ala. Bull. 174 .

On Lychnis flos cuculi ${ }^{1}$ (Peters).

Leptothyrium cylindrium Atkinson.

Cornell Bull. 34 .

On leaves of Arundinaria tecta. Lee County, Auburn, autumn, 1889 (Atkinson).

\section{Family EXCIPULACEAE.}

\section{AMEROSPORIUM Speg.}

Amerosporium oeconomicum Ell. \& Tracy.

Ala. Bull. 175. Cornell Bull. 33.

On Vigna catjang. Lee County, Auburn, July 22, 1890 (Atkinson); October 1, 1891 (Duggar).

DOTHICHIZA Lib.

Dothichiza serotina Atkinson.

Cornell Bull. 33.

On leaves of Prunus serotina. Lee Connty, Auburn (Atkinson).

SCHIZOTHYRELLA Thuem.

Schizothyrella hysteroides Atkinson.

Cornell Buil. 33.

On dead culms of Chrysopogon arenaceus. Lee Connty, Auburn, November 1, 1891 (Duggar).

'This host belongs undoubtedly to another species, Lychnis flos-cuculi not being known from Alabama. (Mohr.) 
Geographical distribution of the fungi of Alabama.

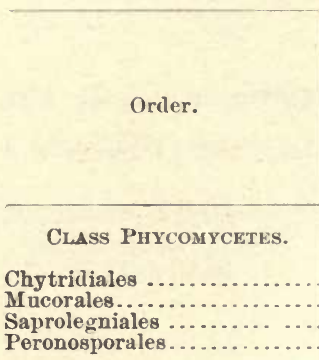

\section{Entomophthorales}

\section{Chass Ascomycetes.}

Exoascales.

Helvellales.

Pezizales

\section{Phacidiales}

Hysteriales

Plectascales

Perisporiales

Hypocreales

Dothideales

Sphaeriales.

\section{Class Basidiomycheses.}

Ustilaginales

Uredinales

A uriculariales

Tremellales

Dacryomycetales.

Exobasidiales.
Synchytriaceae.. Mucoraceae ......

Saprolegniactao .. Albuginaceae.... Peronosporaceae. Entomophthora. ceae.

Exoascaceav...... Geoglossaceae .... Helvellaceae......

Rhizinaceae .......

Pezizaceae........

Ascobolaceae ....

Helotiaceae.......

Mollisiaceae ......

Celidiaceae .......

Patellariaceae ...

Cenangiaceae....

Stictidaceae ......

Tryblidiaccae.... Phacidiaceae .... Hypodermataceae Dichaenaceae..... Hysteriaceae .... Acrospermaceae.. Asper gillaceae....

Erysibaceae..... Perisporiaceae.... Microthyriaceae. Hypomycetaceae. Melanosporaceae. Nectriaceae Hypocreaceae Clavicinitaceae ... Dothideaceac.... Chactomiaceae

Sphaeriaceae ....

Ceratostomataceae Cucurbitariaceae A mphisphaeriaceae

Lophios to mata. ceae.

Mycosphaerellaceac.

Pleosporaceae

Massariaceae....

Gnomoniaceae.

Cly peosphaeria ceae.

Valsaceae.

Melanconidiaceae

Diatrypaceae .....

Melogrammata ceae.

Xylariaceae

Ustilaginaceae

Tilletiaceae

Melampsoraceue.

Pucciniaceae....

Auriculariaceae.

Pilacraceae.......

'rremellaceae....

Dacryom ycetaceae

Exobasidiaceae ...

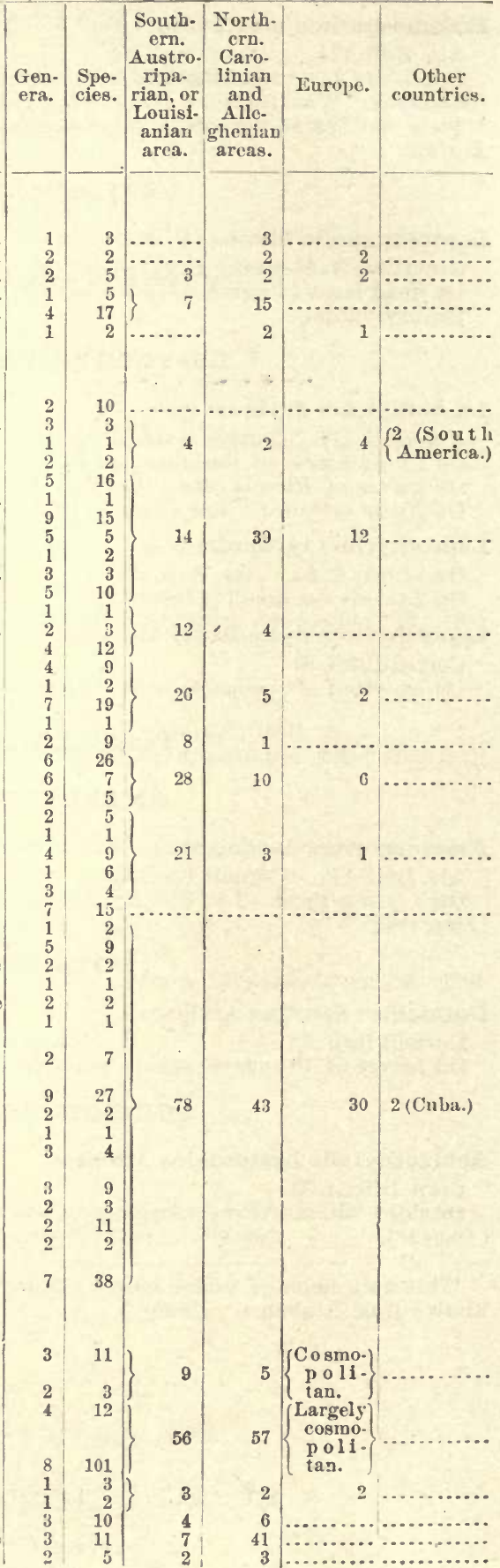


Geographical distribution of the fungi of Alabama--Continued.

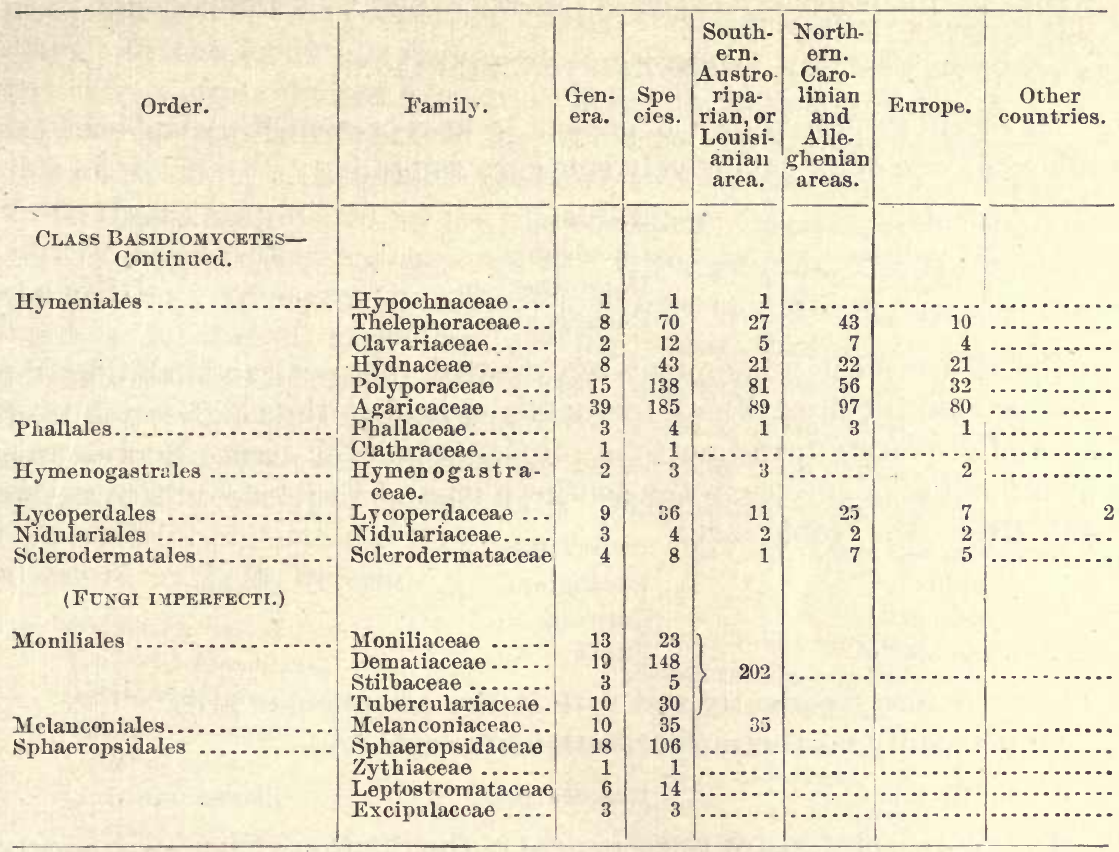

SUMMARY.

Classes, 4. Orders, 30. Families, 80. Genera, 352. Species, 1,385. Of a more southern distribution from the Louisianian to the Carolinian area, 761 species. Of a more northern distribution to the Alleghenian area, 507 species. In conmon with Europe, 212 species.

\section{LICHENS.}

Thanks to the efforts of the late Messrs. Thomas M. Peters of Moulton and Joseph F. Beaumont of Conecuh County, the lichens of northern Alabama and of the upper part of the Maritime Pine belt in the southern section of the State have become well known. These enthusiastic explorers of its cryptogamic flora communicated the results of their field work to Professor Tuckerman. In the Genera Lichenum (1872) and in the Synopsis Lichenum (1882), this author credited 223 species and 2 varieties to the above collectors. Fully one-half of this number are contained in the collection of lichens made by the Honorable Judge Peters, which he presented to the University of Alabama. The lichens collected by the writer in Mobile and Baldwin counties (early in the seventies) have been identified by Mr. Henry Willey of New Bedford and Miss Maria Wilson, and the collections made in later years in the different parts of the State have been examined by Miss Clara E. Cummings of Wellesley College, who has also kindly undertaken the revision of the catalogue of Alabama lichens, for which assistance the writer expresses here his thanks. Lately an interesting contribution to our knowledge of Alabama lichens has been made by the biological survey of Alabama, consisting of 74 species, mostly from 
the vicinity of Auburn, which were kindly placed at the service of the writer by the collectors, Profs. F. S. Earle and Carl Baker.

\section{GENERAI，DISTRIBUTION.}

Of the 49 genera known at present to be represented in Alabama, the following are of an exclusively southern range:

$\begin{array}{lll}\text { Strigula.' } & \text { Glyphis. } & \text { Gyrostomum. } \\ \text { Pyrenastrum. } & \text { Chiodecton. } & \text { Thelotrema. } \\ \text { Lecanactis. } & \text { Heterothecium. } & \\ \text { Trypethelium. } & \text { Coenogonium. } & \end{array}$

These are most numerously represented by species inhabiting the Louisianian life area, which frequently extend to the neighboring tropies and are rarely found north of the Carolinian life area. Represented by a number of species in the southern part of Eastern North America and also in the tropies are:

$\begin{array}{lll}\text { Graphis. } & \text { Leptogium. } & \text { Pyxine. } \\ \text { Pyrenopsis. } & \text { Collema. } & \\ \text { Omphalaria. } & \text { Sticta. } & \end{array}$

These are also frequently met with in the Alleghenian area.

Of decidedly northern distribution are such as-

Verruearia. Rhizocarpon. Placodium.

The representatives of these genera in the Southern States are mostly confined to the mountain region. Elsewhere they are widely scattered from the cooler temperate to the frigid zones and the cooler regions of the Old World.

The following are more or less equally distributed throughout the cooler and warmer zones, and many of them have numerous representatives in corresponding regions of the Old World:

$\begin{array}{lll}\text { Pyrenula. } & \text { Rinodina. } & \text { Cetraria. } \\ \text { Arthonia. } & \text { Leptogium. } & \text { Physma. } \\ \text { Opegrapha. } & \text { Collema. } & \text { Physcia. } \\ \text { Buellia. } & \text { Lecanora. } & \text { Parmelia. } \\ \text { Biatora. } & \text { Placodium. } & \text { Evernia. } \\ \text { Baeomyces. } & \text { Heppia. } & \text { Ramalina. } \\ \text { Gyalecta. } & \text { Pannaria. } & \text { Usnea. } \\ \text { Pertusaria. } & \text { Peltigera. } & \end{array}$

Up to the present 198 species and 26 varieties of lichens have been recognized in Alabama.

\section{REGIONAL DISTRIBUTION.}

Although generally of a wide distribution, the greater number of species and varietal forms of these lowly plants are more or less strictly confined to the several life areas with their floral regions, which share the State. Nearly one-half ( 48.6 per cent) are confined within the limit 
of the warmer temperate zone or the Carolinian and Louisiauian life areas, one-half of this proportion having their home exclusively in the latter. In the mountain region on the ridges of greatest elevation a vertically sharply limited rupestrian lichen formation is met with. At an elevation approaching 2,000 feet the bare Carboniferous sandstone cliff's or the flinty metamorphic rocks which form the brow and summit of the ridges are covered by the black thallus of Umbilicaria pustulata (variety papulosa) not encountered at a lower altitude. Judge Peters, who had been collecting in a section of the mountain region with the highest point scarcely exceeding 1,600 feet, stated that he had not found an Umbilicaria in Alabama. Ashy-gray Endocarpons (E.muhlenbergii), lead-colored saxicole Pannarias, and the white and light-gray incrustations of Verrucarias and Lecanoras invest the rocky crests of these heights with a coating of various tints. The following have been found to prevail throughout the mountain region, having been collected on sandstone by T. M. Peters:
Biatora rufonigra.
Nephroma helveticum.
Lecanora rubina.
Lecanora privigna.
Lecanora cinerea.
Lecanora muralis.
Rinodina thomeae.
Cladonia caespiticia.
Cladonia squanosa.
Cladonia fimbriata.

Collected on limestone:

\begin{abstract}
Pannaria crossophylla.
Pannaria triptophylla.

Pertusaria sorediata.

Physcia obscura.

Leptogium lacerum.

Leptogiun apalachense.

Leptogium pulchellum.

Leptogium juniperinum.

Leptogium myochroum.

Collema callibotrys.
\end{abstract}
Staurothcle disfractella.
Staurothele petersii.
Verrucaria rupestris purpurascens.
Sagedia fuscella.
Placodium aurantiacum.
Placodium ferrugineum.
Omphalaria symphorea. Omphalaria girardi. Omphalaria umbella. Omphalaria melambola. omphalaria schaereri. Collema pustulatun.

Collema tenax and a few other collemaceous lichens, like Pannaria stenophylla, P. petersii, and Heppia despreauxii, prefer the somewhat sheltered, moss-covered rocky shelves, where there is a slight accumulation of earth. These lime-loving lichens are also found in the adjacent valleys on the outcrops of the mountain limestone. In the shallow rocky beds of brooks all over the Warrior table-land, at an elevation of 900 to 1,000 feet, Ephebe pubescens is abundant, where also on the wet rocks of the banks of the head waters of the Sipsey River (Winston County) Endocarpon fuviatile and Lecanora lacustris occur. The ledges of the ferruginous sandstone or conglomerates crowning the crests and flanks of the Orange sand throughout the Coast Pine belt are covered with the black crusts of Lecanora xanthophana.

In the Coast Pine belt, and particularly in the damp Coast plain, lichens abound. The hammocks and wooded swamps which border the 
pine-barren streams are inhabited by a formation of bark lichens, which have their filmy thallus more or less deeply embeduled in the smooth bark of hollies, wax myrtles, magnolias, and red bay (Persea), such being the favorite sites of Glyphis achariana, a large array of species of Arthonia and Graphis, Opegrapha tribulodes, nearly every one of the species Trypethelium and Thelotrema enumerated in the catalogue, and most of Pyrenula, also of-

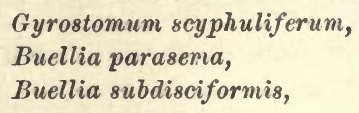

all of a strictly southern distribution. Species with a more developed crustaceous, granular, or agglutinated foliaceous thallus, particularly the Southern Heterotheciums, prefer in similar localities the rough bark of old trees. Such are:

\footnotetext{
Heterothecium leucoxanthum. Heterothecium pachycheilum. Heterothecium domingense. Heterothecium tuberculosum. Pertusaria sp. Collema nigrescens leioplaca.
}

\section{Buellia subpostumum, Biatora suffusa-}

Pannaria molybdaea.

Pannaria nigrocincta.

Physcia crispa.

Pyxine sorediata.

Pyxine picta.

The rough bark of hoary live oaks and of the laurel oak, frequently covered with mosses, is also inhabited by-

Chiodecton rubricinctum.

Sticta aurata.

At the base and on the roots of the live oak near the damp ground abound among mosses the webby clusters of the filamentous alga-like thallus of Coenogonium interpositum. In more open and drier situations the trunks and limbs of smaller trees are the home of-

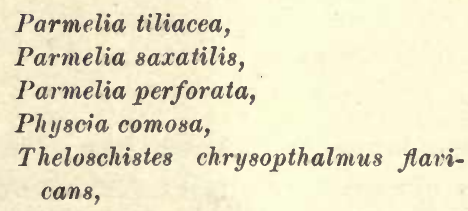

Ramalina laevigata, Ramalina calicaris, Cetraria fendleri, Usnea barbata-

the last in its several varietal forms.

In the humid coast plain lichens inhabiting dead wood are frequent, such as-

Lecanora punicea.

Lecanora subfusca.

Lecanora pallida.
Lecanora varia.

Rinodina favonigella.

Calicium albo-nigrum.

The most sterile patches of loamy sand are frequently covered with-

Cladonia leporina,

Cladonia mitrula,
Cladonia rangiferina alpestris, Baeomyces roseus;

and in shady woods, on decaying stumps and rotten trunks, Cladonia pulchella and Cladonia gracilis are common. 
The following not having hitherto been reported from any other State can be considered as endemic to Alabama:

$\begin{array}{ll}\text { Trypethelium catervarium. } & \text { Pannaria stenophylla. } \\ \text { Omphalaria umbella. } & \text { Staurothele petersii. } \\ \text { Pyrenopsis melambola. } & \text { Graphis solecites. }\end{array}$

\section{LICHENES. ${ }^{1}$ Lichens.}

\section{Family VERRUCARIACEAE.}

\section{Tribe VERRUCARIEAE.}

STRIGULA Fr

Strigula complanata (F́́e. \& Mont.) Nyl.

On leaves of Magnolias.

Louisianian area. Texas to Florida.

\section{PYRENULA Ach.}

Pyrenula thelaena (Ach.) Tuck.

On barks. Mountain region. Lee County, Auburn (Baker \& Earle).

Lawrence County ('Peter's).

Carolinian and Allegheniau areas. South Carolina, North Carolina, and Massachusetts.

Pyrenula punctiformis (Ach.) Naeg. \& Hepp.

On trunks. Mobile County.

Louisianian to Alleghenian area. South Carolina to Now Jersey, New England, and Canada. Europe.

Pyrenula quinqueseptata ( $\mathrm{Nyl}$.) Tuck.

Bark of Ilex. Southeru Alabama (Beaumont).

Louisianian area. South Carolina.

Pyrenula cinchonae (Ach.) Tuck.

On barks. Southern Alabama (Beaumont), Mobile County. Tennessee Valley (Peters).

Louisianian and Carolinian areas. Texas to South Carolina.

Pyrenula tropica (Ach.) Tuck.

Barks. Tennessee Valley (Peters).

Louisianian and Carolinian areas. Louisiana to South Carolina.

Pyrenula aggregata Fée.

On trunks. Conecuh County (Beaumont).

Louisianian area. Texas to Sonth Carolina.

Pyrenula glabrata (Ach.) Mass.

On trunks. Mobile County. Lee County, Auburn (Baker \& Earle).

Louisianian to Alleghenian area. North to New Jersey, Pennsylvania.

Pyrenula mamillana santensis (Tuck.) Nyl.

On barks. Tennessee Valley. Moulton, Conecuh County (Beaumont).

Louisianian and Carolinian area. South Carolina.

Pyrenula nitida Ach.

On bark of Magnolia virginiana, Myrica, etc. Mobile County, common. Lee

County, Auburn (Baker \& Earle). Law rence County, Moulton (Peters).

Louisianian to Alleghenian area. Throughout the Middle and Northern States to New England. Europe.

${ }^{1}$ Without expressing an opinion on the proper grouping of this class of plants, under the yet prevailing uncertainty in egard to their place in the natural system, the writer has in their arrangement followed Dr. Tuckerman. 
Pyrenula nitida nitidella Floerk.

On bark. Conecuh County, Brooklyn (Beaumont).

Louisianian area. Texas to Sonth Carolina. West Europe.

Pyrenula pachycheila Tuck.

On bark. South Alabama (Beaumont).

Louisiana area. Texas to South Carolina.

\section{VERRUCARIA Pers.}

Verrucaria fuscella (Turn.) Ach.

Cherty rocks. Lawrence Connty, Moulton (Peters).

Carolinian and Alleghenian areas. New England. Europe.

Verrucaria rupestris purpurascens Schaer.

Mountain region on limestone rock (Peters).

Carolinian area.

PYRENASTRUM Eschw.

Pyrenastrum astroideum (Fée.) Eschw.

Barks. South Alabama (Beaumont).

Lonisianian area. Texas to South Carolina.

SAGEDIA Fr.

Sagedia cestrensis Tuck.

On cherty rocks. Lawrence County (Peters).

Lonisianian to Alleghenian area. Louisiana, South Carolina, and North Carolina, to Pennsylvania and New England.

\section{TRYPETHELIUM Spreng.}

Trypethelium cruentum Mont.

On bark of magnolias, live oak, etc., in low, damp woods. Mobile County, common. 'Tennessee Valley (Peter's).

Louisianian and Carolinian areas. Mississippi to North Carolina and New Jersey. Tropical America.

Trypethelium scoria Fée.

On barks. Mobile Connty. Conecuh Connty (Beaumont). In damp woods.

Louisianian area. Mississippi to North Carolina.

Trypethelium catervarium (Fée.) Tuck.

Barks. Conecuh County (Beaumont).

Trypethelium scorites ('Tuck.) Nyl.

On hornbeam and Ilex. Mobile County. Conecuh County (Beaumont). Lee

County, Auburn (Baker \& Earle). Endemic.

Louisiauiau and Carolinian areas. To North Carolina.

Trypethelium exocanthum Tuck.

On barks. Conecuh County (Beaumont).

Louisianian area. Louisiana to western Florida.

Trypethelium virens Tuck.

Conecuh County (Beaumont).

Louisianian to Alleghenian area. To South Carolina, Virginia, Ohio, and New England.

Tryphthelium mastoideum Ach.

On bark. Mobile County, Citronelle (Baker).

Louisianian arca.

\section{STAUROTHELE Norm.}

Staurothele petersii Tuck.

Peters coll. No. 1.

On rocks. Lawrence County, Campbell's Gap (Peters). Endemic.

Staurothele diffractella (Nyl.) Tnck.

Mountain region. On limestone rocks. Lawrence County (Peters).

Carolinian and Allegheuian areas. North to New Jersey and New England. 
SEGESTRIA Fr.

Segestria nucula Fr.

On barks. Southern Alabama (Beaumont).

Louisianian area. South Carolina.

\section{Tribe ENDOCARPEAE.}

\section{ENDOCARPON Hedw.}

Endocarpon miniatum (L.) Schaer.

Mountain region. On limestone rocks. Lawrence County (Peters).

Carolinian and Alleghenian areas. North to New England and Canada. Europe.

Endocarpon miniatum aquaticum Schaer. E. fluviatile DC.

Mountain region, damp rocks, low banks of brooks. Lawrence County (Peters).

Carolinian and Alleghenian areas. North to North Carolina, New Jersey, New England. Europe.

Endocarpon miniatum muhlenbergii Ach.

Mountain region. Winston County (Peters).

Carolinian and Alleghenian areas. Mountains of Mexico, Pennsylvania.

Endocarpon arboreum Schw. E. tuckermanii Mont.

Monntain region. Lawrence County (Peters).

Louisianian to Alloghenian area. South Carolina to New England.

\section{Family CALICIACEAE.}

\section{Tribe CALICIEAE.}

\section{CALICIUM Pers.}

Calicium melanophaeum (Pers.) Ach.

On dead wood of red cedar. Mountain region. Lawrence County, Moulton (Peters).

Europe.

Calicium albonigrum $\mathrm{Nyl}$

On dearl wood. Conecuh County (Beaumont).

Louisianian to Alleghenian area. Texas, New York, Massachusetts, California.

\section{Family GRAPHIDACEAE.}

\section{Tribe ARTHONIEAE.}

ARTHONIA Ach.

Arthonia cinnabarina (DC.) Wallr.

On various barks, Tennessee Valley. Lawrence County (Peters).

Louisianian aud Carolinian areas. Texas, Lonisiana to South Carolina, western New York. Europe.

Arthonia rubella (Fée) $\mathrm{Nyl}$.

On barks. Conecuh County (Beaumont). Mobile County.

Louisianian and Carolinian areas. Texas to South Carolina. Europe.

Arthonia taediosa Nyl.

On Ilex and wax myrtle. Mobile County. Conecuh County (Beaumont).

Louisianian to Alleghenian area. South Carolina, Massachusetts.

Arthonia spectabilis Flot.

Mountain region, on various barks. Lawrence County (Peters).

Carolinian to Alleghenian area. Virginia to New England and Ohio. Europe.

Arthonia complanata Fée.

Tennessee Valley. On barks, Lawrence County (Peters).

Carolinian area. South Carolina. South America. 


\section{Tribe GLYPHIDEAE.}

GLYPHIS Ach.

Glyphis achariana Tuck.

On barks, in swamps. Mobile County, frequent. Lawrence County, Moulton (Peters).

Louisianian and Carolinian areas. Texas to Florida, North Caroliua. South America, Brazil.

\section{CHIODECTON Ach.}

Chiodecton rubrocinctum (Ehrh.) Nyl.

In hammocks on live oaks and Magnolia. Mobile County, frequent.

Louisianian area. Mississippi to Florida. South America.

Chiodecton montagnei Tuck. C. lacteum Munt.

On live oaks. 'Mobile County.

Louisianiau area. Cuba.

\section{Tribe OPEGRAPHEAE.}

GRAPHIS Ach.

Graphis scripta Ach.

On bark. Common everywhere.

Louisianian to Alleghevian area. Throughout the Eastern States and Canada. Europe.

Graphis dendritica Ach.

On barks over the State. Mobile County, Conecuh County (Beaumont). Lawrence County (Peters).

Louisianian to Alleghenian area. Texas and Louisiana to Florida and South Carolina and along the coast to New England. Tropical America.

Graphis scalpturata Ach.

Barks. Conecuh County (Beaumont).

Louisianian and Carolinian areas. Louisiana, New Jersey. Tropical America.

Graphis solecites Tuck.

Bark. Conecuh County (Beaumont). Endemic?

Graphis striatula (Ach.) Nyl.

On barks. Mobile County (Mohr); Citronelle (Baker).

Louisianian area. South Carolina. Tropical America.

Graphis elegans (Sm.) Ach.

On bark. Conecuh County (Beaumont).

Louisianian and Carolinian areas. Texas, Louisiana to Florida, New Jersey.

Cuba. Europe.

Graphis afzelii Ach.

On various barks; frequent in pine-barren swamps. Mobile County.

Louisianian area. Texas to Florida, South Carolina, North Caroliua.

Graphis beaumontii Tuck. G.babingtonii Mont., Tuck. Not Nyl.

Conecuh County (Beaumont). Rare.

Louisianian area. South Carolina.

Graphis nitida (Mont. \& Vill.) Nyl.

On barks. Conecuh County (Beaumont).

Louisianian area. South Carolina.

\section{OPEGRAPHA Humb.}

Opegrapha tribulodes Tuck.

On bark. Mobile County, common; Citronelle (Baker \& Larle). Conecuh County

(Beaumont).

Louisianian area. Southern Texas. 
Opegrapha vulgata (Ach.) $\mathrm{Nyl}$.

Barks throughout the State.

Louisianian to Alleghenian area. North to Canada. Europe.

Opegrapha varia (Pers.) Fr.

On barks. Over the State, common.

Louisianian to Allegheuian area. North to Canada. Europe.

\section{Family LECIDEACEAE.}

\section{Tribe LECIDEAE.}

\section{RHIZOCARPON Stitz.}

Rhizocarpon colludens (Fr.) Nyl. Lecidea myrini Fr.

On rocks. Lee County, Auburn (Baker \& Earle).

Carolinian and Alleghenian areas. New Jersey, Ohio, New England.

Rhizocarpon subconcentricum Fr.

On rocks. Lee County, Auburn (Baker \& Earle).

Carolinian area.

\section{BUELLIA De Not.}

Buellia parasema (Ach.) Th. Fries.

Barks. Throughout Mobile County, common.

Cosmopolitan from tropical to Arctic zones. Europe.

Buellia subdisciformis Lightf.

On bark. Mobile County, Citronelle (Baker).

Louisianian area.

Buellia disciformis Fr.

On barks. Mobile County, Citronelle (Baker).

Louisianian and Carolinian areas. Ohio. Europe.

Buellia spuria Schaer. Buellia lactea Tuck.

Mobile County, Citronelle (Baker).

Louisianian to Alleghenian area. Georgia and Tennessee to New England.

Buellia subpostumum Nyl.

On barks. Mobile County, Citronelle (Baker).

LECIDEA Ach.

Lecidea mamillaria Tuck.

Mountain region. Winston County (Peters).

Lecidea tessellina Tuck.

Winston County (Peters).

Lecidea contigua Fr.

On rocks. Winston County (Peters).

Carolinian and Alleghenian areas. New Jersey, New England, Canada. Europe.

Lecidea enteroleuca Fr.

Lee County, Auburn (Baker \& Earle). Mobile Count5.

Louisianian, Carolinian, and Alleghenian areas. New Jersey, Maine, Canada. Europe.

\section{HETEROTHECIUM Flot.}

Heterothecium tuberculosum (Fée) Flot.

Conecuh County (Beaumont, Tuck. Gen. 75).

Western Europe.

Heterothecium pachycheilum Tuck.

Conecuh County (Beaumont).

Louisianian area. Louisiana to South Carolina. Cuba. South America. 
Heterothecium domingense (Pers.) Flot.

On barks of live oak. Mobile County, not rare.

Louisianian area. Louisiana to South Carolina. Cuba.

Heterothecium leucoxanthum (Spreng.) Mass.

On barks of oaks. Mobile County; frequent. Tennessee Valley. Lawrence County (Peters).

Lonisianian to Alleghenian area. Texas to Florida, along the coast to North Carolina; District of Columbia, Maine (Mount Desert), Ohio.

Heterothecium conspersum (Fée) Flot.

Conecuh County (Beaumont).

Louisianian area. Cuba, tropical America.

\section{BIATORA Fr.}

Biatora russellii Tuck.

On limestone rocks. Lawrence County (Peters). Lee County, Auburn (Baker \& Earle).

Carolinian area. North to New Jersey and Ohio.

Biatora rufonigra Tuck.

On rocks. Tenuessee Valley. Lawrence County (Peters).

Carolinian to Alleghenian area. New Jersey, Ohio, Maine.

Biatora petri Tuck.

Rocks. Lawrence Coùnty, Monlton (Peters).

Biatora parvifolia (Pers.) Tuck.

On Magnolia with Chiodecton rubricinctum. Mobile County.

Louisianian to Alleghenian area. Maine (Mount Desert). Cuba.

Biatora suffusa Fr.

Mobile County, Citronelle (Baker).

Louisianian and Carolinian areas. Ohio, New Jersey.

Biatora russula (Ach.) Mont.

On barks. Mobile County, Citronelle (Baker).

Lonisianian to Alleghenian area. North to Ohio and New Jersey; New England (Mount Desert, Maine).

Biatora cyrtella (Ach.) Tuck.

Barks. Mobile County, Citronelle (Baker).

Louisianian to Alleghenian area. New England (White Mountains). Europe.

Biatora viridescens (Schrad.) Fr.

Barks. Mobile.

Louisianian to Alleghenian area. New Jersey, New England. Europe.

Biatora atropurpurea (Mass.) Hepp.

On bark. Conecuh County (Beaumont).

Lonisianian to Alleghenian area. New York, New England, California. Europe.

Biatora hypomela Nyl.

Rotten bark, old trees. Mobile County.

Louisianian area.

Riatora Jarians (Ach.) Tuck.

Un barks. Mobile County.

Lonisianian to Alleghenian area. New Jersey to Ohio, New England (Mount Desert).

Biatora fuscorubella (11offm.) Tuek.

Lawrence County (Peters).

Carolinian area. Ohio. Europe.

\section{Baeomyces roseus Pers.}

BAEOMYCES Pers.

On sandy earth over the State, common.

Louisianian to Alleghenian area. Eastern Uniterl States, Canada. Europe.

Baeomyces absolutus Tuck.

On bare sandy ground. Lawrence County, Moulton (Peters).

Carolinian area. North Carolina. Cuba, Venezuela. 


\section{Tribe COENOGONIEAE.}

\section{COENOGONIUM Ehrenb.}

Coenogonium interpositum $\mathrm{Nyl}$.

In damp woods, on trunk and roots of live oak. Mobile County, abundant.

Louisianian area. Florida, Cuba.

\section{Tribe CLADONIEAE.}

Cladonia Hoffm.

Cladonia symphycarpa epiphylla (Ach.) Nyl.

On earth. Winston County (Peters).

Louisianian to Alleghenian area. Texas to Sonth Carolina, north to New York, Ohio, Illinois, Wisconsin, New England (Maine). Europe.

Cladonia mitrula Tuck.

On sandy earth. Mobile County. Henry County (Baker \& Earle). Lawrence County (Peters).

Louisianian to Alleghenian area. Texas, Louisiana, !" ricli to North Carolina, New Jersey, New England. Cuba, Mexico.

Cladonia pyzidata (L.) Fr.

On rotten wood, stumps. Mobile and Winston counties.

Louisianian area to Boreal region. Over the Eastern United States to Minnesota; Colorado, Canada. Europe.

\section{Cladonia fimbriata tubaeformis Fr.}

Woods, on rotten wood, and on the earth. Over the State.

Louisianian and Carolinian areas. Mississippi to South Carolina, Now Jersey, Ohio, New Mexico, California. Cuba, Europe.

Cladonia gracilis verticillata Fr.

On decayed stumps. Mobile County. Lawrence County (Peters). Dekalb County (Mohr).

Louisianian to Alleghenian area. Louisiana to Florida, South Carolina north to New England.

Cladonia santensis Tuck.

On earth. Lawrence County (Peters).

Carolinian area. Texas to South Carolina.

Cladonia santensis beaumontii Tuck.

Conecuh County (Beaumont).

Louisianian and Carolinian areas. North to North Carolina.

Cladonia squamosa Hoffm.

Mossy earth. Lawrence County (Peters).

Louisianian to Alleghenian area. Lonisiana, South Carolina, Tennessee, Ohio, New Jersey, New England, Canada, British Columbia. Europe.

Cladonia delicata (Ehrh.) Floerk.

Decaying logs. Lawrence County (Peters).

Louisianian and Carolinian areas. Louisiana, South Carolina, Ohio, New Jersey. Europe.

Cladonia caespiticia (Pers.) Floerk.

Sandstone rocks. Winston County (Peters).

Carolinian and Alleghenian areas. South Carolina, New Jersey, Ohio, New England, Canada. Europe.

Cladonia furcata racemosa Floerk.

Lawrence County (Peters).

Carolinian and Alleghenian areas. Virginia, New Jersey, Ohio, New England, Canada. Europe.

Cladonia furcata pungens Fr.

On rocks. Winston County (Peters).

Louisianian to Alleghenian area. Florida to New England, Minnesota. Cuba, 
Cladonia rangiferina (L.) Hoffin.

Lawrence County (Peters).

Louisianian area to Arctic zone. Cosmopolitan.

Cladonia rangiferina sylvatica $L$.

Sterile earth. Etowah County, Gadsden.

Louisianian area to Arctic zone. Florida to Canada. Furope.

Cladonia rangiferina alpestris (L.) Fr. C. rangiferina minor Michx. ?

Sterile pine-barren ridges. Mobile.

Louisianian to Alleghenian area. Florida to New Jersey, New England, Minnesota, Canada. Europe.

Cladonia uncialis (L.) Fr.

Mountain region. On rotten stumps aud on the eartl. Winston County (Peters). Carolinian area to Arctic zone. South Carolina to New England; Canada. Europe.

Cladonia uncialis caroliniana Tuck.

Monntainous woods. Lawrence County (Peters).

Carolinian area. Georgia, Tennessee.

Cladonia cornucopioides (L.) Fr.

On sterile soil. Cullman County.

Carolinian area to Arctic zone. Georgia and North Carolina, through the Middle and Northern States to Canada, British Columbia, and Oregon.

Cladonia pulchella Schw.

Swamps, on decayed wood and trunks. Mobile County, frequent.

Louisianian to Alleghenian area. Texas to Florida; Georgia and South Carolina to New England (Mount Desert, Maine).

Cladonia cristatella Tuck.

Danıp woods, rotten logs. Henry County, Abbeville (Baker \& Earle). Lawrence County (Peters).

Louisianian to Alleghenian area. Texas, Georgia, South Carolina, North Carolina to Pennsylvania, New Jersey, New England (Mount Desert), Ohio to Minuesota.

Cladonia leporina Fr.

Arid sterile soil. Mobile County, lower pine barrens.

Louisianian and Carolinian areas. Texas to Florida, along the coast to New Jersey.

\section{Family PARMELIACEAE.}

Tribe LECANOREAE.

GYROSTOMUM Fr.

Gyrostomum scyphuliferum (Ach.) Fr.

On barks of various trees in pine-barren swamps. Mobile County, not rare.

Louisianian area. Texas to Florida.

\section{THELOTREMA Ach.}

Thelotrema subtile Tuck.

On barks. Mobile County. Conecuh County (Beaumont).

Louisianian to Alleghenian area. Texas to Georgia, north to New Jersey and New England.

Thelotrema domingense (F'́é) Tuck.

Louisianian area. Lonisiana to Georgia.

Thelotrema interpositum (Nyl.) Tuck.

On bark of Magnolia virginiana. Mobile County.

Lonisianian area. West to Texas.

Thelotrema santense Tuck.

On bark. Conecuh County (Beaumont).

Louisianian area. Louisiana to South Carolina. 
Thelotrema glaucescens $\mathrm{Nyl}$.

On barks. Conecuh County (Beaumont).

Louisianian area. Louisiana to Florida, South Carolina. Cnba.

Thelotrema ravenelii (Tuck.) Nyl.

On trunks. Tennessege Valley. Lawrence County, Moulton (Peters). Conecuh County (Beaumont).

Louisianian area. South Carolina.

GYALECTA Ach.

Gyalecta lutea (Dicks.) Tuck.

On lark. Mobile County. Conecuh County (Beaumont).

Louisianian to Alleghenian area. Florida. New Jersey to New England, Ontario west to Illinois and Minnesota. Europe.

Gyalecta cupularis (Hedw.) Tuck.

On limestone rocks. Lawrence County (Peters).

Carolinian and Alleghenian areas. Pennsylvania, New York, Vermont. Europe.

\section{PERTUSARIA DC.}

Pertusaria velata (Turn.) Nyl.

Throughout the State, on trunks.

Louisianian to Alleghenian area. North to Canada.

Pertusaria multipuncta (Ach.) Th. Fries.

On bark. Mobile County, common.

Lonisianian to Alleghenian area. Texas to Florida and throughout to Canada; California, Oregon.

Pertusaria communis DC.

Cn bark and trunks, over the State.

Louisianian to Alleghenian area. Texas to Florida and north to Canada. Europe.

Pertusaria leioplaca (Ach.) Schaer.

On trees over the State.

Louisianian to Alleghenian area. Texas to Florida, north to Canada. Europe.

Pertusaria pustulata (Ach.) Nyl.

On barks. Mobile County. Lee County, Auburn (Baker \& Earle).

Lonisianian to Alleghenian area. Texas to Florida, north to New England. South America, Europe.

Pertusaria wulfenii DC.

On trees. Mobile County.

Louisianian to Alleghenian area. Florida to New Jersey, New England. Europe.

Pertusaria globularis Ach.

Mossy rocks. Lawrence County (Peters).

Carolinian and Alleghenian areas. Pennsylvania, Arkansas.

\section{RINODINA Ach.}

Rinodina flavonigella Tuck.

Rotten wood. Mobile County.

Louisianian area. Georgia, Florida.

Rinodina thomae Tuck.

Mountain region, on rocks. Lee County, Auburn (Baker ff Earle). Winston County (Peter 8), on sandstone.

Rinodina constans (Nyl.) Tuck.

On trees and dead wood. Lawrence Connty (Peters).

Carolinian and Alleghenian areas. South Carolina to New Jersey, New England, Canada. 
LECANORA Ach.

Lecanora rubina (Vill.) Ach.

Mountain region, sandstone rock. Winston County (Peters).

Carolinian and Alleghenian areas, and Boreal region. North to New Jersey and New Englaud, from Texas to Kansas and Minnesota, Rocky Mountains to California, Oregon.

Lecanora muralis (Schreb.) Schaer.

Rocks. Winston County ( Peters).

Carolinian and Alleghenian areas. North to New Jersey, New England, Minnesota, and Canada. Europe.

\section{Lecanora privigna (Ach.) Nyl.}

On rocks. Lawrence County (Peters).

Carolinian and Alleghenian areas. Tennessee, New England (Mount Desert), Canada. Europe.

Lecanora pallida (Schreb.) Shaer. L. albella auct.

Trees and dead wood. Mobile County, Citronelle (Baker \& Earle); common.

Louisianian to Allegheuian area and Boreal region. Florida to New England (Mount Desert; and Canada, west to California and Oregon; Arctic America. Europe.

Lecanora subfusca coilocarpa Ach.

On dead wood and trees. Mobile County, Citronelle (Baker); frequent.

Louisianian to Carolinian area. South Carolina to New Jersey. Europe.

Lecanora hageni Ach.

On trees. Mobile County, Citronelle (Baker). Lawrence County (Peters).

Lonisianian to Alleghenian area. North to Virginia, New Jersey, New England, and Canada.

Lecanora atra (Huds.) Ach.

Rocks. Lawrence County (Peters).

Lonisianian area to Boreal region. Texas to Florida and the Carolinas, New Jersey, California. Europe.

Lecanora punicea Ach.

Old rails. Mobile County, frequent. North Alabama (Peters).

Louisianian and Carolinian areas. Texas and New Mexico to South Carolina; New Jersey (Eckfeld).

Lecanora varia (Ehrh.) Nyl.

On trees and dead wood. Mobile County. Lawrence County (Peters). Over the State.

Louisianian to Alleghenian area. Texas to Florida, thence to Canada, west to Minnesota and Oregon. Europe.

Lecanora cinerea (L.) Sommerf.

On rocks. Lawrence County (Peters).

Carolinian and Alleghenian areas to Arctic zone, New Jersey, New England (Mount Desert), Minnesota. Europe.

Lecanora calcarea contorta Fr.

On limestone rocks. Lawrence County (Peters).

Carolinian area to Arctic zone. Kansas, Texas; Greenland. Europe.

Lecanora lacustris (With.) Nyl.

Rocks in damp places. Lawrence County, Moulton (Peters).

Carolinian and Alleghenian areas to Arctic zone. Now Jersey, Now England, Greenland. Enrope.

\section{Lecanora xanthophana Nyl.}

Ferruginous sandstone ledges. Mobile County, Langdons Station.

Louisianian to Alleghenian area. West Texas, Arkansas, Kansas, and Missouri, east to South Carolina and New Jersey; Canada to the Rocky Mountains, Oregon, California. South America, Andes of Chile, Bolivia. 


\section{PLACODIUM Ach.}

Placodium aurantiacum (Lightf.) Naeg. \& Hepp.

On limestone rocks. Lawrence County (Peters).

Louisianian to Alleghenian area. Texas to Georgia, north to Virginia, New Jersey, and New England; Illinois, Missouri, Arkansas, California. Europe.

Placodium cinnabarinum (Ach.) Anzi.

On rocks. Lawrence County (Peters).

Carolinian to Alleghenian area. North to New England and Ohio, west to Texas, Kansas, and California.

Placodium ferrugineum (Huds.) Hepp.

On limestone rocks. Lawrence County (Peters). Mobile County, Citronelle(Baker \&. Earle), on dead wood.

Louisianian to Alleghenian area and Boreal region. Texas to North Carolina and Virginia, Illinois, California, Alaska. Europe.

\section{Tribe COLLEMEAE.}

\section{LEPTOGIUM Ach.}

Leptogium lacerum (Sw.) Fr.

On limestone rocks, among mosses. Winston County (Peters).

Carolinian and Alleghenian areas. Mountains of Alabama, through the Middle States, Ohio to Maryland, Canada. Europe.

Leptogium apalachense (Tuck.) Nyl.

Limestone rocks and trunks. Lawrence County (Peters).

Carolinian area. Georgia, Missouri.

Leptogium pulchellum (Ach.) Nyl. Collema corticola Tayl. in coll. Peters.

On trees. Winston County (Peters; Mohr, 1880). Lee County, Auburn (Baker \& Earle).

Carolinian and Alleghenian areas. Texas, mountains of Georgia, South Carolina;

Ohio Valley to New England, Canada. South America (New Granada), South Europe.

Leptogium tremelloides (L. f.) Fr.

Trunk and roots of trees throughout the State. Mobile County. Winston County (Peters).

Louisianian to Alleghenian area. New Mexico and Texas to Florida, north to Canada. Europe.

Leptogium marginellum ( $\mathrm{Sw}$.$) Mont.$

On trees. Conecuh County (Beaumont).

Louisianian area. Texas to Florida. West Indies, Mexico.

Leptogium juniperinum Tuck.

On the ground, open woods. Winston Connty (Peters; Mohr, 1880).

Carolinian area. Tennessee, Illinois, Massachusetts.

Leptogium chloromelum (Sw.) Nyl.

Trunks. Lee County, Auburn (Baker \& Earle). Lawrence County (Peters).

Louisianian to Alleghenian area. Texas to Florida, South Carolina to Virginia, Ohio Valley, Now England, Canada. Europe.

Leptogium myochroum saturninum Schaer.

Mountainous woods, trunks. Lawrence County (Peters). Lee County, Auburn (Baker \& Earle). Etowah County near Gadsden (Mohr).

Carolinian and Alleghenian areas. New Mexico to South Carolina, north to New England.

Leptogium muscicola (Sw.) Fr.

Mountain region. On mosses. Lee County (Baker \& Earle).

Carolinian to Alleghenian area. New England, California, British Columbia, Bering Strait. Europe. 


\section{COLLEMA Wigg.}

Collema myriococcum (Ach.) Arn.

Calcareous rocks. Lawrence County (Peters).

Carolinian and Alleghenian ( $($ ) areas. Now Jersey, New York.

Collema pycnocarpum Nyl.

On trunks. Lawrence County (Peters).

Lonisianian to Alleghenian area. Florida to South Carolina, Ohio, Tennessee, Illinois, Arkansas, New England to Canada.

Collema cyrtaspis Tuck.

On trunks. Lee County, Auburn (Baker \& Earle). Winston County (Peters).

Carolinian area. Virginia, New Jersey, Pennsylvania, west to Illinois and Arkansas.

\section{Collema laciniatum Nyl.}

Calcareous rocks. Lawrence County (Peters).

Carolinian area. Kansas.

Collema callibotrys Tuck.

Ou trees. Lee County, Auburn (Baker of Earle). Tennessee Valley, Moulton (Peters).

Louisianian and Carolinian areas. Texas to Florida and South Carolina.

Collema aggregatum Nyl.

On trees. Abbeville (Baker \& Earle).

Louisianian area, Cuba, Mexico, South America.

\section{Collema leptaleum Tuck.}

On trees. Lee County, Anburn (Baker \& Earle). Lawrence County (Peters).

Louisianian to Alleghenian area. Texas and Lonisiana to South Carolina, Virginia, and New England. Europe.

\section{Collema nigrescens (Huds.) Ach.}

On trunks, open woods. Mobile County, Citronelle (Baker).

Lonisianian to Alleghenian area. Florida to Virginia, Pennsylvania, Ohio Valley, Canada, California. Europe.

Collema nigrescens leioplaca T'uck.

On bark and trunks, in the open. Mobile County, frequent.

Louisianian area. Louisiana to Florida, South Carolina.

\section{Collema texanum Tuck.}

On calcareous earth. Lawrence County (Peters).

Carolinian area. Texas (Rio Grande).

Collema tenax (Sw.) Ach.

Mossy limestone rocks. Lawrence County (Peters).

Carolinian and Alleghenian areas. New Jersey to New Eng'and, Missouri.

Collema pustulatum Ach.

Limestone rocks. Lawrence County (Peters).

Carolinian area. Pennsylvania.

\section{OMPHALARIA Dur. \& Mont.}

\section{Omphalaria symphorea (DC.) Tuck.}

Limestone rocks. Lawrence County (Peters).

Carolinian area. Europe.

Omphalaria girardi Dur. \& Mont.

Calcareous rocks. Lawrence County (Peters).

Omphalaria umbella Tuck.

Limestone rocks. Lawrence County (Peters). 


\section{PYRENOPSIS Nyl.}

Pyrenopsis schaereri (Mass.) Nyl.

Calcareous rocks. Lawrence County (Peters).

Carolinian area. Now Jersey, New York, Illinois. Europe.

Pyrenopsis melambola Tuck.

Calcareous rocks. Lawrence County.

Carolinian area.

\section{EPHEBE Fr.}

Ephebe pubescens Fr.

Mountain region. Sandstone rock, beds and banks of brooks. Winston County (Peters). Cullman County (Mohr).

Carolinian and Allegheuian areas to Boreal region. North to New Jersey, New England, Canada, Greenland. Europe.

Ephebe solida Born. Ephebe lesquereuxii Born.

Damp rocks. Marshall County (Lesquereux).

Carolinian and Alleghenian areas. New England.

\section{Tribe PANNARIEAE.}

\section{PANNARIA Delis.}

Pannaria pannosa (Sw.) Delis.

On trees. Mobile County.

Louisianian area. Louisiana, South Carolina. Cuba, South America.

Pannaria nigrocincta Nyl.

On dead trees. Mobile County, Springhill.

Louisianian area. Cuba. South America.

Pannaria rubiginosa (Thunb.) Delis.

Cn rocks. Lawrence County (Peters).

Louisianian to Alleghenian area. Texas to South Carolina; Ohio, Oregon, Cali. fornia. Europe.

Pannaria leucosticta Tuck.

On trees. Mobile County, frequent. Lawrence County (Peters).

Lonisianian to Alleghenian area. Louisiana to Florida, Georgia, New Jersey, and New England.

Pannaria tryptophylla (Ach.) Mass.

On trunks. Mobile County. On sandstone. Lawrence Connty (Peters), eommon.

Louisianian to Alleghenian area. Louisiana, South Caroliua, New Jersey to New England. Europe.

Pannaria crossophylla Tuck.

On rocks. Lawrence County (Peters).

Carolinian to Alleghenian area. Ohio, Pennsylvania, New York, Vermont.

Pannaria molybdaea (Pers.) Tuck.

Mobile County, Springhill, dead trees. Conecuh County (Beaumont).

Louisianian to Alleghenian area. Texas to Florida, South Carolina, New Jersey, Pennsylvania, western Now York. Cuba, South America.

Pannaria molybdaea cronia Nyl.

On rocks. Lawrence County (Peters).

Louisianian to Alleghenian area. 'Texas and Louisiana to Virginia, New Jersey;

New England (Tuckerman).

Pannaria stellata (Tuck.) Nyl.

On trees. Alabama, ex herb. (Willey).

Louisianian area. Florida, South Carolina. 
Pannaria stenophylla Tnck.

Calcareous rocks. Lawrence County (Peters).

Pannaria petersii Tuck.

Calcareous rocks. Lawrence County (Peters).

Carolinian area. New York (Willey).

Pannaria nigra (Hnds.) Nyl.

Calcareous rocks. Lawrence County (Peters).

Carolinian and Aileghenian areas. New Jersey and Illinois to New England and Canada. Europe.

\section{PHYSMA Mass.}

Physma luridum (Mont.) Tuck. Parmelia russellii Tuck. in Peters coll. No. 17.

On hickory trunks. Lawrence County (Peters).

Lonisianian to Alleghenian area. South Carolina, Virginia, New Jersey, New England, west to Missouri. Japan and tropical countries.

HEPPIA Naeg.

Heppia despreauxii (Mont.) Tuck.

On limestone rocks covered with soil. Lawrence County (Peters).

Louisianian and Alleghenian areas. Texas to Florida, North Carolina, New Jersey, New England, Ohio Valley. Canary Islands.

\section{Tribe PELTIGEREAE.}

\section{PELTIGERA Willd.}

Peltigera canina (L. Hoffm.

On mossy earth. Mobile County, Citronelle (Baker). Lee County, Auburn. Dekalb County $(M o h r)$.

Lonisianian area to Boreal region. Over the United States; Canada, British Columbia. Europe.

Peltigera polydactyla (Neck.) Hoffm.

In woods on mossy earth and trunks. Mobile County. Henry County (Baker \& Earle). Etowah ('ounty. Winston County (Mohr).

Louisianian to Alleghenian area. Lonisiana to South Carolina, Northern States to Canada, Rocky Mountains, British Columbia. Mexico.

\section{NEPHROMIUM Ach.}

Nephromium helveticum Ach.

Mountain region. On trees. Winston County (Peters).

Louisianian area to Boreal region. Louisiana, South Carolina, New England, Canada, Arctic America, Oregon, California. Europe.

STICTA Schreb.

\section{Sticta amplissima (Scop.) Mass.}

On trees. Winston County (Mohr).

Carolinian area to Arctic zone. Along the mountains to North Carolina; Pennsylvania, New England, Canada, Arctic America. Enrope.

Sticta erosa (Eschw.) Tuck. Sticta ravenelii in coll. Peters.

Trunks and rocks. Leo County, Auburn (Baker \& Earle). Winston County (Peters).

Louisianian and Carolinian areas. Georgia, Florida, South Carolina. Cuba, Brazil.

Sticta aurata (Sm.) Ach.

On mossy trunks and old trees, live oak hammocks. Mobile County, common; fertile.

Louisianian and Carolinian areas. Louisiana to Florida, along the coast to Southern Massachusetts; Pennsylvania, Ohio. 
Sticta quercizans (Michx.) Ach.

On trunks. Over the State.

Louisianian to Alleghenian area. Texas to Florida, north to New Jersey and Ohio; Oregon. Mexico.

Sticta sylvatica (L.) Ach.

On mossy ground. Lee County, Auburn (Baker \& Earle).

Carolinian and Alleghenian areas. Along the mountains to North Carolina; New Jersey, New England (Mount Desert), Canada. Europe.

Sticta crocata (L.) Ach.

Among mosses. Lee County, Auburn (Baker \& Earle).

Carolinian and Alleghenian areas. Mountains of North Carulina to New England.

\section{Tribe UMBILICARIEAE.}

\section{UMBILICARIA Hoffm.}

\section{Umbilicaria pustulata papulosa Tuck.}

On bare sandstone cliffs. Highest ranges. Dekalb County, Lookout Mountain, near Mentone, 1,800 to 2,000 feet. Talladega County, summit of Chehawhaw Mountain, 2,200 feet.

Carolinian and Alleghenian areas. Mountains of North Carolina.

\section{Tribe PARMELIEAE.}

\section{PYXINE Fr.}

Pyxine picta (Sw.) Tuck.

On trunks in the open. Mobile County, frequent; Citronelle (Baker \& Earle).

Louisianian area. Texas to Georgia, South Carolina. Cuba.

Pyxine sorediata Fr.

On trees. Mobile County. Lawrence County, on rocks ( Peters).

Louisianian to Alleghenian area. Texas to Florida, north to Pennsylvania; New England, west to the Rocky Mountains. Eastern Asia,-Himalayas, East Indies.

\section{PHYSCIA Schreb.}

\section{Physcia speciosa Fr.}

On trunks. Mobile County. Conecuh County (Beaumont).

Louisianian to Allegheuian area. New England west to Wisconsin. Europe.

Physcia hypoleuca (Muhl.) Tuck.

On trunks. Mobile County.

Lonisianian to Alleghenian area. New Mexico and Texas, throughout the Gulf and Atlantic States.

Physcia comosa (Eschw.) Nyl. P. speciosa galactophylla (Willd.) Tuck.

On branches of shrubs and trees. Mobile County, rare.

Louisianiau and Carolinian areas. Gulf and lower Atlantic States, Pennsylvania, Illinois, Mexico.

Physcia crispa (Pers.) Nyl. Parmetia domingensis Mont.

On trees. Mobile County.

Louisianian area. Texas to South Carolina. West Indies, Mexico.

Physcia asteroidea (F'r.) Nyl.

On trees. Lawrence County, Moulton (Peters).

Louisianian and Carolinian areas. Texas to South Carolina, north to New England. Europe.

Physcia stellaris (L.) Tuck.

On trees, rocks, and dead wood. Mobile County. Lawrence County (Peters).

Louisianian to Alleghenian area and Boreal region. Throughont the Atlantic States to New England, Canada, and Arctic America. Europe.

Physcia obscura endochrysea Nyl.

On rocks. Lawrence County (Peters).

Louisianian to Carolinian area. Texas to Georgia. 
Physcia adglutinata (Floerk.) Nyl.

On trees. Lawrence Cunnty (Peters).

Louisianian to Alleghenian area. Texas to West Florida (Beaumont).

South Carolina north co New England, Illinois, Wisconsin.

PARMELIA Ach.

Parmelia perfoliata (Jacq.) Ach.

On trunks, wool, and rocks. Over the State, common.

Louisianian to Alleghenian area. Throughout the Atlantic States to Canada. Mexico, Europe.

Parmelia perlata (L.) Ach.

Mountainous woods, on trees. Winston County (Peters).

Etowah County, Gadsden.

Carolinian and Alleghenian areas. Along the mountains to Ohio, Pennsylvania, New Jersey, New England, and Canada. Mexico, Europe.

Parmelia crinita Ach.

Trunks. Lee County, Anburn (Baker \& Earle).

Carolinian to Alleghenian area. Texas to South Carolina, north to New Jersey and Now England. Cuba, Brazil.

Parmelia laevigata (Sm.) Nyl.

On trees. Mobile County.

Louisianian to Alleghenian area. Louisiana, New Jersey, New Fngland, Canada.

Mexico, Europe.

Parmelia aurulenta Tuck.

On rocks and trees. Lawrence County, on sandstone rocks (Peters). Conecuh County (Beaumont).

Louisianian to Alleghenian area. Louisiana, South Carolina, New England.

Parmelia tiliacea (Hoffm.) Floerk.

On dead trees. Mobile County. Lee County, Auburn (Baker \& Earle).

Louisianian to Alleghenian area. Throughout the Atlantic States to Canada. Europe.

Parmelia borreri Tnrn.

On trees and dead wood. Lee County, Auburn (Baker \& Earle).

Lonisianian to Alleghenian area. Texas to South Carolina, and the Northern States to Canada. Europe.

Parmelia saxatilis (L.) Fr.

On trees and dead trunks. Mobile County, Springhill. Lee County, Auburn (Baker \& Earle).

Lonisianian area to Boreal region. New Mexico, common, northward to Canada and west to the Rocky Mountains; British Columbia, Arctic America. Europe.

Parmelia colpodes (Ach.) Nyl.

On trees. Lee County, Auburn (Baker \& Earle).

Louisianian to Alleghenian area. Lonisiana to North Carolina and New England, Minnesota.

Parmelia conspersa (Ehrh.) Nyl.

On trees. Lee County, Auburn (Baker \& Earle).

Carolinian area and Boreal region. Texas to South Carolina, north to New England, Minnesota, and Canada; Rocky Mountains, British Columbia, Aretic America.

\section{THELOSCHISTES Norm.}

Theloschistes polycarpus (Ehrh.) Turn.

Mountains, dead wood and trees. Winston County (Peters).

Carolinian and Alleghenian areas. New Jersey, Ohio, Minnesota, Maine, Canada to the Rocky Mountains, California, British Columbia. Europe.

Theloschistes chrysophthalmus flavicans Wallr. Evernia flavicans Fr. Physcia flavicans Nyl.

On limbs of trees and shrubs. Mobile County, frequent.

Louisianian area. Texas to Florida and Sonth Carolina, California. Mexico 


\section{Tribe USNEAE.}

USNEA Adans.

\section{Usnea barbata (L.) Fr.}

On trees and dead wood; common througbout.

Louisianian area to Boreal region. From the Gulf to Arctic America. Europe.

Usnea barbata florida Fr.

Dry open woods. Common over the State.

Louisianian to Alleghenian area. From the Gulf to Canada.

Usnea barbata rubiginea Michx.

On trees. Mobile County and over the State.

Louisianian to Alleghenian area. East United States to Canada. Europe.

Usnea barbata dasypogon Fr.

On trees. Open woods in the mountains. Winston County (Peters).

Carolinian to Alleghenian area. North to Canada.

Usnea trichodea Ach.

On trees. Mountain region. Cullman County.

Carolinian to Alleghenian area. North to New England and Nova Scotia.

\section{CETRARIA Ach.}

\section{Cetraria fendleri Tuck.}

On old trees. Mobile County. Lawrence County (Peters).

Louisianian and Carolinian areas. South Carolina, New Jersey, and Maryland, west to Colorado.

Cetraria aurescens Tuck.

On trees. Lawrence County (Peters).

Carolinian and Alleghenian areas. New Jersey, New Englancl.

RAMALINA Ach.

\section{Ramalina rigida (Pers.) Ach.}

On old trees. Mobile County.

Lonisianian and Carolinian areas. Texas, Lonisiana to Florida, and along the coast to New Jersey and New England. Mexico.

Ramalina laevigata Fr.

On trees. Mobile County, not rare.

Louisianian area. Texas, New Mexico, South Carolina. Mexico.

Ramalina calicaris (L.) Fr.

Old sickly trees. Mobile County, frequent.

Louisianian to Alleghenian area. 'Throughout the Eastern United States, Canada. Europe.

Ramalina calicaris canaliculata $\mathrm{Fr}$.

Trees. Mobile County.

Louisianian to Alleghenian area. Mexico. 
Geographical and ecological distribution of the lichens of Alabama.

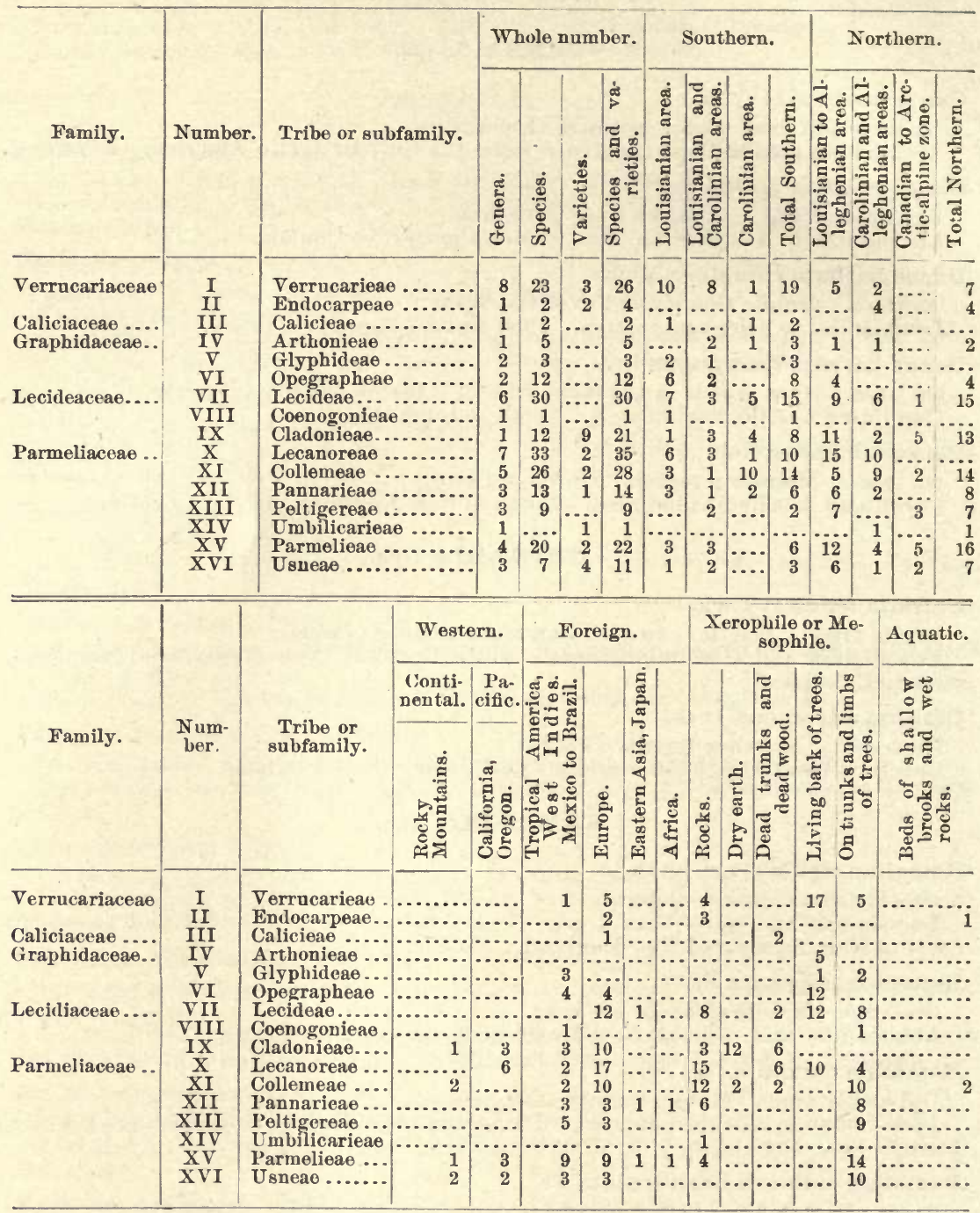

\section{LIVERWORTS.}

With the exception of a sinall number contributed by the Biological Survey of Alabama from the vicinity of Auburn (Metamorphic hills), the greater part of these plants known from Alabama have been collected in Mobile County. The northern part of the State, in regard to liver. worts, is yet a field to be explored. Forty-eight species under 25 genera have at present come to our knowledge from this State, being about two-fifths of the species described in the sixth edition of Gray's Manual. 
Considering the proximity of our Southern region to the tropics, where these plants attain such a high development, the small number of forms which are held in common with tropical America, and which, on this continent, are not found outside of warmer temperate regions, such as Dumortiera, Reboulia, and Sphaerocarpus, is remarkable. Most of the genera represented in greatest numbers in the cooler temperate region (Alleghenian area), and more or less of a cosmopolitan distribution, are met with in every part of the State-for example, Riccia, Ricciella, Marchantia, Riccardia, Cephalozia, Plagiochila, Porella, Scapania, Lejeunea, Frullania, and others. There can be little doubt that some of the genera prevailing in the Northern States and Canada, not yet known from Alabama, will be added to our flora by a closer search for the plants in the Mountain region.

About one-half of the species known from Alabama belong strictly to Eastern North America; 14 species are held in common with Europe, and 11 occur on the Pacific slope, mostly in its northern extension, all of which, with the exception of Asterella tenella, are also widely distributed in the cooler temperate zone of Europe.

Little more than one-half of the liverworts so far reported from the State are of a decided Southern distribution. Strictly confined to the subtropical district (Louisianian life area) are the following:

Marchantia disjuncta.

Sphaerocarpus terrestris.

Fossombronia faveolata.

Plagiochila ludoviciana.

Cephalozia media (?).

Phragmidium xanthocarpa.

Lejeunea austini.
Lejeunea mohrii.

Lejeunea auriculata.

Frullania kunzei.

Frullania caroliniana.

Frullania donnellii.

Anthoceros carolinianus.

Anthoceros ravenelii.

The following are confined within the warmer temperate zone (Carolinian life area):

Riccia lamellosa.
Reboulia hemispherica.
Dumortiera hirsuta.
Pallavicinia lyellii.
Fossombronia angulosa.
Plagiochila undata.

Cephalozia virginica.

Bazzania trilobata.

Phragmicoma clypeata.

Lejeunea serpyllifolia.

Frullania squarrosa.

The species extending to the cooler temperate and frigid regions are scattered over the State from the Gulf shore to its northern limit.

The specimens early collected by the writer were identified by the late Mr. C. F. Austin. His collections of later years have been examined by Professor Underwood, to whom thanks are due for this, as also for his assistance in revising the list of Hepaticae from Alabama. 


\section{Subkingdom BRYOPHYTA.}

\section{Class HEPATICAE. Liverworts.}

\section{Family RICCIACEAE.}

\section{RICCIA L.}

Riccia lutescens Schw.

Mudily banks, lower Alabama. Monroe County.

Louisianian to Alleghenian area. Louisiana, Illinois, Pennsylvania, Minnesota, Untario.

Riccia lamellosa Raddi.

On damp exposed banks. Mobile County, fide Austin.

Louisianian to Alleghenian area. New Jersey, Canada, California. Southern Europe (1taly).

\section{RICCIELLA Bisch.}

Ricciella fluitans (L.) Bisch.

Floating in stagnant pools aud shaded ditches. Mobile County; March.

Louisianian to Alleghenian area. East United States to Ontario. Europe.

\section{Family MARCHANTIACEAE.}

REBOULIA Raddi.

Reboulia hemispherica (L.) Raddi.

Shady banks of streams. Lee County, Auburn (Baker \& Earle).

Carolinian area. Illinois, Ohio, Pennsylvania. Central Europe.

ASTERELLA Beauv.

\section{Asterella tenella Nees.}

Damp borders of fields, copses. Mobile Connty. Lee County, Auburn (Baker of Earle).

Louisianian to Alleghenian area. Maryland, central New York, Nebraska, British Columbia (Vancouver Island).

\section{CONOCEPHALUM Wiggers.}

Conocephalum conicum (L.) Dumort. Fegatella conica Corda.

Shaded damp banks. March, April.

Louisianian to Alleghenian area. Louisiana to Nebraska, British Columbia, and Alaska. Europe.

\section{DUMORTIERA Nees.}

\section{Dumortiera hirsuta Nees.}

Shady damp rocky walls. Winston County. Not infrequent in the so-called rock bouses of the Mountain region.

Carolinian area. North to Pennsylvania.

\section{MARCHANTIA L.}

Marchantia polymorpha L.

On damp ground over the State. Throughont the continent to Alaska. Europe. Cosmopolitan from warmer to frigid zones.

Marchantia disjuncta Sulliv.

Springy places. Monroe County. Claiborne County, bluff of Alabama River (Sullirant, 1853). Lee County, Anburn (Underwood). Mexico, Huatusco, 5,000 feet altitude (Mohr). 


\section{Family METZGERIACEAE.}

\section{SPHAEROCARPUS Michx.}

Sphaerocarpus terrestris Smith. S. micheli Bellardi.

Damp low fields. Coast region.. Mobile, in garden, abundant.

Lonisianian and Carolinian areas. Along the coast to North Carolina and southern Virginia. Southern Europe.

\section{METZGERIA Raddi.}

Metzgeria conjugata Lindb.

On mossy trunks and logs in damp shady woods. Mobile and Winston counties.

Louisianiau to Alleghenian area. Louisiana to Florida, north to Ontario. Vancouver Island.

PELLIA Raddi.

Pellia epiphylla (L.) Nees.

Damp banks. Lee County, Auburn (Baker \& Earle).

Carolinian and Alleghenian areas. Throughout the Eastern United States; Canarla. Europe.

\section{RICCARDIA S. F. Gray.}

Riccardia latifrons Lindb.

Decaying logs. Mobile County. Lee County, Auburn (Baker \& Earle). Not frequent.

Louisianian to Alleghenian area. North to Canada and Vancouver Icland. Europe.

PALLAVICINIA S. F. Gray.

Pallavicinia lyellii S. F. Gray.

Shaded wet places among mosses. Mobile County, frequent. Montgomery County, November to March.

\section{FOSSOMBRONIA Dumort.}

Fossombronia angulosa Raddi.

Low sandy exposed places. Mobile County. Flat open pine barrens, frequent; March.

Louisianian and Alleghenian areas. South Carolina. Europe.

Fossombronia faveolata Lindb.

Mobile County, with the last.

Louisianian area.

\section{Family JUNGERMANNIACEAE.}

PLAGIOCHILA Dumort.

Plagiochila asplenoides (L.) Dumort.

Mossy trunks in swamps. Mobile County.

Lonisianian to Alleghenian area. North to Canada; British Columbia.

Plagiochila ludoviciana Sulliv.

On trees. In swampy hammocks, infrequent (Sullivant, Mohr).

louisianian area. Louisiana.

Plagiochila undata Sulliv.

Wet rocks. Etowah County, Black Creek Falls near Gadsden, July, 1880.

Carolinian area. Georgia.

CEPHALOZIA Dumort.

Cephalozia virginiana Spruce. C. catenulata auct. Not Huebner.

Mossy trunks, decayed logs. Mobile County, swampy hammocks. Lee County, Auburn (Baker \& Earle).

Louisianian and Alleghenian areas. Louisiana and Florida to Virginia.

Cephalozia media Lindb.

Mobile County with the last, fide Austin, 1876. 


\section{ODONTOSCHISMA Dumort.}

Odontoschisma sphagni Dumort.

Decaying logs among mosses. Mobile County, common.

Louisianian to Alleghenian area. Louisiana, Florida to 'Tennessee and Illinois; Ontario. Europe.

Odontoschisma denudata Lindb.

Mobile with the last.

Louisianian to Alleghenian area. Ohio to Canada. Europe.

Bazzania S. F. Gray. Mastigobizym Nees.

Bazzania trilobata (L.) S. F. Gray. Mastigobryum trilobatum Nees. M. tridenticulatum Lindenb. The Southern form.

In swamps. Mobile County, not rare.

Louisianian and Carolinian areas. North to New Jersey. Europe.

SCAPANIA Dumort.

Scapania nemorosa (Schrad.) Dumort.

Damp shaded banks. Over the State, very common.

Louisianian to Alleghenian area. To Canada, British Columbia, and Alaska. Europe.

\section{DIPLOPHYLLUM Dumort.}

Diplophyllum taxifolium Wahl.

Ravines. Lee County, Auburn (Baker \& Earle).

Carolinian and Alleghenian areas. Over the United States to Canada; British Columbia. Europe.

\section{MARSUPELLA Dumort.}

Marsupella sphacelata Dumort.

On wet rocks. Mountain region. Winston County. Etowah County, Black Creek Falls.

Carolinian area to Boreal zones, Atlantic region. Greenland, Spitzbergen. Europe.

PORELLA Dill. Modotheca Dumort.

Porella platyphylla (L.) Lindb.

On damp rocks and trees. Common throughout the State.

Louisianian to Alleghenian area. Through Atlantic America to Canada; Idaho. Vancouver Island. Europe.

Porella pinnata L. P. involuta Hampe.

Trees on banks of streams subject to iuundation. Mobile County, common.

Lonisianian to Alleghenian area. Louisiana to Nova Scotia, west to Missouri and Arkansas. Cuba. Europe.

\section{PHRAGMICOMA Sulliv.}

Phragmicoma clypeata (Schw.) Sulliv.

On trees. Mobile County, common. Lee County, Auburn (Baker \& Earle).

Louisianian to Alleghenian area. Louisiana and Florida to West Virginia and northern Ohio.

Phragmicoma xanthocarpa (L.) Lindb.

On trees. Mobile.

Louisianian area.

Lejeunea austini Lindb.

LEJEUNEA Lib.

On trees. Molvile.

Louisianian area. Louisiana to Florida; Sonth Carolina.

Lejeunea serpyllifolia Dicks. sive L. serpyllifolia americana Lindb.

On trees. Mobile.

Louisianian and Carolinian areas. North to Ohio, New York, Ontario. 
Lejeunea auriculata Hook. \& Wils.

On trees. Mobile.

Louisianian area. Louisiana, Mississippi.

Lejeunea mohrii Aust.

Mossy trunks and roots of trees. Mobile, 1873.

Louisianian area. Louisiana.

FRULLANIA Raddi.

Frullania virginica Lehm.

Bark of trees. Over the State, common. Mobile, Lee, and Wiuston counties.

Louisianian to Alleghenian area. North to Ohio, New York, New Brunswick, and Ontario.

Frullania kunzei Lehm. \& Lindb.

On trees. Mobile.

Louisianian area. Southern States.

Frullania caroliniana Sulliv.

Barks of trees. Mobile County, Citronelle (Baker \& Earle).

Frullania donnelli Aust.

On trees. Mobile County, Citronelle (Baker \& Earle).

Louisianian area. Louisiana to Florida.

Frullania aeolotis Nees.

On trees. Mobile, common.

Louisianian to Alleghenian area. Ohio, New York.

Frullania squarrosa Nees.

On trees. Mobile.

Louisianian and Carolinian areas. Louisiana to central Ohio.

Frullania dilatata Nees.

On trees. Mobile.

Louisianian and Carolinian areas. Europe

Frullania asa-grayana Mont.

Winston and Etowah counties.

Carolinian and Alleghenian areas. Eastern United States and Canada.

\section{Family ANTHOCEROTACEAE.}

ANTHOCEROS L.

Anthoceros punctatus L.

Low fields, damp ground. Mobile County, frequent. March.

Louisianian to Alleghenian area. Missouri, Nebraska, Untario.

Anthoceros laevis L.

Damp low places. Over the State. Mobile County, common in the open flat pine barrens.

Louisianian to Alleghenian area. United States, Canada. Europe.

Anthoceros carolinianus Michx.

Mobile County. With the last, not infrequent.

Louisianian and Carolinian areas. Florida to North Carolina. March.

Anthoceros ravenelii Aust.

Damp fields, low open pine barrens. Mobile County, not rare.

Louisianian area. Louisiana, Florida, South Carolina.

MOSSES.

The first record of Alabama mosses appears in Sullivant's Musci Alleghanienses, where Fontinalis disticha and Dicranum debile are credited to Mobile, collected by Mr. Sullivant in 1843. Prof. Leo Lesquereux explored in 1848 parts of the mountain region of north 15894 19 
Alabama, the Raceoon Mountains in Morgan County, and Lookout Mountain in Dekalb County. The writer communicated his eollection made in southern Alabama, 1868 to 1878 , to the authors of the Manual of the Mosses of North Ameriea, and also to C. F. Austin and to Dr. Karl Mueller in Halle, the latter describing Hypnum homalostegium ${ }^{1}$ as a new species. His collectious made subsequently in different parts of the State were submitted to Mr. Holzinger and Mrs. Elizabeth G. Britton for identification. To the peat mosses special attention was given in the attempt to contribute to the Sphagna exsiccata to be issued by Professor Eaton and Mr. Faxon. Most of the specimens of this difficult genus were placed in the hands of Professor Warnstorf for identification, who found two species among them not described before-Sphagnum mohrii and Sphagnum mobiliense. ${ }^{2}$ To Mrs. Britton thanks are due for the examination of the species of Bruchia and many others and for the revision of the catalogue of Alabama mosses. The collections made recently by the Biological Survey of Alabama in the vicinity of Auburn have added to our knowledge of the distribution of mosses in the State.

To obtain data for the exhibition of the geographic distribution of the mosses known from Alabama, the following authorities were consulted :

Bridel, Bryologia Universa, 1826-27.

Hornschuh \& Sturm, Bryologia Germanica, 1823-1825.

Hornschuh, Musci, in Martius' Flora Brasiliana.

Mueller, Karl, Synopsis Muscorum Frondosorum, Halle, 1851-1853.

Sullivant, W. S., Musci and Hepaticae of the U. S. in Gray, Man. 1856.

Sullivant \& Lesquereux, Musci Boreali-Americani. 1865.

Austin, C. F., Musci Appalachiani, list of labels, 1870.

Bescherelle, E., Prodromus Bryologiae Mexicanae. 1871.

Sullivant, W. S., Icones. 1865-1875.

Lesquereux \& James, Manual of the Mosses of North America, 1884.

Macoun \& Kindberg, Catalogue of Canadian Plants, Part 6. 1872.

Besides these, use has been made of the papers on mosses published by various authors in the contributions of the department of botally, Columbia University, in the Botanical Studies of Minnesota, Vol. 1, and in the botanical reports and floras of New Jersey, New York, West Virginia, Ohio, Illinois, and Nebraska.

In the arrangement of the families, genera, and species, Lesquereux \& James's Manual has been mainly followed.

\section{GENERAL DISTRIBUTION.}

At present 153 species and 13 varieties with 4 subvarieties or forms of Musci are known from Alabama. Of these, 112 species, or 70 per cent, 
belong strictly to Atlantic North America, not considering the stragglers of widest distribution which are also found on the western declivity of the Rocky Mountains. The number of genera occurring in Alabama endemic to this part of the North American continent is small; although it is difficult to state it with exactness on account of the different views held by authors in regard to their limitation. The following are exclusively Eastern North American:
Drummondia.
Clasmatodon.
Thelia.
Pylaisiella.

Fully 60 per cent of the genera are represented in the warmer parts of the globe, chiefly in tropical America. Such are the following, which are of an almost exclusively tropical distribution :
Leucobryum.
Schlotheimia.
Cryphaea.
Syrrhopodon.
Rhizogonium.
Orthostichella.

More or less numerously represented in tropical America are the following:

$\begin{array}{lll}\text { Sphagnum. } & \text { Ptychomitrium. } & \text { Polytrichum. } \\ \text { Dicranella. } & \text { Funaria. } & \text { Fabronia. } \\ \text { Campylopus. } & \text { Bryum. } & \text { Entodon. } \\ \text { Trematodon. } & \text { Bartramia. } & \text { Thuidium. } \\ \text { Fissidens. } & \text { Philonotis. } & \text { Rhynchostegium. } \\ \text { Trichostomum. } & \text { Catharinea. } & \text { Eurhynchium. }\end{array}$

Barbula.

Among genera more feebly represented in the Tropics are:
Mollia.
Leskea.
Dicranum.
Hedwigia.
Plagiothecium.
Desmatodon.
Brachythecium.
Amblystegium.
Hypnum.
Physcomitrium.

The following species of the Alabama flora occur in tropical America, those with an asterisk being exclusively American:

Sphagnum compactum. (West Indies.)

* Sphagnum portoricense. (West Indies.)

* Trematodon longicollis. (To Brazil.)

* Dicranella debilis. (West Indics to Brazil.)

Leucobryum glaucum. (West Indies.)

* Leucobryum pumilum. (West Indies.)

* Fissidens polypodioides. West Indies.)

* Trichostomum macrostegium. (Cuba.)

Funaria hygrometrica. (Cosmopolitan;

West Indies, Mexico, etc.)

Exclusively of northern distribution extending to the Boreal zones are the following:

Sphaerocephalus.

Mnium.

Amphoridium.
Funaria calvescens. (Cosmopolitan; West Indies, Mexico, etc.)

* Polytrichum tenue. (Brazil.)

Rhizogonium spiniforme. (West Indies and Mexico.)

Thuidium delicatulum. (West Indies and Mexico.)

Thuidium microphyllum. (West Indies and Mexico.)

* Raphidostegium microcarpum. (Brazil.) 
To the Arctic region extend 22 species, of which the following are North American :

Sphagnum imbricatum.

Sphagnum cuspidatum torreyanum.

Sphagnum papillosum.

Sphagnum medium.
Polytrichum capillare.

Climacium americanum.

Brachythecium oxycladon.

Raphidostegium recurvans.

The rest of the species are widely distributed in the cooler regions of the Old World.

Of transcontinental species which on the west coast range from California to British Columbia 31 oceur in Alabama, of which only the following are confined to this continent:

Brachythccium oxycladon.

Campylium hispidulum.
Eurhynchium hians.

Raphidostegium recurvans.

The others are almost all cosmopolitan wanderers throughout the cooler temperate region of the Northern Hemisphere, many of them found in Europe. Alabama has 26 species in common with the latter continent, mostly erratic in temperate zones of the globe.

Of anomalous distribution Brachythecium campestre is a striking example, this species being known only from the White Mountains of New England and the Rocky Mountain region from Colorado to British Columbia.

\section{REGIONAL DISTRIBUTION.}

In no other part of the State are mosses found in greater variety and abundance than in the section of the mountain region which embraces the Warrior table-land and the sonthern spurs of the Cumberland Mountains abutting upon the Tennessee Valley. The manifold differ. ences in the topography and geology of this section of the State give rise to a diversity in conditions of climate, exposure, and soil which afford the peculiar habitat to which each species finds itself best adapted, and to which it clings more tenaciously than most plants of a higher order; for, as Professor Lesquereux, the close student of the moss world, aptly remarks, these humble and apparently useless beings have their geological and lithological preferences far better marked than any other kind of vegetable.

The species prevailing in the northern part of the State at an eleva. tion exceeding 1,500 feet are mostly the same as found in the Middle and Northeastern States. On the lower terraces and in the valleys Southern forms intermingle with those of higher latitudes. For example, at the falls of Black Creek near Gadsden, 1,000 feet altitude, the Northern Fissidens adiantoides is associated with the tropical Fissidens polypodioides, and on the Cumberland table-land in Jackson and Morgan counties the Southern Sphagnum macrophyllum, S. cyclophyllum, and $S$. molle muelleri, with $S$. reeurvum vars. and S. cuspidatum torrey. 
anum of the North (800 to 1,200 feet altitude). On the still lower ridges and terraces south of the Tennessee Valley are found the Southern-
Fabronia spp.
Cryphaea sp.
Thelia asprella.
Thelia lescurii.
Bruchia sullivantii.
Bruchia nigricans.

Bruchia curviseta.

Funaria flaricans.

Physcomitrium turbinatum langloisii.

Clasmatodon parvulus.

Thuidium microphyllum.

with the Northern

Climacium americanum.

Campylium chrysophyllum.

Brachythecium laetum.

Stereodon curvifolius.

Campylium hispidulum.

Of aquatic mosses, Fontinalis lescurii is common throughout the mountain region from an elevation of 800 to 2,000 feet. The eastern and most southern of the Appalachian ranges traversing the basin of the Coosa River where the obdurate sandstones and flinty cherts prevail, the arid flanks covered with open pine forests, are as poor in mosses as the rolling pine barrens of the Maritime pine belt. Considering the large area unfavorable to the vegetation of mosses, it is not to be expected that the moss flora will be found as rich and luxuriant as in most of the Middle and Northern Atlantic States.

In the Louisianian area only the lower division of the Coast pine belt has been closely searched for mosses. In the Coast plain, with its ample rainfall, mosses become again more abundant. Many of the declivities of the pine-clad hills and the depressions between them, of the exposed swampy banks of the pine-barren streams, and of the flats bordering the swamps in the plain, are covered with peat mosses (Sphagnum) of various kinds. The greater part of them are common from the Gulf to the Canadian lakes. Such are:

Sphagnum rufescens.

Sphagnum recurvum.
Sphagnum medium.

Sphagnum imbricatum cristatum.

while others are confined to the subtropical region, namely:

Sphagnum macrophyllum.

Sphagnum microcarpum.

Sphagnum ludovicianum.
Sphagnum mobiliense.

Sphagnum mohrianum.

In the open flat pine barrens of the Coast plain flourish during the winter and the first days of spring the following, mostly Southern types:

Bruchia donnellii.

Bruchia sullivantii.

Bruchia ravenelii.

Bruchia drummondii.
Bruchia curviseta.

Astomum ludovicianum.

Fissidens donnellii.

Fissidens ravenelii.

Besides these the following of Northern distribution: 
Other species of the same period are-

Entosthodon drumnondii.

Physcomitrum turbinatum langloisii.

Funaria flavicans.
Funaria serrata.

Polytrichum brachyphyllum.

These are followed, with the advance of spring, by-

Mollia viridula.

Mollia longiseta.

Bartramia radicalis.

Nearly all of this and the preceding group are confined to the Louisianian and adjoining parts of the Carolinian life areas.

The tree-covered swamps and rich hammock land shaded by live oak and magnolia, their air saturated with moisture, offer favorable retreats for mosses, many of which are peculiar to this region. Such are-

Fissidens donnellii.

Raphidostegium microcarpum.

Leptodon immersum.
Schlotheimia sullivantii.

Cryphaea nervosa.

Entodon drummondii.

These grow on trunks and roots of trees. In the deeper recesses of the swamps, on decayed prostrate trunks, are found-

Syrrhopodon floridanus.

Syrrhopodon texanus.

Neckera ludoviciae.

\begin{abstract}
Leucobryum pumilum. Rhizogonium spiniforme. Plagiothecium micans.
\end{abstract}

On the ground and on stones and old walls are frequent-
Desmatodon plinthobius.
Bryum bicolor.
Bryum caespiticium.
Thuidium microphyllum.

Bryum nutans.

In clear swiftly running brooks, attacherl to roots and submersed timber, Fontinalis disticha is frequent, while the southern Dichelyma subulatum occurs on stones in the Chattahoochee River.

\section{Class MUSCI. Mosses.}

Order SPHAGNALFS. Bog or Peat Mosses.

\section{Family SPHAGNACEAE.}

\section{SPHAGNUM I.}

Sphagnum cuspidatum (Ehrh.) Russ. \& Warnst.

Floating in springs and ponds over the State. Mobile County. Raccoon Monntains (Lesquereux). C'ullman County.

Louisianian to Alleghenian area. Louisiana and Florida to Canada.

Sphagnum cuspidatum submersum Schimp.

Shallow pine-barren ponds. Mobile County.

Louisianian to Alleghenian area. North to New Jerscy and Nova Scotia.

- Sphagnum cuspidatum torreyanum (Sulliv.) Lesq. \& James.

Bogs. Raccoon Mountains, Morgan County (Lesquereux).

Louisianian area to Boreal region. Florida north to New England and Canada. 
Sphagnum intermedium (Hoffm.) Russ. \& Warnst. S. recurvum Beauv.

Boggy borders of pine barrens. Mobile County.

Louisianian to Allegheniau area. New Jersey to Michigan and Canarla. Europe.

Sphagnum recurvum viparidita Warnst.

Lee County, Auburn (Baker \&. Earle).

Sphagnum recurvum amblyphyllum Russ.

Lee County, Auburn (Baker \&.Earle).

Sphagnum compactum DC. S. rigidum (Nees \& Hornseh.) Schimp. S. humile Schimp.

Raccoon Mountains (Lesquereux).

Louisianian and Carolinian areas. Florida to New Jersey.

Sphagnum molle Sullir.

Border of ditches; low sandy pine barrens. Mobile County, teste Lesquereux.

Lonisianian and Carolinian areas. Upper Georgia, Table Mountain, and South Carolina to New Jersey.

Sphagnum molle muelleri Braith. S. muelleri Schimp.

Raccoon Mountains (Lesquereux).

Lonisianian and Carolinian areas. Florida, Tennessee, New Jersey.

Sphagnum mobiliense Warnst.

Boggy borders of pine-barren ponds. Mobile County, 1895, with S. cuspidatum.

Sphagnum mohrianum Warnst.

Border pine-barren pond (Kellys Pond). Mobile County, 1895.

Sphagnum subsecundum Nees.

Damp low pine barrens. Mobile County; common to the Hill country.

Louisianian and Carolinian areas. Ohio, New Jersey, Ontario. Europe.

Sphagnum subsecundum contortum (Schultz) Schimp.

Shallow pools, pine barrens. Mobile County.

Sphagnum subsecundum mesophyllum Roell.

With the preceding. Mobile County.

Sphagnum rufescens Limpr.

Boggy places, pine barrens. Mobile County. Lee County, Auburn (Baker \& Earle).

Louisianian to Alleghenian area. New Jersey to Nova Scotia and Newfoundland.

Sphagnum medium Limpr. S. cymbifolium purpurascens Schimp.

Bogs, pine barrens. Mobile County, teste Warnstorf.

Sphagnum medium purpurascens Russ.

Lee County, Anburn (Baker \& Earle).

Carolinian to Alleghenian area. Ontario.

Sphagnum medium glauscescens Warust.

Mobile County, Citronelle (Baker).

Sphagnum papillosum intermedium (Russ.) Warnst.

Boggy pine barrens. Mobile County.

Louisianian to Alleghenian area. New Brunswick.

Sphagnum ludovicianum (Ren. \& Card.) Warnst.

Boggy borders of ponds. Mobile County (Kellys Pond).

Lonisianian area.

Sphagnum portoricense Hampe.

Shaded springy banks. Baldwin County, Point Clear. Not infrequent.

Louisianian and Carolinian areas. New Jersey, east Pennsylvania. 'Tropical (Antilles).

Sphagnum imbricatum cristatum Warnst.

Boggy pine barrens, abundant. Mobile Connty.

Louisianian and Carolinian areas. Along the coast of New Jersey. 
Sphagnum imbricatum glaucescens Warnst.

Mobile County, Citronelle (C. Baker).

Sphagnum imbricatum squarrulosa Warnst.

Lee County, Auburn (Baker \& Earle).

Sphagnum microcarpum Warnst.

Damp pine flats, close to the ground; abundant. Mobile Connty.

Sphagnum cyclophyllum Sulliv. \& Lesq.

Wet sandy ground. Raccoon Mountains (Lesquereux).

Louisianian to Carolinian area. Louisiana to Florida; sonthern New Jersey.

Sphagnum macrophyllum Bernh.

On wet banks of streams and immersed in shallow ponds. Mobile County, Kellys Pond; fertile, March. Washiugtou County. Pine barren swamps; not infrequent. Louisianian and Carolinian areas. Along the coast to North Carolina and New Jersey.

\section{Order ANDREAEALES.}

\section{Family ANDREAEACEAE.}

\section{ANDREAEA Ehrh.}

Andreaea rothii Web. \& Mohr. A. rupestris Turn.

On rocks. Etowah County, near Garlsden, Black Creek Falls, altitude 1,600 feet (Charles Mohr). Winston and Cullman counties, highest ridges, altitude 1,000 to 1,500 feet (Charles Mohr.)

Carolinian area. Mountains of South Carolina; New Jersey. Central and southern Europe.

\section{Order BRY ALES. True mosses.}

\section{Series ACROCARPI.}

\section{Family BRUCHIACEAE.}

\section{BRUCHIA Schwaegr.}

\section{Bruchia sullivantil Aust.}

Saudy exposed ground, pastures, borders of fields. Lee County, Auburn (Baker of Earle).

Louisianian and Carolinian areas.

Bruchia sullivantii nigricans Lesq.

Borders of pools. Marshall County, Raccoon Mountains (Lesquereux).

Carolinian area.

Bruchia donnellii Aust.

Damp sandy ground. Mobile County, flat pine barrens, frequent.

Louisianian area.

Bruchia mohrii K. Mnell. sp. ined.

With the preceding, rare.

Bruchia ravenelii Wils.

On dry loamy sand. Mobile County, Springhill, trodden paths.

Louisianian area. Florida, Sonth Carolina.

Bruchia curviseta Lesq. \& James.

Dry sandy loam.

Louisianian area. Florida.

Bruchia texana Aust.

Damp exposed grount. Mobile Connty, flat pine barrens.

Lonisianiau area. 'Texas. 
Bruchia brevifolia Sulliv.

Dry, exposed sandy ground. Mobile County, Springhill.

Louisianian area. Louisiana to Florida.

Bruchia drummondii Hampe. B. brevipes Hook. \& Wils., not Hook.'

With the above, Mobile County, Springhill.

Louisianiau to Carolinian area. Eastern Louisiana, South Carolina, southern Virginia.

\section{PLEURIDIUM Brid.}

Pleuridium subulatum (Schreb.) Bruch \& Schimp.

Dry exposed ground. Lee County, Auburn, bare hills (Baker \& Earle).

Louisianian and Carolinian areas. Florida to Pennsylvania, Califoruia. Europe.

Pleuridium alternifolium robustum Sulliv. \& Lesq.

In humid depressions on sandstone rocks. Raccoon Mountains (Lesquereux).

Carolinian area. Washington, D. C. Illinois.

\section{ARCHIDIUM Brid.}

Archidium ohioense Schimp.

Meadows and waste fields. Raccoon Mountains (Lesquereux).

Carolinian area. New Jersey, central Ohio.

\section{Family PHASCACEAE.}

\section{ASTOMUM Hampe.}

Astomum ludovicianum Sulliv. A. sullivantii Schimp.

Grassy banks, bare borders of fields. Mobile County, frequent. March, April.

Louisianian and Carolinian areas. Eastern Louisiana to Florida, north to New Jersey and Ohio.

\section{Family WEISIACEAE.}

MOLLIA Schrank.

Mollia viridula (L.) Lindb. Weisia viridula Hedw.

Sandy ground, common throughout. Mobile County, March.

Louisianian to Alleghenian area. Texas to Florida, north to New England, Canada, Northwest Territory, and Vancouver Island. Enrope.

Mollia longiseta (Lesq. \& James). Weisia viridula australis Aust.

On sandy ground, Mobile County. Lee County, Auburn (Baker \&. Earle).

Louisianian and Carolinian areas. Florida to New Jersey.

\section{Family DICRANACEAE.}

TREMATODON Rich.

Trematodon longicollis Rich.

Damp sandy ground. Baldwin County, Magnolia Springs; damp rocks, not common. June.

Louisianian and Carolinian areas. North to New Jersey and Pennsylvania.

DICRANELLA Schimp.

Dicranella debilis (Hook. \& Wils.) Lesq. \& James.

Damp shaded ground. Mobile County; walls of ditches, abundant. December to March.

Louisianian area. Louisiana to Florida and Sonth Carolina. Cuba. 
DICRANUM Hedw.

Dicranum scoparium (L.) Hedw.

Mountainous woods, Winston County, altitude 1,500 feet, on roots of trees, not frequent.

Carolinian and Alleghenian areas. Alabama, southern Alleghenian ranges. Over the continent to the Pacific and to the Arctie zone.

Europe, Asia, Africa.

Dicranum pallidum Br. \& Schimp. D. sabuletorum Ren. \& Card.

Exposed sandy ground. Mobile Connty, arid pine ridges, frequent. Springhill; Citronelle, rolling pine barrens (Baker of Smith).

Lonisianian and Carolinian areas. Mississippi to Florida; New Jersey, Pennsylvania.

\section{CAMPYLOPUS Bril.}

Campylopus subleucogaster (K. Muell.) Lesq. \& James.

Damp clay ground near Mobile. First collected in 1868; very rare.

Lonisianian area.

\section{Family LEUCOBRYACEAE.}

\section{LEUCOBRYUM Hampe.}

Leucobryum glaucum (L.) Schimp.

Dry woods, throughout the State; common. Mobile County, March.

Louisianian to Alleghenian area. Louisiana and Florida, north to Newfonndland and Ontario. Europe.

Leucobryum pumilum (Michx.) E. G. Britton. L. minus (Hampe) Sulliv.

Decaying logs, roots of trees. Mobile Connty, in pine-barren swamps; frequent, May, June.

Louisianian area. Louisiana to Florida.

\section{Family FISSIDENTACEAE.}

FISSIDENS Hedw.

Fissidens minutulus Sulliv.

On dead wood or on the ground in damp shady places. Mobile Connty, fide Austin.

Louisianian and Carolinian areas. Northern and western Rocky Mountains. Oregon, British America.

Fissidens donnellii Aust.

Swamps, roots of trees. Mobile County.

Louisianian area. Florida.

Fissidens raveneiii Sulliv.

Shaded, sandy, damp soil. Mobile County, walls of ditches; March.

Louisianian and Carolinian areas. South Carolina, North Carolina.

Fissidens adiantoides (L.) Hedw.

Shaded damp or wet places. Lee County, Anburn (Baker \& Earle). Winston County. Etowah County, Black Creek Falls; wet rocks, common.

Carolinian and Alleghenian areas. New England, Nova Scotia, Ontario, Vaneonver Island. Europe.

Fissidens subbasilaris Hedw.

Damp shaded places, roots of trees. Mobile County. Lee County, Auburn, frequent.

Louisianian to Alleghenian areas. New Jersey, Pennsylvania, Ohio, North Carolina, Ontario.

Fissidens taxifolius Hedw.

Damp rich ground. Mobile County, Magnolia Grove.

Louisianian to Alleghenian area. Ohio, New Jersey to New England. Europe. 
Fissidens decipiens De Not.

Shaded sandy ground. Mobile County, not frequent.

Louisianian to Alleghenian area. North to New Jersey, Ohio, and Ontario.

Fissidens polypodioides (Sw.) Hedw.

Dripping rocks in the mountains. Etowal County, Gadsden, Black Creek Falls. Stierile; not rare.

Lonisianian area. Louisiana, Florida, Georgia. Mountains of Jamaica and South America.

\section{OCTODICERAS Brid.}

Octodiceras julianum (Savi) Brid. Conomitrium julianum Mont.

In clear rocky springs. Talladega County.

Carolinian and Alleghenian areas. New Jersey, Ohio, and Ontario. South and central Europe.

\section{Family POTTIACEAE.}

\section{DESMATODON Brid.}

Desmatodon plinthobius Lesq. \& Sulliv.

Damp brick walls. Mobile County.

Lonisianian and Carolinian areas. 'Iexas to Georgia, South Carolina, Pennsylvania, Tennessee.

BARBULA Hedw.

Barbula caespitosa Schwaegr.

Woodlands, roots of trees. Montgomery County. Cullman County, Sand Mountain. Winston County, frequent.

Louisianian to Alleghenian area. Georgia, Tennessee to New Jersey, Pennsylvania, New York.

Barbula convoluta Hedw.

In woods, on the ground. Marshall County, Raccoon Mountains (Lesquereux).

Carolinian and Alleghenian areas. Througlıout the Easteru States to Canada; west through the Rocky Mountains to California; British Columbia.

TORTULA Hedw.

Tortula muralis (L.) Hedw. Barbula muralis Timm.

Shaded damp walls. Mobile County, rare. March.

Louisianian and Carolinian areas. South Carolina, Virginia, New Jersey, Pennsylvania. Europe.

\section{DITRICHUM Timm.}

Ditrichum pallidum (Schreb.) Hampe. Trichostomum pallidum Hedw.

On light sandy ground. Over the State, common. April.

United States, Canada. Europe.

\section{TRICHOSTOMUM Smith.}

Trichostomum macrostegium Sulliv. \& Lesq.

On stones and old walls. Mobile County, very rare.

Louisianian area. Louisiana (1)onaldsonville), first collected by C. Mohr, 1873.

\section{Family GRIMMIACEAE.}

\section{GRIMMIA Ehrh.}

Grimmia campestris Burchell. G. leucophaea Grev.

On rocks. Throughont the mountains. Cullman and Winston counties. Dekalb County, Lookout Mountain, frequent; sterile.

Carolinian area. Upper Georgia, Ohio to New York. Central and South Europe, North Africa. 
Grimmia pilifera Beauv. G. pennsylvanica Schwaegr.

On rocks. Cullman County.

Alleghenian (?) and Carolinian areas. Ontario (Niagara Falls), Pennsylvania, New Jersey.

Grimmia acicularis (L.) K. Muell.

On wet roeks in streams. Cullman County.

Canadian to Carolinian area. Newfoundland to British Colnmbia; Maine to New Jersey and southward along the mountains.

\section{Family ORTHOTRICHACEAE.}

\section{ORTHOTRICHUM Hedw.}

Orthotrichum pumilum americanum Vent. O. pumilum Sw.

On trees. Lee County, Anburn (Baker \& Earle).

Carolinian area. New Jersey. Europe.

\section{PTYCHOMITRIUM Bruch \& Schimp.}

Ptychomitrium incurvum (Schwaegr.) Sulliv.

Ou rocks. Cullman County, banks of Ryans Creek; July; not rare.

Carolinian area. Along the mountains from Georgia to northern New York; New Jersey, Ohio.

DRUMMONDIA Hook.

Drummondia clavellata (Schwaegr.) Hook.

On bark of trees. Leo Connty, Auburn (Baker \& Earle). Winston County, not infrequent in the mountains.

Carolinian area. Geurgia to Virginia and Maryland, Ohio Valley.

\section{SCHLOTHEIMIA Brid.}

Schlotheimia sullivantil K. Muell.

Bark of trees. Low damp woods. Mobile, Baldwin, and Montgomery connties, on magnolias; frequent.

Louisiana to Florida; South Carolina.

SYRRHOPODON Schwaegr.

\section{Syrrhopodon texanus Sulliv.}

Damp woods, decaying trunks. Mobile County, swampy hammocks; not rare.

Lonisianian area. Texas to North Carolina.

\section{Syrrhopodon floridanus Sulliv.}

With the preceding.

Louisiana area. From Lonisiana to Florida; less frequent.

\section{AMPHORIDIUM Schimp. ZyGODON Hook. \& Tayl.}

\section{Amphoridium mougeottii Schimp.}

Wet rocks, roots of trees. Etowah County, Black Creek Falls; sterile (fide Holzinger).

Carolinian to Alleghenian area. Along the mountains to Pennsylvania, north to Canada; Rocky Mountains from Colorado to British Columbia. Europe.

Amphoridium lapponicum (Hedw.) Bruch \& Schimp.

With the preceling (fide Holzinger).

Carolinian area to Boreal region. Along the mountains to New Jersey, thence to Canada; Rocky Mountains to British Columbia; Greenland. Alps and boreal Europe. 


\section{Family FUNARIACEAE.}

\section{PHYSCOMITRIUM Brid.}

Physcomitrium turbinatum (Michx.) Brid. P. pyriforme plur. auct. Am.

Grassy banks, borders of fields. Mobile County, abundant; March.

Louisianian to Allegenian area. Eastern North America from Florida to Ontario, west to the Rocky Mountains.

Physcomitrium turbinatum langloisii (Ren. \& Card.) E. G. Britton.

Low ground, February, March. Lee County, Anburn (Baker \& Earle). Mobile County.

Louisianian area. Texas and Louisiana to Florida.

FUNARIA Schreb.

Funaria hygrometrica (L.) Sibth.

On bare sandy or gravelly ground. Throughout; common.

Cosmopolitan.

Funaria calvescens Schwaegr. F. hygrometrica calvescens Br. \& Schimp.

On damp sandy ground. Mobile County, not infrequent; March, April.

Lonisianian and Carolinian areas. Texas to South Carolina. Mexico, South America.

Funaria flavicans Michx.

On damp sandy ground. Mobile County, damp pastures; abundant, March.

Lee County, Auburn, March (Baker \& Earle).

Louisianian and Carolinian areas. Louisiana to New Jersey.

Funaria serrata Brid.

Exposed sandy banks. Mobile County. Lee County, Auburn (Baker \& Earle).

Louisianian and Carolinian areas. Louisiana to Florida. Frequent; March.

\section{ENTOSTHODON Schwaegr.}

Entosthodon drummondii Sulliv.

Bare damp loamy ground. Throughout the lower pine region; pine woods and pastures. Mobile County, frequent. Montgomery County (Sullivant).

Louisianian area. Eastern Louisiana to western Florida. March, April.

\section{Family BRYACEAE.}

\section{BRYUM.}

Bryum erythrocarpum Schwaegr. Bryum sanguineum Brill.

Mountains, north Alabama. Lookont Mountain (Lesquereux). April, June.

Carolinian area. Central and Southern Europe.

Bryum bicolor Dicks.

Sandy soil. Mobile County. Lookout Mountain, with B. erythrocarpum; May (Lesquereux).

Louisianian to Alleghenian area. North to Pennsylvania, New York, Ontario, Illinois, and Nevada. Europe.

Bryum caespiticium L.

Old damp walls. Stones, shady places. Mobile County, not infrequent.

Louisianian to Alleghenian area. Canada to Arctic zone. Europe.

Bryum nutans Schreb.

Damp walls. Mobile County, rare; May.

Throughout the United States; Canada to Aretic zone; Alaska. Europe.

Bryum pulchellum Hedw. B. lescurianum Sulliv.

Lee County, Auburn (Baker \& Earle).

Carolinian area. New Jersey, southern New York. 
Bryum ventricosum Dicks. B.pseudotriquetrum Schwaegr.

Damp shaded walls. Mobile County; May.

Louisianian to Alleghenian area. New Jersey, Ohio, and New York to Canarla; British Columbia to Aretic zone.

Bryum argenteum $\mathrm{L}$.

Old roofs, stoues in damp places. Mobile County.

Common throughout the United States; Canada. Europe.

\section{LEPTOBRYUM Wils.}

Leptobryum pyriforme (L.) Wils. Bryum pyriforme L.

Damp ground, woodlands. Lee County, Auburn (Baker \& Earle).

Carolinian and Alleghenian areas. Along the mountains to West Virginia; Ohio and north to Canada; Colorado and the Rocky Mountains to British Columbia. Europe, Asia.

\section{MNIUM L.}

Mnium affine Bland.

Wooded hills, damp shady places. Throughout the mountain region. Lee County, Auburn (Baker \& Earle). Winston and Etowah counties.

Carolinian and Alleghenian areas. North to Canada. Asia. Cosmopolitan.

Mnium cuspidatum (L.) Hedw.

Lee and Winston counties; sterile.

Mnium cuspidatum var. Astrophyllum cuspidatum pachyphyllum Kindlb. ined. Lee County, Auburn (Baker \& Earle).

\section{RHIZOGONIUM Brid.}

Rhizogonium spiniforme (K. Muell.) Bruch. Mnium spiniforme K. Muell.

Damp shaded swamp on decayed wood. Mobile County, Oakhill Swamp-only locality known in the State.

Louisianian area. Louisiana. Tropical West Indies, South America, Java, Africa (Cape).

SPHAEROCEPHALUS Necker. AulaComnium Schwaegr.

Sphaerocephalus heterostichum Bruch \& Schimp.

Shady hills. Montgomery, Winston, and Cullman counties. Lee County, Auburn. Common throughout the Hill country.

Lonisianian and C'arolinian areas. Throughout the Eastern United States to Canacia (Ontario).

Sphaerocephalus palustris (L.) Lindb.

Low swampy grouna. Mobile County, pine-barren swamps, among bushes; not rare.

Louisianian area to Boreal region. North to Canada and Northwest Territory; Colorado to the Pacific, Alaska. Europe, Siberia.

\section{Family BARTRAMIACEAE.}

BARTRAMIA Helw.

Bartramia pomiformis (L.) Hedw.

Shady woods, rocky banks. Winston County. Etowah County, Gadsien. Leo County, Auburn (Baker \& Earle).

Carolinian and Alleghenian areas. From the Sonthern mountains throughout the Middle and Northern States; Canada west to the Rocky Mountains, British Columbia and Oregon. Europe.

Bartramia radicalis Beauv.

Damp bauks, borders of ditches. Mobile County. Etowah Connty, Gadsclen, on damp rocks.

Louisianian and Carolinian areas, Louisiana to North Carolina, 


\section{PHILONOTIS Brid.}

Philonotis fontana Brid.

Dripping rocks. Etowah County, falls of Black Creek; rare.

Carolinian to Alleghenian area. Thronghout the Middle and Northern States to Canada and Newfoundland, west to British Columbia and the Rocky Mountains, Oregon, and California.

\section{Family POLYTRICHACEAE.}

\section{CATHARINEA Ehrh. Atrichum Beauv.}

Catharinea undulata (L.) Web. \& Mohr.

Exposed sandy grounil over the State.

Louisianian to Alleghenian area. Throughont the United States; Canada. Europe.

Catharinea angustata Brid.

Sandy damp ground. Mobile County. Lee Connty, Auburu. Cullman County, common.

Louisianian to Allegheuian area. North to New York, Canada, and Newfoundland.

Catharinea xanthopelma K. Muell.

Exposed sandy places. Mobile County, rare.

Louisianian area. Louisiana and Texas.

\section{POLYTRICHUM L.}

Polytrichum ohiense Ren. \& Card. P. formosum Sulliv. Not Hedw.

Exposed damp sandy ground. Mobile County, common in damp pine barrens. Winston County.

Louisianian to Alleghenian area. North to Now Jersey, Ohio, and Canada.

Polytrichum commune L.

Open woods in the mountains. Lee County, Auburn (Baker \& Earle). Winston County.

Carolinian area to Boreal region. Throughont Atlantic North America. Europe.

Polytrichum commune perigionale (Michx.) Bruch \& Schimp.

Mountainous woods, on rocks. Winston County, banks of the Sipsey Fork, 1,500 feet.

Carolinian area. South Carolina and northward.

Polytrichum piliferum Schreb.

Rocky flats. Dekalb County, Lookout Mountain, near Mentone, 2,200 feet; September.

Carolinian area to Boreal region. North to Canada; Rocky Mountains, British Columbia, Greenland. Europe.

Polytrichum tenue Menz. Pogonatum brevicaule Brid.

Damp clay banks. Auburn; frequent, April (Baker \& Earle).

Carolinian and Alleghenian areas. Georgia to Pennsylvania and north to Canada (Ontario).

Polytrichum brachyphyllum Michx.

Moist clay banks, roadsides, borders of ditches. Mobile County, December, January. Abundant in Coast plain.

Louisianian and Carolinian areas. South Carolina, along the coast to New Jersey.

Polytrichum capillare Michx.

On rocks. Dekalb County, summit of Lookout Mountain, 2,200 feet.

Carolinian area to Boreal region. Sonth Carolina; New England, White Mountains; New York, Adirondack Mountains; Rocky Mounțains (Colorado); Canada, Greenland, 


\section{Family BUXBAUMIACEAE.}

WEBERA Ehrh.

Webera sessilis (Schmid.) Lindb. Diphyscium foliosum Mohr.

Dry gravelly or sandy bauks. Winston County, near Colliers Creek, 1,500 feet.

Carolinian and Alleghenian areas. Ohio; New Jersey to Canada. Europe.

\section{Series PLEUROCARPI.}

\section{Family FONTINALACEAE.}

\section{FONTINALIS L.}

Fontinalis disticha Hook. \& Wils.

Swift-running brooklets. Lower pine barrens. Mobile County, Citronelle; frequent (Sullivant, Mohr).

Louisianian area. East Louisiana, west Florida.

Fontinalis lescurii Sulliv.

On rocks in streams, mountain region. Dekalb County, Lookout Mountain. Falls of Little River (Lesquereux, 1852, Mohr, 1898), Cullman County, altitude 800 to 2,000 feet, not rare.

Carolinian and Alleghenian areas. New Jersey, New England, Oregon.

\section{DICHEL YMA Myrin.}

Dichelyma subulatum (Beauv.) Myrin.

On rocks in the Chattahoochee River, a few miles below the Alabama State line.

Louisianian area. Louisiana? (Drummond), Georgia.

\section{Family LESKEACEAE.}

\section{ANOMODON Hook. \& Tayl.}

Anomodon rostratus (Hedw.) Schimp.

Roots of trees in the mountains. Lee County, Auburn (Baker \& Earle). Winston County.

Carolinian and Alleghenian areas. Eastern United States to Canada; Vancouver Island. Europe.

Anomodon attenuatus (Schreb.) Huebn.

Mountain region, on trees and roots, banks of streams; particularly on trunks subject to inundation. Lee County, Auburn (Baker \& Earle). Winston County.

Carolinian and Alleghenian areas. Throughout the Eastern United States and Canada; Nova Scotia, Ontario. Europe.

LESKEA Hedw.

Leskea microcarpa Schimp.

Low banks, on roots of trees, in the hill country. Lee County, Auburn (Baker of Earle). Winston County.

Louisianian to Alleghenian area. Louisiana (Langlois), Ohio Valley, New Jersey, New York.

Leskea polycarpa subobtusifolia Kindlb.

Low banks, roots of trees, Lee County, Auburn; with the above.

Carolinian and Alleghenian areas. New Jersey, New York to Canarla; British Columbia, Oregon. Europe.

Leskea denticulata Sulliv.

Lee County, Auburn (Baker \& Earle). Montgomery County.

Louisianian and Carolinian areas. Louisiana (Dr. Joor), Ohio, New Jersey. 
THELIA Sulliv.

Thelia hirtella (Hedw.) Sulliv.

Roots and bark of trees. Mountains of Alabama.

Carolinian and Alleghenian areas. Georgia to New Jersey, Ontario.

Thelia asprella (Schimp.) Sulliv.

Hill country, base of trees. Lee County, Auburn.

Carolinian to Alleghenian area. New Jersey, New York, Canada (Ontario).

Thelia lescurii Sulliv.

Dry shady ground. Lee County, Auburn.

Carolinian area. Southern States (Lesquereux).

\section{Family FABRONIACEAE.}

FABRONIA Raddi.

Fabronia ravenelii Sulliv.

Decayed logs. Lee County, Auburn.

Carolinian area. South Carolina.

Fabronia wrightii brachyphylla Kindb. ined.

Open ground. Lee County, Auburn.

Carolinian area. Texas.

CLASMATODON Hook. \& Tayl.

Clasmatodon parvulus (Hampe) Sulliv.

On trees, Coast plain. Mobile County, frequent on cedars.

Louisianian area. Louisiana to South Carolina.

Clasmatodon parvulus rupestris Sulliv. \& Lesq.

Wet rocks. Lee County, Auburn.

Carolinian area. 'Tennessee.

\section{Family NECKERACEAE.}

\section{NECKERA.}

Neckera (Orthostichella) ludoviciae K. Muell.

Decaying trunks and logs. Swamps. Mobile County, near Cottage Hill; fertile! May, 1873.

Louisianian area. Louisiana (Dr.Joor).

CRYPHAEA Mohr.

Cryphaea glomerata (Brid.) Bruch \& Schimp.

On trees. Mobile and Montgomery counties.

Louisianian and Carolinian areas. Louisiana and along the coast to New Jersey.

Uryphaea pendula Lesq. \& James.

On trees. Lee County, Auburn (Baker \& Earle).

Louisianian and Carolinian $(?)$ areas. Florida, fide Kindberg.

Cryphaea nervosa Bruch \& Schimp.

On trees. Mobile County, rare.

Louisianian area. Louisiana to Florida.

\section{HEDWIGIA Ehrh.}

Hedwigia albicans (Web.) Lindb.

Dry rocks throughout the mountain region. Clay, Winston, Cullman, and Dekalle counties, common.

Carolinian and Alleghenian areas to the Boreal region. Throughout the mountains north to Canada; Greenland; west to the Rocky Mountains and British Columbia.

Hedwigia albicans subnuda Mohr, nom. nov. H. ciliata subnuda Kindb. in Macoun, Cat. Can. Pl. 6: 78. 1892.

Lee County, Auburn (Baker \& Earle).

Carolinian and Alleghenian areas. Ontario.

$15894-20$ 


\section{LEPTODON Mohr.}

Leptodon trichomitrium (Hedw.) Mohr.

Shady woods on trees. Over the State, common.

Lonisianian to Alleghenian area. Throughout the Eastern States to Ontario.

Leptodon immersum Sulliv. \& Lesq.

On trees. Mobile County, frequently with the last.

Lonisianian area. Louisiana to Florida.

Leptodon irriguus Renauld, MS. L. trichomitrion irriguus Revanld.

On wet rocks. Etowah County, Black Creek Falls, near Gadsclen.

Louisianian and Carolinian areas. Florida, Georgia.

LEUCODON Schwaeg.

Leucodon julaceus (Hedw.) Sulliv.

On trees. Abnndant over the State.

Louisianian and Carolinian areas. Along the Atlantic coast to New Jersey and New York.

Leucodon brachypus Brid.

On trees. Winston County. Infrequent.

Carolinian area. North to New Jersey, Nora Scotia, and Ontario

\section{Family ISOTHECIACEAE.}

\section{CLIMACIUM Web. \& Mohr.}

Climacium americanum Brid.

Woods, on damp ground. Not infrequent in mountainous districts. Lee Connty, Auburn (Baker \& Earle). Winston County. Sterile.

Louisianian area. Louisiana (Dr. Joor) to Canada (Ontario) and Newfoundland.

\section{ENTODON K. Muell. Cylindrothecium Bruch \& Schimp.}

Entodon cladorrhizans (Hedw.) K. Muell.

Decaying wood, roots of trees. Mobile County, infrequent. December.

Louisianian to Alleghenian area. Eastern United States, Florida to Canada. Europe.

Entodon brevisetum (Hook. \& Wils.) Jaeg. \& Sauerb.

On rocks and on the ground. Lee County, Auburn (Baker \& Earle).

Carolinian to Alleghenian area. Ohio, Missouri, New Brunswick (fide Kindberg).

Entodon seductrix (Hedw.) K. Muell.

Damp places, on rotten wood and roots of trees and on the ground. Throughout.

Louisianian to Alleghenian area. Common everywhere from Texas and Florida north to Canada. Europe.

Entodon compressus (Hedw.) K. Muell.

Lee County, Auburn, rare (Baker \& Earle).

Carolinian and Alleghenian areas. Ohio, Pennsylvania, Canada (Ontario).

Entodon drummondii (Bruch \& Schimp.) Jaeger \& Sauerb.

In low damp places, woods, on clecaying wood and the bare ground. Mobile County, December. Not infrequent.

Louisianian and Carolinian areas. Louisiana, west Florida, Tennessee. Northern Mexico.

Entodon palatinus Lindb. Platygyrium repens Bruch \& Schimp.

Open woods, roots of trees. Mountain region. Lee County, Auburu (Baker \& Earle). Winston County.

Carolinian and Alleghenian areas. Along the mountains to the Ohio Valley, north to New Englaud (Mount Desert); Rocky Mountains, British America. Europe.

PYLAISIA Bruch \& Schimp.

Pylaisia intricata Bruch \& Schimp.

Damp logs and on trees. Lee County, Auburn (Baker \& Earle). Winston County. Louisianian to Alleghenian area. Florida (Chapman), Georgia. Throughout the

Eastern United States; Rocky Mountains; Ontario. 


\section{Family HYPNACEAE.}

THUIDIUM Bruch \& Schimp.

Thuidium äelicatulum (L.) Mitt.

Shaded banks on the ground, logs, trees, etc. Common throughout.

Louisianian area to Boreal region. Labrador, British North America; West Indies, Mexico, South America.

Thuidium microphyllum (Sw.) Best.

Damp places, on brick walls and rotten wood, and on the ground. Mobile County. Lee County, Auburn (Baker \& Earle).

Louisianian to Alleghenian area. Throughout the Eastern United States; most frequent sonthward. West Indies, Mexico.

\section{BRACHYTHECIUM Schimp.}

Brachythecium oxycladon (Brid.) Jaeg. \& Sauerb.

Mountainous woods, on the ground. Winston County.

Carolinian and Alleghenian areas. North to New England, Canada, New foundland.

Brachythecium acuminatum (Hedw.) Rau \& Hervey.

Mountainous woods, on decayed trunks. Winston County. Lee County, Auburn (Baker \& Earle).

Louisianian to Alleghenian area. Florida to New England; Ontario.

Brachythecium campestre Bruch.

Lee County, Auburn (Baker \& Earle). A strange find entirely out of range; known only from the White Mountains, New England, and the Westeru Rocky Mountains, Idaho, and from British Columbia.

Brachythecium plumosum (Sw.) Bruch \& Schimp.

Damp rocks. Winston County.

Carolinian and Alleghenian areas. North to New England, Ontario, Quebec.

\section{EURHYNCHIUM Bruch \& Schimp.}

Eurhynchium hians (Hedw.) Jaeg. \& Sauerb.

Damp shady borders of woods. Winston County. Lee County, Auburn (Baker \& Earle).

Carolinian and Alleghenian areas. Throughout the Eastern States to Ontario, Nova Scotia, and British ('olumbia.

Eurynchium boscii (Schwaegr.) Jaeg. \& Sauerb.

Grassy damp banks. Mobile County. Lee County, Auburn (Baker \& Earle).

Louisianian to Alleghenian area. Louisiana to Florida, throughout the Eastern States to Ontario.

RAPHIDOSTEGIUM Lesq. \& James.

Raphidostegium microcarpum (K. Muell.) Lesq. \& James. Hypnum microcarpum K. Muell. Leskea adnata Michx.

On trees. Over the State. Mobile County. Lee County, Auburn (Baker \& Earle). Alundant; February, March.

Louisianian and Carolinian areas. Louisiana to Florida, north to New Jersey and Ohio.

Raphidostegium recurvans (Schwägr.) Lesq. \& James.

Roots of trees. Mountain region. Winston County. Not rare.

Carolinian to Alleghenian area. Aloug the mountains to Pennsylvania, New Jersey, and Canada; Newfoundland west to British Columbia.

Raphidostegium carolinianum K. Muell.

In swamps, on rotten wood and roots of trees. Mobile County.

Louisianian and Carolinian areas. Louisiana and Florida to New Jersey.

RHYNCHOSTEGIUM Schimp.

Rhynchostegium serrulatum (Hedw.) Lesq. \& James.

Woodlands, shaded banks, on the ground and on roots of trees and decayed trunks. Mobile County. Lee County, Auburn. Over the State: one of the commorest of mosses.

Louisianian to Alleghenian area. From the Gulf coast to Canada. 
POROTRICHUM Brid. THAMNIUM Sehimp.

Porotrichum alleghaniense (Bruch \& Schimp.) K. Muell.

Wet woods in the mountains. Morgan County, Falkville. Winston County. Not rare; sterile.

Carolinian and Alleghenian areas. Georgia, along the monntains to New York, Ontario, and Nova Scotia.

\section{PLAGIOTHECIUM Sehimp.}

Plagiothecium denticulatum (L.) Bruch \& Schimp.

Mountain region. Lee County, Anburn. Winston County.

Carolinian and Alleghenian areas to Boreal region. 'Thronghout the Eastern United States, Rocky Mountains to the Pacific; California, Alaska. Europe.

Plagiothecium micans Sw. Hypnum albulum K. Muell.

Wet places, on decayed logs. Mobile County. Montgomery Connty (Sullivant). Lee County, Auburn (Baker \& Earle).

Louisianian and Carolinian areas. Louisiana; Florida to New Jersey.

\section{AMBLYSTEGIUM Bruch \& Schimp.}

Amblystegium varium (Hedw.) Lindb. A. radicale Bruch \& Schimp.

Wet places, roots of trees. Mobile County, frequent; April.

Louisianian to Alleghenian area. Louisiana and Florida to New York; Canada, British Columbia, Rocky Mountains; California. Europe.

Amblystegium serpens (L.) Bruch \& Schimp.

Damp ground, prostrate truuks. Mobile County, common over the State.

Lonisianian area to Arctic zone. Throughout the United States; Canada and Labrador; Rocky Mountains to the Pacific. Europe.

Amblystegium fluviatile (Sw.) Bruch \& Schimp.

On rocks in water. Lee County, Auburn (Baker \& Earle).

Carolinian to Alleghenian area. North to New Jersey, New York, and Ohio; Canada (Ontario). Europe.

\section{CAMPYLIUM Mitt.}

Campylium hispidulum (Brid.) Mitt.

On trees. Lee County, Auburn (Baker \& Earle).

Carolinian and Alleghenian areas. New Jersey, Ohio, Canada.

Campylium chrysophyllum (Brid.) Lesq. \& James.

1)amp woods. Lee County, Auburn (Baker \& Earle).

Carolinian and Alleghenian areas. Along the mountains to 'Tennessee, Ohio, New

England; Ontario, New Brunswick.

Campylium unicostatum K. Muell. \& Kindl.

Damp woods, on logs and trunks. Les County, Auburn (Baker \&. Earle).

Carolinian and Alleghenian areas. Canada (Ontario).

HYPNUM L.

\section{Hypnum curvifolius Hedw.}

Woods, on dearl trees and mossy ground. Mountain region. Winston County. Lee County, Auburn (Baker \& Earle). Etowah Connty.

Louisianian, Carolinian, and Alleghenian areas. Georgia north to New Jersey, New York, Canada (Ontario); New Brunswick, Newfoundland.

Hypnum pratensis Koch.

Damp woods, on the ground. Lee County, Auburn (Baker \& Earle).

Carolinian and Alleghenian areas to Boreal region. New Jersey, Now York; Canada (Ontario), Newfoundland, British Columbia, Greenland.

${ }^{1}$ Amblystegium homalostegium Jaeg. \& Sauerb., according to L. S. Cheney doubtfully of this genus, was collected for the only time in Alabama. See Botanical Gazette, vol.24, p. 241 . 


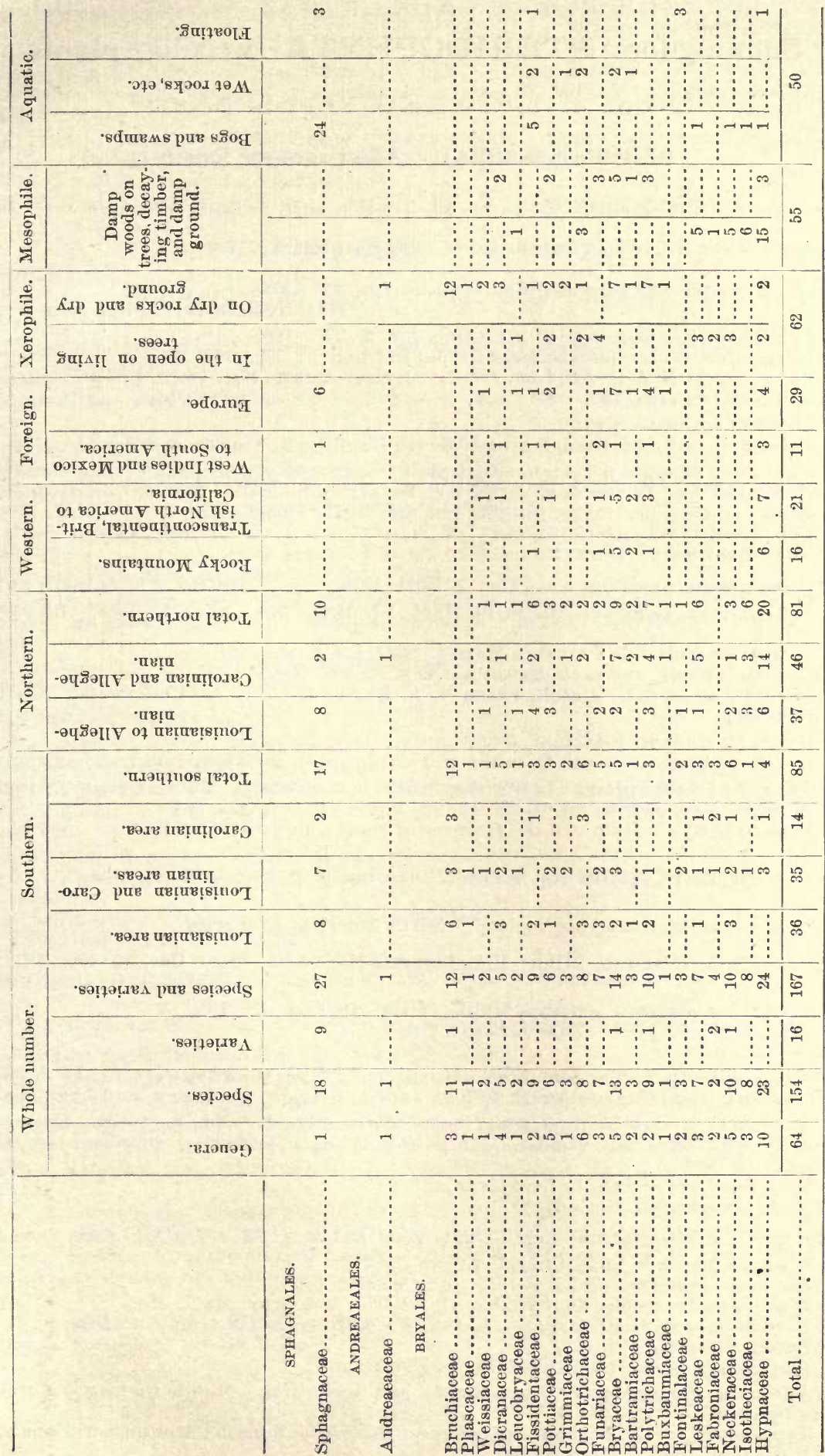




\section{Subkingdom PTERIDOPHYTA. Fernlike plants.}

\section{Order FILICALES. Ferns proper.}

\section{OPHIOGLOSSACEAE. Adder's-tongue Family.}

OPHIOGLOSSUM L. Sp. Pl. 2 : 1062. 1753. AdDER's-TONGUk.

About twenty-five species, mostly of temperate zones.

Ophioglossum crotalophoroides Walt. Fl. Car. 256. 1788.

BULbOUS-ROOTED ADDER'S-TONGUE.

Ophioglossum bulbosum Michx. Fl. Bor. Am. 2:276. 1803.

O. vulgatum var. crotalophoroides Eaton, in Chap. Fl.599. 1860.

Eaton, Ferns N. A. $2: 265, t .85, f .5-\%$. Coulter, Contr. Nat. Herb. $2: 568$. Underwood, Native Ferns, 128.

South America. Chile.

Carolinian and Louisianian areas. South Carolina to Florida and Texas.

Alabama: Mountain region, Coast plain. Exposed grassy banks. Lee County, Auburn, 860 feet (Underwood \& Earle); Metamorphic hills. Mobile County, sandy borders of tields, pastures. Mareh; not rare in the Coast plain.

Type locality: South Carolina.

Herb. Geol. Surv. Herb. Mohr.

Ophioglossum pusillum Nutt. Gen. 2 :248. $1818 . \quad$ DWARF AdDER's-Toxgue. Ophioglossum nudicaule Sturm in Mart. Fl. Bras. fasc. 23:144. 1884. In part. Not L. f.

O. tenerum Mett. fide Prantl in Mart.1. c. 322, t. 8, f. 23. 1884.

O. vulgatum var. nudicaule, Eaton in Chap. Fl. 599. 1860.

Chap. Fl. ed. 3, 637. Eaton, Ferns N. A. $2: 267, t .81, f .4$. Underwood, Native Ferns, 129.

Cuba, Mexico to Brazil.

Louisianian area. South Carolina to Florida, west to Mississippi and Louisiana.

Ala Bama : Coast plain. Low grassy banks in sandy soil. Mobile County, December, 1860 . Very scarce.

Type locality: "Hab. On the margins of ponds, in South Carolina."

BOTRYCHIUM Sw. Schrad. Journ. Bot.2:8. 1800. Grape Fern.

Thirty species, temperate regions. North America, 15 species.

Botrychium obliquum Milde, Mon. Botrych. Nov. Acta. Leop. Car. 20: 109. 1858.

Oblique Grape Fern.

Botrychium ternatum obliquum Muhl.; Willd. Sp. Pl. 5 : 63. 1810.

Gray, Man. ed.6, 694. Eaton, Ferns N. A. 1:150.

MEXico.

Alleghenian to Louisianian area. Nova Scotia and Ontario, west to the Rocky Mountains; New England sonth to New Jersey, Florida, Louisiana, and Arkansas.

ArabaMa: Mountain region to Coast plain. Woods and pastures. Cullman County, 800 feet shady woods. Mobile County, open pastures. October; not frequent.

Type locality: "Hab. in Pensylvania."

Herb. Geol. Surv. Herb. Mohr.

Botrychium biternatum (Lam.) Underwood, Bot. Gaz. 22:407, pl.21. 1896.

Osmunda biternata Lam. Encycl. 4:650. 1797.

Botrypus lunaroides Michx. Fl. Bor. Am. 2:274. 1803.

Botrychium lunaroides Sw. Syn. Fil. 172. 1806. Not Gray, Man., etc.

R. ternatum var. lunaroides D. C. Eaton, Ferns N. A. $1: 148, t .20$, f. 3. 1879.

Eaton, Ferns N. A. l. c.

Louisianian area. North Carolina to Florida.

Alabama: Coast plain. Grassy banks and declivities. Mobile County. March; not frequent.

Type locality: "M. Michaut a découvert cette espèce dans la Caroline méridionale,"

Herb. Geol. Surv. Herb. Mohr. 
Botrychium virginianum (L.) Sw. Schrad. Journ. Bot. 1800, pt. 2:111. 1801.

Osmunda rirginiana L. Sp. P1. 2 : 1064. 1753.

Virginian Grape Fern.

Gray, Man. ed. 6, 695. Waton, Ferns N. A. 1:253. Chap. Fl.599.

Alleghenian to Louisianian area. New Brunswick to British Columbia ; Eastern United States.

Alabama: Throughout the State. Shady woods. Local and rare. Cullman County. Mobile County (the reduced form, B. gracile Pursh).

Type locality : "Hab. in America."

Herb. Geol. Surv. Herb. Mohr.

\section{POLYPODIACEAE. Fern Family.}

POLYPODIUM L. Sp. Pl. 2 : 1082. 1753. POLYPODY.

Three hundred and fifty species or more, mostly tropical and largely American. North America 11.

Polypodium polypodioides (L.) Hitchcock, Rep. Mo. Bot. Gard 4:156. 1893.

Acrostichum polypodioides L. Sp. Pl. 2 : 1068.1753.

Polypodium incanum Sw. Fl. Ind. Occ. 3:1t45. 1806.

Gray, Man. ed. 6, 680. Chap. Fl.588. Eaton, Ferns N. A. 1:197, t. 26. Coulter, Contr. Nat. Herb. $2: 562$. Underwood, Native Ferns, 83.

West Indies, Mexico to Brazil, Chile, South and East Africa.

Carolinian and Louisianian areas. Florida to West V.irginia, Kentucky, southern Ohio, southern Missouri, Arkansas, and Texas.

Alabama: Over the State. Shady and exposed places on trees and rocks. Mobile County, on trees, common. Tuscaloosa County. Cullman County, 800 feet, rocky banks.

Type locality: "Hab. in Virginia, Jamaica."

Herb. Geol. Surv. Herb. Mohr.

Polypodium vulgare L. Sp. Pl. 2 : 1085. 1753.

Common PolyPody.

Gray, Man. ed. 6, 680. Chap. F1.588. Eaton, Ferns N. A. 1:237, t.31, f.1.

Europe, North AFrica, Asia, JAPan.

Boreal region to Carolinian area. Ontario, Hudson Bay to Vancouver Island, New England to New Jersey, south along the mountains to Georgia, Arkansas, and Missouri.

Alabama: Mountain region. Rocky woods. Winston County, banks of Sipsey fork, 1,500 feet. Dekalb County, Lookout Mountain, 1,600 feet. June to August; infrequent.

Type locality: "Hab. in Europae rimis rupium."

Herb. Geol. Surv. Herb. Mohr.

AdIANTUM L. Sp. P1. 2 : 1094. 1753. Maideniair Fern.

Sixty-seven species, largely of tropical America. North America 5.

Adiantum capillus-veneris L. Sp. Pl. 2 : 1096. 1753.

Venus's IIAIr.

Gray, Man. ed. 6, 680. Chap. Fl.591. Eaton, Ferns N. A. 1:281, t. 3\%. Underwood, Native Ferns, 89. Coulter, Contr. Nat. Herb. 2:563. Griseb. Fl. Brit. W. Ind. 666.

Europe, Asia, Africa, West Indies, Mexico to Brazil, Oceania.

Carolinian and Louisianian areas. Central Kentucky, southern Missouri and Arkansas to Utah and California, south from Tennessee to Florida, and southwest Texas.

Alabama : Central Prairie region to Coast plain. Damp limestone cliffs. Montgomery County, Pentulalla Creek. Dallas County, wet rocky banks of Alabama River. Monroe County, shaded rocky borders of brooks, Perdue Hill. Mobile County, adventive on damp shaded brick walls, first observed in 1890 . June to August.

Type locality: "Hab. in Europa australi."

Herb. Geol. Surv. Herb. Molır.

Adiantum pedatum L. Sp. Pl. 2 : 1095. 1753.

Maidenhair.

Gray, Man. ed. 6, 680. Chap. Fl. 590. Eaton, Ferns N. A. 1:135, t. 18, f. 1. Wats. Bot. Calif. 1: 342. Underwood, Native Ferns, 90. 
Kamtchatka, Japan, China, Hrmalayan India.

Boreal region to Carolinian area. Newfoundland, Ontario to Britisl Columbia, Vancouver Island, New England to New Jersey, Ohio Valley to Missouri, Arkansas, and south along the mountains to Georgia.

Alabama : Mountain region. Rich shady woods. Winston County, Colliers Creek, 1,500 feet (T. M. Peters). Dekalb County, Lookout Mountain, 1,600 feet. Clay County, Emersons Gap, 1,800 feet. Cullman County, 800 feet.

Type locality: "Hab. in Canada, Virginia."

Herb. Geol. Surv. Herb. Mohr.

\section{PTERIS L. Sp. Pl. 2 : 1073. 1753. Brake Fern.}

About 103 species, mostly tropical, cosmopolitan. North America, 5 species.

Pteris aquilina L. Sp. Pl. 2 : 1075. 1753.

Common Bracken. Eagle feir. Gray, Man. ed.6,681. Chap. Fl.589. Wats. Bot. Calif. 2:341. Eaton, Ferns N. A. 1:263, t.35. Coulter, Contr. Nat. Herb. 2 : 564. Underwood, Native Ferns, 91.

Cosmopolitan.

Canadian zone to Lonisianian area. Throughont the continent to Mexico.

AlABAMA: Over the State. In sterile open woodlands, abundant everywhere. Type locality: "Hab. in Europae sylvis, praesertim caeduis."

Herb. Geol. Surv. Herb Molır.

Pteris aquilina pseudocaudata Clute, Fern Bull. 8: 39. 1900.

Carolinian and Louisianian areas. Long Island, New Jersey, and Maryland to Florida and Texas along the coast. (Clute.)

Alabama : Central Prairie belt to Coast plain. Sandy shaded banks and thickets. Mobile County, frequent.

Type locality: “Abundant in the 'pine barrens,' Babylon, Long Island."

Pteris serrulata L. f. Suppl.425. 1781.

Chinese Brake.

Chap. Fl. Suppl. 669. Eaton, Ferns N. A. 2:239, t. 28, f. 5. Underwood, Native Ferns, 91.

Tropical Asia.

Louisianian area. South Carolina and Georgia. Probably introduced.

AlabaMa: Coast plain. Shaded banks of brooklets. Mobile County, first observed in 1870. Since spreading along the banks of water courses and ditches, and on old walls. July.

Type locality not ascertained.

Herb. Geol. Surv. Herb. Mohr.

CHeIlanthes Sw. Syn. Fil.126. 1806. Lip Fern.

Over 60 species, temperate and warmer regions. Mexico, South America; North America, chiefly in the arid table-lands west of the Mississippi.

Cheilanthes alabamensis (Buckl.) Kuntze, Linnaea, 20:234. 1847.

Pteris alabamensis Buckl. Am. Journ. Sci. 45 : 177. 1843.

Alabama lip Fern.

Gray, Man. ed.6, 681. Chap. Fl.590. Eaton, Ferns N. A. 2:89, t.5\%,f.\%. Coulter, Contr. Nat. Herb. 2 : 565 . Underwood, Native Ferns, 93.

Carolinian area. Central Kentucky to the mountains of Virginia, North Carolina, and western Texas.

Alabama: Tennessee Valley to Lower hills. Lauderdale County, near Florence, rocky banks of Cypress Creek. Winston County, sandstone cliff's on Sipsey fork, 1,200 feet. Etowah County, Black Creek Falls, 1,200 feet. Bibb County, Pratt's Ferry, on limestoue rock (E. A. Smith).

Type locality: "Grows in tufts on limestone rocks, that form the banks of the Tennessee River, at the foot of the Muscle Shoals, Alabama."

Herb. Geol. Surv. Herb. Mohr.

Cheilanthes lanosa (Michx.) Watt, Trimen's Journ. Bot. 12:48. 1847.

Nephrodium lanosum Michx. Fl. Bor. Am. 2 :270. 1803.

WOOLLY LIP FERN.

Cheilanthes vestita Sw. Syn. Fil. 128. 1806.

Gray, Man. ed. 6, 681. Chap. Fl. 590. Eaton, Ferns N. A. 1:13, t.2.f.2. Underwood, Native Ferns, 93.

Alleghenian and Carolinian areas. British Colnmbia, northwest coast, to eastern base of the Rocky Mountaius, sontheast New York west to Kentucky, Illinois, southern Missouri, Arkansas, and Colorado, and south to Teunessee and North Carolina. 
Alabama: Mountain region. Lower hills, on sandstone rock. Cullman County, 800 feet, Lauderdale County, Florence, rocky banks Cypress Creek. Tuscaloosa County. Bibb County, Pratt's Ferry (E. A. Smith). Not frequent.

Type locality: "Hab.in montibus saxosis Tennassée et Carolinae septentrionalis." Herb. Geol. Surv. Herb. Mohr.

Cheilanthes tomentosa Link, Hort. Berol. 2 : 42. 1833.

Webby Lip Fern.

Gray, Man. ed. 6, 681. Chap. Fl. 590. Eaton, Ferns N. A. 1:345, t. 45, f. 1-5. Coulter,

Contr. Nat. Herb. 2:566. Underwood, Native Ferns, 94.

Carolinian area. West Virginia, Tennessee, 'Texas.

Alabama: Mountain region. Shaded rocks. Cullman County, 800 feet. Blount County, 600 feet, on rocky banks. Talladega County, Alpine Mountain, Signal Station, 1,800 feet, abundant in dense patches on steep rocky declines. Lauderdale County, cliff's on Cypress Creek, 500 fect. August, September; not rare.

Type locality: Texas or Mexico.

Herb. Geol. Surv. Herb Mohr.

PellaeA Link, Fil. Hort. Berol.59. 1841. Cliff Brake.

About 50 species, mostly in arid regions of warmer zones, largely in Sonth Africa, tropical America, and Mexico. Eleven species North American, chiefly from the arid table-lands west of the Mississippi to the Pacific.

Pellaea atropurpurea (L.) Link, Fil. Hort. Berol. 59. 1841. Purple Cliffbrake.

Pteris atropurpurea L. Sp. Pl. 2 : 1076. 1753.

Gray, Man. ed.6, 682. Chap. Fl.589. Eaton, Ferns N.A.2:61, t.54,f.4. Coulter, Contr. Nat. Herb. $2: 564$. Underwood, Native Ferns, 98.

Northern Mexico.

Boreal region to Carolinian area. Labrador, Ontario, British Columbia, Now England, west to Michigan, Missouri, Kansas, Arkansas, south to Now York, Virginia, Kentucky, and Tennessee, along the mountains to North Carolina, Texas.

Alabama: Tennessee Valley. Mountain region. Open woods, on rocks. Lawrence County (Peters). Madison County, Monte Sano, 1,000 teet. Lauderdale County, Florence. Clay County, near Mosley, rocky banks Talladega Creek. Tuscaloosa County, Tannehill (E. A. Smith). Rather local; nowhere abundaut.

Typo locality: "Hab. in Virginia."

Herb. Geol. Surv. Herb. Mohr.

WOODWARDIA J.E. Smith, Mem. Acad. Tor. 5 : 411. 1793. Chain Fern.

About 8 species, temperate regions around the globe.

Woodwardia areolata (L.) Moore, Index Fil. xlv. 1857.

Acrostichum areolatum L. Sp. Pl. 2 : 1069. 1753.

Woodwardia angustifolia J.E. Smith, Mem. Acad. Tor. 5 : 411.1793.

Gray, Man. ed. 6, 683. Chap. Fl.591. Eaton, Ferns N. A. 1: 165, t. 22, f. 2. Underwood, Native Ferns, 103.

Alleghenian to Louisianian area. Coast of New England to Tennessee and Florida, and west to Louisiana and Arkansas.

Arabama : Over the State, in shaded sandy swamps and low wet woods. Mobile, Baldwin, Clark, Montgomery, Cullman counties. Clay County, banks of Talladega Creek, 1,000 feet. Frequent.

Type locality: "Hab. in Virginia, Marilandia."

Herb. Geol. Surv. Herb. Mohr.

Woođwarđ̃ia virginica (L.) J. E. Smith, Mem. Acad. Tor. 5 : 412.1793.

Blechnum virginicum L. Mant. 2 : 307. 1771.

Gray, Man. ed.6, 683. Chap. Fl.591. Eaton, Ferns N. A. 2:45, t.52. Coulter, Contr.

Nat. Herb. 2 : 567. Underwood, Native Ferns, 102.

Alleghenian to Louisianian area. Nova Scotia, Ontario, New England, Michigan, Missouri, south to Ohio, and from New York to North Carolina, Florida, Texas, and Arkansas.

Alabama : Central Pine belt. Coast plain. Damp thickets, borders of woods. Russell County (E. A. Smith). Mobile County. Baldwin Connty, Stockton. Rare iu the interior; more frequent in the alluvial region of the coast.

Type locality not ascertainerl.

Herb. Geol. Surv. Herb. Mohr. 
ASPLENIUM L.Sp.P1.2: 1078. 1753. SPleexwort.

About 330 species, widely diffused over tropical and temperate regions.

Asplenium pinnatifidum Nutt. Gen. Pl.2:251. 1818. Mountain Spleenwort. Gray, Man. ed. 6, 683. Chap. Fl. 592. Eaton, Ferns N. A. 1:61, t. \&, f. 2. Underwood, Native Ferns, 103.

Alleghenian and Carolinian areas. Southeastern Pennsylvania, New Jersey, Kentucky, and Illinois, to southern Missouri, Arkansas, and southeastern Tennessee.

Alabama: Monntain region and Tennessee Valley. Cletts of sandstone rocks. Dekalb County, Lookont Mountain, 1,600 feet. Cullman County, highest ridges, 1,000 feet. Winston County, Colliers Creek (T. M. Peters), 1,500 feet. Marion County, Pikeville (E. A. Smith). Lauderdale County, Florence (M. C. Wilson). June, July; not rare.

Type locality: Crevices of rocks along the Schuylkill; also in Tennessee.

Herb. Geol. Surv. Herb. Mohr.

Asplenium ebenoides R. R. Scott, Journ. Royal Hort. Soc. 1866: 87. 1866.

SCOTT'S SPLEENWORT.

Gray, Man. ed. 6, 684. Chap. Fl. Suppl. 670. Eaton, Ferns N. A. 1:25, t. 4, f. 2.

Underwood, Native Ferns, 103.

Carolinian and Louisianian areas. Sonthern New England, sontheastern Pennsylvania, Kentucky, Illinois, and Missouri. Local and rare.

Alabama : Central Pine belt. Gravelly shaded hillsides. Hale County, Havana (Miss Tutwiler). Marion County, on sandstone rock (E. A. Smith). Rare.

Type locality: Limestone cliffs of the Schuylkill River, near Philadelphia $(S \cot t)$.

Herb. Geol. Surv. Herb. Mohr.

Asplenium platyneuron (L.) Oakes; Eaton, Ferns N. A. 1:24. 1879.

Acrostichum platyneuros L. Sp. Pl. 2 : 1069. 1753.

Asplenium ebeneum Ait. Hort. Kew. 3:462. 1789.

Gray, Man. ed.6,684. Chap. Fl.592. Eaton, Ferns N. A. 1:21, t.4,f.1. Coulter, Contr. Nat. Herb. 2:566. Underwood. Native Ferns, 104.

Alleghenian to Louisianian area. Ontario, New England, throughont the Atlantic States to Florida and the Gulf States to 'Texas, thence to Indian Territory, Arkunsas, and Missouri.

Ala isama : Over the State. Copses and rich woodlands. Cullman County. Montgomery Connty, the form with deeply serrated leaves (A. ebeneum var. serratum auct.). Mobile County. August, Septenber; common.

Type locality: "Hab. in Virginia."

Herb. Geol. Surv. Herb. Mohr.

Asplenium parvulum Mart. \& Gall. Mem. Acad. Brux. 15: [reprint60]. 1842.

LITTLE EBONY SPLEENWORT.

Gray, Man. ed. 6, 684. Chap. Fl. Suppl. 670. Eaton, Ferus N. A. 1:279, t. 36, f. 5,6. Coulter, Contr. Nat. Herb. 2:566. Underwood, Native Ferns, 104.

Mexico.

Carolinian area. South Virginia and Tennessee to South Carolina, west to Texas, Arkansas, and Sonth Missouri.

Alabama: Tennessee Valley to Lower hills. Shaded rocky hillsides, mostly on limestone rock. Lawrence County ( $T . M$. Peters), 1,000 feet. Walker County, Lost Creek. Madison County, Monte Sano, 800 feet. Bibb County, Pratt's Ferry $(E . A$. Smith). Lauderdale County (M. C. Wilson). Clay County, rocky banks Talladega

Creek. July; not infrequent.

Type locality: Mexico.

Herb. Geol. Surv. Herb. Mohr.

Asplenium trichomanes L. Sp. Pl. $2: 1080$. 1753 . Maidenhair Spieenwort. Gray, Man. ed. 6, 684. Chap. Fl. 592. Eaton, Ferns N. A. 1:271, t. 36, f. 1-3. Wats. Bot. Calif. 2: 344. Underwood, Native Ferus, 104.

Europe, Asia, South Africa, New Zealand, West Indies, Mexico, South AMERICA.

Alleghenian and Carolinian areas. Nova Scotia, New Brunswick, Quebec, Ontario to Saskatchewan; British Columbia to Oregon and California; New England west to Michigan, Missouri, Arkansas, and Colorado; south from the Ohio Valley to the mountains of Georgia.

Alabama: Mountain region. Lower hills. Damp sheltered rocks. Lawrence 
County (T. M. Peters), 1, 000 feet. Etowah County, Black Creek Falls, 1,000 feet. Talladega County, Chandler's Springs. Tuscaloosa County (E. A. Snith). Clay County, banks of Talladega Creek. Frequent in the rock houses of the Carboniferous sandstone on the Warrior table-land.

Type locality: "Hab. in Europae fissuris rupium."

Herb. Geol. Surv. Herb. Mohr.

Asplenium augustifolium Michx. Fl. Bor. Am. 2: 265. 1803.

NaRrow-Leaved SPleenwort.

Gray,Man. ed. 6, 685. Chap. Fl. 592. Eaton, Ferns N. A. 2:73, t. 56, f. 1-3. Underwood, Native Ferns, 10 .

Alleghenian and Carolinian areas. Quebec, Ontario, New England, Ohio Valley west to Michigan, Wisconsin, Missouri, Arkansas, and from Virginia along the mountains to North Carolina.

Alabama : Mountain region. Rich woods. Winston County, 1,500 feet; rare.

Type locality: "Hab. ad ripas fluminis Ohio."

Asplenium bradleyi Eaton, Bull. Torr. Club, 4:11. 1873.

BRADLEY'S SPLEENWORT,

Gray, Man. ed. 6, 684. Chap. Fl. Suppl.670. Eaton, Ferus N. A. $2: 39$, t. 51, f. 4-8.

Underwood, Native Ferns, 106.

Carolinian area. Southern New York. Cumberland Mountains of Kentucky and Tennessee.

AlabaMa: Mountain region. Shaded rocks. Dekalb County, Lookout Mountain. Sheltered shelves of rocks, banks of Little River, 1,600 feet. Clay County, Baldrock, 2,200 feet; small specimen, not well developed, July 31, 1896.

Type locality: "Waldens Ridge, Cumberland Mountains, near Coal Creek, East Tennessee." (F. H. Bradley, 1876.)

Herb. Geol. Surv. Herb. Mohr.

Asplenium montanum Willd. Sp. P1. 5 :342. 1810.

Mountain SPleenwor'T.

Gray, Man. ed.6,684. Chap. Fl.592. Eaton, lerns N. A. 2:41, t.51,f. 11. Underwood, Native Ferns, 106.

Alleghenian and Carolinian areas. New England, New York, New Jersev to West Virginia and Kentucky, along the mountains to North Carolina and Georgia.

Alabama: Tennessee Valley. Mountain region. Clefts of rocks. Winston County (T. M. Peters). Dekalb County, Mentone, 1,600 feet. Lauderdale County, near Florence. Marion County, Pikeville (E. A. Smith). Bibb County, Pratt's Ferry (E. A. Smith), 500 feet. Not frequent.

Type locality: "Hab. in altis montibus Carolinae."

Herb. Geol. Surv. Herb. Mohr.

Asplenium ruta-muraria L. Sp. P1. 2:1081. 1753.

Wallrue Spleenwort.

Gray, Man. ed. 6, 684. Chap. Fl. 593. Eaton, Ferns N. A. 1:107, t. 15, f. 1. Underwood, Native Ferns, 106.

Europe, Asia, North Africa.

Alleghenian and Carolinian areas. New England west to Michigan, Ohio, Kentucky, and Arkansas; mountains of Georgia.

Alabama: 'Tennessee Valley. Mountains and Lower hills. Exposed rocks. Winston County, Colliers Creek, 1, 500 feet (T. M. Peters). Dekalb County, Mentone, 1, 600 feet. Etowah County, Black Creek Falls. Colbert County (E.A.Smith). Bibb County, Pratt's Ferry.

Type locality : "Hab. in Europa ex rupium fissuris."

Herb. Geol. Surv. Herb. Mohr.

Asplenium filix-foemina (L.) Bernh. Schrad. Neues Journ. Bot. 1, pt. 2:26. 1806.

Polypodium filix-foemina L. Sp. Pl. 2 : 1090. 1753.

LADY FERN.

Gray, Man. ed. 6,658. Chap. Fl. 593. Eaton, Ferns N. A.2:225, t. 76. Coulter, Contr. Nat. Herb. 2:566. Underwood, Native Ferns, 107.

Europe, Asia.

Boreal region to Carolinian area. Nearly throughout the north temperate zone. From Nova Scotia to British Columbia and Alaska, and from New England south to Florida (Chapman), west to Texas, Arizona, and California.

Alabama: Tennessee Valley to Central Pine belt. Shady woods. Winston County. Madison County, Monte Sano. Talladega County, Chandler Springs.

Tuscaloosa County. Bibl County, Pratt's Ferry. Most frequent in the mountains. Type locality : "Habitat in Europae frigidioris subhumidis."

Herb, Geol, Surv, Herb, Mohr. 
Asplenium acrostichoides Sw. Schrad. Journ. Bot. 1800, pt. $2: 54.1801$.

Asplenium thelypteroides Michx. Fl. Bor. Am. 2:265. 1803.

SilvERY SPLEENWORT.

Gray, Man. ed. 6, 685. Chap. Fl. 593. Eaton, Ferns N. A. 2:33, t. 50. Underwood, Native Ferns, 107.

Canadian zone to Carolinian area. Nova Scotia, New Brnnswick, Quebec to Lake

Superior; Ontario; New England to Minnesota, south alung the monntains to Georgia; rare.

Alabama: Mountain region. Rich woods. Winston County (Undervood).

Type locality not given. Michaux's locality: "Hab. in montibus Virginiae et Carolinae septentrionalis."

Herb. Geol. Surv. Herb. Mohr.

Camptosorus Link, Hort. Berol. 2 : 69. 1833. Walking Leaf.

Two species, one North Ameriean.

Camptosorus rhizophyllus (L.) Link, Hort. Berol. 2 : 69.1833.

Asplenium rhizophylla L. Sp. Pl. 2 : 1078. 1753.

Gray, Man. ed.6,685. Chap. Fl. 591. Eaton, Forns N. A. 1: 55, t. 8, f. 1.

Alleghenian and Carolinian areas. Ontario and Quebec to the Saskatchewan; New England west to Wiscousin, Missouri, Kansas, and Arkansas; sonth through the Obio Valley to Tenuessee, and along the mountains from Virginia to North Carolina and Georgia.

AlabaMa : Mountain region to Central Pine belt. Shaded rocky banks. Cullman Couuty (Miss Mary Mohr). Hale County (E. A. Smith). Infrequent.

Type locality: "Hab. in Jamaica, Virginia, Canada, Siberia."

Herb. Geol. Surv. Herb. Mohr.

PHEGOPTERIS Fée, Gen. Fil. 242. 1850-52. Beech Fern.

Ninety-five species, mostly of north temperate zone.

Phegopteris hexagonoptera (Michx.) Fée, Gen. Fil. 243. 1850-52.

Polypodium hexagonopterum Michx. Fl. Bor. Am. 2:271. 1803.

Gray, Man. ed. 6, 686. Chap. Fl. 588. Eaton, Ferus N. A. 2:147, t. 56.

Alleghenian and Carolinian areas; Sonth Ontario; New England west to Minnesota, Arkansas, and Missouri; south to the mountains of North Carolina and Georgia.

Alabama: Tennessee Valley. Mountain region to Lower hills. Rich woodlanils. Cullman County; Tuscaloosa Connty; Lauderdale County, near Florence. Not raro. Type locality: "Hab. in Carolina et Virginia."

Herb. Geol. Surv. Herb. Mohr.

\section{DRYOPTERIS Adans. Fam. Pl. 2:20. 1763. ShIEll FERN.}

(AsPIDIUM Sw. Schrad. Journ. Bot. 1800, pt. 2:4. 1801).

About 300 specics, mostly of tropical and subtropical regions. North America, 17; Pacifie States, 5; Northern States, Rocky Mountains, and Canada, 13; Southern States, 7.

Dryopteris thelypteris (L.) Gray, Man.630. 1848.

Marsh Simeli) Fern. Acrostichum thelypteris L. Sp. P1. 2:1071. 1753.

Aspidium thelypteris Sw. Schrad. Journ. Bot. 1800, pt. 2:40. 1801.

Gray, Man. ed. 6, 686. Chap. Fl. 594. Eaton, Ferns N: A. 1:233, t. 30. Coulter,

Contr. Nat. Herb. 2:567. Underwood, Native Ferns, 114.

Europe, Siberia, Northern Asia, Himalayan India.

Canadian zone to Lonisianian area. Nova Scotia, Quebec, Ontario to Lake Winnipeg, Manitoba; throughont tho Eastern States from New England to Florida, and west to Texas, Arkansas, and Missouri.

Alabama: Coast plain. Open swainps. Mobile. Montgomery County; abundant. Type locality: "Hab. in Europae septentrionalioris paludibus."

Herb. Geol. Surv. Herb. Mohr.

Dryopteris noveboracensis (L.) Gray, Man. 630. 1848.

Polypodium noreboracense I. Sp. Pl. 2 : 1091. 1753.

New York Sileld FerN.

Aspidium noveboracense Sw. Schrad. Jouru. Bot. 1800, pt. 2 :38. 1801.

Gray, Man. ed. 6, 637. Chap. Fl.591. Eaton, Ferns N. A. 1:49, t. \%. Underwood, Native Ferus, 112. 
Alleghenian and Carolinian areas. Canada, Maritime Provinces, Ontario, New England (Momt Desert) west to Wisconsin, Michigan, Ohio Valley, and south from New York along the mountains to Georgia.

Alabama: Tennessee Valley. Mountain regions and Lower hills. Lauderdale County, Florence. Blount County, Warnock Mountain, 1,100 foet. 'Tuscaloosa County. Fayette County, Fayette (E. A. Smith). Not frequent.

Type locality: "Hab. in Canada. Kalm."

Herb. Geol. Surv. Herb. Mohr.

Dryopteris floridana (Hook.) Kuntze, Rev. Gen. Pl. 2 : 812.1891.

Nephrodium floridanum Hook. Fil. Exot. t.99. 1859.

FLORIDA WOOD FERN.

Aspidium floridanum Eaton in Chap. Fl.595. 1860.

Underwood, Native Ferns, 115. Eaton, Ferns N. A. 2 : 159.

Carolinian and Lonisianian areas. Florida to Louisiana.

Alabama: Metamorphic hills. Low woods. Lee County, near Auburn ( $L . M$.

Underwood), May, 1896. Rare.

Type locality: "East Florida." (S. B. Buckley.)

Herb. Geol. Surv. Herb. Mohr.

Dryopteris marginalis (L.) Gray, Man.632. 1819.

EVERGREeN WOOD FerN.

Polypodium marginale L. Sp. Pl. 2 : 1091. 1753.

Aspidium marginale Sw. Syn. Fil.50. 1810.

Gray, Man. ed. 6, 688. Chap. F1.595. Eaton, Ferns N. A. $2: 69, t .55$. Underwood,

Native Ferns, 116.

Canadian zone to Carolinian area. Nova Scotia, Quebec, Ontario to Saskatchewan, Manitoba, Rocky Mountains; New England (Mount Desert), west to Michigan and the Ohio Valley, and from New York south along the mountains to Georgia and Alabama, west to Arkansas and Missouri.

Alabama: Mountain region to Lower hills. Rocky shaded ravines. Dekalb County, Mentone, 1,600 feet. Cullman Connty, 800 feet. 'Tuscaloosa County (E. $A$. Smith), about 450 feet. Clay County, Baldrock, 2,200 feet. Not frequent.

Type locality: "Hab. in Canada. Kalm."

Dryopteris spinulosa dilatata Underwood, Native Ferns, ed.4,116. 1893.

Polypodium dilatatum Hoffm. Deutsche Fl.2 : 7. 1795.

Dryopteris dilatata Gray, Man. 631. 1848.

Gray, Man. ed. 6, 687. Chap. Fl.595. Eaton, Ferns N. A. $2: 165$.

EUROPE.

Alleghenian and Carolinian areas. Tennessee and North Carolina, along the mountains to New England and Canada; British Columbia to the Pacific; Ohio and Kentucky to Missouri and Arkansas.

ALABAMA: Mountain region, in shady woods. Winston County, rocky, shady deciivities near the Sipsey River. Rare.

Type locality European.

Herb. Geol. Surv. Herb. Mohr.

Dryopteris patens (Sw.) Kuntze, Rev. Gen. Pl. 1:112. 1891.

Aspidium patens Sw. Fl. Ind. Occ.1673. 1797.

A. molle Kunze, Am. Journ. Sci. ser. 2, 6:83. 1848.

Chap. Fl. 594. Wats. Bot. Calif. 2:346. Griseb. Fl. Brit. W. Ind.692. Coulter,

Contr. Nat. Herb. 2 :567. Eaton, Ferns N. A. $2: 181, t .70$. Underwood, Native Ferns, 114.

South Africa, Polynesia, Tropical and Subtropical america.

Louisianian area. Lower South Carolina to Florida, west to Louisiana, Texas, and southern California.

Alabama : Coast plain and Lower division Coast Pine belt. Damp shaded ravines. Mobile County, Mount Vernon. Baldwin County, July, October. Frequent.

Type locality: "Incolit sylvas montium Antillarum."

Herb. Geol. Surv. Herb. Mohr.

POLYSTICHUM Roth, Tent. Fl. Germ. 3:69. 1800.

Polystichum acrostichoides (Michx.) Schott, Gen. Fil. 2 : no. 4. 1834.

Christmas Fern.

Nephrodium acrostichoides Michx. Fl. Bor. Am. 2:267. 1803.

Aspidium acrostichoides Sw. Syu. Fil. 44. 1806.

Dryopteris acrostichoides Kuntze, Rev. Gen. Pl. 2 : 812. 1892. 
Gray, Man. ed. 6, 689. Chap. Fl.595. Eaton, Ferns N. A.1:257, t. 35. Underwood,

Native Ferns, 111.

Alleghenian to Louisianian area. Nova Scotia, New Brunswick, Ontario; New England (Monnt Desert Island), west to Minnesota, Arkansas, and Missouri, south to Florida and the Gulf coast.

Alabama: Over the State. Rich wooded hillsides. Mobileand Baldwin counties. Common.

Type locality: "Hab. in Pensylvania, Carolina, et Tennassée."

Herb. Geol. Surv. Herb. Mohr.

CYSTOPTERIS Bernh. Schrad. Neues. Journ. Bot. 1, pt.2:26. 1806. BladDer FerN.

Five species, temperate regione, Europe, western Asia, Mexico; North America 3.

Cystopteris fragilis (L.) Bernb. Schrad. Neues. Journ. Bot. 1, pt. 2:26. 1806.

Polypodium fragile L. Sp. Pl. 2 : 1091. 1753.

Underwood, Native Ferns, 118. Gray, Man. ed. 6, 689. Chap. Fl.593. Eaton, Ferns N. A. $2: 49, t .53, f .1-8$. Wats. Bot. Calif. $2: 348$.

Most universally distributed over cooler and temperate regions of the globe from the north aretic zone to Patagonia, Sonth Africa, and Tasmania; northern Europe, and North America up to an altitude of 6,000 to 8,000 feet.

Arctic zone to Carolinian area. Boreal America to the mountains of Mexico; in the United States to central Georgia, and in the Rocky Mountains and California.

ALABAMA : Mountain region to Lower hills. In rich woods and shaded damp places. Winston, Cullman, Lauderdale, and Etowah counties. Bibb County, Pratt's Ferry. Fuscaloosa County. Not rare.

Type locality: "Hab. in collibus Europae frigidioris."

Herb. Geol. Surv. Herb. Mohr.

Cystopteris bulbifera (L.) Bernh. Schrad. Neues. Journ. Bot. 1, pt. 2:26. 1806.

Polypodium bulbiferum L. Sp. Pl. 2 : 1091. 1753.

Gray, Man.ed.6, 689. Chap. Fl.594. Eaton, Ferns N.A.2:55, t.53. Underwood,

Native Ferns, 118.

Canadian zone to Carolinian area. Nova Scotia, New Brunswick, Quebec, Ontario; Now England west to Michigan and Wisconsin, Illinois, Missouri, Arkansas; south from New York along the mountains to Tennessee and North Carolina.

Alabama: Tennessee Valley. Mountain region, dripping rocks. Lauderdale County, banks of Teunessee River, also Colbert County, near Sheffield. Etowah County, Black Creek Falls, 800 feet (E. A. Smith). Infrequent.

Type locality: "Hab. in Canada."

Herb. Geol. Surv. Herb. Mohr.

ONOCLEA L. Sp. Pl. $2: 1062.1753$.

Three species found in temperate regions.

Onoclea sensibilis L. Sp. Pl. 2 : 1062.1753.

Sensitive Fern.

Gray, Man. ed. 6, 690. Chap. F1. 596. Eaton, Ferns N. A. 2:195, t.72. Underwood, Native Ferns, 119.

Alleghenian to Louisianian area. New Brunswick, Ontario to Saskatchewan; New England (Mount Desert Island), west to Michigan, Minnesota, Dakota, Nebraska, Kansas, Missouri; south through the Ohio Valley to Florida, west to Arkansas.

Alabama: Lower hills to Coast plain. Low woods. Swampy thickets. Most frequent in the bottoms of the lower Alabama River. Baldwin County, Stockton. July to September.

Type locality : "Hab. in Virginia."

Herb. Geol. Surv. Herb. Mohr.

WOODSIA R. Br. Trans. Linn. Soc. 11:170. 1816.

Fiftcen species of boreal and cooler temperate zones.

Woodsia obtusa (Spreng.) Torr. Cat. Pl. Geol. Surv. N. Y.195. 1840.

Polypodium obtusum Spreng. Anleit. 92. 1804.

Aspidium obtusum Willd. Sp. Pl. 5:254. 1810.

Gray, Man. ed.6,691. Chap. Fl.596. Coulter, Contr. Nat. Herb. 2:568. Eaton,

Ferns N. A. $2: 189, t .71, f .5-8$. Underwood, Native Ferns, 121.

Canadian zone to Carolinian area. Nova Scotia, British Columbia (source of

Columbia River); New England west to Michigan, Wisconsin, Nebraska, south to 


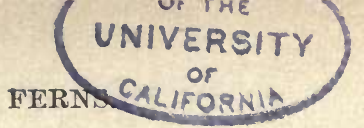

the Ohio Valley, Missouri, and Arkansas; and from New York along the mountains to Georgia, Texas, and Indian Territory.

AlabaMa: Mountain region. Lower hills. Shaded rocky banks. Bibb County, Pratt's Ferry (E. A. Smith). Winston County, valley of Colliers Creek, 1,000 feet. Rare.

Type locality not ascertained. Willdenow's locality: "Hab. in Pennsylvania."

Herb. Geol. Surv. Herb. Mohr.

DENNSTAEDTIA Bernh. Schrad. Journ. Bot. 1800, pt. 2:124. 1801.

(Dicksonia L'Her. Sertum. Angl.30. 1788.)

About 40 species, both hemispheres, chiefly tropical.

Dennstaedtia punctilobula (Michx.) Moore, Index Fil. xcvii, 307. 1857-62.

Nephrodium punctilobulum Michx. Fl. Bor. Am. 2:268. 1803.

Dicksonia pilosiuscula Willd. Enum. 1076. 1809.

Dicksonia punctilobula Gray, Man.628. 1848.

Gray, Man. ed. 6, 691. Chap. F1.597. Eaton, Ferns N. A. 1:339, t.44. Underwood, Native Ferns, 121.

Alleghenian and Carolinian areas. Nova Scotia, Ontario, Quebec, New England (Mount Desert Island), west to Michigan, southern Illinois, Ohio, and Missouri; south from New York along the mountains of North Carolina, Tennessee, and Georgia to central Alabama.

Alabama: Mountain region. Central Pine belt, rocky open woodlands. Winston County, Colliers Creek, 1,000 feet (T. M. Peters). Bibb County, Pratt's Ferry (E. A. Smith), 450 feet. Infrequent. July, August.

Type locality: "Hab. in Canada."

Herb. Geol. Surv. Herb. Mohr.

\section{TRIChOMANES L. Sp. Pl. $2: 1097$. 1753. Bristle Fern.}

About 90 species, in the tropical and warmer temperate regions of both hemispheres.

Trichomanes radicans Sw. Fl. Ind. Occ. $3: 1736$. 1806. Alabama Bristle Fern. Gray, Man. ed.6,692. Chap. Fl.597. Eaton, Ferns N. A. 1:179, t. 24, f. 1. Griseb. Fl. Brit. W. Ind. 655 . Underwood, Native Ferns, 122.

Almost cosmopolitan in temperate Regions. Southern Ireland, Azores, East Indies, Pacific Islands, West Indies, Mexico to Brazil.

Carolinian and Louisianian areas. Central Kentucky, through the Cumberland Mountains to Tennessee and Alabana.

Alabama: Warrior table-land. Central Pine belt. Under the shelter of dripping rocks. Frequent in the so-called rock houses of the Carboniferous sandstone. Winston County, 1,200 feet (T. M. Peters). Franklin County (Beaumont). Marion County, Pikeville (E. A. Smith). Etowah County, Black Creek Falls, 1,000 feet. Lawrence County (Beaumont and Peters). Hale County, Havana (E. A. Smith).

Type locality: "Incolit arbores in montosis Jamaicae."

Herb. Geol. Surv. Herb. Mohr.

Trichomanes petersii Gray, Am. Journ. Sci. ser. 2, 15 : 326. 1853.

Peters's Bristie Fern. 122.

Chap. Fl.597. Eaton, Ferns N. A. 1:183, t. 24, f. 2. Underwood, Native Ferns, Carolinian area.

Alabama: Mountain region. Warrior table-land. Deep clefts of sandstone rock kept perpetually moist by dripping water. Winston County, near east fork of Sipsey River, discovered by T. M. Peters, 1853. Etowah County, falls of Black Creek, near Gadsden, 1,000 feet. Marion County, Pikeville, in rock houses (E. $A$. Smith). Local; rare. Endemic.

Type locality: "Hancock [now Winston] County, Alabama. not far from the Sipsey River; found only on the face of an isolated sandstone rock, within reach of the spray of a waterfall. T. M. Peters, Esq."

Herb. Geol, Surv. Herb. Mohr.

OSMUNDA L. Sp. Pl. 2 : 1063. 1753. Flowering Fern.

Six species, chiefly of the north temperate zone, 3 North American.

Osmunda cinnamomea L. Sp. P1. 2 : 1066. 1753.

Cinnamon Fern.

Gray, Man. ed. 6, 693. Chap. Fl.598. Eaton, Ferns N. A. 1:227, t. 29, f. 3-5.

Underwood, Native Ferns, 124. 
Manchuria, Japan, West Indies (Bermuda, Cuba), Mexico to Brazil.

Canadian zone to Louisianian area. Nova Scotia, Quebec, Lake Superior, Ontario, New England (Mount Desert Island); all over the Atlantic States to Florida, aloug the Gulf coast to Louisiana and Texas; Arkansas, Missouri.

Alabama: Low, swampy, open woods and thickets everywhere. Mobile County. April.

Type locality : "Hab. in Marilandia."

Herb. Geol. Surv. Herb. Mohr.

Osmunda regalis L. Sp. Pl. 2 : 1065. 1753.

ROYAL FERN.

Gray, Man. ed. 6, 693. Chap. Fl. 598. Eaton, Ferns N. A. 1:209, t. 28. Coulter,

Contr. Nat. Herb. 2 568. Underwood, Native Ferns, 124.

Europe, Asia, Afrtca, Cuba, Mexico to Brazil.

Canadian zone to Louisianian area. Newfoundlaud, Nova Scotia, Ontario to Saskatchewan; from Lake Superior to Florida and the Gulf coast, west to Texas, Arkansas, Missouri.

Alabam. : Swampy borders of woods, open marshes. Common throughout the

State. August, September.

Type locality: "Hab. in Europa, Virginia ad fluvios."

Herb. Geol. Surv. Herb. Mohr.

\section{SALVINIACEAE. Water Fern Family.}

AZOLLA Lam. Encycl. 1:343. 1783.

Four species, temperate regions, 1 North American.

Azolla caroliniana Willd. Sp. Pl. 5 :541. 1810.

Gray, Man. ed. 6, 701. Chap. Fl. 602. Wats. Bot. Calif. 2:352. Coulter, Contr. Nat. Herb. 2:559. Underwood, Native Ferns, 128.

Alleghenian to Lonisianian area. Lake Ontario to British Columbia, sonthern New York, west to Ohio, southern Illinois, southern Missouri, Arkansas, Arizona, and California, south to Florida and Texas.

Alabama : Coast plain, floating in still water. Mobile County, abundant in pools and ditches.

Type locality : "Hab. in aquis Carolinae."

Herb. Geol. Surv. Herb. Mohr.

\section{Order EQUISETALES. Horsetails.}

\section{EQUISETACEAE. Horsetail family.}

EQUISETUM L. Sp. Pl. 2 : 1061. 1753.

About 25 species, chicfly of cooler temperate zones. North America, 13.

Equisetum laevigatum A. Br.; Engelm. Am. Journ. Sci. 46:87. 1844.

SMOOTH HonsETAIL.

Gray, Man. ed. 6, 677. Chap. Fl. 585. Milde, Act. Acad. Caes. Leop. 32, pt. 2: 546, t.32. Wats. Bot. Calif. $2: 331$. Conlter, Contr. Nat. Herb. 2:559. Underwood, Native Ferns, 135.

Carolinian and Louisianian areas. North Carolina, Florida, Louisiana, Texas, Missouri, Colorado, British Columbia, Oregon, and California.

Alabama: Central Pine belt. Bibb County, Scottsville (E. A. Smith). August. Rare.

Type locality: "Hab. on poor clayey soil, with Anclropogon and other coarse grasses, at the foot of the rocky Mississippi hills, on the banks of the river below St. Louis." (N. Riehl, 1840.)

Herb. Geol. Surv.

Equisetum robustum A. Br.; Engelm. Am. Journ. Sci. 46: 88. 1844.

STOut Honsetall.

Gray, Man. ed.6, 677. Chap. Fl. Suppl. 669. Wats. Bot. Calif. 2:330. Milde, Act.

Acad. Caes. Leop. 32, pt. 2:532, t.31. Underwood, Native Ferns, 135.

Mexico, British Columbia, California, East indies.

Carolinian to Louisianian area. Ohio, Illinois, southern Missouri, Louisiana, and New Mexico. 
Alabama: Upper division Coast Pine belt, wet banks. Monroe County, Claiborne. Type locality: "Hab. Islands of the Mississippi River in Louisiana. Bory de St.

Vincent." (With other localities in the Mississippi basin, and in the East Indies.) Herb. Mohr.

Equisetum hyemale L. Sp. Pl. 2 : 1062. 1753.

SCOURING RUSH.

Gray, Man, ed. 6, 677. Wats. Bot. Calif. $2: 331$. Coulter, Contr. Nat. Herb. 2 : 559.

Milde, Act. Acad. Caes. Leop. $32: 511, t .29,30$. Underwood, Native Ferns, 135.

EUROPE, AsIa.

Alleghenian and Carolinian areas. Ontario and Quebec, through the mountains to British Columbia; Oregon, California; New England, New York, Ohio Valley, Missouri, Arkansas, and Texas.

Alabama: Mountain region. Winston County; reported by T. M. Peters.

Type locality: "Hab. in Europae sylvis, asperis, nliginosis."

Herb. Geol. Surv.

\section{Order LYCOPODALES. Club mosses.}

\section{LYCOPODIACEAE. Club-moss Family.}

IYCOPODIUM L. Sp. Pl. 2 : 1100 . 1753. ${ }^{1}$

About 100 species, widely distributed over the temperate, but mostly the tropical, zones of the globe. North America, 17 species.

Lycopodium alopecuroides L. Sp. P1. 2 :1102. 1753.

Gray, Man. ed.6,696. Chap. Fl.600. Underwood, Native Ferns, 137.

BRAZIL.

Louisianian to Carolinian area. From Florida west to Mississippi, and north along the coast to North Carolina, Virginia, and New Jersey. .

Alabama : Lower Pine belt and Coast plain. In bogs. Washington, Mobile, and

Baldwin counties. July, August. Frequent.

Type locality: "Hab. in Virginia, Canada."

Herb. Geol. Surv. Herb. Mohr.

Lycopodium adpressum (Chap.) Lloyd \& Underw. Bull. Torr. ('lub, 27 : 153. 1900.

Lycopodium alopecuroides adpressum Chap. Fl. ed. 3, 638. 1897.

L. inundatum var. adpressum Chap. Fl. Suppl.671. 1880.

Louisianian area. Western Florida to Mississippi.

Ala bama: Sandy, open pine barrens, swamps. Mobile County, Grand Bay, boggy pine flats. Baldwin County, Montrose, springy banks. July.

Type locality: "Damp pine barrens [Southern United States]."

Herb. Geol Surv. Herb. Mohr.

Lycopodium pinnatum (Chap.) Lloyd \& Underw. Bull. Torr. Club, 27: 155. 1900.

Lycopodium inundatum pinnatum Chap. Fl.600. 1860.

Louisianian area. Florida to Mississippi.

Type locality: "Low pine barrens, near the coast, West Florida."

AlabaMa: Mobile County, Spring Hill, August, 1897 (B. F. Bush). Lee County, Auburn, October, 1896 (C. F. Baker).

Lycopodium carolinianum L. Sp. P1. 2 : 1104. 1753.

Gray, Man. ed. 6, 697. Chap. Fl.601. Griseb. Fl. Brit. W. Ind..646. Underwood, Native Ferns, 139.

Tropical Africa to tife Caph, East Indies, Tasmania, West Indies to Brazil.

Louisianian and Carolinian areas. From Mississippi along the coast to Florida and north to New York.

Alabama : Coast plain. Low, damp pine barrens. Mobile and Baldwin counties. September to November. Frequent.

"Type locality : "Habitat in Carolina."

Herb. Geol. Surv. Herb. Mohr.

${ }^{1}$ F. E. Lloyd and L. M. Underwood, Revision of the species of Lycopodium of North America, Bull. Torr. Club, vol. 27, p. 147, tt. 2 to 4. 1900. 
Lycopodium porophilum Lloyd \& Underw. Bull. Torr. Club, 27: 150. 1900.

"Intermediate between Lycopodium lucidulum and $L$. selago, having the leaves spreading or somewhat reflexed with the alternation of long leaves and short sporophylls. Leaves not hollowed, but flat as in L. lucidulum."-Underwood.

Carolinian and Alleghenian areas. Kentucky, Indiana, and Wisconsin.

AlabaMa : Winston County, under projecting sandstone rocks near Sipsey River, June 1, 1896 ( L. M. Underwood).

Type locality: Points in Indiana, Wisconsin, Kentucky, and Alabama.

Lycopodium cernuum L. Sp. Pl. 2 :1103. 1753.

Chap. Fl. Suppl.671. Griseb. Fl. Brit. W. Ind. 647. Underwood, Native Ferns, 137. COMMON IN ALL TROPICAL COUNTRIES; AZORES.

Louisianian area. Florida.

Alabama: Coast plain. Springy grassy banks. Mobile County, Springhill, in a ravine near the college. Baldwin County, Montrose. September. Rare.

Type locality: "Hab. in Indiis."

Herb. Mohr.

\section{SELAGINELLACEAE. Selaginella Family.}

SELAGINELLA Beauv. Prodr. Aetheog. 101. 1805.

Two hundred species described, mostly of tropical and subtropical zones. North America, 5 species.

Selaginella rupestris (L.) Spring in Mart. Fl. Bras. 1, pt. 2:119. 1840.

Lycopodium rupestre L. Sp. Pl. 2 :1101. 1753.

Gray, Man. ed. 6, 698. Coulter, Contr. Nat. Herb. 2:558. Underwood, Nat. Ferns, 140.

EUROPE, AFRICA, ASIA.

Alleghenian and Carolinian areas. New Brunswick, Ontario, British Columbia, New England (Mount Desert Island), south to Florida (Chapman); Ohio Valley west to Missouri, Arkansas, 'Texas, and through the Rocky Mountains to California and Oregon.

AlabaMa: Mountain region. Winston County, reported by T.M. Peters. Dekalb County, Lookout Mountain, Mentoue, abundant on rocks; September.

Type locality: "Hab. in Virginia, Canada, Sibiria."

Selaginella apus (L.) Spring in Mart. Fl. Bras. 1, pt. 2:119. 1840.

Lycopodium apodum L. Sp. Pl. 2 :1105. 1753.

Gray, Man. ed. 6, 698. Chap. Fl. 601. Coulter, Contr. Nat. Herb. 2:558.

Alleghenian to Louisianian area. Ontario, southern New England, Michigan, Ohio Valley, south to Florida and Texas.

Alabama: Coosa Valley to Coast plain. Low springy banks. Etowah Connty, near Gadsden, in wet sandy piny woods. Mobile County.

Type locality: "Hab. in Carolina, Virginia, Pensylvania."

Herb. Geol. Surv. Herb. Mohr.

Selaginella ludoviciana A. Br. Ann. Sci. Nat. ser. 4, 13: 58.1860.

Underwood, Native Ferns, 141.

Louisianian area. Western Florida to Lonisiana.

Alabama: Coast plain. Damp exposed ground in the flat pine barrens. Mobile County. Rare.

Type locality: "Hab. in Lonisiana."

Herb; Geol, Surv. Herb. Mohr.

\section{ISOETACEAE. Quillwort Family.}

ISOETES L. Sp. Pl. 2 : 1100.1753.

The only genus of the family. It contains about 50 species, widely distributed over the continents and islands of the world. North America, 21 species.

Isoetes engelmanni valida Engelm. in Gray, Man. ed.5, 677. 1867.

Carolinian area. Delaware, eastern Pennsylvania.

Alabama: Mountain region. Swampy places. Dokalb County, Lookout Mountain above Valleyhead, May, 1899.

Gras, Man. ed. 6, 700. Britt. \& Brown, Ill. Fl. 1: 48. Underwood, Native Ferns, 146. Type locality: "Delaware (W. M. Canby), and Pennsylvania (Prof. Porter)."

Herb. Biltınore. 


\title{
Subkingdom SPERMOPHYTA. True Flowering and Seed-bearing Plants. (Phanerogamae.)
}

\section{Class GYMNOSPERMAE (ARCHISPERMAE),}

\author{
PINACEAE (CONIFERAE). Pine Family
}

\author{
PINUS L.Sp. Pl. 2 : 1000. 1753. PINE.
}

Largest genus of the order, with about 75 species belonging to the cooler and warmer parts of the northern temperate zone. In the Old World about 25 species; in the New World about double that number. North America has 37 species, Eastern North America, 11. Mostly gregarious trees of large size.

Pinus taeda L. Sp. Pl. $2: 1000$. 1753.

Loblolly Pine. Old Field Pine. Rosemary Pine.

Ell. Sk. 2:636. Gray, Man. ed. 6, 490. Chap. Fl. 433. Conlter, Contr. Nat. Herb. 2: 554 .

Carolinian and Louisianian areas. Delaware to North Carolina and Florida west to eastern Texas and southern Arkansas.

Alabama : Monntain region to Coast plain. From the coast to the Warrior tableland. Cullman County, 800 feet. Flowers early to latter part of March.

Type locality: "Hab. in Virginiae, Canadae paludosis."

Economic uses: Important. Valuable timber tree; the largest among the Southern timber pines.

Herb. Geol. Surv. Herb. Mohr.

Pinus heterophylla (Ell.) Sudworth, Bull. Torr. Club, 20:45. 1893.

Pinus taeda var. heterophylla Ell. Sk. 2:636. 1821.

Slash Pine. Cuban Pine.

P. cubensis Griseb. Mem. Am. Acad. 8, pt. 2:530. 1863.

P. elliottii Engelm. 'Trans. St. Louis Acad. $4: 186, t$. 1-3. 1878-1886.

Chap. Fl. Suppl. 650; ed. $3,457$.

Cuba, British Honduras.

Lonisianian area. Coast of South Carolina to Florida, and along the Gulf coast to eastern Louisiana.

Alabama : Outlying islands, Coast plain, and scatteringly throughont the Lower Pine region in the flat woods and swamps bordering the pine-barren streams. Mobile and Baldwin counties. Washington County, Yellowpine. Escambia County, Wallace. Flowers January and February.

Type locality: "Along the marshes near the mouths of the fresh water rivers, (at least in Georgia), this pine is very common."

Economic uses: Of greatest value for its timber and for its resin.

Herb. Geol. Surv. Herb. Mohr.

Pinus palustris Mill. Gard. Dict. ed. 8, no. 14. 1768.

Longieaf Pine. Southern Yellow Pine. Pitch Pine. Heart Pine. Pinus australis Michx. f. Hist. Arb. Am. 1:64, t. 6. 1810.

$2: 554$.

Ell. Sk. 2 : 637. Gray, Man. ed. 6, 491. Chap. Fl. 434. Coulter, Contr. Nat. Herb,

Louisianian and Carolinian areas. From Cape Canaveral and Bay Biscayne, Florida, north along the coast to southern Virginia (Suffolk County), and westward to the Trinity Valley, Texas.

Alabama: Coast plain to the Mountain region to an altitude of near 2,000 feet, forming the immense forests of the Coast and Central Pine belt, and lesser ones in the Coosa Valley. From Talladega County to the Georgia and Alabama State line. Scattered abundantly through the Metamorphic mountains, where this species ascends in Clay County to its greatest elevation on the Chehawhaw Mountain, 2,000 feet. More sparsely diffused in the lower part of the Warrior basin with an outly. ing forest in Walker County (South Lowell). Flowers middle of March.

Type locality not ascertained. Michaux's locality: "Hab. a Carolina septentrionali ad Floridam presertim maritimis."

Economic uses: Of greatest importance fo_ ts timber, as well as for its resin.

Herb. Geol, Surv. Herb. Mohr. 
Pinus echinata Mill. Gard. Diet. ed. 8, no. 12. 1768.

Shortllaf Pine, Yellow Pine.

Pinus mitis Michx. Fl. Bor. Am. 2: 204. 1803.

Ell. Sk. 2:633. Gray, Man. ed. 6, 491. Chap. Fl. 433. Coulter, Contr. Nat. Herb. 2: 554 .

Carolinian and Louisianian areas. Long Island, New York, to Virginia, eastern Kentucky, southeastern Tennessee, and middle Florida, west to Texas, the eastern limit of Indian Territory, and southwestern Missouri.

Alabama: Mountain region to Lower Pine belt. On the highest summits. Frequent among the hard-wood timber growth of the Warrior table-land, more abundant on the lower hills of sandy and gravelly loam from the nortlieast part of 'Tuscaloosa, through Lamar and a part of Fayette County to the Mississippi State line in Marion County. In lesser proportion scattered throughout the Upper division of the Coast Pine belt, and rarely in the Lower Pine region, with its southern limit in Baldwin County, near Stockton, and in Mobile County about Mount Vernon. Flowers March to April.

Type locality not ascertained. Michaux's locality: "Hab. in Virginia, Kentueky et Carolina."

Economic uses: Highly valued for its excellent timber.

Herb. Geol. Surv. Herb. Mohr.

Pinus glabra Walt. Fl. Car. 237. 1788.

Rav. Proc. Ell. Soc. Charleston, 11: 52. Chap. Fl. 433.

Louisianian area. Coast of South Carolina to western Florida, west to eastern Louisiana.

Alabama : Central Prairie region. Upper division Coast Pine belt to Coast plain. Low woods skirting sandy swamps of streams. Marengo County, Luthers Store (E. A. Smith). Butler County, Georgiana. Autauga County, Prattville. Mobile County, Pierce's Landing. Baldwin County, Stockton.

Type locality: South Carolina.

Economic uses: Of little importance for its timber.

Herb. Geol. Surv. Herb. Mohr.

Pinus virginiana Mill. Gard. Dict. ed. 8, no. 9. 1768. Scrub Pine. Jersey Pine. Pinus inops Ait. Hort. Kew. 3 : 367. 1789.

Michx. f. Hist. Arb. Am. 1: 580, t.4. Ell. Sk. 2: 633. Gray, Man. ed. 6, 491. Chap.

Fl. 433 ; ed. 3,456 .

Carolinian area. New Jersey, castern Pennsylvania. Kentucky, southeastern

Indiana, and from Virginia south along the mountains to northern Alabama.

Alabama: Mountain region. Coosa Hills, rocky ridges of Carboniferous sandstone. Winston County, near Sipsey fork, 1,200 feet. Cullman County, 900 feet. Dekalb County, Lookout Mountain, 1,800 feet. St. Clair County, 500 feet. Not abundant.

Type locality not ascertained.

Economic uses: Of little importance except for fuel.

Herb. Geol. Surv. Herb. Mohr.

Pinus clausa (Engelm.) Sargent in Tenth Census U. S. (Cat. For. Trees N. A.) 9:179. 1884 .

Sand Pine. Florida Sprece Pine.

Pinus inops var. clausa Engelm. Bot. Gaz. 2 : 125.1877.

Trans. Acad. Sci. St. Lonis, $4: 183$. Chap. Fl. ed. 3, 456.

Louisianian area. Eastern and western Florida to Perdido Bay.

Alabama: Littoral belt. Drifting sands. Baldwin County, near Bon Seconr.

Only locality; rare.

Type locality: "Apalachicola" (Chapman).

Economic uses: Of no importance except for fuel.

Herb. Gcol. Surv. Herb. Mohr.

TSUGA Carr. Trait. Conif. 185. 1855.

About 7 species. Eastern Asia (Japan). North America, 4.

Tsuga canadensis (L.) Carr. Trait. Conif. 185. 1855.

Pinus canadensis L. Sp. Pl. ed.2, 2: 1421. 1763.

Abies canadensis Michx. Fl. Bor. Am. 2: 206. 1803. Not Miller.

Michx. f. Hist. Arb. An. 1:8, t. 1s. Ell. Sk. 2:639. Gray, Man. ed. 6, 492. Chap.

Fl.,434.

Canadian zone, Alleghenian and Carolinian areas. Nova Scotia, New Brunswick,

Quebec, Ontario; New England west to Wisconsin and Michigan, and along the higher Alleghenian ranges to northern Alabama.

Alabama: Mountain region. Rocky hillsides and ravines. Winston County, east 
fork Sipsey River, altitude 1,200 to 1,500 feet, to Clear Creek Falls, about 800 feet. In detached groves.

Type locality: "Hab. in America septentrionali."

Economic uses: Important timber tree. Bark valuable for tanning.

Herb. Geol. Surv. Herb. Mohr.

TAXODIUM L. C. Rich. Ann. Mus. Par. 16:278. 1810. Bald Cypless,

Three species, 2 in Mexico, 1 in Atlantic North America, 1 in China.

Taxodium distichum (L.) L. C. Rich. Ann. Mns. Par. 16:298. 1810.

Swamp Cypress, Red Cypress, White Cypress, Black Cypress.

Cupressus disticha L. Sp. Pl. 2: 1003. 1753.

Schubertia disticha Mirbel, Mém. Mus. Par. 13:75. 1825.

Michx. f. Hist. Arb. Am. 3:4,t.1. Gray, Man. ed.6,493. Chap. Fl.435. Coulter, Contr. Nat. Herb. $2: 555$.

Mexico.

Carolinian and Louisiauian areas. Southern Delaware west to Kentucks; southern Indiana, Illinois; southern Missouri, Arkansas, 'Tennessee; south throughout the low conntry to Florida, western 'Texas, and northern Mexico. Region of best development, alluvial swamps of the Atlantic coast from North Carolina to west Florida and the lower Alabama, Tombigbee, and Mississippi rivers.

Alabama: Tennessee Valley to the coast in aliuvial soil; January and February; fruit matures first year October to December. Valuable timber tree of largest dimensions.

Type locality : "Hab. in Virginia, Carolina."

Economic uses: Most valuable timber tree, the largest of Atlantic North America. Herb. Geol. Surv. Herb. Mohr.

Taxodium distichum imbricaria (Nutt.) Sudworth, Nomenc. Arb. Fl. U. S. 60. 1897. Pund Cypress, Upland Cypress.

Cupressus disticha var. imbricaria Nutt. Gen. Pl. 2 : 224. 1818.

Louisianian area. From North Carolina to Florida and Mississippi.

Alabama: Lower Pine region. Coast plain. Mobile, Baldwin, and Escambia counties.

Of smaller size than the species, with the leaves reduced in size and closely adpressed to the deciduous branchlets, thus impartıng to the tree a strikingly peculiar aspect. This character, however, is not constant, and the variety can scarcely be maistained, the same individual producing during the earliest stages of growth and on vigoruus adventitious shoots leaves of the ordinary form.

This form passes freely in to the species where the soil conditions are more favorable.

Type locality: "Found from Florida to North Carolina, in swamps and ponds more remote from the sea."

Herb. Geol. Surv. Herb. Mohr.

CHAMAECYPARIS Spach, Hist. Veg. 11:329. 1842. White Cedar.

Six or 7 species. China, Japan, Mexico. North America 2 species, Pacific Coast 1.

Chamaecyparis thyoides (L.) B. S. P. Prel. Cat. N. Y. 71. 1888.

Cupressus thyoides L. Sp. Pl. 2 : 1003.1753.

Thuya sphaeroidea Spreng. Syst. Veg. 3:889. 1826.

Chamaecyparis sphaeroidea Spach, Hist. Veg. 331. 1812.

Michx. f. Hist. Arb. Am. 3:20, t. 12. Ell. Sk. 2:644. Gras, Man. ed. 6, 493. Chap. Fl. 435 .

Carolinian and Louisianian areas. Coast of southern New England to New York, with sonthern New Jersey; coast of Virginia and adjacent parts of North Carolinathis is the region of its greatest development; south aloug the coast to northern Florida and the Gulf coast to eastern Louisiana. Reported also from Ohio, southern Indiana, and southern Illinois.

Alabama : Lower Pine region. Coast plain. In sphagnous swamps of a sour peaty soil. Escambia County, along the head waters of Escambia River. Baldwin County, Fish River. Mobile County, most frequeet on the pinc-barren streams emptying into Mobile Bay and Mobile River. Flowers November, December; fruit ripe in June.

'Type locality: "Hab. in Canada. Kalm."

Herb. Geol. Surv. Herb. Mohr.

JUNIPERUS L. Sp. Pl. 2 : 1038. 1753.

About 25 species. Northern Hemisphere, Europe, Asia to Japan, Mexico. North America 12 species; 3 in the Atlantic States. 
Juniperus virginiana L. Sp. Pl. 2 : 1039. 1753.

Red Cedar. Savin.

Michx. f. Hist. Arb. An. 3:42, t. 5. Ell. Sk. 2:717. Gray, Man. ed. 6, 494. Coulter, Contr. Nat. Herb. $2: 555$.

Alleghenian to Louisianian area. Quebec, Ontario, New England, west to Minnesota, eastern Nebraska, and Texas, and south to Florida and the Gulf coast.

Alabama : Over the State. Flowers latter part of January and in February; fruit matures in Octoler of the first year. Most frequent and in great perfection in the coves and valleys of the Tennessee basin, forming more or less extensive brakes in the limestone ridges of the same region. In the Central Prairie belt and the adjacent Upper division of the Coast Pine belt, once abundaut; at present almost exhausted.

Type locality: "Hab. in Virginia, Carolina."

Economic uses: The timber is highly valuable for pencil wood and other purposes. Medicinally it yields the leaves or tops of Juniperus virginiana U. S. P., 1870. Obsolete. The oil of red cedar, distilled from the wood, is used in perfumery and as an insectifuge.

Herb. Geol. Surv. Herb. Mohr.

Juniperus barbadensis L. Sp. Pl. 2 :1039. 1753.

Juniperus virginiana australis Carr. Trait. Conif. 44. 1855.

Michx. Fl. Bor. Am. 2:246. Griseb. Fl. Brit. W. Iud. 503.

Tree 50 to 60 feet high, the sturdy trunk 16 to 24 inches in diameter, 15 to rarely 25 feet tall; limbs wide-spreading, forming a rather open roundish-oval head, the branches and branchlets drooping; leaves minute, on the younger branches decussately inbricate, deltoid-ovate, bluntish, or on the youngest and most vigorous shoots subulate-lanceolate, acutish; furrow of the oil gland more or less oblonglinear. Fruit (galbulus) globose, glaucous black.

West Indes, Bahamas; Jamaica in the Blue Mountains, antigua.

Louisianan area. Southern coast of South Carolina to Florida and throughout the peninsula, along the gulf shore to Mississippi ; indigenous in the cedar hammocks of the eastern gulf shore. Frequently cultivated about $d$ wellings and naturalized in lower Louisiana and Mississippi.

Alabama: Coast plain and Littoral belt. Cedar hammocks. Mobile County, Bayou Labatre.

Distinguished from Juniperus virginiana by its habit of growth, the character of its leaves, the somewhat longer staminate flowers, and the smaller fruit.

Type locality: "Hab. in America."

Economic uses: Important for its wood, which is most highly esteemed for pencil casings.

\section{Class ANGIOSPERMAE (METASPERMAE),}

\section{Subclass MONOCOTYLEDONES.}

\section{TYPHACEAE. Cat-tail Family.}

TYPHA L. Sp. Pl. $2: 971.1753$.

Twelve species, temperate and tropical regions, 2 North American. Perennial aquatics.

Typha latifolia L. Sp. Pl. 2 : 971. 1753.

Large Cat-tail Flag.

Gray, Man. ed. 6, 547. Chap. Fl. 443. Wats. Bot. Calif. 2:188. Coulter, Coutr.

Nat. Herb. 2: 452 .

Europe, Asia, Nortil Africa.

Alleghenian to Louisianian area. Throughout British North America to the Pacific; from New England to Florida and west to California.

Alabama : Over the State. Shallow ponds and marshes; abounds in the tidewater region. Flowers in June.

Type locality: "Hab. in paludibus Europae."

Herb. Geol. Surv. Herb. Mohr.

Typha angustifolia L. Sp. Pl. 2:971. 1753.

Smaller Cat-tail.

Gray, Man. ed. 6, 547.

Europe.

Alleghenian to Louisianian area. Nova Scotia, Ontario, New England; west to

Michigan and Missouri; coast of New York and New Jersey. 
Alabama: Adventive. In a ditch, suburbs of Mobile (Karl Zimmer), 1886. Not found since.

Type locality: "Hab. in Europae paludibus."

Herb. Geol. Surv. Herb. Mohr.

\section{SPARGANIACEAE. Bur-reed Family.}

SPARGANIUM L. Sp. Pl. 2 :971. 1753.

Eight species, of cooler temperate regions. Eastern North America, 4 species. Perennial aquatics.

Sparganium androcladum (Engelm.) Morong, Bull. Torr. Club, 15 : 78.1888.

Sparganium simplex var. androcladum Engelm. in Gray, Man. ed.5, 481. 1871.

Ell. Sk. 2:521. Gray, Man. ed. 6, 548. Chap. Fl. 443.

Alleghenian to Louisianian area. New Brunswick, Ontario to Saskatchewan and

Vancouver Island; New England west to Minnesota and Missouri, south to Florida, Louisiana, and Arkansas.

Alabama: Throughout the State. Shallow ponds from the Tennessee Valley to the coast. Clay County, Elders, 1,000 feet. Cullman County. Tuscaloosa County, Tannehill (E. A. Smith). Montgomery and Mobile counties. Flowers May to July. Frequent.

Type locality: "From New England southward and especially westward."

Herb. Geol. Surv. Herb. Mohr.

\section{NAJADACEAE. Pondweed Family.}

POTAMOGETON L. Sp. Pl. 1 : 126. 1753. PONDWEED:

About 65 species. Floating aquatic herbs, mostly of the cooler temperate zone. Cosmopolitan. Europe, Asia, North America, 37 species; endemic in Atlantic North America, 14.

Potamogeton pulcher Tuckerm. Am. Journ. Sci. 45:38. 1843.

Bigel. Flor. Bost. 63 (as P. natans L.). Gray, Man. ed. 6, 560. Chap. Fl. Suppl. 652. Morong, Mem. Torr. Club. 3:16, t. 28.

Alleghenian to Louisianian area. From Vermont to Georgia, Louisiana, and Missouri.

Alabama: Central Prairie region. In stagnant water. Montgomery County, "Cypress swamp" near city. October. Rare.

Type locality: "Hab. Ponds and slow streams. Medford, Stoneham [Massachusetts]."

Herb. Geol. Surv. Herb. Mohr.

Potamogeton lonchites Tuckerm. Am. Journ. Sci. ser. 2, 6:226. 1818.

Potamogeton fluitans Roth, Fl. Germ. 1: 72. 1788 \%.

Ell. Sk. 1:221. Gray, Man. ed. 6, 560. Chap. Fl. 446. Coulter, Contr. Nat. Herb. $2: 457$. Wats. Bot. Calif. $2: 196$.

EUROPE.

Alleghenian, Carolinian, and Louisianian areas. Ontario and New England west to Michigan, Minnesota, and Missouri, south to Florida and Texas, and in California.

AlabaMa : Coast plain. So far only observed in the tide-water region. Gently flowing water in the delta of Mobile River. Flowers in June and July. Not infrequent.

Type locality: "In the Charles at Newton and Natick [Massachusetts]."

Herb. Geol. Surv. Herb. Mohr.

Potamogeton alpinus Balbis, Misc. Bot. 13. 1804.

Potamogeton rufescens Schrad. in Cham. Adn. Fl. Ber. 5. 1815.

Gray, Man. ed. 6, 560. Wats. Bot. Calif. 2:195. Coulter, Contr. Nat. Herb. 2: 457 . Morong, Mem. Torr. Club, $3: 19, t$. 30 .

Europe.

Canadian zone to Louisianian area. New Brunswick, Quebec, Vancouver Island, Oregon, California, New York, New Jersey, and western Florida.

\footnotetext{
'Morong, Najadaceae of North America, Mem. Torr. Club, 3: No. 2. 1893.
} 
Alabasra: Coast plain. Shallow pond near the western shore of Mobile Bay shell road, 1885. Locality since obliterated (C. Zimmer). A waif from higher latitudes.

Type locality not ascertained.

Herb. Geol. Surv. Herb. Mohr.

Potamogeton perfoliatus L. Sp. Pl. 1:126. 1753.

Gray, Man. ed.6, 562. Chap. Fl.446. Morong, Mem. Torr. Club, $3: 33, t .40$.

Europe, Guatemala, Nicaragua.

Canadian zone, Alleghenian to Louisiunian area. Nova Scotia, New Brunswick, Quebec, Ontario, New England, west to Michigan and Minnesota, south to New Jersey, western Tennessee, Florida (!), aud Texas.

Alabama : Coast plain. Gently flowing water. Mobile River delta. Dog River. Abundant in this locality.

Type locality: "Hab. in Europae lacubus fluviisque argillosis."

llerb. Geol. Surv. Herb. Mohr.

Potamogeton crispus L. Sp. Pl. 1: 126. 1753.

Gray, Man. ed. 6, 562. Moroug, Mem. 'Torr. Club, $3: 36, t .44$.

TEMPERATE EUROPE.

Alleghenian to Louisianian area. New England to New Jersey, Virginia, and western Florida.

Alabama : Coast plain. Gently flowing water. Mobile County, estuaries of Mobile and Dog rivers. Flowers and matures fruit in July.

Type locality: "Hab. in Europae fossis et rivulis."

Herb. Geol. Surv. Herb. Mohr.

Potamogeton pusillus L. Sp. Pl. 1 : 127. 1753.

Gray, Man. ed. 6, 563. Wats. Bot. Calif. 2:128. Morong, Mom. Torr. Club, 3: 45, t. 53 .

EUROPE.

Alleghenian to Lonisianian area. New Brunswick and Ontario to Saskatchewan; New England (Mount Desert Island) west to Michigan, Missouri, Colorado, and California; New Jersey to Florida, west to Texas.

Alabama : Coast plain. The form with filiform stem, setaceons, cuspidate leaves ( $P$. tenuissimus auct.), estuary Mobile River. Flowers in May. Infrequent.

Type locality: "Hab. in Europae paludibus."

Herb. Geol. Surv. Herb. Mohr.

Potamogeton diversifolius Raf. Med. Rep. ser. 2, $5: 354$. 1808.

Potamogeton hybridus Michx. Fl. Bor. Am. 1: 100. 1803. Not Thuill.

Ell. Sk. 1:222. Gray, Man. ed. 6, 560. Chap. Fl. 446. Coulter, Contr. Nat. Herb.

2:456. - Morong, Mem. Torr. Club, $3: 48, t .55$.

Alleghenian to Louisianian area. New England (Mount Desert Island) west to Michigan, Nebraska, and Missouri, south to New Jersey, Florida, and the Gulf States, extending to western Texas and New Mexico.

Alabama: Central Prairie region to Coast plain. Frequent in pine-barren streams and shallow ponds. Mobile, Baldwin, and Montgomery counties. Flowers in June with mature fruit.

Type locality of $P$. hybridus: "Hab. in aquis stagnantibus Carolinae."

Herb. Geol. Surv. Herb. Mohr.

\section{RUPPIA L. Sp. Pl. 1:127. 1753. DitchgRass.}

Two or 3 species, aquatics, cosmopolitan outside of the Aretic zone. North America, 2 species.

Ruppia maritima L. Sp. P1. 1 : 127. 1753.

Ell. Sk. 1:581. Gray, Man. ed. 6, 564. Chap. Fl. 445. Griseb. Fl. Brit. W. Ind. 506. Wats. Bot. Calif. 2:193. Conlter, Contr. Nat. Herb. 2:457. Morong, Mem. Torr. Club, $3: 55, t .62$.

EUROPE, West INDIES.

Canadian zone to Louisianian area. Along the seacoast. Nova Scotia, New Brunswick, New England (Mount Desert Island), south to Florida and Texas; Pacific coast.

Alabama : Littoral belt. In brackish or saline pools, ditches. Mobile County, Mobile Bay; abundant. Flowers and mature fruit in June. Annual.?

Type locality: "Hal. in Europae maritimis."

Herb. Geol. Surv. Herb, Mohr. 
ZANNICHELLIA L. Sp. Pl. 2:969. 1753. Horned Pondweed.

Nine species described, probably all forms of one. Cosmopolitan aquatics.

Zannichellia palustris L. Sp. P1. 2 : 969. 1753.

Gray, Man. ed.6, 565. Chap. Fl. 445. Wats. Bot. Calif. 2:193. Coulter, Contr.

Nat. Herb. 2:458. Morong, Mem. 'Torr. Club, 3:57, t. 64 .

Europe, Asia, Africa, Philippines, Australia.

Canadian zone to Louisianian area. Nova Scotia, New Brunswick, Ontario to Saskatchewan; New England west to Minnesota, south to Florida and Texas.

Alabama : Coast plain. Pools and still-flowing water, fresh or brackish. Mobile County, estuaries of Mobile and Dog rivers. Baldwin County, Josephine. Copious.

Hlowers in June and July. Annual.?

Type locality: "Hab. in Europae, Virginiae fossis, fluviis."

Herb. Geol. Surv. Herb. Mohr.

NAIAS L. Sp. P1. 2 : 1015.1753.

Ten to 12 species, temperate and tropical regions Northern Hemisphere. North America, 4 species.

Naias guadalupensis (Spreng.) A. Br. Seemann's Journ. Bot. 2 : 276. 1864.

Caulinia guadalupensis Spreng. Syst. 1:20. 1825.

Naias flexilis var. fusiformis CChap. Fl.444. 1860.

Morong, Mem. Torr. Club, 3:60, $t$. 68 .

West Indies, Mexico.

Louisianian area. Western Florida to Louisiana.

Alabama: Gently flowing deep water. Mobile County, estuaries of Mobile and Dog rivers, forming in large part with Ruppia, Zannichellia, Potamogeton perfoliatus, Vallisneria, and Nitella, the dense masses of subaquatic vegetation. Mature fruit in July. Perennial. ?

Type locality: "Insula Guadalupa. Bertero."

Herb. Geol. Surv. Herb. Mohr.

\section{SCHEUCHZERIACEAE. Arrow-Grass Family.}

TRIGLOCHIN L. Sp. Pl. 1:338. 1753. ARrow-Grass.

Marsh plants of frigid and temperate regions. About 10 species. North America, 3 species.

Triglochin striata Ruiz \& Pav. Fl. Peruv. 3 : 72.1802.

Triglochin triandra Michx. Fl. Bor. Am. 1:208. 1803.

Ell. Sk 1:417. Gray, Man. ed. 6,557. Chap. Fl. 447.

South America to Brazil, Oceania, Soutir Africa.

Carolinian to Louisianian area. From Maryland along the coast to Florida and Louisiana.

Alabama: Coast region. Fresh or brackish marshes. Mobile County, marshy banks, mouth of Dog River. Baldwin County. Flowers June and July. Not rare. Perennial.

Type locality : "In Peruviae lacubus et inundatis ad Surco, Miraflores, Lurigancho,

Magdalena et Limae tractus."

Herb. Geol. Surv. Herb. Mohr.

\section{ALISMACEAE. Water-Plantain Family.}

ALISMA L. Sp. Pl. 1:342. 1753.

Ten species; cooler and warmer temperate zone. Europe, America.

Alisma plantago-aquatica L. Sp. Pl. 1:342. 1753.

Water Plantain.

Ell. Sk. 1:434. Gray, Man. ed. 6, 554. Chap. Fl. 448. Wats. Bot. Calif. $2: 200$. Coulter, Contr. Nat. Herb. $2: 454$.

Europe, Asia, Africa, Australia, Mexico.

Canadian zone to Louisianian area. From Nova Scotia across the continent to the Pacific coast, south to Florida and the Gulf of Mexico. 
Alabama: Over the State. Marshes, ditches, borders of ponds. Common everywhere. Flowers July and August. Perennial.

Type locality: "Habitat in Europae aquosis et ad ripas fluviorum lacuum."

Herb. Geol. Surv. Herb. Mohr.

\section{ECHINODORUS Engelm. in Gray, Man. 460. 1848.}

Eight to 10 species, of warmer temperate and tropical America. North America, 3 species. Perenuial aquatic herbs.

Echinodorus radicans (Nutt.) Engelm. in Gray, Man. 460. 1848.

Creeping Water Plantain.

Sagittaria radicans Nutt. Trans. Am. Phil. Soc. ser. 2, 5 : 159. 1833-37.

Gray, Man. ed. 6, 556. Chap. Fl. 448. Coulter, Contr. Nat. Herb. $2: 456$.

Southern Mexico.

Carolinian and Lonisianian areas. Southern Illinois, Missouri, North Carolina to Florida, west to Texas and Arkansas.

Alabama: Coast plain to Central Pine belt. Marshes. Montgomery and Mobile counties. Frequent in the river marshes. Flowers May to July. White.

Type locality not ascertainerl. Eugelmanu's locality, "Swamps, Illinois and soutl ward."

Herb. Geol. Surv. Herb. Mohr.

\section{SAGITTARIA L. Sp. Pl. 2 :993. 1753. ARROWHEAD.}

About 30 species, of warmer temperate regions of both hemispheres, mostly American. North America, 20 species. Pereunial paludial herbs.

Sagittaria latifolia Willd. Sp. Pl. 4:409. 1806. (Form S. latifolia proper, J. G. Smith, Rep. Mo. Bot. Gard. $6: 36$.)

Common arrowhead. Broad-leaved Arrowhead.

Sagittaria variabilis Engelm. in Gray, Man. 461. 1848.

S. sagittaefolia var. variabilis Michel in DC. Monogr. Phan. 3:69. 1881.

S. hastata Pursh, Fl. 396.1814.

Ell. Sk. 2:589. Gray, Man. ed. 6, 554. Chap. Fl. 449. Wats. Bot. Calif. 2: 201.

Coulter, Contr. Nat. Herb. $2: 455$.

Mexico.

Alleghenian to Louisianian area. Nova Scotia to British Columbia and coast of California. From Canada to Florida, through the Gulf States to Mexico.

Alabama : Coast plain. Open marshes, swamps. Mobile County. Undoubtedly over the State. Flowers white, September, October. Abundant in the river marshes about Mobile.

Type locality: "Hab. a Canada ad Carolinam."

Herb. Geol. Surv. Herb. Mohr.

Sagittaria latifolia pubescens (Muhl.) J. G. Smith, Mem. Torr. Club, 5:25. 1894. (Form c, J. G. Smith, Rep. Mo. Bot. Gard. 6:40.)

Sagittaria pubescens Mubl. Cat. 86. 1813.

S. variabilis var. pubescens Engelm. Gray, Man. ed. 5, 555. 1856.

Gray, Man. ed. 6, 555 .

Louisianian area. Georgia, Florida.

Alabama: Central Prairie region to Coast plain. In gently flowing water. Mobile County, Mobile River. Baldwin County, near Daphne, in shaded swamps. Moutgomery County, Cypress Pond. Flowers June to October, 10 to 15 inches high; frequent.

Type locality: "Pensylvania."

Sagittaria viscosa Mohr, Bull. Torr. Club, 24:19, t. 289. 1897.

Clammy Arrowhead.

Monoecious; scape slender, over 2 feet long, branched from the lowest verticil; leaves membranaceous, smooth, broadly ovate, rounded toward the slightly apiculate apex; blade 6 to 7 inches wide, 12 to 14 inches long, deeply sagittate, the broad lobes acute, about 6 inches long, widely diverging; panicle slender, main branch 12 to 13 inches long, the branches about half its leugth; bracts coriaceous, papillose, rugose, viscid, free at the base, oblong-ovate, obtuse; sepals thick and like the bracts papillose, glutinose, ovate-lanceolate; stamens numerous (20 to 25 ), fila-

${ }^{1}$ J. G. Smith, Revision of N. Amer. species of Sagittaria and Lophotocarpus, Sixth Annual Report Mo. Bot. Gard, 1895. 



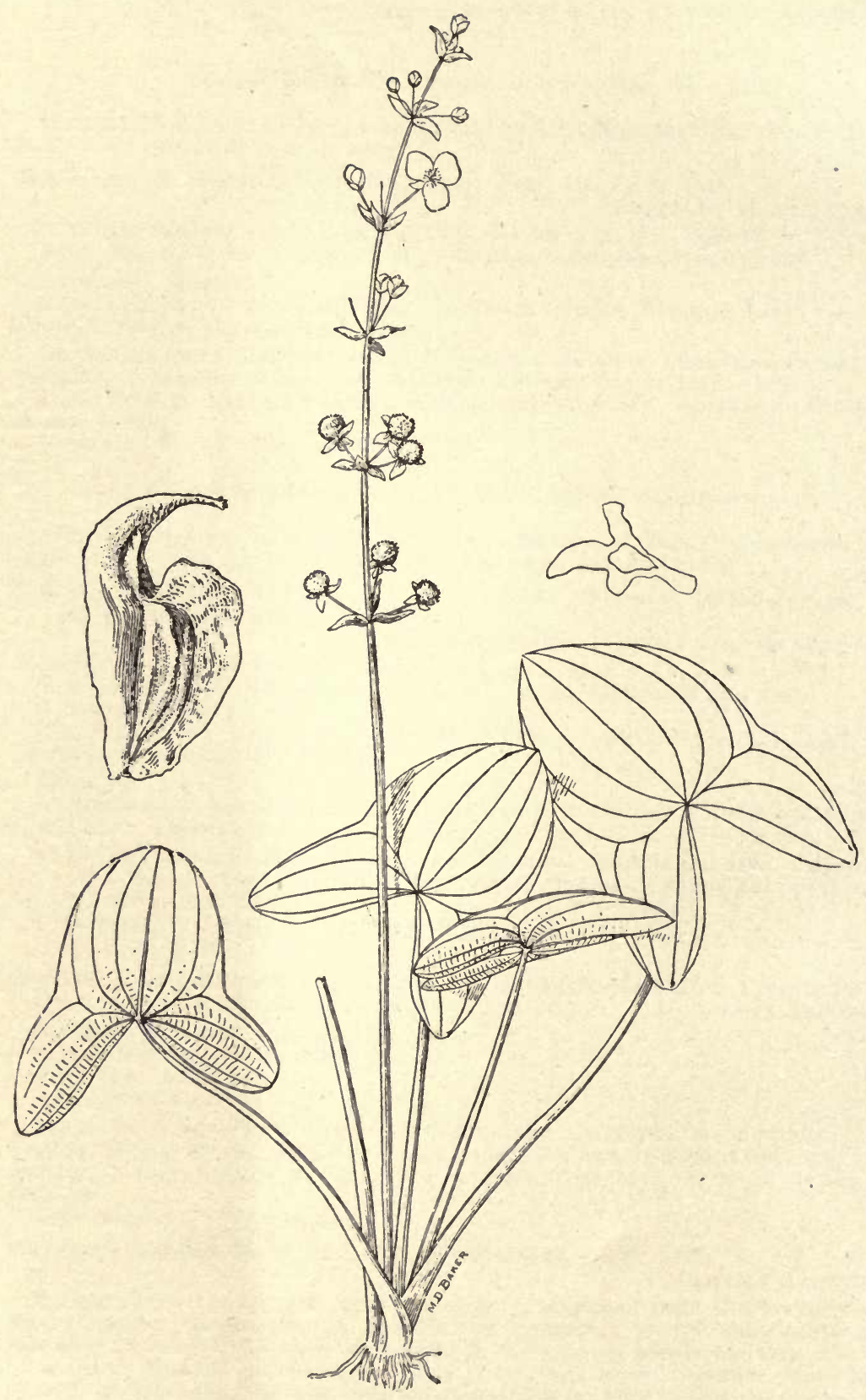

SAGITTARIA LONGIROSTRA AUSTRALIS J. G. SMITH. 
ments two-thirds longer than the anthers, strongly villous near the base; ovary narrowly winged, with a slender erect style; flowers fully three-fourths inch across. Resemblng form b (J. G. Smith) of S. latifolia; at once distinguished, however, by the characters given above.

Louisianian area.

Alabana: Lower Pine region, deep ditches. Mobile, June, 1896. On a second visit to the same locality to get specimens with mature achenia the plants were found to have been destroyed by the cleaning of the ditch.

Type locality: "Deep muddv borders of marsh on the Mobile River."

Herb. Geol. Surv. Herb. Mohr.

Sagittaria montevidensis Cham. \& Schlecht. Linnaea, 2 : 156. 1827.

J. G. Smith, Rep. Mo. Bot. Gard. $6: 57, t .29$.

La Plata River arrowhead.

"Monoecious; petioles stout, rigid, erect, ascending; leaves sagittate, acute or obtuse, 4 to 20 inches long and broad, basal lobes acute, acuminate, widely divergent, glabrous above, sparsely scabrous on the nerves below; scape usually simple, stout, often $2 \frac{1}{2}$ to 3 inches in diameter at the base; verticils numerous, more or less approximate, 2 to 4 lower ones fertile; bracts connate at the base, lanceolate, long-acuminate, the upper undeveloped portion of the scape appearing comose with their projecting tips; staminate pedicels slender, ascending, $\frac{8}{4}$ to $1 \frac{1}{8}$ inches long, longer than the fertile; flowers large, the sepals broadly ovate, obtuse, $\frac{8}{8}$ inch wide, inch long; petals obovate, larger than the sepals; staniens very many, the narrow glandular filaments longer than the linear-oblong authers; achenia ${ }_{1}^{1} 6$ to $\frac{3}{22}$ inch long, narrowly quadrate, obovate, winged on both margins, with a short, slender, oblique beak, and a prominent sub-epidermal resin passage on each side above; fruiting head large, $\frac{5}{8}$ to $1 \frac{1}{4}$ inches in diameter." Established as a ballast plant in California.

South America.

Louisianian area. Coast of North Carolina.

AlabaMa : Coast plain. Marshes and ditches. Mobile County, river marshes and ditches about the city. Flowers July to September. Frequent.

Type locality: "Montevideo et Rio grande do Sul."

Herb. Geol. Surv. Herb. Mohr.

Sagittaria longirostra (Micheli) J. G. Smith, Mem. Torr. Club, 5:26. 1893.

LONG-BEAKED ARROWHEAD.

Sagittaria sagittifolia var. (8) longirostra Micheli in DC. Monogr. Phan. 3:69. 1881. Britt. \& Brown, Ill. Fl. 1: 88.

Carolinian area. Southern Delaware, Pennsylvania, and Kentucky.

Alabama: Lower hills. Coosa County, Stewardsville (Dr. E. A. Smith). July. Rare.

Type locality: "In Alabama (Drummond, 1832)."

Sagittaria longirostra australis J. G. Smith, Bull. Torr. Club, 24 : 20, t. 291. 1897. SOUTHERN LONG-BEAKED ARRowhead.

Plant 6 to 8 inches high, the scape about 20 inches long; leaves ovate-elliptical, obtuse, 3 to 4 inches long, basal lobes obtuse; fertilo pedicels about $\frac{1}{2}$ inch long, exceeding the bracts; achenium less than $\frac{1}{8}$ inch long.

Plate II.

Carolinian area.

Alabama: Mountain region. Shaded swampy creek banks. Cullman County. Type locality: "Collected by Dr. Charles Mohr, Cullman, Ala., August 4, 1896." Type in Herb. Mo. Bot. Gard.

Herb. Geol. Surv. Herb. Mohr.

Sagittaria subulata (L.) Buchenan, Abh. Nat. Ver. Brem. 2 : 49. 1871.

Alisma subulata L. Sp. Pl. 1 : 343. 1753.

Sagittaria pusilla Nutt. Gen. Pl. 213. 1818.

S. natans var. lorata Gray, Man. ed.6,555. 1890. Not Chap.

Gray, Man. 1. c. Chap. Fl. 449.

Carolinian and Louisianian areas. New York, eoast of New Jersey to Florida.

Alabama : Coast plain. Sandy tidewater flats. Mobile County, Frascati. Flowers in September. Rare. One-half inch high.

Type locality: "Hab. in Virginia."

Herb. Geol. Surv. Herb. Mohr.

Sagittaria subulata natans (Michx.) J. G. Smith, Rep. Mo. Bot. Gard.44. 1894.

Sagittaria subulata Michx. Fl. Bor. Am. 2:190. 1803.

S. subulata var. lorata Chap. Fl.449. 1860.

Floating arrowhead. 
Ell. Sk. 2:591. Chap. Fl. 449.

Louisianian area. South Carolina, Florida.

Arabaya: Upper division Coast Pine belt. Fresh water ponds. Washington County, Suggsville (Dr. Denny). Local.

Type locality: "Hab. in Carolina."

Herb. Geol. Surv. Herb. Mohr.

Sagittaria filiformis J. G. Smith, Rep. Mo. Bot. Gard. 6:46, t. 15. 1894.

Filiform Arrowhead.

"Submerged aquatic, with linear filiform phyllodia 6 inches to 2 feet long, $\frac{1}{16}$ to $\frac{1}{8}$ inch wide; scape slender, filiform, 2 to 4 feet long, branching from all but the uppermost verticils; bracts lanceolate, acuminate, $\frac{1}{8}$ to $\frac{3}{16}$ inch long, at length evanescent; pedicels and branches of the scape filiform $1 \frac{1}{2}$ to $3 \frac{1}{2}$ inches long; 1 or 2 flowers of the lowest verticil pistillate, the rest all staminate; verticils 6 to 10 , remote; flowers $\frac{8}{8}$ to $\frac{7}{76}$ inch wide; sepals ovate, obtuse, scarions-margined; petals white, stamens 7; tilaments over twice as long as the anthers; mature achenia not yet collected; ovary obovate, equaled by the slender oblique style. Floating in still water. Dog River, Mobile County, Ala.. Mohr, August 14, 1893."

Louisianian area. Eastern and western Florida.

Type locality: "Dog River, Mobile County, Ala."

Type specimen in Herb. Mo. Bot. Gard.

Herb. Mohr.

Sagittaria lancifolia falcata (Pursh) J. G. Smith, Rep. Mo. Bot. Gard. 6:47, t. 16. 1894.

LANCE-LEA VED SAgitTAiria.

Sagittaria falcata Pursh, Fl. Am. Sept. 2 : 397. 1816.

S. lancifolia media Micheli in DC. Monogr. Phan. 3:73. 1881.

Ell. Sk. 2:591. Gray, Man. ed. 6, 555. Chap. Fl. 449.

Mexico, Central America.

Carolinian and Louisianian aruas. Delaware and Maryland, south along the coast

to Florida and Louisiana.

Alabana : Coast region. Open marshes. Mobile County, river swamp; Bayou Labatre, brackish swamps near the seashore. Flowers July, August; 2 to 3 feet high. Common.

Type locality: "In ponds: Carolina."

Herb. Geol. Surv. Herb. Mohr.

Sagittaria graminea Michx. Fl. Bor. Am. 2 : 190. 1803. Grass-leaved Sagittaria. Ell. Sk. 2:592. Gray, Man. ed. 6,555. Chap. Fl. 449. Coulter, Contr. Nat. Herb. $2: 455$.

Canadian zone to Louisiantan area. Newfoundland, New Brunswick, Ontario, Now England (Mount Desert Island); west to Minnesota, Dakota, Nebraska, Kansas; south to Florida and Texas.

Alabama : Coast region. Shallow ponds, ditches. Mobile County, river marshes. June; frequent.

Type locality: "Hab. in Canada."

Herb. Geol. Surv. Herb. Mohr.

Sagittaria cycloptera (J. G. Smith) Mohr, Bull. Torr. Club, 24:20. 1897.

Pine-barren Sagittaria.

Sagittaria graminea cycloptera J. G. Smith, Rep. Mo. Bot. Gard. 6:52, t. 20. 1894.

"Slender, erect, 8 inches to 2 feet and over high from a horizontal or oblique rhizome; leaves linear-lanceolate, tapering gradually at both ends or reduced to slender attenuate phyllodia; scape simple or branching from the lowest verticil; in ternodes longer than fertile pedicels; bracts and stamens as in the species; achenium $\frac{1}{6}$ to $\frac{1}{4}$ inch long with an abrupt dorsal crest, an arched wing, and a medial vertical resin passage on either side, or when maturing under water only costate or wrinkled."

Louisianian area. South Carolina to Florida and Louisiana.

Alabama : Lower Pine region. Coast plain. Sandy borders of pine-barren ponds. Washington County, Yellow pine, Deerpark. Mobile County, river marshes, Spring -

hill. Flowers June to Angust. Frequent in the Lower Pine region.

'Type locality: "From South Carolina to Florida and Louisiana."

Herb. Geol. Surv. Herb. Mohr.

Sagittaria chapmani (J. G. Smith) Mohr, Bull. Torr. Club, 24:20. 1897.

Chapman's Sagittaria:

Sagittaria graminea chapmani J. G. Smith, Rep. Mo. Bot. Gard. 6:52, t. 21. 1894.

"Twe]ve to 20 inches high; leaves narrowly lanceolate, acute, tapering at base into the petiole, $\frac{8}{4}$ to $1 \frac{1}{8}$ inches wide, 5 to 8 inches long; scape weak, branched or 



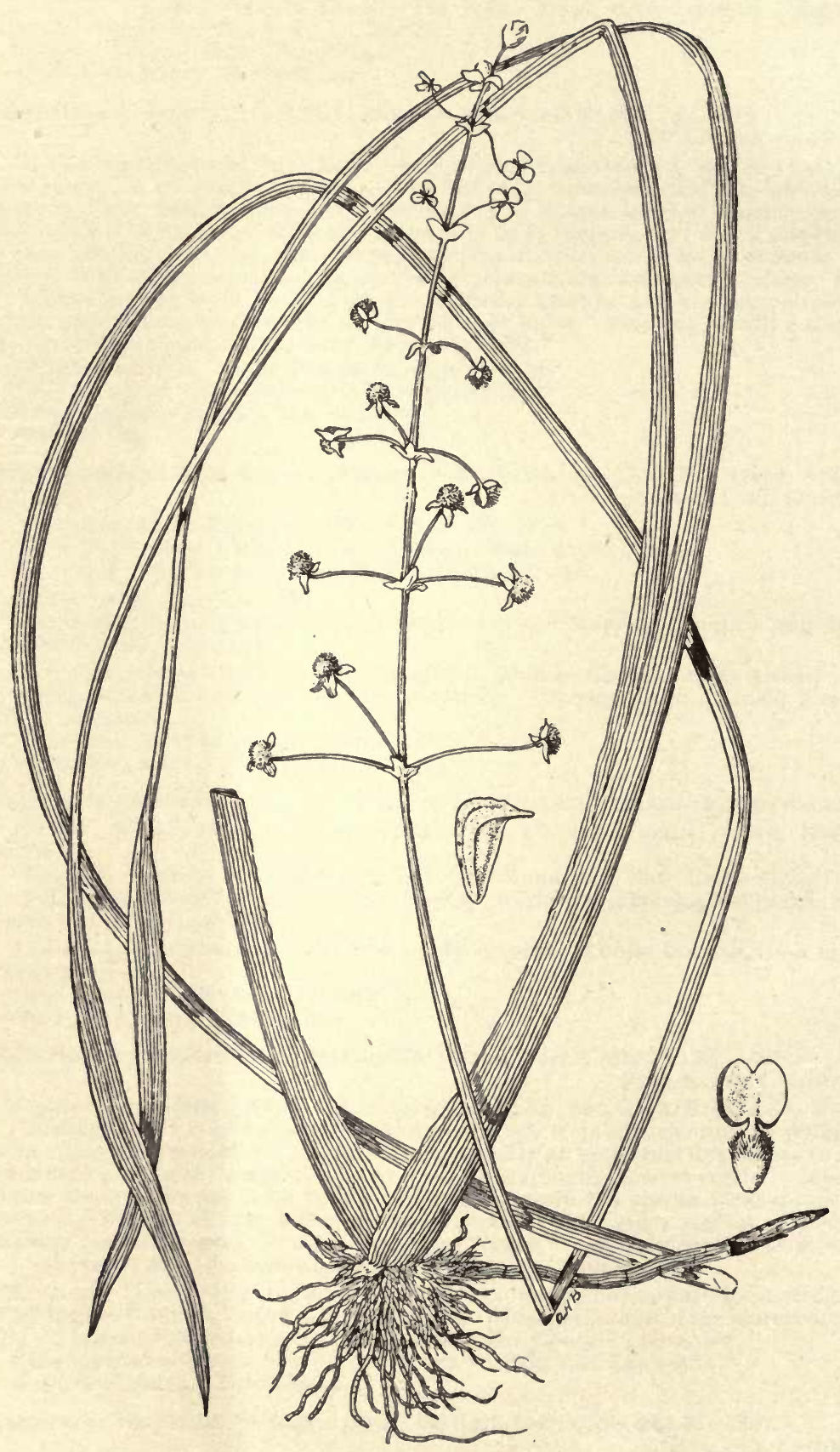

SAgItTARIA MOHRII J. G. SMITH. 
simple, the fertile flowers numerous; bracts lanceolate, acute or acuminate, $\frac{3}{16}$ to $\frac{7}{16}$ inch long, slightly connate at the base; fertile pedicels $\frac{8}{4}$ to 1 inch long; fruiting head ${ }^{3}$ to $\frac{1}{4}$ inch in diameter; achenium almost beakless, $\frac{1}{16}$ inch long, with a narrow dorsal crest, the sides not costate nor winged. Phyllodia oblanceolate, long-acute, $\frac{8}{8}$ to $\frac{8}{4}$ inch wide, 4 to 12 inches long. *** Dedicated to the venerable Southern botanist, Doctor Chapman, by whom it was first collected."

Louisianian area. Western Florida.

Alabama: Marshes, stagnant pools, and wet banks of ereeks. Mobile County, Kelly's pond, marshes Mobile River. Flowers April to June. Niohr, 1880.

Type locality: "In a creek on the roall to Mariana, 3 or 4 miles from Ocheesee, west Florida;' also collected by Dr. Mohr, 1880,*** 1884, in the vicinity of Mobile, Ala."

Herb. Geol. Surv. Herb. Mohr.

Sagittaria mohrii J. G. Smith, Bull. Torr. Club, 24 : 19, t. 289. 1897.

MoHr's SagitTaria.

Leaves lanceolate-linear, long-attennate to the acute apex, tapering gradually at the base to the slender, ascending petioles, 15 to 20 inches long, $\frac{8}{8}$ to $\frac{1}{2}$ inch wide; scape shorter than the leaves, simple, triquetrous above, weak, reclining, decumbent after flowering, frequently ripening its fruit under water, with 6 to 8 verticils, the inflorescence narrowly pyramidal; bracts $\frac{8}{8}$ to $\frac{1}{2}$ inch long, connected to the middle; fertile pedicels spreading, somewhat longer than the sterile, in 3 or 4 verticils, $\frac{1}{2}$ to $\frac{5}{8}$ inch long; sepals oblong, obtuse, $\frac{1}{10}$ to $\frac{1}{8}$ inch long; stameus 9 to 12 , anthers broadiy elliptical; achenium $\frac{1}{16}$ inch long, obliquely cuneate with a short lateral beak, crenulately crested and broad-wingeil on both margins, laterally unicostate or narrowly winged; fruiting head globose, $\frac{1}{4}$ to $\frac{5}{16}$ inch in diameter.

Plate iri.

Partially submerged aquatic, growing in tufts, at the nodes of horizontal stolons.

First collected at Mobile by Charles Mohr, Angust 16, 1895.

Alabaina : Coast plain. Deep muddy ditches and shallow ponds. Mobile, in the open flats forming the watershed between Dog and Mobile rivers (southwestern suburbs). In shallow water and partially exsiccated ground.

Plants were found with the leaf blade narrowly linear, and mostly wanting, the leaves reduced to strict triangular phyllodia. Abundant, August 20, 1896.

Typo locality: "Muddy shallow ponds near the western suburbs of Mobile city, August 18, 1895."

Type in Herb. Mo. Bot. Gard.

Herb. Geol. Surv. Herb. Mohr.

Sagittaria platyphylla (Engelm.) J. G. Smith, Rep. Mo. Bot. Gard. 6:55, t.26. 1894. Broad-LEa Ved SagitTaria.

Sagittaria graminea var. platyphylla Engelm. in Gray, Man. ed. 5, 494. 1867.

Carolinian and Louisianian areas. Missouri to Texas; east from Mississippi and Louisiana to Florida.

Alabama : Coast plain. Muddy ditches, ponds. Mobile. Flowers June to September. Frequent.

Type locality: "Found farther south [than S. graminea]." Smith's locality: "In swamps and ponds from Texas to Mississippi and northward to the 'sunken lands' of Missouri."

Herb. Geol. Surv. Herb. Mohr.

\section{VALLISNERIACEAE. Frogsbit Family.}

PHILOTRIA Raf. Am. Month. Mag. 2:175. 1818.

(Elodea Michx. Fl. Bor. Am. 1:20. 1803. Not Elodes Adans.) (Udora Nutt. Gen. $2: 242$. 1818.)

Five species, aquatic perennial herbs of temperate and tropical regions.

Philotria canadensis (Michx.) Britton, Science, ser. 2, 2:5. 1895. WATER Weed

Elodea canadensis Michx. Fl. Bor. Am. 1:20. 1803.

Gray, Man. ed. 6, 496. Chap. Fl. 450. Wats. Bot. Calif. 2:129. Coulter, Contr. Nat. Herb. $2: 421$.

Canadian zone to Lonisianian area. Quebec and Ontario to Oregon and California; from New Englaud south to New York, New Jersey, and North Carolina.

AlabaMa : Coast region. In gently flowing deep water. Mobile County, estuary Mobile River. Rare.

Type locality: "Hab. in rivulis Canadae."

Herb. Geol. Surv. Herb. Mohr. 
VALLISNERIA L. Sp. Pl. 2:1015. 1753.

Two species, perennial aquatics, of the temperate and warmer regions of both hemispheres.

Vallisneria spiralis L. Sp. Pl. 2:1015. 1753.

Eel Grass.

Vallisneria americann Michx. Fl. Bor. Am. 2:220. 1803.

Ell. Sk. 2:666. Gray, Man. ed. 6, 496. Chap. Fl.451. Conlter, Contr. Nat. Herb.

$2: 422$.

Southeri Europe, Asia, Australia.

Canadian zone to Louisianian area. New Brunswick, Ontario, and New York to Minnesota, Illinois, Missouri, Arkansas, and Tennessee, south to Florida and Texas.

Alabama: Coast region. Gently flowing water. Mobile County, estuaries of Mobile and Dog rivers, Mobile Bay. Flowers in July, fruit in Angust. Abundant. Type locality: "Hab. in Pisae et Florentiae fossis."

Herb. Geol. Surv. Herb. Mohr.

\section{POACEAE (GRAMINEAE). Grass Family.}

TRIPSACUM L. Syst. Pl. ed. 10, 2 : 1261. 1759.

Two species, perennials, of warmer temperate regions in North America.

Tripsacum dactyloides L. Sp. Pl. ed. 2, $2: 1378.1763$.

Spiked Gama Grass.

Ell. Sk. 2:522. Gray, Man. ed.6,636. Chap. Fl. 580. Coulter, Contr. Nat. Herb.

$2: 491$.

BRAZIL.

Alleghenian to Lonisianian area. Southern New England, New York, and Pennsylvania, west to Illinois, Missouri, and Arkansas, south to Florida and Texas.

Alabama: Mountain region. Central Prairie region to Coast plain. Low damp banks. Lee County, Auburn (Baker \& Earle, 650). Montgomery County (E. A. Smith). Wilcox County, near Peachtree. Mobile County. Scattered, not infrequent, but nowhere abundant. Jaly to August.

Type locality: "Hab. in America."

Economic ases: Of some value for forage.

Herb. Geol. Surv. Herb. Mobr.

ERIANThUS Michx. Fl. Bor. Am. 1:54. 1803. Plume Grass.

About 20 species, coarse perennials, of the warmer regious of both hemispheres. Atlantic North America, 6 species.

Erianthus alopecuroides (L.) Ell. Sk. 1:38. 1816. In part.

Andropogon alopecuroides L. Sp. Pl. 2 : 1045. 1753.

Ell. l. c. Gray. Man. ed. 5,651 , in part. Chap. Fl. ed. 3, 595. Coulter, Contr. Nat.

Herb. 2 : 493, in part. Britt. \& Brown, Ill. Fl. 1: 98.

Carolinian to Louisianian area. Kentucky and Missouri; sonth to Tennessee and Georgia.

Alabama : From the coast to the mountains. In wet and dry soil. Cullman and Clay counties. Chambers (E.A. Smith), Mobile, and Baldwin counties. Four to 5 feet high. September. Near the coast; mostly found in swamps. In upper districts in drier soil.

Type locality: "Hab. in America septentrionaliore."

Herb. Geol. Surv. Herb. Mohr.

Erianthus saccharoides Michx. Fl. Bor. Am. 1: 55. 1803.

Foxtall Plume Grass.

Ell. Sk. 1:38, in part. Gray, Man. ed.6,637. Coulter, Contr. Nat. Herb. $2: 493$, in part. Britt. \& Brown, Ill. Fl. 1:99.

Cuba, Mexico, Brazil.

Louisianian and Carolinian areas. From southern Virginia to Florida, west to Louisiana and Texas.

Alabama : Coast plain to Central Prairie region. In deep open marshes, Montgomery County. Mobile County, marshes of Mobile River. Most frequent on the coast. Eight to 10 feet high. October, November.

Type locality: "Hab. a Carolina ad Floridam, in humidis." 
Erianthus brevibarbis Michx. Fl. Bor. Am. 1:55. 1803.

Short-bearded Plume Grass.

Erianthus alopecuroides var. brevibarbis Chap. Fl. 583. 1860.

L. saccharoides subspec. brevibarbis Hackel in DC. Monogr. 6:131. 1889.

Eil. Sk. 1:39. Gray, Man. ed. 6, 637. Coulter, Contr. Nat. Herb. 2:493. Scribner, Grass. Tenn. 18, $t .1, f .8$.

Carolinian and Louisianian areas. Virginia and Tennessee, south to Florida and southeastern Texas.

AlabaMa: Coast plain. Low sandy borders of pine-barren streams. Mobile

County. Baldwin County, Josephine. Not rare. September to October.

Type locality: "Hab. in collibus 'Tennassée et Carolinae."

Herb. Geol. Surv. Herb. Molır.

Erianthus strictus Bald.; Ell. Sk. 1:39. 1816.

Close-panicled Erianthus. Chap. Fl. 583. Conlter, Contr. Nat. Herb. 2:494. Scribner, Grass. Tenn. 18, t. $1, f$. 2.

Carolinian and Louisianian areas. Georgia, southeastern Tennessee, and from Florida to Texas.

Alabama : Lower Pine belt. Margins of swamps. Mobile County, Pierce's Landing, Mount Vernon. Baldwin County, Stockton. September to October. Not infrequent.

Type locality: "Grows near Savannah."

Herb. Geol. Surv. Herb. Mohr.

Erianthus smallii Nash, Bull. N. Y. Bot. Gard. 1:429. 1900.

Tall, densely tufted perennial, 4 to $7 \frac{1}{2}$ feet high; nodes pubescent with long appressed hairs, summit of the culm and floral axis copiously appressed-pulescent; sheaths nearly glabrous; ligule scarious, ciliolate at the apex; leaves 4 to 7 inches long, $\frac{1}{4}$ to $\frac{8}{4}$ inch wide, rough; panicle 8 inches and over long and $1 \frac{1}{2}$ to $2 \frac{1}{2}$ inches wide, its branches erect; spikelets crowded, about equaling the basal hairs; outer scales pilose with long liairs; fourth scale two-toothed at the apex, teeth long-subulate, the awn $\frac{7}{8}$ to a little over an inch long, the included portion long and tightly spiral, the remainder loosely spiral.

Carolinian and Louisianian areas. Tennessee, Georgia, Florida, and Mississippi.

Alabama: Central Prairie region. Low grounds. Montgomery (G. McCarthy, August, 1888).

Related to E. contortus Ell,, but clearly distinct. In E. contortus the summit of the culm and axis of the panicle are glabrons and the spikelets are considerably smaller.

Type locality: "Type collected by Dr. J. K. Small * * * on Stone Mountain, Dekalb County, Ga., Sept. 6 to 12, 1894."

MANISURIS L. Mant. 2 : 164. 1771.

(Rottboellia L. f. Diss. Nov. Gram. 23. 1779.)

About 33 species, warmer temperate and tropical regions in both hemipheres. Atlantic North America, 3 species. Perennials.

Manisuris rugosa chapmani (Hackel) Scribner, Mem. Torr. Club, 5:28. 1894.

Rottboellia rugosa Chap. F1. 575. 1860. Not Nutt.

R. rugosa chapmani Hackel, in DC. Monogr. Phan. 6: 308. 1889.

Chap. Fl. 575.

Louisianian area. North Carolina to Florida and Alabama.

Alabama: Lower Pine region. Coast plain. Borders of sandy, pine-barren swamps. Mobile County, Kelly's pond. Baldwin County, Pierce's Landing. September to October.

Type locality: "Pine-barren swamps and ponds, Florida to North Carolina."

Herb. Geol. Surv. Herb. Mohr.

Manisuris corrugata (Bald.) Mohr. Bull. Torr. Club, 24 :21. 1897.

Corrugated Manisuris.

Rottboellia corrugata Bald. Am. Journ. Sci. 1:355. 1819.

Chap. Fl. 579. Coulter, Contr. Nat. Herb. $2: 492$.

Louisianian area. Georgia and Florida to Texas.

Alabama: Coast plain. Low damp pine barrens. Mobile County, Dog River, pine flats. Angust to September. Frequent.

Type locality: "Discovered between St. Mary's and Jefferson, in Camden County, Georgia, on the 13th of July, 1813."

Herb. Geol. Surv. Herb. Mohr. 
Manisuris corrugata areolata (Hackel) Mohr. Bull. Torr. Clnb, $24: 21.1897$.

Rottboellia corrugata var. areolata Hackel, in DC. Monogr. Phan. 6:309. 1889.

A well-marked variety, the numerous peduncles slender and long-exserted, and the spikes more slender than in the type; spikelets oblong-ovate, less pitted.

Louisianian area.

AlabaMa : Coast plain. Low damp pine barrens. Mobile County.

Type locality: "In pinetis depressis humidis prope Mobile, Alabama (C. Mohr)." Herb. Geol. Surv. Herb. Mohr.

Manisuris Cylindrica (Michx.) Kuntze, Rev. Gen. Pl. 2 : 779. 1891.

Tripsacum cylindricum Michx. Fl. Bor. Am. 1:60. 1803.

This species is not in frequent in Florida and eastern Mississippi, and is to be looked for in western Alabama.

HACKELOCHLOA Kuntze, Rev. Gen. Pl. $2: 777.1891$.

(Manisuris L. Mant. 2:164. 1771. In part.)

A single species, annual, widely distributed over tropical regions.

Hackelochloa granularis (L.) Kuntze, Rev. Gon. Pl. 2 : 777. 1891.

Cenchrus granularis L. Mant. 2:575, App. 1771.

Manisuris granularis Sw. Prodr. 1:25. 1788.

Ell. Sk. 2:521. Chap. Fl.580. Coulter, Contr. Nat. Herb. 2:492. Griseb. Fl. Brit.

W. Ind. 557 .

West Indes and all Tropical Countries.

Louisianian area. South Carolina and Florida, west to Texas and Arizona.

Alabama: Lower Pine belt. Waste and enltivated gronnds. Mobile County, Springhill, Citronelle. June.

Adventive from the tropics and fully established.

Type locality not ascertained.

Herb. Geol. Surv. Herb. Mohr.

ANDROPOGON L. Sp. Pl. 2:1045. 1753.

A genus, as understood at present, of about 200 species; belonging to the warmer regions of the globe. North America, 24 species. All pereunials from longer or shorter scaly or fibrous-rooted rhizomas.

Andropogon tener Kunth, Rev. Gram. 2:565, t. 19\%. 1833.

Slender Beard-Grass. 1889.

Andropogon tener var. genuinus subvar. typicus Hack. in DC. Monogr. Phan. 6 : 378.

Chap. Fl.581. Coulter, Contr. Nat. Herb. $2: 495$.

Cuba, Mexico, Brazil, Argentina.

Louisianian area. Georgia and Florida to Texas.

Alabama : Coosa Valley to Coast plain. Dry hills, gravelly or close sandy soil. Mobile County. Washington County, Yellowpine. Monroe County, Claiborne. Clark County, Choctaw Corner. Calhoun County, Anniston. August to September.

Most frequent in the Lower Pine region.

Type locality: "Crescit in Brasilia meridionali."

Herb. Geol. Surv, Herb. Mohr.

Andropogon scoparius Michx. Fl. Bor. Am. 1:57. 1803.

Ell. Sk. 1: 146. Gray, Man. ed.6, 637. Chap. Fl.581. Conlter, Contr. Nat. Herb.

$2: 495$.

Mexico.

Alleghenian to Louisianian area. From the South Atlantic and Gulf States west to Arizona and California; north to New England and Minnesota; from Ontario to the Saskatchewan; Rocky Mountains, Colorado.

Alabama: Over the State, on poor sandy soil. Common everywhere. Most abundant in dry pine barrens and worn-out fields. Of many forms, difficult to separate.

Type locality: "Hab. in aridis sylvarum Carolinae."

Herb. Geol. Surv. Herb. Mohr.

Andropogon glomeratus (Walt.) B. S. P. Prel. Cat. N. Y. 67. 1888.

Cinna glomerata Walt. Fl. Car. 59. 1788.

Bushy Beanid-Grass.

Andropogon macrourum Michx. Fi. Bor. Am. 1:56. 1803.

Eastern Mexico, Central America, West' Indies. 
Carolinian and Louisianian areas. From Florida along the coast to New York and central Pennsylvania; Gulf States to southeru Missouri and Tennessee.

Alabama: Lower Pine belt. Coast plain. Low damp pine barrens, abounding in flat, barren, and low worn-out ground.

Trpe locality : South Carolina.

Herb. Geol. Surv. Herb. Mohr.

Andropogon glomeratus hirsutior (Hackel) Mohr, Bull. Torr. Club, 24:21. 1897.

Andropogon macrourus var. hirsutior Hackel in DC. Monogr. Phan. 6:409. 1889.

Sheaths with long hairy tubercles, green. Seeds smooth, or roughly fimbriate at the base.

Louisianian area.

Ala bama : Coast plain. Flat pine barrens. Frequent.

Type locality: "Alabama prope Mobile (C. Mohr)."

Herb. Geol. Surv. Herb. Mohr.

Andropogon glomeratus glaucopsis (Ell.) Mohr, Bull. Torr. Club, 24:21. 1897.

Andropogon macrourus var. glaucopsis Ell. Sk. 1:150. 1817.

Louisianian area. Georgia, South Carolina, Florida.

Alabama : In wet soil. Mobile. River marshes. October. Four to 5 feet high, robust. Frequent.

Type locality: "Grows in damp soils [South Carolina and Georgia]."

Herb. Geol. Surv. Herb. Mohr.

Andropogon virginicus L. Sp. Pl. 2 : 1046. 1753.

Broom SEDGE.

Andropogon dissitiflorum Michx. Fl. Bor. Am. 1:57. 1803.

A. vaginatus Ell. Sk. 1 : 148.1816.

A. virginicus var, viridis Hackel in DC. Monogr. Phan. 6:410. 1889.

Gray, Man. ed.6,638. Chap. Fl.582. Coulter, Contr. Nat. Herb. 2: 496.

Carolinian and Louisianian areas. Southern New Fngland to Florida, west to

Texas, Arkansas, Tennessee, Missouri, and southern Illinois.

Alabama: All over the State. In close sandy soil, damp or dry, open pine woods, worn-out fields, and pastures. Most abundant.

Type locality: "Hab. in America."

Herb. Geol. Surv. Herb. Mohr.

Andropogon virginicus dealbatus Mohr; Hackel in DC. Monogr. Phan. 6:411. 1889.

Vasey, Contr. Nat. Herb. 3: 11 .

Base of the smooth leaves covered with white bloom; stems and leaves becoming whitish.

Coast plain. In damp sandy soil. Mobile County. Not common.

Type locality: "Alabama prope Mobile (Mohr)."

Herb. Geol. Surv. Herb. Mohr.

Andropogon capillipes Nash, Bull. N. Y. Bot. Gard. 1 : 431.1900.

Andropogon virginicus glaucus Hackel in DC. Monogr. Phan. 6:411. 1889. Not $d$. glaucus Retz. 1789.

Vasey, Contr. Nat. Herb. $3: 11$.

Glaucous throughout.

Alabama : Coast plain. Close sandy soil. Mobile County. October. Frequent. Type locality : " Florida (Curtiss)."

Herb. Geol. Surv. Herb. Mohr.

Andropogon tracyi Nash, Bull. N. Y. Bot. Gard. 1: 433. 1900.

A tufted glabrous perennial, with the numerous basal leaves about half as long as the culm; culm $1 \frac{1}{2}$ to $2 \frac{1}{2}$ feet long, branched above the middle, nodes of inflorescence barbed with long silky hairs; sheaths shorter than the internodes; ligule scarious; leaves erect, sparingly hirsute on the upper surface near the base, 4 to 8 inches long; inflorescence 8 to 12 inches long, narrow, the branches erect, the racemes in pairs, the sessile spikelets about twice as long as the stout internodes, densely clothed with silvery white hairs, awn about $\frac{8}{8}$ to $\frac{6}{8}$ inch long; pedicellate spikelet wanting or a minute rudimentary scale.

Carolinian and Louisianian areas. Mississippi.

Alabama: Metamorphic hills. Dry soil. Lee County, "Auburn, October, 1897 (F. S. Earle)."

Between $A$. virginicus and $A$. longiberbis. Distinguished from the former by its glabrous sheaths and stout racemes; from the latter, with which it is more nearly related, by the entire absence of the characteristic lanose pubescence.

Type locality: "Type collected by Prof. S. M. Tracy, at Columbus, Miss., October 14, 1895."

$15894-22$ 
Andropogon tetrastachyus Ell. Sk. 1:150. 1816.

FOUR-SPIKED BKakd-GRASS. Andropogon virginicus var. tetrastachyus Hackel in DC. Monogr. 6 : 1889.

Chap. Fl. 581 .

Louisianian area. South Carolina and Florida to Iowa.

A labama: Lower Pine region. Coast plain. Mobile County, open damp pine barrens. October. Frequent.

Type locality: "Grows in damp pine barrens, near Charleston."

Herb. Geol. Surv. Herb. Mohr.

Andropogon mohrii (Hackel) Hackel; Vasey, Contr. Nat. Herb. 3 : 11. 1892.

MOHR's Beard-Grass.

Andropogon liebmani var. mohrii Hackel in DC. Monogr. Phan. 6:413. 1891.

Chap. Fl. ed. 3, 594.

Louisianian area. Florida to Mississippi.

Alabama: Coast plain. Flat damp pine barrens. Mobile County ; first collected

October, 1883 ; Springhill. Not rare.

Type locality: "Alabama : in pinetis uliginosis prope Mobile (Mohr)."

Herb. Geol. Surv. Herb. Mohr.

Andropogon elliottii Chap. Fl.581. 1860.

Elliott's Beard-Grass.

Gray, Man. ed. 6, 638. Coulter, Contr. Nat. Herb. 2 : 496. Chap. Fl. ed. 3, 593.

Lonisianian to Carolinian area. Florida west to Texas, Arkansas, Missouri, and

Tennessee, and north along the coast to Delaware.

Alabama: Lower Pine region. Coast plain. Flat pine barrens, pastures, old

fields, in close sandy soil. Mobile and Baldwin counties. Abundant. October.

Type locality : "Wet or dry pine barrens, Florida to North Carolina."

Herb. Geol. Surv. Herb. Mohr.

Andropogon argyraeus Schult. Mant. 2 : 450. 1824.

Silvery Beard-Grass.

Andropogon argenteus Ell. Sk. 1:148. 1816. Not DC.

A. belvisii Desv. Opusc. 67. 1831.

Gray, Man. ed. 6, 637. Chap. Fl. Suppl. 668. Coulter, Contr. Nat. Herb. $2: 496$.

Chap. Fl. ed. 3, 593.

Carolinian and Louisianian areas. Florida west to Texas, Arizona, Colorado,

Tennessee, and southern Missouri.

Alabama : Coast plain to Coosa Hills. Dry siliceous soil. Calhoun County, Anniston, barren cherty hills. Mobile County. Baldwin County, dry sandy pine ridges. September. Frequent.

Type locality: "Grows in dry soils [South Carolina and Georgia]."

Herb. Geol. Surv. Herb. Mohr.

Andropogon furcatus Muhl.; Willd.Sp. Pl.4:919. 1806. Forked Beard-Grass. Andropogon provincialis subvar. furcatus Hackel in DC. Monogr. Phan. 5 : 442. 1889. Ell. Sk. 1:150. Gray, Man. ed. 6, 637. Chap. Fl.581. Coulter, Contr. Nat. Ilerb.

$2: 496$.

Canadian zone to Louisianian area. From Manitoba and Saskatchewan to Quebec and Ontario, south to the States east of the Mississippi, and Texas.

Ala Bama: Over the State. Dry light soil, open woods, prairies. Cullman County. Calhoun County, Anniston. Tuscaloosa, Montgomery, and Mobilecounties. Frequent. July to August.

Type locality: "Hab. in America boreali."

Herb. Geol. Surv. Herb. Mohr.

CHRYSOPOGON 'Trin. Fund. Agrost. 187. 1820.

Twelve species, mostly perennial. Southern Europe, Asia; 1 species American.

Chrysopogon avenaceus (Michx.) Chap. Fl. 583. 1860.

INDIAN-Grass.

Andropogon avenaceus Michx. Fl. Bor. Am. 1:58. 1803.

A. ciliatus Ell. Sk. $1: 144$. 1816.

Sorghum nutans Gray, Man. 617. 1848.

Gray, Man. ed. 6, 638. Chap. Fl. 583. Conlter, Contr. Nat. Herb. 2:494.

MeXico To Brazil.

Alleghenian to Lonisianian area. Saskatchewan south to Colorado and Texas;

New England to Florida and the Gulf.

Alabama: Throughout the State. Most abundant in dry pine barrens.

Type locality: "Hab. in vastissimis pratis Illinoensibus,"

Herb. Geol. Surv. Herb. Mohr. 
Chrysopogon elliottii Mohr, Bull. Torr. Club. $24: 21.1897$.

Andropogon nutans Ell. Sk. 1:144. 1817. Not L.

DROOPING INDIAN-GRASS.

To this species are referred the forms with the panicle loose, the branches elongated, drooping, and the fertile glumes covered with long silky bairs.

Louisianian area. Carolina to Florida, Mississippi, and 'Tennessee.

Alabama: Lower Pine region. Dry barren pine woods. Mobile and Escambia counties. 'Three to 4 feet high. Common. Perennial.

Type locality : "Grows in arid soils [South Carolina and Georgia]. Very common."

Herb. Geol. Surv. Herb. Mohr.

Chrysopogon nutans lirmeanus Doell in Mart. Fl. Bras. 2, pt. 3:276. 1883.

Andropogon nutans L. Sp. Pl. 2 : 1045. 1753.

A. nutans linneanum Hackel, DC. Monogr. Phan. 6:531. 1889.

Sorghum nutans Chap. F1. 583. 1860.

Chap. Fl. 1. c.; ed. 3, 596.

Brazil, Mexico.

Lonisianian area. North Carolina to Florida, west to Texas.

Alabama: Lower Pine region. Coast plain. In dry close soil. Mobile County, pine woods. August, September; not common

Sten weak, assurgent, branches of the elongaterl narrow panicle short, spikelets scattered, glumes smoothish, the fertile almost black, with a stout long awn. Perennial.

Type locality : "Hab. in Virginia, Jamaica."

Herb. Geol. Surv. Herb. Mohr.

SORGHUM Pers. Syn. Pl. I: 101. 1805.

Thirteen species, belonging to warmer regions of the Old World.

Sorghum halepense (L.) Pers. Syn. Pl. 1:101. 1805.

Johnson-Grass. False Guinea Grass.

Holcus halepensis L. Sp. Pl. 2 : 1047. 1753.

Andropogon halepensis Brot. Fl. Lus. 1:89. 1804.

Coulter, Contr. Nat. Herb. 2:494. Vasey, Contr. Nat. Herb. $3: 13$.

Southern Europe and Western Asia.

Carolinian and Louisianian areas. All over the Southern States. Introduced and escaped from cultivation, becoming a most troublesome and almost ineradicable weed.

Alabama : From the Central Pine belt to the coast. Most abundant in the Central Prairie belt. Perennial.

Type locality: "Hab. in Syria, Mauritania."

Economic uses: Frequently cultivated for hay ancl green forage.

Herb. Geol. Surv. Herb. Mohr.

Sorghum vulgare Pers. Syn. Pl. 1 : 101. 1805.

Chicken Corn, Durrha, Sugar-Corn.

Holcus sorghum L. Sp. Pl. 2 : 1047.1753.

Andropogon sorghum sativus Hackel in DC. Monogr. Phan. 6 : 505.

Escaped from cultivation, becoming a pernicious weed in many parts of the Southern States.

Alabama: Most frequent in the Central Pine belt and Central Prairie region. Annual.

Economic uses: Important for green forage, hay, and grain.

Type locality: "Hab. in India,"

Herb. Geol. Surv.

PASPALUM L. Syst. ed. 10, 2 : 855. 1765.

One hundred and sixty species, perennials, tropical and subtropical regions, mostly American. North America, 28 species, all east of the Rocky Mountains, and chiefly sonth of the Ohio Valley.

Paspalum compressum (Sw.) Nees; Trin. Gram. Panic.96. 1826. Cakpet-Grass.

Milium compressum Sw. Fl. Ind. Occid. 1 : 183. 1788.

Paspalum platycaulon Poir. Encycl. 5:34. 1804.

Coulter, Contr. Nat. Herl, 2 : 500. Griseb. Fl. Brit. W. Ind. 541.

West Indies, Mexico, south to Argentina.

Lonisianian area. Florida to Texas. Naturalized. Coast plain to Mountain region; lower Metamorphic hills. 
Alabama : Close sandy soil; pastures, clearings, roadsides, forming a perfect turf. Mobile, Baldwin, Montgomery, and Tuscaloosa connties. Lee County, Auburn. Abundant.

Type locality: "Hab. in pascuis sterilibus Jamaicae vulgaris."

Economic uses: Valuable for pasture.

Herb. Geol. Surv. Herb. Mohr.

Paspalum paspalodes (Michx.) Scribner, Mem. Torr. Club. 5:29. 1894.

Digitaria paspalodes Michx. Fl. Bor. Am. 1:46. 1803.

Michaux's Paspalum.

Paspalum furcatum Fluegge, Gram. Monogr. 1810.

$P$. digitaria Poir. Encycl. Suppl. 4 : 316. 1816.

Milium paspalodes Ell. Sk. 1: 104. 1817.

Paspalum michauxianum Kunth, Rev. Gram. 1:25. 1835.

P. elliottii Wats. in Gray, Man. ed. 6, 629. 1891.

$2: 500$.

Ell. Sk. 1:104. Gray, Man. ed. 6, 629. Chap. Fl.570. Coulter, Contr. Nat. Herb.

WEST INDIES.

Lonisianian area. North Carolina, along the coast to Florida, west to Texas.

Alabama : Central Prairie region to Coast plain. Shady copses. Mobile and Montgomery counties. Autauga County, Prattville (E. A. Smith). Flowers May to June; not frequent.

Type locality: "Hab. in pascuis aridis, juxta Charleston [S.C.]."

Herb. Geol. Surv. Herb. Mohr.

Paspalum membranaceum Walt. Fl. Car. 75. 1788.

Paspalum vaginatum Ell. Sk. 1: 109. 1816. Not Sw.

$P$. walterianum Schult. Mant. $2: 166.1824$.

Ell. Sk. 1:109. Gray, Man. ed. 6, 628. Chap. Fl. 570. Coulter, Contr. Nat. Herb. 2: 498 .

Carolinian and Louisianian areas. Delaware, along the coast to Florida, west to Texas.

Alabama: Coast plain. Low damp fields and meadows. Mobile County. Baldwin County, Stockton. Frequent. August to September.

Type locality: South Carolina.

Herb. Geol. Surv. Herb. Mohr.

Paspalum conjugatum Bergius, Act. Acarl. Holm. $7: 129$, t. $\delta .1778$.

Chap. Fl. Suppl. 666; edl. 3, 578. Griseb. Fl. Brit. W. Ind. 541.

Conjugatei, Paspalum.

West Indies, Mexico to Brazil, Tropical Arrica, Australia.

Louisianian area. Louisiana, Mississippi.

Alabama : Coast plain. Shaded damp banks. Mobile County. June. Rare.

Probably adventive from the tropics.

Type locality not ascertained.

Herb. Geol. Surv. Herb. Mohr.

Paspalum distichum L. Amoen. Acad. 5:391. 1759.

Joint-Grass.

Ell. Sk. 1:108. Gray, Man. ed. 6, 629. Chap. Fl. 570. Coulter, Contr. Nat. Herb. 2:499. Griseb. Fl. Brit. W. Ind. 511. Wats. Bot. Calif. $2: 257$.

West Xndies, Mexico to Argentina, Chile, East Indies, Australia.

Carolinian and Louisianian areas. North Carolina to Florida, west to 'Texas, and across the plains to southern California.

Alabama : Central Prairie region; damp fields, low banks. Montgomery County, Pentulalla Creek. Mobile County, ditches; common. A pernicious weed in cotton fields. June to August.

Type locality not given.

Herb. Geol. Surv. Herb. Mohr.

Paspalum vaginatum Sw. Fl. Ind. Occ. 1:135. 1779.

SALt Jolnt-Grass.

Paspalum distichum var. vaginatum Griseb. Fl. Brit. W. Ind. 541. 1864.

Chap. Fl. 570. Griseb. 1. c. Coulter, Contr. Nat. Herb. 2: 499.

West Indies, Mexico to Argentina.

Louisianian area. Florida west to Texas along the seacoast.

Alabama : Littoral region, salt marshes. Mobile County, Dauphin Island, West-

fowl River. Baldwin County, Bon Secour. Flowers June to August. Abundant. Type locality: "Hab. in argillosis graminosis Jamaicae."

Herb. Geol. Surv. Herb. Mohr. 
Paspalum longipedunculatum Le Conte, Journ. Phys. 91: 284. '1820.

Slender-stem Paspalum.

Paspalum debile Michx. Fl. Bor. Am. 1: 44. 1803.

$P$. arenarium Schrad.; Schult. Mant. $2: 172$. 1824(?)

Ell. Sk. 1:105. Scribner, Grass. Tenn. 2:35, t. 6, f. 23. Britt. \& Brown, Ill.

Fl. 1 : 108 .

Carolinian area. Kentucky and Temnessee to northern Georgia.

AlabaMa: Monntain region. Sandy exposed grounds, pastures. Dekalb County,

Mentone, 1,800 feet altitude. September 6,1898 . Not frequent.

Type locality: "Hab. in Carolina boreali."

Herb. Geol. Surv. Herb. Mohr.

Paspalum ciliatifolium Michx. Fl. Bor. Am. 1:44. 1803. Fringe-leaf Paspalum.

Paspalum setaceum var. ciliatifolium Vasey, Contr. Nat. Herb. 3: 17. 1892.

Coulter, Contr. Nat. Herb. 2:499. Scribner, Grass. Tenn. $2: 34, t .6, f$. 22. Chap.

Fl. ed. 3,578 .

West Indies, Mexico, Brazil.

Carolinian and Louisianian areas. New Jersey, south to Florida, thence to Texas and Arkansas.

Alabama: Mountain region to Coast plain. Grassy banks in close loamy sand. Lee County, Auburn (Baker \& Earle, 644). Mobile County, along fence rows, roadsides. Baldwin Connty. July, August. Frequent.

Readily recognized by the smoothish shining sheaths and bright green smoothish more or less strongly ciliate leaves.

Type locality: "Hab. in Carolina."

Herb. Geol. Surv. Herb. Mohr.

Paspalum ciliatifolium dasyphyllum (Ell.) Chap. Fl. ed. 3, 578. 1897.

Paspalum dasyphyllum Ell. Sk. 1:105. 1807.

Ell. Sk. 1. c. Chap. Fl. l. c. Britt. \& Brown, Ill. Fl. 1:107.

Carolinian and Louisianian areas. North Carolina to Florida, west to Mississippi.

Alabama : Central Pine belt to Coast plain. Dry sandy pine barrens. Autauga

County, Prattville. Clarke County, Choctaw Corner. Mobile and Baldwin counties.

July to September. Common.

At once distingnished from the type by the somewhat diffuse stems and the dull grayish hairy sheaths and leaves. Rarely found with the above, preferring the arid purely sandy pine ridges.

Type locality: "Grows in dry cultivated ground [South Carolina and Georgia]."

Economic uses: Of some value as a pasture grass of the dry pine barrens, where it is frequent.

Herb. Geol. Surv. Herb. Mohr.

Paspalum laeve Michx. Fl. Bor. Am. 1:44. 1803.

Smooth Paspalum. Ell. Sk. 1:106. Gray, Man. ed.6,628. Chap. Fl. 571. Coulter, Contr. Nat. Herb. $2: 499$. Britt. \& Brown, Ill. Fl. 1:108.

Alleghenian to Louisianian area. Rhorle Island to Kentucky, Missouri, and

Arkansas, south to Florida and Texas.

Alabama: Over the State. Grassy banks. June, July; not uncommon.

Pilose forms; sheaths and leaves more or less covered with villous hairs (Panicum laeve pilosum Scribner); from Lee County, Auburn (Baker \& Earle).

Type locality: "Hab. in Georgia."

Herb. Geol. Surv. Herb. Mohr.

Paspalum praecox Walt. Fl. Car. 75. 1788.

Early-flowering Paspalum.

Paspalum lentiferum Lam. Encycl. 5 : 31. 1804.

Ell. Sk. 1:106. Chap. Fl.571. Coulter, Contr. Nat. Herb. 2 : 499.

Louisianian area. North Carolina, west to eastern Texas.

Alabama : Central and Lower Pine belts. Coast plain. Low wet pine barrens, borders of pine-barren swamps. Autauga County, Prattville (E. A. Smith). Washington County, Yellowpine. Mobilo and Baldwin counties. Frequent. May to June.

Type locality : South Carolina.

Herb. Geol. Surv. Herb. Mohr.

Paspalum praecox curtisianum (Steud.) Vasey, Bull. Torr. Club, 13:165. 1886.

Paspalum curtisianum Steud. Syn. Pl. Glum. 26. 1855.

Louisianian area. Florida to Mississippi.

Alabama: Coast plain. Low flat pine barrens. Mobile County, Dog River flats 
(September, October). Baldwin County, Josephine, pine-barren swamps. Flowers in June. Frequent.

Easily distinguished by the more robust habit of growth, the flower stem 3 to 4 fete high, the numerous spikes 2 to 3 inches loug, and the leaves and sheaths softly villous-pubescent.

Type locality : "M. A. Curtis legit in Carolina."

Herb. Geol. Surv. Herb. Mohr.

Paspalum plicatulum Michx. Fl. Bor. Am. 1:45. 1803.

Paspalum undulatum Poir. Encycl. 5 : 29. 1804.

Ell. Sk. 1:107. Chap. Fl. Suppl. 665; ed. 3, 578. Conlter, Contr. Nat. Herb. 2 : 500.

Griseb. Fl. Brit. W. Ind.542.

West Indies, Mexico! to Argentina.

Louisianian area. South Carolina, Florida!, west to Texas.

Alabama : Coast plain. Dry sandy banks and copses. Baldwin County, Montrose.

Mobile County. Flowers in June; not infrequent.

Type locality: "Hab. in Georgia et Florida."

Herb. Geol. Surv. Herb. Mohr.

Paspalum bifidum (A. Bertol.) Nash, Bull. Torr. Club, 24 : 192.1897.

Arabama Paspalum.

Panicum floridanum Trin. Mem. Acad. St. Petersb. ser. 6, 3, pt. 2:248. 1834. Not P. floridanum Michx.

Panicum bifidum A. Bertol. Mem. Acad. Sci. Bolog. 2: 598, t.41, f. 2. 1850.

P. alabamense Trin.; Steud. Syn. Pl. Gram. 64. 1855.

Paspalum racemulosum Nutt.; Chap. Fl.571. 1860.

Chap. Fl.l. c. Coulter, Contr. Nat. Herb. 2:500.

Louisianian area. North Carolina to Florida, west to Arkansas and eastern Texas.

Arabama : Lower Pine region. Coast plain. Dry grassy pine barrens. Mobile

County, near Whistler, Grand Bay. Angust to October; not frequent.

Type locality: "V. spp. Florida Alabama."

Herb. Geol. Surv. Herb. Mohr.

Paspalum dilatatum Poir. Encycl. 5 : 35. 1804.

Paspalum ovatum Nees in Mart. Fl. Bras. 2 :43. 1829.

Chap. Fl. Suppl. 666; ed. 3, 579. Coulter, Contr. Nat. Herb. 2 :500. Scribner, Grass.

Tenn. 32, t. $5, f .99$.

Brazil, Argentina, Chile.

Carolinian and Louisianian areas. Southern Pennsylvania and southern Virginia to

Florida and Texas.

Alabama : Central Pine belt to Coast plain. Border of fields, ditches, near dwellings. Dallas County, Uniontown. Hale County, Gallion. Baldwin and Mobile connties. Flowers June to August; frequent.

Type locality: "Cette plante a été recueillie à Buenos-Ayres par Commerson."

Economic uses: Valuable for green fodder and hay.

Herb. Geol. Surv. Herb. Mohr.

Paspalum floridanum Michx. Fl. Bor. Am. 1:44. 1803.

Paspalus macrospermus Fluegge, Gram. Monogr. 172. 1810.

Ell. Sk. 1:107. Gray, Man. ed.6,629. Chap. Fl.571. Coulter, Contr. Nat. Herb. $2: 500$.

Carolinian and Louisianian areas. From Florida along the coast to southern Virginia and Delaware, and west along the Gulf coast to Texas; southern Arkansas.

Alabama: Lower Pine region. Coast plain. Copses, roadsiaies, borders of fields, in light dry or damp soil. Mobile, Baldwin, and Escambia counties. June. Frequent. Type locality: "Hab. in Florida et Georgia."

Herb. Geol. Surv. Herb. Mohr.

Paspalum glabratum (Engelm.) Mohr, Bull. Torr. Club, 24:21. 1897.

Smooti Paspalum.

Paspalum floridanum var. glabratum Engelm.; Vasey, Contr. Nat. Herb. 3:20. 1892. Coulter, Contr. Nat. Herb. $2: 500$.

Smooth and glaucous throughout; stem from a stout creeping rootstock $2 \frac{1}{2}$ to 3 feet bigh, more slender than in the last; panicle about 8 inches long with 4 to 6 erect. spreading, short-stalked, more or less distant spikes, 2 to $2 \frac{1}{2}$ inches long; leaves much shorter than the culm; sheaths shorter than the joints; ligule short, blunt, chartaceons; spikelets mostly in 2 rows on the flexuons rachis.

Distinguished at once by the glaucous and glabrous stem and leaves

Louisianian area. North Carolina to Florida, west to Texas. 
Alabama: Lower division of Coast Pine belt, Coast plain. Damp sandy places. Washington County, Yellowpine, borders of ponds. Mobile County, low pine barrens.

Type locality: "North Carolina to Texas and Arkansas."

Herb. Geol. Surv. Herb. Mohr.

Paspalum difforme Le Conte, Journ. Phys. 91: 284. 1820.

Difform Paspalum.

Vasey, Bull. Torr. Club, 13:166. Coulter, Contr. Nat. Herb. 2:500. Chap. Fl. ed. 3,579 .

Louisianian area. North Carolina, Florida to Texas.

Alabama: Coast plain. Damp sandy soil along pine-barren streams. Mobile County. September to October; not rare.

Type locality: "Hab. cum priore," i. e. "in Georgia."

Herb. Mohr.

Paspalum boscianum Fluegge, Gram. Monogr. 170. 1810.

Purplish Paspalum, Bullgrass.

Paspalum undulatum Poir. Encycl. Suppl. 4 :316. 1816.

P. purpurascens Ell. Sk. $1: 108.1816$.

Ell. Sk. l. e. Chap. Fl.571. Vasey, Contr. Nat. Herb. 3 : 19. Scribner, Grass. Tenn. $2: 33, t .5, f .1 \%$.

Carolinian and Louisianian areas. North Carolina, western Tennessee; Florida to Louisiana.

Alabama : Mountain region to Coast plain. Low damp fields and grassy swales. Clay County, Elders, 1,000 feet. Cullman County, 800 feet. Southward everywhere.

Flowers August to October. Abundant, particularly in the Coast plain.

Type locality: "In Carolina detexit Clarissimus Bosc.

Economic uses: Valuable spontaneous hay crop.

Herb. Geol. Surv. Herb. Mohr.

Paspalum virgatum L. Syst. Nat. ed. 10, 855. 1758-59.

Griseb. Fl. Brit. W. Ind. 543.

West Indies, Mexico to Brazil.

Louisianian area. Adventive from tropical America and naturalized in Louisiana and Texas.

A.labama: Low places, roadsides, along ditches, waste ground. May to August. Stems 3 to 4 feet high. First observed in the western suburbs of Mobile, 1895; since extensively spreading into fields and grass plots, threatening to become a worthless weed.

Type locality not ascertained.

Herb. Geol. Surv. Herb. Mohr.

ANTHAENANTIA Beauv. Agrost.48. 1812.

(Aulaxanthus Ell. Sk. $1: 102.1817$. )

Three species, perennials, subtropical America. Southern Atlantic States, 2 species.

Anthaenantia villosa (Michx.) Beauv. Agrost. 48, t. 10, f. \%. 1812.

Phalaris villosa Michx. Fl. Bor. Am. 1:43. 1803.

HaIry ANTHAENantia.

Aulaxanthus ciliatus Ell. Sk. 1:102. 1817.

Louisianian area. South Carolina to Florida and Louisiana.

AlabaMa : Coast Pine belt. Coast plain. Grassy pine barrens, close sandy or gravelly soil. Mobile County, Grandbay. Monroe County, Claiborne. Baldwin County, Montrose. August. Not infrequent.

Type locality: "Hab. in sylvis sabulosis Carolinae."

Herb. Geol. Surv. Herb. Mohr.

Anthaenantia rufa (Ell.) Benth. Journ. Linn. Soc. Bot. 9:39. 1881.

Aulaxanthus rufus Ell. Sk. 1: 103. 1817.

Reddish Anthaenantia.

Panicum rufum Kunth, Rev. Gram. 1:35. 1835.

Ell. Sk. 1. c. Chap. Fl. 577.

Louisianian area. North Carolina, Florida, west to Louisiana.

Alabama: Lower Pine region. Coast plain. Low grassy pine barrens, damp sandy soil. Washington County, Yellowpine. Mobile County, Grandbay. Baldwin County. June, July; more frequent than the last.

Type locality: "Grows in savannas, and damp soils in the pine barrens, midway between Saltcatcher Bridge and Murphys on the Edisto."

Herb. Geol. Surv. Herb. Mohr. 
SYNTHERISMA Walt. Fl. Car. 76. 1788. Finger Grass.

(Digitaria Scop. Fl. Carn. ed. 2, 1:52. 1772. Not Heist. 1763.)

Nearly 20 species, of temperate and tropical regions, mostly annuals.

Syntherisma filiforme (L.) Nash, Bull. Torr. Club, 22:420. 1895.

Panicum filiforme L. Sp. Pl. 1:57. 1753.

Slender Crab Grass.

Paspalum filiforme Sw. Prodr. 22. 1788.

Digitaria filiformis Muhl. Gram. 131. 1817.

Ell. Sk. 1:132. Gray, Man. ed. 6, 630. Chap. Fl. 572. Coulter, Contr. Nat. Herb. 2:501. Griseb. Fl. Brit. W. Ind. 543. Scribner, Grass. Tenn. $2: 39, t$. 7, f. 28.

West Indies, Mexico to Brazil.

Carolinian and Louisianian areas. Massachusetts to Florida, west to Texas, and in Tennessee.

Alabama : Central Pine belt to Coast plain. Dry sandy soil. Monroe, Mobile, and Baldwin counties. July to October, common; abundant throughout the Lower Pine region; annual.

Type locality: "Hab. in America septentrionali. Kalm."

Herb. Geol. Surv. Herb. Mohr.

\section{Syntherisma villosum Walt. Fl. Car. 77. 1778.}

"Culms tufted, $2 \frac{1}{2}$ to 3 feet high, slender, erect, simple, more or less branched above, glabrons; sheaths keeled toward the npper end, the lower papillose-hirsute, the upper nearly glabrous; leaf blades 5 to 7 inches long, flat, erect, smooth beneath, rough above, the lower more or less papillose, the upper glabrous; panicle longexserted, racemes elongated, slender, 8 to 10 inches long, erect, rarely spreading; rachis triangular, hispidulous on the angles; spikelets elliptical, acute, pediceled in threes, or in pairs; first glume wanting, second and third pubescent with long appressed hairs; the second 3-nerved, little shorter than the third; the third 7-nerved; the fourth oblong-ovate to lanceolate, striate, in maturity of a deep chestnut color, apiculate."

Distinct from the closely related Syntherisma filiforme by the much longer and more numerous racemes, narrow spikelets, and striate fourth glume.

Carolinian and Louisianian areas. Georgia and Florida to Texas, Indian Territory, and Illinois.

Alabama : Central Prairie region. Dry pastures, sandy exposed hillsides. Montgomery County, September, 1886. Not frequent. Annual.

Ty pe locality: South Carolina.

Herb. Geol. Surv. Herb. Mohr.

Syntherisma serotinum Walt. Fl. Car. 76. 1788.

Hoary Craib Grass.

Digitaria 8erotina Michx. Fl. Bor. Am. 1: 41. 1803.

D. villosa Ell. Sk. 1: 132. 1816.

Ell. l. c. Cliap. Fl. Suppl. 666; ed.3,581. Coulter, Contr. Nat. Herb. 2:501.

Louisianian area. South Carolina to Florida and Texas.

Alabama : Coast plain. In light sandy soil, pastures, roadsides; perennial; July

to October; frequent. Creeping extensively, forming close mats.

Type locality : South Carolina.

Economic uses: Valuable as a pasture grass on poor sandy land.

Herb. Geol. Surv. Herb. Mohr.

Syntherisma lineare (Krock.) Nash, Bull. Torr. Club, 22:420. 1895.

Panicum lineare Krock. Fl. Sil. 1:95. 1787.

Smooth Crals Grass.

Syntherisma glabrum Schrad. Fl. Germ. 1:163. 1806.

Panicum glabrum Gaudin, Agrost. 1:22. 1811.

Gray, Man. ed. 6, 630. Scribner, Grass. Tenn. $2: 39, t .7, f .2 \%$.

EUROPE.

Canadian zone to Carolinian area. Naturalized in Ontario and New England, thence to Missouri and Tennessee.

Alabama: Tennessee Valley. Waste places, grasis plots. Morgan County, Decatur, banks of Tennessee River. Flowers September and October; not frequent. Annual.

Type locality: "Auf sandigten Inseln der alten Oder neben der Passbruecke, auch an Steindamme nach Rosel, eben im Sande."

Herb. Geol. Surv. Herb. Mohr. 
Syntherisma setosum (Desv.) Nash, Bull. Torr. Club, 25:300. 1898.

Digitaria setosa Desv. in Hamilton, Prodr. Pl. Ind. Occ. 6. 182b.

Panicum hamiltonii Kunth, Enum. 1:84. 1833.

Griseì. Fl. Brit. W. Ind. 544.

Decumbent and rooting at the base; softly pilose below, smooth above; lower sheaths papillose-pilose, the upper longer, smooth; spikes numerous; spikelets in pairs, crowded, frequently with a long bristle at the base; oblong-lanceolate, acute, first glume minute, second 3-nerved, shorter than the spikelet, the third 5 or 7 nerved, greenish.

West Indies, Mexico, and other tropical countries.

Louisianian area. Florida.

Alabama : Fugitive on ballast. Mobile, September, 1891. Annual. A well-marked species, conspicuous by the shining silky villosity covering the lower part of the plant, the strongly-nerved spikelets, and crowded dull greenish racemes.

Type locality West Indian.

Herb. Geol. Surv. Herb. Mohr.

Syntherisma sanguinale (L.) Nash, Bull. Torr. Club, 22:421. 1895.

Panicum sanguinale L. Sp. Pl. 1:57. 1753.

Common Crab Grass.

Digitaria sanguinalis Scop. Fl. Carn. ed. 2, 1:52. 1772.

Syntherisma praecox Walt. Fl. Car. 76. 1788.

Paspalum sanguinale Lam. Tabl. Encyel. 1:176. 1791.

Ell. Sk. 1:131. Gray, Man. ed. 6, 630. Chap. Fl. 572. Coulter, Contr. Nat. Herb.

2:501. Scribner, Grass. Tenn. $2: 38, t .7, f .26$.

TEMPERATE AND WARMER REgIONS. COSMOPOLITAN.

Alleghenian to Louisianian area. Ontario and throughout the Atlantic States, west to Nebraska and Texas.

Alabama : All over the State. Cultivated and waste ground; a very variable and widely diffused weed. Annual.

Type locality : "Hab. in America, Europa australi."

Economic uses: Important spontaneous hay crop.

Herb. Geol. Surv. Herb. Mohr.

Syntherisma fimbriatum (Link) Nash, Bull. Torr. Club, 25:302. 1898.

Digitaria fimbriata Link, Hort. Reg. Bot. Berol. I : 226. 1827.

D. marginata Roth in Griseb. Fl. Brit. W. Ind. 544. 1864. (?)

Culm 2 to $2 \frac{1}{2}$ feet long, prostrate at the base, rooting at the lower nodes, at length branching, smooth; nodes more or less pubescent; lower sheaths papillose-hirsute, upper longer, glabrous; leaves 1 to 3 inches long, flat, erect, glabrous, or more or less pubescent at the base rith a few stiff hairs; paniclelong-exserted; racemes 2 to 3 inches long, erect-spreading, not crowded, mostly in pairs, rachis winged; spikelets lanceolate, very acute, pediceled, in pairs; first glume minute, 3-angular, glabrous; second three-fourths as long as the spikelet, 3 -nerved, pubescent on the margins and between the nerves with long appressed hairs; third seale 7 -nerved exceeding the flowering scales and also pubescent with long appressed hairs, which on the margin become at length widely spreading; fourth glume lanceolate, very acute, yellowish with maturity.

Tropical and subtropical countries. West Indies, Mexico, South AMerica, Australia, tropical Africa, East Indies.

Carolinian and Louisianian areas. District of Columbia to Florida, west to 'Texas, and from Missouri and Kansas southward.

Alabama : Coast plain. Waste places, ballast heaps. Mobile County. August, September; not infrequent. Annual.

Readily distinguished from Syntherisma sanguinale by its longer, narrower, and more acute spikelets with their more copious pubescence, the fringed margins of the third scale, and the smooth nerves.

Type locality not ascertained.

Herb. Geol. Surv. Herb. Mohr.

TRICHOLAENA Schrad. in Schult. Mant. 2: 163. 1824.

Ten species. Africa, tropical America.

Tricholaena insularis (L.) Griseb. Fl. Brit. W. Ind. 557. 1864.

Andropogon insularis L. Pl. Jam. Pugill. 30. 1759.

Panicum insulare G. W. Meyer, Prim. Fl. Esseq. 60.

P. leucophaeum H. B. K. Nov. Gen. et Sp. 1:97. 1815.

Chap. Fl. Suppl. 666; ed. 3, 582. Vasey, Contr. Nat. Herb. 3:25. 1892. Coulter Contr. Nat. Herb. 2 : 502 . 
Tropical Africa, Asia, Wrst Indies, South America. Louisianian area. Florida, Texas.

Alabama: Adventive on ballast. Mobile, July, 1891. Perennial.

Type locality : Jamaica.

Herb. Geol. Surv. Herb. Mohr.

PANICUM L. Sp. P1. 1:55. 1753.

Over 300 distinct species, mostly perennials, of temperate and warm regions, both hemispheres, largely of the warmer parts of America, from New England to Brazil. North America, over 100 species.

Panicum digitarioides Carpenter; M. A. Curtis, Am. Journ. Sei. ser. 2, 7:410. 1849. As synonym.

Maiden Cane.

Panicum curtisii Chap. Fl. 573. 1860.

Louisianian area. Coast of North Carolina to Florida, west to Louisiana.

Alabama : Coast plain and Littoral belt. Marshes. Mobile County. August to

October; frequent. Perennial.

Type locality : "Around Wilmington, N. C."

Herb. Geol. Surv. Herb. Mohr.

Panicum texanum Buck., Prel. Rep. Geol. \& Agric. Surv. Tex. 1866.

Texas Millet.

Vasey, Bull U. S. Dept. Agr. Div. Bot. 25, t. 10. Coulter, Contr. Nat. Herb. 2 : 503. Louisianian area. 'Texas.

Alabama: Adventive with seed oats in cultivated ground. Mobile County. Lee County, Auburn. Perennial.

Type locality: "Austin, Texas."

Herb. Geol. Surv. Herb. Mohr.

Panicum stenodes Grisel. Fl. Brit. W. Ind. 547. 1864.

P. anceps var. strictum Chap. Fl. 573. 1860.

Chap. Fl. ed. 3, 583.

Perennial from a stout rhizoma, $2 \frac{1}{2}$ feet high ; culm wiry, terete, perfectly smooth ; leaves narrowly linear, rigid, erect; panicle mostly terminal, narrow, the filiform branchlets closely adpressed or more or less spreading; spikelets small, straight, acute, on longer or shorter pedicels, crowded mostly on one side of the rachis.

Described by Grisebach as an annual plant.

WEST INDIES TO BRAZIL.

Louisianian area. Florida, along the coast to Mississippi.

Ala bama: Coast plain. Wet sandy ground. Mobile and Baldwin counties. Border of piue barren ponds.

Type locality: "Hab. Jamaica! * * * Trinidad! * * * [Cuba!; Brazil!]."

Herb. Geol. Surv. Herb. Mohr.

Panicum prostratum Lam. Tabl. Encycl. 1:171. 1791.

Chap. Fl. Suppl.666. Vasey, Contr. Nat. Herb. 3:27. Griseb. Fl. Brit. W. Ind. 546. West Indies, Mexico to Brazil, Egypt, Arabia to East Indies, and AusTRALIA.

Louisianian area. Louisiana, adventive from the tropics.

Alabama: A waif on ballast ground; rare. Mobile. August; perennial.

Type locality: "Ex insulis Caribaeis."

Herb. Geol. Surv. Herb. Mohr.

Panicum fasciculatum Sw. Prodr. Veg. Ind. Occ. 1:145. 1797.

Panicum fuscum var. fasciculatum Griseb. Fl. Brit. W. Ind.547. 1864.

Griseb. 1.c.

Tropical AMERICA.

Louisianian area.

Alabama: Adventive. Mobile County. Fugitire on ballast, Angust 10, 1891.

Annual.

Type locality West Indian.

Herb. Geol. Surv. Herb. Mohr.

Panicum grossarium L. Syst. Nat. ed. 10, 871. 1758-59.

Scribner, Bull. U. S. Dept. Agr. Div. Agrost. $7: 61, t .43$.

Stout perennial with the culm creeping at the base and rooting at the joints, 
about 2 feet high. Leaves lanceolate, acuminate at the base, ciliate; sheaths ciliate; panicle of stout rigid alternate spreading branches bearing the more or less crowded, pediceled, ovate, acute spikelets on one side, single or in pairs; flowering glume trausversely rugose.

EAST AND West INDIES, BRAZIL.

Ala Bama : Fugitive on ballast, Mobile, September, 1891.

Type locality not ascertained.

Panicum gymnocarpon Ell. Sk. 1:117. 1817.

Chap. Fl. 573. Coulter, Coutr. Nat. Herb. $2: 509$.

Louisianian area. Coast of Georgia and Florida, west to Texas.

Alabana: Lower division Coast Pine belt. Alluvial forests. Mobile County,

Pierce's Landing; not frequent; perennial.

Type locality: "From specimens collected near Savannah, by Dr. Baldwin."

Herb. Geol. Surv. Herb. Mohr.

Panicum repens L.Sp. Pl. ed. 2, 1:87. 1762.

Creeping Panicum.

Panicum arenarium Brot. Phyt. Lus. 1:15. 1816.

Chap. Fl. Suppl. 666. Coulter, Contr. Nat. Herb. $2: 505$.

Europe, Mexico, Canary Islands.

Louisianian area. Alabama and Texas to Southeast Mexico.

Alabama : Sandy shores. Mobile County, mouth of Mobile River, swampy edge of the river bank, forming dense tussocks. Baldwin County, eastern shore of Mobile Bay, damp sands. July to September; frequent; perennial.

Type locality: "Hab. in Hispania? inde missum a Claud. Alstromoer."

Economic uses: Valuable sand binder.

Herb. Geol. Surv. Herb. Mohr.

Panicum littorale Mohr; Vasey, Bot. Gaz. 3:106. 1878.

Panicum repens confertum Vasey, Contr. Nat. Herb. 3:28. 1891.

P.gouini Fourn. Mex. Pl. 2 :28. 1881.

Conlter, Contr. Nat. Herb. 2 : 505.

MEXICO.

ALABAMA: With the above, frequent; perennial; from long running rootstocks.

Type locality: "Mobile, Ala. * * * Dritting sands of the Gulf coast."

Herb. Geol. Snrv. Herb. Mohr.

Panicum melicarium Michx. Fl. Bor. Am. 1:50. 1803.

Gaping Panicum.

Panicum debile Poir. Encycl. Suppl. 4 :283. 1816. Not Ell.

P. hians Ell. Sk. 1:118. 1817.

Chap. Fl. 573. Coulter, Contr. Nat. Herb. 2 : 504.

Mexico, BraziL.

Louisianian area. North Carolina to Florida, west to Texas.

Alabama: Central Prairie region to Coast plain. Low nunddy places, ditches.

Lee County, Auburn (Baker \& Earle). Montgomery County. Hale County, Gallion.

Wilcox, Monroe, Mobile, and Baldwin counties. Frequent; June to August; perennial.

Type locality: "Hab. in Carolina, Georgia."

Herb. Geol. Surv. Herb. Mohr.

Panicum depauperatum Muhl. Gram.112. 1817.

Impoverished Panicum.

Gray, Man. ed. 6, 633. Chap. Fl. 576. Scribner, Grass. Tenn. $2: 49$, t. 13, f. 49.

Canadiun zone, Alleghenian to Louisianian area. Newfoundland, Nova Scotia, Ontario, New Englaud, west to Minuesota and Nebraska, sou th to Florida and 'Texas; Arkansas.

Alabama: Central Prairie region. Open woods and dry copses. Metamorphic hills. Lee County, Auburn (F.S. Earle). Montgomery County. Infrequent; perennial.

Type locality : "Pennsylvania, Carolina."

Herb. Geol. Surv. Herb. Mohr.

Panicum neuranthum Griseb. Cat. Pl. Cub. 232. 1866.

Nerved Panicum.

Perennial; culm 1 to $1 \frac{1}{2}$ feet high, more or less pubescent, branched from the base; branches erect, \& carcely longer than the leaves; leaves narrow, linear-lanceolate, $\frac{1}{8}$ to $\frac{3}{16}$ inch wille and from 4 to 5 inches long, acuminate, acute, smoothish, strongly manynerved; lignle a ring of stiff hairs; sheaths about as long as the internodes, villous from minute papillæ; panicles mostly included, short, contracted; spikelets on short erect pedicels, obtuse; first glume small, smooth; second and third glumes strongly 7 to 9 nerved, pubescent. Readily distinguished from $P$, angustifolium by the nar- 
rowly linear long, acuminate leaves, the contracted short-stalked panicle, and obtuse spikelets. Perennial.

Vasey, Contr. Nat. Herb. 3:31. Coulter, Contr. Nat. Herb. 2 : 505.

CuBA.

Carolinian and Louisianian areas. Coast of southern Virginia to Florida, Missis. sippi, and eastern 'Texas.

Alabana: Lower Pine region. Metamorphic hills. Dry sandy soil. Mobile County. Lee County, Auburn (F.S.Earle). May, June. Not infrequent.

Type locality: "Cuba orientalis (Wright 3453); occidentalis, in savanis prope Hanabana (Wright ad 1865)."

Herb. Geol. Surv. Herb. Mohr.

Panicum angustifolium Ell. Sk, 1:129, 1817.

Panicum consanguineum Wats. in Gray, Man. ed.6,633. 1889. In part. Not Kunth. $P$. neuranthum ramosum Griseb. Cat. Pl. Cub. 232. 1866.

Ell. Sk. 1. c. Gray, Man. ed.6, 633. Chap. Fl. ed. 3,585. Coulter, Contr. Nat. Herl.

2:516. Scribner, Grass. Tenu. $2: 48, t .12, f .47,48$.

WEST INDIES.

Carolinian and Louisianian areas. Southern Virginia to southeast Teunessee and

Florida, west to Texas.

Alabama: Coast Pine belt. Dry open pine forests. Metamorphic hills. Lee County, Auburn (F.S. Earle). Washington County, Yellowpine. Mobile County, Citronelle. A pril to May. Common. Perennial.

Type locality: "Shaded dry soils [South Carolina, Georgia]."

Robust forms of a dense habit of growth, the crowded leaves narrower and erect, approaching stout forms of Panicum neuranthum, with which this species has been confounded.

Herb. Geol. Surv. Herb. Mohr.

Panicum xanthospermum Scribner \& Mohr, sp. nov.

A low, erect, cespitose, hairy perennial, 5 to 9 inches high, more or less branched from the base, with erect leaves and rather loosely flowered ovate or pyramidal panicles 1 to 2 inches long. Culms, leaves, and sheaths clothed with a soft pubescence of rather long lax hairs; nodes bearded with erect-spreading white hairs; sheaths shorter than the internodes, densely pilose; leaves lanceolate-acuminate, rounded at the base, gradually tapering to the apex, densely pilose beneath, more thinly so above, the margins narrowly cartilaginous, often somewhat involnte toward the apex, those of the stem about $3,1 \frac{1}{2}$ to 3 inches long, 2 to 3 lines wide, the basal ones somewhat shorter. Panicles slightly exserted, lax, pale; rachis smooth or somewhat pilose below; lower branches $\frac{1}{2}$ to 1 inch long, flexuous, gradually shorter above. Spikelets abont 1 line long, elliptical, obtuse, pale jellow or straw. colored, contracted at the base, for the most part long-pedicellate; first glume about one-fourth as long as the spikelet, acute; second and third glumes equaling the flowering glume, about 9-nerved, rather thinly pilose-pubescent with soft, spreadling hairs; flowering glume about $\frac{8}{4}$ of a line long, elliptical, acute, very smooth.

Near $P$. arenicola, from which it differs by its large yellowish spikelets.

Type specimen collected by Dr. Charles Mohr in open sandy soil, Greenville, Butler Count5, Ala., May 8, 1898 .

Panicum cahoonianum Ashe, Journ. Elisha Mitch. Soc. 15: 113. 1898.

Panicum georgianum Ashe, Journ. Elisha Mitch. Soc. 15:36. 1898. Not P.georgicum Spreng.

A low, densely tufted, much-branched, perennial, glabrous or soft-pubescent; culms 4 to 8 inches high; leaves erect or ascending, oblong-lanceolate, 1 to 2 inches and over long, about 2 lines wide, taper-pointer, soft-pubescent or glahrate; panicle short-peduncled, its branches erect-spreading; spikelets $1 \frac{1}{4}$ lines long, broadly elliptical, softly pubescent.

Louisianian area. Georgia and Florida.

Alabama: Coast plain. Dry sandy woods. May, 1882.

Type locality: "Dry sandy soil, southern Georgia and Florida." (Small, Chapman.)

Panicum arenicola Ashe, Journ. Elisha Mitch. Soc. 15 : 56. 1898.

A tufted perennial with erect culms geniculate at the base, 10 to 24 inches high, pubescent at least below; leaves more or less erect, 2 to 3 inches long and $1 \frac{1}{2}$ to 2 lines wide, much smaller above, taper-pointed, sheaths pubescent, panicle longexserted, spreading, 2 to 3 inches long with spreading branches; spikelets obovate, obtuse, little less than 1 line long.

Carolinian and Louisianian area. Eastern North Carolina, western Florida.

Ala BaMa: Lower division of Coast Pine belt. In open sandy pine woods. Mobile Connty, Springhill, abundant. May, 1899.

Type locality: "Chapel Hill, N. C." ( $W . W$. Ashe, June, 1898), and eastern part of State. 
Panicum laxiflorum Lam. Encycl. 4 : 748. 1797.

LOOSE-FLOWERED PANICUM. Gray, Man. ed. 6, 633. Chap. Fl. Suppl. 667. Coulter, Contr. Nat. Herb. 2: 506. Scribner, Grass. Tenn. 51, t. 14, f. 55 .

Alleghenian to Louisianian area. New Brunswick; New York to Florida.

Alabama : Over the State. In light shaded soil. Cullman County, 800 feet. Lee County, Auburn. 'Tuscaloosa, Hale, and Dallas counties. Frequent; May to July; perennial.

Type locality: "Avis d'Amerique septentrionale."

Herb. Geol. Surv. Herb. Mohr.

Panicum pyriforme Nash, Bull. Torr. Club, 26:579. 1899.

A densely tufted low perennial with rather slender weak culms 12 to 16 inches high, finally much branched; stem leaves 2 or 3, thin, lax, smooth on both surfaces, serrulate and rough on the margin, long-acuminate, narrowed to the base, 4 to 8 lines wide, on the branches much shorter, sheaths papillose-hirsute with reflexed hairs; panicle much exserted, ample, ovate, open, with its branches widely spreading, 3 to $4 \frac{1}{2}$ inches long; spikelets rather fow, broadly obovate, pubescont; flowering glume ovate, strongly apiculate.

Louisianian area. Florida, Mississippi.

Alabama: Metamorphic hills to Coast plain. Damp sandy banks. Lee County, Auburn (Baker \& Earle). Mobile and Baldwin counties.

This species includes forms from Florida and the eastern Gulf coast heretotore united with $P$. laxiflorum Lam.

Type locality: "In clay soil, at Orange Bend, Lake County, Fla., March, 1894." (Nash, 239).

Herb. Geol. Surv. Herb. Mohr.

Panicum ciliatum Ell. Sk. 1:126. 1817.

P. ciliatifolium Kunth, Enum. 1:108. 1833.

Ell. Sk.l.c.

A low, somewhat tufted, pale green perennial with an erect, smooth, and slender culm 8 to 12 inches high; sheaths smooth; leaves lanceolate, 1 to 2 inches in length and 2 to 3 lines wide, smooth on both surfaces, and with ciliate margins; basal leaves very numerous; panicle small, 1 to 2 inches long, exserted; spikelets on slender pedicels, obovate, acute, smooth; first glume more than half the length of the second.

Louisianian area. Southeastern North Carolina along the coast to western Florida.

AlabaMa : Coast plain. Damp low sandy soil. Vicinity of Mobile, June, July, in dry open places (Kearney).

Type locality : "Grows in damp soils [South Carolina and Georgia]."

Herb. Geol. Surv. Herb. Mohr.

Panicum consanguineum Kunth, Enum. 1:106. 1833.

Panicum villosum Ell. Sk. 1 : 124. 1817. Not Lam. 1791. Fide G. V. Nash, Bull. Torr. Club, 23:147. 1896.

Ell. Sk.1.c. Gray, Man. ed.6,633. Chap. Fl. ed.3,585.

Carolinian and Louisianian areas. Near the coast from North Carolina to Florida and Lonisiana.

Alabama : Lower division Coast Pine belt. Coast plain. Damp light soil. Baldwin and Mobile counties. Washington County. March to July. Flourishes in the Coast plain throughout the winter.

Type locality : "America septentrionalis."

Herb. Geol. Surv. Herb. Mohr.

Panicum earlei Nash, Bull. Torr. Club, 26:5̆1. 1899.

A densely tufted perennial with slender culm 4 to 6 inches high, smooth; finally brancherl. Stem leaves about 3 , lanceolate, ascending, and like the sheaths sparingly hirsute with long spreading hairs, $\frac{1}{2}$ inch to $1 \frac{1}{4}$ inches long and 1 to 3 lines wide; rough on the margin; panicle broadly ovate, with smooth, spreading branches; spikelets elliptic, obtuse, smooth.

Carolinian area.

Alabama: Metamorphic hills Lee County, Auburn (Earle \& Baker).

Type locality: "Auburn, Lee County, Alabama." (Earle \& Baker, Nos. 1532, 1535.)

Herb. Geol. Surv.

Panicum albo-marginatum Nash, Bull. Torr. Club, 24:40. 1897.

A slender, tufted, smooth perennial, with the rather weak culms simple or branched from near the base, 8 to 14 inches high; leaves lanceolate, mostly clustered near the base, firm, the largest $1 \frac{1}{2}$ to 2 inches long and 3 to 4 lines wide; the few upper leaves much reduced, all with whito thickened margins. Panicles small, 1 to 
$1 \frac{1}{2}$ inches long, long-exserted, oval, the branches ascending; spikelets numerous, small, obovate.

This is regarded by W. W. Ashe as P. ensifolium Bald.1 Collected at Chapel Hill, N. C.

Louisianian area. North Carolina to Georgia and Florida.

Alabama: Coast plain. Low pine barrens in sandy loam. Mobile County, Summerville, June, 1899. Infrequent.

Type locality: "In the low pine land at Eustis, Lake County, Florida." (Nash, 1894, No. 925.)

Herb. Geol. Surv. Herb. Mohr.

Panicum trifolium Nash, Bull. Torr. Club, 26:580. 1899.

A cospitose, smoothish, slender perennial, the mostly simple culm 8 to 16 inches high; stem leaves usually 3 , the uppermost a little below the panicle, firm, erect, narrowly lanceolate, with the margins cartilaginous-thickened, serrulate, from $\frac{1}{2}$ to 2 inches long; basal leaves numerous, about 2 inches long; panicle more or less exserted, broadly ovate, 1 to 2 inches long, with slender ascending branches, spikelets elliptical, densely pubescent.

Carolinian and Louisianian areas. North Carolina to western Florida.

Alabama: Metamorphic hills to Coast plain. Damp woods. Lee County, Anburn (Baker \& Earle). Central Alabama (Buckley). Mobile County. April; uot frequent. Type locality: "Ocmulgeo River swamp, below Macon, Ga." (Ir. J. I. Small, 1895.)

Related to $P$.albo-marginatum, but distinguished by the thinner leaves without white margins and the more slender culm.

Herb. Geol. Surv. Herb. Mohr.

Panicum lucidum Ashe, Journ. Elisha Mitchell Soc. 15 : 47. 1898.

A cespitose, slender, glabrous perennial, the weak culms reclining; sheatlis ciliate at the margin; leaves spreading, 1 inch or less long, narrowly lanceolate, very acute, rather distant; panicle more or less exserted, $1 \frac{1}{2}$ inches long, with spreading branches; spikelets elliptic, acute.

Louisianian area. North Caroliua.

Alabama : Coast plain. Damp woods. Mobile County. May; infrequent. Type locality: "Lake Mattamuskeet, North Carolina." (W. W. Ashe, 1898.)

Panicum curtifolium Nash, Bull. Torr. Club, 26:569. 1899.

A tufted glabrous perennial, with weak culms 8 to 12 inches high, finally much branched; sheaths usually about one-third as loug as the internodes, sparsely pubescent; stem leaves 3 or 4 , widely spreading, short, scarcely over 8 lines long, the basal leaves $1 \frac{1}{2}$ to 2 inches long; panicle considerably exserterl, broadly ovate, its slightly hispid branches widely spreading; spikelets elliptic, glabrous.

Louisianian area. Westeru Florida (?) to Mississippi.

Alabama : Central Pine belt. Coast plain. Boggy borders of pine-barren streams. Tuscaloosa County (Dr. E. A. Smith). Mobile County (T. H. Kearney, July, 1849).

Type locality: “Ocean Springs, Miss." (S. M.Tracy, 1898.)

Herb. Geol. Surv. Herb. Mohr.

Panicum paucipilum Nash, Bull. Torr. Club, 26:573. 1899.

A tufted, almost glabrous, tall perennial with the sparingly branched culm from 2 to 3 feet high; stem leaves 5 to 8 , erect, firm, sometimes ininutely puberul'nt on the lower surface, nsually with a few hair-bearing papillae at the base, from $2 \frac{1}{3}$ to $3 \frac{1}{2}$ inches long and 3 to 5 lines wide; panicle exserted, rather dense, oblong, from 2 to 4 inches long, its brauches erect; spikelets small, numerous, oval, pubescent.

Carolinian and Lonisianian areas. Coast of New Jersey. Mississippi.

Alabama : Coast plain. Mobile County.

Type locality: "Wildwood, N.J." (E.P. Bicknell, May 30, 1897.)

Panicum longipedunculatum Scribner, Grass. Tenn. 2 : 53, t. 16, f. 61. 1894.

A small pubescent somewhat clustered pale-green perennial, the slencler culms 6 to 10 inches high, with a few distant erect-spreading lanceolate leaves, narrowed to the roundish base, 2 to 3 lines wide, soft-pubescent on both sirles and ciliate on the inargin; basal leaves numerons, pubescent and ciliate; panicle about 2 inches long, oval, the axis and branchlets villous-pubescent, the fascicled, slenter branches spreading; spikelets small, $\frac{1}{2}$ line long, obtuse.

Carolinian and Lonisianian areas. Tennessee, North Carolina (Roanoke Island) to Florida. 
Alabama : Coast plain; low damp grassy pine barrens. Mohile County, Summerville, June $1,1899$.

Type locality: "White Cliff Springs [Tennessee], July, 1890; Tullahoma, July, 1892." (Scribner.)

Herb. Geol. Surv. Herb. Mohr.

Panicum parvispiculum Nash, Bull. Torr. Club, 24:347. 1897.

Stems 12 to 20 inches long in tufts, erect to decumbent at the base, appressed-hirsnte; internodes blackish brown, more or less pubescent; sheaths shorter than the internodes, appressed-hirsute to puberulent or glabrous and ciliate on the margins; lignle a ring of copious hairs; leaves erect or ascending, rigid, linear-lanceolate, rough on the margins, glabrous above, pubescent beneath, acuminate at apex, rounded at the base, the primary $1 \frac{1}{4}$ to $4 \frac{1}{3}$ inches long, $\frac{1}{16}$ to $\frac{1}{8}$ inch wide, the later about 2 inches long. Primary panicle broadly ovate, 3 to 4 inchos long, with ascending branches, much divided from the base, frequently pilose at the base; spikelets numerous, small, on divergent pedicels, onter glumes closely pubescent with spreading hairs; the first one-third as long as the spikelet.

Louisianian area. Georgia, Florida.

Alabama : Central Pine belt to Coast plain. Dry open woods, pastures, borders of fields. Tuscaloosa County $(E . A$. Smith $)$. Washington, Baldwin, and Mobile counties, April, May; frequent; perennial.

Type locality: "Darien Junction, McIntosh County, Ga." (I)r.John K. Small).

Herb. Geol. Surv. Herb. Molir.

Panicum longiligulatum Nash, Bull. Torr. Club, 26:575. 1899.

A tufted rather smooth perennial, the slender culm 16 to 20 inches long, fasciculatebranched above, forming dense masses toward the top; stem leaves 4 or 5, erectspreading, narrow, lanceolate, with serrulate margins, 1 to $1 \frac{1}{2}$ inches long, those of the branches smialler; sheaths from one-half to two-thirds as long as the internodes, ligule a ring of long silky hairs; basal leaves thick, broadly lanceolate, $1 \frac{1}{2}$ to 2 inches long; panicle oval, abont 2 inches long, exserted, with spreading branches; spikelets ovate, densely pubescent, with spreading hairs.

Louisianian area. Western Florida.

Alabama: Coast plain. Damp woods. Mobile County (T. H. Kearney, July). Type locality: "Apalachicola, Fla." (Vasey, 1892).

Near $P$. parvispiculum, from which it differs in its more slender culms, its smaller blades, and the glabrous margins of the sheaths (Nash).

Panicum nashianum Scribner, Bull. U. S. Dept. Agr. Div. Agrost. 7: 79, f. 61. 1897. Nash's PaNic Grass.

Slender and finally much branched, perennial, 5 to 10 inches high, with flat short leaves, ciliate on the margin toward the base, and open pyramidal panicles, the flexuous branches widely spreading or reflexed. Closely allied to $P$. demissum Trin.

Carolinian and Louisianian areas. Sou theastern Virginia, along the coast to Florida and Mississippi.

Alabama: Coast plain. Low pine barrens. Mobile Connty. March to May.

Type locality: "Near the coast, Virginia to Mississippi."

Herb. Geol. Surv. Herb. Mohr.

Panicum webberianum Nash, Bull. 'Torr. Club, 23: 149. 1896.

A slender, erect, rather smoothish perennial, with an erect or ascending stem 18 to 24 inches long, smooth except below; sheaths smooth, except the ciliate margins, inflated; leaves erect or erect-spreading, lanceolate, narrowed at the roundish base, 2 to 3 inches long, 3 or 4 lines wide, 7 to 11 nerved, glabrous at the base, sparingly ciliate; panicle 2 to 4 inches long, $\frac{1}{2}$ inch wide, the mostly simple brauches spreading. Louisianian area. Florida.

Alabama : Coast plain, damp pine woods. Mobile County, Summerville, June, 1899.

Type locality: "Low pine land at Eustis, Lake County, Florida." (Nash, May, 1894, No. 787).

Panicum roanokense Ashe, Journ. Elisha Mitch. Soc. 15 : 44. 1898.

A slightly tufted, erect, slender, smooth perennial, the erect enlm about 18 inches high from a geniculate base, in specimens from Alabama faintly hairy at the nodes; leaves narrowly lanceolate, 2 to 3 inches wide, firm, 5 to 7 nerved; panicle $2 \frac{1}{2}$ to 3 inches long, broadly ovate, the slender fascicled branches spreading; spikelets numerous, 1 line long, elliptical, obovate, glabrous.

Carolinian and Louisianian areas. North Carolina, Mississippi.

Alabama: Central Pine belt to Coast plain. In dry woods. Tuscaloosa County (Dr. E. A. Smith). Mobile County. April, May; not frequent.

Type locality: "Roanoke Island, N. C." ( $W . W$. Ashe, June, 1898.) 
Panicum dichotomum L. Sp. Pl. 1:58. 1753.

Forkid Panicum.

Ell. Sk. 1:124. Gray, Man. ed.6, 633. Coulter, Contr. Nat. Herb. 2:506. Britt. \& Brown, Ill. Fl. I: 120.

Alleghenian to Lonisianian area. Canada, throughont the eastern United States, west to Texas.

AlabaMa : Over the State, scattered in dry and damp soil. June; frequent.

Type locality: "Hab. in Virginia."

Herb. Geol. Surv. Herb. Mohr.

Panicum thurowii Scribn. \& Smith, Circ. U. S. Dept. Agr. Div. Agrost. 16:5. 1899.

A rather stout, erect or ascending, pubescent or villous, simple or sparingly branched perennial, 12 to 16 inches high, with 5 or 6 densely white-bearded nodes, sparingly villous sheaths, lanceolate-linear leaves 2.7 to 3.9 inches long, and ovatepyramidal, shortly exserted panicles, 2.7 to 3.1 inches long. Sheaths shorter than the villous internodes, striate and tuberculate above between the strix; ligule a ring of stiff white hairs 1.4 to 1.6 lines long; leaf-blades flat, 3.2 to 4.6 lines wide, softly pubescent on the lower surface, glabrons above, unusually eiliate on the scabrous margins toward the base. There is a very densely villons line on the back where the blade joins the sheath. Axis of the panicle sparingly pilose; the branches subflexuous, villous at the base. Spikelets narrowly elliptical, obtuse, .7 to .9 lines long. First glume one-fifth the length of the 7-nerved, pubescent, and obtuse second and third glumes, which are slightly shorter than the lanceolate elliptical, acute floral glume.

Very closely related to Panicum pubescens Lam., differing in its more densely flowered narrower panicles, smoother spikelets, and simple culms. The leaves and spikelets are purplish.

Louisianian area. Texas, Florida (Lake County).

Alabama : Coast plain. Open pine woods, vicinity of Mobile, June, 1897.

Type locality: "Walker County, Tex." (F. W. Thurow, May, June, 1898, Nos. 9 and 11).

Panicum barbulatum Michx. Fl. Bor. Am. 1:49. 1809.

Bearded Panicum.

Panicum nitidum barbulatum Chap. Fl. ed. 3,586. 1897.

Ell. Sk. 1:127. Chap. 1. c. Scribner, Grass. Tenn. 2:54.

Carolivian and Louisianian areas. New York and New Jersey, south to Florida, west to Mississippi.

Alabama: Over the State. In damp sandy soil. Rare in the mountain region, frequent near the coast. Mobile County.

Type locality : "Hab. in Carolina."

Herb. Geol. Surv. Herb. Mohr.

Panicum haemacarpon Ashe, Journ. Elisha Mitchell Soc. 15:55. 1898.

A somewhat tufted, erect, rather stout perennial, with the culm ascending from the geniculate base, 12 to 18 inches high, at the base villous with spreading hairs, smoothish above; leaves erect, ascending, 1 to 2 inches long, 2 to 3 lines wide, lanceolate, the middle ones largest, more or less pubescent with scattered hairs; sheaths shorter than the internodes, papillate-villous with long, soft, spreading hairs; nodes bearded; panicle $1 \frac{1}{2}$ to 2 inches long, broader than long, wide-spreading, rather fewflowered; spikelets generally red, 1 line long, broadly obovate; first glume one-third as long as the pubescent second and third.

Carolinian and Louisianian areas. District of Columbia, North Carolina, Iowa

Alabama : Coast plain. Dry open woods. Mobile.

Type locality: "District of Columbia, Kearney, 1897; Ashe, North Carolina, Chapel Hill, 1898; Iowa, Carver."

Herb. Geol. Surv. Herb. Mohr.

Panicum pseudopubescens Nash, Bull. Torr. Club, 26:577. 1899.

A densely pubescent perennial, the culms 8 to 16 inches high, branched hirsute with ascending hairs, the nodes barbed; leaves rather firm, lanceolate, serrulate, rough on the margins, 2 to 4 inches long and 3 to 5 lines wide, densely hispid on the lower surface and above with spreading hairs; panicle exserted, broadly ovate, 2 to $3 \frac{1}{2}$ inches long, sporsely hairy; spikelets about 1 line long, obovate, first glume about one-third as long; spikelets ovate, pubescent with spreading hairs.

Carolinian and Louisianian areas.

Alabama : Mountaiu region to Lower Pine belt. Dry and damp open woods. Cnllman County. Lee County, Auburn (Baker \& Earle). Mobilo County, Springhill, Citronelle. May, June; frequent.

Type locality: "Auburn, Lee County, Ala." (Baker \& Earle, No. 1537, etc.)

Distinguished from $P$. pubescens by its much larger spikelets. 
Panicum pubescens Lam. Encycl. 4: 748. 1797.

HaIry Panicum.

Scribner, Grass. Tenn. $2: 52, t .15, f .58$.

Carolinian and Louisianian areas. New Jersey to Tennessee, Florida, and Mississippi (?).

AlabaMa: Mountain region to Coast plain. Dry open woods. Cullman County.

Mobile County, Citronelle. Frequent; perennial.

Type locality: "Basse-Caroline."

Herb. Geol. Surv. Herb. Mohr.

Panicum lanuginosum Ell. Sk. 1 : 123. 1817.

Woolly-stemmed Panicum.

Ell. 1. c. Chap. Fl. ed. 3,586 .

Carolinian and Louisianian areas. Tennessee, Georgia, Florida, Mississippi.

ArabaMa: Mountain region to Coast plain. Copses, shady banks. Cullman County. Chambers County (Baker \& Earle). Mobile County, Whistler, Springhill. April, May; not common; perennial.

Type locality: "Grows in Georgia. Sent to me by Dr. Baldwin."

Herb. Geol. Surv. Herb. Mohr.

Panicum villosissimum Nash, Bull. Torr. Club, 23:149. 1896.

A rather stout, very hairy perennial, more or less tufted from a strong rootstock, the rigid culms erect or ascending, 16 to 24 inches high, villous with long, ascending hairs, barbed above the glabrons nodes; sheaths villous; stem leaves linear-lanceolate, $2 \frac{1}{2}$ to 4 inches long, 3 to 4 lines wide, rounded at the base, erect-spreading, with spreading bairs; panicle $2 \frac{1}{2}$ to $3 \frac{1}{2}$ inches long, equally broad, the numerous slender branchlets fascicled; spikelets obovate, about 1 line long on slender pedicels.

Louisianian area. South Carolina, Georgia, and Florida to eastern Lonisiana.

Alabama: Lower Pine belt. Dry open woods. Mobile County, Springhill, May, June; not infrequent.

Type locality: "Ocmulgee River swamp, below Macon [Georgia]." (Dr. J. K. Small.)

Panicum sphaerocarpon Ell. Sk. 1: 125. 1817.

Round-Fruited Panicum. Chap. Fl. 667. Vasey, Contr. Nat. Herb. 3:32. Coulter, Contr. Nat. Herb. $2: 506$.

Scribner, Grass. Tenn. 2 : 50, t. 13, f. 51, 52.

Carolinian and Louisianian areas. New Jersey to Florida, west to eastern Texas.

Alabama: Mountain region to Coast plain. Grassy swales and damp thickets.

Cullman County, 900 feet altitude. Dallas County, Marion Junction. Washington

County, Yellowpine. May, June; not infrequent; perennial.

Type locality: "Grows in Georgia. Dr. Baldwin."

Herb. Geol. Surv. Herb. Mohr.

Panicum polyanthes Schult. Mant. 2:257. 1824.

Small-Fruited Panicum.

Panicum microcarpon Muhl. Gram.111. 1817. Not Ell. 1817.

P. multiflorum Ell. Sk. 1 :122. 1817 . Not Poir. 1816.

Gray, Man. ed. 6, 633. Chap. Fl. 576. Vasey, Contr. Nat. Herb. 3:32. Coulter,

Contr. Nat. Herb. $2: 506$. Scribner, Grass. Tenn. 2: 50, t. 14, f. 53.

Alleghenian to Louisianian area. New York to Michigan, Missouri, and Tennescee, and from New Jersey to Florida and Louisiana.

Alabama : Over the State. Dampgrassy open places. May; frequent; perennial. Type locality: "Grows in shaded, dry soils [South Carolina and Georgia]."

Herb. Geol. Surv. Herb. Mohr.

Panicum scoparium Lam. Encycl. 4 : 744. 1797.

Panicum 8coparium var. major Vasey, Contr. Nat. Herb. $3: 31$.

P. scoparium genuinum Scribner, Grass. Tenn. 2:48. 1894.

Ell. Sk. 1:119. Gray, Man. ed. 6, 632. Coulter, Contr. Nat. Herb. 2 :507.

Alleghenian to Lonisianian area. Ontario west to British Columbia and Oregon;

New England west to Nebraska and south to Florida, thence to Texas and Arkansas.

Alabama: All over the State. Shaded grassy banks, dry woods, copses. Cullman and Tuscaloosa counties. Washington County, Yellowpine. Mobile County. April to June; frequent; perennial.

Type locality: "Basse Caroline."

Herb. Geol. Surv. Herb. Mohr.

Panicum scribnerianum Nash, Bull. Torr. Club, 22:421. 1895.

SCRIbNer's Panicum.

Panicum scoparium minor Scribner, Bull. Univ. Tenn. $7: 48$. 1894. Not $P$. capillare minus Muhl. 1817.

Panicum 8coparium Wats. \& Coult. in Gray, Man. ed. 6, 632. 1890. Not Lam. 1797.

15894 23 
P. pauciflorum Gray, Man.613. 1848. Not Ell.1817.

Britt. and Brown, Ill. Fl. 1 : 118 .

Culm erect, from 8 to 20 inches high, sparingly pubescent; sheaths papillosepilose; leaves acuminate, rounded or truncate at the base, smooth above, glabrous beneath, spreading; pauicle small, spreading, and, like the spikelets, glabrous or hairy; spikelets turgid, obovoid, about $1 \frac{1}{2}$ lines long.

In our specimens the panicle and spikelets are hairy.

Alleghenian and Carolinian areas. Maine, Ontario, and Minnesota, south to Virginia and Tennessee, west to Kansas and Arizona.

Alabama: Mountain region. Grassy banks. Culluan County. June; rare.

Type locality: "Middle Tennessee (Gattinger)."

Herb. Geol. Surv.

Panicum oligosanthes Schult. Mant. 2 :256. 1824.

Panicum pauciflorum Ell. Sk. 1: 120. 1817. Not R. Br. 1811.

P. scoparium pauciflorum (Ell.) Scribner, Grass. Tenn. 2:48, t. 12, f.46. 1894.

Chap. Fl. 575 .

Carolinian and Louisianian areas. Southern Illinois, South Carolina to Florida and Mississippi.

Ala Bama: Mountain region to Coast Pine belt. Thickets, shady borders of woods in light soil. Lee County, Auburn (Baker \& Earle). Washington County, Yellowpine. Mobile and Baldwin counties. May, June; not rare.

Type locality: "Grows in close damp soils. In Georgia, not very rare."

Herb. Geol. Surv. Herb. Mohr.

Panicum viscidum Ell. Sk. 1 : 123. 1817.

Panicum scoparium Michx. Fl. Bor. Am. 1:49. 1803. Not Lam.

Gray, Man. ed. 6, 632. Chap. Fl. 575. Vasey, Contr. Nat. Herb. 3:32. Coulter,

Contr. Nat. Herb. 2 :507. Scribner, Grass. Tenn. $2: 46, t .11, f .44$.

Carolinian and Louisianian areas. New Jersey to Florida, west to Texas, southern Missouri, and Tenuessec.

Alabama: Mountain region, Metamorphic hills, Central Pine belt to Coast plain. Damp thickets, borders of woods. Lee County, Auburn (Baker \& Earle). Tuscaloosa County (E. A. Smith). Washington County, Yellowpine. Mobile and Baldwin counties. July to August; not common; perennial.

Type locality: "Grows in damp close soils [South Carolina and Georgia]."

Herb. Geol. Surv. Herb. Mohr.

Panicum scabriusculum Ell. Sk. 1:121. 1817.

Chap. Fl. 576. Vasey, Contr. Nat. Herb. 3:33. Coulter, Contr. Nat. Herb. $2: 507$.

Louisianian area. Southeastern North Carolina, Mississippi, and eastern 'Texas.

Alabama : Coast plain. Shaded borders of ditches and ponds. Mobile County,

Ragg's swamp, foot of Springhill. Baldwin County, Bayou Ingram. April, May;

infrequent; perennial.

Type locality: "Sent to me from Savannah by Dr. Baldwin." .

Herb. Geol. Surv. Herb. Mohr.

Panicum commutatum Schult. Mant. 2:242. 1824.

Valziajle Panicum.

Panicum nervosum Muhl. Gram. 116. 1817. Not Lam.

Ell. Sk. 1: 122. Gray, Man. ed.6,632. Chap. Fl. ed. 3,584. Coulter, contr. Nat.

Herb. 2:507. Scribner, Grass. Tenn. $2: 49, t .13, f .50$.

Alleghenian to Louisianian area. Ontario, New England, Pennsylvania, Ohio, and

Tennessee to Florida, Mississippi, Texas, Arkansas, and Missouri.

Alabama: Over the State in shady woods; common. April, May. Perennial.

Type locality not distinctly given.

Herb. Geol. Surv. Herb. Mohr.

Panicum mattamusketense Ashe, Journ. Elisha Mitch. Soc. 15 : 45. 1898.

An erect, rather stont perennial, the strict culm 2 to 4 feet high, barbed at the nodes; lower leaves and sheaths soft-pubescent, the upper glabrous; leaves lanceolate, 3 to 5 inches long, 3 to 4 lines wide, spreading; panicle 3 to 5 inches long, longpeduncled with numerous clustered branches; spikelets ellipsoid, glabrous, pointed, fully 1 line long, first glume one-third the length of spikelet.

Carolinian ( $($ ) and Lonisianian areas. North Carolina.

AlabaMa : Central Pine belt. Shaded damp to wet places, margin of springs. Tuscaloosa County ( $D r . E . A$. Smith). Buckley, locality not given. Our plants differ from the typical material only in the smooth nodes and somewhat shorter leaves.

Type locality: "Lake Mattamuskeet, North Carolina." ( $W . W . A s h e$, June, 1898.)

Herl,. Geol, Surv. Herb. Mohr. 
Panicum joorii Vasey, Contr. Nat. Herb. 3:31 1892.

Chap. Fl. ed. 3, 584.

Carolinian and Louisianian areas. Southwestern Missouri (१), Tennessee, and Louisiana.

Alabama : Central Prairie belt. Damp woods, rich soil. Tuscaloosa County (Dr. E. A. Smith). Hale County. Dallas County. August, September; not infrequent; perennial.

Type locality: "Louisiana (Dr. J. F. Joor) and Mississippi (S. M. Tracy)."

Herb. Geol. Surv. Herb. Mohr.

Panicum latifolium L. Sp. P1. 1:58. 1753.

Panicum walteri Poir. Encycl. Suppl. 4 :282. 1816. Not Pursh 1814.

$P$. porterianum Nash. Bull. Torr. Club, 22:420. 1895.

Eil. Sk. 1:119. Gray, Man. ed.6, 632. Chap. Fl.575; ed. 3, 584.

Coulter, Contr. Nat. Herb. 507. Scribner, Grass. Tenn. $2: 47, t .12, f .45$.

Alleghenian to Louisianian area. Ontario, New England to Florida and Louisiana, and west from Missouri to Arkansas and eastern Texas.

Alabama: Over the State. Mnist thickets and woods. June to September; common, perennial.

Type locality: "Hab. in America."

Herb. Geol. Surv. Herb. Mohr.

Panicum pubifolium Nash, Bull. Torr. Club, 26:577. 1899.

Panicum latifolium molle Vasey, Contr. Nat. Herb. 3:33. 1892. Not P. molle Sw. 1788.

A softly pubescent, densely tufted perennial, the culms 2 to 26 inches high, finally much branched, pubescent with soft spreading hairs, the nodes densely barbed; stem leaves 3 to 5, more or less spreading, minutely serrulate or rough on the margins, ovate-lanceolate, acuminate, gradnally narrowed to the rounded cordate-clasping base; primary panicles usually little exserted, sometimes included at the base, densely pubescent; spikelets about 2 lines long, narrowly obovate, pubescent.

Carolinian and Lonisianian areas. New York to Missouri; south to Florida and Mississippi.

Alabama: Central to Lower Pine belt. Tuscaloosa and Butler counties. Dry rocky woods. May, July, and August. Not rare. Perennial.

Type locality: "Usually in rocky woods, New York to Missouri, south to Florida and Mississippi."

Herb. Geol. Surv. Herb. Mohr.

Panicum clandestinum L. Sp. Pl. 1:58. 1753.

Hispid Panicum.

Gray, Man. ed. 6, 632. Chap. Fl.575. Coulter, Contr. Nat. Herb. 2: 07.

Alleghenian and Carolinian areas. Quebec, Ontario, New England, New York, Michigan, Missouri; thronghout the Ohio Valley, sonth to Texas, and along the mountains from Virginia to Georgia.

AlabaMa : Mountain region. Low damp banks and grassy swales.

Clay County, near Moseley, 1,000 feet altitude; only locality known in the State. August. Perennial.

Type locality: "Hab. in Jamaica, Pensylvania, Kalm."

Herb. Geol. Surv. Herb. Mohr.

Panicum flexile (Gattinger) Scribner, Grass. Tenn. 2:44, t. 10, f. 40. 1894.

Wiry Panic-Grass

Panicum capillare flexile Gattinger, Fl. Tenn. 94. 1887.

Annual; culm 2 to $2 \frac{1}{2}$ feet high, genicnlate and branching at the base, slender, pilose-bearded at the nodes; leaves flat, linear-lanceolate, acute, sparsely hairy, scabrous on the margins, which are pilose at the base; panicle open, the branches capillary, the scabrous spreading pedicels much longer than the lanceolate, acuminate spikelets; first glume triangular, obtuse about one-third the length of the second and third 5 to 7 nerved glumes. Resembling closely $P$. cognatum.

Carolinian and Louisianian areas. Tennessee.

Alabama : Central Prairie region. Exposed places in light soil. Dallas County, Marion Junction. September; local; not frequent; annual.

Type locality: "Abounds in the cedar glades (middle Tennessee)."

Herb. Geol. Surv. J Herb. Mohr.

Panicum cognatum Schult. Mant. 2 :235. 1824.

Autumnal Panic-Grass.

Panicum divergens Muhl. Grảm. 120. 1817. Not H. B. K.

$P$. autumnale Bosc; Spreng. Syst. 1:320. 1825. (?)

Ell. Sk. 1:130. Gray, Man. ed.6, 630. Chap. Fl. 574. Vasey, Contr. Nat. Herb.

$3: 33$. Coulter, Contr. Nat. Herb. 2 : 508. 
Alleghenian to Louisianian area. Lllinois to sonthern Minnesota and Kansas; North Carolina, Georgia, and Mississippi.

Alabana: Mountain region, Central Prairie region. Borders of fields. Lee County, Auburn (Baker \& Earle). Montgomery County. August, September; not rare; perennial.

Type locality: "Hab. in Carolina."

Herb. Geol. Surv. Herb. Mohr.

Panicum proliferum Lam. Encycl. $4: 747.1797$.

Sprouting Panic-Grass.

Panicum geniculatum Muhl. Gram. 123. 1817.

P. proliferum geniculatum Vasey, Contr. Nat. Herb. $3: 34.1892$.

Eil. Sk. 1:117. Chap. Fl. 574. Coulter, Contr. Nat. Herb. 2:508.

Caroliniau and Louisianian areas. Iowa, Missouri, south to eastern Texas, and from New England to Florida and Louisiana.

Alabama: Throughout the State; the typical form rather scarce, found in upper district; the large southern form ( $P$. geniculatum Ell.) 3 to 6 feet high frequent in the Coast plain in low rich soil. August, September. Annual.

The southern piant is a succulent, valuable fodder grass, popularly known as "water grass."

'Type locality: "Cultivée au Jardin du Muséum; son lieu natal ne m’est pas connu." Herb. Geol. Surv. Herb. Mohr.

Panicum verrucosum Muhl. Gram. 113. 1817.

Panicum debile Ell. Sk. 1: 129. 1817.

Gray, Man. ed. 6, 631. Chap. Fl. 574. Vasey, Contr. Nat. Herb. 3:34. Seribner,

Grass. Teun. 2: $45, t .11, f .42$.

Carolinian and Louisianian areas. Coast of New York to Florida, west to

Louisiana.

Aldibama : Coast Pine belt to Coast plain. Low sandy woods, most abundant in flat shaded piue barrens near the coast. Monroe County, Claiborne. Mobile and Bald win connties. Tuscaloosa County, near University. July to August; common; perennial.

Type locality : "Hab. in N. Caesarea, Delaware ot Georgia."

Hert. Geol. Surv. Herb. Mohr.

Panicum rostratum Muhl. Gram. 121. 1817.

Beaked Panicun.

Ell. Sk. 1:118. Gray, Man. ed. 6, 631. Chap. Fl.573. Vasey, Contr. Nat. Herb. 3: 35. Scribner, Grass. Tenn. $2: 41, t .8, f .32$.

Carolinian and Louisianian areas. Southern New York, southern Pennsylvania, west rn Virginia, sonth to Florida, Texas, and Arkansas.

Alabama: Over the State. Damp, close, sandy soil, borders woods, fields, roadsides. Cullman County, 800 feet. Montgomery and Ciarke counties. Monroe County, Claiborne. Mobile and Bald win counties. Frequent; July to October; perennial. Type locality: "Hab. in pratis Penns. Carol. Cherokee."

Herb. Geol. Snrv. Herb. Mohr.

Panicum anceps Michx. Fl. Bor. Am. 1: 48. 1803.

Confounded with Panicum rostratum. Differs from this species in the slender, erect, rigid, and almost perfectly glabrous stem, the contracted panicle with the spikelets more crowded, the uitimate branchlets more or less one-sided, closely appressed to secondary branches; spikelets smaller, ereet.

Louisianian area. South Carolina to Florida.

AlabaMa: Coast plain. Miry borders of pine-barren ponds, with $P$. stenodes, Lobelia paludosa, etc. Mobile County, Kelly's Pond. Baldwin County, Bayou Ingram. June to September; perennial.

Type locality : "Hab. in Carolinae herbosis humidis sylvaticis."

Herb. Geol. Surv. Herb. Mohr.

Panicum longifolium Torr. Fl. N. \& Mid. U.S. 149. 1824.

Britt. \& Brown, 1ll. Fl. 1: 116.

Alleghenian, Carolinian, and Louisianian areas. Rhode Island, along the coast to Florida, west to Texas.

Alabama : Coast plain. Flat damp pine barrens, borders of ponds. Mobile County. July, October; frequent; perennial.

Type locality: "In the pine barrens of New Jersey."

Herb. Geol. Surv. Herb. Mohr.

Panicum elongatum Pursh, Fl. Am. Sept. 1:69. 1814.

Panicum agrostoides elongatum Seribner, Grass. 'Tenn. $2: 42, t .9$, f. 34. 1894.

Britt. \& Brown, Ill. Fl. 1: 115.

Carolinian and Louisianian areas. New Jersey, Virginia, Tennessee. 
ALAB+MA: Mountain region. Rich damp swales. Clay County, bottom of Talladega Creek.

Distinguished from Panicum agrostoides by the longer acuminate spikelets and distinctly pedicellate flowering glume.

Type locality: "In ditches and near ponds: New Jersey to Virginia."

Herb. Geol. Surv. Herb. Mohr.

Panicum elongatum ramosior var. nov.

Stem stouter and taller than in the type, fully 3 feet long, reclining, smooth leaves, 2 feet and over in length, sheaths shorter than the in ternodes; panicle large, widely spreading, pyramidal, 12 to 18 inches long; lower branches 4 to 5 inches long; secondary branches rather clistant, mostly in pairs; spikelets as in the type, pale. By these permanent characters a well marked variety.

Louisianian area. Mississippi.

Alabama: Damp cultivated ground. Mobile County, Pierce's Landing. July, October; abundant; perennial.

Economic uses: Valuable; furnishes a large portion of the spontaneous hay crop of the bottom lands.

Herb. Geol. Surv. Herb. Mohr.

Panicum agrostoides Muhl. Gram. 119. 1817.

Gray, Man. ed.6, 391. Chapm. Fl. ed. 3, 583. Scribner, Grass. Tenn. 2 : 41, t. 9 f. 33. Alleghanian to Louisianian area. Maine and easteru Massachusetts to Nebraska, south to Kentucky and Florida, thence to eastern Texas and Arkansas.

Alabama: Mountain region to Coast plain. Grassy swales and low pine barrens. Clay County, near ldaho mine. Mobile County, pine barrens west of the city. July, August; frequent.

Type locality: "Hab. in pratis humidis, floret Julio, Augusto. Pennsylvania, Georgia, Carolina, Cherokee."

Herb. Geol. Surv. Herb. Mohr.

Panicum virgatum L. Sp. PI. 1:59. 1753.

SWITCM PaNiC-GRass.

Ell. Sk. 1:120. Gray, Man. ed.2, 631. Chap. Fl.573. Coulter, Contr. Nat. Herb. 2 : 508. Scribner, Grass. Tenn. $2: 42$, t. $9, f .35$.

Allegheniau to Louisianian area. Ontario, Saskatchewan, New England, west to Minnesota, Nebraska, and Colorado, south to Florida and Texas.

Alabama : From the Tennessee valley to the coast. Light damp soil. . Calhoun County ( $E$. A. Smith). Mobile and Baldwin counties. Most abundant on sandy borders of tide-water swamps.

A variety of low growth, with short contracted panicle, was observed years ago on arid pine ridges about Grandbay. The specimens collected at the time have been lost, and the plant has not been observed since. There is little doubt that it was identical with $P$. virgatum breviramosum Nash, lately described.

Type locality: "Hab. in Virginia."

Herb. Geol. Surv. Herb. Mohr.

Panicum amarum Ell. Sk. 1:121. 1817.

Seaside Panic-grass.

Gray, Man. ed. 6, 631. Chap. Fl.574. Vasey, Contr. Nat. Herb. $3: 35$.

Carolinian to Louisianian area. Southern New England, along the seashore to Florida.

Alabama: Littoral belt. Sandy beach. Mobile County, Cedar Point (only locality). Very rare; July; perennial.

Type locality: "Among the sand hills on the seashore [South Carolina and "Georgia]."

Herb. Geol. Surv. Herb. Mohr.

Panicum crus-galli L. Sp. Pl. 1:56. 1753. BARNYARd GRAss, Cockspur Grass. Ell. Sk. 1:114. Gray, Man. ed. 6, 633. Chap. Fl. 577. Coulter, Contr. Nat. Herb. 2:502.

Temperate and warmer regions, widely spread over the globe.

Alabama: Throughout the State. Low wet gronnd, cultivated places, border of marshes; annual.

Type locality: "Hab. in Europae et Virginiae cultis."

Varies greatly with the spikelets awnless or with awns of greater or less length.

Panicum walteri Pursh, Fl. 1:66. 1814.

Panicum hirtellum Walt. Fl. Car. 72. 1788. Not All. 1775.

P. hispidum Muhl. Gram. 107. 1817.

Carolinian and Louisianian areas. Florida to Louisiana. 
Alabama: Coast plain. Swamps. Mobile County, river marshes. July. Four to 5 feet high; annual.

Type locality: "Near the salt water: Canada and New York."

Herb. Geol. Surv. Herb. Mohr.

Panicum colonum L. Syst. Nat. ed. 10, 870. 1759.

Panicum walteri Ell. Sk. 1:115. 1816. Not Pursh. 1814.

Chap. Fl. 577. Vasey, Contr. Nat. Herb. $3: 37$. Wats. Bot. Calif. $2: 260$. Coulter,

Contr. Nat. Herb. 2 : 502.' Seribner, Grass. Tenn. $2: 40, t .8, f .30$.

SUbTropical aND tropical BegIONS OF THE GLOBE.

Louisianian area. North Caroliua to Florida ; west to Texas, Arkansas, Arizona, and southern California.

Alabama: Coast plain. Damp grassy banks; frequent. Mobile and Baldwin counties. July to September; annual.

Type locality East Indian.

Herb. Geol. Surv. Herb. Mohr.

Panicum gibbum Ell. Sk. 1 : 116. 1817.

Panicum elliottianum Schult. in Dietr. Syn. Pl. 1:261. 1839.

Hymenachue striata Griseb. Fl. Brit. W. Ind. 554. 1864.

Chap. Fl.573. Scribner, Grass. 'Tenn. 2:40, t.8, f. 31. Vasey, Contr. Nat. Herb. 3 : 37.

West INDIES To GUIANA

Carolinian to Louisianian area. Tennessee, North Carolina, Florida, and Lonisiana.

Alabama: Lower Pine region, Coast plail.. Damp grassy banks, borders of

brooks. Mobile County. July to Augnst; not rare; perennial.

Type locality: "In damp and wet soils [South Carolina and Georgia]."

Herb. Geol. Surv. Herb. Mohr.

Panicum molle Sw. Prodr. Veg. Ind. Occ. 22. 1788.

PARA Grass.

Introduced from the West Indies and cultivated.

Alabama: Rarely cultivated about Mobile and said to have escaped into low places and ditches; perennial.

Economic uses: Valuable; an excellent coarse pasture grass.

Herb. Geol. Surv. Herb. Mohr.

OPLISMENUS Beauv. Agrost. 53. 1812.

(Orthopogon R. Br. Fl. Nov. Holl. 194. 1810.)

Four species, tropical and subtropical regions, mostly American. North America, 1.

Oplismenus setarius (Lam.) Roem. \& Schult. Syst. Veg. 2:484. 1817.

Panicum setarium Lam. Tabl. Encycl. 1:170. 1791.

P. hivtellum Michx. Fl. Bor. Am. 1:47. 1803. Not L.

Orthopogon setarius Spreng. Syst. Veg. 1:306. 1824.

Ell. Sk. 1:115. Chap. Fl. 577. Griseb. Fl. Brit. W. Ind. 545. Vasey, Coutr.

Nat. Herb. 3:37. Coulter, Contr. Nat. Herb. 2:509.

West Indies, Mexico to Brazil.

Louisianian area. Coast of South Carolina to Florida and Texas.

Alabama : Metamorphic hills. Lee County, Auburn (Baker \& Earle, 596). Central Pine belt, Coast plain. Danp shady copses and woods. Mobile and Bald win counties. Tuscaloosa County $(E$. A. Smith). July to September; not infrequent; perennial.

Type locality: "Ex Amer. merid. Commun. a D. Richard."

Herb. Geol. Surv. Herb. Mobr.

CHAETOCHLOA Scribner, Bull. U. S. Dept. Agr. Div. Agrost. 4 : 39. 1897.1

(Chamaerapirs Kuntze, Rev. Gen. Pl. 2 : 767. 1891. Not R. Br.)

(Ixophorus Nash, Bull. Torr. Club, 22:422. 1895. Not Schlecht.)

(Seta Ria Beauv. Agrost. 113. 1812. Not Achar. 1798.)

About 28 species, weedy annuals, of warmer temperate and tropical regions.

Chaetochloa glauca (L.) Scribner, Bull. U. S. Dept. Agr. Div. Agrost. 4 : 39. 1897.

Panicum glaucum L. Sp. P1. 1:56. 1753.

Pigeon Grass.

${ }^{1}$ The North American species of Chaetochloa. By F. Lamson-Scribner \& Elmer D.

Merrill. Bull. 21, U. S. Dept. Agr. Div. Agrost. 1900. 
Setaria glauca Beauv. Agrost. 51. 1812.

Ell. Sk. 1:112. Gray, Man. ed.6,634. Chap. Fl. 578. Conlter, Contr. Nat. Herb. 2:509. Wats. Bot. Calif. $2: 260$.

Europe, Asia.

Canadian zone to Louisianian area. Naturalized and widely distributed from Canada to the Gulf of Mexico and from the Atlantic to the Pacitic coast.

AlabaMa: Over the State. Cultivated and waste places. July, October. A common weed; annual.

Type locality: "Hab. in Indiis."

Herb. Geol. Surv. Herb. Mohr.

Chaetochloa imberbis (Poir.) Scribner, Bull. U. S. Dept. Agr. Div. Agrost. 4:39. 1897.

Panicum imberbe Poir. Encycl. Suppl. 4 : 272. 1816.

$P$. laevigatum Muhl.; Ell. Sk. 1:112. 1817. Including variety.

Setaria laevigata Chap. Fl. ed. 3, 587.

Chaetochloa perennis (Curtiss) Bicknell, Bull. Torr. Club, $25: 107$. 1898. Not Setaria perennis Hall. 1893.

Chap. Fl. l. c. Ell. Sk. l. c.

West Indies, Mexico, South America.

Carolinian and Louisianian areas. New Jersey to Florida, Texas, and New Mexico.

Alabama: Central Pine belt and Central Prairie region. Swampy places. Tuscaloosa County. Apparently rare. July to September. Annual.

Differs from Chaetochloa glauca by the larger involucrate bristles and the base of the leaf blade and throat of the sheath destitute of hairs. Heretofore confounded with the following variety. The distribution of the species is difficult to designate.

Type locality: "In America septentrionali et Brasilia."

Herb. Geol. Surv. Herb. Mohr.

Chaetochloa imberbis perennis (Hall) Scribn. \& Merrill, Bull. U. S. Dept. Agr. Div. Agrost. 21:12. 1900.

Perennial Seaside Pigeon Grass.

Setaria perennis Hall, Trans. Kans. Acad. Sci. 13:102. 1893. Not Chaetochloa perennis Bicknell, Bull. Torr. Club, 25:107. 1898.

Chaetochloa versicolor Bicknell, Bull. 'Torr. Club, 25 : 105, pl. 328. 1898.

Ell. Sk. 1:112, in part, under Setaria laevigata Mull. Chap.Fl. ed. 3, 587, including the typical form. C'oulter, Contr. Nat. Herb. 2:509.

A slender scarcely tufted perennial, 2 to 4 feet high, with slender, compressed, wiry culms, which are naked below, long narrow leaves, and rather slender longexserted panicles from $1 \frac{1}{2}$ to $2 \frac{1}{2}$ inches long; spikelets generally purplish with slender yellowish or yellowish green bristles.

WEST INDIF.s.

Carolinian and Louisianian areas. From southern New England (Connecticut) to southern Florida, Mississippi, Louisiana, in saline marshes along the coast. Westward in alkaline and saline bottoms in Kansas and Indian Territory.

Alabama: Littoral region. Brackish swamps and salt marshes. Mobile and Baldwin counties. One of the most common grasses of the salt marshes with the black rush, Juncus roemerianus. July to October.

Distinguished from the typical form, with which it has been until lately confounded by the more slender habit of growth, the tall culms naked near the base of the leaves, and the more or less purplish spikelets.

Type locality: "Alkaline and saline bottoms in central and southwestern Kansas." Herb. Geol. Surv.

Chaetochloa gracilis (H. B. K.) Scribn. \& Merrill, Bull. U. S. Dept. Agr. Div. Agrost. 21: 15. 1900.

Setaria gracilis H. B. K. Nov. Geu. et Sp. 1:109. 1815.

S. imberbis Roem. \& Schult. of authors.

A slender, smooth, cespitose perennial 12 to 20 inches high from a creeping rootstock, with linear, setaceous leaves, slender spike-like panicles 1 to $2 \frac{1}{2}$ inches long, and 5 to 8 short involucrate bristles, scarcely exceeding the spikelets; flowering glume transversely undulate-rugose.

Cuba, Mexico.

Louisianian area. Florida to Texas.

Alabama : Mobile. Not rare on ballast heaps, and firmly established in damp to wet places at the mouth of the Mobile River. July to September. Adventive from the tropics; perhaps indigenous to southern Texas.

Type locality: "Crescit * * * inter Fusagasuga et Pandi * * * (Regno Novogranatensi.)"

Herb. Geol. Surv. Herb. Mohr. 
Chaetochloa verticillata (L.) Scribner, Bull. U. S. Dept. Agr. Div. Agrost. 4 : 39. 1897.

Panicum verticillatum L. Sp. Pl. ed. 2, 1:82. 1762.

Setaria verticillata Beauv. Agrost. 51. 1812.

Gray, Man. ed.6, 634. Chap. Fl.578.

AlabaMa: Introduced from Europe and sparingly naturalized. Waste grounds.

At Mobile has been found the tropical form with broader leaves, loose spikes with

longer spreading branchlets, the spreading awns twice as long as in the typical form. "May be S. pseudo-verticillata Fouruier,' but can not be determined from description" (E. D. Merrill).

Type locality : "Hab. in Europa australi et Oriente."

Herb. Geol. Surv. Herb. Mohr.

Chaetochloa brevispica Scribn. \& Merrill, Bull. U. S. Dept. Agr. Div. Agrost. 21: 15. 1900.

Panicum verticillatum parviflorum Doell in Mart. Fl. Bras. 2, pt. 2:172. 1877. Not Cenchrus parviforus Poir. 1804.

A low, spreading annual, mnch branched, 4 to 12 inches high, with decumbent, depressed, glabrous culms, lanceolate leaves 2 to 6 inches long; (lense panicles $\frac{1}{2}$ to $1 \frac{1}{2}$ inches long and $\frac{1}{2}$ inch thick, densely flowered; bristles 1 to 3 , purplish, the flowering glume nearly smooth, finely transversely wrinkled.

Mexico, South AMerica, Europe, Africa.

Louisianian area. Louisiana.

Alabama: Fugitive on ballast with $C$.italica germanica, of the same habitat as the latter, but distlngnished by spreading habit, short cylindrical spikes, and smaller spikelets; distinguished from $C$. verticillata by the smaller spikelets.

Type locality: "Prope Rio de Janeiro lecta."

Chaetochloa ambigua (Guss.) Scribn. \& Merrill, Bull. U. S. Dept. Agr. Div. Agrost. 21:18. 1900.

Setaria rerticillata ambigua Guss. Prodr. 1:80. 1827. Not S. ambigua Schrad. 1838.

A cespitose, erect, much brauched annual 8 to 18 inches high, with compressed culms, lanceolate leaves and rather spicate, dense panicle 2 to 4 inches long, its branchlets short and solitary; stout bristles $\frac{1}{4}$ to $\frac{1}{3}$ inch long, upwardly barbellate. Intermediate between $C$. viridis and $C$. verticillata; distinguished from the former by. the subverticillate loose pauicle, stout, short bristles, and scabrous, not pilose, rach is ; from $C$. verticillata by the bristles being upward-barbellate instead of retrorse.

EURope.

Carolinian and Lonisianian areas. New Jersey.

Alabama: Near dwellings. Mobile County (Carl Zimmer, 1884). Introduced.

Type Incality : Sicily (q).

Herb. Geol. Surv.

Chaetochloa viridis (L.) Scribner, Prlll. U. S. Dept. Agr. Div. Agrost. 4 : 39. 1897.

Panicum viride L. Sp. Pl. ed.2, 1:83. 1762.

Setaria viridis Beauv. Agrost. 51. 1812.

Gray, Man. ed. 6, 634. Chap. Fl. 578; ed. 3, 588. Coulter, Contr. Nat. Herb.

$2: 510$. Scribuer, Grass. Tenn. $2: 56, t .16, f .63$.

Naturalized from Europe almost over the continent.

Alabama: Over the State. Waste places around dwellings. Mobile County.

June to September. Not frequent.

Type locality: "Hab. in Europa australi."

Herb. Geol. Surv. Herb. Mohr.

Chaetochloa italica (L.) Seribner, Bull. U. S. Dept. Agr. Div. Agrost. $4: 39.1897$.

Panicum italicum L. Sp. Pl. 1:56. 1753.

ITALIAN OR GOLDEN Miliet.

Setaria italica Beauv. Agrost.51. 1812.

AlabaMa : Cultivated throughout the State, rarely escaping.

Type locality: "Hab. in Indiis."

Economic uses: Important forage and hay crop.

Herb. Mohr.

Chaetochloa italica germanica (Mill.) Scribner, Bnll. U. S. Dept. Agr. Div. Agrost. 6:32. 1897.

Hungarian Grass, German Millet.

Panicum germanicum Mill. Gard. Dict. ed. 8, no.1. 1768.

Setaria germanica Beauv. Agrost. 31. 1812.

Cultivated throughont the State. Mobile, fugitive on ballast grouncl and in waste places; escaped from cultivation. June to August. 
Type locality not ascertained.

Economic uses: Valuable as the last.

Herb. Geol. Surv. Herb. Mohr.

Chaetochloa magna (Griseb.) Scribner, Bull. U. S. Dept. Agr. Dir. Agrost. 4 : 39. 1897.

Setaria magna Griseb. Fl. Brit. W. Ind. 554. 1864.

LARGE SWAMP Millet.

Chap. Fl. ed. 3, 588.

WEST INDIES (BERMUDA).

Carolinian and Lonisianian areas. On the coast from Delaware to Florida and

Louisiana.

Alabama: Coast plain. Grassy marshes, Mobile River. July. Rare. Annual.

'Type locality: "Hab. Janıica!"

Chaetochloa caudata (Lam.) Scribner, Rep. Mo. Bot. Gard. 10:52. 1899.

Panicum caudatum Lam. 'Tabl. Eneycl. 1:171. 1791.

Setaria caudata Roem. \& Schult. Syst Veg. 2:495. 1817.

A slender, somewhat cespitose annual 1 to 2 feet high; the culm branched from the base; the leaves narrowly linear; the panicle elongated (from 5 to 15 inches long), attenuate, few.flowered; the bristles solitary; the spikelets ovate, acute, shortpedicellate.

West Indies, Mexico, South America.

Carolinian and Louisianian areas. New Jersey, along the coast to Mississippi( ( ).

Adventive from tropical America. Indigenous in Florida and sovthern Texas.

AlabaMa: On ballast heaps. Mobile(1891).(?)

Type locality: "E Brasilio. Commers. \& Cayenna. D. Richard."

Herb. Geol. Surv. Herb. Mohr.

CENCHRUS L. Sp. Pl. 2 : 1050. 1753. SANDBUR.

Abont 12 species of tropical and temperate regions of both hemispheres.

Cenchrus tribuloides L. Sp. P1. 2 : 1050. 1753.

COMmon SANDBUR.

Cenchrus carolinianus Walt. Fl. Car. 79. 1788.

Ell. Sk. 1:93. Gray, Man. ed. 6, 634. Chap. Fl. 579. Coulter, Contr. Nat. Herb.

$2: 510$. Wats. Bot. Calif. $2: 261$.

West Indies, Mexico to Brazil.

Carolinian and Louisianian areas. Eastern United States, southern California.

Alabama : From the Tennessee valley to the coast, on sandy waste ground. Most abundant near the coast. Mobile. July to October. A pernicious weed.

Type locality: "Hab. in Virginiae maritiunis."

Herb. Geol. Surv. Herb. Mohr.

Cenchrus macrocephalus Scribner, Bull. U. S. Dept. Agr. Div. Agrost. $17: 110, f$. 406. 1899.

LARGE SANDBUR.

Cenchrus tribuloides macrocephalus Doell in Mart. Fl. Bras. 2, pt. 2:312. 1877.

Brazil, Argentina.

Carolinian and Lonisianian areas. New Jersey along the coast to Louisiana.

AlabaMa: Littoral belt. Shifting sands. Baldwin County, eastern shore of Mobile Bay. Mobile County, dunes of Dauphin Island. Flowers July to October. Not infrequent. Annual.

Stouter than the last, the ascending stems 8 to 12 inches long; spikelets fully twice as large.

Type locality: Brazil.

Cenchrus incertus M. A. Curtis, Bost. Journ. Nat. Hist. 1: 135. 1837.

Cenchrus strictus Chap. Bot. Gaz. $3: 20.1878$.

SOUTHERN SANDBUR.

Chap. Fl. Suppl. 667; ed. 3, 588. Scribner, Bull. U. S. Dept. Agr. Div. Agrost. 17: $109, f .405$.

Louisianian area. North Carolina along the coast to Florida and western Texas.

Alabama : Coast plain to adjoining pine hills. Dry, sandy soil. Mobile and Baldwin counties, shores of Mobile Bay. Mobile County, Springhill. July to October. Often a troublesome wayside weed.

Type locality: "West coast of Florida, Appalachicola and sonthward."

Cenchrus echinatus L. Sp. Pl. 2 : 1050. 1753.

HEDGEHOG GRASS.

Chap. Fl.578. Coulter, Contr. Nat. Herb. 2 : 510 .

West Indies, Mexico to Brazil.

Louisianian area. Coast, North Carolina to Florida. 
Alabala : Coast region. Waste places. Mobile County, Springhill. September,

1891. Annual. Probably adventive from the tropics.

Type locality : "Hab. in Janaica, Curassao."

Herb. Geol. Surv. Herb. Mohr.

Cenchrus myosuroides H. B. K. Nov. Gen. et Sp. $1: 115, t .35 .1815$.

Panicum cenchroides Ell. Sk. 1:111. 1817.

SOUTHERx Hedgehog Grass.

Chap. Fl. Suppl. 667; ed. 3, 588. Vasey, Contr. Nat. Herb. 3:39. Coulter, Contr.

Nat. Herb. 2:511.

Cuba, Peru.

Louisianian area. Coast of Georgia, Florida, and Louisiana.

Alabama: Mobile, adventive with ballast. First observed in 1892-93; plentiful. July to Angust. Perennial.

Typo locality: Island "Cayo Flamingo prope portum Cubensem, Batabano," and shore of Pacific "prope vicum Peruvianorum, Patibilca."

Herb. Geol. Surv. Herb. Mohr.

STENOTAPHRUM Trin. Fund. Agrost. 175. 1820.

Three species, seacoast of tropical and subtropical regions. North America 1.

Stenotaphrum secundum (Walt.) Kuntze, Rev. Gen. P1. 2 : 794.1891.

Ischaemum secundum Walt. Fl. Car. 249. 1788.

St. Augustine Grass.

Stenotaphrum americanum Schrank. Hort. Monach.98. 1819-1824.

Rottboellia dimidiata Sw. Ges. Naturf. Fr. Berl. Mag. 4:89. 1810.

Ell. Sk. 1:179. Chap. Fl. 579. Vasey, Contr. Nat. Herb. 3:40. Coulter, Contr.

Nat. Herb. $2: 511$. Griseb. Fl. Brit. W. Ind. 544.

West Indies, Mexico to Argentina, Sandwich Islands.

Louisianian area. Sandy seashore from South Carolina to Florida and Texas.

Alabama: Littoral belt. Mobile County, Dauphin Island. Baldwin County,

Point Clear, Josephine. Not infrequent. June to August. Perennial. (q)

Typo locality: South Carolina.

Herb. Geol. Surv. Herb. Mohr.

HYDROCHLOA Beauv. Agrost. 165. 1812.

A single aquatic species. Atlantic North America.

Hydrochloa fluitans (Michx.) Nash, Bull. Torr. Club, 23:98. 1896.

Zizania fluitans Michx. Fl. Bor. Am. 1:75. 1803.

Hydrochloa carolinensis Beauv. Agrost. 165. 1812.

Ell. Sk. 2:587. Chap. Fl.549. Vases, Contr. Nat. Herb. $3: 40$.

Louisianian area. North Carolina to Florida and Mississippi.

Alabama: Lower Pine region. Coast plain. Brooks and pine-barren streams.

Baldwin County, Point Clear. Mobile County. June; common. Perennial.

Type locality: "Hab. ad lacum Champlain." (Erroneous.)

Herb. Geol. Surv. Herb. Mohr.

IUZIOLA Juss. Gen. Pl. 33. 1789.

About 6 species; low perennial aquatics. Tropical and subtropical America. United States, 2 species.

Luziola alabamensis Chap. Fl. 584. 1860.

Vasey, Contr. Nat. Herb. 3:40. Chap. Fl.1. c.; ed. 3, 589.

Louisianian area.

Alabama: Lower Pine region. Sandy shallow brooklets. Conecuh County. Mobile County, Langdon Station. June. Not frequent.

Type locality: "Brooklyn, Conecuh County, Alabama. J. F. Beaumont."

Herb. Geol. Surv. Herb. Mohr.

ZIZANIA L. Sp. Pl. 2 :991. 1753. Water OAts.

Perennial aquatic; 1 species. North America and northeastern Asia.

Zizania aquatica L. Sp. Pl. 2 : 991. 1753.

Zizania clavulosa Michx. Fl. Bor. Am. 1: 75.1803.

Ell. Sk. 2 :585. Gray, Man. ed. 6,635. Chap. Fl.549. Coulter, Contr. Nat. Herb.

2:511. Scribner, Grass. Tenn. 2:58. 
Siberia, JAPAN.

Canadian zone to Louisianian area. Newfoundland, Ontario, Manitoba, sonth and west to Florida and 'l'exas, Arkansas, and Missouri.

Alabama : Coast plain principally; copious in water ( 2 to 3 feet deep) in the estuaries of the rivers emptying into Mobile Bay. June to July. Perennial.?

Type locality: "Hab. in Jamaicae, Virginiae inundatis."

Economic uses: Valuable for its highly nutritious seeds.

Herb. Geol. Surv. Herb. Mohr.

ZIZANIOPSIS Doell \& Aschers. in Mart. Fl. Bras. 2, pt. 2: 12. 1871.

One species, warmer temperate North America; Brazil.

Zizaniopsis miliacea (Michx.) Doell \& Aschers.; Baill. Hist. Pl. 12 : 293. 1893.

Water Millet.

Zizania miliacea Michx. Fl. Bor. Am. 1: 74. 1803.

Lonisianian area. North Carolina to Florida, west to eastern Florida and Arkansas.

Alabama: Lower Pine belt. Coast piain. In shailow still-flowing water and marshes burdering streams. Mobile County, river delta. Baldwin County, Stockton. June and July; frequent. Perennial.

Type locality: "Hab. in aquosis Americae septentrionalis."

Herb. Geol. Surv. Herb. Mohr.

HOMALOCENCHRUS Mieg.; Hall. Hist. Stirp. Helv. 2 : 201. 1768.

(Leersia Sw. Nov. Gen. et Sp.21. 1788. Not Hedwig. 1782.)

Five species; perennial marsh grasses of temperate and warmer regions, mostly American.

Homalocenchrus virginicus (Willd.) Britton, Trans. N. Y. Acad. Sci. 9: 14. 1889.

White Grass.

Leersia virginica Willd. Sp. Pl. 1:325. 1797.

Ell. Sk. 1:100. Gray, Man. ed. 6, 635. Chap. Fl. 548. Coulter, Contr. Nat. Herb. 2: 512 . Scribner, Grass. Tenn. $2: 59, t .17, f .68$.

Canadian zone to Louisianian area. Newfoundland, Ontario, and New England, west to Minnesota and Nebraska; sonth to Florida and Texas.

Alabama: Over the State. Swampy woods, shady borders of ponds. Cullman, Tuscaloosa, Montgomery, and Mobile counties. July to September; common.

Type locality: "Hab. in America boreali."

Herlb. Geol. Surv. Herb. Mohr.

Homalocenchrus oryzoides (L.) Pollich, Hist. Pl. Palat. 1:52. 1776.

Phalaris oryzoides L. Sp. Pl. 1:55. 1753.

RiCe-Like Cutgrass.

Leersia oryzoides $\mathrm{Sw}$. Fl. Ind. Oce. 1: 132 .

Ell. Sk. 1: 101. Gray, Man. ed.6, 635. Chap. Fl. 548. Coulter, Contr. Nat. Herb.

$2: 511$. Wats. Bot. Calif. $2: 262$. Scribner, Grass. T'enn. $2: 60, t .1 \%, f .6 \%$.

Europe, temperate Asia, North Africa, West Indies.

Canadiau zone to Louisianian area. Newfoundland, Ontario, and New England (Mount Desert Island); west to Nebraska, Oregon, and California, and throughout the Atlantic States south to Florida, Mississippi, Texas, and Arkansas.

Alabama: All over the State. Alluvial districts, swamps. Montgomery and

Mobile counties. July to September.

Type locality : "Hab. in Virginia paludibus nemorosis."

Herb. Geol. Surv. Herb. Mohr.

Homalocenchrus hexandrus (Sw.) Kuntze, Rev. Gen. Pl. 2 : 773. 1891.

Leersia hexandra Sw. Gen. et Sp. Pl.21. 1788.

SOUTHERN CUTGRASS.

Chap. Fl. 549. Vasey, Contr. Nat. Herb. 3 :41. Coulter, Contr. Nat. Herb. 2 :512.

West In'ies, Mexico to Argentina, Africa, Asia, Australia.

Louisianian area. Florida to Texas.

Alabama : Coast plain. Open swamps. Mobile County, river marshes. June to August. Local; not frequent.

Type locality not ascertained.

Herb. Geol. Surv. Herb. Mohr. 
ORYZA L. Sp. Pl. 1:333. 1753.

Oryza sativa L. Sp. Pl. 1:333. 1753.

RICE.

Cultivated in the States from western Tennessee and North Carolina to the Gulf. Alabama: Here and there voluntary in low fields. Annual.

Type locality: "Hab. forte in Aethiopia, colitur in Indiae paludosis."

Economic uses: Of great value as a grain crop.

PHALARIS L. Sp. Pl. 1:55. 1753.

About half a dozen species, Mediterranean Europe, Central Asia; North America, 1.

Phalaris caroliniana Walt. Fl. Car. 74. 1788.

Phalaris intermedia Bosc; Poir. Encycl. Suppl. 1:300. 1810.

P. americana Ell. Sk. 1:101. 1817.

Chap. k1.569. Coulter, Contr. Nat. Herb. 2:512. Wats. Bot. Calif. 2:264.

Louisianian area. North Carolina to Florida; west to Texas and Arkansas.

Alabama : Central Prairie region to Coast plain. Low grassy places. Mobile County, West Fowl River. Perry County, Uniontown (E. A. Smith). June. 'Not rare; annual.

Type locality: "South Carolina."

Herb. Geol. Surv. Herb. Mohr.

Phalaris canariensis L. Sp. Pl. 1:54. 1753.

Canary Grass.

Introducerl. Rarely spontaneous abont dwellings.

Type locality: "Hab. in Europa australi, Canarijs."

Economic uses: Valuable for its seeds.

ANTHOXANTHUM L. Sp. Pl. 1:28. 1753.

Three species, native of southern Europe.

Anthoxanthum odoratum L. Sp. Pl. 1:28. 1753.

Sweet Vernal Grass.

Ell. Sk. 1:37. Gray, Man. ed. 6, 639. Chap. Fl.569. Conlter, Contr. Nat. Herb.

$2: 503$. Wats. Bot. Calif. $2: 266$.

Europe.

Alleghenian and Carolinian areas. Extensively naturalized in eastern North America and along the Pacific coast.

Alabama: Mountain region. Warrior table-land. Cullman County, 800 feet altitude. May to June; not frequent; perennial.

Type locality: "Hab. in Europae pratis."

Economic uses: Valuable meadow grass.

Herb. Geol. Surv. Herb. Mohr.

\section{ARISTIDA L. Sp. Pl. 82. 1753. Triple-Awned Grass.}

About 100 species. Perennials of warmer regions, largely American. North America, 29 species.

Aristida dichotoma Michx. Fl. Bor. Am. 1:41. 1803.

Poverty Grass.

Ell. Sk. 1:141. Gray, Man. ed. 6,640. Chap. Fl. 555. Conlter, Contr. Nat. Herb. $2: 513$. Seribner, Grass. Tenn. $2: 64, t .19, f .73$.

Alleghenian to Louisianian area. New England, Pennsylvania, and New Jersey, south to Florida, west to Tenuessee, Arkansas, and Texas.

Alabama : Tennessee Valley, Coosa hills to Coast plain. Sandy and gravelly hills, dry sterile soil. Calhoun County, Anniston. Montgomery and Mobile counties. August to September; frequent.

Type locality : "Hab. in Carolina superiore, juxta Lincoln, in glareosis."

Herb. Geol. Surv. Herb. Mohr.

Aristida gracilis Ell. Sk. $1: 142.1817$.

Slender Aristida.

Gray, Man. ed. 6, 640. Chap. Fl.555. Coulter, Contr. Nat. Herb.2:514. Scribner, Grass. Tenu. $2: 64, t .19, f .74$.

Alleghenian to Louisiauian area. Southern New England, New York, and Pennsylvania, south to Florida, and west to 'Texas, Arkansas, and Missouri.

Alabama: Orer the State; in dry gravelly soil. July; common.

Type locality: "In the vicinity of Charleston. Common."

Herb. Geol. Surv. Herb. Mohr. 
Aristida mohrii Nash, Bull. N. Y. Bot. Gard. 1:436. 1900.

A glabrous perennial with very slender culms, leafy ouly towarl the base, $1 \frac{1}{2}$ to 2 foet high, erect; leaves 4, the lowermost sheath distant from the others which are crowded and overlapping, the blades flat, erect, acuminate, 3 to 4 inches long, about $\frac{1}{16}$ inch wide; racemes slender, long-exserted, 8 to 12 inches long, spikelets scattered, about half as long as the internodes, the lowest sometimes very distant, appressed; empty scales scabrous, equal in length, acute, 1-nerved; flowering scale shorter, its awns hispidulous, widely sprearling, Hlat and loosely spiral at the base.

Lonisiana area. Lower Pine belt. Sandy pine ridges, Mobile County.

Related to $A$. simpliciflora, from which it is abundantly distinct. In that species the spikelets are numerous and crowded, with their empty scales smaller, the first scale strongly hispidulous and the lateral awns of the flowering scale more slender than the central awn.

Type locality: "Collected by Dr. Charles Mohr at Springhill, Mobile County, October 4, 1886; *** also secured at the same place by B. F. Bush, Angust 27, 1895."

Herb. Geol. Surv. Herb. Mohr.

Aristida stricta Michx. Fl. Bor. Am. 1:41. 1803.

WIRE GRASS.

Ell. Sk. 1:142. Gray, Man. ed. 6, 640. Chap. Fl. 555. Vasey, Contr. Nat. Herb. $3: 45$. Louisianian area. Southern Virginia to Florida, Louisiana, and southern Arkansas. Alabama: Lower Pine region. Coast plain. Dry sandy pine barrens. Baldwin County, Perdido Bay, Bon secour. Abundant in the counties bordering npon western Florida, the so-called "wire grass connties." Escambia County, Wilson Station.

Covington, Geneva, Henry, aud Mobile counties.

Type locality : "Hab. in Carolina inferiore."

Herb. Geol. Surv. Herb. Mohr.

Aristida spiciformis Ell. Sk. 1 : 141. 1817.

SpiKe-Flowerei) Aristida.

Chap. Fl.555. Vasey, Contr. Nat. Herb. $3: 45$.

Louisianian area. Southern coast of North Carolina to Floridia aud Mississippi.

Alabama : Coast plain. Low damp pine barrens, in close sandy soil. Mobile

County, Bayou Labatre. Angust to September. Not common.

Type locality: "Wet pine barrens [South Carolina and Georgia]."

Herb. Geol. Surv. Herb. Mohr.

Aristida palustris (Chap.) Vasey, Contr. Nat. Herl.3:45. 1892. Swaml' Aristida. Aristida virgata palustris Chap. Fl. 555. 1860.

Louisianian area. Florida to Mississippi.

Alabama: Low wet pine barrens, so-called pine meadows. Mobile County, Dog River flats. July to August; frequent.

'Type locality : "Margins of pine barren ponds, west Florida."

Herb. Geol. Surv. Herb. Mohr.

Aristida purpurascens Poir. Encycl. Suppl. 1:452. 1810.

Gray, Man. ed. 6, 641. Chap. Fl.555. Vasey, Contr. Nat. Herb. 3:46. Coulter, Contr. Nat. Herb. $2: 514$

Carolinian and Louisianian areas. Southeastern Massachusetts, New York, New Jersey to Florida, west to Texas, Arkansas, and southern Missouri.

Alabama: Coosa hills to Coast plain. Dry gravelly or sandy soil. Calhoun County, Anniston, 800 feet. Monroe County, Claiborne. Mobile County, Springhill, Citronelle. Common throughout the dry pine barrens. August, October. Type locality: “Communiquée par M. Bose, qui la recueillie dans la Caroline."

Herb. Geol. Surv. Herb. Mohr.

Aristida lanata Poir. Encycl. Suppl. 1:453. 1810.

WoOl.LY Aristida.

Aristida lanosa Muhl. Gram.174. 1817.

Ell. Sk. 1:143. Gray, Man. ed. 6, 641. Chap. Fl. 554. Coulter, Contr. Nat. Herb. 514.

Carolinian and Louisianian areas. Delaware, Maryland, North Carolina, to

Florida, west to central Texas.

Alabama : Coast plain to hills of the Coosa Valley. Dry gravelly or sandy soil. Calhoun County, Anniston, 800 feet. Montgomery County. Mouroe County, Claiborne. Mobile and Baldwin counties, scattered on the poorest sandy ridges. August and september.

Type locality: "C'ette plante a étś recueille par M. Bosc dans la Caroline."

Herb. Geol. Surv. Herb. Mohr. 
STIPA L. Sp. Pl. 1:78. 1753.

About 100 species native of temperate and warmer regions, particularly on elevated table-lands. North America, 23 species.

Stipa avenacea L. Sp. Pl. 1 : 78.1753. Black OAT Grass. Stipa barbata Michx. Fl. Bor. Am. 1:53. 1803.

Ell. Sk. 1: 139. Gray, Man. ed. 6, 641. Chap. Fl. 554. Vasey, Contr. Nat. Herb. $3: 54$. Coulter, Contr. Nat. Herb. $2: 516$.

Carolinian and Louisianian areas. Southern Now York, Delaware, and Pennsylvania to Florida, west to 'Texas, Arkansas, and southern Missouri.

Alabama: Over the State. Dry sandy hills. Montgomery County. Bibb County, Ashland. Tuscaloosa County (E.A. Smith). Perry County, Uniontown, dry prairies. Mobile County, sandy pine ridges. April and May; frequent.

Type locality: "Hab. in Virginia."

Herb. Geol. Surv. Herb. Mohr.

Stipa setigera Presl, Rel. Haenk. 1:226. 1828.

Stipa neesiana Trin. Mem. Acad. St. Petersb. 5 : 27. 1842.

Alabama: Adventive from Argentina on ballast. Mobile County. June, July, 1886 and 1893.

Type locality not given.

Herb. Geol. Surv. Herb. Mohr.

MUHLENBERGIA Schreb. Gen.44. 1789. DROP-SEED.

About 60 species, mostly South American; Mexico and North America, 37, mostly of the Western plains.

Muhlenbergia trichopodes (Ell.) Chap. Fl.553. 1860. Elliott's Hair Grass. Agrostis trichopodes Ell. Sk. 1:135. 1817.

Muhlenbergia capillaris var. lrichopodes Vasey, Contr. Nat. Herb. 3:66. 1892.

Ell. Sk. l. c. Coulter, Lontr. Nat. Herb. 2:522.

Mexico.

Louisianian area. South Carolina and Florida to Texas.

Alabana: Central Pine belt to Coast plain. Dry woodlands. Hale County, Gallion. Mobile County. Washington and Clarke counties. Perennial.

Type locality: "Chatham County, Georgia, by Dr. Baldwin. Near Charleston."

Herb. Geol. Surv. Herb. Mohr.

Muhlenbergia diffusa Schreb. Beschr. Graes. 2 : 143, t.51. 1772-1779. Nimble: WiLL, Dilepyrum minutiflorum Michx. Fl. Bor. Am. 1:40. 1803.

Ell. Sk. 1: 98. Gray, Man. ed. 6, 644. Chap. Fl. 553. Vasey, Contr. Nat. Herb. 3 : 68.

Scribner, Grass. Tenn. $2: 67, t .20, f .80$.

SoUth BraziL.

Alleghenian to Carolinian area. Ontario and New England; west to Minnesota and Nebraska, south to eastern Texas; and from Now York along the mountains to Georgia.

Alabama: Tennessee Valley. Lower hills. Open woods, pastures. Madison County, Huntsville. Tuscaloosa County. Franklin County, Russellville. June to September. Frequent. Perenuial.

Type locality not ascertained. Michaux's locality: “Hab.ill apricis, pratensibus regionum Kentucky et lllinoensium."

Herb. Geol. Surv. Herb. Mohr.

Muhlenbergia tenuiflora (Willd.) B. S. P. Prel. Cat. Fl. N. Y.67. 1888.

Agrostis tenuiflora Willd. Sp. Pl. 1: 364, 1798.

SleNDer-Flowerei) Hair Grass.

Muhlenbergia willdenovii Trin. Unifl. 188. 1824.

Ell. Sk. 1:134. Gray, Man. ed. 6, 643. Scribner, Grass. Tenn. $2: 68, t$. 21, f. 84 .

Alleghenian to Carolinian area. Ontario and New England to Minnesota, south

to northern Texas, and from New York along the mountains to Tennessee and South Carolina.

Alabama: Collected by S. B. Buckley; locality not stated. Rare. Perenuial.

Type locality: "Hab. in America boreali." 
BRACHYELYTRUM Beauv. Agrost. 39. 1812.

One species, eastern North America.

Brachyelytrum erectum (Schreb.) Beauv. Agrost. 39. 1812.

AWNED BRACHYELYTRUM.

Muhlenbergia erecta Schreb. Beschr. Graes. 2 : 139, t.50. 1772-79.

Muhlenbergia aristata Pers. Syn. 1:73. 1805.

Brachyelytrum aristatum Roem. \& Schult. Syst. Veg. 2:413. 1817.

Ell. Sk. 1:98. Gray, Man. ed. 6, 644. Chap. Fl.553.

Canadian zone to Louisianian area. Nova Scotia, New Brunswick, Ontario, and Now England, west to Minnesota. Nebraska, and Missouri, south to Tennessee, central Alabama, Mississippi, and Arkansas.

Arabama: Tennessee Valley. Warrior table-land. Lower hills. Rich rocky woodlands and copses. Bibb County, Pratt's Ferry. Tuscaloosa County (E. $A$. Smith). Cullman County, 800 feet altitude. Not common. Perennial.

Type locality: "Hab. in Pennsylvania."

Herb. Geol. Surv. Herb. Mohr.

PHLEUM L.Sp. P1. 1:59. 1753.

About 10 species, in temperate zones mostly.

Phleum pratense L. Sp. Pl. 1:59. 1753.

TIмотну.

Gray, Man. ed.6,645.

EUROPE.

AlabaMa: Cultivated in the northern section of the State. Rarely spontaneous by escape. May and June. Perennial.

Type locality: "Hab. in Europae versuris et pratis."

Economic uses: Important hay crop.

Herb. Mohr.

ALOPECURUS L.Sp. Pl.60. 1753. Meadow Foxtail.

Twenty species, temperate regions, Europe, Asia; few in North and South America.

Alopecurus geniculatus I Sp. Pl. 1:60. 1753.

Water Foxtail.

Alopecurus fulvus Smith, wingl. Bot. t. 146\% 1793.

A. aristulatus Michx. Fl. Bor. Am. 1:43. 1803.

A. geniculatus var. aristulatus Torr. Fl. N.\& Mid. U. S. 1:97. 1824.

Gray, Man. ed. 6, 645. Wats. Bot. Calif. $2: 263$. Conlter, Contr. Nat. Herb. $2: 526$. Scribner, Grass. 'Tenn. 2 : 71, t. 23, f. 89.

Canadian zone to Louisianian area. Widely distributed from Canada to British Columbia and California, and from New England west to Nebraska, and south to Mississippi, Louisiana, aud Arkansas.

Alabama: Tennessee Valley to Central Prairie region. Low wet fields. Common. Lauderdale County, Florence. Perry County, Uniontown. Hale County, Gallion.

Tuscaloosa County (E.A. Smith). A pril, May; frequent. Perennial.

Type locality: "Hab. in Europae uliginosis."

Herb. Geol. Surv. Herb. Mohr.

SPOROBOLUS R. Br. Prodr. Fl. N. Holl. 1 : 169. 1810. Drop-seed Grass.

(VIlfa Beauv. Agrost. 16. 1812.)

Eighty species, mostly in warmer and tropical America. North America, 31.

Sporobolus indicus (L.) R. Br. Prodr. FI. N. Holl. I:170. 1810.

Indian Drop-seed Grass, Smut Grass.

Agrostis indica L. Sp. Pl. 1 : 63.1753.

Eil. Sk. 1:138. Gray, Man. ed. 6, 646. Chap. Fl. 550. Coulter, Contr. Nat. Herb.

$2: 518$.

Tropical zONE OF THE OLD AND New WORLDS.

Carolinian and Louisianian areas. Extensively naturalized from southern Virginia to Florida, west to Texas, Arkansas, and Tennessee.

Alabama : Central Pine belt to Coast plain. Dry pastures, roadsides, waste places around dwellings, in light sandy loam. Common. Tuscaloosa, Montgomery, Pike, Monroe, Mobile, and Baldwin counties. July to September. Perennial.

Type locality: "Hab. in India."

Economic uses: Valuable for pasture.

Herb. Geol. Surv. Herb. Mohr. 
Sporobolus tenacissimus (L.) Beauv. Agrost. 126. 1812.

Agrostis tenacissima L. f. Suppl. 197.

Vilfa tenacissima H. B. K. Nov. Gen. et Sp. 1:138. 1815.

West Indies; Mexico to Brazil.

Alabama : Adrentive on ballast. Mobile. First observed, September, 1891, since then to the present time. Perennial.

Sporobolus junceus (Michx.) Kunth, Rev. Gram. 1:68. 1835.

Agrostis juncea Michx. Fl. Bor. Am. 1:52. 1803.

Ell. Sk. 1:137. Gray, Man. ed.6,646. Chap. 11. 550. Coulter, Coutr. Nat. Herb. $2: 520$.

Alleghenian, Carolinian, and Louisianian areas. Reported from sonthern Minnesota, Dakota, Wisconsin, southern Virginia to Florida, and west to Texas.

Alabama : Coosa hills. Central Pine belt to Lower Pine region. Dry rocky hills; most abundant in sandy dry pine barrens. Calhoun County, Anniston, 700 feet. Tuscaloosa County. Clarke County, ('hoctaw Corner. Monroe County, Claiborne. Mobile and Baldwin counties. September to October; common. Perennial.

Herb. Geol. Surv. Herb. Mohr.

Type locality: "Hab. in sabulosis aridis Carolinae."

Sporobolus asper (Michx.) Kunth, Ennm. 1:210. 1833.

ROUGH RUSH-GRASS.

Agrostis aspera Michx. Fl. Bor. Am. 1:52. 1803.

Vilfa drummondii Trin. Unifl. 1824.

Sporobolus asper var. drummondii Vasey, Contr. Nat. Herb. 3:60. 1892.

Ell. Sk. 1:138. Gray, Man. ed. 6, 645. Chap. Fl. 550. Coulter, Contr. Nat. Herb. $2: 519$.

Alleghenian to Louisianian area. New England, Minnesota, Nebraska, southern Missouri, sonth to Florida and the Gulf region; Texas and Arkansas.

Alabama: Tennessee Valley. Coosa hills to the Lower Pine region. Dry rocky hills and pine barrens. Calboun County, Anniston, 700 feet. Mobile and Baldwin counties. Frequent on the sandy pine ridges. September and October. Perennial.

Type locality: "Hab. in collibus rupibusque regionis Illinoensis."

Herb. Geol. Surv. Herb. Mohr.

Sporobolus longifolius (Torr.) Wood, Classbook, 775. 1861.

LONG-LEAVED RUSH-GRASS.

Agrostis longifolia Torrey, Fl. N. \& Mid. U. S.90. 1824.

A. involuta Muhl. Gram. 72. 1817. Not Poir. 1810.

Sporobolus asper Vasey, Contr. U. S. Nat. Herb. 3:59. 1892. Not Kunth, 1833.

Alleghenian and Carolinian areas. New England to Illinois and Kansas, south from Long Island to Mississippi, and west to Texas.

Alabama: Lower Pine region. Dry pine barrens. Mobile County, Springhill. October; not frequent. Perennial.

Type locality of $A$. involuta Muhl.: "Hab. ad Susquehannam, floret Oct. Penns. N. Ebor."

Herb. Geol. Surv. Herb. Mohr.

Sporobolus vaginaeflorus Torr.; Wood, Classbook, 775. 1861.

SHEATHED RUSH-GRASS.

Vilfa vaginaeflora Torr.; Gray, Gram. \& Cyp. Exsic. I: no. 3. 1834.

Sporobolus minor Vasey in Gray, Man. ed.6, 646. 1890.

Gray, Man. ed. 6, 646. Chap. Fl. 551. Coulter, Contr. Nat. Herb, 2:519. Scribner,

Grass. Tenn. $2: 72$, t. 23, f. 92.

Alleghenian to Louisianian area. Ontario and New England to Minnesota and Nebraska, and from New York south to Florida and Texas.

Alabama : Coosa hills. Lower Pine region. Calhoun County, Anniston, 700 feet. Mobile County, Springlill, sandy pine ridges. September to October; infrequent. Annual.

Type locality: "Dry gravelly fields U.S. more common West and South."

Herb. Geol. Surv. Herb. Mohr.

Sporobolus neglectus Nash, Bull. Torr. Club 22:464. 1895. Small Rush-GRass.

Sporobolus vaginaeflorus Vasey in Gray, Man. ed.6,645. 1890. Not Wood.

Gray, Man.1. c. Cliap. Fl. ed.3, 598.

Carolinian and Lonisianian areas. Southern New England to Kentucky, Tennessee, Kansas, and south to Mississippi.

Alabana: Lower Pine region. Barren pine ridges. Mobilo County. October; infrequent. Annual. 
Type locality: "Barren and sandy dry fields; common, especially southward." Herb. Geol. Surv. Herb. Mohr.

Sporobolus virginicus (L.) Kunth, Rev. Gram. 1:67. 1835.

SEASHORE Rush-GRass.

This perennial has not yet been collected in the State, but is not rare on the adjacent shores of Florida and Mississippi, and without doubt occurs within its limits.

LIMNODEA L. H. Dewey in Coulter, Contr. Nat. Herb. 2:518. 1894.

(Thurberia Benth. Journ. Linn. Soc. 19:58. 1882. Not Gray, 1854).

One species; Atlantic North America.

Limnodea arkansana (Nutt.) L. H. Dewey in Coulter, Contr. Nat. Herb. 2 :518. 1894. Greenia arkansana Nutt. Trans. Am. Phil. Soc. 5 : 142. 1837.

Thurberia arkansana Benth. in Vasey, Grasses of U. S. 16, 1883.

Chap. Fl. ed. $3,600$.

Carolinian and Louisianian areas. Arkansas, Indian 'Territory, and Texas, thence to Florida.

AlabaMa : Coast plain. Shell mounds. Baldwin County, Point Clear. Mobile County, Dauphin Island. April to May. Local and rare. Annual.

Type locality not ascertained.

Herb. Geol. Surv. Herb. Mohr.

POLYPOGON Desf. Fl. Atl. 1: 66. 1798.

About a dozen species, inhabiting the warmer regions.

Polypogon monspeliensis (L.) Desf. Fl. Atl. 1:67. 1798. French Beard-Grass. Alopecurus monspeliensis L. Sp. P1. 1:61. 1753.

Gray, Man. ed. 6, 648. Conlter, Contr. Nat. Herb. 2 :518. Wats. Bot. Calif. $2: 270$.

Europe, Asia, North Africa.

Carolinian and Louisianian areas. Adventive on the Atlantic and Gulf coast.

Utab, Nevada, California, and Oregon.

Alabama: Sparingly naturalized, waste places. Baldwin County, east shore

Mobile Bay, banks of Mobile River. June, July; rare. Annual.

Typelocality: "Hab. Monspelii."

Herb. Geol. Surv. Herb. Mohr.

Polypogon littoralis (With.) Smith, Comp. Fl. Brit. ed.2,13. 1816.

Agrostis littoralis With. Bot. Arr. Brit. Pl. ed. 3, 2 : 129. 1796.

SEASIDE BEARD-GRASS.

Wats. Bot. Calif. $2: 270$.

Coasts of Europe, Soutir America.

Introduced on the Atlantic and Gulf coast. California.

Alabama: Shores of Mobile Bay. Mobile County; July. With the last, rare. Anunal.

Type locality: "Hab. in Anglia."

Herb. Mohr.

CINNA L.Sp.Pl. 1:5. 1753.

Two species, perennials; Eastern North America, 2; Europe, 1.

Cinna arundinacea L. Sp. P1. 1:5. 1753.

Europe.

Canadian zone to Louisianian area. Newfoundland, Nova Scotia, and Saskatchewan; New England, west to Michigan, Minnesota, and Missouri, south from New York to Georgia and from Missouri to Texas.

Alabama: Mountain region to Coast plain. Shady woods and swamps. Clay County (E. A. Smith). Cullman County, 800 feet. Tuscaloosa County (E. A.Smith). Mobile County, river marshes. June. Local; infrequent.

Type locality: "Hab. in Canada."

Herb. Geol. Surv. Herb. Mohr. $15894-24$ 
AGROSTIS L. Sp. PI. 1:6. 1753.

About 100 species, chiefly of the north temperate zone. North America, 26.

Agrostis alba L. Sp. Pl. 1:63. 1753. . Flokin. White Brnt Grass. Agrostis alba stolonifera Scribner, Grass.Tenn. 2 : 79, t. 26,f.103. 1894.

Gray, Man. ed. 6, 647. Chap. Fl. ed. 3, 599.

EUROPE.

Extensively naturalized from Canada to the Mexican Gulf.

Alabama: Over the State. Low damp banks. Mobile County, April to May. Perennial.

Type locality: "Hab. in Europae nemoribus."

Economic uses: A fine winter grass.

Herb. Geol.Surv. Herb. Mohr.

Agrostis alba vulgaris (With.) Thurber, in Gray, Man. ed. 6, 647. 1890.

Agrostis vulgaris With. Bot. Arr. Brit. Pl. ed. 3, 132. 1796.

HERD's GRass. REDTOP.

Gray, Man. 1. c. Chap.F'l. ed. 3, 599. Scribner, Grass. Teun. $2: 78, t .26, f .102$.

AlabAMA: Introduced from Europe, and cultivated in the northern part of the

State; rarely escaped. Margins of low fields. Perennial.

Type locality not ascertained.

Herb. Geol. Surv. Herb. Mohr.

Agrostis elliottiana Schult. Mant. $2: 202$. 1824.

Elliott's Bent Grass.

Agrostis arachnoides Ell. Sk. 1:134. 1817. Not Poir. 1810.

Gray, Man. ed.6, 647. Chap. Fl. 552. Coulter, Contr. Nat. Herb. 2:525. Scribner,

Grass.' Tenn. 78, t. 25, f. 101.

Carolinian and Louisianian areas. Kentucky, Tennessee, and South Carolina to western Florida, Alabama, Mississippi, and Texas.

Alabama: Mountain region to the Coast plain. Dry open pastures, roadsides.

Lee County, Auburn (Baker \& Earle, 585). Cullman County, 800 feet. Mobile and

Baldwin counties. April to May; frequent; annual.

Type locality: "Collected near Orangeburg [S. C.] by I. S. Bennett."

Herb. Geol. Surv. Herb. Mohr.

Agrostis hiemalis (Walt.) B.S. P. Prel. Cat. N. Y.68. 1888. Rough Hair Grass. Cornucopiae hiemalis Walt. Fl. Car. 74. 1788.

Agrostis scabra Willd. Sp. 1.1.1:370. 1798.

Trichodium laxiflorum Michx. Fl. Bor. Am. 1:42. 1803.

Ell. Sk. 1:99. Gray, Man. ed. 6, 648. Chap. Fl. 551. Coulter, Contr. Nat. Herb.

2:525. Wats. Bot. Calif. $2: 274$. Scribner, Grass. Tenn. $2: 77, t .25, f .99$.

Allegheuian to Louisianian area. From Nova Scotia, throughout Canada to British Columbia andl Alaska; south from Now Eugland to Florida and the Gulf, west to Texas and California.

Alabama : Over the State, in low sandy fields. Calhoun, Tusealoosa. Montgomery, and Mobile counties. April to May; common; annual.

Type locality : South Carolina.

Herb. Geol. Surv. Herb. Mohr.

Agrostis perennans (Walt.) Tuckerm. Am. Journ. Sci.45:44. 1843. Thin-Grass. Cornucopiae perennans Walt. Fl. Car. 74. 1788.

Trichodium perennans Ell. Sk. 1:99. 1817.

Ell. 1. c. Gray, Man. ed. 6, 648. Chap. Fl. 551. Coulter, Contr. Nat. Herb. $2: 525$.

Scribuer, Grass. Tenn. $2: 76, t .25, f .97$.

Canarian zone to Carolinian area. Quebec, Ontario; New England to Wisconsin, south to Tennessee and South Carolina.

Ala bama: Tennessee Valley. Mountain region. Damp shaded places. Frequeut in the "rock houses" of the Warrior table-land. Winston County. Walker County, from 1,000 to 1,500 feet. Lauderdale County, river hills. June to October. Pereunial. Type locality : South Carolina.

Herb. Geol. Surv. Herb. Mohr.

Agrostis intermedia Scribner, Grass. Tenn. 2:76. 1894. UPLAND Bent Grass. Carolinian and Louisianian areas. Eastern Tennessee, Alabama, Louisiana, and Texas.

Specimeus of a more slender habit and others of a stouter growth are easily confounded with Agrostis perennans on the one band and Agrostis altissima on the other. $A$.intermedia differs from the former by the less spreading more elongated panicle of a pale color, perfectly smooth leaves, the empty glumes nearly equal, and the flower- 
ing glume two-thirds of the length of the empty ones. From the latter it is distinguished by the more slender branches of the panicle, with the spikelets less crowded above the middle of the branches, the smaller spikelets, thinner empty glumes with the midrib less prominent and less scabrous, and the perfectly smooth flowering glumes.

ALABAMA : Coast plain. Low shady banks, borders of woods; in close damp soil. Mobile County. September to October; frequent. Perennial.

'Type locality: "Common in damp places, in thickets and along the borders of woods."

Herb. Geol. Surv. Herb. Mohr.

Agrostis altissima (Walt.) Tuckerm. Am. Journ. Sci. 45 : 44. 1843.

Cornucopiae altissima Walt. Fl. Car. 74. 1788.

Agrostis elata Trin. Mem. Acad. St. Petersb. ser. 6, pt. 2 : 364. 1845.

Trichodium elatum Pursh, Fl. Am. Sept. I:61. 1814.

Gray, Man. ed. 6, 648. Chap. Fl.551. Wats. Bot. Calif. $2: 274$.

Alleghenian, Carolinian, and Louisianian areas. New England and New York to North Carolina; California.

Alabama: Low shaded banks and borders of swamps. Mobile County, October; infrequent.

Type locality : South Carolina.

Herb. Geol. Surv. Herb. Mohr.

CALAMAGROSTIS Adans. Fam. Pl. 2:31. 1763.

About 120 species, temperate zone; North America, 31 species.

Calamagrostis cinnoides (Muhl.) Scribner, Mem. Torr. Club, $5: 42.1894$.

Arundo cinnoides Muhl. Gram. 187. 1817.

REed Bent Grass.

Calamagrostis nuttalliana Steud. Syn. Pl. Gram.190. 1855.

Gray, Man. ed. 6, 650. Chap. Fl. 553. Scribner, Grass. 'Tenn. 2: 80, t. 2\%, f. 105.

Alleghenian and Carolinian areas. New England, Peunsylvania, New Jersey to North Carolina and eastern Tennessee.

Alabama: Tennessee Valley. Mountain region. Lower hills. Moist woodlands. Cullman, Lauderdale, and Tusealoosa counties. June, July; not common. Perennial. Type locality : "Hab. locis siccis et sphagnosis, floret Augusto. Penns. Massachuss." Herb. Geol. Surv. Herb. Mohr.

HOLCUS L. Sp. Pl. 2 : 1048. 1753.

Low annuals. Eight species. Temperate regions, Europe, Africa.

Holcus lanatus L. Sp. Pl. 2 : 1048. 1753.

Velvet Grass.

Gray, Man. ed. 6, 652. Wats. Bot. Calif. $2: 299$. Scribner, Grass. Tenn. $2: 81, t$. 27, $f .106$.

Introduced from Europe. Naturalized from Canada to the Gulf, and in California and Mexico.

Alabama : Adventive with grass seed. Mobile County; escaped from cultivation. Cullman County. May; infrequent. Perennial.

Type locality: "Hab. in Europae pascuis arenosis."

Economic uses: Of some value for hay or pasture on poor land.

Herb. Geol. Surv. Herb. Mohr.

AIRA L. Sp. P1. 1:63. 1753.

Six species; Europe and North Africa.

Aira caryophyllea L. Sp. Pl. 1:66. 1753.

Silvery Hair Grass.

Gray, Man. ed. 6, 653.

Europe, North Africa, Chile.

Naturalized. Ontario, Vancouvers Island; New England to New Jersey, and Tennessee.

Alabama: Dry pastures and openings in the woods. Rather local; extensively spreading of late years. Abundant where it occurs. Cullman County. Lee County, Auburn (Baker \& Earle). Mobile County, Springhill. April. Annual.

Type locality: "Hab. in Angliae, Germaniae, Galliae, glareosis."

Herb. Geol. Surv. Herb. Mohr. 
DESCHAMPSIA Beauv. Agrost.91. 1812.

Perennial. About 20 species, temperate regions of the globe. North America, 8 species.

Deschampsia flexuosa (L.) Trin. Bull. Acad. Sci. St. Petersb. 1:66. 1836.

Aira flexuosa L. Sp. P1. 1:65. 1753.

Common Hair Grass.

Ell. Sk. 1:151. Gray, Man. ed.6,652. Chap. Fl.568.

EUROPE.

Alleghenian area. New England, New York; south along the higher Alleghenian ranges to Georgia, East 'Tennessee, and Missouri.

Alabama : Mountain region. Dry rocky dells. Dekalb County, Lookout Mountain; about 1,800 feet. May to June; rare.

Type locality : "Hab. in Europae petris, rupibus."

Herb. Geol. Surv. Herb. Mohr.

TRISETUM Pers. Syn. 1: §7. 1805.

About 50 species, cooler temperate regions north and south hemispheres. North America, 8.

Trisetum pennsylvanicum (L.) Beauv.; Roem. \& Schult. Syst. Veg. 2: 658. 1817.

Avena pennsylvanica L. Sp. Pl. 1:79. 1753.

SWAMP OAT Grass.

Avena palustris Michx. Fl. Bor. Am. 1:72. 1803.

Trisetum palustre Torr. Fl. N. \& Mid. U. S. 1:126. 1824.

Gray, Man. ed. 6, 653. Chap. Fl.568. Scribner, Grass. Tenn, 2: 82, t. 28, f. 109.

Alleghenian and Carolinian areas. Southern New York, New Jersey, and North Carolina to the mountains of Tennessee and Northern Alabama.

Alabama: Mountain region. Madison County, Gurley's Place, 1,100 feet altitude. June; rare. Pereunial.

Type locality: "Hab. in Pensylvania. Kalm."

Herb. Geol. Surv. Herb. Mohr.

AVENA L. Sp. Pl. 1:79. 1753. OATs.

About 30 species, of cooler regions. United States, 2 species.

Avena fatua L. Sp. Pl. 1:80. 1753 .

WILD OATS.

Gray, Man. ed. 6, 653. Wats. Bot. Calif. $2: 295$.

Europe.

Introduced, sparingly naturalized in a few localities of the Atlantic States. Abundant on the coast of California. Annual.

Alabama: Adventive on ballast and fairly established. Mobile County, Pinto's Island. May to June. Annual.

Type locality: "Hab. in Europae agris inter segetes."

Herb. Geol. Surv. Herb. Mohr.

ARRHENATHERUM Beauv. Agrost. 55. 1812.

Six species in Europe. North Africa. West Asia.

Arrhenatherum elatius (L.) Beauv.; Mert. \& Koch, Deutsch. Fl. 1:546. 1823.

Avena elatior L. Sp. Pl. 1 : 79. 1753.

Arrhenatherum avenaceum Beauv. Agrost. 152. 1812. Name only.

Gray, Man. ed. 6, 652. Chap. Fl.569. Scribner, Grass. Tenn. 2: $83, t .28, f .111$.

Introduced from Europe and naturalized in Ontario and the eastern States, and south to Alabama and Mississippi.

Alabama: Cultivated in the Prairie region, and a frequent escape. Mobile, a fugitive on ballast heaps. Hale County, Gallion. Cullman County. Perennial.

Type locality: "Hab. in Europae maritimis et apricis."

Economic nses: Valuable hay grass.

Herb. Geol. Surv. Herb. Mohr. 
DANTHONIA DC. Fl. France, 3:32. 1805. OAT Grass.

One hundred species, temperate and warmer regions, more than half in South Africa. North America, 5 or 6 species.

Danthonia spicata (L.) Beauv.; Roem. \& Schult. Syst. Veg. 2 : 690. 1817.

Avena spicata L. Sp. P1. 1: 80. 1753.

Common Wild Oat Grass.

A. glumosa Michx. Fl. Bor. Am. 1:72. 1803 .

Gray, Man. ed. 6, 654. Chap. Fl. 569.

Alleghenian to Louisianian area. Newfoundland and Quebec, west to the Pacific;

New England, west to Dakota, south to Florida, Louisiana, and Arkansas.

Alabama: Tennessee Valley to central prairies. Dry copses, border of woods. Madison County. Dallas County, Marion Junction. June, July; not infrequent. Perennial.

Type locality: "Hab. in Pensylvania."

Herb. Geol. Surv. Herb. Mohr.

Danthonia compressa Austin; Peck, Rep. Rey. N. Y. St. Univ. 22: 54. 1869.

Danthonia alleni Aust. Bull. Torr. Club, $3: 21.1872$.

Mountain Wild Oat Grass.

Gray, Man. ed. 6, 654. Chap. Fl. Suppl. 665. Scribner, Grass. Tenn. 2 : 85, t. 29, f. 114.

Alleghenian and Carolinian areas. New England to Pennsylvania and New Jersey, south to North Carolina and Tennessee.

Alabama: Mountain region. Dry rocky ridges. Madison County, Huntsville. May, June; not frequent. Perennial.

Type locality: "Woods. Danube, Herkimer County, [N. Y.], July, 1868. C. F. Austin."

Herb. Geol. Surv. Herb. Mohr.

Danthonia glabra Nash, Bull. Torr. Club, 24:43. 1897. Smooth Wild OAt Grass. Carolinian area. New Jersey to upper Georgia.

Alabama: Mountain region. Rocky ledges. Dekalb County, summit of Lookout Mountain, 2,000 feet altitude. June, 1893. Rare. Perennial.

Type locality: "Tspe specimens collected by Dr. John K. Small, on Little Stone

Mountain, Dekalb County, Georgia, on July 5, 1895."

Herb. Geol. Surv.

Danthonia sericea Nutt. Gen. 1:71. 1818.

Silky Wild OAT Grass.

Avena spicata Ell. Sk. 1 :174. 1817. Not L.

Ell. 1. c. Gray, Man. ed. 6, 654. Chap. Fl.569. Scribner, Grass. Tenn. 84, t. 28, f. 112.

Carolinian to Louisianian area. Florida, along the coast to southern Massachusetts, west to Mississippi and Arkansas.

Alabama: Mountain region to Coast plain. Dry pine barrens. Lee County, Auburn (Baker \& Earle). Washington County, Yellowpine. Escambia, Clarke, Baldwin, and Mobile counties. May; frequent. Perennial.

Type locality: "Grows in the upper districts of Georgia and South Carolina, in high land. Columbia County, Ga."

Herb. Geol. Surv. Herb. Mohr.

GAUDINIA Beauv. Agrost.95. 1812.

Gaudinia fragjlis (L.) Beauv. Agrost. 95. 1812.

Avena fragilis L. Sp. P1. 1:80. 1753.

A fugitive from southern Europe. Mobile County, on ballast. August. Observed once only, 1889.

Type locality: "Hab. in Lusitania, Hispania. Loefl."

Herb. Geol. Surv. Herb. Mohr.

CAPRIOLA Adans. Fam. Pl. 2 : 31. 1763.

(Cynodon Rich.; Pers. Syn. 1 : 85. 1805.)

Capriola dactylon (L.) Kuntze, Rev. Gen. Pl. 2 : 764.1891.

Bermuda Grass.

Panioum dactylon L. Sp. Pl. 1:58. 1753.

Cynodon dactylon Pers. Syn. 1: 85. 1805.

Ell. Sk. 1:133. Gray, Man. ed. 6, 654. Chap. Fl. 557. Scribner, Grass. Tenn. 2 : 86,

t. 29, f. 115 .

SOUTHERN EUROPE.

Naturalized in nearly all warmer regions.

Carolinian and Louisianian areas. Extensively spread in the valleys from Pennsylvania to Florida, west to Texas, sparingly on the Pacific coast. 
Arabama: Tennessee Valles. Central Pine belt. Most abundant from the prairie to the coast region. In light loamy and heavy alluvial soils. Perenuial.

Type locality: "Hab. in Europa anstrali."

Economic uses: Valuable pasture grass.

Herb. Geol. Surv. Herb. Mohr.

SPARTINA Schreb. Gen. 43. 1789.

(Trachynotia Michx. FI. Bor. Am. $1: 63.1803$. )

Seven species. Coarse, perennial marsh grasses of the warmer temperate zone. Nurth America, about 6 species.

Spartina stricta maritima (Walt.) Scribner, Mem. Torr. Club, 45. 1894.

Dactylis maritima Walt. Fl. Car. 77. 1788.

Salt Marsh Grass.

Spartina glabra Muhl. Gram. 54. 1817. 527.

Ell. Sk. 1:95. Gray, Man. ed. 6,627. Chap. Fl.556. Coulter, Contr. Nat. Herb. 2:

Carolinian area. Coast of New York and New Jersey to Florida, west to Texas.

Alabama : Coast plain. River marshes. Mobile County, estuary of Mobile River; Bayou Labatre, salt marshes. July to October; rare.

Type locality: South Carolina.

Herb. Geol. Surv. Herb. Mohr.

Spartina patens (Ait.) Muhl. Gram.55. 1817.

Dactylis patens Ait. Hort. Kew. 1 : 104. 1789.

Trachynotia juncea Michx. Fl. Bor. Am. 1:64. 1803.

Spartina juncea Ell. Sk. 1:94. 1817.

Gray, Mañ. ed. 6, 627. Chap. Fl.556. Coulter, Contr. Nat. Herb. $2: 527$.

Alleghenian, Carolinian, and Louisianian areas. Coast of southern New England, New York to Florida, west to Texas.

AlabaMa: Littoral belt. Deep salt marshes. Mobile and Baldwin counties; abundant, forming the chief growth of the saline marshes. July to August.

Type locality not ascertained. Mublenberg's locality: "Hab. in Carolina."

Herb. Geol. Surv. Herb. Mohr.

Spartina polystachya (Michx.) Ell. Sk. 1:95. 1817.

Salt ReEd Grass.

Trachynotia polystachya Michx. Fl. Bor. Am. 1:64. 1803.

Gray, Man. ed.6, 62. Chap. Fl 556.

Carolinian and Louisianian areas. Southern New England, coast of New York to Florida, west to Louisiana.

Alabama: Coast plain and Littoral belt. In fresh, brackish, and salt marshes.

Mobile County. Baldwin County, Bon Secour, salt marshes. July; common.

Type locality: "Hab. in inundatis maritimis, a Nova Anglia ad Floridam."

Herb. Geol. Surv. Herb. Mohr.

CAMPULOSUS Desv. Bull. Soc. Philom. 2 : 189. 1810.

(Ctenium Panzer, Denkschr. Acad. Muench. 1813, 288, t. 13. 1814.)

(MONOCERA Ell. Sk. 1 : 176. 1817.)

Seven species, warmer regions of the Eastern Hemisphere. South and North America, 4; southeastern United States, 1 species.

Campulosus aroma!icus (Walt.) Scribner, Mem. Bull. Torr. Club, 5 :45. 1894.

Aegilops aromatica Walt. Fl. Car. 249. 1788.

TOOTHACHE Grass.

Chloris monostachya Michx. Fl. Bor. Am. 1:59. 1803.

Monocera aromatica Ell. Sk. 1:177. 1817.

Ctenium americanum Spreng. Syst. 1:274. 1825.

Ell. Sk. 1. c. Gray, Man. ed.6, 654. Chap. F1.558.

Carolinian and Louisianian areas. Southern Virginia to North Carolina; Florida west to Louisiana.

Alabama: Mountain region. Central Pine belt to Coast plain. Sterile, dry, sandy, or damp and exsiccated soil. Sparingly in the open pine woods of a purely sandy soil in the Metamorphic hills. Lee County, Goldhill, about 800 feet. Abundant in the flat poor pine barrens along the coast. July to September. Perennial.

Type locality: South Carolina.

Herb. Geol. Surv. Herb. Mohr. 
CHLORIS Sw. Prodr. Veg. Ind. Occ, 25. 1788.

(Eustachys Desv. Bull. Philom. 2 : 188. 1810.)

Forty species of tropical and subtropical zones in Europe; North America, 8 species.

Chloris swartziana Doell in Mart. Fl. Bras. 2, pt.3:68. 1878. Swartz's Chloris.

Chloris petraea Sw. Fl. Ind. Occ. 1:195. 1797. Not Thunb.

Chap. Fl.557. Griseb. El. Brit. W. Ind. 539.

West Indies, Mexico to Argentina, South Africa.

Louisianian area. Florida, Louisiana, and Texas.

AlaBAMA: Littoral belt, damp grassy banks and copses, near the seashore, in sandy soil. Mobile County, West Fowl River, Dauphin Island. Baldwin County, Bon Secour, Point Clear. Not infrequent. Perennial.

Type locality: "On the rocky coast of Jamaica."

Herb. Geol. Surv. Herb. Mohr.

Chloris prieurii Kunth, Rev. Gram. $2: 441, t .134 .1835$.

Native of Tropical Africa.

Alabana: Fugitive on ballast. Mobile County, September, 1891 and 1892; not observed since. Collected also in North Carolina by Gerald McCarthy. Of this highly ornamental grass, Prof. F. Lamson-Scribner remarks: "It is an interesting species and is well inarked by the row of glands or tubercles on each side of the midrib of the flowering glumes. Similar glands occur upon the paleæ."

Type locality: "Crescit in Senegambia."

Herb. Geol. Surv. Herb. Mohr.

GYMNOPOGON Beauv. Agrost. 41. 1812.

Six species, warmer regions of America; ours perennials. Southern United States, 2 species.

Gymnopogon ambiguus (Michx.) B. S. P. Prel. Cat. N. Y. 1888.

Andropogon ambiguus Michx. Fl. Bor. Am. 1:58. 1803.

BROAD-Leaf GYMNOPOGON.

Gymnopogon racemosus Beauv. Agrost. 164. 1812.

Ell. Sk. 1:145. Gray, Man. ed. 6, 655. Chap. Fl. 556. Coulter, Contr. Nat. Herb.

$2: 529$. Scribner, Grass. Tenn. $2: 88, t .30, f .11 \%$.

Carolinian and Louisianian areas. Southern New Jersey to Florida, west to central Texas, Arkansas, and 'Tennessee.

Alabama : Central and Coast Pine belts. Dry open pine woods. Autauga County. Clarke County, Choctaw Corner. Escambia County, Wilson's Station. Mobile and Bald win counties. Common throughout the Coast Pine belt. July, August; frequent. Perennial.

Type locality: "Hab. in sabulosis Carolinae."

Herb. Geol. Surv. Herb. Mohr.

Gymnopogon brevifolius Trin. Unifl. 238. 1824.

Short-LeAF GymNopogon.

Gymnopogon racemosus var. filiformis Chap. Fl.556. 1860.

Louisianian area. Coast of New Jersey to Florida, west to Louisiana.

Alabama: Coast Pine belt. Coast plain. Dry sandy pine woods. Mobile County, Springhill. Baldwin County, Daphne. Escambia County. July to September; frequent with the last.

Type locality: "V.spp. e Delaware."

Herb. Geol. Surv. Herb. Mohr.

BOUTELOUA Lag. Var. Cienc. y Litt. 2, pt. 4 : 134. 1805.

(Atheropogon Muhl.; Willd.Sp.Pl. 4:937. 1805.)

Perennials. Abont 30 species; elevated continental table-land of Mexico and the Upper and Lower Sonoran areas of North America, 15.

Bouteloua curtipendula (Michx.) Torr. in Emory, Rep.153. 1848. Grama Grass. Chloris curtipendula Michx. Fl. Bor. Am. 1: 59. 1803.

Bouteloua racemosa Lag. Var. Cienc. y Litt. 2, pt. 4: 141. 1805.

Gray, Man. ed.6,656. Chap. Fl. Suppl.663; ed.3,607. Coulter, Contr. Nat. Herb. 2:533.

Mexico, Central America, Peru.

Alleghenian to Louisianian area. Ontario and Manitoba, south to Texas, east to Mississippi. 
Alabama: Central Prairie region. Open prairies, dry calcareous soil. Montgomery, Hale, and Dallas counties. Not infrequent. July to August.

Type locality: "Hab. in aridis regionis Illinoensis ad Wabast et in rupibus prairie du rocher."

Herb. Geol. Surv. Herb. Mohr.

ELEUSINE Gaert. Fruct. et Sem. 1:7, t.1. 1788.

Six species, tropical and subtropical regions of the Old World.

Eleusine indica (L.) Gaert. Fruct. et Sem. 1:8. 1788.

BarNyard Grass.

Cynosurus indicus L. Sp. Pl. 1: 72. 1753.

Ell. Sk. 1:176. Gray, Man. ed.6, 656. Chap. Fl. 558. Coulter, Contr. Nat. Herb.

$2: 533$.

Seribner, Grass.Tenn. $2: 90, t .30, f .120$.

Western Asia, East Indies, South Africa, all over temperate America AND SOUTH TO BRAZIL.

Alleghenian to Louisianian area. Naturalized in the States south of New England, northern Michigan, and Iowa.

Alabama: Over the State. Cultivated and waste places near dwellings. June to September. Common weed. Annual.

Type locality: "Hab. in Indiis."

Herb. Geol. Surv. Herb. Mohr.

Eleusine barcinonensis Costa, Ind. Sem. Hort. Barc. 1859.

Alabama: Ballast weed; adventive from Spain. Mobile County, observed for the past eight years. July to September. Annual.

Type locality: Spain ?.

Herb. Geol. Surv. Herb. Mohr.

DACTYLOCTENIUM Will. Enum.1029. 1809.

One species, a weed in the warmer parts of Asia, Africa, and Australia; West Indies to Argentina.

Dactyloctenium aegyptium (L.) Willd. Enum.1029. 1809. EgYPtian Gikass.

Cynosurus aegyptius L. Sp. Pl. 1:72. 1753.

Chloris mucronata Michx. Fl. Bor. Am. 1:59. 1803.

Eleusine aegyptiaca Pers. Syn. 1:87. 1805.

Ell. Sk. 1:176. Gray, Man. ed. 6,656. Chap. Fl. 558. Coulter, Contr. Nat. Herb. $2: 534$.

Louisianian area. Naturalized North Carolina to Florida, west to Texas.

Alabaya : Central Prairie region to Coast plain, cultivated ground, meadows.

June to August; common. Annual.

Type locality: "Hab. in Africa, Asia, America."

Economic uses: Of some value for hay.

Herb, Geol. Surv. Herb. Mohr.

LEPTOCHLOA Beauv. Agrost. 71. 1812.

Twelve species; warmer regions temperate North America, 1.

Leptochloa nucronata (Michx.) Kunth, Gram. 1:91. 1829-1835. Feather Grass. Eleusine mucronata Michx. Fl. Bor. Am. 1:65. 1803.

Ell. Sk. 1:175. Gray, Man. ed. 6, 657. Chap. Fl. 558. Coulter, Contr. Nat.

Herb. 2:534. Scribner, Grass. Tenn. 2:91, t. 31, f. 121 .

China, East Indies, West Indies, Mexico to Venezuela.

Carolinian and Louisianian areas. Southern Virginia to Florida, west to Texas; Arkansas, southern Missouri, southern Illinois, and Tennessee.

Alabama: From the Coast plain to the Central Pine belt. Sandy fields. Most frequent near the coast. June to July, frequent. Annual.

Type locality: "Hab. in cultis Illinoensibus."

Herb. Geol, Surv. Herb. Mohr.

DIPLACHNE Beanv. Agrost. 80, t. 16, f. 9. 1812.

Fourteen species, warmer regions of both hemispheres.

Diplachne fascicularis (Lam.) Beauv. Agrost. 160. 1812.

Festuca fascicularis Lam. Tabl. Encycl. 1: 189. 1791. 
F. polystachya Michx. Fl. Bor. Am. 1:66. 1803.

Leptochloa fascicularis Gray, Man. 588. 1848.

Gray, Man. ed. 6, 658. Chap. Fl. 559.

West Indies, Mexico, Colombia.

Carolinian and Louisianian areas. Coast of Rhode Island, New York to Florida and Louisiana.

Alabama : Littoral belt. Salt marshes. Mobile County, Dauphin Island. June to July; rare. Perennial.

Type locality: "Ex Amer. merid. Comm. D. Richard."

Herb. Geol. Surv. Herb. Mohr.

PHRAGMITES Trin. Fund. Agrost. 134. 1820.

Three species, temperate and tropical regions, Europe, Asia, and America.

Phragmites phragmites (L.) Karst. Deutsche Fl.379. 1880-1883.

REED.

Arundo phragmites L. Sp. Pl. 1:81. 1753.

Phragmites communis Trin. Fund. Agrost. 134. 1820.

Gray, Man. ed. 6, 658. Chap. Fl. 567. Coulter, Contr. Nat. Herb. 2:537.

Throughout the temperate zones of the Old World, and over the North American continent to Central America.

Canadian zone to Louisianian area, thence to the Pacific coast.

Alabama: Scattered over the State. Abundant in the marshes of the coast region,

Mobile County, river delta. August to October. Perennial.

Type locality: "Hab. in Europae lacubus, fluviis."

Herb. Geol. Surv. Herb. Mohr.

SIEGLINGIA Bernh. Syst. Verz. Pfl. Erl.40. 1800.

(Triodia R. Br. Prodr. Fl. N. Holl. 1 : 182. 1810.)

('Tricuspis Beauv. Agrost. 77. 1812.)

About 27 species, of temperate zones. North America 17, mostly of the Sonoran continental plains.

Sieglingia purpurea (Walt.) Kuntze, Rev. Gen. Pl. 2 : 789.1891.

SAND GRass.

Aira purpurea Walt. Fl. Car. 78. 1788.

Uralepis purpurea Nutt. Gen. 1:62. 1818.

Tricuspis purpurea Gray, Man.589. 1848.

Triplasis purpurea Chap. Fl.560. 1860.

Ell. Sk. 1:152. Gray, Man. ed. 6, 658. Chap. Fl.560. Coulter, Contr. Nat. Herb. 2:539.

Alleghenian to Louisianian area. Southern New England, Ohio, Michigan, Illinois, and New York; south along the coast to Florida and Texas.

Alabama: Littoral belt. Drifting sands on the seashore. Baldwin County, eastern shore of Mobile Bay. July to Angust; frequent; annual.

Type locality: South Carolina.

Herb. Geol. Surv. Herb. Mohr.

Sieglingia americana (Beauv.) Kuntze, Rev. Gen. Pl. 2 : 789.1891.

Triplasis americana Beauv. Agrost. 81, t. 16, f. 10. 1812.

SOUTHERN SAND GRASS.

Uralepis cornuta Ell. Sk. 1:580. 1817.

Louisianian area. Coast of North Carolina to Florida, Mississippi, and Louisiana.

Alabama : Lower Pine belt and Littoral belt. Loose sands. Mobile County, Springhill, on barren pine ridges; Dauphin Island. Drifting sands on the seashore. Baldwin County, shore Bon Secour Bay. July to September; not rare. Perennial.

Type locality: "Ce savant l'a raportée des Etats Unis d'Amerique."

Herb. Geol. Surv. Herb. Mohr.

Sieglingia stricta (Nutt.) Kuntze, Rev. Gen. Pl. 2 : 789. 1891.

NARROW-SPIKED SIEgLINGIA.

Windsoria stricta Nutt. Trans. Am. Phil. Soc. ser. 2, 5 : 147. 1833-1837.

Triodia stricta Vasey, Spec. Rep. U. S. Dept. Agr. 63: 35. 1883.

Coulter, Contr. Nat. Herb. 2 :538. Britt. \& Brown. Ill. Fl. 1: 185, f. 422. Chap. Fl. ed. 3,610 .

Carolinian and Louisianian areas. Mississippi, Louisiana to Texas, Arkansas and Kansas.

Allabama: Central Prairie belt. Wileox County (S. B. Buckley). July; rare. Perennial. 
In our plant spikelets 4 to 6 flowered, lower glumes extending beyond the flowering scales.

Type locality not ascertained.

Herb. Geol. Surv. Herb. Mohr.

Sieglingia ambigua (Ell.) Knntze, Rev. Gen. Pl. 2 : 789. 1891.

Poa ambigua Ell. Sk. 1 : 165. 1817.

ROUND-SPIKKD SIEGLINGIA.

Tricuspis ambigua Chap. Fl. 559.

Triodia ambigua Vasey, Cat. Grass. 66. 1885.

Ell. Sk. 1. c. Coulter, Contr. Nat. Herb. $2: 539$.

Louisianian area. South Carolina, Georgia, Florida, west to Texas.

Alabama : Coast plain. Low swampy pine barrens. Mobile and Baldwin counties. Not rare; July to Angust. Perennial.

Type locality: "Found in the mountains of Carolina, by Dr. Macbride, and in the lower country of Georgia, by Dr. Baldwin."

Herb. Geol. Surv. Herb. Mohr.

Sieglingia chapmani Small, Bull. Torr. Club, 22:365. 1895.

Louisianian area. Georgia and Florida to Texas.

Chapman's Sieglingia.

AlabaMa : Coast plain. Mobile, dry knolls, with Chrysopogon nutans linnaeanus, October 18, 1896. Rare. Perennial.

Type locality: "Growing in sand on the slopes of Currahee Mountain, near Toccoa, Georgia, and along the Yellow River, Gwinnett County, in the same State." Herb. Geol. Surv. Herb. Mohr.

Sieglingia sesleroides (Michx.) Scribner, Mem. Torr. Club, 5 :48. 1894.

Poa sesleroides Michx. Fl. Bor. Am. 1:68. 1803.

False Redtor.

P. quinquefida Pursh, Fl. Am. Sept. 81. 1814.

Triodia cuprea J. F. Jacq. Eclog. Gram. $2: 21.1814$.

Tricuspis sesleroides Torr. Fl. N. \& Mid. U. S. 1:118. 1824.

Ell. Sk. 1: 164. Gray, Man. ed.6, 657. Chap. Fl. 559. Conlter, Contr. Nat. Herb. 2 : 539. Vasey, Agr. Grass. (1884) 85, pl. 82. Scribner, Grass. Tenn. 2: 94, pl. 31, f. 122.

Carolinian area. Southern Now York to Missouri, south to Florida and Texas, Indian Territory.

Alabama: Over the State. Dry borders of woods and fields. July; common. Perennial.

Type locality: "Hab. in regione Illinoensi et in montosis Carolinae."

Herb. Geol. Surv. Herb. Mohr.

EATONIA Raf. Journ. Phys. 89 : 104. 1819.

(REBOULEA Kunth, Rev. Gram. Suppl.20. 1829-1835.)

Three or 4 species, perennials. Eastern United States.

Eatonia obtusata (Michx.) Gray, Man. ed. 2, 558, 1856.

Farly Eatonia.

Aira obtusata Michx. Fl. Bor. Am. 1:62. 1803.

A. trunctata Muhl. Gram. 83. 1817.

Reboulea trunctata Gray, Man. 591. 1848.

Ell. Sk. 1:153. Gray, Man. ed. 6, 659. Chap. Fl. 560. Coulter, Contr. Nat. Herb. $2: 544$. Scribner, Grass. Tenn. $2: 100, t .34, f .134$.

Alleghenian, Carolinian, and Louisianian areas. Ontario to Saskatchewan; New York to Michigan, Minnesota, Illinois, and southern Missouri; from New York south to Florida and west to Texas, Arkansas, and Arizona; on the Pacific coast, Oregon and British Columbia.

Alabama: Tennessee Valley. Lower hills to Coast plain. Dry banks, borders of fields and pastures, frequent. Common near the coast. Mobile County. April and May.

Type locality: "Hab. in aridis, a Carolina ad Floridam"

Herb. Geol. Surv. Herb. Mohr.

Eatonia pennsylvanica (DC.) Gray, Man. ed.2,558. 1856.

Koeleria pennsylvanica DC. Hort. Monsp. 117. 1813.

Aira triflora Ell. Sk. 1:153. 1817.

Aira mollis Muhl. Gram. 82. 1817.

Ell. Sk. 1. c. Gray, Man. ed. 6, 660. Chap. Fl. 560. Coulter, Contr. Nat. Herb. 2 :544.

Scribner, Grass. Tenn. 2 : 99, t. $34, f .133$. 
Boreal region to Carolinian area. New Brunswick, Ontario to Lake Superior and Hudson Bay; New England, Ohio Valley to Missouri; south along the mountains from New York to Georgia, north western Texas and Arkansas.

Alabama: Mountain region. Damp shady woods. Dekalb County, Lookout Mountain, 1,800 feet. Madison County, Montesano, 1,500 feet. Winston County, banks of Sipsey fork, 1,500 feet. Not rare.

Type locality : Pennsylvania?

Herb. Geol. Surv. Herb. Mohr.

Eatonia filiformis (Chap.) Vasey, Bot. Gaz. I1:117. 1886.

Slender Eatonia.

Eatonia pennsylvanica var. filiformis Chap. Fl.560. 1860.

Aira mollis var. Ell. Sk. 1 : 154.1817.

Scribner, Grass. Tenn. 2:99, t. 33, f. 132.

Carolinian and Lonisianian areas. Southern Tennessee, coast of South Carolina to Florida, west to Mississippi.

Alabama: Coast Pine belt, Mountain region. Dry sandy open pine woods. Lee County, Auburn (Baker \& Earle, 607). Mobile County, Springhill. Baldwin County. March to April; not infrequent.

Type locality: "Dry pine barrens, Florida to South Carolina."

Herb. Geol. Surv. Herb. Mohr.

Eatonia nitida (Spreng.) Nash, Bull. Torr. Club, 22:511. 1895.

Slender Glossy Eatonia.

Aira nitida Spreng. Fl. Hal. Mant. 1 : 32. 1807.

Eatonia dudleyi Vasey, Bot. Gaz. 11:116. 1886.

Gray, Man. ed. 6, 660. Britt. \& Brown, Ill. Fl. 1:192. Chap. Fl. ea. 3, 614.

Carolinian and Lonisianian areas. Southern New York, New Jersey, and south to Georgia and Mississippi.

Alabama : Mountain region to Upper division of Coast Pine belt. Dekalb County, near Mentone, 1,800 feet. Madison County, Montesano, 1,500 feet. Lee County, Auburn (Baker \&. Earle, 621). Clarke County, Choctaw Corner. St. Clair County, near Ashville. Flowers in June; not rare in dry rocky woods and copses.

Type locality: "E Pensylvania. Muehlenb."

Herb. Geol. Surv. Herb. Mohr.

ERAGROSTIS Beauv. Agrost. 70. 1812.

About 100 species in all warmer countries, principally in the tropical and subtropical zones. North America 17, chiefly southern.

Eragrostis hypnoides (Lam.) B. S. P. Prel. Cat. N. Y.69. 1888.

Poa hypnoides Iam. Tabl. Encycl. 1 : 185. 1791.

Creeping Meadow Grass.

$P$. reptans Michx. Fl Bor. Am. 1:69, t.11. 1803.

Eragrostis reptans Nees in Mart. Fl. Bras. 2:514. 1829.

Ell. Sk. 1:163. Gray, Man. ed. 6, 660. Chap. Fl. 563. Coulter, Contr. Nat. Herb.

$2: 543$. Scribner, Grass. Tenn. $2: 95, t$. 31, f. 123. Griseb. Fl. Brit. W. Ind. 532.

West Indies, Mexico, Argentina.

Alleghenian to Louisianian area. Ontario and New England, west to Minnesota and Nebraska, south to Florida, west to 'Texas, Arkansas, Missouri, California, and Washington.

Alabama: Central Prairie region. Coast plain, alluvial banks. Montgomery County. Mobile County, Choctaw Bluff, banks of Alabama River. August to September; not frequent. Annual.

Type locality: "Ex America merid. Comm. D. Richard."

Herb. Geol. Surv. Herb. Mohr.

Eragrostis eragrostis (L.) Karst. Deutsch. Fl.389. 1880-1883. Low EraGrostis.

Poa eragrostis L. Sp. Pl. 1:68. 1753.

Eragrostis minor Host, Fl. Aust. 135.1827.

E. poaeoides Beauv. Agrost. 162. 1812.

Gray, Man. ed. 6, 660. Wats. Bot. Calif. 2 : 315.

Southern Europe, western Asia, Africa, West Indies, Brazil.

Alleghemian, Carolinian, and Louisianian areas. Naturalized. Ontario and New York, west to Illinois, Missouri, and Arkansas, and south to Tennessee, Florida, and Texas.

Alabama : Mobile, adventive in cultivated and waste places, about dwellings; ballast heaps. Angust to October; rare. Annual.

Type locality: "Hab. in Italia supra nuros."

Herb. Geol. Surv. Herb. Mohr. 
Eragrostis major (L.) Host, Gram. Austr. 4. 1809.

Briza eragrostis L. SP. Pl. 1:70. 1753.

Eragrostis poaeoides megastachya Gray, Man. ed. 5, 631. 1867.

Ell. Sk. 1:165 Gray, Man. ed. 6, 660. Chap. Fl. 563 Wats. Bot. Calif. 2 : 315.

Coulter, Contr. Nat. Herb. 2: 543. Scribner, Grass. Tenn. 37, $t .31, f$. 124 .

Central Europe, Asia, Africa.

Alleghenian to Louisianian area. Ontario and New England, west to Illinois, Missouri, Minnesota, and Nebraska, from New York to Florida, and west to Texas, Arkansas, and California.

Alabaya : Tennessee Valley. Mountain region to Coast plain. In cultivated and waste gronnd about dwellings. Lauderdale, Cnllman, Tuscaloosa, Hale, Choctaw, and Mobile counties. A frequent garden weed. Annual.

Type locality: "Hab. in Europa australi."

Herb. Geol. Surv. Herb. Mohr.

Eragrostis bahiensis Schult. Mant. 2:318. 1824.

Poa bahiensis Schrad.; Schult. Mant. 2:318. 1824. As synonym.

Griseb. Fl. Brit. W. Ind. 532.

IN ALL TROPICAL COUNTRIES.

Louisianian area.

Alabama : Adventive from the tropies. Mobile County, on ballast, fairly established for the past six years near the shipping. Perennial?

Type locality : "In Brasilia."

Herb. Geol. Surv. Herb. Mohr.

Eragrostis purshii Schrad. Linnaea, 12:454. 1838.

SOUTHERN SPEAR Grass.

Poa caroliniana Spreng. Mant. Fl. Hal. 33. 1807.

Eragrostis caroliniana Seribner, Mem. Torr. Club 5:49. 1894.

Eragrostis pilosa Muhl. Gram. 141. 1817. Not Beauv.

Gray, Man. ed. 6, 661. Chap. Fl. 563. Scribner, Grass. Tenn. 2 : 97, t. 32, f. 126.

Mexico.

Alleghenian to Louisianian area. Ontario, New York, Pennsylvania, and New Jersey, south to Florida, Tennessee, and Lonisiana, and west to Minnesota, Nebraska, Colorado, Nevada, New Mexico, and Arkansas.

Alabama: Over the State. Dry sandy open places. Cullman County, 800 feet. Morgan County, Decatur. Tuscaloosa, Montgomery, and Mobile counties. Abundant, particularly in the sandy fields of the Lower Pine belt. Annual.

Type locality: "America borealis."

Herb. Geol. Surv. Herb. Mohr.

Eragrostis pilosa (L.) Beauv. Agrost. 162. 1812.

Slender Meadow Grass.

Poa pilosa L. Sp. Pl. 1:68. 1753.

Gray, Man. ed. 6, 660. Coulter, Contr. Nat. Herb. 2:543. Scribner, Grass. Tenn.

2: $96, t .32, f .12 \%$.

Widely diffused in the temperate and tropical regions of the globe.

Eurofe, West Indies, Mexico to ARgentina.

Alleghenian to Lonisianian area. Naturalized New York and Pennsylvania, and west to Missouri, Tennessee, Mississippi, and Texas.

Alabama: Waste and cultivated places. Mobile County, August, 1891. Washington Count5, Yellowpine. Not frequent. Annual.

Type locality: "Hab. in Italia."

Herb. Geol. Surv. Herb. Mohr.

Eragrostis nitida (Ell.) Chap. Fl. 564. 1860.

Glossy Eragrostis.

Poa nitida Ell. Sk. 1:162. 1817.

Louisianian area. South Carolina, Florida, and Alabama.

Alabama: Littoral belt. Lower Pine belt. Baldwin County, drifting sands, near the bay shore at Howards. July, rare. Annual.

Type locality: "Grows in cultivated land. Common on Paris Island."

Herb. Geol. Surv. Herb. Mohr.

Eragrostis secundiflora Presl, Rel. Haenk. 1:276. 1830. PURple Love Grass.

Poa interrupta Nutt. Trans. Am. Phil. Soc. 5 : 146. 1835-1837. Not Lam.

P. oxylepis Torr. in Marcy, Expl. Red Riv. 269, t. 19. 1854.

Eragrostis oxylepis Torr. Pac. R. R. Rep. 4:156. 1857.

Vasey, Illust. Am. Grass. 1, pt. 2: $t$. 48. Coulter, Contr. Nat. Herb. $2: 542$. Britt. \& Brown, Ill. Fl. 1:191. Chap. Fl. ed.3,615. 
Mexico, Central America.

Carolinian and Louisianian areas. Southern, middle, and southwestern Tennessee to Texas and Arizona, and east along the Gulf coast to Alabama.

Alabama : Central Prairie region to Coast plain. Autauga County, Prattville. Adrentive with some other plants of the Southwest. Mobile County, bay shore at

Cedar Point. July. Rare. Annual.

Type locality: "Hab. in Mexico."

Herb. Geol. Surv. Herb. Mohr.

Eragrostis pectinacea (Michx.) Steud. Syn. Pl. Gram. 272. 1855.

Purple Eragrostis.

Poa pectinacea Michx. Fl. Bor. Am. 1: 69. 1803.

P. hirsuta Ell. Sk. 1:157. 1817. Not Michx. 1803.

Gray, Man. ed. 6, 661. Chap. Fl.564. Coulter, Contr. Nat. Herb. 2:542. Scribner, Grass. Tenn. 2: $98, t .33, f .131$.

Alleghenian to Louisianian area. Coast of sonthern Massachusetts and in New York, west to Minnesota and Nebraska, and south to Florida and 'Texas.

Alabama : From the Tennessee Valley to the Coast plain. Common and most abundant on sandy pine barrens. Mobile County. August to October. Perennial.

Type locality : "Hab. in arvis Illinoensibus."

Herb. Geol. Surv. Herb. Mohr.

Eragrostis refracta (Muhl.) Scribner, Mem. Torr. Club, 5 : 49. 1894.

MEadow Eragrostis.

Poa refracta Muhl. Gram.146. 1817.

Eragrostris campestris Trin. Bull. Sci. Acad. St. Petersb. 1: 70. 1836.

E. pectinacea var. refracta Chap. Fl.564. 1860.

Ell. Sk. 1:162. Gray, Man. ed.6, 661. Chap. Fl. 564. Coulter, Contr. Nat. Herb. $2: 542$.

Carolinian and Louisianian areas. Delaware, Maryland, and North Carolina to

Florida, west to Texas.

Alabama: Coast plain. Damp flat pine barrens. Mobile County. September; common. Perennial.

Type locality : "Hab. in Carolina."

Herb. Geol. Surv. Herb. Mohr.

Eragrostis lugens Nees in Mart. Fl. Bras. 2:505. 1829.

Coulter, Contr. Nat. Herb. 2 :542. Vasey, Illust. Am. Grass. 1, pt. $2: t$. $4 \%$.

Mexico, (?) Brazil, Montevideo.

Louisianian area. Arizona and Texas to Alabama and Florida.?

Alabama: Adventive with ballast. Mobile. July to September, 1893-94. Annual or perennial.?

Type locality: "Hab. ad Monte-Video et in confinibus Paraguayani, (Sellow.)"

Herb. Geol. Surv. Herb. Mohr.

Eragrostis ciliaris (L.) Link, Hort. Berol. 1:192. 1827.

Fringed Eragrostis.

Poa ciliaris L. Syst. ed. 10, 875. 1759.

Megastachya ciliaris Beauv. Agrost. 74. 1812.

Chap. Fl. 563. Griseb. Fl. Brit. W. Ind.532.

Tropical regions of the Old and New Worlds. Arabia, Africa, Galapagos, West INdies to BraziL.

Louisianian area. South Carolina to Florida, west to Mississippi.

Alabama: Coast plain. Sandy fields, waste places. Mobile County. September and October; frequent. Not remote from dwellings. Probably naturalized from the tropics. Annual.

Type locality : Jamaica?

Herb. Geol. Surv. Herb. Mohr.

Eragrostis glomerata (Walt.) L. H. Dewey, Contr. Nat. Herb. 2 :543. 1894.

Poa glomerata Walt. Fl. Car. 80. 1788.

DENSELY SPIKED ERAgrostis.

P. conferta Ell. Sk. 1:158. 1817.

Eragrostis conferta Trin. Mem. Acad. St. Petersb. ser. 6, 1: 409. 1831.

Ell. Sk. l. c. Chap. Fl. 563. Griseb. Fl. Brit. W. Ind. 533. Coulier, Contr. Nat. Herb. 2 : 543.

West Indies, Mexico to BraziL.

Louisianian area. South Carolina to Florida, west to Texas and Arkansas. 
Alabama : Central Prairie region. Coast plain. Damp grassy places, banks of streams. Mobile County. Autanga County, Prattville. July to August; not rare. Annual.

Type locality: South Carolina.

Herb. Geol. Surv. Herb. Mohr.

Eragrostis capillaris (L.) Nees in Mart. Fl. Bras. 2 : 505. 1829.

LACE Grass.

Poa capillaris L. Sp. Pl. 1:68. 1753.

Gray, Man. ed. 6, 661. Chap. Fl.564. Coulter, Contr. Nat. Herb. $2: 542$.

MeXico, Brazil.

Alleghenian, Carolinian, and Jouisianian areas. New York and Pennsylvania, west to Iowa, Missouri, and Tennessee; sonth to Florida, and west to Texas and Arkansas.

Alabama : Central Pine belt to the Coast Plain. Dry sandy hills, borders of fields and roadsides. Autauga County, Prattville (E. A. Smith). Monroe County, Claiborne. Clarke County, Thomasville. Mobile and Baldwin counties. June, July; frequent. Perennial.

Type locality: "Hab. in Virginia, Canada, D. Kalm."

Herb. Geol. Surv. Herb. Mohr.

Eragrostis hirsuta (Michx.) Nash, Bull. Torr. Club, 23:98. 1896.

Poa hirsuta Michx. Fl. Bor. Am. 1:68. 1803.

ROUGH-HAIRY ERAGRostis.

Lonisianian area. Carolina to Florida.

A stonter and larger plant than the above, with which it has been confounded, 3 feet and over high, leaves longer than the culm, with sheaths hairy; panicle ample, wide-spreading; spikelets scattered, loug pedicellate, 4 to 5 flowered.

Alabama : Central Prairie region. Coast plain. Waste places, roadsicles. Mobile County, near dwellings. Autanga County, Prattville (E.A.Smith). September to November. Perennial.

Type locality: "Hab. in Carolina inferiore."

Herb. Geol. Surv. Herb. Mohr.

MELICA L.Sp. Pl. 1:66. 1753.

Over 30 species, perennials, in the temperate zones of the Old World and America. North America, 12.

Melica mutica Walt. Fl. Car. 78. 1788.

HONEY Grass.

Melica glabra Michx: Fl. Bor. Am. 1:62. 1803. In part.

Melica mutica var. glabra Gray, Man. ed. 5, 626. 1867.

Ell. Sk: 1:154. Gray, Man. ed.6,662. Chap. Fl. 560. Coulter, Contr. Nat. Herb. $2: 545$.

Carolinian and Louisianian areas. Ohio Valley from West Virginia to Missouri aud Arkansas, south to Florida and Texas.

Alabama : Mountain region to Coast plain. Rich open woods and copses. Lee County, Auburn (Underwood \& Earle). Tuscaloosa County. Baldwin County, Point Clear.

Type locality : South Carolina.

Herb. Geol. Surv. Herb. Mohr.

UNIOLA L.Sp. Pl. 1:71. 1753.

Five species, perennials; eastern North America, 4.

Uniola paniculata L. Sp. Pl. 1:71. 1753.

Sea OATS.

Uniola maritima Michx. Fl. Bor. Am. I: 71. 1803.

Ell. Sk. 1:166. Gray, Man. ed. 6, 662. Chap. Fl. 566. Coulter, Contr. Nat. Herb. $2: 545$.

Southern Mexico, Panama, Ecuador.

Lousianian area. Southern Virginia and North Carolina to Florida, thence west to Texas.

Alabama : Littoral region. Drifting sands (dunes) on the seashore. Mobile and Baldwin counties. July, August. Frequent.

'Type locality: "Hab. in Ce":olina."

Herb. Geol. Surv. Herb. Mohr.

Uniola latifolia Michx. Fl. Bor. Am. 1: 70. 1803.

Ell. Sk. 1:167. Gray, Man. ed.6,663. Chap. Fl. 566. Coulter, Contr. Nat. Herb. 
Carolinian and Louisianian areas. Southern Pennsylvania, southern Illinois, and Missouri, south to Florida, west to Texas and Arkansas.

Alabama : Central Prairie belt to Tennessee Valley. Rich wooded banks, shaded borders of streams. Morgan County. Blount County, banks of Mulberry River. Lee County, Auburn. Tuscaloosa County (E. A.Smith).' 'Tallapoosa and Montgomery counties. Dallas County. Wilcox County, Allenton. June, July; frequent.

Type locality: "Hab. in occidentalibus montium Alleghanis."

Herb. Geol. Surv. Herb. Mohr.

Uniola laxa (L.) B. S. P. Prel. Cat. N. Y. 69. 1888.

SLENDER SPIKE-GRASS.

Holcus laxus L. Sp. Pl. 2 : 1048. 1753.

Uniola gracilis Michx. Fl. Bor. Am. 1: 71. 1803.

Ell. Sk. 1:168. Gray, Man. ed. 6,663. Chap. Fl.566. Coulter, Contr. Nat. Herb.

2:545. Scribner, Grass. Tenn. $2: 101, t .35, f .138$.

Carolinian and Louisianian areas. Southern New York, Pennsylvania, and New Jersey, south and west to Florida, Texas, Arkansas, and Tennessee.

Alabama : Tennessee Valley to the Coast plain. Sandy shaded swamps; common all over the Central and Coast Pine belts. July to September.

Typo locality: "Hab. in Virginia, Canada."

Herb. Geol. Surv. Herb. Mohr.

Uniola longifolia Scribner, Bull. Torr. Club, 21:229. 1894.

Chap. Fl. ed. 3, 617 .

LONG-LEAF SPIKE-GRASS.

Louisianian area. Mississippi.

ArabaMa: Mountain region and Coast plain. Low shady places. Lee County, Auburn (Baker \& Earle, 653). Mobile County (T. H. Kearney), July, 1895. Not rare.

Type locality: "Little Stone Mountain, Dekalb County, Georgia, July (John K. Small)," and other localities in Florida, Mississippi, and Tennessee.

Herb Geol. Surv. Herb. Mohr.

Uniola nitida Baldwin; Ell. Sk. 1 : 167. 1817.

Louisianian area. South Carolina to Florida and Mississippi.

Alabama : Lower Pine region and Coast plain. Sandy wet borders of brooks. Mobile County, West Fowl River; Bayou Sara, shaded swampy banks of creek. Not frequent.

Type locality: “Grows at Crooked River bridge, Camden County, Ga.

Herb. Geol. Surv. Herb. Mohr.

DISTICHLIS Raf. Journ. Phys. 89 : 104. 1819.

Two or 3 species, perennials, North America. Saline swamps of the seacoast and alkaline plaius in the interior.

Distichlis spicata (L.) Greene, Bull. Calif. Acad. 2 :415. 1887.

Uniola spicata L. Sp. Pl. 1:71. 1753.

Distichlis maritima Raf. Journ. Phys. 89 :104. 1819.

Brizopyrum spicatum Hook. \& Arn. Bot. Beech. 403. 1840.

Ell. Sk. 1:166. Gray, Man. ed. 6, 663. Chap. Fl. 562. Coulter, Contr. Nat. Herb.

2:546. Wats. Bot. Calif. $2: 306$.

Australia.

Carolinian and Louisianian areas. Coast of New York to Florida, west to Texas. On the Pacific slope, Vancouver Island to California.

Ala Bama : Littoral belt. Salt marshes of the seashore; abundant.

Type locality: "Hab. in Americae borealis maritimis."

Herb. Geol. Surv. Herb. Mohr.

BRIZA L. Sp. P1. 1:70. 1753.

Twelve species, of temperate regions of Europe and Asia.

Briza media L. Sp. Pl. 1:70. 1753.

QUAKING Grass.

Introduced and escaped from cultivation in the Atlantic States from Ontario southward.

Alabama: In several localities in northern and southern parts. Cullman and Mobile counties. Annual.

Type locality: "Hab. in Europae pratis siccioribus."

Herb. Geol, Surv. Herb. Mohr. 
Briza minor L. Sp. Pl. 1 : 70. 1753.

Smaller Quaking Grass.

EUROPE, TROPICAL AMERICA.

Carolinian and Louisianian areas. From New Jersey southward. Adventive and more frequently naturalized than the above.

Alabama : Coast plain. Dry grassy places, roadsides, pastures. Mobile County. May, June. Not rare. Annual.

Type locality: "Hab. in Helvetia, Italia."

Herb. Geol. Surv. Herb. Mohr.

DACTYLIS L.Sp. Pl. 1:71. 1753.

One species, Enrope, temperate Asia, North Africa. Naturalized in North America.

Dactylis glomerata L. Sp. Pl. 1 : 71. 1753.

Fll Sk. 1.155. Gras $2: 104, t .35, f .140$.

Alleghenian to Louisianian area. From Canada to the Gulf.

Alabaima: Over the State. Cultivated and rarely escaped. Perennial.

Type locality: "Hab. in Enropae cultis ruderatis.

Economic uses: Valuable hay crop.

Herb. Geol. Surv. Herb. Mohr.

POA L. Sp. Pl. 1:67. 1753.

About 100 species, cooler and temperate regions of both hemispheres. United States, 35 to 40 .

Poa annua L. Sp. Pl. 1 : 68. 1753.

Spear Grass. Six-wéks Grass.

Ell. Sk. 1:158. Gray, Man. ed. 6, 664. Chap. Fl. 562. Wats. Bot. Calif. $2: 311$. Scribner, Grass. Tenn. $2: 106, t .36, f .141$.

MeXico, Brazil.

Naturalized throughout the continent from Hudson Bay to the Gulf of Mexico, and from the Atlantic to the Pacific coast.

Alabama : All over the State. A winter annual, common in waste places and dooryards. Flowers at Mobile in February; disappears with the advent of summer.

Type locality: "Hab. in Europa ad vias."

Herb. Geol. Surv. Herb. Mohr.

Poa chapmaniana Scribner, Bull. Torr. Club, 21 : 38. 1894.

Poa cristata Chap. Fl.562. 1860. Not Walt.

Chap. Fl. 1. c. Scribner, Grass. Tenn. 2:107, t. 36, f. 142.

Carolinian and Louisianian areas. Central Tennessee to middle Florida.

Alabama: Mountain region. Central Prairie belt. Dry sandy places, borders of fields, roadsides. Cullinan County, 800 feet. Montgomery County. April; not infrequent. Annual.

In small tufts, stems erect.

Type locality of Poa cristata Chap.: "Dry soil around Quincy, middle Florida."

Herb. Geol. Surv. Herb. Mohr.

Poa compressa L. Sp. Pl. 1:69. 1753.

Evglish Blue Grass.

Gray, Man. ed. 6, 664. Chap. Fl. 563. Seribner, Grass. Tenn. 2 : 107, t. 36, f. 143.

Alleghenian to Louisianian area. Considered indigenous in the mountain region of Pennsylvania, northwestern Minuesota, and Nebraska. Naturalized throaghout Nova Scotia, New Brunswick, Ontario, and Atlantic States to the Mississippi.

Alabama: Tennessee Valley. Mountain region to Central Prairie belt, in dry sandy and loamy soil. Cullıan, Tuscaloosa, Hale, and Montgomery counties. May, Juñe; frequent. Perennial.

Type locality: "Hab. in Europae et Americae septentrionalis siccis."

Economic uses: Valuable pasture grass.

Herb. Geol. Surv. Herb. Mohr.

Poa pratensis L. Sp. Pl. 1:67. 1753.

Poa viridis Muhl. Gram. 138. 1817.

Ell. Sk. 1:159. Gray, Man. ed. 6, 665. Chap. Fl.562. Scribner, Grass. Tenn. 2 : 108, t. $36, f .144$.

EUROPE.

Boreal zone to Louisianian area. Indigenons in the mountains of Pennsylvania and northward. Naturalized in the Eastern United States. 
Alabama: Tennessee Valley. Mountain region. Cultivated and rarely escaped to border of fields and meadows. Cullman County. June. Perennial.

Type locality: "Hab. in Europae pratis fertilissimis."

Economic uses: Important pasture and meadow grass.

Herb. Geol. Surv. Herb. Mohr.

Poa trivialis L. Sp. P1. 1:67. 1753.

Rovgh-stalked Meadow Grass.

Gray, Man. ed. 6, 665. Scribner, Grass. Tenn. $2: 108, t .3 \%, f .145$.

Europe, Caucasus, Siberia.

Alleghenian to Lonisianian area. Canada, throughout the Eastern States, and along the mountains south ward to Georgia. Most probably introduced.

Alabama: Tennessee Valley. Mountain region. Madison County, Huntsville.

Cullman County. June; rare. Perennial.

Type locality: "Hab. in Europae, pascuis."

Economic uses: Meadow and pasture grass.

Herb. Geol. Surv. Herb. Mohr.

Poa sylvestris Gray, Man.596. 1848.

Woodland Blue Grass.

Gray, Man. ed. 6, 665. Chap. Fl. Suppl. 663; ed.3,615. Scribner, Grass. Tenn.

$2: 109, t .37, f .147$.

Alleghenian and Carolinian areas. Western New York, western Illinois, Missouri, Wisconsin, Kansas, Arkansas, and 'Tennessee.

Alda lbama : Mountain region. Coosa hills. Calhoun County, mountainous woods near Anniston, 900 feet. Madison County, Montesano, 1,000 feet. Infrequent. Perenniaî.

Type locality: "Rocky banks and meadows, Ohio (and Kentucky), Short! Sullivant! Michigan, and southwestward."

Herb. Geol. Surv. Herb. Mohr.

Poa autumnalis Muhl.; Ell. Sk. 1:159. 1817.

Bending Spear Grass.

Poa flexuosa Muhl. Gram. 148. 1817. Not J. E. Smith. 1803.

Ell. Sk. 1:159. Gray, Man. ed. 6, 666. Chap. Fl. 562. Scribner, Grass. Tenn. $2: 109, t .37, f .146$.

Carolinian and Louisianian areas. Southern New York, Pennsylvania, West Virginia, Kentucky, Tennessee; hill country of North Carolina to middle Florida, west to Texas.

Alabama: Tennessee Valley to Central Prairie belt. In rich shady woods, hillsides. Morgan County. Winston County, Collins Creek, 1,200 feet. Cullman County. Lee County, Auburñ (Baker \& Earle). Montgomery County, Pentulala Creek, 350 feet. April, May. Frequent. Perennial.

Type locality: "From specimens sent by Mr. Herbemont, from Columbia. Found in Georgia by Dr. Baldwin."

Herb. Geol. Surv, Herb. Mohr.

Poa flava L. Sp. Pl. 1:68. 1753.

False Redtop. Fowl Meadow Grass.

Poa serotina Ehrh. Beitr. 6:83. 1791.

Gray, Man. ed. 6, 665 .

Canadian zone to Carolinian area. Indigenous in British North America from the Atlantic to the Pacific. Northern New England west to Minnesota, Nebraska, the Rocky Mountains, and Washington, south to New Jersey. Adventive and escaped from cultivation in the South Atlantic and Gulf States.

Alabama : Cultivated in the mountain region and Tennessee Valley and escaped. Swampy meadows. Cullman County. June; rare. Perennial.

Typo locality: "Hab. in Virginia."

Herb. Geol. Surv. Herb. Mohr.

SCLEROPOA Griseb. Spicil Fl. Rumel. 2 :431. 1844.

Two species, perennials, of the Mediterranean region.

Scleropoa rigida (L.) Griseb. Spicil. Fl. Rumel. 2 : 431. 1844.

Poa rigida L. Amoen. Acad. 4 : 265. 1759.

Festuca rigida Kunth, Rév. Gram. 1:129. 1835.

Adventive from southern Europe.

Alabama : Fugitive on ballast. Mobile.

Type locality: "Hab. in Gallia, Anglia."

Herb. Geol. Surv. Herb. Mohr. 


\section{PANICULARIA Fabr. Enum. Pl. Hort. Helmst. 373. 1763.}

(GLYCERIA R. Br. Prodr. Fl. Nov. Holl. 1:179. 1810.)

Sixteen species of Europe and Asia, mostly perennials; in temperate North America, 12.

Panicularia nervata (Willd.) Kuntze, Rev. Gen. Pl. 2 : 783.1891.

Poa nervata Willd. Sp. P1. $1: 389.1798$.

Fowl Meadow Grass.

P. striata Lam. Tabl. Encycl. 1:183. 1791.

Glyceria.nervata Trin. Mem. Acad. St. Petersh. 6, pt. 1: 365. 1831.

Poa parviflora Pursh, Fl. Am. Sept. 1:80. 1814.

Ell. Sk. 1:157. Gray, Man. ed. 6, 667. Chap. Fl. 561. Coulter, Contr. Nat. Herb. 2:547. Scribner, Grass. Tenn. $2: 112, t .39, f .153$.

Canadian zone, Alleghenian to Louisianian area. Nova Scotia and Quebec and west to Vancouver Island; New England to Minnesota and Nebraska, and south to western Florida and Texas.

Alabama: Tennessee Valley. Mountain region to Central Prairie belt. In swales and wet woods. Cullman County. Blount County, Blount Springs. Lee County, Auburu (Baker \& Earle,592). Montgomery County. Hale County, Gallion. May; not infrequent.

Type locality: "Hab. in America boreali."

Herb. Geol. Surv. Herb. Mohr.

FESTUCA L. Sp. P1. 1 : 73.1753.

About 80 species, mostly of temperate regions. North America, 18 species.

Festuca nutans Willd. Enum. 1 : 116. 1809.

Nodding Fescue Grass.

Ell. Sk. 1:172. Gray, Man. ed. 6,669. Chap. Fl.565. Coulter, Contr. Nat. Herb.

2:548. Scribner, Grass. Tenn. $2: 117, t$. 42, $f .166$.

Alleghenian and Carolinian areas. New Brunswick, Ontario, and Pennsylvania to Nebraska; south from Missouri to Arkansas and Texas, and from Kentucky to South Carolina.

Alabama: Mountain region. Woods and shady copses. Winston County, Collins Creek, 1,300 feet. Dekalb County, Lookout Mountain, 2,000 feet. Lee County, Auburn (Baker \& Earle), 860 feet. Cullman County. Flowers May, June; not infrequent. Perennial.

Type locality: "Hab. in America boreali."

Herb. Geol. Surv. Herb. Mohr.

Festuca shortii Kunth; Wood, Classbook, 794. 1861.

Gray, Man. ed.6,669. Coulter, Contr. Nat. Herb. $2: 548$. Britt. \& Brown, Ill. Fl. $1: 218$.

Carolinian area. Pennsylvania to Kansas; from Kentucky to Tennessee and Mississippi.

Alabama : Mountain region. Metamorphic hills. Lee County, Auburn (Baker of Earle, 619). Only locality known in the State. July. Perennial.

Type locality not given.

Herb. Geol. Surv. Herb. Mohr.

Festuca octoflora Walt. Fl. Car. 81. 1788.

Festuca bromoides Michx. Fl. Bor. Am. 1:66. 1803.

F. tenella Willd. Sp. Pl. 1:419. 1797.

Ell. Sk. 1:168. Gray, Man. ed. 6, 669. Chap. Fl. 565. Wats. Bot. Calif. $2: 317$.

Coulter, Contr. Nat. Herb. 2 : 547.

Mexico, Montevideo, South Africa.

Alleghenian (q) to Louisianian area. Ontario to Vancouver Island; California; throughout the Eastern United States to Texas and Arkansas.

Alabama: Over the State. Dry sandy soil. Flowers March and April; common. Anuual.

Type locality: South Carolina.

Herb. Geol. Snrv. Herb. Mohr.

Festuca octoflora aristulata (Torr.) L. H. Dewey in Coulter, Contr. Nat. Herb. $2: 547$. 1894.

Festuca tenella aristulata Torr. Pacif. R. Rep. 4 : 156. 1857.

Taller and more slender; spikelets narrower, 4 to 6 flowered; awns fully as long as or longer than the flowers.

Carolinian area. Texas and Califoruia. 
Alabama : Mountain region. Lee County, Auburn (Baker of Earle). Annual. Type Jocality: "Hillsides, Napa Valley [California]."

Herb. Geol. Surv. Herb. Mohr.

Festuca sciurea Nutt. Trans. Am. Phil. Soc. 5 : 147. 1837.

Coulter, Contr. Nat. Herb. 2 : 547.

Carolinian and Louisianian areas. Western Texas and Arkansas.

Alabama: Mountain to Central Prairie region. Dry sandy exposed gronnd. Lee County, Auburn (Baker \& Earle). Montgomery County, Chestnut Hill. April ; infrequent and local. Perennial.

Type locality not ascertained.

Herb. Geol. Surv. Herb. Mohr.

BROMUS L. Sp. Pl. 1: 76.1753.

About 150 species. North temperate zone. North America, 45 indigenons species and varieties. ${ }^{1}$

Bromus ciliatus L. Sp. Pl. 1: 76. 1753.

WoOp Chess.

Bromus canadensis Michx. Fl. Bor. Am. 1:219. 1803.

B. pubescens Muhl. Gram. 169. 1817.

Eil. Sk. 1:173. Gray, Man. ed.6, 670. Chap. Fl. ed. 3, 610. Coulter, Contr. Nat. Herb. 2 :548. Scribner, Grass. Tenn. $2: 118, t .42, f .168$. Britt. \& Brown, Ill. Fl. $1: 219$.

Alleghenian, Carolinian, and Louisianian areas. Newfoundland, Manitoba, and British Columbia, south to Florida and Texas.

AlabaMa : Mountain region. Lower hills. Shady banks along streams and damp borders of woods. Cullman, Madison, St. Clair, and Bibb counties. June; frequent. Annual.

The hairy form known as var. purgans alone observed.

Type locality: "Hab. in Canada ; ex semine. D. Kalm."

'Herb. Geol. Surv. Herb. Mohr.

Bromus racemosus L. Sp. Pl. ed. 2, 1:114. 1762.

Erect Chess.

Gray, Man. ed. 6, 670. Chap. Fl. ed. 3, 610. Scribner, Grass. Tenn. $2: 120$, t. 43, f. 179.

EURope, AsIa.

Throughout temperate eastern North America and on the Pacific coast. Naturalized.

Alabama : Over the State. Fields and waste places, more or less frequent. May, June. Annual.

Type locality: "Hab. in Anglia."

Herb. Geol. Surv. Herb. Mohr.

Bromus secalinus L. Sp. Pl. 1: 76.1753.

Cheat or Chess.

Ell. Sk. $1: 172$. Gray, Man. ed. 6, 670. Chap. Fl.566. Coulter, Contr. Nat. Herb.

2:548. Scribner, Grass. Tenn. $2: 119, t .143, f .170$.

EUROPE.

Naturalized all over temperate North America, wherever grain is cultivated.

Alabama : Over the State. A common weed; annual.

Type locality: "Hab. in Europae agris secalinis arenosis."

Herb. Geol. Surv. Herb. Mohr.

Bromus unioloides (Willd.) H. B. K. Nov. Gen. et Sp. 1:151. 1815.

Festuca unioloides Willd. Hort. Berol. 1: 3, 1806.

Rescue Grass. Australian Oats.

Bromus schraderi Kunth, Enum. 1:416. 1833.

Ell. Sk. 1: 171. Chap. Fl.565. Coulter, Contr. Nat. Herb. 2 : 548.

Waryer parts of AMerica to Chile.

Louisianian area. South Carolina to Florida and Texas.

Alabama : Central Prairie belt to Coast plain. In rich soil. Montgomery, Dallas, and Mobile counties. May, June; not rare. Annual.

Type locality: "Hab. in Carolina."

Economic uses: Important for hay and for pasture; not rarely cultivated.

Herb. Geol. Surv. Herb. Mohr.

${ }^{1}$ According to C. L. Shear, Revision of the North American Species of Bromus occurring north of Mexico, Bull. 23, U. S. Dept. Agr. Div. Agrost. 1900. 
LOLIUM L. Sp. PI. 83. 1753.

Six species temperate Europe, Western Asia, North Africa.

Lolium perenne L. Sp. Pl. 1:83. 1753.

Perennial Ray Grass.

Gray, Man. ed. 6, 671. Chap. Fl. ed. 3, 618. Coulter, Contr. Nat. Herb. 2:549. Scribner, Grass. Tenn. $2: 121, t .44, f .174$.

Sparingly escaped in Cauada and the eastern United States.

Alabama : Mobile and Cullman counties. May, Jnne; perennial.

Type locality: "Hab. in Europa ad agrorum versuras solo fertili."

Économic uses: Valuable for pasture and lawn.

Herb. Geol. Surv. Herb. Mohr.

Lolium temulentum L. Sp. Pl. 1:83. 1753.

Gray, Man. ed.6,671. Chap. Fl. ed. 3,618. Wats. Bot. Calif. $2: 323$.

Europe, Western Asia, North Africa.

Introduced with grain and sparingly naturalized in Canada, British Columbia, Oregon, California, and Eastern United States.

Alabama: Collected once in an oat field, Mobile County. The unawned form. July; annual.

Type locality: "Hab. in Europae agris inter Hordeum, Linum."

Herb. Geol. Surv. Herb. Mohr.

HORDEUM L. Sp. Pl. 1:84. 1753. BARLEY.

Twelve species of cooler temperate regions, mostly of the Old World.

Hordeum pusillum Nutt. Gen. 1:87. $1818 . \quad$ DWARF Barley.

Coulter, Contr. Nat. Herb. $2: 550$. Scribner, Grass. Tenn. $2: 125, t .4 \dot{6}, f .181$.

Carolinian and Louisianian areas. Telnessee and North Carolina to Florida, west

to Mississippi, Texas, and Arkansas. Reported from Vancouver Island.

Alabama: Coast plain. Waste places, roadsides. May; not frequent.

Type locality: "On the arid and saline plains of the Missouri."

Herb. Geol. Surv. Herb. Mohr.

Hordeum murinum L. Sp. Pl. 1: 85. 1753.

Alabama: A fugitive from Europe on ballast heaps. Mobile, observed only once. Annual.

Type locality: "Hab. in Europae loeis ruderatis."

Herb. Geol. Surv. Herb. Mohr.

ELYMUS L. Sp. Pl. 1:83. 1753. Lyak Grass.

About 30 species, widely distributed over the temperate regions. Northern Hemisphere. North America, 10 species.

Elymus virginicus L. Sp. Pl. 1:84. 1753.

Terreil, Grass.

Elymus carolinianus Walt. Fl. Car. 82.1788.

Ell. Sk. 1:180. Gray, Man. ed. 6, 673. Chap. Fl. 567. Coulter, Contr. Nat. Herb.

2:550. Scribner, Grass. Tenn. $2: 126, t .46, f .182$.

Canadian zone to Louisianian area. Nova Scotia, Ontario, New England, west to

Minnesota, Nebraska, and south to Texas and Florida.

Alabama: All over the State. Banks of streams. Most frequent north of the Central Pine belt. Cullman County. Blount County, Blount Springs. Lee and Mobile counties. June; rare. Perennial.

Type locality: "Hab. in Virginia."

Herb. Geol. Surv. Herb. Mohr.

Elymus striatus Willd. Sp. Pl. 1:470. 1797. Wild Rye. Slender Lyme Grass. Ell. Sk. 1:180. Gray, Man. ed. 6, 673. Chap. Fl. 567. Coulter, Contr. Nat. Herb.

$2: 550$. Scribner, Grass. Tenn. $2: 127, t .46, f .184$.

Alleghenian to Louisianian area. Ontario and Now England, west to Nebraska, and south to Florida and 'Texas.

Alabama : Over the State. Open copses, borders of woods. Lee County, Auburn (Baker \& Earle, 594). Montgomery and Mobile counties. May to June; not common. Perennial.

Type locality: "Hab. in Ainerica boreali."

Herb. Geol. Surv. Herb. Mohr.

Elymus striatus villosus (Muhl.) Gray, Man. (60.. 1848.

Elymus villosus Muhl. Gram. 175. 1817.

SOFT-HAIRY WILI RYE.

Gray, Man. ed. 6, 673. 
Alleghenian to Louisianian area. New England. Range of the type. Reported from Nebraska.

Alabama : Coast plain. Rocky and dry shaded banks. Mobile County, found only on borders of hammock lands, western bay shore. June. Perennial.

Type locality: "Hab. ad ripas et in siccis Pennsylvaniae, floret Julio."

Herb. Geol. Surv. Herb. Mohr.

Elymus canadensis L. Sp. Pl. 1: 83. 1753.

Canadian Wild Rye or Lyme Grass.

Gray, Man. ed. 6, 673. Coulter, Contr. Nat. Herb, 2:5ño.

Alleghenian to Louisianian area. Canada to Georgia, west to Texas and Arkansas. Alabama: Central prairie. Montgomery, Pentulalla Creek. Dry banks. July. Perennial.

Type locality: “Hab. in Canada. Kalm."

Herb. Geol. Surv. Herb. Mohr.

HYSTRIX Moench, Meth. 294. 1794.

(Asprella Willd. Enum. 132. 1809.)

(Gymnostichum Schreb. Beschr. Graes. 2: 127. 1810.)

Four species, temperate zones. Siberia, New Zealand. North America, 2 species. Hystrix hystrix (L.) Millspaugh, Fl. W. Va.474. 1892.

Bottle Brush Grass.

Elymus hystrix L. Sp. Pl. ed. 2, 1: 124. 1762.

Gymuostichum hystrix Schreb. Beschr. Graes. 2 : 127, $t .4 \% .1810$.

Ell. Sk. 1:181. Gray, Man. ed. 6, 674. Chap. Fl.567. Coulter, Contr. Nat. Herb. 2 : 551 . Scribner, Grass Tenn. $2: 127, t .47, f .183$.

Alleghenian and Carolinian areas. New Brunswick, Ontario; New England to Nebraska, south to Florida and Texas.

Alabama: Mountain region. Cullman County. Blount County, Warnock Mountain. June; not frequent. Perennial.

'Type locality not given.

Herb. Geol. Surv. Herb. Mohr.

ARUNDINARIA Michx. Fl. Bor. Am. 1:73. 1803.

About 24 species, perennials. Temperate America, Asia.

Arundinaria gigantea (Walt.) Chap. Fl.561. 1860.

Arundo gigantea Walt. Fl. Car. 81. 1788.

Ell. Sk. 1:96, in part. Gray, Man. ed. 6, 674. Coulter, Contr. Nat. Herb. 2 : 551.

Seribner, Grass. Tenn. $2: 129, t .4 \%, f .18 \%$.

Carolinian and Louisianian areas. From southern Tennessee and lower North

Carolina to Florida, central 'Texas, and Arkansas.

Alabama : Alluvial banks of all the larger streams. Fruit received from Lauderdale County in 1893, and from Russell County in 1895. April, May. Seed crop in Russell County produced for the first time within the mernory of the present generation, and in greatest abundance.

Type locality: South Carolina.

Herb. Geol. Surv. Herb. Mohr.

Arundinaria tecta (Walt.) Muhl. Gram. 191. 1817. Arundo tecta Walt. Fl. Car. 81. 1788.

Arundinaria macrosperma var. suffruticosa Munro, Trans. Linn. Soc. 26:15. 1868. Ell. Sk. 1:97, in part. Gray, Man. ed. 6, 674. Chap. Fl. 561. Coulter, Contr. Nat. Herb. 2:551. Scribner, Grass. Tenn. 2:129, t. 47, f. 18\%.

Carolinian and Lonisianian areas. Midlle and lower country of the South Atlantic States from southern Virginia to Florida; Kentucky, Ohio, southern Illinois, south western Missouri, and Arkansas to the Gulf States west to Texas.

This is the cane of the canebrakes in the alluvial forests subject only to occasional overflow, and of the damp black lands of the Prairie region.

Alabama : Over the State ontside of the mountains and table-lands; most frequent from the Central Pine region to the coast, along the water courses and in low, damp woods. Flowers April and May; flowering stalks mostly from naked radical shoots, scarcely over 12 or 18 inches high.

Type locality : South Carolina.

Herb. Geol. Surv. Herb. Mohr. 


\title{
CYPERACEAE. Sedge Family.
}

\author{
CYPERUS L. Sp.Pl. 1 : 44. 1753. ${ }^{1}$
}

Over 500 species, mostly in the tropical and warmer temperate zones. North America, endemic, about 60 ; Atlantic, 44; Western Continental, 14; Pacific, 6. Largely Southern.

Cyperus flavescens L. Sp. Pl. 1 : 46. 1753.

Yellowish Cyperus.

Gray, Man. ed. 6, 569. Chap. Fl. 505. Coulter, Contr. Nat. Herb. 2: 460.

South Europe, West Asia, Norti Africa, Mexico, Brazil.

Alleghenian to Louisianian area. From New Englaud west to Michigan, sonth to Florida and Texas.

Alabama: Tennessee Valley and Central Prairie region. Damp banks of water courses. Lauderdale County. Clay County, banks Talladega Creek. Montgomery County. Autauga Connty, Prattville. Tuscaloosa County, Vances Station (E. A. Smith). July to August; not rare.

Type locality : "Hab. in Germaniae, Helvetiae, Galliae paludosis."

Herb. Geol. Surv. Herb. Mohr.

Cyperus diandrus Torr. Cat. Pl. N. Y.90. 1819.

I.OW CYPERUS.

Grav, Man. ed. 6, 569. Chap. Fl. 506. Coulter, Contr. Nat. Herb. $2: 4 f 0$.

Alleghenian to Louisianian area. New Brunswick, Ontario; New England west to Michigan, Missouri, and Nebraska; south from southern New York to Florida and Texas.

Alabama : Central Pine belt to coast. Mobile County. Low grassy banks. August; -infrequent.

Type locality: "Growing in salt marshes. - * * Not uncommon in Hoboken meadows, generally in overflowed sitnations."

Herb. Geol. Surv. Herb. Mohr.

Cyperus nuttallii Eddy in Spreng. Nene Entdeck. 1:240. 1820.

Cyperus caespitosus Torr. Cat. Pl. N. Y. 89. 1819. Not Poir.

C. torreyanus Schult. Mant. 2 : 101. 1824.

Ell. Sk. 1:67, under C. flarescens. Gray, Man. ed.6, 569. Chap. F1. 506.

Carolinian and Louisianian areas. Soutbeastern New England along the coast to

Floricla and west to Mississippi and Arizona.

AlabAMA: Coast plain and Littoral belt. Low sandy fields and brackish or saline marshes. Mobile County, Dauphiu Island. Baldwin County, easteru shore Mobile Bay. August to October; frequent.

Type locality not ascertained; Torrey's locality: "Grows on the borders of salt marshes, and is particularly plentiful on the banks of ditches in Hoboken meadows."

Herb. Geol. Surv. Herb. Mohr.

Cyperus microdontus Torr. Ann. Lyc. N. Y. 3:255. 1836.

Const Cyperus.

Cyperus texensis Steud. Syı. Pl. Cyp.9. 1854.

Gray, Man. ed. 6, 569. Chap. Fl. 506. Coulter, Contr. Nat. Herb. $2: 461$.

MEXICO.

Carolinian and Louisianian areas. Southern Virginia, through the low country to Florida, west to Texas.

Alabama : Coast plain. Springy places, wet sandy soil. Mobile County. Baldwin County, Point Clear. July to September; frequent. Annual.

Type locality: "Salem, N.C. Schweinitz."

Cyperus compressus L. Sp. Pl. 1:46. 1753.

Flat Cyperus.

Ell. Sk. 1:65. Gray, Man. ed.6,570. Chap. Fl. 510. Coulter, Contr. Nat. Herb.

$2: 461$. Griseb. Fl. Brit. W. Ind.562.

West Indies, Mexico to Brazil. Tropicat Africa, Asia.

Louisianian area. Southern Maryland along the coast to Florida, west to Texas.

alaibama : Lower Pine region. Coast plain, miry places, ditches, low cultivated ground. Escambia County, Flomaton. Mobile and Baldwin counties. July to August; common. Anuual.

Type locality: "Hab. in Americae septentrionalis pratis arenosis."

Herb. Geol. Surr. Herb. Mohr.

${ }^{1}$ N. L. Britton, Preliminary List of North American Species of Cyperus, Bull. Torr. Club, vol. 13, pp. 205 to 216. 
Cyperus vegetus Willd. Sp. Pl. 1:283. 1797.

Thrifty CyPenus.

H. C. Watson, Hook. Lond. Journ. Bot. 3:610. 1844.

Mexico, Chile, South Europe.

Lower Sonoran and Louisianian areas. California.

Alabama : Coast plain. Low damp to wet places. Mobile County, banks of Mobile River; marshy ground near Mobile and Ohio Railroad depot, copiously, 1896. July to Angust. Probably alventive from the tropies. Perenniai.

Type locality not given.

Herb. Geol. Surv. Herb. Mohr.

Cyperus pseudovegetus Steud. Syn. Pl. Cyp. 24. 1855. False Thrifty Cyperus. Cyperus vegetus Pursh, Fl. Am. Sept. 1:51. 1814. (Also of Muhl. Ell. Chapman.)

Not of Willd.

Cyperus virens Gray, Man. ed. $2: 493$. 1856. Not of Michx.

C. luzulae var. umbellulatus Britton, Bull. Torr. Club, 13:208. 1886.

C. calcaratus Nees; Wats. in Gray, Man. ed. 6,570. 1890.

Ell. Sk. 1:65. Gray, Man. ed. 6, 570. Chap. Fl. 509; ed. 3,537. Coulter, Contr.

Nat. Herb. $2: 462$.

Carolinian and Louisianian areas. Delaware to Florida, west to Tennessee, Texas, Arkansas, and Indian Territory.

Alabama: Mountain region to Central Prairie belt, damp close soil, exsiccated places. Cullman Couuty, 800 feet. Madison County, Huntsville. Autauga County, Prattville. July to August; frequent. Perennial.

Type locality: "M. Curtis legit in Carolina australi."

Herb. Geol. Surv. Herb. Mohr.

Cyperus virens Michx. Fl. Bor. Am. 1:28. 1803. .

Grhen CyPerus:

Ell. Sk. 1:66. Chap. Fl. 609. Coulter, Contr. Nat. Herb. $2: 462$.

Mexico, Guatemala.

Carolinian and Louisianian areas. Kentucky (Mohr), Tennessee, from North

Carolina south to Florida, west to Texas and Arkansas.

Alabama: Coast plain. Open marshes, ditches. Mobile County. June; 2 or 3 feet high; not rare. Perennial.

Typo locality: "Hab. in Carolina."

Herb. Geol. Surv. Herb. Mohr.

Cyperus ochraceus Vahl, Enum. $2: 325.1806$.

Griseb. Fl. Brit. W. Ind. 563.

West Indies, Mexico, Galapagos.

Louisianian area. Texas and Louisiana.

Alabama: Adventive. Mobile County, swamps bordering Mobile River with C. vegetus Willd. July, 1893; rare. Perennial.

Type locality: "Hab. in insula St. Crucis. West."

Herb. Geol. Surv. Herb. Mohr.

Cyperus haspan L. Sp. Pl. 1:45. 1753.

Sheathed Cyperus.

Cyperus gracilis Muhl. Gram. 18. 1817.

C. leptos Schult. Mant. $2: 105$. 1825.

Ell. Sk. 1:66. Gray, Man. ed. 6, 571. Chap. Fl. 509. Coulter, Contr. Nat. Herb.

$2: 463$. Griseb. Fl. Brit. W. Ind. 564.

West Indies, Mexico to Brazil, Africa, Asia, Australiá.

Louisianian area. Southern Virginia along the coast to Florida, west to Texas.

Alabama: Metamorphic hills to Coast plain. Borders of ponds and ditches. Lee

County, Auburn (F.S.Earle). Mobile and Baldwin counties. August to October;

frequent. Perennial.

Type locality: "Hab. in India, Aethiopia."

Herb. Mohr.

Cyperus dentatus Torr. Fl. N. \& Mid. U. S. 1:61. 1824.

Cyperus parviflorus Muhl. Gram. 19. 1817. Not Vahl.

Gray, Man. ed. 6, 571. Chap. Fl. ed. 3, 536.

Appalachian to Louisiauian area. Coast New England and Now Jersey to West

Virginia and South Carolina.

Alabama : Adventive from Northern States. Mobile County, sandy shores Mobile

Bay. Perennial.

Type locality: "On the banks of rivers and in sandy swamps. In the pine barrens of New Jersey. In Pennsylvania. Muhlenberg."

Herb. Mohr. 
Cyperus multiradiatus (Torr.) Mohr.

Le Conte's Cyperus.

Cyperus dentatus multiradiatus 'Torr. Ann. Lye. N. Y. $3: 272.1836$.

C. lecontii Torr. 1. c. 273.

Chap. Fl. 509.

Louisianian area. Eastern and western Florida, and on the seashore west to Mississippi.

Alabama: Littoral region. Drifting sands on the seashore. Dauphin Island. Eastern shore Mobile Bay, Point Clear, Josephine. June, July; frequent. The long creeping rhizomas deeply buried in the sand. Perennial.

Type locality: "East Florida, Le Conte!; New Orleans, Dr. Ingalls!"

Herb. Mohr.

Cyperus articulatus L. Sp. Pl. 1:44. 1753.

Adrue. Guinea Rúsh.

Ell. Sk. 1:63. Chap. Fl.508. Coulter, Contr. Nat. Herb. $2: 463$. Griseb. Fl. Brit.

W. Ind. 564 .

Acl tropical countiries. Egypt, Cape of Good Hope.

Louisianian area. South Carolina, Florida, west to Texas.

Alabama: Coast plain. Margin of fresh and slightly brackish marshes. Mobile County, river swamps. Baldwin County, Fish River Bay. August, 4 to 5 feet high; frequent. Perennial.

Type locality: "Hab. in Jamaicae rivulis."

Herb. Mohr.

Cyperus articulatus conglomeratus Britton, Bull. Torr. Club, 13:210. 1886.

Louisianian area. Alabama to western Texas.

Alabama : Littoral belt, salt marshes. Baldwin County, Bon Secour. Rare. Perennial. Easily distinguished by the pale spikelets in close capitate clusters.

Type locality: "Valley of the lower Rio Grande (Buckley)."

Herb. Mohr.

Cyperus sphacelatus Rottb. Desc. Nov. Pl. 26; Prog. 21.1773.

Vahl, Enum. 2 : 341. Griseb. Fl. Brit. W. Ind. 565.

WEST INDIES, BRAZIL.

Adventive on ballast in California.

Alabama : Ballast heaps. Mobile, September, 1891.

Type locality not ascertained; Vahl's locality: "Habitat in Surinamo, Cajenna,

Puertorico; in Guinea, Thonning."

Herb. Geol. Surv. Herb. Mohr.

Cyperus rotundus L. Sp. Pl. 1:45. 1753.

Nut Grass.

Cyperus hydra Michx. Fl. Bor. Am. 1:27, 1803.

Ell. Sk. 1:68. Gray, Man. ed. 6, 571. Chap. Fl.506. Griseb. Fl. Brit. W. Ind. 463. Coulter, Contr. Nat. Herb. $2: 463$.

West Indies to Guiana; all tropical and subtropical countries of the Old Wolrd ; Australia.

Louisianian area. From the coast of southern Virginia to Florida, west to Texas.

Alabama: Central Pine belt to the Coast plain. The most abundant and pernicious of weeds in the cultivated lands of the low country. Perennial.

Type locality: "Hab. in India."

Herb. Geol. Surv. Herb. Mohr.

Cyperus esculentus L. Sp. Pl. 1:45. 1753.

Cyperus phymatodes Muhl. Gram. 23. 1817.

C. repens Ell. Sk. 1: 69.1817.

Gray, Man. ed. 6, 571. Chap. Fl. 508. Coulter, Contr. Nat. Herb. 2:463. Griseb. Fl.

Brit. W. Ind. 565 .

An almost cosmopolitan weed in temperate and warmer regions.

South Europe tu South Africa, Australia, West Indes, Atlantic Soutu AMERICA.

Alleghenian to Louisianian area. From New Brunswick, Ontario, and New Eng-

land, west to Nebraska, and throughout Eastern North America to Florida and the

Gulf States; also in California.

Alabama: Over the State. In sandy soil. Most frequent from the Central Prairie region to the coast. A somewhat troublesome weed of uasy extermination. Montgomery, Hale, Escambia, Mobile, and Bald win connties. July, September; frequent. Perennial.

Type locality: "Hab. Monspelii, inque Italia, Oriente."

Herb. Geol. Surv. Herb. Mohr. 
Cyperus strigosus L. Sp. Pl. 1: 47. 1753.

STRIGOSE-SPIKED CYPERUS.

Gray, Man. ed. 6, 571. Chap. Fl. 507. Coulter, Contr. Nat. Herb. 2 : 464.

JAPAN.

Alleghenian to Louisianian area. Ontario and New England, west to Nebraska.

South all over the Atlantic States to Florida and Texas; also in California.

Alabama: Over the State. July to September; frequent. Perennial.

Type locality: "Hab. in paludibus Jamaicae, Virginiae."

Herb. Geol. Surv. Herb. Mohr.

Cyperus strigosus robustior Kunth, Enum. 2 : 88. 1837.

"Spikelets large, elongated, 20 to 30 flowered."

Louisianian area. Westeru Tennessee?, Florida, west to Louisiana and Texas.

Alabama: Open swamps. Mobile County, river marshes. August, September;

2 to 3 feet high; frequent. Perennial.

Type locality: "America borealis et ? merid. (Insulae Sandwicenses, Beechey.)"

Herb. Geol. Surv. Herb. Mohr.

Cyperus stenolepis Torr. Ann. Lyc. N. Y. 3 : 263. 1836.

Pale Marsh Cyperus.

Chap. Fl.507. Coulter, Contr. Nat. Herb. 2: 404.

Louisianian area. North Carolina to Florida and west to Texas.

Alabama : Central Pine belt. Coast plain. In grassy swamps. Mobile County,

river marshes; June. Lee County (Baker \& Earle). Perennial.

Type locality: "Wilmington, N. C., Mr. Curtis!"

Herb. Geol. Surv. Herb. Mohr.

Cyperus dissitiflorus Ann. Lyc. N. Y. 3:266. 1836

Sparskly-Flowered Cyperus.

Chap. Fl. Suppl.659; ed. 3, 534. Coulter, Contr. Nat. Herb. 2:464.

Mexico, Brazil (fide Boeckeler).

Louisıanian area. Florida to western Texas.

Alabama : Coast plain. Rich shaded woods and copses. Mobile County, Dauphin Island. Baldwin County, Blakely. August and September; infrequent. Perennial.

Type locality: “Near New Orleans, Hooker!"

Herb. Geol. Surv. Herb. Mohr.

Cyperus erythrorhizos Muhl. Gram. 20. 1817.

RED-ROOTED CyPerus.

Cyperus tenuiflorus Ell. Sk. 1: 70. 1817. Not Rottboell.

Gray, Man. ed. 6, 571. Chap. Fl.512. Coulter, Contr. Nat. Herb. $2: 465$.

Ell. Sk.l.c.

Alleghenian to Louisianian area. Ontario and New England west to Minnesota, south to the Ohio Valley, Missouri, Arkansas, Texas, and from New York to Florida.

Alabama : Tennessee Valley. Central Prairie region to the Coast plain. Borders of swamps. Lauderdale, Tuscaloosa, Montgomery, Mobile, and Baldwin counties. Frequent. Perennial.

Type locality: "Hab. ad rivos Pennsylvaniae, floret Aug.-Sept. etiam in Carolina Septen. et Georgia."

Herb. Geol. Surv. Herb. Mohr.

Cyperus speciosus Vahl, Enum. 2 :364. 1806.

MichauX's Cyperus.

Cyperus michauxianus Schult. Mant. 2:123. 1824.

Ell. Sk. 1:72. Gray, Man. ed. 6, 572\% Chap. Fl. 507. Wats. Bot. Calif. $2: 215$.

Doulter, Contr. Nat. Herb. $2: 465$.

Alleghenian to Louisianian area. Southern New England, New Jersey west to

Michigan, Minnesota, Missouri, and Tennessee, south to Florida and Texas, and in California.

Alabama : Central Prairie region to the Coast plain. Border of marshes, alluvial swamps. Mobile County, river swamps. Frequent. Anuual. Typo locality: "Hab. in Virgiuia."

Herb. Geol. Surv. Herb. Mohr.

Cyperus engelmanni Steud. Syn. Pl. Cyp.47. 1855.

Gray, Man. ed. 6, 572.

Carolinian and Louisianian areas. Massachusetts west to Wisconsin.

Alabama : Banks of Mobile River. Adventive from the Northern States; observed only once. Perennial.

Type locality : "St. Louis, Mo."

Herb. Geol. Surv. Herb. Mohr. 
Cyperus flavamariscus Griseb. Fl. Brit. W. Ind.567. 1864.

Cyperus flavus Vahl, Enum. 2 :373. 1806.

Coulter, Contr. Nat. Herb. $2: 466$.

West Indies, Mexico to Brazil.

Alabama: A fugitive from the tropies. Mobile County, on ballast ground. September, 1892-93. Annual.

Type locality: "Hab. Jamaica!, Al. ; Antigua!, Wullsch.; Trinidad!; (Cuba! and Mexico to Brazil!)."

Herb. Mohr.

Cyperus ligularis L. Sp. Pl. ed. 2, 1: 70. 1762.

Chap. Fl. Suppl. 659; ed. 3, 534 Griseb. Fl. Brit. W. Ind. 566. Chap. Fl. erl. 3, 534. West Indies, Mexico to Brazil. Tropical africa to the Cape.

Lou:sianian area. Southern Florida.

Alabama: Adventive from the tropics. Mobile, ballast ground, collecterl tirst in 1891, and again in 1895 . Perennial.

Type locality: "Hab. in Jamaica."

Herb. Mohr.

Cyperus ovularis (Michx.) Torr. Ann. Lyc. N. Y. 3:278. 1836.

Kyllingia ovularis Michx. Fl. Bor. Am. 1:29. 1803.

Round-Headed CYPERUS.

Mariscus ovularis Vahl, Enım. 2:375. 1806.

Gray, Man. ed.6, 572. Chap. Fl.511. Coulter, Contr. Nat. Herb. 2:465.

Carolinian and Louisianian areas. Southern New York to Illinois, Missouri, south to Florida, and west to Texas.

AlabaMa: Over the State. Damp grass plots, cultivaterl ground, most frequent in the Coast plain and Central Prairie region. Cullıan, Tuscaloosa, Montgomery, Escambia, Clarke, and Baldwiu counties. July, August. Common. Perennial. Type locality : "Hab. in Georgia et Carolina."

Herb. Geol. Surv. Herb. Mohr.

Cyperus cylindricus (Ell.) Britton, Bull. Torr. Club, 6:339. 1879. Not Chap. 1887.

Mariscus cylindricus Ell. Sk. 1: 74. 1817.

Cyperus ovularis var. cylindricus Torr. Ann. Isyc. N. Y. 3: 279.1836.

Ell. Sk. 1:74. Gray, Man. ed. 6, 572. Coulter, Contr. Nat. Herb. 2:466. Britton,

Bull. Torr. Club, $7: 48, t .3, f .2$.

Carolinian anil Lonisianian areas. Long Island, New York, south to Florida, west

to southwestern Texas.

Alabana: From the coast to the Central Pine belt. Tuscaloosa, Montgomery, Escambia, and Mobile counties. In sandy, dry, and damp soil. Cultivated ground and woods. Most common in the Coast Pine belt. June to August. Perennial.

Type locality: "Grows in cultivated land of almost every description. [South Carolina, Georgia.]"

Herb. Geol. Surv. Herb. Mohr.

Cyperus refractus Engelm.; Boeckl. Linnaea, $36: 369$. 1869-70.

Gray, Man. ed. 6,572. Britt. and Brown, Ill. Fl. 1: 244.

REFlexed Cyperus.

Carolinian and Louisianian areas. New Jersey, Missouri, and North Carolina.

Alabama: Mountain region. Coast plain. Rocky hillsides. Dekalb County, Lookout Mountain, Mentone; frequent. Alpine Mountain uear Renfroe, 1,500 feet. October. Mobile County, lorder of river marshes along the L. \& N. R. R. track. September 18. Adventive. Perennial.

"Type locality: "Missonri."

Herb. Geol. Surv. Herb. Mohr.

Cyperus retrofractus (L.) 'Torr. in Gray, Man.519. 1848.

Scirpus vetrofractus L. Sp. Pl. 1: 50. 1753.

Mariscus retrofiactus Vahl, Enum. $2: 375.1806$.

Fll. Sk. 1: 74. Gray, Man. ed. 6, 572. Chap. Fl. 511. Coulter, Contr. Nat. Herb.

$2: 466$.

Louisianian and Carolinian areas.

Alabama : Lower Pine belt to Mountain region. Dry sterile openings, borders of woods. Cullman County, 800 feet. Antauga County, Prattville. Mobile County, Springhill. Baldwin County. Not infrequent. October, November. Perennial.

Type locality: "Hab. in Virginia."

Herb. Geol. Surv. Herb. Mohr. 
Cyperus lancastriensis Porter; Gray, Man. edl.5, 5\%.5. 1867. Lancaster Cyperus. Gray, Man. ed. 6, 572. Chap. Fl. Suppl. 659.

Carolinian and Louisianian areas. New Jersey and Pennsylvania.

Alabama : Central and Lower Pine region, open copses. Tuscaloosa Connty $(E . A$. Smith). Mobile County, Springhill. October; rare. Perennial.

Type locality: "Rich soil, banks of the Susquehanna near Lancaster, Penn., Prof. Porter."

Herb. Geol. Surv. Herb. Mohr.

Cyperus filiculmis Vahl, Enum. $2: 328.1816$.

Cyperus mariscoides Ell. Sk. 1:67. 1753.

Gray, Man. ed. 6, 570. Chap. Fl. 511. Coulter, Contr. Nat. Herb. 2 : 466.

Alleghenian to Lnuisianian area. Ontario and New England, west to Minnesota, Nebraska, Illinois, and Tennessee; south to Florida, Texas, Arkansas, and Missonri.

Ala Bana : Central Pine belt to Coast plain. In dry pine barrens. Bibb County. Escambia County, Flomaton. Mobile and Baldwin counties. July to August; frequent. Perennial.

Type locality: "Hab. in Carolina."

Herb. Geol. Surv. Herb. Mohr.

Cyperus martindalei Britton, Bull. Torr. Club, 15:98. 1888.

Louisianian area. Western Florida.

Martindale's Cypkres.

Alabama: Lower Pine region. Coast plain, arid sandy places. Mobile County, Langdou's Station, Citronelle, Chastangs Bluff. June, July; not infrequent. Perennial.

Type locality: "Florida."

Herb. Geol. Surv. Herb. Mohr.

Cyperus echinatus (Ell.) Wood, Classbook, 734. 1863.

BALDWIN's Cyperus.

Mariscus echinatus Ell. Sk. 1 : 75, t. $3, f .1 .1816$.

Cyperus baldwinii Torr. An1. Lyc. N. Y. 3:270. 1836.

Eli. Sk. 1:75. Chap. Fl.511. Coulter, Contr. Nat. Herb. 2 : 466.

Carolinian and Louisianian areas. North Carolina to Florida, west to Texas, Arkansas, and southern Missouri.

Alabama : From the Coast Plain to Central Pine belt. Cultivated and waste places. Mobile, Baldwin, and Montgomery counties. Autanga County, Prattville. September to October; frequent. Perennial.

Type locality: "Grows in cultivated land. Very common. [South Carolina, Georgia.]"

Herb. Geol. Surv. Herb. Mohr.

KYLLINGA Rottb. Deser, ot Icon. 12, t. 4, f. 3, 4. 1773.

About 30 to 40 species, of the warmer regions. Africa, North and South America, Australia.

Kyllinga pumila Michx. Fl. Bor. Am. 1:28. 1803.

Low KYLlinga.

Ell. Sk. 1:55. Gray, Man. ed.6, 573. Chap. Fl. 512. Conlter, Contr. Nat. Herb. $2: 466$.

Carolinian and Louisianian areas. Ohio Valley to Missouri, south to Floricla, Texas, and Arkansas.

Alabama: Over the State. Low wet banks. Talladega County, Renfroe. Tuscaloosa and Mobile counties. August to September; not frequent. Annual.

'Type locality: "Hab. in Shavanensium regione, ad amnem Scioto."

Herb. Geol. Surv. Herb. Mohr.

Kyllinga brevifolia Rottb. Descr. \& Icon. 13, t.4, f. 3. 1773.

Kyllinga monocephala L. f. Suppl. 104. 1781. In part.

SHORT-LEAVED KYLlinga.

Ell. Sk. 1: 5ł. Chap. Fl. ed. 3, 540. Griseb. Fl. Brit. W. Ind. 568.

Rhizoma slender, creeping; culm erect, slender, 10 to 20 inches high; leaves linear, flat, single, and much shorter than the stem; Howers in a single globose head; fertile scale with a green serrulate keel conspicuously 7 to 9 nerved, oblong-lanceolate, recurverl-mucronate; twice as long as the pale roundish achenium. Perennial.

West Indies, Mexico to Brazil.

Louisianian area. Coast of southern Georgia and Florida.

Alabama: Coast plain. Damp open places, border of ditches. Mobile County. October and November; not rare.

'Type locality not ascertained.

Herb. Geol. Surv. Herb. Mohr. 
Kyllinga odorata Vahl, Enum. $2: 382$. 1806.

Fragirant Kyllinga.

Kyllinga sesquiflora Torr. Ann. Lyc. N. Y. 3:287. 1836.

Chap. Fl. 5.2.

Louisianian area. Middle Florida to Alabama, Mississippi, and Louisiana.

Alabama : Coast plain to Central Pine belt. Close sandy soil, exposed banks, pastures. Most frequent in the low pine barrens of the Coast plain. Autauga County, Prattville (E. A. Smith). Montgomery, Mobile, and Baldwin counties. July to August. Plant fragrant. Perennial.

Type locality: "Hab. in America meridionali. v. Rohr, Richard."

Herb. Geol. Surv. Herb. Mohr.

DULICHIUM Pers. Syn. 1:65. 1805.

One species, Eastern North America.

Dulichium arundinaceum (L.) Britton, Bull. Torr. Clnb, 21: 29. 1894.

Cyperus arundinaceus L. Sp. Pl. 1: 44. 1753.

C. spathaceus L. Syst. ed. 12, 2: 735. 1767.

Scirpus spathaceus Michx. Fl. Bor. Am. 1:32. 1803.

Dulichium spathaceum Pers. Syn. 1:65. 1805.

Ell. Sk. 1:84. Gray, Man. ed. 6, 573. Chap. Fl. 513. Coulter, Contr. Nat. Herb.

2:467.

Canadian zone to Louisianian area. Nova Scotia and Ontario to the Pacific; V ancouver lsland; New England west to Minnesota and Nebraska, south to Texas, and from the Ohio to Florida.

Alabama: Over the State. Marshy woods. Cullman, Montgomery, and Mobile counties. July to August; frequent. Perennial.

Type locality: "Hab. in Virginia."

Herb. Geol. Surv. Herb. Mohr.

ELEOCHARIS R. Br. Prodr. FI. Nov. Holl. 1 : 221. 1810.

Over 80 species, mostly perennials of tropical and warmer zones, few boreal. North America, 36. Endemic, 22 .

Eleocharis cellulosa Torr. Ann. Lyc. N. Y.3:298. 1836. Cellular SPIKk-RUsh.

Scirpus dictyospermus Wright in Sauv. Fl. Cub.174. 1868.

Chap. Fl.515. Conlter, Contr. Nat. Herb. 2:467.

Bahamas, Cuba; Mexico.

Louisianian area. Florida to western Texas.

Alabama: Shallow, miry ponds. Mobile County, Dog River. Julv to September; rare.

Type locality : "Wet, sandy marshes. Bay St. Louis [Miss.], Dr. Ingalls."

Herb. Geol. Surv. Herb. Mohr.

Eleocharis interstincta (Vahl) Roem. \& Schult. Syst. Veg. 2 : 148. 1817.

Scirpus interstinctus Vahl, Enum. $2: 251.1806$.

KNOTTED SPIKE-RUSH.

S. equisetoides Ell. Sk. 1:79. 1816.

Eleocharis equisetoides Torr. Ann. Lyc. N. Y. 3 : 296. 1836.

Ell. Sk. l. c. Gray, Man. ed. 6, 574. Chap. Fl. 514. Griseb. Fl. Brit. W. Incl. 571.

Coulter, Contr. Nat. Herb. $2: 467$.

Wrist Indies, Mexico.

Carolinian to Louisianian area. Southern New England, west to Michigan, south to North Carolina; Florida to western Texas.

Alabama: Coast plain. Shallow ponds. Mobile County, Kelly's pond. Submerged bauks of Mobile River. Not infrequent. Perennial.

Type locality: "Hab. in Caribaeis. Martfelt."

Herb. Geol. Surv. Herb. Mohr.

Eleocharis mutata (L.) Roem. \& Schult. Syst. Veg. 2 : 155. 1817.

Scirpus mutatus L. Amoen. Acad. $5: 391.1760$.

QUADRANGULAR SPIKk-RUSIr.

S. quadrangulatus Michx. Fl. Bor. Am. 1:30. 1803.

Eleocharis quadrangulata Roem. \& Schult. Syst. Veg. 2 : 155. 1817.

Ell. Sk. 1:78. Gray, Man. ed.6,574. Chap. Fl.515. Griseb. Fl. Brit. W. Ind. 571. Coulter, Contr. Nat. Herb. $2: 467$.

'N. L. Britton, Genus Eleocharis in North America, Journ. N. Y. Micros. Soc., vol. 5, pp. 95 to 111.1889. 
West Indies, Mexico to Brazil, Argentina.

Carolinian and Louisianian areas. Centrak New York to Michigan; south from New Jersey to Florida, west to Arkansas and Texas.

Alabama : Coast plain. Central Prairie region. Shallow'ponds. Mobile County, Choctaw Point. Wilcox County (Buckley). June, oJuly; not rare. Perennial.

Type locality: Jamaica.

Herb. Geol. Surv. Herb. Mohr.

Eleocharis ochreata (Nees) Steud. Syn. Pl. Cyp. 79. 1855.

PALE SPIKE-RUSH.

Eleogenus ochreatus Nees in Mart. Fl. Bras. 2, pt. 1:102. 1842.

Scirpus ocreatus Griseb. Fl. Brit. W. Ind. 570. 1864.

S. anisochaetus Sauv. Fl. Cub. 174. 1868.

Chap. Fl. ed. $3,545$.

"Rhizoma fibrous, stoloniferous; stems low, striate, knotless; sheaths loose, membranaceous, pointless; spikelets ovate-oblong, 5 to 15 flowered; glumes few-ranked, elliptical-oblong, bluntish; style bifid; achenium shining brown, obovate, biconvex, smooth, nearly as long as the bristles; tubercle small, conical, pointed, about onethird as broad as the achenium." Grisebach.

West Indies, Mexico, Central America, Brazil.

Carolinian and Louisianian areas. Southeru Virginia, Florida, Alabama; Rocky Mountains, in thermal springs. (Montana, Yellowstone Park.)

AlabaMA : Coast plain. Exposed muddy places, ditches, and in still flowing water. Mobile Connty, Dauphinway, miry pools; West Fowl River, damp sands near the shore. Baldwin County, Fly Creek. June to July; not infrequent. Perenuial.

Varies greatly in size and habit of growth, according to locality. In moist sand the rhizome is fibrous, tardily stoloniferous; the stem more rigid, 4 to 6 inches high; the spikelets half a line wide, ovate, 5 or 6 flowered. In wet places the rhizomes are more or less stoloniferous, the stem weak, slender; the spikelets 1 to 2 lines long. acute, 15 to 20 flowered. Immersed in still-flowing brooks, the stolons are highly proliferous, the floating flaccid stems 2 to 3 feet long, forming dense mats; the achenes almost black, shining.

Type locality, Brazilian.

Herb. Geol. Surv. Herb. Mohr.

Eleocharis olivacea Torr. Ann. Lyc. N. Y. 3:300. 1836.

Gray, Man. ed. 6, 575, t. 2, f. 1-5. Chap. Fl. 518.

BRIGHT-GREEN SPIKE-RUSH.

Alleghenian to Louisianian area. New England (Mount Desert Island); western New York and New Jersey to North Carolina and Florida, west to Mississippi and Colorado.

Arabana: Lower Pine region. Coast plain. Shaded margins of ponds, ditches. Mobile County. Flowers June, July; not rare. Perennial.

-Type locality: "Pine barrens of Now Jersey!; on Long Island near Babylon!; Tewksbury pond, Mass., B. D. Greene, Esq.!

Herb. Geol. Surv. Herb. Mohr.

Eleocharis capitata (Willd.) R. Br. Prodr. Fl. Nov. Holl. 225. 1810.

Scirpus capitatus Willd. Sp. Pl. 1:294. 1795.

CAPITATE SPIKE-RUSH.

Grây, Man. ed. 6, 574. Chap. Fl.518. Coulter, Contr. Nat. Herb. 2:467. Griseb. Fl. Brit. W. Ind. 570 .

Tropical Asia, Africa, Australia, West Indies, Mexico to Brazil.

Carolinian and Louisianian areas. Maryland to Florida, west to Indiana, Texas, New Mexico, and Oregon.

Alabama: Littoral region. Damp sand near salt water. Mobile County, West Fowl River, western shore Mobile Bay. Flowers July; rare. Annual.

Type locality: "Hab. in Virginia inque insulis Caribaeis."

Herb. Geol. Surv. Herb. Mohr.

Eleocharis ovata (Roth) Roem. \& Schult. Syst. Veg. 2 : 152. 1817.

Scirpus ovatus Roth, Cat. 1:5. 1797.

S. capitatus Walt. Fl. Car. 70. 1788. Not Willd.

S. obtusus Willd. Enum. 1:76. 1809.

Eleocharis obtusa Schult. Mant. 2:89. 1824.

Ell. Sk. 1:77. Gray, Man. ed. 6, 574. Chap. Fl. 518. Coulter, Contr. Nat. Herb.

$2: 468$. Wats. Bot. Calif. $2: 222$.

Central Europe, Asia, Siberia.

Canadian zone to Louisianian area. Nova Scotia and Quebec to British Columbia; New England, west to Nebraska, south to the Gulf and from Florida to Texas and Arkansas. 
Alabama: Tenuessee Valley to the Coast plain. Springy and muddy places. Lee County, Auburn (Baker \& Earle). Lawrence County, Moulton. Cullman County, 800 feet altitude. Tuscaloosa, St. Clair, Washington, and Mobile counties. Flowers June, July; common. Annual.

Specimens from Auburn approach by the broad base of the low tubercle E. engelmanni Steud.

Type locality not ascertained; in Roemer \& Schultes: "In paludosis limosis humidis, aquis stagnantibus, Pensylvaniae."

Herb. Geol. Surv. Herb. Mohr.

Eleocharis montana (H. B. K.) Roem. \& Schult. Syst. Veg. 2 : 153. 1817.

Scirpus montanus H. B. K. Nov. Gen. et Sp. 1:226. 1815.

GLOSSY SPIKE-RUSH.

Eleocharis dombeyana Kunth, Enum. $2: 145.1837$.

E. arenicola 'Torr.; Engelm. \& Gray, Bost. Journ. Nat. Hist. 5 : 237. 1847.

Chap. Fl. 516. Coulter, Contr. Nat. Herb. 2 :469. Wats. Bot. Calif. $2: 222$.

Mexico, South AMerica.

Louisianian area. South Carolina to Florida, west to western Texas, and southern California.

ALABAMA : Coast plain. Miry borders of marshes. Mobile County, river swamps near Three-mile Creek. Rhizoma dark brown, wiry, long-creeping. Flowers in June. In the open forming large patches of bright glossy green. Perennial.

Type locality: "Crescit in monte Quindiu, alt. 1600 hex."

Herb. Geol. Surv. Herb. Mohr.

Eleocharis palustris (L.) Roem. \& Schult. Syst. Veg. 2: 151.1817.

Scirpus palustris L. Sp. Pl. 1:47. 1753.

Creeping SPIKe-RUSH.

Ell. Sk. 1:77. Gray, Man. ed. 6, 575. Chap. Fl.518.

Europe, Asia, Malay Archiphlago, Australasia.

Boreal region to Louisianian area. Throughout North America from the Atlantic to the Pacific.

Form with slender, almost filiform, glaucescent culms.

Alabava: So far observed only in the marshes of the Mobile River, where it is found in abundance. May, June. Perennial.

Type locality : "Hab. in Europae fossis et inundatis."

Herb. Geol. Surv. Herb. Mohr.

Eleocharis acicularis (L.) Roem. \& Schult. Syst. Veg. 2 : 154. 1817.

Scirpus acicularis L. Sp. Pl. 1: 48. 1753.

S. trichodes Muhl. Gram.30. 1817.

Ell. Sk. 1:76. Gray, Man. ed.6,576. Chap. Fl. 518. Wats. Bot. Calif. $2: 221$. Coulter, Contr. Nat. Herb. $2: 468$.

Europe, Asia, Nortir America, Mexico.

Canadian to Lonisianian area. From Nova Scotia and Quebec to the Gulf, and across the continent; from British Columbia to southern California.

Alabama: Throughout the State, in swampy places; common. Pereunial.

Type locality: "Hab. in Europa sub aquis purioribus."

Herb. Geol. Surv. Herb. Mohr.

Eleocharis chaetaria Roem. \& Schult. Syst. Veg. 2 : 154. 1817.

Scirpus chaetarius Spreng. Pngill. 1:4. 1813.

FEW-FLOWERED SPIKE-RUSH.

Heleocharis triflora Boeckl. F'lora, 63:437. 1880.

West Indies, Mexico, Guatemala, East Indies.

Louisianian area.

Alabama: Coast plain. Springy places in sandy soil. Baldwin County, Daphne, August 16. Copiously about the spring. Only localitys known in the United states.

Perennial.

Type locality not ascertained; locality of Roemer \& Schultes: "In graminosis humidiusculis Calcutae."

Herb. Geol. Surv. Herb. Mohr.

Eleocharis tortilis (Link) Schult. Mant. 2:92. 1824.

Scirpus tortilis Link, Jahrb. 3:78. 1820.

S. simplex Ell. Sk. 1: 76. 1816.

Eleocharis simplex Torr. Ann. Lyc. N. Y. 3 : 306. 1836.

Ell. Sk. 1:76. Gray, Man. ed. 6, 574. Chap. Fl. 516. Conlter, Contr. Nat. Herb. $2: 468$. 
Carolinian and Louisianian areas. Shores of Delaware, Maryland to Florida, west to Texas.

Alabama : Coast Pine belt. Margin of springs and brooks. Mobile County, Springhill. June to August; rare. Pereunial.

Type locality: "Von Bose aus Nord-America."

Herb. Geol. Surv. Herb. Mohr.

Eleocharis tuberculosa (Michx.) Roem. \& Schult. Syst. Veg. 2 : 152. 1817.

Scirpus tuberculosa Michx. Fl. Bor. Am. 1: 30. 1803.

LARGE-TUBERCLED SPIKE-RUSH.

Ell. Sk. 1:78. Gray, Man. ed. 6, 574. Chap. Fl. 515. Coulter, Contr. Nat. Herb. 2: 468 .

Carolinian to Louisianiau area. Southern Massachusetts to New Jersey, along the coast to Florida, west to Texas and Arkansas.

Alabama : Central Pine belt to Littoral region, wet miry places. Autanga County, Prattville. Washington County, Yellowpine. Mobile and Baldwin counties; common. July to September. Perennial.

Type locality: "Hab. in Carolina inferiore."

Herb. Geol. Surv. Herb. Mohr.

Eleocharis vivipara Link, Hort. Berol. 1:283. 1827.

SPROUTING SPIKE-RUSH.

Eleocharis prolifera Torr. Ann. Lyc. N. Y. 3:442. 1836 . Not Torr. 1. c. 316.

Kunth, Enum. 2 : 146, Chap. Fl.516, in part.

Carolinian and Louisianian areas. South Carolina and Florida.

Ala Bama: Metamorphic hills. Coast plain, miry margin of ditches and pools. Lee County, Auburn (Baker \& Earle, 564.) Mobile, Dauphinway, June, July; frequent. Perennial.

Easily confounded with E.camptotricha, with which it is not rarely associated; readily distinguished by the more oblong-obovate, pale, less strongly costate, smoothish nut, and the short loose sheaths, lacerate at the top.

Type locality not ascertained ; Kunth's locality : "Carolina ad margines paludum."

Herb. Geol. Surv. Herb. Mohr.

Eleocharis camptotricha Sauv. Fl. Cub. 173. 1868.

HAIRLIKE SPIKE-RUSH.

Elencharis prolifera Torr. Ann. Lyc. N. Y.316. 1836.(?)

Rhizoma descendent, fibrous; stems numerous, filiform, striate, subtriangular, sulcate; sheaths hyaline with the opening oblique, the head compressed, fewflowered; scales about triseriate, ovate, obtuse, brown-hyaline on the sides, with a green keel; stamens 2 or 3 ; achenium milky-white, roundish-oblong, triangular, the angles strongly pitted; tubercle short-conical; style trifid, long; bristles 5 or 6 , retrorsely scabrous, unequal, double the length of the achenium. Easily distinguished from its allies by the white pitted and striated achenium.

Cuba.

Louisianian area. North Carolina, South Carolina, Georgia, Florida, west to Louisiana.

Alabama: Coast plain, border ditches, ponds, exsiccated places. Mobile County. June, July; not frequent. Perennial.

In dense tufts; spikes rarely proliferous.

Type locality: "On the borders of lagoons. Pinar del Rio."

Herb. Geol. Surv. Herb. Mohr.

Eleocharis microcarpa Torr. Ann. Lyc. N. Y. 3:312. 1836.

Chap. Fl.517. Coulter, Contr. Nat. Herb. $2: 468$.

SMALL-FRUITED SPIKE-RUSH.

Carolinian and Louisianian areas. Maryland, southern New Jersey to Florida, west to Texas.

Alabama : Central Prairie region to Coast plain.

Shallow ponds and ditches. Montgomery County (G.McCarthy). Wilcox County (Buckley). Mobile and Baldwin counties. July; not infrequent. Perennial.

Type locality: "Wet places. New Orleans. Dr. Ingalls."

herb. Geol. Surv. Herb. Mohr.

Eleocharis tenuis (Willd.) Schult. Mant. 2 : 89. 1824.

SLENDER SPIKE-RUSH.

Scirpus tenuis Willd. Enum. 1: 76.1809.

Gray, Man. ed.6,575. Chap. F1.517. Coulter, Contr. Nat. Herb. $2: 468$.

Canadian zone to Carolinian area. Nova Scotia, Quebec, and Lake Superior to the Rocky Mountains; New England west to Michigan and Minnesota; throughout the Middle States to Missouri, Arkansas, and Texas. 
Alabama: Tennessee Valley. Warrior table-land to Central Pine belt. Marshy places. Lauderdale County, in the barrens. Cullman County. Tuscaloosa County (E. A. Smith). July; not rare. Perennial.

Type locality : "Hab. in America boreali."

Herb. Geol. Surv. Herb. Mohr.

DICHROMENA Michx. Fl. Bor. Am. 1:37. 1803.

Over a dozen species. Tropical and subtropical America. Perennial.

Dichromena colorata (L.) A. S. Hitchcock, Rep. Mo. Bot. Gard. 4 : 141. 1893.

NARROW-LEAF Dichromena.

Schoenus coloratus L. Sp. Pl. 1: 43. 1753.

Scirpus cephalotes Walt. Fl. Car. 71.1788.

Dichromena leucocephala Michx. Fl. Bor. Am. 1:37. 1803.

Ell. Sk. 1:89. Gray, Man.ed. 6,577. Chap. Fl. 530. Coulter, Contr. Nat. Herb.

2: 469 .

Bermuda, West Indies, Southern Mexico to Brazil.

Carolinian and Louisianian areas. Southern New Jersey to Florida, and west to Texas.

Alabama: Tennessee Valley. Mountain region to Coast plain. Dampopen grassy places. Jackson County, Scottsboro (E. A. Smith). Cullman, Tuscaloosa, and Mobile counties. July, August; frequent.

Typo locality: "Hab. in Jamaica, Bahama."

Herb. Geol. Surv. Herb. Mohr.

Dichromena latifolia Baldw.; Ell. Sk. 1:90. 1817. Broad-Leaf Dichromena. Gray, Man. ed. 6, 577. Chap. Fl. 530. Coulter, Contr. Nat. Herb. 2: 469.

Louisianian area. Southern Virginia, North Carolina to Florida, and west to eastern Texas.

Ala bama : Coast plain. Lower Pineregion. Open swamps. Washington County, Yellowpine. Mobile County. July to August; common.

Type locality: "McIntosh County, Ga., and in Florida."

Herb. Geol. Surv. Herb. Mohr.

FIMBRISTYLIS Vahl, Enum. 2 : 285.1806.

Fimbristylis spadicea (L.) Vahl, Enum. 2 :294. 1806.

Brown Club-RUSIr.

Scirpus spadiceus L. Sp. Pl. 1:51. 1753.

Chap. Fl.521, in part. Griseb. Fl. Brit. W. Ind.372. Coulter, Contr. Nat. Herb.

$2: 470$.

West Indies, Mexico, South to BraziI.

Louisianian area. Georgia and Florida to Texas.

Alabama: Littoral belt, brackish and salt marshes. Mobile and Baldwin counties. July to September. Perennial.

In some localities forming a large part of the glumaceous vegetation of the brackish and salt marshes.

Type locality: "Hab. in Jamaicae fluviis."

Herb. Geol. Surv. Herb. MoLr.

Fimbristylis puberula (Michx.) Vahl, Enum. 2:289. 1806.

Scirpus puberulus Michx. Fl. Bor. Am. 1:31. 1803.

S. ferrugineus Ell. Sk. 1:85. 1816.

Fimbristylis spadicea var. puberula Chap. Fl.522.

Ell. 1. c. Chap. 1. c. Griseb. Fl. Brit. W.Ind.572.

From Southeastern North America to Argentina.

Louisianian area. Caroliua, Florida, and Mississippi.

ArabaMa: Coast plain and Littoral region. Low flat pine barrens and salt marshes. Mobile County, Fowl River Station, flat pine woods in close damp soil. Baldwin County, salt marshes overflowed by the tide. April to July; frequent. Perennial.

Widely differing in the habit of growth and distribution, this plant can not be connected with the last. Growing under the most varying conditions of soil, in the salty marshes on the seashore as well as in the dry pine barrens of the coast region farther inland, it is found without the slightest deviation in its characters.

Type locality: "Hab. in Carolina et Georgia."

Herb. Geol. Surv. Herb. Molr. 
Fimbristylis autumnalis (L.) Roem. \& Schult. Syst. Veg. 2:97. 1817.

Scirpus autumnalis L. Mant. 2:280. 1771.

SLENDER Fimbristylis.

S. mucronulatus Michx. Fl. Bor. Am. 1:31. 1803.

Ell. Sk. 1:82. Gray, Man. ed.6,578. Chap. Fl. 522. Coulter, Contr. Nat. Herb. $2: 470$.

Alleghenian to Louisianian area. New England to southern Michigan, south to Missouri, Arkansas, Tennessee, and from New York to Florida and 'Texas.

Arabama: Throughout the State, in low ground. August to October; abundant. Annual.

'Type locality not ascertained; Roemer \& Schultes' locality: "In Pennsylvania, Virginia, Jamaica."

Herb. Geol. Surv. Herb. Mohr.

STENOPHYLLUS Raf. Neogen.4. 1825.

About 20 species, in subtropical and tropical regions, North America, 5 mostly Southern.

Stenophyllus stenophyllus (Ell.) Britton, Bull. Torr. Club, 21 : 30. 1894.

Scirpus stenoph̄yllus Ell. Sk. 1:83. 1816.

Stenophyllus caespitosus Raf. Neogen. 4.1825.

Isolepis stenophyllis 'Torr. Ann. Lyc. N. Y. 3:353. 1836.

Ell. Sk. 1 :83. Chap. Fl. 523.

Louisianian area. North Carolina to Florida and west to Louisiana.

Alabama: Coast plain. Damp alluvial banks. Mobile County, Choctaw Bluff. September; rare. Annual.

Type locality: "Grows in dry sandy soils. Around Beaufort [S. C.], common. Jaines Island."

Herb. Mohr.

Stenophyllus ciliatifolius (Ell.) Mohr, Bull Torr. Club, 24 : 2亡. 1897.

Scirpus ciliatifolius Ell. Sk. 1:82. 1816.

Fringed StenopilyluUs.

Isolepis ciliatifolia Torr. Ann. Lyc. N. Y. 3 : 352.1836.

Stenophyllus capillaris (I.) Britton, Bull. Torr. Club, 21:30. 1894. In part.

Ell. Sk. 1 : 82. Chap. Fl.523. Griseb. Fl. Brit. W. Ind. 572.

Tropical Africa, Asia, West Indies, Mexico to Brazil.

Louisianian area. North Carolina to Florida and Texas.

Alabama: Lower Pine region. Coast plain. Dry sandy fields. Mobile County, Springhill. Baldwin County, Daphne. September to October; frequent. Anmual. Stems setaceous, rigid, a foot and over in length; umbel, many-rayed; bracts short, achene firely pitted in longitudinal rows.

Type locality : "Grows in damp soils. Two miles from Beanfort [S. C.], near the main road."

Herb. Geol. Surv. Herb. Mohr.

Stenophyllus capillaris (L.) Britton, Bull. Torr. Club, 21:30. 1894. In part.

Scirpus capillaris L. Sp. Pl. 1:49. 1753. In part.

HaIRLike STENOPHYluUs.

Isolepis capillaris Roem. \& Schult. Syst. 2: 18. 1817.

Fimbristylis capillaris Gray, Man. 530. 1848.

Gray, Man. ed. 6, 578. Chap. Fl. 522. Wats. Bot. Calif. 2:236. Coulter, Contr. Nat. Herb. $2: 470$.

Alleghenian and Carolinian areas. New England to Michigau and Minnesota, and south along the mountains to Tenuessee and Florida (Chapman); west to Arkansas, Missouri, Texas, and the Pacific.

AlabaMA: Mountain region, exposed rocky places. Clay County, Chewahaw range, Baldrock, 2,200 feet, in crevices. July 30 (C. Mohr and E. A. Smith).

Grows in tufts, from 2 to 6 inches high; copious. Differs from the last, with which it was united by Dr. Britton, by the low habit of its growth and decided northern range of distribution. The characters are as follows:

Stem capillary, weak, 2 to 4 , rarely 6 , inches long, as long as or scarcely double the length of the leaves; umbel simple with 2 or rarely more sessile or short-stalked spikelets, bracts capillary short or elongated, achene less tumid at the top; seen under the lens, with sharp transverse wrinkles.

Type locality: "Hab. in Virginia, Aethiopia, Zeylona."

Herb. Geol. Surv. Herb. Mohr.

$15894 \div 26$ 
Stenophyllus capillaris coarctatus (E1l.) Britton, Bull. Torr. Club, 21:30. 1894.

Scirpus coarctatus Ell. Sk. 1:83. 1816.

Close-FloWered SteNopHyLLUS.

Isolepsis coarctatus Torr. Ann. Lyc. N. Y. 3:352. 1836.

Ell. Sk. 1: 83. Chap. Fl.523.

Louisianian area. Coast of South Carolina to Florida, and west to Louisiana.

Alabama: Lower Pine region. Dry pine ridges, sandy fieids. Mobile County, Cottage Hill. September; infrequent. Annual.

Type locality: "Grows in very dry sandy soils. Around Beanfort, common."

Herb. Geol. Surv. Herb. Mohr.

SCIRPUS L. Sp. P1. 1:47. 1753. ${ }^{1}$

About 250 species; cosmopolitan from the subaretic to tropical zones.

Scirpus nanus Spreng. Pugill. 1:4. 1815.

Dwarf Salt-water Rush.

Scirpus parvulus Roem. \& Schult. Syst. Veg. 2 : 124. 1817.

S. capillaceus Ell. Sk. 1:75. 1816.

Eleocharis pygmaea 'Torr. Ann. Lyc. N. Y. 3 : 313. 1836.

Gray, Man. ed. 6, 576. Chap. F1. 518. Conlter, Contr. Nat. Herb. $2: 471$.

Skacoast of Europe, South Africa.

Alleghenian to Lonisiauian area. New Brunswick, Quebec, Vancouver Island, south to Florida, Texas, and California?

Alabama : Littoral belt. Muddy banks occasionally overflowed by salt water.

Dauphin Island. Bald win County, Perdido Bay. Perennial.

Type locality (Spreng. Syst.): "Ad lacum Koelmensem flor. halens."

Herb. Geol. Surv. Herb. Mohr.

Scirpus carinatus (Hook. \& Arn.) Gray, Proc. Am. Acad. 7 : 392. 1868. Not Smith, Engl. F1. 1:60. 1824.

Keeled Club-rush.

Isolepis carinata Hook. \& Arn.; Torr. Ann. Lyc. N. Y. 3 : 349. 1836.

Chap. Fl. Suppl. 66. Wats. Bot. Calif. 2:217. Conlter, Contr. Nat. Herb. $2: 471$.

Louisianian area. Mississippi to Texas and Arkansas.

Alabama: Credited to the State by Britton. Coast plain?

Type locality : "Near New Orleans, T. Drummond!; on the Arkansas River, Nuttall!"

Herb. Geol. Surv. Herb. Møhr.

Scirpus cubensis Poepp. \& Kunth in Kunth, Enum. 2 : 172. 1837.

Scirpus ablepharus Griseb. Cat. Pl. Cub. 240. 1866.

Cuban Club-rush.

Oxycaryum 8chomburkianum Nees in Mart. Fl. Bras. 2, pt. 1:90. 1842.

Chap. Fl. Suppl. 660 ; ed. 3, 548.

Cuba. South America, Africa.

Louisianian area. Louisiana.

Alabana : Coast region. Open swamps. Mobile County, estuary of Mobile River.

Three-mile Creek, on floating rotting timber. August; rare. Perennial.

Type locality: "Cuba in paludibus. (Poeppig legit.)"

Herb. Geol. Surv. Herb. Mohr.

Scirpus debilis Pursh, Fl. Am. Sept. 1:55. 1814.

Weak Club-rush.

Ell.Sk. 1:79. Gray, Man. ed. 6, 580. Chap. Fl.519.

Alleghenian and Carolinian areas. New England, west to Michigan, Minnesota, and Nebraska, south to South Carolina and Georgia.

AlabaMa: Withont specific locality, Britt. \& Brown, Ill. Fl. 1:264. Annual.

Type locality: "Iu wet meadows: Penusylvania."

Scirpus americanus Pers. Syn. 1:68. 1805.

Three-hdGen Club-rusir.

Scirpus triqueter Michx. Fl. Bor. Am. 2:30. 1803. Not L.

S. pungens Vahl, Enum. $2: 255.1806$.

Eil. Sk. 1:80. Gray, Man. ed.6, 579. Chap. Fl.519. Wats. Bot. Calif. 2 : 218. Coulter, Contr. Nat. Herb, $2: 471$.

Mexico, South America.

Throughout North America, on beaches, and borders fresh and saline swamps from the Arctic regions to the Gulf.

${ }^{1} \mathrm{~N}$. L. Britton, list of species of the genera Scirpns and Rynchospora occurring in North America, Trans. N. Y. Acad. Sci., vol.11, pp. 74 to 93.1892. 
Alabama: Coast region. Brackish and salt marshes. Mobilo and Baldwin counties. July to September; common. Perennial.

Type locality : "Hab. in Carolina inferiore."

Herb. Geol. Surv. Herb. Mohr.

Scirpus cylindricus (Torr.) Britton, Trans. N. Y. Acad. Sci. 11: 79. 1892.

CANBY's Bulrush.

Scirpus maritimus var. cylindricus Torr. Ann. Lyc. N. Y. 3 : 325. 1836.

S. leptolepis Chap. Fl. 520. 1860.

S. canbyi Gray, Am. Journ. Sci. ser. 2, 38 : 289. 1864.

Gray, Man. ed.6,580. Chap. Fl. 20.

Carolinian and Louisianian areas. Coast of Maryland to Florida, and west to Mississippi and Louisiana.

Alabama : Coast plain and Lower Pine region. In still-flowing water. Pine-barren streams. Mobile and Baldwin counties. May to July; frequent.

Rhizonia fibrous, with slender runners. Perennial.

Type locality: "Georgia, Dr. Baldwin!"

Herb. Geol. Surv. Herb. Mohr.

Scirpus olneyi Gray, Bost. Journ. Nat. Hist. 5 :238. 1845.

OlNeY's Bulrush. Gray, Man. ed. 6, 579. Chap. Fl.519. Coulter, Contr. Nat. Herb. $2: 471$. Wats. Bot. Calif. $2: 218$.

Mexico.

Alleghenian to Louisianian area. Southern New England along the tide-water region to Florida, west to Texas, New Mexico, and California.

Alabama: Coast plain and Littoral belt. In fresh, brackish, and salt marshes. Mobile County, swamps in the delta of Mobile River. Baldwin County, Bon Secour, salt marshes. 5 uly to October; common. Perennial.

Stem 4 to 5 feet high, from a long creeping rhizoma.

Type locality: "In a salt marsh on the Seekonk River, Rhode Island, Mr. S. T. Olney." Also "detected on the coast of Now Jersey by * * * Dr. Knieskern."

Herb. Geol. Surv. Herb. Mohr.

Scirpus lacustris L. Sp. Pl. 1:48. 1753.

LARGE BULRUSh.

Scirpus validus Vahl, Enum. 2:268. 1806.

Ell. Sk. 1:81. Gray, Man. ed.6, 580. Chap. Fl.520. Wats. Bot. Calif. $2: 219$. Coulter, Contr. Nat. Herb. 2:471. Griseb. Fl. Brit. W. Ind.571.

Under several forms, widely distributed in temperate and warmer regions.

Europe, Asia, Oceania, North and South America.

All over the North American continent from British America to the Gulf, west to the Rocky Mountains and the Pacific coast.

AlabaMa: Over the State. In gently-flowing waters, lakes, and deep ponds. Tuscaloosa, Mobile, and Bald win counties. July, August; common. Perennial.

'Type locality: "Hab. in Europae aquis puris stagnantibus et fluviatilibus.

Herb. Geol. Surv. Herb. Mohr.

Scirpus divaricatus Ell. Sk. 1:88, t.2,f.4. 1816.

SPREAding BuLrush.

Ell.1.c. Chap. 520.

Louisianian area. Sonth Carolina, Georgia, and from western Florida to Louisiana. Alabama: Upper division Coast Pine belt. Shaded swamps. Henry Connty, headwaters of Choctawhatchee River, near Echo. July; rare. Perennial.

Type locality: "Grows in the pine barren between Bees Creek and Perrysburg [S. C.]."

Herb. Geol. Surv.

Scirpus robustus Pursh, Fl. Am. Sept. 1:56. 1814.

Salt-marsh Bulrush.

Scirpus maritimus var. macrostachyus Michx. Fl. Bor. Am. 1:32. 1803. Not S. macrostatchyus Lam.

Ell. Sk. 1:86. Gray, Man. ed. 6, 581. Chap. Fl. 520. Coulter, Contr. Nat. Herb. $2: 472$.

Alleghenian to Louisianian area. Nova Scotia; New England to Florida, west to Texas along the shore.

Alabama: Littoral region. Brackish and salt marshes. Mobile County, West Fowl River. July. Perennial.

Type locality: "In salt marshes and on the banks of rivers, common."

Horb. Mohr.

Scirpus fluviatilis (Torr.) Gray, Man. 527. 1848.

River Club-rush.

Scirpus maritimus var. fluviatilis Torr. Ann. Lyc. N. Y. $3: 324.1836$.

Gray, Man. ed. 6, 581. Britt. \& Brown. Ill. Fl. 1:268. 
Alleghenian to Louisianian area. Quebec; New England to Minuesota, Kansas, Illinois, and sontli from New York to Florida.

Alabama : Coast plain. Deep marshes. Mobile County, banks kast Fowl River. July; rare. Perennial.

Type locality: "Common in the western parts of the State of New York, Dr. Gray!; on the Missouri above St. Louis, Dr. Baldwin!"

Herb. Geol. Surr.

Scirpus polyphyllus Vahl, Enum. 2:274. 1806.

LeaFy BULRUSH.

Scirpus exaltatus Pursh, Fl. Am. Sept. 1 : 56. 1814.

Ell. Sk. 1:87, 88. Gray, Man. ed. 6, 582. Chap. F1.520.

Alleghenian and Carolinian areas. Southern New England to North Carolina.

Alabama: Mountain region. Grassy swamps. Winston County, Colliers Creek,

1,600 feet. August; rare. Perennial.

Type locality: "Hab. in America boreali ?"

Herb. Geol. Surv. Herb. Mohr.

Scirpus cyperinus eriophorum (Michx.) Britton, Trans. N. Y. Acad. 11: 82. 1892.

Scirpus eriophorum Michx. Fl. Bor. Am. 1:33. 1803.

WOOL Grass.

Eriophorum cyperinum var. laxum Gray, Man.ed. 6, 582. 1860.

Ell. Sk. 1:91. Gray, Man.1.c. Chap. Fl. 521.

Alleghenian to Louisianian area. New Brunswick and Ontario sonth to Florida and along the Gulf to Louisiana.

Alabama: Central Pine region to Coast plain. Grassy swamps. Tuscaloosa,

Mobile, and Baldwin counties. July to August; frequent. Perennial.

Type locality: "Hab. a Virginia ad Georgiam."

Herb. Geol. Surv.

Scirpus lineatus Michx. Fl. Bor. Am. 1:32. 1803.

RedDish BULrusH.

Trichophorum lineatum Pers. Syn. 1:69. 1805.

Eriophorum lineatum Benth. \& Hook. Gen. Pl. 3 : 1052. 1883.

Ell. Sk. I:87. Gray, Man. ed. 6, 582. Chap. Fl. 521. Coulter, Contr. Nat. Herb. $2: 472$.

Alleghenian to Louisianian area. Ontario, New Englaud west to Michigan, Minnesota, Kansas, and Missouri, south to l'lorida and Louisiana.

Alabama: Tennessee Valley to the coast. Most frequent in the Coast Pine belt. Swanupy banks of pine-barren streams. Washington County, Yellowpine. Mobile and Baldwin counties. Juls, August; not infrequent. Perennial.

Type locality: "Hab. in Carolina."

Herb. Geol. Surv. Herb. Mohr.

FUIRENA Rottb. Deser. et Icon. 70, $t$. 19, f. 3. 1773.' Ummrklla Grass.

About 25 species. Perennial. Tropical and warmer temperate America. Atlantic North America, 6.

Fuirena scirpoidea Michx. Fl. Bor. Am. 1:38, t.\%. 1803.

E11. Sk. 1:54. Chap. Fl. 5̌14.

Louisianian area. Coast of Georgia and Florida to Louisiana.

AlabaMA: Littoral belt. Springy banks and brackish sandy swamps. Baldwin County, eastern shore of Mobile Bay, Point Clear. Mobile Connty, West Fowl River, Dauphin Island. July to Angust; frequent.

Type locality: "Hab. in paludosis aestate exsiccabilibus Floridae."

Herb. Geol. Surv. Herb. Mohr.

Fuirena squarrosa breviseta Coville, Bull. Torr. Club. 17: 6. 1890.

Fuirena squarrosa Chap. Fl.514. 1860.

F. squarrosa $\alpha$ 'Torr. Ann. Lye. N. Y. $3: 291.1836$.

Coulter, Contr. Nat. Herb. $2: 473$.

Lonisianian area. From North Carolina to Florida ; west to Lonisiana and eastern T'exas.

Alabama: Coast plain. Borders of grassy swamps and ditches. Mobile County. July; infrequent.

'Frederick V. Coville, Revision of the United States species of Fuirena, Bull. Torr. Club, vol. 17, pp. 1 to 8.1890. 
Type locality of F. squarrosa $\alpha$ Torr.: "Swamps; North Carolina to Florida." Collections are eited in North Carolina, South Carolina, Georgia, Alabama, and Louisiana.

Herb. Geol. Surv. Herb. Mohr.

Fuirena squarrosa hispida (Ell.) Chap. Fl.514. 1860.

Fuirena hispida Ell. Sk. 1:579. 1817-21.

Ell. Sk. 1:579. Gray, Man. ed. 6, 583. Coulter, Contr. Nat. Herb. 2: 473.

Carolinian and Louisianian areas. New York, Kentucky, south to Florida, and west to eastern Texas.

Alabama: Central Pine belt to the Coast plain. Grassy swamps, borders of brooks. Tuscaloosa, Montgomery, Mobile, and Baldwin counties. July; frequeut.

Type locality: "Grows in great abundance around ponds in the middle districts of Georgia and Carolina, first sent to we from Milledgeville by Dr. Boykin."

Herb. Geol. Surv. Herb. Mohr.

HEMICARPHA Nees \& Arn. Edinb. New Ph. Journ. $17: 263.1834$.

About 4 species, annuals; temperate and tropical zones. North America, 2.

Hemicarpha micrantha (Vahl) Britton, Bull. Torr. Club, 15:104. 1888.

Scirpus micranthus Vahl, Enum. 2:254. 1806.

HeMiCARPHA.

S. subsquarrosus Muhl. Gram. 39. 1817.

Hemicarpha subsquarrosa Nees in Mart. Fl. Bras. 2, pt.1:61. t.4,f.1. 1842.

Gray, Man. ed.6, 583. Chap. Fl. 513. Wats. Bot..Calif. 2:120. Coulter, Contr. Nat. Herb. 2 : 473 . Griseb. Fl. Brit. W. Ind. 572.

West Indies, Mexico to Brazil.

Carolinian and Louisianian areas. Sunthern New England west to Michigan, Missonri, and southern Illinois; south to Florida, and west to Texas, New Mexico, Arizona, and California.

Alabama : Upper division Coast Pine belt, Coast plain. Low, damp sandy ground, most frequent in flat open grassy pine barrens. Washington County, Yellowpine, Clarke County, Choctaw Corner. Mobile County. May to June; common.

Type loeality: "Hab. in America meridionali? Richard."

Herb. Geol. Surv. Herb. Mohr.

LIPOCARPHA R. Br. App. Tuckey Exp. Congo, 459. 1818.

Seven species, tropies of both hemispheres.

Lipocarpha maculata (Michx.) Torr. Ann. Lyc. N. Y. 3:288. 1836.

Kyllingia maculata Michx. Fl. Bor. Am. 1:29. 1803.

AMERICAN LIPOCARPHA.

Ell. Sk. 1:55. Gray, Man. ed. 6, 584. Chap. Fl.513.

CuBa.

Carolinian and Louisianian areas. Southern Virginia, North Carolina, Florida, and Alabama.

Alabama: Central Prairie region. Autauga County, Prattville (E. A. Smith). Rare. Annual.

Type locality : "Hab. in Carolina."

Herb. Geol. Surv. Herb. Mohr.

RYNCHOSPORA Vahl, Enu:m. $2: 229.1806$.

About 200 species, chiefly of the warmer temperate and tropical regions, mostly American. North America, 44. Perennials. 1

Rynchospora tracyi Britton, Trans. N. Y. Acad. 11:84. 18y2.

Tracy's Horned Rush.

Ceratoschoenus capitatus Chap. Fl. 529. 1860. Not R. capitata Roem. \& Schult.

Lonisianian area. Florida and Alabama.

Alabama: Littoral belt. Brackish swamps. Baldwin County, Josephine, muddy shore of Bayou La Launch. June, July; rare.

Type locality: "Pine-barren ponds, middle and west Florida."

Herb. Geol. Surv. Herb. Mohr.

'N. L. Britton, List of species of the genera Scirpus and Rynchospora in North America, Trans. N. Y. Acad. Sci., vol. 11, pp. 74 to 93. 1892. 
Rynchospora corniculata (Lam.) Gray, Ann. Lyc. N. Y. 3 :205. 1835-36.

Schoenus corniculatus Lam. Tabl. Encycl. 1:137. 1791.

LARGE HORNED RUSH.

Rynchospora longirostris Ell. Sk. 1:59. 1816.

Ell. l. c. Gray, Man. ed.6,586. Chap. Fl. 528. Coulter, Contr. Nat. Herb. $2: 473$.

Carolinian and Louisiauian areas. Southern Pennsylvania, Virginia, and North Carolina to Florida, eastern Texas, and Arkansas.

Alabama : Central Pine belt to Coast piain. Wet sandy ground, ditches, marshes. Tuscaloosa, Montgomery, Clarke, Washington, Mobile, and Bald win counties. July to September; frequent.

Type locality : "E Florida, Carolina."

Herb. Geol. Surv. Herb. Mohr.

Rynchospora pusilla Chap.; M. A. Curtis, Am. Journ. Sci.ser. 2, 7: 409. 1849.

Humble Beaked Rush.

Rynchospora intermixta Sauv. Fl. Cub.184. 1873.

Chap. Fl. 528; ed.3, 556. Coulter, Contr. Nat. Herb. 2:474. Griseb. Fl. Brit. W. Ind.576.

Cuba.

Louisianian area. Florida and Alabama to Texas.

Alabama: Coast plain. Damp flat pine barrens. Mobile County, Portersville. August, September; rare.

Type locality (in Chapman's Flora): "Margin of pine-barren ponds, middle and west llorida."

Herb. Geol. Surv. Herb. Mohr.

Rynchospora divergens Chap.; M. A. Curtis, Am. Jonrn. Sei. ser. 2, 7 :409. 1849.

Rynchospora lamprosperma Sauv. Fl. Cub. 184. 1873.

Divergent Beaked RUsh.

Chap. Fl.528; ed. 3, 556.

WEST INDIES.

Louisianian area. South Carolina to Florida.

Alabama: Coast plain. Damp pine barrens. Mobile County. June to August; frequent.

Type locality: "This plant was sent me a year or two since from the Santee by

Mr. Ravenel."

Herb. Geol. Surv. Herb. Mohr.

Rynchospora chapmanii M. A. Curtis, Am. Journ. Sci. ser. 2, 7:409, 1849.

Chap. Fl.528; ed. 3, 556.

CHAPMAN's BEAKED RUSH.

Louisianian area. North Carolina to Florida and Louisiana.

Alabama: Coast plain. Flat damp pine barrens. Mobile County, Bayou La

Batre. July to September. Abundant.

Type locality: "Wilmington, N. C. I have received this from the Santee (Ravenel); and also from Dr. Chapman of Florida."

llerb. Geol. Surv. Herb. Mohr.

Rynchospora oligantha Gray, Ann. Lyc. N. Y. 3 :212. 1835.

Chap. F1.524. Coulter, Contr. Nat. Herb. $2: 474$.

FeW-FLowered Beaked Rush.

Carolinian and Louisianian areas. North Carolina to Florida and Texas

Alabama: Coast plain. Lower Pine region. Low open pine barrens. Mobile

County. May, June; not common.

Type locality: "Fayetteville, N.C. Schweinitz " * *; near Wilmingtou, N. C., Mr. Curtis."

Herb. Geol. Surv. Herb. Mohr.

Rynchospora plumosa Ell. Sk. 1:58. 1816.

Rynchospora penniseta Griseb. Cat. Pl. Cub. 244. 1866.

Ell. Sk.1. c. Chap. Fl. 524. Coulter, Contr. Nat. Herb. $2: 474$.

Cuba.

Carolinian and Louisianian areas. North Carolina to Florida, west to eastern Texas.

Alabama: Coast plain. Low open pine barrens. Mobile and Baldwin counties. June, July ; frequent.

Type locality: "Grows in dry pine barrens. Common around Beaufort. Near St.

Mary's-Dr. Baldwin."

Herb. Geol. Surv. Herb. Mohr. 
Rynchospora intermedia (Chap.) Britton, Trans. N. Y. Acad. Sci. 11:87. 1892.

Pine-barReN Beaked Rush.

Rynchospora plumosa var. intermedia Chap. Fl.524. 1860.

Chap. Fl. 1. c. Coulter, Contr. Nat. Herb. $2: 474$.

Louisianian area. Florida to Louisiana.

Arabama: Coast plain. Lower Pine region. Dry sandy pine barrens. Mobile County, Springhill. Baldwin County, Bayou Ingram. June, July ; not rare.

Type locality: "Sandy pine barrens, often dry places, Florida."

Herb. Geol. Surv. Herb. Mohr.

Rynchospora alba (L.)Vahl, Enum. 2 :236. 1806.

White Beaked RUSH.

Schoenus albus L. Sp. Pl. 1: 44. 1753.

Ell. Sk. 1:57. Gray, Man. ed. 6, 585. Coulter, Contr. Nat. Herb. 2 : 474.

EUROPE, ASIA.

Boreal region to Louisianian area. Newfoundland to Alaska andl Oregon, south on the high monntain ranges and in the plain to Florida, west to Texas.

Alabama : Coast plain. Boggy pine barrens. Bayou La Batre. August, September; infrequent.

Type locality : "Hab. in Europae borealis paludibus."

Herb. Geol. Surv. Herb. Mohr.

Rynchospora glomerata (L.) Vahl, Enụm. 2 : 234. 1806.

Schoenus glomeratus L. Sp. Pl. 1:44. 1753.

S. capitellatus Michx. Fl. Bor. Am. 1: 36. 1803.

Ell. Sk. 1:61. Gray, Man. ed.6, 585. Chap. Pl. 527. Coulter, Contr. Nat. Herb.

$2: 474$.

Alleghenian to Louisianian area. New England west to Michigan, south to West Virginia, Florida, Texas, and Arkansas.

AluABama: All over the State. Wet places, open ground and in woodlands. Cnllman, Montgomery, Mobile, and Baldwin counties. July to september; frequent.

Type locality: "Hab. in Virginia."

Herb. Mohr.

Rynchospora glomerata paniculata (Gray) Chap. Fl.528. 1860.

Paniculate Beaked Rush.

Rynchospora paniculata Gray, Ann. Lyc. N. Y. 3:211. 1835-36.

Chap. F1. l. c. Coulter, Contr. Nat. Herb. 2:474.

Carolinian and Louisianian areas. South Atlantic and Gulf States. Maryland to Texas.

Aldbama: Mountain region to Coast plain. Low damp places, ditches. Lee County, Auburn (Baker \& Earle, 872). Mobile; not rare.

Type locality: "Now Orleans, T. Drummond, (in Herb. Torr.); middle Florida, Dr. Chapman."

Herb. Geol. Surv. Herb. Mohr.

Rynchospora axillaris (Lam.) Britton, Bull. Torr. Club, 15: 104. 1888.

Schoenus axillaris Lam.Tabl. Encycl. 1: 137. 1791.

Rynchospora cephalantha Gray, Ann. Lyc. N. Y. $3: 218$. 1835-36.

Gray, Man. ed.6, 585 . Chap. Fl.528.

Carolinian and Louisianian areas. Long Island, along the coast to Florida, west to Lonisiana and Arkansas.

Alabama: Central Pine belt to Coast plain. Sandy swamps, ditches. Clay County, Chewahaw Mountain, 2,400 feet. Tuscaloosa, Washington, and Mobile counties. July, August; not common.

Type locality: "E Carolina. D. Fraser."

Herb. Geol. Surv. Herb. Mohr.

Rynchospora filifolia Torr. Ann. Lyc. N. Y. $3: 366.1836$.

Filiform-leavel Beaked Rush.

Chap. Fl.527. Coulter, Contr. Nat. Herb. $2: 475$.

Louisianian area. North Carolina to Florida and west to eastern Texas.

Alabama: Mountain region, Lower Pine region. Coast plain. Damp sandy borders of brooks and ponds. Lee County, Auburn (Baker \& Earle, 577). Mobile County, Citronelle. Washington County, Yellowpine. Baldwin County, Josephine. July; frequent.

Type locality: "North Carolina, Mr. Curtis!; middle Florida, Dr. Chapman."

Herb. Geol. Surv. Herb. Mohr. 
Rynchospora fuscoides Clarke; Britton, Trans. N. Y. Acad. 11:89. 1892.

Brown Beaked Rush.

Rynchospora fascicularis var. distans Chap. Fl. 527. Not R. distans (Michx.) Ell.

R. filifolia Sauv. Fl. Cub. 180. 1873. Not Torr.

Chap. l. c. Coulter, Contr. Nat. Herb. 2: 475 .

CuBA.

Louisianian area. Florida to Texas.

Alabama: Coast plain. Low sandy pine barrens. Mobile County. Baldwin

County, Bayou La Launch. June, July; not infrequent.

Type locality (Chapman): "Low pine barrens, Florida to North Carolina."

Herb. Geol. Surv. Herb. Mohr.

Rynchospora fascicularis (Michx.) Vahl, Enum. 2:23ł. 1806.

Schoenus fascicularis Michx. Fl. Bor. Am. 1:37. 1803.

Fasciculate Beaked Rush.

Ell. Sk. 1:60. Chap. Fl. 527.

Varies greatly in number and length of bristles, from few to more than 6, from one-third to the full length of the achenium.

Louisianiau area. North Carolina to Florida and west to Louisiana.

Alabama: Coast plain. Borders of ponds, ditches. Mobile and Baldwin counties. June; frequent.

Type locality: "Hab. in Carolina."

Herb. Geol. Surv. Herb. Mohr.

Rynchospora gracilenta Gray, Ann. Lyc. N. Y. 3:216. 1835-36.

Slender Beaked Rusir.

Gray, Man. ed. 6,585. Chap. Fl. 527. Coulter, Contr. Nat. Herb. 2:475.

Carolinian to Louisianian area. Sonthern New York and New Jersey to Florida, west to Texas.

Alabana : Central Pine belt, Coast Pine belt. Coast plain. Low wet woods and pine-barren ponds. Washington County, Yellowpine. Mobile County. August, September; common.

Type locality: "Pine barrens of New Jersey; Aug.-Sept. Philipstown, Putnam County, N. Y., Dr. Barratt; Salem, N. C., Schweinitz."

Herb. Geol. Surv. Herb. Mohr.

Rynchospora baldwinii Gray, Ann. Lyc. N. Y. 3 :210. 1835-36.

Chap. Fl. 526.

BALDWIN' BEAKED RUSH.

Louisianian area. North Carolina and Florida to Mississippi.

Al.ABama: Coast plain. Flat damp pine barrens. Mobile and Baldwin counties. July, August.

Type locality: "Georgia, in pine-barren swamps, between the Satilla and Altamaha rivers, December, 1816.' Dr. Baldwin."

Herb. Geol. Surv. Herb. Mohr.

Rynchospora ciliaris (Michx.) Mohr.

Fringe-Leaf Beakel Rush.

Schoenus ciliaris Michx. FI. Bor. Am. 1:36. 1803.

Rynchospora ciliata Vahl, Enum. 2 : 235. 1806.

Chap. Fl. 526.

Louisianian area. North Carolina to Florida, west to Mississippi.

Alabama: Coast plain. Damp low pine barrens. Mobile County. June, July; not rare.

Typelocality: "Hab. in Florida."

Herb. Geol. Surv. Herb. Mohr.

Rynchospora grayii Kunth, Enum. 2:539. 1837.

Gray's Beaken Rush.

Rynchospora distans Ell. Sk. 1:59. 1816. Not Schoenus distans Michx.

R. elliottii Gray, Ann. Lyc. N. Y. $3: 204.1835$. Not Dietrich.

Chap. Fl.526. Conlter, Contr. Nat. Herb. 2: 475.

Louisianian area. North Carolina to Florida, west to Texas.

Alabama : Coast Pine belt. Coast plain. Open dry pine woods, in stiff soil. Baldwin and Mobile counties.

Type locality (Gray): "In damp savannahs, Wilmington, N. C., Mr. Curtis; Havanna, Ga., and New Smyrna, Florida? Dr. Baldwin (sub nom. R. distans.); Gadsden Countv, middle Florida, Dr. Chapman."

Herb. Geol. Surv, Herb. Mohr. 
Rynchospora dodecandra Baldwin; Gray, Ann. Lye. N. Y. $3: 207$. 1835-36.

LaRGe-Frutted Beaked Rush.

Rynchospora megalocarpa Gray, Ann. Lyc. N. Y. 3 : 208. 1835-36.

Chap. Fl. 526.

Louisianian area. Coast of North Carolina and Florida to Mississippi.

Alabama : Littoral belt. Arid loose sands, near the seashore. In the copses covering old dunes. Mobile County, Dauphin Island. Baldwin County, eastern shore Mobile Bay, Perdido Bay. May, June; not infrequent.

Type locality: "Near the seashore, Fort George Island, east Florida, April, 1817.' Dr. Baldwin."

Herb. Geol. Surv. Herb. Mohr.

Rynchospora cymosa (Willd.) Ell. Sk. 1:58. 1816.

WaYSIDE BEAKED RUSH.

Schoenus cymosus Willd. Sp. Pl. 1:265. 1797.

Ell. l. c. Gray, Man. ed.6,584. Chap. Fl.524. Coulter, Contr. Nat. Herb. 2:475.

Carolinian and Louisianian areas. Southern Pennsylvania, New Jersey to Florida, Texas, Arkansas, and Indian Territory.

Alabama: Mountain region to Coast plain. Damp light soil. Cullman County. Lee County, Auburn (Baker \& Earle, 578). Washington County, Yellowpine. Baldwin and Mobile counties; frequent.

Type locality: "Hab. in America boreali."

Herb. Geol. Surv. Herb. Mohr.

Rynchospora cymosa globularis Chap. Fl.525. 1860.

Chap. 1. c.

Louisianian area. Florida to Louisiana.

Alabama: Coast plain. Low exsiceated places. Baldwin and Mobile counties.

May; common.

'Type locality: "Low ground, Florida and northward."

Herb. Geol. Surv. Herb. Mohr.

Rynchospora compressa Carey; Chap. Fl.525. 1860. Flat-fruiten Beaked Rush. Rynchospora cymosa compressa (Carey) Britton, 'Trans. N. Y. Acad. 11: 91. 1892.

CuBA.

Louisianian area. Florida.

Alabava: Central Prairie region, Coast Pine belt. Borders of ponds. Wileox

County (S. B. Buckley). Baldwin County, Wolfs Bayou. June; rare.

'Type locality: "Margins of pine-barren ponds, west Florida."

Herb. Geol. Surv. Herb. Mohr.

Rynchospora torreyana Gray, Ann. Lyc. N. Y. 3:197. 1835-36.

Graj, Man. ed. 6, 584. Chap. Fl.524.

'TORREY'S BEAKED RUSH.

Carolinian and Louisianian areas. New Jersey to Florida, west to Louisiana.

Alabama : Coast Pine belt to the seashore. Grassy swamps, borders of pine-barren ponds. Mobile and Baldwin counties. Washington County, Yellowpine. August, September; frequent.

Type locality: "Monmouth County, N. J., Torrey; also in wet grouud, near Quaker Bridge, N. J."

Herb. Geol. Surv. Herb. Mohr.

Rynchospora rariflora (Michx.) Lill. Sk. 1:58. 1816.

Sparsely-flowiered Beaked Rush.

Schoenus rariflorus Michx. Fl. Bor. Am. 1: 35. 1803.

Ell. Sk. 1. c. Chap. Fl. 524. Coulter, Contr. Nat. Herb. 2 : 475.

Louisianian area. North Carolina to Florida, west to Texas.

Alabama : Mountain region, Lower Metamorphic hills, Lower Pine region to Coast plain. Boggy pine barrens. Lee County, Auburn (Baker \& Earle, 515). Mobile and Baldwin counties. July to September; abundant.

Type locality : "Hab. in Georgia."

Herb. Geol. Surv. Herb. Mohr.

Rynchospora microcarpa Baldwin; Gray, Aun. Lyc. N. Y. 3 :202. 1835-36.

Chap. Fl.525. Coulter, Contr. Nat. Herł. 2: 475 .

SMALL-FRUITED BEAKED RUSH.

BaHamas (Eggers).

Louisianian area. North Carolina to Florida, west to eastern Texas.

Alabama: Coast plaiu. Borders of pine-barren ponds, ditches. Mobile and Baldwin counties. Specimens from Mobile County mostly with 3 bristles shorter than the nut. 
Type locality: "In wet savannas. St. Marys, Fla., Dr. Baldwin; Wilmington, N. C., Mr. Curtis."

Herb. Geol. Surv. Herb. Mohr.

Rynchospora caduca Ell. Sk. 1:62. 1816.

Rrverside Beaked Rush.

Ell. l. c. Chap. Fl.526. Coulter, Contr. Nat. Herb. $2: 475$.

Louisianian area. North Carolina to Florida, west to 'Texas.

Alabama : Coast plain. Wet margins of marshes and streams. Mobile County, river marshes. July, August; abuudant.

Economic uses: Cut by the negroes for green folder.

Type locality: "Around Charleston, common."

Herb. Geol. Surv. Herb. Mohr.

Rynchospora schoenoides (Ell.) Britton, Trans. N. Y. Acad.11:92. 1892.

Scirpus schoenoides Ell. Sk. 1:89. 1816 .

Elliott's Beaked RUsi.

Rhynchospora multiflora Gray, Ann. Lyc. N. Y. 3 : 200. 1835-36.

R. elliottii Dietr. Syn. Pl. 1 : 189. 1839.

Eil. l.c. Chap. Fl.525. Coulter, Contr. Nat. Herb. $2: 475$.

Louisianian area. Georgia and Florida west to Louisiana.

Alabama : Coosa Valley to the Coast plain. Ditches, border of ponds. Etowah

County, Ballplay, low pine woods. Mobile and Baldwin counties. July.

Type locality: "Found near Savannah by Dr. Baldwin."

Herb. Geol. Surv. Herb. Mohr.

Rynchospora inexpansa (Michx.) Vahl, Enum. 2:232. 1806.

Schoenus inexpansus Michx. Fl. Bor. Am. 1:35. 1803.

NARROW-SPIKED BeAKED RUSH.

Ell. Sk. 1:61. Gray, Man. ed.6,584. Chap. Fl. 525. Conlter, Contr. Nat. Herb.

$2: 476$.

Carolinian and Louisianian areas. Southern Virginia to Florida, west to western Louisiana and Texas?

Alabama : Mountain region to Coast plain. Low miry places. Cullman, Montgomery, Washington, and Mobile counties; common.

Type locality: "Hab. in Carolina."

Herb. Geol. Surv.

Rynchospora miliacea (Lam.) Gray, Ann. Lyc. N. Y. 3: 198. 1835.

Schoenus miliaceus Lam. Tabl. Encycl. 1 : 137. 1791.

Panic-like Beaked Rush.

S. sparsus Michx. Fl. Bor. Am. 1: 35. 1803.

Ell. Sk. 1:62. Chap. Hl.526.

CUBA.

Louisianian area. North Carolina to Florida and Mississippi.

Alabama: Central Prairie belt to Coast plain. Springy places in shady woods. Montgomery County, Pentulalla Creek. Autauga County $(E, d$. Smith). Baldwin Connty, Point Clear. July to August; infrequent.

Type locality: "E Carolina merid. D. Fraser."

Herb. Geol. Surv. Herb. Mohr.

Rynchospora stenophylla Chap. Fl.525. 1860.

Rynchospora tenuifolia Griseb. Cat. PI. Cub.244. 1866.

Chap. Fl. 525 .

CUBA.

Louisianian area. South Carolina to Florida.

Alabama : Coast Pine belt. Borders pine-barren ponds. Mobile County, Grand Bay. July, 1889 ; very rare.

Type locality: "Low grassy pine barrens, Apalachicola [Fla.]."

Herb. Geol. Surv. Herb. Mohr.

CLADIUM P. Br. Civ. \& N. Hist. Jam. 14. 1756. Twig Rusi.

Three species, of temperate and warmer zones. Enrope, America. Coarse perenuial marsh plants.

Cladium mariscoides (Mubl.) Torr. Ann. Lyc. N. Y. 3 : 372. 1836.

TwIG RusH.

Schoenus mariscoides Muhl. Gram.4. 1817.

Gray, Man. ed. 6, 586.

Alloghenian to Louisianian area. New Brunswick, Ontario, New England, west to Michigan, Iowa, and Minnesota, south to Delaware and Florida. 
Alabama : Littoral region, brackish marshes. Baldwin County, Bayou La Launch. June, July; rare. Perennial.

Type locality: "Hab. in spongiosis Pennsylvaniae, floret Julio."

Herb. Geol. Surv. Herb. Mohr.

Cladium effusum (Sw.) Torr. Ann. Lyc. N. Y. $3: 374.1836$.

Saw Grass.

Schoenus effusus Sw. Prodr. Veg. Ind. Occ. 19. 1788.

Ell. Sk. 1. c. Chan. Fl.530. Coulter, Contr. Nat. Herb. $2: 476$.

Louisianian area. North Carolina to Florida, west to southwestern Texas and Arkansas.

Alabama: Coast plain, Littoral belt. Deep marshes, fresh or brackish. Mobile County, river swamps. Baldwin County, Bon Secour, saline marshes. July, August; frequent. Perennial.

Type locality: West Indian. Torrey's locality: "Ponds and fresh marshes. Wilmington and Newbern, N. C., Mr. Curtis! \& Mr. Croom!; South Carolina, Elliott; New Orleans and Texas, T. Drummond."

Herb. Geol. Surv. Herb. Mohr.

SCLERIA Berg. Kongl. Acad. Sv. Handl. $26: 142, t .4, f .5 .1765 .{ }^{\prime}$ Nut Rush.

About 100 species, perennials, of warmer temperate and tropical regions.

Scleria triglomerata Michx. Fl. Bor. Am. 2 : 168. 1803.

Tall Nut Rush.

Ell. Sk. 2:558. Gray, Man. ed.6,586. Chap. Fl.531.

BraziL.

Alleghenian to Louisianian area. Ontario; New England (Massachusetts), west to Michigan and Minnesota, south to New Jersey, the Carolinas, Florida, Arkansas, Missouri, Illinois, Tennessee, and Kentucky.

Alabama: Over the State, open woods, in light soil. June, July; frequent.

Type locality: "Hab. in Carolina."

Herb. Geol. Surv. Herb. Mohr.

Scleria oligantha Michx. Fl. Bor. Am.2:167. 1803. Few-Flowered Nut Rush. Ell. Sk. 2:557. Gray, Man. ed. 6, 587. Chap. Fl.531. Coulter, Contr. Herb. $2: 476$.

CuBA.

Carolinian and Louisianian areas. Virginia to Florida, west to Texas.

Alabama : Mountain region, Central Pine belt. Dry copses. Lee County, Auburn (Baker \& Earle, 582). Tuscaloosa County (E. A. Smith). May; rare.

Type locality: "Hab. in pratensibus sylvaticis Carolinae."

Herb. Geol. Surv. Herb. Mohr.

Scleria torreyana Walp. Ann. 3:696. 1852-53.

TORREY's NUT RUSH.

Scleria reticularis Muhl. Gram. 266. 1817. Not Michx.

S. laxa Torr. Ann. Lyc. N. Y. $3: 376.1836$. Not R. Br.

Gray, Man. ed. 6, 587. Chap. Fl. 531; ed. 3, 559. Coulter, Contr. Nat. Herb. $2: 476$.

Cuba, Mexico to Brazil, Peru.

Carolinian and Louisianian areas. New Jersey to Florida, west to Texas.

Alabama: Coast plain. Low wet pine barrens. Mobile and Baldwin counties.

August, September; not infrequent.

Type locality: "Hab. in Carolina septentrionali."

Herb. Geol. Surv. Herb. Mohr.

Scleria ciliata Michx. Fl. Am. 2 : 167. 1803.

Southern Nut Rush.

Ell. Sk. 2 : 559 . Chap. Fl. 531.

Carolinian and Louisianian areas. South Carolina to Florida.

Alabama: Mountain region. Lower Pine belt and Coast plain. Dry pine barrens. Lee County, Auburn (Baker \& Earle, 580). Mobile County, Grand Bay, Springhill. June to August.

Type locality: "Hab. in Carolina."

Herb. Geol. Surv. Herb. Mohr.

Scleria elliottii Chap. Fl.531. 1860.

Elliott's Nut RUSH.

Scleria hirtella var. strigosa E11. Sk. 2 :560. 1821-24.

CuBA.

Louisianian area. North Carolina to Florida, west to Louisiana.

'N. L. Britton, Revision of the North American species of the genue Sclerı, Ann. N. Y. Acad. Sci. vol. 3, pp. 228 to 237.1885. 
Ala bama: Coast plain. Dry pine barrens. Mobilo County. July; not frequent. Type locality of Elliott's plant: "Collected by Dr. Baldwin on the confines of Georgia and Florida."

Herb. Geol. Surv. Herb. Mohr.

Scleria pauciflora glabra Chap. F1.532. 1860.

Smooth Nut Rush.

Scleria pauciflora var. $\beta$ Torr. Ann. Lyc. N. Y. 3 :378. 1836.

Chap. F1. 532 .

Louisianian area. North Carolina to Florida, Alabama, and Mississippi.

Alabama: Littoral belt, dry sands near the seashore. Baldwin County, Perdido Bay. June; rare.

Type locality: "Sandy pine barrens, Florida."

Herb. Geol. Surv. Herb. Mohr.

Scleria caroliniana Willd. Sp. Pl. $4: 318.1804$.

Carolina Nut Rusir. Scleria hirtella Michx. F1. Bor. Am. 2:168. 1803. (Fide Willd.) Not Sw. 1788.

Ell. Sk. 2 :560. Chap. Fl. 532 .

Louisianian area. South Carolina to Florida, west to Mississippi.

Alabama: Lower Pine region. Grassy pine barreus, springy places. Mobile County, Grand Bay, Bayon Sara. June, July; not infrequent.

"Type locality: "Hab. in sylvis Carolinae."

Herb. Mohr.

Scleria gracilis Ell. Sk. 2 : 557. 1821-24.

Sleniner Nut Rush.

Ell. Sk. 1. c. Chap. Fl. 532.

Cuba.

Louisianian area. South Carolina to Florida, along the Gulf coast to Mississippi. Arabama: Littoral region. Drifting sands on the seashore. Baldwin County, Perdido Bay. Jume, July; rare.

Type locality: "Collected by Dr. Baldwin near St. Marys, Ga."

Herb. Geol. Surv. Herb. Mohr.

Scleria hirtella Sw. Prodr. Veg. Ind. Occ. 19. 1788.

Michaux's Nut Rush. Scleria interrupta Michx. Fl. Bor. Am. 2 : 168. 1803. Not L. C. Rich.

S. michauxii Chap. Fl. 532. 1860.

Ell. Sk. 2:561. Chap. F1. 1. c. ; ed. 3,560. Griseb. F1. Brit. W. Ind. 579.

West Indies, Mexico to Brazil, Peru, Chile, Central and Souti Africa. Louisianian area. Florida to Louisiana.

Alabama: Lower Pine region. Damp grassy pine barrens. Mobile County, Grand Bay. July; infrequent.

Type locality (Swartz, Fl. Ind. Occ.): " Hab. in montosis nemorosis Jamaicae."

Herb. Geol. Surv. Herb. Mohr.

Scleria Baldwinir Torr., found at Pascagonla and in western Flurida, is to be looked for on our coast.

CAREX L. Sp. Pl. 2 : 972. 1753.เ

Nearly 1,000 species described, of which more than half are recognized as valid, prevailing chiefly in cooler temperate regions. North America north of Mexico, about 270. Eastern United States and adjacent parts of Canada, 133. Southern States (Carolinian and Louisianian areas), 85. Western continental region, west of eastern Texas, Arkansas, and Missouri to the Pacifie slope and the adjacent parts of British North America, about 100 species. Alabama 61 species, a number doubtless to be inereased on closer exploration by the aldition of some of the species frequent in the adjacent States, but whicl have not yet been observed within its limits. A few not in the herbarium of the Geological Survey have been admitter on the authority of the late'T. M. Peters, who gave to the investigation of this genus in northern Alabama his special attention.

The species have been arranged according to L. H. Bailey's Synopsis.

Carex collinsii Nutt. Gen. 2 : 205. 1818.

Collins's ShDGe.

Carex 8ubulata Michx. Fl. Bor. Am. 2:173. 1803. Not Gmel. or Schk.

C. michauxii Dew. Am. Journ. Sci. 10:273. 1826.

Gray, Man. ed. 6,592.

Alleghenian and Carolinian areas. New England (Rhode Island), southern New York, Pennsylvania, and along the mountains to Georgia.

${ }^{1}$ I. H. Bailey, jr., Preliminary Synopsis of North American Carices, Proc. Am. Acad., vol. 22, pp. 59 to 157. 1886. L. H. Bailey, jr., 'Types of varions species of the genus Carex, Mem. Torr. Bot. Club, vol. 1, pp. 1 to 86.1890. 
Alabama : Mountain region, Tennessee Valley ( $T$. M. Peters).

Type locality: "In the most shady sphagnose swamps; New Jersey."

Carex folliculata L. Sp. Pl. 2 :978. 1753.

LONG SEDGE.

Carex xanthophysa Wahl. Kongl. Vet. Acad. Handl. ser. 2, 24: 152. 1802.

C. folliculata var. xanthophysa Dow. Am. Journ. Sci. ser. 2, 42 : 325. 1866.

Gray, Man. ed. 6, 592.

Canadian zone to Carolinian area. Newfoundland, Nova Scotia, and Ontario; New

England west to Michigan, south to West Virginia.

Alabama: TennesseeValley. Banks of streams. Lawrence County (T. M. Peters).

May; rare.

Type locality: "Hab. in Canada. Kalm."

jerb. Geol. Surv. Herb. Mohr.

Carex folliculata australis Bailey, Proc. Am. Acad. 22 :62. 1886.

Carex folliculata Ell. Sk. 2 : 545, 1821-24. (\&)

SOUTHERN LONG SEDGE.

C. folliculata $\beta$ Boott, Ill.91. 1858 .

Chap. F'l. ed. 3, 572 .

Louisianian area. Sonth Carolina to Florida, west to Louisiana (Hale!).

Alabama : Lower Pine region. Coast plain. Damp banks of pine-barren streams.

Washington County, Yellowpine. Mobile County. Ballwin County, Josephine.

May, June; frequont.

Typelocality (Bailey): "Florida and northward, Chapman; New Orleans, Herb.;

St. A ugustine, Fla., Canby; damp pine land, Santee Canal, Sonth Carolina, Ravenel."

Herb. Geol. Surv. Herb. Mohr.

Carex intumescens Rudge, Trans. Linn. Soc. 7:97, t. 9, f.3. 1804. Bladder Sedge. Carex folliculata Wahl. Kongl. Vet. Acad. Haudl. ser. 2, 24:152. 1803. Not. I.

Gray, Man. ed. 6, 592. Chap. Fl. 541.

Canadian zone to Louisianian area. Newfoundland, Queber, and Ontario; Atlantic and Gulf States west to Lonisiana.

Alabama : Over the State. Damp shady places. Cullman, Tuscaloosa, Montgomery, Washington, and Mobile counties. April, May; common.

'Type locality: "Hab. in Carolina."

Herb. Geol. Surv. Herb. Mohr.

Carex lupulina Muhl.; Willd. Sp. Pl. 4 : 266. 1805.

HOP SEDGE.

Carex lurida Bailey, Proc. Am. Acad. 22 :63. 1886. Not Walll.

Ell. Sk. 2:544. Gray, Man. ed. 6, 593. Chap. Fl.543. Coulter, Contr. Nat. Herb.

$2: 477$.

Canadian zone to Louisianian area. Ontario and New England to Florida and along the Gulf to Texas.

Alabama: Over the State. Wooded swamps, grassy swales. Mobile County, forms with pedunculate spikes. Frequent.

Type locality : "Hab. in Pensylrania."

Herb. Geol. Surv. Herb. Mohr.

Carex louisianica Bailey, Bull. Torr. Club, 20:428. 1893.

LOUISIANA SEIGE.

Carex halei Carey; Chap. Fl. 543. 1860. Not Dewey.

Chap. Fl. 543. Britt. \& Brown, Ill. Fl. 1 : 294.

Carolinian to Louisianian area. Florida to Texas aud Arkansas; southern Missouri, fide Britton \& Brown.

Alabama : Coast plain. Swampy alluvial forests. Baldwiu County, Stockton. October. Very rare in the State.

Type locality of C. halei Carey: "13anks of the Apalachicola River, Florida, and westward."

Herb. Geol. Surv. Herb. Mohr.

Carex grandis Bailey, Mem. Torr. Club, 1: 13. 1889.

LARGE CAREX.

Carex gigantea Dewey, Am. Journ. Sci. 11:164. 1826. Not Rudge. 1804.

Gray, Man. ed. 6, 593. Chap. Fl. 543. Coulter, Contr. Nat. Herb. 2 : 477.

Carolinian and Louisianian areas. Kentucky and Delaware to Florida and eastern Texas.

Alabama: Lower Pine region. Shaded swampy banks of streams. Washington County, Yellowpine, headwaters of Escatawba River. July; rare.

Type locality not ascertained; Bailey's locality: “Kentucky, Short, Delaware, Canby, Commons, and southward."

Herb. Geol. Surv. Herb. Mohr. 
Carex elliottii Schw. I Torr. Ann. Ljc. N. Y. 1:35\%. 1825. Elliott's SedGe.

Carex castanea Ell. Sk. 2 :546. 1821-24.

C. baldwiniana Dew. Am. Journ. Sci. 26:107. 1834.

Ell. Sk. $2: 546$. C'hap. Fl. 544.

Louisianian area. North Carolina to Florida, west to Mississippi."

Alabama : Coast plain. Boggy margins of brooks. Mobile Connty, Fowl River Station, Grand Bay. April, May; infrequent.

Type locality: "In wet pine barrens. Chatham County, Ga., Elliott."

Herb. Geol. Surv. Herb. Mohr.

Carex turgescens Torr. Ann. Lyc. N. Y. $3: 419.1836$.

PINE-BARREN SEDGE.

Chap. Fl. 544.

Louisianian area. North Carolina to Florida, west to Louisiana.

Ala Bama : Lower Pine region. Coast plain: Low banks of pine-barren streams. Mobile County, Grand Bay, Mount Vernon. April, May ; not rare.

Typo locality: "New Orleans, Dr. T. Ingalls!"

Herb. Geol. Surv. Herb. Mohr.

Carex lurida Wahl. Kongl. Vet. Acad. Handl. ser. 2, 24 : 153. 1803. Sallow SEDGF. Carex tentaculata Muhl.; Willd. Sp. Pl. 4 :266. 1805.

Grav, Man. ed. 6, 595. Chap. Fl. 543. Coulter, Contr. Nat. Herl., 2 : 477.

Canadian zone to Louisianian area. Nova Scotia, New Brunswick, Ontario, and

Now England, west to Minuesota, Missonri; New York, sonth to Alabama, Louisiana, Texas, and Arkansas.

Alabama: Mountain region to Coast plain. Grassy swales. Lawrence County (T. M. Peters). Blount County, bottom of Mulberry River. Tuscaloosa County (E. A. Smith). Lee County, Auburn (Baker $\mathcal{S} \cdot$ Earle). Mobile County, western shore Mobile Bay. May, June; not comınon.

Type locality not ascertained; Muhlenberg's locality: " Hab. in Pensylvania."

Herb. Geol. Surv. Herb. Mohr.

Carex baileyi Britton, Bull. Torr. Club, 22:220. 1895.

BAILEY'S SEDGE.

Carex tentaculata var. gracilis Boott, Ill. 94. 1858. Not C. gracilis R. Br. 1810. Britt. and Brown, Ill. Fl. 1 : 299.

Carolinian to Louisianian area. Southern New England to Virginia and Tennessee. Alabama: Central Pine belt to Coast plain. Swamps. Tuscaloosa and Mobile counties. May, June; not infrequent.

'Type locality: "Tennessee, Lesquereux." Vermont, Chapman.

Herb. Geol. Surv. Herb. Mohr.

Carex frankii Kunth, Enum. $2: 498,1837$.

FRANK'S SEDGE.

Carex stenolepis Torr. Ann. Lyc. N. Y. 3:420. 1836. Not Lessing, 1831.

Gray, Man. ed. 6,596. Chap. F1.537. Coulter, Contr. Nat. Herb. $2: 478$.

Carolinian to Louisianian area. Pennsylvania and Ohio Valley to upper Georgia, Louisiana, and Texas.

Alabama: Central Pine belt to Coast plain. Boggy woods. 'Tusealoosa County (E. A. Smith). Mobile County. July; not frequent.

Type locality: "Baltimore Pennsylvaniae."

Herb. Geol. Surv. Herb. Mohr.

Carex squarrosa L. Sp. P1. 2:973. 1753.

SqUARROSE SEDGE.

Carex typhina Michx. Fl. Bor. Am. 2 : 169. 1803.

Ell. Sk. 2 :526. Gray, Man. ed. 6, 596. Chap. Fl. 537. Coulter, Contr. Nat. Herb.

$2: 478$.

Alleghenian and Carolinian areas. Ontario and New England, west to Michigan and New York, and from the Ohio Valley to Missouri, Georgia, Texas, and Arkansas.

Aladiama : Mountain region. Damp woods. Cullman County. June; rare in the

State.

'Type locality : "Hab. in Canada, Kalm."

Herb. Geol. Surv. Herb. Mohr.

Carex torta Boott; Tuckerm. Enum. Metb. 11. 1843.

TWISTED SEDGE.

Boott, Ill.63, t. 169. Gray, Man. ed. 6,600.

Alleghenian and Carolinian aroas. Vermont south along the mountains to North Carolina.

Alabama: Tennessee Valley. Lawrence County, Big Nancy Creek ( $T$. M. Peter $)$. Type locality (Boott, 11l.): "In America septentrionali. Now England to Now York.

Herb. Geol. Surv. Herb. Mohr. 
Carex crinita Lam. Encyel. 3:393. 1789.

Fringed SEDGk.

Ell. Sk. 2 :536. -Gray, Man. ed. 6, 601. Coulter, Contr. Nat. Herb. 2: 479.

Canadian zone to Carolinian area. Nova Scotia and Ontario; New England west to Minnesota; south from New York to Florida and Texas.

Alabana : Mountain region. Walker County (T. M. Peters). Lee County, Auburn (Baker \& Earle, 540).

Type locality: "Cette plante croit dans la Virginie."

Herb. Geol. Surv. Herb. Mohr.

Carex glaucescens Ell. Sk. 2 : 553. 1821-24.

Palf Sedge.

Chap. Fl. 542.

Louisianian area. South Carolina to Florida, west to Mississippi. Distribution not well defined, the species being by most authors confounded with C. verrucosa Mnhl. The latter, though it occurs in the lower South, appears to be mainly of a more northern distribution.

Alabama : Lower Pine belt, Coast plain. Borders of pine-barren ponds. Clark, Washington, and Mobile counties. Frequent.

A bundantly distinct from C. verrucosa by the almost nerveless, glaucous perigynia, which are much longer than the blade of the scales and almost as long as their rough awns. Leaves flattish and generally broader.

Type locality: "Grows around pine-barren ponds [South Carolina and Georgia]." Herb. Geol. Surv. Herb. Mohr.

Carex verrucosa Muhl. Gram.261. 1817.

WARTY-FRUITED SEDGE.

Ell. Sk. 2 :555. Chap. Fl.542; ed. 3, 570.

Carolinian and Louisianian areas. North Carolina to Florida, west to eastern Texas.

Alabama: Almost certainly in the State, but specific locality can not be given.

Type locality: "Hab. in Georgia et Carolina."

Herb. Geol. Surv.

Carex virescens Muhl.; Willd. Sp.Pl. 4 : 251. 1805.

Downy Green SeDGe.

Gray, Man. ed. 6, 602 .

Sovtr America.

Alleghenian and Carolinian areas. Ontario; New England west to New York and Michigan south to Tennessee, along the mountains to North Carolina, and in Missouri and Arkansas.

Alabama : Mountain region. Shaded rocky hillsides. Winston County, Colliers Creek, 1,600 feet. Dekalb County, Lookout Mountain, uear Mentone, 1,800 feet. June; infrequent.

Type locality: "Hab. in Pensylvania."

Herb. Geol. Surv. Herb. Mohr.

Carex triceps Michx. Fl. Bor. Am. 2 : 170. 1803.

SMOOTH GREeN SEDGE.

Carex viridula Schwein. \& Torr. Ann. Lyc. N. Y. 1:320. 1825.

Ell. Sk. 2:538. Bailey, Mem. Torr. Club, 1:34 (Types of Carices, No.41). Chap. Fl. 537.

Carolinian and Louisianian areas. Carolina to Texas.

Alabama : Mountain to Central Prairie region. Low wet woods in heavy clay soil. Lee County, Auburn (Baker \& Earle, 526). Limestone County, Athens (Baker \& Earle, 545). Dallas County, Experiment Station near Uniontown. Local; rare.

This decidedly Southern plant is clearly distinet by the slender habit of its growth, the smaller fertile spikes, and the smooth achenia.

'Type locality: "Hab. in Carolina."

Herb. Geol. Surv. Herb. Mohr.

Carex hirsuta Willd. Sp. P1. 4 :252. 1805.

Hirsute Sedge.

Carex triceps hirsuta Bailey, Mem. Torr. Club, 1:35. 1889.

C. triceps Boott, Ill. t. 128.1858.

Ell. Sk. 2:538. Gray, Man. ed. 5, 602. Chap. Fl. 537. Coulter, Contr. Nat. Herb. $2: 479$.

Alleghenian and Carolinian areas. Ontario; New England to Missouri; south to Florida?, Alabama, and central Texas.

Alabama: Tennessee Valley. Mountain region to coast plain; common throughout.

Type locality: "Hab. in America boreali."

Herb. Mohr. 
Carex caroliniana Schwein. Ann. Lyc. N. Y. 1:67. 1824.

Carolina Senge. Carex smithii Porter; Olney, Car. Bor. Am.2, name only. 1871. Not Tansch. 1821. C. triceps smithii Bailey, Bot. Gaz. 13: 88. 1888.

Gray, Man. ed.6, 603. Coulter, Contr. Nat. Herb. $2: 479$.

Carolinian and Louisianian areas. New Jersey to Florida, west to Mississippi, Texas, and Arkansas.

AlabaMa: Mountain region to Coast plain. Damp shady places, copses, borders of roods. Mobile County, April. Cullman County. Wilcox County (Buckley). April; common; most abundant near the coast.

Type locality: "Carolina."

Herì. G зol. Surv. Herb. Mohr.

Carex cherokeensis Schwein. Ann. Lyc. N.Y.1:71. 1824.

Cherokfe Sedge.

Carcx recuria Muhl. Gram.262. 1817.

Schwein. \& Torr. Ann. Lyc. N. Y. 1:369, t. 25, f.1. Chap. Fl.542, Wats. Bot. Calif.

2: 248 . Coulter, Contr. Nat. Herb. $2: 480$.

Carolinian and Louisianian areas. Western Florida to mointains of north western

Georgia, west to Mississippi, Louisiana, central Texas, and California.

Alabama : Central Prairie region. Rich damp forests. Montgomery County, Ala-

bama River bottom. Henry and Franklin counties. Wilcox County (Buckley). May,

June; frequent in the region.

Type locality: "Cherokee."

Herb. Geol. Surv. Herb. Mohr.

Carex oblita Steud. Syn. Pl. Cyp. 231. 1855.

DARK Green Sedge.

Carex glabra Boott, Ill. 1: 93. 1858.

C. venusta glabra Bailey, Proc. Am. Acad. 22 :105. 1886.

Gray, Man. eil. 6, 604, as C.venusta minor Boeckl. Britt. \& Brown, Ill. Fl. 1:321.

Carolinian and Louisianian areas. New York, Pennsylvania, New Jersey, and western Louisiana (Hale).

Aldibama: Mountain region and Coast plain. Grassy swamps along streams. Washington County, Yellowpine. Mobile County, Dog River. Lee County, Auburn (Baker \& Earle, 534).

Type locality: "Herb. Drummond, no. 434. New Orleans."

Herb. Geol. Surv. Herb. Mohr.

Carex debilis pubera Gray, Man. ed.5,593. 1868.

Elegant SEDGE.

Carex renusta Boott, Ill. 1:51. 1858.

Gray, Man. ed. 6, 604.

Carolinian and Louisianian areas. Sonthern Pennsylvania,Virginia south to North

Carolina, eastern Lonisiana, and Mississippi.

Alabama: Central Pine belt. Tuscaloosa County (E. A. Smith). May; rare.

Type locality: "Bear Meadows, Centre County, Penn., Prof. Porter."

Herb. Geol. Surv. Herb. Mohr.

Carex debilis proliza Bailey, Proc. Am. Acad. 22 : 105. 1886.

Carex debilis var. Boott, Ill. 1:92. 1858.

DIFFUSE-FLOWERED SEDGE.

Chap. Fl.511, in part. Conlter, Contr. Nat. Herb. $2: 480$, as C. debilis Michx.

Carolinian and Louisianian areas. South Carolina to Florida, west to Texas.

Alabama : Lower Pine region. Coast Pine belt. Swampy banks of pine-barren streams. Mobile Connty, Citronelle, Springhill. Baldwin Connty. April, May; not infrequent.

'Type locality : "Florida, Chapman, to Louisiana, Drummond, Hale, Langlois."

Herb. Geol. Surv. Herb. Mohr.

Carex oxylepis Torr. \& Hook. in Torr. Ann. Lyc. N. Y. $3: 409.1836$.

Chap. Fl.538. Coulter, Contr. Nat. Herb. $2: 479$.

SHARP-SCALED SEDGE.

Lonisianiau area. Sonth Carolina, western Florida to Louisiana and Texas.

Alabana: Central Prairie region. Low open woods. Wilcox Connty ( $S$. $B$.

Buckley). Dallas County, near Uniontown. June; rare.

Type locality : "Texas, T. Drummond!"

Herb. Geol. Surv. Herb. Mohr.

Carex amphibola Steud. Syn. Pl. Cyp. 234. 1855.

Narrow-leaved Sedge.

Carex grisea angustifolia Boott, Ill. 1 :34. 1858.

C. cryptandra Schwein.; Olney in Hall's Pl. Tex. 25. 1873.

C. grisea var. (१) rigida Bailey, Mem. Torr. Club, 1:56. 1889. 
Gray, Man. ed.6,605. Chap. Fl.540. Britt. \& Brown, Ill. Fl. 1:321.

Carolinian and Louisianian areas. New Jersey, southern Virginia, sonthern Ohio, Florida, Mississippi, and western Louisiana (Hale).

Alabama: Mountain region. Central Prairie region. Lawrence County (T. $M$.

Peters). Wilcox County (S. B. Buckley). Rare.

Type locality: "America septentrionalis."

Herb. Geol. Surv. Herb. Mohr.

Carex flaccosperma Dewey, Am. Journ. Sci. ser. 2, 2 : 245. 1846.

Carex xanthosperma Dewey, Am. Journ. Sci. ser. 2, 42:334. 1866.

'THIN-FRUITED SEDrEe.

Chap. Fl. ed. 3, 567. Coulter, Contr. Nat. Herb. $2: 480$.

Louisianian area. Florida west to western Louisiana (Hale) and Texas.

Alabama: Central Prairie belt. Shady woods. Montgomery County, banks of

Pentulalla Creek. Not frequent.

Type locality: "Florida and Louisiana, Dr. Leavenworth."

Herb. Geol. Surv. Herb. Mohr.

Carex granularis Muhl.; Willd. Sp. Pl. 4:279. 1805.

Meadow Sedgr.

Ell.Sk. 2:548. Gray, Man. ed.6,605. Chap. Fl.540.

Alleghenian to Louisianian area. New Brunswick, Ontario, west to Manitoba; New England to Minnesota, south to New Jersey; Virginia, Ohio Valley to Missouri, south to Tennessee and Mississippi.

Alabama: Mountain and Central Prairie region. Walker County (T. M. Peters).

Wilcox County (Buckley). Lee County, Auburn (Baker \& Earle, 526).

Type locality: "Hab. in Pennsylvania."

Herb. Geol. Surv. Herb. Mohr.

Carex laxiflora Lam. Encycl. 3 : 392. 1789.

LOOSE-FLOWERED SEDGE.

Carex anceps Muhl.; Willd. Sp. Pl. 4 :278. 1805.

C. anceps angustifolia Dewey in Wood, Bot. 423. 1845.

Gray, Man. ed.6,607. Chap. Fl.540. In part.

Alleghenian to Louisianian area. Ontario, Eastern States, west to Texas.

Alabama: From the mountains to Central Prairie region. Shady woods and moist copses. Cullman County, 800 feet. Clark County, Choctaw Corner. Common.

Type locality: "Cette espèce bien distincte croit dans le New-York, la Pensylvanie \& la Virginie."

Herb. Geol. Surv. Herb. Mohr.

Carex laxiflora varians Bailey, Mem. Torr. Clnb. 1:32. 1889.

Carex laxiflora striatula Carey in Gray, Man. ed. 2, 524. 1856. Not C. striatula

Michx. 1803.

C. blanda Dewey, Am. Journ. Sci. 10:45. 1826.

Gray, Man. ed. 6, 607. Coulter, Contr. Nat. Herb. $2: 481$

Canadian zone, Alleghenian and Carolinian areas. Ontario; New England (Mount

Desert Island), throughout the Eastern States to North Carolina.

Alabama: Mountain region. Shady woods. Blount County, banks of Mulberry

River. Cullman County. Lee County, Auburn. June; rare.

Type locality : "Now Hampshire to Now Jersey, Minnesuta, and Kansas."

Herb. Geol. Surv. Herb. Mohr.

Carex laxiflora patulifolia (Dewey) Carey in Gray, Man. ed. 2, 524.

BROAD-LEAF LOOSE-FLOWERED SEDGE.

Carex plantaginea Schk. Riedgr. Nacht. 63, f. 195. 1806. Not Lam. 1789.

C. anceps patulifolia Dewey in Wood, Bot.423. 1845.

C. laxiflora var. plantaginea Boott, Ill. 1:37. 1858.

Gray, Man. ed. 6,607.

Alleghenian and Carolinian areas. New England to Michigan, southward to North Carolina.

Alabama : Mountain region. Shady copses. Blount County, Blount Springs.

Walker County (T.M. Peters; Beaumont). Not rare.

Type locality of $C$. plantaginea Schk.: "Hab. in sylvis Virginiae, Carolinae, Pensylvaniae."

Herb. Geol. Surv. Herb. Mohr.

Carex striatula Michx. Fl. Bor. Am. 2:173. 1803.

MichauX's SedGe.

Carex tetanica Ell. Sk. 2 : 549. 1824. Not Schk.

C. ignota Dewey, Am. Journ. Sci. ser. 2, 8: 348. 1849.

C. laxiflora michauxii Bailes, Mem. Torr. Club, 1:32. 1889.

C. laxiflora Boott, Ill. $1: 36, t .89$. 1858. 
Ell. Sk. l.c. Chap. Fl.540. Conlter, Contr. Nat. Herb. 2: 481.

Carolinian and Louisianian areas. Carolina to Florida, west to Loussana and Texas.

Alabama: Mountain region to Central Prairie region. Rich woodlands. Blount County, Blount Springs. Tuscaloosa County. Wilcox County (S. B. Buckley). June; local, infrequent.

Type locality: "Hab. in Carolina."

Herb. Geol. Surv. Herb. Mohr.

Carex styloflexa Buckl. Am. Journ. Sei. 45 : 174. 1843.

Bent-Fruited Sedge.

Carex fusiformis Chap. Dew. Am. Journ. Sci. ser. 2, 6:244. 1849.

C. laxiflora var. styloflexa Boott, 11l. 1:37. 1858.

Gray, Man. ed. 6, 608. Chap. Fl.540. Coulter, Contr. Nat. Herb. $2: 481$.

Carolinian and Louisianian areas. Southern Pennsylvania, New Jersey to

Florida, west to Louisiana and Texas.

Alabama: Tennessee Valley. Monntain region to Coast plain, in damp shady woods. Winston County, Collier's Creek. Lawrence County (T.M. Pelers). Wilcox County (Buckley). Mobile County. June; not frequent.

Type locality: "Mountains, Macon County, N. C."

Herb. Geol. Surv. Herb. Mohr.

Carex albursina Sheldon, Bull. Torr. Club, 20:284. 1893.

Carex laxiflora var. latifolia Boott, Ill. 1:38. 1858. Not C. latifolia Moench.

Gray, Man. ed. 6, 607. Britt. \& Brown, Ill. Fl. 1:329.

Alleghenian to Carolinian area. New Eugland to Minnesota, Ohio, and Virginia.

Alabama: Mountain region. Madison County, Montesano, 1,500 feet.

Type locality (Boott): "New York, Knieskern. Ohio, Sullivant. Kentucky, Short." Herb. Geol. Surv. Herb. Mohr.

Carex digitalis Willả.Sp. Pl. 4:298. 1805.

Carex oligocarpa Muhl. Gram. 242. 1817.

C. vanvleckii Schwein. Anu. Lyc. N. Y. 1:69. 1824.

Ell. Sk. 2:551. Gray, Man. ed.6, 608. Chap. Fl.541.

Alleghenian to Louisianian area. Ontario; New England west to Michigan and

Illinois, south to New York, Virginia, North Carolina, Mississippi, and western Louisiana (Hale).

Alabama: Mountain region. Shaded rocky hillsides. Winston County, Colliers Creek, 1,500 feet; not rare.

Type locality: "Hab. in Pensylvania."

Herb. Geol. Surv. Herb. Mohr.

Carex picta Steud. Syn. Pl. Cyp. 184. 1855.

BootT's SEDGE.

Carex boottiana Benth.; Boott, Bost. Journ. Nat. Hist. 5 : 112. 1845̃. Not Hook. \& Arn. 1841.

Gray, Man. ed. 6, 610. Chap. Fl. 536.

Carolinian area. Indiana.

Alabama: Mountain region. Shaded rocky shelves. Winston County, Sipsey

Valley. Local, rare.

Type locality: "Drummond (sine nr.) Louisiana. New Orleans."

Herb. Geol. Surv. Herb. Mohr.

Carex nigromarginata Schwein. Ann. Lyc. N. Y. 1 : 68. 1824. BLACK-EDGED SedGe. Carex lucorum var. nigro-marginata Chap. Fl. 539. 1860.

Gray, Man. ed. 6, 613. Chap. Fl. ed. 3, 567.

Alleghenian and Carolinian areas. New York, New Jersey, along the mountains to

North Carolina.

AlabaMa: Mountain region. Dry rocky billsides. Winston County, Colliers

Creek, 1,500 feet. September; local, not frequent.

'Type locality: "Carolina."

Herb. Geol. Surv. Herb. Mohr.

Carex floridana Schw. Ann. Lyc. N. Y. 1:306. 1825.

Chap. Fl. ed. 3, 567. Coulter, Contr. Nat. Herb. $2: 482$.

Lonisianian area. South Carolina to Florida, west to Texas.

Alabama : Coast plain. Dry grassy places. Mobilo County, Monroe Park (Carl

Baker). March; rare.

Type locality : "In the sands of east Florida."

Herb. Geol. Surv. Herb. Mohr. 
Carex dasycarpa Muhl. Gram. 236. 1817.

HAIRY-FruiteD SEDGE.

Ell. Sk. 2:541. Chap. Fl. 539.

Lonisianian area. Sonth Carolina to Florida.

Alabama: Coast plain. Dry sandy copses and open woods. Baldwin County,

Point Clear. Not frequent.

Type locality: "Hab. in Carolina."

Herb. Geol. Surv. Herb. Mohr.

Carex willdenovii Schk. Riedgr. Nacht. 33, f. 145. 1806. Willdenow's Sedge. Alleghenian and Carolinian areas. New Englauıl west to Michigan, south to North Carolina.

AlabaMa: Mountain region. Winston County ( $T . M$. Peters). Rare.

Type locality: "Aus Pensylvanien."

Herb. Geol. Surv. Herb. Mohr.

Carex leptalea Wahl. Kongl. Vet. Acad. Handl. ser 2, 24:139. 1803.

Carex polytrichoides Muhl.; Willd. Sp. Pl. 4:213. 1805.

C. microstachya Michx. Fl. Bor. Am. 2:169. 1803. Not Ehrh.

Gray, Man. ed. 6, 613. Chap. Fl. 536. Coulter, Contr. Nat. Herb. 2 : 482.

Canadian zone to Louisianian area. From New foundland through Canada to the Pacific, and from British Columbia to Oregon; south to Florida and Texas.

Alabama: Over the State. Boggy places. Lee County, Auburn (Baker \& Earle, 525). Tuscaloosa and Mobile counties. April to June; common. Abundant in the coast plain.

Type locality not ascertained ; locality of $C$.polytrichoides: "Hab. in Pennsylvania."

Herb. Geol. Surv. Herb. Mohr.

Carex stipata Muhl.; Willd. Sp. Pl. 4 :233. 1805.

Awl-Fruited Carex.

Carex vulpinoidea Torr. Ann. Lyc. N. Y. 3:390. 1836. Not Michx.

Ell. Sk. 2:529. Gray, Man. ed. 6, 614 .

MEXICO? JAPAN.

Alleghenian to Lonisianian area. Newfoundland to Ontario and Pacific coast.

Thronghout Eastern United States. Texas to Mexico.

Alabama: Mountain region. Lower Pine belt. Swampy places. Lee County,

Auburn. Washington County, Yellowpine. April; not common.

Type locality: "Hab. in Pennsylvania."

Herb. Geol. Surv. Herb. Mohr.

Carex stipata uberior Mohr.

Carex stipata maxima Bailey, Proc. Am. Acad. $22: 135$. 1887. Name only. Not $C$. maxima Scop.

C. stipata Chap. Fl.533. 1860.

Chap. l. c. Coulter, Contr. Nat. Herb. 2: 483.

From a stout rootstock, robust; stem 2 to almost 3 feet high, $\frac{8}{8}$ to $\frac{1}{2}$ inch thick at the very spongy base, acutely 3 -angled, concave on the sides; leaves nearly as long as the stem, $\frac{8}{8}$ to $\frac{1}{2}$ inch wide, flaccid, long acuminate to a sharp almost filiform point; panicle ovate-lanceolate, fully 2 inches long, and 1 inch wide at the somewhat decompound base. Peryginia with stronger nerves. Plant pale.

This well-marked variety has been confounded with the type. The description of C.stipata Chap. clearly points to our plant. Professor Bailey ascribes to Chapman the untenable name C. stipata maxima, which appears, however, not to have been published, but which doubtless has reference to this plant. C. stipata in Coulter's Botany of Western Texas (Contr. Nat. Herb. vol. 2) clearly belongs here.

Louisianian area. Florida to Texas.

AlabaMa: Coast plain. In deep morasses, growing in dense clumps. Mobile Comuty; open deep river swamps along the old telegraph road. April.

Type locality: Mobile County, Ala.

Herb. Geol. Surv. Herb. Mohr.

Carex vulpinoidea Michx. Fl. Bor. Am. 2 : 169. 1803.

Carex multiflora Muhl.; Willd. Sp. Pl. 4 : 243. 1805.

Many-Flowered Carex.

Ell. Sk. 2:530. Gray, Man. ed.6,615. Chap. Fl.533.

Mexico, Colombia.

Canadian to Louisianian area. Eastern Canada to Lakes Superior and Winnipeg, throughout the Eastern States to Florida, west to Louisiana. 
Alabama: Over the State. Grassy swales. Tennessee Valley. Cullman, Tuscaloosa, Montgomery, and Mobile counties. May; abundant.

Type locality: "Hab. in Canada et Nova Anglia."

Herb. Geol. Surv. Herb. Mohr.

Carex rosea radiata Dewey, Am. Journ. Sci. 10:276. 1826.

STEllate SedGe.

Carex neglecta Tuckerm. Enum. Meth. 19. 1843.

C. rosea minor Boott, Ill. 1:81. 1858 .

Gray, Man. ed.6,616. Chap. Fl.534. Britt. \& Brown, Ill. Fl. 1:347.

Alleghenian and Carolinian areas. Ontario and southern New Eugland, west to

Michigan, south to West Virginia and North Carolina.

Alabama: Mountain region. Central Pine belt. Dry open woods. Blount

County. Autauga County, Prattville. June.

Type locality (Dewey): "This variety is credited to our country by Wahlenberg.

It is often found about woods," * * *.

Herb. Geol. Surv.

Carex texensis (Torr.) Bailey, Mem. Torr. Club, 5 : 97. 1894.

Texan SEDGe.

Carex rosea var. texensis 'Torr.; Bailey, Mem. Torr. Club, 1:57. 1889.

Gray, Man. ed. 6,616. Coulter, Contr. Nat. Herb. $2: 483$.

Carolinian and Louisianian areas. Southern Illinois, Mississippi, and Louisiana.

AlabaMa: Mountain region. Dry hills. Blount County, Blount Springs. June;

not frequent.

Type locality: "Mount Carmel, southern Illinois, Schneck, and from Alabama to Texas."

Herb. Geol. Surv. Herb. Mohr.

Carex retrofleza Muhl.; Willd. Sp. Pl. 4 :235. 1805. RefleX-Flowered Sedge. Carex rosea retroflexa T'orr. Ann. Lyc. N. Y. 3: 389. 1836.

Ell. Sk. 2:528. Gray, Man. ed.6,616. Chap. Fl.534. Coulter, Contr. Nat. Herb.

$2: 483$.

Alleghenian, Carolinian, and Louisianian areas. Outario, New England, west to Michigan, south to West Virginia, North Carolina, Georgia, Florida, Mississippi, Lonisiaua (Carpenter), to Texas.

Alabama : Mountain region. Dry hillsides. Winston County, Colliers Creek,

1,500 feet. Madison County, Montesano, 800 feet. June; infrequent.

Type locality : "Hab. in Pennsylvania."

Herb. Geol. Surv. Herb. Mohr.

Carex muhlenbergii Schk. Riedgr. Nacht.12, f. 178. 1806. Munlenberg's Sedge. Ell. Sk. 2:529. Gray, Man. ed. 6, 617. Chap. Fl. 534. Coulter, Contr. Nat. Herb. $2: 484$.

MeXico, Chile.

Alleghenian to Lousianian area. Ontario: New England west to Minnesota,

Dakota, aud Nebraska, south to Texas and Florida.

Alabama: Throughont the State. Dry open woods. Montgomery County. Baldwin County, Point Clear. April; infrequent.

Typo locality: "Hab. in America boreali."

Herb. Geol. Surv. Herb. Mohr.

Carex muhlenbergii xalapensis (Kunth) Britton, Mem. Torr. Club, 5 : 86. 1894.

Carex xalapensis Kunth, Enum. 2:380. 1837.

C. muhlenbergii var. enervis Boott, Ill. 3:124. 1862.

Gray, Man. ed. 6,617. Britt. \& Browu, Ill. Fl. 1:349.

MeXico.

Carolinian and Lonisianian areas. Southern New York, New Jersey, District of

Columbia, Missouri, 'Texas.

Alabama : Central Prairie region. Low woods. Dallas County, Uniontown. June; rare.

'Type locality: "Xalapa Mexicanorum."

Herb. Geol. Surv. Herb. Mohr.

Carex sparganioides Muhl.; Willd. Sp. Pl. 4 : 237. 1805.

Ell. Sk. 2:531. Gray, Man. ed.6,616. Chap. Fl.534.

Alleghenian to Louisianian area. Ontario, through the Eastern States to Georgia.

Ala bama: Central Pine belt. Rich woods. Winston County (T.M. Peters). June;

infrequent.

Type locality: "Hab. in Pensylvania."

Herb. Geol. Surv. Herb. Mohr. 
Carex cephalophora Muhl.; Willd.Sp. Pl.4:220. 1803.

Oval-headed Sedge. Ell. Sk. 2:526. Gray, Man. ed.6, 617. Chap. Fl. 534. Coulter, Contr. Nat. Herb. $2: 483$.

Alleghenian to Louisianian area. Ontario and New England, west to Michigan and Iowa; through the Ohio Valley and Southern Atlantic States, west to Texas.

Ala Bama: Mountain region, Central Pine belt. Cullman County. Tuscaloosa County (E. A. Smith). May; not infrequent.

Type locality: "Hab. in Pensylvania."

Herb. Geol. Surv. Herb. Mohr.

Carex leavenworthii Dewey, Am. Journ. Sci. ser. 2, 2:246. 1846.

Carex cephalophora var. angustifolia Boott, Ill. 3 : 123. 1862.

LeAVENworth's SedGe.

Gray, Man. ed. 6, 617. Conlter, Contr. Nat. Herb. $2: 483$.

Alleghenian to Louisianian area. South to the Gulf, and from Florida to Texas.

Alabama : Mountain region. Coast plain. Dry open woods. Cullman County. Madison County, Huntsville (Baker \& Earle, 537). Blount County, Blount Springs.

Mobile County. June; not infrequent.

Type locality: "Louisiana, Dr. Leavenworth."

Herb. Geol. Surv. Herb. Mohr.

Carex sterilis Willd. Sp. Pl. 4:208. 1805.

LitTle Prickly Sedge.

Carex stellulata and C. echinata Amer. authors.

C. sterilis Boott, Ill. 1:56, t. 146. 1858.

C. echinata var. microstachys Boeckl. Linnaea, 39:125. 1875.

C. sterilis excelsior Bailey, Bull. Torr. Club, 20:424. 1894.

Gray, Man. ed. 6, 618. Chap. Fl.534. Wats. Bot. Calif. $2: 236$.

Mexico.

Alleghenian to Louisianian area. Ontario; through the Rocky Mountains to the Pacific; from Vancourer Island to California; New England, throngh the Atlantic States to Florida, west to Texas, Colorado, Arizona, Montana, and Nevada.

Alabama : Mountain region to Coast plain. Shaded boggy places. Lee County, Auburn (Baker \& Earle, 537). Madison County, Huntsville. Cullman County. Mobile County, Springhill, Mount Vernon. Baldwin County, Point Clear. April, May; not infrequent.

Type locality: "Hab. in Pensylvania."

Herb. Geol. Surv. Herb. Mohr.

Carex atlantica Bailey, Bull. Torr. Club, 20:425. 1893.

EASTERN Sedge.

Carex stellulata conferta Chap. Fl. 534. Not C. conferta Koch. 1860.

C. echinata var. conferta Bailey, Cat. N. A. Carices. 1884.

Gray, Man. ed. 6, 618. Chap. Fl. 534. Britt. \& Brown, Ill. Fl. 1: 350.

Canadian zone to Louisianian area. Along the coast from Newfoundland to Florida and Mississippi.

Ala Bama : Coast plain to the Mountain region. Boggy banks of streams. Mobile County, Springhill, Mount Vernon. Cullman County. May; frequent in swamps and along pine-barren streams.

Type locality: "Follows the coast from Newfoundland to Florida."

Herb، Geol. Surv. Herb. Mohr.

Carex interior Bailey, Bull. Torr. Club, 20:426. 1893.

INLAND SEDGE.

Carex scirpoides Sartwell, Exsic. No. 36. 1848.

C. stellulata var. scirpoides Boott, Ill. 1:56, t. 146* *. 1858.

Britt. \& Brown, Ill. Fl. 1:350, f. 176.

Alleghenian and Carolinian areas. Maine to Minnesota; south to Florida.

Alabama: Mountaiu region. Woods. Madison County, Montesano, 1,200 to 1,500

feet. Lee County, Auburn (Baker \& Earle, 556). Infrequent.

Type locality: "Bogs and swamps in the interior country from Maine to Minnesota and Kansas."

Herb. Geol. Surv. Herb. Mohr.

Carex bromoides Schk. Riedgr. Nacht. 8, f. 176. 1806.

BROME-LIKE SEDGE.

Ell. Sk. 2:528. Gray, Man. ed. 6, 619. Chap. Fl. 533.

EUROPE.

Alleghenian to Louisianian area. New Brunswick and Ontario, thence to the Pacific, and from British Columbia to California; New England west to Michigan and Missouri; south from New York to Florida and west to Louisiana. 
Alabama: Central Prairie region. Low woods. Montgomery County, Pentulalla

Creek. Infrequent.

Type locality: "Hab. in Pensylvania."

Herb. Geol. Surv. Herb. Mohr.

Carex tribuloides turbata Bailey, Mem. 'Torr. Club, 1:55. 1889.

Carex lagopodioides var. Boott, III. $3: 117, t .371, f .1 .1862$.

BLUNT BROOM SEDGE.

Alleghenian to Louisianian area. Southern New England to Michigan; south to Alabama and Lonisiana.

Alabama: Central Prairie region. Coast plain and open marshes. Dallas County, Uniontown, in low wet woods. Mobile County, river marshes. Mav, June; not rare.

'Type locality: "Shady copses and woods, Massachusetts to Michigan and southward to Alabama, Mohr, and Louisiana, Langlois."

Herb. Geol. Surv. Herb. Mohr.

Carex scoparia Schk. Riedgr. Nacht. 20, f. 175. 1806.

Pointed Broom Sedge.

Carex scoparia var. minor Boott, Ill. 3:116, t. 369 . 1862.

Alleghenian and Carolinian areas. Nova Scotia and Manitoba; New England, west to Minuesota, Iowa, Missouri, Colorado; south along the mountains to North Carolina.

Alabama: Mountain region. Blount County, Mulberry River. June; rare.

Type locality: "Hab. in America boreali."

Herb, Geol. Surv. Herb. Mohr.

Carex albolutescens Schwein. Ann. Lyc. N. Y. 1:66. 1824. Bailey, Bull. Torr. Club, 20:422. 1893.

Greenish-White Sedge.

Carex straminea var. foenea Torr. Ann. Lyc. N. Y. 3:395. 1836. Not C. foenea

Willd. 1809.

Gray, Man. ed. 6, 622. Coulter, Contr. Nat. Herb. $2: 484$.

Alleghenian to Louisianian area. From Florida along the coast to New England; (Mount Desert Island) west along the Gulf shore to 'Texas.

Aldabama : Coast plain and Littoral region. Marshes, ditches. Mobile aud Baldwin counties. May, June; common.

Type locality: "Carolina and Pennsylvania."

Herb. Geol. Surv. Herb. Mohr.

Carex festucacea Willd. Sp. Pl. 4:242. 1805.

Fescue Sedge.

Carex straninea Schk. Riedgr. Nacht. 23, f. 174. 1806.

C. straminea var. brevior Dewey, Am. Journ. Sci. 11:158. 1826.

C. straminea festucacea 'Tuckerm. Enum. Meth. 18. 1843.

C. straninea typica Boott, Ill. 3:121, t. 38\%. 1862.

$2: 484$.

Mexico.

Alleghenian to Louisianian area. Ontario ;ew England west to Michigan, Minnesota, Dakota, and Nebraska; south from Now York to Florida and west to Texas.

Alaibama: Undoubtedly over the State. Central Pine belt to Coast plain. Dry woods, copses. Tuscaloosa County (E.A.Smith). Mobile County, Springhill. April, May; frequent.

Type locality: "Hab. in America boreali."

Herb. Geol. Surv. Herb. Mohr.

Carex alata Torr. Ann. Lyc. N. Y. 3 : 396. 1836.

Broad-WINGED SEDGe.

Carex straminea alata (Torr.) Bailey, Carex Cat. 1884.

Gray, Man. ed. 6, 622. Chap. Fl. 535. Britt. \& Brown, Ill. Fl. 1:359.

Canadian zoue to Lonisianian area. Ontario west to Manitoba; Now England (Mount Desert Island) to Michigan, southern Illinois, and along the coast south to Florida, Alabama, and Mississippi.

Alabama: Coast plain. Swamps. Mobile County, river marshes. May. Three to 5 feet high. Frequent.

'Type locality: "Newbern, N. C., Mr. Croom!; Macon, Georgia, Dr. Loomis!"

Herb. Geol. Surv. Herb. Mohr. 
Of the extensive genus Carex, represented by about 500 valid species and distinct varietal forms, 60 species, including well-marked varieties, have been recoguized in Alabama.

The following are strictly inhabitants of the mountain region, held in common with the Northern United States within the Carolinian area, and extending to the Alleghenian area and to Canada:

Carex collinaii.

Carex folliculata.

Carex squarrosa.

Carex torta.

Carex gynandra.

Carex virescens.
Carex laxiflora varians.

Carex laxiflora patulifolia.

Carex albursina.

Carex digitalis.

Carex picta.

Carex nigromarginata.
Carex villdenovii.

Carex sparganioides.

Carex interior.

Carex retroflexa.

Carex cephalophora.

Carex scoparia.

Species held in common with the Northern States, extending to the Central Pine belt in the Louisianian area:

Carex granularis.

Carex laxiflora.

Carex bromoides.

Extending throughout the State:

\section{Carex intumescens.}

Carex lurida.

Carex hirsuta.

Carex sterilis.

\section{Carex stipata.}

Carex festucacea.

Carex rosea radiata.

Carex learenworthii.
Carex leptatea.

Carex tribuloides turbata.

Carex muhlenbergii.

Carex styloflexa.

Southern forms most frequent in the Louisianian area and sparingly met with in the adjacent regions of the Carolinian area, north to the Ohio Valley:

Carex grandis. Carex frankii.

Carex debilis pubera.
Carex baileyi. Carex amphibola. Carex striatula.
Carex caroliniana.

Carex oblita.

Carex triceps.

Southern species confine to the Louisianian area and west to Texas:
Carex louisianica.
Carex elliottii.
Carex folliculata australis.
Carex turgescens.
Carex flaccosperma.
Carex verrucosa.
Carex oxylepis.
Carex cherokeensis.
Carex debilis prolixa.
Carex floridana.

Carex texensis.

Carex muhlenbergii xalapensis.

Species confined to the coast and extending north to New England:

Carex atlantica.

Carex albolutescens.

Carex alata.

Species also in foreign lands:

Mexico:

Carex stipata.

Carex muhlenbergii.

Japan: Carex stipata.

Europe: Carex bromoides.
Carex muhlenbergii xalapensis. Carex sterilis.
Carex festucacea.

Carex vulpinoidea.

\section{ARECACEAE (PALMAE). Palms.}

SABAL Adans. Fam. Nat. 2 : 495. 1763. Palmetro.

Six species, of tropical and subtropical America. Nortb America, 2.

Sabal minus (Jacq.) Pers. Syn. 1:399. 1805.

Dwarf Palmetto. Blue Palmetto.

Corypha minor Jacq. Hort. Vind. 3:8. 1776. Not Blanco. 1837.

C. pumila Walt. Fl. Car. 119. 1788.

Chamaerops acaulis Michx. Fl. Bor. Am. 1:207. 1803.

Sabal adansoni Guersent, Bull. Soc. Phil. 3: 206, t. 25. 1803.

Ell. Sk. 1:430. Chap. Fl. 438.

Louisianian area. North Carolina to Florida, west to Louisiana. 
Alabama: Central Pine belt to the Coast plain. Rich wooded bottoms. June; frequent. Common south of the Central Pine belt.

Economic uses: The leaves valuable for braiding.

Type locality: "In Carolina."

Herb. Geol. Surv. Herb. Mohr.

SERENOA Benth. \& Hook. Gen. Pl. 3:926. 1883.

A single species, Southern Atlantic States.

Serenoa serrulata (Michx.) Benth. \& Hook. Gen. Pl. 3:926. 1883. Saw Palmetto. Chamaerops serrulata Michx. Fl. Bor. Am. 1:206. 1803.

Fll. Sk. 1:431. Chap. Fl.438; ed. 3, 462 .

Louisianian area. South Carolina to Florida, west to Louisiana.

Alabama : Coast plain. Sandy flat pine barrens, on the islands and all over the Coast plain. June; frequent. Shrub.

Economic uses: The ripe drupes are nsed medicinally; the fiber of the stems is used in place of hair in plaster; brushes are made from the roots, and tannin is extracted from the leaves.

Type locality : "Hab. in maritimis Carolinae et Georgiae."

Herb. Geol. Surv. Herb. Mohr.

RHAPIDOPHYLLUM H. Wendl. \& Drude, Bot. Zeit. 34:803. 1876.

One species. Southeastern North America.

Rhapidophyllum hystrix H. Wendl. \& Drude, Bot. Zeit. 34:803. 1876.

Chamaerops hystrix Fraser; Pursh, Fl. 1:240. 1814.

Blue Palmetto.

Chap. Fl. 438; ed. $3,463$.

Carolinian and Louisianian areas. South Carolina, Florida.

Alabama: Southern edge of Metamorphic hills. Low shady woods. Lee County, Auburn (Earle \&. Tracy, 1899). Only locality known in the State.

Type locality: "Near the town of Savannah, Georgia."

\section{ARACEAE. Arum Family.}

ACORUS L. Sp. Pl. 1:324. 1753.

Two species, temperate regions, Europe, Asia; North America, 1.

Acorus calamus L. Sp. Pl. 1:324. 1753.

Sweet Flag. Calamus.

Ell. Sk. 1:403. Gray, Man. ed.6,551. Chap. Fl. 442.

Canadian zone to Louisianian area. Canada to Saskatchewan and throngh the United States east of the Mississippi River, west to Nebraska and Kansas.

EUROPE.

Alabama: Scattered over the State. Border of swamps. Mobile and Montgomery connties. Perennial.

Economic uses: The root forms the "sweet flag root" or "Calamus" of the U.S. Pharmacopœia.

Type locality: "Hab. in Europae * " * fossis paludosis."

Herb. Geol. Surv. Herb. Mohr.

ORONTIUM L. Sp. PI. 1:324. 1753.

Single aquatic species. Atlantic North America.

Orontium aquaticum L. Sp. Pl. 1:324. 1753.

Golden Clur.

Ell. Sk. 1: 404. Gray, Man. ed. 6, 551. Chap. Fl. 442.

Alleghenian to Lousiauian area. Southern Massachusetts to Florida, west to eastern Texas and southern Missouri.

AlabaMA: Over the State. In still-flowing water; ponds. Clay County, Shinbone Valley, 1,000 feet. Cullman County. Mobile County, February 15. Common. Perennial.

Type locality: "Hab. in Virginiae, Canadae paludibus scaturiginibus."

Herb. Geol. Surv. Herb. Mohr. 
PELTANDRA Raf. Journ. Phys. 89 : 103. 1819.

Two species, paludial perennials. Southeastern North America.

Peltandra sagittifolia (Michx.) Morong, Mem. Torr. Club, 5 : 102. 1894.

White Arrow-Arum. Wild Calla lily.

Calla sagittifolia Michx. Fl. Bor. Am. 2 : 187. 1803.

Calladium glaucum Ell. Sk. 2 : 631. 1821-24.

Peltandra alba Raf. New. Fl. N. Am. 1: 88. 1836.

Xanthosoma sagittifolia Chap. Fl.441. 1860. Not Schult.

Ell. Sk. 1. c. Gray, Man. ed.6,550. Chap. Fl.441; ed. 3, 465.

Louisianian area. North Carolina to Florida, along the Gulf coast to Mississippi.

AlabaMa : Coast region. Boggy borders of pine-barren streams. Mobile and Bald win counties. Flowers in June. Spadix white, fruit scarlet. July to August; not rare.

Type locality: "Hab. in paludosis Georgiae et Floridae."

Herb. Geol. Surv. Herb. Mohr.

Peltandra virginica (L.) Kunth, Enum. 3:43. 1841.

Green Arum.

Arum virginicum L. Sp. Pl. 2:966. 1753.

Peltandra undulata Raf. Journ. Phys. 89 : 103. 1819.

Calla virginica Michx. Fl. Bor. Am. 2: 187. 1803.

Ell. Sk. 2:630. Gray, Man. ed. 6, 550. Chap. Fl.440.

Alleghenian to Louisianian area. Ontario; New England, west to Michigan; lower Ohio Valley, south to Florida and Louisiana.

Alabama: Tennessee Valley. Central Pine belt to Coast plain. Low muddy places. Most abundant near the coast. Mobile County. Tuscaloosa County (E. $A$. Smith). Flowers in April; green. Common.

The whole plant is acrid.

Type locality: "Hab. in Virginia."

Herb. Geol. Surv. Herb. Mohr.

ARISAEMA Mart. Flora, 14:459. 1831.

About 50 species, perennials, of temperate and subtropical regions. Eastern Asia, North America. Atlantic North America, 2.

Arisaema quinatum Schott, Syn. Aroid.28. 1856.

Arum quinatum Nutt. Gen. 2 : 222. 1818.

Arum polymorphum Buckl. Am. Journ. Sei. 45:173. 1843.

Arisaema polymorphum Chap. Fl. 440. 1860.

Ell. Sk. $2: 629$. Chap. Fl. ed. 3, 464.

Carolinian and Louisianian areas. North Carolina, Georgia.

Alabama: Mountain region. Upper division Coast Pine belt. Rich wooded hillsides. Winston County, Colliers Creek, altitude 1,300 feet. Clarke County, Choctaw Corner, altitude 250 feet. Flowers April, May. Spathe white. Infrequent.

Distinguished from Arum triphyllum by the quiuate or subquinats second leaf, by the acute, rather slender (not inflated), spathe, and by the slender spadix tapering to the obtuse (not clavate) apex.

'Type locality: "In Georgia;-Dr. Baldwyn."

Arisaema triphyllum (L.) Torr. Fl. N. Y. 2:239. 1843.

INDIAN TURNIP.

Arum triphyllum L. Sp. Pl. $2: 965$. 1753.

Ell. Sk. 2:629. Gray, Man. ed.6, 549. Chap. Fl. 440.

Alleghenian to Louisianian area. Nova Scotia and Ontario; New England, west to Minnesota, south to the Ohio Valley, Florida, and Lonisiana.

Alabama: Over the State. Rich wooded hillsides, copses. Winston County, 1,500 fret. Clay, Cullman, Tuscaloosa, Clarke, Mobile, and Baldwin counties. April, May; not common.

The plant with leaves of 5 segments from the mountains of Winston County is found too closely connected with the type by forms from Clarke County, with the lateral leaflets more or less deeply two-parted, to be considered distinct.

Economic uses: The root, known as "Indian turnip," is used medicinally. Type locality : "Hab. in Virginia, Brasilia."

Herb. Geol. Surv. Herb. Mohr. 
Arisaema dracontium (L.) Schott, Melet. 1:17. 1832.

Dragon-Root.

Arum dracontium L. Sp. P1. 2 : 964. 1753.

Ell. Sk. 2:629. Gray, Man. ed. 6, 549. Chap. Fl. 440. Coulter, Contr. Nat. Herb. $2: 453$.

Alleghenian to Louisianian area. Ontario; New England, west to Minnesota, south to Ohio Valley; Florida to eastern Texas.

Alabama: Mountain region to Lower Pine belt. Rich copses. Cullman County. Tuscaloosa County (E. A. Smith). Clarke County, Choctaw Corner. April; not frequent.

Type locality: "Hab. in America."

Herb. Geol. Surv. Herb. Mohr.

\section{LEMNACEAE. Duckweed Family.}

SPIRODELA Schleid. Linnaea, 13:391. 1829. DUCKWEED.

A single species, of temperate regions.

Spirodela polyrhiza (L.) Schleid. Linnaea, 13:391. 1839.

Lemna polyrhiza L. Sp. P1. 2 : 970.1753.

Ell. Sk. 2:518. Gray, Man. ed.6, 552. Chap. Fl. 443. Coulter, Contr. Nat. Herb. $2: 453$.

Europe, Siberia, Asia, Australia, Madeira, Norti and Soutil America, West Indies to Central America.

Boreal region to Louisianian area. Cauada from the Atlantic to the Pacific Ocean.

Throughout the Atlantic Eastern States, west to Texas and Arkansas.

Alabama : All over the State. Stagnant waters. Mobile County; frequent.

Type locality: "Hab. in. Europae paludibus, fossis."

Herb. Geol. Surv. Herb. Mohr.

LEMNA L. Sp.Pl. $2: 970.1753$.

Six species, of temperate and warmer regions, Floating, almost cosmopolitan, plants.

Lemna minor L. Sp. Pl. 2 : 970. 1753.

Europe, Africa, Australia, North America, West Indies to South America. Canadian zone to Louisianian area. All over the continent to north latitude $58^{\circ}$. Alabama: Over the State in pools, stagnant water; common everywhere. Mobile County; February, March.

'Type locality : "Hab. in Europae aquis quietis."

Herb. Mohr.

Lemna trisulca L. Sp. Pl. 2:970. 1753.

Star DUCKWEED.

Gray, Man. ed. 6, 552. Coulter, Contr. Nat. Herb. 2 : 453.

Distribution as wide as that of the last.

EUrope.

Alabama: Over the State. In stagnant water. Mobile County. March. Type locality : "Hab. in Europae sub aquis pigris puris."

Herb. Mohr.

\section{MAYACACEAE. Mayaca Family.}

MAYACA Aubl. Pl. Guian. 1:42. 1775.

Seven species, tropical and subtropical aquatics, America. Atlantic North America, southern, 1 species.

Mayaca aubleti Michx. Fl. Bor. Am. 1:26. 1803.

Mosslike Mayaca.

Mayaca fluviatilis Aubl. Pl. Guian. 1:42, 1775.

M. michauxii Schott \& Endl. Melet. 1:24. 1832.

Ell. Sk. 1:50. Gray, Man. ed.6, 538. Chap. Fl.499. Griseb. Fl. Brit. W. Ind.526.

West Indies, Mexico, Guiana to Brazil.

Louisianian area. North Carolina to Florida, west to Texas.

Alabama: Central Prairie region to the coast. Shallow ponds, springy places, wet banks, pine-barren streams. Eufaula County (E.A.Smith). Clarke, Washington, Mobile, and Baldwin counties. Flowers lilac, June to July; abundant. Perennial. Type locality : "Hab. a Carolina ad Floridam."

Herb. Geol. Surv. Herb. Mohr. 


\section{XYRIDACEAE. Yellow-eyed Grass Family.}

XYRIS L. Sp. Pl. 1 : 42 . 1753.

About 50 species, mostly of the tropical and subtropical zone. Perennials, chiefly in America, Australia, Africa. North America, 14.

Xyris ambigua Beyr. in Kunth, Enum. 4: 13. 1843.

Tyris stricta Chap. Fl. 500. 1860.

BEYRICH'S YELLOW-EYED GRASS.

X. rhombipetala Sauv. Fl. Cub. 160. 1868.

Chap. Fl. 500.

CUBA.

Louisianian area. North Carolina to Florida, west to eastern Texas.

Alabama: Lower Pine region. Coast plain. Sandy wet borders of pine-barren streams, ponds, ditches. Washington County, Yellowpine. Escambia, Mobile, and Baldwin counties. Flowers yellow, July, August; frequent.

Type locality: "Georgia, ad ripas paludum."

Herb. Geol. Surv. Herb. Mohr.

Xyris flexuosa Muhl. Cat. 5. 1813.

Bulbous Yellow-Eyed Grass.

Xyris bulbosa Kunth, Enum. 4:11. 1843.

Eil. Sk. 1:51. Gray, Man. ed. 6, 537. Chap. Fl.500. Coulter, Contr. Nat. Herb. $2: 442$.

Alleghenian to Louisianian area. Ontario and New England west to Minnesota, south to New Jersey, Florida, 'Texas, Arkausas, and southern Missouri.

Alabama: Mountain region to the Coast plain. Wet sandy soil. Lee County, Auburn (Baker \& Earle). Dekalb County, De Seto Falls. Cullman County, 800 fe t altitude. Chilton County (E. A. Smith). Washington County, Yellowpine. Autauga and Mobile counties. July, August; frequent.

Type locality: "Georgia, Virginia."

Herb. Geol. Surv. Herb. Mohr.

Xyris elliottii Chap. Fl.500. 1860.

Elliott's YeLLOW-eyed Grass.

Chap. Fl.1.c.

Louisianian area. South Carolina to Florida, Mississippi.

Alabama: Coast Pine belt. Coast plain. Sandy swamps. Clarke County, Choctaw Corner. Monroe County, Claiborue. Escambia, Mobile, and Baldwin counties. July to October; common.

Type locality : "Wet grassy pine barrens, Florida to South Carolina."

Herb. Geol. Surv. Herb. Mohr.

Xyris communis Kunth, Enum. 4:12. 1843.

Common Yellow-Eyed Grass.

Xyris difformis Chap. F1.500. 1860.

X. gymnoptera Griseb. Cat. Pl. Cub. 223. 1866.

$X$. laxifolia Mart. Flora, 24, Beibl. 2 :53. 1841.

Chap. Fl.l.c.

Cuba, West Indies to Brazil, Argentina.

Carolinian to Louisianian area. Maryland to Florida and western Louisiana.

AlaBAma: Lower hills to Coast plain. Damp grassy banks, etc. Dekalb County, Valley Head. Lee County (J.D. Smith). Mobile County. July; infrequent.

Type locality: "Cajenna (Desf.), Caracas (E. Otto).

Herb. Geol. Surv. Herb. Mohr.

Xyris serotina Chap. Fl.500. 1860.

Louisianian area. Western Florida.

Alabama : Coast plain. Shallow pine-barren ponds. Mobile County, Kelly's pond. October; rare.

Type locality: "Pine-barren swamps, west Florida."

Herb. Geol. Surv. Herb. Mohr.

Xyris caroliniana Walt. Fl. Car. 69. 1788.

Xyris elata Chap. Fl.501. 1860.

Gray, Man. ed.6,537. Chap. Fl. 501. 1860.

Alleghenian to Louisianian area. New England, New York, south to Florida and the Gulf States, to western Louisiana.

${ }^{3}$ Heinrich Ries, Review of the North American species of Xyris, Bull. Torr. Club, vol. $19, \mathrm{pp} .35$ to 43.1892 . 
Alabama: Throughout the Central and Coast Pine belts. Springy places in woods. Lee County, Auburn (Baker \& Earle). Clarke, Monroe, and Washington counties. July; not rare.

Type locality: "South Carolina.

Herb. Geol. Surv. Herb. Mohr.

Xyris iridifolia Chap. F1.501. 1860.

SWORD-Lear Yellow-EYed Grass.

Chap. Fl. 1.c. Coulter, Contr. Nat. Herb. 2 : 442.

Louisianian area. Florida, west to southeastern Texas (Brazos River).

Alabama: Mountain region, Metamorphic hills, Central Prairie region to Coast plain. Low wet pine barrens, border swamps. Lee County, Auburn (Baker \& Earle). Wilcox County (S. B. Buckley). Washington County, Yellowpine. Mobile County. July.

Type locality: "Shallow ponds, Apalachicola, Fla."

Herb. Geol. Surv. Herb. Mohr.

Xyris fimbriata Ell. Sk. 1:52. 1816.

Fringed Yellow-eyed Grass.

Gray, Man. ed.6,573. Chap. Fl. 501.

Carolinian and Louisianian area. Southern New Jersey, Virginia, South Carolina to Florida, west to Mississippi and Louisiana.

Arabama: Lower Pine region, Coast plain. Low wet pine barrens. Mobile County, Kelly's pond, Springhill. September; not frequent.

Type locality : "Sent from Georgia by Dr. Baldwin."

Herb. Mohr.

Xyris torta Smith in Rees, Cycl. no. 11. 1819.

Xyris conocephala Sauv. Fl. Cub. 159. 1868.

Gray, Man. ed. 6, 537. Chap. Fl.537.

CUBA.

Carolinian and Lonisianian areas. New Jersey to Florida, west to Texas, Arkansas.

Alabama: Mountain region, Metamorphic hills. Central Pine belt to the coast. Lee County, Auburn (Baker \& Earle). Washington and Mobile counties. June; commion.

Type locality: "Gathered in North America by Kalm."

Herb. Geol. Surv. Herb. Mohr.

Xyris torta pallescens var. nov.

Pale Twisted Xyris.

Slender, 8 to 10 inches high, glaucous, leaves narrow, linear, $\frac{1}{16}$ inch wide, very tortwous, greenish-brown at the base; flowering heads more conical and acute than in the type, greenish, flowers white.

Louisianian area. Western Florida.

Alabama: Littoral be]t. Drifting sands, shore of Perdido Bay. Mobile County, Dauphin Island. June; infrequent.

Type locality: First observed on Santa Rosa Island, Florida. July 4, 1874.

Herb. Geol. Surv. Herb. Mohr.

Xyris baldwiniana Schult. Mant. 1:351. 1822. BALdwin's Yellow-EYed Grass. Xyris juncea Bald.; Ell. Sk. 1:53. 1816. Not R. Br.

$X$. tenuifolia Chap. Fl. 502. 1860.

X. setacea Chap. Suppl. 658. 1880.

Ell. Sk. l.c. Chap. Fl. 502. Coulter, Contr. Nat. Herb. 2:442.

Louisianian area. South Carolina to Florida, and west to Texas.

AI.ABAMa: Lower Pine region. Borders of pine-barren ponds. Washington County, Fairfort. Mobile County, Chastangs Bluff. September; not rare.

Type locality: "Grows in damp situations in the pine barrens near St. Mary's [Ga.]."

Herb. Geol Surv. Herb. Mohr.

\section{ERIOCAULACEAE. Pipewort Family.}

ERIOCAULON L. Sp. Pl. 1:87. 1753.

About 110 species, perennials, of subtropical and tropical regions of Asia, Africa, and Australia, South and North America. North America 3, two of them south. eastern, one extending north to New England and to south western Europe.

Eriocaulon decangulare L. Sp. Pl. 1:87. 1753.

Ten-angled Pipewort.

Ell. Sk. 2 :565. Gray, Man. ed.6,567. Chap. Fl. 503. Coulter, Contr. Nat. Herb. $2: 459$. 
CUBA.

Carolinian and Louisianian areas. Coast of New Jersey to Florida, west to Texas.

Alabama : Lower Pine region. Coast plain. Shallow pine-barren 8 wamps. Mobile County. July to October; abundant.

'Type locality: "Hab. in Americae septentrionalis paludibus."

Herb. Geol. Surv. Herb. Mohr.

Eriocaulon compressum Lam. Encycl. 3 : 276. 1789.

Flattened Pipewort.

Eriocaulon gnaphalodes Michx. Fl. Bor. Am. 2 : 165. 1803.

Ell. Sk. 2 :565. Gray, Man. ed.6,567. Chap. Fl. 503.

Carolinian and Louisianian areas.

Alabama : Central Pine belt to Coast plain. Boggy swamps, muddy ditches in the pine barrens. Abundant in the Coast plain. May to October.

'Type locality: "Cette plante croít dans la Caroline méridionale."

Herb. Geol. Surv. Herb. Mohr.

IACHNOCAULON Kunth, Enum. 3 : 497. 1841.

Four species, sontheastern North America. Perennials.

Lachnocaulon anceps (Walt.) Morong, Bull. Torr. Club, 18:360. 1891.

Eriocaulon anceps Walt. Fl. Car. 83. 1788.

HaIRY Pipewolrt.

E. villosum' Michx. Fl. Bor. Am. 2 : 166.1803.

Lachnocaulon michauxii Kunth, Enum. 3:497. 1841.

Ell. Sk. 2 :566. Gray, Man. ed. 6, 567. Chap. Fl.504.

Carolinian and Louisianian areas. Sandy close soil. Southern Virginia to Florida, west to Mississippi.

Alabama: Throughout the Coast Pine belt. Most frequent in the Coast plain. Washington County, Yellowpine. Mobile and Baldwin counties. March to June. Hlowers white. Common.

Type locality : "South Carolina."

Herb. Geol. Surv. Herb. Mohr.

Lachnocaulon glabrum Koernicke, Linnaea, 27:568. 1854. SмоOTH PIPEWorT. Chap. Fl. 504.

Louisianian area. Florida.

Alabama: Littoral belt. Sandy shore of West Fowl River. Only locality. April 20.1868. Rare.

Type locality: "America borealis: Florida attul. Cabanis."

Herb. Geol. Surv. Herb. Mohr.

DUPATYA Vell. Fl. Flum. 35, no. 42. 1825.

(Paepalanthus Mart. Nov. Act. Caes. 18 : 13. 1833-1835.)

About 215 species, South America; mostly Brazil. Perennials.

Dupatya flavidula (Michx.) Kuntze, Rev. Gen. P1.2:745. 1891. Yellow Dupatia. Eriocaulon flavidulum Michx. Fl. Bor. Am. 2 : 166. 1803.

Paepalanthus favidulus Kunth, Enum. 3:532. 1841.

Ell. Sk. 2:566. Chap. Fl. 503.

Carolinian and Louisianian areas. North Carolina to Florida.

Alabama: Littoral region. Damp sandy pine barrens. Baldwin Connty, Josephine, in wet sand forming dense tufts. Flowers yellowish, appearing in June and July. Infrequent.

Type locality : "Hab. in Carolina."

Herb. Geol. Surv. Herb. Mohr.

\section{BROMELIACEAE.}

TILLANDSIA L. Sp. Pl. 1:286. 1753.

About 120 species, perennials. Epiphytes, mostly in subtropical and tropical America; southeastern North America, 1.

Tillandsia usneoides L. Sp. Pl. ed. 2, 1:411. 1762.

Moss. Spanish Moss.

Ell. Sk. 1:379. Gray, Man. ed. 6, 511. Chap. Fl. 472. Coulter, Contr. Nat. Herb.

2: 426. Griseb. Fl. Br. W. Ind. 598 . 
West Indies, Mexico to Uruguay, Chile.

Carolinian and Louisianian areas. Southeastern Virginia to Florida, west to southern Texas.

Alsabama: Central Pine belt to the coast. Damp banks, on trees. Autauga County to Mobile County, alluvial districts; most abundant. Flowers blue, June.

Type locality: "Hab. in Virginiae, Jamaicae, Brasiliae arboribus."

Herb. Geol. Surv. Herb. Mohr.

\section{COMMELINACEAE.}

COMMELINA L. Sp. Pl. 1:40. 1753.

About 88 species, warmer regions of Asia, Africa, Australia, America. Atlantic North America, 5.

Commelina communis L. Sp. Pl. 1:40. 1753. Asiatic or Common Day-flower. Commelina vulgaris Schmidel, Icon. Pl. 159, t. 40, 41. 1762.

C. villdenovii Kunth, Enum. 4:37. 1843.

Chap. Fl.497, in part.? Britt. \& Brown, Ill. Fl. 1 : 376.

Asia.

Carolinian and Louisianian areas. Adventive and naturalized. Southern New

York and New Jersey to Florida and Louisiana.

Ala Bama : Lower hills to Coast plain. Cultivated and waste ground. Jefferson County, Jonesboro (E.A.Smith). Mobile County. July to October; a garden weed. Annual.

Type locality: "Hab. in America."

Herb. Geol. Surv. Herb. Mohr.

Commelina nudiflora L. Sp. P1. 1:41. 1753.

CREEIING DAY-FLOWER.

Commelina communis Walt. Fl. Car.68. 1788. Not L.

C. caroliniana Walt. 1. c.

C. cayennensis L. C. Rich. Act. N. Soc. Nat. Hist. Par. 1:106. 1792.

C. agraria Kunth, Enum. 4:38. 1843.

Ell. Sk. 1:48. Gray, Man. ed. 6, 538. Coulter, Contr. Nat. Herb. 2:443. Griseb.

Fl. Brit. W. Ind.524. Chap. Fl. ed. $3,524$.

West Indies, Mexico to Brazil, Canary Islands, Galapagos, Tropical AFrica.

Carolinian and Louisianian areas. Delaware to Florida, west to Texas and Missouri.

Alabama : Central Pine belt to Coast plain. Cultivated ground. A common gar-

den weed. Mobile. September to November. Flowers blue. Annual.? Type locality : "Hab. in India."

Herb. Geol. Surv. Herb. Mohr.

Commelina erecta I. Sp. Pl. 1:41. 1753.

Slender Day-FLower.

Ell. Sk. 1:48, in part. Gray, Man. ed. 6, 539. Chap. Fl. 497. Conlter, Contr.

Nat. Herb. $2: 443$.

Mexico to Brazil, Peru.

Carolinian and Louisianian areas. Pennsylvania to Florida, west to Texas.

Alabama: Mountain region. Lower hills to Coast plain. Light exposed soil, grassy banks, pastures. Mobile County. Lee County, Auburn. August, September. Flowers blue. Perennial.

Type locality: "Hab. in Virginia."

Herb. Geol. Surv. Herb. Mohr.

Commelina virginica L. Sp. Pl. ed. 2, 1:61. 1762.

VIRGINIA DAY-FLOWER.

Commelina angustifolia Michx. Fl. Bor. Am. 1:24. 1803.

Gray, Man. ed. 6, 539. Chap. F1.497.

BaHAMAS, PaRaguay.

Carolinian and Louisianian areas. Southern New York to Michigan and Nebraska, south to Florida.

Alabama: Central Pine belt to Coast plain. Tuscaloosa County (F. A. Smith). Lee County, Auburn (F.S. Earle). Frequent. Perennial.

Type locality: "Hab. in Virginia."

Herb. Geol. Surv. Herb. Mohr. 
Commelina hirtella Vahl, Ennm. 2:166. 1806.

Hirtelious Commelina.

Commelina longifolia Michx. Fl. Bor. Am. 1:23. 1803.

C. erecta Gray, Man. ed. 5, 546. 1867. Not L.

Ell. Sk. 1:49. Gras, Man. ed. 6,538. Chap. Fl. 498.

Mexico, Brazil, Peru.

Carolinian area. Pennsylvania and New Jersey to Florida; Ohio Valley west to Missouri.

Ala BAMA: Mountain region to Coast plain. Damp banks. Lee Connty, Auburn (Baker \& Earle). Cullman and Mobile counties. August; not frequent. Perennial. Type locality: "Hab. in umbrosis sylvarum Virginiae et Carolinae. Richard."

Herb. Geol. Surv. Herb. Mohr.

TRADESCANTIA L. Sp. Pl. $1: 288.1753$.

Thirty-two species, perennials, temperate and tropical America. North America about 12.

Tradescantia reflexa Raf. New Fl.pt. 2, 87. 1836.

COMMON SPIDERWORT.

Tradescantia canaliculata Raf. Atl. Journ. 150. 1832. ?

Alleghenian to Louisianian area. Wisconsin (Lapham) and Minnesota; Sonth Carolina to Florida, west to Texas, Indian Territory, and Arizona.

Alabama: Mountain region to Coast plain. Metamorphic hills. Shaded copses, grassy banks in light loamy soil. Lee County, Auburn (Earle \& Underwood). Mobile County. Abundant in cultivated and abandoned ground and on waysides. Flowers cerulean blue, anthers golden-yellow. March, April. Fruit ripe in May and June. Common.

Type locality not ascertained.

Herb. Geol. Surv. Herb. Mohr.

Tradescantia hirsuticaulis Small, Bull. Torr. Club, 24:233. 1897.

HiRsute-STEMmED SPIDERWORT.

Louisianian area. Georgia and Florida to western Lonisiana (Carpenter).

Alabama : Central Prairie regiön. Coast plain. Open dry hillsides, in sandy soil. Montgomery and Mobile counties. April to June; not frequent.

Type locality: "Sandy places, Georgia to Florida; occurs at 400 meters on Stone Mountain."

Herb. Mohr.

Tradescantia montana Shuttl.; Britt. \& Brown, Ill. Fl. 1:377. 1896.

MOUNTAIN SPIDERWORT.

Carolinian and Lonisianian areas. Virginia to South Carolina.

Alabama: Metamorphic and Lower hills. Tuscaloosa County (E.A.Smith). Lee Connty, Auburn (Baker \& Earle). Flowers May; rare.

Type locality (Small): North Carolina, Rugel.

Herb. Geol. Surv. Herb. Mohr.

\section{PONTEDERIACEAE. Pickerel Weed Family.}

PONTEDERIA L.Sp. Pl. 1:288. 1753.

Twenty-three spezies, warmer regions, mostly American. North America, 1.

Pontederia cordata L. Sp. Pl. 1:288. 1753.

WAMPEe Pickerel-Weed.

Ell. Sk. 1 :382. Gray, Man. ed.6,536. Chap. Fl.496. Conlter, Contr. Nat. Herb. $2: 441$.

Mexico and Central America to Argentina.

Canadian zone to Louisianian area. Nova Scotia and Ontario to Saskatchewan; throughout the Eastern United States and west to Arkansas and eastern Texas.

Alabama: Over the State. Ponds, marshes, and borders of streams. Mobile County. April to July; common.

Type locality: "Hab.in Virginiae aquosis."

Herb. Geol. Surv. Herb. Mohr.

${ }^{1}$ John K. Small, Tradescantia in the Southern States, Bull. Torr. Club, vol. 24, pp. 228 to 236.1897. 
Heteranthera Ruiz \& Pav. Gen. Pl. Fl. Per. et Chil. 9. 1794. Water StarGrass. (Schollera Schreb. Gen. 785. 1789. Not Roth. 1788.)

Nine species, aquatic, perennial, warmer regions of America.

Heteranthera dubia (Jacq.) Morong, Mem. Torr. Club, 5 : 105. 1894.

Commelina dubia Jacq. Obs. Bot. 3:9, t.59. 1768.

Golden-Flowered Water Star.

Leptanthus gramineus Michx. Fl. Bor. Am. 1: 25, t. 5, f. 2. 1803.

Heteranthera graminea Vahl, Enum. 2:45. 1806.

Schollera graminea Gray, Man.511. 1848.

Gray, Man. ed. 6, 536. Chap. Fl.497. Coulter, Contr. Nat. Herb. $2: 441$. Wats. Bot. Calif. $2: 178$.

CUBA.

Alleghenian to Louisianian area. Nova Scotia, Ontario; New England west to Ohio and Minnesota, south to Florida, and west to Texas and Arkansas.

Alabama: Tennessee Valley to the seashore. Sluggish streams, under water. Lauderdale County, Tennessee River (E.A.Smith). Mobile and Baldiwin counties, in the river delta and upper part of Mobile Bay; abundant. Jnne. Flowers yellow. Type locality: "Haud procnl a montibus in rivulo Jacobi dicto."

Herb. Geol. Surv. Herb. Mohr.

Heteranthera reniformis Ruiz \& Pav. Prodr. Fl. Per. 1:43. 1798. Mud Plantain. Leptanthus reniformis Michx. Fl. Bor. Am. 1:25. 1803.

Gray, Man. ed.6, 536. Chap. Fl. ed. 3, 524. Griseb. Fl. Brit. W. Ind.590.

West Indies, Mexico to Argentina, Paraguay, Peru.

Carolinian to Louisianian area. New York, Illinois, and eastern Kansas.

Alabama: Coast plain. Mobile County, muddy ditches. July. Flowers pale blue. Not frequent.

Type locality: "Hab. in Provincia Cereado, in paludibus et stagnatis Lurin, Limae, Surco, Miraflores, Magdalena et Lurigancho.

Herb. Geol. Surv. Herb. Mohr.

\section{JUNCACEAE. Rush Family.}

\section{JUNCUS L. Sp. Pl. 1:325. 1753. Rusir.}

One hundred and seventy-six species, cosmopolitan. North America, 60 ; North Atlantic States, 30 to 35; Southern, 20. Chiefly perennials.

Juncus effusus L. Sp. Pl. 1 : 326. 1753.

Soft Rush.

Ell. Sk. 1:405. Gray, Man. ed.6,540. Chap. Fl.493. Coulter, Contr. Nat. Herb 2:447. Wats. Bot. Calif. $2: 206$.

Europe, Asia, Africa, America, Australia, New Zealand.

Canadian zone to Louisianian area. Newfoundland, Quebec, and Ontario to the Pacific; from Vancouver's Island to California; throughout the Eastern States to Florida and Texas.

Alabama: Over the State. Common in low damp places. June.

Type locality: "Hab. in Europae uliginosis."

Herb. Geol. Surv. Herb. Mohr.

Juncus roemerianus Scheele, Linnaea, $22: 348.1849$.

Salt RUSH.

Juncus maritimus Chap. Fl.493. 1860. Not Lam.

Chap. Fl.1. c.; ed. 3, 520. Coulter, Contr. Nat. Herb. 2 : 447.

Carolinian and Lonisianian areas. Seashore of New Jersey to Florida, west to Texas.

Alabama : Littoral region. Salt and brackish swamps, covering the large salt marshes, overflowed by the tide. Mobile and Baldwin counties. July. Abundant. Type locality: "Galveston Island auf feuchtem Muschelsand : Roemer."

Herb. Geol. Surv. Herb. Mohr.

Juncus bufonius fasciculatus Koch, Syn. Fl. Germ. ed.2, 845. 1843.

SoutherN EURope.

Louisianian area. Southeastern States.

Alabama : Coast plain. Damp sandy soil. Mobile County; not frequent. May; annual. 
Differs from the type by the low habit of growth (rarely 2 inches high), habitat, and Southern distribution.

Type locality: "Haec varietas in planitie Rhenana occurrit, (zwischen Maintz und Worms.)"

Herb. Geol. Surv. Herb. Mohr.

Juncus tenuis Willd. Sp. Pl. 2 : 214.1799.

SLENDER RUSH.

Juncus bicornis Michx. Fl. Bor. Am. 1: 191. 1803.

Ell. Sk. 1: 406. Gray, Man. ed. 6, 542. Chap. Fl.493. Coulter, Contr. Nat. Herb. 2 : 446. Wats. Bot. Calif. 2: 207. Griseb. Fl. Brit. W. Ind.581.

Western Europe, West Indies, Mexico, South America.

Hudsonian zone to Louisianian area. Nova Scotia, Hudson Bay, Ontario, west to Vancouver Island, Oregon, California; from New England to the Gulf, west to Texas.

Alabama: Over the State. Sandy wet soil, ditches. Mobile County. May to June; abundant.

The reduced form, 4 to 8 inches high, with the flowers in close clusters $(J$. congestus Engelm.) prevails in the Coast plain in close damp soil.

Type locality: "Hab. in America boreali."

Herb. Mohr.

Juncus dichotomus Ell. Sk. 1: 406.1817.

FoRKed RUSH.

Gray, Man.ed.6, 542. Chap. Fl. 493. Coulter, Contr. Nat. Herb. 2 : 446.

Carolinian and Louisianian areas. New Jersey to Florida, west to eastern Texas.

Alabama : Coast Pine belt. Sandy borders of ditches, ponds. Mobile and Baldwin counties. Most common near the coast. May, June.

Type locality: "In wet pastures and close, stiff soils [South Carolina and Georgia]; very common."

Herb. Mohr.

Juncus setaceus Rostk. Monogr. Junc. 13, t. 1, f. 2. 1801.

Awl-Leaved Rush.

Ell. Sk. 1: 405. Gray, Man. ed. 6, 541. Chap. Fl.493. Coulter, Contr. Nat. Herb. $2: 446$.

Carolinian and Louisianian areas. Southern Virginia and North Carolina to East Tennessee, Louisiana, eastern Texas, and Missouri.

Alabama : Mountain region, Metamorphic hills. Central Pine belt to Coast plain. Shaded swamps. Lee County, Auburn (Baker \& Earle, 511). Tuscaloosa County. Autauga County, Prattville (E. A. Smith). Mobile County. June. Flowers reddish brown. Not frequent.

Type locality: "Hab. in Pensylvania."

Herb. Geol. Surv. Herb. Mohr.

Juncus marginatus Rostk. Monogr. Junc. 38. 1801.

Gray, Man. ed. 6, 542. Chap. Fl. 495.

Northern Mexico.

Alleghenian to Louisianian area. Ontario, New England west to Michigan and Missouri and south to Florida and Louisiana.

Alabama: Teunessee Valley to Coast plain. Grassy swales, border of ditches. Cullman, Tuscaloosa, Montgomery, Washington, Mobile, and Baldwin counties. May; common.

Type locality: "Hab. in Pensylvania."

Herb. Mohr.

Juncus marginatus aristulatus (Michx.) Coville, Proc. Biol. Soc. Wash. 8:123. 1893. Juncus aristulatus Michx. Fl. Bor. Am. 1:192. 1803.

J. biflorus Ell. Sk. $1: 407.1817$.

Gray, Man. ed. 6,542. Chap. Fl.495. Coulter, Contr. Nat. Herb. 2 : 450.

Carolinian and Louisianian areas. Now Jersey and Delaware to Florida, west to eastern Texas.

AlabaMa: Mountain region to Coast plain. Shaded damp banks pine-barren streams. Lee County, Auburn (Baker \& Earle, 510). Mobilo County. Baldwin County, Fly Creek. June; frequent.

A form with weak slender nodding stems, the 3 or 4 flowered heads in a compact panicle. In shallow miry ponds. Mobile County, Springhill.

Type locality: "Hab. in Georgia et Carolina."

Herb. Geol. Surv. Herb. Mohr. 
Juncus repens Michx. Fl. Bor. Am. 1:191. 1803.

Creeping Rush.

Cephaloxys flabellata Desv. Journ. Bot. 1 : 324, t. 2. 1808.

Ell. Sk. 1:408. Gray, Man. ed.6, 541. Chap. Fl. 496; ed. 3,523. Coulter, Contr.

Nat. Herb. $2: 450$.

CuBA.

Carolinian and Louisianian areas. North Carolina to Florida, west to Texas and Arkansas.

Alabama: Coast plain. Muddy ditches and borders of swamps. Mobile County. Type locality: "Hab. in Carolina et Georgia."

Herb. Geol. Surv. Herb. Mohr.

Juncus torreyi Coville, Bull. Torr. Club. 22 :303. 1895.

Juncus nodosus var. megacephalus Torr. Fl. N. Y. $2: 326.1843$.

J. megacephalus Wood, Bot. ed. 2, 7 ㄴ. 1861. Not Curtis, 1835.

Gray, Man. ed. 6, 545. Coulter, Contr. Nat. Herb. 2:448. Wats. Bot. Calif. $2: 208$.

Britt. \& Brown, Ill. Fl. 1: 392.

Alleghenian to Lonisianian area. Ontario west to Saskatchewan; New England to Minnesota, west to Colorado, California, Oregon south to Mississippi and Texas.

AlabaMa: Mountain region, Central prairies, and Coast plain. Open prairies and pine forests. Lee County, Auburn (Baker \& Earle). Montgomery County. Mobile County, Langdon's Station. July; not frequent.

Type locality not ascertained; Wood's locality: "Borders of streams and lakes,

New York to Wisconsin, south to Florida."

Herb. Geol. Surv. Herb. Mohr.

Juncus brachycarpus Engelm. Trans. Acad. St. Louis $2: 467.1868$.

SHORT-FRUITED RUSH.

Gray, Man. ed. 6, 544. Chap. Fl. ed. 3, 521. Coulter, Contr. Nat. Herb. 2 : 448

Britt. \& Brown, Ill. Fl. 1 : 393.

Carolinian and Louisianian areas. Southern Ontario, Kentucky, and Missouri, south to Tennessee, Mississippi, and Texas.

Alabama: Central Prairie region. Open grassy places. Montgomery County. July; not frequent.

Type locality: "In the Mississippi Valley from central Ohio, Michigan, and Mllinois to Missouri! Kentucky, Mississippi, Louisiana, and Texas; also, if the locality is correctly reported, near Charleston, S. C.

Herb. Mohr. Herb. Geol. Surv.

Juncus polycephalus Michx. Fl. Bor. Am. 1: 192. 1803.

MANY-HEADED RUSH.

Juncus nodosus polycephalus Pers. Syn. I:384. 1805.

J. scirpoides var. polycephalus forma minor Engelm. Trans. St. Louis Acad. 2: 468. 1868.

J.engelmanni Buchenau, Krit. Verz. Junc. 67. 1880.

Ell. Sk. 1:409. Gray, Man. ed. 6, 545. Coulter, Contr. Nat. Herb. 2:447. Britt.

\& Brown, Ill. Fl. 1 : 393 .

Louisianian area. Sonthern Virginia? and North Carolina to Florida, west to Texas.

Alabama : Lower Pine region and Coast plain. Border of pine-barren swamps, brooks, and ditches. Washington County, Yellowpine. Baldwin and Mobile counties. July, October; frequent.

Type locality: "Hab. in Georgia et Carolina."

Herb. Geol. Surv. Herb. Mohr.

Juncus scirpoides Lam. Encycl. $3: 267.1789$.

Prickly-headed Rush.

Juncus polycephalus tenuifolius Michx. Fl. Bor. Am. 1: 193. 1803.

J. echinatus Ell. Sk. $1: 410$. Not Muhl.

J. macrostemon J. Gay; La Harpe, Monogr. Junc. 140. 1825.

J. scirpoides var. macrostemon Engelm. Trans. St. Louis Acad. $2: 467.1868$.

J. scirpoides genuinus Buchenau, Monogr. Junc. 323. 1890.

Ell. Sk. 1:410. Gray, Man. ed. 6, 545. Chap. Fl. 494. Coulter, Contr. Nat. Herb.

2 : 448 .

Carolinian and Louisianian areas. New England to Florida, west to Texas and

Arkansas.

Alabama: Central Pine region to Coast plain. Miry places, ditches. Tuscaloosa County (E.A. Smith). Bibb, Washington, and Mobile counties. June, July; common. Type locality: "Cette plante crolt dans la Caroline méridionale, d'où elle a été rapportée par M. Fraser."

Herb. Geol. Surv. Herb. Mohr. 
Juncus canadensis J. Gay; La Harpe, Monogr. Junc. 134. 1825.

Canada Rush. Juncus canadensis longicaudatus Engelm. Trans. St. Louis Acad. $2: 474.1868$.

Alleghenian and Carolinian areas. New Brunswick, Ontario; New England west to Minnesota, south to Ohio, eastern Temnessee, and Arkansas.

AlabaMa: Mountain region. Metamorphic hills. Lee County, Auburn ( $F . S$. Earle). October; infrequent.

Type locality : "Hab. in Canada."

Herb. Geol. Surv. Herb. Mohr.

Juncus trigonocarpus Steud. Syn. Pl. Cyp. 308. 1855.

Juncus caudatus Chap. Fl. 495. 1860.

Triangulak-Frinted RUSH.

Louisianian area. Florida to Mississippi.

Alabama: Lower Pine region. Pine-barren bogs. Escambia County, Wallace. Washington County, Yellowpine. Mobile County, Grandbay. September, October; not infrequent.

Type locality : "Carolina."

Herb. Geol. Surv. Herb. Mohr.

Juncus elliottii Chap. Fl.494. 1860.

ElliotT's Rush.

Juncus acuminatus Ell. Sk. 1:409. 1817. Not Michx.

Louisianian area. Coast of North Carolina to Florida and eastern Texas.

Alabama: Lower Pine region. Coast plain. Damp pine barrens, springy places, ditches. Washington County, Yellowpine. Mobile County. Most common in the coast plain. April, May.

Type locality: "Bogs and ditches, Florida to North Carolina."

Herb. Geol. Surv. Herb. Mohr.

Juncus elliottii polyanthemus var. nov.

Elliotr's MaNy-Flowered Rush.

Mr. Coville first pointed ont this remarkable form as a possible variety of J.elliottii, from which it is at once distinguished by the robust habit of growth and the large inflorescence, resembling in this respect $J$. robustus. Stem 2 to $2 \frac{1}{2}$ feet high; leaves from 10 to 15 inches long, flat, long-acuminate; branches of the lateral and terminal panicle erect, spreading, having the very numerous (100 to 200) 4 to 6 flowered heads on very short or longer branchlets, by intergrading forms insensibly passing into the type.

Louisianian area.

AlabaMa : Coast plain. Low pine barrens, border ditches and swamps. Baldwin County, Point Clear. Mobile County, with the type. Frequent.

Type locality: Mobile.

Herb. Geol. Surv. Herb. Mohr.

Juncus acuminatus Michx. Fl. Bor. Am. I:192.

SHARP-FRUITED RUSH. Gray, Man. ed.6,544. Chap. Fl.494. Coulter, Contr. Nat. Herb. 2 : 44.9.

MeXico.

Alleghenian, Carolinian, and Louisianian areas. Ontario; New England (Mount Desert Island) to Tennessee and Arkansas.

Alabama: Central Pine belt. Mountain region. Tuscaloosa County (D) $E$. A. Smith). Lee County, Auburn (F. S. Earle). Rare.

Type locality: "Hab. in Carolina inferiore."

Herb. Geol. Surv. Herb. Mohr.

Juncus acuminatus debilis (Gray) Engelm. Trans. St. Lonis Acad. 2 : 463. 1868.

Juncus debilis Gray, Man. 506. 1848.

WHAK RUSH.

Gray, Man. ed.6,544. Chap. Fl. ed. 3, 521 .

Carolinian and Louisianian areas. New Jersey to South Carolina, west to Louisiana, Arkansas, and Missouri.

Alabama : Mountain region. Central Pine belt. Lee County, Auburn (Baker \& Earle). Tuscaloosa County. St. Clair County, flat woods in open miry or exsiccaterl ground. Mobile County, Springhill, springy places. May, June.

Type locality : "Wet swamps, conmon southward and westward."

Herb. Geol. Surv. Herb. Mohr.

Juncus diffusissimus Buckl. Pruc. Acad. Phila. 1862: 9. 1862.

Diffuse Rustr.

Juncus acuminatus var. diffusissimus Engelm. Trans. St. Lonis Acad. $2: 466.1868$.

Chap. Fl. ed. 3, 521. Coulter, Contr. Nat. Herb. 2: 449.

Carolinian and Louisianian areas. Tennessee, west to Kansas; Alabama to Louisiana, Arkansas, and eastern Texas. 
Alabama: Lower Pine region. Coast plain; wet sandy places, shallow ditches. Mobile County. May, June; not rare.

Type locality: "Northwestern Texas."

Herb. Geol. Surv. Herb. Mohr.

JUNCOIDES Adans. Fam. Pl. $2: 47.1763$.

(Luzula DC. Fl. Fr. $3: 158$. 1805.)

Forty species, of temperate regions, mostly European. North America, 16.

Juncoides campestre (L.) Kuntze, Rev. Gen. P1. 2 : 722.1891.

Juncus campestris L. Sp. Pl. 1:329. 1753.

CoMmon Wood RUSH.

Luzula campestris DC. Fl. Fr. 3: 161.1805.

Ell. Sk. 1:410. Gray, Man. ed. 6, 546. Chap. Fl. 493. Coulter, Contr. Nat. Herb.

2: 451 . Wats. Bot. Calif. $2: 203$.

Europe, Asia, North Africa, New Zealand.

Boreal region to Louisianian area. From Greenland to Alaska. All over Eastern North America to California.

Alabama: All over the State. Dry hills. Mobile County. April; frequent. Perennial.

Type locality : "Hab. in Europae pascuis siceioribus."

Herb. Geol. Surv. Herb. Mohr.

\section{LILIACEAE. Lily Family.'}

TOFIELDIA Huds. Fl. Angl. 2 : 157. 1778. False AspHODEL.

lourteen species, mostly of colder temperate regions. North America, the Andes, Asia.

Tofieldia racemosa (Walt.) B. S. P. Cat. N. Y.55. 1888.

Melanthium racemosum Walt. Fl. Car. 126. 1788.

Narthecium pubens Michx. Fl. Bor. Am. 1:209. 1803.

Tofieldic pubescens Pers. Syn. 1:399. 1805.

Ell. Sk. 1: 424. Gray, Man. ed. 6, 532. Chap. Fl. 492.

Lonisianian area. New Jersey, North Carolina to Florida, west to Louisiana.

Alabama : Central Pine belt to Coast plain. Damp pine barrens, borders of ponds and swamps. July; frequent. Flowers white. Perennial.

Type locality: South Carolina.

Herb. Geol. Surv. Herb. Mohr.

CHAMAELIRIUM Willd. Mag. Nat. Fr. Berl. 2:18. 1808.

One species, perennial; North America.

Chamaelirium luteum (L.) Gray, Man.503. 1848.

DeVIL's BIT.

Veratrum luteum L. Sp. Pl. 2 : 1044. 1753.

Melanthium dioicum Walt. Fl. Car. 126. 1788.

Chamaelirium carolinianum Willd. Mag. Nat. Fr. Berl. 2 : 19. 1808.

Helonias dioica Pursh, FI. Am. Sept. 243. 1814.

F1l. Sk. 1:423. Gray, Man. ed. 6, 532. Chap. Fl. 491.

Carolinian and Louisianian areas. Ontario, southern Now England to Michigan, western New York, Illinois, Kentucky, Tennessee, South Atlantic and Gulf States to Louisiana.

Alabama: Over the State. Dry open woods; most frequent in the pine barrens. May, June; common. Flowers white.

Economic uses: The root, called "starwort," or "unicorn root," is used medicinally. Type locality: "Hab. in Virginia, Canada."

Herb. Geol. Surv. Herb. Mohr.

'S. Watson, Revision of the North American Liliaceae, Proc. Am. Acad., vol. 14, pp. 213 to 288,1879 . 
CHROSPERMA Raf. Neogen. 3. 1825.

(Amianthium Gray, Ann. Lyc. N. Y. $4: 121$. 1837.)

One species, perennial; South Atlantic North America.

Chrosperma muscaetoxicum (Walt.) Kuntze, Rev. Gen. Pl. 2: 708. 1891.

Melanthium muscaetoxicum Walt. Fl. Car. 125. 1788.

Helonias erythrosperma Michx. Fl. Bor. Am. I:212. 1803.

Amianthium muscaetoxicum Gray, Ann. Lyc. N. Y. 4:122. 1837.

Ell. Sk. 1:421. Gray, Man. ed.6, 535. Chap. Fl. 490.

Carolinian and Louisianian areas. New Jersey to Florida, west to Louisiana and Arkansas.

Alabama: Coosa Valley and Central Pine belt to Lower Pine region. Chilton County. Washington County, Yellowpine. Clarke, Baldwin, and Mobile counties. April, May; frequent. Root poisonous.

Type locality: South Carolina.

Herb. Geol. Surv. Herb. Mohr.

ZYGADENUS Michx. Fl. Bor. Am. 1:213. 1803.

Nine species, perennials. Mexico, North America, 8.

Zygadenus angustifolius (Michx.) Wats. Proc. Am. Acad. 14:280. 1879.

Helonias angustifolia Michx. Fl. Bor. Am. I:212. 1803.

NARROW-LEAF ZYGADENUS.

Amianthium angustifolium Gray, Ann. Lyc. N. Y. 4:124. 1837.

Ell. Sk. 1:421. Chap. Fl. 490.

Louisianian area. South Carolina to Florida, west to Mississippi.

Alabama: Lower Coast Pine belt. Shady copses. Clarke county, Choctaw Corner. Mobile County, Fowl River Station, Cottagehill. April, May. Flowers sordid white. Rare.

Type locality: "Hab. in herbosis fruticetis sylvarum humidis Carolinae inferioris."

Herb. Geol. Surv. Herb. Mohr.

Zygadenus glaberrimus Michx. Fl. Bor: Am. 1:214, t. 22. 1803.

Ell. Sk. 1: 420. Chap. Fl. 488.

LARGE-FLOWERED ZYGADENUS.

Carolinian and Louisianian areas. Virginia, North Carolina, Florida, west to Louisiana.

Alabama : Lower Pine region. Coast plain. Grassy pine barrens. Washington County, Yellowpine. Mobile and Baldwin counties. June, July; not rare.

Type locality : Hab. in herbosis, humidis, Carolinae inferioris."

Herb. Geol. Surv. Herb. Mohr.

Zygadenus leimanthoides (Gray) Wats. Proc. Am. Acad. 14: 280.1879.

Amianthium leimanthoides Gray, Ann. Lyc. N. Y. 4: 125. 1837.

Gray, Man. ed. 6, 535. Chap. Fl. 489; ed. 3, 516.

Carolinian area. From New Jersey along the mountains to Georgia.

Alabama: Mountain region. Swampy places. Rare.

Type locality not ascertained.

Herb. Biltmore.

STENANTHIUM Kunth, Enum. 4 : 180. 1843.

Five species, perennials, northern Asia, Mexico. North America, 4.

Stenanthium gramineum (Ker-Gawl.) Morong, Mem. Torr. Bot. Club, 5 : 110. 1894.

Helonias graminea Ker-Gawl. Bot. Mag. t. 1599. 1814.

Veratrum angustifolium Pursh, Fl. Am. Sept. 242. 1814.

Stenanthium angustifolium Kunth, Enum. 4:190. 1843.

Ell. Sk. 1:423. Gray, Mau. ed. 6, 534. Chap. Fl. 489.

Carolinian area. Virginia and Kentucky to North Carolina and Georgia; Arkansas. 
Alabama: Central Pine belt. Grassy damp banks. Chilton County, Verbena Station (E. A. Smith). Rare.

Type locality: "Native of North America."

Herb. Geol. Surv. Herb. Mohr.

MELANTHIUM L. Sp. Pl. 1:339. 1753.

Three species, perennials, Atlantie North Ameriea.

Melanthium virginicum L. Sp. Pl. 1:339. 1753.

BuNCh Flower.

M. polygamum Desr. in Lam. Encycl. 4 : 25. 1797.

Ell. Sk. 1:41x. Gray, Man. ed. 6,533. Chap. Fl. 488.

Alleghenian and Louisianian areas. New England to Minnesota and Missouri; Southern Atlantic and Gulf States to Texas.

Alabama: Over the State. Shaded swampy banks. Cullman County, 800 feet altitude. Tallapoosa Connty. Escambia County, Flomaton. Mobile County. July, August. Flowers white. Not rare.

Type locality: "Hab. in Virginia."

Herb. Geol. Surv. Herb. Mohr.

UVULARIA L. Sp. Pl. 1 : 304. 1753.

Four species, perennials. Atlantie North Ameriea.

Uvularia grandiflora J. E. Smith, Exot. Bot. 1:99, t. 51. 1804-05.

Ell. Sk. 1: 391. Gray, Man. ed.6,528. Chap. Fl. 487.

LARGE-FLOWERED BELLWORT.

Alleghenian and Carolinian areas. From New Brunswick and Ontario to Minnesota, Iowa; New England to the Ohio Valley and south along the mountains to eastern Tennessee and Georgia.

Alabama: Mountain region. Rich shady woods. Madison County, Montesano, 1,500 feet. Tuscaloosa County. April. Flowers dingy yellow. Rare.

Type locality: "Received from North America."

Herb. Geol. Surv. Herb. Mohr.

Uvularia perfoliata L. Sp. Pl. 1 : 304. 1753.

Perfoliate Bellwort.

Uvularia perfoliata minor Michx. Fl. Bor. Am. 1: 199. 1803.

E11. Sk. 1:390. Gray, Man. ed. 6, 527. Chap. Fl. 487. Coulter, Contr. Nat. Herb.

$2: 439$.

Alleghenian and Carolinian areas. Range as in the last.

AlabaMa: Mountains and Lower hills. Rich wooded hillsides. Lee County, Auburn (Baker \& Earle). Winston and Cullman counties. Tallapoosa County, Dadeville. Clarke County, Choctaw Corner. April. Flowers yellowish. Not rare. Type locality: "Hab. in Virginia, Canada."

Herb. Mohr.

Uvularia puberula Michx. Fl. Bor. Am. 1: 199. 1803.

Mountain BeLlwort.

Oakesia puberula Wats. Proc. Am. Acad. 14 : 269. 1879.

Ell. Sk. 1:391. Gray, Man. ed. 6,528. Chap. F1. 487.

Carolinian area. Mountains of Virginia to Tennessee, North Carolina.

Alabama: Mountain region. Rich woods. Madison County, Montesano, 1,500 feet. May; rare.

Type locality: "Hab. in altissimis montibus Carolinae."

Herb. Geol. Surv. Herb. Mohr.

Uvularia sessilifolia L. Sp. Pl. 1:305. 1753.

OAKES'S BELLWORT.

Oakesia sessilifolia Wats. Proc. Am. Acad. 14:269. 1879.

Ell. Sk. 1:392. Gray, Man. ed.6,528. Chap. Fl. 487.

Alleghenian and Carolinian areas. New Brunswick, Nova Scotia, and Ontario; New Englaud to Iowa, Minnesota, and Nebraska; Ohio Valley, Missouri, and Kansas; Now York south to Florida.

Alabama: Mountain region. Lower hills. In sbady rich woods. Cullman County. Tusealoosa County (E.A. Smith). Lee County, Auburn (Baker \& Earle). April; rare.

Type locality: "Hab. in Canada Kalm."

Herb. Geol. Surv. Herb. Mohr. 
ALLIUM L. Sp. Pl. 1:294. 1753.

About 250 species, perennial; Europe, extratropical Asia, North Africa, Mexico, South America. North America, about 30 to 35. Southeru States, 5.

Allium canadense L. Sp. Pl. 2 : 1195. 1753.

Wild Garlic.

Ell. Sk. 1:385. Gray, Man. ed.6,522. Chap. Fl. 482. Coulter, Contr. Nat. Herb. $2: 433$.

Alleghenian to Louisianian area. Ontario, New England to Minnesota and Nebraska, south throughout the Eastern States, west to central Texas and Arkansas.

Alabama ; From the Tennessee Valley to the coast. Damp banks and cultivated ground. Franklin County, Russellville. Cullman County. Tuscaloosa, Dallas, and Mobile counties. In some localities becoming a vile weed. April. Flowers pink. Type locality: "Hab. in Canada. Kalm."

Herb. Geol. Surv. Herb. Mohr.

Allium mutabile Michx. Fl. Bor. Am. 1:195. 1803.

WILD ONION.

Ell. Sk. 1: 386. Chap. F1.482. Coulter, Contr. Nat. Herb. $2: 433$.

Carolinian and Louisianian areas. North Carolina to Florida, west to Texas, New Mexico, Arkansas, and Missouri.

Alabama: Tennessee Valley to Coast plain. Damp grassy places, prairies. Tuscaloosa County. Dallas County, Uniontown. Montgomery and Mobile counties. May. Flowers pink. Frequent.

Type locality : "Hab. in Georgiae meridionalibus."

Herb. Geol. Surv. Herb. Mohr.

Allium vineale L. Sp. P1. 1:299. 1753.

Wild Onion, Wild Garlic.

Gray, Man. ed. 6, 522.

Europe.

Carolinian and Louisianian areas. Naturalized from New England to South Carolina.

Alabama : Of late adventive. Lee County, Auburn (F.S. Earle). March, 1896. A vile weed.

Type locality: "Hab. in Germania."

Herb. Geol. Surv. Herb. Mohr.

NOTHOSCORDUM Kunth, Enum. 4 :457. 1843.

Ten species, perennials, tropical America to Chile. China, 1; North America, 1.

Nothoscordum bivalve (L.) Britton in Britt. \& Brown, Ill. Fl. 1:415. 1896.

Ornithogalum bivalve L. Sp. P1. 1 : 306. 1753.

Yellow False Garidc.

Allium ornithogaloides Walt. Fl. Car.121. 1788.

A. striatum Jacq. Coll. Suppl. 51. 1796.

Nothoscordum striatum Kunth, Enum. 4:495. 1843.

Ell. Sk. 1:384. Gray, Man. ed. 6,522. Chap. Fl. 482. Coulter, Contr. Nat. Herb.

$2: 434$. Griseb. Fl. Brit. W. Ind. 581 .

West Indies, MeXico to Chile.

Carolinian and Louisianian areas. From Southern Virginia to Florida and the Gulf, west to Texas, Arkansas, Missouri, and Nebraska 9

Alabama: Over the State.

Type locality: "Hab. in Virginia."

Herb. Geol. Surv. Herb. Mohr.

LILIUM L. Sp. Pl. I:303. 1753.

Lilium canadense L. Sp. Pl. 1:303. 1753.

NoDding LiLY.

Ell. Sk. 1:388. Gray, Man. ed.6,529. Chap. Fl. 484 .

Alleghenian and Carolinian areas. Nova Scotia, New Brunswick, Quebec, and Ontario; New England west to Miunesota, Nebraska, and Missouri, south along the mountains to Georgia.

Alabama: Credited to the State in Britton \& Brown, Illustrated Flora.

Type locality: "Hab. in Canada."

Lilium carolinianum Michx. Fl. Bor. Am. 1:197. 1803. Southern Spottrd Lily.

Lilium martagon Walt. Fl. Car. 123. 1788. Not L.

L. michauxii Poir. Encycl. 3 : 457. 1803. 
L. superbum var. carolinianum Chap. Fl.484. 1860.

Ell. Sk. 1:388. Chap. Fl. 484.

Carolinian and Louisianian areas. North Carolina to Florida, west to Mississippi, Louisiana, and Arkansas.

Alabama : Mountain region to Lower Pine belt. Dry woods. Cullman County. Shelby County (E.A. Smith). Mobile County. Flowers orange vermilion with small brown spots. July; not rare.

Type locality : "Hab. in herbosis humidis Carolinae inferioris."

Herb. Geol. Surv. Herb. Mohr.

Lilium catesbaei Walt. Fl. Car. 123. 1788.

Catesby's Lily.

Ell. Sk. 1:387. Gray, Man. ed.6,529. Chap. Fl. 484.

Carolinian and Louisianian areas. North Carolina to Florida, west to Mississippi and southern Missouri.

Alabama: Coast plain. Low wet pine barrens. Mobile and Baldwin counties. Flowers scarlet, with orange. July; not rare.

Type locality: "South Carolina."

Herb. Mohr.

ERYTHRONIUM L.Sp. Pl. 1:305. 1753.

Seven species, perennials, north temperate zone, Japan. North America, 5. Atlantic States, 2.

Erythronium americanum Ker-Gawl. Bot. Mag. 27 : t. 1113.1808.

Yel.

Erythronium dens-canis Michx. Fl. Bor. Am. 1: 198. 1803 . Not L.

Ell. Sk. 1:389. Gray, Man. ed. 6, 528. Chap. Fl. 484.

Alleghenian and Carolinian areas. Nova Scotia and Onturio; New England west to Minnesota, Missouri, and Arkansas; New York to the Ohio Valley; sonth to middle Florida.

Alabama: Lower hills. Rich shaded banks. Tuscaloosa County (E. A. Smith). March to April. Flowers yellow, spotted brown. Rare.

Type locality of $E$.dens-canis Michx. : "Hab. in frigidioribus Americae septentrionalis."

Herb. Geol. Surv. Herb. Mohr.

QUAMASIA Raf. Am. Month. Mag. 2 : 265. 1818.

(Camassia Lindl. Bot. Reg. t. 1486. 1832.)

Four species, perennials, North American. Eastern 1, Pacific 3.

Quamasia esculenta (Ker-Gawl.) Coville, Proc. Biol. Soc. Wash. 11:65. 1897.

Scilla esculenta Ker-Gawl. Bot. Mag. 38 : t. 15\%4. 1813.

WILD HYACINTH.

Phalangium esculentum Nutt.; Ker-Gawl. Bot. Mag. 38: t.1574. 1813. As synonym.

Lemotrys hyacinthina Raf. Fl. Tellur. 3:51. 1836.

Camassia fraseri Torr. Pac. R. Rep. 2 [pt. 4]: 176. 1855.

Scilla fraseri Gray, Man. ed. 2, 469. 1856.

Quamasia hyacinthina Britton in Britt. \& Brown, Ill. Fl. 1:423. 1896.

Gray, Man. ed. 6, 523. Chap. Fl. Suppl. 656. Conlter, Contr. Nat. Herb. 2: 435.

Alleghenian and Carolinian areas. Ontario; Peunsylvania to Minnesota and through the Ohio Valley to Missouri, south along the lower mountains to Georgia.

Alabama: Prairie region. Rich copses. Sumter County, Livingston (E. $A$. Smith). Flowers lilac. April; infrequent.

Type locality: According to F.V. Coville, op. cit., the type specimens probably cane from near St. Louis, Mo.

Herb. Geol. Surv. Herb. Mohr.

YUCCA L. Sp. Pl. 1:319. 1753.

About 1 dozen species, of warmer and temperate Mexico, Central America, and North America; arid plains of the Lower Sonoran area to the Pacific. East of the Mississippi River 2 species.

Yucca aloifolia L. Sp. Pl. 1:319. 1753.

SPANISH DAGGER.

Ell. Sk. 1:401. Chap. Fl. 485 . Griseb. Fl. Brit. W. Ind. 582.

Mexico, WeSt INDIES.

Louisianian area. North Carolina along the coast to Florida and Louisiana. 
Ala Bama: Coast Pine belt. Dry sandy banks and openings, most frequent near the coast. Clarke County, Suggsville (Dr. Denny). Washington, Mobile, and Baldwin counties. Common; 10 to 20 feet high. June, July. Flowers white, fetid ; fruiting sparingly in October and November.

Type locality: "Hab. in Jamaica, Vera Cruz."

Herb. Geol. Surv. Herb. Mohr.

Yucca filamentosa L. Sp. P1. 1:319. 1753.

Bear Grass.

Ell. Sk. 1:400. Gray, Man. ed. 6, 524. Chap. F'l. 485.

Carolinian and Louisianian areas. Maryland, southern Virginia along the coast to Florida, and throughout the eastern Gulf States.

Alabama : From the Tennessee Valley to the coast. Dry sandy or rocky woods. Cullman County, 800 feet. Tuscaloosa County. Clarke County, Choctaw Corner. Choctaw County, Bladon. Mobile and Baldwin counties. Flowers white. June; common. Perennial.

Type locality: "Hab. in Virginia."

Herb. Mohr.

VAGNERA Adans. Fam. Pl. 2 : 496. 1763. FAlse Solomon's Seal.

(Smilacina Desf. Ann. Mus. Par. 9:51. 1807.)

About 11 species, perennials, mountains of tropical America and Mexico. North America, 5. Japan.

Vagnera racemosa (L.) Morong, Mem. Torr. Club, 5 : 114. 1894.

Convallaria racemosa L. Sp. Pl. 1: 315. 1753.

Smilacina racemosa Desf. Ann. Mus. Par. 9;51. 1807.

Ell. Sk. 1:395. Gray, Man. ed. 6, 525. Chap. Fl. 481.

Alleghenian and Carolinian areas. Nova Scotia and Ontario to Saskatchewan; New England throughout the Atlantic States to Sonth Carolina and Mississippi.

Alabama : From the Tenuessee Valley to Upper division of Coast Pine belt. Rich woods. Lawrence County. Winston County, Colliers Creek, 1,500 feet $(T$. $M$. Peters). Tuscaloosa County (E. A. Smith). Lee Connty, Auburn (Baker \& Earle). Clarke County. Flowers, April, May; white. May, June; not rare.

Type locality : "Hab. in Virginia, Canada."

Herb. Geol. Surv. Herb. Mohr.

DISPORUM Salisb. Trans. Hort. Soc. 1:331. 1812.

(Prosartes Don, Ann. Nat. Hist. 4 : 341. 1840.)

Twelve species, perennials. East Asia, North America, mountains of tropical America. North America, 7.

Disporum lanuginosum (Michx.) Nichols, Dict. Gard. 1:485. 1884.

Streptopus lanuginosus Michx. Fl. Bor. Am. 1:201. 1803.

Prosartes lanuginosa Don, Trans. Linn. Soc. 18: 532. 1841.

Gray, Man. ed.6,527. Chap. Fl. 487.

Alleghenian and Carolinian areas. Ontario; western New York along the mountains to Georgia.

Alabama: Mountain region. Rich shaded woods. Dekalb County, Lookout Mountain, 1,500 feet. Madison County, Montesano, 1,500 feet. April; not frequent.

Type locality : "Hab. in altis montibus Carolinae meridionalis."

Herb. Geol. Surv. Herb. Mohr.

POLYGONATUM Adans. Fam. Pl. 2:54. 1763.

Twenty species, perennials, temperate northern hemisphere. Japan. North America, 4.

Polygonatum biflorum (Walt.) E1l. Sk. 1:393. 1817. SMall Solomon's Seal.

Convallaria biflora Walt. Fl. Car. 122. 1788.

Ell. Sk. 1: 393. Gray, Man. ed.6, 525. Chap. F1. 481.

Alleghenian and Carolinian areas. Nova Scotia, New Brunswick, and Ontario; New England west to Minnesota and Nebraska; Ohio Valley to Missouri and Kansas; along the lower mountains south to Georgia. 
Alabama: Mountain region and Lower hills. Rich shaded hillsides, borders of woods. Lee County, Auburn (Baker \& Earle). Tuscaloosa County (E. A. Smith). Cullman County. April, May. Flowers greenish.

Type locality: South Carolina.

Herb. Geol Surv. Herb: Mohr.

Polygonatum commutatum (Roem. \& Schult.) Dietr.; Otto \& Dietr. Gartenz. $3: 223$. 1835 . LARGE Solomon's Seal.

Convallaria commutata Roem. \& Schultz. Syst. Veg. 7 : 1671.1830.

Polygonatum giganteum Dietr.; Otto \& Dietr. Gartenz. 1835 : 222. 1835.

Gray, Man. ed. 6, 525. Chap. Fl. Suppl. 656; ed. 3, 507.

Canadian zone to Carolinian area. Western Ontario to Saskatchewan; New England west to Minnesota, south to the Ohio Valley, Missouri, and Teunessee, and along the mountains to Georgia.

Alabama: Mountain region. Shaded hillsides. Dekalb County, near summit of Lookout Mountain, 1,800 feet. Flowers greenish. May; rare.

Economic uses: The rhizomas of both species, as "Solomon's seal," are nsed medicinally, mostly in domestic practice.

Type locality: "Ad specimen in Herb. cli Martius a D". Schweinitz in Pennsylvania lectum."

Herb. Geol. Surv. Herb. Mohr.

MEDEOLA L. Sp. Pl. 1:339. 1753.

One species, perennial; Atlantic North America.

Medeola virginiana L. Sp. Pl. 1 :339. 1753.

INDIAN CUCUMBER.

Ell. Sk. 1:425. Gray, Man. ed.6,530. Chap. Fl. 479.

Alleghenian to Louisianian area. New Brunswick, Ontario, New England, to middle Florida and eastern Louisiana.

Alabama: Tennessee Valley to the Lower Pine belt. Shady woods. Franklin and Cnllman counties. Tuscaloosa County (E. A. Smith). Hale and Gallion counties. Escambia County, Flomaton. May; not infrequent. Perennial.

Type locality: "Hab. in Virginia."

Herb. Geol. Surv. Herb. Mohr.

TRILLIUM L. Sp. P1. 1 : 339. 1753.

Fourteen or 15 species, perennials, temperate North America. One to Japan and Himalayas.

Trillium sessile L. Sp. Pl. 1:340. 1753 .

WAKE-ROBIN.

Ell. Sk. 1:426. Gray, Man. ed.6,530. Chap. F'l.477.

Alleghenian and Carolinian areas. Pennsylvania, west to Minnesota; Ohio Valley to Missouri; south from New Jersey to Georgia, along the mountains.

Alabama: Lower hills. Shady woods. Tuscaloosa County (E. A. Smith). Flowers maroon purple. March; not frequent.

Type locality: "Hab. in Virginia, Carolina."

Herb. Geol. Surv. Herb. Mohr.

Trillium underwoodii Small, Bull. Torr. Club, 24: 174. 1897.

UNDERWOOD'S WAKE-ROBIN.

Carolinian and Louisianian areas. Tennessee, South Carolina, middle Florida.

Alabama : Mountain region, Lower Pine region. Rich woods. Mobile County, Chastangs Bluff. Leo County, Auburn (Underwood \& Earle). Flowers greenish. March; infrequent.

Type locality: "In woods and fields, North Carolina to Tennessee, south to Florida and Alabama."

Herb. Geol. Surv. Herb. Mohr.

Trillium viride Beck, Am. Journ. Sci. 11:178. 1826.

Trillium viridescens Nutt. Trans. Am. Phil. Soc. ser. 2, 5 : 155. 1837.

T. sessile var. nuttallii Wats. Proc. Am. Acad. $14: 273$. 1879.

Stem rough-pubescent, at least at the top; leaves oblong-ovate or broadly ovate, acutish or somewhat obtuse, blotched, short-attenuate at the base; sepals lanceolate or linear-lanceolate; petals clawed, linear, acute, longer than the sepals, greenish purple; stamens one-third the length of the petals; filanients shorter than the anthers.

Carolinian area. Tennessee, Missonri, and Arkansas. 
AlabaMa : Mountain region. Rich shady woods. Blount County, Warnock Mountain, 1,500 feet altitude... April, May; infrequent.

Type locality (Beck, Bot. U. S.): "Shrdy woods. Miss[ouri]."

Trillium erectum L. Sp. Pl. 1:340. 1753.

ILL-SCENTED WAKL-ROBIN.

Trillium pendulum Willd. Neue Schrift. 3:421. 1801.

T. rhomboideum Michx. Fl. Bor. Am. 1:215. 1803.

Ell. Sk. 1: 427. Gray, Man. ed. 6, 530. Chap. Fl. 478.

East Siberia, JaPan.

Alleghenian and Carolinian areas. Nova Scotia and Ontario; from New England, throughout the Ohio Valley, to Missouri, south along the monntains to Georgia.

Alabama : Lower hills. Woods. Jefferson County. Flowers white. April; infrequent.

Economic uses: The rhizomas of this, T. sessile and T. cernuum, are indiscriminately collected for medicinal use under the name of birth-root. Used by the aborigines, and now in eclectic practice.

Type locality: "Hab. in Virginia."

Herb. Geol. Surv. Herb. Mohr.

Trillium stylosum Nutt. Gen. 1:239. 1818.

Catesby's WAKE-ROBiN.

Trillium catesbaei Ell. Sk. 1:429, and T. nervosum Ell.1.c.

Ell. Sk. l. c. Chap. Fl. 479.

Carolinian area. Mountains of Carolina and Georgia.

Alabama : Mountain region. Rich shaded banks. Dekalb County, Mentone, 1,600

feet. Auburn County (F.S. Farle).

Type locality: "Upper Carolina and Georgia."

Herb. Geol. Surv. Herb. Mohr.

Trillium recurvatum lanceolatum Wats. Proc. Am. Acad. 14 : 273.1879.

Trillium lanceolatum Boykin, name only, in Herb. Torr.

Chap. Fl. Suppl. 656; ed. 3, 505.

Carolinian area. Georgia.

Alabama : Ascribed to this State by Chapman, Flora, l, c.

Type Jocality: "Georgia and Alabama."

Trillium cernuum L. Sp. P1. 1:339. 1753.

Ell. Sk. 1:428. Gray, Man. ed.6, 531. Chap. Fl.478.

NoDding TrILLIUM.

Canadian zone to Carolinian area. Newfoundland, Nova Scotia, Ontario; New England south to New Jersey along the mountains to Georgia.

Alabama : Lower hills. Tuscaloosa County (E. A. Smith). Flowers March, April. Rare. Perennial.

Type locality: "Hab. in Carolina."

Herb. Geol. Surv. Herb. Mohr.

ALETRIS L. Sp. Pl. 1:319. 1753.

Two species, perennials, Eastern Asia, North America. Atlantic America, 2.

Aletris farinosa L. Sp. Pl. 1: 319. 1753.

White STAR Grass.

Aletris alba Michx. Fl. Bor. Am. 1:189. 1803.

Ell. Sk 1:398. Gray, Man. ed.6,513. Chap. Fl. 470.

Alleghenian to Louisianian area. Ontario and New England west to Minnesota, from New York south to Florida, west to Arkansas and Missouri.

Alabama : Central Pine belt to the Coast plain. Damp light soil, prairies, borders of swamps; most frequent in the pine barrens. Autauga County, Prattville. Chilton, Washington, Mobile, and Baldwin counties. Flowers white. May, June; frequent.

Economic uses: The root, as "colic root," is used medicinally.

Type locality : "Hab. in America septentrionali."

Herb. Geol. Surv. Herb. Mohr.

Aletris aurea Walt. Fl. Car. 121. 1788.

Golden Star Grass.

Ell. Sk. 1:399. Gray, Man. ed.6,513. Chap. Fl.470. Coulter, Contr. Nat. Herb. $2: 426$.

Carolinian and Louisianian areas. Pine barrens. New Jersey along the coast to Florida, west to eastern Texas.

Alabama: Coast Pine belt to the Coast plain. Low damp pine barrens. Wash- 
ington County, Yellowpine. Clarke County, Thomasville. Baldwin and Mobile counties. Flowers yellow. June to August; common.

Type locality: South Caroliua.

Herb. Geol. Surv. Herb. Mohr.

\section{STEMONACEAE.}

CROOMIA Torr.; Torr. \& Gr. Fl. N. A. 1:663. 1840.

Two species, perennial. Southern Japau, southeastern North America.

Croomia pauciflora Torr.; Torr. \& Gray, Fl. N. Am. 1 : 663.1840.

Croomia.

Cissampelos pauciflora Nutt. Journ. Acad. Phila. 7 : 11. 1834.(?)

Chap. Fl. 480.

Louisianian area. Georgia, middle Florida.

A tabama: Lower hills. Shaded banks. Tuscaloosa County (E. A. Smith), Flowers maroon purple. March, April; local, rare.

Type locality: "Aspalaga, middle Florida on the Apalachicola River under the shade of Torreya taxifolia, Mr. Croom! Dr. Chapman!"

Herb. Mohr.

\section{SMILACEAE. Smilax Family.}

SMILAX L. Sp. Pl. 2 : 1028. 1753. GREeNBrier.

About 200 species. Tropical and warmer temperate America; few in Japan. North America, 17. Perennials; mostly shrubby climbers.

Smilax herbacea L. Sp. Pl. 2 : 1030. 1753.

Carrion Flower.

Smilax pulverulenta Michx. Fl. Bor. Am. 2 :238. 1803.

Coprosmanthus herbaceus Kunth, Enum. $5: 265.1850$.

Smilax peduncularis Muhl.; Willd. Sp. Pl. 4:786. 1806.

Coprosmanthus peduncularis Kunth, Enum. 5 : 264.1850.

Ell. Sk. 2:702. Gray, Man. ed. 6,520. Chap. Fl.477. Coulter, Contr. Nat. Herb. $2: 432$.

JAPAN.

Alleghenian and Carolinian areas. New Brunswick, Ontario, Manitoba, and Saskatchewan; New England to Minuesota and Nebraska; Ohio Valley to Missouri; from New York south to Tennessee and western Louisiana (Hale), eastern Texas, and Arkansas.

AlabaMA: Mountain region. Dry copses. Winston County, Colliers Creek $(T$. M. Peters). Tuscaloosa County (E.A.Smith). Flowers green, ill-scented. May; not common. Perennial.

Type locality: "Hab. in Virginia, Marylandia."

Herb. Geol. Surv. Herb. Mohr.

Smilax ecirrhata (Engelm.) Wats. in Gray, Man. ed.6,520. 1890.

Carrion Flower.

Coprosmanthus herbacea var. ecirrhata Engelm.; Kunth. Enum. $5: 266.1850$.

Smilax herbacea var. ecirrhata Gray; DC. Monogr. Phan. 1:52. 1878.

S. herbacea Ell. Sk. $2: 702$. 1821-24.

Coprosmanthus herbaceus Kunth, Enum. 5:264. 1850.

Gray, Man. ed. 6, 520. Chap. Fl. ed. 3, 504.

Alleghenian and Carolinian areas. Virginia west to Michigan and Missouri, south to Georgia.

Alabama: Mountain region. Lower hills. Shady copses, rich woods. Lee County, Auburn (F.S. Earle). Cullman County. Tuscaloosa County (E.A.Smith). April, May. Flowers with odor of carrion. Not infrequent.

Type locality not separately given.

Herb. Geol. Surv. Herb. Mohr.

Smilax glauca Walt. Fl. Car. 245. 1788. Sarsaparilla. Glaucous Greenbrier. Ell. Sk. 2:697. Gray, Man. ed.6,520. Chap. Fl. 476. Conlter, Contr. Nat. Herb. $2: 432$.

Mrxico.

Alleghenian and Carolinian areas. Sonthern New England to Florida, west to Texas, Arkansas, and southern Missouri.

${ }^{1}$ Thomas Morong, The Smilaceae of North and Central America, Bull. 'Torr. Club, vol. 21 , pp. 419 to 443.1894 . 
Alabama : From the Tennessee Valley to the Coast plain. Most frequent in the Central and Coast Pine belt. Damp thickets, banks of streams. Lee County, Auburn. Tuscaloosa County (E.A.Smith). Washington County (Dr. Denny). Hale County, Big Prairie Creek. Mobile and Baldwin counties. Frequent. Climbing over bushes and small trees. Flowers in May; sweet-scented. Fruit in October and November; black.

Type locality: South Carolina.

Herb. Geol. Surv. Herb. Mohr.

Smilax rotundifolia L. Sp. Pl. 2: 1030.1753.

LOW BAMBOO-BRIER.

Smilax caduca L. Sp. Pl. 2:1030. 1753. Not Ell.

S. quadrangulata Willd. Sp. Pl. 4 : 775.1806.

Ell. Sk. 2:700. Gray, Man. ed. 6, 520. Chap. Fl.477. Coulter, Contr. Nat. Herb. $2: 432$.

Mexico, West Indies, Central America.

Alleghenian and Carolinian areas. New England, west to Minnesota, Colorado, Arkansas, and Missouri, sonth to New Jersey, Virginia, and Tennessee, and along the mountains to Georgia.

Alabama: Mountain region. Lower hills. Woods, damp places. Lee County, Auburn (Baker \& Earle). Dekalb County, Lookont Mountain, 1,800 feet. Winston and Tuscaloosa counties. The form with four-angled stem (var. quadrangularis auct.) prevailing. April, May; not rare.

Type locality: "Hab.in Canada. Kalm."

Herb. Geol. Surv. Herb. Mohr.

Smilax pseudo-china L.Sp. Pl. 2 : 1031. 1753.

False China-Root.

Ell. Sk. 2:700. Gray, Man. ed.6, 521. Chap. Fl. 475.

Alleghenian, Carolinian, and Louisianran areas, District of Columbia and West Virginia to Florida, west to Louisiana, Texas, Arkansas, and Nebraska.

Alabama : Monntain region. Metamorphic hills to the Coast Pine belt. Damp thickets. I (Dr. Denny). Mobile County. Flowers, April; fruit, October. Berries, black; not frequent.

Economic uses: The tuberous rhizoma is used in domestic medicine.

Type locality: "Hab. in Virginia, Jamaica."

Herb. Mohr.

Smilax bona-nox L. Sp. Pl. 2 : 1030. 1753.

BAMBOO-BRIER.

Smilax hastata Willd. Sp. P1. 4 :782. 1806.

S. tamnoides Gray, Man.485. 1848. Not L.

S. hederaefolia Kunth, Enum. $5: 209$. 1850. Not Mill.

Ell. Sk. 2:696. Gray, Man. ed. 6, 520. Chap. Fl.475. Coulter, Contr. Nat. Herb.

$2: 432$.

Alleghenian to Louisianian area. Southern New England to Florida, west to Texas, Arkansas, sonthern Illinois, Missouri, and Kansas.

AlabaMa : All over the State. Most frequent in the pine barren swamps of the Coast Pine belt. Cherokee, Cullman, Montgomery, Clarke, Mobile, and Baldwin counties. Flowers, April, May; fruit, October. Berries, black. Frequent. Shrub.

Foliage in lower districts persistent; in low, damp situations, climbing high; the old branches, with broad, flat spines, frequently scurfy from tufts of short, stellate hairs. In dry, rocky soil, low, bushy, trailing on the ground, the leaves halberd or fiddle shaped, their margin and midrib bristly. The various forms presented by this highly variable species, described under various names, are inseparable, almost insensibly blending.

Type locality: "Hab. in Carolina."

Herb. Geol. Surv. Herb. Mohr.

Smilax auriculata Walt. Fl. Car. 245. 1788.

SAND BAMBOO-BRIER.

Smilax ovata Fil. Sk. 2 :698. 1821-24. Not Pursh.

S. beyrichii Kunth, Enum. 5:207. 1850 .

Ell. 1. c. Chap. Fl. 476.

Lonisianian area. North Carolina along the coast to Florida and Mississippi.

Alabama : Coast plain. Littoral region; in loose sand. Mobile County, foot of Springhill, climbing trees 15 feet high. Baldwin County, on the sandy bay shore, bushy, trailing. April, May; flowers fragrant; frnit matures in October; black. Not rare.

Walter's description applies well to our plant, and agrees also perfectly with Chapman's description; for these reasons Walter's name is maintained.

Type locality: South Carolina.

Herb. Geol. Surv. Herb. Mohr. 
Smilax laurifolia L. Sp. Pl. 2 : 1030. 1753.

BAX-LEAF BAMBOO.

Ell. Sk. 2:699. Gray, Man. ed.6,521. Chap. Fl 476.

Carolinian and Louisianian areas. Southern New Jersey to Florida, west to. Louisiana and Arkansas.

Alabama : Central Pine belt to Coast plain. Wooded swamps, most frequent in alluvial soil. Tuscaloosa County (R. D. Nerius \& Wyman). Montgomery, Washington, Clarke, Mobile, and Baldwin counties. Flowers in May; fruit matures second year, November, December; black. Common.

A stout vine with long branches, climbing over trees.

'Type locality : "Hab.in Virginia, Carolima."

Herb. Geol. Surv. Herb. Mohr.

Smilax pumila Walt. Fl. Car. 244. 1788.

DWARF SMILAX.

Smilax pubera Michx. Fl. Bor. Am. 2 : 238. 1803.

Ell. Sk. 2:699. Chap. Fl. 476.

Louisianian area. South Carolina, Florida, Louisiana, and eastern Texas (Cass County).

Alabama: Metamorphic hills. Coast Pine belt. Shady banks in pine woods. Lee County, Auburn (F. S. Earle). Clarke County (Dr. Denny). Escambia County, Wilson's Station. Mobile County, Springhill. Maỹ fruit October, November; scarlet. Plants with white berries have been observed. Frequent.

Type locality: South Carolina.

Herb. Geol. Surv. Herb. Mohr.

Smilax walteri Pursh, Fl. Am. Sept. 1:249. 1814.

Coral Sitilax.

Smilax caduca Ell. Sk. 2: 701. 1824. Not L.

Ell. Sk. 1:c. Gray, Man. ed.6,520. Chap. Fl. 476.

Carolinian and Louisianian areas. New Jersey, Virginia, and Tennessee; southern Atlantic and Gulf States to Louisiana.

Alabama : Coast Pine belt. Coast plain. Wooded swamps. Clarke County, Suggsville (Dr. Denny). Mobile and Baldwin counties. May. Fruit ripe October, November; berries scarlet, persistent over winter, matures the second year. Frequent.

Type locality: "In the lower sandy countries of Virginia and Caroliua, on river sides.'

Herb. Geol. Surv. Herb. Mohr.

Smilax lanceolata L. Sp. P1. 2 : 1031. 1753.

SWEET-SCENTED SMILAX.

Smilax ovata Pursh, Fl. Am. Sept. 1:249. 1814.

Ell. Sk. 2:698. Gray, Man. ed.6,521. Chap. Fl. 476. Coulter, Contr. Nat. Herb. $2: 433$.

Carolinian and Louisianian areas. Southern Virginia, North Carolina to Florida, west to eastern Texas.

Ala baмa: Central Prairie region to Coast plain. Rich borders of woods aud shaded swamps. Pike County, Troy. Montgomery and Mobile counties. Flowers, May, Jnne; fruit matures the second year in the fall; red.

An elegant evergreen vine with many long slender branches. Much used for decorations in winter.

Type locality: "Hab. in Virginia."

Herb. Geol. Surv. Herb. Mohr.

\title{
HAEMODORACEAE. Bloodwort Family.
}

\author{
GYROTHECA Salisb. Trans. Hort. Soc. 1:327. 1812.
}

(LACHNANTHES Ell. Sk. $1: 47 . \quad 1817$.

One species, perennial, Atlantic North America. Sonthern.

Gyrotheca capitata (Walt.) Morong, Bull. Torr. Club. 20:472. 1893. ReI Root. Anonymus capitata Walt. Fl. Car. 69.1788.

Heritiera gmelini Michx. Fl. Bor. Am. 1:21. 1803.

Gyrotheca tinctoria Salisb. Trans. Hort. Soc. 1:327. 1812.

Lachnanthes tinctoria Ell. Sk. 1:47. 1816.

Gray, Man. ed. 6, 512. Chap. Fl. 469.

Carolinian and Louisianian areas. Rhode Island, New Jersey to Florida, west to Mississippi. 
Alabana : Coast Pine belt. Low damp pine barrens. Mobile and Baldwin counties. Washington County, Yellowpine. August, September. Flowers yellowish, rhizoma bloody red. Frequent.

Type locality: South Carolina.

Herb. Geol. Surv. Herb. Mohr.

\section{AMARYLLIDACEAE. Amaryllis Family.}

ATAMOSCO Adans. Fam. Pl. 2: 57. 1763.

(Zephy ranthes Herb. App. Bot. Reg. 36. 1821.)

About 30 species, perennials, mostly Mexican and South American. South Africa, warmer North America 1.

Atamosco atamasco (L.) Greene, Pittonia, 3: 187. 1897.

Atamasco Lily. Amaryllis atamasco L. Sp. Pl. $1: 292.1753$.

Ell. Sk. 1:384. Gray, Man. ed. 6,516. Chap. Fl. 466.

Carolinian and Louisianian areas. Pennsylvania, Virginia, south to Florida, west to Louisiana.

Alabama : Central Prairie region to Coast plain. Grassy damp copses. Montgomery County. Autauga County, Prattville (E.A.Smith). Mobile County. Mareh, April. Flowers white, rose-tinted. Not common.

Type locality: "Hab. in Virginia."

Herb. Geol. Surv. Herb. Mohr.

HYMENOCALLIS Salisb. Trans. Hort. Soc. 1 :338. 1812.

About 20 species, paludial, perennials. West Indies, Mexico to Brazil. North America. South Atlantic States 7.

Hymenocallis occidentalis (Le Conte) Kunth, Enum. 5: 856. 1850.

Pancratium carolinianum L. Sp. Pl. 1 : 291. 1753. ?

P. occidentale Le Conte, Ann. Lyc. N. Y. 3:146. 1830-1836.

Gray, Man. ed. 6,516. Chap. Fl.467.

Carolinian and Louisianian areas. Southern Ilinois, Missouri, North Carolina, Georgia, Florida, Louisiana, and Arkansas.

Alabama: Mountain region to Coast plain. Deeply snaded swamps. Cullman County. Autauga County, Prattville (E. A. Smith). Mobile County, alluvial forests. May, June. Flowers white, fragrant. Not rare.

Type locality: "This species is found in the western parts of the State of Georgia and in Tennessee and Kentucky."

Herb. Geol. Surv. Herb. Mohr.

Hymenocallis rotatum (Ker-Gawl.) Kunth, Enum. 5 :679. 1850.

SPIDER LILY.

Pancratium mexicanum L. Sp. Pl. 1: 290. 1753.

P. rotatum Ker-Gawl. Bot. Mag. 21: t.82\%. 1805.

Chap. Fl. 467.

MEXICO.

Louisianian area. North Carolina to Florida, west to Louisiana.

Alaband : Coast plain. Open grassy marshes. Mobile County, river swamps. Baldwin County, Stockton. April, May. Flowers white, sweet-scented. Frequent. 'Type locality of Pancratium mexicanum: Hab. in Mexico." Of P. rotatum: "A native of Carolina."

Herb. Mohr.

Hymenocallis coronarium (Le Conte) Kunth, Enum. 5 : 855. 1850.

Pancratium coronarium Le Conte, Ann. Lyc. N. Y. $3: 145, t .4, f .7$ to 9. 1830-36.

Chap. Fl. 467.

Louisianian area. Georgia, South Carolina.

Alabama : Central Pine belt. Tuscaloosa County (E. A. Smith). Wet rocks in Warrior River.

Type locality: "In Savannah River at the rapids, a few miles above Augusta, where it covers the rocky islets. I have also seen it in the Congaree River at Columbia, in South Carolina."

Herb. Geol. Surv. Herb. Mohr. 


\section{CRINUM L. Sp. P1. 2 : 92.1753.}

About 60 species, perennials. West Indies, South America, North America. South Atlantic States, 1.

Crinum americanum L. Sp. Pl. 1 : 292. 1753.

Chap. Fl. 468. Coulter, Contr. Nat. Herb. $2: 430$ b.

Mexico, Cuba.

Louisianian area. Florida to Louisiana, eastern Texas, and Arkansas.

Alabama: Coast plain. Open marshes and river swamps. Mobile and Baldwin counties. May to July. Flowers white, fragrant; anthers purple. Frequent.

Type locality: "Hab. in America."

Herb. Geol. Surv. Herb. Mohr.

AGAVE L. Sp. Pl. 1 : 323. 1753. American Alok.

About 100 species, perennials, mostly Mexican. United States 14, mostly southwestern continental and on the Pacific slope (Lower Sonoran area). Atlantic States, 1.

Agave virginica L. Sp. Pl. $1: 323.1753$. False Aloe. Thick-Leaved SNake Root. 429.

Ell. Sk. 1:402. Gray, Man. ed.6, 516. Chap. Fl.468. Coulter, Contr. Nat. Herb. 2 :

Carolinian and Louisianian areas. Maryland, Virginia, southern Indiana, Missouri ; throughout the South Atlantic and Gulf States west to the Rio Grande in Texas.

Alabama: Over the State. Dry rocky and sandy soil, open woods. Most frequent in the mountains. Lawrence County, Moulton. Cullman, Tuscaloosa, Montgowery, Washington, Mobile, and Baldwin counties. July.

Typo locality: "Hab. in Virginia."

Herb. Geol. Surv. Herb. Mohr.

HYPOXIS L. Syst. ed. 10, 2 : 986. 1759.

Fifty species; tropical Asia, Africa, Australia, tropical and Atlantic America. United States, 3.

Hypoxis hirsuta (L.) Coville, Mem. Torr. Club. 5 : 118. 1894.

Ornithogalum hirsutum L. Sp. Pl. 1 : 306. 1753.

Hypoxis erecta L. Syst. ed. 10, $2: 986.1759$.

Ell. Sk. 1:396. Gray, Man. ed. 6, 517. Chap. Fl. 468. Coulter, Contr. Nat. Herb. $2 \cdot 429$.

Canadian zone to Lou isianian area. Assiniboia, Ontario; throughout the Atlantic States west to Texas, Arkansas, and eastern Kansas.

Alabama: Over the State. Open grassy woods. Prairies; common everywhere.

Flowers yellow. March to July.

Type locality: "Hab. in Virginia, Canada."

Herb. Geol. Surv. Herb. Mohr.

Hypoxis rigida Chap. Fl. ed. 3, 495.

Louisianian area. Western Florida.

Alabama : Lower Pine region, near the coast. Dry pine barrens. Mobile County, Springhill (F. W. Bush.) August. Rare.

Type locality: "Low pine barrens, near the coast, West Florida."

Herb. Mohr.

LOPHIOLA Ker-Gawl. Bot, Mag. 40:t. 1596. 1814.

One species, North America. South Atlantic States.

Lophiola americana (Pursh) Coville, Mem. Torr. Bot. Club, 5 : 118. 1894.

Conostylis americana Pursh. Fl. Am. Sept. 1: 224, t. 6. 1814.

Lophiola aurea Ker. Gawl. Bot. Mag. $t$. 1596. 1814.

Ell. Sk. 1:403. Gray, Man. ed. 6,512. Chap. Fl. 470.

Carolinian and Louisianian areas. New Jersey, along the coast to Florida, west to Mississippi.

Alabama : Lower Pine belt. Coast plain. Boggy pine-barren swamps. Escambia County, Flomaton. Mobile and Baldwin counties. Flowers in June, July; yellow. Frequent. Perennial.

Type locality: "In boggy soil, on the pine barrens of New Jersey and Carolina." Herb. Geol. Surv. Herb. Mohr. 


\section{DIOSCOREACEAE. Yam Family.}

DIOSCOREA L. Sp. P1. $2: 1032.1753$.

About 150 species, peremial climbers, of the warmer parts of the globe, largely American. Japan.

Dioscorea villosa L. Sp. Pl. 2 : 1033. 1753.

WiLd YaM. Ell. Sk. 2:704. Gray, Man. ed. 6, 517. Chap. Fl. 474. Coulter, Contr. Nat. Herb. $2: 430$.

Alleghenian to Louisianian area. Southern Ontario, southern New England; throughout the Atlantic States to Florida and Texas.

Alabama: All over the State, in damp woods. Cullman, Tuscaloosa, Jackson, Clarke and Mobile counties. May; frequent.

Economic uses: 'The root, under the name of "wild yam root," is used nonofficially in medicine.

Type locality : "Hab. in Virginia, Florida."

Herb. Geol. Surv. Herb. Mohr

\section{IRIDACEAE. Iris Family.}

IRIS L. Sp. Pl. 1 : 38 . 1753.

Near 100 species, perennials, warmer and temperate zones of the Northern Hemisphere. North America, 20. Japan.

Iris versicolor L. Sp. Pl. 1:39. 1753.

Blue Flag.

El1. Sk. 1:45. Gray, Man. ed. 6, 513. Chap. Fl. 472.

Canadian zone to Lonisianian area. Newfoundland, Ontario, Manitoba, New Fngland west to Minnesota and Nebraska, south to Florida and Louisiana.

Alabama: Thronghout the State. Marshes, ponds. Montgomery, Mobile, and Baldwin counties. Flowers azure. April.

Economic uses: The rhizoma, under the name of "blue flag root" is used medicinally.

'Type locality: "Hab. in Virginia, Marilandia, Pensylvania."

Ilerb. Geol. Surv. Herb. Mohr.

Iris hexagona Walt. Fl. Car. 66. 1788.

Southern Blue Flag.

Iris rirginica Michx. Fl. Bor. Am. 1:22. 1803.

Ell. Sk. 1:46. Chap. Fl. ed. 3, כ00. Britt. \& Br. Ill. Fl. 1:448, f. 1070.

Louisianian and Carolinian areas. Texas and Louisiana to Florida and South Carolina; Missouri, Kentucky (Britton \& Brown).

AlABA.MA : Coast plain in the tide-water region. Open deep marshes. Mobile County, estnary of Mobile River and adjacent marshes, with Iris versicolor, Cicuta maculata, etc.

Flowers April. Outer perianth deep cerulean blue with an orange-yellow, sparsely hairy crest, inner pale azure. One and one-half to 3 feet high. Abundant.

Type locality : South Carolina.

Iris verna L. Sp. Pl. 1:39. 175s.

DWARF IRIS.

Gray, Man. ed.6,514. Chap. Fl.473.

Carolinian and Louisianian areas. Western Pennsylvania, Kentucky south from Virginia to Georgia.

Alabama: Coast Pine belt. Dry pine ridges. Washington Connty, Yellowpine. Escambia County, Flomaton. Monroe County. Baldwin County, Stockton. Mobile County, Springhill. March, April. Flowers pale azure. Frequent.

Economic uses: Planted for ornament.

Type locality: "Hab. in Virginia."

Herb. Geol. Surv. Herb. Mohr.

Iris cristata Ait. Hort. Kew. 1:70. 1789.

Crested Iris.

Ell. Sk. 1:44. Gray, Man. ed.6,514. Chap. Fl. 473.

Caroliuian area. Maryland, Virginia to Iowa, south to North Carolina, and along the mountains to Georgia.

Alabama: Mountain region to Lower hills. Damp, shady banks. Winston County, Colliers Creek, 1,500 feet. Cullman County. Tuscaloosa County (E. A. Smith).

Flowers pale blue. April, May; not frequent.

Economic uses: Ornamental plant, grown in borders.

'Type locality: "Native of North America."

Herb. Geol. Surv. Herb. Mohr.

$15894-29$ 
GEMMINGIA Fabr. Enum. Pl. Hort. Helmst. 1759.

(Belamcanda Adans. Fam. Pl. $2: 60$. 1763.)

(Pardanthus Ker-Gawl. in Koen. \& Sims, Ann. Bot. $1: 246.1805$. )

Gemmingia chinensis (L.) Kuntze, Rev. Gen. Pl. $2: 701.1891$.

Ixia chinensis L. Sp. Pl. 1:36. 1753.

Pardanthus chinensis Ker-Gawl. in Koen. \& Sims, Ann. Bot. 1:246. 1805.

Belamcanda chinensis (L.) DC. Red. Lil. 3:t. 121. 1807.

Gray, Man. ed. 6,515.

Carolinian area. Introduced from China, naturalized. Maryland, Missouri, Sonth Atlantic States.

Alabama: Tennessee Valley to Coast Pine belt. Roadsides, waste places. Jackson County, Scottsboro. Jefferson County. Choctaw County, Bladon. Flowers orange, spotted with crimson. July; not common.

Type locality: "Hab. in India."

Herb. Geol. Surv. Herb. Mohr.

SISYRINCHIUM L. Sp. Pl. 2 :954. 1753.' BLUe-EYE1) Grass.

Perennial herbs, about 90 species, all American. From the Atlantic coast to southern Chile. Mexico to South America (mostly tropical), about 50 species; United States and British North America, 40; Eastern United States and Canada, 11 or 12; Southern States to Texas, 13; Western, 10.

Sisyrinchium graminoides Bicknell, Bull. Torr. Club.23:133, t. 263.

STOUT BLUE-Eyed Grass.

Sisyrinchium gramineum Curtis, Bot. Mag. t. 464. 1799. Not Lam.

S. anceps Wats. in Gray, Man. ed. 6, 515. 1890. Not Cavanilles.

S. bermudianum of American authors, not Linnaeus.

Carolinian area. New Jersey to Florida, west to southern Indiana.

Alabama : Lower Pine region. Coast plain. In grassy pine woods. Mobile County. Flowers cerulean blue. April, May; not rare.

Type locality of $S$. gramineum Curtis: "A native of Virginia."

Herb. Geol. Surv. Herb. Mohr.

Sisyrinchium corymbosum Bicknell, Bull. Torr. Club, 26:218. 1899.

From 1 to $1 \frac{1}{2}$ feet high from an ascending rootstock crowded with coarse (not fibrillous) rootlets. Stem flat, narrowly wing-margined, smooth-edged; inflorescence fastigiate, subcorymbosely branched above; branches 3 to 6 inches long; leaves rigid, erect, often surpassing the first internode of the stem, slightly ciliolate toward the acute apex; lowest bracteal leaf erect; bracts nearly equal, acute, carinate at the base with hyaline edges; flowers numerous, sky-blue, on slender pedicels exceeding the bracts. April, May.

Readily distinguished by its branches, subcorymbose inflorescence, and long, stiff, erect leaves.

Louisianian area. Eastern Florida.

Alabama : Coast plain. Damp, grassy banks. Mobile County, frequent. "Specimens from Mobile present apparently a reduced form of the type, more slender and less branched, with elongated bracteal leaf."

Type locality: “Florida: 'Pine barrens near Jacksonville,' A. H. Curtiss. * * * Alabama: Mobile, Dr. Chas. Mohr."

Herb. Geol. Surv. Herb. Mohr.

Sisyrinchium carolinianum Bicknell, Bull. Torr. Club. 26:221. 1899.

In loose tufts, fibrous-coated at the base, from an ascending or erect rootstock with clustered and coarsely fibrous roots. Stem erect, slender, with two or three nodes, about one-eighth inch wide, broadly margined with serrulate edges; leaves frequently much shorter than the stem, rather thin, erect, $\frac{1}{8}$ to $\frac{1}{4}$ inch wide, distinctly serrulate; nodes of the stem with 2 or 3 long peduncles subtended by a foliaceous bracteal leaf; bracts subequal, attenuate toward the apex or obtuse, mucronulate; flowers 3 to 8 on slightly exserted pedicels, violet blue. April.

Carolinian and Louisianian areas. Western North Carolina, South Carolina, and from Georgia to Mississippi.

${ }^{1}$ E. P. Bicknell, The blue-eyed grasses of the Eastern United States, Bull. Torr. Club, vol.23, pp. 130 to 136. 1896. Same author, Studies in Sisyrinchium, op. cit., vol. 26, pp. 217 to 231 . 1899. 
Alabama: Metamorphic hills. Lee County (Baker \& Earle). Mobile County, April, 1899 (Earle).

Specimens from Mobile and Mississippi "are aberrant and may represent yet another species."

Type locality: "Western North Carolina and central South Carolina to Georgia, Alabama, and Mississippi."

Type in Herb. N. Y. Bot. Gard.

Sisyrinchium scoparium Bicknell, Bull. Torr. Club, $26: 227.1899$.

From 6 to 20 inches high, in close tufts from a fibrillous base and a contracted rootstock with coarse fibrous roots. Stem, like the leaves, very narrow and smooth; the striatewing margins roughish on the edges above; leaves erect, very slender, generally shorter than the stems; inflorescence somewhat flabellately short-branched from the two (sometimes one) nodes bearing one or two slender, short peduncles; bracteal leaf long, slender; bracts strongly striate, acuminate, subequal, tips finally spreading; flowers 6 to 11, violet blue. April.

Louisianian area. Mississippi.

Alabama: Coast plain. Mobile County, March (Earle).

Type locality: "Coast of Mississippi. Biloxi, April 27, 1898, C. F. Baker."

Sisyrinchium fuscatum. Bull. Torr. Club, $26: 225.1899$.

In tufts 8 to 20 inches high, from rather stout rootstocks with clustering fibrous roots. Stem long, slender, erect, narrow, the edges of the narrow wing minutely denticulate; leaves narrow, slender, shorter than the stem, firm, acute or subterete at the apex, bracteal leaves short, attenuated above, surpassed by the two closely approximate, erect, slender peduncles 1 to 2 inches long; bracts almost equal, striate, cuspidate, acuminate; flowers 3 to 8 on more or less exserted erect pedicels. April.

Louisianian area.

Alabama : Lower Pine region. Mobile and Escambia counties, April (C. F. Baker). Type locality: "Western Florida to Mississippi."

Herb. Biol. Surv., Auburn.

Sisyrinchium rosulatum Bicknell, Bull. Torr. Club, 26:228. 1899.

Prostrate or ascending, from rosulate tufts; roots short-branched, woody, with fibrillous rootlets. In the smaller tufts stem short, from under $\frac{1}{2}$ to $1 \frac{1}{2}$ inches long; in stouter plants from 6 to 8 inches long, slender, subterete, narrowly margined with serrulate edges; basal leaves from 1 to 3 inches long, narrow, the broadened base hyaline-margined, more or less attenuate toward the acute apex, denticulate-serrulate; stem leaves much shorter than the peduncles, flat-sheathing; peduncles slender, 1 to 4 inches long, the outer bracts more attenuate and somewhat larger; flowers of a reddish purple or wine color. April.

Louisianian area. South Carolina.

Alabama: Dry open places, borders of paths and pastures.

"Very distinct from any of our Eastern North American species, having its affinity with certain South American forms, and a Central American and Mexican species."

Type locality: "Dry open places in sandy soil, coast of South Carolina and Alabama."

Herb. Geol. Surv. Herb. Mohr.

Sisyrinchium albidum Raf. Atlant. Journ. 17. 1832.

Bicknell, Bull. Torr. Club, $26: 346$.

Glaucous or glaucescent; stem from 8 to 18 inches high, leaves about half the length of the stem, $\frac{1}{16}$ to $\frac{1}{8}$ inch wide, acute, smooth-edged or serrulate above; stem flat, wings thin, usually broader than the stem proper, smooth or serrulate on the edges; spathe terminal, single with nnequal bracts, the primordial 1 to $2 \frac{1}{2}$ inches long, more than twice as long as the inner bract, foliaceous, attenuate, and mostly acute; flowers often as many as nine in the spathe, petals white to pale violet; capsule globose, depressed, seed umbilicate pitted. (Condensed from Bicknell.)

Alleghenian to Louisianian area. From Kentucky to Indiana, Michigan, Illinois, and Missouri ; sonth to Tennessee, North Carolina, Mississippi, and Louisiana.

Alabama: Lower hills. Tuscaloosa County (Dr. E. A, Smith). Rare.

Type locality (Bicknell): West Kentucky.

Herb. Geol. Surv. 


\section{BURMANNIACEAE. Burmannia Family.}

BURMANNIA L. Sp. Pl. 1:287. 1753.

Twenty species, mostly in tropical regions of both hemispheres. Southeastern North America, 2. Tiny, almost leafless, saprophytic annuals.

Burmannia biflora L. Sp. Pl. 1:287. 1753.

TWO-FLOWERED BURMANNiA.

Tripterella caerulea Nutt. Gen. 1:22. 1818.

Ell. Sk. 1:43. Gray, Man. ed.'6, 497. Chap. Fl.451. Coulter, Contr. Nat. Herb. $2: 422$.

WEST INDIES.

Carolinian and Lonisianian areas. Sonthern Virginia to Florida, west to eastern 'T'exas.

Ala bama : Lower Pine region. Coast plain. Peaty soil of pine barrens. Mobile County, Springhill. Flowers lavender blue. October, November.

Type locality: "Hab. in Virginiae palndosis."

Herb. Geol. Surv. Herb. Mohr.

Burmannia capitata Mart. Nov. Gen. et Sp. 1:12. 1824.

Capteate Buriannia.

Vogelia capitata Gmelin, Syst. 107.1791.

Tripterella capitata Michx. Fl. Bor. An 1:19, $t$. 3. 1803.

Ell. Sk. 1:43, Chap. Fl. 452. Griseb. Fl. Brit. W. Ind. 606.

West Indies, Cayenne, Brazil.

Louisianian area. From Florida to North Carolina, west to Louisiana.

Ala Bama: Coast plain. Boggy pine barrens. Mobile and Baldwin counties.

Flowers lavender blue. October, November; frequent.

Type locality: "Hab. in udis Carolinae etiamque Cayennae."

Herb. Geol. Surv. Herb. Mohr.

APTERIA Nutt. Journ. Acad. Phila. $7: 64, t .9 .1834$.

Three species, saprophytes, of tropical and subtropical America.

A.pteria setacea Nutt. Journ. Acad. Phila. $7: 64$, t. 9. 1834.

Lilac Apteria. Apteria lilacina Miers, Trans. Linn. Soc. 18: 144. 1841. Chap. Fl. 452.

West Indies to tropical Brazil.

Louisianian area. Florida to Georgia, west to Lonisiana.

Alabama: Coast plain. Shaded banks among decayerl leaves. Mobile County, Bayou La Batre. Bald win Clounty, Stockton. Flowers, like the whole plant, tinged with lilac. July to September; not frequent. Perennial.

Clearly subsisting on decomposing vegetable matter. 'The rootlets of the numerous contorted stems have never been found in organic connection with the roots of the surronnding herbaceous or woody plants.

Type locality not ascertained.

Herb. Geol. Surv. Herl. Mohr.

\section{ORCHIDACEAE. Orchis Family.}

\section{CYPRIPEDIUM L. Sp. P1. 2 : 951. 1753.}

About 50 species, perennials, Europe, Asia, temperate Mexico, Central America. North America, 12.

Cypripedium hirsutum Mill. Dict. ed. 8, no. 3. 1768.

LAR(iE LAAIY'S SIIPPIR.

Cypripedium calceolus $\beta$ L. Sp. Pl. 2 : 951. 1753.

C. pubescens Willd. Sp. Pl. 4 : 143. 1805.

Ell. Sk. 2:508. Gray, Man ed. 6,511 Chap. F1. 464.

Canadian zone to Carolinian area. Nova Scotia, New 13runswick, Qnebec, and

Ontario to the Rocky Mountains; New England, west to Minnesota, Nebraska, and Colorado; thronghout the Eastern States, sonth along the mountains to Georgia.

Ala baMa : Mountain region to Upper division of Coast Pine belt. Rich woods. Madison County, Montesano. Clarke County, Choctaw Corner. Flowers dingy rellow. April; infrequent. 
Economic uses: The rhizome with the rootlets, under the name of "nervine root," is used medicinally.

Type locality not ascertained.

Herb. Geol. Surv. Herb. Mohr.

Cypripedium parviflorum Salisb. Trans. Linn. Soc. 1 : 77. 1791.

SMaller Yellow Lady's Slipper.

Cypripedium calceolus Michx. Fl. Bor. Am. 2 : 161. 1803. Not L.

Ell. Sk. 2:507. Gray, Man. ed. 6,511. Chap. Fl. 464.

Canadian zone to Carolinian area. Newfoundland and Ontario to Saskatchewan and Rocky Mountains; New England, west to Minnesota; through the Atlantic States to Mississippi and Arkansas.

Alabaia : Mountain region. Open woods and copses. Clay County, Elders, 1,000 feet. Madison County, Montesano. Dekalb County, Lookout Mountain, 1,600 feet. Cullman County. Flowers yellow, fragrant. May; not frequent.

Economic uses: "The root is used like that of the last under the same name.

Type locality : "Sponte nascentem in Virginia legit H. Marshall."

Herb. Geol. Surv. Herb. Mohr.

Cypripedium acaule Ait. Hort. Kew. 3 : 303. 1789.

Purple Lady's Slipper. Moccasin Flower.

Cypripedium humile Salisb. Trans. Linn. Soc. 1:79. 1791.

Ell. Sk. $2: 509$. Gray, Man. ed. 6, 511. Chap. Fl. 464.

Boreal region (Hudsonian zone) to the Carolinian area. Newfoundland, Nova Scotia and Ontario and to the arctic circle; throughout the continent east of the Mississippi River as far south as the District of Columbia and along the mountains to North Carolina.

AlabaMa: Mountain region. Shady woods, in boggy damp places. Cullman County, Beaver's Mill, in boggy woods, 700 feet altitude. Dekalb County, Lookout Mountain, damp banks of Little River. Perianth white with purple lip. May; infrequent.

Type locality: "Native of North America."

Herb. Geol. Surv. Herb. Mohr.

ORCHIS L. Sp. Pl. 2 :939. 1753. ORCHIs.

About 80 species, mostly of temperate Europe and Asia. North Africa. North America, 3.

Orchis spectabilis L. Sp. Pl. 2 : 943. 1753.

SHOWY ORCHIS.

Orchis humilis Michx. Fl. Bor. Am. 2:155. 1803.

Ell. Sk. 2 :487. Gray, Man. ed. 6, 506. Chap. Fl. 458.

Alleghenian and Carolinian areas. New Brunswick and Ontario; New England west to Minnesota, Dakota, and Nebraska, south to the Ohio Valley, Missouri, and Arkansas, and along the mountains to Georgia.

Alabama: Mountain region. Rich woods. Madison County, Montesano, 1,500 feet. Flowers rose red. May; rare.

Type locality: "Hab. in Virginia. D. Gronovius."

Herb. Geol. Surv. Herb. Mohr.

HABENARIA Willd. Sp. P1. $4: 44.1805$.

(Platanthera Rich. Ann. Mus. Par. 4 : 48. 1808.)

Four hundred and fifty to 500) species, perennials, widely distributerl over temperate and warmer regions, chiefly Asia, Europe, America. North America, 35 to 40 species; Eastern North America, 20.

Habenaria clavellata (Michx.) Spreng. Syst. 3:689. 1826.

Orchis clavellata Michx. Fl. Bor. Am. 2 : 155. 1803.

SMali Green WoOI OrChis.

O. tridentata Willd. Sp. Pl. 4:41. 1805.

Habenaria tridentata Hook. Exot. Fl. 2 : t.81. 1825.

Ell. Sk. 2:486. Gray. Man. ed. 6, 506. Ch:p. Fl. 459.

Canadian zone to Lonisianian area. Newfonudland, Quebec, Ontario; New England west to Minnesota, Missouri, and Arkansas; sonthern New Jersey to western Florida and Mississippi.

Alabana: Metamorphic hills. Central Pine belt to Coast plain. Shaded boggy woods. Lee County, Auburn (F.S. Earle). Tuscaloosa County, Vance's Station. Montgomery County, Pentulalla Creek. Escambia County, Wilson's Station. Mon- 
roe County, Claiborne. Mobile and Baldwin counties. Flowers white. July, August; frequent.

Type locality: "Hab. in Carolina."

Herb. Mohr.

Habenaria nivea (Nutt.) Spreng. Syst. 3 : 689. 1826.

SNOWY-WHIT: ORCHIS.

Orchis nivea Nutt. Gen. $2: 188.1818$.

Ell. Sk. 2:485. Gray, Man. ed. 6, 507. Chap. Fl. 459.

Louisianian area. South Carolina to Florida, west to Jonisiana and Arkansas.

Alabama: Lower Coast Pine belt. Grassy pine barrens. Washington County,

Healing Springs. Escambia Connty, Flomaton. Mobile and Baldwin connties.

Flowers white. July, Angust; not infrequent.

Type locality: "Betwixt Saint Marys and Satilla River, west Florida."

Herb. Mohr.

Habenaria flava (L.) Gray, Am. Journ. Sci. 38 : 308. 1840.

Orchis flava L. Sp. Pl. $2: 942.1753$.

O. virescens Willd. Sp. Pl. $4: 37.1805$.

Habenaria virescens Spreng. Syst. $3: 688.1826$.

Gray, Man. ed. 6, 507. Chap. Fl. 459.

Alleghenian and Carolinian areas. Ontario; New England west to Minuesota, Ohio to Arkansas and Tennessee.

Alabama: Mountain region. Metamorphic hills. Lee County, Auburn $(F, S$.

Earle \&. Underwood). June; rare.

Type locality: "Hab. in Virginia."

Herb. Geol. Surv. Herb. Mohr.

Habenaria integra (Nutt.) Spreng. Syst. 3 : 689. 1826.

Orchis integra Nutt. Gen. 2 : 188.1818.

SMall Southern Yellow Orchis.

Gymnadenia flava Lindl. Gen. \& Sp. Orch. 279, 1835.

Eil. Sk. 2:485. Gray, Man. ed.6, 506. Chap. Fl. 549. Britt. \& Br. Ill. Fl. 1: 463.

Carolinian and Louisianian areas. New York, west to Louisiana.

Alabama : Mountains to the Coast plain. Low damp pine woods. Randolph County, Pinetucky. 'Tusealoosa County (E.A. Smith). Washington County, Yellowpine. Baldwin and Mobile counties. Flowers deep orange. July, August; widely dispersed over the State. Infrequent.

Type locality: "In the swamps of New Jersey."

Herb. Geol. Surv. Herb. Mohr.

Habenaria cristata (Michx.) R. Br. in Ait. Hort. Kew. ed. 2, 5 : 194. 1813.

Orchis cristata Michx. Fl. Bor. Am. 2 : 156. 1803.

Ell. Sk. 2:483. Gray, Man. ed. 6, 508. Chap. Fl.460.

Carolinian and Louisianian areas. Southern New Jersey to Florida, west to Louisiana and southern Missouri.

Alabama : Mountain region to Coast plaiu. Damp woods, light soil. Clay County, Shinbone Valley, 1,000 feet altitude. Cullman Connty, 800 feet. Autauga County (E. A. Smith). Washington Connty, Yellowpine. Mobile County, Springhill, 220 feet, shaded springy banks. Flowers orange. August; not rare.

Type locality: "Hab. in sylvis Carolinae."

Herb. Geol. Surv. Herb. Mohr.

Habenaria ciliaris (L.) R. Br. in Ait. Hort. Kew. ed. 2, 5 : 194. 1813.

Orchis ciliaris L. Sp. P1. 2 : 939.1753.

YELLOW-FRINGED ORCHIS.

Ell. Sk. 2:483. Gray, Man. ed. 6,509. Chap. Fl. 460.

Alleghenian to Louisianian area. Ontario, New England, Ohio Valley, Florida, Louisiana, and Arkansas.

Alabama : Over the State. Boggy meadows. Lauderdale County. Clay County, 2,000 feet. Cullman, Tuscaloosa, Montgomery, Choctaw, Washington,Clarke, Baldwin, and Mobile counties. Flowers orauge-yellow. June to Augnst; common.

'Type locality: "Hab. in Virginia, Canada."

Herb. Geol. Surv. Herb. Mohr.

Habenaria blephariglottis (Willd.) Torr. Comp. 317. 1826.

Orchis blephariglottis Willd. Sp. P1. 4:9. 1805.

O. ciliaris var. alba Michx. Fl. Bor. Am. 2:156. 1803. Not O. alba Lam. 1778.

Habenaria ciliaris var. blephariglottis Chap. Fl. 460. 1860.

Ell. Sk. 2 : 483. Gray, Man. ed. 6, 509. Chap. Fl.1. c. 
Canadian zone to Louisianian area. Newfoundland, Quebec, Ontario ; New England, New York, southern Michigan, Ohio, south from New Jersey to Florida, west to Louisiana.

AlabaMa: Central Pine belt to Coast plain. Swampy shaded banks. Elmore County (E. A. Smith). Tuscaloosa County. Mobile County, Grand Bay, Whistler.

Flowers white. July; not common.

Type locality: "Haib. in Pennsylvania."

Herb. Geol. Surv. Herb. Mohr.

Habenaria blephariglottis holopetala (Lindl.) Gray, Man. ed. 5, 502. 1867.

Platanthera holopetala Lindl. Gen. \& Sp. Orch. 291. 1835.

Gray, Man. ed. 6, 509.

Canadian zone to Carolinian area. Newfoundland, Ontario, and New York.

Alabama: Central Pine belt. Tuscaloosa County (E. A. Smith); rare.

Type locality not ascertained.

Herb. Geol. Surv. Herb. Mohr.

Habenaria lacera (Michx.) R. Br. Prodr. Fl. Nov. Holl. 1:312. 1816. RAGGed OrChIs. Orchis lacera Michx. Fl. Bor. Am. 2 : 156. 1803.

Ell. Sk. 2 :484. Gray, Man. ed. 6, 509. Chap. Fl. 460.

Canadian zone to Louisianian area. Nova Scotia, New Brunswick, Ontario; New England west to Minnesota, Missouri, and Arkansas, sonth from New Jersey to South Carolina.

Alabaina: Central Pine belt. Autanga County (E. A. Smith). Lee County, Auburn (Underwood \& Earle). Flowers yellowish white. August; rare.

Type locality: "Hab. in Carolina."

Herb. Geol. Surv. Herb. Mohr.

Habenaria peramoena Gray, Am. Journ. Sci. 38 : 310. 1840.

Fringeless Purple Orchis.

Orchis incisa Pursh, Fl. Am. Sept. 2 : 589. 1814. Not Willd.

O. fissa Pursh, Fl. Am. Sept. 2 :589. 1814. Not Willd.

Gray, Man. ed.6,510. Chap. Fl. 461.

Alleghenian and Carolinian areas. Mountains of North Carolina to Pennsylvania and Now Jersey.

Alabama: Tennessee Valley. Low damp meadows. Lauderdale County ( $J$. $H$. Pruitton). Barrens near the Tennessee and Alabama State line. Flowers July 4, 1896.

Type locality of Orchis incisa Pursh: "In low meadows: New York to Virginia." Of O. fissa Pursh: "In mountain meadows: Pennsylvania to Virginia."

Herb. Geol. Surv. Herb. Mohr.

Habenaria quinqueseta (Michx.).

MichauX's ORChis.

Orchis quinqueseta Michx. Fl. Bor. Am. 2 : 155. 1803.

Habenaria michauxii Nutt. Gen. $2: 189$. 1818.

Ell. Sk. 2 : $489 . \quad$ Chap. Fl. 461 ; ed. $3,487$.

Louisianian area. South Carolina and Florida to western Louisiana (Hale).

Alabama: Central Pine belt. Tuscaloosa County (E. A. Smith); scarce.

Type locality: "Hab. in Carolina."

Herb. Geol. Surv. Herb. Mohr.

Habenaria repens Nutt. Gen. Pl. 2 : 190. 1818.

Ell. Sk. $2: 489$. Chap. Fl. 461.

Louisianian area. South Carolina to Florida, west to Mississippi and Louisiana.

Alabama: Coast plain. Border of swamps and ditches. Ballwin County, Point

Clear. Flowers green. October. lina."

Type locality: "On the margins of ponds near Savannah, in Georgia and in Caro-

Herb. Geol. Surv. Herb. Mohr.

POGONIA Juss. Gen. Pl. 65. 1789.

Forty-three species, mostly of warmer regions. Eastern North America, 5. Japan. Perennials.

Pogonia ophioglossoides (L.) Ker-Gawl. in Lindl. Bot. Reg. 2 : t. 148. 1816.

Arethusa ophioglossoides L. Sp. P1. 2 : 951. 1753.

SNAKE-MOUTH.

Ell. Sk. $2: 495$. Gray, Man. ed. 6, 505. Chap. Fl. 457. 
JAPAN.

Canadian zone to Lonisianian area. Newfoundland, Quebec, and Ontario; New England west to Minnesota, sonth to Florida and Louisiana.

Alabama : All over the State. Bogs and pine-barren swamps. Lawrence, Cullman, Montgomery, Autanga, Wileox, Clarke, Washington, Mobile, and Baldwin counties. Flowers pale purplish. April, May. Frequent.

Type locality: "Hab. in Virginia, Canada."

Herb. Geol. Surv. Herb. Mohr.

Pogonia divaricata (L.) R. Br. in Ait. Hort. Kew. ed. 2, 5 : 203. 1313.

SpReading Pogonia.

Arethusa divaricata L. Sp. Pl. 2 : 951. 1753.

Ell. Sk. 2:4!6. Gray, Man. ed. 6, 505. Chap. Fl. 458.

Carolinian and Louisianian areas. From the South Atlantic and Eastern Gulf States north to eastern Tennessee and New Jersey.

Alabama : Central Pine belt to Coast plain. Borders of ponds, springy places; most frequent in the low pine barrens of the Coast plain. Escambia County. Tuscaloosa County (E.A.Smith). Mobile and Baldwin counties. Flowers flesh-color. April, May; frequent with the last.

Type locality: "Hab. in Americae borealis paludosis."

Herb. Geol. Surv. Herb. Mohr.

Pogonia verticillata (Willd.) Nutt. Gen. $2: 192.1818$.

Whorlai) Pogonia.

Arethusa verticillata Willd. Sp. Pl. 4 : 81.1805.

Ell. Sk. 2:497. Gray, Man. ed. 6, 505. Chap. Fl. 458.

Alloghenian and Louisianian areas. Ontario; New England, Eastern States west to Michigan, Ohio Valley to the Gulf States; from Florida to westeru Louisiana.

Alabama: Central Pine belt. Shady woods. Tuscaloosa County,(E.A. Smith). March; rare.

Type locality: Hab. in Pensylvania, Marylandia.

Herb. Geol. Surv. Herb. Mohr.

GYROSTACHYS Pers. Syn. 2:511. 1807.

(Spiranthes L. C. Rich. Mem. Mus. Par. 4:42. 1818.)

Fifty or more species, perennials, widely distributed over warmer and temperate regions. Japan, Europe. Atlantic America, 10 to 12.

Gyrostachys cernua (L.) Kuntze, Rev. Gen. Pl. 664. 1891.

Ophrys cernua L. Sp. Pl. 2 : 946. 1753

Drooping Ladies' Tresses.

Spiranthes cernua L. C. Rich. Orchid. Ann. 37. 1817.

Ell. Sk. 2:492. Gray, Man. ed. 6,502. Chap. Fl.462. Coulter, Contr. Nat. Herb. $2: 424$.

Alleghenian to Lonisianian area. Nova Scotia to Ontario; New England, west to Minnesota, Nebraska, Missouri, and Arkansas, south through the Ohio Valley to South Atlantic and Gulf States.

Alabama: Over the State. Low prairies and damp pine barrens. Cullman, Tuscaloosa, Escambia, Mobile, and Bald win counties. Flowers white. October, November; frequent.

Type locality : "Hab. in Virginia, Canada."

Herb. Geol. Surv. Herb. Mohr.

Gyrostachys gracilis (Bigelow) Kuntze, Rev. Gen. Pl. 2 :664. 1891.

Neottia gracilis Bigelow, Fl. Bost. ed. 2 : 322. 1824.

Slender Ladme' Tresses.

Gray, Man. ed. 6, 503. Chap. Fl. 462. Conlter, Contr. Nat. Herb. $2: 424$.

Canadian zone to Lonisianian area. Nova Scotia, New Brunswick, and Ontario to Lake Winnipeg and Mackenzie River; New England west to Minnesota, south to Texas and Florida.

Alabama : All over the State. Most frequent in dry pine barrens. Cullman, Chilton, Washington, Clarke, Choctaw, Mobile, and Baldwin counties. Flowers white. April to June; frequent.

Type locality : "In dry hilly woods [near Boston]."

Herb. Geol. Surv. Herb. Mohr. 
Gyrostachys praecox(Walt.) Kuntze, Rev. Gen. Pl. 2 : 663. 1891.

Limodorum praecox Walt. Fl. Car. 221. 1788.

Early Ladiks' Tresses.

Neottia tortilis Willd. Sp. P1. $4: 74.1805$.

Spiranthes praecox Gray, Man. ed. 6, 503. 1890.

Ell. Sk. 2:491. Gray, Man.1. c. Chap. Fl. 462.

Carolinian and Louisianian areas. South Atlantic and Gulf States, west to Louisiana, north from Florida to sonthern Massachusetts.

Alabama: Central Pine belt to Coast plain. Damp sandy pine barrens. Mobile, Baldwin, Clarke, Washington, and Tuscaloosa counties. Flowers white. May; frequent.

Type locality: South Carolina.

Herb. Geol. Surv. Herb. Mohr.

Gyrostachys odorata (Nutt.) Kuntze, Rev. Gen. Pl. 2 : 664. 1891.

SWeet-scented Ladies' Tresses.

Neottia odorata Nutt. Journ. Acad. Phila. 7 : 98. 1834.

Spiranthes odorata Lindl. Gen. \& Sp. Orch. 467. 1840.

Chap. Fl. 462.

Louisianian area. Northwestern Louisiana to western Florida, north to North Carolina.

Alabama : Coast plain. Wet alluvial banks. Mobile County, alluvial forests on the Alabama River, Pierces Landing. Flowers white, fragrant. October. Not frequent.

Type locality: "Along the borders of the Neuse River, at Newbern, in North Carolina, on the wet and muddy shores."

Herb. Geol. Surv. Herb. Mohr.

Gyrostachys brevifolia (Chap.) Kuntze, Rev. Gen. P1. 2:664. 1891.

Spiranthes brevifolia Chap. Fl.462.

Short-Leaved Ladies' Tregses.

Chap. Fl.l.c.

Louisianian area. Alabama to western Florida.

Alabama: Coast plain. Low grassy pine barrens. Mobile County, Bayou Coden. November, 1869. Flowers white. October, November. Very scarce.

Type locality: "Open grassy swamps in the pine barrens, Apalachicola, Fla."

Herb. Geol. Surv. Herb. Mohr.

PERAMIUM Salisb. Trans. Hort. Soc. 1 : 301. 1812.

(GoodyerA R. Br. in Ait. Hort. Kew. ed. $2,5: 197$. 1813.)

Twenty-five species, perennials, north temperate regions to tropical Asia. New Caledonia, Europe, Siberia. North America, 3.

Peramium pubescens (Willd.) MacMillan, Metasp. Minn. Val. 172. 1892.

Neottia pubescens Willd. Sp. Pl. 4 : 76. 1805.

Downy Rattlesnake Plantain.

Goodyera pubescens R. Br. in Ait. Hort. Kew. ed. 2, 5 : 198. 1813.

Ell. Sk. 2:491. Gray, Man. ed. 6, 503. Chap. Fl. 463.

Alleghenian to Louisianian area. Ontario; Now England west to Minnesota, south to Georgia and Florida.

Alabama: Mountain region Upper division Coast Pine belt. Shady woods Winston County (T. M. Peters). Clarke County, Choctaw Corner (E. A. Smith). Flowers white. Julv, August; infrequent.

Type locality : "Hab. a Canada ad Floridam."

Herb. Geol. Surv.

ACHROANTHES Raf. Med. Rep. ser. 2, 5 :352. 1808.

(Microstylis Nutt. Gen. 2 : 196. 1818.)

About 70 species, temperate North Hemisphere, tropical Asia and America. North America, 2 or 3.

Achroanthes unifolia (Michx.) Raf. Med. Rep. ser. 2, 5 : 352. 1808.

Malaxis unifolia Michx. Fl. Bor. Am. 2 : 157. 180 ?.

Green AdDersmouth.

Microstylis ophioglossoides Nutt. Gen. 2 :196. 1818.

Ell. Sk. 2:503. Gray, Man. ed.6, 498. Chap. Fl. 453. 
Canadian zone to Louisianian area. Newfoundland, Ontario, Manitoba ; New England west to Minnesota, south to Florida, Lonisiana, and Arkansas.

Alabama: Mountain region to Coast plain. Low shady woods. Lee County, Auburn (F. S. Earle). Tuscaloosa Connty (E. A. Smith). Baldwin Connty, Stockton. Flowers white. July, Angust; rare.

Type locality: "Hab. in umbrosis sylvarum, a Carolina ad Floridam."

Herb. Geol. Snrv. Herb. Mohr.

\section{LEPTORCHIS Thouars, Nouv. Bull. Soc. Philom. 314. 1808.}

(Liparis L. C. Rich. Mem. Mus. Par. 4 : 43. 1818.)

Near 100 species, of temperate and warmer regions. Japan. North America, 2.

Leptorchis liliifolia (L.) Kuntze, Rev. Gen. Pl. 2 : 671.1891.

Ophrys liliifolia L. Sp. P1. 2 : 946. 1753.

Liparis liliifolia L. C. Rich. Lindl. Bot. Reg. 11: t. 882. 1825.

Ell. Sk. 2:503. Gray, Man. ed. 6, 499. Chap. Fl.454.

JAPAN.

Alleghenian and Lousianian areas. New England west to Minnesota, Ohio Valley to Missouri, sonth to New Jersey, Carolina, and Georgia.

Alabama: Tennessee Valley. Mountain region. Shaded copses in rich rocky soil. Franklin County, Russellville. Lee County, Auburn (Baker \& Earle). Flowers, white. June; infrequent.

Type locality : "Hab. in Virginiae, Canadae, Sneciae paludibus."

Herb. Geol. Surv. Herb. Mohr.

Leptorchis loeselii (L.) MacMillan, Metasp. Minn. Val.173. 1892.

Ophrys loeselii L. Sp. Pl. 2 : 947. 1753.

Liparis loeselii L. C. Rich. Lindl. Bot. Reg. 11: t. 88\%. 1825.

Gray, Man. ed. 6, 499.

Europe, Asia.

Alleghenian and Carolinian areas. New Brunswick, Nova Scotia, and Quebec, west to Saskatchewan and Minnesota, south to New Jersey and Maryland, west to southern Illinois and Missouri.

AlabaMa : Mountain region. Metamorphic hills. Lee County, Auburn (Baker \& Earle), 800 feet altitude. May; rare.

Type locality: "Hab. in Sueciae, Borussiae paludibus."

CORALIORHIZA R. Br. in Ait. Hort. Kew. edl. 2, 5 :209. 1813.

Twelve species, pale almost leafless parasites, temperate regions, Europe, Asia, Mexico. North America, 7.

Corallorhiza odontorhiza (Willd.) Nutt. Gen. 2 : 197. 1818.

Cymbidium odontorhizon Willd. Sp. Pl. 4 : 110. 1805.

SMALL-Flowered CORAL-ROOT.

Ell. Sk. 2:505. Gray, Man. ed.6, 500. Chap. Fl. 454.

Alleghenian to Louisianian area. Southern New England, west to Michigan; Ohio Valley to Missouri; New Jersey, sonth to middle Florida, Texas, and Arkansas.

Alabama : Mountain region. Lower hills. Shady woods about the roots of trees. Cullman Connty, Holmes Gap. Tuscaloosa County, March (E. A. Smith). August; not frequent.

Type locality: "Hab. in Canada, Nova Anglia, Pensylvania, Virginia."

Herb. Geol.Surv. Herb. Mohr.

Corallorhiza wisteriana Conrad, Journ. Acad. Phila. 6: 145. 1820.

Britt. \& Br. Ill. Fl. 1: 478.

Wister's Coral-Root.

Carolinian and Louisianian areas. Massachusetts to Ohio, Florida, and Texas.

Arabama: Central Pine belt. In woods. Tuscaloosa Connty (E. A. Smith).

Augnist; local, rare.

Type locality not ascertained.

Herb. Geol. Surv. Herb. Mohr. 
TIPULARIA Nutt. Gen. 2 :195. 1818.

Single species, perennial, from solid bulbs. Atlantic North America, Japan. Tipularia unifolia (Muhl.) B. S. P. Prel. Cat. N. Y.51. 1888.

Limodorum unifolium Muhl. Cat.81. 1813.

Tipularia discolor Nutt. Geu. 2:195. 1818.

Ell. Sk. 2:502. Gray, Man. ed. 6, 499. Chap. Fl. 456.

Alleghenian to Louisianian area. Southern New England, west to Michigan, south to New Jersey, North Carolina, and Georgia, west to western Lonisiana and Arkansas.

AlabaMa : Mountain region to Coast plain. Rich shady woods. Winston County, Colliers Creek, 1,500 feet altitude, wooded hillsides. Tuscaloosa County, Vances Station (E. A. Smith). Mobile County, Bayou La Batre, rich hummock on Little River. Flowers yellowish green. June; infrequent, local.

Type locality: "Nova Caesarea-Georgia."

Herb. Geol. Surr. Herb. Mohr.

LIMODORUM L. Sp. Pl. 2 :950. 1753.

(Calopogon R. Br. in Ait. Hort. Kew. ed. 2, 5 :204. 1813.)

Four species, perennials, Atlantic North America.

Limodorum tuberosum L. Sp. Pl. 2 :950. 1753.

GRASS-PINK.

Calopogon pulchellus R. Br. in Ait. Hort. Kew. ed. 2, 5 :204. 1813. 425.

Ell. Sk. 2 :499. Gray, Man. ed.6, 505. Chap. F1.456. Coulter, Contr. Nat. Herb.

Canadian zone to Louisianian area. Newfoundland, Nova Scotia, and Ontario, New England west to Minnesota, south to Florida and western Texas (Rio Grande).

Alabama: All over the State. Springy places, most frequent in boggy pine barrens. Flowers rose-color. April to June. The most beautiful of our orchids ; frequent.

Type locality: "Hab. in America septentrionali."

Herb. Geol. Surv. Herb. Mohr.

Limodorum pallidum (Chap.) Mohr, Bull. Torr. Club, 24 : 23. 1897.

Calopogon pallidus Chap. Fl.457. 1860.

Palei-flowhed Calopogon.

Chap. Fl. l. c.

Louisianian area. Western Florida to North Carolina, west to the Red River, Lonisiana.

AlabaMa: Lower Pine region and Coast plain. Bogrs in pine barrens. Mobile Couuty, Grand Bay, Citronelle. Baldwin County. Escambia County, Flomaton. Washington County, Yellowpine. Flowers white to pale pink. May, June; not rare.

Scape 12 to 20 inches high from a small tuber, with 4, rarely 6 , flowers in the loose raceme.

Type locality: "Wet pine barrens, west Florida, near the coast, to North Carolina."

Herb. Geol. Surv. Herb. Mohr.

Limodorum parviflorum (Lindl.) Nash, Bull. Torr. Club, 22 : 158. 1895.

SMall-Flowered Calopogon.

Calopogon parviflorus Lindl. Gen. \& Sp. Orch. 424. 1840.

Calopogon pulchellus var. graminifolius Ell. sk. 2 : 499. 1824.

Ell. Sk. l. c. Chap. Fl. 457.

Louisianian area. From North Carolina to Florida, west to Louisiana (Red River).

Alabama : Lower Pine region near the coast. Grassy pine ridges. Mobile County,

Mount Vernon, Grand Bay. Flowers pale pink. March, April ; not frequent.

Stem 10 to 12 inches high from a thick tuberous root, connected with one or two horizontal tubers 4 to 6 lines long.

Type locality not ascertained.

Herb. Geol. Surv. Herb. Mohr.

Limodorum multiflorum (Lindl.)Mohr, Bull. Torr. Club, 24 : 23.1897.

Many-Flowered Calopogon.

Calopogon multiflorus Lindl. Gen. \& Sp. Orch. 425. 1840.

Chap. Fl. 457.

Louisiauian area. Floriàa and Alabama. 
Alabama: Coast plain. Flat damp pine barrens. Mobile County, Fowl River Station. Flowers deep rose purple. April; rare.

Type locality not ascertained.

Herb. Geol. Surv. Herb. Mohr.

PONTHIEVA R. Br. in Ait. Hort. Kew. ed. 2, 5 : 199. 1813.

Ten species, warmer America. Southeasteru America, 1.

Ponthieva racemosa (Walt.) ManY-Flowered Pontureva.

Arethusa racemosa Walt. F1. Car. 222. 1788.

Ophrys pubera Michx. Fl. Bor. Am. 2:158. 1803.

Ponthieva glandulosa R. Br. in Ait. Hort. Kew. ed. 2, $5: 200.1813$.

Cranichis multiflora Nutt. Gen. 2 : 191. 1818.

Ell. Sk. 2:493. Chap. Fl. ed.3. 464. Griseb. Fl. Brit. W. Ind. 638.

Wrat Indies, Mexico, Ecuador.

Louisianian area. Florida, North Carolina.

Alabama : Lower hills to Upper division Coast Pine belt. Rich shady woods. Talladega County, Adins Mill (E. A. Smith). Clarke County, Suggsville (Dr. Denny). May, June; local and rare. Perennial.

Type locality: South Carolina.

Herb. Geol. Surv. Herb. Mohr.

HEXALECTRIS Raf. Neogen.4. 1825.

A monotypical saprophyte. Eastern North America.

Hexalectris aphyllus (Nutt.) Gray, Man. ed. 6, 501. 1890.

Bletia aphylla Nutt. Gen. 2 : 194. 1818.

Hexalectris squamosus Raf. Fl. Tell. 4:48, 1836.

Ell. Sk. 2 : 501 . Gray, Man. ed. 6, 501. Chap. Fl. 456.

Northern Mexico.

Louisianian to Carolinian area. Florida to North Carolina, Kentucky, Missouri, Arkansas, and Texas.

Alabáma: Mountain region to Lower hills. Shaded copses, rich hillsides. Clay County, Shinbone Valley, 800 feet. Cullman County. Bibb County, Centerville. Tuscaloosa County, Vances Station (E. A. Smith). Flowers light brown purplish, with purple veins. July, August; not frequent. Never observed in the low country. Type locality: "In Carolina and Florida."

Herb. Geol. Surv. Herb. Mohr.

APLECTRUM Nutt. Gen. 2 : 197. 1818.

One species, temperate North America.

Aplectrum spicatum (Walt.) B. S. P. Prel. Cat. Pl. N. Y. 51. 1881. Arethusa spicata Walt. Fl. Car. 222. 1788.

Cymbidium hyemale Willd. Sp. Pl. 4:107. 1805.

Aplectrum hyemale Nutt. Gen. 2:198. 1818.

Corallorhiza hyemale Bart. Fl. N. A. 2:52. 1822.

Ell. Sk. 2:505. Gray, Man. ed.6, 500. Chap. Fl. 455.

Canadian zone to Carolinian area. Outario to Saskatchewan; New England west to Michigan, Minnesota; Ohio Valley sonth to Georgia.

Alabama: Tennessee Valley. Lawrence County, Big Nancy (T. M. Peters). Perennial.

Has of late not been observed in the State.

Type locality : South Carolina.

Herb. Geol. Surv. Herb. Mohr.

\section{EPIDENDRUM L. Sp. Pl. 2:952. 1753.}

About 400 species, mostly tropical America. Southeastern North America, 5.

Epidendrum conopseum R. Br. in Ait. Hort. Kew. ed. 2, 5:219. 1813.

Louisianian area. South Carolina to Florida, west to Alabama and Mississippi.

Alabama: Coast plain. Epiphytic on large magnolias and live oaks in dense damp woods on hammocks. Mobile County. Baldwin County, Blakely. Flowers green, fragrant. July; not rare. Peremnial.

Type locality: "Native of Florida. Mr. William Bartram."

Herb. Geol. Surv. Herb. Mohr. 


\section{Subclass DICOTYLEDONES.}

Series ARCHICHLAMY DEAE (Choripetalous and apetalous orders).

\section{SAURURACEAE. Lizard's-tail Family.}

SAURURUS L.Sp. Pl. 1 : 341. 1753.

One species, Atlantic North America.

Saururus cernuus L. Sp. Pl. $1: 341.1753$.

LIZARD's TAIL.

Ell. Sk. 1:432. Gray, Man. ed. 6, 446. Chap. Fl. 398.

Alleghenian to Louisianian area. New England west to Missouri, sonth to the Gulf. From Florida to Louisiana and Arkansas.

Alabama: Over the State. Swamps and muddy banks. Flowers white. June to Angust: common. Perennial.

Type locality: "Hab. in Marilandia, Virginia."

Herb. Mohr.

\section{JUGLANDACEAE. Walnut Family.}

JUGLANS L.Sp. Pl. 2 : 997. 1753.

About 7 species, temperate regions of the North Hemisphere. North America, 4. Deciduous trees.

Juglans nigra L. Sp. Pl. 2:997. 1753.

Black Walnut.

Ell. Sk. 2:622. Grav, Man. ed.6,467. Chap. Fl. 419. Coulter, Contr. Nat. Herb. 2:412. Sargent, Silv. N. A. $7: 212, t .333$.

Alleghenian to Lonisianian area. Southern Ontario; New England west to Minnesota, eastern Nebraska, and eastern Kansas; south to western Florida and western Texas.

Alabama: Tennessee Valley, to the upper part of the Coast Pine belt. Scattered in rich bottom lands; spreading southward along the banks of the larger rivers. Becoming scarce, and almost completely exhauster in the Central Prairie region, where it was once most frequently found.

Economic uses: Important for its highly valuable timber.

Type locality : "Hab. in Virginia, Marilandia."

Herb. Geol. Surv. Herb. Mohr.

Juglans cinerea L. Sp.Pl.ed.2, $2: 1415$. 1763. Butternut. White Walnut. Ell. Sk. 2:622. Gray, Man. ed. 6, 467. Chap. Fl. 419. Sargent, Silv. N. A. 7:118, t.332.

Alleghenian and Carolinian areas. Ontario, New Brunswick; New England west to Minnesota, south from Delaware along the mountains to Georgia.

Alabama: Mountain region. Rich woods. Winston County, Colliers Creek. Limestone County (E. A. Smith). May; fruit ripe in October. Only known from a few localities.

Economic uses: Of little importance as a timber tree. The inner bark of the root, butternut bark-Juglans, U. S. Pharmacopœia-is used medicinally.

Typè locality: "Hab. in America septentrionali."

Herb. Geol. Surv. Herb. Mohr.

HICORIA Raf. Med. Rep. ser. 2, $5: 352.1808$. Нickory.

(CARYa Nutt. Gen. 2:221. 1818.)

Ten species; Atlantic North America, 9; Mexico, 1; Southern States, 8. Decirluous trees.

Hicoria pecan (Marsh.) Britton, Bull. Torr. Club, 15 : 282.1888.

Juglans pecan Marsh. Arb. Am. 69. 1785.

J. olivaeformis Michx. Fl. Bor. Am. 2:192. 1803.

Carya olivaeformis Nutt. Gen. 2:221. 1818.

Gray, Man. ed. 6, 468. Chap. Fl.418. Coulter, Contr. Nat. Herb. $2: 410$. Sargent, Silv. N. A. $7: 137$, t. 333. 
Northern Mexico.

Caroliuian and Louisianian area. Iowa, southern Illinois, southwestern 'Texas, Indian Territory, northern Mexico; south from sonthern Missouri to Texas and central Mississippi.

Alabama : Contral Prairie region. Rich woodlands. Hale County, Gallion. Dallas County, Uniontown. Marengo County, Demopolis. Undoubtedly indigenous. Extensively cultivated near the coast.

Economic uses: Valuable nut-tree. Its timber also valuable.

Type locality: "This tree is said to grow plenty in the neighborhood of the Illinois River, and other parts to the westward.

Herb. Geol. Surv. Herb. Mohr.

Hicoria ovata (Mill.) Britton, Bull. Torr. Club, 283. 1888.

SCALY-BARK Hickory. SHell-bark Hickory.

Juglans ovata Mill. Gard. Dict. ed. 8, no. 6. 1768.

Carya alba Nutt. Gen. 2 : 221. 1818.

Ell.Sk. 2:624. Gray, Man. ed. 6, 468. Chap. Fl. 418. Coulter, Contr. Nat. Herb. 2:410. Sargent, Silv. N. A. 7:153, t. 146, $14 \%$.

Alleghenian to Louisianian area. Valley of St. Lawrence River; New England west to Minnesota; from eastern Kansas to eastern Texas, and through Louisiana and Mississippi to western Florida.

Alabama: Tennessee Valley. Mountain region to Upper division of the Coast Pine belt. Rich woods.

Type locality not ascertained.

Hicoria alba (L.) Britton, Bull. Torr. Club, $15: 283.1888$.

Juglans alba L. Sp. Pl. 2 : 997. 1753.

White-heart Hickory. Mockeinut.

J. tomentosa Lam. Encycl. 4:504. 1797.

Carya tomentosa Nutt. Gen. $2: 221.1818$.

Ell. Sk. 2:625. Gray, Man. ed. 6, 468. Chap. Fl.419. Conlter, Contr. Nat. Herb.

$2: 411$. Sargent, Silv. N. A. 7:161, t. 150, 151 .

Alleghenian to Louisianian area. Ontario; New England west to eastern Kansas, south to eastern Texas, and from Massachusetts to Cape Canaveral, Fla.

Alabama : Over the State. Flowers April, May; fruit matures October, Novem-

ber. Frequent in damp and dry soil.

Economic uses: Scarcely less valuable than the last for timber and for fuel.

Type locality: "Hab. in Virginia."

Herb. Geol. Surv. Herb. Mohr.

Hicoria glabra (Mill.) Britton, Bull. Torr. Club, $15: 284.1888$. Pignut Hickory.

Juglans glabra Mill. Gard. Dict. ed. 8 , no. 5.

Carya porcina Nutt. Gen. $2: 222.1818$.

Ell. Sk. 2:627. Gray, Man. ed. 6, 469. Chap. Fl. 419; ed. 3, 442. Coulter, Contr. Nat. Herb. $2: 411$. Sargent, Silv. N. A. $7: 165$.

Alleghenian to Louisianian area. Ontario (shores of Lake Erie); southern Maine, west to eastern Kansas; south to peninsular Florida, Lonisiana, and eastern Texas (Nueces Valley).

Alabama: Over the State. One of the most frequent deciduous trees of the nplands. Flowers in April; fruit matures October, November. Nut somewhat bitter.

Economic uses: Large timber tree of minor value; excellent for fuel.

Type locality not ascertained.

Herb. Geol. Surv. Herb. Mohr.

Hicoria villosa (Sargent) Ashe, Bull. Torr. Club, $24: 481$. 1897. Hoary Pignut.

Hicoria glabra villosa Sargent, Silv. N. A. 7:167. 1895.

H. pallida Ashe, Notes on Hickories. 1896. In part.

Carolinian area. Delaware and Virginia to North Carolina and Georgia.

Alaibama : Lower hills to Upper division of Coast Pine belt. Dekalb County, Mentone. Madison County, Montesano. Jefferson and Tuscaloosa counties. Heury County, Abbeville. Flowers in April; fruit ripe in October. The most frequent of upland hickories throughout the mountain region and lower hills on poor sandy or. rocky ridges.

Tree of medium size, scarcely over 40 feet, the trunk 15 to 18 inches in diameter, with a firm, thick, roughish bark; sterile flowers produced from the base of the youngest shoot; buds small, ovate or oval, pointed, somewhat stipitate, the terminal of 6 to 9 , the lateral of 5 to 7 , imbricated scales; leaves with 7 to 9 leaflets, covered on their lower surface with silvery peltate scales, as also the peduncles, bracts, calyx 
lobes, and bud scales; leaflets, petioles, and branchlets clothed with a soft villous pubescence, noticed particularly during the earlier part of the season. Fruit variable in size and form, from almost globular to slightly pear-shaped, usually subglobose. Husk rather thin, between $\frac{1}{12}$ and $\frac{1}{8}$ inch thick, with the sutures slightly or prominently ribled, splitting to or nearly to the base, scarcely mucronate at the top and pointed at the base. Thick walled.

Type locality (Sargent): "Missouri, neighborhood of Allenton."

Economic uses: Valuable for its timber.

Herb. Geol. Surv. Herb. Mohr.

Hicoria carolinae-septentrionalis Ashe, Notes on Hickories. 1896.

Britt. \& Br. Ill. Fl. $3: 511$.

SOUTHERN SHAGBakK Hickoky.

Carolinian area. Delaware to Georgia and Tennessee.

Alabama: Tennessee Valley. Mountain region. Rich upland forests of hard woods. Morgau County, Falkville. Cullman County. Frequent in the coves of the 'Tennessee Valley.

Economic uses: Timber valuable, equal to that of the white hickory (H.ovata) of the bottom land, with which it has been heretofore confounded. Nuts with a large, sweet, fine-flavored kernel.

Type locality not ascertained.

Hicoria myristicaeformis (Michx.)Britton, Bull. Torr. Club, 15 :284. 1888.

Juglans myristicaeformis Michx. f. Hist. Arb. Am. 211. 1810.

Carya myristicaeformis Nutt. Gen. $2: 222.1818$.

Ell. Sk. 2:628. Chap. Fl. 419. Coulter, Contr. Nat. Herb. $2: 411$. Sargent, Silv. N. A. $7: 145, t .142,143$.

NoRThern Mexico.

Louisianian area. South Carolina to central Mississippi, southern Arkansas, and southwestern Texas.

Alabava : Central Prairie region. Rich uplands and second bottoms. Marengo County, Demopolis. Hale County, Gallion. Dallas County, Uniontown. Flowers in April; fruit ripe in November. Local.

Economic uses: Large timber tree. Excellent fuel.

Type locality (Michx. trans.): Near Charleston, "in the parish of Goose Creek." Herb. Mohr.

Hicoria minima (Marsh.) Britton, Bull. Torr. Club, 15 : 284. 1888.

Juglans alba minima Marsh. Arb. Am. 68. 1785.

J. miuima Borkh. Forst. Bot. 1:760. 1800 .

Carya amara Nutt. Gen. 2:222. 1818.

Ell. Sk. 2:626. Gray, Man. ed. 6, 469. Chap. F1. 419 . Coulter, Contr. Nat. Herb. 2:411. Sargent, Silv. N. A. $7: 141, t$. 340,341 .

Alleghenian to Louisianian area. Ontario, Quebec, New England, west to Minnesota, eastern Nebraska, eastern Kansas, and Indian 'Territory, south to western Florida and Mississippi to the valley of the Trinity, Texas.

Alabama : Lower hills and Central Prairie region. Most frequent in the hills of the lower Warrior and Cahaba coal basin; rarely over medinm size. Montgomery County, bottoms of Alabama River. Flowers in April; fruit ripe in October.

Economic uses: Of little value except for fuel.

Type locality: North America.

Herb. Geol. Surv. Herb. Mohr.

Hicoria aquatica (Michx.) Britton, Bull. Torr. Club. 15 : 284. 1888.

Water Hickory. Bitter Pecan.

Juglans aquatica Michx. f. Hist. Arb. Am. 1:182, t.5. 1810.

Carya aquatica Nutt. Gen. $2: 222.1818$.

Ell. Sk. 2:627. Chap. Fl.419. Conlter, Contr. Nat. Herb. 2:411. Sargent, Silv. N. A. $7: 149, t .144,145$.

Louisianian to Carolinian area. From eastern Texas (Brazos River) to Mississippi and Florida (Cape Malabar), north to North Carolina, southwestern Tennessee, and southern Arkansas.

AlabaMa: Alluvial region. River banks subject to frequent overflow. Baldwin - County, near Stockton. Mobile and Montgomery counties. Flowers in May; fruit ripe in October; bitter. Not common.

Economic uses: Of little importance.

Type locality (Michx. trans.): "Confined to the Southern States * * * in swamps, and ditches which surround the rice fields."

Herb. Geol. Surv. Herb. Mohr. 


\section{MYRICACEAE. Wax-Myrtle Family.}

MYRICA L. Sp. Pl. 2 : 1024. 1753.

Thirty to 35 species, trees and shrubs, of warmer and cooler temperate regions of Europe, Asia, Africa, North America. United States, 6.

Myrica cerifera L. Sp. Pl. 2 : 1024. 1753.

Southern Wax Myrtle. Candle Berry.

Myrica cerifera var. arborescens Michx. Fl. Bor. Am. 2 :228. 1803.

Ell. Sk. 2:678. Chap. Fl. 426; ed. 3, 450. Sargent, Silv. N. A. 9:87, t. 459 .

Carolinian and Louisianian areas. Florida through the Maritime Pine belt; along the coast to Maryland, west to the Sabine Valley, northeastern Texas (Cass County, Mohr), and southeru Arkansas.

Alabama: Central Prairie region to the seacoast. Sandy and alluvial swamps. Most frequent and in greatest perfection in the coast region, reaching 30 to 40 fect in beight and over 12 inches in diameter. A shrub in the upper districts. Mobile, Baldwin, Escambia, Clarke, and Montgomery counties. Flowers in February; fruit ripe in October. Common.

Economic uses: 'The berries yield wax.

Type locality: "Hab. in Carolina, Virginia, Pensylvania."

Herb. Geol. Surv. Herb. Mohr.

Myrica pumila (Michx.) Small, Bull. Torr. Club, 23:126. 1893.

DWarf Wax Myrtle.

Myrica cerifera var. pumila Michx. Fl. Bor. Am. 2:228. 1803.

Chap. Fl. 427.

Carolinian and Louisianian areas. North Carolina to Florida, west to Mississippi.

AlabaMa : Mountain region to Coast plain. In open pine woods. Dry sandy soil. Cullman County, 800 feet. Autauga County, Kingston. Most frequent on sandy ridges in the Lower Pine region. Mobile and Baldwin counties. Scarcely over a foot high. Flowers in March; fruit ripe in October, size of a pin head, profuse. Common; strictly distinct, extending in the interior much farther north than the last.

Type locality: "Hab. in aridis, a Carolina ad Floridam."

Herb. Mohr.

Myrica carolinensis Mill. Gard. Dict. ed. 8, no. 3. 1868.

Bayberry. Candle Berry.

Myrica cerifera var. media Michx. Fl. Bor. Am. 2:228. 1803.

EIl. Sk. 2:678. Gray, Man. ed. 6, 470, in part. Chap. Fl. 427; ed. 3, 450.

Canadian zone to Louisianian area. In the coast region. Nova Scotia, New

Brunswick, New England to Florida, west to eastern Louisiana.

Alabama: Coast plain. Swampy borders of pine-barren streams and sandy swamps. Mobile and Baldwin counties. Flowers in March; fruit ripe October, Novenber. Not rare.

Rarely over 8 or 10 feet high, foliage partially persistent over winter, leaves and bark highly aromatic, pungent.

Eeonomic nses: The bark of the root, as "bayberry bark," is used medicinally.

Type locality: "Hab. a Nova Anglia ad Floridam, in udis et juxta rivulis."

Herb. Mohr.

Myrica inodora Bartram, Travels, 405. 1791.

BARTRAM'S WAX MYRTLE.

Chap. Fl. 427. Sargent, Silv. N. A. 9:91, 460.

Louisianian area. Florida to South Carolina west to Mississippi (Pearl River Valley).

Ala Baya: Coast plain. Swamps along pine-barren streans. Mobile County, Springhill, Whistler. Baldwin County, Stockton. Flowers February, March ; fruit ripe September, October. Tree 15 to 25 feet high, diameter 3 inches; mustly shrubby.

Economic uses: The berries, called " eandle berries," yield wax.

Type locality: "Taensa Bluff” on the Mobile River, Angust 5, 1776.

Herb. Mohr.

\section{SALICACAE. Willow Family.}

POPULUS L. Sp. PI. 2 :1034. 1753. Poplar. Cottonwoon.

About 20 species, temperate zone of the Northern Hemisphere. North America, 9; Atlantic States 5 or 6. 
Populus deltoides Marsh. Arb. Am. 106. 1785.

Populus carolinensis Moench. Verz. P1. 81. 1785.

Carolina Poplar. Big Cottonwood.

P. monilifera Ait. Hort. Kew. $3: 406.1789$.

$P$. angulata Ait. Hort. Kew. 3:407. 1789.

$P$. angulosa Michx. Fl. Bor. Am. 2:243. 1803.

Fil. Sk. 2:711. Gray, Man. ed. 6, 487. Chap. Fl. 431. Coulter, Contr. Nat.

Herb. 2:420. Sargent, Silv. N. A. 9:179, t. 494, 495.

Alleghenian to Louisianian area. Ontario west to the eastern base of the Rocky Mountains; New England west to Minnesota, Colorado, and Nevada, south to Florida and western Texas.

Alabava: Tennessee Valley to the coast. Most frequent in alluvial swamps on the lower Alabama and Tombigbee rivers.

Economic uses: A timber tree.

Type locality: North America.

Herb. Mohr.

Populus heterophylla L. Sp. Pl. 2 : 1034. 1753.

Swamp Cottonwood. Black Cottonwood.

Ell. Sk. 2:712. Gray, Man. ed. 6, 487. Chap. Fl. 431. Sargent, Silv. N. A. $9: 163, t .489$.

Caroliniau and Louisianian areas. Southern New England, Ohio Valley, Tennessee, Missouri, to Florida and western Louisiana.

Alabama: Chiefly bottoms, margins of swampy forests. Montgomery and Clarke counties. Mobile County, Mount Vernon. Baldwin County, Stockton. Flowere middle of February.

Economic uses: 'Timber tree.

Type locality: "Hab, in Virginia."

Herb. Mohr.

Populus alba L. Sp. Pl. 2 : 1034. 1753.

Silver-Leaf Poplar.

Gray, Man. ed. 6, 486. Chap. Fl. 431.

Introduced and escaped from cultivation through the State. Mobile County.

Type locality: "Hab. in Europa temperatiori."

SALIX L.Sp. PI. 2 : 1015. 1753. WILLOW.

One hundred and sixty species, cooler and temperate zones of Nortbern Hemisphere. Trees and shrubs.

Salix nigra Marsh. Arb. Am. 139. 1785.

Salix caroliniana Michx. Fl. Bor. Am. 2 :226. 1803.

Ell. Sk. 2:670. Gray, Man. ed. 6, 480. Chap. Fl. 430. Coulter, Contr. Nat. Herb. $2: 419$. Wats. Bot. Calif. $2: 83$. Sargent, Silv. N. A. $9: 103, t$. 462.

Alleghenian and Carolinian areas. Throughont eastern North America to Florida, and west to Texas, Nebraska, Colorado, Arizona, and California.

Alabana: All over the State. Wet banks of streams, lakes, ponds. Flowers in April.

Economic uses: Of some value for its wood. The bark, as "black willow bark," is used medicinally.

Type locality: North America.

Herb. Mohr.

Salix wardi Bebb, Gard. \& For. 8: 363. 1895.

WARD'S WILLOW.

Salix nigra var. wardi Bebb in Ward, Bull. U. S. Nat. Mus. $22: 114.1881$.

Gray, Man. ed. 6, 481 . Britt. \& Br. Ill. Fl. 1:495, f. 1174.

Carolinian and Louisianian areas. District of Columbia west to Missouri, south to western Florida and Indian Territory.

Alabama : Tennessee Valley. So far only knowu from Lauderdale County in the river hills on gravelly banks of streams.

Type locality: "First met with among the rocks on the river bottom adjacent to the Chain Bridge and Little Falls [Potomac River, D. C.]."

Herb. Mohr.

Salix cordata Muhl.; Willd. Neue Schrift. Gesell. Nat. Fr. Berlin $4: 236, t .6, f .3$. 1803.

HEART-LEAF Willow.

Alleghenian to Lonisianian area. New Brunswick to British Columbia, south to Virginia, west to Missouri, Colorado, and California.

Alabama: Central Prairie region. Low banks of water courses. Butler County, $15894-30$ 
banks of Muscle Creek. Shrub about 8 feet high. Only locality known in the

State Collected May 16, 1898.

Type locality : Pennsylvania?

Herb. Geol. Surv. Herb. Mohr.

Salix humilis Marsh. Arb. Am. 140. 1785.

Salix longirostris Michx. Fl. Bor. Am. 2 : 226. 1803.

Ell. Sk. 2:669. Gray, Man. ed. 6, 483 . Chap. Fl. 430.

Alleghenian and Carolinian areas. Nova Scotia, Ontario, New England, New Jersey, and along the mountains to North Carolina, west to Minnesota and Nebraska.

Alabama: Tennessee Valley. In the barrens, flat gravelly ground. Lauderdale County. Shrub 3 or 4 feet high.

Type locality not specifically given.

Herb. Mohr.

\section{BETULACEAE. Birch Family.}

CARPINUS L. Sp. Pl. 2 :998. 1753.

Twelve species, temperate regions of Europe, Asia, North America. North America and Mexico, 1 . Small deciduous trees.

Carpinus caroliniana Walt. Fl. Car. 236. 1788.

IRONWOOD. HORNBEAM.

Carpinus americana Michx. Fl. Bor. Am. 2:201. 1803.

Ell. Sk. 2:618. Gray, Man. ed. 6, 474. Chap. Fl. 425. Coulter, Contr. Nat. Herb.

$2: 413$. Sargent, Silv. N. A. $8: 42, t .44 \%$.

Alleghenian to Louisianian area. Ontario to Georgian Bay; New England west to Minuesota and eastern Kansas, south to Tampa Bay, Florida, and through the Gulf States to eastern Texas and southern Arkansas.

Alabama : All over the State. In low rich woods. Common throughout. Flowers in May; fruit ripe in October. A tree below medium size.

Economic uses: The wood valuable for ninor purposes.

Type locality: South Ciaroliua.

Herb. Geol. Surv. Herb. Mohr.

OSTRYA Scop. Fl. Carn.414. 1760.

Two species, Southern Europe. Japan, 1; Mexico and North America, 1.

Deciduous trees.

Ostrya virginiana (Mill.) Willd. Sp. Pl. 4:469. 1805. Hop HornbeaM. Irowwood. Carpinus virginiana Mill. Gard. Dict. ed. 8, no. 4. 1768.

Ostrya americana Michx. Fl. Bor. Am. 2:202. 1803.

Ell. Sk. 2:618. Gray, Man. ed. 6, 474. Chap. Fl. 426. Coulter, Contr. Nat. Herb.

$2: 414$. Sargent, Silv. N. A. $9: 34, t .445$.

Mexico, Guatemala.

Alleghenian and Louisianian areas. Ontario throughout the Atlantic States to

Tampa Bay, Florida, west to eastern Texas, Arkansas, Indian 'Territory, and eastern Kansas.

Alabama: Tennessee Valley to. Upper division of Coast Pine belt in calcareous soil. Lauderdale and Montgomery counties. Flowers April, May.

Economic uses: 'The wood is useful.

Type locality not ascertained.

Herb. Geol. Surv. Herb. Mohr.

CORYLUS L. Sp. Pl. 2 : 998. 1753. Hazelnut.

Seven species, temperate Europe, Asia. North America, 2. Shrubs.

Corylus rostrata Ait. Hort. Kew. $3: 364$. 1789.

BEAKED HAZELNUT.

Ell. Sk. 2:612. Gray, Man. ed. 6, 474. Chap. Fl. 425.

Alleghenian and Carolinian areas. Nova Scotia, New Brunswick, Quebec, and Ontario to Saskatchewan, British Columbia to Pacific coast; Now England west to Minuesota, Colorado to the Pacific, Washington; south from New Jersey to upper Carolina and Georgia.

Alabama: Monntain region. Lower hills. Shrub 3 to 4 feet high, most freqnent in the Metamorphic hills. Clay, Tallapoosa, and Randolph counties. Tuscaloosa County ( $E$. A. Smith). 9 Flowers in March; frnit ripe September, October.

Economic uses: The nuts are edible. 
Type locality: "Native of North America."

Herb. Geol. Surv. Herb. Mohr.

Corylus americana Walt. Fl. Car. 236. 1788.

Ell. Sk. 2:611. Gray, Man. ed. 6, 474. Chap. Fl. 425.

Alleghenian and Carolinian areas. Ontario to Assiniboia; New England west to Minnesota, Dakota, Nebraska, and Arkansas, south to New Jersey, upper district of Carolina and Georgia.

Alabama: 'Tennessee Valley. Coosa Valley, dry woods. Claiborne County, (E.A.Smith). Lauderdale County, river hills. Flowers in Mareh; fruit ripe September, October. Not frequent.

Economic uses: 'The nuts are edible.

Type locality: South Carolina.

Herb. Geol. Surv. Herb. Mohr.

BETULA L. Sp. Pl. 2 : 982. 1753. BirCH.

About 30 species, boreal and temperate zones of Northern Hemisphere, Europe and Asia. North America, 11. Deciduous trees.

Betula lenta L. Sp. Pl. 2:983. 1753. Cherry Birch. Mountain Mahogany. Betula excelsa Ait. Hort. Kew. 3 : 337. 1789.

Ell. Sk. 2:617. Gray, Man. ed.6:471. Chap. Fl. 428. Sargent, Silv. N. A. 9:50, t. 447 .

Canadian zone, Alleghenian and Carolinian areas. Newfoundland, Ontario; New England to northern Delaware, south along the mountains 3,000 to 5,000 feet to Georgia.

AlABAma: Mountain region. Rocky ridges of greatest elevation. Clay County, Chehawhaw Range, 2,400 feet; shrubby, scarcely over 4 feet high. Winston County, rocky bauks Sipsey fork, 1,600 feet; tree of medium size. Very rare.

Economic uses: On its extreme southeru limit of no importance, being of stunted growth.

Type locality: "Hab. in Virginia, Canada."

Herb. Geol. Surv. Herb. Mohr.

Betula nigra L. Sp. Pl. 2 :982. 1753.

BIAACK BIRCH.

Betula rubra Michx. f. Hist. Arb. Am. 2 : 142. 1812.

Ell. Sk. 2:616. Gray, Man. ed. 6, 472. Chap. Fl. 428. Coulter, Contr. Nat. Herb.

$2: 413$. Sargent, Silv. N. A. 9:61, t. 45\%.

Alleghenian to Louisianian area. New England, west to Minnesota, Nebraska, and eastern Kansas, south to New Jersey, Florida, and the Gulf States, west to Texas and Arkansas.

Alabama: Over the State. Of largest dimensions and most frequent on river lanks of the Lower hills, as for example, on the Mulberry Fork of the Warrior River in Blount County, and Marriotts Creek in Cullman County.

Economic uses: Timber tree of lesser value.

Type locality: "Hab. in Virginia; Canada."

Herb. Geol. Surv. Herb. Mohr.

ALNUS Gaertn. Fruct. $2: 54$, t.90. 1791. Alder.

Fourteen species, cooler and temperate regions. Europe, Asia, South America, South Africa. Extratropical South America. North America, 8 species. Deciduous trees.

Alnus rugosa (Du Roi) Koch, Dendrol. 2 : 635.1872.

Betula alnus rugosa Du Roi, Harbk. 1 : 112. 1771.

Alnus serrulata Willd. Sp. Pl. 4 : 336.1805.

Ell. Sk. 2:567. Gray, Man. ed.6, 473. Chap. Fl. 429. Coulter, Contr. Nat. Herb. $2: 413$.

Alleghenian to Louisianian area. New England west to Michigan, south to Florida and the Gulf States, west to eastern Texas and Arkansas.

Alabama: Throughout the State. Low banks of streams, common. Flowers in February.

Economic uses: The bark, known as "alder bark," is used as a dyestuff, and in domestic medicine.

Type locality of A. serrulata : "Hab. a Pensylvania ad Carolinam."

Herb. Geol. Surv. Herb, Mohr. 


\section{FAGACEAE. Beech Family.}

FAGUS L. Sp. Pl. 2 : 997. 1753. BEECH.

Four species, deciduons trees. Europe and temperate North America.

Fagus americana (Muench.) Sweet, Hort. Brit.370. 1826.

AMERICAN BEECH.

Fagus americana (latifolia) Muench. Hausv. 5 : 162. 1770.

F. sylvatica atropunicea Marsh. Arb. Am. 45. 1785.

$F$. ferruginea Ait. Hort. Kew. 3:362. 1789.

Eil. Sk. 2:613. Gray, Man. ed. 6, 480. Chap. Fl. 425. Coulter, Contr. Nat. Herb. 2:418. Sargent, Silv. N. A. $9: 27, t$. 444. 1895.

Alleghenian to Louisianian area. Nova Scotia, New Brunswick, and Ontario to Georgian Bay; New England, through the Atlantic and Gulf States; Wisconsin, south to valley of Trinity River, Texas, and Arkansas.

Alabama : All over the State. Rich woods. Common ou the hammock lands of the coast. Baldwin County, stockton. Mobile County.

Economic uses: 'Timber tree.

Type locality not ascertained.

Herb. Geol. Surv. Herb. Mohr.

\section{CastaneA Adans. Fam. Pl. $2: 375.1763$. Chestnut.}

Three species, deciduous trees, temperate Europe and North America.

Castanea dentata (Marsh.) Borkh. Forst. Bot. 1:741. 1800. American Chestrut.

Fagu8 castanea dentata Marsh. Arb. Am. 46. 1785.

Castanea vesca americana Michx. Fl. Bor. Am. 2:193. 1803.

Ell. Sk. 2:614. Gray, Man. ed. 6:479. Chap. Fl. 424. Sargent, Silv. N. A. 9:11, t. $440,441.1896$.

Alleghenian, Caroliniau, and Louisianian areas. Southern Ontario, New England, west to southern Michigan, southern Illinois, from Delaware along the mountains to South Carolina and Georgia.

AIdBAma : Mountain region to Lower hills. Tuscaloosa County, most frequent on the rocky ridges of the table-lands, above an elevation of 800 feet. Cullman, Dekalb, Morgan, and Winston counties. Flowers in May; fruit ripe in October. Frequent. South of the hill country at present almost extinct. In the mountains, the region of its best development, young trees of thrifty growth are scarcely met with.

Economic uses: Important timber and nut tree.

Type locality: North America.

Herb. Geol. Surv. Herb. Mohr.

Castanea pumila (L.) Mill. Gard. Dict. ed. 8, no.2. 1768.

Chinguarin. Fagus pumila L. Sp. Pl. 2 : 998. 1753.

Ell. Sk. 2:615. Gray, Man. edl. 6, 479. Chap. Fl. 424. Coulter, Contr. Nat. Herb. $2: 418$. Sargent, Silv. N. A. $9: 15, t .442,443$.

Carolinian and Lonisianian areas. Sonthern Pennsylvania to Florida, west to eastern Texas, Arkansas, Missouri, southern Indiana, and eastern 'Tennessee.

Alabama: From the Tennessee Valley to the Gulf. Dry open woods, copses. Flowers white, May; fruit ripe in September and October. A small tree, often shrubby ; frequent.

Economic uses: The nuts are edible.

Type locality: "Hab. in America septentrionali."

Herb. Geol. Surv. Herb. Mohr.

\section{QUERCUS L. Sp. Pl. 2 :994. 1753. OAK.'}

About 250 species, widely distributed throngh the Northern Hemisphere. Europe, Asia, Mexico, North Anerica, 40; South Atlantic North America, 24; Pacific, 13; Middle States, New England, 10. Deciduous and evergreen trees; more rarely shrubbj.

Quercus alba I.Sp. Pl. 2 :996. 1753.

White OAK. RidGe White OAK.

Ell. Sk. 2:607. Gray, Man.ed.6, 475. Chap. Fl. 423. Coulter, Contr. Nat. Herb. $2: 414$. Sargent, Silv. N. A. $8: 16, t .356,35 \%$.

Alleghenian to Lonisianian area. Quebec, Ontario; New England west to Minnesota, Nebraska, eastern Kansas, south to the St. Johns River and Tampa Bay, and from Florida to eastern Texas. 
AlabaMa: Throughont the State. In rich woodlands. Flowers in April; fruit ripe in October. Most frequent, and attaining greatest perfection, in the rich terraces atove the alluvial bottoms and in similar situations in the valleys and coves of the upper Alabama and Tombigbee rivers and their tributaries. South of the Central Prairie region of little importance.

Economic uses: One of the most valuable of our hard wood timber trees. The bark is the "white oak bark, Quereus alba," of the United States Pharmacopœia.

Type locality: "Hab. in Virginia."

Herb. Geol. Surv. Herb. Mohr.

Quercus minor (Marsh.) Sargent, Gard. \& For. 2: 471. 1889.

Post OAK.

Quercus alba minor Marsh. Arb. Am. 120. 1785.

Q. stellata Wangenh. Am. 78, t. 6, f. 15. 1787.

Q. obtusiloba Michx. Hist. Chên. Am. no. 1, t. 1. 1801.

Eil. Sk. 2:606. Gray, Man. ed. 6, 475. Chap. Fl. 423. Coulter, Contr. Nat. Herb. $2: 414$. Sargent, Silv. N. A. 8: $37, t .368,369$.

Carolinian and Lonisianian areas. Southern Outario, southern New England to eastern Nebraska and Kansas, south to Florida and west to central Texas.

Alabava: All over the State. In the uplands of the Tennessee Valley with a richer clay soil a good sized timber tree. Most frequent in the open woods of the Central Prairie region. In the Upper division of the Coast Pine belt of a more sturdy growth, inferior in size in the poorer soils of the Warrior table-lands, the lower hills, and the pine barrens. Flowers in April; fruit ripe in October.

Economic uses: Valnable timber tree.

Type locality: North America.

Herb. Geol. Surv. Herb. Mohr.

Quercus lyrata Walt. Fl. Car. 235. 1788.

OVERCUP OAK.

Ell. Sk. 2:607. Gray, Man. ed. 6, 475. Chap. Fl. 423. Coulter, Contr. Nat. Herb.

$2: 414$. Sargent, Silv. N. A. 8: $47, t .374$.

Carolinian and Louisianian areas. North Carolina along the coast to Florida, west to the lower Brazos. Texas, sonthern Arkansas, and southeru Missouri.

Alirama : Central Prairie region to the Mobile River. Of best development and most frequently met with in the swampy alluvial bottoms of the Alabama River in the center of the State. Much reduced in size near the coast. Montgomery Connty, 80 to 90 feet high, $2 \frac{1}{2}$ feet diameter. Mobile County, Battles Creek, small tree.

Economic uses: Valuable timber tree.

Type locality: South Carolina.

Herb. Geol. Surv. Herb. Mohr.

Quercus prinus L. Sp. Pl. 2 :995. 1753.

Mountain Oak. Tan-bark Oak. Chestnut Oak.

Quercus prinus monticola Michx. Hist. Chên. Am. no. 5, t. \%. 1801.

Q. montana Willd. Sp. Pl. 4:440. 1805.

Eil. Sk. 2:609. Gray, Man. ed. 6, 476. Chap. Fl.424. Sargent, Silv. N. A. 8:51, t. $35 \%, 376$.

Alleghenian and Carolinian areas. Southern Ontario, southern New England, New York, New Jersey, south throughont the Alleghenian Mountains to Georgia.

Alabama: Mount:in region. Rocky woods and hillsides. Of large dimensions and most frequent on the table-lands above 800 feet. Stunted, scarcely reaching medium size, on rocky and gravelly ridges in the Coosa Valley. Cullman and Morgan counties. Dekalb County, Lookout Mountain ridges. Winston, Marshall, Cleburne, and Talladega counties. Calhomn County, about Anniston, 800 feet, of low growth.

Ecouomic uses: Valuable timber tree; most important for tan bark.

Type locality: "Hab. in America boreali."

Herb. Geol. Surv. Herb. Mohr.

Quercus acuminata (Michx.) Sargent, Gard. \& For. 8:93. 1895.

Yellow Chestnut Oak. Chinquapin OAK (in Alabama).

Quercus prinus acuminata Michx. Hist. Chên. Am. no. 5, t.8. 1801.

Q. castanea Willd. Neue Schrift. 3:391. 1807. Not Née.

Q. muhlenbergii Engelm. Trans. St. Louis Acad. 3:391. 1877.

Eil. Sk. 2:610. Gray, Man. ed. 6, 476. Chap. Fl. 424. Coulter, Contr. Nat. Herb.

2:415. Sargent, Silv. N. A. 8:55, t.37\%.

Alleghenian and Carolinian areas. New England (Vermont), northern New York, Ohio Valley west to Missouri, south to Now Jersey and along the mountains to northern Alabama, west to Texas and Arkansas.

Alabama : Tennessee Valley and Mountain region to Lower hills. Lawrence 
County, Big Nancy. Morgan, Madison, and Lauderdale counties. Bibb County,

Tionus. Not frequent. Prefers a calcareous soil.

Economic uses: Of little importance.

Tspe locality not ascertained. Locality in Michx. Fl.: "Hab. in montibus Alleghanis."

Herb. Geol. Surv. Herb. Mohr.

Quercus michauxii Nutt. Gen. 2:215. 1818.

COW OAK. Basket OAK.

Quercus prinus var. michauxii Chap. Fl.424. 1860.

Ell. Sk. 2:609. Gray, Man. ed. 6, 476. Chap. Fl. 424. Coulter, Contr. Nat. Herb. $2: 414$. Sargent. Silv. N. A. 8:67, t.382.

Carolinian and Louisianian areas. Delaware to Florida, southern Indiana, Missouri. Thronghout the Gulf States to Texas and Arkansas.

Alabama: Thronghout the State. In rich bottom lands, snbject only to oceasional overflow. Most frequent and of largest dimensions in the Tennessee Valley, on the Alabama and Tombigbee rivers and their larger trihutaries north of the lower Coast Pine belt. Rare in the Pine region and in the Coast plain. Mobile Connty, Bayou La Batre.

Economic uses: Of great importance as the most abundant source of white oak timber.

Type locality: "Indigenous to allnvial lands, from the Delaware to St. Marys in west Florida."

Herb. Geol. Surv. Herb. Mohr.

Quercus brevilobata (Torr.) Sargent, Gard. \& For. 8: 93. 1895.

Texan White Oak. Pin Oak. Bastari Oak.

Quercus obtusifolia var. brevilobata Torr. Bot. Mex. Bounıl. 206. 1858.

Quercus durandii Buckl. Proc. Phila. Acad. $1860: 445.1861$.

Chap. Fla. ed. 3, 447. Coulter, Contr. Nat. Herb. $2: 415$. Sargent, Silv. N. A. $8: 71,384$.

Carolinian and Lonisianian areas. Georgia to Alabama, central Mississippi, and western Texas.

Alabama: Mountain region to Central Prairie region. On rich calcareous ridges. Blount County, valley of Mulberry Fork; Warnock Monntain, 600 feet. Bibb County, Prutt's Ferry (E. A. Smith). Most frequent and of best dlevelopment in the Prairie region, between the Alaliama and Tombigbee rivers. Hale County, Gallion. Dallas County, Uniontown. Wilcox County (Buckley). Frequently 80 feet high and 2 feet in diameter.

Economic uses: Of sone value for its timber and for fuel.

Typo locality : "Mountain gorges near How ards Springs, western Texas (Bigelow)."

Herb. Geol. Surv. Herb. Mohr.

Quercus virginiana Mill. Dict. ed. 8, no.16. 1768.

Quercus sempervirens Walt. F'l. Car. 234. 1788.

Q. virens Ait. Hort. Kenv. 3:356. 1789.

Eil. Sk. 2:595. Gray, Man. edl. 6, 477. Chap. Fl. 421. Conlter, Contr. Nat. Herb.

2:416. Sargent, Silv. N. A. 8:99, 395 .

Cuba, Northern Mexico, Costa Rica.

Lonisianian area. Coast of the South Atlantie and Gulf States, from southern

Virginia to Texas.

Alabana : Coast plain, and adjacent pine liils; scarcely seen north of latitude $31^{\circ}$.

Mobile and Baldwin counties. Flowers middle of April; fruit ripe, October,

November.

Economic nses: Valuable for its timber. The bark is used in tanning.

Type locality not ascertained.

Herb. Geol. Surv. Herb. Mohr.

Quercus virginiana maritima (Michx.) Sargent, Silv. N. A.8:100. 1895.

Quercns phellos maritima Michx. Hist. Chên. Am. no. 7, t. 13, f. 3. 1801.

Q. maritima Willd. Sp. Pl. 4:424. 1805 .

Q. virens maritima Cliap. Fl.421. 1860.

Eil. Sk. 2:596. Chap. Fl.l. c.

Louisianian area. Sonth Carolina to Florida.

Alabama: Littoral region. Drifting sands near the seashore. Mobile County, Navy Cove.

Type locality: "Hab. in Carolina."

Herb. Geol. Surv. Herb. Mohr. 
Quercus texana Buckl. Proc. Acad. Phila. $1860: 444.1861$.

'T'exan OAK. Southern Red OAK. Spotted OAK.

Sargent, Gard. \& For. $7: 81$; Silv. N. A. 8: 129. Coulter, Contr. Nat. Herb. 2 : 416.

Carolinian and Louisianian areas. From the Gulf and Southern Atlantic States to Tennessee, western Kentucky, southern Indiana, southern Illinois, Iowa, southern Missouri, Arkansas, and the Colorado Valley in Texas.

A labama: 'Tennessee Valley to the coast In rich low woods. Morgan County, Falkville. Cullnan County. Monroe County, Claiborne. Clarke County, Choctaw Corner. Mobile County, Pierce's Landing. Bald win County, Stockton.

Economic uses: Important timber tree. The bark, under name of "red-oak bark," is userl medicinally.

Type locality: Texas.

Herb. Geol. Surv. Herb. Mohr.

Quercus coccinea Muench. Hausv. 5 : 254. 1770.

SCARLET OAK.

Quercus rubra $\beta$ L. Sp. Pl. ed. 2, 2 : 1414. 1763.

Ell. Sk. 2:602. Gray, Man. ed.6, 477. Chap. Hl. 422. Sargent, Silv. N. A. 8 : 133, t. 412 .

Alleghenian and Carolinian areas. Southern Delaware to Tennessee, along the mountains to Georgia.

Alabama : Mountain region. Dry uplands, sandy and rocky soil. Table-land of Warrior River; frequent. Highlands of Coosa Valley rarely below 800 feet. Lawrence, Winston, Dekalb, Cullman, and Etowah counties.

Economic uses: Of little value except for fencing and fuel.

Type locality not ascertained.

Herb. Geol. Surv. Herb. Mohr.

Quercus rubra L. Sp. Pl. 2:996. 1753.

RED OAK.

Ell. Sk. 2:602. Gray, Man. ed. 6.477. Chap. Fl. 422. Coulter, Contr. Nat. Herb.

$2: 416$.

Aileghenian and Carolinian areas. Canada to Georgia and Mississippi.?

Alabama: Mountain region. Dekalb County, frequent on Lookout Monntain. Jefferson County, Red Mountain, near Birmingham (Sargent).

Type locality: "Hab. in Virginia, Carolina."

Economic uses: Timber tree of inoderate value. The bark is the "red oak bark," Quercus rubra, of the U.S. Pharmacopœia.

Quercus velutina Lam. Encycl. 1:721. 1783. Black OAK. Quercitron OAK. Quercus discolor Ait. Hort. Kew. 3 : 358. 1789.

Q. tinctoria Bartram, Travels, 37. 1791. Name only.

Q. tinctoria Michx. Hist. Chên. Am. no. 13, t. 25. 1801.

Q. coccinea var. tinctoria Gray, Man. ed. 5, 454. 1868.

Ell. Sk. 2:601. Gray, Man. ed. 6,477. Chap. Fl. 422. Sargent, Silv. N. A. 8 : 37, t. 415,416 .

Alleghenian to Lonisianian area. Southern Ontario, Minnesota, southern Maine, sonth to Florida, Louisiana, and Arkansas.

Alabama: From the Tennessee Valley over the mountains to the Upper division of the Coast Pine belt. In the Lower Pine region of stunted growth. Flowers April; fruit ripe in October. Frequent on the table-lands.

Economic uses: Timber tree. Bark used in tanning and for dyestuff-"quercitron bark."

Type locality: "On le dit originaire de l'Amérique septentrionale."

Herb. Geol. Surv. Herb. Mohr.

Quercus catesbaei Michx. Hist. Chên. Am. no. 17, t. 29, 30. 1801.

TURKEY OAK. BarReN OAK. FORKED-Leaf Black Jack.

Ell. Sk. 2:603. Chap. Fl. 422. Sargent, Silv. N. A. $8: 143$, t. $41 \%$.

Louisianian area. Coast of North Carolina, south to Cape Malabar, Florida, and west to Louisiana (east of the Mississippi).

Alabama: Central Pine belt to the coast. On sterile sandy pine ridges. Autauga County, Kingston, and throughout the Coast Pine belt. Flowers March; frnit ripe in October. Small tree. Abundant in sandy pine barrens.

Economic uses: For fuel.

Type locality not ascertained. Locality in Michx. Fl.: "Hab. in Marylandia, Virginia, et Carolina."

Herb. Geol. Surv. Herb. Mohr. 
Quercus digitata (Marsh.) Sudworth, Gard. \& For. 5:98. 1892.

SPANISH OAK. RED OAK (in northern Alabama).

Querous nigra digitata Marsh. Arb. Am. 121. 1785.

Q. cuneata Wangenh. N. Am. Holzart. $78, t .5$, f. 14.1787.

Q. falcata Michx. Hist. Chên. Am. no. 16, t. 28. 1801.

Ell. Sk. 2:604. Gray, Man. ed. 6,478. Chap. Fl. 422. Coulter, Contr. Nat. Herb. 2:417. Sargent, Silv. N. A. 8:147, t. 420 .

Carolinian and Louisianian areas. From the valley of the Brazos, Texas, through the Gulf and Atlantic Southern States west to Tennessee, Arkansas, Missouri, and north to New Jersey.

Alabama: Throughout the State, excepting the highest summits, to the coast. Of largest size in the bench lands of the Tennessee Valley and in rich bottoms. Most common, but of inferior quality, on the uplands. Mobile County. Flowers March and April; fruit ripe in October.

Economic uses: Valuable timber tree. The bark used for tanning.

Type locality: North America.

Herb. Geol. Surv. Herb. Mohr.

Quercus pagodaefolia (Ell.) Ashe, Bot. Gaz. 24 : 375.1897.

SPANISH OAK.

Quercus falcata var. pagodaefolia Ell. Sk. 2 : 605. 1821-24.

Carolinian and Louisianian areas. Georgia to North Carolina, west to Louisiana and Arkansas.

Ala Bama: Central Prairie region to the Tennessee Valley. Damp alluvial forests. Morgan County, Falkville. Hale County.

To this species have been somewhat dubiously referred the forms differing more or less in their foliage from the typical $Q$. digitata of the uplands and confined to the rich damp forests of the valleys.

Tree of large size, 90 to 100 feet high and from 2 to 3 feet and over in diameter.

Economic uses: Fine timber tree.

Type locality: "This tree I first noticed on the banks of the Roanoke in North Carolina, along the road from Petersburg to Raleigh. I have since seen it near Granby, S. C."

Quercus marylandica Muench. Hausv. 5 : 253. 1770.

BLACK JACK.

Quercus nigra Wangenh. N. Am. Holzart. 133. 1781.

Ell. Sk. 2:600. Gray, Man. ed. 6, 478. Chap. Fl. 421. Coulter, Contr. Nat. Herb. $2: 417$. Sargent, Silv. N. A. 8: 861, $t .426,42 \%$.

Alleghenian? to Louisianian area. Long Island, New York; west from northern Ohio to Minnesota, eastern Kansas, Indian Territory; south from New Jersey to Florida, through the Gulf States to the Nueces Valley, Texas.

Alabama : Over the State. Mobile County, April; common.

Economic uses: For fuel.

Type locality not ascertained.

Herb. Geol. Surv. Herb. Mohr.

Quercus nigra L. Sp. Pl. 2 : 995.1753.

WATER OAK.

Quercus nigra aquatica Lam. Encycl. 1: 721. 1783.

Q. aquatica Walt. Fl. Car. 234. 1788.

Ell. Sk. 2:599. Gray, Man. ed. 6, 478. Chap. Fl. 421. Coulter, Contr. Nat. Herb.

2:417. Sargent, Silv. N. A. $8: 165, t .428$.

Carolinian and Louisianian areas. From the Colorado Valley, Texas to Florida; north to Delaware, sonthwestern Tennessee, and southern Missouri.

AsabaMa : Tennessee Valley to the coast. Low rich woods and sandy pine-barren swamps. Clay County, Talladega Creek, 1,000 feet. Cullman County, 800 feet. Morgan County, Falkville. Madison and every county south. Flowers March; fruit ripe in October, November. Common.

Economic uses: 'Timber tree. A common shade tree.

Type locality: "Hab. in America septentrionali."

Herb. Geol. Surv. Herb. Mohr.

Quercus laurifolia Michx. Hist. Chên. Am. no. 10, t.1\%. 1801.

Quercus phellos laurifolia Chap. Fl.420. 1860.

Ell. Sk. 2:597. Chap. F1.420. Sargent, Silv. N. A. 8: 169, t. 429.

Carolinian and Louisianian areas. Eastern Gulf States to Florida (Mosquito

Inlet). North along the Atlantic coast to the Dismal Swamp in Virginia. 
Alabama: Central Pine belt to the Coast plain. Low rich woods. In great perfection in the Central Prairie belt and Coast plain. Frequent.

Economic uses: Little valued for the timber, most esteemed as an evergreen shade tree.

Tspe locality not ascertained. Locality of Michx. Fl.: "Hab. in Carolina meridionali et Georgia."

Herb. Geol. Surv. Herb. Mohr.

Quercus phellos L. Sp. P1. 2 : 994.1753.

Ell. Sk. 2: 593. Gray, Man. ed. 6, 479. Chap. Fl. 420. Coulter, Contr. Nat. Herb. 2:417. Sargent, Silv. N. A. 8: 179, $t .433$.

Carolinian and Louisianian areas. Staten Island, New York, aloug the coast to northeastern, Florida and the central parts of the Gulf States to the Sabine Valley, Texas.

Alabama: Tennessee Valley to Central Pine belt. In the bottom lands, borders of swamps. Most frequent in the coves of the Tennessee basin in low woods of a cold damp soil. Morgan County, Falk,ville, 600 feet. Franklin County, Russellville. Tuscaloosa County. Farther south rare.

Economic uses: Timber tree.

Type locality: "Hab. in America septentrionali."

Herb. Geol. Surv. Herb. Mohr.

Quercus myrtifolia Willd. Sp. Pl. 4 : 424.1805.

SFASIDE SCRUb OAK.

Quercus phellos var. arenaria Chap. Fl. 420. 1860.

Ell. Sk. 2: 597. Chap. Fl. 420, ed. 3, 445. Sargent, Silv. N. A. $8: 123$, t. 408.

Louisianian area. Coast from South Carolina to Florida, west to Alabama.

AlabaMa: Littoral region. Scarcely over 6 to 8 feet high, covering the drifting sands of the seacoast and islands. Baldwin County, Fish River, Navy Cove, Perdido Bay.

Type locality: "Hab. in Carolina."

Herb. Geol. Surv. Herb. Mohr.

Quercus brevifolia (Lam.) Sargent, Silv. N. A. 8:171, $t$ 431. 1893.

UPLAND Willow OAK. BLUE JaCk.

Quercus phellos brevifolia Lam. Encycl. 1:722. 1783.

Q. humilis Walt. Fl. Car. 234. 1788.

Q. cinerea Micbx. Hist. Chề. Am. no. 8, t.146. 1801.

Ell. Sk. 2:594. Chap. Fl. 421. Coulter, Contr. Nat. Herb. 2:417.

Carolinian and Louisianian areas. Gulf States west to the Brazos Valley, Texas.

From Florida (Cape Malabar) along the coast to North Carolina.

Alabama : Lower hills. Central and Coast Pine belt. Common in the dry sandy pine barrens. Walker County, South Lowell.

Economic uses: Valuable for fuel.

Type locality: "Il croit dans un terroir sec et maigre" [in North America].

Herb. Geol. Surv. Herb. Mohr.

Quercus imbricaria Michx. Hist. Chên. Am. no. 9, t. 15, 16. 1801. Shingle OAK. 432 .

Ell. Sk. 2:598. Gray, Man. ed. 6, 478. Chap. Fl. 420. Sargent, Silv. N. A. 8: 175,

Alleghenian and Carolinian areas. Western Pennsylvania through the Ohio Valley to southern Michigan, southern Wisconsin, southern Nebraska, southern Kansas, and Missouri, south to Virginia and 'Tennessee, and along the mountains to Georgia.

Alabama: Coosa Valley. Etowah County, about 600 feet altitude, near Gadsden. One single tree at the present known.

Type locality not ascertained. Locality in Michx. Fl.: "Hab. in montibus Alleghanis."

Herb. Geol. Surv. Herb. Mohr.

Quercus heterophylla Michx. f. Hist. Arb. Am. 2:87, t. 16. 1813. Bartram OAк.

Coulter, Contr. Nat. Herb. $2: 417$.

Believed to be a hybrid of $Q$. phellos and velutina or rubra or coccinea.

Carolinian area. Sparsely diffused and local from Staten Island to Delaware, North Carolina, northern Alabama, and northeastern Texas.

Alabama: Tennessee Valley. In low woods. Morgan County, Falkville, about 600 feet. Associated with willow, black, and Texas oak. Only locality known in the State.

Type (Michx. trans.) locality: "On the banks of the Schuylkill River, four miles from Philadelphia."

Herb. Geol. Surv. Herb. Mohr. 


\section{ULMACEAE. Elm Family.}

ULMUS L. Sp. Pl. 1:225. 1753. ELM.

Sixteen species, of temperate region of North Hemisphere and in the mountains of the tropics. Deciduons trees.

Ulmus americana L. Sp. Pl. 1 : 226. 1753.

White ELM.

Ell. Sk. 1: 333. Gray, Man. ed. 6, 462. Chap. Fl. 416. Conlter, Contr. Nat. Herb. 2: 406. Sargent, Silv. N. A. $7: 43, t .311$.

Canadian zone to Louisianian area. Ontario to Saskatchewan, $53^{\circ}$ latitude; New England west to Kansas, Nebraska, Dakota, Arkansas, and the headwaters of Missouri River, south through the Ohio Valley and the South Atlantic and Gulf States to Florida, Texas, and Arkansas.

Alabama : All over the State. In rich woods. Nowhere abundant. Tuscaloosa and Cullman conuties. Jefferson County, Birmingham. Montgomery and Mobile counties. Flowers in February ; fruit ripe in May.

Economic uses: Timber and ornamental tree. Frequently planted for shade.

Type locality: "Hab. in Virginia."

Herb. Geol. Surv. Herb. Mohr.

Ulmus alata Miehx. Fl. Am. Bor. 1:173. 1803.

WaHoo. Winged Elm.

Ell. Sk. 1:334. Gray, Man. ed.6, 462. Chap. Fl.417. Coulter, Contr. Nat. Herb.

2:406. Sargent, Silv. N. A. $7: 51, t .313$.

Carolinian and Louisianian areas. Southern Virginia, middle Tenuessee, southern

Indiana, Missouri, Arkansas, Indian Territory, south and west from North Carolina to Florida, Alabama, and the valley of the Trinity River in Texas.

Alabama : Over the State. Low wouds, banks of streams. Landerdale, Cullman. and Antauga counties. Baldwin County, Stockton. Of largest development in the low forests of the Central prairies. Forty to 60 feet high, 12 to 18 inches in diameter. Economic uses: 'Timber tree.

Type locality: "Hab. in I irginia et Carolina inferiore."

IIerb. Geol. Surv. Herb. Mohr.

Ulmus fulva Michx. Fl. Bor. Am. 1: 172. 1803.

Slippery Elm. Red Elit.

Ulmus pubescens Walt. Fl. Car. 112. 1788.

Ell. Sk. 1:333. Gray, Man. ed. 6, 462. Chap. Fl. 416. Coulter, Contr. Nat. Herb.

$2: 406$. Sargent, Silv. N. A. 7:53, t. 305 .

Cauadian zone to Louisianian area. Quebec, Ontario; New England, west to Minuesota, Nebraska, eastern Kansas, and Missouri; sonth to western Florila and the Gulf States, to the valley of San Antonio River, Texas.

Alabama: Rich bottoms. Cullman County. Jackson County, Stevenson. Montgomery County. Iutanga County, banks of Alabana River. Flowers in February ; fruit ripe in April. Not frequent. Not observed sonth of Montgomery.

Economic uses: Of little importance for its timber. The bark is the "slippery elm bark," or "Ulmus," of the U. S. Pharmacopoia.

Type locality: "Hab. in Canada, Vermont, Connecticnt, montibus Alleghanis, ete.

frigid. Americe regionibus."

Herb. Geol. Surv. Herb. Mohr.

Ulmus serotina Sargent, Bot. Gaz. 27: 92.1899.

Ulmus racemosa Chap. Fl. ed.2,649. 1887. Same, ed.3,440. 1897.

A stately tree, trunk 30 to 40 feet high, and 2 to 3 feet in diameter. "Leaves oblongobovate, acuminate, variously oblique at the base, coarsely ancl doubly crenate-serrate, glabrous and lustrous above, puberulous below on the prominent midrib and veins; flowers perfect, autumnal, racemose, long-pedicellate; calyx six-parted, its divisions oblong-obovate, rounderl at the apex; ovary sessile, narrowed at the base, hirsute; samaras stipulate, oblong-elliptical, deeply two-parted at the apex, ciliate on the margins ; seed obovate, raphe conspicuous."

Carolinian area. North Carolina, French Broad River (Rugel, 1842). Tennessee, limestone ridges near Nashville (Gattinger). Georgia, near Rome (Boynton); also planted in the streets (Sargent).

Alabama : Mountain region. Limestone ridges, Madison County.

'There can be no loubt that the large trees with bark-winged branchlets met with in the forests of the Cretaceous plain of the Central Prairie belt when observed in flower and fruit will be found to belong to this late-blooming elm.

Type locality not specifically given. Specimens cited from points already mentioned. 
PLANera Gmel. Syst. Pl. 1: 150. 1791. Planer Tree.

Monotypical North American deciduous aquatic treo.

Planera aquatica (Walt.) Gmel. Syst. Pl. 1: 150. 1791.

Anonymos aquatica Walt. Fl. Car. 230. 1788.

Planera gmelini Michx. Fl. Bor. Am. 2 : 248. 1803.

Ell. Sk. 2:584. Gray, Man. ed. 6, 463. Chap. Fl. 417. Coulter, Contr. Nat. Herb.

2:407. Sargent, Silv. N. A. 7:61, 316 .

Carolinian and Louisianian areas. From the Trinity Valley, Texas, southern Arkansas to southern Alabama and western Florida along the Atlantic coast to North Carolina (Cape Fear. River). Western Tennessee, southern Illinois (Gray, Man.).

Alabama: Central Pine belt to Coast plain. Densely shaded river banks almost perpetually overflowed. Montgomery County. Clarke County, Lisbon. Mobile County, Mount Vernon (Davis Lake). Flowers February; fruit ripe early in April, not rare. A low tree 20 to 30 feet high, scarcely over 1 foot in diameter.

Type locality: South Carolina.

Herb. Geol. Surv. Herb. Mohr.

Celtis L. Sp. Pl. 2 : 1044. 1753. Nettle Trke.

Fifty to 60 species, temperate and warmer regions. North America, 5 or 6 . United States and Canada, 2 or 3 . Decidnous trees, more rarely shrubs.

Celtis mississippiensis Bosc, Encycl. Agr. 7 : 577.1822.

SOUthern HaCkBerry. SUgarberry.

Celtis laevigata Willd. Berl. Baumz. ed. 2, 81. 1811.

Gray, Man. ed. 6, 463 . Coulter, Contr. Nat. Herb. 2:407. Sargent, Silv. N. A. 7: $71, t .318$.

Carolinian and Louisianian areas. Frequent all over the Gulf and South Atlantic States to middle Tennessee, southern Illinois, south western Kentucky, west to central Texas, Arkansas, Indian Territory, and sonthern Kansas.

Alabama: From the Tennessee Valley to the coast plain, excepting the valleys of the highest level in the mountain region. In rich woods. Of largest size and most frequent in the bottom lands of the Alabama and Tombigbee rivers and their larger tributaries. Lauderdale and Florence counties. Cullman County, Marriotts Creek. Tuscaloosa, Montgomery and Mobile counties. Baldwin County, Stockton. Frequent.

Economic uses: Valuable timber tree.

Type locality not ascertained.

Herb. Geol. Surv. Herb. Mohr.

Celtis occidentalis L. Sp. Pl. 2 : 1044. 1753.

SUGARBERRY. HACKBERRY. Gray, Man. ed. 6, 463. Chap. Fl. 417. Coulter, Contr. Nat. Herb. 2: 407.

Alleghenian and Carolinian areas. New England to Ontario, Minnesota, Nebraska, and Colorado, south to 'Texas, and from Now Jersey to Tennessee and Georgia.

Alabana: Metamorphic hills. Rocky banks. Clay County (Baker \& Earle).

At its southern limit a tree of about medium size.

Type locality : "Hab in Virginia."

Celtis occidentalis pumila (Pursh) Gray, Man. ed. 2, 397. 1856.

Ccltis pumila Pursh, Fl. Am. Sept. 1:200. 1814.

SCRUBBY SUGARBERRY.

Gray, Man. ed. 6, 463. Chap. Fl. 417.

Carolinian and Louisianian areas. Maryland to western Florida, Texas, and southern Arkansas.

Alabama: Prairie region. Upper division Coast Pine belt. Dry rocky banks and hillsides. Hale County, bald prairies, Gallion. Straggling shrub, rarely over 10 feet high. Flowers April ; fruit ripe September, purplish black.

Type locality: "On the banks of rivers: Maryland and Virginia."

Herb. Geol. Surv. Herb. Mohr.

\section{MORACEAE. Mulberry Family.}

TOXYLON Raf. Am. Month. Mag. $2: 118.1817$. Bors D'ARC.

(Maclura Nutt. Gen. $2: 233.1818$. )

Toxylon pomiferum Raf. Am. Month. Mag. 2 : 118. 1817.

Maclura aurantiaca Nutt. Gen. 2 : 234. 1818.

Gray, Man. ed.6, 464. Coulter, Contr. Nat. Herb. $2: 408$. Sargent, Silv. N. A. $7: 89$,

t. 122, 123. 
Carolinian and Lonisianian areas. Northwestern and central Texas and southern Arkansas

Ala Bama: Introduced from the Southwest, and frequently cultivated for hedges. Not rarely naturalized about fields and dwellings, chiefly in the Prairie region.

Flowers in April. Fruit ripe in October.

Economic nses: Valuable for the wood; hedge plant.

Type locality not ascertained.

Herb. Geol. Surv. Herb. Mohr.

BROUSSONETIA L'Herit.; Vent. Tabl. 3 :547. 1799.

Two species, China, Japan. Trees.

Broussonetia papyrifera (L.) Vent. 'J'abl. 3:548. 1799.

PAPER Mulberiry.

Morus papyrifera L. Sp. Pl. 2 : 986.1753.

Introdnced from Japan. Frequently cultivated in the Southern States as a shade tree; not infrequently of spontaneous growth, and difficult to eradicate.

Alabama : Mobile and Montgomery counties.

Type locality: "Hab. in Japonia."

Herb. Geol. Surv. Herb. Mohr.

\section{MORUS L.Sp.Pl.986. 1753. MULbERRY.}

Ten species, temperate Northern Hemisphere, tropical mountains. United States and Canada, 2. Deciduous trees.

Morus rubra L. Sp. Pl. 2 : 986. 1753.

RED MULberRY.

Ell. Sk. 2 :574. Gray, Man. ed. 6, 464. Chap. Fl. 415. Coulter, Contr. Nat. Herb. $2: 408$. Sargent, Silv. N. A. 7: 79, $t, 320$.

Alleghenian to Louisianian area. Southern Ontario; New England, west to Dakota, Nebraska, and Kansas, south to the Gulf States; from Florida to Texas and Arkansas.

Alabama : Throughout the State, in low rich woods, to the delta of Mobile River.

Baldwin County, Stockton. Mobile Connty, Mount Vernon. Flowers March; fruit ripe in $\mathrm{July}$. Not common.

A large tree in the upper division of the State.

Economic uses: Timber tree. The berries are edible.

Type locality: "Hab. in Virginia."

Herb. Geol. Surv. Herb. Mohr.

Morus alba L. Sp. Pl. 2 : 986.1753.

White Mulberiry.

Ell. Sk. 2 :574. Gray, Man. ed. 6, 464. ('hap. Fl.415; ed. 3, 438.

Introduced from Europe, occasionally spontaneons around dwellings. Mobile County.

Economic uses: The form known as Morus multicaulis was at one time largely cultivated for silkworms.

Type locality: "Hab. in China."

CANNABIS L. Sp. Pl. $2: 1027.1783$.

Annual. East India, Europe.

Cannabis sativa L. Sp. Pl. 2 :1027. 1753.

HEMP.

Gray, Man. ed. 6, 463.

Rarely adventive on ballast. Mobile County.

'Type locality: "Hab. in India."

Herb. Geol. Surv.

HUMULUS L. Sp. Pl. 2 : 1028. 1753. HoP.

Two species, temperate regions of the globe. Japan. North America, 1. Perennial climbing herbs.

Humulus lupulus L. Sp. Pl. 2 : 1028. 1753.

Common hop Plant.

Ell. Sk. 2:695. Gray, Man. ed.6,464. Chap. Fl. 414.

EUROPE.

Alleghenian and Carolinian areas. Ontario to Manitoba and British Columbia, New England and thronghout the Eastern States.

Arabama : Hills, borders of woods near dwellings. Scarcely indigenous. Cullman County. Flowers greenish; July, August. 
Economic uses: Here and there cultivated for its strobules used in making yeast and for medicinal purposes. "Humulus." United States Pharmacopœia.

Type locality: "Hab. in Europae sepibus et ad radices montium."

Herb. Geol. Surv. Herb. Mohr.

\section{URTICACEAE. Nettle Family.}

URTICA L. Sp.P1. 2 : 983. 1753. NetTle.

From 30 to 40 species, mostly in colder and cooler temperate regions. America about 30 species, North America 10, Eastern States 2, exclusive of naturalized species. Herbs.

Urtica gracilis Ait. Hort. Kew. $3: 341.1789$.

Common American Nettle.

Urtica procera Willd. Sp. Pl. $4: 353.1805$.

Ell. Sk. 2 : 571. Gray, Man. ed. 6, 465. Chap. Fl.412. Coulter, Contr. Nat. Herb. $2: 408$

Hudsonian zone to Louisianian aren. Nova Scotia, New Brunswick, and Ontario, north to Mackenzie River, west to the base of the Rocky Mountains, New England west to Minnesota and Nebraska, south to Florida, Texas, and Arkansas.

Ala Bama: Over the State to the coast. Border of swamps, waste places. Mobile County.

July, Angust; common. Perennial.

Type locality: "Native of Hudsou's Bay."

Herb. Geol. Surv. Herb. Mohr.

Urtica dioica L. Sp. Pl. 2 :984. 1753.

Large Stinging Nettle.

Ell. Sk. 2:571. Gray, Man. ed.6, 465. Chap. Fl.412. Coulter, Contr. Nat. Herb.

$2: 408$

Introduced from Europe; naturalized tliroughout the continent from Canada to Mexico.

Alabama: Over the State. Waste places. Lawrence County, Moulton. Mobile County, ballast ground. July, August; not frequent. Perennial.

Type locality : "Hab. in Europae ruderatis."

Herb. Geol. Surv. Herb. Mohr.

Urtica urens L. Sp. Pl. 2 : 984.1753.

Smaller Stinging NetTle.

Ell. Sk. 2 :570. Gray, Man. ed. 6, 465. Chap. Fl. 412. Coulter, Contr. Nat. Herb. $2: 408$.

Adventive from Europe, naturalized from Canada to Mexico.

Alabama: Autauga County, Prattville (E. A. Smith). Mobile County, ballast heaps. July, August; rare. Annual.

Type locality : "Hab. in Enropae cultis."

Herb. Geol. Surv. Herb. Mohr.

Urtica chamaedroides Pursh, Fl. Am. Sept. 1:113. 1814.

PURPlish NetTi.e.

Urtica purpurascens Nutt. Trans. Am. Phil. Soc. n. ser. 5 : 169. 1837.

Ell. Sk. 2:570. Gray, Man. ed. 6, 465. Chap. Fl. 412. Coulter, Contr. Nat. Herb. $2: 408$.

Mexico.

Carolinian and Louisianian areas. Kentucky to the Gulf States.

Alabama: Central Pine belt. Tuscaloosa County (E. A. Smith); rare. Annual. Type locality: "On the islands of Georgia: St. Simons, \&c."

Herb. Geol. Surv. Herb. Mohr.

URTICASTRUM Fabr. Enum. 204. 1759.

(Laportea Gaud. Bot. Voy. Freyc. 498. 1826.)

About 2 species, in tropical Asia, Africa, Australia, Mexico. Temperate North America, 1.

Urticastrum divaricatum (L.) Kuntze, Rev. Gen. Pl. 2:635. 1891. Wood Nettue.

Urtica divaricata and U. canadensis L. Sp. Pl. 2:985. 1753.

Laportea canadensis Gand. Bot. Voy. Freyc. 498. 1826.

Ell. Sk. 2:573. Gray, Man. ed. 6, 465. Chap. Fl. 413.

Alleghenian and Louisianian areas. New Brunswick, Nova Scotia, Quebec, and Ontario to Saskatchewan Valley; New England throughout the Eastern States to Florida, west to Lonisiana. 
Alabama: Over the State. Moist rich thickets and woods. Flowers July, August; common.

Type locality: "Hab. in Virginia, Canada."

Herb. Geol. Surv. Herb. Mohr.

\section{ADICEA Raf. Ann. Nat. 179. 1815. Clukar Weed.}

(PILEA Lindl. Coll. t. 4. 1821.)

One hundred and twenty-five species, mostly in the tropics. Temperate North Ameriea.

Adicea pumila (L.) Raf.; Torr. Fl. N. Y. $2: 223$. As synonym. 1843. Rich Weri).

Urtica pumila L. Sp. Pl. 2 : 984. 1753.

Pilea pumila Gray, Man. ed. 1, 437. 1848.

Ell. Sk. 2:569. Gray, Man. ed. 6, 466. Chap. Fl. 413.

Alleghenian and Carolinian areas. New Brunswick and Ontario; New England, west to Minnesota, Nebraska, and Kansas, south to New Jersey, Georgia, and northern Alabama.

Alabama: Mountain region. Rich damp woods. Madison County, Montesano. Lee Connty, Auburn (F.S.Earle). Cullman County. Walker County (E. A. Smith). Not common.

Type locality: "Hab. in Canada."

Herb. Geol. Surv. Herb. Mohr.

Adicea microphylla herniarioides (Sw.) Kuntze Rev, Gen. Pl. 2:622. 1891.

Urtica herniarioides Sw. Vet. Akad. Handl. Stockh. 8: 64. 1787.

Pilea herniarioides Lindl. Coll. Bot sub t. 4. 1821.

Pilea microphylla herniarioides Wedd. in DC. Prodr. 16, pt. 1:106. 1869.

Lonisianian area.

Alabama : Mobile. Escaped from cultivation. Light, shaded ground. July, August.

Type locality (Sw. Fl. Ind. Oce.): "Hab. supra saxa in rivulis et fluviis Domingensibus."

Herb. Geol. Surv. Herb. Mohr.

BOEHMERIA Jacq. Stirp. Am. 246, t. 15\% 1763.

About 45 species, mostly tropical and subtropical, but extending to extratropical North America and Japan. North America, 1.

Boehmeria cylindrica (L.) Willd. Sp. Pl. 4 : 340. 1809.

False NetTi.e.

Urtica cylindrica L. Sp. Pl. 1396. 1753.

U. capitata Willd.Sp. Pl. $4: 363.1809$.

Eil. Sk. 2:568. Gray, Man. ed. 6, 466. Chap. Fl.414. Coulter, Contr. Nat. Herl. 2:409. Griseb. Fl. Brit. W. Ind. 160.

West India Islands, Mexico to Argentina.

Alleghenian to Loulsianian area. Ontario; New England west to Minnesota, south to Florida and through the Gulf States to Texas, Arkansas, and Missouri.

Ala Bama: Throughout the State. Damp thickets and woods. July, August; frequent. Perenuial.

Type locality: "Hab. in Jamaica, Virginia, Canada."

Herb. Geol. Surv. Herb. Mohr.

Boehmeria nivea (L.) Gaud. Bot. Voy. Freye. 499. 1826.

Ramie Plant.

Urtica nivea L. Sp. Pl. 2 : 985 . 1753.

In the southern part of the State found here and there as an escape from cultiviltion. Perennial.

Boehmeria tenacissima (Roxb.) Gaud., cultivated with the above, also occurs.

Economic uses: Valuable fiber plant.

Type locality: "Hab. in Chinae muris."

Herb. Geol. Surv.

PARIETARIA L. Sp.Pl. $2: 1052$. 1753. Pellitoky.

Eight species, mostly of temperate regions. North America, 2.

Parietaria pennsylvanica Muhl.; Willd. Sp. Pl.4: 955. 1805.

Ell. Sk. 2:575. Gray, Man. ed. 6, 466. Chap. Fl.413. Coulter, Contr. Nat. Herb. 2: 409 . 
Alleghenian and Carolinian areas. Ontario to British Columbia; southern New England throughont the Atlantic States west to Colorado and Nevada, south along the monntains to Georgia.

AlabaMa: Mountain region. Shaded rocky copses, woods, on limestone rocks. Mudison County, Montesano, 1,200 feet. May ; rare. Annual.

Type locality : "Hab. in Pensylvania."

Herb. Geol. Surv. Herb. Mohr.

Parietaria officinalis erecta (Mert. \& Koch) Weddell, Monogr. Urt. 507. 1856.

Parietaria erecta Mert. \& Koch, Deutschl. Fl. 1:825. 1823.

Adventive with ballast from Mediterranean Europe. Mobile County, 1891.

Annual.

Herb. Mohr.

\section{LORANTHACEAE. Mistletoe Family.}

PHORADENDRON Nutt. Journ. Acad. Phila. ser. 2, 1:185. 1847-1850.

About 80 species, tropical, subtropical, and warmer temperate America. United States, 4 or 5 species. Shrub, parasitical on trees.

Phoradendron flavescens (Pursh) Nutt.; Gray, Mall. ed.2, 383. 1856.

Viscum flavescens Pursh, Fl. Am. Sept. 1:114. 1814.

Ell. Sk. 2: 677. Gray, Man. ed.6, 450. Chap. Fl. 397.

Carolinian and Lou isianian areas. From Florida to Texas and Arkansas; north to New Jersey, west to southern Illinois; sontheru Miesouri.

Alabama: Throughout. Parasitic on various hard-wood trees. In the Central Prairies and southward. Most frequent on the water oak. Flowers in February and March. Fruit ripe October, November; berries white. Common.

Economic uses: The young twigs and leaves are used medicinally.

Type locality : "[North America.] Parasitic on oaks and other trees ; rare."

Herb. Geol. Surv. Herb. Mohr.

\section{SANTALACEAE. Sandalwood Family.}

COMANDRA Nutt. Gen. $1: 157.1818$.

Four species, perennial herbs. Europe. North America, 3.

Comandra umbellata (L.) Nutt. Gen. 1:157. 1818.

Thesium umbellatum L. Sp. Pl. 1: 208. 1753.

Ell. Sk. 1:311. Gray, Man. ed. 6, 450. Chap. Fl. 396; ed. 3, 417. Coulter, Contr.

Nat. Herb. $2: 385$.

Cinadian zone to Carolinian area. Ontario to Manitoba and the Rocky Mountains; New England southward along the mountains to Georgia, west to Missouri, Arkansas, and Texas.

Alabama : Mountain region. Warrior table-land. Rocky copses, dry open places. Morgan Connty, June, 1899. Jackson County, Sand Mountain, near Starkey Creek. Flowers greenish white. Perennial; parasitic on the roots of trees. Infrequent.

Type locality: "Hab. in Virginiae, Pensylvaniae pascuis siccis. Kalm."

Herb. Biltmore.

NESTRONIA Raf. New Fl. 3:12. 1836.

(DARBYA Gray, Am. Journ. Sci. ser. 2, 1:388. 1846.)

One species, southern Atlantic North America. Low shrub.

Nestronia umbellulata Raf. New Fl. 3:13. 1836.

Darbya umbellulala Gray, Am. Journ. Sci. ser. 2, 1:388. 1846.

Chap. Fl. 396.

Carolinian area. North Caroliua, central Georgia.

Alabama: Mountain region. Warrior table-land, 800 feet. Shaded hillsides. Cullman County. Lee County, near Auburn. Rocky shaded banks, not rare (Baker \& Earle). Flowers greenish. Only male plants have been met with in the State. May, rare.

Type locality : "Near Milledgeville, Ga.," Dr. Boykin, and at Macon, Prof. Darby: also at Lincoln, N. C., Mr. M. A. Curtis.

Herb. Geol. Surv. Herb. Mohr. 


\section{ARISTOLOCHIACEAE. Birthwort Family.}

ARISTOLOCHIA L. Sp. Pl. $2: 960.1753$.

About 170 species, mostly tropical, of the Northern Hemisphere. North America, 7; eastern United States, 3 . Climbing perennial herbs or shrubs.

Aristolochia serpentaria L. Sp. Pl. 2 : 961. 1753.

VIRGINIA SNAKEROOT.

Ell. Sk. 2:511. Gray, Man. ed.6,445. Chap. Fl.372, in part.

Carolinian and Louisianian areas. From the eastern Gulf States and Florida north and west to Connecticut, the Ohio Valley, Missouri, and Arkansas.

Alabama : Tennessee Valley to Lower Pine region. Dry open woods. Lee County, Auburn (F.S. Earle). Autauga County, Prattville(E. A. Smith). Washingtou, Clarke, Mobile, and Baldwin counties. Flowers maroon purple. May; not frequent. Perennial.

Economic uses: The root, known as Virginia snakeroot, is the "Serpentaria" of the United States Pharmacopœia.

Type locality: "Hab. in Virginia."

Herb. Mohr.

Aristolochia nashii Kearney, Bull. Torr. Club, 21:485. 1894.

NARROW-LEAF VIRGINIA SNaKEROOT.

Stem mostly simple, erect, slender, flexuose from a short rootstock with numerous crowded fibrous roots; leaves from linear-lanceolate to oblong-lanceolate, obtuse at the apex, narrowly sagittate to auriculate at the base, short-petioled; peduncles 1 to 3 near the base of the stem, one-flowered, slender, pubescent above; capsule villous, especially upon the ribs.

Louisianian to Carolinian area. Florida.

Alabava : Lower Pine region, Mountain region. Open dry woods. Mobile County; not rare in sandy rolling pine woods. Cullman County. Jackson County, on Sand Mountain (Boynton) in light soil. Flowers in May Not infrequent.

Readily distinguished from $A$. serpentaria by the narrow, short-petioled leaves.

Type locality : "Collected at Lake Ella, Fla., in 1894, by Mr. George V. Nash."

Aristolochia sagittata Mnhl.; Duchartre in DC. Prodr. 15,pt. 1:434. 1864. As synonym.

Aristolochia hastata Nutt. Gen. $2: 200$. 1818. Not H. B. K. 1817.

Ell. Sk. $2: 512$.

Carolinian area. South Carolina.

AlabaMa : Lower hills and mountain region. Dry open woods. Cullman County. Type locality not specifically given.

Aristolochia macrophylla Lam. Encycl. 1: 255. 1783. Lakge-Leaved PiPe Vine. Aristolochia sipho L'Her. Stirp. Nov. 13. 1784.

Ell. Sk. 2:510. Gray, Man. ed.6, 454. Chap. Fl. 372.

Alleghenian and Carolinian areas. Pennsylvania west to Missouri and Minnesota, south aloug the mountains to Tennessee, North Carolina, and Georgia.

Alabama: Mountain region. Winston County (T. M. Peters). Woody climber; not collected of late.

Type locality: "Cette plante croit naturellement dans l'Amérique septentrionale, and vraisemblament dans la Virginie."

Aristolochia tomentosa Sims, Bot. Mag. t. 1369. 1811.

Hoary Pipe Vine.

Ell. Sk. 2:511. Gray, Man. ed.6, 445. Chap. Fl.372.

Carolinian and Louisianian areas. Mountaius of North Carolina to Florida, central Tennessee, north and west to southern Illinois, southern Missouri, and Arkansas.

Alabama : Lower hills. Central Pine belt to Upper division of Coast Pine belt; river banks. Blount County, Mulberry River. Tuscalonsa and Bibb counties. Clarke County, Suggsville (Dr. Denny). Flowers greenish brown; June. Climbing over bushes and small trees; not rare. Perennial.

Type locality: "Native of North America."

Herb. Geol. Surv. Herb. Mohr.

ASARUM L.Sp. Pl. 1:442. 1753.

Thirteen species, temperate regions Northern Hemisphere. Europe. Japan, 7. North America, 4. Low percnnials. 
Asarum virginicum L. Sp. Pl. 1: 442 . 1753.

WILD GINGer. Colic Root. Ell. Sk. 1:532. Gray, Man. ed.6, 445. Chap. Fl.371.

Alleghenian and Carolinian areas. Virginia along the mountains to North Carolina, Georgia, and eastern Tennesseè.

Alabama: Mountain region to Lower hills. Rich shaded copses and hillsides.

Tuscaloosa County (E. A. Smith). Flowers maroon; March, April; rare.

Type locality: "Hab. in Virginia, terra Mariana, Carolina."

Herb. Geol. Surv. Herb. Mohr.

Asarum macranthum (Shuttlew.) Small, Mem. Torr. Club, 5:136. 1894.

LARGE-FLOWERED WILD GINGER. Asarum virginicum var. grandiflorum Michx. ; Duchartre in DC. Prodr. 15 : 426. 1864. Asarum grandiflorum Small, Mem. Torr. Club, 4:150. 1894. Not Klotzsch.

Homotropa macranthum Shuttlew.; Small \& Heller, Mem. Torr. Club, 3:11. 1892.

As synonym.

Carolinian area. West Virginia to northern Alabama.

Alabama: Higher mountain ranges. Rocky shaded banks, Dekalb County. On

Lookout Mountain, near Mentone 1,800 to 2,000 feet. June 3. Only locality known

in the State. Flowers purple brown; bright-spotted inside.

Type locality: "Collected by Rugel in 1841 on the Broad River, N. C."

Herb. Geol. Surv. Herb. Mohr.

Asarum arifolium Michx. Fl. Bor. Am. 1: 279. 1803.

Southern. WiLd Ginger.

Ell. Sk. 1:532. Gray, Man. ed.6, 445. Chap. Fl. 371.

Carolinian and Louisianian areas. West Virginia and eastern Tennessee to the low country of the Atlantic and Gulf States, west to Louisiana.

Alabaya : Central Pine belt. ('oast plain. Rich shaded hillsides. Tuscaloosa,

Clarke, Mobile, and Baldwin counties. Flowers maroon. March; common.

Economic uses: The root of the several species is used medicinally under the names of "wild ginger" and "colic root."

Type locality : "Hab. in umbrosis sylvis Carolinae inferioris."

Herb. Mohr.

\section{POLYGONACEAE. Buckwheat Family.}

ERIOGONUM Michx. Fl. Bor. Am. 1:246. 1803.

About 100 species, almost exclusively confined to the Sonoran area from Texas to the Pacific. Southeastern Atlantic States, 2. Herbs, chiefly perennial.

Erigonum tomentosum Michx. Fl. Bor. Am. 1:246. 1803. Downy Eriogonum.

Ell. Sk. 1: 465. Chap. Fl. 392.

Louisianian area. South Carolina, Georgia, western Florida.

Alabava: Upper division of Coast Pine belt. Dry sandy pine ridges in the so-called wire-grass counties. Henry County, Abbeyville. Dale County, Ozark. Geneva County (E. A. Smith). Flowers white. August to October; not rare.

Type locality: "Hab. in aridissimis, pinetis Carolinae et Georgiae."

Herb. Geol. Surv. Herb. Mohr.

RUMEX L. Sp. Pl. 1:333. 1753. DOCK.'

About 100 species, cosmopolitan in the Northern Hemisphere. North America, 20. Eastern States and adjoining Provinces of Canada, 9. Herbs mostly perennial.

Rumex acetosella L. Sp. Pl. 1:338. 1753.

SAND SoRrel.

Ell. Sk. 1:415. Gray, Man. ed. 6, 439. Chap. Fl.386. Coulter, Contr. Nat. Herb. $2: 379$.

EURope.

Canadian zone to Louisianian area. Naturalized over the continent.

Alabama: Over the State. In light sandy soil, waste places, worn-out fields.

Flowers reddish. April, May. An abundant and troublesome weed. Annual.

Type locality: "Hab. in Europae pascuis et arvis arenosis."

Herb. Geol. Surv. Herb. Mohr.

${ }^{1}$ William Trelease, The species of Rumex north of Mexico, Report Mo. Bot. Gard., vol. 3 , pp. 74 to 95.1892 .

$15894-31$ 
Rumex hastatulus Baldwin in Ell. Sk. I: 416. 1817.

FNGELMANN's SORREL.

Rumex engelmannii Meiss. in DC. Prodr. 14:64. 1856.

Gray, Man. ed. 6, 439. Chap. Fl. 386. Coulter, Contr. Nat. Herb. $2: 379$.

Carolinian and Louisianian areas. Southeastern New York and New Jersey to

Florida, west to Texas and Arkansas.

Alabama: Central Prairie region to Coast plain. Dry sandy soil. Montgomery,

Perry, and Marion counties. Baldwin Connty, Point Clear. Not frequent. Annual. Type locality: "Arid cultivated land in the south of Georgia and east Florida."

Herb. Geol. Surv. Herb. Mohr.

Rumex altissimus Wood, Classbook, 477. 1855.

PALE DOCK.

Rumex britannicus Meiss. in DC. Prodr. 14:47. 1856. Not L. 1753.

Gray, Man. ed. 6, 438. Coulter, Contr. Nat. Herb. $2: 380$.

Alleghenian and Carolinian areas. Massachusetts west to Dakota, Nebraska, and Kansas, south from New Jersey to Florida and Texas.

Alabama: Central Prairie region to Coast plain. Deep marshes, muddy borlers of streams, ditches. Autauga County', Prattville. Mobile and Baldwin counties. May, June; common.

Type locality: "Marshy prairies and borders of streams, Indiana!"

Herb. Geol. Surv. Herb. Mohr.

Rumex verticillatus L. Sp. Pl. 1 : 334. 1753.

SWamp Dock.

Ell. Sk. 1:413, inter R. britannicus. Gray, Man. ed.6.438. Chap. Fl.385. Conlter,

Contr. Nat. Herb. $2: 380$.

Alleghenian to Louisianian area. Quebec, Ontario; New England west to Minnesota, south from Missouri to Texas, south from New York to Florida and Louisiana.

Alabama: Deep open swamps, ditches. Most frequent in the Coast plain. Two and one-half to 3 feet high. Flowers April, May.

Type locality: "Hah. in Virginia."

Herb. Geol. Surv. Herb. Mohr.

Rumex crispus L. Sp. Pl. 1:335. 1753.

CURled DOCK. Yellow DOCK.

Ell. Sk. 1:414. Gray, Man. ed. 6, 438. Chap. Fl.385. Coulter, Contr. Nat. Herb.

$2: 379$.

Introduced from Europe, widespread over the continent from the Atlantic to the

Pacific slope, and from Canada to the Gulf.

Alabama: Over the State. Damp grassy places, waste and cultivated ground.

May, June; common everywhere.

Economic uses: The root is the "yellow dock" or "Rumex" of the United States

Pharmacopoia.

Type locality: "Hab. in Europae suculentis."

Herb. Geol. Surv. Herb. Mnhr.

Rumex britannicus L. Sp. Pl. 1:334. 1753.

Great Water Dock.

Rumex orbiculatus Gray, Man. ed.5, 420. 1867.

Gray, Man. ed. 6, 438.

Mexico.

Canadian zone to Louisianian area. New Brunswick, Quebec, Ontario; New England west to Michigan, Iowa, Minnesota, Dakota, Kansas, Missouri, and Illinois, south to New Jersey and Georgia.

Alabama: Mobile County, river swamps. July; rare.

Type locality: "Hab. in Virginia."

Herb. Geol. Surv. Herb. Mohr.

Rumex sanguineus L. Sp. Pl. 1:334. 1753.

Ell. Sk 1: 413 Gray, Man. ed. 6, 438.

The form with greenish veins (var, viridis Smith in Trelease, Rep. Mo. Bot. Gard. 3 : 90. 1892).

EUROPE.

Alleghenian and Carolinian areas.

AlabaMa: Tuscaloosa County ( $E$. A. Smith). Sparingly naturalized.

Type locality: "Hab. in Virginia." (But probably native in Europe.)

Herb. Mohr.

Rumex pulcher L. Sp. Pl. 1:336. 1753.

SLENDER DoCK.

Ell. Sk. 1:413. Chap. Fl. 386.

MEDITERRANEAN EUROPE.

Carolinian and Louisianian areas. 
Alabama : Adventive. Coast plain. Fully naturalized. Roadsides, ditches, borders of swamps about Mobile. May. Becoming a common wayside weed. Perennial.

Type locality : "Hab. in Gallia, Italia, Veronae."

Herb. Geol. Surv. Herb. Mohr.

Rumex conglomeratus Murr. Prodr. Fl. Goett.52. 1770.

Fugitive from Europe with ballast.

Alabama : Mobile, ballast heaps, October, 1893 ; rare.

Type locality not ascertained.

Herb. Geol. Surv. Herb. Mohr.

Rumex cuneifolius Campdera, Monogr. Rumex, 66,95. 1819. Wedge-Leaf Dock. Spreng. Syst. Veg. 2 : 159.

Perennial. Stem 12 to 18 inches long, assurgent, simple or branched from the base, roughish; leaves thickish, oblong-ovate, obtuse, cuneate at the base, crenately denticulate; flowering branches nearly leafless; flowers almost sessile, in dense whorls; valves, scarcely over 1 line long, crenulate, with 3 callosities.

Argentina, Montevideo, Chile, South Africa.

Louisianian area. Adventive in ballast from Buenos Ayres, and firmly established in western Florida (Pensacola).

Alabama : Dry sandy places. Mobile County, near and on ballast heaps. Flowers in June; fruit ripe in August.

First observed in 1891. Spreading along the river banks. 1895.

Type locality: "Hab. in Buenos Ayres."

Herb. Geol. Surv. Herb. Mohr.

Rumex obtusifolius L. Sp. Pl. 1: 335. 1753.

BITTER DOCK.

Gray, Man. edl.6, 438. Chap. Fl. 385. Coulter, Contr. Nat. Herb. $2: 381$.

Alleghenian to Louisianian area. Introduced from Europe. Naturalized over the North American continent.

Alabama: All over the State, in cultivated and waste grounds; a coarse and troublesome weed. May.

Economic uses: The root is used indiscriminately with the yellow dock for medicine. Type locality: "Hab. in Germania, Helvetia, Gallia, Anglia."

Herb. Geol. Surv. Herb. Mohr.

RUMeX obTUSIFolius $\times$ CRISPUS. This hybrid has been collected in St. Clair County, near Ashville. September. On roadsides.

POLYGONUM L. Sp. Pl. 1: 359. $1753 .{ }^{1}$

About 150 species, cosmopolitan, mostly northern. North America and Mexico, about 50 species. Atlantic North Ameriea, 21. Ours all herbs.

Polygonum aviculare L. Sp. Pl. I : 362.1753.

WAYSIDE KNOTWEED.

Ell. Sk. 1:453. Gray, Man. ed. 6, 439.' Chap. Fl. 390.

Cosmopolitan in the temperate regions. Europe, Asia, North Africa, Mexico, South America.

Boreal zones to Louisianian area. Over the North American continent; most fraquent east of the Rocky Mountains.

AlabaMa: Over the State. Roalsides, waste places, everywhere in the interior. May to October. Rare near the coast. Annual.

Type locality : "Hab. in Europae cultis ruderatis."

Herb. Geol. Surv. Herb. Mohr.

Polygonum erectum L. Sp. P1. 1:363. 1753.

Erect Door Weed.

Polygonum aviculure var. erectum Roth, Tent. Fl. Germ. 1:174. 1788. Gray, Man. ed. 6, 440. Chap. Fl. 390. Coulter, Contr. Nat. Herb. 2:375. Wats. Bot. Calif. 2:11.

EUROPE.

Alleghenian to Louisianian area. Ontario; New England south to New Jersey and Georgia.

Alabama: Central Pine belt and Central Prairie region. In yards, waste places. Tuscaloosa County (E. A. Smith). Dallas Countv, Uniontown. Montgomery County. June; not common. Annual.

Type locality: "Hab. in Philadelphia, enata ex seminibus D. Kalmii."

Herb. Geol. Surv. Herb. Mohr.

${ }^{1}$ John K. Small, A preliminary list of American species of Polygonum, Bull. Torr. Club, $19: 351$. 1892 . 
Polygonum tenue Michx. Fl. Am. Bor. 1:238. 1803.

Gray, Man. ed. 6, 440.

Alloghenian and Carolinian areas. From Ontario to the Pacific coast; New England south to New Jersey, along the mountains to Georgia, and west to Arizona and California.

Ala bama: Mountain region. Exposed rocky soil. Dekalb County, Mentone.

September. Frequent on Lookout Mountain.

Type locality: : "Hab. in Canada."

Polygonum maritimum L. Sp. Pl. $1: 361$. 1753.

Polygonum aviculare var. littorale Chap. Fl. 390.

Ell. Sk. 1:453. Gray, Man. ed. 6, 439.

EUROPE.

Canadian zone to Louisianian area. Seacoast from Nova Scotia to Georgia and Alabama.

Alabama : Mobile County, banks of Alabama River, near the shipping. To all appearance adventive with ballast. August, September. Perennial.

Type locality: "Hab. Monspelii, in Italia, Virginia."

Herb. Geol. Surv. Herb. Mohr.

Polygonum bellardi All. Fl. Ped. 2 :207. 1785.

Britt. \& Br. Ill. Fl. 1:562.

Southern Europe, Western Asia.

Louisianian area.

Ala bama: Adventive with ballast. Mobile, 1884, and September, 1893. Stems numerous from the same root; prostrate, rigid, over 2 feet long, forming large patches. Annual.

Type locality: "In arvis inter Bussolino e Bardassan [Piedmont]."

Herb. Geol. Surv. Herb. Mohr.

Polygonum lapathifolium L. Sp. P1. 1:360. 1753.

Gray, Man. ed. 6, 440. Coulter, Contr. Nat. Herb. 2 : 376.

Alabama : Naturalized about Mobile. June; rare. Annual.

Type locality: "Hab. in Gallia."

Herb. Geol. Surv. Herb. Mohr.

Polygonum incarnatum Ell. Sk. 1:456. 1817.

Polygonum lapathifolium incarnatum Gray, Man. ed. 6, 440. 1890.

Ell. Sk. l. c. Gray, Man. l. c. Chap. Fl. 388. Coulter, Contr. Nat. Herb. 2 : 376

Alleghenian to Louisianian area. Nova Scotia, New Brunswick, Ontario, British Columbia, Vancouver's Island; from Vermont and western New York west to Nebraska, and throughout the Ohio Valley to Missouri, Arkansas, and Colorarlo, south to Florida and eastern Texas.

Alabama: Over the State. Low cultivated ground, damp places. Cullman, Montgomery, and Mobile counties. Flowers Alesh color. September, October; frequent. Anuual.

Type locality: "Ditches and shallow ponds [South Carolina and Georgia]."

Herb. Geol. Surv. Herb. Mohr.

Polygonum pennsylvanicum L. Sp. Pl. 1:362. 1753.

Ell. Sk. 1:457. Gray, Man. ed.6, 440. Chap. Fl. 388. Coulter, Contr. Nat. Herb. $2: 376$.

NORTHERN MEXico.

Alleghenian to Louisianian area. New Brunswick and Ontario; New England west to Dakota, Nebraska, and California, south to Florida and Texas.

Alabama: Over the State. Low damp places, ditches. Montgomery and Mobile counties. Flowers rose color. July to September; frequent. Annual.

Type locality: "Hab. in Pensylvania. Kalm."

Herb. Geol. Surv. Herb. Mohr.

Polygonum portoricense Bertero, Meiss. in DC. Prodr. 14:121. 1856.

Dense-flowered Persicaria.

Polygonum densiflorum Meiss. in Mart. Fl. Bras. 5:13. 1855. Not Blume.

Chap. Fl. 388. Britt. \& Br. Ill. Fl. 1:556, $f$. 1322. Griseb. Fl. Brit. W. Ind. 161 (as Polygonum glabrum Willd.).

West Indies to Brazil, Eastern Asia.

Carolinian and Louisianian areas. Florida, eastern Texas, southeastern Missouri. 
Alabama : Coast plain. Shaded swamps. Mobile County, swampy alluvial forest on the old telegraph road, copious. Hale County, Greensboro. Flowers bright pink. October. Annual.

Type locality: West Indies.

Herb. Geol. Surv. Herb. Mohr.

Polygonum persicaria L. Sp. Pl. 1:361. 1753.

LADY's Thumb.

Gray, Man. ed. 6, 441. Chap. Fl. 389. Coulter, Contr. Nat. Herb. 2 : 377.

Introduced from Europe. Extensively naturalized all over the continent.

Alabana: Over the State. Ditches, low places. Most frequent in the Central Prairie belt. Tuscaloosa County (E.A.Smith). Dallas County, Uniontown. Mobile County, ballast ground. Flowers greenish white. June to October; not common Annual.

Type locality: "Hab. in Europae cultis."

Herb. Geol. Surv. Herb. Mohr.

Polygonum setaceum Baldwin; Ell. Sk. 1:455. 1817.

Chap. Fl.389. Coulter, Contr. Nat. Herb. $2: 377$.

Lonisianian area. Georgia to Texas and Arkansas.

Alabama : Central Prairie belt. Ditches, borders of ponds. Montgomery County.

Lee County, Auburn (Baker \& Earle). Flowers white. October; rare. Annual.

Type locality: "In clayey soils, Savannah; St. Marys, Ga. Baldwin."

Herb. Geol. Surv. Herb. Mohr.

Polygonum hydropiperoides Michx. Fl. Bor. Am. 1 :239. 1803.

Polygonum mite Pers. Syn. 1:440. 1805.

Mild Water Pepper.

Ell. Sk. 1:456. Gray, Man. ed.6, 441. Chap. Fl.389. Coulter, Contr. Nat. Herb. $2: 377$.

Alleghenian to Louisianian area. New Brunswick, Ontario; New England, west to Nebraska ; south to Florida, Texas, Arkansas, and Missouri.

Alabama: All over the State, border of swamps, shallow ponds, ditches. Most abundant from the Central Pine belt to the coast. Montgomery, Escambia, and Mobile counties. Flowers white. July to October; abundant. Perennial.

Type locality: "Hab. in Pennsylvania, Virginia, Carolina."

Herb. Geol. Surv. Herb. Mohr.

Polygonum punctatum Ell. Sk. 1 : 455. 1817. Smart Weed. Water Pepper.

Polygonum acre H. B. K. Nov. Gen. 2 : 179. 1817. Not Lam.

Ell. Sk.1.c. Gray, Man. ed. 6, 442. Chap. Fl. 389. Coulter, Contr. Nat. Herb. 2 : 377. Griseb. Fl. Brit. W. Ind.161.

Alleghenian and Lonisianian areas. Ontario; New England west to Dakota and Nebraska, south to Florida and Texas.

Alabama: Over the State. Wet places. Flowers white. July to October; common. Perennial.

Type locality: "In ditches and shallow ponds [South Carolina and Georgia]."

Herb. Geol. Surv. Herb. Mohr.

Polygonum hydropiper L. Sp. Pl. 1 : 361. 1753.

Gray, Man. ed. 6, 441. Couiter, Contr. Nat. Herb. 2 : 377.

EUROPE.

Alleghenian and Louisianian areas. Thronghout the continent. Mostly naturalized from Europe

Alabama : Low wet places. Dallas County, Uniontown. June; rare. Perennial. Type locality: "Hab. in Europae subhumidis."

Herb. Geol. Surv. Herb. Mohr.

Polygonum opelousanum Riddell; Small, Bull. Torr. Club, 19: 354. 1892.

OPElousas Persicaria.

Polygonum opelousanum Riddell, Cat. Fl. Lnd. in N. Orl. Med. \& Surg. Journ. 1852.

Name only.

Britt. \& Br. Ill. Fl. 1: 559 .

Mexico.

Louisianian area. Louisiana and Texas.

Al.abama : Coast plain. Muddy border of ponds. Mobile County, foot of Springhill. Flowers white. May, 1897; copious. Lee County, Auburn (F.S. Earle). Not rare. Perennial.

'Type locality: "Louisiana: Low prairies near Opelousas (Carpenter, 26)."

Herb. Geol. Surv. Herb. Mohr. 
Polygonum virginianum L. Sp. Pl. 1:360. 1753.

VIRGINIA KNOTWEED.

Ell. Sk. 1:454. Gray, Man. ed. 6, 442. Chap. Fl. 390.

Alleghenian to Louisianian area. Ontario, southern New England, west to Nebraska, south to Florida, Louisiana, Arkansas, and Missouri.

Alabama : From the Tennessee Valley to the Coast plain. Damp woods and copses. Bottoms. Lauderdale County. Franklin County, Russellville. Cullman and Talladega counties. Chilton County (E. A. Smith). Montgomery, Clarke, Escambia, and

Mobile counties. Flowers green. July to September; frequent. Perennial. Type locality: "Hab. in Virginia."

Herb. Geol. Surv. Herb. Mohr.

Polygonum sagittatum L. Sp. Pl. 1:363. 1753.

ARROW-LEaVed Tear-THumb. Ell. Sk. 1:458. Gray, Man. ed. 6, 442. Chap. Fl. 390. Coulter, Contr. Nat. Herb.

$2: 378$

\section{Asta, Siberia.}

Canadian zone to Louisianian area. Newfoundland, Illinois, Ontario, New England, west to Dakota, Nebraska, Ohio Valley, Missouri, and Kansas, south to Florida and 'Texas.

Alabama : Mountain region to Central Prairie belt. Low damp thickets. Clay County. Autauga County, Prattville (E. A. Smith). Dallas County, Uniontown. Lee County. Auburn. Annual.

Type locality : "Hab. in Virginiae, Marilandiae madidis."

Herb. Geol. Surv, Herb. Mohr.

Polygonum convolvulus L. Sp. Pl. 1:364. 1753.

BLACK BIND WeEd. Ell. Sk. 1:459. Gray, Man. ed. 6, 442. Chap. Fl. 390. Coulter, Contr. Nat. Herb. $2: 378$.

Europe, Mexico.

Alleghenian to Louisianian area. Ontario, west to the Pacific, most probably introduced; New England, throughout the Eastern States to the Gulf, Texas, and Mexico.

Alabama: Coast plain. Waste places. Mobile County on ballast. June to August; frequent. Annual.

Type locality: "Hab. in Europae agris."

Herb. Geol. Surv. Herb. Mohr.

Polygonum cristatum Engelm. \& Gr. Bost. Journ. Nat. Hist. 5 : 259. 1847.

Coulter, Contr. Nat. Herb. $2: 378$.

Climbing False Buckwheat.

Carolinian and Louisianian areas. Southern Georgia, Indian Territory, and Texas.

Alaliama: Over the State. In thickets and cultivated ground, climbing over bnshes. Cullman, Bibb, Montgomery, and Mobile counties. A pernicious bindweed.

The specimens from Alabama so far observed, referred to $P$. dumetorum and $P$. scandens, belong to this species.

Type locality : "Margins of woods, \&c. near Industry [Texas]."

Herb.Geol. Surv. Herb. Mohr.

THYSANELLA Gray, Bost. Journ. Nat. Hist. 5 : 24. 1845.

Ono species. Southern Atlantic North America.

Thysanella fimbriata (Ell.) Gray, Bost. Journ. Nat. Hist. 5 : 24.1845.

Polygonum fimbriatum Ell. Sk. 1:583. 1817.

Fringed THYSANELla.

Ell.1. c. Chap. Fl.391.

Lonisianian area. Georgia, Florida.

Alabama: Upper division Coast Pine belt. Arid sandy ridges. Geneva County (E. A.Smith). Flowers white. September; rare. Annual.

Type locality: "Grows on the poorest pine barrens, on the high ridges between the

Flint and Chattahoochie rivers, along what is termed the Federal road."

Herb. Geol. Surv. Herb. Mohr.

POLYGONELLA Michx. Fl. Bor. Am. 2:240. 1803.

Seven species, herbs or shrubs. Southeastern North America, 6 .

Polygonella polygama (Vent.) Gray, Bost. Journ. Nat. Hist. 5 : 231. 1817.

Polygonum polygamum Vent. Jard. Cels. 665. 1800.

OCtOBER Flower.

Polygonella parvifolia Michx. Fl. Bor. Am. 2:241. 1803. 
Eil. Sk. 1: 458. Chap. Fl. 386.

Louisianian area. Coast of North Carolina to Florida and Mississippi.

Alabama: Littoral region. Loose sands. Baldwin County, Fish River Bay, shore of Perdido Bay. Hlowers white to pink. October, November; not frequent. Shrubby.

Type locality not ascertained.

Herb. Geol. Surv. Herb. Mohr.

Polygonella gracilis (Nutt.) Meiss. in DC. Prodr. 14: 80, 1856.

Polygonum gracile Nutt. Gen. 1:255. 1818.

SLENDER Jointweed.

Chap. Fl. 387.

Louisianian area. On the coast of South Carolina to Florida and Mississippi.

Alabama : Littoral region. Drifting sands. Baldwin County, Point Clear.

Annual.

Type locality : "In Georgia? Dr. Baldwyn."

Herb. Geol. Surv. Herb. Mohr.

Polygonella americana (Fisch. \& Mey.) Small, Mem. Torr. Clnb, 5 : 141. 1894.

AMERICAN JOINTWEED.

Gonopyrum americanum Fisch. \& Mey., Mem. Acad. St. Petersb. ser. 6, 4:144. 1840.

Polygonella ericoides Engelm. \& Gray, Bost. Journ. Nat. Hist. $5: 230.1845$.

$P$. meissneriana Schuttlew.; Meiss. in DC. Prodr. $14: 81.1856$.

Chap. Fl. 387.

Carolinian area. Georgia, southwestern Texas (Riddell), Arkansas.

Alabama: Mountain region. Limestone hills. Blount County, Warnock Mountain, about 1,000 feet altitude (Miss Mary Mohr). Jackson County, Pisgah. Flowers rose color. August; rare. Perennial.

Type locality not ascertained.

Herb. Geol. Surv. Herb. Mohr.

BRUNNICHIA Banks; Gaertn. Fruct. $1: 213, t .45$, f. 2. 1788.

One species, perennial climber, southern Atlantic North America.

Brunnichia cirrhosa Banks; Gaertn. Fruct. 1:214, t.45. 1788.

Rajania orata Walt. Fl. Car. 247. 1788.

Ladies' Ear Drops.

Ell. Sk. 1:521. Gray, Man. ed. 6, 444. Chap. Fl. 392.

Carolinian and Louisianian areas. Gulf coast and southern Atlantic slope to central 'Tennessee, southern Illinois; and Arkansas.

Alabama: Tennessee Valley to the coast, banks of streams, common. Central Prairie region. Landerdale County, Florence, banks of Tennessee River. Hale, Dallas, Montgomery, and Mobile counties. Flowers greenish white. July, August. Type locality : "Hab. in Bahama."

Herb. Geol. Surv. Herb. Mohr.

\section{CHENOPODIACEAE. Goosefoot Family.}

\section{CHENOPODIUM L.Sp. Pl. 1:218. 1753. Goosefoot. Pigweed.}

About 50 species, almost cosmopolitan, including some of the most common weeds, numbers of them naturalized in America. About 8 species native in North America.

Chenopodium album L. Sp. Pl. 1 : 219. 1753.

LAMB'S QUARTERS.

Ell. Sk. 1:330. Gray, Man. ed. 6, 432. Chap. Fl.376. Coulter, Contr. Nat. Herb.

$2: 367$. Wats. Bot. Calif. $2: 46$.

Common weed, introduced from Europe, naturalized over the continent.

Alabama: Throughont the State. In cultivated and waste places. Mobile County, frequent on the sea beach. July, August. Annual.

Type locality: "Hab. in agris Europae."

Herb. Geol. Surv. Herb. Mohr.

Chenopodium glaucum L. Sp. Pl. 1:220. 1753.

OAK-Leaved Goosefoot.

Gray, Man. ed. 6, 432.

Introduced from Europe. Naturalized in New York and New Jersey.

Alabama: Near dwellings. Baldwin County, Blakely. Annual.

Type locality: "Hab. ad Europae fimeta."

Herb. Geol. Surv. Herb. Mohr. 
Chenopodium berlandieri Moq. Chenop. Enum. 23. 1840.

Coulter, Conir. Nat. Herb. $2: 367$.

BerLANDIER's GOOSEFOOT.

Carolinian and Louisianian areas. Southern Missouri to Texas and Florida.

Alabama : Littoral region. Damp gravelly beach. West Fowl River and outlying islands. July. 3 to 4 feet high. Annual.

Type locality: "Circa Mexico. Berlandier 1906."

Herb. Geol. Surv. Herb. Mohr.

Chenopodium murale L. Sp. Pl. 1 : 219. 1753.

Nettle-Leaved Gcosefoot.

Ell. Sk. 1:329. Gray, Man. ed. 6, 432. Chap. Fl. 376. Coulter, Contr. Nat. Herb.

$2: 367$. Wats. Bot. Calif. $2: 46$.

Europe, North Africa, West INdies, and Brazil.

Alleghenian to Louisianian area. Southern New England west to Michigan and Missouri, sonth to Florida and Texas.

Alabama : Coast plain. Waste places. Mobile, near the shipping and on ballast.

July to September; not rare. Anuual.

Type locality: "Hab. in Europae muris aggeribusque."

Herb. Geol. Surv. Herb. Mohr.

Chenopodium vulvaria L. Sp. Pl. 1:220. 1753.

ILL-SCENTED GOOSEFOOT. SOUTHERN EUROPE.

Alabama : Coast plain. Adventive on ballast. Mobile County. July, August. Anuual.

Fetid annual weed; observed in 1886, and each succeeding year.

Type locality: "Hab. in Europae cultis oleraceis."

Chenopodium anthelminticum L. Sp. Pl. 1:220. 1753.

WORMSEED.

Chenopodium ambrosioides var. anthelminticum Gray, Man. ed. 5, 408. 1867.

Ell. Sk. 1: 331. Gray, Man. ed.6, 433. Chap. F1. 377. Coulter, Contr. Nat. Herb.

$2: 368$.

West India Islands, Mexico to.Argentina.

Over the North American continent.

Ala bama : Over the State, excepting the higher mountain ranges. Roadsides. waste places. July to September; a common weed. Annual.

Ecunomic uses: The seeds, "American wormseed," Chenopodium United States

Pharmacopœia, are used medicinally.

Type locality: "Hab. in Pensylvania, Bonaria." .

Herb. Geol. Surv. Herb. Mohr.

Chenopodium ambrosioides L. Sp. Pl. 1:219. 1753.

Mexican Tea.

Ell. Sk. 1: 330. Gray, Man. ed. 6, 433.

Carolinian and Lonisianian areas. Probably introduced from tropical America and naturalized in all warmer parts of the globe.

Alabama : Coast plain. Mobile County, gardens, waste places. July, August.

Annual.

Economic uses: The seeds are used like those of the above.

Type locality: "Hab. in Mexico, Lusitania."

Herb. Geol. Surv. Herb. Mohr.

Chenopodium botrys L. Sp. Pl. 1 : 219. 1753.

Jerusalem OAK.

Ell. Sk. 1:330. Gray, Man. ed. 6, 433. Chap. Fl.376. Coulter, Contr. Nat. Herb.

$2: 368$.

Introduced from southern Europe, all over temperate and warmer North America.

Alabama: Over the State. Waste ground, near dwellings. Tuscaloosa County.

Mobile County, ballast. July, August. Annual.

Type locality: "Hab. in Europae australis arenosis."

Herb. Geol. Surv. Herb. Mohr.

Chenopodium rubrum L. Sp. Pl. 1 : 218. 1753.

Coast Blite.

Blitum maritimum Natt. Gen. Add. 1818.

B. rubrum Reich. Fl. Germ. Exsic. 582. 1832.

Gray, Man. ed. 6, 432. Coulter, Contr. Nat. Herb. $2: 367$.

Canadian zone to Louisianian area. New foundland, Ontario; New England west to

British Colnmbia, California; New Jersey west to Kansas, Indian 'Territory, Colorado, and California. 
Alabama: Waste places. Adventive with ballast. Mobile, wharf. June, 1893. Annual.

Type locality: "Hab. in Europae cultis, ruderatis.

Herb. Geol. Surv.

ROUBIEVA Moq. Ann. Sci. Nat. ser. 2, 1:292. 1834.

One species, South America.

Roubieva multifida (L.) Moq. Ann. Sci. Nat. ser. 2, 1:293, t.10. 1834.

Chenopodium multifidum L. Sp. Pl. 1:220. 1753.

Cutleaf Goosefoot.

South America, Sicily (naturalized).

Carolinian and Louisianian areas. Adventive along the seashore from New Jersey to western Florida.

Alabama : Coast plain. Mobile County. June, July; a frequent ballast weed; perennial. Observed since 1887.

Type locality : "Hab. in Bonaria."

Herb. Geol. Surv. Herb. Mohr.

ATRIPLEX L. Sp. Pl. 2 : 1052. 1753. ORACHE.

About 120 species. Cosmopolitan, mostly in maritime regions and alkaline plains of the interior. North America, 40.

Atriplex arenaria Nutt. Gen. 1:198. 1818.

SAND ORaChe.

Obione arenaria Moq. Chenop. Enum. 71. 1840.

Ell. Sk. 2:578. Gray, Man. ed.6, 434. Chap. Fl. 377.

MExico, Brazil.

Carolinian and Louisianian areas. From the shores of southern New England to Florida, west to Mississippi.

AlabaMa : Littoral region. Sandy beaches, subject to occasional overflow by the tide. Mobile County, West Fowl River. July; not rare. Annual.

Type locality: "On the sandy seacoast of New. Jersey."

Herb. Geol. Surv. Herb. Mohr.

Atriplex hastata L. Sp. Pl. 2 : 1053. 1753.

HaLberd-Leaf Orache.

Atriplex patula var. hastata Gray, Man. ed.5, 409. 1867.

Gray, Man. ed. 6, 434. Chap. Fl.377.

Alleghenian and Louisianian areas. New Brunswick, Ontario, lake shore, south along the seashore to Florida.

Alabama : Coast plain. Mobile. 'To all appearance adventive with ballast. July. Annual.

Type locality: "Hab. in Europa frigidiori."

Herb. Geol. Surv. Herb. Mohr.

DONDIA Adans. Fam. Pl. 2:261. 1763.

Sueda Forsk. Fl. Aegypt. Arab. 69, t. 186. 1775.

Six species, warmer regions North Hemisphere, mostly North American.

Dondia linearis (Ell.).

Tall Sea-blite.

Salsola linearis Ell. Sk. 1:332. 1817.

Sueda linearis Moq. Chenop. Enum. 130. 1840.

Chenopodium maritimum Walt. Fl. Car.111. 1788. Not L.

Ell. Sk. l. c. Chap. El. ed. 3, 406.

CUBA.

Louisianian area. Seacoast from South Carolina to Florida.

Alabama : Littoral region. Sandy low beach. Mobile County, West Fowl River. July; not frequent. Annual.

Type locality (Elliott): "Grows along the margin of the ocean [South Carolina and Georgia]."

Herb. Geol. Surv. Herb. Mohr.

SALICORNIA L.Sp. Pl. 1:3. 1753.

Eight species, seashores of the Old and New World. 
Salicornia bigelovii Torr. Bot. Mex. Bound. Surv. 184. 1859.

Bigelow's Glasswort.

Salicornia mucronata Bigelow, Fl. Bost. ed. 2,2. 1824. Not Lag. 1817.

Gray, Man. ed. 6, 434. Coulter, Contr. Nat. Herb. $2: 370$.

Alleghenian to Louisiauian area. Nova Scotia on the coast to New England, south to Florida and Texas.

AlabaMa: Littoral region. Saline marshes on the seashore. Mobile County,

West Fowl River. Cat Island. July, August; not rare. Annual.

Type locality: "On the beach at Brazos Santiago, May; Schott."

Herb. Geol. Surv. Herb. Mohr.

Salicornia ambigua Michx. Fl. Bor. Am. 1:2. 1803.

SHRUBBY SAMPHIRE.

Ell. Sk. 1:4. 1817. Gray, Man. ed. 6, 435. Chap. Fl. 378. Coulter, Contr. Nat.

Herb. 2:370.

Carolinian and Louisianian areas. On the seashore from Massachusetts to Florida, west to Texas; Pacific coast from Vancouver's Island to California.

Alabama: Littoral region. Wet sands and shallow salt marshes. Mobile County,

Dauphin Island, West Fowl River. July, August; frequent. Perennial.

Type locality. "Hab. in Carolinae scirpetis maritimis."

Herb Geol Surv. Herb. Mohr.

SALSOLA L. Sp. Pl. 1:222. 1753. SALTwORT.

About 40 species, temperate regions North Hemisphere. Mostly on salty plains of the interior.

Salsola kali L. Sp. Pl. 1 :222. 1753.

Common SaLTwORT.

Salsola caroliniana Michx. Fl. Bor. Am. 1: 174. 1803.

Ell. Sk. 1:331. Gray, Man. ed. 6:435. Chap. F]. 378.

EURope.

Alleghenian to Louisianian area. Ontario, Nova Scotia, New Brunswick; Now England south to Florida and Mississippi.

Alabama: Littoral region. Loose sands on the coast. Baldwin County, east shore Mobile Bay; not rare. Annual.

Type locality: " Hab. in Europae litoribus maris."

Herb. Geol. Surv. Herb. Mohr.

\section{AMARANTHACEAE. Amaranth Family.}

AMARANTHUS L. Sp. Pl. 2 :989. 1753.

About 50 species, warm temperate and tropical regions of the globe. Many cosmopolitan weeds. North America, 6 truly indigenous, and an equal number iutroducerl in cultivated grounds.

Amaranthus retroflexus L. Sp. Pl. 2 :991. 1753.

Green Amaranth.

Gray, Man. ed. 6, 428. Coulter, Contr. Nat. Herb. $2: 358$.

SoUth AMErica, Europe.

All over the continent. Cultivated ground, waste places, chiefly Northern.

Alabama: Over the State. In cultivated ancl waste ground. Mobile County.

Angust, September; not frequent. A coarse weed. Annual.

Type locality: "Hab. in Pensylvania. Kalm."

Herb. Geol. Surv. Herb. Mohr.

Amaranthus hybridus L. Sp. Pl. 2 : 990. 1753.

PigWeed.

Amaranthus hypochondriacus L. Sp. PL. 2 : 991. 1753.

A. chlorostachys Willd. Amaranth. 34, t. 10, f. 19.1790.

A. chlorostachys var. hybridus Gray, Man. ed. 6, 428. 1890.

Gray, Man. ed. 6, 428. Chap. Fl. 380. Coulter, Contr. Nat. Herb. 2 : 358.

All over tropical and temperate America.

Alabama: Over the State. Introduced in cultivated ground, waste places.

Variable; common weed. July to October. Annual.

Type locality: "Hab. in Virginia."

Herb. Geol. Surv. Herb. Mohr.

Amaranthus spinosus L. Sp. Pl. 2 : 991. 1753.

SPiny Pigween.

Gray, Man. ed. 6, 428. Chap. Fl. 380. Coulter, Contr. Nat. Herb. 2: 359.

Eastern North America from New York to the Gulf, Texas, and Arkansas. Introduced from tropical Amorica. 
Alabama : Over the State. Cultivated ground. July to October. Abundant. A most tronblesome weed. Annual.

Type locality: "Hab. in Indiis."

Herb. Geol. Surv. Herb. Mohr.

Amaranthus graecizans L. Sp. Pl. 2 : 990. 1753.

TUMBLEWHeD.

Amaranthus albus L. Sp. Pl. ed. 2, 2 : 1404. 1763.

Gray, Man. ed. 6, 428. Coulter, Contr. Nat. Herb. $2: 359$. Chap. Fl. 380.

Mediterranean region of Europe, Mexico.

Alleghenian to Louisianian area. Ontario to British Columbia; southern New

Eugland and New York to Pennsylvania, thence to Louisiana, Texas, and Arkansas. Alabama: Found only on ballast. Mobile County. July, August; rare. Annual. Type locality: "Hab. in Virginia."

Herb. Geol. Surv. Herb. Mohr.

Amaranthus deflexus L. Mant. 2 :295. 1771.

Low Amaranth.

Euxolus deflexus Raf. Fl. Tell. 3:42. 1836.

Britt. \& Br. Ill. Fl. 1:590. Chap. Fl. ed. 3, 400.

Brazil, Peru, Southern Europe, Africa.

Alabama: Adventive on ballast. Mobile County. September, 1891. Annual.

Also observed in Pensacola, Fla.

Type locality not given.

Herb. Geol. Surv. Herb. Mohr.

Amaranthus muricatus Moq. in DC. Prodr. 13, pt. 2:276. 1849.

MURICATE AMARANTH.

Peru, Brazil.

Alabama: Fugitive from South America, on ballast. Mobile County. September, 1891. Annual.

'Type locality: "Prope Mendoza (Gillies!) et Buenos-Avres (Tweedie!)."

Herb. Geol. Surv. Herb. Mohr.

SCLEROPUS Schrad. Ind. Sem. Hort. Goett. 1835.

One species, West Indies, Florida.

Scleropus crassipes (Schlecht.) Moq. in DC. Prodr. 13, pt. 2:271. 1849.

Amaranthus crassipes Schlecht. Linnaea, 6:757. 1831.

Scleropus amarantoides Schrad. Ind. Sem. Hort. Goett. 1835.

Chap. Fl. 381. Griseb. Fl. Brit. W. Ind. 68.

West Indies, Mexico, Peru.

Louisianian area. Southern Florida.

AlabaMA : Fugitive on ballast. Mobile County. October, 1892, 1893. Annual.

Type locality: "In locis paludosis ad rivulos insulae Sti. Thomae."

Herb. Geol. Surv. Herb. Mohr.

ACNIDA L. Sp. Pl. 2 : 1027. 1753.

Four or 5 species, North America, West Indies. Coarse paludial herbs.

Acnida cannabina L. Sp. Pl. 2 : 1027. 1753.

Water Hemp.

Ell. Sk. 2:694. Gray, Man. ed.6, 429. Chap. Fl. 381.

Alleghenian to Louisianian area. Southern New England, along the coast to Florida, Mississippi, and eastern Louisiana.

AlabaMa : Coast plain. Margin of brackish marshes. Mobile County, month of

Dog River, One-mile Creek, 5 to 6 feet high, October 8, 1896. Not frequent. Annual. 'Type locality: "Hab. in Virginia paludibus salsis."

Herb. Geol. Surv. Herb. Mohr.

ALTERNANTHERA R. Br. Prodr. Fl. Nov. Holl.417. 1810.

A vaguely limited genus of abont 16 species, of the subtropical and tropical zones. Southeastern Atlantic North America, 4.

Alternanthera polygonoides R. Br. Prodr. Fl. Nov. Hol.417. 1827.

Gomphrena polygonoides L. Sp. Pl. 1:225. 1753.

Telanthera polygonoides Moq. in DC. Prodr. 13, pt. 2: 363. 1849.

Chap. Fl. 383. Griseb. Fl. Brit. W. Ind. 67. 
West Indies, Mexico to Argentina.

Louisianian area. Coast of South Carolina to southern Florida.

Alabama: Adventive on ballast. Mobile County, September, 1886 to 1895 . Perennial.

Type locality: "Iu America littoribus maris."

Herb. Geol. Surv. Herb. Mohr.

Alternanthera pungens H. B. K. Nov. Gen. \& Sp. 2 :206. 1817.

Telanthera pungens Moq. in DC. Prodr. 13, pt. 2:371. 1849.

Alternanthera achyrantha var. leiantha Mart. Fl. Bras. 5, pt. $1: 183, t .55 .1855$.

Alabama: Fugitive from the West Indies on ballast lieaps. Mobile County. August to October. Flowers white; perennial. Observed for a series of years until destroyed.

Type locality : "Crescit in ripa Orinoci prope nobilem cataractam Maypurensium." Herb. Geol. Surv. Herb. Mohr.

Alternanthera repens (L.) Kuntze, Rev. Gen.Pl.2:536. 1891. ForTy KNot. Achyranthes repens L. Sp. Pl. 1 : 225. 1753.

Alternanthera achyrantha. R. Br. Fl. Nov. Holl.413. 1810.

Illecebrum achyrantha Walt. Fl. Car. 103. 1788.

Ell. Sk. 1:309. Chap. Fl. 382. Griseb. Fl. Brit. W. Ind. 67. Coulter, Contr. Nat.

Herb. 2 : 361.

In most of the warmer regions of the globe.

West Indies to Argentina, Southern Europe, Asia.

Louisianian area. South Carolina to Florida and Texas.

Alabava : Coast plain. Dry exposed places near dwellings. Mobile, pavements and sidewalks, streets of the city. Flowers white. August to November. Perennial.

Economic nses: The herb is used domestically as a medicine.

Type locality : "Hab. in Turcomannia."

Herb. Geol. Surv. Herb. Mohr.

TELANTHERA R. Br. in Tuckey, Congo Exp. 477. 1818.

About 56 species, littoral plants; perennials. West Indies to Brazil.

Telanthera philoxeroides acutifolia Moq. in DC. Prodr. 13, pt.2:363. 1849.

Mart. Fl. Bras. 5, pt. 1: t. 51, f. 11.

Stem slender, 2 or 3 feet long, decumbent, rooting in the mud; lower part submersed, upper part ascending; round, hollow, fleshy, pubescent in lines and at the internodes, else smooth like the opposite, oblong-lanceolate, slightly acuminate leaves which are attenuated at the base into is short, broad, pubescent petiole. Flowers white in roundish heads, borne near the apex of the stems on a stout peduncle shorter than the leaves. The scarious bracts ovate, cuspidate, shorter than the 5-carinate, 3-nerved, acute, glabrous sepals.

West INdies, Brazil.

Alabama : Stagnating tide-water streams. Mobile County. One-mile Creek, near its month, filling completely the bed of the creek. Flowers white. September, 1897. Alventive.

Type locality: "In Brasiliâ prope S. Paul civitatem, * * *, circa Bahiam * * *, prope Buenos-Ayres."

Herb. Geol. Surv. Herb. Mohr.

ACHYRANTHES L. Sp. Pl. 1:204. 1753.

Tropical and subtropical regions.

Achyranthes aspera obtusifolia (Lam.) Griseb. Fl. Brit. W. Ind. 62. 1864.

Achyranthes obtusifolia Lam. Encycl. 1:545. 1783.

West Indies, United States, East Indies.

Alabama: Fugitive from the neighboring tropics. Mobile County, ballast grounds. Perennial.

Type locality : "Cette plante crolt naturellement dans l'Inde."

Herb. Geol. Surv. Herb. Mohr.

CELOSIA L. Sp. Pl. 1:205. 1753.

About 35 species, tropical zone.

Celosia margaritacea L. Sp. Pl. ed. 2, 1:297. 1762.

Fugitive from the tropics, on ballast. Mobile County. Annual.

Type locality: "Hab. in America."

Herb. Geol. Surv. Herb. Mohr. 
FROELICHIA Moench, Meth. 50. 1794.

Ten species, in warmer regions. America, United States to Brazil.

Froelichia floridana (Nutt.) Moq. in DC. Prodr. 13, pt. 2:420. 1849.

Oplotheca floridana Nutt. Gen. 2 : 79. 1818.

Florida Froelichia.

Ell. Sk.2:155. Gray, Man. ed.6,430. Chap. Fl. 384. Coulter, Contr. Nat. Herb. $2: 363$.

West Indies, Mexico.

Alleghenian to Louisianian area. Wisconsin and southern Minnesota to Nebraska and Colorarlo; Illinois south to Georgia and Florida, thence west to Texas and Arkansas.

Alabama: Littoral region. Dry sands. Baldwin County, eastern shore of Mobile Bay. June, July; not freqnent. Annual.

Type locality: "On the banks of the Altamaha River. Baldwyn."

Herb. Geol. Surv. Herb. Mohr.

\section{BATIDACEAE. Batis Family.}

BATIS P. Br. Hist. Jam. 1:356. 1756.

A single species, a frutescent halophyte of the warmer parts of America.

Batis maritima L. Syst. ed. 10, 1380. 1759.

Batis.

Chap. Fl. 411. Griseb. Fl. Brit. W. Ind. 61.

West Indies, Mexico to Venezuela.

Louisianian area. Western Florida to Texas.

Ala bama : Littoral region. Saline marshes. Mobile County, shores of Mississippi Sound and outlying islands. July; not infrequent. Shrub.

Type locality not ascertained, probably West Indian.

Herb. Geol. Surv. Herb. Mohr.

\section{PHYTOLACCACEAE. Pokeweed Family.}

PHYTOLACCA L. Sp. Pl. 1 : 441. 1753. Pokeberky. PoKeWeed.

Abont 11 species, widely diffused over the Old World and America. Perennial herbs.

Phytolacca decandra L. Sp. Pl. ed. 2, 1:631. 1762.

COMmon PoKeberry.

Ell. Sk. 1:530. Gray, Man. ed. 6, 436. Chap. Fl. 375. Coulter, Contr. Nat Herb.

$2: 372$.

SOUTHERN EUROPE (introduced).

Allerhenian and Louisianian areas. Ontario and New England west to Minnesota, south to Florida, Texas, and Irkansas.

Alabama: Over the State. Border of woods, ficlds, copses, in fertile soil. Tuscaloosa, Cullman, Montgomery, and Mobile counties. Flowers rose-pink, July to October; berries purplish black, September, October. Frequent.

Economic uses: The rout is the "pokeroot," "hy tolaccae radix," and the berries, the "pokeberry," "Phytolaccae fructus," of the United States Pharmacopœia.

Typo locality: "Hab. in Virginia."

Herb. Geol. Surv. Herb. Mohr.

\section{NYCTAGINACEAE. Four o'clock Family.}

ALLIONIA Loefl. Iter. Hisp. 181. 1758.

OxyвaPHUS L'Her.; Willd. Sp. Pl. 1 : 105. 1797.

Abont 10 species, perennial. North America to Mexico.

Allionia albida Walt. Fl. Car. 84. 1788.

Pale Umbrellawort.

Oxybaphus albida Chois. in DC. Prodr. 13, pt. 2:434. 1849.

Ell. Sk. 1:187. Chap. Fl. 373; ed. 3, 393. Coulter, Contr. Nat. Herb. 2:352.

Louisianian area. South Carolina to Florida, Mississippi, 'Texas, Arkansas, and Tennessee. 
Alabama : Central Prairie region. Dry hills. Montgomery County. Flowers white or pale pink. July to September; local and rare. Perennial.

Type locality: "South Carolina."

Herb. Geol. Surv. Herb. Mohr.

Allionia nyctaginea Michx. Fl. Bor. Am. 1:100. 1803.

Oxybaphus nyctagineus Sweet, Hort. Brit. 429. 18:i0.

Gray, Man. ed. 6, 425. Chap. Fl. Suppl. 644; ed. 3, 393. Coulter, Contr. Nat. Herb. 2: 351.

Canadian zone to Carolinian area. Manitoba to northern Saskatchewan; Minnesota, Wisconsin, Nebraska, Missouri, Tennessee, Arkansas, and western Texas.

Alabama: Mountain region. Tennessee basin. Rocky dry copses, border of woods. Madison County, Montesano, about 1,000 feet. Flowers purplish red. May, June; rare. Perennial.

Stem simple, 12 to 15 inches high, from a stout cylindrical rootstock.

Type locality: "Hab. ad ripas fluminis Tennassée."

Herb. Geol. Surv. Herb. Mohr.

BOERHAVIA L. Gen. Pl. ed. 5, 4. 1753.

About 20 species, annuals, tropical and subtropical zones. North America, 19; western Texas, 15; South Atlantic States, 3.

Boerhavia erecta L. Sp. Pl. 1: 3. 1753.

Erect Boerilavia.

Ell. Sk. 1:41. Chap. Fl.373. Coulter, Contr. Nat. Herb. 2:356. Griseb. Fl. Brit.

W.Ind. 69.

West Indies, Mexico, Galapagos Islands.

Louisianian area. South Carolina to Florida, west to Texas.

Alabama: Central Prairie region to Coast plain. Dry cultivated and waite places, about dwellings. Flowers pale red. July to October; common. Anuual.

Type locality: "Hab. in Vera Cruce."

Herb. Geol. Surv.

Boerhavia hirsuta Willd. Phyt. no. 3. 1794.

Hairy Bokrhavia.

Chap. Fl. 373. Coulter, Contr. Nat. Herb. 2 : 356 . Griseb. Fl. Brit. W. Ind. 69.

West Indies, Mexico to Guiana, Galapagos Islands.

Louisianian area. Southern Florida. Southwestern Texas.

Ala Bama: Fugitive from the tropics. On ballast ground, Mobile County, september, 1893.

Type locality (Willd. Sp. Pl.): "Hab. in siccis arenosis Jamaicae."

Herb. Geol. Surv.

\section{AIZOACEAE. Figwort Family.}

MOLLUGO L. Sp. Pl. 1 : 89. 1753. INDIAN CHICKWEED.

About 1 dozen species, in warmer parts of the globe.

Mollugo verticillata L. Sp. Pl. 1:89. 1753.

Carpetiveed.

Ell. Sk. 1:183. Gray, Man. ed. 6, 198. Chap. Fl. 48. Coulter, Contr. Nat. Herb.

2: 138. Griseb. Fl. Brit. W. Ind. 56.

West Indies, Mexico to Argentina.

Naturalized and widely diffused through temperate and warmer North America.

From Ontario to the Columbia River, south to the Gulf and sonthern California.

Alabama : All over the State. In cultivated and waste ground. June to October. Common. Annual.

Type locality: "Hab. in Africa, Virginia."

Herb. Geol. Surv. Herb. Mohr.

SESUVIUM L. Sjst. ed. 10, 1058. 1759.

Four species of the seacoast and inland saline places in warm regions. North America, 2 or 3 species.

Sesuvium portulacastrum Syst. Nat. ed. 10, 1058. 1759. Larger Sea Puisiane. Ell. Sk. 1:555. Chap. Fl.44. Coulter, Contr. Nat. Herb. 2:137. Wats. Bot. Calif. 1:251. Griseb. Fl. Brit. W. Ind.57.

Widely distributed on the seacoasts of tropical and subtropical regions. 
Asia, Africa, West Indies to Argentina.

Louisianian area. South Carolina to Florida, west to Texas and California.

Alabama : Sandy sea beaches exposed to the waves. Mobile County, Sand Island.

Flowers red. December; not common. Perennial.

The prostrate and ascending stems, many from the same rootstock, and from 8 to 12 inches loug, cover large patches.

Type locality (L. Sp. Pl. ed. 2): "Hab. in Indiae maritimis."

Herb. Geol. Surv. Herb. Mohr.

Sesuvium revolutifolium Ortega, Hort. Matrit. 19. 1800.

Sesuvium sessile Pers. Syn. 2 : 39. 1805.

S. portulacastrum DC. Hist. Pl. Grass. t. 9.

S. portulacastrum var. subsessile Gray, Pl. Wright. 1:13. 1853.

South America; North America, alkali plains of western Texas to southeastern California.

Alabama : Fugitive on ballast, Mobile County, September, 1892 . Annual.

Type locality not ascertained.

Herb. Geol. Surv. Herb. Mohr.

Sesuvium maritimum (Walt.) B. S. P. Prel. Cat. Fl. N. Y.20. 1888. SEA Purslane. Pharnaceum maritimum Walt. Fl. Car. 117. 1788.

Sesuvium pentandrum Ell. Sk. 1:556. 1817.

Ell. Sk. 1.c. Gray, Man. ed.6, 198. Chap. Fl. 44.

Carolinian and Louisianian areas. Seacoast from Long Island to Florida, west to Mississippi.

Alabama : Littoral region. Saline pools on sandy beaches. Mobile County, Dauphin Island. Flowers greenish white. August; not frequent. Annual?

Type locality : South Carolina.

Herb. Geol. Surv. Herb. Mohr.

\section{PORTULACACEAE. Purslane Family.}

\section{PORTULACA L.Sp. Pl. 1:445. 1753.}

About 16 species, of warmer temperate and tropical regions, chiefly American. North America, 10; west of the Mississippi, 5; Eastern Atlantic States, 2.

Portulaca oleracea L. Sp. P1. 1:445. 1753.

Common Purslane.

Ell. Sk. 1:534. Gray, Man. ed. 6,90. Chap. Fl. 44. Wats. Bot. Calif. $1: 74$.

Cosmopolitan. Widely and abundantly diffused in temperate regions. Doubtfully indigenous in the Atlantic region of North America. Naturalized from southern Ontario to the Gulf and across the continent.

Alabama: Over the State. In cultivated ground. Flowers yellow; May to September. Ripens its seeds to the close of the season. Common everywhere. Annual. Type locality : " Hab. in Europa australi, India, Insula Ascensionis, America."

Herb. Geol. Surv. Herb. Mohr.

Portulaca pilosa L. Sp. Pl. 1:445. 1753. Rfid-Flowering Purslane. Gray, Man. ed. 6,91. Chap. Fl. 44. Coulter, Contr. Nat. Herb. 2:32. Wats. Bot. Calif. 1:74. Griseb. Fl. Brit. W. Ind. 57.

West Indies, Mexico to Peru, Brazil.

Louisianian area. From Texas to Florida and North Carolina; also California.

Alabama: Lower Pine region to Central Pine belt. Dry sandy places. Mobile County, Grand Bay, about dwellings. Autanga County, Prattville (E. A. Smith) Flowers July, August. Annual.

Apparently introduced from the tropics.

Type locality: "Hab. in America meridionali."

Ierb. Geol. Surv. Herb. Mohr.

TALINUM Adans. Fam. Pl. 2:245. 1763.

Fifteen species, warmer parts America, West Indies to Brazil: United States, 8; Southern States, 1.

Talinum teretifolium Pursh, Fl. Am. Sept. 2 :365. 1814.

Purple Talinum.

Ell. Sk. 1:535. Gray, Man. ed.6,91. Chap. Fl. 44.

Alleghenian and Caroliniau areas. Southeastern New York; Pennsylvania south to North Carolina and Georgia, northwest from Indiana to Minnesota, Nebraska, Arkansas, and Colorado. 
Alabama : Mountain region. On exposed rocks. Clay County, Baldrock, 2, 200 feet. Cullman County, 800 feet (Misses Emily and Mary Mohr). Blount County, Warnock Mountains, 1,000 feet. Walker County, Clear Creek Falls. Flowers rose purple, July; not frequent, local. Perennial.

Type locality: "On sunny rocks: Delaware and Virginia."

Herb. Geol. Surv. Herb. Mohr.

CLAYTONIA L. Sp. P1. 1:204. 1753.

About 20 species, perennials, boreal and temperate regions, chiefly western North America. Atlantic United States, 2.

Claytonia virginica L. Sp. Pl. 1 : 204. 1753.

Vikginian SPRING BeaUty.

Ell. Sk. 1:306. Gray, Man. ed.6,91. Chap. Fl.44.

Canadian zone to Carolinian area. Nova Scotia, New Brunswick, and Ontario to Saskatchewan and Alaska; New England west to Minnesota and Nebraska, south throughout the Ohio Valley, west to Missouri and Arkansas, and from Virginia along the mountains to Georgia.

Alabama : Mountain region. Tennessee basin. In rich copses and open woods. Lawrence County, Moulton. Jackson County, Scottsboro. Flowers white or pale rose. April, May; rare.

Type locality: "Hab. in Virginia."

Herb. Geol, Surv. Herb. Mohr.

\section{ALSINACEAE. Pink Family.}

AGROSTEMMA I.Sp. Pl. 1:435. 1753.

Agrostemma githago L. Sp. Pl. 1:435. 1753.

CORN-COCKLE.

Gray, Man. ed. 6, 85. Chap. Fl.52.

Introduced from Europe with grain. Canada throughout the Eastern Atlantic and Gulf States, sparingly diffused southward.

Alabama : Over the State. Roadsides, borders of fields. Tuscaloosa County. Mobile County, ballast ground. Flowers purple. June, July; not frequent. Annual. Type locality: "Hab. inter Europae segetes."

Herb. Geol. Surv. Herb. Mohr.

SILENE L. Sp. Pl. 1:416. 1753.

Three hundred and more species, temperate regions Northern Hemisphere; most frequent in the Old World. Europe, 150 species, North America, about 30 ; of these nearly one-third adventive from Europe. Western North America 16, Atlantic States about 15 , indigenous 9.

Silene stellata (L.) Ait. Hort. Kew. ed. 2, 3: 84. 1811.

Starry Campion.

Cucubalus stellatus L. Sp. Pl. 1 :414. 1753.

Ell. Sk. 1: 514. Gray, Man. ed. 6, 84. Chap. Fl.51.

Alleghenian and Carolinian areas. Rhode Island west to Minnesota, Colorado, and Utah, south to the Ohio Valley and Arkansas, and along the mountains to Georgia.

Alabama: Mountain region to Central Pine belt. Rich shaded banks. Clay County, Emory's Gap, 1,600 feet. Cullman County, 800 feet. Bibb County. Tuscaloosa County, 400 feet (E. A. Smith). Flowers white. July, August; not common. Perennial.

Type locality : "Hab. in Virginia, Canada."

Herb. Geol. Surv. Herb. Mohr.

Silene ovata Pursh, Fl. Am. Sept. 1: 316. 1816.

Ell. Sk. 1:517. Chap. Fl.51. Torr. \& Gray, Fl. N. A. 1: 190.

Carolinian and Louisianian areas. Mountains of North Carolina to Georgia.

Alabama: Mountain region. Central Prairie region. Dry sandy banks. Montgomery County, ravines on Chinquapin Hill. Cullman County (Miss M. Mohr). Flowers white. August; rare. Perennial.

Type locality : "In the western part of Georgia and Carolina."

Herb. Geol. Surv. Herb. Mohr.

Silene rotundifolia Nutt. Gen. 1:288. 1818.

Round-leaved Campion.

Gray, Man. ed. 6,84. Chap. Fl.51.

Carolinian and Louisianian areas. Kentucky; Tennessee, Cumberland Mountains. AlabaMa: Mountain region. Shady rocks. Winston County, Colliers Creek, 1,500 
feet. Dekalb County, Lookont Mountain, near Mentone, 1,600 feet. Flowers scarlet. July; infrequent. Perennial.

Type locality: "In the State of Ohio and Tennessee, on the moist ledges of rocks." Herb. Geol. Surv. Herb. Mohr.

Silene caroliniana Walt. Fl. Car. 142. 1788.

WILD PINK.

Silene pennsylvanica Michx. Fl. Bor. Am. 1:272. 1803.

Ell. Sk. 1:515. Gray, Man. ed. 6, 84. Chap. Fl. 51.

Carolinian area. Eastern New England to New Jersey, West Virginia, Ohio, and

Tennessee, and along the mountains to Georgia.

Alabama : Mountain region. Rocky banks and hillsides. Cullman County (Misses Mohr). Flowers white to pale pink. April; rare. Perennial.

Type locality: South Carolina.

Herb. Geol. Surv. Herb. Mohr.

Silene virginica L. Sp. Pl. 1:419. 1753.

Fire Pink. Catchely.

Ell. Sk. 1:516, in part. Gray, Man. ed. 6, 84. Chap. Fl. 51.

Carolinian and Louisianian areas. Southwestern Ontario; western New York, west to Minnesota, south to the Ohio Valley, west to Missouri and Arkansas, and from New Jersey to western Florida and Mississippi.

Alabama : Tennessee Valley. Mountain region to Upper division of Coast Pine belt. Open woods. Cullman, Tuscaloosa, and Montgomery counties. Clarke County, Choctaw Corner. Flowers crimson. April to June; frequent. Perennial.

Type locality: "Hab. in Virginia."

Herb. Geol. Surv. Herb. Mohr.

Silene regia Sims, Bot. Mag. $41: t$. 1724. 1815.

Royal Catchily.

Gray, Man. ed. 6, 84. Chap. Fl. 51.

Carolinian area. Prairies Ohio, Kentucky, southern Missouri.

Alabama: Lower hills. Upper division Coast Pine belt. Open woods. Bibb County, Pratt's Ferry. Butler County (E. A.Smith). Wilcox County, prairies (S. B. Buckley). Flowers deep scarlet. Perennial.

Type locality: "Native of North-America. Found by Mr. Nuttall, * * * in the environs of St. Louis, on the Mississippi; from whose seeds our plant was raised."

Herb. Geol. Surv. Herb. Mohr.

Silene antirrhina L. Sp. Pl. 1:419. 1753.

SNAPDRAGON CATCHFLY.

Ell. Sk. 1:517. Gray, Man. ed. 6,84. Chap. Fl. 52. Coulter, Contr. Nat. Herb. 2:29. Wats. Bot. Calif. 1:63.

Alleghenian and Louisianian areas. From Canada to Florida and Tennessee, west to Colorado; British Columbia.

Alabama : Over the State. Cultivated ground, roadsides. Mobile County. Flowers white. April; frequont. Annual.

Type locality: "Hab. in Virginia, Carolina."

Herb. Geol. Surv. Herb. Mohr.

Silene anglica L. Sp. Pl. 1 : 416. 1753.

Silene gallica L. Sp. P1. 1:417. 1753.

Introduced.

Alabama : Fugitive from Europe. Ballast ground, Mobile County. Not frequent. Annual.

Type locality : "Hab. in Anglia, Gallia."

Herb. Geol. Surv. Herb. Mohr.

SAPONARIA L. Sp. Pl. $1: 408.1753$.

Saponaria officinalis L. Sp. PI. 1: 408. 1753.

SOAPWORT.

Ell. Sk. 1:514. Gray, Man. ed. 6, 83. Chap. Fl.52.

Naturalized from Europe. Nova Scotia, Ontario, and throughout the Atlantio States.

Alabama : Adventive all over the State. Most frequent in central and upper districts. Roadsides, borders of fields and gardens. Clay, Cullman, Autauga, and Mobile counties. Flowers pink, frequently double. July, August. Perennial.

Economic uses: The root, called "soap root," is used medicinally.

Type locality: "Hab. in Europa media."

Herb. Geol. Surv. Herb. Mohr.

$15894-32$ 
VACCARIA Medic. Phil. Bot. 1: 96.1789.

Vaccaria vaccaria (L.) Brittou in Britt. \& Br. Ill. Fl. 2 : 18.1897.

Cowherb.

Saponaria vaccaria L. Sp. Pl. 1: 409.1753.

Vaccaria vulgaris Host. Fl. Aust. 1:518. 1827.

Gray, Man. ed. 6, 83.

Adventive from Europe. Occasionally met with in Canada and throughout the Atlantic States, and in Colorado.

Alabama : Mobile County, cultivated ground. Flowers May, June; pink. Rare. Annual.

Type locality : "Hab. inter segetes Galliae, Germaniae."

Herb. Geol. Surv. Herb. Mohr.

SAGINA L. Sp. Pl. 1 : 128. 1753. Pearlwort.

About 12 species, temperate regions of Europe and North America.

Sagina decumbens (Ell.) Torr. \& Gray, Fl. N. A. 1: 177. 1838.

Spergula decumbens Ell. Sk. 1 : 523. 1817.

Gray, Man. ed.6, 89. Chap. Fl. 48; ed. 3, 41.

Carolinian and Louisianian areas. New York west to southern Illinois and Missouri, south to North Carolina, Georgia, Florida, and sonthern Arkansas.

Ala bama: Mountain region. Central Pine belt. Pastures, roadsides. Cullman

County. Tuscaloosa County (E.A. Smith). Flowers April; rare. Annual.

Type locality: "Grows in fields and pastures [South Carolina and Georgia]."

Herb. Geol. Surv. Herb. Mohr.

Sagina decumbens smithii (Gray) Wats. Bibl. Index, 105. 1878.

Sagina subulata 8mithii Gray, Man. ed. 5, 95. 1867.

Gray, Man. ed. 6, 89. 1890.

Carolinian and Louisianian areas. Coast of New Jersey to Florida, west to Mississippi.

Alabama: Central Prairie region to Coast plain. In dry sandy soil. Barren fields, roadsides. Montgomery and Mobile counties. Flowers March, April; very common. Annual.

The plants examined from the lower countries of Georgia, Florida, and Mississippi belong to this variety. From the remark of Elliott, "Seeds roughish under a strong microscope," it appears that some of the plants under his type belong to this variety.

Type locality: "Near Philadelphia, in waste ground, and sandy fields, \&c., Somers Point, N.J."

Herb. Geol. Surv. Herb. Mohr.

CERASTIUM L.Sp. Pl. 1:437. 1753.

Fifty to 60 species of the temperate regions Northern Hemisphere. North Anerica, 9 .

Cerastium longipedunculatum Muhl. Cat.46. 1813.

NOdDing CHICKWEED.

Cerastium nutans Raf. Prec. Decouv. 36. 1814.

Gray, Man. ed. 6,88. Chap. Fl.50.

Mexico.

Hudsonian zone to Carolinian area. Nova Scotia and Ontario to Hudsous Bay, British Columbia, and Vanconver; New England west to Minnesota, Nebraska, the Rocky Mountains, and Washington, south to Ohio, Tennessee, and North Carolina.

Alabama : Lower hills. Tuscaloosa County (E.A. Smith). Flowers white. May; rare. Annual.

Type locality: "Pensylvania."

Herb. Geol. Surv. Herb. Mohr.

Cerastium viscosum L. Sp. Pl. 1:437. 1753.

Mouse-ear Chickweed.

Cerastium glomeratım Thuill. Fl. Paris, ed. 2, 226. 1796.

Gray, Man. ed. 6, 88. Chap. Fl. 50.

EUROPE.

Widely spread over North Anerica from Canada to the Gulf. Most probably introduced. 
Alabama: Over the State. Roadsides, pastures, in dry ground. Mobile County.

Flowers February, March; common. Annual.

Type locality: "Hab. in Europae pratis macilentis."

Herb. Geol. Surv. Herb. Mohr.

EUROPE.

Cerastium vulgatum L. Sp. Pl. ed. 2, 1:627. 1762. Larger Mouse-ear ChICKWeed. Cerastium triviale Link, Enum. Hort. Berol. 1: 433.1821.

Gray, Man. ed. 6, 88. Chap. Fl. 50. Coulter, Contr. Nat. Herb. 2:29.

Naturalized from Europe. Distribution of the last, less frequent.

AlabaMA : All over the State. In gardens, borders of fields, grass plots. Flowers white. March, April; less common than the above. Annual.

Type locality: "Hab. in Scaniae et Europae australioris pratis, areis."

Herb. Geol. Surv. Herb. Mohr.

ALSINE L. Sp. P1. 1:272. 1753.

(Stellaria L. Sp. Pl. 1:421. 1753.)

Abont 75 species, temperate regions Northern Hemisphere.

Alsine media L. Sp. Pl. 1:272. 1753.

Common Chickweed.

Gray, Man. ed. 6, 86. Chap. Fl. 50.

Europe.

Throughout the continent; introduced.

Alabama: Abundant on cultivated ground and in damp waste places. One of the most common of our winter annuals.

Type locality: "Hab. in Europae cultis."

Herb. Geol. Surv. Herb. Mohr.

Alsine pubera (Michx.) Britton, Mem. Torr. Club. 4:107. 1893.

Stellaria pubera Michx. Fl. Bor. Am. 1:273. 1803.

SOFT HaIRY STARWORT.

Ell. Sk. 1:517. Gray, Man. ed. 6, 87. Chap. Fl. 50.

Carolinian area.

Alabama: Rich woods, in the hills. Tuscaloosa County. May, June; not frequent. Perennial.

'Type locality: "Hab. in montibus sylvaticis Carolinae septentrionalis."

Herb. Geol. Surv. Herb. Mohr.

\section{Alsine pubera tennesseensis var. nov.}

Perennial, from a slender, ereeping rootstock, stem ascending, 6 to 8 inches high, smoothish; leaves broadly ovate $\frac{1}{2}$ inch wide, sessile or petiolulate, calyx lobes more or lessobtuse or acutish, almost as long as the petals.

Readily distinguished from the type by the foliage of rich dark green, broader leaves, and stouter habit of growth.

Carolinian area. Kentucky.

Alabama : Rich shaded banks. Tuscumbia County, shaded rocky shelves, bluffs of the Tennessee River near Sheffield. Madison County, Montesano (Baker \&.Earle).

Dr. J.Small finds our plant identical with specimens collected in Kentucky by Dr. Short.

Intermediate forms from the knobs in Southern Indiana connect it with the type. (Mohr.)

Type locality: The stations mentioned above.

Herb. Geol. Surv. Herb. Mohr.

ARENARIA L. Sp. P]. $1: 423.1753$.

(ALsine Wahl. Fl. Suppl.127. 1812. Not L.)

About 150 species, widely distributed over the globe, mostly in cool temperate, alpine, and arctic regions. North America, 30. Southern United States, 5 .

Arenaria stricta Michx. Fl. Bor. Am. 1: 274. 1803.

MichaUX's SaNDWORT.

Arenaria michauxii Hook. f. Trans. Linn. Soc. 23: 287. 1867.

2:30.

Ell. Sk. 1:521. Gray, Man. ed. 6, 85. Chap. Fl. 49. Coulter, Contr. Nat. Herb.

Canadian zone to Carolinian area.

Ontario to Lake Superior and Saskatchewan; New England west to Michigan, 
Wisconsin, sonth from southern New York and New Jersey along the mountains to Georgia; mountains of southwestern Texas.

Alabama: Mountain region at greatest elevations. On rocks. Winston County

(T.M. Peters). Flowers white. June, July. Perennial.

Type locality: "Hab. in rupibus Novae Angliae, Canadae."

Herb. Geol. Surv. Herb. Mohr.

Arenaria patula Michx. Fl. Bor. Am. 1:273. 1803.

PITCheR's SaNdWolrt.

Arenaria pitcheri Nutt.; Torr. \& Gray, Fl. N. A. 1:180. 1838.

Gray, Man. ed. 6, 86. Chap. Fl. 49.

Carolinian area. Southern Virginia, west to southern Illinois, southern Missouri, and Arkansas, south to North Carolina, Tennessee, and southwestern Texas. (Riddell, in herb.)

Alabama: Mountain region. Tennessee basin. Lawrence Connty. Madison County, Huntsville. Jackson County, Scottsboro. Frequent on exposed limestone rocks. Occasionally on river banks in the lower country. Sumter County, Espes Station (E. A.Smith). Baldwin County, Point Clear, adventive from the upper country on drifted rubbish on the bay shore. Flowers white. May. Annual.

Type locality: "Hab. in rupibus eirca Knoxville."

Herb. Geol. Surv. Herb. Mohr.

Arenaria brevifolia Nutt.; Torr. \& Gray, Fl. N. A. 1:180. 1838.

Chap. Fl. 49.

Carolinian area. Mountains of Georgia.

Alabama : Mountain region. Exposed sandstone rocks. Dekalb County, summit of Lookout Mountain, 2,000 feet. Flowers white. June; rare. Annual.

Type locality: "On rocks, Georgia, Nuttall!"

Herb. Geol. Surv. Herb. Mohr.

Arenaria serpyllifolia L. Sp. Pl. 1:423. 1753.

ThymeleaF SANDWOKT.

Ell. Sk. 1:518. Gray, Man. ed. 6, 85. Chap. Fl. 49.

Europe.

Canadian zone to Carolinian area. Nova Scotia, Ontario, New England along the mountains to Georgia. Naturalized.?

AldBama: Mountain region. On dry or damp rocky places, to all appearances indigenous. Madison County, Montesano, about 1,000 feet. Jackson County, Scottsboro. Flowers white. May; not infrequent. Annual.

Type locality: "Hab. in Europae sylvis glareosis."

Herb. Geol. Surv. Herb. Mohr.

Arenaria lanuginosa Rohrb. in Mart. Fl. Bras. 14, pt. $2: 274$, t.63. 1872.

Spergulastrum lanuginosum Michx. Fl. Bor. Am. 1:275. 1803.

SPREADING StakWORT.

Arenaria diffusa Ell. Sk. 1:519. 1817.

Stellaria lanuginosa Torr. \& Gray, Fl. N. Am. 1:187. 1838.

Ell. Sk. l. c. Chap. Fl. 49.

Mexico, Central America to Argentina.

Carolinian and Louisianian areas. North Carolina to Florida, west to Mississippi.

Alabama : Tennessee Valley. Coast plain. Shady copses, thickets in dry soil.

Franklin County, Russellville. Mobile and Baldwin counties. Most frequent near the coast. Perennial.

Type locality uot ascertained; Michaux's locality: "Hab. in meridionalibus Americae septentrionali."

Herb. Geol. Surv. Herb. Mohr.

SPERGULA L. Sp. PI. 1:440. 1753.

Two or three species of temperate Europe and Asia. Widely naturalized weeds in fields.

Spergula arvensis L. Sp. Pl. 1 : 440. 175 ?

Corn SPURry.

Ell. Sk. 1:523. Gray, Man. ed.6,90. Chap. Fl. 48.

EUROPE.

Naturalized from Canada to the Gulf and sparingly on the Pacific coast.

Ala Bama : Coast plain. Abundant in sandy low fields, pastures. Mobile County.

Flowers white. March. Annual.

Economic uses: Useful for fodder; valuable for early pasture.

Type locality : "Hab. in Europae agris."

Herb. Geol. Surv. Herb. Mohr. 
TISSA Adans. Fam. Pl. 2:507. 1763.

(SPergularia Pers. Syn. 1:504. 1805.)

About 20 species. Seacoast and saline inland stations of temperate regions, Northern Hemisphere. North America, 6.

Tissa marina (L.) Britton, Bull. Torr. Club, 16:127. 1889.

SAND SPURRY.

Arenaria rubra var. marina L. Sp. Pl. 1: 423. 1753.

Spergularia salina Presl, Fl. Cech. 95. 1819.

Buda marina Dumort. Fl. Belg. 110. 1827.

Gray, Man. ed. 6, 89. Wats. Bot. Calif. 1:71. 1876. Coulter, Contr. Nat. Herb. 2 :30. 1891.

Europe, Mexico to Brazil.

Alleghenian to Louisianian area. Nova Scotia, New Brunswick, seashore; saline plains west to the Rocky Mountains, British Columbia, and California; New England along the seashore to Florida, west to Texas.

Alabama: Littoral region. Brackish sands. Mobile County, West Fowl River. Fruit purplish. May. Seeds with rough projections, scarcely margined. Rare. Annual.

Type locality: "Hab. in litoribus marinis."

Herb. Geol. Surv. Herb. Mohr.

Tissa rubra (L.) Britton, Bull. Torr. Club, 16:127. 1889. Pink SANd SPURry. Arenaria rubra L. Sp. Pl. 1:423. 1753.

Spergularia rubra Presl, Fl. Cech.93. 1819.

Buda rubra Dumort. Fl. Belg. 110. 1827.

Chap. Fl. 48. Gray, Man. ed. 6, 89.

EUROPE.

Alleghenian to Louisianian area. Nova Scotia, New Brunswick; New England south to Virginia and Florida.

Alabama: Adventive on ballast. Mobile County, found once. Annual.

Type locality: "Hab. in Europae arenosis collibus."

Herb. Geol. Surv. Herb. Mohr.

STIPULICIDA Michx. Fl. Bor. Am. 1:26. 1803.

A single species, sonthern United States.

Stipulicida setacea Michx. Fl. Bor. Am. 1:26, t.6. 1803.

Tiny STIPUlicida.

Ell. Sk. 1:51. Chap. Fl. 47.

Louisianian area. North Carolina, Florida, west to Mississippi.

Alabama : Littoral region, Central Pine belt. Baldwin County, drifting sands.

Eastern shore of Mobile Bay. Autauga County, Prattville, gravelly banks of streams.

April to June; not rare. Annual.

Type locality: "Hab. in sabulosis aridis Carolinae."

Herb. Geol. Surv. Herb. Mohr.

POLYCARPON I. Syst. ed. 10, 881. 1759.

Six species, warmer and temperate regions of both hemispheres.

Polycarpon tetraphyllum L.f. Suppl. 116. 1781.

Ell. Sk. 1: 182 . Chap. F'l. 48.

SOUHHERN EUROPE.

Louisianian area. Cosmopolitan in warmer regions. Introduced into South Carolina and Georgia.

Alabama : Coast plain. Sandy exposed soil. Mobile County, on ballast ground, and in waste places along the river front. Annual.

Type locality (Willd. Sp. Pl.): "Hab. in Italiae, Istriae, G. Narbonensis vineis.

Herb. Geol. Surv. Herb. Mohr.

PARONYCHIA Adans. Fam. Pl. 2 :272. 1763. WhItLOW-wort.

About 40 species, in warmer regions of the Northeru Hemisphere. North America, 9 or 10 . Southern States, 5. 
Paronychia baldwinii (Torr. \& Gray) Chap. Fl.46. 1860.

Anychia baldwinii Torr. \& Gray, Fl. N. Am. 1:172. 1838.

BALDWIN'S WHITLOW-WORT.

Chap. Fl. l. c. ; ed. $3,397$.

Louisianian area. Western Florida.

Alabama: Littoral region. Sandy soil. Baldwin County, Fish River Bay. Flowers in September and October; rare. Annual to biennial.

'Type locality: "Florida, Baldwin! West Florida, Mr. Ware! Middle Florida, Ir. Chapman!"

Herb. Geol. Surv. Herb. Mohr.

SIPHONYCHIA Torr. \& Gray, Fl. N. Am. 1:172. 1838.

Four species, seacoast of southern Atlantic America.

Siphonychia erecta Chap. Fl.47. 1860.

LARGER WHITLOW-WORT.

Chap. Fl. l. c.; ed. 3, 397.

Louisianian area. Coast of western Florida to Mississippi.

Alabama: Littoral region. Drifting sands of the seashore. Baldwin County. Mobile County, Dauphin Island. Flowers white. July, August; not rare. Perennial. Type locality: "Sands along the west coast of Florida."

Herb. Geol. Surv. Herb. Mohr.

Siphonychia diffusa Chap. Fl. 47. 1860.

Chap. Fl. l. c.; ed. $3,398$.

Louisianian area. Florida.

Alabama : Littoral region. Dry sandy shores. Baldwin County, Bayou La Launch.

Flowers white. Rare. Annual.

Type locality: "Dry sandy pine barrens, Florida."

Herb. Geol. Surv. Herb. Mohr.

ANYCHIA Michx. Fl. Bor. Am. 1:112. 1803. FORKed CHICK'vend.

Two species, Atlantic America.

Anychia dichotoma Michx. Fl. Bor. Am. 1:112. 1803.

Anychia canadensis Ell. Sk. 1:307. 1817. Not Queria canadensis L. Gray, Man. ed. 6, 426. Chap. Fl. 46.

Alleghenian and Carolinian areas. New England west to Missouri, sonth to Tennessee and upper districts of North Carolina, thence to Georgia.

Alabama: Mountain region and Lower hills. Exposed sandy or gravelly hillsides. Clay County, shaded shelves of rocks; abundant. Chehawhaw Mountain, 2,400 feet. Dekalb County, Lookout Mountain, 2,000 feet. Calhoun County, near Anniston, 700 feet. September; not infrequent. Perennial.

Type locality : "Hab. in collibus calcariis Pensylvaniae superioris et Kentucky." Herb. Geol. Surv. Herb. Mohr.

\section{HERNIARIA L.}

About 15 species, perennials, of the Mediterranean region.

Herniaria incana Lam. Encyel. 3 : 124. 1789.

Southern Europe.

Alabama : Fugitive on ballast. Mobile County. June; rarely observed. Perennial.

Type locality: "Dauphiné * * * proche le Bourg-d'Oisans."

Herb. Geol. Surv. Herb. Mohr.

POL Y CARPAEA Lam. Journ. Hist. Nat. Par. $2:$ 8, t. 25. 1792.

(Mollia Willd. Hort. Berol. 11, t. 11. 1806.)

About 30 species; shrubby; warmer regions of the Old World.

Polycarpaea alsinefolia (Spreng.).

Mollia alsinefolia Spreng. Syst. 1:795. 1825.

SOUTHERN EUROPE.

Alabama: Fugitive on ballast. Mobile County. June. Perennial.

Type locality : "Sicilia."

Herb. Geol. Surv, . Herb. Mohr. 


\section{NYMPHAEACEAE. Water Lily Family.}

NELUMBO Adans. Fam. Pl. $2: 76$. 1763. SACREd BeAN.

Two species, temperate and tropical America.

Nelumbo lutea (Willd.) Pers. Syn. 2 : 92. 1805. Nelumbo. Water Chinquapin. Nelumbium luteum Willd. Sp. Pl. 2 :1259. 1799.

Ell. Sk. 2:67. Gray. Man. ed. 6, 55. Chap. Fl. 18. Coulter, Contr. Nat. Herb.

2:11. Gray, Syn. Fl. N. A. 1, pt. 1:75.

WES'T INDIES.

Alleghanian to Louisianian area. Ontario; New England west to Minnesota, south to Illinois, Missouri, Tennessee, Arkansas, and Florida, and to the Rio Grande, Texas.

Alabama: Central Prairie belt to Coast plain. In deep still-flowing water. Montgomery County. Geneva County (E. A. Smith): Mobile County, in the delta. Flowers yellow. May, June. Perennial.

Type locality: "Hab. in Virginiae, Carolinae, Floridae fluviis."

Herb. Geol. Surv. Herb. Mohr.

Economic uses: The farinaceous tubers and the seeds are edible. Ornamental aquatic.

Nelumbo NuCIFerum Gaertn. Fruet. 1:72. 1788.

N. speciosum Willd. Sp. Pl. $2: 1258.1799$.

For a few years past cultivated in a few places, this plant of eastern Asia has made its appearance spontaneously in Kelly's pond, beyond the western suburbs of Mobile, growing vigorously and producing its flowers perfectly. June 18, 1897. Pereunial.

CABOMBA Aubl. Pl. Guian. 1:321. 1775.

Three species, of warmer America. Atlantic North America, 1.

Cabomba caroliniana Gray, Ann. Lyc. N. Y. 4:47. 1837. Carolinian Cabomba. Cabomba aubleti Michx. Fl. Bor. Am. 1:206. 1803. In part.

Ell. Sk. 1:416. Gray, Man. ed. 6, 55. Chap. Fl. 19. Coulter, Contr. Nat. Herb. 2:11. Gray, Syn. Fl. 1, pt. 1: 74 .

Caroliuian and Louisianian areas. Southern Illinois, western Tennessee, from North Carolina to Florida, west to Texas.

Alabama : Lower Pine region. Coast plain. In stagnant and still-flowing water.

Flowers white. May, June; not infrequent. Perennial.

Type locality of C. aubleti Michx.: "Hab. in aquosis Carolinae et Georgiae."

Herb. Geol. Surv. Herb. Mohr.

BRASENIA Schreb. Gen. Pl.372. 1789. Water SHIELd.

(Hydropeltis Michx. Fl. Bor. Am. 1 : 324. 1803.)

Brasenia purpurea (Michx.) Casp. in Engl. \& Prantl, Nat. Pfl. 3, pt. 2: 6. 1890.

Purple Water Shimld.

Hydropeltis purpurea Michx. Fl. Bor. Am. 1:324, t. 29. 1803.

Menyanthes peltata Thunb. Nov. Act. Upsal. $7: 142.1815$.

Brasenia peltata Pursh, Fl. Am. Sept. 2 :389. 1814.

Ell. Sk. 2: 66. Gray, Man. ed. 6, 55. Chap. Fl. 19. Gray, Syn. Fl. N. A. 1, pt. 1:74.

Asia, Africa, Australia, Cuba.

Alleghenian to Ionisianian area. Nova Scotia, Quebec, Ontario; New England to Minnesota, south to the Gulf, Texas, and Arkansas, west to California and Washington.

Alabama : Throughout the State. In still water, ponds, ditches. Flowers maroon purple. May to July; frequent. Perennial.

Type locality: "Hab. in aquis tranquillis Carolinae inferioris et Provinciae Tennassée."

Herb. Geol. Surv. Herb. Mohr. 
CAstalla Salisb. in Koen. \& Sims, Ann. Bot. 2:71. 1805. Pond Lily.

'I'hirty-two species, temperate regions, Northern Hemisphere. North America, 6. Eastern States and Cauada, 3.

Castalia odorata (Dryand.) Woodv. \& Wood in Rees, Cycl. 6: no. 1. 1806.

SWEET-SCENTED WATER LILY.

Nymphaea alba Michx. Fl. Bor. Am. 1 : 311. 1803. Not L.

N. odorata Dryand, in Ait. Hort. Kew. 2 : 227. 1789.

Castalia pudica Salisb. in Koen. \& Sims, Ann. Bot. 2: 72. 1805.

Ell. Sk. 2: 7. Gray, Man. ed. 6, 55. Chap. Fl. 19. Gray, Syn. Fl. N. A. 1, pt. 1: 76.

Canadian zone to Louisianian area. Nova Scotia, Quebec, Ontario; Eastern United States to the Gulf, Louisiana, Arkansas, and Missouri.

Alabama: Orer the State. Still waters, ponds, ditches; common. Flowers white, fragrant. April to June. Perennial.

Type locality (Ait. Hort. Kew. ed. 2): "Native of North America and the east of Siberia."

Herb. Geol. Surv. Herb. Mohr.

Castalia odorata rosea (Pursh) Britton.

ROSE-COLORED WATER LiLY.

Nymphaea odorata var. rosea Pursh, Fl. Am. Sept. 2 : 369. 1816.

Distribution that of the type.

Alabama: Coast plain. Ponds. Mobile County, Springhill. Flowers rose-tinted. April, May; rare.

Type locality: "In ponds and slow-flowing waters: Canada to Carolina."

Herb. Geol. Surv. Herb. Mohr.

NYMPHAEA L.Sp. Pl. 1:510. 1753.

(Nuphar Sibth. \& Smith, Fl. Graec. Prodr. 1:391. 1806.)

Three or 4 species, mostly of the north temperate zone.

Nymphaea advena Soland. in Ait. Hort. Kew. 2 : 226. 1789.

Yellow POND Lily. SPatter DOCK.

Nuphar advena R. Br. in Ait. Hort. Kew. ed. 2, 3:295. 1811.

Ell. Sk. 2: 8. Gray, Man. ed. 6, 56. Chap. Fl. 20. Coulter, Contr. Nat. Herb. 2 : 12. Gray, Syn. Fl. N. A. 1, pt. 1: 77.

Canadian zone to Louisianian area. Nova Scotia, Quebec, Ontario, and Manitoba to British Columbia; Eastern United States to the Rocky Mountains.

Alabama: Over the State. Stagnant and still-flowing water. Flowers bright yellow. June, July.

Type locality: "Native of North America."

Herb. Geol. Surv. Herb. Mohr.

Nymphaea sagittifolia Walt. Fl. Car. 155. 1788. Southern Yellow Pond Lily. Nuphar sagittifolia Pursh, Fl. Am. Sept. 2 : 370. 1814.

Ell. Sk. 2:8, Gray, Man. ed.6, 56. Chap. Fl.20. Gray, Syn. Fl. N. A. 1, pt. 1: 78.

Carolinian and Louisianian areas. Southern Illinois, southern Indiana and North Carolina to Florida, west to southern Mississippi.

Alabama : Central Pine belt to Coast plain. Still-flowing water. Most frequent in the Coast region. Tuscaloosa County (E.A. Smith). Montgomery, Mobile, and Baldwin counties. Flowers lemon-yellow. June, July; not rare.

Type locality: South Carolina.

Herb. Geol. Surv. Herb. Mohr.

\section{CERATOPHYLLACEAE. Hornwort Family.}

CERATOPHYLLUM L. Sp. Pl. 2 : 992. 1753.

A few species, perhaps forms of one, temperate regions.

Ceratophyllum demersum L. Sp. Pl. 2 : 992 . 1753.

HoRnwort.

Gray, Man. ed. 6, 488. Chap. Fl. 398. Coulter, Contr. Nat. Herb. 2:420. Wats. Bot. Calif. 2: 78.

Europe, Siberia to Japan.

Alleghenian to Louisianian area. Ontario; Now England to the Gulf; across the continent to Nevada and California.

Alabama: Over the State. In stagnant water. Abundant. Mobile County.

Type locality: "Hab. in Europae fossis majoribus sub aqua."

Herb. Geol. Surv. Herb. Mohr. 


\section{MAGNOLIACEAE. Magnolia family.}

MAGNOLIA L. Sp. PI. 1: 535.1753.

Twenty-one species, warmer temperate to tropical regions of eastern Asia; Mexieo. Atlantic North America, 7.

Magnolia foetida (L.) Sargent, Silv. N. A. 1:3, t. 1, 2.

Maginolia.

Magnolia virginiana var. foetida L. Sp. Pl. 1:536. 1753.

Magnolia grandiflora L. Syst. Nat. ed. 10, 2:1082. 1759.

Ell. Sk. $2: 36$. Chap. Fl. 13. Gray, Syu. Fl. 1, pt. 1:59.

Louisianian area. Atlantic coast region from Cape Fear River, North Carolina, south to Mosquito Inlet and Tampa Bay, Florida, west along the coastal plain of the Gulf States to eastern Texas and southern Arkansas south of latitude $32^{\circ} 30^{\prime}$.

Ala BAMA : Coast plain to northern limit of Central Prairie region from Russell County on the Alabama and Georgia State line to Autauga County, Prattville, and to Sumter County. Cuba, on the Alabama and Mississippi State line. In deep light loamy soil rich in humus, not subject to overflow. Tree 70 to 100 feet high and from 2 to 3 feet in diameter. Flowers white, heavily fragrant. April to June; frequent.

Economic uses: Timber tree. Successfully cultivated for ornament in the Tennessee Valley and in the Mountain region to an elevation of 800 feet. Cullman County. The bark is used medicinally.

Type locality : "Hab. in Virginia, Carolina."

Herb. Geol. Surv. Herb. Mohr.

Magnolia virginiana L. Sp. Pl. 1:535. 1753.

White Bay. Sweet Bay. Beaver Tree.

Magnolia virginiana var. glauca L. Sp. Pl. 1: 535. 1753.

M. glauca L. Sp. Pl. ed. 2, 1: 755. 1763.

Ell. Sk. 2:37. Gray, Man. ed. 6, 49. Chap. Fl. 13. Sargent, Silv. N. A. 1:5, t.3. Gray, Syn. Fl. N. A. 1, pt. 1:59.

Alleghenian to Lonisianian area. Massachusetts (Cape Ann) along the coast to Bay Biscayne and Tampa, Fla.; through the Gulf States to southwestern Arkansas, and to Trinity River in Texas.

Alabama : Lower hills. Central Pine belt to the coast. Extreme northern station, Etowah County, Ballplay. Lamar County, Vernon. 'Tuscaloosa County. Most frequent in the sandy swamps of the Coast Pine belt. Tree 60 to 70 feet high. Flowers white, fragrant. May, June.

Economic uses. Of some value for its wood. The bark is used medicinally under the name of "white bay bark."

Type locality: "Hab. in Virginia, Carolina."

Herb. Geol. Surv. Herb. Mohr.

Magnolia acuminata L. Sp. Pl. ed. 2, 1: 756. 1763.

Cucumber Tree.

Ell. Sk. 2:37. Grav, Man. ed. 6, 49. Chap. Fl.14. Sargent, Silv. N. A. 1: 7, t. 4, 5. Gray, Syn. Fl. N. A. 1, pt. 1:61.

Carolinian and Louisianian area. Western New York to southern Illinois; southern Pennsylvania and West Virginia to Mississippi and southwestern Arkansas. In mountainons districts mostly.

Alabama : Most frequent in the Mountain region. More rarely in the Coast plain. Rich wooded hillsides. Madison County, Montesano, 1,200 feet. Cullman County, 800 feet. Lamar County, Vernon. Pike, Troy, Wilcox, and Clarke counties. Baldwin County, Stockton, extreme southern station. Flowers white or greenish white. April. Fruit ripe in September.

Economic uses: Timber tree.

Type locality: "Hab. in Pensylvania."

Herb. Geol. Surv. Herb. Mohr.

Magnolia acuminata cordata (Michx.) Sargent, Am. Journ. Sci. ser. 3, 32: 473. 1886.

Magnolia cordata Michx. Fl. Bor. Am. 1: 328. 1803. YELLOW-FLOWERED MAGNOLIA.

Ell. Sk. 2: 38. Chap. Fl. 14. Gray, Syn. Fl.N. A. 1, pt.1:61.

Carolinian area. Middle Georgia.

AlabaMa: Mountain region, Winston County. Abundant in a secluded valley on a tributary of Sipsey Fork, 1,200 feet. Flowers greenish-yellow to lemon-yellow, end of April (April 26, 1880). Only locality known in the State. Tree 60 to 70 feet high, 18 to 20 inches in diameter. 
Type locality : "Hab. in collibus apricis Carolinae superioris et Georgiae."

Herb. Geol. Surv. Herb. Mohr.

Magnolia tripetala L. Sp. Pl.ed.2, 1:756. 1762.

ElKwood. Umbrelia Tree.

Magnolia umbrella Lam. Encycl. 3 : 673. 1783.

Ell. Sk. 2:38. Gray, Man. ed. 6, 49. Sargent, Silv. N. A. 1:13, t.9, 10. Chap. Fl. 13.

Caroliuian and Louisianian areas. Southeastern Pennsylvania, south along the mountains to Georgia and northeastern Mississippi.

Alabama: Mountain region to Upper division Coast Pine belt. Rich hillsides. Winston County. Autanga County, Prattville. Clarke County (E. A. Smith).

Small tree. Flowers white, May, June; not frequent.

Economic uses: An ornamental tree.

Type locality: "Hab. in Carolina, rarius in Virginia."

Herb. Geol. Surv. Herb. Mohr.

Magnolia fraseri Walt. Fl. Car. 159. 1788.

Fraser's Magnolia.

Magnolia auriculata Lam. Encycl. 3:673. 1783.

Ell. Sk. 2:39. Gray, Man. ed.6,50. Chap. Fl. 14. Sargent, Silv. N. A. 1:19, t.11, 12. Gray, Syn. Fl. 1, pt. 1: 60 .

Carolinian and Louisianian areas. From Virginia along the mountains to Ala. bama and Pearl River Valley, Mississippi.

Alabama: Central Pine belt, Upper division Coast Pine belt. Chilton County, Knight's Ferry. Clarke County, Suggsville (Dr. Denny). Butler County, Monterey (E. A. Smith). Flowers white, June; infrequent.

A slender tree 25 to 30 feet high.

Type locality: South Carolina.

Herb. Geol. Surv. Herb. Mohr.

Magnolia macrophylla Michx. Fl. Bor. Am. 1:327. 1803.

Large-leaf Cucumber Tree.

Ell. Sk. 2 :40. Gray, Man. ed.6, 49. Chap. Fl.14. Sargent, Silv. N. A. 1:11, t. \%

Carolinian and Louisianian areas. Southeastern Kentucky, North Carolina to western Florida, and the Gulf States to the Mississippi River.

Alabama: Mountain region to the coast. Rich woods on hillsides and in ravines. Most frequent and of best development in the valleys of the mountain region and among the hills in the upper division of the Coast Pine belt, where trees were observed 16 to 30 inches in diameter. Rare in the Lower division of the Pine belt. Winston, Cullman, Clarke, Mobile, and Baldwin counties. Flowers April, May.

Economic uses: Ornamental.

Type locality: "Hab. in regionibus occidentalibus fluvio Tennassće trajectis."

Herb. Geol. Surv. Herb. Mohr.

LIRIODENDRON L. Sp. P1. 1:535. 1753.

A single species of Eastern North America.

Liriodendron tulipifera L. Sp. P1. 1:535. 1753. Tulip Tree. Yellow Poplar. Ell. Sk. 2:40. Gray, Man. ed. 6, 50. Chap. Fl. 14. Sargent, Silv. N. A. 1:19, t. 13, 14. Gray, Syn. Fl. N. A. 1, pt. 1:61.

Alleghenian to Louisianian area. Southern New England.west to southern Michigan, southward to Florida and to the Gulf States. East of the Mississippi to latitude $31^{\circ}$. Outlying region, southern Missouri and southeastern Arkansas.

Alabama: Mountain region to Lower Pine belt. Of greatest development in the Tennessee Valley. Less frequent in the rich lands above overflow in the Central Prairie region and Upper division of the Coast Pine belt. Flowers April, May.

Large tree, 100 to 120 feet high, 2 to 4 feet and over in diameter.

Economic uses: First-class timber tree. The bark, "yellow-poplar bark," is used medicinally.

Type locality: "Hab. in America septentrionali."

Herb. Geol. Surv. Herb. Mohr.

ILLICIUM L. Syst. ed. 10, 2 : 1050. 1759.

Four species; China and Japan, 2. South Atlantic North America, 2.

Illicium floridanum Ellis, Phil. Trans. 60:524, $t$. 12. 1770. Florida Star Anise.

Chap. Fl. 13. Gray, Syn. Fl. N. A. 1, pt. 1:59.

Louisianian area. Florida to Louisiana.

Alabama : Central Pine belt to the coast. Rich low woods. Most frequent in the 
Coast Pine belt in the semi-swampy woods bordering pine-barren streams. Mobile, Baldwin, Monroe, Clarke, Washington, Montgomery, Hale, and Tuscaloosa counties. Lamar County, Vernon. Flowers maroon, March, April. Shrub 6 to 8 feet high. lll-scented.

Type locality not ascertained.

Herb. Geol. Surv. Herb. Mohr.

SCHIZANDRA Michx. Fl. Bor. Am. 2:218. 1803.

Three or 4 species, woody climbers, warmer regions of Asia. South Atlantic North America, 1.

Schizandra coccinea Michx. Fl. Bor. Am. 2:219, t.4\% 1803.

SCARLET-FruIted SchizaNdRa. Wild SARSAParilla.

Ell. Sk. 2:582. Chap. Fl. 13. Gray, Syn. Fl. N. A. 1, pt. 1:58.

Louisianian area. Sonth Carolina to Florida, western Louisiana (Red River, Jos. Hale).

Alabama: Central Prairie region. In rich woods, bottoms. Marengo County, Luther's Store. Flowers deep crimson, June. Berries scarlet. Ripe August, September. Rare.

A climbing shrub, stem 20 to 25 feet long.

Economic uses: The aromatic stem, called "wild sarsaparilla," is used like sassafras as a domestic remedy.

Type locality : "Hab. in umbrosis Carolinae et Georgiae."

Herb. Geol, Surv. Herb. Mohr.

\section{ANONACEAE. Custard Apple Family.}

ASIMINA Adans. Fam. Pl. $2: 365$. 1763. ${ }^{1}$

About 7 species, trees and shrubs of warmer America. Atlantic North America 6, chiefly Southern.

Asimina triloba (L.) Dunal, Monogr. Anon. 83. 1817.

PAPAW.

Anona triloba L. Sp. P1.537. 1753.

Uvaria triloba Torr. \& Gray, F1. N. A. 1:45. 1838.

Ell. Sk. $2: 42$. Gray, Man. ed. 6, 50. Chap. Fl. 15. Sargent, Silv. N. A. 1:23, t. $15,16$. Gray, S.rn. Fl. N. A. 1, pt. 1:63.

Alleghenian to Louisianian area. Ontario, western New York, and central Pennsylvania, west to Michigan, southeastern Nebraska, and Kansas, south throughout the Ohio Valley to the pine belt of the South Atlantic and Gulf States, and west to eastern Texas and Arkansas.

Alabama: Tennessee Valley to the Upper division of the Coast Pine belt. Richwoods. Montgomery County. Autauga County, Prattville (southern limit). Common throughout the Mountain region. Flowers brown. March, April; fruit yellow, pulpy, edible. August, September; frequent.

Small tree, 10 to 15 feet high.

Economic uses: The fruit is edible.

Trpe locality: "Hab. in Carolina."

Herb. Geol. Surv. Herb. Mohr.

Asimina parviftora (Michx.) Dunal, Monogr. Anon. 82, t. 9. 1817.

SMALL-Flowered PAPaW.

Orchidocarpum parviflorum Michx. Fl. Bor. Am. 1: 329. 1803.

Uvaria parviflora Torr. \& Gray, Fl. N. A. 1:45. 1838.

Ell. Sk. 2:41. Chap. Fl.15. Gray, Syn. Fl. N.A. 1, pt.1:63.

Carolinian and Louisianian areas.

AlabaMa : Lower Mountain region to Coast plain. Most frequent throughout the Lower Pine belt. In sandy dry open woods. Lee County, Auburn (Baker \& Earle). Cullman, Tuscaloosa, and Clarke counties. Wilcox County (Buckley). Washington, Baldwin, and Mobile counties. Flowers greenish purple, April; fruit August, September; common.

Shrub 2 to 4 feet high.

Type locality: "Hab. in Carolina et Georgia."

Herb. Geol. Surv. Herb. Mohr.

${ }^{1}$ Geo. Nash, Revision of the Genus Asimina in North America, Bull. Torr. Club, vol. 23, pp. 234 to 241 . 1896. 
Asimina pygmaea (Bartram) Gray, Bot. Gaz. 11:164. 1886. Not Dunal. 1817.

Anona pygmaea Bartram, Travels, 18, t. 1. 1791.

Low Asimina.

Ell. Sk. 2 : $43 . \quad$ Chap. Fl. 15.

Louisianian area. Georgia and Florida.

Alabama : Upper division of Coast Pine belt. Dale County (E. A. Smith). Flowers white, August; rare.

Type locality: "Hab. in Carolina et Florida."

Herb. Geol. Surv. Herb. Mobr.

Sand hills near "the ferry on St. Ille about sixty miles south of the Altamaha."

\section{RANUNCULACEAE. Crowfoot Family.}

HYDRASTIS I. Syst. ed. 10, 1088. 1759.

Two species. Atlantic North America, Japan. Perennial herbs.

Hydrastis canadensis L. Sp. Pl. ed. 2, 1: 784. 1762.

Yellowroot. Yallow PUCCOON.

Gray, Man. ed. 6, 48. Chap. Fl.11. Gray, Syn. F1. N. A. 1, pt. 1:56.

Alleghenian and Carolinian areas. Southwestern Ontario, New York to Wisconsin, Iowa, Missouri, Arkansas, and the Ohio Valley, south along the mountains to Georgia.

Ala bama: Tennessee Valley to the Coast Pine belt. Rich shady woods. Cullman County. Chilton County, Knight's Ferry. Flowers greenish white, April; rare. Perennial.

Economic uses: The root is the "golden seal" or "Hydrastis" of the U.S. Phurmacopœia.

Type locality: "Hab. in Canadae aquis."

Herb. Geol. Surv. Herb. Mohr.

ISOPYRUM L. Sp. Pl. 1:557. 1753.

Seven species, temperate zones North Hemisphere. Europe, eastern Asia. Perennial herbs.

Isopyrum biternatum (Raf.) Torr. \& Gray, Fl. N. A. 1:660. 1840.

Enemion biternatum Raf. Journ. Phys. 91: 70. 1820.

Mountain Wind Flower.

Gray, Man. ed. 6, 44. Chap. Fl.9. Gray, Syn. Fl. N. A. 1, pt. 1:40.

Alleghenian and Carolinian areas. Ontario, southwestern Virginia to Minnesota, south to North Carolina.

Alabama : Tennessee Valley to Lower hills. Rich shady woods and banks. Lauderdale County, Florence, bluffs of the Tennessee River. Tuscaloosa and Cullman counties. Flowers white, Fobruary, March. Not infrequent; perennial.

Type locality: Kentucky (Short).

Herb. Geol. Surv. Herb. Mohr.

ZANTHORHIZA L'Her. Stirp. Nov. 79. 1784.

One species, Atlantic North Anerica. A low shrub.

Zanthorhiza apiifolia L'Her. Stirp. Nov. 79, t.34. 1784.

SHrub Yeliowroot.

Ell. Sk. 1:377. Gray, Man. ed. 6, 48. Chap. Fl. 11. Gray, Syn. Fl. N. A. 1, pt. 1: 56.

Alleghenian to Louisianian area. Allegheny Mountains, from southwestern New York to Florida, Kentucky, and Tennessee.

Ala Bama: Tennessee Valley to Lower Pine region, most frequent in the mountains. Shaded banks of brooks. Clay County, waterfall near Pulpit Rock, 2,200 feet. Cullman, Madison, Tuscaloosa, Clarke, Choctaw, and Mobile counties.

Shrub $\frac{1}{2}$ to 1 foot high.

Economic uses: The root, known as "yellow root," is used medicinally and as a dye.

Type locality: "Hab. in Georgia. Bartram. Carolina."

Herb. Geol. Surv. Herb. Mohr.

ACTAEA L. Sp. Pl. 1: 504. 1753.

Two species, temperate regions Northern Hemisphere. Europe, Atlantie North America. 
Actaea alba (L.) Mill. Gard. Dict. ed. 8, no. 2. 1768.

WIITE BANEBERRY. Actaea spicata var. alba L. Sp. P1. 1 : 504. 1753.

Ell. Sk. 2:15. Gray, Man. ed.6, 48. Chap. Fl.11. Gray, Syn. Fl. N. A. 1, pt. 1:55. Alleghenian and Carolinian areas. Nova Scotia and Ontario, west to British Columbia; southern New England, Ohio Valley to Arkansas, along the mountains to South Carolina.

Alabama: Mountain region to Central Pine belt. Lee County, Auburn (Baker \& Earle). Cullman County. Madison County, Montesano. Tuscaloosa Connty (E. A. Smith). Flowers white, April ; berries white, ripe in July ; infrequent. Perennial. Type locality: "Hab. in nemoribus Americae."

Herb. Geol. Surv. Herb. Mohr.

CIMICIFUgA L. Amoen. Acad. 8: 193. 1774. Bugbane.

About 10 species. Eastern Europe, Asia, North America, 3.

Cimicifuga racemosa (L.) Nutt. Geu. 2 : 15. 1818.

Black Coliosir. Actaea racemosa L. Sp. Pl. 1:504. 1753.

Ell. Sk. 2: 16. Gray, Man. ed.6, 47. Chap. Fl. 11. Gray, Syn. Fl. N. A. 1, pt. 1:54. Alleghenian to Carolinian area. Southern Ontario, southwestern New England, west to Wisconsin, south along the mountains to Georgia, Arkansas, central Missouri.

Alubama: Tennessee Valley. Coosa Hills. Mountain region. Rich open woods, chiefly in calcareous soil. Blount County, Blount Springs. Dekalb County, Vallevhead, 1,000 feet (E. A. Smith). St. Clair and Tallapoosa counties. Flowers white, June; fruit ripe in July; frequent. Perennial.

Economic uses: The root is the "black snakeroot" or "Cimicifuga" of the United States Pharmacopœia.

Type locality : "Hab. in Florida, Virginia, Canada."

Herb. Geol. Surv. Herb. Mohr.

AQUILEGIA L. Sp. Pl. 1 : 533.1753.

About 50 species described. Temperate regions Northern Hemisphere. North America about 14.

Aquilegia canadensis L. Sp. Pl. 1:533. 1753.

Wild Columbine.

Ell. Sk. 2:20. Gray, Man. ed. 6, 46. Chap. Fl.9. Gray, Syn. Fl. N. A. 1, pt. 1: 44.

Mexico.

Canarlian zone to Carolinian area. Quebec and Ontario west to Manitoba, Saskatchewan, and the Rocky Mountains. New England to Nebraska and Dakota, south along the mountains to western Florida.

Alabama: Tennessee Valley. Prairie region. Rocky woods. Lauderdale County, bluff's Tennessee River (M. C. Wilson). Autauga County, Prattville (E.A.Smith). Flowers coral-red, June; not frequent.

Type locality: "Hab. in Virginia, Canada."

Herb. Geol. Surv. Herb. Mohr.

\section{DELPHINIUM L. Sp. Pl. 1 : 530. 1753.}

About 120 species described. Herbs. Temperate and monntainous regions of the Northern Hemisphere. North America 25, Atlantic 4. Ours perennial.

Delphinium carolinianum Walt. Fl. Car. 155. 1788.

AZURE LARKSPUR.

Delphinum azureum Michx. Fl. Bor. Am. 1:314. 1803.

Ell. Sk. 2:18. Gray, Man. ed. 6, 46. Chap. Fl. 10. Gray, Syn. Fl. N. A. 1, pt.

1:46. Coulter, Contr. Nat. Herb. $2: 9$.

\section{MEXico.}

Cauadian zone to Carolinian areas. Manitoba, Saskatchewan; Wyoming, Nebraska, Missouri, and western Illinois; south from North Carolina to western Florida, west to Louisiana, Arkansas, and Texas.

Alabama: Tennessee valley to Central Prairie region. Open copses. Lawrence County, Moulton. Bibb County, Tionus. Dallas, Montgomery, Autauga counties. Lee County, Auburn (Baker \& Earle, 18). Flowers azure. April, May; not rare. Perennial. Most frequent in the limestone valleys and central prairies.

Type locality: South Carolina.

Herb. Geol. Surv. Herb. Mohr.

Delphinium urceolatum Jacq. Coll. 1: 153. 1786.

TALL LakKspur.

Delphinium exaltatum Ait. Hort. Kew. 2 : 244. 1789.

Ell. Sk. 2:19. Gray, Man. ed.6, 46. Chap. Fl.10. Gray, Syn. Fl. N. A. 1, pt. 1: 46. 
Alleghenian, Carolinian, and Louisianian areas. Minnesota, Nebraska, Missouri, and central Ohio to North Carolina and along the mountains to South Carolina.

Alabama: Tennessee Valley to Central Prairie region. Border of woods, rich copses. Lawrence County, Moulton. Dallas Connty, Marion Junction. Flowers purplish blue. June; infrequent. Perennial.

Type locality not ascertained.

Herb. Geol. Surv. Herb. Mohr.

Delphinium tricorne Michx. Fl. Bor. Am. 1:314. 1803.

DWARF LARKSIUR.

Ell. Sk. 2:18. Gray, Man. ed.6, 46. Chap. Fl.10. Gray, Syn. Fl. N. A. 1, pt. 1:45.

Alleghenian and Carolinian areas. Minnesota; Ohio Valley to Missouri, Arkansas; Pennsylvania south along the mountains to Georgia.

Alabama: Tenuessee Valley. Lower hills. Rich open woods, damp clas soil. Landerdale County, Florence (M. C. Wilson). Bibb County, Scottville (E. A. Smith). Flowers pale blue (in specimens from Florence white). April ; rare. Perennial.

Type locality: "Hab. in altissimis montibus Carolinae."

Herb. Geol. Surv. Herb. Mohr.

ACONITUM L.Sp. Pl. 1 : 532. 1753.

Sixty species, temperate and mountain regions Northern Hemisphere. North America, 5. Perennial herbs.

Aconitum uncinatum L. Sp. Pl. ed.2, 1:750. 1762.

WILD MonkshoOd.

Ell. Sk. 2:20. Gray, Man. ed.6, 47. Chap. Fl. 10. Gray, Syn. Fl. N. A. 1, pt. 1:53.

Carolinian area. Wisconsin; southern New York to Pennsylvania, District of Columbia, south along the monntains to South Carolina.

Alabama: Mountain region. Dekalb Connty, Mentone. Blount County, Murphrees Valley (E. A. Smith). Flowers dark blue, September; rare.

Type locality: "Hab. in Philadelphia."

Herb. Geol. Surv. Herb. Mohr.

ANEMONE L. Sp. Pl. $1: 538.1753 .^{1}$

About 90 species, including Pulsatilla and Hepatica, all of temperate regions or mountains in the tropics. Europe, Asia. Three species in the Southern Hemisphere, South Africa, Australia. North America, 20.

Perennial herbs.

Anemone quinquefolia L. Sp. Pl. 1:541. 1753.

American Wind Flower. Anemone nemorosa var. quinquefolia Gray, Man. ed. 6, 38. 1890.

A. nemorosa auct. Am.

Ell. Sk. 2:53. Gray, Man. ed.6, 38. Chap. Fl. 4. Gray, Syn. Fl. N. A. 1, pt. 1:13. Siberia, Amurland.

Boreal region to Carolinian area. Hudson Bay to Alaska; Rocky Mountains to California; New England to Minnesota, south through the Ohio Valley; New York to South Carolina.

Alabama : Mountain region to Lower hills, copses, border of woods. Madison County, Huntsville. Cullman and Tuscaloosa counties. Flowers white. April; not rare.

Type locality: "Hab. in Virginia, Canada. Kalm."

Herb. Geol. Surv. Herb. Mohr.

Anemone decapetala Ard. Animad. Spec. Alt. 24, 1. 12. 1764. Southern Anemone. Anemone trilobata Juss. Ann. Mus. Par. $3: 248, t .21, f$. 3. 1804.

A. heterophylla Nutt.; Torr. \& Gray, Fl. N. A. $1: 12$. 1838. As synonym.

Coulter, Contr. Nat. Herb. 2:8, in part. Gray, Syn. Fl. N. A. 1, pt.1:10.

Mexico, Southern Brazil, Argentina.

Carolinian and Louisianian areas. West to north western Louisiana, Arkansas, and Texas, north to the Great Plains.

Alabama : Central Prairie region. Wilcox County (S. B. Buckley). Auburn County (Underwood \& Earle). Tuscaloosa County (E.A.Smith). Flowers pale blue. May; rare.

Type locality not ascertained.

Herb. Geol. Surv. Herb. Mohr.

${ }^{1}$ N. L. Britton, The American species of the genus Anemone, and the genera which have been referred to it, Annals of the N. Y. Acad. Sci. vol. 6, pp. 215 to 238. 1891. 
Anemone caroliniana Walt. Fl. Car. 157. 1788.

Prairie Anemone.

Ell. Sk. 2:53. Gray, Man. ed. 6, 37. Chap. Fl.4. Gray, Syn. Fl. N. A. 1, pt. 1:11. Coulter, Contr. Nat. Herb. $2: 8$, in part.

Alleghenian and Carolinian areas. Illinois to Nebraska and Dakota; south from North Carolina to upper Georgia, western Louisiana, and Texas.

Alabama: Tennessee Valley. Lower hills. Open woods. Lauderdale County, Florence (M. C. Wilson). Tuscaloosa County (E. A. Smith). Flowers purplish to white. March, April; not frequent.

Type locality: South Carolina.

Herb. Geol. Surv. Herb. Mohr.

Anemone virginiana L. Sp. Pl. 1:540. 1753.

Virginian Anemone.

Ell. Sk. 2:54. Gray, Man. ed.6, 37. Chap. Fl.5. Gray, Syn. Fl. N. A. 1, pt. 1:11.

Alleghenian and Carolinian areas. New Bruuswick; Manitoba, northwest to latitude $55^{\circ}$ through the Rocky Mountains to Vancouver; New England; Ohio Valley to Kansas; from New York along the mountains to Georgia.

Alabama: Mountain region to Lower hills. Rocky woods and copses. Lee County, Auburn (Baker \& Earle). Madison County, Montesano, 1,500 feet. Cullman County. St. Clair County, Coosa Hills, 700 feet. 'Tuscaloosa County (E. A. Smith). Flowers white. April, May; not rare.

Type locality: "Hab. in Virginia."

Herb. Geol. Surv. Herb. Mohr.

HEPATICA Scop. Fl. Carn. 567. 1760. LIVERWORT.

Three species, north temperate regions. Perennial herbs.

Hepatica hepatica (L.) Karst. Deutsch. Fl. 559. 1880-83.

LIVERWORT.

Anemone hepatica L. Sp. Pl. 1:538. 1753.

Hepatica triloba Chaix. in Vill. Hist. Pl. Dauph. 1 : 336. 1786.

Ell. Sk. 2:55. Gray, Man. ed.6,38. Chap. Fl. 5.

Europe, Siberia, China, Japan.

Boreal region to Louisianian area. Hudson Strait, Alaska; New Brunswick, west to Winnipeg; Ohio Valley, south to western Florida.

Alabama: Tennessee Valley to Upper division Coast Pine belt. Shady hillsides and woods. Cullman County. Lauderdale County, Florence. Tuscaloosa County. Clarke County (Dr. Denny). Flowers white or purplish, March; not frequent. Perennial.

Econowic uses: The herb, known as "liverwort," or "Hepatica," is used medicinally.

Type locality: "Hab. in Europae nemoribus lapidosis."

Herb. Geol. Surv. Herb. Mohr.

SYNDESMON Hoffmg. Flora, 15, pt. 2, Intell. Bl. No. 4:34. 1832.

(ANemonella Spach, Hist. Veg. 7 : 239. 1839.)

One species, Atlantic States.

Syndesmon thalictroides (L.) Hofting. Fl. 15, pt. 2, Intell. Bl. No. 4:34. 1832.

Anemone thalictroides L. Sp. P1. 1:542. 1753.

Rue Anemone.

Thalictrum anemonoides Michx. Fl. Bor. Am. 1:322. 1803.

Anemonella thalictroides Spach, Hist. Veg. 7:240. 1839.

Ell. Sk. 2:52. Gray, Man. ed. 6, 39. Chap. Fl. 6.

Alleghenian and Carolinian areas.

Alabama: 'Tennessee Valley, Mountain region to Lower hills. Open copses and woods. Lauderdale, Lawrence, Winston, Cullman, Tuscaloosa, and St. Clair counties. Flowers white; April, May. Not rare. Perennial.

Type locality: "Hab. in Virginia, Canada."

Herb. Geol. Surv. Herb. Mohr. 
CLEMATIS L. Sp. P1. 1: 543.1753.

Over 150 species described, perennials, mostly climbers, inhabiting temperate and tropical regions. Enrope 8 species, United States and Canada 20, with 5 strictly defined varieties.

Clematis virginiana L. Amoen. Acad. 4 : 275. 1759.

VIRGIN BowER.

Ell. Sk. 2:44. Gray, Man. ed.6,35. Chap. Fl.4. Gray, Syn. Fl. N. A. 1, pt. 1:4.

Alleghenian to Louisianian area. Nova Scotia and Ontario to Lake Winnepeg; New England west to Nebraska, south to Florida, Louisiana, and Arkansas.

Alabama: Mountain region to Upper division Coast Pine belt. Rich banks. Winston County. Calhoun County (E. A. Smith). Lee County, Auburn (F. S. Earle). Tuscaloosa and Monroe counties. Flowers white, fragrant, July, August; fruit in October. Climber.

Type locality : "Hab. in Pensylvania."

Herb. Geol. Surv. Herb. Mohr.

Clematis catesbyana Pursh, Fl. Am. Sept. 2 : 736.1816.

Catesb y's Clematis.

Ell. Sk. 2:44. Chap. Fl.4. Gray, Syn. Fl. N. A. 1, pt. 1:4.

Carolinian area. South Carolina to Florida and Mississippi

Alabama: Upper division Coast Pine belt. Iry copses, borders of woods. Clarke County, Suggsville (Dr. Denny). Flowers white, August; fruit ripe in October. Climber.

Type locality : "In South Carolina. Catesby."

Herb. Geol. Surv. Herb. Mohr.

Clematis viorna L.Sp. Pl. $1: 543$.

LeATHer Flower.

Ell. Sk. 2:46. Gray, Man. ed. 6, 36. Chap. Fl. 3. Coulter, Contr. Nat. Herb. 2 : 7. Gray, Syu. Fl. N. A, 1, pt. 1 : 5.

Carolinian area. Southern Pennsylvania, West Virginia, central Ohio, and Missouri, south to Tennessee and upper Georgia.

Alabama: Tennessee Valley to Central Pine belt. Banks of streams. Franklin County, Russellville. Autauga County (E. A. Smith). Flowers reddish purple (Indian purple). June; not frequent. Climber.

Type locality: "Hab. in Virginia, Carolina."

Herb. Geol. Surv. Herb. Mohr.

Clematis reticulata Walt. Fl. Car. 156. 1788.

Netted-Leaved Clematis.

Ell. Sk. 2:47. Chap. Fl. 4. Coulter, Contr. Nat. Herb. $2: 7$. Gray, Syn. Fl. N. A.

1, pt. $1: 6$.

Louisianian area. South Carolina and Florida, west to Texas and Arkansas.

Alabama : Upper division Coast Pine belt. Dry sandy copses. Couecuh County, Evergreen (Baker of Earle). Clarke County, Suggsville (Dr. Denny). Flowers maroon purple. June; not frequent. Climber.

Type locality: South Carolina.

Herb. Geol. Surv. Herb. Mohr.

Clematis crispa L. Sp. P1. 1: 543. 1753.

WAVY-FLOWERED CleMATIS.

Clematis cylindrica Sims, Bot. Mag. 1160. 1816.

Ell. Sk. 2:49. Gray, Man. ed.6,36. Chap. Fl.3. Coulter, Contr. Nat. Herb. $2: 7$. Gray, Syv. Fl. N. A. 1, pt. 1: 7 .

Carolinian and Louisianian areas. Southern Virginia along the coast to Florida and through the Gulf States to Texas to the one bundredth meridian; Arkansas and southern Missouri.

Alabama: Central Pine belt to the coast. Low swampy thickets. Tuscaloosa County. Pike County, Troy. Dallas County, Uniontown. Autauga, Baldwin, and Mobile counties. Flowers lilac. May. Climber.

Type locality: "Hab. in Carolina."

Herb. Geol. Surv. Herb. Mohr.

Clematis crispa walteri (Pursh) Gray, Bot. Mag. under t.6594. 1881.

Clematis walteri Pursh, Fl. Am. Sept. 2 : 384. 1814.

C. lineariloba DC. Syst. 1:155. 1818.

Ell. Sk. 2:45. Gray, Syn. Fl. N. A. 1, pt. 1: 7.

Louisianian area. South Carolina to Texas.

Alabama : Coast plain. Low shaded banks. Mobile. Flowers lilac. May; rare.

Low climber.

Type locality: "In Carolina, v. s. in Herb. Walter,"

Herb. Geol. Surv. Herb. Mohr. 
MYOSURUS L. Sp. P1. 1:284. 1753. Mousetall.

Five species, temperate regions. Europe, North America.

Myosurus minimus L. Sp. Pl. 1:284. 1753.

Gray, Man. ed. 6, 40. Chap.Fl.6. Gray, Syn. Fl. N. A. 1, pt. 1:19.

EUROPE.

Canadian zone to Lonisianian area. Ontario and Northwest Territory to British Columbia and Vancouver's Island; southern Illinois, Missouri, and Arkansas to Florida and Louisiana.

AlabaMa : Central Pine belt. C'entral Prairie region. Low alluvial soil. Tuscaloosa County (E.A. Smith). Montgomery County. Flowers greenish. May; not frequent. Annual.

Type locality: "Hab. in Europae collibus apricis aridis."

Herb. Geol. Surv. Herb. Mohr.

TRAUTVetTeria Fisch. \& Mey. Ind. Sem. Petrop. 1:22. 1834. False Bugbane.

Two species, perennials, temperate North America.

Trautvetteria carolinensis (Walt.) Vail, Mem. Torr. Bot. Club, 2:42. 1890.

Hydrastis carolinensis Walt. Fl. Car. 156. 1788.

Cimicifuga palmata Michx. Fl. Bor. Am. 1:316. 1803.

Trautvetteria palmata Fisch. \& Mey. Ind. Sem. Petrop. 1:22. 1834.

Ell. Sk. 2:17. Gray, Man. ed.6, 40. Chap. Fl. 6. Gray, Syn. Fl. N. A. 1, pt. 1: 18.

Alleghenian and Carolinian areas. Maryland and Virginia, south along the mountains to Georgia.

Alabama : Mountain region. Damp borders of woods. Cullman County, 800 feet. Flowers white, June; not frequent.

Type locality: South Carolina.

Herb. Geol. Surv. Herb. Mohr.

RANUNCULUS L. Sp. Pl. 1:548. 1753.

A iarge cosmopolitan genus of about 200 species, mostly perennial herbs (ours with yellow flowers), most frequent in temperate regions of the Northern Hemisphere. North America 52.

Ranunculus tener nom. nov.

SLENDER SPEARWORT.

Ranunculus trachyspermus Engelm.; Engelm. \& Gray, Bost. Journ. Nat. Hist. 5 : 211.

1847. Not Ell. 1821-24.

Gray, Syn. Fl. N. A. 1, pt. 1:25.

Mexico.

Carolinian and Louisianian areas. (Lower Sonoran area, western Texas.)

Alabama: Southern edge of Metamorphic hills. Lee County, Auburn, March, 1897 (Baker \& Earle). Rare. Annual.

'Type locality: "Margin of ponds near Houston, \&c."

Herb. Geol. Surv. Herb. Mohr.

Ranunculus pusillus Poir. Encycl. 6:99. 1804.

SMall. Spearwort.

Ranunculus flammula Walt. Fl. Car. 159. Not L.

Ell. Sk. 2:57. Gray, Man. ed. 6, 42. Chap. Fl. 7. Coulter, Contr. Nat. Herb. $2: 8$. Gray, Syn. Fl. N. A. 1, pt. 1:26.

Carolinian area. Staten Island, New York, New Jersey, along the low couptry to Florida, west to Texas, southern Arkansas, and 'Tennessee.

Alabama: Tennessee Valley. Central Prairie region to Coast plain. Most common in the low country, in ditches, wet fields, shallow ponds. Lawrence County, Moulton. Mobile and Baldwin counties. April; abundant. Perennial.

Type locality: "Cette plante croit dans la Caroline, dans les lieux humides \& marécageux."

Herb. Geol. Surv. Herb. Mohr.

Ranunculus pusillus lindheimeri Gray, Proc. Am. Acad. 21:367. 1886.

Ranunculus trachyspermus lindheimeri Engelm. Bost. Journ. Nat. Hist. 5 : 211. 1845.

Coulter, Contr. Nat. Herb. 2 : 8. Gray, Syn. Fl. N: A. 1, pt.1:26.

Louisianian area. Louisiana and Texas; California.

Alabama : Coast plain. Exposed miry places, ditches. Mobile, Lee County, Auburn (Baker \& Earle). Flowers March, April; frequent. Perennial.

$15894-33$ 
A stronger plant than the type, stem 8 to 16 inches high, branched, achenes turgid, slightly margined, and more roughish-papillose.

Type locality: "Near Houston, \&c."

Herb. Geol. Surv. Herb. Mohr.

Ranunculus abortivus L. Sp. P1. 1:551. 1753.

Abortive-Flowered Crowfoot.

Ranunculus nitidus Walt. Fl. Car. 159. 1788.

Ell. Sk. 2:58. Gray, Man. ed.6, 42. Chap. Fl. 7. Gray, Syn. Fl. N. A. 1, pt. 1:32.

Canadian zone to Louisianian area. Nova Scotia, Quebec, and Ontario to British Columbia; New England west to the Rocky Mountains, south to western Florida.

Alabama : Mountain region to Central Prairie regiou. Low shaded banks. Madison County, Montesano. Tuscaloosa County (E. A. Smith). Perry County, Uniontown. Lee County, Auburn (Baker \& Earle). April; not frequent. Perennial.

Type locality: "Hab. in Virginia, Canada."

Herb. Geol. Surv. Herb. Mohr.

Ranunculus micranthus Nutt.; Torr. \& Gray, Fl. IJ. A. 1:18. 1838.

SMALL-FLOWERED CROWFOOT.

Ranunculus abortivus var. micranthus Gray, Man. ed.5,44. 1867.

Gray, Man. ed.6, 42. Gray, Syn. Fl. N. A. 1, pt. 1: 32.

Canadian zone to Louisianian area. Ontario, British Columbia; Massachusetts west to Minnesota, Missouri, Arkansas, and Colorado, south to Tennessee.

Alabama: Tennessee Valley. Central Prairie region. Low pastures. Lauderdale and Montgomery counties. May; not rare. Perennial.

Type locality: "Margin of ponds throughout the upper and western part of Missouri; likewise in Arkansas, collected by Dr. Pitcher."

Herb. Geol. Surv. Herb. Mohr.

Ranunculus recurvatus Poir. Encycl. 6:125. 1804.

Silvan Crowfoot.

Ell. Sk. 2: 63. Gray, Man. ed. 6, 43. Chap. Fl. 8. Gray, Syn. Fl. N. A. 1, pt. $1: 33$.

Canadian zone to Louisianian area. Nova Scotia, Ontario; southern New

England west to Minnesota. Nebraska south to Florida, Louisiana, and Arkansas.

Alabama: Tennessee Valley to Upper division Coast Pine belt. Damp rich woods, most frequent throughout the mountains. Lauderdale, Cullman, Madison, and Blount counties. Lee County, Auburn (Baker \& Earle, 34). Tuscaloosa County. Clarke County, Thomasville. April, May; frequent. Perennial.

Type locality: "Cette plante crolt en Amérique, dans les environs de New York."

Herb. Geol. Surv. Herb. Mohr.

Ranunculus sceleratus L.Sp. Pl. 1:551. 1753.

Celery-leaved or Cursed Crowfoot.

Ell. Sk. 2 :59. Gray, Man. ed.6, 42. Chap. Fl.8. Gray, Syn. Fl. N. A. 1, pt. 1: 33.

Europe, Asia, India, China, Siberia.

Canadian zone to Louisianian area. Throughout Atlantic North America west to

British Columbia and Arizona.

Alabama : Coast plain. Wet ditches, muddy places. Mobile County. April, May.

Acrid, poisonous. Annual.

Type locality: "Hab. ad Europae fossas et paludes."

Herb. Geol. Surv. Herb. Mohr.

Ranunculus hispidus Michx. Fl. Bor. Am. 1:321. 1803.

MaRYland ButTerCup. Ranunculus repens var. marylandicus Torr. \& Gray, Fl. N. A. 1:21. 1838.

Ell. Sk. 2:62. Gray, Syn. Fl. N. A. 1, pt. 1:36.

Alleghenian to Louisianian area. Ontario to Georgia.

Alabama: Tennessee Valley. Mountain region to coast plain. Lee County, Aubaru (Baker \& Earle, 32). Shady banks and borders of woods. Lauderdale County, Florence (M. C. Wilson). Cullman and Mobile counties. Flowers in April; scattered, not frequent. Perenuial.

Type locality: "Hab.in umbrosis sylvis Carolinae inferioris."

Herb. Geol. Surv. Herb. Mohr.

Ranunculus palmatus Ell. Sk. 2 : 61. 1821-24.

SoUthern Buttercups. Ranunculus septentrionalis Gray, Proe. Am. Acad. 21:376. 1886. In part. Not Poir.

Ell.1. c. Chap. Fl. 8. Gray, Syn. Fl. N. A. 1, pt. 1: 37.

Carolinian and Louisianian areas. South Carolina, Tennessee, and Florida. Flowers in May. 
Alabama: Mountain region. Madison County, Huntsville. Flowers in May. Perennial.

Type locality: "Grows in St. John's Berkley."

Herb. Geol. Surv. Herb. Mohr.

Ranunculus fascicularis Muhl. Cat.54. 1813.

Early Buttercup. Gray, Man. ed. 6, 43. Coulter, Contr. Nat. Herb. 2:9. Gray, Syn. Fl. N. A. 1, pt. $1: 37$.

Alleghenian to Louisianian area. Ontario and New England west to Minnesota, south to Virginia, the Ohio Valley, Missouri, and Tennessee to Alabama, Louisiana, Arkansas, and Texas.

Alabama: Tennessee Valley. Rocky woods. Damp or dry calcareous soil. Jackson County, Scottsboro. Madison County, Montesano. April, May; not frequent. Perennial.

Type locality: "Pensylvania."

Herb. Geol. Surv. Herb. Mohr.

Ranunculus mu ricatus L. Sp. Pl. 1 : 555.1753.

Prickly-Fruited BUtTerCUP. Ell. Sk. 2:64. Gray, Man. ed.6, 44. Chap. Fl.7. Gray, Syn. Fl. N. A. 1, pt. 1:38.

Europe.

Carolinian and Louisianian areas. From Virginia to California and southern Oregon; naturalized along the coast from Virginia to Florida and to Louisiana.

Alabama: Coast plain. Ditches, suburbs of Mobile. April, May. Annual.

Type locality: "Hab. in Europae australis fossis et humentibus."

Herb. Geol. Surv. Herb. Mohr.

Ranunculus parviflorus L.Sp. Pl. ed. 2, 1:780. 1763.

Ranunculus trachyspermus Ell. Sk. 2 : 65. 1821-24. SMAll-Flowered CRowfoot. SOUTH Europe.

Carolinian and Louisianian areas. Naturalized from Maryland to Florida, west to Arkansas.

Alabama : Central Pine belt to Coast plain. Damp waste ground near dwellings.

Tuscaloosa, Montgomery, and Mobile counties. Flowers in April ; common. Annual. Type locality: "Hab. in Europa australi."

Herb. Geol. Surv. Herb. Mohr.

Ranunculus acris L. Sp. Pl. 1:554. 1753.

TALL Buttercups.

Gray, Man. ed. 6, 44.

EUROPE.

Alleghenian to Loinisianian area. Most common in Canada and the Northern States. Alabama : Adventive. Grass plots. Mobile. May; rare. Perennial. Type locality : "Hab. in Europae pratis, pascuis."

Herb. Geol. Surv.

BATRACHIUM S. F. Gray, Nat. Arr. Br. Pl. 2:720. 1821.

About 20 species, aquatice; temperate regions of the Northern Hemisphere.

Batrachium divaricatum (Schrank.) Wimm. Fl. Schles. 10. 1841.

Frogweed.

Ranunculus divaricatus Schrank. Baier. Fl. 2 : 104. 1789.

R. circinatus Sibth.; J. E. Smith, Fl. Brit. 2,596. 1800.

R. aquatilis var. divaricatus Gray, Man. ed.2, 7. 1856.

Gray, Man. ed.6, 40. 'Gray, Syn. Fl. N. A. 1, pt. 1:21.

Europe, Asia, North AFrica.

Canadian zone to Louisianian area. Manitoba to British Columbia; eastern United

States west to Nebraska, Colorado, Nevada, and Oregon, south to Alabama and western Texas.

Alabama : Coast plain. Gently-flowing water. Mobile County, estuary Mobile River and Dog River. Flowers white. May to July; not frequent. Perennial. Type locality: "Stille Wasser allenthalben [Bavaria]."

Herb. Mohr.

THALICTRUM L.Sp.Pl.1:545. 1753, Meadow Rue.

About 70 species, temperate regions Northern Hemisphere. Perennial herbs.

Thalictrum clavatum DC. Syst. 1: 171. 1818.

Mountain Meadow Rue.

Gray, Man. ed. 6, 39. Chap. Fl. 6. Gray, Syn. Fl. N. A. 1, pt.1:15.

Carolinian area. Southern Alleghenies from West Virginia to Georgia. 
Alabama: Mountain region. Springy rocky banks. Clay County, Mosley, 1,000 feet. Winston County, Davids Creek, 1,500 feet. Lawrence County, Mountain Home, 900 feet. Flowers white. April, May; not frequent.

Type locality : "Hab. in America boreali. Michaux."

Herb. Geol. Surv. Herb. Mohr.

Thalictrum polygamum Muhl. Cat. 54. 1813.

Tall Meadow Rue.

Thalictrum pubescens Pursh, Fl. Am. Sept. 388. 1814. In part.

T. cornuti Torr. \& Gray, Fl. N. A. 1:38. 1838. Not L.

T. corynellum DC. Syst. 1: 172 . 1818.

Gray, Man. ed.6, 39; Syn. Fl. N. A. 1, pt. 1:17. Chap. Fl. ed. 3, 5.

Canadian zone to Carolinian area. New Brunswick and Ontario, New England and New York, west to Missouri, south along the mountains to Tennessee and North Carolina.

Alabama : Coosa hills. Low damp copses. Calhoun County, near Jacksonville. Flowers white. June; rare.

Type locality: "Pensylvania."

Herb. Geol. Surv. Herb. Mohr.

Thalictrum purpurascens L. Sp. Pl. 1 :546. 1753.

Purplisil Meadow Rue.

Thalictrum rugosum Pursh, Fl. Am. Sept. 2 : 388. 1816.

T. revolutum DC. Syst. 1 : 173.1818.

Ell. Sk. 2:51. Gray, Man. ed. 6, 39. Chap. Fl.5. Coulter, Contr. Nat. Herb. 2 : 7. Gray, Syn. Fl. N. A. 1, pt. 1:17.

Canadian to Louisianian area. Quebec and Ontario, New England west to Dakota and Nebraska, south to 'Texas, Florida, and Arkansas.

Alabama: Tennessee Valley. Mountain region. Rocky open woods. Lee County, Auburn (Baker \& Earle). Lauderdale County, Florence. Madison County, Gurley. Flowers greenish white to purplish. May; infrequent.

Type locality: "Hab. in Canada?"

Herb. Geol. Surv. Herb. Mohr.

Thalictrum dioicum L. Sp. Pl. 1:545. 1753.

Smooth Meadow Rue.

Thalictrum laevigatum Michx. Fl. Bor. Am. 1: 322. 1803.

T. carolinianum Bose in DC. Syst. $1: 174.1824$.

Ell. Sk. 2: 50. Gray, Man. ed.6, 39. Chap. Fl.5. Gray, Syn. Fl. N. A. 1, pt. 1: 17.

Boreal zone to Carolinian area. Canada to north latitude $67^{\circ}$, across the continent to the Pacific; throughout the northeastern United States, along the mountains to South Carolina.

Alabama: Mountain region. Rich wooded hillsides. Madisom County, Montesano, 1,500 feet. Flowers greenish. April; not frequent.

Type locality: "Hab. in Canada."

Herb. Geol. Surv. Herb. Mohr.

Thalictrum debile Buckl. Am. Journ. Sci.45:175. 1843. Weak Meadow Rue. Chap. Fl.5. Gray, Syn. Fl.N. A. 1, pt. 1:18. Coulter, Contr. Nat. Herb. $2: 7$.

Louisianian area.

Alabama: Central Prairie region. Rich woods. Wilcox County, Allentown. Hlowers white. April ; local, rare. Perennial. The stem and leaves decay and disappear about the 1st of May.

Type locality: "Rich woodlands near Allenton, Wilcox County, Alabama."

Herb. Geol. Surv. Herb. Mohr.

ADONIS L.Sp. Pl. 1: 547. 1753.

Twenty species, warmer Europe and Asia.

Adonis annua L. Sp. Pl. 1 : 547. 1753.

Pheasant's Fye.

Adonis autumnalis I.S. Sp. Pl. ed. 2, 1 : 771. 1762.

Gray, Man. ed. 6, 40. Gray, Syn. Fl. N. A. 1, pt. $1: 19$.

Adventive from Europe; a low annual, sparingly naturalized in the Atlantic States.

Alabama: Tennessee Valley. Coast plain. Waste places, borders of fields. Jackson County, Scottsboro. Tuscaloosa County. Mobile, on ballast heaps. Flowers scarlet with dark spot in the center. May, June; infrequent. Annual.

Type locality: "Hab. inter segetes Europae australis."

Herb. Geol. Surv. Herb. Mohr. 


\section{BERBERIDACEAE. Barberry Family.}

PODOPHYLLUM L. Sp. Pl. 1:505. 1753.

Five species, temperate and warmer regions, eastern Asia, Japan, China. North America, 1.

Podophyllum peltatum L. Sp. Pl. 1 : 505. 1753.

MANDRAKE. MAY APPLE.

Ell. Sk. 2: 14. Gray, Man. ed.6, 54. Chap. Fl. 18. Gray, Syn. Fl. N. A. 1, pt. 1:72.

Alleghenian to Louisianian area. Ontario and New England west to Minnesota, Nebraska, and Kansas, south to westeru Florida, Louisiana, and Arkansas.

Alabama : Tennessee Valley to the Coast plain. Most frequent in open rich woods in calcareous soil throughout the mountains sonthward, rare. Winston, Lawrence, Madison, 'Tuscaloosa, and Clarke counties. Baldwin County, Silvers Mill. Flowers white, March; fruit ripe in May Perennial.

Economic uses: The root, "mandrake root," "Podophyllum," United States Pharmacopœia, is used medicinally.

Type locality : "Hab. in America septentrionali."

Herb. Geol. Surv. Herb. Mohr.

CAULOPHYLLUM Michx. Fl. Bor. Am. 1:204. 1803.

Caulophyllum thalictroides (L.) Michx. Fl. Bor. Am. 1:205. 1803. Blue Cohosh. Leontice thalictroides L. Sp. Pl. 1:312. 1753.

Ell. Sk. 1:411. Gray, Man. ed. 6, 53. Chap. Fl. 17. Gray, Syn. Fl. N. A. 1, pt. 1: 70. JAPAN, MaNCHURIa.

Alleghenian and Carolinian areas. New Brunswick, Quebec, Ontario ; New England west to Minnesota and Nebraska; Ohio Valley to Missouri; south along the mountains to South Carolina.

Alabama: Mountain region. Rich shady woods. Madison County, Montesano, 1,500 feet. Flowers white, May 1; fruit ripe in June; rare. Perennial.

Economic uses: The rhizoma and roots are the blue cohosh of medicine- "Caulophyllum," United States Pharmacopœia.

Type locality: "Hab. in Virginia."

Herb. Geol. Surv. Herb. Mohr.

\section{MENISPERMACEAE. Moonseed Family.}

CEBATHA Forsk. Fl. Aegypt. 171. 1755.

(Cocculus DC. Syst. Veg. 1:515. 1818.)

Abont 30 species, perennials, climbers, tropical Asia, Africa, Australia. Sonth Atlantic North America, 1.

Cebatha carolina (L.) Britton, Mem. Torr. Club 5:162. 1894.

Menispermum carolinum L. Sp. Pl. 1:340. 1753.

Carolina Moonseed.

Cocculus carolinus DC. Syst. Veg. 1:524. 1818.

Gray, Man. ed.6, 51. Chap. Fl.16. Coulter, Contr. Nat. Herb. $2: 10$. Gray, Syn. Fl. N. A. 1, pt. 1:65.

Mexico:

Carolinian and Louisianian areas. Southern Illinois, southern Missouri south to Florida to eastern Texas.

Alabama : Tennessee Valley. Lower hills. Upper division Coast Pine belt. Banks of streams, low borders of woods. Clay County, Talladega Creek, 800 feet. Lauderdale County, Florence. Franklin, Tuscaloosa, Hale, Dallas, and Autauga counties, Clarke County, Suggsville (Dr. Denny). Flowers greenish white, July. Fruit scarlet.

October. Climber; frequent.

Type locality: "Hab. in Carolina."

Herb. Geol. Surv. Herb. Mohr. 
CALYCOCARPUM Nutt.; Torr. \& Gray, Fl. N.A. 1:48. 1838.

One species, perennial climber, South Atlantic North America.

Calycocarpum lyoni (Pursh) Gray, Gen. Ill. 1: 76. 1848.

Menispermum lyoni Pursh, Fl. Am. Sept. 2:371. 1816.

Gray, Man. ed. 6, 51. Chap. Fl. 16. Gray, Syu. Fl. N. A. 1, pt. 1:66.

Carolinian and Louisianian areas. Southern Illinois, southern Missouri and from southern Kentucky and Tennessee to Florida.

Alabama: Tennessee Valley to Central Pine belt. Rich damp banks. Mostly in alluvial soil. Lauderdale County. Franklin County, Russellville. Blount County, Mulberry River. Tuscaloosa County. Flowers white, June. Fruit ripe September, October, black; twining over bushes.

Type locality: "In Kentucky and Tennassee."

Herb. Geol. Surv. Herb. Mohr.

\section{BUTNERIACEAE (CALYCANTHACEAE). Calycanthus Family.}

BUTNERIA Duhamel, Trait. Arb. 113, t. 45. 1755.

(Beurera, Ehret. Pl. Rar. t.13. 1755.)

(Calycanthus L. Syst. ed. 10, 1066. 1759.)

Five species, shrubs, temperate North America and Japan.

Butneria fertilis (Walt.) Kearney, Bull. Torr. Clnb, 21:175. 1894.

Smooth Calycanthus. Mountain SpICe-wood.

Calycanthus fertilis Walt. Fl. Car.151. 1788.

C. glaucus and C. laevigatus Willd. Enum.559. 1809.

C. inodorus Ell. Sk. 1:576. 1824.

Ell. Sk. l.c. Gray, Man. ed.6, 168. Chap. Fl. 130.

Alleghenian and Carolinian areas. Allegheny Mountains from Pennsylvania and Virginia to Georgia.

AlabaMa : Monntain region, Coosa hills. Low damp thickets, borders of streams. Dekalb County, Mentone, banks of Little River, 1,800 feet. St. Clair County, Coosa Hills, 650 feet. Lee Connty, Auburn (Baker \& Earle). Flowers maroon purple, June; fruit ripe in September and October, remaining to the next season. Deleterious to cattle. Shrub 6 to 8 feet high.

Economic uses: Ornamental shrub.

Type locality: South Carolina.

Herb. Geol. Surv. Herb. Mohr.

Butneria florida (L.) Kearney, Bull. Torr. Club, 21: 175. 1894.

Calycanthus foridus L. Syst. ed. 10, 1066. 1759.

Calycanthus. Carolina allspice.

C. sterilis Walt. Fl. Car. 151. 1788.

Ell. Sk. 1:576. Gray, Man. ed. 6, 167. Chap. Fl. 130.

Carolinian and Louisianian areas. North Carolina to Florida, west to Mississippi.

Aldibama : Lower Pine region, border of pine-barren streams. Escambia, Baldwin, and Mobile counties. Flowers maroon purple, April; fruit rarely seen. Frequent in the Lower Pine region, thus far not observed north of the Coast Pine belt.

Type locality not ascertained.

Economic uses: Ornamental shrub.

Herb. Geol. Surv. Herb. Mohr.

\section{LAURACEAE. Laurel Family.}

PERSEA Gaertn. Fruct. $3: 222$. 1805.

Ten species, trees, of subtropical and tropical America.

Persea borbonia (L.) Spreng. Syst. 2 : 268. 1824.

RED BAY.

Laurus borbonia L. Sp. P1. 1:370. 1753.

L. carolinensis Michx. Fl. Bor. Am. 1:245. 1803.

Persea carolinensis Nees, Syst. 150. 1836.

Ell. Sk. 1:461. Gray, Man. ed.6, 447. Chap. Fl. 393. Coulter, Contr. Nat. Herl. $2: 383$. Sargent, Silv. N. A. $5: 4, t .301$.

Carolinian and Louisianian areas. Southeastern Virginia south to Bay Biscayne and Cape Romanes. Florida west to eastern Texas and Arkansas. 
Alabama: Central Prairie region to Coast plain. Swampy alluvial forests. Montgomery, Escambia, Baldwin, and Mobile counties. Flowers white, June; fruit purplish black (plum purple), September, October. Tree 60 to 70 feet high. Appears to be in the Gulf region less frequent than in the South Atlantic States. Full-sized trees rarely met with.

Type locality : "Hab. in Carolina, Virginia."

Economic uses: Timber tree.

Herb. Geol. Surv. Herb. Mohr.

Persea pubescens (Pursh) Sargent, Silv. N.A. 5:7, t.302. 1895. SWAMP RED BAY.

Laurus carolinensis var. pubescens Pursh, Fl. Am. Sept. 1:276. 1814.

Persea carolinensis var. palustris Chap. Fl.393. 1860.

Chap. Fl.1.e.

Louisianian area. North Carolina along the coast region to Florida and Mississippi.

AlabaMa : Lower Pine region. Coast plain. Alluvial river swamps and pinebarren ponds. Mobile, Baldwin, and Escambia counties. Flowers white, June; fruit purplish black, October.

Shrubby in poor sandy pine barrens; on rich borders of streams and in alluvial forests a tree from 50 to 60 feet high and 12 to 16 inches in diameter, or frequently a large shrub.

Type locality: "In deep cedar and cypress swamps: Virginia to Louisiana."

Economic uses: Valuable for the wood.

Herb. Geol. Surv. Herb. Mohr.

SASSAFRAS Nees \& Eberm. Handb. Ph. Bot. 2:418. 1831.

One species, temperate North America.

Sassafras sassafras (L.) Karst. Deutsch. Fl.505. 1882.

SASSAFras.

Laurus 8assafras L. Sp. Pl. 1 :371. 1753.

Sassafras officinale Nees \& Eberm. Handb. Ph. Bot. 2 : 418. 1831.

Ell. Sk. 1:464. Gray, Man. ed. 6, 447. Chap. Fl.394. Coulter, Contr. Nat. Herb. $2: 383$.

Alleghenian to Louisianian area. Ontario; eastern Massachusetts to southeastern Iowa and eastern Kansas, south to western Florida, and through the Gulf States to the Brazos Valley, Texas, Indian Territory, and Arkansas.

Alabama: Throughout the State. Light and rich soil. Woodlands and in the open; of best development in the rich forests of the 'Tennessee Valley and upper Alabama River. Flowers yellowish, April. Fruit purplish black, September, October.

On poor soil rarely above medium size; in rich bottom lands 70 to 80 feet high and 2 feet in diameter.

Economic uses: Timber tree. The bark of the root is used medicinally-"Sassafras," United States Pharmacopœia.

Type locality : "Hab. in Virginia, Carolina, Florida."

Herb. Geol. Surv. Herb. Mohr.

\section{BENZOIN Fabr. Enum. Pl. Hort. Helmst. 1763. Pond Spice.}

(Lindera Thunb. Diss. Nov. Gen. 3 : 44. 1783.)

Ten species. Eastern Asia. Eastern North America, 2.

Benzoin benzoin (L.) Coulter, Mem. Torr. Club, 5 : 164. 1894.

Laurus benzoin L. Sp. P1. 1:370. 1753.

SPICEWOOd.' Feverbush.

Benzoin aestivale and B. odoriferum Nees, Syst. 495. 1832.

Lindera benzoin Blume, Mus. Bot. Lugd. 1:324. 1857.

Ell. Sk. 1:463. Gray, Man. ed. 6, 447. Chap. Fl. 394. Coulter, Contr. Nat. Herb. 2:383.

Alleghenian to Louisianian area. Ontario; eastern Massachusetts west to Michigan and Missouri, south to Florida and central Texas.

Alabama: Tennessee Valley to Central Prairie region. Low shady woods. Madison, Hale, and Wilcox counties. Flowers greenish, March. Fruit scarlet, September. Shrub 4 to 6 feet high. Not rare in the prairie region.

Type locality: "Hab. in Virginia."

Herb, Geol. Surv. Herb. Mohr. 
Benzoin melissaefolium (Walt.) Nees, Syst. 494. 1836.

Laurus melissaefolia Walt. Fl. Car. 134. 1788.

Lindera melissaefolia Blume, Mus. Bot. Lugd. 1:324. 1857.

Ell. Sk. 1:464. Gray, Man. ed. 6, 447. Chap. Fl. 394.

Carolinian and Louisianian areas. Louisiana to Florida, and along the Atlantic coast to Virginia. west to southern Illinois and southern Missouri.

Alabama: Central Prairie region. Low thickets, border of woods. Wilcox County, Allenton (S. B. Buckley). Flowers yellowish, February, March; rare. Shrub 2 to 3 feet high.

Type locality: South Carolina.

Herb. Geol. Surv. Herb. Mohr.

\section{PAPAVERACEAE. Poppy Family.}

SANGUINARIA L. Sp. PI. 1:505. 1753.

One species, eastern North America.

Sanguinaria canadensis L. Sp. Pl. 1:505. 1753.

Red Puccoon.

Ell. Sk. 2:13. Gray, Man. ed. 6,58. Chap. Fl.22. Gray, Strn. Fl. N. A. 1, pt. 1:86.

Alleghenian to Louisianian area. Quebec, Ontario, Manitoba; New England west to Dakota, south to northorn Florida and Louisiana.

Alabama: Mountain region. Rocky woods. Winston County, Colliers Creek, 1,500 feet. Dekalb County, Lookout Mountain, 1,600 feet. 'Tuscaloosa County, 350 teet $(E . A$. Smith). Mobile County (Wm. McNeal). Flowers white; March, April. Perennial.

Economic uses: The root is the "bloodroot" or "Sanguinaria" of the United States Pharmacopœia.

Type locality: "Hab. in America septentrionali."

Herb. Geol. Surv. Herb. Mohr.

\section{ARgemoNe L. Sp. Pl. 1:508. 1753. Prickly Poppy.}

Five species, warmer regions of America, Mexico. Western Texas. Annuals or biennials.

Argemone mexicana L. Sp. Pl. 1:508. 1753.

Mexican Prickly Poppy.

Ell. Sk. $2: 13$. Gray, Man. ed. 6, 59. Chap. Fl. 21. Coulter, Contr. Nat. Herb.

2:12. Gray, Syn. Fl. N. A. 1, pt. 1:87.

Mexico.

Carolinian and Louisianian areas. Adventive sparingly in North Atlantic ports, frequent on the South Atlantic and Gulf coast.

Alabama : Mobile County, roadsides, waste places near dwellings. Flowers lemon yellow; April, May; not rare.

Type locality: "Hab. in Mexico, Jamaica, Caribaeis nune in Europa australi."

Herb. Geol. Surv. Herb. Mohr.

Argemone alba Lestib. Bot. Belg. ed. 2, 3, pt. 2:132. 1799.

Argemone albiflora Hornem. Hort. Hafn. 439. 1815.

Argemone mexicana albiflora DC. Prodr. 1:120. 1824.

A. georgiana Croom, Am. Journ. Sci. 25:75. 1834.

Gray, Syn. Fl. N.A. 1, pt. $1: 88$.

Alleghenian and Louisianian areas. Nebraska to Texas, South Atlantic States to Louisiana.

Alabama: Coast plain. Waste places. Mobile. Flowers white, April, May; not rare. Annual.

'Type locality not ascertained.

Herb. Geol. Surv. Herb. Mohr.

BICUCULla Adans. Fam. Pl. 2, App.:23. 1763.

(Dicentra Bernh. Linnaea, 8:468. 1833.)

Fifteen species, temperate regions Northern Hemisphere. Asia, North America. Perennial herbs.

Bicuculla cucullaria (L.) Millsp. Bull. W. Va. Exp. Sta. 2:327. 1892.

Fumaria cucullaria L. Sp. Pl. 2:699. 1753.

Diclytra cucullaria DC. Syst. 2 : 108. 1821. 
Dicentra cucullaria Torr. Fl. N. Y. 1:45. 1843.

Gray, Man. ed. 6, 60. Chap. Fl. 23. Gray, Syn. Fl. 1, pt. 1:95.

Canadian zone to Carolinian area. Nova Scotia, Quebec, and Ontario to the Pacific coast; New England west to Minnesota, south to the Ohio Valley and Mis. souri, and along the mountains from New York to North Carolina.

Alabama : Mountain region to Lower hills. Wooded hillsides. Cullman County, rich soil (Miss Mary Mohr). Tuscaloosa County (E. A. Smith). Flowers, fleshcolored; March, A pril. Not frequent, local.

Type locality: "Hab. in Virginia, Canada."

Herb. Geol. Surv. Herb. Mohr.

CAPNOIDES Adans. Fam. Pl. 2:431. 1763.

(Corydalis Vent. Choix. 19. 1803.)

About 100 species, temperate and warmer regions, Mediterranean Europe. Northeastern Asia, southern Africa. North America, 10. Ours biennial.

Capnoides flavulum (Raf.) Kuntze, Rev. Gen. Pl. 1:14. 1891.

Corydalis flavula Raf.; DC. Prodr. 1:129. 1824.

Yellowish CORYDalis.

Gray, Man. ed. 6, 61. Chap. Fl. Suppl. 604; ed.3, 22. Gray, Syn. Fl. N. A. 1, pt. 1:98.

Carolinian and Louisianian areas. Ontario to Pennsylvania and Virginia, south to Tennessee, west to Louisiana, Arkansas, and southern Missouri.

Alabama: Tennessee Valley. Lower hills to Coast plain. Gravelly open places. Lauderdale County, Florence (M. C. Wilson). Tuscaloosa County (E. A. Smith). Mobile County. Flowers yellow, April, May. Scattered, not frequent.

Type locality: "Circa Philadelphiam."

Herb. Geol. Surv. Herb. Mohr.

Capnoides micranthum (Engelm.) Britton, Mem. Torr. Club, 5 :166. 1894.

Small-Flowered Cordyalis.

Corydalis aurea var. micrantha Engelm. in Gray, Man. ed. 5, 62. 1867.

C. micrantha Gray, Bot. Gaz. 11: 189. 1886.

Gray, Man. 1. c.; ed.6, 61. Chap. Fl. ed. 3,22. Gray, Syn. Fl. 1, pt. 1:98.

Alleghenian to Louisianian area. North Carolina, Minnesota, and Nebraska to Uintah Mountains (Utah); Iowa and Missouri south to Texas.

Alabama: Lower Pine region. Open sandy places. Mobile County, Springhill. Observed for the first time April, 1895, in cultivated ground; abundant. Flowers all cleistogamous, outer petals wanting, crest of inner petals little developed, anthers closely adhering to the stigma.

Type locality: "Western Illinois and St. Louis, Riehl."

Herb. Geol. Surv. Herb. Mohr.

FUMARIA L. Sp. Pl. $2: 699.1753$.

Fumaria officinalis L. Sp. Pl. 2 : 700. 1753.

Common Fumitory.

Ell. Sk. 2 :179. Gray, Man. ed. 6, 61. Annual.

Alabama: Adventive from Europe on ballast. Mobile. Observed since 1882 every season; not spreading beyond the ballast grounds.

'Type locality: "Hab. in Europae agris, cultis."

Herb. Geol. Surv. Herb. Mohr.

Fumaria vaillantii Loisel. Desv. Journ. Bot. 2 : 358. 1809.

SOUTHERN EUROPE.

Alabama : Fugitive on ballast. Mobile, with the above. May, July, 1884 to 1894. Type locality: European.

Herb. Mohr.

\section{BRASSICACEAE. Mustard Family.}

LEPIDIUM L.Sp. Pl. 2 :643. 1753.

About 100 species, temperate regions both henispheres. North America, 16. Annuals.

Lepidium virginicum L. Sp. Pl. 2 : 645.1753.

Wild PePpergrass.

Ell. Sk. 2: 140. Gray, Man. ed.6, 73. Chap. Fl.30. Gray, Syn. Fl. N. A. 1, pt. 1: 126. Griseb. Fl. Brit. W. Ind. 14. 
West Indies, Mexico, Guatemala.

Alleghenian to Lonisianian area. From Ontario, Quebec throughout the Atlantic United States to the Gulf, west to Arkansas and Nebraska.

Alabama : Over the State. Waste places, roadsides, in dry soil. Common.

Type locality: "Hab. in Virginiae, Jamaicae glareosis."

Herb. Geol. Surv. Herb. Mohr.

Lepidium ruderale L. Sp. Pl. 2: 645. 1753.

European Peppergrass.

Gray, Man. ed.6, 73; Syn. Fl. N. A. 1, pt. 1:128.

EUROPE.

Sparingly adventive on the Atlantic and the Gulf coast.

Alabama : Coast plain. Waste places. Mobile County, ballast heaps near mouth of the river, July 18, 1888. Baldwin County, Navy Cove, August 28, 1879.

Type locality: "Hab. in Europae ruderatis et ad vias."

Herb. Geol. Surv. Herb. Mohr.

Lepidium apetalum Willd.Sp. Pl. 3:439. 1805.

Lepidium micranthum var. apetalum Ledeb. Fl. Ross. 1:205. 1842.

L. intermedium Gray, Man. ed. 2, 6. 1856.

Gray, Man. ed. 6, 73; Syn. Fl. N. A. 1, pt. 1:127.

North AsIa, EuRope.

New England to Texas.

Alabama: Adventive on ballast. Mobile County, July.

Type locality: "Hab. in Sibiria."

Herb. Geol. Surv.

CORONOPUS Gaertn. Fruct. 2 : 293. 1791. Swine Cress.

(Senebiera Poir. Eneycl. $7: 76.1806$.

Twelve species, temperate regions, both hemispheres.

Coronopus coronopus (L.) Karst. Deutsch. Fl. 673. 1880-1883.

Wart Cress.

Cochlearia coronopus I. Sp. Pl. 2 : 648.1753.

Coronopus ruellii All. Fl. Ped. 1: 256. 1785.

Senebiera coronopus Poir. Encycl. 7 : 76. 1806.

Ell. Sk. 2 : 139. Gray, Man. ed. 6, 74. Chap. Fl. 30. Gray, Syn. Fl. N. A. 1, pt. $1: 130$.

EUROPE.

Naturalized in the Middle States, and in the ports from Rhode Island to Florida.

Alabama: Coast region. Adventive with ballast. Mobile County, Pinto Island. April, 1879. May, 1896. Annual. Firmly established in waste places about the shipping.

Type locality: "Hab. in Europae apricis, nudis."

Herb. Geol. Surv. Herb. Mohr.

Coronopus didymus (L.) J. E. Smith, Fl. Brit. 3:691. 1800.

Peppergrass.

Lepidium didymus L. Mant. 92. 1776.

Senebiera pinnatifida DC. Mem. Soc. Hist. Nat. Par. 1:144. 1799.

S. didyma Pers. Syn. 2: 185 . 1815.

Ell. Sk. 2:139. Gray, Man. ed. 6, 74. Chap. Fl. 30. Wats. Bot. Calif. 1:48. Grisel).

Fl. Brit. W. Ind. 14. Gray, Syn. Fl. N. A. 1, pt. 1:130.

Europe, Brazil, Nortir America.

Alleghenian to Louisianian area. Naturalized in Canada and the North Atlantic States, west to Vancouver and California, and from Florida to Texas and Arkansas.

Alabama: Tenuessee Valley to Coast plain. Damp open ground, pastures, grass plots. Lawrence County, Moulton. Tuscaloosa and Mobile connties. Flowers white, March to May; a common weed. Winter annual.

Type locality not ascertained.

Herb. Geol. Surv. Herb. Mohr.

CAKILE Gaertn. Fruct. $2: 287$. 1791. SFA Rocket.

Four maritime species, temperate and warmer regions. Europe, West Indies. North America, 2. Annuals.

Cakile maritima Scop. Fl. Carn. ed. 2, $2: 35.1772$.

Europe.

Carolinian and Louisianian areas. Adventive on ballast in Middle Atlantic and Southern ports. 
Alabama: A fugitive on ballast. Mobile, August, 1891 (not seen since).

Herb. Geol. Surv.

Cakile chapmani Millspaugh in lit.

Cakile maritima var. aequalis Chap. Fl.31. 1860. Not C. aequalis L'Her. 1827.

Gray, Syn. Fl. N. A. 1, pt. 1:132. Griseb. Fl. Brit. W. Ind.14.

WeSt INDIES.

Louisianian area. Florida to Mississippi.

Alabama : Wet sands and borders of sandy saline pools on the seashore, Dauphin Island. Flowers purplish. June to August; frequent. Annual.

Prostrate, tardily ascending, much branched, 1 to 2 feet long; racemes elongated, 4 to 6 inches long.

Type locality : "Drifting sands along the coast."

Herb. Geol. Surv. Herb. Mohr.

SISYMBRIUM L. Sp. Pl. $2: 657.1753$.

Fifty species (Engl. \& Prantl), temperate regions both hemispheres.

Sisymbrium officinale Scop. Fl. Carn.ed.2,2:26. 1772. HedGe Mustard. Erysimum officinale L. Sp. Pl. 2 : 660.1753.

Ell. Sk. 2:148. Gray, Man. ed.6, 72. Chap. Fl. 28. Wats. Bot. Calif. 1:41. Gray, Syn. Fl. N. A. 1, pt. $1: 137$.

Europe.

Alleghenian to Louisianian area. Naturalized and widely distribnted from Canada to the Gulf; also in California.

Alabava : Over the State. Wasteplaces, common wayside weed. Flowers yellow. Annual.

Type locality : "Hab. in ruderatis et circa vias."

iterb. Geol. Surv. Herb. Mohr.

BRASSICA L. Sp. Pl. 2 :666. 1753.

Fifty species, Europe and Asia; including the many cultivated varieties of cabbages, turnips, ruta-baga, colza, and mustard.

Brassica campestris L.Sp. Pl. 2 :666. 1753.

TURnip. RUta-13aga.

EUROPE.

Escaped from cultivation and adventive in the wild form over the continent.

Alabama : Fugitive on ballast heaps. Mobile, Maj.

Type locality : "Hab. in agris non argillosis Europae."

Herb. Geol. Surv. Herb. Mohr.

Brassica nigra (L.) Koch in Roehl. Deutschl. Fl. ed. 3, 4 : 713. 1833.

Sinapis nigra L. Sp. Pl. 2 : 668.1753.

Black Mustard.

Gray, Man. ed. 6, 72. Chap. Fl. ed. 3, 28. Britt. \& Br. Ill. Fl. 2 : 118.

EUROPE.

Alleghenian to Louisianian area. Extensively naturalized in fields and waste places in the Northern States.

Alabama : Adventive on ballast. Mobile County. Annual.

Economic uses: The seed is the "black mustard seed" or "Sinapis" of the United States Pharmacopœia.

Type locality: "Hab. in aggeribus ruderatis Europae septentrionalioris."

Herb. Geol. Surv. Herb. Mohr.

\section{DIPLOTAXIS DC. Syst. 2 : 628. 1821.}

About a dozen species. Central and southern Europe.

Diplotaxis muralis (L.) DC. Syst. 2 : 634. 1824.

WALL ROCKET.

Sisymbrium murale L. Sp. Pl. 2 : 658. 1753.

Gray, Syn. Fl. N. A. 1, pt. 1:134. Britt. \& Br. Ill. Fl. $2: 120$.

Europe.

Alleghenian to Louisianian area. Adventive with ballast near seaports from eastern Canada to western Florida.

Alabama: On ballast along the Mobile River, observed every year for the past fifteen years. Flowers buff yellow; May to September. A common ill-scented ballast weed. Annual or biennial.

Type locality: "Hab. Gallia, Sicilia."

Herb. Geol. Surv. Herb. Mohr. 
Diplotaxis tenuifolia (L.) DC. Syst. 2 :632. 1821. Narrow-Leaf Sand Mustard.

Sisymbrium tenuifolium L. Cent. Pl. 1: 18. 1755. Amoen. Acad. 4: 279. 1788.

Gray, Syn. Fl. N. A. 1, pt. 1:134. Britt. \& Br. Ill. Fl. 2: 120.

EUROPE.

From the same region, and found in about the same situations as the above.

Alabama : Less frequent than the last on ballast heaps at Mobile. Peremial.

Type locality: "Hab. in Gallia, Italia, Helvetia."

Herb. Mohr.

IODANTHUS Torr. \& Gray, Fl. N. A. 1:72. 1838.

(Thelypodium Wats. Index, 73. 1878.)

A single species, Atlantic North America.

Iodanthus pinnatifidus (Michx.) Steud. Nomenc. ed.2,812. 1841. VIOLET Rocket. Hesperis pinnatifida Michx. Fl. Bor. Anı. 2:31. 1803.

Iodanthus hesperidoides Torr. \& Gray in Gray, Gen. Ill. 1: 134, t. 54. 1848.

Gray, Man. ed. 6, 72; Chap. Fl. 25. Gray, Syn. Fl. N. A.1, pt. 1:150. Engl. \& Prantl, Nat. Pfl. 3, Abt. 2: 183 .

Alleghenian to Carolinian area. Western Pennsylvania, Ohio Valley, and Minnesota, south to Texas and Arkansas.

Alabama: Tennessee Valley. Rich woods. Lawrence County, Moulton. Lauderdale County, Florence (M. C. Wilson). Flowers violet, April, May; fruit ripe in July. Not frequent. Perennial.

Type locality: "Hab. in humidis sylvarum Tennassée."

Herb. Geol. Surv. Herb. Mohr.

RORIPA Scop. Fl. Carn.520. 1760.

(Nasturtium R. Br. in Ait. Hort. Kew. ed. 2, $4: 109$. 1812.)

Fifty species, temperate regions, Northern Hemisphere. North America, 13.

Roripa nasturtium (L.) Rusby, Mem. Torr. Club, 3, pt. 3:5. 1893. Water Cress. Nasturtium officinale R. Br. in Ait. Hort. Kew. ed. 2, 4:110. 1812.

Sisymbrium nasturtium L. Sp. Pl. 2 : 657. 1753.

Ell. Sk. 2:145. Gray, Man. ed. 6, 69. Chap. F1.25. Wats. Bot. Calif. 1:43. Coulter,

Contr. Nat. Herb. 2 : 16. Gray, Syn. Fl. N. A. 1, pt. 1:146.

EUrope, Asia, South America (introduced).

Alleghenian to Louisianian area. Naturalized and profusely distributed from

Nova Scotia and Ontario to the Gulf, west to Texas, Colorado, Utab, and California. Alabama: Sparingly over the State. Shallow brooks. Mobile County, Spring-

hill. Jofferson County (E.A. Smith). Flowers white; April. Perenuial.

Economic uses: The fresh herb, "water cress," is uscd nedicinally and as a salad. Type locality: "Hab. in Europa et America septentrionali ad fontes."

Herb. Geol. Surv. Herb. Mohr.

Roripa sylvestris (L.) Bess. Enum. 27. 1821.

Yellow Criss.

Sisymbrium sylvestre L. Sp. Pl. 2 : 675.1753.

Nasturtium sylvestre R. Br. in Ait. Hort. Kew. ed. 2, 4:110. 1812.

Gray, Man. ed. 6, 69. Chap. Fl. ed. 3, 24. Gray, Syn. Fl. N. A. 1, pt. 1: 147.

Europe, Asia.

Carolinian and Louisianian areas. Naturalized from Massachusetts to Virginia,

Illinois, and Missouri.

Ala baMA: Fully established in shallow marshes and muddy ditches. Mobile.

Observed for the past fifteen years, constantly spreading. Flowers deep yellow;

April to June. Frequent. Perennial.

Type locality: "Hab. in Helvetiae, Germaniae, Galliae ruderatis."

Herb. Geol. Surv. Herb. Mohr. •

Roripa sessiliflora (Nutt.) A. S. Hitchcock, Spring Fl. Manhat. 18. 1894.

Earty Field Cress.

Nasturtium sessiliflorum Nutt. in Torr. \& Gray, F1. 1:73. 1838. (Gray, Gen. Illust.

$1: 132, t$. 53.)

Gray, Man. ed. 6, 70. Chap. Fl.24. Coulter, Contr. Nat. Herb. 2:17. Gray, Syn. Fl.

N. A. 1, pt. $1: 149$.

Carolinian and Louisianian areas. Virginia and Kentucky to Missouri, south from

Teunessee to Florida and western Texas. 
Alabama : Coast plain. Damp open places, borders of ditehes, low fields. Flowers yellow. March; frequent. Winter. Anuual or biennial.

Type locality: "'Banks of the Mississippi,' Nuttall: Kentucky? Rafinesque!"

Herb. Geol. Surv. Herb. Mohr.

Roripa walteri (Ell.) Mohr, Bull. Torr. Club, 24 : 23. 1897.

WALTER's CRESS.

Sisymbrium valteri Ell. Sk. 2 : 146. 1824.

Nasturtium tanacetifolium Hook. \& Arn. Hook. Journ. Bot. 1 : 190.

Sisymbrium tanacetifolium Walt. Fl. Car. 174. 1788. Not L.

Ell. Sk. l. c. Chap. Fl. 24. Coulter, Contr. Nat. Herb. 2: 17. Gray, Syn. Fl. N. A. 1, pt. $1: 148$.

Northern Mexico.

Louisianian area. South Carolina to Florida, west to Louisiana, Arkansas, and western Texas.

Alabama: Coast plain. Damp open ground border ditches, low fields. Mobile County. Flowers pale yellow. February, March; fruit. April; frequent. Winter annual.

Type locality : "Common around Charleston and Beaufort."

Herb. Geol. Surv. Herb. Mohr.

CARDAMINE L.Sp. P1. 2 :654. 1753.

About 50 species, cooler and warmer zones of Northern Hemisphere. Few in South America. Europe.

Cardamine pennsylvanica Muhl.; Willd.Sp. Pl.3:486. 1800.

Cardamine hirsuta auct. Am. Not L.

Small Bitter Cress,

Ell. Sk. 2:144. Gray, Man. ed.6, 65, as to the type. Chap. Fl.26. Gray, Syn. Fl. N. A. 1, pt. 1: 158.

JAMAICA.

Boreal zone to Louisianian area. Nova Scotia to the Arctic Sea; Ontario (Macoun) to the Pacific; California north to Alaska; New England west to Dakota and Montana, south to Florida, Louisiana, and Arkansas.

Alabama: Central Pine belt to Coast plain. Wet places, ditches. Conecub County, Evergreen (Baker \& Earle, 43). Tuscaloosa County (E. A. Smith). Mobile County. Most frequent in the Coast plain. Flowers white, February, March; fruit ripe in April. Annual.

'Type locality: "Hab. in Pennsylvania."

Herb. Geol. Surv. Herb. Mohr.

Cardamine bulbosa (Schreb.) B. S. P. Prel. Cat. N. Y.4. 1888.

Bulbous-rooted Bitter Cress.

Arabis bulbosa Schreb.; Muhl. Trans Am. Phil. Soc. 3:174. 1793.

Thlaspi tuberosum Nutt. Gen. 2:65. 1818.

Cardamine rhomboidea DC. Syst. $2: 246.1821$.

Gray, Man. ed. 6, 65. Chap. Fl.25. Gray, Syn. Fl. N. A. 1, pt. 1:156.

Canadian zone to Carolinian area. Nova Scotia, Ontario, and New England, west to Dakota, south to the Ohio Valley, Missouri, Tennessee, North Carolina, and Florida.

Alabama: Central Pine belt. Wet springy places. Tuscaloosa County, Epes Station. Hale County, Havana (E. A. Smith). Flowers white; March, April. Not frequent. Perennial.

Type locality (Muhl. Cat.): "Pensylvania."

Herb. Geol. Surv. Herb. Mohr.

DENTARIA L. Sp. Pl. $2: 653.1753$.

Fifteen species, temperate region Northern Hemisphere, Europe, Asia. North America 10. Perennial herbs,

Dentaria diphylla Michx. Fl. Bor. Am. 2:30. 1803.

PePper-RoOT.

Ell. Sk. 2:142. Gray, Man. ed. 6, 64. Chap. Fl. 26. Gray, Syn. Fl. N. A. 1, pt. $1: 153$.

Alleghenian and Carolinian areas. New Brunswick, Ontario, Quebec; New England west to Minnesota; sonthern West Virginia to Ohio, and along the mountains to South Carolina. 
Alabama: Tennessee Valley. Lower hills. Rich shaded woods. Lauderdale County, Florence (M. C. Wilson). Tuscaloosa County (E. A. Smith). Flowers yellowish white; April. Not rare.

Type locality: "In sylvis vastis Tennassée et montibus altissimis Carolinae."

Herb. Geol. Surv. Herb. Mohr.

Dentaria laciniata Muhl.; Willd. Sp. Pl. 3:479. 1800.

LOBED TOOTHWORT.

Dentaria concatenata Michx. Гl. Bor. Am. 2:30. 1803.

Ell. Sk. 2:142. Gray, Man. ed.6,64. Chap. Fl.26. Gray, Syn. Fl. N. A. 1, pt. $1: 153$.

Alleghenian to Lonisianian area. Quebec and Outario; New England west to

Minnesota and Nebraska, south to western Florida, and through the Ohio Valley to Missouri.

Alabama: Rich woods. Tennessee Valley throughout the mountains to Lower hills. Madison County, Montesano. Tuscaloosa and Chilton counties. Flowers pale rose color; March, April.

Type locality: "Hab. in Pensylvania."

Herb. Geol. Surv. Herb. Mohr.

Dentaria laciniata multifida (Mnhl.) J. F. James, Bot. Gaz. 13:234. 1888.

Dentaria multifida Muhl. Cat. 60. 1813.

Finely-loBed ToothWokt.

Ell. Sk. 2:142. Chap. Fl. 26. Gray, Syn. Fl. N. A. 1, pt. 1: 153.

Carolinian and Louisianian areas. 'Tennessee, North and South Carolina.

Alabama: Tennessee Valley to Lower hills. Lauderdale County, Florenee ( $\boldsymbol{M}$. $C$.

Wilson). Tuscaloosa County (E.A.Smith). Flowers pale flesh-color; March, April. Rare.

Plants from Florenee, with the divisions of the leaves wider, conneet with the type.

Type locality: "Carolina, Cherokee."

Herb. Geol. Surv. Herb. Mohr.

Dentaria heterophylla Nutt. Gen. 2 :66. 1818.

Cardamine heterophylla Wood, Bot. \& Fl.38. 1870.

Gray, Man. ed.6,64. Chap. Fl.26. Gray, Șrn. Fi. N. A. 1, pt. 1:153.

Carolinian and Louisianian areas. New Jersey, Pennsylvania, and West Virginia to Tennessee.

Alabama: Central Pine belt. Hale County, Havana (E. A. Smith). April 29; rare.

Type locality: "In western Pennsylvania (in the shady firwoods on the banks of Wishahikon Creek, a few miles from Philadelphia)."

Herb. Geol. Surv. Herb. Mohr.

LEAVENWORTHIA Torr. Ann. Lyc. N. Y. 4:87. 1848.

Four species, eastern North America. Low winter annuals.

Leavenworthia aurea Torr. Ann. Lyc. N. Y. 4:88, t. 5. 1848.

Golden-Flow ERed Leaveniwolithia.

Chap. Fl. 27. Gray, Syn. Fl. N. A. 1, pt. 1:152. Gray. Ill. 1:140, t. 5\%.

Carolinian area. Tennessee, Arkansas, and northwestern Texas.

Alabama: Tennessee Valley. Limestone flats. Jackson County, Scottsboro, in the cedar glades, abundant. Flowers yellow. March. Collected fruiting specimens only May 5. Local.

Differs from Gray's figure in the more numerous divisions of the leaves, 5 to 7 pairs.

Type locality: Vicinity of Fort Towson, Arkansas; also in Texas and in Jefferson

County, Alabama; Dr. M. C. Leavenworth!

Herb. Geol. Surv. Herb. Mohr.

Leavenworthia uniflora (Michx.) Britt. Mem. 'Torr. Club, 5 : 171. 1894.

Cardamine uniflora Michx. Fl. Bor. Am. 2:29. 1803.

Leavenworthia michauxii 'Torr. Ann. Lyc. N. Y. 2: 89. 1848.

Gray, Man. ed. 6, 63. Cliap. Fl. 27. Gray, Syn. Fl. N. A. 1, pt. 1:152.

Carolinian area. Kentucky, Indiana?, and Missouri, south to Tennessee and Arkansas.

Alabama : Mountain region. Limestone ledges. Madison County, Montesano, at 800 to 1,000 feet. Collected in fruit only, May 1, 1880. Local. Annual.

Type locality: "Hab. in rupibus circa Knoxville."

Herb. Geol. Surv. Herb. Mohr.

Leavenworthia torulosa Gray, Bot. Gaz. $5: 26.1880$.

Necklace Leavenworthia.

Gray, Man. ed. 6, 64. Gray, Syn. Fl. N. A. 1, pt. 1: 152. Chap_Fl. ed. 3, 26.

Carolinian area. Kentucky and Tennessee. 
AlABAMA: With the above, apparently more rare. Annual.

Type locality: "Barrens of Kentucky, Short. Very abundant near Nashville,

Tennessee, Dr. Gattinger."

Herb. Geol. Surv. Herb. Mohr.

BURSA Weber in Wigg. Prim. Fl. Hols. 47. 1780.

(Capsella Medic. Pfl. Gatt. 1:85. 1792.)

Four species, north temperate zone.

Bursa bursa-pastoris (L.) Britton, Mem. Torr. Club, 5 : 172.1894.

Thlaspi bursa-pastoris L. Sp. Pl. 2 : 647. 1753.

Shupherd's Purse.

Capeella bursa-pastoris Medic. Pfl. Gatt. 1:85. 1792.

Ell. Sk. 2: 141. Gray, Man. ed. 6, 73. Chap. Fl. 30.

An almost cosmopolitan weed, of northern temperate regions.

Europe.

Naturalized in America, spread almost over the continent.

Alabama: Over the state. Waste places, sandy fields, common everywhere. Flowers white, March to May. Annual.

Type locality: "Hab. in Europae cultis ruderatis."

Herb. Geol. Surv. Herb. Mohr.

DRABA L. Sp. Pl. 2 :642. 1753. Whitlow Grass.

One hundred and fifty species, temperate zone. Arctic and Alpine regions Northern Hemisphere. North America, 34 species. Low perennials or annuals.

Draba caroliniana Walt. Fl. Car. 174. 1788.

Carolina Whitlow Grass.

Ell. Sk. 2 :138. Gray, Man. ed.6,68. Chap. Fl. 29. Gray, Syn. Fl. N. A. 1, pt. 1:106.

Alleghenian to Louisianian area. Southern Ontario; eastern Massachusetts, west to Nebraska, south to the Ohio Valley, 'Tennessee, Missouri, and Arkansas, and from New York to Georgia.

Alabama: Mountain and Central Prairie regions. Sandy fields, grassy hillsides.

Lee County, Auburn (Underwood \& Earle). Montgomery County. Flowers white;

March. Not frequent. Winter annual.

Type locality: South Carolina.

Herb. Geol. Surv. Herb. Mohr.

Draba cuneifolia Nutt.; Torr. \& Graf, Fl. N. A. 1:108. 1838.

WEDGE-LEAF WHITLOW GRASS.

Gray, Man. ed. 6, 68. Chap. Fl.29. Gray, Syn. Fl. N. A. 1, pt. 1:107.

Carolinian and Louisianian areas. Southwestern Kentucky, southern Illinois, Missouri, south to Tennessee, Georgia, western Florida, west to Arkansas, south western Texas, southern Utah, California.

Alabama: Central Prairie region. Sandy fields. Sumter County, Epes Store (E. A. Smith), March 25. Annual.

Type locality: "Grassy places around St. Louis, Mo. Also in Arkansas and west Florida, Nuttall! Kentucky, Short!"

Herb. Geol. Surv. Herb. Mohr.

Draba brachycarpa Nutt.; Torr. \& Gray, Fl. N. A 1: 108. 1838.

SMALL-FRUITED WhitLow GRASS.

Gray, Man. ed. 6, 68. Chap. Fl.29. Gray, Syn. Fl. N. A. 1, pt.1:107.

Carolinian and Louisianian areas. Virginia, Kentucky, southern Illinois, and

Missouri; south from Tennessee to central Georgia and western Florida; Oregon.

Alabama: Tennessee Valley to Coast plain. Open grassy places, low hills. Madison County, Hnntsville. Montgomery County, similar situations. Baldwin and Mobile counties, sandy shores of Mobile Bay. Flowers white; May. Annual. Type locality: "Near St. Louis, Mo.; and in Arkansas, Nuttall! Milledgeville, Ga., Dr. Boykin! Macon, Ga., Mr. Loomis!"

Herb. Geol. Surv. Herb Mohr.

STENOPHRAGMA Celak. Oester. Bot. Zeitsch. 27:177. 1877.

Stenophragma thaliana (L.) Celak. Oester. Bot. Zeitsch. $27: 177.1877$.

Arabis thaliana L. Sp. Pl. 2 :665. 1753.

Mouse-ear Cress.

Sisymbrium thalianum Gay, Ann. Sci. Nat. 7:399. 1826.

Gray, Man. ed. 6, 72. Chap. Fl. 26. Gray, Syn. Fl. N. A. 1, pt. 1:140. 


\section{EUROPE.}

A humble naturalized weed, frequent in Ontario and New England, thence west to West Virginia and Kentucky, and south to Florida and Mississippi.

Alabama : Over the State. Borders of sandy fields, waste places. Madison County, Hnntsville. Tuscaloosa, Montgomery, Mobile, and Bald win counties. Flowers white. March; not common. Annual.

'Type locality: "Hab. in Europae septentrionalioris sabulosis."

Herb. Geol. Surv. Herb. Mohr.

ARABIS L. Sp. Pl. 664. 1753.

One hundred distinct species, of temperate regions, chiefly in the Northern Hemisphere; few in South America and Australia. North America 38.

Arabis virginica (L.) Trelease, Branner \& Coville, Rep. Geol. Surv. Ark. 1884, $4: 165$. 1891 . Southern SAND Cress.

Cardamine virginica L. Sp. Pl. 2:656. 1753.

Arabis ludoviciana C. A. Meyer, Ind. Sem. Hort. Petrop. 9:60. 1834.

Gray, Man. ed. 6, 66. Chap. Fl. ed. 3, 27. Coulter, Contr. Nat. Herb. 2:19. Gray, Syn. Fi. N. A. 1, pt. 1:161.

Carolinian and Louisianian areas. Virginia to South Carolina, west to Texas, Arkansas, Missouri, and southern California.

Alabama : Central Pine belt to Coast plain. Open sandy places, borders of fields. Tuscaloosa, Montgomery, and Mobile counties; frequent in the Coast plain. Flowors white. February, Mareh. Winter annual.

Type locality: "Hab. in Virginia."

Herb. Geol. Surv. Herb. Mohr.

Arabis patens Sulliv. Am. Journ. Sci. 42:49. 1842.

Open Rock Cress.

Gray, Man. ed. 6, 6b. Chap. Fl. 27. Gray, Syn. Fl. N. A. 1, pt. 1:162.

Carolinian area. New York and West Virginia to Ohio and Missouri, south from Tennessee to northwestern Georgia (Cave Springs).

Alabama : Central Prairie belt. Damp shaded limestone rocks. Bibb County;, banks Little Cahaba River, Pratts Ferry. June; rare. Annual or biennial. Type locality : "Rocky banks of the Scioto River, near Columbus, Ohio."

Herb. Mohr.

Arabis laevigata (Muhl.) Poir. Eneycl. Suppl. 1:411. 1810.

SMooth Rock Cress. Sickle Pod.

Turritis laevigata Muhl.; Willd. Sp. Pl. 3:543. 1801.

Gray, Man. ed. 6, 66. Chap. Fl. 28. Gray, Syn. Fl. N. A. 1, pt. 1:162.

Alleghenian to Louisianian area. Quebec, Ontario; New England west to Minnesota, south to Ohio Valley and 'Tennessee.

Alabama: Central Pine belt. Rocky banks. Tuscaloosa County (E. A. Smith). Bibb County, bank of Little Cahaba River. Flowers March, fruit June; not frequent. Annual.

Type locality: "Hab. in Pensylvania."

Herb. Geol. Surv. Herb. Mohr.

Arabis canadensis L. Sp. Pl. 2 : 665.1753.

SICKLI POD.

Ell. Sk. $2: 148$. Gray, Man. ed. 6, 66. Chap. Fl. 28.

Alleghenian and Carolinian areas. Ontario and New England west to Minnesota, south to Missouri, Georgia, Texas, and Arkansas.

Alabama: Mountain region. Madison County, Huntsville (Baker \& Earle).

Flowers June. Infrequent. Annual or biennial.

Type locality not given.

Herb. Geol. Surv. Herb. Mohr.

\section{CAPPARIDACEAE. Caper Family.}

CLEOME L. Sp. Pl. 2 :671. 1753.

Seven species, subtropical and tropical regions, chiefly South America.

Cleome spinosa L. Sp. Pl. ed. 2, 2 :939. 1763.

SPINY CLEOME.

Cleome pungens Willd. Enum.689. 1809.

Chap. Fl. 32. Gray, Syn. Fl. N. A. 1, pt. 1:183.

West Indies, South America.

Louisianian area. Adventive North Carolina to Louisiana and Arkansas. 
Alabama: Lower hills. Coast plain. Waste places. Shelby County, Cahaba (E. A.Smith). Mobile, a frequent ballast weed. Flowers pale purple; June, July. Annual.

Type locality : "Hab. in America meridionali."

Herb. Geol. Surv. Herb. Mohr.

Cleome aculeata L. Syst. ed. 12, $3: 232.1767$.

Prickly Cleome.

Griseb. Fl. Brit. W. Incl. 16.

West Indies, Guiana.

Alabama : Fugitive with ballast. Mobile. Collected once only, at Hunter's Wharf, June 4, 1893, with seeds perfectly mature. Annual.

Type locality: "Hab. i" America. D. Zaega."

Herb. Geol. Surv. Herb. Mohr.

Cleome pentaphylla L. Sp. Pl. ed.2, $2: 938$. 1762.

Five-Leaved Gynandropsis. Gynandropsis pentaphylla DC. Prodr. 1:238. 1821.

Ell. Sk. 2:150. Chap. Fl. 32. Gray, Syn. Fl. N. A. 1, pt. $1: 183$.

ASIA, EgYPT.

Warmer parts of America. Most probably introduced from the Old World. Escaped from cultivation, Georgia to Louisiana.

Alabama : Central Pine belt to Coast plain. An escape from gardens, and introduced with ballast; fuirly naturalized. Tuscaloosa County. Autanga County, Prattville. Mobile County. Flowers rose-color; June, July. Annual.

Type locality: "Hab. in Indiis."

Herb. Geol. Surv. Herb. Mohr.

Cleome viscosa L. Sp. Pl. 2 : 672 . 1753.

Ceylon, Malabar, West Africa, introduced in warmer America.

Gray, Syn. Fl. N. A. 1, pt. 1:183.

Alabama: Adventive with ballast. Mobile. Observed from 1878 to 1895 . Flowers yellow; Angust, September. Annual. Also reported on ballast from Philadelphia. Annual.

Type locality: "Hab. in Zeylona, Malabaria."

Herb. Geol. Surv. Herb. Mohr.

POLANISIA Raf. Journ. Phys. 89: 98. 1819.

Thirty species, warmer regions of the Old and New World, Northern Hemisphere. Annuals.

Polanisia trachysperma Torr. \& Gray, Fl. N. A. 1:669. 1840.

Rough-seeded Polanisia.

Polanisia uniglandulosa Torr. Pac. R. Rep. 4:67. 1857. Not DC.

Gray, Mau. ed.6, 75. Chap. F1. Suppl. 606; ed. 3, 32. Coulter. Contr. Nat. Herb

2:23. Gray, Syn. Fl. N. A. 1, pt. 1:182.

Mexico.

Sporadically diffused over the western part of the continent. Manitoba to Colo rado, Oregon, Arizona, and 'I'rxas.

Alabama: Metamorphic hills. Waste places. Tallapoosa County, Dadeville, 550 feet; only station. Most probably adventive from the southwest. Flowers pink; July. Rare and local. Annual.

Type locality: "Texas, Drummond!"

Herb. Geol. Surv. Herb. Mohr.

Polanisia tenuifolia Torr. \& Gray, Fl. N. A. 1:123. 1838. Narrow-leaf Polanisia . Chap. Fl. 31. Gray, Syn. Fl. N. A. 1, pt. 1:182. 1895.

Louisianian area. Coast of Georgia and Florida.

Alabana: Sandy hills. Dale County (E. A. Smith). Annual. Type locality: "Georgia, LeConte!"

Herb. Geol. Surv. Herb. Mohr.

$15894-34$ 


\section{RESEDACEAE. Mignonette Family.}

RESEDA L. Sp. Pl. 1 : 449. 1753. MignoNettr.

Sixty species, Mediterranean Europe, Africa.

Reseda lutea L. Sp. Pl. 1:448. 1753.

Yellow C'Ut-Leaved Mignonette.

Europe.

Carolinian area. Adventive on ballast on the eoast of southern New Engiand and southward.

Ala Bama: Fugitive on ballast. Mobile, July, 1885. Annual.

'Type locality: "Hab. in Europae australioris montibus cretaceis."

Herb. Geol. Surv. Herb. Mohr.

\section{SARRACENIACEAE. Pitcher Plant Family.}

SARRACENIA L. Sp. Pl. 1:510. 1753.

Six species, perennials, chiefly south Atlantic North America.

Sarracenia purpurea L. Sp. Pl. 1:510. 1753.

SIDF-SADDLF Flower.

Ell. Sk. 2:9. Gray, Man. ed. 6, 57. Chap. Fl. 21).

Boreal zone to Louisianian area. From Labrador, Newfoundlaud, and Nova Scotia through Canada to the Rocky Mountains; New England to Florida and Louisiana.

Ala baMa: Throughout the Coast Pine belt. Coast plain. Sphagnous bogs. Clarke, Geneva, Escambia, Baldwin, and Mobile counties. Flowers pale purple; Mareh, April. Not infrequent.

Type locality: "Hab. in Americae septentrionalis ulis."

Herb. Geol. Surv. Herb. Mohr.

Sarracenia psittacina Michx. Fl. Bor. Am. 1:311. 1803.

Parrot Beak. Pitcher Plant.

Chap. Fl. 20. Gray, Syn. Fl. N. A. 1, pt. 1:80.

Louisianian area. Coast of Georgia aud Florida to Louisiana.

Alabama: Lower Pine region. Cloast plain. Damp and boggy pine barrens. Mobile, Baldwin, and Washington counties. Flowers pomegranate-purple; April. Not rare.

Type locality: "Hab. ab urbe Augusta Georgiae ad Floridam."

Herb. Geol. Surv. Herb. Mohr.

Sarracenia rubra Walt. Fl. Car. 152. 1788.

Rhd-Flowered Trumpet-leaf or Pitcher Plant.

Ell. Sk. 2:10. Chap. Fl. 21. Gray, Syn. Fl. N. A. 1, pt. 1:80.

Louisianian area. North Carolina and Florida to Mississippi.

Alabama: Lower Pine region. Coast plain. Damp sandy pine barrens, pinemearlows. Mobile County, Bayou LaBatre. Washington County, Vinegar Bend. Flowers reddish purple (wine-purple); April. Not rare.

Economie uses: The rootstocks of $S$. rubra, $S$. drummondii, and S. purpurea are reputed to possess therapentical properties.

Type locality : South Carolina.

Herb. Geol. Surv. Herb. Mohr.

Sarracenia drummondii Croom, Ann. Lye. N. Y. 4:100, t. 6. 1848.

Chap. Fl.21. Gray, Syn. Fl. N. A. 1, pt.1:80.

DRUMMOND TRUMPET-LeAF.

Louisianian area. South western Georgia and western Florida, west to Mississippi.

Alabama: Lower Piue region. Coast plain. Boggy pine barrens from Geneva to Washingtun County. Baldwin and Mobile counties. Flowers maroou purple. April; frequent.

Type locality: "Near the town of Appalachicola in Florida. Abundant on the western borders of the Appalachicola River below Ocheesee. Dr. A. W. Chapman, in lit."

Herb. Geol. Surv. Herb. Mohr.

Sarracenia flava L. Sp. Pl. 1:510. 1753.

Yellow TRUMPET-LeAF.

Ell. Sk. 2:10. Gray, Man. ed.6,57. Chap. Fl.21. Gray, Syn. Fl. N. A. 1, pt. 1:81.

Carolinian and Louisianian areas. Virginia to Florida, west to Louisiana. 
Alabama: Central Pine belt to the coast. Wet places, borders ponds, ditches, throughont the Coast Piue belt. Flowers canary yellow. April; frequent.

Type locality: "Hab. in Americae septentrionalis udis."

Herb. Geol. Surv. Herb. Mohr.

Sarracenia catesbaei Ell. Sk. 2 :11. 1821-24.

Catesby's Trumpet-leaf.

Carolinian area. South Carolina.

Alabama : Mountain region. Dekalb County. Wet banks of Little River, near De Soto Falls, 2,000 feet altitude. Flowers yellow. June. Only locality known in the state.

'Type locality: “My specimens * * * were collected by Dr. McBride along tho margins of the rivulets amidst the high.sandhills of Chestertield district in Sonth Caroliua."

Readily distinguished from the very closely allied Sarracenia flava by the strictly erect leaves with ventral wing narrower and the sides of the broad dark purple veined lamina scarcely if at all retlexed.

\section{DROSERACEAE. Sundew Family.}

DROSERA L. Sp. Pl. 281. 1753. SUNDEW.

About 100 species, all regions except Pacific islands. North America, 8.

Drosera brevifolia Pursh, Fl. Am. Sept. 1: 211. 1814. Short-Leaf Sundew. Chap. Fl. 37.

Louisianian area. Coast of North Carolina to Florida, west to Mississippi and Louisiana.

Alabama : Coast plain. Damp open pine barrens. Mobile. Flowers pale pink. April. Frequent. Annual.

Type locality : "In sandy swamps of Georgia. Enslen."

Herb. Geol. Surv. Herb. Mohr.

Drosera capillaris Poir. Encycl. $6: 299.1804$.

Capillaky Sundew.

Drosera brevifolia var. major Hook. Journ. Bot. 1 : 194. 1834.

Chav. Fl. 37 .

Jouisianian area. South Carolina to Florida, west to Mississippi and Texas.

Alabama : Lower Pine region. Coast plain. Low damp pine barrens, borders ponds, ditches. Geneva County (E.A.Smith). Mobile. Flowers white; April. Not rare. Annual.

Type locality : "Cette plante croit à la Caroline."

Herb. Geol. Surv. Herb. Mohr.

Drosera intermedia Hayne in Schrad. Journ. Bot. 1800, pt.1:37. 1801.

Drosera longifolia Michx. FJ. Bor. Am. 1 : 186. 1803. Not L.

LONGLEAF SUNDEW.

D. americana Willd. Enum. 340. 1809.

D. foliosa Ell. Sk. 1:376. 1817.

D. longifolia var. americana DC Prodr. 1:318. 1824.

Eil. Sk. 1:376. Gray Man ed 6, 178. Chap. Fl. 37. Griseb. Fl. Brit. W. Ind. 27.

Northern Europe, Western Asia, Kamtchatka, West Indies, Brazil.

Canadian zone to Louisianian area. New Brunswick, Ontario, and Manitoba to latitude $53^{\circ}$. New England, Maine west to Minnesota, south along the Atlantic coast to Florida and Louisiana.

Alabama : Coast Pine belt. Bogs and shallow ponds. Washington County, Yellowpine. Escambia, Baldwin, and Mobile counties. Flowers white; April, May. Frequent. Perennial.

Type locality : "Hab. in uliginosis turfosis," Germany.

Herb. Geol. Surv. Herb. Mohr.

Drosera filiformis Raf. Med. Rep. ser. 2, 5:360. 1808.

Drosera tenuifolia Willd. Enum. 340, 1809.

Gray, Man. ed. 6, 179. Chap. F1.37.

Alleghenian to Louisianian area. Coast of Massachusetts and New Jersey to Florida, west to Mississippi.

Alabama: Coast plain. Low damp pine barrens. Mobile and Baldwin counties.

Flowers rose pink; May Frequently covering large patches; not rare. Perennial.

Type locality (Torr. \& Gray, Fl.): "Delaware (Rafinesque)."

Herb. Geol. Surv. Herb. Mohr. 


\section{PODOSTEMACEAE. River Weed Family.}

About 12 species, perennial aquatics of wide distribution.

PODOSTEMON Michx. Fl. Bor. Am. 2 : 164. 1803.

Two species aquatic perennials. North American.

Podostemon abrotanoides Nutt. Journ. Acad. Phila. 7:105. 1834. Rrvkrweed. Chap. Fl. 399.

Carolinian area. Eastern Pennsylvania, Tennessee, and Georgia.

Ala BaMa: Mountain region. On rocks, in swiftly-running st:eams. Blount

County, Mulberry fork, Warrior River. Flowers not seen; June.

Type locality (Chapman): "Gravelly places in Chattahoochee River, Nuttall."

Herb. Geol. Surv. Herb. Mohr.

Podostemon ceratophyllum Michx. Fl. Bor. Am. 2:165. 1803.

Ell. Sk. 2:517. Gray, Man. ed. 6, 444. Chap. Fl. 399.

Carolinian area. Ontario; New York to Ohio; south from New Jersey to upper Georgia.

Alabama : Monntain region. Rocky river beds. Lee County, Auburn (Baker \& Earle). June. Only locality known in the State.

Type locality: "Hab. in rupibus saltus fluvii Ohio, juxta Louisville."

\section{CRASSULACEAE. Orpine Family.}

SEDUM L. Sp. Pl. 1:430. 1753.

About 150 species, chiefly perennials, mostly of the cooler and temperate regions of the Old World, chiefly Northern Hemisphere. North America, about 13.

Sedum pulchellum Michx. Fl. Bor. Am. 1:277. 1803.

Pretty Stonecrop.

Ell. Sk. 1:529. Gray, Man. edl. 6, 177. Chap. Fl. 150.

Carolinian area. West Virginia and Kentucky, west to southern Illinois, southeru

Missouri and Arkansas, south to Tennessee, and along the mountains to Georgia.

Alabama: Tennessee Valley. Mountain region. Rocky bluffis and hillsides. Landerdale and Florence counties. Madison County, south declivity of Montesano on limestone rock, abundant. Flowers white; May 1. Local, abundant.

Type locality: "Hab. in rupibus circa Knoxville," Tenn.

Herb. Geol. Surv. Herb. Mohr.

Sedum nevii Gray, Man. ed.5, 172. 1867.

Gray, Man. ed. 6, 177. Chap. Fl. 150.

Carolinian area. Mountains of Virginia and Tennessee.

Alabama: Lower hills. Rocky cliff's. Tuscaloosia County (R. D. Nevius). Bibb County, Pratt's Fenry. Shaderl damp rocks Little Cahaba River. Flowers white, June. Local and rare, forming dense tuits.

Type locality: "Mountains of Virginia (Saltpond Mountain, W. M. Canby) to Alabama (R. D. Nerius)."

Herb. Geol. Surv. Herb. Mohr.

Sedum teruatum Michx. Fl. Bor. Am. 1:277. 1803.

Ternate Stonecrop.

Ell. Sk. 1:529. Gray, Man. ed. 6, 177. Chap. Fl. 150.

Carolinian area. Southern Penusylvania, Ohio Valley from Virginia south along the monntains to Georgia and Arkansas.

Alabama: Tennessee Valley. Mountain region. Lower hills. Rocky woods. Lauderdale County, Florence. Dekalb County, Mentone. Cullman County (Miss Mary Mohr). Tuscaloosa County (E. A. Smith). Flowers white, May. Not rare.

Type locality: "Hab. in rupibus occidentalibus Pennsylvaniae, Virginiae et Carolinae."

Herb. Geol. Surv. Herb. Mohr.

DIAMORPHA Nutt. Gen. 1:293. 1818.

Single species, Southern Atlantic North America.

Diamorpha pusilla (Michx.) Nutt. Gen. 1: 293. 1818.

Sedum pusillum Michx. Fl. Bor. Am. 1:276. 1803.

Ell. Sk. 1:530. Chap. Fl. 150.

Carolinian area. South Carolina. 
Alabama: Mountain region. Wet sandstone rocks. Walker County ( $T . M$. Peters). Flowers white. Rare. Perennial.

Type locality: "Hab. in Carolina septentrionali, loco dicto Flat-rock."

Herb. Geol. Surv. Herb. Mohr.

TILlafa L. Sp. Pl. 1 : 128. 1753. Tillaea.

Cosmopolitan genus of about 20 species. North America, 4.

Tillaea aquatica L. Sp. Pl. $1: 128.1753$.

Pigmy-Ween.

Tillaea simplex Nutt. Journ. Acad. Phil:a. 1:114. 1817.

Gray, Man. ed.6, 177. Chap. Fl. Suppl.622; ed. 3, 150.

EUROPE.

Alleghenian to Louisianian area. Southeastern Massachusetts to Maryland and southeastern Pennsylvania.

Alabama: Coast plain. Low wet pine barrens, border of ponds. Mobile. March; rare. Annual.

Type locality: "Hab. in Europae inundatis."

Herb. Geol. Surv. Herb. Mohr.

PENTHORUM L.Sp. Pl. 1 : 432 . 1753.

Two species. China, North America.

Penthorum sedoides L. Sp. Pl. 1:432. 1753.

Ditch StONECROP.

Ell. Sk. 1:528. Gray, Man. ed. 6, 176. Chap. Fl.151.

China, Japan.

Allegheuian to Louisianian area. New Brunswick, Quebec, Ontario; New England west to Minnesota, Nebraska, and Kansas, south to 'Texas and Florida.

Alabama: Tennessee Valley to Coast Pine belt. Wet woods. Tuscaloosa County. Clarke County, Choctaw Corner; most southern station. Common. Perennial.

Type locality: "Hab. in Virginia."

Herb. Geol. Surv. Herb. Mohr.

\section{SAXIFRAGACEAE. Saxifrage Family.}

THEROFON Raf. New Fl. N. A. 4 : 66.1836.

(Boykinia Nutt. Journ. Acad. Phila. 7:113. 1834. Not Raf.)

Therofon aconitifolium (Nutt.) Millsp. Bull. W. Va. Agr. Exp. Sta. 2:361. 1892.

Boykinia aconitifolia Nutt. Journ. Acad. Phila. 7 : 113. 1834.

Gray, Man. ed. 6, 170. Chap. Fl. 153.

Carolinian area. Mountains of southern Virginia along the mountains to Georgia.

Alabama : Mountain region. Damp rocky banks of streams. Dekalb County, banks of Little River, 1,800 feet. Walker County, wet rocks on Clear Creek Falls. Flowers white; June, July. Rare. Perennial.

Type locality: "In the valleys of the Alleghany Mountains, probably in Virginia or North Carolina. * * * In Muhlenberg's herbarium."

Herb. Geol. Surv. Herb. Mohr.

SAXIFRAGA L. Sp. Pl. 1:398. 1753.

Two hundred species, chiefly perennials, mostly mountainous, alpine, North and Sonth Hemisphere, Europe, South America. North America, 45.

Saxifraga virginiensis Michx. Fl. Bor. Am. 1:269. 1803.

Ell. Sk. 1:511. Gray, Man. ed. 6, 170. Chap. Fl. 153.

Canadian zone to Caroliniau area. New Brunswick west to the Pacific. New England (Mount Desert Island, Maine) west to Michigan, West Virginia, Ohio, and Kentucky, sonth along the mountains to Georgia.

Alabama: Teunessee Valley to Lower hills. Shaded rocky banks. Frequent throughont the mountains. Winston County, 1,500 feet. Dekalb County, Lookout Mountain. Tuscaloosa Connty, 300 to 400 feet; most southerly station. Flowers yellow; March, April.

Type locality: "Hab. in rupibus Pensylvaniae, Virginiae et in montibus Carolinae."

Herb. Geol. Surv. Herb. Mohr. 
TIARELLA L. Sp. Pl. 1:405. 1753. FAlse MitreWort.

Four or 5 species, Asia. North America, 3.

Tiarella cordifolia L. Sp. Pl. 1: 405. 1753.

False Mitrewort.

Gray, Man. ed. 6, 171. Chap. Fl. 154.

Nolrth western Asia, Siberia.

Alleghenian to Louisianian area. Nova Scotia, Ontario; New England west to Minnesota, south to Tennessee, North Carolina, and Mississippi.

Ala bama : Tennessee Valley. Mountain region to Coast Pine belt. Damp shaded banks and rocky woods. Lauderdale, Lawrence, Winston, Walker, and Tuscaloosia counties. Clarke County, Snggsville (Dr. Denny); most southerly station. Flowers white, April; not common. Perennial.

Type locality : "Hab. in America et Asia septentrionali."

Herb. Geol. Surv. Herb. Mohr.

HEUCHERA I. Sp. Pl. 1: 226. 1753.

Twenty-four species, perennials. Atlantic and Pacific North America to the mountains of Mexico.

Heuchera americana L. Sp. Pl. 1:226. 1753.

ALUM Root.

Ell. Sk. 1:337. Gray, Man. ed. 6, 172. Chap. Fl. 152.

Alleghenian and Carolinian areas. Southern Ontario; Connecticut west to Minnesota, south to Arkansas; Ohio Valley, and along the mountains to Georgia.

Alabama: Tennessee Valley. Mountain region. Rocky open woods. Lauderdale, Cullman, and Blount counties. 'Tuscaloosa County (E. A. Smith); most southerly station. Flowers white, April; not common.

Economic uses: The root, called "alum root," is used medicinally.

Type locality: "Hab. in Virginia."

Herb. Geol. Surv. Herb. Mohr.

Heuchera rugelii Shuttlew.; Kunze, Linnaea, 20:43. 1847. RUGeL's Alum Root. Gray, Man. ed. 6, 172. Chap. Fl. Suppl. 62ż; ed.3, 144.

Carolinian area. Mountains of Virginia, west to Kentucky and southern Illinois, south on the mountains from Tennessee to Georgia.

Ala Bana : Mountain region. Damp shaded sandstone rocks. Winston County, Collier's Creek, 1,500 feet. Lawrence County, Mountain Home; in the so-called rock houses. Cullman County. Flowers white, July, Angust; infrequent.

Type locality : "Broad River, North Carolina." Rugel.

Herb. Geol. Surv. Herb. Mohr.

Heuchera hispida Pursh, Fl. Am. Sept. 1:188. 1814.

Heuchera richardsonii R. Br. in Frankl. Journ. 766, t. 29. 1823.

Gray, Man. ed. 6, 172. Chap. Fl. 144.

Canadian zone to Carolinian area.

Alabama: Metamorphic hills. On rocks. Talladega County, Kahatchee

Mountain, June, 1899 (C. D. Beadle).

Type locality: "On high mountains of Virginia and Carolina."

Herb. Biltmore.

Heuchera hispida hirsuticaulis Wheelock, Bull. Torr. Club, 17 : 199.1870. Carolinian area. Illinois and Missouri.

Alabama: Tennessee Valley. Damp shaded cliffs, banks of Tennessee River.

Tuscaloosa County (E. A. Smith). Flowers June; rare.

'Type locality: "Missouri.-St. Lonis, Engelmanu; Louisiana, Pech."

Herb. Geol. Surv. Herb. Mohr.

\section{LEPUROPETALON Ell. Sk. 1:370. 1817.}

One species, southeastern North America.

Lepuropetalon spathulatum (Mubl.) Ell. Sk. 1:370. 1817.

Pyxidanthera 8pathulata Mnhl. Cat. 24. 1813.

Ell. Sk. 1. c. Chap. Fl. 152.

Louisianian area. Georgia and South Carolina.

Alabama: Coast plain. Damp grassy banks in sandy soil. Mobile County. Flowers in March; not common. A small annual, hidden in the grass and easily overlooked.

Type locality: "Carolina."

Herb. Geol. Surv. Herb. Mohr. 
PARNASSIA L. Sp. Pl. 1: 273. 1753.

Nineteen species, temperate and cooler regions, Northern Hemisphere, Europe, Asia. North America, 6.

Parnassia asarifolia Vent. Jard. Malmais. 39. 1803. Arabacca-leaf Parnassia.

Ell. Sk. 1:372. Gray, Man. ed.6, 173. Chap. Fl. 38.

Carolinian area. Allegheny Mountains from Virginia to Georgia.

Ala BaMa: Mountain region. Clay County, Shinbone Valley, 1,000 feet. Margins of brooklets. Without flowers; rare. Perennial.

'Type locality not ascertained.

Herb. Geol. Surv. Herb. Mohr.

Parnaseia grandifolia DC. Prodr. 1:320, 1824, which occurs from sonth western Virginia to Florida, is not infrequent in the Pearl River Valley, Poplarville, Miss., and is to be looked for in the western parts of the long-leaf pine belt of this State.

Parnassia Caroliniana Michx. Fl. Bor. Am. $1: 184$, 1803, is not rare in southeastern Mississippi, and is to be looked for in southwestern Alabama.

PHILADELPHUS L. Sp. PI. 1: 470. 1753. SYRINGA.

About 20 species, shrubs, temperate regions. Japan, Himalayas. North America 6.

Philadelphus grandiflorus Willd. Ennm. 511. 1809. LARGE-FLowered SYringa.

Ell. Sk. 1:538. Gray, Man. ed. 6, 174. Chap. Fl. 156.

Carolinian and Louisianian areas. Mountains of Virginia to Georgia.

Alabama: Mountain region. Metamorphic hills. Lee County, Auburn (Cnderwood \& Earle), April, 1896. Tuscaloosa County (E. A. Smith).

Economic uses: An ornamental shrub.

Type locality: "Hab. in America loreali."

Herb. Geol. Surv. Herb. Mohr.

Philadelphus inodorus L. Sp. Pl. 1:470. 1753.

ODORLESS SYRINGA.

Ell. Sk. 1:538. Gray, Man. ed. 6, 174. Chap. Fl. 156.

Carolinian and Lonisianian areas. Mountains of Virginia to Sonth Carolina.

Arabana : Central Prairie region. Upper division Coast Pine belt. Dry copses, hillsides. Wilcox County (S. B. Buckley). Clarke C'ounty, Lisbon, calcareous bluffs of Alabama River. Flowers white, May. Shrub 4 to 6 feet high; not frequent.

Economic uses: Ornamental.

Type locality: "Hab. in Carolina."

Herb. Geol. Surv. Herb. Mohr.

Philadelphus hirsutus Nutt. Gen. 1:301. 1818.

Rot:GH-HAIRY SYIINGA.

Chap. Fl. 156.

Carolinian area. Cumberland Mountains of Tennessee. Mountains of North Carolina and Arkansas.

Alabama: Tennessee Valley and Mountain region. Dekalb County, cliffs Lookout Mountain, 1,600 to 1,800 feet, near Mentone. Lauderdale County, Florence, rocky banks Cypress Creek. Flowers white, May, first days of June. Shrub 3 or 4 feet high; infrequent.

Type lorality: "On the rocky banks of French Broad river, Tennessee, near the Warm Springs, abundant."

Herb. Geol. Surv. Herb. Mohr.

HYDRANGEA L. Sp. Pl. $1: 397$. 1753. HYDRANGEA.

Thirty species, warmer temperate eastern Asia. Atlantic North America.

Hydrangea arborescens L. Sp. Pl. 1 : 397. 1753. Wild Hydrangea. Sevenbark.

Hydrangea vulgaris Michx. Fl. Bor. Am. 1:268. 1803.

Eil. Sk. 1:509. Gray, Man. ed.6, 173. Chap. Fl. 155.

Carolinian and Lonisianian areas. Southern New York, Pennsylvania. Western Ohio Valley to Missouri, south to Florida, Mississippi, and Arkansas.

Alabama: Tennessee Valley to Central Pine belt. Wooded hillsides. Shaded banks of streams. Clay County, Moseley. Lauderdale County, Florence. Dekalb and Cullman connties. Walker County, near Jasper. Tinscaloosa County. Bibb County (E. A. Smith). Flowers white, June. Shrub $1 \frac{1}{2}$ to 2 feet high.

Economic uses: The root, muler the name "Hydrangea," is used medicinally.

Type locality: "Hab. in Virginia."

Herb. Geol. Surv. Herb. Mohr. 
Hydrangea arborescens cordata (Pursh) Torr. \& Gray, Fl. N. A. 1:591. 1848.

Hydrangea cordata Pursh, Fl. Am. Sept. 1:309. 1817.

WILD HYDRANGEA.

Eil. Sk. 1:509.

Carolinian area. Monntains of Tennessee, Carolina, and Georgia.

Alabama : Mountain region. Lower hills. Shaded rich hillsides, rocky woods. Clay County, 'Talladega Creek, near Moseley, 1,000 feet. Tuscaloosa County. Winston County, 1,500 feet. Flowers white, July. Shrub 6 to 8 feet high; vot frequent.

In the extreme form quite distinct, connected however with the type by intergrading forms.

Type locality : "On the monntains of Carolina."

Herb. Geol. Surv. Herb. Mohr.

Hydrangea cinerea Small, Bull. Torr. Club, $25: 148.1898$.

Robust shrub, 3 to 4 feet high. Leaves thinnish, broadly ovate to elliptical, aen." minate, more or less cordate at the base, $2 \frac{1}{2}$ to $3 \frac{1}{3}$ inches wide, about 5 inches long, cinereous-canescent on the lower side, petioles about half the length of the leaf blades; corymbs spreading; radiate sterile flowers not numerous, their calyx lobes roundish, obtuse; stamens long-exserted; capsules small, crowned by the 2 or 3 erect-spreading styles.

Carolinian area. Tennessee, Georgia.

AlabaMa : Mountain region, 'lennessee Valley. Shaded rocky banks and ravines. Tuscaloosa Connty. Lauderdale County, Florence, banks of the Tennessee River. June, 1892.

Resembles the mountain forms of Hydrangea arborescens with broad, cordateleaves, pale beneath; recognized, however, at first sight by its more robust habit of growth, the cinereous close pubescence of the lower sicle of the leaves, the more widely spreading cymes, the obtuse round calyx lobes of the ray flowers, and the conspicnously exserted stamens. gia."

Type locality: "Western slopes of theAllegheny Monntains, Tennesseo and Geor-

Herb. Geol. Surv. Herb. Mohr.

Hydrangea quercifolia Bartram, Travels, 382, t. 7 (ed. 2, 380). 1791.

Ell. Sk. 1:510. Chap. Fl.155.

OAK-LEAF Hydrangea. Sevenbalk.

Carolinian and Lonisianian areas. Georgia and Florida to Louisiana.

Alabama : Mountain region to Coast plain. Wooded hillsides, ravines, high banks of streams. Abuudant throughout the mountains and lower hills. Sparsely scattered throughout the Prairie region and Coast Pine belt. Winston, Madison, Cullman, and T'nscaloosa counties. Escambia County, Flomaton. Mobile County, shell bank on Dog River. Flowers white, April, May. Shrub 4 to 6 feet high.

Economic uses: Ornamental and cultivated. The bark, "sevenbark," is used in demestic medicine.

Type locality : Region of the Oemulgee River, southern Georgia.

Herb. Geol. Surv. Herb. Mohr.

ITEA L. Sp. Pl. 1:199. 1753.

One species, sonthern Atlantic North America.

Itea virginica L. Sp. Pl. 1:199. 1753.

Virginian Itra.

Ell. Sk. 1:293. Gray, Man. ed.6, 17t. Chap. Fl. 155.

Carolinian and Lonisianian areas. Sonthern New .Jersey along the Atlantic slope to Floridis and throughont the Gulf States to Lonisiana anil Arkansas.

Alabama: Tennessee Valley to the Coast plain. Sliaded wet borders of streams, most common in the Lower Pine region and Coast plaiu. Landerdale. Cullnan, Nontgomery, and Mobile connties. Flowers white; end of May, June. Shrub 4 to 6 feet high; common.

Type locality : "Hab. in Virginia."

Herb. Geol. Surv. Herb. Mohr.

DECUMARIA I.Sp. Pl.ed. 2, 2:1663. 1763.

Two species, China. Southeastern North America 1.

Decumaria barbara L. Sp. Pl. ed. 2, 2 : 1663. 1763.

Carolina Decumaria.

Decumaria sarmentosa Lll. Sk. 1:534. 1817-21.

Ell. Sk. l.c. Gray, Man. ed.6, 174. Chap. Fl.15\%.

Carolinian and Lonisianian areas. Southern Virginia (Dismal Swamp), along the

Atlantic slope to Florida, and throughout the Gulf States to Lonisiana. 
Alabama: Tennessee Valley to Coast plain. Alluvial woods, low shaded banks of streams. Lauderdale, Cullman, Tuscaloosa, Moutgomery, Clarke, and Mobile counties. Flowers white, fragrant; May. A rooting climber ascending high trees. Frequent.

Type locality: "Hab. an in Africa? Schreber."

Herb. Geol. Surv. Herb. Mohr.

\section{GROSSULARIACEAE.}

RIBES L. Sp. Pl. $1: 200.1753$.

Abont 60 species, mostly of the north temperate zone and in the Andes. North America 46, mostly Western. East of the Rocky Mountains, 14.

Ribes curvata Small, Bull. Torr. Club, 23 :295. 1896.

Armed with subulate spines; leaves orbicular, smooth ish, $\frac{8}{4}$ inch to 4 inches in diame. ter, 3-lobed, on short petioles, the lobes toothed; flowers small, solitary, on short twisted pedicels subtended by two 3 -lobed ciliate bractlets; calyx segments linear, reflexel and recurved, whitish; petals oblong, obtuse, white; stamens conspicuous, anthers red; berries globose, $\frac{1}{4}$ to $\frac{1}{8}$ inch in diameter, black. A low diffuse shrub 2 to $2 \frac{1}{2}$ feet high, with purplish recurved or conspicuously drooping branchlets. Flowers early in May; fruit matures July.

Carolinian area. Georgia.

Alabama: Mountain region. Marshall County, near Short Creek (G. C. Boynton). Type locality: "On the slopes of Stone Mountain, Georgia."

Herb. Biltmore.

Ribes cynosbati L. Sp. Pl. 1 : 202. 1753 .

Gray, Man. ed. 6, 175. Chap. Fl. ed. 3, 148.

JAPAN.

Alleghenian and Carolinian areas. New Brunswick, along the mountains to Georgia, west to Minnesota and Missouri.

Alabala : Mountain region. Rocky woods, Marshall County, rare.

Type locality: "Hab in Canada. Kalm."

Herb. Biltmore.

\section{HAMAMELIDACEAE. Witch Hazel Family.}

FOTHERGILLA Murr. Syst. Veg. 418. 1774.

Two species, Asia (Himalayas). Atlantic North America.

Fothergilla carolina (I.) Britton, Mem. Torr. Club, 5: 180. 1894.

Hamamelis virginiana carolina L. Mant. 2 : 333. 1771.

Carolina Fothergilla.

Fothergilla gardeni Murr. Syst. Veg. 418. 1774 .

F. alnifolia L. f. Suppl.267. 1781.

$F$. major Loddiges, Bot. Cab. t. 1520. 1825-33.

Eil. Sk. 1:547. Gray, Man. ed. 6, 180. Chap. Fl. 157.

Carolinian and Louisianian areas. Southern Virginia and North Carolina to Florida.

Alabama: Tennessee Valley. Central Prairie belt. Swampy borders ol streams. L iuderdale County, Florence (M. C. Wilson). Cullman County, rocky banks (Mirs E. Mohr). Antanga County, Prattville. Marshall County, banks of Short Creek May 22, in fruit (G.C. Boynton). Flowers white, stamens tinged with pink, appearing before the leaves; March, April. Local, rare; shrub rarely over 3 feet high.

Type locality not given.

Herb. Geol. Surv. Herb. Mohr.

HAMAMELIS L. Sp. PI. 1:124. 1753.

Three species. Japan. Atlantic North America.

Hamamelis virginiana L. Sp. Pl. 1 : 124. 1753.

Witch HaZeL.

Ell. Sk. 1:219. Gray, Man. ed.6, 179. Chap. Fl. 157. Sargent, Silv. N. A. 5:3, t. 198 .

Canadian zone to Louisianian area. Nova Scotia, New Brunswick, Quebec, Outario; New England (Mount Desert Island, Maine) west to Michigan and Nebraska, south to nortbern Florida and eastern Texas. (Sargent).

Alabama: Thronghout the State. Damp woods. Flowers yellow, October, November; fruit ripe June, July. Shrub, rarely a small tree, 10 to 12 feet high. 
Economic uses: The leaves are the witch hazel or "Hamamelis" of the United States Pharmacopœia.

Type locality: "Hab. in Virginia."

Herb. Geol. Surv. Herb. Mohr.

LIQUIDAMBAR L. Sp. Pl. 2 : 999. 1753. SWeet-Gum Tree.

Fonr species, Asia, Atlantic North America and Mexico.

Liquidambar styraciflua L. Sp. Pl. 2 : 999. 1753. Sweet Gum. Red Gum. Bilsted. Ell. Sk. 2:621. Gray, Man. ed. 6, 180. Chap. Fl. 157. Sargent, Silv. N. A. 5: 18, t. 199.

Mexico, Guatemala.

Carolinian and Louisianian areas. Sontheastern Connecticut, southern New York, New Jersey, West Virginia, and Ohio Valley to southenstern Missouri and Arkansas, south to Florida and throughout the Gulf States to the 'Trinity Valley, Texas.

Ala bama: Over the State. Rich bottoms and border of swamps. In greatest development sonth of the region of Lower hills to the Coast Pine belt. Flowers green, February, March.

Economic uses: Valuable timber tree. The balsamic exudation, "sweet gum," and the bark, "sweet-gum bark," are used medicinally.

Type locality: "Hab. in Virginia, Mexico."

Herb. Geol. Surv. Herb. Mohr.

\section{PLATANACEAE. Plane Tree Family.}

PlatanUs L. Sp. Pl. $2: 999$. 1753. Plane Tree. Buttonwood.

Three species, Europe, Asia. North America, 2.

Platanus occidentalis L. Sp. Pl. 2 :999. $1753 . \quad$ Sycamork. Buttonwood.

Ell. Sk. 2:620. Gray, Man. ed. 6, 467. Chap. Fl. 418. Coulter, Contr. Nat. Herb.

$2: 410$. Sargent, Silv. N. A. 7:10:2.

Alleghenian to Lonisianian area. Ontario, southern Maine, west to Nebrasku and

Kans:1s and sou th throughout the Ohio Valley to Florida, eastern Texas, and Arkansas.

Alabama: Over the State. In bottom lausls, chiefly in the central sections, farther south sparsely seattered, and in the coast region scarcely indigenous. Flowers May; fruit ripe September.

Type locality: "Hab. in America septentrionali."

Herb. Geol. Surv. Herb. Mohr.

\section{ROSACEAE. Rose Family.}

OPULASTER Medic. Pfl. Anat. $2: 109.1799$.

(Physocarpa Raf. New Fl. N.A. 3: 73. 1836.)

(Neillia Don, Prodr. Fl. Nep. 228. 1825.)

Four or 5 species shrubs, mountains of Asia. North America, 2.

Opulaster opulifolius (L.) Kuntze, Rev. Gen. Pl. 2 : 949. 1891.

NINEBARK.

Spiraea opulifolia L. Sp. Pl. 1:489. 1753.

Physocarpa opulifolia Raf. New Fl. N. A. 3: 73. 1836

Neillia opulifolia Benth. \& Hook. Gen. Pl. 1:612. 1865.

Ell. Sk. 1:560. Gray, Man. ed.6, 153. Chap. Fl. 120.

Alleghenian and Carolinian areas. Quebec and Ontario to Saskatchewan; New England west to Minnesota, Nelıraska, and Colorado, sonth to New York, Ohio, Illinois, southeastern Missouri, Arkansas, and from West Virginia to Georgia.

Alabama: Tennessee Valley. Metamorphic hills. Rocky banks of streams. I auderdale County, Florence, banks of Cypress Creek (M.C. Wilson). Lee County, Auburn (Earle). Flowers white, April. Shrub 8 to 12 feet high; rare.

Type locality : "Hab. in Virginia, Canada."

Herb. Geol. Surv. Herb. Mohr.

SPIRAEA L. Sp.Pl. 1 : 489. 1753. SPIRAka.

Forty species shrubs or perennial herbs of the temperate North Hemisphere, Europe, Asia. North America, 4 or 5.

Spiraea corymbosa Raf. Prec. Decouv. 36. 1814.

MEADOW-SWEET.

Spiraea betulaefolia var. corymbosa Wats. in Gray, Man. ed. 6, 153. 1890. 



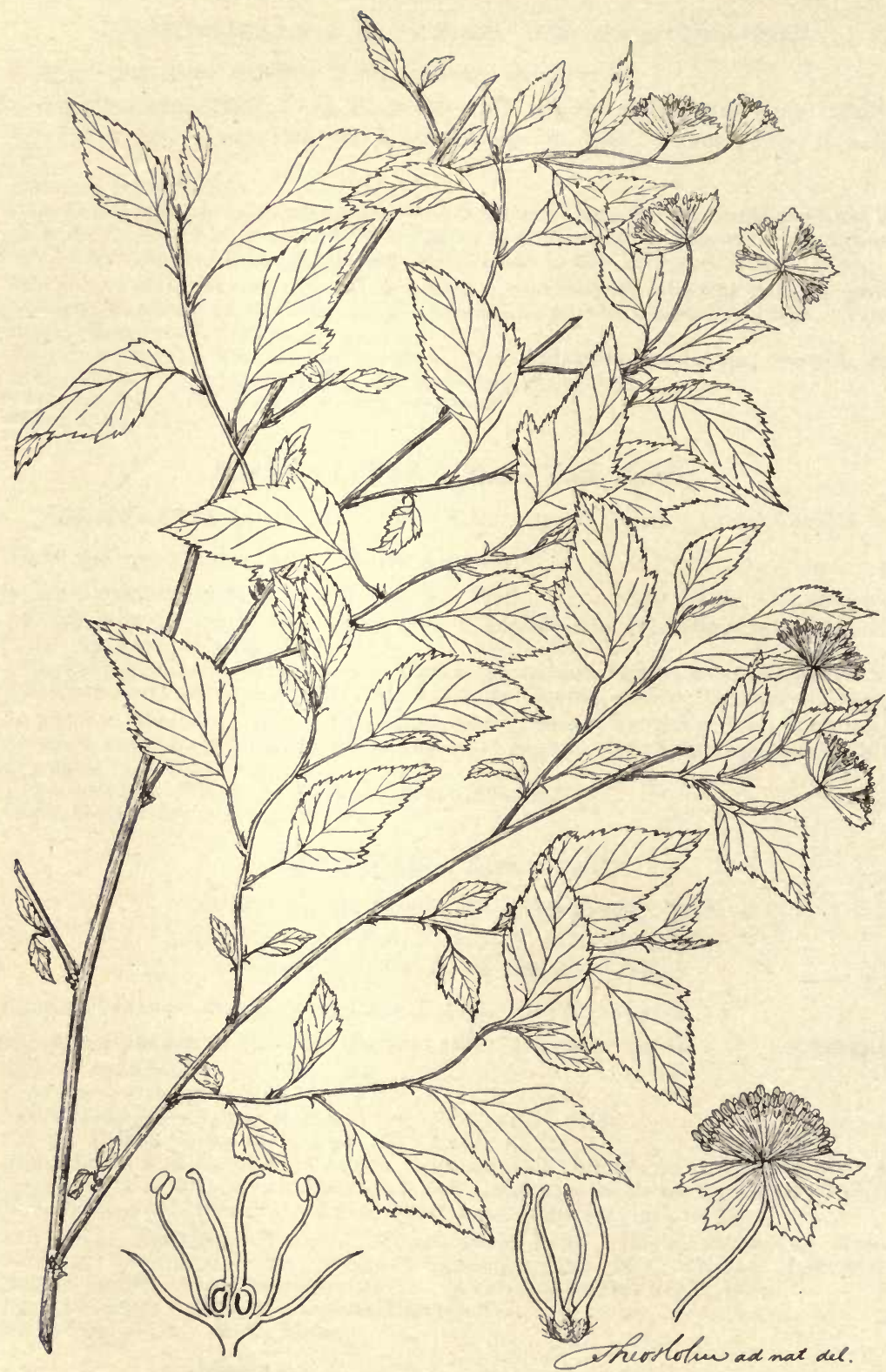

Neviusia alabamensis Gray. 
Gray, Man. ed. 6, $153 . \quad$ Chap. Fl. Suppl. 619; ed. 3, 132.

Alleghenian and Carolinian areas. New York, mountains of Pennsylvania, West Virginia, Kentncky, and southern Missonri, south to Georgia.

AlabaMa: Tennessee Valley. Wooded hillsides. Landerdale County, Florence. Banks of Cypress Creek (M.C. Wilson). Flowers May, June. Rare.

Type locality not ascertainerl.

Herb. Geol. Surv. Herb. Mohr.

ARUNCUS Adans. Fam. Pl. 2:295. 1763.

(SPIRAEA L. Sp. Pl. $1: 489$. 1753. In part.)

Two species, temperate Europe. North America 1.

Aruncus aruncus (L.) Karst. Deutsch. Fl. 779. 1880-1883.

Spiraea aruncus L. Sp. Pl. 1 : 490. 1753.

Ell. Sk. 1:513. Gray, Man. ed.6, 153. Chap. Fl.121.

Boreal region to Carolinian area. Canada, Lake Superior to British Colnmbia; Alaska; mountains of New York and Pennsylvania; Ohio I alley to Missouri.

Alabama : Mountain region. Damp thickets. Cullman Connty. Frausin Connty, Russellville. Perennial.

Type locality: "Hab. in Austriae, Alvorniae montanis."

Herb. Geol. Surv. Herb. Mohr.

PORTERANTHUS Britton, Mem. Torr. Club, 4:115. 1894.

(Gillenia Moench. Meth. Suppl.286. 1802. Not Gillena Adans. 1763.)

Two species, Atlantic North America.

Porteranthus stipulatus (Muhl.) Britton, Mem. Torr. Club, 4:115. 1894.

Spiraea stipulata Muhl.; Willd. Ėnum. 542. 1809.

INDIAN PhYsIC.

S. stipulacea Pursh, Fl. Am. Sept. 343. 1814.

Gillenia stipulacer Nutt. Gen. 1:307. 1818.

Ell. Sk. 1:562. Gray. Man.ı.l. 6, 154. Chap. Fl. 122.

Carolinian and Lonisianian areas. West Virginia, thronghout the Ohio Valley, wesíern Missouri, Arkansas, south to Tennessee, and along the mountains to South Carolna and Georgia.

Alabama: Mountain region to Central Pine belt. Rich borders of woods and shaded banks. Cullman County. Truscaloosa County (E. A. Smith). Autauga County, Prattrille. Flowers white; not infrequent. Perennial.

Economic uses: The root, "wild ipecac," is used medicinally.

Type locality: "Hab. in Pensylvania."

Herb. Geol. Surv. Herb. Mohr.

Porteranthus trifoliatus (L.) Britton, Mem. Torr. Club, 4:115. 1894.

Spiraea trifoliata L. Sp. P1. 1:490. 1753.

Gillenia trifoliata Moench. Meth. Suppl.286. 1802.

Ell. Sk. 1:562. Gray, Man. ed. 6, 154. Chap. Fl. 121.

Alleghenian and Carolinian areas. Ontario, Michigan, New York to West Virginia, eastern Tennessee along the mountains to Sonth Carolina and Georgia; rare west of the Alleghanies.

Alabama: Mountain region. Rich woods. Cullman County. Flowers white. June. Only station knowu. Perennial.

Type locality: "Hab. in Virginia, Canada.."

Herb. Geol. Surv. Herb. Mohr.

NEVIUsIA Gray, Mem. Am. Acad.n. ser. $6: 373, t .30 .1859$.

Single species, South Atlantic North America.

Neviusía alabamensis Gray, Mem. Am. Acad.n. ser. 6 : 374. 1859.

Chap. Fl. 121.

Alabama Neviusia.

On the border of the Carolinian and Louisianian areas.

Alabama: Lower hills. Shaded sandstone cliffs on the banks of the Warrior River, in the vicinity of Tuscaloosa ( $E$. A. Smith). Flowers white, March, appearing before the leaves. Shrub 3 to 4 feet high. One of the rarest plants, confiner to the above locality.

Plate IV.

Type locality: “In praeruptis umbrosis prope Tuscaloosan Alabamae, ubi legit Dom. R. D. Nevius."

Herb. Geol. Surv. Herb. Mohr. 
RUBUS L. Sp. Pl. 1:492. 1753. ${ }^{1}$

Abont 200 accepted species, mostly shrubs by, of temperate and warmer regions in Northern Hemisphere. Europe, abont 56 species. Asia, Mexico. North America, 25. Rubus argutus Link, Enum. Hort. Berol 2:60. 1822.

Rubus frondosus Bigel. Fl. Bost. ed. 2, 199. 1824.

Rubus villosus var. frondosus Torr. Fl. N. \& Mid. U. S. 1:487. 1824.

Rubus suberectus Hook. Fl. Bor. Am. i :179. 1833.

Ell. Sk. $2: 567$, under $R$. villosus. Gray, Man. ed. 6, 155, in part. Chap. Fl. ed. 3. Britt. \& Br. Ill. Fl. $2: 202$.

Alleghenian to Louisianian area. New Brunswick, Lake Superior, throughout New England, south to Florida, west to Kansas, Indian Territory, Arkansas, and Texas.

Alabama: Over the State. Light sandy soil, old fields, borders and opeuings of woods. Flowers white, latter part of March (Mobile), April; fruit ripe June, shining black, juicy, largely consumed. Abundant $\theta$ rerywhere; 6 to 8 feet ligh.

Economic uses: The common blackberry ot the market used fresh and for preserves and for making cordial and wine. The root is the "blackberry root," "Rubus," United States Pharmacopœia, in part.

Type locality: "In America septentrionali."

Herb. Geol. Surv. Herb. Mohr.

Rubus argutus floridus (Tratt.) Bailey, Ev. Nat. Fruits, 385, f. 91. 1898.

Rubus floridus Tratt. Ros. Monogr. 3:73. 1823.

Differs from the typical form by the short and large-flowered clusters, the floral leaves wedge-oborate and rounded at the top.

Carolinian and Louisianian areas. Range not well known. Western Florida, Mississippi.

AlabaMa : Metanorphic Hills, Central Pine belt to the Coast plain. Light sandy soil. Lee County, Auburn (F.S. Earle). Mobile and Tuscaloosa connties. Not rare.

Type locality (Bailey): "Trattinick says that Enslen collected this in North America."

Herb. Geol. Surv.

Rubus trivialis Michx. Fl. Bor. Am. 1:296. 1803.

Southern Dewberry.

Ell. Sk. 1:569. Gray, Man. ed.6, 156. Chap. Fl. 125. Coulter, Contr. Nat. Herb. $2: 104$.

Carolinian aud Louisianian areas. West Virginia; all over the South Atlantic and Gulf States, west to Texas, Arkansas, and sonthern Missouri.

Alabama: Throughont. In light soil, open places, roalsides, old fields. Flowers white, February (1nth, Mobile), March; fruit ripe April, black.

Common low trailing shrub, foliage persistent.

Economic uses: The root is used indiscriminately with the above in medicine.

The large, juicy, palatable fruit is the dewberry of the Alabama market.

Type locality: "Hab. in Carolina et Pensylvania ubique frequens."

Herb. Geol. Surv. Herb. Mohr.

Rubus invisus Bailey, Ev. Nat. Fruits, 374, $f .75,86$.

Rubus canadensis var. invisus Bailey, Am. Gard. 12: 83. 1891.

Leaflets oval to ovate-oblong, large, rather thin, coarsely and simply toothed; peduncles forking into 2 or 3 divisions, pedicels long; flowers large, sepals foliaceous.

Carolinian area. Maine, New York, west to Kansas and Missouri, sonth to north

Alabama.

Alabama: Mountain region. Dry, rocky banks. Dekalb County, summit of Lookont Mountain near Mentone, 2,000 feet altitude. Apparently scarce.

Economic uses: This furnishes the Bartel dewberry of cultivation.

Rubus enslenii Tratt. Ros. Monogr. 3: 73. 1823.

Rubus villosus var. humifusus Torr. \& Gray, Fl. N. A. 1: 455. 1840.

Rubus baileyanus Britton, Mem. 'Torr. Club, 5: 185. 1894.

Britt. \& Br. Ill. Fl. 2 : 204. Bailey, Ev. Nat. Fruits, 375, f. $8 \%$.

Weak, trailing, the slender sten with fow weak priekles; flowers solitary or in twos; fruit small, loose. (Bailey.)

Carolinian area. Southwestern Michigan, eastern New York.

AlabaMa: Mountain region. Warrior tableland. Metamorphic Hills. Dekalb County on Lookout Mountain with the last. Lee County, Auburn (F.S. Earle). Not frequent.

${ }^{1}$ L. H. Bailey, Sketch of the evolution of our uative fruits, pp. 274 to 385.1898. 
Rubus cuneifolius Pursh, Fl. Am. Sept. 1:347. 1814.

Rubus parvifolius Walt. Fil. Car. 149. 1788. Not L.

Ell. Sk. 1:568. Gray, Man. ed. 6, 155. Chap. Fl. 125.

Carolinian and Louisianian areas. Southeru New York, New Jersey, southern Atlantic States to western Florida (Mohr), west to Tennessee, southern Missouri, Arkansas, and Mississippi.

Alabama: 'Tennessee Valley to Lower Pine region. Dry sandy, gravelly, or rocky soil. Openings and borders of woods, old fields. Lauderdale County, Florence. Cullman County. Tuscaloosa County $(E . A$. Smilh). Wilcox and Escambia counties. Flowers white to pale rose-color, April ; fruit ripe June, July, oblong, large, juicy, sweet. Generally diffused over the low hills and prairies; nowhere abundant.

Economic uses: "The "Topsy" variety of blackberry originated from this species.

Type locality: "In sandy fields and woods: New Jersey and Carolina."

Herb. Geol. Surv. Herb. Mohr.

Rubus hispidus L. Sp. Pl. 1 :493. 1753.

RUNNING SWAMP BLACKBERKY.

Rubus ovalis Michx. Fl. Bor. Am. 1:298. 1803.

Gray, Man. ed. 6, 155. Chap. Fl. 125.

Alleghenian and Carolinian areas. Canada; New England south along the mountains to South Carolina.

Ala Bama: Mountain region, low damp sandy or gravelly places. Dekalb County, on Lookout Mountain near Mentone, 1,800 feet altitude. Lee County, Auburn, 860 feet (Baker \& Earle).

Type locality: "Hab. in Canada. Kalm."

Herb. Geol. Surv. Herb. Mohr.

Rubus occidentalis L. Sp. Pl. 1:493. 1753.

Black Raspberky.

Ell. Sk. 1:568. Gray, Man. ed. 6, 155. Chap. Fl. 125.

Alleghenian to Carolinian area. Quebec, Ontario; New England west to Minnesota, Nebraska, Colorado, and Oregon, south to Ohio and West Virginia, and along the mountains to Georgia.

A rabama : Mountain region. Rocky places. Highest elevations of the Warrior tableland. Madison County, Montesauo, 1,500 feet. Dekalb County, Mentone, 1,800 feet altitude. Flowers April; fruit ripe June, black, juicy, well-flavored. Not frequent. Frequently transplanted by the settlers to their gardens.

Type locality: "Hab. in Canada. Kalm."

Economic uses: This is the blackcap raspberry.

Herb. Geol. Surv. Herb. Mohr.

FRAGARIA L. Sp. Pl. 1 : 494. 1753.

Three to 4 species, perennials, temperate regions, Northern Hemisphere, mountains of South America.

Fragaria virginiana Duchesne, Hist. Nat. Frais. 204. 1766.

Wild STRAW BERRY.

Fragaria virginiana illinoensis (Prince) Gras, Man. ed. 5, 155. 1867.

F. illinoensis Prince, Gray, Man. ed.5, 155. 1867. As synonym.

Gray, Man. ed. 6, 158. Chap. Fl. 124.

Alleghenian to Louisianian area. Ontario; western New York to Minnesota, west to Washington, south from Mississippi to Louisiana and Arizona.

Alabama: Tennessee Valley to Central prairies. Open grassy glades and prairies. Franklin County, Russellville. Lawrence County, Moulton. Flowers, May; fruit matures in June and July.

As stated by Bartram and by the oldest settlers of the present time, this strawberry was formerly found in great abundance in the glades of the Mountain region and the Central prairies, where it is at present rarely met with.

Ty pe locality not ascertained.

Herb. Geol. Surv. Herb. Mohr.

DUCHESNEA Smith, Trans. Linn. Soc. 10:372. 1811.

Duchesnea indica (Andr.) Focke in Engl. \& Prantl, Nat. Pfl. 3, Abt. 3: 33.1888.

Fragaria indica Andr. Bot. Repos. t. 479. 1807.

STRAWBERRY GERANIUM.

Potentilla durandii Torr. \& Gray, Fl. N. A. 1:444. 1840.

Gray, Man. ed. 6, 158. Chap. Fl. Suppl. 620; ed.3, 136.

Adventive from India.

Alabama: Central Pine belt to Coast plain. Widely spread in damp copses, shaded borders of fields, roadsides. Tuscaloosa, Baldwin, Monroe, and Mobile coun- 
ties. Flowers yellow; ripens its crimson fruit almost thronghout the year. Com. mon, abundant about Mobile.

Type locality not ascertained.

Herb. Geol. Surve. Herb. Mohr.

POTENTILLA L. Sp. Pl. 1 :495. 1753.

About 200 species, herbaceous or shrubloy perennials, more or less strictly defined, boreal and temperate regions, Northern Hemisphere, a few in the Andes of Sontl America, Europe, Asia. North America about 50.

Potentilla canadensis L. Sp. Pl. 1 : 498. 1753.

Canada Cinquefoll.

Potentilla simplex Michx. Fl. Bor. Am. 1 : 303. 1803.

Ell. Sk 1:574. Gray, Man. ed. 6, 160. Chap. Fl. 124.

Alleghenian to Louisianian area. Nova Scotia, Ontario; throughout the Atlantic States from New Englanil to Florida and from Minnesota to Louisiani.

Alabava: Tennessee Valley. Mountain region to Central Prairie region. Dry open copses, pastures. Lawrence County, Moulton. Madison, Cullman, Tuscaloosa, aud Montgomery counties. Flowers yellow, April, May. Commou. Perennial.

The smooth forms with sarmentous stems (P. simplex Michx., Ell.) are most prevalent.

Type locality : "Hab. in Canada. Kalm."

Herb. Geol. Surv. Herb. Mohr.

GEUM L. Sp. Pl. 1:500. 1753.

Forty-four species, perennials, mostly in colder and arctic regions. Few in the Southern Hemisphere.

Geum canadense Jacq. Hort. Vind. 2 : 82, t. 175. 1772.

Geum carolinianum Walt. Fl. Car. 150. 1788.

Geum album Gmel. Syst. Nat. 2:861. 1791.

Michx. Fl. Bor. Am. 1:301. Ell. Sk. 1:572. Gray, Man. ed. 6, 156. Chap. Fl. ed. 3,134 .

Alleghenian to Louisianian area. Nova Scotia, New Brunswick, Ontario; New England west to Minnesota and Nebraska, south to western Florida and Mississippi.

Alabama: Tennessee Valley. Mountain region to Central Pine belt. Borders of woods, copses. Franklin County, Russellville. Cullman, Madison, Blount, and 'l'uscaloosa counties. Flowers white. May, June; not frequent. Perenuial.

The various forms from different localities present not even varietal distinctions.

Type locality given only as implied in the name.

Herb. Geol. Surv. Herb. Mohr.

AGRIMONIA L. Sp. Pl. 1:448. 1753. AGRIMONY.'

Twelve or 14 species, northern temperate zone, Europe, Asia; few in western South America. North America, 5.

Agrimonia mollis (Torr. \& Gray) Britton, Bull. Torr. Club, 19 : 221. 1892.

SOFt Hairy Agrimony.

Agrimonia eupatoria var. mollis Torr. \& Gray, Fl. N. A. 1: 431. 1838.

A. pubescens Wallr. Beitr. 1:45, t. 1, f. \%. 1842.

Chap. Fl. ed. 3, 133.

Carolinian and Louisianian areas. New England, and Long Island, Now York, to North Carolina and Georgia.

Alabama: Mountain region. Deeply shaded ravines. Cullman County, Holmes

Gap, 1,200) feet. Flowers yellow. July ; rare. Perennial.

Type locality: "Red River, Dr. Pitcher!"

Herb. Geol. Snrv. Herb. Mohr.

Agrimonia striata Michx. Fl. Bor. Am. 1:287. 1803.

SMall-Flowered Agrimony.

Agrimonia eupatoria var. parviflora Hook. Fl. Am. Bor. 1: 196. 1832.

A. eupatorium $\mathrm{L}$. of most American anthors.

A. microcarpa Wallr. Beitr. Bot. 1:42. 1842.

Carolinian and Louisianian areas. Southeastern New York, Ohio, North Carolina to western Louisiana (Hale).

' E. P. Bicknell, North American species of Agrimonia, Bull. Torr. Bot. Club, vol. 23, pp. 508 to 523.1897. 
Alabama : Central Pine belt. Tuscaloosa County (E. A. Smith). Autauga County, Prattville. Flowers yellowish. July; not infrequent. Perennial.

Type locality: "Hab. iu Canada."

Herb. Geol. Surv. Herb. Mohr.

Agrimonia parviflora Soland. in Ait. Hort. Kew.2:130. 1789. SWEet AGRIMony. Agrimonia suaveolens Pursh, Fl. Am. Sept. 1: 336. 1814.

Ell. Sk. 1:536. Gras, Man. ed. 6, 161. Chap. Fl. 122.

Allegheuian and Caroliuian areas. Ontario; New York west to Michigan, south to the Ohio Valley, Tennessee; upper districts of Georgia.

Alabama : Mountain region. Metamorphic and Coosa hills. Borders of fields and woods. Clay Connty, Elders, 1,000 feet. Flowers yellow. July, August; not common. Perennial.

Type locality : "Native of North America."

Herb. Geol. Surv. Herb. Mohr.

Agrimonia pumila Muhl. Cat.47. 1813. Britt. \& Br. Ill. Fl. 2:226. 1897.

SMALL-LEAF AGR1MONY.

Carolinian and Louisianian areas. Eastern Pennsylvania and Maryland to Florida and Louisiana.

Alabama : Coast plain. Open dry woods. Baldwin County, Stockton. Mobile County. Flowers yellow. September, October; not frequent. Perennial.

Type locality: "Miss[ouri]."

Herb. Geol. Surv. Herb. Mohr.

Agrimonia incisa Torr. \& Gray, Fl. N. A. $1: 431$.

Cut-leaf Agrimony.

Chap. Fl. 122.

Louisianian area. Georgia and Florida.

Alabama : Coast plain. Copses, border of woods, close soil. Mobile County, old Telegraph road, Springhill. Not frequent. Perennial.

Type locality: "North Carolina! Georgia, Le Conte! Alabama, Dr. Gates! Tampa Bay, Florida, Dr. Burrows!"

Herb. Geol. Surv. Herb. Mohr.

ROSA L. Sp. Pl. 1 : 491.1753.

Large genus, of the temperate and warmer parts of the Northern Hemisphere. Over 500 have been described, of which about 100 are considered distinct. North America 20 to 25 . Shrubs.

Rosa setigera Michx. Fl. Bor. Am. 1:295. 1803.

Prairie Rose.

Rosa rubifolia $\mathrm{R}$. Br. in Ait. Hort. Kew. ed. 2, 3 : 260. 1811.

Ell. Sk. 1: 565. Gray, Man. ed. 6, 162. Chap. Fl. 125. Coulter, Contr. Nat. Herb. 2:106.

Alleghenian and Carolinian areas. Ontario; Now York, west to Michigan and Nebraska, south to Ohio Valley and Missouri, and from 'Tennessee to Georgia, Lonisiana, Texas, and Arkansas.

Alabama : Tennessee Valley to Coast plain. Copses, borders of woods, rich soil. Morgan County, Falkville. Dekalb County, Lookout Mountain. Dallas Connty,

Uniontown. Hale County. Flowers rose-red. June; not rare in the Prairie region.

Stem weak, flexuous with a tendency to climb; leaves large, leaflets 3 , broadly ovate, 3 inches long by $1 \frac{1}{2}$ inches wide, smooth; corymb few-flowered.

Type locality: "Hab. in Carolina inferiore."

Herb. Geol. Surv. Herb. Mohr.

Rosa humilis Marsh. Arb. Am. 136. 1785.

LOW WILD Rose.

Rosa parviflora Ehrh. Beitr. 4 :21. 1798.

R. caroliniana Michx. Fl. Bor. Am. 1:295. 1803.

R. lucida anct. Am., in part.

Ell. Sk. 1:563. Gray, Man. ed. 6, 163. Chap. Fl. 126.

Alleghenian and Carolinian areas. New England west to Minnesota; New York sonth to Virginia, Ohio Valley to Missouri, and from Tennessee to Georgia, Alabama, Mississippi, western Louisiaua, Arkansas, Texas, and Indian Territory.

Alabama: From the Tennessee Valley and Coosa Valley to the Central Prairie region. Open copses, border of woods, damp or dry soil. Madison County, Hunts. ville. Talladega County, rocky summit of Alpine Mountaiu, near Renfrow, 1,800 feet. St. Clair County, damp flat woods near Ashville. Tuscaloosa County (E.A. Smith). Dallas County, 250 feet altitude. Hale County (Watson). Wilcox County (Buckley). Clay County, Delta Divide, altitude 1,700 feet (stout form). Flowers piuk. May, Juue; frequent. One to 2 feet high. 
Type locality not specifically given.

Herb. Geol. Surv. Herb. Mohr.

Rosa laevigata Michx. Fl. Bor. Am. 1:295. 1803.

Cherokee Rosk.

Rosa sinica Ait. Hort. Kew. ed. 2, 3 : 261. 1811.

Ell. Sk. 1: 566. Chap Fl. 126.

China, Japan.

Louisianian area. Origin obscure. Coast region of South Atlantic and Gulf States, west to Louisiana.

Alabama: 'Throughout the Coast plain. Flowers white, Febriary to April; fruit dark dingy red, September. Common. Perhaps of prehistoric introduction.

Economic uses: Useful as a hedge plant.

Type locality : "Hab. in Georgia."

Herb. Geol. Surv. Herb. Mohr.

Rosa bracteata Wendl. Bot. Beob. 50. 1798.

Macartney Rose.

Louisianian area. Adventive from Asia. Distribution as in the last.

Alabama : Coast plail in hedgerows. Mobile County. Flowers white; July to September; less frerjuent.

Economic uses: A hedge plant.

Type locality Eastern Asiatic.

Herb. Geol. Surv. Herb. Mohr.

Rosa multiflora Thuub. Fl. Japon. 214. 1789.

Many-hlowered Hedge Rose.

China, Japan.

Louisianian area. Introduced. Lonisiana.

Alabama: Coast plain. Mobile. An evergreen climber frequent in hedges, borders of fields, and woodlands. Flowers white to pale pink; March, April.

Economic uses: An ornamental liedge plant.

Type locality Eastern Asiatic.

Herb. Geol. Surv. Herb. Mohr.

Rosa rubiginosa L. Mant. 2 : 564.1771.

Eglantine Rose. Sweet Brier.

Rosa eglanteria Mill. Dict. ed. 8, no. 4. 1768. Not L.

R. suaveolens Pursh, Fl. Am. Sept. 1:346. 1814.

Ell. Sk. 1:566. Gray, Man. ed. 6, 164. Chap. Fl. 126.

Introduced from Europe. Naturalized from Ontario to upper South Carolina.

Alabama: Mountain region. Fence rows, waysides, dry places. Clay County, Shinbone Valley.

Type locality: "Hab. in Europa australi. Mygind."

Herb. Geol. Surv. Herb. Mohr.

Rosa canina L. Sp. Pl. 1 : 491. 1753.

Gray, Man. ed. 6, 163.

EUROPE.

Carolinian and Louisianian areas. Naturalized from Europe, in the North Atlantic and Middle States.

Alabama : Naturalized. Hedges. Mobile County, Summerville, on the Davenport place. Flowers white; April 26, 1895. Rare.

Type locality: "Hab. in Europa."

Herb. Geol. Surv. Herb. Mohr.

COTONEASTER Medic. Phil. Bot. 1:155. 1789.

Twenty to 30 species, temperate Northern Hemisphere. Europe. Northern Asia, Himalayas.

Cotoneaster pyracanthus (L.) Spach, Hist. Veg. 2 : 73. 1834.

Mespilus pyracantha L. Sp. Pl. 1:478. 1798.

Fire THORN. Evergiren 'THORN.

Crataegus pyracantha Medic. Geschich. 84. 1798.

SOUTHERN EUROPE.

AlABAMA : Introduced for a hedge plant and sparingly escaped from cultivation near Mobile. Flowers white, May; fruit ripe October, scarlet, remaining in profusion. during the winter.

Type locality : "Hab. in Galloprovinciae, Italiae sepibus."

Herb. Geol. Surv. Herb. Mohr. 
PYRUS L. Sp. Pl. 1:479. 1753.

Forty species, temperate regions Northern Hemisphere. North America, 7. Trees and shrubs.

Pyrus angustifolia Ait. Hort. Kow. 2 : 176. 1789.

Southern Crabapple.

Malus angustifolia Michx. Fl. Bor. Am. 1: 292. 1803.

Ell. Sk. 1: 559. Gray, Man. ed. 6, 164. Chap. Fl. 128. Sargent, Silv. N. A. 4: 75, t. 1 \%

Carolinian and Louisianian areas. Southern Peunsylvania, south to western Virginia and Florida, and thronghout the Gulf States to Louisiana, west to sonthern Illinois, southern Missouri, and Arkansas.

Ala bama: Throughont the State. Open woods, copses. Clay County. Madison County, 1,800 feet. Cullman, Tuscaloosa, Dallas, and Mobile connties. Flowers pale rose color, frayrant, A príl; fruit ripe September, yellow to orange. Most abundant in the wet cold soil of the flat woods (Coosa Valley).

Economic uses: The fruit is used for conserves.

Type locality: "Native of North America."

Herb. Geol Surv. Herb. Mohr.

ARONIA Pers. Syn. 2 : 39. 1807. ChOKkBERY.

Five species, north temperate regions, Northern Hemisphere. Atlantic North America.

Aronia arbutifolia (L.) Ell. Sk. 1:556. 1817-21.

RED CHOKEBERRY.

Mespilus arbutifolia L. Sp. P1. 1:478. 1753.

M. arbutifolia var. erythrocarpa Michx. Fl. Bor. Am. 1:292. 1803.

Ell. Sk. 1:556. Gray, Man. ed. 6, 16t. Chap. Fl. 128.

Canadian zone to Louisianian area. Newfoundland, Quebec, Ontario; New England west to Minnesota and Dakota, sonth to Florida, west to Louisiana and Arkansas.

Alabama: Over the State. Banks of streams and wet borilers of swamps. Most abundant in the pine-barren swamps of the Lower Pine belt and Coast plain. Flowers early in March, on the coast, to April. Fruit ripe August to October, scarlet, remaining over the winter.

In the mountains an arborescent form occurs, 12 to 18 feet in height, the stem fully $1 \frac{1}{2}$ inches in diameter and elear of branches for nearly half its height. Che-aw-ha Mountain. Cullman ('ounty.

Type locality: "Hab. in Virginia."

Herb. Geol. Surv. Herb. Mohr.

AMELANCHIER Medic. Phil. Bot. 1: 155. 1789.

About 12 species, temperate regions Northern Hemisphere. North America, 9? Small-sized trees and shrnbs.

Amelanchier canadensis (L.) Medic. Geschich. 79. 1793.

JUNEBERKY. SERVICEBERRY.

Mespilus canadensis L. Sp. PI. 1:478. 1753.

M. canadensis var. cordata Michx. Fl. Bor. Am. 1:291. 1803.

Amelanchier canadensis var. botryapium Torr. \& Gray, Fl. N. A. 1:473. 1840.

Canadian zone to Louisianian area. Newfonndland, Quebec, Ontario; New England west to Minnesota, Missouri, and Dakota, south to Florida, Louisiana, and Arkansas.

Alabama: Over the State. Cnllman, Blount, Truscaloosa, and Mobile counties. Flowers white, March, April. Fruit purplish black. June. Small tree, 20 to 30 feet high.

Fconomic uses: The fruit is edible.

Type locality: "Hab. in Virginia, Canada."

Herb. Geol. Surv. Herb. Mohr.

Amelanchier botryapium (L. f.) DC. Prodr. 2 :632. 1825. Junererry. Shadbush.

Pyrus botryapium L. f. Suppl. 255. 1781.

Mespilus canadensis var. obovalis Michx. Fl. Bor. Am. 1:291. 1803.

Pyrus sanguinea Pursh, Fl. Am. Sept. 1:340. 1814.

P. ovalis Bigel. Fl. Bost. ed. 2, 195. 1824.

Amelanchier canadensis var. oblongifolia Torr. \& Gray, Fl. N. A. 1:473. 1840.

Ell. Sk. 1:558. Gray, Man. ed.6, 167. Chap. Fl. 129?

Range same as of the last. 
Alabama: Tennessee Valley. Lauderdaie Connty, near Florence (M. C. Wilson).

Flowers latter part of February and in March; fruit ripe by end of May.

Economic uses: 'The fruit is erlible.

Type locality not ascertained.

Herb. Geol. Surv. Herb. Mohr.

CRATAGGUS L. Sp. Pl. 1:475. 1753.

Fifty or more distinct species, north temperate regions, Asia, Europe, Mexico. North America, 25 or more. Trees of smaller size and shrubs.

Crataegus spathulata Michx. Fl. Bor. Am. 1:288. 1803.

SUGak Haw.

Ell. Sk. 1:552. Gray, Man. ed.6,165. Chap. Fl.126. Coulter, Contr. Nat. Herb. $2: 107$.

Carclinian and Louisianian areas. Sonthern Virginia to middle Florida, Texas, and southern Arkansas.

Aldbama: Tennessee Valley to Upper division of Coast Pine belt. 1)amp copses and woods, banks of streams. Morgan County, Falkville. Cullman and Blount counties. Lee County, Auburn, 800 feet. 'Tuscaloosa, Montgomery, and Autauga counties. Flowers wbite, April; fruit ripe October, November, scarlet, sweet. Large shrub or small tree 12 to 18 feet high, frequent. Most abundant in the mountains and Lower hill country.

Type locality: "Hab. in Carolina ntraque et Virginia."

Herb. Geol. Surv. Herb. Mohr.

Crataegus viridis L. Sp. Pl. I: 476. 1753.

TreE HAw.

Crataegus arborescens Ell. Sk. 1:550. 1821.

Gray, Man. ed. 6, 165. C'hap. Fl. 127.

Carolinian and Louisianian areas. South Carolina, Florida, and throughout the Gulf States to eastern Texas, along the Mississippi River reaching sontheru Illinois and St. Louis, Mo.

Alabama : Mountain region to Coast plain. Low damp copses, borders of woods. Clay County, banks of Talladega Creek. Dallas County, Marion Junction. Halo County, Gallion. Wilcox County (Buckley). Clarke County. Mobile County, Mount Vernon. Baldwin County, Stockton. Flowers white, odor nanseating; last week of March, beginning of April. Fruit ripe October, November; flame color.

A pretty tree, 20 to 25 feet high. Most frequent in the bottoms of the Alaba:: . and Tombigbee rivers, occasionally subject to overflow.

Type locality : "Hab. in Virginia."

Herb. Geol. Surv. Herb. Mohr.

Crataegus apiifolia (Marsh.) Michx. Fl. Bor. Am. 1:287. 1803.

Palisley Haw.

Mespilus apiifolia Marsh. Arb. Am. 89. 1785.

Ell. Sk. 1:552. Gray, Man. ed.6, 165. Chap. F1. 127. Sargent, Silv. N. A. 4:111,

t. 188 .

Carolinian and Louisianian areas. Florida along the coast to southern Virginia, throughout the Gulf States to Louisiana, southern Arkansas, and southern Missouri.

Alabama: Tennessee Valley to the Coast plain. Damp woods, river bauks. Morgan County, Falkville. Clay Connty, Hollins. Cnllman Connty. Tuscaloosa County (E. A.Smith). Lee County, Auburn (Baker \& Earle). Hale, Dallas, and Montgomery counties. Baldwin County, banks of Tensaw River. Mobile County, Mount Vernon. Flowers white; middle of March to first week of April; fruit ripe. October, scarlet. A largeshrub, commonly 10 to 15 feet high; not rarely arborescent, 15 to 20 feet high. Most frequent in the Prairie region and Upper division of the Coast Pine belt.

'Type locality not specifically given. Michaux's locality: "Hab.in humidis sylvarun Carolinae."

Herb. Geol. Surv. Herl. Mohr.

Crataegus rotundifolia (Ehrh.) Borck. in Roem. Arch. 1, pt. 3:87. 1798.

Mespilus rotundifolia Ehrh. Beitr. 3 : 20. 1788.

Glaniviak Haw.

Crataeg"1 glandulosa Willd. Sp. Pl. 2:1002. 1800. Not Solander. 1789.

Carolinian and Louisianian areas. Soutbern New England to Indiana and Florida.

Alabama: Central Prairies to Mountain region. Dry open woods and copses; rocky or gravelly soil. Butler County, Greenville. 'Tuscaloosa County, bauks Warrior River with Crataegus coccinea. Jlount County, Bangor. Flowers early in Mar. Not rare.

Tree 16 to 25 feet high, 4 to 6 inches in diameter, with dark close bark. Differs 
from its nearest relative, Crataegus coccinea, by its glandular petioles, its very glandular bractlets and ealyx lobes, and its stout long spines.

Type locality not ascertained.

Crataegus sargenti Beadle, Bot. Gaz. 28:407. 1899.'

An intricately branched tree rarely over 18 feet high, or more frequently a large shrub from 6 to 15 feet high, with one or several stems covered with an ashy gray, more or less scaly bark; branches spreading, armed with straight or curved spines 1 to $2 \frac{1}{2}$ inches long; leaves thin to subcoriaceons, slightly pubescent when young, soon smooth, ovate to ovate-lanceolate or round-cordate, 1 to $4 \frac{1}{2}$ inches long and from $\frac{1}{3}$ to 2 inches wide, acute, rounded, or abruptly contracted at the base into a wing-margined petiole, irregularly doubly serrate and iucisely lobed, the serratures tipped with minute glands; stipules linear-lanceolate, glandular, or on vigorous shoots foliaceous and lunate; flowers in a few few-flowered, more or less pubescent corymbs, stamens normally 20 , pistils 3 to 5 ; fruit globose or depressed-globose, nearly $\frac{1}{2}$ inch in dianıeter, yellow to orange, with a thin, firm flesh, and including 3 to 5 bony, thick-walled nutlets.

C. sargenti is a most distinct and showy species, belonging to a very natural group which in the herbaria are preserved under the names of C. rotundifolia, C. glandulosa, and C.coccinea, titles which correctly belong to widely different plants.

Carolinian area. Northern Georgia (Rome) to southeastern Tennessee.

Alabana: Mountain region. Rocky woods and bluffs. DeKalb County (Beadle). Flowers about 1st of May when the leaves are almost fully grown. Fruit ripens and falls about the middle of September.

'Type locality: "Near Valleyhead, Ala."

Crataegus boyntoni Beadle, Bot. Gaz. 28: 409. 1899.

A tree seldom more than 18 feet high, or frequently a large branching shrub from 6 to 12 feet high, the trunk from 6 to 9 feet in length and 4 to 8 inches in diameter, with stout ascending branches which form a narrow, occasionally a flat-topped head, the spines straight or curved, $1 \frac{1}{4}$ to 28 inehes long. Leaves yellowish green, paler beneath, glabrous or with a few scattered hairs along the midrib and larger veins, broadly ovate or oval, acute at the apex, rounded or narrowed at the base into the margined glandular petiole, or on vigorous shoots deltoid-ovate, sharply and irregularly serrate, doubly serrate, or ineisely 5 to 7 lobed; stipules linear, glandular, caducous, or on strong shoots foliaceous and lunate, glandular-serrate; flowers large, from 9 lines to nearly 1 inch in diameter, borne on glabrous pedicels with one or two glandular bractlets, in short 4 to 10 flowered corymbs; stamens 10, anthers light yellow; pistils 3 to 5 ; fruit dull yellowish green to russet-red, depressed-globose, angled, about $1 \frac{1}{2}$ inches long and 8 lines wide.

Closely related to the last, but distinguished by the many-flowered glabrous corymbs and shorter stamens, and by the different habit of growth. Many specimens are preserved in herbaria, the greater part of which are also labeled $C$. coccinca, C. glandulosa, or C. rotundifolia. C. rotundifolia of Britton and Brown's Illustrated Flora is in part to be referred to this species. (The material collected by the writer near Greenville, Ala., is most likely to be united with it, which would extend its southern range to the Louisiana area. Mohr.)

Carolinian area. Pennsylvania, Delaware to Virginia, Tennessee, and Georgia.

ALABAMA : Mountain region; banks of streams, and even in the shallow dry soil of uplands; copses and fields. Flowers before the middle of May; fruit ripens and falls early in October.

Type locality: "Biltmore, N. C."

Crataegus mollis (Torr. \& Gray) Scheele, Linnaea, 21:569. 1848. Downy Haw.

Crataegus coccinea var. mollis Torr. \& Gray, Fl. N. A. 1:465. 1840.

Gray, Man. ed. 6, 165. Coulter, Contr. Nat. Herb. 2: 107.

Mexico.

Alleghenian to Louisianian area. Now England; Massachusetts west to Michigan, Minuesota, and Iowa, south to Arkansas, Tennessee, and Texas.

Alabama : Mountain region to Upper division Coast Pine belt. Rich wooded banks. Cullman County. Hale County, Gallion. Clark County. Jackson County (Dr. Denny), April 12, 1852. Flowers white, April ; fruit ripe October, crimson. A small tree, 20 to 25 feet high, sparsely scattered in the valleys of the mountain region, and more frequent in the prairies.

1 The descriptions of this and following speeies of Crataegus, with the accompanying notes, are mainly drawn from C. D. Beadle, Studies in Crataegus, Bot. Gazette, vol. 28 , pp. 405 to 417 . 1899 . 
Type locality: “Ohio, Mr. Lea! Indiana, Dr. Clapp! Kentucky, Dr. Short! Texas, Drummond."

Herb. Geol. Surv. Herb. Mohr.

Crataegus biltmoreana Beadle, Bot. Gaz. 28 : 405. 1899.

Biltmore Thorn.

A shrub 3 to 15 feet high, with a reddish brown bark and chestnut-brown or reddish brown brauches, stout, slightly curved spines 1 to 2 inches long, and large flowers in simple 5 to 7 flowered pubescent corymbs. The leaves are thin, membranaceous, roughish but rather inconspicuously pubescent, green above, paler beneatl, ovate to round-ovate, usually wed ge-shaped at the base, acutely incised, or slightly 5 to 9 lobed, sharply and irregularly serrate to near the base, bearing, like the petiole, a few dark-colored stalked glands. The flowers are borne on strict pubescent pedicels; petals orbicular, contracted into a short claw; stamens 10, ant hers yellow; styles 3 to 5, calyx obconic, pubescent or tormentose, with the dentate or pectinate glandular lobes 3 lines long; fruit yellow or yellowish green to orange, containing from 3 to 5 depressed-globose obtusely angled nutlets.

Usually confounder with Eastern forms of C'. mollis ('Torr. \& Gray) Scheele, from which it may le known by its smaller size, simple corymbs, and later time of flowering, and by the color and texture of its fruit.

Carolinian area. From Pennsylvania and Virginia to eastern Teunessee, North Carolina, and Georgia.

Alabama: Mountain region. Dry, rocky woodlands. DeKalb County, Lookout Mountain (Beadle, May, 1900). Flowers after the middle of May.

Type locality: "Vicinity of Biltmore, N. C."

Herb. Geol. Surv. Herb. Mohr.

Crataegus tomentosa chapmani Beadle, Bot. Gaz. 25 :360. 1898.

Crataegus tomentosa microcarpa Chap. Fl. ed.3, 139. 1897. Not. C. microcarpa Lindl. 1836.

Chap. Fl. l. c.

Carolinian area. Georgia.

Alabama: Tennessee Valley. Mountain region. Jackson County, Sand Mountain (C. D. Beadle). Etowah County, Gadsden (G. C. Boynton). Small treo or shrub. Flowers in May.

Type locality: "River banks near Rome, Ga."

Biltmore Herb.

Crataegus crus-galli L. Sp. Pl. 1:476. 1753.

Cockspur Thorn.

Ell. Sk. 1:548. Gray, Man. ed. 6, 166. Chap. Fl. 127. Conlter, Contr. Nat. Herb.

2:107. Sargent, Silv. N. A. $4: 91, t .178$.

Alleghenian to Louisianian area. Southern Ontario, Michigan, and Missouri, south to Florida, west to Texas and Arkansas.

Alabama: Tennessee Valley to Central prairies. Wooded banks, copses, in close damp soil. Morgan, Madison, Cullman, Montgomery, Dallas, and Halo Counties. Flowers white, April; fruit ripe October, dull red. Small tree, 15 to 25 feet. Frequent in the valleys and prairies.

Type locality not given. In L. Sp. Pl. ed. 2: "Hab. in Virginia."

Herb. Geol. Surv. Herb. Mohr.

Crataegus collina Chap. Fl. ed. 3, 140. 1897.

Carolinian area. Southeastern Tennessee, North Carolina, and northern Georgia.

Alabama: Mountain region to Lower hills. Rocky and gravelly hills. Dekalb County. Jeffersou County, Red Mountain near Birmingham (Sargent). Tuscaloosa County, rocky banks of Warrior River. Etowah County, Gadsden (C. I). Beadle). Jackson County, Sand Mountain (Biltmore Herb.), Mobile County (Biltmore Herb.). Flowers April. Fruit mature October, red. Not rare.

Tall shrub or sinall tree.

Type locality: "Rocky hillsides, north Georgia and Tennessee."

Herb. Geol. Surv. Herb. Mohr.

Crataegus mohri Beadle, Bot. Gaz. 28 : 416. 1899.

A tree 18 to 30 feet high, with a slender trunk 4 to 8 inches in diameter, unarmed or sparsely spiny, or in unfavorable situations a large erect branching shrub, the branches ascending or nearly horizontal, forming an oblong or occasionally a round compact head, the branchlets and smaller branches zigzag with slightly curved or straight spines from 1 to 2 inches long. Leaves cuneate-obovate, or on vigorous shoots from ovate to orbicular, 18 to $2 \frac{8}{4}$ inches long and $\frac{5}{8}$ to $1 \frac{1}{4}$ inches wide, acute or rounded at the apex and contracted below into winged or margined petioles from 4 
to nearly 11 lines long, sharply and irregularly serrate to or below the middle, entire or nearly so at the base, more or less pubescent when young, dark green ancl lustrous above, pale below, becoming thick and coriaceous; flowers unmerous, large, from 7 to 8 lines in diameter, disposed in slender, elongated, and often flexuous, bracteate corymbs, more or less hairy at flowering time; calyx narrow-obconic, mostly glabrous, with linear-lanceolate, mostly entire or slightly glaudular-serrate lobes reflexed after flowering, the orbicular petals with undulate or erose borders; stamens normally 20 , styles 3 to 5 ; fruit globose, abuut 4 lines in diameter, dark red or greenish red or covered witlı black blotehes; nutlets 3 to 5 , thick-walled.

Crataegns mohri has usually been confounded with $C$. crus-galli L., or more recently with $C$. collina Chapm. From the former it may be distinguished by the pilose corymbs, smaller and more globular fruit, and more numerous and smiller nutlets, and by the ontline of the leaf and habit of growth, and from the latter by the later time of flowering, and smaller lustrous leaves. This beautiful and most distinct species is dedicated to Dr. Charles Mohr, of Mobile, Ala. (Beadle.)

Carolinian area. Mississippi northward to middle Tennessee.

Arabama: Mountain region to Central Prairie belt. Reaches its best development in the rich and fresh soil of flat wools in the center of the State, but not infrequently ascends into the poorer and drier soils of the mountains and hills. Flowers abont 1st of May; fruit ripens in October, remaining until early in the winter.

Type locality : "Vicinity of Rome, Ga."

Crataegus triflora Chapm. Fl. ed. 2, Suppl. 2, 684. 1892.

Chapm. Fl. ed. 3, 139.

A large shrub or small tree from 6 to 20 feet high, with the main stem simple or branching near the base into several shoots, armed with numerous spines, the branches ascending, intricately divided near the summit into many short pilose or pubescent branchlets, forming an oblong, occasionally rounded or flat-topped head. Leaves at first thin, dark green above, paler beneath, somewhat roughish and sparsely pubescent on the upper surface, more densely so below, ovate, elliptical, or slightly obovate, acute at the apex, rounded or abruptly contracted at the base into winged or margined petioles, ou the fertile branches from 1 to 4 inches long and from $\frac{1}{2}$ inch to 2 inches wide, on vigorous shoots 5 and 6 inches long and about 3 inches wide, sharply and irregularly serrate, or donbly serrate and incisely lobed, with a number of black-tipped glands near the base, as also on the petiole; stipules lanceolate, densely glandular, caducous; flowers $\frac{8}{4}$ inch wide, in mostly 3-flowered, pilose, softly pubescent corymbs, the lateral pedicels longer; calyx densely pilose, with persistent glandular-serrate lobes twice as long as the tube; stamens 20 ; styles 3 to 5 ; fruit globose, 6 to 7 lines in diameter, pubescent, bright red.

Carolinian area. Northwestern Georgia.

AlabaMa : Mountain region to Lower hills. Rocky hills, Jefferson County, Birminghan (C. L. Boynton). DeKalb County? Flowers early in May; fruit ripe in September.

Type locality: "Cliffs of the Coosa River, Georgia."

Crataegus austromontana Beadle, Bot. Gaz. 28:412. 1899.

A straggling shrub 3 to 12 feet high, two or three main stems arising from large roots or horizontal rootstocks, or forming more or less united groups or clumps, occupying a surface of 5 to 10 square feet, the branches unarmed or with an occasional spine on a young plant or vigorous shoot, the branchlets pubescent or tomentose. Leaves orbicular or broadly ovate, $1 \frac{1}{2}$ to 4 iuches long, roughish-pubescent on both surfaces, acute at the apex, contracted at the rounded truncate or sometimes subcordate base in to the margined petiole, sharply irregularly serrate or incisely lobed, and at the base glandular like the petioles; flowers large, in simple 2 to 5 flowered, mostly 3 -flowered cymes, borne on stont hairy pedicels from $\frac{8}{8}$ to 1 inch long; stamens 10 ; styles 3 to 5 ; calyx pubescent, broad with glandular-serrate lobes; fruit large, $\frac{1}{2}$ inch or a little over in diameter, bright red, and frequently punctate, containing 3 to 5 bony nutlets.

Close to $C$. triflora, but mas, as stated by the anthor, be recognized by its smaller size, broader leaves, fewer stamens, and the larger and coarser seeds.

Carolinian area. Eastern and middle Tennessee (Cumberland district).

Alabama: Mountain region. Rocky woods and banks throughout the Sand Mountain district. Flowers early in May; fruit ripens in the latter part of September.

Type locality: "Vicinity of Vallerhead, Ala."

Herb. Geol. Surv. ex Herb. Biltmore.

Crataegus silvicola Beadle, Bot. Gaz. 28: 414. 1899.

A tree in low and moist woods, from 18 to 30 feet high, with the trunk sometimes 8 inches in diameter, with a close-fissured or scaly gray or reddish-brown bark, and armed with stout spines, the branches spreading or ascending, forming a round or 
flat-topped head, armed with straight or curved spines $\frac{8}{4}$ inch to $2 \frac{1}{2}$ inches long. Leaves ovate or round-ovate, acute, rounderl or narrowed at the base, from $1 \frac{1}{4}$ to 4 inches long, bright or yellowish green, roughisl or scabrous-pubescent above, piller and generally smooth below, flowers borne on strict, short pedicels 3 to 7 lines loner; stameus 10 ; styles 3 to 5 ; fruit globose, about $\frac{1}{2}$ inch in diameter, reil or greenish yellow.

Resembles the several forms of $C$. coccinea from the Sonth Atlantic region, from which it may be distinguished by the rongh leaves, which are less incised and broader and longer in outline, and by the short, strict, and stout pedicels.

Carolinian area. Northwest Georgia.

AlabAMA : Northern part of State in the "flat woods," and occasionally in the higher and drier woodlands.

Type locality : "Vicinity of Gadsden, Ala."

Crataegus punctata Jacq. Hort. Vind. 1: 10, t. 28. 1770.

DotTe1) Haw.

Ell. Sk. 1:548. Gray, Man. ed. 6, 166. Chap. Fl. 127.

Alleghenian to Louisianian area. Ontario, New York, central Michigan to Missouri and Arkansas, south to Georgia.

Alabama: Mountain region. Lower hills. Border of hilly woods. Cullman County. Tuscaloosa County (E. A. Smith). Lee County, Auburn (Baker \& Earle, 140). Flowers March, April.

Type locality : "Huc transvecta * * * sub arboris Americanae ignotae titulo." Herb. Geol. Surv. Herb. Mohr.

Crataegus flava Ait. Hort. Kew. 2 : 169. 1789.

SUMmer Haw.

Crataegus flava var. pubescens Gray, Man. ed. 5, 160. 1867. 1785 .

C. flexispina Sargent, Gard. \& For.2:424. 1889. Not Mespilus flexispina Muench.

Ell. Sk. 1 : 5ீ51. Gray, Man. ed.6, 166. Chap. Fl. 128. Sargent, Silv. N. A. 4 : 113, t. 189. Carolinian and Louisianian area. West Virginia to Floricla, west to Lonisiania, Arkansas, and southern Missouri.

Alabama: Mountain region to Coast Pine belt. Sandy banks, dry copses. Cullman County. Monroe County, Claiborne. Henry County, Ozark. Baldwin County. Flowers March, April ; fruit ripe September, reddish or greenish yellow. Not frequent in the Mountain region; more abundant throughout the Lower Pine belt.

Small tree 20 to 25 feet high, with drooping branches and gray shreddy bark.

Economic uses: The large fruit is used for preserves.

Type locality: "Native of North America."

Herb. Geol. Surv. Herb. Mohr.

Crataegus elliptica Ait. Hort. Kew. 2 : 168. 1789.

Glandular Summer Haw.

Cratcegus flava elliptica Sargent, Silv. N. A. 4:114, t. 190. 1893.

C. flava var. pubescens Gray, Man. ed. 5, 160. 1867.

Gray, Man. ed.6, 166. Chap. Fl. 128. Sargent, 1. c. iana.

Carolinian and Louisianian areas. Southern Virginia, Tennessee, Florida to Lonis-

Alabama : Lower Pine region. Coast plain. Open glades, dry copses. Washington County. Mobile County, Citronelle. Flowers April 10; fruit ripe September, glossy, bright red, medium size. 'Tree 15 to 20 feet. Frequent.

Type locality : "Native of North America."

Herb. Geol. Surv. Herb. Mohr.

Crataegus aestivalis Torr. \& Gray, Fl. N. A. 1:468. 1840.

ApPle Haw. MaY IIAw.

Ell. Sk. 1: 552, as C.viridis. Chap. Fl. 127. Sargent, Silv. N. A. 4:119, t. 192.

Louisianian area. Low country of South Carolina, Georgia, and Florida, west to Mississippi, castern Texas (Mohr), and Arkansas.

Ala bama: Lower Pine region. Edges of pine-barren swamps, Mobile County, Mount Vernon, Pierce's Landing, Alabama River. Washington County, Yellowpine. Hlowers white or pale pink, appearing before the leaves, February 15 ; fruit ripe April 10, reddish, mellow, fine-flavored. On the overflowed banks of Davicls Lake, near Mount Vernon, trees of slender growth fully 25 feet high have been observed.

Type locality: "Along the low wet banks of ponds and rivers, South Carolina! and Georgia! to Florida! Louisiana! and Arkansas!"

Economic uses: 'The fruit is edible.

Herb. Geol. Surv. Herb. Mohr.

Crataegus uniflora Muench. Hausv. 5 : 147. 1770.

DWARF Thore.

Crataegus parvifolia Ait. Hort. Kew. 2:169. 1789.

C. tomentosa Michx. Fl. Bor. Am. 1:289. 1803. Not L. 
Ell. Sk. 1:547. Gray, Man. ell. 6, 166. Chap. Fl. 128. Sargent, Silv. N. A. $4: 117, t$. 191 .

Carolinian and Louisianian areas. New Jersey to Florida, west to Lonisiana and sonthern Arkansas.

Alabama: Over the State. Dry open copses. Cullman and Mobile counties. Flowers March (20, Mobile); fruit ripe October, November, greenish yellow, size of a hazel nut. Frequent. A straggling shrub 2 or 3 feet high.

Type locality not ascertained.

Herb. Geol. Surv. Herb. Mohr.

PRUNUS L. Sp. Pl. 1 : 473.1753.

About 80 species, temperate region, North Hemisplere. North Ameriea 20 species.

Prunus americana Marsh. Arb. Am.111. 1785.

Wili) Red or Yellow Plum.

Prunus hiemalis Michx. Fl. Bor. Am. 1:284. 1803.

Ell. Sk. 1:542. Gray, Man. ell. 6, 151. Chap. Fl. 119. Conlter, Contr. Nat. Herb.

$2: 102$. Sargent, Silv. N. A. $4: 19, t .150$.

Mexico.

Alleghenian to Louisianian area. Canada to Saskatchervan; New England west to Minnesota, Dakota, and Colorado, south to western Florida and Texas.

Alabama: Mountain region. Tennessee Valley. Wooded hillsides and banks of streams. Lauderdale County (Dr. Moody). Cullman Countr. Clay County, Delta Divide, 1,500 feet. Flowers white, March, April; fruit yellow to red, July. Nowhere abundant in the State. Tree 20 to 25 feet high.

Economic uses: The wood is useful and the fruit edible. Cnltivated in various races.

Type locality not specifically given.

Herb. Geol. Surv. Herb. Mohr.

Prunus hortulana Bailey, Gard. \& For. 5:90. 1892.

Garden Wild Plum.

Chap. Fl. ed. 3, 131, as Prunus maritima. Sargent, Silva. N. A. 4:24.

Louisianian and Carolinian areas. Illinois (Oquawka), Missouri (near St. Louis, etc.), and probably in southern Illinois, Indiana, Kentucky, and Tennessee, and through Arkansas to eistern Texas.

Alabana : Littoral region. Dry banks. Mobile County, not rare on the so-called "shellbanks." Near Coden and Bayou La Battre. Flowers in March ; fruit greenish red, with a slight bloom, about the size of the Chickasaw plum, ripe in September and October.

Prunus angustifolia Marsh. Arb. Am. 111. 1785.

Chickasaw Plum.

Prunus chicasa Michx. Fl. Bor. Am. 1: 284. 1803.

Ell. Sk. 1:542. Gray, Man. ed. 6, 152. Chap. Fl. 119. Sargent, Silv. N. A. 4:25, t. 15.2.

Most probably introduced by the aborigines from the south western sections of the Mississippi Valley into the region east of the Mississippi. Copiously disseminated from Maryland to Florida and from Missouri to 'Texas.

Alabama : All over the State. In light sandy soil, old fields, pastures. Flowers middle of February to March; fruit ripe Jnne, yellow and reddish. Largely cultivated in many varieties and crosses with Prunus americana.

Type locality: Native of the Southern States. Apparently described from the cultivated tree.

Herb. Geol. Surv. Herb. Mohr.

Prunus umbellata Ell. Sk. 1 : 541.1821.

Prairie Plum. Southern Sloe.

Chap. Fl.119. Sargent, Silv. N. A. $4: 33, t .1 \tilde{3}$.

Louisianian area. South Carolina to Florida, west to Mississippi, Lonisiana, and southern Missouri (Tracy!).

Alabama : Central Prairie region to Coast plain. Dry sandy copses, open woods, borders of fields. Montgomery, Clark, Escambia, Balilwin, and Mobile connties. Flowers February (Mobile) to middle of March; fruit ripe July, plum-purple. 'Tree 15 to 25 feet high ; frequent.

Economic nses: The fruit is made into preserves.

Type locality: "Grows in very dry, sandy soils," South Carolina and Georgia.

Herb. Geol. Surv. Herb. Mohr. 
Prunus injucunda Small, Bull. Torr. Club, 25:149. 1898. Carolinian area. Georgia.

AlabaMa : Mountain region, rocky summits. Talladega County, among sandstone cliffs, Alpine Mountain, near the Signal Station, September, 1892. Without fruit.

Type locality: "In sandy soil on the granite districts about Stone Mountain, Ga."

Prunus gracilis Engelm. \& Gray, Bost. Journ. Nat. Hist. $5: 243.1847$.

Carolinian area. Tennessee, Kansas, Texas.

Low PLUM.

Alabama: Mountain region. Metamorphic hills. Sandy open copses. Dekalb County. Lookout Mountain, near Mentone. Lee County (Baker f- Earle). Low shrub. Flowers in March. Infrequent.

Type locality : "Open post-oak woods west of the Brazos."

Prunus serotina Ehrh. Beitr. 3:20. 1788.

Ell. Sk. 1:541. Gray, Man. ed. 6, 152. Chap. Fl. 120. Coulter, Contr. Nat. Herb. 2:103. Sargent, Silr. N. A. 4:50, t. 159.

Mexico, Peru, Colombia.

Canadian zone to Louisianian area. Newfoundland, Ontario, and Manitoba; New Eugland west to Dakota, south to Florilla, and throughout the Gulf States to Texas and Arizona; mountains of Mexico.

Ala BAMA: Over the State. Scattered through the mountains, more rarely in the lower districts, where it is scarcely indigenous, disseminated by birds. Flowers white, March, April; fruit ripe in June, black, palatable.

Economic uses: A most valuable timber tree. The inner bark is the "wild cherry bark," "l'runus virginiana," of the United States Pharmacopюia.

'Type locality not ascertained.

Herb. Geol. Surv. Herb. Mohr.

Prunus serotina neo-montana (Small) Sudworth, Nomencl. Arb. Fl. U. S. 245. 1897. Mountain Black Cherry.

Cerasus serotina var. montana Small, Mem. Torr. Club, 4 : 114. 1893.

Prunus serotina montana Britt. Mem. Torr. Club, 5: 357.1894. Not Prunus montana Marsh., 1785, nor Koch, 1854.

Allegheniau and Carolinian areas. Southwestern Virginia to Georgia.

Alabama: Mountaiu region. Open rocky summits of the higher ranges. Talladega County, Alpine Mountain, near the llagstafi station, 1,800 to 2,000 feet; first observerl in 1892. Clay County, Che-aw-ha Mountain, bare cliffis, 2,400 feet; July 31 , fruit not quite mature. Tree 25 to 35 feet high, bark very rongh and with drooping branches.

Type locality: "On the "balds" near the summit of" White Top Mountain, 5,500 feet altitude, southwestern Virginia.

Herb. Geol. Surv. Herb. Mohr.

Prunus alabamensis sp. nov.

Alabama Cherry.

A tree below medium size, 25 to 30 feet high, and scarcely over 6 inches in diameter; leaves rather thick, broadly ovate, rounded or slightly narrowed at the base, from 3 to 4 inches long and 1 to $1_{\frac{1}{2}}$ inches wide, short-acuminate, blunt or acutish, bluntly serrate, with the teeth rather distant and close adpressed, glandular-tipped, smooth and of a deep green above, dull on the lower surface, and finely pubescent by short simple or forked hairs, which along the midrib and principal veinlets becone longer, villous, and more dense, the veinlets somewhat dark, prominent; racomes elongated, strict, erect (never drooping), the rachis and pedicels, like the calyx, closely pubescent.

In the specimens from Red Mountain the petals already withered were mostly shed. Drupe reddish to black, the few seen in shape and size similar to those of Prunus serotina.

The trunk is clear of limbs for the height of about 8 to 10 feet, the limbs spreading and finally inclined to be drooping.

A distinct species readily recognized by the characters of the leaves and inflorescence as described.

Carolinian area. Georgia (Meriwether County, Beadle, 1899).

Alabama : Mountain region. Red Mountain, near Birmingham, on the benches of siliceons ferruginous strata, about 1,000 to 1,200 feet altitude; just past flowering May 11, 1898. 'Talladega County, Childersburg (Biltmore Herb. 1899).

Prunus caroliniana Ait. Hort. Kew. 2:540. 1789.

Mock Orange. Iaurel Cherry. Wild Peach.

Ell. Sk. 1:540. Chap. Fl. 120. Coulter, Contr. Nat. Herb. 2 : 103. Sargent, Silv. N. A. $4: 50, t .160$. 
Louisianian area. North Carolina, valley Cape Fear River to Florida, west to eastern 'Texas.

Ala bama : Central Prairie region to Coast plain. Rich banks of streams. Pike County, Troy. Mobile County, reported from the swamps of Chickasa Creek. Flowers white, February, March; very rare in the wild state. More evidence is wanted before it can be considered truly indigenous in the State.

Economic uses: Ornamental. The leaves are poisonous.

Type locality: "Native of South Carolina."

Herb. Geol. Surv. Herb. Mohr.

CHRYSOBALANUS L. Sp. Pl.ed. 2, 1:513. 1762.

Three species, tropical regions.

Chrysobalanus oblongifolius Michx. Fl. Bor. Am. 1: 283. 1803.

Deer Plum.

Ell. Sk. 1:539. Chap. Fl. 119.

Louisianian area. Georgia and Florida west to Mississippi.

Alabama : Coast Pine belt. Dry pine woods. Throughont the upper and lower divisions; frequent. Monroe County, Claiborne. Mobile County, Springhill. Flowers white, June; fruit ripe in September, yellowish redl. Low shrub, stems creeping.

Type locality: "Hab. in sabulosis sylvarum Georgiae et Floridae."

Herb. Geol. Surv. Herb. Mohr.

\section{VICIACEAE (LEGUMINOSAE). Vetch Family.}

ALBIZzIA Durazz. Mag. Tose.3, iv:11. 1772.

Thirty species, tropical regions of the Old World.

Albizzia julibrissin (Willd.) Durazz. Mag. Tosc. 3, iv : 11. 1772.

Silk Tree.

Mimosa julibrissin Willd. Sp. Pl. 4:1065. 1806.

Grisel. Fl. Brit. W. Ind.223. Chap. Fl. Suppl. 619; ed. 3, 128.

Asia Minor to China. Cultivated in all warmer countries.

Louisianian area. Florida to Louisiana.

Alabama : Coast plain. A rare escape from garlens. Flowers white, with pink stamens; May. Tree 12 to 18 feet high.

Type locality: "Hab. in Oriente."

Herb. Geol. Surv. Herb. Mohr.

ACACIA Adans. Fam. Pl. $2: 319.1763$.

A large genus of about 425 species, tropical countries of both hemispheres.

Acacia farnesiana (L.) Willd. Sp. Pl. $4: 1083$. 1805. Opoponax. Sweet ACACia. Mimosa farnesiana L. Sp. Pl. 1:521. 1753.

Chap. Fl. Suppl. 619; ed. 3, 128 . Conlter, Contr. Nat. Herb. 2: 99. Sargent, Silv. N. A. $3: 119, t .141$.

Tropical America, West Indies. Extensively cultivated in the warmer regions of the globe.

Louisianian area. Naturalized from western Texas, along the Gulf shore to South Carolina.

Alabama : Coast plain. Dry waste places. Mobile County. Flowers deep yellow, highly fragrant; November to March. Frequent along the western shore of Mobile Bay. Shrub or small tree.

Type locality: "Hab. in Domingo."

Herb. Geol. Surv. Herb. Mohr.

NEPTUNIA Lonr. Fl. Cochinch. 1:653. 1790.

Eight species, of tropical regions Northern and Southern bemispheres. North America 1.

Neptunia lutea (Leavenworth) Benth. in Hook. Journ. Bot. 4:356. 1842.

Mimosa virgata Bartram, Travels, (ed.2,419.) 1791. Not L.

Acacia lutea Leavenworth, Am. Journ. Sci. 7:61. 1821.

Neptunia virgata Branner \& Coville, Ark. Geol. Surv. Ann. Rep. 1888, 4: 178. 1891. Desmanthus luteus Benth.; Chap. Fl. ed. 3, 128.1897.

Torr. \& Gray, Fl. N. A. 1: 403 . Chap. Fl. 117; ed. 3, 128. Coulter, Contr. Nat. Herb. 2: 95 . 
Lonisianian area. Florida west to Mississippi, Louisiana, Texas, and sonthern Arkansas.

Alabama: Central Prairies. Coast plain. Open grassy places. Greene County (Leavenworth). Mobile County, Portersville, West Fowl River. Flowers July to September. Infrequent. Perennial.

Type locality: "In the prairies of Green County, Ala."

Herb. Geol. Surv. Herb. Mohr.

MORONGIA Brittou, Mem. Torr. Club, 5:191. 1894. Sensitive Brier.

(Schrankia Willd.Sp. Pl. $4: 1041$. 1806. Not Medic. 1792.)

Four species, warmer, temperate, and tropical Ameriea. Perennials.

Morongia angustata (Torr. \& Gray) Britton, Mem. Torr. Club, 5 : 191. 1894.

Schrankia angustata Torr. \& Gray, F1. N. A. 1:401. 1840.

Gray, Man. ed. 6, 149. Chap. Fl.116. Coulter, Contr. Nat. Herb. 2:98.

Carolinian and Louisianian areas. Southern Virginia to Florida, west to Texas, Arkansas, 'Tennessee, and Missouri.

Ala bama: Over the State. Open woods, pastures, old fields, dry light soil. Cullman, 'Tuscaloosa, Washington. Monroe, and Mobile counties. Flowers pink, May to July. Prostrate stems 2 to 3 feet long. Frequent.

Type locality: "With the preceding [M. uncinata $]$, South Carolina, Georgia, Texas, Irummond."

Herb. Geol. Surv. Herb. Mohr.

Morongia horridula (Michx.).

Mimosa horridula Michx. Fl. Bor. Am. 2 : 254. 1803.

Schrankia angustata var. brachycarpa Chap. Fl.116. 1860.

S. horridula Chap. Fl. ed. 3, 127. 1897.

Chap. Fl.l.c.

Louisianian area. Florida to North Carolina? west to Louisiana.

Alabama: Coast Pine belt. Dry pine woods. Clarke County, Suggsville (I)r. Denny). Washington County, Yellowpiue. Mobile County. Flowers pink, July. Less frequent than the above.

Type locality : "Hab. a Virginia ad Floridam."

Herb. Geol. Surv. Herb. Mohr.

ACUAN Medie. Theod. Spec.62. 1786.

(Desmanthus Willd. Sp. Pl. $4: 1044$. 1806.)

Ten species, South Atlantie America, West Indies.

Acuan illinoense (Michx.) Kuntze, Rev. Gen. Pl. 1: 158. 1891.

Mimosa illinoensis Michx. Fl. Bor. Am. 2:254. 1803.

Acacia brachyloba Willd. Sp. Pl. 4 :1071. 1806.

Desmanthus brachylobus Benth. in Hook. Bot. Journ. 4 : 358. 1842.

Gray, Man. ed. 6, 149. Chap. Fl. Suppl. 618; ed.3, 128. Coulter, Contr. Nat. Herb. $2: 96$.

Carolinian and Louisianian areas. Southern Virginia, Kentucky, Missouri, Minnesota, south to Tennessee, Mississippi, Arkansas, Louisiana, and Texas.

Alabama: Prairie region. Coast plain. Grassy open place. Montgomery County, open prairies, banks of Pentulalla Creek. Mobile County, shore of Mississippi Sound at Ceclar Point. Flowers white, July. Perennial.

Type locality: "Hab. in pratensibus regionis Illinoensis."

Herb. Geol. Surv. Herb. Mohr.

\section{PARKINSONIA L. Sp. Pl. 1:375. 1753.}

About 11 arborescent species, South Africa. Warmer and tropieal America, 4.

Parkinsonia aculeata L. Sp. Pl. 1 : 375 .

Chap. Fl. Suppl.618; ed.3, 126. Coulter, Contr. Nat. Herb $2: 94$.

West Indies, Texas, Mexico. Cultivated in all tropical countries.

Louisianian area. Cultivated and escaped. South western Florida to California.

Alabama : Coast plain. Waste places, not rarely escaped. Flowers yellow, June,

July. Tree 15 to 20 feet high.

Economic uses: Ornamental.

Type locality: "Hab. in America calidiori."

Herb. Geol. Surv. Herb. Mohr. 
CERCIS L. Sp. Pl. 1:374. 1753.

Four species, temperate Europe, eastern Asia. North America, 3. Snall trees.

Cercis canadensis L. Sp. Pl. 1:376. 1753.

RED BUD.

Ell. Sk. 1:470. Gray, Man. ed. 6, 147. Chap. Fl. 114. Sargent, Silv. N. A. 3:93, t. 133.

Alleghenian to Louisianian area. Western Pennsylvania, west to southern Michigan, Missouri, Nebraska, and Kansas, south to western Florida, Mississippi, Lonisiana, and Arkansas.

Alabama : From the Tennessee Valley to Central Pine belt. Rich woods. Madison County, Montesano. Cullman County. Tuscaloosa County (E. A. Smith). Mobile County; hardly of spontaneous growth. Flowers rose pink, February 25; fruit ripe in August. Small tree, most frequent in the mountains.

Economic uses: The wood is useful.

Type locality: "Hab. in Virginia."

Herb. Geol. Surv. Herb. Mohr.

CASSIA L. Sp. Pl. 1:376. 1753.

Three hundred and tifty or more species, herbs or shrnbs, in warmer, mostly tropical, regions Northern and Sonthern Hemispheres. North America, 27.

Cassia occidentalis L. Sp. Pl. 1:377. 1753.

Ell. Sk. 1:471. Gray, Man. ed. 6, 148. Chap. Fl. 114. Coulter, Contr. Nat. Herb. 2:92. Griseb. Fl. Brit. W. Ind. 209.

West Indies, Mexico to BraziL. Widely spread over all tropical countries.

Carolinian and Louisianian areas. Southern Virginia, southern Incliana, and Tennessee to Florida, west to Arkansas.

Alabama: Tennessee Valley to Coast plain. Naturalized, cultivated and waste places near dwellings. Franklin County, Russellville. Autauga County, Prattville. Clay County, Talladega Creek. Mobile County. Flowers July; fruit ripe August to September; common weed of gardens and roadsides.

Type locality: "Hab. in Janaica."

Herb. Geol. Surv. Herb. Mohr.

Cassia tora L. Sp. Pl. 1:376. 1753.

Cassia obtusifolia L. Sp. Pl. 1:377. 1753. 209.

Ell. Sk. 1:471. Gray, Man. ed. 6, 147. Chap. Fl. 114. Griseb. Fl. Brit. W. Ind.

West Indies, Mexico to Argentina, Tropical Africa, Asia.

Carolinian and Louisianian areas. Missouri, southern Illinois, and Virginia, south to Florida and Arkansas.

Alabama: Over the State. Cultivated and waste places. Jackson, Marshall, Montgomery, and Mobile counties. Flowers yellow, June to August; fruit ripe September, October. Common weed. Annual.

Type locality : "Hab. in India."

Herb. Geol. Surv. Herb. Mohr.

Cassia marilandica L. Sp. Pl. 1:378. 1753.

Will SenNa.

Ell. Sk. 1:473. Gray, Man ed.6,147. Chap. Fl.114.

Carolinian and Louisianian areas. New England west to Michigan, Missouri, and Arkansas, south to Florida and Louisiana.

Alabama: Scattered throughout the State. Gravelly banks and bottoms. Clay County, Delta. Tallapoosa and Autauga counties. Clarke County (Dr. Denny). Mobile County, Whistler. Flowers yellow, July to Angust; fruit ripe September, October. Not common. Perennial.

Economic uses: The leaves, "American senna," are used medicinally.

Type locality: "Hab. in Virginia, Marilandia."

Herb. Mohr.

CHAMAECRISTA Greene, Pittonia, $3: 238$. $1897 .^{1}$

Forty or more species, herbaceous anuuals anil suffrutescent perennials. Mostly of the West Indies, northern Mexico, South and North Amevica, a few in Eastern Asia and in Africa. Eastern North America (U. S.), 7.

${ }^{1}$ E. L. Greene, Pittonia, vol. 3, pp. 238 to 243. 1897. Same author, op. cit., vol. 4, pp. 25 to 32. 1899. C. L. Pollard, Bull. Torr. Club, vol.21, pp. 208 to 222. 1894. Vol.22, pp. 513 to 516.1895 . 
Chamaecrista fascicularis (Michx.) Greene, Pittonia, 3 : 242. 1897.

Cassia fascicularis Michx. Fl. Bor. Am. 1:262. 1803.

C. chamaecrista L. Sp. Pl. $1: 379$. 1753. ( 8$)$

Ell. Sk. 1:473. Gray, Man. ed. 6, 148. Chap. Fl. 115. Conlter, Contr. Nat. Herb. $2: 92$.

Alleghenian to Lonisianian area. New England west to Minnesota, Dakot:1, Nebraska, Colorado, south to Florida and west to Texas.

Alabama: Over the State. Dry sunny places; fields and open copses. Clay County. Tuscaloosa, Clarke, Washington, and Mobile counties. Flowers bright yellow, Angust, September. Common; annual.

Type locality: "Hab. in Penusylvania et Virginia."

Herb. Geol. Surv. Herb. Mohr.

Chamaecrista robusta (Pollard) Pollard; Heller, Cat. N. A. Pl. ed. 2, 5. 1900.

Robust Sensitive Pea.

C. chamaecrista var. Torr, \& Gray, Fl. N. A. 1:396. 1840.

C. chaniaecrista robusta Pollard, Bull. 'Torr. Club, 21:218. 1894.

Cassia robusta Pollard, Bull. 'Torr. Club, 24:150. 1897.

Robust, 12 to 18 inches high, erect, branches more or less pubeseent; leaves $1 \frac{1}{2}$ to $2 \frac{1}{2}$ inches long, $\frac{1}{2}$ to $\frac{8}{4}$ inch wide, leaflets 8 to 15 pairs, $\frac{1}{8}$ inch long, $\frac{1}{8}$ inch wide, asymmetric, linear, obtuse, glabrous; petiole $\frac{1}{4}$ inch long, with a small, patellar subsessile gland in the middle; rachis pubescent; stipules linear-lanceolate, acumiuate, like the sepals strongly ciliate; the large, golden-yellow petals donble the length of the sepals; legumes in pairs, erect on spreading elongated peduncles, linear, 1 to $1 \frac{1}{2}$ inches long, pubescent with long spreading hairs.

Carolinian and Louisianian areas. Kentucky.

Alabama: Mountain region. Lower Pine region. Open copses, borders of woods. Clay County, Delta, 1,600 feet. Washington County (E. A. Smith). Annual.

Type locality: "Collected by Dr. C. W. Short in the mountains of Kentucky."

Herb. Geol. Surv. Herb. Mohr.

Chamaecrista mississippiensis (Pollard) Pollard; Heller, Cat. N. A. Pl. ed. 3, 5. 1900.

Cassia mississippiensis Pollard, Bull. Torr. Club, 21:219. 1894.

"Low, branching, suffruticose, stem terete, glabrous; leaves subcoriaceons, pubescent, 8 to 14 foliate; leaflets small, elliptical or obovate, mucronate; * * * petiolar gland minute, cupuliform, sessile * * * ; stipules acutely linear, memliranaceous, persistent; peduncles $1 \mathrm{~cm}$. long, axillary, 1-flowered ; flower large, * * * anthers 10, rostrate. all perfect, the lower 5 larger, yellow, the upper smaller and reddish; sepals lance-linear, slightly pubescent, not surpassing the petals; legume turgid, linear, sparsely pubescent

Louisianian area. Mississippi.

Alabama: Coast plain. Dry sandy borders of fields. Mobile Connty, loose sands western shore Mobile Bay. Flowers yellow. Perennial.

Type locality: "Collected by Miss K. Skeehan, 1889, at Ocean Springs, Miss."

Herb. Geol. Surv. Herb. Mohr.

Chamaecrista chamaecristoides (Colladon) Greene, Pittonia, $4: 20.1899$.

Cassia chamaecristoides Colladon, Hist. Cass. 134. 1816.

Cassia depressa Pollard, Bull. Torr. Club, 22:515. 1895.

Chamaecrista depres8a Greene, Pittonia, 3:242. 1897.

Low, slender, diffusely branched, branches assnrgent, finely strigose-pubescent; leaves 1 to $1 \frac{1}{2}$ inches long, $\frac{1}{3}$ inch wide, leaflets 10 to 15 pairs linear, narrow, acutish, the midnerve bent toward the upper margin, excurrent in a long fine cusp, midrib and margin rough; stipules small, linear; in our plant the small gland slightly stipitate.

Carolinian and Louisianian areas. Florida and Missouri.

Alabama : Coast plain, damp shaded banks. Baldwin County, Daphne. Angust 23, 1896, flower buds scarcely developed. Perennial.

Type locality not ascertained.

Herb. Geol. Surv. Herb. Mohr.

Chamaecrista multipinnata (Pollard) Greene, Pittonia, 3 :243. 1897.

Many-leaved Sensitive Pea.

Cassia multipinnata Pollard, Ball. Torr. Club, 22 :515. 1895.

Slender, tall, erect, more or less branched; stem slightly woody at base, pubescent; leaves lanceolate-elliptical in outline, 20 to 25 foliolate * * *; leaflets $10 \mathrm{~mm}$. long, $1_{\frac{1}{2}} \mathrm{~mm}$. wide, glabrous, narrowly linear, cuspidate; petiolar gland minute, depressed-cupuliform, substipitate; * * * flowers scattered, sessile, the corolla 
quite irregular, its small yellow petals not much exceeding the narrow, scariousedged sepals; legume linear, compressed, pubescent, or even hirsute, * * * 2 to $2 \frac{1}{2} \mathrm{~cm}$. long * * *."

"Separable from nictitans by the narrowly linear, very numerous, leaflets, the more hairy pod, and the late period of flowering."

Carolinian and Louisianian a reas. Florida to Mississippi.

Alabama : Damp shaded banks, grassy horders of fields. Mobile County, Monroe

Park. Baldwin County, Daphne. Cullman County. Lee County, Auburn (Iaker \& Earle). Flowers yellow; August 23. Annual.

Type locality: "Near Jacksonville [Fla.], A. H. Curtiss * * * 1894. Tallahassee, G. V. Nash * * * 1895."

Herb. Geol. Surv. Herb. Mohr.

Chamaecrista aspera mohrii (Pollard) Pollard; Heller, Cat. N. A. Pl. ed. 2, 5. 1900. Mohr's Hoary Sensitive Pea.

Cassia aspera mohrii Pollard, Bull. Torr. Club, 24 : 151. 1897.

"Leaflets hoary-pubescent with stiff white hairs on both sides, petiolar gland depressed-eupuliform, substipitate."

Louisianian area.

Alabama: Borders sandy fields and pine woods. Mobile. Flowers August; rare. Annual.

Type locality: "Collected in Mobile in 1878 by Dr. Mohr."

Herb. Geol. Surv. (type speeimen). Herb. Mohr.

Chamaecrista nictitans (L.) Moench. Meth. 272. 1794.

Cassia nictitans L. Sp. Pl. $1: 380.1753$.

Ell. Sk. 1:474. Gray, Man. ed. 6, 148. Chap. Fl.115. Coulter, Contr. Nat. Herb. 2: 92 .

Alleghenian and Carolinian areas. Massachusetts aud central New York, throughout the Ohio Valley, south to Georgia, Arkansas, and Texas.

Alabama : Mountain region. Open places, old fields. Dekalb County, Lookout Mountain, Mentone. September 1. Infrequent.

Type locality: "Hab. in Virginia."

Herb. Geol. Surv. Herb. Mohr.

GLEDITSIA L. Sp. Pl. 2 : 1056. 1753. HoNeY Locust.

Five species eastern Asia. North America, 2. 'Trees.

Gleditsia triacanthos L. Sp. Pl. $2: 1056.1753$.

Honey Locust.

Ell. Sk. 2:709. Gray, Man. ed. 6, 149. Chap. Fl. 115. Coulter, Contr. Nat. Herb. 2:95. Sargent, Silv. N. A. 3:75, t. 125 .

Carolinian and Lonisianian area. Pennsvlvania, western Virginia to Missouri, south to Florida, and through the Gulf region to Texas ancl Arkansas.

Alabama: Throughout the State in bottom lands. Lauderlale, Blount, and Montgomery counties. May; fruit ripe October. Large tree, 50 to 80 feet high. Most fiequent on the larger tributaries of the Alabama River; spreading in clearings, olıl fields, and waste places, south ward to the coast and becoming troublesome. Type locality: "Hab. in Virginia."

Herb. Geol. Surv. Herb. Mohr.

CLADRASTIS Raf. Noog. 1. 1825.

One species, South Atlantic America.

Cladrastis lutea (Michx.) Koch, Dendrol. 1:6. 1869.

Virgilia lutea Michx. f. Arb. Am. 3: 266, t. 3. 1813.

Cladrastis tinctoria Raf. Neogen. 1.1825.

Gray, Man. ed. 6, 127. Chap. Fl. 113. Sargent, Silv. N. A. 3:55, t. 19, 20.

Carolinian area. (ientral Kentucky, 'Teunessee, and North Carolina.

Alabama: Tennessee Valley. Shaded bluffs. ('olbert County, Sheffield Landing on the Tennessee River (M. C. Wilson). Flowers white. May. Small tree; rare.

Economic uses: An ornamental tree.

Type locality (Michx. f. Arb. Am. trans.): "Confined to that part of west Tennessee which lies between the thirty-fifth and thirty-seventh degrees of latitude."

Herb. Geol. Surv, Herb. Mohr. 
BAPtisia Vent. Dee. Gen. Nov. 9. 1808.

Fourteen species, perennials, Atlantic North America, largely southeastern.

Baptisia lanceolata (Walt.) Ell. Sk. 1:467. 1817.

Lanceolate False Indigo.

Sophora lanceolata Walt. Fl. Car. 135. 1788.

Podalyria uniflora Michx. Fl. Bor. Am. 1:263. 1803.

Ell. Sk. 1 :467. Chap. Fl. 111.

Louisianian area. Florida to North Carolina, west to Louisiana and Arkansas.

Ala bama: Lower Pine region. Dry pine barrens. Baldwin County. Flowers yellow. April; rare.

Almost glalorous, flowers mostly single, rarely in pairs.

Type locality: South Carolina.

Herb. Geol. Surv. Herb. Molır.

Baptisia leucantha Torr. \& Gray, Fl. N. A. 1:385. 1840.

Gray, Man. ed. 6, 126. Chap. Fl.112.

WHITE-FLOW ERED FALSE INDigo.

Carolinian and Louisianian areas. Michigan, Minnesota, Nebraska, south to Ohio, Missouri, Arkansas, and Louisiana.

Alabama: Louisianian area. Damp banks. Washington County. Flowers white. May; rare.

Type locality: "In rich alluvial soil, Upper Canada (near Lake Erie), Michigan! Ohio! to Louisiana!"

Herb. Geol. Surv. Herb. Mohr.

Baptisia megacarpa Chap. Fl.111. 1860.

Chap. Fl. ed. 3, 121.

Carolinian and Louisianian areas. Georgia, middle Florida.

Alabama: Mountain region. Metamorphic hills. Open woodlands. Tallapoosa County, Dadeville (Biltmore Herb. 1899). Flowers pale yellow, May. Perennial. Rare.

Type locality: "light rich soil, Gadsden County, middle Florida, and along the Flint River, near Albany, Ga."

THERMOPSIS R. Br. in Ait. Hort. Kew. ed. 2, 3: 3. 1811.

One hundred and twenty-three species, perennial herbs. Siberia, IIimalayan India. North America, 7.

Thermopsis fraxinifolia Nutt. in Torr. \& Gray, Fl. N. A. 1: 387. 1840.

Chap. Fl. 113.

Carolinian area. North Carolina.

Alabama: Mountain region. Dekalb County, Lookout Mountain near Mentone (May, 1899, Miss Loring). Rare.

Type locality: "Found chiefly upon the Catawba ridge, North Carolina, in open bushy forests."

CROTALARIA L. Sp. Pl. 2 : 714. 1753. RATTLE-PO1).

Two hundred and fifty species, of warmer regions of both hemispheres.

Crotalaria rotundifolia (Walt.) Poir. Encycl. Suppl. 2 :402. 1811.

Anonymos rotundifolia Walt. Fl. Car. 181. 1788.

ROUND-LEAF RATTLE BOX.

Crotalaria sagittifolia var. rotundifolia Michx. Fl. Bor. Am. 2 : 5ૅ. 1803.

C. ovalis Pursh, Fl. Am. Sept. 2 : 469. 1814.

Ell. Sk. 2 : 194. Chap. Fl. 89.

Mexico, South AMERICA.

Carolinian and Louisianian areas. Virginia, North Carolina to Floricla, west to

Louisiana.

Alabama: Mountain region to Coast plain. Dry sandy open woods. Cullman County, 800 feet. Pike County, Troy. Chilton County, Verbena (E. A. Smith). Leo County, A uburn, 860 feet (Baker \& Earle). Escambia County (Baker \& Earle). Mobile

County. Flowers yellow. May, June; fruit black, June. Most frequent throughout

the Central and Coast Pine belts. Perenuial.

Type locality: South Carolina.

Herb. Geol. Surv. Herb. Mohr.

Crotalaria sagittalis L. Sp. P1. 2 : 714.1753.

Common RattLe-PEA.

Ell. Sk. 2 :293. Gray, Man. ed.6, 127. Chap. Fl. 89. 
Mexico, Brazil, Peru.

Alleghenian to Louisianian area. Massachusetts and New York west to Iowa and Nebraska, south to Florida, Louisiana, and Arkansas.

Alabama: Tennessee Valley to the Upper division of Coast Pine belt. Dry sandy banks. Cullman, Choctaw, Lee, and Tuscaloosa couties. Flowers yellow; July, August. Nowhere common. Anuual.

Type locality: "Hab. in Brasilia, Virginia."

Herb. Geol. Surv. Herb. Mohr.

Crotalaria purshii DC. Prodr. 2 : 124. 1825.

Pursh's Rattle Box.

Crotalaria laevigata Pursh, Fl. Am. Sept 2:469. 1814. Not Lam.

C. parviflora Pursh, FI. Am. Sept. 2 : 469. 1814. Not Roth.

Eil. Sk. $2: 193 . \quad$ Chap. Fl. 89.

Louisianian area. Florida to South Carolina, west to eastern Louisiana.

Alabaya : Lower Pine region. Coast plain. Damp pine barrens on sandy loam.

Baldwin and Mobile counties. Flowers April, May. Not rare. Perennial.

Typo locality: "In Virginia et Carolina."

Herb. Geol. Surv. Herb. Mohr.

Crotalaria brownei Bertero, DC. Prodr. 2 : 130. 1825.

Brown's Crotalaria.

Crotalaria striata DC. Prodr. 2 : 131 . 1825.

Griseb. Fl. Brit. W. Ind. 180.

Tropical countries of the New and old World.

Louisianian area.

Alabama: Adventive with ballast. Observed 1890 to 1895. Aunual.

Type locality: "In Jamaica ad rivulos frequens."

Herb. Geol. Surv. Herb. Mohr.

LUPINUS Sp.P1. 2 : 721. 1753. LUPINE.

About 100 species, warmer temperate regions Mediterranean Europe, Mexico, South America. Northwestern America, 60. Eastern Uniterl States, 4 or 5.

Lupinus gracilis Nutt. Journ. Acad. Phila. $7: 115$. 1834. Not Agardh. 1835.

Lupinus nuttallii Wats. Proc. Am. Acad. 8:526. 1873.

NutTall's Lupine.

L. perennis var. gracilis Chap. Fl. 89. 1860.

Chap. FI. 89.

Lonisianian area. South Carolina and Florida.

Alabama : Lower Pine region. Dry sandy pine barrens. Mobile County, Springhill. Flowers pale blue; April. Frequent in dry sandy pine barrens near the coast. Easily distinguisher from Lupinus perennis by the slender decumbent stem with stiff spreading hairs, bearing scarcely more than one slender drooping raceme Type locality : "Georgia, Florida, and westward to Mississippi."

Herb. Geol. Surv. Herb. Mohr.

Lupinus diffusus Nutt. Gen. 2:93. 1818.

SPREAding LUPine.

Ell. Sk. 2:192. Chap. Fl. 90.

Louisianian area. Florida to North Carolina, west to Mississippi.

Alabama: Lower Pine region. Arid sandy pine ridges. Mobile and Baldwin counties. Flowers pale blue, March, April; fruit ripe May, June. Frequent. Perennial.

Type locality: "Around Wilmington, and in many other parts of North and South Carolina, in the barren forests of the Quercus catesbaei and Q. nigra."

Herb. Geol. Surv. Herb. Mohr.

Lupinus villosus Willd. Sp. P1. 3 : 1029. 1805.

HaIRY LUPine.

Lupinus pilosus Walt. Fl. Car. 180. 1788. Not L.

Ell. Sk. 2 : 191. Chap. Fl. 89.

Louisianian area. Florida to North Carolina, west to Louisiaua.

AlabaMa : Lower Pine region. Coast plain. Grassy damp pine barrens. Flowers "reddish purple with a dark spot in the center of the vexillum." Flowers a couple of weeks later than the last, and affects situations of a heavier soil, retentive of moisture. Not infrequent. Biennial.

Type locality: "Hab. in Carolina et in insula Trinitatis."

Herb. Geol. Surv. Herb. Mohr. 
MEDICAGO L. Sp. P1. $2: 778.1753$.

About 40 species, Mediterranean Europc, mostly western Asia.

Medicago lupulina L. Sp. Pl. 2 : 779. 1753.

Black Mridck.

Ell. Sk. $2: 247$. Gray, Man. od.6, 130. Chap. Fl.90. Wats. Bot. Calif. 1: 133.

Alleghenian to Lonisianian area. Introduced from Europe. Thoroughly naturalized from Canada to the Gulf, British Columbia, and California.

Alabama: Throughout the State. Dry open banks, roadsides, waste places. Flowers yellow; April to June. A common weed. Annual.

Type locality: "Hab. in Europae pratis."

Herb. Geol. Surv. Herb. Mohr.

Medicago denticulata Willd. Sp. Pl. 3 : 1414. 1801.

Southeirn Europe.

Introduced and sparingly naturalized from Ontario to the Gulf and on the Pacitic coast.

Alabama: A persistent ballast plant. Mobile. Flowers yellow. April; frequent. Annual.

Type locality: "Hab. in Europa australi."

Herb. Geol. Surv. Herb. Mohr.

Medicago apiculata Willd. Sp. Pl. 3 :1414. 1805.

Adventive on ballast from southern Europe. Mobile. June, 1884. Annual.

Type locality : "Hab. in Europa australi."

Herb. Geol. Surv.

Medicago minima Lam. Encycl. 3 : 636. 1789.

SOUTHERN EURope.

Louisianian area. Adventive on the South Atlantic and Gulf coasts.

Alabama : Mobile, ballast grounds; well established, spariugly spreading to waste places. Flowers Jellow, March, April; fruit ripe May, June, after which the plant dies.

Type locality: "Cette espèce croît naturellement en Europe dans les champs, le long des chemins. Elle est commune anx environs de Paris."

Herb. Geol. Surv. Herb. Mohr.

Medicago arabica (L.) All. Fl. Ped. 1:315. 1785.

Spotted Bur Clover.

Medicago polymorpha arabica L. Sp. Pl. ed. 2, 2:1098. 1763.

M. maculata Sibth. Fl. Oxon. 232. 1794.

Europe.

Introduced and sparingly naturalized from New England to the Gulf.

Alabama: Borders of fields, grassy banks. Mobile. March, April. Anuual.

Economic uses: Valuable fodder plant.

Type locality: "Hab. in Europa australi."

Herb. Geol. Surv. Herb. Mohr.

Medicago orbicularis (L.) All. Fl. Ped. I:314. 1785.

Medicago polymorpha var. orbicularis L. Sp. Pl. 2 : 779.1753.

Alabama: A fugitive from southern Europe on ballast. July, 1893. Annual.

Type locality (L. Sp. Pl. el. 2): "Hab. in Enropa australi."

Herb. Geol. Surv. Herb. Mohr.

Medicago sativa L. Sp. Pl. 2 : 778. 1753.

LuCern. Alfalia.

Alabama: Cultivated in the northern and central districts; scarcely of spontaneous growth. Perennial.

Economic uses: Valnable forage plant.

Type locality: "Hab. in Hispaniae, Galliae apricis."

Herb. Geol. Surv.

MELILOTUS Juss. Gen. Pl. 3556. 1789.

Abont 20 species, warmer temperate Europe, subtropical western Asia. Adrentive in North America.

Melilotus alba Desr. in Lam. Encycl. 4:63. 1797.

Wiite Melilot. Boknara Clover.

Gray, Man. ed.6, 129. Chap. Fl.90. Coulter, Contr. Nat. Herb. 2 : 74. Wats. Bot. Calif. $1: 132$.

Alleghenian to Louisianian area. Introduced from Europe and naturalized in waste places from New Englaud and Canada to the Gulf. 
Alabama : Extensively cultivated in the Prairie region and freqnently escaped on roadsides. Mobile, on ballast. Flowers white; May, June. Biennial.

Economic uses: Valuable forage plant.

Type locality: "Cette espèce croit naturellement dans la Sibérie. On la trouve aussi en Europe."

Herb. Geol. Surv. Herb. Mohr.

Melilotus indica All. Fl. Ped. 1:308. 1785.

Small-hlowered Melilot.

Melilotus parviflora Desf. Fl. Atlant. 2 : 192.1800.

Coulter, Contr. Nat. Herb. 2 : 73.

Warmer Parts of Europe anl) Asia.

Lonisianian area. Naturalized in South Carolina, Florinla, and Mississippi.

Alabama: Central Prairie region and Coast plain. Dallas Conuty, Uniontown. Mobile, waste places. Flowers yellow; May to June. Abundant in the Prairie region, more scarce about Mobile. Annual.

Economic uses: Forage plant of some value.

Type locality: "In pascuis, \& ad vias collium calidiorum."

Herb. Geol. Surv. Herb. Mohr.

Melilotus officinalis (L.) Lam. Fl. Fr. 2 : 594. 1778.

Trifolium melilotus officinale L. Sp. Pl. 2: 765. 1753.

Common Yellow Melilot.

Gray, Man. ed. 6, 129. Chap. Fl.90.

EURope.

Introduced, northern and southern Atlantic States.

Alabama: Sparingly naturalized about Tuscaloosa, waste places (E. A. Smith).

Economic uses. Of some value for forage. The herlb with the flowers is used medicinally.

Type locality : "Hab. in Europae campestribus."

Herb. Geol. Surv.

TRIFOLIUM L.Sp. Pl. 2:764. 1753. Clover.

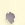

About 250 species, of temperate and subtropical regions, Northern Hemisphere. North America 40, mostly northwestern. Atlantic America, 5.

Trifolium reflexum L. Sp. Pl. 2 : 766.1753.

Buffalo Clover.

Ell. Sk. 2:202. Gray, Man. ed. 6. 128. Chap. Fl. 91. Coulter, Contr. Nat. Herb. $2: 74$.

Mexico.

Carolinian and Louisianian areas. Southwestern Ontario; New York, central Ohio, Missouri, Arkansas, rexas, Louisiana, through the Gulf States to North Carolina and Virginia.

Alabama: Tennessee Valley to Upper division Coast Pine belt. Open woods, pastures, close soil. Franklin County, Russellville. Cullman County, 800 feet. Tuscaloosa and Autauga counties. Clarke County, Choctaw Corner. Vexillum of flowers rose-red, keel and wings white. April, May; most frequent in the Prairie region. Annual.

Type locality: "Hab. in Virginia."

Herb. Geol. Surv, Herb. Mohr.

Trifolium carolinianum Michx. Fl. Bor. Am.2:58. 1803. Wild White Clover.

Ell. Sk.2:200. Gray, Man. ed. 6, 129. Chap. Fl. 91. Coulter, Contr. Nat. Herb. $2: 74$.

Louisianian area. North Carolina to Florida, west to southern Arkansas and eastern Texas.

Alabama: Central Pine belt to Coast plain. Open grassy banks, borders fields and woods. Flowers white. March, April. Produces new shoots and abundance of leaves during winter. Common; most abundant iu the Coast plain. Perennial.

Type locality ; "Hab. in Carolina, circa Charlestowu."

Herb. Geol. Surv. Herb. Mohr.

Trifolium pratense L. Sp. Pl. 2 : 768. 1753.

Red Clover.

Cultivated in northern and central districts; a frequent escape all over the State. April, May. Perennial.

Economic uses: Most valuable forage plant and ameliorating crop.

Type locality: "Hab. in Europae graminosis."

Trifolium repens L. Sp. Pl. 2 : 767. 1753.

White Clover.

Ell. Sk. $2: 201$. Gray, Man. ed. 6, 129. Chap. Fl.91.

$15894-36$ 
Naturalized from Europe. From Canada to the Gulf; west to Louisiana and Nebraska.

Alabana: Throughout the State. Roadsides, waste places, pastures, in damp rich soil. Flowers white. April to June; common. Perennial.

Economic uses: Valuable for pasture. Fine bee plant.

Type locality: "Hab. in Europae pascuis."

Herb. Geol. Surv. Herb. Mohr.

Trifolium resupinatum L. Sp. Pl. ed. 2, 2: 1086. 1753.

EUrope.

Alabama: Adventive with ballast. Mohile.June, 1887; not observed of late vears. Type locality: "Hab. in Anglia, Belgio."

Herb. Geol. Snrv.

Trifolium procumbens L. Sp. Pl. 2 : 772. 1753.

Low Yhliow Chover.

Gray, Man. ed.6, 129. Chap. Fl.91.

Europe.

Alleghenian and Carolinian areas. Introduces and fully naturalized from Canada along the coast to upper districts of South Atlantic and Gulf States west to Arkansas.

Alabama: Tennessee Valley. Copses, horder of woods, roadsides. Madison County, Huntsville. Franklin County, Russellville. Flowers yellow, May, June. Frequent. Annual.

Type locality: "Hab. in Europae campestribus."

Herb. Geol. Surv. Herb. Mohr.

Trifolium dubium Sibth. Fl. Oxon. 231. 1794.

LASSFR YelLow Trefold.

Trifolium minus Smith, Engl. Bot.t. 1256. 1799.

T. procumbens var. minus Koch, Fl. Ger. ed. 2, 195. 1843.

EURope.

Carolinian area. Sparingly naturalized.

Alabama : Mountain region. Metamorphic hills. Cultivated ground. Lee County, Auburn (Earle \& Vnderwood). Flowers yellow, March, April, Rare. Anuual.

Type locality: "Meadows-pastures," Oxford, England.

Herb. Geol. Surv. Herb. Mohr.

LOTUS L. Sp. Pl. 2 : 773. 1753. Horned Clover.

(HosaCkia Dougl.; Benth. Bot. Reg. 15 : under t. 125\%. 1829.)

About 100 species, of temperate regions Europe. North America, chiefly western, abont 30 .

Lotus americanus (Nutt.) Bisch. Litt. Ber. Linnaea, 14:132. 1840.

Trigonella americana Nutt. Gen. 2 : 120. 1818.

American Horned Clover.

Lotus sericeus Pursh, Fl. Am. Sept. $2: 489$. 1816. Not DC. 1813.

Hosackia purshiana Benth. Bot. Reg. 15: under t. 125\%. 1829.

Coulter, Contr. Nat. Herb. 2 : 75.

Widely distributed west of the Mississippi to the Pacific and from the upper Missouri to Texas.

Alabama: Adventive with wool from the Southwest near the site of an old woolen mill at Prattville. June, 1880. Annual.

Type locality: "On the dry and open alluvial soils of the Missouri, from the river Platte to the mountains."

Herb. Geol. Surv. Herb. Mohr.

Lotus corniculatus L. Sp. Pl. 2 : 775.1753.

Common Horned Ciover.

Adventive from Enrope with ballast. Mobile, June, 1888. Perennial.

Type locality: "Hab. in Europae pratis."

Herb. Geol. Surv. Herb. Mohr.

PSORALEA L. Sp. Pl. 2 : $762.1753 .{ }^{1}$

About 100 species, perennials, temperate and warmer regions of the globe. Sonth Africa. North America, 30. Eastern States, 10.

Psoralea pedunculata (Mill.) Vail, Bull. Torr. Club, 21: 114. 1849.

Hedysarum pedunculatum Mill. Gard. Dict. ed. 8, no. 17. 1768.

'Anna M. Vail, A study of the genus Psoralea in America, Bull. Torr. Clul, vol. 21, pp. 91 to 119.1844. 
Trifolium psoraloides Walt. Fl. Car. 184. 1788.

P'soralea melilotuides Michx. Fl. Bor. Am. 2:58. 1803.

P. eglandulosa Ell. Sk. 2 : 198.1824.

Ell. Sk. l. c. Gray, Man. edl.6, 130. Chap. Fl.92.

Carolinian and Louisianian areas. Southern Indiana, Missouri, Kansas, Arkansas, Louisiana, and Mississippi to North Carolina and Tennessee.

Alabama: Tennessee Valley. Mountain region to Coast Pine belt. Gravelly and rocky places. Landerdale County, in the barrens. Winston County (T. M. Peters). St. Clair County, Coosa hills; abundant. Tuscaloosa County (E. A. Smith). Wilcox County (Buckley). Clarke County, Choctaw Corner. Washington County, Yellowpine. Flowers June, July. Fruit purplish. Frequent. Rootstock long, cylindrical.

'Type locality not ascertained.

Herb. Geol. Surv. Herb. Mohr.

Psoralea simplex Nutt.; Torr. \& Gray, Fl. N. A. 1 : 303.1840.

Anna M. Vail, Bull. Torr. Club, 21:110.

Lonisianian area. Southern Mississippi to Louisiana, Texas, Arkansas, and Indian Territory.

Alabama: Lower Pine region to Coast plain. Springy grassy banks, low wet thickets. Washington County, Yellow pine. Mobile County, Mon Louis Island. Flowers deep blue. June. One and one half to 2 feet high. From a turbinate tuberous thick spinclle-slıaped or cylindrical rootstock, over 6 inches in length. Rare.

Type locality: "Plains of Red River, Arkansas, Nuttall! Texas, Drummond!"

Herb. Geol. Surv. Herb. Mohr.

Psoralea canescens Michx. Fl. Bor. Am. 2:57. 1803.

Ell. Sk. 2 : 195. Chap. Fl. 92.

Louisianian area. Florida to North Carolina and Georgia.

Alabama: Lower Pine region. Dry gravelly pine barrens. Baldwin County, bluffs at Montrose. Flowers maize-yellow, May, June. Rootstock fusiform. Not frequent.

Type locality: "Hab. in Carolina et Georgia."

Herb. Geol. Surv. Herb, Mohr.

AMORPHA I. Sp. Pl. 2 : 713. 1753. FALSE INDIGO.

Eight species, shrubs, temperate North America.

Amorpha fruticosa L. Sp. Pl. 2:713. 1753.

Ell. Sk. 2:188. Gray, Man. ed. 6, 132. Chap. Fl.93. Conlter, Contr. Nat. Herb. $2: 76$.

Carolinian and Louisianian areas. Pennsylvania to Florida, west to Texas, Arkansas, Colorado, and Manitoba, near Lake IVinnipeg.

Alabama : Throughout the State. Damp shady bottom lands, low banks of streams. Flowers deep blue, April. May.

Type locality: "Hab. in Carolina."

Herb. Geol. Surv. Herb. Mohr.

Amorpha glabra Desf. Tabl. Hort. Par. 192. 1804.

Smooth Amorpha.

Torr. \& Gray, Fl. 1:305. Beadle, Bot. Gaz. $25: 279$.

Suffrutescent, perennial, 3 to $4 \frac{1}{2}$ inches high, nearly glabrous; stem slender, erect or ascending, leafy throughout, purplish and more or less verrucose; leaves 6 to 8 inches long and 1 to $1 \frac{1}{4}$ inches wide, with 12 to 20 pairs of oblong or elliptical petiolulate leaflets, apiculate by the excurrent midrib; spikes densely flowered, 6 to 8 inches long, panicled; flowers short-pedicelled; vexillum violet-blue, style hairy; calyx glinilular, more or less villons on the margins of the unequal divisions, pod oneseeded, about 3 lines long and 1 line wide, glandular-roughened, the dorsal suture straight. ${ }^{1}$

Lonisianian area. Coast of North Carolina to Florida.

Alabama: Coast plain, borders of swamps. Mobile County, West Fowl River; marshes of Mobile River. Flowers blue. May, June. Infrequent.

'Type locality not ascertained.

Amorpha virgata Small, Bull. Torr. Club, 21:17. 1894. Mountain False Indigo. Carolinian area. Mountains of Georgia.

Alabama: Mountain region. Rocky woods. Jackson County, wooded ridges at Gurley's, 1,200 feet. Clay County, Che-aw-ba Mountain, 2,000 to 2,400 feet. To all appearances not rare on the highest ranges. 
Type locality: "Northern and western slopes of Stone Mountain, Dekalb County, Ga."

Herb. Geol. Surv. Herb. Mohr.

PAROSELA Cav. Desc. 185. 1803.

(DALEA Willd.Sp. Pl. 3 :1336. 1801. Not P. Brown nor Gaert.)

Parosela dalea (L.) Britton, Mem. Torr. Club, 196. 1894.

Psoralea dalea L. Sp. Pl. 2 : 764. 1753.

Dalea alopecuroides Willd. Sp. Pl. 3 : 1336. 1803.

D. linnaea Michx. Fl. Bor. Am. 2 :57. 1803.

Ell. Sk. 2 : 195. Gray, Man. ed. 6, 132. Coulter, Contr. Nat. Herl. 2 : 77.

Mexico.

Alleghenian and Carolinian areas. Minnesota, Dakota, and Nebraska to the Rocky Mountains; Colorado, Illinois, and Missouri south to Arkansas and Texas.

Alabama: Fide Dr. Chapman. Has of late not been observed in the State. Annual.

Type locality: "Hab. in America."

Herb. Geol. Surv. Herb. Mohr.

KUHNISTERA Lam. Encycl. $3: 370.1789$.

(Petalostemon Michx. Fl. Bor. Am. 2 : 48. 1803.)

About 35 species, perennials, of temperate North Anerica, eastern and continental, mostly southern.

Kuhnistera candida (Willd.) Kuntze, Rev. Gen. Pl. 1: 192. 1891.

White-flowerei) Prairie Clover.

Dalea candida Willd. Sp. Pl. 3 : 1337. 1801.

Petalostemon candidus Michx.; Willd. Sp. Pl. 3:1337. 1801. As synonym.

Gray, Man. ed.6, 133. Chap. Fl. Suppl.615; ed.3, 101. Coulter, Contr. Nat. Herb. 2:79.

Mexico.

Alleghenian to Louisianian area. Prairie region thronghont the Mississippi Valley nor ${ }^{\prime}$ to Saskatchewan, Minnesota, Nebraska, south to Texas, Lonisiana, Kentucky, and Tennessee.

Al.abama: Central Prairie region. Dry prairies. Montgomery County, Prattville. Sunter and Pickens counties $(\mathscr{E}, A$. Smith). Flowers white, June. Not infrequent.

Type locality: "In Tennessee et in regione Illinoensi."

Herb. Geol. Surv. Herb. Mohr.

Kuhnistera gracilis (Nutt.) Kuntze, Rev. Gen. Pl. 1:192. 1891.

Petalostemon gracilis Nutt. Journ. Acad. Phila. 7: 92.1834.

Chap. Fl.93. Coulter, Contr. Nat. Herb. 2:79.

Louisianian area. Western Florida to Texas.

Alabama: Jower Pine region. Grassy pine barrens. Mobile County (Gates).

Baldwin County. "Flowers white; September, October. Frequent.

Type locality: "Lower part of Alabama and Florida."

Herb. Geol. Surv. Herb. Mohr.

Kuhnistera carnea (Michx.) Kuntze, Rev. Gen. Pl. I: 192. 1891.

Incarnate-Flowered Prairie Clover.

Petalostemon carneus Michx. Fl. Bor. Am. 2 : 49. 1803.

P.roseus Nutt. Am. Journ. Sci. ser. 1, $5: 298.1822$.

Louisianian area. Georgia and Florida.

Alabama : Lower Pine region. Sandy pine ridges. Henry County (E. A. Smith).

Flowers white. July. Not seen westward.

Type locality: "Hab. in Georgia et Florida."

Herb. Geol. Surv. Herb. Mohr.

Kuhnistera gattingeri Heller, Bull. Torr. Club, 23 : 121. 1896.

Carolinian area. Tennessee.

Gattinger's Prairie Clover.

Alabama: Tennessee Valley. Central Prairie region. Open grassy places on rocky calcareons soil. Franklin Connty, Russellville. Hale Connty, Gallion, in the

' A. A. Heller, Notes on Kuhnistera, Bull. Torr. Club, vol. 23, pp. 119 to 125. 1896. 
so-called bald prairies. June 20. Flowers bright rose-purple, or rather pink. Rare.

The plant from Russellville, with the spikes more lax and the ealyx with a longer shining silvery pubescence. An ornamental plant worthy of cultivation.

'Type locality: "About Nashville and Lavergne, Teun." Also collected "at Russellville, Ala."

Herb. Geol. Surv. Herb. Mohr.

Kuhnistera purpurea (Vent.) MacMillan, Metasp. Minn. Vall. 329. 1892.

Dalea purpurea Vent. Jard̄. Cels. t. 40. 1800.

Purple Prairie Clover.

Petalostemon violar eus Michx. Fl. Bor. Am. 2 : 50, t. 37, f. 2. 1803.

Gray, Man ed.6, 132. Coulter, Contr. Nat. Herb. 2 :79. Chap. Fl. ed. 3, 101.

Alleghenian to Lonisianian area. Canada; northwestern plains to Saskatchewan; Manitoba, Nebraska, Minnesota to Missouri, south from Tennessee to Arkansas and northwestern Texas.

Alabama: Prairie region. Autauga County. Adventive from the West $(E . A$. Smith, July, 1874). Sole locality known in the State.

Type locality not ascertaiued.

Herb. Geol. Surv. Herb. Mohr.

Kuhnistera pinnata (Walt.) Kuntze, Rev. Gen. Pl. 1:192. 1891.

Anonymos pinnata Walt. Fl. Car. 103.1788.

Pine-barren Prairie Clover.

Kuhnistera carolinensis Lam. Encycl. $3: 370.1789$.

Petalostemon corymbosus Michx. Fil. Bor. Am. 2:50. 1803.

Ell. Sk. $2: 176 . \quad$ Chap. Fl. 93.

Louisianian area. Florida through the coast region to North Carolina, west to Mississippi.

Alabama: Lower Pine region. Dry sandy pine barrens. Washington, Monroe, Bald win, and Mobile counties. Flowers white, July, September; fruit ripe October. Frequent.

Type locality: South Carolina.

Herb. Geol. Surv. Herb. Mohr.

INDIGOFERA L. Sp. Pl. 2 : 751. 1753.

Two hundred and twenty species, of tropical and subtropical regions, Asia, Central and South Afriea, Mexico, Sonth America. North America, 2.

Indigofera caroliniana Walt. Fl. Car. 187. 1788.

WILD INDIGO.

Ell. Sk. 2 :244. Chap. Fl. 96.

Lonisianian area. Coast of North Carolina to Florida, west to western Louisiana (Hale).

Alabama: Central Prairio region. Exposed sandy banks. Montgomery County, on Pentulalla Creek, July, 1880. Flowers yellowish brown, June. Infrequent.

Type locality : South Carolina.

Herb. Geol. Surv. Herb. Mohr.

Indigofera miniata Ort. Hort. Matr. Dee.98. 1797-1800.

VERMILION-FLOWERED INDIGO.

CUBA.

Ala bama: Fugitive on ballast. Mobile, September, 1892, with seed well matured.

Not ohserved since.

Type locality doubtless Cuban.

Herb. Geol. Surv. Herb. Mohr.

Indigofera tinctoria L. Sp. P1. 2 : 1061. 1753.

IND1GO.

Alabama: Molbile. An escape from the plantations of the earliest settlers.

'Type locality: "Hab. in India."

Herb. Geol. Surv.

CRACCA L. Sp. Pl. 2 : 752. 1753. Goat's RUe.'

(Tephrosia Pers. Syn. 2 :328. 1803.)

One liundred and twenty species; perennial herbs, mostly in warmer regions. Eastern Asia, tropical South Africa. West Indies, South Anerica. Eastern North America 14, mostly southern.

'Anna M. Vail, Review of North American Species of the Genus Cracea, Bull. Torr. Club, vol.22, pp. 25 to 36.1895. 
Cracca virginiana L. Sp. Pl. 2 : 752. 1753.

Common Goat's Rue.

Galega virginiana L. Sp. Pl. ed. 2, 2:1062. 1763.

Tephrosia virginiana Pers. Syn. 2 :329. 1807.

Ell. Sk. $2: 245$. Gray, Man. ed. 6, 133. Chap. Fl. 95.

Alleghenian to Lonisianian area. Sonthern Ontario; Michigan to southern Kansas, southward thronghout the region east of the Mississippi to the Gulf, west'to Louisiana and Arkansas.

Alabama: Over the State. Dry open woods. Flowers crean-color with pink, June. Common.

Type locality: "Hab. in Virginia, Canada."

Herb. Geol. Surv. Herb. Mohr.

Cracca onobrychoides (Nutt.) Kuntze, Rev. Gen. Pl. 1: 175. 1891.

SaInForn-like Goat's Rue.

Tephrosia onobrychoides Nutt. Journ. Acad. Phila. 7 : 104.1834.

Chap. Fl. Suppl. 615; ed. 3, 104.

Carolinian and Louisianian areas. Indian Territory, Arkansas, Texas, and Louisiana.

Alabama : Coast plain. Low grassy pine barrens. Mobile County, West Fowl

River. Flowers white, tinged with purple, July. Local and rare.

Type locality: "In the plains of Arkansas."

Herb. Geol. Surv. Herb. Molır.

Cracca spicata (Walt.) Kuntze, Rev. Gen. Pl. 1: 175. 1891.

Galega spicata Walt. Fl. Car. 188. 1788.

G. villosa Michx. Fl. Bor. Am. 2: 67. 1803.

Tephrosia spicata Torr. \& Gray, Fl. N. A. 1:296. 1838.

Ell. Sk. 2:246. Gray, Man. ed.6, 133. Chap. Fl. 95.

Carolinian and Louisianian areas. Delaware, eastern Virginia to Florida, west to Mississippi and Tennessee.

Alabama: Tennessee Valley to Coast plain. Dry open sandy woods. Clay County, Talladega Mountain, 1,800 feet. Cullman County, 800 feet. 'Tuscaloosa and Mobile counties. Flowers white, turning bright purple. June to August.

Type loeality: Sonth Carolina.

Herb. Geol. Surv. Herl, Mohr.

Cracca spicata flexuosa (Chap.) Vail, Bull. Torr. Club, 22: 30. 1895.

Smooth GoAt's RUe.

Tephrosia flexuosa Chap.; Torr. \& Gray, Fl. N. A. 1:297. 1838. As synonym. Louisianian area to Florida.

Alabama: Lower Pine region. Sandy pine barrens. Mobile County, Springhill. Flowers pale pink. July; rare.

Type locality: "Middle Florida, Dr. Chapman!"

Herb. Geol. Surv. Herb. Mohr.

Cracca smallii (Small)Vail, Bull. Torr. Club, 22:33. 1895. Small's Goat's Rul. Cracca intermedia Small. Bull. Torr. Club, 21:303. 1894. Not Tephrosia intermedia Graham.

Pubescent thronghout and somewhat viscid. Stem 18 to 24 inches long, spreading, branched from the base, flexuous, assurgent; stipules subulate, caducous; leaves oblong-ovate in outline; leaflets oblong-ovate, truneate at the apex; flowers solitary or geminate, remote.

Louisianian area. Georgia aud Florida.

Alabama : Lower Pine region. Barren pine ridges. Mobile Connty, Snringhill.

Flowers in June. Not infrequent. Low, from a thick woody root.

Type locality: "Dry and poor blackjack thickets abont Jacksonville, Fla."

Herb. Geol. Surv. Herb. Mohr.

Cracca hispidula (Michx.) Kuntze, Rev. Gen. Pl. 1:175. 1891.

Galega hispidula Michx. Fl. Bor. Aın. 2:68. 1803.

Hispidulous Goat's Ruk.

Tephrosia hispidula Pers. Syn. 2:329. 1807.

Ell. Sk. 2:245. Gray, Man. ed. 6, 133. Chap. Fl.95.

Carolinian and Lonisianian areas. Virginia along the low country to Florida, west to Mississippi.

Alabama: Lower Pine region. Coast plain. Dry and damp pine barrens. Mobile County. Flowers white to pink. June to - eptember; frequent. Root woody, cylindrical. 
Type locality: "Hab. in Virginia, Carolina et Georgia."

Herb. Geol. Surv. Herb. Mohr.

Cracca chrysophylla (Pursh) Kuntze, Rev. Gen. Pl. 1: 174. 1891.

Tephrosia chrysophylla Pursh, Fl. Am. Sept. 2 : 489. 1814.

Prostrate Goat's Rue.

T. prostrata Nutt. Gen. $2: 120.1818$.

Ell. Sk. $2: 246$. Chap. Fl. 95 .

Louisianian area. Georgia and Florida west to Louisiana.

Alabama: Lower Pine region. Sandy pine barrens. Mobile Connty. Baldwin

County, Stockton. Flowers white and purplish, July, September. Frequent.

Type locality: "In Georgia. Enslen."

Herb. Geol. Surv. Herb. Mohr.

Cracca cinerea (L.) Morong, Ann. N. Y. Acad. Sci. 7:79. 1892.

Galega cinerea L. Amoen. Acad. 5 : 403. 1759.

Cinereous Tephrosia.

Tephrosia cinerea Pers. Syn. 2:528. 1807.

From a stout ligneous root. Stems prostrate, diffuse or ascending, $1 \frac{1}{2}$ to 2 feet or more long, appressed cinereous pubescent, becoming glabrate with age; stipnles $\frac{1}{8}$ to $\frac{3}{8}$ inch long, subulate, acuminate, persisting; petioles $\frac{1}{8}$ to $\frac{1}{2}$ inch long; leaflets 16 or 17, linear-oblong, 1 to 2 inches long, $\frac{1}{8}$ to $\frac{8}{8}$ inch broad, obtuse or acnitish at the apex, glabrous above, cinereous, strigose, or pubescent beneath, becoming often glabrate with age; racemes 3 to $3 \frac{1}{2}$ inches long; flowers geminate or in clusters, scattered; bracts subulate or setaceons, persisting, legumen 1 to $1 \frac{1}{4}$ inches long, $\frac{1}{8}$ inch wide, spreading, cinereous-pubescent or glabrate, straight. (Vail, shortened.)

Griseb. Fl. Brit. W Ind. 182.

West Indies, Mrexico to Brazil, Montevideo.

Ala bama: Introduced with ballast. Mobile, first observed in 1886, established since near the shipping. Flowers white, with purple; May, June. Trailing stems 2 to 4 fert long. 1 ruit ripe in July.

Type locality: Jamaica.

Herb. Geol. Surv. Herb. Mohr.

KRAUNHIA Raf. Med. Rep. ser. 2, $5: 352.1808$. Wisteria Nutt. Gen. 2:115. 1818.

Four species, eastern Asia. South Atlantic North America, 1.

Kraunhia frutescens (L.) Greene, Pittonia, 2:175. 1891. American Wisteria. Glycine frutescens L. Sp. Pl. 2 : 753.1753.

Wisteria speciosa Nutt. Gen. 2 : 116. 1818.

W. frutescens Poir. Tabl. Encycl. 3 : 674. 1823.

Ell.Sk. 2:237. Gray, Man. ed. 6, 134. Chap. Fl.95. Conlter, Contr. Nat. Herb. 2:81.

Carolinian and Louisianian areas. Sonthern Virginia and Temnessee west to southern Indiana, Illinois, and Missouri, sonth to Texas, Lonisiana, and Florida to North Carolina.

Alabama: Central Prairie region to Coast plain. Swampy borders of woods. Wilcox County, Pineapple. Clarke County, Suggsville.(I)r. Denny). Mobile County. Flowers deep blue; May to July. Shrub climbing high trees. Most frequent in the coast plain.

Econonie uses: Ornamental.

Type locality: "Hab. in Carolina."

Herb. Geol. Surv. Herb. Mohr.

ROBINIA L. Sp. Pl. 2 : 722.1753.

Six species, temperate North America. Treos or shrubs.

Robinia pseudacacia L. Sp. PI. 2 : 722.1753.

BLACK LoCUST.

Ell. Sk. 2 :242. Gray, Man. ed.6, 134. Chap. Fl.94. Sargent, Silv. N. A. 3: 39, t. 112.

Carolinian and Lonisianian areas. From Penusylvania thronghout the Allegheny ranges to Georgia.

Ala bama: Mountain region. Rich woods, calcareous soil. Dekalb County, Lookout Mountain below Mentone, 1,500 feet; indigenous. In the lower country cultivated and widely disseminated in waste places. Flowers white; May.

Economic uses: Valuable for its wood. Ornamental shade tree.

Type locality: "Hab. in Virvinia."

Herb. Geol. Surv. Hẹlb. Mohr. 
Robinia viscosa Vent. Jard. Cels. t.4. 1800.

Ell. Sk. 2 :242. Gray, Man. ed.6, 134. Chap. Fl. 94.

Carolinian area. South Carolina, Georgia.

Ala Bama: Mountain region. Dry open woods. Dekalb County, Mentone. Flowers pale pink. Slender shrub, 3 to 4 feet high. Rare; only locality known in the State.

Type locality not ascertained.

Robinia hispida L. Mant. 1: 101. 1767.

Carolinian zone. Virginia along the Alleghenies to Georgia.

Alabaya: Mountain region. Metamorphic hills. Clay County, elevated ridges between Ironaton and Moseley, Che-aw-ha Mountain, 2,400 feet. Flowers rose-color. Shrub scarcely 5 feet high.

Economic uses: Planted for ormament.

Type locality: "Hab. in Carolina, Carthagena."

Herb. Geol. Surv. Herb. Mohr.

ASTRAGALUS I. Sp. Pl. 2 : 755. 1753.

About 1,200 to 1,300 species, herbs, ours perennial. Cooler and temperate continental regions, Asia. Norı America 150 to 200, mostly between the Mississippi and the Pacific coast. Atlantic region, 12.

Astragalus carolinianus L. Sp. Pl. 2 :757. 1753.

Carolina Milk Vetch.

Astragalus canadensis L. Sp. Pl. 2 : 757. 1753.

Ell. Sk. 2: 226. Gray, Man. ed. 6, 135. Chap. Fl.97.

Canadian zone to Carolinian area. Ontario and Quebec to Hudson Bay, west to Saskatchewan. Western New York to Minnesota, Nebraska, and Kansas, through Colorado to the interior basin, south to Chio, 'Tennessee, Virginia, and the mountains of South Carolina.

Alaisama: Tennessee Valley. Landerdale County, Florence (M. C. Wilson).

Flowers greenish white; May, Juue. Rare.

A glabrous form, tall, 3 to 4 feet high.

'Type locality of A. carolinianus: "Hab. in Carolina." Of $A$. canadensis: "Hab. in Virininia, Canada."

Herb. Geol. Surv. Herb. Mohr.

Astragalus villosus Michx. Fl. Bor. Am. 2:67. 1803.

Chap. Fl. 98.

Louisianian area. Georgia and Florida.

Alabama: J.ower Pine region. Dry sandy pine woods. Mobile and Baldwin counties. Flowers dingy cream color. March (12th). Not infrequent.

Type locality: "Hab. in Georgia."

Herb. Geol. Surv. Herb. Mohr.

Astragaius tennesseensis Gray in Chap. Fl. 98. 1860. Tennessek MrLk Vercir. Astragalus plattensis var. tennesseensis Gray, Proc. Am. Acarl. 6:103. 1864.

Gray, Man. ed. 6, 135. Chap. F'.98.

Carolinian area. Tennessee.

Alabava: 'Tennessee Valley. Reported from LaGrange (I'rofessor Hutch). Lallderdale Connty, Floreuce.

Type locality: "Hills near Nashville, Tennessee, Lesquereux, and Lagrange, Alabama, Professor Hatch."

Herb. Geol. Surv. Herb. Mohr.

GLOTTIDIUM Desv. Jouru. Bot. 1:119, 1.1. 1813.

One species, annual, South Atlantic North America.

Glottidium vesicarium (Jacq.) Desv. Journ. Bot. 119, t.1. 1813.

Robinia resicaria Jacq. Icon. 1:t.148. 1781.

Aeschynomene platycarpa Michx. Fl. Bor. Am. 2: 75. 1803.

Sesbania plalycarpa Pers. Ench. 2 :316. 1807.

Glottidium floridanum Desv. Journ. Bot. 1:119, t. 1. 1813.

Sesbania resicaria Ell. Sk. 2 : 222. 1824.

Ell. Sk. 1. c. Chap. Fl.97. Coulter, Contr. Nat. Herb. $2: 82$.

Louisianian area. South Carolina to Florida.

Ala BAMA: Coast plain. Low moist gromul, muddy borders of marshes. Mobile and Bald win. Flowers yellow to deep scarlet. July, Angust. Abundant along the borlers of Mobile River marshes.

Type locality not ascertained.

Herb, Geol. Surv, Herb, Mohr, 
SESBAN Adans. Fam. Pl. 2 : 327. 1763.

About 15 species, subtropical and tropical regions, mostly of the Northern Hemisphere; Asia, America. Southeastern North America, 1.

Sesban macrocarpum Muhl.; Ell. Sk. 2 :221. 1824.

Ell. 1. c. Chap. Fl.97. Coulter, Contr. Nat. Herb. 2 : 81.

Louisianian area. South Carolina to Florida, west to Texas.

Alabama: Upper Division Coast Pine belt to Coast plain. Low damp ground, margins of ponds. Flowers yellow, dotted with scarlet, June to August; fruit ripens September, October. Frequent. Abundant in tide-water districts.

A coarse tall weed not infrequently invading cultivated grouuds.

Type locality: "Grows around ponds. Not common. Paris Island."

Herl, Geol. Surv. Herb. Mohr.

Sesban occidentale Pers. Ench. $2: 316.1807$.

WEST INDIES.

A fugitive with ballast, Mobile. Observed once only in Octoler; killerl by frost before seeds ripened.

Herb. Geol. Surv.

DAUBENTONIA DC. Mém. Légum. 285. 1825.

Four species, tropical regions. Africa, Central America, Brazil.

Daubentonia longifolia (Cav.) DC. Mém. Légum. 285. 1825.

Aeschynomene longifolia Cav. Icon. $4: 8, t$. 315. 1797. Not Ortega.

Piscidia longifolia Willd. Sp. Pl. 3:920. 1800.

Sesbania cavanillesii Wats. Proc. Am. Acad. 17: 342. 1882.

Coulter, Contr. Nat. Herb. $2: 81$.

Mexico.

Adrentive along the Gulf coast. From western Texas to Mississippi (Biloxi, collected June, 1893) and Florida.

Alabama: Low places. Mobile, in a ditch beyoud the western suburbs. July, 1892 ; not observed since. Flowers bright yellow. Shrub 4 to 6 feet high Annual. Type locality: "Hab. in Nova-Hispania."

Herb. Geol. Surv. Herb. Mohr.

Daubentonia punicea (Cav.) DC. Mém. Légum. 286. 1825.

Piscidia punicea Cav. Icon. 4 : $t .316$.

Sesbania punicea Benth. ex Chap. Fl. ed. 3, 106. 1897.

Mrexico.

Texas to western Florida along the Gulf shore. Alventive or most probably escaped from cultivation. Observed copiously at Pensacola (July, 1878). Also at Apalachicola!

Alabama: Littoral region. Mobile County, low pine barrens. Dauphin Island, June, 1893. Flowers deep vermilion to carmine. Rare. Shrubby, 3 to 4 feet high. Type locality: "Hab. in America calidiore."

Herb. Geol. Surv. Herb. Mohr.

AESCHYNOMENE L. Sp. Pl. 2 : 713. 753. Sensitive Jointed Vé́ch.

About 55 species, tropical and subtropical regions both hemispheres, largely South America.

Aeschynomene virginica (L.) B. S. P. Prel. Cat. N. Y. 13. 1888.

Hispid Sensitive Jointed Vetch.

Hedysarum virginicum L. Sp. PI. 2 : 750. 1753.

Aeschynomene hispida Willd. Sp. Pl. 3 : 1163. 1803.

Ell. Sk. 2 :220. Gray, Man. ed. 6, 138. Chap. Fl.99.

Carolinian and Louisianian areas. Sontheastern Pennsylvania and tide-water region to Florida and Louisiana.

Alabama: Coast plain. Marshes. Mobile and Baldwin counties. Flowers yellow, August, September. Common. Perennial.

Type locality: "Hab. in Virginia."

Herb. Geol. Surv. Herb. Mohr.

Aeschynomene viscidula Michx. Fl. Bor. Am. 2 : 74. 1803.

Ell. Sk. $2: 220$. Chap $\cdot$ Fl. 39 .

Louisianian area, South Carolina to Florida, west to Mississippi (Horn Island). 
Alabama : Littoral region. Damp sandy soil. Mobile Connty, Danphin Islanil. July; very rare. Pereunial.

Type locality: "Hab. in areuosis insulae Cumberland et Floridae."

Herb. Geol. Surv. Herb. Mohr.

STYLOSANTHeS Sw. Prodr. Fl. Ind. Oce. 108. 1788. Penchl Fower.

About 25 species, tropical regions, West Indies, Mexico to Brazil, eastern Asia, Afriea. North America, 1.

Stylosanthes biflora (L.) B. S. P. Prel. Cat. N. Y.13. 1888.

Trifolium biflorum L. Sp. Pl. 2 : 773. 1753.

Stylosanthes elatior Sw. Svensk Acad. IIandl. 1789:296, t.11, f. 2. 1789.

S. hispida var. nudiuscula Michx. Fl. Bor. Am. 2: 75. 1803.

Ell. Sk. 2 :203. Gray, Man. ed. 6, 142. Chap. Fl. 100.

Northerv Mexico, South and West Africa.

Carolinian and Lonisianian areas. New York (Long Island), New Jersey, and West Virginia to sonthern Indiana, southern Illinois, Missouri, and Arkansas, south to the Gulf from Florida to Louisiana.

Alabama: Over the State. Dry light soil. Flowers yellow, June, July. Comwon; abundant in the pine barrens. Perennial.

Type looality: "Hab. in Virginia, Canada."

Herb. Geol. Surv. Herb. Mohr.

Stylosanthes biflora hispidissima (Michx.)

Hispid Pencil Flower.

Stylosanthes hispida var. hispidissima Michx. Fl. Bor. Am. 2:75. 1803.

A taller plant, stem over 2 feet long, assurgent, with elose appressed pubescence and hispid with long stiff spreading hairs; leaves, stipules, and calyx lobes hispictciliate.

Louisianian area.

Alabana: Lower Pine region. Coast plain. Dry sancly places. Mobile County (Gates). Flowers yellow. Perennial.

Type locality: "Hab. in Virginia et Carolina."

Herb. Geol. Surv. Herb. Mohr.

Stylosanthes riparia Kearney, Bull. Torr. Clıb, 24 : 565. 1897.

Decumbent Pencil Flower.

Perennial, with several stems from the strong woody root, decumbent, widely spreading, much branched; petioles pubescent, slightly exserted from the stipular sheath; stipules large, inflaterl, appressed-pubescent with two subulate aristate teeth. Leaves elliptical to cuneate-obovate, subspinescent-cuspidate. Spikelets of the inflorescence bracted, 1-flowered; prophyllum deeply lobed; loment strongly reticulated, gibbons with a strongly hooked beak.

Carolinian to Lonisianian area. Delaware, North Carolina, Florida.

Ala bama : Metamorphic hills. Dry sandy places. Lee County, Auburn (Baker of Earle, July, 1897). Dekalb County, Mentone. Local.

Type locality: "Banks of the French Broad River near Wolf Creek ['Teunessee]." Herb. Geol. Surv. Herb. Mohr.

ZORNIA Gmel. Syst. 2:1096. 1791.

Eleven species, warmer regions of both hemispheres, largely in tropical America to Brazil.

Zornia bracteata (Walt.) Gmel. Syst. 2 : 1096. 1791.

BRACTED ZORNiA.

Anonymus bracteata Walt. Fl. Car. 181. 1788.

Zornia tetraphylla Michx. Fl. Bor. Am. 2:76, t. 41. 1803.

Ell. Sk. 2:219. Chap. Fl. 100. Coulter, Contr. Nat. Herh. 2 : 85.

North Mexico, West and South Africa.

Caroliuian and Louisianian areas. Southern Virginia, North Carolina west to eastern Texas.

Alabama: Lower Pine region. Dry sandy pine barrens. Washington Connty. Monroe Connty, Claiborne. Baldwin and Mobile counties. Flowers yellow. July. Frequent. Perennial.

Type locality: South Carolina.

Herb. Geol. Surv. Herb. Mohr. 
MEIBOMIA Adans. Fam. Pl. $2: 509.1763 .{ }^{1}$ TICK TreForL.

(HedYSARUM L.Sp. Pl. 2 : 749. 1753. In part.)

(Desmodium Desv. Journ. Bot. ser. 2, 1: 122. 1813.)

About 160 species. Perenuial herbs; mostly of warm and temperate North and South America, Africa, and Australia. United States and Canada, 39.

Meibomia nudiflora (L.) Kuntze, Rev. Gen. Pl. 1:197. 1891.

Hedysarum nudiflorum L. Sp. Pl. 2 : 749. 1753.

Naked-stemmed Phavine.

Desnoodium nudiflorum DC. Prodr. 2: 330. 1825.

Ell. sk. 2: 209. Gray, Man. ed. 6, 138. Chap. Fl. 102.

Alleghenian to Louisianian area. Ontario, sonthern New England to Florida, west. rn Minnesota to Arkansas.

Alarana : All over the State. Shady woods. Clay County, 1,600 feet. Franklin County, Russellville. Cullman County. Bibb County, Pratt's Ferry. Autuuga County, Prattville. Moutgomery, Clarke, and Mobile counties. Flowers purplish white. July to August; nowhere alsundant.

Type locality: "Hab. in Virginia."

Herb. Geol. Surv. Herb. Mohr.

Meibomia grandiflora (Walt.)Kuntze, Rev. Gen. P1. 1: 196. 1891.

Hedysarum grandiflorum Walt. Fl. Car. 185. 1788.

Large-flowered Peavine.

H. acuminatum Michx. Fl. Bor. Am. 2: 72. 1803.

Desmodium acuminatum DC. Prodr. 2: 329. 1825.

Ell. Sk. 2: 209. Gray, Man. ed. 6, 139. Chap. Fl. 102.

Alleghenian to Louisianian area. Ontario; New England west to Minnesota and Nebraska, south to Florida, Louisiana, and Arkansas.

Alabama: Over the State. Rich woods. Franklin County, Russellville. Cullman and Bibb counties. Montgomery County, Pintlalla Creek. Mobile County. Flowers purplish, July, A ugust; not infrequent.

Type locality: South ('arolina.

Herb. Geol. Surv. Herb. Mohr.

Meibomia pauciflora (Nutt.) Kuntze, Rev. Gen. Pl. 1: 198. 1891.

Hedysarum pauciflorum Nutt. Gen. Pl. 2: 109. 1818.

Few-Flowered Peavine.

Desmodium pauciflorum DC. Prodr. 2 :330. 1825.

Gray, Man. ed. 6, 139. Chap. Fl. 101.

Alleghenian to Louisianian area. Southern Ontario; Pennsylvania to Michigau and Missonri, south to Arkansas, and from 'Tenuessee to Florida and Louisiana.

Alalsama: Central Prairie region. Rich shaded woods. Montgomery County, Pintlalla Creek. Flowers purplisl,, June, July; not frequent.

Type locality: "In the shady forests of Ohio, Kentucky, and Tennessee (common around Lexington, $\mathrm{Ky}$.)."

Herb. Geol. Surv. Herb. Mohr.

Meibomia arenicola Vail, Bull. Torr. Club, 23:140. 1896.

Striped Tick Trefoil.

Hedysarum lineatum Michx. Fl. Bor. Am. 2: 72. 1803. . Not L. 1759.

Desmodium lineatum D(;. Prodr. 2:330. 1825.

Meibonia lineata Kuntze, Rev. Gen. Pl. 1: 196. 1891.

Ell. Sk. 2:218. Gray, Man. ed. 6, 141. Chap. Fl. 104.

Carolinian area. Maryland and Virginia to Florida, west to Lonisiana.

Alabama: Mountain region. Metamorphic hills to Coast plain. Grassy pine woods. Lee County, Auburn (F.S. Earle), 860 feet. Mobile and Baldwin connties. Flowers purplish, Sentember, October; frequent. Perennial.

Type locality of Hedysarum lineatum Michx.: "Hab. in Carolina."

Herb. Geol. Surv. Herb. Mohr.

Meibomia michauxii Vail, Bull. Torr. Club, 23:140. 1896.

ROUND-Leaf TiCK T'ReFoil.

Hedysarum rotundifolium Michx. Fl. Bor. Am. 2:72. 1803. Not Vahl.

Desmodium rotundifolium DC. Prodr. $2: 330.1825$.

Meibomia rotundifolia Kuntze, Rev. Gen. Pl. 1:197. 1891.

'Anna M. Vail, A preliminary list of the species of the genus Meibomia Heist. occurring in the United States and British America, Bull. Torr. Club, vol. 19, pp. 107 to 118. 1892 . 
Ell. Sk. 2 :213. Gray, Man. ed. 6, 139. Chap. Fl. 103.

Alleghenian to Louisianian area. Ontario; Now England to Michigan and Missouri, sonth to Florida, Louisiana, and Arkansas.

Alabama: Over the State. Dry light soil, open woods. Flowers rose-color, August to October. Common, particularly in the pine barrens. Perennial.

A smoothish form, leaves etrongly reticulated and with elongated peduncles; occurs on rocky declivities of Alpine Mountain, Talladega County.

Type locality: "Hab. in Carolina."

Herb. Geol. Surv. Herb. Mohr.

Meibomia ochroleuca (M. A. Curtis) Kuntze, Rev. Gen. Pl. 1:198. 1891.

Desmodium ochroleucum M. A. Curtis; Canby, Proc. Acad. Phila. 1864 : 17. 1864.

Carolinian area.

Alabama : Mountain region. Open rocky woods. Dekalb County, brow of Lookout Mountain near Mentone. Flowers whitish, Augnst.

Type locality: "In au open woodland, one mile south of 'Public Landing' (on Chingoteague Bay), Worcester County, Md."

Meibomia glabella (Michx.) Kuntze, Rev. Gen. Pl. 1 : 198. 1891. Low Tick TreforL.

Hedysarum glabellum Michx. Fl. Bor. Am. 2:73. 1803.

Desmodium humifusum Beck, Bot. 86. 1833.

Ell. Sk. 2:211. Gray, Man. ed. 6, 139 . Chap. Fl. 103.

Alleghenian and Carolinian areas. North and South Carolina.

AlabAMA: Mountain region. Rocky woods. 'Ialladega County, rocky summit of Alpine Mountain near Renfroe, 1,600 feet, trailing over the sandstone cliffis. October; rare.

Agrees perfectly with Michanx's type.

Type locality : "Hab. in Carolina inferiore."

Herb. Geol. Surv. Herb. Mohr.

Meibomia stricta (Pursh) Kuntze, Rev. Gen. Pl. 1: 198. 1891. Erect Tick Trefoll. Hedysarum strictum Pursh, Fl. Am. Sept. 2:483. 1814.

Desmodium strictum DC. Prodr. 2 : 329. 1825.

Ell. Sk. 2:210. Gray, Man. ed. 6, 140. Chap. Fl. 103.

Carolinian and Louisianian areas. New Jersey to Florida, west to Louisiana and Arkansas.

Alabama : Central Pine belt to Lower Pine region. Autauga, Montgomery, Escan bia, Mobile, and Baldwin counties. Flowers purpiish, August, September; frequent, particularly in the pine forests.

Type locality: "In pine-woods of New Jersey."

Herb. Geol. Surv. Herb. Mohr.

Meibomia tenuifolia (Torr. \& Gray) Kuntze, Rev. Gen. Pl. I:198. 1891.

NARROW-LEAF TICK TREFOIL.

Desmodium tenuifolium Torr. \& Gray, Fl. N. A. 1:363. 1838.

Chap. Fl. 103.

Louisianian area. Florida to North Carolina, west to western Louisiana and Missouri.

Alabama: Central Prairie belt to Lower Pine region. Dry sandy pine barrens. Wilcox County (Buckley). Washington, Baldwin, and Mobile counties. Flowers purplish, September, October; frequent.

Type locality: "In sharly sandy places, Wilmington, N. C., Mr. Curtis! Florida, Dr. Chapman! Alabama, Mi. Buckley! Westorn Lonisiana, Dr. Hale!"

Herb. Geol. Surv. Herb. Mohr.

Meibomia canescens (L.) Kuntze, Rev. Gen. Pl. 1 : 195. 1891. Hoary Tick Treroil.

Hedysarum canescens L. Sp. Pl. 2: 748. 1753.

H. viridiflorum Willd. Sp. Pl. 3:1192. Not L.

H. scaberrimum Ell. Sk. 2 : 217. 1824.

Desmodium canescens DC. Prodr. 2:328. 1825.

Ell. Sk. 1. c. Gray, Man. ed. 6, 139. Chap. Fl. 102.

Alleghenian to Carolinian area. Ontario; New England (Vermont) west to Min. nesota and Nebraska, south to eastern Texas, and from New York to Florida and Arkansas.

Alabama: Tennessee Valley to Coast plain. Shaded borders of woods. Clay Connty, Shinbone Valley, 1,000 feet. Franklin County, Russellville. Talladega. and Mobile connties. Flowers deep rose-color, Augnst, September.

Type locality: "Hal). in Virginia, Canada."

Herb. Geol. Surv. Herb. Mohr. 
Meibomia bracteosa (Michx.) Kuntze, Rev. Gen. Pl. 1: 195. 1891.

Hedysarum bracteosum Michx. Fl. Bor. Ain. 2 : 73. 1803.

BRACTED TICK TREFoIL.

H. cuspidatum Muhl.; Willd. Sp. Pl. 3 : 1198. 1801.

Desmodium bracteosum DC. Prodr. 2 : 329. 1825.

D. cuspidatum Hook. Comp. Bot. Mag. 1:23. 1835.

Ell. Sk. 2 :213. Gray, Man. ed.6,139. Chap. Fl. 102.

Alleghenian to Carolinian area. Ontario and New England west to Michigan and Missouri, south to Texas; New York to Florida.

Alabama : Coosa Valley. Barren hillsides. Calhom Comnty, Anniston. Flowers violet purple, September. Rare; never observed in the low country.

Type locality : "Hab. in montosis Virginiae et Carolinae."

Herb. Geol. Surv. Herb. Mohr.

Meibomia longifolia (Torr. \& Gray) Vail, Bull. Torr. Club, 23:140. 1896.

Desmodium canadense var. longifolium Torr. \& Gray, Fl. N. A. 1 : 365.1840

D. longifolium Nutt.; Torr. \& Gray, Fl. N. A. 1:365. 1840. As synonym.

Carolinian area. Illinois to Kansas aud Arkansas; Louisiana.

Alabama : Mountain region. Woods. Dekalb County, Lookont Mountain near the mineral spriug of Loring's Hotel. Flowers rose purple, Angust 26, 1898.

Type locality: "Arkansas, Nuttall! Dr. Pitcher!"

Meibomia paniculata (L.) Knntze, Rev. Gen. Pl. 1: 198. 1891.

TiCK Trefoil.

Hedysarum paniculatum L. Sp. Pl. 2 : 749. 1753.

Desmodium paniculatum DC. Prodr. 2:329. 1825.

2: 85 .

Ell. Sk. 2: 210. Gray, Man. ed. 6, 140. Chap. Fl. 103. Coulter, Contr. Nat. Herb.

Alleghenian to Louisianian area. Ontario; New England west to the Dakotas and Nebraska, south to Texas, and from New York to Florida.

Alabama: Over the State. Dry woods. Flowers purplish, July, September.

Common. Perennial.

Type locality : "Hab. in Virginia."

Herb. Geol. Surv. Herb. Mohr.

Meibomia viridiflora (L.) Kuntze, Rev. Gen. Pl. 1 : 197. 1891.

Hedysarum viridiflorum L. Sp. Pl. 2 : 748. 1753.

GREENISH-FLOWERED' TICK TREHOIL.

Desmodium viridiflorum Beck, Bot.84. 1833. Not DC.

Ell. Sk. 2:217. Gray, Man. ed.6, 140. Chap. Fl. 102.

Carolinian and Lonisianian areas. Sonthern New York, Ohio to Missouri, sontl to Florida and western Louisiana.

Alabama : Mobile (Gates); not yet recorded in the State from any other locality 'Type locality : "Hab. in Virginia."

Herb. Geol. Surv. Herb. Mohr.

Meibomia dillenii (Darl.) Kuntze, Rev. Gen. Pl. 1 : 195. 1891.

Desmodium dillenii Darlington, Fl. Cest.414. 1837.

Dillenius' TICK TReFoll.

Gray, Man. ed. 6, 140. Chap. Fl. 10:3.

Alleghenian to Lonisianian area. Ontario; New England, west to Minnesota,

Nebraska, and Missouri, south to Florida and Louisiana.

Alabama : Over the State. Dry woods and copses. Tennessee Valley to Mobile County. Flowers purple, July, Angust. Common.

Pa.

Type locality: "Woodlands and borders of thickets: frequent." Chester County,

Herb. Geol. Surv. Herb. Mohr.

Meibomia laevigata (Nutt.) Kuntze, Rev. Gen. Pl. 1:198. 1891.

Hedysarum laevigatum Nutt. Gen. 2 : 109. 1818.

Smooti Trck Trefoll.

Desmodium laevigatum DC. Prodr. 2 : 329. 1825.

Ell. Sk. 2:215. Gray, Man.ed. 6, 140. Chap. Fl. 103.

Carolinian area. Southern New York, Tennessee, Missouri, and Arkansas; from South Carolina to Florida.

AlabaMa : Mountain region. Dry wooded hillsides. Lee County, Auburn (F.S. Earle). Talladega County, Chandler Springs, rocky ridges, 1,200 feet. Summit of highest ridge, Alpine Mountains, near the Signal Station, 1,800 feet. Flowers purplish, September.

Type locality: "In the forests of New Jersey."

Herb. Geol. Surv. Herb. Mohr. 
Meibomia rhombifolia (Ell.) Vail, Bull. Torr. Club, $19: 113.1892$.

Hedysarum rhombifolium Ell. Sk. 2 : 216. 1824.

Desmodium rhombifolium DC. Prodr. $2: 330.1825$.

D. floridanum Chap. Fl.102. 1860.

Meibomia floridana Kuntze, Rev. Gen. Pl. 1 : 198. 1891.

Ell. Sk. 1. c. Chap. Fl. l.c. Britt. \& Br. Ill. Fl. 2 : 318.

Carolinian and Lonisianian areas. Virginia to Florida, west to Lonisiana.

Alabama: Mountain region. Open woods in sandy and gravelly soil. Dekalb County, Mentone. Flowers rose-purple, September.

Type locality: "Grows in dry soils about Beanfort," S. C.

Meibomia rigida (Ell.) Kuntze, Rev. Gen. Pl. 1 : 198. 1891.

RigID 'TICK TreFoll.

Hedysarum rigidum Ell. Sk. 2 :215. 1824.

Desmodium rigidum 1C. Prodr. $2: 330.1825$.

Ell. Sk. 1.c. Gray, Man. ed. 6, 140. Chap. Fl. 104.

Alleghenian and Louisianian areas. Massachusetts, west to Illinois and Missonri, south to Florida.

Alabama: Mountain region to Central Prairies. Dry copses, open woods. Calhoun County, Anniston. Tallarlega and Montgomery connties. Monroe County, Claiborne (E. A. Smith). Most frequent on the rocky barren ridges of the Coosa Valley. Type loeality: "Grows in dry soils," South Carolina, Georgia.

Herb. Geol. Surv. Herb. Mohr.

Meibomia obtusa (Muhl.) Vail, Bull. Torr. Clnb, 19:115. 1892.

Ciliath-leaf Trck Trefoil.

Hedysarum obtusum Muhl.; Willd. Sp. Pl. 3 : 1190. 1803.

H. ciliare Muhl.; Willd. Sp. Pl. 3:1196. 1803.

Desmodium ciliare DC. Prodr. 2:329. 1825.

Ell. Sk. 2:212. Gray, Man. ed.6, 140. Chap. Fl. 104.

Mexico.

Alleghenian to Louisianian area. Southern Ontario; sonthern New York and West Virginia to Illinois, Missouri, and Arkansas, sonth to the Gulf; from Florida to western Louisiana.

Alabama: Over the State. Dry barren hillsides, copses, copious in the cherty hills, siliceous Metamorphic ridges of the Coosa, and the sandy pine barrens to the coast. Flowers purplish, September, October. Not rare.

Type locality: "Hab. in Pensylvania."

Herb. Geol. Surv. Herb. Mohr.

Meibomia maryłandica (L.) Kuntze, Rev. Gen. Pl. 1 : 198. 1891.

Hedysarum marylandicum L. Sp. P1. 2 : 748. 1753.

ilaryLand Tick Treroll.

H. obtusum Pursh, Fl. Am. Sept. 2: 482. 1814. Not Muhl.

Desmodium marylandicun Boott in Darl. Fl. Cest. ed.2,412. 1837. Not DC.

Ell. Sk. 2 :214. Gray, Man. ed. 6, 140. Chap. Fl.104.

Alleghenian to Louisianian area. New England west to Michigan; Ohio Valley to Missonri and Arkansas, south to western Florida and eastern Louisiana.

Alabama: Mountain region. Coosa Valley. 'Talladega County, Chandler's Spring, 1,200 feet. Calhoun County, Anniston, rocky hills, 800 feet. Flowers purplish, August, September. Not rare.

'Type locality: "Hab. in Carolina, Virginia."

Herb. Geol. Surv. Herb. Mohr.

LESPEDEZA Michx. Fl. Bor. Am. 2 :70, 1803. ${ }^{1}$

Abont 35 species, mostly perennial herbs, of the warmer temperate regions of eastern Asia. North America 12, mostly Atlantic.

Lespedeza repens (L.) Bart. Prodr. Fl. Phila. 2 : 77, 1818. Creering Lespedeza.

Hedysarum repens L. Sp. Pl. 2 : 749. 1753.

Lespedeza prostrata Ell. Sk. 2:208. 1824.

Ell. Sk. 1. e. Gray, Man. ed.6, 141, in part. Chap. Fl.100, in part.

Alleghenian to Louisianian area. Southern New lingland, New York, and New Jersey, west to Minnesota, south to Virginia and Florida, the Ohio Valley, and Texas.

${ }^{1}$ N. L. Britton, The North American species of the genus Lespedeza, Trans. N.Y. Acad. Sci., vol. 12, pp. 57 to 68.1893. 
Alabama: Undoubtedly diffused over the State, confounded with the following. So far collected only in the Lower Pine region, in dry sandy places, where it is common. Washington County, Yellowpine. Mobile. Flowers purplish, June, July. Frequent.

Type loeality: "Hab. in Virginia."

Herb. Geol. Surv. Herb. Mohr.

Lespedeza procumbens Michx. Fl. Bor. Am. 2:70. 1803. Trailing Lespedeza. Ell. Sk. 2:207. Gray, Man. ed. 6, 141, in part. Chap. Fl. 100, in part. Conlter, Contr. Nat. Herb. 2 : 86, in part.

Alleghenian to Louisianian area. Massachusetts to Florida, west to Missonri, Arkansas, and Lonisiana.

Alabama: Tennessee Valley to Coast plain. Coosa hills. Dry places, borders of fields. Lawrence County, Mountain Home. Talladega County, near Alpine Station.

Dekalb Connty, Lookont Mountain. Molile County. Flowers rose-color, September. Type locality: "Hab. in Virginia et Carolina."

Herb. Geol. Surv. Herb. Mohr.

Lespedeza nuttallii Darlington, Fl. Cest. ed.2, 420.' 1837.

Nuttali's Busie Clover.

Lespedeza virgata Nutt.; Torr. \& Gray, Fl. N. A. 1:368. 1840. Not DC.

L. stuvei var. $\gamma$ Torr. \& Gray, Fl. N. A. I: 368. 1840.

Alleghenian and Carolinian areas. New England to Michigan and Kansas.

Arabama: Mountain region. Talladega County, dry cherty hills about Renfroe, 800 feet altitude, October 14. Dekalb County, Lookont Mountain. Rare.

Type locality: "Dry hills; Mica slate range," Chester County, Pa.

Herb. Geol. Surv. Herb. Mohr.

Lespedeza violacea (L.) Pers. Syn. 2 :318. 1807.

Hedysarum violaceum L. Sp. Pl. 2 : 749. 1753.

Gray, Man. ed.6,141. Chap. Fl. ed. 3,110.

Mexico.

Alleghenian to Louisianian area. New England to Florida, west to Minnesota, Kansas, and Louisiana.

Alabama: Mountain region, open woods and copses. Dekalb County, near Mentone, 1,600 to 1,800 feet altitude. ll lowers pale pink, September. Not rare.

'Type locality: "Hab. in Virginia."

Lespedeza stuvei angustifolia Britton, Trans. N. Y. Acad. Sci. 12:63. 1893.

Carolinian area. New Jersey and southern Pennsylvania to Missouri, south to North Carolina and Texas.

Ala Bama : Mountain region. Dry calcareous hills. Madison County, Montesano, 1,200 feet altitude. Flowers, August. Rare.

Type locality: "New Jersey and southern Pennsylvania, to North Carolina, Missouri, and 'Texas."

Herb. Mohr.

Lespedeza frutescens (L.) Britton, Mem. Torr. Club, 5 : 205. 1894. Not Ell.

Hedysarum frutescens L. Sp. Pl. 1: 748. 1753.

Bush Clover.

Lespedeza stuvei intermedia Wats. in Gray, Man. ed. 6, 141. 1890.

Gray, Man. l. c.

Alleghenian to Louisianian area. New England west to Michigan, south to Illinois, Arkansas, Texas, and Florida.

Alabama: Monntain region. Rocky woods. Talladega County, Alpine Mountains near Renfroe, 800 feet, October. Apparently rare, only a single specimen collected.

Type locality: "Hab. in Virginia."

Herb. Mohr.

Lespedeza virginica (L.) Britton, Trans. N. Y. Acad. Sci. 12 : 64. 1893.

Medicago virginica L. Sp. P1. 2 : 778. 1753.

Virginian Bush Clover.

Hedysarum reticulatum Muhl.; Willd. Sp. Pl. 3 :1194. 1803.

Lespedeza sessiliflora Michx. Fl. Bor. Am. 2 :70. 1803.

L. reticulata Pers. Syn. 2:318. 1807 .

L. violacea var. angustifolia Torr. \& Gray, Fl. N. A. 1:367. 1840.

Ell. Sk. 2:204. Gray, Man. ed. 6, 141. Chap. Fl.101. 
Alleghenian to Louisianiau area. Ontario; Now England west to Minnesota, south to the Ohio Valley, Missouri, and Arkansas; from New York to Florida and through the Gulf States to Louisiana.

Alabana: Tennessee Valley to the Lower Pine region. Dry sandy or gravelly copses. Madison and Clay counties. Talladega Mountains, near Elders, 2,000 feet. Lee County, Auburn. Madison County, Huntsville, 650 feet. Cullman County, 800 feet. Calhoun County, Anniston. Walker County, Dent (E. A. Smith). Clarke Connty. Mobile County, Springhill. Flowers purple, July to September. Frequent. Type locality: "Hab. in Virginia."

Herb. Geol. Surv. Herb. Mohr.

Lespedeza hirta (L.) Ell. Sk. 2 :207. 1824.

Bush Clover. Bristly-halrei) Bush Clover.

Hedysarum hirtum L. Sp. Pl. 2 : 748. 1753.

Lespedeza polystachya Michx. Fl. Bor. Am. 2:71, t. 40. 1803.

Ell. Sk.1. c. Gray, Man. ed. 6, 141. Chap. Fl.101.

Alleghenian to Louisianian area. Ontario and New England west to Minnesota, south to Arkansas, and from New York to Florida and through the Gulf States to Louisiana.

Alabama: Throughout. Dry barren soil, copses, worn-out fields. Flowers yellowish white, July, August. Common.

Type locality: "Hab. in Virginia."

Herb. Geol. Surv. Herb. Mohr.

Lespedeza capitata Michx. Fl. Bor. Am. 2 :71. 1803.

White Bush Clover.

Hedysarum frutescens Willd. Sp. Pl. $3: 1193$. 1803. Not L.

Lespedeza frutescens Ell. Sk. 2 : 206. 1824.

Ell. 1. c. Gray, Man. ed.6,142. Chap. Fl.101.

Alleghenian to Lonisianian area. Ontario; Vermont west to Minuesotal and

Nebraska, south to Arkansas; from New York south to Florida and Louisiana.

Alabama: Throughout same localities as last. Dry open fields and copses.

Flowers white, June, september. Frequent. Perennial.

Type locality: "Hab. in Virginia et Carolina."

Herb. Geol. Surv. Herb. Mohr.

Lespedeza striata (Thunb. ) Hook. \& Arn. Bot. Beech. 226. 1841.

Hedysarum striatum Thunb. Fl. Japon. 289. 1784.

Lespedeza. Japanese Clover.

ChiNa, JAPAN.

Carolinian and Louisianian areas.

Adventive from eastern Asia and during the past thirty years extensively and copiously spread over the Southern States from Maryland to the Gulf and southern Arkansas.

AlabaMa ; All over the State. In dry uplands. Flowers purplish, blooming and ripening the seeds thronghout the summer. First observed in Montgomery County, 1867, Mobile County, 1869. Of greatest thrift and abundance in the calcareous soils of the prairie region. Annual.

Economic uses: Fodder plant, important for pasture and as spontaneous hay crop. Type locality: Japanese; not specifically given.

Herb. Geol. Surv. Herb. Mohr.

VICIA L.Sp. Pl. 734. 1753. VetCh.

About 120 species, climbing herbs, temperate regions Northern Hemisphere. North America, 11 or 12.

Vicia acutifolia Ell. Sk. 2 : 225. 1824.

Acute-leaved Vetch.

Ell. Sk. 1. c. Chap. Fl. 98.

Louisianian area. Georgia and middle Florida.

Alabama: Coast plain. Grassy banks. Mobile County. Flowers pearl blue,

May. Not frequent. Perennial.

Type locality: "Grows in Seriven county, Ga."

Herb. Geol. Surv. Herb. Mohr.

Vicia micrantha Nutt.; Torr. \&. Gray, Fl. N. A. 1:271. 1838.

Chap. F1.98. Coulter, Contr. Nat. Herb. $2: 86$.

SMALI,-FLOWERED VeTCH.

Carolinian and Louisianian areas. Tennessee, Arkansas, Texas and western Loni-

wiana to western Florida. 
Arabava: Mountain region. Lower Metamorphic hills. Central Prairie region, limestone hills. Lee County, Auburn (Baker \& Earle, 134). Wileox County (Buckley). Flowers pearl blue, April. Rare. Annual.

Type locality: "Prairies and woods of Arkansas, Nuttall! Louisiana and Texas, Dr. Leavenworth! on the Red River, Dr. Hale!"

Herb. Geol. Surv. Herb. Mohr.

Vicia caroliniana Walt. Fl. Car. 182. 1788.

WHITE-FLOWERED VETCH.

Vicia parviflora Michx. Fl. Bor. Am. 2 : 69. 1803.

Ell. Sk. 2 :224. Gray, Man.ed. 6, 143. Chap. Fl. 98.

Alleghenian to Lonisianian area. Ontario; New York west to Minnesota, Missouri, and Arkansas, south from New York to western Virginia, eastern Tennessce, and Georgia.

AlabaMa: Mountain region to Coast plain. Cullman County, 800 feet. Winstou and Blount counties. Tusealoosa County (E.A. smith). Mobilo County, Chunchulia. Flowers white; April. Not infrequent. Perennial.

Type locality: South Carolina.

Herb. Geol. Surv. Herb. Mohr.

Vicia ludoviciana Nutt.; Torr. \& Gray, F1. N. A. 1:271. 1840.

Louisiana Vetch. Deer Pea.

Chap. Fl. Suppl.616; ed. 3, 107. Coulter, Contr. Nat. Herb. 2 : 87.

Louisianian area. Texas, Louisiana, and Mississippi.

Arabama : Coast plain. Low grassy places. Rich damp soil. Mobile County, West Fowl River. Flowers azure; April. Not frequent. Annual.

Type locality: "Grassy places on the Red River, and in 'Texas, Dr. Iearenvorth! 'In Lonisiana, Mr. Tainturier,' Nuttall."

Herb. Geol. Surv. Herb. Molir.

Vicia hugeri Small, Bull. Torr. Club, 24:490. 1897.

HugER's Vetch.

Slender, bright green, minutely pubescent or glabrate in age; ascendingdecumbent, more or less angled; leaves 2 to $2 \frac{1}{2}$ inches long, short-petioled, leatlets 10 to 12 , linear, $\frac{1}{2}$ to $\frac{7}{8}$ inch long, with short petiolules; pednncles 2 to 3 inches long in secund racemes, 10 to 14 flowered ; flowers small, white or pinkish, searcely $\frac{1}{4}$ inch long, calyx teeth triangular about $\frac{1}{3}$ as long as the tube, pods linear-oblong, inch long.

Carolinian area. Georgia.

Alabama : Metamorphic hills. Open woods. Lee County, Auburn, Mareh, April, 1896, 1897 (Underwood \& Eurle).

Type locality : "In open woods, Georgia and Alabama."

Herb. Geol. Surv. Herb. Mohr.

Vicia tetrasperma (L.) Moench, Meth. 148. 1794.

Wild Lentil.

Ercum tetraspermum L. Sp. Pl. 2 : 738.1753.

EUROpE.

Alabama: Adventive with ballast. Mobile, May, 1879; not found since. Annnal. 'Type locality: "Hab. inter Europae segetes."

Herb. Geol. Surv. Herb. Mohr.

Vicia hirsuta (L.) Koch, Syn. Fl. Germ. Helv. 191. 1837.

Hairy Vetch.

Ervum hirsutum L. Sp. Pl. 2: 738.1753.

Vicia mitchellii Raf. Prec. Decour. 37. 1814.

Evrope.

Carolinian area. Naturalized coast of New England to New Jersey. Annual.

Alabama: Adventive with ballast. Mobile, 1869.

Type locality: "Hab. in Europae agris."

Herb. Geol. Surr. Herb. Mohr.

Vicia sativa L. Sp. Pl. 2 : 736. 1753.

Ell. Sk. 2 :224. Gray, Man. ed. 6, 143. Chap.Fl. 18.

EUROPE.

Alleghenian and Carolinian areas. Introduced and cscaped from cultivation. Naturalized in many localities from New England to the Giulf:

Alabama : Fully established locally. Borders of fields, waste and cultivated places. Tuscaloosa, Montgomery, and Mobile counties. Flowers March, April. Annual.

'Type locality : "Hab. inter Europae segetes hodie."

Herb. Geol. Surv. Herb. Mohr. 
CICER L. Sp. PI. 2 : 738.1753.

Cicer arietinum L.:Sp. Pl. 2: 738. 1753.

Comnon Chick Pea.

SoUTh EUROPE.

Adventive on ballast. Mobile, June, 1888. Anunal.

Economic uses: 'The seeds are userl for food.

'Type locality: "Hab. inter Hispaniae, Italiao segetes."

Herb. Geol. Surv.

\section{LATHYRUS L. Sp. Pl. 2 : 729. 1753. Everlasting Pea.}

About 100 species, chiefly perennials, Northern Hemisphere. Europe, northern Asia. North America, 15.

Lathyrus venosus Muhl.; Willd. Sp. Pl. 3 : 1092. 1803.

Gray, Man. ed. 6, 143. Chap. Fl.99.

Canadian zone to Carolinian area. British North America, Lake Superior region to latitude $50^{\circ}$, anil across the continent to Washington; New York, west to Minnesota, Kansas, and Colorado; New Jersey to the Ohio V:lley, and along the mountains to Georgia.

Alabama: Mountain region. Dry woods. Cullman County. Flowers purple;

June. Not frequent. Perennial.

Tvpe locality: "Hab. in Pensylvania."

Herb. Geol. Surr. Herb. Mohr.

BRADBURYA Raf. Fl. Lud.104. 1817.

(Centroseva Benth. Ann. Wien. Mus. 2 :117. 1838.)

Thirty species, tropical America. Sontheastern North Ameriea, 1.

Bradburya virginiana (L.) Kuntze, Rev. Gen. Pl. 1:164. 1891.

Clitoria rirginiana L. Sp. Pl. 2: 753. 1753.

Virginian Buttehliy Pea.

Centrosema virginiana Benth. Ann. Wien. Mus. 2: 120. 1838.

$2: 87$.

Ell. Sk. 2:240. Gray, Man. ed. 6, 145. Chap. Fl. 107. Conlter, Contr. Nat. Herb.

West Indies, Mexico to Brazil.

Carolinian and Louisianian areas. Maryland, through the low country to Florida, west to Texas and Arkansas.

Alabama: Central Pine belt to Coast plain. Dry copses, loorders of woods and fields. Tuscaloosa Connty (E.A.Smith). Antanga ('ounty. Wishington County, Yellowpine. Mobile Connty. Flowers purplish; June, August. Not infrequent, particularly in the pine barrens. Perennial.

Type locality: "Hab. in Virginia."

Herb. Geol. Surv. Herb. Mohr.

Clitoria L.Sp. Pl. 2 : 753. 1753. Butterfly Pea.

About thirty species, warmer regions of both hemispheres exclusive of Enrope. North America, 1.

Clitoria mariana L. Sp. Pl. 2 : 753. 1753.

Maryland Butterfly Pea.

Ell.Sk. 2:241. Gray, Man. ed. 6, 146. Chap. Fl. 107. Coulter, Contr. Nat. Herb. $2: 88$.

Carolinian and Louisianian areas. New York and New Jersey to Florida, west to Texas, Arkansas, and sonthern Missouri.

A rabama: Temessee Valley to Coast plain. Open woods, dry copses. Lauderdale County. Clay County, Shinbone Valley, 1,000 feet. Cullman County. Shelly County. Clarke and Mobile counties. Flowers aznre; May to July. Frequent, most so in central and lower districts. Perennial.

Type locality : "Hab. in America septentrionali."

Herb. Geol. Surv. Herb. Mohr.

FALCATA Gmel. Syst. $2: 1131.1796$.

Amphicarpa Ell. Jonrn. Acad. Phila, 1:372. 1817.

Fifteen species, Japau, Himalayan India, North and South America.

Falcata comosa (L.) Kuntze, Rev. Gen. Pl. 1 : 182. 1891.

Hog Peanut.

Glycine comosa L. Sp. Pl. 2 : 754. 1753.

Glycine monoica L. Sp. Pl. ed. 2, 2: 1023. 1763. 
Amphicarpa monoica Ell. Jonrn. Acall. Phila. 1 : 373. 1817.

Ell. Sk. 2:232. Gray, Man. ed. 6, 146. Chap. Fl. 107. Britt. \& Br. Ill. Fl. 2 : 235.

Alleghenian to Lonisianian area. New Brunswick to Manitoba; New England west to Nebraska and Kansas, south to Florida, west to Arkansas.

Alabama: Mountain region, damp thickets. Dekalb County, Mentone. Flowers white, September. Not common.

Type locality: "Hab. in Virginiae madidis umbrosis."

Herb. Geol. Surv. Herb. Mohr.

Falcata pitcheri (Torr. \& Gray) Kuntze, Rev, Gen. Pl. 1:182. 1891.

Pitcher's Hog Peanut.

Amphicarpaea pitcheri Torr. \& Gray, Fl. N. A. 1:292. 1838.

Gray, Man. ed.6, 146. Britt. \& Br. Ill. Fl. 2: 235.

Carolinian and Lonisıanian areas. Indiana, north Louisiana, and east Texas.

Alabama: Metamorphic hills. Cleburne County (Dr. E. A. Smith). August; rare.

Our specimens differ from the plant west of the Mississippi in their more slender and less densely hirsute stems, smaller and thinner leaflets, and closer racemes approaching the last.

'Type locality: "Red River, Arkansas, Dr. Pitcher!"

APIOS Moench, Meth. 165. 1794.

Five species. Japan, China, Himalayan India, Eastern North America.

Apios apios (L.) MacMillan, Bull. Torr. Club, 19:15. 1892.

Groundnut.

Glycine apios L. Sp. Pl. 2 : 753. 1753.

A pios tuberosa Moench, Meth. 165. 1794.

Ell. Sk. 2:232. Gray, Man. edl.6, 144. Chap. Fl.105.

Alleghenian to Lonisianian area. New Brunswick, Quebec, Ontario; southern New England west to Dakota, Missouri, Kansas, and Nebraska, south from New York to Ohio Valley, Florida, and the eastern Gulf States; Louisiana to Arkansas.

Alabama: Mountain region to Coast plain. Low damp thickets, borders of woods. Clay County, Shinbone Valley, 1,000 feet. Cullman County. Winston County, Colliers Creek, 1,200 feet. Madison County, Montesano. Mobile County, river swamp. Flowers blue; July to September. Frequent. Perennial.

Type locality: "Hab. in Virginia."

Herb. Geol. Surv. Herb. Mohr.

ERYTHRINA L.Sp. Pl. 2 : 706. 1753.

About 30 species, tropical and subtropical regions both hemispheres, largely of tropical America. Atlantic North America, 1.

Erythrina herbacea L. Sp. Pl. 2 : 706. 1753.

Coral Plant.

Ell. Sk. 2:190. Chap. Fl. 107.

Louisianian area. South Carolina to Florida, west to Mississippi.

Alabani. Lower Pine region to Coast plaiu. In dry close soil. Margin of woods, copses. Clarke County $(E . A$. Smith). Escambia Connty, Flomaton. Washington County, Yellowpine. Mobile County. Flowers carmine, May; frnit ripe September, seeds scarlet. Not infrequent thronghout the Coast Pine belt. Pereunial from a thick tuberous root.

Type locality: "Hab. in Carolina, Mississippi.".

Herb. Geol. Surv. Herb. Mohr.

VIGNA Savi, in DC. Prodr. 2:401. 1824.

About 30 species, warmer regions of both hemispheres, mostly tropical American. South Atlantic North America, 1.

Vigna luteola (Jacq.) Benth. in Mart. Fl. Bras. 15, pt. 1: 194, t. $50, f .2 . \quad$ 1859-62.

Dolichos luteolus Jacq. Hort. Vind. 1: 39, t. 90. 1770.

Vigna glabra Savi in DC. Prodr. 2: 401. 1824.

Ell. Sk. 2:231. Chap. Fl. 1C6. Griseb. Fl. 195.

West Indies, Mexico to Brazil, Peru.

Louisianian area. Coast South Carolina to Florida, west to Texas.

Alabama: Coast plain. Low banks of rivers, borders of fresh and brackish marshes in the tide-water district. Mobilo and Baldwin counties. Flowers yellow. May to September; frequent. Perennial. 
Type locality (Jacq. Hort. Vind.): "Semina hujus plantae mecum ex Americes zona torrida attuli.

Herb. Geol. Surv. Herb. Mohr.

Vigna catjang (L.) Walp. Linnaea, 13:533. 1839.

Cow Pea.

Dolichos catjang L. Mant. 2 : 269. 1771.

Introduced from eastern Asia and extensively cultivated. In many varieties per-

haps hybridized with Dolichos sinensis L. (Cent. Pl. 2 :28).

Sparsely escaped from cultivation.

'Type locality: "Hab. in India orientali."

Herb. Geol. Surv.

DIOCLEA H. B. K. Nov. Gen. \& Sp. 6:437. 1823.

About 16 species, of warmer America.

Dioclea multiflora (Torr. \& Gray).

Dolichus multiflorus Torr. \& Gray, FI. N. A. 1:281. 1838.

BoYKIN's DiOcLea.

.Dioclea boykinii Gray; Wats. Bibl, Ind. 219. 1878.

Chap. Fl. 110.

Louisianian area. Sonthern Georria, Mississippi, Louisiana, and Arkausas.

Alabama: C'entral Prairie region. Rich hottoms. Hale Countr, Gallion, Prairie Creek. Flowers purple. June. So far only locally observed. Perennial from a slender running rootstock several for.t in lengtl, climbing over bushes. It has been observed in abundance throughout the Mississippi bottom and along the Lochapahila in Mississippi, and tiere can be no doubt that the plant is also frequent in the river bottoms in the western parts of the State, which so far have been but slightly explored.

Type locality: "Alluvial banks of the Oeonee River, Georgia, Dr. Boykin! Arkansas, Dr. Learenworth!"

Herl. Geol. Surv. Herb. Mohr.

GALACTIA P. Browne, Hist. Jam. 298. 1756. ${ }^{1}$

About 50 species, perennials, of warmer America, West Indies, Mexico. Lastern North America, 14.

Galactia regularis (L.) B. S. P. Prel. Cat. N. Y. 14. 1888.

Milk Pea.

Dolichos regularis L. Sp. Pl. 2 : 726. 1753.

Galactia glabella Michx. Fl. Bor. Am. 2:62. 1803.

Ell. Sk. 2: 239. Gray, Man. ed. 6, 146. Chap. Fl. 109.

Carolinian and Louisianian areas. Southern New York and New Jersey, south to Florida, west to Louisiana.

Alabama: Central Pine belt to Lower Pine region. Dry sandy woods. Antanga County, Prattville. Clarke County. Monroe County, Claiborne. Mobile and Baldwin counties. Flowers purplish. June, July. Frequent in the rolling pine barrens. The form with oblong-ovate, acute leaves, var. $\beta$ Torr. \& Gray, Fl. N. A. 1:287, from Prattville.

Type locality: "Hab. in Virginia."

Herl. Geol. Surv. Herb. Mohr.

Galactia volubilis (L.) Britton, Mem. Torr. Club, 5 : 208. 1894.

Hedysarum volubile L. Sp. Pl. 2 : 750. 1753.

Twining Milk Pea.

Galactia mollis Nutt. Gen.2:117. 1818. Not Michx. 1803.

G. pilosa Ell. Sk. $2: 238$. 1824 . Not Nutt.

G. macrei M. A. Curtis, Bost. Journ. Nat. Hist. 1: 120. 1837.

Ell. Sk. 2:238. Gray, Man. ed. 6, 146. Chap. Fl. 108.

Carolinian and Louisianian areas. Sonthern Now York, Pennsylvania, Virginia,

Tennessee; North Carolina to Flurida, west to Louisiana and Arkansas.

Alabama: Tennessee Valley to the coast. The type chiefly in upper districts to

Central Pine belt. Flowers purple. July to September; frequent.

Type locality: "Hab. in America septentrionali."

Herb. Geol. Surv. Herb. Mohr.

Galactia volubilis mississippiensis Vail, Bull. Torr. Clnb, 22 : 508. 1895.

Louisianian area. North Carolina.

'Anna M. Vail, A study of the genus Galaetia in North America, Bull. Torr. Club, vol.22, pp. 500 to 511. 1895 . 
Ala bama : Lower Pine region. Coast plain. July, Angust. Not rare. By intergrading forms closely connected with the type.

'Type locality: "Missonri, Arkansas, Indian Territory, and Louisiana."

Herb. Geol. Surv. Herb. Mohr.

Galactia volubilis intermedia Vail, Bull. Torr. Club, 22 : 508.1895.

Galactia pilosa angustifolia Torr. \& Gray, Fl. N. A. 1:287. 1840.

Louisianian area. Coast region. Western Florida and Mississippi.

Alabama: Sandy borders of river marshes and shores of marine inlets, Mobile. Flowers pale purple. August, September. Not rare. Close to the last, but easily distiuguished by the more slender, almost filiform, stems, twining over low bushes, the amost.glabrous leaves, which are bright green, smoothish, from lance-linear to linear, obtuse or acute, and the numerous peduncles, longer than the leaves.

'Type locality: "Florida to Louisiana."

Herb. Geol. Surv. Herb. Mohr.

Galactia floridana Torr. \& Gray, Fl. N. A. 1:288. $1838 . \quad$ Flokida Milk PeA. Chap. Fl. 108.

Louisianian area. Western coast of Florida.

Arabama: Lower Pine region, near the coast. Dry sandy pine barrens. Mobile County, Springhill. Flowers pink or pale purple. August; fruit ripens in September; rare.

Type locality: "Sandy places about Tampa Bay, Florida, Dr. Burrows!"

Herb. Geol. Surv. Herl). Mohr.

Galactia erecta (Walt.) Vail, Bull. Torr. Club, $22: 502$. 1895. Erect Milk Pea. Ervum erectum Walt. Fl. Car. 187. 1788.

Galactia sessiliflora Torr. \& Gray, Fl. N. A. 1:288. 1838.

Chap. Fl. 109.

Lonisianian area. Florida to Mississippi.

Alabama: Lower Pine region. Dry sandy pine barrens. Washington and Escambia connties. Mobile County, Springhill. Flowers white. May, June; frequent. Rootstock stont, fusiform.

Type locality: South Carolina.

Herb. Geol. Surv. Herb. Mohr.

PHASEOLUS L. Sp. Pl. 2 : 723. 1753. BEAN.

(Strophostyles Ell. Sk. 2 :229. 1821-24.)

About 160 species, warmer regions of the globe.

Phaseolus polystachyus (L.) B. S. P. Prel. Cat. N. Y. 15. 1888.

Dolichos polystachyus L. Sp. Pl. 2 : 726. 1753.

Phaseolus perennis Walt. Fi. Car. 182. 1788.

Ell. Sk. 2:228. Gray, Man. ed. 6, 144. Chap. Fl. 106.

Alleghenian to Louisianian area. New England west to Minnesota, Dakotas, Nebraska, Kansas, south to the Ohio Valley, and from New York to Florida.

Alabama: Monntain region to Coast plaiu. Shady dry woods. Dekalb County, Mentone, 1,600 feet. Talladega County, summit Alpine Mountains, near the Signal Station, 1,800 feet, and near Renfroe, 1,200 feet. Mobile County, West Fowl River. Collected in fruit September, October. In the barren rocky soil of the mountains somewhat depauperated. Rare. Perenuial.

Type locality: "Hab. in Virginia."

Herb. Geol. Surv. Herb. Mohr.

Phaseolus helvolus L. Sp. Pl. 2 : 724. 1753.

Angular-Leaf Bean.

Phaseolus diversifolius Pers. Syn. 2 : 296. 1807.

$P$. angulatus Ort. Nov. Pl. 24. 1797.

Strophostyles angulosa Ell. Sk. 2:229. 1824.

Ell. Sk. 2:229. Gray, Man. ed. 6, 144. Chap. Fl. 106. Coulter, Contr. Nat. Herb.
2:90.

Alleghenian to Louisianian area. Quebec, Ontario; New England west to Minnesota, Nebraska, and Kansas, south to Florida, Louisiana, and Texas.

Alabama: Central Prairie region to Coast plain. Damp thickets. Montgomery County, Pintlala Creek. Mobile County. Flowers pale greenish purple; July. Infrequent; chiefly near the coast. Perennial.

'Type locality: "Hab. in Carolina."

Herb. Geol. Surv. Herb. Mohr. 
Phaseolus umbellatus (Mnhl.) Britton, Trans. N. Y. Acad. 9:10. 1889.

Glycine umbellata Muhl.; Willd. Sp. Pl. 3: 1058. 1803.

Fragrant Wili Bean.

Strophostyles peduncularis Ell. Sk. 2:230. 1824.

Phaseolus helvolus Torr. \& Gray, Fl. N. A. 1:280. 1848. Not L.

Eil. Sk. 2:230. Gray, Man. ed.6, 145. Chap. Fl. 106 (inter P.helvolus L.). Conlter, Contr. Nat. Herb. $2: 90$.

Carolinian and Louisianian areas. Long Island (New York) to Florida and throughout the Ohio Valley to the Ginf.

.Alabama: Over the State, with the exception of the highest mountain ranges. Dry siliceous soil. Lauderdale, Calhoun, Tuscaloosa, and Mobile counties. Flowers rose pink, fragrant; July to September. Common, most abundant on the cherty bills of the Coosa Valley and dry sandy fields near the coast. Perennial.

Type locality: "Hab. in Pensylvania."

Herb. Geol. Surv. Herb. Mohr.

Phaseolus semierectus L. Mant. 1: 100. 1767.

Stem silky-pubescent or glabrate, erect, twining near the top; leaves ovate to lanceolate; peduncles elongated, longer than the leaves; flowers umbellately clustered; pedicels short, at length recurved; calyx 5-toothed; teeth ovate-lanceolate, pointer, the superior somewhat shorter; legumen subcylindrical, sericeous or glabrescent, with a linear, acuminate beak, straight or reflex. (Condensed from Griseb. Fl. Brit. W. Ind. 197.)

West Indies, Mexico to Brazil, Peru, East Indies.

Alabama: Adventive on ballast. Flowers buff yellow, with a rark purple spot in the center. To all appearance firmly established. Perennial.

Type locality (Willd.Sp. Pl.): "Hab. in America calidiore."

Herb. Geol. Surv. Herb. Mohr.

RHYNCHOSIA Lour. Fl. Cochin.562. 1793.

About 100 species, perennial herbs or shrubs, warmer temperate tropical regious of both hemispheres.

Rhynchosia erecta (Walt.) DC. Prodr. 2 : 384. 1825.

Trifolium erectum Walt. Fl. Car. 184. 1788.

Glycine tomentosa var. erecta Michx. Fl. Bor. Am. 63. 1803.

Rhynchosia tomentosa var. erecta 'Torr. \& Gray, Fl. N. A. I:285. 1840.

Ell. Sk. 2:235. Gray, Man. ed.6, 147. Chap. Fl. 105.

Carolinian and Louisianian areas. Delaware to Florida, west to Lonisiana, Arkansas, and 'Tennessee.

Alabama: Tennessee Valley to Lower Pine region. Dry open woods. Calhoun Connty, Anniston. Marshall, Cullman, Autaugua, Clarke, Monroe, Mobile, and Baldwin counties. Flowers yellow. June to Angust; frequent, particularly in the pine forests with a closer soil.

Type locality: South Carolina.

Herb. Geol. Surv. Herb. Mohr.

Rhynchosia simplicifolia (Walt.) Wood, Bot. \& Fl.96. 1870.

Trifolium simplicifolium Walt. Fl. Car. 184. 1788.

Glycine tomentosa monophylla. Michx. Fl. Bor. Am. 2 : 63.1803.

Rhynchosia reniformis DC. Prodr. 2 : 384.1825.

lihynchosia tomentosa var. monophylla Torr. \& Gray, Fl. N. A. 1:284. 1840.

Ell. Sk.2:234. Gray, Man. ed.6, 147. Chap. Fl. 105.

Carolinian and Louisianian areas. Sonthern Virginia; North Carolina to Florida, west to Louisiaua and Arkansas.

Ala bama: Mountain region, Metamorphic hills. Central Pine belt to Coast plain. Dry sandy borders of fields, pastures, open pine woods. Lee County, Auburu (Baker \& Earle). Tallapoosa, Autauga. Mobile. May, June. Common throughout the dry pine barrens.

Type locality : South Carolina.

Herb. Geol, Surv. Herb. Mohr.

Rhynchosia tomentosa (L.) Hook. \& Arn. Comp. Bot. Mag. 1 : 23. 1835.

Glycine tomentosa L. Sp. PI. 2 : 754. 1753.

Trailing Ritynchosia.

G. tomentosa volubilis Michx. Fl. Bor. Am. 2: 63. 1803.

Arcyphyllum difforme Ell. Journ. Acad. Phila. i: 372 . 1817.

Rhynchosia difformis DC. Prodr. 2 : 384. 1825. 
Ell. Sk. 2 : $234 . \quad$ Chap. Fl. 105.

Carolinian and Louisianian areas. North Carolina, Texas to Arkansas, south to Florida and Mississippi.

Arabama: Mountain region. Talladega County, Chandler Springs, 1,200 feet. September; rare.

Type locality: "Hab. in Virginia."

Herb. Geol. Surv. Herb. Mohr.

Rhynchosia minima (L.) DC. Prodr. 2 : 385.1825.

Dolichos minimus L. Sp. PI. 2 : 726. 1753.

Smallest-hlowered Rhynchosia.

Glycine reflexa Nutt. Gen. 2:115. 1818.

Ell. Sk. 2 :236. Chap. Fl. 104. Grisel. Fl. Brit. W. Ind. 190.

West Indies, Mexico to Brazil, Tropical Asia, Africa.

Louisianian area. Florida along the coast to Louisiana.

AlabaMa : Littoral region. Damp thickets. Mobile County, West Fowl River.

Flowers yellow; August. Climbing over bushes. Not frequent.

Type locality: "Hab. in Jamaica."

Herb. Geol. Surv. Herb. Mohr.

Rynchosia galactioides (Nutt.) Endl.; Walp. Rep. 1:790. 1842.

Pitcheria galactoides Nutt. Journ. Acad. Phila. 7:93. 1834.

Pine-ibarken Rhynchosia.

Chap. Fl. 105.

Louisianian area. Middle Florida to Mississippi.

Alabama: Lower Pine region. Dry sandy pine barrens. Mobile and baldwin counties. Washington, Yellowpine. Flowers yellow, vexillum rufous by fine close striae. July, August.

One of the most characteristic plants, peculiar to the rolling pine barrens of the Lower Pine regrion.

'I'ype locality: "Alabama and west Florida."

Herb. Geol. Surv. Herb. Mohr.

\section{GERANIACEAE. Geranium Family.}

GERANIUM L.Sp. Pl. $2: 676.1753$.

One hundred and sixty species, temperate regions of the globe. North America, 6.

Geranium carolinianum L. Sp. Pl. 2 : 682 . 1753.

Common Cranesibir.L.

Ell. Sk. 2 :157. Gray, Man. ed. 6, 104. Chap. Fl. 65. Coulter, Contr. Nat. Herb.

2:50. Wats. Bot. Calif. $1: 93$.

Boreal zone to Lonisianian area. British North America from Nova Seotia to the

Pacific and the Aretic Circle. From Canada to the Gulf, west to Texas and southern Califoruia.

Alabama: Over the State. Cultivated and waste grounds. Flowers lilac purple;

March, April. A common winter weed. Annual.

Type locality: "Hab. in Carolina, Virginia."

Herb. Geol. Surr. Herb. Mohr.

Geranium maculatum L. Sp. Pl. 2 : 681. 1753.

Spotted Geranium. Wild Cranesbill.

Ell. Sk. 2:157. Gray, Man. ed. 6, 103. Chap. Fl. 65.

Alleghenian and Carolinian areas. Nova Scotia, Quebec, Ontario; New England to upper districts of the Carolinas and Georgia, west to Minnesota, Kansas, and Arkansas.

ALABama : Tennessee Valley to Lower hills. Rocky copses and open woods. Lauderdale County. Madison Connty, near Huntsville, sunny hills. Cullman and Tuscaloosa counties. Flowers purplish red; April, May. Not frequent. Perennial.

Economic uses: The root-"cranesbill," "Geranium," U. S. Pharmacopœia-is used merlicinally.

Type locality: ".Jab. in Carolina, Virginia, Sibiria."

Herb. Geol. Surv. Herb. Mohr.

ERODIUM L'Her. Geran. t.1. 1787.

About 50 species, widely dispersed in the Old World.

Erodium cicutarium (L.) L'Her.; Ait. Hort. Kew. 2: 41t. 1789.

l'in-clover. alfilaria (in California).

Geranium cicutarium L. Sp. Pl. 2 : 680. 1753. 
EUROPF.

Naturulized; widely diffused on the Pacific coast from British Columbia to sonthern California. Rare in the Atlantic States.

Alabana: Adventive with ballast. Mobile; June. Rare. Observed for several seasons maturing seeds well. Annual.

Economic uses: Considered on the Pacific as one of the most valuable wild pasture plants.

Type locality : "Hab. in Europae sterilibus cultis."

Herb. Geol. Surv. Herb. Mohr.

\section{OXALIDACEAE. Wood-sorrel Family.}

OXALIS I. Sp. Pl. 1:433. 1753.'

About 200 species, chiefly of tropical America, Sonth Africa. North America 17, Atlantic 8.

Oxalis corniculata L. Sp. Pl. 1: 435.1753.

Creeping Solket.

Ell. Sk. 1:526. Gray, Man. erl. 6, 105. Chap. Fl. ed.3,65. Coulter, Contr. Nat.

Herb. 2:52. Wats. Bot. Calif. 1:96.

Europe, Northern Africa, Asia, Mexico, Cosmopolitan.

Carolinian and Lonisianian areas. Indigenous in the interior in Missouri, Arkansas, Texas, and California, and from all appearances in the Gulf States.

Alabama: Cultivated and waste places. Tuscaloosa County (E. A. Smith). Lee County, Auburn (Baker \& Earle, 103). Mobile. Flowers yellow; March, May. Not rare. Easily recognized by the low prostrate habit of its growth. Perennial from a creeping rootstock.

Type locality: "Hab. in Italia, Sicilia."

Herb. Geol. Surv. Herb. Mohr.

Oxalis stricta L. Sp. Pl. 1:435. 1753.

Common Yellow SORkel.

Oxalis corniculata var stricta sav. in Lam. Encycl. 4:683. 1797.

Ell. Sk. 1:526. Gray, Man. edl. 6, 105, in part. Chap. Fl. ed. 3, 65. Coulter, Contr. Nat. Herb. 2:52. Britt. \& Br. Ill. Fl. $2: 346$.

Stem mostly simple, erect or branched at the base from a slender perennial rootstock, 6 to 8 inches high; leaves smoothish or strigosely pubescent, $\frac{8}{4}$ inch to $1 \frac{1}{2}$ inches wide; leaflets little wider than long, fleshy, smoothish, ciliate, broadly emargiuate, the cellnlar structure prominent under the lens; peduncles umbellate, longer than the leaves, 2 to 6 inches long, axillars from the clustered leaves; perlicels $\frac{1}{2}$ to $\frac{5}{8}$ inch long, almost horizontally deflexed in fruit; pods columnar, abruptly pointed with the short styles, $\frac{1}{2}$ to $\frac{7}{8}$ inch long, seed somewhat acute at the base with strong interrupted transverse ridges. Flowers yellow, small.

Alleghenian to Louisianian area. Canada; New England to Dakota, south to the Gulf of Mexico.

Alabama: Over the State. In low damp ground, grassy banks, fields, and woods. Flowers May. Common. Annual or pereunial.

'Type locality: "Hab. in Virginia."

Herb. Mohr.

Oxalis recurva Ell. Sk. $1: 526.1817$.

LARGE-FLOWERED WOOD SORREL.

Ell. Sk.1.c. Chap. Fl. ed. 3, 65. Britt. \& Br. Ill.Fl. 2:347.

$A$ more slender plant than the above, perennial. Stenis mostly several from the wiry stoloniferous rhizoma, rigid, scarcely over 6 inches in length; leaflets thinner, about $\frac{8}{8}$ inch wide and scarcely as long, the cellular structure less prominent under the lens; peduncles slender, umbellate, longer than the leaves, hirsute with strigose adpressed hairs; pedicels 2 to 4 in the umbellate cluster, almost filiform, incurved and at length reflexed; pod acnminate, crowned with the long styles; seeds with uninterrupted transverse ridges.2

Carolinian and Lonisianian area. North western Virginia at sea level, southwestern Virginia at 2,000 feet; sontheastern Kentucky, North Carolina, South Carolina at sea level.

${ }^{1}$ J. K. Small, Two species of Oxalis, Bull. Torr. Club, vol. 21, pp. 471 to 479. 1894. Same author, A neglected species of Oxalis and its relatives, op. cit., vol. 23, pp. 265 to 269.1896.

${ }_{2}$ See J. K. Small, Bull. Torr. Club, 21 : 471, t. 222. 
Alabama: Mountain region to Lower Pine belt. Dry open copses. Cullman County, 800 feet. Lee County, Auburn (Baker \& Earle, 97). 'Tuscaloosa County, 300 feet. Mobile County, Citronelle, 200 feet. Flowers yellow; March, April; frequent in the rolling pine barrens of the Lower Pine belt.

Trpe locality: "Grows in cultivated land. Very common near Charleston, intermingled with Oxalis stricta, with which it has been confounded."

Herb. Geol. Surv. Herb. Mohr.

Oxalis cymosa Small, Bull. Torr. Club, 23:267. 1896. Yellow Prairie Sorrel.

Britt. \& Br. Ill. Fl. 2 : 347.

Typically erect, slender, 10 to 15 inches high, stem wiry, somewhat woody at the base, branched above, smoothish, the luxuriant foliage of a bright green. Leaves from $\frac{8}{4}$ to $1 \frac{1}{2}$ inches in diameter on slender wiry petioles, $1 \frac{1}{2}$ to 3 inches long; leaflets broader than long, acutely notched at the apex; peduncles wiry, slender, 3 to $4 \frac{1}{2}$ inches long; pedicels $\frac{1}{8}$ to $\frac{3}{16}$ inch long, erect, subtended by small linear-lanceolate bractlets, and like the pedicels villous-pubescent; flowers pale yellow, small, sepals lanceolate, rather obtuse; petals clouble the length of the sepals, many-nerved, capsule columnar, $\frac{5}{12}$ to $\frac{7}{18}$ inch long, the seeds marked with continnous ridges.

Alleghenian to Louisianian area. Ontario to Lake Superior and Nebraska, south to the Gulf of Mexico.

Alarama: Mountain region to Central prairies. Borders of fields and woods. Lee Connty, Auburn (Earle \& Underwood). Tuscaloosa County. Dallas County, Uniontown. Flowers lemon-yellow; end of April to June. Frequent. Perennial.

Type locality: Ontario to the Lake Superior region and Nebraska, south to the Gulf of Mexico.

Herb. Geol. Surv. Herb. Mohr.

Oxalis grandis Small, Bull. Torr. Club, 21:475. 1894.

Great Yellow Woon Solrel.

Oxalis recurra Trelease, Mem. Bost. Soc. Nat. Hist. 4 : 89. 1888. Not Ell.

Chap. Fl. ed. 3, 65 . Britt. \& Br. Ill. Fl. $2: 347$.

Anuual or biennial by a slender rootstock. Stem rather stout, erect, simple or sparingly branched, grooved, sparsely villous by scattered hairs, leafy above; leaves large $1 \frac{1}{2}$ to $1 \frac{5}{8}$ inches wide; leaflets unequal, broader than long, with a shallow but acute sinus, acute at the base, slightly ciliate, hairy on the veins, the revolute margin purplish brown; inflorescence subcymose or cymose; peduncles 3 to $4 \frac{1}{2}$ inches long, as long as or longer than the leaves; pedicels $\frac{1}{2}$ inch long, erect, not reflexed in firuit; flowers large, petals $\frac{1}{2}$ inch long, three times longer than the linear-oblong segments of the calyx, pod narrowly oblong, acute, seeds oblong, acute with interrupted transverse ridges and 2 longitudinal crests on the back.

Carolinian area. Pennsylvania to Ohio and Illinois; south to Virginia and North Carolina, altitude 2,500 feet; through the Cumberland mountains of Kentucky and Teunessee.

Alabama: Mountain region. Rich woods. Dekalb Connty, Lookout Mountain, near Mentone, 1,600 feet, May 31. 'Talladega County, Renfroe, 1,000 feet. Lee County, Auburn (Earle \&. Underwood).

Type locality: Many stations are cited within the above range.

Herb. Geol. Surv. Herb. Mohr.

Oxalis violacea L. Sp. P1. 1:434. 1753.

Ell. Sk. 1:525. Gray, Man. ed. 6, 105. Chap. Fl. 63. Coulter, Contr. Nat. Herb. $2: 52$.

Cuba.

Alleghenian to Louisianian area. Southern New England to Colorado, south to Florida, west to Texas and Arkansas.

Alabama: Tennessee Valley to Coast plain. Lauderdale and Montgomery counties. Mobile. Flowers rose-purple; April. Not infrequent. Perennial.

Type locality: "Hab. in Virginia, Canada."

Herb. Geol. Surv. Herb. Mohr.

\section{IINACEAE. Flax Family.}

LINUM L. Sp. Pl. 1:277. 1753.

Ninety species, temperate and warmer regions, cosmopolitan.

Linum virginianum L. Sp. Pl. 1:279. 1753.

Ell. Sk. 1:375. Gray, Man. ed. 6, 102. Chap. Fl. 62. Coulter, Contr. Nat. Herb.

$2: 46$. 
Northern Mexico.

Alleghenian to Louisianian area. New England west to Michigan; Ohio Valley to Missouri, south to Arkansas and Texas, and from New York to Florilla and Louisiana.

Alabama: Undoubtedly scattered throughout the State in dry sandy soil, collected, however, ouly in a few localities. Lower hills. Fayette County (E. A. Smith). Mobile County. Citronelle. Flowers yellow. April, May. Not infrequent in the dry pine barreus of the Lower Pine belt. Perennial.

Type locality: "Hab. in Virginia, Pensylvania."

Herb. Geol. Surv. Herb. Mohr.

Linum medium (Planch.) Britt. \& Br. Ill. Fl. 2 : 349. 1897.

Linum rirginianum var. medium Planch. Lond. Journ. Bot. 7:480. 1848.

Carolinian and Lonisianian areas. Ontario to Florida and Texas.

Alabama: Dry sandy woods. Mobile County, Springhill, Citronelle. Baldwin County, Josephine. Flowers pale yellow. July, August. Not frequent. Peremial. Type locality: "Canada, lacus Huron, Dr. Todd ** * ; Kentucky, Dr. Short."

Herb. Geol. Surv. Herb. Mohr.

Linum floridanum (Planch.) Trelease, Trans. St. Louis Aead. 2 : 13. 1886.

Southerv Yellow Flax.

Linum virginianum var. floridanum Planch. Lond. Journ. Bot. 7:480. 1848.

Chap. Fl. ed. 3,64 .

Carolinian and Louisianian areas. Florida.

Alabama : Mountain region. Lower Metamorphic hills. Lee County, near Auburn (Baker of Earle, 93). Coast plain. Low damp pine barrens. Mobile and Bald win counties. Flowers pale yellow. May, June. Frequent. Perennial.

Type locality : "Florida, Dr. Chapman."

Herb. Geol. Surv. Herb. Mohr.

Linum striatum Walt. Fl. Car. 118. 1788.

SWAMP Yellow FlaX. Gray, Man. ed.6, 102. Chap. Fl.63; ed.3, 64. Coulter, Contr. Nat. Herb. $2: 47$.

Alleghenian to Louisianian area. Southern Ontario; eastern Massachusetts and New York to Missouri and Nebraska; sonth from Tennessee to Florida, west to Texas.

Alabama : Mountain region to Coast plain. Moist thickets. Clay County, Shinbone Valley, 1,000 feet. Fayette County (E. A. Smith). Montgomery and Mobile counties. Flowers sellow. May, June. Frequent. Several stems from the same root. Perennial.

Type locality: South Carolina.

Herb. Geol. Surv. Herb. Mohr.

Linum sulcatum Riddell, Suppl. Cat. Ohio Pl. 10. 1836. Grooved Yellow Flax. Linum boottii Planch. Lond. Journ. Bot. 7:475. 1848.

Gray, Man. ed. 6, 102. Chap. Fl. 63. Coulter, Contr. Nat. Herb. 2 : 47.

Alleghenian to Louisianian area. Ontario; Northwest 'Territory, Massachusetts, west to Minnesota, Dakota, Nebraska, southern Ohio Valley, Missouri, Arkansas, and Texas.

Alabama: Central Prairie region. Dry open ground. Autauga County near

Prattville, quite abundant. Flowers pale yellow; June. Local. Annual. Type locality: "Dover, Ohio, August 30, 1830," ex. Herb. Riddell.

Herb. Geol. Surv. Herb. Mohr.

Linum berlandieri Hook. Bot. Mag. 63 : t. 3480. 1836.

Coulter, Contr. Nat. Herb. $2: 47$.

AlabaMa: Adventive through wool on the dumping ground of the old woolen mills, Prattville, Antauga County. Collected July, 1880. Perennial.

'Type locality: "Texas." Found by Berlandier at "Bejar" and later by Drummond "at Rio Brazos and San Felipe."

Herb. Geol. Surr.

\section{ZYGOPHYLLACEAE. Bean-Caper Family.}

KALLSTROEMIA Scop. Introd. 212. 1777.

Twelve species, warmer regions. Asia, America.

Kallstroemia maxima (L.) Torr. \& Gray, Fl. N. A. 1:213. 1840.

Tribulus maximus L. Sp. Pl. 1:386. 1753.

Largest Caltrops.

Griseb. Fl. Brit. W. Ind. 134. 
West Indes, Mexico.

Carolinian and Lonisianiau areas. Florida, Texas, Arizona, New Mexico, and Kansas.

Alabama : Coast plain. Waste places. Adventive from the southwest on ballast. Mobile.

Type locality : "Hab. in Jamaicae aridis."

Herb. Geol. Surv. Herb. Mohr.

\section{RUTACEAE. Rue Family.}

\section{ZANTHOXYLUM L. Sp. Pl. 1:270. 1753.}

About 80 valid species, mostly of the tropical and warmer regions of Asia. North America, 4. Trees or shrubs.

Zanthoxylum clava-herculis L. S1. Pl. 1:270. 1753.

Southern Prickly Ash.

Zanthoxylum carolinianum Lam. Encycl. 2:39. 1786.

Z. tricarpum Michx. Fl. Bor. Am. 2 :235. 1803.

Ell. Sk. 2: 690, 691. Gray, Man. ed. 6, 107. Chap. Fl. 66. Coulter, Contr. Nat. Herb. 2 :54. Sargent, Silv. N. A. 1:67, t. 28, 29.

WEST INDIES.

Louisianian area. North Carolina along the coast to Florida and west to Texas.

Aldisama : Central Pine belt to Coast plain. In light soil, border of woods. Tuscaloosa, Hale, Marengo, Dallas, Montgomery, Clarke, Mobile, and Baldwin connties. Flowers greenish white, middle of April; fruit ripe August. Small tree, 20 to 25 feet high; diameter 6 to 8 inches. Frequent.

Most frequent in the hammock lands of the coast plains.

Economic uses: The bark, "Southern prickly ash lark"_"Zanthoxylum," United States Pharmacopoia-and the ripeseeds, "prickly ash berries," are used in medicine. Type locality: "Hab. in Jamaica, Carolina, Virginia."

Herb. Geol. Surv. Herb. Mohr.

\section{PTELEA L. Sp. PI. 1:118. 1753.}

Six species, warmer North America. Trees or shrubs.

Ptelea trifoliata L. Sp. Pl. 1:118. 1753.

Shrubiry 'TrewoIL.

Ell. Sk. 1:210. Gray, Man. ed. 6, 107. Chap. Fl. 66. Coulter, Contr. Nat. Herb. $2: 54$.

Alleghenian to Louisianian area. Southern Ontario; Long Island, New York, to Michigan, south to West Virginia, through the Ohio Valley to Missouri, and Arkansas; from New Jersey south to Middle Florida, west through the middle districts of the Gulf States to central 'Texas.

Alabama: Central Pine belt to Upper division Coast Pine belt. Rocky banks. Bibb County. Clarke County, Lisbon, blutfs on Alabama River; May. Collected in fruit July 23. Shrub 3 to 4 feet high. Not frequent.

Type locality: "Hab. in Virginia."

Herb. Geol. Surv. Herb. Mohr.

\section{SIMARUBACEAE. Simaruba Family.}

AILANThus Desf. Mém. Acad. Paris, 1786: 265, t. $s .1789$.

Three species, Eastern Asia.

Ailanthus glandulosa Desf. Mém. Acad. Paris, 1786: 265, t. $s .1789$.

China.

Tree of Heaven.

Introduced and escaped from cultivation; perfectly natura]ized throughont the Carolinian and Louisianian areas. Spreading in waste places, borders of woods and copses.

Ala Bama : Throughout the State. In numerous localities often forming dense thickets; objectionable on account of its spreading habit, and the disagreeable odor of the male flowers. Teunessee Valley. Montgomery. Mobile. Flowers in June. Type locality not ascertained.

Herb. Geol. Surv. Herb. Mohr. 


\section{MELIACEAE. Melia Family.}

MELIA L. Sp. Pl. 1:558. 1753.

Twenty-five species, warm regions of the Old World. Trees.

Pride of China. Beal Tree.

Melia azedarach L. Sp. Pl. 1:558. 1753.

Western Asia to China AND Japan. Cultivated in warmer countries.

Introduced and extensively cultivated for ornament throughont the Louisianian area. South Carolina to Florida, west to Texas. Lscaped to waste places.

Alabama: Mobile, waste places. March 15; flowers lilac, fragrant; frnit ripe in October, amber-colored, retained through the winter.

Economic uses: Of some value for lumber. Ornamental shade tree. The bark is the "China bark" of medicine.

Type locality: "Hab. in Syria."

\section{POLYGalaceaE. Polygala Family,}

\section{POLYGALA L. Sp. Pl. $2: 701.1753 .^{1}$}

About 200 species, temperate and warmer regions of the globe. North America, 38. Western and Pacific, 21. Eastern, 27. Southern, 26 or 27.

Polygala cymosa Walt. Fl. Car. 179. 1788.

Pine-barken Pond Milkwort.

Polygala corymbosa Michx. Fl. Bor. Am. 2 : 54. 1803. In part.

Ell. Sk. 2:187. Gray, Man. ed. 6, 122. Chap. Fl. 82.

Carolinian and Louisianian areas. Florida, along the coast to North Carolina, New Jersey, and Delaware, "est to eastern Louisiana.

Alabama : Lower Pine region. Coast plain. Bogs and shallow ponds. Mobile and Baldwin counties. Flowers bright yellow; June, July. Frequent. Annual or biennial. One and one-half to 2 feet high. Common in open, boggy pine-barren swamps.

'Type locality: South Carolina.

Herb. Geol. Surv. Herb. Mohr.

Polygala ramosa Ell. Sk. 2 : 186.1822.

Low-Brancired MiLKwokt.

Polygala corymbosa Nntt. Gen. Pl. 2 : 89. 181. Not Michx.

Ell. Sk. l. c. Gray, Man. ed. 6, 122. Chap. 11. 82.

Carolinian and Louisianian areas. Distribution as in the last.

Alabama: Lower Pine region. Coast plain. Flat damp pine barrens, borklers of pine-barren ponds. Mobile and Baldwin counties. Flowers yellow; June. Frequent. Eight to 12 inches high. Biennial.

Type locality: "Grows in ponds in the flat pine barrens, intermingled with the $P$. corymbosa," South Carolina and Georgia.

Herb. Geol. Surv. Herb. Mohr.

Polygala lutea L. Sp. Pl. $2: 705.1753$.

Ell. Sk. 2:185. Gray, Malı. ed.6, 122. Chap. Fl. 83 .

Carolinian to Lonisianian area. From Florida aloug the coast to New Jersey, and west to eastern Louisiana.

Alabama : Central Pine belt to Coast plain. Damp light soil, copses, open woods. Chilton and Autauga counties. Montgomery to Mobile and Baldwin counties. Flowers deep orange; April to Angust. Common and most frequent in the low pine barrens of the Coast plain. Six to 8 inches high. Anuual or biennial.

Type locality: "Hab. in Virginia."

Herb. Geol. Surv. Herb. Mohr.

Polygala nana (Michx.) DC. Prodr. 1:328. 1825.

DWARF MILKWORT.

Polygala lutea var. nana Michx. Fl. Bor. Am. 2:54. 1803.

P. viridescens Walt. Fl. Car. 178. 1788. Not $L$.

Eil. Sk. 2: 186. Chap. Fl. 83.

Carolinian and Lonisianian areas. South Carolina to Florida, and west to eastern Lolisiana.

${ }^{1}$ Wm. E. Wheelock, The genus Polygala in North America, Mem. 'Torr. Club, vol. 2, pp. 109 to 152 . 1891 . 
Alabama : Lower hills to Coast plain. Low sandy pine woods. Lee County, Auburn (Underwood \& Earle). Antauga County. Elmore County (E. A. Smith). Clarke County, Thomasville. Mobile and Baldwin counties. Frequent throughout the Crast Pine belt to the coast. Flowers citron-yellow; April to July. Frequent. Biennial. Stem assurgent 4 to 6 inches long.

Type locality: "In pratis udis Carolinae."

Herb. Geol. Surv. Herb. Mohr.

Polygala cruciata L. Sp. Pl. 2 : 706. 1753.

Crossleaf Milkwoirt.

Ell. Sk. 2 : 183. Gray, Man. ed.6, 121. Chap. Fl. 84 .

Alleghenian to Louisianian area. Southern Massachusetts and Minnesota to Virginia, Kentucky, Tennessee, and North Carolina, south to Florida, and west to northwestern Louisiana.

Alabama: Mountain region to the Coast plain. In damp open pine woods. Cullman County, 800 feet. Etowah County, Gadsden (G.R. Vasey). Monroe, Escambia, Washington, Mobile, and Baldwin counties. Flowers purple; June to October. Common and abundant in the lower pine barrens of the coast. Four to 8 inches high. Annual.

Type locality: "Hab. in Virginia."

Herb. Geol. Surv. Herb. Mohr.

Polygala brevifolia Nutt. Gen. 2:89. 1818.

Shortleaf Milkwort.

Gray, Man. ed. 6, 122. Chap. Fl. 84.

Carolinian and Louisianian areas. From New Jersey along the const to Florida, west to Mississippi.

Alabama : Coast plain. Damp shaded banks, low thickets. Mobile and Baldwin counties. Flowers purple; July. Not infrequent. Annual.

Type locality: "Margins of sandy swamps, New Jersey, also in Ohio."

Herb. Geol. Surv. Herb. Mohr.

Polygala hookeri Torr. \& Gray, Fl. N. A. I: 671. 1840.

HOOKER'S MILKWORT.

Polygala attenuata Hook. Journ. Bot. I:195. 1834.

Chap. Fl. 84 .

Louisianian area. Western Florida to eastern Louisiana.

AlabaMa: Lower Pine region, Coast plain. Damp grassy pine barreus. Mobile County, Grandbas. Baldwin County, Daphne. Flowers.purplish; June. Infrequent. Annual.

Type locality of P.attenuata Hook. : "Jacksonville, Louisiana."

Herb. Geol. Surv. Herb. Mohr.

Polygala boykinii Nutt. Journ. Acad. Phila. 7 : 86. 1834.

Chap. F1. 85.

Carolinian and Louisianian areas. Georgia and western Florida to Mississippi.

Alabama: Lower hills to Central Prairie region. Open woods. Lee County, Auburn (Baker \& Earle). Blount County (J.D. Smith). 'Tuscaloosa Connty (E. A. Smith). Shelby County. Perry County (J.D. Smith). Bibb County, Pratts Ferry. St. Clair County, Ashville. Autauga County, Prattville. Hale County. Flowers white; June to August. Most frequent in the dry sterile hills of the Central Pine belt aud the Coosa Valley. One to 2 feet high. Perennial.

'Type locality: "In Georgia and Florida; discovered by my friend Dr. Boykin."

Herb. Geol. Surv. Herb. Mohr.

Polygala verticillata L. Sp. Pl. 2 : 706. 1753.

Ell. Sk. 2 : 182. Grıy, Man. ed. 6, 122. Chap. Fl. 85. Coulter, Contr. Nat. Herb. $2: 26$.

Alleghenian to Louisianian area Ontario to Saskatchewan; New England west to Michigan, Dakota, and the Rocky Mountains; Wyoming to Utah, Colorado, Nebraska, Kansas, and Arkansas; from New England throughout the eastern States to the Gulf and T'exas.

Arabama: Over the State. Gravelly open woods, barren soil. Flowers greenish or purplish; July, August. Common in the pine-barren hills about Mobile. Annual. 'Type locality: "Hab. in Virginia."

Herb. Geol. Surv. Herb. Mohr.

Polygala ambigua Nutt. Gen. 2 : 89. 1818.

Ambiguous Milkwort.

Polygala verticillata var. ambigua Wood, Bot. \& Fl.80. 1870. Gray, Man. ed.6, 122. Chap. Fl. Suppl. 614 ; ed. $3,92$.

Carolinian and Lonisianian areas. New Jersey to West Virginia, Illinois, Missouri, Arkansas; Tennessee to Upper Georgia and northwestern Lonisiana.

Alabama: Mountain region to Coast Pine belt. Dry sandy or gravelly copses. Cullman, Blount, and 'Tuscaloosa connties. Wilcox County (Buckley). Mobile. 
Flowers purplish; June, July. Common; most frequent throughout the Central Pine belt. Annual.

Type locality: "In New Jersey aud Virginia; in forests and on roadsides near ditches."

Herb. Geol. Surv. Herb. Mohr.

Polygala incarnata L. Sp. P1. 2: 701. 1753.

NUDe-STEMmed MrLKWORT.

Ell. Sk. 2: 185. Grav, Man. ed. 6, 121. Chap. Fl. 84.

Carolinian to Louisianian area. New Jersey to Virginia, west to Illinois, Missonri, Kansas, Arkansas; southern Tennessee to the Gulf, and from Florida to 'l'exas.

Alabama : Mountain region to Coast plain. Dry sandy pine woods. Lee County, Auburn. Flowers pale pink. May to September, frequent. Annual.

Type locality : "Hab. in Virginia, Canada."

Herb. Geol. Surv. Herb. Mohr.

Polygala viridescens L. Sp. Pl. 2 : 705. 1753.

Greenish-Flowered Milkwort.

Polygala sanguinea L. Sp. Pl. 2 : 705. 1753.

1. purpurea Nutt. Gen. 2 : 88. 1818.

Eil. Sk. 2: 184. Gray, Man. ed. 6, 121. Chap. Fl. 83.

Alleghenian and Carolinian areas. Ontario; New England west to Minnesuta, and New York, Kansas, and Arkansas, and south to Georgia, Mississippi, and north western Louisiana.

Alabama : Central Pine belt. Dry woods. Tuscaloosa County, Windham Springs, about 450 feet $(E . A$. Smith $)$. Flowers pale purplish; July. Only locality known in the State. Anuual.

'Type locality: "Hab. in Virginia."

Herb. Geol. Surv. Herb. Mohr.

Polygala curtissii Gray, Man. ed. 5, 121. 1867.

Curtiss's MiLkwort.

Gray, Man. ed. 6, 121. Chap. Fl. Suppl. 614; ed. 3, 90.

Caroliniau area. Sonthern Pennsylvavia, Maryland, West Virginı, Kentucky, aud south along the mountaius to Georgia.

AlabaMa : Mountain region. Loe County, Auburn (Baker \& Earle). Clay County: Che-aw-lia Mountain, common to 2,000 feet altitude. Coosa hills, sandy wet places. Cullman County, 800 feet. Calhoun County, Anniston, 600 feet. Flowers bright pink; July. Local, not infrequent. Annual.

Type locality : "Near Alexandria, Va., A. H. Curtiss."

Herb. Geol. Surv. Herb. Mohr.

Polygala mariana Mill. Dict. ed. 8, no. 6. 1768.

Marylani Milk-wORT.

Polygala fastigiata Nutt. Gen. 2 : 89. 1818.

P. sanguinea Torr. \& Gray, Fl. N. A. 1:126. 1840. Excl.syn.

Gray, Man. ed. 6,121. Chap. Fl. 83.

Carolinian and Louisianian area. Delaware and Virginia sonth to Florida, west to Texas and Arkansas.

Alabama: Mountain region. Metamorphic hills. Central Prairio region to Coast plain. Damp grassy places. Lee Connty, Auburn (Baker \& Earle). Dallas, Selma (1)r. Cahill). Mobile County, West Fowl River. Flowers purple. June. Infrequent. Annual.

'Type locality not ascertained.

Herb. Geol. Surv. Herb. Mohr.

Polygala nuttallii Torr. \& Gras,, Fl. N. A. 1:670. 1840.

Nuttall's Milkwort.

Polygala sanguinea Nutt. Gen. 2 :88. 1818. Not L.

P. ambigua Torr. \& Gray, Fl. N. A. 1:130. 1838. Not Nutt.

Ell. Sk. 2: 184. Gray, Man. ed.6,121. Chap. Fl. 83.

Carolinian to Lonisianian area. Coast of New England, New Jersey, Delaware, soutl to West Virginia, Kentucky, Tennessee, and central Georgia.

A labama: Central Pine belt. Tuscaloosa County (E. A. Smith). Flowers purplo; July. Only locality known in the State. Anuual.

'Iype locality of Polygala sanguinea Nutt. : "In the low pine barrens of New Jersey." Herb. Geol. Surv. Herb. Mohr.

Polygala chapmani Torr. \& Gray, Fl. N. A. I:131. 1840. Chapman's Mirkwort. Chap. Fl. 83.

Lonisianian area. Western Florida to Mississippi.

Arabama: Coast plain. Damp grassy pine barrens. Mobile County. Flowers pale purple; May, June. Not rare. Slender, 8 to 12 inches high. Aunual. 'Type locality: "West Florida, Dr. Chapman."

Herb. Geol. Surv. Herb. Mohr. 
$=$ 


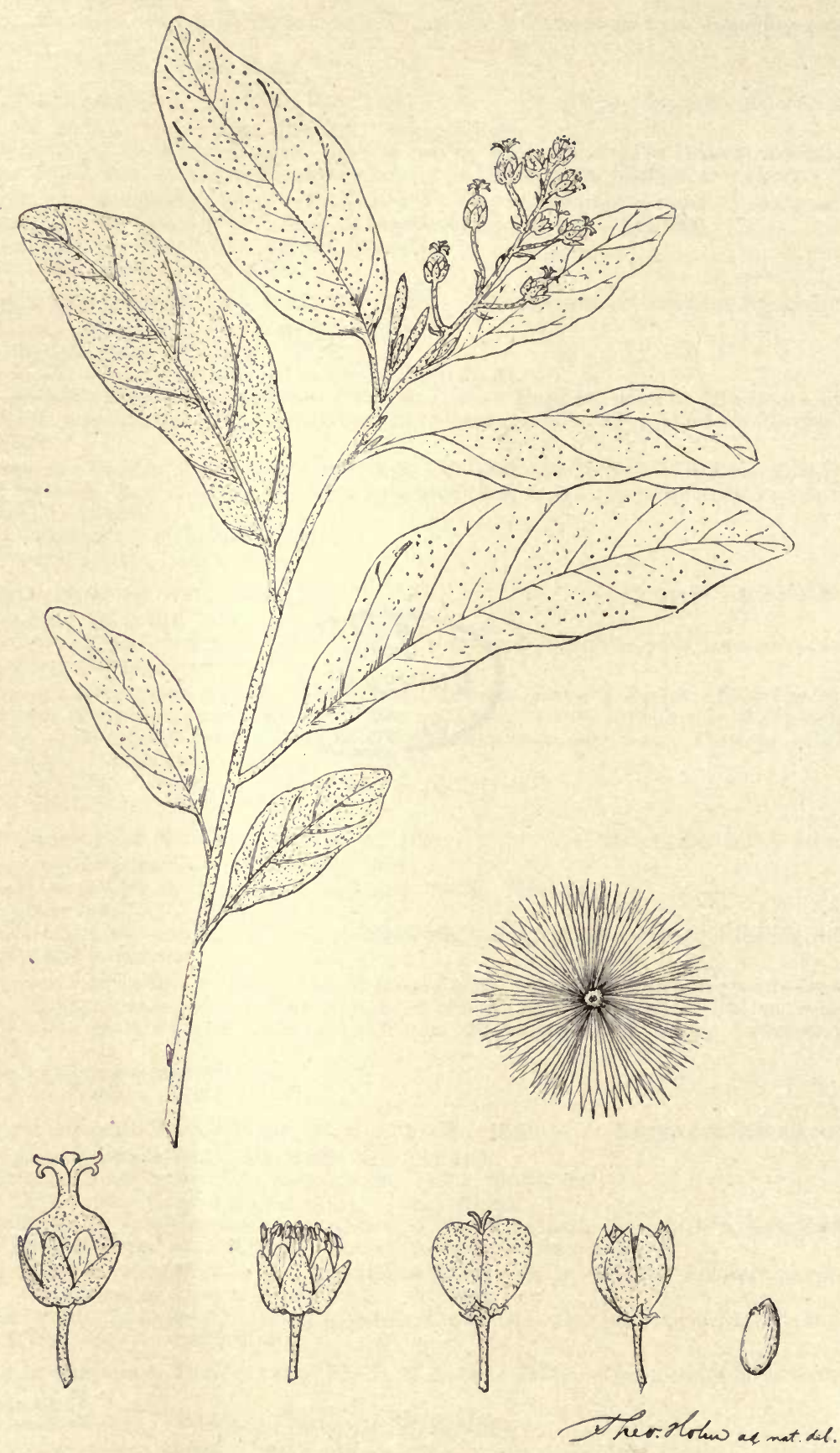

Croton alabamensis E. A. Smith. 
Polygala polygama Walt. Fl. Car. 179. 1788.

Polygamous Milikwort.

Ell. Sk. 2:181. Gray, Man. ed. 6,120. Chap. Fl.84.

Alleghenian to Lonisianian area. Ontario ; New England west to Michigan, Wisconsin, and northern Illinois, south to Florida, and throngh the Gulf States to Tezas.

Alabama : Mountain region to Coast plain. Clay County, Moseley, 1,000 feet. Low grassy places. Cullman County. Lee County, Auburn (Baker \& Earle). Mobile County, West Fowl River, Perdido Bay. Flat grassy pine barrens. Flowers pink; April, May. Not rare in the coast plain. Perennial.

Type locality : South Carolina.

Herb. Geol. Surv. Herb. Mohr.

Polygala grandiflora Walt. Fl. Car. 179. 1788.

LARGE-FLOWERED MILKWORT.

Polygala pubescens Muhl. Cat. 66. 1813.

Ell. Sk. 2: 180. Chap. Fl. 84.

Louisianian area. Florida to South Carolina, west to Mississippi.

Alabama: Central Prairie region to Coast plain. Dry copses, borders of woods. Autauga, Montgomery, Monroe, and Baldwin counties. Flowers deep purple; June to October. Frequent. Perennial.

Type locality: South Carolina.

Herb. Geol. Surv. Herb. Mohr.

\section{EUPHORBIACEAE. Spurge Family.}

PHYLLANTHUS L. Sp. Pl. 981. 1753.

About 400 species, mostly of tropical America, few in Eastern Asia and Southern Hemisphere.

Phyllanthus carolinensis Walt. Fl. Car. 228. 1788.

Carolina Phyllantiugs.

Ell. Sk. 2:661. Gray, Man. 9d.6, 457. Chap. Fl. 409. Conlter, Contr. Nat. Herb. $2: 395$.

Carolinian and Louisianian areas. Pennsylvania and Indliana to the Gulf States.

Arabama: Tennessee Valley to the Coast plain. Low damp banks. Walker County (E. A. Smith). Etowah County, Gadsden. Mobile County. Angust. Frequent. Anunal.

Type locality: South Carolina.

Herb. Geol. Surv. Herb. Mohr.

CROTON L. Sp. Pl. 2 : 1004. 1753.

Four hundred and twenty species, subtropical and tropical regions of both hemispheres, largely South American. North America, 24.

Croton alabamensis E. A. Smith; Chap. Fl. Suppl.648. 1887. Alabama Croton.

Mohr, Gard. \& For. 2 : 592, f. 150. 1889.

On the limit of the Carolinian and Louisianian areas.

Arabama: Bibb County, Pratts Ferry, Little Cahaba Valley, rocky woods. Flowers end of March to middle of April. Fruit ripe at the end of May. Shrub 8 to 10 feet high, strictly confined to rocky low banks in the valley of the Little Ćahaba, forming dense thickets over several acres. Associated with Quercus brevilobata and Q.acuminata. First collected by E. A. Smith, 1874. Mature seeds collected by Mohr, June 1, 1882.

Type locality : "Central Alabama."

Herb. Geol. Surv. Herb. Mohr.

Croton punctatus Jacq. Coll. 1: 166. 1786.

Plate V.

Croton argyranthemus Michx. Fl. Bor. Am. 2 : 215. 1803.

Ell. Sk. 2:617. Chap. Fl. 407. Coulter, Contr. Nat. Herb. 2 : 397.

Louisianian area. Coast of South Carolina to Florilla and western Texas.

Alabama : Lower Pine region. Dry pine barrens. Ball win Connty. Flowers in

May. Shrubby at the base. Not frequent. Eight to 12 inches high. Perennial.

Type locality : "In Carolina sponte crescit."

Herb. Geol. Surv. Herb. Mohr.

Croton monanthogynus Michx. Fl. Bor. Am. 2 : 215. 1803.

Gray, Man. ed. 6, 458. Chap. Fl. 408.

Low Spreading Croton.

Carolinian area. Southern Indiana to Missouri, Kansas, and Arkansas, south from North Carolina and Tennessee. 
Alabama: Tenuessee Valley. Exposed calcareous hills. Angnst to October; frequent. Annual.

Type locality: "Hab. in Tennassée, juxta Nashville."

Herb. Geol. Surv. Herb. Mohr.

Croton capitatus Michx. Fl. Bor. Am. 2 :214. 1803.

Woolly Croton.

Gray, Man. ed.6, 458. Chap. Fl. Suppl.648: ed..3, 430. Coulter, Contr. Nat. Herb. $2: 399$.

Northern Mexico.

Carolinian and Louisianian areas. Illinois, Missouri, and eastern Kansas south to Tennessee, Arkansas, Texas, and western Louisiana.

Aldabana: Tennessee Valley to Coast plain. Widely scattered, chiefly a wayside plant. Morgan County, cerlar plain, border fields and roads. Shelby County, Calera, about the railroad station. Talladega County, Syllacauga (E. A. Smith). Mobile, borders Birmingham and Mobile Railroad track. August to October. Aunual.

Type locality: "Hab. in regione Illinoensi."

Herb. Geol. Surv. Herb. Mohr.

Croton texensis (Klotzsch) Muell. Arg. in DC. Prodr. 15, pt. 2:692. 1862.

Hendecandra texensis Klotzsch in Wiegm. Archiv. 7:252. 1841.

Texas Croton.

Gray, Man. ed. 6, 458. Chap. Fl. Suppl. 618; ed. 3, 430. Coulter, Contr. Nat. Herb.

$2: 400$.

Carolinian area. Western Louisiana, Texas, and Arizona.

Alabama : Lower bills. Waste places. Roalsilles. Tallapoosa County, Dadeville. Jefferson County, Birmingham, copionsly about railroad yards. Adventive from the Southwest. Flowers July, August. Annual.

Type locality: "In Arkansas $*^{*} *$, in Texas * * * , et magis septen-

Herb. Geol. Surv. Herb. Mohr.

Croton glandulosus L. Amoen. Acad. 5 : 409. 1760.

Glandula Croton.

Ell. Sk. 2:647. Gray, Man. ed.6, 458. Chap. Fl.408. Coulter, Contr. Nat. Herb.

$2: 399$.

West Indies, Mexico, South America to Brazil.

Carolinian and Louisianian areas. Southern Illinois, Missouri, southern Kansas, Arkansas; from eastern Virginia south to the Gulf, and from Florida to 'Texas.

Alaibama: Mountain region to the Coast plain. Dry sandy fields, waste places. Autanga County. Clay County, Elders, 1,000 feet. Montgomery, Clarke, and Mobile counties. August to October. A common weed. Annual.

Type locality: Jamaica.

Herb. Geol. Surv. Herb. Mohr.

CROTONOPSIS Michx. Fl. Bor. Am. 2 : 185, t. 46. 1803.

Single species, Atlantic North America.

Crotonopsis linearis Michx. Fl. Bor. Am. 2 : 186. 1803.

Ell. Sk. 2:583. Gray, Man. ed.6, 459. Chap. Fl. 408.

Carolinian and Louisianian areas. New England west to Kansas, south to Florida and Arkansas.

Alabama: Mountain region. Central Pine belt, dry places. Etowah Comnty, Black Creek Falls. 'Tuscaloosa County (E. A. Smith). August; not frequent. Annual.

Type locality: "Hab. in maritimis Carolinae, juxta Long-bay, et in regione Illin oensi."

Herb. Geol. Surv. Herb. Mohr.

CROZOPHORA Neck. Elem. $2: 337.1790$. LitMUS HerB.

Crozophora tinctoria Juss. Tent. Euphor. 28, t. \%. 1824.

Croton tinctorius L.Sp. Pl. 2 : 1004. 1753.

Spain, Nortu Africa.

Alabama: Adventive with ballast, Mobile. September, 1891. Not observed lately. Anmul.

Type locality : "Hab. Monspelii."

Herb. Geol. Surv. 
ACALYPHA L. Sp. Pl. 2: 1003. 1753.

Two hundred and thirty species, mostly of tropical America. North America, 6. Acalypha virginica L. Sp. Pl. $2: 1003$. 1753. Virginia Three-seeded Mercury. Ell. Sk. 2 : 645. Gray, Man. ed. 6, 459. Chap. Fl. 405. Coulter, Contr. Nat. Herb. 2: 402 .

Alleghenian to Louisianian area. Ontario; New England west to Minnesota and Nebraska, south to Flurida and Texas.

Alabama: Throughout the State, waste and cultivated ground. Flowers throughout the summer. Common. Annual.

Type locality: "Hab. in Zeylona, Virginia."

Herb. Geol. Surv. Herb. Mohr.

Acalypha gracilens Gray, Man. 408. 1848.

Slender Three-SEeded MrRcury. Acalypha virginica gracilens Muell. Arg. Linnaea, 34:45. 1865.

Gray, Man. ed. 6, 459. Chap. Fl.406.

Carolinian and Louisianian areas. Coast southern New England to Florida, west to Illinois, eastern Kansas, Arkansas, and Texas.

Alabama: Mountain region to Coast plain. Dry sandy soil. Woods, cultivated and waste places. Clay County, Che-aw-ha range, 2,000 feet, in pine forests. Tuscaloosa County (E. A. Smith). Mobile County. Flowers, July to September; frequent. Annual.

Type locality: "Sandy dry soil, New Jersey and southward."

Herb. Geol. Surv. Herb. Mohr.

Acalypha ostryaefolia Ridd. Syn. Fl. W. States, 33. 1835.

Carolina Three-Seeded Mercury.

Acalypha caroliniana Ell. Sk. $2: 645$. 1824. Not Walt.

Ell. 1. c. Gray, Man. ed. 6, 460. Chap. Fl. 406.

Carolinian and Louisianian areas. New Jersey west to Ohio, Missouri, and Arkansas, south to Florida and Louisiana.

Alabama : Central Prairie region to Coast plain. Cultivated ground, waste places, damp rich soil. Autauga County, Prattville. Monroe County, Claiborne. Clarke County (Dr. Denny.) Mobile County. July to September; frequent in the coast plain. Annual

Type locality: "Found by Mr. T. G. Lea, on one of the Kentucky hills opposite Cincinnati."

Herb. Geol. Surv. Herb. Mohr.

TRAGIA L. Sp. P1. $2: 980.1753$.

Fifty species, of warmer temperate and chiefly tropical America to Brazil. North America, 4.

Tragia nepetaefolia Cav. Icon. 6:37, t. 55\%,f.1. 1801.

Nettle-Leaf Tragia.

Tragia urticaefolia Michx. Fl. Bor. Am. 2:176. 1803.

Ell. Sk. 2:564. Gray, Man. ed. 6, 460. Chap. Fl. 406. Coulter, Contr. Nat. Herb. $2: 404$.

Mexico.

Carolinian and Louisianian areas. Florida to North Carolina, west to Texas, Arkansas, and southern Missouri.

Alabama : Mountain region. Central Pine belt to Coast plain. Dry sandy soil, open copses, borders of fields and woods. Clay County, Che-aw-ha Mountain, 2,400 feet. Bibb County $(E, A$. Smith). Talladega County, Renfroe. Cullman, Montgomery, and Tuscaloosa counties. Butler County, Bladon. Mobile County. Frequent. Perennial.

Type locality: "Hab. inter Ixmiquilpan et Cimapan Novae-Hispaniae oppida."

Herb. Geol. Surv. Herb. Mohr.

Tragia urens L. Sp. Pl. ed. 2, 2 : 1391.1763.

Stinging Tragia.

Tragia innocua Walt. Fl. Car. 229. 1788.

Ell. Sk. 2:563. Gray, Man. ed.6, 460. Chap. Fl. 407. Coulter, Contr. Nat. Herb. $2: 404$.

Carolinian and Lonisianian areas. Southern Virginia to Florida and Texas.

Alabama: Central Prairie region to Coast Pine belt. Dry sandy places, pine barrens. Montgomery, Butler, and Mobile counties. Flowers Jnly, August; common in the pine barrens. Perennial. 
Form with narrow linear leaves, smoothish ( $T$. linearifolia Ell.). Bald win County, sandy shores of Mobile Bay, Point Clear. Rare.

Type locality: "Hab. in Virginia."

Herb. Geol. Surv. Herb. Mohr.

MERCURIALIS L. Sp. Pl. 2 : 1037. 1753.

Seven species, Europe.

Mercurialis annua L. Sp. Pl. 2 : 1037. 1753.

DoG's Mercury.

Adventive from Europe.

Alabama : Mobile, ballast weed, observed for over 30 years, common about the shipping. Annual.

Type locality: "Hab. in Europae temperatae umbrosis."

Herb. Geol. Surv. Herb. Mohr.

RICINUS L. Sp. PI. 2 : 1007. 1753.

One species, tropical Africa. Introduced, naturalized in all tropical conntries.

Ricinus communis L. Sp. Pl. 2 : 1007. 1753.

Castor Oil Bean.

Gray, Mau. ed. 6, 460. Chap. Fl. 409.

Carolinian and Louisianian areas. Escaped from cultivation.

Alabama : Naturalized throughout the State in numerous localities near dwellings. Annual.

Type locality : "Hab. in India utraque, Africa, Europa australi."

Herb. Geol. Surv. Herb. Mohr.

JATROPHA L. Sp. Pl. $2: 1006.1753$.

Seventy species, of tropical America. North America, 5 .

Jatropha stimulosa Michx. Fl. Bor. Am. 2 :216. 1803.

SPURGe NetTle.

Jatropha urens var. stimulosa Muell. Arg. in DC. Prodr. 15, pt. 2: 1101. 1866.

Ell. Sk. 2 :649. Gray, Man. ed. 6, 457. Chap. Fl. 409.

Carolinian and Louisianian areas. Coast of southern Virginia and North Carolina to Florida, west to Arkansas and Texas.

Alabama: Central Pine belt to Coast plain. Dry sandy pine barrens. Autauga, Montgomery, Escambia, and Mobile counties. Flowers white, May to July. Common. Perennial.

Type locality: "In parte meridionali Americae septentrionalis, in Virginia prope Portsmouth, *** , in Carolina *** , in Alabama ** * , Florida."

Herb. Geol. Surv. Herb. Mohr.

STILLINGIA L. Mant. I:19. 1767.

Fifteen species, eastern Asia, Pacific islands. Southern North America, 5.

Stillingia sylvatica L. Mant. $1: 126.1767$.

Queen's Delight.

Ell. Sk. 2:650. Gray, Man. ed. 6, 461. Chap. Fl. 404. Coulter, Contr. Nat. Herb. $2: 404$.

Carolinian and Louisianian areas. Southeastern Virginia to Florida, west to Louisiana, Arkansas, and Texas.

Alabama : Central Pine belt to Coast plain. Light dry soil, open woods, copses. Chilton County. Autauga County (E. A. Smith). Clarke County (Dr. Denny). Monroe, Baldwin, and Mobile counties. Flowers yellow, April to June. Frequent in the pine barrens. Perennial.

Economic uses: 'The root is the "queen's root" of medicine-"Stillingia," United States Pharmacopeia.

Type locality : "Hab. in Carolinae pinetis."

Herb. Geol. Surv. Herb. Mohr.

SEBASTIANIA Spreng. Neue Entdeck. $2: 118, t .3 .1821$.

Abont 405 species, mostly of tropical America and southeastern North America. Tropics of the Old World.

Sebastiania ligustrina Muell. Arg. in DC. Prodr. 15, pt. 2:1165. 1866.

Stillingia ligustrina Michx. Fl. Bor. Am. 2:213. 1803.

Ell. Sk. 2 : 651 . Chap. Fl. 405.

Louisianian area. North Carolina to Florida, west to Louisiana. 
Alabama : Central Prairie region to Coast plain. Shady banks of streams. Montgomery County, Pintlala. Choctaw County. Clarke County (Dr. Denny). Mobile County. Four to 8 feet high. Frequent, particularly in the upper division of the Coast Pine belt.

Type locality: "Hab. in sylvarum umbrosis, ad ripas amnium Carolinae et Georgiae."

Herb. Geol. Surv. Herb. Mohr.

SAPIUM P. Br. Hist. Jam. 338. 1756.

About 25 species, tropics of both hemispheres.

Sapium sebiferum Roxb. Fl. Ind. 3:693. 1824.

Croton sebiferum L. Sp. Pl. 2:1004. 1753.

Stillingia sebifera Michx. Fl. Bor. Am. 2:213. 1803.

Ell. Sk. $2: 651$. Chap. Fl. 405.

China, Japan.

Louisianian area. Georgia, Louisiana. Introduced and cultivated for a shade tree.

Alabama : Coast plain. Mobile. Rarely escaped to waste grounds.

Type Jocality: "Hab. in Chinae humidis. Osbeck."

Herb. Geol. Surv. Herb. Mohr.

EUPHORBIA L. Sp. Pl. $1: 450$. 1753. ${ }^{1}$ SPURGE.

About 700 species, temperate and tropical regions. Europe, Asia, America. North America, 55 to 60 . Largely Southern. South Atlantic States, 35.

Euphorbia polygonifolia L. Sp. Pl. 1 : 455. 1753.

Seaside Spurge.

Ell. Sk. 2:656. Gray, Man. ed. 6, 452. Chap. Fl. 404. Coulter, Contr. Nat. Herb. 2: 387 .

Alleghenian to Louisianian area. Nova Scotia, Ontario, Illinois (shores of the Great Lakes); New York south to Florida, west to Texas.

AlabaMa: Littoral region. Drifting sands of the seashore. Baldwin and Mobile connties and adjacent islands. Flowers July to October; frequent. Annual.

Type locality: "Hab. in Canada, Virginia."

llerb. Geol. Surv. Herb. Mohr.

Euphorbia cordifolia Ell. Sk. 2 : 656. 1821-24.

Heartleaf Seaside Spurge.

Ell. Sk. l. c. Chap. Fl.404. Coulter, Contr. Nat. Herb. $2: 388$.

Louisianian area. North Carolina to Florida and west to Mississippi.

Alabama : Littoral region. Drifting sand. Eastern shore of Mobile Bay. Baldwin County. Mobile County, Dauphin Island. June to August; rare. Annual. Type locality: "In cultivated land, common around Beaufort," S. C.

Herb. Geol. Surv. Herb. Mohr.

Euphorbia serpens H. B. K. Nov. Gen. \& Sp. 2:52. 1817.

Creiping SpUrge.

Gray, Man. ed.6, 453. Chap. Fl. Suppl.646; ed. 3, 425. Coulter, Contr. Nat. Herb. $2: 388$.

Mexico, South America.

Carolinian to Louisianian area. Tennessee, Illinois, southern Kansas, and Texas.

Alabama : Coast plain. Waste places, roadsides. Mobile County. Most probably adventive from the Southwest. August, September. Annual.

Type locality: "Crescit in umbrosis Cumanae prope Bordones et Punta Araya."

Herb. Geol. Surv. Herb. Mohr.

Euphorbia humistrata Engelm. in Gray, Man. ed. 2, 386. 1856.

Low Spreading Spurge.

Gray, Man. ed.6, 453. Chap..Fl. Suppl.646; ed.3, 426. Coulter, Contr. Nat. Herb.

Carolinian and Louisianian areas. Shaded sandy ground, grassy banks. New Jersey, Ohio, southern Missouri, Tennessee, Mississippi.

Ala bama: Lower Pine region. Coast plain. Baldwin County. Eastern shore Mobile Bay. Mobile County, Springhill. Flowers August to October. Not infrequent with the following, and of the same habit of growth. Annual.

Type locality: "Banks of the Mississippi and lower Ohio, in rich alluvial soil, and southwestward."

Herb. Geol. Surv. Herb. Mohr.

1 J. B. S. Norton, North American species of Euphorbia section Tithymalus, Eleventh Aunual Report of the Missouri Botanical Garden, pp. 85 to 144.1899. 
Euphorbia garberi Engelm.; Chap. Fl. Suppl. 616. 1860. Garber's Spurge.

Chap. Fl. ed. 3, 425.

Louisianian area. Southern Florida.

Alabama : Coast plain. Waste places, dry sandy or gravelly soil. Mobile County, on the banks of the Mobile River near One-mile Creek. Flowers July to September. Annual.

Perhaps adventive with ballast. Abundant in this locality.

Type locality: "Sandy coast, South Florida."

Herb. Geol. Surv. Herb. Mohr.

Euphorbia maculata L. Sp. Pl. 1 : 455.1753.

SPOTTED SPURGE.

Euphorbia thymifolia Pursh, Fl. Am. Sept. 2 : 606. 1814.

Ell. Sk. 2:654. Gray, Man. ed. 6, 453. Chap. Fl. 403. Coulter, Contr. Nat. Herb. $2: 389$.

Alleghenian to Louisianian area. New England west to the Dakotas, Nebraska, Colorado, Missouri, Arkansas, and southward to the Gulf from Florida to Texas.

Alabama : Over the State. Roadsides, waste places, fields. July to November; common everywhere. Annual.

Type locality: "Hab. in America septentrionali."

Herb. Geol. Surv. Herb. Mohr.

Euphorbia nutans Lag. Gen. \& Sp.17. 1816.

Field SPURgk.

Euphorbia preslii Guss. Fl. Sicc. Prodr. 539. 1827.

E. hypericifolia many American authors. Not L.

E. hypericifolia var. communis Engelm. Bot. Mex. Bound. 188. 1853.

Ell. Sk. 2:654. Gray, Man. ed. 6, 453. Chap. Fl. 403; ed. 3, 425. Coulter, Contr.

Nat. Herb. $2: 387$.

Central America, Ecuador.

Alleghenian to Louisianian area. Ontario; New England west to Dakotas, Nebraska, Arkansas, and Texas, and throughout the States east of the Mississippi.

Alabama: Over the State. Fields, cultivated ground. Common. Annual.

Type locality: "Hab. in N. H." (i. e. Nova Hispania).

Herb. Geol. Surv. Herb. Mohr.

Euphorbia pilulifera discolor Engelm. in Torr. Bot. Mex. Bound. 188. 1859.

VARIEGATED SPURGE.

Diffuse, leaves very oblique at the base, subrhomboidal, sharply serrate, purplishspotted; stipules subulate; capsule small, pilose; seeds minute, ovate, acute, undulate-tuberculate. Stems $\frac{1}{2}$ to 1 foot long, leaves from 1 to $1 \frac{1}{2}$ inches long. Differs in shape and color of leaves from the usual forms of Euphorbia pilulifera; involucre only $\frac{1}{2}$ line long, heads 3 to 4 lines in diameter; seeds scarcely more than $\frac{1}{8}$ line long.

Our plant differs slightly in its assurgent to erect stem, and its seeds with a few faint rugae and faintly punctate. The densely flowered cymules are on peduncles 2 to 3 lines long; the appendages of the pilose involucre are small, red.

SONORA (Thurber).

Louisianian area. Florida and Texas.

Alabama : Coast plain. In cultivated and waste grounds. Flowers throughout the summer and fall. Annual.

During the past ten years extensively spreading and becoming a troublesome garden weed.

Type locality: "Sonora; Thurber, Wright, No.1842, in part. Mr. Blodgett found it in Florida."

Herb. Geol. Surv. Herb. Mohr.

Euphorbia marginata Pursh, Fl. Am. Sept. 2 : 607. 1814.

Gray, Man. ed. 6, 454.

LARGE HLOWERING SPURGE.

Alleghenian and Caroliuian areas. Ohio to Minnesota and Colorado.

Alabama : Escaped from cultivation. Autauga County, Prattville (E. A. Smith). Annual.

Type locality: "On the Yellowstone River. M. Lewis."

Herb. Geol. Surv.

Euphorbia corollata L. Sp. Pl. 1 : 459. 1753.

Flowerixg SPURGe.

Ell. Sk. 2:659. Gray, Man. ed. 6, 454. Chap. Fl. 400. Coulter, Contr. Nat. Herb. $2: 391$.

Alleghenian, Carolinian, and Lonisianian areas. Now York west to Nebraska, south to Texas and Florida. 
Ala13ama : Over the State. Dry exposed soil everywhere. Flowers white; June to October. Perennial.

Type locality: "Hab. in Virginia, Canada."

Herb. Geol. Surv. Herb. Mohr.

Euphorbia corollata angustifolia Ell. Sk. 2 : 659. 1821-24.

Ell. Sk. 1. c. Chap. F1. 401.

Narrow-leaf Flowtering Spurge.

Louisianian area. South Carolina to Florida, west to Mississippi.

Alabama: Lower Pine region. Sandy pine ridges. Mobile County, Springhill. Escambia County. July, August; not infrequent. A very distinct variety. Perennial.

Type locality: "Collected by Mr. Caradeux in St. Thomas, near Charleston."

Herb. Geol. Surv. Herb. Mohr.

Euphorbia mercurialina Michx. Fl. Bor. Am. 2 : 212. 1803.

Chap. Fl. Suppl. 646. Chap. Fl. ed. 3,422.

Dog's Mercury Spurge.

Carolinian area. Tennessee.

Alabama: Mountain region. Sunny rocky hillsides. Madison County, Montesano, 800 feet. Limestone ledges. May, 10 to 18 inches high from a thick ligneous root. Only locality known in the State. Perennial.

Type locality: "Hab. in collibus, circa Knoxville."

Herb. Geol. Surv. Herb. Mohr.

Euphorbia floridana Chap. F1. 401. 1860.

Florida Spurge.

Euphorbia sphaerosperma Shuttlew.; Boissier in DC. Prodr. 15, pt. 2: 102.1866.

Chap. Fl. 1. c.; ed. $3,423$.

Louisianian area. Florida.

Alabama: Lower Pine region. Dry sandy fields, open pine ridges. Escambia County, Flomaton, aud adjacent parts of Florida. June. Perennial.

Type locality: "Dry pine barrens middle Florida."

Herb. Geol Surv. Herb. Mohr.

Euphorbia inundata Torr.; Chap. Fl.402. 1860.

SWAMP SPURGE.

Chap. Fl.1.c.

Louisianian area. Florida.

Alabama: Coast plain. Low damp pine barrens. Baldwin Connty, Zundel's, April, 1879. Local. Rare, not observed during late years; locality drained and under cultivation. Perennial.

Type locality : "Pine-barren swamps, Florida."

Herb. Geol. Surv. Herb. Mohr.

Euphorbia obtusata Pursh, Fl. Am. Sept. 2: 606. 1814.

Euphorbia helioscopia? Ell. Sk. 2:658. 1824. Not L.

Ell. Sk. 1. c. Gray, Man. ed. 6, 455. Chap. Fl. 401. Coulter, Contr. Nat. Herb. 2: 393 .

Carolinian and Louisianian areas. Virginia and Ohio, west to Missouri, Iowa, Kaneas, and Colorado, south to South Carolina and Texas.

Alabama: Central Prairie region. Shady banks. Sumter County (E.A.Smith). Wilcox County (S. B. Buckley). Flowers May, June. Perennial.

Type locality: "In cultivated grounds: Virginia, near Staunton."

Herb. Geol. Surv. Herb. Mohr.

Euphorbia dictyosperma Fisch. \& Mey. Ind. Sem. Petrop. 2:37. 1835.

Reticulate-SEeded SPURge.

Euphorbia arkansana Engelm. \& Gray, Bost. Journ. Nat. Hist. 5 : 261. 1845.

Gray, Man. ed. 6, 455. Chap. Fl. ed. 3, 423. Coulter, Contr. Nat. Herb. 2 : 393. Britt. \& Br. Ill. Fl. 2 : 379.

Louisianian and Carolinian areas. From Louisiana to Georgia; Texas, Arkansas, Indian Territory, Missouri, and west to Colorado.

Alabama: Tennessee Valley, Russellville. Central Prairie region. Hale County, Gallion. Wilcox County (Buckley). June; not frequent. Annual or biennial.

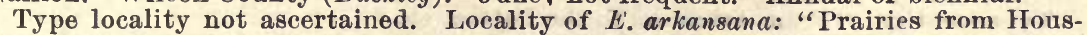
ton to the Colorado. * * * Also, Fort Gibson, Arkansas, Engelmann, and western Louisiana, Dr. Hale."

Herb. Geol. Surv. Herb. Mohr. 
Euphorbia commutata Engelm. in Gray, Man. ed. 2, 389. 1856.

TINTED SFUkGe.

Gray, Man. ed. 6, 456. Chap. Fl. 401. Coulter, Contr. Nat. Herb. 2 : 394.

Carolinian to Louisianian area. Ontario and Minnesota; Maryland; Ohio Valley to Missouri, south to Texas and western Florida.

Alabama : Central Prairie region. Shaded banks. Sumter County (E. A. Smith). Wilcox County (S. B. Buckley). June; infrequent. Biennial.

Type localiy: "Along water courses from Virginia toward the mountains to Ohio and westward."

Herb. Geol. Surv. Herb. Mohr.

Euphorbia peplus L. Sp. Pl. 1:456. 1753.

Gray, Man. ed. 6, 456.

EUROPE.

Alleghenian and Louisianian areas. Naturalized in Massachusetts and western

New York.

Alabama: Adventive, with ballast and firmly established near the wharves of Mobile. April, May. Annual.

Type locality: "Hab. in Europae cultis oleraceis."

Herb. Geol. Surv. Herb. Mohr.

Euphorbia tetrapora Engelm. in Torr. Bot. Mex. Bound. 191. 1859.

Chap. Fl. ed. 2, 646; ed. 3, 423. Coulter, Contr. Nat. Herb. 2: 394.

Carolinian and Louisianian areas. Texas, Indian Territory, Louisiana, Georgia.

AlabaMa: Coast plain. Waste open places. Most probably adventive from the

Southwest. Found only once.

Type locality: "Georgia; Boykin. Louisiana; Hale. Texas; Lindheimer, Wright.

Herb. Geol. Surv. Herb. Mohr.

Euphorbia cyparissias L. Sp. P1. 1:461. 1753.

EURope.

Alleghenian to Louisianian area. Naturalized in the Atlantic States.

Alabama: Mobile. Fugitive on ballast; rarely observed. Perennial.

Type locality: "Hab. in Misnia, Bohemia, Helvetia, G. Narbonensi."

Herb. Geol. Surv. Herb. Mohr.

\section{CALLITRICHACEAE. Water Starwort Family.}

CALLITRICHE L.Sp. P1. 2 : $969.1753 .{ }^{\prime}$

Fifteen to 20 ra'her obscurely defined species, temperate Europe. North America, 11.

Callitriche austini Engelm. in Gray, Man. ed.5, 428. 1867.

-

Austin's Water Starwort.

Callitriche deflexa var. austini Hegelm. Verh. Bot. Brand. 9 : 15. 1867.

Gray, Man. ed. 6, 182. Chap. Fl. Suppl. 646; ed. 3, 420.

Central and South America.

Carolinian and Lonisianian areas. New York, New Jersey, Illinois, Missouri, Arkansas, Texas, and Louisiana.

Ala bama: Tennessee Valley. Shaded damp soil. Franklin County, Russellville.

Lee County, Auburn (Baker \& Earle). In rich woods, June 28, 1892. Rare. Annual.

Type locality : "On damp soil in open woods, fields, and roads New York and New

Jersey (C. F. Austin) to Illinois, Missouri, Texas, Mexico, and South America."

Herb. Geol. Surv. Herb. Mohr.

Callitriche nuttallii Torr. Pac. R. Rep. 4:135. 1856. Nuttall's Water Starwort.

Callitriche pedunculosa Nutt. Trans. Am. Phil. Soc. n. ser. 5 :140. 1837. Not Arnott.

Carolinian and Louisianian areas. Arkansas, Mississippi, and Lonisiana.

Alabama: Coast plain. On damp open ground. Mobile County. Flowers February, March; fruit ripens April. Frequent. Epigaeus, forming dense mats; herb sweet-scented. Annual.

Type locality : "From Arkansas to the Pottoe, etc."

Herb. Geol. Surv. Herb. Mohr.

1 Thomas Morong, Notes on North American Halorageae, Bull. Torr. Club, vol. 18, pp. 232 to 239 (Callitriche). 1891. 
Callitriche peploides Nutt. Trans. Am. Phil. Soc. n. ser. 5: 141. 1837.

Callitriche drummondii Hegelm. Monogr. Callit. 60. 1864.

DRUMMOND's WATER STARWORT.

Chap. Fl. Suppl. 645 ; ed. 3, 420.

CuBA.

Louisianian area. Arkansas and Louisiana.

Alabama: Coast plain. Damp ground in the shade of dwellings. Flowers February, March. A more delicate plant than the last; sweet-scented. Annual.

Type locality: "On the banks of the Mississippi and on the margins of ponds."

Herb. Geol. Surv. Herb. Mohr.

Callitriche heterophylla Pursh, Fl. Am. Sept. 1:3. 1814.

Ell. Sk. 1:4. Gray, Man. ed. 6, 182. Chap. Fl.398.

AMERICAN WATER StaRWORT.

Carolinian to Louisianian area. New England (Morong) west to Missouri, Colorado, Arkansas, Texas, and Louisiana, and from New Jersey to Florida.

Alabama: Undoubtedly all over the State. In stagnant water, ditches. Collected from but few localities. Montgomery and Mobile counties. February; common. Annual.

A form with short stems, the linear to linear-spathulate leaves scarcely $\frac{1}{4}$ inch long, in muddy soil.

Type locality: "In springs and rivulets, very common."

Herb. Mohr.

Callitriche palustris L. Sp. P1. 2 : 969.1753.

EARLy Water StaRWORT.

Callitriche verna L. Fl. Suec. ed. 2, 2. 1755.

Gray, Man. ed. 6, 182.

EUROPE.

Alleghenian to Louisianian area. Canada to Florida and from Missouri to Arkansas.

AlaBAMA: A form with the leaves all linear, growing in shallow ponds, entirely submerged. The typical form has not been observed. Annual.

'Type locality: "Hab. in Europae fossis, paludibus."

Herb. Geol. Surv.

\title{
EMPETRACEAE. Crowberry Family.
}

\author{
CerAtiola Michx. Fl. 2:222. 1803.
}

Monotypical shrub. Southeastern North America.

Ceratiola ericoides Michx. Fl. Bor. Am. 2 :222. 1803. Heatherlike Ceratiola. Ell. Sk. 2 : 676. Chap. Fl.411.

Louisianian area. South Carolina, Florida to Mississippi.

Alabama : Lower Pine region. Arid barren sands. Washington County to Mobile County; not infrequent. Flowers reddish; August, September.

Type locality: "Hab. in aridis sabulosis Georgiae et Floridae."

Herb. Geol. Surv. Herb. Mohr.

\section{BUXACEAE. Box Family.}

PACHYSANDRA Michx. Fl. Bor. Am. $2: 177, t .45 .1803$.

Two species, Japan and Atlantic North America.

Pachysandra procumbens Michx. Fl. Bor. Am. 2 : 178. 1803. Low Pachysandra. Gray, Man. ed. 6, 456. Chap. Fl. 410.

Carolinian and Louisianian area. Kentucky, West Virginia, along the Alleghenies to Tennessee, western Florida, and Louisiana.

AlabaMa: Mountain region. Rich woods. Winston County, valley of Sipsey fork, 1,400 feet ( $T . M$. Peters). Marshall County, Collinsville (G.C. Boynton). Local and rare. Perennial.

'Type locality: "Hab. in occidentalibus montium Alléghanis."

Herb. Geol. Surv. 


\section{ANACARDIACEAE. Cashew Family.}

COTINUS Adans. Fam. Pl. $2: 345.1763$.

Two species, southern Europe, Asia. South Atlantic North America. Trees and shrubs.

Cotinus cotinoides (Nutt.) Britton, Mem. Torr. Club, 5:216. 1894.

american SMoke Tree. Chittam WoOd.

Rhus cotinoides Nutt.; Torr. \& Gray, Fl. N. A. 1:216. 1838.

Cotinus americanus Nutt. Sylv. N. A. 3:1, t. 81. 1849. 1857.

Gray, Man. ed. 6, 119. Chap. Fl. 70.

Carolinian area. Indian Territory. Western Texas, valley of Medina River; Tennessee, Cheat Mountains; southwestern Missouri.

AlabaMa: Mountain region. Rocky woods. On the ridges where the carboniferous sandstone immediately overlies the limestone strata at an elevation of 900 to 1,200 feet. Madison County, high knob at the Bailey place near Newmarket, there first discovered by S. B. Buckley in 1840 and rediscovered by Mohr in 1882. Montesano range, copious coppice growth. Jackson County, summit of limestone ridge, rising above the Gurley place, extensive grove of original growth. Flowers middle of April; fruit ripe at end of May. Drupes smooth, dark brown; tree 25, rarely 35, feet high, 8 to 10 inches in diameter.

Plate VI.

Economic uses: The fine-grained deep yellow wood was formerly employed for fence posts; used by the negroes for kindling. The bark, like the wood, is used for dyeing. Ornamental.

Type locality (Torr. \& Gray): "On the high rocky banks of Grand River, Arkansas, Nuttall!"

Herb. Geol. Surv. Herb. Mohr.

RHUS L.Sp. Pl. 1:265. 1753.

One hundred and twenty species, of temperate and warmer regions, South America Asia. North America 14. Trees and shrubs.

Rhus copallina L. Sp. Pl. 1: 266. 1753.

Sumach. Dwarf Sumach.

Ell. Sk. 1:362. Gray, Man. ed. 6, 119. Chap. Fl. 69. Coulter, Contr. Nat. Herb. 2: 67 . Sargent, Silv. N. A. 3: $19, t$. 104.

Alleghenian to Louisianian area. Ontario, New England west to Minnesota and Nebraska, south to the Gulf, and from Florida to Texas.

AlaBama: Throughout the State. Hilly rocky woods and dry sandy pine barrens. Flowers green; fruit ripe in August, dark red, acıdulous. Large shrub, more rarely arborescent. Most abundant and of largest size in the rocky hills of the Lower hill country and Upper division of the Coast Pine belt.

Economic uses: The leaves are used for tanning.

Type locality: "Hab. in America septentrionali."

Herb. Geol. Surv. Herb. Mohr.

Rhus glabra L. Sp. P1. 1:265. 1753.

Smootir Sumacir.

Ell. Sk. 1:361. Gray, Man. ed. 6, 119. Chap. Fl. 69.

Alleghenian to Louisianian area. Ontario to Saskatchewan. New England west to Nebraska, Colorado, Arkansas, and Arizona; from New York to Florida and western Louisiana.

Alabama: Throughout, on barren, gravelly, or rocky soil. Flowers greenish white; June. Fruit ripe in September and October, crimson, acid. Shrub 8 to 15 feet high.

Economic uses: The leaves are used for tanning and dyeing. The fruit is the sumach, "Rhus glabra," of the United States Pharmacopoia.

Type locality : "Hab. in America septentrionali."

Herb. Geol. Surv. Herb. Mohr.

Rhus vernix L. Sp. Pl. 1 : 265. 1753.

Poison Sumacir. Poison Elder.

Rhus venenata DC. Prodr. $2: 68$. 1825.

Ell. Sk. 1:362. Gray, Man. ed. 6, 119. Chap. Fl. 69. Sargent, Silv. N. A. 3:23,

t. 107,108 .

Alleghenian, Carolinian, and Louisianian areas. Western Ontario; New England west to Minnesota, south to the Gulf, and from Florida to western Louisiana.

Alabama: Throughout, excepting the higher mountain ranges. Swamps. Cullman County, Meriotts Creek, 600 feet. Flowers white, May; fruit ripe in Septem- 


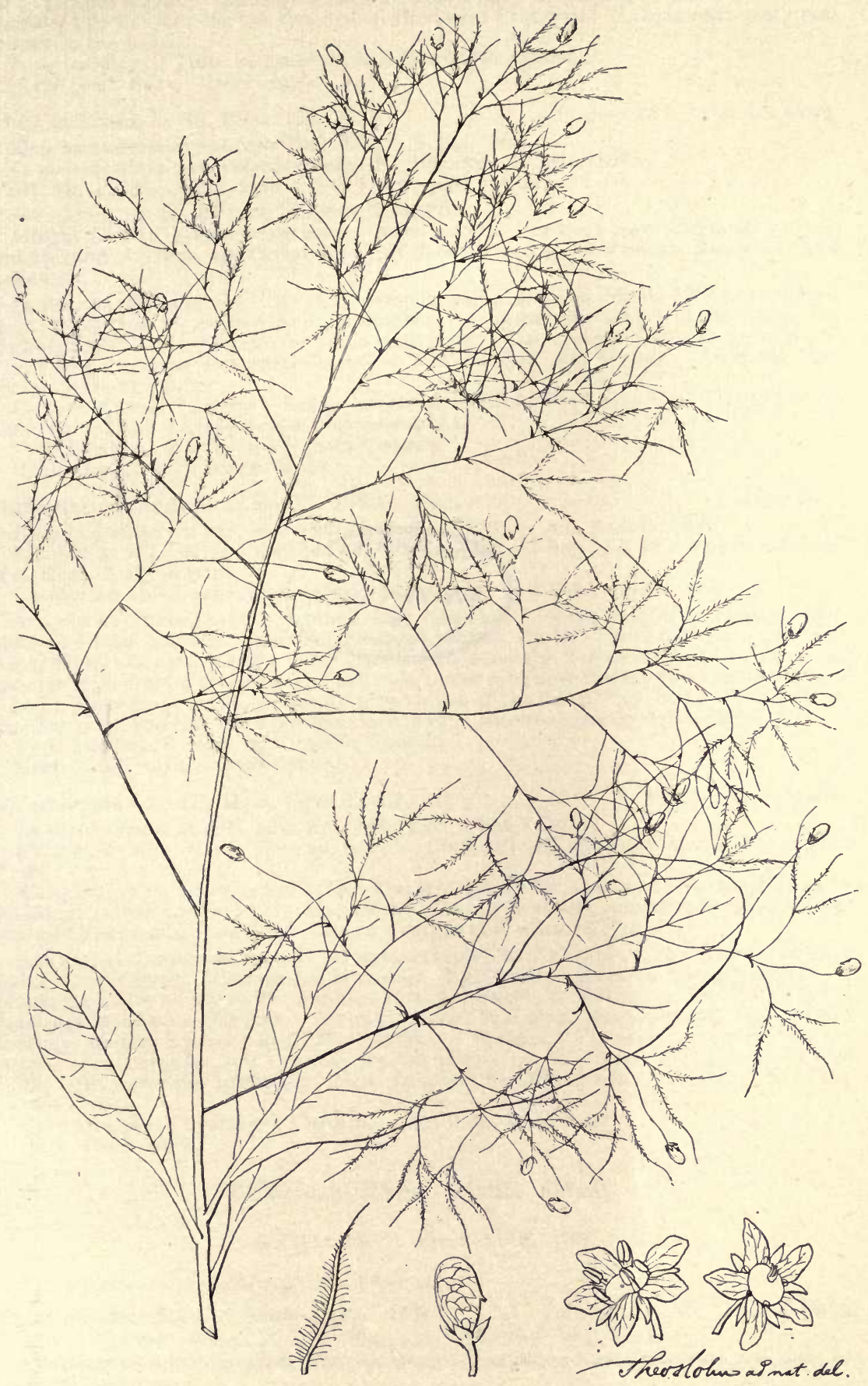

COTINUS COTINOIDES (NUTT.) BRITTON. 

ber. Drupes white. Tall shrub 10 to 18 feet high; frequently arborescent. Most abundant in the pine-barren swamps of the Coast Pine belt. Leaves extremely poisonous to the touch.

Type locality: "Hab. in America septentrionali, Japonia."

Herb. Geol. Surv. Herb. Mohr.

Rhus radicans L. Sp. Pl. 1:266. 1753.

Poison IVy. Poison Vine.

Rhus toxicodendron radicans Torr. Fl. U. S. 324. 1824.

R. toxicodendron var. vulgare Michx. Fl. Bor. Am. 1:183. 1803.

Ell. Sk. $1: 363$. Gray, Man. ed. 6, 119, in part. Chap. Fl. 69.

Sakhalin, Japan, Kurile Islands, Mexico.

Alleghenian to Louisianian area. Nova Scotia, Ontario; New England west to Dakota and Arizona, south to the Gulf from Florida to western Louisiana and Arkansas.

AlabaMa: Throughout. In rich damp woods. Bottom lands. Flowers white, May; fruit ripe in August and September. A stout root climber, ascending the highest trees; lateral branches 3 to 4 feet long. Also creeping on the ground and over rocks. Leaves soft, entire, more or less toothed and incised. Like the last, poisonous to the touch.

Economic uses: The fresh leaves are used medicinally, being the "Rhus toxicodendron" of the United States Pharmacopeia.

Type locality : "Hab. in Virginia, Canada."

Herb. Geol. Surv. Herb. Mohr.

Rhus toxicodendron L. Sp. Pl. 1:266. 1753.

PoIson OAK.

Rhus toxicodendron var. quercifolium Michx. Fl. Bor. Am. 1:183. 1803.

Ell. Sk. 1:363. Gray, Man. ed. 6, 119, in part. Chap. Fl. 69. Coulter, Contr. Nat. Herb. 2: 68, in part.

Carolinian and Louisianian areas. New Jersey to Florida and Texas.

AlabaMa: Thronghout, but much less frequent. In dry sterile soil, barren hillsides and pine barrens. Flowers greenish white; April. Fruit ripe in August and September. Drupes white. Low shrub, 1 to scarcely 2 feet high, with an erect, slender stem from a creeping slender root, never climbing, leaves thick, obtusely trilobed. Most frequent in the sandy pine ridges of the Coast Pine belt. Forms intergrading with the last have not been met with. Leaves equally deleterious.

'Type locality: "Hab. in Virginia, Canada."

Herb. Geol. Surv. Herb. Mohr.

Rhus aromatica Ait. Hort. Kew. 1:367. 1789.

Fragrant Sumach.

Rhue canadensis Marsh. Arb. Am. 129. 1785. Not Nutt.

Ell. Sk. 1:364. Gray, Man. ed. 6, 119. Chap. Fl. 69. Coulter, Contr. Nat. Herb. $2: 68$.

Alleghenian to Lonisianian area. Ontario and New England; Vermont west to Michigan, south to West Virginia; Ohio Valley to Missouri, southern Kansas, Arkansas, and Texas, and from Tennessee to Georgia and western Florida.

Alabama: Tennessee Valley. Mountain region to the Upper division of Coast Pine belt. Clay County, Che-aw-ha Mountain, 2,400 feet. Madison County, flanks of Montesano, 600 to 800 feet. Jackson County, Gurley's, 800 feet. Dekalb County, Lookout Mountain, 800 feet. Blount County, Warnock Mountain, 800 feet. Dale County, Ozark, scarcely over 250 feet above the sea. Flowers yellowish, March, April. Fruit ripe in June; drupes scarlet, aromatic. A slender shrub, 8 to 12 feet high, with wandlike branches. Most frequent on the calcareous slopes of the Tennessee Valley.

Type locality: "Native of Carolina. Mr. John Bartram."

Herb. Geol. Surv.

\title{
CYRILLACEAE. Cyrilla Family.
}

\author{
CYRILLA L. Mant. 1:50. 1767.
}

One species, southeastern North America.

Cyrilla racemiflora L. Mant. 1: 50. 1767.

Leatherwoon. Black Ti-ti.

Ell. Sk. 1:294. Chap, Fl. 272. Sargent, Silv. N. A. 2:3, t. 51.

Louisianian area. Western Florida along the coast to North Carolina and west to eastern Louisiana.

Alabama : Central Pine belt to Coast plain. Sandy swamps, borders of pine-barren streams. Autauga County (E. A. Smith). Lee County, Anburn (Baker \& Earle). 
Clarke, Escambia, Washington, Baldwin, and Molvile counties. Flowers white, June. Shrub or more frequently low tree, 15 to 30 feet high and 6 to 12 inches in diameter. Most frequent in the Lower Piue region and Coast plain, forming dense thickets. 'Type locality: "Hab. in Carolinae pinetis humentibus."

Herb. Geol. Surv. Herb. Mohr.

CLIFTONIA Banks in Gaert. f. Fruct. Suppl. 246, t. 225. 1805.

(MYlocaryum Willd. Enum. Fl. 54. 1807.)

Cliftonia monophylla (Lam.) Britton, Bull. Torr. Club, 16:310. 1889.

Ptelea monophylla Lam. Illust. 1:336. 1791.

Ti-ti. Buck wheat Tree.

Cliftonia nitida Gaert. f. Fruct. $3: 247, t$. 225, f. 5. 1805.

Milocaryum ligustrinum Willd. Enum. 454. 1807.

Cliftonia ligustrina Spreng. Syst. 2:316. 1825.

Ell. Sk. 1:508. Chap. Fl. 273. Sargent, Silv. N. A. $2: 7$, t. 52.

Louisianian area. Georgia, Florida west to eastern Louisiana.

Alabama : Upper division Coast Pine belt to Coast plain. Wet pine barrens, in sour peaty soil. Flowers white, slightly fragrant, middle of Mareh to April. Large shrub to tree of almost medium size, 25 to 35 feet high, and 8 to 12 inches in diameter, forming almost impenetrable thickets, acres in extent-the so-called ti-ti swamps.

Economic uses: 'The wood is excellent fuel.

Type locality: "E Carolinia. Fraser."

Herb. Geol. Surv. Herb. Mohr.

\section{ILICACEAE. Holly Family. ${ }^{1}$}

\section{ILEX L. Sp. Pl. 1:125. 1753.}

About 150 species, warm temperate regions of both hemispheres. Europe, Asia, South America. North America, 14 or 15, largely Southeastern. Trees or shrubs.

Ilex opaca Ait. Hort. Kew. 1 : 169. 1789.

HoLwy.

Ell. Sk. 2:679. Gray, Man. ed. 6, 108. Chap. Fl. 269. Coulter, Contr. Nat. Herb.

$2: 56$. Sargent, Silv. N. A. 1:107, $t .45$.

Carolinian and Louisianian areas. Southeastern Massachusetts, New York to Florida, west to the Trinity Valley, Texas, Arkansas, and southeastern Missouri.

Alabama: Throughout the State. Rich woodlands. Flowers white, April; fruit ripe in September and October, scarlet, remaining over winter. From 25 to 40 feet high and 10 to 15 inches in diameter. Of largest size and most frequent in the rich second bottom lands of the Prairie region and Upper division of the Coast Pine belt.

Economic uses: An ornamental tree, the wood useful.

Type locality: "Native of Carolina."

Herb. Geol. Surv. Herb. Mohr.

Ilex cassine L. Sp. Pl. 1 : 125. 1753. Not Walt.

DAHOON HOLLY.

Ilex dahoon Walt. Fl. Car. 241. 1788.

I. laurifolia Nutt. Am. Journ. Sci. 5:289. 1822.

Ell. Sk. 2:680. Gray, Man. ed.6, 108. Chap. Fl. 269. Sargent, Silv. N. A. 1:108, t. 46 .

Louisianian area. Southeastern Virginia along the coast to valley of St. Johns River; Florida along the coast to Mississippi.

Alabama : Coast plain. Alluvial swamps. Baldwin County, Stockton. Mobile County, swamps of Mobile and Dog rivers. Flowers sordid white, April ; fruit ripe in September and October, scarlet. Among the dense swamp growth a stout shrub; in more exposed situations from 20 to fully 35 feet high and 6 to 12 inches in diameter. Not common.

Type locality: "Hab. in Carolina."

Herb. Geol. Surv. Herb. Mohr.

Ilex myrtifolia Walt. Fl. Car. 241. 1788.

MYrTLE-LEAF DAHOON HOLLY.

Ilex angustifolia Willd. Enum. 172. 1807.

I. dahoon var. myrtifolia Chap. Fl. 269.

Ell. Sk. 2 : 681. Chap. Fl. l. c.

Louisianian area. North Carolina to Floricla and western Louisiana.

${ }^{1} \mathrm{Wm}$. Trelease, Revision of North American Ilicineae and Celastraceae, Trans. St. Louis Acad. Sci, vol. 5, pp. 343 to 348. 1889. 
Alabama: Lower Pine region and Coast plain. Margins of sandy pine-barren ponds. Mobile County, Whistler, Grand Bay. Flowers white, April; fruit ripe in September, October, dull purplish red. A low tree 15 to 20 feet high and 4 to 6 inches in diameter, with wide-spreading limbs. Not rare.

Type locality: South Carolina.

Herb. Geol. Surv. Herb. Mohr.

Ilex vomitoria Ait. Hort. Kew. 1:170. 1789.

YAUPON.

Ilex cassine Walt. Fl. Car. 241. 1788. Not L.

Ell. Sk. 2:681. Gray, Man. ed. 6, 108. Chap. Fl. 269. Sargent, Silv. N. A. 1:111,

t. 48. Coulter, Contr. Nat. Herb. $2: 56$.

Carolinian and Louisianian areas. Southeastern Virginia to St. Johns River, Florida west to the Colorado Valley, Texas.

Alabama : Coast plain. Borders of low sandy woods and open copses, clearings. Mobile County. Baldwin Connty and outlying islands. Flowers white, April; fruit vermilion red, October; remains until the next flowering season. Large shrub; more frequently small tree 15 to 25 feet high, 4 to 8 inches diameter. Common.

Economic uses: Leaves used sometimes as a substitute for tea; chief constituent of the "black drink" of the Indians.

Type locality: "Native of west Florida."

Herb. Geol. Surv.

Ilex decidua Walt. Fl. Car. 241. 1788.

Privet. Deciduous Holly.

Ilex prinoides Ait: Hort. Kew. 1 : 169. 1789.

Ell. Sk. 2:682. Gray, Man. ed.6, 108. Chap. Fl. 269. Coulter, Contr. Nat. Herb.

2:56. Sargent, Silv. N.A. 1:113, $t .49$.

Carolinian and Louisianian areas. Southern Virginia, Tennessee to Florida, west

to Texas, Arkansas, southern Kansas, Missouri, and southern Illinois.

Alabama: Tennessee Valley to the Coast plain. Low wet woods. Winston County, Sipsey Valley. Morgan County, Falkville. Blount County, on Mulberry River. Montgomery County, Pintlalla Creek. Dallas County. Mobile County, Mount Vernon. Baldwin County, Stockton. Flowers white, March, April; fruit ripe in October, scarlet, remaining on the bare branches until late in winter. Shrub

8 to 10 feet high, rarely arborescent; frequent.

Type locality: South Carolina.

Herb. Geol. Surv. Herb. Mohr.

Ilex longipes Chap.; Trelease, Trans. St. Louis Acad. 5 : 346. 1889.

Chap. Fl. ed. $3,82$.

Long-Peduncled Privet.

Carolinian and Louisianian areas. Tennessee and North Carolina.

Alabaya: Mountain region. Upper division of the Coast Pine belt, rocky or gravelly banks of streams. Cullman County, 800 feet. Clarke County, Thomas. ville. Wilcox County (Buckley). Flowers white, April; ripe fruit not seen. Shrub 3 to 4 feet high; infrequent.

Type locality: "North Carolina (Buckley) to Tennessee (Gattinger), Alabama (Buckley, Beaumont), and Louisiana (Drummond)."

Herb. Geol. Surv. Herb. Mohr.

Nlex caroliniana Walt. Fl. Car. 141. 1788.

Carolina Privet.

Prinos ambiguus Michx. Fl. 2:236. 1803.

Ilex ambigua Chap. Fl.269. 1860.

Ell. Sk. 2:705. Chap. Fl. 269.

Louisianian area. North Carolina to Florida, west to Louisiana.

AlabaMa: Lower Pine region. Sandy banks of pine-barren streams. Mobile County, Whistler, Bogue Home Creek, Springhill. Flowers white, April; fruit ripe October, $\frac{1}{4}$ to $\frac{8}{8}$ inch in diameter, coral red, translucent. Deciduous shrub 4 to 6 feet high, with wandlike branches; not frequent.

Type locality: South Carolina.

Herb. Geol. Surv. Herb. Mohr.

Ilex monticola Gray, Man. ed. 2, 264. 1856.

Mountain Privet.

Ilex montana Gray, Man. 276. 1848. Not Prinus montanus Sw. 1788.

Gray, Man. ed. 6, 108. Chap. Fl. Suppl. 633; ed.3, 82.

Alleghenian and Carolinian areas. Mountains of Now York and Pennsylvania, south along the Alleghenies to Tennessee and North Carolina.

Alabama: Mountain region. Damp rocky banks of brooks. Dekalb County, Lookout Mountain near Mentone, 1,600 feet. Cullman County, 1,000 feet, Jones Chapel. Flowers April; ripe fruit not seen. Shrub or small tree; infrequent. 
Type locality: "Damp woods, Taconic and Catskill Mountains, Now York, and Alleghenies from Pennsylvania southward."

Herb. Geol. Surv. Herb. Mohr.

Mlex monticola mollis (Gray) Britton, Mem. Torr. Club, 5:217. 1894.

Ilex mollis Gray, Man. ed. 5, 306. 1867.

Gray, Man. ed. 6, 108.

Carolinian area. Alleghenies from Pennsylvania to North Carolina and Tennessee.

AlabaMa: Mountain region. Lee County, Auburn (F.S. Earle). Rare.

Type locality: "Burgoons Gap, Alleghenies of Pennsylvania (J.R. Lovrie, Porter), and along the mountains in the Southern States."

Herb. Geol. Surv. Herb. Mohr.

Ilex coriacea (Pursh) Chap. Fl.270. 1860.

TALL INKBERRY.

Prinos coriaceus Pursh, Fl. Am. Sept. 1:221. 1814.

Mex lucida Torr. \& Gray; Wats. Bibl. Ind. 159. 1878.

Ell. Sk. 2:708. Chap. Fl. 270 .

Louisianian area. Georgia and Florida to eastern Louisiana.

Alabama : Coast plain. Swamps along pine-barren streams. Lee County, Anburn (Baker \& Earle). Baldwin County, Point Clear. Mobile County. Flowers white, April; fruit ripe in September and October, shining black. Tall evergreen shrub 8 to 15 feet high; frequent.

Type locality: "In sandy woods, near the banks of rivers: Georgia. Enslen."

Herb. Geol. Surv. Herb. Mohr.

Mlex glabra (L.) Gray, Man. ed. 2, 264. 1856.

INKBERRY.

Prinos glaber L. Sp. Pl. 1 : 330. 1753.

Ell. Sk. 2: 707. Gray, Man. ed. 6, 109. Chap. Fl. 270.

Alleghenian, Carolinian, and Louisianian areas. Nova Scotia on the seashore; coast of Massachusetts south to Virginia and Florida, west to Louisiana.

Alabama : Central Pine belt to Coast plain. Low sandy pine barrens. Antanga and Elmore counties. Macon County, south to Mobile and Baldwin counties. Flower's white, May; fruit ripe in October, black, remaining over winter. Evergreen shrub 3 to 4 feet high; common, in the flat pine woods along the coast.

Economic uses: Like most of the species of the genus, a good bee plant.

Type locality: "Hab. in Canada. Kalm."

Herb. Geol. Surv. Herb. Mohr.

Hex verticillata (L.) Gray, Man. ed.2, 264. 1856. Black Alder. Winter Berry. Prinos verticillatus L. Sp. Pl. 1: 330. 1753.

Ell. Sk. 2:706. Gray, Man. ed. 6, 109. Chap. Fl. 270.

Alleghenian to Louisianian area. New York, Pennsylvania, and Virginia, west to sonthern Illinois, Missouri, and Arkansas, south to Florida, and along the Gulf to Louisiana.

Alabama: Throughout the State. Low banks of streams, alluvial swamps. Cullman County, 800 feet. Montgomery County. Baldwin County, Stockton. Flowers dull white, April; fruit ripe in October; drupes scarlet. Decidnous shrub 6 to 10 feet high. Nowhere abundant. Some forms of this polymorphous shrub might be referred to the var. padifolia (Willd., Torr. \& Gray).

Economic uses: The bark was officially recognized in earlier editions of the United

States Pharmacopœia under the name of black alder bark.

Type locality: "Hab. in Virginia."

Herb. Geol. Surv. Herb. Mohr.

\section{CELASTRACEAE. Staff-tree Family.}

\section{EUONYMUS I. Sp. Pl. 197. 1753. StafF Trev.}

Abont 60 species, temperate regions, mountains of India, China, Japan, Europe. North America, 3.

Euonymus americanus L. Sp. Pl. 1: 197. 1753.

StraWBERry BUSH.

Ell. Sk. 1:292. Gray, Man. ed. 6, 110. Chap. Fl. 76.

Carolinian and Lonisianian areas. New York, West Virginia, and Tennessee to Florida, west to Louisiana, Arkansas, and Missouri.

Ala bama : Mountain region to Central Pine belt. Light soil, on shady banks and in woodlands. Clay County, banks of Talladega Creek, 800 to 1,000 feet. Lee 
County, Auburn (Earle \& Underwood). Tuscaloosa, Montgomery, Clark, Baldwin, and Mobile connties. Flowers greenish, April; fruit ripe in September and October. Frequent.

Type locality: "Hab. in Virginia."

Herb. Geol. Surv. Ilerb. Mohr.

Euonymus atropurpureus Jacq. Hort. Vind. 2 : 5, t. 120.1772.

Strawberry Tree. Burning Bush.

Ell. Sk. I: 293. Gray, Man. ed. 6, 110. Chap. Fl. 76.

Alleghenian and Carolinian areas. Ontario to Montana, New York to Ohio, Missouri, Arkansas, and Indian Territory, south to Virginia and along the mountains to Georgia.

Alabama : Mountain region. Jackson County, Gurley place in cultivation, said to have been transplanted from the woods of the vicinity.

Economic uses: The bark is used medicinally. That of the root is the Euonymus of the U.S. Pharmacopøia.

CeldastruS L. Sp. Pl. 196. 1753.

About 135 species, temperate to tropical regions of both hemispheres. North America, 1.

Celastrus scandens L. Sp. P1. 1:196. 1753. Wax-work. False Bitter-sweet.

Gray, Man. ed. 6, 110. Chap. Fl. 77.

Alleghenian and Carolinian areas. Ontario; Lake Superior to Manitoba; New England west to Minnesota, Nebraska, and Kansas, south to the mountains of Tennessee and North Carolina, and in New Mexico.

AlabaMa: Mountain region. Ridges of highest elevation, rocky banks. Dekalb County, Lookout Mountain, Mentone, 1,800 to 2,000 feet. Flowers greenish, June; fruit ripe in October. Climbing shrub; infrequent.

Economic uses: The bark is used as a domestic medicine.

Type locality: "Hab. in Canada."

Herb. Geol. Surv. Herb. Mohr.

\section{STAPHYLEACEAE. Bladder Nut Family.}

STAPHYLEA L. Sp. Pl. 1 : 270. 1753.

Seven species, temperate Europe. Eastern Asia, 1. North America, 2.

Staphylea trifolia L. Sp. Pl. 1: 270. 1753.

American Bladder Nut.

Ell. Sk. 1: 369. Gray, Man. ed. 6, 118. Chap. Fl. 77.

Alleghenian and Carolinian area. Quebec and Ontario; New York to West Virginia, west to Missouri and Arkansas, south to Tennessee and South Carolina.

Alabama: Tennessee Valley. Moist shady borders of woods and copses. Lauderdale County, Florence, bluff's of Tennessee River (M. C. Wilson), 600 feet. Flowers white, purple-tinged, April; rare. Shrub 8 to 10 feet high.

Type locality : "Hab. in Virginia."

Herb. Geol. Surv. Herb. Mohr.

\section{ACERACEAE. Maple Family.}

ACER L. Sp. P1. 2 : 1056. $1753 .{ }^{1}$

Sixty species, temperate regions Northern Hemisphere, eastern Asia. North America, 13 or 14 species. Trees.

Acer saccharum Marsh. Arb. Am. 4. 1785. Sugar Maple. Rock Maple. Acer saccharinum Wang. N. Am. Holzart. 36, t. 11,f. 26. 1787. Not L.

Acer barbatum Sargent, Silv. N. A. 2:97, t.90. 1893. Not Michx.

Ell. Sk. 1:450. Gray, Man. ed. 6, 117. Chap. Fl. 80.

Canadian zone to Carolinian area. Newfoundland and Nova Scotia to Manitoba; New England west to Minnesota, south to Missouri and Arkansas, and from New York along the mountains to Tennessee and Georgia.

${ }^{1}$ Chas. G. Sargent, Silv. N. Am. vol. 2, pp. 79 to 113.1893.

William Trelease, The sugar maples, with a winter synopsis of all North American maples, Ann. Rep. Mo. Bot. Gard., pp. 88 to 106. 1894. 
Alabama: Monntain region. Rich wooded slopes. Madison County, Huntsville, 75 feet high. Seemingly not frequent.

Economic uses: Fine timber tree. Sugar tree of the north, tapped for its saccharine sap.

Type locality: North American; not specifically given.

Herb. Geol. Surv. Herb. Mohr.

Acer saccharum barbatum (Michx.) Trelease, Ann. Rep. Mo. Bot. Gard. 5: 94. 1894.

Acer barbatum Michx. Fl. Bor. Am. 2:252. 1803.

Acer rugelii Pax, Engler's Bot. Jahrb. 7:243. 1886.

Chap. Fl. ed. $3,87$.

Alleghenian and Carolinian areas. Sonthern Connecticut, southern New York and New Jersey, west to Michigan, Missouri, and 'T'enuessee.

Alabama: Mountain region to Upper division Coast Pine belt. Wooded hills. Clay County, banks of Talladega Creek, 800 to 1,000 feet. Pike County, near Troy (Walnut Creek). Butler County, Mount Sterling, on limestone hills; not rare. The Alabama tree agrees perfectly with Pursh's description; as observed in the State it is scarcely over medium size; the leaves smaller than in the type, generally acntely 3 lobed, with open rounded sinuses, pale to glaucous beneath. Although toward its northern limit closely connected with the type, in its southern range this form is easily recognized as a well-marked variety. Further, judging by the phrase, "A. foliis breviter trilobis," and by his giving Carolina for the home of the tree, there can be little doubt that Michaux in the description of his Acer barbatum had this Southern tree in mind.

Type locality : "Hab. in Carolina."

Herb. Geol. Surv. Herb. Mohr.

Acer leucoderme Small, Bull. Torr. Club, 22 :367. 1894.

Pale-bark Maple. Acer floridanum acuminatum Trelease, Rep. Mo. Bot. Gard. 5 : 99, $t .11$. 1894. Not Dorr. 1825.

Carolinian and Louisianian areas. North Carolina to Georgia.

AlabaMa : Dry rocky banks and wooded hills. Mountain region to Upper division Coast Pine belt. Cullman County, 800 feet, June 18, 1891. Blount County, Warnock Mountain, 800 feet. Walker County, Wolf Creek. Butler County, Mount Sterling. A sturdy tree, rarely over 30 feet high; branches low; bark light gray, almost white. Large-leaved forms approach forms of Acer saccharum barbatum; easily distinguished by the white bark.

Type locality: "Two rocky canyons, that of the Yadkin River, in Stanley County, N. C., and especially that of the Yellow River, in Gwinnett County, Ga."

Herb. Mohr.

Acer floridanum (Chap.) Pax, Engler's Bot. Jahrb. 9 : 243. 1886. Florida Maple. Acer saccharinum var. floridanum Chap. F1.81. 1860.

A. barbatum var. floridanum Sargent, Silv. N. A. $2: 100, t .91$.

A. mexicanum Gray, Proc. Am. Acad. $5: 176.1862$.

Chap. Fl. l. c.; ed. $3,87$.

mexico, Central America.

Louisianian area. Georgia and Florida west to Louisiana and Arkansas.

Alabama: Central Prairie region and Upper division Coast Pine belt. Rocky banks and hillsides. Bibb County, Tionus. Pike Connty, Girard, Troy. Monroe County, Claiborne. A small tree, scarcely over 25 or 30 feet high, 6 to 8 inches in diameter. Not infrequent.

Type locality : "Upland woods, middle Florida."

Herb. Geol. Surv. Herb. Mohr.

Acer saccharinum L. Sp. Pl. 2 : 1055. 1753.

Acer dasycarpum Ehrh. Beitr. 4: 24. 1789.

Ell. Sk. 1:449. Gray, Man. ed. 6, 117. Chap. Fl. 81.

Alleghenian to Louisianian area. New Brunswick and Ontario; New England west to Minnesota, Dakota, Kansas, Arkansas, aud Indian Territory, south through the Ohio Valley to western Florida and Louisiana.

Alabama: T'ennessee Valley. Following the larger streams to the alluvial lands in the Coast plain. Banks of streams. Tusealoosa and Montgomery counties. Mobile County, Mount Vernon. Flowers February and March. Fruit ripe in May and June; tree 50 to 60 feet high, 8 to 15 inches in diameter. Trees of full size in the lower valley of the Warrior River. Frequent among the second growth of the bottom lands.

Economic uses: A handsome shade tree, the wood of little valne except for fnel.

Type locality: "Hab. in Pennsylvania. Kalm."

Herb. Geol. Surv. Herb. Mohr. 
Acer rubrum L. Sp. P1. 2 :1055. 1753.

Red Maple. Swamp Maple.

Ell. Sk. 1:449. Gray, Man. ed.6, 618. Chap. Fl. 81. Sargent, Silv. N. A. 2 : 107, t.94.

Alleghenian to Louisianian area. New Brunswick, Ontario; New England west to Dakota, south to Florida, and along the Gulf to Texas and Arkansas.

Alabama: Over the State. Swampy woods and low river banks. Flowers scarlet. February, March; fruit ripe April, red.

Economic uses: The wood is used in cabinet making.

Type locality: "Hab. in Virginia, Pennsylvania."

Herb. Geol. Surv. Herb. Mohr.

Acer drummondii Hook. \& Arn.; Hook. Journ. Bot. 1: 200. 1834.

Acer vibrum drummondii Sargent, For. N. A. 50. 1884.

Drummond's Red Maple.

Louisianian area. Western Louisiana and Mississippi.

Alabama: Coast plain. Swampy alluvial forests. Mobile County, Mount Vernon. Inundated banks of Davids Lake. Flowers in February; fruit ripe middle of April, purplish (wine-purple). Thirty to 35 feet high, 10 to 12 inches in diameter. Not frequent.

In the Mississippi and Yazoo bottoms, where this tree is frequent, forms have been observed with the leaves less deeply lobed and with slighter pubescence, approaching $A$. rubrum.

Type locality: "New Orleans," Drummond.

Herb. Geol. Surv. Herb. Mohr.

Acer negundo L. Sp. Pl. 2:1056. 1753.

BOX ELDER.

Negundo aceroides Moench, Meth. 334. 1794.

Ell. Sk. 2:452. Gray, Man. ed. 6, 118. Chap. Fl. 81. Coulter, Contr. Nat. Herb. $2: 66$. Sargent, Silv. N. A. $2: 111, t .96$.

Alleghenian to Louisianian area. Ontario and Saskatchewan; New England, west to Minnesota, Dakota, Montana, and Utah, south to Florida, Louisiana, Arkansas, Texas, and eastern Arizona.

Alabama : Tennessee Valley to Lower hills. Morgan County. Lawrence County, Moulton. Madison and Blount counties. Franklin County, Russellville. Tuscaloosa County (E. A. Smith). Flowers in March; not frequent. A tree of sturdy grow th, rarely over 50 feet high, 12 to 16 inches in diameter.

Type locality: "Hab. in Virginia."

Herb. Geol. Surv. Herb. Mohr.

\section{AESCULACEAE. Horse Chestnut Family.}

AESCULUS L. Sp. Pl.344. 1753.

Fifteen species, temperate Asia. North America, 6.

Aesculus glabra Willd. Enum. 405. 1809.

Fetid Buckeye.

Gray, Man. ed. 6, 116. Chap. Fl. 79. Sargent, Silv. N. A. 2:55, t. 67, 68 .

Carolinian area. Pennsylvania west to Michigan, south to the Ohio Valley and Missouri, and along the Alleghenian Monntains to Georgia.

Alabama: Tennessee Valley. Mountain region. Calcareous wooded hills. Madison County, Huntsville, 800 feet. Winston County; Blount County, Warnock Mountain, 700 feet. Flowers yellow, May; fruit ripe in September. A tree from 40 to 50 feet high. Not infrequent in the limestone region of the Tenuessee Valley, elsewhere rare.

Type locality: "Hab. in America boreali."

Herb. Mohr.

Aesculus octandra Marsh. Arb. Am.4. 1785.

YELLOW BUCKEYE.

Aesculus lutea Wang. Schrift. Nat. Freund. Ber. 8:133, t. 6. 1788.

Aesculus flava Ait. Hort. Kew. 1:494. 1789.

Ell. Sk. 1:436. Gray, Man. ed. 6, 116. Chap. Fl. 80. Sargent, Silv. N. A. 2:59, t. 69 .

Alleghenian and Carolinian areas. Allegheny Mountains from Pennsylvania to northern Georgia, west to Iowa, Indian Territory, and eastern Texas.

Alabama: Mountain region. Rich wooded hillsides. Madison County, Montesano, grove of fine trees 75 to 80 feet high, near the Big Spring, 1,300 feet altitude. Local and rare.

Economic uses: Timber tree.

Type locality not distinctly given. Tree designated as "New river Horse Chestnut.'

Herb. Geol. Surv. Herb. Mohr. 
Aesculus pavia L. Sp. Pl. 1: 344. 1753.

RED BUCKEYE.

Ell. Sk. 1:435. Gray. Man. ed. 6,116. Chap. Fl. 79.

Carolinian and Louisianian area. Penusylvania and southeastern Virginia south to Florida, west to Louisiana, Arkansas, and southern Missouri.

Alabama: Thronghout the State, below 800 feet altitude. Borders of open copses in moderately fertile soil. Madison, County, Huntsville. Tuscaloosa, Montgomery Mobile, and Baldwin counties. Flowers scarlet, March, April; fruit ripe October. On the hills of the Tennessee Valley, frequently 10 to 12 feet high. Most common in the open rich copses of the Coast plain, there a shrub, rarely over 8 feet high.

Economic uses: Oruamental.

Type locality: "Hab. in Carolina, Brasilia."

Herb. Geol. Surv. Herb. Mohr.

Aesculus parviflora Walt. Fl. Car. 128. 1788.

SPIKED BUCKEYE.

Aesculus macrostachya Michx. Fl. Bor. Am. 1:220. 1803.

Ell. Sk. 1:436. Chap. Fl. 80.

Carolinian and Louisianian area. Mountain region to Upper division Coast Pine belt. Shady hillsides and wooded bauks. Clay County, Shinbone Valley, 800 to 1,000 feet. Blount County, 450 feet. Jefferson, Tuscaloosa, Henry, and Franklin counties. Monroe Connty, Claiborne. Flowers white, June; fruit ripe in October. Shrub 4 to 8 feet high; frequent.

Economic uses: Highly ornamental.

Type locality: South Carolina.

Herb. Geol. Surv. - Herb. Mohr.

\section{SAPINDACEAE. Soapberry Family.}

CARDIOSPERMUM L. Sp. P1. 1 : 366. 1753.

Four species of tropical America.

Cardiospermum halicacabum L. Sp. Pl. 1:366. 1753.

BaLloon Vine.

Ell. Sk. 1:460. Chap. Fl. 79. Griseb. Fl. Brit. W. Ind. 122.

East and West Indies.

Louisianian area. South Carolina, Florida, and Texas.

Alabama: Mountain region. Central Pine belt. Thickets. Clay County, Moseley. Autanga County, Prattville $(D r . J$. Smith). Bibb County (E.A. Smith). An old escape from cultivation.

Type locality: "Hab. in Indiis."

Herb. Geol. Surv.

SAPINDUS L. Sp. Pl. 1:367. 1753.

Sapindus marginatus Willd. Enum. Pl. 432. 1809.

Chap. Fl. 79. Coulter, Contr. Nat. Herb. 2 : 66.

WILd CHina. SoApherry.

Mexico.

Louisianian area. Louisiana, Mississippi?, Texas, Arkansas, New Mexico (lowa?, Kansas?).

Alabama : Mobile. Adventive near an old place in the pine hills on the road to the Bienville waterworks; most probably an escape from cultivation. Hale County, Gallion. Cultivated and spontancous by escape. Tree 20 to 25 feet high. Flowers June; fruit October, black.

Type locality: "Hab. in Carolina, Georgia."

Herb. Geol. Surv.

\section{RHAMNACEAE. Buckthorn Family.}

BERCHEMIA Necker, Elem. 2 : 122.1790.

Ten species, East Indies. Southeastern North America.

Berchemia scandens (Hill) Trelease in Trans. St. Louis Acad. 5 : 361.1889.

SUPPLE JACK. RATTAN VINE.

Rhamnus 8candens Hill, Hort. Kew. 453, t. 20. 1768.

R. volubilis L. f. Suppl. 132. 1781.

Berchemia volubilis DC. Prodr. 2:22. 1825.

Ell. Sk. 1:290. Gray, Man. ed.6,111. Chap. Fl. 73. Coulter, Contr, Nat. Herb. $2: 59$. 
Carolinian and Louisianian areas. Virginia, Kentucky, and Missouri, snuth to Tennessee and Florida, west to eastern Texas and Arkansas.

Alabama: Central Pine belt to Coast plain. Low thickets. Flowers greenish yellow, June; fruit ripe in Oetober, plum-purple. A vigorous climbing shrub with slender stem and supple branches, ascending high trees; frequent. Of most vigorous growth and greatest frequence in the Central Prairie region and on rich banks of water courses.

Type locality (Hill, Veg. Syst.): "Native of Carolina."

Herb. Geol. Surv. Herb. Mohr.

RHAMNUS L. Sp. Pl. 193. 1753.

About 75 species, of temperate regions North Hemisphere, Asia. North America, 8. Shrubs or trees.

Rhamnus lanceolata Pursh; Fl. Am. Sept. 1:166. 1814.

BUCKTHORN.

Gray, Man. ed.6,112. Chap. Fl. 73.

Carolinian and Louisianian areas. Kentucky, Virginia, and Tennessee.

Alabama: Central Prairie region. Shady banks. Sumter County, Epes Station (E. A. Snith). Wilcox County (Buckley). Butler County. Rare.

Type locality: "On the side of hills : Tennassee. Lyon."

Herb. Geol. Surv.

Rhamnus caroliniana Walt. Fl. Car. 101. 1788. Indian Cherry. Yellow Wood. Frangula caroliniana Gray, Man. ed. 5, 115. 1867.

Ell. Sk. 1:289. Gray, Man. ed. 6, 112. Chap. Fl. 73. Sargent, Silv. N. A. $2: 31$, t. 61 .

Carolinian and Louisianian areas. New Jersey, Missouri, and Arkansas, south to Florida and Louisiana.

ArABAMA: Mountain region to the coast. Shaded banks and rich hillsides, preferring calcareous soils. Clay County, Shinbone Valley, 1,000 feet. Madison County, New Market, 650 feet; Huntsville. Jackson County. Franklin County, Russellville. Baldwin County, shell banks. Flowers greenish, May; drupes black. Tree 18 to 25 feet high; 6 to 8 inches diameter. Most frequent on the calcareous hills of the Tennessee Valley; not rare.

Type locality: South Carolina.

Herb. Geol. Surv. Herb. Mohr.

SAGERETIA Brongn. Ann. Sci. Nat. 10:359. 1827.

Ten species, warmer regions of Asia. South and North America, 2.

Sageretia minutiflora (Michx.). MichauX's Sageretia.

Rhamnus minutiflorus Michx. Fl. Bor. Am. 1:154. 1803.

Sageretia michauxii Brongn. Ann. Sci. Nat. 10:360, t. 13, f. 2. 1827.

Ell. Sk. 1:289. Chap. Fl. 73.

Louisianian area. Coast of Carolina to Florida, west to Mississippi.

Alabama: Coast plain. Gravelly, sandy exposed or wooded banks. Mobile. Flowers white, October; fruit ripe the following summer, dark red. In exposed dry situations on the shores of Mobile Bay. A straggling shrub 6 to 10 feet high. On the borders of low rich woods a vigorous climber, ascending high trees.

Type locality: "Hab. in maritimis, a Carolina septentrionali ad Floridam."

Herb. Geol. Surv. Herb. Mohr.

ZIZYPHUS Gaert. Fruct. 1:43. 1788.

Zizyphus zizyphus (L.) Karst. Deutsche Fl. 870. 1880-1883.

Rhannus zizyphus L. Sp. Pl. 1:194. 1753.

Common JuJube Tree.

Zizyphus vulgaris Lam. Encycl. 1:185. 1791.

Mediterranean Europe.

Alabama : Mobile County. Escaped from cultivation. Flowers April, May ; fruit mature July. Medium-sized tree.

Economic uses: The fruit, under the name of "jujube berries," "Baccae jujubebae," is used medicinally.

Type locality : "Hab. in Europa australi."

Herb. Geol. Surv. Herb. Mohr. 
CEANOTHUS L.Sp. PI. 1 : 195. 1753.

About 40 species, temperate western North America, a few extending into Mexico. East of the Mississippi about 4 species.

Ceanothus americanus L. Sp. P1.1:195. 1753. New Jersey Tea. Red Root. Ell. Sk. 1:290. Gray, Man. ed. 6, 112. Chap. Fl. 74. Coulter, Contr. Nat. Herl, 2 : 61. Alleghenian to Louisianian area. Ontario, Manitoba; New England west to Nebraska and Arkansas, sonth to Florida and Texas.

Alabama: Tennessee Valley to Central Pine belt. Dry woods. Lauderdale and Cullman counties. Tuscaloosa County (E. A. Smith). Flowers May, June. Shrubby, 2 to 4 feet high.

The typical plant seems to be confined to the northern part of the State, having so far not been observed south of the Central Pine belt.

Economic uses: The root, known as "red root," is used medicinally.

Type locality: "Hab. in Virginia, Carolina."

Herb. Geol. Surv. Herb. Mohr.

Ceanothus americanus intermedius (Pursh) Torr. \& Gray, Fl. N. A. 1:264. 1838. Lesser Ceanothus. Red Root.

Ceanothus intermedius Pursh, Fl. Am. Sept. 1:167. 1814.

Ceanothus americanus pitcheri Torr. \& Gray, Fl. N. A. 1:264. 1838.

Carolinian and Louisianian areas. Tennessee, Carolina, Florida, west to eastern Louisiana.

Alabama: Lower hills to Coast plain. Dry sandy copses, open woods. Blount County, Mulberry River Valley. Montgomery, Baldwin, and Mobile counties. Shrub 1, or scarcely 2, feet high. Differs from the type by the small leaves from $\frac{1}{2}$ to $\frac{8}{4}$ inch wide and rarely over $1 \frac{1}{2}$ inches in length, oval or ovate-oblong, more or less rounded at the base, obtuse, or but slightly pointed, mucronately crenulate or serrulate; thyrsus roundish to oval, looser-Howered, rarely $1 \frac{1}{2}$ inches long. This variety includes a number of forms prevailing in the Southern States, described under various names, which, however, can not be separated.

Type locality: "In the woods of Tennassee. Lyon."

Herb. Geol. Surv. Herb. Mohr.

\section{BALSAMINACEAE. Balsam Family.}

IMPATIENS L. Sp. Pl.37. 1753. JeWEL WeEd. TOUCH-ML-NOT.

One hundred and forty to 150 species, mostly of tropical Asia, Africa, a few in temperate Europe. North America, 2.

Impatiens biflora Walt. Fl. Car. 219. 1788.

SPOTTED TOUCH-ME-NOT. Impatiens noli-tangere var. $\beta$ Michx. Fl. Bor. Am. 2 : 149. 1803. Not L.

I. fulva Nutt. Gen. $1: 146.1818$.

Ell. Sk. 1: 304. Gray, Man. ed.6, 106. Chap. Fl. 65.

Canadian zone to Carolinian area. Canada to northern latitude $66^{\circ}$. Alaska; New Englind west to Minnesota and Nebraska, south from New York to Florida, and along the Gulf to Louisiana and Arkansas.

AlabaMa: Mountain region. Damp shady copses, in rich soil. Clay County, banks of Talladega Creek, 800 to 1,000 feet. Cullman County. Clelurue County. Coosa County, Bradford (E. A. Smith). Flowers deep orange with reddish brown spots. July; not common. Annual.

Type locality: South Carolina.

Herb. Geol. Surv. Herb. Mohr.

Impatiens aurea Mnhl. Cat.26. 1813.

YELLOW-FLOWERED TOUCH-ME-NOT.

Impatiens noli-tangere $\beta$ Michx. Fl. Bor. Am. 2 : 149. 1803.

I. pallida Nutt. Gen. 1: 143. 1818.

Ell. Sk. 1:303. Graj, Man. ed. 6, 106. Chap. Fl. 65.

Alleghenian and Carolinian areas. Ontario to Saskatchewan; New England west to Minnesota and Nebraska, reaching the Pacific shore in Washington; south from Missouri to Arkansas and Lonisiana, and from New York to Florida.

Alabama: Mountain region to Lower hills. Springy places, grassy swales. Cullman County. Tuscaloosa County (E.A. Smith). Nlowers bright yellow. July; infrequent. Annual.

Type locality : "Pennsylvania."

Herb. Geol, Surv. Herb. Mohr. 


\section{VITACEAE. Grape Family.}

PARTHENOCISSUS Planch. in DC. Monogr. Phan. 5, pt. 2: 447. 1887.

About 10 species, temperate Eastern Asia. North America, 1. Woody climbers. Parthenocissus quinquefolia (L.) Planch. in DC. Monogr. Phan. 5, pt. 2: 448. 1887.

Hedera quinquefolia L. Sp. Pl. 1:202. 1753.

Virginia Creeper.

Ampelopsis quinquefolia Michx. Fl. Bor. Am. 1: 160. 1803.

2: 63 .

Cuba.

Alleghenian to Louisianian area. Quebec, Ontario, Manitoba; New England west to Dakota, Nebraska, and Colorado, south to the Gulf; from Florida to western T'exas and Arkansas.

Alabama: All over the State. Rich wooded banks of water courses. Flowers white; May, June; fruit ripe October, drupes dark blue. Climbing over bushes and high trees; common.

Economic uses: Ornamental creeper.

Type locality : "Hab. in Canada."

Herb. Geol. Surv. Herb. Mohr.

AMPELOPSIS Michx. Fl. Bor. Am. 1:159. 1803.

(Crssus Pers. Syn. 1:143. 1805. Not L. 1753.)

Fourteen species, temperate Asia. Eastern North America, 3. Woody climbers.

Ampelopsis arborea (L.) Rusly in Mem. Torr. Club, 5:221. 1894. Pepperidge.

Vitis arborea L. Sp. Pl. 1:203. 1753.

Ampelopsis bipinnata Michx. Fl. Bor. Am. 1:160. 1803.

Cissus stans Pers. Syn. 1:143. 1805.

Ell. Sk. 1:304. Gray, Man. ed. 6, 114. Chap. Fl. 70. Coulter, Contr. Nat. Herb. $2: 63$.

Cuba, Northern Mexico.

Carolinian and Louisianian areas. Virginia, southern Illinois, southeastern Missouri and Arkansas, south to the Gulf, extending from Florida to eastern Texas.

Alabama : Central Pine belt to Coast plain. Low borders of woods. Tuscaloosa County (E.A.Smith). Montgomery and Mobile counties. Flowers white, June; fruit ripe in September, drupes black. Frequent, on bushes, or ascending high trees. Type locality : "Hab. in Carolina, Virginia."

Herb. Geol. Surv. Herb. Mohr.

Ampelopsis incisa (Nutt.) Desmoul. in Dur. Monogr. de Vigne, 59. 18-.

Vitis incisa Nutt.; Torr. \& Gray, Fl. N. A. 1:243. 1838.

Shaside Cissus.

Chap. Fl. 70. Coulter, Contr. Nat. Herb. 2:63.

Louisianian area. Coast of Florida to Mississippi, western Texas, and southern Arkansas.

Alabama: Littoral belt. Drifting sands on the seashore. Baldwin County, eastern shore Mobile Bay, Dauphin Island, Sand Island. Flowers June. An evergreen shrub, trailing or climbing over bushes; infrequent.

Type locality: "Prairies and copses, Texas and Arkansas, Dr. Leavenworth! Arkansas, Nuttall!"

Herb. Geol. Surv. Herb. Mohr.

Ampelopsis cordata Michx. Fl. Bor. Am. 1: 159. 1803.

Cordate Cissus.

Cissus ampelopsis Pers. Syn. 1: 142. 1805.

Vitis indivisa Willd. Berl. Baumg. ed. 2, 538. 1811.

Ell. Sk. 1:305. Gray, Man. ed. 6, 114. Chap. Fl. 71. Coulter, Contr. Nat. Herb. 2 : 63.

Carolinian and Louisianian areas. Southern Virginia south to Florida, west to Arkansas and southern Missouri.

Alabama: Over the State in the valleys to the coast. River banks. Franklin County, Russellville. Tuscaloosa County (E. A. Smith). Dallas County, Big Prairie Creek. Monroe County, Claiborne. Baldwin and Mobile counties. Frequent, climbing over bushes 6 to 8 feet high.

Type loeality: "Hab. in dumetosis regionis Illinoensis et ad ripas amıis Savannah."

Herb. Geol. Surv. Herb. Mohr. 


\section{VITIS L. Sp̉. Pl. 1:200. 1753. Grapevine. ${ }^{1}$}

Thirty species in northern and temperate regions of both hemispheres. Europe, northern Asia. North America, 15; Atlantic, 14. Woody climbers.

Vitis aestivalis Michx. Fl. Bor. Am. 2:230. 1803.

Summer Grape.

Ell. Sk. 2:688. Gray, Man. ed.6, 113. Chap. Fl. 71. Coulter, Contr. Nat. Herb. $2: 62$.

\section{Northern Mexico.}

Alleghenian to Louisianian area. Southern Ontario; southern New England west to Minnesota and Nebraska, south to western Texas, and from New York to Florida.

Alabama: Over the State. In damp thickets and bottom lands. Flowers April, May; fruit ripe August, September. Berries black with a bloom, pleasant. Common. Ascends the highest trees. In rich bottoms, 4 to 6 inches in diameter.

Economic uses: One of the most important of American wine grapes; mother plant of the Cunningham, Herbemont, Lenoir, and Black Spanish varieties of the Gulf region.

Type locality: "Hab. in sylvis, a Virginia ad Carolinam."

Herb. Geol. Surv. Herb. Mohr.

Vitis cinerea Engelm. in Bushberg, Cat. ed. 3, 17. 1883.

Downy Grape.

Vitis aestivalis var. cinerea Engelm. in Gray, Man. ed. 5, 679. 1867.

Gray. Man. ed. 6, 113. Chap. Fl. ed. 3, 73.

Carolinian and Louisiauian areas. Central Illinois to Kansas, and to Texas, 'Tennessee, and Mississippi.

Alabama : Central Prairie region to Coast plain. Low thickets, banks of streams. Hale County, Gallion, Big Prairie Creek. Mobile County, Springhill, Steins Creek. Type locality: "Rich bottom lands in the Mississippi Valley, lllinois and southward."

Herb. Geol. Surv. Herb. Mohr.

Vitis cordifolia Michx. Fl. Bor. Am. 2 :231. 1803. Wintre Grape. Frost Grape.

Ell. Sk. 2:688. Gray, Man. ed. 6, 113. Chap. Fl. 71. Coulter, Contr. Nat. Herb.

$2: 62$.

Alleghenian to Carolinian area. Ontario; New England west to Minnesota, Nebraska, and Kansas, south to Arkansas and Texas, and to Tennessee and Georgia.

AlabaMa: Mountain region. Banks of streams. Lee County, Auburn (Baker of Earle). Blount County, Warnock Mountain, about 800 feet. Clay County, Shinbone Valley, Elders, 1,000 feet. Frequent in the higher valleys; not met with in the low country.

Type locality: "Hab. a Pensylvania ad Floridam."

Herb. Mohr.

Vitis bicolor Le Conte, Proc. Acad. Phila. 6: 272. 1852.

Blue Glipk or Winter Grape.

Vitis aestivalis var. bicolor Gras, Man. ed. 6, 113. 1890.

V. aestivalis Darlington, Flora Cestrica, 151. 1837. Fide Le Conte. Not Michx. Gray, Man. ed. 6, l. c.

Alleghenian and Carolinian areas. Northern New York to North Carolina.

Alabama : Mountain region. Rocky summits. Calhoun County, Anniston, high. est ridges, 800 to 1,000 feet, with Pinus australis and Quercus prinus; trailing over the rocks of flinty chert. Collected September 19, with ripe fruit. 'Talladega County, Alpine Mountains, 1,800 feet. Che-aw-ha Mountains, 2,400 feet, on cliff's, associated with Lonicera flava, Rubus villosus, and Robinia viscosa. The trailing vines from 10 to 12 feet long. Ripe berries black, without bloom, juicy, sweet, and of a pleasant flavor, worthy the attention of the cultivator.

Type locality: "From Pennsylvania to Virginia."

Herb. Geol. Surv. Herb. Mohr.

V. vulpina L. Sp. Pl. 1:203. 1753.

Riverside Grape.

Vitis riparia Michx. Fl. Bor. Am. 2 : 231. 1803.

Vitis cordifolia var. riparia Gray, Man, ed.5,113. 1867.

Ell. Sk. 2:688. Gray, Man. ed. 6, 114. Coulter, Contr. Nat. Herb. 2 : 63.

Alleghenian to Louisianian area. New Brunswick and Ontario to Lake Winnipeg; New England west to Minnesota and Nebraska, south to Missouri and Texas, Florida, and Louisiana.

${ }^{1}$ George Engelmann, The True Grapevines of the United States, in Bushberg, Cat. ed. 3, St. Lonis. 1883. 
Alabama: Upper division Coast Pine belt. Clarke County, Lisbon, calcareous bluffs on the Alabama River. Flowers in June. Rare.

Economic uses: Important for its resistance to the ravages of the Phylloxera, hence largely used in Europe as a stock for grafting those varieties of Vitis vinifera upon which are specially liable to destruction by the insect plague.

Type locality: "Hab. ad ripas et in insulis fluviorum Óhio, Mississippi, etc."

Herb. Geol. Surv. Herb. Mohr.

Vitis rotundifolia Michx. Fl. Bor. Am. 2 :231. 1803. Bullace Grape. Muscadine.

Vitis vulpina Torr. \& Gray, Fl. N. A. 1 :245. 1838. Not L.

Ell. Sk. 2:687. Gray, Man. ed. 6, 114. Chap. Fl. 71.

Carolinian and Louisianian areas. Virginia, sonthern Kentucky, Tennessee to Florida, west to Louisiana, western Texas, and southern Missouri.

Alabama: Over the State except on ridges of an elevation exceeding 1,000 or 1,200 feet. In light sandy soil, low woods and banks. Flowers second week of May to June. Fruit ripe August to September. Berries large, plin-purple. Plants of spontaneous growth have been observed near Mobile bearing light amber-colored berries. In rich bottom lands climbing high tress. Most common throughout the Coast Pine belt.

Economic uses: Important as a table and wine grape. Mother plant of the Scuppernong, 'Thomas, and Flowers grapes.

Type locality : "Hab. a Virginia ad Floridam."

Herb. Geol. Surv. Herb. Mohr.

\section{TILIACEAE. Linden Family.}

TILIA L. Sp. P1. 1:514. 1753.

About 12 species, temperate and cooler regions of Northern Hemisphere. North America, 3. Trees.

Tilia americana L. Sp. P1. 1:514. 1753.

BASSWOOD. LINDEN.

Ell. Sk. 2:2. Gray, Man. ed. 6, 101. Chap. Fl. 59. Coulter, Contr. Nat. Herb. 2 : 46. Sargent, Silv. N. A. 1:52, t. 24,25 .

Canadian zone to Louisianian area. New Brunswick and Quebec to Manitoba; Now England west to Minnesota and Nebraska, south to Georgia, Texas, and Arkansas.

Alabama : Mountain region. Upper division Coast Pine belt. Rich woods. Cullman, 600 feet. Blount County, Warnock Mountain, 1,000 feet. Madison County, Gurley. Clarke County (Dr. Denny). Flowers white, fragraut. A large timber tree in the mountains, of inferior size southward. Not common.

Economic uses: Timber tree.

Type locality : "Hab. in Virginia, Canada."

Herb. Geol. Surv. Herb. Mohr.

Tilia heterophylla Vent. Mem. Acad. Par. $4: 16, t .5$. 1802.

SiLVER-LEAF LINDEN.

Gray, Man. ed.6, 101. Chap. Fl.60. Sargent, Silv. N. A. 1: 57, t. 28, 29.

Carolinian and Louisianian areas. Pennsylvania along the mountains to Georgia and Florida.

Alabama: Tennessee Valley to Central Prairie region. Rich woods. Cullman County (Baker \& Earle). Franklin County, Russellville. Madison County, Huntsville. Clarke County, Thomasville.

Type locality not ascertained.

Herb. Geol. Surv. Herb. Mohr.

CORCHORUS L. Sp. P1. 2 : 746, ed.3. 1764.

About 35 species, tropical regions of Asia and America. Africa.

Corchorus hirtus glabellus Gray, Syn. Fl. N. Am. 1, pt. 1: 342. 1897.

CAP-PODDED CORChORUS.

Corchorus pilolobus Gray, Pl. Wright. 1:24. 1852. Not Link.

C. siliquosus Torr. \& Gray, Fl. N. A. 1:239. 1838. Not L.

Gray, Gen. Ill. 2: 94, t. 13\%. Chap. Fl. ed. 3, 55. Coulter, Contr. Nat. Herb. 2 : 45.

Louisianian area. Coast of Florida to Texas; Arizona; Mexico.

Alabama: Central Pine belt to Coast plain. Cultivated ground. Tuscaloosa County (E. A. Smith). Mobile County (Gates). Flowers yellow, August, September; not rare. Weed, annual.

'Type locality: "Florida to southern Texas and Arizona. (Mexico)."

Herb. Geol. Surv. Herb. Mohr. 
Corchorus aestuans L. Syst. ed. 10, 2 : 1079. 1759.

Griseb. Fl. Brit. W. I. 97.

West INDIES, South America.

Alabama: Adventive with ballast. Mobile, September, 1894. Annual.

Type locality not originally given. In L. Sp. Pl. ed. 2 : "Hab. in America calidiore." Herb. Geol. Surv.

\section{MALVACEAE. Mallow Family.}

ABUTILON Gaertn. Fruct. 2:251, t. 135. 1791.

Seventy species, warmer regions of both hemispheres.

Abutilon abutilon (L.) Rusby, Mem. Torr Club, 5 :222. 1893-94. Velvet Leaf. Sida abutilon L. Sp. Pl. 2 : 685.1753.

Abutilon avicennae Gaertn. Fruct. $2: 251, t .135 .1791$.

Ell. Sk. 2 :162. Gray, Man. ed.6,99. Chap. Fl.55.

INDIA, widely spread in the warmer conntries.

Carolinian and Louisianian areas. Naturalized thronghout the Atlantic States.

Alabama : All over the State in cultivated gronnds and on roadsides. Flowers yellow, June to September; not common. Annual.

Type locality: "Hab. in Indiis."

Herb. Geol. Surv. Herb. Mohr.

MODIOLA Moench, Meth. 619. 1794.

About half a dozen species, warmer regions South America to Brazil. North America, 1.

Modiola caroliniana (L.) Don, Hist. Dichl. Pl. 1:466. 1831. Carolina Mallow. Malva caroliniana L. Sp. Pl. 2 : 688. 1753.

Modiola multifida Moench, Meth. 619. 1794.

Ell. Sk. $2: 163$. Gray, Man. ed. 6, 100. Chap. Fl.56. Griseb. Fl. Brit. W. Ind. 72.

West Indies, Southifrn Mexico, South America, Juan Fernandez.

Carolinian and Louisianian areas. Southern Virginia and North Carolina to Florida, west to Louisiana.

Alabama: Central Pine belt to Coast plain. Light sandy soil, roadsides, waste places. Tuscaloosa County (E.A. Smith). Mobile Connty. Flowers searlet, May to July. A common weed. Perennial.

Type locality: "Hab. in Carolina."

Herb. Geol. Surv. Herb. Mohr.

MALVA L. Sp. P1. 2:687. 1753.

Thirty species, temperate regions, Europe.

Malva rotundifolia L. Sp. Pl. 2 : 688 . 1753.

Adventive from Enrope, naturalized in the Eastern United States.

Alabama : Over the State, near dwellings. Mobile and Baldwin counties. Flowers in June, July. Not frequent. Annual.

Type locality: "Hab. in Europae ruderatis, viis, plateis."

Herb. Geol. Surv. Herb. Mohr.

Malva brasiliensis Jesr. in Lam. Encyel. 3 : 744. 1789.

Brazilian Mallow.

Fugitive on ballast from the tropics. Mobile, first collected June, 1893.

Type locality: "Au Bresil, oì elle fut tronvée, par Commerson, à l'ile anx Chats, dans la rade de Rio-Janeiro."

CALLIRRHOE Nutt. Journ. Acad. Phila. 2 : 181. 1821.

Seven species. Perennial herbs, North American.

Callirrhoe papaver (Cav.) Gray, Pl. Fendl. 17. 1849.

PopPylike Malalow.

Malva papaver Cav. Diss. 2 : $64, t .15, f .3 .1790$.

M. nuttalloides Croom, Am. Journ. Sci. 26:313, 328. 1834.

Chap. Fl.53.

Louisianian area. Georgia and Florida, west to Louisiana and Arkansas. 
Atabama: Lower Piue region. Grassy glades. Washington County, Healing Springs. Flowers purple (magenta), August; infrequent. Perennial.

Type locality: "Hab. in Luisiana. Observata a D. Fontenette."

Herb. Geol. Surv. Herb. Mohr.

Callirrhoe alceoides (Michx.) Gray, Pl. Fendl. 18. 1849.

ALCEA-Like MaLLOW.

Sida alceoides Michx. Fl. Bor. Am. 2 : 44. 1803.

Gray, Man. ed.6, 98 . Chap. Fl. 54. Conlter, Contr. Nat. Herb. $2: 36$.

Carolinian and Louisianian areas. Southern Kentucky to Nebraska and Texas.

Ala Bana: Central Pine belt. Bibb County (E. A. Smith). Flowerspurple, August; rare. Perennial.

Type locality: "Hab. in glareosis Kentucky et Tennassée."

Herb. Geol. Surv. Herb. Mohr.

Callirrhoe triangulata (Leavenworth) Grav, Pl. Fendl. 18. 1849.

Triangular-Leaf Mallow.

Malva triangulata Ieavenworth, Am. Journ. Sci. 7:62. 1824.

Gray, Man. ed. 6, 98. Chap. Fl.53.

Carolinian and Louisianian areas. Indiana, Missouri, Minnesota, and southern Mississippi.

Alabama: Prairie region. Montgomery County (Leavenworth). Not collected since in the State. Plentiful near Alabama State line on the banks of the Tombigbee River in Mississippi. Perennial.

Type locality: "Montgomery County, Alabama."

Herb. Geol. Surv. Herb. Mohr.

SIDA L. Sp. P1. 2 :683. 1753. SidA.

Eighty species, subtropical and tropical regions of the globe. North and South America, about 50.

Sida cordifolia L. Sp. PI. 2 : 684.1753.

Velvety SidA.

Griseb. Fl. Brit. W. Ind. 73. Gray, Syn. F1. 1, pt. 1: 323.

West Indies, Mexico to Brazil.

Louisiana area. Florida, Louisiana.

Alabama : Fugitive on ballast. Mobile, September, 1893; not found since. Perennial.

Type locality: "Hab. in India."

Herb. Geol. Surv. Herb. Mohr.

Sida spinosa L. Sp. Pl. 2 : 683.1753.

SPINY SIDA.

Ell. Sk. 2 : 161. Gray, Man. ed. 6, 99. Chap. Fl. 54. Griseb. Fl. Brit. W. Ind. 74.

WIDELY DIFFUSED OVER WARMER REGIONS.

Carolinian and Louisianian areas. Southern New York, Ohio Valley, Missouri, south to the Gulf, from Florida to Louisiana.

Alabama: Over the State. Cultivated ground, waste places. Flowers yellow, June to November; a common weed. Annual.

Type locality: "Hab. in India utraque."

Herb. Geol. Surv. Herb. Mohr.

Sida urens L. Sp. Pl. ed. 2, 2 : 963. 1763.

Griseb. Fl. Brit. W. Ind. 75.

Tropical america and Africa.

Alabama: Mobile. Eugitive on ballast. September, 1889. Rarely observed.

Perennial.

Stems 2 to $2 \frac{1}{2}$ feet long, slender, trailing.

Type locality : "Hab. in Jamaica."

Herb. Geol. Surv. Herb. Mohr.

Sida acuta Burm. Fl. Ind. 147. 1768.

ACUTE-FRUITED SIDA.

Sida carpinifolia auct.

S. glabra Nutt. Journ. Acad. Phila. 7 :90. 1834.

Gray, Syn. Fl. N. A. 1, pt. 1: 324.

Tropical Regions.

Louisianian area. Florida. Most probably introduced.

Alabama : Coast plain. Waste places near dwellings. A frequent ballast weed.

Flowers deep yellow, July to October. Perennial.

'Type locality : "Hab. in India."

Herb. Geol. Surv. Herb. Mohr. 
Sida acuta carpinifolia Schumann, in Mart. Fl. Bras. 12, pt. 3:326. 1891.

Sida carpinifolia L. f. Suppl. 307. 1781.

Gray, Syn. Fl. N. A. 1, pt. 1: 324. Griseb. Fl. Brit. W. Ind. 73.

Tropical regions, America, Africa, East Indies.

Lonisianian area. Florida.

AlabaMa: Lower Pine region. Coast plain. Sparingly naturalized; more frequently adventive on ballast heaps. Mobile County, Springhill, waste places near the hotel (F. W. Bush). Flowers August.

Type locality: Many provinces of Brazil are cited with Paraguay and English and French Guiana, "preterea inter tropicos ntriusque orbis herba ruderalis vulgaris."

Herb. Geol. Surv. Herb. Mohr.

Sida rhombifolia L. Sp. Pl. 2 : 684.1753.

RHOMBLEAF SiDA.

Ell. Sk. 2 :160. Chap. Fl.55. Griseb. Fl. Brit. W. Ind. 74.

CosMopolitaN IN WARMER REGIONS.

Carolinian and Louisianian areas. North Carolina to Florida, west to Lonisiana.

Alabama : Central Pine belt to the Coast plain. Dry pastures, waste and cultivated places. Mobile County, a common roadside weed, most probably naturalized from the adjacent tropics; never met with distant from dwellings. Flowers yellow, May to October.

Type locality: "Hab. in India utraque.

Herb. Geol. Surv. Herb. Mohr.

Sida elliottii Torr. \& Gray, Fl. N. A. 1 : 231. 1838.

Sida gracilis Ell. Sk. 2 :159. 1824. Not Richard.

ElliotT's Sida.

Southeastern Mexico.

Carolinian and Lonisianian areas. South Carolina to Florida, west to Tennessee and Mississippi.

Alabama : Central Pine belt to Lower Pine region. In light dry soil, open copses. Montgomery, Autanga, and Washington counties. Flowers pale yellow; June, Angust. Not infrequent.

Type locality: "Sandy soil ; Sonth Carolina, Elliott; Georgia, Dr. Boykin! Florida, Croom! Dr. Chapman!"

Herb. Geol. Surv. Herb. Mohr.

Sida linifolia Cav. Diss. 1:14, t. 2, f. 1. 1790.

Griseb. Fl. Brit. W. Ind. 76.

Tropical america and Africa.

Alabama: Fugitive on ballast. Mobile. September. Ripened seeds perfectly in 1892 and 1893.

Type locality: "Hab. in Insula Caienae et in Peru, ubi eam observavit D. Jos. de Jussieu."

Herb. Geol. Surv. Herb. Mohr.

MALVASTRUM Gray, Pl. Fendl.21. 1849.

Malvastrum angustum Gray, Pl. Fendl.22. 1849.

False Mallow.

Sida hispida Pursh, Fl. Am. Sept. 2 : 452. 1814. (१)

Ell. Sk. 2 : 159. Gray, Man. ed. 6,99. Chap. Fl.54.

Carolinian and Louisianian areas. Western Tennessee, southern Missouri, and

Kansas.

Alabama: Central Pine belt. Tallapoosa County (E. A. Smith). August, 1873. Annual.

Type locality: “This is probably Pursh's plant; but I have not seen it from Georgia. Drummond gathered it at St. Louis, whence I have also received it from Dr. Engelmann; and Nuttall found depauperate specimens on the plains of Red River." Herb. Mohr.

Malvastrum spicatum (L.) Gray, Pl. Fendl. 22. 1849.

Malva spicata L. Syst. ed. 10, 2 : 1146. 1759.

Griseb. Fl. Brit. W. Ind. 72.

Alabama: Fugitive from the tropics on ballast. Mobile, August, 1892. Not met with since.

Type locality not originally given. In L. Sp. Pl. ed. 2: “Hab. in Jamaica."

Herb. Geol. Surv. Herb. Mohr. 
HIBISCUS L.Sp. Pl. 2 : 693.1753.

About 180 species, chiefly in subtropical and tropical zones, both hemispheres. North America, 15.

Hibiscus aculeatus Walt. Fl. Car. 177. 1788.

Rovgir Rose Mallow.

Hibiscus scaber Michx. Fl. Bor. Am. 2: 45. 1803.

Ell. Sk. 2:169. Chap. Fl. 57.

Louisianian area. South Carolina to Florida, west to Louisiana.

Alabana: Central Prairie region to Lower Pine region. Grassy pine barrens. Crenshaw County (E. A. Smith). Clarke, Washington, Baldwin, and Mobile counties. Flowers pale yellow, with a dark purple spot in the center, July, August; frequent. Perennial.

.Type locality: South Carolina.

Herb. Geol. Surv. Herb. Mohr.

Hibiscus moscheutos L. Sp. Pl. 2 :693. 1753.

Swamp Rose Mallow.

Ell. Sk. 2:165. Gray, Man. ed. 6, 100. Chap. Fl. 57.

Alleghenian to Louisianian area. Southern New England; west to Michigan and Missouri, south to Florida and through the Gulf States to Louisiana.

Arabama: Tennessee Valley to the Coast plain. Swampy banks of streams, borders of marshes. Talladega County, Ironaton. Cullman County, 800 feet. Jefferson County, Elyton (E.A.Smith). Mobile County. Flowers June, July. The form with white flowers. Common in the tide-water districts. Perennial.

Type locality: "Hab. in Canada, Virginia."

Herb. Geol. Surv. Herb. Mohr.

Hibiscus lasiocarpus Cav. Diss. 3 : 159, t. 70, f. 1. 1787.

HoARY Hibiscus.

Hibiscus incanus Schrad. Sert. Han. t. 24. 1798.

Ell. Sk. 2 :167. Gray, Man. ed.6, 100, in part. Chap. Fl. 58; ed.3, 51.

Carolinian and Louisianian areas. Kentucky, Illinois, Missouri, and Arkansas, south to South Carolina, middle Florida, and western Louisiana.

Alabama: Central Pine belt. Prairie region. Low wet woods. Tuscaloosa County (E. A. Smith). Montgomery County. Flowers large, sulphur-yellow, crimson spot in center; July. Three to 4 feet high. Rare. Perennial.

Type locality: "V.S. unicum exemplar apud D. de Jussieu."

Herb. Geol. Surv. Herb. Mohr.

Hibiscus militaris Cav. Diss. 6: 352, t. 198, f. 2. 1788.

Hibiscus virginicus Walt. Fl. Car. 177. 1788. Not L.

Halbert-Leaf Rose MaLlow.

Ell. Sk. 2:168. Gray, Man. ed. 6, 100. Chap. Fl.58.

Carolinian and Louisianian areas. Pennsylvania, Ohio, Missouri, Arkansas, south from West Virginia to Georgia, Mississippi, and Louisiana.

Alabama : Central Prairie region to Coast plain. Low banks of streams. Dallas County, Cahaba (G.R. Vasey). Baldwin County, banks of Tennessee River. Flowers rose-pink, June. Three to 4 feet high. Not frequent. Perennial.

Type locality: "Hab. in Ludoviciana."

Herb. Geol. Surv. Herb. Mohr.

Hibiscus syriacus L. Sp. Pl. 2 : 695 . 1753.

Althea Tree.

Mediterranean EURope, Syria.

Alabama: A rare escape from gardens in several localities of the State.' Mobile County. Small tree.

Type locality: "Hab. in Sýria."

Herb. Geol. Surv.

KOSTELETZKYA Presl, Rel. Haenk. 2 : 130, t. \%о. 1836.

About 6 species subtropical and tropical America, chiefly Mexican.

Kosteletzkya virginica (L.) Gray, Gen. Ill. 2 : 80, t. 132. 1849.

Hibiscus virginicus L. Sp. Pl. 2: 697. 1753.

VIRGINIA KOSTELETZKYA.

Ell. Sk. 2 : 167. Gray, Man. ed. 6, 100. Chap. Fl. 57.

Carolinian and Louisianian areas. Long Island, New York to Florida, west to Louisiana.

Alabama : Coast plain. Littoral region, river marshes, fresh or slightly brackish.

Mobile County. Flowers pink, June to August; 3 to 4 feet high. Perennial.

'Type locałity: "Hab. in Virginiae paludosis salsis."

Herb. Geol. Surv. Herl, Mohr. 
Kosteletzkya altheaefolia Gray, Pl. Wright. 1: 23. 1850.

ALtilea-Like Kosteletzkya.

Kosteletzkya virginica altheaefolia Chup. Fl.57. 1860.

Louisianian area. Coast of Florida to Mississippi.

Alabama: Littoral region. Saline marshes on the seashore. Mobile County, West Fowl River. Perennial. More sleuder than the type. Stellate-pubescent, tomentose. Intermediate forms less hoary and with the flowers more remote thau in the specimens from Florida, are frequently met with.

Type locality: "Near Manatee, South Florida, Rugel."

Herb. Geol. Surv. Herb. Mohr.

\section{THEACEAE. Tea Family.}

GORDONIA Ellis, Phil. Trans. 70:518, t.11. 1770.

About 16 species of subtropical and tropical eastern Asia, and Southern Atlantic North America. Southeastern United States, 2.

Gordonia lasianthus L. Mant. $2: 570.1771$.

LOBLOLLY BAY.

Hypericum lasianthus L. Sp. Pl. 2 : 783. 1753.

Ell. Sk. 2 : 171. Gray, Man. ed.6,96. Chap. Fl.60. Sargent, Silv. 1:41, t.21.

Carolinian and Louisianian areas. Coast of southern Virginia, North Carolina to

Florida, west to the Mississippi River.

Alabama : Coast plain. Deep wooded swamps. Mobile County, banks of the Chickasaw Bogue near Whistler. Flowers white, June; 15 to 20 feet in height and 6 to 8 inches in diameter. Rare. Only locality known in the State.

Type locality: "Hab. in Carolina, Surinamo. J. Bartsch."

Herb. Geol. Surv. Herb. Mohr.

STEWARTIA L. Sp. Pl. 2 : 698. 1753.

Two species, eastern North America.

Stewartia malacodendron L. Sp. Pl. 2 : 698. 1753.

Virginia Stewartia.

Stewartia virginica Cav. Diss. 5 : t. 158, f.2. 1787.

Ell. Sk. 2 : 172. Gray, Man. ed. 6,96. Chap. Fl.61.

Carolinian and Louisianian areas. Virginia to Florida, west to western Louisiana

AlabaMa : Mountain region to Coast plain. Rich wooded banks and shady hillsides. Cullman County, 800 feet altitude. Tuscaloosa County (E. A. Smith). Mobile County, western shore Mobile Bay, Maguolia Grove, 1879. Not observed in this locality of late years. Flowers white, stamens purple, May. Deciduous shrub, 6 to 10 feet high. Infrequent.

Type locality: "Hab. in Virginia."

Herb. Geol. Surv. Herb. Mohr.

Stewartia pentagyna L'Her. Stirp. 155, t. 74. 1784.

Mountain Stewartia.

Malachodendron ovatum Cav. Diss. $5: t$. 158, f. 2. 1787.

Ell. Sk. $2: 173$. Gray, Man, ed. 6,96. Chap. Fl. 61.

Carolinian area. Mountains, sonthern Kentucky and Virginia to Georgia.

Alabama: Mountain region. Rich woods. Cullman. Flowers pale eream color. June. Shrub 6 to 10 feet high, confined to the mountains; less frequent than the above.

Type locality : "Hab. in Virginia."

Herb. Geol. Surv. Herb. Mohr.

\section{STERCULIACEAE. Sterculia Family.}

STERCULIA L. Sp. Pl. 2 : 1007. 1753.

Eighty to 90 species, tropics of both hemispheres, largely Asiatic.

Sterculia platanifolia L. f. Suppl. 423. 1781.

China, Japan.

Sycamore-leaf Steirculia. Japanese Varnish Tree.

Ala BaMA : Introdnced in the coast region; escaped from cultivation. Mobile. A pretty tree, 35 to 40 feet high. Flowers June.

Type locality :

Herb. Geol. Surv. 
MELOCHIA L. Sp. P1. 2 : 932. 1753.

Abont 35 species, mostly of tropical America.

Melochia corchorifolia L. Sp. Pl. 2: 675. 1753.

Hirsute Melochia.

Melochia hirsuta Chap. Fl. Suppl.610. 1883. Not Cav.

Chap. Fl. Suppl. 610; ed. 3, 54.

WeST INDIES TO BRAZIL.

Louisianian area. Southern Georgia, naturalized.

Alabama : Coast plain. Adventive on ballast. Mobile. Flowers purplish, July to September; fruit ripe October. A perennial weed, first observed on newly broken ground in the suburbs of Mobile, October, 1874. Subsequently seen on ballast, and since 1882 spreading abundantly in cultivated ground, where it has become a pernicious weed, very injurious to the hay crop.

Type locality: "Hab. in India."

Herb. Geol. Surv. Herb. Mohr.

WAITHERIA L. Sp. Pl. 2 : 673. 1753.

Sixteen species, tropical America. Perenuials.

Waltheria americana 1.Sp. P1. 2 : 673. 1753.

American Waltheria.

Chap. Fl. 59. Griseb. Fl. Brit. W. Ind. 95.

West Indies, Mexico to BraziL.

Tropical Florida.

Alabama: Adventive with ballast. Mobile, September, 1892-93. Not oloserved lately.

Type locality : "Hab. in Bahama, Barbiches, Surinamo."

Herb. Geol. Surv. Herb. Mohr.

\section{HYPERICACEAE. St. Johns-wort Family. ${ }^{1}$}

ASCYRUM L. Sp. P1. 2 : 788. 1753.

Five species, undershrubs, warmer temperate regions, West Indies, Mexieo, Atlantic North America.

Ascyrum multicaule Michx. Fl. Bor. Am. 2: 77. 1803.

St. Andrew's Croiss. Ascyrum crux-andreae L. Sp. P1. 2: 788. 1753. In part, and of most American authors.

Ell. Sk. $2: 22$, in part. Gray, Man. ed.6, 92, in part. Chap. Fl. 38, in part; ed. 3, 56. Carolinian and Lonisianian areas. Southern New England west to sonthern Illinois, Missouri, and Nebraska, south to the Gulf, from Florida to Louisiana and Arkansas.

Alabaya: Damp and dry borders of woods, open copses. Lauderdale Conuty. Morgan County, Falkville. Cullman County. Tuscaloosa County (E. A. Smith). Clarke, Monroe, Baldwin, and Mobile counties. Flowers July to October. Shrubby at the base, 2 to' 3 feet high. A low form with compact branches, and smaller glaucous leaves occurs on dry hills in the mountainous region. Clay County, Delta, 1,700 feet.

Considering the confusion existing between Ascyrum crux-andreae and A. hypericoides 1., the first of these names has been replaced by Hypericum multicaule Michx. This species embraces all the northern forms described under $A$. crux-andreae and those of the same specific characters occurring sonthward.

'Tspe locality : "Hab in Virginia, Carolina."

Herb. Geol. Surv. Herb. Mohr.

Ascyrum hypericoides L. Sp. Pl. ed. 2 : 1107. 1763. Southern St. Peter's-wort. Ascyrum crux-andreae var. angustifolium Nutt. Gen. 2 : 16.1818 (?)

A. crux-andreae of most Southern authors.

Coulter, Contr. Nat. Herb. 2: 34. Griseb. Fl. Brit. W. Ind. 112.

West Indies, Mexico.

Louisianian area. South Carolina to Florida, west to Texas and southern Arkansas.

Alabama: Lower Pine region. Sandy pine barrens in dry and damp soil. Escambia, Washington, Baldwin, and Mobile counties. Flowers July to September; frequent. Densely branched shrub $1_{\frac{1}{2}}$ to 2 feet high.

Type locality: "Hab. in Virginia, Jamaica."

Herb. Geol. Surv. Herb. Mohr. 
Ascyrum stans Michx. Fl. Bor. Am. 2: 77. 1803.

Standing Ascyrum. Ascyrum hypericoides L. Sp. Pl. 2 : 788. 1753. In part.

Ell. Sk. 2:22. Gray, Man. ed. 6, 92. Chap. Fl. 39. Coulter, Contr. Nat. Herb. 2:34.

Carolinian and Louisianian areas. New Jersey and Pennsylvania to Florida, west to Louisiana, eastern Texas, and Arkansas.

Alabama: Mountain region to Coast plain. Cullman County, low woods. Washington, Escambia, Baldwin, and Mobile counties. In flat damp pine barrens. Flowers yellow. July to August; frequent. Undershrub.

Type locality: "Hab. in Carolina."

Herb. Geol. Surv. Herb. Mohr.

Ascyrum pumilum Michx. Fl. Bor. Am. 2 : 77. $1803 . \quad$ Dwarf St. Peter's-wort. Ell. sk. 2:21. Chap. Fl. 39.

Louisianian area. Georgia and Florida, west to Mississippi.

Alabama : Lower Pine region. Coast plain. Dry light soil, open woods. Washington, Baldwin, and Mobile counties. Flowers sulphur-yellow, March, April ; frequent. Shrubly at the base.

Type locality: "Hab. in Georgia."

Herb. Geol. Surv. Herb. Mohr.

HYPERICUM L. Sp. Pl. 2 : 783. 1753.1 ST. JOHN's-WORT.

About 160 species, chiefly in the north temperate zone. North America 35, Atlantic 31. Shrubby or herbaceous perennial more rarely annuals. Mostly shrubby and yellow-flowered.

Hypericum prolificum L. Mant. 1:106. 1767.

SHRUBBY ST. JOHN's-WORT.

Ell. Sk. 2:30. Gray, Man. ed.6,93. Chap. Fl. 39.

Alleghenian to Louisianian area. New Jersey west to Michigan, Minnesota, Missouri, and Arkansas, south to Georgia.

Alabama: Tennessee Valley. Rocky banks. Lauderdale County (M. C. Wilson). Flowers golden yellow. June, July. Rare. Two to 3 feet high.

Type locality : "Hab. in America septentrionali."

Herb. Geol. Surv. Herb. Mohr.

Eypericum aureum Bartram, Travels, 383 (ed.2, 381). 1791.

GOLDEN-FLOWERKD ST. JOHN'S-WORT.

Hypericum amoenum Pursh, Fl. Am. Sept. $2: 375$. 1816.

Ell. Sk. 2 : $31 . \quad$ Chap. Fl. 40.

Carolinian area. South Carolina, Georgia, and Tennessee.

Alabama: Tennessee Valley. Mountain region. Exposed limestone hills. Lawrence County, Moulton. Madison County, Moutesano, 800 feet. Clay Connty, Shinbone Valley, July 28, with mature capsules. Flowers golden yellow, May, June. Local, infrequent. Shrubby at the base, 8 to 12 inches high.

Type locality: "On the steep dry banks" of a "large and deep creek, a branch of the Flint [Patse-Liga Creek, Ga.]"

Herb. Geol. Surv. Herb. Mohr.

Hypericum myrtifolium Lam. Encycl. 4:180. 1796.

Hypericum glaucum Michx. Fl. Bor. Am. 2:78. 1803.

Louisianian area. South Carolina to Florida, west to Mississippi.

Alabama : Coast plain. Borders of pine-barren ponds. Baldwin County. Mobile County, Dauphin Island. Flowers June, July; not infrequent in the flat pine barrens.

Type locality not given.

Herb. Geol. Surv. Herb. Mohr.

Hypericum fasciculatum Lam. Encycl. 4:160. 1797.

Hypericum nitidum Lam. Encycl. 4 : 160. 1797.

TALL NARROW-LEa Ved ST. JOHN's-WORT.

Ell. Sk. 2:28. Chap. Fl. 40.

Louisianian area. North Carolına to Florida, west to Louisiana.

AlabaMa: Coast plain. Inundated margins of pine-barren streams. Baldwin County, Rock Creek. Flowers July. Shrub 3 to 5 feet high, not rarely the stem

${ }_{1}^{1}$ John M. Coulter, Revision of North American Hypericaceae, Bot. Gaz. vol. 11, pp. 78 to 88 and 106 to 112 . 1886 . 
simple below with slender drooping branches; very handsome when loaded with the bright yellow flowers.

'Type locality: "Cette espèce crôt naturellement daus la Caroline."

Herb. Geol. Surv. Herb. Mohr.

Hypericum aspalathoides Willd. Sp. Pl. 3 :1451. 1805.

SHORT-LeAF ST. JoHN's-WORT.

Hypericum fasciculatum var. aspalathoides Torr. \& Gray, Fl. N. A.1:672. 1840.

Ell. Sk. 2:27. Chap. Fl.40; ed.3, 57.

Louisianian area. South Carelina to Florida and Mississippi.

Alabama: Coast plain. Boggy pine barrens. Baldwin and Mobile counties. Flowers golden yellow, August, September. Abundant. Low bushy shrub with erect-spreading rigid branches, frequently forming extensive patches about shallow pine-barren ponds.

Type locality: "Hab. in Carolina.

Herb. Geol. Surv. Herb. Mohr.

Hypericum galioides Lam. Encycl. 4 : 161. 1796.

GLOssy St. JoHn's-wort.

Chap. Fl. 40; ed. 3, 57.

Louisianian area. South Carolina and Florida to Mississippi and Louisiana.

Alabama : Central Pine belt. Tuscaloosa County, Tannehill (E. A. Smith). Flowers, July.

Specimens from the above locality represent the form described by Lamarck and the typical form of Chapman of this polymorphous species. The leaves are densely crowded, thick, glossy above, margins revolute, with a callous whitish point, the sepals linear like the leaves, equal or unequal, longer or shorter than the petals.

Type locality : "Cet arbuste croit naturellement dans la Caroline mèridionale."

Herb. Geol. Surv. Herb. Mohr.

Hypericum galioides pallidum nom. nov.

Hypericum galioides ambiguum Chap. Fl. 40. 1860. Not H. ambiguum Ell.

Louisianian area. Georgia, Florida, and Mississippi.

Chap. Fl. 40.

Alabama: Lower Pine region. Coast plain. Shaded borders of ditches and swamps in alluvial forests. Clarke and Escambia counties. Baldwin County, Stuckton. Flowers June to September. Frequent.

Shrubby at the base, diffusely branched and at once recognized by the thin clull pale linear-lanceolate, flat leaves, shorter and broader than in the type, $\frac{1}{4}$ inch wide, 1 to $1 \frac{1}{2}$ inches long, obtuse, minutely pointed, and the margins scarcely revolute, sepals foliaceous, broadly lanceolate, suddenly contracted at the base, sharply acuminate, equal, shorter than or as long as the petals, pedicels bibracteolate. Strikingly as in its extreme form this variety differs from the type, intermediate forms occur connecting the two insensibly.

Type locality (Chap. Fl.): "River swamps, Florida."

Herb. Geol. Surv. Herb. Mohr.

Hypericum cistifolium Lam. Encycl. 4: 158. 1796. Not Torr. \& Gray, nor Chap. Fl. 41.

Hypericum nudiflorum Michx. Fl. Bor. Am. 2:78. 1803.

Eil. Sk. 2:32. Gray, Man. ed. 5, 84. Chap. Fl. 41. Torr. \& Gray, Fl. N. A. 1 : 162. Chap. Fl. ed. 3,58 .

Carolinian and Louisianian areas. Florida to North Carolina, west to Louisiana (Hale), Arkansas, southern Missouri, and southern Illinois.

Alabama: Coast plain. Border of swamps in alluvial forests. Mobile County, swamp of Three-mile Creek, June 15. Infrequent. Perennial.

Type locality not given.

Herb. Geol. Surv. Herb. Mohr.

Hypericum sphaerocarpum Michx. Fl. Bor. Am. 2 : 78. 1803.

ROUND-Fruited ST. JoHN's-WORT.

Hypericum cistifolium Gray, Man. ed.6, 94. 1890. Chap. Fl.ed. 3, 59. 1897. Not Lam. Gray, Man. ed. $5,85$.

Carolinian and Louisianian areas. Kentucky, Tennessee, southern Illinois, and Missouri.

Alabama: Tennessee Valley to Central Prairie region. Sunny calcareous rocky hillsides, open prairies. Franklin County, Russellville, 600 feet. Madison County, Montesano, 800 feet. Hale County, Gallion, so-called bald prairies, abont 250 feet.

Flowers May, June; not frequent. Shrubby at the base, 8 to 12 inches high.

Perennial.

Type locality: "Hab. in Kentucky."

Herb. Geol. Surv, Herb. Mohr. 
Hypericum opacum Torr. \& Gray, Fl. N. A. 1 : 163. 1838.

DULL OPAQUK-LEA Veid ST. JOHN'S-WORT.

Hypericum cistifolium Wats. Index, 125. 1878. Not Lam.

Chap. Fl. ed. 3,58 .

Louisianian area. Georgia, and Florida, west to Lonisiana. (Hale!)

ArabaMa: Coast plain. Low open pine barrens, borders of ditches aud ponils. Baldwin and Mobile counties. Flowers July, August; frequent. Shrubby at the base; stem simple, erect $1 \frac{1}{2}$ to 2 feet high.

Flowers of the naked eyme mostly sessile, sepals broadly ovate, half as long as the petals, and a remarked by Chapman, the dark reddish brown capsules with the. sutures deep,$j$ impressed. Elliott's $H$. rosmarinifolium can not be referred to this species. Perennial.

'Type locality: "Georgia, Mrs. Miller! Ir. Loomis! Alabama, Dr. Gates!"

Herb. Geol. Surv. Herb. Mohr.

Hypericum ellipticum Hook. Fl. Bor. Am. 1:110. 1830.

Gray, Man. ed. 6, 94.

NORTHERN ST. JOHN's-Wort.

Canadian zone, Alleghenian and Carolinian areas. Quebec to Lake Wiunipeg, southern New England, Pennsylvania, and New Jersey.

AlabaMa: Coosa Valley. Low damp pine woods. Etowah County, Gadsden. Only a single specimen of this fine species has been collected. July, 1880; rare. Perennial.

Type locality: "Canada to Lake Winnipeg. Mr.Cleghorn; Dr. Richardson. Lake

Huron. Dr. Todd."

Herb. Geol. Surv. Herb. Mohr.

Hypericum virgatum acutifolium (Ell.) Coulter, Bot. Ga\%. 11: 106. 1886.

ANGULAR-STEMMED St. JoHN's-WORT. ERECT St. JohN's-Wort.

Hypericum acutifolium Ell. Sk. 2 : 26. 1824.

H. angulosum Michx. Fl. Bor. Am. 2 : 78.

Ell. Sk. l.c. Chap. Fl. 41.

Carolinian area. Georgia and Florida.

Alabama: Coosa Valley. Lower hills. Etowah County, Gadsden, low pine woods. Jefferson County, Elyton (E. A. Smith). Flowers July; rare. Herbaceous. Type locality: "Sent to me from Milledgeville in Georgia by Dr. Boykin."

Herb. Geol. Surv. Herb. Mohr.

Hypericum pilosum Walt. Fl. Car. 190. 1788.

HOARY ST. JOHN's-Wont.

Hypericum simplex Michx. Fl. Bor. Am. 2: 80. 1803.

Ell. Sk. 2 :26. Chap. Fl. 41.

Carolinian and Louisianian areas. South Carolina to Florida, west to Louisiana (Hale).

Alabama: Coosa Valley to Coast plain. Wet sandy or gravelly places in pine forests. Etowah County, Gadsden. Mobile County. Flowers chrome-yellow. July, Angust; frequent in the Lower Pine region and Coast plain. Perennial.

Type locality: South Carolina.

Herb. Geol. Surv. Herb. Mohr.

Hypericum maculatum Walt. Fl. Car. 189. 1788.

SPOTTED ST. JoHN's-WonT.

Hypericum corymbosum Muhl.; Willd. Sp. Pl. 3 : 1457. 1805.

Ell. Sk. 2 :27. Gray, Man. ed.6,94. Chap. Fl. 40.

Alleghenian to Lonisianian area. Qnebec, Ontario; New England west to Minnesota, Missouri, and Arkansas, south to the Gulf, from Florida to Lonisiana.

Alabama: Orer the State. Borders of woods and fields. Flowers canary-yellow; June to August. Common. Perennial.

Type locality: South Carolina.

Herb. Geol. Surv. Herb. Mohr.

Hypericum mutilum L. Sp. Pl. 2 : 787. 1753.

SMALLER ST. JOHN's-WORT.

Hypericum quinquenervium Walt. Fl. Car. 190. 1788.

Ell. Sk. $2: 24$. Gray, Man. ed. 6, 95. Chap. Fl.41. Coulter, Contr. Nat. Fîerb. $2: 35$. Mexico.

Alleghenian to Louisianian area. Canada, New England, west to Minnesota to the Gulf from Florida to Texas.

Alabama: Over the State. Wet, springy places. Flowers deep yellow; June to October. Common. Annual.

Type locality; "Hab. in Virginia, Canada."

Herb. Geol. Surv. Herb. Mohr. 
Hypericum gymnanthum Engelm. \& Gray, Bost. Journ. Nat. Hist. 5 : 212. 1847.

BARE-FLOWERED ST. JOHN'S-WOKT.

Gray, Man. ed. 6, 95. Coulter, Contr. Nat. Herb. 2 : 35. Chap. Fl. ed. 3, 60.

Alleghenian to Lonisianian area. New England, Vermont, Minnesota, Illinois, Arkansas, Delaware, Pennsylvania, South Carolina, and Georgia.

AlabaMa: Coast plain. Exposed wet places, ditches. Mobile County. F'lowers deep yellow; May. Not rare. Annual.

Type locality: "Clayey soil in pine woods near Houston [Texas]. June. Also in Lonisiana, Arkansas, \&c., not uncommon."

Herb. Geol. Surv. Herb. Mohr.

Hypericum canadense L.Sp. Pl. 2: 785. 1753.

Canada St. John's-wort.

Ell. Sk. 2 :24. Gray, Man. ed. 6, 95. Chap. Fl. 42.

Canadian, Alleghenian to Louisianian area. Newfoundland, Ontario; New England west to Minnesota, Nebraska, and Arkansas, south to Florida.

Alabama: Mountain region. Central prairies. Damp rocky banks. Culluman County, 800 feet. Autauga County, Prattville (E. A. Smith). Flowers orange; June. Not frequent. Annual.

Type locality: "Hab. in Canada. Kalm."

Herb. Geol. Surv. Herb. Mohr.

Hypericum drummondii (Grev. \& Hook.) Torr. \& Gray, Fl. N. A. 1:165. 1838.

DRUMMOND's ST. JOHN's-WORT.

Sarothra drummondii Grev. \& Hook. Bot. Misc. 3 : 236. 1833.

Gray, Man. ed.6,95. Chap. Fl. 42.

Carolinian and Louisianian areas. Western Illinois, southern Missouri, Kansas, Arkansas, and Tennessee to South Carolina and Florida, thence west to Louisiana (Hale).

Alabama: Mountain region to Coast plain. Open dry places, pastures. Cullman County, 800 feet. Montgomery and Mobile counties. Flowers deep yellow ; September, October. Not rare. Eight to 10 inches high. Annual.

Type locality: "Near St. Louis, on the Missouri. Drummond."

Herb. Geol. Surv. Herb. Mohr.

Hypericum gentianoides (L.) B. S. P. Prel. Cat. N. Y.9. 1888.

Sarothra gentianoides L. Sp. P1. 1:272. 1753.

Orange Grass. Pine-weed.

Hypericum nudicaule Walt. Fl. Car. 190. 1788.

H. sarothra Michx. Fl. Bor. Am. 2 : 79. 1803.

Ell. Sk. 1:371. Gray, Man. ed. 6,95. Chap. Fl. 42.

Carolinian and Louisianian areas. New England, Illinois, and Missouri south to the Gulf; Florida to Lonisiana and Arkansas.

AlabaMa: Throughout. In sandy open places, fields, pastures. Flowers orange; July to October. Common; most abundant in the pine barrens. Annual.

Type locality: "Hab. in Virginiae, Pensylvaniae apricis glareosis."

Herb. Geol. Surv. Herb. Mohr.

TRIADENUM Raf. Med. Rep. ser. 2, 5 :352. 1808.

Two species paludial perennials. Eastern North America.

Triadenum petiolatum (Walt.) Ref. Med. Rep. ser. 2, 5:352. 1808.

Hypericum petiolatum Walt. Fl. Car. 191. 1788.

Marsir St. John's-wont.

Elodes petiolata Pursh, Fl. Am. Sept. 379. 1816.

Ell. Sk. 2:34. Gray, Man. ed.6,95. Chap. Fl. 42.

Carolinian and Louisianian areas. New Jersey to Florida, west to Kentucky, southern Tennessee to Florida and Arkansas.

Alabama : Central Prairie region, Coast plain. Borders of swamps. Montyomery County. Washington County, Yellowpine. Mobile County. On rotten logs in river swamps. Flowers rose-pink; July. Infrequent.

Type locality : South Carolina.

Herb. Geol. Surv. Herb. Mohr.

Triadeuum virginicum (L.) Raf. Fl. Tell. 3:79. 1836.

Purple Virginia St. John's-Wort.

Hypericum virginicum L. Sp. Pl. ed. 2, 2:1104. 1763.

Hypericum campanulatum Walt. Fl. Car. 191. 1788.

Elodea campanulata Pursh, Fl. Am. Sept. 2: 379. 1814.

Ell. Sk. 2 :33. Gray, Man. od. 6, 95. Chap. Fl. 42. 
Alleghenian to Louisianian area. Labrador to New England, west to Michigan and Nebraska, south to the Gulf and from Florida to Louisiana.

Alabama : Central Pine belt to Coast plain. Low wet places. Autauga and Mobile counties. Flowers pink, July; not infrequent. Perennial.

Type locality: "Hab. in Pensylvania."

Herb. Geol. Surv. Herb. Mohr.

\section{CISTACEAE. Rock Rose Family.}

\section{HELIANTHEMUM Pers. Syn. 2 : 75. 1805.}

One hundred and ten species, warmer regions of Europe, mostly Mediterranean and American; Mexico to Brazil. North America, 10. Ours small, slender shrubs. Helianthemum carolinianum (Walt.) Michx. Fl. Bor. Am. 1:307. 1803.

Cistus carolinianus Walt. Fl. Car. 152. 1788.

Carolina Rock-Rosk.

Ell. Sk. 2:5. Chap. F1. 35. Coulter, Contr. Nat. Herb. $2: 24$.

Louisianian area. Florida to North Carolina, west to Texas.

Alabama : Lower Pine region. Coast plain, dry sandy pine barrens. Mobile and Baldwin counties. Flowers bright yellow, large; March, April. Frequent.

Type locality: South Carolina.

Herb. Geol. Surv. Herb. Mohr.

Helianthemum arenicola Chap. Fl. 35. 1860.

SEASIDE ROCK-ROSE.

Chap. F1. 35. Gray, Syn. Fl. N. A. 1, pt. 1: 190.

Louisianian area. Western Florida to Mississippi.

Alabama: Littoral region. Drifting sand near the seashore. Baldwin County, Point Clear. Flowers yellow, April, May. Not frequent. 'The woody lower part of the stems buried in the sand.

Type locality: "Drifting sands near the coast, West Florida."

Herb. Geol. Surv. Herb. Mohr.

Helianthemum georgianum Chap. Fl. ed. 3, 36. 1897.

Georgia Rock-Rose.

Louisianian area. Georgia, eastern Florida (St. Augustine, Garber), eastern Mississippi (Columbus, Mohr) to western Louisiana (Hale).

Alabama : Coast plain. Sunny hillsides in poor sandy soil. Mobile County, foot of Springhill. Baldwin County, Montrose. Flowers yellow (canary), May, June. Local. In frequent, but abounding at the locality covering large patches with Opuntia rafinesqii and Cenchrus tribuloides.

Shrublet 8 to 10 inches high, widely branched above the base, flowers $\frac{1}{2}$ inch wide, distant or more or less crowded.

Type locality: "Hab. in Georgia, Carolina."

Herb. Geol. Surv. Herb. Mohr.

Helianthemum rosmarinifolium Pursh, Fl. Am. Sept. 2 :364. 1814.

Ell. Sk. 2:6. Chap. Fl. ed. 3, 36.

Louisianian area. Georgia to Mississippi.

Alabama: Central Prairie belt. Dry sandy banks, Dallas County, near Selma, August, 1899 (Biltmore Herb.).

Type locality: "In pine barrens: Georgia. Enslen."

LECHEA L.Sp. P1. I: 90 . 1753.1

Atlantic North America 14, perennial herbs.

Lechea minor L. Sp. Pl. 1:90. 1753.

THyme-Leaf Lechea.

Lechea thymifolia Michx. Fl. Bor. Am. 1: 77. 1803.

Lechea novae-caesareae Aust.; Gray, Man. ed. 5, 81. 1867.

Ell. Sk. 1:185. Gray, Man. ed. 6, 677; Syn. Fl. N. A. 1, pt. 1: 192. Chap. Fl. ed. 3, 37. Alleghenian, Carolinian, and Louisianian areas. Coast of New England to Michigan, south to Florida, west to Mississippi.

Alabama: Mountain region, Coast plain. Dry exposed places. Cullman County, 800 feet. Baldwin County, eastern shore of Mobile Bay. Mobile County, open dry pine woods. Angust to October. Frequent near the coast.

Type locality : "Hab. in Canadae sylvis glareosis."

Herb. Geol. Surv. Herb. Mohr.

${ }^{1}$ N. L. Britton, A revision of the genus Lechea, Bull. Torr. Club, vol. 21, pp. 244 to 253. 1894. 
Lechea racemulosa Michx. Fl. Bor. Am. 1:77. 1803.

RaCeMose LeCHEA. Ell. Sk. 1: 184. Gray, Man. ed.6, 78. Chap. Fl. ed.3, 37. Gray, Syn. Fl. N. A. I, pt. $1: 193$

Carolinian and Louisianian areas. Southern New England west to Iowa, south from Tennessee to South Carolina.

Alabama : Mountain region, in dry rocky soil. Clay County, Baldrock, 2,200 feet. Marshall County, on Lookout Mountain range, 1,200 feet. Cullman County, 800 feet.

Blount County. July; frequent.

Type locality: "Hab. in Virginia."

Herb. Geol. Surv. Herb. Mohr.

Lechea villosa Ell. Sk. 1:184. 1817.

Pinweed.

Lechea major Michx. Fl. Bor. Am. 1: 76. 1803. Not L.

Ell. Sk.1.c. Gray, Man. ed.6, 77; Syn. Fl. N. A. 1, pt.1:192. Chap. Fl. 36; ed. 3, 37. Alleghenian to Louisianian area. Ontario; southern Now England to Michigan, Missouri, and Arkausas, south to Florida.

Alabama : Throughout. Dry sterile soil, worn-out fields, pastures. Most abundant in the Lower Pine region and Coast plain. Flowers May, June. $1 \frac{1}{2}$ to 2 feet high. Type locality of L. major Michx.: "Hab. in apricis aridis Carolinae."

Herb. Geol. Surv. Herb. Mohr.

Lechea divaricata Shuttleworth; Britton, Bull. Torr. Club, 21:249. 1894. Lechea major divaricata Gray, Syn. Fl. N. A. 1, pt. 1: 192.1895.

MEXICO.

Louisianian area. Florida to Texas.

Divaricately-branched Pinweed.

Alabama: Coast plain, littoral region. Dry sandy banks. Baldwin County, eastern shore Mobile Bay (Battle's Wharf). Sanily exposed shore of Fish River Bay, October 4, 1894. Running shoots fully developed, divaricately branched, canescently villous with long spreading or adpressed hairs like the fascicled, ovate, slightly pointed leaves. Stem 8 to 10 inches high, smoothish below, divaricately branched above the middle. Flowers September, October; not frequent.

Type locality: "Florida (Rugel, Garber, Curtiss), Texas (E. Palmer, No. 2025)."

Lechea tenuifolia Michx. Fl. Bor. Am. 1: 77. 1803.

NARROW-LEAF LECHEA.

Lechea minor var. $y$ Torr. \& Gray, Fl. N. A. 1:154. 1838.

Ell. Sk. 1:185. Gray, Man. ed. 6, 77. Chap. Fl. 37, in part. Gray, Syn. Fl. N. A. 1, pt. $1: 193$.

CUBA.

Alleghenian to Louisianian area. Eastern Massachusetts to Wisconsin, south to Florida, Texas, and Arkansas.

Alabama : Coast Pine belt. Dry open places, sandy pine ridges, old fields. Mobile and Baldwin counties. Flowers September, October; common.

Type locality: "Hab. in collibus sabulosis juxta amnem Santee."

Herb. Geol. Surv. Herb. Mohr.

Lechea patula Leggett, Bull. Torr. Club, 6:251. 1875.

Spreading Lechea. Gray, Syn. Fl. N. A. 1, pt. 1: 194.

Louisianian area. South Carolina to Florida, west to Mississippi?

Alabama : Coast plain. Dry sandy pine ridges. Mobile County, Springhill; rare. Type locality: South Carolina and Florida.

Herb. Geol. Surv. Herb. Mohr.

Lechea torreyi Leggett; Britton, Bull. Torr. Club, 21:251. 1894.

Lechea racemulosa Hook. Journ. Bot. I: 193. 1834. Not Michx.

TORREY'S LECHEA.

Lechea cinerea torreyi Chap. Fl. ed. 3, 37. 1897.

Gray, Syn. Fl. N. A. 1, pt. 1: 194.

Louisianian area. South Carolina to Florida, west to Mississippi (Horn Island).

Alabama : Littoral region. Dry sands, near seashore. Baldwin County, eastern shore Mobile Bay. Mobil County, Dauphin Island. Flowers June, July; rare.

"Type locality of L. racemulosa Hook.: "Covington, Louisiana." Of $L$. torreyi :

"Florida and South Carolina."

Herb. Geol. Surv. Herb. Mohr.

Lechea legettii Britt. \& Holl. Prel. Cat. N. Y.6. 1888.

LEGETT'S LECHEA.

Lechea minor Lam. Tabl. Encycl. $1: 221, t .52, f .1$. 1791. Not L.

Gray, Syn. Fl. N. A. 1, pt. 1: 193.

Carolinian and Louisianian areas. Long Island, New York, Pennsylvania, and Virginia, south to South Carolina and Florida, west to Arkansas. 
Alabama: Mountain region to Coast plain. Dry rocky or sandy places. Lee County, Auburn (Baker \& Earle, No. 55). Cullman County, 800 feet. Dale County, Ozark. Mobile County, Springhill, on sandy pine ridges. Flowers July, August.

Type locality: "E Canada."

Herb. Geol. Surv. Herb. Mohr.

\section{VIOLACEAE. Violet Family.}

VIOLA L. Sp. Pl. $2: 933$. 1753. 1

About 150 species, in temperate regions, ehiefly of the Northern Hemisphere. North America 36, Atlantic 25.

Viola pedata L. Sp. Pl. 2 : 933. 1753. BIRD'S-FOOT VIOLET.

Viola pedata var. bicolor Pursh; Raf. in DC. Prodr. 1:291. 1824.

Viola pedata inornata Greene, Pittonia, 3: 35. 1898.

Gray, Man. ed. 6, 78. Gray, Syn. Fl. N. A. 1, pt. 1:195.

Carolinian and Louisianian area. Southern New England, New Jersey, and southern Missouri, south to Tennessee and Mississippi.

Alabama: Tennessee Valley, Mountain region. Metamorphic hills. Dry grassy banks, open copses. Lawrence County, Moulton. Madison County, Montesano (Boynton, Herb. Biltnore.) Tuscaloosa County (E. A. Smith). Lee County, Auburn (F.S. Earle). Flowers April; not infrequent.

Type locality: "Hab. in Virginia."

Herb. Geol. Snrv.

Viola palmata L. Sp. Pl. 2 : 933.1753.

BLUE WOOD-VIOLET.

Viola heterophylla Muhl. Cat. 25. 1813.

Viola palmata var. vulgaris Ell. Sk. 1:300. 1817.

Viola cucullata var. palmata Gray, Man. ed.5, 78. 1867.

Ell. Sk. l. c. Gray, Man. ed.6, 79. Chap. Fl. 33. Syn. Fl. N. A. 1, pt. 1:196.

Alleghenian to Louisianian area. Nova Scotia, Ontario; New England, west to Minnesota, Nebraska, and Arkansas, south to Florida and Louisiana.

AlabaMa: Over the State. In light dry soil. Most abundant in the pine forests of the Maritime Pine belt. Flowers sky-blue, March. Common. Perennial.

Type locality: "Hab. in Virginia."

Herb. Geol. Surv. Herb. Mohr.

Viola palmata dilatata Ell. Sk. 1:300. 1817.

Ell. l. c.

Carolinian and Louisianian areas. Georgia, Louisiana.

Alabama: Mountain region to Lower Pine belt. In dry sandy soil. Lee County (Baker \& Earle). Mobile County, pine uplands.

Type locality: "Upper districts of Georgia and Carolina."

Viola brittoniana Pollard, Bot. Gaz. 26: 332.

Viola atlantica Britton, Bull. Torr. Club, 24:92. 1897. Not V.atlantica Pomel,1874.

Britton \& Br. Ill. Fl. 2: 446.

Carolinian and Louisianian areas. Coast of southern New England to New Jersey southward along the coast. Eastern Louisiana (Feliciana, Carpenter).

Alabama: Lower Pine belt. Mobile County, in dry pine woods. Flowers bright blue, March 15. Frequent.

Viola vicinalis Greene, Pittonia, 4:9. 1899.

LARGE-FLOWERE1) VIOLET.

Viola insignis Pollard, Bot. Gaz. 26:334. 1898. Not Richter. 1888.

Glabrous from a stout erect rhizome; leaves rather firm, thickish, the margin slightly revolute, triangular in outline, obtuse at the apex, truncate at the base, the early incised and the later varieusly lobed, the 3 to 5 lobes broad to linear, deeply pinnatifid, the middle lobe al ways the largest, the low est pair more or less runcinate, the divisions crenately denticulate; peduncles shorter or longer than the leaves; flowers large, the lateral petals bearded with glistening hairs, spur short, sepals narrowly lanceolate, acute.

Louisianian area. Florida.

Alabama: Coast plain. In dry sandy pine woods. Mobile County. Infrequent.

Type locality of $V$. insignis Pollard: "Dry pine barrens, northern Florida. * * * Curtiss no. 4518a, Jacksonville; A. Fredholm no. 425, Duval County.'

1 Charles L. Pollard, The purple-flowered, stemless violets of the Atlantic coast, Proc. Biol. Soc. Washington, vol. 10 , pp. 85 to 92.1896 Same author, Further observations on the eastern acaulescent violets, Bot. Gaz. vol. 26, pp. 325 to $342,1898$. 
Viola carolina Greene, Pittonia, 3:259. 1898.

Carolina Violet.

Acaulescent, low, foliage thickish, depressed; leaves flat, cordate-ovate or roundcordat $\theta$, basal lobes broadly rounded, with a more or less open sinus, margins crenulate, sparsely ciliate, minutely hairy above, densely pubescent on the lower side like the peduncles and petioles, the latter longer than the leaf blade; sepals obtuse, petals pale purplish blue, little hairy at the base, spur large, prominently saccate.

Very distinct from Viola papilionacea by the above characters.

Louisianian area. North Caroliua and Georgia near the coast.

Alabama: Lower Pine region. Borders of copses, dry grassy pastures. Mobile County, Springhill. March 14, 1898.

Type locality: "Wilmington, N. C." (Wm. Canby).

Viola alabamensis Pollard, Proc. Biol. Soc. Wash. $13: 169.1900$.

"Acaulescent, of dwarf and spreading habit, from slender nearly vertical rootstocks; leaves small, sparingly hirsute, the blade cordate, suborbicular, 1.5 to $2 \mathrm{~cm}$. in length, the slender petiole as long or twice as long; flowering scapes greatly exceeding the foliage ( 7 to $8 \mathrm{~cm}$. long) the flower purple, $2.5 \mathrm{~cm}$. in diameter; petals broadly oblong, the margins obscurely erose or fimbriate; sepals small, ovate-lanceolate; cleistogamous flowers and fruit not observed."

Carolinian and Louisianian areas.

ALABAMA: Mountain region. Upper division of Coast Pine belt. Border of woods and open copses. Cullman County, March 22, 1899. Clarke County, Suggsville (Dr. Denny, March 25, 1852).

Type locality: Suggsville, Clarke County, Ala. (Erroneously given as "Sucksville, Washington County, Alabama.")

Herb. Geol. Surv. Herb. Mohr. (Type specimens in both.)

Viola papilionacea Pursh, Fl. Am. Sept. 1:173. 1814. Cомmon Wood Vrolet.

Viola cucullata Le Conte, Ann. Lyc. N.Y. $2: 137$. 1828. Not Ait. Fide Greene, Pittonia, $4: 140$.

V. communis Pollard, Bot. Gaz. 26 : 336. 1898. Not Wittrock.

$V$.obliqua and $V$. cucullata of recent authors, not of Hill or Ait.

Ell. Sk. 1:299. Gray, Man. ed. 6, 79, in part. Chap. Fl. 33, in part.

Carolinian and Louisianian areas. New York, Pennsylvania, south to Florida.

Alabama: Over the State. Woods and copses. Damp and dry soil. Flowers pale blue; February, March; common. Perennial.

Type locality: "Near Philadelphia in wet places."

Herb. Geol. Surv. Herb. Mohr.

Viola villosa Walt. Fl. Car. 219. 1788.

SOFT HAIRY VIOLET.

Viola cucullata var. cordata Gray, Man. ed. 5, 78. 1867. In part.

Fiola palmata villosa Robinson in Gray, Syn. F1. Am. 1, pt.1:196. 1895.

Ell. Sk. 1:297. Chap. Fl. 33. Gray, Syn. Fl. N. A. l. c.

Carolinian and Louisianian areas. Southern New York, eastern Pennsylvania, Missouri, and Arkansas, south to North Carolina and Florida.

Alabama: Mountain region. Metamorphic hills. Lee County, Auburn, 800 feet.

Flowers pale blue. March; rare. Perennial.

Type locality: "South Carolina."

Herb. Geol. Surv. Herb. Mohr.

Viola sagittata Ait. Hort. Kew. 3 :287. 1789.

ARROW-LEAT VIOLET.

Gray, Man. ed. 6, 79. Chap. Fl.33. Gray, Syn. Fl. N. A. 1, pt. 1: 196.

Alleghenian and Carolinian areas. Nova Scotia, Quebec, and Ontario; New England to Minnesota, south to New Jersey, Virginia, Tennessee, Missouri, and Arkansas.

Alabama: Lower hills. Open woods in light dry ground. 'Tuscaloosa County

(E. A. Smith). Flowers blue. April; not frequent. Perennial.

Type locality: "Native of Pennsylvania."

Herb. Geol. Surv. Herb. Mohr.

Viola leconteana G. Don, Hist. Dichl. Pl. 1 : 324. 1831.

SwEeT WOOD VIOLET.

Viola amoena Le Conte, Ann. Lyc. N. Y. 2: 144. 1828. Not Symons. 1798.

V. blanda palustriformis Gray, Bot. Gaz. 11: 255.1886.

V. blanda amoena B.S. P. Prel. Cat. N. Y.6. 1888.

V. alsophila Greene, Pittonia, 4: 7.1899.

Britt. \&. Br. Ill. Fl. 2 : 450.

Alleghenian and Carolinian areas. Now York along the mountains to Georgia.

Alabama: Mountain region. Wet rocky ledges. Winston County, Sipsey Valley, 1,500 feet. Flowers cream color, faintly sweet-scented. May; rare. Perennial.

Type locality: "Native of North America in humid woods, in the State of New

York and New Jersey, and from Pennsylvania to Virginia."

Herb. Geol. Surv, Herb. Mohr. 
Viola primulaefolia L. Sp. P1. 2 :934. 1753.

Primrose-Leaved Violet.

Ell. Sk. 1:297. Gray, Man. ed.6, 80. Chap. Fl.33. Gray, Syn. Fl. N. A. 1, pt. 1: 198. Carolinian and Louisianian areas. Southern New England to Virginia, west to

Louisiana and Missouri.

Alabama: Tennessee Valley. Mountain region. Cullman County, 800 feet, Lee County, Auburn. Tuscaloosa County. Low damp banks. Flowers white. March, April; abundant. Perennial.

Type locality: "Hab. in Sibiria, Virginia."

Herb. Geol. Surv. Herb. Mohr.

Viola primulaefolia australis Pollard, Bot. Gaz. 26:342. 1898.

Louisianian area. Throughout the southern States.

Arabama : Coast Pine belt and Coast plain. In similar situations with the type. Mobile County. March, April.

Type locality: "A. Fredholm, No. 431, Duval County, Florida."

Viola lanceolata L. Sp. Pl. 2: 934. 1753.

LANCE-LEAF VIOLET,

Ell. Sk. 1:296. Gray, Man. ed. 6, 80. Chap. Fl. 33. Coulter, Contr. Nat. Herb. $2: 25$. Gray, Syn. Fl. N. A. 1, pt. 1:198.

Alleghenian to Louisianian area. New Brunswick, and Ontario; New England, west to Minnesota, south to Virginia, Tennessee, and Floridu, west to eastern Texas.

Alabama: Central Pine belt to Coast plain. Low wet places. Tuscaloosa Connty (E. A. Smith). Montgomery, Washington, and Mobile counties. Flowers white. April; frequent. Perennial.

Type locality: "Hab. in Canada, Sibiria."

Herb. Geol. Surv. Herb. Mohr.

Viola hastata Michx. Fl. Bor. Am. 2 : 149. 1803.

HALbert-LEAVEd VIOLET.

Ell. Sk. 1:302. Gray, Man. ed.6, 80. Chap. Fl. 34. Gray, Syn. Fl. N. A. 1, pt. 1:201.

Carolinian and Louisianian areas. West Virginia, Tennessee, upper Georgia, west

Florida, and Arkansas.

Alabama: Monntain region to Lower hills. Rich woods. Lawrence Conuty. Moulton County (T. M. Peters). Lee County, Auburn (F. S. Earle). Flowers yellow. May; not frequent. Perennial.

Type locality : "Hab. in altis montibus Carolinae."

Herb. Geol. Surv. Herb. Mohr.

Viola tripartita Ell. Sk. 1 :302. 1817.

Viola hastata tripartita Gray, Syn. Fl. 1, pt.1:201. 1895.

Ell. Sk.1.c. Chap. Fl. ed. 3, 34.

Carolinian area. Mountains of North Carolina to Georgia.

Alabama: Metamorphic Hills. Lee County, Auburn.

Type locality: "From specimens collected near Athens, Georgia, by Mr. Green."

Viola tripartita glaberrima (Ging.) Harper, Bull. Torr. Club, 27 :337. 1899.

Viola hastata glaberrima Ging. in DC. Prodr. 1:300. 1824.

Carolinian area. Georgia, Alabama.

Alabama: Central Pine belt. Tuscaloosa County, near the city (E. A. Smith).

Running into the type by intermediate forms.

Type locality: "In sylvis et collibus Carolinae septentrionalis."

Viola pubescens Ait. Hort. Kew. 3:290. 1789.

DOWNY YelLOW Violet.

Viola pensylvanica Michx. FI. Bor. Am. 2: 149. 1803.

Gray, Man. ed.6, 80. Chap. Fl.34. Gray, Syn. Fl. N. A. 1, pt. 1:202.

Alleghenian and Carolinian areas. Ontario to Manitolaa; New England west to Minnesota, Missouri, and Arkansas, south along the mountains to Georgia.

Alabama: Tennessee Valley. Mountain region. Damp wooded banks. Landerdale County, Florence (M. C. Wilson). Winston County, 1,500 feet. Cullman Connty, 800 feet. Tuscaloosa County $(E . A$. Smith). Flowers yellow. April, May; not rare. Perennial.

Type locality: "Native of North America."

Herb. Geol. Surv. Herb. Mohr.

Viola scabriuscula Schwein.; Torr. \& Gray, Fl. N. A. 1:142. 1838. As synonym. SMOOTHISH YeLLOW VIOLET.

Viola pubescens scabriuscula Torr. \& Gray, Fl. N. A. 1:202. 1838.

Gray, Man. ed. 6, 80. Gray, Syn. Fl. N. A. 1, pt. 1: 202.

Carolinian area. Penusylvania, Kentucky, and Tennessee.

Alabaya : Tnscaloosa County (E.A.Smith). Perennials.

'Type locality: "Pennsylvania, Darlington! Kentucky, Dr. Short!"

Herb. Geol. Surv. Herb. Mohr. 
Viola striata Ait. Hort. Kew. 3:290. 1789.

Pale Violet.

Viola debilis Michx. Fl. Bor. Am. 2 : 150. 1803.

Ell. Sk. 1:301. Gray, Man. ed. 6, 80. Chap. Fl. 34. Gray, Syn. Fl. N. A. 1, pt. $1: 202$.

Alleghenian to Carolinian area. Ontario; New England west to Michigan and Minnesota, south to West Virginia, northern Ohio, Illinois, and Missouri and along the mountains to Georgia.

AlabaMA: Mountain region. Damp and wet rocky banks. Winston County, valley of Sipsey Fork, 1,500 feet. Clay County, Moseley, 1,000 feet. July 27, with mature capsules. Flowers cream color. May; rare. Perennial.

Type locality: "Native of North America."

Herb. Geol. Surv. Herb. Mohr.

Viola multicaulis (Torr. \& Gray) Britton, Mem. Torr. Club, 5:227. 1894.

Viola canina Walt. Fl. Car. 219. 1788. Not L.

V. muhlenbergii var. multicaulis Torr. \& Gray, Fl. N. A. 1:140. 1838.

V. canina var. multicaulis Gray, Bot. Gaz. 11:292. 1886.

Chap. Fl. 34. Gray, Man. ed.6, 81. Coulter, Contr. Nat. Herb. 2: 25. Gray, Syn.

Fl. N. A. 1, pt. $1: 203$.

Carolinian and Louisianian areas. Kentucky to Florida, west to Louisiana, Texas, and Arkansas.

Alabama: Central Pine belt to Upper division of Coast Pine belt. Shaded rocky banks. Clay County, Tuscaloosa County $(E . A$. Smith). Clarke County, Thomasville. Flowers white. April; infrequent. Perennial.

Type locality: "Rocks near Kentucky River, Short."

Herb. Geol. Surv. Herb. Mohr.

Viola rostrata Pursh, Fl. Am. Sept. 1: 174. 1816.

LONG-SPURRED VIOLET

Gray, Man. ed.6, 81. Chap. Fl. 34. Gray, Syn. Fl. 1, pt. 1:204.

Alleghenian and Carolinian areas. Ontario and New England west to Michigan, sonth to Virginia and along the mountains to Georgia.

Ala Bama: Mountain region, dripping rocks. Winston County, Valley of Sipsey

Fork, 1,500 feet. Flowers white. April, May; rare. Perennial.,

Type locality: "On shady rocks : near Eastown, Pensylvania."

Herb. Geol. Surv. Herb. Mohr.

Viola rafinesquii Greene, Pittonia, 4:9. 1899.

Wild Pansy.

Viola tenella Raf. Am. Med. Mag. 4 : 191. 1819. Name only. Not Poir. 1810.

Viola arvensis Ell. Sk. 1:302. 1817. Not Murray. 1770.

Viola tricolor var. arvensis Hook. Fl. Bor. Am. 1: 88. 1830. Not DC.

Ell. Sk. 1: 302, as V. arvensis. Chap. Fl.34. Gray, Man. ed. 6, 81. Coulter, Contr.

Nat. Herb. 2 : 25.

Alleghenian to Louisianian area. Canada to Texas.

Alabama : Central Pine belt. Central Prairie region. Tuscaloosa County (E. $d$.

Smith). Montgomery County. Flowers white; March. Annual or biennial.

Type locality not ascertained.

Herb. Geol. Surv. Herb. Mohr.

Viola tricolor L. Sp. Pl. 2 : 935. 1753.

Panst.

Introduced from Europe, escaped from cultivation and partially naturalized in many parts of Eastern North America.

Ala BAMA : Mobile on ballast heaps, Pinto Island. April. Annual.

Type locality: "Hab. in Europae cultis."

Herb. Geol. Surv. Herb. Mohr.

CUBELIUM Raf. Cat. Bot. Gard. Trans. 13, name only. 1824. Jackson, Index Kew. 1: 663.1893.

Cubelium concolor (Forst.) Raf.; Jackson, Index Kew. 1: 663. 1893.

Viola concolor Forst. Trans. Linn. Soc. 6:309. 1802.

Solea concolor Ging. in DC. Prodr. 1: 306. 1824.

Ell. Sk. 1:303. Gray, Man. ed. 6, 81. Chap. Fl. 35.

Carolinian and Louisianian areas. Southern Ontario; New York and Ohio Valley

to Missouri and Arkansas, along the lower Alleghenian ranges to Georgia.

Alabama: Tennessee Valley to Upper division Coast Pine belt. Rich woods.

Lauderdale, Cullman, and Tuscaloosa counties. Clarke County (Dr. Denny).

Flowers greenish. May; not frequent. Perennial.

Type locality: "Hab. in uliginosis Americae Septentrional is."

Herb. Geol. Surv. Herb. Mohr. 


\section{PASSIFLORACEAE. Passion Flower Family.}

PASSIFLORA L.Sp. P1. 2:959. 1753.

About 130 species, chiefly of tropical America from West Indies to Brazil. North America 9.

Passiflora incarnata L. Sp. Pl. 2 :959. 1753. Maypop. Common Passion Flower,

Ell. Sk. 2 :153. Gray, Man. ed.6, 194. Chap. Fl. 147. Coulter, Contr. Nat. Herb. $2: 121$.

Cuba, Brazil, Peru.

Carolinian and Louisianian areas. Virginia west to Kentucky; Missouri and Arkansas, south to Florida, and throughout the Gulf States to western Texas.

Alabama: Tennessee Valley to the Coast plain. Dry, waste, and cultivated ground. Cullman County, 800 feet. Mobile County. Flowers purple and white; April, May. Fruit ripe June, July, greenish yellow, the pulp edible. Perennial.

Type locality: "Hab. in Virginia, Brasilia, Peru."

Herb. Geol. Surv. Herb. Mohr.

Passiflora lutea L. Sp. Pl. 2 :958. 1753.

Yellow Passion Flower.

Ell. Sk. 2:154. Gray, Man. ed. 6, 194. Chap. Fl.147.

Carolinian and Louisianian areas. Virginia and Ohio to Missouri, south to Florida, west to Louisiana and Arkansas.

Alabama: Tennessee Valley to Coast plain. Damp thickets. Morgan County, Decatur. Cullman County, 800 feet. Tuscaloosa County. Jefferson County ( $E$. $A$. Smith). Clarke County (Dr. Denny). Mobile County. Flowers dull yellow; June. Not rare. Climbing over bushes. Perennial.

Type locality: "Hab. in Virginiae, Jamaicae glareosis, saxosis."

Herb. Geol. Surv. Herb. Mohr.

\section{CACTACEAE. Cactus Family.}

OPUNTIA Mill. Gard. Dict. ed.7. 1759. Prickly Pear.

About 150 species, of subtropical and tropical America. North America, mostly western (Sonoran areas) and adjacent parts of Mexico 101.

Rafinesque's Prickly Pear.

Opuntia humifusa Raf. Med. Bot. 2: 247. 1830.

Cactus humifusus Raf. Ann. Nat. 15. 1820.

Opuntia mesacantha Raf.; Seringe, Bull. Bot. Gen. 216. 1830.

Opuntia rafinesquii Engelm. Syn. Cact. 295. 1856.

Gray, Man. ed. 6, 197. Chap. Fl. ed. 3, 171. Coulter, Contr. Nat. Herb. 2 : 135.

Alleghenian to Lonisianian area. Ontario, southern New England, Minnesota, Wisconsin and Missouri to Texas and Louisiana.

Alabama: Tennessee Valley to Coast plain. Flowers sulphur-yellow, April, May. Fruit ripe June, July; pulp purple. Abundant in the limestone hills of the Tennessee Valley and common in the dry sandy pine barrens of the Lower Pine region and Coast plain. Perennial.

Type locality nnknown.

Herb. Geol. Surv. Herb. Mohr.

Opuntia opuntia (L.) Coulter, Contr. Nat. Herb. 3:432. 1896.

Cactus opuntia L. Sp. Pl. 1:468. 1753.

Opuntia vulgaris Mill. Dict. ed. 8, no. 1. 1768.

Gray, Man, ed. 6, 197. Chap. Fl. 144, ed.3, 171.

Carolinian and Louisianian areas. Southeastern Massachusetts along the coast to Florida.

Alabama : Coast plain. Shell banks. Mobile County, Dauphin Island. Perennial. Type locality : "Hab. in America, Peru, Virginia, nuno in Hispania, Lusitania."

Herb. Geol. Surv.

Opuntia pes-corvi Le Conte; Chap. Fl.145. 1860.

C'rowfoot Cactus.

Chap. Fl. 145.

Louisianian area. Georgia and Florida, west to Mississippi.

Alabama: Littoral region. Drifting sands on the seashore. Mobile County, Dauphin Island, Navy Cove. Flowers rose purplish; April, May. Not frequent.

Perennial.

'Type locality: "Barren sandy places along the coast, Florida and Georgia."

Herb. Geol. Surv. Herb. Mohr. 


\section{THYMELEACEAE. Mezereum Family.}

DIRCA L. Sp. Pl. 1 : 356. 1753. Moose-wood.

Two species, Eastern United States; California, 1. North America Atlantic, 1.

Dirca palustris L. Sp. Pl. I: 358. 1753.

LEATHERWOOD.

Ell. Sk. 1:448. Gray, Man. ed. 6, 448. Chap. Fl. 395.

Alleghenian to Lonisianian area. New Brunswick, Ontario, and New England west to Minnesota, Missouri, and Arkansas, and from New York south to Florida.

Ala BaMA : Upper division of the Coast Pine belt. Rich wooded hillsides. Clarke County (Dr. Denny). Monroe County, Claiborne Landing. Flowers yellow, February. Shrub 3 to 4 feet high.

Type locality : "Hab. in Virginiae paludosis."

Herb. Geol. Surv. Herb. Mohr.

\section{IYTHRACEAE. Loosestrife Family.}

ROTALA L. Mant. 2:175. 1772.

Rotala ramosior (L.) Koehne, in Mart. Fl. Bras. 13, pt. 2:192. 1875.

Branched Rotala.

Ammannia ramosior L. Sp. Pl. I: 120. 1753.

A. humilis Michx. Fl. Bor. Am. 1:99. 1803.

Eil. Sk. 1:218. Chap. Fl. 134. Gray, Man. ed. 6, 184. Coulter, Contr. Nat. Herb. 2:112. Griseb. Fl. Brit. W. Ind. 270.

West Indies, Mexico to BraziL.

Carolinian and Louisianian areas. Southern New England along the coast to Georgia, west to Texas and north to Oregon.

Alabama : Lower hills to Coast plain. Ditches. Cullman County, 800 feet. Shelby County (E. A. Smith). Mobile County. Flowers purple; July to September. Frequent. Annual.

Type locality: "Hab. in Virginia. D. Gronovius."

llerb. Geol. Surv. Herb. Mohr.

AMMANNIA L. Sp. Pl. 1:120. 1753.

Eighteen species, warmer regions of Asia, Africa, America. North America, 3.

Ammannia coccinea Rottb. Pl. Hort. Havn. Descr. 7. 1773. Scarlet Ammannia.

Ammannia latifolia Torr. \& Gray, Fl. N. A. 1:480. 1838. Not L.

Gray, Man. ed. 6, 185. Chap. Fl. ed. 3, 158. Coulter, Contr. Nat. Herb. 2 : 112. Griseb. Fl. Brit. W. Ind. 270.

Cuba to BraziL.

Carolinian and Louisianian areas. New Jersey west to Indiana, Missouri, Kansas, and Arkansas, south to Florida and Texas.

Ala bama : Coast plain. Muddy places. Mobile County. Flowers red; August, September. Rare. Annual.

Type locality unknown.

Herb. Geul. Surv. Herb. Mohr.

IYTHRUM L. Sp. Pl. 1 : 446. 1753.

Twenty-three species, diffused over the temperate regions of the globe. North America 5.

Lythrum ale.tum Pursh, Fl. Am. Sept. I: 334. 1814. Wing-Stemmed Loosestrife. Ell. Sk. 1:545. Gray, Man. ed.6, 185. Chap. Fl.134, in part. Coulter, Contr. Nat.

Herb. 2 : 112.

Mexico.

Alleghenian to Louisianian area. Ontario; New England west to Minnesota, Nebraska, Colorado, south from New Jersey to Florida, Louisiana, western Texas, aud Arkansas.

Alabama: Prairie region. Greene County, Pleasant Ridge (E.A.Smith). Flowers purple, August; rare. Perennial.

Type locality: "In lower Georgia. Enslen."

Herb. Geol. Surv. Herb. Mohr. 
Lythrum lanceolatum Ell. Sk. 1:544. 1817-21.

LANCE-LEAF LOOSESTRIFE.

Ell. Sk. 1. c. Chap. Fl. 134, in part. Coulter, Contr. Nat. Herb. 2:112.

Lonisianian area. South Carolina, Georgia, Louisiana, and Texas.

Alabama : Central Prairie region to Coast plain. Low damp places. Montgomery and Mobile counties. Flowers lilac-purple; July, August. Apparently local; in some places abundant in damp low fields. Perennial.

Type locality: "Grows in ditches, swamps, etc.," South Carolina and Georgia.

Herb. Geol. Surv. Herb. Mohr.

Lythrum lineare L. Sp. Pl. 1 : 447. 1753.

Seaside Loosestriff.

Ell. Sk. 1:545. Gray, Man. ed. 6, 185. Chap. Fl. 134, Coulter, Contr. Nat. Herb.

2:112.

Carolinian and Louisianian areas. New Jersey along the coast to Florida, west to Louisiana and Texas.

AlabaMa : Coast plain, Littoral belt. Slightly brackish and salt marshes.

Flowers lavender purple; frequent. Perennial.

Type locality: "Hab. in Virginia."

Herb. Geol.Surv. Herb. Mohr.

Lythrum thymifolium L. Sp. Pl. 1 : 447. 1753.

Mediterranean Europe.

Alabama : A fugitive on ballast. Mobile, September, 1893.

Type locality: "Hab. in Italiae et Narbonensis uliginosis."

Herb. Geol. Surv.

DECODON J.F. Gmel. Syst. 2 :677. 1791.

Two species, West Indies, Mexico to Argentina. Atlantic North America, 1.

Decodon verticillatus (L.) Ell. Sk. 1:544. 1821.

Lythrum verticillatum L. Sp. Pl. 1: 446.1753.

WHORLED-FLOWERED LOOSESTRIFE.

Decodon aquaticus J. F. Gmel. Syst. $2: 677.1791$.

Nesaea rerticillata H. B. K. 6 : 191.1823.

Ell. Sk. 1:544. Gray, Man. ed. 6, 186. Chap. Fl. 134.

Alleghenian, Carolinian, and Louisianian areas. Ontario and Quebec; New England, west to Missouri, south to the Gulf, extending from Florida to Lonisiana.

Ala bama : Central Pine belt. Springy, marshy places. Bibb County. Tuscaloosa County (E. A.Smith). The smooth form, Decodon verticillatus glaber 'Torr. \& Gr. Fl. N.A. 1:483. Flowers purpli-h; July, August. Not frequent. Perennial.

Type locality: "Hab. in Virginia."

Herb. Geol. Surv. Herb. Mohr.

PARSONSIA P. Br. Hist. Jam. 199. 1756.

About 160 species, subtropical and tropical America. North America, 3.

Parsonsia petiqlata (L.) Rusby, Mem. Torr. Club, 5 :231. 1894. Clamm Cupinea. Lythrum petiolatum L. Sp. Pl. 1:446. 1753.

Cuphea viscosissima Jacq. Hort. Vind. 2 : 83, t. 17\%. 1772.

C. petiolata Koehne, Engler's Jahrb. $2: 173.1882$.

Gray, ed. 6, 186. Chap. Fl. 135.

West INDIES to BraziL.

Carolinian and Louisianian areas. Sontheastern New England west to Missouri, Arkansas, and West Virginia, south to Georgia.

AlabaMa: Lower hills to Central Prairie region. Dry exposed places. Walker County, Lost Creek (E.A.Smith). Greene County (Leavenworth). Flowers purple; August, September. Not frequent. Annual.

Type locality: "Hab. in Virginia."

Herb. Geol. Surv. Herb. Mohr.

LAGERSTROEMIA L. Syst. ed. 10:1076. 1758-59.

Lagerstroemia indica L. Syst. ed. 10:1076. 1758-59. Native of Asia, cultivated in all warm countries. This ornamental tree has not infrequently escaped about hedge rows.

Alabama: Mobile County. July, August.

Type locality (L. Sp. Pl. ed. 2): "Hab. in China."

Herb. Geol. Surv. 


\section{MELASTOMACEAE. Melastoma Family.}

RHEXIA L. Sp. Pl. 1 : 346. 1753.

Nine species, perennial. Atlantic North America, chiefly Southern.

Rhexia mariana L. Sp. Pl. 1: 346. 1753.

maryland Meadow Beauty.

Ell. Sk. 1:437. Gray, Man.ed.6, 183. Chap. Fl.132.

Carolinian and Lonisianian areas. New Jersey to West Virginia, Kentucky, Tennessee, and Florida, west to Louisiana. Rare in the Ohio Valley, Missouri, and Arkansas.

AlabaMa: Mountain region. Lower hills to the Coast plain. Damp borders of woods. Lee County, Auburn (Baker \& Earle, 166). Cullman, Autanga, Montgomery, and Mobile counties. Flowers pink; June, August. Common.

Type locality: "Hab. in Marilandia."

Herb. Geol. Surv. Herb. Mohr.

Rhexia lanceolata Walt. Fl. Car. 129. 1788.

Lance-Leaf Meadow Beauty.

Rhexia mariana exalbida Michx. Fl. Bor. Am. 1:221. 1803.

Rhexia angustifolia Nutt. Gen. 1:244. 1818.

Ell. Sk. 1:438. Chap. Fl. 132, in part.

Louisianian area. North Carolina to Florida and west to Louisiana.

Ala bama: Lower Pine region. Coast plain. Damp thickets. Mobile County. Flowers white; August. Frequent. Branched at the base, from a ligneous spreading root.

Type Jocality: South Carolina.

Herb. Geol. Surv. Herb. Mohr.

Rhexia floridana Nash, Bull. Torr. Club $22: 150$. 1895. Florida Meadow Beauty.

Dark green, branched from the woody base; leaves sessile, linear, smooth on both sides, 1-nerved; calyx nearly smooth with a fow bristly hairs, calyx lobes broad at the base, petals with a short mucro, seeds flat, spiral with serrulate edges.

Louisianian area. Florida to Mississippi.

Alabama: Lower Pine region. Coast plain. Low borders of woods. Mobile County, Springhill. Flowers purple; July. Not frequent. Perennial.

Type locality: "Wet clay soil on east bauk of canal leading from Hick's Prairie, near Eustis."

Herb. Geol. Surv. Herb. Mohr.

Rhexia virginica L. Sp. Pl. 1 :346. 1753.

Virginia Meadow Beauty.

Ell. Sk. 1: 439 . Gray, Man. ed, 183. Chap. Fl. 132.

Carolinian and Lonisianian areas. Southern Ontario, southeastern New England, and New York west to Uhio, Indiana, Missouri, and Kansas, south along the low country to Florida, west to Louisianli, and Arkausas.

Alabama: Over the State. Damp shady banks, borders of rivulets. Lee County, Auburn (Earle \&. Underwood). Cullman County, 800 feet. Autauga, Mobile, and

Baldwin counties. Flowers pale purple; July. Frequent.

Type localit,v : "Hab. in Virginia."

Herb. Geol. Surv. Herb. Mohr.

Rhexia stricta Pursh, Fl. Am. Sept. 1:258. 1816.

Swamp Meadow Beauty.

Ell. Sk. 1:439. Chap. Fl. 132.

Louisianian area. South Carolina to Florida, west to Louisiana. Boggy margins of pine-barren swamps.

Alabama: Coast plain. Wet borders of pine-barren ponds. Mobile County. Flowers crimson; July. Not infrequent. Perennial. Two to $2 \frac{1}{2}$ feet high, conspicuous by the rich clusters of gaily colored flowers.

Type locality: "In the bogs of Lower Carolina and Georgia."

Herb. Geol. Surv. Herb. Mohr.

Rhexia glabella Michx. Fl. Bor. Am. 1:222. 1803.

DEer Grass.

Ell. Sk. 1 : 438. Chap. Fl. 132.

Louisianian area. North Carolina to Florida, west to eastern Louisiana.

Alabama : Central Pine belt to Coast plain. Grassy pine barrens. Elmore County, Coosada Station (E. A. Smith). Clarke, Monroe, Washington, Baldwin, and Mobile counties. Flowers deep pink, large, June, July. Frequent. Common in the pine barrens of the Coast plain.

Type locality: "Hab. in sylvis Carolinae et Georgiae."

Herb. Geol. Surv. Herb. Mohr. 
Rhexia ciliosa Michx. Fl. Bor. Am. 1:221. 1803.

Fringed Meadow Beauty.

Ell. Sk. 1:439. Gray, Man. od.6,183. Chap. Fl.132.

Caroliuian and Louisianian areas. North Carolina to Florida and west to Louisiana.

Alabama : Central Pine belt to Coast plain. Boggy borders of pine-barren streams. Autanga County, Prattville. Clarke County (Dr.Denny). Monroe, Washington, and Mobile counties. Flowers rose-pink, June, July. Frequent.

Type locality : "Hab. in Carolina inferiore."

Herb. Geol. Surv. Herb. Mohr.

Rhexia lutea Walt. Fl. Car. 130. 1788.

Yellow Mkadow Beauty.

Ell. Sk. 1:440. Chap. Fl. 133.

Louisianian area. North Carolina to Florida and west to Louisiana.

Alabama: Coast plain. Miry borders of ponds and ditches, low damp pine barrens. Mobile and Baldwin counties. Flowers golden yellow; May, June. Frequeut. Type locality: South Carolina.

Herb. Geol. Surv. Herb. Mohr.

\section{ONAGRACEAE. Evening Primrose Family.}

JUSSIAEA L. Sp. Pl. 1:388. 1753.

Thirty-six species, aquatic and paludial perennial berbe, chiefly of warmer temperate and tropical America to Brazil. North America, 5.

Jussiaea diffusa Forsk. Fl. Aegypt. 2 : 10. 1775.

Creeping Jussiaka.

Jussiaea repens $\mathrm{Sw}$. Obs. 172. 1892 . Not $\mathrm{L}$.

J. sioartziana DC. Prodr. 3 :54. 1828.

Gray, Man. ed. 6, 187. Chap. Fl. Suppl. 620 ed. 3, 163. Griseb. Fl. Brit. W. Ind. 272,

in part. Coulter, Contr. Nat. Herb. 2:113.

West INDies, South America.

Carolinian and Louisianian areas. New York and Illinois, south to Florida, and west to Texas and Arkansas.

Alabama : Central Prairie region. Shallow ponds, ditches. Montgomery County. Flowers yellow; June to September. Abundant in the Coast plain. Floating and rooting.

Type locality: "Rosettae ad ripam Nili, in marginibus agrorum."

Herb. Geol. Surv. Herb. Mohr.

Jussiaea decurrens (Walt.) DC. Prodr. 3:56. 1828.

Decurrent-Leaf Jussiaka.

Ludvigia decurrens Walt. Fl. Car. 89. 1788.

Ell. Sk. 1:217. Gray, Man. ed.6, 187. Chap. Fl.140. Griseb. Fl. Brit. W. Ind. 272.

West INDIEs to BraziL.

Carolinian and Louisianian areas. Virginia south to Florida, and west to Louisiana, Arkansas, and southern Illinois.

Alabama : Over the State. Tennessee Valley. Franklin County, Russellville, low thickets. Cullman County, 600 feet. Blount, Montgomery, and Mobile counties.

Flowers yellow, July, August. Frequent; abundant in the coast region.

Type locality: South Carolina.

Herb. Geol. Surv. Herb. Mohr.

Jussiaea pilosa H. B. K. Nov. Gen. \& Sp. 6:801, t.532. 1818.

Jussiaea leptocarpa Nutt. Gen. 1:279. 1818.

J. variabilis G. F. W. Meyer, Prim. Fl. Esseq. 174. 1818.

Chap. Fl. 140. Griseb. Fl. Brit. W. Ind. 272.

West Indies, Mexico to Brazil.

Carolinian and Louisianian areas. Florida to Louisiana, Arkansas, and Missouri.

Alabama: Central Prairie region. Coast plain. Wet places, ditches, borders swamps. Antauga County (E. A. Smith). Montgomery, Baldwin, and Mobile counties. Flowers yellow, August to October. Frequent; abounding on the mud flats at the mouth of Mobile River.

Type locality: "Caracas, on the banks of the river Apures."

Herb. Geol. Surv. Herb. Mohr.

Jussiaea suffruticosa L. Sp. Pl. 1: 388. 1753.

West Indies, Mexico to Brazil, East Indies.

Louisianian area. 
Alabama: Coast plain. Swampy river banks. Mobile County, near the mouth of Mobile River; only locality. Occurring near ballast heaps; presumably a fugitive from the tropies; not recently collected. Flowers yellow, July. Perennial.

Type locality: "Hab. in India."

Herb. Geol. Surv. Herb. Mohr.

Jussiaea peruviana L. Sp. Pl. ed. 2, 1:555. 1762.

Jussiaea macrocarpa H. B. K. Nov. Gen. 6:802, t.533. 1818.

J. hirta Vahl, Eclog. 2 : 31. 1798.

Griseb. Fl. Brit. W. Ind. 273.

West Indies, Mexico to Brazil.

Louisianian area. Florida.

Al.aBama : Adventive on the banks of Mobile River with the last. Flowers yellow, July.

Type locality: "Hab. in Lima."

Herb. Geol. Surv. Herb. Mohr

LUDWIGIA L. Sp.P1. $1: 118$. 1753. Bastard Loosestrife.

About 60 species, perennials, warmer regions of Europe, Asia, and Africa. Atlantic North America, 24.

Ludwigia alternifolia L. Sp. Pl. 1 :118. 1753. Common BASTARD Loosestrife. Ell. Sk. 1:217. Gray, Man. ed.6, 187. Chap. Fl. 140.

Carolinian and Louisianian areas. Southeastern New England, New York west to Michigan, Ohio Valley, and Missouri, sonth to Florida, Louisiaua, and Arkansas.

Alabama: Tennessee Valley to the Coast plain. Low wet thickets. Lee County, Auburn (Baker \& Earle, 170). Coosa County, Mount Olive, 1,200 feet. Franklin County, Russellville. Cullman County, 800 feet. Autauga, Montgomery, and Mobile counties.

Flowers yellow; August, September. Frequent.

Type locality: "Hab. in Virginia."

Herb. Geol. Surv. Herb. Mohr.

Ludwigia alternifolia linearifolia Britton, Bull. Torr. Club, 17 : 315.1890. Carolinian area. West Virginia to Florida and Mississippi.

AlabaMa: Coast plain. Border of marshes. Mobile County. Flowers August; common.

Type locality not given. In Britt. \& Br. Ill. Fl.: West Virginia.

Herb. Geol. Surv. Herb. Mohr.

Ludwigia hirtella Raf. Med. Rep. N. Y. ser.2, $5: 358.1808$.

Ludwigia hirsuta Pursh, Fl. Am. Sept. 1: 110. 1816.

ROUGHish HaIRY LUdWIGIA.

Ludwigia pilosa Ell. Sk. 1:216. 1821. Not Walt.

Gray, Man. ed. 6, 187. Chap. Fl. 141.

Carolinian and Louisianian areas. New Jersey to Florida, west to Louisiana and Arkansas.

Alabama: Coast Pine belt, Coast plain. Monroe, Washington, Baldwin, and

Mobile counties. Flowers yellow; June, July. Frequent.

Type locality : "Near Baltimore, in a wood."

Herb. Geol. Surv. Herb. Mohr.

Ludwigia virgata Michx. Fl. Bor. Am. 1:89. 1803. Slender-Stemmed Ludwigia. Ell. Sk. 1:216. Chap. Fl. 141.

Carolinian and Louisianian areas. South Carolina to Florida, west to Louisiana and 'Tennessee (Gattinger).

Alabama : Lower Pine region, Coast plain. Sandy pine barrens. Flowers yellow; May, June. Frequent.

Type locality: "Hab. in aridis sylvis Carolinae inferioris."

Herb. Geol. Surv. Herb. Mohr.

Ludwigia linearis Walt. Fl. Car. 89. 1788.

NARROW-LEAF LUDWIGIA.

Ludwigia angustifolia Michx. Fl. Bor. Am. 1:88. 1803.

Ell. Sk. 1:215. Gray, Man. ed. 6, 188. Chap. Fl. 141 .

Carolinian and Louisianian areas. Southern New Jersey to Florida, west to Louisiana.

Alabama: Central Pine belt to Coast plain. Boggy pine barrens. Chilton County, Clanton. Mobile County. Dekalb County, Mentone. Flowers yellow. August, September; frequent. Most abundant in the Coast plain.

Type locality: South Carolina.

Herb. Geol. Surv. Herb. Mohr. 
Ludwigia linifolia Poir. Suppl. 3: 513. 1813.

Flax-leaf Ludwigia.

Chap. Fl. 141.

Louisianian area. North Carolina to Florida.

Alabama: Lower Pine region. Border pine-barren ponds. Mobile County. Grand Bay. Flowers August 16 (1869); rare.

Type locality: "Cette plante crolt dans l'Amérique septentrionale."

Herb. Geol. Surv. Herb. Mohr.

Ludwigia glandulosa Walt. Fl. Car. 88. 1788.

Ludwigia brachycarpa Lam. Encycl. 3 : 331. 1789.

L. cylindrica Ell. Sk. 1:213. 1818.

Gray, Man. ed. 6, 188. Chap. Fl. 141.

Carolinian and Louisianian area. South Carolina to Florida, west to Louisiana and Arkansas and southern Illinois.

Alabama: Coosa Valley. Coast plain. Shady swampy places. Etowah County, near Gadsden, pine woods, 450 feet. Mobile County, swampy thickets, Dauphinway; river swamp on the telegraph road, Grand Bay. Flowers July to September; not

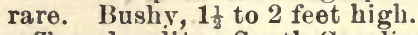

Type locality: South Carolina.

Herb. Geol. Surv. Herb. Mohr.

Ludwigia pilosa Walt. Fl. Car. 89. 1788.

HoARy LUdWigia.

Ludwigia mollis Michx. Fl. Bor. Am. 1: 90. 1803.

Ell. Sk. 1:214. Chap. Fl. 141.

Louisianian area. South Carolina and Florida to Lonisiana.

Alabama: Central Prairie region to Coast plain. Elmore County, Coosada station (E. A. Smith). Montgomery County, etc. Miry borders of ponds, ditches. Flowers July; frequent. Abundant throughont the Lower Pine region and Coast plain.

Type locality: South Carolina.

Herb. Geol. Surv. Herb. Mohr.

ISNARDIA L. Sp. Pl. 1:120. 1753.

Isnardia palustris L. Sp. Pl. 1: 120. 1753.

Water PURSLaNe.

Ludvigia palustris Ell. Sk. 1:211. 1821.

Gray, Man. ed. 6, 188. Chap. Fl. 142. Coulter, Contr. Nat. Herb. 2:113. Griseb. Fl. Brit. W. Ind. 271.

A cosmopolitan weed, Europe, western Asia, East and West Indies, Mexico.

Alleghenian to Lonisianian areas. Nova Scotia to the Saskatchewan, sonth to the Gulf, west to New Mexico.

Alabama : All over the State. In miry soil and stagnant pools, floating and root lng, June to October.

Type loeality: "Habitat in Galliae, Alsatiae, Russiae, Virginiae fluviis."

Herb. Geol. Surv. Herb. Mohr.

EPILOBIUM L. Sp. Pl. 1 :347: 1753.

One hundred and sixty species, cooler and temperate regions of the globe. Europe, Asia. North America, about 38.

Epilobium coloratum Mnhl.; Will. Enum. 1:411. 1809.

Epilobium tetragonum Pursh, Fl. 1: 250. 1814.

Colored WiLlow-Heri.

Ell. Sk. 1: 445. Gray, Man. ed.6, 189. Chap. Fl. 141.

Alleghenian and Carolinian areas. Nova Scotia to Saskatchewan and the Rocky

Monutains; New England west to Dakota, Nebraska, and Kansas, south from New

York to West Virginia; Ohio Valley to Missouri and along the mountains to South Carolina.

Alabama : Mountain region. Metamorphic hills. Cleburne County, Arbacoochee,

1,200 feet. Flowers rose-pink; July. Rare. Perennial.

'Type locality: "Hab. in Pensylvania."

Herb. Geol. Surv. Herb. Mohr. 
ONAGRA Adans. Fam. P1. 2:85. 1763.

Eight species, temperate North America.

Onagra biennis (L.) Scop. Fl. Carn. ed. 2, 1:269. 1772.

Oenothera biennis L. Sp. Pl. 1:346. 1753.

Common Evening Primrose.

Ell. Sk. 1:441. Gray, Man. ed. 6, 190. Chap. Fl. 138. Coulter, Contr. Nat. Herb.

2: 115 .

Naturalized in temperate regions of the Old World.

Boreal zone to Louisianian area. Throughout the continent.

Alabama : All over the State. Borders of fields, roadsides, and copses. Flowers pale vellow; June, July. Common. Annual. In bottom lands 8 to 10 feet high.

Type locality: "Hab. in Virginia unde 1614, nunc vulgaris Europae.

Herb. Geol. Surv. Herb. Mohr.

OENOTHERA L. Sp. PI. 1:346. 1753.

Twenty species, temperate North America.

Oenothera humifusa Nutt. Gen. 1:245. 1818.

Seaside Evening Primrose.

Oenothera sinuata var. humifusa Torr. \& Gray, Fl. N. A. 1:494. 1838.

Gray. Man. ed. 6, 190. Chap. Fl. 138.

Mexico, Guatemala.

Carolinian and Louisianian areas. New Jersey along the coast to Florida, west to Louisiana.

Alabama : Littoral region. Drifting sands on the seashore. Shores Mobile Bay and of the islands. Flowers pale yellow. April, May. Frequent. Perennial.

Type locality: "Near Cumberland Island, Florida, on the seacoast. Dr. Baldwyn."

Herb. Geol. Surv. Herb. Mohr.

Oenothera laciniata Hill, Veg. Syst. 12, App.: 64, t. 10. 1767.

Oenothera sinuata L. Mant. 2 : 228. 1771.

Sinuate-lhaved Evening Primrose.

O. minima Pursh, Fl. Am. Sept. 1:26, t. 15. 1814.

Ell. Sk. 1:443. Gray, Man. ed. 6, 190. Chap. Fl. 138. Coulter, Contr. Nat. Herb. 2: 115 .

North Mexico.

Carolinian and Louisianian areas. New Jersey to Florida, west to Louisiana, Texas, Arkansas, and Missouri

Alabama: Central Pine belt. Coast plain. Sandy light soil, waste and cultivated places. Flowers pale yellow, turning rufescent in fading; April, May. A winter annual and biennial. Radieal leaves form during the winter and early spring a dense rosette. Bieunial. A reduced form with simple stems 1 to 2 inches high (Oenothera minima Nutt.) is frequent throughout in grassy places.

Type locality: "Native of Carolina."

Herb. Geol. Surv. Herb. Mohr.

Oenothera laciniata grandis Britton in Britt. \& Br., Ill. Fl. 2:487. 1897.

Oenothera sinuata var. grandiflora Wats. Proc. Am. Acad.8:581. 1872. Not O.grandiflora Ait. 1789.

Coulter, Contr. Nat. Herb. 2 : 115.

Alleghenian to Louisianian area. Indiana to Minnesota and Nebraska, south to Arkansas, Texas, and Mississippi.

Alabama: Mountain region, Metamorphic hills. Lee County, Auburn $(F, S$. Earle.) Flowers yellow; Neptember, October. Rare. Biennial.

Type locality (Britton): "Missouri and Kansas, south to Texas."

Herb. Geol. Surv. Herb. Mohr.

KNEIFFIA Spach, Hist. Veg. 4 : 373. 1835.

Three species, temperate North America.

Kneiffia fruticosa (L.) Raimann, in Engl. \& Prantl, Nat. Pfl. 3, Abt. 7:214. 1893.

Oenothera fruticosa L. Sp. P1. 1 : 346. 1753.

SUNDROPS.

Kneiffia suffruticosa Spach, Hist. Veg. 4:374. 1835.

Ell. Sk. 1:442. Gray, Man. ed.6, 191. Chap. Fl.139.

Carolinian and Louisianian areas. New York, southern Michigan, Virginia, and the Ohio Valley to Missouri and Arkansas, south to Florida and Louisiana. 
Alabama: Tennessee Valley to the Coast plain. Open woods and banks. Lawrence County. Cullman County, 800 feet. Dekalb County, Mentone, 1,600 feet. Autauga County, Prattville. Mobile County. Flowers lemon-yellow; May. Frequent. Perennial.

Type locality: "Hab. in Virginia."

Herb. Geol. Surv. Herb. Mohr.

Kneiffia linearis (Michx.) Spach, Hist. Veg. $4: 376.1835$. Pine-Barren Sundrops. Oenothera linearis Michx. Fl. Bor. Am. 1 : 225. 1803.

O. fruticosa var. linearis Wats. Proc. Am. Acad. 8:584. 1873.

Eli. Sk. 1:444. Gray, Man. ed. 6, 191. Chap. Fl.139.

Carolinian and Louisianian areas. Southern Virginia along the coast to Florida, west to Louisiana.

Alabama : Lower Pine belt. Coast plain. In dry sandy pine forests. Escambia, Washington, Baldwin, and Mobile counties. Flowers yellow; June. Frequent. Perennial.

Type locality: "Hab. in Carolina superiore."

Herb. Geol. Surv. Herb. Mohr.

XYLOPLEURUM Spach, Hist. Veg. 4 : 378. 1835.

Ten species, Mexico, sonthern United States.

Xylopleurum speciosum (Nutt.) Raimann, in Engl. \& Prantl, Nat. Pfl. Fam. 5, Abt. $7: 214$. 1893.

Show y Evening Primrose.

Oenothera speciosa Nutt. Journ. Acad. Phila. 2 : 119. 1821.

Xylopleurum nuttallii Spach, Hist. Veg. $4: 378.1835$.

Gray, Man. ed. 6, 191. Coulter, Contr. Nat. Herb. 2 : 115.

Louisianian area. Southern Tennessee, Mississippi, southern Arkansas, and Texas.

Alabama: Central Prairie region. Coast plain. Borders of fields, grass plots. Dallas County, Uniontown. Hale County, Gallion. Mobile County. Flowers rosepink, with darker veins, yellowish at the base, slightly fragrant, diurnal, very handsome; May, June. Local; abundant. Perennial. Of late observed to spread in the Coast plain, where it is found on roadsides and grassy banks, most probably escaped from cultivation.

Type locality apparently the uplands of Lonisiana.

Herb. Geol. Surv. Herb. Mohr.

GAURA L. Sp. Pl. 1:347. 1753. GaURA.

Gaura angustifolia Michx. Fl. Bor. Am. 1:226. 1803.

NaRrow-Leaf GaURa.

Ell. Sk. 1: 445. Chap. Fl. 138.

Louisianian area. Coast of North Carolina to Florida, west to Lonisiana.

Alabama: Coast plain. Littoral region. Dry gravelly banks and sandy shores. Bald win and Mobile counties. Flowers white, pale pink on fading; August to October. Frequent on the shores of Mobile Bay and on the islands. Biennial.

Type locality : "Hab. in Carolina inferiore."

Herb. Geol. Surv. Herb. Mohr.

Gaura michauxii Spach, Nouv. Ann. Mus. Paris, 4 : 379. 1835.

Michaux's Gaura.

Gaura filipes Spach, Nouv. Ann. Mus. Paris, 4 : 379.1835.

Gray, Man. ed.6, 193. Chap. Fl.138.

Carolinian and Louisianian areas. Virginia, Ohio, Missouri, and Arkansas; south from Kentucky to Florida and Lonisiana.

Alabama: Mountain region. Central Pine belt to Coast plain. Dry sundy open woods. Cullman County, 800 feet. Montgomery, Autauga, Clarke, Washington, and Mobile counties. Flowers pink; July to September. Common; most frequent in grassy pine barrens of the Coast Pine belt. Perennial.

Type locality not ascertained.

Herb. Geol. Surv. Herb. Mohr.

Gaura longiflora Spach, Nouv. Ann. Mus. Paris, 4 : 59. 1835.

Gaura biennis var. pitcheri Torr. \& Gray, Fl. N. A.517. 1840. (8)

Chap. Fl. ed. 3, 161 .

Carolinian area. Northern Georgia.

Alabama : Fide Chapman.

Type locality not ascertained.

Herb. Geol. Surv. Herb. Mohr. 
CIRCAEA L. Sp. P1. 1:9. 1753.

Seven species, boreal and cooler temperate regions, Europe, Asia. North America, 3. Circaea lutetiana L. Sp. Pl. 1:9. 1753.

ENCHANTER's Nightshade.

Ell. Sk. 1:7. Gray, Man. ed. 6, 193. Chap. Fl. 143.

Europe, Northern Africa, Northern Asia to China.

Canadian to Carolinian area. Nova Scotia, Quebec; New England west to Minnesota and the Rocky Mountains, south to the Ohio Valley, Missouri, Arkansas, Tennessee, and Georgia.

Alabava: Mountain region. Rich woods. Madison County, Montesano, 1,500 feet. Cullman County, 800 feet. Winston County, 1,200 feet. Flowers white; May. Not infrequent. Perennial.

Type locality: "Hab. in Europae et Americae borealis nemoribus."

Herb. Mohr.

\section{HALORAGIDACEAE. Water Milfoil Family.}

PROSERPINACA L.Sp.P1. 1:88. 1753.

Two species, perennial aquatics, eastern North America.

Proserpinaca palustris L. Sp. P1. 1: 88. 1753.

SWamp Mermaid-Weed!

Ell. Sk. 1: 181. Gray, Man. ed.6, 181. Chap. Fl. 143. Coulter, Contr. Nat. Herb.

2:111.

Cuba, Mexico, Guatemala.

Alleghenian to Louisianian area. New Brunswick; New England and New York west to Minnesota, south to the Ohio Valley, Missouri, Kansas, Arkansas, Florida, and Louisiana.

Alabama: Central Prairie region to Coast plain. Ponds and ditches. Montgomery, Escambia, Washington, and Mobile counties. Flowers May to August. Common, particularly in the pine-barren ponds of the Coast plain.

Type locality : "Hab. in Virginiae paludibus."

Herb. Geol. Surv. Herb. Mohr.

Proserpinaca pectinata Lam. Tabl. Encycl. $1: 214, t .50, f .1$. 1791.

Proserpinaca palustris var. Michx. Fl. Bor. Am. 1: 76. 1803.

Ell. Sk. 1:182. Gray, Man. ed. 6, 182. Chap. Fl.143. Coulter, Contr. Nat. Herb. $2: 111$.

Carolinian and Lonisianian areas. Southern Now England along the coast to Florida, west to Texas.

Alabama: Coast plain. Sandy pine barren swamps. Baldwin and Mobile counties. Flowers May, June. Common.

Type locality: “Ex America septentrionale."

Herb. Geol. Surv. Herb. Mohr.

MYRIOPHYLLUM L.Sp. Pl. 2 : 992. 1753.

About 20 species, perennial aquatics, cosmopolitan. North America, 12.

Myriophyllum laxum Shuttlow.; Chap. Fl.143. 1860. Southern Water Milforl. Louisianian area. Florida.

Alabama: Lower Pine belt. Coast plain. Deep ponds. Washington County, Yellowpine. Baldwin County, Sibleys Mill. Flowers pale purple; August, September. Rare.

Type locality: "Ponds and lakes, middle and west Florida."

Herb. Geol. Surv. Herb. Mohr.

Myriophyllum pinnatum (Walt.) B. S.P.Prel. Cat. N. Y.16. 1888.

Potamogeton pinnatum Walt. Fl. Car. 90, 1788.

Myriophyllum scabratum Michx. Fl. Bor. Am. 2:190. 1803.

Ell. Sk.2:588. Gray, Man. ed.6, 181. Chap. Fl.144.

Carolinian and Louisianian areas. New Jersey, Illinois, Missouri, and Arkansas.

Alabama: Mountain region. Coast plain. In deep gently flowing or almost stagnant water. Madison County, Huntsville, Big Spriugs (Baker \& Earle, 163). Mobile County, estuary of Dog River. Flowers purple, July. Rare.

Type locality: South Carolina.

Herb. Mohr. 


\section{ARALIACEAE. Ginseng Family.}

ARALIA L. Sp. Pl. 1:273. 1753.

Thirty species, warmer and temperate northeastern Asia. North America, 7. Woody or herbaceous perennials.

Aralia racemosa L. Sp. Pl. 1:273. 1753.

SPIKENARD.

Ell. Sk. 1:373. Gray, Man. ed.6,213. Chap. Fl.166.

Canadian to Carolinian area. Nova Scotia, New Brunswick, and Ontario; New England west to Miunesota, Nebraska, Colorado, and Montana; southeru Ohio Valley to Missouri, and along the mountains to Georgia.

AlabaMa: Mountain region. Rich woodlands. Winston County, Davidson Creek, 1,500 feet. Rare. Perennial.

Economic uses: "The root is used medicinally under the name of spikenard.

'Ty pe locality: "Hab. in Canada."

Herb. Geol. Surv. Herb. Mohr.

Aralia spinosa L. Sp. Pl. 1:273. 1753.

ANGelica Tree.

Ell. Sk. 1:372. Gray, Man. ed. 6, 213. Chap. Fl. 166. Sargent, Silv. N. A. 5:56, t. 211.

Carolinian and Louisianian areas. Virginia and Ohio to Missouri and Arkansas, south to Floricla, west to Louisiana.

Alabama: Throughout, exeepting the highest summits. Damp borders of woods and copses. Cullman County, Mariots Creek, 600 feet. Arborescent, clear trunk 30 feet high, 5 to 6 inches in diameter. Clarke and Mobile counties. Flowers white; June. Frequent, principally throughout the Coast Pine belt.

Ornamental.

Type locality: "Hab. in Virginia.".

Herb. Geol. Surv. Herb. Mohr.

PANAX L. Sp. Pl. $2: 1058.1753$. Ginseng.

About 30 species, temperate Asia. Atlantic North America, 2.

Panax quinquefolia L. Sp. P1. 2 : 1058. 1753.

GiNSENG.

Aralia quinquefolia Decaisne \& Planch. Rev. Hort. ser. 14, 3:105. 1854.

Gray, Man. ed.6, 213. Chap. Fl.167.

Carolinian and Louisianian areas. Ontario, throughout the eastern United States to Georgia.

Alabama: Mountain region to Upper division Coast Pine belt. Rich hilly woodlands. Madison County, Montesano, 1,500 feet. Monroe County, 300 to 350 feet. Flowers May. Widely diffised over the mountain and hill country and in the calcareous hills of the Tertiary formation as far south as Monroe County. Perennial.

Economic uses: The root is the ginseng of commerce.

Type locality: "Hab. in Canada, Pensylvania, Virginia."

Herb. Geol. Surv. Herb. Mohr.

\section{APIACEAE. Parsley Family.}

DAUCUS L. Sp. Pl. 1:242. 1753. Carrot.

Fifty species, temperate and warmer temperate regions of Europe, northern Afric , Asia. North America, 1.

Daucus pusillus Michx. Fl. Bor. Am. 1:164. 1803.

Lesser Cakrot.

Ell. Sk. 1:349. Chap. Fl. 161. Coulter, Contr. Nat. Herb. $2: 140$.

Mexico.

Louisianian area. South Carolina to Florida, west to Texas. On the Pacific coast from British Columbia to Mexico.

Alabama: Central Pine region to Coast plain. Dry open sandy or gravelly places, pastures, roadsides. Tuscaloosa, Montgomery, Clark, and Mobile counties. Flowers white; June. Common. Annual.

Type locality: "Hab. in campestribus Carolinae."

Herb. Geol. Surv. Herb. Mohr.

Daucus carota L. Sp. P1. 1 : 242. 1753.

Wild Carrot.

Alleghenian to Louisianian area. Common in the North. Gray, Man. ed.6, 201. Chap. Fl. ed. 3, 182. Britt. \& Br. Ill. Fl. 2: 510. 
Alabama: Fugitive from Europe on ballast. Mobile County. Rare. Mother plant of the garden carrot, Daucus carota sativa. Annual.

Herb. Geol. Surv.

CAUCALIS L. Sp. Pl. 1 : 240. 1753.

Caucalis nodosa (L.) Huds. Fl. Angl. ed.2,114. 1778. Knotted Hede Parsley. Tordylium nodosum L. Sp. Pl. 1:240. 1753.

SOUTHERN EUROPE.

Ala bama : Fugitive on ballast. Mobile County, July, 1884. Annual. Type locality : "Hab. in Gallia, Italia ad vias."

Herb. Mohr.

TREPOCARPUS Nutt.; DC. Mém. Omb. 56. 1829.

One species, Atlantic North America.

Trepocarpus aethusae Nutt.; DC. Mém. Omb. 56, t.14. 1829. AethUSA-LIKE TREPOCARPUS.

Chap. Fl. Suppl.623; ed.3,182. Coulter, Contr. Nat. Herb. 2:140.

Louisianian area. Southern Arkansas, Texas, and Mississippi.

Alabama : Prairie region. Coast plain. Damp shaded banks, borders of fields. Hale County, Galliou, banks of Big Prairie Creek. Mobile County, Pinto Island; banks of Mobile River. May, June. Annual.

'Type locality: "Le territoire d'Arkansa."

Herb. Geol. Surv.

ANGELICA L. Sp. PI. 1:250. 1753.

Thirty-five species, temperate regions of both hemispheres. North America 16, chiefly western. Eastern North America, 3.

Angelica villosa (Walt.) B. S. P. Prel. Cat. N. Y. 22. 1888.

ANGHLICO.

Ferula villosa Walt. Fl. Car. 115.1788.

Angelica hirsuta Muhl. Cat. ed.2, 30. 1818.

Ell. Sk. 1:352. Gray, Man. ed. 6, 201. Chap. Fl. 164.

Carolinian area. New York along the mountains to Georgia.

Alabalia:- Mountain region to Lower Pine belt. Dry hills, border of woods, copses. Cullman County, 800 feet. Talladega County, Chandlers Springs, 800 feet. Lee County, Auburn (Earle). Montgomery County, Pintlala, 250 feet. Mobile County, dry grassy pine barrens. Flowers white; May. Not rare. Root said to be poisonous. Perenuial.

Type locality: South Carolina.

Herb. Geol. Surv. Herb. Mohr.

OXYPOLIS Raf. Neog. 2. 1825.

(Tiedemannia DC. Mém. Omb.51. 1829.)

(Archemora DC.Mém. Omb.51. 1829.)

Five species, perennials, Atlantic North America.

Oxypolis filiformis (Walt.) Britton, Mem. Torr. Club, 5 :239. 1894.

Oenanthe filiformis Walt. Fl. Car.113. 1788.

'Terete Oxypolis. False Dropwort.

O. teretifolia Muhl. Cat. 32. 1813.

Sium teretifolium Ell. Sk. 1: 354. 1817.

Tiedemannia teretifolia DC. Prodr. 4:187. 1830.

Ell. Sk. 1:354. Gray, Man. ed. 6, 202. Chap. Fl. 165.

Carolinian and Louisianian areas. Delaware along the coast to Florida, west to Louisiana.

Alabama : Central Pine region to Coast plaiu. Wet borders of swamps. Escanbia, Washington, Mobile, and Baldwin counties. Flowers white, June; fruit ripe in July and Angust. Frequent. Abundant in the pine-barren bogs of the coast.

Type locality: South Carolina.

Herb. Geol. Surv. Herb. Mohr.

Oxypolis rigiadior (L.) Raf. in Seringe, Bull. Bot.218. 1830.

Cowbane.

Sium rigidius L. Sp. Pl. 1 : 251. 1753.

Archemora rigida DC. Prodr. 4 : 188. 1830.

$15894-41$ 
Tiedemannia rigida Conlt. \& Rose, Bot. Gaz. 12 : 74. 1887.

Ell. Sk. 1 : 354. Gray, Man. ed.6, 202. Chap. Fl. 165.

Alleghenian, Carolinian, and Louisianian areas. Michigan; New York south to

Florida, west to Louisiana.

Alabama : Mountain region. Low grassy banks. Lee County, Auburn (Earle). Mobile County, banks of pine-barren streams. Flowers white; July, August. Fre- quent.

Type locality: "Hab. in Virginia."

Herb. Geol. Surv. Herb. Mohr.

Oxypolis rigidior longifolius (Pursh) Britton, Mem. Torr. Clnb, 5 : 239. 1894.

LONGLEAF COWBane.

Sium longifolium Pursh, Fl. Am. Sept. 1: 194. 1816.

Oenanthe ambigua Nutt. Gen. 1:189. 1818.

Carolinian and Louisianian areas. New Jersey to Florida, west to Louisiana.

Ala Bama: With the type, into which it merges by intermediate forms. Mobile.

Less frequent.

These plants are suspected to be poisonons, and, as stated by Pursh, are deleterions to horned eattle.

Type locality: "In ditches and bogs: New Jersey."

Herb. Geol. Surv. Herb. Mohr.

POLYTAENIA DC. Mém. Omb.53, t. 13. 1829.

One species, Atlantic North America.

Polytaenia nuttallii DC. Mém. Omb. 53, t. 13. 1829.

Nuttall's Polytaenia.

Tordylium americanum Nutt.; DC. Prodr. 4:196. 1830. As synonym.

Gray, Man. ed.6, 203. Chap. Fl. Suppl.623; ed.3, 182. Coulter, Contr. Nat. Herb. $2: 142$.

Carolinian and Louisianian areas. Southern Illinois to Nebraska, south to Texas, Mississippi, and Tennessee.

Ala baMa : Lower hills. Prairie region. Dry barren places. Lee County, Auburn (Baker \& Earle, 174). Walker County (E. A. Smith). Hale County, Gallion, bald prairies. Flowers gamboge-yellow; June, July. Not common. Perennial.

Type locality : "Le territoire d'Arkansa."

Herb. Geol. Surv. Herb. Mohr.

THASPIUM Nutt. Gen. $1: 196.1818$.

Three species, Atlantic North America.

Thaspium barbinode (Michx.) Nutt. Gen. 1:196. 1818. Barbed Meadori Parsnip. Ligusticum barbinode Michx. Fl. Bor. Am. 1: 167. 1803.

Ell. Sk. 1:352. Gray, Man. ed. 6, 204. Chap. Fl. 163.

Alleghenian and Carolinian areas. Ontario; New York west to Minnesota and Nebraska, south to the Ohio Valley, Missouri, and Arkansas, and from New Jersey along the mountains to Tennessee and Georgia.

Alabama: Mountaiu region to Central Prairies. Rich shady banks. Madison County, Montesano, 1,500 feet. Montgomery County, Pintlalla, about 250 feet. Flowers dull yellow; April, May. Infrequent. Perennial.

Type locality : "Hab. in Carolina superiore."

Herb. Geol. Surv. Herb. Mohr.

Thaspium pinnatifidum (Buckl.) Gray, Man. ed. 2, 155. 1856.

Moujtain Meadow Parsnip.

Zizia pinnatifia Buckl. Am. Journ. Sci. 45 : 175.1843.

Gray, Man. ed. 6, 204. Chap. Fl. 163.

Carolinian area. Barrens of Kentucky, along the Alleghenies to Tennessee and North Carolina.

AsabaMa: Monntain region. Rich woodlands, shady ravines. Dekalb County, Lookout Mountain, near Mentone, 1,600 feet. Flowers white; June. Rare. Perennial.

Type locality: "Banks of the French Broad River near the Warm Springs, and near Sugar Town Falls, Macon County, North Carolina."

Herb. Geol. Surv. Herb. Mohr.

Thaspium trifoliatum aureum (Nutt.) Britton, Mem. Torr. Club, 5 : 240. 1894.

Thaspium aureum Nutt. Gen. 1: 196. 1818. Golden-Flowered Meadow Parsip.

T, aureum var, trifoliatum Coult, \& Rose, Bot. Gaz. $12 ; 136,1887$, 
Gray, Man. ed. 6, 204. Chap. Fl. 163.

Alleghenian, Carolinian, and Louisianian area. Quebec, Ontario; Minnesota and Ohio Valley, south to Florida, west to Arkansas.

Aldabama : Mountain region to Coast plain. Dry copses, border of woods. Cullman, Tuscaloosa, Hale, and Mobile counties. Flowers pale yellow, May, June. Not infrequent. Perennial.

Type locality not specifically given.

Herb. Geol. Surv. Herb. Mohr.

IIGUSTICUM I. Sp. Pl. I:250. 1753.

About 20 species, temperate regions, North Hemisphere. North America 9, chiefly western.

Ligusticum canadense (L.) Britton, Mem. Torr. Club, 5:240. 1894.

Ferula canadensis L. Sp. P1. 1:247. 1753.

CANAdA LOVAGE. NONDO.

Ligusticum actaeifolium Michx. Fl. Bor. Am. 1:166. 1803.

Gray, Man. ed.6,205. Chap. Fl. 163.

Carolinian area. Ontario?; Virginia along the mountains to Tennessee, North Carolina, and Georgia.

Alabama: Mountain region. Rich wooded hillsides. Dekalb County, Lookout Mountain; Mentone, 1,600 feet, and near Collinsville. Cullman County, 800 feet. Flowers June. Scattered; not infrequent. Three to 5 feet high. Perennial.

Economic uses: The root, called "white root," is used in domestic medicine.

Type locality : "Hab. in Virginia."

Herb. Geol. Surv. Herb. Mohr.

AETHUSA L. Sp. Pl. 1:256. 1753.

Aethusa cynapium L. Sp. Pl. 1:256. 1753.

Foor's ParsLey.

Adventive from Europe, and naturalized northeast.

Alarama: Fugitive on ballast. Mobile, June, 1892-1894. A fetid poisonous weed. Annual.

"Hab inter Europae olera."

Herb. Geol. Surv. Herb. Mohr.

CYNOSCYADIUM DC. Mém. Omb. 44, t.11. 1829.

Two species, Atlantic North America.

Cynoscyadium pinnatum DC. Mém. Omb. 45, t.11. 1829.

Aethusa pinnata Eat. \& Wright; N. A. Bot.116. 1840.

Pinnate Dog's Parsley.

Chap. Fl. Suppl. 623; ed.3, 180. Coulter, Contr. Nat. Herb. 2 : 143.

Carolinian area. Arkansas, Texas, and Louisiana.

Alabama: Lower hills. Walker County (E. A. Smith). August; local, rare. Perennial.

A low depauperate form, 4 or 5 inches high.

Type locality : "L'Amerique septentrionale, aux environs du fleuve Arkansa."

Herb. Geol. Surv. Herb. Mohr.

ERYNGIU்M L. Sp. Pl. 1 : 232. 1753. ERYNGO.

About 100 species, chicfly perennials; temperate and warmer regions of the globe. North America 22, from the Atlantic to the Pacific.

Fryngium yuccifolium Michx. Fl. Bor. Am. 1:164. 1803. Button SNakeroot. Eryngium aquaticum L. Sp. Pl. ed. 2, 1:336. 1762 . In part. Not ed.1, 1:132.

Ell. Sk. 1:342. Gray, Man. ed. 6,211. Chap. Fl. 160. Coulter, Contr. Nat. Herb. $2: 143$.

Carolinian and Louisianian areas. New Jersey to Missouri and Nebraska, south to Florida, Texas, and Arkansas.

Alabana : Over the State. Damp or dry sandy and gravelly soil. Cullman, Bibb, and Mobile counties. July, August; common. Perennial.

In the coast region stout and tall forms prevail, bearing the very numerous globose

heads disposed in a compound umbel with the ultimate branches ternate.

Economic uses: The root, called "corn snakeroot," is used medicinally.

Type locality: "Hab. in Virginia."

Herb. Geol. Surv. Herb. Mohr. 
Eryngium synchaetum (Gray) Coult. \& Rose, Contr. Nat. Herb. 7 : 44. 1900.

Eryngium yuocaefolium synchaetum Gray; Coult. \& Rose, Rev. N. A. Umb. 94. 1888.

Chap. Fl. ed. 3, 176.

Perenuial from a slender rootstock; stem slender, 1 to 2 feet tall; leaves linear with numerous soft bristles in clusters of 2 to 4 ; styles slender, elongated, imparting to the round head a bristly appearance.

Louisianian area. Florida to Louisiana.

Alabama : Lower Pine belt and Coast plain. Low damp pine barrens. Mobile County, Bayou Sara, Springhill. Flowers June to Angust; common. Perennial.

Type locality: "Florida (Chapman, Curtiss, Palmer), Louisiana, near New Orleans (Dr. Ingalls, in 1835)."

Herb. Geol. Surv. Herb. Mohr.

Eryngium integrifolium Walt. Fl. Car. 112. 1788.

BLUE-FLOWERED ERYNGO.

Eryngium virgatum Lam. Encyel. 4 : 757. 1797.

E. americanum Spreng. in Roem. \& Schult. Syst. 6:337. 1820.

Eryngium ovalifolium Michx. Fl. Bor. Am. 1: 163. 1803.

Ell. Sk. 1:343. Chap. Fl. 160. Coulter, Contr. Nat. Herb. 2 : 144.

Carolinian and Louisianian area. North Carolina to Florida, west to eastern Texas.

AlabaMa: Mountain region to Coast plain. Low wet pine woods. Cullman County, 800 feet. Tuscaloosa County ( $G$. R. Vasey). Chilton County, Verbena Station (E. A. Smith). Autauga, Clarke, Washington, and Mobile counties. Flowers pale blue; July, August. Frequent. Perennial.

Infrequent in the interior, abundant in the Lower Pine region and Coast plain.

Type locality: Described from specimens in Jussieu's herbarium, "ou elle se trouve sans indication de lieu natal".

Herb. Geol. Surv. Herb. Mohr.

Eryngium prostratum Nutt.; DC. Prodr. 4:92. 1825.

Creeping Eryngo.

Eryngium baldwinii var. $\beta$ Torr. \& Gray, Fl. N. A. 1:605. 1838.

Gray, Man. ed. 6, 212. Chap. Fl. ed. 3, 177. Coulter, Contr. Nat. Herb. $2: 144$.

Carclinian and Louisianian areas. Kentucky and Tennessee to Georgia and

Florida, west to Louisiana, Texas, Arkansas, and southeastern Missouri.

Alabama: Central Prairie region to Coast plain. Shady damp banks of streams. Autauga County, Prattville. Mobile County, wet borders of ponds. Flowers pale blue; June to August; stems numerous, prostrate, rooting at the internodes; not frequent.

Type locality: "In Americae borealis territorio Arkansano detexit cl. Nuttall." Herb. Geol. Surv. Herb. Mohr.

\section{SANICULA L. Sp. Pl. 1:235. 1753.1}

Thirteen species, temperate Europe, Asia. North America, 10.

Sanicula marilandica L. Sp. P1. 1 : 235. 1753.

MARYLAND SANICle.

Ell. Sk. 1 : 348, in part. Gray, Man. ed. 6, 212. Chap. Fl. 159.

Alleghenian to Lonisianian area. Nova Scotia, Ontario, and British Columbia to the Pacific coast; New England west to Nebraska, the Rocky Mountains, and Montana; south along the mountains to Georgia.

Alabama : Mountain region to Upper division Coast Pine belt. Rich woodlands, copses. Cullman County. Tuscaloosa County (E. A. Smith). Lee County, Auburn (Baker \& Earle). Flowers yellowish; May. Scattered, not frequent; rootstock stout; perennial.

Type locality: "Hab. in Marilandia, Virginia."

Herb. Geol. Surv. Herb. Mohr.

Sanicula gregaria Bicknell, Bull. Torr. Club, 22:354. 1895. Gregalious Sanicle. Britt. \& Br. III. Fl. 2 : 524

Carolinian and Louisianian area. New York, Virginia west to Wisconsin, eastern Nebraska, Kansas, Arkansas, and Louisiana.

Alabama: Central Pine belt. Woods. Tuscaloosa and Bibb counties. May. Perennial. There can be but little doubt that with future search the species will turn up in the mountain region.

Type locality : "Described from specimens collected in Van Cortlandt Park, N. Y." Herb. Geol. Surv. Herb. Mohr.

${ }^{1}$ Eugene P. Bicknell, The genus Sanionla in the Eastern United States, Bull. Torr, Club, vol. 22, pp. 351 to 361 . 1895. 
Sanicula canadensis L. Sp. Pl. 1:235. 1753.

Canada Sanicle.

Sanicula marylandica var. canadensis Torr. Fl. N. \& Mid. U. S. 302. 1824.

S. floridana Bicknell, Bull. Torr. Club, 24 :581. 1897.

Ell. Sk. 1:348, in part. Gray, Man. ed. 6, 212. Chap. Fl.159.

Carolinian and Louisianian area. Massachusetts west to Kansas and Nebraska, south to Florida and Louisiana.

AlabaMa : Mountain region to Coast plain. Dry light soil, open copses, borders of woods. Lee County, Auburn (Baker \& Earle). Clay County, Delta, 1,600 feet. Tuscaloosa and Mobile counties. Flowers greenish white; June. Frequent. Perennial trom a weak fibrous root.

A form agreeing with Sanicula floridana Bicknell, is known from Mobile C'ounty and from Lee County (Auburn, Baker \& Earle); but Coulter \& Rose find themselves unable to separate it from this species.

Type locality: "Hab. in Virginia."

Herb. Geol. Surv. Herb. Mohr.

Sanicula smallii Bicknell, Bull. Torr. Club, 24:578. 1897.

Closely allied to Sanicula canadensis; distinguished by the more simple stem once or twice dichotomously brauched, the larger, closely sessile fruit, the styles little longer than the linear-subulate rigid and separate calyx segments.

Carolinian and Louisianian areas. Tennessee to Georgia and Florida.

Alabaya: Mountain region to Upper, division of Maritime Pine belt. Shady woods. Madison County, summit of Montesano, 1,500 feet (L.M. Underwood). Cullman County. Lee County, Auburn (F. S. Earle). Tuscaloosa (E. A. Smith). Clarke County, Choctaw Corner. April, May; not infrequent.

Type locality: "Tennessee: Jackson ****. Georgia: base of Little Stone Mountain * * *. Florida: Tallahassee."

Herb. Geol. Surv. Herb. Mohr.

TAENIDIA Drude in Engl. \& Prantl, Nat. Pfl. 3, Abt. 8: 195. 1898.

A monotypical perennial of eastern North America.

Taenidia integerrima Drude in Engl. \& Prantl, Nat. Pfl. 3, Abt. 8:195, $f$ 64. 1898. Smyrium integerrimum L. Sp. PI. 1:263. 1753.

Zizia integerrima DC. Rep. Pl. Jard. Gènove, 3: 7. 1830.

Pimpinella integerrima Gray, Proc. Am. Acad. 7:345. 1868.

Ell. Sk. 1:360. Gray, Man.ed. 6, 206. Chap. Fl. 163.

Alleghenian, Carolinian, and Louisianian areas. Quebec, Ontario; New England, west to Minnesota, Nebraska, Kansas, and Arkansas; Ohio Valley, Tennessee, along the mountains to Georgia.

Alabama: Mountain region. Rocky woods. Madison County, Montesano, 1,500 feet. Dekalb County, Lookout Mountain, near Mentone, 1,600 feet. Flowers yellow; May. Infrequent. Perennial.

Type locality: "Hab. in Virginia."

Herb. Geol. Surv. Herb. Mohr.

BUPLEURUM L. Sp. Pl. 1:236. 1753.

Sixty species or more, mostly of the Old World. Northwestern North America, 1.

Bupleurum rotundifolium L. Sp. Pl. 1 : 236. 1753.

Thoroughwax.

Europe.

Caro inian area. Naturalized. New York to North Carolina, west to Missouri and Arkansas.

Alabama: Lower hills. In cultivated ground. Tuscaloosa County (E. A. Smith). June; not frequent.

Type locality: "Hab. inter Europae australis segetes."

Herb. Geol. Surv.

CHAEROPHYLIUM L. Sp. Pl. 1:258. 1758.

About 40 species, temperate regions, Northern Hemisphere. Southern Europe. North America, 3.

Chaerophyllum procumbens (L.) Crantz, Class. Umb. 77. 1767. WILd Chkrvil. Scandix procumbens L. Sp. Pl. 1:257. 1753.

Fil. Sk. 1:357. Gray, Man. ed.6, 210. Chap. Fl. 165.

Caroliniau and Louisianian areas. New York, west to the Ohio Valley, Missouri, and Arkansas, south from New Jersey to Tennessee, South Carolina, and Mississippi. 
Alabama : Lower hills. Tuscaloosa County. Flowers white; April. Not frequent. Type locality: "Hab, in Virginia."

Herb. Mohr.

Chaerophyllum tainturieri Hook. Comp. Bot. Mag. 1:47. 1835.

TAinturier's Chervil.

Chaerophyllum procumbens var. tainturieri Coult. \&ose, Bot. Gaz.12:160. 1887.

Chap. Fl.165. Coulter, Contr. Nat. Herb. 2: 146.

Carolinian and Lonisianian areas. Southern Virginia, Tennessee, and Missouri, sonth to Florida and Texas.

Alabama : Lower hills to Coast plain. Metamorphic hills. Shaded banks, borders of fields. Lee County, Auburn. Dallas County, Marion Junction. Montgomery and Mobile counties. Flowers white; April. Frequent. Annual.

Type locality: "New Orleans" (M. Tainturier).

Herb. Geol. Surv. Herb. Mohr.

SCANDIX L.Sp. Pl. 1 : 256. 1753.

Scandix pecten-veneris L. Sp. Pl. 1 : 256. 1753.

EUROPE, North AsIa.

Arabama: Fugitive on ballast. Mobile; May. Observed in 1886 and 1892.

Type locality: "Hab. inter Germaniae et Europae australioris segetes."

Herb. Geol. Surv. Herb. Mohr.

WASHINGTONIA Raf. Am. Month. Mag. 2 : 176. 1818.

(Osmorhiza Raf. Am. Month. Mag. 2 : 176. 1818.)

(Glycosma Nutt.; Torr. \& Gray, Fl. N. A. 1 : 639. 1840.)

Twelve species, Atlantic and western North America.

Washingtonia claytoni (Michx.) Britton in Britt. \& Br. Ill. F1. 2:530. 1897.

Myrrhis claytoni Michx. Fl. Bor. Am. 1: 170. 1803.

Sweet Cicely.

Osmorhiza brevistylis DC. Prodr. 4:232. 1830.

O. claytoni C. B. Clarke in Hook. Fl. Brit. Ind. 2 : 690. 1879.

Ell. Sk. 1:358. Gray, Man. ed.6,210. Chap. Fl. 166.

Alleghenian and Carolinian areas. Nova Scotia, Quebec, Ontario; New England, west to Minnesota, south to the Ohio Valley, Missouri, and Arkansas, and along the mountains to Georgia.

Alabama: Monntain region. Rich woodlands. Madison County, Montesano, 1,500 feet. Root sweet, aromatic. Perennial.

Type locality: "Hab. in montibus Alleghanis."

Herb. Mohr.

Washingtonia longistylis (Torr.) Britton in Britt. \& Br. Ill. Fl. 2 :530. 1897.

Myrrhis longistylis Torr. Fl. N. \& Mid. U.S. 310. 1824.

SMOOTHER SWEeT CiCely.

Osmorhiza longistylis DC. Prodr. 4 : 232. 1830.

Gray, Man. ed.6, 210.

JAPAN.

Alleghenian and Carolinian areas. New Brunswiok and Quebec to Manitoba;

New Jersey to Minnesota, Dakota, and Nebraska, south along the mountains to Georgia.

Alabama: Lower hills. Tuscaloosa County (E. A. Smith). Flowers in June.

Very rare. Perennial.

Type locality: "In wet meadows near Albany, New York. Tracy. Near Geneva, N.Y. Paine. June. Near Hudson, N. Y. Alsop, \&c."

Herb. Geol. Surv. Herb. Mohr.

CONIUM L. Sp. P1. 1 : 243. 1753.

Two species, biennials. Europe, Asia.

Conium maculatum L. Sp. Pl. 1: 243. 1753.

Poison HeMLOCK.

Gray, Man. ed. 6, 209.

EUROPE.

Naturalized in New England, Pennsylvania, Iowa, and Minnesota.

Alabama : Coast plain. Adventive on ballast. Waste places. Mobile County, banks of Mobile River. Flowers white; May. Two to 3 feet high. 
Herb. Geol. Surv. Herb. Mohr.

Type locality: "Hab. in Europae cultis, agris, ruderatis."

Economic uses: An extremely poisonous herb, the "Conium" of the United States Pharmacopœia.

SIUM L. Sp. Pl. 1:251. 1753.

About 10 species, temperate regions. Europe, South Africa. North America, 3.

Sium cicutaefolium J. F. Gmel. Syst. 2 : 482. 1791.

Water Parsnip.

Sium lineare Michx. Fl. Bor. Am. 1:167. 1803.

Gray, Man. ed. 6, 207. Chap. F1. 162. Coulter, Contr. Nat. Herb. 2 : 146.

Eastern Russia, Northern Asia.

Throughout North America from Labrador to the Galf; from Florida to California.

Alabama: Coast plain. Deep marshes. Mobile County. Flowers in June; locally frequent. Perennial. Four to 6 feet high, submerged leaves pinnately dissected.

Type locality (J. G. Gmel. Fl. Sib.): "Nascitur ab Obo fluvio in omni ulteriori Sibiria tam hnmidis quam siccis locis."

Herb. Geol. Surv. Herb. Mohr.

APIUM L. Sp. Pl. 1:264. 1753. Celery.

Fourteen species, Europe.

Apium ammi (L.) Urban, Fl. Bras. 11, pt.1:341, t.91. 1879. - Marsh Parsley.

Sison ammi L. Sp. Pl. 1 : 252. 1753.

Heliosciadium leptophyllum DC. Prodr. 4 :105. 1830.

Apium leptophyllum F. Muell.; Benth. Fl. Austral. 3 : 372. 1866.

Chap. Fl. ed. 3, 178. Coulter, Contr. Nat. Herb. 2 : 147. Griseb. Fl. Brit. W. Ind. 308.

West indies, Mexico to Argentina, Chile, Australia.

Louisianian area. Florida to Louisiana and western Texas.

Alabama: Central Prairie region to Coast plain. A weed in damp waste places and on borders of low fields. Tuscaloosa County. Flowers April, May; abundant near the coast. Annual.

Type locality: "Hab. in Apulia, Aegypto."

Herb. Geol. Surv. Herb. Mohr.

ZIZIA Koch, Nov. Act. Caes. Leop. Acad. 12 :128. 1824.

Three species, Atlantic North America.

Zizia cordata (Walt.) DC. Prodr. 4 : 100. 1830.

Smyrnium cordatum Walt. Fl. Car. 114. 1788.

Thaspium trifoliatum var. apterum Gray, Man. ed. 2, 156. 1856.

Ell. Sk. 1:35๊9. Gray, Man. ed. 6, 208. Chap. Fl. ed.3, 180.

Carolinian area. West Virginia along the Alleghenies to Georgia.

Alabama : Mountain region. Rich shady woods. Dekalb County, Lookout Mountain, near Mentone, 1,600 feet. Lee Connty. Flowers yellow; June. Rare. Perennial.

Type locality: South Carolina.

Herb. Geol. Surv. Herb. Mohr.

CICUTA L. Sp. Pl. 1 :255. 1753.

Abont 12 species, temperate Europe, Asia, Mexico. North America, 8.

Cicuta curtisii Coult. \& Rose, Contr. Nat. Herb. 7: 97. 1900.

Alleghenian to Lonisianian area. Sonthern Virginia, southern Kentucky, North Carolina (altitnde 4,500 ft.) to Florida and Louisiana.

Alabama: Over the State. In swamps. Talladega County, Sylacanga (Pollard \&

Maxon). Tuscaloosa and Mobile counties.

Type locality : "Banks of streams, Duval County, Florida; collected by Curtiss."

Herb. Geol. Surv, Herb. Mohr.

DERINGA Adans. Fam. Pl. $2: 498.1763$.

One species.

(Cryptotaknia DC. Mém. Omb. 42. 1829.)

Deringa canadensis (L.) Kuntze, Rev. Gen. Pl. 1 :266. 1891.

Sison canadense L. Sp. Pl. 1 : 252. 1753.

Chaerophyllum canadense Crantz, Class. Umb. 79.1767.

HoRNWORT. 
Cryptotaenia canadensis DC. Mém. Omb.42. 1829.

Ell.Sk. 1:358. Gray, Man. ed. 6, 207. Chap. Fl. 161. Coulter, Contr. Nat. Herb. $2: 147$.

China, Japan.

Alleghenian to Louisianian area. Quebec; New England west to Nebraska, southern Ohio Valley to eastern Kansas and Arkansas, and from New York along the mountains to Georgia.

Alabama : Mountain region to Central Pine belt. Woodlands. Cullman County 800 feet. Montgomery County, Pintlalla Creok. Flowers white; July. Scattered, in frequent. Perenuial.

Type locality : "Hab. in America septentrionali."

Herb. Geol. Surv. Herb. Mohr.

SPERMOLEPIS Raf. Neog. 2. 1825.

(Leptocaulis Nutt. DC. Mém. Omb. 39. 1829.)

Two species, southeastern North America.

Spermolepis divaricatus (Walt.) Britton, Mem. Torr. Club, 5 : 244. 1894.

Daucus divaricatus Walt. Fl. Car.114. 1788.

SPREADING SPERMOLEPIS.

Leptocaulis divaricatus DC. Mém. Omb. 39. 1829.

Gray, Man. ed.6, 209. Chap. Fl. 161. Coulter, Contr. Nat. Herb. 2 : 148.

Louisianian area. North Carolina to Florida, west to Texas and Arkansas.

Alabama : Lower Pine region. Coast plain. Sandy and gravelly banks, pastures, open copses. Most abundant near the coast. Mobile and Baldwin connties. Flowers white, April, May; fruit ripe in June. Common. Annual.

Type locality: South Carolina.

Herb. Geol. Surv. Herb. Mohr.

Spermolepis echinatus (Nutt.) Britton in Britt. \& Br. Ill. Fl. 2: 537. 1897.

Leptolepis echinatus Nutt.; DC. Prodr. 4 : 107. 1830.

Prickly-Fruited SPERMolepis.

Chap. Fl. Suppl. 623.; ed.3, 178. Coulter, Contr. Nat. Herb. 2 : 148.

Louisianian area. Arkansas and Texas to Arizona and southern California.

Alabama : Lower Pine region. Coast plain. Sandy exposed dry or damp places. Borders of fields, copses. Mobile County, border of swamps vear Choctaw Point, Grand Bay, dry copses in the pine barrens. Flowers white, April, May; frutt ripe in June. Local, infrequent. Easily disseminated by the adherent echinate bristles of the fruit. Annual.

Type locality : "In Amer. bor. ad Red-River."

Herb. Geol. Surv. Herb. Mohr.

PTILIMNIOM Raf. Journ. Phys. 89:258. 1819.

(Discopleura DC. Mém. Omb.38. 1829.)

Three species, annuals; Atlantic North America, 2. West Texas, 1.

Ptilimnium capillaceum (Michx.) Raf.; Seringe, Bull. Bot. 217, f. 33. 1830.

Ammi majus Walt. Fl. Car. 113. 1788. Not L.

A. capillaceum Michx. Fl. Bor. Am. 1:164. 1803.

Discopleura capillacea DC. Mém. Omb. 38. 1829.

Ell. Sk. 1:349. Gray, Man. ed. 6, 209. Chap. Fl. 162. Coulter, Contr. Nat. Herb.

$2: 148$.

Carolinian and Lonisianian areas. Coast southern New England to Florida, west to Texas.

Ala Bama: Coast plain. Ditches, borders of marshes. Baldwin aud Mobile connties. Flowers white, May, June; fruit ripe July, August. Commou; rarely seen above the tide-water districts. Annual.

Type locality: "Hab. in campestribus Carolinae."

Herb. Geol. Surv. Herb. Mohr.

Ptilimnium nuttallii (DC.) Britton, Mem. Torr. Club, 5 :244. 1893-94.

Discopleura nuttallii DC. Mém. Omb. 38. 1829.

NUTTALL'S MOCK Bishop's WeEv.

D. capillacea var. nuttallii Coult. \& Rose, Bot. Gaz. 12 : 292. 1887.

Gray, Mall. ed. 6, 209. Chap. Fl. 162. Coulter, Contr. Nat. Herb. $2: 148$.

Carolinian and Louisianian areas. Kentucky, southern Illinois, Missouri, and Arkansas, south from eastern Tennessee to Florida, west to Texas. 
Ala Bama: Coosa Valley to Coast plain. Damp sandy or gravelly places. Etowah County, Ballplay, open damp pine flats. Henry. Franklin, and Mobile counties. Flowers white, July, August; fruit ripe October. Infrequent; met with more frequently in the interior. Annual.

Type locality : "In North America at Red River."

Herb. Geol. Surv. Herb. Mohr.

AMMI L. Sp. Pl. $1: 243.1753$.

Seven species. Warmer temperate Europe, Asia.

Ammi visnaga Lam. Fl. Fr. 3:462. 1778.

TOOTHPICK Bishop's WeED.

Mediterranean Europe, Western Asia, Nortiern Africa.

Ala Bama: Adventive on ballast, Mobile. Flowers white, May, June; fruit ripe August, September. Constant on the same locality for the past ten years without spreading. Biennial.

Herb. Geol. Surv. Herb, Mohr.

Type locality: "Cette plante croit dans les Provinces méridionales de la France et dans le Levant."

Anmi majus L. Sp. Pl. 1 : 243. 1753.

Greater Bishop's Weed.

From the same region as the last; introduced at Mobile, and here and there escaped from gardens. A showy annual 4 or 5 feet high, unfolding its numerous large umbels of white flowers in May and June. Biennial.

Type locality : "Hab. in Europa australi."

Herb. Geol. Surv.

HYDROCOTYLE L. Sp. Pl. 1:234. 1753.

About 75 species, perennials, widely distributed over warmer regions, chiefly in the Southern Hemisphere. North America, 9.

Hydrocotyle umbellata L. Sp. Pl. 1:234. 1753.

Water Pennywort.

Ell. Sk. 1: 346. Gray, Man. ed. 6, 211. Chap. Fl. 159. Coulter, Contr. Nat. Herb.

2:149. Griseb. Fl. Brit. W.Ind.307.

West Indies, Mexico, South America, Galapagos Islañd.

Carolinian and Louisianian areas. Southeastern New England; west to Michigan, south along the coast to Florida; west to Texas.

Al.abaMa : Central Prairie region to Coast plain. Stagnating water, deep ditches, miry pools, often floating. Autauga, Montgomery, Baldwin, and Mobile counties. Flowers in May. Abundant on the wet borders of the river swamps in the coast plain.

Type locality : "Hab. in America."

Herb. Geol. Surv. Herb. Mohr.

Hydrocotyle canbyi Coult. \& Rose, Bot. Gaz. 12 :103. 1887.

Canby's Pennywort.

Hydrocotyle umbellata ambigua Gray, Man. ed.5,190. 1867. Not H. ambigua Pursh. Gray, Man. ed. 6, 211.

Carolinian and Louisianian areas. New Jersey and Maryland.

Alabama : Coast plain. Muddy borders of ponds. Mobile County; rare.

Type locality: "New Jersey to Maryland."

Herb. Geol. Surv. Herb. Mohr.

Hydrocotyle verticillata Thunb. Diss. 2 : 415. 1798.

Whorled PeNNyWort.

Hydrocotyle interrupta Muhl. Cat. 30. 1813.

Eil. Sk. 1:345. Gray, Man. ed. 6, 211. Chap. Fl. 159. Coulter, Contr. Nat. Herb. $2: 149$.

Mexico, Brazil.

Carolinian and Louisianian areas. Coast southern Massachusetts to Florida, west to Louisiana, Texas, Arkansas, Arizona, and southern California.

Alabama : Central Prairie region to Coast plain. Damp and wet places. Montgomery County. Barbour County. Eufaula County (E. A. Smith). Baldwin and Mobile counties; abundant.

Type locality not ascertained.

Herb. Geol. Surv. Herb. Mohr.

Hydrocotyle ranunculoides L. f. Suppl. 177. 1781. Crowfoot-Like Prennywort.

Ell. Sk. 1: 346. Gray, Man. ed. 6, 211. Chap. Fl. 159, Coulter, Contr. Nat. Herb.

$2: 149$. 
Mexico to Brazil, Argentina, Perc.

Carolinian and Louisianian areas. Pennsylvania, Virginia to Florida, west to

Lonisiana, Texas, and California.

Alabama: Coast plain. Staguant water, ditches, shallow ponds. Mobile County. Flowers May; common.

Type locality: "Hab. in Mexico. Mutis."

Herb. Geol. Surv. Herb. Mohr.

CENTELLA L. Pl. Rar. Afr. 28. 1760. (Amoen. Acad. 6:112.)

Centella asiatica (L.) Urban, in Mart. Fl. Bras. 11. pt. 1: 287. 1879.

Hydrocotyle asiatica L. Sp. Pl. 1 : 234. 1753.

Asiatic Pennywort.

H. repanda Pers. Syn. 1:302. 1805.

Ell. Sk. 1:347. Gray, Man. ed. 6, 211. Chap. Fl. 159. Coulter, Contr. Nat. Herb. 2:149.

West Indies, Mexico to Argentina, Chile, Eastern and Soutiern Africa, East Indies, New Zealand, Pacific Islands.

Alabama : Central Pine belt to Coast plain. Close, damp soil in miry ground; abundant. Perennial.

Type locality: "Hab. in India."

Herb. Geol. Surv. Herb. Mohr.

\section{CORNACEAE. Dogwood Family.}

CORNUS L. Sr. Pl. 1 : 117. 1753. DogwOOD. CORNel.

Over 30 species, temperate regions both hemispheres, Europe, Asia, mountains of tropical America (Mexico, Peru). North America, 18; Atlantic, 11.

Cornus stricta Lam. Eneycl. 2 :116. 1786.

STIFF CORNel.

Cornus fastigiata Michx. Fl. Bor. Am. 1:92. 1803.

Ell. Sk. 1:209. Gray, Man. ed. 6,215. Chap. Fl. 167.

Carolinian and Louisianian areas. Virginia to Florida and Mississippi.

Alabama: Over the State. Low, open woods; banks of streams. Lee County, Auburn, 860 feet (Earle \& Cnderwood). Limestone County, Athons (Baker \& Earle). Mobile County, swampy woods, Three Mile Creek. Baldwin County, Stockton. Flowers in May; anthers bluish. Fruit mature in September, sordid blue, stone globose, smooth. Large shrub to small tree, 12 to 18 feet high. Common in the Coast plain.

Type locality: “Nous le croyons originaire de l'Amérique septentrionale."

Herb. Geol. Surv. Herb. Mohr.

Cornus amomum Mill. Gard. Dict. ed. 8, no. 5. 1768.

Cornus sericea L. Mant. 2 :199. 1771.

Silky-Leaved Swamp Dogwood.

C. lanuginosa Michx. Fl. Bor. Am. 1:92. 1803.

Ell. Sk. $1: 208$. Gray, Man. ed. 6, 214. Chap. Fl. 167. Conlter, Contr. Nat. Herb. $2: 150$.

Alleghenian to Louisianian area. Nova Scotia and Ontario; Now England, west to Dakota, Nebraska, and Arkansas, south to the Gulf from Florida to Texas.

Alabama : Mountain region to Upper division of Coast Pine Belt. Swampy banks of streams. Cullman County, 800 feet. Montgomery, Bibb, and Clarke counties. Flowers white with blue anthers, May; fruit ripe in September, dark blue. Shrul 8 to 12 feet high.

Economic uses: The bark, under the name of "swamp dogwood bark," is used. medicinally.

Type locality: "Found in all northern parts of America, * * * being natives of the woods in Virginia, New England, Maryland, and Carolina."

Herb. Geol. Surv. Herb. Mohr.

Cornus asperifolia Michx. Fl. Bor. Am. 1: 93. 1803.

Rough-Leaved CORNel. Ell. Sk. 1: 209. Gray, Man. ed. 6, 214. Chap. Fl.167. Coulter, Contr. Nat. Herb $2: 150$.

Alleghenian and Carolinian areas. Ontario and Minnesota, south to Texas, and in eastern Tennessee and North Carolina.

Alabama: Tennessee Valley. Dry limestone hills. Thickets. Franklin County, Russellville. Flowers in May. Shrubs 8 to 12 feet high. The only locality known in the State.

Type locality: "Hab. in sylvis umbrosis Carolinae inferioris."

Herb. Geol. Surv. Herb. Mohr. 
Cornus florida L. Sp. Pl. 1:117. 1753.

Flowering Dogwoon.

Ell. Sk. 1:207. Gray, Man. ed 6, 214. Chap. Fl.168. Coulter, Contr. Nat. Herb. $2: 150$.

Alleghenian to Louisianian area. Southern Ontario, southern New Fngland, west to Michigan and southern Minnesota, and south to Florida and eastern Texas.

AlabaMa : Over the State. Upland forests, moderately rich soil. Flowers April, May; floral bracts large, petaloid, white. Fruit ripe October to November; scarlet. Economic uses: The wood is valuable, and the bark, known as "dogwood bark," is used medicinally. Very showy in flower and in fruit.

Type locality: "Hab. in Virginia."

Herb. Geol. Surv. Herb. Mohr.

NYSSA L. Sp. Pl. 2 : 1058. 1753. Black Gum. Sour Gum.

About 7 species, trees. East Asia. Atlantic North America, 4.

Nyssa sylvatica Marsh. Arb. Am.97. 1785.

Highland Black Gum. Pepperidge.

Nyssa aquatica L. Sp. Pl. 2 : 1058. 1753 . In part.

N. multiflora Wangenh. Am. Holz.46, t. 16. 1787.

N. villosa Michx. Fll. Bor. Am. 2 : 258. 1803.

Eil. Sk. 2:684. Gray, Man. ed.6, 215. Chap. Fl. 168. Coulter, Contr. Nat. Herb.

$2: 151$.

Sargent, Silv. N. A. $5: 75, t .21 \%$.

Carolinian and Louisianian areas. Ontario; southern New England west to Michigan and south to the Galf, extending from Florida to eastern Texas.

Alabama: Over the State to the Lower Pine region. Most frequent in the upland forests. Winston County, 1,200 feet. Cullman County, 1,000 feet. Marshall County, 1,000 feet. Flowers yellowish green, April; fruit ripe September, October; drupe purple. A tree of large size, 80 to 90 feet high and 2 to 3 feet in diameter. Frequent on the table-lands of the Warrior basin in shallow depressions. Reduced in size on the uplands of the Coast Pine belt.

Economic uses: Timber tree.

Type locality: "This grows naturally in Pennsylvania and perhaps elsewhere."

Herb. Geol. Surv. Herb. Mohr.

Nyssa biflora Walt. Fl. Car.253. 1788.

N. sylvatica var. biflora Sargent, Silv. N. A. 5 : 76. 1893.

Ell. Sk. $2: 684$. Chap. Fl. 168 .

Louisianian area. In swamps. North Carolina to Florida, west to eastern 'Texas.

Alabama : Central Pine belt to Coast plain. Swampy borders of pine-barren streams. Flowers in April ; fruit ripe August, September; purplish black. Tree rarely over 60 feet high and from 16 to 18 inches in diameter, prevailing in the Lower Pine region and Coast plain. Further studies in the field are needed to establish with certainty the northern limit of this tree in the State.

Economic uses: Of less importance than the last.

Type locality : South Carolina.

Herb. Geol. Surv. Herb. Mohr.

Nyssa aquatica L. Sp. Pl. 2 : 1058. 1753. In part.

N. uniflora Wangenh. Am. Holzart. 83, t. 27, f. 5\%. 1787.

N. tomentosa Michx. f. Hist. Arb. Am. 2 : 259. 1803.

N. grandidentata Michx. f. Hist. Arb. Am. 2:252, t. 19. 1812.

Ell. Sk. 2:685. Gray, Man. ed.6,215. Chap. Fl.168. Coulter, Contr. Nat. Herb. 2: 151 .

Carolinian and Louisianian areas. Southern Virginia, southern Illinois, southeastern Missouri, and western Tennessee, south to Florida, Texas, and Arkansas.

Alabama : Central Pine belt to Coast plain. Swampy forests; frequent. Most often associated with the bald cypress in the deep swamps on the banks of the Alabama and Tombigbee rivers and their larger tributaries. Autauga County. Montgomery to Mobile County. Flowers yellowish green; April (Mount Vernon). Fruit plum-purple, ripe in October. One of the largest of the timber trees of the Atlantic forest, 110 to 125 feet high.

'Type locality: "Hab. in Americae septentrionalis aquosis."

Herb. Geol. Surv, Herb. Mohr. 
SYMPETATAE.

\section{CLETHRACEAE. White Alder Family.}

CLETHRA L. Sp. Pl. 1 : 396. 1753.

Abont 30 species, warm temperate regions Northern Hemisphere, Canary Islands, easteru Asia. North America, Alleghenian region, 2. Shruls or trees.

Clethra alnifolia L. Sp. Pl. 1 :396. 1753. White Alder. Sweet Peprer Bush.

Ell. Sk. 1:502. Gray, Man. ed. 6, 322. Chap. Fl. 264; ed. 3, 289.

Alleghenian to Lonisianian area. New England (Mount Desert Island), along the coast to Florida, west to eastern Louisiana.

Alabama : Central Pine belt to Coast plain. Low wet thickets. Flowers white ; June, July. Shrub 3 or 4 feet high, frequent; eommon in the Coast plain on swampy banks of pine-barren streams.

Type locality: "Hab. in Carolina, Virginia, Pensylvania."

Herb. Geol. Surv. Herb. Mohr.

\section{PYRolaceat. Pyrola Family.}

CHIMAPHItA Pursh, Fl. Am. Sept. 1 :279. 1814.

Four species, temperate Europe. Eastern Asia. North America, 3. Herbaeeons perennials.

Chimaphila maculata (L.) Pursh, Fl. Am. Sept. 1: 300. 1814.

Pyrola maculata L. Sp. Pl. 1 : 396. 1753.

SPOTTED WINTERGREEN.

Ell. Sk. 1:505. Gray, Man. ed. 6, 323. Chap. Fl. 267. Gray, Syn. Fl. N. A. 2, pt. $1: 45$.

Carolinian area. Ontario, New England. Lower ranges of the Alleghenies to North Carolina and Georgia.

Ala Bama : Mountain region. Rieh wooded hillsides. Morgan County, Falkville, $80 \mathrm{C}$ feet. Winston County, 1,500 feet. Flowers June.

Type locality: "Hab. in Americae septentrionalis sylvis."

Herb. Geol. Surv. Herb. Mohr.

\section{MONOTROPACEAE. Pinesap Family.}

MONOTROPA L. Sp. Pl. 1:387. 1753.

Two species, colorless perennial saprophytes rooting in vegetable mold. North America, 1.

Monotropa uniflora L. Sp. P1. 2 : 387. 1753.

Indian Pipe.

Ell. Sk. 1:477. Gray, Man. ed.6, 325. Chap. Fl. 268. Coulter, Contr. Nat. Herb. 2:254. Wats. Bot. Calif. $1: 463$. Gray, Syn. Fl. 2, pt. $1: 49$.

Eastern Asia, Himalayan India, Mexico, Sovtir America.

Canadian zone to Louisianian area. Nova Scotia, New Brunswick, Lake Superior, Ontario, south throughout the eastern United States, west to the Rocky Mountains and Oregon.

AlabaMa: Throughout the State; scattered. Reported from the Tennessee Valley. Cullman, Autauga, and Mobile counties. Flowers September, October; not rare, under pines and deciduous trees; local, most frequent in the pine forests of the Coast plain.

Type locality: "Hab. iu Marilandia, Virginia, Canada."

Herb. Geol. Surv. Herb. Mohr.

\section{HYPOPITYS Adans. Fam. 2:443. 1763.}

A monotypic genus. North temperate zone. Habit of the last.

Hypopitys hypopitys (L.) Small, Mem. Torr. Club, 4 : 137. 1894.

Pinksap.

Monotropa hypopitys L. Sp. PI. 1:387. 1753.

Hypopitys monotropa Crantz, Inst. 2 : 467.1766.

Ell. Sk. 1: 478. Gray, Man. ed. 6, 326. Chap. Fl. 268. Coulter, Contr. Nat. Herb. 2:254. Gray, Syn. Fl.2, pt. 1:50. 
Mexico, Japan, Europe.

Alleghenian and Carolinian areas. Nova Scotia, Ontario; New England west to Michigan, south to Virginia, and along the mountains to Georgia, Texas, and Arkansas; also in Oregon.

Alabama : Mountain region. Shady woods. Cullman County, 800 feet. Flowers white. May, rare and local, under coniferous and amentaceous trees. Perennial.

Type locality: "Hab. in Sueciae, Germaniae, Angliae, Canadae sylvis."

Herb. Geol. Surv. Herb. Mohr.

\section{ERICACEAE. Heath Family.}

AZALEA L. Sp. Pl. I: 150. 1753.

About 40 species, Himalayan India, China. North America, 6; chiefly Appalachian.

Azalea arborescens Pursh, Fl. Am. Sept. 1:152. 1816.

SWEET-SCENTED AZALEA.

Rhododendron arborescens Torr. Fl. N.\& Mid. U. S. 425.1824.

Gray, Man. ed. 6, 320. Chap. Fl. 265. Gray, Syn. Fl. N.A. 2, pt. 1: 40.

Carolinian area. Sontheru Pennsylvania, Virginia, and along the mountains to Georgia.

Alabama: Mountain region. Rocky banks of streams. Dekalb County, Mentone, 1,800 feet. C'lay County, Talladega Mountain, 2,200 feet. Cullman County, 800 feet. Flowers white with purple stamens, fragrant. Not infrequent, particularly on rocky banks of water courses on the Warrior table-land. Shrub 6 to 12 feet high.

Type locality: "On rivulets, near the Blue Mountains: Pensylvania."

Economic uses: Ornamental.

Herb. Geol. Surv. Herb. Mohr.

Azalea viscosa L. Sp. Pl. $1: 151$. 1753. Clammy Azalea. Swamp Honeysuckle. Rhododendron viscosum Torr. Fl. N. \& Mid. U.S.424. 1824.

Ell. Sk. 1:241. Gray, Man. ed.6, 320. Chap. Fl. 265. Gray, Syn. Fl. N. A. 2, pt. $1: 40$.

Carolinian and Louisianian areas. Southern New England, along the coast to Florida, west to Louisiana and Arkansas.

Alabana : Mountain region to Coast plain. Swampy banks of streams. Cullman County, 800 feet. Clarke. Bald win, and Mobile counties. Flowers white, fragrant; June, July. Frequent. Shrub 15 feet high.

Type locality: "Hab. in Virginia."

Herb. Geol. Surv. Herb. Mohr.

Azalea viscosa glauca (Lam.) Michx. Fl. Bor. Am. 1:151. 1803.

CinNaMon HoNeYsuckLe.

Azalea glauca Lam. Tabl. Encycl. $1: 493$, t. 110,f.2. 1793.

Ell. Sk. 1:241. Gray, Man. ed.6,320. Gray, Syn. Fl. N. A. 2, pt. 1:41.

Carolinian area. West Virginia along the mountains to Georgia.

Alabana: Mountain region. Rocky banks of brooks. Clay County, waterfall near Pulpit Rock, 2,200 feet. Lee County, Auburn (Earle \& Underwood). Flowers white, May; 3 to 5 feet high.

Typo locality: "Ex America sept."

Herb. Geol. Surv. Herb. Mohr.

Azalea nudiflora L. Sp. P1. ed. 2, 1:214. 1762.

Purple azalea. Common Honeysuckle.

Rhododendron nudiflorum Torr. Fl. N. \& Mid. U. S. 424. 1824.

Ell. Sk. 1:240. Gray, Man. ed. 6, 320. Chap. Hl. 265. Coulter, Contr. Nat. Herb. $2: 253$. Gray, Syn. Fl. N. A.2, pt. 1:41.

Carolinian and Louisianian areas. New England west to northern Ohio, southwestern Missouri, Arkansas, south to the Gulf from Florida to Texas.

Alabama: Over the State. From the Coast plain to the mountains. Damp copses and woods. Flowers white, pale pink, or orange; A pril, May. Shrub 2 to 6 feet high. Varies greatly in habit of growth, inflorescence, and color of flowers. On the tablelands and in the mountains forms of lower anc. more compact growth, the flowers in dense clusters, snowy white (var. alba Pursh) or incarnate, prevail. In the lower country forms of taller growth, the flowers in looser clusters, pale pink to rose-pink, are prevalent. In the coast region (Mobile County, Springhill) forms with flame or deep orange colored flowers are met with (var. rutilans Pursh).

Economic uses: The flowers of all the above species are rich in boney, which is 
saicl to be possessed of narcotic qualities like the honey from other members of the same family, the effects of which, however, have in this section never been observed. Ornamental.

Type locality: "Hab. in Virginiae siccis."

Herb. Geol. Surv. Herb. Mohr.

\section{RHODODENDRON L. Sp. Pl. 1:392. 1753.}

About 100 species, frigid to temperate regions, Europe, India, China. North America, 7.

Rhododendron catawbiense Michx. Fl. Bor. Am. 1:258. 1803.

Catawba Rhododendron. Rose Bay.

Gray, Man. ed. 6, 321. Chap. Fl.266. Gray, Syn. Fl. N. A. 2, pt. 1:42.

Alleghenian and Carolinian areas. Mountains of southwestern Virginia, 2,500 feet; North Carolina, 6,000 feet; eastern Tennessee.

Alabama: Mountain region. Rocky damp banks of streams. Dekalb County, Lookout Mountain, banks of Little River, 1,800 feet. Jackson County, Pisgah (M. C. Wilson). Six to 8 feet high; flowers lilac-purple.

Economic uses: Ornamental.

Type locality: " Hab. in montibus excelsis Carolinae septentrionalis juxta originem amnis Catawba."

Herb. Geol. Surv. Herb. Mohr.

KALMIA L. Sp. Pl. 1 :391. 1753.

Six species, Atlantic North America. West Indies, 1.

Kalmia latifolia L. Sp. Pl. 1 : 391. 1753.

Calico Bush. Poison Ivy of the Southern States.

Ell. Sk. 1:481. Gray, Man. ed.6,319. Chap. Fl. 264. Gray, Syn. Fl. N. A. 2, pt. 1: 38. Sargent, Silv. N. A. $5: 13, t .236,23 \%$.

Alleghenian to Louisianan area. New England and New York to northeru Ohio, from West Virginia south to the Gulf and from western Florida to Louisiana, Arkansas, and North Carolina, 4,400 feet altitude.

Alabama: Over the State. Rocky woodlands, gravelly exposed or shaded banks, siliceous soil. Flowers white, April, May. Common. Shrub or small tree.

Economic uses: The leaves, known as "poison ivy," are used medicinally. They are deleterious to cattle.

Type locality: "Hab. in Marilandia, Virginia, Pensylvania."

Herb. Geol. Surv. Herb. Mohr.

Kalmia hirsuta Walt. Fl. Car. 138. 1788.

WICKY.

Ell. Sk. I: 482. Gray, Man. ed.6, 319. Chap. Fl. 264. Gray, Syn. Fl. N. A. 2, pt. $1: 39$.

Louisianian area. Coast of North Carolina to western Florida and Mississippi.

Alabama : Coast plain. Low sandy pine barrens. Flowers rose-pink, May. Not rare. Low shrub 6 to 15 inches high.

Type locality : South Carolina.

Herb. Geol. Surv. Herb. Mohr.

LEUCOTHOE Don, Edinb. New Phil. Journ. 17:159. 1834.

About 35 species, shrubs, chiefly American. Japan. North America, 6; mostly Atlantic.

Lencothoe axillaris (Lam.) Don, Edinb. New Phil. Journ. $17: 159.1834$.

Downy Fetter-Bush.

Andromeda axillaris Lam. Encycl. 1 : 157. 1783.

Ell. Sk. 1:487, in part. Gray, Man. ed.6,317. Chap. Fl.261. Gray, Syn. Fl. N. A.

2, pt. $1: 34$.

Louisianian area. Coast of North Carolina to Florida, west to Mississippi.

AlabaMa: Lower Pine region. Coast plain. Wet borders of rivulets, swampy thickets and woods in the pine barrens. Flowers white, April. Common. Shrub 2 to 3 feet high.

Type locality: "Cette plante croit dans l'Amérique septentrionale."

Herb. Geol. Surv. Herb. Mohr.

Ieucothoe racemosa (L.) Gray, Man. ed.2, 252. 1856. RACEMose Fetter-Bush. Andromeda racemosa L. Sp. Pl. 1: 394. 1753.

Ell. Sk. 1:492, Gray, Man. ed, 6, 317, Chap. Fl.262, Gray, Syn. Fl. N. A. 2 : 35, 
Carolinian and Louisianian areas. Southern New England, along the coast to Florida, west to Arkansas and sonthwestern Missouri.

Alabama : Lower Pine region. Coast plain. Borders of wooded swamps. Mobile and Bald win counties. Flowers rose-pink; April. Frequent. Shrub 4 to 8 feet high. Type locality: "Hab. in Pensylvania. Kalm."

Herb. Geol. Surv. Herb. Mohr.

Leucothoe recurva (Buckl.) Gray, Man. ed. 2, 252. 1856.

Andromeda recurva Buckl. Am. Journ. Sci. 45:172. 1843.

Carolinian area. Mountains of Virginia to North Carolina and Tennessee.

AlabaMA: Credited to the State in Gray, Syn. Fl. N. A. 2, pt.1:35.

Type locality: "Mountains near Paint Rock, Tennessee, and the warm springs, North Carolina."

Herb. Geol. Surv. Herb. Mohr.

PIERIS Don, Edinb. New Phil. Journ. 17:159. 1834.

About 12 species, Himalayan India, Japan, Cuba. North America, 4. Shrubs.

Pieris nitida (Bartr.) Benth. \& Hook. Gen. Pl. 2 :588. 1876. Shining Fetter-Bush. Andromeda nitida Bartram; Marsh. Arb. Am. 8. 1788.

Chap. Fl.263. Gray, Syn. Fl. N. A.2, pt. 1:32.

Cuba.

Louisianian area. North Carolina to Florida, west to Mississippi and eastern

Louisiana.

Alabama : Lower Pine region. Coast plain. Open boggy pine barrens. Swampy borders of rivulets. Flowers rose-pink; April.

Type lócality: "This shrub grows naturally in Carolina and Florida."

Herb. Geol. Surv. Herb. Mohr.

Pieris phillyreaefolia (Hook.) DC. Prodr. 7:599. 1839.

LOW ANDROMEDA.

Andromeda phillyreaefolia Hook. Icon. t. 122. 1837.

Chap. Fl.262. Gray, Syn. Fl. N. A. 2, pt.1:31.

Louisianian area. Western Florida.

Alabama : Coast plain. Low sandy banks of pine-barren streams. Mobile County, on Bayou d'Eau Douce. Flowers white, February 18. Rare; only locality known in the State. Shrub 5 to 8 inches high.

Type locality: "Apalachicola, W. Florida. Mr. Drummond."

Herb. Geol. Surv. Herb. Mohr.

XOLISMA Raf. Am. Month. Mag. 4 : 193. 1819.

About 10 species, shrubs, West Indies and North America; one circumpolar.

Xolisma ligustrina (L.) Britton, Mem. Torr. Club, 4 :135. 1894.

Vaccinium ligustrinum L. Sp. P1. 1:351. 1753.

Privet-Like Xolisma.

Andromeda ligustrina Muhl. Cat.43. 1813.

A. paniculata var. nudiflora Michx. Fl. Bor. Am. 1:255. 1803.

Ell. Sk. 1:490. Gray, Man. ed. 6, 316. Chap. Fl.263. Gray, Syn. Fl. N. A. 2, pt. 1: 33.

Alleghenian and Carolinian areas. Southern New England west to Mjchigan, Missouri, and Arkansas; Virginia and West Virginia along the mountains to eastern Tennessee and Georgia.

Alabama: Mountain region. Damp rocky banks. Clay County, Che-aw-ha Mountain, at the waterfall, 2,300 feet, July 29, with ripe capsules. Lee Countr, Auburn, 850 feet altitude, May 10 (Earle \& Underwood). Infrequent.

Arborescent shrub, 10 to 15 feet high, sparsely pubescent; distinct by the almost leafless slender loose-flowered racemes, pedicels mostly single, over $\frac{1}{2}$ inch in length. The plants from the higher mountains answer perfectly to the type. Specimens from Cullman County with the leaves pubescent on both sides, racemes paniculate and more dense, the flowers with shorter pedicels, several from the same bud, approach closely the following.

Type locality: "Hab. in Pensylvania. Kalm."

Herb. Geol. Surv. Herb. Mohr.

Xolisma ligustrina foliosiflora (Michx.) Mohr, Bull. Torr. Club, 24 :24. 1897. Andromeda paniculata var. foliosiflora Michx. Fl. Bor. Am. 1:255. 1803.

Andromeda fiondosa Pursh, Fl. Am. Sept. 1:295. 1814.

Lyonia frondosa Nutt. Gen, 1; 266, 1818. 
Andromeda ligustrina var. pubescens Gray, Syn. Fl. N. A. 2, pt. 1:33. 1878.

Ell. Sk. 1:490. Gray, Man. ed. 6, 316. Chap. Fl.263. Gray, Syn. Fl. N. A.1.c.

"The extreme form from the Atlantic coast and Gulf region has a decidedly different aspect from the typical form, and is distinguished by the dense panicles with stoutly pediceled flowers, 3 or 4 from the same bud, and also by its pubescence. It is intimately connected with the type by intergrading forms frequently met with farther north and can only take varietal rank." Mohr.

Carolinian and Louisianian areas. Virginia, along the low country to Florida, west to Lonisiana.

Alabama: Central Prairie region to Coast plain. Swampy banks of streams. Montgomery County, banks of eypress poud on the Alabama River. Most frequent in the Coast plain, on the borders of pine-barren streams, scarcely over 3 feet in height. Type locality: "In sylvis Carolinae inferioris."

Herb. Geol. Surv. Herb. Mohr.

OXYDENDRUM DC. Prodr. 7 :601. 1839.

One species, Atlantic North America.

Oxydendrum arboreum (L.) DC. Prodr. 7:601. 1839.

SOURWOOD.

Andromeda arborea I. Sp. Pl. 1 : 394. 1753.

Ell. Sk. 1:491. Gray, Man. ed. 6, 317. Chap. Fl. 263. Gray, Syn. Fl. N. A. 2, pt. 1:33. Sargent, Silv. N. A. $5: 135, t$. 235.

Carolinian and Louisianian areas. Pennsylvania and West Virginia, along the mountains to Georgia and Florida, west to Arkansas and southern Missouri.

Alabama: Mountain region to the Coast plain. Flowers white; July. Tree 30 te 40 feet high, 12 inches and over in diameter. Most frequent and in greatest perfection in the siliceous dry soil of the table-lands. In the swamps of the low country, rarely 20 feet high or over 5 inches in diameter.

Economic uses: Of some value for the wood. It is also of ornamental use.

Type locality: "Hab. in Virginia, Carolina."

Herb. Geol. Surv. Herb. Mohr.

EPIGAEA L.Sp. Pl. 1:395. 1753.

Two species. Japan, 1. Atlantic North America, 1.

Epigaea repens L. Sp. Pl. 1: 395. 1753.

Trailing Arbutus.

Ell. Sk. 1:501. Graj, Man. ed. 6, 315. Chap. Fl. 261. Gray, Syn. Fl. N. A. 2, pt. 1: 29.

Canadian zone to Lonisianian area. Nova Scotia and Canada to Lake Superior and the Saskatchewan Valley; New England, west to Michigan, south to Florida and Mississippi.

Alabama : Mountain region. Central Pine belt. Lower Pine region. In rocky or sandy and gravelly woods. Cullinan County. Autauga County (E. A. Smith). Mobile County, Springhill, Citronelle. Flowers pale pink; February, March. Four to 6 inches long, trailing. Frequent. Perennial.

Economic uses: "The herb, known as "gravel plant," is used medicinally.

Type locality: "Hab. in Virginiae, Canadae pinetis."

Herb. Geol. Surv. Herb. Mohr.

GAULTHERIA L. Sp. Pl. 1:395. 1753.

Ninety to 100 species, temperate regions and in the mountains of the tropics in both hemispheres, Asia, America. North America, 3. Shrubby or herbaceous perenuial evergreens.

Gaultheria procumbens L. Sp. P1. 1 : 395 .

WINTERGREEN.

Ell. Sk. 1:501. Gray, Man. ed. 6, 315. Chap. Fl. 261. Gray, Syn. Fl. N. A. 2, pt. 1: 30.

Alleghenian and Carolinian areas. Maritime provinces of Canada; New England, New York, New Jersey, south along the mountains to North Carolina (4,000 feet) and Georgia.

Ala baMa : Mountain region. One single specimen collected by G. R. Vasey. Locality not givell.

Economic uses: The herb called "wintergreen" is used medicinally, and the essential oil distilled from the herb is the "Oleum gaultheriae" of the United States Pharmacopocia.

Type locality: "Hab. in Canadae sterilibus arenosis."

Herb. Geol. Surv. Herb. Mohr. 


\section{VACCINIACEAE. Huckleberry Family.}

GAYLUSSACIA H. B. K. Nov. Gen. $3: 275.1818$.

About 40 species, South America, chiefly in Brazil. Eastern North America, 6. Shrubs.

Gaylussacia dumosa (Andr.) Torr. \& Gray; Gray, Man.259. 1818.

Faccinium dumosum Andr. Bot. Rep. 11: t. 112. 1799.

DWARW HUCKLEBERIY.

V. frondosum Michx. Fl. Bor. Am. 1:234. 1803. Not L. $1: 19$.

Ell. Sk. 1:497. Gray, Man. ed. 6,311. Chap. Fl. 258. Gray, Syn. Fl. N. A. 2, pt.

Alleghenian to Louisianian area. New Brunswick, Nova Scotia; New Eugland south along the coast to Florida, west to eastern Louisiana.

Alabama : Mountain region to Lower Pine region. Dry barren siliceous soil. Clay County, ascending to 2.000 feet, Emorys Gap. Flowers white, April; fruit ripe in June, July, shining black, smooth or slightly hispid.

Shrubby from a horizontally creeping root 4 to 8 inches high. Rare iu the monntains, abundant in the dry pine barrens of the coast region.

Type locality : "Introduced fiom North America in the year 1783."

Herb. Geol. Surv. Herb. Molir.

Gaylussacia hirtella (Ait.f.) Klotzsch, Linnaea, 24: 48. 1851.

Vaccinium hirtellum Ait. f. Hort. Kew. ed. 2, 2 :357. 1811.

HAIRY HUCKLEBERRY.

Gaylussacia dumosa hirtella Gray, Man. 259. 1848.

Chap. Fl. 258; erl. 3, 280. Gray, Syn. Fl. N. A. 2, pt. 1:19.

Carolinian and Louisianian areas. Virginia, along the coast to Florida, and west to Mississippi.

Alabama: Lower Pine region. Coast plain. Wet sandy borders of pine-barren streauns. IVashington and Mobile counties. Flowers white; May, several weeks later than G. dumosa. Fruit ripeus July, August; black, hispid hy stiff hairs, insipid. Most frequent in the Coast plain and the adjacent Lower Pine region. Shrub 2 to 3 fect high. The habit of growth, habitat, and the other obvious permanent characters render this mesophile shrub sufficiently distinct to warrant its separation from

$V$. dumosum and to have its specific rank restored.

Type locality: "Native of North America."

Herb. Geol. Surv. Herb. Mohr.

Gaylussacia frondosa tomentosa Gray, Syn. Fl. N. A. 2, pt. 1: 19.1878.

HoARY HUCKLEBERRY.

Gaylussacia tomentosa Pursh; Gray, Syn. Fl. N. A. 2, pt. 1: 19. 1878. As synonym.

Readily distinguished from the type by the low slender growth, scarcely over a foot in height, branched and leafy from the base, by the close, short, more or less ferruginous pubescence of the branches and on the lower side of the leaves, which are from 1 to $1 \frac{1}{2}$ inches long, $\frac{1}{2}$ to $\frac{5}{8}$ inch wide, oblong-ovate, attenuated toward the base, almost sessile, finely and prominently reticulated; and further by the short erect-spreading pedicels scarcely over $\frac{1}{8}$ inch long.

Louisianian area. Georgia to eastern Florida.

Alabama: Lower Pine region. Coast plain. Shaded border of woods. Mobile County, Springhill. Flowers white; April. Not infrequent. Specimens collected by Professors Earle and Underwood at Auburn of a glaucons hue; pubescence pale, reticulation of the leaves wider and less prominent, and the racemes longer and loosely flowered, connect this variety with the northern typical form.

Type locality : "Georgia, Enslin. E. Florida, Dr. E. Palmer."

Herb. (Keol. Surv. Herb. Mohr.

VACCINIUM L.Sp. Pl. 1:349. 1753. Blueberry. BILbERry.

Over 100 species, extra tropical regions, Northern Hemisphere, excepting the African species. North America, 24 to 26. Shrubs, rarely arborescent.

Vaccinium arboreum Marsh. Arb. Am. 157. 1785. FArkleberry. SparikLeberry.

Ell. Sk. 1 : 495. Gray, Man. ed. 6, 312. Chap. Fl. 259. Gray, Syn. Fl. N. A. 2, pt. $1: 20$. Sargent, Silv. N. A. $5: 119, t$. 230.

Carolinian and Louisianian areas. Central Tennessee, west to southern Illinois, southern Missouri and Arkansas, south to North Carolina, Florida, and Louisiana.

Alabama : Mountain region to Coast plain. Barren, siliceous soil, open woods and copses. Flowers white, April to June; fruit ripe September to December, shining $15894-42$ 
black, dry, insipid. Clay County, near Pulpit Rock, 2,200 feet. On these summits a straggling shrub, scarcely over 3 or 4 feet high, herries ripening in December (winterberry). In the pine barrens of the Coast Pine helt a tree from 10 to 30 feet high and 3 to 10 inches in diameter.

Economic uses: Of some value for the fine-grained wood.

Type locality: "This grows naturally in Carolina."

Herb. Geol. Surv. Herb. Mohr.

Vaccinium stamineum L. Sp. Pl. 1:350. 1753.

Deeriberry. SQuaw Huckleberry.

Ell. Sk. 1:496. Gray, Man. ed. 6, 312. Chap. Fl. 259. Gray, Syn. Fl. N. A. 2, pt. 1 : 21.

Caroliniau and Louisianian areas. Ontario; New England along the coast to

Virginia; western Ohio to Missouri and Arkansas, south to Florida and Texas.

Alabama: Over the State. In dry or damp barren soil, open wools, borders of thickets. Flowers white, A pril; fruit ripe in July and Angust, greenish, acerb.

Not rare. One to 2 feet high, smoothish or pubescent.

In the pine barrens about Mobile a low form, scarcely over 6 inches high, with spreading branches anil silky tomentose ciliate leaves, is not rare.

Type locality: "Hab. in America septentrionali."

Herb. Geol. Surv. Herb. Mohr.

\section{Vaccinium melanocarpum.}

Southern Gooseberiry.

Vaccinium 8tamineum melanocarpum Mobr, Bull. Torr. Club, 24:25. 1897.

Shrub erect, 2 to 4 feet high; leaves oblong-lanceolate, 2 to 4 inches long, $\frac{8}{4}$ to 1 inch wide, like the branchlets smoothish or slightly pubescent; racemes elongated, 2 to $2 \frac{1}{2}$ inches long, loose, 4 to 8 flowered; pedicels slender, drooping, from the axils of persistent ovate-oblong bracts; berries fully $\frac{8}{8}$ inch in diameter, shining-black, with a juicy pulp, palatable, of a somewhat aromatic flavor. The shrub bending under the load of its berries gracefully suspended on the slender racemes presents a pretty sight.

Carolinian area. Southwestern Missouri (Ozark Hills).

Alabama: Tennessee Valley. Mountain region. Lower hills. Woods on rocky or gravelly soil. Lauderdale County, barreus. Dekall County, Lookout Mountain, 1,000 to 1,800 feet. St. Clair County, Coosa Hills, copiously near Springville. Lee County, Auburn (Baker \& Earle, 316).

Although resembling larger-leaved and stouter forms of $V$. stamineum, this shrub, confined to the mountain region, appears sufficiently distinct to be regarded as a proper species. The erect habit of growth, the numerous branches alivays erect, the erect-spreading large leaves, the strictly racemose inflorescence, the slender pedicels proceeding mostly singly from the oblong to ovate to linear bracts, and the large juicy fruit of a dark plum-purple color, ripening much earlier than in the allied species, distinguish it at once from the same.

Specimens collected by Letterman in 1875 in southwestern Missouri, near Iron Mountain, and preserved in the Engelmann herbarium belong here. The collector was struck by the peculiar aspect of this shrub. After describing it in a letter to Dr. Engelmann as a plant 3 to 5 feet high, with the berries, some pyriform, some globose, of dark purple, and a pleasant flavor when ripe, while unripe or partially ripe, bitter, he adds enthusiastically: "I would wish you could see the bushes freighted with their purple, and, I might add, to my taste, delicions fruit."

Economic uses: 'The berries are eagerly cousumed by man and beast.

Type locality: "Mountain region" of Alabama. More specifically, St. Clair County, near Ashville, July, 1880.

Herb. Geol. Surv. Herb. Mohr.

\section{Vaccinium melanocarpum candicans var. nov.}

To all appearance of lower stature; leaves smaller than in the type, the lower surface covered with a close, fine, almost milk-white tomentum.

Alabama: Lee County, Auburn (Baker of Earle), Auginst, 1897.

Herb. Geol. Surv. Herb. Mohr.

\section{Vaccinium melanocarpum sericeum var. nov.}

Branchlets, leaves, and unripe fruit with a soft, silky, appressed pubescence; leaves ample; dark green.

AlabaMa: With the type. Rocky wooded hills near Springville, St. Clair County, May 28, 1892.

Herb. Geol. Surv. Herb. Mohr. 


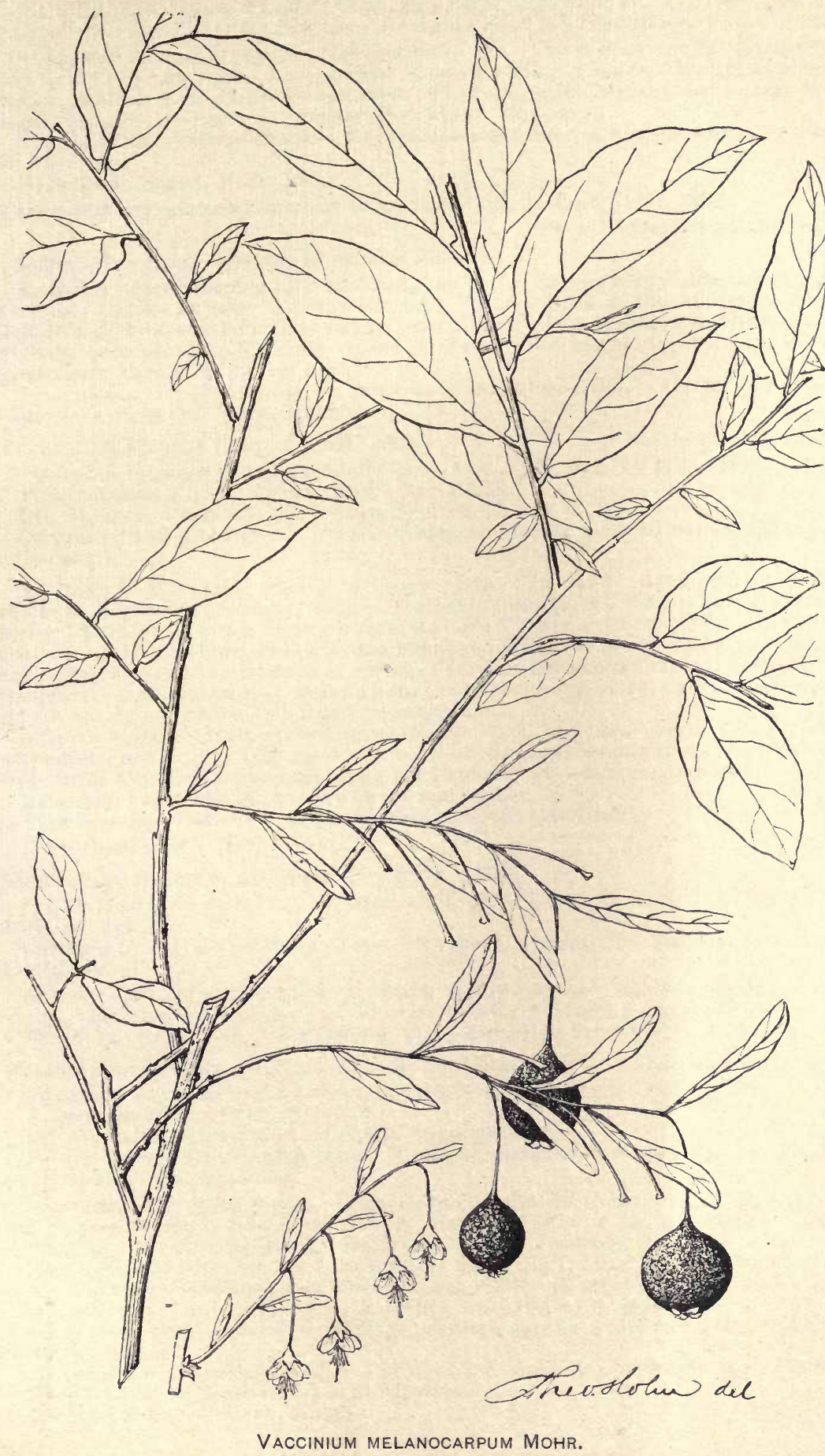



Vaccinium myrsinites Lam. Encycl. 1: 73. 1789.

EVERGREEN BLUEBERRY.

Ell. Sk. 1:494. Chap. Fl. 260. Gray, Syn. Fl. N. A. 2, pt.1:21.

Carolinian and Louisianian areas. Georgia; Florida to Louisiana.

Alabama : Mountain region. Metamorphic hills. Lower Pineregion. Coastplain. Dry sandy pine barrens. Lee County, Auburn (Baker \& Earle, 305). Clay, Washington, Mobile, and Baldwin counties. Flowers pink, March; fruit ripe, May; black, insipid. Evergreen, 5 to 10 inches high. Common.

Type locality: "Cette espèce croit abondamment dans la Floride, aux environs de St. Angustin."

Herb. Geol. Surv. Herb. Mohr.

Vaccinium myrsinites glaucum Gray, Syn. Fl. N. A. 2, pt. 1:21. 1878.

Pale Evergreen Blueberry.

Louisianian area. Eastern Louisiana, Mississippi.

Alabama : Motamorphic hills to Coast Pine belt. Barren rocky hills and dry pine barrens. Clarke County, Choctaw Corner. Cherty hills of the buhrstone strata. Mobile and Baldwin conuties, sandy pine ridges. Lee County, Auburn (Earle). Flowers pale pink, April; fruit ripens in June. Not frequent; abundant in some localities. Shrub 1 to $1 \frac{1}{2}$ feet high.

Type locality: "New Orleans? (Drummond) to Alabama, \&c." (Evidently wrong).

Herb. Geol. Surv. Herb. Mohr.

Vaccinium elliottii Chap. Fl. 260. 1860.

ELLIOTT'S BLUEBERRY.

Vaccinium virgatum var. parvifolium Gray, Syn. Fl. N. A. 2, pt.1:22. 1878.

V. myrtil!oides Ell. Sk. 1:500. 1818. Not Michx.

Ell. Sk. l. c. Chap. Fl. l. c. Gray, Syn. Fl. N. A. l. c.

Carolinian and Louisianian areas. Georgia; Florida west to eastern Texas and Arkansas.

Alabama: Mountain region to Coast plain. In sandy damp ground. Low thickets, borders of swampy woods. Cullman County, 800 feet. Low gravelly or rocky banks of streams. Lee County, Auburn (Baker \& Earle). Monroe County, Claiborne. Washington, Baldwin, and Mobile counties. Flowers white to pale pink, appearing during the first days of spring (Febrnary 10) on the naked branches before the leaves; fruit ripens May (20) and June; berries shining black, small, sweet, mostly single, rarely more than two from the same bul.

Shrub 6 to 8 feet high, branching from the base, branches green, slender, erect, ultimately reclining. The most frequent of the blueberries in the low country, frequently forming the boscage along the banks of pine-barren streams.

Economic uses: The berries are sweet and edible.

Type locality: "River swamps, Florida to South Carolina."

Herb. Geol. Surv. Herb. Mohr.

Vaccinium virgatum Ait. Hort. Kew. $2: 12$. 1789.

Ell. Sk. 1:498, in part? Gray, Man. ed.6, 312. Chap. Fl.ed.3, 283. Gray, Syn.

Fl. 2, pt. 1:21.

Carolinian and Louisianian areas. Southern Virginia to Florida and eastern

Louisiana.

Alabama: Coast plain. Dry or damp sandy copses. Baldwin County, Point Clear; open live oak hammocks. Flowers middle of March; mature fruit not seen. Shrub 3 to 6 feet high, with slender, erect-spreading branches; not frequent.

Vaccinium tenellum Ait. Hort. Kew. 2 : 12.1789.

Gale-leaf Blueberry.

Vaccinium virgatum tenellum Gray, Syn. Fl. N. A. 2, pt. 1:22. 1878.

V. galezans Michx. Fl. 1:232. 1803.

Ell. Sk. 1:499. Gray, Man. ed. 6,312. Chap. Fl. 260.

Carolinian and Louisianian areas. Coast of southern New Jersey to Florida, west to Mississippi and Arkansas.

Alabama: Mountain region. Metamorphic hills to Coast plain. Shady banks and copses in sandy soil. Lee County, Auburn (Baker \& Earle). Mobile County, Citronelle and One-mile Creek. Baldwin County, Montrose. April.

Low, somewhat decumbent, $1 \frac{1}{2}$ to scarcely 2 feet high ; branchlets brownish-pubescent, as are the lanceolate, mucronate leaves which are acute at both ends; serrulate above the base; from $\frac{8}{4}$ to 2 inches long, $\frac{3}{6}$ to $\frac{1}{2}$ inch wide. Flowers in subsessile or sessile, mostly umbellate, clusters, corolla ovate to oblong, appearing with the leaves.

By the above characters readily distinguished from stunted forms of $V$. elliottii.

Type locality: "Native of North America."

Herb. Geol. Surv. Herb. Mohr. 
Vaccinium vacillans Kalm; Torr. Fl. N. Y. 1:444. 1843.

LOW BLUEiBRRY.

Gray, Man. ed. 6, 313. Chap. Fl. Suppl. 633; ed. 3, 283. Gray, Syn. Fl. N. A. 2, pt. $1: 22$.

Carolinian area. Ontario, southern New England, west to Michigan to Ohio Valley, Missouri, and along the mountains to North Carolina.

Alabama : Mountaiu region. Woodlands, open copses and in rocky or sandy soil. Cullnan County, 800 feet altitnde. Lee County, Auburn (Baker \& Earle). Flowers greenish yellow, calyx tipped with red. April; fruit ripe in August. Low, 6 to 8 inches high. Not rare.

Econonic nses: 'The fruit is edible.

Type locality : "Dry hills and open woods, common. Middle States."

Herb. Geol. Surv. Herb. Mohr.

Vaccinium corymbosum L. Sp. Pl. 1:350. 1753.

Common Blueberry.

Vaccinium disomorphum Michx. Fl. Bor. Am. 1:231. 1803.

Ell. Sk. 1:498. Gray, Man. ed. 6, 313. Chap. Fl.260, in part. Gray, Syn. Fl. N. A.

2 , pt. $1: 22$.

Canadian zone to Louisianian area. Newfoundland, Quebec, Ontario; New England west to Michigan, Illinois, Missouri, Arkansas; south along the mountains to Georgia, west to Louisiana.

Alabama: Mountain region. Copses and open woods. Clay County, Che-aw-ha Mountain, near the waterfall and Pulpit Rock, 2,200 feet. Cullman County, 850 feet.

Winston County, 1,200 feet. Lee County, A uburn (Baker \& Earle). Flowers in April ;

fruit matures in September, not seen. Local and infrequent.

Economic uses: 'The fruit is the common blueberry.

Type locality : "Hab. in America septentrionali. Kalm."

Herb. Geol. Surv. Herb. Mohr.

Vaccinium corymbosum amoenum (Ait.) Gray, Syn. Fl. N. A. 2, pt. 1:23. 1878.

Vaccinium amoenum Ait. Hort. Kew. 2:12. 1789.

Near to type; a lower shrub; flowers in dense clusters on naked branches, reddish, appearing with the leaves; leaves while young pubescent, lanceolate, lat'r broadly ovate to ovate-lanceolate. serrate-ciliate, the teeth appressed, pubescent on the midrib, glabrous, shining, green on both sides.

Gray, Man. ed. 6, 313 .

Carolinian and Lonisianian areas. Along the coast from New Jersey to Florida.

AlabaMa : Lower Pine region. Coast plain. Shaded banks in damp soil. Mobile County, Mount Vernon, near David's Lake; Three-mile Creek. Flowers April 10; fruit matures in June. Not common.

Type locality : "Native of North America."

Herb. Geol. Surv. Herb. Mohr.

Vaccinium fuscatum Ait. Hort. Kew. 2 : 11.1789.

Fuscous Blueberry.

Vaccinium corymbosum fuscatum Gray, Syn. Fl. N. A. 2, pt. 1:23. 1878.

Ell. Sk. 1:499. Gray, 1. c.

Louisianian area. South Carolina to Florida, west to Mississippi and Arkansas.

Alabama: Central Prairie region to Coast Plain. Shaded dry sandy banks of streams and near swamps. Autanga Connty, Prattville. Baldwin County, live oak hammock near Zundels. Flowers in March: fruit not seen.

Shrub, with straggling branches, 2 to 4 feet high, the branches fuscons-pubescent; leaves distichous, with a fuscous pubescence beneath. Identical with the species in the Gray Herbarium marked "Mobile, 1839."

Type locality: "Native of North America."

Herb. Geol. Surv. Herb. Mohr.

Vaccinium pallidum Ait. Hort. Kew. 2 : 10. 1789.

Mountain Blueberry.

Vaccinium corymbosum pallidum Gray, Man. ed.5, 292. 1867.

V. constablaei Gray, Am. Journ. Sci. 13:42. 1841 .

Gray, Man. ed. 6, 313. Chap. Fl.260. Gray, Syn. Fl. N. A. 2, pt. 1: 23.

Alleghenian and Carolinian areas. West Virginia to North Carolina, ulong the higher ranges of the Alleghenies.

Alabama: Mountain region. Dekalb Conuty, summit of Lookout Mountain, 2,000

feet. Cullman County, highest ridges 1,000 feet.

Type locality: "Native of North America."

Herb. Geol. Surv. Herb. Mohr. 


\section{DIAPENSIACEAE. Diapensia Family.}

GALAX L. Sp. Pl. I:200. 1753.

One species, Atlantic America.

Galax aphylla L. Sp. Pl. 1:200. 1753.

Galax.

Ell. Sk. 1: 295. Gray, Man. ed. 6, 327. Chap. Fl. 268. Gray, Syn. Fl. N. A. 2, pt. $1: 53$.

Alleghenian and Carolinian areas. Alleghenian Mountain ranges from 2,100 to 5,000 feet, from southwestern Virginia to Georgia.

Alabama: Dekalb County, summit of Lookout Mountain, near the falls of Little River, 1,800 to 2,000 feet. On damp, shaded rocks. Clay County, waterfall near Pulpit Rock, shaded borders of rivulets, 2,300 feet. July; abundant.

Economic uses: The leaves are used for winter decoration.

Type locality: "Hab. in Virginia.

Herb. Geol. Surv. Herb. Mohr.

\section{PRIMULACEAE. Primrose Family.}

НоTTONIA L.Sp.PI. I:145. 1753.

Two species, perennial aquatics; temperate Europe and North America, each 1.

Hottonia inflata Ell. Sk. I:231. 1817.

Water Violet. Featherfoll.

Ell. Sk.1.c. Gray, Man. ed. 6, 328. Chap. Fl. 279. Gray, Syn. Fl. N. A. 2, pt. 1: 57.

Carolinian and Louisianian areas. Southeastern Mississippi to western Georgia,

Louisiana, and Arkansas.

Alabama : Ceutral Prairie region. Floating in gently flowing or stagnant water. Dallas County, Selma. Lawrence County (L.Johnson $)$. Flowers white; May. Rare. Type locality: "Sent from Milledgeville, Georgia, by Dr. Boykin."

Herb. Geol. Surv. Herb. Mohr.

SAMOLUS L.Sp. Pl. 1:171. 1755.

Eight species, chiefly warmer regions in both hemispheres. Southern Africa, South America, United States. North America, 2.

Samolus floribundus H. B. K. Nov. Gen. 2 :224. 1817.

Water Pimpernel.

Samolus valerandi var. americana Gray, Man. ed. 2, 274. 1856.

Ell. Sk. 1:263. Gray, Man. ed. 6, 332. Chap. Fl. 282. Coulter, Contr. Nat. Herb. 2:256. Wats. Bot. Calif. 1:470. Gray, Syn. Fl. N. A. 2, pt. 1: 64 .

South America, Mexico.

Carolinian area. Ontario to the Gulf, westward to the Pacific Ocean.

ArabaMa: Over the State. Shaded swamps, wet woods. Montgomery, Choctaw, and Mobile counties. Flowers white; April to July. Frequent, chiefly near the coast. Annual or biennial.

Type locality: "Crescit in maritimis Peruviae juxta portum Callao de Lima."

Herb. Geol. Surv. Herb. Mohr.

LYSIMACHIA L. Sp. Pl. 1:146. 1753.

Sixty to seventy species, perennial herbs, temperate and subtropical regions both hemispheres. North America, 5.

Lysimachia quadrifolia L. Sp. Pl. 1 : 147. 1753.

Four-Leaf Loosestrife.

Lysimachia punctata Walt. Fl. Car.92. 1788. Not L.

L. hirsuta Michx. Fl. Bor. Am. 1: 127. 1803.

Ell. Sk. 1: 234. Gray, Man. ed. 6, 331. Chap. Fl. 280. Gray, Syn. Fl. N. A. 2, pt. $1: 62$.

Carolinian area. Ontario and New England west to Minnesota, south from New York to upper Georgia.

Alabama : Mountain region. Damp siliceous soil, open woods. Cullman County. Flowers yellow; June. Not rare on the Sand Mountain. Dekalb County, Lookout Mountain.

Tspe locality: "Hab. in Virginia."

Herb. Geol. Surv. Herb. Mohr. 
STEIRONEMA Raf. Ann. Gen. Phys. 7:192. 1820.

About 5 species, perennials, Atlantic North America.

Steironema ciliatum (L.) Raf. Ann. Gen. Phys. 7:192. 1820.

Lysimachia ciliata L. Sp. Pl. 1: 147. 1753.

Fringe-leaf Steironema.

Ell. Sk. 1:233. Gray, Man. ed. 6, 330. Chap. Fl. 280. Coulter, Contr. Nat. Herb. 2:255. Gray, Syn. Fl. N. A. 2, pt. 1:61.

Alleghenian and Carolinian areas. Nova Scotia to Quebec and Ontario, thence through the Rocky Mountains to the Pacific coast; New England to Georgia, Arkansas, and Now Mexico.

Alabama: Tennessee Valley. Mountain region. Low damp thickets, borders of rivulets. Landerdale County, river hills. Clay County, Shinboue Valley, near Elders, 1,000 feet. Lee County, Auburn (Baker \& Earle, 333). Flowers yellow; June. Infrequent.

Type locality: "Hab. in Virginia, Canada."

Herb. Geol. Surv. Herb. Mohr.

Steironema tonsum (Wood) Bicknell in Britt. \& Br. Ill. Fl. 2: 590.1897

Lysimachia ciliata var. tonsa Woor, Classbook, 505. 1861.

Steironema intermedium Kearney, Bull. Torr. Club, 21 : 264, t. 209. 1894.

Mountain Steironema.

Stem erect, or reclining, $1 \frac{1}{2}$ to 2 feet high, leaves from broadly ovate to ovate lanceolate, $1 \frac{1}{2}$ to 2 inches long and $\frac{8}{4}$ to $1 \frac{1}{4}$ inches wide, entire, minutely ciliolate, the floral much smaller; pedicels slender but rigid, scarcely over $1 \frac{1}{2}$ inches long. 'The fluwers in verticillate clusters, subterminal and terminal on the branches of t'de open panicle, golden yellow, segments of the calyx ovate-lancerlate, acute, siarcely onethird longer than the mature capsule. Easily distinguished from smaller for'ns of the above by the inflorescence and short calyx lobes.

Carolinian area. Virginia, Kentuckr, and Tennessee.

Alabama : Mountain region. Exposed sandstone cliffs. Talladega County, summit of Alpine Mountain, signal station, 1,800 feet. Decumbent on bare rocks. Clay County, Che-aw-ha Monntain, signal station, 2,400 feet, abundant; Delta Divide near Idaho mine, 1,800 feet. Flowers golden yellow, July; capsules ripe in September. Not infrerpuent; local.

Type locality: "Mountains East Teunessee, near the Cumberland Gap."

Herb. Mohr.

Steironema lanceolatum (Walt.) Gray, Proc. Am. Acad.12:63. 1876.

Lysimachia lanceolata Walt. Fl. Car.92. 1788.

LANCE-LEAF STEIRONEMA.

L. hybrida Michx. Fl. Bor. Am. 1:126. 1803.

Ell. Sk. 1:235. Gray, Man. ed. 6,330. Chap. Fl. 280. Gray, Syn. Fl. N. A. 2, pt. $1: 61$.

Carolinian and Louisianian areas. Ontario, New England, west to Minnesota, Dakota, Nebraska, southern Ohio Valley to Missouri, and from New York to Georgia and Mississsppi.

Alabama : Tennessee Valley. Upper division of the Coast Pine belt. Wet close soil, borders woods, thickets. Franklin County, Russellville. Cullman County. Choctaw County, Bladen Springs; Lee County, Auburn. Flowers yellow, June, July. Not common.

Type locality: South Carolina.

Herb. Mohr.

Steironema lanceolatum angustifolium Gray, Syn. Fl.2, pt.1: 62. 1878.

Lysimachia angustifolia Lam. Tabl. Encycl. t. 440. 1791.

Lysimachia heterophylla Michx. Fl. Bor. Am. 1: 126. 1803.

Carolinian area. Virginia, Georgia.

AlabaMa: Mountain region. Lee County, Auburn (Baker \& Earle). Flowers in June. Not frequent.

ANAGALLIS L. Sp. Pl. 1 : 148. 1753.

Twelve species, temperate Europe, western Asia.

Anagallis arvensis L. Sp. Pl. 1: 148. 1753.

Common Pimpernel.

Ell.Sk. 1:235. Gray, Man. ed.6, 331. Chap. Fl. 281. Wats. Bot. Calif. 1:469.

EUROPE.

Adventive and partially naturalized on the Atlantic coast from Canada to Florida, Arkansas, and California. 
Alabama: Fugitive on ballast. Mobile; not rare aboint the shipping. Flowers scarlet; April, May. Annual.

Type locality: "Hab. in Europae arvis."

Herb. Geol. Surv.

Anagallis arvensis caerulea (Lam.) Ledeb. Fl. Ross. 3 :30. 1846.

Angallis caerulea Lam. Fl. Fr. 2 :285. 1788.

Blue-flowered Pimpernel.

EUROPE.

Alabama: Fugitive on ballast. Flowers azure. Annual. Observed almost every season with the last. Annual.

Type locality not ascertained.

Herb. Geol. Surv.

CENTUNCULUS L. Sp. Pl. 1:116. 1753.

Three species, temperate Europe. North America, 1.

Centunculus minimus L. Sp. Pl. 1:116. 1753.

Chaff IVeed.

Centunculus lanceolatus Michx. Fl. Bor. Am. 1:93. 1803.

Ell. Sk. 1:203. Gray, Man. ed. 6, 332. Chap. Fl. 281. Coulter, Contr. Nat. Herb.

$2: 256$. Wats. Bot. Calif. $1: 469$. Gray, Syn. Fl. N. A.2, pt. $1: 64$.

Europe, Northern Asia, South America (Brazil), Australia.

Alleghenian, Carolinian, and Lonisianian areas. Saskatchewan; Minnesota, Nebraska, Dakota, and Oregon, south from southern Illinois to Tennessee, and near the coast from North Carolina to Florida, Arkansas, and Texas.

Alabama : Coast plain. Open, damp, sandy places. Mobile County, West Fowl River. Flowers pink; March, April. Not infrequent. Annual.

Type locality: "Hab. in Italiae, Galliae, Germaniae, Scaniae arenosis."

Herb. Geol. Surv. Herb. Mobr.

\section{DODECATHEON L. Sp. Pl. 1:144. 1753. AMERICAN Cowslip.}

About 10 species, Asia. North America, 1.

Dodecatheon meadia L. Sp. Pl. 1 : 144. 1753.

Shooting Star.

Gray, Man. ed. 6, 329. Chap. Fl. 281. Coulter, Contr. Nat. Herb. 2:255. Wats. Bot

Calif. 1:467. Gray, Syn. Fl. N. A. 2, pt.1:57.

Alleghenian to Louisianian area. Maryland west to Wisconsin, from Virginia to

Missouri and Arkansas; southward to Georgia, Mississippi, and Texas.

Alabama: Central Prairie region. Rich banks. Wilcox County (S. B. Buckley).

Flowers pale purple; June. Rare. Perennial.

'Type locality: "Hab. in Virginia."

Herb. Geol. Surv. Herb. Mohr.

\section{PLUMBAGINACEAE. Leadwort Family.}

LIMONIUM Adans. Fam. Pl. $2: 283.1763$.

(Statice Willd. Sp. Pl. 1:1552. 1798.)

One hundred and twenty species, temperate Europe.

Limonium carolinianum (Walt.) Britton, Mem. Torr. Club, 5 : 255. 1893.

Statice caroliniana Walt. Fl. Car. 118. 1788.

MARSh ROSEMARY.

Statice limonium var. carolinianum Gray, Man. ed. 2 :270. 1856.

Ell. Sk. 1:374. Gray, Man. ed. 6, 327. Chap. Fl. 278. Coulter, Contr. Nat. Herb. $2: 254$. Gray, Syn. Fl. N. A. 2, 1:54.

Boreal zone to Louisianian area. From Labrador and Newfoundland along the coast to Florida, and west to the coast of Texas.

Alabama: Littoral region. Saline marshes. Mobile and Baldwin counties. Flowers purplish blue; September to November. Frequent among the rushes and high marsh grass on the seashore. Perennial.

Economic uses: The root, known as "marsh rosemary," was formerly used in medicine.

Type locality: South Carolina.

Herb. Geol. Surv. Herb. Mohr. 


\section{SAPOTACEAE. Sapodilla Family}

BUMELIA Sw. Prodr. 49. 1788.

About 30 species, trees and shrubs, warmer temperate, but chiefly of subtropical and tropical America. Sontheru Atlantic North America, 4.

Bumelia lanuginosa (Michx.) Pers. Syn. 1:237. 1805.

False Buckthorn.

Sideroxylon lanuginosum Michx. Fl. Bor. Am. 1:122. 1803.

Ell. Sk. 1:288. Gray, Man. ed. 6, 333. Chap. Fl. 275. Conlter, Contr. Nat. Herb. 2:256. Sargent, Silv. N. A. 5:171, t. 247. Gray, Syn. Fl. N. A. 2, pt. 1:68.

Carolinian and Louisianian areas. Sonthern Illinois and Missouri, south to Texas and east to Florida and Georgia.

Alabama: Tennessee Valley. Coast plain. Open woods, in damp rocky or gravelly soil. Franklin County, Russellville. Pike County, Troy. Mobile County. Flowers in June; fruit ripe September, black. Not infrequent in the Coast plain, along the western shore of Mobile Bay. Tree rarely over 40 feet high.

Type locality : "Hab. in dumosis humidis Georgiae."

Herb. Geol. Surv. Herb. Mohr.

Bumelia lycioides (L.) Pers. Syn. 1:237. 1805.

Southeir BuCKTHoRN.

Sideroxylon lycioides L. Sp. Pl. ed. 2, 1:279. 1762.

Ell. Sk. 1:287. Gray, Man. ed. 6, 332. Chap. Fl. 275. Coulter, Contr. Nat. Herb.

2:257. Gray, Syn. Fl. N. A.2, pt. 1:68. Sargent, Silv. N. A. 5:173, t. 248 .

Carolinian and Lonisianian areas. Coast of Virginia, south to Florida, west to 'l'exas, Arkansas, Missonri, and southern Illinois.

Alabama: Prairie region. Dry open woods, copses, calcareous soil. Dallas County. Wilcox County (Buckley). Flowers greenish white, March; fruit ripe in October, shining black. Not frequent.

Type locality: "Hab. in Canada."

Herb. Geol. Surv. Herb. Mohr.

\section{EBENACEAE. Ebony Family.}

DIOSPYROS L. Sp. Pl. 2 : 1057. 1753.

About 160 species, eastern Asia. North America, 2. Trees.

Diospyros virginiana L. Sp. P1. 2 : 1057. 1753.

Persimmon.

Ell. Sk. 2:712. Gray, Man. ed.6, 333. Chap. Fl. 273. Coulter, Contr. Nat. Herb. $2: 257$. Gray, Syn. Fl. N. A. 2, pt. 1:69. Sargent, Silv. N. A. 6: 7, t. 264 .

Carolinian and Louisianian areas. Sonthern Conuecticut and New York, to the Ohio Valley, Missouri, and Arkansas, south to Florida, and along the Gulf to eastern Texas.

Alabama: All over the State. Flowers May; fruit ripe in September ancl October, orange buff. 'Tree of medium size, 40 to 50 feet high, rarely over 12 inches in diameter. Produces in the Coast plain its fruit in greatest perfection, with few seeds and a rich sweet pulp, ripening early in September.

Economic uses: Valuable for its wood. The unripe fruit, "Diospyros," is an obsolete medicine. 'The mature fruit is used for food.

Type locality: "Hab. in Awerica septentrionali."

Herb. Geol. Surv. Herb. Mohr.

\section{STYRACACEAE. Storax Family.}

MOHRODENDRON Britton, Gard. \& For. 6:463. 1893.

(Halesia Ellis; L. Syst. ed. 10, 2 :1044. 1759. Not P. Br. 1756.)

(Mohria Britton, Gard. \& For. 6:434. 1893. Not Sw. 1806.)

(Carlomohria Greene, Erythea, 1:236. 1893.)

Three species, Atlantic North America, Southern. Trees.

Mohrodendron carolinum (L.) Britton, Gard. \& For. 6 : 463. 1893.

Cakolina Silverbeli Tree. Opossum Wood.

Halesia carolina L. Syst. ed. 10, 2 : 1044. 1759.

H. tetraptera L. Sp. P1. ed. 2, 1:636. 1762.

Eil. Sk. 1:507. Gray, Man. ed. 6, 334. Chap. Fl. 271. Gray, Syn. Fl. N. A. 2, pt. $1: 71$.

Carolinian area. West Virginia, along the mountains to Tennessee and Florida? 
Alabama : Tennessee Valley. Mountain region to Metamorphic hills. Rich banks of streams. Lauderdale County (M. C. Wilson). Cullman County, 800 feet. Talladega County, Chandler's Springs, 1,000 feet. Flowers white, April ; fruitripe September and Oetober. Tree 40 to 60 feet high and from 12 to 24 inches in oiameter. Frequent throughout the lower Mountain region.

Economic uses: An ornamental tree.

Type locality not given. Locality of H. tetraptera: "Hab. in Carolina."

Herb. Geol. Surv. Herb. Mohr.

Mohrodendron dipterum (L.) Britton, Gard. \& For. 6:463. 1893.

SOUTHern Silver-bell Tree. SNowdrop Tree.

Halesia diptera Sp. Pl. ed. 2, 1:636. 1762.

Ell. Sk. 1:508. Chap. Fl.271. Gray, Syn. Fl. N. A. 2.pt.1:71. Sargent, Silv. N. A. $6: 23, t .251$.

Louisianian area. Georgia and Florida to eastern Louisiana.

Alabama : Upper division Coast Pine belt to the Coast plain. Swampy river banks. Clarke County (Dr.Denny). Mobile County. Flowers white, March to first week in April, appearing with the leaves just unfolding; fruit ripe July. Tree 20 to 25 feet high, 6 to 8 inehes in diameter. Most frequent in the Coast plain.

Economic uses: Ornamental.

Type locality: "Hab. in Carolina. D. Garden."

Herb. Geol. Surv. Herb. Mohr.

STYRAX L. Sp. Pl. 1 : 444. 1753.

About 70 species, warmer temperate and tropical regions of both hemispheres, Asia and America. North America, 5. Small trees or shrubs.

Styrax americana Lam. Encycl. 1:82. 1783.

American Storax.

Styrax laevis Walt. F1. Car. 140. 1788.

S. glabrum Michx. Fl. Bor. Am. 2 : 41. 1803.

Ell. Sk. 1:506 or 507. Gray, Man. ed. 6, 334. Chap. Fl. 271. Gray, Syn. Fl. N. A. 2, pt. $1: 71$.

Carolinian and Louisianian areas. Virginia to Florida, west to Lonisiana, Arkansas, and southern Missouri.

Alabama : Mountain region. Coast plain. Swampy thickets and alluvial forests. Dekalb County, Lookont Mountain, 1,600 foet. Cullman County. Lee ('ounty, Auburn (Earle \& Underwood). Baldwin Connty, Stockton, in swampy forests of the river delta. Hlowers white, fragrant; March, April. Not rare. Slender sbrub, 4 to 6 feet high.

Type locality : "Cette arbrissean croit dans l'Amérique septentrionale."

Herb. Geol. Surv. 'Herb. Mohr.

Styrax pulverulenta Michx. Fl. Bor. A m. 2 : 41. 1803.

Powdery Stoliax.

Ell. Sk. 1:506. Gray, Man. ed. 6, 334. Chap. Fl.271. Conlter, Contr. Nat. Herb. $2: 258$. Gras, Syn. Fl. N. A. 2, pt. 1:72.

Louisianian area. Southeasteru Virginia and North Carolina, along the coast to Florida, west to eastern Texas and Arkansas.

Alabama: Lower Pine region. Coast plain. Pine-barren swamps. Washington, Baldwin, and Mobile counties. Flowers white, April. Frequent in the Coast plain.

Low, rarely over $2 \frac{1}{2}$ feet high.

Type locality: "Hab. in sylvis Carolinae."

Herb. Geol. Surv. Herb. Mohr.

Styrax grandifolia Ait. Ilort. Kew. 2: 75. 1789.

LARGE-FLOWERED STORAX.

Styrax grandiflorum Michx. Fl. Bor. Am. 2 : 41. 1803.

Eli. Sk. 1:505. Gray, Man. ed.6, 331. Chap. Fl. 271. Gray, Syn. Fl. N. A. 2, pt. $1: 7 \%$.

Carolinian and Louisianian areas. Southeastern Virginia (q) and North Carolina, south and west to Louisiana.

Alabama: Mountain region. Metamorphic hills. Coast Pine belt. Shady borders of woods. Lee County, Auburn (Baker \& Earle, 342). Choctaw Connty, Mount Sterling. Clarke County (Dr. Denny). Monroe and Baldwin counties. Mobile County, Mount Vernon. Flowers white, April. Not infrequent. Shrub 10 to 12 feet high.

Economic uses: Ornamental like the others of the same genus.

Type locality: "Native of South Carolina."

Herb. Geol. Surv. Herb. Mohr. 


\section{SYMPLOCACEAE. Sweetleaf Family.}

SYMPLOCOS L.Sp. Pl. ed. 2, 1: 747. 1763.

About 175 species, subtropical and tropical regions, eastern Asia, and South America to Brazil. North America, 1.

Symplocos tinctoria (L.) L'Her. Trans. Linn. Soc. 1:176. 1791.

Hopea tinctoria L. Mant. 1: 105. 1767.

Ell. Sk. 2:173. Gray, Man. ed. 6, 335. Chap. Fl.272. Gray, Syn. Fl. N. A. 2, pt. 1: 70. Sargent, Silv. N. A. $6: 15$, t. 256.

Carolinian and Lonisianian areas. Delaware to Tennessee, North Carolina $(3,000$ feet altitude), Georgia, Florida, west to Louisiana.

Alabama : 'Tennessee Valley to the Coast plain. Low woods, swampy banks of streams. Morgan County, Falkville. Cullman, Monroe, Baldwin, and Mobile coun. ties. Flowers yellow, fragrant; March, April. Fruit ripo in August and September; yellowish brown. A shrub, or frequently a small tree 15 to 20 feet high ; leaves partially persistent, of sweet taste, much relished by horses and cattle. The fragrant flowers are visited by hosts of hymenopterous insects.

Economic uses: The leaves are nsed for dyeing.

'Type locality: "Hab, in Carolina."

Herb. Geol. Surv. Herb. Mohr.

\section{OLEACEAE. Olive Family.}

FRAXINUS L. Sp. Pl. 2 : 1057. 1753.

About 40 species, trees, north temperate zone, Europe, Asia. North America, 12.

Fraxinus americana L. Sp. Pl. 2 : 1057. 1753.

WHITE AsH.

Fraxinus alba Marsh. Arb.51. 1785.

F. acuminata Lam. Encycl. 2 : 542 . 1786.

Ell. Sk. 2:672. Gray, Man. ed. 6, 335. Chap. Fl. 369. Gray, Syn. Fl. N. A. 2, pt.

1:74. Sargent, Silv. N. A. $6: 43, t .268$.

Alloghenian, Carolinian, and Louisianian areas. Nova Scotia, New Brunswick, Quebec, Ontario; New England, west to northern Minnesota, Nebraska, and Arkansas; sonthern Ohio Valley to the Gulf, and from Florida to Lonisiana.

Alabana: Over the State. Rich woodlands, above overflow. At greatest perfection in the 'lennessee Valley and about the upper waters of the Tombigbee and Alabama rivers; frequent.

As has been observed in many localities in the Gulf States, the fruit of the sonthern tree is more slender and of smaller size than northward, in barren localities passing freely into the following form.

Economic uses: Important timber tree. The inner bark is used in domestic medicine.

Type locality: "Hab. in Carolina, Virginia."

Herb. Geol. Surv.

Fraxinus americana curtissii (Vasey) Sudworth, Nomenc. Arb. Fl. U. S. 327. 1897. SMall-FRUitei) WHite AsH.

Fraxinus albicans Buckley, Proc. Acad. Phila. 1862:4. 1862. In part.

F. curtissii Vasey, Rep. Com. Agr. 1875:168. 1876.

F. americana var. microcarpa Gray, Syn. Fl. N. A.2, pt. 1:75. 1878.

Carolinian and Lonisianian areas. Tennessee.

Alabava: Tennessee Valley. Prairie region. Morgan County, Cedar Plains. Madison County, near Huntsville, rocky foothills with reil cedar. Eufaula (Curtiss). As observed in northern Alabama a tree below medium size, differing strikingly in aspect from the typical form; the bark dark and very rough, the low spreading branches drooping. Fruit about half the size of that of the type, often abortive.

'Type locality: "Eufala, Ala." Curtiss.

Herb. Mohr.

Fraxinus biltmoreana Beadle, Bot. Gaz. $25: 358.1898$.

Biltmore Asu.

Younger shoots pubescent. Leaves 8 to 12 inches long, leaflets 7 to 9 , ovate to oblong-ovate, acuminate, sometimes falcately rounded and inequilateral at the hase, entire or obscurely denticulate, pubescent especially aloag the veins; petioles finely pubescent; samaras in open, nearly glabrous panicles, from $1 \frac{1}{4}$ to 2 inches long, $\frac{1}{4}$ inch wide, the wing from 2 to 3 times the length of the elliptical, unmargined, many-nerved body. 
Tree little above medium size, from 40 to nearly 60 feet high and over a foot in diameter, with stont branches aud spreading branchlets.

Distinguished from $F$. americana by the velvety twigs and petioles, clove-brown buds, and the elliptical body of the large samara.

Carolinian area. North Carolina and northern Georgia.

Alabama : Mountain region; Coosa hills, rocky creek banks. Cullman County.

St. Clair County, near Ashville. Jackson County, Sandl Mountain (Biltmore Herb.), from 700 to 900 feet altitude. Local and scarce, individnals occurring singly.

The tree on Rines Creek, Cullman County, fully 16 inches in diameter and 60 feet high.

Economic uses: Timber tree.

Type locality: "Biltmore, N.C." (Altitude 1,900 feet.)

Herb. Geol. Surv. Herb. Mohr.

Fraxinus lanceolata Borkh. Handb. Forst. Bot. $1: 826.1800$.

Green Ash.

Fraxinus viridis Michx. Hist. Arb. Am. 3 :115. t. 10. 1813.

Gray, Man. ed. 6, 336. Chap. Fl. 370. Conlter, Contr. Nat. Herb. 2:259. Gray, Syn. Fl. N. A. 2, pt. 1:75. Sargent, Silv. N. A. 6:5, t. 27\%.

Alleghenian to Louisianian area. Ontario to Saskatchewan; New Eugland west to Minnesota, the eastern ranges of the Rocky Mountains, Montana, and Utah: southward to Florida and the Gulf States, extending to Texas and eastern and northern Arizona.

Alabama: Throughout the State. In low forests subject to overflow. Flowers March, April; fruit ripe .July. A tree of medium to large size, of best development in the alluvial forests of the lower Alabama and Tombigbee rivers, where trees over 2 feet in diameter are not infrequently met with.

Economic uses: Timber tree; important for lumber and fuel.

Type locality :

Herb. Geol. Surv. Herb. Mohr.

Fraxinus caroliniana Mill. Gard. Dict. ed. 8, no. 6. 1786. WAter Ash. Pop Ash. Fraxinus platycarpa Michx. Fl. Bor. Am. 2 : 256. 1803.

Ell. Sk. 2:673. Gray, Man. ed. 6, 336. Chap. Fl.370. Gray, Syn. Fl. N. A. 2, pt. 1: 75. Sargent, Silv. N. A. $6: 35, t .274$.

Carolinian and Louisianian areas. Southeastorn Virginia along the coast to southern Florida, west to Louisiana and southern Arkansas.

Alabama. Central Pine belt to Coast plain. Deep swamps of alluvial forests, wet shaded banks of pine-barreu streams. Tuscaloosa, Clarke, Baldwin, and Mobile counties. Flowers February (16th), fruit shed in October. Frequent. Tree below medium size, rarely over 30 feet high and 12 inches in diameter. Frequent.

Type locality: "Raised from seeds which were sent from Carolina in the year 1824, by Mr. Catesby."

Herb. Geol. Surv. Herb. Mohr.

Fraxinus quadrangulata Michx. Fl. Bor. Am. 2:255. 1803.

Blue Ash.

Grap, Man. ed. 6, 336. Chap. Fl. 370. Gray, Syn. Fl. N. A.2, pt.1 : 75 . Sargent, Silv. N. A. $6: 35, t .263$.

Alleghenian and Carolinian areas. Ontario, Michigan, Iowa, Missouri, Arkansas, and the mountains of North Carolina.

Alabama: Tennessee Valley. Dry limestone hills and cedar brakes. Madison County, Huntsville. Jackson County, Scottsboro. Occurring only on the northern declivity of the 'Tennessee Valley, greatly reduced in size, scarcely over 30 feet high, and 6 to 8 inches in diameter. Not frequent.

Type locality: "Hab. in Kentucky et Tennassée."

Herb. Geol. Surv. Herb. Mohr.

ADELIA P. Br. Hist. Jam. 361. 1756.

(Forestiera Poir. Encycl. Suppl. 2 :664. 1811.)

Ten species. West Indies, warmer North America, 8.

Adelia acuminata Michx. Fl. Bor. Am. $2: 225$, t. 48. 1803.

Forestiera acuminata Poir. Encycl. Suppl. 2 :664. 1811.

Ell. Sk. 2 : 675. Gray, Man. ed. 6, 336. Chap. Fl. 370. Gray, Syn. Fl. N. A. 2, pt. 1: 76. Coulter, Contr. Nat. Herb. $2: 260$.

Carolinian and Louisianian areas. Fennessee, sou thern Illinois, southern Missouri, and Arkansas, south to Florida, west to Texas and the Colorado Valley.

Alabama: Lower Pine region. Coast plain. Miry banks of rivers. Mobile County, Mount Vernon Baldwin County, Stockton. Flowers March, April; fruit ripe, not frequent, September, October, black. 
Shrub 8 to 15 feet high, frequently arborescent. Not frequent.

Type locality: "Hab. al ripas fluviorum Carolinae et Georgiae."

Herb. Geol. Surv. Herb. Mohr.

Adelia ligustrina Michx. Fl. Bor. Am. 2 :224. 1803.

Privet-like Adelia.

Forestiera ligustrina Poir. Encycl. Suppl. 2 : 664. 1811.

Chap. Fl.370. Gray, Syn. Fl. N. A. 2, pt. 1:76.

Carolinian and Louisianian areas. Tennessee, Georgia, and Florida (Chapman.)

Alabama: Tennessee Valley. Lower hills. Madison County, foothills of Montesano, 600 to 800 feet altitude, forming a large part of the shrubby growth of the cedar-clad limestone ridges. Bibb County, Pratt's Ferry. Flowers greenish white, frequented by hosts of honey-seeking insects. Shrub 6 to 8 feet high.

Type locality: "Hah. in fruticetis Illinoensibus, Tennassée, \&c." (It does not occur, however, in Illinois.)

Herb. Geol. Surv. Herb. Mohr.

CHIONANTHUS L. Sp. PI. 1: 8. 1753.

'Two species, China. Atlantic North America, 1.

Chionanthus virginica L. Sp. Pl. 1:8. 1753. Fringe tree. Old-Man's Beard. Ell. Sk. 1:6. Gray, Man. ed. 6, 337. Chap. Fl. 369. Conlter, Contr. Nat. Herb. $2: 260$. Gray, Syn. Fl. N. A. 2, pt. 1: 77. Sargent. Silv. N. A. 6:60, t.27\%.

Carolinian and Lonisianian areas. New Jersey, Pennsylvania, and West Virginia to Missouri and Arkansas, south to Florida and Texas.

Alabama: Over the State. Rich wooded banks along streams. Flowers April; fruit ripo September, October, black; frequent. Shrub 4 to 10 feet high, frequently small tree 10 to 15 feet high, 4 inches in diamet'r.

Economic nses: Ornamental. The bark of the ront, called "flowering-ash bark," is used in domestic medicine.

Type locality: "Hab. in America septentrionali."

Herb. Geol. Surv.

\section{OSMANTHUS Lour. Fl. Cochin. t.28. 1790.}

Seven species, evergreen trees, subtropical and tropical eastern Asia, Pacific islands. South Atlantic North America, 1.

Osmanthus americana (L.) Benth. \& Hook. Gen. Pl. 2:677. 1876.

Olea americana L. Mant. 1:24. 1767.

Devil-woon. American Olive.

Ell. Sk. 1:5. Chap. Fl. 369. Gray, Syn. Fl. N. A. 2, pt. 1: 78. Sargent, Silv. N. A. $6: 65, t .278$.

Louisianian area. Coast of North Carolina to Florida, west to Louisiana.

Alabama: Lower Pine region. Coast plain. Swampy woods along streams. Mobile and Baldwin counties. Flowers cream color, April, fragrant; fruit ripe in September, shining lolack, frequent. Tree 20 to 40 feet high, 8 to 12 inches in dianteter.

Economic uses: Ornamental.

Type locality: "Hab. in Carolina."

Herb. Geol. Surv. Herb. Mohr.

\section{LOGANIACEAE. Logania Family.}

GELSEMIUM Juss. Gen. 150. 1789.

Two species, woody climbers, eastern Asia. North America, 1.

Gelsemium sempervirens (L.) Ait. f. Hort. Kew. 2:61. 1811. Yellow Jessaminr. Bignonia semperrirens L. Sp. Pl. 2 : 623.1753.

Gelsemium nitidum Michx. Fl. Bor. Am. 1:120. 1803.

Ell. Sk. 1:311. Gray, Man. ed. 6, 345. Chap. Fl. 183. Gray, Syn. Fl. N. A.2, pt. 1:107. Coulter, Contr. Nat. Herb. $2: 271$.

Carolinian and Louisianian areas. Eastern Virginia to Florida, west to Texas and Arkansas.

AlabaMa: Mountain region to Coast plain. Damp thickets. Cullman County, 800 feet. 'Tuscaloosa, Autauga, Jhoctaw, Clarke, Mobile, and Baldwin counties. Flowers golden yellow, February, March; fragrant. Common. Climbing high from long creeping roots. Most abundaut throughout the Coast Pine belt. The whole plant poisonous. 
Economic uses: The root is the "yellow jessamine root" or "Gelsemium" of the United States Pharmacopœia.

Type locality: "Hab. in Virginia."

Herb. Geol. Surv. Herb. Mohr.

SPIGELIA L. Sp. P1. 1:149. 1753.

Over 60 species, warmer North America, West Indies to Brazil. North America, 5. Spigelia marilandica L. Syst. ed. 12, 734. 1767.

INDIAN PiNK.

Lonicera marilandica L. Sp. Pl. 1: 175. 1753.

Ell. Sk. 1:236. Gray, Man. eil.6, 346. Chap. Fl.182. Coulter, Contr. Nat. Herb. $2: 271$. Gray, Syn. Fl. N. A. 2, pt. 1: 108.

Carolinian and Louisianian areas. New Jersey west to Wisconsin, Missouri, and Arkansas, south to Florida and the Gulf to Texas.

Alabama: Tennessee Valley to Lower Pine region. Rich open woods and copses. Morgan County, Decatur. St. Clair County, Springville. Montgomery County, Pintlalla Creek. Dallas County. Escambia County, Flomaton. Flowers scarlet outside, yellowish inside; May. Not infrequent. Pereunial; 1 to $1 \frac{1}{2}$ feet high. Scattered throughout the rich valleys and prairies.

Econonic uses: The root is the "pinkroot" or "Spigelia" of the United States Pharmacopœia.

Type locility: "Hab. in Virginia, Marilandia, Caroliua."

Herb. Geol. Surv. Herb. Mohr.

CYNOCTONUM J. G. Gmelin, Syst. 2 : 443. 1791.

(Mrtreola R. Br. Prodr. Fl. Nov. Holl. 1:450. 1810.)

Four species, Asia, Australia. South and North America, 2.

Cynoctonum mitreola (L. ) Britton, Mem. Torr. Club, 5 :258. 1894. Mitek-Wort.

Ophiorrhiza mitreola J. Sp. Pl. 1 : 150. 1753.

Cynoctonum petiolatum J. G. Gmelin, Syst. 2 : 443. 1791.

Mitreola petiolata Torr. \& Gray, Fl. N. A. 2:45. 1841.

Ell. Sk. 1:238. Gray, Man. ed. 6, 346. Chap. Fl. 182. Coulter, Contr. Nat. Herb. 2:272. Gray, Syn. Fl. N. A. 2, pt. 1:108.

Mexico, West INdies, Venezuela.

Carolinian and Louisianian areas. Southeastern Virginia to Florida, west to Texas and Arkansas.

Alabama : Central Pine belt to Coast plain. Springy banks. Tuscaloosa County (E. A. Smith). Monroe, Baldwin, and Mobile counties. Flowers white, July to September. Frequent. 'Ten to 20 inches high. Annual.

Type locality: "Hab. in America meridionale."

Herb. Geol. Surv. Herb. Mohr.

Cynoctonum sessilifolium (Walt.) J. G. Gmelin, Syst. 2 : 443. 1791.

Anonymos sessilifolium Walt. Fl. Car. 108. 1788.

SESSILE-LEAF Miter-WORT.

Ophiorrhiza mitreola Michx. Fl. Bor. Am. 1:148. 1803. Not L.

Mitreola sessilifolia Torr. \& Gray, Fl. N. A. 2:45. 1841.

Ell. Sk. 1:237. Chap. Fl. 182. Gray, Syu. Fl. N. A. 2, pt. 1: 108.

Louisianian area. Lower North Carolina to Florida and west to Lonisiana.

Alabama : Lower Pine region. Coast plain. Springy places in the pine woods. Washington County, Yellowpine. Escambia, Monroe, Baldwin, and Mobile counties. Flowers white, June, August; frequent. Six to 10 inches high. Annual.

Type locality: South Carolina.

Herb. Geol. Surv. Herb. Mohr.

POLYPREMUM L. Sp.P1. 1:111. 1753.

Single species. South Atlantic North America, West Indies, Mexico.

Polypremum procumbens L. Sp. Pl. 1:111. 1753. Procumbent Polypremum.

Ell. Sk. 1:200. Gray, Man. ed. 6, 346. Chap. Fl. 182. Coulter, Contr. Nat. Herb. 2:272. Gray, Syn. Fl. N. A. 2, pt. 1:109.

West Indies, Mexico.

Carolinian and Louisianian areas. Maryland to Florida, west to Texas.

Alabama: Mountain region to Coast plain. Worn out, sandy fields, roadsides, pastures. Cullman County, rocky banks, 800 feet. Flowers white; August to November. Common; in greatest abundance in the pine barrens. Perennial.

Type locality: "Hab. in Carolina, Virginia."

Herb. Geol. Surv. Herb. Mohr. 


\section{GENTIANACEAE. Gentian Family.}

SABBATIA Adans. Fam. Pl. 2:503. 1763.

Thirteen species, Atlantic North America, ehiefly southeastern.

Sabbatia macrophylla Hook. Comp. Bot. Mag. 1: 171. 1835.

Chap. Fl. 353. Gray, Syn. Fl. N. A. 2, pt. 1:114.

LARGE-LEAF SABBATIA.

Louisianian area. Georgia, Florida, west to eastern Louisiana

Alabama: Lower Pine region, Coast plain. Open grassy pine-barren swamps. Washington County, Yellowpine. Clarke County (Dr. Denny). Monroe and Baldwin counties. Flowers white; May, June. Frequent. One and one-half to $2 \frac{1}{2}$ feet high; perennial, from a long cylindrical rootstock.

Type locality: "Covington," La. (Drummond).

Herb. Mohr.

Sabbatia angustifolia (Michx.) Britton, Mem. Torr. Club, 5 : 259. 1894.

White-Flowered AMERICAN Centaury.

Chironia angularis var. angustifolia Michx. Fl. Bor. Am. 1: 147. 1803.

Sabbatia brachiata Ell. Sk. $1: 284.1817$.

Ell. Sk. l. c. Gray, Man. ed. 6, 348. Chap. Fl. 353. Gray, Syn. Fl. N. A. 2, pt. 1: 114.

Carolinian and Louisianian areas. Indiana; North Carolina to Florida, west to eastern Louisiana.

Alabama: Coast Pine belt. Coast plain. Dry grassy pine barrens. Clarke County (Dr. Denny). Washington County, Yellowpine. Mobile and Baldwin coun. ties. Flowers, pale rose to white, with yellow eye; May, June. Ten to 12 inches high. Annual or bienuial.

Type locality: "Hab. in uliginosis sabulosis Carolinae inferioris."

Herb. Geol. Surv. Herb. Mohr.

Sabbatia angularis (L.) Pursh, Fl. Am. Sept. 1: 137. 1814. American Centaury. Chironia angularis L. Sp. Pl. 1: 190. 1753.

Ell. Sk. 1:285. Gray, Man. ed. 6, 348. Chap. Fl.353. Gray, Syn. Fl. N. A. 2, pt. $1: 114$.

Carolinian and Louisianian areas. Southern New England to Michigan; southern Ohio Valley to Missouri and Arkansas to the Gulf, from Florida to Louisiana.

Alabama: Over the State. Rich woodlands. Clay County, Shinbone Valley, 1,000 feet. Culluan County, 800 feet. Tuscaloosa County. Choctaw County, Bladen. Mobile County. Flowers pink; June. Not common; scattered. Anuual.

Economic uses: The herb, "American centaury," "Sabbatia," is an obsolete nedicine.

Type locality: "Hab. in Virginia. Kalm."

Herb. Geol. Surv. Herb. Mohr.

Sabbatia calycina (Lam.) Heller, Bull. Torr. Club, 21 : 24. 1894.

Gentiana calycina Lam. Encycl. 2 : 638. 1786.

Calycine Sabibatia.

Chironia calycosa Michx. Fl. Bor. Am. 1:147. 1803.

Sabbatia calycosa Pursh, Fl. Am. Sept. 1: 138. 1814.

Ell. Sk. 1:285. Gray, Man. ed.6, 348. Chap. Fl. 354. Coulter, Contr. Nat. Herb.

2:274. Gray, Syn. Fl. N. A. 2, pt. 1:114.

Cuba.

Carolinian and Louisianian areas. Virginia, North Carolina along the coast to

Florida, wèst to 'Texas and Arkansas.

Alabama: Central Pine belt to Coast plain. Swampy alluvial forests. libb County (E. A. Smith). Autauga County, Prattville (E.A. Smith). Baldwin County. Alluvial forest on 'Tensaw River. Flowers pink; August. Not frequent. Annual. Type locality: "Cette plante croit à la Louisiane."

Herb. Geol. Surv. Herb. Mohr.

Sabbatia stellaris Pursh, Fl. Am. Sept. 1:137. 1814.

Seaside Sabbatia.

Sabbatia gracilis Ell. Sk. 1 : 284. 1817. Not Salisb.

Ell. Sk. l. c. Gray, Man. ed. 6, 348. Chap. Fl.354. Gray, Syn. Fl. N. A. 2, pt. 1:115.

Carolinian and Louisianian areas. Seashore of southern New England to Florida, west to Lonisiana.

Alabama: Littoral region. Saline flats occasionally overflowed by the tide. Mobile County, West Fowl River, Dauphin Island. Baldwin County, Bon Secour. Flowers pale rose to white, yellow star in center; July, August. Not infrequent. Annual. 
Type locality: "In salt marshes: New York, New Jersey, \&c."

Herb. Geol. Surv. Herb. Mohr.

Sabbatia campanulata (L.) Torr. Fl. N. \& Mid. U. S. 1:217. 1824.

Chironia campanulata L. Sp. Pl. 1:190. 1753.

Slender Sabibatia.

C. gracilis Michx. Fl. Bor. Am. 1:146. 1803.

Sabbatia gracilis Salisb. Parad. Lond. t. 32. 1806.

Gray, Man. ed. 6, 318. Chap. Fl. 354. Gray, Syn. Fl. N. A. 2, pt. 1:115.

Cuba.

Carolinian and Louisianian areas. Virginia to Tennessee, south to Florida, west to Louisiana.

ALABAMA: Throughout the State. Low damp banks and shallow grassy swamps. Cullman County, 800 feet, rocky banks of creeks. Chilton County (E. A. Smith). Washington County, Yellowpine. Mobile and Baldwin counties. Flowers rose-pink; June. Common. Aunual. Abundant in flat damp pine barrens of the Coast plain and Lower Pine region.

Type locality : "Hab. in Canada. Kalm."

Herb. Geol. Surv. Herb. Mohr.

Sabbatia dodecandra (L.) B. S. P. Prel. Cat. N. Y. 36. 1888.

Chironia dodecandra L. Sp. Pl. 1 : 190. 1753.

C. chloroides Michx. Fl. Bor. Am. 1: 147. 1803.

Sabbatia chloroides Pursh, Fl. Am. Sept. 1 : 138. 1814.

Ell. Sk. 1:286. Gray, Man. ed. 6, 349. Chap. Fl. 354. Gray, Syn. Fl. N.A. 2, pt. $1: 115$.

Carolinian and Louisianian areas. Southern New England on the coast to Florida, west to Louisiana.

Alabama : Lower Pine belt. Flat damp pine barrens, borders of ponds. Washington County, Vinegar Bend, abundant. Mobile County. Flowers rose-purple; June. Not frequent; local. Biennial.

Type locality: "Hab. in Virginia."

Herb. Geol. Surv. Herb. Mohr.

Sabbatia dodecandra stricta (Gray) Mohr, Bull. Torr. Club, 24 : 26. 1897.

Sabbatia chloroides var. stricta Gray, Syn. Fl. N. A. 2, pt. 1:115. 1878.

Gray, Syn. Fl. N. A.l.c.

Louisianian area. Coast of South Carolina (\&) and Florida.

Alabama: Littoral region. Brackish sandy swamps. Baldwin County, Wulfs Bayou near Perdido Bay. Biennial, 2 to 3 feet high; stem slender, strictly erect, with long internodes; leaves linear-lanceolate. June 20, flowers not yet open; very distinct from the type in the habit of its growth.

Type locality: "South Carolina?, Alabama, and Florida."

Herb. Geol. Surv.

Sabbatia gentianoides Ell. Sk. 1:286. 1817.

Gentian-like Sabibatia.

Ell. Sk.1. c. Chap. Fl. 354. Gray, Syn. Fl. N. A.2, pt. 1:115. Coulter, Contr. Nat. Herb. $2: 274$.

Iouisianian area. Georgia and Florida, west to Texas.

Alabama: Coast plain. Low damp pine barrens. Baldwin County. Mobile County, Whistler. Flowers rose-pink; July, August. Frequent. Bieunial.

Type locality: "From specimens collected by Mr. Abbot, in Bullock County, Ga., growing in and around the shallow pine-barren ponds."

Herb. Geol. Surv. Herb. Mohr.

Sabbatia boykinii Gray, Syn. Fl. N. A.2, pt.1:116. 1887.

BOYKIN'S SABBATIA.

Chap. Fl. 354. Gray, Syn. Fl. N. A.1.c.

Carolinian area. Upper Georgia.

Alabama: Mountain region. Open rocky or gravelly woods. Cullman, Tallapoosa, Randolph, and Chambers counties. Walker County (E. A. Smith). Annual or bieunial.

Type locality : "Middle or Upper Georgia, Boykin."

Herb. Geol. Surv. Herb. Mohr.

GENTIANA L. Sp. Pl. 1:227. 1753.

About 301 species, widely distributed over cooler regions of the globe. Europe, northern Asia. North America, 38. 
Ell. Sk. 1:339. Gray, Man. ed. 6, 350. Chap. Fl. 356. Gray, Syn. Fl. N. A. 2, pt.

Carolinian area. Ontario, New York, Penusylvania, West Virginia, Tennessee, and Georgia.

Alabama : Tennessee Valley. Mountain region and Lower hills. Shaded banks. Lauderdale County, Florence (M. C. Wilson). Culluan County. Talladega County, Renfroe, 600 feet. Tuscaluosa County (E. A. Smith). Flowers cerulean blue; October, November. Frequent. Perennial.

'Type locality: "Hab. in Virginia."

Herb. Geol. Surv. Herb. Mohr.

Gentiana elliottii Chap. Fl. 356. 1860.

Gentiana catesbaei Ell. Sk. 1:339. 1817. Not Walt.

E1l. Sk. 1. c. Chap. Fl. 1. c. Gray, Syn. Fl. N. A. 2, pt. 1:122.

Louisianian area. South Carolina to Florida, west to Mississippi and Lonisiana.

Alabama: Central Pine belt to Coast plain. Damp meadows, low wet woods.

Mobile and Tuscaloosa counties. Flowers large; purplish blue, with green veins, open; October, November. In frequent. Stems 15 to 18 inches long. Perennial.

Type locality: "Banks of streams aud ditches, in the lower and middle districts." Herb. Geol. Surv. Herb. Mohr.

Gentiana villosa L. Sp. Pl. $1: 228.1753$.

SAMISON'S SNAKE-ROOT.

Gentiana ochroleuca Froel. Gent. 35. 1796.

G. 8aponaria Walt. Fl. Car. 109. 1788. Not L.

$1: 123$

Ell. Sk. 1:340. Gray, Man. ed. 6, 351. Chap. Fl. 355. Gray, Syn. Fl. N. A. 2, pt.

Carolinian and Louisianian areas. Pennsylvania to Florida, west to Louisiana.

Ala Bama: Over the State. From the Tennessee Valley to the coast. Dry woodlands. Cullman, Tuscaloosa, and Mobile counties. Flowers greenish yellow; October. Not infrequent; most common in dry grassy pine barrens of the Coast Pine belt. Low, 6 to 10 inches. Perennial.

Economic uses: The roots of this and G. elliottii, under the name of "Sampson's snake-root," are used in domestic medicine.

Type locality: "Hab. in Virginia."

Herb. Geol. Surv. Herb. Mohr.

Gentiana andrewsii Griseb. Gent. 287. 1839.

Closed Gentian.

Gray, Man. ed.6, 351. Chap. Fl. 356. Gray, Syn. Fl. N. A. 2, pt. 1: 123.

Alleghenian and Carolinian areas. Quebec. Ontario; New England west to Minnesota; Virginia to Missouri, Arkansas, and Tenuessee; and south along the mountains to Georgia.

Alabama : Mountain region. Winston County, near fork of Sipsey River, reported by T. M. Peters. Perennial.

Type locality not given.

Herb. Geol. Surv. Herb. Mohr.

FRASERA Walt. Fl. Car. 87. 1788.

Eight species; North America, Pacific and Atlantic.

Frasera carolinensis Walt. Fl. Car. 88. 1788.

American Colombo.

Ell. Sk. 1:205. Gray, Man. ed. 6, 352. Chap. Fl. 357. Gray, Syn. Fl. N. A.

2, pt. $1: 125$.

Carolinian area. Ontario; New York, southern Ohio, southern Illinois, south from

West Virginia along the mountains to Georgia.

Alabama : Mountain region. Upper division Coast Pine belt. Rich upland forests.

Lawrence County, near Gumpond, 1,200 feet. Blount County, Bangor. Clarke County, Suggsville (Dr. Denny). Flowers greenish yellow; May. Infrequent.

Perennial. "Two to 3 feet high from a large fusiform root.

Economic uses: The root, known as "American colombo," is used in medicine.

Type locality : South Carolina.

Herb. Geol. Surv. Herb. Mohr.

OBOLARIA L.Sp. P1. $2: 632.1753$.

Single species, saprophytic perennial, Atlantic North America.

Obolaria virginica L. Sp. Pl. 2 : 632.1753.

Pennywort.

Graj, Man. ed. 6, 353. Chap. Fl. 357. Gray, Syn. Fl. N. A.2, pt. 1: 127. Coulter,

Contr. Nat. Herb. 2 : 275.

Carolinian area. New Jersey to eastern Illinois, 'T nnessce south to Georgia. 
AlabaMa: Mountain region. Lower hills. Moist woods. Dekalb County, Lookout Mountain, near Mentone, 1,600 feet. Tuscaloosa County (E.A.Smith). Flowers purplish; May. Local and rare.

Type locality : "Hab. in Virginia."

Herb. Geol. Surv.

BARTONIA Muhl.; Willd. Neue Schrift. Ges. Nat. Fr. Berlin, 3 :444. 1801.

Two species, leafless saprophytic annuals, Atlantic North America.

Bartonia virginica (L.) B. S. P. Prel. Cat. N. Y. 36. 1888. Autumnal Bartonia. Sagina virginica L. Sp. Pl. I: 128. 1753.

Bartonia tenella Willd. Neue Schrift. Ges. Nat. Fr. Berlin, 3:445. 1801.

Centaurella autumnalis Pursh, Fl. Am. Sept. 1:100. 1814.

Ell. Sk. 1: 204. Gray, Man. ed. 6, 352. Chap. Fl. 357. Gray, Syn. Fl. N. A. 2, pt. $1: 127$.

Alleghenian to Lonisianian area. Newfoundland (Gray); northern New England (Mount Desert Island), south to Florida, west to Mississippi and Missouri.

Alabama : Mountain Region to Coast plain. In shaded springy places. Cullman County, 800 feet. Mobile and Baldwin counties. Flowers greenish white; October. Frequent; common on swampy borders of pine-barren streams.

Type locality : "Hab. in Virginia inter muscos ad margines fontium. D. Gronovius." Herb. Geol. Surv. Herb. Mohr.

Bartonia verna (Michx.) Mnhl. Cat. 16. 1813.

Centaurella verna Michx. Fl. Bor. Am. 1: 98, t. 12, f. 1. 1803.

Ell. Sk. 1:204. Gray, Man. ed. 6, 353. Chap. Fl. 357. Gray, Syn. Fl. N. A.

2, pt. $1: 127$.

Carolinian (q) and Louisianian areas. Southeastern Virginia to Florida, west to Mississippi.

Alabama : Coast plain. Flat damp pine barrens under the shelter of low bushes. Mobile County. Flowers white, early in February; 2 to 3 inches high. Not infrequent.

Type locality : "Hab. in sphagnosis Carolinae inferioris."

Herb. Geol. Surv. Herb. Mohr.

LIMNANTHEMUM S. G. Gmel. Nov. Act. Petrop. $14: 527, t .17, f .2 .1769$.

About 20 species, aquatics, warmer temperate and tropical regions, both hemispheres. North America, 2.

Limnanthemum lacunosum (Vent.) Griseb. Geut. 347. 1839.

Pitted Floating Heart.

Villarsia lacunosa Vent. Choix des Plantes, 9. 1803.

$V$. cordata Ell. Sk. $1: 230$. 1817 . 128.

Eil. Sk. l. c. Gray, Man. ed.6,353. Chap. Fl. 358. Gray, Syn. Fl. N. A. 2, pt. 1:

Alleghenian, Carolinian, and Louisianian areas. Nova Scotia, New Brunswick, Quebec, Ontario; southern New England to Missouri and Arkansas, and along the coast to Florida and Mississippi.

Alabama: Lower Pine regiou. Coast plain. In deep ponds. Mobile County. Flowers pale pink; March, April. Frequent. Perennial.

'Type locality not ascertained.

Herb. Geol. Surv. Herb. Mohr.

\section{APOCYNACEAE. Dogbane Family.}

AMSONIA Walt. Fl. Car. :8. 1788.

Seven species, perennial herbs, Japan. North America, 6.

Amsonia amsonia (L.) Britton, Mem. Torr. Club. 5 : 262. 1894.

TABERNAEMONTANA's AMSONIA.

Tabernaemontana amsonia L. Sp. Pl. ed. 2, 1:308. 1762.

Amsonia tabernaemontana Walt. Fl. Car. 98. 1788.

A. latifolia Michx. Fl. Bor. Am. 1:121. 1803.

Ell. Sk. 1:313. Gray, Man. ed. 6, 338. Chap. Fl. 360. Gray, Syn. Fl. N. A.

2, pt. 1:81. Coulter, Contr. Nat. Herb. $2: 262$.

Carolinian and Louisianian areas. North Carolina to Florida, west to Texas and Arkansas, north to southern Missonri and southern Illinois. 
Alabama: Tennessee Valley. Central Pine belt. Coast plain. Rich shady woods. Lauderdale County, Florence (M. C. Wilson). Tusealoosa County (E. A. Smith). Mobile County, Mount Vernon. Flowers laveuder-blue; April. Not rare.

Type locality: "Hab. in Virginia."

Herb. Geol. Surv. Herb. Mohr.

Amsonia ciliata Walt. Fl. Car. 98. 1788.

Tabernaemontana angustifolia Ait. Hort. Kew. 1:300. 1789.

Amsonia angustifolia Michx. Fl. Bor. Am. 1:121. 1803.

Ell. Sk. 1:314. Chap. Fl. 360. Gray, Syn. Fl. N. A. 2, pt. 1:81. Conlter, Contr. Nat. Herb. $2: 262$.

Louisianian area. North Carolina to Flurida, west to Texas and Arkansas.

Alabama : Central Pine belt to Coast plain. Dry light soil. Bibb County ( $E$. $A$. Smith). Baldwin County, Bon Secour, loose sands, open pine woods. Flowers pale blue; June. Not frequent.

Type locality: South Carolina.

Herb. Geol. Surv. Herb. Mohr.

APOCYNUM L. Sp. Pl. 1 : 213. 1753.

Abont 8 species, perennial herbs, southern Enrope to temperate Asia. North America, 5 .

Apocynum cannabinum L. Sp. Pl. 1:213. 1753.

Canadian Hemp. Indian Hemp. Choctaw Root.

Ell. Sk. 1:315. Gray, Man. ed. 6, 338. Chap. Fl. 358. Gray, Syn. Fl. N. A. 2, pt.1: 83. Wats. Bot. Calif. 1:473. Coulter, Contr. Nat. Herb. $2: 262$.

Cuba.

Carolinian and Lonisianian areas. Ontario to New England, west to Minnesota, south through the Ohio Valley to the Gulf, from Florida west to Texas and Arizona, and from southern California to Oregon.

Alabama : Coosa hills. Central Prairie region to Coast plain. Damp grassy banks. St. Clair County, Shoal Creek. Dallas County. Baldwin County, Point Clear. Flowers paie purplish. Frequent. One and one-half to 2 feet high from a woody cylindrical nearly horizontal root.

Economic uses: The root is the "Canadian hemp root" or "Apocynum" of the United States Pharmacopœia; the "squaw root" of the Choctaw Indians.

Type locality: "Hab. in Canada, Virginia."

Herb. Geol. Surv. Herb. Mohr.

TRACHELOSPERMUM Lemair, Jard. Fleur. 1: t. 61. 1851.

Seven species, Japan, Himalayan India. North America, 1.

Trachelospermum difforme (Walt.) Gray, Syn. Fl. N. A. 2, pt. 1: 85. 1878.

Echites difformis Walt. Fl. Car.98. 1788.

Forsteronia difformis A. DC. Prodr. 8:437. 1844.

Ell. Sk. 1: 312. Gray, Man. ed. 6, 338; Syn. Fl. 2, pt.1: 85. Chap. Fl.359. Coulter, Contr. Nat. Herb. $2: 263$.

Carolinian and Lou isianian areas. Southern Virginia to Florida, west to Texas.

Alabama: Tennessee Valley to Coast plain. Low, wet, alluvial banks. Morgan County, Cedar Plains. Walker County (E. A. Smith). Tusealoosa, Montgomery, and Mobile counties. Flowers eream-color; June, July. Common. Trailing and climbing over liushes. Perennial.

Tyne locality: South Carolina.

Herb. Geol. Surv. Herb. Mohr.

\section{ASCLEPIADACEAE. Milkweed Family.}

ASCLEPIAS L. Sp. Pl. 1 : 214. 1753.

Eighty-five species, perennial herbs, cooler temperate and tropical regions of both hemispheres. North America, 55.

Asclepias tuberosa L. Sp. Pl. 1:217. 1753.

BUTterfly WEED.

Ell. Sk. 1:325. Gray, Man. ed. 6, 340. Chap. Fl. 365. Gray, Syn. Fl. N. A. 2, pt. 1: 89. Conlter, Contr. Nat. Herb. $2: 265$.

Alleghenian, Carolinian, and Louisianian areas. Ontario; New England west to Minnesota, Dakota, and Colorado, south to Florida, Texas, and Arizona. 
Alabama: Over the State. Dry siliceous soil, borders of woorls, fields. Cullman County, 800 feet. Bibb, Montgomers, and Mobile counties. Frequent; most commou on dry pine ridges.

Economic uses: The root is the "pleurisy root" or "Asclepias" of the United States Pharmacopœia.

Type locality : "Hab. in America boreali."

Herb. Geol. Surv. Herb. Mohr.

Asclepias lanceolata Walt. Fl. Car. 105. 1788. Sparshly Flowered Milkweed. Asclepias paupercula Michx. Fl. Bor. Am. 1:118. 1803.

Ell. Sk. 1:323. Gray, Man. ed. 6, 340. Chap. Fl. 363. Gray, Syn. Fl. N. A. 2, pt. 1 : 90. Coulter, Contr. Nat. Herb. $2: 265$.

Carolinian and Louisianian areas. Coast of New Jersey to Florida, west to Texas.

Alabama : Lower Pine region. Coast plain. Boggy pine barrens, river marshes. Washington County, Yellowpine. Baldwin and Mobile counties. Flowers vermil-

ion-orange, May, June; frequent.

Type locality: Sonth Carolina.

Herb. Geol. Surv. Herb. Mohr.

Asclepias obtusifolia Michx. Fl. Bor. Am. 1:115. 1803.

Asclepias purpurascens Walt. Fl. Car. 105. 1788. Not L.

Obtuse-Leaved Milkwerd,

Ell. Sk. 1:321. Gray, Man. ed. 6, 341. Chap. Fl. 364. Gray, Syn. Fl. N. A. 2, pt. 1: 91. Coulter, Contr. Nat. Herb. $2: 266$.

Alleghenian to Louisianian area. New England west to Dakota, Nebraska, Missouri, and Colorado, and from New York to Florida, 'Texas, ancl Arkansas.

Alabama : Mountain region to Coast plain. Dry borders of fields and woods. Clay County, near Ironaton, 1,200 feet. Bibb, St. Clair, and Baldwin counties. Lee County, Auburn. Mobile County. Flowers pink, June. Not infrequent.

Type locality: "Hab. a Virginia ad Carolinam."

Herb. Geol. Surv. Herb. Mohr.

Asclepias humistrata Walt. Fl. Car. 105. 1788.

RABBIT's MILKWEed.

Asclepias amplexicaulis Michx. Fl. Bor. Am. 1:115. 1803.

Ell. Sk. 1:322. Chap. Fl.364. Gray, Syn. Fl. N. A. 2, pt.1:92.

Lonisianian area. North Carolina to Florida, west to Mississippi.

Alabama: Lower Pine region near the coast. Dry pineridges. Mobile and Baldwin counties. Flowers pale pink, greenish; April, May; fragrant. Frequent. Stems decumbent, 2 to 3 feet long.

Type locality : South Carolina.

Herb. Geol. Surv. Herb. Mohr.

Asclepias variegata L. Sp. Pl. 1:215. 1753.

VARiegated Milkweed.

Ell. Sk. 1:324. Gray, Man. ed. 6, 342. Chap. Fl. 362. Gray, Syn. Fl. N. A. 2, pt. $1: 93$.

('arolinian and Louisianian areas. Virginia, southern Ohio, Missouri, Arkansas, south to Florida, west to Louisiana.

Alabama: Scattered over the State. Dry open places, borders of fields. Lee County, Auburn (Baker \& Earle). Lauderdale, Cullman, Clarke, and Mobile counties. Flowers white, with purplish center; May. Nowhere abundant.

Type locality: "Hab. in America boreali."

Herb. Geol. Surv. Herb. Mohr.

Asclepias obovata Ell. Sk. 1:321. 1817.

Ell. Sk.1. c. Chap. Fl.363. Gray, Syn. Fl. N. A. 2, pt. 1: 95.

Louisianian area. South Carolina to Florida.

Alabama: Central Prairio region to Lower Pine region. Open woods, pastures, gravelly light soil. Autauga County (E. A.Smith). Montgomery County. Mobile County, open pine woods near Springhill. Baldwin County. Dallas County, Marion Junction. Flowers greenish, purplish tinged, June to August. Not infrequent; most frequently met with on the bald prairies.

'Type locality : "Louisville, Georgia."

Herb. Geol. Surv. Herb. Mohr.

Asclepias quadrifolia Jacq. Obs. pt. 2, 8, t. 33. 1767.

Four-Leaved Milkweed. Ell. Sk. 1:319. Gray, Man. ed. 6, 342. Chap. Fı. 36̋. Gray, Syn. Fl. N. A. 2, pt. $1: 96$.

Alleghenian and Carolinian areas. Ontario; New England west to Wisconsin, Ohio Valley to Missouri and Arkansas, and south from New York along the mountains to Georgia. 
Alabama: Mountain region; ranges of greatest elevation. Dry rocky hillsides and open woods. Dekalb County, Lookont Mountain, 1,400 to 1,600 feet. Flowers pale pink; May, June. Rare.

Type locality: "Crescit in Virginia, unde specimina Clayton misit."

-Herb. Geol. Surv. Herb. Mohr.

Asclepias perennis Walt. F1. Car.107. 1788.

SMall-FLOWered MilKWeed.

Asclepias parviflora Ait. Hort. Kew. ed. 1, 1:307. 1789.

Ell. Sk. 1:323. Gray, Man. ed. 6, 342. Chap. Fl. 365. Gray, Spn. Fl. N. A. 2, pt.1:96. Carolinian and Louisianian areas. Southern Indiana to Arkansas and Texas, and from South Carolina to Florida and Mississippi.

Alabama: Central Pine belt to Coast Pine belt. Muddy alluvial banks. Bibb, Montgomery, and Washington counties. Mobile County, banks of Alabama River (Chastangs). Flowers white; June, July. Not rare. Lower part of stem and roots woody.

Type locality: Sonth Carolina.

Herb. Geol Surv. Herb. Mohr.

Asclepias verticillata L. Sp. Pl. 1:217. 1753.

WhorLed Milk WeED.

Ell. Sk. 1:324. Gray, Man. ed. 6, 342. Chap. Fl. 365. Gray, Syn. Fl. N. A. 2, pt. 1: 97. Alleghenian to Louisianian area. Ontario to Manitoba; New England west to Minnesota, south to Florida and Texas.

Alabama : Tennessee Valley to Upper division of Coast Pine belt. Rocky or sandy ridges, dry or damp soil. Lauderdale County, in the barreus. Clay County, on Che-aw-ha Mountain, 2,200 feet altitude. Tuscaloosa and Clarke counties. Flowers greenish; June, July. Frequent.

Type locality: "Hab. in Virginia."

Herb. Geol. Surv. Herb. Mohr.

Asclepias verticillata linearis (Scheele) Pollard, Bull. Torr. Club $24: 156.1897$. Asclepias linearis Scheele, Linnaea, 21:758. 1848.

A. verticillata 8ubverticillata Gray, Proc. Am. Acad. 12 : 71. 1876.

Gray, Syn. Fl. N. A. 2, pt. 1:97. Coulter, Contr. Nat. Herb. 2: 267.

NorTHERN MEXICo.

Louisianian area. Mississippi, western Texas, and New Mexico.

Alabana : Central Prairie region. Damp woods. Autauga Connty, Prattville. Flowers greenish; July. Rare; most probably adventive from Texas.

Type locality: "Bei Neubraunfels [Texas]: Lindheimer."

Herb. Geol. Surv.

Asclepias michauxii Decsne. in DC. Prodr. 8:569. 1844. Michaux's Milkweed. Asclepias angustifolia Ell. Sk. 1:325. 1817. Not Schweig. 1812.

Chap. Fl.365. Gray, Syn. Fl. N. A. 2, pt. 1:97.

Louisianian area. South Carolina to Florida, west to eastern Lonisiana.

Alabama: Lower Pine region and Coast plain. Flat or rolling santly pine barrens. Flowers pale purple and greenish-not orange, as stated by Elliott; April,

May. Not rare. Many ascending stems from a stont woody root.

Type locality: "America septentrionalis."

Herb. Geol. Surv. Herb. Mohr.

ACERATES Ell. Sk. 1:316. 1817.

Seven species, perennial herbs, eastern North America.

Acerates floridana (Lam.) A. S. Hitchcock, Trans. St. Louis Acad. 5 : 508.1891.

Asclepias floridana Lam. Encycl. 1: 284. 1783.

Florida Green MiLKW Eed.

A. longifolia Michx. Fl. Bor. Am 1:116. 1803.

Acerates longifolia Ell. Sk. $1: 317.1817$.

Ell. Sk. 1. c. Gray, Man. ed. 6,343; Syn. Fl. N. A. 2, 1:99. Chap.Fl.366. Coulter,

Contr. Nat. Herb. $2: 268$.

Carolinian and Louisianian areas. Ohio to Michigan, Missouri, Arkansas, and

Texas; and from Tennessee to Florida and Louisiana.

Alabama: Central Prairie region to Coast plain. In wet grassy places. Autauga County (E. A. Smith). Montgumery and Mobile counties. Flowers greenish white, April, May; not infrequent. One to $1 \frac{1}{2}$ feet high.

Type locality : "Cette plante crolt dans la Floride \& an Mississipi."

Herb. Geol. Surv. Herb. Mohr. 
ASCLEPIODORA Gray, Proc.Am. Acad. 12:66. 1876.

Two species, perennials, Atlantic North America, sonthwestward.

Asclepiodora viridis (Walt.) Gray, Proc. Am. Acad. 12 : 66. 1876.

Asclepias viridis Walt. Fl. Car. 107. 1788.

Anantherix paniculata Nutt. Trans. Am. Phil. Soc. 5 : 203. 1837.

Acerates paniculata Decsne. in DC. Prodr. 8: 521. 1844.

Ell. Sk. 1 :327. Gray, Man. ed. 6, 339. Chap. Fl. 366. Gray, Syn. Fl. N. A. 2, pt.

1:89. Conlter, Contr. Nat. Herb. $2: 265$.

Carolinian and Louisianian areas. Southern Illinois, southern Missouri, Arkansas, and from central Tennessee south to Florida, west to Louisiana, Texas, New Mexico, and Utah.

Alabama: Central Prairie region. Sunny dry places, borders of fields, and pastures. Dallas County (E. A. Smith). Montgomery County. Flowers dark purplish green; April, May. Not rare.

Type locality : Sonth Carolina.

Herb. Geol. Surv. Herb. Mohr.

AMPELANUS Raf.; Britton, Bull. Torr. Club, 21:314. 1894.

(Enslenia Nutt. Gen. 1:164. 1818. Not Raf. 1817.)

Ampelanus albidus (Nutt.) Britton, Bull. Torr. Club, 21:314. 1894. SAND Vine.

Enslenia albida Nutt. Gen.1: 165. 1818.

Gray, Man. ed.6,343. Chap. Fl. ed. 3, 349. Gray, Syn.Fl. N. A.2,1:100. Britt. \& Br. Ill. Fl. $3: 16$.

Carolinian and Louisianian areas. Southern Pennsylvania, Ohio Valley, Missouri, and Kansas; south from Kentucky to upper Georgia, northern Mississippi, Texas, and Arkansas.

Alabama : Tennessee Valley. Banks of streams. Jackson and Stevenson counties (Herb Biltmore). Rare.

Type locality: "Near Shepherdstown, on the gravelly banks of the Potomac, Virginia. * * * On the high sandy banks of the river Scioto, etc., also near Cincinnati."

Herb. Biltmore.

CYNANCHUM L. Sp. Pl. 1:212. 1753.

Abont 100 species, warmer regions of North and South Africa, Asia, West Indies, and America. Atlantic America, 2. Southern.

Cynanchum palustre (Pursh) Heller, Cat. N. A. Pl. 106. 1898

Ceropegia palustris Pursh, Fl. Am. Sept. 1: 184. 1814.

Seaside Winding MilKWeEd.

Lyonia maritima Ell. Sk. 1:316. 1817.

Seutera maritima Decsne. in DC. Prodr. 8:590. 1846.

Vincetoxicum palustre Gray, Syn. Fl. N. A. 2, pt. $1: 102.1878$.

Ell. Sk. 1:316. Chap. Fl. 367. Gray, Syn. Fl. N. A. 2, 1. c. Coulter, Contr. Nat. Herb. 2 :269. Griseb. Fl. Brit. W. Ind. 418.

Cuba, Bahamas.

Louisianian area. Seashore of South Carolina to Florida, west to Texas.

Alabama : Littoral region. Mobile and Baldwin counties, salt marshes. Flowers greenish; June, July. Abundant. Perennial, twining around the coarser glumaceous marsh plants.

Type locality: "In salt marshes, winding around Scirpi and Junci: Carolina. Lyon."

Herb. Geol. Surv. Herb. Mohr.

VINCETOXICUM Walt. FI. Car. 104. 1788.

(Gonolobus Michx. Fl. Bor. Am. 1:119. 1803.)

About 65 to 70 species, trailing or winding perennials; West Indies, South America, Mexico. Atlantic North America, chiefly Southeru, about 17.

Vincetoxicum gonocarpus laevis (Michx.) Britton, Mem. Torr. Club, 5:266. 1894.

Gonolobus laevis Michx. Fl. Bor. Am. 1:119. 1803.

SMOOTH ANGLE-POD.

Gray, Man. ed. 6, 344. Gray, Syn. Fi. N. A. 2, pt. 1:103. Coulter, Contr. Nat. Herb. $2: 269$. 
Carolinian and Louisianian areas. West Virginia and Ohio south to Tennessee, Mississippi, Arkansas, and Texas.

Alabama : Lower hills and Prairie region. Damp thickets. Bibb County (E. A. Smith). Dallas County, Marion Junction. Flowers pansy-purple; May, June. Not frequent. Stem trailing, smooth, leaves flaccid, thin, smoothish.

Type locality : "Hab. in dumetosis ripariis Fluminis Mississippi."

Herb. Geol. Surv. Herb. Mohr.

Vincetoxicum hirsutum (Michx.) Britton, Mem. Torr. Club, 5:266. 1894.

Gonolobus hirsutus Michx. Fl. Bor. Am. 1:119. 1803.

Ell. Sk. 1:328. Gras, Man. ed. 6, 344. Chap. Fl. 368. Gray, Syn. Fl. N. A. 2, pt. $1: 104$.

Carolinian and Louisianian areas. Maryland and Virginia to Tennessee and Mississippi.

Alabama: Mountain region. Central Pine belt. Shady copses in rich soil. Cullman Connty. Lee County, Auburn (Baker \& Earle, 349). Jackson County,

Stevenson. Flowers maroon purple; May, June. Not infrequent.

Type locality: "Hab. in sylvis Carolinae."

Herb. Geol.Surv. Herb. Mohr.

Vincetoxicum carolinense (Jacq.) Britton, Mem. Torr. Clnb. 5 : 265. 1894.

Cynanchum carolinensis Jacq. Coll. 2 : 288. 1788.

Gonolobus carolinensis R. Br. Mem. Wern. Soc. 1: 35. 1809.

Gray, Man. ed. 6, 345. Chap. Fl. ed. 3, 351. Gray, Syn. Fl. N. A. 2, pt. 1 : 104.

Carolinian and Louisianian areas.

AlabaMa: Mountain region to Coast plain. Thickets in rich soil. Tuscaloosa County (E. A. Smith). Cullman and Baldwin counties. Flowers brown purple; May, June. Not frequent.

Type locality: Given only as implied in the name.

Herb. Geol. Surv. Herb. Mohr.

Vincetoxicum baldwinianum (Sweet) Britton, Mem. Torr. Club. 5 : 265. 1894.

Gonolobus baldwinianus Sweet, Hort. Brit. ed. 2,360. 1830.

BALDWIN'S ANGLE-POD.

G. macrophyllus Ell. Sk. 1: 327. 1817. Not Michx.

Gray, Syn. Fl. N. A.2, pt. 1: 104 .

Lonisianian area. Georgia and Arkansas.

Alabama : Prairie region and Upper division Coast Pine belt. Wooded hills. Wilcox County (S. B. Buckley). Clarke County, Thomasville. Flowers dingy white, fetid; April. Fruit not seen. Local; rare. Stem trailing on the ground.

Type locality: "Savannah."

Herb. Geol. Surv. Herb. Mohr.

\title{
CONVOLVULACEAE. Morning Glory Family.
}

\author{
IPOMOEA L.Sp.Pl. 1:159. 1753.
}

About 350 species, warmer regions of the globe, largely American.

Ipomoea coccinea L. Sp. Pl. 1:160. 1753.

Scarlet Morning Glory.

Ipomoea luteola Jacq. Icon. Rar. t. 135. 1781.

Quamoclit coccinea Moench, Meth. 453. 1794.

Ell. Sk. 1:258. Gray, Man. ed. 6, 368. Cliap. Fl.341. Gray, Syn. Fl. N. A. 2, pt.

1:209. Coulter, Contr. Nat. Herb. 2 : 289.

Tropical America, East Indies, Souti Africa.

Carolinian area. Introduced and partially naturalized in Virginia, southern Ohio, and solithern Missouri, southward from Tennessee to Florida, and west to Texas, New Mexico, and Arizona.

Alabama: Mountain region: In cultivated ground. Cullman and Talladega counties. Flowers flame color; August, September. Not frequent. Annual. Type locality: "Hab. in Domingo."

Herb. Geol. Surv. Herb. Mohr.

Ipomoea quamoclit L. Sp. Pl. 1:159. 1753.

Cypress Vine.

Quamoclit vulgaris Choisy in DC. Prodr. 9: 336. 1845.

Gray, Man. ed. 6, 368. Chap. Fl. 341. Gray, Syn. Fl. N. A. 2, pt. 1: 209.

SOUTH AMERICA.

Extensively cultivated in gardens throughont the Southern States, and a frequent escape in fields and grounds near dwellings. 
Alabama: Thronghout the State. Here and there. Molile County. crimson, July, August. Not infrequent of spontaneous growth. Annual. Type locality: "Hab. in India."

Herb. Geol. Surv. Herb. Mohr.

Ipomoea barbigera Sweet, Fl. Gard. t. 86. 1818.

Bearded Morring GLORY.

Pharbitis barbigera Don, Hist. Dichl. P1. 4 : 262. 1838.

"Stem downy; leaves cordate, acuminate, entire, hairy on both surfaces, lobes rounded; pednncles 1-flowered, shorter than the petioles, bibracteate near the calyx; sepals acuminate, spreading, reflexed, densely bearded at the base; the campanulately funnel-shaped corolla 5 .lobed, slightly crenulate, limb aznre, the tube nearly white ; capsule smooth, 3-celled, cells 2-seeded, seeds black, roughish-downy."

Our plaut differs from the above description solely in the peduncles with two, or seldon three, flowers. Mr. Charles L. Pollard, on comparing it with the illustration of Sweet, finds it to differ in no essential point.

Strangely overlooked by the botanists in this country.

Carolinian and Lonisianian areas. Mississippi.

AlabaMa: Mountain region to the Coast plain in cultivated ground. Flowers from Angust to close of the season. An annual of most vigorous and rapid growth, with the fleshy stem $\frac{1}{4}$ to nearly $\frac{1}{2}$ inch thick. Climbing and twining over bushes and trees, and producing its seeds in abundance, this. plant is one of the most injurious of the bind weeds which infest the garden and field. Most abundant from the Ceutral Prairies to the coast.

'Type locality : "Native of North America."

Herb. Geol. Surv. Herb. Mohr.

Ipomoea hederacea Jacq. Icon. Rar. t. 36. 1781.

Pharbitis hederacea Chois. in DC. Prodr. 9:343. 1845.

Ipomoea nil of American authors.

Ell. Sk. 1:259. Gray, Man. ed.6, 368. Griseb. Fl. Brit. W. Ind. 473.

West Indies, Mexico to Brazil, Australia.

Carolinian and Lonisianian areas. In the Atlantic States from New York and Pennsylvania to Tennessee.

Adventive from the South. Indigenous from North Carolina to Florida and west to Louisiana, Arkansas, and southern Missouri.

Alabama: Mountain region to Coast plain. Border of thickets and in fields. Clay County, near Ironaton. Cullman and Tuscaloosa counties. Lee County. Antauga County (F.S.Earle). Mobile County, waste places. Flowers violet-purple, apparently rare in the low country. Annual.

Type locality: "Hab. in America."

Herb. Geol. Surv. Herb. Mohr.

Ipomoea purpurea (L.) Roth, Bot. Abh. 27. 1787.

Convolvulus purpureus L. Sp. Pl. ed. 2, 1:219. 1762.

Pharbitis hispida Chois. in DC. Prodr. 9:345. 1815.

Ell. Sk. 1:252. Gray, Man. ed. 6, 369. Chap. Fl. 342. Griseb. Fl. Brit. W. Ind. 473.

Tropical America. Naturalized in tropical comutries.

Carolinian and Louisianian areas. Introduced and escaped from cultivation. Naturalized from North Carolina to Louisiana and westward.

Alabama: Over the State. In cultivated ground near dwellings. Talladega County, Ironaton. Clay County, Ashland, 1,700 feet. Cnllman County, 800 feet. Lee County, Aubirn (Earle). Mobile County. Flowers white to pink, purple, violet, and blue; Angust to October. Escaped from cnltivation; in some localities a pernicious weed. Annnal.

Type locality: "Hab. in America."

Herb. Geol. Surv. Herb. Mohr.

Ipomoea pes-caprae (L). Sweet, Hort. Lond. ed. 2, 289. 1818-1820. ROUND-LEAF IPOMOEA. GOAT'S-FOOT SEASIDE IPOMOEA.

Colvolvulus pes-caprae L. Sp. Pl. 1 : 159. 1753.

Ipomoea orbicularis Ell. Sk. 1:257. 1817.

Ell. Sk. 1. c. Chap. Fl. 342. Gray, Syn. Fl. N. A. 2, pt. 1:211. Coulter, Contr. Nat.

Herb. 2:290. Griseb. Fl. Brit W. Ind.470.

Seashores of the Tropics in Both hemispheres. West Indies to Brazil.

Louisianian area. Sandy sea beaches from South Carolina to Florida, west to Texas.

Alabama: Littoral region, sandy shores near the surf. Baldwin County, Perdido Bay. Mobile County, Big Dauphin Island. Flowers purple; July to October; not frequent. Creeping, 2 feet and over. Perennial.

Type locality: "Hab. in India."

Herb. Geol. Surv. Herb. Mohr. 
Ipomoea acetosaefolia (Vahl) Roem. \& Schult. Syst. 4 : 246. 1819.

WhITE-BLOOMING : EASIDE MORNING GLORY.

Convolvulus acetosaefolius Vahl, Ecl. Am. 1:18. 1790.

C. obtusilobus Michx. Fl. Bor. Am. 1: 139. 1803.

Batatas acetosaefolius and B. littoralis Chois. Convolv. Rar. 124. 1838.

Convolvulus littoralis Dietrich, Syn. P1. 1:675. 1839.

Ell. Sk. 1:252. Chap. Fl. 341. Gray, Syn. Fl. N. A. 2, pt.1:211. Coulter, Contr.

Nat. Herb. 2:290. Griseb. Fl. Brit. W. Ind. 471.

West INDIES To BraziL.

Lonisianian area. Seacoast of Sonth Carolina to Florida, west to Texas.

AlabaMa : Littoral region, dunes of drifting sand near the surf. Baldwin County, Josephine, Perdido Bay. Mobile County, Dauphin Island. Flowers white; July, August. Not frequent. Creeping, stems 3 to 4 feet long, the slender creeping roots deeply buried in the sanil. Perennial.

Type locality not ascertained.

Herb. Geol. Surv. Herb. Mohr.

Ipomoea jalapa Pursh, Fl. Am. Sept. 1:146. 1814.

FALSE JALAP.

Convolvulus jalapa L. Mant. 1:43. 1767.

Ipomoea macrorhiza Michx. Fl. Bor. Am. 1: 141: 1803.

I. michauxii Sweet, Hort. Lond. 288. 1818.

Ell. Sk. 1: 253. Chap. Fl. 343. Gray, Syn. Fl. 2, pt. 1:211. Coulter, Contr. Nat.

Herb. 2 : 290. Griseb. Fl. Brit.W. Ind. 469.

Jamaica, Mexico to Brazil.

Louisianian area. South Carolina to Florida and Texas.

Alabama : Coast plain. Mobile County. Frequently cultivated, rarely escaped to waste places and hedge rows. Apparently not indigenons. Flowers pink; August.

A strong climber from a large and ponderous root. Perennial.

Economic nses: Oruamental climber.

Type locality : "Near the sea shore of Georgia and Florida."

Herb. Geol. Surv.

Ipomoea pandurata (L.) Meyer, Prim. Fl. Essequ. 100. 1818.

Wild Potato. Common White Bindweed.

Convolvulus panduratus L. Sp. P1. 1: 153. 1753.

Ell. Sk. $1: 254$. Gray, Man. ed. 6, 369. Chap. Fl. 343. Gray, Syn. Fl. N. A. 2, pt.

1:211. Coulter, Contr. Nat. Herb. 2:290. Griseb. Fl. Brit. W. Ind. 468.

West Indies, Mexico to BraziL.

Carolinian and Louisianian areas. Ontario; southern New York west to Michigan and Missouri, south to the Gulf, and from Florida to Texas and Arkansas.

Alabama: Throughout the State in the valley lands. Most abundant south of the Central Pine belt to the Coast plain. In light warm soil, fields, pastures. Flowers white, with a dark purple spot in center; July, August. Seeds ripe August to October. Many stems, from a large fleshy tuberous root; inost troublesome weed in the rich agricultural lands. Perennial.

'Type locality : "Hab. in Virginiae arenosis."

Herb. Geol. Surv. Herb. Mohr.

Ipomoea sagittata Poir. Voy. Barb. $2: 122$. 1789. Arrow-Leaf Morning Glory.

Convolvulus speciosus Walt. Fl. Car. 93. 1788.

C. sagittifolius Michx. Fl. Bor. Am. 1: 138. 1803.

Ell. Sk. 1:254. Chap. Fl. 344. Gray, Syn. Fl. N. A.2, pt. 1:212. Coulter, Contr.

Nat. Herb. $2: 290$.

Cuba, Spain, North America.

Louisianian area. Coast of North Carolina to Florida, west to Texas.

Alabama: Coast plain. Littoral region. Slightly brackish and salt marsies. Mobile County, river marshes; Dauphin Island and West Fowl River salt marshes. Baldwin County, Point Clear. Flowers bright pink to light purple, closing early in the forenoon; July, Algust; frequent. Twining around tall marsh weeds.

Perennial.

Type locality not ascertained.

Herb. Geol. Surv. Herb. Mohr.

Ipomoea lacunosa L. Sp. Pl. 1 : 161. 1753.

White Star Ipomoea.

Ell. Sk. 1:259. Gray, Man. ed. 6, 369. Chap. Fl. 343. Gray, Syn. Fl. N. A. 2.pt. $1: 213$. Conlter, Contr. Nat. Herb. $2: 291$.

Carolinian and Louisianian areas. Penusylvania, Virginia, Ohio Valley, Missouri and Arkansas, south to Florida and along the Gulf to 'Texas. 
Alabama : Mountain region. Metamorphic hills to the Coast plain. In waste and eultivated ground. Mobile Connty. Lee County, Auburn (Earle). Flowers white, September, October; common. Plants with border of corolla pale purple are not rarely met with (Mobile). Annual.

Type locality: "Hab. in Carolina."

Herb. Geol. Surv. Herb. Mohr.

Ipomoea carolina (L.) Pursh, Fl. Am. Sept. 1: 145. 1814.

Convolvulus carolinus L. Sp. Pl. I : 154. 1753.

Carolina Morning Glory.

Ipomoea trichocarpa Ell. Sk. 1:258. 1817.

Ipomoea commutata Roem. \& Schult. Syst. 4 : 228.1819.

Ell. Sk. 1. 厄. Clap. Fl.342. Gray, syn. Fl. N. A.2, pt.1:213. Coulter, Contr. Nat. Herb. 2 : 291 .

Carolinian and Louisianian areas. North Carolina to Florida, west to Texas and southern Arkansas.

Alabama : Central Prairie region to Coast plain. Thickets and cultivated ground. Mobile Connty, in damp rich ground. Corolla large, 18 inches long, 1 inch wide, pink or purple, August, September; pods ripe, September, October. Trailing and climbing over bushes. Perennial.

'Type locality: "Hab. in Carolina."

Herb. Geol. Surv. Herb. Mohr.

JACQUEMONTIA Chois. Mem. Soc. Phys. Gen. 6 : 476.1833.

About 36 species, mostly annuals, chiefly of tropical America.

Jacquemontia tamnifolia (L.) Griseb. Fl. Brit. W. Ind.474. 1864.

Ipomoea tamnifolia L. Sp. Pl. 1:162. 1753.

Convolvulus tamnifolius Ell. Sk. 1: 256. 1817.

Chap. Fl. 342. Gray, Syn. Fl. N. A. 2, pt. 1:214. Coulter, Contr. Nat. Herb. 2 : 292. Griseb. l. c.

WEST INDIES TO BRAZIL.

Louisianian area. South Carolina to Florida west to Texas.

Alabama : Central Pine belt to Coast plain. In cultivated ground. Flowers azure; July to October. Annual. Twining or trailing. A troublesome weed.

Type locality: "Hab. in Carolina."

Herb. Geol. Surv. Herb. Mohr.

BREWERIA R. Br. Pr. Fl. Nov. Holl. 1: 487, 1810.

(STYlisma Raf. Neogen. 2. 1825.)

About 30 species, warmer regions of the globe. South Atlantic America, 4.

Breweria humistrata (Walt.) Gray, Syn. Fl. N. A. 2, pt. 1: 217. 1878.

Convolvulus humistratus Walt. Fl. Car. 94. 1788.

LOW BREWERIA.

C. tenellus Lam. Tabl. Encycl. Ill. 1 : 459. 1791.

Stylisma humistrata Chap. Fl. 346. 1860.

Ell. Sk. 1:250. Gray, Man. ed. 6, 370. Chap. Fl. 346.

Carolinian and Louisianian areas. Southern Virginia along the coast to Florida, west to Louisiana.

Alabama : Central Pine belt to Lower Pine region. Dry pine barrens. Autauga, Bibb, Clarke, Washington, Escambia, Bald win, and Mobile counties. Flowers white, June to Augnst; common, creeping. Perennial.

Type locality: South Carolina.

Herb. Geol. Surv. Herb. Mohr.

Breweria aquatica (Walt.) Gray, Syn. Fl. N. A. 2, pt. 1 :217. 1878.

Convolvulus aquaticus Walt. Fl. Car.94. 1788.

Aquatic Breweria.

Stylisma aquatica Chap. Fl. 346. 1860.

Ell. Sk. 1:250. Chap. Fl. l. c. Gray, Syn. Fl. N. A.1.c.

Carolinian and Louisianian areas. Florida, middle Georgia, North Carolina.

Alabama : Coosa Valley. Low damp pine woods. Etowah County, Ballplay, 450

feet. Flowers purple; July (1880). Rare. Perennial.

Type locality: South Carolina.

Herb. Geol. Surv. 
Breweria pickeringii (M. A. Curtis) Gray, Syn. Fl. N. A. 2, pt. 1:217. 1878.

Pickering's Breweria.

Convolvulus pickeringii M. A. Curtis, Bost. Journ. N. Hist. 1 129. 1837.

Gray, Man. ed. 6, 370. Chap. Fl. 346. Conlter, Contr. Nat. Herb. 2 : 293.

Carolinian area. New Jersey and southern Illinois, south to North Carolina and Texas.

Alabama: Mountain region. Winston Connty, reported by T. M. Peters. Perennial.

Type locality: "North Carolina, about Wilmington (Curtis)."

CONVOLVULUS L.Sp. Pl. 1: 153. 1753.

(Calystegia K. Br. Prodr. 483. 1810.)

About 160 species, temperate and warmer regions, largely in the Mediterranean region and Asiatic. North America, 12.

Convolvulus repens L. Sp. Pl. 1: 158. 1753.

Creeping Bineweed.

Calystegia catesbeiana Pursh, Fl. Am. Sept. 2 : 729.1814.

C. sepium var. pubescens Gray, Man. ed. 5, 376. 1876.

Convolvulus sepium var. repens Gray, Syu. Fl. N. A. 2, pt. 1: 215.1878.

Ell. Sk. 1:255. Gray, Man. ed. 6, 370. Chap. Fl.345, in part. Coulter, Contr. Nat.

Herb. 2 : 292.

Alleghenian to Lousianian area. Canada, New Jersey west to Michigan, south to Florida, Texas, and New Mexico.

Alabama : Central Pine belt to Upper division of Coast Pine belt. Damp shaded thickets. 'Tuscaloosa County (E.A.Smith). Clarke County, 'Thomasville. Flowers white or faint rosc-color; April, May. Not frequent. Perennial.

Type locality: "Hab. in Americae maritimis."

Herb. Geol. Surv. Herb. Mohr.

Convolvulus arvensis L. Sp. Pl. 1 : 153. 1753.

Common Field Bindweed.

Gray, Man. ed. 6, 370. Chap. Fl. ed. 3,329. Gray, Syn. Fl. N. A. 2, pt. 1:216.

EUROPE.

Naturalized in the Northern and Middle United States.

Alabama: Adventive with ballast. Mobile County. Flowers pink; June, August. Frequent. Spreading slowly to waste places and likely to become a troublesome weed. Perennial.

Type locality : "Hab. in Europae agris."

Herb. Geol. Surv. Herb. Mohr.

Convolvulus incanus Vahl, Symb. Bot. 3:23. 1794.

HOARY BINDWEED.

Convolvulus bonariensis and C. dissectus Cav. Icon. 5, t.480. 1799.

Gray, Syn. Fl. N. A. 2, pt. 1:216. Conlter, Coutr. Nat. Herb. 2:292.

Louisianian area. Arkansas, Texas, and Arizona.

AI.ABama : Adventive from the Southwest. Mobilo County. In an oat field, most probably introduced from Texas with seed oats. Flowers pink; July, August. Perennial.

Type locality: "Hab. in America australi."

Herb. Geol. Surv. Herb. Mohr.

EVOLVULUS L. Sp. Pl. ed. 2, 1:391. 1763.

Eighty-five species, of tropical and subtropical regions, particularly in South America. North America, 6; Southwestern.

Evolvulus alsinoides L. Sp. Pl. ed. 2, $1: 392$.

Chickweed-like Evolvulus.

Gray, Syn. Fl. N. A. 2, pt. 1:218. Chap. Fl. ed.3,330. Griseb. Fl. Brit. W. Ind. 475.

Coulter, Contr. Nat. Herb. 2 : 293.

Throughout the Tropics.

Louisianian area. Florida to Texas.

Alabama: Littoral region. Dry rich banks. Mobile County, Dauphin Island, shell banks. Flowers pearl-blue; July, August. Rare and local. Perenuial.?

Type locality: "Hab. in Malabaria, Zejlona, Bisnagaria, Bahama."

Herb. Geol. Surv. Herb. Mohr. 
DICHONDRA Forst. Char. Gen. Pl. 39, t. 40. 1776.

Five species, warmer regions of the globe.

Dichondra evolvulacea (L. f.) Britton, Mem. Torr. Club 5 : 268. 1894.

Sibthorpia evolvulacea L. f. Suppl. 288. 1781.

Carolina Dichondra.

Dichondra repens Forst. Fl. Ins. Anst. Prodr. 2. 1786. Name only.

D. carolinensis Michx. Fl. Bor. Am. 1: 136. 1803.

Eil. Sk. 1:338. Gray, Man. ed. 6, 368. Chap. Fl. 346. Gray, Syn. Fl. N. A. 2, pt. $1: 208$. Coulter, Contr. Nat. Herb. $2: 289$.

West Indies to Patagonia. Cosmopolitan in warmer zones of the globe.

Carolinian and Lonisianian areas. Southern Virginia aloug the coast to Florida, west to 'Texas and Arkansas.

Alabama : Lower Pine belt. Coast plain. Damp, grassy banks. Mobile and Baldwin counties. Flowers greenish; March, April. Abundant; perennial.

Type locality: "Hab. in Nova Granada. D. Mutis."

Herb. Geol. Surv. Herb. Mohr.

\section{CUSCUTACEAE. Dodder Family.}

CUSCUTA L. Sp. Pl. 1: 124. 1753.

About 100 species, annuals, leafless winding parasitic plants, of warmer and temperate zones, both hemispheres. North America, 21.

Cuscuta arvensis Beyrich; Hook. Fl. Bor. Am. 2: 77. As synonym. 1834.

Field Dodder.

Gray, Man. ed. 6, 371. Chap. Fl. 347. Gray, Syn. Fl. N. A. 2, pt. 1:220. Coulter, Contr. Nat. Herb. 2 : 294.

Alleghenian, Carolinian, and Lonisianian areas. Nova Scotia, Ontario, Manitoba, New York west to Minnesota, Rocky Mountains to Oregon; south to Florida, west to Texas and California.

Alabama: Mountain region. Coast plain. Dry gravelly or sandy exposed places. Cullman County. Lee County, Auburn (F. S. Earle). Mobile County. Flowers, June to August; on small herbs. Stem slender, filiform. Forms with larger flowers, calyx papillose to verrucose, occur near the seashore on Solidago pauciflosculosa and Myricas; not rare.

Type locality : "N. W. America. Douglas."

Herb. Geol. Surv. Herb. Mohr.

Cuscuta inđecora Chois. Mem. Soc. Gen. $9: 278, t . \&, f .5$. 1841. Seaside DoDder. C. neuropetala Engelm. Am. Journ. Sci. 45:75. 1843.

Cuscuta pulcherrima Scheele, Linnaea, 21:750. 1848.

C. decora Engelm. Trans. St. Louis Acad. 1:501. 1859.

Gray, Man. ed. 6, 371. Chap. Fl. 347. Gray, Syn. Fl. N. A.2, pt. 1:221. Coulter, Contr. Nat. Herb. 2 : 294. Griseb. Fl. Brit. W. Ind. 476.

West Indies to ARguntina.

Carolinian and Louisianian areas. Southern Illinois to Florida, westward to Texas, Arizona, and California.

Alabama : Coast plain. Littoral region. Dry sandy places near the seashore and damp sandy borders of brackish swamps. Mobile and Baldwin counties. Petals white, anthers purple. August. On coarse herbs and small shrubs, such as Solidago and Myrica; frequent.

Varies infinitely in the size of flowers, smoothness of calyx, and looseness or compactness of inflorescence, the intergrading forms blending almost imperceptibly. with the varietal forms which have been described. Forms with largo flowers in looser cymes, the calyx and corolla less papillose, distinguished as C. pulcherrima and $C$. neuropetala, occur in damp situations; in the dry sands the flowers are smaller, strongly verrucose papillose, the lobes of the corolla with a strongly inflexed point, and the flowers in dense clusters, such forms responding to $C$. indecora Engelm.

Type locality (fide Engelmann): On the Rio Grande. (Berlandier.)

Herb. Geol. Surv. Herb. Mohr.

Cuscuta obtusiflora glandulosa Engelm. Trans. Acad. St. Louis 1:492. 1859.

Chap. Fl. ed. 3, 332. Coulter, Contr. Nat. Herb. 2 : 294.

WEST INDIRS (BAIIAMAS).

Louisianian area. North Carolina to Florida, west to Texas and New Mexico. 
Alabama: Coast plain. Swampy thickets. Mobile County, parasite on Rubus argutus. Old telegraph road. September, October.

Type locality: 'The distribution given is Georgia, Florida, Louisiana, western Texas, Bahama Islands, and Cuba.

Herb. Geol. Surv. Herb. Mohr.

Cuscuta gronovii Willd.; Róem. \& Schult. Syst. 6:205. 1820. LARGe Lovevine. C. vulgivaga Engelm. Am. Journ. Sci. 43 : 338, t. 6, f. 12-16. 1842.

Eil. Sk. $1: 220$. Gray, Man. ed. 6, 372. Chap. Fl. 347. Gras, Syn. Fl. N. A. 2, pt. 1:221. Conlter, Contr. Nat. Herb. $2: 295$.

Alleghenian to Louisianian area. Nova Scotia, New Brunswick, Quebec, Ontario, and throughout the Atlantic United States.

Alabama: Over the State. In thickets and borders of woods. Flowers white; July, September. On varions shrnbs and trees; the stoutest of our species, the long stems of deep orange color, asceniling small trees and often entwining their crown. Common.

Type locality: “In Virginia."

Herb. Geol. Surv. Herb. Mohr.

Cuscuta compacta Juss.; Chois. Mem. Soc.Gen. $9: 281$, t. 4, f. 2. 1841.

CoMpaCt-Flowered Lovevine.

Gray, Man. ed.6,372. Chap. Fl.347; ed. 3, 332. Gray, Syn. Fl. N. A. 2, pt. 1: 222.

Carolinian and Louisianian areas. Southern New York and Ohio to Missonri and Arkansas, and from New Jersey south to Florida and west to Texas.

Alabama : Over the State. Shady damp thickets bordering water courses, infesting large shrubs, Ilex, Andromeda, Rhus, etc. Flow ors white; September, October. Common throughout; most abundant in the coast plain.

Type locality not ascertained.

Herb. Geol. Surv. Herb. Mohr.

Cuscuta suaveolens Seringe, Ann. Sci. Phys. Nat. Agric. et Indust. 3: 519.1810.

LUCERN OR ALFALFA DODDER.

Cuscuta racemosa var. chiliana Engelm. Trans. St. Louis Acad. Sci. 1 :505. 1859.

Gray, Syn. Fl. N. A. 2, pt. 1:221.

Chile, Irazil ; introduced into Europe.

Adventive from Chile into California. Introduced in the South Atlantic region with lucern seed from California.

Alabama : Montgomery County. Observed for the first time July 10, 1889, in a patch of lucern, growing luxuriantly, and proving most destructive to its host. In order to prevent the spread of this plant, on advice, the crop was plowed under before the seeds were matured. It has since not been seen or heard of from any other locality in the State.

Type locality not ascertained; apparently Chilean.

Herb. Geol. Surv. Herb. Mohr.

\section{POLEMONIACEAE. Phlox Family.}

PHLOX L. Sp. Pl. 1 : 151. 1753.

Thirty species, mostly perennials, in temperate North America and Siberia. Eastern United States, 12.

Phlox paniculata L. Sp. Pl. 1:151. 1753. Paniculate Phlox. Sweet William. Ell. Sk. 1:242. Gray, Man. ed. 6, 354. Chap. Fl.337. Gray, Syn. Fl. N. A. 2, pt. 1: 129.

Carolinian and Louisianian areas. Pennsylvania west to Missouri and Arkansas, south to Georgia.

Alabama: Central Prairie region. Thickets and rich copses. Montgomery County. Flowers bright purple; October. Not frequent.

Type locality: "Hab. in America septentrionali. Collinson."

Herb. Geol. Surv. ILerb. Mohr.

Phlox paniculata acuminata (Pursh) Chap. Fl.338. 1860.

Phlox acuminata Pursh, F1. Am. Sept. 2 : 730. 1816.

Ell. Sk. 1:242. Chap. Fl. 1.c.

A well-marked variety, well described by Pursh. At once recognized by the soft pubescence, dark green foliage, and the ovate-lanceolate acuminate leaves attenuated at the base into a more or less margined petiole, only the uppermost sessile, and by the short calyx lobes.

Carolinian and Louisianian areas. South Carolina and Georgia. 
Alabama: Damp thickets along the banks of streams. Clay County, Shinbone Valley, 1,200 feet; Coosa County, Mount Olive, 1,506 feet. Lee County, Auburn (Baker \& Earle). Flowers pale pink to white; July, August; infrequent. Perennial, 2 to $2 \frac{1}{2}$ feet high.

Our specimens are identical with a specimen from northwestern Georgia (Rome) collected by Dr. Chapman.

Type locality: "On the mountains of Georgia and Carolina. Lyon."

Herb. Geol. Surv. Herb. Mohr.

Phlox maculata L. Sp. Pl. 1 : 152. 1753.

Spotted Phlox.

Phlox pyramidalis Smith, Exot. Bot. $2: 55$, t. $8 \%$. 1805.

Ell. Sk. 1:243 and 244. Gray, Man. ed.6, 354. Chap. Fl.338. Gray, Syn. Fl. N. A.

2, pt. $1: 129$.

Carolinian and Lonisianian areas. New Jersey and Virginia, west to Missouri and Arkansas, south to Tennessee, Florida, and Mississippi.

Alabama: Mountain region to Central prairies. In damp flat woods. Cullman, Tusealoosa, and Montgomerg counties. Lee County, Auburn. Flowers rose-pink; June, July. Not rare; abundant on the Warrior table-land.

Type locality: "Hab. in Virginia. Kalm."

Herb. Geol. Surv. Herb. Mohr.

Phlox ovata L.Sp.Pl. 1:152. 1753.

Carolina Phlox.

Phlox carolina L. Sp. Pl. ed. 2, 1:215. 1762.

Ell. Sk. 1:245. Gray, Man, ed. 6, 355. Chap. Fl. 338. Gray, Syn. Fl. N. A. 2, pt.

$1: 130$.

Louisianian area. North Carolina.

Alabama: Upper division Coast Pine belt. Rich shaded hillsides. Calcareous soil. Monroe Connty. Flowers pale pink; July. Rare. Stems weak; approaches closely forms of the next.

Type locality: "Hab. in Virginia."

Herb. Geol. Surv. Herb. Mohr.

Phlox glaberrima L. Sp. Pl. 1 : 152. 1753.

SMooth PhLox.

Ell. Sk. 1:246. Gray, Man. ed. 6, 355. Chap. Fl.338. Gray, Syn. Fl. N. A. 2, pt. $1: 130$.

Carolinian and Lonisianian areas. Ohio Valley, Missouri, and Arkansas, south to Tenuessee and North Carolina.

Alabama: Mountain region to Lower Pine region. Open woods, in light soil. Cullman County, 800 feet. Montgomery County. Autauga County, Prattville. Bibb County, 500 feet. Washington County, Fairford, 200 feet. Mobile County, Bayou Sara. Flowers pink; May, June. Not infrequent.

Type localitı : "Hab. in Virginia."

Herb. Geol. Surv. Herb. Mohr.

Phlox floridana Benth. in DC. Prodr. 9:304. 1845.

Florida Phlox.

Chap. Fl.339. Gray, Syn. Fl. N. A. 2, pt. 1: 130.

Louisianian area. Middle and western Florida.

Ala l3ama: Central Prairie region. Rich open woods, thickets in the prairies. Madison County, Huntsville, Montesano (Baker). Montgomery County, Pintlalla Creek. Butler County, Georgiana. Flowers rose-purple; July. Kare. Perennial; 1 to $1 \frac{1}{2}$ feet high.

Type locality: "In Florida (Chapmann!)."

Herb. Geol. Surv. Herb. Mohr.

Phlox pilosa L. Sp. Pl. I: 152. 1753.

HaIRY Phlox.

Phlox aristata Michx. Fl. Bor. Am. 1:144. 1803.

Ell. Sk. 1:247. Gray, Man. ed. 6, 355. Chap. Fl. 339. Gray, Syn. Fl. N. A. 2, pt. $1: 130$. Coulter, Contr. Nat. Herb. $2: 276$.

Alleghenian, Carolinian, and Louisianian areas. Ontario, Manitoba, Minnesota and Nebraska, south to Missouri, Arkansas, and Texas, and from New Jersey to Florida.

Alabama: Tennessee Valley to Central Prairie region. Open copses, border of woods. Cullman County. Dallas County, Uniontown. Flowers pink; May. Not frequent. Perennial.

'Type locality: "Hab. in Virginia."

Herb. Geol. Surv. Herb. Mohr.

Phlox pilosa detonsa Gray, Proc. Am. Acad. 8: 251. 1870.

Gray, Syn. Fl. N. A. 2, pt. 1:130. Coulter, Contr. Nat. Herb. 2 : 276.

Louisianian area. Florida to Texas. 
Alabama: Lower Pine region. Dry sandy pine rilges. Mobile and Baldwin counties. Flowers pink; April, May. Common.

Type locality: "Florida, Alabama, Louisiana, Texas."

Herb. Geol. Surv. Herb. Mohr.

Phlox amoena Sims, Bot. Mag. $31:$ t. 1308. 1810.

Early philox.

Phlox pilosa var. walteri Gray, Man. ed. 2, 331. 1856.

P. pilosa Walt. Fl. Car.90. 1788. Not L.

P. valteri Chap. Fl. 339.1860 .

Eil. Sk. 1:247. Gray, Man. ed. 6, 355. Chap. Fl. l. c. Gray, Syn. Fl. N. A. 2, pt. 1:130.

Carolinian and Louisianian areas. Southern Virginia west to Kentucky, southwestern Missonri, and Arkansas, south along the mountaius to Tennessee and Florida, wos's to Mississippi.

Alabama: Tennessee Valley to the Coast plain. In light siliceous soil, open hills and open copses. Winston County, Sipsey Valley, 1,200 feet. Cullman County, 800 feet. Lee County, Auburn (Earle \& Underwood). Clarke, Escambia, Mobile, aud Baldwin counties. Flowers purplish pink; March to May. Frequent, most so in the grassy pine barrens of the Lower Pine region.

Type locality: "Near the Santée Canal, in South-Carolina."

Herb. Geol. Surv. Herb. Mohr.

Phlox divaricata L. Sp. Pl. 1: 152. 1753.

Blue Phlox. Sweet William.

Ell. Sk. 1:248. Gray, Man. ed. 6, 355. Chap. Fl. 338. Gray, Syn. 1'. N. A. 2, pt. 1:131.

Alleghenian to Lonisianian area. Ontario and northwestern New York, west to Minnesota, Missouri, and Arkansas, and south to the Gulf, from Florida to western Louisiana.

Alabama: Mountain region to Upper division of Coast Pine belt. Rich open woods. Madison County, Montesano, 1,500 feet. Franklin County, Russellville. Clarke County, Thomasville. Tuscaloosa County (E. A.Smith). Flowers lavender-

blue; April. Not infrequent, mostly in the mountains.

Type locality: "Hab in Virginia."

Herb. Geol. Surv. Herb. Mohr.

Phlox reptans Michx. k'. Bor. Am. 1: 145. 1803.

Creeping Purple Phlox.

Ell. Sk. 1:248. Gray, Man. ed. 6, 355. Chap. Fl. 338. Gray, Syn. Fl. N. A. 2, pt. $1: 131$.

Carolinian area. Allegheny Mountains from Pennsylvania to Kentucky, Tennessee, and Georgia.

Alabama: Mountain region. Cullman County, 800 to 1,000 feet (Mis8 M. Mohr). Flowers rose-purple; June. Rare.

'Type locality: "Hab. in excelsis montibus Carolinae occidentalis."

Herb. Geol. Surv. Herb Mohr.

GILIA Ruiz \& Pav. Prodr. Fl. Per. 25, t.4. 1794.

Abont 75 species, Chile, Peru. North America, chiefly Western, about 50. South Atlantic, 1.

Gilia coronopifolia (Willd.) Pers. Syn. 1:187. 1805.

Spanisir Cypress.

Cantua coronopifolia Willd. Sp. Pl. 1:879. 1797.

Ipomopsis elegans Michx. Fl. Bor. Am. 1:142. 1803.

Polemonium rubrum L. Sp. Pl. 1: 163. 1753.

Ell. Sk. 1:260. Chap. Fl. 339. Gray, Syn. Fl. N. A. 2, pt. 1:145. Coulter, Contr.

Nat. Herb. $2: 277$.

Carolinian and Louisianian areas. South Carolina to Florida, Arkansas, and Texas.

Ala bama : Lower hills. Dry exposed places. Bibb County, Pratts Ferry. Flowers scarlet; June, July. Biennial herb, $1 \frac{1}{2}$ to 2 feet high, very showy.

Economic uses: Frequently cnltivated for ornament, under the name "Spanish larkspur."

Type locality : "Hab. in Carolinae citerioris arenosis."

Herb. Geol. Surv.

POLEMONIUM L. Sp. Pl. 1:162. 1753.

About 15 species, temperate Europe, Asia, Chile. North America, 8; mostly Westeri.

Polemonium reptans L. Syst. ed. 10, 925. 1789.

Greek Valerian.

Ell. Sk. 1:261. Gray, Man. ed. 6, 356. Chap. Fl. 340. Gray, Syn. Fl. N. A. 2, pt. $1: 151$. 
Alleghenian and Carolinian areas. Minnesota, New York, Virginia, west to Missouri, Arkansas, south along the mountains to upper Georgia and northern Mississippi.

AlabaMa: Mountain region. Lower hills. Shady rich woodlands. Madison Connty, Montesano, 1,500 feet. Tuscaloosa County (E. A. Smith). Flowers cerulean blue; April, May. Not frequent. Perennial.

Type locality (L. Sp. Pl. ed.2): "Hab. in Virginia."

Herb. Geol. Surv. Herb. Mohr.

\section{HYDROPHYLLACEAE. Water-leaf Family.}

HYDROPHYLLUM L. Sp. Pl. 1:146. 1753.

Six species, temperate North America. Eastern North America, 4.

Hydrophyllum macrophyllum Nutt. Journ. Acad. Phila. 7 : 111. 1834.

LARGER WATER-LEAF.

Gray, Man. ed. 6, 357. Chap. Fl. Suppl. 639; ed. 3, 355. Gray, Syn. Fl. N. A. 2, pt. 1: 154 .

Alleghenian and Carolinian areas. Southwestern Virginia, mountains, 4,000 feet, to Missouri, south to 'Tennessee and northern Mississippi.

Alabama: Monntain region. Rich woods. Madison County, Montesano, 1,500 feet. Flowers pale buff; April. Rare. Perennial.

Type locality: "In the forests of Kentucky. Discovered by Dr. Short."

Herb. Geol. Surv.

NEMOPHILA Nutt. Journ. Acad. Phila. 2 : 179. 1822. Nemophila.

Nine species, mostly Western North America. Pacific slope, 7.

Nemophila microcalyx (Nutt.) Fisch. \& Mey. Sert. Petrop. 1846.

Eastern Nemophila.

Ellisia microcalyx Nutt. Trans. Am. Phil. Soc. ser. 2, 5:191. 1837.

Chap. Fl. 334. Gray, Syn. Fl. N. A. 2, pt. 1:157. Coulter, Contr. Nat. Herl. $2: 279$.

Carolinian and Louisianian areas. Virginia, Tennessee, lower Georgia, and Florida, west to Texas and Arkansas.

Alabama: Central Pine belt to Coast plain. Damp shady borders of woods and copses. 'Tuscaloosa County (E. A. Smith). Mobile County. Flowers white; March. Not infrequent. Annual.

Type locality: "In Arkansas, Alabama, etc."

Herb. Geol. Surv. Herb. Mohr.

PHACELIA Juss. Gen. Pl. 127. 1789.

About 80 species, Chilean Andes, mountains of Mexico. North America, 55; ehiefly southwestern and Pacific. Eastern North America, 9.

Phacelia bipinnatifida Michx. Fl. Bor. Am. 1: 134, t. 16. 1803.

Bipinnatifid-leaf Phacelia.

Gray, Man. ed. 6, 359. Chap. Fl. 335. Gray, Syn. Fl. N. A. 2, pt. 1:161.

Alleghenian and Carolinian areas. West Virginia to altitude 3,500 feet; Kentucky to Missonri, and along the Alleghenies to Tennessee and North Carolina.

Alabama: Tennessee Valley. Mountain region. Shaded rocky hillsides. Lauderdale County (M.C. Wilson). Jackson County, Gurley's farm, 1,000 feet. Madison County, Montesano, 1,500 feet. Flowers sky-blue; April. Not infrequent. Biennial.

Type locality: "Hab. in sylvis occidentalibus montium Alléghenis et Kentucky."

Herb. Geol. Surv. Herb. Mohr.

Phacelia brevistylis Buckl. Am. Journ. Sci. 45 : 172.1843.

Phacelia bipinnatifida var. brevistylis Gray, Syn. Fl. N. A. 2, pt. 1:161.

Gray, Syn. Fl. N. A. 1.c.

Alabama: Lower hill». Tuscaloosa County (R. A. Nevius). Local and rare. Biennial.

Type locality : "Limestone rocks, Hamburg, Wilcox County, Alabama."

Herb. Geol. Surv. 
Phacelia purshii Juckl. Am. Journ. Sci. $45: 171.1843$.

Phacelia fimbriata Pursh, Fl. Am. Sept. 1:140. 1814. Not Michx.

Ell. Sk. 1:236, in part. Gray, Man. ed. 6, 359. Chap. Fl. 335. Gray, Syn. Fl. N. A. 2, pt. 1: 162 .

Carolinian area. Western Pennsylvania and Virginia to Missouri, Arkansas, and Minnesota (\&), south to Tennessee and North Caroliua.

Alabama : Tennessee Valley. Mountain region. Shaded banks, horders of woods, copses. Franklin County, Russellville. Madison County, Huntsville, shaded rocky banks. Tuscaloosa County (E. A. Smith). Flowers pale blue; $\Lambda$ pril, May. Not frequent. Annual.

Type locality: "Western and Southern States."

Herb. Geol. Surv. Herb. Mohr.

Phacelia dubia (L.) Small, Bull. Torr. Club, 21:303. 1894.

Polemonium dubium L. Sp. P1. I:163. 1753.

SMall-Flowered Phacelia.

Phacelia parviflora Pursh, Fl. Am. Sept. 1:140. 1816.

$P$. pusilla Buckl. Am. Journ. Sci. 45:172. 1843.

Chap. Fl. 335. Gray, Syn. Fl. N.A.2, pt.1:162. Coulter, Contr. Nat. Herb. $2: 280$.

Carolinian and Louisianian areas. Pennsylvania and Ohio to Missouri and Texas and to North Carolina.

Alabama : Metamorphic hills. Central Prairie region. Shaded rocky banks. Lee County, Auburn (Earle \& Cnderwood). Wilcox County (Buckley). Flowerspale blue; May. Local; infrequent. Four to 6 inches high. Annual.

Type locality: "Hab. in Virginia."

Herb. Geol. Surv. Herb. Mohr.

Phacelia fimbriata Michx. Fl. Bor. Am. 1:134. 1803. Fringe-flowreded Pilacelia. Gray, Man. ed. 6, 359. Chap. Fl. 335. Gray, Syn. Fl. N. A. 2, pt. 1: 162.

Carolinian area. Southwestern Virginia, 4,800 feet; North Carolina.

Alabaila: Mountain region fide Graj. Annual.

Type locality: "Hab. in excelsis montibus Carolinae."

Herb. Geol. Surv. Herb. Mohr.

NAMA L. Sp. Pl. 1:226. 1753.

(Hydrolea L. Sp. Pl. ed. 2, 1:328. 1762.)

Nama quadrivalvis (Walt.) Kuntze, Rev. Gen. Pl. $2: 435.1891$.

Hydrolea quadrivalvis Walt. Fl. Car. 110. 1788.

H. caroliniana Michx. Fl. Bor. Am. 1:177. 1803.

Ell. Sk. 1:336. Chap. Fl. 336. Gray, Syn. Fl. N. A. 2, pt. 1: 176.

Louisianian area. North Carolina to Florida, west to Louisiana and Missouri.

Alabama : Coast plain. Muddy banks, ditches. Mobile County. Flowers sky-

blue; Augnst, September. Common. Pereunial.

Type locality: South Carolina.

Herb. Mohr. Herb. Geol. Surv.

Nama ovata (Nutt.) Britton, Mem. 'Torr. Club, $5: 272$. 1894. Ovate-Leaf Nama. Hydrolea orata Nutt. 'Trans. Am. Phil. Soc. ser. 2, 5 : 196. 1835-1837.

Chap. Fl. Suppl. 640; ed. 3, 357. Gray, Syn Fl. N. A. 2, pt. 1:176. Coulter, Contr.

Nat. Herb. $2: 282$.

Louisianian area. Southern Missouri, Arkansas, and Texas to Mississippi.

Alabama : Central Prairie region; borders of ponds and ditches. Hale County, Gallion. Autauga County, Prattville $(E, A$. Smith $)$. Flowers azure; June. Not frequent. Perennial.

Type locality: "On the margins of ponds, Arkansas."

Herb. Geol. Surv. Herb. Mohr.

MARILAUNIDIUM Kuntze, Rev. Gen.Pl. 2 : 434. 1891.

(Nama L. Syst. ed. 10, $2: 950$. 1759. Not L. Sp. Pl. 1:226. 1753.)

Two species, annual weeds, Western North America and West Indies.

Marilaunidium jamaicense (L.) Kuntze, Rev. Gen. Pl. 2 : 434. 1891.

Nama jamaicensis L. Syst. ed. 10,93. 1759.

JAMAICA CONEFLOWER.

Chap. Fl. 337. Gray. Syn. Fl. N. A.2, pt. 1:174. Coulter, Contr. Nat. Herb. $2: 280$.

Griseb. Fl. Brit. W. Ind. 477. 
Whest Indies, Mexico, Central America.

Louisianian area. Florida to Texas.

Alabama: Coast plain. Waste places, roadsides. Mobile County. Flowers white; June to October. Common about the city. Annual.

Type locality (L. Sp. Pl. ed.2): "Hab. in Jamaica."

Herb. Geol. Surv.

\section{BORAGINACEAE. Borage Family.}

HELIOTROPIUM L. Sp. Pl. I:130. 1753.

One hundred and fifteen species, warmer regions of the globe. North America, 14, Southern and Southwestern.

Heliotropium europaeum L. Sp. Pl. 1 : 130. 1753.

European Heliotrope.

EUROPE.

Carolinian and Louisianian areas. Sparingly naturalized from southern New York to the Gulf.

Alabama: Tennessee Valley and Coast plain. Waste places. Morgan County, Decatur. Lawrence County, Moulton, near dwellings. Mobile County, persistent near the shipping and on ballast heaps. Flowers white; August, October. Not infrequent. Annual.

Type locality : "Hab. in Europa australi."

Herb. Geol. Surv. Herb. Mohr.

Heliotropium curassavicum L. Sp. Pl. 1: 130. 1753.

Seaside Heliotrope.

Ell. Sk. 1:224. Gray, Man. ed. 6, 361. Chap. Fl. 330. Gray, Syn. Fl. N. A. 2, pt. 1: 185. Coulter, Contr. Nat. Herb. $2: 285$.

West Indies, Mexico to Cinle, Australia.

Carolinian to Louisianian area. Seashore of southern Virginia to Florida, west to

Texas and southern Illinois. Saline desert region of the interior to Oregon.

A labama: Littoral region. Saline marshes. Mobile and Baldwin counties.

Flowers pearl blve; July to Oetober. Frequent. Perennial.

Type locality: "Hab. in Americae calidioris maritimis."

Herb. Geol. Surv. Herb. Mohr.

Heliotropium tenellum (Nutt.) Torr. in Macy's Rep. 304, t. 14. 1853.

Lithospermum tenellum Nutt. Trans. Am. Phil. Soc. 5 : 188. 1837.

Gray, Man. ed. 6, 361. Chap. Fl. Suppl. 639; ed.3,359. Gray, Syn. Fl. N. A. 2, pt. 1:184. Coulter, Contr. Nat. Herb. $2: 285$.

South America, Australia.

Carolinian and Louisianian areas. Southern Missouri and Kansas to western

Tennessee, Alabama, and Texas.

Alabama : Central Prairie region. Dry exposed places, pastures, roadsides. Montgomery County. Flowers white; July. Infrequent. Annual.

Type locality: "In arid places in the prairies of Red River," Arkansas.

Herb. Geol. Surv. Herb. Mohr.

Heliotropium indicum L. Sp. Pl. 1:130. 1753.

INDIAN HELIOTROPE. Ell. Sk. 1:224. Gray, Man. ed. 6, 362. Chap. Fl. 330. Gray, Syn. Fl. N. A. 2, pt.

$1: 186$.

Introduced from the Tropies. Fully naturalized in the Ohio Valley, and thence to Florida and the eastern Gulf States.

Ala bama: Tennessee Valley and along the river valleys to the coast. Cultivated and waste grounds. Tuscaloosa County. Flowers azure; August to October. Everywhere, southward common. Annual.

Type locality: "Hab. in India utraque."

Herb. Geol. Surv. Herb. Mohr.

Heliotropium anchusaefolium Poir. Encyel. Suppl. 3 : 23. 1813.

Chap. Fl. Suppl. 639; ed. 3, 360. Gray, Syn. Fl. N. A. 2, pt. 1:186.

Southern Brazil, Argentina.

Louisianian area. Sparingly naturalized. Florida, middle Georgia.

Alabama: Central Prairie region. Waste places near dwellings. Montgomery

County. Flowers rose-purple; July. Not frequent. Perennial.

Type locality: "Cette plante croit à Buenos-Ayres."

Herb. Geol. Surv. 


\section{CYNOGLOSSUM L. Sp. Pl. 1 : 134. 1753. Hound's-ToNGue.}

Seventy-eight species, temperate and warmer regions, Northern Hemisphere, Europe, northern Africa, western Asia, India. North America, 7; endemic, 6.

Cynoglossum officinale L. Sp. P1. 1:134. 1753.

Common Hound's-Tongue. Gray, Man. ed. 6, 362. Chap. Fl. 333. Gray, Syn. Fl. N. A. 2, pt. 1:187.

EUROPE.

Alleghenian and Carolinian areas. Naturalized in Canada, Missouri, and Arkansas, and from the Ohio Valley to North Carolina and upper Georgia.

Alabama : Tennessee Valley. Waste places, roadsides. Morgan Coanty, Decatur. Lawrence County, Moulton. Flowers dark purple; June to September. Not frequent. Annual or biennial.

Type locality: "Hab. in Europae ruderatis."

Herb. Geol. Surv.

Cynoglossum virginianum L. Sp. P1. 1: 134. 1753.

WILD COMFREY.

Cynoglossum amplexicaule Michx. Fl. Bor. Am. 1 : 132 . 1803.

Ell. Sk. 1:228. Gray, Man. ed. 6, 364. Chap. Fl. 333. Gray, Syn. Fl. N. A. 2, 1: 188.

Alleghenian and Carolinian areas. Ontario, Quebec; New England west to Minnesota, Ohio Valley to Missouri, Kansas, and Arkansas, south along the mountains from New York to Tennessee and North Carolina.

Alabama: Mountain region. Rich woodlands. Lawrence County, 1,200 feet. Winston County, 1,500 feet. Madison County, Montesano, 1,500 feet. Dekalb County, Lookout Mountain, 1,800 feet. Flowers sky-blue; April, May. Not rare. Perennial.

Type locality: "Hab. in Virginia."

Herb. Geol. Surv. Herb. Mohr.

LAPPULA Moench, Meth.416. 1794.

(Echinospermum Sw.; Lehm. Asperif. 113. 1818.)

About 40 species, temperate regions, mostly Northern Hemisphere. South Africa, Australia. North America, 7 or 8.

Lappula virginiana (L.) Greene, Pittonia, 2 : 182.1891.

BEGGAR'S LiCE.

Myosotis virginiana L. Sp. Pl. I: 131. 1753.

Echinospernum virginicum Lehm. Asperif. 117. 1818.

Cynoglossum morrisoni DC. Prodr. 10: 155. 1846.

Ell. Sk. 1:225. Gray, Man. ed. 6, 362. Chap. Fl. 333. Gray, Syn. Fl. N. A. 2, pt. $1: 189$.

Alleghenian to Louisianian area. New Brunswick, Ontario, and Lake Superior; New England west to Minnesota and Nebraska, south to the Ohio Valley, Missouri, and Kansas, and from New York along the mountains to South Carolina.

Alabama: Mountain region to Upper division of Coast Pine belt. Damp shady borders of woods, copses. Cullman County, 800 feet. Tuscaloosa County. Clarke County, Suggsville, 300 feet (Dr. Denny). Flowers pale blue; July. Not frequent. Biennial.

Type locality: "Hab. in Virginia."

Herb. Geol. Surv. Herb. Mohr.

MERTENSIA Roth, Catal. Bot. 1: 34. 1797.

About 14 species. Temperate Europe, Asia. North America, 7 or 8.

Mertensia virginica (L.) DC. Prodr. 10:88. 1846.

VIRGINIA LUNGWORT.

Pulmonaria virginica L. Sp. Pl. 1: 135. 1753.

Ell. Sk. $1: 228$. Gray, Man. ed. 6, 364. Chap. Fl.332. Gray, Syn. Fl. N. A. 2, pt. $1: 200$.

Carolinian area. Sonthern Ontario and New York, Ohio Valley to Missouri and Arkansas, sonth from Now Jersey to the mountains of South Carolina.

Alabama: Tennessee Valley. Mountain region. Rich wooded banks of streams. Lauderdale County, Florence (M. C. Wilson). Winston County, Sipsey Valley (T.M. Peters). Flowers purple; May. Infrequent. Perennial.

Type locality : "Hab. in Virginia."

Herb. Geol. Surv. Herb. Mohr. 
MYOSOTIS L.Sp. P1. 1: 131. 1753.

Forty species, temperate and colder regions, mostly of the Northern Hemisphere. Europe, northern Asia. North America, 6; endemic, 4.

Myosotis virginica (L.) B. S. P. Prel. Cat. N. Y. 37. 1888.

Lycopsis virginica L. Sp. Pl. 1:139. 1753.

Vernal Forget-Me-NOT.

Miyosotis verna Nutt. Gen. Add. 1818.

M. stricta Gray, Man. 338. 1848. Not Link.

Gray, Man. ed. 6,365. Chap. Fl. 333. Gray, Syn. Fl. N. A. 2, pt. 1: 202. Coulter,

Contr. Nat. Herb. $2: 287$.

Carolinian and Louisianian areas. Ontario; New England west to Minnesota, the Ohio Valley, Missouri, and Arkansas, south from Virginia to middle Georgia.

Alabama: Mountain region to Coast Pine belt. Open places, borders of fields. Lee County, Auburn (Baker \& Earle). Madison Cunaty, Huntsville, 800 feet. Dry calcareous hillsides. Tuscaloosa County. Montgomery Connty, prairies near Pintlalla Creek, about 250 feet altitude. Clarke County, Thomasville. Flowers white; April. Not rare. Annual.

Type locality: "Hab. in Virginia ad vias."

Herb. Geol. Surv. Aerb. Mohr.

Myosotis verna macrosperma Chap. Fl. 333. 1860.

Gray, Syn. Fl. N. A. 2, pt. 1: 203. Coulter, Contr. Nat. Herb. $2: 287$.

Carolinian and Louisianian areas. Florida to Texas, northwest to British Columbia and Oregon.

Alabama: Metamorphic hills to Coast plain. Open dry prairies. Montgomery County. Lee County, Auburn (Baker \& Earle). Mobile County. Flowers April. Annual.

Type locality: "Florida and westward."

Herb. Geol. Surv. Herb. Mohr.

\section{LITHOSPERMUM L. Sp. Pl. 1:132. 1753. GROMWELL.}

About 40 species, colder and warmer temperate regions of Europe and Asia. North America, 11; Atlantic, 7.

Lithospermum arvense L. Sp. Pl. 1:132. 1753.

GromWell.

Gray, Man. ed. 6, 365. Chap. Fl. 331. Gray, Syn. Fl. N. A. 2, pt. 1: 203.

EURope.

Carolinian area. Naturalized from southeastern Canada to Florida and west tJ

Arkansas.

Alabama: Orer the State. In grain fields. Tennessee Valley. Mobile County.

Flowers white; June, Jnly. Found sparingly. Annual.

Type locality: "Hab. in Europae agris et arvis."

Herb. Geol. Surv. Herb. Mohr.

Lithospermum canescens (Michx.) Lehm. Asperif. 305. 1818.

Batschia canescens Michx. Fl. Bor. Am. 1:130. 1803.

Ell. Sk. 1:227. Gray, Man. ed. 6, 366. Chap. Fl. 332. Gray, Syn. Fl. N. A. 2, pt. 1: 204 .

Alleghenian and Carolinian areas. Ontario to Saskatchewan; New York west to Minnesota and Nebraska, prairies of Ohio, Illinois, Missouri, Arkansas, and New Mexico; south from New Jersey and West Virginia to Tennessee and Sonth Carolina.

Alabama: Mountain region. Dry exposed hillsides. Madison Countr, Montesano, calcareous rocky banks, 1,000 feet. Lauderdale County, Florence (M. C. Wil$80 n)$. Lawrence County, open rocky woods about Gumpond, 800 feet. Flowers deep yellow; April, May. Not infrequent. Perennial.

Type locality: "Hab. in collibus sylvaticis Tennassée."

Herb. Geol. Surv. Herb. Mohr.

Lithospermum tuberosum Rugel; DC.Prodr. 10:76. 1846.

Chap. Fl. 332. Gray, Syn. Fl. N. A. 2, pt. 1:203.

TUBEROUS-ROOTED GROMWELL.

Carolinian and Louisianian areas. Western Florida.

Alabama: Mountain region to Coast Pine belt. Rocky or gravelly banks. Lauderdale County, Florence (M. C. Wilson). Greene County, Knoxville. Madison County, limestone hills, flank Montesano, 800 to 1,000 feet. Tuscaloosa County ( $E$. 
A. Smith). Clarke County, Suggsville (Dr. Denny). Mobile County, a slender depauperated form. Flowers white; March, April. Infrequent. Several stems, more or less decumbent from the tuberously thickened root. Perennial.

Type locality: "In Floridis prope Aspalaga (Rugel!)."

Herb. Geol. Surv. Herb. Mohr.

ONOSMODIUM Michx. Fl. Bor. Am. 1:132. 1803.

Six species, temperate North America, Mexico. United States and British North America, 5.

Onosmodium carolinianum (Lam.) A. DC. Prodr. 10:70. 1846.

Carolina false Gromwell.

Lithospermum carolinianum Lam. Tabl. Encycl. 1:367. 1791.

Gray, Man. ed.6, 366. Chap. Fl.331. Gray, Syn. Fl. N. A. 2, pt.1:206. Coulter, Contr. Nat. Herb. 2 : 288.

Alleghenian to Louisianian area. Ontario, western New York, and western Pennsylvania to Missouri, Miunesota, Nebraska, and Colorado; Ohio Valley to Missouri and Arkansas; and from New Jersey to Florida and Texas.

Alabama : Throughout the State. Grassy open places, open woods and copses, in light soil. Lauderdale, Cullman, Clarke, Washington, and Mobile counties. Flowers yellowish white; May, June. Fruit ripe July. Common. Most frequent in the Coast Pine belt. Perennial.

Type locality: "E Carolinia. D. Fraser."

Herb. Geol. Surv. Herb. Mohr.

Onosmodium virginianum (L.) A. DC. Prodr. 10:70. 1846.

Lithospermum virginianum L. Sp. Pl. I: 132. 1753.

Virginia False Gromwell.

Onosmodium hispidum Michx. Fl. Bor. Am. 1:133. 1803.

Ell. Sk. 1:226. Gray, Man. ed. 6, 366. Chap. Fl. 331. Gray, Syn. Fl. N. A. 2, pt. $1: 206$.

Carolinian and Louisianian areas. New England and New Jersey, west to Ohio, Missouri, and Arkansas, south to the Gulf States from Florida to Louisiana.

Alabama : Central Pine belt to Coast plain. Grassy banks, open copses, light soil. Tuscaloosa County (E. A. Smith). Autauga, Clarke, and Mobile counties. Flowers dingy white; May. Not infrequent. Perennial.

Type locality: "Hab. in Virginia."

Herb. Geol. Surv. Herb. Mohr.

\section{VERBENACEAE. Vervain Family.}

VERBENA. L.Sp. Pl. $1: 18$. 1753. Vervain.

About 80 species, extratropical and tropical zones of both hemispheres, chiefly South and Southwestern America. Europe, 1; North America, 16.

Verbena officinalis L. Sp. Pl. 1:20. 1753.

Common Vervain.

Verbena spuria L. Sp. Pl. 1:20. 1753.

Ell. Sk. 2:97. Gray, Man. ed. 6, 401. Chap. Fl.307. Gray, Syn. Fl. N. A. 2, pt. 1: 335. Coulter, Contr. Nat. Herb. 2:327. Wats. Bot. Calif. 1:608.

EUROPE. Cosmopolitan in warmer temperate regions.

Naturalized from New Jersey to Florida, west to Texas, Arizona, and southern California.

AlabaMa: Throughout the State, waysides, borders of fields. Most frequent in the Tennessee Valley and in the Coast plain. Mobile County, on the coast; a common wayside weed. Flowers lilac; July to October. Annual.

'Type locality: "Hab. in Enropae mediterraneae ruderatis."

Herb. Geol. Surv. Herb. Mohr.

Verbena xutha Lehm. Ind. Sem. Hort. Hamb. 1834.

Verbena lucaeana Walp. Rep. 4 : 23. 1844-1848.

Gray, Syn. Fl. N. A. 2, pt. 1:335. Coulter, Contr. Nat. Herb. 2 : 327.

MExico.

Louisianian area. Louisiana and Texas to southern California.

Alabama: Littoral region. Baldwin County, Nary Cove, waste places. Most probably adventive from the southwest. Flowers purple, August. Local and rare. A coarse weed, 2 to 3 feet high. Perennial.

Type locality not ascertained.

Herb. Geol. Surv. Herb. Mohr. 
Verbena urticaefolia L. Sp. Pl. 1:20. 1753.

White Vervain.

Ell. Sk. 2:98. Gray, Man. ed. 6, 402. Chap. Fl. 307. Gray, Syn. FI. N. A. 2, pt.

1:335. Coulter, Contr. Nat. Herb. 2 :327. Griseb. Fl. Brit. W. Ind. 493.

West Injies, Mexico, Central America.

Alleghenian, Carolinian, and Louisianian areas. Quebec, Ontario; New England west to Nebraska, south to the Gulf from Florida to Texas.

Alarama: Over the State. Damp low thickets, borders of fields and woods. Flowers white or blue; July to October. Common everywhere. A coarse weed, 2 to 3 feet high. Perennial. A form with blue flowers and the leaves rougher with the above in the Coast plain.

Type locality: "Hab. in Virginiae, Canadae aridís."

Herb. Geol. Surv. Herb. Mohr.

Verbena carolina L. Sp. Pl. ed. 2, 1:29. 1762.

Carolina Vervain.

Verbena caroliniana Michx. Fl. Bor. Am. 2:14. 1803.

Phryma carolinensis Walt. Fl. Car. 166. 1788.

Ell. Sk. 2:99. Chap. Fl. 307. Gray, Syn. Fl. N. A. 2, pt. 1:336.

Mexico, Guatemala.

Louisianian area. North Carolina to Florida, west to Louisiana.

Alabama : Central Pine belt to Lower Pine region. Dry sandy soil. Open copses and open pine woods. Bibb, Autauga, Montgomery, Clarke, Washington, Escambia, Mobile, and Baldwin counties. Flowers pink; June, July. Common. Perennial. One to $1 \frac{1}{3}$ feet high. Most frequent in the dry pine barrens of the Coast Pine belt. Type locality: "Hab. in America septentrionali."

Herb. Geol. Surv. Herb. Mohr.

Verbena angustifolia Michx. Fl. Bor. Am. 2:14. 1803. Narrow-leaf Vervain. Gray, Man. ed.6, 402. Chap. Fl. 307. Gray, Syn. Fl. N. A. 2, pt. 1:336.

Alleghenian and Carolinian areas. Ontario; New England, west to Minnesota; southern Ohio Valley, Missouri, Arkansas, and Tennessee.

Alabama: Tennessee Valley to Central Prairie region. Exposed places, borders of tields, pastures. Jackson County, Stevenson, 600 feet. Madison and Marshall counties. Morgan County, Decatur. Montgomery County. Flowers blue; May to July. Frequent. Most frequent in the stiff calcareons clay soil all over the Tennessee Valley. Perennial.

Type locality: "Hab. in Tennassée et in comitatu Carlisle, Pennsylvaniae."

Herb. Geol. Surv. Herb. Mohr.

Verbena hastata L. Sp. Pl. 1:20. 1753.

Blue Vervain.

Verbena paniculata Lam. Encyel. 8:548. 1808.

Ell. Sk. 1:97. Gray, Man. ed. 6, 402. Chap. Fl. 307. Gray, Syn. Fl. N. A. 2, pt. $1: 336$.

Alleghenian and Carolinian areas. Nova Scotia and Quebec to Manitoba; New England west to Minnesota, Missouri, Arkansas, New Mexico, California, and south through the Ohio Valley to Tennessee, South Carolina, and Georgia.

Alabama: Tennessee Valley. Jackson County, Stevenson (E. A. Smith). Scarce.

Perennial.

Type locality: "Hab. in Canadao humidis."

Herb. Geol. Surv.

Verbena bracteosa Michx. Fl. Bor. Am. 2:13. 1803.

Verbena canescens Chap. Fl.307. 1860. Not H. B. K.

Gray, Man. ed.6, 402. Gray, Syn. Fl. N. A. 2, pt. 1:336. Coulter, Contr. Nat. Herb. $2: 327$.

Alleghenian to Lonisianian area. Saskatchewan, British Columbia; Minnesota, Michigan, the Ohio Valley, Missouri, Arkansas, southern Tennessee, and from Florida to Texas.

Alabama: Tennessee Valley. Lawrence County, Moulton. Tuscaloosa, Montgomery, and Mobile counties. Open sandy places, pastures, roadsides. Always near dwellings. Flowers purplish; July to September. Not frequent. Annual or perennial.

Type locality: "Hab. in regione Illinoensi et in urbe Nash-ville."

Herb. Geol. Surv.

Verbena canadensis (L.) Britton, Mem. Torr. Club, 5 :276. 1894.

Buchnera canadensis L. Mant. 1:88. 1767.

Aublet's Verbena.

Verbena aubletia Jacq. Hort. Vindeb. $2: 82, t, 176.1772$.

Ell. Sk. 2:96. Gray, Man. ed. 6, 402. Chap. Fl. 307. Gray, Syn. Fl. N. A. 2, pt. 1: 337.

Coulter, Contr. Nat. Herb. ? : 328. 
Carolinian and Lonisianian areas. Southern Illinois, southern Missouri, south to Texas and east to Florida and South Carolina.

Alabama: Prairie region. Dry prairies. Wilcox County (S. B. Buckley). Tuscaloosa County (E.A. Smith). Flowers rose-purple, showy; March, April. Rare; frequently cultivated. Perennial.

Type locality: "Hab. in Virginia."

Herb. Geol. Surv. Herb. Mohr.

Verbena rigida Spreng. Syst. Veg. 4, pt. 2:230. 1827.

Rigid Veribena.

Verbena venosa (iill \& Hook. in Hook. Bot. Misc. 1:167. 1830.

Introduced from Brazil and escaped from cultivation. Naturalized on the Gulf coast and in sonthern Texas.

Alabama: Mobile County, roadsides, waste places near dwellings. Flowers carmine; April, May. Not infrequent. Perennial.

Type locality: "Rio Grande. Sello." (Brazil.)

Herb. Geol. Surv. Herb. Mohr.

Verbena bonariensis L. Sp. Pl. ed. 2, 1:28. 1762.

Adventive from southern Brazil, Argentina.

AlabaMa : Mobile County, fugitive on ballast. Flowers purplish; July. A coarse branching plant, 2 to 3 feet high. Observed first July, 1893, and subsequent seasons; spreading to roadsides. Perennial.

Type locality : "Hab. in agro Bonariensi."

Herb. Geol. Surv. Herb. Mohr.

Verbena tenera Spreng. Syst. Veg. 2 : 750. 1827.

Adventive from southern Brazil, Argentina.

Alabama: Mobile Connty, fugitive on ballast (Hunter's Wharf). Flower deep blue; August, September. 1893-1895. Low creeping, the suffruticose stem 1 to 2 feet long. Perennial.

Type locality: "Monte Video. Sello."

Herb. Geol. Surv. Herb. Mohr.

Verbena canescens H. B. K. Nov. Gen. \& Sp. 2 : 274, t. 136. 1814.

Adventive from Mexico.

Mobile County, on ballast heaps. June to November, 1892-1894. Flowers lilac.

Perennial.

Type locality: "Crescit in montibus Mexicanorum, prope Guanaxuato, Marfil et fodinam Belgrado, alt. 1000-1250 hex."

Herb. Geol. Surv.

ABENA Necker, Elem. Bot. 1. 1790.

(Stachytarpieta Vahl, Enum. 1:205. 1805.)

About 40 species, tropical America.

Abena jamaicensis (L.) A. S. Hitchcock in Trelease, Rep. Mo. Bot. Gard. 1893.

Verbena jamaicensis L. Sp. Pl. 1: 19. 1753.

Stachytarpheta jamaicensis Vahl, Enum. 1:206. 1805.

Gray, Syn. Fl. N. A. 2, pt. 1:334. Griseb. Fl. Brit. W. Ind. 494.

West INDIES, Souti AMERICA.

Louisianian area. Sonthern Florida.

Alabama : Fugitive on ballast. Mobile County, September, 1893. Not observed since. Annual.

Type locality: "Hab. in Jamaica et Caribaeis."

Herb. Geol. Surv. Herb. Mohr.

BOUCHEA Cham. Linnaea, 7:253. 1832.

Tropical regions of Africa, India, America.

Bouchea prismatica (L.) Kuntze, Rev. Gen. Pl.2:502. 1891.

Verbena prismatica L. Sp. Pl. 1: 19. 1753.

Stachytarpheta prismatica Vahl, Enum. 1:205. 1805.

Bouchea ehrenbergii Cham. Linnaea, 7:253. 1832.

Gray, Syn. Fl. N. A. 2, pt. 1:334. Griseb. Fl. Brit. W. Ind. 493. 
West Indies, Mexico, Venezuela.

Louisianian and Lower Sonoran areas. Southern Arizona.

Alabama: Fugitive on ballast. Mobile County, September, 1893-94. Flowers deep blue. Annual.

Type locality: "Hab. in Jamaica."

Herb. Geol. Surv. Herb. Mohr.

IIPPIA L. Sp. Pl. 2 : 633.1753.

Ninety species, chiefly tropical America. West Indies to Brazil. Argentina.

Lippia nodiflora (L.) Michx. Fl. Bor. Am. 2:15. 1803.

Verbèna nodiflora L. Sp. PI. 1:20. 1753.

Spatulate-leaved Fog Fruit.

Ell. Sk. 2:101. Chap. Fl.308. Gray, Syn. Fl. N. A. 2, pt.1:339. Coulter, Contr. Nat. Herb. $2: 329$.

CosMopolitan, on the coasts of warmer regions.

Louisianian area. South Carolina and Florida to Texas.

Alabama : Coast plain. Littoral regions. Damp sandy places. Mobile County.

Baldwin County. Flowers pink; May to November. Abundant. Closely ereeping.

Perennial.

Type locality: "Hab. in Virginia."

Herb. Geol. Surv. Herb. Mohr.

Lippia Janceolata Michx. Fl. Bor. Am. 2 : 15. 1803.

LaNCe-leaf Fog Fruit. Ell. Sk. 2 : 101. Gray, Man. ed. 6, 402. Coulter, Contr. Nat. Herb. 2 : 329.

Mexico.

Carolinian and Louisianian areas. Pennsylvania to Michigan, Missouri, Arkansas, and Texas, and from West Virginia to Tennessee.

Alabama: Lower hills. Damp banks. Tuscaloosa County (E. A. Smith). Rare. Perennial.

Type locality: "Hab. in Carolina juxta amniculum Ashley."

Herb. Geol. Surv. Herb. Mohr.

LANTANA L.Sp.Pl. 2: 627. 1753.

Fifty species, tropical, chiefly of the West Indies and South America to Brazil. Trees or shrubby.

Lantana camara L. Sp. Pl. 2:627. 1753.

Ell. Sk. 2:102. Chap. Fl. 308. Gray, Syn. Fl.N. A.2, pt.1:340. Coulter, Contr.

Nat. Herb. $2: 329$. Griseb. Fl. Brit. W. Ind. 495.

West Indies, Mexico. to Brazil.

Louisianian area. Southern Georgia, Florida, southwestern Texas.

Alabama : Coast plain. Waste places near dwellings, escaped from cultivation. Flowers orange and deep flame color; May to October. Fruit a bluish black, shining berry. Not infrequent. Shrub 3 to 4 feet high.

'Type locality : "Hab. in America calidiore."

Herb. Geol. Surv. Herb. Mohr.

CALLICARPA L. Sp. Pl. 1:111. 1753.

About 35 species, eastern Asia, New Holland, West Indies. North America, 1.

Callicarpa americana L. Sp. Pl. 1:111. 1753.

French MULberRy.

Ell. Sk. 1: 199. Gray, Man. ed. 6, 403. Chap. Fl. 309. Gray, Syn. Fl. N. A. 2, pt. 1:340. Coulter, Contr. Nat. Herb. $2: 330$.

Carolinian and Louisianian areas. West Virginia, central Tennessee to Florida, and west to Texas.

Alabama: Mountain region to Coast plain. Dry open woods and copses. Clay County, Moseley, 1,000 feet. Cullman County, 800 feet. Lee County, Auburn, 860 feet. Autauga, Clarke, Lscambia, and Mobile counties. Flowers pink; June, July. Fruit ripe September, October; rose-pink. Common. A form with white berries not rare about Mobile. Shrub 6 to 10 feet high.

Type locality: "Hab. in Virginia, Carolina."

Herb. Geol. Surv. Herb. Mohr. 
PHRYMA L. Sp. Pl. 2 :601. 1753.

One species, eastern Asia, Japan, North America.

Phryma leptostachya L. Sp. Pl. 2 : 601. 1753.

LOPSEED.

Ell. Sk. 2:96. Gray, Man. ed. 6, 403. Chap. Fl. 316. Gray, Syn. Fl. N. A. 2, pt. 1: 334 .

Alleghenian to Louisianian area. New Brunswick, Quebec, Ontario; New England west to Minnesota and Nebraska, south to the Ohio Valley, Missouri, and Arkansas, and from New York to Florida and northern Mississippi.

Alabama: Tennessee Valley and valleys in the mountain region. Damp, rich forests. Blount County, bottom lands of Mulberry Fork. Flowers purplish; June. Not common. Perennial.

Type locality: "Hab. in America septentrionali."

Herb. Geol. Surv. Herb. Mohr.

\section{NEPETACEAE. Mint Family.}

MESOSPHAERUM P. Br. Hist. Jam. 257. 1756. SWAMP Basil.

(Hyptis Jacq. Coll. 1:101. 1786.)

About 250 species of tropical and subtropical America. West Indies to Brazil. United States, 4.

Mesosphaerum rugosum (L.) Pollard, Bull. Torr. Club, 24 : 156. 1897.

Clinopodium rugosum L. Sp. Pl. ed. 2, 2:822. 1763.

Hyptis radiata Willd. Sp. Pl. 3: 84 . 1800.

Ell. Sk. 2:78. Chap. Fl. 312. Gray, Syn. Fl. N. A. 2, pt. 1:350. Coulter, Contr. Nat. Herb. $2: 333$.

Louisianian area. North Carolina to Florida, west to Texas.

Alabama: Central Pine belt. Lower Pine region. Margins of pine-barren ponds. Autanga County (E. A. Smith). Flowers white, purplish-dotted; July, Angust. Common. Stem from a creeping rootstock, simple, 2 to 4 feet high. Abundant throughout the Lower Pine region. Perennial.

Type locality: "Hab. in Caroliua, Jamaica, Gallia aequinoctiali."

Herb. Geol. Surv. Herb. Mohr.

COLLINSONIA L. Sp. Pl. 1:28. 1753. Horse Balm.

Four species, perennials. Eastern North America.

Collinsonia scabriuscula Ait. Hort. Kew. 1:47. 1789.

Collinsonia tuberosa Michx. Fl. Bor. Am. 1: 17. 1803.

C. scabra Pursh, 1:20. 1814.

Eil. Sk. 1:35, 36. Chap. Fl. 316. Gray, Syn. Fl. N. A. 2, pt. 1: 351. iana.

Carolinian and Louisianian areas. South Carolina to Florida and eastern Louis-

Alabama: Mountain region to Lower Pine region. Damp thickets. Cullman County, 800 feet. Cleburne County, Wood's mine, 1,000 feet. Lee County, Opelika. Escambia County, Wilson Station, 250 feet, shaded borders of pine-barren streams. Flowers yellowish white with purple spots; September, October. Not rare. From a thick tuber-like root, 2 to $2 \frac{1}{2}$ feet high.

Type locality: "Native of East Florida. Mr. John Bartram."

Herb. Geol. Surv. Herb. Mohr.

Collinsonia canadensis L. Sp. Pl. 1:28. 1753.

Canadian Horse Balm.

Ell. Sk. 1:34. Gray, Man. ed. 6, 407. Chap. Fl. 315. Gray, Syu. Fl. N. A. 2, pt. 1:351.

Alleghenian and Carolinian areas. Western Ontario; New England and New York, west to Michigan and Wisconsin, south to the Ohio Valley and Tennessee, and along the mountains to middle Florida and northern Mississippi.

AldbaMa: Mountain region. Rich woodlands. Winston County, 1,500 feet ( $T$. $M$. Peter s). Cullman County, 800 feet. Flowers lemon-yellow; July, August. Two to 3 feet high. From a hard, knotty, thick rootstock; infrequent.

Economic uses: The root is the "stone root" of medicine.

Type locality: "Hab. in Virginiae, Canadae sylvis."

Herb. Geol. Surv. Herb. Mohr. 
Collinsonia anisata Sims, Bot. Mag. 29 : t.1213. 1809.

Citronella.

Ell. Sk. 1:37. Chap. Fl. 316. Gray, Syn. Fl. N. A. 2, pt. 1: 351.

Louisianian area. South Carolina to Florida, west to Mississippi.

Alabama : Metamorphichills. Coast Pine belt. Coast plain. Shaded banks. Lee County, Auburn (F. S. Earle). Clarke County, Suggsville (Dr. Denny). Mobile and Baldwin counties. Flowers yellow; September, October. Frequent. Perennial. From a ligneous root; $1 \frac{1}{2}$ to 2 feet high.

Economic uses: The anise-scented leaves yield "citronella tea," used medicinally. Type locality: "A native of South Carolina."

Herb. Geol. Surv. Herb. Mohr.

PERILLA Ard.; L. Gen. Pl. ed. 6, Add. 578. 1764. East India Basil.

One or 2 species, Eastern Asia, India, China.

Perilla frutescens (L.) Britton, Mem. Torr. Club, 5 :277. 1894.

Ocimum frutescens L. Sp. Pl. 2:597. 1753.

Perilla ocymoides L. Gen. Pl. ed. 6, add. 578. 1764.

India, China.

Introduced and naturalized. District of Columbia and sonthward.

Alabama : Coast plain. In low shaded or exposed waste places. Flowers purple; October. A coarse annual, escaped from cultivation, lecoming a common wayside weed.

Type locality: "Hab. in India."

Herb. Geol. Surv. Herb. Mohr.

MENTHA L. Sp. Pl. 2:576. 1753. Mint.

Thirty to 40 species, chiefly in temperate regions, Northern Hemisphere. Europe, northern Asia. North America, endemic, 1. About 1 dozen species, naturalized from Europe.

Mentha piperita L. Sp. P1. 1:576. 1753.

Peppeimint.

Europe.

Escaped from cultivation to low damp places. Flowers pink; July. Infrequent. Perennial.

Economic uses: The herb forms the "peppermint" or "Mentha piperita" of the

United States Pharmacopœia.

Type locality: "Hab. in Anglia."

Herb. Geol. Surv. Herb. Mohr.

Mentha spicata L. Sp. Pl. 1:576. 1753.

Spearmint, Applemint.

Mentha viridis L. Sp. Pl. ed. 2, 2: 804. 1763.

Europe.

Escaped from cultivation and naturalized; low damp places; ditches; more frequent than the last. July, August. Perennial.

Economic uses: The herb is the "Spearmint," "Mentha viridis" of the United States Pharmacopœia.

Type locality: "Hab. in Dania, Germania, Anglia, Gallia."

Herb. Geol. Surv. Herb. Mohr.

Mentha rotundifolia (L.) Huds. Fl. Angl.221. 1762. Applemint. False Catnip. Mentha spicata var. rotundifolia L. Sp. Pl. 1:576. 1753.

SOUTHERN Europe.

Carolinian and Louisianian areas. Naturalized on the Atlantic coast from southern New England to Florida and on the Gulf coast.

Alabama: Coast plain. Low damp places, ditches. Mobile County. Flowers, June to September. Common. An aromatic perennial, $1 \frac{1}{2}$ to 2 feet high.

Economic uses: The herb is used as a substitute for catnip.

Type locality : Same as of last.

Herb. Geol. Surv. Herb. Mohr.

IYCOPUS L. Sp. Pl. 1:21. 1753. WATER HOARHOUND.

Ten species, temperate regions of the Old World. Australia. North America, 6.

Lycopus virginicus L. Sp. Pl. 1:21. 1753.

BUGLEWEED,

Ell. Sk. 1:25. Gray, Man. ed.6, 408. Chap. Fl.313. Gray, Syn. Fl. N. A. 2, pt. 1: 353.

Boreal zone to Louisianian area. Labrador across the continent to British Columbia and Oregon; New England to Nebraska, south to Florida and Louisiana. 
Alabama: Tennessee Valley to Lower hills. Low, wet, shaded places, bottom lands. Lee County, Auburn (F. S. Earle). Lauderdale, Blount, and Jefferson counties. Flowers purplish; June. Roots stoloniferous. Perennial.

Economic uses: The herb, under the name of "bugleweed," is used medicinally. Type locality: "Hab. in Virginia."

Herb. Geol. Surv. Herb. Mohr.

Lycopus rubellus Moench, Meth. Suppl.146. 1802.

REDDISII BUGLEWEED.

Gray, Man. ed. 6, 408. Chap. Fl. ed. 3, 375. Gray, Syn. Fl. N. A. 2, pt. 1: 353.

Carolinian and Lonisianian areas. New Jersey to Florida, west to Louisiana, Arkansas and sontluwestern Missouri.

Alabama : Lower Pine region, Coast plain. Borders of swamps, ditchas. Mobile County. Flowers white to pale pink; August to October. Common. Stoloniferous, 2 to $2 \frac{1}{2}$ feet high. Perennial.

Type locality not ascertained.

Herb. Geol. Surv. Herb. Mohr.

CUNILA L. Syst. ed. 10, 2 : 1359. 1759.

Fifteen species, North America, Mexico. South America to Argentina.

Cunila origanoides (L.) Britton, Mem. Torr. Club, 5 : 278. 1894. American Dittany. Satureia origanoides L. Sp. Pl. 2:568. 1753.

Cunila mariana L. Syst. ed. 10, 1359. 1759.

$1: 353$.

Ell. Sk. 1:27. Gray, Man. ed. 6, 409. Chap. Fl. 313. Gray, Syn. Fl. N. A. 2, pt.

Carolinian area. New Jersey, Virginia, and the Ohio Valley to Missouri, Arkansas, and 'Tennessee, and along the mountains to North Carolina and northern Mississippi.

Alabama : Tennessee Valley, Mountain region, Lower hills. Dry rocky woods and hillsides. Lauderdale County. Cullman County, 800 feet. Blount and Tuscaloosa counties. Flowers purplish; July, August. Frequent. Perennial.

Economic uses: The herb called "mountain dittany" is used in domestic medicine. Type locality : "Hab. in Virginia."

Herb. Geol. Surv. Herb. Mohr.

KOELLIA Moench, Meth.417. 1794.

(Brachystemon Michx. Fl. Bor. Am. 2:5. 1803.)

(Pycnanthemum Michx. Fl. Bor. Am. 2: 7. 1803.)

Sixteen species, perennial herbs, Atlantic America, Alleghenian, and Southerr. Pacific, 1.

Koellia nuda (Nutt.) Kuntze, Rev. Gen. Pl. 2:520. 1891.

Pycnanthemum nudum Nutt. Gen. $2: 34.1818$.

Bare STEMMED Horsemint.

Ell. Sk. 2:81. Chap. Fl. 315. Gray, Syn. Fl. N. A. 2, pt. $1: 354$.

Louisianian area. South Carolina (low country) and Georgia.

Alabama: Upper division Coast Pine belt. Grassy shaded banks in sandy soil. Dale County (Chapman). Flowers white; August, September, rare.

Type locality: "In the mountains of Carolina and Georgia."

Herb. Geol. Surv. Herb. Mohr.

Koellia hyssopifolia (Benth.) Britton, Mem. Torr. Club 5 : 279. 1894.

HYSSOP-Leaf Mountain Mint.

Pycnanthemum hys8opifolium Benth. Lab. Gen. \& Sp. 329. 1834.

$P$. aristatum var. hyssopifolium Gray, Syn. Fl. N. A.2, pt. 1:354. 1878.

Chap. Fl. 314. Gray, Man. ed. 6, 409.

Carolinian and Louisianian areas. North Carolina to Florida.

Alabama: Central Pine belt. Dry open places. Tuscaloosa County. Chilton County (E. A. Smith). Flowers white; July. Rare.

Type locality: "Hab. in America boreali : in Virginia herb. Hooker! Carolina Bosc! Georgia Torrey! Louisiana Drummond!"

Herb. Geol. Surv. Herb. Mohr.

Koellia flexuosa (Walt.) MacMillan, Metasp. Minn. Val.452. 1892.

Virginian Thyme.

Satureja thymus virginicus L. Mant. 2:409. 1771. Not Satureja virginiana L. 1753. Origanum flexuosum Walt. Fl. Car. 165. 1788.

Pycnanthemum linifolium Pursh, Fl. Am. Sept. 1:409. 1814. 
Ell. Sk. 2 : 82. Gray, Man. ed. 6, 410. Chap. Fl.315. Gray, Syn. Fl. N. A. 2, pt. 1: 354. Coulter, Contr. Nat. Herb. $2: 334$.

Carolinian and Louisianian areas. Ontario and southern New England to Virginia, west to Missouri, Arkansas, and Tennessee, sou ${ }^{+} h$ to Florida and west to Texas.

Alabama: Tennessee Valley. Mountain region to Central Prairie belt. Close damp exposed ground, meadows, and prairies. Lauderdale County, abundant in the harrens. Cullman County, 800 feet altitude. Tuscaloosa County (E. A. Smith). Montgomery and Dallas counties. Flowers June, July. Abuudant in low wet prairies and in the barrens.

Economic uses: The herb known as "mountain mint" or "Pycnanthemum" is used medicinally.

Type locality: Sonth Carolina.

Herb. Geol. Surv. Herb. Mohr.

Koellia pycnanthemoides (Leavenw.) Kuntze, Rev. Gen. Pl. 2:520. 1891.

Mountain BasiL.

Tullia pycnanthemoides Leavenw. Am. Journ. Sci. $20: 343$, t. 5.1830.

Pycnanthenum tullia Benth. Lab. Gen. \& Sp. 328. 1834.

Gray, Man. ed. 6, 410. Chap. Fl. ed. 3, 376. Gray, Syn. Fl. N. A. 2, pt. 1: 3ొ55.

Carolinian and Louisianian areas. Southern Virginia and along the mountains to 'Tennessee, North Carolina, and Georgia.

Alabama: Mountain region, Coosa hills. Dry copses and borders of woods. Clay County, Talladega Mountains to 2,200 feet altitude. Cullman County, 800

feet. Talladega County, Chandler Springs, 1,200 feet; Renfroe, 800 feet altitude. Lee County, Auburn. Calhoun County, Anniston. Flowers purplish; August, September. Frequent.

Type locality: "Paint Mountain in Eastern Tennessee."

Herb. Geol. Surv. Herb. Mohr.

Koellia albescens (Torr. \& Gr.) Kuntze, Rev. Gen. PI. 2:520. 1891

WHITISH BASIL.

Pycnanthemum albescens Torr. \& Gr.; Gray, Am. Journ. Sci.42:45. 1842.

$P$. incanum var. albescens Chap. Fl.314. 1860.

Chap. Fl.1. c. Gray, Syn. Fl. N. A. 2, pt. 1:356. Coulter, Contr. Nat. Herb. 2 : 335. Louisianian area. Florida to Texas and Arkansas.

Alabama : Lower Pine region. Coast plain. Dry borders of woods, fence rows. Flowers white; July to September. Slightly fragrant.

Type locality: "Hab. in Louisiana, Ingalls, Hale, et Alabama, Gates."

Herb. Geol. Surv. Herb. Mohr.

Koellia montana (Michx.) Kuntze, Rev. Gen. Pl. 2:520. 1891.

Pycnanthemum montanum Michx. Fl. Bor. Am. 2: 8. 1803.

Ell. Sk. 2:80. Chap. Fl.315. Gray, Syn. Fl. N. A. 2, pt. 1:356.

Carolinian area. Mountains southern Virginia, Tennessee to Georgia.

Alabama. Mountain region. Fide Gray. Not observed lately.

'Type locality: "Hab. in altis montibus Carolinae."

HEDEOMA Pers. Syn. $2: 131.1807$.

Twelve species. South and North America, 10; mostly Southwestern in the Lower Sonoran area.

Hedeoma pulegioides (L.) Pers. Sỹ. 2 : 131. 1807.

American Pennyroyal.

Melissa pulegioides L. Sp. P1. 2 : 593.1753.

Cunila pulegioides L. Sp. Pl. ed. 2, 1:30. 1762.

Ell. Sk. 1:28. Gray, Man. ed.6, 412. Chap. Fl.316. Gray, Syn. Fl. N. A. 2, pt. 1: 362.

Alleghenian, Carolinian, and Louisianian areas. Coast of Nova Scotia, New Brunswick, Quebec, and Ontario; southern New England west to Iowa, south to the Ohio Valley, Missouri, Arkansas, and Tennessee, and along the mountains to Georgia.

Alabama: Tennessee Valley. Mountain region. Metamorphic hills. Dry open woods and hillsides. Madison County, Huntsville. Lauderdale County. Cullman County, 800 feet. 'Tallapoosa County, Dadeville. Tuscaloosa County. Abundant wherever it occurs. Annual.

Economic uses: The herb is the "pennyroyal" or "Hedeoma" of the United States Pharmacopœia.

Type locality: "Hab. in Virginia, Canada."

Herb. Mohr. 
DICERANDRA Benth. Bot. Reg. 15, sub t. 1300. 1829.

(Ceranthera Ell. Sk. $2: 93$. 1821-24. Not Beauv.1807, nor Raf. 1818.)

Two species, annuals. Southeastern North America.

Dicerandra linearifolia (Ell.) Benth. Bot. Reg. 15, sub t. 1300. 1829.

Ceranthera linearifolia Ell. Sk. 2 : 94. 1821-24.

LARge-Flowered PenNyroyal.

Dicerandra linearis Benth. Lab. Gen. \& Sp.413. 1834.

Ell. Sk.1. c. Chap. Fl.318. Gray, Syn. Fl. N. A. 2, pt. 1: 365.

Louisianian area. Georgia and Florida.

Alabama: Coast plain. Dry sandy pine barrens. Dale County (E. A. Smith). Baldwin County, Stockton. Flowers pale pink, purple-spotted; August, September. Not frequent. Local. Highly aromatic.

Type locality: "Grows abundantly in the high pine barren ridges between the Flint and Chatahouchie rivers."

Herb. Geol. Surv. Herb. Mohr.

CLINOPODIUM L. Sp. Pl. 2:587. 1753.

(Calamintha Moench, Meth. 408. 1794.)

About 40 species, temperate regions Northern Hemisphere. Europe, northern Asia. North America, 9.

Clinopodium nepeta (L.) Kuntze, Rev. Gen. Pl. $2: 515.1891$.

Melissa nepeta L. Sp. Pl. 2 :593. 1891.

Calanintha nepeta Savi, Fl. Pis. 197. 1798.

Gray, Man. ed. 6, 411. Chap. Fl. 317. Gray, Syn. Fl. N. A. 2, pt. 1:359.

Europe.

Carolinian area. Naturalized from Maryland and Tennessee to upper Georgia.

Alabama: Tennessee Valley to Central Pine belt. Dry rocky or gravelly exposed ground. Morgan County, Decatur. Lawrence County, Moulton. Blount County, Blount Springs. Etowah County, Gadsden, banks of Coosa River. 'Tuscaloosa County. Mobile County, on ballast. Flowers July to September. Most frequent in the calcareous soils of the T'enuessee Valley and all the higher river valleys where the limestone is exposed. Perennial.

Type locality: "Hab. in Italiae, Galliae, Angliae, Helvetiae, aggeribus glareosis."

Herb. Geol. Surv. Herb. Mohr.

Clinopodium carolinianum (Walt.) Kuntze, Rev. Gen. Pl. 2:515. 1891.

Thymbra caroliniana Walt. Fl. Car. 162. 1788.

Thymus carolinianus Michx. Fl. Bor. Am. 2:9. 1803.

Calamintha grandiflora Pursh, Fl. Am. Sept. 2:414. 1814.

Melissa caroliniana Benth. Lab. Gen. \& Sp. 388. 1834.

Ell. Sk. 2:93. Chap. Fl. 317. Gray, Syn. Fl. N. A. 2, pt. 1:360.

Louisianian area. South Carolina to Florida, west to Mississippi.

Alabama : Central region to Coast Pine belt. Dry hills, open woods. Lee County (E. A. Smith). Coffee Connty, Elba. Choctaw County, Butler. Mobile County, Pierce's Landing, in dry pine woods. Flowers purple. Local, not frequent. Shrubby at the base. Perennial.

Type locality: South Carolina.

Herb. Geol. Surv. Herb. Mohr.

Clinopodium coccineum (Nutt.) Kuntze, Rev. Gen. Pl. 2:515. 1891.

Cunila coccinea Nutt.; Hook. Exot. Fl. 2 : $t .163 .1825$.

Scarlet Balm.

Melissa coccinea Spreng. Syst. $2: 224$. 1827.

Calamintha coccinea Gray, Syn. Fl. N. A. 2, pt. 1:360. 1878.

Chap. Fl. 317. Gray, Syn. Fl. 1.c.

Louisianian area. Western Florida.

Alabama: Lower Pine region. Coast plain. Dry sandy pine ridges. Mobile County, Springhill. Baldwin County, Montrose. Flowers deep scarlet, not rarely orange or saturn-red; September, November. Local; frequent on the hills near the coast, covering large patches. Shrub $1 \frac{1}{2}$ to 2 feet; when in full bloom, one of the handsomest of our pine-barren plants.

Type locality: "So named by Mr. Nuttall, from a dried specimen brought by Mr.

Ware to Philadelphia from Florida."

Herb. Geol. Surv. Herb. Mohr. 
CONRADINA Gray, Proc. Am. Acad. 8:244. 1872.

Two species, southeastern United States.

Conradina canescens (Torr. \& Gray) Gray, Proc. Am. Acad. 8:244. 1872.

Seaside Balm.

Calamintha canescens Torr. \& Gray; Benth. in DC. Prodr. 12:229. 1846.

Chap. Fl.318; ed. 3, 380. Gray, Syn. Fl. N. A. 2, pt. 1: 361. 1878.

Louisianian area. Sandy seashores, eastern Florida, Indian River, Tampa Bay, western Florida.

Ala bama: Coast plain. Drifting sands, mostly close to the seashore. Mobile County, Navy Cove. Baldwin County, Perdido Bay. On the road from Bay Minnette to Stockton, high sandy ridges. Flowers lilac; September, October. Not rare. Shrub $1 \frac{1}{2}$ to 3 feet high.

Type locality: "In Florida ad Tampa Bay (h. Gray!) ad Apalachicola (Drumm.!)." Herb. Geol. Surv. Herb. Mohr.

SALVIA L. Sp. Pl. 1:23. 1753. SAgE.

Four hundred and fifty species, temperate and warmer regions, cosmopolitan.

Salvia coccinea Juss.; Murr. Comm. Goett. 1:86, t. 1. 1778.

SCARLET-FLOWERED SALVIA.

Ell. Sk. 1:32. Gray, Syn. Fl. N. A. 2, pt. 1:368. Coulter, Contr. Nat. Herb. 2 : 338.

West Indies, Mexico to Brazil.

Louisianian area. Coast of South Carolina, Florida, and southern Texas.

AlabaMa: Coast plain. Adventive from the adjacent tropical regions. Mobile County, waste places, hedge rows, near dwellings. Flowers scarlet; June, July.

Infrequent. Perennial.

Economic uses: Ornamental.

Type locality not ascertained.

Herb. Geol. Surv. Herb. Mohr.

Salvia azurea Lam. Journ. Hist. Nat. 1: 409. 1792.

Azure Salvia.

Ell. Sk. 1:33. Chap. Fl.319. Gray, Syn. Fl. N. A. 2, pt. 1:369. Coulter, Contr.

Nat. Herb. $2: 338$.

Carolinian and Louisianian areas. South Carolina to Florida, west to Texas and Arkansas.

Alabama : Lower hills to Coast plain. Cullman County, southern border, about 500 or 600 feet. Lee, Bibb, Montgomery, Mobile, aud Baldwin counties. Flowers azure; September, October. Most frequent in the Lower Pine region. A form with white flowers is not rarely met with. 'Two to 4 feet high. Perennial.

Type locality (Lam. Encycl.): "Cette plante croit dans la Caroline meridionale." Herb. Geol. Surv. Herb. Mohr.

Salvia urticifolia L. Sp. P1. 1:24. 1753.

Nettle-leaf Salvia.

Ell. Sk. 1:32. Gray, Man. ed. 6, 413. Chap. Fl. 319. Gray, Syn. Fl. N. A. 2, pt. 1:370.

Carolinian and Louisianian areas. Southern Kentucky and Tennessee, along the mountains to Georgia.

Alabama: Mountain region to Central Pine belt. Lee Count 5 , Auburn (Baker \& Earle). Madison County, Huntsville, 600 to 700 feet. Bibb County (E. A. Smith). Tuscaloosa County. Elmore County, Robinsou Springs. Flowers deep blue; May. Perennial.

Type locality: "Hab. in Virginia."

Herb. Geol. Surv. Herb. Mohr.

Salvia chapmani Gray, Syn. Fl. N.A.2, pt. 1:370. 1878.

Salvia urticaefolia var. major Chap. Fl.319. 1860.

Chap. Fl. 1. c.; ed. 3, 387. Gray, Syn. Fl.l. c.

Carolinian and Louisianian areas. Georgia and Florida.

Alabama: Buckley, fide Gray, l. c.; not collected lately in the State. Perennial. Type locality: "Middle Florida, Chapman. Alabama, Buckley."

Herb. Geol. Surv. Herb. Mohr.

Salvia lyrata L. Sp. Pl. 1:23. 1753.

MEADOW SAGE.

Ell. Sk. 1:31. Gray, Man. ed. 6, 413. Chap. Fl.319. Gray, Syn. Fl. N. A. 2, pt. 1:

367. Coulter, Contr. Nat. Herb. $2: 337$.

Carolinian and Louisianian areas. New Jersey to Virginia, west to Missouri and Arkansas, south to Florida and the Gulf coast to Texas. 
Alabaya : Tennessee Valley to the Coast plain. Damp grassy woodlands and

banks. Mobile County. Flowers sky-blue; early in April. Common. Perennial. Type locality: "Hab. in Virginia."

Herb. Geol. Surv. Herb. Mohr.

Salvia verbenacea L. Sp. Pl. 1:25. 1753.

Vervain-Leaf Sage.

Salvia claytoni Ell. Sk. 1: 32.1816.

Gray, Syn. Fl. N. A. 2, pt. 1: 372.

Adventive from Europe. Sparingly naturalized on the coast of South Carolina.

Alabama: Adventive on ballast. Mobile County. Becoming sparingly naturalized, not spreading. Observed for the past ten years. Perennial.

Type locality: "Hab. in Europae pascuis."

Herb. Geol. Surv. Herb. Mohr.

MONAKDA L. Sp. Pl. 1:22. 1753. HORSEMINT.

Ten species, Atlantic North America, chiefly Alleghenian.

Monarda fistulosa L. Sp. Pl. 1:22. 1753.

WILD BERGAMOT.

Ell. Sk. 1:29. Gray, Man. ed. 6, 414. Chap. Fl. 320. Gray, Syn. Fl. N. A. 2, pt. 1:

374. Coulter, Contr. Nat. Herb. $2: 339$.

Alleghenian and Carolinian areas. Ontario to Lake Superior; Quebec and New

England west to Minnesota, Nebraska, and Dakota; west and south from Virginia

to Missonri and Texas, and along the mountains to Georgia.

Alabama : Mountain region, Coosa hills. Open rocky woods, fence rows, thickets.

Cullman County. St. Clair County, Springville. Madison County, Huntsville.

Flowers pink; June. Common. Perennial.

Type locality: "Hab. in Canada."

Herb. Geol. Surv. Herb. Mohr.

Monarda scabra Beck, Am. Journ. Sci.10:260. 1826. Scabrous Wild Bergamot. Monarda fistulosa var. mollis Benth. Lab. Gen. \& Sp. 317. 1833 . In part.

Ell. Sk. 1: 28. Gray, Man. ed. 6, 414; Syn. El. N. A. 2, pt. 1:374.

Carolinian area. Canada across the plains to the Pacific coast; Tennessee, Arkansas, and Indian Territory to Arizona and Texas.

Alabama : Mountain region. Cullman County, rocky woods, copses; June. Not frequent. Perennial.

Type locality: "Woods on the banks of the Mississippi River, one mile north of St. Louis."

Herb. Geol. Surv. Herb. Mohr.

Monarda bradburyana Beck, Am. Journ. Sci.10:260. 1826.

Bradbury's Monarda.

Gray, Man. ed.6, 414. Chap. Fl. ed.3, 382. Gray, Syn. Fl. N. A. 2, pt. 1: 374 .

Carolinian area. Tennessee, sonthern Ohio, Illinois, Missouri, and Kansas, and along the mountains to Georgia.

Alabama: Mountain region. Coosa hills, sunny hillsides, open woods. Madison County, Huntsville, 1,000 feet. Cullman County, 800 feet. St. Clair County, hills of Shoal Creek, 650 feet. Flowers pink; June. Not rare. Perennial.

Type locality: "Barrens north of St. Louis."

Herb. Geol. Surv. Herb. Mohr.

Monarda punctata L. Sp. Pl. 1:22. 1753.

DotTed HoRsemint.

Monarda lutea Michx. Fl. Bor. Am 1:16. 1803. Coulter, Contr. Nat. Herb. 2 :339.

Ell. Sk. 1:30. Gray, Man. ed. 6, 414. Chap. Fl. 320. Gray, Syn. Fl. N. A. 2, pt.

1:375. Coulter, Contr. Nat. Herb. 2 : 339.

Caroliuian and Louisianian areas. New York west to southern Minnesota and Colorado, south to the Gulf from Florida to Texas.

Alabama: Throughout. Dry sandy soil, borders of fields, pastures, waysides.

Flowers yellow with dark dots; July to October. Common. Perennial.

Economic uses: The leaves and tops, called "horsemint," or "Monarda," are an obsolete medicinal agent.

Type locality: "Hab. in Virginia."

Herb. Geol. Surv. Herb. Mohr.

Monarda citriodora Cerv.; Lag. Nov. Gen. \& Sp. 2. 1816.

LEMON-SCRNTED MONARIA.

Monarda aristata Nutt. Trans. Am. Phil. Soc. n. ser. 5 : 186. 1833-1837.

Gray, Man. ed. 6, 415. Gray, Syn. Fl. N. A. 2, pt. 1:375. Conlter, Contr. Nat. Herb.

$2: 339$.

Carolinian and Louisianian areas. Nebraska to Colorado, Arizona, and Texas. 
Alabama: Prairie region. Borders of fields and grassy banks. Hale County, Gallion, associated with Xylopleurum speciosum in the black prairies. Flowers pink, the bracts rose-colored; June, July. Mobile County, adventive from the Southwest; waste places. Perennial.

Type locality: "Hab. in Nova Hispania."

Herb. Geol. Surv. Herb. Mohr.

BLEPHILIA Raf. Journ. Phys. $89: 98.1819$.

Two species, perennial, Atlantic North America.

Blephilia ciliata (L.) Raf. Jonrn. Phys. 89:98. 1819.

Ciliated Blephilia.

Monarda ciliata L. Sp. P1. 1:23. 1753.

Ell. Sk. 1: 30. Gray, Man. ed. 6, 415. Chap. F1. 321. Gray, Syn. Fl. N. A. 2, pt. $1: 376$.

Carolinian and Louisianian areas. New York west to Wisconsin, south to the Ohio Valley to Tennessee, and along the mountains to Georgia.

Alabama: Tennessee Valley. Mountain region. Dry borders of woods, open copses. Lauderdale, Franklin, Madison (Huntsville), and Cullman counties. Flowers mauve color; June, July.

Type locality: "Hab. in Virginia."

Herb. Geol. Surv. Herb. Mohr.

NEPETA L. Sp. Pl. 2 : 570.1753.

Temperate and warmer regions of the Old World.

Nepeta cataria L. Sp. Pl. 2 :570. 1753.

Catnip.

Ell. Sk. 2: 71. Gray, Man. ed. 6, 416. Chap. Fl.321. Gray, Syn. Fl. N. A. 2, pt. $1: 377$.

Europe, Western Asia.

Introduced and naturalized throughout Atlantic North America.

Alabama: Mountain region. Clay County, Shinbone Valley. Talladega County, Chandler's Spring, Septenber, 1892. Perennial.

Economic uses: Leaves and tops, under the name of "catnip" or "cataria," are an obsolete medicinal material.

Type locality: "Hab. in Europa."

Herb. Geol. Surv. Herb. Mohr.

SCUTELLARIA L. Sp. Pl. 2:598. 1753. SKullCAP.

About 100 species, chiefly perennials, temperate regions of the globe. Within the Tropics in the mountains. North America, 23; Atlantic, 13; Pacific, 7.

Scutellaria lateriflora L. Sp. Pl. 2 : 598. 1753.

MaD-DOG SkUllcaP. 378.

Ell. Sk. 2:92. Gray, Man. өd. 6, 417. Chap. Fl.324. Gray, Syn. Fl. N. A. 2, pt. 1:

Canadian zone to Louisianian area. Canadian Provinces from Anticosti to Oregon; New England (Mount Desert Island), west to Minnesota and Nebraska, south to the Gulf from Florida to Texas, and in New Mexico.

Alabama: Over the State. Wet thickets along streams. Mobile County, banks of Mobile River. Flowers pale blue. Plant 2 to 3 foet high. Perennial. Not common.

Type locality: "Hab. in Canada, Virginia."

Herb. Geol. Surv.

Scutellaria cordifolia Muhl. Cat. 56. 1813.

Heart-leaf Skulleap.

Scutellaria versicolor Nutt. Gen. 2 : 38. 1818. 378.

Ell. Sk. 2:91. Gray, Man. ed. 6, 417. Chap.Fl.322. Gray, Syn. Fl.N.A.2, pt. 1:

Carolinian and Louisianian areas. Southern New York, Pennsylvania, Virginia, and the Ohio Valley to Missouri and Arkansas, south to Tennessee, and along the mountains to South Carolina.

Alabama : Mountain region to Lower hills. Shady borders of woods. Madison County, Huntsville. Jackson County, Gurley, 1,000 feet altitude. Tuscaloosa County (E. A. Smith). Corolla sky-blue, white in the tube. Flowers in June. Perennial.

Type locality: "Car. Pens. * * * Missis."

Herb. Geol. Surv. Herb. Mohr.

Scutellaria cordifolia minor (Chap.).

Scutellaria versicolor minor Chap. Fl.323. 1860. 
S. rugosa Wood, Proc. Am. Assoc. 176. 1853.

Carolinian and Louisianian areas. Virginia? and Georgia.

Alabama: Mountain region. Metamorphic hills. Lee Connty, Auburn ( $F$. $S$. Earle). Coosa hills. St. Clair County, Ashville. Flowers June, July. Not frequent. Perennial.

Type locality: "Near Washington, Wilkes County, Ga."

Herb. Mohr.

Scutellaria montana Chap. Bot. Gaz. 3:11. 1878.

Chap. Fl. ed. 3, 385. Gray, Syn. Fl. 2, pt. 1:379.

Carolinian area. Southern Tennessee, Cumberland Mountains. Georgia.

Alabama: Mountain region. Dry open woods. Jackson County, near Stevenson (L. Boynton, May, 1899).

The specimens from Jackson County differ from the type by the but slightly pubescent stem and glabrous leaves with prominent pale nerves.

Scutellaria incana Muhl. Cat. 56. 1813.

Scutellaria canescens Nutt. Gen. $2: 38.1818$.

S. serrata Spreng. Syst. 2:703. 1825. Not Andr.

S. canescens punctata Chap. Fl. 323. 1860.

Gray, Man. ed.6, 417. Chap. Fl. ed. 3, 385. Gray, Syn. Fl. N. A. 2, pt. $1: 379$.

Carolinian and Lonisianian areas. Pennsylvania to llliuois, south to North Carolina, Georgia, and Florida.

Alabama: Mountain region to Lower Pine belt. Open copses, borders of woods. Cullman, Blount, Tuscaloosa, Monroe, and Mobile counties. Flowers azure, June, July. Not frequent. Variable.

Onr specimens from various localities in the State agree more or less closely with the Southern form of this polymorphous species described by Chapman as Scutellaria canescens punctata, which is too closely connected with the typical form by intergradations to be considered of varietal value.

Type locality: "Pens. Ohio."

Herb. Geol. Surv. Herb. Mohr.

Scutellaria pilosa Michx. Fl. Bor. Am. 2 : 11. 1803.

Ell. Sk. 2:91. Gray, Man. ed. 6, 417. Chap. Fl. 323. Gray, Syn. Fl. N. A. 2, pt. 1. 379. Coulter, Contr. Nat. Herb. 2 : 341.

Carolinian and Louisianian areas. Southern New York, Virginia, west to Michigan, south to Florida and Texas.

Alabama : Central Pine belt to Coast plain. Dry sterile soil, open woods. Lee County, Auburn (Baker \& Earle). Tuscaloosa County (E. A. Smith). Mobile and Baldwin counties. Flowers azure; May. Frequent. Chiefly in the Lower Pine region on barren sandy ridges.

Typo locality: "Hab. in Carolina et Georgia."

Herb. Geol. Surv. Herb. Mohr.

Scutellaria integrifolia L. Sp. Pl. 2 :599. 1753.

Scutellaria hys8opifolia L. Sp. P1. 2:599. 1753.

Ell. Sk. 2 : 88. Gray, Man. ed. 6, 418. Chap. Fl. 323. Gray, Syn. Fl. N. A. 2, pt. 1: 379.

Coulter, Contr. Nat. Herb. $2: 341$.

Alleghenian, Carolinian, and Louisianian areas. Massachusetts to New Jersey,

Virginia, Tennessee, and Florida, west to Texas, Arkansas, and southern Missouri.

Alabama: Mountain region to Coast plain. Dry open woods. Dekalb Connty,

Mentone, 1,600 feet. Cullman Connty, 800 feet. Dallas County, Marion Junction.

Mobile and Bald win counties. Flowers pale blue; May, June. Perennial. Frequent.

Type Jocality: "Hab. in Virginia, Canada."

Scutellaria integrifolia major Chap. Fl. 323. 1860.

A well-marked variety, readily distinguished by the stouter habit of growth, the larger leaves ( 1 to 2 inches long), the upper oblong to oblong-ovate entire, coarsely crenate, long-petioled, and rounded at the apex.

Carolinian and Louisianian areas. North Carolina to Florida.

Alabama: Mountain region. Central Prairie belt. Low places. Dekalb County, Lookout Mountain, 1,600 feet. Dallas Connty, Marion Junction. Not infrequent.

Flowers pale blue; May.

Type locality: "Swamps, Florida, and northward."

Scutellaria campestris Britton, Mem. Torr. Club, 5:283. 1894.

Campestrian Skulicap.

Seutellaria parvula var. mollis Gray, Syn. Fl. N. A. 2, pt. 1: 380.1878 . Not Scutellaria mollis R. Br. 
Gray, Syn. Fl. N.A.l. c.

Carolinian area. Southern Illinois and Tennessee.

ArabaMa: Mountain region. Calcareous hills. Madison County, Huntsville. Jackson County, Scottsboro, cedar flats. Flowers dark blue; May. Not frequent. Stem low, ascending. Perennial.

Type locality: "Sandy banks of the Mississippi, at Oquawka, S. Illinois, etc., $H . N$. Patterson.

Herb. Geol. Surv. Herb. Mohr.

\section{PRUNELLA L.Sp. Pl. $2: 600.1753$.}

Five species, cosmopolitan in temperate regions.

Prunella vulgaris L. Sp. Pl. 2 :600. 1753.

SelF-HeAL.

Ell. Sk. 2 :87. Gray, Man. ed. 6, 419. Chap. Fl. 322. Gray, Syn. Fl. N. A. 2, pt. $1: 382$.

Temperate Europe, Asia, Northern Africa, Australia, America.

Boreal region to Louisianian area. From Canada across the continent to the Pacific, Alaska, and California, and through the Eastern United States to Nebraska and New Mexico.

Alabala: Tennessee Valley to Central Prairie belt. Damp pastures and open woods. Lauderdale and Montgomery counties. Flowers purple; July, August. Common. Perennial.

Type locality: "Hab. in Europae pascuis."

Herb. Geol. Surv. Herb. Mohr.

PHYSOSTEGIA Benth. Lab. Gen. \& Sp.504. 1834.

Three species, North America.

Physostegia virginiana (L.) Benth. Lab. Gen. \& Sp. 504. 1834.

Dracocephalum virginianum L. Sp. Pl. 2:594. 1753.

False Dragon's-Head.

Fll. Sk. 2:84. Gray, Man. ed. 6, 419. Chap. Fl. 325. Gray, Syn. Fl. N. A. 2, pt. 1: 383 . Coulter, Contr. Nat. Herb. $2: 342$.

Mexico.

Alleghenian to Louisianian area. Quebec, Ontario, Manitoba; New England west to Dakota; Ohio Valley to Missouri and Arkansas, and south to Florida and Texas.

Alabama: Central Pine belt. Bibb County (E.A.Smith). Flowers pink purplish; July. Not frequent. Perennial.

Type locality: "Hab. in America septentrionali."

Herb. Geol. Surv. Herb. Mohr.

\section{MARRUBIUM L. Sp.Pl. 2 : 582.1753.}

About 40 species, cooler and warmer temperate regions of the Old World.

Marrubium vulgare L. Sp. P1. 2: 583. 1753.

HOARHOUND.

Alleghenian to Louisianian area. Introduced from Europe and naturalized from Ontario to the Gulf.

Alabama: Over the State. In open waste ground, near dwellings. Frequent in many localities. Flowers white; July to September. Peremial.

Economic uses: The herb is the "Marrubium" or "hoarhound" of the United States Pharmacopœia.

Type locality: "Hab. in Europae borealioris ruderatis."

Herb. Geol. Surv. Herb. Mohr.

STACHYS L. Sp. Pl. $2: 580$. 1753. WOUNDWORT.

One hundred and fifty species, temperate regions and tropical mountains, cosmopolitan.

Stachys agraria Cham. \& Schlecht, Linnaea, 5:100. 1830.

Gray, Syn. Fl. N. A. 2, pt. 1:386. Coulter, Contr. Nat. Herb. $2: 343$.

Mexico.

Louisianian area. Southwestern Texas.

AlabaMa: Coast plain. Mobile County, fugitive on ballast. Flowers carmine;

July. Observed in 1893 and subsequently. Annual.

Type locality: "Jalapae, circa nrbem."

Herb. Geol. Surv. Herb. Mohr. 
Stachys cordata Riddell, Suppl. Cat. Oh. Pl.15. 1846.

WOODLAND WOUNDWORT.

Stachys 8ylvatica Nutt. Gen. $2: 30$. 1818. Not L.

Gray, Man. ed.6, 422. Chap. Fl. Suppl.639; ed.3, 389. Gray, Syn. Fl. N. A. 2, pt. $1: 387$.

Carolinian and Louisianian areas. New Jersey to West Virginia, Ohio, and Tennessee.

Alabama: Mountain region. Shady damp borders of woods, thickets. Blount County banks of Mulberry River. Flowers red; June. Infrequent. Perennial.

Type locality: "Grows in woods throughont middle, southern, and western portions of Ohio."

Herb. Geol. Surv. Herb. Mohr. (type specimen).

Stachys aspera Michx. Fl. Bor. Am. 2:5. 1803.

HISPID WOUNDWORT.

Stachys hispida Pursh, Fl. Am. Sept. 2 : 407. 1814.

Ell. Sk. 2:75. Gray, Man. ed. 6, 422. Chap. Fl. 326. Gray, Syn. Fl. N. A. 2, pt. 1:387.

Carolinian and Louisianian areas. Ontario; New England and throughout the Eastern United States to South Carolina, west to Arkansas.

Aldana : Central Pine belt. Shaded banks along streams. Tuscaloosa County (E. A. Smith). Flowers crimson; June to August. Perennial.

Type locality: "Hab. in campestribus Carolinae."

Herb. Geol. Surv. Herb. Mohr.

BALLOTA L. Sp. P1. 2 :582. 1753. BlaCK Hoarhound.

Twenty-five species, perennials of the Old World, Europe, northern Africa, northern Asia.

Ballota nigra L. Sp. Pl. 2 : 582.1753.

Gray, Man. ed. 6, 420. Gray, Syn. Fl. 2, pt. 1: 384.

EUROPE.

Naturalized in New England, New York, and Pennsylvania.

Alabama: Adventive with ballast. Mobile County. Flowers erimson; July to

October. Observed for a series of years in the same locality, not spreading.

Type locality : "Hab. in Europae ruderatis."

Herb. Geol. Surv. Herb. Mohr.

LEONOTIS R. Br.; Ait. f. in Ait. Hort. Kew. ed. 2, 3:409. 1811.

Abont 12 species widely diffused through tropical countries of both hemispheres.

Leonotis nepetaefolia (L.) R. Br. Bot. Reg. 4 : t. 281. 1818.

LION's EARS.

Phlomis nepetaefolia L. Sp. Pl. 2:586. 1753.

Chap. Fl.326. Gray, Syn. Fl. N. A. 2, pt. 1: 384.

Tropical Africa and Asia.

Louisianian area. Naturalized in Georgia and Florida to Louisiana.

AlabaMa : Coast plain. Waste places, roadsides, perfectly naturalized. Flowers orange; July to October. Annual.

Type locality: "Hab. Surinami?"

Herb. Geol. Surv. Herb. Mohr.

LEONURUS L. Sp. Pl. 1:584. 1753.

Ten species, Europe, northern Asia.

Leonurus cardiaca L. Sp. Pl. 2 :584. 1753.

Common Motherwort.

Ell. Sk. 2:77. Gray, Man. ed. 6, 420. Chap, Fl. 326. Gray, Syn. Fl. N. A. 2, pt. $1: 385$.

Europe.

Alleghenian to Louisianian area. Naturalized from Canada to Florida and Louisiana.

AlabAMA: Over the State. Waste places, in manured ground near dwellings.

Flowers pale pink; June to Angust. Not frequent. Perennial.

Type locality: "Hab. in Europae ruderatis."

Herb. Geol. Surv. Herb. Mohr. 
LAMIUM L. Sp. P1. 2 :579. 1753. Dead Nettle.

Forty species, Old World, Europe, northern Asia, northern Africa.

Lamium amplexicaule L. Sp. Pl.2:579. 1753. Common Garden Dead Nettle. Ell. Sk. 2:73. Gray, Man. ed. 6, 421. Chap. Fl. 325. Gray, Syn. Fl. N. A. 2, pt. 1:385.

EUROPE.

Alleghenian to Louisianian area. Naturalized from Ontario to the Gulf.

Alabama: Over the State. Everywhere in culivated land. Flowers purple; February to May. A most abundant winter annual.

Type locality: "Hab. in Europae cultis."

Herb. Geol. Surv. Herb. Mohr.

TRIChOStema L. Sp. Pl. $2: 598$. 1753. Bilue Curls.

Eight species, North America, Atlantic, 2.

Trichostema dichotomum L. Sp. P1. 2 :598. 1753.

Common Blúe Curls. Ell. Sk. 2 :94. Gray, Man. ed. 6, 405. Chap. Fl. 327. Gray, Syn. Fl. N. A. 2, pt. 1:348. Coulter, Contr. Nat. Herb. 2:332.

Carolinian and Louisianian areas. Southern New England and central New York west to Missouri and Arkansas, south to the Gulf from Florida to Texas.

Alabama: Throughont. Sandy fields and pastures. Lauderdale, Tuscaloosa, Montgomery, and Mobile counties. Flowers azure; July to September. Frequent. Annual.

Type locality: "Hab. in Virginia, Pennsylvania."

Herb. Geol. Surv. Herb. Mohr.

Trichostema lineare Nutt. Gen. 2:39. 1818.

Linear-leaved Blue Curls.

Trichostema brachiatum Lam. Encycl. 8:84. 1768. Not L.

Ell. Sk. 2:95. Gray, Man. ed.6, 405. Chap. Fl. 327. Gray, Syn. Fl. N. A. 2, pt. $1: 348$.

Carolinian and Louisianian areas. Southeastern Connecticut, along the coast to Florida; west to Louisiana and Arkansas.

Alabama: Central Pine belt to Coast plain. Sandy pastures, borders of fields, dry copses. Tuscaloosa, Montgomery, Baldwin, and Mobile counties. Flowers azure; July, August. Frequent. Annual.

Type locality: "In the sandy fields of New Jersey, also in the vicinity of Philadelphia, in arid situations."

Herb. Geol. Surv. Herb. Mohr.

ISANTHUS Michx. Fl. Bor. Am. 2:3, t.30. 1803. False Pennyroyal.

One species, Eastern North America.

Isanthus brachiatus (L.) B. S.P. Prel. Cat. N. Y.44. 1887. False Penny royal.

Trichostema brachiatum L. Sp. P1. 2: 598. 1753.

Isanthus coeruleus Michx. Fl. Bor. Am. 2: $3, t .30$.

Gras, Man. ed. 6, 406. Chap. Fl. 327. Gray, Syn. Fl. 2, pt. 1:349. Coulter,

Contr. Nat. Herb. $2: 332$.

Carolinian area. Ontario and New England west to Michigan, south to New Jersey, through the Ohio Valley to Missouri, Arkansas, and Tennessee, and along the mountains to Georgia.

Alabama: Tennessee Valley to Lower hills. Dry sterile places. Lauderdale County, barrens. Jefferson County, Jonesboro $(E . A$. Smith). Flowers cerulean blue; July. Not frequent. Annual.

Type locality: "Hab. in America septentrionali."

Herb. Geol. Surv. Herb. Mohr.

TEUCRIUM L. Sp. Pl. 2:562. 1753. Germander.

About 100 species, cosmopolitan excepting boreal regions. Europe, Asia. North America, 4.

Teucrium canadense L. Sp. Pl. 2:564. 1753.

WOOD SAGE.

Ell. Sk. 2:69. Gray, Man. ed.6, 406. Chap. Fl. 328. Gray, Syn. Fl. N. A. 2, pt. 1:349. Coulter, Contr. Nat. Herb. $2: 333$.

Mexico. 
Alleghenian to Louisianian area. Nova Scotia, Ontario; New England west to Nebraska, south to Florida and the Gulf, west to Texas.

Alabama: Over the State. Damp thickets, low banks. Cullman, Tusealoosa, Montgomery, and Mobile counties. Flowers rose-purple; July to September. Not infrequent. Perennial.

Type locality : "Hab. in Canada."

Herb. Geol. Surv. Herb. Mohr.

Teucrium nashii Kearney, Bull. Torr. Club, 21:484. 1894. Nasi's Germander. Canescent by a fine closely appressed pubescence; leaves short-petioled, oblonglanceolate, acute at both ends, dark green and minutely appressed-pubescent above, beneath white tomentose with the veins prominent, finely equally serrate; calyx white tomentose.

Louisianian area. Florida.

Alabama : Coast plain. Damp shaded banks. Mobile County, foot of Springhill,

Portersville. Flowers pale purple; May. Not frequent. Pereunial.

Type locality: "Collected in middle Florida in 1836, by Dr. Chapman; in Duval County, Florida. by Mr. A. H. Curtiss * * *, and near Eustis, Florida, in 1894, by Mr. George V. Nash."

Herb. Geol. Surv. Herb. Mohr.

Teucrium cubense L. Mant. 1:80. 1767.

Gray, Syn. Fl. N. A. 2, pt. 1: 349. Coulter, Contr. Nat. Herb. 2 : 333.

West Indies, Mexico, Brazil, Argentina.

Louisianian area. Southern Florida to southwestern Texas and southeastern California.

Alabama : Adventive on ballast. Mobile County; August, September; collected in 1889 and 1893. Annual.

Type locality: "Hab. in Cubae humidiusculis."

Herb. Geol. Surv. Herb. Mohr.

\section{SOLANACEAE. Nightshade Family.}

PHYSALODES Boehm. in Ludwig, Def. 42.1760.

(NICANDR $\triangle$ dans. Fam. Pl. $2: 219.1763$.

One species, Peru.

Physalodes physalodes (L。) Britton, Mem. Torr. Club, 5 : 287. 1894.

Atropa physalodes L. Sp. Pl. 1: 181. 1753.

Physalis peruviana Mill. Gard. Dict. ed. 8 , no. 16. 1768. Not L.

Ell. Sk. 1:277. Gray, Man. ed, 6, 376. Chap. Fl. 351. Gray, Syn. F1. N. A. 2, pt. $1: 237$.

Carolinian area. Adventive and naturalized from southern Ontario to Pennsylvania, Ohio, and Missouri, and along the mountains to North Carolina.

Alabama: Mountain region. Waste places, near dwellings. Winston County, 1,500 feet. Clay County, suminit of Delta divide, 1,600 feet. Flowers purplish; July, August. Not frequent. Annual.

Type locality: "Hab. in Peru. D. B. Jussieu."

Herb. Geol. Surv. Herb. Mohr.

LYCIUM L. Sp. Pl. 1 : 191. 1753.

Seventy species, warmer and tropical regions, both hemispheres. Shrubs often spinose. Northern Europs, Asia, north and south Africa, West Indies to Brazil. North America, 14; South Atlantic States, 1.

Lycium carolinianum Walt. Fl. Car. 84. 1788.

Carolina Box Tionn.

Ell. Sk. 1:200. Chap. Fl. 351. Gray, Syn. Fl. N. A. 2, pt.1:238. Coulter, Contr. Nat. Herb. 2:302.

Lonisianian area. South Carolina to Florida, west to Texas.

Alabama: Littoral region. Swampy sea beach. Mobile County, West Fowl River. Baldwin County. Flowers blue, June; fruit ripe October, flame scarlet.

Not infrequent. Shrub 2 to 3 feet high.

Type locality: South Carolina.

Herb. Geol. Surv. Herb. Mohr. 
About 50 species, perennial herbs and annuals. Warmer regions of the globe, chiefly American. North America, 37.

Physalis pubescens L. Sp. Pl. 1:183. 1753.

Soft-hairy Ground Cherry.

Physalis hirsuta Dunal in DC. Prodr. 13, pt. 1:445. 1852.

Gray, Man. ed. 6, 375 . Chap. Fl. ed. 3, 323. Gray, Syn. Fl. N. A. 2, pt. 1:234. Coulter, Contr. Nat. Herb. $2: 300$. Wats. Bot. Calif. $1: 541$.

West Indies, Mwxico, Central and South America.

Carolinian and Louisianian areas. Maryland to Florida, Pennsylvania, sonthwest to Missouri, Arkausas, 'Texas, Arizona, and Califoruia.

Alabama : Mountain region. Borders of fields, pastures. Cullman County, $80 \theta$ feet altitude. August. Not frequent. Annual.

Type locality: "Hab. in India utraque."

Herb. Geol. Surv. Herb. Mohr.

Physalis pruinosa L. Sp. Pl. 1: 184. 1753.

Primrose Ground Cherry.

Ell. Sk. 1: 280. (?)

Alleghenian and Carolinian areas. New England west to Michigan and Iowa, south to Georgia and Florida.

Alabama: Mountain region. Waste places. Winston County, near Colliers Creek, 1,500 feet altitude. May; rare. Annual.

Type locality: "Hab. in America."

Herb. Geol. Surv. Herb. Mohr.

Physalis barbadensis Jacq. Misc. 2 : 359. 1781. (Icôn.t. 39.)

Barbadoes Ground Cherry.

Physalis obscura viscido-pubescens Michx. Fl. Bor. Am. 1: 149. 1803.

P. obscura pubescens Pursh, Fl. Am. Sept. 1: 157. 1814.

P. pruinosa Ell. Sk. 1:279. 1817.

Anuual, stem erect or spreading acntely 3 or 4 angled, pubescent, viscid, or nearly glabrous, leaves lieart-shaped, acute or abruptly acuminate, sharply repand-dentate, pubescent with short hairs; peduncles short; calyx generally densely viscid-hirsute, lobes lanceolate-acuminate, corolla $\frac{3}{8}$ inch wide, anthers purplish, fruiting calyx about 1 inch long, acuminate, reticulate, retuse at the base.

Cuba, Mexico, Venezuela.

Carolinian to Louisianian area. Pennsylvania to Missouri and Indian Territory, south to Florida, Louisiana, and Texas.

Alabama : Coast plain. Waste ground. Mobile County. September. Frequent. Annual.

Type locality not giren except as implied in the name.

Herb. Geol. Surv. Herb. Mohr.

Physalis barbadensis obscura (Michx.) Rydberg, Mem. Torr. Club, 4:327. 1896. Physalis angulata Walt. Fl. Car. 99. 1788. Not L.

P. obscura Michx. Fl. Bor. Am. 1:149. 1803.

$P$. brasiliensis Sendtner in Mart. Fl. Bras. 10:131. 1854.

Gray, Syn. Fl. N. A. 2, pt. 1:234. Chap. Fl. ed. 3, 323.

West Indies, Mexic) To Brazil.

Louisianian area. Georgia and Florida, west to Texas and Arkansas.

Alabama: Coast plain. Cultivated ground, waste places about dwellings. Flowers small, corolla greenish yellow, brown in the throat; July to September. Fruit ripe September, October. Berry yellowish green. Common garden weed. Annual.

Type locality: "Hab. in Carolina."

Herb. Geol. Surv. Herb. Mohr.

Physalis carpenteri Riddell; Chap. Bot. Gaz. 3:11. 1878. As synonym.

Chap. Fl. ed. 3, 325.

Louisianian area. Louisiana and Florida.

Arabama: Central Prairie region. Wilcox County (S. B. Buckley), 1840; not collected since.

Type locality: "East Feliciana, La. (Prof. Carpenter).”

'P. A. Rydberg, The North American Species of Physalis and Related Genera, Mem. Torr. Club, vol. 4, pp. 297 to 364.1896. 
Physalis angulata L. Sp. Pl. 1:183. 1753.

Physalis linkiana Nees, Linnaea, 6:471. 1831.

P. ungulata var. linkiana Gray, Syn. Fl. N. A. 2, pt. 1:234. 1878.

$2: 300$.

Ell. Sk. 1:278. Gray, Man. ed. 6,375. Chap. Fl. 351. Coulter, Contr. Nat. Herb.

West Indres, Mexico to Brazil, Peru.

Carolinian and Louisianian areas. Southern Illinois to Missonri and Arkansas; North Carolina to Florida and Texas.

Alabama: Over the State. Borders of pastures, fields. Clay County, Dempsey, 1,000 feet altitude. Lee County, Auburn (Earle). Franklin County, Russellville. Calhoun and Mobile connties. Flowers dingy yellow; August to October. Berry greenish yellow. Common; an abundant weed in the Lower Pine region. Annual. Type locality: "Hab. in India utraque."

Herb. Geol. Surv. Herb. Mohr.

Physalis virginiana Mill. Gard. Dict. ed. 8, no. 4, t. 138. 1768.

Virginia Ground Cherry.

Physalis lanceolata Roem. \& Schult. Syst. Veg. 4:673. 1824.

$P$. pennsylvanica Gray, Man. ed. 5, 382. 1867. Not L.

Gray, Man. ed. 6, 375, mainly. Coulter, Contr. Nat. Herb. $2: 301$, under P. lanceolata.

Alleghenian to Louisianian area. Ontario to Manitoba; New York west to Michigan, Kansas, and Colorado; south to Florida, Texas, and Arkansas.

Alabama: Over the State. In rich soil, exposed places, open copses, borders of fields and woods. Winston County, Colliers Creek, 1,500 feet altitnde-tho specimens ronghish-pubescent by short, flat, somewhat recurved hairs, particularly along the angles of the stems and branches, and on the margins of the leaves. Tuscaloosa County (E. A. Smith), specimens responding to the typical form; of rellowish hue, villous-pubescent, the broader leaves obtusely sinuate-dentate. Lee County, Auburn (Earle), a form very similar to the plant from Wiuston County. Autanga County, Prattville, very low-branched from the decumbent base, else like the typical form. Clarke County, Thomasville. Mobile County, narrow-leaved forms of a darker green, the leaves from 1 to $1 \frac{1}{4}$ inches long, $\frac{8}{8}$ to scarcely over $\frac{5}{8}$ inch wide, more or l.'ss pubescent, but less so than the type, corolla lemon-yellow, fuscous in the center, anthers yellow. Frequent, widely diffused, and variable; the typical form in richer soil.

Type locality : "The seeds * * * were sent me from Philadelphia by Dr. Bensil, who found the plants growing there naturally."

Herb. Geol. Surv. Herb. Mohr.

Physalis virginiana intermedia Rydberg, Mem. Torr. Clab, 4 : 345. 1896.

Perennial from a stout rootstock; stem slightly angled, slender, 8 to 10 inches high, sparsely hairy; leaves membranaceons, dark green, almost glabrous, ovate to ovate-lanceolate, rather obtuse, tapering into a winged petiole, entire or slightly sinuate.

Carolinian and Louisianian areas. Indiana and Mississippi to Texas.

Alabama: Upper division Coast Pine belt. Shaded copses. Clarke County, Thomasville. Hale County, Gallion. Flowers pale yellow, purplish in the center; April, June. Not frequent. Perennial.

Type locality: "Southern States: S. B. Buckley (type)."

Herb. Geol. Surv. Herb. Mohr.

Physalis ciliosa Rydberg, Mem. Torr. Club, 4:346. 1896.

Ciliate Ground Cherry.

Perennial from a slender ereeping rootstock, erect; branched, 8 to 10 inches high, stem terete, like the pedicels and calyx lobes ciliate with long jointed hairs, leaves $1 \frac{1}{2}$ to 2 inches long, ovate, truncate or slightly cordate at the base, subentire, sparsely hairy on tho veins, thin; peduncles very slender, fruiting calyx ovoidpyramidal, sunken at the base.

Carolinian and Louisianian areas. Tennessee, Georgia, and Florida.

Ala Bama: Upper division of Coast Pine belt. Borders of woods. Clarke County, Thomasville. Flowers yellow, faintly darker in the throat; April. Rare; only locality known in the State.

Type locality: "Florida: Chapman."

Herb. Geol. Surv. Herb. Mohr.

Physalis arenicola T. H. Kearney, Bull. Torr. Club, 21:485. 1894.

Perennial, branched from the rootstock; branches erect, slender, pubescent with simple hairs; leaves ovate to ovate-oblong, irregularly angulate, or angulate-dentate, obtuse, unequal at the base, appressed ciliate; flowers on slender pubescent pedicels as long as or longer than the petioles; calyx pubescent; corolla light yellow 
with a brown-purple spot in the center; anthers yellow; fruiting calyx ovate-pyramidal with the teeth much shorter than the tube; berry light yellow.

Louisianian area.

Alabama: Lower Pine belt. Grassy pine barrens. Mobile County, Springhill (Bush). July, August; perennial.

Type locality: "Collected in light sandy soil along railroad embankments near Enstis, Fla., in 1894, by Mr. George V. Nash."

Herb. Geol. Surv. Herb. Mohr.

Physalis heterophylla Nees, Linnaea, 6:463. 1831.

Viscous Ground Cherry.

Physalis viscosa Pursh, Fl. Am. Sept. 1 : 157. 1814.

P. virginiana Gray, Syn. Fl. N. A. 2, pt. 1:235. 1878.

Gray, Man. ed.6, 375. Gray, Syn. Fl.N. A.l.c. Chap. Fl. ed.3, 324. Coulter, Contr.

Nat. Herb. $2: 300$.

Alleghenian to Louisianian area. New Brunswick to Saskatchewan; Illinois to

Nebraska and Colorado, south to Florida and Texas.

Alabama : Lower hills. Dry woods. Tuscaloosa County (E. A.Smith). Flowers yellow, brownish in the throat; anthers yellow. June; not infrequent. Perennial.

Type locality: "Hab. in America boreali. Herb. Willd., ad exemplum a Muehlenbergio missum. In collibus argillosis Pennsylvaniae Poeppig legit," etc.

Herb. Geol. Surv. Herb. Mohr.

Physalis heterophylla nyctaginea (Dunal) Rydberg in Chap. Fl. ed.3, 324. 1897. Physalis obscura Torr. Fl. N. \& Mid. U. S. 233. 1824. Not Michx.

$P$. nyctaginea Dunal in DC. Prodr. 13, pt. 1:440. 1852.

Chap. Fl. l. c. Britt. \& Br. Ill. Fl. 3:131.

Closely allied to Physalis heterophylla ambigua, from which it differs in the firmer, almost silky-pubescent, more acuminate, dark-green leaves, and the shorter, more acute lobes of the calyx.

Carolinian and Louisianian areas. Khode Island to Iowa, south to Florida and Louisiana.

Alabama : Lower Pine region. Dry sandy pine woods. Mobile County, Spring-

hill. Flowers July; infrequent.

Type locality : "In America boreali."

Herb. Geol. Surv. Herb. Mohr.

Physalis monticola sp. nov.

Mountain Ground Cherry.

Perennial from a horizontal rootstock. Stem 12 to 16 inches high, simple and slightly strigose-pubescent below, assurgent; branches erect, becoming villouspubescent like the inflorescence by flat-jointed, not stellate, hairs; leaves oblongovate to ovate-lanceolate, tapering at both ends, acutish, very oblique at the base, decurrent on the narrowly wing-margined petiole, repand-toothed, or subentire, ciliolate on the margin, the blade $1 \frac{1}{2}$ to $2 \frac{1}{2}$ inches long and $\frac{8}{4}$ to $1 \frac{1}{4}$ inches broad, almost glabrous above, slightly pubescent beneath, densely so along the midrib; peduncle $\frac{1}{4}$ inch long, suberect and like the base of the calyx and margins of its lobes villous-pubescent and more or less viscid; calyx lobes broadly lanceolate; corolla about $\frac{8}{4}$ inch wide, dingy yellow, sordid purplish in the center; anthers pale yellow; fruiting calyx ovoid, acuminate, deeply sunk at the base, obtusely angular; berry yellowish geeen.

Readily distinguished from the varieties of Physalis heterophylla, its nearest allies, by the more slender habit of growth, the smoother stem, the almost glabrate, more membranaceons leaves, cuneate at the base, etc. June. Specimens just coming into bloom, collected near Mentone in 1892, were by Mr. Rydberg pronounced to belong probally to an undescribed species, the imperfect material, however, not warranting a description. This opinion was confirmed by the perfect fruiting specimens collected at the same locality in September, $18 \mathrm{C} z$, which fully reveal the characters of this apparently strictly local species.

Carolinian area.

Alabama: Mountain region. Borders of copses, exposed places, in gravelly or rocky soil. Dekalb County, table-land of Lookout Mountain at Mentone, 1,800 feet altitude, near Loring Spring Hotel. Flowers in June; fruit September 16 (1898).

Herb. Geol. Surv. Herb. Mohr.

Physalis viscosa L. Sp. Pl. 1:183. 1753.

Stellate Ground Cherry.

Physalis pennsylvanica L. Sp. Pl. ed. 2, 2:1670. 1763.

$P$. tomentosa Walt. Fl. Car.99. 1788. Not Medic.

P. walteri Nutt. Journ. Acad. Phila. 7 : 112. 1834.

Gray, Man. ed. 6, 376. Chap. Fl. ed. 3, 324. Coulter, Contr. Nat. Herb. 2 : 301. Gray, Syn. Fl. N. A. 2, pt. 1: 236. 


\section{Mexico to Brazil, Argentina.}

Louisianian area. Seashore from Virginia to Florida, west to Texas.

Alabana : Coast plain. Dry gravelly banks of Mobile. River, Mobile and Ohio Railroad wharf. To all appearance adventive with ballast. Observed from 1890 up to 1897, when the locality was covered with buildings. Flowers pale yellow, with a brownish center; June to October. Berries clammy yellow. Perennial.

Type locality: "Hab. in Virginia, Bonaria."

Herb. Mohr.

Physalis viscosa maritima (Curtis) Rydberg, Mem. Torr. Club, 4 : 357. 1897.

Seaside Stellate Ground Cherry.

Physalis maritima Curtis, Am. Journ. Sci. ser. 2, 7:407. 1849.

P. viscosa spathulaefolia Gray, Syn. Fl. N.A.2, pt. 1:236. 1878.

Gray, 1. c. Coulter, Contr. Nat. Herb. $2: 301$.

Louisianian area. North Carolina to Florida and Texas.

Alabama: Littoral region. Sands on the seashore. Baldwin County, eastern shore Mobile Bay near Point Clear, July, 1881 ; very rare. Collected also at Springhill near the hotel, in sandy pine uplands, more than 30 miles distant from the seashore, August 8, 1897. Perennial.

Our specimens agree perfectly with the type duplicate of Curtis from the Riddellian herb. in Herb. Mohr. Readily distinguished by the closer and denser pubescence and the oblong spathulate leares gradually tapering into the petiole, of a firmer texture. Peduncles about 1 inch long, like the calyx more densely pubescent than in the type; corolla larger, $\frac{1}{2}$ to $\frac{8}{4}$ inch wide. Perennial.

Type locality: "Sandy seashore of North Carolina, and occasionally a few miles in the interior."

Herb. Geol. Surv. Herb. Mohr.

Physalis fuscomaculata De Rouville; Dunal, in DC. Prodr. 13, pt. 1: 437. 1852. South America.

Alabama : Fugitive on ballast, Mobile County. Corolla dingy yellow with dark spot in the center; anthers yellow.

Perennial from a stout simple rootstock, decumbent or ascending. Stems terete with decurrent ridges, a little pruinose stellate-pubescent; leaves 2 to 3 inches long, 1 to $1 \frac{1}{2}$ inches wide, ovate, entire or repand, some what oblique at the base, the upper often opposite; petioles $\frac{8}{4}$ to 1 inch long; peduncles as long as or longer than the petioles; calyx pruinose on the margins, stellate-ciliate; lobes triangular, shorter than the tube (Rydberg).

Varies greatly in size and form of the leaves, which on vigorous stems are 3 to 4 inches long and fully 2 inches wide, obtusely repand or sinuate dentate, sparsely pruinose by the very short stellate hairs. Easily distinguished by the dark green color of the leaves, the pubescence, and the low branching habit from $P$. viscosa.

This interesting waif from the La Plata River country associated with Verbena bonariensis, from the same region, has held its own, confined to a single spot, for the past dozen years without spreading.

Type locality: "E Buenos Ayres? cum lanis allata ad portem Juvenalem prope montem Pessulanum legit cl. Touchy."

Herb. Geol. Surv. Herb. Mohr.

Physalis angustifolia Nutt. Journ. Acad. Phila. 7:113. 1834.

Narkow-leaf Seaside Ground Cherry.

Gray, Syn. Fl. N. A. 2, pt. 1:236. Chap. Fl. 350.

Louisianian area. Seashore of Florida to Louisiana.

Alabama : Littoral region. Drifting sand, shores of Mobile Bay and the Gulf. Flowers May, June: corolla yellow, purplish in the center, anthers yellow. Fruit ripe July, August; berries deep orange. the creeping base of the stems deeply buried in the sand. Perennial.

Type locality: "West Florida, probably on the sandy coast. N. A. Ware, Esq."

Herb. Geol. Surv. Herb. Mohr.

SOLANUM L. Sp. PI. 1 : 184. 1753.

About 900 species, herbaceous and woody perennials and annuals of warmer temperate and tropical regions.

Solanum nigrum L. Sp. P1. 1 : 186. 1753.

Common Nightshade.

Ell. Sk. 1:280. Gray, Man, ed. 6, 374. Chap. Fl. 348. Coulter, Contr. Nat. Herb.

2:297. Wats. Bot. Calif. 1:583.

Cosmopolitan in Temperate and Warmer Regions. 
Alabama: Orer the State; waste places. Flowers white, Jnne to October; fruit ripe August to October. Abundant. Annual.

Type locality: "Hab. in Orbis totius cultis."

Herb. Geol. Surv. Herb. Mohr.

Solanum gracile Dunal in DC. Prodr. 13, pt.1:54. 1852. Slender Nigitshade.

Erroneously referred to S. hirsutum by Mohr in Bull. Torr. Club, 24:26. 1897.

Annual, $1 \frac{1}{2}$ to 2 feet high, erect or decumbent at the base, stem and branches terete, somewhat cinereous by the close pubescence; leaves oblong-ovate, attenuated, cuneate at the base, acutish, pubescent and ciliate, $\frac{8}{4}$ to $1 \frac{1}{2}$ inches long, $\frac{8}{8}$ to $\frac{5}{8}$ inch wide, shortpetioled; peduncles extra-axillary, about $\frac{1}{2}$ inch long, spreading-reflexed in fruit; pedicels umbellate or subumbellate, shorter than the peduncles; flowers small; calyx lobes short, rather obtuse; filaments smooth; style bearded at the base; fruit black, of a bronzy hue, $\frac{1}{4}$ inch in diameter.

Southern Brazil, Argentina.

Alabama: A common ballast weed spreading over low waste places. Mobile County, abundant in thickets bordering the swamps along the Mobile River. Producing its fruit to perfection throughout the summer and fall.

Type locality: "In Brasiliae provincia Rio de Janeiro * * * eirea Buenos Ayres * * * in Montevideo * * * in Chili ad Rancagua."

Herb. Geol. Surv. Ilerb. Mohr.

Solanum rubrum Mill. Dict. ed. 8, no.4. 1768.

RED NightShade.

Solanum nodiflorum var. rubrum Griseb. Fl. Brit. W. Ind. 437. 1864.

The form with black berries.

Annual from a long fibrous root. Stem smoothish, muricately denticulate along the angles, like the branchlets; leaves repand-denticulate or subentire, peduncles erect-spreading, about $\frac{1}{2}$ inch long; pedicels somewhat shorter, strongly reflexed in fruit, flowers smaller than in the last with the short calyx lobes oval, obtuse.

Tropical America.

Louisianian area. Western Florida.

Alabama : Mobile County, like the last, a common and persistent ballast weed slowly spreading to waysides along the river front. June to October.

'Type locality: "The seeds * * * came from the West Indies."

Herb. Geol. Surv. Herb. Mohr.

Solanum pseudocapsicum L. Sp. Pl. 1:184. 1753.

Jerusalem Cherry.

Gray, Syn. Fl. N. A. 2, pt. $1: 228$.

Madeira, Azores.

Louisianian area. Naturalized in Florida and South Carolina.

Alabama: Metamorphic hills. This erect low shrub appears to be well established in thickets and hedge rows. Tallapoosa County, near Dadeville. Lee County, Auburn (Earle \& Underwood). Flowers in June. Fruit globose, scarlet.

Type locality: "Hab. in Madera."

Herb. Geol. Surv. Herb. Mohr.

Solanum aculeatissimum Jaeq. Icon. Rar. t. 41. 1781-1793.

SPINy Nightshade.

Solanum mammosum Ell. Sk. 1:281. 1817. Not L. ( \&)

Chap. Fl. 349. Gray, Syn. Fl. N. A. 2, pt. 1:230. Coulter, Contr. Nat. Herb. 2 : 298.

Griseb. Fl. Brit. W. Ind. 442.

West Indies, Mexico to Brazil, Ceylon.

Louisianian area. Texas along the coast to Florida and North Carolina.

Alabama: Lower Pine belt to Littoral belt. Dry sandy pastures. Baldwin County, shores of Fish River Bay, October 4, in fruit; berries $\frac{8}{4}$ ineh in diameter, bright flame-scarlet. Infrequent. Suffrutescent. Springhill, waste ground, near the hotel.

Type locality not ascertained.

Herb. Geol. Surv. Herb. Mohr.

Solanum sisymbrifolium Lam. Tabl. Encycl. 2 : 25. 1793.

Solanum balbisii Dunal, Hist. Solan. 232, t.3. 1813.

Chap. Fl. Suppl.641; ed.3, 322. Gray, Syn.Fl. N. A. 2, pt. 1:230. Coulter, Contr.

Nat. Herb. $2: 298$.

Peri, Soutirern Brazil, Buenos Ayres.

Louisianian area. Naturalized from Georgia and Florida to Texas.

Alabama : Central Prairie belt to Coast plain. Adventive from South America. Waste places, near dwellings. Montgomery, roadsides in the suburbs. Mobile County, waste places along the banks of the river. Flowers pale blue, May to July; 
fruit ripe August to October, size of a cherry, carmine-red, shining. Perennial, shrubby at the base, densely branched, forming bushes 2 to 3 feet high, attractive when in full bloom or loaded with fruit. The most frequent and persistent of our ballast plants. Perenuial.

Type locality : "Ex agro Bonariense. * * * Commers. herb."

Herb. Geol. Surv. Herb. Mohr.

Solanum carolinense L. Sp. Pl. 1 : 187. 1753.

HoRse NetTle.

Ell. Sk. 1:282. Gray, Man. ell. 6, 374. Chap. Fl. 349. Gray, Syn. Fl. N. A. 2, pt.

1: 230. Coulter, Contr. Nat. Herb. 2 : 298.

Carolinian and Louisianian areas. Southern Connecticnt and New York west to Missouri and Arkansas, south to Florida and Texas.

Alabama: Over the State. In high sandy open gronnd, fields, pastures, roadsides. Corolla white or pearl blwe; June to October. Fruit ripens August to October; orange. In all sections equally abundant. A most pernicious weed in garden and field. Perennial.

Type locality: "Hab. in Carolina."

Herb. Geol. Surv. Herb. Mohr.

Solanum elaeagnifolium Cav. Icon. $3: 22, t$. 243. 1794. Silver-leaf Nrghtshade. Gray, Man. edl. 6, 374. Gray, Syn. Fl. N. A. 2, pt. 1:230. Coulter, Contr. Nat. Herb. 2 : 298. Wats. Bot. Calif. 1:539.

Chile, Mexico.

Carolinian, Louisianian, and Sonoran areas. Texas, Kansas, and California.

Alabama: Adventive from the Southwest. Waste places Mobile County, roadsides, ballast grounds. Flowers pale blue; June. Rare. One to $1 \frac{1}{2}$ feet high. Perennial.

Type locality: “Hab. in America calidiore."

Herb. Guol. Surv. Herb. Mohr.

Solanum torvum Sw. Prodr. Veg. Ind. Occ. 47. 1788.

Griseb. Fl. Brit. W. Ind. 441.

West Indies, Mexico to Brazil, Ecuador, East Indies.

Alabama: Adventive with ballast. Mobile County. Flowers pale blue or purplish; August, September. Fruit ripe in October; berries black. Three to 4 feet high.

This coarse shrubby plant rarely survives the winter. It propagates from the perfectly mature seed almost one year after another.

Type locality: "India occidentalis."

Herb. Geol. Surv. Herb. Mohr.

Capsicum L. Sp. P1. 1:270. 1753. Cayenne Pepper.

Thirty species, tropical America.

Capsicum baccatum L. Mant. 1:47. 1767.

Bird Pepper. Chili. Gray, Syn. Fl. N. A. 2, pt. 1:231. Coulter, Contr. Nat. Herb. 2:299. Wats. Bot. Calif. 1:340. Grisel. 11. Brit. W. Ind. 436.

Introduced from Soutr America and naturalized in all Tropicar, Countries.

Lower Sonoran and Louisianian areas. Escaped from cultivation and partially naturalized from California to Florida.

Alabama : Waste places a bout dwellings. Mobile County, Dauphin Island, where it is frequent, of spontaneous growth. June, 1893. Shrubby.

Economic uses: 'The highly pungent berries are used as a condiment-the chili of the Mexicans. They furnish Cayenne pepper, the Capsicum of the U.S. Pharmacopoia.

Type locality: "Hab. in Indiis."

Herb. Geol. Surv. Herb. Mohr.

DATURA L. Sp. Pl. $1: 179.1753$. ThORN APPLe.

Fifteen species, warmer regions, Northern Hemisphere.

Datura tatula L. Sp. Pl. ed. 2, 1: 256. 1762.

Purple Thorn Apple.

Ell. Sk. 1:277. Gray, Man, ed.6, 377. Chap. Fl. 352. Gray, Syn. Fl. N. A. 2, pt.1: 240. Wats. Bot. Calif. 1:544. Griseb. Fl. Brit. W. Ind. 434.

South AMErica.

Carolinian and Louisianian areas. Naturalized from Ontario and New York, west to Iowa, Missouri, and Arkansas, south to Florida and Louisiana. Perhaps indigenous on the South Atlantic and Gulf coasts. 
Alabama: Over the State. Rubbish heaps, yards, pastures, about dwellings. Flowers violet; July to October; fruit ripe, September, October. Common everywhere. Annual.

Economic uses: The leaves are used in domestic practice as a substitute for Stramonium.

Type locality not given.

Herb. Geol. Surv. Herb. Mohr.

Datura stramonium L. Sp. Pl. 1:179. 1753.

Common THORN APPle. JAMESTOWN OR Jimson WeEd.

Ell. Sk. 1: 275. Gray, Man. ed. 6, 377. Chap. Fl. 352. Gray, Syn. Fl. N. A. 2, pt. 1:240. Griseb. F1. Brit. W. Ind. 434. Wats. Bot. Calif. $1: 544$.

Temperate and Tropical Regions of the Globe. Mexico, Brazil.

Carolinian aud Louisianian areas. New Brunswick, Quebec, and Ontario, to Florida and Louisiana, west to Missouri, Arkansas, and California.

Alabama: Adventive, coast region. Waste places, ballast ground. Mobile County. Flowers white, July to September; fruit ripe, September, October. Of late years frequently observed on ballast heaps, spreading to adjacent waste places.

Not recorded from the interior. Two to 3 feet high. Annual.

Economic uses: The leaves and seeds are used medicinally, forming the Stramonium leaves, thorn-apple seeds; "Stramonii folia," "Stramonii semen" of the United States Pharmacopœia.

T'ype locality: "Hab. in America, nunc vulgaris per Europam."

Herb. Geol. Surv. Herb. Mohr.

Datura meteloides Dunal in DC. Prodr. 13, pt. 1:544. 1852. Metel-Like Datura. Gray, Syn. Fl. N. A. 2, pt. 1:240. Coulter, Contr. Nat. Herb. 2 : 302. Wats. Bot. Calif. 1: 544 .

Northern MExico.

Lower Sonoran and Louisianian areas. Sonthwestern Texas, Arizona, and sonthern California.

Alabama: Adventive from southwestern Texas. Autauga County, near Prattville. Roadsides. Flowers mauve purple; June. Infrequent. Annual.

Type locality: "In calidis Novae Hispaniae regionibus."

Herb. Geol. Surv.

NICOTIANA L. Sp. Pl. 1: 180. 1753.

Fifty species, warmer temperate and tropical America. Northern and Southern hemispheres. North America, 10, endemic.

Nicotiana glauca Graham in Hook. Bot. Mag. 55: 2837. 1828.

Brazil, Argentina.

Adventive with ballast, western Florida, Pennsacola (1872 and 1893.)

Alabama: Baldwin County, Navy Cove, Angust, September, 1896 (Dr. Fowler). Arborescent, 10 to 12 feet high.

Type locality : Raised from seeds sent "from Buenos Ayres."

Herb. Geol. surv. Herb. Mohr.

Nicotiana longiflora Cav. Desc. 106. 1802.

LONG-FLOWERED TOBACCO.

Adventive from Chile, Buenos Ayres.

Alabama: Mobile County, fugitive on ballast. Flowers greenish white; July. Annual.

Type locality not ascertained.

Herb. Geol. Surv. Herb. Mohr.

Nicotiana repanda Willd.; Lehm. Nicot. 40, $t$. 3. 1818. REPAND-LEAF ToBACCO. Gray, Syn. Fl. N. A. 2, pt. 1: 242. Coulter, Contr. Nat. Herb. 2 : 303.

Mexico, Cuba.

Low er Sonoran area. Southwestern Texas.

Alabama : Autanga County, Prattville; waste places. Adventive years ago from southwestern Texas or Mexico with wool. Annual.

Type locality : "Hab. in Cuba."

Herb. Geol. Surv. Herb. Mohr. 
JABOROSA Juss. Gen. Pl.125. 1789.

Six species, southern Brazil, Argentina, Chile.

Jaborosa integrifolia Lam. Encycl. 3 : 189. 1789.

Perenuial, low, stemless; leaves and scapes from a long creeping rhizoma, deeply buried beneath the surface.

Buenos Ayres.

Adventive with ballast. Mobile Connty. Flowers white, fragrant, opening in the evening; July to October; seeds ripen perfectly. Persistent in the same locality for years. Transplanted into garlens proves to be a rapidly spreading weed, difficult to eradicate. Perencial.

Type locality: "Commerson a trouvé cette plante aux environs de Buenos-Aires." Herb. Geol. Surv. Herb. Mohr.

PETUNIA Juss. Ann. Mus. Par. $2: 215$, t. 4\%. 1803.

About 12 species, South American herbs.

Petunia parviflora Juss. Ann. Mus. Par. 2 : 216, t.47. 1803.

Small-rlowered Petunia.

Gray, Syn. Fl. N. A. 2, pt. 1:243. Coulter, Contr. Nat. Herb. 2: 304 . Wats. Bot. Calif. 1:546.

Mexico to Argentina.

Louisianian area. Texas, west to California, east to Louisiana and Florida.

Alabama : Coast plain. Waste ground, also on ballast. Mobile County. July ; not infrequent. Annual.

Type locality: "De l'embouchure de la Plata."

Herb. Geol. Surv. Herb. Mohr.

Petunia violacea Lindl. Bot. Reg. 19: t. 1626. 1833.

Argentina, Uruguay.

Adventive on ballast. Mobile County. Flowers rose-purple; June. First observed in 1896. Annual.

Type locality: "A native of Buenos Ayres."

Herb. Geol. Surv.

\section{SCROPHOLARIACEAE. Figwort Family.}

\section{VERBASCUM L. Sp. Pl. $1: 177$. 1753. MUlLeiN.}

One hundred and sixty species, temperate and warm regions Northern Hemisphere, largely Mediterranean Europe. North America, 4. Naturalized from Europe.

Verbascum thapsus L. Sp. P1. 1:177. 1753.

Throughout Atlantic North America from Ontario to the Gulf.

Alabama: Over the State. Dry fields, pastures. Flowers yellow; April, May. Common. Annual.

Economic uses: The flowers and leaves, under the name of "mullein flowers,"

"mullein leaves," are used medicinally.

Type locality: "Hab. in Europae glareosis sterilibus."

Herb. Geol. Surv.

Verbascum blattaria L. Sp. Pl. 1: 178. 1753.

Of the same distribution as the last.

Motri Mullir.

Alabama: Over the State. Flowers pale yellow or rose-tinted; July, August. Annual. A frequent wayside weed, less common than the last.

'Type locality: "Hab. in Europae australioris locis argillaceis."

Herb. Geol. Surv.

ELATINOIDES Wetts. in Engl. \& Prantl, Nat. Pfl. Fam.4, Abt. 3b:58. 1891.

Twenty-three species, Mediterranean region Europe, Africa. North America, 2; naturalized.

Elatinoides elatine (L.) Wetts. in Engl. \& Prantl, Nat. Pfl. Fam. 4, Abt. 3b : 58. 1891. Antirrhinum elatine L. Sp. Pl. 2: 612.1753.

Linaria elatine Mill. Gard. Dict. ed.8, no. 16. 1768.

EURope. 
Carolinian area. Naturalized from Canada, along the Atlantic eoast to North Carolina. Annual.

Alabama: Fugitive on ballast. Mobile County. Flowers June, July.

Type locality: "Hab. in Germaniae, Angliae, Galliae, Italiae arvis."

Herb. Geol. Surv.

Elatinoides spuria (L.) Wetts. in Engl. \& Prantl. Nat. Pfl. Fam. 4, Abt. 3b : 58. 1891. Antirrhinum spurium L. Sp. Pl. 2 :613. 1753.

Linaria spuria Mill. Gard. Dict. ed 8, no. 15. 1768.

Europe.

Sparingly naturalized on the Atlantic coast. Philadelphia, on ballast.

Alabama : Fugitive on ballast with the last. Mobile County. Flowers yellow; July. Both species ripen their seed perfectly, and make their appearance almost every season without spreading.

Type locality: "Hab. in Germaniae, Angliae, Galliae, Italiae arvis."

Herb. Geol. Surv. Herb. Mohr.

LINARIA Juss. Gen. Pl. 120. 1789.

About 150 species, temperate regions, Northern Hemisphere. North America, 2.

Linaria canadensis (L.) Dumont, Bot. Cult. 2 : 96. 1802.

WILD TOAD-Flax.

Antirrhinum canadense L. Sp. Pl. 2:618. 1753.

Ell. Sk. 2:113. Gray, Man. ed. 6, 379. Chap. Fl. 290. Gray, Syn. Fl. N. A. 2, pt.

1:250. Coulter, Contr. Nat. Herb. $2: 306$. Wats. Bot. Cal. 1:548.

Mexico.

Alleghenian to Louisianian area. Nova Scotia, New Brunswick; New England south to Florida, west to Texas, the Rocky Mountains, and California.

Alabama: Over the State. In gravelly or sandy soil. Cultivated and waste ground. Flowers purplish blue; March, April. Common. Annual.

Type locality: "Hab. in Virginia, Canada."

Herb. Geol. Surv. Herb. Mohr.

Linaria floridana Chap. Fl. 290. 1860.

Florida toad-flax.

Chap. Fl. ed. 3, 309. Gray, Syn. Fl. N. A. 2, pt. 1: 250.

Louisianian area. Western Florida to Mississippi.

Alabama: Littoral region. Drifting sands at or near the seashore. Baldwin County, eastern shore Mobile Bay, Perdido Bay. Flowers blue; April, May. Frequent. Biennial.

Type locality: "Drifting sands near the coast, West Florida."

Herb. Geol. Surv. Herb. Mohr.

Linaria linaria (L.) Karst. Deutsch. Fl. 947. 1880-1883.

Common Toad-FLaX.

Antirrhinum linaria L. Sp. Pl. 2:616. 1753.

Linaria vulgaris Mill. Gard. Dict. ed. 8, no. 1. 1768.

Gray, Man. ed. 6, 379. Chap. Fl. 290. Graj, Syn. Fl. N. A. 2, pt. $1: 251$.

EUROPE.

Naturalized. New Brunswick and New England, and throughout the Atlantic States to Mississippi and Tennessee.

Alabama : Tennessee Valley to lower hills. Waste places. Lauderdale and Tuscaloosa counties. Flowers yellow; May, June. Not frequent; most probably escaped from cultivation. Perennial.

Type locality: "Hab. in Europae ruderatis."

Herb. Geol. Surv. Herb. Mohr.

SCROPHULARIA L. Sp. Pl. 2 :619. 1753. FigWORT.

About 120 species, warmer temperate regions, Northern Hemisphere, Europe, Asia. North America, 3.

Scrophularia marilandica L. Sp. Pl. 2:619. 1753.

Maryland Figwort.

Ell. Sk. 2: 106. Gray, Man. ed. 6, 380. Chap. Fl. 289. Gray, Syn. Fl. N. A. 2, pt. $1: 258$.

Alleghenian to Louisianian area. Quebec, Ontario; New England west to Minnesota, Nebraska, and Oregon, south to Florida, Lonisiana, Arkansas, and Colorado.

Alabama: Tennessee Valley. Mountain region. Damp thickets, borders of woods. Morgan County, Falkville. Talladega County, Chandler Springs, 1,200 feet. Cle- 
burne Connty, Woodsmine. Flowers greenish; August, September. Not common.

Perennial.

Type locality: "Hab. in Virginia."

Herb. Geol. Surv. Herb. Mohr.

CHELONE L. Sp. Pl. 2 : 611. 1753.

Three species, perennials, North American.

Chelone glabra L. Sp. Pl. 2: 611. 1753.

TURTLE-IIEAD.

Ell. Sk. 2 : 126. Gray, Man. ed. 6, 381. Chap. Fl. 289. Gray, Syn. Fl. N. A. 2, pt. 1: 258 .

Canadian to Louisianian area. Newfoundland, Nova Scotia, Quebec; New England to New Jersey, west to Missouri and Arkansas, and south to Florida?

Alabama: Mountain region to Central Prairie region. Damp shaded banks. Talladega County, Renfroe, 600 feet. Cleburne County. Autanga County, Prattville. Pike County, 'Troy (D. Langdon). Flowers white; September, October.

Not infrequent.

Economic uses: The leares, called "snake-head leaves," are used in domestic medicine.

Type locality: "Hab. in Virginia, Canada."

Herb. Geol. Surv. Herb. Mohr.

Chelone lyoni Pursh, Fl. Am. Sept. 2 :737. 1814.

Ell. Sk. 2:127. Chap. Fl. 289; ed. 3, 308. Gray, Syn. Fl. N. A. 2, pt. 1: 259.

Carolinian area. North Carolina, Georgia.

Alabama: Mountain region. Damp woods and copses. Jackson County, Sand Mountain (C. L. Boynton), Pisgah.

Type locality: "In Upper Carolina and Georgia. Lyon."

Herb. Geol. Surv. ex Biltmore Herb.

PENTSTEMON Soland.in Ait.Hort. Kew. 3:511. 1789.

About 100 species, perennial herbs, rarely shrubby. Mexico. North America, 71. East of the Mississippi, 5 .

Pentstemon hirsutus (L.) Willd. Sp. Pl. 3 :227. 1801. Pubescent Beard-tongue.

Chelone hirsuta L. Sp. Pl. 2 : 611. 1753.

Penstemon pubescens Soland. in Ait. Hort. Kew. 3 : 360. 1789.

Ell. Sk. 2:129. Gray, Man. ell. 6, 381. Chap. Fl. 290. Gray, Syn. Fl. N. A. 2, pt. 1: 268. Coulter, Contr. Nat. Herb. $2: 309$.

Alleghenian to Lonisianian area. Ontario to Minnesota and Iowa; New England west to Missouri and Arkansas, south to Florida, and along the Gulf to Texas.

Alabama: Tennessee Valley to Coast plain. Dry sandy or gravelly soil. Borlers of thickets and woods. Lauderdale County. Cullman County, 800 feet. Montgomery, Clarke, and Mobile counties. Flowers pale rose-purple; April, June. Frequent.

Varies greatly according to exposure and soil conditions. In the sterile, dry soil of the pine barrens the pubescence is fine and close, the leaves narrowly lanceolate, smoothish, and slightly denticulate. In the mountains on shaded borders of woods and in thickets of a richer soil forms prevail with the stem sparingly hairy and the inflorescence as well as the leaves viscidly hirsute, the latter more broadly sinuate or repand-deaticulate, agreeing closely with the type described by Willdenow. (Specimens from Cullman County belong here.)

Type locality: "Hab. in Virginia."

Herb. Geol. Surv. Herb. Mohr.

Pentstemon digitalis Nutt. Trans. Am. Phil. Soc. ser. 2, 5 : 181. 1833-1837.

Foxglove Beard-tongue.

Chelone digitalis Sweet, Brit. Fl. Gard. 2 : t. 120. 1825-1827.

Pentstemon laevigatus var. digitalis Gray, Syn. Fl. N. A. 2, pt. 1: 268. 1878.

Gray, Man. ed. 6, 382. Britt. \& Br. Ill. Fl. 3:152. 1898.

Carolinian area. New York, Illinois, south to Georgia, west to Arkansas.

AlabaMa: Mountain region. Dekalb County, Mentone. Cullman County (Miss Mary Mohr). Madison County, Huntsville (Underwood). Flowers white; May, June. Not frequent.

Type locality : "Arkansas 'Territory." "In wet woods and prairies ; common."

Herb. Geol. Surv. Herb. Mohr. 
Pentstemon pentstemon (L.) Britton, Mem. Torr. Club, 5 : 291. 1894.

Chelone pentstemon L. Sp. Pl. ed. 2, 2: 850. 1762.

SMOOTHISH BEARD-TONGUE.

Pentstemon laevigatus Soland. in Ait. Hort. Kew. 2:361. 1789.

P. laevigatus var. multiflorus Chap. Fl. ed. 3, 309. 1897.

Ell. Sk. 2:128. Gray, Man. ed. 6, 381. Chap. Fl. 290" Gray, Syn. Fl. N. A. 2, pt.

$1: 268$.

Carolinian area. Virginia and Pennsylvania west to Missouri and Arkansas, south to Tennessee and Georgia.

Alabama : Mountain region. Madison County, Huntsville (Prof. L. M. Underwood). Flowers in April. Infrequent.

Type locality: "Hab. in Virginia."

Herb. Geol. Surv. Herb. Mohr.

Pentstemon smallii Heller, Bull. Torr. Club, 21:25. 1894.

Perennial, $1 \frac{1}{2}$ to 4 feet high, glabrous below. Radical leaves oval to ovate; cauline leaves lanceolate or ovate-lanceolate, 2 to 5 incbes long, 1 to 3 inches wide, almost connected by the clasping bases, smoothish or softly pubescent, serrate, the uppermost entire; inflorescence more or less pubescent like the scarious-margined, lanceolate calyx lobes; corolla bright purple, the lower lip densely bearded with yellow hairs; sterile filament bearded to the base, most densely above.

Carolinian area Tennessee, North Carolina, and northern Georgia.

Alabama: Mountain region. Dry open woods. Madison Connty, Huntsville ( $L$. M. Underwood). Dekalb County, Lookout Mountain, near Loring's Spring Hotel, altitude 2,000 feet ( C. Mohr).

Type locality: "Collected by the writer on Blowing Rock Mountain, Caldwell County, N.C."

PAULOWNIA Sieb. \& Zucc. Fl. Jap. 1:25, t. 10. 1835.

One species, Japan.

Paulownia tomentosa (Thunb.) Baill. Hist. Pl. 9:434. 1888.

Paulownia.

Bignonia tomentosa Thunb. Fl. Jap. 252. 1784.

Paulownia imperialis Sieb. \& Zucc. Fl. Jap. 1: 27. 1835.

Louisianian area. Introduced, and in the lower Southern States here and there escaped from cultivation.

Alabama : Central prairies. In waste places about $d$ wellings. Pike County, Troy. Mentgomery County. Flowers cerulean blue; February, March.

Type locality: "Crescit in insula Nipon et prope Nagasaki."

Herb. Geol. Surv.

MIMULUS L. Sp. Pl. 2 :634. 1753. MONKey Flower.

Over 60 species, perennial herbs, about 59 eastern tropical America, Mexico. and chiefly northwestern America. United States 28. Atlantic, 3.

Mimulus alatus Soland. in Ait. Hort. Kew. 2 :361. 1789.

Ell. Sk. 2:125. Gray, Man. ed. 6, 383. Chap. Fl. 291. Gray, Syn. Fl. N. A. 2, pt. 1:276. Coulter, Contr. Nat. Herb. $2: 309$.

Carolinian area. New York west to Michigan, the Ohio Valley, Missouri, and Arkansas; south to Florida and Texas.

Alabama : Mountain region to Lower hills. Damp grassy banks, margin of rivulets. Clay County, Moseley, 1,000 feet altitude. Cullman and Blount counties. Bibb County (E. A. Smith). Tuscaloosa County. Flowers mauve-purple; August. One and one-half to 2 feet high. Not common. Perennial.

Type locality: "Native of North America."

Herb. Geol. Surv. Herb. Mohr.

GRATIOLA L.Sp.Pl. 1:17. 1753. HEDGE HyssoP.

Twenty-five species, low perennials; temperate Europe. North America, 14. Atlantic, 12, mostly Southern.

Gratiola floridana Nutt. Journ. Acad. Phila. 7: 103. 1834.

Chap. Fl.292. Gray, Syn. Fl. N. A.pt. 2, 1: 281.

Florida Hedge Hyssop.

Carolinian and Lovisianian areas. Southeastern Tennessee, Georgia, and Florida.

Alabama: 'Tennessee Valley to Central Prairie region. Wet places in the woods. Lawrence County, Moulton, 600 feet. Franklin County, Russellville. Cullman 
County, 800 feet. Lee County, Auburn (Earle \& Underwood). Etowah County, Attalla (E. A. Smith). Montgomery County. Flowers white, limb rose-purple; April, May. Frequent.

Type locality: "Near Chipola, in West Florida."

Herb. Geol. Surv. Herb. Mohr.

Gratiola virginiana L. Sp. Pl. 1:17. 1753.

Common HedGe Hyssor.

Gray, Man. ed. 6, 384. Chap. Fl. 292. Gray, Syn. Fl. N. A. 2, pt. 1: 281. Coulter, Contr. Nat. Herb. $2: 311$. Wats. Bot. Calif. $1: 570$.

Alleghenian, Carolinian, and Louisianian areas. Quebec and Ontario west to British Columbia, Oregon, and California; New England west to Minnesota and Nebraska, south from the Ohio Valley, Missouri, and Arkansas to Florida and Texas.

Alabama: Mountain region. Muddy banks. Dekalb County, Mentone. Springy banks of Little River, 1,800 feet. Flowers yellowish white; June. Apparently rare in the State.

Type locality: "Hab. in Virginia."

Herb. Geol. Surv. Herb. Mohr.

Gratiola sphaerocarpa Ell. Sk. 1:14. 1816.

Round-Fruited Hedge Hyssop.

Gratiola acuminata Vahl, Enum. 1:92. Not Walt.

Ell. Sk. l. c. Gray, Man. ed. 6, 384. Chap. Fl. 292. Gray, Syn. Fl. N. A. 2, pt. 1:282. Coulter, Contr. Nat. Herb. $2: 311$.

\section{Mexico.}

Carolinian and Louisianian areas. Coast of New Jersey, West Virginia, southern Illinois, southern Missouri and Arkansas, south to Florida and Texas.

Alabama : Central Pine belt to Coast plain. Springy banks, borders of rivulets. Tuscaloosa County (E. A. Smith). Dekalb County, Mentone. Mobile County. Flowers white; May. Frequent.

Type locality : "Grows in ponds 4 miles from Charleston, on the Neck."

Herb. Geol. Surv. Herb. Mohr.

Gratiola aurea Muhl. Cat. 2. 1813.

Yellow-Flowered HedGe Hyssor. Ell. Sk. 1:13. Gray, Man. ed. 6, 385. Chap. Fl. 293. Gray, Syn. Fl. N. A. 2, pt. $1: 282$.

Alleghenian, Carolinian, and Louisianian areas. Quebec, Ontario, and New England to Florida.

Alabama: Coast plain. Borders of ditches. Flowers golden yellow; April to September. Not common.

Type locality: "N. Angl. N. Caes. Car."

Herb. Geol. Surv. Herb. Mohr.

Gratiola pilosa Michx. Fl. Bor. Am. 1:7. 1803.

Pilose Hedge Hyssop.

Gratiola peruviana Walt. Fl. Car. 62. 1788. Not L.

Ell. Sk. 1:13. Gray, Man. ed. 6, 385. Chap. Fl. 293. Gray, Syn. Fl. N. A. 2, pt. $1: 283$. Coulter, Contr. Nat. Herb. $2: 311$.

Carolinian and Louisianian areas. Coast of New Jersey to Florida, west to Texas.

Alabama: Central Pine belt to Coast plain. Low damp places, borders of ponds. Dekalb County, Valleyhead. Autauga County (E. A. Smith). Monroe, Mobile, and Baldwin counties. Flowers July to September; frequent. Most common in the low sandy pine flats of the Coast plain.

Type locality: "Hab. in Carolinae inferioris uliginosis."

Herb. Geol. Surv. Herb. Mohr.

Gratiola hispida (Benth.) Pollard, Bull. Torr. Club, 24:157. 1897.

Rovgh Hedge Hyssop.

Sophronanthe hispida Benth.; Lindl. Intr. Nat. Syst. ed. 2, 445. 1836.

Gratiola subulata Baldw.; Benth. in DC. Prodr. 10:405. 1846.

Chap. Fl. 293. Gray, Syn. Fl. N. A. 2, pt. 1: 283.

Louisianian area. Florida, along the coast to Mississippi.

Alabama: Littoral region. Dry sands on the Gulf shore. Baldwin County, Navy Cove, Bon Secuur Bay. Flowers white; June, July; plant shrubby at the base. Frequent.

Type locality (DC. Prodr.): "In Florida (Chapman! Baldwin!), ad Apalachicola (Drummond!)."

Herb. Geol. Surv. Herb. Mohr. 
CONOBEA Aubl. Pl. Guian. $2: 639$, t. 258. 1775.

Seven species, tropical America.

Conobea multifida (Michx.) Benth. in DC. Prodr. 10:391. 1846.

Capraria multifida Michx. Fl. Bor. Am. 2 : 22. 1803.

Cutleaf Conobea.

Gray, Man. ed.6, 383. Chap. Fl. Suppl.636; ed. 3, 311. Gray, Syn. Fl. N. A. 2, pt. 1 : 279. Coulter, Contr. Nat. Herb. $2: 310$.

Carolinian and Louisianian areas. Ohio to Missouri, Arkansas, and Texas. Adventive on ballast at New York and Philarlelphia.

Alabana : Coast region. Adventive on ballast from the west. Mobile County. Flowers June, July; rare. Annual.

Type locality: "Hab. in ripis arenosis fluminum amniculorumque, in Tennassée et Illinoensi regione."

Herb. Geol. Surv, Herb. Mohr.

MONNIERA P. Br. Hist. Jam. 269, t.28, f.3. 1755.

(BACOPA Aubl. Pl. Guian. $1: 128, t$. 49. 1775.)

(Herpestis Gaert. Fruct. $3: 186, t .214, f .6$. 1805.)

About 60 species, perennial herbs, subtropical and tropical regions of both hemispheres. Asia. Chiefly American. North America, 6.

Monniera acuminata (Walt.) Kuntze, Rev. Gen. P1. 2 : 463. 1891.

Gratiola acuminata Walt. Fl. Car. 61. 1788.

Blackening Hedge Hyssop.

Herpestis nigrescens Benth. Comp. Bot. Mag. 2 : 56.1836.

Ell. Sk. 1:15. Gray, Man. ed. 6, 383. Chap. Fl. 291. Gray, Syn. Fl. N. A. 2, pt. 1: 280. Coulter, Contr. Nat. Herb. $2: 310$.

Carolinian and Louisianian areas. Maryland, along the coast to North Carolina and Florida, west to Tennessee, Arkansas, Texas, and Louisiana.

Alabama: Tennessee Valley to Coast plain. Low damp places, thickets, and pastures. Morgan County, Falkville, covering low abancloned fields. Tuscaloosa, Montgomery, Clarke, Baldwin, and Mobile counties. Frequent; 1 to $1 \frac{1}{2}$ feet high.

'Type locality: South Carolina.

Herb. Geol. Surv. Herb. Mohr.

Monniera chamaedryoides peduncularis (Benth.).

Peduncled Germandek-like Hedge Hyssop.

Herpestis peduncularis Benth. Comp. Bot. Mag. 2: 56.1836.

H. chamaedryoides var. peduncularis Gray, Syn. Fl. N. A. 2, pt. 1:280. 1878.

Chap. Fl. 291. Gray, l. c. Coulter, Contr. Nat. Herb. 2:310. Chap. Fl. ed. 3, 310.

NoRTherN Mexico?

Louisianian area. Florida to Texas.

Alabama: Upper Division Coast Pine belt to Coast plain. Low waste places, borders of ditches. Clarke County, Suggsville (Dr. Denny). Mobile County. Flowers yellow; April, May. Not frequent. Low, diffusely branching.

Type locality: "Texas on the Rio Brazos, Drummond."

Herb. Geol. Surv. Herb. Mohr.

Monniera monniera (L.) Britton, Mem. Torr. Club, 5 : 292. 1894.

Creeping Monniera.

Gratiola monniera L. Cent. Pl. 2 : 1756. (Amoen. Acad. 4 : 307.)

Monniera cuneifolia Michx. F1. Bor. Am. 2:22. 1803.

Herpestis monniera H. B. K. Nov. Gen. \& Sp. 2:366. 1817.

Ell. Sk. 2:103. Gray, Mall. ed.6,384. Chap. Fl.292. Gray, Syn. Fl. N. A. 2, pt.1:

281. Coulter, Contr. Nat. Herb. 2:310. Griseb. Fl. Brit. W. Ind.430.

Cosmopolitan on Tropical, aNd SUPtropical Coasts.

Louisianian area. Maryland (Gray), coast of North Carolina to Florida, west to Texas.

Alabama : Coast plain and Littoral region. Margin of tide-water swamps, fresh and brackish, to the seashore. Flowers pale blue; May to October. Abundant. Low, creeping, 1 to 2 feet long; perennial.

Type locality: "Hab. in Jamaica."

Herb. Geol. Surv. Herb. Mohr.

$15894-46$ 
Monniera caroliniana (Walt.) Kuntze, Kev. Gen. Pl. 2 : 463. 1891.

Obolaria caroliniana Walt. Fl. Car. 166. 1788.

Monniera amılexicaulis Michx. Fl. Bor. Am. 2 :22. 1803.

Herpestis amplexicaulis Pursh, Fl. Am. Sept. 2:418. 1814. 280.

Ell. Sk. 2 :104. Gray, Man. ed. 6, 384. Chap. Fl. 292. Gray, Syn. Fl. N. A. 2, pt. 1 :

Carolinian and Louisianian areas. Maryland to Florida, west to Louisiana.

Alabama: Central Prairie region. Borders of pouds. Barbour County, Eufaula (E. A. Smith). Flowers blue; August. Rare.

Type locality: South Carolina.

Herb. Geol. Surv. Herl. Mohr.

MICRANTHEMUM Michx. Fl. Bor. Am. 1:10. 1803.

Sixteen species, low herbs, tropical and subtropical America. Atlantic North America, 2; low aquatics.

Micranthemum orbiculatum Michx. Fl. Bor. Am. 1:10, t.2. 1803.

Ell. Sk. 1: 17. Chap. Fl. 295. Gray, Syn. Fl. N. A. 2, pt. 1:284. Coulter, Contr. Nat. Herb. 2 : 312.

West Indies, Central America, Brazil, Peru.

Louisianian area. North Carolina to Florida and western Texas.

Alabama : Coast plain. Muddy banks, shallow ponds. Mobile and Baldwin counties. Flowers white; May to October. Common; creeping in dense tufts. Perennial.

Type locality: "Hab. in udis opacisque sylvarum Carolinae et Georgiae."

Herb. Geol. Surv. Herb. Mohr.

Micranthemum orbiculatum emarginatum (Ell.) Mohr, Bull. Torr. Club, 24 : 26. 1897.

Micranthemum emarginatum Ell. Sk. 1:18. 1816.

Lonisianian area. Georgia, Lonisiana.

Alabama: Coast plain. Gently-flowing brooklets. Baldwin County, Daphne.

Not frequent. Perenuial.

The orbiculate leaves from $\frac{1}{4}$ tu over $\frac{1}{2}$ inch wide, slightly emarginate, the 3 basal nerves more prominent. Flowers closely sessile, smaller than in the type. Stems 6 to 8 inches long, floating in clear brooklets.

Type locality: "Grows in ditches and wet places-Vall' Ombrosa, Great Ogeechee. In the upper country, common."

Herb. Geol. Surv. Herb. Mohr.

II YSANTHES Raf. Ann. Nat. 13. 1820.

Ten species, annuals, warmer regions of the globe. Atlantic North America, 5, chiefly Southern.

Ilysanthes gratioloides (L.) Benth. in DC. Prodr. 10:419. 1846.

HEDGE-HYSSOP-LIKE ILYSANTHES.

.Capraria gratioloides L. Sp. Pl. ed. 2, $2: 876.1763$.

Gratiola anagallidea Michx. Fl. Bor. Am. 1:5. 1803.

Ilysanthes riparia Raf. Ann. Nat. 13. 1820.

Lindernia dilatata Muhl. Cat. 59. 1813.

Ell. Sk. 1: 16. Gray, Man. ed. 6, 385. Chap. Fl. 294. Gray, Syn. Fl N. A. 2, pt. 1: 283. Coulter, Contr. Nat. Herb. $2: 311$.

Soutil America, eastern Asia.

Carolinian and Louisianian areas. New Brunswick, Ontario, and Minnesota to Oregon and the Sierra Nevada; throughout the States east of the Mississippi River.

Alabama: From the Tennessee Valley to the Coast plain. Muddy borders of streams, exposed muddy banks. Flowers white; June to September. Abundant. Type locality: "Hab. in Virginiae aquosis."

Herb. Geol. Surv. Herb. Mohr.

Ilysanthes attenuata (Muhl.) J. K. Small, Bull. Torr. Club, 23:297. 1896.

Lindernia attenuata Muhl. Cat. 59. 1813.

Gratiola attenuata Spreng. Syst. 1: 39. 1824.

By later authors confounded with the last.

Alleghenian and Carolinian areas. Outario, Wisconsin, Missouri, south to Georgia. 
Alabama: Mountain region, miry places. Dekalb Connty, Mentone. Lee County, Auburn (Baker \& Earle). Flowers July. Rare and local.

'Type locality: "Pens."

Herb. Geol. Surv. Herb. Mohr.

Ilysanthes refracta (Ell.) Benth. in DC. Prodr. 10:418. 1846.

Lindernia refracta Ell. Sk. 1:579. 1821.

L. monticola Nutt. Gen. Add. 1818.

Ell. 1. c. Chap. Fl. 294, ed. 3,313. Gray, Syn. Fl. N. A. 2, pt. 1:283.

Carolinian area. North Carolina to Georgia.

Alabama: Mountain region. Wet rocks. Dekalb County, Lookout Mountain, Desoto Falls, May (C. L, Boynton) and near Gadsden. Etowah County, Black Creek Falls.

Type locality: "Grows around the margins of ponds in Barnwell district, Sonth Carolina; in Burke County, and near Milledgeville, Georgia."

Herb. Geol. Surv. ex Biltmore Herb.

SCOPARIA L.Sp. PI. 1:116. 1763.

About 6 species, small undershrubs or herbs, tropical America to Brazil.

Scoparia dulcis L. Sp. Pl. 1:116. 1753.

Chap. Fl. 296. Gray, Syn. Fl. N. A. 2, pt. 1:284. Coulter, Contr. Nat. Herb. $2: 312$. Griseb. Fl. Brit. W. Ind. 427.

Cosmopolitan in THe Tropics.

Louisianian area. Florida to southwestern Texas.

Alabama: Coast plain. Fugitive on ballast. Mobile County, July, 1885; rarely met with. Annual.

Type locality : "Hab. in Jamaica, Curassao."

Herb. Mohr.

VERONICA L. Sp. Pl. 1:9. 1753.

About 200 species, annuals and perennials, cooler temperate regions both hemispheres. Europe, western Asia, New Zealand. North America, 11.

Veronica peregrina L. s̀p. Pl. 1:14. 1753.

NECK WEED.

Veronica caroliniana Walt. Fl. Car. 61. 1788.

Ell. Sk. 1:10. Gray, Man. ed. 6, 387. Chap. Fl.295. Gray, Syn. Fl. N. A. 2, pt. 1: 288. Coulter, Contr. Nat. Herb. 2 :312. Wats. Bot. Calif. 572.

Mexico, South America.

Boreal region to Louisianian area. Throughout the continent. From near the arctic circle to the Gulf of Mexico.

Alabama: Over the State. In damp cultivated ground. Flowers pale blue; February to May. A most common winter annual, 4 to 6 inches high.

'Type locality: "Hab. in Enropae hortis, arvisque."

Herb. Geol. Surv.

Veronica arvensis L. Sp. Pl. 1:13. 1753.

CORN SPEEDWFLL.

Ell. Sk. 1:9. Gray, Man. ed. 6, 387. Chap. F1. 296. Gray, Syn. Fl. N. A. 2, pt. $1: 288$.

Eurore.

Naturalized. Maritime provinces of Canada and along the Atlantic coast to Florida and Lonisiana.

Alabama: Coast plain. Cultivated ground, waste places. Flowers blue; February to May. Common winter weed; annual.

Type locality: "Hab. in Europae arvis, cultis."

Herb. Geol. Surv.

Veronica agrestis L.Sp. P1. 1:13. 1753.

Gray, Man. ed. 6, 387. Chap. Fl. 296. Gray, Syn. Fl. N. A. 2, pt. 1: 288.

Carolinian to Louisianian area. Introduced along the Atlantic and Gulf coasts from Now England to Florida and Louisiana.

Alabama : Coast region. Ballast ground. Mobile County, May; rare. Annual. Type locality: "Hab. in Europae cultis, arvis."

Herb. Geol. Surv. Herb. Mohr.

Veronica serpyllifolia L. Sp. P1. 1 :12. 1753.

THYME-LEAF SPEEDWELL.

Ell. Sk. 1:8. Gray, Man. ed.6, 387. Chap. Fl. 295. Gray, Syn. Fl. N. A. 2, pt. 1:288.

Europe, Asia, Nortuern Africa. 
Boreal region to Carolinian area. Labrador. Thronghout Canada to the aretic circle, across the continent, and throughout the North Atlantic States west to New Mexico and Nevala, south along the mountains to Georgia.

Alabama: Tennesseo Valley. Damp shady places on calcareous banks. Madison County, Montesano, 800 feet. Jackson County, Gurleys, 1,000 feet altitude; Scottsboro, 800 feet. Flowers lilac, May; not frequent. Perennial.

Type locality: "In Europa et America septentrionali ad vias, agros."

Herb. Geol. Surv. Herb. Mohr.

Veronica anagallis-aquatica L. Sp. PI. 1:12. 1753.

Water SPEEDWELL.

Gray, Man. ed. 6, 386. Chap. Fl. ed. 3, 314. Gray, Syn. Fl. N. A. 2, pt. 1 : 287.

EUROPE.

Alleghenian to Louisianian area. Canada to British Columbia, south to Tennessee. Alabama: Fugitive on ballast. Mobile County, June, 1894. Wet banks, Mobile River.

'Type locality: "Hab. in Europa ad fossas."

Herb. Geol. Surv. Herb. Mohr.

LEPTANDRA Nutt. Gen. 1:7. 1818.

Two species, perennial, eastern Asia, Siberia. North America, 1.

Leptandra virginica (L.) Nutt. Gen. Pl. 1:7. 1818.

Veronica virginica L. Sp. Pl. 1:9. 1753.

Gray, Man. ed. 6, 386. Chap. Fl. 295. Gray, Syn. Fl. N. A. 2, pt. $1: 286$.

Alleghenian to Lonisianian area. Ontario to Manitoba, Minnesota, and Nebraska ; New England south to New Jersey, and from the Ohio Valley to Missouri and Arkansas, and along the monntains to Tennessee and Georgia.

Alabama: Mountain region to Central Prairies. Rich woods. Cullman and Bibb counties. Autanga County, Prattville. Sumter County. Flowers cerulean blue; August. Not frequent; 2 to 3 feet high.

Economic uses: The root is the "blackroot" or "Leptandra" of the United States Pharmacopoia.

'Type locality: "Hab. in Virginia."

Herb. Geol. Surv. Herb. Mohr.

AFZELIA J. G. Gmelin, Syst. 2 :927. 1796.

(Seymeria Pursh, Fl. Am. Sept. $2: 736.1814$. )

Nine species, annual or perennial herbs. Mexico. North America,5. Madagascar, 1.

Afzelia cassioides J. G. Gmelin, Syst. 2:927. 1796.

Thin-Leaved Afzelia.

Anonymos cassioides Walt. Fl. Car. 171. 1788.

Gerardia afzelia Michx. Fl. Bor. Am. 2:20. 1803.

Seymeria tenuifolia Pursh, Fl. Am. Sept. 2 : 737. 1814.

Ell. Sk. 2:122. Chap. Fl. 297. Gray, Syn. Fl. N. A. 2, pt. 1: 289. Coulter, Contr. Nat. Herb. $2: 313$.

Carolinian and Louisianian areas. North Carolina to Florida, west to southeastern Tennessee and Mississippi.

Arabama : Central Pine belt to Lower Pine region. Dry sandy pine forest. Bibb County (E. A. Smith). Baldwin and Mobile connties. Corolla of flowers ycllow, with rufous lip; September to November. Not infrequent. Annual.

Type locality: Suuth Carolina.

Herb. Geol. Surv. Herb. Mohr.

Afzelia pectinata (Pursh) Kuntze, Rev. Gen. Pl. 2: 457. 1891.

Pectinate-leaf Afzielia.

Seymeria pectinata Pursh, Fl. Am. Sept. 2 : 737. 1814.

Ell. Sk. 2:122. Chap. Fl. 297. Gray, Syn. Fl. 2, pt.1:290. Coulter, Contr. Nat. Herb. 2 : 313 .

Carolinian and Louisianian areas. South Carolina to Florida, west to Texas.

Ala bama: Mountain region. Metamorphic hills to Lower Pine region. Dry pine riclges. Lee County, Auburn (Earle). Mobile County, Chastang's Bluff. Flowers yellow; September, October. Not frequent. Annual.

'Type locality: "In South Carolina. Catesby."

Herl, Geol. Surv. Herb. Mohr. 
MACRANTHERA Torr.; Benth. in Hook. Comp. Bot. Mag. 1:203. 1835.

One species, South Atlantic North America.

Macranthera fuchsioides (Nutt.) Torr.; Benth. in Hook. Comp. Bot. Mag. 1:203. 1835.

Fuchisia-like Macranthera.

Conradia fuchsioides Nutt. Journ. Acad. Phila. 7:88, t. 11, 1:. 1834.

Chap. Fl. 297. Gray, Syn. Fl. N. A. 2, pt. 1:290.

Lonisianian area. Georgia, Florida, and eastern Louisiana (?).

Alabama : Central Pine belt to Lower Pine region. Sandy borders of swamps and brooks. Tuscaloosa County (E. A. Smith). Escambia County. Baldwin Connty, Stockton. Mobile County, Springhill. Flowers yellow to flame color; August, September. Not infrequent. A coarse biennial.

Type locality not specifically given. In Bentham: "Southern States of North America. Louisiana. (Irummond.)"

Herb. Geol. Surv. Herb. Nohr.

DASYSTOMA Raf. Journ. Phys. $89: 99.1819$.

Eight species, coarse perennial yellow-flowered herbs, Atlantic North America, 8. Dasystoma pectinata (Nutt.) Benth. in DC. Prodr. 10:521. 1846.

Pectinate False Foxglove.

Gerardia pedicularia pectinata Nutt. Gen. Pl. 2:48. 1818.

Chap. Fl. 298. Gray, Syn. Fl. N. A. 2, pt. 1:291.

Carolinian and Louisianian areas. North Carolina to Florida, west to Mississippi and Arkansas.

Alabama: Throughout the State. Arid rocky or sandy soil. Clay County, Cheaw-ha Mountain, 2,200 feet. Washington, Escambia, Clarke, Mobile, and Baldwin counties. Flowers yellow; August, September. Frequent.

Type locality: "In the sandy pine forests of Carolina and Georgia."

Herb. Geol. Surv. Herb. Mohr.

Dasystoma flava (L.) Wood, Bot. \& Flor. 230. 1873. Downy False Foxglove.

Gerardia flava L. Sp. Pl. 2 : 610. 1753.

Dasystomia pubescens Benth. in DC. Prodr. 10:520. 1846.

Ell. Sk. 2:119. Gray, Man. ed. 6, 389. Chap. Fl. 298. Gray, Syn. Fl. N. A. 2, pt. $1: 291$.

Carolinian area. Ontario and New England, west to southern Michigan, through the Ohio Valley to Missouri and Arkansas, and from Tennessee along the mountains to Georgia.

Alabama: Mountain region. Coosa hills. Metamorphic ranges. Rocky woods. Calhonn County, Anniston, about 1,000 feet. Clay Connty, Che-aw-ha Mountain, 2,400 feet altitude. Flowers yellow; August, September. Not infrequent on the Metamorphic formations of greatest elevation.

Type locality: "Hal). in Virginia, Canada."

Herb. Geol. Surv. Herb. Mohr.

Dasystoma virginica (L. ) Britton, Mem. Torr. Club, 5 : 29.. 1894.

Rhinanthus virginicus L. Sp. P1. 2 : 603. 1753.

Gerardia quercifolia Pursh, Fl. Am. Sept. 2 : 423.1814. 291.

Ell. Sk. 2 :120. Gray, Man. ed.6, 389. Chap. Fl.298. Gray, Syn. Fl. N. A. 2, pt. 1:

Carolinian and Louisianian areas. Ontario and New England, west to Michigan, south to Florida, Lonisiana, and Arkansas.

Alabama: Tennesseo Valley. Mountain region. Lauderdale and Cullnan coun-

ties. Calloun County, Anniston.

Type locality: "Hab. in Virginia."

Herb. Geol. Surv. Herb. Mohr.

Dasystoma laevigata (Raf.) Chap. Fl. Suppl.636. 1883.

Gerardia laevigata Raf. Ann. Nat.13. 1820.

Dasystoma quercifolia var. (\&) integrifolia Benth. in DC. Prodr. 10:520. 1846.

Gra., Man. eil. 6,389. Chap.1. c.; ed.3, 313. Gray, Syn. Fl. N. A. 2, pt. 1: 291.

Carolinian to Lonisianian area. Southern Michigan, Illinois, and Tennessee to Georgia.

Alabama: Lower Metamorphic hills. Central Pine belt. Chilton County (E. A. Smith). August. Lee County, Auburn (Baker \& Earle). 
Type locality: "It grows on the knob hills of Kentucky, the Cumberland mountains and the Alleghany."

Herb. Geol. Surv. Herb. Mohr.

GERARDIA I.Sp. Pl.2:610. 1753. Gerardia.

About fifty species, perenuial or annual purple-flowered herbs. Mexico, South America, Brazil. Warmer temperate North America, 23, mostly Eastern.

Gerardia auriculata Michx. Fl. Bor. Am. 2:20. 1803.

auriculate false foxglovk.

Otophylla michauxii Benth. DC. Prodr. 10:512. 1846.

Gray, Man. ed. 6, 389. Chap. F1. 298. Gray, Syn. Fl. 2, pt. 1: 292.

Alleghenian to l.onisianian area. Western Pennsylvania to Missonri and Minnesota, south from New Jersey to North Carolina.

Alabama: (Buckley, 1840). Station not given and plant not found since. Annual. Type locality: "Hab. in pratis regionis Illinoensis."

Herb. Geol. Surv. Herb. Mohr.

Gerardia linifolia Nutt. Gen. Pl. 2:47. 1818.

Fll Sk 118 . $1: 292$.

CUBA.

Carolinian and Lonisianian areas. Delaware to Florida.

Alabama: Central Pine belt. Open pine forests. Elmore County (E. A. Smith).

Flowers August, rare. Perennial.

Type locality: "From Wilmington, North Carolina, to Florilla."

Herb. Geol. Surv. Herb. Mohr.

Gerardia purpurea L. Sp. Pl. $2: 610.1753$.

Purple Gerardia.

Ell. Sk. 2:116. Gray, Man. ed. 6,390. Chap. Fl. 299. Gray, Syn. Fl. N. A.2, pt.

1:293. Conlter, Contr. Nat. Herb. $2: 314$.

Alleghenian and Carolinian areas. Southern Ontario and New England, west to

Minnesota and Nebraska, south to Arkansas, and from New York to Florida, and west to Texas.

Alabama: Mountain region. Metamorphic hills. Damp copses. Clay Connty (E. A. Smith). Cullman County. Annual.

Type locality : "Hab. in Virginia, Canada."

Herb. Geol. Surv. Herb. Mohr.

Gerardia fasciculata Ell. Sk. 2:115. 1817.

Fascicled Gerardia.

Gerardia purpurea var. fasciculata Chap. Fl. 300. 1860.

Ell. Sk.J.c. Chap. Fl.1.c. Gray, Syn. Fl. N. A. 2, pt.1:293. Coulter, Contr. Nat. Herb. 2 : 314.

AlabaMa : Coast plain. Low damp pine barrens, borders of rivers, marshes, fresh or brackish. Flowers September, October. One and one-half to $2 \frac{1}{2}$ feet high. Frequent.

Gradnally passes into forms with simpler stems, and leaves and flowers much reduced in size, approaching $G$. paupercula. Annual.

Type locality: "On Eding's Island near Beaufort very common."

Herb. Geol. Surv. Herb. Mohr.

Gerardia paupercula (Gray) Britton, Mem. Torr. Club, 5 : 295. 1894.

Depauperate Gerardia.

Gerardia purpurea var. paupercula Gray, Syn. Fl. 2, pt.1:293. 1878.

Gray, Man. ed. 6, 390.

Alleghenian, Carolinian, and Louisianian areas. Ontario to Saskatchewan; coast of New England west to Pennsylvania, northern Illinois, and Wisconsin.

Alabama : Coast plain. Low pine barrens. Mobile County. The maritime form the stem weak, slender, fully 2 feet high, branched from the base, the numerous branches elongated, spreading. Flowers numerous, small, $\frac{1}{4}$ to $\frac{5}{8}$ inch long. September, October; not infrequent. Auuual.

Type locality: "Lower Canada to Saskatchewan, and sonthward from coast of New England to Pennsylvania, northern Illinois, and Wisconsin."

Herb. Geol. Surv. Herb. Mohr.

Gerardia maritima Raf. N. Y. Med. Rep.ser. 2, 5:361. 1808. Seaside Geralrdia.

Gerardia purpurea var. crassifolia Pursh, Fl. Am. Sept. $2: 422,1814$.

Gray, Man. ed. 6, 390. Chap. Fl. 300. Gray, Syn.Fl. N. A.2, pt. 1:293. Coulter,

Contr. Nat. Herb. $2: 314$. 
- Alleghenian to Louisianian area. Coast of Maine, along the seashore to Florida, west to Texas.

Alabama: Littoral region. Salt marshes. Baldwin and Mobilecounties. Flowers pink; June, July. Frequent. Annual.

Type locality: "Found in the islands of Egg-Harbour, in New-Jersey."

Herb. Geol. Surv. Herb. Mohr.

Gerardia plukenetii Ell. Sk. 2:114. 1817.

Plukenet's Gerardia.

Gerardia setacea Chap. Fl. 300. Not Walt., Ell., Pursh, or Nutt.

Ell. Sk. 2:114. Chap. Fl. 300. Gray, Syn. Fl. N. A. 2, pt. 1:293.

Carolinian and Louisianian areas. Georgia and Florida to Mississippi.

Alabama: Mountain region to Lower Pine region. Dry gravelly or sandy woods. Lee County, Auburn, 800 feet altitude (Earle). Talladega County, Renfrue, rocky hillsides, 700 feet. Mobile and Baldwin counties. Flowers rose-pink; September, October. Common. Abundant in dry open pine barrens of the Lower Pine region.

Annual.

Plants with white flowers not rare about Mobile.

Type locality: "Grows in wet spungy soils, very common between the Oakmulgee and Chatahouchie rivers."

Herb. Geol. Surv. Herb. Mohr.

Gerardia setacea Walt. Fl. Car. 170. 1788.

Gray, Syn. Fl. N. A. 2, pt. 1:294.

Louisianian area.

Ala bama: Coast plain. Dry sandy pine woods. Mobile County. October; infrequent.

Type locality: South Carolina.

Herb. Geol. Surv. Herb. Mohr.

Gerardia filifolia Nutt. Gen. Pl. $2: 48.1818$.

Filmform-leaved Gerardia. Ell. Sk. 2:116. Chap. Fl. ed. 3, 319. Gray, Syn. Fl. N. A. 2, pt. 1: 293.

Louisianian area. Southern Georgia to Lonisiana.

Alabama : Coast plain. Alabama (fide Gray). Annual.

Type locality: "In West Florida. Dr. Baldwyn."

Gerardia tenuifolia Vahl, Symb. Bot. 3 : 79. 1794.

Thin-Leaved Gerardia. Anonymos erecta Walt. Fl. Car. 170.1788 (?)

Ell. Sk. 2:117. Gray, Man. ed. 6, 390. Chap. Fl. 300. Gray, Syn. Fl. N. A. 2, pt. 1: 294 .

Alleghenian, Carolinian, and Louisianian areas. Ontario and New England west to Minnesota; Ohio Valley to Missouri; south along the mountains to Tennessee, Georgia, and Florida.

Alabama: Mountain region. Dry open woods. Cullman County. Flowers pale rose; August. Annual.

Type locality not ascertained.

Herb. Mohr.

Gerardia tenuifolia asperula Gray, Bot. Gaz.4:153. 1879.

Gray, Man. ed.6, 390. Gray, Syn. Fl. N. A. ed. 2, 2, pt. 1:452.

Carolinian area. Michigan to Indiana, Missouri, western Louisiana, and Tennessee.

Alabama: Mountain region. Dry rocky hillsides. Talladega County, Chandler Spring, 1,000 feet. Flowers pale purple; September, October. Annual.

Type locality: "Collected at St Croix, Wisconsin, and in Fillmore Co., Minnesota"; also received from Michigan and St. Louis.

Herb. Geol. Surv. Herb. Mohr.

Gerardia skinneriana Wood, Classbook, 408. 1847. Small-Lenved Gerardia. Gerardia parvifolia Chap. Fl. 300. 1860.

Gray, Man. ed.6, 390. Chap. l. c. Gray, Syn. Fl. N. A. 2, pt. 1: 294.

Carolinian area. Southern Massachusetts, along the coast to North Carolina and Florida, west to Louisiana.

Alabama : Coast plain. In damp sandy pine woods. Mobile and Baldwin counties. Flowers pale pink; October. Frequent. Low spreading. Annual.

Type locality: "I detected this delicate species in July, 1846, in Greene, Co., Ia." Herb. Geol. Surv. Herb. Mohr.

Gerardia aphylla Nutt. Gen. 2:47. 1818.

LEAFLESS GeraRdia. Ell. Sk. 2:114. Chap. Fl. 299. Gray, Syn. Fl. N. A. 2, pt. 1: 295.

Louisianian area. South Carolina to Florida and Louisiana. 
Alabama : Coast plain. Low sandy damp pine barrens. Mobile County. Flowers rose-purple; Octoler, November. Not infrequent in the pine flats near log River and Whistler. One to $1 \frac{1}{3}$ feet long, ascending. Annual.

Type locality: "From North Carolina to Florida, where it was first detected by Dr. Baldwyn."

Herb. Geol. Snrv. Herb. Mohr.

BUCHNERA L. Sp. Pl. I:630. 1753.

Thirty species, ereet perennials or bienuials, tropieal regions both hemispheres, chiefly American. United States and Mexico to Brazil. New Holland, South Africa, East Indies. North Ameriea, 2.

Buchnera americana L. Sp. Pl. 2 : 630. 1753.

BLUE-HeARTS.

Ell. Sk. 1:112. Gray, Man. ed. 6, 388. Chap. Fl. 297. Gray, Syn. Fl. N. A. 2, pt. 1:289.

Alleghenian to Carolinian area. New York west to Michigan and Wisconsin; southern Virginia to Ohio, Tennessee, southern Missouri, and Arkansas.

Alabama : Mountain region to Lower hills. Dry open woods. Cullman, Walker, and Tusealoosa counties. Clay County, Moseley, 1,200 feet. Flowers violet, May to July. Not rare. Perennial.

'Type loeality: "Hab. in Virginia, Canada."

Herb. Geol. Surv. Herb. Mohr.

Buchnera elongata Sw. Prodr. Veg. Ind. Oce. 92. 1788. Southern Blue-hearts.

Chap. Fl. 297. Gray, Syn. Fl. N. A. 2, pt. 1:289. Coulter, Contr. Nat. Herb. 2 : 313. Griseb. Fl. Brit. W. Ind. 428.

West Indies, Mexico to Brazil.

Louisianian area. North Carolina to Florida, west to Texas.

Alabama: Lower Pine region. Coast plain. Dry pine woods. Washington County, Yellowpine. Eseambia, Baldwin, and Mobile eounties. Flowers violet to deep blue; May, June. Common. Perennial.

Type locality: "India oceidentalis, Jamaica."

Herb. Geol. Surv. Herb. Mohr.

SCHWALBEA L. Sp. Pl. 2 : 606. 1753.

One species, Atlantic North America.

Schwalbea americana L. Sp. Pl. 2 : 606. 1753.

Chaff-Seed.

Ell. Sk. 2 :131. Gray, Man. ed.6, 391. Chap. Fl. 301. Gray, Syu. Fl. N. A. 2, pt. $1: 305$.

Carolinian and Louisianian areas. Southeastern New England along the eoast to Florida, west to Lonisiana.

Alabama: Lower Pine region. Coast plain. Grassy pine barrens. Mobile County, Bayou Sara. Flowers yellow; May. Not rare. Perennial.

Type locality: "Hab. in Ameriea septentrionali."

Herb. Geol. Surv. Herb. Mohr.

CASTILLEJA Mutis; L. f. Suppl.47. 1781.

Thirty to 40 species. Ameriean, chiefly South America, northern Asia.

Castilleja coccinea (L.) Spreng. Syst. Veg. 2: 775. 1825.

PAINTED CUP.

Bartsia coccinea L. Sp. Pl. 2:602. 1753.

Gray, Man. ed. 6, 390. Chap. Fl. 301. Gray, Syn. Fl. N. A. 2, pt.1:295. Coulter, Contr. Nat. Herb. 2 : 315.

Alleghenian and Carolinian areas. Ontario to Manitolua, Maine to northwestern New York and Minnesota; sonthern New Jersey, throngliout the Ohio Valley to Missouri, south to Tennessee, Mississippi, Arkansas, and Texas.

Alabama: Coosa Valley. Etowah County (E. A. Smith). July. Corolla greenish yellow, floral braets searlet. Infrequent. Annual.

Type locality : "Hab. in Virginia, Noveboraco."

Herb. Geol. Surv. Herb. Mohr.

PEDICULARIS L. Sp. Pl. 2 : 603. 1753.

Abont 125 species, of aretie and temperate regions of Europe, North America, northern Asia, Himalayan India.

Pedicularis canadensis L. Mant. 1:86. 1767.

WoOn Betony. Canada Lousewort. 
Pedicularis gladiata Michx. Fl. Bor. Am. 2:18. 1803.

Ell. Sk. 2:123. Gray, Man. ed. 6, 392. Chap. Fl. 301. Gray, Syn. Fl. N. A. 2, pt. $1: 307$.

Mexico.

Alleghenian and Louisianian areas. Nova Scotia to Manitoba and Saskatehewan; New England to Dakota, south to Florida and Louisiana.

Alabama : Over the State. Flowers April, greenish yellow. Common. Perennial. Type locality : "Hab. in America septentrionali. Kalm."

Herb. Geol. Surv. Herb Mohr.

\section{PINGUICULACEAE. Butterwort Family.}

\section{PINGUICULA L. Sp. Pl. 1: 17. 1753. BUTtERWORT.}

Thirty species, perennial herbs, insectivorous, belonging to temperate and subtropical regions. North America, 5.

Pinguicula lutea Walt. Fl. Car. 63. 1788.

YELLOW ButTERWORT.

Ell. Sk. 1:19. Chap. Fl. 284. Gray, Syn. Fl. N. A. 2, pt. 1:318.

Louisianian area. North Carolina to Florida and Louisiana.

Alabama: Coast plain. Low damp pine barrens. Mobile and Baldwin eounties.

Flowers lemon-yellow, March, April; common.

Type locality: South Carolina.

Herb. Geol. Surv. Herb. Mohr.

Pinguicula elatior Michx. Fl. Bor. Am. 1:11. 1803.

Ell. Sk. 1:18. Chap. Fl. 284. Gray, Syn. Fl. N. A. 2, pt. 1:318.

Louisianian area. North Carolina to Florida.

Alabama : Louisianian area. In the low country of Alabama (Gray, Syn. Fl.).

Type locality: "Hab. in paludibus apricis Georgiae et Carolinae."

Pinguicula planifolia Chap. Fl. ed. 3, 303. 1897.

Pinguicula australis Chap. Fl. 284. 1860. Not Nutt.

Chap. 1. c. Gray, Syn. Fl. N. A. 2, pt. 1:318, in part.

Lonisianian area. Lower North Carulina to Florida and Mississippi.

Alabama : Lower division of Coast Pino belt. Inundated borders of pine-barren

streams. Mobile County. Flowers amethyst-blue, A pril, May; not infrequent.

Type locality: "Shallow ponds, west Florida, near the coast."

Heılb. Geol. Surv. Herb. Mohr.

Pinguicula pumila Michx. Fl. Bor. Am. 1: 11. 1803.

Pinguicula australis Nutt. Journ. Acad. Phila. 7:103. 1834.

Ell. Sk. 1:19. Gray, Syn. Fl. N. A. 2, pt. 1:317.

Louisianian area. Georgia and Florida to southwestern Louisiana (Calcasieu River).

Alabama: Louisianian area. Damp sandy pine barrens. Baldwin and Mobile counties. Flats of Mobile River, Mount Vernon.

Type locality : "Hab. in humidis apricis Georgiae."

UTRICULARIA L. Sp. Pl. 1:18. 1753.

(Lentibularia Adans:, including Megacista DC.)

About 150 species, aquatic perennials, insectivorous, of the temperate and warmer regions of the globe. North America, 15.

Utricularia inflata Walt. Fl. Car. 64. 1788.

WHORLED BLADDERWORT.

Utricularia ceratophylla Michx. Fl. Bor. Am. I:12. 1803.

Ell. Sk. 1:20. Gray, Man. ed. 6, 396. Chap. Fl. 282. Gray, Syn. Fl. N. A. 2, pt. $1: 315$. Coulter, Contr. Nat. Herb. $2: 317$.

Alleghenian, Carolinian, and Louisianian areas. Maine (Mount Desert Island) along the coast to Florida and Texas.

AlabaMa : Coast plain. Floating in stagnant water, ponds. Mobile County. Flowers yellow; June, July; not frequent.

Type locality: South Carolina.

Herb. Geol. Surv. 11frb. Mohr.

Utricularia vulgaris L. Sp. PI. 1 : 18. 1753.

COMMON BLADDERWORT.

Gray, Man. ed.6, 396. Chap. Fl. 282. Gray, Syn. Fl. N. A. 2, pt. 1:315. Coulter,

Contr. Nat. Herb. $2: 317$. Wats. Bot. Calif: $1: 581$. 
Europe, Northern Asia, North Africa.

Boreal region to Lonisianian area. Over the coutinent from subarctic regions to the Gulf, and from the South Atlantic States to the Sierra Nevada, California.

Alabama: So far only known from the Coast plaiu. In deep still-flowing water. Mobile County, Dog River, near the estuary; rare. A robust plant, totally immersed; stems 3 to 4 feet in length, profusely branched.

Type locality: "Hab. in Europae fossis paludibus profundioribus."

Herb. Geol. Surv. Herb. Mohr.

Utricularia gibba L. Sp. Pl. 1: 18. 1753.

LESSER BLADDERWORT.

Utricularia fornicata Le Conte, Ann. Lyc. N. Y. 1:76. 1824.

U. minor Torr. Fl. N. Y. $2: 21$. 1843 . Not L.

Ell. Sk. 1: 22. Gray, Man. ed. 6, 396. Chap. Fl. 283. Gray, Syn. Fl. N. A. 2, pt. 1: 315 .

Alleghenian and Louisianian areas. Ontario to New England; Maine (Mount Desert Island) west to Michigan, south to southern Tennessee, North Carolina, and Florida. ber.

Ala Bama: Shallow grassy pine-barren ponds. Mobile County. September, Octo-

Type locality: “Hab. in Virginia."

Herb. Geol. Surv. Herb. Mohr.

Utricularia biflora Lam. Tabl. Encyel. 1:50. 1791.

TWO-FLOWERED BLADDERWORT.

Utricularia longirostris Le Conte, Ann. Lyc. N. Y. 1:76. 1824.

U. fibrosa Chap. Fl. 283. 1860 . Not Walt.

Ell. Sk. 1:23. Gray, Man. ed. 6, 396. Chap. Fl. ed. 3, 301. Gray, Syn. Fl. N. A. 2, pt. 1:315. Coulter, Contr. Nat. Herb. $2: 317$.

Louisianian area. Southern Illinois, North Carolina to Florida and Louisiana.

Alabama : Coast plain. Shallow ponds. Floating or rooting in the ooze and mud. Mobile County, shallow ditches with Eleocharis and Hydrochloa. Montgomery County. Flowers yellow; July to September; not infrequent.

Type locality: "E Carolinia. Fraser."

Herb. Geol. Surv. Herb. Mohr.

Utricularia fibrosa Walt. Fl. Car. 64. 1788.

Utricularia striata Le Conte, Ann:Lyc. N. Y. 1:75. 1824.

Ell. Sk. 1:20. Gray, Man. ed. 6, 396. Chap. Fl. 282; ed.3, 301. Gray, Syn. Fl. N. A. 2, pt. $1: 316$.

Carolinian and Lousianian areas. Coast of New Jersey to Florida, west to Mississippi.

Alabama : Coast plain. Open sphagnous swamps, rooting in the ooze and floating in shallow pouds. Mobile County, Grand Bay. Baldwin County, Zundels, in sphagnous swamps. Flowers yellow; August. Not frequent. Floating stems 3 to 4 inches long; whorls of the finely divided leaves crowded. Scape 6 to 8 inches high. Type locality: South Carolina.

Herb. Geol. Surv. Herb. Mohr.

Utricularia purpurea Walt. Fl. Car.64. 1788.

Utricularia 8accata Ell. Sk. 1:21. 1817.

Ell.1.c. Gray, Man. ed. 6, 397. Chap. Fl. 283. Gray, Syn. Fl. N. A. 2, pt. 1: 316.

Alleghenian to Louisianian area. Coast of Maine (Mount Desert Island) to Florida, west to northern Pennsylvania and Indiana.

Alabama: Coast Pine belt. Deep ponds or still-flowing water in pine-barren streans. Bald win County, Sibley's mill. Washington County, Yellowpine. Geneva County (E. A. Smith). Flowers rose-purple; July to.September. Floating stem 1 to 2 feet long.

Differs from the northern plant in its smaller flowers, as also observed by Pursh.' Type locality: Sonth Carolina.

Herb. Geol. Surv. Herb. Mohr.

Utricularia juncea Vahl, Enum. 1:202. 1805.

RUSIY-LIKE BLADDERWORT.

Utricularia personata Le Conte, Ann. Lyc. N. Y. 1:77. 1824. Fide Gray.

Ell. Sk. 1:23. Chap..Fl. ed.3, 302. Gray, Syn. Fl. N. A. ed.2, 2, pt. 1:455. 1886.

Cuba, Brazil.

Louisianian area. Eastern North Carolina in the coast region, Florida, and Texas. 
AlabaMa: Lower Pine region and Coast plain. Low, wet, grassy pine barrens. Escambia County, Wilson's Station. Mobile County, Bayou Labatre. Flowers deep sellow; September. Frequent.

Type locality: "Hab. in Cajenna. Richard; Portorico. West."

Herb. Geol. Surv. Herb. Mohr.

Utricularia subulata L. Sp. Pl. 1:18. 17 .53.

Setaceous Bladderwort.

Ctricularia setacea Michx. Fl. Bor. Am. 1:12. 1803.

Ell. Sk. 1:23. Gray, Man. ed. 6, 397. Chap. Fl. 283. Gray, Syn. Fl. N. A. 2, pt. 1: 316. Coulter, Contr. Nat. Herb. $2: 317$. Griseb. Fl. Brit. W. Ind. 391.

West Indies, Mexico to Brazil.

Carolinian and Louisianian areas. From New Jersey to Florida and Texas near the coast.

Alabama: Throughout the Coast Pine belt and Coast plain. In sandy wet places. Borders of springs, very common. Flowers from April throughout the summer. The leaf and bladder-bearing radical shoots form, before the development of the scapes, dense green tufts which disappear before the spring season is over.

Type locality: "Hab. in Virginia."

Herb. Geol. Surv. Herb. Mohr.

\section{OROBANCHACEAE. Broom Rape Family.}

THALESIA Raf. Am. Month. Mag. $2: 267.1818$.

(ApHyllon Gray, Man. 290. 1848.)

About 3 species, root parasites. Atlantic North America, 2.

Thalesia uniflora (L.) Britton, Mem. Torr. Club, 5 :298. 1894.

ONE-FLOWERED CANCER ROOT.

Orobanche uniflora L. Sp. Pl. 2 : 633. 1753.

Aphyllon uniflorum Torr. \& Gray; Gray, Man. 290. 1848.

Ell. Sk. 2:135. Gray, Man. edl. 6, 394. Chap. Fl. 287. Gray, Syn. Fl. N. A. 2, pt. 1:

312. Coulter, Contr. Nat. Herb. $2: 316$. Wats. Bot. Calif. 1:584.

Canadian zone to Carolinian area. New foundland and Ontario to Lake Superior, and through British Columbia to Vancouver Island, Oregon, aud California.

Alabama: Mountain region. Dry gravelly hillsides. Cullman Connty (Miss M. Mohr); rare. Parasitic on roots of various plants.

Type locality: "Hab. in Virginia."

Herb. Geol. Surv. Herb. Mohr.

CONOPHOLIS Wallr. Orob. 78. 1825. Root Parasite.

Single species. United States. Mexico.

Conopholis americana (L.) Wallr. Orob. 78. 1825.

Orobanche americana L. Mant. 1:88. 1767.

Ell. Sk. 2:135. Gray, Man. ed. 6, 394. Chap. Fl. 286. Gray, Syn. Fl. N. A. 2, pt. 1:313.

Alleghenian to Caroliuian area. Ontario and New England west to central Michigan, south to the Ohio Valley, North Carolina, and Florida (Chapman).

Alabama: Mountain region. Lower hills. Shady rich woods, among decaying leaves. Madison County, Huntsville, 1,000 feet. Cullman County. Flowers in April. Rootstocks forming dense clusters, undoubtedly parasitic on rootlets of shrubs, etc. Never observed in the low country.

Type locality : "Hab. in Carolina ad radices arborum et fruticum. Garden."

Herb. Geol. Surv. Herb. Mohr.

LEPTAMNIUM Raf. Am. Month. Mag. 2: 267. February, 1818.

(EPIFAGUS Nutt. Gen. $2: 60.1818$. )

Single species, root parasite, Eastern North America.

Leptamnium virginianum (L.; Raf.; Gray, Syn. Fl. N. A. 2, pt. 1:314. 1878. As synonym.

BEECH-DROPS,

Orobanche virginiana L. Sp. Pl. 2 : 633.1753.

Epifagus americana Nutt. Gen. 2:60. 1818. 
Epiphegus virginiana Bart. Comp. Fl. Phil. 2:50. 1818.

Ell. Sk. 2:136. Gray, Man. ed. 6, 394. Chap. Fl.286. Gray, Syn.Fl. N.. A. 2, pt. $1: 314$.

Mexico.

Alleghenian and Carolinian areas. Ontario, Nova Seotia, New England, west to Wisconsin and Missouri, south to Florida.

Alabama: Tennessee Valley. Mountain region. Lower hills. In the shade of beech trees. Lauderdale County, Florence (M. C. Wilson). Cullman County, 800 feet altitude. Talladega County, near Renfroe, 800 feet altitude, October. Clustered on roots of beech.

Type locality: "Hab. in Virginia."

Herb. Geol. Surv. Herb. Mohr.

\section{BIGNONIACEAE. Bignonia Family.}

BIGNONIA L.Sp. Pl. $2: 622$. 1753.

About 150 species, extensively in warmer and tropical America. North America, 1. Trees and woody climbers.

Bignonia crucigera L. Sp. Pl. 2 :624. 1753.

Cross-Vine.

Bignonia capreolata L. Sp. Pl. 2 : 624.1753.

Ell. Sk. 2:107. Gray, Man. ed. 6, 398. Chap. Fl. 285. Gray, Syn. Fl. N. A. 2, pt. $1: 319$.

Carolinian area. Lower Ohio Valley to Missonri and Arkansas, soutl to Florida and Louisiana.

Alabama : Over the State, excepting the higher mountain ranges. In rich ground. Clay County, Elders, 1,000 feet, to Mobile County. Flowers orange and dnll red;

April. A vigorous woody climber, ascending tall trees. Common.

Economic uses: An ornamental vine.

Type locality: "Hab. in Virginia et australiori America."

Herb. Geol. Surv. Herb. Mohı

TECOMA Juss. Gen.134. 1789.

Twenty-three species of the warmer regions in both hemispheres.

Tecoma radicans (L.) DC. Prodr. 9 :223. 1845.

Bignonia radicans L. Sp. Pl. 2 : 624.1753.

Eli. Sk. 2 : 107. Gray, Man. ed. 6, 398. Chap. Fl. 285. Gray, Syn. Fl. N. A. 2, pt. $1: 319$.

Carolinian and Lonisianian areas. Sonthern Ontario, probably natnralized. Southern Pennsylvania to southern Missonri and Arkansas, sonth to Lonisiana and Florida.

Alabama: Range as in the last. Borders of woods and fields. Flowers orange to flame color. June to August. Climbing high by aerial rootlets; becoming in open cultivated ground a pernicious creeper. Common.

Economic uses: Oruamental.

'Type locality: "Hab. in America."

Herb. Geol. Surv. Herb. Mohr.

CATALPA Scop. Introd. 170. 1771.

Six species, West Indies, south Atlantic North America, China, Japan.

Catalpa catalpa (L.) Karst. Deutsch. Fl. 927. 1880-1883.

Catal.pa Tree.

Bignonia catalpa L. Sp. Pl. 2 : 622.1753.

Catalpa bignonioides Walt. Fl. Car. 64. 1788.

Ell. Sk. 1:24. Gray, Man. ed.6, 399. Chap. Fl.285. Gray, Syn. Fl. N. A. 2, pt. 1:

319. Sargent, Silv. N. A. 6: 86, t. 288, 289.

Carolinian and Louisianian areas. Southwestern Georgia, western Florida, to Mississippi.

Alabama: Monntain region to Coast plain. In the valleps. River banks. Winston County, east fork Sipsey River, 1,500 feet. Baldwin County, Stockton, delta of Mobile River. Flowers white, mottled with purple and orange; April, May. Tree 40 to 60 feet high. Not rare.

Economic nses: Valuable for the timber; ornamental sharle tree.

Type locality : "Hab. in Japonia, Carolina."

Herb. Geol. Surv. Herb. Mohr. 


\section{PEDALIACEAE. Sesame Family.}

MARTYNIA L. Sp. Pl. $2: 618.1753$.

About a dozen species, of warmer America.

Martynia louisiana Mill. Dict. ed.8, no. 3. 1768.

Unicorn Plant.

Martynia proboscidea Glox. Obs. 14. 1785.

Ell. Sk. 2:130. Gray, Man. ed.6,399. Chap. Fl. 285. Gray, Syn. Fl. 2, pt. 1:321. Coulter, Contr. Nat. Herb. $2: 319$.

MEXICO.

Southeru Ohio west to southern Missouri and Arkansas, south to Florida and Texas. Alabana: Central Pine belt. Waste places. Tuscaloosa County (E. A. Smith). Flowers July; rare. Annual.

Type locality: "Grows naturally in Lonisiana."

Herb. Geol. Surv. Herb. Mohr.

Martynia diandra Glox. Obs. 14, t.1. 1785.

Adventive with ballast from Mexico. Flowers yellow with purple spots; June, July. Fetid. Annual.

Type locality: "Hab. ad Americae Veram Crucem."

Herb. Geol. Surv. Herb. Mohr.

\section{ACANTHACEAE. Acanthus Family.}

HYGROPHILA R. Br. Prodr. Nov. Holl. 1:479. 1810.

Fifteen species, lacustrine perennials, of tropical America, tropical Asia, New Holland, North America. South Atlantic States, 1.

Hygrophila lacustris DC. Prodr. 11 : 86. 1857. SMald-Flowered Hygrophila. Chap. Fl. Suppl.673; ed. 3, 364. Coulter, Contr. Nat. Herb. 2 : 321.

Mexico.

Louisianian area. Western Florida to Texas.

Alabama : Coast plain. Shaded muddy banks. Mobile County. Flowers pale blue, June; not frequent. Perennial.

Type locality: "In lacu (laguna) de Jalapa * * * , in Louisiana * * * , Madissonville."

Herb. Geol. Surv. Herb. Mohr.

RUELLIA L. Sp. Pl. 2 : 634. 1753. (Inclusive of Dipteracanthus Nees.)

One hundred and twenty species, perennials, chiefly tropical America, a few in South Africa and tropical Asia. Atlantic North America, 7.

Ruellia pedunculata Torr.; Gray, Sỹn. Fl. N. A. 2, pt. 1: 325.

Louisianian area. Western Louisiana and Arkansas.

Peduncled Ruellia.

Alabama : Lower Pine region. Pine woods. Mobile County, Grand Bay. Flowers purplish blue; July. Rare and local.

Type locality: "Dry woods, in W. Louisiana, J. Hale. Arkansas, Bigelow, Mrs. Harris."

Herb. Geol. Surv. Herb. Mohr.

Ruellia noctiflora (Nees) Gray, Syn. Fl. N. A. 2, pt. 1: 326.

Night-Blooming RUellia.

Dipteracanthus noctiflorus Nees in DC. Prodr. 11:123. 1847.

Chap. Fl. 304. Gray, Syn. Fl. N. A. 1. c.

Iouisianian area. Loulsiana and Mississippi to western Florida and Georgia.

Alabama : Coast plain. Flat grassy pine barrens along the coast. Mobile County, Bayou Labatre. Flowers white, fragrant, opening in the evening and during the night; September, October. Six to 12 inches high. Not frequent; loeal.

Type locality: "In Savannahs Altamahae Georgiae (Le Conte 1. c.), in campis graminosis inter S. Marks et Port Leou Floridae (Rugel! ****), Texas, (Drummond * * * )."

Herb. Mohr.

Ruellia ciliosa Pursh, Fl. Am. Sept. $2: 420.1814$.

Finibitated Ruellia.

Ell. Sk, 2:110. Gray, Man. ed. 6, 400. Chap. Fl. 303. 
Carolinian area. West Virginia to Michigan, Illinois, and Missouri, south to Florida and western Louisiana (Hale).

Alabama: Tennessee Valley to the Coast Pine belt. Monroe County, Perdue Hill. Flowers pale purplish blue; July. Scattered, not frequent.

Type locality: "Near Savannah, Georgia."

Herb. Geol. Surv. Herb. Mohr.

Ruellia ciliosa humilis (Nutt.) Britton, Trans. Am. Acad. Sci. 9: 185.1890.

Low Fimbriated RUellia.

Ruellia humilis Nutt. Trans. Am. Phil. Soc. ser. 2, 5 : 182. 1833-37.

R. ciliosa longiflora Gray, Syn. Fl. N. A. 2, pt. 1:326. 1878.

Gray, l. c. Coulter, Contr. Nat. Herb. 2:322.

Caroliuian and Louisianian areas. Western Florida to Texas, Arkansas, and sonthern Missouri.

Alabama: Central Pine belt to Coast plain. Dry open woods, pine forests. Tusealoosa County (E. A. Smith). Clarke County, Thomasville. Baldwin and Mobile connties. Flowers pale purplish (lilac); April to June. Common.

Type locality: "On rocks in the upland forests and prairies," Arkansas.

Herb. Geol. Surv. Herb. Mohr.

Ruellia ciliosa parviflora (Nees) Britton, Mem. Torr. Club, 5 : 300. 1894.

SMall-Flowered Fimbriated RuFllia.

Dipteracanthus ciliosus var. parviflorus Nees in DC. Prodr. 11: 123. 1847.

Ruellia ciliosa ambigua Gray, Syn. Fl. N. A. 2, pt. 1:326. 1878.

Gray, Man. ed. 6, 400. Gray, Syn. Fl. l. e.

Carolinian and Louisianian areas. Virginia and Kentucky south to Florida, west to Mississippi.

Alabama : Mountain region, Metamorphic hills. Upper division Coast Pine belt. Hilly open woods. Lee County, Auburn (Baker \& Earle). Monroe and Clarke counties.

Type locality: "Ad Ky fluvinm."

Herb. Geol. Surv. Herb. Mohr.

Ruella ciliosa hybrida (Pursh) Gray, Syn. Fl. N. A. 2, pt. 1: 326.

Hirsute Fimbriated Ruellia.

Ruellia hybrida Pursh, Fl. Am. Sept. 2 : 420. 1816.

R. hirsuta Ell. Sk. 2: 109. 1817.

Ell. 1. c. Gray, l. c.

Carolinian and Louisianian areas. New Jersey (Britton), South Carolina, Georgia, and Mississippi.

Alabama: Mountain region. Metamorphic hills. Central Prairie region. Dry open ground, pastures. Lee County, Anburn (Baker of Earle). Montgomery County, Pintlalla Creek, July, 1882. Flowers purplish blue to white; July. Not frequent.

Type locality: "In sandy fields near Savannah, Georgia."

Herb. Geol. Surv. Herb. Mohr.

Ruellia strepens L. Sp. Pl. 2 : 634. 1753.

Dipteracanthus.

Dipteracanthus 8trepens Nees in DC. Prodr. 11:123. 1847.

Ell. Sk. 2:108. Gray, Man. ed. 6, 400. Chap. Fl. 304. Gray, Syll. Fl. N. A. 2, pt. 1:327. Coulter, Contr. Nat. Herb. $2: 322$.

Alleghenian and Carolinian areas. Pennsylvania west to Miehigan and Wisconsin, sonth to the Ohio Valley and Tennessee to Georgia and 'Texas.

Alabama : Monntain region to Lower hills. Borders of woods and thickets. Clay County, Moseley, 1,000 to 1,200 feet. Talladega County, Ironaton. Tuscaloosa County (E. A. Smith). Flowers blue; June, July. Not frequent.

Type locality : "Hab. in Virginia, Caroliua."

Herb. Geol. Surv. Herb. Mohr.

DIANTHERA L. Sp. Pl. 1:27. 1753.

One hundred species, paludial perennial herbs, mostly of warmer regions, chiefly American.

Dianthera americana L. Sp. Pl. 1:27. 1753. Dense-flowered Water Willow.

Justicia pedunculosa Michx. Fl. Bor. Am. 1: 7. 1803.

Justicia americana Vahl, Enum. 1:140. 1805.

Ell. Sk. 1:11. Gray, Man. ed. 6, 401. Chap. Fl. 304. Gray, Syn. Fl. N. A. 2, pt. 1:329. Coulter, Contr. Nat. Herb. $2: 324$.

Alleghenian to Louisiauian area. Quebec, Ontario; New Lugland west to Michigan; Ohio Valley to Missouri, south to Florida and 'Texas. 
Alabama: Tennesseo Valley to Coast plain. Gently-flowing water. Cullman

County, 800 feet altitude. Mobile County. Flowers azure; June. Frequent.

Type locality : "Hab. in Virginia."

Herb. Geol. Surv. Herb. Mohr.

Dianthera ovata Walt. Fl. Car. 63. 1788.

LOW WATER WILLOW.

Justicia humilis Michx. Fl. Bor. Am. 1: 8. 1803.

Dianthera humilis Engelm. \& Gray; Gray, Syn. Fl. N. A. 2, pt. 1:329.

Chap. Fl. 304. Gray, Syn. Fl. N. A.1. c. Coulter, Contr. Nat. Herl 2 : 324.

Louisianian area. Lower Sonth Carolina to Florida, west to Texas and Arkansas.

Alabama: Coast plain. Wet muddy banks of streams, shaded ditches, shallow pools. Mobile and Baldwin counties. Flowers blue; July to September. Not infrequent.

Type locality: South Carolina.

Herb. Geol. Surv. Herb. Mohr.

Dianthera ovata lanceolata Chap. F'l. 304. 1860.

Louisianian area. Florida.

Alabama : Upper division Coast Pine belt. Muddy banks. Wilcox Connty, Allenton, June 27, 1893.

Type locality: "River banks, Florida."

Herb. Geol. Surv. Herb. Mohr.

YEATESIA Small. Bull. Torr. Club. 23:410. 1896.

(Gatesia Gray, Proc. Am. Acad. 13:365. 1878. Not Bertol. 1848.)

Perennial monotype, south Atlantic America.

Yeatesia laetevirens (Buckley) Small, Bull. Torr. Club, 23:410. 1896.

Rhytiglossa viridiflora Nees in Mart. Fl. Bras. 9: 346. 1840.

Justicia laetevirens Buckley, Am. Journ. Sci. 45 : 176. 1843.

Dicliptera halei Riddell, N. Orl. Med. Journ. 1852. (Cat. Fl. Lud.) Chap. Fl. 305. 1860.

Gatesia laetevirens Gray, Proc. Am. Acad. 13 : 365. 1878.

Chap. Fl. 1. c. Gray, Syn. Fl. N. A. 2, pt. 1:330. Coulter, Contr. Nat. Herb. 2 : 325.

Carolinian and Louisianian areas. Louisiana to western Texas.

Alabama : Lower hills. Central Prairie region. Rich copses, borders of woods. Bibb County, Pratt's Ferry. Montgomery County, banks of Pintlalla Creek. Flowers pale purple; June, July. Said to open in the night, the corolla dropping early next day ( $\mathrm{Dr}$. Cabell)

Type locality : "Near rivers in shady woods, Wilcox Co., Alabama."

Herb. Geol. Surv. Herb. Mohr.

\section{PLANTAGINACEAE. Plantain Family.}

\section{PLANTAGO L. Sp. Pl. 1:112. 1753. Plantain.}

About 200 species, mostly temperate regions.

Plantago major L. Sp. Pl. 1: 112.

Common Wayside Plantain. Gray, Man. ed.6, 423. Chap. Fl.277. Gray, Syn. Fl. N. A. 2, pt. 1:389.

Europe, North Africa, Northern and Western Asia.

Naturalized from Europe. Almost throughout the continent.

Alabama : Over the State. Low waste places near dwellings, waysides, borders of ditches. Flowers May to August; common. Perennial.

Type locality: "Hab. in Europa ad vias."

Herb. Geol. Surv. Herb. Mohr.

Plantago cordata Lam. Tabl. 1:338. 1796.

Gras, Syn. Fl. N. A. 2, pt. 1:389. Gray, Man. ed.6, 423.

Carolinian aud Louisianian areas. New York, Wisconsin, Lonisiana.

Alabama: Fide Gray.

Type locality : "E Canada."

Plantago rugelii Decsne. in DC. Prodr. 13, pt. 1: 700. 1852.

Plantago major Ell. Sk. 1:201. 1817.

Ell. Sk. l. c. Gray, Man. ed. 6, 423. Chap. Fl. 277. Gray, Syn. Fl. N. A. 2, pt. 1:389.

Coulter, Contr. Nat. Herb. $2: 344$. 
Alleghenian and Carolinian areas. Quebec, Ontario; New England, west to Minuesota and Nebraska, south to Georgia and Arkansas.

Ala baMa: Over the State. In close damp soil, pastures, waste places, borders of fields. Common. Most abundant in upper districts. Perennial.

Type locality: "Am. sept. ad colles et ad vias, prope Decatur, Alabama sept."

Herb. Geol. Surv, Herb. Mohr.

Plantago maritima L. Sp. Pl. 1:114. 1753.

Seaside Plantain.

Adventive from Enrope with ballast. Mobile County; rare. Perennial.

Type locality: "Hab. in littoribus mari[ti]mis Europae borealis."

Herb. Geol. Surv. Herb. Mohr.

Plantago coronopus L. Sp. Pl. 1 :115. 1753.

Adventive with ballast. Mobile County; rare.

Type locality: "Hab. in Europae glareosis."

Herb. Mohr.

Plantago lanceolata L. Sp. Pl. 1:113. 1753.

Rib Grass. English Plantain. Ell. Sk. 1:202. Gray, Man. ed. 6, 423. Chap. Fl. 278. Gray, Syn. Fl. N. A. 2, pt. $1: 391$.

LUUROPE.

Extensively naturalized in Atlantic North America from Canada to the Gulf.

Alabama: Over the State. In cultivated ground. Mobile County. May to July. Perennial.

Type locality: "Hab. in Europae campis sterilibus."

Herb. Geol. Surv. Herb. Mohr.

Plantago aristata Michx. Fl. Bor. Am. 1:95. 1803.

Plantago patagonica aristata Gray, Man. ed. 2, 269. 1859.

Gray, Man. ed. 6, 424. Chap. Fl. Suppl. 634; ed. 3, 391. Gray, Syu. Fl. N. A. 2, pt.

$1: 391$. Coulter, Contr. Nat. Herb $2: 345$.

Carolinian and Louisianian areas. Southern New York to Tennessee and upper Georgia.

Alabama: Mountain region to Central Pine belt. Dry, sandy ground. Clay

County, Moseley. 'Tuscaloosa County. Flowers July, August. Not rare. Perennial. Type locality: "Hab. in pratensibus Illinoensium."

Herb. Geol. Surv. Herb. Mohr.

Plantago virginica L. Sp. Pl. 1 : 113.1753.

Common Plantain.

Ell. Sk. 1:201. Gray, Man. ed. 6, 424. Chap. Fl. 278. Gray, Syn. Fl. N. A. 2, pt.

1:391. Coulter, Contr. Nat. Herb. 2 : 345 .

Carolinian and Louisianian areas. Southern New England to southern Illinois and

Missouri, south to Florida, and west to Texas and Arkansas.

Alabama: Over the State. Dry sandy fields. April to June. Abundant. Annnal. Type locality: "Hab. in Virginia."

Herb. Geol. Surv. Herb. Mohr.

Plantago virginica purpurascens (Nutt.).

Plantago purpurascens Nutt.; Rapin, Mém. Soc. Linn. Par. 6: 454. 1827.

$P$. occidentalis Decsne. in DC. Prodr. 13, pt. 1: 722. 1852.

$P$. virginica longifolia Gray, Syn. Fl. N. A. 2, pt. 1:392. 1878.

Gray, Syn. Fl. N. A. l. c. Coult. Contr. Nat. Herb. $2: 345$.

Mexico.

Louisianian area. Southern Arkansas and Texas to southern Arizona.

Alabama: Coast plain. Pastures and waysides, in saudy soil. Mobile County, Summerville. June. Only locality known in the state.

Plantago heterophylla Nutt. Trans. Am. Phil. Soc. ser. 2,5 : $177 . \quad 1833-1837$.

Many-seedhi Plantain.

Gray, Mau. ed. 6, 424. Chap. Fl. 278. Gray, Syn. Fl. N. A. 2, pt.1:392. Coulter,

Contr. Nat. Herb. $2: 345$.

Carolinian and Louisianian areas. Virginia to Tennessee and Florida, west to Texas and Arkansas.

AlabaMa: Tennessee Valley to Coast plain. Low damp fields, pastures. Lawrence County, Moulton. Tuscaloosa County. Lee County, Auburn (Earle). Mobile County. Flowers, April, May; frequent. Annual.

Type locality: "On the banks of the Mississippi and Arkansas; abundant."

Herb. Geol. Surv. Herb. Mohr. 



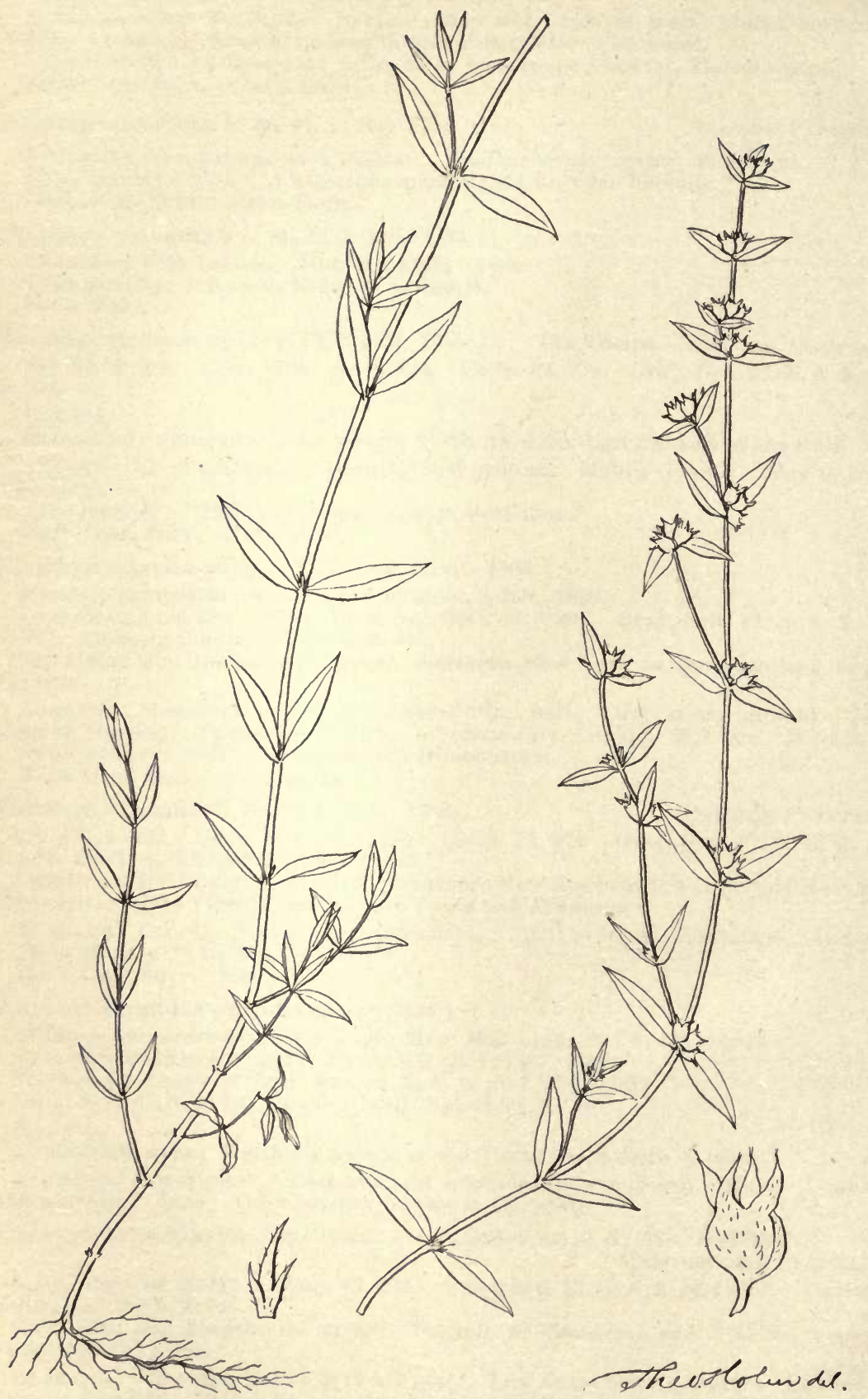

OldenLANDIA LITTORALIS MOHR. 


\section{RUBIACEAE. Madder Family.}

OLDENLANDIA L.Sp. Pl. $1: 119.1753$.

About 175 species, annual and perennial herbs, subtropical and tropical regions. West Indies, South America. North America, 3.

Oldenlandia boscii (DC.) Chap. Fl. 181. 1860.

Hedyotis boscii DC. Prodr. 4:420. 1830.

Chap. Fl. 1. c. Gray, Syn. Fl. N. A. 1, pt.2:27. 1878. Coulter, Contr. Nat. Herb.

$2: 160$.

Louisianian area. South Carolina to Louisiana, Arkansas, and Texas.

Alabama: Coast plain. Border ponds, ditches. Mobile County. Flowers pale pink, July; not rare. Perennial.

'Type locality : "In Carolina legit cl. Bosc."

Herb. Geol. Surv. Herb. Mohr.

Oldenlandia uniflora L. Sp. Pl. 1:119. 1753.

Oldenlandia glomerata Michx. Fl. Bor. Am. 1:83. 1803.

Hedyotis glomerata Ell. Sk. 1:188. 1817.

Ell. Sk. 1. c. Gray, Man. ed. 6, 224. Chap. Fl.101, in part.

Gray, Syn. Fl. N. A. 1, pt. 2:27, in part. Coulter, Contr. Nat. Herb. $2: 160$, in part.

Carolinian and Louisianian areas. Long Island, New York to Florida, west to Lonisiana

Alabama : Coast plain. Springy sandy places. Mobile County, Chastang's Bluff.

This plant agrees in its essential characters with the plant described by Linnaeus and Miehaux, and subsequently by Pursh and Elliott. A low perennial, the stem prostrate, 6 to 8 inches long, profusely branched from the base; the slender grooved stems hirsute on the angles; the leaves membranaceous, ovate to ovate-lanceolate, attenuate toward the base into a winged, ciliate, distinet petiole; the flowers in close axillary and terminal clusters, the calyx lobes foliaceous, longer than the globose, hirsute capsule.

'Type locality: "Hab. in Virginia."

Herb. Geol. Surv. Herb. Mohr.

Oldenlandia littoralis Mohr, Bull. Torr. Club, 24 : 27. 1897.

Hedyotis glomerata Torr. \& Gray, Fl. N. A. 2:42. 1841. In part.

Oldenlandia glomerata Gray, Syn. Fl. N. A. 1, pt. 2:27. 1878. In part.

O. glomerata Chap. 184, in part.

Confounded with the last, from which it is, however, clearly distinct. A more robust plant, the stem mostly erect or with a slightly decumbent base, simple or with erect-spreading branches, terete, smooth; the leaves thickish, lanceolate to oblong-lanceolate, acute, sessile, glabrous, only slightly hirsute on the midrib and the margin, $\frac{1}{8}$ to $\frac{1}{4}$ inch wide, $\frac{8}{8}$ to $\frac{5}{8}$ inch long; the flowers mostly in sessile axillary clusters, the calyx lobes as long as or shorter than the smoothish capsules. Flowers pearl-blue; September, October. Annual.

Louisianian area. North Carolina to Florida, and west to Mississippi.

Alabama : Coast plain. Murldy banks in the tide-water region, borders of brackish and saline swamps. Frequently covering large patches on the salty flats flooded only by the highest tides. Mobile and Baldwin counties.

Type locality: "Mobile."

Herb. Geol. Surv. Herb. Mohr.

HOUSTONIA I. Sp. Pl. 1:105. 1753.

About 25 species, Mexiean and North American. Eastern United States and Texas, 17.

Houstonia caerulea L. Sp. Pl. 1 :105. 1753.

BLuets.

Hedyotis caerulea Hook. Fl. Am. Bor. 1 : 286. 1833.

Ell. Sk. 1: 192. Gray, Man. ed. 6, 223. Chap. Fl. 180. Gray, Syn. Fl. N. A. 1, pt. $2: 24$.

Mexico.

Canadian zone to Louisianian area. Nova Scotia, New Brunswick, Quebec, New England, west to Michigan; Ohio Valley south to upper Georgia.

Alabama : Tennessee Valley. Mountain region to Upper division Coast Pine belt. Open woods, pastures. Lauderdale County, Florence. Cullman County, 800 feet. Jefferson County, near Birmingham. Clarke County, Choctaw Corner. Flowers 
lilac purple to nearly white, yellow in the center. April. Perennial, from slender running shoots.

Type locality: "Hab. in Virginia."

Herb. Geol. Surv. Herb. Mohr.

Houstonia minor (Michx.) Britton, Mem. Torr. Clab, 5:302. 1894.

Houstonia linnaei var. minor Michx. Fl. Bor. Am. 1:85. 1803.

SOUTHERN BLuets.

H. patens Ell. Sk. 1 : 191 . 1817.

Chap. Fl. Suppl. 625; ed.3, 199. Gray, Syn. Fl. N. A. 1, pt.2:24. Coulter, Contr.

Nat. Herb. $2: 158$.

Carolinian and Lonisianian areas Southern Virginia, southern Teunessee from

North Carolina to Florida, west to Texas.

Ala Bama : Coast plain. Dry and damp light exposed ground. Mobile and Baldwin counties. Flowers eerulean blue; early in February, March. Common. Winter aunual.

Type locality : "Hab. in maritimis arenosis, a Virginia ad Floridam."

Herb. Geol. Surv. Herb. Mohr.

Houstonia minima Beck, Am. Journ. Sci. 10:262. 1826.

Smallest Bluets.

Hedyotis minima Torr. \& Gray, Fl. N. A. 2:38. 1841.

Gray, Man. ed.6, 223. Gray, Syn. Fl. N. A. 1, pt. 2:25. Coulter, Contr. Nat. Herb.

$2: 158$.

Carolinian area. Missouri, Arkansas, and Texas.

Alabama : Mountain region. Dry grassy banks and hillsides. Madison County,

Huntsville, 750 feet altitude. Flowers sky-blue; March. Rare. Anuual.

Type locality : "Fields about half a mile west of St. Louis."

Herb. Geol. Surv. Herb. Mohr.

Houstonia rotundifolia Michx. Fl. Bor. Am. 1:85. 1803. Roundleaf Houstonia. Oldenlandia rotundifolia Chap. Fl. 180. 1860.

Ell. Sk. 1:193. Chap. Fl. l. e. Gray, Syn. Fl. N. A. 1, pt. 2:25.

Louisianian area. South Carolina to Florida, west to Lonisiana.

Alabama: Lower Pine region. Coast plain. Saudy damp or wet pine barrens.

Mobile aud Baldwin counties. Flowers white; early February, March. Common;

dense tufts. Perennial.

An apetalous form, in dry sandy pine barrens. Flowers May and June. Frequent in the Coast Pine belt. Choctaw County, Bladen Springs. Eseamlia County near

Flomaton.

Type locality: "Hab. in apricis submaritimis Floridae, et Carolinae."

Herb. Geol. Surv. Herb. Mohr.

Houstonia purpurea L. Sp. Pl. 1: 105. 1753.

Purple Houstonia.

Hedyotis purpurea Torr. \& Gray, Fl. N. A. 2: 40. 1841.

Oldenlandia purpurea Gray, Man. ed. 2, 173. 1856.

Ell. Sk. 1:193. Gray, Man. ed. 6, 223. Chap. Fl. 180. Gray, Syn. Fl. N. A. 1, pt.

$2: 26$.

Carolinian area. Maryland to Missouri and Arkansas, sonth to middle Georgia.

Alabama: Mountain to Central Prairie region. Open woods, copses. Metamorphic hills. Lee County, Auburn, 860 feet (Earle \&. Vnderwood). 'T'nscaloosa County (E.A.Smith). Montgomery County, wooded hills. Flowers pale rose-purple; April. Perennial.

In the Alabama plant the corolla is scarcely double the leugth of the calyx.

'Type locality: "Hab. in Virginia."

Herb. Geol. Surv. Herb. Mohr.

Houstoniา Iongifolia Gaert. Fruct. $1: 226, t .49, f .8 .1788$. Longleaf Houstonia. Oldenlandia purpurea var. longifolia Gray, Man. ed. 2,173. 1856.

Houstonia purpurea longifolia Gray, Syn. Fl. N. A. 1, 1t. 2:26. 1884.

Gray, Man. ed. 6, 223. Chap. Fl.181. Gray, Syn. Fl. N. A. l.c.

Canadian zone, Alleghenian and Carolinian areas. Canada to Saskatchewan;

New England west to Missouri and Arkansas, south from New Jersey along the mountains to Georgia.

Ala Bama: Mountain region. Dry open wools. Lee County, Auburn (Earle of Cnderwood, 1896). Flowers purplish; April. Rare and local. Perennial.

Type locality not given.

Herb. Geol. Surv.

Houstonia tenuifolia Nutt. Gen. 1:95. 1818.

NARROW-LEAF HOUSTONIA.

Hedyotis longifolia var. tenuifolia Torr. \& Gras, Fl. N. A. 2:40. 1841.

Houstonia purpurea var. tenuifolia Gray, Syn. Fl. N. A. 1, pt. 2:26. 1884.

Gray, Man. ed.6, 224. Chap. Fl. 181. 
Carolinian area. Mountains of West Virginia, southeastern Tennessee, and of North Carolina.

Alabama: Mountain region. Dry gravelly or rocky woods. Clay County, Che-aw-ha Mountain, 2,400 feet altitnde. Cullman County, 800 feet. Etowah County, Lookont Mountain, 1,200 feet. Flowers pale purplish; July, Angust. Not rare. Perennial.

Type locality: "Near the confluence of Pidgeon river, and the French Broad, Tennessee, on dry gravelly hille."

Herb. Geol. Surv. Herb. Mohr.

Houstonia calycosa (Shuttlew.).

Calycose Houstonia.

Hedyotis calycosa Shuttlew.; Gray, Pl. Wright. 1:81. 1852.

Houstonia purpurea calycosa Gray, Syn. Fl. N. A. 1, pt. 2:26. 1884.

Gray, Man. edl. 6, 224.

Carolinian area. Illinois, Arkansas, and West Virginia.

Alabama: Mountain region. Metamorphic hills. Dry open woods. Tallapoosa County, Dadeville, July, 1877. Rare and local. Perennial.

Type locality (Syn. Fi. N.A.): "Monntains of Alabama (Rugel) to Arkansas (Nuttall), and Illinois (E. Hall); also collected by Drummond."

Herb. Geol. Surv. Herb. Mohr.

Houstonia angustifolia Michx. Fl. Bor. Am. 1:85. 1803. Erect-Leaf Houstonia. Hedyotis stenophylla Torr. \& Gray, Fl. N. A. 2:41. 1841.

Oldenlandia angusiifolia Gray, Pl. Wright, 2:68. 1853.

E!l. Sk. 1:192. Gray, Man. ed. 6, 224. Chap. Fl. 181. Gray, Syn. Fl. N. A. 1, pt. $2: 26$. Coulter, Contr. Nat. Herb. $2: 159$.

Carolinian and Louisianian areas. Southwestern Illinois, Missouri, Arkansas, and Texas, east to Tennessee, North Carolina, and Florida.

Ald BAMA : Mountain region to Coast plain. Dry rocky or gravelly ridges. Cullman County, 800 feet altitude. Montgomery County. Barbour County, Eufaula (E. A. Smith). Bladen County, near Maguolia. Flowers rose-pink; June. Not rare.

Perennial from a suffrutescent multicipital rootstock.

Type locality: "Hab. in submaritimis Floridae."

Herb. Geol. Surv. Herb. Mohr.

CEPHALANTHUS L. Sp. Pl. I:95. 1753.

About one-half dozen species, warmer temperate North America, Asia, Africa. ?

Cephalanthus occidentalis L. Sp. Pl. 1:95. 1753.

BUTtonBush.

EIl. Sk. 1: 186. Gray, Man. ed. 6, 224. Chap. Fl. 176. Gray, Syn. Fl. N. A. 1, pt.

2:29. Coulter, Contr. Nat. Herb. 2:160. Wats. Bot. Calif. 1:282.

Ccba, Mrxico.

Allegbenian to Louisianian area. New Brunswick and Quebec to the Gulf, throughout the continent to California.

Alabama: Throughout the State. Inundated banks. Shallow stagnant water. Flowers white; July, August. Shrub 6 to 15 feet high.

Economic uses: The bark of the root, under name of "buttonbush bark," is used medicinally.

Type locality: "Hab. in America septentrionali."

Herb. Geol. Surv. Herb. Mohr.

MItChella L. Sp. Pl. I: 111. 1753. Partridge Berry.

Two species, perennial creeping herbs, Japan. Atlantic North America, 1.

Mitchella repens L. Sp. Pl. 1:111. 1753.

Ell. Sk. 1: 198. Gray, Man. ed. 6, 225. Chap. Fl.176. Gray, Syn. Fl. N.A. 1, pt. 2:31.

Coulter, Contr. Nat. Herb. $2: 160$.

NoRTHERN Mexico.

Alleghenian, Carolinian, and Louisianian areas. Nova Scotia, Ontario; New

England west to sonthern Illinois, south to Florida, Texas, and Arkansas.

Alabama: Over the State. Dry shady woods and shaded banks. Flowers rosepink; April to June. Fruit ripe July to October; scarlet. Common. Evergreen. Perennial.

Economic uses: The herb-_"partridge berry"-is used medicinally. Ornamental.

Type locality: "Hab. in Carolina, Terra Mariana, Virginia."

Herb. Geol. Surv. Herb. Mohr. 
SPERMACOCE L. Sp. Pl. 1: 102. 1753.

Eighty species, low herbs, tropical regions, mostly American.

Spermacoce glabra Michx. Fl. Bor. Am. 1: 82. 1803.

SMOOTH BuTTONWEED.

Gray, Man. ed.6, 225. Chap. Fl. 174. Gray, Syn. Fl. N. A. 1, pt. 2:34. Coulter, Contr. Nat. Herb. 2 : 161.

Carolinian and Louisianian areas. Southern Ohio and western 'Tennessee to Florida, Texas, and Arkansas.

Alabama: Lower Pine region. Coast plain. Low fields, bottom lands. Washington, Mobile, and Baldwin counties. Flowers white; August to October. Not common. Annual weed.

Type locality: "Hab. ad ripas fluminis Ohio et Mississippi."

Herb. Geol. Surv. Herb. Mohr.

Spermacoce parviflora (Meyer) Gray, Syn. Fl. N. A. 1, pt. 2: 34. 1878.

SMALL-FLOWERED ButToNWEed.

Borreria parviflora Meyer, Prim. Fl. Essequib. 83. 1818.

B. mierantha Torr. \& Gray, Fl. N. A. 2 : 28. 1841.

Chap. Fl. 175. Gray, Syn. Fl. N. A.l.c.

West Indies, Mexico, South America.

Louisianian area. Sonthern Florida.

Alabama: Lower Pine region. Waste places. Monroe County, Mount Pleasant (E. A. Smith). Annual.

Type locality : "Hab. in St. Domingo et herbario clariss. Mertensii inest."

Herb. Geol. Surv. Herb. Mohr.

RICHARDIA L. Sp. Pl. 2:330. 1753.

(Richaizdsonia H. B. K. Nov. Gen. \& Sp. $3: 350.1820$. )

Ten species, low annuals or pereunials, mostly tropical America.

Richardia scabra L. Sp. Pl. 1:3æ0. 1753.

Mexican Clover.

Richardsonia 8cabra St. Hilaire, Pl. Us. Bras. 8, t. $8 . \quad$ 1824-28.

Chap. Fl. Suppl. 624; ed. 3, 194. Gray, Syn. Fl. N. A. 1, pt. $2: 32$.

West Indies, Mexico to Brazil.

Louisianian area. Adventive from the Tropics and fully naturalized on the coast of Georgia, in Florida, and thence to Mississippi.

Ala bava : Lower Pine region. Coast plain. Dry sandy waste places. Flowers white; June to October and November. Abundant in cultivated ground. A luxuriant annual; assurgent stems 2 to 3 feet long. Occasionally in the northern part of the State, in gardens. Cullman Connty.

Economic uses: Valuable fodder plant.

Type locality: "Hab. in Vera Cruce."

Herb. Geol. Surv. Herb. Mohr.

DIODIA L.Sp. Pl. 1:104. 1753.

About 30 species, annual or perennial low herbs, mostly of tropical America.

Diodia virginiana L. Sp. Pl. 1: 104. 1753.

Common Button Flower.

Diodia tetragona Walt. Fl. Car. 87. 1788.

Ell. Sk. 1:190. Gray, Man. ed. 6, 225. Chap. Fl. 175. Gray, Syn. Fl. N. A. 1, pt.

2:35. Coulter, Contr. Nat. Herl, $2: 161$.

Carolinian and Louisianian areas. New Jersey throngh the lower country to

Florida, west to 'Texas and Arkansas.

Alabama : Over the State, except the highest mountain ranges. In low enltivated ground, waste places, roadsides. Clay County, Delta, 1,700 feet. Cullman County, 800 feet. Flowers white; June to October. Abundant weed. Perennial. Type locality: "Hab. in Virginiau aquosis."

Herb. Geol. Surv. Herb. Molir.

Diodia teres Walt. Fl. Car. 87. 1788.

Spermacoce diodina Michx. Fl. Bor. Am. 1: 82. 1803.

Gray, Man. ed. 6, 225. Chap. Fl. 176. Gray, Syn. Fl. N. A.1, pt.2:35. Coulter, Contr. Nat. Herb. 2 : 162. 
Carolinian and Louisianian areas. Eastern Pennsylvania and New Jersey, south to Florida, west to Texas and Arkansas.

Alabama: Mountain region to Coast plain. Sandy or gravelly exposed soil. Roadsides, pastures, and tields. Clay County, Delta divide, 1,800 feet. Randolph County, Lamar. Montgomery to Mobile Connty. Flowers rose-purple, throughout the summer. Common wayside weed. Annual.

Type locality: South Carolina.

Herb. Geol. Surv. Herb. Mohr.

\section{GALIUM L. Sp. Pl. 1:105. 1753. Ladies' BeDstraw.}

Two hundred and fifty species described, about 200 distinct, mostly perennial herbs of temperate and warmer regions. North America 35, Atlantic 14, in terior 9, Pacific 14.

Galium aparine L. Sp. Pl. 1:108. 1753.

Cleavers. Goose Grass.

Gray, Man. ed.6, 226. Chap. Fl. Suppl. 625; ed. 3, 192. Gray, Syn. Fl. 1, pt. 2: 36.

Coulter, Contr. Nat. Herb. 2 : 163.

Europe, Northern Asia, JapaN.

Boreal zone to Louisianian area. British North America. From the Atlantic to the Pacific coast. Aleutian Islands, New England, south to Florida and the Gulf States, west to California.

Alabama: Over the State. Moist thickets. Flowers white; April, May. Annual. Type locality: "Hab. in Europae cultis et ruderatis."

Herb. Geol. Surv. Herb. Mohr.

Galium pilosum Ait. Hort. Kew. 1: 145. 1789.

Hairy Ladies' Bedstraw.

Ell. Sk. 1:196. Gray, Man. ed. 6, 226. Chap. Fl. 174. Gray, Syn. Fl. N. A. 1, pt.

$2: 37$. Coulter, Contr. Nat. Herb. $2: 162$.

Carolinian area. Ontario, southern New England west to Michigan; southern

Ohio Valley, Missouri, Arkansas to Florida and Texas.

Alabama: Momntain region to Upper division Coast Pine belt. Shaded banks.

Clay County. Flowers white; July. Not rare. Perennial.

Type locality: "Native of North America."

Herb. Geol. Surv.

Galium pilosum puncticulosum (Michx.) Torr. \& Gray, Fl. N. A. 2 :24. 1841.

Puncticulate Ladies' Bedstraw.

Galium puncticulosum Michx. Fl. Bor. Am. 1:80. 1803.

Ell. Sk. 1:196. Gray, Man. ed. 6. 226. Chap. Fl. Suppl.625; ed. 3, 192 . Gray, Syn.

Fl. N. A. 1, pt. 2:37. 1884. Conlter, Contr. Nat. Herb. 2:162.

Caroliuian and Louisianian areas. Southern Virginia to Florida, west to Texas and Arkansas.

Alabama: Coast Pine belt to Coast plain. Dry shady copses and thickets. Clarke, Washington, Monroe, Baldwin, and Mobile eounties. Flowers purplish; June. Frequent. Perennial.

Type locality: "Hab. in Carolina inferiore."

Herb. Geol. Surv. Herb. Mohr.

Galium circaezans Michx. Fl. Bor. Am. 1:80. 1803.

WILD LICORICE.

Ell. Sk. I:197. Gray, Man. ed. 6, 226. Chap. Fl. 174. Gray, Syn. Fl. N. A. 1, pt. 2:37. Coulter, Contr. Nat. Herb. 2:162.

Alleghenian to Louisianian area. Quebec, Ontario ; New England west to Michigan, south through Missouri and Arkansas, and from New York to northern Florida and Mississippi.

Alabama : Monntain region to Upper division Coast Pine belt. Rich shady woods. Dekalb County, Mentone, 1,600 feet. Clay County, Talladega Mountains, 2,000 feet. Madison County, Montesano, 1,500 feet. Cullman County, 800 feet. Clarke County, Choctaw Corner, 400 feet. Flowers white; May, June. Not rare. Perennial.

Type locality: "Hab. in Carolina."

Herb. Geol. Surv. Herb. Mohr.

Galium trifidum L. Sp. Pl. 1: 105. 1753.

Small Bedstraw.

Ell. Sk. 1:194. Gray, Man. ed. 6, 227. Chap. Fl 174. Gray, Syn. Fl. N. A. 1, pt. $2: 38$. Coulter, Contr. Nat. Herb. $2: 162$. Wats. Bot. Calif. 1:284. 
EUrope, Dahuria, Japan.

Boreal zone to Lonisiauian area. British North America to latitude $68^{\circ}$. From the Atlantic to the Pacific coast. New England (Maine, Mount Desert Island) to Georgia, Mississippi, western Louisiana, Texas, and California.

Alabama: So far only observed in the Coast pliin. Open marshes. Mobile County, banks of Mobile River. Flowers white; May, June. Weak, assurgeut, diffusely branched. Perennial.

A form of more robust gruwth, with broader leaves, nearly $\frac{1}{8}$ inch wide and $\frac{1}{2}$ to $\frac{8}{4}$ inch long, larger fruit, approaching var. latifolium Torr. On rotten logs, banks of Mobile River. July, September.

Type locality: "Hab. in Canada. Kalm."

Herb. Geol. Surv. Herb. Mohr.

Galium triflorum Michx. Fl. Bor. Am. 1:80. 1803. Sweet-scented Bedstraw.

Ell. Sk. 1:197. Gray, Man. ed. 6, 227. Chap. Fl. 174. Gray, Syn. Fl. N. A. 1, pt. $2: 39$. Wats. Bot. Calif. $1: 284$.

Europe, Asia, to Japan.

Boreal zone to Lonisianian area. Canada from the Atlantic to the Pacific. New England west to Nebraska, Colorado, and Calfornia, sonth to Florida and northern Mississippi.

Alabama: Mountain region. Lower hille. Rich shady woods. Landerdale Connty. Tuscaloosa County (E. A. Smith). April, May. Local; not frequent. Perennial.

Type locality: "In umbrosis Canadae sylvis."

Herb. Geol. Surv. Herb. Mohr.

Galium uniflorum Michx. Fl. Bor. Am. 1:79. 1803.

Black-fruited Ladies' Bedstraw.

Ell. Sk. 1:195. Chap. Fl. 174. Gray, Syn. Fl. N. A. 1, pt. 2:41.

Louisianian area. Sonth Carolina to Florida, west to Louisiana.

Alabama : Coast plain. Shaded rich woods. Upland hammocks. Mobile County, Springhill. Baldwin Connty, Montrose. Flowers white; July, Augnst. Fruit August, September; plum-purple, with a bloom. Not rare. Perennial.

Type locality: "Hab. in Carolina."

Herb. Geol. Surv. Herb. Mohr.

Galium hispidulum Michx. Fl. Bor. Am. 1: 79. 1303. Scarlet-Fruited Bedstraw. Rubia peregrina Walt. Fl. Car. 86. 1788. Not L.

R. brownei Michx. Fl. Bor. Am. 1: 81 .

$2: 42$

Ell. Sk. 1:195. Gray, Man. ed. 6, 227. Chap. Fl. 173. Gray, Syn. Fl. N. A. 1, pt.

Louisianian area. North Carolina to Florida, west to Louisiana.

Alabama: Coast plain. Dry copses and sliaded banks. Mobile and Baldwin counties. Flowers greenish white; fruit scarlet. May, June. Perennial, from a woody creeping base. Frequent.

Type locality: "Hab. in Carolina inferiore."

Herb. Geol. Surv. Herb. Mohr.

\section{VIBURNACEAE. Honeysuckle Family.}

SAMBUCUS L. Sp. Pl. 1:269. 1753. ElDEk.

Twenty species, temperate regions, excepting Africa.

Sambucus canadensis L. Sp. Pl. 1:269. 1753.

American Eldier.

Ell. Sk. 1: 368. Gray, Man. ed. 6, 217. Chap. Fl.171. Gray, Syn. Fl. N. A. 1, pt. 2:9.

Canadian zone to Louisianian area. Through Eastern North America firom New Brunswick and Saskatchewan to the Gulf, west to Dakota, mountains of Colorado, Utah, and Arizona, to 'Texas.

Alabama: Orer the State. Damp thickets and shaded banks. Flowers May, June. Fruit ripe September; berries shining black. Shrub or tree 15 to 20 feet high.

Economic nses: The bark, fruit, and flowers are the "elder" or "Sambucus" of the United States Pharmacopeia.

Type locality: "Hab. in Canada. D. Kalm."

Herb. Geol. Surv. Herb. Mohr. 
VIBURNUM L. Sp. Pl. 1:267. 1753.

About 100 species, temperate and warmer regions of the Northern Hemisphere, Europe, Asia, West Indies, Mexico, South America, Andes, Madagascar, North America, 14. Pacific, 1.

Viburnum acerifolium L.Sp. Pl. 1:268. 1753.

Maple-leaf Arrowwood. $2: 10$

Ell. Sk. 1:364. Gray, Mau. ed. 6, 218. Chap. Fl. 171. Gray, Syn. Fl. N. A. 1, pt.

Alleghenian, Carolinian, and Louisianian areas. Ontario to Saskatchewan, southern New England, west to Michigan, Missouri, and Arkansas, south to middle Florida and western Louisiana (Hale).

Alabama: Mountain region to Coast plain. Dry rocky woods. Clay County, Che-aw-ha Mountain, 2,400 feet. Clarke County, Choctaw Corner; rocky cherty ridges, Suggsville (Dr. Denny). Baldwin County, Point Clear. Flowers white; April. Fruit ripe September; black. Not rare. Slender shrub 3 to 4 feet high.

This is the plant from the mountains, with the fruit flat, ovate, $\frac{1}{4}$ inch wide, $\frac{5}{8}$ inch long, stone bisulcate on one side, with three grooves on the other.

Type locality: "Hab. in Virginia."

Herb. Geol. Surv. Herb. Mohr.

Viburnum molle Michx. Fl. Bor. Am. 1:180. 1803.

SOFT-HAIRY ARROWWOOD.

Viburnum dentatum var. scabrellum Torr. \& Gray, Fl. N. A.2:16. 1841.

V. scabrellum Chap. Fl. 172. 1860.

Gray, Man. ed. 6, 218. Chap. 1. c. Gray, Syn. Fl. N. A. 1, pt. 2:11. Coulter,

Contr. Nat. Herb. $2: 156$.

Carolinian and Louisianian areas. Southern coast of New England to Florida, west to Louisiana and Texas.

Alabama : Lower Pine region. Coast plain. Damp shaded banks along streams. Escambia and Mobile counties. Flowers in June; fruit ripe in September; small, black. Shrub 4 to 6 feet high.

Type locality : "Hab. in Kentucky, circa Danville."

Herb. Geol. Surv. Herb. Mohr.

Viburnum cassinoides L. Sp. Pl. ed. 2, 1:384. 1762.

WITHE ROD.

Viburnum nudum var. cassinoides Torr. \& Gray, Fl. N. A. 2 :14. 1841.

Ell. Sk. 1:366. Gray, Man. ed.6, 218. Chap.Fl. ed.3,190. Gray, Syn. Fl. N. A.1, pt. $2: 11$.

Canadian zone to Carolinian area. Northern Newfoundland to Quebec and Saskatchewan; Now England, New Jersey, and along the mountains to North Carolina.

Alabama: Mountain region. Damp thickets, banks of streams. Dekalb County, Mentone, on Little Kiver above the falls. Flowers May, Juue; fruit October, black. Shrub 4 to 5 feet high.

Economic uses: Ornamental.

Type locality : "Hab. in America septentrionali."

Herb. Geol. Surv. Herb. Mohr.

Viburnum rufotomentosu.n Small, Bull. Torr. Club, 23:410. 1896.

SOUTHERN BLACK HAW.

Viburnum prunifolium var. ferrugineum Torr. \& Gray, Fl. N. A. 2: 15. 1841.

V. ferrugineum Small, Mem.'Torr. Club, $4: 123, t .78$. 1894. Not Raf. 1838.

Carolinian and Louisianian areas. Southern Virginia to Georgia, Misissippi, Lonisiana, and western Texas.

Alabama: Mountain Region to Upper division Coast Pine belt. Dry woods. Morgan County, Falkville, 600 feet. Cullman County, 800 feet. Lamar County, near Vernon. Tuscaloosa County (E. A. Smith). Blount County, Warnock Mountain, 900 feet. Clarke County, Suggsville (Dr. Denny). Wilcox County (Buckley). Flowers April, May; fruit ripe October; large, black, sweet, palatable. Tree 15 to 25 feet high.

Economic uses: The bark, like that of the closely allied northern species, V. prunifolium, is used in medicine-"black-haw barik," "Viburnum prunifolium," United States Pharmacopœia.

Type locality (Torr. \& Gray): "N. Carolina! and Georgia! to Louisiana! and Arkansas!"

Herb. Geol. Surv. Herb. Mohr. 
Viburnum nudum L. Sp. Pl. 1:268. 1753. Possum Haw.

Viburnum nudum var. claytonii Torr. \& Gray, Fl. N. A. 2:14. 1841.

Ell. Sk. 1:365. Gray, Man. ed.6, 219. Chap. Fl. 171. Gray, Syn. Fl. N. A. 1, pt. 2: 11.

Carolinian and Louisianian areas. Southern New England, West Virginia, south to Florida, Louisiana, and Arkansas.

Alabama: Mountain region to Coast plain. Swampy thickets. Clay County, 1,000 feet. Cullman, Henry, Franklin, Washington, Montgomery, Mouroe, Baldwin, and Mobile counties. Flowers white; April, May. Fruit ripe September; black, with bluish bloom.

Most frequent in the sandy swamps, borders of pine-barren streams. Shrub, not infrequently somewhat arborescent, 8 to 16 feet high.

Type locality: "Hab. in Virginia."

Herb. Geol. Surv. Herb. Mohr.

Viburnum nitidum Ait. Hort. Kew. 1:371. 1789.

Viburnum nudum var. angustifolium Torr. \& Gray, Fl. N. A. 2: 14. 1841.

Gray, Syn. Fl. N. A. 1, pt. 2:12.

Slender shrub, 15 to 20 feet high, branches weak, drooping or reelining, leaves smooth, shining above, lanceolate to oblong, acute to acuminate, entire or obscurely crenulate; branchlets quadrangular, sparingly scurfy; berries smaller than in the above, oblong, acute, $\frac{1}{8}$ inch wide, $\frac{1}{4}$ inch long.

Louisianian area. North Carolina to Florida, west to Mississippi.

Alabama : Lower Pine region. Coast plain. Wooded swampy banks of pinebarren streams. Mobile and Baldwin counties. Flowers white, May. Berries ripe September, October; bluish black. Frequent.

Type locality: "Native of North America."

Herb. Geol. Surv. Herb. Mohr.

TRIOSTEUM L. Sp. Pl. 1:176. 1753.

Four species, peremnial herbs, temperate North America, Himalayan India, China. Triosteum perfoliatum L. Sp. Pl. 1:176. 1753. TINker's Root. Fever Root. Triosteum major Michx. Fl. Bor. Am. 1: 107. 1803.

Ell. Sk. 1:269. Gray, Man. erl. 6, 219. Chap. Fl. 170. Gray, Syn. Fl. N. A. 1, pt. $2: 12$.

Alleghenian to Louisianian area. Quebec, Ontario; New England west to Minnesota, south to the Ohio Valley, Missouri, Arkansas, and Tennessee, and along the mountains to Georgia.

Alabama : Central Prairie region. Rich woods. Montgomery County, Pintlalla Creek. Flowers white, April; fruit ripe July, scarlet. Local and rare. Perennial, from a large woody root.

Economic uses: The root, under the name of "Tinker's root," is used medicinally. Type locality: "Hab. in America septentrionali."

Herb. Geol. Surv. Herb. Mohr.

Triosteum angustifolium L. Sp. Pl. 1: 176. 1753.

Triosteum minus Michx. Fl. Bor. Am. 1:107. 1803

Ell. Sk. 1:270. Gray, Man. ed. 6, 219. Chap. Fl. 170. Gray, Syn. Fl. N. A. 1, pt. $2: 12$.

Carolinian and Louisianian areas. Virginia to Missonri and Arkansas, sonth to North Carolina and Georgia.

Aluana : Tennessee Valley. Rich eopses. Lauderdale County, Greenhill $(H$. Stutts). Flowers May; fruit ripe in .J une. Local and rare.

Type locality: "Hab. in Virginia."

Herb. Geol. Surv. Herb. Mohr.

SYMPHORICARPOS Juss. Gen. Pl. 211. 1789.

Nine species, temperate Mexico. North America, 7.

Symphoricarpos symphoricarpos (L.) MeMillan, Bull. Torr. Club, 19: 15. 1892.

Lonicera symphoricarpos L. Sp. Pl. 1:175. 1753.

Coral Berry.

Symphoricarpos orbiculata Moench, Meth. 503. 1794.

Symphoricarpos vulyaris Michx. Fl. Bor. Am. 1: 106. 1803.

Ell. Sk. 1:273. Gray, Man. ed. 6, 220. Chap. Fl. 169. Gray, Syn. Fl. N. A. 1, pt.

$2: 13$. 
Alleghenian and Carolinian areas. Western New York west to Minnesota, Nebraska, and Dakota, southern Ohio Valley, Missouri, and Arkansas, aud from New Jersey along the mountains to Georgia.

AlabaMa : Tennessee Valley, Mountain region. Rocky wooded hills in calcareous soil. Lauderdale County, river hills. Jackson County, Gurleys, summits of calcareous ridges, 1,200 feet. Flowers pale pink, May; fruit ripe September, October, purplish red. Not rare, local. Shrub 3 feet high.

Type locality: " Hab. in Virginia, Carolina."

Herb. Geol. Surv. Herb. Mohr.

LONICERA L. Sp. Pl. 1:173. 1753.

-

About 100 species, shrubs, temperate and warmer temperate regions Northern Hemisphere. Europe; mountains tropical Asia. North America, 20.

Lonicera sempervirens L. Sp. Pl. 1:173. 1753.

TRUMPET HONEYSUCKLE.

Caprifolium sempervirens Michx. Fl. Bor. Am. I: 105. 1803.

Ell. Sk. 1:270. Gray, Man. ed. 6, 221. Chap. Fl. 170. Gray, Syn. Fl. N. A. 1, pt.

$2: 16$. Coulter, Contr. Nat. Herb. $2: 157$.

Mexico.

Carolinian and Louisianian areas. Southeastern New York, New Jersey, Ohio, Indiana, Missouri, Arkansas and Tennessee, south to Florida, west to Texas.

Alabama : Monntain region to Coast plain. Cullman, Tuscaloosa, Montgomery, Washington, Eseambia, Monroe, Mobile, and Baldwin counties. Flowers vermilionred outside, flame-colored inside; April. Fruit ripe September. Frequent. Climbing high.

Economic uses: Planted for ornament.

Type locality : "Hab. in Virginia, Mexico."

Herb. Geol. Surv. Herb. Mohr.

Lonicera flava Sims, Bot. Mag. $32: t$. 1318. 1810.

YELLOW WOODBINE OR HONEYSUCKLE.

Caprifolium fraseri Pursh, Fl. Am. Sept. 1: 160. 1814.

Ell. Sk. 1:271. Chap. Fl. 170. Gray, syn. Fl. N. A. 1, pt. 2: 17.

Carolinian area. South Carolina.

Alabana: Mountain region. Exposed siliceous rocks on the highest summits. Clity County, Che-aw-ha Mountain, 2,400 feet. Talladega County, Alpine Mountain, near Renfroe, 1,600 feet, trailing over rocks. Rare. Collected in Clay County, July 31 , the berries just beginning to color.

Economic uses: Ornamental.

Type locality: "Exposed and rocky summit of the Paris mountain in Sonth Carolina." (Fraser.)

Herb. Geol. Surv. Herb. Mohr.

Lonicera japonica Thunb. Fl. Jap. 89. 1784.

JaPANese Honeysuckle.

Introduced from Japan. Escaped from cultivation and naturalized in several of the Southern States, north to Virginia.

Alabama: Over the State. Low damp thickets. Mobile and Baldwin counties.

Flowers white to purple; April. Climber.

Type locality : "Crescit prope Nagasaki."

Herb. Geol. Surv. Herb. Mohr.

Lonicera longiflora (Sabine) DC. Prodr. 4 : 333.1830.

LONG-FLOWERED HONEYSUCKLE.

Caprifolium longiflorum Sabine; Lindl. Bot. Reg. 15 : t. 1232. 1829.

China AND NePal.

Introduced and cultivated with the above.

Al.abama: Mobile County. Flowers white, fragrant, fading to buff yellow. May.

Climber. Escaped and not infrequently of spontaneous growth.

Herb. Geol. Surv. Herb. Mohr.

DIERVILLA Moench, Meth. 492. 1794.

Six or 7 species, North America, Japan.

Diervilla sessilifolia Buckley, Am. Journ. Sci. 45:174. 1843.

Sessile-Leaf Bush Honeysuckle.

Chap. Fl.170. Gray, Syn. Fl. N. A. 1, pt. 2:19.

Carolinian area. Mountains of North Carolina and southeastern Tennessee. 
Ala Bama : Monntain region. Exposed rocky hillsides. Northern Alabama(Buckley). Flowers brownish yellow; July. Rare. Low shrub.

Type locality: "Mountains of North Carolina."

Herb. Geol. Surv. Herb. Mohr.

Diervilla rivularis Gattinger, Bot. Gaz. $13: 191.1888$.

Shrub 2 to 5 feet high. Branchlets terete; leaves subsessile, ovate or oblong. lanceolate, acuminate, whitish below, all parts hirsutely pubescent; cymes often numerons, 3 to 6 flowered; corolla slightly bilabiate, the upper three divisions in close contact, the lower more spreading; calyx lobes slender, lanceolate-subulat". Flowers larger and handsomer than in 1 . . sessilifolia.

Carolinian area. Tennessee.

Alabama: Mountain region. Damp rocks. Dekalb County, Lookout Mountain, Desoto Falls, near Mentone. Flowers July; yellow.

In our specimens the towers are smaller than in $D$. sessilifolia, the cymes densely Howered, and, like the fruit, viscid-pubescent.

Type locality: "On the banks of 'Lula Falls,' Lookout Mountain, a few miles across the Tennessee line in Georgia."

\section{VALERIANACEAE. Valerian Family.}

V NLERIANELLA Pollich, Hist. Pl. Pal. 1:29. 1776.

(Fedia Gaert. Fruct. $2: 36$. 1788.)

About 50 species, temperate Europe. North America, 15.

Valerianella radiata (L.) Dufr. Hist. Val.57. 1811.

Wild Lamb Salad.

Valerianella locusta var. radiata L. Sp. Pl. 1:34. 1753.

Fedia radiata Michx. Fl. Bor. Am. 1: 18. 1803.

Ell. Sk. 1:42. Gray, Man. ed. 6, 229. Chap. Fl. 184. Gray, Syn. Fl. N. A. 1, pt. $2: 45$. Coulter, Contr. Nat. Herb. $2: 164$.

Alleghenian to Louisianian area. Pennsylvania to Michigan, south to Florida, west to Texas and Arkansas.

Alabama: Over the State. In low damp ground, fields, waysides. Cullman County. Tuscaloosa County (E. A. Smith). Lee County, Auburn. Mobile County. Flowers white; March, April. Frequent. Annual.

Type locality: "Hab. in Marilandiae arvis."

Herb. Geol. Snrv. Herb. Mohr.

\section{DIPSACEAE. Teasel Family.}

DIPSACUS L. Sp. Pl. 1:97. 1753.

Twelve species, warmer temperate regions, Europe, chiefly Mediterranean.

Dipsacus sylvestris Huds. Fl. Angl. 49. 1762.

WiLD Trasel.

EURope.

Adventive. Sparingly naturalized in the Atlantic States.

Ala bama : Coast region, on ballast. Mobile County. June; infrequent. Annual. Type locality: "Hab. in incultis frequens."

Herb. Geol. Surv. Herb. Mohr.

\section{CUCURBITACEAE. Cucumber Family.}

CUCUMIS I.Sp. Pl. 2 : 1010.1753.

Twenty-six species, warmer regions.

Cucumis colocynthis L. Sp. Pl. ed. 2, 2:1435. 1763.

Colocynth.

Adventive from Asia, Africa, southern Europe.

Alabama : Fugitive on ballast. Collected with seeds fully matured October, 1883 and 1884. A coarse ereeping annual.

Economic nses: The fruit is the "Colocynthis" of the United States Pharmacopœia.

Type locality not given.

Herb. Geol. Surv. Herb. Mohr. 
ECBALIUM A. Rich. Dict. Class. Hist. Nat. 619. 1824.

One species, Mediterranean Europe.

Ecbalium elaterium (L.) A. Rich. Dict. Class. Hist. Nat. 619. 1824.

Momordica elaterium L. Sp. P1. ed. 2, 2 : 1434. 1763.

Common Squirting CuCumber.

Fugitive on ballast. Mobile County, May, 1883. Annual.

Economic uses: 'The fruit is used medicinally for Elaterium.

'Type locality: "Hab. in Enropa australi."

Herl. Geol. Surv. Herb. Mohr.

MOMORDICA L. Sp. Pl. 2:1009. 1753.

Twenty-five species, tropical Asia and Africa.

Momordica charantia L. Sp. Pl. 2: 1009.

Balsam Pear.

Tropical Asia, naturalized in warmer America.

AdVentive From the Tropics.

Louisianian area. Georgia and Florida.

Ala bama: Ballast ground, waste places near the shipping. Flowers yellow; August to October. Fruit copper-red, seed coat crimson. Frequent on every ballast heap, spreading to waste places in the vicinity. First collected in 1887. Annual.

Type locality: "Hab. in India."

Herb. Geol. Surv. Herb. Mohr.

I.AGENARIA Seringe, Mem. Soc. Phil. Genev. ser. 3, 1:25. 1825.

Half dozen species, tropical Asia and Africa.

Lagenaria vulgaris (L.) Seringe, Mem. Soc. Phil. Genev, ser. 3, 1: 25. 1825.

Cucurbita lagenaria L. Sp. Pl. ed. 2, 2 : 1434. 1763.

Common Gourd Calabash.

Ell. Sk. 2:662. 'Torr. \& Gray, Fl. N. A. 1:545. 1841. Coulter, Contr. Nat. Herb.

$2: 123$.

Sabtropical and tropical regions of the Old World. Extensively naturalized in the New World.

Carolinian and Louisianian areas. Regarded as introduced and naturalized in the South Atlantic and Gulf States, althongli cultivated by the aborigines at the arrival of the earliest settlers.

Alabama: In the lower country, near dwellings, borders of pastures and fields. Flowers white; throughont the summer. Fruit ripe September to November. Not infrequent. A rank coarse climber. Perennial.

Ecomonic uses: The matured ligneons fruit, for vessels and various ntensils.

'Type locality: "Hab. in Americae rignis."

Herb. Geol. Surv.

TRIANOSPERMA Mart. Syst. Mat. Med. Bras. 79. 1843.

Eight or 9 species, warmer America.

Trianosperma boykinii (Torr. \& Gray) Roem. Syn. Pepon. 2 : 45. 1846.

Bryonia boykinii Torr. \& Gray, Fl. N. A. 1:540. 1840.

BOYKIN'S BRYONY.

Cayaponia boykinii Cognianx in DC. Monogr. Phan. 3 : 746. 1881.

Chap. Fl. 148.

Lonisianian area. Georgia to Louisiana and Arkansas.

Alabama : Central Prairie region. Low shaded banks. Wilcox Connty (S. B. Buckley, 1840). Flowers greenish white; June, July. Fruit ripe Augnst; red. Very rare. Perennial herb from a fusiform root, climbing over bushes.

Type locality: "Low ground along streams, Georgia, Dr. Boykin! Alabama, Mr. Buckloy! Louisiana, 1rr. Carpenter! Dr. Hale!"

Herb; Geol. Surv.

MELOTHRIA L. Sp. Pl. 1:35. 1753.

Sixty species, warm $\mathbf{r}$ regions, Asia, America. North Ameriea, 2.

Melothria pendula L. Sp. Pl. 1:35. 1753.

Ell. Sk. 2:662. Grav, Man. er. 6, 196. Chap. Fl. 149. Coulter, Contr. Nat. Herb. 2: 124 . 
West Indes, South America.

Carolinian and Lonisianian areas. Sonthern Virginia to Florida, west to Texas and Arkansas.

Alabama : Tonnessee Valley to Coast plain. Shady banks. Lauderdale Connty. Cullman Connty, 800 feet altitude. Tuscaloosa and Mobile counties. Flowers citron yellow; August to October. Fruit ripe October; black. Slender perennial, running over herbs and small bushes. Annual.

Type locality: "Hab. in Canada, Virginia, Jamaica."

Herb. Geol. Surv. Herb. Mohr.

SICYOS L. Sp. Pl. 2 : 1013.1753.

About 35 species, warmer regions both hemispleres. America, Anstralia. North America, 2.

Sicyos angulatus L. Sp. Pl. 2 : 1013. 1753.

ONE-SEEDKD Bur CuCuMBer.

Ell. Sk. 2: 663. Gray, Man. ed. 6, 195. Chap. Fl. 149. Coulter, Contr. Nat. Herb. 2 : 125.

Russia, Caucasus.

Alleghenian to Louisianian area. Quebec, Ontario, New England, west to Minnesota, Nebraska, and Arkansas; Ohio Valley and New Jersey to Florida and Texas.

Alabama: Central Prairie region. Thickets along streams. Autanga Connty, House Bluft (E. A. Smith). Fruit greenish white; September. Rare. Climbing over bushes. Annual.

Type locality: "Hab. in Canada, Mexico."

Herb. Geol. Surv. Herb. Mohr.

\section{CAMPANULACEAE. Bluebell Family.}

CAMPANULA I. Sp. Pl. 1 : 163. 1753.

Two hundred and fifty species, herbs, temperate regions, Nortlern Hemisphere. Europe. North America, 13. Atlantic, 5.

Campanula americana L. Sp. Pl. 1 : 161. 1753.

TALL BELINLOW HE.

Campanula acuminata Michx. Fl. Bor. Am. 1:108. 1803.

Ell. Sk. 1:262. Gray, Man. ed. 6,309. Chap. Fl. 256. Gray, Syn. Fl. N. A. 2, pt. $1: 14$.

Alleghenian to Louisianian area. New Brunswick, Ontario, and Minnesota, westeru New York south to Georgia.

Alabama: Central Prairie region to Central Pine belt. Rich shaded banks. Coosa County (E. A. Smith). Dallas County, Marion Junction. Flowers azure; July to September. Infrequent. Annual or biennial.

Type locality : "Hab. in America."

Herb. Geol. Surr. Herb. Mohr.

Campanula divaricata Michx. Fl. Bor. Am. 1: 109. 1803.

Ell. Sk. 1: 262. Gray, Man. ed. 6, 309. Chap. Fl. 256. Gray, Syn. Fl. N. A. 2 , pt. $1: 13.1878$.

Carolinian area. Virginia, southeastern Kentucky, along the mountains to Georgia.

Alabama: Mountain region. Dry rocky woods. Clay County, waterfall near Pulpit Rock, 2,000 feet. Calhoun County, Anniston. 'Talladega County, Chandler Springs, 1,000 feet, exposed rocks. Cleburne County, rocky banks of 'Tallapoosa River. Bibb County, Pratt's Ferry, 450 feet. Flowers cerulean bIue; August, September. Frequent. Perennial.

Type locality : "Hab. in altis montibus Carolinae."

Herb. Geol. Surv. Herb. Mohr.

LEGOUZIA Durand, Fl. Bomrg. 2 : 26. 1782.

(Specularia Heist.; A. DC. Monogr. Camp. 344. 1830.)

Ten species, warmer tenıperate regions of both hemispheres. Europe, South America. North America, 4.

Legouzia biflora (Rniz \& Pav.) Britton, Men. 'Torr. Club, 5 :309. 1894.

TWO-FLOWERED VENUS's LOOKING GLAsS.

Campanula biflora Ruiz \& Pav. Fl. Peruv. 2:55, t. 200, f. b. 1799.

Specularia biflora Gray, Proc. Am. Acall. 11:82. 1876. 
Chap. Fl. Suppl. 632; ed. 3,279. Gray, Syn. Fl. N. A. 2, pt. 1:11. 1878. Coulter,

Contr. Nat. Herb. 2:252. Wats. Bot. Calif. 1: 446 .

Mexico, South America.

Lonisianian area. South Carolina to Florida, west to Texas, Arkansas, and California.

Alabama: Coast plain. Exposed light soil. Fields, pastures. Baldwin and Mobile counties. Flowers purplish blue; March to May. Frequent. Winter annual, 4 to 8 inches high.

Type locality: "Hab. in Peruviae collibus arenosis ad Cercado, Cantae et Chancay Provincias."

Herb. Geol. Surv. Herb. Mohr.

Legouzia perfoliata (L.) Britton, Mem. Torr. Club, 5 : 309.

Campanula perfoliata L. Sp. Pl. 1:169. 1753.

Perfoliate Venus's Looking Glass.

C. amplexicaulis Michx. Fl. Bor. Am. 1:108. 1803.

Ell. Sk. 1:262. Gray, Man. ed. 6, 308. Chap. Fl. 257. Gray, Syn. Fl. N. A. 2, pt.

$1: 11$. Coulter, Contr. Nat. Herb. 2:252. Wats. Bot. Calif. 1:447.

Mexico, Chile.

Alleghenian to Louisianian area. Ontario, British Columbia, Oregon, California, Utah; New England south to Florida, and through the Gulf States to Texas.

Alabama: Over the State. Dry sandy or gravelly ground, cultivated and waste

places. Flowers purplish blue; April to June. Common. Annual.

Type locality: "Hab. in Virginia."

Herb. Geol. Surv. Herb. Mohr.

\section{LOBELIA L. Sp. Pl. $2: 929.1753$. LOBEliA.}

Alout 225 species, temperate and warmer regions both hemispheres. Largely American to Chile, Asia, South Africa. North America, 23; Atlantic, 20.

Lobelia cardinalis L. Sp. Pl. $2: 930.1753$.

Cardinal Flower.

Ell. Sk. 1:268. Gray, Man. ed. 6, 305. Chap. Fl.254. Gray, Syn. Fl. N. A. 2, pt.1:3. Coulter, Contr. Nat. Herb. $2: 251$.

Alleghenian to Louisianian area. Nova Scotia, New Brunswick, Ontario; New Englanil west to Minnesota, south to Missouri, Texas, and from Florida to Louisiana.

Arabama : Over the State. Rich, shaded, swampy banks. Morgan, Cullman, and

Mobile counties. Flowers crimson; August, September. Frequent. Perennial.

Type locality: "Hab. in Virginia."

Herb. Geol. Surv. Herb. Mohr.

Lobelia brevifolia Nutt.; DC. Prodr. 7, pt. 2:377. 1839.

SHORT-LEAF LOBELIA.

Chap. Fl. 254. Gray, Syn. Fl. N. A. 2, pt. 1:3.

Lonisianian area. Florida to Louisiana.

Alabana : Coast plain. Low, damp pine barrens; springy places. Mobile and Baldwin counties. Flowers azure; September, October. Not rare. Ten to 20 inches

high. Perennial.

Type locality: "In Alabama Americae bor."

Herb. Geol. Surv. Herb. Mohr.

Lobelia syphilitica L. Sp. Pl. 2 :931. 1753.

LARGE BLUE-FLOWERED LOBELIA.

Ell. Sk. 1:266. Gray, Man. ed. 6, 306. Chap. Fl.254. Gray, Syn. Fl. N. A. 2, pt. 1: 4.

Alleghenian to Carolinian area. Ontario, Minnesota, Nebraska, and Dakota, sonth to the Ohio Valley, Missouri, and Arkansas, and from New.Jersey along the mountains to Georgia.

Alabama: Mountain region. Damp borders of streams. Clay County, Elders, 1,000 feet altitude. Talladega County, Riddell's Mill, banks of 'Talladega Creek. Flowers sky-blue; August, September. Infrequent. Perennial.

Type locality: "Hab. in Virginia."

Herb. Geol. Surv. Herb. Mohr.

Lobelia puberula Michx. Fl. Bor. Am. 2 : 152. 1803.

DOWNY LOBELIA.

Ell. Sk. 1:267. Gray, Man. ed. 6, 306. Chap. Fl. 254. Gray, Syn. Fl. N. A. 2, pt. 1:4.

Coulter, Contr. Nat. Herb. $2: 251$.

Carclinian and Louisianian areas. Southern New Jersey to Florida, west to Texas.

Alabama : Mountain region to Coast plain. Damp sandy ground, low borders of thickets. Lee County, Auburn (Baker of Earle). Talladega County, Renfroe Valley, about 600 feet. Montyomery, Clarke, Monroe, Baldwin, and Mobile Counties. Flowers cerulean blue; August to October. Common. Most frequent in the pine barrens. Perenuial.

Type locality : "Hab. in Carolina."

Herb. Geol. Surv. Herb. Mohr. 
Lobelia puberula laeviuscula nom. nov.

Lobelia puberula glabella Hook. Bot. Mag. 61: t. 3292. 1834. Not Ell. 1817.

L. glandulosa var. oblusifolia DC. Prodr. 7, pt. 2:378. 1839. Not L. obtusifolia

Willd. 1819.

Gray, Syn. Fl. N. A. 2, pt. 1:4.

Carolinian and Louisianian areas. North Carolina to Florida and Texas.

Alabama: Mountain region. 'Talladega County, near Riddell's Mill, Chandler

Spriugs. September. Infrequent. Local 10 to 15 inches high. Perennial.

Type locality of $L$. glandulosa obtusifolia: "In Alabama."

Herb. Geol. Surv. Herb. Mohr.

Lobelia amoena glandulifera Gray, Syn. Fl. N. A. 2, pt. 1:4. 1878.

Lobelia glandulosa DC. Prodr. 7, pt.2:378. 1839. In part. Not Walt.

Gray, l. c.

Carolinian and Louisianian areas. Sonthern Virginia, North Carolina, to Florida.

AlabaMa : Monntain region, Metamorphic hills. Lee County, Auburn (F. S. Earle).

Flowers bright blue (campanula-blue); October. Rare. Only locałity known in

the State. Perennial.

Type locality: "Moist grounds, S. Virginia to Florida and Alabama."

Herb. Geol. Surv. Herb. Mohr.

Lobelia paludosa Nutt. Gen. 2 : 75. 1818.

Gray, Man. ed. 6, 307. Chap. Fl. 255. Gray, Syn. Fl. N. A. 2, pt. 1:5.

Carolinian and Louisianian areas. Delaware and along the coast to Florida,

thence west to Louisiana.

Alabama: Coast plain. Swampy borders of pine-barren ponds. Baldwin and

Mobile counties. Flowers lilac: July to September. Frequent. Perennial.

Type locality: "In deep sphagnose swamps, from Sussex County in Delaware to Georgia."

Herb. Geol. Surv. Herb. Mohr.

Lobelia appendiculata DC. Prodr. 7, pt. 2:376. 1839.

A Pl'ENDAGKD LOBELAa.

Gray, Syn. Fl. N. A. 2, pt. 1:5. Coulter, Contr. Nat. Herb. $2: 251$.

Louisianian area. Louisiana, Texas, and Arkansas.

Alabama : Central Prairie region. Open post-oak wools. Dallas County, Marion

Junction, Uniontown. Flowers May, June. Annual.

Type locality: "In Texas. (Drumm.! in h. Benth.)"

- Herb. Geol. Surv. Herb. Mohr.

Lobelia gattingeri Gray, Proc. Am. Acad. 17:221. 1882.

Chap. Fl. Suppl. 632; ed. 3, 277. Gray, Syn. Fl. N. A. 2, pt. 1:394. 1884.

Carolinian and Louisianian areas. Middle Tennessee.

Alabama: Central Prairie region. Dry limestone prairies. Montgomery County,

Pintlalla Creek. Flowers July; sky-blue, resembling the last. Annual.

'Type locality: "Middle Tennessee, in springy places of calcareous bluffs and in cedir barrens, Ir. Gattinger."

Herb. Geol. Surv. Herb. Mohr.

Lobelia leptostachys DC. Prodr. 7, pt. $2: 376.1839$.

SLENDER-SPIKED LOBELIA.

Gray, Man. ed. 6, 306. Chap. Fl. 254. Gray, Syn. Fl. N. A. 2, pt. 1: 6.

Carolinian and Lonisianiau areas. Southern Ohio to southern Missouri, Arkansas, south from Virginia to Georgia.

Alabama: Mountain to Central Prairie region. Dry borders of woods, open copses. Clay County, Delta divide, 1,600 feet altitude. Etowah County, near Gadsden, 1,000 feet altitude. Blount County. Jefferson County, Windham Springs (E A.Smith). Antanga Connty, Prattville. Flowers pale blue; June, July. Not infrequent. Perennial.

Type locality: "In Carolina meridiouali." Fraser.

Herb. Geol. Surv. Herb. Mohr.

Lobelia spicata Lam. Encycl. 3 :587. 1789.

SPIKED LOHELia.

Lobelia claytoniana Michx. Fl. Bor. Am. 2 : 153. 1803.

Ell. Sk. 1:265. Gray, Man. ed. 6, 306. Chap. Fl. 255. Gray, S5n. Fl. N. A. 2, pt. 1:6. Alleghenian to Louisianian area. Ontario, New England south to the Ohio Valley, Missouri, and along the mountains to Georgia.

Ala Bama : Distribution as in the last. 'Talladega County, Riddell's Mill. Etowah and Montgomery counties. Flowers pale blue; June, July. Not freqnent. Perennial.

Type locality: "Cette plante croit dans le Canada."

Herb. Geol. Surv. Herb. Mohr. 
Lobelia nuttallii Roem. \& Schult. Syst. 5 : 39. 1819.

NutTall's LoBelia.

Lobelia gracilis Nutt. Gen. 2 : 77. 1818. Not Andr.

Gray, Man. ed. 6, 307. Chap. Fl. 255; ed. 3, 276; Gray, Syn. Fl. N. A. 2, pt. 1: 7 .

Carolinian and Louisianiav areas. New Jersey, Pennsylvania, to Georgia.

Alabama : Over the State. Low damp banks. Cullman County, 800 feet. Clay

County, Talladega Creek, 1,000 feet altitude. Tuscaloosa and Mobile counties.

Flowers pale purplish blue; July, August. Frequent. Annual.

Type locality: "Ad margines siccas paludun sabulosorum a nova Caesarea ad Carolinam."

Herb. Geol. Surv. Herb. Mohr.

Lobelia inflata L. Sp. Pl. 2 : 931. 1753.

INdian TOBacco. Lobelia.

Ell. Sk. 1:266. Gray, Man. ed.6, 307. Chap. El. 254. Gray, Syn. Fl. N. A. 2, pt. 1: 7.

Alleghenian to Carolinian area. Maritime provinces of Canada to Hudson Bay and Saskatchewan. New England west to Minnesota, south to the Ohio Valley, Missouri, and Arkansas, and from New York to upper Georgia.

Aldisam: Mountain region. Clay County, Elders, 1,000 feet altitude. Talladega County, Riddell's Mill, 1,000 feet. Cullman County, 800 feet. Blount County, Blount Springs, on the hills, 800 feet. Not rare. Coarse. Annual.

Economic uses: The herb (leaves and tops) forms the "Lobelia" of the United States Pharmacopœia, and the seeds are also recognized.

Type locality: "Hab. in Virginia, C'anada."

Herb. Geol. Surv. Herb. Mohr.

\section{CICHORIACEAE. Chicory Family.}

CICHORIUM L.Sp. PI. 2 : 813. 1753.

Three species, temperate Europe, Asia.

Cichorium intybus L. Sp. Pl. 2 : 813. 1753.

Common Chicory.

Gray, Man. ed. 6, 298. Gray, Syn. Fl. N. A. 1, pt. $2: 412$.

Alleghenian and Carolinian areas. Naturalized in Canada and the United States, west to Arkansas. More rarely south of the Ohio River.

Alabama: Mobile County. A rare ballast weed. Flowersazure; July. Perennial Type locality: "Hab. in Europa ad margines agrorum viarumque."

Herb. Geol. Surv. Herb. Mohr.

ADOPOGON Neck. Elem. 1:55. 1790.

(Krigia Schreb. Gen. Pl. 532. 1791.)

Five species, herbs. North America.

Adopogon carolinianum (Walt.) Britton, Mem. Torr. Club, 5 : 346. 1894.

CaRolina DWARF DaNdelion.

Hyoseris virginica L. Sp. Pl. 2 : 809. 1753. Not Tragopogon virginicum L.

H. caroliniana Walt. Fl. Car. 194. 1788.

Krigia rirginica Willd. Sp. Pl. $3: 1618.1804$.

K. caroliniana Nutt. Gen. 2 : 126.1818.

Ell. Sk. $2: 264,265$. Gray, Man. ed. 6, 298. Chap. Fl.249. Gray, Syn. Fl. N. A. 1, pt.

$2: 411$. Coulter, Contr. Nat. Herb. $2: 246$.

Alleghenian to Louisianian area. Western Ontario to New York, Ohio Valley to

Missouri and Arkansas, south to Florida and Texas.

Alabama: Over the State. Exposed dry light soil. Flowers orange; March, May. Common. Annual.

Type locality: South Carolina.

Herb. Geol. Surv. Herb. Mohr.

Adopogon virginicum (L.) Kuntze, Rev. Gen. Pl. 1:304. 1891.

Tragopogon virginicum L. Sp. Pl. 2 : 789. 1753.

Virginia Dwarf Dandelion.

Krigia amplexicaulis Nutt. Gen. 2 :127. 1818.

Cynthia virginica Don, Edinb. Phil. Journ. 12 :309. 1829.

Ell. Sk. 2 :266. Gray, Man. ed. 6, 298. Chap. Fl. 249.

Carolinian area. Southern Ontario to Lake Winnipeg, Ohio to Arkansas and south to Georgia.

Alabama: Mountain region to Lower hills. Openings in the woods, borders of thickets and fields. Cullman County. Tuscaloosa County $(E . A$. Smith). Flowers orange; June. Frequent. Perennial.

Type locality: "Hab. in Virginia, Canada. Kalm."

Herb. Geol. Surv. Herb. Mohr. 
Adopogon dandelion (L.) Kuntze, Rev. Gen. Pl. 1:304. 1891. DWarF Dandelion.

Tragopogon dandelion L. Sp. Pl. ed. 2, 2 : 1111. 1763.

Krigia dandelion Nutt. Gen. 2:127. 1818.

Cynthia dandelion DC. Prodr. 7:89. 1838.

Ell. Sk. 2 :265. Gray, Man. ed.6, 298. Chap. Fl.249. Gray, Syn. Fl. N. A. 1, pt.

$2: 412$. Coulter, Contr. Nat. Herb. $2: 247$.

Carolinian and Louisianian areas. Maryland to Florida, west to Texas and Arkansas.

Alabama : Tennessee Valley. Mountain region to Coast plain. Sparsely diffused. Lauderdale County. Tuscaloosa County (E.A. Smith). Dallas County, Uniontown (E. A. Smith). Morgan County. Hale County, Gallion. Mobile County. Hlowers yellow; April, May; again in October (at Mobile). Not frequent. Perennial.

Typo locality: "Hab. in Virginia."

Herb. Geol. Surv. Herb. Mohr.

SCOLYMUS L. Sp. Pl. 2:813. 1753.

Three or four species, Mediterranean region.

Scolymus grandiflorus Desf. Fl. Atlant. 2:240, t. 218. 1800.

Alabama: Adventive from southern Europe. Mobile County, fugitive on ballast. Type locality: "In arvis incultis vulgatissima" (Northern Africa).

Herb. Geol. Surv. Herb. Mohr.

SERINEA Raf. Fl. Ludov. 149. 1817.

One species.

(APOGON Ell. Sk. $2: 267$. 1821-24.)

Serinea oppositifolia (Raf.) Kuntze, Rev. Gen. Pl. 1:364. 1891.

Krigia oppositifolia Raf. Fl. Ludov. 57. 1817.

Apogon humilis Ell. Sk. 2 :267. 1821-24.

Ell. Sk. 1. c. Chap. Fl.249. Gray, Syn. Fl. N. A. 1, pt. 2:411. Conlter, Contr. Nit. Herb. $2: 246$.

Carolinian and Louisianian areas. South Carolina to Florida and Texas and Arkansas.

Alabama: Mountain region to Coast plain. Sandy exposed soil. Cultivated and waste places, pastures. Cullman and 'Tuscaloosa counties. Lee County, Auburn (Baker \& Earle). Mobile and Bald win counties. Flowers deep yellow; March, April. Abundant in the lower country. Annual.

Type locality not specifically given.

Herb. Geol. Surv. Herb. Mohr.

Thirty-five species.

PICRIS L. Sp. Pl. 2 : 792.1753.

Picris pauciflora Willd. Sp. Pl. 3 : 1557. 1804.

SOUTHERN EuRope.

Alabama: Ballast weed. Mobile County, fugitive, collected in 1884; not found since. Annual?

Type locality: "Hab. in Gallia australi."

Herb. Geol. Surv. Herb. Mohr.

HIERACIUM L. Sp. Pl. 2 : 799. 1753.

Five hundred nominal species, not well defined; perennials of both hemispheres, largely European and northeru Asiatic. North America, 24, endemic; Atlantic, 9.

Hieracium scribneri Small, Bull. Torr. Club, 21 : 20, t. 12\%. 1897.

Perennial, somewhat glaucescent, sparingly or diffusely branched above, leafy, somewhat pubescent below with loug spreading hairs; peduncles and pedicels glabrous or densely glandular. Lowest leaves oblong or oblong spatulate on winged petioles, acute, acumiuate at the base, the upper oblanceolate, oblong to linearlanceolate, sonetimes even fiddle-shaped, sessile, acute, with a few scattered spine-like teeth, nearly glabrous; inflorescence more or less corymbose-paniculate; involucre nearly glabrous or glandular; achenes columnar, somewhat constricted under the rim of the summit; pappus not exceeding the involucral bracts.

"A very well marked species, with much the foliage of $H$. paniculatum, but far more nearly the habit and inflorescence of $H$. venosum, which latter it is like in its vernal flowering."-E. L. Greene.

Carolinian area. Southeastern Tennessee and north western Georgia.

Platil IX. 


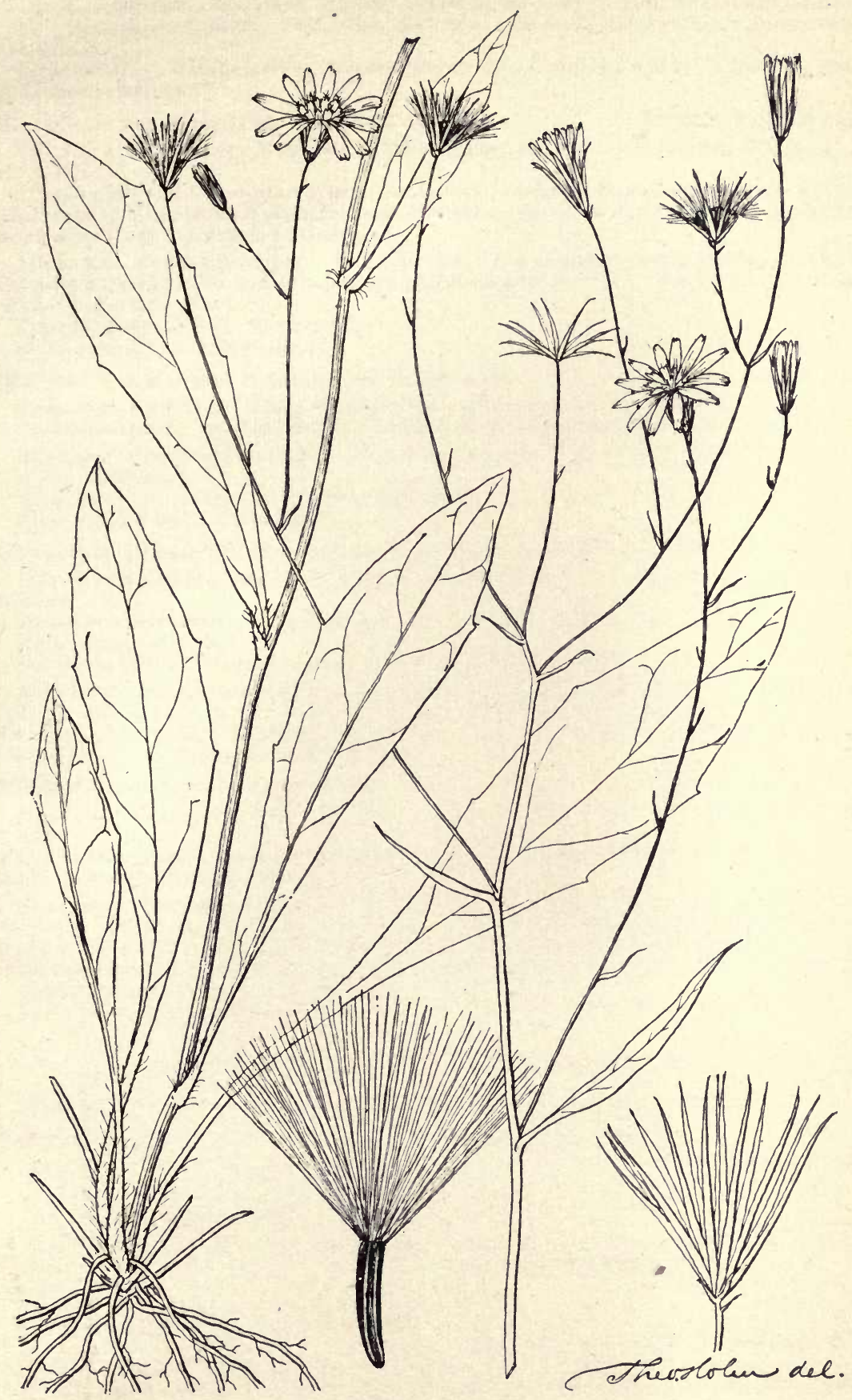



Arabama : Metamorphic and Coosa hills. Exposed rocky hillsides. Dekalb County, Mentone, 1,600 feet. Calhoun County, Anniston, 800 feet. St. Clair County, Springville. Tallapoosa County, Dadeville, 900 feet. Flowers deep yellow; June, July. Not rare.

Type locality : “Collected on Lookout Mountain, 'Tennessee, May 21, 1890, by Prof. F. Lamson-Scribner."

Hieracium venosum L. Sp. P1. 2 : 800. 1753.

RATTLESNAKE WELD.

Ell. Sk. 2:262. Gray, Man. ed. 6, 299. Chap. Fl. 250. Gray, Syn. Fl. N. A. 2, pt. $1: 425$.

Alleghenian and Carolinian areas. Ontario to Saskatchewan; southeru New England west to Minnesota, Nebraska, and Montana, sonth to Arkansas, and along the mountains from Tennessee to Georgia.

Alabama: Mountain region. Dry hillsides. Clay County, near Moseley, banks of Talladega Creek, 1,000 feet (Franklin's place, August 2, 1896). Lee County, Auburn (Baker \& Earle). Rare.

'Type locality: "Hab. in Virginia."

Herb. Geol. Surv. Herb. Mohr.

Hieracium marianum Willd. Sp. Pl. 3 : 1572. 1804. Maryland Hawkweed. Gray, Man. ed.6, 300. Chap. Fl. ed.3,272. Gray, Syn. Fl.2, pt. 1:426.

Carolinian area. Rhode Island, sonthern New York, Pennsylvania, Kentucky. Alabama: Metamorphic hills. Dry open copses. Lee County, Auburn (Baker of Earle). October.

Type locality: "Hab. in America boreali."

Herb. Geol. Surv. Herb. Mohr.

Hieracium greenii Porter \& Britton, Bull. Torr. Club, 20: 120. 1893.

Pilosella spathulata Schultz Bip. Flora, 45:439. 1862. Not Hieracium spathulatum Scheele. 1863.

Hieracium marianum var. spathulatum Gray, Syn. Fl. 2, pt.1:455. 1886.

Gray, Man. ed. 6, 300.

Carolinian area. Pennsylvania, Virginia, West Virginia.

Ala Bama : Metamorphic hills. Lee County, Auburn (Baker \& Earle). October.

Typo loeality: "In dry soil, Tuscarora Mountain, Huntingdon Co. * * * Two-Top Mountain, Franklin Co., Penn. * * * Mountains of Clinton Co., Penn. * * * Peaks of Otter, Virginia."

Hieracium gronovii L. Sp. P1. 2 : 802. 1753.

Common HaWKWEed. Ell. Sk. 2:263. Gray, Man. ed.6, 300. Chap. Fl. 250. Gray, Syn. Fl. N. A. 1, pt. $2: 426$.

Carolinian area. Southern Ontario: New York west to Missouri and Arkansas, south to the Gulf, from Florida to Louisiana.

Alabama: 'I'hroughout the State. Exposed light soil. Open dry woods. Very variable. In the dry pine barrens of the coast are found persistent forms with the stem leafy to the narrow elongated dense panicle, and the radical leaves strongly hirsute with long shaggy hairs (var. hirsutissimum Torr. \& Gray, Fl. N. A. $2: 427$ ). Perennial. Type locality: "Hab. in Virginia, Pensylvania."

Herb. Gecl. Surv. Herb. Mohr.

TARAXACUM Haller, Stirp. Helv. 1:23. 1768.

Twenty-two species, perennial herbs, temperate Europe, Asia.

Taraxacum taraxacum (L.) Karst. Deutsch. Fl. 1138. 1880-83.

Leontodon taraxacum L. Sp. Pl. 2 : 798. 1753.

Taraxacum officinale Web. Prim. Fl. Hols.56. 1780.

T. dens-leonis Desf. Fl. Atl. 2 : 228. 1800.

Ell. Sk. 2:250. Gray, Man. ed. 6, 303. Chap. Fl. 252. Gray, Syn. Fl. N. A. 1, pt.

$2: 440$. Coulter, Contr. Nat. Herb. $2: 249$.

Europe.

Naturalized nearly orer the continent.

Alabama: Throughout the State. Blossoms from February to May, again in

October. Common everywhere. Perennial.

Economic uses: The root is the "Taraxacum" or "dandelion root" of the United

States Pharmacopœia.

Type locality: "Hab. in Europae pascuis."

Herb. Geol. Surv. Herb. Mohr. 
SITILIAS Raf. New Fl. N.A. $4: 85.1836$.

(Pyrrhopappus DC. Prodr. 7 : 144. 1838.)

Six species. Mexico. North America, 4. Atlantic, 2.

Sitilias caroliniana (Walt.)Raf. New Fl. N. A. 4 : 85.

False Dandelion.

Leontodon carolinianum Walt. Fl. Car. 192. 1788.

Scorzonera pinnatifida Michx. Fl. Bor. Am. 2: 89. 1803.

Barkhousia caroliniana Nutt. Gen. 2 : 126.1818.

Pyrrhopappus carolinianus DC. Prodr. $7: 144$. 1838.

Ell. Sk. 2 :251. Gray, Man. ed. 6, 303. Chap. Fl.252. Gray, Syn. Fl. N. A. 1, pt.

$2: 441$. Conlter, Contr. Nat. Herb. $2: 249$.

Carolinian and Louisianian areas. Maryland to Florida, west to Texas.

Alabama : Tennessee Valley to the Coastplain. Lightdamp soil, grassy banks. Lee County, Auburn (Baker \& Earle). Morgan County, Decatur. Cullman, Tuscaloosa, Clarke, and Mobile counties. Flowers pale vellow; April to June. Common. Perennial.

Type locality: Sonth Carolina.

Herb. Geol. Surv. Herb. Mohr.

LACTUCA L. Sp. Pl. 2 : 795.1753.

Abont 90 species, temperate regions, Europe, Asia, Africa. Atlantic North America (endemic), 9.

Lactuca canadensis L. Sp. Pl. 2 : 796. 1753.

WiLd LetTUCE.

Lactuca elongata Muhl.; Willd. Sp. Pl. 3 : 1525. 1804.

Ell. Sk. 2:252. Gray, Man. ed.6, 304. Chap. Fl. ed. 3, 274. Gray, Syn. Fl. N. A. 1, pt. $2: 442$.

Alleghenian to Louisianian area. Ontario to Saskatchewan, New England west to Minnesota and Nebraska, south to Arkansas, and from southern New England to Georgia.

Alabaya: 'Tennessee Valley to Central Pine belt. Borders of fields and copses. Lawrence and Tuscaloosa counties. Lee Connty, Auburn (Baker \& Earle, 268). Flowers yellow; August, September. Not frequent. Anuual.

Type locality: "Hab. in Canada. Kalm."

Herb. Geol. Surv. Herb. Mohr.

Lactuca sagittifolia Ell. Sk. 2 : 253. 1821-24.

DeVIL'S InoNWEEL.

Lactuca integrifolia Bigel. Fl. Bost. ed. 2, 287. 1824. Not Nutt.

Ell. Sk.1. e. Gray, Man. ed. 6, 304. Chap. Fl. 252; ed. 3, 274. Gray, Syn. Fl. N. A. 1, pt. $2: 442$.

Alleghenian to Louisianian area. New England west to Michigan, south to the Uhio Valley, Missouri, and along the coast from New York to Florida.

Alabama: Over the State. Low rich lands. Damp banks. Clay County, ShinboneValley, 1,000 feet. Cullman County, 800 feet. Tuscaloosa County. Mobile County, margin of river swamps. Flowers yellow. Not common. Six to 8 feet high. Biennial or perennial. S. C.

Type locality: "Along the margin of a creek, in the neighborhood of Columbia," Herb. Geol. Surv. Herb. Mohr.

Lactuca graminifolia Michx. Fl. Bor. Am. 2 : 85. 1803.

NaRrow-Leak Wild LetTtice.

Lactuca elongata var. graminifolia Chap. Fl.252. 1860.

Ell. Sk. 2:253. Chap. Fl.1. e.; ed.3, 274. Gray, Syn. Fl. N. A. 1, pt. 2:442. Coulter, Contr. Nat. Herl. $2: 249$.

Carolinian and Louisianian areas. South Carolina to Florida, west to Texas.

Alabama: Mountain region. Lower Pine region. Coast plain. Dry or damp places, borders of woods, copses. Lee County, Auburn (Baker \& Earle, 269). Mobile County. Flowers sordid white or straw yellow. Two to 3 feet high. Frequent in the Coast plain. Annual.

Type locality : "Hab. in Carolina inferiore."

Herb. Geol. Surv. Herb. Molır.

Lactuca hirsuta Muhl. Cat. 69. 1813.

REDDISH-FLOWERED LETTUCE.

Lactuca sanguinea Bigel. Fl. Bost. ed. 2, 287. 1824.

L. elongata var. sanguinea Torr. \& Gray, Fl. N. A. 2:496. 1843. 
Gray, Man. ed. 6, 304. Gray, Syn. Fl. N. A. 1, pt. 2:442. Conlter, Contr. Nat. Herb. $2: 249$.

Carolinian area. Southeastern Massachusetts, northwestern Virginia, Ohio to Missouri, sonth along the monntains to Georgia.

Alabama: Mountain region. Dry exposed places. Madison County, Montesano, 1,500 feet. Culluan County, in barren old ticlds, clearings. Flowers purplish; not uncommon. Biennial.

Type locality: "Pens."

Herb. Geol. Surv. Herb. Mohr.

Lactuca floridana (L.) Gaert. Frnet. 2 : 362. 1791.

BLUE-Flowered Fall Wild LetTuce.

Sunchus floridanus L. Sp. PI. 2 : 794. 1753.

Mulgedium floridanum DC. Prodr. 7 : 249. 1838.

Carolinian and Louisianian areas. Penusylvania to Florida and Texas, west to Ohio, Missouri, and Arkansas.

Ell. Sk. 2 :255. Gray, Man. ed. 6, 304. Chap. Fl.253. Gray, Syn. Fl. N. A. 1, pt. $2: 443$. Conlter, Contr. Nat. Herb. $2: 250$.

Alabana: All over the State. Rich damp banks, borders of ditches and thickets. Madison County, near iluntsville. Mobile County. Flowers deep blue; May, June.

Frequent. Annual or biennial.

Type locality: "Hab. in Virvinia, Canada."

Herb. Geol. Surv. Herb. Mohr.

Lactuca villosa Jacq. Hort. Schoen. 3 : 62, t. 36\% 1798.

Acuminate-leaf Wild Lettuce.

Sonchus acuminatus Willd. Sp. Pl. 3 : 152.1804.

Mulgedium acuminatum DC. Prodr. 7:250. 1838.

Lactuca acuminata Gray, Proc. Am. Acad. 19: 73. 1883.

Ell. Sk. 2:255. Gray, Man. ed. 6, 304. Chap. Fl. 252. Gray, Syn. Fl. N. A. 1, pt.

$2: 443$.

Carolinian and Louisianian areas. Southern New England, west to Ohio and Missouri, south from New Jersey to Florida and Lonisiana.

Alabana: Upper division Coast Pine belt. Thickets, shady copses. Clarke Connty, Suggsville (Dr. Denny). Flowers blue; August. Rare. Annual or biennial. Type locality not ascertained.

Herb. Geol. Surv. Herb. Mohr.

NABALUS Cass. Dict. $34: 94.1826$.

(Prenanthes L. Sp. Pl. 2 : 797. 1753. In part.)

Abont 20 species, perennial herbs, North America. Eastern North America, 9.

Nabalus serpentaria (Pursh) Hook. Fl. Bor. Am. 1:294. 1833.

Prenanthes serpentaria Pursh, Fl. Am. Sept. 2 : 499, t. 24. 1814.

Nabalus fraseri DC. Prodr. 7:241. 1838.

Ell. Sk. 2:261. Gray, Man. ed.6,301. Chap. Fl.251. Gray, Syn. Fl. N. A. 1, pt. $2: 434$.

Canadian zone to Louisianian area. Newfoundland,.Quebec, and Ontario; New York and Ohio, south from Tennessee to Florida.

Alabama : Mountain region to Coast plain. Dry open woods in light soil. Calhoun County, Anniston. Cullman County. Tuscaloosa County (E. A. Smith). Washington, Clarke, and Mobile counties. Flowers white; July, August. Most frequent in the pine barrens.

Economic uses: One of the reputed remedies for snake bites.

Type locality: "On the mountains of Virginia and Carolina."

llerb. Geol. Surv. Herb. Mohr.

$\mathbf{N}$ abalus serpentaria barbatus ('Torr. \& Gray).

Nabalus fraseri var. barbatus Torr. \& Gray, Fl. N. A. 2 : 481. 1843.

Prenanthes crepidinea Ell. Sk. 2 :259. 1821-24. Not Michx.

P. serpentaria barhata Gray, Syn. Fl. N. A. 1, pt. 2:434. 1884.

Ell. Sk.1. c. Chap. Fl. 251. Gray, Syn. Fl. N. A.1. e.

Alleghenian and Carolinian areas. Mountainous North Carolina to Georgia up to 6,000 feet altitude.

Alabama: Mountain region. Cullman County, 1,000 feet. Northern Alabama (Buckley).

Type locality of Prenanthes crepidinea Ell.: "Grows in the mountains of Carolina." Herb. Geol. Surv. Herb. Mohr. 
Nabalus altissimus (L.) Hook. Fl. Bor. Am. 1:294. 1834. 'TALL Whrte LetTuce. Prenanthes altissıma L. Sp. Pl. 2 : 797.1753.

P. deltoidea Ell. Sk. 2:257. 1824.

Eil. Sk. l. c. Gray, Man. ed.6,302. Chap. Fl. 251. Gray, Syn. Fl. N. A. 1, pt.2: 434. Canadian to Carolinian area. Newfouudland, Ontario, and New England; Ohio

Valley to Missouri and Arkansas, and from New York south along the mountains to Georgia.

AlabaMa: Mountain regiou. Lower hills. Rich woodlands. Cleburne Connty

(Dr.L.A.Smith). 'Tuscaloosa County, August, September.

Type locality: "Hab. in Virginia, Canada."

Herb. Geol. Surv. Herb. Mohr.

SONCHUS L. Sp. Pl. 2 : 793. 1753.

Forty-five species, temperate Europe. Annual weeds diffused in North America, 4.

Sonchus asper (L.) All. Fl. Pedem. 1:222. 1785.

PRICKLY SOW-THISTLE.

Sonchus oleraceus var. asper L. Sp. Pl. 2 : 794.1753.

S. carolinianus Walt. Fl. Car. 192. 1788.

S. spinulosus Bigel. Fl. Bost. ed. 2, 290. 1824.

Ell. Sk. 2:255. Gray, Man. ed.6,305. Chap. Fl.253. Coulter, Contr. Nat. Herb.

$2: 250$.

Canadian zone to Lonisianian area. Over the continent from Canada to Florida and British Columbia to California.

Alabama: Over the State. Common weed in cultivated and waste ground.

Flowers March to June. Annual.

Type locality: "Hab. in Europae cultis."

Herb. Geol. Surv. Herb. Mohr.

Sonchus oleraceus L. Sp. Pl. 2 : 794 . 1753.

Common Sow-THIStLe.

Ell. Sk. 2 : 254. Gray, Man. ed.6, 305. Chap. Fl. 253. Coulter, Contr. Nat. Herb. $2: 250$.

Distribution as in the last.

Alabama: With the above. February to July. Annual.

'Type-Iocality: "Hab. in Europae cultis."

Herb.Geol. Surv. Herb. Mohr.

Sonchus tenerrimus L. Sp. PI. 2 : 794. 1753.

SOUTHERN EUROpE.

Adventive on ballast in South Carolina and sonthern California.

Alabana: Mobile County, fugitive on ballast. Rare. Annual.

Type locality: "Hab. in Monspelii, Florentiae."

Herb. Geol. Surv. Herb. Mohr.

\section{AMBROSIACEAE. Ragweed Family.}

IVA L. Sp. Pl. $2: 988$. 1753.

About 12 species, North American. Atlantic, 5.

Iva ciliata Willd. Sp. Pl. $3: 2386$. 1804.

Annual Marsh Elder.

Iva annua Michx. Fl. Bor. Am. $2: 184.1803$. Not L.

Gray, Man. ed.6, 272. Gray, Syn. Fl. N. A. 1, pt. 2:246. Coulter, Contr. Nat. Herb. $2: 208$.

Alleghenian to Louisianian area. Illinois west to Nebraska, southern Arkansas, north western Louisiana, Texas, and New Mexico.

Ala bama : Coast plain. Mobile County. In cultivated fields. Adventive with grain seed from the West. Flowers in July. The form with elongated floral bracts. Ânuual.

Type locality: "Hab. in Anerica boreali."

Herb. Mohr.

Iva imbricata Walt. Fl. Car. 232. 1788.

Ell. Sk. 2:475. Chap. Fl. 222. Gray, Syn. Fl. N. A. 1, pt. $2: 246$.

Louisianian area. North Carolina to Florida and Mississippi.

Alabama: Littoral region. Damp sandy beach. Mobile County, West Fowl River. Flowers greenish yellow. In fiequent. A shrubby evergreen with succulent leaves. Perennial. Shrubby at the base.

Type locality: South Carolina.

Herb. Geol. Surv. Herb. Mohr. 
Ell. Sk. 2:474. Gray, Man. ed. 6, 272. Chap. Fl. 222. Gray, Syn. Fl. N. A. 1, pt. 2:247. Conlter, Contr. Nat. Herb. $2: 208$.

Carolinian to Louisianian area. Coast of Massachusetts to Florida, west to Texas.

AlabAMA: Coast plain. Submaritime and Littoral region. Muddy brackish shores and marshes near the sea beach. Mobile County, estuary of the Mobile River; West Fowl River; Dauphin Island. Baldwin County, Point Clear. Shrub 5 to 6 feet high.

'Type locality : "Hab. in Virginia, Peru."

Herb. Geol. Surv. Herb. Mohr.

AMBROSIA L.Sp. P1. $2: 987.1753$.

Twenty-five species, Mediterranean region of the Old World, Sandwich Islands, temperate warmer America. North America, 8. Atlantic, 4.

Ambrosia trifida L. Sp. Pl. 2 :987. 1753.

Tall Ragweed.

E11. Sk. 2:476. Gray, Man. ed.6, 273. Chap. Fl.223. Gray, Sýn. Fl. N. A. 1, pt. 2:

249. Coulter, Contr. Nat. Herb. $2: 209$.

Cuba, Mexico.

Alleghenian to Louisianian area. Quebec and Ontario to Manitoba; New England west to Minnesota, south to the Gulf; from Florida west to 'Texas, Arkansas, and Colorado.

Alabama: Throughout the State. In rich damp soil, alluvial banks, borders of low fields. Abundant in the rich valley lands and the black lands of the prairie region. July to September. Annual.

Type locality: "Hab. in Virginia, Canada."

Herb. Geol. Surv. Herl. Mohr.

Ambrosia artemisiaefolia L. Sp. P1. 2: 988. 1753.

HogWeED. BitTerWeed.

Ell. Sk. 2:477. Gray, Man.ed. 6, 273. Chap. Fl. 223. Gray, Syn. Fl. N. A. 1, pt. 2:

249. Coulter, Contr. Nat. Herb. $2: 210$.

Cuba, Mexico, Brazil.

Alleghenian to Louisianian area. Nova Scotia to Saskatchewan and the Pacific coast. All over the Eastern United States, west to Arkansas and Texas.

AlabaMA: Over the State. Dry cultivated ground; the commonest of weerls.

July to September. Annual.

Type locality: "Hab. in Virginia, Pensylvania."

Herb. Geol. Surv. Herb. Mohr.

Ambrosia psilostachya DC. Prodr. 5:526. 1836.

Prairie Ragweed.

Gray, Man. ed.6, 273. Gray, Syn. Fl. N. A.1, pt. 2:250. Coulter, Contr. Nat. Herb. $2: 210$.

Alleghenıan to Carolinian area. Illinois west to Saskatchewan.

Alabama: Adventive from Texas with wool. Autanga Connty, Prattville. Perenuial.

'Type locality : "In Mexico inter San-Fernando et Matamoros legit cl. Berlandier." Herb. Geol. Surv. Herb. Mohr.

XANTHIUM L.Sp.P1. 2:987. 1753.

Abont 5 species, temperate and warmer regions of the Old and New World. North America, endemic, 1; native, 3.

Xanthium strumarium L. Sp. P1. 2 :987. 1753.

Cocklebur. Burween.

Ell. Sk. 2 : 479, in part. Gray, Man. ed. 6, 274. Chap. Fl.224; ed.3, 245. Gray, Syu. Fl. N. A. 1, pt. 2:521. Conlter, Contr. Nat. Herb. $2: 210$.

Europe, Asia.

Alleghenian to Louisianian area. Naturalized thronghout the eastern United States to Nebraska and Texas.

Alabava: Over the State, about dwellings and in cultivated and waste places. Tuscaloosa and Mobile connties. Apparently not abundant.

Type locality: "Hab. in Enropa, Canada, Virginia, Jamaica, Zeylona, Japonia."

Xanthiurn canadense Mill. Dict. ed. 8, no. 2. 1768.

CоскLевUR.

Xanthinm echinatum Murr. Comm. Goett. 6:32, t.4. 1783.

Ell. Sk. 2:479. (\&) Gray, Man. edl. 6, 274. Chap. Fl. 224. Gray, Syn. Fl. N. A. 1, pt.

$2: 252 . \quad$ Coulter, Contr. Nat. Herb. $2: 211$. 
Alleghenian to Lonisianian area. Canada and Northwest 'Territory ; New England west to Nebraska; sonth to the Gulf from Floricla to 'Texas; west to California.

Alabama: Over the State. Cultivated and waste ground. July to October; common everywhere. Most abundant in rich bottom lands and prairies. Annual.

'Type locality: "Grows naturally in North America."

Herb. Geol. Surv. Herb. Mohr.

Xanthium spinosum L. Sp. Pl. 2 :987. 1753.

Ell. Sk. 2:479. Gray, Man. ed. 6, 274. Chap. Fl.224. Gray, Syn. Fl. N. A. 1, pt. 2:

253. Coulter, Contr. Nat. Herb. $2: 210$.

Tropical America, Europe.

Carolinian and Lonisianian areas. Naturalized in the greater river valleys and along railroads from the enast of sontheru Massachusetts to the District of Colnmbia, Ohio, and Missonri, and from Floridce to Texas.

Alabama : Over the State. Waste places, waysides, Tennessee Valley. Morgan County, Decatur. Montgomery and Mobile counties. August to October. Annual. Type locality: "Hab. in Lusitania."

Herb. Geol. Surv. Herb. Mohr.

\section{CARDUACEAE. Thistle Family.}

VERNONIA Schreb. Gen. PI. $2: 541.1791$.

Four hundred and fifty to 500 species, perennials. Africa, Asia; about one-half in warmer America. North America, 12. Atlantic, 11.

Vernonia gigantea (Walt.) Britton; Kearney, Bull.'Torr.Club,20:485. 1893. In part.

Chry8ocoma gigantea Walt. Fl. Car. 196. 1788.

InONWEED.

Vermonia altis8ima Nutt. Gen. 2:134. 1818.

Ell. Sk. 2:289. Gray, Man. ed. 6, 238. Chap. Fl. 188. Gray, Syn. Fl. N. A. 1, pt. 2: 90, in part. Coulter, Contr. Nat. Herb. 2: 175.

Carolinian and Louisianiau areus. Pennsylvania, Illinois, Missouri, and Arkansas; south from West Virginia to T'ennessee and Florida; west to Lonisiana and 'Texas.

Alabama : Mountain region to Coast plain. Low borders of fields, openings, pas. tures. Clay County, Elders, 1,060 feet; Moseley, on hottom lands of 'Talladera Creek. Mobile County, Angnst, September. A common weed; the form with larger heads and the leaves tomentose-pubescent beneath (V.praealtu Michx.) prevailing in the low country, 4 to 6 feet bigh.

Type locality: soutlı ('arolina.

Herb. Geol. Surv. Herb. Mohr.

Vernonia maxima Suall, Bull. Torr. Club, 27:280. 1900.

Erect, 3 to 9 feet high, briuching above; leaves narrowly elliptical to lanceolate, acuminate, narrowed into a short petiole, subsessile, 4 to 7 inches long, sharply serrate, glabrous or slightly pubescent; involucre hemispheric, rounded at the base, about $\frac{3}{16}$ inch high, the ovate, acnte or more or less mucronate, ciliate bracts appressed. Heretofore confounded with the closely related $r$. gigantea, which differs from it in the longer involncre narrowed at the base, with the bracts more or less spreading.

Caroliuian and Louisianian areas. Western Virginia, Kentncky, Ohio, Missouri, western Florida (Mohr of Chapman), Mississippi.

Alabama: Mountain region. Dry copses, borclers of woods. C'nllman County, Octolier, 1896. Not frequent. ana.'

Typo loeality: "In low ground, Ohio to Missomri, sonth to Alabana and Jonisi-

Vernonia fasciculata Michx. Fl. Bor. Am. 2:94. 1803.

Fasciculate-Flow ERed VeirNoNia.

Gray, Mau. ed. 6, 238. Gray, Syn. Fl. N. A. 1, pt. 2: 90. Coulter, Contr. Nat. Herb. $2: 175$.

Alleghenian and Carolinian areas. Michigan west to Minuesota, Dakota, and Nebraska; southem Ohio Valley, Missouri, and Arkansas; south along the mountains from 'Tennessee to upper (ieorgia.

Alabama: Mountain region. Shally thickets, woods. Lee County, Anburu (Baker \& Earle, 187). Calhoun (ounty, Auniston mountainons woods, 1,000 leet. altitude. Talladega Connty, near Renfroe, 1,000 foet altitude. Clay Connty, bottom of Talladega Creek. Elders, Delta, 1,000 10 1,700 feet altitude. Flowers pale 
purplish, pappus whitish; Angust. Fourtor feet high. Common thronghout the Coosa hills.

Type locality: "Hab. in pratis Illinoensibus."

Herb. Geol. Surv. Herb. Mohr.

Vernonia graminifolia (Walt.)

NARROW-LEAF VERNONIA.

Chrysocoma graminifolia Walt. Fl. Car. 196. 1788.

Vernonia angustifolia Michx. Fl. Bor. Am. 2 : 94. 1803.

V. scaberrima Nutt. Gen. 2 : 134. 1818.

Ell. Sk. $2: 286,287$. Chap. Fl. 188. Gray, Syn. Fl. N. A. 1, pt. 2: 90. Coulter, Contr.

Nat. Herb. $2: 175$.

Louisianian area. North Carolina to Florida, west to Texas and Arkansas.

Alabama: Central Pine belt to Coast plain. Dry pine forests. Autanga County (E. A. Smith). Monroe, Washington, Escambia, Baldwin, and Mobile counties. Flowers solferino-purple; Angust, September. Frequent throughout the pine belts. Two to 3 feet high.

Type locality : South Carolina.

Herb. Geol. Surv. Herb. Mohr.

STOKESIA I'Her. Sert. Angl. 27, t. 3S. 1788.

One species, South Atlantic North America.

Stokesia laevis (Hill) Greene, Erythea, 1:3. 1893. Azulk-Flowerkd Stokesia. Carthamus laevis Hill, Hort. Kew. 57. 1768.

Stokesia cyanea L'Her. Sert. Angl. 27, t. 38. 1788.

Cartesia centauroides Cass. Bull. Soc. Philom. 1816: 198. 1816.

Chap. Fl. 188. Gray, Syn. Fl. N. A. 1, pt. 2:88.

Louisianian area. South Carolina to Florida and eastern Louisiana.

Alabama: Lower Pine region. Moist copses. Washington County. Mobile County, Bayou Sara. Flowers cernlean; May, June. Not infrequent. Perennial; $1 \frac{1}{2}$ to 2 feet high.

Type locality not ascertained.

Herb. Geol. Surv. Herb. Mohr.

ELEPHANTOPUS L. Sp. Pl. $2: 814.1753$.

About 14 species, perennials of subtropical and tropical regions. West Indies to Brazil. North America, 3.

Elephantopus carolinianus Willd. Sp. Pl. 3 : 2390. 1804.

Elephantopus scaber Walt. Fl. Car. 217. 1788. Not L.

Carolina klephiant's-Foot.

Ell. Sk. 2:480. Gray, Man. ed. 6, 237. Chap. Fl. 188. Gray, Syn. Fl. N. A. 1, pt.

$2: 88$. Coulter, Contr. Nat. Herb. $2: 175$.

Carolinian and Louisianian areas. Pennsylvania, Ohio Valley to Missouri, Kansas, Arkansas, sonth to Florida, and the Gulf States to Texas.

Alabana: Over the State, except the higher mountain ranges. Open dry woods, borders of fields, pastures. Clay Connty, banks of 'Talladega Creek, 1,000 feet, Ironaton. Calhoun County, Anniston. Cullmau County. Mobile County. Flowers rose purple, July to September. Common.

Type locality: "Hab. in Carolina, Florida, Jamaica."

Herb. Geol. Surv. Herb. Mohr.

Elephantopus tomentosus L. Sp. Pl. 2 : 814. 1753.

HOARY Elephant's-FoOT.

Gray, Man. ell.6, 237. Chap. Fl.189. Gray, Syn. Fl. N. A. 1, pt. 2:88.

Carolinian and Louisianian areas. Virginia to Florida and Louisiana.

Alabama : Lower hills to Coast plain. Dry and open woods. Tuscaloosa County

( $\boldsymbol{E}$. A. Smith). Mobile County. Flowers September. Frequent.

Type locality : "Hab. in Virginia."

Herb. Geol. Surv. Herb. Mohr.

Elephantopus nudatus Gray, Proc. Am. Acad.15:47. 1880.

Gray, Syn. Fl. N. A. 2, pt. 2:88. 1884.

BARE-STEMMED ELEPHANT'S-FOOT.

Curolinian and Lonisianian areas. Delaware to Georgia, western Louisiana, and Arkansas.

AlabaMa: Metamorphic hills. Low woods. Lee County, Auburn (C. F. Baker), October, 1896.

Type locality : " 'Oxford, Delaware, and thence common southward,' Canbv; near Snow Hill, Maryland, Bebb."

Herb. Geol. Surv. Herb. Mohr. 


\section{SCLEROLEPIS Cass. Bull. Soc. Philom. 1816:198. 1816.}

Single species, Eastern North America.

Sclerolepis uniflora (Walt.) Porter, Mem. Torr. Clnb, 5 :311. 1894.

Ethulia uniflora Walt. Fl. Car. 195. 1788.

ONE-FLOWERE1) SCLEROLEPIS.

Sparganophorus verticillatus Michx. Fl. Bor. Am. 2 : 98. 1803.

Sclerolepis verticillata Cass. Dict. 48 : 155. 1827.

Gray, Man. ed. 6, 238. Chap. Fl. 190. Gray, Syn. Fl. N. A. 1, pt. $2: 92$.

Carolinian and Lonisianian areas. New Jersey to Florida.

Alabama: Central Prairie region. Coast plain. Wet places. Wilcox County (S. B. Buckley). Baldwin County, Point Clear. Flowers sky-blne; May. Rare. Perennial.

Type locality : South Carolina.

Herb. Geol. Surv. Herb. Mohr.

AGERATUM L. Sp. Pl. ed. 2, 2:1175. 1763.

Abont 30 species, tropical regions, mostly American. North America, 3.

Ageratum conyzoides I.Sp. Pl. ed. 2, 2:1175. 1763.

Mexican Ageratum.

Ageratum mexicanum Sims, Bot. Mag. 52 : $t$.2524. 1787.

Chap. Fl. 189. Gray, Syn. Fl. N. A, 1, pt. 2 :93. Griseb. Fl. Brit. W. Ind. 356.

Cuba to Brazil, Pacific Islands, East Indies, Tropical Africa.

Lonisianian area. Coast of Georgia to Florida. Naturalized.

Arabana: Coast plain. Escaped from cultivation. Waste and cultivated places near dwellings. Mobile Connty. Flowers lilac; July to October. Becoming a troublesome weed in the gardens. Annual.

Type locality: "Hab. in America."

Herb. Geol. Surv. Herb. Mohr.

\section{EUPATORIUM I. Sp. Pl. 2:836. 1753. ThOkOUGHWORT.}

Four hundred and seventy-five species, perennial herbs, rarely shrubby, temperate to tropical regions, chiefly tropical America, United States, Argentiua, Asia, Europe. North America, 45 or 50; Atlantic, 26; Western Continental, 14 ; Pacific, 1.

Eupatorium capillifolium (Lam.) Small, Bull. Torr. Club, 5 : 311.1894.

Artemisia capillifolia Lam. Encycl. 1:267. 1783.

Eupatorium foeniculoides Walt. Fl. Car. 199.1788.

E. foeniculaceum Willd. Sp. Pl. 3:1750. 1804.

Ell. Sk. 2 : 294. Gray, Man. ed. 6, 239. Chap. Fl. 196. Gray, Syn. Fl. 1, pt. 2 : 97.

Cuba.

Carolinian and Louisianian area. Delaware to Florida and Louisiana.

Ala bama : Mountain region to the Coast. Low fields, pastures, open woods. Cullman County, 600 feet aititule. Clay County, Ironaton, 800 feet altitude. Chambers County and southward. Flowers white; October, November. When bruised, it emits the odor of fennel. Most abundant in the damp Coast plain.

Type locality: "On la croit originaire des Indes orientales \& de la Chine." (Mistaken.)

Herb. Geol. Surv. Herb. Mohr.

Eupatorium leptophyllum DC. Prodr. 5 : 176.1836.

Stem $2 \frac{1}{2}$ to $3 \frac{1}{2}$ feet high, smoothish, round, erect, paniculately branched; leaves undivided, linear, smooth; racemes spiciform, elongated, somewhat secundly. branched, the terminal branches and branchlets paniculately disposed; flowerin: heads 3 to 5 flowered on short perlicels, involncral scales lanceolate with a narow white margin. "Habitus inflorescentiae Solidaginis, caeterum F. foeniculaceo affine." DC. 1.c.)

Lonisianian area. Sonth Georgia, Florida to Mississippi.

Alabama : Lower Pine region. Coast plain. Dry open pine varrens, old sandy fields with E. compositifolium. Mobile County, Springhill. October, November. Frequent.

In habit of growth near $E$. capillifolium; distingnisherl at once by the simple entire smoothish leaves.

'Type locality: "In Georgia circa Savanuah a cl. Herbemont lecta."

Herb. Geol. Surv. Herb. Mohr. 


\section{LITARY
ONIVERS ERITY}

C of 


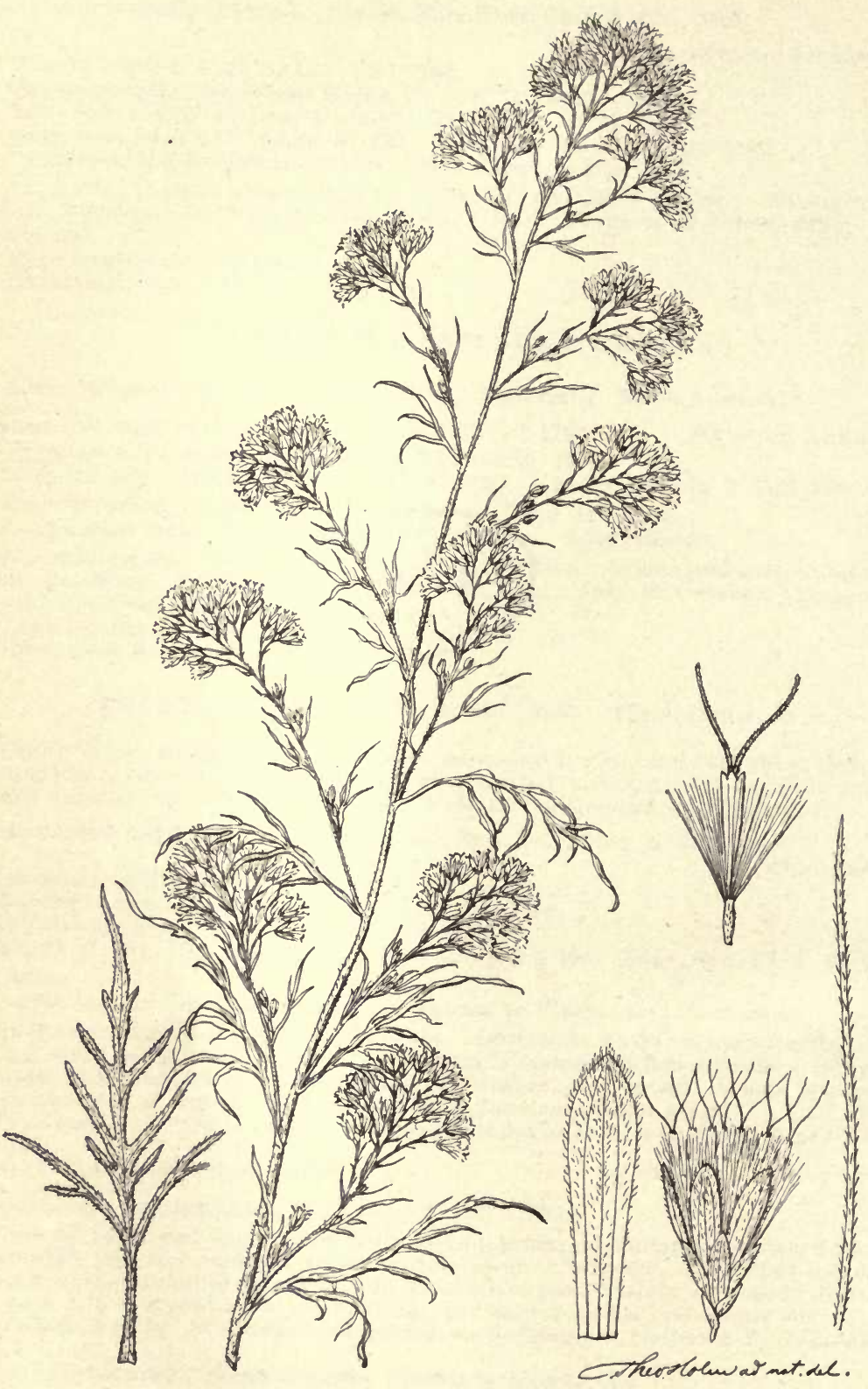

Eupatorium smithil Greene \& Mohr. 
Eupatorium compositifolium Walt. Fl. Car. 199. 1788.

Eupatorium coronopifolium Willd. Sp. Pl. 3 : 1750. 1804.

Crysocoma coronopifolia Michx. Fl. Bor. Am. 2:102. 1803.

Ell. Sk. 2:294. Chap. Fl. 196. Gray, Syn. Fl. N. A. 1, pt. $2: 97$. Coulter, Contr.

Nat. Herb. $2: 178$.

Carolinian and Louisianian areas.

Alabama: Mountain region to Coast plain. Arid sandy soil. Open copses, pastures, old fields, borders of woods. Clay County, Ironaton, 800 feet altitude. Chambers and Dallas counties, ete., to Mobile County. Flowers white; October, Novemher.

Most abundant in the Coast Pine belt, covering old fields, pastures, ete. Type locality: South Caroliua.

Herb. Geol. Surv. Herb. Mohr.

\section{Eupatorium smithii Greene \& Mohr.}

Stem 3 to 5 feet high, slender, puberulent, terete; basal and lower leaves unknown, upper cauline with long linear or lanceolate rachis and a few linear segments, or the floral wholly linear and with or without a few short lobes or teeth; inflorescence an elongated compound thyrsus a foot long or more; heads about 2 lines long; 5 to 8 flowered, involucre bracts oblong, obtuse, not mucronate, scarions-margined, inclistinctly 3-nerved; style branches long and filiform; pappus scabrous.

A fourth member of the small group as heretofore known consisting only of $E$. compositifolium, E. capillifolium, and L. leptophyllum. All of the latter have narrow panicles of racemed heads, while in $E$. smithii these are glomerate on short lateral branches, and formed as a whole into a long narrow thyrsus.

Plate X.

Carolinian area.

Alabama: Mountain region. Metamorphic hills. Chambers Connty. Flowers in September. Rare and local.

Type locality: The only known specimen is from Chambers County, where it was collecterl in September, 1874, by Dr. F. A. Smith.

Herb. Geol. Surv. Herb. Mohr.

Eupatorium pinnatifidum Ell. Sk. 2 : 295. 1821-24.

PinNatifin Eupatorium.

Chap. Fl. 195. Gray, Syn. Fl. N. A. 1, pt. $2: 97$.

Louisianian area. North Carolina to Florida.

Arabama: Mountain region, Metamorphic hills. Central prairies. Damp borders of thickets. Lee County, Auburn (F. S. Earle). Chambers County (E. A. Smith). Dallas County, Mount Pleasant (E. A.Smith). Flowers Septenber; infrequent and local.

Type locality : "Grows in damp soils in the middle districts of Carolina."

Herb. Geol. Sinrv. Herb. Mohr.

Eupatorium purpureum L. Sp. Pl. 2 :838. 1753.

Trumpht-Weni). PUrPli Boneset.

Eupatorium trifoliatum L. Sp. Pl. 2:837. 1753.

E. ternifolium Ell. Sk. 2 :306. 1824.

Ell. Sk. l. c. Gray, Man. ed. 6, 239, in part. Chap. Fl. erl. 3, 213, in part. Gray, Syn. Fl. N. A. 1, pt. 2:94. Coulter, Contr. Nat. Herb. $2: 177$.

Alleghenian to Lonisianian area. New Brunswick to Manituba; New Lngland west to Dakota and Nebraska, south and east from Colorado to Texas and Florida.

Ala Bama: Throughout. Low thickets and shaded banks. Flowers pale purple.

August. Most frequent in the monntains.

Type locality: "Hab. in America septentrionali."

Herb. Geol. Surv. Herb. Mohr.

Eupatorium maculatum I. Amoen. Acad. 4 :288. 1755.

SPOTTED Trumpet-WeEd. QUeFe of The MFalow.

Eupatorium purpureum var. maculatum Darl. Fl. Cestr. 453.

Ell. Sk. 2:308. Gray, Syn. Fl. 1, pt. 2:96. Conlter, Contr. Nat. Herl,. $2: 177$.

Britt. \& Br. Ill. Fl. $3: 307$.

Alleghenian to Louisianian area. Distribution as in the last.

Alabama: 'Throughout. Common in the lower districts. Flowers pink to winepurple. Four to 6 feet high.

Type locality: "Hab. in America septentrionali."

Herb. Geol. Surv. Herb. Mohr.

Eupatorium amoenum Pursh, Fl. Am. Sept. 2 :514. 1814. I_ow Trumpet-Wenn.

Eupatorium purpureum amoenum Gray, Syn. Fl. 2, pt. 1:96. 1884.

E. maculatum amoenum Britton, Mem. Torr. Club, 5:312. 1894.

Gray, Man. ed. 6, 239. Chap. Fl. ed. 3, 213. Britt. \& Br. Ill. Fl. 3, 307.

Carolinian area. New York and North Carolina, New Jersey, sonth to Virginia, and aloug the mountains to Georgia. 
Alabama: Mountain region. Rich woods and shadod banks. Clay County, banks of Talladega Creek. Dekalb County, Mentoue, flanks of Lookont Monntain, altitude 1,600 feet. Flowers pale pink to bright rose-red. August, September. Infrequent. Rarely over 2 feet high.

Differences in habit of growth and distribution and in the permanency of its listinctive characters, observed in specimens from widely distant localities, render this plant sufficiently clistinct to be restored to the rank of valid species.

Type locality: "On the New Jersey mountains."

Herb. Geol. Surv. Herb. Mohr.

Eupatorium album L. Mant. 1:111. 1767.

WHite-FLOWERED EUPATORIUM.

Eupatorium glandulosum Michx. Fl. Bor. Am. 2 : 98. 1803.

Ell. Sk. 2 : 298. Gray, Man. ed. 6, 239. Chap. Fl. 195. Gray, Syn. Fl. N. A. 1, pt. $2: 98$.

Carolinian and Louisianian areas. New York, Long Island; Nortlı Carolina, eastern Tennessee, and Florida, west to Arkansas.

Alabama: Mountain region to Coast plain. Dry siliceous soil. Open woods. Flowers white; July to October. 'Ten to 12 inches high. Common throughont the Metamorphie monntains to 2,400 feet altitude. Che-aw-ha Mountain, and all over the pine-barren ridges.

Type locality: "Hab. in Pensylvania. Barthram."

Herb. Geol. Surv. Herb. Mohr.

\section{Eupatorium mohrii Greene.}

Stems slender, solitary, erect, 1 to 2 feet high, from a thick somewhat tuberiform ascending, or almost horizontal, root or rootstock, the whole herbage scabrous-pubescent and impressed-punctate; leaves opposite, sessile, narrowly lanceolate, nore or less remotely serrate-toothed, or the uppermost entire, 1 to 2 inches long; eyınose corymb broad, loose and open, more or less obviously dichotomous; bracts of the involucre few and obloug-linear, obtuse, hardly at all scarious-margined, pubescent and resinous-dotted; pappus subplumose.

Louisianian area.

Plate XI.

Alabama : Lower Pine region aud Coast plain. Damp open pine woods. Mobile County, flat pine barrens, 1878; Springhill, 1880 (Rev. A. B. Langlois).

Type locality as just given.

Herb. Geol. Surv. Herb. Mohr.

Eupatorium serotinum Michx. Fl. Bor. Am. 2: 100. 1803.

Ell. Sk. 2 :305. Gray, Man. ed. 6, 239. Chap. Fl. 196. Gray, Syu. Fl. N. A. 1, pt. 2:97. Coulter, Contr. Nat. Herb. $2: 178$.

Mexico.

Ohio Valley to Missouri, Kansas, Arkansas, south to Florida and throngh the Gulf States to Texas.

Alabama: Tennessee Valley. Central Prairie region to Coast plain. Low rich borders of woods and thickets. Lauderdale County. Jackson County, Stevenson (E. A. Smith). Montgomery County. Mobile County, borders of swamps. Flowers white; October, November. Three to 5 feet high. Not common.

'lype locality: "Hab. in scirpetis Carolinae maritimis."

Herb. Geol. Surv. Herb. Mohr.

Eupatorium lecheaefolium Greene, Pittonia, 3: 177. 1897.

Eupatorium hys8opifolium angustissimum Mohr, Bull. Torr. Club, 24: 27. 1897. Not E. angustissimum Spreng.

Erect $1 \frac{1}{2}$ to 2 feet high, stems fow from a few elongated fibrous roots, parted low and at the summit into many slender corymbose branches, all adpressı.d, puberulent; leaves glabrate, strongly punctate, all narrowly linear, the canline about $1 \frac{1}{2}$ inches long, spreading, bearing in their axils fuscicles of short, sterile, slender, very leafy branchlets; heads very many and small in an amplecompound somewhat flat-topped cyme; the 4 or 5 main bracts of the involucre oblong-linear, acutish, glandular; achenes small, strongly glandular.

Ala bama : Upper division of Coast Pine belt. Dale County (E. A. Smith). Angust, 1880.

Type locality: "Northern Florida, Sept., 1895, Geo. V. Nash."

Herb. Geol. Surv. Herb. Mohr.

Eupatorium hyssopifolium L. Sp. Pl. 2 : 836. 1753.

Eupatorium torreyanum Short, 2d Suppl. Cat. Pl. Ky. 5. 1836.

E. hys8opifolium laciniatum Gray, Syn. Fl. 1, pt. 2:98. 1884. In part.

Gray, 1. c. Chap. Fl. ed. 3, 213, in part.

Carolinian and Lonisianian areas. Pennsylvania, Kentucky, Tennessee, and North Carolina to Florida and 'Texas. 


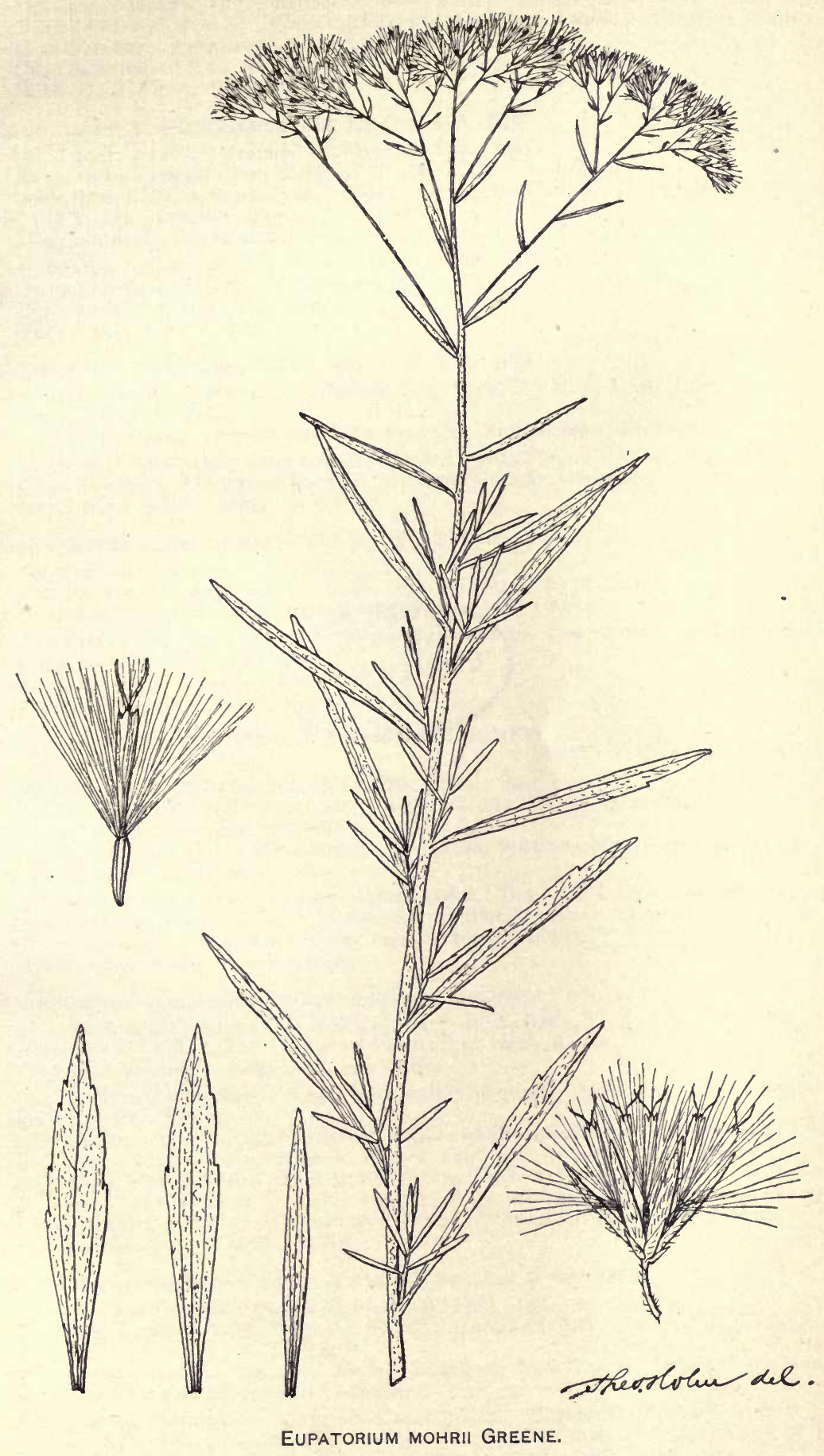


() 
Alabama: Metamorphic hills to Coast plain. Damp sterile soil. Lee County, Auburn (Baker \& larle). Washington and Mobile counties. Flowers white; August to ()etoler. Frequent.

Type locality: "Hab. in Virginia."

Herb. Geol. Surv. Herb. Mohr.

Eupatorium linearifolium Walt. Fl. Car. 199. 1788.

DC. Prodr. 5 :177. Greene, Pittonia, 3:180. 1897.

Eupatorium hyssopifolium L. Sp. P1 2:836. 1753. In part.

Gray, S. n. Fl. N. A. 2, pt. 1:98, in part. Gray, Man. ed. 6, 241, in part. Britt. \& Br.

IIl. Fl. $3: 309$. Coulter, Contr. Nat. Herb. $2: 178$, in part.

Alleghenian to Louisianian area. Massachusetts to Florida and T'exas.

Ala bava: Metamorphic hills. Danı light soil, pastures, etc. Lee Connty, Anburn (Baker \& Earle). Mobile Connty, with the last. Frequent.

Type locality: Sonth Carolina.

Herb. Geol. Surv. Herb. Mohr.

Eupatorium tortifolium Chap. Bot. Gaz. 3:5. 1878

Eupatorium hyssopifolium tortifolium Gray, Syn. Fl. N. A. 1, pt. 2:98. 1884.

Chap. Fl. ed. $3,214$.

Louisianian area. Sonth Carolina, Georgia, and western Florida.

Alabama : Dry sandy pine ridges. Dale County, near Ozark; July, 1880.

'Type locality : "Dry pine barreus, Decatur County, Georgia."

Herb. Geol. Surv. Horb. Mohr.

Eupatorium cuneifolium Willd. Sp. Pl. 3:1753. 1804.

Eupatorium glaucescens Ell. Sk. 2 :297. 1821-24.

Ell. Sk. l. c. Chap. Fl. 194. Gray, Syn. Fl. N. A. 2, pt. $2: 98$

Louisianian area. South Carolina, Georgia, and Florida.

Alabama: Mountain region. Metamorphic hills. Leo County, Auburn. Flowers white; October (F. S. Earle).

'Type locality : "Hab. in Carolina."

Herb. Geol. Surv. Herb. Mohr.

Eupatorium semiserratum DC. Prodr, 5:177. 1836

SMALL-FLOWERED EUPATORIUM.

Eupatorium parviflorum Ell. Sk. $2: 299$. 1824. Not Swart\%.

Ell. 1. c. Gray, Man. edl. 6, 240. Chap. Fl. 194. Gray, Syn. Fl. N. A. 1, pt. $2: 98$.

Conlter, Contr. Nat. Herl. $2: 178$.

Carolinian and Louisianian areas. Virginia, sonthern Tennessee to Florida, west to T'exas and Arkansas.

Alabama : Lower Pine region. Coast plain. Dry and damp sandy grounds, roadsides, pastures, etc. Flowers white; September, October. Common.

Type locality: "Collecterl in St. Thomas by Caradenx."

Herb. Geol. Surv. Herb. Mohr.

Eupatorium semiserratum lancifolium Gray, Syn. Fl. N. A. 1, pt. 2:98.

Eupatorium parviflorum var. lancifolium Torr. \& Gray, Fl. N. A. 2:85. 1842.

Gray, Syu. Fl. N.A.1. c. Coulter, Contr. Nat. Herlı. 2:178.

Louisianian area. Louisiana and Texas.

Alabama : Coast plain. Low, open sandy ground. Mobile County. September; not frequent. Local.

.Indged by the strikingly different aspect of the specimens from western Louisiana (Hale), one would not hesitate to regard this rarivty as a distinct species. Specimens from Mobile differ from the Western form only by the finer and more close puhescence of the stem. Closely connected by intergrading forms with the type.

Typo locality: "W. Lonisiana and Texas, Irummond, Leavenworth, Hale."

Herb. Geol. Surv. Herb. Mohr.

Eupatorium verbenaefolium Michx. Fl. Bor. Am. 2:98. 1803.

Eupatorium teucrifolium Willd. Sp. Pl. 3:1753. 1805.

Ell. Sk. 2:301. Gray, Man. ed. 6, 240. Chap. Fl. 195 Gray, Syn. Fl. N. A. 1, pt. $2: 99$.

Carolinian and Louisianian areas. Sonthern New England, New York, and New Jersey to Florida and eastern Luvisiana.

Alabama: Mountain region to Coast plain. Exposed or shady damp places. Clay County, shady banks of 'Tulladega Creek. Cullman Connty, banks of Eightmilo Creek. Clarke County. Mobile County, flat, damp pine barrens. Flowers september, October; frequent in the flat pine barrens of the Coast plain. 
This variable species comprises two forms which are closely connected by intermediate forms and difficult to separate, although the extreme forms from the mountain region appear quite distinct by the petiolate, broader, less acnminate, and more coarsely serrate leaves. From the material examined in the National Herbarium this form appears to prevail in the Northern States. Specimens from the coast pine barrens agree exactly with the descrintion of Michanx, having the stem divided above into long, slender, few-leaved fastigiate branches bearing a rather close corymb, and the acuminate Jeaves with the truncate base sessile. May provo a good variety.

Type locality: "Hab.in hnmidis Carolinae."

Herb. Geol. Surv. Herb. Mohr.

Eupatorium rotundifolium L. Sp. Pl. 2 : 837 . 1753.

False HoarHoUND.

Fll. Sk. 2:300. Gray, Man. ed.6,240. Chap. Fl. 195. Gray, Syn. Fl. N. A. 1, pt.2: 99. Coulter, Contr. Nat. Herb. $2: 178$.

Carolinian and Louisianian areas. New Jersey to Florida, west to Texas; Ohio Valley to Missouri and Arkansas.

Alabama: Over the State. Open dry ground. Clay County, Shinbone Valley, Elders, 1,000 feet. Cullman County, 800 feet altitude. Mobile Connty. Flowers white; August, September.

Type locality: "Hab. in Virginia, Canarla."

Herb. Geol. Surv. Herb. Molir.

Eupatorium pubescens Muhl.; Willd.Sp. Pl. 3:1755. 1804.

Eupatorium rotundifolium var, oratum Torr.; DC. Prodr. 5:178. 1836.

E. rotundifolium var. pubescens B. S. P. Prel. Cat. N. Y. 25. 1888.

Ell. Sk. 2:301. Gray, Man. ed.6, 240; Syn. Fl. N. A. 1, pt.2:99.

Carolinian and Louisianian areas. Southeastern New England to sonthern Virginia and Florida, west to Mississippi.

Afabama: Mountain region to Coast plain. Open damp places. Lee County, Auburn (Baker \& Earle). Mobile County. Flowers white; August. Frequent.

Type locality: "Hab.in America boreali."

Herb. Geol. Snrv. Herb. Mohr.

Eupatorium sessilifolium L. Sp. Pl. 2 : 837. 1753.

UPLANI BONESET:

Eupatorium truncatum Ell. Sk. 2:298. 1821-24. Not Muhl.

Gray, Man. ed. 6, 240. Chap. Fl. 195. (irly, Syn. Fl. N. A. 1, pt. 2 : 99.

Alleghenian and Carolinian areas. New England, northwestern Now York?, northeastern Ohio, Michigan, Missonri, sonth from Virginia along the mountains to South Carolina.

Alabama: Mountain region. Dry open woods; table-lands of Warrior Basin. Dekalb County, Sand Mountain, 1,500 feet. Flowers white; Angust, September. Rare.

'Type locality: "Hab. in Virginia."

Herb. Geol. Surv. Herb. Mohr.

Eupatorium perfoliatum L. Sp. Pl. 2 : 838. 1753.

BONESET. THOROYGHWORT.

Ell. Sk. 2:302. Gray, Man. ed.6, 241. Chap. Fl. 196. Gray, Syn. Fl. N. A. 1, pt. $2: 99$. Alleghenian to Louisianian area. Nova Scotia, Now Brunswick, Ontario: Now England, west to Minnesota, Nobraska, and Dakota, south to Arkansas; and from the Ohio Valley to Florida, and west to Louisiana.

Alabama : Over the State. Damp shady banks; thickets. Clay County, Elders, 1,000 feet altitude, to Mobile; borrers of river swamps. Flowers white; July to Soptember. Frequent.

Economic uses: The herb is the boneset or Eupatorium of the Uniterl States Pha-macopoia.

Type locality : "Hab. in Virginiae ayuosis."

Herb. Geol. Surv. Herb. Mohr.

Eupatorium incarnatum Walt. Fl. Car. 200. 1788.

Difeuse Eupatorium.

Ell. Sk. 2:305. Chap. Fl. 196. Gray, Syn. Fl. N. A. 1, pt. 2:101. Coulter, Contr. Nat. Herb. $2: 179$.

Louisianian area. North Carolina to Florida, west to western Ionisiana and Texas.

Alabama: Lower hills. Damp thickets. Tusculoosil County. Flowers azure. July; 2 to 3 feet high; weak, reclining local. Only locality observed. June, 188:3 (C. Mohr).

$$
\text { Type locality: South Carolina. }
$$

Herb. Geol. Surv. Herb. Mohr. 
Eupatorium ageratoides (L.) L. f. Suppl. 355. 1781.

White SANICLE.

Ageratum altissimum I. Sp. PJ. ed. 2, 2 :1176. 1763.

Ell. Sk. 2:303. Gray, Man. ed. 6, 241. Chap. Fl. 196; ed. 3, 216. Coulter, Contr. Nat. Herb. $2: 179$.

Alleghenian and Carolinian areas. Canada to New England, south to 'Tennessee, and along the mountains to Georgia.

Alabama : Lower hills. Shaded ravines. Tuscaloosa County. Flowers white; Oetober. Sole locality in the State. Our plant differs from the type in its slender and simple habit of growth. Stem solitary, simple; leaves ovate; acmininate; petioles slender. Resembles Eupatorium frasieri described in Poir. Suppl. Lam. Encycl. 2:600; Planch. t. 672, fig. 4.

Type locality: "Hab. in Canada, Virginia."

Herb. Geol. Surv. Herb. Mohr.

Eupatorium ageratoides angustatum Gray, Syn. Fl. N. A. 1, pt. 2:101.

Gray, Syn. Fl. l. c. Coulter, Contr. Nat. Herb. $2: 179$.

Carolinian and Louisianian areas. Texas and Louisiana.

Alaliana: Teunessee Valley. Landerdale County; shaded banks; Tennessee River (M. C. Wilson). July, 1894. Flowers white. Local and rare.

Type locality: "W. Louisiana, Hale. Texas, Wright, Lindheimer."

Herb. Geol. Surv. Herb. Mohr.

Eupatorium aromaticum L. Sp. Pl. 2 : 839. 1753.

WILD HOARHOUND.

Eupatorium ceanothifolium Muhl.; Willd. Sp. Pl. 3 : 1755. 1804.

Ell. Sk. 2: 304. Gray, Man. ed. 6, 241. Gray, Syn. Fl. N. A. 1, pt. 2:101. Chap.

Fl.196.

Carolinian and Louisianian areas. Southeastern Massachusetts to Florida, west to Mississippi, southwestern Missouri.

Alabama : Mountain region to Coast plain. Dry open pine woods. Clay County, Hollins, 1,000 feet altitude. Talladega County, near Reufroe, 1,000 feet altitude. Etowah County, Gadsden. Chilton County, Verbena. Clarke, IVashington, and Mobile counties. Flowers white; September, October. Common in the pine barrens. Bruised, of an unpleasant odor.

Type locality: "Hab. in Virginia."

Herb. Geol. Surv. Herb. Mohr.

Eupatorium coelestinum L. Sp. P]. 2 : 838. 1753.

MIST , LOWER.

Conoclinum coelestinum DC. Prodr. 5 : 135.1836.

Ell. Sk. $2: 306$. Gray, Man. ed. 6, 241. Chap. Fl. 197. Gray, Syn. Fl. N. A. 1, pt.

$2: 102$. Coulter, Contr. Nat. Herb. $2: 179$.

\section{Cura.}

Carolinian and Louisianian areas. New Jersey, Virginia, Ohio Valley to sonthern Missouri and Arkansas, south to Florida and the Gulf States to 'Texas.

Alabama: Coast Pine belt. Damp thickets, borders of ditches. Escambia, Washington and Mobile counties. Flowers cerulean blue; Augnst to October. Particularly abundant in the Coast plain. A common weed in cultivated and waste places, aud on roadsides.

Type locality: "Hab. in Carolina, Virginia."

Herb. Geol. Surv. Herb. Mohr.

WILLUGHBAEYA Neck. Elem. 1:82. 1792.

(MIKANIA Willd.Sp.Pl. 3 : 1742. 1804.)

About 150 species, mostly elimbing perenuial herbs or shrubs, tropical America, chietly Brazilian.

Willughbaeya scandens (L.) Kuntze, Rev. Gen. Pl. 1:371. 1891. Climbing Boneset. Eupatorium scandens L. Sp. Pl. 2:836. 1753.

Mikania scandens Willd. Sp. Pl. 3:1743. 1804.

Ell. Sk. 2:292. Gray, Man. ed. 6, 239. Chap. Fl. 197. Gray, Syn. Fl. N. A. 1, pt. 2:94. Coulter, Contr. Nat. Herb. $2: 176$.

Carolinian area. Coast of southern Massachusetts to Florida, and west to Texas.

Alabama: Mountain region to Coast plain. Low damp thickets. Clay County, banks of 'Talladega Creek, 1,000 feet altitude. Cullman County, 800 feet altitude. Mobile County. Flowers pale purple; August, November. Most abundant in the Lower Pine region aud Coast plain. Herbaceous climber.

Type locality: "Hab. in aquosis Virginiae."

Herb. Geol. Surv. Herb. Mohr. 
KUHNIA L. Sp. Pl. erl. 2, $2: 1662 . \quad: 763$.

Four species, perennial herbs. Mexico and Arizona, 1; Atlantic United States, 3.

Kuhnia eupatorioides L. Sp. Pl. ed. 2, 2 : 1662. 1763.

FAlse BONESET.

Eupatorium alternifolium Ard. Sp. Bot. 2:40. 1764.

Gray, Man. ed. 6, 241. Chap. Fl. 193, iu part. Gray, Syu. Fl. 1, pt.2:103. Coulter, Contr. Nat. Herb. $2: 180$.

Carolinian area. New Jersey to Georgia, west to West Virginia, Ohio, Missouri, and 'Jexis.

Alabama: Mountain region. Metamorphic hills. Dry open woods. Lee County, Auburn; September, October (Baker of Earle).

Type locality: "Hab. in Pensylvania, unde vivan attulit Adam Kuhn."

Herb. Geol. Surv. Herb. Mohr.

Kuhnia glutinosa Ell. Sk. $2: 292$. 1821-24.

Praikie False Boneset.

Kuhnia suaveolens Fresen. Enum. Sem. Hort. Francof. 1838.

K. eupatorioides var. corymbulosa Torr. \& Gray, Fl. N. A. 2:78. 1841.

Gray, Man. ed. 6, 241. Gray, Syn. Fl. 1, pt. 2:103. Coulter, Contr. Nat. Herb. 2 : 180. Alleghenian to Louisianian area. Kentucky ( $\mathrm{Dr}$. Short) to Illinois, Missouri, Minnesota, and South Dakota, and south to Texas.

Alabana: Central Prairie region. Dry open places. Montgomery. September. Not frequent.

Type locality: "Grows in the prairies of the Alabama."

Herb. Geol. Surv. Herb. Mohr.

Kuhnia kuhnia (Gaert.) Mohr, 3ull. Torr. Club, 24:28. 1897.

Critonia kuhnia Gaert. Fruct. 2 : 411. 1791.

SOUTHERN FALSE BONeset.

Kuhnia critonia Willd. Sp. Pl. $3: 1773.1804$.

K. paniculata Cass. Dict. 24 : 516. 1821.

K. eupatorioides var. gracilis 'Torr. \& Gray, Fl. N. A. 2 : 78. 1841.

Ell. Sk. 2:291. Gray, Syn. kl. 1, pt. 2:103.

Louisianian area. Carolina to Florida, west to Mississippi.

Alabama: Lower Pine region. Dry pine barrens. Mobile County, Springhill. September, October. Frequent.

'Type locality not given. Of Kuhnia critonia: "Hab. in Pensylvania, Virginia." Herb. Geol. Surv. Herb. Mohr.

COLEOSANTHUS Cass. Bull. Soc. Philo. 1817:67. 1817.

(BRICKELLIA Ell. Sk. 2 :290. 1821-24.)

About 40 species. Perennial herbs and undershrubs, chiefly of Mexico and the arljacent parts of the United States. North America, 30. Eastern United States, 1.

Coleosanthus cordifolius (Ell.) Kuntze, Rev. Gen. Pl. 1:328. 1891.

Brickellia cordifolia Ell. Sk. 2 :290. 1821-24.

Heart-leaf Brickellia.

Chap. Fl. 193. Gray, Syu. Fl. N. A. 1, pt. 2:105.

Lousianian area. Georgianind Florida.

Alabana: Upper division C'oust Pine belt. Hilly woods. Lee County, Auburn (Baker \& Earle). Dale Connty, August 21 (1880) (E. A. Smith). Flowers pale purplish; local. Rare.

Type locality: "Grows on the sides of hills in the western districts of Georgia."

Herb. Geol. Surv. Herb. Mohr.

LACINARIA Hill. Veg. Syst. $4: 49, t .46 .1762$.

(Liatis Schreber, Gen. Pl.542. 1791.)

About 16 species. Perennial herbs. Eastern North America.

Lacinaria elegans (Walt.) Kuutze, Rev. Gen. P1.349. 1891.

Staehelina elegans Walt. 1.1. Car. 202. 1788.

Liatris elegans Willd. Pl. 1635.1804.

Ell. Sk. 2:279. Gray, Man. ed. 6, 242. Chap. Fl.191. Gray, Syn. Fl. N. A. 1, pt. $2: 109$.

Carolinian and Louisianian areas. Southern Virginia to Florida, west to Arkansas and south western Missouri. 
Alabama : Central Pine belt. Coast plain. Dry open woods, pastures. Autauga, Clarke, Monroe, Baldwin, and Mobile counties. Flowers rose-pink; August, September. Frequent. One and one-half to 2 feet high.

Type locality: South Carolina.

Herb. Geol. Surv. Herb. Mohr.

Lacinaria squarrosa (L.) Hill, Veg. Syst. 4:49. 1762.

Blazing STAR.

Serratula squarrosa L. Sp. P1. 2 : 8:8. 1753.

Liatris squarrosa Willd. Sp. Pl. 3 : 1634. 1804.

Ell. Sk. 2:282. Gray, Man. ed. 6, 242. Chap. Fl. 191. Gray, Syu. Fl. N. A. 1, pt.

$2: 109$. Coulter, Contr. Nat. Herb. 2 : 182.

Alleghenian to Louisianiau area. Ohio Valley to Missouri, Minnesota, Nebraska, and Dakota, south to Florida, and through the Gulf States to Texas and Arkansas.

Alabama: Tennessee Valley to Coast plain. Dry sterile soil, woods. Cullman, Chilton, Clarke, and Mobile counties. Flowers wine-purple; August, September.

Rather frequent in the pine barrens.

Type locality: "Hab. in Virginia."

Herb. Geol. Surv. Herb. Molir.

Lacinaria scariosa (L.) Hill, Veg. Syst. 4 : 49. 1762.

Comion Blazing STAR.

Serratula scariosa L. Sp. P1. 2 : 818. 1753.

Liatris scariosa Willd. Sp. Pl. 3:1635. 1804.

Ell. Sk. 2:280. Gray, Man. ed. 6, 242. Chap. Fl. 192. Gray, Syn. Fl. N. A. 1, pt.

2:110. Coulter, Contr. Nat. Herb. $2: 182$.

Alleghenian to Louisianian area. Ontario; New England west to Minnesota and

Nebraska; Ohio Valley to Missonri and Arkansas, south to Florida and T'exas.

Alabama: Tennessee Valley. Coast plain. Dry open woods. Laulerdale County.

Mobile County, Springhill. Flowers deep pink or pale purple: August, September.

Not frequent.

Type locality : "Hab. in Virginia."

Herb. Geol. Surv. Herb. Mohr.

Lacinaria scariosa squarrulosa (Michx.) Small, Mem. Torr. Club, 4:128. 1894.

Liatris 8quarrulosa Michx. Fl. Bor. Am. 2 :92. 1803.

L. heterophylla R. Br. in Ait. Hort. Kew. ed. 2, 4:503. 1813.

Ell. Sk. 2 :281, in part. Gray, Syn. Fl. N. A. 1, pt. 2:110. Coulter, Contr. Nat. Herb.

$2: 182$.

Carolinian area. North Carolina.

Alabama: Mountain region. Wooded rocky hillsides. Tallarlega County, Chandler Springs, on exposed rocks, 1,500 feet altitude. Alpiue Mountain, near Renfroe, 1,000 feet. Flowers purple; September. Not frequent; never seen in the low country. Twelve to 18 inches high.

Type locality not given.

Herb. Geol, Snrv. Herb. Mohr.

Lacinaria spicata (L.) Kuntze, Rev. Gen. Pl. 1:349. 1891.

Serratula spicata L. Sp. P1. 2 : 819. 1753.

SPIKED Button SNaKeroot.

Liatris spicata Willd.Sp. Pl. 3:1636. 1804.

Ell. Sk. $2: 273$. Gray, Man. ed. 6, 243. Chap. Fl. 192. Gray, Syn. Fl. N. A.1, pt. $2: 111$.

Alleghenian to Louisianian area. Ontario and southern New England, west to Michigan and Minnesota, west and south from New York to the Ohio Valley, Missouri, Arkansas, Florida, and Louisiana.

Alabama : Central Pine belt to Coast plain. Shelby County, Calera. ( $/$ hilton, Baldwin, and Mobile counties. Flowers pale rose color. Septeriber, October; frequent. 'T'uree to 4 feet high. Commou in the flat, damp pine barrens near the coast, the involucral bracts here frequently covered with a resinous exudation (Liatris resinosa Nutt.).

Type locality : "Hab. in America septentrionali."

Herb. Geol. Surv. Herb. Mohr.

Lacinaria graminifolia (Walt.) Kuntze, Rev. Gen. Pl. 1 : 349. 1891.

Anonymos graminifolius Walt. Fl. Car. 197. 1788.

Liatris graminifolia Pursh, Fl. Am. Sept. 2:508. 1814. Not Willd. 1804.

Ell. Sk. 2 :274. Gray, Man. ed.6, 243. Chap. Fl. 192. Gray, Syn. Fl. N. A. 1, pt.

$2: 111$.

Carolinian area. Virginia, along the coast to the middle and upper country of South Carolina and Grorgia. 
Ala bama: Monutain region. Summits of the higher ridges on bare rocks. Calhoun County, highest ridges near Anniston. Tallarlega County, Chandler Springs, 1,200 to 1,500 feet. Alpine Mountain Signal Station, 1,800 feet. Clay County, rocky banks Talladega Creek, 1,000 feet; near Pulpit Rock, 2,200 feet altitude. Cullman County, 800 feet. Flowers pale rose; September. One to $1 \frac{1}{2}$ feet high; not rare. In tufts from the confluent irregularly shaped rootstocks. Not observed outside of the mountainous region.

Type locality: South Carolina.

Herb. Geol. Surv. Herb. Mohr.

Lacinaria graminifolia pilosa (Ait.) Britton, Mem. 'Torr. Club, $5: 314.1894$.

Serratula pilosa Ait. Hort. Kew. 3 : 138. 1789.

Liatris graminifolia var. dubia Grav. Man. ed. 2, 185. 1856.

Gray, Man. ed. 6, 243. Gray, Syn. Fla. N. A. 1, pt. 2:111.

Carolinian to Louisianian area. Coast of New Jersey to Florida and Mississippi.

Alabama: Central Pine belt to Coast plain. Damp gravelly or sandy soil. Antanga County, near Prattville. Chilton County, Verbeua. Mobile County. Flowers, September, October; frequent. One and one-half to $3 \frac{1}{2}$ feet high. Common in the low pine barrens of the coast, where it is iound from 2 to $3 \frac{1}{3}$ feet high. Glabrous, with larger heads and inflorescence often panieled.

Type locality: "Native of North America."

Lacinaria tenuifolia (Nutt.) Kuntze, Rev. Gen. Pl. 1:349. 1891.

SleNder-Leaved Blazing Stak.

Lacinaria tenuifolia Nutt. Gen. Pl. 2:131. 1818.

Ell. Sk. 2:275. Chap. Fl. 191. Gray, Syn. Fl. N. A. 1, pt. 2:112. 1884.

Carolinian area. Carolina to Georgia.

Alabama: Mountain region. Dry woods. Walker County (E.A.Smith). Flowers August; local and rare.

Type locality : "In the sandy forests of North and South Carolina."

Herb. Geol. Surv. Herb. Mohr.

Zacinaria gracilis Pursh, Fl. Am. Sept. 2:508. 1814.

Slender Blazing Stak.

Liatris pauciflosculosa Nutt. Journ. Acad. Phila. 7:71. 1834. Chap. Fl.191. Gray, Syn. Fl. N. A. i, pt. 2:111.

Louisianian area. Georgia and Florida to Louisiana.

Alabama: Lower Pine region. Dry sandy pine barreus. Baldwin and Mobile counties. Flowers purple; September, October. Frequent. One and one-half to 3 feet high. Frequently more or less panicled.

Economic uses: Highly ornamental.

Type locality: "In Georgia. Bartram."

Herb. Geol. Surv. Herb. Mohr.

TRILISA Cass. Bull. Soc. Philom. 1818:140. 1818.

'T'wo species, perennials; South Atlantic North America.

Trilisa odoratissima (Walt.) Cass. Bull. Soc. Philom. 1818:140. 1818.

Vanilla Plant. Sweet-scented Deertongue.

Anonymos odoratissima Walt. Fl. Car. 198. 1788.

Liatris odoratissima Michx. Fl. Bor. Am. 2:93. 1803.

Ell. Sk. 2:283. Gray, Man. ed.'6, 243. Chap. Fl. 192. Gray, Syn. Fl. N. A. 1, pt. 2: 113 .

Carolinian and Louisianian areas. Southern Virginia, along the coast to Florida and eastern Lonisiana.

Alabama : Coast Pine belt and Coast plain. Clark, Butler, Choctaw, Monroe, Washington, Baldwin, and Mobile counties. Flowers Angust, October. Abundant in the flat pine barrens of the coast plain.

Type locality : South Carolina.

Herb. Geol. Surv. Herb. Mohr.

CARPHEPHORUS Cass. Bull. Soc. Philom. 1816:198. 1816.

Three species, perennials, southeastern North Ameriea.

Carphephorus pseudo-liatris Cass. Bull. Soc. Philom. 1816: 198. 1816.

Louisianian area. Florida to Mississippi. 
Alabava : Coast plain. Damp pine barrens. Mobile County, Dog River. Flowers purple red; September, October. Not rare. Purennial.

Type locality not given. "Ce genre ** * a pour type une plante de l'Herbier de M. de Jussieu."

Herb. Geol. Surv. Herb. Mohr.

AMPHIACHYRIS Nutt. Trans. Phil. Soc. $7: 313.1841$.

Two species, perennial herbs. North America, Western.

Amphiachyris dracunculoides(DC.) Nutt. Trans. Am. Phil. Soc. n. ser. 7:313. 1841. Brachyris dracunculoides DC. Mém. Soc. Phys. Genèr. 7, pt. 2: 265, t. 1. 1836.

Gray, Man. ed. 6, 244. Gray, Syn. Fl. N. A. 1, pt. 2:116. Conlter, Contr. Nat. Herb. $2: 184$.

Carolinian area. Kansas to Texas.

Alabama: Tennessee Valley. Open grassy places. Colbert County (E. A. Smith). Flowers yellow. Local and rare.

Type locality (DC. Prodr.): "In territorio Arkansano semina legit cl. de Pourtalès. Herb. Mohr.

GRINDELIA Willd. Gesell. Nat. Fr. Berl. Mag. 1:260. 1807.

'Twenty-five species, perennial herbs or undershrubs, Mexico, South America. North America, chiefly Western, 12.

Grindelia lanceolata Nutt. Journ. Acad. Phil. 7 : 73. 1834.

Lance-leaf Grindelia or Gum Plant.

Gray, Man. ed. 6, 244. Chap. Fl. Siıpl.627; ed.3, 237. Gray, Syn. Fl. N. A. 1, pt. 2:

118. Coulter, Contr. Nat. Herb. $2: 184$.

Carolinian and Lonisianian areas. Texas, Louisiana, Arkansas, Mississippi, and Tennessee.

Alabama : Lower hills. Jefferson County, Jonesboro. Flowers yellow; August. Local and rare.

Type locality: "In Arkansas. T. Nuttall and Dr. Pitcher."

Herb. Geol. Surv. Herb. Mohr.

HeterotheCA Cass. Bull. Soc. Philom. 1817:137. 1817.

Five or six species, perennial herbs, Mexico. Atlantic North America, 2.

Heterotheca subaxillaris (Lam.) Britton \& Rusby, Trans. N. Y. Acad. Sci. 7: 10. 1087.

Inula subaxillaris Lam. Encyel. 3:259. 1789.

I. scabra Pursh, Fl. Am. Sept. 2: 532. 1814.

Heterotheca lamarkii Cass. Dict. Sci. Nat. 21:131. 1821.

Chrysopsis scabra Nutt. Gen. 2:151. 1818.

Heterotheca scabra Torr. \& Gray, Fl. 2 : 251. 1841.

Ell. Sk. $2: 339 . \quad$ Gray, Man. ed. 6, 244. Chap. Fl. 215. Gray, Syn. Fl. N. A. 1, pt.

$2: 120$. Coulter, Contr. Nat. Herb. $2: 184$.

Nolithery Mexico.

Coast of North Carolina to Florida, west to Texas, southern Arizona, Arkansas, and southeastern Kansas.

Alabana : Coast plain. Submaritime and Littoral region. Drifting sands. Baldwin Comty, eastern shore Mobile Bay. Mobile County, Dauphin Island. Flowers golden yellow; August to October. Common.

Type locality: "Cette Inule croit dans la Caroline, le Maryland, * * *."

Herb. Geol. Surv. Herb. Mohr.

CHRYSOPSIS Nutt. Gen. Pl. $2: 150$. 1818. Golden Aster.

About 20 species, perennials. Flowers yellow. Atlantic North America, 11.

Chrysopsis graminifolia (Michx.) Nutt. Gen. Pl. 2 : 151. 1818.

Inula graminifolia Michx. Fl. Bor. Am. 2:122. 1803.

Silver-leaf Golden Aster.

Ell. Sk. 2:334. Gray, Man. ed. 6, 244. Chap. Fl. 216. Gray, Syn. Fl. N. A. 1, pt. 2: 121. Coulter, Contr. Nat. Herb. 2: 185.

Mexico.

Carolinian and Lonisianian areas. Delaware, Virginia to Florida, west to Arkansas. 
Alabama: Mountain region to Coast plain. Sandy soil, open woods, eopses, old

fields. Flowers August to October. Common; abundant in the dry pine barrens. Includes $C$. argentea Nutt.

Type locality : "Hab. a Carolina ad Floridam, frequens."

Herb. Geol. Surv. Herb. Mohr.

Chrysopsis oligantha Chap. Fl. 216. 1860. LARGE-FLowere1 GOLDEN Aster. C'hrysopsis graminifolia Gray, Syn. Fl. N. A.1, pt.2:121. 1878. In part. Not Nutt. Chap. Fl. ed. 3, 236.

Lonisianian area. Florida.

Alabama: Coast plain. Low damp pine barrens. Baldwin County, near Josephine; wet borders of Wolf Bayou. June. Rare.

At once distinguished from the above by the more robust habit of growth, by its habitat, and by the few naked flowering scapes with the heads nearly twice the size. Type locality: "Low pine barrens, Florida."

Herb. Geol. Surv. Herb. Mohr.

Chrysopsis trichophylla Nutt. Gen. Pl. 2 : 150. 1818. Hoary-Leaf Golden Aster. Ell. Sk. 2 :336. Chap. Fl. 216. Gray, Syn. Fl. N. A. 1, pt. 2:122.

Lonisianian area. North Carolina to Florida and Lonisiana.

Alabama : Lower Pine region. Grassy pine barrens. Escambia County, Wilson Station. Flowers October. Not infrequent.

Type locality: "In North and South Carolina and Georgia."

Herb. Geol. Surv. Herb. Mohr.

Chrysopsis hyssopifolia Nutt. Journ. Acad. Phila. 7 : 67. 1834.

Chap. Fl.216. Gray, Syn. Fl. N. A. 1, pt. 2:122.

HYSSOP-LEAY GOLDEN Aster.

Louisianian area. Western Florida.

Alabama: Coast plain. Submaritime sand hills. Baldwin County, Montrose, on the declivity of the Red Bluff. Rare. Only locality known in the State.

Type locality : "In West Florida, discovered and collected by Mr. Ware."

Herb. Geol. Surv. Herb. Mohr.

Chrysopsis mariana (L. ) Nutt. Gen. Pl.2:151. 1818. Maryland Golinen Aster. Inula mariana L. Sp. Pl. ed. 2, $2: 1240.1763$.

Ell. Sk. 2:335. Gray, Man. ed. 6, 245. Chap. Fl.216. Gray, Syn. Fl. N. A. 1, pt. $2: 122$.

Carolinian and Lonisianian areas. Coast of New York to Florida, west to Louisiana.

Ala bama : Mountain region to Coast plain. Dry sandy soil, open woods. Clay County, Hollins, 1,200 feet. Cullman County, 800 feet altitude. Calhoun County, Auniston. Talladega County, Rentroe, 1,000 feet altitude. Mobile County. August,

October. Common.

Type locality: "Hab. in America septentrionali."

Herb. Mohr.

Chrysopsis pilosa (Walt.) Britton, Mem. Torr. Club, 5 :316. 1894.

HoARy Golden Aster.

Evigeron pilosum Walt. F1. Car. 206. 1788. Not C.pilosa. Nutt.

Inula gossypina Michx. Fl. Bor. Am. 2: 122. 1803.

Chrysopsis gossypina Nutt. Gen. 2:150. 1818.

122.

Ell. Sk. 2:337. Gray, Man. ell.6, 245. Chap. Fl.216. Gray, Syn. Fl. N. A. 1, pt. 2:

Louisianian area. North Carolina, and along the coast to Florida and Louisiana.

Alabama : Lower Pine belt to Coast plain. Dry pine woods. Escambia, Bal 1win, and Mobile counties. October, November. Not infrequent.

Type locality: South Carolina.

Herb. Geol. Surv. Herb. Mohr.

Chrysopsis villosa (Pursh) Nutt. Gen.2:150. 1818.

Westere Golonen Aster.

Amellus villosus Pursh, Fl. Am. Sept. 2: 564. 1814.

Gray, Man. ed. 6, 245. Chap. Fl.217. Gray, Syn. Fl. N. A. 1, pt. 2: 122. Coulter, Contr. Nat. Herb. 2: 185 .

Carolinian to Louisianian area, as to the typical form. Kentncky, Illinois, Arkansas, Texas, and Mississippi.

Alabama: Reported by Chapmau from western Alabama.

Type locality: "On the Missouri."

Herb. Molir. 
ISOPAPPUS Torr. \& Gray, Fl. N. A. 2:239. 1842.

Two species, North Ameriea, Atlantic and Western.

Isopappus divaricatus (Nutt.) 'Torr. \& Gray, Fl. N. A. 2:239. 1842.

Spreading Golden Aster.

Inula (Chrysopsis) divaricata Nutt. Gen. 2 : 152. 1818.

Aplopappus diraricatus Gray, Syn. Fl. N. A. 1, pt. 2: 13̈0. 1884.

Gray, Man. ed.6, 245. Chap. Fi. 215. Gray, Syn. Fl. N. A.l. c. Conlter, Contr. Nat. Herb. 2 : 187.

Carolinian and Louisianian areas. Southern Kansas to central Texas, and Florida to Georgia.

Alabama: Lower hills. Central Prairie region. Dry sandy exposed places, roadsides. Chambers Connty (E. A. Smith). Talladega County, Sylacanga. Montgomery County. Flowers yellow; September, October. Local and frequent.

Type locality: "In the vicinity of Savannah in Georgia, common." Discovered by Dr. Baldwyn.

Herb. Geol. Surv. Herb. Mohr.

CHONDROPHORA Raf. New Fl. N. A. 4:79. 1836.

(BIgklowia DC. Prodr. 5 : 329. 1836. Not Spreng.)

Two species, perennials, eastern North America.

Chondrophora nudata (Michx.) Britton, Mem. Torr. Club, 5 :317. 1894.

Chrysocoma nudata Michx. Fl. Bor. Am. 2 : 101. 1803.

Bigelovia nudata DC. Prodr. 5 :329. 1836.

141.

Ell. Sk. 2:309. Gray, Man. ed.6,246. Chap. Fl.215. Gray, Syn. Fl. N. A. 1, pt. 2:

Carolinian and Louisianian areas. Virginia, along the coast to Florida and eastern Louisiana.

Alabama : Coast plain. Low pine barrens. Mobile and Baldwin counties. Flowers yellow; September, October. Very common.

Type locality: "Hab. in humidis Carolinae."

Herb. Mohr.

Chondrophora virgata (Nutt.) Greene, Erythea, 3: 91. 1895.

Chrysocoma viryata Nutt. Gen. 2:137. 1818.

Bigeloria nudata var. viryata Torr. \& Gray, Fl. N. A. 2 : 232. 1842.

Chondrophora nudata vir/atı Britton, Mem. Torr. Club, 5:317. 1894.

Nearly allied to the above by its inflorescence and the morphological characters of the flowers, but differing widely in its habit of growth, range of distribution, and foliage, and deserving to be recognized as a distinct species. The many-headed rootstock produces numerous stont shoots erowded with the filiform leaves, forming dense tufts. In the Alabama specimens and others from Lonisiana all the leaves are filiform. It is only in a specimen from 'Texas that a tendency can be observed to the development of a wider leaf blade. These linear lanceolate leaves found in young shoots are not over $\frac{1}{16}$ inch wide, acnte, channeled toward the base and without lateral nerves.

On comparison with Nuttall's type in the herbarium of the Academy of Science, Mr. Thomas Meehan finds the Alabama plant identical with Nuttall's specimen, on which the radical leaves are wanting. Nuttall says: "Nearly allied to Chrysocoma nudata, but distinct, and resembles more Solidago tenuifolia, with which it mingles and is easily confounded."

Carolinian (?) and Lonisianian areas. New Jersey (?), western Lonisiana (Hale), Texas, (Riddell).

AIABama: Mountain region. Damp mossy roeks. Dekalb Connty, Lookont Mountain, rocky banks of Little River alove the falls, 1,800 feet. Angust, September.

'Type locality: "On the borders of swamps in New Jersey, near the seacoast."

(Has never been found since in that State.)

Herb. Geol. Surv. Herb. Mohr.

BRINTONIA Greene, Erythea, 3: 89. 1895.

One species. Eastern North America.

Brintonia discoidea Greene, Erythea, 3:89. 1895.

Solidago discoidea Torr. \& Gray, Fl. N. A. 2: 195. 1842.

Aster discoidens Ell. Sk. 2 : 358. 18:1.

Ell. Sk. l. “. Chap. Fl. 208. Gray, Syn. Fl. N. A. 1, pt. 2:144.

Louisianian area. Georgia to Floriıla, west to Louisiana. 
Alabama: Central Pine belt to Coast plain. Rich borders of woods and shady copses. Tuscaloosa County $(\boldsymbol{E}$. A. Smith). Baldwin County, Point Clear. Flowers white, purplish tinged; September, October. Not frequent.

Type locality: "Grows very abundantly in the rich high lands between the Alabama and Chatahouchie rivers."

Herb. Geol. Surv. Herb. Mohr.

SOLIDAGO L. Sp. P1. $2: 878.1753$.

Eighty species, perennial herbs, mostly with bright yellow flowers. Except 3 or 4, all North American; a few Mexican. Atlantic, 42.

Solidago petiolaris Ait. Hort. Kew. 3 :216. 1789.

Bushy Golden-RoD.

Solidago elata Ell. Sk. 2 :389. 1821-24. (?) Not Pursh. 1814.

Ell. Sk. l.e. Gray, Man. ed. 6, 246. Chap. Fl. 210. Gray, Syn. Fl. N. A. 2, pt. $2: 144$.

Carolinian and Louisianian areas. Southern Illinois, southwestern Missouri, and Arkansas, south from North Carolina to Florida, west to Mississippi and Texas.

Alabama: Mountain region. Metamorphic hills. Lower Pine region. Dry grassy woods. Lee County, Auburn. Escambia County, in dry piue barrens. Flowers in October; infrequeut. Two to 3 feet high.

Type locality: "Native of North America."

Herb. Geol. Surv. Herb. Mohr.

Solidago caesia L. Sp. Pl. 2: 879. 1753.

Ell. Sk. 2:385. Gray, Man. ed. 6, 247. Chap. Fl.209. Gray, Syn. Fl. N. A. 1, pt. $2: 145$.

Alleghenian and Carolinian areas. Ontario; New England, west to Minnesota, south to the Ohio Valley, Missouri, Arkansas, and to the Gulf from Florida to Texas.

Alabama: Mountain region. Open damp woods. Clay County, waterfall near Pulpit Rock, 2,200 feet altitnde. Cullman County. Flowers, July, August. Frequent in the mountains.

Type locality: "Hab. in America septentrionali."

Herb. Geol. Surv. Herb. Mohr.

Solidago caesia paniculata Gray, Proc. Am. Acad. 17 :189. 1882.

SOUTHERN BLUE-STEM GOLDEN-ROD.

Solidago gracilis Poir. Encyel. 8:476. 1808. Not Hill, Hort. Kew. 22. 1768.

Gray, Syn. Fl. N. A. 1, pt. $2: 145$.

Carolinian and Louisianian areas. Delaware to Florida, west to Mississippi.

Alabana: Mountains to Coast plain. Open dre woods. Calhoun Connty, Anniston. On dry cherty hills, 800 feet altitude. Talladega County, Renfroe, 800 feet. Tuscaloosa County. Baldwin County, Stockton, at sea level, in dry sandy pine woods. Frequent.

Type locality (Gray, Syn. Fl.): "A form of drier aud open grounds, commoner in S. States."

Herb. Geol. Surv. Herb. Mohr.

Solidago flexicaulis L. Sp. Pl. 2 : 879. 1753.

Solidago latifolia L. Sp. Pl. 2 : 879. 1753.

Gray, Man. ed. 6, 247. Chap. Fl. 208. Gray, Syn. Fl. N. A. 1, pt. 2: 145.

Alleghenian and Carolinian areas. Nova Scotia, New Brunswick, aud Ontario; New England, west to Minnesota; from New York south and west to West Virginia, the Ohio Valley, and Missouri, and along the Allegheny Mountains to Georgia.

Ala Bama : Tennessee Valley to Lower hills in Coosa Valley. Rich hillsides, shaded roeky banks. Lauderdale County, bluff's of the Tennessee River (M. C. Wilson). Talladega County, Alpiue Mountains, 2,000 feet. Calhoun County, Anniston, 700 feet. St. Clair County, Springville, 450 feet altitude. Flowers, September, October.

Not infrequent.

Type locality: "Hab. in Canada."

Herb. Geol. Surv. Herb. Mohr.

Solidago curtisii Torr. \& Gray, Fl. N.A. 2:200. 1841.

CURTIS'S GOLDEN-ROD.

Gray, Man ed. 6, 247. Chap. Fl. 209. Gray, Syn. Fl. N. A. 1, pt. 2:146

Carolinian and Louisianian areas. Virginia, along the mountains to Tennessee and North Carolina.

AlabaMa: Mountain region. Lower hills, hilly woods. Cullman County, Holmes Gap, 1,000 fert. Cullinan County. Flowers, September, October. Local; not frequent. Type locality: "Monntains of North Carolina Mr. Mr. A. Curtis!"

Herb. Geol. Surv. Herb. Mohr. 
Solidago bicolor L. Mant. 1:114. 1767.

WIITE GOLDEN-ROD. SILVER-ROD. Ell. Sk. 2:382. Gray, Man. ed. 6, 247. Chap. Nl. ed. 3,229. Gray, Syn. Fl. N. A. 1, pt. $2: 146$.

Canadian zone to Carolinian area. Nova Scotia, New Brumswick, and Ontario to Saskatcbewan, north to latitude $53^{\circ}$; New England, west to Minnesota, south to Pennsylvania and Ohio, and along the mountains to North Carolina.

Ala Bama: Mountain region. Dry open woods. Talladlega County, Alpine Mountains; Signal station, 2,000 feet. Calhoun Connty, Anniston. Rare.

Type locality : "Hah. in America septentrionali."

Herb. Geol. Surv. Herb. Mohr.

Solidago hispida Muhl.; Willd. Sp. P1. 3 : 2063. 1804.

Solidago hirsuta Nutt. Journ. Acad. Phila. $7: 103.1834$.

Solidago bicolor var. concolor Torr. \& Gray, Fl. N. A. 2 : 197. 1842.

Gray, Man. ed.6, 247. Chap. Fl. ed. 3, 229. Gray, Syn. Fl. N. A. 1, pt. $2: 146$.

Alleghenian and Carolinian areas. Nova Scotia, New Brunswick, Ontario, and

New England to New Jersey and Pennsylvania, west to Missouri, and sonth along the monntains to Georgia.

Alabama: Mountain regiou. On the highest ridges, rockr woods and copses. Dekalb County, rocky summit of Lookout Mountain, 2,000 feet altitude, September, 1898. Jackson County, Pisgah. Not frequent.

Type locality: "Hab. in Pensylvania."

Solidago buckleyi Torr. \& Gray, Fl. N. A.2 : 198. 1842. BuCKLeY'S Golden-Rod. Gray, Syn. Fl. N. A. 2, pt. $2: 147$.

Carolinian and Louisianian areas. Sonthwestern Virginia, North Carolina, and Alabama.

Alabama : Middle Alabarna (Buckley). Station not given.

'Type locality: "Interior of Alabama, Mr. S. B. Buckley!"

Solidago sempervirens L. Sp. Pl. 2 : 878. 1753.

EvERgREen GOLDEN-ROD. Ell. Sk. 2:379. Gray, Man. ed. 6, 248. Chap. Fl.211. Gray, Syn. Fl. N. A. 1, pt. $2: 149$. Bermuda, MEXiCo.

Alleghenian to Louisianian area. Seacoast of Nova Scotia, New Brunswick, sonth along the coast to Florida, west to Lonisian a.

Alabama: Coast plain. Borders of tidal marshes. Mobile Connty. Flowers

August. Not rare.

Type locality: "Hab. in Noveboraco. Canada."

Herb. Mohr.

Solidago stricta Ait. Hort. Kew. 3 :216. 1789.

STraight GOLDEN-Rod.

Solidago virgata Michx. Fl. Bor. Am. 2 : 117. 1803.

Ell. Sk. 2:384. Gray, Man. ed. 6, 248. Chap. Fl. 211. Gray, Syn. Fl. N. A. 1, pt.

$2: 149$. Conlter, Contr. Nat. Herb. 2 : 189.

Carolinian and Louisiauian areas. Southern New Jersey along the coast to Florida and Texas.

Alabama: Coast plain. Damp flat pine barrens. Mobile and Baldwin counties.

October. Common.

Type locality : "Native of North America."

Herb. Geol. Surv. Herb. Mohr.

Solidago angustifolia Ell. Sk. $2: 388$. 1821-24.

NARROW-LEAF GOLDEN-ROD.

Solidago stricta var. angustifolia Gray, Syn. Fl. N. A. 1, pt. 2: 150. 1884.

Ell. 1. c. Chap. Fl.211. Coulter, Contr. Nat. Herb. 2: 189.

Louisianian area. Coast of South Carolina to Florida, west to Texas.

Alabama: Coast plain, submaritime. Low damp pine barrens. Baldwin and Mobile counties. Flowers golden yellow; October. Common on borders of swamps along the shores of Mobile Bay and river estuaries; 3 to 5 feet high.

Type locality: "Grows in rich soils. Found on Parish Island, near Beaufort."

Herb. Geol. Surv. Herb. Mohr.

Solidago puberula pulverulenta (Nutt.) Chap. Fl.210. 1860.

Solidago pulverulenta Nutt. Gen. 2 : 161. 1818.

DUSTY-DOWNY GOLDEN-ROD.

E1l. Sk. 2:384. Chap. Fl.1. c. Gray, Syn. Fl. N. A. 1, pt. 2: 150.

Louisianian area. Georgia to Louisiana.

Alabama: Lower Pine region. Coast plain. Dry sandy pine barrens. Mobile

County. Springhill; September to Novernber. Not rare.

Type locality: "In Georgia and Florida.-Dr. Baldwyn."

Herb. Geol. Surv. Herb. Mohr. 
Solidago odora Ait. Hort. Kew. 3 : 214. 1789.

SWEET-SCENTED GOLDEN-ROD.

Solidago vetrorsa Michx. Fl. Bor. Am. 2 : 117. 1803.

Ell. Sk. 2:376. Gray, Man. ed. 6, 249. Chap. Fl. 213. Gray, Syn. Fl. N. A. 1, pt.

2:150. Conlter, Contr. Nat. Herl. 2 : 189.

Mexico.

Carolinian and Lonisianian areas. Southeastern New England. Rare in the Ohio Valley, south along the coast to Florida, and from Tennessee to the Gulf, west to Texas.

Alabama: From the Mountain region to the Coast plain. Dry sandy or gravelly soil, open woods. Also abundant in dry sandy pine barrens. July, August; conmon. When bruiserl, of a sweet anise-like odlor.

Type locality: "Native of North America."

Herb. Geol. Surv. Herb. Mohr.

Solidago odora inodora Gray, Man. ed.5, 244. 1867.

SCentless Golden-RoD. A form with somewhat broader leaves, less punctate, and odorless when bruised. In Alabama confined to the higher monntain ridges. Clay Connty, Che-aw-ha Mountain, 2,400 feet altitude. Rare.

Type locality not given.

Herb. Mohr.

Solidago fistulosa Mill. Dict. ed.8, no. 19. 1768.

VIILOUS GOLIDN-ROD.

Solidago pilosa Walt. Fl. Car. 207. 1788. Not Mill.

S. pyramidata Pursh, Fl. Am. Sept. 2 :537. 1814.

S. villosa Ell. Sk. 2 : 372. 1821-24.

Ell. Sk. l. c. Gray, Man. ed. 6, 249. Chap. Fl. 213. Gray, Syn. Fl. N. A. 1, pt.

$2: 151$.

Carolinian and Louisianian areas. New Jersey and Virginia, south along the low country to Florida and Lonisiana.

Alabama: Coast plain. Damp borders of ponds and swamps. Baldwin and

Mobile counties. Flowers September to November. Common.

Type locality: "Grows naturally in North America."

Herb. Geol. Surv. Herb. Mohr.

Solidago erecta Pursl, l'l. Am. Sept. 2 :542. 1816.

Erect Golden-Roi).

Solidago speciosa var. anqustata 'Torr. \& Gray, Fl. N. A. $2: 205,1842$.

Ell. Sk. 2:385. Gray, Man. ed. 6, 249. Chap. Fl.210. Gray, Syn. Fl. N. A. 1, pt.

2:152. Coulter, Contr. Nat. Herb. 2:189.

Alleghenian and Carolinian areas. Minnesota to New England; Ohio Valley to

Tennessee and along the mountains to Georgia.

AlabaMa: Mountain region. Madison County, Montesano, 1,200 feet altitude.

Dry open woods. Cullman County, 800 feet altitude. Calhoun Connty, Anniston.

Talladega County, Chandler Springs, rocky ridges, 1,200 feet. September, October.

Not common.

Type locality: "In North Ameriea."

Herb. Geol. Surv. Herb. Mohr.

Solidago patula Muhl.; Willd. Sp. Pl. 3 :2059. 1804. Shagreen-leaf Golden-rod. Gray, Man. ed.6,249. Chap. Fl.211. Gray, Syn. Fl. N. A. 1, pt. 2:152. Coulter, Contr. Nat. Herb. 2 : 189.

Alleghenian and Carolinian areas. Ontario; Ohio to Minnesota, sonth to Tennesseo and Texas.

Alabama: Mountain region. Swampy thickets. Lee County, Auburn (Bater of

Earle). Flowers October; 3 feet high.

Type locality: "Hal,. in Pensylvania."

Herb. Geol. Surv. Herb. Mohr.

Solidago salicina Ell. Sk. 2 :389. 1821.

WILLOW GOL1BEN-ROD.

Solidago patula var. strictula Torr. \& Gray, Fl. N. A. 2 :213. 1842.

Ell. Sk. 1. c. Chap. Fl. 212. Gray, Syn. Fl. N. A. 1, pt. 2:152.

Louisianian area. Georgia to Lonisiana.

Alabama: Mountain region. Metamorphic hills. Coast plain. Damp places. Lee

County, Auburn (F.S. Earle). Mobile County, Bay shell road. September; rare.

'Type locality: "Common in the oak land in the western districts of Georgia."

Herb. Geol. Surv. Herb. Mohr.

Solidago amplexicaulis Torr. \& Gray, Fl. N. A. 2 :218. 1842.

Chap. Fl.213. Gray, Syn. Fl. N. A. 1, pt. 2:153.

Clasping-Leak GOLden-1zod.

Carolinian area. Florida to Louisiana. 
Alabama : Tennessee Valley. Mountain region to Lower hills. Rich shady woods, rocky banks. Lauderdale County, near Florence; bluft's on the 'Tennessee River. Madison County, Montesano, near the spring, 1,500 feet. 'Talladega County, Alpine Mountain, 2,000 feet, shaded rocky banks, copious. Winston County, 1,500 feet altitude. September, October. Not rare. Never seen in the low country.

Trpe locality: "Lonisiana, Dr. Leavenworth! Missonri, Mr. Duerinck? (Also"

Middle Florida, Dr. Chapman!)."

Herb. Geol. Surv. Herb. Mohr.

Solidago rugosa Mill. Dict. ed. 8, no. 25. 1768.

Higi GOLDEN-ROD.

Solidago altissima Ait. Hort. Kew. 3:212. 1789. Not L.

S. villosa Pursh, Fl. Am. Sept. 2 : 537. 1814.

Ell. Sk. 2:372. Gray, Man. ed.6, 249. Chap. Fl. 212. Gray, Syn. Fl. N. A. 1, pt.

2:153. Coulter, Contr. Nat. Herb. $2: 189$

Canadian zone to Louisianian area. Nova Scotia, New Brunswick; Ontario to

Lake Superior; Minnesota south to Floricla and Texas.

Alabama : Over the State. Damp thickets, borders of low fields. September,

October. Common.

Type locality: "Grows naturally in New England."

Herb. Geol. Surv. Herb. Mohr.

Soliđago ulmifolia Muhl.; Willd. Sp. Pl. 3:2060. 18C4. Elar-LeaF GoldeN-Rod. Ell. Sk. 2:373. Pursh, Fl. Am. Sept. 2:538. Gray, Man. ed. 6, 250. Chap. Fl. 212. Gray, Syu. Fl. N. A. 1, pt. $2: 153$. Coulter, Contr. Nat. Herb. 2:189.

Carolinian and Louisianian areas. New England west to Iowa, southern Ohio Valley to Missouri and Arkansas, and along the mountains to Georgia.

Alabama: Mountain region. Central Prairie belt. Rich copses. T'alladega County, Alpine Mountain, 1,800 feet. Dallas County, Marion Junction. September,

October. Not frequent.

Type locality: "Hab. in Pensylvania."

Herb. Geol. Surv. Herb. Mohr.

Solidago neglecta Torr. \& Gray, Fl. N. A. $2: 213.1842$. Gray, Man. ed. 6, 250. Gray, Syn. Fl. N. A. 1, pt. $2: 154$.

Alleghenian and Carolinian areas. Ontario, New Brunswick; Maine to Minnesota,

New York and Ohio to Illinois.

Alabama : Mountain region. Metamorphic hills. Lee County, Auburn (Baker \& Earle), September, 1896. Only locality known in the State.

Type locality: "In swamps, Massachusetts! and New York! to North Carolina! and Indiana!"

Herb. Geol. Surv. Herb. Mohr.

Solidago boottii Hook. Comp. Bot. Mag. 1:97. 1835.

BOOTT'S GOLDEN-ROD.

Gray, Man. ed. 6, 250. Chap. F1.212. Gray, Syn. Fl. N. A. 1, pt. 2:154. Conlter,

Contr. Nat. Herb. 2 : 190.

Carolinian and Louisianian areas. Southwestern Virginia to Georgia and Florida, west to Texas and Arkansas.

Alabama: Mountain region. Coast Pine belt. Coast plain. Dry woods. Lee County, Auburn (Earle). Clarke County (Dr. Denny). Washington, Escambia, and Mobile counties. August to October. Frequent in the pire barrens.

'Type locality: "Louisiana." (Drummond.)

Herb. Mohr.

Solidago yadkinensis (Porter) Small, Bull. Torr. Clrb, 22 :368. 1895.

Solidago boottii yadkinensis Porter, Bull. Torr. Club, 19: 129. 1892.

Slender, glabrous, from a chaffy rootstock; stem $1 \frac{1}{2}$ to 3 feet high ; leaves lanceolate to linear, acute, acuminate; petioles winged, 2 to 4 inches long; the cauline leaves sessile, acute at the apex, with a few distant teeth, involucre campanulate, 25 to 35 flowered; involucral bracts oblong-linear, obtuse, with a dark green midrib; achenes pubescent with few spreading hairs.

Carolinian area. North Carolina and Georgia.

Alabama : Mountain region. Open woods and copses. Jackson County, Pisgah. Type locality: "Collected on the Yadkin River, North Carolina, by Messrs. Small \&. Heller, Aug. 18, 1891."

Herb. Biltmore.

Solidago brachyphylla Chap.; Torr. \& Gray, Fl. N. A. 2 :218. 1842.

SHORT-LEAF GOLDEN-ROD

Solidago boottii var. brachyphylla Gray, Proc. Am. Acad. 17: 195. 1882.

Chap. Fl.213. Gray, Syn. Fl. N. A. 1, pt. 2:154.

Carolinian and Lonisianian areas. Georgia and Florida to Mississippi. 
Alabama: Mountain region to Coast plain. Dry open grassy pine barrens. Lee County, Auburn, 800 feet altitude (Earle). Escambia County, near Wilson's Station. Mobile County, Bay shell road. October; not frequent.

Type locality: "Middle Florida, in fertile soil, Dr. Chapman! Dr. Alexander! Georgia \& Alabama, Baldwin! Le Conte."

Herb. Geol. Surv. Herb. Mohr.

\section{Solidago pallescens Molir, sp. nov.}

Stem from a stout erect rootstock, slender, $2 \frac{1}{2}$ to $3 \frac{1}{2}$ feet high, simple or paniculately branched above, sparsely pubescent; radical leaves 3 to $3 \frac{1}{2}$ inches long, ovate-oblong, narrowed at the base into a winged petiole; lower eanline leaves ovate, attenuate into broadly margined petioles, acuminate, mucronulate, irregularly dentate toward the apex, the upper ovate to oblong, sessile, rather obtuse; rameal leaves gradually reduced to small bracts subtending the flowering heads, all of a firm texture, paleglaucescent, particularly on the lower surface, ciliate, with prominent midrib; racemes slender, erect or spreading, secund; flowering heads small, involneral bracts obtuse, glabrous, except on the slightly hairy margin; achenes silky-pubescent, with a rigid scabrous pappus.

Resembles Solidago brachyphylla, but is abundantly distinct by the pale glaucescence, etc.

Carolinian area.

Alabama : Metamorphic hills. Lee County, Auburn, October, 1896 (Baker \& Earle). Type locality as just given.

Solidago arguta Ait. Hort. Kew. 3:213. 1789.

SiraRP-SERRATE GOLDEN-ROD.

Solidago muhlenbergii Torr. \& Gray, Fl. N. A. $2: 214$. 1842.

Ell. Sk. 2:374. Gray, Man. ed. 6, 250. Chap. Fl. 212. Gray, Syn. Fl. N. A. 1, pt. $2: 154$.

Alleghenian and Carolinian areas. Ontario and New England, west and south to Indiana, Minnesota, sonthwestern Virginia, Kentucky, and Tennessee, and along the mountains to Georgia.

AlabaMa: Mountain region. Damp grassy openings. Clay County, waterfall near Pulpit Rock, 2,200 feet, grassy swale. July, Angust; rare.

Type locality : "Native of North America."

Herb. Geol. Surv. Herb. Mohr.

\section{Solidago vaseyi nom. nov.}

Solidago arguta caroliniana Gray, Syn. Fl. N. A. 1, pt. $2: 155.1884$. Not Erigeron carolinianus L.

Chap. Fl. ed. 3, 231. Gray, Syn. Fl. N. A.1 c.

Over 2 feet high; stem glabrous below, branches and inflorescence pubescent; leaves smooth, the radical and lower cauline ample, from $1 \frac{1}{2}$ to 2 inches wide and $3 \frac{1}{2}$ to 4 inches long, ovate-lanceolate, sharply serrate, the upper lanceolate, acuminate, entire, all on short-winged petioles, acute; flowering beads large, 14 or 15 flowered, numerous, racemose in the axils of the leaves in short paniculate clusters; involuere puberulent; achenes densely silky-hairy. This plant has little in common with S. arguta, and is strikingly distinct by the characters noted.

Carolinian area. Mountains of North Carolina (Roan Mountain, 5,000 feet), 'Tennessee, and northwestern Georgia.

Alabana: Mountain region to Coosa Hills. Wooded summits and slopes of hills. Cullman Countr, Holmes Gap, 1,200 feet altitude. Clay County, Che-aw-ha Mountain. St. Clair County, near Ashville (G.R. Vasey). August; very rare.

Type locality (Gray): "Mountains of North Carolina and of adjacent South Carolina and Georgia, G. R. Vasey, J. Donnell Smith."

Herl. Geol. Surv. Herb. Mohr.

\section{Solidago serotina gigantea (Ait.) Gray, Proc. Am. Acad. 17:180. 1882.}

LARGE LATE-FLOWERING GOLDEN-1ROD.

Solidago gigantea Ait. Hort. Kew. 3:211. 1789.

S. gigantea Willd. 3:2056. 1804. Not Ait.

Gray, Man. ed. 6, 251. Chap. Fl. 214. Gray, Syn. Fl. N. A. 1, pt. 2: 156.

Boreal region to Carolinian area. Newfoundland through Canada to north latitude $50^{\circ}$ to the Pacific, south to Georgia, west to Texas, and across the plains to Nevada.

Alabama: Mountain region? A single specimen collected by G. R. Vasey, in

"North Alabama," 1878.

Type locality: "Native of North America."

Herb. Geol. Surv. Herb. Mohr. 
Solidago canadensis L. Sp. Pl. 2 : 878. 1753.

Common Golden-Rod.

Solidago altissima L. Sp. Pl. 2 : 878, 1753.

Ell. Sk. 2:369. Gray, Man. ed. 6, 251. Chap. Fl. 214. Gray, Syn. Fl. N. A. 1, pt.

$2: 157$. Coulter, Contr. Nat. Herb. $2: 190$.

Boreal region to the Gulf of Mexico, west to British Columbia; from Florida to

Texas and the mountains of Arizona.

Alabama: Over the State. Open dry or damp places. Mobile County, borders of swamps, Mobile River, and of fields. October. Three to 4 feet high.

Type locality: "Hab. in Virginia, Canada."

Herb. Mohr.

Solidago canadensis scabriuscula Porter, Mem. Torr. Club, 5:318. 1894.

Solidago canadensis var. scabra Torr. \& Gray, Fl. N. A. 2:224. 1841. Not S. scabra Willd.

Gray, Syn. Fl. N. A. 1, pt. $2: 157$. Coulter, Contr. Nat. Herb. $2: 190$.

Alleghenian and Carolinian areas. Canadian northwest territory. Pennsylvania to Georgia, west to Texas.

Alabama: Coast plain. Dry and damp open places, embankments, roadsides. Mobile County. October. Not infrequent in the low country.

Type locaiity: "Pennsylvania! to Georgia! and west to Saskatchawan! Louisiaua! and 'Texas!"

Herb. Geol. Surv. Herb. Mohr.

Solidago nemoralis Ait. Hort. Kew. 3 : 213. 1789.

Ell. Sk. $2: 373$. Gray, Man. ed. 6, 251. Chap. Fl. 214. Gray, Syn. Fl. N. A. 1, pt.

$2: 158$. Coulter. Contr. Nat. Herb. $2: 190$.

Alleghenian, Carolinian, and Louisianian areas. Canada from Anticosti to the Rocky Mountains; throughout the Eastern United States, south to Georgia and Florida,? west to Texas, Arizona, and Utah.

Alabama: Tennessee Valley to Lower hills. Dry open places. Talladega County. Shelby County, Montevallo. September, October; common; not seen in the low country.

Type locality: "Native of North America."

Herb. Geol. Surv. Herb. Mohr.

CHRYSOMA Nntt. .Journ. Acad. Phila. 7 : 67. 1834.

Thirteen species. West Indies, 1. North America, Pacific slope, 11; Atlantic, 1.

Chrysoma pauciflosculosa Greene, Erythea, 3: 8. 1895.

FEW-HLOWERED GOLDEN-ROD.

Solidago panciflosculosa Michx. Fl. Bor. Am. 2:116. 1803.

Chrysoma solidaginoides Nutt. Journ. Acad. Phila. $7: 67.1834$.

Ell. Sk. $2: 382$. Chap. Fl. 214. Gray, Syn. Fl. N. A. 1, pt. 2:161.

Louisianian area. Seashore of South Carolina to Florida, Mississippi.

Arabama : Littoral belt. Loose sands. Baldwin County, eastern shore of Mobile Bay; Point Clear; Fish River Bay. Mobile County, Dauphin Island. Frequent. Shrubby evergreen, 2 to 3 feet high.

Type locality: "Hab. in sabulosis aridis Carolinae."

Herb. Geol. Surv. Herb. Mohr.

EUTHAMIA Nutt. Gen. 2:162. 1818.

Four species, perennials, Atlantic North America.

Euthamia caroliniana (L.) Greene, Mem. Torr. Club, 5 : 321.1894.

Evigeron carolinianum L. Sp. Pl. 2 : 863. 1753.

Solidago tenuifolia Pursh, Fl. Am. Sept. 2:540. 1816.

Euthamia tenuifolia Nutt. Gen. 2 : 162. 1818.

Ell. Sk. 2:392. Gray, Man. ed.6,252. Chap. Fl.214. Gray, Syn. Fl. N. A. 1, pt.

2:161. Coulter, Contr. Nat. Herb. $2: 191$.

Carolinian and Louisianian areas. Coast of New England and New York to Florida, west to Texas.

Alabama : Lower Pine region. Coast plain. Close gravelly or sandy soil, borders of ditches, low pastures. Mobile and Baldwin counties. September to November. A bundant.

Type locality : "Hab. in Carolina."

Herb. Geol. Surv. Herb. Mohr. 
Euthamia graminifolia (L.) Nutt. Gen. 2 : 162.1818.

LANCE-LEAF EUTHAMIA.

Chrysocoma graminifolia L. Sp. Pl. 2 : 841. 1753.

Solidago lanceolata L. Mant. 1: 114. 1767.

S. graminifolia Ell. Sk. 2 : 391.1824.

Eli. Sk. 1. c. Gray, Man. ed.6, 252. Gray, Syn. Fl. N. A. 1, pt. 2: 160. Chap. Fl. 214.

Boreal zone to Lonisianian area. Canada to north latitude 64. Maine (Mount

Desert Islaud) to Nebraska, Montana, and the Rocky Mountains, sonth from New

York to Florida, west to Lonisiana and Arkansas.

Ala bama : Lower Pine region. Coast plain. Moist grassy places, borders of fields.

Mobile County. Less common than the last.

Type locality: "Hab. in Canala. Kalm."

Herb. Mohr.

BRACHYCHAETA 'Torr. \& Gray, Fl. N. A. $2: 194.1842$.

One species, Atlantic North America.

Brachychaeta sphacelata (Raf.) Britton; Kearney, Bull. Torr. Club, 20:484. 1893.

Solidago sphacelata Raf. Ann. Nat. 14. 1820.

Brachychaeta cordata'Torr. \& Gray, Fl. N. A. 2 : 195.1842.

Solidago cordata Short, Trans. Journ. Med. 7:599. 1834.

Gray, Man. ed. 6, 253. Chap. Fl. ed. 3, 233. Gray, Syn. Fl. N. A. 2, pt. 1: 161

Carolinian area. Kentucky and Tennessee and along the mountains from North Carolina to Georgia.

Alabama: Tennessee Valley. Mountain region. Dry rich wools and hills. Landerdale County, Florenee (M. C. Wilson). Calhoun Connty, Anniston, 800 feet. Talladega County, Riddell's Mill. Not infrequent. Perennial.

Type locality: "It grows on the hills of Kentucky and Virginia."

Herb. Geol. Surv. Herb. Mohr.

\section{BELLIS L. Sp. Pl. 2 : 886.1753. DAISY.}

Ten species, Europe; mostly Merliterranean. North America, 1.

Bellis integrifolia Michx. Fl. Bor. Am. 2 : 131. 1803.

Western Daisy.

Gray, Man. ed. 6, 253. Chap. Fl. Suppl. 627; ed.3, 227. Gray, Syn. Fl. N. A. 1, pt. 2 :

163. Coulter, Contr. Nat. Herb. 2 : 191.

Carolinian area. Kentucky, Tennessee, Arkansas, and Texas.

Alabama: Tennessee Valley. Shaded rich banks, ealcareous soil. Jackson County, Scottsboro. Ray flowers pale violet; May. Not frequent. Perennial.

Type loeality: "Hab. ad ripas rivulorum et in collibus umbrosis 'Tennassée."

Herb. Geol. Surv. Herb. Mohr.

BOLTONIA L'Her. Sert. Angl.27. 1788.

Seven species, perennial herbs, Atlantic North America.

Boltonia diffusa Ell. Sk. 2 :400. 1821-24.

Spreading Boltonia.

Ell. Sk. l. c. Gray, Man. ed.6, 254. Chap. Fl. 207. Gray, Syn. Fl. N. A. 1, pt. 2: 166. Coulter, Contr. Nat. Herb. 2: 193.

Carolinian and Louisianian areas. Southern Illinois and Tennessee to Georgia aud liorida, west to 'Texas.

Alabama : Central Prairie belt to Coast plain. Damp soil, borders of low fields and marshes. Perry Connty (John Donnell Smith). Mobile County, river marshes. Kays white. August, September; frequent.

Type locality: "Grows in damp rich soils between the Chattahonchie and Alabama."

Herb. Geol. Surv. Herb. Mohr.

SERICOCARPUS Nees, Gen.\& Sp. Ast. 148. 1833. White-topped Aster.

Four species, chiefly Atlantie North America. Pacific, 1. Perennials.

Sericocarpus linifolius (L.) B. S. P. Prel. Cat. N. Y.26. 1888.

Conyza linifolia L. Sp. Pl. 2 : 861. 1753.

NARROW-LEAF WIITTE-TOPPED ASTER.

Aster solidagineus Michx. Fl. Bor. Am. 2 : 108. 1803.

Sericocarpus solidagineus Nees, Gen. \& Sp. Ast. 149. 1833. 
Ell. Sk. 2:340. Gray, Man. ed. 6, 255. Chap. Fl. 197. Gray, Syn. F'l. N. A. 1, pt. $2: 171$.

Carolinian and Louisianian areas. New York and Ohio Valley to Tennessee; North Carolina to Georgia.

Alabama: Over the State. Damp light soil, open woods. Lauderdale County, in the barrens. Clay County, Elders, 1,000 feet altitude. Cullman and Mobile counties. Flowers white; July, Angust. Not rare.

Type locality: "Hab. in America septentrionali."

Herb. Geol. Surv.

Sericocarpus asteroides (L.) B. S. P. Prel. Cat. N. Y. 26. 1888.

Conyza asteroides L. Sp. Pl. 2:861. 1753.

LARGE-FLOWERED WHITE-TOPPED Aster.

Sericocarpus conyzoides Nees, Gen. \& Sp. Ast. 150. 1833.

Ell. Sk. 2:341. Gray, Man. ed. 6, 254. Chap. Fl. 197. Gray, Syn. Fl. N. A. 1, pt. $2: 171$.

Alleghenian to Carolinian area. New England, northwestern New York, Minnesota, Ohio, Tennessee, and along the mountains to Upper Carolina and Georgia.

Alabama : Mountain region. Lower liills. Clay County, Che-aw-ha Mountain, 2,400 feet altitude. Cullman County, 800 feet altitude. Tallapoosa County, Dadeville. Lee County, Auburn. Talladega County, Renfroe, 800 feet altitude. Flowers July, August; rays white, disk flowers yellow. Frequent. Common on sterile rocky ridges of the Metamorphic rocks.

Typo locality: "Hab. in America septentrionali."

Herb. Geol. Surv. Herb. Mohr.

Sericocarpus bifoliatus (Walt.) Porter, Mem. Torr. Clnb, 5 :322. 1894.

Conyza bifoliata Walt. Fl. Car. 204. 1788.

Aster tortifolius Michx. Fl. Bor. Am. 2:109. 1803.

Sericocarpus tortifolius Nees. Gen. \& Sp. Ast. 151. 1833.

Ell. Sk. $2: 341$. Gray, Man. ed. 6, 255. Chap. Fl. 198. Gray, Syn. Fl. N. A.

1, pt. $2: 172$.

Carolinian and Louisianian areas. Southern Virginia along the low country to North Carolina and Florida, west to Louisiana.

Arabama : Central Pine belt to Coast plain. Dry pine woods. Autauga County, Chilton County. Lee County, Auburn (Earle). Montgomery, Clarke, and Washington counties. Baldwin and Mobile counties. Flowers white; July to October. Frequent. Common in the pine barrens of the Cuast Pine belt.

Type locality: South Carolina.

Herb. Geol. Surv. Herb. Mohr.

\section{ASTER L.Sp. Pl. 2:872. 1753. Aster. Starwort.}

From 200 to 250 species, recognized as valid; perennials. Europe, Asia, South Africa; largely American. North America, 125 (Gray); Atlantic, 100.

Aster paludosus Ait. Hort. Kew. 3:201. $1783 . \quad$ Swamp Aster.

Ell. Sk. 2:343. Gray, Man. ed. 6, 255. Chap. Fl. 199. Gray, Syn. Fl. N. A. 1, pt. 2:

174. Conlter, Contr. Nat. Herb. 2 : 194.

Carolinian and Louisianian areas. North Carolina to Florida, west to central Texas.

Alabama: Tennessee Valley. Lower Pine region. Coast plain. Low places, borders of ditches. Lawrence County, Mountainhome. Clarke and Mobile counties. Flowers sky-blue; Angust, September. Most frequent in the Coast plain in damp sandy ground.

Type locality: "Native of the Swamps of Carolina."

Herb. Geol. Surv. Herb. Mohr.

Aster divaricatus L. Sp. Pl. 2 : 873. 1753.

Aster corynıosus Ait. Hort. Kew. 3 : 207. 1789.

Ell. Sk. 2:365. Gray, Man. ed. 6, 255. Chap. Fl. 198. Gray, Syn. Fl. N. A. 1, pt. $2: 174$.

Alleghenian to Carolinian area. Quebec to Lake Superior and Manitoba; New England west to Minnesota; Ohio Valley, and from New Jersey south along the monintains to Tennessee and Georgia.

AlabaMa: Mountain region. Shady woodlands. Cullman County (Miss Mary Mohr). Walker County (E.A.Smith). Ray flowers pale purple; August, September. Not frequent.

Type locality: "Hab. in Virginia."

Herb. Geol. Surv. Herb. Mohr. 
Aster oblongifolius Nutt. Gen. 2 : 156. 1818.

Prairie Aster.

Gray, Man.ed.6, 257. Gray, Syn.Fl. N. A. 1, pt.2:178. Chap. Fl.ed.3, 223. Coulter, Contr. Nat. Herb. $2: 194$.

Carolinian to Louisianian area. Illinois and Missouri to Minnesota and Nebraska;

Penusylvania and Virginia south to 'Tennessee, west to Texas and Arkansas.

AlabaMa : Mountain region. Central prairies. Dry banks and hillsides. Madison Connty, Huntsville, sunny hillsides, flank of Montesano, 1,000 feet altitude. Lee Connty, Auburn. 'Tuscaloosa County. Montgomery County, in the prairies. Flowers azure; September, October. Infrequent.

Type locality: "On the banks of the Missouri."

Herb. Geol. Surv. Herb. Mohr.

Aster puniceus L. Sp. Pl. 2 : 875. 1753.

Purple-stemmed Aster.

Gray, Man. ed. 6, 263. Gray, Syn. Fl. N. A. 1, pt. 2 : 195. Chap. Fl. ed. 3, 223.

Alleghenian and Carolinian areas. Nova Scotia and maritime Canada to the Rocky Mountains; New England west to Minnesota, Dakota, West Virginia, to northern Illinois, mountains of North Carolina, and northwestern Georgia.

Alabama : Mountain region. Metamorphic hills. Swampy borders of woods. Lee County, Auburn (F.S. Earle). Flowers violet to purple; September, October. Rare; only locality known in the State.

Type locality: "Hab. in America septentrionali."

Herb. Geol. Surv. Herb. Mohr.

Aster concolor L. Sp. Pl. ed. 2, 2 : 1228.1763.

Southern Silky Aster. 180.

Ell. Sk. 2 :350. Gray, Man. ed.6, 258. Chap. Fl. 200. Gray, Syn. Fl. N. A. 1. pt. 2:

Carolinian and Louisianian arens. Southern New England and Now York to southern Ohio, Tennessee, and Florida, and west to Mississippi.

AlabaMa : Metamorphic hills to Coast plain. Dry pine woods. Mobile County, sandy pine ridges. Tallapoosa County (E.A.Smith). Lee County, Auburn, sterile hills. Rays violet; October, November. Frequent.

Type locality: "Hab. in Virginia."

Herb. Geol. Surv. Herb. Mohr.

Aster gracilis Nutt. Gen. 2:158. 1818.

Slender Asthr.

Gray, Man. ed. 6, 256. Chap. Fl. 199. Gray, Syn. Fl. N. A. 2, pt. 1: 176. Britt. \&

Br. Ill. Fl. $3: 373$.

Carolinian area. New Jersey, Kentucky, and Tennessee.

Alabama: Mountain region. Open woods. Dekalb County, Lookout Mountain, near Mentone. Flowers azure; September. Infrequent.

'I'spe locality: "In the Savannahs of Kentucky and Tennessee."

Herb. Geol. Surv. Herb. Mohr.

Aster adnatus Nutt. Journ. Acad. Phila. $7: 82$. 1834-1837.

SMatL-Leaf Aster.

Aster microphyllus Torr.; Lindl. in DC. Prodr. 5 :244. 1835.

Chap. Fl. 200. Gray, Syn. Fl. N. A. 1, pt. $2: 180$.

Lonisianian area. Florida to Mississippi.

Alabama: Lower Pine region, barren pine ridges. Mobile Connty, Springhill

(Gates). Flowers violet; October, November. Not infrequent.

Type locality: "In Alabama and West Florida. Mr. Ware."

Herb. Geol. Surv. Herb. Mohr.

Aster patens Ait. Hort. Kew. 3 : 201. 1789.

SPREADING Aster.

Aster amplexicaulis Michx. Fl. Bor. Am. 2 : 114. 1803.

Ell. Sk. 2:361. Gray, Man. ed.'6, 258. Chap. Fl. 200. Gray, Syn. Fl. N. A. 1, pt. 2 : 180. Coulter, Contr. Nat. Herb. 2 : 195.

Alleghenian to Louisianian area. New Brunswick, Ontario; Massachusetts west, to Minnesota and Nebraska; south to the Ohio Valley, Missouri, and Arkansas, and from New Jersey to Florida and Texas.

Aldisama : Tennessee Valley to Coast plain. Dry open copses, hillsides, borders of woods. Cullman County. 'Talladega County, Renfroe; Alpine Mountain, 1,800 feet. Not seen in the low country.

Type locality : "Native of Virginia."

Herb. Geol. Surv. Herb. Mohr.

Aster patens tenuicaulis nom. nov.

Slender SPRFading A.jTER.

Aster patens gracilis Hook. Comp. Bot. Mag. 1:97. 1835. Not A. gracilis Nntt. 1818. Gray, Syn. Fl. N. A. 1, pt. 2: 180. Coulter, Contr. Nat. Herb. 2 : 195.

Carolinian and Louisianian areas. Tennessee (Gattinger) to Lonisiana and Texas. 
Arabama: Lower Pine region. Coast plain. Damp or dry sandy places, borders of woods, copses. Washing ton and Mobile counties. Flower azure; August, September. Common in the Coast plain.

Type locality (Hook.): “Jacksonville,” Fla.

Herb. Geol. Surv. Herb. Mohr.

Aster shortii Hook. Fl. Bor. Am. 2:9. 1834.

SHORT's Aster.

Gray, Man. ed. 6, 258. Chap. Fl. 201. Gray, Syu. Fl. N. A. 1, pt. 2:181.

Alabama: Mountain region, Central Pine belt. Madison County, Montesano, 1,500 feet. Lee County, Auburn $(F . S$. Earle). Talladega County. Tuscaloosa County, 400 feet altitude. Flowers purplish; October.

Growing on the arid rocky ridges of the Metamorphic hills and of the Carboniferous conglomerates, our specimens differ from plants from the Ohio Valley by their slender habit of growth, widely spreading branches, the more attenuated leaves, roughishpubescent beneath, and the less numerons, smaller flowering heads.

Type locality: "Found by Dr. Short, on eliffs of the Kentucky River."

Herb. Geol. Surv. Herb. Mohr.

Aster camptosorus Sinall, Bull. Torr. Club, 24 : 339. 1897.

Stems slender, erect, simple, 2 to 3 feet tall, glabrous or slightly pubescent near the top; leaves few, lanceolate, 4 to 6 inches long (including the slender petiole), attenuate from near the base to the finely acute apex, entire, undulate, resembling the leaves of Camptosorus rhizophyllus, hispid beneath, with a scattered pubescence, the lower deeply cordate at the rounded base, the upper subcordate or truncate; heads usually few; perlicels angled, bearing miuute appressed bracts, scrabrous; involucres cylindric-eampanulate or turbinate, $\frac{3}{8}$ to $\frac{1}{4}$ inch high; bracts liuearsubulate, incurved, with a narrow green midrib and green acute tip.

Carolinian area. Georgia.

Alabama: Mountain region. On the highest ridges in dry open woods. Talladega County, Alpine Mountains, near the signal station, 1,800 feet, September 24, 1892. Lee County, Anburn (Baker \& Earle), 1896.

Distributed in 1893 as a hirtellous form of $A$. shortii, which in aspect resembles closely this plant, from which it is distinguished by the characters of the involucre as pointed out by Dr. Small.

Type locality: "Wright's mill, 5 miles south of Auburn, Ala." (C. F. Baker). "Mountains of Georgia" (Buckley).

Herb. Geol. Surv. Herb. Mohr.

Aster azureus Lindl.; Hook. Comp. Bot. Mag. 1:98. 1835.

SKY-BLUE ASTER.

Gray, Man. ed. 6, 258. Chap. Fl. 201. Gray, Syn. Fl. N. A. 1, pt. 2: 181. Coulter, Contr. Nat. Herb. $2: 195$.

Alleghenian to Carolinian area. Ontario and Michigan west to Nebraska, south to Missouri and western Louisiana, and from Ohio to the mountains of northwestern Georgia.

Alabama: Mountain region. Open rocky woods. Tallarlega County, Renfroe, ou the Alpine Mountain, about 1,600 feet altitude. Flowers bright blue; October. Rare; only locality known in the State.

Type locality: "St. Louis," Mo.

Herb. Geol. Surv. Herb. Mohr.

Aster undulatus L. Sp. Pl. 2 : 875. 1753.

WAVY-LEAF ASTER.

Gray, Man. ed. 6, 258. Chap. Fl. 201. Gray, Syn. Fl. N. A. 1, pt. 2: 181.

Alleghenian to Lonisianiau area. New Brunswick, Ontario; New England west to Minnesota and Nebraska, south to the Ohio Valley, Missouri, and Arkansas; from New York to Florida, and west to Lonisiana.

A labama: 'Tennessee Valley to Central Pine belt. Dry open woods, copses. Madison County, Huntsville. Cullman County. Talladega County, Chandler Springs, Alpine Mountain, 1,800 feet altitude. Flowers violet; September, October. Frequent; not observed in the low eountry.

Type locality: "Hab. in America septentrionali."

Herb. Geol. Surv. Herb. Mohr.

Aster undulatus diversifolius (Michx.) Gray, Syn. Fl. N. A. 1, pt. 2: 181. 1884.

Aster diversifolius Michx. Fl. Bor. Am. 2 :113. 1803.

ROUGHISH Astek.

A. scaber Ell. Sk. 2:363. 1821-24.

A. asperulus Torr. \& Gray, F1. N. A. $2: 120$. 1841. Not Walt. 1788.

A. baldwini Torr. \& Gray, Fl. N. A. 2:127. 1841. In part.

Ell. Sk. l. c. Gray, Syn. Fl. N. A.l. c.

Carolinian and Louisianian areas. South Carolina to Georgia. 
Alabama: Mountain region. Drr exposed rocky places, mountainous woods. Talladega Connty, Alpine Mountains, 1,800 feet; Renfroo, 1,000 feet. Calhoun County, Anniston, lighest ridges, about 1,000 feet altitude. Flowers cerulean blue; September, October. Not infrequent.

Type locality : "Hab. in Carolina."

Herb. Geol. Surv. Herb. Mohr.

Aster undulatus loriformis Burgess in Britt. \& Br. Ill. Fl. 3:365. 1898.

Alleghenian and Carolinian areas. New England, Pennsylvania, Virginia.

Alubama: Mountain region. Dekalb County, Lookout Mountain. New York to South Carolina.

'Type locality: “F.astern Massachusetts to Virginia and Pennsylvania.”

Herb. Geol. Surv. Herb. Mohr.

Aster cordifolius L. Sp. Pl. 2:875. 1753.

Heart-Leaf Aster.

Ell. Sk. 2 :361. Gray, Man. ed. 6, 259. Chap. Fl. 202. Gray, Syn. Fl. N. A. 1, pt. $2: 182$.

Alleghenian and Carolinian areas. Nova Scotia, Ontario; New England west to Minnesota and Nebraska; through the Ohio Valley to Missouri, Arkansas, and Tennessee, and south along the mountains to Georgia.

Alabama: Tennessee Valley. Mountain region. Woodlands and thickets. Landerdale County, Florence (M. C. Wilson). Cnllman County. Flowers pale purplish blue; September, Octolier. Not frequent.

Type locality: "Hab. in America \& Asia septentrionali."

Herb. Geol. Surv. Herb. Mohr.

Aster cordifolius polycephalus Porter, Bull. Torr. Clnb, $21: 120$. 1894.

"More robust and branched than the type; leaves smaller, the npper ones and the bracts ovate and sessile; panicle ample; heads usually smaller and very numerous. Rays deep blue and the disk florets dark purple (as in A. lateriflorus), or both of them sometimes pale or whitish."

AlabaMa: Lauderdale County.

Type locality: "Everywhere with the typical form in New Jersey and Eastern Pennsylvania."

Herb. Geol. Surv.

Aster lowrieanus Porter, Bull. Torr. Club, 21: 121. 1894.

Aster cordifolius var. laevigatus Porter, Bull. Torr. Club, 16:67. 1889. Not A.laevigatus Lam.

Aster leiophyllus Porter, Bull. Torr. Club, $20: 254$, t. 15\%. 1893. Not Franch. \& Sav. Britt. \& Brown, Ill. Fl. 3: 363 .

Carolinian area. Southern Connecticut and southern New York to Pennsylvania, Virginia, Ohio, and Kentucky, and southward along the mountains to Tennessee.

Alabama: Tennessee Valley. Open woods. Bluffs on the Tennessee River near Florence (M. C. Wilson). September. Not frequent.

Type locality: "Common in New Jersey and Pennsylvania, as well as westward and south ward."

Aster sagittifolius Wedem.; Willd. Sp. Pl. 3:2035.

Arrow-leaf Aster.

Ell. Sk. 2:362. Gray, Man. ed. 6, 259. Chap. Fl. 202. Gray, Syn. Fl. N. A. 1, pt. $2: 182$.

Alleghenian and Carolinian areas. New Brunswick, Ontario; New England west to Minnesota and Dakota; from New York to the Ohio Valley and along the mountains to Georgia.

Alabama: Mountain region. Dry open woods. Lee County, Auburn (Earle). Talladega Connty, Alpine Mountain, 1,800 feet ; Renfroe, 800 feet; Chandler Springs, 1,500 feet. Cullman County, 800 feet. Calloun County, Anniston, 800 feet altitude; cherty ridges. Rays sky-blue; September, October. Not common.

Type locality: "Hab. in America boreali."

Herb. Geol. Surv. Herb. Mohr.

Aster purpuratus Nees, Gen. \& Sp. Ast. 118. 1833.

WAND-Like Aster.

Aster virgatus Ell. Sk. 2 : 353. 1824. Not of Moench.

Ell. Sk. 1. c. Gray, Man. ed. 6, 259. Chap. Fl. 201. Gray, Syn. Fl. N. A. 1, pt. 2:

183. Conlter, Contr. Nat. Herb. $2: 195$.

Louisianiau area. Coast of North Carolina to Florida, west to Texas and Arkansas.

AlabaMa: Lower Pine region. Coast plain. Along shaded grassy banks, pine-

barren streams. Escambia County, Wallace. Washingtou and Mobile counties.

Flowers cerulean blue. Not infrequent.

Type locality: "Creseit in America septentrionali?"

Herb. Geol. Surv. Herb. Mohr. 
Aster laevis L. Sp. Pl. $2: 876.1753$.

SMOOTI Aster.

Ell. Sk. 2 : 352. Gray, Man. ed. 6, 259. Chap. Fl. 200; ed. 3, 220. In part. Gray, Syn. Fl. N. A. 1, pt. 2: 183 . Coulter, Contr. Nat. Herb. $2: 195$, in part.

Canadian zone to Carolinian area. ('anada to north latitude 53 , west to the

Rocky Mountains; New England west to Minnesota and Nebraska, sonth to the Ohio

Valley and Tennessee, and along the mountains to Georgia.

Alabama: Mountain region. Dry open woods. Ta!ladega County, Chandler Springs. Lee County, Anburn. September, October; not frequent.

Type locality : "Hab. in America septentrionali. Kalm."

Herb. Geol. Surv. Herb. Mohr.

Aster laevis amplifolius Porter, Mem. Torr. Club, $5: 324.1894$.

Aster laevis var. latifolius Porter, Bull. Torr. Chub, 21:121. 1894. Not A. latifolius

Desf.

Leaves glaucous, broadly ovate, strongly amplexicaul.

Distribution as in the type.

Alabama: Mountain region. Borders of woods, copses. Madison County, Montesano, ealcareous hillsiles, about 1,000 feet altitude. Flowers cerulean blue; October. Apparently not frequent.

Type locality: "Specimens of this variety exist in the Torrey Herbarium, ond it has also been collected in the neighborhood of Easton, Pennsylvania."

Herb. Geol. Surv.

Aster ericoides L. Sp. Pl. 2:875. 1753.

Heath-like Aster. Ell. Sk. 2 : 348. Gray, Man. ed.6, 260. Chap. Fl. 202. Gray, Syn. Fl. N. A. 1, pt. $2: 184$.

Alleghenian to Lonisianian area. Southern Ontario and New England, west to Minnesota, south to Florida and Mississippi.

Alabama: Over the State. Light exposed soil, fence rows, roadsides, borders of woods. Madison, Cullman, and Clay counties. Rays white; Octoler, November. Common.

Type locality: "Hab. in America septentrionali."

Herb. Geol. Surv. Herb. Mohr.

Aster ericoides pilosus (Willı.) Porter, Mem. Torr. Club, 5 : 323. 1894.

Aster villosus Michx. Fl. Bor. Am. 2 : 113. 1803. Not Thunb. 1800.

Aster pilosus Willd. Sp. Pl. $3: 2025.1803$.

A. ericoides var. villosus Torr. \& Gray, Fl. N. A. 2:124. 1841.

Gray, Man. ed. 6, 260 Chap. Fl. 202. Gray, Syn. Fl. N. A. 1, pt. $2: 184$.

Alleghenian to Lonisiauian area. Ontario to Minnesota; New York, West Virginia, Ohio, 'Tennessee, and North Carolina.

Alabama: Tennessee Valley. Coast plain. Roadsides, fence rows. Cullman County. Lauderdale Comnty, Florence (M.C. Wilson). Lee County, Auburn. Mobile County. Frequent north of the Coast Pine belt.

Type locality of dster pilosus Willd.: "Hab. in America boreali in regione Illinoensium."

Herb. Geol. Surv. Herb. Mohr.

Aster ericoides platyphyllus Torr. \& Gray, Fl. N. A. 2 :124. 1841.

Chap. Fl. 202. Britt. \& Br. Ill. Fl. $3: 379$.

Carolinian area. Indiaua to North Carolina and Georgia.

Ala Bama : Metamorphic and Lower hills. Light sandy or gravelly soil, borders of fields. Lee County, Auburn (Baker \& Earle). Tuscaloosa County. Flowers white; October.

Type locality: "North Carolina, Schweinitz! Mr. Curtis! Indiana, Dr. Clapp."

Herb. Geol. Surv. Herb. Mohr.

Aster multiflorus Ait. Hort. Kew. 3 : 203. 1789.

MANY-Flowered Aster.

Aster multiflorus var. stricticaulis 'Torr. \& Gray, Fl. N. A. 2 :125. 1841.

Ell. Sk. 2:349. Gray, Man. ed.6, 260. Chap. Fl. 202. Gray, Syn. Fl. N. A. 1, pt. 2:

1ъ5. Coulter, Contr. Nat. Herb. $2: 195$.

MeXico.

Canadian zone and Carolinian area. Ontario to Saskatchewan and the Rocky Mountains to north latitude 490; New England, west to Minnesota, Nebraska, and Montana; from New York soutb to Georgia, Mississippi, Texas, Arkansas, and Arizona, 
Alabama: Central praisies. Dry fields. Montgomery County. Dallas County, Marion Junction, open prairies. Flowers white; October. Not frequent. Type locality: "Native of North America."

Herb. Geol. Surv. Herb Mohr.

Aster dumosus L. Sp. Pl. 2 : 873. 1753.

BusHy Aster.

Ell. Sk. 2:347. Gray, Man. ed. 6, 260. Chap. Fl. 203. Gray, Syn. Fl. N. A. 1, pt. 2 :

185. Coulter, Contr. Nat. Herb. $2: 196$.

Alleghenian to Lonisianian area. Southern Ontario; New England to Michigan; Ohio Valley to Missouri, south to the Gulf, and from Florida to 'Texas and Arkansas.

Alabama: Mountain region to Coast plain. Shaded grassy banks, damp or dry sandy soil. Cullman and Mobile counties. Rays pale violet, almost white; October. Common; abundant on the grassy banks along pine-barren streans.

'Type locality: "Hab. in America septentrionali."

Herb. Geol. Surv. Herb. Mohr.

Aster dumosus coridifolius (Michx.) Torr. \& Gray, Fl. N. A. $2: 128.1841$.

Aster coridifolius Michx. Fl. Bor. Am. 2: 112. 1803.

A. foliolosus Ell. Sk. 2 :345. 1821-24. Not Ait.

Eil. Sk. 1. c. Chap. Fl. 203. Gray, Syn. Fl. N. A. 1, pt. 2: 186.

Louisianian area. South Carolina and Florida to Louisiana.

Alabama : Central Prairie region to Coast plain. Low damp exposed places, borders of ditches, swamps in low pine barrens. Montgomery, Dallas, Baldwin, and Mobile counties. Flower rays white; October, November. Abundant in the prairies aud damp flat pine barrens near the coast. Passes gradually into the following. Type locality: "Hab. in aridis sylvarum Carolinae inferioris."

Herb. Geol. Surv. Herb. Mohr.

Aster dumosus subulaefolius Torr. \& Gray, Fl. N. A. 2 : 128. 1841.

Conlter, Contr. Nat. Herb. $2: 196$.

Small-leaf Bushy Aster.

Lonisianian area. South Carolina; Florida to Texas.

Alabama: Lower Pine region. Coast plain. Low open pine barrens. Rays white; October. Frequent.

Type locality: “Texas, Drummond! Western Louisiana, Dr. Leavenworth!”

Herb. Geol. Surv. Herb. Mohr.

Aster vimineus foliolosus (Ait.) Gray, Syn. Fl. N. A. 1, pt. 2 : 186.

Aster foliolosus Ait. Hort. Kew. 3 : 202. 1789.

Many-leaved Willow Aster.

A. tenuifolius Ell. Sk. $2: 347$. Not L.

Ell. Sk.1. c. Gray, Man. ed. 6, 261. Gray, Syn. Fl. N. A. 1, pt. 2: 186.

Allegherian to Carolinian area. Ontario, New England, west to Minnesota, Missouri, and Arkansas, south to Florida and Arkansas.

Ala bama: Mountain region. Damp open woods. Cullman County. Leo County, Anburn ( $F . S$. Earle). September.

Type locality: "Native of North America."

Herb. Geol. Surv. Herb. Mohr.

Aster lateriflorus (L.) Britton, Trans. N. Y.Acad. Sci. $9: 10.1889$.

Solidago lateriflora L. Sp. PI. 2: 879.1753.

DIFYUSE ASTER.

Aster diffilsus Ait. Hort. Kew. $3: 205.1789$.

Aster miser Nutt. Gen. $2: 158.1818$.

Gray, Man. ed 6, 261. Chap. F1. 203; ed. 3, 222. Gray, Syn. Fl. N. A. 1, pt. 2: 186. Coulter, Contr. Nat. Herb. $2: 196$.

Alleghenian and Carolinian areas. Nova Scotia, Ontario; throughout the Eastern Uniterl States, west to 'Texas.

Alabama: Mountain region to Lower hills. Tuscaloosa County. Talladega County, Alpine Mountains. Lee County, Auburn, 860 feet. Not observed in the low country. Not frequent.

Type locality: "Hab. in America septentrionali. Kalm."

Herb. Geol. Surv. Herb. Mohr.

Aster lateriflorus glomerellus (Torr. \& Gray) Burgess in Britt. \& Br. Ill. Fl. 3 : 380. 1898.

Aster miser var. glomerellus Torr. \& Gray, Fl. N. A. 2, pt. 1:130. 1841.

Carolinian and Louisianian areas. New York, Virginia. 
Alabama : Lower hills. Wooded banks. Tuscaloosa County. October. Type locality indeterminate.

Herb. Geol. Surv. Herb. Mohr.

Aster lateriflorus pendulus (Ait.) Burgess in Britt. \& Br. Ill. Fl. 3 : 380. 1898. Aster pendulus Ait. Hort. Kew. $3: 204.1789$.

Carolinian area. New York, Virginia.

Alabama: Lower hills. Tuscaloosa Comnty. Flowers in October. Not frequent. Type locality: "Native of North America."

Herb. Geol. Surv. Herb. Mohr.

Aster tradescanti L. Sp. Pl. 2: 876. 1753.

Tradescant'e Aster.

Ell. Sk. 2 : 358. Gray, Man. ed. 6, 261, in part. Gray, Syn. Fl. N. A. 1, pt. 2: 187.

Canadian zone to Carolinian area. Ontario to Saskatehewan; sonthern New Eug-

land, and thronghout the States east of the Mississippi to Carolina and Georgia.

AlabaMa: So far known in Alabama only from Tuscaloosa County, there collected by E. A. Smith.

Type locality: "Hab. in Virginia."

Herb. Geol. Surv: Herb. Molir.

Aster salicifolius subasper (Lindl.) Gray, Syn. Fl. N. A. 1, pt. $2: 188.1884$.

ROUGHISH WILLOW-LEAF ASTER.

Aster subasper Lindl. Hook. Comp. Bot. Mag. 1:97. 1835.

Gray, Man. ed. 6, 261. Gray, l. c. Conlter, Contr. Nat. Herb. 2 : 196.

Carolinian area. Illinois and Texas.

AlabaMa: Mountain region. Coast plain. Deep grassy banks along streans. Cullman County. Mobile County, Whistler, banks of Bogneho'ma Creek. Flowers white; October. Not frequent.

Type locality: "St. Louis," Mo.

Herb. Geol. Surv.

Aster paniculatus Lam. Encycl. 1:306. 1783.

Paniculate Aster.

Gray, Man. ed. 6, 261. Chap. Fl. ed. 3, 222.

Canadian zone to Louisianian area. Canada; from the Atlantic west to the Rocky

Mountains; from New England west to Nebraska, south to Florida and Lonisiana.

Alabama : Mountain region to Coast plain. Low grassy banks. Cullman County. Mobile County, Whistler, banks of Chickasaha Creek. Flowers pale purple; October. Not frequent.

Type locality: "Cette Astère croit dans l'Amérique septentrionale."

Herb. Geol. Surv.

Aster tenuifolius L. Sp. Pl. 2:873. 1753.

SALT-MARSh ASter. Aster flexuosus Nutt. Gen. $2: 154.1818$.

Ell. Sk. $2: 343$. Gray, Man. ed. 6, 264. Chap. Fl. 206; ed. 3, 224. Gray, Syn. Fl.

N. A. 1, pt. $2: 202$.

Alleghenian to Louisianian -area. Coast of Massachusetts to Florida, west to Louisiana.

ALABANA: Coast plain and Littoral region, slightly brackish and saline marshes. West shore of Mobile Bay, near Dog River; West Fowl River. Flowers, October; rare.

Type locality: "Hab: in America septentrionali."

Herb. Geol. Surv. Herb. Mohr.

Aster exilis Ell. Sk. $2: 344.1821$.

Seaside Aster.

Tripolium dicaricatum Nutt. Trans. Am. Phil. Soc. 1:296. 1834.

Aster divaricatus Torr. \& Gray. Fl. N. A. 2 : 163. 1841. Not L.

Ell. Sk. 1. c. Chap. Fl.205; ed. 3, 225. Gras, Syn. Fl. N. A. 1, pt. 2: 203.

Louisianian area. Georgia and Florida, west to Texas.

Alabaira : Coast plain. Low wet exposer places, borders of ditches and marshes.

Mobile and Baldwin counties. Flowers pale purplish blue (lilac). October, Novem-

ber. Common.

'Tpe locality: "Grows in damp soils in the western districts of Georgia."

Herb. Geol. Surv. Herb. Mohr.

Aster subulatus Michx. Fl. Bor. Am. 2 : 111. 1803.

Spreading Aster.

Aster linifolius Torr. \& Gray, Fl. N. A. $2: 162$. 1841. Not L.

Ell. Sk. 2:345. Gray, Man. ed. 6, 264. Chap. Fl. 205; ed. 3, 224. Gray, Syn. Fl.

N. A. 1, pt. $2: 204$.

Carolinian to Louisianian area. Coast of New England to Florida. 
Alabama : Coast plain. Low swampy banks of Mobile River. August. The sole localitr.

Type locality: "Hab. in maritimis paludosis Pennsylvaniae et Carolinae."

Herb. Geol.Surv. Herb. Mohr.

More material is needed to define with absolute acenracy the species enumeratei above of this extensive and ditfienlt geuus, particularly of the willow-leaf group (Vulgares), which is but scantily represented in our collections of the 101 species and rarieties, confined to the region east of the Mississippi River and the adjacent territory to the verge of the treeless plains, 26 species with 11 well marked varieties have been recognized in Alabama. Three species are peculiar to the Lonisianian area and most frequent in the Coast plain aud Maritime Pine belt, extending from Texas to North Carolina and seareely straying worthward beyond the sonthern border of eastern Virginia. These are Aster purpuralus, A. exilis, A. adnatus, the last not extending west of the Mississippi River. Confined to the same area are the rarieties-Aster patens tenuicaulis, $A$. dumosus coridifolius, and $A$. dumosus subulat folius.

ERIGERON L. Sp. Pl. 2 : 863.1753.

Fully 150 species of both hemispheres, chiefly Ameriean, a small number of South Africa. Anstralia, and the Old World. North America, 70 to 75 ; Atlantic, 18.

Erigeron amnuus (L.) Pers. Srn. 2 : 431. 1807.

DAISY. SWEet SCABIOUS.

Aster aиниив L. Sp. Pl. 2 :875. 1753.

Erigeron heterophyllus Muhl.; Willd. Sp. Pl. $3: 1956.1804$.

Gray, Mau. ed.6, 265. Chap. Fl. Suppl.627; ed.3, 226. Gray, Syn. Fl. N. A. 1, pt. $2: 218$.

Central Europe, introducei.

Alleghenian to Louisianiau area. Nova Scotia, Ontario, and Quebee; New England west to Minnesota, Montana, Oregon, California, sonth to the Gulf, from Florida to Arkansas.

Alabama: Over the State. Scattered. Most frequent in the Central Prairie region in pastures and old fields. Mobile Comnty, in damp ground, waste places, borlers of ditches, waysides. Flowers white, often tinged with purple; June, July ; appearing on the eoast, as if introdnced.

Type locality: "Hab. in Canada."

Herb. Geol. Surv. Herb. Mohr.

Erigeron ramosus (Walt.) B. S. P. Prel. Cat. N. Y.27. 1888.

Daisy flleabane.

Doronicum ramosum Walt. Fl. Car. 205. 1788.

Erigeron strigosns Mull.; Willd. Sp. P]. 3 : 1956. 1804.

Ell. Sk. 2:394. Gray, Man. ed.6,265. Chap. Fl. 206. Gray, Syn. Fl. N. A. 1, pt. 2: 219. Coulter, Contr. Nat. Herb. $2: 199$. Wats. Bot. Calif. $1: 331$.

Canadian zone to Louisianian area. Ontario to Manitoba; sonth to the Gulf of Mexico, from Florida to Texas; west from the Atlantic to Minnesota, Nebraska, Montana, and the Pacitic.

Ara BaMA: Over the State. Dry, exposed ground. Abundant in fields, worn-out grass lauds, pastures. Flowers white; May, July. Bienuial.

Type locality: South Carolina.

Herb. Geol. Surv. Herb. Mohr.

Erigeron ramosus beyrichii (Fisch. \& Mey.) Smith \& Pounds, Bot. Surv. Nebr. 2 : 11. 1893.

Erigeron strigosus beyrichii Gray, Syn. Fl. N. A. 1, pt. 2:219. 1884.

Stenactis beyrichii Fisch. \& Mey. Ind. Sem. Petrop. 5:27. 1838.

Gray, Srn. Fl. N. A.l.c.

Nebraska, Arkansas, Texas, and Carolina.

Alabama: Tennessee Valley. Wooded hills on limestone beuches. Lee County, Auburn (Baker \& Earle, 254). Franklin Count5, Russellville. Cedar woods of Locust Dell farm. Copious. Flowers white; June. Biennial.

Type locality not ascertained.

Herb. Geol. Surv. Herb. Mohr.

Erigeron pulchellus Michx. Fl. Bor. Am. 2 :124. 1803.

Lilac-Flowered Daisy Fleabain.

Erigeron bellidifolius Muhl.; Willd. Sp. Pl. 3: 1958. 1804.

Gray, Man. ed.6, 266. Chap. Fl.206. Gray, Syn. Fl. N. A. 1. pt. 2:216.

Canadian zone to Lonisianian area. Ontario to Hudson Bay and Manitoba; New Englaud west to Minnesota: south from New Jersey to Sonth Carolina, Tennessee, westeru Louisiaua, aud 'Texas. 
Alabama: Mountain region to Lower hills. Rich, open woodlands. Cullman County, 800 feet. 'Tuscaloosa ('ounty (L. A. Smith). Flowers lilac; April, May. Not common. Perennial.

Type locality: "Hab. in Canada, Pennsylvania et montibus Carolinae."

Herb. Geol. Surv. Herb. Mohr.

Erigeron philadelphicus L. Sp. Pl. 2 : 863. 1753. Philadelphia Daisy Fleabane. Gray, Man. ed.6, 266. Chap. Fl. 206. Gray, Syu. Fl. N. A.1, pt.2:217. Wats. Bot. Calif. 1:321. Coulter, Contr. Nat. Herb. $2: 198$.

Boreal region to Louisianian area. Ontario and Quebec worth to the arctic circle, south to the eastern Gulf region, west to Oregon and California.

Alabama: Over the State. Borders of woods and fields. Mobile County, abundant. Flowers white, more or less tinged with purple; April, May. Of late vears becoming a troublesome wayside wetd, infesting lawns and waste grounds. Biennial.

Economic uses: The herb, under name of "Erigeron," is used medicinally, as are likewise $E$. canadensis, $E$. annuus, and $E$.ramosus.

Type locality: "Hab. in Canada. Kalm."

Herb. Mohr.

Erigeron quercifolius Lan. Tabl. Encycl. $3: 258$, .. 681, f.4. 1823.

Southern Daisy Fleaibane.

Erigeron philadelphicus Michx. Fl. Bor. Am. 2:123. 1803. Not L. Ell. Sk. 2:396.

Gray, Syn. Fl. N.A. 1, pt. 2:217. Coulter, Contr. Nat. Herb. 2:198.

Louisianian area. South Carolina to Florida and Texas.

Alabama: Coast plain. Low grassy banks and loorders of woods. Mobile

County. Flowers white to bluish; April. Common. Biennial.

With the last an aggressive weed in grass plats, meadows, etc.

Type locality not given.

Herb. Geol. Surv. Herb. Mohr.

Erigeron vernus (L.) Torr. \& Gray, Fl. N. A. 2:176. 1841.

Vernal ERIGERON.

Aster vernus L. Sp. Pl. 2 : 876. 1753.

Erigeron nudicaule Michx. Fl. Bor. Am. 2 : 124. 1803.

Ell. Sk. 2:392. Gray, Man. ed. 6, 266. Chap. Fl. 206; ed. 3, 226.

Carolinian and Louisianian areas. Virginia along the coast to North Carolina,

Florida, and eastern Louisiana.

Alabama : Coast plain. Flat damp pine barrens. Flowers white; f pril to June.

Frequent. Pereunial.

'Type locality: "Hab. in Virginia."

Herb. Geol. Surv. Herb. Mohr.

LEPTILON Raf. Am. Monthly Mag. 2:268. 1818.

(Ceanotus Raf. Fl. Tell. $2: 50.1836$.

Annual or biennial herbs. Asiatic and North American species, about 20.

Leptilon canadense (L.) Britton in Britt. and Br. Ill. Fl. 3: 391. 1898.

Erigeron canadensis L. Sp. Pl. 2 : 863. 1753.

Horseweed. Canada Fleabane.

Gray, Man. ed. 6, 265. Ell. Sk. 2:397. Chap. Fl. 206. Gray, Syn. Fl. N. A. 1, pt. $2: 221$.

Conlter, Contr. Nat. Herb. 2 : 198. Wats. Bot. Calif. 2 : 331.

Europe. Northern Asia. North America, throughout the continent.

Alabama: Over the State. Abundant weed. Flowers July to October.

Type locality: "Hab. in Canada, Virginia, nunc in Europa australi."

Herb. Geol. Surv. Herb. Mohr.

Leptilon divaricatum (Michx.) Raf. Fl. Tell. 2 : 265. 1818.

Erigeron divaricatus Michx. Fl. Bor. Am. 2 : 123. 1803.

Gray, Man. ed. 6, 265. Chap. Fl. ed. 3, 226. Gray, Syn. Fl. N. A. 1, pt.2:221.

Coulter, Contr. Nat. Herb. 2: 198.

Alleghenian and Carolinian areas. Indiana, Illinois to Minnesota, Nebraska, south to Colorado, Arkansas, Texas, Tennessee.

Alabama: Tennessee Valley. Pastures, waste places, meadows. Franklin County, Russellville, Lawrence County, Moulton. Flowers June to August. Adventive from the west, spreading and becoming a pernicions weed injurious to grass lands. Annual.

'Type locality: "Hab. in pratensibus Illinoensibus, prope Kaskaskia."

Herb. Geol. Surv. Herb. Mohr. 
Leptilon linifolius (Willı.) Heller, Cat. N. A. Pl. ed. 2, 212. 1900.

Evigeron linifolius Willa. Sp. Pl. 3 : 1955. 1804.

Conyza sinuata Ell. Sk. 2:323. 1821-24.

C. ambigua DC. Prodr. 5:289. 1×35.

Ell. sk. l. e. Chap. Fl. ed.3, 226. Gray, Syn. Fl. N. A. 1, pt. 2:220. Griseb. Fl. Brit. W. Ind. 365 .

Argentina to Mexico, the West Indies, and tho Southern United States.

Lonisianian area. Introlucerl from the tropies. Coast of South Carolina to Florida.

Alabaya: Coast plain to Central Prairie belt. Waste places about dwelliugs. Mobile and Montgomery counties. July to Oetober. Common. Fully naturalized. Perennial.

Type locality not given.

DOELLINGERIA Nees, Gen. \& Sp. Ast. 173. 1836.

White-flowered perennials of eastern North America. Four species.

Doellingeria umbellata (Mill.) Nees, Gen. \& Sp. Ast. 178. 1833.

Aster umbellatus Mill. Gard. Dict. ed. 8, no. 22. 1768.

Diplopappus umbellatus Hook. Fl. Bor. Am. 2 : 22.1834.

Ell. Sk. 2:367. Gray, Man. ed.6,263. Chap. Fl.ed. 3, 225. Gray, Syn. Fl. N. A.

1, pt. 2:196. Coulter, Contr. Nat. Herb. 2:196.

Boreal region to Louisianian area. Southern Labrador to the Gulf of Mexico; from

Newfoundland to Saskatchervan and south to Texas.

Alabama: Over the State. Damp shaded banks. Common.

Type locality: "From Philadelphia, where it grows naturally."

Herb. Geol. Surv. Herb. Mohr.

Doellingeria humilis (Willd.) Britton, in Britt. \& Br. Ill. Fl.3:392. 1898.

Broad-LeaF Flat-TOP White ASTER.

Aster humilis Willd. Sp. Pl. 3:2038, 1804.

Doellingeria amygdalina Nees, Gen. \& Sp. Ast. 179. 1833.

Diplopappus cornifolius Lincll. in Hook. Comp. Bot. Mag. 1:98. 1840.

D. amygdalinus Torr. \& Gray, Fl. N. A. 2:183. 1841.

Aster umbellatus latifolius Gray, Syn. Fl. N. A. 1, pt. 2:197. 1884.

Gray, Man. ed. 6, 263. Gray, Syn. Fl. 1. c. Coulter, Contr. Nat. Herb. 2: 196. Chap.

Fl. ed. $3,225$.

Carolinian and Louisianian areas. Southeastern Pennsylvania, New Jersey, along the coast to Florida, and west to Texas.

Alabana : Lower Pine region. Coast plain, banks of pine-barren streams. Mobile County. September, October. Not conimon.

Type locality: "Hab. in Pensylvania."

Herb. Geol. Surv. Herb. Mohr

Doellingeria infirma (Michx.) Greene, Pittonia, 3:52. 1896.

Aster infirmus Michx. Fl. Bor. Am. 2 : 109. 1803.

A. cornifolius Muhl.; Willd. Sp. Pl. 3 :2039. 1803.

Doellingeria cornifolia Nees, Gen. \& Sp. Ast. 181.1832.

Ell. Sk.2:366. Gray, Man. ell. 6, 263. Gray, Syn. Fl. N. A.1, pt. 2:197. Chap. Fl. ed. 3,225 .

Carolinian area. Southern New England to New Jersey, Penusylvania, western Virginia, and along the mountains to Georgia.

AlabaMa : Mountain region. Open damp woocis and copses. Cullman County. Aligust, September. Not frequent.

'Iype lorality: "Hab. a Canada ad Carolinam, per tractus montinm."

IONACTIS Greene, Pittonia, 3:245. 1897.

Perennial xerophile herbs of central aud eastern North America. Species, 3.

Ionactís linariifolius (L.) Greene, Pittonia, 3:245. 1897. Aster linariffolius L. Sp. Pl. 2 :874. 1753.

Diplopapp" 8 linariifolius Hook. Fl. Bor. Am. 2 :21. 1834.

Canadian zone to Lonisianian area. Newfonndland to Quebec; New England to Minnesota and sonth to Florida and Texas. 
Alabama: Orer the State. Dry exposed siliceous soil, open copses and woods. Rays bright blue; October, November. Common. Most common ou barren sandy ridues in the coast pine barrens.

Type locality: "Hab. in America septentrionali."

Herb. Geol. Surv. Herb. Mohr.

CONYZA L.Sp. PI. 2:861. 1753.

Conyza coulteri Gray, Syn. Fl. N. A. 1, pt. $2: 221.1884$.

Coulter, Contr. Nat. Herb. $2: 200$.

Alabama: Fugitive from the Sonthwest, on ballast. Mobile County. Observed once in Septemlier, 1890.

Tspe locality: "River bottoms, \&c., W. Texas and Colorado to Arizona and California."

Herb. Geol. Surv.

BACCHARIS L.Sp. Pl. 2: 860. 1753.

About 275 species, evergreen shrubs and undershrubs, American, chiefly of tropical aud warmer temperate South America. North America, 19; Atlantic, 3.

Baccharis halimifolia L. Sp. Pl. $2: 860.1753$.

Groundsel Tree.

Ell. Sk. 2:319. Gray, Man. ed. 6, 266. Chap. Fl. 217. Gray, Syn. Fl. N. A. 1, pt:2 : 222. Coulter, Contr. Nat. Herb. 1:200.

Carolinian to Louisianian area. Coast of New York aud New Jersey to Florida, west to Texas.

Alabana : Coast plain. Littoral belt. Fresh aud brackish marshes. Mobile and Baldwin counties. Flowers white: Octolver. Evergreen shrub, 5 to 10 feet high.

Type locality: "Hab. in Virginia."

Herb. Geol. Surv. Herb. Mohr.

Baccharis angustifolia Michx. Fl. Bor. Am. 2: 125. 1803.

NARROW-LEAF Groundser.

Ell. Sk. $2: 318$. Chap. Fl. 218. Gray, Ș̣n. Fl. N. A. 1, pt.2:222. Coulter, Contr.

Nat. Herb. $2: 200$.

Mexico.

Louisianian area. Seashore South Carolina to Florida, west to Texas and saline plains of southern Arizona.

Alabama: Littoral belt. Salt marshes. Mobile County, Navy Cove. Flowers September, October. Four to 6 feet high. Much less frequent than the last.

Type locality : "Hab. in scirpetis maritimis, a Carolina ad Floridam."

Herb. Geol. Surv. Herb. Mohr.

PLU CHEA Cass. Bull. Soc. Philom. $1817: 31.1817$.

About 30 species, of warmer regions. Four in the Southern United States.

Pluchea camphorata (L.) DC. Prodr. 5 :451. 1836.

Salt-marsh Fleabane.

Erigeron camphoratum L. Sp. Pl. 2 : 864. 1753.

Conyza camphorata Ell. Sk. $2: 321$.

Ell. Sk. 1. c. Gray, Man. ed. 6, 267. Chap. Fl.218. Gray, Syn. Fl. N. A. 1, pt. 2 :226.

Conlter, Contr. Nat. Herb. 2 : 201. Wats. Bot. Calif. $1: 335$.

Mexico, Cuba.

Carolinian and Louisianian areas. Coast of southern New England to Florida, west to Texas and Arizona; coast of California.

AlabaMa : Submaritime and Littoral region. In brackish and saline swamps. Mobile County. Baldwin Connty, shores of Mobile Bay and outlying islands. Flowers deep pink; September, October. Frequent. Annual.

Type locality; "Hab. in Virginia."

Herb. Geol. Surv. Herb. Mohr.

Pluchea petiolata Cass. Dict. Sci. Nat. $42: 2.1836 .{ }^{1}$ Strong-scented Pluchea.

Pluchea foetida DC. Prodr. 5:452. 1836. Not Baccharis foetida L.

Gray, Syn. Fl. N. A. 1, pt. 2:226, in part, as P. camphorata. Chap. Fl. ed. 3, 238. 
Two and one-half to 4 feet high, stem stont, sulcate to angled, leaves thinner and larger than in the above, from $1 \frac{1}{2}$ to 3 inches and over wide, pointed at both ends, tapering into sleuder petioles $\frac{3}{4}$ to 1 inch long; flowering heads smaller, with merely resinous-granulose (not pulescent) involucral scales. Flowers pale purplish brown.

Carolinian and Lonisianian areas. Kentucky, Indiana, Ohio, Tennessee, North Carolina to Florida, west to Mississippi.

Alabama: Orer the State. Low damp places, bauks of streams, ditches, borders of fresh-water swamps. Talladega and Tuscaloosa comnties. Lee County, Auburn (Baker \& Earle). Montgomery, Mobile, and Bald win counties; September, Oetober. Frequent. Annual.

Type locality not ascertained.

Herb. Geol. Surv. Herb. Mohr.

Pluchea foetida (L.) B. S. P. Prel. Cat. N. Y. 28. 1888.

Baccharis foetida L. Sp. Pl. 2 : 861. 1753.

B. viscosa Walt. Fl. Car. 202. 1788.

Pluchea bifrons DC. Prodr. 5 : 451.1836.

Carolinian and Louisianian areas. Coast of New Jersey to Florida, west to Texas.

Ell. Sk. 2:322. Gray, Man. ed.6, 267. Chap. Fl. ed.3, 238. Gray, Ssu. Fl. N. A. 1, pt. 2:226. Conlter, Contr. Nat. Herb. 2: 201.

Alabaya : Lower Pine region. Coast plain: Low damp places, borders of ditches and pine-barren ponds. Washington County, Yellowpine. Mobile and Baldwin counties. Flowers white; August to October. Frequent. Perennial.

Type locality: "Hab. in Virginia."

Herb. Geol. Surv. Herb. Mohr.

Pluchea adnata (Humb. \& Bonpl.).

Baccharis adnata Humb. \& Bonpl.; Willd. Enum.870. 1809.

Pluchea subdecurrens Cass. Dict. Sci. Nat. $42: 4.1826$.

Mexico.

Alabama : Adventive with ballast.

Perennial from a ligneous root; stem ascending $1 \frac{1}{2}$ to 2 feet high, corymbosely branched, winged by the decurrent base of the lanceolate, denticulate leaves, which are on the lower side glandular-punctate; flowering heads sessile, crowded on the euds of the branches. Not infrequent. Ripens the seeds and makes its alpearance one year after another in the same locality. withont spreading. Annual.

Type locality: "Hab. in America meridionali."

Herb. Geol. Surv.

PTEROCAULON Ell. Sk. $2: 323$. 1821-24. BLACK ROOT.

Two species, perennial, Sonth Atlautic North America.

Pterocaulon undulatum (Walt.).

Gnaphaliuin undulatum Walt. ' 1. Car. 203. 1788.

Conyza polystachya Michx. Fl. Bor. Am. 2: 126. 1803.

Pterocaulon polystachyum Ell. Sk. 2 : 324. 1821-24.

Ell.1. c. Chap. Fl.219. Gras, Svil. Fl. N. A. 1, pt. $2: 226$.

Lousianian area. Coast of North Carolina to Florida.

Alabama : Coast plain. Dry open grassy pine barrens. Baldwin Count,y, about the waters of Perdido Bay. Flowers white; May, June. Infrequent; not observed farther to the west.

Type locality: South Carolina.

Herb. Geol. Surv. Herb. Mohr.

ANTENNARIA Gaert. Fruct. 2 :410. 1791.

About 36 species, Europe, Asia, America. North America, 12; A tlantic, 3.

Antennaria plantaginifolia (L.) Richards. App. Frank. Jouru. ed. 2, 30. 1823.

Guaphalium plantaginifolium L. Sp. P1. 2:850. 1753.

Ell. Sk. 2:327. Gray, Man. ed. 6, 267. Chap. Fl. 243. Gray, Syn. Fl. N. A. 1, pt. $2: 233$. Coulter, Contr. Nat. Herb. $2: 202$.

Boreal region to Carolinian area. Hudson's Bay tnroughout Canada and the Atlantic United States, Florida, Louisiana, and 'Texas. 
Alabama: Monntain region to Central Pine oelt. Dry rocky or gravelly hills. Dekalb County, Lookout Mountain. Clay, Cullman, Calhoun, St. Clair, and 'Talladega connties. Flowers white; April. Common throughout the mountains and lower hills. Not observed in the low country.

Type locality: "Hab. in Virginia."

Herb. Mohr.

\section{GNAPHALIUM L. Sp. Pl. 2:850. 1753.}

One hundred and twenty species, cosmopolitan, Europe, northern Asia. North America, 15; Atlantic, 5; endemic, 4.

Gnaphalium helleri Britton, Bull. Torr. Club. $20: 280.1893$.

Britt. \& Br. Ill. Fl. 3 : 401. 1898.

Heller's Life Everlasting.

Carolinian area. Southeastern Virginia aud along the mountains to Georgia.

Alabava: Monntain regiou. Open woods and copses. Dekalb County, Lookout Mountain, 1,800 feet, near Mentone. Flowers September; apparently not rare.

Similar to G. obtusifolium, from which, however, it is at once distinguished by the close, densely glandular, not tomentose, pubescence.

Type locality: "In fields, Southeastern Virginia (Heller) to Georgia (Boykin)."

Gnaphalium obtusifolium L. Sp. Pl. 2:851. 1753.

SweEt Life Everlastixg.

Ginaphalium polycephalum Michx. Fl. Bor. Am. 2:127. 1803.

Ell. Sk.2:325. Gray, Man.ed.6, 268. Chap. Fl.243; ed.3, 239. Gray, Syn. Fl. 1, pt. $2: 234$.

Canadian zone, Alleghenian to Louisianian area. Nova Scotia, Quebec, Ontario; New England west to Minnesota, south to the Gulf, from Florida to Texas, Arkansas, and Missouri.

Alabana: Over the State. Dry borders of woods, pastures, old fields. Flowers white; July to October. Frequent. Annual.

Economic uses: The herb, "life everlasting," is used in dom sati ? medicia :

Type locality : "Hab. in Virginia, Pensylvania."

Herb. Geol. Surv. Herb. Mohr.

Gnaphalium purpuseum L. Sp. P1. 2 : 854. 1803.

Purple Cudwed.

Ell. Sk. 2:325. Gray, Mau. edl. 6, 269. Chap. Fl. 243. Gray, Syn. Fl. N. A, 1, pt.

$2: 236$. Coulter, Contr. Nat. Herb. $2: 203$.

Mexico.

Alleglenian to Louisianian area. British Colnmbia; southern New England to Florida, west to Texas, Arkansas, and Missouri.

Alaba.na: Over the State. In light exposed soil, waste and cultivated places. An annual or bienuial winter weel.

Type locality: "Hab. in "Carolina, Virginia, Pensylvania."

Herb. Geol. Surv. Herb. Mohr.

Gnaphalium spathulatum Lam. Encycl. 2 : 758. 1786.

To this species is somewhat doubtfully referred the sonthern form included by late anthors in the last, but which is at once recognized as distinct by the loose and longer, persistently arachnoid, wool covering the stem and leaves. The stem is mostly simple from the perennial root; the leaves are rather thin, green above but slightly cinereous beneath, broadly spatulate; the lower clusters of the flowering heads, borne on shorter or longer peduncles, form a conspicnously leafy racemose inflorescence. The inner involncral seales are linear, acute, and shining.

West INDies, South AMerica.

Louisianian area.

Alabalia: Prairie region to Coast plain. Montgomery and Mobile counties; waste grounds, roadsides, and pastures, near dwellings. Probably introduced from the tropics and perfectly naturalized. Flowers white; throughout the summer. Not infrequent.

Type locality: "Nous ignorons sou lieu natal; mais nous la soupçonnons d'Amérique. * * * Pent-être vient elle du Cap de Bonne Espérance."

Herb. Geol. Surv. Herb. Mohr.

POLYMNIA I.Sp. Pl. 2:926. 1753.

Ten to 12 species, perennial herbs, American, from Argentina to Canada. North America, 2.

Polymnia canadensig L. Sp. P1. 2 :926. 1753.

Canada Leaf-cup.

Ell. Sk. 2:471. Gray, Man. ed.6, 269. Chap. Fl. 219. Gray, Syn. Fl. N. A. 1, pt. $2: 238$. 
Alleghenian and Carolinian areas. Ontario and sonthern New England, west to Minnesota; Ohio Valley to Missouri, Kansas, and Arkansas, and south along the mountains to South Carolina.

Alabana : Mountain region. Rich wooded hills. Nekalb County, Mentone, 1,800 feet altitude. Madison County, Montesano, 1,500 feet altitude. Clay County, rocky banks Talladega Creek, 1,000 feet altitude. Flowers yellowish white; May. Not frequent.

Type locality: "Hab. in Canada. Kalm."

Herb. Geol. Surv. Herb. Molır.

Polymnia canadensis radiata Gray, Sṛn. Fl. N. A. 1, pt. 2 : 238. 1884.

Carolinian area. Illinois, Arkansas, and Kansas.

Al.ABAira: Monntain region. Madison Connty, flank of Montesano, on limestone rocks. Clay Connty. Flowers sordid yellow; not frequent.

Type locality: "Extends to Hot Springs, Arkansas, F. L. Harrey."

Herb. Geol. Surv. Herb. Mohr.

Polymnia uvedalia L. Sp. Pl. ed. 2, 2 : 1303. 1763.

Bear Foot.

Ell. Sk. 2:471. Gray, Man. ed. 6, 270. Chap. Fl. 219. Gray, Syn. Fl. N. A. 1, pt. $2: 238$. Coulter, Contr. Nat. Herb. $2: 204$.

Carolinian and Louisianian areas. Western New York, Pennsylvania, west to Missouri and Arkansas, south to Genrgia and Florida.

Alabama : Tennessee Valley to Coast plain. Shady borders of woods, copses, in rich soil. Lauderdale County, Florence (M.C. Wilson). Tuscaloosa, Montgomery, Clarke, Baldwin, and Mobile counties. Flowers yellow; April, May.

Economic uses: The root, called "bear foot," is used in domestic medicine Type locality: "Hal, in Virginia."

Herb. Geol. Surv. Herb. Mohr.

SILPHIUM L. Sp. Pl. 2 :919. 1753.

About 12 or 13 species, peremnial herbs. Temperate Eastern North America.

Silphium laciniatum L. Sp. Pl. $2: 919.1753$.

Compass Plant.

Silphium gummiferum Ell. Sk. 2 :460. 1821-24.

Ell. Sk. l.c. Gray, Man. ed. 6, 270. Chap. Fl. 220. Gray, Syn. Fl. N. A. 1, pt. 2: 242.

Conlter, Contr. Nat. Herb. 2 : 205.

Alleghenian to Louisianian area. Dakota, Minnesota, Olio to Missouri, drkansas, and Colorado; south from Tennessee to Georgia, west to Texas.

Ala bama: Prairie region to Lower division of Coast Pine belt. Montgomery County, prairies on Pintlalla Creek. Monroe County, Claiborne. Flowers July, August; not rare.

Type locality: "Hab. in America septentrionali, Mississippi. Collinson."

Herb. Geol. Surr. Herb. Mohr.

Silphium terebinthinaceum Jacq. Hort. Viudeb. 1:t.43. 1770. PRaIrie Dock.

Ell. Sk. 2:463. Gray, Man. ed. 6, 270. Chap. Fl. 220. Gray, Syn. Fl. N. A. 1, pt. $2: 242$.

Allegheuian and Carolinian areas. Ohio, Michigan, west to Dakota, Nebraska, south to Arkansas, and from Kentncky along the mountains to Georgia.

Alabana: Lower hills. Grassy openings, borders of fields. Calboun County, Weaver (E. A. Smith). August; local and rare.

Type locality unknown ("Patriam ignoro").

Silphium compositum Michx. Fl. Bor. Am. 2 : 145. 1803. SOUtherN Rosinweed.

Ell. Sk. 2:462. Chap. Fl.220; ed.3,241. Gray, Syn. Fl. N. A. 1, pt. 2:241.

Carolinian and Lonisianian areas. North Carolina, along the monntains to Georgia.

Alabama: Mountain region to Central Pine belt. Drs gravelly or rocky ridges. Cullman Connty. Tuscaloosa County, 450 fect altitnde. Clay Connty, 2,000 feet altitude, barren pine ridges. Talladega, Tallapoosa, and Chilton counties. Flowers Jnly, August; frequent; most abundant thronghout the arid siliceons pine-clad rilges of the Metamorphic region.

Varies greatly in form and size of the leares, from ovate pinnatisected (S. compositum var. michauxii Torr. \& Gr.) to rotund; or nniform, cordate, more or less lobed (S. compositum var. reniforme Torr. \& Gr.), and broadly ovate subcordate unequally and obtusely toothed (S. compositum var. ovalifolium Torr. \& Gr.).

Type locality: "Hab. in sylvis maritimis, a Carolina ad Floridam."

Herb. Geol. Surv. Herb. Mohr. 



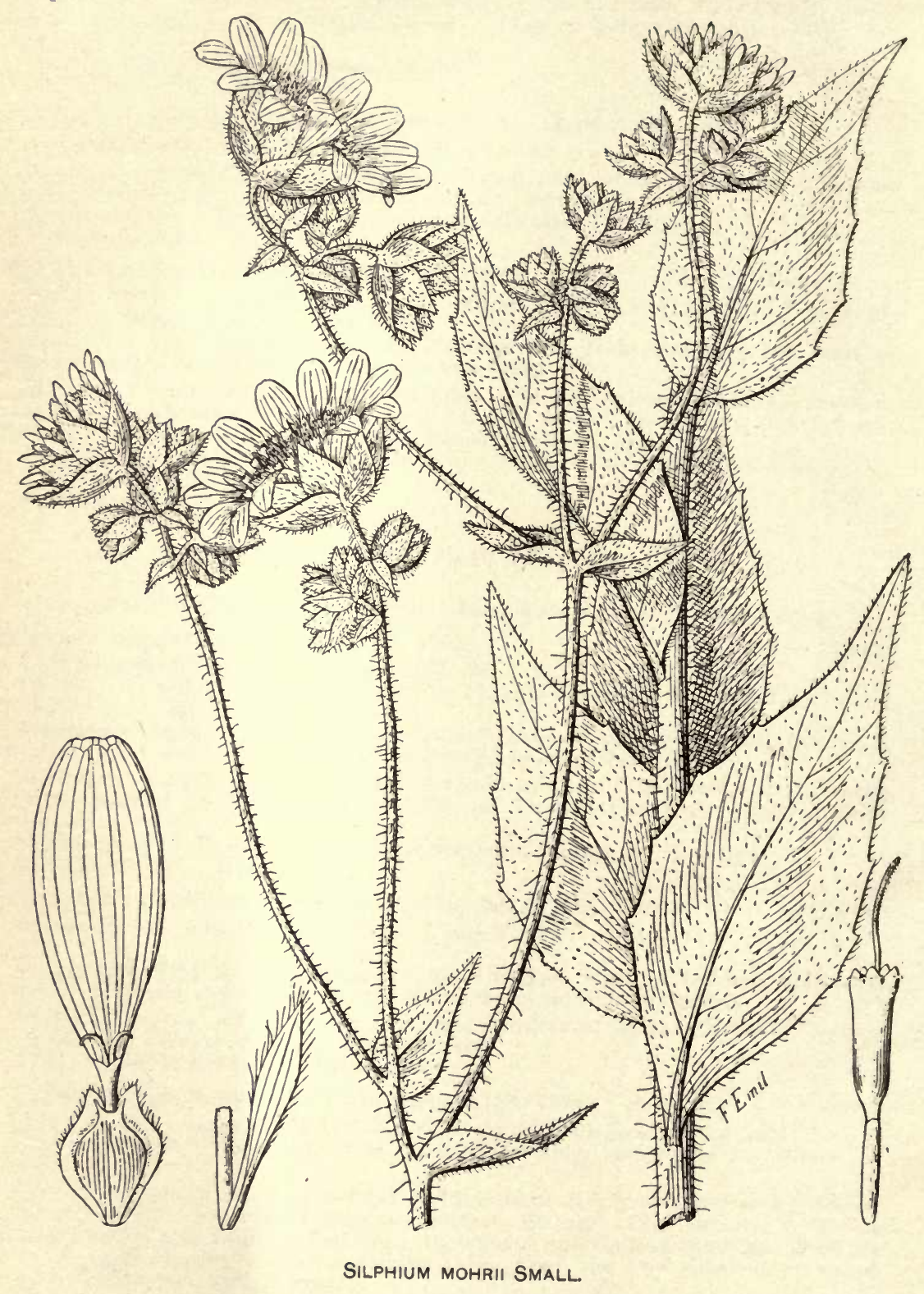




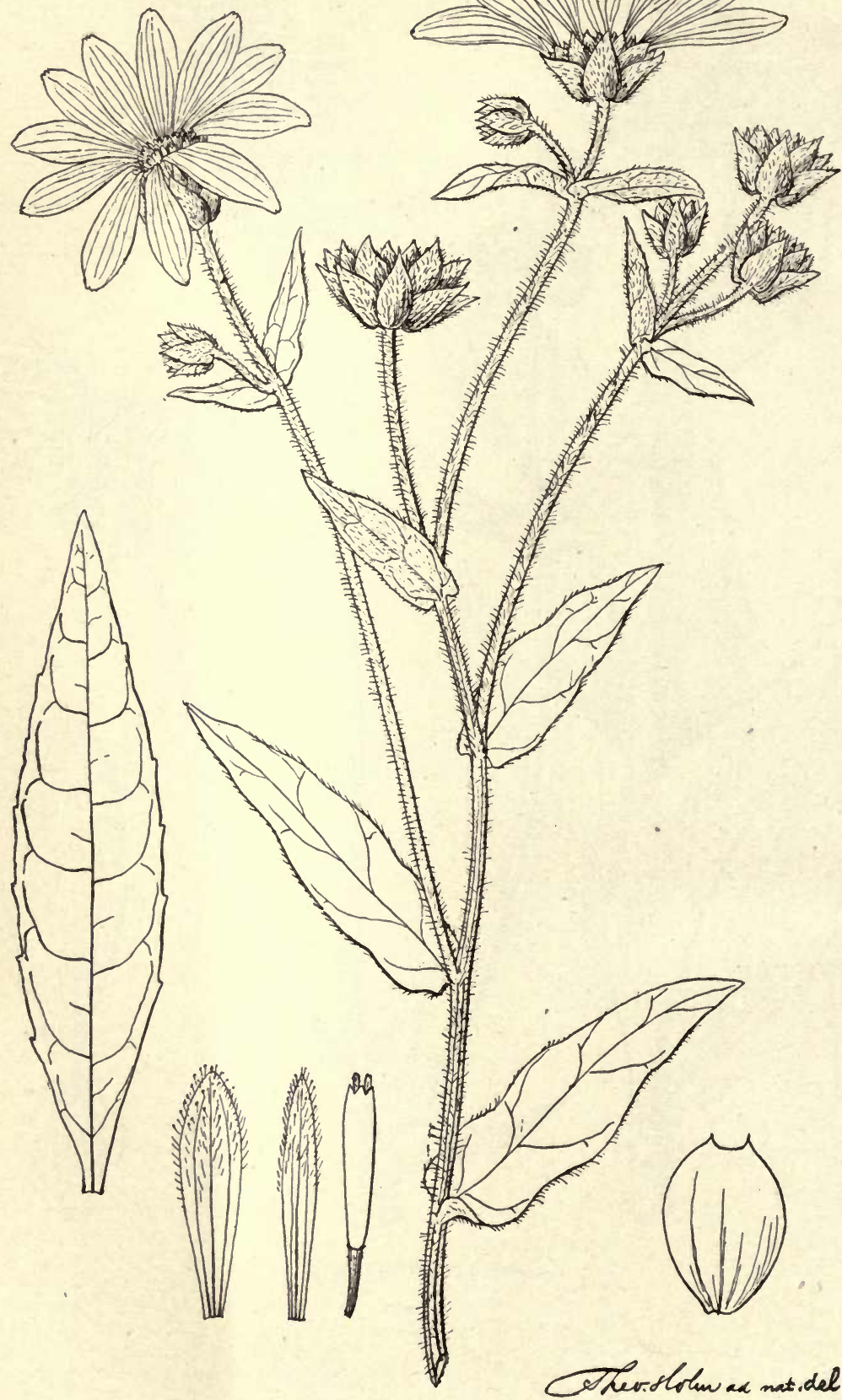

Silphium gatesil MOHR. 
Silphium radula Nutt. Trans. Am. Phil. Soc. 7 :341. 1834.

S. scaberrimum var. Torr. \& Gray, Fl. N. A. 2:279. 1842.

Gray, Sy:ı. Fl. N.A. 1, pt. 2:240. Coulter, Contr. Nat. Herb. $2: 205$.

Carolinian and Louisianian areas. Southern Arkansas, Texas, and Louisiana.

Alabaya : Mountain region. Grassy glades; dry borders of fieldis. Clay County, Mount Olive, 1,500 feet altitude. July, August; frequent.

Type locality: "Covington," Louisiana (Drummond).

Herb. Geol. Surv. Herb. Mohr.

Silphium scaberrimum Ell. Sk. 2 :466. 1824.

Scaibrous Rosinweris.

Ell. Sk. l.c. Gray, Syn. Fl. N. A. 1, pt. 2: 240. Conlter, Contr. Nat. Herb. $2: 20$ Ј.

Carolinian and Lonisianian areas. Western Georgia to Louisiana, Arkansas, and Texas.

Alabama: Central prairies. Upper division Coast Pine belt. Prairies, Wilcox County? (Buckley). Monroe County, Claiborne. Lee County, Auburn (Baker \& Earle). Etowah Connty, Gadsden (G.R. Tasey). July; infrequent.

Type locality : "Grows in the western districts of Georgia."

Herb. Geol. Surv. Herb. Mohr.

Silphium mohrii Small, Bull. Torr. Bot. Club, 24:493. 1897. MoHR's Rosinweed.

Perennial, coarse, very hispid thronghont with shagg $y$ hairs. Stem erect, $2 \frac{2}{8}$ to $3 \frac{1}{3}$ ft.tall, simple below, branched above, finely-channeled in age; leaves alternate, ovate-lauceolate, or narrowly ovate-lanceolate, or normally ovate, 2 to 6 in. long, acuminate at the apex, remotely serrate with prominen teeth, except near the base or apex, sessile or nearly so; heads $1 \frac{1}{8}$ to $1 \frac{2}{8}$ in. broad, pediceled; involncres broadly campanulate, the bracts lanceolate to ovate-lanceolate, 4 to 7 lines long, acute or somewhat acuminate; corollas about $4 \mathrm{~mm}$. long, the segments ovate, rather obtuse; rays yellow, elliptic-oblong, 5 to 7 lines long, undulately 3 -toothed at the apex; achenes obovate, more or less constricted at both ends, about 3 lines long, winged.

Exposed rocky declivities. Cullman County.

A very distinct species of the much confused genus Silphium, related to what I understand as S. asperrimum Hook., hitherto called S. scaberrimum. It can easily be distinguished by the copious shaggy pubescence which clothes the foliage up to the flowers. The peculiarly toothed leaves with their less rounded bases and the smaller heads with their narrow bracts and shorter rays are additional diagnostic characters.

"The species is named in bonor of Dr. Charles Mohr."

Carolinian area. Tennessee (Gattinger).

Alabama: Mountain region. Exposed rocky declivities. Cullman Connty. October, 1894. Rare.

Type loçality: "In dry or rocky soil, Cullman, Alabama, October, 1885."

Herb. Geol. Surv. Herb. Mohr.

\section{Silphium gatesii sp. nov.}

Stem $2 \frac{1}{2}$ to 3 feet high, terete, hispid-pilose throughout with long white hairs jointed above the inflated papillose base, above the middle more or less covered by short flat tawny hairs forming on the upper part of the stem and the branches a close tomentiı!; leaves all alternate, acutish, scabrous above, paler and less harsh beneath, the radical and lower cauline leaves 6 to 8 inches long, $\frac{1}{2}$ to $\frac{8}{4}$ inch wide, narrowed at the base into a slender winged petiole one-third of the length of the sparsely sinuatedentate leaf blade, the upper sessile with a more or less cordate base, sparsely denticulate or entire; corymbose branches erect-spreading; flowering heads more or less numerous, large; involucral bracts tomentose-hairy on the outside, scabrous-hirsute above, hispidulons-ciliate, oblong-acute, the outer longer then the disk; rays nearly $1 \frac{1}{2}$ inches long, golden yellow; achenes obovate, rither oblong, narrow-winged, slightly enarginate, teeth minute or wanting.

Plate XIII.

Resembles narrow-leaved forms of $S$. asteriscus, from which it is distinguished at once by the peculiar pubescence, the thinner narrower leares, and the oblong-ovate achenes almost or entirely destitute of teeth. There is a form with broad leaves und wing.

Named in commemoration of Hezekiah Gates of Mobile, one of the earliest contrib. utors of Alabama plants to Torrey and Grar's Flora of North America, to whom Dr. Gray dedicated his genus Gatesia, a name found untenable and lately replaced by Yatesia.

Carolinian area. 
AtabaMa: Momntain region. Cullman County, growing on gravelly borders of fields, with $S$. mohrii, blooming about two months earlier. May $28,1895$.

Trpe locality as just given.

Herb. Nohr.

Silphium asteriscus L. Sp. Pl. 2 : 920. 1753.

Common Rosinweed.

Ell. Sk. 2:469. Gray, Man. ed. 6, 270. Chap. Fl. 220. Gray, Syn. Fl. N. A. 1, pt.

$2: 241$.

Carolınian and Lonisianian areas. North Carolina to Florida and Louisiana.

Alabama: Over the State. Dry rocky or gravelly open woods and copses. Clay County, Shinbone Valley, 1,000 feet altitude. Cullman County. Montgomery and Mobile counties.

Type locality: "Hab. in Virginia, Carolina."

Silphium asteriscus angustatum Gray, Syn. Fl. N. A. ed. 2, 1, pt. 2: 449. 1886.

Lonisianian area. Western Florida.

Alabana: Pine region. Grassy open pine woods. Baldwin and Mobile counties.

Flowers June, July. Not frequent.

Typo locality: "Chat tahooche, Florida, A. H. Curtiss."

Herb. Geol. Surv. Herb. Mohr.

Silphium dentatum Ell. Sk. 2 : 468. 1821-1824.

Silphium asteriscus var. scabrum Nutt. Gen. 2 : 183. 1818.

S. asteriscus laericaule DC. Prodr. 5:512. 1836.

S. asteriscus var. dentatum Chap. Fl. 221. 1860.

Ell. Sk.1. c. . Gray, Syn. Fl. N. A. 1, pt. 2: 241. Chap. Fl. ed. 3, 241.

Alabaya: Mountain region to Central prairies. Rocky dry woods, open copses. Talladega County, Riddell's Mill. Montgomery County, bald rocky prairies, Pintlalla Creek. Wilcox County (Buckley). Lee County, Anburn (Baker \& Earle, 283).

In our specimens the stem is glabrous throughout, the leaves are ovate-lanceolate acute, pilose, scabrons above, softer and paler underneath, thin; the lower opposite on short hirsute petioles, the upper sessile, alternate. Bracts of the involncre smooth, ciliate, the inuer broadly orate; by this character the species becomes widely remote from $S$. asteriscus, with which it has by most botanists been connected.

Type locality: "Grows in the western districts of Georgia."

Herb. Geol. Surv. Herb. Mohr.

Silphium trifoliatum L. Sp. Pl. 2: 920. 1753.

Silphium ternifolium Michx. Fl. Bor. Am. 2 : 146. 1803.

EII. Sk. 2: 466. Gray, Mall. ed. 6, 270. Chap. Fl. 220. Gray, Syn. Fl. N. A. 1, pt. 2: 241 .

Carolinian and Louisiauian areas. Pennsylvania to Ohio, sontb to Tennessee and upper Georgia.

AlabaMa : Mountain region to Central prairies. Margins of fields and rich open copses. Clay County, Mount Olive. Cullman County. Montgomery County, Pintlalla Creek. Blount County, Blount Springs. Flowers, July, August; 5 to 6 feet high. Not infrequent.

Type locality: "Hab. in Virginia."

Herb. Geol. Surv. Herl. Mohr.

Silphium laevigatum Pursh, Fl. Am. Sept. 2: 578. 1814.

Silphium trifoliatum latifolium Gray, Syn. Fl. N. A. 1, pt. 2: 241.1884.

Ell. Sk. 2: $46 \pi$. Gray, Syn. Fl. l. c.

Carolinian area. Lower South Carolinia and middle Georgia.

AlabaMa : Mountain region. Open woods. Walker County, South Lowell. Blount and Cullman counties. Lee County, Auburn (Baker \& Earle, 284). Flowers June to August. Not rare.

Considering that $S$. integrifolium is not found in the lower parts of the Sonthern States, and that the clescription of Pursh is founded on Enslen's plant collected in western Georgia, there can be no donbt about its identity with the plant clescribed by Elliott under the same name; accordingly Pursh's name is to be kept up.

In view of the many donbtful forms which occur in the southern extension of the Allegheny Mountains, and which have been either described as distinct species or consillered as varieties and often confounded with one another, it is not withorit hesitation that the forms regarded as new by the writer are here introduced, especially when confronted by the confusion of the nomenclature of this group.

Typo locality: "In Georgia. Enslen."

Herb. Geol. Surv. Herb. Mohr. 
ACANTł.USPERMUM Schrank. Pl. Rar. Hort. Monac. 2:t. 53. 1819.

Four species, annuals, Sonth America.

Acanthospermum australe (L.).

Melampodium australe L. Sp. Pl. ed. 2, 2 : 1309. 1763.

Acanthospermum brasilum -chrank. Pl. Rar. Hort. Monac. $2: t$. 53. 1819.

Centrospermum xanthioides H. B. K. Nov. Gen. \& Sp. 4:271. 1820.

Acanthosper'mum xanthioides DC. Prodr. 5:521. 1836.

Chap. Fl. Suppl. 628; ed. 3, 240. Gray, Syn. Fl. N. A. 1, pt. 2: 239. 1884.

Soutir America to Brazil.

Louisianian area. Adventive in South Carolina and Florida.

Alabana : Lower Pine region. Coast plain. Waste ground; aloug railroad tracks. Escambia and Mobile counties. Flowers greenish white; June to October. A frequent ballast weed. Reported from Lee County, Auburn.

'Type locality: "Hab. in Cumana."

Herb. Geol. Surv. Herb. Mohr.

Acanthospermum humile (Sw.) DC. Prodr. 5:522. 1836.

Melampodium humile Sw. Prodr. Veg. Ind. Oce. 114. 1785.

Chap. Fl. ed. 3, 240. Gray, Syn. Fl. N. A. 1, pt. $2: 240$.

West INDIES TO BRAZIL.

Louisianian area. Adrentive. Ports of western Florida and occasionally at New York and Philadelphia.

AlabaMa: Ballast grounds. Mobile County. July to October. Obnoxious and persistent ballast weed, spreading slowly along the river front.

Type locality: "Jamaica, Domingo."

Herb. Geol. Surv. Herb. Mohr.

BERLANDIERA DC. Prodr. 5 :517. 1836.

Four species, perennials, South Atlantic North America and adjoining Sonoran (Texano-Mexican) region. South Atlantic, 2.

Berlandiera pumila (Michx.) Nutt. Trans. Am. Phil. Soc. ser. 2, $7: 342$. 1840.

Silphium pumilum Michx. Fl. Bor. Am. 2 : 146. 1803.

DOWNY BERLANDIERA.

Berlandiera tomentosa Nutt. Trans. Am. Phil. Soc. ser. $2,7: 343.1840$.

Ell. Sk. $2: 469$. Chap. Fl. 221. Gray, Syn. Fl. N. A. 1, pt. 2:243. Coulter, Contr.

Nat. Herb. $2: 206$.

Louisianian area. North Carolina to Florida and Arkansas.

AlabaMa : Coast plain. Sandy pine forests. Baldwin County, Blackwater River.

Flowers yellow; July. Rare.

Type locality: "Hab. in Florida."

Herb. Geol. Surv. Herb. Mohr.

CHRYSOGONUM L.Sp. Pl. 2 :920. 1753.

One species, Atlantic North America.

Chrysogonum virginianum L. Sp. Pl. $2: 920$. 1753.

Golden DaIsy.

Ell. Sk. 2:472. Gray, Man. ed. 6, 271. Chap. Fl. 219. Gray, Syn. Fl. N. A. 1, pt. $2: 243$

Carolinian and Louisianian areas. Southern Penusylvania to Florida and Louisiana.

AlabaMa : Lower Pine region. Coast plain. Dry open woods. Mobile Connty, sandy pine ridges. Flowers golden yellow; March, April. Not common. Perennial, Type locality: "Hab. in Virginia."

Herb. Geol. Surv. Herb. Mohr.

PARTHENIUM L.Sp.Pl. $2: 988.1753$.

Ten species, perennials, West Indies, Mexico. North America, 7.

Parthenium hysterophorus L. Sp. Pl. 2:988. 1753.

Chap. Fl. 222. Gray, Syn. Fl. N. A. 1, pt. 2: 244. Conlter, Contr. Nat. Herb. 2 : 207.

West Indies, Mexico.

Louisiauian area. Florida to Lonisiana. Most probably naturalized from the Tropics. 
Alabama: Coast plain. Waste places near dwellings. Common in the streets of Mobile. Flowers white; June, July. Anuual.

Trpe locality: "Hab. in Jamaicae glareosis."

Herb. Mohr.

Parthenium integrifolium L. Sp. Pl. 2:988. 1753.

Ell. Sk. 2:474. Gray, Man. ed. 6, 272. Chap. Fl. 222. Gray, Syn. Fl. N. A. 1, pt. $2: 245$. Coulter, Contr. Nat. Herb. $2: 208$.

Carolinian area. Maryland, Virginia west to Missouri? and Arkansas; along the mountains to Georgia.

Alabama: Mountain region. Dry barren woodlands. Clar Countr, Emerson's Gap, 1,800 feet. Tallapoosa, Cherokee, Lee, and Cullman counties. Flowers white; July, August. Most frequent on the harren Metamorphie hills. Perennial.

Type locality: "Hab. in Virginia."

Herb. Geol. Surv. Herb. Molir.

HELIOPSIS Pers. Syn. 2 :473. 1807.

Seven species. Perennials. Mexico, Central America. North America, 4.

Heliopsis minor (Hook.)

SMaller OXEYE.

Heliopsis laevis var. minor Hook. Comp. Bot. Mag. 1:98. 1835.

H. gracilis Nutt. Trans. Am. Phil. Soc. n. ser. 7:353. 1840.

H. laevis var. gracilis Torr. \& Gray, Fl. N. A. 2:303. 1842.

Chap. Fl. ed. 3, 247. Gray, Syu. Fl. N. A. 1, pt. 2: 255.

Carolinian and Lonisianian areas. Georgia, to western Florida, Lonisiana, and Arkansas.

Alabaya: Mountain region. Lower hills. Thickets and shadr woods. Clay County, Delta divide, 1,800 feet altitude. Cullman County. Blount County (J.I). Simith). Tuscaloosa Connty. Flowers sellow; July, August. Tro to 4 feet high; branched from the base.

Type locality: "Covington, N. Orl."

Herb. Geol. Surr. Herb. Mohr.

Heliopsis helianthoides (L.) B. S. P. Prel. Cat. N. Y. 28. 1888.

Buphthalmum helianthoides L. Sp. P1. 2:904. 1753.

Heliopsis laexis Pers. Syn. 2 : 473. 1807.

Ell. Sk. 2 :407.' Gray, Man. ed. 6, 275. Chap. Fl. 225.

Carolinian area. Southern Ontario and New York, west to Missouri and Arkansas, and from New Jersey sonth along the mountains to Georgia and Mississippi.

Alabama: Mountain region. Dry open woods. Lee County, Auburn (Baker of Earle, 289). Cullman County. Flowers yellow; July; not frequent.

Type locality: "Hab. in America septentrionali.

Herb. Geol. Surv. Herb. Mohr.

ECLIPTA L. Mant. $2: 157$. 1771.

About 4 species, tropical regious both hemispheres.

Eclipta alba (L.) Hassk. Pl. Jav. Rar. 528. 1848.

Verbesina alba L. Sp. Pl. 2:902. 1753.

Eclipta erecta L. Mant. $2: 286.1771$.

E. procumbens Miehx. Fl. Bor. An. 2:129. 1803.

Eil. Sk. 2:403 Gray, Man. ed.6, 275. Chap. Fl. 224. Gray, Srn. Fl. N. A. 1, pt. 2:

256. Conlter, Contr. Nat. Herb. 2:213. Griseb. Fl. Brit. W. Ind. 370.

All Tropical Coustries.

Carolinian and Louisianian areas. New Jersey, Virginia, Ohio Valley to Missouri, Arkansas, sonth to Florida and Texas.

AlabaMa: Tennessee Valley to Coast plain. In cultivated ground. June to September. Common. Annual.

'Type locality : "Hab. in Virginia, Surinamo."

Herb. Geol. Surr. Herb. Mohr. 
MELANTHERA Rohr. Skriv. Nat. Selsk. Kjöb. 2 :213. 1792.

Abont 8 species in warmer Africa and America. North America, 3. South Atlantic. Melanthera hastata (Walt.) Michx. Fl. Bor. Am. 2 : 107. 1803.

Athanasia hastata Walt. Fl. Car. 201. 1788.

Halberd-leaf Melanthera.

Ell. Sk. 2:314. Chap. Fl. 225. Gray, Syn. Fl. N. A. pt. 1, 2: 257.

West Indies, Mexico.

Louisianian area. Coast of South Carolina to Florida and Louisiana.

Alabama: Coast plain. Damp thickets and borders of woods. Mobile County, muddy banks. Perennial.

Type locality: Sonth Carolina.

Herb. Geol. Surv. Herb. Mohr.

SPILANTHES Jacq. Stirp. Am. t. 214. 1763.

About 40 species, perennials, tropical zones both hemispheres, largely American, West Indies to Brazil. North America, 1.

Spilanthes repens (Walt.) Michx. El. Bor. Am. 2 : 131. 1803.

Anthemis repens Walt. Fl. Car. 211. 1788.

Creeping Spilanthes. Acmella repens Ell. Sk. 2: 406.1824.

Ell. sk.1.`. Chap. Fl. 237. Gray, Syn. Fl.N.A. 1, pt.2:258. Coulter, Contr. Nat. Herb. 2 : 214 .

Louisianian area. South Carolina to Florida, Texas, and Arkansas.

ALABAMA : Coast plain. Low damp places, damp thickets, and cultivated ground. Baldwin and Mobile counties. Flowers deep yellow; August to October. Common. Type locality: South Carolina.

Herb. Geol. Surv. Herb. Mohr.

RUDBECKIA L.Sp. PI. 2 :906. 1753.

About 30 species, chiefly perennials, Mexico, North America. Atlantic, 19.

Rudbeckia triloba L. Sp. Pl. 2:907. 1753.

MayY-Flowered CONe-Flower. Ell. Sk. 2 :452. Gray, Man. ed. 6, 276. Chap. Fl. 227. Gray, Syn. Fl. N. A. 1, pt. $2: 259$.

Carolinian and Louisianian areas. Pennsylvania and Ohio to Missouri and Michigan, south along the mountains to Georgia and middle Florida, west to Louisiana and Arkansas.

ALABAMA: Mountain region to Central Prairie region. Thickets, fence rows. Talladega and Montgomery connties. Rays golden yellow, disk purplish black; August, September. Not infrequent. Bienuial.

Type locality: "Hab. in Virginia."

Herb. Geol. Surv. Herb. Mohr.

Rudbeckia hirta L. Sp. Pl. 2 : 907. 1753.

Rovgh-STEMMed Cone-Flower. Ell. Sk. 2:457. Gray, Man. ed. 6, 276. Chap. Fl.227. Gray, Syn. F1. N. A. 1, pt. $2: 260$. Coulter, Contr. Nat. Herb. $2: 215$.

Alleghenian, Carolinian, and Lonisianian areas. Southern Ontario and northwestern New York to the Ohio Valley and Missouri; south from New Jersey to Florida, west to Texas and Arkansas.

AlabaMa: Tennessee Valley to the Coast plain. In dry light soil, open woods. Rays yellow, frequently orange at base, disk purplish black; June to September. Common; abundant throughout the pine woods. Biennial.

Type locality: "Hab. in Virginia, Canada."

Herb. Geol. Surv. Herb. Mohr.

Rudbeckia monticola Small, Torreya, 1: - 1901.

Britt. \& Br. Ill. Fl. 3: 416. 1898.

Carolinian area. Mountains of North Carolina to Georgia, Alabama, etc.

AlamaMa: Mountain regiou. Copses and woods. Dekalb County, Lookont Mountain, near Mentone, 1,800 to 2,000 feet altitude. Flowers golden yellow; September. Rare.

Type locality: "Georgia: Estotoah Falls, Angust 11-12, 1893, Small (type)." 
Rudbeckia fulgida Ait. Hort. Kew, $3: 251.1789$.

GOIDEN CONE-FLOWER.

Rudbechia chrysomelu Michx. Fl. Bor. Am. 2 : 143. 1803.

R. discolor Ell. Sk. $2: 454$. 18:1-24. (?)

Ell. Sk. 1.c. Gras, Mau. ed.6, 276. Chap. Fl.227. Gray, Syu. Fl. N. A. 1, pt. 2: 260.

Coulter, Contr. Nat. Herb. $2: 215$.

Carolinian and Louisianian areas. New Jersey, Pennsylvania, Virginia, Ohio Val-

ley to Missouri and Arkausas, sonth along the monntains to Georgia, Florida, and Texis.

Aldana : Central Prairie region. Dry woods. Montgomery County (J. Douncll Smith). Flowers July, August; infrequent. Perennial.

Type locality: "Native of North America."

Herb. Geol. surv. Herb. Mohr.

Rudbeckia spathulata Michx. Fl. Bor. Am. 2: 144. 1803.

Field Cone-flower. Ell. Sk. 2 : 455. Gray, Man. el. 6, 276. Chap. Fl. 227. Gray, Syn. Fl. N. A. 1, pt. $2: 261$.

Cilrolinian and Louisianian areas. Virginia and Tennessee to Georgia and middle Florida.

Arabama: Mountain region. Coast plain. Open wools, copses, and dry fiells. Cullman, 'Talladega, Clay, and Lee comnties. Mobile Counts, uear Whistler, in the pine barrens. Flowers August, September. Common in the upper distriets, rare in the Coast Piue Belt. Perenuial.

Trpe locality: "Hab. in montibus Carolinae."

Herb. Geol. Surv. Herlb. Mohr.

Rudbeckia heliopsidis Tord. \& Gray, Fl. N. A. 2:310. 1842.

Chap. Fl. 227. Gray, Srn. F1. N. A. 1, pt. 2: 261.

Carolinian area. Georgia.

Alabama: Mountain region. Open woods in light sands soil. Dry pine forests. Cherokee County (Buckley). Lee County (J. Donnell Smith). Dekalb County on Lookont Mountain, Mentone. Angust, September. Local and rare. Perennial.

Type locality: "Pine wools, \&c., $\alpha$. Columbus, Georgia, Dr. Boykin! $\beta$. Cherokee country of Alabama, in wet places, Mr. Buckley!."

Herb. Geol. Surv. Herb. Mohr.

Rudbeckia laciniata L. Sp. Pl. 2 :906. 1753.

TALl CONE-FLOWER.

Ell. Sk. 2:451. Gray, Man. ed.6, 276. Chap. Fl. 227. Gray, Ș̣n. Fl. N. A. 1, pt. $2: 262$.

Alleghenian and Carolinian areas. Quebec and Ontario to Manitoba; New York to Minuesota; Ohio Valley to western Missouri, Arkansas, New Mexico, and Arizoun; sonth from New Jersey to Georgia.

Alabama: Mountain region. Bottom lands, rich banks. Clay County, Talladega Creek, 1,000 feet. Flowers canary-yellow; August, September. Six to 8 feet high. Not rare. Perenuial.

'Type locality: "Hab. in Virginia, Canada."

Herb. Geol. Surv. Herb. Mohr.

Rudbeckia laciniata humilis Gray, Syn. Fl. N. A. 1, pt. 2:262. 1884.

Alleghenian and Carolinian areas. Allegheny Mountains, Virginia to Georgia.

Ala Bama: Mountain region. Talladega County, Riddell's Mill, 1,500 feet altitude.

Lee Counts, Auburn (Baker \& Earle). Infrequent. Perennial.

Type locality: "Mountains of Virginia, Georgia."

Herb. Mohr.

Rudbeckia amplexicaulis Vahl, Skriv. Nat. Selsk. Kjöb. 2, pt. 2:29, t.4. 1793.

Dracopis amplexicanlis Cass. Diet. Sci. Nat. $35: 273.1836$.

Gray, Syll. Fl. N. A. 1, pt. 2:263. Conlter, Contr. Nat. Herb. $2: 214$.

Lonisianian area. Westeru Texas, Arkansas, and Louisiana.

AlabaMa: Central prairies. Coast plain. Low fields, waste places. Dallas County, Marion Junction, borders of low fields, with Gaillardia pulchella and other prairie plants. Mobile County, waste places; adventive from the South west. Annual

Type locality not ascertained.

Herb. Geol. Surv. Herb. Mohr.

Rudbeckia glabra DC. Prodr. 5:556. 1836.

SMOOTH CONE-FLOWER.

Rudbeckia nitida var. longifolia Gray, Syn. Fl. N. A. 1, pt. 2:262.

Louisianian area. Georgia to Florida.

Alabama : Central Pine belt. "Tuskegee, Beaumont." Not collected recently.

Type locality : "In Georgia, cirea Savannah?" 
RATIBIDA Raf. Am. Month. Mag. 2 : 268. 1818.

(Lepachys Raf. Jomru. Phys. 89:100. 1819.)

Four species, North America, chiefly sonthwestern. Atlantic, 1.

Ratibida pinnata (Vent.) Barnhart, Bull. Torr. Club, 24:410. 1897.

liudbeckia pinnata Vent. Jard. Cols. t.71. 1800.

Lepachys pinnata Torr. \& Gray, Fl. N. A. 2:314. 1842.

Ell. Sk. 2:450. Gray, Man. ed.6, 277. Chap. Fl.228. Gray, Syn. Fl. N. A. 1, pt. 2 : 263.

Alleghenian to Lonisianian area. Western New York to Michigan, Iowa, Minnesota, and Nebraska, south from Pennsylvania and the Ohio Valley to Arkansas, Louisiana, Tennessee, and middle Florida.

AlabaMA : Mountain region. Central Prairie region. Dry banks, borders of fields. Madison County, Montesano. Montgomery and Dallas connties. Hale County, pike near Troy. Flowers canary-yellow, disk pale purplish. Not rare in the Central Prairic belt.

Typo locality not ascertained.

Herb. Geol. Surv. Herb. Mohr.

BRAUNERIA Neck. Elem. 1:17. 1790.

(Echivacea Moench, Meth.591. 1794.)

Two species, perennials, Atlantic North America, chiefly southern.

Brauneria purpurea (L.) Britton, Mem. Torr. Club, 5 :334. 1894.

Rudbeckia purpurea L. Sp. P1. 2:907. 1753.

Black Sampiox. Perple Cone-flower.

Echinacea purpurea Moench, Meth. 591. 1794.

Ell. Sk. 2:449. Gray, Man. ed.6,275. Chap. Fl.226. Gray, Syn. Fl. N. A. 1, 1t. 2 : 258.

Carolinian and Louisianian areas. Virginia and Ohio Valley to Missouri, south to Tennessee and Georgia, west to Louisiana and Arkansas.

Alabama: Temnessee Valley to Central Pine belt. Open woods and prairies.

Lauclerdale and Cullman counties. Tuscaloosa County (E. A. Smith).

'Trpe locality: "Hab. in Virginia, Carolina."

Herb. Geol. Surv. Herb. Molir.

Braumeria pallida (Nutt.) Britton, Mem. Torr. Club, 5:333. P+LE Cone-Flower. Rudbeckia pallida Nutt. Journ. Acad. Phila. 7: 77. 1834.

Echinacea angustifolia DC. Prodr. 5 : 554. 1836.

Gray, Man. ed. 6, 275. Chap. Fl. 226. Gray, Syn. Fl. N. A. 1, pt. 2: 258. Coulter,

Contr. Nat. Herb. 2 : 214.

Alleghenian and Carolinian areas. Manitoba, latitude $49^{\circ}$; Minuesota, and Michigan, west to Nebraska aud Colorado, south from Tennessee to Georgia and Texas.

Alabana: Central prairies. Hale County, Gallion. Flowers pink; June, July. Rare.

'Type locality : "Arkansas. Collected by myself and Dr. Pitcher."

Herb. Geol. Surv. Herb. Mohr.

TETRAGONOTHECA L. Sp. P1. 2:903. 1753.

Three species, perennials, North America. Atlantic, 1.

Tetragonotheca helianthoides L. Sp. P1. 2 :903.

False SUyflower. 255.

Ell. Sk. 2:407. Gray, Man. ed.6, 274. Chap. Fl. 226. Gray, Syn.Fl. N. A. 1, pt. 2:

Carolinian and Louisianian areas. Coast of Virginia, south to Florida and Missis. sippi.

Alabama: Central Pine belt to Lower Pine region. Bibb, Monroe, Baldwin, and

Mobile counties. Flowers in May and not rarely again in August. Frequent.

'Tye locality: "Hab. in Virginia."

Herb. Geol. Surv. Herb. Mohr.

STEMMODONTIA Cass. Dict. Sci. Nat. 46:407. 1827.

(Wenelia Jacq. Enum. Pl. Carib. 8. 1760. Not Loefl. It. Hisp. 180. 1758.)

(Niebuhria Neck. Elem. $1: 30$. 1790. Not Scop. Introd.134. 1777.)

(Wollastonia DC.: Decsne. Nouv. Ann. Mus. Par. 3 : 414. 1834.)

About 50 species, tropical America. 
Stemmodontia asperrima (Spreug.).

Buphthalmum asperrimum spreng. Nen. Entileck. $2: 140$. 1821. Not Wollastonia asperrima Decsue. Nouv. Aun. Mus. Par. 3 :114. 1834. Nor Wedelia asperrima Benth. Fl. Austral. $3: 539.1866$.

Anomostephium buphthalmoides DC. Prodr. 5:560. 1836.

Tedelia buphthalmoides Griseb. Goett. Abh. $7: 235.1857$.

Seruneum buphthalmoides Kuntze, Rev. Geu. Pl. 1:365. 1891.

WEST INDIES.

Alabana: Adrentire with ballast. Mobile County. Flowers golden yellow; Angust, September. Persistent on the ballast heaps and adjoining waste places. July. First observed 1884. Perennial.

Typo locality not a scertained. Locality of Anomostephium buphthalmoides: "Guadalupa (Bertero! Krauss!), loco dicto Pointe-à-Pitre (Perotte!)."

Herb. Geol. Surv. Herb. Mohr.

BORRICHIA Adaus. Fam. Pl. $2: 130.1763$.

Six species, tropical America. Shrubby or suffruticose. South Atlantic North America, 2.

Borrichia frutescens (L.) DC. Prodr. 5 : 489. 1836.

Buphthalmum frutescens IaSp. Pl. 2:903. 1753.

Ell. Sk. 2:408. Gray, Man. ell. 6, 277. Chap. Fl. 224. Gray, Syn. Fl. N. A. 1, pt. 2: 265 . Coulter, Contr. Nat. Herb. $2: 216$.

Mexico, West INDies.

Carolinian and Louisianian areas. Seashore of Virginia to Florida and Texas.

Ala BaMa : Littoral region. Salt marshes. Mobile and Baldwin counties. Flowers jellow; Angust, October. Frequent. Slirubby at the base. Perennial.

Type locality: "Hab. in Jamaica, Virginia."

Herb. Geol. Surv. Herb. Molır.

HELIANTHUS L. Sp. Pl. 2 :904. 1753.

About 60 species, perennials, chiefly American. Mexico, Central and Sonth America. North America, 40; Atlantic, 23; interior, 8; Pacific, 10.

Helianthus debilis Nutt. 'Trans. Am. Phil. Soc. ser. 2, 7:367. 1841.

EARLY SUNFLOWER.

Chap. Fl. 229. Gray, Syu. Fl. N. A. 1, pt. $2: 273$. Coulter, Coutr. Nat. Herb. $2: 217$. Louisianian area. Florida to western Louisiana aud Texas.

Alabama : Coast plain. Adventive in cultivated fields. May, 1888; not observed since. Anuual.

'Type locality: "The sea-coast of East Florida. (Dr. Baldwin.)"

Herb. Geol. Surv. Herb. Mohr.

Helianthus angustifolius L. Sp. Pl. 2 : 906. 1753.

NarRow-Leaf SUNFlower.

Ell. Sk. $2: 415$. Gray, Man. ed. 6, 278. Chap. Fl. 229. Gray, Syn. Fl. N. A. 1, pt. 2 :

273. Coulter, Coutr. Nat. Herb. 2:218.

Carolinian and Lonisianian areas. New Jersey to Florida, west to Texas, Arkansus, southeru Missouri, Kentucky, aud Tennessee.

Alibama: 'Teunessee Valley to the Coast plain. Damp and dry sandy soil, borders of thickets, woods, and fields. Morgan Connty. Cullman County, 800 feet. Autanga, Clarke, and Mobile counties, etc. Rays golden yellow; disk brownish. Common; most abuudant throughout the Coast Pine belt.

Type locality: "Hab. in Virginia."

Herb. Geol. Surv. Herb. Mohr.

\section{Helianthus angustifolius nemorosus var. nov.}

Radical and lower cauline leaves from roundish-ovate to broadly lanceolate and acute. Very variable, in one extreme closely approaching $H$. floridanus Gray,' and in the other counected with the type by intergrading forms, and hence of doubtful varietal value.

Alalians: Shaded, springy banks. Mobile County, Spriughill. October, November. 
Helianthus radula (Pursh) Torr. \& Gray, Fl. N. A. 2 :321. 1841.

RAYLESS SUNFLOWER.

Rudbeckia radula Pursh, Fl. Am. Sept. 2:575. 1814.

$R$. apetala $\therefore$ itt. Journ. Acad. Phila. 7: 77.1834.

Ell. Sk. 2: 456. Chap. Fl. 229. Gray, Syn. Fl. N. A. 1, pt. 2: 274.

Lonisianian area. Georgia, Florida to Lonisiana.

AlabaMa: Coast Pine belt. Dry pine barrens. Rays mostly wanting, or when present reduced; disk pansy-purple; September, October. Abundant throughont the pine uplands of the Coast Pine belt.

Type locality: "In Georgia. Bartram."

Herb. Geol. Surv. Herb. Mohr.

Helianthus heterophyllus Nutt. Journ. Acad. Phila. 7 : 74.1834.

Nude-STKMmed Sunflower.

Chap. Fl.229. Gray, Syn. Fl. N. A. 1, pt. 2: 274 .

Lonisianian area. Coast of North Carolina to Florida and Louisiana.

Ala Bana: Coast plain. Flat damp piue barrens. Mobile and Baldwin counties. October, November. Frequent.

Type locality: "In Alabama."

Herb. Geol. Surv. Herb. Mohr.

Helianthus atrorubens L. Sp. Pl. 2: 906. 1753.

DARK-PURPLE SUNFLOWRR.

Ell. Sk. 2:414. Gray, Man. ed. 6, 278. Chap. Fl. 229. Gray, Syn. Fl. 1, pt. 2: 274.

Carolinian and Louisianian areas. Lower Virginia to Florida, west to Louisiana and Arkansas.

Al.abama : Teuuessee Valley. Monntain region. Lower hills. Dry open woods. Dekalb County, Valleyhead, 1,100 feet. Clay County, Moseley. 1,000 foet altitude. Cullman Connty. Shelby County, Montevallo. Lee County, Auburn. Rays yellow, disk dark purple; September, Oetober. Frequent in mountainous distriets.

'Type locality: "Hab. in Virginia."

Herb. Geol. Surv. Herb. Mohr.

Helianthus mollis Lam. Encycl. 3:85. 1789.

VeLVETY SUNFLOWKR.

Helianthus canescens Michx. F]. Bor. Am. 2 : 140. 1803.

H. pubescens Willd. Sp. Pl. $3: 2240.1804$.

kil. Sk. 2:418. Griy, Man. ed. 6, 279. Chap. Fl. 230. Gray, Syn. Fl. N. A. 1, pt.

$2: 276$. Coulter, Coutr. Nat. Herb. $2: 218$.

Carolinian area. Southern Ohio to Missouri and Arkansas, sonth from Tennessee to Georgia.

Ala l3AMA: Mountain region. Coosa Valley. Damp grassy banks in the pine forests. Walker County, near Sonth Lowell. Etowah County, near Ballplay. Damp gravelly pine woods, local and rare.

Type locality: "Nous la croyons originaire de l'Amerique septentrionale."

Herb. Geol. Surv. Herb. Mohr.

Helianthus tomentosus Michx. Fl. Bor. Am. 2 : 141. 1803.

Ell. Sk. 2:424. Chap. Fl. 230. Gray, Man.ed.6,279. Gray, Syn. Fl. N. A. 1, pt. $2: 276$.

Carolinian and Louisianian areas. West Virginia, Carolina, and Georgia.

Alabama: Monntain region to Upper division Coast Pine belt, borders of thickets and of woorls. Clay County, Monnt (llive, 1,400 feet. Tallapoosa Connty, Dadeville, 800 feet altitude. Dallas County, Marion Junction. Choctaw County, Bladen Spriugs. Clarke County (Ir Denny). Flowers August, September. Four to 6 feet high. Not infrequent.

Type locality: "Hab. in pratensibus Illinoensibus."

Herb. Geol. Surv. Herb. Mohr.

Helianthus microcephalus Torr. \& Gray, Fl. N. A. 2: 329. 1842.

Small-Flowered SUNFlower.

Helianthus divaricatus Michx. Fl. Bor. Am. 2:141. 1803. Not I.

H. parriflorus Bernh.; Spreng. Syst. Veg. 3:617. 1816. Not H. B. K. 1820.

Ell. Sk. 2:427. Gray, Man. ed.6, 279. Chap. Fl. 231. Gray, Syn. Fl. N. A. 1, pt. 2: 278.

Carolinian and Lonisianian areas. West Virginia, Pennsylvania; Ohio Valley south along the mountains to Georgia, Florida, Louisiana, and Arkansas. 
Alabama: Nonntain region to Central Pine belt. Dry open woods. Clay Conuty, Filders, 1,000 feet. Cullman Conuty, 800 feet. 'Tuscalonsa Connty, 450 feet. Perry county (J.D. Smith). Frequent; common thronghout the Warrior table-land.

Type locality: "Upper Canada! * * * Western Penusylvania! Obio! Indiana! and Kentucky! to tho westeru part of Georgia! and to Lonisiana! $\gamma$ Covington, Lonisiana, Drummond!"

Herb. Geol. Surv. Herb. Molır.

Helianthus divaricatus L.Sp. Pl. 2 : 906.1753.

DIVARICATE SUNFLOWER.

Helianthus truncatus Schwein.; Ell. Sk. 2 : 416. 1824.

Ell. Sk. l. c. Gray, Man, erl.6,280. Chap. Fl.231. Gray, Syn. Fl. N. A. 1, pt. 2: 279. Alleghenian, Carolinian, anı Louisianian areas. Ontario to Manitoba; Now England, west to Dakota, south to the Ohio Valley, Missonri, Kansas, and Nebraska, and from New York to Florida and northern Louisiana.

- Alabama: Diffused thronghout the State. Dry open woods. Clay County, Mount Olive. Lauderdale. Madison, Marshall, Cullman, and Mobile counties. On sandy pine ridges. Flowers July, Angust. Most frequent in the mountains; local in the Lower Pine region.

l'ype locality: "Hab. in Ameriea septentrionali."

Herb. Geol. Surv. Herb. Mohr.

Helianthus hirsutus Raf. Ann. Nat. 14. 1820.

Helianthus diversifolius Ell. Sk. 2 :423. 1821. Forma.

Gray, Man. ed. 6, 280. Chap. Fl. 231. Gray, Syn. Fl. N. A. 1, pt. 2:279. Conlter,

Coutr. Nit. Herb. 2 : 219.

Alleghenian and Carolinian areas. Ohio, Michigan to Minnesota, south from

West Virginia to Tennessee, Georgia, Louisiana, Texas, and Arkansas.

Alabama: Mountain region to Upper division Coast Pine belt. Dry open woods. Clay Connty, Mount Olive. Shelby County, Calera (E. A. Smith). Mouroe County,

Mount Pleasant. Flowers July, August. Not infrequent.

Type locality: "I found it on the knob hills of Kentucky."

Herb. Geol.surv. Herb. Mohr.

Helianthus hirsutus trachyphyllus Torr. \& Gray, Fl. N. A. 2 : 329. 1842.

Gray, Syn. Fl. N. A. 1, pt. 2:279.

Carolinian area. Arkansas.

Alabama : Monutain region. Dry open copses, borders of fields. Clay County, near Mount Olive, 1,500 feet. August: not frequent.

'Type lueality : "Arkansas, Dr. Pitcher!"

Herb.Geol Ṡurv. Herb. Mohr.

Helianthus hirsutus stenophyllus T'orr. \& Gray, Fl. N. A. 2:329. 1842.

Gray, Syn. Fl. N. A. 1, pt. 2: 279. Coulter, Contr. Nat. Herb. 2 : 219.

Louisianian area. Mississippi, Lonisiana, and Texas.

Alabama: Lower Pine region. Dry open wouds. Mobile County. Flowers Angust, September. Stem mostly simple; 1 to $1 \frac{1}{2}$ feet high. Not frequeut.

Type locality: “Westeru Lowisiana, Dr. Hale! Dr. Leavenworth! 'Texas, Irummond!"

Herb. Mohr.

Helianthus tracheliifolius Mill. fiard. Dict. ed. 8, no. 7. 1768.

Gray, Man. erl. 6, 280. Gray, Syn. Fl. N. A. 1, pt. $2: 280$.

Carolinian area. New York aud Pennsylvania to Missouri and Arkansas, south along the monntaius to Tennessee.

Alabama : Monntain region. Lee County, Auburn (Baker \& Earle, 260). July; rare. Only locality known.

Type locality: "All these species of Sun-flowers are natives of America."

Herb. Geol. surv. Herb. Mohr.

Helianthus strumosus L. Sp. Pl. 2:905. 1753.

Gray, Man. ed.6, 280. Chap. Fl.231. Gray, Syu. Fl. N. A. 1, pt. 2: 279.

Alleghenian and Carolinian areas. Ontario, Now England, west to Minnesota and Missouri, south to Arkansas, and from New York to Tennessee, and along the moun. tains to Georgia.

Aldiama : Mountain region. Lee Connty, Auburn (Baker $\&$ Earle). July; rare. Type locality : "Hab. in Canada."

Herb. Geol. Surv. Herb. Mohr. 
Helianthus longifolius Pursh, F]. 2:571. 1814.

Ell. Sk. 2: 417. Gray, Syn. Fl. 1, pt. 2: 278.

Carolinian area. Western Georgia.

Alabaya : Monntain region. Damp roeky glades. De Kalb County, on Lookout Mountain, De Soto Falls (Herb. Biltmore), Marshall County (Herb. Biltmore, 1900).

Local and rare. September, October.

Type locality: "In the western parts of Georgia. Lyon."

Herb. Geol. Surv. Herb. Mohr.

Helianthus schweinitzii Torr. \& Gray, Fl. N. A. 2 : 330. 1842.

Chap. Fl. 231. Gray, Syn. Fl. N. A. 1, pt. 2: 278.

Carolinian area. Western North Carolina and middle Georgia.

Aldbama : Mountain region. Dry borders of woods. Lee County, Anburn. Cullman County. September, October; infrequent.

'Type locality: "Near Salem, North Carolina, Schweinitz! and in Mecklenburg County. Mr. M. A. Curtis!"

Herb. Geol. Surv. Herb. Mohr.

Helianthus glaucus Small, Bull. 'Torr. Club, $25: 480.1898$.

Carolinian area. North Carolina. Georgia.

SOUTHKRN SMOOTH SUNFLOWER.

Arabana: Mountain region. Dry open woods. Cullman County. Two to $3 \frac{1}{2}$ feet high.

"Perennial, deep green. Stems erect, 9 to $18 \mathrm{dm}$. tall, widely branching, smooth, glabrous and glancons; leaves opposite; blades somewhat leathery, firm, lanceolate, acuminate, sharply serrate, very scal,rous above, tomentulose beneath, narrowed into short-margined petioles; heads rather small; involucres campanulate, 8 to $10 \mathrm{~mm}$. high; bracts few, lanceolate or oblong with a lanceolate tip, more or less strougly spreading, white eiliate; rays yellow, oblong, 1 to $1.5 \mathrm{~cm}$. long, often 5 to 7 ; disk beconing $1 \mathrm{~cm}$. broad; disk-corollas $4 \mathrm{~mm}$. long; segments lanceolate to oblonglanceolate; disk bracts commonly 3 -toothed at the apex, minutely pubescent; achenes 3 to 3.5 min. long, oblong-obovoil, with two slender barbed teeth."

Type locality: "Dunn's Mountain, Rowan County, North Carolina, August, 1894; Stone Mountain and vicinity, Georgia, and on Little Stone Mountain, Georgia, September, 1894."

Herb. Geol. Surv. Herb. Mohr.

VERBESINA L. Sp. Pl. 2 : 901.1753.

(Actinomeris Nutt. Gen. Pl. 2 : 181. 1818.)

Genus variously limited; perennials. South America. North America, 9 species; Atlantic, 7.

Verbesina occidentalis (L.) Walt. Fl. Car. 213. 1788.

WAYSIDE CROWNBEARD.

Siegesbeckia occidentalis L. Sp. P1. 2 :900. 1753.

Verbesina siegesbeckia Michx. Fl. Bor. Am. 2:134. 1803.

Ell. Sk. 2:411. Gray, Man. ed. 6, 281. Chap. Fl.237. Gray, Syn. Fl. N. A. 1, pt. $2: 287$.

Carolinian and Louisianian areas. Southern Ohio, Illinois, and Tennessee, sonth to Florida and Louisiana.

Alabama : Central Pine belt to the Coast plain. Damp places, borders of thickets, fields, waysides; August, September. Four to 5 feet high; coarse. One of the most abundant wayside weeds of the Coast plain.

Type locality: "Hab. in Virginia."

Herb. Geol. Surv. Herb. Mohr.

Verbesina virg̀inica 1. Sp. Pl. 2 : 901.1753.

WHITE CrownteakD.

Ell. Sk. 2:410. Gray, Man. ed. 6, 281. Chap. Fl. 238. Gray, Syn. Fl. N. A. 1, pt. $2: 287$. Coulter, Contr. Nat. Herb. $2: 221$.

Mexico.

Carolinian and Louisianian areas. Virginia to Florida, west to Texas and Arkansas.

Ala bama : Central Pine region to Coast plain. In rieh soil, borders of fields and woods. Montyomery and Mobile counties. Flowers sordid white; September. Six to 8 feet high. Sparsely diffused.

Type locality: "Hab. in Virginia."

Herb. Geol. Surv. Herb. Mohr. 
Verbesina aristata (Ell.) Heller, Cat. N. A. Pl. el. 2, 218. 1900.

Helianthus aristatus Ell. Sk. 2 :428. 1821-24.

Bare-stemmed Crownibard.

Actinomeris nudicaulis Nutt. 'Trans. Am. Phil. Soc. n. ser. $7: 364.1841$.

Verbesina undicaulis Gray, Proc. Am. Acad. 19: 12. 1883.

Ell. Sk. l. c. Gray, Syu. Fl. N. A. 1, pt.2:288. Chap. Fl. 233; ed. 3, 255.

Carolinian and Louisianian areas. Georgia and Florida.

Alabana: Mountain region. Lower Pine belt. Lee County, Auburn, dry metamorphic hills, 860 feet. Mobile County, Grand Bay, sandy open pine ridges. Flowers golden yellow; June, July. Local and infrequent. Perennial.

'Type locality: "Grows in dry sessile soils in the western districts of Georgia."

Herb. Geol. Surv. Herb. Mohr.

Verbesina helianthoides Michx. Fl. Bor. Am. 2 : 135. 1803.

Actinomeris helianthoides Nutt. Gen. 2 : 181. 1818.

SUNflower-like Crownibard.

Ell. Sk. 2:413. Gray, Man. ed.6, 281. Chap. Fl. 233. Gray, Syn. Fl. N. A. 1, pt.

$2: 288$. Conlter, Contr. Nat. Herb. $2: 221$.

Carolinían area. Ohio Valley, Missouri, and Arkansas, and from Tennessee south to upper Georgia.

Alabana : 'Tennessee Valley. Lower hills. Borders of woods and fields. Lauderdale County, in the barrens. Bibl County, Pratt's Ferry. July; local and rare.

Type locality: "Hab. in occidentalibus Alléghanis, territorio Tennassée, et regione Illinoensi."

Herb. Geol. Surv. Herb. Mohr.

Verbesina enceliodes (Cav.) Gray, Syn. Fl. N. A. 1, pt. 2:288. 1884.

Ximinesia encelioides Cav. Icon. 2 : 60, t. 178. 1793.

ENCelia-like Crownibard.

Chap. Fl. Suppl. 630; ed.3, 255. Coulter, Contr. Nat.Herb. 2:221. Gray, Syn. Fl. N.A.1.c.

Mexico.

Louisianian area. Southern Florida, Texas, Arizona, and sonthern Colorado.

AlabaMa : Coast plain. Adventive in ballast. Mobile Connty. Autauga Conuty, Prattville, waste places, adventive from southwestern Texas with wool. Flowers golilen yellow; July, September. A frequent and persistent ballast weed.

Type locality: "Hab. in Mexico."

Herb. Geol. Surv. Herb. Mohr.

Verbesina alternifolia (L.) Britton; Kearney, Bull. Torr. Club, 20:485. 1893.

Coreopsis alternifolia L. Sp. Pl. 2 : 909. 1753.

CROWNBEARD.

detinomeris squarrosa Nutt. Gen. 2 : 181. 1818.

A. alternifolia DC. Prodr. $5: 575.1836$.

Ell. Sk. 2:413. Gray, Man. ed.6, 281. Chap. Fl. 232. Gray, Syn. Fl. N. A. 1, pt. $2: 289$.

Carolinian and Louisianian areas. Western New York to Michigan, Olio Valley

to Missouri, Nebraska, from West Virginia sonth to Florida and Louisiana.

Alabama: T'ennessee Valley to Lower hills. Rich bottom lands, borders of fields and woods. Clay County, Elders, 1,000 leet. Blount County, banks of Mulberry Fork. Flowers yellow. Not frequent. Eight to 10 feet high.

Type locality: "Hab. in Virginia, Canada."

Herb. Mohr.

\section{COREOPSIS L.Sp. Pl. 2 : 907. 1753. TICKSEED.}

About 50 species, more or less tropical; Africa, Sandwich Islands, chiefly warmer America. North America, 28; Atlantic, chiefly southern, 23; Lower Sonoran ('TexanoMexican), 5; Pacific, 1.

Coreopsis gladiata Walt. Fl. Car. $2: 215$. 1788.

Ell. Sk. 2:444. Chap. Fl. 235. Gray, Syn. Fl. N. A. 1, pt. $2: 290$.

Louisianian area. South Carolina to Florida, and Mississippi to Louisiana.

Alabama: Lower Pine belt. Damp grassy pine barrens. Washington County,

Yellowpine. Rare. Pereunial.

Type locality: South Carolina.

Herb. Geol. Surv. Herb. Mohr.

Coreopsis angustifolia Ait. Hort. Kew. 3 :253. 1789.

Ell. Sk. 2:443. Chap. Fl.235. Gray, Syn. Fl. N. A. 1, pt. 2:290. Coulter, Contr.

Nat. Herb. 2: 222 .

Louisianian area. Coast of North Carolina to Florida, west to 'Texas. 
AlabaMa : Coast plain. Flat damp pine barrens. Baldwin and Mobile counties. Rays golden yellow, disk almost black. September, October. Perennial. Type locality : "Native of Carolina and Florida."

Herb. Geol. Surv. Herb. Mohr.

Coreopsis tinctoria Nutt. Jonrn. Acad. Phila. 2 : 114. 1821.

Gray, Man. ed. 6, 282. Gray, Syn. Fl. N. A. 1, pt. 2:291. Coulter, Contr. Nat. Herb. $2: 222$.

Alleghenian and Carolinian areas. Saskatchewan to north latitude $49^{\circ}$; Minnesota, Arkansas, Texas, Colorallo, and Arizona.

Alabama : Rarely escaped from cultivation. Mobile County, waste places. May. A well known garden annual.

'Type locality: "Throughout the Arkausas territory to the banks of Red River, chietly in the prairies which are subject to temporary inundation."

Herb. Geol. Surv. Herb. Mohr.

Coreopsis drummondii (D. Don) Torr. \& Gray, Fl. N. A. 2 : 345. 1842.

Calliopsis drummondii D. Don in Sweet, Brit. Fl. Gard. ser. 2, t. 315. 1831-38.

Gray. Syn. Fl. N. A. 1, pt. 2: 291. Conlter, Contr. Nat. Herb. 2 : 222.

Louisiauian area. Western Louisiana and Texas.

Alabama: Coast plain. Naturalized. Escaped from cultivation, or arlventive from the Southwest. Grassy glades. Kaldwin County, Daphne, along the eastern shore of Mobile Bay. In similar situations observed on the shore of Mississippi Sound (Paseagoula, Miss.). May, June. A frequent garden annual.

'Type locality (Torr. \& Gr.): "Texas, Drummond!"

Herb. Geol. Surv. Herb. Mohr.

Coreopsis grandiflora Hogg; Sweet, Brit. Fl. Gard. 2 : t. 175. 1825-27.

Chap. F1.235. Gray, Syn. Fl. N. A. 1, pt. 2:292. Coulter, Contr. Nat. Herb. $2: 222$.

Carolinian and Louisianian areas. Georgia and western Florida to Texas, Arkansas, and southern Missouri.

Alabama: Monntain region to Upper division Coast Pine belt. Damp and dry light soil. Grissy exposed places, borders of woods. Cullman, Blount, and Bibb counties. Hale County, Gallion. Henry County, Ozark. Lee County, Auburn (Earle \&. Baker). Flowers yellow; June, Angust. Perennial.

Type locality : Received "from North America, sent by Mr. Hogg from New York." Herb. Geol. Surv. Herb. Mohr.

Coreopsis lanceolata L. Sp. Pl. 2 : 908.1753.

Ell. Sk. 2:433. Gray, Man. ed. 6, 282. Chap. Fl. 235. Gray, Syn. Fl. N. A. I, pt. $2: 292$.

Alleghenian and Carolinian areas. Shore of Lake Superior, Ontario; Virginia and North Carolina to Florida, west to Louisiana, Arkansas, Missouri, and Illinois.

Alabama : Mountain region to Central prairies. Dry light soil. Open woods and prairies. Dekalb County, Mentone, 1,600 feet. Cullman County, 800 feet. Bibb County, 500 feet. Lee County, Auburn (Baker \& Earle). Montgomery County, Pintlalla Creek. Hale County, Gallion. Blount County. Wilcox County (Buckley).

Flowers yellow. Frequent. Perennial.

Type locality : "Hab. in Carolina."

Herb. Geol. Sinrv. Herb. Mohr.

Coreopsis crassifolia Ait. Hort. Kew. 3 : 253. 1789.

Hairy Coreopsis.

Coreopsis lanceolata var. villosa Michx. Fl. Bor. Am. 2: 137. 1803.

Ell. Sk. 2:434. Gray, Man. ed. 6, 282. Chap. Fl. 235. Gray, Syn. Fl. N. A. 1, pt. 2: 292.

Carolinian and Lonisianian areas. Sonth Carolina to western Florida.

Alabama: Lower Pine region. Exposed sterile ground. Fscambia County, on the Alabama and Florida State line, dry pine ridges. Shelby County, exposed exsiccated openings in the flat woods. Flowers June. Not frequent. Perennial.

Trpe locality : "Native of Carolina."

Herb. Geol. Surv. Herb. Mohr.

Coreopsis pubescens Ell. Sk. 2 : 441. 1821-24.

Star Ticksend.

Ell. Sk. 1.c. Gray, Man. ed. 6,282. Chap. Fl. Suppl. 630; ed.3, 257. Gray, Syn. Fl. N. A. 1, pt. $2: 293$.

Carolinian and Lonisianian areas. Mountains of North Carolina to Greorgia, western Florida, and Missonri (Gray). 
Aluabama: Tennessee Valley to Central Prairio belt. Rich banks, horders of woods. Landerdale Connty, Florence (M. C. Wilson). Clay County, Talladega Creek, 1,000 feet. Culluan County. Blount County, bauks of Mulberry Fork. Hale County, Gallion. Wilcox Connty (Buckley). Flowers yellow; June, July. Perennial from a stout root 2 or 3 feet high. Frequent in the valleys of the Warrior table-land, the Coosa Valley, and the upper part of the Prairie belt. Perennial. Type locality: "Grows in the western districts of Georgia."

Herb. Geol. Surv. Herb. Mohr.

Coreopsis auriculata L. Sp. Pl. 2 : 908. 1753.

MEADOW COREOPSIS.

Ell. Sk. 2 : 436. Gray, Man. ed. 6, 282. Chap. Fl. 235; Suppl.630; ed.3, 257. Gray, Syn. Fl. N. A. 1, pt. 2: 293 .

Carolinian and Lonisianian areas, Virginia to Ohio, south along the mountains to Georgia.

Ala baMa : Mountain region co Central Pine bolt. Openings in rich woods, grassy banks. Winston County, Collier Creek, 1,500 feet. Dekall County, Mentone, 1,600 feet altitude. Cnllman and Tuscaloosa counties. Flowers deep yellow; April, May. Perennial from a stoloniferous rootstock. Not rare in the mountain region. Type locality : "Hab. in Virginia."

Herb. Geol. Surv. Herb. Mohr.

Coreopsis verticillata L. Sp. Pl. 2 : 907. 1753.

WHORLED TICKSEED.

Coreopsis tenuifolia Ehrh. Beitr. 7 : 168. 1792.

Ell. Sk. 2 : 439. Gray, Man ed. 6, 283. Chap. Fl. 234. Gray, Syn. Fl. N. A. 1, pt. 2 : 293. Carolinian area. Ontario, Maryland, and Virginia, along the monntains to North Carolina and Georgia, west to Missmri and Arkansas.

Ala BaMa: Mountain region; rocky woods. Dekalb County, Desoto Falls on Lookout Mountain. Lee County, Auburn (Earle).

'Type locality : "Hab. in Virginia."

Herb. Geol. Surv. Herb. Mohr.

Coreopsis delphinifolia Lam. Encycl. 2:108. 1786.

LARKSPUR TICKSEED.

Coreopsis rerticillata var. linearis Michx. Fl. Bor. Am. 2 : 139. 1803.

Ell. Sk. 2:438. Gray, Man. ed. 6, 283. Gray, Svn. Fl. N. A. 1, pt. $2: 293$.

Carolinian area. Virginia? and North Carolina aloug the mountains to Georgia.

AlabaMa : Reported by 'Torrey and Gray; not collected lately.

Type locality : "Cette plante croit dans la Virginie."

Coreopsis major Walt. Fl. Car. 214. 1788.

Coreopsis senifolia Michx. Fl. Bor. Am. 2 : 138. 1803.

Ell. Sk. 2:438. Gray, Man. ed. 6, 283. Chap. Fl.235. Gray, Syn. Fl. N. A. 1, pt. $2: 294$.

Louisianian area. North Carolina to Florida and Louisiana.

ALABa.ma : Monntain region to the Coast plain. Dry sandy or rocks woods. Clay County, Che-aw-ha Mountain, 2,400 feet. Mobile County, little above sea level. Flowers July, Angust. Common. Abundant in the dry pine barrens. Perennial. Type Jocality: South Carolina.

Herb. Geol. Surv. Herb. Mohr.

Coreopsis major oemleri (Ell.) Britton, Mem. Torr. Club, 4 : 131. 1893.

Coreopsis oemleri Ell. Sk. 2 : 435. 1821-24.

OEMLER'S 'TICKSEED.

C. stellata Nutt. Journ. Acad. Phila. 7: 76. 1834.

C. senifolia stellata Torr. \& Gray, Fl. N. A. 2: 342, 1842.

Ell. Sk. l.c. Gray, Man. ed.6, 283. Chap. Fl. 236. Gray, Syn. Fl. 1, pt. $2: 294$.

Carolinian area. Virginia and Kentucky to Tenuessee and Georgia.

Alaba.Ma : Monntain region. Metamorphic hills. Lee County, Auburn (Baker \& Earle). Perennial.

Type locality: "Collected near the junction of the Broad and Saluda rivers by Mr. Oemler."

Herb. Geol. Surv. Herb. Mohr.

Coreopsis tripteris L. Sp. Pl. 2 : 908. 1753.

Tall Coreopsis.

Ell. Sk. 2:442. Gray, Man. ed. 6, 283. Chap. Fl. 234. Gray, Syn. Fl. N. A. 1, pt. $2: 294$.

Carolinian area. Southern Pennsylvania and Virginia, west to Michigan and Wisconsin; Ohio Valley to Missouri and Arkansas, sout! along the mountains to Georgia and middle Florida, and west to western Louisiana. 
Alabama: Tennessee Valley. Mountain region. Damp thickets. Lawrence County, Moulton. Lauderdale County. Clay County, bottoms of T'alladega Creek, 1,000 feet. Cullman and Coosa counties. Lee Connty, Auburn. Frequent. Perennial.

'Type locality: "Hab. in Virginia."

Herb. Geol. Surv. Herb. Mohr.

\section{BIDENS L. Sp. Pl. 2 : 831. 1753. Bur MaRIGOLD.}

Abont 65 species, temperate and warmer regions, ehiefly American. North America, 12 or more. (Including Coreopsis, section Diodonta, Torr. \& Gray.)

Bidens frondosa L. Sp. Pl. $2: 832$. 1753. Stick-tight. Common BegGar Tick. Ell. Sk. 2:431. Gray, Man. ed. 6, 284. Chap. Fl.236. Gray, Syn. Fl. N. A. 1, pt. $2: 296$. Coulter, Contr. Nat. Herb. $2: 223$.

Canadian zone to Louisianian area. Nova Scotia to Saskatchewan, south to the Gulf from Florida to Texas.

Alabama: Over the State. Low rich soil, borders of fields. Common pernicious weed. Annual.

Type locality: "Hab. in America septentrionali."

Herb. Geol. Surv. Herb. Mohr.

Bidens laevis (L.) B. S. P. Prel. Cat. N. Y.29. 1888.

Helianthus laevis L. Sp. P1. 2 :906. 1753.

LARge-Flowered BUR Marigold.

Bidens chrysanthemoides Michx. Fl. Bor. Am. 2 : 136. 1803.

Ell. sk. 2:429. Gray, Man. ed.6, 285. Chap. Fl. 237. Gray, syn. Fl. N. A. 1, pt. 2:296. Coulter, Contr. Nat. Herb. 2 : 223.

Mexico, South America.

Canadian zone to Louisianian area. Nova Seotia, Ontario to Manitoba, west to California, and sonth to Florida and western 'Texas.

Alabama: Over the State. Muldy places, ditches, marshes. Flowers golden yellow; October, November. Most abundant in the Coast plain. Annual.

Type locality: "Hab. in Virginia."

Herb, Geol. Surv. Herb. Mohr.

Bidens leucantha Willd. Sp. Pl. 3 : 1719. 1804.

WhITE-FLOWERED SPANISH NEEDLES.

Chap. Fl. 237. Gray, Syn. Fl. N. A. 1, pt. 2: 297. Griseb. Fl. Brit. W. Ind. 373.

Mexico, West indies to Chile and nearly All 'Tropical Countries.

Louisianian area. Southern Florida.

Ala Bama: Coast plain. Fugitive on ballast. Mobile County, observed from 1889 to 189\%. Rays white, disk yellow. Annual.

Type locality : "Hab. in America calidiore."

Herb. Geol. Surv. Herb. Mohr.

Bidens bipinnata L. Sp. P1. 2 : 832. 1753.

Spanish NeEdles.

Ell. Sk. 2:432. Gray, Mau. ed. 6, 285. Chap. Fl. 237. Gray, Syu. Fl. N. A. 1, pt. 2: 297. Coulter, Contr. Nat. Herb. $2: 223$.

Carolinian aud Louisianian areas. Southern New Eugland, west to Ohio, Missouri, and Arkansas, south from New York to Florida and T'exas.

Alabama: Orer the State. Borders of fields, waste places. September, October. Common in bottom lands; a troublesome weed. Annual.

Type locality: "Hab. in Virginia."

Herb. Geol. Surv. Herb. Mohr.

Bidens coronata (L.) Fisch.; Stend. Nom. Bot. ed. 2, 202. 1840.

Coreopsis coronata L. Sp. Pl. ed. 2, $2: 1281.1763$.

Golden-FLow ERed Coreopsis.

C. aurea Ait. Hort. Kew. 3 : 252. 1789.

C. mitis Michx. Fl. Bor. Am. 140. 1803.

Ell. Sk. 2:440. Gray, Man. ed.6, 283. Chap. Fl. 233. Gray, Syn. Fl. N. A. 1, pt. $2: 294$.

Carolinian and Louisianian areas. Virginia to Florida, west to Louisiana.

Alabama : Lower Pine region. Coast plain. Shaded wet swamps. Mobile and

Baldwin counties. September, Oetober; common. Annual.

Type locality: "Hab. in Virginia."

Herb. Geol. Surv. Herb. Mohr. 
Bidens coronata leptophylla (Nutt.)

PINE-BARIEN CUREOPSIS.

Diodonta leptophylla Nutt. Trans. Am. Phil. Soc. ser.2, 7:360. 1841.

Coreopsis aurea var. leptophylla 'Torr. \& Gray, Fl. N. A. 2 :339. 1842.

Among the forms of this polymorphous type this is the only one with permanent eliaracters and deserviug of varietal rani $\mathrm{k}$. It is recognized by its more rigid habit of growth, the leaves pinnately 3 to 5 divided, with the terminal divisions linear, elongated, sparingly toothed and the lateral shorter-lobed or ineised. Annual.

Alabama: Coast plain. Open pine barrens. Mobile County. Flowers bright yellow; Oetober.

Typo locality: "Georgia. (Dr. Baldwyn.)"

Herb. Geol. Surv. Herb. Mohr.

Bidens involucrata (Nutt.) Britton, Bull. Torr. Clıb, 20:281. 1893.

Western Bur Marigold.

Coreopsis involucrata Nutt. Journ. Acad. Phila. 7 : 74. 1834.

Gray, Man. ed. 6, 284. Gray, Syn. Fl. N. A. 1, pt. 2 : 295. Coulter, Contr. Nat. Herb. $2:-23$

C'arolinian and Louisianian areas. Southwestern Illinois, Missonri, and Arkansas, soutl to Texas and westeru Louisiana.

Alabama : Mountain region. Damp open places, pastures, open woodlauds. Cullman Connty. Flowers August. Rare. Annual.

'Type locality : "In Arkansas. Collected ly myself and Dr. Pitcher."

Herb. Geol. Surv. Herb. Mohr.

Bidens discoidea (Torr. \& Gray) Britton, Bull. Torr. Club, 20:281. 1893.

Low SWAMi' Marigold.

Coreopsis discoidea Torr. \& Grar, Fl. N. A. 2 :339. 1842.

Gray, Man. ed. 6, 284. Chap. Fl. 233. Gray, Syn. Fl. N. A. 1, pt. 2:295. Coulter, Contr. Nat. Herb. $2: 223$.

Carolinian and Louisianian areas. Connecticut, Ohio, western Illinois, Virginia, eastern Lonisiana to T'exas.

Alabama : Central Pine belt. Coast plain. Wet thickets. Montgomery County, Cypress poul. Mobile County, wooded swamps along the old telegraph road. October 18. (Ine to 3 feet high, deusely branched. Not common. Aunual.

'Type locality: "Wet places and swamps, Columbus, Ohio, Mr. Sullivant! Feliciana, Louisiana, Dr. Carpenter! Westeru Louisiana, Dr. Hale! 'Texas, Drummond! Virginia, Mr. Rugel!"

Herb. Geol. Surv. Herb. Mohr.

GALINSOGA Rui\% \& Pav. Prodr. Fl. Peru, 110, t. 24. 1794.

About 5 species, annual herbs, warmer temperate and tropical America.

Galinsoga parviflora Cav. Icon. $3: 41$, t. 281.1749.

Gray, Man. el. 6, 286. Gray, Syu. Fl. N. A. 1, pt. 2:303.

Caroliniau and Lonisianian areas. Eastern Massachusetts to Oregron, North Carolina, and Missomri. Naturalized from tropical America.

Ala Ba.ma : Coast plain. Cultivated and waste places. Mobilo Coanty; becoming a troublesome weed.

Type locality: "Hab. in Peruvia."

Herb. Geol. Surv. Herb. Mohr.

ACTINOSPERMUM Ell. Sk. $2: 448,1821-24$.

(Balduina Nutt. Gen. $2: 175$. 1818. Not Baldwinia Raf. 1818.)

Actinospermum uniflorum (Nutt.) Barnhart, Bull. Torr. Club, 24 : 411. 1897.

Balduina uniflora Nutt. Gen. 2 : 175. 1818.

ONE-HEADED ACtiNospermum.

Ell. Sk. 2:447. Gray, Man. ed. 6, 286. Chap. Fl. 240. Gray, Syn. Fl. N. A. 1, pt. $2: 302$.

Louisiauian area. Coast of southern Virginia to Florida and eastern Louisiana.

Ala bama : Coast plain. Flat, damp pine barrens. Baldwin and Mobile counties.

Flowers deep yellow; August, September. Frequent. Perennial.

'Typ locality: "In open grassy swamps from the maritime parts of Virginia to Florida."

Herb. Geol. Surv. Herb. Mohr. 
Actinospermum angustifolium (Pursh) Torr. \& Gray, Fl. N. A. 2:389. 1842.

Buphthalmum angustifolium Pursh, Fl. Am. Sept. 2 :564. 1814.

Balduina multiflora Nutt. Geu. 2:176. 1818.

Ell. Sk. 2 :447. Chap. Fl.241. Gray, Syu. Fl. N. A. 1, pt. 2:302.

Louisianian area. Georgia to Florida.

Alabama: Coast plain. Drifting sands. Baldwin Connty, eastern shore Mobile

Bay, Point Clear. Flowers vellow; August, September. Rare. Annual or biennial. 'Type locality: "In Georgia and Florida. Bartram."

Herb. Geol. Surv. Herb. Mohr.

MARSHALLIA Schreb. Gen. Pl. 810. 1789.'

Four species, perennial herbs, South Atlantic North America.

Marshallia graminifolia (Walt.) Small, Bull. Torr. Club, 25:482. 1898.

Athanasia graminifolia Walt. Fl. Car.201. 1788.

Narrow-Leaf Marsiallia.

Marshallia angustifolia Pursh, Fl. Am. Sept. 2:520. 1814.

Ell. Sk. 2:316. Cliap. F1.211. Gray, Syn. Fl. N. A. 1, pt.2:303. Boynton \& Beadle,

Biltmore Bot. Stud. 1:4, t.9.

Louisianian area. North Carolina to Florida and western Lonisiana.

Alabama: Coast plain. Flat damp pine barrens. Mobile County, Bayon Labatre. Flowers pale lilac; August. Not frequent. Perennial.

'Type locality : South Carolina.

Herb. Geol. Surv. Herb. Mohr.

Marshallia graminifolia cyananthera Ell. Sk. 2 : 316. 1821-24.

Boynton \& Beadle, Biltmore Bot. Stud. 1:4, t. 10.

LANCE-Leaf Marsiallia.

Louisianian area. Florida, Georgia.

Alabama: Lower Pine belt. Damp pine woods. Escambia County, Flomaton (Biltmore Herb.). Rare.

Type locality : "Collected by Dr. Baldwin, near St. Marys, Georgia."

Marshallia obovata (Walt.) Beadle \& Boynton, Biltmore Bot. Stud. 1:5, t.5. 1901. Athanasia oborata Walt. Fl. Car. 201. 1788.

Persoonia lanceolata Michx. Fl. Bor. Am. 2: 105. 1803.

Trattenickia lanceolata Pers. Syn. 2: 403. 1807.

Marshallia lanceolata Pursh, F1. Am. Sept. 2:519. 1814.

Ell. Sk. 2:315. Chap. Fl. 241; ed. 3, 260. Gray, Syn. Fl. N. A. 1, pt. $2: 303$.

Carolinian and Louisianian areas. North Carolina, South Carolina, Florida.

Alabama : Mountain region and Lower hills. Dry open woods. Cherokee County (C. Mohr). Lee County, Auburn (Baker \& Earle). Flowers pale pink; June. Not frequent.

Type locality: South Carolina.

Herb. Geol. Surv. Herb. Mohr.

Marshallia trinervia (Walt.) Porter, Bull. Torr. Club, 5 : 337. 1894.

dthanasia trinervia Walt. Fl. Car. 201. 1788.

Triple-Nerved Marshallia.

Marshallia latifolia Pursh, Fl. Am. Sept. 2:519. 1814.

Carolinian area. Virginia and North Carolina.

Alabama : Mountain region. Lower hills. Dry open woods. Cullman County. Bibb County, limestone cliffs, banks of Little Cahaba River. Tuscaloosa Connty, Windham Springs ( $\boldsymbol{E}$. A. Smith). Flowers pale pink; July. Infrequent.

Type locality: South Carolina.

Herb. Geol. Surv. Herb. Mohr.

Marshallia mohri Beadle \& Boynton, Biltmore Bot. Stud. 1: 8, t.3. 1901.

Perennial $\frac{1}{2}$ foot to $2 \frac{1}{2}$ feet tall; leaves ovate-lanceolate, 6 to 10 inches long, including the petiole, $\frac{5}{8}$ inch to $1 \frac{1}{4}$ inches wide, tho uppermost much reduced in size, obtuse, gradually narrowed into the petiole, which is as long as the blade, the uppermost acute or obtuse, sessile, prominently 3-nerved, glabrous, entire, of a firm texture in age; stem angled, striate, glabrous to near the top, branched above the middle; heads usually several, containing from 30 to 75 or more flowers; involucral bracts thin at flowering time, ovate-lanceolate, acute at the apex, with conspicuous hyaline borders below the middle; corollas slender, pubescent, slightly if at all

${ }^{1}$ C. D. Beadle and F. E. Boynton, Revision of the Species of Marshallia, Biltinore Botanical Studies, vol. 1, p. 3. 1901. 
dilated at the throat; pappus scales acute; achenes ribbed, very bairy; chaff of the receptacle linear, acute.

Carolinian area. Georgia. (Lookout Mountain, Ruth, 638 and 662.)

Alabama: Morthtain region. Cullman Connty. Springy places, grassy glades. Flowers pale lilac-purple. June. Mature achenes August 14, 1893.

Type locality: "The type specimen was collected by Dr. Charles Mohr * * * at Cullman, Cullman County, Alabama, June 24, 1893.

Herb. Geol. Surv. Herb. Biltmore (type specimen).

FLAVERIA Juss. Gen. Pl. 186. 1789.

(Brotera Spreng. Schrad.Jonrn. Bot. 1800, pt. $2: 186$, t.5. 1801.)

About 7 species, tropical America. North America, 5. Lower Sonoran area (Texano-Mexican region ).

Flaveria trinervia (Spreng.).

CONTRA Yerisa.

Oedera trinervia Spreng. Bot. Gart. Halle, 63. 1800.

Brotera contrayeria Spreng. Schrad. Jonrn. Bot. 1800, pt.2:t.5. 1801. Not Milleria contrayerva Cav. Icon. $1: 2, t .4 .1791$.

Nauenburgia trinervala Willd. Sp. P1. 3:2393. 1803.

Brotera trinervata Hers. Syn. 2:498. 1807.

Flareria repanda Lag. Gen. \& Sp. Nov. 33. 1816.

Gray, Syn. H1. N. A. 1, pt. 2:354. Coulter, Contr. Nat. Herb. 2 : 23 ร.

Mreico, Argentina.

Louisianian area. Western Texas and Arizona to Mexico.

Alabama: Adventive with ballast. Mobile Conuty; frequentlyobserved. Annual. 'Type locality (Spreng. Schrad. Journ.): "Um Huanuco in Peru."

Herb. Geol. Surv. Herb. Mohr.

HYMENOXYS Cass. Dict. Sci. Nat. 55 : 278. 1828.

Three species, South Ameriean herbs.

Hymenoxys anthemoides (Juss.) Cass. Dict. Sci. Nat.55:278. 1828.

Hymenopappus anthemoides Juss. Ann. Mus. Par. 2 : 426. 1803.

BuEnos Ayres.

Alabama: Adrentive on ballast. Mobile County. Flowers yellow; July, Augnst. Type locality: "Ex Bouaria."

Herb. Geol. Surv. Herb. Mohr.

HELENIUM L.Sp. Pl. $2: 886$. 1753.

About 25 species, biennial or perennial herbs, Mexico. North America, 20; Atlantic, 11.

Helenium tenuifolium Nutt. Journ. Acad. Phila. 7 : 66. 1834.

BITTERWEED.

Chap. Fl.239. Gray, Syn. Fl. N. A. 1, pt. 2:347. Coulter, Contr. Nat. Herb. $2: 231$.

Carolinian and Lonisianian areas. Arkansas, Texas, and Louisiana to Alabama and North Carolina.

Alabama : Central Prairie region to Coast plain. Waste plices, roalsides. Bladen Springs, July, 1859. Common. Mobile County, apparently arlventive from the Sonthwest. Now naturalized from the coast to the northern limit of the Central Pine belt, along the railioads in great abundance, infesting pastures, waste lands, waysides. One of the most obnoxions of weeds. July to October. Perennial.

'Type locality: "The States of Mississippi and Alabama."

Herb. Mohr.

Helenium nudiflorum Nutt. Trans. Am. Phil. Soc. n. ser. 7 : 384.1841.

LOW SNEEZE Wred.

Leptopoda brachypoda Torr. \& Gray, Fl. N. A.2:388. 1842.

Gray, Man. ed. 6, 287. Chap. Fl. 240. Gray, Syn. Fl. N. A. 1, pt. 2: 349 . Coulter, Contr. Nat. Herb. $2: 232$.

Carolinian and Louisianian areas. Southwestern Illinois to Arkansas and Texas, eastward to Florida and North Carolina.

Arabama : Central prairies to Coast plain. Waste places, exsiccated exposed ground, pastures. Moutgomery, Washington, Clarke, Monroe, Baldwin, and Mobile counties. Rays yellow, disk deep reddish brown; June, Angust. Frequent, particularly in the coast plain. Perennial.

'Type locality: "The plains of Red River, Arkansa."

Herb. Geol. Surv. Herb. Mohr. 
Helenium parviflorum Nntt. Trans. Am. Phil. Soc. $7: 384.1841$.

SMALt-FLOWERED SNeEze Weed.

Chap. Fl. 239. Gray, Syn. Fl. N. A. 1, pt. 2: 349.

Lollisianian area. Georgia.

Arabama: Central Pine belt. Perry County (J. Donnell Smith). Lee Connty, Auburn (F. S. Earle). Local and rare. Perennial.

Type locality: "Georgia."

Helenium autumnale L. Sp. PI. 2 : 886. 1753.

Common SNeEze Whed.

Ell. Sk. 2:401. Gray, Mall. el. 6, 287 Chap. Fl. 239. Gray, Syn. Fl. N. A. 1, pt. 2: 349. Coulter, Contr. Nat. Herb. 2:232. Wats. Bot. Calif. 1: 393 .

Alleghenian to Lonisianian area. Quebec and Untario to the Pacific; from New York west to Minnesota; Ohio Valley to Missouri, Arkansas, Arizona, and Nevarla; from Florida to Texas.

Alabama : Over the State. Low banks, borders of ditches, etc. August to Octo-

ber. Common. Perennial.

Type locality : "Hab. in America septentrionali."

Herb. Geol. Surv. Herb. Mohr.

Helenium autumnale pubescens (Ait.) Britton, Mem. Torr. Club, 5 : 339. 1894.

Helenium pubercens Ait. Hort. Kew. 3 : 227. 178 ?.

Alabama: Coast plain. Damp thickets. Mobile County. Flowers September; not infrequent. Three to 4 feet high, closely pubescent, leaves ovate to ovate lanceolate, obtuse, crowded on the stem up to the many-flowered corsmb, strongly decurrent. Perennial.

'Type locality : "Native of North America."

Herb. Geol. Surv. Herb. Mohr.

Helenium integrifolium (M. A. Curtis).

Curtis's Helenium.

Leptopoda integrifolia M. A. Curtis; Torr. \& Grar, Fl. N. A. 2:387. 1842.

L. brevifolia var. $\beta$. Torr. \& Gray, Fl. N. A. $2: 387$. 1842.

Helenium curtisii Gray, Syn. Fl. N. A. 1, pt. 2:350. 1884.

Gray, Syn. Fl.1. c. Chap. Fl. ell. 3, 263.

Lonisianian area. North Carolina.

Alabana: Coast plain. Low wet pine barrens, swampy banks of streams and margins of ponds. Mobile C'ounty, banks of Deer Creek and Fowl River. Rays golden yellow, drooping; April, May. Not frequent. Perennial. Growing with H. brevifolium and easily confonnded with stouter forms of that species, froni which it is readily distinguished by the shining silvery blunt scales of the pappus.

Type locality: "Raleigh, N. Carolina, Mr. Curtis!"

Herb. Geol. Surv. Herb. Mohr.

Helenium nuttallii Gray, Proc. Am. Acad. 9 : 204.1874.

Nuttall's Helenium.

Leptopoda helenium Nutt. Gen. 2 : 174.1818.

L. decurrens McBride; Ell. Sk. $2: 446$. 1821-24.

Ell. Sk. 1. c. Chap. Fl. 240. Gray, Syn. Fl. N. A. 1, pt. $2: 350$.

Louisianian area. South Carolin i to Florida and Louisiana.

Ala Bama : Coast plain. Low damp pine barrens, borders of ponds and ditches. Mobile and Baldwin counties. Flowers yellow; April, May. Not infrequent. Perennial.

Type locality: "Sonth Carolina to Florida and Lonisiana."

Herb. Geol. Surv. Herb. Mohr.

Helenium vernale Walt. Fl. Car. 210. 1788.

Vernal Helenium.

Leptopoda puberula McBride; Ell. Sk. 2 : 445. 1821-24. Not H. puberulum DC.

Ell. Sk. 1. c. Chap. Fl.240. Gray, Syn. Fl. N. A. 1, pt. 2 : 350.

Louisianian area. Coast of North Carolina to Floricla and Mississippi.

Alabama: Lower Pine region. Coast plain. Low bauks along pine-barren streams. Washington County, Yellowpine. Mobile County. Not common. Perennial.

'Type locality: South Carolina.

Herb. Geol. Surv. Herb. Mohì.

Helenium brevifolium (Nutt.) Gray, Proc. Am. Acad. 9 : 205.1874.

Short leaf Helenium.

Leptopoda brevifolia Nutt. Trans. Am. Phil. Soc. ser. 2, 7:372. 1841.

Chap. Fl. 240. Gray, Syn. Fl. N. A. 1, pt. 2: 351.

Carolinian and Louisianian areas. North Carolina to Florida and Mississippi. 
AldBama: Mountain region. Coast plain. Wet sandy soil, borlers of woods. Cullinan County, 800 feet, wet pine woods. South throughout the pine barrens in low wet places. Mobile County. Rays yellow, disk brown. Common. Perennial.

Type locality not ascertained.

Herb. Geol. Surv. Herb. Mohr.

GAILLARDIA Fong. Mem. Acal. Sei. Par. $1786: 5, t .1,2.1786$.

Ten species, Mexico, North America, chietly southwestern. Atlantie, 2.

Gaillardia lanceolata Michx. Fl. Bor. Am. $2: 142$. 1803. Lavee-Leaf Gail.t.ARdia. Gaillardia bicolor Pursh, Fl. Am. Sept. 2 :572. 1814. Not Willd.

Ell. Sk. 2:449. Gray, Man. ed. 6, 288. Chap. Fl. 238. (iray, Syn. Fl. N. A. 1, pt. 2: 352. Conlter, Contr. Nat. Herb. $2: 233$.

Carolinian and Louisianian areas. South Carolina to Florida, west to Texas, Arkansas, and southern Kansas.

Alabama: Central Pine belt to Coast plain. Dry san iy pine woods. Antauga County (E.A. Smith). Common throughout the Pine belt in dry pine barrens. Rays dark yellow, with purplish veins; disk pansy-purple. Variable; in barren exposed soil with the leaves narrowly linear and heads rayless. Angust, September. Annual.

Type locality: "Hab. a Carolina ad Floridam, in aridis."

- Herb. Geol. Surv. Herb. Mohr.

\section{Gaillardia lanceolata flavovirens var. nov.}

Stem slightly canescent, leaves narrowly linear, strongly denticulate; flowering beads without rays, the disk flowers greenish yellow. Though different in aspect, this variety presents no characters of specific value; the lobes of the corolla are equally tipped with a candate cusp, and the receptacle destitute of fibrils.

Alabama: Coast plain. Dry pine barrens, in loosesand. Baldwin Connty, between Pou Secour anıl Perdido Bay. June. Annual.

Type locality: Bald win County, Ala.

Herb. Geol. Surv. Herb. Mohr.

Gaillardia pulchella Fong. Mem. Acad. Sci. Par. 1786:5. 1786.

Gray, Syn. Fl. N. A. 1, pt. 2:352. Coulter, Contr. Nat. Herb. $2: 233$.

Mexico.

Louisianian area. Western Louisiana, Arkansas, and Texas to Arizona.

Alabama : Prairie region. Coast plain. Dry grassy banks. Dallas County, Marion Junction, horders of fielels, with Rudbeckia amplexicaulis, scarcely indigenous?' Mobile County, Pinto Island. A pril, May. Copious on gravelly marle ground ; undonbtedly adventive with ballast. Annual.

Economic uses: Oruamental, frequent in cultivation.

Type locality: "Mexic'o."

Herb, Gool. Srrv. Herb. Mohr.

ACHILLEA I. Sp. Pl. 2 : 898. 1753. YARRow.

Eighty species, peremnial herbs, temperate regions, chiefly of the Old World.

Achillea millefolium L. Sp. Pl. 2 : 899. 1753.

MiLlefoll Yarkow.

Ell. Sk. 2:405. Gray, Man. ed. 6, 289. Chap. Fl. 242. Gray, Syn. Fl. N. A. 1, pt. 2:363. Coulter, Contr. Nat. Herb. $2: 239$. Wats. Bot. Calif. $1: 400$.

All over the Northern Hemisphere. From Labrador to Alaska, south to the Gulf; from Florida to Texas and California.

Alabama: Throughout the State. Frequent and perhaps indigenons in the northern section. Sonth ward rare and most probably introduced. Mobile Connty, Wheelerville. 'The softly villous form ( $A$. lanata Koch).

Economic uses: The herb, under the name of "millefolium," is an obsolete medicinal plant.

Type locality: "Hab. in Europae pascuis pratisque."

Herb. Mohr.

ANTHEMIS J.Sp. Pl. 2 : 893. 1755.

One hundred species, Old World herbs.

Anthemis cotula L. Sp. Pl. 2:894. 1753.

May Weed, Dog Fennel.

Maruta cotula DC. Prodr. 6:13. 1837.

Ell. Sk. 2: 405. Gray, Man. ed. 6, 288. Chap. Fl. 241. Gray, Syu. Fl. N. A. 1, pt. $2: 362$. Conlter, Contr. Nat. Herb. $2: 239$. Wats. Bot. Calif. $1: 401$. 
EUROPE.

Extensively naturalized from Canada to the Gulf of Mexico, west to Texas. Sparingly iutroduced in California.

Ala Bama : Throughout the State. Flowers April to June; most abuudant in central and upper districts; waysides and waste places. Aunual.

Type locality: "Hab. in Europae ruderatis, praecipue in Ucrania."

Herb. Geol. Surv. Herb. Mohr.

Anthemis arvensis L. Sp. Pl. 2: 894. 1753.

field Camomile.

Gray, Man. ed.6, 288.

EUROPE.

Adventive in several localities on the Atlantic coast; District of Columbia.

Ala liama : Fugitive on ballast. Mobile County. June; rare. Annual.

Type locality: "Hab. in Europa, praesertim Sueciae agris."

Herb. Geol. Snrv. Herb. Mohr.

M.+TRICARIA L. Sp. Pl. 2:890. 1753. Wild Camomile.

Fifty species; temperate regions of the Old World.

Matricaria inodora maritima (L.) Babington, Man. Brit. Pot. ed.5, 179. 1862.

Seaside Wild Camomile.

Matricaria maritima L. Sp. Pl. 2 :891. 1753.

Pyrethrum maritimum Smith, Eng. Bot. 2:901. 1790-1814.

Alabama: Arventive from Europe with ballast. Mobile County. Flowers white; Augnst. Ubserved for the past twelve years. Perennial.

'Type locality : "Hab. in Europae septentrionalis littoribus maris."

Herb. Geol. Surv. Herb. Mohr.

CHRYSANTHEMUM L. Sp. Pl. 2:888. 1753.

One huudred and forty species, perennial and annual herbs; temperate and warmer regions of the Old World.

Chrysanthemum leucanthemum L. Sp. Pl. 2:888. 1753.

Leucanthemum rulgare Lam. Fl. Fr. 2 : 137. 1778.

OXRYe Daisy. Whiteweed.

Ell. Sk. 2:400. Gray, Man. ed.6, 289. Chap. F1. 242. Gray, Syn. F1. N. A. 1, pt. 2:365. Wats. Bot. Calif. 1:401.

EUROPk.

Alleghenian to Carolinian area. Naturalized from Canada to the Pacific, and thronghout the Atlantic United States to the Gulf from Florida to Lonisiana.

AlabaMa: Throughout the State. Pastures and grass lands. Not rarely cultivated for ornament and apt to escape, becoming a troublesome weed; May, July. Perennial.

Tspe locality : "Hab.in pratis Europae."

Herb. Geol. Surv, Herb. Mohr.

Chrysanthemum parthenium (L.) Pers. Syn. 2:462. 1807.

Feverfew.

Matricaria parthenium L. Sp. Pl. 2:890. 1753.

Gray, Man. ed. 6, 289. Gray, Syu. Fl. N. A. 1, pt. 2:365.

Europe.

Alleghenian to Louisianian area. Escaped from cultivation from Canada to Florida and Louisiana.

Alabama: Mobile County, waste places. Flowers white, August, September.

Not frequent. Perennial.

Economic uses: 'The herb, under name of "feverfew," is used medicinally.

Type locality: "Hab. in Europae cultis, ruderatis."

Herb. Geol. Surv. Herb. Mohr.

Chrysanthemum coronarium L. Sp. Pl. 2 : 890. 1753.

MARIGOLD.

Gray, Syn. Fl. N. A. 1, pt. $2: 364$.

Alabama: Fugitive on ballast, from southern Europe. Mobile County. Flowers golden yellow; July, August. Annual.

Type locality : "Hab. in Creta, Sicılia."

Herb. Geol. Surv. Herb. Mohr. 
Chrysanthemum segetum L.Sp. Pl. 2: 889. 1753.

CORN MaRigold.

Gray, Syn. Fl. N. A. 1, pt. 2:364.

EUROPE.

Adventive with ballast on the Canadian coast and Atlantic ports.

Ala baMa : Fugitive on ballast. Mobile Comnty, with the last. Flowers golden yellow. Annual.

Type locality: "Hab. in Scaniae, Germaniae, Belgii, Angliae, Galliae agris."

Herb. Geol. Surv. Herb. Mohr.

ARTEMISIA L. Sp. Pl. 2 : 845. 1753. WORMWOOD.

About 150 species considered valid, Northern Hemisphere, Europe, Asia. North America, 40; mostly on the Western table-lands.

Artemisia vulgaris L. Sp. Pl. 2:848. 1753.

MUGWORT.

Gray, Man. ed. 6, 291. Gray, Syn.Fl. N. A. 1, pt. 2:372.

EUROPE.

Boreal region. Canada to the arctic circle indigenous; southward introduced.

Alabama : Fingitive on ballast. Mobile County; July, 1894 and 1895. Perennial. Type locality: "Hab. in Europae cultis, ruderatis.

Herb. Geol. Surv. Herb. Mohr.

ERECHTITES Raf. Fl. Ludov. 65. 1817.

About 12 spocies, annuals, Australia, Eastern America.

Erechtites hieracifolia (L.). Raf.; DC. Prodr. 6: 294. 1837.

Senerio hieracifolius L. Sp. Pl. 2 : 866.1753.

Ell. Sk. 2: 328. Gray, Man. ed.6, 294. Chal. Fl. 244. Gray, Syn. Fl. N. A. 1, pt. $2: 396$.

Alleghenian to Louisianian area. Nova Scotia and Canada to Saskatchewan, south to the Gulf, from Florida to Louisiana and Arkansas.

Alabana : Over the State. Rich woodlands. Throughout the summer; common. Annual.

Typelocality: "Hab. iu America septentrionali."

Herb. Geol. Surv.

SENECIO L. Sp. Pl. 2 : 866. 1753. Groundshl. RAGWort.

About 1,200 species, cosmopolitan, shrubs and herbs. North America, 75; largely Western, interior, and Pacific. Atlantic, 10.

Senecio earlei Small, Bull. Torr. Club, 25 : 147. 1898.

Perennial, densely cottony below, sparingly so or glabrate above. Stem mostly simple, 12 to 20 inches high, with numerous basal leaves, which are oval or oblong, obtuse or retuse, serrate; petioles longer than the blades; stem-leaves pinnatifid, linear-lanceolate or oblong, the lower petioled, the upper sessile; pedicels slender.

Carolinian area. Tennessee.

Alabama : Mountain region. Lee County, Auburn, September (Earle s. Underwood). Differs from the closely related Senecio tomentosus by its almost wholly glabrous foliage, shorter petioles, more rounded and more finely toothed leaves, more open inflorescence, and more numerons heads.

Type locality: "Alabama: Auburn, Lee County, 1896, Earle \& Underwood. 'Tennessee: Knoxville, Knox County, 1897, Ruth."

Herb. Geol. Surv. Herb. Mohr.

Senecio smallii Britton, Mem. Torr. Club, 4:132. 1893.

Senecio aureus angustifolius Britton, Mem. Torr. Clıb, $2: 39$. 1890. Not S. angustifolius Willd. 1804.

Carolinian area. Monntains of Virginia, North Carolina, and eastern Tenuessee.

Alabama: Mountain region. Metamorphic hills. Dry open woods, pastures, old

fields. Randolph County, Wedowee. Lee County, Auburn (Earle f Underwood).

Never met with in the low conntry. Flowers golden yellow; May. Perennial.

Type locality: Near the "Peaks of Otter," in the Blue Ridge, Va.

Herb. Geol. Surv. Herb. Mohr.

Senecio obovatus Muhl.; Willd. Sp. Pl. 3 : 1999. 1804.

OVATE-LEAY RAGWORT.

Senecio aureus var. obocatus Torr. \& Gray, Fl. N. A. 2 : 442.1843.

S. elliottii 'Torr. \& Gray, Fl. N. A. 2 : 443. 1843. 
Ell. Sk. 2 : 329. Gray, Man. ed. 6, 293. Chap. Fl. 245. Gray, Syn. Fl. N. A. 1, pt. 2: 391. C'oulter, Contr. Nat. Herb. $2: 242$.

Alleghenian and Carolinian areas. Nova Scotia, Quebec, and Ontario to British Colunibia; Now Eugland west to Minnesota, southward from New York along the monntains to Georgia and Arkansas.

Alabama: Mountain region to Central Pine belt. Dry hills, open woods. Lawrence and Cullman connties. Lee County, Auburu (Earle \& Baker). Bibb County, Pratt's Ferry. Hale County, Havana (E.A.Smith). May; not frequent. Perennial.

Type locality: "Hab. in America boreali."

Herb. Geol. Surv. Herb. Mohr.

Senecio memmingeri Britton, Bull. Torr. Club, 25: 147. 1897.

Memminger's Butter Weed.

Glabrous, or nearly so, 1 to 2 feet high, with tufts of basal leaves which are 4 to 8 inches long, the blades bipinnatificl, louger than the petioles, the segments oblong or obovate iu outline, more or less cuneate at the base, coarsely toothed or incised; stem loaves similar, but usually more finely divided; corymbs 2 to 6 inches broad; heads numerous; achenes pubescent.

"Most closely related to Senecio millefolium, but clearly distinguished by the broader leaf segments."

Carolinian area. North Carolina.

Alabama: Monntain region. Metamorphic hills. Dry rocky hills. Lee County, Auburn (Underwood \& Earle). May 16, 1896. Rare. Perennial.

Type locality: "The original specimens of this species were collected in Henderson County, North Carolina, by E. R. Memminger, in 1887."

Herb. Geol. Surv.

Senecio lobatus Pers. Syn. 2 : 436. 1807.

Butter Ween.

Senecio lyratus Michx. Fl. Bor. Ain. $2: 120$. 1803. Not L.

Ell. Sk. 2:332. Gray, Man. ed. 6, 293. Chap. Fl. 245. Gray, Syn. Fl. N. A. 1, pt. 2:394. Coulter, Contr. Nat. Herb. 2 : 241.

Carolinian and Louisianian areas. North Carolina to Florida, west to Texas, Arkansas, Missouri, and southern Illinois.

Alabaya : Tennessee Valley to Coast. Bottom lands, low fields. Flowers April,

May. Abundaut in the rich damp lauds of the Prairie region. Annual or biennial. Type locality: "Hab. in Carolinae nemoribus."

Herb. Geol. Surv. Herb. Mohr.

Senecio vulgaris L. Sp. Pl. 2 : 867. 1753.

Groundsel.

EUROPE.

Boreal region to the Carolinian and Louisianian areas. Naturalized. Newfoundland and Labrador, Hudson's Bay. Northern United States.

AlabaMa: Adventive on ballast; seemingly persistent. June to August. Annual. Type locality: "Hab. in Europae cultis, ruderatis, succulentis."

Herb. Geol. surv. Herb. Mohr.

MESADENIA Raf. Loud. Gard. Mag. 8:247. 1832. Indian Plantain.

(Cacalia L. Sp. Pl. $2: 834$. 1753.)

About 12 species, perennial herbs, Northern Hemisphere. Temperate regions, Europe, Asia. North America, 10; Atlantic, 9.

Mesadenia reniformis (Muhl.) Raf. New Fl. 4: 79. 1836.

Cacalia reniformis Muhl.; Willd. Sp. Pl. 3 : 1735. 1804. Greater Indian Pleantain. Gray, Man. ed. 6, 294. Chap. Fl. 244. Gray, Syn. Fl. N. A. 1, pt.2:395.

Alleghenian and Carolinian areas. New Jersey aud Penusylvania to Ohio Valley, Missouri, and Minnesota, south along the mountains to Georgia.

Alabama: Mountain region. Rich calcareous hillsıdes. Blount County, near

Blount Springs. Flowers white; June. Local and infrequent.

Type locality: "Hab.in Pensylvania."

Herb. Geol. Surv. Herb. Mohr.

Mesadenia atriplicifolia (L.) Raf. New Fl. 4: 79. 1836. Pale Indian Plantarn.

Cacalia atriplicifolia L. Sp. Pl. 2 : 835. 1753.

Ell. Sk. $2: 310$. Gray, Man. ed.6, 294. Chap. Fl. 244. Gray, Syn. Fl. N. A. 1, pt. $2: 395$. 
Alleghenian and Carolinian areas. Canada; western New York and Michigan to Minnesota, south to the Ohio Valley, Missouri, and Arkansas, and along the mountains to Georgia.

Ala baMa: Mountain region to Lower hills. Rich woodlands. Tallapoosa and Tuscaloosa counties. Flowers white; June. Four to 5 feet. Not frequent. Type locality: "Hab. in Virginia, Canada."

Herb. Geol. Surv. Herb. Mohr.

Mesadenia ovata (Walt.) Raf. New Fl. 4 : 79. 1836. Ovate-leaf Indian Plantain. Cacalia orata Walt. Fl. Car. 196. 1788.

Ell. Sk. 2:310. Chap. Fl. 244. Gray, Syn. Fl. N. A. 1, pt. 2: 395.

Louisianian area. Georgia to western Florida and west to Lonisiana.

Ala bama : Central prairies. Damp thickets, open 'woods. Montgomery County. Lee County, Auburn (Earle). Flowers white; July to September. Rare. Local. Type locality: South Carolina.

Herb. Geol. Surv. Herb. Mohr.

Mesadenia tuberosa (Nutt.) Britton in Britt. \& Br. Ill. Fl. $3: 474$.

Cacalia tuberosa Nutt. Gen. $2: 138.1818$.

TUberous-rooted Indian Plantain.

Mesadenia plantaginea Raf. New Fl. 4:79. 1836.

Gray, Man. ed. 6, 294. Chap. Fl. 244. Gray, Sin. Fl. N. A. 1, pt. 2:396. Conlter,

Contr. Nat. Herb. $2: 242$.

Alleghenian to Louisianian area. Ontario and Ohio to Missouri, Michigan, and Minnesota, south along the monntains to Georgia and Florida, west to l'exas and Arkansas.

Alabama: Central Prairie belt. Low banks and fields. Hale County, Gallion. Dallas County, Uniontown (E. A. Smith). Flowers white; July, Angust. Not frequent.

Type locality: "On shady hills near Natchez on the banks of the Mississippi, and also around St. Louis."

Herb. Geol. Surv. Herb. Mohr.

Mesadenia lanceolata (Nutt.) Raf. New Fl. 4 : 79. 1836.

Cacalia lanceolata Nutt. Gen. $2: 138.1818$.

Lance-leaf Indian Plantain.

Ell. Sk. $2: 311$. Chap. Fl. 215. Gray, Syn. Fl. N. A. 1, pt. 2: 396 .

Louisianian area. Georgia and Florida to Louisiana.

Alabama: Coast plain. Swampy banks along pine-barren streams, grassy river marshes. Mobile and Baldwin counties. Flowers white; Angust, September. Three to 6 feet high. Frequent; abundant in the submaritime marshes, fresh or slightly brackish.

Type locality: "In Georgia and Florida.-Dr. Baldwyn."

Herb. Geol. Surv.

ARCTIUM L.Sp.Pl. 2 : 816. 1753.

Six species, perennial herbs, temperate Europe, Asia.

Arctium minus Schk. Bot. Handb.3:49. 1803.

SMALLER BURDOCK.

Lappa minor DC. Fl. Fr. 4 : 77. 1805.

EUROPE.

Naturalized, Canada and eastern United States.

Alabama: Tennessee Valley. Waste places. Marshall County, Gunthersville.

Decatur. July, August.

Type locality not ascertained.

Herb. Geol. Surv.

CARDUUS L. Sp. Pl. 2 : 820. 1753. Thistle.

About 250 species, perennials, temperate regions. Europe, Asia. North America, 37; Atlantic, 12.

Carduus spinosissimus Walt. Fl. Car. 194. 1788.

YELLOW THISTLE.

Cirsium horridulum Michx. Fl. Bor. Am. 2: 90. 1803.

Cnicus horridulus Pursh, FI. Am. Sept. 2 :507. 1814.

Gray, Man. ed. 6, 295. Chap. Fl.248. Gray, Syn. Fl. N. A. 1, pt. 2:400. Coulter, Contr. Nat. Herb. $2: 243$. 
Carolinian and Louisianian areas. Coast sonthern New England to Florida and Texas.

Alabama: Central Prairie region to Coast plain. Low rich ground, borders of woods. Montgomery, Mobile, and Baldwin counties. Flowers yellow; March, April. Six to 8 feet. Common; prevailing in the coast region. Perennial.

Type localitv: South Carolina.

Herb. Geol. Surv. Herb. Mohr.

Carduus spinosissimus elliottii (Torr. \& Gray) Porter, Mem. Torr. Club, $5: 345$. 1894.

ElliotT's Thistle.

Cirsium horridulum var. elliottii Torr. \& Gray, F1. N. A. 2, pt. 1:460. 1843.

Ell. Sk. $2: 272$.

Carolinian and Louisianian areas. North Carolina to Georgia and Florida.

AlabaMa: Mountain region to Central Prairie belt. Dry light soil. Pastures, openings in the woods, waysides. Cullman and Tuscaloosa counties. Lee County, Auburn (Baker \& Earle). Montgomery County. Flowers purple (wine purple). Not common. Two to 3 feet high.

Type locality: "Southern States, Elliott. Florida, Dr. Chapman!"

Herb. Geol. Surv. Herb. Mohr.

Carduus virginianus L.Sp. Pl. 2: 824. 1753.

Virginia Thistle.

Cirsium virginianum Michx. Fl. Bor. Am. 2: 90. 1803.

Cnicus virginianus Pursh, Fl. Am. Sept. 2:506. 1814.

Ell. Sk. 2:270. Gray, Man. ed. 6, 296. Chap. Fl. 247. Gray, Syn. Fl. N. A. 1, pt. $2: 404$. Coulter, Contr. Nat. Herb. $2: 244$.

Alabama : Mountain region to Coast plain. Dry open woods. Cullman County, dry fields. Talladega County, near Chandler springs, rocky pine forests, 1,000 feet altitude; Renfroe, 800 feet altitude. Bibb and Mobile counties. Flowers purple; August to October. Not common.

Type locality: "Hab. in,Virginia."

Herb. Geol. Surv. Herb. Mohr.

Carduus altissimus L. Sp. P1. 2 : 824.1753.

Tall Thistle.

Cnicus altissimus Willd. Sp. Pl. 3 : 1671. 1804.

Cirsium altissimum Spreng. Syst. 3:373. 1826.

Ell. Sk. 2 :268. Gray, Man. ed. 6, 296. Chap. Fl.247. Gray, Syn. Fl. N. A. 1, pt. 2: 404. Coulter, Contr. Nat. Herb. 2: 243.

Carolinian and Louisianian areas. Pennsylvania, Ohio to Missouri, south to

Tennessee and Georgia, west to Louisiana and Texas.

Alabama : Mountain region to Coast plain. Damp thickets. Clay County, Shiubone Valley. Chambers County (E. A. Smith). Lee County, Auburn (Earle). Flowers purple; September, October. Not common.

Type locality : "Hab. in Carolina."

Herb. Geol. Surv. Herb. Mohr.

Carduus glaber Nutt. Gen. 2 : 129. 1818.

Sмоотн Thistle.

Cnicus glaber Ell. Sk. 2 : 270. 1824.

Cirsium nuttallii DC. Prodr. 6:651. 1836.

Ell. Sk. 2 :270. Chap. Fl. 247. Gray, Syn. Fl. N. A. 1, pt. $2: 404$.

Carolinian and Louisianian areas. South Carolina and Florida to Mississippi.

Alabama: Littoral region. Dry pine woods. Mobile County, Dauphin Island.

Type locality: "Hab. in New Jersey."

Herb. Geol. Surv. Herb. Mohr.

Carduus lecontei (Torr. \& Gray) Pollard, Bull. Torr. Club, 24 :157. 1897.

Cirsium lecontei Torr. \& Gray, Fl. N. A. 2: 458. 1843.

Lolisianian area. Georgia to eastern Louisiana.

Alabama: Coast plain. Low damp pine barrens. Mobile County. Flowers greenish yellow; July. Not rare. Involucre very viscid.

Type locality: "Georgia, Leconte! Covington, Louisiana, Drummond!"

Herb. Geol. Surv. Herb. Mohr.

Carduus arvensis (L.) Robs. Brit. Fl. 163. 1777.

Canada or Cursed Thistle.

Serratula arvensis L. Sp. Pl. 2 : 820. 1753.

Cirsium arvense Scop. Fl. Car. ed. 2, 2:126. 1772.

Cnicus arvensis Hoffm. Deutsch. Fl. ed. 2, 1, pt. 2: 130. 1804.

Gray, Man. ed. 6, 296. Gray, Syn. Fl. N. A. 1, pt. 2:398. 
EURope.

Canadian zone to Carolinian area. Newfouudland to Saskatchewan, aud to Northern and Middle States.

Alabama : Adventive from Europe on ballast heaps. Mobile County, August, 1893. Observed through several seasons; not spreading.

Type locality: "Hab. in Europae eultis agris."

Herb. Geol. Surv. Herb. Mohr.

Carduus lanceolatus L. Sp. PI. 2 : 821. 1753.

Common 'THISTLE.

Cirsium lanceolatum Scop. Fl. Carn. ed. 2, 2:130. 1772.

Cnicus lanceolatus Willd. Prodr. Fl. Ber. 259. 1787.

Europk.

Naturalized throughont Canada to Vancouver Island, and in the Eastern United States.

Alabama: Diffused through the State. Waste places, roadsides. Clay County, near Ironaton. Mobile County, near the shipping. July; rare.

Type locality: "Hab. in Europae cultis ruderatis."

Herl. Geol. surv. Herb. Mohr.

Carduus pycnocephalus L. Sp. Pl. ed. 2, 2: 1151. 1763.

Eurupe.

On ballast, Camiden, N. J. (Martindale).

Alabama: Mobile Comty. Adventive on ballast. 'Three to 4 feet high; flowers pale red. Perennial. Observed 1889.

Type locality: "Hab. in Europa australi."

Herb. Geol. Surv. Herb. Mohr.

\section{ONOPORDON L. Sp. Pl. $2: 827$. 1753. CotToN 'Thistle.}

About 12 species, natives of the Old World.

Onopordon acanthium L. Sp. Pl. 2 : 827. 1753.

Carolinian area. Adventive in southern New England, other Atlantic States, and the Ohio Valley.

Alabama: Fugitive on ballast. Mobile County, August, 1887. Perennial.

Type locality: "Hab. in Europae ruderatis, cultis."

Herb. Geol Surv. Herb. Mohr.

MARIANA Hill, Veg. Syst. 4 : 19. 1762. MıL 'ThIstlk.

(SILybum Gaert. Fruet. $2: 378, t .162 .1791$. )

One species. Mediterranean region.

Mariana mariana (L.) Hill, Hort. Kew. 61. 1768.

Carduus marianus L. Sp. Pl. $2: 823.1753$.

Silybum marianum Gaert. Fruct. 2:378, t.162. 1791.

Gray, Syn. Fl. N. A. 1, pt. 2:405. Wats. Bot. Calif. $1: 421$.

Milk Thistle.

Mediterranean Europe.

Adventive in California.

Arabama: Fugitive on ballast. Mobile County. Flowers purple; May. Three to 4 feet high. Annual.

'Type locality: "Hab in Angliae, Galliae, Italiae ageribus ruderatis."

Herb. Geol. Surv. Herb. Mohr.

CNICUS L. Sp. PI. 2:826. 1753.

One species, Mediterranean countries.

Cnicus benedictus L. Sp. Pl. 2 : 826.1753.

Blfissed 'Thistle.

Centaurea benedicta L. Sp. Pl. ed. 2, 2 : 1296. 1763.

Gray, Man. ed. 6, 297. Gray, Syn. Fl. N. A. 1, pt. 2: 406. Coulter, Contr. Nat. Herb. $2: 244$.

SoUTHERN EUROPE.

Carolinian area. Naturalized in southern Atlantic seaports, in the interior of 'Texas, and in California. 
Alabama: Metamorphic hills and Central Prairie region. Pastures, waste places. Montgomery County, copious. Lee County, Auburn, perfectly naturalized. Flowers white; April. Annual?

Type locality: "Hab. in Chio, Lemno, Hispania ad versuras agrorum."

Herb. Geol. Surv. Herb. Mohr.

Centaurea L. Sp. Pl. 2: 909. 1753. Centaurea.

About 350 species, Old World, European Asia.

Centaurea calcitrapa L. Sp. Pl. 2 :917. 1753.

Star Thistle.

Gray, Man. ed.6, 297. Gray, Syn.Fl. N. A. 1, pt. 2: 406.

EUROPE.

Adventive in seaports from New York southward.

Alabama : Fugitive on ballast. Mobile County. Flowers red; August. Annual. Type locality: "Hab. in Helvetia, Anglia, et Europa australiori secus vias."

Herb. Geol. Surv. Herb. Mohr.

Centaurea melitensis L. Sp. Pl. 2 :917. 1753.

Lombardy StaR Thistle.

Wats. Bot. Calif. $1: 420$.

Mediterranean Europe.

Adventive in California.

Alabama : Fugitive on ballast. Mobile County. Flowers yellowish; June.

Type locality: "Hab. in Melita."

Herb. Geol. Surv. Herb. Mohr.

THYRSANTHEMA Neck. Elem. 1:6. 1790.

(Chaptalia Vent. Jard. Cels. t. 61. 1800.)

Eight species, warmer America. South Atlantic North America, 1.

Thyrsanthema semiflosculare (Walt.) Kuntze, Rev. Gen. Pl. 1:369. 1891.

Perdicium semiflosculare Walt. Fl. Car. 204. 1788.

Vernal Chaptalia.

Tussilago integrifolia Michx. Fl. Bor. Am. 2:121. 1803.

Chaptalia tomentosa Vent. Jard. Cels. t.61. 1800.

C. integrifolia Nutt. Gen. 182. 1818.

Eil. Sk. 2:459. Chap. Fl. 248. Gray, S5n. Fl. N. A. 1, pt. 2:408. Coulter, Contr. Nat. Herb. $2: 245$.

Louisianian area. South Carolina to Florida, west to Texas.

Alabama: Lower Pine region. Coast plain. Flat damp pine barrens. Mobile and Baldwin counties. Flowers white, purple tinged; February, March. Common. Perennial.

Type locality: South Carolina.

Herb. Geol. Surv. Herb. Mohr. 



\section{THE SPONTANEOUS FLORA OF ALABAMA IN ITS RELATION TO AGRICULTURE.}

The relation of flora to soil has long been recognized by the observing agriculturist, who judges the fertility of the virgin soil by the quality and vigor of the tree growth which it supports. The consideration of the laws which control the distribution of species within certain limits which are recognized as the boundary lines of the life zones of our continent points at once to the crops naturally adapted to them. Directing the attention to the influence of the secondary factors, by which species and their associations are restricted to minor areas within the principal zones, recognized as subordinate floral regions, it becomes evident that among these factors the physical and chemical conditions of the soil are most potent. The character of the vegetation becomes thus clearly the indicator of the soil conditions. Guided further by practical experience and the teachings of science, the fitness of the land for the production of a special crop can often be ascertained by the farmer from the character of the vegetation alone, without having to resort to costly and time-consuming experimentation. In Alabama, as well as in the adjoining States, where the efforts of the agriculturist have been and still are almost entirely confined to a single crop (cotton), recorded experiences of this kind are greatly wanting. The writer has, however, made the attempt to bring together the facts observed by him in this direction, which might serve to stimulate the further investigation of a subject of great practical importance to the farmer.

Beginning, in the consideration of the relations of the flora to the agricultural interests, with the subtropical part of the State (the Louisianian life area), the following facts, serving as unfailing guides, present themselves. In the Coast plain, where the upland hammocks prevail, with their growth of evergreen oaks (live oak, laurel oak) and magnolias, with their variety of shrubbery - where the Cuban pine in its best development has replaced the original heavy growth of long-leaf pine, with gallberry bushes for the undergrowth, and the ground covered by a dense turf of horn rushés (Rynchospora), tall broom grasses (Andropogon virginicus, A. glomeratus), Manisuris, Paspalum (P.praecox), with golden-rods (Solidago stricta, S. angustifolia, Euthamia graminifolia, E. caroliniana), numerous Eupatoriums, blazing star (Lacinaria spicata), Aster (A.dumosus and others)-there is always found a soil of light 
sandy loam, rich in vegetable matter on the surface, underlaid by a more compact subsoil of great depth, and at a short distance beneath the surface damp throughout the year, but not deficient in drainage. A soil of this character, in this low latitude, unites all the requirements for the rapid growth of the pecan tree, yielding nuts of finest quality. The presence of the mesophile herbaceous plant associations, forming the original plant covering-that is, such as prefer a soil of a moderate amount of moisture and a good drainage-points to the fitness of the soil for the cultivation of early vegetables in the field during the fall and winter seasons, where, in this part of the Louisianian zone, the proximity of the sea offers greater protection against the injuries caused by sudden and extreme changes of temperature, followed by light frosts. Among the fruit trees most successfuliy grown in the coast region the fig is to be included, which, in the closer and damper soil, is less liable to suffer from the causes mentioned.

In the region of the Lower division of the Coast Pine belt or the rolling pine hills (dry pine barrens), the long-leaf pine reigns supreme, with a scanty undergrowth of black jack, blue jack (Quercus mary. landica, Q. brevifolia), and downy yellow haw (Crataegus elliptica). Herbaceous xerophile associations form a dense carpet beneath, consisting of a variety of panic grasses and Paspalums, broom sedge (Andropogon scoparius) and many species of the pea family-tick trefoils (Meibomia), bush clovers (Lespedeza), prairie clovers (Kuhnistera), goat's rue (Cracca smallii, C. hispidula, C. virginiana)-blazing star (Lacinaria elegans), vanilla plant (Trilisa odoratissima), golden-rods (Solidago puberula pul. verulenta, S. odora, etc.), golden asters (Chrysopsis mariana, C. pilosa), asters (Aster patens, Ionactis linariifolius), sunflowers (Helianthus radula). These give character to the flora and indicate a soil of warm sandy loam, with a somewhat clayey subsoil capable of retaining moisture. The pine lands where such conditions prevail are particularly adapted to the growth of pears of A siatic origin, such as the Le Conte and the Keiffer, and the scuppernong grape, and the growing of the peach gives much promise. Watermelons are raised in large quantity and of best quality. The sweet potato, under the application of proper fertilizers, yields large crops, and throughout the pine belt forms one of the most important food products. Treated in the same way, corn, particularly the white variety, yields satisfactory crops, and the tropical sugar cane is grown with equal success.

In the Upper division of the Coast Pine belt with its arboreal vegetation of a mixed growth of coniferous and hard-wood trees, particularly where the short-leaf pine mingles freely with upland oaks, npland hickories, and the chinquapin chestnut, a light sandy loam of a grayish or pale buff color frequently prevails, underlaid by a retentive sub. soil. This class of soils, particularly where they cover the low undu. lating hills, is found especially favorable for the cultivation of the strawberry. Soils of a very similar character, and equally adapted to 
this crop, are, on the Warrior table-land, indicated by the mixed growth of pines (Pinus taeda, $P$. echinata) and deciduous trees. Judging by the success achieved with leaf tobaceo of highest grade on soils of the same character in the lower part of the South Atlantic States, from North Carolina to middle Florida, it can reasonably be supposed that this profitable crop can be, not less successfully, raised in southern Alabama.

In the same floral region, and also in the eastern extension of the Prairie belt, post oak, associated with black oak (Quercus tinctoria), southern red oak (Q. texana), and mockernut and pignut hickory, with a slight sprinkling of short-leaf pine, forms open forests, with tall rosinweeds, sunflowers, and phloxes in the openings, indicating a warm, loamy, generous soil, which is of a deep chocolate to a deep reddish color, resting upon ledges of the "rotten limestone." On the hills with this soil covering the peach produces its choicest kinds of fruit from the earlier part of June to August, and the Concord grape yields its blackpurple clusters in perfection. The dense forests of cow oak (Quercus michauxii), Texas white oak (Q. brevilobata (Torr.) Sargent, Q. durandii Buckley), nutmeg, scaly-bark, and bitternut hickories, frequently invested with the drapery of the Spanish moss, and in low damp situations more deficient in drainage, the switch cane (Arundinaria tecta), forming impenetrable thickets, are the sure indications of a deep black calcareous soil, rich in humus, such as is characteristic of the Western prairies, noted for greatest fertility. In the eastern Gulf States this soil is also noted for its rich yield of forage crops of the pea family (Leguminosae), of which the white melilot (Melilotus alba) has proved the most profitable and of greatest value as an ameliorating crop.

The so-called bald prairies, originally bare of tree growth, present a varied herbaceous vegetation of a xerophile character, including various grasses, the Compositae already mentioned, golden-flowered St. Johnsworts, Umbelliferae (Polytaenia nuttallii), white and purple flowered prairie clovers (Kuhnistera candida, $K$. gattingeri), pinkflowered evening primrose (Xylopleurum speciosum), etc. This vegetation denotes a shallow and drier prairie soil, which, though easily worn out, is adapted to all kinds of root crops and forage plants.

On the Metamorphic hills of the Mountain region the extensive oak forests (white oak, Southern red oak, black oak (Quercus velutina)), point to a deep fertile soil, the result of the decomposition of the basic hornblendic rocks and schists. In years past these lands were to a large extent devoted to the production of sinall grains, chiefly wheat, but owing to the pressure of competition with the wheat fields of the vir. gin prairie soils of the far Northwest, these lands are at present, in the South, almost entirely given over to the cultivation of cotton and of indian corn. The peanut is said to thrive especially well on the lands of the above character. Sorghum is largely raised throughout this Metamorphic area to supply fully the need of sirup. Its region can be 
said to coincide with the belt most favorable to the raising of the peach, as is clearly shown by the success achieved by the growers of this fruit on a large scale in the adjoining parts of Georgia of the same geological formation.

The drifted loamy sands and pebbles of more recent formations overlie to a large extent the heavier and stronger calcareous marls and clayey strata of the old Tertiary, Cretaceous, and Paleozoic formations. Their mingling, indicated by a mixed growth of pines and hardwood trees (mostly oaks), gives rise to a combination of conditions most favorable to the production of cotton, with regard both to the quality of the staple and the amount of the yield. The resultant soils consist of deep mellow loams of a warm and generous character, which are of moderate and lasting fertility, more or less porous and hence naturally well drained, and mostly highly ferruginous. Such soils are peculiarly well adapted for the production of a cotton plant of a sturdy growth, which being restrained from the too exuberant development of branches and leaves tends to a more prolific yield of the organs of reproduction; that is, the fruit. They are at the same time more easy of cultivation and less favorable to the rank production of grasses and other weeds, which in wet seasons greatly injure the crop, but which on lands of this character are easier to overcome. Accordingly the uplands in which this combination of soil conditions prevails, compris. ing the larger part of the arable area in the State, offer decided advantages to the grower of its great staple crop over the most fertile alluvial valley lands.

The forests of deciduous-leaved trees, which cover the uplands in the Tennessee Valley, with their varied growth, chiefly of white oak, Southern red oak, black oak, shagbark and mockernut hickory, tulip tree (poplar), walnut, elm, maple, white ash, chestnut, and linden, indicate calcareous, fertile, and somewhat heavy strong soils. These soils, from a reddish to a brown color, yield fine crops of cotton and corn, tilled ground being devoted to these in about equal proportion. On the lands of this character, prevailing over the larger part of the Tennessee Valley and the larger outlying valleys, in the drainage area of the Warrior and Coosa rivers, the cultivation of red clover enters successfully into the system of farming, and north of the Tennessee River the estabiishment of the blue grass pasture becomes possible. Apples and pears of numerous varieties cultivated farther north, as well as the peach, are grown successfully on the hills; and the dark grapes on the flanks of the valleys make a fine table wine. 


\section{LIST OF THE PLANTS CULTIVATED IN ALABAMA.}

In the following enumeration all the species more or less frequently grown in the different floral regions of the State are mentioned, those of greater economic importance being indicated by an asterisk. Only the leading and standard varieties with their most popular strains grown in the field, gardens, orchards, and pleasure grounds have been given a place. It is only among the trees and shrubs that the species most frequently planted for ornamental purposes have been admitted. The herbaceous ornamental plants cultivated in Alabama are excluded.

GRASSES, CULTIVATED FOR FORAGE AND FOR THEIR GRAIN.

* Zea mays L.

Corn. Indian Corn.

South America.

* Oryza sativa $L$.

Rice, Upland and Lowland.

Louisianian area.

Asia.

Euchlaena mexicana Schrad. (Reana luxurians Dur.)

Teosinte. Guatemala Grass.

Coast plain. Lower Pine region. Not frequent.

Mexico, Central America.

* Sorghum vulgare Pers. (Variety known as durra.) Chicken Corn. Kafir Corn. Over the State for forage and for the grain.

Asia, Africa.

Sorghum vulgare Pers. (Variety known as cernuum.) SwAN-NECK CoRN. As the above.

Asia, North Africa.

* Sorghum vulgare Pers. (Variety known as saccharatum.)

Chinese Sugar Cane. Early amber Cane.

Central and northern part of the State, for sirup and forage, with the African Inphee canes.

* Sorghum vulgare Pers. (Variety known as technicum.)

Broom Corn.

Central Prairie region; grown for its tops, used in making brooms.

* Sorghum halepense (L.) Pers.

False Guinea Grass. Johnson Grass. Louisianian area, chiefly in the Central Prairie region, for soiling and hay.

Western Asia, northern Africa.

Saccharum officinarum $L$.

Tropical Sugar Cane. Ribbon Cane.

From the Coast plain to Upper division of the Coast Pine belt.

Tropical Asia. 
Panicum maximum Jacq. (P.jumentorum Pers.)

Guinea Grass.

In the Coast plain; rarely.

Western Africa.

Panicum molle Sw. (P.barbinode Trin.)

Para Grass.

Coast plain. Rarely.

West Indies.

Pennisetum typhoideum Richards. (Penicillaria spicata Willd.)

Cat-tail Millet.

Coast Pine belt to Central Prairie region, for green forage.

East Indies, tropicál Africa.

${ }^{*}$ Chaetochloa italica (L.) Scribner. (Setaria italica Roem. \& Schult.)

Over the State, chiefly sonthward, for hay.

Millet. Golden Millet.

Southern Europe.

Chaetochloa italica germanica (Mill.) Seribner.

Hungarian Grass.

Over the State.

Enrope, northern Africa.

Phleum pratense $\mathrm{L}$.

Timotuy Grass.

Tennessee Valley; not frequent.

Europe.

Agrostis alba $\mathrm{L}$.

For early pasture and meadow grass; rarely.

Europe.

* Agrostis alba vulgaris (With.) Thurber.

Mountain region, Tennessee Valley.

Europe.

Arrhenatherum elatius (L.) Beanv.

Rarely in the Prairie region.

Europe.

* Capriola dactylon (L.) Kuntze. (Cynodon dactylon Pers.). Bermona Grass. Chiefly in the Lonisianian area.

East Indies.

* Avena sativa L.

Oats. Texas Rust-proof Red Oats. Throughout the State; sonthward, cut and cured in the milk.

Enrope.

* Dactylis glomerata L.

OrChard Grass.

Northern part of the State.

Europe.

Poa pratensis L.

Mountain region and Tennessee Valley.

Europe.

Poa trivialis $\mathrm{L}$.

Among meadow grasses. Nortliward.

Europe.

Poa compressa L.

White Bent Grass. Fiorin.

ReDtop. Herd's Grass.

Meadow OAT Grass.

Prairie region and northward, for pasture.

Europe.

Rovgh Meadow Grass.

BuUn Grass. 
Poa arachnifera 'Torr.

Texas Blue Grass.

Coast plain to Prairie region, for winter pasture; rarely. Central Texas.

Festuca pratensis Huds.

Meadow Fescue.

Tennessee Valley, among meadow grasses.

Bromus unioloides (Willd.) H. B. K.

Resche Grass. Schrader's Grass. Arctic Grass.

Central Prairie region and northward.

Lolium perenne L.

ENGLish RaY Grass.

Lawn and pasture grass.

Lolium italicum L.

ITALIAN RAY GRASS.

Lawn and pasture grass.

Europe.

* Secale cereale L.

RYE.

Chiefly in the mountain region and Tennessee Valley, for grain crop and for winter pasture.

Europe.

Triticum vulgare $\mathrm{L}$.

WHEAT.

Mostly Mediterranean bearded winter wheats. Mountain region, Tennessee Valley. Europe.

Hordeum sativum L.

BARLEY.

Rarely in the northern part of the State. Principally for winter pasture.

Europe.

HERBACEOUS PLANTS CULTIVATED FOR THEIR ROOTS.

Cyperus esculentus L.

Chupa.

Louisianian area, mostly iu the Coast Pine belt.

North Africa.

* Allium cepa L.

ONION.

Allium ascalonicum $\mathrm{L}$.

ShaLLOT.

Western Asia.

Allium sativum L.

GarLic.

Rarely. Southern Europe.

Allium porrum L.

LEKK.

Western Asia.

Beta vulgaris rapacea Koch.

Mangel-wurzel. Sugar Beet. Ren Beet. Southern Europe.

* Brassica campestris ruta-baga Vilmorin.

Swedish Turnip. RUta-baga. Europe.

* Brassica rapa esculenta DC.

TURNIP.

Europe.

Raphanus sativus $\mathrm{L}$.

RADISH.

Europe.

* Daucus carota L. Europe.

Carrot. 
*Ipomoea batatas (L.) Poir. (Batatas edulis Chois.)

Sweet Potato.

Bermudas, red and white, leaves entire, tubers farinaceous. Brazilian yams, leaves lobed, tubers white, farinaceous. Spanish or sweet yams (so called), leaves lobed, tubers white or yellow, sugary.

Mexico.

* Solanum tuberosum L.

Irish Potato.

America.

The early red and white sorts on the truck farms near the coast for early shipment.

Helianthus tuberosus L.

Jerusalem Artichoke.

Tragopogon porrifolius L.

SALSIFY.

Rarely.

\section{PLANTS CULTIVATED FOR THEIR J.EAVES AND STEMS.}

(Garden vegetables and forage crops.)

Asparagus officinalis $\mathrm{L}$.

Asparagus.

Europe.

Spinacia oleracea L.

SPINACH.

Europe.

Boehmeria nivea Gaud., and B. tenacissima Roxb. China Grass. Ramik.

Fiber plants. At present almost abandoned; the young green stems here and there cut for green fodder.

Tetragonia expansa Ait.

New Zealand Spinach.

Rarely. Australia.

Lepidium sativum $\mathrm{L}$.

Europe.

Roripa nasturtium (L.) Rusby.

Water Cress.

Europe.

Sinapis alba L.

White MUSTaRd.

Europe. Chiefly for greens.

Brassica oleracea botrytis L.

Cauliflower.

Europe.

* Brassica oleracea capitata I.

Cabbage.

* Brassica oleracea acephala DC.

Kale. Collards.

Brassica oleracea gongylodes L.

KOHL-RABI.

Rarely.

* Trifolium pratense I.

Red Clover.

Mountain regions and Tennessee Valley.

Europe.

Trifolium hybridum I.

Alsike Clover.

With the above.

Europe.

Trifolium incarnatum L.

Scarlet Clover. Turkish Clover.

Lately in the Central Prairie region and Pine belt. Not frequently. 
Medicago sativa $\mathbf{L}$.

Lucern. Alfalfa.

Prairie region. Tennessee Valley. Not frequently.

Medicago arabica (L.) All. (Medicago maculata Sibth.)

Bur Clover.

Rarely. Coast region and Teunessee Valley.

Mediterranean region.

* Melilotus alba Desr.

White Melilot. Bokhara Clover.

Chiefly in the Central Prairie region.

Lespedeza striata Hook. \& Arn.

Japanest Clover.

Mostly spontaneous.

Vicia sativa $L$.

VETCH.

Here and there for early green fodder.

Foeniculum foeniculum (L.) Karst.

Europe. Pot herb.

Anthriscus cerefolium L.

Chervil.

Europe. Pot herb.

Petroselinum sativum Hoffm.

PaRsley.

Southern Europe.

Apium graveolens L.

Celery.

Blanched stems.

Southern Europe.

Ocimum basilicum L.

SWEeT BASIL.

India. Pot herb.

Mentha piperita L.

Peppenmint.

In a small way.

Europe.

Mentha spicata L.

SPEARMinT.

In a small way.

Europe.

Thymus vulgaris $L$. and T. serpyllum $L$.

Thyme.

Europe. Pot herbs.

Salvia officinalis $\mathrm{L}$.

SAGE.

Nicotiana tabacum $\mathrm{L}$.

Toвacco.

West'Indies. South America.

Cichorium endivia L.

Endive.

Southern Europe.

* Lactuca sativa L.

LetTuCe.

Southern Asia, southwestern Asia.

HERBACEOUS PLANTS CULTIVATED FOR THEIR FRUITS AND SEEDS.

Fagopyrum fagopyrum (L.) Karst.

BUCKWHEAT.

For feed for fowls and for green fodder; bee plant.

Northern Asia.

* Fragaria vesca L. and F. virginiana L.

STRAWBERRY. 
* Arachis hypogaea L.

Peanut. Pindar. Goomer Pea. Brazil.

Cicer arietinum $\mathrm{L}$.

Chick Pea.

Rarely. Central Prairie region.

Mediterranean region, Asia.

* Vigna catjang (L.) Walp.

Cowpea.

Ası.

Glycine hispida Moench.

Soy Bean. Soja Bean. Japanese Pea.

Louisianian area; rarely at present.

Eastern Asia.

* Pisum sativum L.

Garden Pea.

* Phaseolus vulgaris L.

Kidney Bean. Pole Bean.

Asia.

* Phaseolus vulgaris nanus DC.

Bush Bean.

Phaseolus lunatus $\mathrm{L}$.

LIMA BeAN.

Phaseolus multiflorus Willd.

Flowering Bean.

Rarely for the seeds, mostly for ornament.

*Abelmoschus esculentus Moench. (Hibiscus esculentus L.) Oква. Gumbo.

* Gossypium herbaceum L.

Cotton. UrLaNd CotTon.

Asia.

Gossypium barbadense L.

Sea Island Cotton.

Coast plain; rarely.

South America.

* Lycopersicum esculentum Miller.

Tomato.

South America.

Solanum melongena $\mathrm{L}$.

Eggrlant.

Capsicum annuum L.

Large Red Pepper. Sweet Pepper.

Brazil.

Capsicum frutescens L. and C. baccatum L. Chile and Bird's-eye Peppers. India, tropical America.

* Cucurbita maxima Duchesne and C. pepo L.

Planted in the cornfields.

Large Pumpkin. Chenge Pumpkin.

Asia, America?

* Cucurbita melopepo L.

Squash. Crookneck Squash. Cushaw. Vegetalbe Marrow. Asia, Africa, America.

* Citrullus vulgaris Schrad.

WATERMELON.

In greatest perfection in the Pine region. Africa.

* Cucumis sativus L.

Cucumber. Asia.

* Cucumis melo reticulatus Ser.

Netted Melon. Muskmelon. 
* Cucumis melo cantelupa Ser.

Cantaloupe. Sugar Melon. Asia, Africa.

Cucumis anguria L.

GHerkin.

Coast plain.

West Indies.

Lagenaria vulgaris gourda Ser.

Bottle Gourd.

Louisianian area.

Asia, America.

Lagenaria vulgaris clavata Ser.

TRumpet Gourd.

Louisianian area.

Asia, America?

Sechium edule (Jacq.) Swartz.

Mexican Squash. Chayote.

Coast plain. Rarely.

Mexico.

Cynara scolymus L.

Artichoke.

Louisianian area, here and there. Rarely.

Southern Europe.

TREES AND SHRUBS CULTIVATED FOR THEIR FRUI'.

* Hicoria pecan (Marsh.) Britton.

Pecan Nut.

Chiefly in the coast plain.

Juglans regia $\mathrm{L}$.

ENglish Walnut.

Here and there in the northern part of the State.

* Ficus carica L.

FIG.

Coast plain to Lower hills.

Morus nigra $\mathrm{L}$.

Black Mulberiry. Russian Mulberry.

Most frequent in the Pine belt.

* Pyrus communis L.

Pear.

* Pyrus sinensis Lindl.

Peak.

Sand pear and its derivatives, the Le Conte and Keiffer pears.

Mostly cultivated in the Coast Pine belt.

Eastern Asia.

* Pyrus malus L.

APple.

Chiefly in the Mountain region and Tennessee Valley.

Europe.

Cydonia sinensis Thou.

Chinese Quince.

Southward.

Cydonia cydonia (L.) Pers.

Common Quince.

Northward.

Europe.

Eriobotrya japonica Lindl.

Loquat. Japanese Plum or Japanese Medlar. Coast plain.

Japan.

* Prunus angustifolia Marsh.

Chickasaw Plum. Golden Drop. 
* Prunus americana Marsh.

Prunus triflora Roxb.

Coast to the mountains.

Japan.

*Amygdalus persica L. Asia.

Amygdalus persica nectarina Ait.

Upper districts.

Rubus occidentalis L.

Rubus idaeus L.

Rubus argutus Link.

Rubus trivialis Michx. and R. invisus Bailey

Punica granatum L.

Lower Pine region, Coast plain.

Mediterranean region.

Citrus aurantium L.
Wild goose Plum. Red and Yellow Plum. Japanese Plums. Kelsey and Botan Plums.

On the seacoast. Mobile Bay, Perdido Bay. Cultivated extensively before the great freeze in the winter of 1879-80. At present only in well-sheltered localities.

Citrus bigaradia Loisel.

Bitter Orange.

On the seacoast.

Zizyphus vulgaris $\mathrm{L}$.

JUJUBE-BERRY.

Lower Pine region. Coast plain. Here and there.

Vitis labrusca L.

Fox Grape.

Sonthern varieties: Catawba, Diana, Isabella. Northern varieties: "Concord, Ives seedling.

* Vitis aestivalis Michx.

SUMMER GRAPE.

Virginia seedling, Norton's Virginia, "Herbemont, Cynthiana.

* Vitis rotundifolia Michx.

Muscadine Grape. Bullace Grape.

Flowers, Thomas, "Scuppernong.

Chiefly in the Coast Pine belt.

\section{CULTIVATED FOR SHADE TREES AND FOR ORNAMEN'T.}

Cycas revoluta Thunb.

Fern Palm.

Coast plain.

Japan.

Nageia chinensis (Roxb.) Kuntze. (Podocarpus sinensis Teijsm. \& Binn.)

Coast plain. Evergreen shrub.

Japan.

Cupressus sempervirens L.

Cypress.

Cypress of southern Europe.

Coast plain to Central Prairie belt.

Cupressus funebris Endl.

WeEping Cypress.

Louisianian area.

China. 
Biotia orientalis Don.

Small tree or shrub.

Asia.

Cunninghamia sinensis $\mathrm{R}$. Br.

Chinese Cunninghamia.

Lower Pine region, Coast plain.

China.

Araucaria imbricata Pav.

Chilean Pine.

From the Coast plain to Lower hills.

chile.

Cedrus deodara Loul.

Deodara Cedar.

Coast to Lower hills.

Himalayan Iudia.

Salix babylonica L.

WEEPING WILLOW.

Asia.

Populus alba $\mathrm{L}$.

Wiitte ok Silver Poplate.

Europe, North Africa, Asia.

Quercus virginiana Mill.

LIVE OAK.

Lower Pine region. Coast plain.

Quercus laurifolia Michx.

Laurel Oak.

Coast plain to Lower hills.

Quercus nigra L. (Q.aquaticu Walt.).

WATER OAK.

Most frequent in the Coast Pine belt.

Broussonetia papyrifera Vent.

Paper Mulberky.

Eastern Asia.

Toxylon pomiferum Raf. (Maclura aurantiaca Nutt.).

Osagn Orange.

Magnolia foetida (L.) Sargent. (Magnolia grandiflora L.).

Magnolia. Northward to the 'Tennessee Valley.

Magnolia obovata Thunb.

Purple-Floweied Magnolia. J:1pan.

Michelia fuscata (Andr.) Blume. (Magnolia fuscata Andr). .

Coast plain. Lower Pine region.

Japan.

Cinnamomum camphora (L.) Nees \& Eberm.

Camphor Trie.

Coast plain, harrly at Mobile (before the great freeze of 1899). Tree 20 years old, 20 feet and over in height.

China.

Pittosporum tobira Ait.

Sweet-scented Pittosporum.

Large shrub. Mobile.

Japau.

Platanus occidentalis $\mathrm{L}$.

SYCAMORK.

Shade tree.

Rosa banksiana R. Br.

BANKS'S Rose.

Coast plain. Lower Pine region.

India, China.

Rosa laevigata Michx.

Cherokee Rose.

For hedges.

China, Ameriea? 
Rosa bracteata Wendl

MCCartene Rose.

Hedge plant.

Eastern Asia.

Rosa multiflora Thunb.

MANY-FLOWEREI) ROSE.

Hedge plant.

China, Japan.

Rosa damascena Mill., R. centifolia I., R. alba L., R. eglanteria I.. R. indica I. In a great many varieties, strains, and hybrids.

Photinia serrulata Lindl.

SerRUi.ate-Leaf PHotinia.

Fine evergreen shrub or small tree. Coast plain.

Eastern Asia.

Cotoneaster pyracantha (I.) Spae

Pyracantila.

Coast Pine belt. Herlge plant.

Southern Europe.

Cydonia japonica $\mathrm{L}$.

Japan.

Prunus caroliniana Ait.

Mock Orange.

Coast plain to Central Prairie region.

Acacia farnesiama Willı.

Sweet Acacia.

Coast plain.

West Indies, southern Asia.

Albizzia julibrissin (Willd.) Duraz\%.

Coast plain to Central Prairie region.

Southwestern Asia.

Parkinsonia aculeata $\mathrm{L}$.

PrickLy PaRKINSONIA.

Elegant small troe. Coust plain, Lower Pine rogion.

Sonth America.

Kraunhia chinensis (Sims) Greene. (Wisteria chinensis DC.) Cunver Wistaria. Most froquently enltivated elimber from the Coast plain to the Prairie region.

Robinia pseudacacia $I$.

JHACK LUCUST.

Melia azedarach $\mathrm{L}$.

China-bierry 'J'kek.

Frequent in the Coast plain and Lower Pine region.

Southern Asia.

Sapindus marginatus Willd.

SOAP-BERRY TREK.

Prairio rogion, Coast plain. larely. Sonthern Florida.

Ailanthus glandulosus Desf.

Abandoned of late years.

China.

Sapium sebiferum Roxb.

TALLOW-BerRy 'THei.

Coast plain. Rarely.

China.

Buxus sempervirens $I$.

Box.

Enrope.

Acer saccharinum L. (A. dasycarpum Ehrh.)

Northern part of tho State. Shade troe.

White Marle. 
Acer rubrum L.

RED MAPLe.

With the last.

Acer saccharum Marsh. and A. saccharum barbatum (Michx.) Trelease.

Hard Maples.

In the Tennessee Valley. Fine shade trees.

Hibiscus syriacus $\mathrm{L}$.

Altiea.

Coast plain.

South western Asia.

Firmiana platanifolia (L.f.) R. Br. By misnomer called Japanesh Varnish Trea. Eastern Asia.

Thea japonica (L.) Nois. (Camellia japonica Thuub.)

JAPONICA. Japan.

Thea chinensis $\mathrm{L}$.

Chinese Tea.

Coast plain to Central Prairie region. Oruamental evergreen

China.

Lagerstroemia indica $\mathrm{L}$.

Crape Myrtee.

Lower Pine region, Coast plain, frequent.

Eist Indies.

Myrtus communis L.

MYRTLE.

Coast plain to Central Prairie region.

Soutbern Europe.

Euonymus japonicus

Japanese Strawierry Busir.

Coast plain to Central Prairie region.

Japan.

Osmanthus fragrans (Thunb.) Lour.

SWent Olive. Coast plain, 15 to 18 feet high. Mobile. Japan, China.

Ligustrum japonicum Thunb.

Japan Privet. Coast plain.

Ligustrum vulgare italicum Miller.

Evergiken Privet. Coast plain.

Paulownia tomentosa ('Thunb.) Baill.

Royal Paulownia. Flowers at Mobile, February.

Japan.

Nerium oleander L.

Oleander.

Coast region.

Mediterranean region.

Catalpa catalpa (Walt.) Karst.

Catalpa Tree.

Viburnum odoratissimum Ker-Gawl.

SWEET-SCENTED VIBURNUM.

Coast plain. Evergreen tree, 20 to 30 feet high.

China.

Gardenia florida $\mathrm{L}$.

Cape Jessamine.

Coast plain.

China.

Azalea indica, many varieties and hybrids.

Azalka. -

Coast plain.

India. 



\section{TABULAR STATEMENT OF THE PLANTS OF ALABAMA.}

Subkingdom MYXOTHALLOPHYTA.

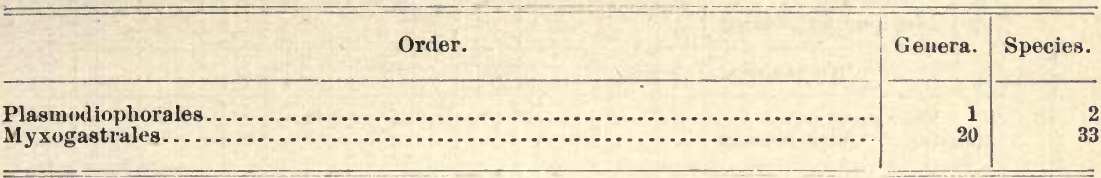

\section{Subkingdom EUTHALLOPHYTA.}

Class :

Euphycaceae (Algae).

Bacillariales (Diatoms)

Chloropliyceae (Green algae)

Cliarales (stoneworts)

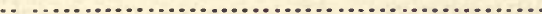

Phaeophyceae (Brown seaweeds)

Rhodophyceae (Red algae)

Class:

Eumycetes (Fungi).

Phycomycetes

Ascomycetes .

Basidiomycetes

Fungi imperfecti.

Lichenes.

Subkingdom BRYOPHYTA. Liverworts and mosses.

\begin{tabular}{|c|c|c|c|c|}
\hline Class : Hepaticae (Liverworts). & Genera. & Species. & Varieties. & $\begin{array}{c}\text { Species } \\
\text { and } \\
\text { varieties. }\end{array}$ \\
\hline 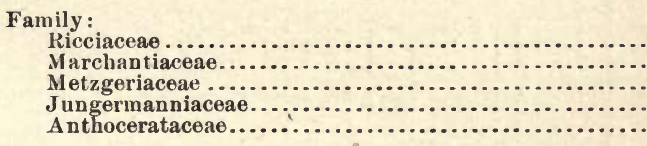 & $\begin{array}{r}2 \\
5 \\
6 \\
11 \\
1\end{array}$ & $\begin{array}{r}3 \\
6 \\
7 \\
20 \\
3\end{array}$ & $\begin{array}{r}\cdots \\
7 \\
1\end{array}$ & $\begin{array}{r}3 \\
6 \\
7 \\
27 \\
4\end{array}$ \\
\hline Class: Musci (Mosses). & & & & \\
\hline 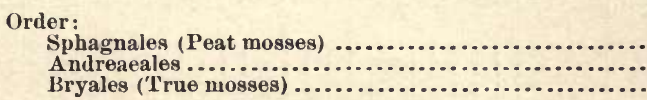 & $\begin{array}{r}1 \\
1 \\
62\end{array}$ & $\begin{array}{r}14 \\
130 \\
130\end{array}$ & 13 & $\begin{array}{r}27 \\
1 \\
140\end{array}$ \\
\hline
\end{tabular}

Subkingdom PTERIDOPHYTA.

\begin{tabular}{|c|c|c|c|c|c|c|c|c|c|c|c|c|c|c|c|}
\hline Fanily. & 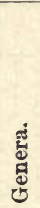 & 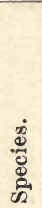 & 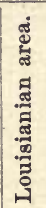 & 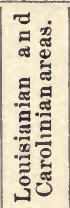 & 苟 & 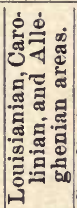 & 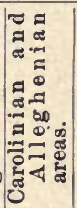 & 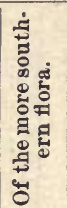 & 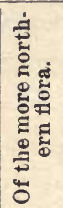 & 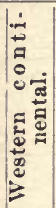 & 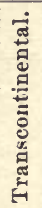 & 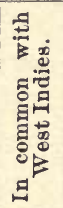 & 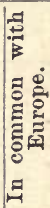 & 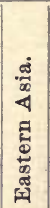 & 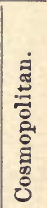 \\
\hline & 2 & 5 & 2 & $z$ & - & 1 & & 4 & 1 & & & 2 & 1 & 1 & \\
\hline & 1 & 2 & - . & & 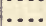 & 2 & & ". & 2 & & 1 & 2 & 1 & $\ldots$ & \\
\hline .. & 1 & 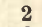 & ... & & 1 & & 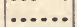 & $?$ & & & $\ldots$ & & & & \\
\hline .. & 15 & 38 & 2 & 6 & 4 & 6 & 20 & 12 & 26 & & 2 & 7 & 7 & 7 & \\
\hline .. & 1 & 1 & .. & $\ldots$ & $\ldots$ & 1 & & $\ldots$ & & & $\ldots$ & $\ldots$ & & - & \\
\hline . & 1 & 3 & 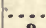 & & & 1 & & & & & & & & & \\
\hline . & 1 & 7 & $\begin{array}{l}3 \\
1\end{array}$ & & . & $\cdots$ & & 1 & 2 & $\ldots$ & 2 & 2 & $\cdots$ & 1 & \\
\hline $\tan ($ & 1 & 1 & . & $\ldots$ & 1 & 1 & & 1 & . & $\ldots$ & $\ldots$ & ....... & $\ldots$ & $\ldots$ & \\
\hline
\end{tabular}




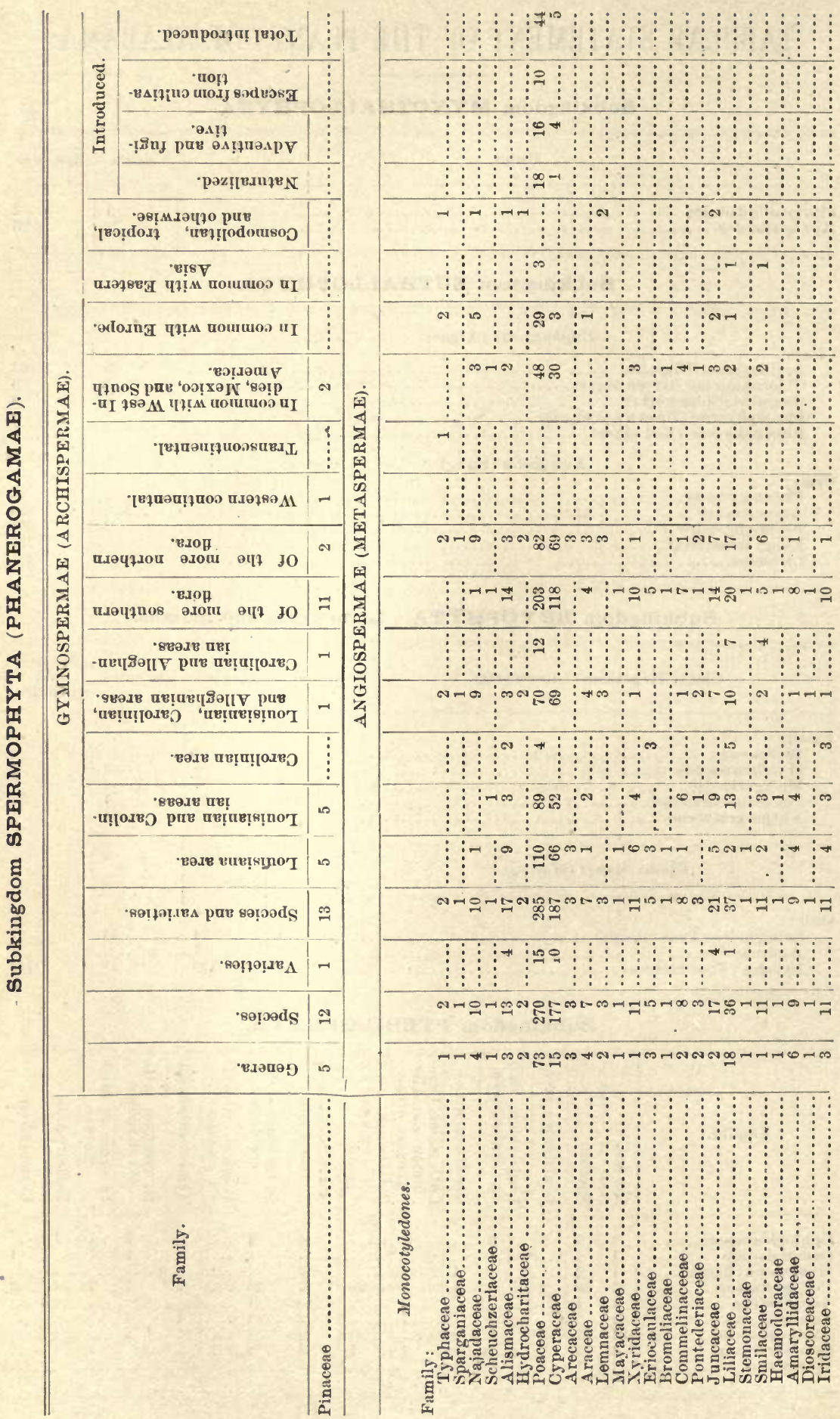




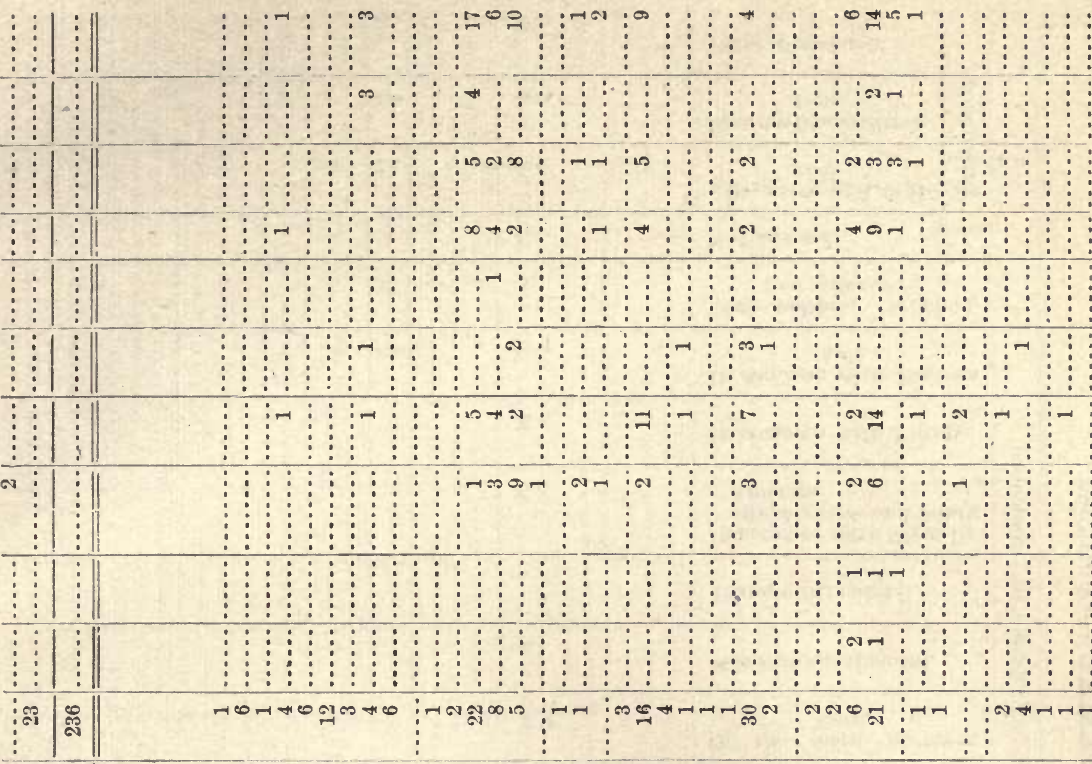

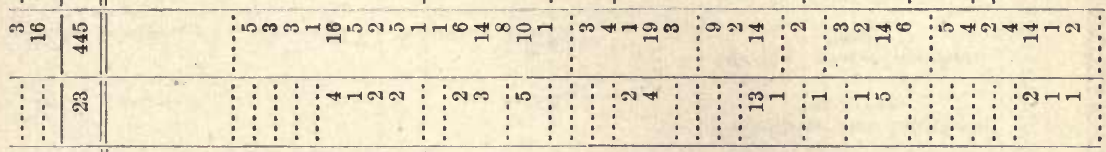

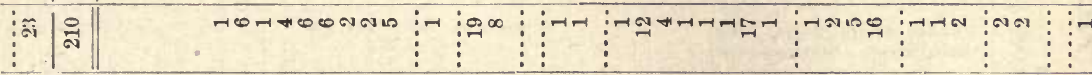

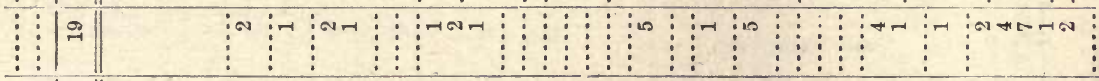

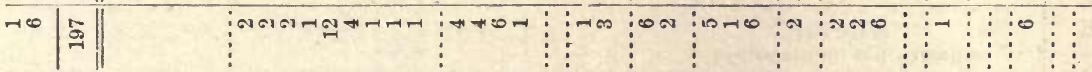

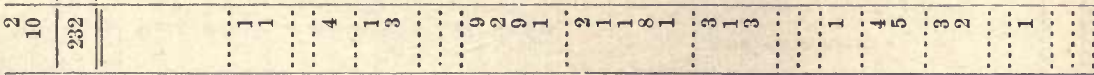

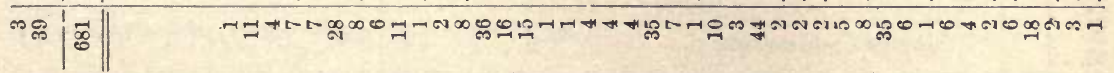

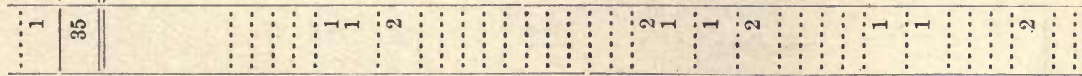

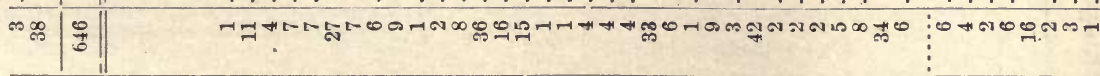

งा

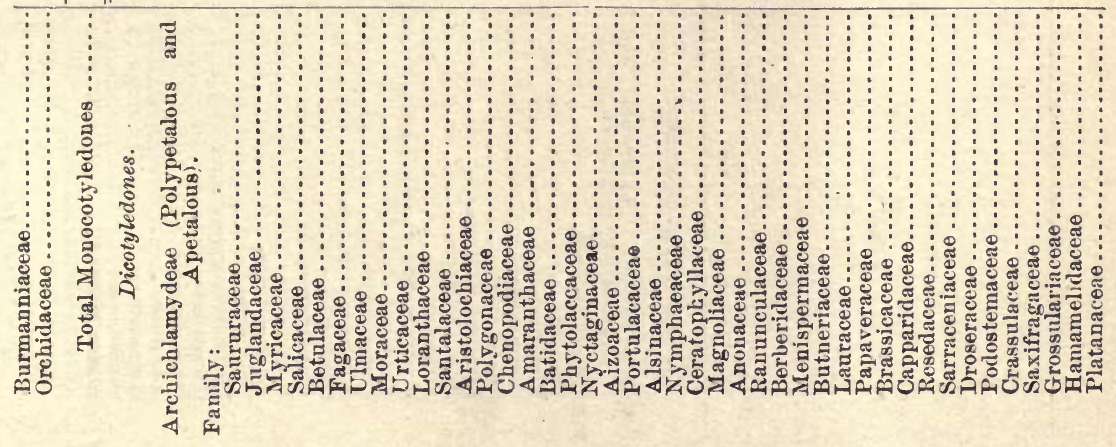




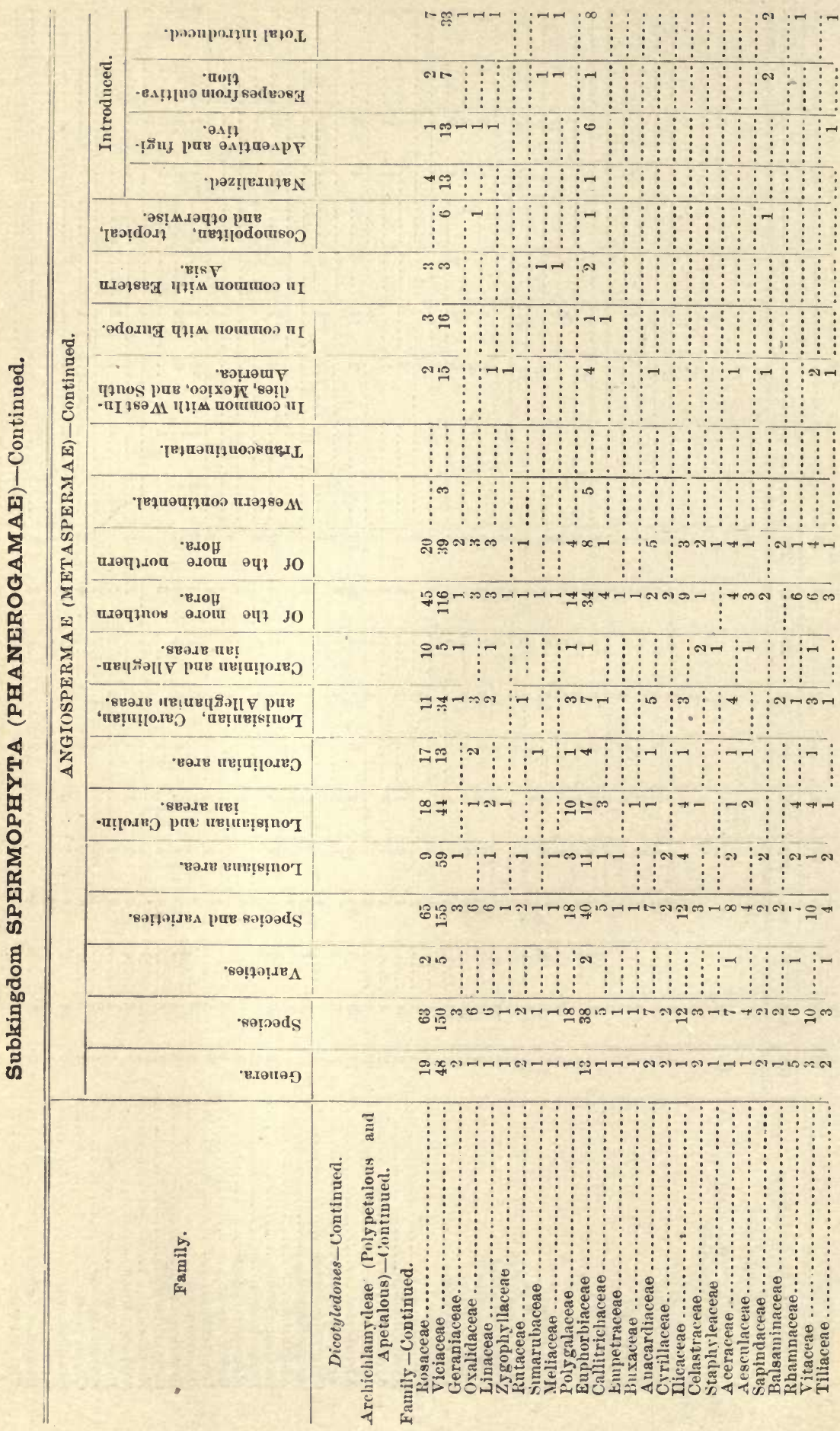




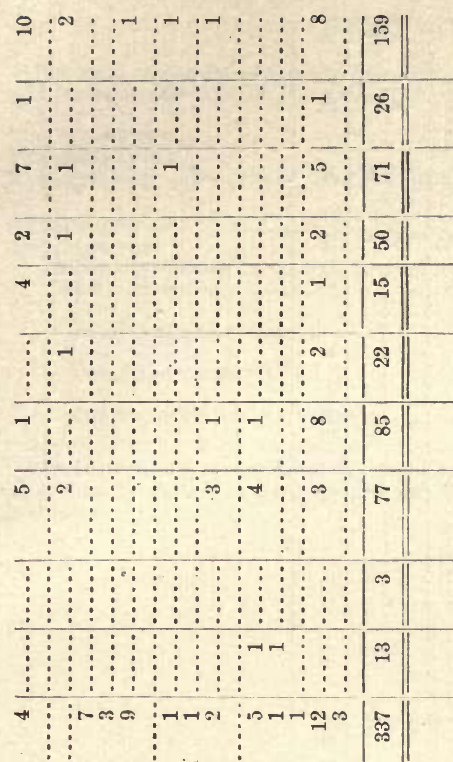

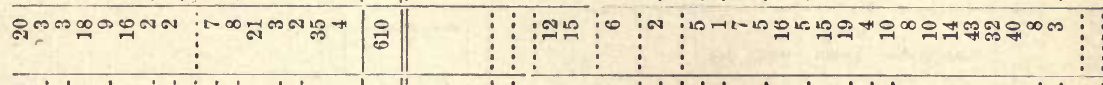

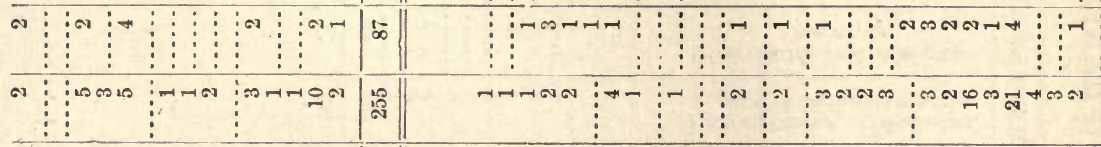

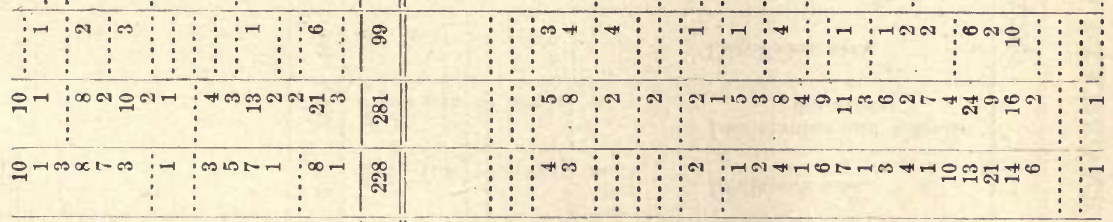

Aีm :

a

สmm

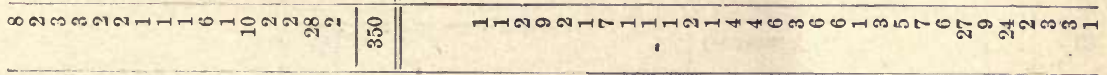

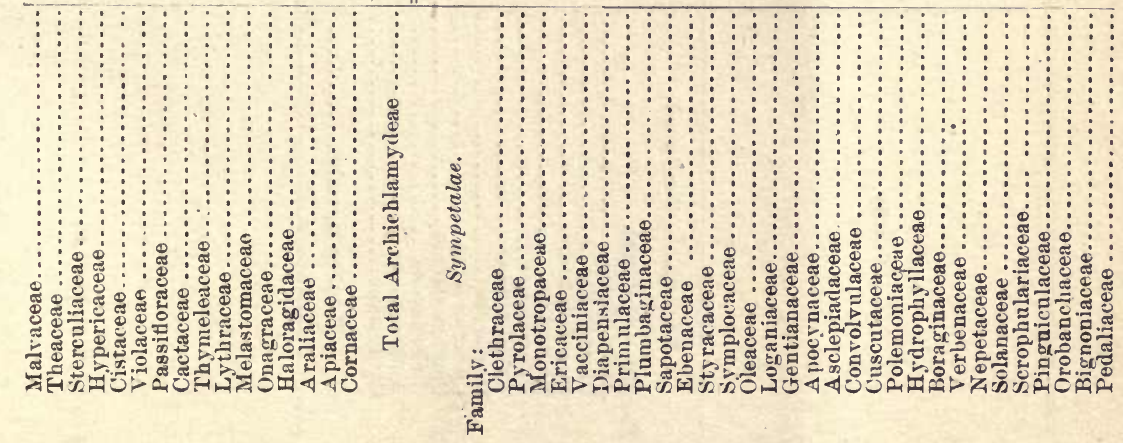




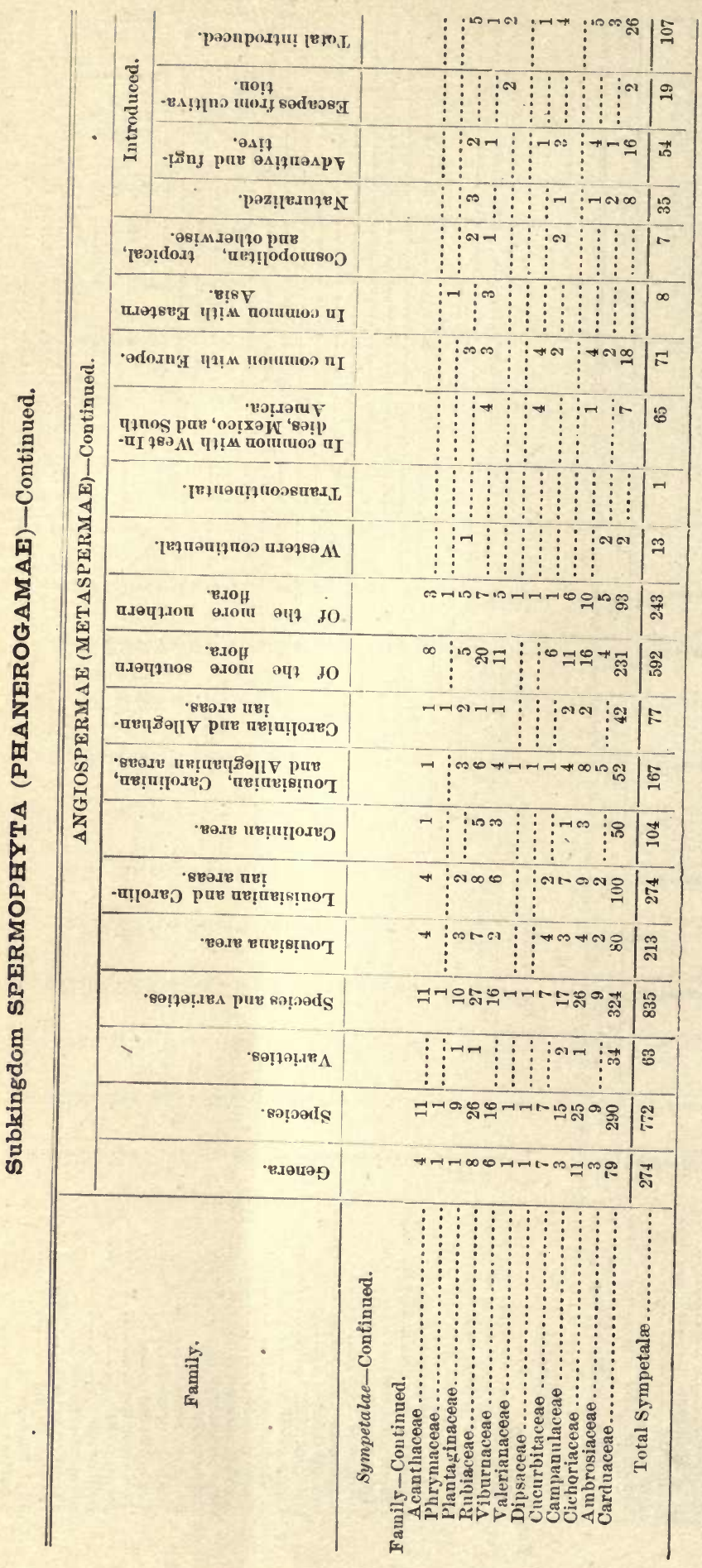




\section{SUMMARY.}

The total numbers of the species and varieties known at present to grow without eultivation in Alabama, enumerated in the catalogue, are as follows:1

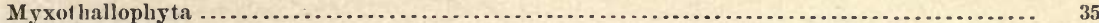

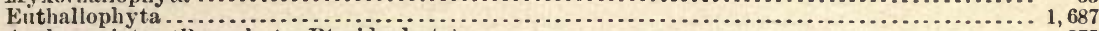

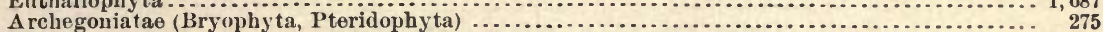

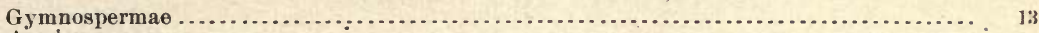

Angiospermae:

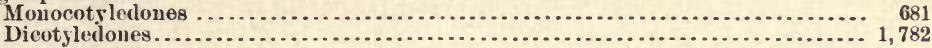

Total Angiospermae ..................................................... 463

Total Spermophyta ............................................ 2,476

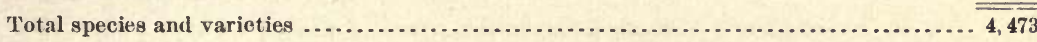

ISome of the forms of Panicum of the dichotomum group and some of the new species of Crataegus, described by Professor Sargent and Mr. Beadle since the catalogue has been in press, were too late for inclusion. 



\section{ERRORS ANI) ADIDITIONS.}

Pp. 11, 59, etc. For Chehawlıaw Mountain read Che-aw-ha Mountain.

P. 15. For Wistaria read Wisteria.

P. 16. For Q. breviloba read Q. brevilobata.

P. 38, foot note 1. Read: Cichoriaceae, Ambrosiaceae, and Cardnacene.

P. 38. The figures in this summary are to be corrected by those of the tabular stalement, pp. 837 to 843.

P. 45. After Ilex romitoria in list insert Cratac!gus spp.

P. 45. For Rhododendron spp. in list read Azalea spp.

P. 88. For Salix tristis read Salix humilis.

P. 114. For Helianthemum ramuliflorum read Helianthemum georgianum.

P. 149. For G. A. Beaumont read .J. F. Beanmont.

P. 253. Under Phyllosticta lencocarpae, instead of Pyrus sp. read Bumelia lycioides.

Pp. 336 to 389. The following grasses have come lately to notice:

Andropogon bakeri Scribner \& Ball. Mobile Connty.

Andropogon scoparius polycladns Seribner \& Ball. Mobile Comty.

raspalum altissimum Le Conte. Mobile County.

Panicum malacon Nash. Butler County.

Panicum equilaterale Scribner. Baldwin County, Stockton.

Elymus glabriflorus (Vasey) Scribner. De Kalb County, Lookont Mountain near Mentone.

P.469. After Quercus minor insert:

Quercus boyntoni Beadle, Biltmore Bot. Stnd. 1: 48. 1901.

Curolinian area.

Alabama: Mountain region. Etowah Connty, near Gadsden (C. L. Boymlon), April. Shrubby, 3 to 15 feet high.

P. 623. Before Triadenum virginicnm insert:

Triadenum longifolium Small, Bull. Torr. Clıb, $25: 140.1898$.

LONG-LEAF MARSH ST. JOHN'S-WORT.

Leaves oblong-lanceolate, thinnish, oltuse, or notched at the apex, truncate or subcordate at the bave, sessile; eymes terminal and axillary, few-flowered; flowers sessile or short-peduncled; sepals lanceolate or linear-lanceolate, acuminate; capsules small, acnte, striate.

Louisianian area. Western Florida.

Alabama : Central Prairie region. Low wet places, Sumpter County. Flowers in July.

Type locality: In fossis prope Snmmerville [Sumpterville?], Alabama, et ad tiuv. Apalachicola, Florida, legit Rugel, Aug.-Oct., 1843.

P. 696. Before Pliryna insert:

\section{PHRYMACEAE. Phryma Family.}

and transpose, with genns, to p. 735, before Plantaginaceae.

P.797. After Rudbeckia hirta insert:

Rudbeckia strigosa Nutt. Trans. Am. Phil. Soc. ker. 2, 7 : 354. 1840.

Rudbeckia hirta var. $\beta$ Torr. \& Gray, Fl. N. A. 2:307. 1842. (Fide Thomas V. Moore). 
Lonisianian area. Western Louisiana; Texas.

Ala bama : Coast plain. Sandy pine woods. Mobile County, May, 1901 (Mohr). Local. July. Perennial.

Clearly distinct.

Herb. Geol. Surv.

Rudbeckia chapmani Boynton \& Bealle, Biltınore Bot. Stud. 1 : 14.1901.

Chapman's Conerlower.

Perennial, $1 \frac{1}{2}$ to 3 feet high; radical leaves 8 to 16 inches long (including petiole), broadly ovate-lanceolate, $2 \frac{1}{2}$ to 4 inches wide, harshly but inconspicnously pubescent, 5 or 7 nerved, truncate or cordate at the base, dentate or coarsely crenulatedentate; cauline leaves ovate-lanceolate, rouncled or narrowed at the base, subdentate or nearly entire, petioled; stems conspicuously angled, striate, sparingly pubescent or glabrous, branched near the summit; involucre foliaceous, imbricated, glabrate, or with lines of soft hairs on the margin and nerves; rays 12 to 16 , about an inch long, 2 or 3 toothed at the apex; clisk hemispherical, dark purple; chaff of the receptacle abruptly pointer at the apex and ciliate with a few short hairs; pappus a shallow coroniform border.

Carolinian area.

Alalbama: Monntain region. North Alabama (G. R. Vasey), 1878; no specific locality given.

Type locality: "Mountains of Grorgia (Dr. A. W. Chapman, no locality; Dr. D. P. Cleaveland, Dalton, Ga.) and Alabuna (Dr. G. Vasey [G. R. Vasey ${ }^{\text {? }}$ ], 1878)."

P. 753. After Elephantopus carolinianus insert:

Elephantopus violaceus Schultz Bip. Linnaea, 20 : 517. 1847.

Ilentification on the authority of C. F. Baker.

Carolinian area.

Alabama : Coast plain. Mobile. Octolver. 


\section{INDEX.}

[Synonyms are printed in italics. Species names in regular catalogue place are indexed only in the case of a few large genera.]

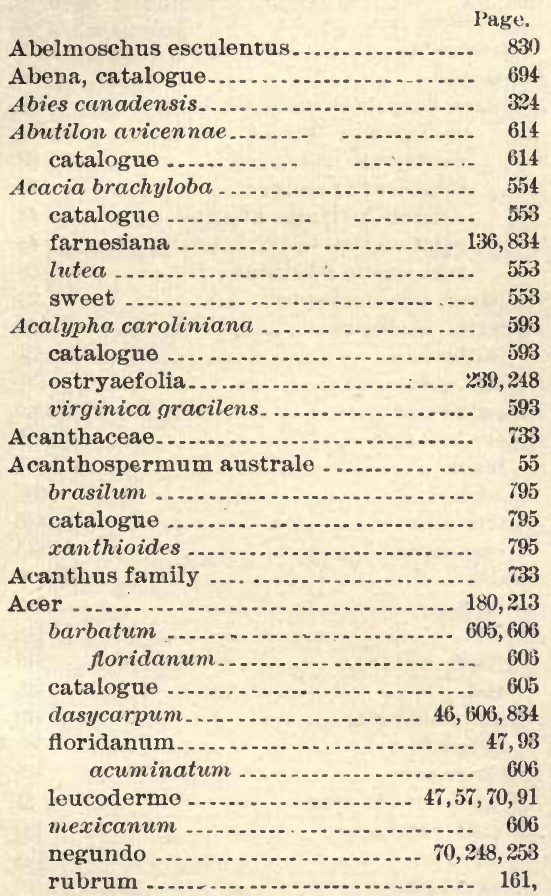

$166,180,181,182,251,252,253,260,835$ drummondii ..................... 607

rugelii.................................... 606

saccharinum ....................... 46, 834

saccharinum ........................ 605

floridanum..................... 606

saccharum.................... 47,80,84,835

barbatum ............ 47,61, 70,84, 102,835

barbatum ....................... 606

Aceraceae ............................. 605

Acerates, catalogue ...................... 676

longifolia ............................ $\quad 6 \%$

paniculata ........................... 677

Acetabula .............................. 156

Achillea, catalogue...................... 812

lanata.............................. 812

Achlya, catalogue ..................... 151

Achroanthes, catalogue................. $\quad 457$ unifolia ............................ 66

Achyranthes, catalogue................. 492 obtusifolia .......................... 492

repens ............................ 492
Page.

Acmella repens.......................... 797

Acnida, catalogue ...................... 491

Aconitum, catalogue ................... 510

Acorus, catalogue ...................... 424

Acrocarpi ................................

Acrospermaceae ..................... 164,262

Acrospermum, catalogne ................ $\quad 164$

Acrostichum areolatum................... 313 platyneuros ........................... 314

polypodioides ......................... 311

thelypteris ......................... 316

Actaea alba . ................................. 93

catalogue ........................... 508

racemosa ......................... 509

spicata alba.......................... 509

Actinocyclus, catalogue................. 144

Actinomeris............................. 803 alternifolia ......................... 804

helianthoides ........................ 804

nudicaulis .......................... 804

squarrosa ........................... 801

Actinospermum . ...................... 808

catalogue .... ...................... 808

Actynoptychus, catalogne ............... 143

Acuan brachycarpus ................... 108

catalogue ......................... 554

illinoensis............................ 104

Addersmouth, green ................... 457

Adder's-tongue.......................... 310,440

family ............................. 310

yellow ................................. 440

Adelia, catalogue ...................... $66 \%$

ligustrina .......................... 57,102

privet-like .......................... 668

Adiantum capill us-veneris . ............. 86, 108

catalogue ........................... 311

pedatum ........................... 74

Adicea, catalogue ...................... $\quad 478$

microphylla hernarioides ............ 56

urticaefolia .......................... 102

Adonis autumnalis ..................... 516

catalogue .......................... 516

Adopegon, catalogue .................... 751

Adrue............................... 392

Adventive plants....................... 54

Aecidia ................................. 193

Aecidium............................... 190

catalogue ......................... 192

mariae-wilsoni........................ 193

oldenlandianum ..................... 193

petersii ............................... 193

petersii.............................. 193

Aegilops aromatica..................... 374 
J'ane.

Aeschynomene, catalogue ............. 569 hispida ............................. 569 longifolia .......................... 509 platycarpa .......................... 568 virginica........................... 1288

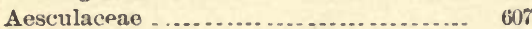

Aesculus, catalogue $\ldots . . . . . . . . . . . . . . .6 \quad 60 \%$ flava ............................... 607 glabra ................................ 80,84 lutea ............................. 607 macrostuchya ...................... 608 octandra.

$46,80,84$ parviflora 92,109 pavia $8.5,109,166,254$ sup

Aethusa, catalogue. pinnata

Afzelia cassinoides catalogue pectinata

Agaric, fly

Agaricaceae . ......................... 216, 263

Agaricules ............................ 197

Agaricinae ........................... 220

Agtrics .............................. 170

Agaricus ater ........................ 2:25 catalogue

Agave americana

catalogue

virginica

Ageratum altissimum.

catalogue

mexicanum mexicanum

Agriculture, relation to spontaneous flora

Agrimonia, catalogue eupatoria mollis parviflora

eupatorium

incisa.

microcarpa.

mollis

parviflora.

pubescens.

suaveolens.

Agrimony -

Agrostemma, catalogue

Agrostis

alba.

stolonifera.

vulgaris

altissima

arachnoides

aspera.

catalogue

elata.

hiemalis

indica

intermedia.

involuta

juncea.

littoralis

longifolia

perennans

scabra....

tenacissima
Agrostis-Continued.

tenuiflora ..........................

trichopodes .......................... 366

vulgaris ........................... 370

Agyrium, catalogue.................... 159

Ailanthus, catalogue.................. 588

glandulosus ........................ 834

Aira, catalogue ...................... $3{ }_{1}$

flexuosa .......................... 372

mollis.............................. 378,379

nitida ............................. $\quad 379$

obtusata .......................... 378

purpurea ........................ 377

triflora............................ 378

truncata. ......................... $3 \pi 8$

Aizoaceae............................. 494

Alabama flora, biological relations...... 44 ecological relations............... 44 relation to adjoining .............. 39 relation to foreign ............... 3! relation to trans-Atlantic ......... relation to tropical American .... 41 systematic relations ............. 38

River, physiography ................

Albizzia, catalogue ..................... 553

julibrissin ........................ 136, 834

Albugo, catalogue ...................... 151

Albuginaceae ......................... 151,260

Aller .............................. 43,467

black............................. 604

white ..............................

Aletris alba ............................ 443

catalogne .......................... 443

Alfalfa ................................ 560.8:9

Altilaria ............................. $5 * 3$

Algaw ................................. 14:

fresh-water........................ 142

red .............................. 148

Alisma, catalogue ...................... $3: 9$

subulata........................... 331

Alismaceae ........................... $\quad 3: 9$

Alleghenian life area.................... 31

Allionia, catalogue ....................... 493

hirsuta ............................. 105

nyctaginea....................... 83

Allium .............. . . . . . . . . . . . . . . . .

ascalonicum ....................... $8: 7$

canadense ........................ 98

catalogue ........................... 439

cepa ................................ $\quad 8: 27$

ornithogaloides................... 4339

porrum ............................ 827

sativum ......................... $8: 8$

Allspice, Carolina ..................... 109,518

Alnus ....................... 139, 194, 195,202, 208 catalogue ......................... $46 i$ rugosa ....... 154, 166, 16\%,177, 179, 180, 181, 198 serrulata............................ 467

Alow, American ......................... 448

false............................ 448

Alopecurus aristulatus ................. 367

catalogue ........................ $\quad 367$

fulvus ............................ 367

geniculatus aristulatus............... 367

monspeliensis ........................ 369

Alsike clover ......................... $\quad \forall 28$

Alsinaceae ........................... 496 
Page.

Alsine ................................... 499

catalogue ......................... 499

pubera tennesseensis.... ............ 86

Alternanthera achyrantha .............. 492

leiantha....................... 492

catalogue .............................. 491

Althea .................................. 835

rosea ............................ 239

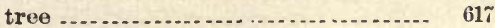

Alum root .............................. 534

Amanita, catalogue................... $\quad 228$

Amanitupsis, catalogue ................. 228

Amaranth family . . ................... 490,491

Amaranthaceae ....................... 490

Amaranthus albus ........................ 491

catalogue ............................. 490

chlorostachys....................... 490

hybridus......................... 490

crassipes .......................... 491

hybridus .......................... 55

hypochondriacus.................... 490

retroflexus........................ $55,151,253$

sp .................................... 151

spinosus.............................. 50.50

Amaryllidaceae ........................ 447

Amaryllis atamasco ..................... 447

family.

Amblystegium ................................

catalogue

homalostegium ...........................

radicale

Ambrosia artemisiaefolia ...... 152, 165, 171, 173, 174, 175 catalogue trifida. $165,171,191$

Ambrosiaceae ......................... 756 addendum . ......................... 845

Amelanchier.......................... $\quad 261$

canadensis .......................... 64

botryapium ....................... 545

oblongifolia........................ 545

catalogue .......................... 545

Amellus villosus............................ $\quad 770$

American centaury ...................... 670

colombo............................ 672

Amerosporium, catalogue .............. 261

Amianthium .............................. 437

angustifolium ......................... 437

leimanthoides........................ 43\%

muscaetoxicum ...................... $\quad 437$

Ammannia, catalogue ................... 631

humilis............................. 631

latifolia ............................... 631

ramosior ................................ 631

Ammi capillaceum........................ 648 catalogue .......................... 649 majus .............................. 56

majus ............................... 648

Amorpha, catalogue ..................... 563 fruticosa . . . . . . . .

glabra ............................. 123

virgata............................... 61,63

Ampelanus, catalogue.................. 677

Ampelopsis.............................. 174

arborea ............................. 101

bipinnata ........................... 611
Page.

Ampelopsis-Continued.

catalogue ........................... 611

cordata .................................. 101

incisa............................. 130

quinquefolia ........................ 611

Amphiacharys, catalogne............... $\quad 769$

dracunculoides ...................... 83

Amphicarpa ........................... $5 \%$

monoica............................. $5 \boldsymbol{5}^{2}$

Anphicarpaea pitcheri .................... 579

Amphiprora, catalogue ................ 146

elegans ............................... 146

vitrea .............................. 143

Amphisphaeriaceae .................. 173, 262

Amphitetras, catalogue................. 144

Amphora, catalogue ................. 146

Amphoridium .... ..................... 291

catalogue ........................... 300

Amsonia amsonia....................... 184

angustifolia......................... 674

ciliata ............................ $\quad 97$

catalogue ........................... $\quad 673$

latifolia .............................

tabernaemontana ..................... 673

Amygdalus persica ..... 154,189,235 236, 256, 832 nectarina ..................... 832

Anacardiaceae........................... 600

Anagallis, catalogue.................... 669

Anantherix paniculata.................. 677

Andreaea, catalogue .................... $\quad 296$

rupestris............................ 290

Andreaeaceae........................... 296, 309

And reaeales . . . . . . . . . . . . . . . . . . . . . . . 29 296, 309

Andromeda ....................... 14, 45, 47,258

acuminata .......................... 168

arborea................................. 656

axillaris................................ 654

frondosa ............................... 655

ligustrina ........................... 655

pubescens ......................... 656

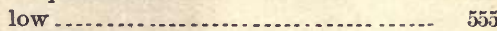

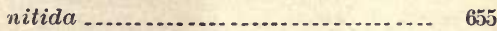

paniculata foliosiflora ................ 655 nudiflora........................ 655

phillyreaefolia....................... 655

racemosa........................... 654

recurva............................ 655

recurved ............................ 655

Andropogon ............................ 256

alopecuroides ......................... 334

ambiguus ........................... 375

argenteus .......................... 338

argyraeus ......................... 113, 187

avenaceus ............................ 338

bakeri................................ 845

belvisii .............................. 338

catalogue ............................. 336

ciliatus.............................. 338

dissitiflorum ......................... 337

elliottii............................... 120

furcatus ................. $61,73,104,187,257$

glaucus ............................... 337

glomeratus .................... 123, 183,821

glaucopsis ...................... 128

halepensis ............................ $\quad 339$

insularis ............................ 345 
Audropogon-Contiuued.

liebmanii mohrii....................... 338

longiberbis .......................... 337

macrourum ........................ 336

macrourus glaucopsis ................ $33 \%$

hirsutior ......................... $33 \pi$

mohrii ............................. 119

nutans ............................ 339

linneanum ...................... 339

provincialis furcatus .................. 3338 scoparius ............6 61, 73, 114, 183, 187, 822 polycladus ....................... 845

sorghum sativus........................ 339

sp .............................. 171, 186, 187

tener............................... 113, 120

genuinus typicus.................. 336

tetrastachyus...................... 119

vaginatus ............................ $33 \%$

virginicus .......................... 74 ,

66, 88, 116,171, 175, 186, 187,337,821

dealbatus ....................... 120

glaucus ......................... 120, 337

tetrastachyus ................... 3338

viriclis........................... 337

Andropogoneae ........................ 63

Anemone caroliniana ..................... 83, 93

catalogue ........................... 510

decapetala ......................... 188, 194

hepatica........................... 511

heterophylla....................... 510

nemorosa........................... 510

quinquefolia .................... 510

prairie ............................. 511

quinquefolia ......................... 75,93

rue ............ ................... 511

Sonthern ......................... 510

thalictroides .......................... 511

trilobata ........................... 510

Virginian ......................... 511

virginiana . .................... $75,85,93,260$

Anemonella ............................ 511

thalictroides ......................... 511

Angallis caerulea........................ 663

Angelica .............................. 641

catalogue ......................... 641

hirsuta ............................ 641

tree .............................. 70,640

villosa............................ 64,245

Angelina, catalogue ................... 162

Angiosperma

Angle-pod, Baldwin's.................... 678

hirsute ............................ 678

smooth ........................... 677

Anise, Florida star...................... 506

Anomodon1, catalogue .................... 304

Anomostephium buphthalmoides ........ 800

buphthalnoides ..................... 800

Anona pygmaea .......................... 508

triloba ........................ ... 507

Anonacear............................ 507

Anonymos aquatica ...................... 475

bracteata........................... 570

capitata.......................... 446

cassioides .......................... 724

erecta............................. 727

graminifolius ....................... $\quad 767$

odoratissima........................ 768

pinnata ........................... 565
Anonymos-Continued. Page.

rotundifolic ......................... 555

sessilifolium ........................ 669

Antennaria, catalogue ............... 168, 790

Anthaenantia.......................... 343

catalogue ......................... 343

rufa ............................. 116

villosa ............................ 113

Anthemis, catalogue .................. 812

cotula ............................. 55

repens ............................. $\quad 79 \%$

Anthoceros carolinianus ................ 285

catalogue ........................ $\quad 289$

ravenelii........................... 285

Anthocerotaceae ........................ $\quad 289$

Anthostoma, catalogue ................ 177

Anthostomella, catalogue.............. 177

Anthoxanthum, catalogue............... 364

Anthriscus cerefolium.................. 889

Antirrhinum canadense ................. $\quad \% 17$

elatine.............................. 716

linaria ........................... 717

spurium ......................... 717

Antrichum ............................ 303

Anychia baldwinii....................... 502

canadensis ......................... 502

catalugue ......................... 502

dichotoma .......................... 63

Aphyllon ............................. 731

uniflorum .......................... $\quad 731$

Apiaceae.............................. 640

Apios apios ........................... 165,245

catalogue ........................ 579

tuberosa.......................... 579

Apiospora, catalogue.................. 174

Apiosporium, catalogue ................. 168

Apium, catalogue ..... . . ................... 647

graveolens........................ 829

leptophyllum ....................... 647

Aplectrum, catalogue ................. 460

hyemale ........................... 460

Aplopappus divaricatus .................

Apocynaceae........................... $6 \% 3$

Apocynum cannabinum ................ 68

catalogue ......................... 674

Apogon............................... 752

humilis............................ $\tau_{52}$

Apple of peru .......................... 708 thorn .............................. 714,715

tribe .............................. 46

Applemint . . . ......................... 697

Apples ................ 31, 43, 69, 80,89, 254, 824,831 in Tennessee Valley ................ 824

Apteria ............................... 51

catalogue ......................... 452

lilac .............................. 452

lilacina........................... 452

setacea .......................... 123

Aquilegia, catalogue .................... " 509

Arabis bulbosa .......................... 525

catalogue .......................... 528

laevigata.......................... 83

ludoviciana ......................... 528

patens.............................. 94

thaliana......................... 527

virginica .......................... 152

Aracene ................................ 424

Arachis hypogaea ................. 69, 243,830 
I'age.

Arachnion, catalogue

Aralia, catalogue quinquefolia ....................... 640 racemosa $70,255,260$ spinosa.

\section{0}

Araliaceae

Araucaria imbricata spp

Arboreal plant associations.

Arbutus, trailing

Archemora rigida

Archiclulamydeae

Archidium, catalogue

Archispermae

Arcticgrass

or arctic-alpine life zone

Arctium, catalogue.

Arcyphyllum difforme

Arcyria, catalogue

Arecaceae

Arenaria brevifolia

catalogue

diffusa

patula

pitcheri

rubra.

marina.

serpyllifolia

stricta

Arethusa divaricata

ophioglossoides.

racemosa

spicata.

verticillata

Argemone albiflora

catalogue

georgiana

mexicana albiflora

Arisaema, catalogue

dracontium

polymorphum.

quinatum

Aristida, catalogue.

dichotoma

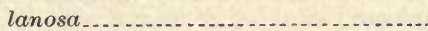

palustris

purpurascens.

minor.

simpliciflora $\ldots \ldots \ldots \ldots$

simplicifolia ........................ 113

spiciformis ........................ 124

stricta _........................... 109, 113

virgata palustris...................... 365

Aristolochia, catalogue ................. 480

hastata........................... 480

serpentaria ........................ 480

sipho ................ 480

tomentosa ............................ 101

Aristolochiaceae .... .................... 480

Armillaria, catalogue................... 227

Aronia arbutifolia ................... 64, 71

ca.talogue .......................... 545

Arrhenatherum avenaceum ............. $\quad 372$

catalogue ............................ 372

elatius ........................... 826
Page.

Arrhytidia, catalogue ................... 196

Arrow grass ............................ 329

family ....................... 329

Arrowhead ...................... 50,330,332

Arrowleaf .... . . ....................... 49

Arrowwood ............................ 107, 743

Artemisia, catalogue....................... 814

capillifolia ......................... 760

vulgaris ............................. 56

Arthonia ...................... 264,266

catalogue . . . . . . . . . . . . . . . . . . . 269

Arthonieae ............................ 269,284

Artichoke .............................. 828, 831

Arum dracontium ........................ 426

family .............................. $\quad 424$

polymorphum ...................... 425

quinatum ............................ 425

triphyllum ........................ 425

virginicum ........................ 495

Aruncus, catalogue ....................... $\quad 539$

Arundinaria. . . .............. 15\%, 162, 169, 173, 174

catalogue ........................... 389

macrosperma.................. 45, 58, 102, 103 suffruticosa ........................ 389

tecta .............................. 45, 102 ,

$103,123,126,15 \tau, 160,164,170,172,174,175$,

$181,196,237,238,244,246,248,252,261,823$

Arundo cinnoides......................... 371

gigantea............................. 389

phragmites ........................... 377

tecta.............................. 389

Asarum arifolium ....................... 123

catalogue ............................ 480

grandiflorum ....................... 481

macranthum ...................... 79

virginicum . ........................... 66,182 grandiflorum ..................... 481

Asclepiadaceae ......................... 674

Asclepias amplexicaulis ................. 114,675

angustifolia ............................ 676

catalogue ........................... 674

floridana ............................. 676

humistrata ........................... 114

lanceolata.......................... 50

linearis................................. 676

longifolia $\ldots . . . \ldots \ldots \ldots$

michauxii........................... 114

obovata ............................... 104

obtusifolia ............................ 240

parviflora ........................... 676

paupercula........................... 675

purpurascens ....................... 675

quadrifolia........................... 79

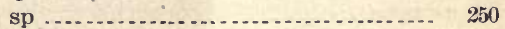

tuberosa . . . .

variegata $\ldots . . . . . . . .68$

verticillata subverticillata ........... 676

viridis.............................. 677

Asclepiodora . ........................ 677

catalogue ........................ 677

viridis ............................... 104

Ascobolaceae ........................ 157,262

Ascobolus, catalogue ................... 157

conglomerata ....................... 162

Ascomycetes.......................... 154, 262

Ascyrum ................................ 121

catalogue.......................... 619 
Ascyrum-Continued. crux-andreae. angustifolium

Page.

619

619

hypericoides ................. 1:0, $6: 0$ pumilum ......................... 114

stans . . . . . . . . . . . . . . . . . . . .... 1:20,238

Ash.

\section{Biltmore}

$14,43,46,666$

blu

81,667

Carolina

$46,6 \%, 124$

green

$46,125,66 \%$

pop .................................... 66

small-fruited white.

Southern prickly ..... ............ . 102, 120

vater

white ........... $81,84,86,92,102,110,666,824$

Asimina ................................. 193

catalogue ........................... 507

low 508

parviflora ............................. 112

triloba ........................ $66,101,102$

Asparagus . .............................. 828

officinalis............................ 828

Aspergillaceae........................ 164,262

Aspergillales................................ 164

Aspergillus, catalogue .................... 164

Asphodel, false ............................. 436

Aspidiotns obscurus. ................... . 169, 249

Aspidium................................. 316

acrostichoides ........................ 317

floridanum ........................... 317

marginale ........................... 317

molle ................................ 317

noveboracense.................... 316

obtusum ............................. 318

patens ............................... 317

thelypteris............................ 316

Asplenium angustifolium ................ $\quad 74$

bradleyi.............................. 78

catalogue ......................... 314

ebeneum............................... 314

filix-foemina ....................... 78,94

montanum ....................... $73,78,94$

parvulum ......................... $73,78,94$

pinnatifidum ......................... 73, 78

platyneuron ....................... 74,123

rhizophylla.......................... 316

ruta-muraria ......................... 73,94

thelypteroides......................... 316

trichomanes ....................... $76,78,94$

Asprella ................................ 389

Aster ....................... 152, 188, 192, 254,788

adnatus ....................... 115, 780,786

antplexicaulis........................ 780

annuus ............................ 786

asperulus............................ 781

azureus ............................. 781

baldwini ......................... 781

camptosorus. .................... 62,93,781

catalogue ......................... 779

concolor............................ 115, 780

cordifolius .......................... 83, 782

coridifolius ......................... 784

laevigatus. ....................... 788

polycephalus ..................... 782

cornifolius ............................ $\quad 788$

corymbosus.
Aster-Continued. Page.

diffusus .............................. $\quad 784$

discoideus............................ 7

divaricatus ......................... 74,779

divaricatus ........................ $\quad 785$

diversifolius ....................... 781

dumosus . . . . . . . .................. 184, 784,821

coridifolius .................... 784,786

subulaefolius ............... 66,784, 786

ericoides . . . . . . . . 783

pilosus.......................... 783

platyphyllus..................... 783

villosus........................... 783

exilis ............................. 785,786

flexuosus ............................ 785

foliolosus ............................. 784 golden ................6 $67,769,770,771,822$

gracilis............................. 780

humilis............................ 788

infirmus.......................... 788

laevis . .............................. 62,783

amplifolius ..................... 783

latifolius....................... 83

latifolius......................... 783

laevigatus .......................... 782

lateriflorus ................ 64, 165, 782,784 glomerellus...................... 784

pendulus.......................... 785

latifolius .......................... 783

leiophyllus. ....................... 782

linariifolius.......................... 788

linifolius ............................ 785

lowrieanus ....................... 78 \%

microphyllus ........................ 780

miser............................... 784

glomerellus...................... 784

multitlorus .......................... 783

stricticaulis ...................... 783

oblongifolius ......................... 83,780

paludosus ......................... 126, 779

paniculatus............................ 785

patens ................... 62, 67, 105, 780, 822 gracilis........................... 780 tenuicaulis................. 115, 780,786

pendulus ........................... 785

pilosus .............................. 783

pilosus ............................... 788

puniceus ........................... 184, 780

purpuratus ................... 126, 789,786

purpureus.......................... 66

sagittifolius $\ldots \ldots \ldots \ldots \ldots \ldots \ldots \ldots .62,66,782$

salicifolius subasper ................ 785

scaber ............................. 781

shortii ......................... $66,93,781$

solidagineus ........................ 778

subasper ........................... 785

subulatus .......................... 785

tenuifollus ........................ 784,785

tortifolius........................... 779

tradescanti ..................... 165, 184.785

umbellatus ............................. 788

latifolius ......................... $\quad 788$

undulatus................. $62,67,105,184,781$

diversifolius .................... 62,781

loriformis..................... 782

vernus .............................. 787

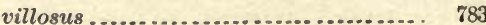


Aster-Continued.

vimineus foliolosus

Page.

64,784

virgatus

782

white-topped ...................... 778,779

Asters .......... 83, 115, 236, 239, 778-785, 821, 822 blue

Asterella, catalogue.

tenella

Asterina, catalogue

Astomum, catalogue

ludovicianum.

sulivantii

Astraeus, catalogue

Astragalus canadensis

carolinianus

catalogue

plattensis tennesseensis

villosus

Astrophyllum cuspidatum pachyphyllum.

Atamosco atamasco

catalogue .................................

lily

Athanasia graminifolia

hastata.

obovata.

trinervia

Atheropogon

Atkinson, G. F.. fungi

Atriplex arenaria

catalogue

patula hastata

Atropa physalodes

Aulacodiscus, catalogue

Aulacomnium.

Aulaxanthus

ciliatus

rufus

Auliscus, catalogue radiatus.

Aulographum, catalogue ................ 162

Auriculariaceae ........................ 194, 262

Anriculariales. .......................... 194, 262

Auricularia, catalogue.................... 194

Austin, C. F., liverworts identified........ 285 mosses identified ...................... 290

Austral life region ........................ $\quad 31$ zone, lower...................... 32 zone, upper ...................... 31

Australian oats......................... $38 \%$

Austroriparian area ..................... 94

life area............................. 32

Avena sativa ........... 183, 188, 190, $238,249,826$ catalogue ........................... 372 elatior............................... 372

fragilis ............................... 373

glumosa............................. 373

palustris ........................... 372

pennsylvanica........................ 372

spicata $\ldots . . \ldots \ldots \ldots \ldots$

Avens, white ........................... 542

Azalea ................. 14, 15, 45,47,71,89,835,845

arborescens........................ $57,71,78$

catalogue ........................... 653

glauca................................ 683

indica ............................ 835

nudiflora.................... $71,191,196,254$
Azalea-Continued. Page.

sweet-scented ...................... 71,653

viscosa glauca . ...................... 64,66

Azaleas, indian ....................... 136

Azolla .................................. 48

caroliniana ...................... 125

catalogue . . . . . .

Baccharis adnata $\ldots . . . . . . . . . . . . . . . .790$

angustifolia......................... 132

catalogue .... . . . .

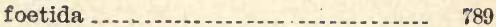

foetida.............................. $\quad 790$

halimifolia ......................... 45, 132

viscosa ........................... 790

Bacillariaceae .......................... 143

Bacillariales .............................. 143

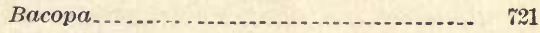

Bacteriastrum curvatum .................. 144

varians............................... 144

Badhamia, catalogue .................... 141

Baeomyces................................ 264

catalogue ............................. 272

roseus............................ 266

Baker, C. F., fungi......................... 149

lichens ............................ 264

Prof. Carl, botanical collection...... 18

Bald prairies......................... 48, 104 vegetation and soil ................ 823

Balduina................................... 808

multiflora ........................... 809

uniflora

Baldwinia ................................... 808

multiflora ........................ 130

uniflora . .................... 121

Balloon vine .... .......................... 608

Ballota, catalogue ........................ 706

Balm, Canadian horse................... 696

purple horse............................ 696

scarlet ............................... 700

seaside ............................... $\quad 701$

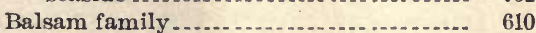

pear................................... 747

Balsaminaceae............................ 610

Bamboo ...................... 102

bay-leaf .................................. 446

brier .......................... $68,10 \%, 445$

tribe .................................. 45

Baneberry, white...................... 509

Baptisia, catalogue .................. 558

Barberry family ......................... 517

Barbula ....... ........................ 291

catalogue .......................... 299

muralis .............................. 299

Barkhousia caroliniana .................. 751

Barlaea ............................... 156

Barley .................................... 827

dwarf ..................................... 388

Barnyard grass....... ................ 357,376

Barrens and river hills, vegetation....... 88

Bartonla ................................. 673

catalogue ............................ 673

verna

virginica ................................. 126

tenella............................. 673

Bartram, William, botanical exploration. 13 
Puge

Bartramia ........................... 291

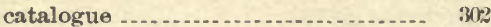

radicalis ............................ 994

Bartramiaceae ........................ 302, 309

Bartsia coccinea ...........................

Basidiomycetes ........................ 18:3, 2ti2, 2013

Basidiophora, catalogut ...... .......... 15:2

Basil, East India......................... 697 mountain . .......................... 699

scarlet ................................ 115

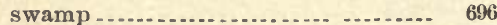

sweet ............................. 829

whitish ............................. 699

Basswood ......................... $72,89,109,613$

Batatas acetosaefolius................... 680

edulis................................ 898

littoralis ............................. 680

Batidaceae ................................ 493

Batis, catulogue ........................ 493

family .................................... 493

maritima .............................. 13:

Batrachium, catalogue.................. 515

divaricatum .......................... 49, 12\%

Batrachospermum ...................... $12 \%$

catalogue ............................ 148

Butschia canescens ..................... 691

Bayberry .... ............................ 464

Bay, loblolly

red

$47,96,100,266,518, ; 19$

rose

sweet ............................ 14,504,505

white ...................... 47,117,125,505

Bazzania, catalogne ..................... 288 trilobata ............................. 285

Bead tree ... . . . . . . . . . . . . . . . . . . . . . . . . . 588

Beaked rushes. ............... 406, $407,408,409,410$

Bean, angular-leaf....................... 581

bush................................... 830

caper family ......................... 586

flowering ............................ 830

kidney ............................ 830

lima ............................. 830

pole ................................ 830

sacred ................................ 50.3

soy ................................ 830

wild .................................. 581,582

Beans ................................ 135, 830

Bear foot............................. 792

grass ................................... 441

Beard grass ...................... 123, 336, 338, 369 tongue ........................... 718,719

Beaumont, J.F., botanical collection..... 17 fungi................................. 149

lichens ................................ 263

Beaver tree............................... 505

Bedstraw ........................... 741,742

Beech .............. 43, 16, 72,86, 100, $109,122,468$ American .......................... 468

family..... ......................... 468

drots ............................... 731

Beot, red

sugar................................. 32

Beets

Beggar lice .......... 690

tick .................................. 807

Belamcanda .......................... 450

chinensis
Bellis, catalogue -

integrifolia ......................... 83

Bellwort .................................. 438

Belonidium, catalogue .................. 158

Belonium, catalogue .................... 157

Bent grass, Elliott's ..................... 370

Reed ............................ 371

tall ................................. 371

upland .......................... $3 \pi 0$

white . . ........................... 370,820

Benton, fungi -.......................... 149

Benzoin aestivale ....................... 519

benzoin ........................... 101, 247

catalogue ............................ 519

odoriferum ......................... 519

Berberidaceae.......................... $51 \%$

Berchemia, catalogue .................. 608 volubilis .... .................... $\pi 1,101,608$

Bergamot, wild .......................

Berkeley, M. J., fungi ..... . ............. 148, 149

Berlandiera, catalogue .................. 795

downy ................................... 795

tomentosa......................... 795

Bermuda grass ................... $56,105,373,826$

Beta vulgaris........................... 240

rapacea

Betula .......................... 163, 198,213, 252

alnus-rugosa .......................... 467

catalogue ........................... 46 .

excelsa .............................. $46 t$

lenta ................................ 64,72

nigra............................... 251

rubra............................ $46 \%$

Betulaceae............................. 466

Beurera................................. 518

Biatora ............................... 264

catalogue ........................ $2{ }^{2} 2$

rufonigra ........................... 265

suffusa . . . . . . . . . .

Bicuculla, catalogue................... 590 cucullaria . ............................. 75,93

Biddulphia aurita ...................... 144

Biddulphioideae ....................... 144

Bidens, catalogue....................... $80^{\pi}$

chrysanthemoides................... $80 \%$

coronata leptophylla............... 121

involucrata . ........................ 75,125

frondosa ........................... 1ik3, 16

sp.................................. 153

Bigelovia ............................... 1:1

nudata .............................. $\pi \tau_{1}$

virgata.......................... $\pi 1$

Bigelowia .............................. $\pi \tau_{1}$

Bignonia ............................... 168

capreolata .......................... $\pi 1,164$

capreolata.......................... $73:$

catalogue .......................... 732

catalpa ............................ . 732

erucigera ......................... 101

family ......

radicans ............................ $73: 2$

semperivens ....................... 668

tomentosa. 719

Blgnoniaceae .......................... 732

Bllberry .............................. 107, 657

Bilsted ............................... 538 
Page.

Bindweed $68(1,681,689$

black

Biological survey, lichens mosses

Biotia orientalis

Birch.

black .

cherry

family

sweet

Birthwort family

Bishop's weed, greater mock.

Nuttall's toothpick

Bitternut

Bittersweet

$$
\text { false }
$$

Bitterweed $54,75 \%, 810$

Black rush sampson walnut

Blackberry

sand
Black-jack $\quad 4 \%, 59,60,68,88,96,98,10 \%, 112,472,822$

$540,541,832$ forked-leaf.

Blackroot ..

Bladder nut, American family

Bladderwort $40,52,80,117,729,730,731$

Blazing star $766,767,821,822$

Blechnum virginicum ...................... 313

Blephilia, catalogue ................... ciliata

Bletia aphylla.

Blitum maritimum rubrum

Bloodwort family

Blue curls.

flag grass .

Canada

English

Kentucky .

in Tennessee Valley

Texas.

Bluebell family

Blue-eyed grass ........................... 450

Bluehearts............................. 728

Blue-jack ................. 91,96, 112, 131, 473,822

Bluets...... . . .......................... 737, 738

Boehmeria, catalogue.................... 478 cylindrica .......................... 240

nivea ............................... 828

tenacissima ......................... 828

tenacissima ......................... 478

Boerhavia, catalogue.................... 494 erect ................................ 494

hairy ................................ 494

Bois d'arc ................ . . . . . . . . . . 475

Bokhara clover........................... 829

Boletineae .............................. 214

Boletinus, catalogue.................... 216

Boletopsis............................. 216

Boletus ...................................... 151,216

catalogue ........................... 214
Page.

Boltonia, catalogwe ..................... $7 \% 8$

diffusa ................. 128

Boneset, climbing ...................... 76 i

false ....................................... 766

prairie false ......................... 766

purple ................................ $\quad 761$

upland ................................ 764

Borage family .......................... 689

Boraginaceae .... . . ....................... 689

Boreal life region......................... $\quad 30$

Borreria micrantha.................... 740 parviflora............................ $\quad 740$

Borrichia. catalogue .................... 800 frutescens ..... 139

Botanical explorations of Alabama, history

11,13

Botrychium, catalogue.................. 310

gracile ........................... 311

lunaroides ........................... $\quad 310$

obliquum ........................ 74,121

ternatum-lunaroides.................. 310 obliquum ..................... 310

virginicum ........................... 74

Botrypus lunaroides.................... 310

Botrytis, catalogue....................... $\quad 235$

Bottle brush grass ...................... $\quad 389$

Bouchea, catalogue ...................... 694 ehrenbergii........................... 694

Bouteloua, catalogue ..................... 375 curtipendula ............................... 104 racemosa............................. $3 \%$

Bovista, catalogue...................... 233

Bovistella, catalogue.................... 232

Bowman's root ............................ 539

Box ..................................... 834

elder ........................ 41, $70,89,60 \%$

family ................................ 599

thorn ................................ 708

Boykinia ................................. 73,533 aconitifolic .......................... 533

Brachychaeta, catalogue................ 778

cordata............................ 83,7 78

sphacelata ......................... 63, 66, 83

Brachyelytrum aristatum ...... ......... 367

awned............................. $36 \%$

catalogue ............................ 36 \%

erectum .... .......................... 74

Brachyris dracunculoides ................. $\quad 769$

Brachystemon............................ 698

Brachythecium......................... 291

campestre ......................... 292

catalogue ......................... 307

laetum .............................. 293

oxycladon .............................. 292

Bracken, common ...................... 312

Bradburya, catalogue .................... 578 virginica.............................. 97

Brake, Chinese ......................... 312 cliff ................................... 313

cypress ................................ 124

Brasenia, catalogue .................... 503 peltata............................. 126 peltata .............................. 503

Brassica .................................... 134 catalogue ............................ 5:23

campestris ruta-baga .................. $\quad 827$ oleracea..................... 151, 153, 241, 246 
Brassica-Continned.

Page.

oleracea-continued

acephala

botrytis ............................

capitata ....................................

gongylodes

rapa esculenta.

Brassicaceae.

Brauneria, catalogue.

pallida

purpurea

Bremia, catalogue.

Breweria

catalogue

humistrata.

Brickellia

Brickellia cordifolia

Brintonia, catalogue ......................... discoidea

Britton, Mrs. E. G., mosses revised ......

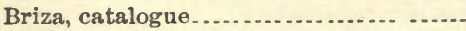
eragrostis.

Brizopyrum spicatum ...................

Bromeliaceae

Bromus canadensis

catalogue

pubescens.

schraderi.

unioloides........................... 104,827

Broom corn ............................. 825 grass . ............................. 336, 821

rape iamily .......................... 731

rapes ............................. 52

sedges . . .............................. $333 \%, 422$

Brotera ................................ 810

contrayerva...................... 810

trinervata........................... 810

Broussonetia............................. 228

catalogue ......................... 476

papyrifera ......................... 136, 833

Bruchia brevipes......................... $29 \%$

catalogue .......................... 296

curviseta ............................ 293

donnellii ............................ 293

drummondil .......................... 293

nigricans........................... 293

ravenelii ............................ 293

sullivantii.......................... 293

Bruchiaceae ......................... 296, 309

Brunnichia ............................ 123

catalogne .......................... $48 \%$

cirrhosa............................ 101

Bryaceae............................. 301,309

Bryales ................................. 296, 309

Bryonia boykinii...................... 747

Bryony ................................ $\quad 747$

Bryophyta ........................... 286

Bryum ................................ 291

bicolor ............................. 294

caespiticium ........................ 294

catalogue ........................... 301

erythrotarpum ........................ 301

lescurianum.......................... 301

nutans ........................... 294

pseudotriquetrum
Bryum-Continued. Page.

pyriforme .......................... 302

sanguineum ............................ 301

Buchnera canadensis ..................... 693

catalogue ............................ $\quad 728$

elongata ........................... 114

Buckleya ............................... 16

Buckeye .......................... 32,80,607,608 fetid ............................. 84, 608

Ohio............................... 46

red ....................... 14,85, 109, 133, 608

small-flowered......................... 92

spiked .............................. 608

sweet .............................. 84

white-flowered ...................... 108

yellow ............................ 607

Buckley, Samuel Botsford, botanical ex-

ploration............................ 16

Buckthorn . ............................ 82, 609

family ................................ 608

Carolina ....................... $99,101,133$

false................................. 664

false Southern...................... $\quad 99$

Southern.............................. 664

Buckwheat .............................. 829

climbing false ........................ 486

family.............................. 481

treo .................................. 602

Buda marina ............................ 501 rubra.............................. 501

Buellia ................................. 264

catalogue .......................... $2 \% 1$

lactea .............................. $2 \pi 1$

parasema ........................... 266

subdisciformis...................... 266

subpostumum ...................... 266

Bugbane ............................... 509

false ............................... 513

Bugleweed ............................. 697, 698

Buhrstone ridges ....................... 107

Bulgaria .............................. 157, 158

catalogue ........................... 160

Bullgrass ............................... 135, 343

Bulrush ........................... 49, 403,404

Bumelia................................. 80

catalogue .......................... 664

lanuginosa .......................... 82 lycioides . ....................... 82, 99,845

Bunch flower ............................ 438

Buphthalmum angustifolium ............ 809

asperrinı um.......................... 800

fiutescens ............................ 800

helianthoides ...................... 796

Bupleurum, catalogne .................. 645

Bur cucumber ........................ 748

marigold .......................... 807,808

reed family ........................ $32 \pi$

reods ................................. 50

Burdock .............................. 816

Burmannia, catalogue ................. 452

family ............................... 452

Burmanniaceae......................... 452

Burmannias ........................... 51

Burning bush .......................... 605, 834

Bursa, catalogue..................... 527

Burweed ............................ 757 
Page.

Bush formation

Butneria, catalogu

fertilis

$57,67,78$

Florida

109,118

Butneriaceae .......................... 518

Buttercup ............................ 514,515

Butterfly weed ............................ 68

Butternut ............................. 72,461

Butterweed............................ 815

Butterwort family ...................... 729

Butterworts ............................. 52, 729

Buttonbush............................ 739

Buttonflower .............................. $\quad 740$

Buttonweed ............................ 740

Buttonwood $\ldots 5 . . . . . . .5$

Buxaceae

Buxbaumiaceae ........... . . . . . . . . ... 304, 309

Buxus sempervirens .................... 834

Cabbage ....................... 134, 135, 246,828

Cabomba aubleti ......................... 503 aubleti ................................ 503 caroliniana ......................... 126 carolinian .......................... 503

catalogue ........................... 503

Cacalia

atriplicifolia......................... 815

lanceolata.......... . . . . . . . . . . . . 50,816

ovata ................................. 816

reniformis ........................... 815

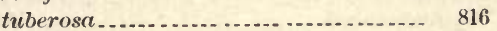

Cactaceae ............................. 630

Cactus crow foot . . . . . . . . . . . . . . . . . . ... 630

family .................................... 630

humifusus.......................... $\quad 630$

opuntia ............................ 630

Caeoma agrimoniae ................... 185 nitens ................................ 191

Caesalpiniaceae

Cahaba River, physiography .............

Cakile aequalis.

catalogne

maritima aequalis

geniculata........................ 129

Calabash..... ......................... 747

common gourd ...................... 747

Calaglossa............................. 148

Calamagrostis, catalogue ............... 371 nuttalliana .......................... 370

Calcmintha . . . . ...................... 97,700 canescens........................... 701 coccinea ............................ 115, 700 grandiflora........................... 700

nepeta........................... 700

scarlet............................... 15

Calamus ................................ 424

Caldesiella fermiginosa.................. 205

Caliciaceae............................ 269,284

Calicieae. ............................. 269,289

Calicium albo-nigrum.................... 266 catalogue ............................ 269

Calico bush ............................... 654

Calla lily, wild.......................... 425 sagittifolia......................... 425

virginica.
Calladium glaucum ....................... 425

Callicarpa, catalogue .................... 695

Calliopsis dmumondii .................... 805

Callirrhoe, catalogue..................... 614

Callitrichaceae ............................ 598

Callitriche, catalogue .................. 598

deflexa austini...................... 598

drummondii ........................... 599

heterophylla......................... 49

pendunculosa ..................... 598

verna

Calonectria, catalogue $\ldots \ldots \ldots \ldots \ldots$

Calonema, catalogue ................... 140

Calopogon ............................ 459

multiflorus . .......................... 459

pallidus ............................. 459

parviflorus .......................... 114,459

pulchellus ............................ 459

graminifolius .................... 459

Calostoma, catalogue................... 232

Caltrops ................................. 586

Calvatia, catalogue .................... 232

Calycanthaceae ........................ 518

Calycanthus .............................. 14,57

Calycanthus. ....................... $78,109,118,518$

family ......................... 518

fertilis ............................. 518

floridus ................................ 518

glaucus............................ 67,518

laevigatus ........................... 518

inodorus ............................. 518

lowland.............................. 109

sterilis ........ 518

Calycocarpum, catalogue................ 518

lyoni .............................. 101,110

Calystegia ............................ 682

catesbeiana ........................ 682

sepium pubescens ..................... 682

Camassia .................. 440

fraseri ............................. 440

Cambrian slates....................... 68

Camellia japoniea ....................... 136, 259 japonica .............................. 835

Camomile................................ 813 wild ...................... 813

Campanula acuminata.................. $\quad \mathbf{7 4 8}$ amplexicaulis........................ 749

biflora.............................. 748

catalogue ............................ 748

divaricata ........................ 63, 93,94

perfoliata......................... 749

Campanulaceae ......................... $\quad 748$

Campestrian associations of Central Prai-

ries.................................... 104 flora................................. 48

Camphor tree ........................... 136, 833

Campion, round-leaved................. 496 southern ............................. 496 starry ................................. 496

Camptosorus, catalogue ................ 316 rhizophyllus......................... 73,781

Camptothecium ....................... 291

Campulosus aromaticus ................ 66, 124 catalogue ............................. 374

Campylodiscus, catalogue .............. 146 
Campylium, catalogue

chrysophyllum ......................

hispidulnm .........................

Campylopus ........................... 291

catalogue .................................

Canada blue grass ...................... 826

lovage .............................. 643

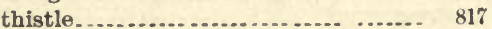

Canadian hemp......................... $6 \tilde{4}$

life zone $\ldots . . . . . \ldots$

Canary grass .................................. 364

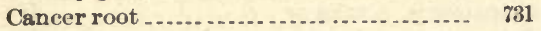

Candie berry ............................ 464

Candy grass ............................ 380

Cane ............ . . . . . . . . . . . 45, 58, 102, 103, 389 early amber......................... 825 maiden.............................. 346 mutton ............................. 103 sugar ...................... 3:,95, 110, 134, 8:5 switch .............................. 45, 102

Canebrakes ............................. 102

Cannabis, catalogue ...................... 476

Cantaloupe .................................. 831

Cantharelleae .......................... 216

Cantherellus aurantiacus................ 168

catalogue ............................ 216

cibarius ............................. 216

Cantua coronopifolia .................. 686

Cape jessamine .......................... 835

Caper family ........................... 528

Capnodium ............................ 168

Capnoides, catalogue ..................... 521

Capparidaceae.......................... 528

Capraria gratioloides ................... 722 nultifida ......................... 721

Caprifolium fraseri .................... $\quad 745$

longiflorum ........................ 745

sempervirens......................... 745

Capriola, catalogue ...................... $\quad 373$ dactylon ........................ 56, 105, 820

Capsella................................ 527 bursa-pastoris..................... 527

Capsicum annuum .................... 247,830 baccatum .......................... 830 catalogue ........................... $\quad \mathbf{7 1 4}$ frutescens .......................... 830

Carboniferous cunglomerates ........... 69 sandstones ........................ 69

Cardamine, catalogue .................. 525 heterophylla........................ 526 hirsuta ............................... 153

hirsuta ........................... 525 rhomboidea ......................... 595 uniflora ............................ 526 virginica ........................... $\quad 528$

Cardinal flower'........................ $\quad 749$

Cardiospermum,catalogue.............. 608

Carduaceae........................ 62,67,758

Carduus altissimus ....................... 65 catalogue .......................... 816 elliotii................................ 105 martanus ............................ 818

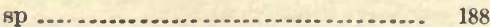
virginicus........................... $7 t$

Carex albolutescens. ............... 128,422,423

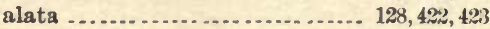
albursina 418,423
Carex-Continued.

Page. amphibola ......................... 416, 423 anceps............................. $41 \%$ angnustifolia .................... 417 patulifolia ...................... 117 atlantica . . ..................... 1:0,4:1,4:3 baileyi ........................... 9\%, 1:6,414 baldwiniana ........................ 413 blanda ........................... $41 \%$ boottiana .......................... 73,418 bromoides ......................... 4:1,4:3 caroliniana .................... 123, 416,4:3 castanea ........................... 414 catalogue .......................... 412 cephalophora ................... $73,4: 21,423$ angustifolia ....................... 421 cherokeensis ...................... 98, 416,423 collinsii .......................... 412,423 conferta .......... . . . . . . . crinita ........................... 415

cryptandra....................... 416 dasycarpa ......................... 132, 419 debilis ............................... 416 prolixa.................... 123,416,423 pubera ...................... 97, 98,416

digitalis.......................... $73,418,4 \geqslant 3$

distribution ......................... 483 echinata conferta.................... 421 microstachys ....................... 421

elliottii........................ 126,414,4:3 festucacea ........................ 114,42

flaccosperına..................... $41 \%, 423$

floridana ........... ............... 418,4 49

foenea ........................... 422

folliculata .......................... 41:3,4:3 australis ..................... 126,413,4:3

folliculata $\beta$......................... 413 xanthophysa ..................... 413

frankii ............................. 414

fusifornits.......................... 418

gigantea ........................... 413

glabra ............................. 416

glaucescens .......................... 415

gracilis............................ 414

grundis ............................ 413

granularis ..................... $76,41 \%, 4: 3$ grisec, angustifolia .................. 416 vigida .......................... 416

gynandra .......................... 423

halei............................... 413

hirsuta... ................... $88,123,415,423$

ignota ............................. 417

interior ..........................421,423

intumescens . ................. $76,126,413,423$

lagopodioides ....................... 40.

large .............................. 413

latifolia .......................... 418

laxiflora .................. $73, \mathbf{7 4 , 4 1}, 4 \% 23$

laxiflora............................ 417

latifolia........................ 418

michauxii....................... 417

patulifolia .................. $74,417,423$

plantaginea.................... 417

striatula ........................ 417

styloflexa........................... 418

varians ................. $73,74,417,423$

leavenworthil ...................... 73,421 
Carex-Continued.

leptalea

Page.

126,419

louisianica

413,42

lucorum nigromarginata

418

lupulina......................... $75,76,413$ lurida...........65, $65,76,98,128,188,414,423$ lurida ............................... 413 maxima............................. 419 michauxii........................... 412 microstachya ....................... 419 muhlenbergii....................... 114,420 enervis ......................... 420 xalapensis . . ................... 420 423 multiflora............................ 419 neglecta ........................... 420 nigromarginata .................. $73,418,423$ oblita ............................. 98, 416, 423 oligocarpa ......................... 418 oxylepsis . ......................... 98,416,483 Peters collection .................... 17 picta ............................ $73,418,423$ plantaginea......................... 417 polytrichoides.......................... 419 recurva............................... 416 retroflexa......................... 420,4:3 rosea minor ....................... 420 radiata......................... $4: 20$ retroflexa........................ 490 texensis........................ 420 scirpoides ........................... 421 scoparia .................. . . . . . 422,423 minor 4 (2) smithii ............................. 416 sparganioides.

sp $50,187,188$ squarrosa . ....................... $76,414,423$ stellulata........................... 421 conferta.......................... 421 scirpoides ....................... 421 stenolepis .......................... 414 sterilis ..................... $98,126,421,423$ excelsior ...................... 421

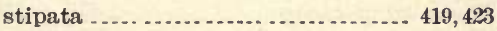
maxima ......................... 125 maxima ......................... 419 uberior .......................... 419

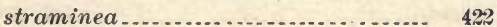
alata ........................... 420 brevior .......................... 422 festucacea.......................... 42\% foenea............................. 422 typica ........................... 422 striatula .......................... 417, 4:23

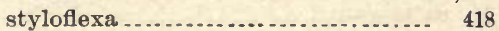
subulata .......................... 412 tentaculata ........................ 414 gracilis............................ 414 tetanicu........................... 417 texensis . ............................ 420,423 torta .......................... $76,414,423$ tribuloides turbata.................. 422 triceps . . .......................... 415,423 hirsuta........................ 415 smithii........................ 416 turgescens . . ................... 126,414,423 typhina ......................... 414 vanvleckii.
"Carex-Continued. Page. venusta ........................... 416 glabra ........................... 416 verrucosa ................... 97, 189, 415,493 virescens ..................... $73,79,415,423$ viridula ............................ 415 vulpinoidea................. (65, 125, 419,423 vulpinoidea .......................... 419 willdenovii ....................... 419,423 xalapensis........................ 420 xanthophysa .......................... 413 xanthosperma.................... 417 Carlomohria ............................... 664 Carolinian area, characteristic plants...: 64 in Alabama ..................... 5

life area............................. 31

Carpet grass ......................... 56, 120,339

Carpetweed .............................. 494

Carphephorus, catalogue ............... 768 pseudoliatris ........................ 121

Carpinus......................... 173, 181, 194, 199 caroliniana ....... 46, $61,154,16 \%, 181,23 \%, 248$ catalogue ........................... 466

virginiana ........................ 466

Carrion flower. ........................ 444

Carrot ..................................... 640,827

Cartesia centauroides .................... 759

Carthamus laevis ........................ 759

Carver, G. W., fungi...................... 150

Carya .................................. 461

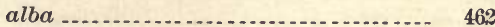

amara .............................. 463

aquatica ........................... 463

olivaeformis ........................ 461

porcina ............................ $46^{2}$

tomentosa......................... 462

Caryospora, catalogue ................... $\quad 173$

Cashew family ........................... $\quad 600$

Cassava tree, large ....................... $\quad 136$

Cassia aspera mohrii ...................... $55 \%$

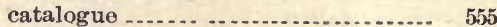

chamaecrista ....................... 61,65

chamaecrista ....................... 556

robusta............................ 556

chamaecristoides..................... 556

depressa.......................... 556

fascicularis .......................... 556

marylandica ......................... 65

mississippiensis.................... 131

mississippiensis..................... 556

multipinnata ................... 65, 104,243

multipinnata ...................... 556

nictitans . . .......................... 243,557

nictitans ................................. 557

obtusifolia ........................ 555

occidentalis..................... $55,240,243$

robusta.......................... 556

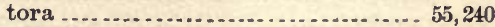

Castalia ................................ 49

catalogue ......................... 504

odorata ............................ 126, 243

pudica .............................. 504

Castanea, catalogue ..................... 468

dentata .......................... 47,60 pumila ......................... 109,251,261

vesca americana.................... 468

Castilleja canadensis..................... 52 catalogue .......................... 728 
Page.

Castor bean $61,732,835$

Catalpa

bignonioides

catalogue catalpa

Catastoma, catalogu

Catchfly

royal

snapdragon

Catharinea catalogue

Catnip.

Cat-tail family. smaller.

Cat-tails

Cancalis, catalogue

Cauliflower.

Caulinia guadalupensis.................. 329

Cauloglossum, catalogue................ 232

Caulophyllum, catalogue ................ $51 \%$ thalictroides.

Cayaponia boykinii.

Cayenne pepper .

Ceanotus

73: 835 253 67 497 497 291 303 $56,697,703$ americanus pitcheri. catalogue intermedius.

Cebatha carolina catalogue

Cedar

8,83

deodar

glades 81,82

hammocks ......................... 102 red .... 47, 81, 82, 84. 85, 100, 102, 108, 133, 269, 326 uses

white. $43,4 \tau, 11 \%, 124,125,325,326$

Cedrus deodara 136,833

Celastraceae............................ 604

Celastrus, catalogue.................... 605 scandens ............................ 78

Celery .................................. 647,829

Celidiaceae ........................... 159, 262

Celosia, catalogue ....................... 492

Celtis.................................. 43,246

catalogue .......................... 475

laevigata............................. 475

mississippiensis. . ............. 46,92, 102, 251

occidentalis........................ 167 pumila .......................... 475

Cenangella, catalogue ................... 159

Cenangiacere .......................... 159,262

Cenangium ............................... 160 catalogue ........................... 159

Cenchrus carolinianus................... 361 catalogue .......................... 361 granularis ......................... 336

incertus ........................... 129 megacephalus ....................... 129 parviflorus. .......................... $\quad 360$ strictus ............................ 361 tribuloides macrocephalus .................... 361

Centaurea benedicta.................... 818 catalogue ............................ . 810

Centaurella autumnalis ................. 673 verna............................ 673
Page.

Centella. catalogue ..................... 650 stricta............................. 120

Central continental life area............. 31 Pine belt, features................... 96

Prairie region, features ............... 98

Centrosema ............................ $5 \pi 8$ virginiana ....................... $5 \pi 8$

Centrospermum xanthioides.............. 795

Centunculus, catalogue ................. 663 lanceolatus.......................... 663

Century plant ........................... 137

Cephalanthus.......................... $\quad 259$ catalogue .......................... 739 occidertalis................. 159, 166, 179, 240 Cephaloxys flabellata ..................... 434 Cephalozia . ............................. 285 catalogue . ........................... 28i catenulata . .......................... $28 \pi$ media ............................... 285 virginica ............................. $28 j$

Ceranthera............................. 700 linearifolia ....................... 115, 700 linifolia ............................ 109

Cerastium arvense ..................... 258 catalogue ........................... 498 glomeratum ......................... 498 nutans .............................. 498 sp.... ............................... 159 triviale ............................... 499 viscosum......................... 258

Cerasus serotina montana................ 552 Ceratiola ericoides .................... 112, 130 catalogue ......................... 599

heatheriike ......................... 599

Ceratiomyxa, catalogue ................ 142

Ceratiomyxaceao......................... 142

Ceratophyllaceae....................... 504

Ceratophyllum ........................... 49 catalogue ........................ 504

Ceratoschcenus capitatus................ 405

Ceratostoma, catalogue .................. 173

Ceratustomataceae.................... 173, 262

C'erataulus, catalogue................. 144 turgidus ............................. 144

Ceratophyllum demersum .............. 127

Cercis ............................... 43, 179, 180 canadensis ..............6 61,85, 101,240,254 catalogue ........................... 555

Cercospora, catalogue ........ . . . . . . . 239-245

Cercosporella, catalogue................. $\quad 236$

Cereals, list............................ 825-827

Cerebella andropogonis.................. $\quad 250$ catalogue ........................... 250

Ceropegia palustris..................... 677

Cstraria................................. 264 catalogue ............................ 2843 fendleri ............................... 26.

Chaerophyllum canadense ............... 647 catalogue ........................... 645 procumbens tainturieri................ 646

Chaetoceros, eatalogue.................. 144

Chaetochloa, catalogue................... 358 glauca.......................... 244, 359,260 gracilis ............................ 359 imberbis perennis ..................... 132 italica ........................... 95, 236, 820 germanica .................... 3601,826 
Chaetochloa-Continued.

perennis

perennis.

versicolor

Chaetomiaceae ...................... 162, 262

Chaetomium, catalogue.................. 172

Chaetosphaeria, catalogue ............... 172

Chaff-seed ........................... 728

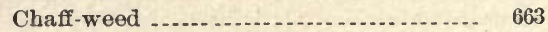

Chamaecrista......................... 131

catalogue $\ldots . . .6 \ldots$

depressa ............................ 556

Chamaecyparis ................ 43

catalogue ............................. 325

spharoidea ........................... 325

thyoides ............................ 117

Chamaelirium, catalogue ............... 436 carolinianum ....................... 436

Chamaeraphis........................... 358

Chamaerops acaulis ................... 483 hystrix .............................. 424

serrulata ........................... 424

Chantarelle ........................... 216

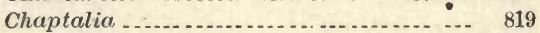

integrifolia ........................ 819

semifloscularis .................... 120

tomentosa .......................... 819

vernal................................ 819

Chara, catalogue ..................... 147

Characeae............................ 142,147

Charales ............................... 147

Charcoal, supplied by pine forests ....... 60

Cnayote.................................. 831

Cheat

Che-aw-ha Mountain, correction of er-

ror ..................................... 845

Cheilanthes alabamensis................ 73,94

catalogue .. ........................ 312

lanosa ............................. 73,94

tomentosa ......................... 63, 73

vestita.......................... 312

Chelone, catalogue ..................... 718

digitalis....................... 718

hirsuta .......................... $\quad 718$

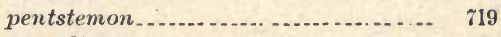

Chenopodiaceae ...................... $48 \tau$

Chenopodium ambrosioides anthelminti-

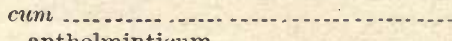

anthelminticum .................... 239

berlandieri............................ 132

catalogue ......................... 487

maritimum ........................ 489

multifidum ...... ................... 489

Cherry ..................... 31, 43,46 Alabama .......................... 552

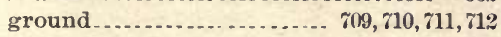
laurel .............................. 552 mountain black..................... 552 sea .................................. 132

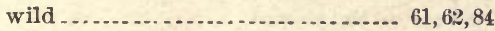
Chervil.................................. 829 wild . ............................... 645,646

Chess................................... 387 Chestnut...... 14,32, 47, 59, 60,61, 63, 70,89, 214, 824 American .......................... 468 chinquapin ....................... 822 Chicken corn ........................ 339, 895 rage.

Chick-pea . ............................. 578, 830

Chickweed, common ................... 499

forked ................................ 502

indian............................. 494

mouse-ear.......................... 498

nodding ................................ 498

Chicory .................................... 751

family .................................... 751

Chili ....................... 714

Chimaphila, catalogue.................. 652

maculata........................... 87

umbellata............................... 66

China grass $\ldots$

root ........................ 445

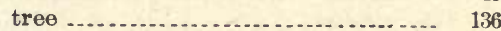

berry tree....................... 834

Chinese tallow tree...................... 136

tea .................................. 835

Chinquapin .............................. 109, 468

water . . . . .

Chiodecton ............................. 264

catalogue ........................ 270

lacteum ......................... 270

rubricinctum ...................... 266,272

Chionanthus, catalogue ................. 668

virginica...................... $71,109,122$

Chironia angularis ...................... 670

angustifolia........................ 670

calycosa............................ 670

campanulata....................... 671

chloroides. ............................ 671

dodecandra ........................... 671

gracilis............................ 671

Chittamwood..................... 34,600

Chloris, catalogue ...................... 375

curtipendula........................ $\quad 375$

monostachya........................... 374

mucronata ........................... 376

petraea.................................. 375

Swartz's ................................ 375

Chlorophyceae ................... 146

Chlorosplenium, catalogue

Choctaw root............................. 674

Chokeberry ..............................

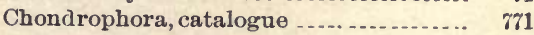
nudata .............................. 121 virgata . . . .

virgata................................

Chromosporium, catalogue .............. $\quad 237$

Chrosperma, catalogue ................... 137

muscaetoxicum..................... $6 i, 114$

Chrysanthemum, catalogue.............. 813

parthenium .......................... 56

sp ..................... 168

Chrysobalanus, catalogue................ $\quad 553$

obtusifolius .................... 115

Chrysocoma coronopifolia ............ 761 gigantea............................... 758 graminifolia ......................... 759,778 nudata ................................. 771 nudata $\ldots . . . . . . . . . .67 \%$ virgata ............................. 771

Chrysogonum, catalogue ................ 795 virginianum ....................... 114

Chrysoma, catalogue ...................

pauciflosculosa ........................ 130

solidaginoides........................ $\quad 777$ 
Chrysomyxa, catalogue ................. 184

Chrysopogon avenaceus ................. 73 , $160,170,175,176,183,188,191,238,250,25 \%, 261$ catalogue ............................ 338 elliottii............................. 113, 114

linnaeanus.......................... 113

nutans linnaeanus................ 120,378

Chrysopsis ............................ 115

divaricuta ......................... 771

argentea . .......................... $\quad \gamma_{70}$

catalogue ........................... $\quad 769$

gossypina .......................... 770

graminifolia .................. 62,67, 115,243

graminifolia ....................... $\quad 770$

hyssopifolia ...................... 109,115

mariana...................... 62,67, 74,8:2

pilosa................................ 822

scabra ............................... 769

trichophylla . .................... 115

Chufa ............................... 827

wild ................................ 392

Chytridiales .......................... 150,262

Cicer arietinum ........................ 830

catalogue ........................... 578

Cichoriaceae........................... 751

Cichorium, catalogue ..................... 751

endivia.............................. 829

Cicuta, catalogue ........................ 647 maculata..................... 50, $76,128,419$

Cimicifuga, catalogue ................. $\quad 509$ palmata........................... 513

racemosa........................... 75

Cinna arundinacea .................... 237,239 catalogue ............................. 369

glomerata ........................... 336

Cinnamomum camphora................ 136

Cinquefoil, Canada ...................... 542

Cintractia ............................ 183

Circasa, catalogue........................ 639

lutetiana..........................

Cirsium altissimum .................... 817

arvense........................... 817

horridulum ....................... 816

elliottii....................... 817

lanceolatum........................ 818

lecontei............................. 817

nuttallii............................ 817

virginianum ........................ 817

Cissampelos pauciflora .................. 444

Cissus ..................................... 123 ampelopsis ........................ 611

seaside ............................. 611

stans .............................. 611

Cistaceae ............................ 624

Cistus ................................. 115 carolinianus ........................ 624

Citronella ............................. 15,697

Citrullus vulgaris.............. 240,247, 250, 830

Citrus aurantium amara ................. 832 sinensis .......................... 832

limon ............................. 253

Cladium, catalogue..................... 410 effusum ...................... 49, 128, 132, 411

Cladonia caespiticia.................... 265 catalogue ........................... 273

fimbriata .......................... 265

gracilis............................. 266
Cladonia-Continued.

leporina............................ 266

mitrula .............................. 266

pulchella............................ 266

rangiferina alpestris................. 266

minor .......................... $2 \pi 4$

squamose ........................... 265

Cladoniene. ............................ 273, 284

Cladosporium ........................... 243

catalogue ........................... 233

Cladrastis, catalogue .................... 557

tinctoria ............................ 80,85

tinctoria ....................... 557

Clasmatodon............................. 291

catalogue ........ . . . 305

parvulus . .............................. 293

Clathraceae ............................ 229, 263

Clathroptychiaceae ..................... 140

Clathroptychium, catalogue ............. 140

Clathrus. catalogue..................... 229

Claudopus, catalogue .................... 224

Clavaria, catalogue ....................... 20.

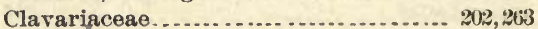

Claviceps, catalogue.................. $\quad 170$

Clavicipitaceae ......................... 170, 262

Claytonla, catalogue .................. 496

virginica .......................... 83

Clear weed ............................... 478

Cleavers ............................... 741

Clematis, catalogue..................... 512 catesbaei ........................... 109

crispa ................................ 109

cylindrica ......................... 512

lineariloba......................... 512

reticulata ............................ 109

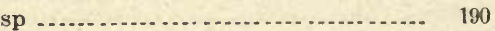

virginiana ........................ 71

valteri .......................... 512

Cleome, catalogue .................... $5: 28$

clammy ............................ 599

prickly . ............................ $5: 99$

pungens ............................. 528

spiny .................................. 528

Clethra \&lnifolia ...................... 118

catalogue ......................... 652

Clethraceae ............................. 652

Cliftonia, catalogue ..................... 602

ligustrina ........................... 60.2 monophylla.................... 96,118, 122 nitida ............................ 602

Climacium .............................. 291 americanum ..................... 2992,293

catalogue ............................ 306

Climate of Alabama.................. 24

Clinopodium carolinianum ............ 97, 108

catalogue ............................ 700

coccineum ........................ 15,115

mugosum ............................ 696

Clitocybe, catalogue................... $\quad 2: 6$

Clitopilus, catalogue .................... $2 \% 4$

Clitoria, catalogue....................... $\quad 578$

mariana.......................... 240

virginiana ........................ 578

Cloudiness in Alabama ................... $\quad 27$

Clover................................... 68,89

alsike............................... 828

Bokhara ......................... 105, 560 
Clover-Continued.

buffalo

bur.

bush

horned

Japanese

Mexican

prairie

purple

red. searlet

Turkish

white yellow

Club moss family

Page.

Club mosses

561

Club-rush. $67,88,99,575,822$

Clypeosphar

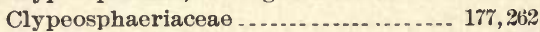

Cnicus altissimus ........................ 817

arvensis ............................. 817

benedictus......................... 56,105

catalogue ............................. 818

glaber ............................. 817

horridulus ........................... 816

lanceolatus.......................... 818

virginianus ...................... 817

Coal measures......................... 69, 84

of Cahaba Valley, etc.............. 90

region of ......................... 20

Coast blite .............................. 488

Pine belt, adapted crops ........... 822,823

belt, Lower division. ............. 110

belt, Upper division............... 106

belt, vegetation and soil ........ 8:2, 823

plain, features ..................... 118

vegetation and soil............... 821

Coastal plain. physiographical features .........

Coccomyces, catalogue...................

Cocculus carolinus.

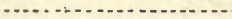

Cocklebur................................ 757

Cockspur grass ......................... 357

Coenogonieae......................... 273,284

Coenogonium ........................... 264

catalogue ............................ 273

interpositum ...................... 266

Cohosh, black ......................... 509 blue ................................. 517

Coleosanthus, catalogue ................ 766 cordatus ........................... 109 cordifolius ............................ 65

Coleosporium, catalogue................. 184 sonchi-arvensis......................... 184

Colic root .... . . . . . . . . . . . . . . . . .

Collards . . . . . . . . . . . . 828

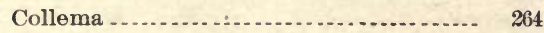

callibotrys ........................... 265

catalogue ........................... 278

corticola........................... 277

nigrescens leioplaca................... 266

pustulatum ......................... 265

tenax .............................. 265

Collemeae. $2 i 7,284$
Colletotrichum Paga

Collinsonia anisata ..................... 15,66

canadensis .......................... 108

catalogue ........................... 696

scabra ................................. 696

tuberosa ............................ 696

Columbine, wild ......................... 509

Collybia, catalogue ...................... 225

Colocynth............................. 746

Comandra............................. 52

catalogue ............................ 479

Comatricha, catalogue ................ 142

Comfrey, wild .................... 690

Commelina .............................. 431

agraria............................. 430

angustifolia........................ 430

caroliniand ........................ 430

catalogue ........................ 430

cayennensis ........................ 430

communis....................... . 430

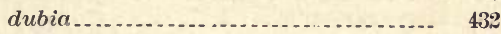

erecta............................ 66

longifolia ........................... 431

nudiflora............................. 97

virginica ........................ 97

vulgaris ............................. 430

willdenovii........................... 430

Commelinaceae......................... 430

Compass plant. ......................... 792

Compositae......... 61, 63, 74,91, 108, 114, 121, 175

Cone-flower ..................... 688, 797, 798, 799

Confervales ............................. 147

Coniferae .............................. 323

Coniophora, catalogue................. 199

Coniosporium, catalogue................ 237

Conium, catalogue....................... 646

Conobea................................... 721

catalogue ........................ 721

Conocephalum, catalogue............... $\quad 286$

Conoclinum coelestinum.... ............. 765

Conomitrium julianum ................... 299

Conopholis americana................... $\quad 52$ catalogue ............................. 731

Conostylis americana .................... 448

Conralia fuchsioides .................... 725

Conradina canescens ..................... 130

catalogue ........................... 701

Contrayerba.......................... 810

Convallaria biflora ...................... 441 commutata .......................... 442

racemosa........................... 441

Convolvulaceae......................... 678

Convolvulus acetosaefolius............... 680

aquaticus ........................... 681

bonariensis......................... 682

carolinus............................. 681

catalogue .......................... 682

dissectus ............................... 682

humistratus ........................... 681

jalapa ............................ 680

obtusilobus ............................... 680

panduratus .......................... 680

pes-caprae........................... 679

pickeringii........................ 682

purpureus............................ 679

sagittifolius ....

sepium ............................... 184 
Convolvulus-Continued.

Page. Corn-Continued.

Page. sepium repens......................... 68:

sp .................................... 188

speciosus ............................ 680

tamnifolius ......................... 681

tenellus............................ 681

Conyza ambiguct ....................... 788

asteroides ........................... $\quad 779$

bifoliata ......................... $\quad 779$

camphorata........................... 789

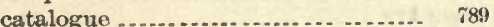

linifolia.............................. 778

polystachya .......................... 790

sinuata................................ 788

Coprineae. .............................. 217

Coprinus, catalogue................... 217

picaceus........................... 217

Coprosmanthus herbaceus ................ 444

ecirrhatus........................... 444

peduncularis........................ 444

Cousa River, physiography ............. 24

valley, region of.................... 21

Coral berry ............................ 80, 744

plant ............................. 579

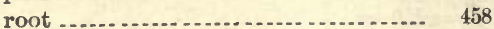

Corallorhiza ............................ 51

catalogue ........................... 458

hyemale .............................. 460

Corchorus, catalogue ................... 613 pilolobus ............................. 613

siliquosus ............................. 613

Cord grass ................................ 49

Cordyceps, catalogue . . ............... 170

Coreopsis .................... 64, 805, 806, 807,808 alternifolia ......................... 804

angustifolia.......................... 121

aurea.............................. 807

leptophylla...................... 808

auriculata ........................... 67,74

catalogue ........................... 804

coronata ........................... 807

crassifolia................................. 68

discoidea............................ 808

grandiflora .................. 74.75

involucrata ......................... 808

lanceolata............................ 104

villosa ............................ 805

major

mitis ............................. 807

oemleri.... ....................... 806

pubescens............................ 65,74

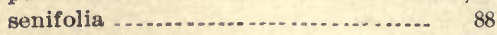

senifolin ............................ 806

stellata......................... 806

stellata............................ 806

tenuifolia ............................ 806

tripteris ........................ $65,76,88$

verticillata ........................ 64

linearis............................... 800

Corn ..... 32, 80, 83, 89, 104, 110, 134, 822, 823, 824, 825

broom ............................. 825

chicken ......................... 256, 339, 825

cockle................................ 496

fleld ............................... 135

indian .................. 31, 32, 68, 95, 105, 825

in Coast Pine belt ..................... 822

in Tennesseo Valley ................... 824

Jerusalem ........................... 256

kafir ........................ 95, 125, 190, 825

on metamorphic hills................. $8 * 3$

sugar................................. 339

swan-neck ......................... 825

sweet................................ 135

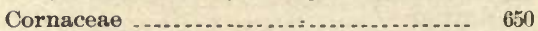

Cornel ................................ 650

Cornucopiae altissima .................. $3 \tilde{1} 1$

hiemalis........................... $\quad 3 \pi 0$

perennans...... . .

Cornus ............................ $18,200,260$

amomum .......................... 160

asperifolia ....................... 82

catalogue ............................ 650

fastigiata ........................... 650

Florida........................ 46.61,112, 167

lanuginosa $\ldots . . . . . . . . . . . . . . . . . . . .60$

sericea ............................... 650

stricta ........................... 122

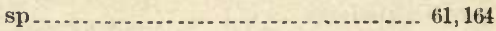

Coronopus, catalogue $\ldots . . . . . . . . . . . .5 \%$

didymus. .......................... 55

ruellii................................. 5

Corticium ..................................... 201

catalogue ........................... 197

Cortinarius, catalogue .................. 223

Cotinus cotinoides .................... 16, 34,84

Cotoneaster, catalogue................... 544

pyracantha ......................... 834

Corydalis ............................... 521

aurea micrantha..................... 521

flavula ............................. 521

micrantha ......................... 521

small-flowered..................... 521

yellowish ........................... 521

Corylopsis ............................... 40

Corylus americana...................... 61

catalogue ......................... 446

Coryneum .............................. 25?

catalogue ............................ 251

Corypha minor........................... $4: 23$ pumila ............................. 423

Coscinodiscus, catalogue ................. 143

Cotinus am cricunus..................... 600 catalogue ........................... 600

Cotton ................. $32,68,69,80,83,89,95,99$,

$105,110,134,169,249,821,8: 33,824,830$ in Tennessee Valley .................. 824

on metamorphic hills.................. $\quad 8: 3$

on recent formations ................. $8: 4$ sea island ........................... 8330 upland ............................. 830

Cottonwood .................. 43,46, 125, 461, 465 big ............................... 465 black ............................... 125,465

swamp ............................ 465

Cowbane ............................ 641,642

Cowherb................................. 498

Cowpea ..................... 32, 135, 580, 663, 830

Cowslip ................................ 663

American ............................. 663

Cox, Hon.J. D., list of diatoms ............ 142

Crab apple .............................. 99

southern ......... 14,61, 68, 71,99, 122, 545 grass ....................... 56, 135, $344-346$ 
Cracca

catalogue ............................. 565

chrysophylla ....................... 115

hispidula .................... 115,120,245,822

intermedia .......................... 566

smallii ............................ 114,822

spicata

flexuosa........................ 115

virginiana ................. $60,61,67,68,822$

Cranesbill, common ...................... 583

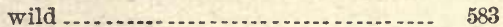

Cranichis multiflora.................... 460

Crassulaceae ............................ 532

Crataegus ....................... 165, 185, 200,252

aestivalis . ............................ 46,125

apiifolia ........................ 68,122,125

arborescens .......................... 546

austromontana ...................... 78

biltmoreana ..................... 78

catalogue ............................ 546

coccinea ............6 61, 71,82,99,546,547,550 mollis

collina

91,549

crus-galli

$61,68,71,86,99,549$

elliptica

$112,125,822$

flava ............................ 61,99, 257

elliptica .......................... 550

pubescens ....................... $\quad 550$

flexispina ............................ 550

glandulosa ........................ 547

glandulosa

microcarpa ........ 548

mohri ......... ..................... 91,549

mollis ............................ $71,99,548$

parvifolia ............................ 550

pyracantha ........................... 238

pyracantha .......................... 544

rotundifolia ........................ 547

sargenti............................... 78,547

spathulata .............. 68, 71, $86,91,185,186$

sp_........................ 167,246,247,251,845

tomentosa ........................... 550

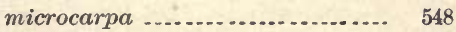

triflora............................. 91,549

uniflora .............................. 71

viridis. ....................... 99, 122, 125, 550

Craterellus, catalogue................... 201

lateritius............................ 201

Creeper, Virginia . ..................... 101, 122

Creepers, woody ......................... 130

Crepidotus, catalogue ................... $\quad 223$

Cress, bitter ............................. 555

cultivated........................... 152

early field ............................ 524

mouse-ear ,......................... 527

open rock ............................ 528

smooth rock ........................ 528

southern sand ...................... 528

swine ........................... 522

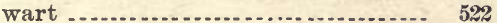

water .............................. 828

yellow ............................... 524

Cribraria, catalogue .................... 140

Cribrariaceae............................. 140

Crinum, catalogue ..................... 448

Critonia kuhnia ....................... 766
Croomia Page.

catalogue .......................... 444

pauciflora............................ 92

Cross vine ..................... 15, 71, 101, 732

Crotalaria, catalogue ................. 558

laevigata........................... 559

ovalis ............................. 559

parviflora ............................. $\quad 559$

sagittifolia rotundifolia............... 558

striata ......................... $\quad 559$

Croton ........................ 185,241,591,592 alabamensis. .................. 35,39;92,93 argyranthemus ....................... 591

catalogue ............................ 591

punctatus........................... 115

sebiferum ........................... 595

tinctorius ........................... 592

Crotonopsis, catalogue................. 592

Crowberry family ........................ 599

Crowfoot ......................... 514,515

Egyptian. ............................ 56

family ................................. 508

water ............ 49

Crownbeard .......................... 803,804

Crozophora, catalogue.................. 592

Crucibulum, catalogue................... $\quad 233$

Cruciferae .............................. 153

Cryphaea ................................ 291

catalogue .......................... 305

nervosa ............................ 294

sp................................. 293

Cryptosporium ........................... 261

Cryptotaenia .............................. 647

canadensis ............................ 648

Crystalline rocks, region ................. 19

Ctenium................................. 374

americanum ...................... 374

Cubelium concolor ..................... 75

Cucubalus stellatus ..................... 496

Cucumber ............................ 135,830

common squirting.................... 747

family .................................. 746

indian............................... 442

one-seeded bur ..................... 748

treo ..................... $32,46,60,84,99,505$

common ....................... 72

large-leaf ..................... 109, 506

Cucumis anguria ......................... 831

catalogue ............................. 746

melo cantelupa ...................... 831

reticulatus..................... 830

sativus ............................. 830

Cucurbita lagenaria..................... 747

maxima............................ 830

melopepo ......................... 830

pepo.................................. 830

Cucurbitaceae......................... $\quad 746$

Cucurbitariaceae...................... 173,262

Cudweed, plantain-leaf ................. $\quad 790$

purple .................................. 791

Cultivated plants, list for State........ 825-834

Cultural plants of Central Prairie re-

gion ................................... 105

of Coast Pine belt .............. 110,133

of Lower Coosa hills .............. 68

of Tennessee Valley ................ 89

of Warrior and Coosa basins ..... 79 
Culver's root

Cummings, Clara E., lichens revised.... 263

Cunila coccined.............. 700

catalogue $\ldots \ldots . . . . . . . . . . . . .698$

mariana ............................ 698

mulegioides .......................... $\quad 699$

Cunningliam, K. M., diatoms ......... 142

Cumninghamia chinensis................ 136

Chinese ............................. 136

sinensis ....................... 833

Cuphea, clammy ...................... 632

petiolata ............................ 632

viscosissima ......................... 632

Cumessus disticha....................... 325

imbricaria ...................... 325

funebris. ....................... 136, 832

sempervirens . . ..... . . . . . . . . . . ..... 136, 832

thyoides ............................. 325

Cup seed 518

vine ................................ 101

Curtis, M. A., fungi .................... 148, 149

Cuscuta ................................. 52

catalogue .......................... 683

decora..................................... 683

indecora ........................... 130,683

neuropetala ........................ 683

pulcherrima.......................... 683

racemosa chiliand. ............ 684

vulgivaga ........................ 684

Cuscutacere ........................... 6883

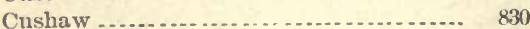

Custard apple family .................. $\quad 507$

Cutgrass .................................. 363

Cutleaf conobea......................... 721

Cyathus, catalogue .................... 233

Cycas revoluta ...................... 137,832

Cyclosporales.......................... 147

Cydonia............................... 255

cydonia ........................... 831

japonica........................ 185, 834

sinensis ............................ 831

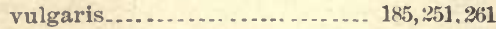

Cylindrosporium, catalogue ............. 251

Cylindrothecium....................... 306

Cymbella, catalogue .................... 146

Cymbidium hyemale ...................... 460 odontorhizon........................ 458

Cynanchum carolinensis................. 678 catalogue .......................... 677

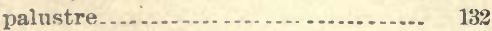

Cynara scolymus ....................... 831

Cynoctonum, catalogue................ 669 petiolatum .......................... 669 sessilifolium ........................ 116

Cynodon ................................ 373 dactylon ............................. 373,826

Cymoglossum amplexicuule .............. 690 catalogue ......................... 690

morrisoni .......................... 690 virginicum........................ 75

Cynoscyadium, catalogue............... 643

Cynosurus aegyptius ..................... $\quad 376$ indicus ............................. 376

Cynthia dandelion.................... 752 virginica .......................... 751

Cyperaceae ........... $73,88,98,114,119,126,390$
Pnge.

50,183

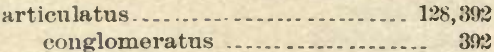

arundinaceus ......................... 396

baldwinii .......................... 395

caespitosus ........................... 390

calcaratus............................. 391

catalogue ......................... 390

compressus ........................... 126

compressus ......................... 390

cylindricus ........................... 394

dentatus ............................. 391

multiradiatus..................... 392

diandrus .......................... 390

dissitiflorus........................ 125, 393

echinatus ......................... 189, 395

engelmanni........................... 393

ery throrhizos ...................... 128, 393

esculentus . . ........................ 392, 827

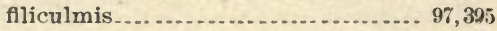

flavamariscus ........................... 394

flavescens ...................... 65,390

flavescens ............................ 390

flavus .............................. 394

gracilis................................. 391

green ............................. 391

haspan .................... 66,126,127,391

Lancaster .............................. 395

lancastriensis ....................... 395

lecontei ............................. 130,392

leptos................................ 391

ligularis............................. 394

low ................................... 390

luzulae vmbellulatus .................. 391

mariscoides .......................... 395

martindalei......................... 114, 395

michauxianus........................ 393

microdontus ........................ 390

multiradiatus ...................... 392

nuttallii............................. 127

ochraceus........................... 391

ovularis ......................... 88,97,394

cylindricus. ....................... 394

parviflorus........................... 391

phymatodes .......................... 394

psendovegetus ................... 75,98,391

refractus ........................... 394

repens ............................. 392

retrofractus................... 114, 189,394

rotundus......................... 5i, 104, 189

spathoceus ............................ 396

speciosus .......................... 128, 393

sphacelatus .......................... 399

stenolepis ...................... $66,128,393$

strigosus ......................... 128, 130, 393

robustior ........................ $39: 3$

tenuiflorus ........................... 393

texensis ............................ 390

torreyanus ....................... 390

vegetus ............................. 391

vegetus ................................ 391

virens............................ 127, 391

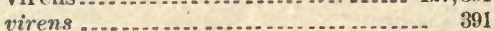

Cyphella, catalogue ................... 20.2

Cypress.......................... 43,46,117,832

bald .................................. 110,325

black............................. 325 
Cypress-Continued.

brakes.

Page.

dwarfed

pond ............................ 117, 125,325

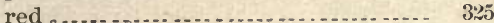

somber............................ 136

Spanish ............................. 686

swamp ............................. 325

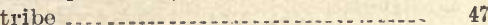

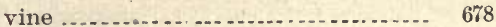

weeping ............................ 136, 832

white ................................ 325

Cypripedium acaulo ................. 79

calceolus ............................. 452,453

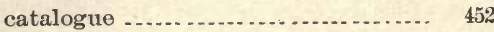

hirsutum.......................... 110

humile................................ 453

parviflorum............................ 75,83

pubescens............................ 452

Cyrilla, catalogue........................ 601

family ............................... 601

racemiflora .................... 118, 122, 162

Cyrillaceae ............................... 601

Cystopleura, catalogue.................. 146

Cystopteris bulbifera .................... 86

catalogue ........................ 318

fragilis . . . . .

Cystopus .............................. 151, 152

bliti ................................... 151

Cytospora, catalogue .................. 256

Dacryomyces, catalogue.................. 195

Dacryomycetaceae ....................... 195, 262

Dacryomycetales ........................ 195, 262

Dactylis, catalogue........................ 384

glomerata............................. 826

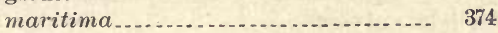

patens......... ....................... 374

Dactyloctenium aegyptiacum .......... 56

aegyptium ......................... 183,245

catalogue ............................. 376

Daedalea, catalogue ...................... $\quad 212$

cinerea .............................. 212

sepium ............................ 170

Daisy

fleabane

$786,795,813$

.

golden

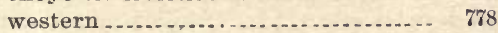

Daldinia, catalogue ..................... 182

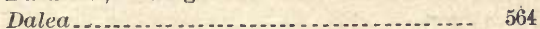

alopecuroides ....................... 564 candida............................. 564

linnaea.............................. 564

purpurea............................ 565

Dandelion, carolina dwarf................ 751

false................................ 754

common ............................. 753

dwarf ................................... 752

Danthonia alleni........................ $\quad 373$

catalogue ............................ 373

compressa ......................... $\quad 79$

glabra................................... $\quad 79$

sericea ............................. 66,113

Darbya................................ 52

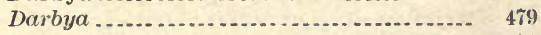

umbellulata ......................... 66,71

umbellulata......................... 479
Page.

Darluca, catalogue ..................... $\quad 256$

Dasyscypha, catalogue................... $\quad 157$

Dasystoma, catalogue .................... $\quad 725$

flava .............................. 63,192

pedicularia ....................... 115, 120

pubescens ............................ 725

quercifolia integrifolia.............. 725

virginica............................. 74

Datura................................ 715

catalogue ........................... 714

stramonium ...............

Daubentonia, catalogue.................. 569

Daucus carota.......................... 827

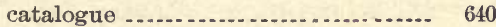

divaricatus........................... 648

Day-flower. ........................... 430

Dead nettle............................. 707

Decodon aquaticus ...................... 632

catalogue ............................ 632

verticillatus glaber .................. 632

Decumaria barbara ...................... 122

catalogué ......................... 536

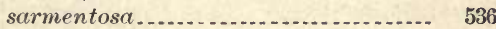

Deergrass.............................. 633

Deerberry ................................. 107,658

Deërtongue, sweet-scented .............. 768

Delesseriaceae............................ 148

Delphinium azureum .................. 509 catalogue ........................... 509

exaltatum ............................ 509

tricorne............................ 83

Dematiaceae ............................. 237,263

Dennstaedtia, catalogue ................. $\quad 319$

Dentaria, catalogue..................... $\quad 525$ concatenata........................ 526

diphylla............................. 75

laciniata .......................... 83, 85

multifida. ........................ 93

multifida............................. 526

Deodar cedar........................... 833

Depazea................................. 182 kalmicola ............................. 174

Deringa canadensis ...................... $\quad 75$ catalogue ............................ 647

Dermatea, catalogue..................... 160

Deschampsia, catalogue .................. $\quad 372$

flexuosa........................... 79

Desmanthus............................. 108,554

brachylobus ........................ 554

luteus ................................. 553

Desmatodon ............................ 291

catalogue

plinthobius .......................... 294

Desmodium ............................. 571

acuminatum ........................ 571

bracteosum........................... 573

canadense longifolium ................ 573

canescens............................. 572

ciliare ............................. 574

cuspidatum ............................ 573

dillenii............................... 573

floridanum ........................ 574

humifusum ............................ 572

laevigatum ......................... 573

lineatum ........................... 571

marylandicum ........................ 574

nudiflorum........................... $5 \tau 1$ 
Desmodium-Continued.

Page.

ochroleucum
paniculatum
pauciflorum
rhombifolium
rigidum
rotundifolium
strictum
tenuifolium
viridiflom

Devil's bit shoestring

Devilwood (1) 1.2) 668

Dewberry

iamouthern

iamorpha, catalogue

Dianthera, catalogue.................. 734 humilis............................... 735

Dianthus, barbatus..................... 258

Diapensia family ....................... 661

Diapensiaceae .............................. 661

Diaporthe, catalogue.................... 177

Diatoma auritum.......................... 144

Diatomaceae ........................... 143

Diatoms................................ 142, 143

Diatrypaceae ............................ 178,262

Diatrype .............................. 179

catalogue

disciformis virescens................... 178

stigma ............................... 169

Diatrypella, catalogue ................. 179 quercina ........................... 179

Dicentra .............................. 520 cucullaria........................... 521

Dicerandra, catalogue ................... 700 linearis............................. 700

Dichaena, catalogue...................... 162

Dichaonaceae......................... 162,267

Dichelyma.............................. 291 catalogue ............................. 304 subulatum........................... 294

Dichondra ..................................... 683 catalogue ............................ 683 carolinensis.......................... 683 repens............................. 683

Dichromena........................... 127 catalogue ......................... 400 colorata............................. 76 leucocephala ......................... 400

Dicksonia .............................. 319

pilosiuscula ....................... 319

punctilobula........................ 73,78

punctilobula .......................... 319

Dicliptera halei........................ $\quad 735$

Diclytra cucullaria...................... 520

Dicotyledones .......................... 48, 461

Dicranaceae ......................... 297,309

Dicranella, catalogue................. 297 debilis................................ 291

Dicranum............................ 291 catalogue ............................ 298

debile ............................... $\quad 289$

sabuletorum ........................ 298

Dictydium, catalogue.................. 140

umbilicatum ........................ 140

Dictyoneis, catalogue .................. 145
Dictyophora, catalogrue Page.

Dictyophora, catalogue ................... $\quad 230$

Didymiaceae............................. 141

Didymium, catalogue ................... 141

Didymosphaeria........................ 174 eumorpha ........................ 175

Diervilla, catalogue..................... $\quad \mathbf{7 4 5}$ rivularis ........................... 78 sessilifolia ........................ 746

Digitaria.............................. 344 filiformis............................ 344

fimbriata........................... 345

marginata ......................... 345

sanguinalis ........................... 345

serotina ............................ 344

setosa ............................... 345

villosa............................... 344

Dilepyrum minutiflorum .................. 366

Dimerosporium, catalogue............... 167 orbiculare.......................... 168

Dioclea................................ 102

boykinii........................... 580

catalogue ............................ $\quad 580$

multiflora.......................... 102

Diodia, catalogue ........................ 740 teres .......................... 65, 187,241

tetragona ........................... $\quad 740$

virginiana ........................ 65,241

Diodonta leptophylla.......... . ....... 808

Dioscorea, catalogue .................... 449

Dioscoreaceae ........................... $\quad 449$

Diospyros, catalogue ................... 664 virginiana ................... 32,46,241, 255

Diphyscium foliosum ..................... 304

Diplachne................................. $\quad 376$ catalogue ........................... $\quad 376$

Diplodia, catalogue..................... $\quad 256$

Diplopappus amygdalinus............... 788 cornifolius .......................... 788

linariifolius......................... $\quad 788$ umbellatus................................ 788

Diplophyllum, catalogue ................. $\quad 288$

Diplotaxis, catalogue.................... 523

Dipsaceas................................ 746

Dipsacus, catalogue ................... 746

Dipteracanthus ciliosus parviflorus ....... 734 noctiflorus ............................ $\quad 733$ strepens ............................ 734

Dirca, catalogue........................ 631 palustris............................ 108, 193

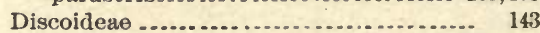

Discopleura ............................ 648 capillacea ........................... 648

nuttallii....................... 648

nuttallii ........................... 648

Discosia, catalogue ..................... 260

Disporum, catalogue .................... 441

lanuginosum ..................... 85

Distichlis, catalogue .................... 383 maritima ........................... 383 spicata ........................ 50,132,133

Distribution of plants, geological influences.............................. 34 principles...................... 27

Ditch grass............................. 328

Ditrichum, catalogue ................... 299

Dittany ................................ 698 
Page.

Dock

bitter

curled.

great water

pale

prairie

slender.

spatter

swamp.

wedge-leaf

yellow.

Dodder

Dodecatheon, catalogue.................. 663

Doellingeria amygdalina................ 788

catalogue .......................... 788

cornifolia ........................... 788

infirma.......................... 75

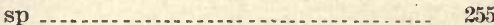

Dog fennel........................ 760$), 761,812$

Dogbane ................................... 674

family .................................... 673

Dog's parsley ............................ 643

Dogwood .......... 14, 46, 61, 70,88, 89, 107, 112, 650 family .............................. 650

flowering ........................... 651

rough-leaf ......................... 82

silky-leaved swamp ................... 650

swamp _....................... 61, 122,125

Dolichos ................................... 176

catjang............................. 830

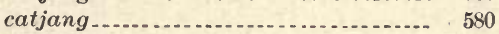

luteolus . .

minimus ............................ 583

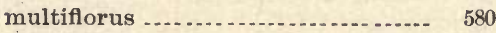

polystachyus ........................ 581

regularis............................. 580

sinensis ............................ 580

Dondia, catalogue .................... 489 linearis............................. 129

Door weed, erect ......................... 483

Doronicum ramosum ................... 786

Dothichiza, catalogue. ................. 261

Dothichloe aristidae ...................... 171

hypoxylon ......................... 171

Dothideaceae ............................... 170, 262

Dothideales.............................. 170,262

Dothidella catalogue .................. 170

Dothidia .................................. 161

Dothiora, catalogue.................... 160

Dothiorella, catalogue ...... . . . . . . . . $\quad 256$

Draba brachycarpa ....................... 82

caroliniana......................... 82

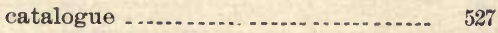

Dracocephalum virginianum ............. 705

Dracopis amplexicaulis ................. 798

Dragon-root ........................... 426

Dragon's-head, false ..................... 705

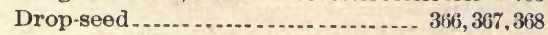

Dropwort, false ......................... 641

Drosera ................................... 52

americana ........................ 531

brevifolia .......................... 120

brevifolia major ...................... 531

capillaris.............................. 120

catalogue .......................... 531

fliformis............................ 11\%, 120

foliosa ............................. 5331
Drosera-Continued.

Page.

intermedia........................ 49,117

longifolia ........................... 531

americana ..................... 531

tenuifolia ............................ 531

Droseraceae ............................. 531

Drummondia .............................. 291

catalogue ......................... 300

Dryopteris acrostichoides . .......... 74,123,317

catalogue .......................... 316

dilatata ........................... 317

floridana ........................... 65,66

marginalis .................... $63,74,78,94$

noveboracensis ....................... 74

patens................................. 123

Duchesnea, catalogue ................... 541

indica ............................. 191

Duckweed ............................. 48,426

family .............. 426

Duggar, B. M., fungi ......

Dulichium arundinaceum ............... $\quad 126$

catalogue ....................... 396

spathaceum .......................... 396

Dumortiera. .............................. . . 76,285

catalogue .......................... 286

hirsuta............................. 285

Dupatia, catalogne.................... 429

Durrha ......... .................... 95, 135, 339

Earle, Prof. F. S., botanical collection .... 18

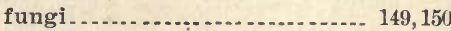

lichens ............................ 264

Eatonia ........................... 378,379

catalogue ............................ 378

dudleyi .............................. 379

filiformis........................ 66

pennsylvanica ........................ 78

pennsylvanica filiformis.............. 379

Ebenaceae .............................. 664

Ebony family .......................... 664

Ecbalium, catalogue.................... 747

Echinacea.............................. $\quad 799$

angustifolia........................ 799

purpurea........................... 799

Echinodorus, catalogue ................. $\quad 330$

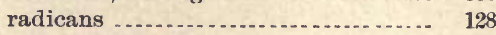

Echinodothis, catalogue............... $\quad 170$

Echinospermum........................ 690 virginicum ........................... 690

Echites difformis........................ 674

Eclipta, catalogue ...................... 796

erecta ............................. 796

procumbens .......................... 796

white-flowered ........................ 796

Eelgrass . . . . . . . . 334

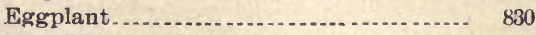

Egyptian grass ......................... 376

Elatinoides, catalogue.................. $\quad 716$

Elder.................................. 742

annual marsh ..................... 756

box..................................... 89

marsh . . . . . . . . .

seaside marsh ...................... 756

shrubby marsh ....................... 757

Eleocharis acicularis.............. $76,116,126$ arenicola .......................... 398

camptotricha $\ldots . . . . . . . . . . . . . . . .126,399$ 
Elencharis-Continued.

capitata............................... 133

catalogue ........................... 396

cellulosa ............................ 126

dombeyana............................. 298

engelmanni ........................... 398

equisetoides ............................. 396

interstincta........................ 126

mutata........................... 126

obtusa ............................... 397

ovata............................... 76,98

palustris ............................ 128

prolifera ............................ 399

pygmaea

quadrangulata..................... 396

simplex ............................ 398

tenuis................................ 76,88

tuberculosa.................... 98, 116, 126

vivipara ........................... 126

Eleogenus ochreatus..................... 397

Elephantopus carolinianus................. 184

catalogue .......................... 759

nudatus............................. 184

scaber ............................... 759

tomentosus ......................... 184, 241

violaceus............................. 846

Elephant's foot ......................... 759

Eleusine aegyptiaca ...................... $\quad 376$

catalogue

indica ............................ 65, 104, 135

mucronata

Eleutheromyces catalogue ............ $\quad 170$

Elkwood .............................. 506

Ellisia microcalyx ..................... 687

Elm ............. 14,41,46,60, 72, 100, 125, 474,824 family ............................. 474 red ..................................... 474

slippery ............................. 474

Southern rock .................... 47

white ........................... 102, 474

winged ................................. 89,474

Elodea ................................ 333

campanulata ....................... 623

cunadensis ............................ 333

Elodes ..................................... 333

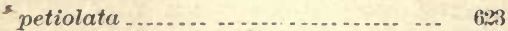

Elymus ...................... 174, 175, 239, 249,257

crerolinianus ....................... 388

catalogue ......................... 388

glabriflorus............................ 845

villosus............................ 388

virginicus........................... 104

Empetraceae ......................... 112,599

Empusa, catalogue.................... 153

Endemic plants......................... $\quad 38$

Endive ................................. 898

Endocarpeae......................... 269, 284

Endocarpon ............................. 265

catalogue ............................ 269

fluviatile ............................. 265

fluviatile .............................. 269

muhlenbergii ......................... 265

tuckermanii........................ 269

Endothya, catalogue ................... 179

Enemion biternatum .................... 508

English ray grass ........................ $82 \tau$
Page.

Enslenia .............................. 67

albida .............................. 677

Enteridion, catalogue.................... 140

Entodon ............................... 291

catalogue .......................... 306

drummondii ...................... 294

Entoloma, catalogue .................... $\quad 224$

Entomophthoraceae................... 153, 26\%

Entomophthorales ..................... 153, 260\%

Entomosporium, catalogue ............... 261

Entosthodon, catalogue ................. 301 drummondii .......................... 294

Entyloma, catalogue ...................... 184

Ephebe, catalogue...................... $2 \%$ lesquereuxii............................ 279

pubescens ............................ 20.5

Epicoccum, catalogue ................... 249

Epidendron .............................. 41,51

Epidendrum, catalogue ................. $460(0)$ conopseum ....................... 123, 460

Epifugnis ................................ 731 americana ......................... 731

Epigaea, catalogue ..................... (itst repens............................... 114

Epilobium, catalogue tetragonum ....................... 636

Epiphegus virginiana .................. 52, 73:2

Epiphytes.............................. 4:29

Epiphytic plant associations............. 50

Epithemia zebra ......................... 146

Equisetaceae.......................... 43,32)

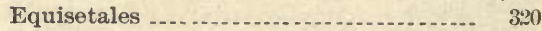

Equisetum, catalogue ................... $3: 20$

Eragrostis ...................... 379, 380, 381, 382 campestris.......................... $1 \% 1$

campestris........................... 381

capillaris.............................. 104, 105

caroliniana ......................... $\quad 380$

catalogue .......................... $\quad 3 \pi 9$

conferta ............................ 381

glomerata......................... 123

hirsuta ........................... $9 \%$

minor ................................ 379

oxylepis ............................... 358

pectinacea .......................... $7 \%$

refracta ........................ 381

pilosa .............................. $\quad 380$

pocteoides.............................. 379

megastacliya

purshii ............................... 104,380

refracta........................... 104, 105

reptans.............................. 379

tenuis ............................. 171, 186

Erechtites, catalogue..................... 814 hieracifolia .................... 165, 241, 258

Erect grass .............................. $38 \tilde{7}$

Erianthus ................. 163, 164, 170, 171, 175, 257 alopecuroides......................... 61, 73 brevibarbis ...................... 3335

hrevibarbis ......................... 123

catalogue ............................ 3334

contortus .......................... 250 (1),335

saccharoides ........................ 123

brevibarbis . 335

strictus .......................... 123, 125

Erica .................................. 112 
Page.

Ericaceae

653

Erigeron $48,152,787$ annuus bellidifolius ............................ 786 camphoratum ..................... 789 canadensis ......................... 787 carolinianum ....................... $\quad 777$ carolinianus ........................ $\quad 776$ catalogue ................ 786

divaricatus........................... 787

heterophyllus ........................ $780^{\circ}$

linifolius............................ 788

nudicaule ............................ 787

philadelphicus ....................... 787

pilosum ............................. $\quad 770$

strigosus $\ldots 86$

beyrichii......................... 786

ramosus........ 787

Erinella, catalogue..................... 158

Eriobocrya japonica ..................... 135, 831

Eriocaulaceae ......................... 428

Eriocaulon anceps ....................... 429

catalogue ......................... 428

decangulare ....................... 117

flavidulum .......................... 429

gnaphalodes.......................... $4: 29$

villosum

Eriogonum, catalogue .................... 481

downy ......................... 481

tomentosum .......................... 109

Eriophorum cyperinum laxum ............ 404

lineatum ........................... 404

Erodium, catalogue ................... 583

Ervum erectum .......................... 581

hirsutum ........................... 577

tetraspermum ........................ 577

Eryngium anericanum.................... 614

aquaticum ......................... 120

aquaticum ............................ 643

baldwinii............................. 644

catalogue ............................ 643

ovalifolium .................... 120,126,644

prostratum ......................... 126

synchaetum ....................... 120

virgatum ............................ 644

yuccaefolium synchaetum ............ 644

Eryngo ................................. 643

blue-flowered ........................ 644

creeping ............................. 644

Erysibaceae ......................... 165, 262

Erysibe, catalogue ...................... 165

Erysimum officinale ...................... $\quad 523$

Erysiphe ............................... 167

Erythrina, catalogue .................... $\quad 5 \% 9$ herbacea ............................. 114

Erythronium, catalogue ................. 440 dens-canis.......................... 440

Ethulia uniflora ......................... $\quad 760$

Euchlaena luxurians...................... 183 mexicana ........................ 135, 825

Eumycetes. .............................. 150

Eunotia, catalogue ...................... 144

Euonymus, catalogue .................. 604 japonicus ............................. 835

Eupatorium ........................... 1 1 $4,8: 21$ ageratoides ....................... 65,765 angustatum
Eupatorium-Continued.
album .......................... (i) 62,762

Page.

alternifolium ..................... 766

altissimum ............................ 104

amoenum ......................... 761

angustissimum ...................... 762

aromaticum ................. 60,62, 115, 765

capillifolium .................... 121, 76$), 761$

catalogue ........................ 760

ceanothifolium ......................... 765

coelestinum ........................... 765

compositifolium ................... 760,761

coronopifolium ....................... 109,115

coronopifolium ................. 169,115, 761

cuneifolium ............................ 763

diffuse ................................ 764

foeniculaceum ...................... 760

foeniculoides........................ 760

frasieri................................. 765

glandulosum ....................... 762

glaucescens.......................... 763

hyssopifolium ....................... 762

hyssopifolium ....................... 763

angustissimum ................... 762

laciniatum ........................ 762

tortifolium _....................... 763

incarnatum ........................ 93, 764

lecheaefolium ....................... 109, 662

leptophyllum . ........... 1(99, 115, 1:1, $\% 60,761$

linearifolium ..................... 121, 763

maculatum ....................... 76,761 amoenum ...................... 65, 761

mohrii ......................... 121, 762

parviflorum ......................... 763

lancifolium ....................... 763

perfoliatum ........................ $\% 64$

pinnatifidum ..................... $66, ; 61$

pubescens .......................... 121, 764

purpureum ......................... 192, 61

amoenum ...................... $\% 61$

maculatum................... 761

rotundifolium ................... 239,764

ovatum ............................ 764

pubescens ....................... 764

scandens ............................ 765

semiser ratum ..................... 121, 663

lancifolium ... ................ 763

serotinum ...................... 104, 762

sessilifolium ....................... 74,764

smithii ................................. $r 61$

ternifolium ........................ $\% 61$

teucrifolium ........................ 763

torreyanum .......................... 762

tortifolium ........................ 109, 763

trifoliatum .........................

truncatum .......................... $\quad 764$

verbenaefolium _................ 121, 192, 7633

Euphorbiaceae ........................... 591

Euphorbia ............................. 242

arkansana .......................... 597

arkansana ...................... 597

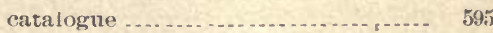

corollata angustifolia ................ 114

dictyosperma........................ 104

floridana ........................... 114,115

helioscopia ......................... 597

humistrata ......................... 115 
Euphorbia-Continued.

hypericifolia

$$
\text { communis }
$$

inundata.

nutans.

obtusata

pilulifera

polygonifolia

preslii

sphaerosperma

thymifolia

Eupodiscus argus. catalogue

Euphyceae.

Eurhynchium catalogue

hians.

Eustachys

Euthallophyta

Euthamia caroliniana

catalogue

graminifolia

tenuifolia

Eutypa spinosa

Eutypella

cerviculata

glandulosa

heteracantha

sp.

Euvalsa

Euxolus deflexus

Evening primrose. family

Evernia flavicans.

Evolvulus alsinoides catalogue

Excipulaceae

Exidia, catalogue glandulosa

Exoascaceae

Exoascales

Exoascus, catalogue

Exobasidiaceae.

Exobasidiales

Exobasidium, catalogue

Exotic subtropical trees.

Fabronia catalogue spp........

Fabroniaceae

Fagaceae.

Fagopyrum fagopylum.

Fagus. americana. catalogue ferruginea. castanea dentata. latifolia. pumila sylvatica atropunicea

Falcata, catalogue. comosa.

False boneset, southern foxglove garlic jalap
Page.

596

596

119,120 $66,186,192,238$

83

Furkleberry -

Page.

4.5, 89, 122, 657

Fascicularis polystachya................ 3 3ri

Favolus, catalogue.................... 213

Feather grass ........................ 376

Featherfoil ........................... 661

Fedia .............................. 746

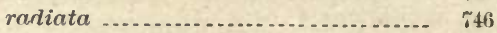

Fegatella conica ........................ 286

Fern .............. 43, 74, $76,121,123,261,310,311$

Alabama bristle ................... 319

lip ............................. 312

beech ............................. 316

bladder ............................ 318

brake ........................... 312

bristle.............................. 319

brittle.............................. 318

chain ............................ 313

christmas ......................... 31 \%

cinnamon .......................... 319

coarse............................. 1:5

eagle .............................. 312

ebony ............................. 314

evergreen wood ..................... $31 \%$

family ............................. 311

Florida wood ...................... $31 \%$

flowering .......................... $\quad 319$

grape ............................... $\quad 310$

lady ... .................. 315

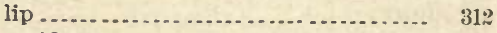

maidenhair ....................... 108,311

marsh shield ........................ 316

New York shield .................... 316

Peter's bristle. ...................... 319

royal ............................. 123,3:20

sensitive .......................... 318

spreading wood. ................... 317

Virginia grape...................... 311

webby lip......................... 313

woolly lip ........................... 312

Ferula canadensis ..................... 643

villosa ............................... 641

Fescue grass........................... 386

Festuca bromoides....................... 386

catalogue ......................... $\quad 386$

fascicularis ........................ 376

nutans ............................ 74

pratensis.......................... 887

rigida ........................... 385

shortii ............................. 74

tenella ........................... 386

aristulata........................ 386

unioloides........................... 387

Fetter-bush .......................... 122

downy ........................... 654

racemose.......................... 654

shining ........................... 655

Fever root............................ $\quad \boldsymbol{7 4 4}$

Feverbush ........................... 519

Feverfew .......................... 56,813

Ficus carica.............. 191, 235, 238, 240, 247, 831

Fig . ................... 96, 106, 110,136, 822, 831

Figs in the Coast plain................ 822

Figwort.............................. 717

family ........................ 494, 716

Filicales.............................. 310

Fimbristylis autumnalis................ 183

capillaris........................... 401

castanea .......................... 132 
Fimbristylis-Continued.

catalogue.

puberula

spadicea puberula

Finger grass

Fiorin

Firmiana platanifolia

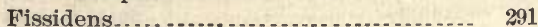

adiantoides ......................... 292

catalogue .......................... 298

donnellii . . . .......................... 293, 294

minutulus .......................... 293

polypodioides........................ 291,292

ravenelii ............................ 293

subbasilaris........................... 293

taxifolius . ......... 293

Fissidentaceae.......................... 298,309

Fistulina, catalogue .................... 214

Fistulineae ............................... 213

Flag, blue ................................ 449

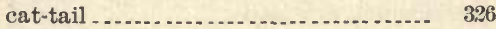

sweet ................................ 424

Flammula, catalogue.................... 223

Flatwoods ................................. 21

Flaveria, catalogue ...................... 810 repanda .............................. 810

Flax family .............................. 585 yellow ............................. 585, 586

Fleabane.............................. 48

Canada................................. 787

daisy ............................. 786, 787

lilac-flowered daisy .................... $\quad 786$

Philadelphia daisy .................... $\quad 787$

southern daisy ....................... 787

Floating heart............................. 49 pitted

Flora of Alabama, general character.... $\quad 37$ relation to southern neighbors.... 41

Floral regions of Alabama................ $\quad 57$

Fly poison .............................. 437

Foeniculum foeniculum ............... $\quad 829$

Fog-fruit............................... 695

Fomes, catalogue ...................... 207

Fontinalaceae .......................... 304, 309

Fontinalis .............................. 77,291

catalogue ............................ 304 disticha ......................... 127, 289, 294 lescurii............................... 77,293

Forage crops, list....................... 828, 829 grasses, list ...................... 825-827

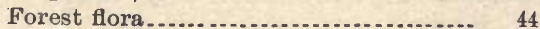

Forestiera............................. 667 acuminata .......................... 667

ligustrina ........................... 668

Forests, deciduous ...................... 46 evergreen............................. 47

Forget-me-not .......................... 691

Forsteronia difformis..................... 674

Forty knot.............................. 492

Fossombronia angulosa.................. 285 catalogue ........................... 287 foveolata.

Fothergilla catalogue gardeni major
Four o'clock family.

Page.

Foxglove, false ......................... 725, 726

Foxtail, green $\ldots \ldots \ldots \ldots$

meadow .............................. 367

water .............................. 367

Fracchiaea, eatalogue................... 173

Fragaria, catalogue ...................... 541

illinoensis ............................ 541

indica ............................. 541

vesca $\ldots . \ldots \ldots \ldots \ldots \ldots \ldots . . .174,829$

virginiana.......................... 889

illinoensis_....................... 541

Fragilarioidea

Frangula caroliniana ................. 609

Frankia, catalogue ....................... 139

Frasera carolinensis................... 75,110

catalogue ............................ 672

Fraxinus......................... 192, $221,255,260$

acuminata .......................... 666

alba $\ldots . . \ldots \ldots$

albicans.................................... 666

americana . . .................... 46, $86,102,667$ curtissii ............................ 81

microcarpa..................... 666

caroliniana....................... 46,251,258

catalogue ............................. 666

curtissii ............................. 666

lanceolata.............................. 46

platycarpa ............................ 67

platycarpa .................... 251, 258,667

quadrangulata........................ 81

viridis................................. 667

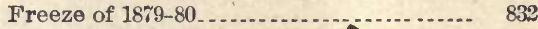
$1899 \ldots \ldots . . . . . .26,833$

Fresh-water plants.................... $\quad 49$

Fringe tree ........................ 71,109,668 northern .......................... 122

Froelichia, catalogue .................... 493

floridana ....................... 130

Frogsbit family ........................... 333

Frogweed ............................ 515

Frullania ................................ 285

caroliniana............................ 285

catalogue ......................... 289

donnellii ............................... 285

kunzei ................................ 285

squarrosa ............................. 285

Frustulia, catalogue.................. 145

Fucaceae................................. 147

Fugitive plants.......................... 55

Fuirena, catalogue .................... 404

hispida ............................. 405

scirpoidea............................ 131

sp................................... 188

squarrosa $\ldots . \ldots \ldots \ldots \ldots \ldots \ldots . . \ldots \ldots$

squarrosa .......................... 404

squarrosa $\alpha \ldots \ldots . . . . . . . . . . . . . . . . \quad 405$

breviseta........................ 127

hispida......................... 97, 127

Fuligo, catalogue ....................... 141

Fumaria, catalogue ...................... 521

cucullaria ... 520

Fumitory, common..................... 521

Funaria calvescens ........................ 291

catalogue ............................ 301

flavicans ............................. 293, 294

hygrometrica........................ 291

calvescens .......................... 301

serrata ............................ 294 
Page.

Funariaceae

301,309

Fungi

caroliniani exsiccati.

history of collections

imperfecti

Fusarium

catalogue

erubescens

Fusicladum, catalogue

Fusisporium

Gaillardia bicolor

catalogue

lanceolata

pulchella.

149

148

235-263

169

248

248

237

248

812

812

66

Galactia, catalogue ..................... 580

eructa ............................... 115

floridana ............................. 115

glabella ............................. $\quad 580$

macrei................................ 580

mollis ................................ 580

pilosa ............................. 580

angustifolia....................... 581

sessiliflora........................... 581

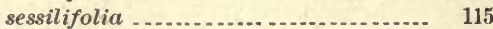

volubilis............................. 115, 242

mississipiensis .................. 115

Galax ........................ 661

aphylla.............................. 78

catalogue ........................... 661

Galega cinerea......................... 567

hispidula............................ 566

spicata ............................. 566

villosa ............................ 566

virginiana .......................... 566

Galera, catalogue........................ 223

Galingales ............................. 50

Galinsoga, catalogue .................. 808

Galium ................................ 161,242

catalogue ......................... 741

circaezans............................... 75,87

pilosum puncticulosum ............. 242

puncticulosum ........................ 741

trifolium latifolium.................. $\quad 742$

Gall of the earth......................... 755

Gallberry ............................... 821

Gama grass, spiked ...................... 334

Garden cress_............................ 828

vegetables, list..................... 828, 899

Gardenia............................... 137 florida............................ 835

Garlic .................................. 827

wild ............................... 439

yellow false......................... 439

Gates, Hezekiah, botanical explora-

tion ................................... 16

Gatesia............................... 16, 735

laetevirens ........................... 735

Gaultheria, catalogue ................... 656

Gaura.... ............................. 638

biennis pitcheri ..................... 638

catalogue ........................... 638

filipes .............................. 638

michauxii............................ 104

Gaylussacia, catalogue .................

dumosa .......................60, $607,112,657$

hirtella

657

frondosa.
Gaylussacia-Continued.

Page.

spp ............................... 45

tomentosa........................

Geaster, catalogue ....................... 233

Gelsemium .............................. 109

catalogue .......................... 668

nitidum ............................. 668

sempervirens....................... 123, 169

Gemmingia, catalogue ................ 450

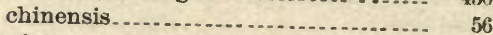

Gentian ........................... 120,6 61.672

family.............................. $6 \sigma_{0}$

Gentiana calycina ....................... 670

catalogue ............................ 671

catesbaei .......................... 671,672

elliottii ...............................

ochroleuca......................... 672

saponaria.......................... 65

saponaria ........................... $6 \boldsymbol{6}_{2}$

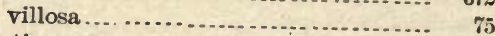

Gentianaceae ........................... $6 \boldsymbol{6}_{0}$

Geoglossaceae ......................... 155, 262

Geoglossum, catalogue................... 155

glutinosum ............................ 155

Geraniaceae .......................... 583

Geranium carolinianum ................. 153

catalogue ........................... 583

cicutarium ......................... 583

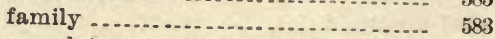

maculatum .......................... 83

spotted................................. 583

strawberry ......................... 541

Gerardia........................... 5:, 726,727

afzelia ............................ 724

aphylla........................... 121

catalogue ............................. 726

flammeae .......................... 15

flava ................................ $\quad$ 25

laevigata............................

maritima .......................... 132

parvifolia ......................... 727

paupercula .................... 120,121,726

pedicularia pectinata................ 725

purpurea crassifolia................. 726

fasciculata...................... 726

paupercula....................... $\quad 726$

quercifolia ... .................... 725

setaced .......................... 727

skinneriana.......................... 121

tenuifolia ...................... $65,74,190$

asperula .......................

Germander ........................... 707

Nash's ........................... 708

Geum album .......................... 542

carolinianum ........................ 54:

catalogue ........................... 54:

Gherkin ................................. 831

Gibberella, catalogue ................. 169

Gilia, catalogue .......................... 686

coronopifolia ...................... 94

Gillena............................... 539

Gillenia ............................. 75, 539

stipulacea ........................... 539

trifoliata .......................... 539

Ginger, wild ............................ 481

Ginseng ................................... 640

family ............................ 640 
Page.

Gladiolus

Glasswort, Bigelow's ...................... 490

Glaucidium .............................. 40

Glechoma hederacea ................... 257

Gleditsia.................................. 163 catalogue .......................... 557 triacanthos ................... 46,83, 207, 260

Glenospora, catalogue.................. 237

Gloeoporus, eatalogue ................... 213

Gloeosporium ampelophagum ............. $\quad 250$ catalogue .......................... 250

Gloniella ................................. 163

Gloniopsis praelongum .................. 163 smilacis ........................... 163

Glonium, catalogue .................... 162

Glottidium, catalogne .................. 568 floridanum........................ 128 floridanum........................... 568

Glyceria................................. 386 nervata ............................ 386

Glycine, American ...................... 15 apios ................................... 579 comosa ............................. $5 \% 8$ frutescens ........................... 567 hispida............................. 830 monoica .............................. 578

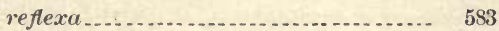
tomentosa............................. 582 erecta ................ 582 monophylla ..................... 582 volubilis ............................ 582 umbellata .......................... 582

Glycosma

Glyphidea ......................... 270,284

Glyphis .................................... 264

achariana

catalogue ............................ 270

Gnaphalium, catalogue ............... 791 obtusifolium ....................... 791 plantaginifolium ..................... 790 polycephalum ......................... $\quad 791$ purpurenm ................... 153, 189, 192,242 sp ................................. 184, 251 undulatum ............................ 790

Gnomonia, catalogue.................. 177 Gnomoniaceae....................... 177,262 Goat's rue .......................... 565-567,822

Golden aster......................... $769,770,771$ club .............................. 127,424

drop .................................... 831 eyed grass . ........................... 119 rod ............. 64,67,83,130,772- $778,821,822$

Gomphidius, catalogue................. 217

Gomphrena polygonoides .................. 491

Gonolobus ............................... 102,677 baldwinianus .......................... 678 carolinensis......................... 678 hirsutus ............................. 678

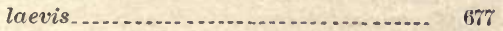
macrophyllus ...................... 678

Gonopyrum americanum ................. 48 \%

Goodyera................................ 73,457 pubescens............................ 457

Goose grass .............................. 741

Gooseberry, garden .................... 6 6 southern ........................... 658 wild
Goosefont, Berlandier's ................. 488

cutleaf ........................... 489

family ............................... 487

ill-scented ......................... 488

nettle-leaved.......................... 488

oak-leaved .......................... 487

(*ordonia, catalogue.................... 618

Gossy pium barbadense ................... 830

herbaceum ...................... 9.j, 169

$172,174,175,235,236,242,246,248$,

$249,250,252,253,255,256,259,830$

Gourd . ................................ 54,831

bottle ............................. 831

trumpet........................... 831

Gracilaria, catalogue.................... 148

Grama grass ............................... 375

Gramineae.............................. 334

Grammatophora, catalogue ............ 145

Grape .................................. 15,32,

$69,80,89,96,110,167,250,612,613,832$

blue (112

bullace .................... 15, 101, 123,613, 83\%

Concord .............................. 893

downy .............................. 612

family............................... 611

fox ............ $83: 2$

frost ................... 61,612

Le Conte's ............................... 62

muscadine ............................. 832

river .................................. 108

riverside .......................

scuppernong ....................... 136, 82 ;

summer..................... $71,101,122,612$

winter ............................. 612

Grapes ........................ 106, 134, 136,824

in Tennessee Valley ................... 824

in Upper Coast Pine belt............... $\quad 823$

Grapevine ............................ 612

Graphidaceae .......................... 269, 284

Graphiola, catalogue ................... 184

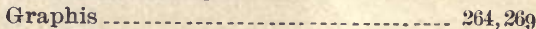

babingtonii ......................... 270

catalogue .............................. 270

solecites............................... 267

Grass family ................................. 334 pink ................................. 459

Grasses for forage or grain, list ..... ... 825-827

Gratiola acuminata .................. 720, 721

anagallidea .......................... 7\%2

cttenuata....................... 722

catalogue .......................... 719

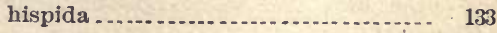

monniera ........................... 721

peruviana.......................... 720

subulata........................... 720

Gravelly hills of short-leaf pine, etc...... 90

Greek valerian ................... 686

Green algae................................ 146

arum ................................. 425

foxtail .............................. 360

Greenbrier ............................. 101,444 glaucous ............................. 444

Greenia arkansana .................... 369

Grevillea, descriptions of fungi ......... 149

Grimmia ............................... 79

catalogue ........................... 299

leucophrea .......................... $\quad 299$

pennsylvanica ..................... $\quad 299$ 
Grimmlaceae .......................... 299, 309

Grindelia, catalogue..................... $\quad 769$

lanceolata........................... 83

Gromwell. ............................... 691-692

Carolina false ......................... 392

tuberous-rooted ...................... 691

Virginia false......................... $\quad 392$

Grossulariaceae ........................ $53 \pi$

Ground cherry ................ $709,710,711,712$

Groundnut ............................ 69,579

Groundsel ....................... 45, $789,814,815$

Guadinia, catalogue ..................... 373

Guatemala grass ..................... 135, 895

Guepinia, catalogue.................... 196

Guignardia, catalogue .................. 174

Guinea grass . ............................. 135, 826

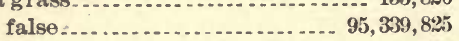

Gum .................................... 651

black......................... 3*, 68,117, 125

Carolina black ....................... 46

highland .............................. $\tau_{0}$

large sweet .......................... 92

plant ............................... 769

red .......................... 92,100,117,538

southern black ........................ 651

sweet. ................... 32, 41, 46,92,100,538

tupelo............................. 110,124

Gumbo................................ 830

Gyalecta ................................. 264

catalogne ............................ 2i5

Gymnadenia flava ...................... 454

Gymuoconia, catalogue ................... 191

Gymnopogon ............................. $\quad 375$

ambiguus .......................... 97,113

brevifolius.......................... 113

catalogue ........................... 375

racemosus .............................. 375

filiformis ....................... $\quad 375$

Gymnospermae........................... 323

Gymnosporangium ....................... 186

catalogue ........................... 185

Gymnosporium........................... 237

Gymnostichum.......................... 389

Gynandropsis, five-leaved ............... 529

pentaphylla......................... 56

pentaphylla ........................ 529

Gyrostachys brevifolia ................ 124

catalogue .......................... 456

gracilis.............................. 114

odorata ............................ 125

praecox ........................... 97, 114

Gyrostomum ........................... 264

catalogue .......................... 274

scyphuliferum........................ 266

Gyrotheca, catalogue ................. 446

tinctoria ........................... 117

tinctoria ........................... 446

Habenaria blepháriglottis .............. $\quad 126$

catalogue .......................... 453

clavellata ........................... 128

ciliarls ............................... 64,75

blephariglottis .................. 454

cristata ........................... 116, 126

flava .............................. 66
Habenaria-Continued.

Page.

lacera ................................ 60

michauxii ......................... 455

nivea .............................. 120

repens ............................. 120

spp .................................. 51

tridentata........................... 453

virescens .......................... 454

Habitat, definition ...................... 34

Hackberry ........................... 43, 100, 102

southern . ....................... 46,92,475

Hackelochloa, catalogue .................. 336 granularis . ...................... 55

Haemodoraceae ...................... 446

Hair grass. ..................... 366, 370,371,372

Halesia .......................... 89,118, 122, 664

carolina........................... 664

diptera ........................... 14, 15, 665

tetraptera ........................... 6605

tetraptera............................ 664

Halophytes ................... 49,50,127, 129, $13 \%$

Halophytic plant associatious .... ........ 37 plants of salt marshes................. 132 of strand ........................ 129

Haloragidaceae.......................... 639

Hamamelidaceae ............ . . . . . ....... $53 \pi$

Hamamelis, catalogue.................... $\quad 537$

virginiana ......................... 16j

virginiana carolina ................... 537

Hammock lands ......................... 121,294

Hammocks, cedar ........................ 99

Hard-wood timber ....................... 84, 87

Harpocephalum, catalogue .............. 237

Haw ............................... 41,46, 122, 822

apple ............................. 46,125, 550

black ............................... 82,88

dotted............................. 550

downy ............................. 71,547

glandular .......................... 546

May ............................... 550

opossum ......................... 118, 744

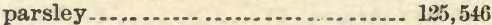

red .................................. 82,99

scarlet . ............................ 71,99

southern black ...................... 743

sugar............................... 546

summer....................... 99,112,550

winter ........................... 71

Hawkweed ........................... 753

Hawthorns . . . ....................... $61,86,91,99$

shrubby........................... 68

Hay .................................. 135

Hazelnut............................... 43,89

American .......................... 61

beaked .............................. 466

Heath ............................... 118

family $\ldots . . . \ldots \ldots \ldots \ldots$

Heather.............................. 112

family.............................. 47

Hedeoma, catalogue.................... 699

Hedera quinquefolia .................... 611

Hedge hyssop ....................... $719,720,721$

Hedgehog grass ....................... 361,362

Hedwigia . . . . . . . ......................... 79,291

catalogue .......................... 305

ciliata subnuda ....................... 305 
Hedyotis boscii........................... 737

caerulea........................... $73_{i}$

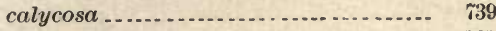

glomerata ........................... 737

longifolia tenuifolia .................. 738

minima ........................... 738

purpurea ............................ 738

stenophylla......................... 739

Hedysarum ........................... 571

acuminatum ........................ 571

bracteosum........................... 573

canescens............................ 572

ciliare .................................. 574

cuspidatum .......................... $\quad 573$

frutescens ......................... 575,576

glabellum ............................ 572

grandiflorum ........................ 571

hirtum ........................... 576

laevigatum ......................... 573

lineatum............................ 571

lineatum ............................ 571

marylandicum ....................... 574

nudiflorum............................. 571

obtusum............................... 574

paniculatum ...................... 573

pauciflorum .......................... 571

pedunculatum ..................... 562

repens ............................. 574

reticulatum .......................... 575

vhombifolium ...................... 574

rigidum _............................ 574

rotundifolium ...................... 571

scaberrimum ........................ 572

strictum ............................ 572,576

violaceum .......................... 575

viridiflorum ..................... 572,573

virginicum ......................... 569

volubile ............................. 580

Helenium .............................. 811

brevifolium ......................... 116,811

catalogue ........................... 810

curtisii ............................... 811

helenium ............................ 119

integrifolium...................... 120

puberulum ......................... 811

pubescens ............................ 811

tenuifolium ........................ 54

vernum ............................. 120

Heleocharis triflora...................... 398

Helianthemum arenicola ............... 130

carolinianum ...................... 114, 120

catalogue .......................... 624

georgianum ....................... 845

ramuniflorum ..................... 114

correction of error ............... 845

Helianthus ....................... 48, 184, 188, 192 angustifolius ........................ 188

annuus............................. 165, 188

aristatus ............................ 804

atropurpureus............................. 64

atrorubens........................... 74

canescens........................... 801

catalogue ............................ 800

divaricatus ....................... $64,74,104$

divaricatus......................... 801

diversifolius......................... 802

floridanus............................ 800
Helianthus-Continued.

Page.

glaucus............................. 74

heterophyllus ...................... 121

hirsutus..................... 64,74, 104, 108 trachyphyllus ................... 64

laevis.................................. 807

microcephalus..................... 64,74

mollis............................... 91

parviflorus ............................. 801

pubescens........................... 801

radula............................ 115,82?

schweinitzii ........................ 64,74

strumosus ............................ 64

tomentosus ....................... 64,65, 108

truncatus ............................ 802

tracheliifolius ........................ 64

tuberosus ............................ 188,828

Heliom yces, catalogue ................... 222

Heliopsis................................. 64

catalogue

gracilis............................. 796

hellanthoides ...................... 64, 74

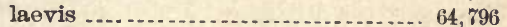

gracilis......................... 796

minor ........................ 796

minor ................................. 64

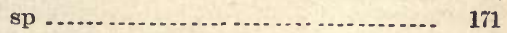

Heliosciadium leptophyllum .............. 647

Heliotrope ............................. 689

Heliotropium, catalogue................. 689

curassavicum..................... 133

tenellum ........................... 104

Helminthocladiaceae...................... 148

Helninthosporium........................ 243

catalogue ........................ 2338

dubium............................. 2338

interseminatum..................... 246

petersii........................... 247

Helonias angustifolia ................... 437

dioica ............................ 436

erythrosperma ........................ 437

graminea........................... 437

Helotiaceae ............................. 157,262

Helvellaceae . . .......................... 155, 262

Helvellales. ............................... 155, 262

Hemiarcyria, catalogue ................. 140

Hemicarpha ........................... 405

catalogue........................... 405

subsquarrosa....................... 405

Femiparasites ......................... 52

Hemisaprophytes ...................... 51

Hemlock ......................... 34, 72, 324, 647

water ........................... 50

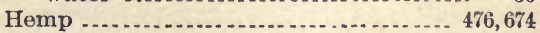

Canadian.......................... 674

water ............................... 491

Hendecandra texensis ................... 592

Hendersonia ............................ 260

catalogue............................. $25 \%$

cydoniae.............................. $25 \%$

donacis.............................. 257

Hepatica, catalogue .................... 511 hepatica.......................... 67, 73,108

triloba.............................. 511

Hepaticae ...... ......................... 286

Heppia $\ldots . . . \ldots \ldots$

catalogue ........................... 280

despreauxii ........................ 265 
Page.

Heptameria, catalogue................. 174 Herbaceous associations of Cahaba Val-

ley of Central Pine belt

plant associations .

plants grown for fruits and seeds, list.

grown for rocts, list.

$8: 9-831$

$82 \pi$

Herd's grass

Heritiera gmelini.

$370,8 \% 6$

Herniaria, catalogue

Herpestis .

monniera.

nigrescens ............................. $7 \% 1$

peduncularis........................ 721

Herpotrichia, catalogue............... 172

Hesperis pinnatifida...................... 524

Heteranthera.

catalogue

graminea.

Heterosporium, catalogue sambuci

Heterotheca

catalogue

Iamarkii

scabra

subaxillaris

Heterothecium

catalogue

domingense.

leucoxanthum

pachycheilum

southern

tuberculosum

Heuchera americana

catalogue

hispida hirsuticaulis

richardsonii..

rugelii

villosa

Hexalectris .

catalogue

squamosus

Hibiscus aculeatus

catalogue

esculentus

esculentus

hoary

incanus

incanus

moscheutos

scaber

syriacus.

$169,192,249$

virginicus

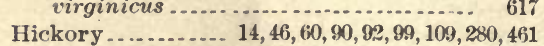
bitternut 100,823 mockernut $86,88,96,110,823,824$ nutmeg $95,100,101,463,823$ pale-leaf $47,60,91$ pignut ...... 59,60,63, 66, 70,91, 98, 133, 462, 823 scaly-bark 462,823 shagbark $60,101,824$

shellbark

84,462

southern shagbark

87,463

shellbark
Hickory-Continued.

upland ........................... $82:$

water ........................... 4i, 1:25, 4i3

white-heart ........................ $4(12$

Hicoria ............ 163, 166, 194, 199, 204, 208,260 alba ..................... 47, 100, 195, 197, 261

aquatica .......................... 46, 45

carolinae-septentrionalis............ 47,87

catalogue ........................... 461

glabra ................................ 47,60

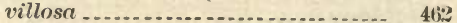

minima ......................... 46,100

myristicaefornis .................... 41,95 ovata ............... 46,84, 178, $25 \%, 260,463$ pallida ............................ 462 pecan .......................... 41, 100, 831

villosa ............................. $4 \pi, 91$

Hieracium, catalogue ................. 752

gronovii hirsutissimum ............. 753

marianum ...................... 64

spathulatum. ................... 753

paniculatum ...................... 64, 752

scribneri........................... 64

spathulatum ......................... 753

venosum ....................... 64, 66, 752

Hill country of Alabama............... 92 prairies ............................... 99

Hirneola ............................... 194

Hoarhound ......................... 56, 705

black ............................... 706

false .................................. $\quad ; 64$

water .............................. 697

Hogweed.............................. 757

Holcus, catalogue........................ 371

halepensts ........................... 339

laxus . ................................ 383

sorghum ........................... $\quad 339$

Hollies .................................. 266

Holly ...................... 14,45, 47, 109, 12:, 602

common............................. 122

dahoon .......................... 45, 47, 125

deciduous . . . ....................... 86, 102

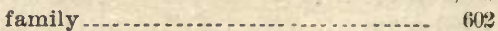

mountain ........................... 71

Yaupon ............................ 45

Holzinger, mosses, identified ............ $\quad 290$

Homalocenchrus ....................... 50 catalogue ........................ 563

hexandrus ......................... 128

oryzoides ......................... 1\%5

virginicus ..................... $76,125,239$

Homotropa macranthum ................ 481

Honey grass ........................... 382

Honeysuckle ........................... 71,745

cinnamon ........................... 653

common............................ 653

family ........................... 742

swamp ............................. 653

Hop .................................. 165, 476

hornbeam......................... 41

tree, trefoil ........................... 99

Hopea tinctoria .......................... 666

Hordeum, catalogue.................... 388

sativum ............................ 827

vulgare .......................... 188, 189

Hornbeam ............. . 43, 46,61,86, 125, 268, 466 lop .......................... $41,82,83$ 
Page.

Hornwort $49,504,647$ family ................................. 504

Horse balm ............................ 696 brier ............................... 71 chestnut family ................... 607 sugar ............................... 45,666 nettle .............................. 714

Horsemint ......................... 698, 702

Hor'setail family . . . . . . . . . . . . . . . . . . . . 320

Horsetails................................ $3: 0$

Horseweed ............................. 787

Hosackia ................................ $56 \%$ purshiana......................... 562

Hottonia, catalogue ................... 661 inflata............................... 49

Hound's-tongue ....................... 690

Houstonia ............................. 738,739 caerulea............................. 75,108 catalogue ........................... 737 linnaei minor ....................... 738 longifolia ........................ 66 patens................. 1:20,152, 153, 193,258 patens ............................ 738 purpurea calycosa .................. $\quad 739$ longifolia _..................... 738

tenuifolia ........................ 738

rotundifolia ....................... 114

tenuifolia

Huckleberry 107,657 dwarf family.

hairy

hoary

small-leaved

squaw

Hudsonian life zone

Humaria

Humboldt, plant zones

Humulus. catalogue

Hungarian grass

Hyacinth, wild.

Hydnaceae

Hydnum ferrugineum

Hydrangea arborescens cordata ...........................64, 78 $135,360,826$

203,263 $195,203,205$

catalogue ........................ 535 cordata.............................. 536 quercifolia ......................... 71,92 vulgaris........................... 535

Hydrastis ............................... 40 canadensis .......................... 75 carolinensis.......................... 513 catalogue

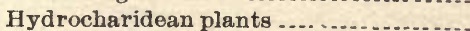

Hydrocharitaceae ..........................

Hydrochloa carolinensis . catalogue

fluitans

Hydrocotyle asiatica catalogue interrupta ranunculoides repanda
Hydrocotyle-Continued. umbellata.......................... 189,242 ambigua... . . . . . . . 649 verticillata ....................... 120, 128

Hydrodictyaceae ........................ 146

Hydrodictyon, catalogue ............... 146

Hydrolea ............................... 688 caroliniana ......................... 688 ovata............................... 688 quadrivalvis .............. 688

Hydropeltis .................................. 503 purpurea......................... 503

Hydrophyllaceae ........................ 687

Hydrophyllum, catalogue ............. 687

Hydrophytes ........................... 48 floating ......................... 127 hydrocharidian ....................... 126

Limnaean class ....................... 126

Hydrophytic herbaceous plants of pine barrens .............................. 126 plant associations ................. 37, 48, 76 plants of Coast Pine belt .............. 116

Hygrophila, catalogue ................... 733

Hygrophoreae......................... 217

Hygrophorus, catalogue ................ 217

Hymenachne striatas................... 358

Hymeniales .......................... 197,263

Hymenocallis, catalogue ................ 447 occidentalis......................... 77,125 rotata ............................... 50

Hymenochaete, catalogue.............. 201

Hymenogastraceae.................... 230, 263

Hymenogastrales ........................ 230,263

Hymenopappus anthemoides ............. 810

Hymenoscypha, cataiogue .............. 158

Hymenoxys, catalogue.................. 810

Hyoseris caroliniana .................... 751 virginica..............................

Hypericaceae........................ 44,619

Hypericum ......................... 121 acutifolium .......................... 629

ambiguum .......................... 621

amoenum ......................... 620

angulosum ....................... 622

aspalathoides .................... 121,131,621

aureum .......................... 83,620

campanulatum..................... 623

canadense........................... 623

catalogue .......................... 620

cistifolium ........................... 621

cistifolium ........................... 621,622

corymbosum ......................... 622

drummondii ....................... 66,623

ellipticùm .......................... 622

fasciculatum .................... 126,630 aspalathoides ..................... $6 \% 1$

galioides ............................. 621

ambiguum....................... 621

pallidum ...................... 621

gentianoides........................ 623

glaucum............................ 620

gymnathum ........................ 623

lasianthus........................... 618

maculatum ........................ 622 mutilum .................... 186, 238, 250,622 myrtifolium ........................ 121,620 
Hypericum-Continued.

nitidum ................................ 69

nudicaule .............................. 623

nudiflorum .......................... 125

nudiflorum ............................. 621

opacum ........................... 121,620

petiolatum ........................... $6: 23$

pilosum ........................... $\quad 622$

prolificum ........................ 83, 85,620

quinquenervium ...................... $\quad 622$

rosmarinifolium..................... 6:2

sarothra .............. 623

simplex

sphaerocarpon ...................... 83,104

sphaerocarpum........................ 621

spp................................. 120,193

virgatum ........................... 75

acutifolium ...................... 622

virginicum .......................... 186

virginicum ............................ $6: 33$

Hypholoma, catalogue .................. 222

Hyphomycetes........................... 235

Hypnaceae............................ 307,309

Hypnum .................................. 291

albulum ............................... 308

catalogue ............................ 308

homalosteginm ..................... 290

microcarpum ........................ 307

Hypochnaceae. .......................... 197, 263

Hypochnus, catalogue .................. 197

Hypocrea, catalogue ..................... 170

Hypocreaceae .......................... 170,262

Hypocreales ............................. 168, 262

Hypoderma, catalogue .................... 161

Hypodermataceae...................... 161,262

Hypomyces, catalogue .................... 168

aurantius .............................. 168

Hypomycetaceae . . . . . . . . . . . . . . . ..... 168,262

Hypopitys .............................. 51 catalogue .......................... 652 monotrope ........................... 652

Hypoxis. catalogue ...................... 448 erecta............................... 448

Hypoxylon ........................... 178,179 catalogue ........................... 180

Hyptis..................................... 696 radiata ........................ 168, 191, 696

Hyssop, hedge...................... $719,720,721$

Hysteriaceae .......................... 162,262

Hysteriales ............................ 161,262

Hysterium ................................ 159,16\%

catalogne .......................... 163.

Hysteroglonium, catalogue............. 163

Hysterographium, catalogue ............ 163

Hysteropatella, catalogue .............. 159

Hystrix, catalogue ...................... 389

Ilex ................ 160, 197, 251,260, $267,268,269$ ambigua.............................. 603

angustifolia.......................... 602

caroliniana....................... 122, 125

cassine ............................. 45, 122

cassine .......................... 603

catalogue ........................... 602

corlacea............................. 122, 163

dahoon ............................. 602

myrtifolia...................... 602

decidua ...................... 86, 102, 125, 248
Ilex-Continued. Page.

dubia ............................... 71

glabra............................. 116,118

laurifolia ........................... 602

longipes......................... $71,109,125$

lucida ............................... 118

lucida ............................... 604

mollis ............................... 604

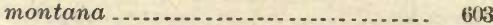

monticola ....................... $67,71,78$

mollis .......................... 71

myrtiflora .......................... 118

opaca _.... 64, 122, 161, 168, 176.209, 211, 259, 260

prinoides............................. 159

prinoides............................. 603

verticillata........................ 161, 180

padifolia ........................ 604

vomitoria ......................... 45, 122

correction of error .............. 845

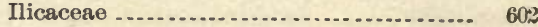

Illecebrum achyrantha................... $49 \%$

Illicinm ................................ 15

catalogue ......................... 506

floriđanum ................ 45, 96, 109, 118, 163 sweet ......................... 14,47,96, 109

Illosporium, catalogue.................. 248

Ilysanthes, catalogue .................. 722

riparia ..............................

Impatiens aurea...................... 153,193

biflora...................... 65, 102, 187, 193

catalogue ........................... 610

fulva ................................ 65

fulva .............................. 611

noli-tangere $\beta$....................... 610

pallida .............................. 610

Indian corn ..................... 31, 32, 68, 823, 825 cherry ............................ 609

cucumber............................. 44:

grass ................................ 338

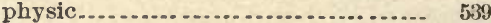

pink ..................................... 669

pipe ............................... 652

plantain .......................... 815,816

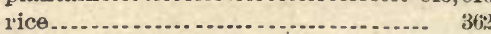

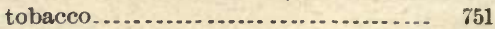

turnip............................. 425

Indigo ................................. 565

false .............................. 563, 558

vermilion-flowered................ . 565

wild .................................. 565

Indigofera, catalogue................... 565

Inkberry ................................ $\quad 116$

tall .................................. 604

Inocybe, catalogue ......................

Insectivorous plants .....................

Introduced plants ........................ . .53

Inula divaricata......................... $\%$ $\% 1$

gossypina ........................... $\quad \eta_{i 0}$

graminifolia ........................ $\quad 769$

mariana............................. $\quad 770$

scabra .............................. 769

subaxillaris ......................... 769

Iodanthus, catalogue.................. 524 hesperidoides........................ 524

Ionactis, catalogue ..................... 788

linariffolius ....................... 115, 82

Ipomoea.......................... 164,679, 680

batatas...................... 69, 152, 253,828 
Ipomoea-Continued.

barbigera

carnota .........

catalogue ......................... 678

commutata ...................... 681

hederacea.......................... 65

luteola ............................... 678

macrorhiza ......................... 680

michauxii............................ 680

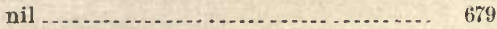

orbicularis......................... 679

pandurata ....................... 152,184

pes-caprae .......................... 129

purpurea .................... 56, 152, 184, 239

sagittata ........................... 128, 133

sp ....................................... 184

tamnifolia ......................... 152,681

trichocarpa ......................... 681

Ipomopsis elegans ........................ 686

Iridaceae............................... 449

Iris, catalogue........................... 449

cristata

family ............................ 449

hexagona ........................ 50

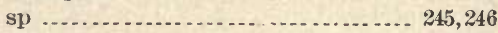

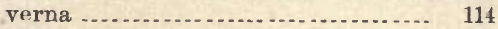

versicolor.......................... 50,449

virginica ........................ 449

Irish potatoes.................. $69,134,135,828$

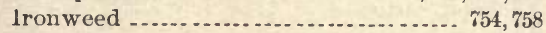

Ironwood ............................. 466

Irpex, catalogue..................... 206

Isanthus brachiatus. ..................... 83

catalogue .......................... 707

coeruleus........................... 707

Isaria, catalogue ....................... 247

flabelliformis ........................ 182

Isariopsis, catalogue ................... 247

Ischaemum secundum .................... 362

Isnardia, catalogue..................... 636

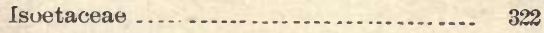

Isoetes, catalogue....................... 322

engelmanni valida................... 79

Isolepis capillaris..................... 401

carinata............................ 402

ciliatifolia ........................... 401

coarctatus.......................... 40:

stenophyllus........................ 401

Isopappus, catalogue ................... 771

divaricatus ......................... 105

Isopyrum biternatum ................. 93

catalogue ........................... 508

Isotheciacea $\ldots$........................... 306, 309

Italian ray grass .......................... 827

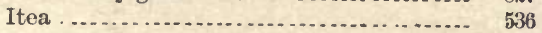

catalogue ......................... 536

Iva annua.......................... 756

catalogue ........................ 756

frutescens ........................ 45, 132

imbricata .......................... 129

Ivy, poison ..................... 101, 601, 654

Ixic chinensis ............................. $\quad 450$

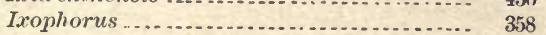

Jaborosa, catalogue..................... 716

Jacquemontia, eatalogue................. 681 tamnifolia
Jalap, false ............................ 680

Jamestown weed ....................... 715

Japonica ................................. 835

Jatropha, catalogue .................... 594

carthaginiensis .................... 136

stimulosa ......................... 114,242

urens stimulosa ....................... 594

Jerusalem artichoke ..................... 828 cherry ........................... 713

Jessamine .......................... 137, 668,835 cape ............................... 137 yellow ......................... 15, 109, 123

Jimson weed . ............................ 715

Johnson grass ..................... 95, 135, 339, 825

Joint-grass .............................. $\quad 340$

Jointweed, American ..................... 487 slender............................. 487

Juglandaceae........................... 461

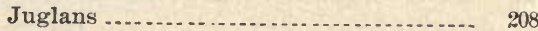

alba ............................... 462

minima

aquatica ........................... 463

catalogue .......................... 461

cinerea.............................. 72.252

glabra .............................. 462

minima ............................ 463

myristicaeformis ..................... 463

nigra . ............................. 46, 84

olivaeformis ........................ 461

ovata................................. 462

pecan ................................ 461

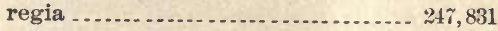

tomentosa

Jujube berry ............................... 832

tree, common ....................... 609

Juncaceae ............................... 432

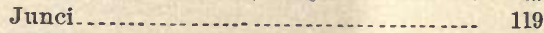

Juncoides, catalogue ..................... 436

Juncus. . ............................. 50, 76,186

acuminatus .......................... 435

debilis............................ 68

diffusissimus...................... 435

aristulatus ........................... 433

bicornis ............................ 433

biflorus.............................. 433

bufonius fascicularis ................ 119

campestris ........................... 436

canadensis ........................... 65

longicaudatus...................... 435

catalogue .................. 432

caudatus ............................ 435

congestus ........................... 433

debilis............................... 435

diffusissimus ...................... 119

echinatus......................... 434

elliottii............................. 119, 435

engelmanni...................... 434

macrostemon........................ 434

marginatus ........................ 76,119

aristulatus..................... 119

maritimus.......................... 432

megacephalus ........................ 434

nodosus megacephalus ................ 434

polycephalus minor............... 434

polycephalus ....................... 1:8

tenuifolius .......................... 434 
Juncus-Continued.

Page.

repens $50,132,359$

roemerianus.

128

scirpoides.

genuinus

macrostemion

polycephalus ...................... 434

torreyi .............................. 114

trigonocarpus ....................... 117

June grass ............................... 384

Juneberry ............................ 545

Jungermanniaceae ....................... 287

Juniper .................................. 117

Juniperus................ 161, 162, 197, 199, 20\%, $23 \%$

barbadensis.......................... 42, 133

catalogue ........................... 325

virginiana .............. 81,102, 186, 203,3226 australis .....

Jussiaea, catalogue...................... 634

creeping .................................. 634

decurrens......................... 242, 250

diffusa . . . . . . . . . . . . . . .

hirta .............................. 635

leptocarpa ........................ 242, 258

leptocarpa ......................... 634

macrocarpa ........................ 635

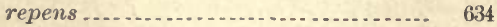

svoartziana ........................... 634

variabilis ............................ 634

Justicia americana ..................... 734

humilis ............................ 735

pedunculosa....................... 734

laetevirens ............................ 735

Kafir corn

$95,125,190,825$

Kale..................................... 135, 828

Kallstroemia, catalogue ................. 586

Kalmia................................. 174

catalogue .......................... 654

evergreen ........................... 71

latifolia .............. 45, $64,71,78,89,118,174$

Kneiffia, catalogue.................... 637

linearis............................. 114

suffruticosa........................ 68

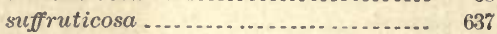

Kneifflella............................... 203

Knotweed, Virginia ...................... 486 wayside .............................. 483

Kobresia monocephala ................. $11 y$ odorata ........................... 97,119 pumila

Koeleria pennsylvanica.................. 378

Koellia ................................ 189,236 albescens ........................... 108,115

catalogue .......................... 698

nuda .............................. 109

pycnanthemoides...................66,77

Kohl-rabi .............................. 828

Kosteletzkya, althea-like ............... $\quad 618$

catalogue .......................... 617

virginica $\ldots \ldots \ldots \ldots \ldots \ldots \ldots \ldots \ldots \ldots . . \ldots 128,618$

altheaefolia ...................... 133

altheaefolia ....................... 618

Kraunhia, catalogue . ................ 567

chinensis .......................... 834

frutescens ......................... 15, 122

Krigia _............................... 751

amplexicaulis ..................... 751
Krigia-Continued. Page.

caroliniana ......................... 751

dandelion ........................... 752

virginica ........................... 751

Kuhnia, catalogue .................... 766

critonia ............................. 766

eupatorioides....................... 105

corymbulosa....................... 766

gracilis........................... 766

kuhnia ........................... 115

northern......................... 105

paniculata .......................... $\quad 766$

suaveolens........................... 766

Kuhnistera . . ......................... 83,822

candida ............................ 104,823

carolinensis ........................ $5(6)$

catalogue .......................... 564

gattingeri......................... 83,823

pinnata............................... 115

purpurea........................... 104

Kyllinga .......................... 390,396

catalogue ......................... 395

maculata........................... 405

monocephala......................... 395

ovularis .............................. 394

sesquiflora........................... 396

Lace grass .............................. 382

Lachnanthes .............................. 446

tinctoria ........................ 446

Lachnea, catlogue....................... 155

Lachnella, catalogue ................... $\quad 157$

Lachnocaulon anceps .................... 114

catalogue .......................... $4: 29$

michauxii ........................... $4: 29$

Lacinaria .............................. 115

catalogue ......................... 766

elegans......................... 97, 115, 892

gracilis . . . . . . . . . . . .

graminifolia .................. $62,63,73,184$ pilosa........................... 121

scariosa ............................ 115

squarrulosa..................... 62

spicata ............................. 821

tenuifolia ............................ 768

Lactarieae ............................. 217

Lactarius .............................. 168

catalogue............................ 217

Lactuca acuminata ..................... 755

canadensis ............................ 253

catalogue........................... 754

elongata.......................... 754

graminifolia .................... 754

sanguinea ...................... 754

hirsuta ............................ 74

integrifolia ........................ 754

leucophaea........................... 258

sagittaefolia ....................... 74

sanguinea......................... 754

sativa .............................. 899

sp. .............................. 152, 165, 256

Ladies' bedstraw ......................... 711

ear drops........................... 48 48

tresses............................ 456,457

Iady's slipper.......................... 452,453

thumb ............................. 485

Jaestadia ............................... 174 
Page.

Lagenaria, catalogue

747

vulgaris clavata

gourda $\ldots . . .831$

Lagerstroemia, catalogue ............... 632

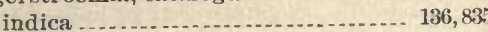

Lamb's quarters ........................ 487

Lamium amplexicaule ................... 55, 15:

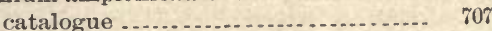

I antana, catalogue...................... 695

Lanzia, catalogue ..................... 157

Laportea canadensis ........................... 477

Lappa minor............................. 816

Lappula, catalogue

Larkspur, azure.

dwarf.

tall

Lasiosphaeria, catalogue ...............

Lathyrus, catalogue venosus

Lauraceae

Laurel family

mountain

poison

Laurestines

Laurus

benzoin.

borbonia

camphura.

carolinensis

pubescens.

melissaefolia

sassofras

Leadwort family

Leaf-cup

Leather flower

Leatherwood

catalogue

michanxii

torulosa

uniflora

Lecanactis

Lecanidion

Lecanora.

albella.

catalogue

cinerea.

lacustris

muralis

pallida

privigna

punicea

rubina

varia

xanthophana

Lecanoreae

Lechea.

catalogue

cinerea torreyi

leggettii

Leggett's

major

divaricata

minor

minor $\gamma$.

narrow-leaf
Lechea-Continued.

Page.

novae-caesareae

racemose............................ 625

racemulosa ......................... 74

racemulosa.......................... 625

spreading ............................ 625

tenuifolia ............................ 115

thyme-leaf .............................. 624

thymifolia .............................. 624

torreyi ............................. 131, 625

Torrey's ............................. 695

villosa ............................. 115

Lecidea, catalogue...................... $2 \pi 1$

myrini .......... $2 \pi 1$

Lecideaceae.............................. 271,284

Lecideae .... . . . . . . . . . . . . . . . . . . . . 271,281

Le Conte pear in Coast Pine belt......... 8 8

Leek........................................ 827

Leersia .................................. 76,363

hexandra.......................... 363

oryzoides............................... 363

virginica ............................ 363

Legouzia, catalogue ..................... 748

perfoliata .......................... 259

Leguminosaé . ...................... 61,91,114,8

Leguminosae ............................ 6 61,553

Leitneria floridana .................... 35

Lejeunea .................................. 285

auriculata .......................... 285

austini .............................. 285

catalogue . . .......................... 288

mohrii ............................ 285

serpyllifolia ........................... 285

americana ...................... 288

Lemanea, catalogue ................... 148

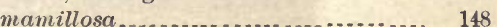

Lemaneaceae.......................... 142, 148

Lembosia, catalogue..................... 163

Lemna; catalogue . ..................... 426 minor ........................... 48,126

polyrhiza......................... 426

trisulca _...... 48, 126

Lemnacere ........................... 426

Lemon ........................... 253

Lemotrys hyacinthina ....................., 440

Lentil, wild .............................. 57

Lentibularia ............................ $7 \% 9$

Lentinus, catalogue ..................... 220

Lentomita, catalogue.................... 173

Lenzites, catalogue ....................... 212

Leocarpus, catalogue...................... 141

Leonotis, catalogue...................... 706

Leontice thalictroides .................... $\quad 517$

Leontodon carolinianum................ 754

taraxacum ........................... 753

Leonurus cardiaca ..................... 56

catalogue ............................ 706

Lepachys .............................. 799

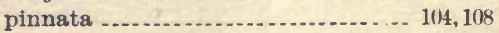

pinnata........................... 799

Lepidium ................................ 15

catalogue ......................... $5: 21$

didymus............................. 52.2

intermedium .......................... 5iv

micranthum apetalum................ $5 \approx$

sativum......................... 828

virginicum ..................... 152,258 
Page.

Lepiota, catalogue

Leptamnium, catalogue. virginianum

Leptandra, catalogue

Leptanthus gramineus reniformis

Leptilon, catalogue

Leptobryum, catalogue.

Leptocaulis divaricatus

Leptochloa, catalogue. fascicularis mucronati

Leptodon, catalogue

immersum trichomitrion irriguus

Leptogium.

apalachense.

catalogue

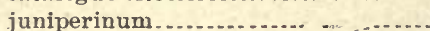

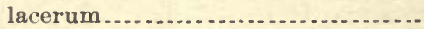

myochroum

pulchellum

Leptuglossum, catalogue ..................

Leptolepis echinatus.

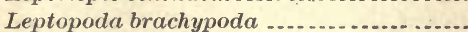
brevifolia $\beta$..

decurrens

helenium

integrifolia

pulerula.

Leptorchis, catalogue

$$
\text { liliifolia }
$$

Leptosphaeria, catalogue

Leptostroma hypophyllum

Leptostromataceae.

Leptostromella, catalogue

Leptothyrium, catalogue

Lepuropetalon, catalogue .............. 534

Leskea ................................... 291 adnata............................ 307 catalogue ............................. 304

Leskeaceae ............................. 304, 309

Lespedeza

$74,193,822$

capitata $61,67,186$

catalogue

574

frutescens

61,67

frutescens

576

hirta .................... 60,61,67,186

nutallii ............................. 61,67

polystachya ........................ 576

procumbens ....................... 186

prostrata........................... 574

repens.......................... $60,115,186$

reticulata .......................... 186

reticulata ........................... $575^{\circ}$

sessiliflora......................... 575

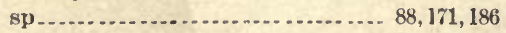

striata...................... 54, $88,166,829$

stuvei ............................... 186

stuvei............................ 575

intermedia ...................... 575

violacea ........................... 186

angustifolia.................... 575

virgata ........................... 575

yirginica ..................6 $61,67,115,186$
Page.

Lesquereux \& James, Manual of Mosses. $\quad 290$

Lesquereux Leo, mosses.................. 289

Lettuce .................................. 829

reddish-flowered ..................... 754

sea................................ 147

tall white ........................... 756

wild .............................. 754,755

Leucanthemum vulgare................... 813

Leucobryaceae ........................... 298,309

Leucobryum ................................. 291

catalogue ......................... 298

glaucum .......................... 291

minus ................................ 298

pumilum ........................... 291, 294

Leucodun, catalogue .................... 306

Leucothoe ................................. 168

axillaris.......................... 45, 118, 120

catalogue ......................... 654

catesbaei .............................. 168

Liatris ........................... 766

elegans.............................. 766

graminifolia........................ 767

dubia........................... 768

heterophylla ...................... 767

odoratissima ........................ 768

pauciflosculosa...................... 768

resinosa.......................... 767

scuriosa ........................... $\quad 767$

spicata ............................. $\quad 767$

squarrosa .......................... 767

sqarrulosa ......................... $\quad 767$

Lived applanata....................... 140

spermoides ........................... 140

Lichen, large .......................... 78

Lichenes ................................ 267

Lichens ........................... 63, 263, 265, 267

author's collection ................... 2633

distribution ........................ 264-267

history of collections ................. 263

Licorice, wild ............................ 741

Life everlasting ......................... 791

zones of Alabama ................... $\quad 57$

Ligusticun actaeifolium .................. 643

barbinode ........................... 642

canadense......................... 79

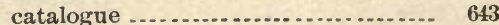

Ligustrum japonicum ................. 136, 835

vulgare italicum ................... 835

Liliaceae................................ 436

Lilies ..................................... 96

Lilium, catalogue....................... 439

catesbaei............................. 124

martagon ............................ 439

michauxii........................... 439

superbum carolinianum.............. 440

Lily ................................ 439,440

atamasco .......................... 123

family ................................ 436

nodding.............................. 439

pond ................................ 504

rose-colored water ................... 504

sacred............................... 503

southern spotted ..................... 439

splder............................. 50,447

sweet-scented water .................. 504

water ............................., 49 
Lily-Coutinued.

wild calla

yellow pond

Lima bean.

Limnaean plant associations.

Limnanthemum, catalogue lacunosum.

Page.

Limnodea arkansana catalogue

Limodorum

catalogue.

multiflorum

pallidum

parviflorum

praecox

tuberosum

unifolium.

Limonium carolinianum catalogue

Linaria, catalogue

elatine

floridana.

spuria.

vulgaris

Linden family

silver-leaf

Lindens

Lindera

benzoin..

melissaefolia.

Lindernia attenuata

dilatata.

monticola.

refracta.

Linum boottii.

catalogue

floridanum

medium

sulcatum

virginianum floridanum .................. medium

Lion's ears

Liparis

liliifolia.

loeselii

Lipocarpha, American

catalogue .

Lippia, catalogue cuneifolia $14,60,84,100,613,824$

Liquidambar $163,169,179,181,194,198,205,213$

catalogue styraciflua $32,46,92,242$

Liriodendron

$159,163,173,181,195,203,236,506$ tulipifera ............ $32,46,84,166,167,184,253$

Lithophytic plant association

Lithospermum canescens

carolinianum

catalogue

tenellum

tuberosum

(1,

Liverworts collon

collections........................... 284

distribution ......................... 285

Lizard's tail ........................... 125, 461

family ......................... 461

amoena ......................... 241,242

glandulifera ........................ 65

appendaged ........................ 98,750

brevifolia......................... 121

catalogue ......................... $\quad 749$

claytoniana............................ 750

glandulosa .......................... 750

obtusifolia ...................... 750

gracilis.............................. 751

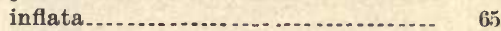

obtusifolia ......................... 750

paludosa ............................ 127, 356

puberula........................... 121, 189

glabella ........................ 750

syphilitica ............................. 65

Locust .................................. 14,834

black........................... $77,56 \%, 834$

clammy ............................. 568

honey ................... 14,46,83,92,110,55\%

Logania family .......................... 668

Loganiaceae ............................ 668

Lolium, catalogue......................... 388

italicum............................ 827

perenne............................ 827

Lonicera, catalogce.................... 745

flava ............................... 62,612

marylandica..................... 669

sempervirens......................... 122

symiphoricarpos ...................... $\quad 744$

Lookout Mountain, vegetation ........... 77

Loosestrife, bastard......................

family ............................... 631

four-leaf ............................ 661

lance-leaf ............................. 632

seaside .................................. 639

whorled-flowered .................... 630

wing-stemmed ......................... 631

Lophidium, catalogue.................... 164

Lophiola aurea ............................ 117

aurea............................... 448

catalogue ........................... 448

Lophiostoma, catalogue................. 174

Lophiostomataceae .................... 174,262

Lophodermium, catalogue .............. 162

L.opseed .................................. 696

Loquat................................. 32, 96, 831

tree .................................. 135

Loranthaceae ........................ $\quad 479$

Lotus, catalogue ......................... 562 sericeus................................ 562

Lousewort, Canada ..................... Canadian ........................... 5:

Louisianian area or flora .................. 94 flora.................................... 32

Love vine................................ 52, 684

I,ower Coosa hills, vegetation ........... 66 hill country .......................... 89

Lucern................................ 560,829

Ludwigia alternifolia.................. $65,75,242$ angustifolia.......................... 635 brachycarpa....................... 636

Litmus herb.......... 599

Littoral belt........................... 129 
Ludwigia - Continued.

catalogue

cylindrica

decurrens

hirsuta

hirtella.

linearis

mollis

palustris.

pilosa

Luffa acutangula

Lungwort.

Lupine, hoary

Lupines

Lupinus, catalogue

diffusus

gracilis

nuttallii

perennis gracilis.

pilosus

villosus

Luziola alabamensis. catalogue

Luzula campestris

Lychnis flos-cuculi.

Lycium carolinianum catalogue

Lycogala, catalogue

Lycoperdaceae

Page.

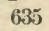

635

634

635

120

636

636

635

241

690

123

559

559

114

559

114

559

559

559

12()$, 123$

Lycoperdales

Lycoperdon . catalogue

Lycopersicum esculentum

Lycopodales 238,830

Lycopodiaceae

Lycopodium alopecuroides . ......... 65, 66, 117 adpressum _..................... 127 adpressum ....................... 321

apodum .............................. 3202

carolinianum ..................... 51.121

catalogue .......................... 321

cernuum ............................. 51, 123

inundatum adpressum ................ 321

pinnatum ........................ 321

rupestre ............................ 322

Lycopsis virginica ....................... 691

Lycopus, catalogue...................... 697

rubellus............................. 243

virginicus.......................... 193

Lyme grass ............................. 388,389

Lyonia frondosa ............................. 655

maritima......................... 677

Lysimachia ungustifolia ................ 662

catalogue .......................... 661

ciliata................................... 662

tonsa ........................... 660

heterophylla......................... 662

hirsuta ........................... 661

hybrida ........................... 662

lanceolata.......................... 662

punctata .............................661

quadrifolia

Lythraceae

Lythrum, catalogue.

lineare
Lythrum-Continued.

petiolatum

Page.

verticillatum

(632)

6i332

Maclura

475

auranticaca................... 162, 2533,4\%5, 833

McNeil, Wm., diatoms.................... 142

Macranthera, catalogue.................

fuchsioides .......................... 15, 115

Mucrophoma, catalogue................ 255

Macropodia .............................. 156

Macrosporium, catalogue ................ $\quad 246$

Madder family ......................... $\quad 737$

Magnolia . .......................... 15, 32, 47, 96 , $99,100,109,117,122,123,125,133,136,158,182$, $209,235,266,267,268,270,272,294,505,821,833$ acuminata ............. $32,46,72,179,180,182$ cordata

46,, 2

auviculata .................... 14,506

catalogue ............................ 505

cordata ............................. 505

deciduous-leaved .....................

fainily ............................ 46,47,505

foetida ........................ 14, 95, 109,833

Fraser's........................... 92, 506

fuscata . .............................. 833

glauca .................... 168, 178, 18\%,256.505

grandiflora ........................ 95, 505,833

large-leaf ........................... 92

macrophylla.................. 14,79,92,109

obovata .............................. 833

tripetala ......................... $\quad 92$

umbrella ........................... $\tau_{2}$

umbrella ........................... 506

virginiana ... 168, 178, 180, 182, 253, 256, 267, 274 foetida ......................... 505 glauca............................ 505

yellow-flowered ..................... $72,5(5)$

Magnoliaceae . ............................. 46,50;

Mahogany, mountain .................... 467

Maiden cane ............................... 346

Maidenhair ............................. 311

Southern ........................ 86

Maize .............................. 31

millo .............................. 135

Malachodendron ovatum ................. 618

Malaxis unifolia.......................... 457

Mallow............................... 614-617

Brazilian ........................... 614

Carolina. ............................ 614

common........................... 614

false................................ 616

family ................................ 614

rose .......................... $50,614,615,61 \%$

Malus angustifolia ...................... 185

coronaria .......................... 185

malus .................... 165, 175, 185, 243, 254

angustifolia....................... 545

Malva caroliniana

catalogue ............................. 614

nuttalloides .......................... 614

papaver ............................ $\quad 614$

spicata ............................ 616

Iriangulata ......................... 615

Malvaceae ............................... 614

Malvastrum, catalogue .................. 616

Mandrake............................... 517

Mangel-wurzel ........................ $8: 2$ 
Page.

Manisuris ............................ $3335,336,823$ catalogue ........................... 335 corrugata............................. 119

cylindrica............................ 336 granularis ... ...................... 336 rugosa .............................. 127

Maple ....................... 43,46,57,61, 824,835

family

605

Florida

47,606

hard

$47,61,606,835$

Northern sugar

70

pale-bark

77,606

red

607

rock

Rugel's hard.

small-leaf sugar

89,102

silver.

soft

606

Southern pale-bark ................... $\quad 50$ sugar.................... $5 \pi, 80,84,89,102,605$ swamp ........................... 117,607

white ............................. 834

white-bark ......................... 47,91

Marasmieae............................. 220

Marasmius, catalogue .................... 221

Marchantia ............................ 285

catalogue ............................. 286

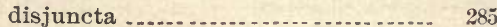

Marchantiaceae ........................ $\quad 286$

Mariana, catalogue ..................... 818

Marigold ............................. $80 \%, 808,813$

corn ................................ 814

Marilaunidium, catalogue ............... 688

Mariscus cylindricus........................ 394

echinatus.............................. 395

ovularis .............................. 394

retrofractus.......................... 394

Maritime Pine region ....................... 106

Marrubium, catalogue ................... 705

vulgare .............................. 56

Marsh elder ........................ 45, 756,757 annual ......................... 756

seaside .......................... 756

shrubby ........................... 757

parsley ................................ 647

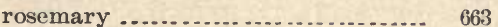

Marshallia .............................. 809

angustifolia........................ 809

catalogue ......................... 809

lanceolata.............................. 94

lanceolata........................... 809

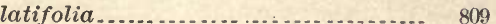

Marsupella, catalogue................... 288

Martynia, catalogue.................... $\quad \pi 33$ proboscidea .......................... 733

Maruta cotula ........................ 812

Massariaceae ........................ 1 $1 \%, 26 \%$

Massarina, catalogue ..................... 176

Mastigobryum ............................. 288

tridenticulatum ...................... 288

trilobatum

Matricaria, catalogue

maritima.

parthenium

May apple

Mayaca aubletii

catalogue
Mayaca-Continued.

moss-like............................... 426

family ............................... 426

fluviatilis .......................... 426

michauxii............................. 426

Mayaceae ................................ 426

Maypop ..... ............................. 630

Mayweed .......................... 55, 812

Meadow beauty . ..................... 633,634

fescue............................. 827

grass ............................ 68, 379,380

fowl ............................... 385, 386

parsnip ............................ 642

rue, mountain ..................... 515,516

sage .................................... 701

sweet.............................. 538

Medeola, catalogue...................... 442

Medicago arabica........................ 829

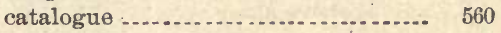

maculata........................... 135

maculata........................... 560,829

polymorpha arabica ................. 560

orbicularis ...................... 560

sativa ............................ 899

virginica ........................... 575

Medick, black ........................... 560

Medlar, Japanese................... 32, 96, 135, 831

Megastachya ciliaris ...................... 381

Meibomia ....................... 60, 74, 186, 822

arenicola............................ 61

hracteosa ........................... 67

canescens ............................ 88

catalogue ......................... 571

dillenii ............................. 88, 253

floridana............................ 574

glabella ............................. 61,67

laevigata.............................. 61

lineata ............................. 571

marylandica. ........................ 61,67

michauxii............................... 61

mollis ............................... 241,246

obtusa ............................... 61,67

paniculata ........................... 186

pauciflora.......................... 83

rigida _..................... 61,67

rotundifolia ........................ 115, 186

rotundifolia ......................... 571

rugosa .............................. 61

sp ................... $88,166,167,193,241,253$

stricta ............................... 97,115

Melampsoraceae ....................... 184, 262

Melampodium australe.................. 795

humile ........................... 795

Melampsora, catalogue .................. 185

Melampsoraceae ........................ 184

Melanconiaceae ...................... 25(1),263

Melanconiales ......................... 250,263

Melanconidaceae ..................... 178,26:

Melanconis, catalogue.................... 178

Melanconium, catalogue ................ 252

Melanosporaceae ...................... 169, 262

Melanthera, catalogue ................. 797

halberd-leaf .......................... 797

Melanthium, catalogue................. 438

dioicum ........................... 436

muscaetoxicum ...................... 437

polyganum ............................ 438

racemosum.......................... 436 
Prge.

Melasmia, catalogue

Melastoma family

Melastomaceae

$160,160,178,179,010,242,217,248,219,2 \% 3,834$ catalogue ........................... 588 family ................................ 588

Melica, catalogue ........................ glabra mutica .............................. 73,123 glabra ............................. 389

Meliaceae ................................ 588

Melilot, common yellow................. 561 small-flowered....................... 561 white $105,580,823,829$

Melilotus alba ..................... 105, 250, 823,829 catalogue .......................... 560 parviflora ............................. 561

Meliola amphitricha..................... 164 catalogue ............................ 164

Melissa caroliniana coccinea nepeta. pulegioides

Melochia hirsuta

Melogramma

Melogrammataceae

Melon, netted. sugar.

Melons

Melosira sulcata

Melothria, catalogue......................

Menispermaceae

Menispermum carolinum ................... lyoni

Mentha, catalogue

cita rotundifolia 56 rotundifolia viridis.

Menyanthes peltata.

Mercurialis, catalogue

Mercury, dog's. three-seeded.

Mermaid-weed, comb swamp.

Merriam, life zones

Mertensia, catalogue virginica

Merulieae

Merulius, catalogue

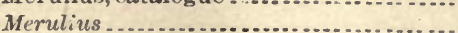

Meracienia, catalogue

lanceolata.

plantaginea

plantaginifolia

tuberosa

Mesophile forests of Cahaba Valley .................. of Central Pine belt. ............... of Central Prairie region ......... of Coast Pine belt ............... 109, 11 of Coast Plain ....................... 118 of pine barrens ................... 12: of Tennessee Valley............ 83
Mesophile forests-Continued.

herbaceous plant associations

Page.

72, i4, 85, 96

plants of Coast Pine belt......... 110,118

plants of Coast Plain............... 119

plants of Central Pine belt....... 10

plant associations ..................... 64

plants of dunes ....................... 131

of main shora.................... 132

of outlying islands ................ 13:

Mesophytic plant associations........... 37

Mesosphaerium, catalogue............. 168,696

Mespilus apiifolia ........................ 540

arbutifolia........................... 545

erythrocarpa..................... 545

canadensis........................... 545

cordata ........................... 545

obovalis ............................ 545

flexispina ............................. 550

pyracantha ......................... 54

rotundifolia ......................... 540

Metamorphic hills, adapted crops ........ $8: 4$ vegetation . ........................ 6

vegetation and soil............... 8

strata ............................

Metaspermae........................... $\quad 326$

Metasphaeria, catalogue ............... 175

Metzgeria, catalogue ..................... $28 \tau$

Metzgeriaceae.......................... $28 \pi$

Mexican tea .............................. 488

Mezereum family ..................... 631

Michelia fuscata......................... 136, 833

Micranthemum, catalogue ............... . $\tau 2 \%$ emarginatum .......................

Microcera, catalogue .................... $\quad 249$

Micropeltis, catalogue................... 168

Microsphaera, catalogue ................. 166

calocladophora ..................... 160

semitosta........................... 166

Microstroma, catalogue................ $19 \%$

Microstylis ............................... $45 \%$

ophioglossoides .................... $45 \%$

Microthyriaceae ....................... 168, $200^{\circ}$

Mignonette ..................................... 530

family ............................ 530

Mikania............................... 765

scandens ...............................

Mildew, grape .......................... 153

Milfoil, southern water ................. 639

rough water .........................

water ............................... 49

Milium compressum ..................... 339 paspalodes ............................ $\quad 340$

Milk pea ........................... 580, 581

Milkweed ............................. $6 \pi 4-67$

family .............................. 674

swamp ............................ 50

Milkwort, ambiguous .................. 589

cross-leaf ........................ 589

Chapman's ......................... 590

Curtiss's ........................... 590

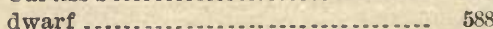

greenish-flowered ................... 590

Hoker's ............................. 589

large-flowered ..................... 591

low-branched ..................... 588 
Milkwort-Continued.

Page.

Maryland

nude-stemmed

590

Nuttall's

pine-barren pond

polygamous

short-leaf

Milleria contrayerva

Millet cat-tail German 360

golden $135,360,826$

Italian

$95,135,360$

pearl

Texas

water

Milocriryum ligustrinum

Mimosa farnesiana

horridula.

illinoensis

julibrissin

virgata

Mimulus alatus

catalogue

Mint

family

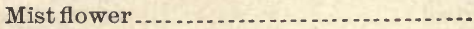

Mistletoe, American family

Mitchella, catalogue repens.

Miterwort false

Mitreola petiolata. sessilifolia

Mitrula, catalogue

Mnium catalogue spiniforme

Moccasin flower

Mock orange.. 453

Mockernut

Modiola. catalogue multifida multifida

Modotheca

Mohria.

Mohrodendron carolinum catalogue 552,834 824 40 dipterum

61,89

664 $6,118,122$

Mollia............................... 291

Mollia.................................. 502

catalogue .......................... $\quad 297$

alsinefolia . ........................... 502

longiseta............................ 294

viridula............................. 294

Mollisiaceae ........................... 158, 262

Momordica, catalogue .................. 747 elaterium .......................... 747

Monarda ................................. 702

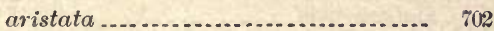

bradburiana ......................... 74 catalogue ............................. 702

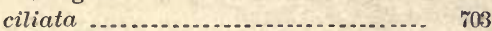

citriodora.
Monarda-Continued.

Page.

fistulosa ............................. 68,74 mollis ......................... 702

lutea ............................. 702

russelliana........................... 68

Monilia, catalogue....................... 235

Moniliaceae............................ 235, 263

Moniliales............................. 235, 263

Monkey flower .......................... $\quad 719$

Monkshood, wild ....................... $\quad 510$

Monniera, creeping ..................... 721

Monocera ............................... 374

aromatica............................ $3 \pi_{4}$

Monocotyledones........................ 48, 326

Monotropa............................. 51 catalogue ........................... 652 hypopitys ............................. 652

Monotropaceae.......................... 652

Monniera amplexicaulis.................. 722 catalogue ............................ 721 cuneifolia.......................... 721 monniera ............................ 133

Montagniella, catalogue................. 171

Moonseed, carolina ..................... 517

Moose-wood............................. 631

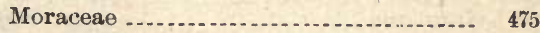

Morchella, catalogue .................... 155

Morning-glory ....................... 129, 678-681 family ............................ 678

Morongia, catalogue..................... 554 horridula . ......................... 108

Morus ................................ 163,248 rubra .......................... 167, 176,243 catalogue ......................... 476 nigra ................................. 831 papyrifera ......................... 476

Moss, peat................... 116,117, 119, 125, 293 Spanish .................... 14, 50,96,100, 122 water ................................ 127

Mosses................................... 79,266, $277,287,288,289,290,292,293,294,296,307,429$ bibliography .......................... 290 author's collections ................... $\quad 290$ distribution . ....................... 290-294 history of collections................. $\quad 289$

Motherwort .......................... 56, 706

Mountain region, features ani climate... 58 spicewood............................ 57 wind flower $\ldots \ldots \ldots$

Mouse ears . .

Mousetail ................................ 513

Mucedineae ............................... 235

Mucor, catalogue ....................... 151 ramosus ............................. 151

Mucoraceae............................ 151,262

Mucorales ............................. 151, 262

Mueller, Karl, inosses identified .......... 290

Mugwort .............................. 56,814

Muhlenbergia aristata.................. 367 capillaris trichopodes................... 366 catalogue ............................ 366 erecta ............................. 367 diffusa ................... $65,74,171,191,243$ trichopodes......................... 9\%, 120 willdenovii.............................. 366

Mulberry ................. 14,41, 100,4 $46,695,831$ black................................ 831 family............................. 475 
Mnlberry-Continued.

paper

Page.

red $136,476,833$

.

Mulgedium acuminatum ................

floridanum.......................... 755

Mullein

Mullugo, catalogue....................... 494

Muscadine ............................ 613

Musci .................................... 290,294

Muskmeion ............................... 830

Mustard, black ........................... $5: 33$

family ................................ 521

hedge ............................. 523,584

sand....

Mutinus, catalogue..................... $\quad 229$

Mycena, catalogue .......................

Mrcosphaere:lu, catalogue ............. 174 gossypina .......................... 242

Mycosphaerellaceae................... 174,262

Mylocarpum ............................. 602

Myosotis, catalogue ....................... 691

stricta................................ 691

verna .............................. 104

verna .............................. 691

virginiana ........................ 690

Myosurus, catalogue.................... 513

Myricaceae ............................ 46t

Myrica, catalogue ...................... 464 cerifera .................. 15, 45, 118, 122, 161 arborescens ....................... 464 media ......................... 464 pumila............................ 464 inodora ..................... 15,45, 118, 125

Myriogenospora, catalogue .............. 171

Myriophyllum, catalogue................ 639 scabratum .............................. 639

laxum.............................. $12 \gamma$

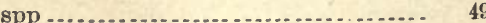

My rothecium, catalogue............... 249

Myrrhis claytoni......................... 646 longistylis......................... 646

Myrtle .............................. 835 crape............................ 136, 632,835 wax .................... 122, 130, 131, 266, 269

Myrtus communis....................... 835

Myxogastrales ........................... 139

Myxomycetes............................ 139

Myxormia, catalogue .................... 252

Myxothallophyta ...................... 139

Nabalus, catalogue..................... 755

fraseri .............................. 74

fraseri

barbatus

Naematelia

Nageia chinensis

Naias, catalogue flexilis fusiformis ......................

Najadaceae.

Najas spp

Nama

catalogue jamaicensis

Narthecium pubens

Nasturtium

officinale

sessiliflorum
Nosturtium-Continued. Page.

sylvestre.............................. 5:4

tanacetifolium ...................... 525

Naturalized plants ...................... 53

Naucoria, catalogue .................... $\quad 224$

Nauenburgia trinervata................ 810

Navicula, catalogue................... $\quad 145$

lewisiana ........................... 145

marginata .......................... 145

Naviculoidea .......................... 145

Neckera, catalogue ..................... 305

ludoviciae ............................ 294

Neckeraceae............................ 305, 309

Neckweed ................................ 723

Nectarine ........................... 832

Nectria................................. 169

catalogue ........................... 169

Nectriaceae ........................... 169, 262

Nectrioidaceae........................... 260

Negundo aceroides....................... 607

Neillia ................................. 538

opulifolia .......................... 538

Nelumbium luteum ...................... 503 speciosum ........................... 503

Nelumbo............................... 49

Nelumbo................................ 503

lutea .............................. 127

Nemalionales.............................. 148

Nemophila............................. 687

catalogue .......................... $68 \tilde{r}$

microcalyx ......................... 123

Neocosmospora, catalogue .............. 169

vasinfecta .................... 249

Neokneiffia, catalogue ................... 203

Neottia gracilis ......................... 456 odorata ............................. $45 \pi$

pubescens ............................ 457

tortilis ............................. $45 \%$

Nepeta, catalogue....................... 703

cataria ............................. 56

Nepetaceae ........................... 696

Nephrodium acrostichoides............... 317 catalogne ............................ $\quad 280$

floridanum ........................ 317

lanosum ........................ 312

punctilobulum....................... 319

Nephroma helveticum .................. 265

Neptunia, catalogue ..................... 553

virgata............................. 553

Nerium oleander...................... 168,83;

Nesaea verticillata ..................... 632

Nestronia, catalogue .................... 479

Nettle................................ $\quad \gamma_{14}$

common American ................... $\quad 477$

false ............................... 478

family ........................... 477

purplish ........................... 477

spurge ............................... 594

stinging ........................... $47 \%$

tree ................................ 475

wood............................... 477

Nevius, Rev. R. D., botanical collection... 17

Neviusia .............................. 17,40 alabamensis ... ................ 3.5, 3., 91,92

catalogue .......................... 539

New Zealand spinach .................. 828

Newman, C. L., fungi .................... 149

Nicandra 
Nicotiana, catalogue

tabacum

Nidularia, catalogue

Nidulariaceae

Nidulariales

Niebuhria

Nightshade, common

enchanter's.

family

red

silver-leaí

slender

spiny .

Nimble Will

Ninebark

Niptera, catalogue

Nitella

acuminata

catalogue

Nitzschia, catalogne

Nodding lily.

Nomenclature, rules followed

Nondo

Nothoscordum, catalogue

striatum

Nummularia, catalogue.

Nuphar.

advena

sagittifolia

sagittifolia

Nut grass rush.

Nyrtaginaceae

Nyctalis, catalogue

Nymphaea

advena

alba

catalogue

oclorata

$$
\text { rosea. }
$$

Nymphaeaceae

Nyssa

aquatica
aquatica
biflora.
grandidentata
multiflora
multiflora
sylvatica
$\quad$ biflora
tomentosa
uniflora
villosa

6,12

651

117

651

651

68

651

70,261

651

651

651

651

Oak

barren

$14,43,109,161,179,833$

Bartram

$96,131,471$

basket.

473

470

bastard ........................... 470

black....... $47,60,70,84,91,96,98,471,8: 3,824$

black-jack

chestnut ....................... 32,57,91,469

chinquapin . .................... 83, 91,469

common. white

10

cow ....... 46, 61, 72,86,87,92, 100,110,470,8:3

Jerusalem ........................... 488
Oak-Continued.

Page.

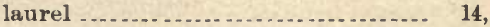
$47,92,95,100), 1112,109,122,131,366,472,821,833$ live . ........... $30,47,121,122,123,129,130$; $131,133,266,268,270,272,280,294,470,821,833$ mountain ........... $47,57,59,60,63,70,83,469$ overcup................... 46,95, 100, 125,469 pin

$91,100,470$

post .......................... 46, $60,68,70$

$87,89,91,96,98,99,100,10 \%, 108,469,8 \% 3$ quercitron ......................... 471

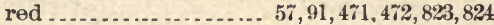
sand .................................. 130 scarlet ....................... 47,57,70,471 seaside scrub ....................... 473 shingle ............................... 473 Southern red............ 92, 102,110,125,471 Spanish .............................. 32, 46 , $60,70,86,87,89,92,96,98,110,112,131,472$ spotted.............................. 471

tan-bark ......................... $70,77,469$ Texas .................... 61, 68,86,110,470 white ................... 91, 100, 470,823 Turkey ...................... 95,96,112,471 willow ............................... 473 water ......... $61,92,100,109,122,125,472,833$ white - $46,60,70,77,84,86,87,88,99,214,468,824$ willow .................. 58,61,86,87,92,473 Oaks ............................... 46,47 ,

$57,60,61,77,84,88,90,99,101,112,117,272,273$ upland ...................... 66,90,91, 82. Oakesia puberula ..................... 438 sessilifolia . . . ....................... 438

Oat grass ........................ 366, 372, 373 meadow ......................... 826

sea ................................... 130

Oats ................. 68, 104, 105,110,135, 372, 826

Australian........................... 387

sea .................................... 382

water .............................. 362

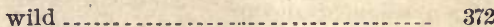

Obione arenaria ........................ 489

Obolaria caroliniana ................... 722 catalogue ................................ 672

virginica. ....................... 75,93

Ocimum basilicum ...................... 829 frutescens ............................ 697

Octaviana, catalogue.................... $\quad 230$

October flower ......................... 486

Octodiceras, catalogue ................... $\quad 299$

catalogue ........................... 144

Odontia, catalogue ..................... 203

Odontoschisma, catalogue .............. 288

Oedera trinervia ......................... 810

Oenanthe ambigua..................... 642 filiformis......................... 641

teretifolia ........................... 641

Oenothera biennis....................... 637 catalogue ........................... 637

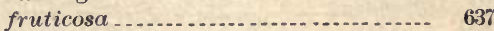

linearis......................... 638

grandiflora ........................ 637

humifusa ............................ 130

laciniata _........ 151, 15:

linearis .............................. 638

minima .......................... 637 
Oenothera-Continued.

Page.

sinuata

grandiflora ....................... 637

humifusa........................ 637

speciosa ............................ 638

Ohleria, catalogne.................... 173

Oidium......................... 23i

Okra ..................................... 830

Oldenlandia angustifolia ................ 739

boscii _.............................. 126

catalogue ............................ 737

glomerata

littoralis . . ......................... 126, 133

purpurea............................. 738

longifolia ...................... 738

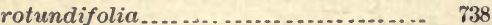

Old-man's beard .......................... 668

Olea americana.......................... 668

Oleaceae ................................ 666

Oleander............................... 835

Olive, American ...............14,45,4\%,122, 688 evergreen American .................. 122 family

Ombrophila, catalogue ............... 157, 158

Omphalia, catalogue .....................

Omphalaria ............................ 264

catalogue ......................... 278

girardi........................... 265

melambola ........................... 265

schaereri............................ 265

symphorea.......................... 265

umbella ............................. 265,267

Onagra iennis .................... 65, 104, 165

catalogue ........................... 637

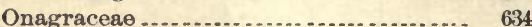

Onegyna .................................... 194

Onion ............................. $82^{2}$

wild ................................. 439

Onoclea, catalogue................... 318

sengibilis ............................ 125

Onopordon, catalogue ................ 818

Onosmodium, catalogue..................

hispidum......................... $\quad 692$

Opegrapha.............................. 264

catalogue ......................... 270

tribulodes............................ 266

Opegrapheae......................... 2r0,284

Ophiobolus, catalogue.................. 175

Ophiodothis, catalogue................... 171

Ophioglossaceae ......................... 43,310

Ophioglossum bulbosum .................... $\quad 310$

catalogue ............................ $\quad 310$

crotalophoroides ............... 65, 66,121

nudicaule ........................... 310

tenerum ............................... 310

vulgatum crotalophoroides ............ 310

nudicaule ...................... $\quad 310$

Ophiorrhiza mitreola .................... 669

Ophryscernua............................ 456

liliifolia........................... 458

loeselii.............................. 458

pubera............................. 460

Oplitrichum, catalogue................ 236

Oplismenus, catalogne ................... 355

hirtellus............................ 123

setarius ............................ 358

Oplotheca floridana.................... 493
Page.

sweet

Opossum wood ........................ 664

Opulaster, catalogue ................... 538

Opuntia, catalogue...................... 630

crus-corvi ........................... 131

mesacantha ........................ 630

rafinesquii ........................... 83,624

rafinesquii .......................... 630

vulgaris ............................ 630

Orache, halberd-leaf ...................... 489 sand ............................... 489

Orange.................................. 135, 832

bitter ............................... 96, 839

grass . ................................ 623

mock .............................. 552, 834

osage . . ......... . . . . . . . . . . . . . . . . . 475, 833

sweet ............................... 96, 832

Orbilia, catalogue ...................... 158

Orchard grass .......................... 384, 826

Orchid ................................. 120

opiphytic .......................... 123

Orchidaceae ........................... 452

Orchidocarpum parviflomum .............. 507

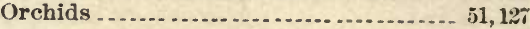

Orchis.... ......................... 452-45.

alba .................................. 454

blephariglottis ........................ 454

catalogue ............................. 453

ciliaris ............................... 454

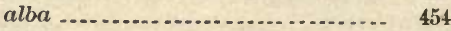

clavellata ........................... 453

crane-fly ........................... 459

cristata ........................... 454

family ................................ 452

fen $\ldots \ldots \ldots \ldots$

fissa .............................. 455

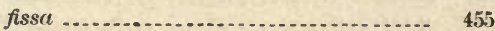

flava ................................ 454

humilis .............................. 453

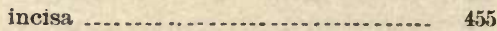

incisa ............................... 455

integra ............................. 454

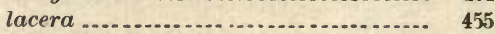

nivea ................................ 454

quinqueseta ....................... 455

ragged .............................. 455

showy ................................ 453

snowy-white....................... 454

spectabilis .......................... 75

tridentata.......................... 453

virescens ........................... 454

white-fringed........................ 454

yellow-f ringed...................... 454

Organotopic flora ....................... $\quad 50$

Origanum flexuosum...................... 698

Ornithogalum bivalve .................... 139

hirsutum ........................... 448

Orobanchaceae ........................ 52, 731

Orobanche americana .................... 731

uniflora ............................ $\quad 731$

virginiana .......................... $\quad 731$

Orontium aquaticum ................... 77,127

catalogue ........................... 424

Orpine family ......................... 532

Orthopogon ............................ $\quad 358$

setarius............................ 358 
Page.

Orthostichella

291

Orthotrichaceae

300,309

Orthotrichum, catalogue

300

pumilum

300

Oryza, catalogue

364

sativa

95,825

Osage orange .......................... 475

Osmanthus americana ................. 164 americanus ...................... 45, 1:2, 125

catalogne .......................... 668

fragrans .......................... 835, 136

major ............................. 136

Osmorhiza .............................. 646

brevistylis ............................ 646

claytoni ........................... 646

longistylis ............................ 646

Osmunda biternata ....................... 310

americana ........................... 466

catalogue ........................... 319

cinnamomea ...................... 64, 125

regalis ............................. 123, 125

virginiana ......................... 311

Ostrya

virginiana . ........... 82,83, 154, 180, 197, 198

Otidea, catalogue ....................... 156

Otophylla nichauxii.................... $\quad 726$

Ovularia, catalogue.................... $\quad 235$

Oxalidaceae............................. 584

Oxalis, catalogue ...................... 584

corniculata stricta................... 584

fillipes ............................. 114

grandis............................... 65,79

recurva ............................. 74,114

recurva.............................. 585

stricta.............................. 585

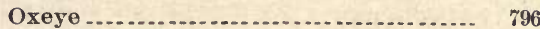

Oxybaphus ............................... 493

albida ................................. 493

nyctagineus ........................... 494

Oxycaryum schomburkianum............ 402

Oxydendrum arboreum.............. 4 4 $, \mathbf{i}, 70,118$

catalogue ........................... 656

Oxypolis, catalogue ..................... 611

teretifolia............................... 128

Pachysandra, catalogue ................ 599

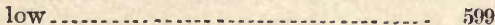

Pacific life area ........................ 31

Paepalanthus ............................ 429 flavidulus .......................... $\quad 429$

Painted cup ............................ 52,728

Paleozoic strata ....................... 58

Pallavicinia, catalogue.................. $\quad 287$ lyellii ............................... 285

Palm, arrowroot ................... 137

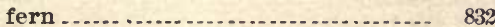

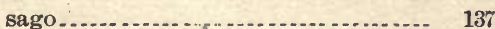

Palmae.................................. 483

Palmetto ................................. 423 blue...................... 96,122, 125, 423,424 dwarf .......................... 32,41,96,423 saw ............................... 131,424

Palms.................................... 423

Paludial forest of Coast Pine belt..... 109, 117 of Coast plain ..................... 124 of pine barrens................... 125 plants
Prge.

Palustrian plants...................... 49

Panaeolus, catalogue ................... 222

Panax, catalogue........................ 610

quinquefolium ................... 75,108

Pancratium carolinianum .............. 447 coronarium .......................... 447

mexicanum ........................ 447 occidentale............................ 447 rotatum ........................... 447

Panic grass . ..................... 351,354-357, 822

Panicularia, catalogue ................. 386 nervata ......................... 76

Panicum agrostidiforme ................ .65 agrostoides ......................... 357 elongatum ............................ 356

alabamense ......................... 342 albo-marginatum ................... 349, 350 amarum ............................. 357 anceps ........................... 98, 356 anceps .............................. 167

strictum ......................... 346

angustifolium ..................... 113,348 angustifolium ......................... 347

arenarium .......................... 347

arenicola .............................. 113

arenicola.......................... 348

autumnale ............................ 104

autumnale ........................... 355

barbinode.......................... 95

barbinode ............................ 826

barbulatum ......................... 352

beaked ............................ 356

bearded ................................... 352

bifidum ............................. 312

cahoonianum ....................... 318

capillare flexile ........................ $\quad 355$

minus ............................ 353

catalogue .......................... 346

caudatum .............................. 361

cenchroides. ....................... 362

ciliatifolium ........................ 349

ciliatum ............................. 349

clandestinum ....................... 65,355

cognatum ......................... 105, 355

colonum ........................... 358

commutatum .................. 65, 76, 88,354

consanguineum ....................... 349

consanguineum ........................ 348

creeping ............................ 34 i

crus-galli ............................ 357

curtifolinm ........................... 350

curtisii ............................. 346

dactylon............................ 373

debile............................... 347, 356

demissum ............................ 351

demissum .......................... 351

depauperatum .... ................ 347

dichotomum ................... 171,242,352

digitarioides ........................ 128, 346

divergens............................. 355

earlei............................... 349

elliottianum ........................ 358

elongatum ................... 65, 171,246,256

ramosior ...................... 357

ensifolium ......................... 359

equilaterale.......................... 845

fasciculatum ...................... 346 
Panicum-Continued.

Page.
113

fliforme

344

filiforme

$104,105,355$

flexile

342

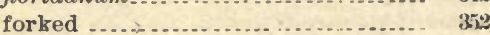

fuscum fasciculatum ................ 346

gaping ................................ 347

geniculatum ....................... 3350

georgianum ...................... 348

georgicum ......................... 348

germanicum ...................... 360

gibbum ........................... 123,358

glabrum ............................. 344

glaucum ............................. 358

gouini.............................. 347

grossarium ....................... 346, 347

gymnocarpon ..................... 125,347

haomacarpon ....................... 352

hairy .................................... 353

hamiltonii ......................... 345

hians .............................. 347

hirtellum........................... 357,358

hispid ............................ 355

hispidum .......................... $\quad 357$

imberbe............................. $\quad 359$

impoverished ........................ 347

insulare ............................ 345

italicum .............................. 360

joorii ................................. 355

jumentorum....................... 135

jumentorum ........................ 826

laeve ................................ 341

pilosum ........................ 311

laevigatum . ..................... 359

lanuginosum....................... 113,353

latifolium ...................... 65, 171,355

molle ............................. 355

laxiflorum ......................... $\quad 349$

leucophaeum ........................ 345

lineare .............................. 344

littorale ........................... 129,347

longifolium ......................... 356

longiligulatum...................... 351

longipedunculatum ................ $\quad 120$

loose-flowered ...................... $\quad 349$

lucidùm ............................ $\quad 350$

malacon.......................... 845

mattamusketense ................... 354

maximum .......................... 188, 826

melicarium ...................... 97,98, 347

microcarpon ......................... 353

molle.......................... 135, 358, 826

multiflorum......................... 353

nashianum ..................... 97,113,357

nerved ........................... $34 i$

nervosum ............................ 354

neuranthum................. 113,347,348 ramosum...................... 348

nitidum barbulatum................. 352

oligosanthes .......................... 354

parvispiculum...................... 351

pauciflorum ........................ 113

pauciflorum ........................... 354

paucipilum .......................... 350

polyanthes..................... $65,76,116,353$

porterianum .......................... 35,

proliferum.......................... 356

inflatum ......................, 123
Panicum proliferum-Continued. Page. geniculatum ..................... 356 prostratum ......................... 346 pseudopubescens ..................... 352

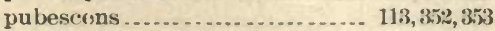
pubifolium .......................... 355 purple ............................ 358 pyriforme ........................ 349 repens............................ 1:29,347 confertum ........................ 347 roanokense ......................... 351 rostratum ............... $65,76,123,167,356$ round-fruited ........................... 353 rufum .............................. 343 sanguinale ..................... 135, 258,345 scabriusculum . . . ..................... 123,354 scoparium . ......................... 353 scoparium .......................... 353,354 genuinum ...................... 353 major ............................. 353 minor ........................... 3 pauciflorum ...................... 354

scribnerianum....................... 353

Scribner's............................ 353

serotinum ........................... 120

setarium ............................. $\quad 358$

small-fruited .......................... 353 sp ..................... 171, 236, 237, 238,254 sphaerocarpon .................... $76,113,353$ stenodes ............................ 12 $\%, 316$ stenodes ............................. $350^{\circ}$

texanum. ........................... 340

thurowii ............................

trifolium........................... 350

variable ............................ 354

verrucosum . . ...................... 123,356

verticillatum ......................... 360 parviforum ....................... 360

villosissimum ...................... 353

villosum .............................. 349 virgatum ............ 128, 188, 189, 190, $255,35 \%$ breviramosum ................... 357

viride .............................. $\quad 359$ viscidum. .......................... 123, 354

walteri............................... 357

valteri . ............................. 355,358

webberianum....................... 351

woolly-stemmed..................... 353

xanthospermum .................. 109, 348

Pannaria............................... 264

catalogue ............................ 269

crossophylla ........................ 265 molybdaea........................... 260

nigrocincta .......................... 266

petersii ........................... 26i

saxicole ............................. 265

stenophylla ....................... 265, 267

triptophylla ....................... 265

Pannarieae ............................ 279, 284

Pansy ................................... 153

Wild ............................ 699

Panus, catalogue ....................... 221

flabelliformis ........................ 223

Papaveraceae........................... $5: 0$

Papaw ............................ 86, 101,102

small-flowered....................... 507

Para grass ......................... 95, 135, 358,826

Paralia, catalogue....................... 143

Parasitic plant associations ............. 51 
Page.

Pardanthus

chinensis

Parietaria, catalogue erecta

Paris .

Parkinsonia aculeata catalogue prickly

Parmelia catalogue domingensis............................ perforata russellii saxatilis (n)

tiliacea ........................... 266

Parmeliaceae. 274,284

Parmelieae 281,284

Parnassia 5335 asarifolia catalogue

Parodiella, catalogue ......................

Paronychia, catalogue riparia .

Parosela, catalogue.

Parrot beak

Parsley family.

fool's

knotted hedge

marsh.

pinnate dog's.

Parsnip, meadow. mountain meadow water

Parsonsia, catalogue

Parthenium, catalogue integrifolium

Parthenocissus, catalogue quinquefolia

Partridge berry

Paspalum

Alabama

altissimum

arenarium

bifidum

boscianum

catalogue

ciliatifolium .

dasyphyllum

ciliatum.

compressum .................... 56, 120, 250

compressum........................ 339

conjugatum ........................ 340

curtisianum......................... 341

dasyphyllum ........................ 97,113

dasyphyllum ........................ 341

debile................................ 341

difforme ........................... 113,343

digitaria. $56,97,104,135,248,349$

dilatatum

104,340

distichum

vaginatum

341

early-flowering

340

elliottii.

filiforme

113,342

glabratum
Paspalum-Continued.

Page.

fringe-leaf . ......................... 341

furcatum.......................... 340

glabratum ....................... 116,342

laeve ....................... 65, 104, 171, 257

large-flowered...................... 342

lentiferum ............................ 341

longipedunculatum .................. 341

membranaceum ................... 127,340

michauxianum ..................... 123

michauxianum ...................... 340

ovatum ............................ 342

paspalodes .......................... 340

platycaulon .......................... 339

plicatulum..................... 113, 2336, 342

praecox............... 97, 119, 123, 127,341,821

curtisianum ..................... 341

purplish .............................. 343

purpurascens........................ 343

racemulosum........................ 113,34:

sanguinale ........................... 345

setaceum ........................ 113, 171

ciliatifolium ...................... 341

sp $\ldots$

undulatum ......................... 342,343

vaginatum . ......................... 132, 340

vaginatum ........................ 340

virgatum .......................... 343

walterianum ........................ 340

Walter's .............................. $\quad 340$

Paspalus macrospermus .................. 34:

Passiflora, catalogue ................... 630

incarnata ....................... 241,245

Passifloraceae ......................... 630

Passion flower, common ................. 630

family ............................. 630

yellow .............................. 630

Patellaria, catalogue .................. 159

rhabarbarina ....................... 160

Patellariaceae ......................... 159,262

Patinella, catalogue ..................... 159

Paulownia ............................. 719

catalogue ........................ 719

imperialis.......................... 719

tomentosa ......................... 835

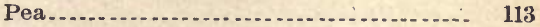

butterfly ........................... $\quad 578$

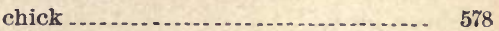

deer .................................. 577

erect milk......................... 581

everlasting ........................... 578

family ....................... 61, 67,822,823

garden .............................. 830

goober ........................... 830

Japanese ........................... 830

milk ............................. 580,581

sensitive ............................ 556,55\%

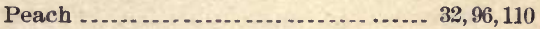

wild .................................. 552

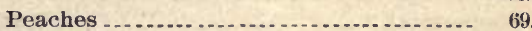

$80,89,106,134,136,256,822,823,832$

in Coast Pine belt . . . ..... . . . . . . . . . . 8 822, 823

Tennessee Valley .................. $8: 24$

Peanut................................ 8 823,830

hog ................................ 578,579

on metamorphic hills... .............. $\quad 823$

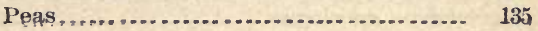


Page.

Pecan ....

bitter ................................. 95, 463 nut................. 136, 461

Pecans in the Coast plain ................ 822

Pedaliaceae ................................ 733

Pedicularis canadensis................... 52

catalogue ............................ 728

gladiata........................... 729

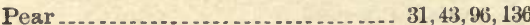

balsam ............................. 747

Keiffer in Coast Pine belt ............ 8

Keiffer............................. 8 8:28, 831

Le Conte............................. 8:2:, 831

prickly ............................... 133,630

sand ................................... 831

Pearlwort.............................. .. 498

Pears_............................... 69,80,89,831

in Tennessee Valley .......... . ......... 824

Peat mosses, author's study .............. $\quad 290$

Peavine .................................. 571

Pellaea atropurpurea .................... 73

catalogue 313

Pellia, catalogue........................ 287

Pellitory ................................... 478

Peltandra alba ............................ 425

catalogue ........................... 425

sagittifolia......................... 66, 643

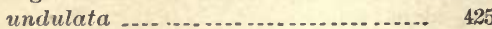

virginica.......................... 77,125

Peltigera................................. 264

catalogue .......................... 280

polydactyla ....................... 266

Peltigereae ............................. 280,284

Pencil flower

Penicillaria spicata........................ 95 spicata ............................. 826

Pennisetum typhoideum . ................ $\quad 826$

Pennyroyal ........................... 699, 700 false

Pennywort ....................... 649,650,672

Penthorum, catalogue ................... 533

Pentstemon, catalogue................... 718

hirsutus .................. 98,114, 193,243

laevigatus............................. 719

digitalis......................... $\quad 718$

multiflorus .......................

pubescens ............................. $\quad \pi 18$

Pepper, bird........................... 714

bird's-eye............................. 830

Cayenne ............................ 714

Chile ................................ 830

large red............................... 830

sweet................................. 830

water .............................. 485

Pepperbush, sweet ..................... 65\%

Peppergrass . . .......................... 5:2, 828

European .......................... 5:2

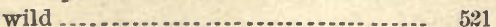

Pepperidge ............................ 611,651

Peppermint ....................... 56,697,829

Pepperroot .............................. 525

Peppers, red............................ 247

Peramium, catalogue.................... 457 repens.

Perdicium semiflosculare..................

Perennial ray grass .......................

Perichaena, catalogue.
Periconia, catalogue .................... $\quad 237$

Peridermium, catalogne ................ 192

Perilla, catulogue ....................... 697 frutescens ............................ 56

Perilla ocymoides.......................... 697

Perisporiaceae......................... 167,26:2

Perisporiales ............................ 165,20\%

Perisporium, catalogue ................. $16 \%$

Peronospora calotheca ................... 15: catalogue ............................ 15in

seymourii ............................ 152

Peronosporaceae ...................... 152,26\%

Peronosporales ......................... 151,262

Persea . ............................. 159,170,266

Persea ...................................... 266

borbonica ............................ 100

carolina.............................. 96

carolinensis......................... 518

palustris ......................... 519

catalogue ......................... 518

palustris ........................... 164,244

Persicaria, bristly ........................ 485

dense-flowered ....................... 484

opelousas ............................ 485

Persimmon .................... 32, $46,66,68,70,664$

Persoonia lanceolata ...................... 809

Pertusaria ............................. 264,266

catalogue ........................... $2{ }_{25}$

sorediata............................ 265

Pestalozzia, catalogue ................... $\$ 51$

Pestalozziella, catalogne ................ 252

Petalostemon ........................... 564

candidus ........................... 564

carneus .............................. 561

corymbosus.......................... 56ij

gracilis............................. 564

roseus .................................. 564

violaceus............................... 565

Peters, T. M., botanical exploration....... 17

fungi ............................. 148, 149

lichens . . . . ........................ 263,265

Petroselinum sativum .................. $\quad 8: 29$

Petunia

catalogue .......................... 716

Peziza.......................... 156,15i, 158, 159

alboviolacea ......................... 158

catalogue ........................... 150

phlebophora........................ 156

psammophila ........................ 237

Pezizaceae . .............................. 155, 20.2

Pezizales.................................. 155, 260

Pezizella .................................. 158

Pezicula rhabarbarina................... 160

Phacelia ............................. 687,688

bipinnata ........................... 68

brevistylis ....................... 92

bipinnatifida brevistylis.............. 687

catalogue ........................... 687

dubia................................. 66

fimbriata......................... 688

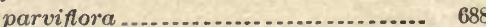

purshii . ............................ 83,93, 108

pusilla .............................. 688

Phacidiaceae ......................... 160,262

Phacidiales ............................. 160,262

Phacidium, catalogue ................... 161

Phaeodon, catalogue ..................... 205 
Page.

Pbaeophyceae

Phalangium esculentum

Phalaris americana

catalogue

intermedia.

oryzoides.

villosa.

364

364

364

363

343

Phallaceae 229,263

Phallales 229,263

Phallus, catalogue.................... 230

Phanerogamcie.......................... 383

Pharbitis barbigera ....................... 679

hederacea.

hispida

$6 \% 9$

679

Pharnaceum maritinum

495

Phascaceae

$29 \%, 309$

Phaseolus angulatus

catalogue

diversifolius

helvolus

helvolus

582

lunatus.

582

multiflorus

255,830

perennis...

polystachyus

581

vulgaris... ............ 169,187,240,250,830

nanus ........................ 830

Pheasant's eye......................... 516

Phegopteris catalogue ................. $\quad 316$

hexagonoptera ..................... $\pi 4,94$

Phialea .................................. 158

Philadelphus, catalogue ................ 535

grandiflorus ........................ 66

hirsutus........................... 78

inodorus ......................... 108

Philonotis ............................... 291

catalogue ........................... 303

Philotria .............................. 49

canadensis ..... .................... 127

catalogne ............................ 333

Phlebia, catalogue..................... 203

Phleospora, catalogue .................... $\quad 260$

Phleum, catalogue ....................... $\quad 367$ pratense .......................... 826

Phlomis nepetaefolia .................... $\quad 706$

Phlox .................................. 684-686

acuminatc .......................... 684

amoena ........................... $6 \pi, 114$

aristata .......................... 685

carolina............................ 685

catalogue ........................... 684

divaricata.......................... 68,75

family .............................. 684

floridana ............................ 243

Florida .............................. 685

maculata.................. $65,68,75,88,243$

paniculata .......................... 65

pilosa ............................. 686

detonsa ............................ 114

valteri......................... 686

pyrantidalis......................... 685

sp .................................... 165

walteri $\ldots \ldots \ldots \ldots \ldots \ldots \ldots \ldots \ldots \ldots$

Phloxes ................................. $8 \approx 3$

Phlyetaena, catalogue ................. $\quad 259$

$15894-57$
Page.

Pholiota, catalogue...................... 224

Phoma, catalogue .... ................. 254 maculare.......................... 255

Phoradendron, catalogue .............. 479 flavescens......................... 52

Photinia serrulata...................... 834

Phragmicoma, catalogue................. $\quad 288$ clypeata......................... 285

Phragmidium, catalogue ................ 191 fragariastri...................... 191 xanthocarpa ....................... $\quad 285$

Phragmites .............................. $\quad 49$

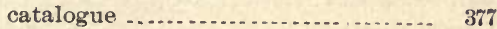

communis ......................... 128,377

Phryma carolinensis.................... 693 catalogue .......................... 696

family ............................... 845

leptostachya......................... 75

Phrymaceae........................... 845

Phycomycetes........................ 150,262

Phyllachora, catalogue.................. 171

Phyllactinia, catalogue ................. 167 guttata........................... 167

Phyllanthus, catalogue ................. 591

Phyllosticta, catalogue ................. 252

desmodii ........................... 253

Physalis angulata ..................... 65,709 angulata ............................ 709

linkiana........................ $\quad \% 10$

angustifolia ...................... 130

brasiliensis..........................

ciliosa ............................... 110

heterophylla..................... 711

ambigua ......................... $\quad 711$

hirsuta ........................... 709

lanceolata.......................... $\quad 710$

linkiana............................. $\quad 710$

maritima........................ $\quad 712$

nyctaginea....................... 711

obscura ............................ 709,711

pubescens......................... 709

viscido-pubescens................. 709

pennsylvanica ..................... 710,711

peruviana......................... 708

pruinosa .......................... 74

pruinosa ........................... $\quad 709$

pubescens.......................... 74

virginiana ..................... $74,110,114$

virginiana ......................... 711

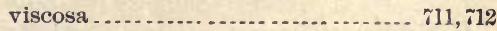

viscosa ............................ 711

spcthulcefolia ................. 712

tomentosa.......................... 711

valteri............................ 711

Physalodes, catalogue .................. 708

physalodes.......................... 65

Physalospora, catalogue ................ $\quad 176$

Physaraceae........................... 141

Physarum, catalogue.................... 141

chrysotrichum....................... 141

Physcia ............................. 264

catalogue .......................... 281

comosa . .......................... 266

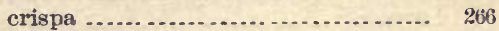

flavicans .......................... 282

obscura .............................. 265

speciosa galactophylla.............. 281 
Page.

Physcomitrium ......................... $: 91$ catalogue ........................... 301 pyriforme ............................ 301 turbinatum langloisii . .............. 293.294

Physocarpa .......................... 538 opulifolia ........................... 538

Physma ................................... $\$ 264$ catalogue .......................... 230

Physostegia, catalogue..................

Phytolacca.......................... 250,259 catalogue ......................... 493 decandra ......................... 242, 254

Phytolaccaceae......................... 493

Pickerel weed .......................... 50,431 family ........................... 431

Picris, catalogue.......................

Pieris, catalogue......................... 650 . nitida ..................... 45.66,118,12)

Pigeon grass.......................... 358,359

Piggotia, catalogue..................... $\quad 260$

Pigmy weed ......................... 533

Pignut ......................... 47,6 $\%, 96,462,8 \approx 3$

Pigweed .............................. $48 \tau$

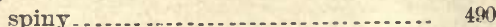

Pilacraceae ........................... 194.262

Pilacre, catalogue ....................... 194

Pilea

hermiarioides....................... 4 is

microphylla herniarioides............ 478 pumila .............................. 478

Pileolaria brevipes........................ 187

Pilosella spathulata .....................

Pimpernel, blue-flowered ................ 663 common ........................... 662 water ............................ 661,662

Pimpinella integerrima................ 85 integerrima ........................... 645

Pinaceae............................... $3: 3$

Pin-clover ............................ 583

Pindar . . . . . 830

Pine........................... 43,109, 159,821 barren flats......................... 116 Chilean ........................... 136, 833 Cuban..... 42,47,116,11\%, 118, 122, 139, 131,323 family .............................. 323 Florida spruce....................... 324 heart................................ $3: 3$ Jersey ............................. 324 loblolly ................................ 47 , $58,68,70,92,99,11 \%, 118,122,3: 3$ long-leaf...................... 47,58,59, $60,62,66,91,96,99,106,10 \%, 110$, $112,113,118,131,134,323,821,822$

meadows .......................... 129

old field ............................... $3: 3$

pitch .............................. 320

rosemary ......................... $3: 3$

sand ............................... 131, 324

scrub................... $32,57,68,70,77,324$

short-leaf ......................... $4 \pi$ $60,68,70,7 \%, 90,99,109,11 \%, 324,822,823$

slash ............................. 42,323

Southern ......................... 32,47

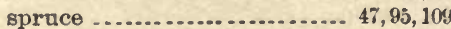

yellow ......................... 323

spruce ......................... 96,99,324

yellow ........................... 32, 324
Pines ......................... Page.

84. 90, 95, 110, 11: 124, 247, 255, 323, 324, 325

Piresap .............................. 65: family............................. 652

Pineweed ............................... $6: 3$

Pinguicula .............................. $5 \%$ australis .............................

catalogue ......................... $\quad 7 \% g$

lutea ............................... 120

planifolia .......................... $12 \mathrm{t}$

pumila .............................. 120

Pinguiculaseae .......................... $\quad 729$

Pinguiculas............................. 120

Pink family ............................ $49 t$

fire ............................... $49 \%$

Indian .......................... $6 \mathbf{7}, 669$

wild ............................. 497

Pinus .......... 15\%, 195, 19\%, 206, 20\%, 210, 213,225

australis ......................... 612

australis ............................ 323

cancidensis ......................... 824

catalogue ............................. 323

clausa .............................. 131

cubensis............................. 323

echinat $\ldots . . . \ldots \ldots \ldots \ldots . . .14,32,70,16 \%, 192,8 \% 3$ elliottii................................ $3: 3$

glabra........................ 95, 96.99, 109

inops .............................. 324

clausa ........................... 324

mitis ............................... 324

palustris ........................ 55, 19?, 210 serotina......................... 192

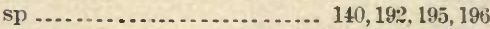
taeda ......................... $58,70,192,823$ heterophylla ...................... $3: 3$ virginiana ................... 32, 5 ז, 70,192 Pinweed ................................ 115,625

Pipevine, hoary ........................ 480

large-leaved .......................... 480

Pipewort ............................ 4:28, $4: 29$

family ............................. 423

Pipeworts ............................. 12\%

Piricularia............................ 233

catalogue ........................... $2 \$ 36$

Piscidia longifolia....................... 569 punicen ........................... 569

Pisum sativum ........................ 165, 830

Pitcheria galactoides .................... 583

Pitcher plant ........................ 117,530 family ............................. 530

Pittosporum, fragrant ................. 13i tobira ............................. 13i 833

Placodium ............................. 264 aurantiacum........................ 2835

catalogue ........................... $2 \%$

ferrugineum..................... 265

Plagiochila ............................ 255 catalogue ......................... 25

ludoviciana ......................... 25.

Plagiothecium ........................... 2291 catalogue ........................ 308

Plagiotropis, catalogue ............... 146 micans ............................. 291

Plane tree ............................. $\quad 538$

family............................ 538

Planera aquatica ........................ 46 catalogue ......................... 475 
Page.

Planer tree $46,125,475$ gmelini

475

Plan of present work .................. 12

Plantago aristata...................... 153 catalogue ......................... major ............................... occidentalis patagonica aristata .................... $\quad 736$ purpurascens ......................... $\quad 736$ sp virginica longifolia

Plantaginaceae

Plantain, common wayside

downy rattlesnake .....................

English

family .............................. $\quad$ r35

greater indian ...................... 815

indian .............................. 815,816

lance-leaf indian.................... $\quad 716$

many-seeded.......................... 736

mud .................................. 432

ovate-leaf ........................... 816

pale indian. ........................... 815

seaside ................................. $\quad 736$

tuberous-rooted indian ................ 816

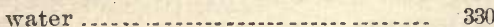

Plantains ....................... 735 , 736

Plant associations ........................ 25 distribution, secondary influences.... 33 formations........................... 35

Plants grown for leaves and stems, list. 828,829 of Alabama, tabular statement........ 837

Plasmodiophoraceae ..................... 139

Plasmodiophorales ...................... 139

Plasmopara, catalogue .................. 153

Platanus .......................... 169,178,179 catalogue ........................... 538 occidentalis ........................ 166, 833

Platanaceae............................... 538

Platanthera............................. 453 holopetala................................. 455

Platygyrium repens..................... 306

Plectascales ............................ 164, 262

Pleospora, catalogue ................... $\quad 176$

Pleosporaceae ......................... 174, 262

Pleuridium, catalogue .................. $29 \%$

Pleurocarpi .............................. 304

Pleurosigma, catalogue .................. 145

Pleurotus, catalogue .................... 225

Plicariella, catalogue ..................... 156

Plowrightia, catalogue................... 172

Pluchea bifrons .......................... 790

campborata........................ $\quad 789$

catalogue ......................... $\quad$ i89

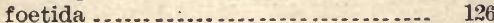

foetida ............................. $\quad 789$

subdecurrens......................... 790

Plum.................................. $31,43,96$

American .......................... 5i

botan ................................. 832

Chickasaw .......................... 551,831

deer ................................ 553

Japanese ........................... 831, 832

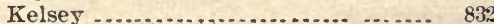

prairie ........................ 99, 1 20,551
Plum-Continued.

Puge.
red
$61,85,832$

sea ................................. 133

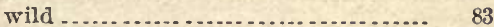

garden ........................... 551

goose ........................... 832

yellow .............................. 551

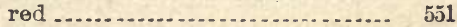

yellow .............................. 832

Plumbaginacea

Plume grass ............................. 334, 335

Plums. ................... 46, 57,61, 99, 106, 831, 832

Pluteus, catalogue .......................... 224

Poa ambigua............................... $3 \pi 8$

arachnifera ......................... 827

autumnalis ........................ 74

bahiensis ........................... 380

capillaris .......................... 382

caroliniana .......................... 380

catalogue ............................ 384

chapmaniana ........................ 73

ciliaris .............................. 381

compressa . ......................... 104,826

conferta........................... 381

cristata ............................ 384

eragrostis ................................ 379

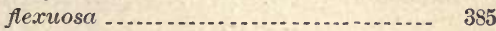

glomerata ........................... 381

hirsuta ................................ 381

hypnoides ............................ $\quad 3 \% 9$

interrupta......................... 380

nervata............................. 386

nitida ............................. 380

oxylepis ........................... 380

parviflora .............................. 386

pectinacea............................. 381

pilosa .............................. 380

pratensis.............................. 826

quinquefida ......................... 378

refracta ............................ 381

reptans ............................... $\quad 379$

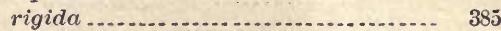

serotina .............................. 385

sesleroides ............................ 378

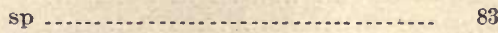

striata ............................ 386

sylvestris ...........................

trivialis .............................. 826

viridis ................................ 384

Poaceae ................................ 73,119

Podalyria uniflora ...................... 558

Podocarpus sinensis ....................... 832

Podophyllum, catalogue ............... 517 peltatum ......................... $75,189,254$

Podosphaera, catalogue................. 165 kunzei............................. 165

Podostemon .......................... 49

abrotanoides........................ in

catalogue .......................... 531

ceratophyllum..................... $\%$

Podostemaceae ........................ 532

Pogonatum brevicaule ...................... 303

Pogonia ................................. 51

catalogue ......................... 455

divaricata ....................... 97,126

ophioglossoides .................... 126 
Poison darnel

elder

hemlock

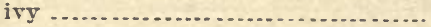

oak

vine

Pokeberry, coms

Pokeweed

family

Polanisia, catalogue uniglanidulosa

Pole bean

Polemoniaceae

Polemonium, catalogue

dioium

reptans

rubrum.

Polyactis.

Polycarpaea, catalogue

Polycarpon, catalogue

Polygala ambigua

attenuata

cittenuata

boykinii.

catalogue

chapmani

corymbosa.

cruciata

curtisii

family

fastigiata

hookeri.

incarnata

lutea

nana

mariana

nana.

polygama

pubescens

purpurea

sanguinea

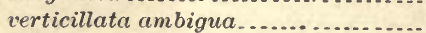

viridescens

Polygalaceae.

Polygonacea

Polygonatum biflc

catalogue

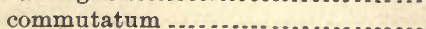

giganteum

Polygonella, catalogue

ericoides.

gracilis

meissneriana.

parvifolia.

polygama

Polygonum acre

aviculare erectum

littorale

catalogue

densiflorum

dumetorum

fimbriatum

glabrum.

gracile.

hydropiper

mite

opelousanum
Page.

388

600

646

601

601

601

493

493

493

529

ธี?9

830

684

686

688

93

686

235

502

501

590

589

589

105

588

120

588

120

65

588

590

120

66,88

120
Polygonum-Continued.

pennsylvanicum.................. 183,189

polygamum ......................... 486

portoricense ....................... 125

punctatum......................... $\quad 240$

sagittatum ....................... 65

scandens ......................... 244,486

setaceum ......................... 187

sp ................................ 18\% 189

Polymnia canadensis radiata ........... 83

catalogue .......................... $\quad 791$

uvedalia .............................. 65

Polypodiaceae ......................... 311

Polypodium ........................... 41

catalogue .......................... $\quad 310$

bulbiferum .......................... 318

dilatatum .................. $31 \%$

filix-foemina ........................ 315

fragile ............................. $\quad 318$

hexagonopterum .................... 316

incanum .......................... 51,311

marginale......................... 317

noveboracense ................. 316

obtusum ........................... $\quad 318$

polypodioides...................... 51

vulgare ........................... 51, 73

Polypogon, catalogue ................. \$69

Polyporaceae .... ..................... 206,263

Polyporeae ............................. 206

Polyporus ................... 20\%, 208,210,211,213

catalogue ........................ 208

flavo-squamosus...................... $\quad 209$

nigropurpurascens................... 213

perennis......................... 211

plebeius.......................... 209

resinosus ........................... 168

Polypody .............................. 311

Polypremum, catalogue................ 669

Polysaccum, catalogue ................... 234

Polystichum, catalogue................. 317

Polystictus, catalogue ................. $\quad 210$

Polytaenia, catalogue.................. 642

nuttalli ........................... 104,8:3

Polythrincium, catalogue............... $\quad 238$

Polytrichaceae ........................ 303, 309

Polytrichum ............................. 291

brachyphyllum.................... 294

capillare ......................... 29:2

catalogue ......................... 303

formosum .......................... 303

tenue.............................. $\quad 291$

Pomegranate ..................... 96, 136, 83:

Pond lily ................................. 504 yellow ............................. 504

Pond spice............................ 519

Pondweed .............................. 327

family ............................ 327

horned ............................. $\quad 329$

Pondweeds ............................... 49

Pontederia, catalog ne.................. 431

cordata .......................... 50,128

Pontederiaceae........................ 431

Ponthleva ............................. 460

catalogue ......................... 460

glandulosa ....................... 460

Poplar ............................... 464, 824

Carolina ............................. 465

silver........................... 833 
Page.

Poplar-Continued. silver-leaf........................... 465 white .............................. 833 yellow ............................ 84,506

Poppy family.......................... 520 prickly............................. 520

Populus................................ 43 alba ................................... 833 angulata............................ 465 carolinensis......................... 465 catalogue ......................... 464 deltoides............................ 185 grandidentata ...................... 185

heterophylla........................ 185 monilifera ......................... 185, 465

Porella................................... 285

catalogue .......................... 288 involuta............................. $\quad \approx 88$

Poria, catalogue ........................ 206

Poronia, catalogue ...................... 182

Porothelium, catalogue................. 213

Porotrichum, catalogue .................. $\quad 308$

Porteranthus, catalogue ................. 539 stipulaceus ......................... 75,93 trifoliatus .......................... 75

Portulaca, catalogue .................. 495 oleracea............................ 55, 152

Portulacaceae ......................... 495

Post-oak prairies ........................ 98

Potamogeton, catalogue ................ 327

crispus............................. $12 \%$

diversifolius . ......................... 126

fluitans .............................. $32 \pi$

hybridus. ........................... 127

hybridus................................ 328

lonchites ............................ $12^{\gamma}$

nutans .............................. $32 \gamma$

perfoliatus........................... 127, 329

pinnatum ............................ 639

pusillus .............................. 127

spp ................................. 49

rufescens............................ 32

tenuissimus ........................... 328

Potato .................................. 31

wild .............................. 680

Potatoes, Irish. ...................... 69, 80, 828 sweet . .................. 80,110,134,822,828

Potentilla, catalogue ................... 542 durandii........................... 541

simplex............................. 542

Pottiaceae ........................... 299, 809

Poverty grass ........................... 124, 364

Prairie belt, root and forage crops...... 823 vegetation and soil ................ 823 region.

Prairies.

Prenanthes.............................. 755

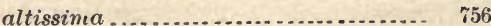

crepidinea .......................... 755

crepidinea .......................... 755

deltoidea............................. $\quad \mathbf{7 5 6}$

serpentaria ......................... 755

barbata ......................... 755

Prickly ash, southern ............... 102,587 pear.............................. 133,630

poppy, Mexican ..................... 5:20

Pride of China.
Primrose ............................. 823

erening ...................... $634,637,638$

family ................................ 661

Primulaceae............................ 661

Prinos ambiguus......................... 603

coriaceus........................... 604

glaber .............................. 604

montanus.......................... 603

verticillatus........................... 604

Privet.... ............................. 57

Carolina .......................... 608

evergreen.......................... 835

Japan ................................. 835

Japanese.......................... 136

mountain ......................... 603

southern .......................... $5 \tilde{6}, 102$

swamp. ............................. 667

Procumbent Polypremum ................ $\quad 669$

Prosartes................................ 441

lanuginosa ........................ 441

Proserpinaca, catalogue .................. 639 palustris ............................... 639

sp .................................. 193

Prosthemium, catalogue ................. 25i

Protococcales........................... 146

Prunella, catalogue..................... 705 vulgaris............................... 257

Prunus ................................. 201,211

americana ... 57,61,83,85, 165, 172, 189,551,832 angustifolia ........... 154, 172, 189, 208, 251, 831

avium .............................. 240

caroliniana ....................... 171, 834

catalogue .......................... 551

cerasus. .............................. 165

chicasa ............................. 551

hiemalis............................ 551

injucunda......................... 62

maritima .......................... 551

serotina ...................6. $61,84,154,163$,

$172,189,209,250,251,254,260,261,552$

montana ....................... 552

neomontana .................... 62

sp .............................. 251,257

triflora ..................... 154,162,235, 832

umbellata....................... 99, 122, 172

Psammophytes ........................... 129

Psanimophytes ........................... 129

Psathyrella, catalogue ................. 2:2

Pseudauliscus, catalogue ................. 143

Pseudohelotium sacchariferum ........... 158

Psilopezia, catalogue ..................... $\quad 155$

Psoralea ................................ 88

canescens ........................ 115

catalogue ......................... 562

dalea ................................ 564

eglandulosa ........................ 563

melilotoides......................... 563

pedunculata ......................... $\quad 67$

simplex . 116

Psylocybe, catalngue ..................... 222

Ptelea, catalogue ......................... 587 monophylla ........................ 600

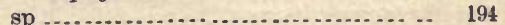
trifoliata ....................... 99, 108, 194

Pteridophyta ............................. 312

Pteridophytes ........................... 48,49

Pteris alabamensis........................ 312 aquilina ........................... 123 
Pteris-Continued.

atropurpurea

catalogue

Pterocaulon, catalogue

polystachyum.

pycnnstachyum

undulatum.

Ptilimnium capillaceum catalogue

Ptychomitrium. catalogue

Puccinia andropogi.

andropogi.

catalogue

coronata

cyperi

emaculuta.

graminis

lateritia.

maydis

pekiana

pruni-spinosae

rubigovera

silphii

tanaceti

virgata.

xanthii.

Pacciniaceae

Pucciniastrum, catalogue.

Puccoon.................................. 691

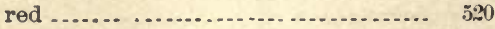

yellow................................ 508

Pulmonaria virginica .................... $\quad 690$

Purple love grass .................... 380

Punica granatum...................... 136, 832

Purslane, common...................... 495

family ............................... 495

sea .............................. 494, 495

water ...................................... 636

Pumpkin, cheese........................ 830

large ................................ 830

Pycnanthemum ......................... 698

albescens ............................ 699

aristatum hyssopifolium .............. 698

hyssopifolium ........................ 698

incanuin albescens................... 699

linifolium........................... 698

montanum .......................... 699

nudum ............................ 698

tullia .............................. 699

Pylaisia, catalogue ....................... 306

Pylaisiella . ............................ 291

Prracantha.............................. 834

Pyrenastrum ........................... $\quad 264$

catalogue ......................... 269

Pyrenopsis............................. 264

catalogue ......................... $2 \%$

melambola......................... 267

Pyrenopeziza, catalogue............... 158

Pyrenula .............................. 234, 266

catalogue ....................... $26 i$

Pyrethrum maritimum .................. 813

Pyrola family........................... 652

maculata........................... 65.5

Pyrolaceae............................. 652

Pyrrhopappus........................ 754

carolinianus ........................ 754
Page.

Pyrus angustifolia $61, \pi 1,49,122$ botryapitem ......................... 545

catalogue ......................... 545 communis .................. 246, 254, 256, 831

leucocarpa......................... 253

malus .............................. 831

ovalis .................................... 545

sanguinea.......................... 545

sinensis ............................ 831

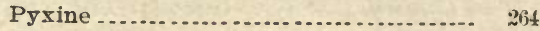

catalogue .......................... 281

picta .............................. $23 b$

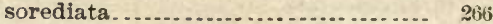

Pyxidanthera spathulata................. 534

Quaking grass.......................... 3\$3,384

Quamasia ............................ 40

catalogue .......................... 440

esculenta .......................... 98

hyacinthina....................... $\quad 440$

Quamoclit coccinea .................... $6{ }_{8}$

quamoclit .......................... 56

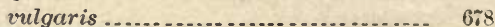

Queen of the meadow................... $\quad 761$

Queen's delight ......................... 594

Quercus......................... 140,157,158,

$159,162,173,1 \% 7,179,180,181,195,19 \%, 199,201$,

20:2, 203, 204, 205, 206, 208, 212, 220, 238, 239, 250 acuminata . ................. $32,5 \%, 91,469,091$ alba ......... 46, 60,70, 7\%, 155, 165, 181, 192, 468 minor ......................... 469 aquatica............................. 117 aquatica .......................... 61,154 ,

$161,162,166,16 \tau, 1 \% \tau, 181,192,249,250,4 \tau 2,833$ boyntoni ............................. 845 brevifolia ....................... 154, 433,822 brevilobata ......... 16,41,93,100,470, 591, $8: 33$ breviloba, correction of error ........ 845 castanea ........................... $\quad 469$ catalogue ........................ 468 catesbaei....................... 95,4 11,559 cinerea .............................. $4 \pi 3$ coccinea .................... 4i $, 5 \tilde{\imath}, 4 \pi 1,4 \pi 3$ tinctoria ......................... $4 \pi 1$ cuneata ............................ $4 \tau_{2}$ digitata ............. 32, $46,60,8 \%, 154,254,4 \% 2$ discolor .............................. $4 \pi 1$ durandii... ......................... $8: 3$ durandii ............................ $16,4{ }_{4} 0$ falcata ........................ 46,87,472 pagodaefolia..................... $\quad 472$ hemisphaerica...................... 14 heterophylla........................ 473 humilis ............................. 4 4 \% imbricaria .......................... $\quad 473$ laurifolia...... 95, 100, 102, 109, 117, 161, 472,833 lyrata ..........................46,85, 100,469 marylandica....... 4\%,60,154,166,16\%,4\%2,8\%2 maritima .......................... $4 \% 0$ michauxi1................ $46,61, \pi 2,470,823$ minor......... 46, 60,154,166,16\%, 192, 24\%, 469 montana ........................... 469 muhlenbergii......................... 469 myrtifolia ........................ 130, 473 nigra..................... $61,109,154,161$, $162,166,167,177,181,192,249,250,472,559,833$ 
Quercus-Continued.

Page.

nigra

aquaticu

$16 \%, 4 \% 2$

digitata

obtusifolia brevilobat

obtusiloba .......................... 469

pagodaefolia ....................... $4 \% 2$

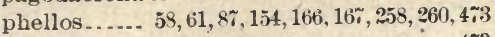

arenaria ...................... 473

brevifolia ........................ 473

laurifolia ....................... $4 \tau^{2}$

maritima ....................... $4: 0$

prinus

$47,5 \%, 60,469,612$

acuminata ...................... $\quad 469$

michanxii....................... 470

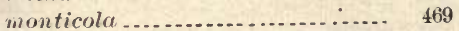

rubra ............... $5 \pi, 154,166,252,4 \% 1,473$

rubra $\beta$........................... 4 41

sempervirens........................ 40

sp ............................... $15 \tilde{\text { z }}$

$161,163,166,177,179,180,192,194,195,252$

stellata............................ 469 texana .................61,102, 210,4;1,823 tinctoria ............................. 883

tinctoria ............................ 471

velutina . ........... $47,60,70,160,471,473,823$

virens ........................... $4 \%$

maritima ...................... 470

virginiana $\ldots \ldots \ldots \ldots \ldots \ldots \ldots 41,121,4 \pi 0,833$

naritima....................... $4 \%$

Queria canadensis...................... 502

Quillwort family ....................... 322

Quince.................................. 831

Chinese ........................... 831

common .......................... 831

Radishes . . .......................... 135, $82 \%$

Radulum, catalogue..................... 203

Ragweed .............................. $75 \pi$

family ............................. $\quad \pi 56$

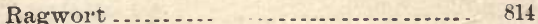

Rainfall in Alabama .................. $\quad 26$

Rajania ovata ....................... 487

Ramalina ............................. 264

calicaris $\ldots \ldots \ldots$

catalogue......................... $\quad 283$

laevigata............................ 266

Ramie............................. 478,828

Ramularia, catalogue .................. 2236 tulasnei ............................... 174

Range, definition ...................... 34

Ranunculaceae ......................... 508

Ranunculus abortivus micranthus ........ 514

aquatilis divaricatus ................. 515

catalogue .......................... 513

circinatus .......................... 515

divaricatus.......................... 515

fascicularis ......................... 83

flammula........................... 513

nitidus.............................. 514

recurvatus........................ $\% 5,108$

repens marylandicus.................. 514

sceleratus.......................... 128

septentrionalis...................... 514

trachyspermus ..................... 513,515

lindheimeri ................... 513

Raphanus sativus ..................... $8: 27$
Page.

Raphidostegium, catalogue ............. 307 microcarpum . ....................... 291,294 recurvans ......................... 292

Raspberry ............................ 83: black .............................. 541

black-cap .......................... 832

Ratibida, catalogue .................... $\quad 799$

Rattan vine ......................... 608

Rattlebox, Pursh's ...... . . .............. $\quad 559$ lound-leaf ........................ 558

Rattlepea ............................... 558

Rattlepod............................ 558

Rattlesnake weed ...................... 753

Ravenel, fungi ......................... 148

Ray grass............................ 827

Reana luxurians........................ 825

Reboulea ............................. $3 \pi 8$ truncata ........................... 378

Reboulia .............................. 285 catalogue .. . . . . . .

hemispherica ........................ 285

Recent formations, character of soils .... 824

Red a]gae ............................. 148 root ............................ 446,610

Redbud ..................... 14, 61, $85,89,101,555$

Red top .............................. $3{ }^{2} 0,826$ false ................................ 378,385

Reed .............................. 45,377 grass . ............................ 369,374

marshes........................... 128

switch cane....................... 389

Rescue grass............................ 827

Reseda, catalogue...................... 530

Resedaceae .......................... 530

Reticularia, catalogue .................. 141

Reticulariaceae........................... 141

Rhabdospora, catalogue ................ 259

Rbamnaceae ........................... 608

Rhamnus caroliniana ................ 82,99, 101 catalogue ......................... 609 minutiflorus ........................ 609 scandens ........................... 608 volubilis............................ 608 zizyphus........................... 609

Rhapidophyllum, catalogue ............ $4 \mathbf{2 4}$

Rhexia angustifolia ..................... 633 catalogue ........................... 633

ciliosa ........................... 120

lanceolata.......................... 1:33

mariana .......................... 116, 123

exalbida ...................... 633

stricta .......................... 116,127

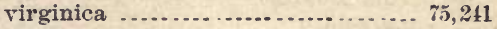

Rhinanthus virginicus.................. 725

Rhinotrichum, catalogue ............... 235

Rhizina, eatalogue..................... 155

Rhizinaceae........................... 155, 262

Rhizocarpon......................... 264 catalogue ......................... $2 \pi 1$

Rhizogonium .......................... 291

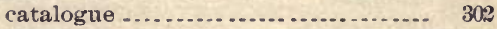
spiniforme ......................... 291,291

Rhizopogon, catalogue................ 230

Rhododendron arborescens .............. 653 catalogue ......................... 654

Catawba.............................. 654

catawbiense ....................... 77 
Rhododendron-Continued.

nudiflorum .

Page.

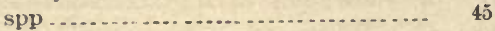

spp., correction of errur ............. 845

viscosum .......................... 653

Rhodophyceae......................... 148

Rhodymeniales .......................... 148

Rhus ............................. 160, 256

aromatica........................... 55,85

canadensis......................... 601

catalogue .......................... 60

copallina ..........................

cotinoides .......................... 600

glabra ............................ 66,244

radicans .......................... 101

toxicodendron .................... 18 ,244

quercifolium .................... 601

radicans ....................... 601

vulgare ......................... 601

venenata........................ 600

vernix ........................... 244

Rhynchosia, catalogue ................. 582

difformis ......................... 582

galactioides....................... 115

reniformis ....................... 582

simplicifolia ........................ 115

tomentosa erecta. ..................... 582 monophylla ..................... 589

Rhynchospora. (See Rynchospora.)

Rhynchostegium

catalogue

Rhytidhysterium, catalogue.

Rhytiglossa viridiflora...................

Rhytisma, catalogue ................... 161 petersii........................... 161

Rib grass .............................. 736

Ribbon cane ...........................

Ribes, catalogue....................... $53 \tilde{i}$

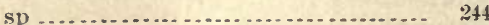

Riccardia ............................ 245 catalogue ....................... $28 \%$

Riccia ........................................... catalogue ........................ 286

lamellosa........................ 285

Ricciaceae ................................ 286

Ricciella ............................. 285

catalogue ......................... 286

Rice $\ldots \ldots \ldots \ldots \ldots \ldots \ldots . . \ldots 2,95,134,362,364,825$ Indian ............................ 362 water ............................ 49 wild .......................... $36 \%$

Rich weed ............................ $4 \pi 8$

Richardia africana.................... 244 catalogne ........................ $\quad 740$ scabra............................. $55,13 j$

Richardsonia ......................... 740

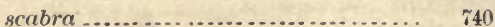

Ricinus, catalogue..................... 594 communis....................... 56

Rinodina............................ 264 catalogue ......................... $2 \pi j$ flavonigella ..................... 266 thomeae .......................... 205

River marsh plants.................... $12 \%$

River system..........................

Riverweed

family......................... 532
Robinia ............................... 14

catalogue ........................ $56 \%$

hispida........................... 63

pseudacacia..................... $\%$ \%, 2010, 834

vesicaria ............................ 568

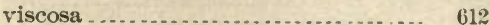

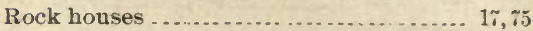

Rocket, violet ......................... 5:4

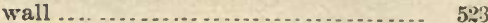

Rockrose, Carolina.................... 624

family .............................. 624

Georgia .......................... 624

seaside ............................. 624

Rocktripe........................... 63

Roestelia auranticaca .................... 185

flaviformis. ........................ 186

pirata ........................... 185

Rolling pine uplands................... 112

Root crops, list . ...................... $8: 2 \gamma$

parasite............................ 731

Roripa, eatalogue................... 5: 54 nasturtium ......................... 82.

Rosa................................. 165, 251 alba .................................. 834

banksiana........................... 833

bracteata ........................ 834

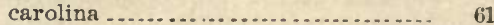

caroliniana ........................ 543

catalogue ......................... 513

centifolia ......................... 834

damascena........................ 831

eglanteria ........................ 544,83t

humilis......................... $63,68,191$

indica .......................... $83 t$

laerigata........................ 54,833

lucicla ........................... 543

multiflora........................ 834

parviflora.......................... 513

rubifolia ........................... 543

sinica .......................... 544

sp .................................... $24 t$

sucuveolens ......................... 543

Rosaceae ........................... 538

Rose, Bank's ............................

bay ............................. $65 t$

Cherokee ................... 54, 123.544,833

eglantine ........................ 544

family ............................. 538

hedge ............................ 544

low wild ............................... 543

Macartney ....................... 544,834

many-flowered ................... 834

prairie ............................ ist3

Rosellinia, catalogue ................. 173

Rosemary ............................ 663

Rosinweed.......... 14,4s, 64, $74,792,793,794,823$

Rotala. catalogue.................... $0: 1$

Rottboellia........................... 333 ;

corrugata........................... 35

areolata 336

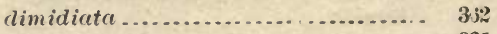

vugosc ............................... 33;

chapmani ....................... 335

Roubieva, catalogue ................... 4 s 9

Roxburghia........................... 40

Royal paulownia ...................... 835

Rubia brownei .........................

peregrina ........................ 742 
Page.

Rubiaceae ............ $73 \pi$

Rubus........................... 162,251,252,258 argutus .. 163,164,1 $66,184,191,192,247,249,832$ baileyanus .......................... 540 canadensis .......................... 6 ?

invisus .......................... 540

catalogue ......................... 540

cuneifolius ......................... 191,244

enslenii .............................. 8

floridus............................. $\quad 510$

frondosus ............................ 540

hispidus........................... $\quad \pi 8$

idaeus............................... 832

invisus............................ 8:32

occidentalis......................... 832

ovalis .............................. 541

parvifolius........................... 541

sp .............................. 191,258

suberectus............................ 540

trivialis ....................... 191, 258,832

villosus . . ............................ 62,612

villosus ...... 163,164,176, 184, 191, 192, 249,540 frondosus ...................... 540 humifusus........................ 540

Rudbeckia ............................ 48,64

amplexicaulis ..................... 105,812

apetala............................. 801

catalogue ........................... $79 \%$

chapmani ........................... 846

chrysomela........................... 798

discolor. ................................. 798

heliopsidis ........................... 64

hirta ............................ $\quad \pi 4$

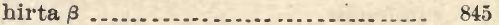

laciniata ............................ 65

nitida longifolia.................... $\quad 798$

pallida ............................. $\quad 799$

pinnata ............................. 799

purpurea........................... 799

radula ............................... 801

spathulata .......................... 64,74

strigosa ................................ 845

triloba ............................... 64

trilobata .............................. 104

Rue family .......................... $58 \%$

meadow .......................... 515,516

Ruellia ............................... 733, 734

catalogue ........................... $\quad \pi 33$

ciliosa .............................. 241

ambigua........................... $\quad \pi 34$

bumilis......................... 115

longiflora ....................... 734

hirsuta ........................... $\quad \pi 34$

humilis................................ $\quad 734$

hybrida ........................... 734

noctiflora ........................ 121

pedunculata ......................... 115

Rumex............................... 236

altissimus ......................... 50,128

britannicus .......................... 482

britannicus ......................... 482

catalogue ........................... 481

engelmannii ........................ 48

orbiculatus ......................... 482

sp .................................... 235

viridis.................................
Page.

Ruppia................

catalogue .......................... 328

maritima ............................ 127

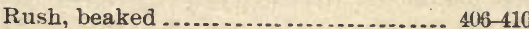

black ................................ 50

club ................................ 400

common wood ..................... 436

family .............................. 432

grass ................................ 368, 369

Guinea ............................ 392

horn .............................. 119

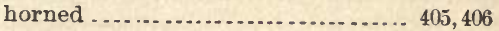

nut ........................... 116,411,412

round ............................ 50,116

salt ............................... $3 \pi 44,432$

salt-water.......................... 402

scouring ......................... 32

soft ............................... 432

spike ....................... 19

twig ............................... 410

weak ............................. 435

Rushes ........... 50, 119, 432, 433, 434, 435, 436, 821

beaked ............... 116, $406,40 \tau, 408,409,410$

Russian mulberry ....................... 831

Russula ..................... 168

catalogue ......................... 219

Ruta-baga .......................... 5:3,827

Rutaceae.............................. 587

Rye .......................... 68, 80, 135, 827

Rynchospora .......................... 821

alba .............................. 407

axillaris....................... 97, 126, 407

baldwinii ......................... 119,408

caduca ............................. 128,410

capitata............................ 405

catalogue .......................... 405

cephalcutha ....................... 407

chapmani . .......................... 119,406

ciliaris . . . . . ..................... 119,408

ciliata............................. 408

compressa .......................... 409

corniculata ....................... 128, 406

cymusa........................... 119,409

compressa ...................... 409

globularis...................... 119, 409

distans .......................... 408

distans ............................. 408

divergens.......................... 119, 406

dodecandra . . ...................... 132, 409

elliottii............................. 408,410

fascicularis ......................... 126, 408

distans.......................... 408

filifolia ............................. 407

filifolia ......................... 408

form $x$ tion......................... 119

fuscoides........................... 408

glomerata ...................... 187, 40\%,421

paniculata ...................... 407

gracilenta...................... 119, 126,408

grayii ............................... 114, 408

inexpansa........................ 410

intermedia......................... 114,407

intermixta ......................... 406

lamprosperma ...................... 406

longirostris .......................... 406

megalocarpa ....................... 409 
Rynchospora-Continued.

microcarpa

Page.

miliacea

$119.4(19$

miliacea.

126.410

multiflora

multiflora............................ $\$ 10$

oligantha ...................... $116,119,400$

paniculata .......................... 407

penniseta ............................. 406

plumosa ...................... 116,119, 406

intermedia ...................... 40 \%

pusilla ............................. 116, 119

rariflora ....................... 116,119, 409

schoencides.......................... 410

stenophylla...................... $\quad 410$

tenuifolia ........................... $\quad \$ 10$

torreyana......................... 131, 409

tracyi .................................. 405

Rynchosporae .......................... 119

Sabal.

$41,15 \%$

adansonii ................... 96,122,177, 18

adansoni............................ 423

catalogue ............................ 42

sp ................................. 164,1\%

Sabbatia angustifolia .................... 114

boykinii .............................. 74,93

Boykin's .............................. $6 \pi 1$

brachiata ............................ $6 \%$

calycina............................. 125

calycine............................... $\quad 6 \%$

calycosa............................. $\quad 6 \pi 0$

campanulata ........................ 116

catalogue ........................... $6 \%$

chloroides........................... 671

stricta......................... 671

dodecandra ........................... 116

gentian-like......................... 671

gentianoides.......................... 120

gracilis . ........................... 6\%0,671

large-flowered...................... $6 \%$

large-leaf ........................... $6 r 0$

macrophylla........................ 117

seaside .............................. 670

slender............................. 671

stellaris............................. 133

Saccharum officinarum......... 95, 237, 249, 825

Sage..................................... 899

blue ................................. 15

meadow.............................. $\quad \tau_{01}$

vervain-leaf ......................... 702

wood .................................. 707

Sagedia, catalogue...................... 268

fuscella .............................. $\quad 265$

Sageretia, catalogue.................... 609

michauxii........................... 122

michauxii........................... 609

Michaux's . .......................... 609

Sagina, catalogue ....................... 498

subulata smithii .................... 498

virginica ........................... 673

Sagittaria ................... 50,116,128,332,333

catalogue ......................... 330

chapmani ......................... 116, 126

cycloptera .......................... 116

falcata ............................. 332

lanceolata........................ 128

fliformis ........................ $12 \tau$
Sagittaria-Continued. Page.

gramined ............................ 333

chapmani....................... 332

cycloptera........................ 332

platyphylla ...................... 333

hastaita.............................. 3330

lancifolia media.................... 332

latifolia ...................... $\approx .128,244,331$

longirostris australis................

mohri ............................. 126

montevidensis...................... 128

natans ............................ 49

lorata .......................... 331

platyphylla ........................ 126

pubescens ............................. 330

pusilla ............................... 331

radicans ........................... 330

sagittaefolia variabilis............... $\quad 330$

sagittifolia longirostra................

subulata ............................ 331

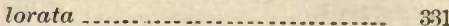

variabilis ............................ 330

pubescens ........................ $\quad 330$

St. Andrew's Cross ...................... 619

St. A ugustine grass ...................... 362

St. John's-wort ................. 621, 622, 623, 823 family .......................... 44,619

long-leaf marsh...................... 84.5

shrubby ............................ 85

St. Peter's-wort, dwarf .................. 620

southern ........................... 619

Salicaceae........................... 464

Salicornia ambigua ..................... $13: 2$

bigelovii ............................. 13?

catalogue .......................... 489

mucronata........................... 490

Salvia ................................. 115

azurea ........................ 15, 115, 01

grandiflora .................... -189

catalogue .......................... 701

claytoni ............................ $\gamma_{02}$

nettle-leaf ........................... $\quad \pi 01$

officinalis .......................... $8: 29$

scarlet-flowered ..................... $\quad 701$

urticaefolia ......................... 83

major ........................... $\quad \gamma_{01}$

Salviniaceae ............................ 320

Salix ............................ 182,204,212

babylonica ......................... $\$ 33$

caroliniana ........................ 495

catalogue ........................ $\$ 6.5$

f ragilis ............................... 185

humilis............................ 845

longirostris ........................ 466

nigra ................................ 184

wardi ......................... 465

sp ..................................... 184

tristis . . ............................ 88

tristis, correction of error ........... 845

Salsify ................................ $8: 28$

Salsola caroliniana..................... $\quad 490$

catalogue ......................... $\quad 490$

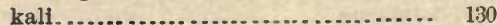

linearis........................... 489

Salt grass ............................... 50

marsh grass........................ $3 \pi_{t}$

Saltwort, common .................... 490 
Page.

Sambucus cauadensis . . 166, 194,240, 241, 246, 258 catalogme ...................... 742

Samolus, catalogue ..................... 661 valerandi americana ................. 661

Samplire, shrubby .................... $\quad 490$

Sandalwood family .................... 479

Sand bur ....................... 129, 130,36i. grass ................................. $3 \approx \tau$

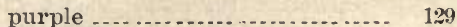
southern........................ 129 hills

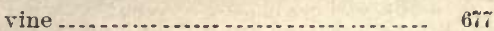

Sandwort, Michaux's................... 499

Pitcher's.......................... $\quad 500$

shortleaf .......................... 500

thymeleaf ........................... 500

Sanguinaria canadensis. ............... 75,93 catalogue . ........................ 520

Sanicle, Canada......................... 645

gregarious .......................... 644

Maryland .......................... 644

white ........................... 765

Sanicula canadensis. ................. 123,645 catalogue ........................... 644

floridana.......................... 645

floridana......................... 645

marilandira ........................ 66, 75

canculensis..................... 64.5

sp .......................... 151,184, 190, 194

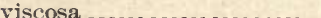

Santalaceae........................ 479

Sapindaceae ........................... 608

Sapindus, catalogue ..................... 608

marginatus ......................... 834

Sapium, catalogue..................... 595 sebiferum....................... 136,834

Sapodilla family ............................. 664

Saponaria, catalogue ................... $\quad 49$ vaccaria........................... 498

Sapotaceae ............................ 664

Saprolegnia, catalogne.................. 151

Saprolegniaceae....................... 151, 26:2

Saprolegniales........................ 151,262

Saprophytic plant association............ 51

Saprophytes.......................... 51

Sarcoscypha, catalogue ................. $15 \tilde{1}$

Sargassum, catalogue ................... $14 i$

Sarothra drummondii................... 623 gentianoides ......................... 623

Sarracenia ..................... 52,11 $\mathbf{1}, 120,12 \tau$ catalogue ......................... 530 cateshaei......................... 79 drummondii ...................... 117,530 flava ............................. 531 psittacina ......................... 117

purpurea ........................ 117,530

rubra ............................. 11\%, 530

Sarraceniaceae ........................ $\quad 530$

Sarsaparilla:.......................... 44

wild ............................... 507

Sassafras. . ................ 32,46, 66, $70,84,160,519$ catalogue .......................... 519

officincile .......................... 519

sassafras. . ................ $32,46,198,212,257$

Satureia origanoides ................... $\quad 698$

Satuveja thymus virginicus .............. 698

Saururaceae .......................... 461
Saururus, catalogue ..................... 461

cernuus ........................... 125, 244

Savin ............................... 42,43,326

Saw grass ............................. 49,411

Saxifraga, catalogue ................... 533

virginica ..........................

virginiensis ......................... 93

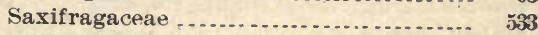

Saxifrage family ....................... 533

Scabious, sweet ........................ 786

Sea-blite, tall .......................... 489

island cotton ........................ 830

lettuce ............................. 147

rocket.............................. 522

Sebastiania, catalogue ................... 594

Secale cereale........... 174, 188, 189, 239, 259, 827

Sechium edule.......................... 831

Sedge . ............................ 130,412-422 broom.......................... $337,422,822$

family ......................... 390

grasses ............................ 98

Sedges ........................ 50, 128,412-4을

Sedum, catalogue ....................... 532 nevii ............................. 94

pulchellum .......................... 83

pusillum ........................... 532

ternatum ......................... 79

Segestria, catalogue .................. 269

Selaginella, catalogue.................. 322

family ........................ 322

Selaginellaceae ........................ 43, 322

Self-heal ............................... 705

Senebiera ............................. $5: 2$

coronopus ........................ $5 \% 2$

didyme ........................... $5: 2$

pinnatifida ...................... 5\%

sp ................................. 152

Senecio angustifolia..................... 814

aureus angustifolia................... 814

obovatus ......................... 814

balsamitae ........................... 69

catalogue ......................... 814

earlei .............................. 68

elliottii.............................. 814

hieracifolins ........................ 814

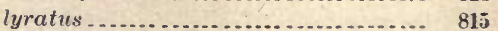

millefolium ........................ 815

obovatus............................ 73

tomentosus ........................ 814

Senna, wild ......................... 555

Sensitive brier .......................... 554

Sepedonium, catalogue ................ 235

Septogloeum, catalogue ................ 252

Septonema, catalogue................... 238

Septoric ................................... 259

catalogue .......................... 257

Serenoa.............................. 41

catalogue ........................... 424

Sericocarpus asteroides .............. 62, 66, 74

bifoliatus ........................ 62,115

catalogue ........................... $\quad 778$

conyzoides ......................... 779

solidagineus ........................ $\quad 778$

tortifolius.......................... 60

tortifolius ........................... 779

Serinea, catalogue .................. 
Page.

Serratula arvensis ...................... 81 pilosa ...........

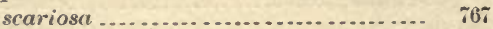

spicata ............................. $\quad ; 6 i$

squarrosa ............. 76 t

Seruneum buphthalmoides .............. 800

Service berry . ........................ 46,545

Sesame family ......................... $\quad 733$

Sesban, catalogue ...................... 569

Sesbania caranillesii

macrocarpa.......................... 128

platycarpa ...................................

punicea ............................. 569

vesicaria .

Sesuvium, catalogue .................. 494

pentandrum ....................... 495

portulacastrum .................... 129,495

subsessile ......................... 495

sessile

Setaria $\ldots 260,35 \mathrm{~s}$

caudata ............................ 361

germanica .......................... \$360

glaucr.............................. $\quad 359$

gracilis .............................. $\quad 359$

imberbis........................... ... 359

italica $\ldots . .360,826$

laevigata......................... 359

magna ............................. 361

perennis ........................... $\quad 359$

pseudo-verticillata .................... 360

verticillata........................... 360

ambigna ....................... 360

viridis ............................ 360

Seutera maritima...................... $6 \pi$

Sevenbark ......................... $7 \mathbf{1 , 5 3 5 , 5 3 6}$

seymeria...............................

pectinata.........................

tennifolia ......................... $\tau_{24}$

Scandix, catalogue $\ldots . . . \ldots . . . . .646$

procumbens ......................... 645

Scapania ............................. 285

catalogue .......................... 288

Scarlet basil ........................... 115

Scilla .................................. 40

esculenta........................... 440

fraseri

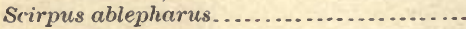

acicularis

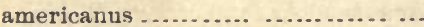

anisochaetus

autumnalis.

canbyi

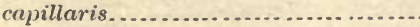

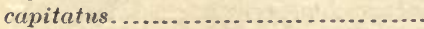

catalogue ............................

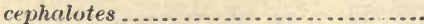

chaetarius.............................

ciliatifolius ...........................

coarctatus ...........................................

cylindricus ............................

cyperinus eriophorum ................

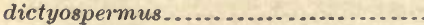

equisetoides

eriophomem ..........................

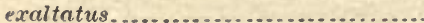

ferrugineus
Scirpus-Continued.

fluviatilis .......................... 128

interstinctus....................... 396

lacustris.... . . ....................... 125

leptolepis........................... 403

macrostachyus ................... . 403

maritimus ....................... 49,50

cylindricus...................... 443

fluviatilis .......................... 403

macrostachyus ................. 403

micranthus.......................... 405

montanus .......................... 398

mucronulatus ...................... 401

mutatus ............................. 396

obtusus ........................... $39 \%$

ocreatus........................... 397

olneyi............................. 128

ovatus .............................. 397

palustris ......................... 398

parvulus .......................... 402

polyphyllus......................... 76

puberulus ......................... 400

pungens............................ 40.. 40

quadrangulatus ................... 396

retrofvactus........................... 394

robustus ............................ 133

schoenvides......................... 410

simplex........................... 398

spadiceus.... ........................ 400

spathaceus ......................... 396

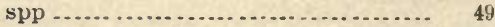

stenophyllus........................ 401

subsquarrosus..................... 405

tenuis ............................. $\quad 399$

tortilis ............................ 398

trichodes ........................... 393

triqueter ........................... $4\left({ }^{\prime}\right)$

tuberculosa ........................ $\quad 399$

validus ............................ 403

Scheuchzeriaceae ...................... $\quad 329$

schizandra ........................... 40

catalogue ........................ 50 \%

coccinea............................. 101

Schizophylleae ...................... 220

Schizophyllum, catalogue.............. 220

Schizothyrella, catalogue............... 261

Schlotheimia ........................ 291

catalogue ........................ 300

sullivantii........................... 294

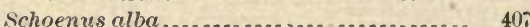

axillaris.......................... 407

capitellatus ....................... 407

ciliaris ........................... 408

coloratus ......................... 400

corniculatus ....................... 406

cymosus ............................. 409

distans .......................... 408

effusus........................... 411

fascicularis ....................... 408

glomeratus ......................... $40 \pi$

inexpansus........................ 410

mariscoides ......................... 410

miliaceus.......................... 410

rariflomes .......................... 409

sparsus ............................ 410

Schollera ............................. 432

graminea ......................... 432 
Page.

Schrader's grass

Schrankic angustuta ....

brachycarpa ...................... horridula ............................

Schubertia disticha .................... 395

Schwalbea americana.................. 114 catalogue ........................ 728

Schweinitz, Baron von, fungi............ 148

Scirrhia, catalogue................... $\quad 1$ r $^{2}$

Scleria bald winii .................... $\quad 412$

caroliniana ...................... 64,116

catalogue .......................... 411

ciliata............................. 114

elliottii............................. 114

gracilis............................ 131

hirtella........................... 412

strigosa ........................ 411

interrupta ........................ 412

laxa ............................... 411

michauxii......................... 412

pauciflora $\beta . . . . . . . . . . . . . . . . . . .412$

glabra.......................... 131

reticularis.......................... 411

torreyana........................ 124,127

triglomerata......................... 98

Sclerodermataceae.................... 234,263

Sclerodermatales ....................... 234, 263

Scleroderris, catalogue ................. 160

Sclerolepis, catalogue ................... $\quad 760$ verticillata.

Scleropa, catalogue.

Scleropus amarantoides .................. 491

catalogue ......................... 491

Scolecotrichum, catalogue ............... $\quad 238$

Scolymus, catalogue.................... 752

Scoparia, catalogue..................... $\approx 23$

Scorias, eatalogue ...................... 167

Scorzonera pinnatifida.................. $\quad$ i54

Scrophularia, catalogue............... $\quad 717$

Scrophulariaceae....................... $\quad 716$

Scuppernong grape in Coast Pine belt ... 823

Scutellaria campestris ................... 83

canescens .......................... 704

punctata....................... 108

punctata......................... 704

catalogue ........................ 703

hyssopifolic ......................... $\quad 704$

incana ............................... 75

mollis ............................. $; 04$

parvela mollis ........................ $\quad 704$

pilosa ............................... 114

rugosa............................. 704

serrctata........................... $\quad \gamma 04$

versicolor ..........................

minor ........................... 703

Shadbush ............................. 545

Shallot.............................. $8 \%$

Shell hammocks...................... 133

Shepherd's purse ........................ $5: \%$

Shittimwood ...........................

Shooting star.......................... 663

Shrubs ............................... 99,101

evergreen ........................... 132

hardy ........................... 136

low .............................. 130

Shrubby plant associations.............. 44

Sibthorpia evolvulacea ................... 683
Page.

Sickle pod ............................. $\quad 528$

Sicyos, catalogue ....................... $\quad 748$

Sida abutilon .......................... 614

acute-fruiteå ....................... 615

alceoides ............................ 615

carpinifolia........................ 615,616

catalogue .......................... 615

elliottii........................... 108

Elliott's . . ........................... 616

glabra ............................ 615

gracilis............................ 616

hispida.......................... 616

rhombleaf ........................ 616

rhombifolia........................ 55

spinosa ............................ 55,188

spiny ................................ 615

velvety .......................... 615

Side-saddle flower ..................... $\quad 530$

Sideroxylon lanuginosum ................. 664

lycioides ............................ 664

Siegesbeckia occidentalis ................ 803

Sieglingia ............................ $3 \approx 7,378$

americana ......................... $\quad 129$

catalogue .......................... $37 \pi$

chapmani ........................ 120

poaeformis ....................... 119

purpurea ........................... 129

seslerioides .......... $73,104,189,191,255,257$

Silene caroliniana .................... 73

catalogue ......................... 496

gallica ............................ 497

ovata.............................. 105

pennsylvanica ...................... 49 \%

regia .............................. 94

rotundifolia ....................... 73

stellata............................. 63

virginica ............................ 67,259

Silk tassel tree ........................... 834

Silk tree............................... 136, 553

Silphium............................. 14

asperrimum .................. 64, 108, 793

asteriscus...................... 190, 793,794

angustatum ..................... 115

dentatum ........................ 794

laevicaule ......................... 794

sccibrum .......................... $\quad 794$

catalogue .......................... 792

compositum .................. 62, 66, 74,244

michauxii ...................... 792

ovalifolium ....................... $\quad 792$

reniforme......................

dentatum .......................... 64

gatesii................................ 74

gummiferum...................... 792

integrifolium ....................... 794

intermedium ....................... 64

laciniatum ...................... 48, 104, 108

laevigatum .................. 64, 74, 108, 190

mohrii ........................... 74,794

pumilum ............................ 795

radula ............................ 793

scaberrimum ................... 104, 793

scaberrimum ....................... $\quad 793$

sp . . .

terebinthinaceum ................. 64

ternifolium .......................... $\quad 794$

trifoliatum .................... $64,74,104$

latifolium ....................... $\quad 794$ 
Page.

Silurian dolomites sandstones

Silverbell

$14,118,1: 5$

Carolina

89,92

mountain

tree

Carolina

Southern

Silver rod

Silybum marianum

Simaruba family

Simarubaceae

Sinapis alba nigra.

Siphonychia, catalogue diffusa erecta

130,131

Sison ammi canadense

Sistotrema, catalogue

Sisymbrium, catalogue murale

nasturtium.

sylvestre

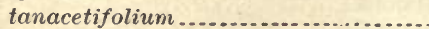

tenuifolium.

thalianum.

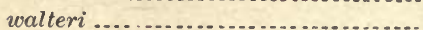

Sisyrinchium anceps.

bermudianum

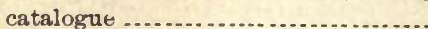

gramineum

gramineum.

Sitilias caroliniana catalogue

m, catalogue .......................... 64

cicutaefolium........................ 128

latifolium .......................... 50

lineare ............................ 647

longifolium ............................ 642

rigidius ............................. 641

teretifolium .......................... 641

Skullcap ................................ 703-704

Slime molds ............................. 139

Sloe, soutbern ............................ 551

Small grains on metamorphic hills...... 823

Smart weed .......................... 485

Smilaceae............................... 444

Smilacina.............................. 253, 441

racemosa......................... 441

Smilax .................... 123, 163,1 1\%4,1\%7, 181

auriculata........................... 130

beyrichii........................... 445

bona-nox........................ 68, 101

pandurata ...................... $10 \tau$

caduca ........................... 445,446

catalogue .......................... 444

coral ................................ 446

dwarf ............................ 446

ecirrhata ........................... 66

family............................... 444

glauca............................. 243

hastata............................ 445

hederaefolia ......................... 445

herbacea ............................ 444

ecirrhata
Smilax-Continued.

Page.

lauceolata........................ 101

laurifolia ................... $68,9 \tau, 101, \approx 13$

ovata ............................ 445.448

peduncularis........................ 444

pubera ............................. 446

pulverulenta......................... 44

pumila .............................. 66

quadrangulata...................... 445

rotundifolia .......................... $6 *$, 1

sp ........................ 1r6,178,244.24

sweet-scented...................... 446

tamnoides........................... 445

Smoke tree ............................. 8

American.................. 16,34,84, 85,600

Smut grass .............................. $36 \tau$

Smyrnium cordatum .................... 64 .

integerrimum ....................... 645

Snake-mouth .......................... 455

Snakeroot ............................... $6 \sigma^{2}$

button ............................ 643

Sampson's .......................... $6 \sigma_{2}$

spiked button ....................... $\tau_{6}$

thick-leaved ........................ 448

virginia .............................. 480

Sneeze weed .......................... 810,811

Snowdrop tree .......................... 665

Soapberry ............................. 608

family ............................. 608

tree ............................... 834

Soapwort ............................. 497

Soja bean .............................. $8: 30$

Solanaceae............................. 708

Solanum balbisii........................ 713

carolinense ........................ 16ij

catalogne ......................... 712

hirsutum ......................... $\quad \pi 13$

mammosum ........................ $\quad$ i13

melongena......................... 830

nigrum.......................... 240, 244

nodiflorum rubrum .................. $\quad \pi 13$

tuberosum..................... 244,249, 288

Solea concolor . ........................ $6: 9$

Solenia, cutalogue ...................... 202

Solidago .......................... 115, 158, 161, 236

Solidago................................. 130

altissima ..........................

amplexicaulis ..............66.68,83,93.7\%4

angustifolia.................. 121, $7 \% 3,821$

arguta .......................... 64, 766

bicolor ........................ 63,64,

concolor........................

boottii ...............................

brachyphylla....................

yadkinensis ......................

brachyphylla .................. 66, $755, \pi 66$

buckleyi ............................ $7 \% 3$

caesia ........................ $74,184,772$ axillaris......................... 68 paniculata ........................

canadensis ................ 161, 192, $246, \pi$ \% scabra......................... 777

scabruiscula .................... $\quad 777$

catalogue ........................ 772

cordata............................. 778

curtisii...................... 68,93, $7 \tau_{2}$

erecta ..................... 63,64, 74,774

fistulosa.......................... 
Solidago-Continued.

flexicaulis

Page.

gigantea $75,93,7 \%$

gracitis - -

graminifolia. ....................... $7 \% 8$

hirsuta .............................

hispida.............................

lanceolata..........................

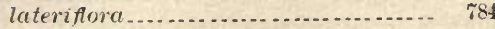

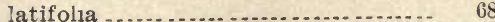

latifolva ...........................

muhlenbergii........................ $\%$ \%6 neglecta .

$64,65,775$

nemoralis $62,64,93,7 \%$

odora $60,62,115,7 \% 4,822$ inodora $64,7 \% 4$

\section{ovata} $6 \tilde{6}$

pallescens 65,766

patula. strictula $77 \pm$ pauciflosculosa ....................... 683 pauciflosculosa....................... $\%$ 71 petiolaris

$97,115,772$ puberula pulverulenta.

$115,7 \% 3,8 \%$ pulverulenta pyramiciata

retrorsa $7 \% 4$

rugosa

184,775

salicina

774

scabra $7 \%$

sempervirens

128, ส73 serotina

gigantea

sp ................................ 184, 192, 236 speciosa angustata.................... 774

sphacelata ........................... 778

stricta......................... 121, 773,821 angustifolia.....................

tenuifolia .......................... $\tau_{11}$

tenuifolia ............................. $\pi \%$

ulmifolia............................

vaseyi............................... 75,776

villosa ........................... 774,775

virgata ............................. 773

yadkinensis.......................... $7 \%$

Solomon's seal......................... 441,442

Sonchus acuminatus..................... 755

carolinianus .......................... 756

catalogue ........................... 756

floridanus ............................ 755

oleraceus ............................ 259 asper ............................. 756

spinulosus........................... 756

Sonoran life area, lower .................. $\quad 32$ area, upper .........................

Sophora lanceolata ..................... 558

sophronanthe hispida ................... $\quad 720$

Sorghum......................... 32, 68, 135, 823

catalogue .......................... 339

cernuum .............................. 190

halepense ......................... 95

$104,105,135,171,190,239,245,251,255,825$ on metamorphic hills ................. 823 nutans ............................. 339,339 saccharatum...................... 69 sativum............................ 104 sp $183,255,256$
Sorghum-Continued. vulgare

Page.

cernuum......................... 825 durra ........................... 8 saccharatum ..................... $8: 5$ technicum ....................... 825

Sorosporium, catalogue ................ 183 everhartii .......................... 183

Sorrel, common yellow .................. 584, 585 Engelmann's ......................... 49 ? sand ................................ 481

Sour grasses............................ 119

Sourwood ......................... 47. $70,88,656$

Southern juncaceous formation .......... 132

Sow-thistle, common ...................... $\quad 756$ prickly ............................. 756

Soy bean ............................ 830

Spanish cypress . ........................ 686 dagger ......................... 4 4 i, 131, 440 moss ................................ 499

needles............................ 807

Sparassis, catalogue.... ............ 203

Sparganiaceae.......................... 327

Sparganium, catalogue ................... 327 simplex androcladum ................. 327 sp................................. 50

Sparganophorus verticillatus.............. . 560

Sparkleberry ............................ 657

Spartina, catalogue...................... 374 cynosuroides ....................... 128

glabra ............................... 374

juncea ............................... $3 \pi_{4}$

patens............................... 133

polystachya $. . . \ldots \ldots \ldots \ldots . . . . . . .128,132,133$ spp......................................... 49,50

Spatter-dock ............................ 49

Spear grass .......................... 380,384,385

Spearmint .......................... $697,8 \mathbf{2 9}$

Spearwort, slender.................... 513 small ............................... 513

Specularia ............................ $\quad 748$ biflora.............................. $\quad \% 48$

Speedwell, corn ........................ 谟 thyme-leaf ...........................

water ............................... 724

Spegazzinia, catalogue.................. $\quad 249$

Spergula arvensis ...................... 5

catalogue ............................ 500

decumbens.......................... 498

Spergularia .............................. 501

rubra............................. 501

salina ............................... 501

Spergulastrum lanuginosum ........... 500

Spermacoce, catalogue................... $\quad$ $\%$

diodina ............................. $\quad 740$

glabra ............................. 189, 190

Spermolepis, catalogue .................. 648

Spermophyta ........................... $3: 3$

Sphacelia, catalogue................... 248

Sphaerella.............................. 174

Sphaeria ............... 1\%3,1 $\pi, 1 \pi 5,1 \% 6,1 \%, 180$

catalogue ......................... 182

Spaeriaceae ........................ 172, 262

Sphaeriales....................... 1 1 $2,182,262$

Sphaerococcaceae ....................... 148

Sphaerocarpus ........................... 285

catalogue ........................ 287 
Sphaerocarpus-Continued. micheli. terrestris

Sphaerocephalus catalogua

Sphaeronema

Sphaeropsidaceae

Sphaeropsidales.

Sphceropsis. catalogue maculans

Sphaerospora, catalogue.

Sphaerostemon

Sphaerostilbe, catalogue.

Sphaerotheca, catalogue.

Sphagnaceae

Sphagnales

Sphagnum

catalogue

compactum

cuspidatum

- torreyanum

cyclophyllum

cymbifolium purpurciscens

humile

imbricatum cristatum

$116,119,292,293$

intermedium ...................... 119

Iudovicianum......................... 293

macrophyllum ................. 116,292,293

medium ............................. 292, 293

microcarpum ....................... 293

mojiliense .......................... 290, 293

mohrianum ......................... 2293

mohrii $\quad 290$

molle muelleri..................... 292

muelleri.............................. 295

papillosum........................ 29:

portoricense........................ 291

recurvum..................... 116, 292, 293

recurvun ............................ 295

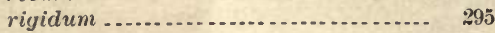

rufescens .......................... $\quad 293$

Spice bush ............................ 101

pond ............................. 519

Spicewood ............................ 14,519

mountain ......................... 518

Spiderwort ............................ 431

Spigelia, catalogue ..................... 669

marilandica......................... 67

Spike-grass .......................... 382,383

Spikenard ........................... 640

Spike-rush, bright green ............... 397

Spike-rushes........................... 396-399

Spiranthes .............................. 114

Spirodela ............................... 48

polyrhiza ........................... 126

Spleenworts ........................... 314316

Sporobolus asper ................. 172, 189,244 asper.............................. 368 drummondii .................... 333

catalogue ......................... 367 indicus ............................ 1\%1,239

junceus ............................ 114

longifolius ........................... 114

minor ............................... 368

neglectus .......................... 114

vaginaeflorus...................... 114
Sporobolus-Continued. Page. vagincaeflor"us .......................... 3is

virginicus ............................ 369

Sporodesmium, catalogue .............. $\quad 246$

Sporonema, catalogue ................. $\quad 259$

Sporotrichum, catalogue ............... $\$ 236$

Spilanthes, catalogue................... creeping ........................... 79

Spinach ............................. 828

Spinacia oleracea ...................... 828

Spircued ............................... 539

aruncus ............................ 539

betulaefolia corymbosa ............... $53 s^{3}$

catalogue ........................... 538

opulifolia ......................... 538

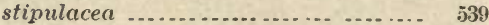

stipulata ........................... 539

trifoliata......................... 539

Spircunthes ............................... 456

brevifolia ........................... $45 \tilde{t}$

cernua ............................. $\quad 456$

odorata ............................ $45 \pi$

praecox .............................. $45 \%$

Spirodela, catalogue .................... $\quad 4 * 6$

Spontaneous flora, relation to agricul-

ture

Sporidinia, catalogue.................. 151

Spring beauty, Virginian ................ $\quad 496$

Spumaria, catalogue ..................... 141

Spumariaceae ........................... 141

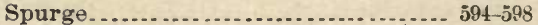

family ............................ 591

Spurry, corn ......................... 500

sand .................................. 501

Squash................................ 830,831

Mexican . . ........................ 831

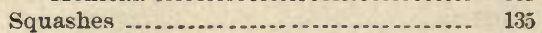

Squaw root......................... 731

Stachys, catalogue ..................... 705

cordata .............................. 75

hispida........................... 506

sylvatica ............................ 706

Stachytarpheta ........................ 694

janıaicensis ......................... 694

prismatica ............................ 694

Staehelina elegans....................... 760

Staff tree ............................... 604

family ......................... 604

Staganopsis, catalogue ................ $\quad 260$

Stagonospora, catalogue................ $25 \tilde{~}$

Staphylea, catalogue.................... 605

trifolia ............................. 80

Staphyleaceae......................... 605

Star grass ........................... 443,448

Starwort ......................... $436, \pi 79$

soft hairy .......................... 499

spreading ........................... 500

pine ............................... $\quad$ 88

water ............................ 598, 599

statice ............................... 663

caroliniana ........................ 663

limonium carolinianum.............. 663

Staurone is aspera ....................... 14i)

catalogue ......................... 145

pulchella ............................ 145

Staurothele, catalogue ................. $\quad 268$

disfractella .......................... 265

petersii .......................... 265, 267

Steganosporium, catalogue............ $\quad 252$ 
Page.

Steironema, catalogue

intermedium......................... $66^{\circ}$ ciliatum......................... $65,88,98$

lanceolatum ........................ 88,98

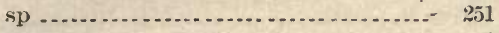

tonsum ............................... 63

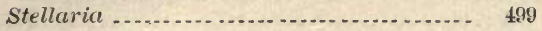

lanuginosa........................ 500

pubera........................... $\quad 499$

Stemmodontia, catalogue............... $\quad 799$

Stemonaceae ............................ 44

Stemonitaceae......................... 141

Stemonitis, catalogue ................... 141

Stenactis beyrichii ........................ $\quad 786$

Stencuthium angustifolium.............. 437

catalogne......................... 137

Stenophragma, catalogue................ $5: 7$

Stenophyllus ........................ 401,402 caespitosus.......................... 401

capillaris................................ 63

capillaris............................. 401

catalogue .......................... 401

ciliatifolius ......................... 114

Stenotaphrum americanum .............. $\quad 362$

catalogue .......................... 362

secundatum ...................... 129

Stephanandra ........................... 40

Sterculia, catalogue.................. 618

family ...................... 618

Sterculiaceae ........................... 618

Stereodon.............................. 291

curvifoljus........................... 293

Stereum ............................. 199, 201

versicolor ............................ 247

Stewartia ............................... 14

catalogue $\ldots \ldots \ldots \ldots \ldots \ldots \ldots \ldots \ldots$

virginica ........................... 15,618

Stick-tight ............................. 807

Sticta .................................. 264

aurata......................................... 266

catalogue ........................... 280

quercizans ........................ 266

ravenelii ............................. 280

Stictidaceae ........................... 160,262

Stilbaceae ............................. 247,263

Stilbum, catalogue ...................... 247

Stillingia, catalogne...................... 594

ligustrina .......................... 594

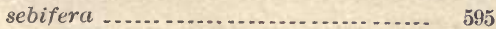

sylvatica............................ 114

Stipa barbata ........................... 366

catalogue ........................... 360

neesiana . ........................... 366

Stipulicida, catalogue................. 501

setacea .............................. 130

tiny ...................................... 501

Stokesia, catalogue................... cyanea ................................

laevis

Stonecrop, ditch

little

Nevius' ...............................

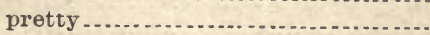

ternate

three-leaf .
Page.

Storax ......................... 43

American ........................... 665

bush ............................. 14,118

large-leaved ..................... 109

family ................................ 664

large-flowered......................... 665

powdery ............................... 665

Strumonii folia ..................... 715

semen ........................... 715

Strawberry . ................... $80,110,8: 22,829$

bush ................................ 604,605

Japanese......................... 835

i11 Upper Coast Pine belt .............. 822

wild .............................. 541

Strawberries ............................. 134

Streptopus lanuginosus.................. 441 .

Streptothrix, catalogue ............... . 237

Strigula................................. 264

catalogue .......................... 267

Strobilomyces, catalogue $\ldots . . . . \ldots \ldots \ldots . . . .216$

Stropharia, catalogue..................... 224

Strophostyles angulosa ................... 581

helvola ........................... 67

peduncularis.......................... 582

Stylisma .............................. 681

aquatica ........................... 681

humistrata................................. 681

Stylosanthes.......................... 88

biflora hispidissima ................ 115

catalogue ......................... 570

elatior................................ $55^{2} 0$

hispida hispidissima................ $5 \pi 0$

nudiuscula. ..................... 570

Styracaceae................................. 664

Styrax americana ..................... 125

catalogue ......................... 665

glabrum ............................ 665

grandiflorum ....................... 665

grandifolia.......................... 109

laevis.............................. 665

pulverulenta ...................... 118

Stysanus, catalogue .................... $\quad 247$

Stuartia, fringed ........................ 71

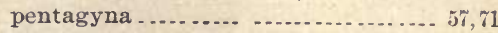

Virginia............................

virginica ............................

Subcarboniferous limestone........... $67,84,93$

rocks ................................ 69

Sueda .................................. 129, 489

linearis............................. 489

Sugar beet ............................. $8: 27$

cane . . ....................... 32, 134, 8*2, 825

Chinese ....................... 68,825

in Coast Pine belt ................ $\quad 8 \% 2$

corr.................................. 339

maple .................. $5 \pi, 80,84,89,102,605$

small-leaf ........................ 89

melon ........................... 831

Sugarberry, scrublby .................... 475

Sullivant, Alabama mosses ................ $\quad 289$

Sumac ............................. $\tilde{5} \tilde{i}, 66,88$

aromatic . .......................... 57,85

dwarf ............................. 600

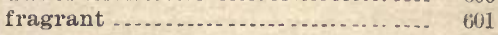

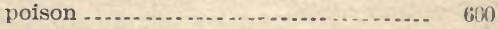

mooth ............................... 60 
Page.

Sundew $49,117,120,531$

family

531

Sundews

Sundrops pine-barren

52,127

Sunflower

Sunflowers

799-803

Supple-jack. $48,64,74,8: 20,823$

Suriraja, catalogue

$11.101,608$

Surirelloideue

Sweet acaciá.

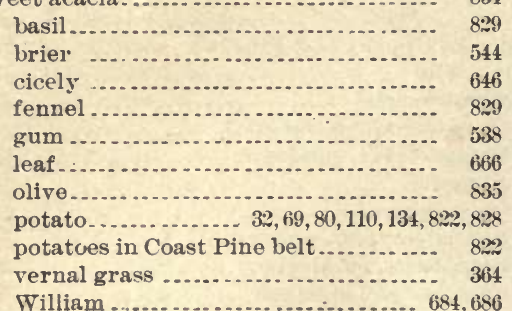

Swedish turnip 84,680

Sycainore 538,833

Symbiotic plant association .............

Symbiots ............................. 51

Sympetalae ........................... 652

Symphoricarpos, catalogue............... $\quad 744$

orbiculata.......................... 744

symphoricarpos ..................... 80

vulgaris .............................. $\quad 744$

Symplocacea .......................... 666

Symplocos ........................... 201,259

catalogue ........................... 660

tinctoria ........................... 45

Synchytriaceae........................ 150,262

Synchytrium, catalogue ................ 150

Syndesmon, catalogue .................. 511 thalictroides ..................... 67, 75,93

Syntherisma, catalogue................. 344

fliforme .......................... 34

glabrum ............................ 344

praecox ........................... 345

sanguinale........ 56, 65, 135, 183, 221, 236, 258 serotina......................... 120

Syringa ............................... 535 vulgaris............................ 160

Syrrhopodon ......................... 291

catalogue ......................... 300

floridanus......................... 294

texanus ............................... 294

Systematic arrangement followed ...... 12

Tabernaemontana amsonia ............. 673 angustifolia......................... 674

Tabular statement of plants of Alabama. $\quad 837$

Taenidia, catalogue..................... $\quad 645$

Talauma.............................. 42

Talinum, catalogue.................... 495 purple ............................ 495 round-leaf ......................... $\quad 79$ teretifolium . . ..................... 63,79

Tallow tree ............................ 595

Tallow-berry tree....................... 834

Taphria, catalogue .................... 154

Taraxacum, catalogue ................. dens-leonis ......................... 753

officinale
Taxodium ...........................

catalogue ........................ 325

distichum.......................... 46

imbricaria ...................... 117

Taxus floridana ........................ 34

Taylor, Dr, George H., diatoms ......... 142

Tea................................... $\$ 26$

Chinese ........................... 835

family ............................. 618

Mexican .......................... 488

New Jersey......................... 610

Tear-thumb, arrow-leared............... 486

Teasel family ........................... $\quad \tau_{t 6}$

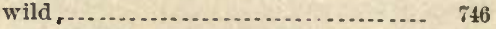

Tecoma, catalogue ..................... radicans .................... $\approx 1,101,166,244$

Telanthera, catalogue................. 492 polygonoides........................... 491 pungens ............................. 493

Temperatures in Alabama............... 25

Tennessee Valley, features................ 80

region of ....................... 21

regetation ...................... 81

regetation and soils.............. 824

Teosinte ............................. 135, 895

Tephrosia .............................. 115, 565

chrysophylla ....................... 567

cinerea ............................. 567

flexuosa ............................ 566

hispidula.......................... 566

intermedia.......................... 566

onobrychoides........................ 566

prostrata... ........................ 567

spicate ............................ 566

virginiana .......................... 566

Terpsinoë, catalogue ................... 144

Terrell grass ........................... 388

Tetragonia expansa ...................... 823

Tetragonotheca, catalogie............... $\quad 799$

helianthoides ......................... 114

Tetraploa, catalogue .................... 246

Teucrium, catalogue ................... 70 \%

Thalesia, catalogue ..................... $\quad 731$

uniflora ............................ 52

Thalictrum anemonoides ................ 511

carolinianum ....................... 516

catalogue .......................... 515

clavatum .......................... 73,78

cornuti.............................. 516

corynellum......................... 516

debile .............................. 16,110

dioicum ........................... 85

laevigatum ......................... 516

pubescens.......................... 516

revolutum ............................ 516

rugosum ........................... 516

Thallophytes ........................ 14:

Thamnium .......................... 308

Thaspium aureum .................... 102

aureum.........

trifoliatum ..................... $7 t$

trifoliatum ...................... 612

barbinode ........................... 79

catalogue ........................... 64:

pinnatifidum ..................... $\quad \pi$

trifoliatum apterum................. 647

Thea chinensis....................... 835

japonica.......................... 835 
Page.

Theaceae .............................. 618

Thecospora vaccinorum ................. 185

Thelephora ........................... 200 micieneri ............................ 201

Thelephoraceae ..................... 197, 263

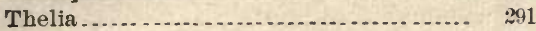

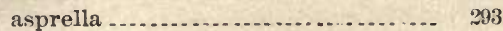

catalogue ......................... 305

lescurii.............................. 293

Theloschistes, catalogue ................ 28\%

chrysopthalinus flavicans............. $\quad 266$

Thelotrema......................... 264, 266 catalogue . ........................... 274

Thrlypodium ............................ 524

Thermopsis, catalogue ................. 558

Therofon aconitifolium .................. $\quad 73$

catalogne .......................... 533

Thesium umbellatum .................... 479

Thin grass ............................ $76,3 \pi 0$

Thistie ....................... 816, $817,818,819$

blessed ........................... 56,818

Canada.............................. 817

common............................ 818

cotton........................... 818

cursed ... ........................... 817

Elliott's_... ....................... 817

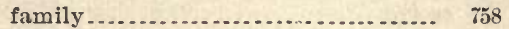

milk.............................. 818

smooth .......................... 817

star................................. 819

tall .................................... 817

Virginia . . .............................. 817

yellow................................. 816

Thlaspi bursa-pastoris .................. $52 \tau$

tuberosum ............................ 525

Thorn apple ...................... 54, 714,715

common......................... 715

purple ............................ $\quad: 14$

biltmore ........................... 548

black............................. 99

cockspur . . . ....................... $21,99,548$

dwarf .............................. 550

evergreen ........................ 544

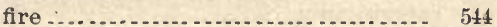

Thoroughwax ....................... 645

Thoroughwort ..................... 760,764

Thuidium........................... 291

catalogue ........................ 307

delicatulum........................ 291

microphyllum . .................. 291, 293, 294

Thurberia ............................ 133,369

arkansana .......................... 369

Thuya sphaeroidea ..................... 325

Thymbra caroliniana...................... $\quad \pi 00$

Thyme _............................ 698, 700,829

Thymelteaceae .......................... 631

Thymus carolinianus ..................... $\quad 700$

serpyllum ....................... $\quad 829$

vulgaris.......................... 829

Thyrsanthema, catalogue ............... 819

Thysanella, catalogue.................. 486 fringed ............................... 486

Tiarella, catalogue.................... $\mathbf{5 3 4}$ cordifolia .......................... 75,79

Tick seed ............... 572,573,574,804,805,806

Tick trefoil ................ $67,88,99,5 \pi 1-5 i t, 822$

Tiedemannia.
Page.

rigida ............................. 64 ?

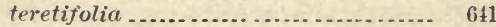

Tilia ............................. 203,205,206 americana . . ........................ 72,195

catalogne ............................ 613

heterophylla ................... $72,84,109$

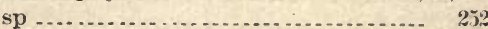

Tillaea ............................... 533,613

catalogue ........................... 533

simplex ........................... 1:26,533

Tillandsia............................ 41

catalogne ........................ 429

usneoides .......................... 50

Tilletiaceae ......................... 184,262

Timnthy ............................... 367,826

Tinker's root ........................... 744

Tipularia, catalogue................... 459

discolor............................. 459

unifolia ............................ 73

Tissa, catalogue ........................ 501 marina ..... ...................... 133

Ti-ti ............................ 47,96, 122,60? black................................. 601

Tithymalus ........................... 595

Toad-flax .............................. $\quad ; 17$

Tobacco............................. 715, 829

in Upper Coast Pine belt ............ 823

indian............................ 751

leaf ................................ $8: 3$

Tofieldia, catalogue ................... 436

pubens............................ 66

pubescens........................... 436

racemosa ............................ $12 \tau$

Tolyposporella, catalogue ............. 183

Tomato ..................... 135, 235, 249, 830

Tombigbee River, physiography ......... 23

Toothache grass ...................... 124,3i4

Toothwort ............................ $5: 6$

Tordylium americanum .................. 642 nodosum ........................... 641

Torreya.............................. 34 taxifolia ................................ 44

Tortula, catalogue ..................... 299

Touch-me-not .......................... 610

Toxylon, catalogue..................... 475 pomiferum .................. 162, 253,255, 833

Trabutia, ca.alogue ................... 1\%

Trachelospermum, catalogue............ $6 \%$

Trachynotia juncea ...................... $3 \pi 4$ polystachya ........................... 374

Tradescantia canaliculata ............... 431

catalogue .......................... 431

Tragia, catalogue ................... 593

innocua ............................. 593

linearifolia ........................... 594

urticaefolia ........................ 74,105

urticaefoiia ......................... 593

Tragopogon dandelion ................... 752 porrifolius........................ 15:2,8:2 virginicum ........................ $\pi 51$ virginicum ......................... $\quad 751$

Trailing arbutus ...................... 656

Trametes, catalogue .................... 212

Transition life zone ..................... 31

Trattenickia lanceolata .................. 809

Trautvetteria carolinensis.............. 75

catalogne .......................... 513

palmata............................. 513 
Page.

Tree of heaven ....................... 58\%, 834

Trees and shrubs for fruit............. \&31, 832

for shade or ornament, list..... $832-834$

Trefoil, lesser yellow ..................... 5 562 tick ...................... $66,88,99,571,822$ shrubby ........................... 587

Trematodon ........................... $\quad 291$

catalogue .......................... $\quad 297$

longicollis............................ 291

Tremella, catalogne................... 195

sp .................................. 255

Tremellaceae ........................ 194, 262

Tremellales............................. 194, 262

Tremellodon, catalogue................ 195

Trepocarpus............................ 102 catalogue ........................... 641

aethusae ........................... 102

Triadenum, catalogue .................. 623 longifolium ........................ 845

Trianosperma, catalogue ..............

Tribulus maximus ......................... 586

Triceratium, catalogue................... 144 sculptum ............................ 144

Trichia, catalogue ...................... $\quad 139$

Trichiaceae ............................. 139

Trichodium elatum ..................... $\quad 3 \pi 1$ laxiflorum ............................ 370 perennans .......................... $\quad 3 \% 0$

Tricholaena, catalogue................. 345

Tricholoma, catalogue ................... $\quad 226$

Trichomanes, catalogue.................. 319 petersii ......................... 17,39, 76 radicans

Trichophorum lineatum

Trichesphaeria, catalogut

Trichostema brachiatum.................. catalogue ......................... 70 \%

Trichostomum ......................... 291 catalogue ......................... $\quad 299$ macrostegium ....................... 291 pallidum .......................... 299

Trichothecium, catalngue .............. 235

Tricuspis ................................ $37 \%$ ambigua ............................. 378 purpurea.......................... 37 sesleroides............................ 378

Trifolium biflorum -................... $5 \%$ carolinianum ...................... 153 catalogue .......................... 561 erectum .......................... 582 hybridum ..................... 187,238,828 incarnatum ........................... $8: 8$ meliloius offici.rale.................... 561 minus ............................ 562 pratense .......................... 18\%,8\% procumbens minus .................... 562 psoraloides........................... 563 reflexum............................ 74,238 simplicifolium .................... 582 sp ................................... 187

Triglochin, catalog $10 . . . . . . . . . . . . . . . . \quad 399$ striata ............................. 128 triandra .......................... $\quad 329$

Trigonella americana ................... $\quad 562$

Trilisa, catalogue ....................... $\quad 768$ odoratissima................... 114,121,822
Trillium catesbaci .................... 443

catalogue .......................... 442

cernuum........................... 443

lanceolatum ......................... 443

nervosum........................... 443

nodding ............................ 443

pendulum ........................... 443

rhomboiderm ....................... 443

sessile ........................... 443

nuttallii......................... 442

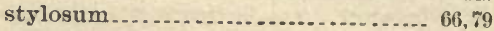

underwoodii ...................... 66

viridescens ........................... 442

Triodia............................... 377

ambigua........................... 378

cuprea ............................. 378

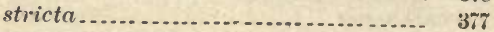

Triosteum, catalogue .................. $\quad$ i44

major............................... 744

minus ............................... $\quad 74$

Triplasis americana .................... 377 purpurea ........................... $3 \pi 7$

Tripodiscus argus....................... 144

Tripolium divaricatum...................

Triposporium, catalogue................ 247

Tripsacum, catalogue.................... 334 cylindricum.......................... 336 dactyloides ......................... 189,248

Tripterella caerulea ..................... 452 capitata............................. 45\%

Trisetum, catalogue ................... $\quad 3 \pi 2$ palustre .............................. 372

Triticum vulgare .................. 183, 189,82

Tropaeolum ........................ 245

Tropical life region ...................... $\quad 33$

Truck farming in Alabama .............. 134

Trumpet vine ........................ 15, $\% 1$

Trumpet-leaf ......................... 530,531

Trumpet-weed ......................... $\quad \pi 61$

Tryblidiaceae ........................ 160,262

Tryblidiella, catalogue ................. 160

Trypethelium ........................ 264,266 catalogue ......................... 268

catervarium ....................... 267

Tsuga ............................. 197,206, 208 canadensis ...................... 34, 72,158 catalogue .......................... 324

Tubercularia, catalogue ................ $\quad 247$

Tuberculariaceae ..................... 24\%,263

Tubulina, catalogue ................... 140

'Tuckerman, Alabama lichens............ $\quad 263$

Tulip tree ...... 31, 46,60, $70,84,89,92,100,506,824$

Tullia pycnan themoides ................ 699

Tumbleweed ........................... 491

Tumion taxifolium...................... 34

Tuomeya, catalogue................... 148

Tupelo gum ............................ 46

Turnip ............................. 135, 5:3,827 indian ............................ 425

Swedish............................ 827

Turritis laevigata...................... 528

Turtle-head............................ $\quad 718$

Tussilago integrifolia..................... 819

Tylostoma, catalogue .................. $\quad 230$

Tympunis ................................ 159 pinastra........................... 160 
Page

Typha, catalogue........................ $3: 26$ latifolia ......................... 128, 1\%2 sp ....................................... 49

Typhaceae.

127,333

Udora

474

Ulmaceae

164,171

Ulmus

$46,16 \%, 25 \%$

alata americana

$46,72,100,102,16 \%, 204,251$ australis

catalogue

46,474

pubescens

474

racemosa.

195

Ulocolla foliacea

Ulva, catalogue

Ulvaceae

147

Umbelliferae ............................. 823

Umbilicaria ............................ 63

catalogue ............................. 281

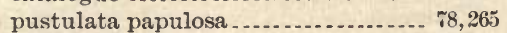

Umbilicarieae ...................... 265), 281, 284

Umbrella grass ........................... 404 tree .......................... $72,92,136,506$

Umbrellawort, heart-leaf............... 494 pale .................................. 493

Uncinula, catalogue ..................... 166

Underwood, Prof. L. M., botanical collection

fungi.

liverworts revised

Unicorn plant root

Uniola, catalogue gracilis

latifolia .

laxa.

maritima

paniculata

spicata

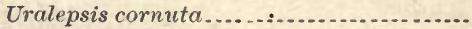
purpurea

Uredinales.

Uredo appendiculate $\ldots 186,18$ catalogne

hyptidis .

leguminosomum miniata.

Urnula, catalogue .......................

Uromyces, catalogue

medicaginis-falcatae

spermacoces.

terebinthi

trifolii

Urosporella, catalogue ...................

Urtica canadensis

capitata

catalogue

cylindrica

divaricata

herniarioides

nivea..

procera

purpurascens

Urticaceae
Urticastrum, catalogne ................. 477

Usnea................................... 264

barbata ............................ 266

catalogue ............................. 283

Usneae................................ 283, 284

Ustilaginaceae .......................... 183, 2692

Ustilaginales .......................... 183, 262

Ustilago avenae .......................... $\quad 249$

catalogue ........................... 183

cesatii.............................. 183

Ustulina, catalogue..................... 181

Utricularia ............................... 52

biflora................................. $\quad 126$

catalogue .......................... $\quad \gamma_{29}$

ceratophylla ........................ $\quad 729$

fibrosa.............................. $\quad 730$

fornicata .......................... $\quad 730$

gibba............................... 126

inflata.......................... 49, 126

juncea............................. 117

longirostris ......................... 730

minor ............................... 730

personiata ............................ $\quad 730$

purpurea ......................... 49,127

saccata............................ 730

setacea............................... 731

striata.............................. $\quad 730$

subulata . .......................... 117

vulgaris........................... 49,12\%

Uvaria parviflora

triloba.............................. $50 \%$

Uvularia, catalogue...................... 438

grandiflora ......................... 85,93

perfoliata........................... 66

minor ........................... 438

puberula............................ 75,85

sessitifolia........................ $65,75,93$

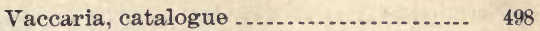

vulgaris ........................... 498

Vacciniaceae........................... 657

Vaccinium...................... 45, 166, 196, 201

amoenum ......................... 660

arboreum . .................. 45, 122, 161, 254

catalogue .......................... $65 \%$

constablaei........................... 660

corymbosum ........................ 6i 185

pallidum ........................ 660

fuscatum ......................... 660

disomorphum ...................... 660

dumosum ........................... $65 \%$

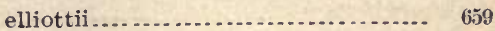

frondosum . . . . ..................... 657

galezans............................ $\quad 659$

hirtellum ............................ $65 \%$

ligustrinum -...................... 655

melanocarpum .................... 67, 78

myrsinites ........................... 107,112

glaucum ........................ 112

myrtilloides......................... $\quad 659$

pallidum ............................ 78

stamineum ............. $60,71,107,112,658$ melanocarpum .................... 658

tenellum ........................... 71

vacillans ........................ $66,67,71$

virgatum parvifolium ................ 659

tenellum ...................... 659 
Page.

Vagnera, catalogue racemosa

$66,75,253$

Valerian .............................. 686 family ........................... $\quad \boldsymbol{7 t 6}$

Valerianaceae ........................... $i t 6$

Valerianella, catalogue.................. $\quad \varpi 6$ locusta radiuta ....................... $\quad$ it6

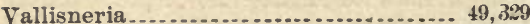
americana ............................. 334 catalogue ............................ 334 spiralis .............................. 127

Valsa, catalogue .......................... 178

Valsaceae.......................... 177, 262

Valsaria, catalogue ..................... 178

Vanilla plant ........................... 768,822

Varnish tree, Japanese . .................. 618,835

Vegetable marrow ....................... 830

Vegetables, early, in the Coast plain ...... 802

Velvet grass ................................ $3 \pi 1$ leaf.

Venus's comb............................. 646

hair

looking-glass, perfoliate

two-Howered

Veratrum angustifolium luteum

Verbascum blattaria catalogue

Verbena angustifolia

aubletia

Aublets .

bonariensis

canadensis

canescens

Carolina.

caroliniana.

caroliniana

catalogue.

jamaicensis

lucaeana ..............................

nodiflora

paniculata......................

prismatica

rigid.

spuria

urticaefolia ..........................

venosa

Verbenaceae

Verbesina.

alba

alternifolia ................................

aristata

catalogue

helianthoides

nudicaulis

occidentalis

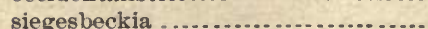

Vermicularia, catalogue ................

Vernonia .......................... 184, 758

altissima $\ldots \ldots \ldots \ldots \ldots \ldots \ldots \ldots \ldots \ldots \ldots . \ldots \ldots \ldots$

altissima .......................... 758

augustifolia......................... 245

angustifolia.......................... $\quad$ 559

catalogue ......................... 758

fasciculata
Vernonia-Continued.

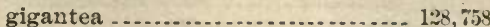

graminifolia ........................ $9 \pi, 115$

noveboracensis ...................... 245

praealta............................

scabervima ........................... 759

Veronica arvensis..................... 5i)

caroliniana ..........................

catalogue ........................... $\quad$ i23

peregrina ............................ 55

virginica ........................... 724

Verrucaria .............................. 264

catalogue ......................... 268

rupestris purpurascens. ............... 20.5

Verrucariaceae........................ 26\%.284

Verrucarias ........................... 205

Verrucarieae ........................... 26\% 284

Vervain.................................. 692,693

blue .............................. 693

Carolina ............................. 693

common ........................... 692

family ............................. 692

narrow-leaf......................... 693

white ............................... 693

Vetch .............. 135, 553, 568,569,5\%6,5\%7,829

common ......................... $5 \pi$

family ............................... 553

hairy ............................ 577

milk............................. 568

Viburnaceae ........................... 742

Viburnum ............................ 238

acerifolium ...................... 63,107

cassinoides........................... $\pi$

catalogue .......................... $\quad 74$

Chinese ........................... 136

dentatum .......................... 78

scabrellum ........................ $\quad 743$

ferrugineum ........................ 743

molle ............................... 118

nitidum .......................... 118

nudum .......................... 118, 153 angustifolinm ..................... $\quad$ it4

cassinoides...................... 743

claytonii ........................ 744

odoratissimum .................... 136,835

prunifolium ......................... 8 8,743

fermugineum.................... 743

scabrellum ........................... 743

sp.................................... 181

Vicia caroliniana ...................... $\quad 74$

catalogue ......................... 576

mitchellii............................ $5 \pi 7$

parviflorch ......................... 577

sativa ............................ 135, 829

Viciaceae .............................. 61,553

Vigna, catalogne ...................... $\quad 5 \pi 9$ catjang ......... 169,1\%6,23\%, 241, 246, 255, 261 glabra........................... 128

glabra ............................ 579

sinensis ............................ 830

Vilfa ............................... 367

drummondii ........................ 368

tenacissima .......................... 368

vaginaeflora ........................ 368

Villarsia cordat $\ldots . . . . . . . . . . . . . . . . . . .763$

lacunosa ......................... $6 \boldsymbol{w}_{3}$ 


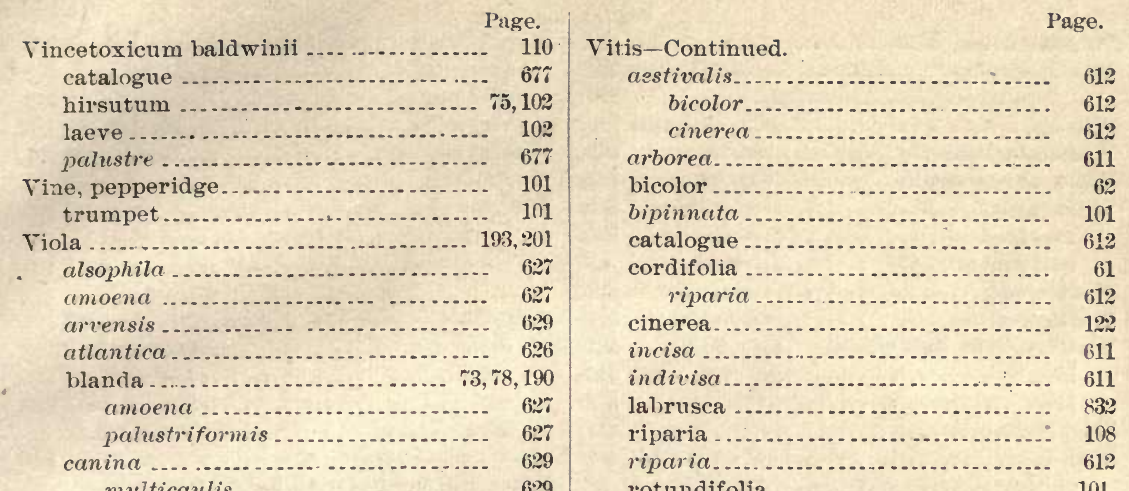

mutticaulis ..................... $6: 9$

cata'ogue ......................... 626

communis ............................ $62 \%$

concolor........................... 629

cucullata............................ $62 \%$

cordata ......................... 627

palmata........................... $\quad 626$

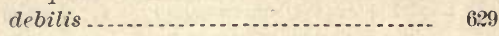

hastata............................

glaberrima....................... $6: 8$

tripartita ...................... $6: 28$

heterophylla......................... 626

insignis .............................. 626

muhlenbergii multicaulis............. 629

multicaulis . ...................... $73,75,78$

obliqua........................... 193, 627

odorata ........................... 245

palmata............................ 114

villosa........................... 627

vulgaris ........................ $6: 6$

papilionacea ....................... 133, $6: 7$

pedata ............................... 193

bicolor........................... 626

inornata ........................ 606

pensylvanica........................ 6028

primulaefolia....................... $\quad 259$

pubescens ............................. $\% 5,93$

scabriuscula..................... $6: 28$

rafinescuii .......................... 153

rostrata.......................... 73,78

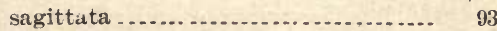

septemloba ........................ 114

sp ..................................... 190

striata ............................ $\pi 3$

tenella ............................ 153,629

tricolor . ..................... $56,153,1 \% 6,254$ arvensis .......................... $6: 9$

villosa ............................ 65, 245

Violaceae ............................. $626-629$

Violet .................................... 620

water ............................ 661

wood ............................... $6: 6,6: \gamma$

Virgilia lutea......................... $55 \%$

Virginia creeper ....................... 611

Virgin's bower........................ 71,512

Viscum flavescens........................ 479

Vitaceae ................................. 611

Viticulture on table-lands .............. 89

Vitis ......................... 153,163, 167, 169, aestivalis

$1 \% 2,1 \% 4,1 \% 9,181,19 \tau, 20 \%, 225,245,250,252$
$153,163,172,173,1 \% 4,195,248,254,832$

vinifera.......................... 174.613

vulpina ............................ 613

Vogelia capitata....................... 452

Volutella, catalogue ................... 248

Wahoo ................................. $4 \pi 4$

Wake-robin ....................... 442,443

Walking leaf ........................... 316

Walnut ........................ 43,44,824,831

black................ 14,46,84,8\%,92, 100, 461

Englisl1............................. 831

family .............................. 461

white .... ....................... 461

Waltheria, catalogue.................. 619

Warming's classification ................ 36

Warnstorf, peat mosses identified ....... $\quad 290$

Warrior and Coosa table-lands ........... 69 regetation ....................... $\quad \tau_{0}$

Washingtonia, catalogue................ 646

claytoni............................ 85

longistylis ......................... 93

Water feather........................ 49

fern family ........................ $\quad 320$

hemlock .......................... 50

hemp........................... 491

lily ............................... 49,504

family .......................... 503

milfoil family ....................... 639

milfoils . . . . . . . . . . . . . . . . . . . . . . 49,639

plantain ................. 329

creeping ...................... 330

family .......................... 329

pepper, mild ...................... 48̃

rice.................................. 49

shield,purple...................... 503

star ........................... 49, 43:

starwort family .................... 598

Waterleaf . . .......................... 687

family ............................. $68 \%$

Watermelon....... .......... 134, 240,8 82, 830

Water'melons in Coast Pine belt.......... $8: 2$

Waterweed ............................. 333

Wax myrtle_ $15,41,4 i, 4 i, 122,130,131,266,269,464$ family ........................... 464

tree .............................. 15

Waxwork ............................. 605

Webera. catalogue

Wedelia............................... 799

asperrima......................... 800

buphthalnioides ..................... 800 
Page,

Weisiaceae............................. $\$ 29 \pi$

Weisia viridula ........................... 297

unstralis .......................... $\quad 29 \pi$

Wheat . ........................ $68,80,823,827$

White alder family ...................... 65 ?

White arrow-arum ..................... 425

White grass ............................ 363

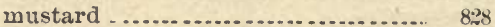

oak timber......................... 87

Whiteweed ........................... 813

Whitlow grass........................... $52 \tau$

Whitlow wort, Bald win's............... 50 ?

larger............................... 502

low.................................. 502

Wicky . ................................. 654

Wild bean .......................... 581,582

cherry ............................. 61,62

China ............................... 608

garlic ............................. 439

ginger, southern ...................... 481

large-flowered ................... 481

lamb salad ............................ 746

lettuce ............................... 755

oat grass . . . . . . .

onion .............................. 439

Willey, Henry, lichens identified ........ 263

Willow..................... 43, 88, 89, 465, 466, 833

black ................................. 125, 465

dense-flowered ........................ 734

family.............................. 464

heart-leaf ........................... 465

prairie .............................. 465

Ward's. ............................. 465

weeping .............................. 833

herb, colored ......................... 636

Willughbya scandens ........... 128, 165, 190, 243

Willughbaeya, catalogue................ 765

Wilson, Maria, lichens identified......... 263

Wind flower, American ................. 510

Winds in Alabama .................... 26

Windsoria stricta ...................... $3 \pi$

Winter berry ................................. 604

Wintergreen ............................ 656 spottod..................................... 652

Wire grass ........................ 109, 113,365

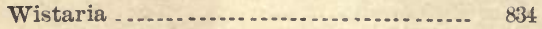

American ............................. 122

corrected to Wisteria ................. 845

Wisteria ............................. 567

chinensis............................ 834

Chinese ............................ 834

frutescens ........................... 15,567

speciosa ............................ 567

Witch hazel ............................. 537

family .......................... 537

Withe rod ............................ $\quad \pi 43$

Whortleberry .......................... 45,89

Wollastonia............................ $\quad 799$ asperrima.......................... 800

Wood betony ..........................

Woodbine............................. 122

Woodsia, catalogue...................... 318 obtusa ............................ 73,94

Wood sorrel family .................... 584 violet...........................6 626,627
Page.

Wood wardia angustifolia.......... 123, 125, 313 areolata ............................ 185

catalogue ........................... 313

virginica ....................... 1æ3, 125, 126

Wool grass ............................. 1æ3, 404

Wormseed ............................. 488,814

Wound wort ........................... 705

hispid .............................. 706

woodland ............................ 706

Xanthium canadense .................. 165, 191

catalogue .......................... $\quad 757$

echinatum ......................... $\quad 657$

sp .................................... 259

strumarium ........................ 191

Xanthosoma sagittifolia ................. $\quad 425$

Xerophile campestrian flora.............. 63

forests ....................... 59, 0

of Cahaba Valley ................. 91

of Central Pine belt................ 96

of Central Prairie region .......... 98

of Coast Pine belt .............. 10\%,112

of Tennessee Valley................ 81

herbaceous associations ............. $72,8 *, 96$

plants of Coast Pine belt ......... 108, 113

plant associations ..................... 48,67

plants of dry sands . .................. $\quad 129$

of dunes ........................ 130

of sandy dry hammocks.......... 131

rupestrian associations ............... 63

Xerophytic plant associations........... $\quad 37$

Xerotus, catalogue ...................... $\quad 2 \geqslant 0$

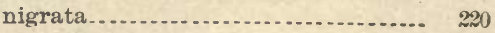

Ximinesia encelioides...................... 804

Xolisma, catalogue ........................ 655 ligustrina ............64,66, 161, 166, 185, 196

Xylaria, catalogue...................... 182

Xylariaceae............................ 179, 262

Xylogramma, catalogue.................. 160

Xylopleurum nuttallii................... 638

catalogue .......................... 638

speciosum....................... 105, 703, $8: 3$

Xyridaceae ........................... 119,427

Xyris................................. 116, 238

ambigua ......................... 127

bulbosa ............................. 427

caroliniana ......................... 97

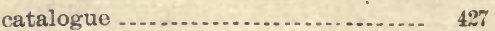

communis......................... 127

conocephala......................... 428

difformis ............................... $\quad 427$

elata .............................. 427

fimbriata ......................... 127

flexuosa............................... 75

gymnoptera ........................ 427

iridifolia ...........................66, 66

juncea ................................ 428

laxifolia ............................ $4: 27$

rhombipetala......................... $4: 27$

serotina.......................... 127

setacea .............................. $4: 28$

stricta............................... 427

tenuifolia .......................... $4: 28$

torta ............................. $9 \pi$

pallescens....................... 131 
Page.

Yam family wild.

Yams

Yard grasses

Yarrow

Yaupon

Yeatesia, catalogue

laetevirens

Yellow-eyed grass. family.

Yellowroot, shrub.

Yellowwood Northern

Yew, Florida

Yucca aloifolia catalogue .

filamentosa treculeana

Yuccas

Zamia integrifolia

Zannichellia catalogue palustris

anthoriza apiifolia catalogue

Zanthoxylum carolinianum

catalogue

clava-herculis

tricarpum
419

449

828

135

812

\%, 122, 603 735 -. 94 $42 \pi, 428$

$42 \pi$

ว08 $80,55 \%, 609$

85

34
34 $47,96,131$ 440 06 137 $13 \pi$ 49,329 329 $12 \%$ 75 508 508 587 587 102,122 587
Zea mays ..

Zephyranthes

Page.

Zizania ................................ 49

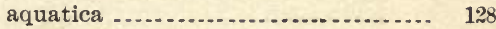

catalogue ........................... 362

clavulosa ............................ 362

fluitans............................... 362

miliacea .............................. 363

Zizaniopsis............................. 49

catalogue .......................... 363

miliacea........................... 128

Zizia, catalogue.......................... 64:

integerrima ......................... 645

pinnatifida............................

Zizyphus, catalogue..................... 609

vulgaris..................................... 832

vulgaris........................... 609

Zornia bracteata ....................... 114

catalogue ......................... 50

tetraphylla........................ $5 \tilde{50}$

Zygadenus ............................... 437

angustifolius ........................ 114

catalogue ......................... 43 .

glaberrimus ......................... 120

Zygodesmus, catalogue ................ $23 \tau$

Zygodon ................................. 300

Zygophyllaceae.......................... 586

Zythiaceae............................. 260, 263

$15894-59$

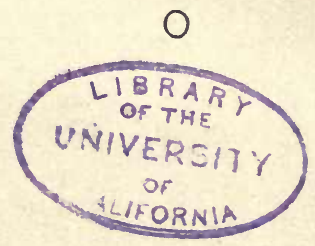






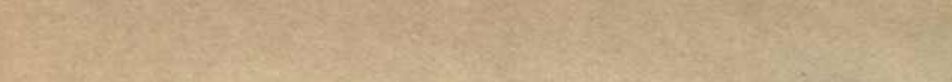



GENERAL LIBRARY

UNIVERSITY OF CALIFORNIA-BERKELEY

\section{RETURN TO DESK FROM WHICH BORROWED}

This book is due on the last date stamped below, or on the date to which renewed.

Renewed books are subject to immediate recall.

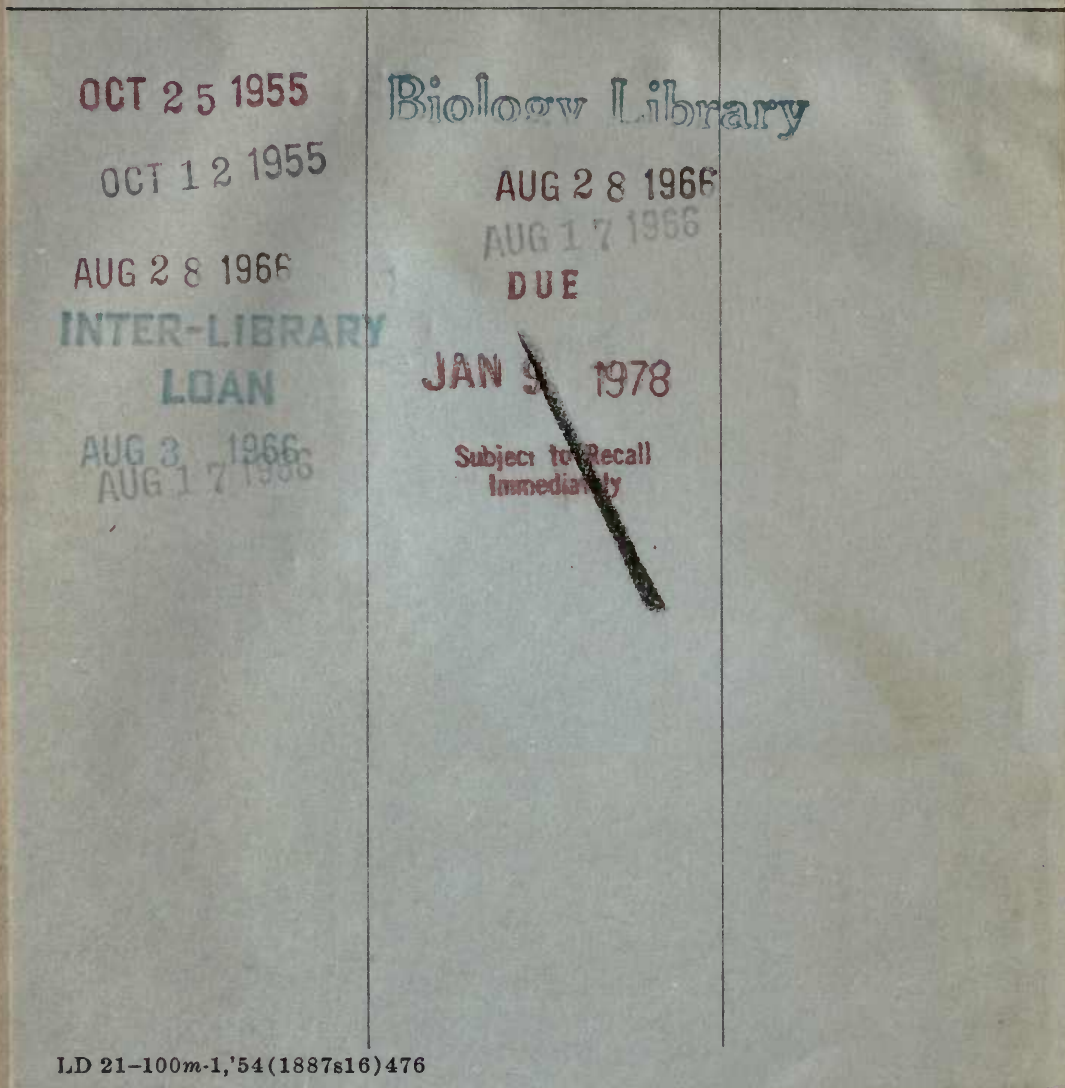



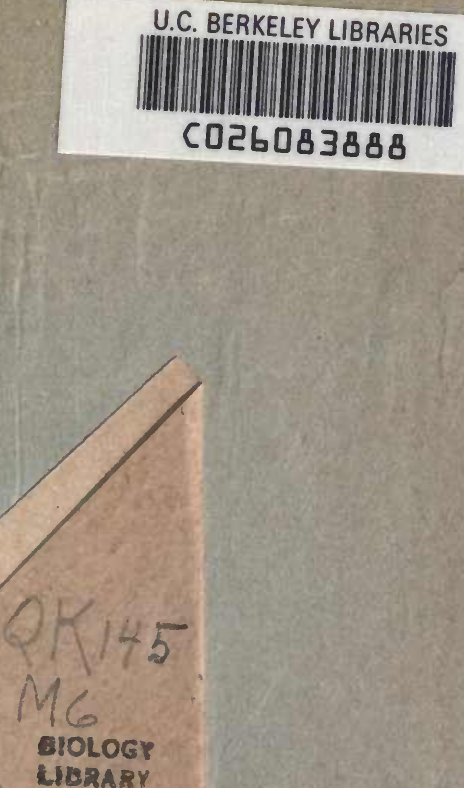

ala. 


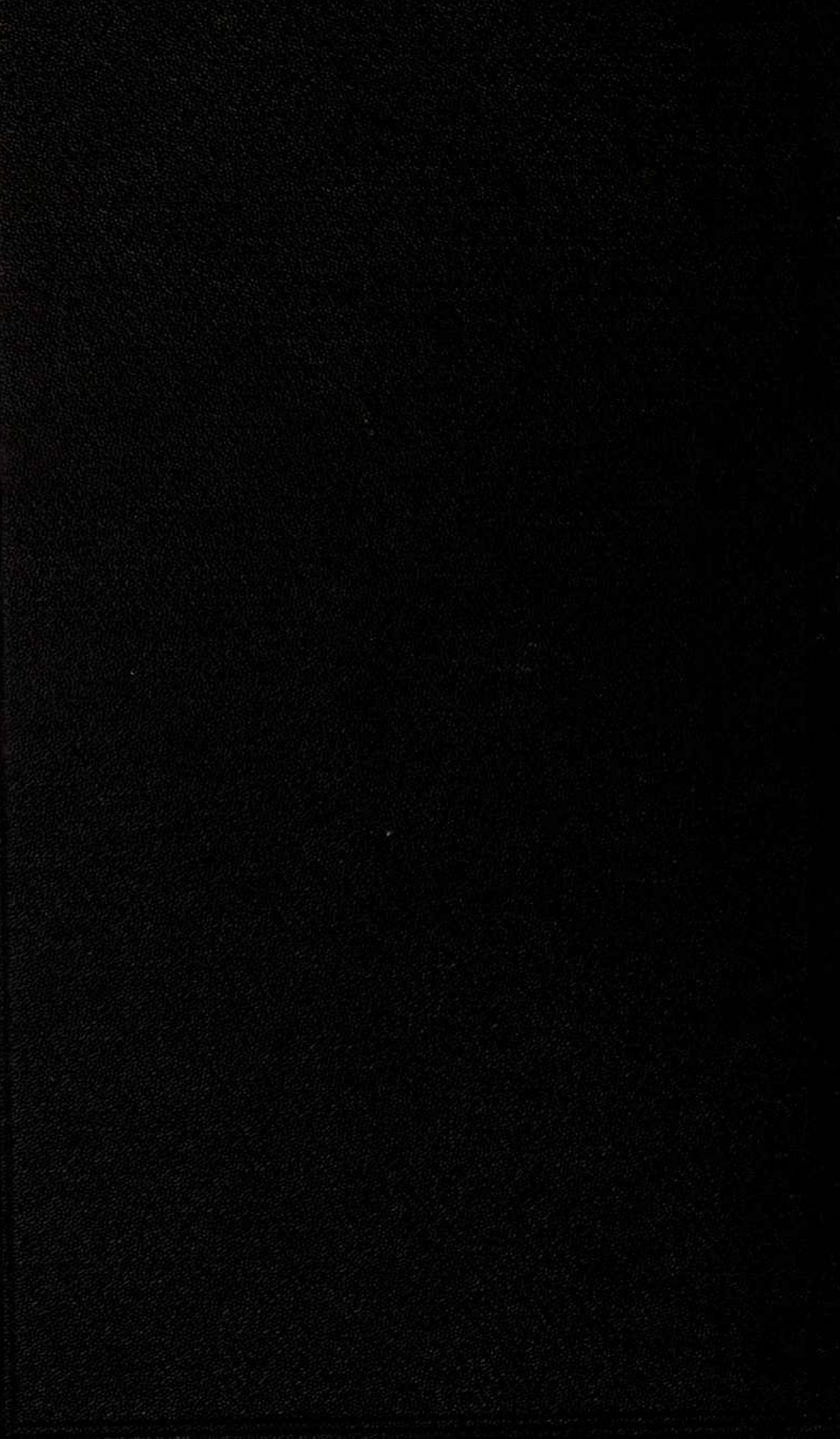

